\title{
Fiscal Year 2007 Phased Construction Completion Report for the Zone 2 Soils, Slabs, and Subsurface Structures at East Tennessee Technology Park, Oak Ridge, Tennessee
}
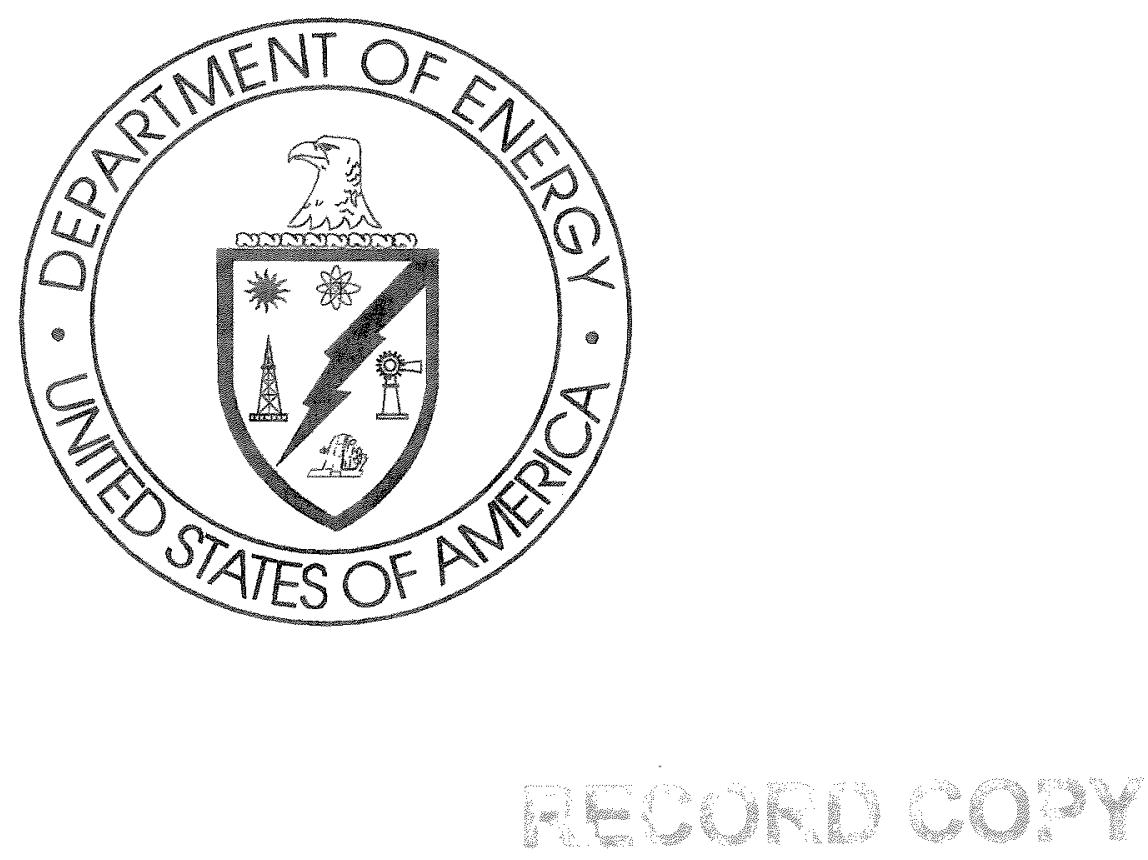

This document is approved for public release per review by:

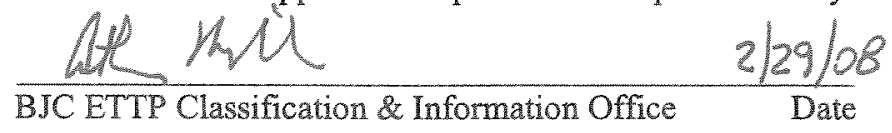




\section{OAK RIDGE PROGRAM DIVISION DOCUMENT REVIEW FORM}

DOCUMENT TITLE: Fiscal Year Phased Construction Completion Report for the Zone 2 Soils, Slabs, and Subsurface Structures at East Tennessee Technology Park, Oak Ridge, Tennessee

DOCUMENT NUMBER: DOE/OR/01-2723\&D1

\section{DATE COMMENTS ARE DUE:}

March 18, 2008

NAME OF REVIEWER: Constance Jones

ORGANIZATION: EPA Region IV

\section{DATE COMMENTS TRANSMITTED}

\begin{tabular}{|c|c|c|c|c|}
\hline $\begin{array}{c}\text { COMMENT } \\
\text { NO. }\end{array}$ & $\begin{array}{l}\text { SECT/ } \\
\text { PAGE }\end{array}$ & COMMENT & RESPONSE & ACCEPTANCE \\
\hline 1 & $\begin{array}{l}\text { Section } 2.2 .4 \text {, Program } \\
\text { Execution, Page 13, } \\
\text { paragraph } 1\end{array}$ & $\begin{array}{l}\text { This paragraph how soil samples are collected. In } \\
\text { comparison, in paragraph } 3 \text { Encore }{ }^{\circledR} \text { samplers are } \\
\text { specified. The text is unclear in paragraph } 1 \text { whether } \\
\text { the standard protocol as compared to paragraph } 3 \text {. As } \\
\text { this document identifies the implementation of an } \\
\text { investigation and remediation program, it is important } \\
\text { to completely describe the activities as conducted in } \\
\text { the field and not assume the reader is aware of all } \\
\text { aspects of the remedial action program. }\end{array}$ & $\begin{array}{l}\text { Paragraph four is revised to read: } \\
\text { The acetate liners were split in the field and } \\
\text { the core was screened for the presence of } \\
\text { VOCs. If VOCs were detected above } 5 \mathrm{ppm} \\
\text { using a hand-held photoionization detector, a } \\
\text { discrete interval soil sample was collected for } \\
\text { VOC analyses using EnCore® samplers. At a } \\
\text { burial trench site (e.g., EU Z2-41), the waste } \\
\text { matrix was commonly comprised of course } \\
\text { materials, debris, rubble, and fill materials, } \\
\text { which precluded the use of EnCore } ® \text { samplers } \\
\text { for VOC analysis. Approved sample } \\
\text { containers were used at these sites and } \\
\text { managed according to EPA Region IV } \\
\text { protocols (EPA 2002). }\end{array}$ & \\
\hline
\end{tabular}


OAK RIDGE PROGRAM DIVISION DOCUMENT REVIEW FORM

\begin{tabular}{|c|c|c|c|c|}
\hline $\begin{array}{c}\text { COMMENT } \\
\text { NO. }\end{array}$ & $\begin{array}{l}\text { SECT/ } \\
\text { PAGE }\end{array}$ & COMMENT & RESPONSE & ACCEPTANCE \\
\hline 2 & $\begin{array}{l}\text { Section 3.2, Dynamic } \\
\text { Verification Strategy, } \\
\text { Page 23, paragraph } 1\end{array}$ & $\begin{array}{l}\text { Please evaluate the text to ensure that the appropriate } \\
\text { reference is made to Zone } 2 \text { and not Zone } 1 \text {, which } \\
\text { presumes the acreage has "little or no contamination." }\end{array}$ & $\begin{array}{l}\text { Paragraph re vised as follows: } \\
\text { The DVS was developed as required by the } \\
\text { Zone } 2 \text { ROD and designed to provide } \\
\text { sufficient data to fill data gaps and conduct } \\
\text { final status assessments for all of Zone } 2 \text {. } \\
\text { DVS also was designed to facilitate real-time } \\
\text { decision making. This strategy focused on the } \\
\text { soil characterization portion of the Zone } 2 \\
\text { ROD to determine where action was needed. } \\
\text { Acreage classification was used to } \\
\text { progressively focus the investigation efforts } \\
\text { in areas where there was a moderate to high } \\
\text { probability of soil contamination (see } \\
\text { Sect. 2.1.3). The DVS also helped verify } \\
\text { information from previous investigations } \\
\text { because of the presumption that the vast } \\
\text { majority of acreage in Zone } 2 \text { hadlittle or ne } \\
\text { contamination. This strategy was designed to } \\
\text { ebtain data to support the presumption and to } \\
\text { incorporate flexibility to facilitate rapid } \\
\text { collection of additional data if the } \\
\text { presumption proved false based on data } \\
\text { results. The strategy was to gather adequate } \\
\text { data with minimal iterations of site } \\
\text { investigation planning and mobilization. }\end{array}$ & \\
\hline 3 & $\begin{array}{l}\text { Section 4.1.1, Exposure } \\
\text { Unit Z2-01, page } 33\end{array}$ & $\begin{array}{l}\text { In the last full paragraph, please briefly describe why } \\
\text { the monitoring ceased in } 1995 \text {. This is important } \\
\text { information to convey since mercury was detected } \\
\text { above the MCL. }\end{array}$ & $\begin{array}{l}\text { Monitoring was performed under a previous } \\
\text { groundwater monitoring program (IWQP) that } \\
\text { was discontinued. The existing data are } \\
\text { insufficient to adequately assess the } \\
\text { importance of the mercury MCL exceedance. }\end{array}$ & \\
\hline 4 & $\begin{array}{l}\text { Section } 4.1 .2 \text {, page } 36, \\
\text { paragraph } 2\end{array}$ & $\begin{array}{l}\text { Please correct the two typographical errors in the first } \\
\text { line. }\end{array}$ & $\begin{array}{l}\text { Paragraph revised as follows: } \\
\text { There were five sample locations in-that } \\
\text { consisted of twop-systematic grid locations in } \\
\text { the Class } 2 \mathrm{SU} \text {, one biased location in the } \\
\text { Class } 2 \mathrm{SU} \text {, one PCB confirmatory sample, and }\end{array}$ & \\
\hline
\end{tabular}




\section{OAK RIDGE PROGRAM DIVISION DOCUMENT REVIEW FORM}

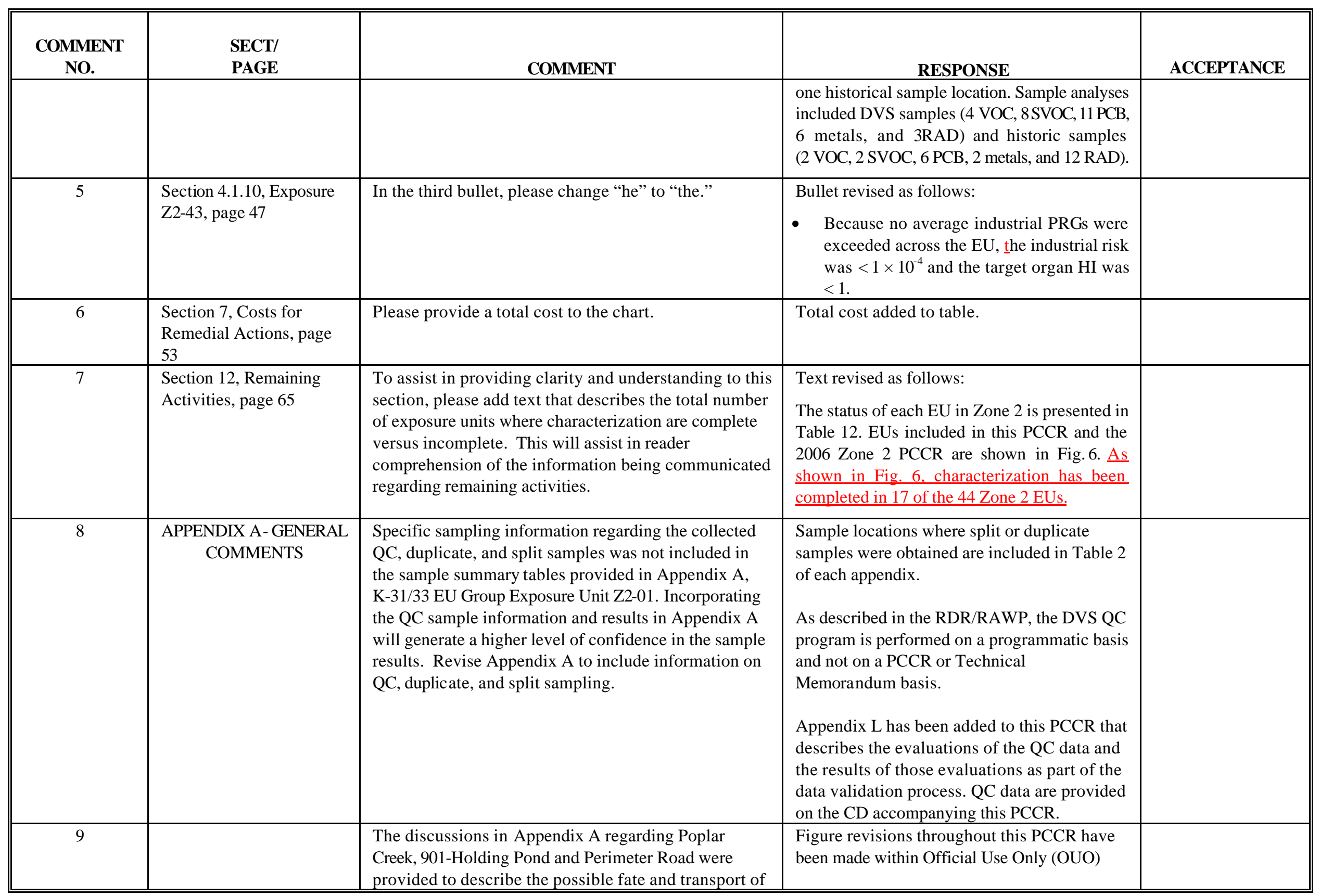


OAK RIDGE PROGRAM DIVISION DOCUMENT REVIEW FORM

\begin{tabular}{|c|c|c|c|c|}
\hline $\begin{array}{l}\text { COMMENT } \\
\text { NO. }\end{array}$ & $\begin{array}{l}\text { SECT/ } \\
\text { PAGE }\end{array}$ & COMMENT & RESPONSE & ACCEPTANCE \\
\hline & & $\begin{array}{l}\text { the contaminants of concern. However, there was no } \\
\text { depiction of these locations on a figure. Consider } \\
\text { revising a figure in Appendix A to include the location } \\
\text { of Poplar Creek, 901- Holding Pond and Perimeter } \\
\text { Road. }\end{array}$ & $\begin{array}{l}\text { constraints. Text that refers to figures has } \\
\text { also avoided reference to OUO. } \\
\text { The locations of Poplar Creek, K-901 Holding } \\
\text { Pond, and Perimeter Road have been added to } \\
\text { Fig. A.1. }\end{array}$ & \\
\hline 10 & $\begin{array}{l}\quad \text { APPENDIX A- } \\
\text { SPECIFIC COMMENTS } \\
\text { Section 2.2.5, EU } \\
\text { Evaluation, Page A-10 }\end{array}$ & $\begin{array}{l}\text { The third sentence of the second paragraph states "A } \\
\text { rusted drum and several mounds of soil containing } \\
\text { debris were identified and sampled." However, the first } \\
\text { paragraph on Page A-11 states "...one of these } \\
\text { samples is associated with a 55-gal drum and the other } \\
\text { is a composite sample of a soil mound." Revise } \\
\text { Appendix A to address the number of soil mounds } \\
\text { identified in EU-Z2-01 and clarify the number of soil } \\
\text { mounds sampled. If only one soil mound was sampled, } \\
\text { explain the significance of the soil mound and the level } \\
\text { of confidence surrounding the results from the soil } \\
\text { mound. }\end{array}$ & $\begin{array}{l}\text { Two biased samples collected in Zone } 2 \text { EU- } \\
01 \text { based on visual observation include a } \\
\text { mound of soil with a rusted } 55 \text {-gal drum and } \\
\text { one sample from a mound of several yards of } \\
\text { soil with visible rubble and debris. Small earth } \\
\text { mounds along old forest roads that have no } \\
\text { obvious rubble or debris constituents were } \\
\text { not sampled because they appeared to be } \\
\text { associated with brush clearing for the old } \\
\text { forest access roads. } \\
\text { Appendix A text has been revised for } \\
\text { clarification. }\end{array}$ & \\
\hline 11 & $\begin{array}{l}\text { Section } 2.2 .5, \text { EU } \\
\text { Evaluation, Page A-11 }\end{array}$ & $\begin{array}{l}\text { Page A-11 discusses the sampling selection for Class } 3 \\
\text { SU sample collection. Three sediment accumulation } \\
\text { areas which received run-off from anthropogenic } \\
\text { features were identified during the Class } 3 \text { SU } \\
\text { walkover. However, it was later stated "The } \\
\text { radiological SL was not exceeded during the Class } 3 \mathrm{SU} \\
\text { walkover assessment and no biased sampling was } \\
\text { performed based on radiological field characterization." } \\
\text { Revise Appendix A to specify the locations of these } \\
\text { sediment accumulation areas and provide an } \\
\text { explanation for to the absence of biased sampling from } \\
\text { these areas. }\end{array}$ & $\begin{array}{l}\text { All of Zone } 2 \text { EU-01 was initially classified as } \\
\text { a Class } 3 \text { SU. A Class } 3 \text { walkover assessment } \\
\text { was performed that included the use of a } \\
\text { FIDLER instrument. There was no instance or } \\
\text { area where the radiological conditions were } \\
\text { elevated, the radiological screening level was } \\
\text { not exceeded, and there was no sampling } \\
\text { done based on the radiological survey results. } \\
\text { There is a requirement under the Zone } 2 \text { ROD } \\
\text { that a minimum of five samples be collected in } \\
\text { each EU even if all indications are that there is } \\
\text { no soil contamination present. Two locations } \\
\text { were selected on soil mounds that contained } \\
\text { debris and rubble (see response to Comment } \\
\text { 10). Three additional sample locations were } \\
\text { selected in sediment accumulation areas that } \\
\text { received run-off from large portions of the EU } \\
\text { to meet the minimum number of samples as }\end{array}$ & \\
\hline
\end{tabular}


OAK RIDGE PROGRAM DIVISION DOCUMENT REVIEW FORM

\begin{tabular}{|c|c|c|c|c|}
\hline $\begin{array}{c}\text { COMMENT } \\
\text { NO. }\end{array}$ & $\begin{array}{l}\text { SECT/ } \\
\text { PAGE }\end{array}$ & COMMENT & RESPONSE & ACCEPTANCE \\
\hline & & & $\begin{array}{l}\text { required by the ROD. One additional sample } \\
\text { was placed in the former cooling water basin } \\
\text { fill. } \\
\text { Text has been added to Appendix A for } \\
\text { clarification }\end{array}$ & \\
\hline 12 & $\begin{array}{l}\text { Table A.2, Exposure Unit } \\
\text { Z2-01 Sample Summary, } \\
\text { Page A-27 }\end{array}$ & $\begin{array}{l}\text { Please provide information regarding samples collected } \\
\text { in EU-Z2-01. From Table A.2 it was observed that } \\
\text { sample location Z2-EU01-301 was collected as a Class } 2 \\
\text { SU. However, the text of Section } 2.2 .3 \text {, Class } 3 \text { and } \\
\text { Class } 4 \text { SUs, identified sample location Z2-EU01-301 as } \\
\text { a Class } 3 \text { SU. Review this information and revise } \\
\text { Appendix A to clarify the Class SU level for sample } \\
\text { location Z2-EU01-301. }\end{array}$ & $\begin{array}{l}\text { The sample location in question is Z2-EU01- } \\
\text { 306. All of Z2-EU01 was initially classified as a } \\
\text { Class } 3 \text { SU. Initial sampling, including } \\
\text { Z2-EU01-306, was performed. The results of } \\
\text { the first round of sampling reported elevated } \\
\text { PCBs in the sample from the } 306 \text { location. This } \\
\text { area was reclassified under DVS protocol as a } \\
\text { Class } 2 \text { SU. The reclassification occurred after } \\
\text { the initial samples were collected. The sample } \\
\text { collected at the } 306 \text { location was taken when } \\
\text { the area was a Class } 3 \text { soil unit and the } \\
\text { location was subsequently incorporated into } \\
\text { a Class } 2 \text { SU based on first round results. } \\
\text { Text has been added in Sect. } 2.2 .5 \text {, page A-11, } \\
\text { for clarification. }\end{array}$ & \\
\hline 13 & $\begin{array}{l}\text { APPENDIX B- SPECIFIC } \\
\quad \text { COMMENTS } \\
\text { Section 2.2.4, } \\
\text { Infrastructure, Page B-10 }\end{array}$ & $\begin{array}{l}\text { This section discusses the collection of sediment } \\
\text { samples from the two K-762 transformer vaults. Two } \\
\text { transformer vaults (sample locations Z2-EU3B-305 and } \\
\text { Z2-EU3B-306) were selected as representative of the } 20 \\
\text { transformer vaults located in EU Z2-03. Analytical } \\
\text { results for two sample locations, Z2-EU3B-305 and Z2- } \\
\text { EU3B-306 (page } 16 \text { ), indicated lead concentrations } \\
(1,970 \text { and } 5,990 \mathrm{mg} / \mathrm{kg} \text {, respectively) that exceed the } \\
\text { industrial PRG of } 800 \mathrm{mg} / \mathrm{kg} \text {. Due to the high lead } \\
\text { detections in these two K-762 transformer vaults, it is } \\
\text { recommended that all vaults be sampled if sufficient } \\
\text { sediment is available. In addition, performing a } \\
\text { weighted average over the entire EU for risk } \\
\text { determination may be inappropriate due to the isolated } \\
\text { nature of the vaults. A similar condition exists in the }\end{array}$ & $\begin{array}{l}\text { The two transformer vaults were selected for } \\
\text { sampling because they had accumulated } \\
\text { sediments that were accessible for sampling. } \\
\text { The remaining vaults either had no sediment } \\
\text { or the sediment was inaccessible for sampling } \\
\text { or both. Text to this effect has been added to } \\
\text { Sect. 2.2.4. } \\
\text { The process for evaluating risk in Zone } 2 \text { soils } \\
\text { assumes the industrial worker will conduct } \\
\text { activities throughout the whole EU for } \\
2000 \text { hours per year. Furthermore, risk is } \\
\text { evaluated for the volume of soil defined by } \\
\text { the surface area of the EU to a depth of } 10 \mathrm{ft} \text {. } \\
\text { Therefore, the EU average concentration }\end{array}$ & \\
\hline
\end{tabular}


OAK RIDGE PROGRAM DIVISION DOCUMENT REVIEW FORM

\begin{tabular}{|c|c|c|c|c|}
\hline $\begin{array}{c}\text { COMMENT } \\
\text { NO. }\end{array}$ & $\begin{array}{l}\text { SECT/ } \\
\text { PAGE }\end{array}$ & COMMENT & RESPONSE & ACCEPTANCE \\
\hline & & $\begin{array}{l}\text { concrete pit located next to the railroad tracks. } \\
\text { Concrete pit sample Z2-EU3B-304 had lead detected at } \\
9,560 \mathrm{mg} / \mathrm{kg} \text { and is also an isolated area. On pageB-14, } \\
\text { it is stated that the volume of sediment inside the } \\
\text { concrete pits was minimal and was contained within } \\
\text { the concrete structure. Assuming the sediment } \\
\text { contained in the transformer vaults is similarly limited } \\
\text { in volume a removal action for these lead-contaminated } \\
\text { sediments is reasonable and should be considered. } \\
\text { Revise this section to address the recommended } \\
\text { actions for the transformer vaults and the concrete pit. } \\
\text { Also, revise the risk analysis to consider the } \\
\text { transformer vaults and concrete pit as a separate unit } \\
\text { not to be averaged over the entire EU. }\end{array}$ & $\begin{array}{l}\text { comparison is the only appropriate method for } \\
\text { evaluating whether the limits placed on ris } \mathrm{k} \\
\text { by the Zone } 2 \text { ROD are being exceeded. In the } \\
\text { case of the vaults and concrete pit, the } \\
\text { combined surface areas are small relative to } \\
\text { the } 15 \text {-acre EU and the thicknesses of the } \\
\text { sediments with high lead concentrations are } \\
\text { also small relative to the 10-ft depth of the EU. } \\
\text { It is concluded that when the volume of } \\
\text { sediment with elevated lead concentrations is } \\
\text { averaged over the volume of soil in the EU, } \\
\text { that lead will not cause an exceedance of the } \\
\text { risk constraints of the Zone } 2 \text { ROD. }\end{array}$ & \\
\hline 14 & $\begin{array}{l}\text { Section 2.2.5, EU } \\
\text { Evaluations; PCB } \\
\text { Immunoassay Test Kit } \\
\text { Confirmation Samples, } \\
\text { Page B-19 }\end{array}$ & $\begin{array}{l}\text { In Section } 2.2 .5 \text {, PCB Immunoassay test kits (test kits) } \\
\text { were used to define Class } 2 \text { SU boundaries in } \\
\text { previously unclassified acreage. One test kit result } \\
\text { from sample location Z2-EU3-209 exceeded the Avg RL } \\
\text { of } 10,000 \mathrm{ug} / \mathrm{kg} \text { for PCBs. Confirmatory soil samples } \\
\text { were collected from the Z2-EU3-209 sample location } \\
\text { and two other locations, Z2-EU3-206 and Z2-EI3-219, } \\
\text { and sent to a fixed base laboratory for analysis. The } \\
\text { analytical results from confirmatory samples were } \\
\text { below detection limits for PCBs. Revise the Technical } \\
\text { Memorandum to present the immunoassay results for } \\
\text { the three PCB samples for which confirmation samples } \\
\text { were collected. Additionally, discuss the false positive } \\
\text { result for location Z2-EU3-209 and the ramifications } \\
\text { that this result has on the level of confidence for the } \\
\text { immunoassay tests. }\end{array}$ & $\begin{array}{l}\text { PCB test kits were used to identify areas } \\
\text { within the switchyards where contamination } \\
\text { was present. This field screening approach } \\
\text { was identified in the DQO review and was } \\
\text { agreed to by Core Team members. The } \\
\text { immunoassay kits are designed to detect } \\
\text { PCBs at quantifiable limits, however, the kits } \\
\text { are also sensitive to other organic } \\
\text { compounds. Positive results from these } \\
\text { screening kits can occur where certain SVOC } \\
\text { compounds are present. These false positive } \\
\text { results for PCBs were treated as indicators of } \\
\text { contamination, and any location where assay } \\
\text { kits reported positive results was ultimately } \\
\text { included in a Class } 2 \text { SU. Samples from the } \\
\text { defined Class } 2 \text { SUs were sent to the } \\
\text { laboratory. False positive results for PCBs } \\
\text { often did have detectable levels of PAH } \\
\text { compounds and little or no PCBs. This was } \\
\text { considered a conservative approach by the } \\
\text { Core Team and the subsequent actions where } \\
\text { taken with Core Team concurrence } \\
\text { (Concurrence Log No. } 78 \text { ). }\end{array}$ & \\
\hline
\end{tabular}


OAK RIDGE PROGRAM DIVISION DOCUMENT REVIEW FORM

\begin{tabular}{|c|c|c|c|c|}
\hline $\begin{array}{l}\text { COMMENT } \\
\text { NO. }\end{array}$ & $\begin{array}{l}\text { SECT/ } \\
\text { PAGE }\end{array}$ & COMMENT & $\begin{array}{r}\text { RESPONSE } \\
\end{array}$ & ACCEPTANCE \\
\hline & & & $\begin{array}{l}\text { Text to this effect has been added to } \\
\text { Sect. 2.2.5. Laboratory sample results are } \\
\text { included in Appendix B. }\end{array}$ & \\
\hline 15 & $\begin{array}{c}\text { APPENDIX C - } \\
\text { GENERAL COMMENTS }\end{array}$ & $\begin{array}{l}\text { Specific sampling information regarding the collected } \\
\text { QC, duplicate and split samples } \\
\text { was absent from the sample summary tables available } \\
\text { for this appendix. Incorporating the QC sample } \\
\text { information and results in Appendix } \mathrm{C} \text { will generate a } \\
\text { higher level of confidence in the sample results. Revise } \\
\text { Appendix C to include information on QC, duplicate, } \\
\text { and split sampling. }\end{array}$ & $\begin{array}{l}\text { The DVS QC program is performed on a } \\
\text { programmatic basis and not on a PCCR or } \\
\text { Technical Memorandum basis. } \\
\text { Appendix L has been added to this PCCR that } \\
\text { describes the evaluation of the QC data and } \\
\text { the results of those evaluations as part of the } \\
\text { data validation process. QC data are provided } \\
\text { on the CD accompanying this PCCR. }\end{array}$ & \\
\hline 16 & & $\begin{array}{l}\text { Discussion regarding the Poplar Creek location was } \\
\text { provided throughout Appendix C. However, no } \\
\text { depiction of this location was provided on a figure. By } \\
\text { specifying the Poplar Creek location in a figure, a better } \\
\text { understanding of the geography and importance of } \\
\text { this location can be gained. Revise Appendix C to } \\
\text { identify the location of Poplar Creek on a figure. }\end{array}$ & $\begin{array}{l}\text { Figure revisions made throughout this PCCR } \\
\text { have been made within Official Use Only } \\
\text { (OUO) constraints. Text that refers to figures } \\
\text { has also avoided reference to OUO. } \\
\text { The location of Poplar Creek has been added } \\
\text { to Figure C.1. }\end{array}$ & \\
\hline 17 & $\begin{array}{l}\text { APPENDIX C - SPECIFIC } \\
\qquad \text { COMMENTS } \\
\text { Section 2.1.2.1, Class } 2 \\
\text { SU Radiological } \\
\text { Walkover Survey, } \\
\text { Page C-6 }\end{array}$ & $\begin{array}{l}\text { The text discusses the BAR survey around sample } \\
\text { location RAD228. The objective of performing a BAR } \\
\text { survey is to define the extent of contamination. It is } \\
\text { stated within this section that "The BAR survey action } \\
\text { level was exceeded at several discrete points. However, } \\
\text { an area could not be defined." By not identifying the } \\
\text { area exceeding the BAR survey action level, the } \\
\text { objective of performing a Class } 2 \text { SU BAR survey is } \\
\text { not met. This area could be defined through the } \\
\text { identification and sampling of additional sample } \\
\text { locations. Based on sampling performed at additional } \\
\text { locations, or an alternate, equivalent method, revise } \\
\text { Appendix C, to present a defined area where the BAR } \\
\text { survey action level was exceeded. }\end{array}$ & $\begin{array}{l}\text { Details of the radiological surveys and a map } \\
\text { of the survey areas are included in the survey } \\
\text { report produced in support of the } 2007 \text { PCCR } \\
\text { (Class } 3 \text { Soil Unit Walkover Assessments and } \\
\text { Radiological Surveys for FY } 2007 \text { Exposure } \\
\text { Units in Zone 2, East Tennessee Technology } \\
\text { Park, Oak Ridge, Tennessee, BJC/OR-2691). } \\
\text { Production of a separate supporting } \\
\text { document for radiological and Class } 3 \text { surveys } \\
\text { are done to reduce the size of the Technical } \\
\text { Memoranda, and this approach was agreed to } \\
\text { by Core Team members. } \\
\text { A description of the Class } 3 \text { assessment } \\
\text { process is in Sect. } 2.2 .3 \text { of the PCCR. }\end{array}$ & \\
\hline
\end{tabular}


OAK RIDGE PROGRAM DIVISION DOCUMENT REVIEW FORM

\begin{tabular}{|c|c|c|c|c|}
\hline $\begin{array}{c}\text { COMMENT } \\
\text { NO. }\end{array}$ & $\begin{array}{l}\text { SECT/ } \\
\text { PAGE }\end{array}$ & COMMENT & RESPONSE & ACCEPTANCE \\
\hline & & & $\begin{array}{l}\text { The text below has been added to Sect. } 2.1 .3 \text { of } \\
\text { Appendix C: } \\
\text { As described in the survey description, a very } \\
\text { small spot, }<1 \mathrm{ft}^{2} \text { in extent, was defined in } \\
\text { proximity to the RAD } 228 \text { location. This is the } \\
\text { only spot that exc eeded survey screening } \\
\text { levels. A biased sample was collected at this } \\
\text { spot, and did not report elevated radioactive } \\
\text { contamination. }\end{array}$ & \\
\hline 18 & $\begin{array}{l}\text { Section } 2.2 .5, \mathrm{EU} \\
\text { Evaluation, Page C-11 }\end{array}$ & $\begin{array}{l}\text { It is mentioned that two well pairs, UNW-044/ BRW031 } \\
\text { and UNW083/BRW-063, are used to monitor the } \\
\text { groundwater at EU Z2-08. However, these two } \\
\text { groundwater monitoring well pairs are not } \\
\text { identified/depicted on a figure. By incorporating the } \\
\text { well pair locations on a figure, a higher level of } \\
\text { confidence in the data provided by these wells can be } \\
\text { achieved. Revise Appendix C to include a figure which } \\
\text { indicates the locations of these two groundwater well } \\
\text { pairs. }\end{array}$ & $\begin{array}{l}\text { Figure revisions made throughout this PCCR } \\
\text { have been made within Official Use Only } \\
\text { (OUO) constraints. Text that refers to figures } \\
\text { has also avoided reference to OUO. } \\
\text { Well BRW-062 and well pairs UNW-044/ } \\
\text { BRW-031 and UNW-083/BRW-063 have been } \\
\text { added to Fig. C-5. }\end{array}$ & \\
\hline 19 & $\begin{array}{l}\text { Section } 2.2 .5, \mathrm{EU} \\
\text { Evaluation, Page C-12 }\end{array}$ & $\begin{array}{l}\text { This section discusses the sampling results for the } \\
\text { Class } 3 \text { SU walkover assessment. In particular, four } \\
\text { inactive valve vaults were selected for dynamic } \\
\text { verification strategy (DVS) biased sampling because } \\
\text { they were “....representative of } 25 \text { inactive valve vaults } \\
\text { in the EU.” An explanation for the selection of the four } \\
\text { inactive valve vaults was not provided. Revised } \\
\text { Appendix A to explain the significance of the four } \\
\text { inactive valve vault locations selected for biased } \\
\text { sampling. }\end{array}$ & $\begin{array}{l}\text { Valve vaults are shallow concrete boxes that } \\
\text { formerly contained large control valves for } \\
\text { RCW lines. These vaults were covered and } \\
\text { the lines that flowed through the vaults } \\
\text { contained water. Also, most of the vaults are } \\
\text { raised slightly above the ground surface. } \\
\text { These vaults now commonly contain standing } \\
\text { water and have little or no sediment. The four } \\
\text { vaults identified for sampling were the only } \\
\text { vaults that contained enough sediment to } \\
\text { sample. Since there is no source of sediment } \\
\text { contamination from the lines and sediment } \\
\text { present is probably from surface runoff, the } \\
\text { four vaults that contained some sediment } \\
\text { were considered worst case conditions. The } \\
\text { sample results for these four vault samples are } \\
\text { presented in tabular form in Appendix C. }\end{array}$ & \\
\hline
\end{tabular}


OAK RIDGE PROGRAM DIVISION DOCUMENT REVIEW FORM

\begin{tabular}{|c|c|c|c|c|}
\hline $\begin{array}{l}\text { COMMENT } \\
\text { NO. }\end{array}$ & $\begin{array}{l}\text { SECT/ } \\
\text { PAGE }\end{array}$ & COMMENT & RESPONSE & ACCEPTANCE \\
\hline & & & $\begin{array}{l}\text { Documentation for vault sampling is in Core } \\
\text { Team Concurrence No. FCN-ETTP-Zone 2-08. } \\
\text { Text has been added to Appendix C for } \\
\text { clarification. }\end{array}$ & \\
\hline 20 & $\begin{array}{c}\text { APPENDIX D - } \\
\text { GENERAL COMMENTS }\end{array}$ & $\begin{array}{l}\text { Specific sampling information regarding the collected } \\
\text { QC, duplicate, and split samples was absent from the } \\
\text { sample summary tables available in the Appendix D, } \\
\text { K-25 EU Group Z2-23 Technical Memorandum. } \\
\text { Incorporating the QC sample information and results in } \\
\text { Appendix D will generate a higher level of confidence } \\
\text { in the sample results. Revise Appendix D to include } \\
\text { information on QC, duplicate, and split sampling. }\end{array}$ & $\begin{array}{l}\text { The DVS QC program is performed on a } \\
\text { programmatic basis and not on a PCCR or } \\
\text { Technical Memorandum basis. } \\
\text { Appendix L has been added to this PCCR that } \\
\text { describes the evaluations of the QC data and } \\
\text { the results of those evaluations as part of the } \\
\text { data validation process. QC data are provided } \\
\text { on the CD accompanying this PCCR. }\end{array}$ & \\
\hline 21 & $\begin{array}{l}\quad \text { APPENDIX D - } \\
\text { SPECIFIC COMMENTS } \\
\text { Section 2.1.3.2, Class } 3 \\
\text { and Class 4 SU } \\
\text { Anthropogenic Features, } \\
\text { Page D-7 }\end{array}$ & $\begin{array}{l}\text { Page D-7 discusses the walkover assessment. An } \\
\text { anthropogenic feature, the RCW line valve vault, was } \\
\text { identified during the Class } 3 \text { SU walkover assessment. } \\
\text { The text states "The RCW line valve vault was } \\
\text { surveyed for radiation and inspected for visual } \\
\text { evidence of chemical contamination. No significant } \\
\text { accumulation of sediment was present. Therefore, the } \\
\text { valve vault was not identified for biased sampling." } \\
\text { Although inadequate sample volume prohibited } \\
\text { sampling at this location, the text offered no discussion } \\
\text { of the results from the radiation survey. Revise } \\
\text { Appendix D to include a brief summary of the results } \\
\text { from the radiation survey at the RCW line valve vault. }\end{array}$ & $\begin{array}{l}\text { Details of the radiological surveys and a map of } \\
\text { the survey areas are included in the survey } \\
\text { report produced in support of the } 2007 \text { PCCR } \\
\text { (Class } 3 \text { Soil Unit Walkover Assessments and } \\
\text { Radiological Surveys for FY } 2007 \text { Exposure } \\
\text { Units in Zone 2, East Tennessee Technology } \\
\text { Park, Oak Ridge, Tennessee, BJC/OR-2691). } \\
\text { Production of a separate supporting document } \\
\text { for radiological and Class } 3 \text { surveys were done } \\
\text { to reduce the size of the Technical Memoranda } \\
\text { and were agreed to by the Core Team members. } \\
\text { Text has been added that describes the results } \\
\text { of the radiological survey. }\end{array}$ & \\
\hline 22 & $\begin{array}{l}\text { Section 2.2.5, EU } \\
\text { Evaluation, Page D-13 }\end{array}$ & $\begin{array}{l}\text { Section 2.2.5, page D-13, provides a detailed summary } \\
\text { of the four Class } 3 \text { SU DVS biased samples collected } \\
\text { from the K-1652 UST. According to Table D.2., EU } \\
\text { Z2-23 Sample Summary Table (page D-28), the four } \\
\text { samples collected from the UST sample location } \\
\text { (Z2-EU23B-317, Z2-EU23B-318, Z2-EU23B-19 and } \\
\text { Z2-EU23B-20) were analyzed for VOCs, metals, DROs, } \\
\text { GROs) and SVOCs. However, no discussion regarding } \\
\text { the results from the VOC analysis for the four samples } \\
\text { was included in Section 2.2.5. Revise Appendix D to }\end{array}$ & $\begin{array}{l}\text { VOCs were analyzed for in all four samples } \\
\text { but were not detected. Text to this effect was } \\
\text { inadvertently left out. Appendix D will be } \\
\text { revised to include this text. }\end{array}$ & \\
\hline
\end{tabular}


OAK RIDGE PROGRAM DIVISION DOCUMENT REVIEW FORM

\begin{tabular}{|c|c|c|c|c|}
\hline $\begin{array}{l}\text { COMMENT } \\
\text { NO. }\end{array}$ & $\begin{array}{l}\text { SECT/ } \\
\text { PAGE }\end{array}$ & COMMENT & RESPONSE & ACCEPTANCE \\
\hline & & $\begin{array}{l}\text { include and discuss the results from the VOC analysis } \\
\text { for samples Z2-EU23B-317, Z2-EU23B-318, Z2-EU23B- } \\
19 \text { and Z2-EU23B-20. }\end{array}$ & & \\
\hline 23 & $\begin{array}{l}\text { Section 3.3, Summary and } \\
\text { Conclusions, Page D-22 }\end{array}$ & $\begin{array}{l}\text { Page D-22 presents a discussion regarding the } \\
\text { potential threat that U-234 may pose to groundwater. } \\
\text { Although four sediment accumulation area } \\
\text { surface/subsurface soil sample locations exceeded the } \\
\text { groundwater screening level (SL), it is stated that } \\
\text { "...there are no U-234 MCL exceedances in area } \\
\text { groundwater wells. It is concluded U-234 does not } \\
\text { pose a threat to groundwater because of the relative } \\
\text { immobility of U-234 in ETTP soils and the small area } \\
\text { impacted at the accumulation area." In Section } 2.2 .5 \text {, } \\
\text { EU Evaluation, it is stated in last paragraph on page D- } \\
9 \text { that "No groundwater monitoring wells are located in } \\
\text { EU Z2-23. The closest wells are to the west around the } \\
\text { K-27 building and along Poplar Creek." This statement } \\
\text { creates an uncertainty surrounding the confidence in } \\
\text { stating that U-234 has not impacted groundwater at } \\
\text { EU-Z2-23. Parallel to the first concern, another } \\
\text { observation surrounding the groundwater threat } \\
\text { surfaced. In first paragraph of Section } 2.2 .5 \text {, EU } \\
\text { Evaluation on page D-10, discussions regarding the } \\
\text { sediment accumulation area are presented. It is stated } \\
\text { that, "The contaminants present are in a small isolated } \\
\text { surface depression, and infiltration does occur at this } \\
\text { location. The mass of contaminants present is minimal } \\
\text { and would not pose a threat to local groundwater." } \\
\text { However, no evidence illustrating the impact of } \\
\text { infiltration, stagnant movement and the mass of } \\
\text { contaminants is provided. Revise Appendix D to } \\
\text { provide supplemental information/data (e.g., technical } \\
\text { references on the immobility of U-234 in soils, historical } \\
\text { data) that supports the claim that U-234 contaminants } \\
\text { pose minimal or no threat to groundwater at EU-Z2- } 23 \text {. }\end{array}$ & $\begin{array}{l}\text { In the area where these three sample locations } \\
\text { reported elevated U- } 234 \text { in soils, there are } \\
\text { three additional sample locations that bound } \\
\text { the extent of the surface soil impact that } \\
\text { reported no uranium contamination. All of the } \\
\text { samples were collected within an area } \\
\text { approximately } 15 \times 15 \mathrm{ft} \text {. The surface soil } \\
\text { contamination was very limited in extent and } \\
\text { represented a very small total mass of } \\
\text { contamination. No impact to local } \\
\text { groundwater by radioactive contaminants was } \\
\text { observed at locations west of the K-27 } \\
\text { building, where soil and building } \\
\text { contamination levels were much higher than } \\
\text { at this location and where groundwater wells } \\
\text { are in immediate proximity to the areas of soil } \\
\text { contamination. } \\
\text { Text added briefly explains the reasons for U } \\
\text { immobility in ETTP soils. A more thorough } \\
\text { presentation can be found in Section } 6 \text { of the } \\
\text { Final Sitewide Remedial Investigation and } \\
\text { Feasibility Study for East Tennessee } \\
\text { Technology Park, Oak Ridge, Tennessee } \\
\text { (DOE/OR/01-2279\&D3), November } 2007 \text {. }\end{array}$ & \\
\hline 24 & APPENDIX E & No comments were generated. & Noted. & \\
\hline
\end{tabular}


OAK RIDGE PROGRAM DIVISION DOCUMENT REVIEW FORM

\begin{tabular}{|c|c|c|c|c|}
\hline $\begin{array}{c}\text { COMMENT } \\
\text { NO. }\end{array}$ & $\begin{array}{l}\text { SECT/ } \\
\text { PAGE }\end{array}$ & COMMENT & RESPONSE & ACCEPTANCE \\
\hline 25 & $\begin{array}{c}\text { APPENDIX F - } \\
\text { GENERAL COMMENTS }\end{array}$ & $\begin{array}{l}\text { Specific sampling information regarding the collected } \\
\text { QC, duplicate, and split samples was absent from the } \\
\text { sample summary tables available in the Appendix F, } \\
\text { Haul Road Exposure Unit Group Z2-28 Technical } \\
\text { Memorandum. Incorporating the QC sample } \\
\text { information and results in Appendix F will generate a } \\
\text { higher level of confidence in the sample results. Please } \\
\text { revise Appendix F to include information on QC, } \\
\text { duplicate, and split sampling. }\end{array}$ & $\begin{array}{l}\text { The DVS QC program is performed on a } \\
\text { programmatic basis and not on a PCCR or } \\
\text { Technical Memorandum basis. } \\
\text { Appendix L has been added to this PCCR that } \\
\text { describes the evaluations of the QC data and } \\
\text { the results of those evaluations as part of the } \\
\text { data validation process. Quality control data } \\
\text { are provided on the CD accompanying this } \\
\text { PCCR. }\end{array}$ & \\
\hline 26 & & $\begin{array}{l}\text { Discussions regarding the location of Haul Road can } \\
\text { be found throughout Appendix F. While the Haul Road } \\
\text { location is mentioned, it is not depicted on a figure. } \\
\text { Please revise } \\
\text { Appendix F to include a figure denoting the location of } \\
\text { Haul Road. }\end{array}$ & $\begin{array}{l}\text { Figure revisions made throughout this PCCR } \\
\text { have been made within Official Use Only } \\
\text { (OUO) constraints. Text that refers to figures } \\
\text { has also avoided reference to OUO. } \\
\text { The location of the Haul Road was not added } \\
\text { to the figures in Appendix F_because it is } \\
\text { considered OUO. }\end{array}$ & \\
\hline 27 & $\begin{array}{l}\text { APPENDIX F- SPECIFIC } \\
\quad \text { COMMENTS } \\
\text { Section 2.1.1.3, Class } 1 \\
\text { SU Soil Sampling, Page F- } \\
7\end{array}$ & $\begin{array}{l}\text { The text discusses the DVS Class } 1 \text { SU sampling in EU } \\
\text { Z2-28. A confirmation sample, Z2-EU28B-114, and two } \\
\text { composite step-out samples, Z2-EU28B-115 and Z2- } \\
\text { EU28B-116, were collected from the historical sample } \\
\text { location, RAD205. The text discusses that both step- } \\
\text { out samples were four-point composite samples. } \\
\text { However, Table F.2., EU Z2-28 Sample Summary Table, } \\
\text { depicts sample location Z2-EU28B-115 as a five-point } \\
\text { composite sample. Review this information and revise } \\
\text { Appendix F to clarify the number of points that were } \\
\text { sampled for composite sample Z2-EU28B-115. }\end{array}$ & $\begin{array}{l}\text { Table F.2 is correct regarding the number of } \\
\text { points making up the composite sample at } \\
\text { location Z2-EU28B-115; it is a five-point } \\
\text { composite sample. Text in Appendix F will be } \\
\text { changed to be consistent with the table. }\end{array}$ & \\
\hline 28 & $\begin{array}{l}\text { Section 2.1.2, Class } 2 \\
\text { SUs, Page F-8 }\end{array}$ & $\begin{array}{l}\text { Section 2.1.2, Page F-8 discusses the sample locations } \\
\text { for Class } 2 \text { SUs. The historical location, RAD212, is } \\
\text { specifically described on Page F-8. Along with } \\
\text { historical location RAD209, several historical locations, } \\
\text { RAD210, RAD214 and RAD212, were originally } \\
\text { intended to be considered in one investigation. } \\
\text { However, the text later states in the second bulleted }\end{array}$ & $\begin{array}{l}\text { The radiological walkover survey at the } \\
\text { RAD209 location is described in Appendix F, } \\
\text { Sect. 2.1.2.1, as RAD209/212. As described in } \\
\text { the text, it was the radiological walkover } \\
\text { survey of combined areas } 209 / 212 \text { that } \\
\text { prompted a separate assessment of the } \\
\text { RAD209 area. Analytical results for sampling }\end{array}$ & \\
\hline
\end{tabular}


OAK RIDGE PROGRAM DIVISION DOCUMENT REVIEW FORM

\begin{tabular}{|c|c|c|c|c|}
\hline $\begin{array}{l}\text { COMMENT } \\
\text { NO. }\end{array}$ & $\begin{array}{l}\text { SECT/ } \\
\text { PAGE }\end{array}$ & COMMENT & RESPONSE & ACCEPTANCE \\
\hline & & $\begin{array}{l}\text { item on Page F-8 that "...it was decided that the } \\
\text { location of RAD209 would be investigated } \\
\text { independently of the other locations based on the } \\
\text { BAR survey results." Revise Appendix F to include } \\
\text { additional analytical data/information supporting the } \\
\text { independent investigation of historical sample location } \\
\text { RAD209. }\end{array}$ & $\begin{array}{l}\text { conducted in the RAD209 area are presented } \\
\text { in Sect. 2.2.5 under the heading DVS Class } 2 \\
\text { SU Area Definition Sampling at RAD209. }\end{array}$ & \\
\hline 29 & $\begin{array}{l}\text { Section 2.1.2.3, Class } 2 \\
\text { SU Soil Sampling, Page F- } \\
9\end{array}$ & $\begin{array}{l}\text { The text contains details surrounding the samples } \\
\text { collected from the historical sample locations. Sample } \\
\text { Z2 EU28B-121 was described as having been collected } \\
\text { from historical location RAD209. However, Table F.2., } \\
\text { EU Z2-28 Sample Summary Table, noted sample Z2- } \\
\text { EU28B-12 was collected from historical sample location } \\
\text { RAD207. Review this information and revise Appendix } \\
\text { F to clarify the historical sample location associated } \\
\text { with Z2-EU28B-121. }\end{array}$ & $\begin{array}{l}\text { Table F. } 2 \text { is incorrect in this regard. The table } \\
\text { will be revised to state sample location } \\
\text { Z2-EU28B-121 is affiliated with RAD209. This } \\
\text { is consistent with the text and with Fig. F.5 } \\
\text { that shows Z2-EU28B-121 and RAD209 are } \\
\text { co-located. }\end{array}$ & \\
\hline 30 & $\begin{array}{l}\text { APPENDIX G - SPECIFIC } \\
\text { COMMENTS } \\
\text { Section 2.2.5, EU } \\
\text { Evaluation, Page G-8 }\end{array}$ & $\begin{array}{l}\text { In the groundwater evaluation section, reference is } \\
\text { made to two groundwater monitoring wells located in } \\
\text { the northern portion of EU Z2-34 server as an } \\
\text { engineered control for the dispersion of } \\
\text { polychloroethene and tetrachloroethene. By specifying } \\
\text { the locations of these wells on a figure, a higher level } \\
\text { of confidence would be established regarding the } \\
\text { ability of thee wells to control and monitor dispersion. } \\
\text { It is recommended that Appendix G be revised to } \\
\text { include a figure that illustrates the locations of the two } \\
\text { groundwater monitoring wells. }\end{array}$ & $\begin{array}{l}\text { Figure revisions made throughout this PCCR } \\
\text { have been made within Official Use Only } \\
\text { (OUO) constraints. Text that refers to figures } \\
\text { has also avoided reference to OUO. } \\
\text { Groundwater monitoring wells BRW-113 and } \\
\text { BRW-114 have been added to Fig. G.4. }\end{array}$ & \\
\hline 31 & $\begin{array}{c}\text { APPENDIX H - GENERAL } \\
\text { COMMENTS }\end{array}$ & $\begin{array}{l}\text { In the tables provided in Section } 2.2 .5 \text {, EU Evaluation, } \\
\text { samples which exceeded the Industrial Preliminary } \\
\text { Remedial Goal (Ind PRG) are listed. These tables list } \\
\text { only the location where the maximum concentration } \\
\text { was detected. Further, additional sample locations } \\
\text { where the Ind PRGs were exceeded were not listed or } \\
\text { discussed in Appendix H, EU Z2-37 K-1070-C/D and } \\
\text { Downgradient Area Group, Technical Memorandum } \\
\text { (Memorandum). Revise the text to include a list of all }\end{array}$ & $\begin{array}{l}\text { Inclusion of the maximum concentration and } \\
\text { its location in the summary tables has its } \\
\text { origin in a request from EPA. Because the } \\
\text { purpose of the PRG evaluation is to estimate } \\
\text { the likelihood a chemical or radionuclide will } \\
\text { create an unacceptable risk, and because a } \\
\text { risk assessment will evaluate the weighted } \\
\text { average concentration across an EU, citing } \\
\text { individual locations at which a PRG is } \\
\text { exceeded adds no value to the PRG }\end{array}$ & \\
\hline
\end{tabular}


OAK RIDGE PROGRAM DIVISION DOCUMENT REVIEW FORM

\begin{tabular}{|c|c|c|c|c|}
\hline $\begin{array}{l}\text { COMMENT } \\
\text { NO. }\end{array}$ & $\begin{array}{l}\text { SECT/ } \\
\text { PAGE }\end{array}$ & COMMENT & RESPONSE & ACCEPTANCE \\
\hline & & $\begin{array}{l}\text { sample locations where the Industrial PRG was } \\
\text { exceeded. }\end{array}$ & $\begin{array}{l}\text { evaluation. The data CD included with this } \\
\text { PCCR presents each individual analytical } \\
\text { result, and the PRG values used in the PRG } \\
\text { evaluation are presented in the PCCR. } \\
\text { Refer to Sects. } 3.3 .1 \text { and } 3.3 .2 \text { of the PCCR for } \\
\text { a description of the Ind PRG evaluation. }\end{array}$ & \\
\hline 32 & & $\begin{array}{l}\text { The procedures adopted in performing the background } \\
\text { comparison for the radiological c contaminants of } \\
\text { concerns; Potassium-40 (K-40), Radium-226 (Ra-226), } \\
\text { Thorium-228 (Th-228) and Thorium-232 (Th-232) are } \\
\text { discussed in Section 3.3, Summary and Conclusions. } \\
\text { To evaluate their risk, the sum of Ra-226, Th- } 230 \text { and } \\
\text { Th-232 detected concentrations is compared to the } \\
\text { mutual Zone } 2 \text { soils average remediation level (Avg } \\
\text { RL) which is } 5 \text { pico Curies per gram (pCi/g). It is } \\
\text { concluded that the summed values do not exceed the } \\
\text { Avg RL and would therefore not be evaluated further. } \\
\text { However, when the average concentrations for Ra-226, } \\
\text { Th-228 and Th-232 are summed and averaged, the } \\
\text { resulting value is } 4.6 \text { pCi/g. This value is significantly } \\
\text { close to the Avg RL and would suggest that further } \\
\text { investigation should be warranted. In addition, it was } \\
\text { observed in Section } 3.3 \text { that the screening procedures } \\
\text { adopted for K- } 40 \text { included the average detected } \\
\text { concentration as opposed to the maximum detection } \\
\text { concentration. The concern surrounding this } \\
\text { observation is that the average detected concentration } \\
\text { does not reflect the true nature of the potential threat } \\
\text { posed for EU-37. Provide justification that the adopted } \\
\text { screening/background procedures are adequate. } \\
\text { Revise the text as appropriate. }\end{array}$ & $\begin{array}{l}\text { The procedure for calculating the Ra/Th } \\
\text { decay series "concentrations" is explained in } \\
\text { Sect. } 3.3 .2 \text { of the PCCR. In summary, for each } \\
\text { sample, the background concentration is } \\
\text { subtracted from the Ra-226, Th- } 230 \text {, and Th- } \\
232 \text { analytical results. If the resulting value is } \\
<0 \text {, the value is set to } 0 \text {. Then the } \\
\text { background-corrected concentration of Th- } \\
232 \text { is added to the larger of the background } \\
\text { concentrations of Ra-226 or Th- } 230 \text {. The } \\
\text { result is the Ra/Th decay series } \\
\text { "concentration". Review of the data for EU } \\
\text { Z2-37 shows that the highest Ra/Th decay } \\
\text { series "concentration" is } 3.25 \text { pCi/g in the } \\
\text { sample from location RAD } 85 \text {. The average } \\
\text { value for the EU is } 0.804 \text {. } \\
\text { The purpose of evaluating K- } 40 \text { in Sect. } 3.3 \\
\text { was to test if K- } 40 \text { was likely to create an } \\
\text { unacceptable risk in a quantitative risk } \\
\text { calculation. The average detected } \\
\text { concentration was used because the } \\
\text { quantitative risk calculation will evaluate the } \\
\text { weighted average concentration of K- } 40 \text { over } \\
\text { the EU and will use one-half the detection } \\
\text { limit for nondetects. Thus, by using the } \\
\text { average detected concentration, the } \\
\text { evaluation performed in Sect. } 3.3 \text { was a } \\
\text { conservative estimate of the likelihood that } \\
\text { K- } 40 \text { would create an unacceptable risk. }\end{array}$ & \\
\hline
\end{tabular}




\section{OAK RIDGE PROGRAM DIVISION DOCUMENT REVIEW FORM}

\begin{tabular}{|c|c|c|c|c|}
\hline $\begin{array}{l}\text { COMMENT } \\
\text { NO. }\end{array}$ & $\begin{array}{l}\text { SECT/ } \\
\text { PAGE }\end{array}$ & COMMENT & RESPONSE & ACCEPTANCE \\
\hline 33 & $\begin{array}{l}\text { APPENDIX H -SPECIFIC } \\
\qquad \text { COMMENTS } \\
\text { Section H.2.1.3.4, Class } 3 \\
\text { and Class 4 SU Biased } \\
\text { Sampling, Page H-7 }\end{array}$ & $\begin{array}{l}\text { In this section, locations for biased samples were } \\
\text { described; specifically, the three biased samples } \\
\text { associated with the SW-31 spring. The significance of } \\
\text { the three sample locations was the geographic location } \\
\text { in relation to the spring. Providing topographical maps } \\
\text { highlighting the elevation changes within this EU } \\
\text { would provide supplemental information that would } \\
\text { generate a better understanding of the geographic } \\
\text { nature of this EU. It is recommended that a topographic } \\
\text { map be included in the document. }\end{array}$ & $\begin{array}{l}\text { Figure revisions made throughout this PCCR } \\
\text { have been made within Official Use Only } \\
\text { (OUO) constraints. Text that refers to figures } \\
\text { has also avoided reference to OUO. } \\
\text { Available topographic contours are } \\
\text { pre-construction and do little to enhance } \\
\text { understanding the elevation changes around } \\
\text { the SW-31 spring. Groundwater flow lines } \\
\text { added to Figure H.3. }\end{array}$ & \\
\hline 34 & $\begin{array}{l}\text { Section H.2.1.3.4, Class } 3 \\
\text { and Class } 4 \text { SU Biased } \\
\text { Sampling, Page H-7 }\end{array}$ & $\begin{array}{l}\text { Within Section H.2.1.3.4, the location 'Avenue D' is } \\
\text { mentioned. Avenue D has significance because two } \\
\text { biased sediment samples were collected from this } \\
\text { location. However, this location could not be identified } \\
\text { on any of the figures provided with the Appendix H - } \\
\text { EU-Z2-37 packet. Please revise the text o identify the } \\
\text { location of Avenue D on a figure. }\end{array}$ & $\begin{array}{l}\text { Figure revisions made throughout this PCCR } \\
\text { have been made within Official Use Only } \\
\text { (OUO) constraints. Text that refers to figures } \\
\text { has also avoided reference to OUO. } \\
\text { The location of Avenue D added to Figures } \\
\text { H.2 and H.3. }\end{array}$ & \\
\hline 35 & $\begin{array}{l}\text { Section } 2.2 .3 \text {, Class } 3 \text { and } \\
\text { Class } 4 \text { SUs, Page H-7 }\end{array}$ & $\begin{array}{l}\text { In Section } 2.2 .3 \text {, discussions involving the sample } \\
\text { locations are provided. It is stated in the third sentence } \\
\text { of this section that three historical sample locations are } \\
\text { not discussed in the document and are not listed in the } \\
\text { table included within this section. Explain the } \\
\text { significance of these samples, their respective } \\
\text { locations, and the rationale for their absence from the } \\
\text { document. Please revise the text to address this issue. }\end{array}$ & $\begin{array}{l}\text { The text in Sect. } 2.2 .3 \text { explains that these } \\
\text { sample locations are not discussed in the } \\
\text { document and are not included in the table } \\
\text { because the samples collected from them were } \\
\text { analyzed only for alpha activity and } \\
\text { beta/gamma activity with results reported in } \\
\text { cpm. Soil analytical data are evaluated in the } \\
\text { Technical Memoranda so that EU } \\
\text { compositions can be compared to the Zone } 2 \\
\text { ROD constraints on risk and impacts to } \\
\text { groundwater. The cpm unit is } \\
\text { quasi-quantitative and is not appropriate for } \\
\text { evaluating risk or assessing the impact to } \\
\text { groundwater. Therefore, the samples are not } \\
\text { included in the EU evaluation. However, data } \\
\text { for these two samples are included in the data } \\
\text { CD in the PCCR. } \\
\text { Text to this effect has been added to } \\
\text { Appendix H. }\end{array}$ & \\
\hline
\end{tabular}


OAK RIDGE PROGRAM DIVISION DOCUMENT REVIEW FORM

\begin{tabular}{|c|c|c|c|c|}
\hline $\begin{array}{l}\text { COMMENT } \\
\text { NO. }\end{array}$ & $\begin{array}{l}\text { SECT/ } \\
\text { PAGE }\end{array}$ & COMMENT & RESPONSE & ACCEPTANCE \\
\hline 36 & $\begin{array}{l}\text { Section } 2.2 .5, \text { EU } \\
\text { Evaluation, Page H-10 }\end{array}$ & $\begin{array}{l}\text { Within Section } 2.2 .5 \text { of the Memorandum, } \\
\text { discussion of the CSM is provided. On page H-10, it } \\
\text { was stated that several monitoring wells have reported } \\
\text { elevated concentrations of specified analytes. } \\
\text { Providing the location of the monitoring wells would } \\
\text { lend further support to the results of the EU } \\
\text { evaluation. Revise the appendix to specify the location } \\
\text { of the monitoring wells located in EU-37 in a figure or } \\
\text { in the text. }\end{array}$ & $\begin{array}{l}\text { Figure revisions made throughout this PCCR } \\
\text { have been made within Official Use Only } \\
\text { (OUO) constraints. Text that refers to figures } \\
\text { has also avoided reference to OUO. } \\
\text { Monitoring well locations added to Fig. H.3. }\end{array}$ & \\
\hline 37 & $\begin{array}{l}\text { Section } 2.2 .5, \text { EU } \\
\text { Evaluation, Page H-10 }\end{array}$ & $\begin{array}{l}\text { This Section } 2.2 .5 \text { discusses selection of } \\
\text { DVS sample locations around the SW-31 spring. } \\
\text { However, there is no information or data that justifies } \\
\text { the necessity of collecting DVS samples at the SW- } 31 \\
\text { spring. Revise the text to provide a reference which } \\
\text { includes information regarding the SW-31 spring area } \\
\text { and supports the need to collect biased samples at this } \\
\text { area. If no reference is available, include an explanation } \\
\text { which addresses this concern. }\end{array}$ & $\begin{array}{l}\text { Section } 2.2 .5 \text { text under the heading "DVS Soil } \\
\text { Sampling Associated with the SW-31 Spring" } \\
\text { states that sampling was conducted to } \\
\text { investigate any lingering effects of the SW-31 } \\
\text { Spring on surrounding soil. } \\
\text { This text has been changed to the following: } \\
\text { Three biased sample locations were selected } \\
\text { to investigate possible soil contamination } \\
\text { resulting from overflow of the SW } 31 \text { Spring } \\
\text { sump. Biased sampling around the SW-31 } \\
\text { Spring }\end{array}$ & \\
\hline 38 & $\begin{array}{l}\text { Figure H.3, EU Z2-37 } \\
\text { Sample Locations, Page } \\
\text { H-31 }\end{array}$ & $\begin{array}{l}\text { Sample point locations are identified in Figure H-3. An } \\
\text { examination of the sample locations at which } \\
\text { exceedances of the Avg RL, Max RL, GW SL and/or } \\
\text { the Ind PRG were reported indicated that the samples } \\
\text { were concentrated in a specific region of the EU. } \\
\text { General groundwater flow patterns within EU-41 are } \\
\text { depicted in K-1070-C/D and Downgradient Area } \\
\text { Exposure Unit Group Z2-41, Appendix I, Figure 3, EU } \\
\text { Z2-41 Class } 3 \text { Walkover Assessment Locations. Due to } \\
\text { the relative locations of EU-41 and EU-37, as well as } \\
\text { the locations of samples that exceeded the parameters } \\
\text { listed above, a contour map depicting groundwater } \\
\text { flow in EU-37 would foster a clearer understanding of } \\
\text { the transport of contaminated groundwater within }\end{array}$ & $\begin{array}{l}\text { Figure revisions made throughout this PCCR } \\
\text { have been made within Official Use Only } \\
\text { (OUO) constraints. Text that refers to figures } \\
\text { has also avoided reference to OUO. } \\
\text { Groundwater and surface water flow } \\
\text { directions added to Fig. H.3. }\end{array}$ & \\
\hline
\end{tabular}


OAK RIDGE PROGRAM DIVISION DOCUMENT REVIEW FORM

\begin{tabular}{|c|c|c|c|c|}
\hline $\begin{array}{l}\text { COMMENT } \\
\text { NO. }\end{array}$ & $\begin{array}{l}\text { SECT/ } \\
\text { PAGE }\end{array}$ & COMMENT & RESPONSE & ACCEPTANCE \\
\hline & & $\begin{array}{l}\text { EU-37 as well as between EU-41 and EU-37. Consider } \\
\text { modifying Figure H.3 of the document to include } \\
\text { information related to groundwater flow within EU-37. }\end{array}$ & & \\
\hline 39 & $\begin{array}{l}\text { Table H.2, EU Z2-37 } \\
\text { Sample Summary, Page H- } \\
33\end{array}$ & $\begin{array}{l}\text { In Table H.2, information pertaining to each sample } \\
\text { collected at EU-37 was provided. Within this table, it } \\
\text { was observed that the sampling procedures adopted } \\
\text { for samples Z2-EU37B-303 and Z2-EU37B-304 included } \\
\text { three sample intervals of } 0-0.5,0.5-2.0 \text {, and } 1.5 \text { feet } \\
\text { within } 2-10 \text { feet. The significance of the depth interval } \\
\text { from } 2 \text { to } 10 \text { feet is not clear. By selecting such a large } \\
\text { interval, producing a result that adequately represents } \\
\text { the vertical extent of the sample location would be } \\
\text { questionable. Please revise the text to explain the } \\
\text { significance of selecting the } 2-10 \text { feet depth interval. }\end{array}$ & $\begin{array}{l}\text { Risk from Zone } 2 \text { soils is evaluated over the } \\
\text { volume of soil defined by the surface area of } \\
\text { each EU to a depth of } 10 \mathrm{ft} \text {. To quantify soil } \\
\text { compositions to the prescribed depth, } 10-\mathrm{ft} \\
\text { soil cores were collected and composited. The } \\
\text { DVS protocol for compositing states that } \\
\text { samples will be collected and composited from } \\
\text { three depth intervals along each core ( } 0-0.5 \mathrm{ft} \text {, } \\
0.5-2.0 \mathrm{ft} \text {, and } 2.0-10 \mathrm{ft}) \text {. Further, the protocol } \\
\text { states that the sample in the } 2-10 \mathrm{ft} \text { interval } \\
\text { will be selected at the location along the core } \\
\text { with the highest radiation measurement made } \\
\text { during the core radiation scan. } \\
\text { As described in the RDR/RAWP, this } \\
\text { approach assumes the industrial worker will } \\
\text { have equal access to the } 0 \text { - } 10 \mathrm{ft} \text { interval } \\
\text { across the EU. In those cases where process } \\
\text { knowledge suggests the upper portion of that } \\
\text { depth interval may exhibit preferential } \\
\text { contamination, bias is awarded to the shallow } \\
\text { depth interval. }\end{array}$ & \\
\hline 40 & $\begin{array}{l}\text { Table H.2, EU Z2-37 } \\
\text { Sample Summary, Page H- } \\
33\end{array}$ & $\begin{array}{l}\text { A second observation noted within Table H.2 is the } \\
\text { presence of a duplicate sample for sample Z2-EU37B- } \\
301 \text { and a split sample for sample Z2-EU37B-302. The } \\
\text { sample results for both the duplicate and split samples } \\
\text { were not listed within the Appendix. Please revise the } \\
\text { document to include the results for both the duplicate } \\
\text { and split samples. }\end{array}$ & $\begin{array}{l}\text { The DVS QC program is performed on a } \\
\text { programmatic basis and not on a PCCR or } \\
\text { Technical Memorandum basis. } \\
\text { Appendix L has been added to this PCCR that } \\
\text { describes the evaluations of the QC data and } \\
\text { the results of those evaluations as part of the } \\
\text { data validation process. QC data are provided } \\
\text { on the CD accompanying this PCCR. }\end{array}$ & \\
\hline 41 & $\begin{array}{l}\text { APPENDIX I - GENERAL } \\
\text { COMMENTS }\end{array}$ & $\begin{array}{l}\text { In Section 1.3, Summary Description, a brief description } \\
\text { of the EU Z2-41 location is provided. According to the } \\
\text { description, EU Z2-41 is located on a hill at the eastern }\end{array}$ & $\begin{array}{l}\text { Figure revisions made throughout this PCCR } \\
\text { have been made within Official Use Only }\end{array}$ & \\
\hline
\end{tabular}


OAK RIDGE PROGRAM DIVISION DOCUMENT REVIEW FORM

\begin{tabular}{|c|c|c|c|c|}
\hline $\begin{array}{c}\text { COMMENT } \\
\text { NO. }\end{array}$ & $\begin{array}{l}\text { SECT/ } \\
\text { PAGE }\end{array}$ & COMMENT & RESPONSE & ACCEPTANCE \\
\hline & & $\begin{array}{l}\text { edge of the ETTP. This description is further } \\
\text { supported by Figure 1, EU Z2-41 Location Map, which } \\
\text { depicts the geographic relation of EU Z2- } 41 \text { to the } \\
\text { other Zone } 2 \text { locations. After reviewing the information } \\
\text { in both Section } 1.3 \text { and Figure 1, concerns regarding } \\
\text { the groundwater movement and possible contaminant } \\
\text { transport pathways to other media are generated. } \\
\text { Attempts to visualize these elements are hindered by } \\
\text { the absence of a topographical and/or contour map of } \\
\text { the EU. Revise the document to provide a reference } \\
\text { which includes an existing topographical and/or } \\
\text { contour map(s) of Zone } 2 \text {. If a reference is not } \\
\text { available, provide these supplemental figures in the } \\
\text { revised document. }\end{array}$ & $\begin{array}{l}\text { (OUO) constraints. Text that refers to figures } \\
\text { has also avoided reference to OUO. } \\
\text { Available topographic contours are } \\
\text { pre-construction and do little to enhance } \\
\text { understanding the topography at EU Z2-41. } \\
\text { Groundwater flow lines added to Figure H.3 } \\
\text { for that reason. }\end{array}$ & \\
\hline 42 & & $\begin{array}{l}\text { In Section 2.2.5, EU Evaluation, the CSM for the EU Z2- } \\
41 \text { is described. Evaluations of potential groundwater } \\
\text { contamination sources are provided on Pages } 14 \text { and } \\
\text { 15. Several locations are referenced in this section and } \\
\text { are used as landmarks to assist in vis ualizing the } \\
\text { general groundwater flow direction. This observation } \\
\text { was first noted at the top of page } 15 \text { of Section } 2.2 .5 \\
\text { where it states, "One historic source area and } \\
\text { associated plume is located at the south end of the } \\
\text { K-1070-D trenches, with the plume extending to the } \\
\text { west from the trenches to a point north of the K-1200 } \\
\text { centrifuge building where the flow turns to the south } \\
\text { and pools on the north side of the building beneath the } \\
\text { patrol road." Attempts to identify the K-1200 } \\
\text { centrifuge building and the patrol road in the provided } \\
\text { figures were unsuccessful. Revise the text to provide a } \\
\text { reference in which these landmarks are identified. If a } \\
\text { reference is not available, include the landmark } \\
\text { locations on a revised figure. }\end{array}$ & 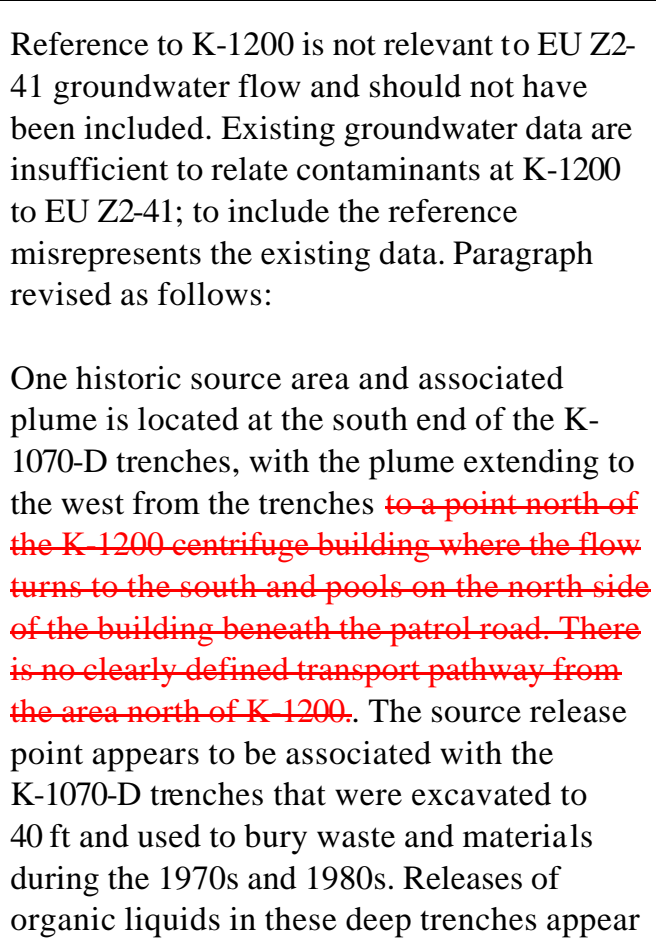 & \\
\hline
\end{tabular}


OAK RIDGE PROGRAM DIVISION DOCUMENT REVIEW FORM

\begin{tabular}{|c|c|c|c|c|}
\hline $\begin{array}{l}\text { COMMENT } \\
\text { NO. }\end{array}$ & $\begin{array}{l}\text { SECT/ } \\
\text { PAGE }\end{array}$ & COMMENT & RESPONSE & ACCEPTANCE \\
\hline & & & $\begin{array}{l}\text { to have migrated vertically downward into the } \\
\text { Rome rock mass. }\end{array}$ & \\
\hline 43 & & $\begin{array}{l}\text { The figures provided with the document depict } \\
\text { important and useful information which supports the } \\
\text { text. However, several figures were difficult to review } \\
\text { due to the quality of the images; specifically, Figure } 7 \text {, } \\
\text { EU Z2-41 Conceptual Site Model Block Diagram. This } \\
\text { figure presented visual challenges due to the distorted } \\
\text { and small print of the text and legend. Revise the } \\
\text { document to provide higher quality images for the } \\
\text { attached figures. }\end{array}$ & $\begin{array}{l}\text { Figure revisions made throughout this PCCR } \\
\text { have been made within Official Use Only } \\
\text { (OUO) constraints. Text that refers to figures } \\
\text { has also avoided reference to OUO. } \\
\text { A more legible figure is being used. }\end{array}$ & \\
\hline 44 & $\begin{array}{l}\text { APPENDIX I -SPECIFIC } \\
\quad \text { COMMENTS } \\
\text { Section 2.1.1.1, Class } 1 \\
\text { SU Radiological } \\
\text { Walkover Survey, Page I- } \\
6\end{array}$ & $\begin{array}{l}\text { In Section 2.1.1.1, discussion regarding the biased area } \\
\text { radiation (BAR) surveys for the Class } 1 \text { SU was } \\
\text { provided. It was mentioned that no radiological } \\
\text { surveys were conducted at the K-1071 Concrete Pad } \\
\text { FFA Sites (Concrete Pad) because the radiological } \\
\text { contamination was known to have exceeded the Avg } \\
\text { RL for Uranium- } 235 \text { and Uranium- } 238 \text { (U- } 235 \text { and U-238, } \\
\text { respectively). Although surface concentrations of the } \\
\text { Concrete Pad were determined to have exceeded the } \\
\text { Avg RL, it is recommended that additional information } \\
\text { be included in the document describing how the } \\
\text { boundaries of the Concrete Pad (i.e., the area to be } \\
\text { remediated) were determined. }\end{array}$ & $\begin{array}{l}\text { Boundaries of the concrete pad were } \\
\text { documented in the K-1070-C/D RI and are } \\
\text { recognizable today by the elevated soil } \\
\text { mound that resulted from placement of soil } \\
\text { over the concrete pad. The soil was placed } \\
\text { there to protect the industrial worker from } \\
\text { unnecessary exposure to radiation until the } \\
\text { concrete pad is removed. A description of the } \\
\text { elevated soil mound has been added to } \\
\text { Sect. } 2.1 .1 \text { to help the reader understand how } \\
\text { the boundaries of the concrete pad are } \\
\text { recognized. } \\
\text { Text in Appendix I has been revised and } \\
\text { Fig. I. } 2 \text { has been revised to show the concrete } \\
\text { pad. }\end{array}$ & \\
\hline 45 & $\begin{array}{l}\text { Section } 2.2 .1 \text {, Class } 1 \\
\text { SUs, Page I-9 }\end{array}$ & $\begin{array}{l}\text { In Section } 2.2 .1,22 \text { historical and six DVS samples were } \\
\text { collected from the Class } 1 \text { SU. In the table presented on } \\
\text { Page 9, it was observed that one DVS sample was } \\
\text { collected from the Z2-EU41D-100 location and analyzed } \\
\text { for radiological analytes. However, no data or } \\
\text { information was provided in the document in reference } \\
\text { to this sample. Revise the text to include the } \\
\text { radiological data results from sample location Z2- } \\
\text { EU41D-100. }\end{array}$ & $\begin{array}{l}\text { Analytical data from the sample collected from } \\
\text { Z2-EU41D-100 are summarized in Sect. } 2.2 .5 \\
\text { under the EU Z2-41 RAD91 Class } 1 \mathrm{SU} \\
\text { heading. Only radionuclide analytical results } \\
\text { were summarized because only radionuclides } \\
\text { were analyzed in the two samples from RAD91 } \\
\text { and Z2-EU41D-100. In the data summary, the } \\
\text { detect frequencies are all X/2, which means } \\
\text { two samples were included in the summary. } \\
\text { The two sample locations (RAD91 and }\end{array}$ & \\
\hline
\end{tabular}


OAK RIDGE PROGRAM DIVISION DOCUMENT REVIEW FORM

\begin{tabular}{|c|c|c|c|c|}
\hline $\begin{array}{l}\text { COMMENT } \\
\text { NO. }\end{array}$ & $\begin{array}{l}\text { SECT/ } \\
\text { PAGE }\end{array}$ & COMMENT & RESPONSE & ACCEPTANCE \\
\hline & & & $\begin{array}{l}\text { Z2-EU41D-100), as referenced in the text } \\
\text { describing the evaluation of EU Z2-41 RAD91 } \\
\text { Class } 1 \text { SU, are presented in Sect. 2.2.1. Only } \\
\text { RAD91 appears in the data summary because } \\
\text { it is the location for all maximum results. } \\
\text { Text in Sect. } 2.2 .5 \text { revised to refer to sample } \\
\text { location Z2-EU41D-100 and to explain that } \\
\text { only radionuclides were included in the } \\
\text { analysis because they were the only } \\
\text { exceedances in RAD } 91 \text {. }\end{array}$ & \\
\hline 46 & $\begin{array}{l}\text { Section } 2.2 .5, \text { EU } \\
\text { Evaluation, Page I-14 }\end{array}$ & $\begin{array}{l}\text { The primary conceptual model is presented and } \\
\text { evidence supporting the presence of monitoring wells } \\
\text { is observed. To further support the conceptual model, } \\
\text { revise the document to present the monitoring well } \\
\text { locations referenced in this section. }\end{array}$ & $\begin{array}{l}\text { Figure revisions made throughout this PCCR } \\
\text { have been made within Official Use Only } \\
\text { (OUO) constraints. Text that refers to figures } \\
\text { has als o avoided reference to OUO. } \\
\text { Monitoring well locations added to Fig. I.4. }\end{array}$ & \\
\hline 47 & $\begin{array}{l}\text { Section } 3.3 \text {, Summary and } \\
\text { Conclusions, Page I-42 }\end{array}$ & $\begin{array}{l}\text { In this section, conclusions for groundwater remedial } \\
\text { action are provided. The fourth paragraph on Page I- } 42 \\
\text { describes the immobility of radionuclides in soils and } \\
\text { as a result, their proposed absence from groundwater } \\
\text { plumes. The paragraph further explains that } \\
\text { monitoring wells have not reported the presence of } \\
\text { radionuclides and; therefore, do not present a potential } \\
\text { threat to the groundwater at EU-Z2-41. Later, it was } \\
\text { documented that radionuclides at the Concrete Pad } \\
\text { exceeded the GW SL. There was no information in the } \\
\text { text identifying the groundwater screening levels; thus, } \\
\text { it was assumed that the GW SL values were associated } \\
\text { with the soil-to-groundwater migration pathway. } \\
\text { Please revise the text to identify the type of GW SL } \\
\text { referred to in Section 3.3. }\end{array}$ & $\begin{array}{l}\text { Soils that report elevated radioisotopic } \\
\text { concentrations will be removed as part of the } \\
\text { soils RA and will not pose a threat to local } \\
\text { groundwater, so a model run is not required to } \\
\text { support the action/no action determination. } \\
\text { The SLs will be referred in the Appendix I text } \\
\text { as ROD defined SLs. } \\
\text { See the response to Comment } 45 \\
\text { Samples of soils at the concrete pad } \\
\text { exceeding GW SLs will be removed as part of } \\
\text { the recommended action. These soils, and the } \\
\text { historic sample from RAD } 91 \text { that could not be } \\
\text { confirmed, are the only samples within the EU } \\
\text { that exceeded GW SLs. There will be no soil in } \\
\text { the EU above GW SLs after the RA work is } \\
\text { complete. Also, see text added in Sect. } 4.2 \text { of } \\
\text { the Appendix I. }\end{array}$ & \\
\hline
\end{tabular}


OAK RIDGE PROGRAM DIVISION DOCUMENT REVIEW FORM

\begin{tabular}{|c|c|c|c|c|}
\hline $\begin{array}{c}\text { COMMENT } \\
\text { NO. }\end{array}$ & $\begin{array}{l}\text { SECT/ } \\
\text { PAGE }\end{array}$ & COMMENT & RESPONSE & ACCEPTANCE \\
\hline 48 & $\begin{array}{l}\text { Section 3.3, Summary and } \\
\text { Conclusions, Page I-42 } \\
\text { and Page I- } 43\end{array}$ & $\begin{array}{l}\text { Section } 3.3 \text { concludes that uranium isotopes and } \\
\text { chlorinated solvents at the Concrete Pad Class } 1 \mathrm{SU} \\
\text { are potential threats to groundwater. Later, Section 4.1, } \\
\text { Decision and Remediation Activities, proposes the } \\
\text { removal of } 50 \text { cubic yards of contaminated material to } \\
\text { address, in part, the threat to groundwater. The text } \\
\text { should be revised to provide additional information } \\
\text { demonstrating that the proposed level of remediation } \\
\text { addresses the potential threat to groundwater from } \\
\text { both uranium isotopes and chlorinated solvents at the } \\
\text { Concrete Pad Class } 1 \text { SU. }\end{array}$ & $\begin{array}{l}\text { All soil sample locations that have reported } \\
\text { COC concentrations above GW SLs will be } \\
\text { removed as part of the remedial action. There } \\
\text { will be no potential source left at this site post } \\
\text { RA. } \\
\text { A statement to this effect will be added to the } \\
\text { Appendix I text. } \\
\text { Text has been added in Sect. } 4.1 \text { page I- } 43 \text { that } \\
\text { describes the Soils Program responsibility as } \\
\text { defined by the Zone } 2 \text { Interim Soils ROD } \\
\text { regarding contamination in bedrock as a } \\
\text { threat to GW. }\end{array}$ & \\
\hline 49 & $\begin{array}{l}\text { Section } 4.1 \text {, Decision and } \\
\text { Remediation Activities, } \\
\text { Page I-43 }\end{array}$ & $\begin{array}{l}\text { The Concrete Pad was evaluated as a Class } 1 \text { SU. } \\
\text { Twenty-eight sample locations were selected for the } \\
\text { Concrete Pad area. The data from the sample locations } \\
\text { determined that the site presented a potential threat to } \\
\text { the groundwater. Excavating and removing the } \\
\text { contaminated soil was prescribed as the remedial } \\
\text { action. In Section } 4.1 \text { it was decided that } 50 \text { cy of } \\
\text { contaminated material will be removed. However, no } \\
\text { data or supplemental information was provided in the } \\
\text { document to support the estimated volume (e.g., } \\
\text { calculations, data). In addition, individual estimated } \\
\text { volumes and/or surface areas for concrete and soil } \\
\text { were not mentioned. Please revise the document to } \\
\text { include information describing how the volume and } \\
\text { areal extent of the concrete and soil to be removed was } \\
\text { determined. It is important to ensure that estimates for } \\
\text { concrete and soil (as well as total material to be } \\
\text { remediated) are provided for this planned action. }\end{array}$ & $\begin{array}{l}\text { Additional information has been provided in } \\
\text { Sect. 4.2, along with a figure for the area of } \\
\text { proposed excavation. An estimate for soil } \\
\text { volume and concrete volumes is also } \\
\text { provided. Figure I. } 2 \text { revised to show the } \\
\text { location of the Concrete Pad Class } 1 \text { SU. }\end{array}$ & \\
\hline 50 & $\begin{array}{l}\text { Table 2, EU Z2-41 Sample } \\
\text { Summary, Page I-53 }\end{array}$ & $\begin{array}{l}\text { In Table 2, EU Z2-41 Sample Summary, sample } \\
\text { information is provided; in particular, the sample } \\
\text { interval selected for each sample. For the majority of } \\
\text { the samples collected in } 2005 \text { and } 2006 \text {, a 'three interval } \\
\text { composite plus a deeper interval sample' is specified. }\end{array}$ & $\begin{array}{l}\text { Decisions on risk and remedial actions in } \\
\text { Zone } 2 \text { soils are based on soil compositions in } \\
\text { the } 0-10 \text {-ft-depth interval. Soil samples from } \\
\text { depth intervals }>10 \mathrm{ft} \text { typically are not } \\
\text { discussed or tabulated in the Technical }\end{array}$ & \\
\hline
\end{tabular}


OAK RIDGE PROGRAM DIVISION DOCUMENT REVIEW FORM

\begin{tabular}{|c|c|c|c|c|}
\hline $\begin{array}{c}\text { COMMENT } \\
\text { NO. }\end{array}$ & $\begin{array}{l}\text { SECT/ } \\
\text { PAGE }\end{array}$ & COMMENT & RESPONSE & ACCEPTANCE \\
\hline & & $\begin{array}{l}\text { Other than reference to the } 0 \text { to } 10 \text { feet interval, the text } \\
\text { does not discuss the specification or selection of } \\
\text { sample intervals or identify the depth of the deeper } \\
\text { interval. Please revise the document to discuss the } \\
\text { specification of the sample intervals used in the } 2005 \\
\text { and } 2006 \text { soil sampling events. }\end{array}$ & $\begin{array}{l}\text { Memoranda unless they elucidate conditions } \\
\text { in the 0-10-ft-depth interval (e.g., post- } \\
\text { remedial action confirmation sampling when } \\
\text { an excavation is deeper than } 10 \mathrm{ft} \text { ). } \\
\text { Selection of the intervals to incorporate in the } \\
\text { composite samples is described in the } \\
\text { RDR/RAWP and is not repeated in every TM } \\
\text { in an effort to reduce repetition and } \\
\text { redundancy. Sample aliquots were selected } \\
\text { where the RAD core screen showed the } \\
\text { highest readings or at physical boundaries or } \\
\text { interfaces in the recovered core. Under the } \\
\text { DVS program, the risk exposure scenario does } \\
\text { not differentiate by depth. The assumption is } \\
\text { all soils are equally accessible for exposure of } \\
\text { an industrial worker. Since there is no risk } \\
\text { weighting by depth equivalent, aliquots of } \\
\text { soil can be composited to be representative of } \\
\text { the entire } 0 \text {-10 ft soil interval. } \\
\text { Sampling results for all depths are presented } \\
\text { for each sample location in the data CD and } \\
\text { on tables in the Appendices included with } \\
\text { this PCCR. }\end{array}$ & \\
\hline 51 & $\begin{array}{l}\text { APPENDIX J -SPECIFIC } \\
\text { COMMENTS } \\
\text { Section 2.1.2.1, Class } 2 \\
\text { SU Radiological } \\
\text { Walkover Survey, Page J- } \\
6\end{array}$ & $\begin{array}{l}\text { This section addresses radiological walkover } \\
\text { surveying in the Class } 2 \text { SU of the EU Z2- } 43 \text {. This } \\
\text { section states, "No walkover surveys were conducted } \\
\text { because the area is paved." Since the required } \\
\text { radiological surveys were not conducted for this SU, } \\
\text { there is concern that future degradation of the paved } \\
\text { surface may provide an exposure pathway for } \\
\text { underlying media that has not been adequately } \\
\text { screened for radiological contamination. Table 3-11, } \\
\text { Additional sampling and surveying requirements in } \\
\text { Class } 2 \text { Soil Units at the South Park Area (page 3-15) of } \\
\text { the South Park Area, DQO Scoping Package for EUs }\end{array}$ & $\begin{array}{l}\text { The results of the historical radiological } \\
\text { walkover surveys in EU Z2-43 are presented } \\
\text { in the DQO scoping document. The Class } 2 \\
\text { SU in EU } 43 \text { is associated with a lay-down } \\
\text { yard that was used in the 1940s during the } \\
\text { plant construction phase. This site was paved } \\
\text { in the } 1950 \text { s. Since the area has been covered } \\
\text { by asphalt through most of the operational } \\
\text { phase of the facility, sampling of the soils } \\
\text { beneath the pavement was the only } \\
\text { characterization activity required under the } \\
\text { EU-specific DQOs. }\end{array}$ & \\
\hline
\end{tabular}


OAK RIDGE PROGRAM DIVISION DOCUMENT REVIEW FORM

\begin{tabular}{|c|c|c|c|c|}
\hline $\begin{array}{l}\text { COMMENT } \\
\text { NO. }\end{array}$ & $\begin{array}{l}\text { SECT/ } \\
\text { PAGE }\end{array}$ & COMMENT & RESPONSE & ACCEPTANCE \\
\hline & & $\begin{array}{l}\mathrm{Z} 2-33, \mathrm{Z} 2-34 \text {, and Z2-43 dated June } 2006 \text {, indicates a } \\
\text { radiological walkover survey of this Class } 2 \mathrm{SU} \text { is not } \\
\text { required because existing radiological walkover } \\
\text { surveys provide sufficient coverage to satisfy the } \\
\text { dynamic verification strategy (DVS) requirements. } \\
\text { Please revise the document to provide historical } \\
\text { radiological survey results for this area to verify that } \\
\text { the DVS requirements have been met. }\end{array}$ & See response to Comment \#39. & \\
\hline 52 & $\begin{array}{l}\text { Section 2.1.3.4, Class } 3 \\
\text { and Class } 4 \text { SU Biased } \\
\text { Sampling, Page J- } 7\end{array}$ & $\begin{array}{l}\text { This section describes the sampling practices and } \\
\text { procedures adopted for EU Z2-43. It is stated in the } \\
\text { first paragraph that "A four-point composite surface } \\
\text { soil sample was collected at each of the sediment } \\
\text { accumulation areas." The appendix should explain the } \\
\text { selection and significance of collecting four-point } \\
\text { composite sediment samples and where the individual } \\
\text { aliquots were collected. }\end{array}$ & $\begin{array}{l}\text { Four-point composite sampling is standard } \\
\text { practice under DVS at sediment accumulation } \\
\text { areas. The rationale is explained in the } \\
\text { RDR/RAWP. }\end{array}$ & \\
\hline 53 & $\begin{array}{l}\text { Table 2, EU Z2-43 sample } \\
\text { summary, Page J-21 }\end{array}$ & $\begin{array}{l}\text { Table } 2 \text { presents a summary of the sampling parameters } \\
\text { selected for EU Z2-43. In this table, one-point } \\
\text { composite samples are indicated. It is unclear what the } \\
\text { term one-point composite sample refers to. Please } \\
\text { revise the text to clarify what a one-point composite } \\
\text { consists of. }\end{array}$ & $\begin{array}{l}\text { One-point composite sample refers to a single } \\
\text { homogenized sample interval. The term } \\
\text { "one-point composite" will be avoided in } \\
\text { future technical memoranda. }\end{array}$ & \\
\hline 54 & $\begin{array}{l}\quad \text { APPENDIX K - } \\
\text { SPECIFIC COMMENTS } \\
\text { Section 1.2, EU Z2-37 } \\
\text { Acreage, Page } 5\end{array}$ & $\begin{array}{l}\text { In Section } 1.2 \text { of the Mitchell Branch Exposure Unit } \\
\text { Group EU Z2-44, Appendix K, a brief description of the } \\
\text { site is provided; specifically the acreage. A statement } \\
\text { was included which exempted the characterization of } \\
\text { the TSCA incinerator from the DQO Scoping Package. } \\
\text { In Section 2, DQO Evaluation of the Mitchell Branch } \\
\text { Group, (Page 2-1) of the Mitchell Branch Group DQO } \\
\text { Scoping Package; Exposure Units Z2-29, Z2-30, Z2-35, } \\
\text { Z2-29, and Z2-44 dated June 2006, (DQO) the text } \\
\text { states that the total area of EU Z2-44 excludes the K- } \\
\text { 1420 Building and TSCA incinerator. No adequate } \\
\text { justification has been provided for exclusion of the two } \\
\text { areas of concern, although discussed within the DQO } \\
\text { meetings. Justification for excluding these areas should } \\
\text { include providing historical and/or recent }\end{array}$ & $\begin{array}{l}\text { Building } 1420 \text { was in place at the time the } \\
\text { DQO package was prepared. The building has } \\
\text { since been demolished and the footprint of } \\
\text { the building was turned over to the DVS } \\
\text { program. Once D\&D has occurred, the } \\
\text { in-place concrete and infrastructure that } \\
\text { remains is evaluated by the DVS process as } \\
\text { defined in Sect. } 3 \text { of the DQO package. The } \\
\text { slab of the K-1420 building has been included } \\
\text { in the DVS program since the DQO package } \\
\text { was prepared because building D\&D is } \\
\text { complete. This building is in EU Z2-39 and will } \\
\text { be addressed in the EU Z2-39 Technical } \\
\text { Memorandum. }\end{array}$ & \\
\hline
\end{tabular}


OAK RIDGE PROGRAM DIVISION DOCUMENT REVIEW FORM

\begin{tabular}{|c|c|c|c|c|}
\hline $\begin{array}{l}\text { COMMENT } \\
\text { NO. }\end{array}$ & $\begin{array}{l}\text { SECT/ } \\
\text { PAGE }\end{array}$ & COMMENT & RESPONSE & ACCEPTANCE \\
\hline & & $\begin{array}{l}\text { documentation from the RCRA demonstrating that } \\
\text { these two areas do not contribute contamination to } \\
\text { other areas of EU Z2-44. If no contribution has yet } \\
\text { been determined, the document should provide } \\
\text { information when this assessment will be made } \\
\text { including when additional sampling will be conducted } \\
\text { within and around these two facilities. }\end{array}$ & $\begin{array}{l}\text { With regard to the TSCA incinerator, this is } \\
\text { an active facility and is receiving and } \\
\text { processing waste materials. The facility and } \\
\text { the footprint around the facility were } \\
\text { exempted from DVS characterization at this } \\
\text { time. The remaining soils in EU Z2-44 were } \\
\text { evaluated by the DVS process and as was } \\
\text { agreed to by the FFA managers. } \\
\text { The following text has been added to } \\
\text { Appendix K for clarification: "When the } \\
\text { TSCA site is closed (no closure data has been } \\
\text { announced as of this writing), the facility and } \\
\text { surrounding area exempted from the DVS } \\
\text { evaluation will be completed." }\end{array}$ & \\
\hline 55 & $\begin{array}{l}\text { Section 2.1.2.1, Class } 2 \\
\text { SU Radiological } \\
\text { Walkover Survey, Page } 6\end{array}$ & $\begin{array}{l}\text { Section } 2.1 .2 .1 \text { provides descriptions of the radiological } \\
\text { walkover survey were provided. In the fifth sentence of } \\
\text { this section, it was stated that two individual radiation } \\
\text { measurements, located along the northern boundary of } \\
\text { EU Z2-44, were observed to have either met or } \\
\text { exceeded the action level. It is later stated in Section } \\
2.1 .2 .1 \text { that the two readings correspond to single } \\
\text { points with no appreciable extent. No biased samples } \\
\text { were collected and no additional evaluation of the two } \\
\text { points, except to state that they were single, isolated } \\
\text { points, was offered. Revise the text to provide } \\
\text { information explaining how it was determined that the } \\
\text { two points were single, isolated points with no } \\
\text { appreciable extent. }\end{array}$ & $\begin{array}{l}\text { Details of the radiological surveys and a map } \\
\text { of the survey areas are included in the } \\
\text { document produced in support of the } 2007 \\
\text { PCCR [Class } 3 \text { Soil Unit Walkover } \\
\text { Assessments and Radiological Surveys for } \\
\text { FY } 2007 \text { Exposure Units in Zone 2, East } \\
\text { Tennessee Technology Park, } \\
\text { Oak Ridge, Tennessee (BJC/OR-2691)]. } \\
\text { Production of a separate supporting document } \\
\text { for radiological and Class } 3 \text { surveys were done } \\
\text { to reduce the size of the Technical Memoranda } \\
\text { and were agreed to by the Core Team members. }\end{array}$ & \\
\hline 56 & $\begin{array}{l}\text { Section } 2.2 .5, \text { EU } \\
\text { Evaluation, Page } 10\end{array}$ & $\begin{array}{l}\text { In the first full paragraph on page } 10 \text {, potential releases } \\
\text { of contaminants from the landfill site are discussed. } \\
\text { The release from the buried material to the groundwater } \\
\text { is considered to be low to moderate due to the } \\
\text { implemented engineered control. However, it is } \\
\text { mentioned that flooding conditions can impact the } \\
\text { landfill materials and increase the chance for leaching } \\
\text { and transporting of the contaminants to the }\end{array}$ & $\begin{array}{l}\text { Soil samples where collected from the landfill, } \\
\text { and no elevated concentrations of } \\
\text { contaminants were identified at } \\
\text { concentrations that failed groundwater } \\
\text { screening criteria. Leaching was considered } \\
\text { as a model for intermedia contaminant transfer } \\
\text { during DQOs development. The program was } \\
\text { executed and samples were collected and }\end{array}$ & \\
\hline
\end{tabular}




\section{OAK RIDGE PROGRAM DIVISION DOCUMENT REVIEW FORM}

\begin{tabular}{||l|l|l|l||}
\hline \hline $\begin{array}{c}\text { COMMENT } \\
\text { NO. }\end{array}$ & $\begin{array}{l}\text { SECT/ } \\
\text { PAGE }\end{array}$ & \multicolumn{1}{c||}{ COMMENT } & \multicolumn{1}{c||}{ RESPONSE } \\
\hline & & $\begin{array}{l}\text { groundwater. Considering that flooding has occurred } \\
\text { in the past, this observation suggests that the landfill } \\
\text { could serve as a possible contributor to groundwater } \\
\text { contamination. It is suggested to revise the text to } \\
\text { provide supplemental evidence and/or justification in } \\
\text { support of the statement: "Subsequent leaching and } \\
\text { transport during these conditions [flooding] is } \\
\text { considered to be a minimal potential threat to Mitchell } \\
\text { Branch." }\end{array}$ & $\begin{array}{l}\text { analyzed for the presence of a full suite of } \\
\text { constituents. Because no elevated } \\
\text { concentrations of contaminants where } \\
\text { present in the landfill materials samples, } \\
\text { leaching was not a means of intermedia } \\
\text { transfer. } \\
\text { Text has been added to Sect. 1.3 describing } \\
\text { the materials in the K-1070-G Burial Ground. }\end{array}$ \\
\hline
\end{tabular}




\section{Fiscal Year 2007 Phased Construction Completion Report for the Zone 2 Soils, Slabs, and Subsurface Structures at East Tennessee Technology Park, Oak Ridge, Tennessee}

Date Issued—September 2007March 2008

Prepared for the

U.S. Department of Energy

Office of Environmental Management

BECHTEL JACOBS COMPANY LLC

managing the

Accelerated Cleanup Activities at the

East Tennessee Technology Park

under contract DE-AC05-98OR22700

for the

U.S. DEPARTMENT OF ENERGY 
Reference to any specific commercial product, process or service by trade name, trademark, manufacturer, or otherwise does not necessarily constitute or imply its endorsement, recommendation, or favoring by the United States Government or any agency thereof or its contractors or subcontractors. 


\section{CONTENTS}

EXECUTIVE SUMMARY ES-1ES 3

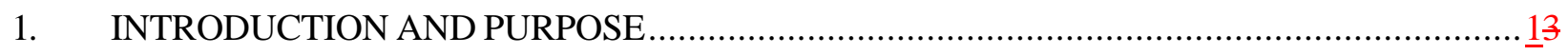

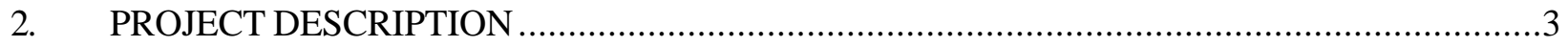

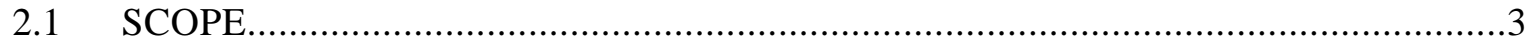

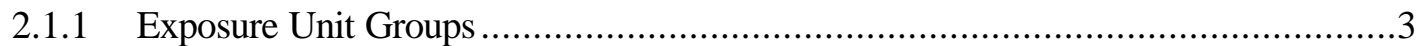

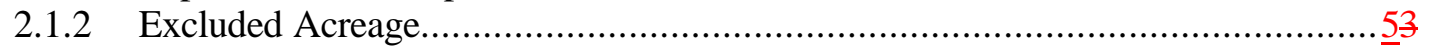

2.1.3 Data Quality Objectives and Soil Unit Classifications …............................... 5 z

2.1.4 Federal Facility Agreement Sites ......................................................... 53

2.2 DVS CHARACTERIZATION APPROACH.................................................. 5

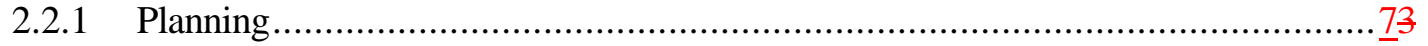

2.2.1.1 SU classification............................................................

2.2.1.2 DQO scoping …............................................................

2.2.2 Class 1 and Class 2 SU Characterization Approach.................................... 8 $z$

2.2.3 Class 3 and Class 4 SU Characterization Approach..................................... 10

2.2.4 Program Execution .................................................................... 123

2.2.5 Action/No Further Action Decision/Communication .............................. 143

2.2.6 Documentation and Records .....................................................

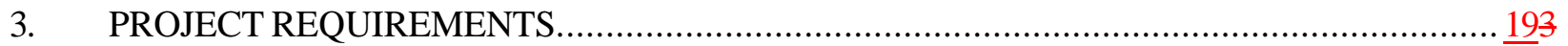

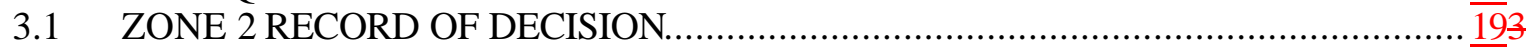

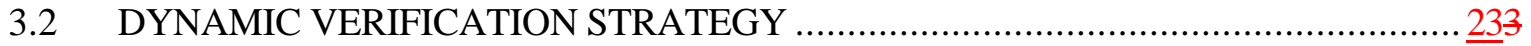

3.3 FINAL STATUS EVALUATION PROCESS …......................................... 243

3.3.1 Action/No Further Action Decision ....................................................... $\overline{24} 3$

3.3.2 Special Data Uses and Considerations ............................................... $\overline{27} \overline{7}$

3.3.3 Qualitative Risk Screening for Unrestricted Use ................................... $\underline{28} 3$

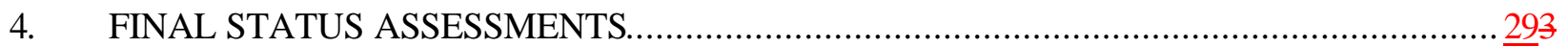

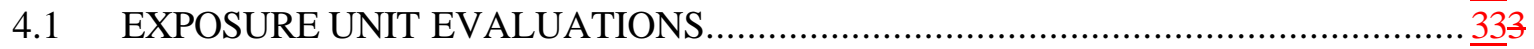

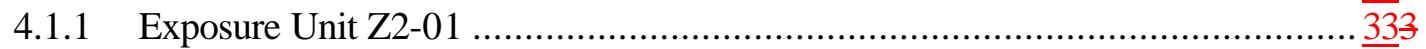

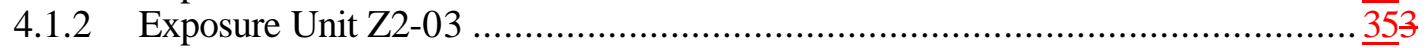

4.1.3 Exposure Unit Z2-08 …...........................................................

4.1.4 Exposure Unit Z2-23 …..................................................

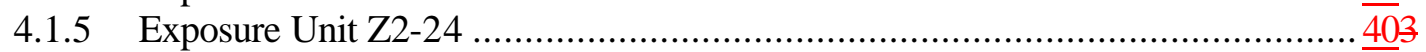

4.1.6 Exposure Unit Z2-28 ….................................................. $\overline{41}_{3}$

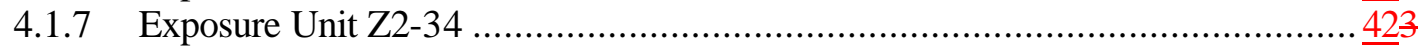

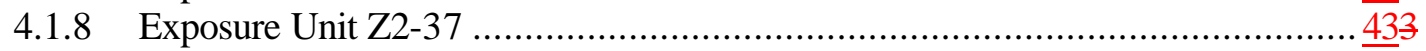

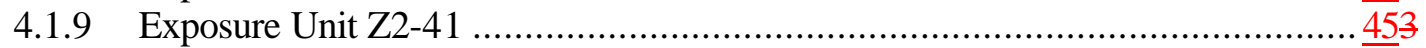

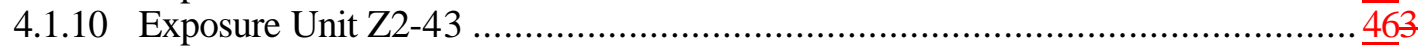

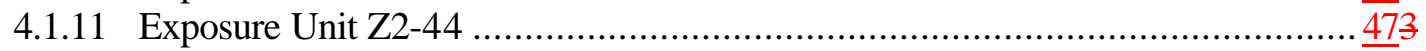

4.2 COMPLETED REMEDIAL ACTIONS.................................................. 48$\}$

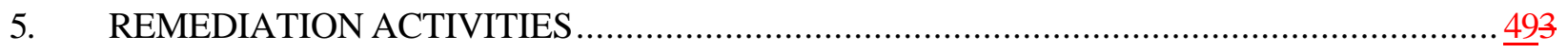

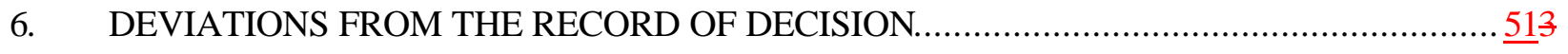

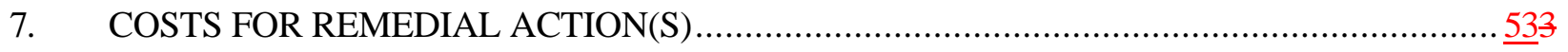


8. WASTE MANAGEMENT AND TRANSPORTAION ACTIVITIES FOR REMEDIAL

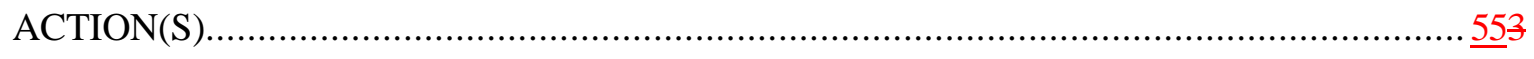

9. OPERATIONS AND MAINTENANCE .......................................................... 573

10. MONITORING SCHEDULE AND/OR EXPECTATIONS.............................................. 593

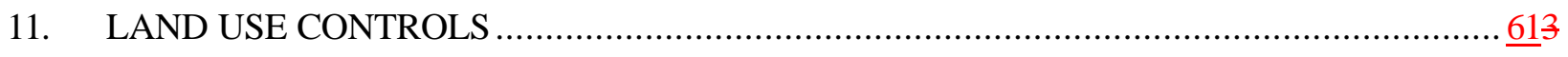

11.1 LAND USE CONTROLS UNDER ZONE 2 DVS............................................ 613

11.2 POSSIBLE LIFTING OF LAND USE CONTROLS..........................................

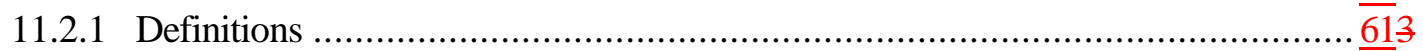

11.2.2 Industrial Controls at Depth........................................................... 613

11.2.3 Potential Unrestricted Use ..........................................................

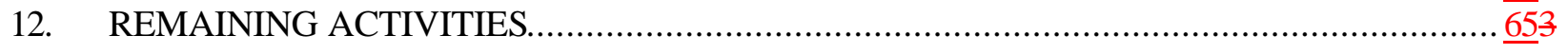

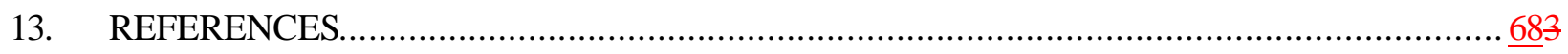

APPENDIX A: EXPOSURE UNIT Z2-01, K-31/K-33 AREA ............................................ A-1

APPENDIX B: EXPOSURE UNIT Z2-03, K-31/K-33 AREA.................................................... B-1

APPENDIX C: EXPOSURE UNIT Z2-08, K-31/K-33 AREA.................................................... C-1

APPENDIX D: EXPOSURE UNIT Z2-23, K-25 AREA …....................................................... D-1

APPENDIX E: EXPOSURE UNIT Z2-24, MAIN PLANT AREA ............................................. E-1

APPENDIX F: EXPOSURE UNIT Z2-28, HAUL ROAD AREA ............................................

APPENDIX G: EXPOSURE UNIT Z2-34, SOUTH PARK AREA................................................ G-1

APPENDIX H: EXPOSURE UNIT Z2-37, K-1070 C/D AREA .......................................................

APPENDIX I: EXPOSURE UNIT Z2-41, K-1070 C/D AREA.............................................. I-1

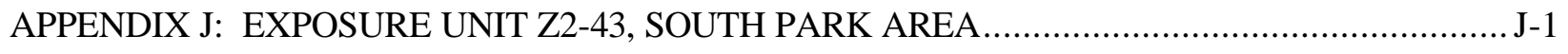

APPENDIX K: EXPOSURE UNIT Z2-44, MITCHELL BRANCH AREA...................................... 


\section{FIGURES}

1. ETTP site map with Zone 2 DQO scoping EU groups and EUs...........................................2 23

2. Zone 2 EUs included in the FY 2007 PCCR............................................................... 43

3. Zone 2 DVS Class 1 and Class 2 SU sampling and analysis decision process flow....................... 93

4. Zone 2 DVS Class 3 and Class 4 SU sampling and analysis decision process flow..................... 11$\}$

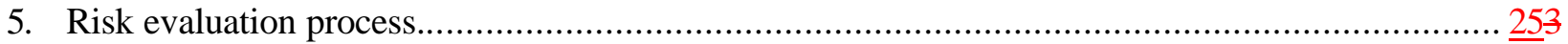

6. ETTP Zone 2 EUs included in this and the FY 2006 Zone 2 PCCR ..................................... 673

\section{TABLES}

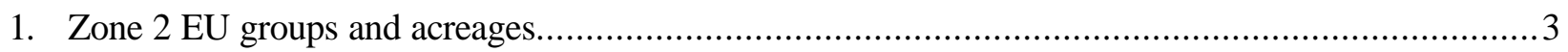

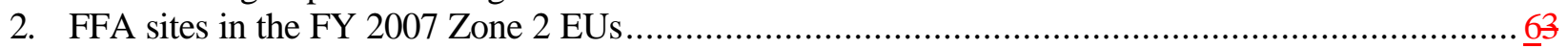

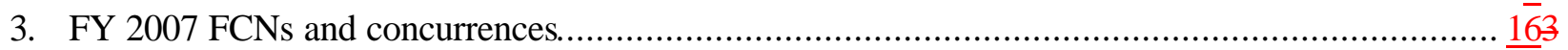

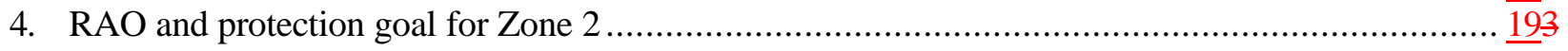

5. Chemicals and radionuclides required for analysis in Zone 2 DVS samples and

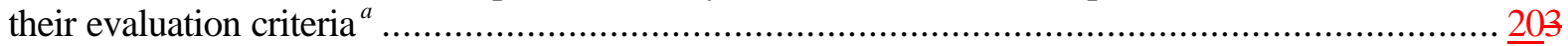

6. DVS decision rules for Zone 2 soils ................................................................. 243

7. DVS evaluation summary for the FY 2007 Zone 2 EUs.................................................... 293

8. Final status assessment summary for FY 2007 Zone 2 EUs............................................ $\underline{31} z$

9. Summary of conclusions for FY 2007 EU Zone 2 ROD Appendix A FFA sites ....................... $\underline{33}\}$

10. EUs with restricted/unrestricted land use below $10 \mathrm{ft}$.....................................................

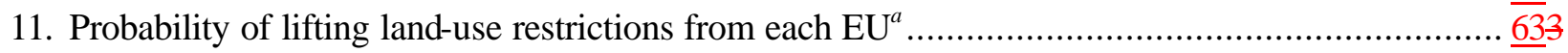

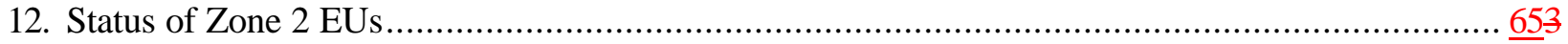




\section{ACRONYMS}

\begin{tabular}{|c|c|}
\hline AP & assessment point \\
\hline ARL & average remediation level \\
\hline BAR & biased area remediation \\
\hline bgs & below ground surface \\
\hline $\mathrm{COC}$ & contaminant of concern \\
\hline CSM & conceptual site model \\
\hline D\&D & deactivation and demolition \\
\hline DOE & U.S. Department of Energy \\
\hline DP & discretionary point \\
\hline DQO & data quality objective \\
\hline DRO & diesel-range organic \\
\hline DVS & Dynamic Verification Strategy \\
\hline DWP & Dynamic Work Plan \\
\hline ELCR & excess lifetime cancer risk \\
\hline EPA & U.S. Environmental Protection Agency \\
\hline ETTP & East Tennessee Technology Park \\
\hline EU & exposure unit \\
\hline $\mathrm{FCN}$ & Field Change Notice \\
\hline FFA & Federal Facility Agreement \\
\hline FY & fiscal year \\
\hline FIDLER & field instrument for the detection of low energy radiation \\
\hline GRO & gasoline-range organic \\
\hline HI & hazard index \\
\hline MARSSIM & Multi-Agency Radiation Survey and Site Investigation Manual \\
\hline MCL & maximum contaminant level \\
\hline MP & mid-point \\
\hline NFA & no further action \\
\hline OREIS & Oak Ridge Environmental Information System \\
\hline PCB & polychlorinated biphenyl \\
\hline PCCR & Phased Construction Completion Report \\
\hline PRG & preliminary remediation goal \\
\hline QAPP & Quality Assurance Program Plan \\
\hline QC & quality control \\
\hline RA & remedial action \\
\hline RAO & remedial action objective \\
\hline RAR & Remedial Action Report \\
\hline RDR/RAWP & Remedial Design Report/Remedial Action Work Plan \\
\hline $\mathrm{RCW}$ & recirculating cooling water \\
\hline RL & remediation level \\
\hline ROD & Record of Decision \\
\hline SL & screening level \\
\hline SOP & standard operating procedure \\
\hline SU & soil unit \\
\hline SVOC & semivolatile organic compound \\
\hline TAL & target analyte list \\
\hline TDEC & Tennessee Department of Environment and Conservation \\
\hline TM & technical memorandum \\
\hline TSCAI & Toxic Substances Control Act of 1976 Incinerator \\
\hline UST & underground storage tank \\
\hline VOC & volatile organic compound \\
\hline
\end{tabular}




\section{EXECUTIVE SUMMARY}

It was acknowledged in the Record of Decision for Soil, Buried Waste, and Subsurface Structure Actions in Zone 2 East Tennessee Technology Park, Oak Ridge, Tennessee (DOE/OR/01-2161\&D2) (Zone 2 ROD) that most of the 800 acres in Zone 2 have been contaminated, but that sufficient data to confirm the levels of contamination was lacking. The Zone 2 ROD further specified that a sampling strategy for filling the data gaps would be developed. The Remedial Design Report/Remedial Action Work Plan for Zone 2 Soils, Slabs, and Subsurface Structures, East Tennessee Technology Park, Oak Ridge, Tennessee (DOE/OR/01-2222\&D2) (Zone 2 RDR/RAWP) defined the sampling strategy as the Dynamic Verification Strategy (DVS), generally following the approach used for characterization of the Zone 1 exposure units (EUs).

The Zone 2 ROD divided the Zone 2 area into seven geographic areas and 44 EUs. To facilitate the data quality objectives (DQOs) of the DVS process, the Zone 2 RDR/RAWP regrouped the 44 EUs into 12 DQO scoping EU groups. These groups facilitated the DQO process by placing similar facilities and their support facilities together, and allowed identification of data gaps. The EU groups were no longer pertinent after DQO planning was completed and characterization was conducted as areas became accessible. As the opportunity to complete characterization became available, the planned DVS program was executed and completed in fiscal year (FY) 2007 for the eleven EUs addressed in this document (Z2-01, Z2-03, Z2-08, Z2-23, Z2-24, Z2-28, Z2-34, Z2-37, Z2-41, Z2-43, and Z2-44). Remedial actions (RAs) were also performed in EUs Z2-33, Z2-35, and Z2-36. These activities are described in Sects. 5 through 10. Performance of these RAs does not enable the EUs to meet the Zone 2 ROD remedial action objective risk criteria. DVS characterization and/or additional RAs have not been completed. The purpose of this Phased Construction Completion Report (PCCR) for Zone 2 is to address the following:

- Document DVS characterization results for the accessible EUs in FY 2007;

- Describe and document the risk evaluation for each EU, and determine if the EU met the Zone 2 ROD requirements for unrestricted industrial use to $10 \mathrm{ft}$ bgs;

- Identify additional areas not defined in the Zone 2 ROD that require remediation based on the DVS evaluation results; and

- $\quad$ Describe the RAs performed in Zone 2.

A total of approximately 195.5 acres are addressed in the EUs included in this PCCR. Based on the results of DVS evaluation, approximately 143 acres have been recommended for unrestricted industrial use to $10 \mathrm{ft}$ bgs. Within this acreage, 16 Federal Facility Agreement (FFA) sites are addressed, and the following 14 have been evaluated and recommended for no further action (NFA):

- K-892-J Cooling Tower Basin in EU Z2-01,

- K-33 Recirculating Cooling Water (RCW) Lines Leak Sites in EU Z2-08,

- K-892-G Cooling Tower Basin in EU Z2-08,

- K-892-H Cooling Tower Basin in EU Z2-08,

- K-897-A Oil Containment Structure in EU Z2-08,

- K-300 Area Service Station in EU Z2-23,

- K-1070-G Burial Ground in EU Z2-44,

- K-762 Switchyard Soils in EU Z2-03, 
- K-762 Valve Vaults 1 and 2 in EU Z2-03,

- K-897-L Oil Containment Structure in EU Z2-03,

- K-897-M Oil Containment Structure in EU Z2-03,

- K-1414 Garage Diesel Tank/Soils in EU Z2-37,

- $\mathrm{K}-1070$ Pits in EU Z2-41, and

- $\quad \mathrm{K}-1070-\mathrm{C} / \mathrm{D}$ Burial Ground in EU Z2-41.

Two FFA sites not recommended for an NFA determination until the removal actions (RAs) are complete include the following:

- K-1407-C Soil Piles (Rusty's Mountain) in EU Z2-28, and

- $\quad \mathrm{K}-1071$ Concrete Pad in EU Z2-41.

Remaining activities needed in EU Z2-28 include RA soil removal at 16 historical and DVS sample locations with maximum remediation level exceedances and at areas within a circular area $50 \mathrm{ft}$ in diameter centered on each location. It is estimated that approximately $600 \mathrm{yd}^{3}$ of contaminated soil will need to be removed.

Remaining activities needed in EU Z2-41 include RA of the K-1071 concrete pad and immediately surrounding soil as specified in the Zone 2 ROD. It is estimated that approximately $50 \mathrm{yd}^{3}$ of contaminated soil will need to be removed.

Following completion of these RAs, the remainder of EUs Z2-28 and Z2-41 should be recommended for NFA.

The Zone 2 ROD RAs were developed to support reindustrialization of the East Tennessee Technology Park (ETTP) site as a commercial industrial park. Remediation criteria were designed for protection of a future industrial worker who normally would not have the potential for exposure to soils at depths below $10 \mathrm{ft}$ bgs. Accordingly, the Zone 2 ROD requires land use controls to prevent disturbance of soils below $10 \mathrm{ft}$ in depth and to restrict future land use to industria/commercial activities. In response to stakeholder comments, the U.S. Department of Energy has agreed to re-evaluate the need for such land use restrictions. This document includes a screening evaluation to determine the likelihood of land use controls in portions of Zone 2 being modified to: (1) eliminate the restriction on disturbance of soils below $10 \mathrm{ft}$ bgs where data indicate the absence of residual contamination at any depth that would result in an unacceptable risk to the future industrial worker, and (2) permit alternative land uses that would be protective of future site occupants. Results of this screening evaluation indicate a high probability that the restrictions on disturbing soil below $10 \mathrm{ft}$ bgs could be safely eliminated for 5 of the 11 EUs considered in this document (195.5 acres total). A qualitative screening evaluation considered the likelihood of unrestricted land use being protective of future site occupants. Based on this qualitative assessment, all 195.5 acres addressed in this PCCR were assigned a low probability for consideration of release for unrestricted land use.

This PCCR is divided into a main document (Sects. 1 through 13) and 11 appendices. The main text addresses the purposes for this PCCR and the RAs performed as described above. Additional supporting detail for each EU (e.g., field work summaries, maps, survey results, and data summaries) is provided in individual technical memoranda (Appendices A through K). Historical and DVS analyticaldata used in support of this PCCR are provided on a compact disc attached to this document and can be accessed through the Oak Ridge Environmental Information System. 


\section{INTRODUCTION AND PURPOSE}

The purpose of this Phased Construction Completion Report (PCCR) is to present the fiscal year (FY) 2007 results of characterization activities and recommended remedial actions (RAs) for 11 exposure units (EUs) in Zone 2 (Z2-01, Z2-03, Z2-08, Z2-23, Z2-24, Z2-28, Z2-34, Z2-37, Z2-41, Z2-43, and Z2-44) at the East Tennessee Technology Park (ETTP), which is located in the northwest corner of the U.S. Department of Energy (DOE) Oak Ridge Reservation in Oak Ridge, Tennessee (Fig. 1). ETTP encompasses a total land area of approximately 5000 acres that has been subdivided into three zonesZone 1 ( 1400 acres), Zone 2 ( 800 acres), and the Boundary Area ( 2800 acres).

Zone 2, which encompasses the highly industrialized portion of ETTP shown in Fig. 1, consists of all formerly secured areas of the facility, including the large processing buildings and direct support facilities; experimental laboratorie s and chemical and materials handling facilities; materials storage and waste disposal facilities; secure document records libraries; and shipping and receiving warehouses. The Zone 2 Record of Decision for Soil, Buried Waste, and Subsurface Structure Actions in Zone 2, East Tennessee Technology Park, Oak Ridge, Tennessee (DOE 2005) (Zone 2 ROD) specifies the future end use for Zone 2 acreage as uncontrolled industrial for the upper $10 \mathrm{ft}$ of soils.

Characterization activities in these areas were conducted in compliance with the Zone 2 ROD and the Dynamic Verification Strategy (DVS) and data quality objectives (DQOs) presented in the Remedial Design Report/Remedial Action Work Plan for Zone 2 Soils, Slabs, and Subsurface Structures, East Tennessee Technology Park, Oak Ridge, Tennessee (DOE 2007) (Zone 2 RDR/RAWP). The purpose of this PCCR is to address the following:

- Document DVS characterization results for the accessible EUs in FY 2007;

- Describe and document the risk evaluation for each EU, and determine if the EU met the Zone 2 ROD requirements for unrestricted industrial use to $10 \mathrm{ft}$ bgs;

- Identify additional areas not defined in the Zone 2 ROD that require remediation based on the DVS evaluation results; and

- $\quad$ Describe the RAs performed in Zone 2.

The Zone 2 ROD divided the Zone 2 area into 7 geographic areas and 44 EUs. To facilitate the DQOs of the DVS process, the Zone 2 RDR/RAWP regrouped the 44 EUs into 12 DQO scoping EU groups. These groups facilitated the DQO process by placing similar facilities and their support facilities together and allowed identification of data gaps. The EU groups were no longer pertinent after DQO

planning was completed, and characterization was conducted as areas became accessible. As the opportunity to complete characterization became available, the planned DVS program was executed and completed in FY 2007 for the 11 EUs addressed in this document.

The main body of this report describes both the DVS process and scope of work performed and the RAs completed. The scope and approach for performing DVS activities performed in FY 2007 that lead to action/no further action decisions are presented in Sects. 2 through 4. RAs performed in FY 2007 are presented in Sects. 5 through 10. Future land use is described in Sect. 11, and the status of all Zone 2 EUs as of this PCCR is presented in Sect. 12. 


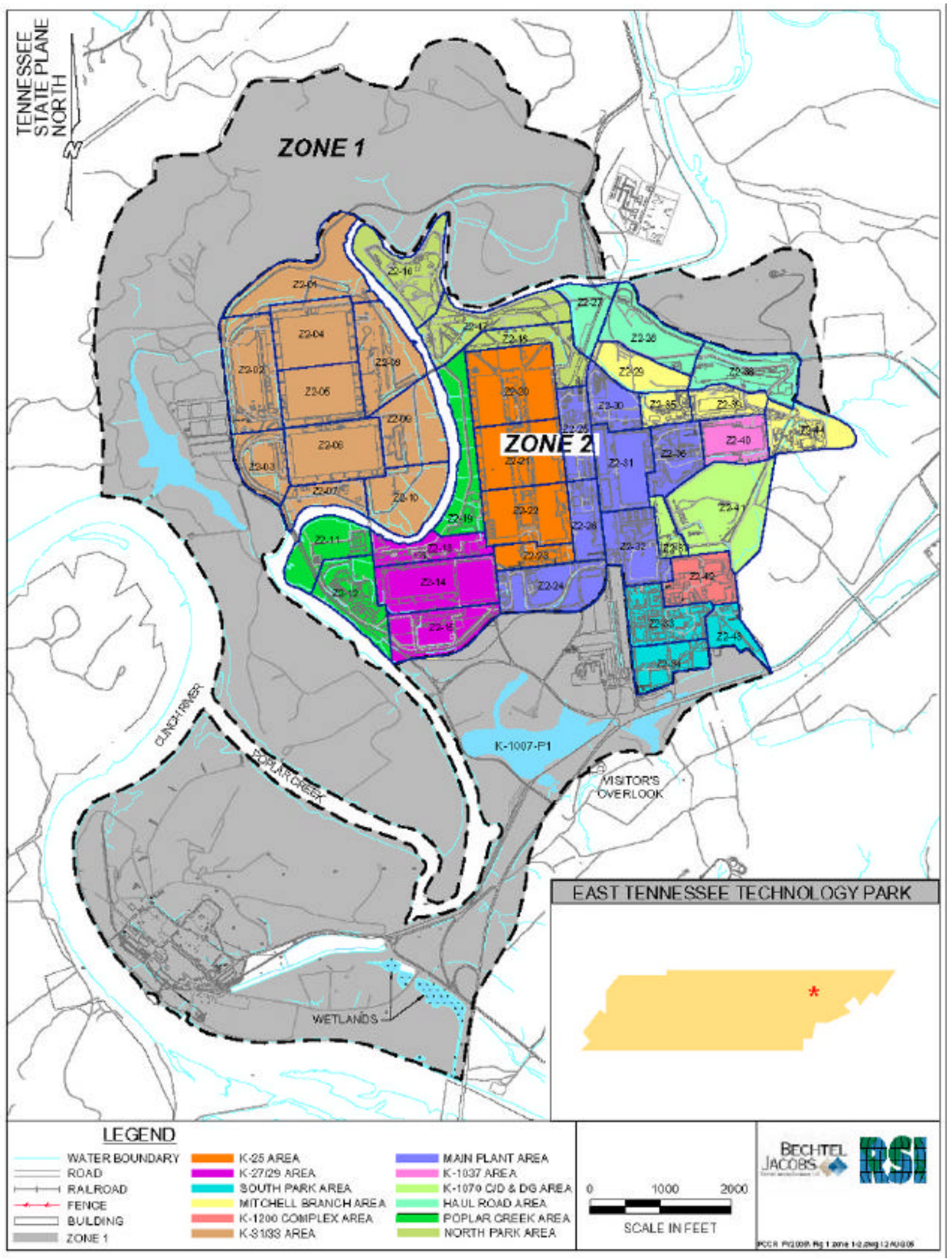

Fig. 1. ETTP site map with Zone 2 DQO scoping EU groups and EUs. 


\section{PROJECT DESCRIPTION}

\subsection{SCOPE}

\subsubsection{Exposure Unit Groups}

The Zone 2 ROD divided Zone 2 into 44 EUs that range in size from 5.9 acres (EU Z2-37) to 38 acres (EU Z2-41). The distribution of Zone 2 EUs included in this PCCR and their comparative size is shown on Fig. 2. The EU represents a hypothetical area over which an industrial worker would be exposed to contaminated soil in the interval 0-10 ft bgs. The acreage of each EU was calculated based on the estimated EU boundaries defined in the Zone 2 ROD. For the Zone 2 DVS characterization program, EU boundaries and acreage calculations were refined. Acreages presented in this document have been rounded to one decimal place. Calculation of the acreages has resulted in some discrepancies from acreages reported in the ROD. These discrepancies are due to the boundary refinement and an increased level of accuracy.

To facilitate DQO development and planning, the 44 EUs within Zone 2 were divided into 12 EU groups in the Zone 2 RDR/RAWP (Fig. 1). Field activities were directed as the opportunity for access to the various areas arose. Coordination between deactivation and demolition (D\&D) activities and assets utilization priorities were the primary drivers in execution of the DVS characterization program. Therefore, EU groups were not completed in their entirety. Each Zone 2 EU is evaluated and discussed in an EU-specific technical memorandum (TM) (Appendices A through K to this report). The EUs included in this PCCR are shown in Fig. 2. The Zone 2 EU groups, EUs, and the associated total EU group acreages are shown in Table 1.

Table 1. Zone 2 EU groups and acreages

\begin{tabular}{llc}
\hline \multicolumn{1}{c}{ EU Group } & \multicolumn{1}{c}{ EUs } & Acreage \\
\hline K-31/K-33 Area & Z2-01, Z2-02, Z2-03, Z2-04, Z2-05, Z2-06, Z2-07, Z2-08, & 223.6 \\
& Z2-09, Z2-10 & \\
Poplar Creek Area & Z2-11, Z2-12, Z2-19 & 58.5 \\
K-27/K-29 Area & Z2-13, Z2-14, Z2-15 & 60.5 \\
North Park Area & Z2-16, Z2-17, Z2-18 & 62.9 \\
K-25 Area & Z2-20, Z2-21, Z2-22, Z2-23 & 87.6 \\
Main Plant Area & Z2-24, Z2-25, Z2-26, Z2-31, Z2-32, Z2-36 & 100.9 \\
Haul Road Area & Z2-27, Z2-28, Z2-38 & 52.3 \\
Mitchell Branch Area & Z2-29, Z2-30, Z2-35, Z2-39, Z2-44 & 59.7 \\
K-1037 Area & Z2-40 & 13.8 \\
K-1070-C/D and Downgradient Area & Z2-37, Z2-41 & 44.0 \\
K-1200 Complex Area & Z2-42 & 15.5 \\
South Park Area & Z2-33, Z2-34, Z2-43 & 39.7 \\
\hline \multicolumn{2}{l}{} & \\
\hline
\end{tabular}




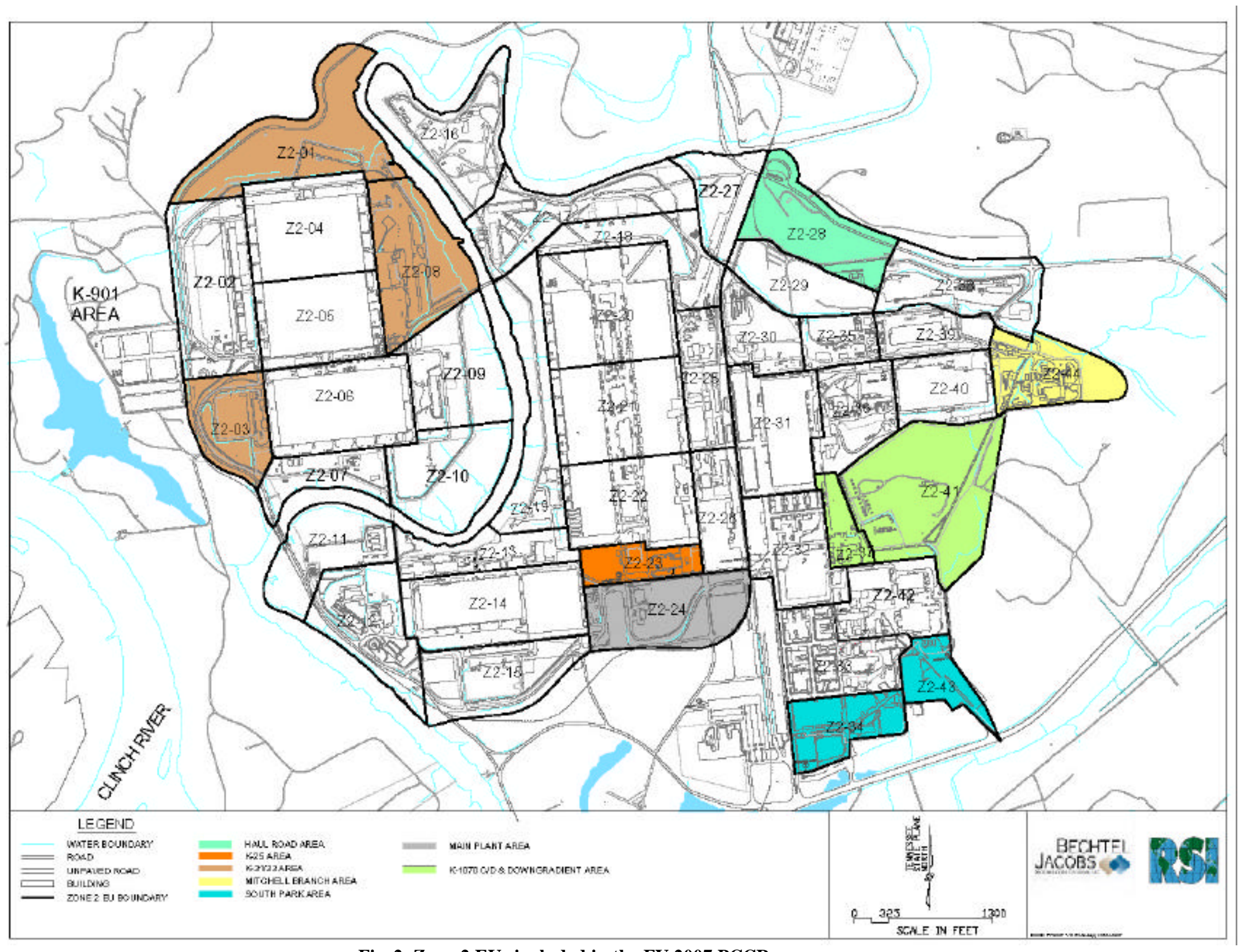

Fig. 2. Zone 2 EUs included in the FY 2007 PCCR. 


\subsubsection{Excluded Acreage}

With the exception of the active TSCA incinerator facility in EU Z2-44 (6 acres), which was exempted from characterization in the DQO scoping package, all acreage in each of the EUs discussed in this document is included in its entirety.

\subsubsection{Data Quality Objectives and Soil Unit Classifications}

The first action taken under the DVS characterization program was to assemble the DQO scoping packages, which are Core Team documents that give a compilation and evaluation of facility records and present results of previous sampling that provided the bases for soil unit (SU) classification and determination of additional sampling needs. The Multi-Agency Radiation Survey and Site Investigation Manual (MARSSIM), which describes the probability that an area has been impacted and the extent of the impact forms the basis for classification, was generally followed for SU classification. The SU classification was used to develop a graded approach to the level of scrutiny so that soils with the highest probability of contamination received the highest level of scrutiny and those with the lowest probability of contamination received the lowest level of scrutiny. The SUs were classified as follows:

- Class 1 -high to moderate probability that contaminants exceed RAOs,

- Class 2-moderate to low probability that contaminants exceed RAOs,

- Class 3-impacted areas with low probability of contamination above RAOs, or

- Class 4-no impact from anthropogenic activities (no Class 4 SU areas were identified in Zone 2).

The breakdown of soil classification for the acreage addressed by this PCCR includes the following:

- 0.07 acre in Class 1 SUs,

- 4.8 acres in Class 2 SUs,

- 190.7 acres in Class 3 SUs (not including 6 exempt acres in EU 44), and

- 0 acres in Class 4 SUs.

In each case, the probability of contamination was based on a thorough review of historical data, aerial photographs, records, and personnel interviews. Soil sampling activities under the DVS focused primarily on Class 1 and Class 2 SUs. The SUs were evaluated by walkover assessments, which included historic photograph analysis, records research, visual inspection, limited radiological survey, and selected biased sampling based on walkover assessment observations and measurements.

\subsubsection{Federal Facility Agreement Sites}

There were 16 Federal Facility Agreement (FFA) sites (DOE 1992) in the Zone 2 EUs that are addressed in this PCCR. Final status assessments for 14 of these sites are made in this PCCR as summarized in Table 2.

\subsection{DVS CHARACTERIZATION APPROACH}

This section presents the DVS approach to soils characterization and the rationale to support conclusions drawn from the characterization results. Through characterization activities, DVS provides information to support decisions on whether action is required. Additionally, DVS supports decisions on the extent of an action and, through confirmation sampling, whether the action is complete. In this 
section, the DVS characterization approach and the communications necessary to make key decisions throughout the DVS process are discussed. Decisions and communications required during remediation are also discussed. The DVS process is further defined in the Zone 2 RDR/RAWP.

The DVS process was designed to provide sufficient data to determine where RA was needed. To meet this goal, a sampling strategy was developed based on the likelihood of RA being required.

Table 2. FFA sites in the FY 2007 Zone 2 EUs

\begin{tabular}{|c|c|c|c|}
\hline \multicolumn{4}{|c|}{$\begin{array}{l}\text { Final status } \\
\text { assessed in this }\end{array}$} \\
\hline K-892-J Cooling Tower Basin & $\mathrm{Z} 2-01$ & Yes & \\
\hline K-762 Switchyard Soils & $\mathrm{Z} 2-03$ & Yes & \\
\hline K-762 Valve Vaults 1 and 2 & Z2-03 & Yes & \\
\hline K-897-L Oil Containment Structure & $\mathrm{Z} 2-03$ & Yes & \\
\hline K-897-M Oil Containment Structure & Z2-03 & Yes & \\
\hline K-33 RCW Lines Leak Site & $\mathrm{Z} 2-08$ & Yes & \\
\hline K-892-G Cooling Tower Basin & $\mathrm{Z} 2-08$ & Yes & \\
\hline K-892-H Cooling Tower Basin & Z2-08 & Yes & \\
\hline K-897-A Oil Containment Structure & Z2-08 & Yes & \\
\hline K-300 Area Service Station & $\mathrm{Z} 2-23$ & Yes & \\
\hline $\begin{array}{l}\text { K-1407-C Soil Piles (Rusty’s } \\
\text { Mountain) }\end{array}$ & $\mathrm{Z} 2-28$ & No & $\begin{array}{l}\text { Final status contingent on completion of } \\
\text { recommended remedial action }\end{array}$ \\
\hline K-1414 Garage Diesel Tank/Soils & Z2-37 & Yes & \\
\hline K-1070-C/D Burial Ground & $\mathrm{Z} 2-41$ & Yes & \\
\hline K-1070 Pits & $\mathrm{Z} 2-41$ & Yes & \\
\hline K-1071 Concrete Pad & $\mathrm{Z} 2-41$ & No & $\begin{array}{l}\text { Final status contingent on completion of } \\
\text { recommended remedial action }\end{array}$ \\
\hline K-1070-G Burial Ground & $\mathrm{Z} 2-44$ & Yes & \\
\hline $\begin{array}{l}\mathrm{EU}=\text { exposure unit } \\
\text { FFA }=\text { Federal Facility Agreement }\end{array}$ & $\begin{array}{l}\mathrm{FY}=1 \\
\mathrm{RCW}\end{array}$ & ating & \\
\hline
\end{tabular}

The DVS characterization approach has six key components, including the following:

- Planning (Sect. 2.2.1), including acreage classification (Sect. 2.2.1.1) and DQO scoping (Sect. 2.2.1.2);

- Class 1 and Class 2 SU characterization approach (Sect. 2.2.2);

- Class 3 and Class 4 SU characterization approach (Sect. 2.2.3);

- Program execution (Sect. 2.2.4);

- Action/no further action (NFA) decision/communication (Sect. 2.2.5); and

- Documentation and records (Sect. 2.2.6).

During the planning stage (first component), the acres of interest were classified into SUs according to their potential level of contamination as described in Sect. 2.1.3, and the DQOs were applied to develop a sampling plan. Because they had different probabilities for the presence of contamination, different SU classifications had different characterization strategies (second and third component). However, a base survey and sampling program was developed for all SU classifications and presented during DQO scoping. This base program was modified during field implementation as work was conducted and additional characterization needs were identified. The Class 1 and Class 2 SU base program consisted of radiological walkover and geophysical surveys, where appropriate, and systematic 
sampling supplemented by biased sampling. The Class 3 and Class 4 SU base program primarily consisted of visual inspections and radiological screening surveys with biased sampling conducted based on inspection and survey observations. Execution techniques to accomplish SU characterization were carried out in the field (fourth component). The next stage was the RA Core Team decision making and communication, which was associated with all sampling programs (fifth component).

The RA Core Team was created to help streamline planning and accelerate the completion of all actions to be performed at ETTP to accelerate site closure. The RA Core Team approach is a formalized, consensus-based process in which members reach agreement on key closure issues and strategies. The RA Team consists of representatives from parties to the FFA-DOE, U.S. Environmental Protection Agency (EPA), and Tennessee Department of Environment and Conservation (TDEC) as well as DOE's accelerated closure contractor. The primary function of the RA Core Team is to make programmatic decisions that facilitate and guide specific projects as ETTP progresses toward closure.

The following subsections provide an overview of each of the first four DVS characterization process components.

\subsubsection{Planning}

SU classification and DQO scoping for sampling plan development were two key parts of the planning component, both of which required RA Core Team concurrence.

\subsubsection{SU classification}

To begin planning, the land area within each EU Group was classified as either impacted or non-impacted by ETTP plant activities. This initial classification included compilation and review of existing information from historic aerial photographs, maps, drawings, and other facility records. After classification as impacted/non-impacted, land areas were assigned SU classifications as defined in Sect. 2.1.3. FFA sites are typically designated as Class 1 or Class 2 SUs.

\subsubsection{DQO scoping}

Once the area under consideration was classified into a SU, the quantity and quality of existing data and other information was evaluated against the DQO requirements for sufficiency and quality, and a DQO scoping plan for base program surveying, sampling, and analysis was developed. Some of the work described below (e.g., field survey results) was used to design the DQO scoping plan and is considered part of the planning process. A DQO scoping plan was presented to the RA Core Team for concurrence, including the SU classifications, at DQO scoping meetings. The DQO scoping meeting for the work described in this PCCR was conducted on January 19, 2005. The agreed-to plan was then documented in the Dynamic Work Plan (DWP). Any additional sampling and analysis was added to the program with RA Core Team concurrence. The DWP identified sample locations and analysis requirements, including the use of realtime field measurements where applicable. The DWP applicable to this PCCR is the Zone 2 Dynamic Work Plan, East Tennessee Technology Park, Oak Ridge, Tennessee (BJC 2007).

Per the DVS process, a portion of characterization samples was analyzed for an extensive list of potential contaminants. Fixed laboratory analyses were performed for a suite of analytes [volatile organic compounds (VOCs), semivolatile organic compounds (SVOCs), target analyte list (TAL) metals, polychlorinated biphenyls (PCBs), and a radiological analytical suite that included gamma spectroscopy, alpha spectroscopy, thorium-isotopic, uranium-isotopic, technetium-99, and radium-specific analyses]. 
All identified contamination was evaluated in determining if action was needed for the EU. Decisions were based on evaluation of identified contamination, including the following:

- primary and secondary contaminants of concern (COCs), which are identified in the Zone 2 ROD;

- contaminants of potential concern, which are identified during the risk evaluation process; and

- EU-specific COCs, which are contaminants identified during characterization that result in an unacceptable EU risk.

Documentation included a summary of existing data, an assessment of data gaps in DQO scoping packages, and documentation of the base survey and sampling program in the Zone 2 DWP. Concurrence on the base program was reached by the Core Team and documented on concurrence forms.

\subsubsection{Class 1 and Class 2 SU Characterization Approach}

Implementation of the Class 1 and Class 2 SU characterization program included the following steps. Details on each step are provided in Sect. A.8 of the Quality Assurance Project Plan for Soil Characterization Activities under the Dynamic Verification Strategy at the East Tennessee Technology Park, Oak Ridge, Tennessee (QAPP), which is included in the Zone 2 RDR/RAWP (DOE 2007) as Appendix A.

- Step 1 (not applicable in Zone 2) — completion of an ecological impact assessment prior to significant disturbance.

- Step 2 (not applicable in Zone 2)—Clearing to provide access (as required).

- Step 3-Performance of radiological walkover surveys (where historic surveys are unavailable) and geophysical surveys [burial sites and underground storage tank (UST) sites].

- Step 4-Selection of systematic sampling locations and additional biased sampling locations based on survey results.

- Step 5-Performance of base program and initial biased sampling.

- Step 6-Evaluation of field and laboratory data.

- Step 7-Selection of additional biased sampling locations based on field measurements and laboratory results.

A flow diagram outlining details of this characterization approach and associated decisions made for Class 1 and Class 2 SUs is shown in Fig. 3. Along with the planning component (acreage classification and DQOs) defined in Sects. 2.2.1.1 and 2.2.1.2, Steps 1 through 4 above constitute the base program for characterizing Class 1 and Class 2 SUs.

Field radiological and geophysical surveys (Step 3) were performed prior to the actual sampling activity. A lead time of several weeks to months allowed evaluation of the survey data and supported the selection of a set of biased sampling locations to evaluate the results. Geophysical surveys were used to define the boundaries of buried waste at landfill disposal sites or the presence of other buried objects (USTs) and materials.

Radiological walkover surveys were used to define the limits of radiological contamination in surface soils. The decision to have biased sampling locations where elevated radiological readings or geophysical anomalies were encountered (Step 4) was made after reviewing results of the radiological walkover and geophysical surveys. (These survey results were used hter during the confirmation 


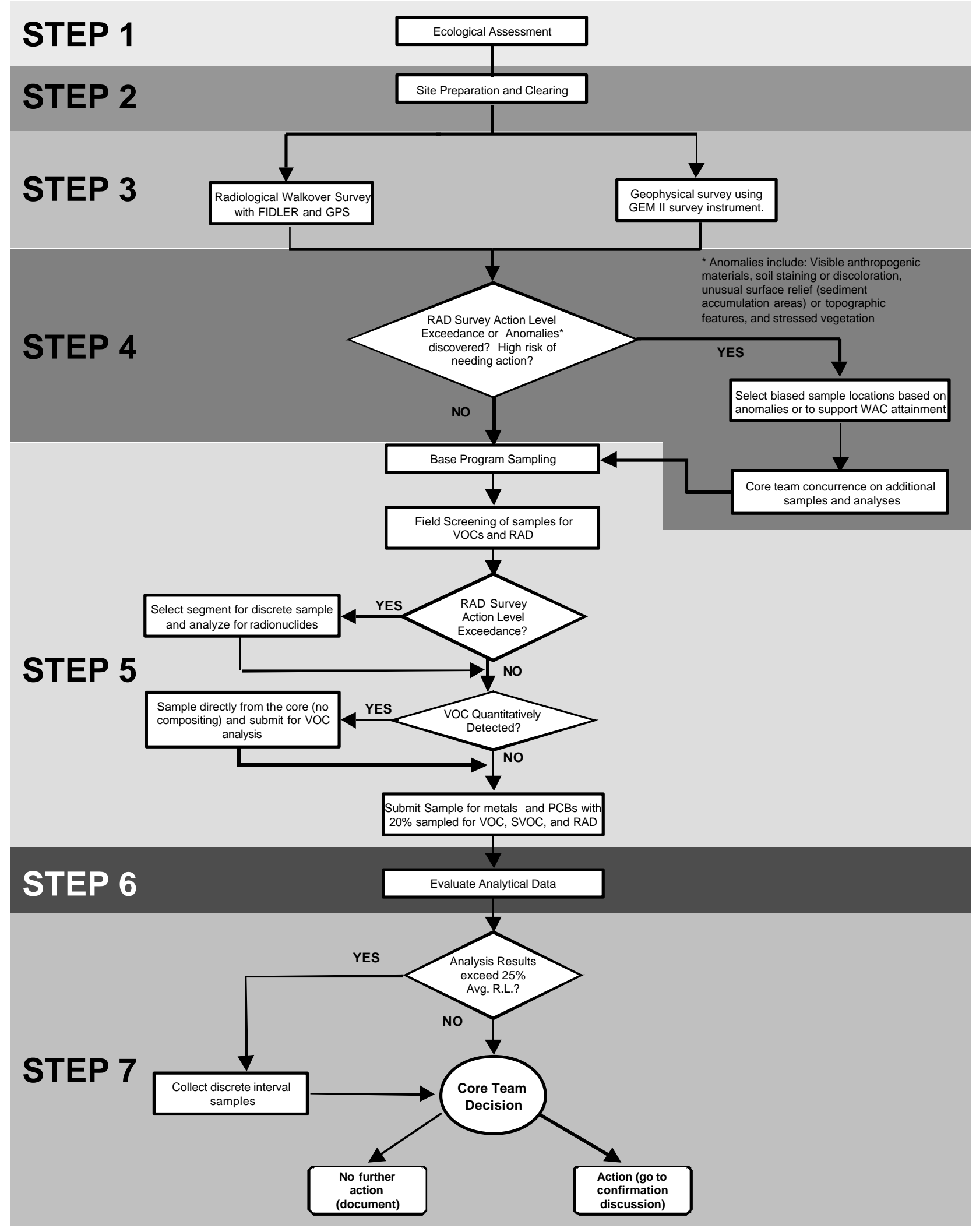

Fig. 3. Zone 2 DVS Class 1 and Class 2 SU sampling and analysis decision process flow. 
sampling phase to assist in identifying potential excavation boundaries.) After concurrence from the RA Core Team, any identified biased sampling locations identified from these survey results were included in the base sampling program.

With the base program defined and agreed to by the RA Core Team, characterization field work began (Step 5). Each EU Group was characterized according to the specific details initially presented during DQO scoping and finalized in the DWP. Soil sampling was performed using standard field methods and following EPA Region 4 standard operating procedures (SOPs).

Geoprobe $^{\circledR}$ sampling was the predominant method of sample acquisition for subsurface soil to depths up to $30 \mathrm{ft}$. Surface and shallow interval soil sampling was performed predominantly using hand augers. The standard DVS sampling methodology was to composite samples taken from the 0- to 6-in. interval, the 6-in. to 2-ft interval, and the 2-10- $\mathrm{ft}$ interval. The sample composite protocol is presented in Attachment $\mathrm{C}$ to the QAPP. Discrete interval samples were collected based on the following two criteria (Steps 5, 6, and 7):

- A field screening method showed an elevated level for a COC in a segment of a core; or

- Initial analytical results from samples submitted to a laboratory showed an action level [25\% of an average remediation levels (RLs)] for one or more COCs were exceeded in the composited sample (Steps 6 and 7).

For the first criterion, field screening methods were used as part of the field characterization activity (Step 5). Two field screening methods were used on soil cores-VOC screening using hand-held meters and radiological screening using core-scanning devices developed specifically for the DVS program. Field screening was to allow sample collection for laboratory analysis of the specific core intervals most likely to have contamination in addition to collection of the composited sample. Collection of the mostlikely contaminated segment of the core ensured that existing contamination was represented in the analytical results. Recognition of potential VOC contamination also allowed the segment of the core to be collected for VOC analysis prior to compositing. VOCs were not analyzed in composite samples.

The second criterion was based on analysis of laboratory results. The base program required that all samples were analyzed for TAL metals and PCBs. To support the risk assessment, a randomly-selected $20 \%$ of all samples were also analyzed for VOC (discrete interval), SVOC, and radiological analyses (Step 5). If laboratory-reported results indicated that action levels were exceeded in any of the randomly selected samples, the location with elevated results was resampled for the specific parameters of concern and three discrete intervals were sent for analysis: 0-6 in., $6 \mathrm{in} .-2 \mathrm{ft}$, and a selected interval in the 2-10 ft interval(Steps 6 and 7).

Current EPA laboratory analytical methods were used to provide risk assessment quality data as required by the DQO process and as stipulated in the DWP for all composite samples, discrete samples, and the samples sent for full-suite analysis. All of the information collected was documented in he appropriate EU Group TM (Appendices A through K).

\subsubsection{Class 3 and Class 4 SU Characterization Approach}

A flow diagram outlining the characterization approach taken and the associated decisions made for Class 3 and Class 4 SUs is presented in Fig. 4. The following statements were considered during decision making:

- Are there anthropogenic features, areas of elevated radiation, or sediment accumulation areas that require biased sampling and analysis?

- Does the EU exceed RAOs stated in the Zone 2 ROD and, therefore, require action? (Results from Class 1 and 2 SU evaluations, if applicable, are needed to make this final EU-level assessment.) 


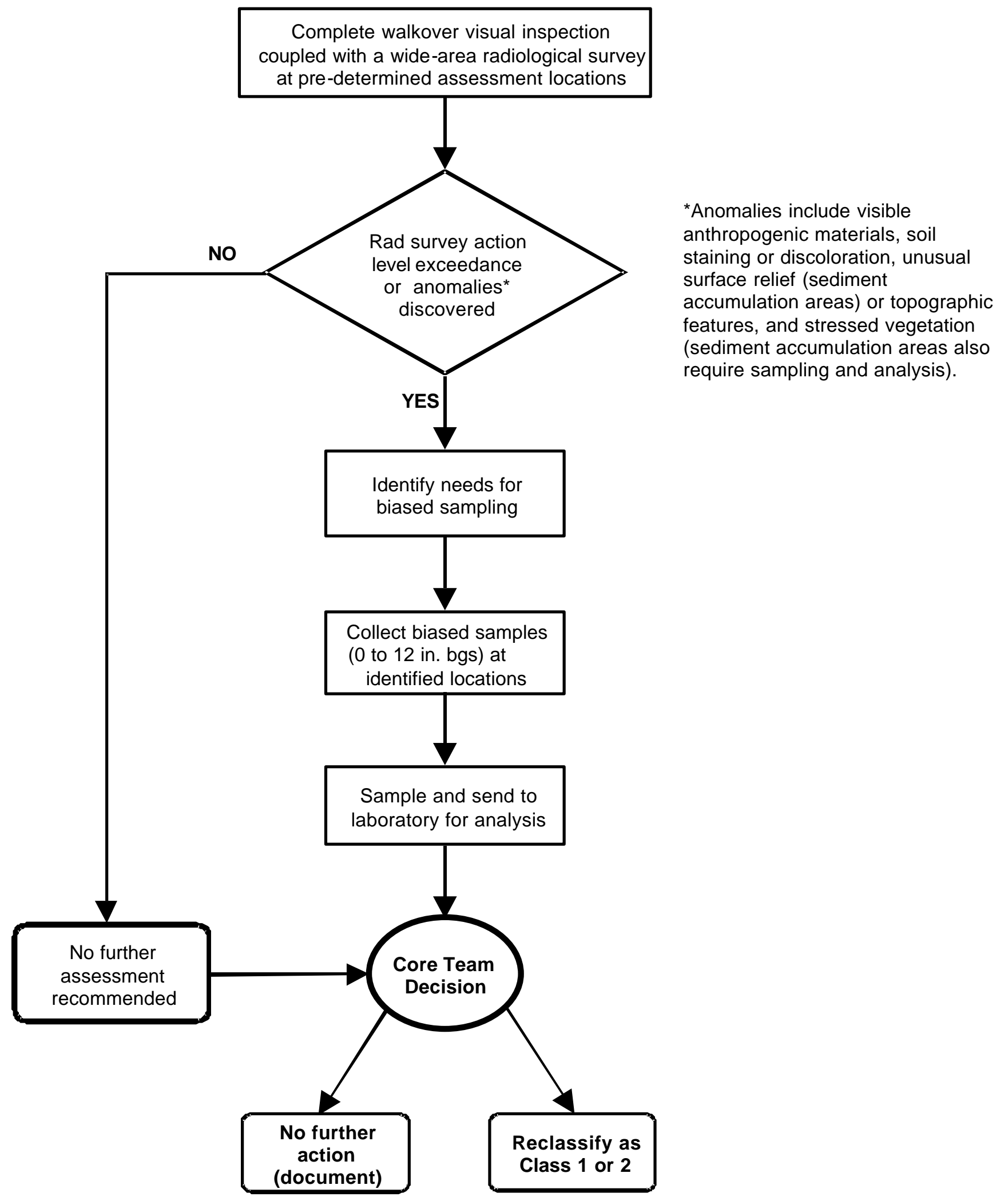

Fig. 4. Zone 2 DVS Class 3 and Class 4 SU sampling and analysis decision process flow. 
Assessment of the Class 3 and Class 4 SU acreage proceeded independently of the Class 1 and Class $2 \mathrm{SU}$ investigations and were performed during the winter, when possible, to facilitate inspection in heavily wooded portions of Zone 2. These assessments were conducted in accordance with the Class 3 and Class 4 Soil Unit Walkover Assessment Protocol (DOE 2007, Attachment C). The approach began with visual walkover inspections conducted to systematically inspect Class 3 and Class 4 SUs along transects to established systematic grid assessment locations, map-observed features, and collect radiological screening data to support the action/NFA decision.

These assessments focused on identifying anthropogenic features, delineating boundaries of the features, and determining if sampling of the features was warranted. Anthropogenic features identified in the Class 3 and Class 4 SUs are broadly inclusive of anything present as the result of any human activity. Identifying any unnatural conditions in the remote areas of the site where little to no industrial activity occurred is a very conservative approach to the site assessment protocol for clearing large tracts of peripheral lands in Zone 2. Anthropogenic features as defined in the Class 3 and Class 4 SU walkover assessment protocol were to include areas of radiation survey anomalous readings (above two times area background), visible anthropogenic materials (such as concrete, asphalt, metal debris, rubble, and rubbish), soil staining or discoloration, and/or stressed vegetation. In addition, crews were instructed to identify areas of unusual topographic relief, low areas where sediment would accumulate, and mounds of soil that appeared to be unusual for the local topographic conditions. This very broad definition of anthropogenic features provided a thorough assessment of the Class 3 and Class 4 SUs in Zone 2.

A systematic grid with a random starting point was used to establish each assessment point (AP), with approximately one point per acre. A field instrument for detection of low-energy radiation (FIDLER) (Ludlum® 44-17 detector, 2 in. $\times 2 \mathrm{~mm}$ ) was used by the survey crews. Background conditions were established for the EU group based on the Class 3 and Class 4 Soil Unit Walkover Assessment Protocol (DOE 2007, Attachment C). The screening level (SL), which determined the need for further consideration and detailed evaluation, was twice the group mean background value. Approximately halfway to each AP, a mid-point (MP) was counted and surface features de scribed. Class 3 and Class 4 SU radiological surveys were conducted at APs, MPs, and discretionary points (DPs) during their SU walkover assessments. Anthropogenic features or areas of elevated activity away from APs and MPs were also characterized with 30-second counts of the FIDLER as a discretionary survey point.

Biased soil samples from identified anomalies were collected and analyzed for metals, radionuclides, and PCBs. Approximately $20 \%$ of the biased samples were sent for a larger suite of analytes to aid in identifying potentially unrecognized, site-related soil contaminants.

Biased sampling locations also were identified in sediment accumulation areas, which are defined as areas where runoff from large portions of the SU and surrounding areas converge and have the potential for sediment deposition. Chemical and radiological composition of sediment accumulation area soils or sediments is representative of the upstream conditions, and elevated levels of contamination are indicative of an upgradient source. Biased samples collected from sediment accumulation areas were sent to a laboratory for radionuclide, metal, VOC, SVOC, and PCB analysis for identification of previously unrecognized site-related soil contaminants.

\subsubsection{Program Execution}

Soil sample collection was performed following EPA Region IV standard sampling methods and SOPs. The DVS base program sampling was tailored to site-specific conditions and collected samples in the 0-10-ft depths in all Class 1 and Class 2 SUs. There were several conceptual site models (CSMs) in Zone 2 that include surface and subsurface models that described the potential contaminant source and potential release to the environment. 
The DVS program in the Class 1 and 2 SUs required at least $20 \%$ of all sample locations be drilled and sampled to a depth of $10 \mathrm{ft}$ bgs. Sample borings were completed using Geoprobe ${ }^{\circledR}$ direct-push equipment (Models 54DT and 54LT). Samples were collected in acetate liners and capped upon recovery. All boreholes were logged and described according to EPA Region IV guidance (EPA 2002), and all soil cores were scanned in the field for the presence of radioactive contaminants using the ModelT Radiological Soil Core Screening System. The core screening action level was set to correspond to approximately $80 \%$ of the ARL for U-238 $(40 \mathrm{pCi} / \mathrm{g})$. The SL for the core scanner was based on a background soil core for which a daily baseline value was determined. The SL varied slightly from day to day in response to local ambient radiological conditions and natural activity of the background soils specific for the EU Group. SLs were set at the observed daily baseline (commonly in the range of $135-150 \mathrm{cpm})$, plus $65 \mathrm{cpm}$. SLs were in the range of $200 \mathrm{cpm}( \pm 20 \mathrm{cpm})$, which provided $100 \%$ accuracy for identifying gamma-emitting radioactive contamination in soils in excess of $40 \mathrm{pCi} / \mathrm{g}$.

Results of field activities completed in this PCCR indicate the SLs of baseline plus $65 \mathrm{cpm}$ is consistently identifying radiological constituents at $10 \mathrm{pCi} / \mathrm{g}$ or greater in soil cores. When the SL was exceeded, a discrete interval soil sample was collected for radiological analysis.

The acetate liners were split in the field and the core was screened for the presence of VOCs. Where VOCs were detected above 5ppm using a hand-held photoionization detector, a discrete interval soil sample was collected for VOC analyses using EnCore ${ }^{\circledR}$ samplers. At burial trench sites (EU Z2-41), the waste matrix was commonly comprised of course materials, debris, rubble, and fill materials, which precluded the use of EnCore ${ }^{\circledR}$ samplers for VOC analysis. Approved sample containers were used at these sites and managed according to EPA Region IV protocols (EPA 2002).

At base program sampling locations, three intervals of the soil core were composited according to the protocol described in the QAPP (DOE 2007, Appendix C). The compositing procedure stipulates that equal volumes of soil from the surface 0.5 -ft interval, $0.5-2-\mathrm{ft}$ interval, and a selected section of core in the 2-10-ft interval are collected and thoroughly mixed to form a composite soil sample. The interval selected for inclusion in the soil composite was based on visual observation of the sample and targeted to select the most contaminated portion of the soil core. Selection was made based on visual observations such as staining, odor, soil contacts, obvious waste, or the presence of unnatural materials. This compositing methodology provides a physical composite that represents the average contaminant profile for the entire 010-ft interval. All base program composite samples were analyzed for PCBs and TAL metals and screened in the field for the presence of VOCs (> $5 \mathrm{ppm}$ ) and radioactivity (in excess of two times background). Discrete interval samples were collected for VOC and radiological analyses if field SLs were exceeded [refer to the Zone 2QAPP (DOE 2007) for specific procedures].

The DVS program requires $20 \%$ of all sample locations be drilled and sampled to $10 \mathrm{ft}$ bgs. At surface contamination sites such as the K-762 Switchyard in EU Z2-03, the base program focused on the 0-2-ft interval where contaminant releases would have occurred. However, $20 \%$ of the locations were drilled and sampled to $10 \mathrm{ft}$ bgs. At the underground storage tank (UST) sites and buried utilities and infrastructure sites, all borings were drilled and sampled to $10 \mathrm{ft}$ bgs or to native material, whichever was deeper. The program also requires at least $20 \%$ of all samples be analyzed for a full suite of COCs, including VOCs, SVOCs, metals, PCBs, and radioisotopes. Locations to be drilled to depth and samples for full suite analyses were randomly selected. This selection process results in full suite analyses being performed on both surface and shallow interval samples as well as on some deep soil samples.

Changes to the base program plan inclu ded dropping inaccessible sample locations (e.g., areas of steep slopes or obstructions such as roads or heavy dead fall areas) and moving locations due to shallow refusal (e.g., buried concrete and metallic debris and rubble). These changes were documented on Field Change Notice (FCN) forms and presented to the Core Team for concurrence. Drops and moves occurred at $<5 \%$ of the base program planned locations. Locations moved more than $5 \mathrm{ft}$ from the planned grid node are identified by the inclusion of an "M" character in the location ID (e.g., Z2-EU28M-101). 
At sites of surface contamination, the base program plan stipulated sampling the $0-2-\mathrm{ft}$ interval to focus the evaluation in the interval where contamination levels would be the highest. Sampling in these areas was performed using the Geoprobe ${ }^{\circledR}$ equipment and 0-2-ft, two-interval composite samples using the standard sampling method. In these areas, $20 \%$ of the base program sample locations were drilled to $10 \mathrm{ft}$ at randomly selected locations and $20 \%$ of all locations (0-2 ft and to depth) were analyzed for a full suite of constituents. Soil cores at these sites, and at the landfill sites, also were screened in the field for VOC and radiological contamination.

In addition to the base program sampling, biased sampling was performed. These locations were selected based on the results of geophysical surveys, radiological walkover surveys, and "step-out" locations to base program samples that indicated significant concentrations of contamination occurred. Biased samples drilled to $10 \mathrm{ft}$ were collected in three discrete intervals (from the 0.5 - $\mathrm{ft}$ interval, $0.5-2 \mathrm{ft}$ interval, and a selected section of core in the $210-\mathrm{ft}$ interval). Surface soil samples were generally collected as five-point composite samples to provide area coverage of radiological surface anomalies, surface-distributed mounds of soils, or small waste piles. The intent of surface compositing was to provide an average contaminant profile for a localized surface area.

Sampling procedures and methods complied with EPA Region IV guidance. Sampling equipment, shipping containers, and quality assurance/quality control (QC) requirements also followed EPA Region IV guidance. Standard laboratory analytical methods were used, and data management and QC procedures complied with EPA criteria. Detailed discussion of field and laboratory requirements is included in the Zone 2 RDR/RAWP (DOE 2007).

\subsubsection{Action/No Further Action Decision/Communication}

Once results of the field work and analytical work were received, the RA Core Team evaluated the data and decided if action was appropriate. The action/NFA decision was based on one or more of the following criteria:

- Exceedance of a maximum RL at any location,

- Exceedance of an average RL across the EU,

- Unacceptable future threat to groundwater, and/or

- Unacceptable cumulative excess lifetime cancer risk (ELCR) of $>1 \times 10^{-4}$ and hazard index (HI) of $>1$ across the EU.

Sample results were evaluated for the 0-10-ft soil interval and were not depth dependent. Contamination anywhere within the $010-\mathrm{ft}$ interval had an equal weighting in the risk assessment and was presumed to be equally accessible to an industrial worker. Soil sample compositing provided data representative of the 0-10-ft interval. Discrete interval sampling was selecte d based on field screening for VOCs and radioactivity identified by screening the soil core. This approach provided a very conservative evaluation of soil conditions and had an equivalent consideration in the risk assessment methodology. Selection of intervals for inclusion in soil core composite samples was based on visual observation and included the portion of the soil core with the highest probability of contamination. Visual cues included but were not limited to bedding contacts, porous and permeable intervals, staining, and odor. Discrete sample interval depth information is included in the data set on the compact disc provided with this document. Major stratigraphic differences (i.e., $2 \mathrm{ft}$ of cover material over fill) are referenced in the text where appropriate.

An area-weighted mean of the data in each EU was used to compare the average composition of the EU to the average RLs. Risk was evaluated by area-weighting the results. Because data within an EU was unevenly distributed across the SUs (i.e., SUs with greater probability of contamination had a higher 
density of samples), weighting was based on the areal extent of the SUs. For those SUs with little probability of contamination and therefore few, if any, sample results (i.e., Class 3 and Class 4 SUs), background concentrations of COCs as defined in the Soil Background Supplemental Data Set for the East Tennessee Technology Park, Oak Ridge, Tennessee (DOE 2003) were used in the weighted average calculations for the EU risk assessments and comparison to average RLs.

Data collected for the original background data set for ETTP (DOE 1993a) was not representative of ETTP site soils, nor were the associated statistical calculations performed in accordance with then current EPA guidance. To resolve the issues, additional samples were collected and statistics were recalculated to comply with EPA guidance. Samples were collected from the B soil horizon of the Rome and Upper Knox formations to supplement the original data set. These samples were collected from approximately 12-24 in. bgs and were only analyzed for radiological constituents and inorganic elements. The comparison of site data versus background data in this PCCR was made using methods from Guidance for Comparing Background and Chemical Concentrations in Soil for CERCLA Sites (EPA 2002). Soil background data used in this document is presented in Soil Background Supplemental Data Set for the East Tennessee Technology Park, Oak Ridge, Tennessee (DOE 2003) and not from the earlier report.

If elevated concentrations (i.e., above background) were found, sample results were used (even if sparse) after the SU was reclassified as a Class 1 or Class 2 SU. Results of the action/NFA evaluation were documented in the EU Group TM, which were provided to the RA Core Team for early review but are formally submitted for approval as appendices to this PCCR. Data, maps, cross sections, and any other useful information was also provided on the project webpage to facilitate decision making.

The risk remedial action objective (RAO) was developed in the Zone 2 ROD to allow the identification of new COCs because of uncertainty that all COCs had been identified in the historical data sets. If the risk assessment identified contaminants requiring remediation that do not have associated RLs, remediation was recommended if the risk was found to be unacceptable.

\subsubsection{Documentation and Records}

All information, data, documents, and records necessary to support the decisions presented in this PCCR are transferred to the post-decision document file upon approval of the PCCR. A list of referenced documents that will become part of the file are provided in Sect. 13. Additional records contained within the file but not listed in Sect. 13 include but are not limited to FCNs, Core Team concurrence forms, and analytical data packages. The post-decision document file is available to the public through the DOE Oak Ridge Office Information Center. Analytical data, field data, and sample location maps are archived in and made available to the public through the Oak Ridge Environmental Information System (OREIS).

Over the course of FY 2007, the use of concurrences has been expanded by the RA Core Team to include more diverse issues (e.g., limited RAs, RDR/RAWP and WHP revisions/additions, sampling protocols) than in previous years. Table 3 lists the Zone 2 FCNs and concurrences submitted to and reached by the RA Core Team in FY 2007 that pertain to the EUs in this PCCR. 
Table 3. FY 2007 FCNs and concurrences

\begin{tabular}{|c|c|c|c|}
\hline FCN number & Title or description & Date submitted & Date approved \\
\hline FCN-ETTP-Zone 2-009 & $\begin{array}{l}\text { K-31/K-33 EU Group DQO Scoping Package } \\
\text { Biased Sample Additions (EU Z2-01, Z2-02, } \\
\text { Z2-07) }\end{array}$ & $5 / 11 / 2006$ & $6 / 7 / 2006$ \\
\hline FCN-ETTP-Zone 2-010 & $\begin{array}{l}\text { K-31/K-33 EU Group DQO Scoping Package } \\
\text { Biased Sample Additions (EU Z2-01, Z2-02, } \\
\text { Z2-03, Z2-08, Z2-09, Z2-10) }\end{array}$ & $6 / 22 / 2006$ & $7 / 5 / 2006$ \\
\hline FCN-ETTP-Zone 2-012 & $\begin{array}{l}\text { K-31/K-33 EU Group DQO Scoping Package } \\
\text { Sample Point Additions (EU Z2-01) }\end{array}$ & $7 / 12 / 2007$ & $7 / 20 / 2006$ \\
\hline FCN-ETTP-Zone 2-017 & $\begin{array}{l}\text { South Park Area EU Group DQO Scoping } \\
\text { Package Class } 3 \text { Samp le Additions (Z2- } \\
\text { EU33, EU34, EU43) }\end{array}$ & $8 / 31 / 2006$ & $9 / 13 / 06$ \\
\hline FCN-ETTP-Zone 2-018 & $\begin{array}{l}\text { K-31/K-33 Area EU Group DQO Scoping } \\
\text { Package Inactive RCW Valve Vault Sample } \\
\text { Additions (Z2-EU08) }\end{array}$ & $11 / 6 / 2006$ & $11 / 8 / 06$ \\
\hline FCN-ETTP-Zone 2-018 & $\begin{array}{l}\text { K-31/K-33 Area EU Group DQO Scoping } \\
\text { Package Inactive RCW Valve Vault Sample } \\
\text { Additions (Z2-EU08) }\end{array}$ & $11 / 6 / 2006$ & $11 / 8 / 2006$ \\
\hline FCN-ETTP-Zone 2-019 & $\begin{array}{l}\text { South Park Area EU Group DQO Scoping } \\
\text { Package Sample Classification Changes } \\
\text { (Z2-EU33) }\end{array}$ & $11 / 3 / 2006$ & $11 / 13 / 2006$ \\
\hline FCN-ETTP-Zone 2-020 & $\begin{array}{l}\text { South Park Area EU Group DQO Scoping } \\
\text { Package RAB Definition in area South of } \\
\text { K-1004-J (Z2-EU33) }\end{array}$ & $11 / 3 / 2006$ & $11 / 8 / 2006$ \\
\hline FCN-ETTP-Zone 2-021 & $\begin{array}{l}\text { South Park Area EU Group DQO Scoping } \\
\text { Package Acid Dilution Pit Sample Additions } \\
\text { (Z2-EU33) }\end{array}$ & $12 / 5 / 2006$ & $1 / 5 / 2007$ \\
\hline FCN-ETTP-Zone 2-022 & $\begin{array}{l}\text { Poplar Creek Area EU Group DQO Scoping } \\
\text { Package Biased Concrete Sample Point } \\
\text { Additions (Z2-EU19) }\end{array}$ & $2 / 8 / 2007$ & $3 / 20 / 2007$ \\
\hline FCN-ETTP-Zone 2-023 & $\begin{array}{l}\text { North Park Area EU Group DQO Scoping } \\
\text { Package Radiological Survey Revisions } \\
\text { (Z2-EU16) }\end{array}$ & $12 / 13 / 2006$ & $1 / 5 / 2007$ \\
\hline FCN-ETTP-Zone 2-024 & $\begin{array}{l}\text { Poplar Creek Area EU Group DQO Scoping } \\
\text { Package Biased Concrete Sample Additions } \\
\text { (Z2-EU19) }\end{array}$ & $12 / 20 / 2006$ & $1 / 5 / 2007$ \\
\hline FCN-ETTP-Zone 2-025 & $\begin{array}{l}\text { K-25 EU Group DQO Scoping Package } \\
\text { Technical Brief (Z2-EU20, 21, and 22) }\end{array}$ & $12 / 19 / 2006$ & $1 / 5 / 2007$ \\
\hline FCN-ETTP-Zone 2-026 & $\begin{array}{l}\text { Main Plan EU Group DQO Scoping Package } \\
\text { Backfilling the K-1501 basement (Z2-EU36) }\end{array}$ & $12 / 20 / 2006$ & $1 / 5 / 2007$ \\
\hline FCN-ETTP-Zone 2-027 & $\begin{array}{l}\text { Poplar Creek EU Group DQO Scoping } \\
\text { Package Backfilling the K-834 Valve House }\end{array}$ & $12 / 21 / 2006$ & $1 / 5 / 2007$ \\
\hline FCN-ETTP-Zone 2-028 & $\begin{array}{l}\text { K-27 and K-29 Building EU Group DQO } \\
\text { Scoping Package Radiological Survey } \\
\text { Revisions (Z2-EU13) }\end{array}$ & $1 / 31 / 2007$ & $2 / 2 / 2007$ \\
\hline
\end{tabular}


Table 3. (continued)

\begin{tabular}{|c|c|c|c|}
\hline FCN number & Title or description & Date submitted & Date approved \\
\hline FCN-ETTP-Zone 2-029 & $\begin{array}{l}\text { South Park Area EU Group DQO Scoping } \\
\text { Package limited soil remediation at K-1004-L } \\
\text { (Z2-EU33) }\end{array}$ & $1 / 5 / 2007$ & $1 / 5 / 2007$ \\
\hline FCN-ETTP-Zone 2-030 & $\begin{array}{l}\text { Mitchell Branch Area EU Group DQO } \\
\text { Scoping Package omit sampling in K-1420 } \\
\text { basement (Z2-EU39) }\end{array}$ & $1 / 29 / 2007$ & $\begin{array}{l}\text { Rejected on } \\
1 / 31 / 2007\end{array}$ \\
\hline FCN-ETTP-Zone 2-031 & $\begin{array}{l}\text { Main Plant EU Group DQO Scoping Package } \\
\text { biased sampling in K-1401 pits (Z2-EU31) }\end{array}$ & 2/7/2007 & $3 / 20 / 2007$ \\
\hline FCN-ETTP-Zone 2-032 & $\begin{array}{l}\text { Mitchell Branch Area EU Group DQO } \\
\text { Scoping Package biased and WAC sampling } \\
\text { (Z2-EU29) }\end{array}$ & 2/9/2007 & $3 / 20 / 2007$ \\
\hline FCN-ETTP-Zone 2-034 & $\begin{array}{l}\text { Mitchell Branch Area EU Group DQO } \\
\text { Scoping Package backfill } 1407 \text { E\&F Ponds } \\
\text { (Z2-EU35) }\end{array}$ & $\begin{array}{l}\text { 2/15/2007. } \\
\text { Rev. } 1 \text { sent } \\
\text { 2/19/2007; } \\
\text { Rev. } 4 \text { sent } \\
\text { 2/21/2007 }\end{array}$ & $\begin{array}{l}\text { Interim approval } \\
2 / 15-24 / 2007 ; \\
\text { final approval } \\
2 / 22 / 2007\end{array}$ \\
\hline FCN-ETTP-Zone 2-035 & $\begin{array}{l}\text { Main Plant EU Group DQO Scoping Package } \\
\text { biased sampling in K-1501 sump (Z2-EU36) }\end{array}$ & $3 / 7 / 2007$ & $3 / 20 / 2007$ \\
\hline FCN-ETTP-Zone 2-038 & $\begin{array}{l}\text { Main Plant EU Group DQO Scoping Package } \\
\text { biased sampling in K-1501 pit (Z2-EU36) }\end{array}$ & $3 / 29 / 2007$ & $4 / 12 / 2007$ \\
\hline FCN-ETTP-Zone 2-039 & $\begin{array}{l}\text { South Park Area EU Group DQO Scoping } \\
\text { Package for biased sampling adjacent to } \\
\text { K-1225 (Z2-EU33) }\end{array}$ & $4 / 4 / 2007$ & $4 / 23 / 2007$ \\
\hline FCN-ETTP-Zone 2-040 & $\begin{array}{l}\text { Mitchell Branch Area EU Group DQO } \\
\text { Scoping Package biased sampling (Z2-EU44) }\end{array}$ & $4 / 18 / 2007$ & $4 / 23 / 2007$ \\
\hline FCN-ETTP-Zone 2-041 & Zone 1 UST Remedial Action & $5 / 8 / 2007$ & $5 / 24 / 2007$ \\
\hline FCN-ETTP-Zone 2-042 & $\begin{array}{l}\text { Main Plant EU Group DQO Scoping Package } \\
\text { backfill four K-1401 pits (pits 1,2, 30, } \\
\text { and 31) (Z2-EU31) }\end{array}$ & $5 / 1 / 2007$ & $5 / 31 / 2007$ \\
\hline FCN-ETTP-Zone 2-043 & $\begin{array}{l}\text { Main Plant EU Group DQO Scoping Package } \\
\text { backfill the K-1501 pit (Z2-EU36) }\end{array}$ & $5 / 15 / 2007$ & $5 / 24 / 2007$ \\
\hline FCN-ETTP-Zone 2-044 & $\begin{array}{l}\text { Mitchell Branch Area EU Group DQO } \\
\text { Scoping Package backfill the K-1420 } \\
\text { basement (Z2-EU39) }\end{array}$ & $5 / 10 / 2007$ & $5 / 21 / 2007$ \\
\hline FCN-ETTP-Zone 2-045 & $\begin{array}{l}\text { South Park Area EU Group DQO Scoping } \\
\text { Package for step out sampling downgradient } \\
\text { of the K-1004 dilution pits (Z2-EU33) }\end{array}$ & $5 / 15 / 2007$ & $5 / 24 / 2007$ \\
\hline FCN-ETTP-Zone 2-046 & $\begin{array}{l}\text { South Park Area EU Group DQO Scoping } \\
\text { Package for sampling the K-1006 dilution pit } \\
\text { (Z2-EU33) }\end{array}$ & $5 / 18 / 2007$ & $5 / 22 / 2007$ \\
\hline FCN-ETTP-Zone 2-047 & $\begin{array}{l}\text { Poplar Creek EU Group DQO Scoping } \\
\text { Package adding slabs to Zone } 2 \text { WHP } \\
\text { (Z2 EUs } 12 \text { and } 13 \text { ) }\end{array}$ & $5 / 18 / 2007$ & $5 / 30 / 2007$ \\
\hline FCN-ETTP-Zone 2-048 & All of Zone 2 sampling protocol revisions & $5 / 25 / 2007$ & $5 / 30 / 2007$ \\
\hline FCN-ETTP-Zone 2-053 & $\begin{array}{l}\text { South Park Area EU Group DQO Scoping } \\
\text { Package for dilution pits RA (Z2-EU33) }\end{array}$ & $6 / 21 / 2007$ & $7 / 3 / 2007$ \\
\hline
\end{tabular}


Table 3. (continued)

\begin{tabular}{|c|c|c|c|}
\hline FCN number & Title or description & Date submitted & Date approved \\
\hline FCN-ETTP-Zone 2-054 & $\begin{array}{l}\text { South Park Area EU Group DQO Scoping } \\
\text { Package for biased sampling in Manhole } \\
(\mathrm{MH}) 057 \text { (Z2-EU33) }\end{array}$ & $\begin{array}{l}7 / 2 / 2007 \\
\text { revision sent } \\
7 / 23 / 2007\end{array}$ & $8 / 21 / 2007$ \\
\hline FCN-ETTP-Zone 2-055 & $\begin{array}{l}\text { North Park Area EU Group DQO Scoping } \\
\text { Package for adding K-1066 scrap to the } \\
\text { Zone } 2 \text { WHP (Z2-EU33) }\end{array}$ & $\begin{array}{l}\text { 7/3/2007; revised } \\
7 / 11 \& 20 / 2007\end{array}$ & $8 / 21 / 2007$ \\
\hline FCN-ETTP-Zone 2-056 & $\begin{array}{l}\text { K-31/K-33 EU Group DQO Scoping Package } \\
\text { for adding UF } \mathrm{UF}_{6} \text { cylinders from K-33 Building } \\
\text { to the Waste Handling Plan (Z2-EU04) }\end{array}$ & $\begin{array}{l}7 / 3 / 2007 \\
\text { reissued } \\
8 / 16 / 2007\end{array}$ & $9 / 5 / 2007$ \\
\hline FCN-ETTP-Zone 2-057 & $\begin{array}{l}\text { Main Plant EU Group DQO Scoping Package } \\
\text { omit wall sampling in K-1401 basement and } \\
\text { backfill basement (Z2-EU31) }\end{array}$ & $7 / 26 / 2007$ & Pending \\
\hline FCN-ETTP-Zone 2-058 & $\begin{array}{l}\text { Mitchell Branch Area EU Group DQO } \\
\text { Scoping Package use Quik-Solid in the } \\
\text { K-1420 basement (Z2-EU39) }\end{array}$ & $7 / 30 / 2007$ & $8 / 2 / 2007$ \\
\hline FCN-ETTP-Zone 2-059 & $\begin{array}{l}\text { K-1070-C/D and Downgradient Area Group } \\
\text { DQO Scoping Package omit mid points } \\
\text { (Z2-EU41) }\end{array}$ & $7 / 23 / 2007$ & $8 / 2 / 2007$ \\
\hline FCN-ETTP-Zone 2-063 & $\begin{array}{l}\text { South Park Area EU Group DQO Scoping } \\
\text { Package for adding BOS Labs dilution pit } \\
\text { waste to the Zone } 2 \text { WHP (Z2-EU33) }\end{array}$ & $8 / 16 / 2007$ & $9 / 5 / 2007$ \\
\hline FCN-ETTP-Zone 2-064 & $\begin{array}{l}\text { South Park Area EU Group DQO Scoping } \\
\text { Package for closing BOS Labs dilution pit at } \\
\text { K-1006 in place (Z2-EU33) }\end{array}$ & $8 / 23 / 2007$ & $9 / 5 / 2007$ \\
\hline
\end{tabular}

BOS $=$ Balance of Site

$\mathrm{DQO}=$ data quality objective

ETTP $=$ East Tennessee Technology Park

EMWMF $=$ Environmental Management Waste Management Facility

$\mathrm{EU}=$ exposure unit

FCN $=$ Field Change Notice

HVSS $=$ Happy Valley Service Station

ORR = Oak Ridge Reservation

$\mathrm{RA}=$ remedial action

$\mathrm{RAB}=$ radiation area boundary

$\mathrm{RCW}=$ recirculating water

UST $=$ underground storage tank

$\mathrm{WAC}=$ waste acceptance criteria

$\mathrm{WHP}=$ Waste Handling Plan 


\section{PROJECT REQUIREMENTS}

Requirements for the characterization activities, final status assessments, and RAs originated with the Zone 2 ROD. The Zone 2 ROD presents certain specific soil RAs required in Zone 2 and provides general guidelines for addressing the remainder of the soils in this Zone. In response to the guidelines for addressing Zone 2 soils, the DVS was developed to present specific requirements for addressing soils and making action/NFA decisions. It is further stated in Sect. 1.5 of the Zone 2 ROD that additional contaminants could be identified during remedy implementation or confirmation.

\subsection{ZONE 2 RECORD OF DECISION}

The Zone 2 ROD presents the selected remedy for environmental remediation of contaminated areas within Zone 2 at ETTP. An evaluation of existing data performed in the Zone 2 ROD determined the following sites had sufficient characterization data to demonstrate unacceptable risk and warrant additional characterization and/or selection of an action for soil:

- K-1070-B Old Burial Ground,

- K-1420 Soils,

- K-1004-J Lab complex,

- K-1401 Facility,

- K-1070-C/D Area, and

- Zone 2 miscellaneous soils.

In addition, the Zone 2 ROD specifies that a DVS be developed to address the characterization of soils in other areas in the Zone with insufficient data to determine if an action is required. The key criterion in the Zone 2 ROD for the action/NFA decision and a successful RA is the RAO, which is presented in Table 4.

Table 4. RAO and protection goal for Zone 2

Remediation issue

Future land use

Groundwater resources
Protection goal

Protect human health under an unrestricted industrial land use to a risk level not to exceed $1 \times 10^{-4}$

Control leaching and migration from contaminated soil to help minimize further impacts to groundwater

$\mathrm{RAO}=$ remedial action objective

Other key parts of the ROD include the determination of future land use as unrestricted industrialto $10 \mathrm{ft} \mathrm{bgs}$, protection of the industrial worker from soil exposure identified as the primary risk driver, development of a risk assessment methodology based on EUs, and definition of soil COCs with corresponding soil RLs (two RLs were established for each COC in the ROD). The maximum RL is the concentration that a COC may not exceed at any location within an EU. The average RL is the average COC concentration within an EU which, when exceeded, means the RAO risk protection goal has not been met. The Zone 2 ROD COCs, chemicals and radionuclides required for analysis, and associa ted RLs are presented in Table 5. 
Table 5. Chemicals and radionuclides required for analysis in Zone 2 DVS samples and their evaluation criteria ${ }^{a}$

\begin{tabular}{|c|c|c|c|c|c|c|}
\hline $\begin{array}{l}\text { Chemicals and } \\
\text { radionuclides }\end{array}$ & $\begin{array}{c}\text { Maximum } \\
\text { RL }\end{array}$ & $\begin{array}{c}\text { Average } \\
\text { RL }\end{array}$ & $\begin{array}{l}\text { Industrial } \\
\text { PRG }\left(1^{-5}\right) \\
\end{array}$ & Background & $\begin{array}{c}\text { Groundwater } \\
\text { SL }\end{array}$ & $\begin{array}{l}\text { Residential } \\
\text { PRG }\left(10^{-6}\right) \\
\end{array}$ \\
\hline \multicolumn{7}{|c|}{ Metals $(\mathrm{mg} / \mathrm{kg})(\mathrm{mg} / \mathrm{L}$ for groundwater $)$} \\
\hline Aluminum & & & 100,000 & 40,300 & & 7,614 \\
\hline Antimony & & & 410 & 1.52 & 144 & 3.1 \\
\hline Arsenic $^{b}$ & 900 & 300 & 16 & 14.95 & 66.3 & 0.39 \\
\hline Barium & & & 67,000 & 124.93 & 9,150 & 537 \\
\hline Beryllium & 6,000 & 2,000 & 1,900 & 2.20 & & 15 \\
\hline Boron & & & 100,000 & & & 1,600 \\
\hline Cadmium & & & 450 & $0.22 \mathrm{U}$ & & 3.7 \\
\hline Calcium & & & & 2400 & & \\
\hline Chromium & & & 640 & 44.88 & 172 & 22 \\
\hline Cobalt & & & 130,000 & 42.00 & & 138 \\
\hline Copper & & & 41,000 & 22.48 & & 313 \\
\hline Iron & & & 100,000 & 58,600 & & 2,346 \\
\hline Lead & & & 800 & 37.91 & 3,370 & 400 \\
\hline Lithium & & & 20,000 & 48.94 & & 156 \\
\hline Magnesium & & & & 3,300 & & \\
\hline Manganese & & & 19,000 & 2,200 & & 176 \\
\hline Mercury $^{b}$ & 1,800 & 600 & 310 & 0.17 & & 2.35 \\
\hline Molybdenum & & & 5,100 & & & 39 \\
\hline Nickel & & & 20,000 & 26.07 & & 156 \\
\hline Potassium & & & & $5,074.69$ & & \\
\hline Selenium & & & 5,100 & 1.47 & & 39 \\
\hline Silver & & & 5,100 & $0.6 \mathrm{U}$ & & 39 \\
\hline Sodium & & & & 497 & & \\
\hline Thallium & & & 67 & $0.4 \mathrm{U}$ & 10.8 & 0.52 \\
\hline Uranium & & & 200 & & & 1.56 \\
\hline Vanadium & & & 1,000 & 65.47 & & 7.8 \\
\hline Zinc & & & 100,000 & 89.70 & & 2,346 \\
\hline \multicolumn{7}{|c|}{ Radionuclides (pCi/g) (ug/L for groundwater) } \\
\hline Cesium $137^{b}$ & 20 & 2 & 1.1 & & & 0.06 \\
\hline Cobalt-60 & & & 0.6 & & & 0.04 \\
\hline \multicolumn{7}{|l|}{ Gross alpha activity } \\
\hline Gross beta activity & & & & & & \\
\hline Neptunium-237 & 50 & 5 & 2.7 & & & 0.13 \\
\hline Potassium-40 & & & 2.7 & 32.12 & & 0.11 \\
\hline Radium-226 $6^{b, c}$ & 15 & 5 & 0.26 & 1.25 & & 0.01 \\
\hline Technetium-99 & & & 9,000 & & & 0.25 \\
\hline Thorium $230^{b, c}$ & 15 & 5 & 210 & 1.20 & & 3.5 \\
\hline Thorium $232^{b, c}$ & 15 & 5 & 0.176 & 1.95 & & 0.01 \\
\hline Uranium- $234^{b, c}$ & 7,000 & 700 & 330 & 1.47 & 61.1 & 4.02 \\
\hline Uranium- $235^{b, c}$ & 80 & 8 & 4.0 & & 61.1 & 0.2 \\
\hline Uranium-238 & 500 & 50 & 18 & 1.47 & 61.1 & 0.74 \\
\hline \multicolumn{7}{|l|}{ Pesticides and PCBs (ug/kg) } \\
\hline PCB-1016 ${ }^{b}$ & 100,000 & 10,000 & 37,000 & & & 393 \\
\hline PCB-1221 ${ }^{b}$ & 100,000 & 10,000 & 7,436 & & & 112 \\
\hline PCB $-1232^{b}$ & 100,000 & 10,000 & 7,436 & & & 112 \\
\hline PCB- $1242^{b}$ & 100,000 & 10,000 & 7,436 & & & 112 \\
\hline PCB- $1248^{b}$ & 100,000 & 10,000 & 7,436 & & & 112 \\
\hline PCB- $1254^{b}$ & 100,000 & 10,000 & 7,436 & & & 112 \\
\hline PCB- $1260^{b}$ & 100,000 & 10,000 & 7,436 & & & 112 \\
\hline Polychlorinated biphenyl $l^{b}$ & 100,000 & 10,000 & 7,436 & & & 112 \\
\hline
\end{tabular}


Table 5. (continued)

\begin{tabular}{|c|c|c|c|c|c|}
\hline $\begin{array}{l}\text { Chemicals and } \\
\text { radionuclides }\end{array}$ & $\begin{array}{cc}\text { Maximum } & \text { Average } \\
\text { RL } & \text { RL }\end{array}$ & $\begin{array}{l}\text { Industrial } \\
\text { PRG }\left(10^{-5}\right)\end{array}$ & Background & $\begin{array}{c}\text { Groundwater } \\
\text { SL }\end{array}$ & $\begin{array}{l}\text { Residential } \\
\text { PRG }\left(1^{-6}\right)\end{array}$ \\
\hline \multicolumn{6}{|c|}{ Semivolatile Organic Compounds (ug/kg) (ug/L for groundwater) } \\
\hline 1,2,4-Trichlorobenzene & & 220,000 & & & 6,216 \\
\hline 1,2-Dichlorobenzene & & 600,000 & & & 110,330 \\
\hline 1,3-Dichlorobenzene & & 600,000 & & & 53,135 \\
\hline 1,4-Dichlorobenzene & & 79,000 & & & 3,447 \\
\hline 2,3,4,6-Tetrachlorophenol & & $18,000,000$ & & & 183,309 \\
\hline 2,4,5-Trichlorophenol & & $62,000,000$ & & & 611,031 \\
\hline 2,4,6-Trichlorophenol & & 62,000 & & & 611 \\
\hline 2,4-Dichlorophenol & & $1,800,000$ & & & 18,331 \\
\hline 2,4-Dimethylphenol & & $12,000,000$ & & & 122,206 \\
\hline 2,4-Dinitrophenol & & $1,200,000$ & & & 12,221 \\
\hline 2,4-Dinitrotoluene & & 25,000 & & & 715 \\
\hline 2,6-Dinitrotoluene & & 25,000 & & & 715 \\
\hline 2-Chloronaphthalene & & $23,000,000$ & & & 493,664 \\
\hline 2-Chlorophenol & & 240,000 & & & 6,340 \\
\hline 2-Methyl-4,6-dinitrophenol & & 62,000 & & & 611 \\
\hline 2-Methylnaphthalene & & 190,000 & & & 5,592 \\
\hline 2-Methylphenol & & $31,000,000$ & & & 305,515 \\
\hline 2-Nitrobenzenamine & & $1,800,000$ & & & 18,277 \\
\hline \multicolumn{6}{|l|}{ 2-Nitrophenol } \\
\hline 3,3'-Dichlorobenzidine & & 38,000 & & & 1,081 \\
\hline 3-Nitrobenzenamine & & 18,000 & & & 1,833 \\
\hline \multicolumn{6}{|l|}{$\begin{array}{l}\text { 4-Bromophenyl phenyl } \\
\text { ether }\end{array}$} \\
\hline \multicolumn{6}{|l|}{ 4-Chloro-3-methylphenol } \\
\hline 4-Chlorobenzenamine & & $2,500,000$ & & & 24,441 \\
\hline \multicolumn{6}{|l|}{ 4-Chlorophenyl phenyl } \\
\hline 4-Methylphenol & & 3100000 & & & \\
\hline 4-Nitrobenzenamine & & 180,000 & & & $\begin{array}{l}310,000 \\
18,330\end{array}$ \\
\hline \multicolumn{6}{|l|}{ 4-Nitrophenol } \\
\hline Acenaphthene & & $29,000,000$ & & & 370,000 \\
\hline Acenaphthylene & & $29,000,000$ & & & 370,000 \\
\hline Aniline & & $3,000,000$ & & & 42,742 \\
\hline Anthracene & & $100,000,000$ & & & $2,200,000$ \\
\hline Benz(a)anthracene & & 21,000 & & & 621 \\
\hline Benzenemethanol & & $100,000,000$ & & & 1,833 \\
\hline Benzo(a)pyrene & & 2,100 & & & 62 \\
\hline Benzo(b)fluoranthene & & 21,000 & & & 621 \\
\hline Benzo(ghi)perylene & & $29,000,000$ & & & 231,595 \\
\hline Benzo(k)fluoranthene & & 210,000 & & & 6,215 \\
\hline Benzoic acid & & $100,000,000$ & & & $24,000,000$ \\
\hline \multicolumn{6}{|l|}{$\begin{array}{l}\text { Bis(2-chloroethoxy) } \\
\text { methane }\end{array}$} \\
\hline Bis(2-chloroethyl) ether & & 5,800 & & & 218 \\
\hline \multicolumn{6}{|l|}{ Bis(2-chloroisopropyl) } \\
\hline ether & & 74,000 & & & 2,884 \\
\hline Bis(2-ethylhexyl)phthalate & & $1,200,000$ & & $2,350,000$ & 34,741 \\
\hline Butyl benzyl phthalate & & $100,000,000$ & & & $1,200,000$ \\
\hline Carbazole & & 860,000 & & & 24,319 \\
\hline Chrysene & & $2,100,000$ & & & 62,146 \\
\hline Di-n-butyl phthalate & & $62,000,000$ & & & 611,000 \\
\hline Di-n-octylphthalate & & $25,000,000$ & & & 244,000 \\
\hline
\end{tabular}


Table 5. (continued)

\begin{tabular}{|c|c|c|c|c|c|c|}
\hline $\begin{array}{l}\text { Chemicals and } \\
\text { radionuclides }\end{array}$ & $\begin{array}{c}\text { Maximum } \\
\text { RL } \\
\end{array}$ & $\begin{array}{c}\text { Average } \\
\text { RL }\end{array}$ & $\begin{array}{l}\text { Industrial } \\
\text { PRG }\left(1^{-5}\right) \\
\end{array}$ & Background & $\begin{array}{c}\text { Groundwater } \\
\text { SL } \\
\end{array}$ & $\begin{array}{l}\text { Residential } \\
\text { PRG }\left(10^{-6}\right) \\
\end{array}$ \\
\hline Dibenz(a,h)anthracene & & & 2,100 & & & 62 \\
\hline Dibenzofuran & & & $1,600,000$ & & & 14,526 \\
\hline Diethyl phthalate & & & $100,000,000$ & & & $4,900,000$ \\
\hline Dimethyl phthalate & & & $100,000,000$ & & & $61,000,000$ \\
\hline Diphenyldiazene & & & 160,000 & & & 4,422 \\
\hline Fluoranthene & & & $22,000,000$ & & & 230,000 \\
\hline Fluorene & & & $26,000,000$ & & & 275,000 \\
\hline Hexachlorobenzene & & & 11,000 & & & 304 \\
\hline Hexachlorobutadiene & & & 180,000 & & & 1,833 \\
\hline \multicolumn{7}{|l|}{ Hexachloro- } \\
\hline Hexachloroethane & & & 620,000 & & & 6,110 \\
\hline Indeno( $1,2,3$-cd)pyrene & & & 21,000 & & & 621 \\
\hline Isophorone & & & $5,100,000$ & & & 512,000 \\
\hline \multicolumn{6}{|l|}{ N-Nitroso-di-n- } & 69.5 \\
\hline N-Nitrosodimethylamine & & & 340 & & & 9.54 \\
\hline N-Nitrosodiphenylamine & & & $3,500,000$ & & & 99,261 \\
\hline Naphthalene & & & 190,000 & & & 5,592 \\
\hline Nitrobenzene & & & 100,000 & & & 1,964 \\
\hline Pentachlorophenol & & & 90,000 & & & 2,979 \\
\hline Phenanthrene & & & $29,000,000$ & & & 23,160 \\
\hline Phenol & & & $100,000,000$ & & & $1,800,000$ \\
\hline Pyrene & & & $29,000,000$ & & & 231,600 \\
\hline Pyridine & & & 620,000 & & & 6,110 \\
\hline \multicolumn{7}{|c|}{ Volatile Organic Compounds (ug/kg) (ug/L for groundwater) } \\
\hline 1,1,1-Trichloroethane & & & $1,200,000$ & & 97,900 & 198,200 \\
\hline $1,1,2,2$-Tetrachloroethane & & & 9,300 & & & 408 \\
\hline 1,1,2-Trichloroethane & & & 16,000 & & 1370 & 729 \\
\hline 1,1-Dichloroethane & & & $1,700,000$ & & & 50,640 \\
\hline 1,1-Dichloroethene & & & 410,000 & & 1750 & 12,350 \\
\hline 1,2-Dichloroethane & & & 6,000 & & 729 & 278 \\
\hline 1,2-Dichloropropane & & & 7,000 & & & 342 \\
\hline 2-Butanone & & & $110,000,000$ & & & $2,230,000$ \\
\hline \multicolumn{7}{|l|}{ 2-Hexanone } \\
\hline 4-Methyl-2-pentanone & & & $47,000,000$ & & & 528,100 \\
\hline Acetone & & & $54,000,000$ & & & $1,413,000$ \\
\hline Benzene & & & 14,000 & & 1150 & 643 \\
\hline Bromodichloromethane & & & 18,000 & & & 824 \\
\hline Bromoform & & & $2,200,000$ & & & 61,570 \\
\hline Bromomethane & & & 13,000 & & & 390 \\
\hline Carbon disulfide & & & 720,000 & & & 35,530 \\
\hline Carbon tetrachloride & & & 5,500 & & 2770 & 217 \\
\hline Chlorobenzene & & & 530,000 & & & 15,070 \\
\hline Chloroethane & & & 65,000 & & & 3,026 \\
\hline Chloroform & & & 4,700 & & 1230 & 221 \\
\hline Chloromethane & & & 160,000 & & & 4,685 \\
\hline Dibromochloromethane & & & 26,000 & & & 1,109 \\
\hline Ethylbenzene & & & 400,000 & & & 186,400 \\
\hline Methylene chloride & & & 210,000 & & 241 & 9,107 \\
\hline Styrene & & & $1,700,000$ & & & 438,210 \\
\hline Tetrachloroethene & & & 13,000 & & 4720 & 484 \\
\hline Toluene & & & 520,000 & & 502,000 & 65,600 \\
\hline
\end{tabular}


Table 5. (continued)

\begin{tabular}{|c|c|c|c|c|c|c|}
\hline $\begin{array}{l}\text { Chemicals and } \\
\text { radionuclides }\end{array}$ & $\begin{array}{c}\text { Maximum } \\
\text { RL }\end{array}$ & $\begin{array}{c}\text { Average } \\
\text { RL }\end{array}$ & $\begin{array}{l}\text { Industrial } \\
\text { PRG }\left(1^{-5}\right)\end{array}$ & Background & $\begin{array}{c}\text { Groundwater } \\
\text { SL }\end{array}$ & $\begin{array}{l}\text { Residential } \\
\text { PRG }\left(\mathbf{1 0}^{-6}\right)\end{array}$ \\
\hline Total Xylene & & & 420,000 & & & 27,000 \\
\hline Trichloroethene & & & 1,100 & & 1720 & 53 \\
\hline Vinyl chloride & & & 7,500 & & 176 & 79 \\
\hline cis-1,2-Dichloroethene & & & 150,000 & & & 4,294 \\
\hline cis-1,3-Dichloropropene & & & 18,000 & & & 777 \\
\hline trans-1,2-Dichloroethene & & & 230,000 & & & 6,949 \\
\hline trans-1,3-Dichloropropene & & & 18,000 & & & 777 \\
\hline Diesel Range Organics ${ }^{d}$ & & & & & $100 \mathrm{mg} / \mathrm{kg}$ & \\
\hline Gasoline Range Organics ${ }^{d}$ & & & & & $100 \mathrm{mg} / \mathrm{kg}$ & \\
\hline
\end{tabular}

${ }^{a}$ Chemicals and radionuclides listed include all of the Zone 2 soils COCs and other chemical and radionuclides considered to be potential contaminants at ETTP. Analytical laboratories for DVS samples often report the results for chemicals and radionuclides not listed here and historical data may include analyses for chemicals and radionuclides not reported in DVS samples. When there is a detection in either a DVS or historical sample of a chemical or radionuclide not listed here, the concentration is compared to its $1 \times 10^{5}$ industrial PRG and $1 \times 10^{6}$ residential PRG, which can be found at http://epa-prgs.ornl.gov/cgi-bin/epa-prgs/rad_calc (RAD) and http://www.epa.gov/region09/waste/sfund/prg (Chemical).

${ }^{b}$ Zone 2 ROD contaminant of concern.

${ }^{c}$ Radium-226, Thorium-230, and Thorium-232 are evaluated by a computational method that det ermines the primary RAD constituent and the daughters of the primary radionuclide; the total activity of the primary plus daughters is then compared to established Zone 2 RLs.

${ }^{d}$ Diesel-range organics and gasoline-range organics apply when there is an UST under investigation. The 100- $\mathrm{mg} / \mathrm{kg}$ limit for protection of groundwater is based on State of Tennessee UST regulations.

$\mathrm{COC}=$ contaminant of concern $\quad \mathrm{RAD}=$ radiological

DVS $=$ Dynamic Verification Strategy $\quad R L=$ remediation level

ETTP $=$ East Tennessee Technology Park $\quad$ ROD $=$ Record of Decision

$\mathrm{PRG}=$ preliminary remediation goal $\quad$ UST $=$ underground storage tank

The Zone 2 ROD requires that all of Zone 2 be evaluated for unrestricted use with data from the industrial use scenario. In areas where the information indicates there is little chance for unacceptable contamination, restrictions will not be imposed (see Sect. 11).

\subsection{DYNAMIC VERIFICATION STRATEGY}

The DVS was developed as required by the Zone 2 ROD and designed to provide sufficient data to fill data gaps and conduct final status assessments for all of Zone 2. DVS also was designed to facilitate real-time decision making. This strategy focused on the soil characterization portion of the Zone 2 ROD to determine where action was needed. Acreage classification was used to progressively focus the investigation efforts in areas where there was a moderate to high probability of soil contamination (see Sect. 2.1.3). The DVS also helped verify information from previous investigations because of the presumption that the vast majority of acreage in Zone 2 had little or no contamination. This strategy was designed to obtain data to support the presumption and-to incorporate flexibility to facilitate rapid collection of additional data if the presumption proved false based on data results. The strategy was to gather adequate data with minimal iterations of site investigation planning and mobilization.

The DVS addressed requirements of the Zone 2 ROD RAO with the DQO process. Step 5 of the DVS DQOs presented four decision rules whereby any particular land area in Zone 2 was deemed to have met the RAO requirements (see Table 6). 
Table 6. DVS decision rules for Zone 2 soils

\begin{tabular}{|c|c|c|c|}
\hline \multicolumn{4}{|l|}{ Decision } \\
\hline Rule & If & Then & Otherwise \\
\hline 1 & $\begin{array}{l}\text { Concentration of any COC in a } \\
\text { localized area ("hot spot" nominally } \\
50-\mathrm{ft} \text { radius) within an EU to a depth } \\
\text { of } 10 \mathrm{ft} \text { exceeds the maximum RL }\end{array}$ & $\begin{array}{l}\text { Remediate localized area of elevated } \\
\text { contamination until the COC concentration is } \\
\text { less than the maximum RL }\end{array}$ & $\begin{array}{l}\text { NFA for } \\
\text { protection of } \\
\text { industrial worker }\end{array}$ \\
\hline 2 & $\begin{array}{l}\text { Mean concentration value of any soil } \\
\text { COC to a depth of } 10 \mathrm{ft} \text { exceeds the } \\
\text { average RL within an EU }\end{array}$ & $\begin{array}{l}\text { Remediate elevated areas of contamination } \\
\text { until the mean COC concentration over the EU } \\
\text { is less than the respective RL }\end{array}$ & $\begin{array}{l}\text { NFA for } \\
\text { protection of } \\
\text { industrial worker }\end{array}$ \\
\hline 3 & $\begin{array}{l}\text { Industrial risk across the EU to a depth } \\
\text { of } 10 \mathrm{ft} \text { is }>1 \times 10^{-4} \text { ELCR or target } \\
\text { organ HIs exceed } 1\end{array}$ & $\begin{array}{l}\text { Remediate elevated areas of contamination } \\
\text { until residual risk over the EU is below the risk } \\
\text { levels. Evaluate the need for action if target } \\
\text { HIs exceed } 1\end{array}$ & $\begin{array}{l}\text { NFA for } \\
\text { protection of } \\
\text { industrial worker }\end{array}$ \\
\hline 4 & $\begin{array}{l}\text { Site-specific contaminants in } \\
\text { groundwater exceed MCL or } \\
\text { site-specific, mass-based soil SLs }{ }^{a} \\
\text { calculated for a site for the protection } \\
\text { of groundwater are exceeded above } \\
\text { the water table or bedrock surface } \\
\text { (whichever is shallower) }\end{array}$ & Evaluate the impacts of remediating the site & $\begin{array}{l}\text { NFA for the } \\
\text { protection of } \\
\text { groundwater }\end{array}$ \\
\hline
\end{tabular}

${ }^{a}$ Soil SLs for the protection of groundwater are presented in the Record of Decision for Soil, Buried Waste, and Subsurface Structure Actions in Zone 2, East Tennessee Technology Park, Oak Ridge, Tennessee, DOE/OR/01-2161\&D2, U.S. Department of Energy, Office of Environmental Management, Oak Ridge, TN.

$\mathrm{COC}=$ contaminant of concern DVS $=$ Dynamic Verification Strategy

ELCR $=$ excess lifetime cancer risk

$\mathrm{EU}=$ exposure unit

$\mathrm{HI}=$ hazard index

\author{
$\mathrm{MCL}=$ maximum contaminant level \\ NFA $=$ no further action \\ $\mathrm{RL}=$ remediation level \\ $\mathrm{SL}=$ screening level
}

\subsection{FINAL STATUS EVALUATION PROCESS}

The final status recommendation for action/NFA of each Zone $2 \mathrm{EU}$ as presented in this document was determined by evaluating the EU in terms of the four decision rules. Descriptions of the action/NFA evaluation processes for each decision rule are presented in Sect. 3.3.1. A discussion of special data uses and considerations in the action/NFA evaluations is included in Sect. 3.3.2. As defined in the Zone 2 ROD, a risk screening was performed to evaluate the industrial land use of each EU. A qualitative risk screening was also conducted against $1 \times 10^{-6}$ residential preliminary remediation goals (PRGs) to evaluate unrestricted use of each EU. A description of this evaluation is presented in Sect. 3.3.3.

\subsubsection{Action/No Further Action Decision}

The process whereby EUs are evaluated against the four DVS decision rules (see Sect. 3.2) is described in the following text and presented graphically in Fig. 5 as Steps 1 through 4.

Decision Rule 1-Maximum RL Evaluation. Zone 2 soils chemical and radionuclide COC concentrations are screened against their maximum (not to exceed) RLs as defined in the Zone 2 ROD. If any compound is detected at a concentration above its maximum RL, an action is required. Maximum RLs and the COCs they are applied to are presented in Table 5. 


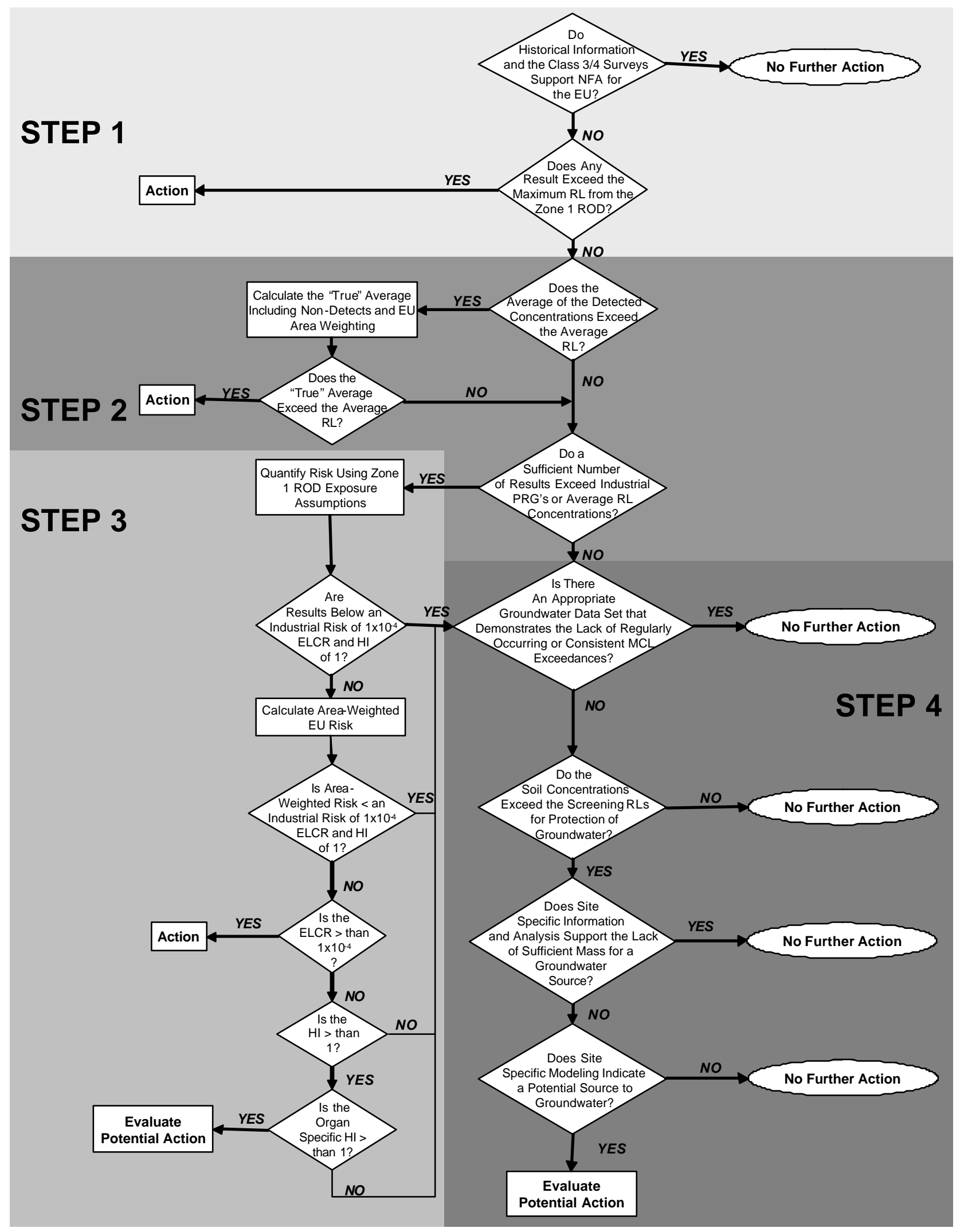

Fig. 5. Risk evaluation process. 
Decision Rule 2-Average RL Evaluation. The mean value of the detected concentrations for each Zone 2 soils COC across an EU is screened against the respective average RL. If the average detected concentration of any COC across an EU is less than the average RL for that COC, then the overall average concentration of the COC (which includes non-detected results and area weighting) must also be below the average RL.

If the EU average detected concentration of soils COC exceeds the average RL for that COC, then the EU average is calculated using the detected values and half the detection limit for all the non-detect results. If the EU average for this calculation is still in excess of the Zone 2 average RLs, then an area-weighted mean for the EU is calculated (see Sect. 3.3.2). If the area-weighted mean concentration of the COC is above the Zone 2 average RL for the COC, then an action is required. Average RLs and the COCs they are applied to are presented in Table 5.

Decision Rule $3^{1}$-Cumulative Risk Assessment. The first step in evaluating the cumulative risk associated with an EU is to perform a risk screen to determine if further assessment in the form of a risk calculation is required. The risk screen consists of comparing the data to average RLs and an EPA Region IX ELCR $<1 \times 10^{-5}$ or HI of 1 . If the concentration of any chemical or radionuclide exceeds either an average RL or an industrial PRG (except as described in Sect. 3.3.2), then the complete EU data set is evaluated to determine if the cumulative effect of all chemicals and radionuclides in the EU would cause the EU to fail the $1 \times 10^{-4}$ risk criterion established in the Zone 2 ROD. If such a determination is made, a risk calculation ${ }^{2}$ is conducted as described below. Additional detail on the risk calculation is documented in Supporting Documentation for Preliminary Remediation Goals Used in the Dynamic Verification Strategy Sampling Program, East Tennessee Technology Park, Oak Ridge, TN, BJC/OR-2383 (BJC 2006). EPA Region IX $1 \times 10^{-5}$ industrial PRGs for chemicals and radionuclides analyzed under the DVS are presented in Table 5.

If it is determined by the risk screen that a risk calculation is required, then risk is calculated in accordance with the Zone 2 ROD by first calculating the risk based on the available EU data. If the calculated risk is below an industrial $1 \times 10^{-4}$ ELCR or target organ HI of 1 , then NFA is appropriate. If not, EU area-weighted calculations are performed.

Because data collection is focused on areas of potential contamination, the resultant data population is more representative of specific portions of an EU than the total EU, and it is the total EU over which risk is to be evaluated according to the Zone 2 ROD. To account for this over emphasis of potentially contaminated areas, an area-weighted risk calculation is performed for the EU. To do this, an area-weighted average is calculated for each chemical and radionuclide in the EU according to the area-weighted averaging method described in Sect. 3.3.2, and the cumulative risk is calculated on the area-weighted averages according to the guidelines in the Zone 2 RDR/RAWP (DOE 2007).

If the area-weighted calculation results in an acceptable ELCR $\left(<1 \times 10^{-4}\right)$ and HI $(<1)$, a NFA determination can be made. However, if the area-weighted calculation results in an unacceptable ELCR $\left(>1 \times 10^{-4}\right)$, the EU cannot be cleared for industrial land use and an action determination is made. If the area-weighted approach results in an unacceptable HI $(>1)$, an individual target organ $\mathrm{HI}$ review is conducted. If individual target organ HIs exceed 1, an assessment of the need for action is conducted in accordance with the Zone 2 RDR/RAWP (DOE 2007).

Decision Rule 4-Threat to groundwater. A threat to groundwater by Zone 2 soils is evaluated by first reviewing existing area groundwater data for maximum contaminant level (MCL) exceedances that occur on a regular basis. If the groundwater data are sufficient and there are no consistent MCL exceedances, then NFA is appropriate. If the groundwater data are insufficient to discern regular MCL exceedances, or the data are sufficient and regular MCL exceedances are observed, then soil

\footnotetext{
${ }^{l}$ Radium and thorium isotopes are excluded from the risk evaluation (see Sect. 3.3.2 for further discussion).

${ }^{2}$ Number of samples to adequately characterize the EU and evaluate risk is determined in the DQO scoping process with the Core Team. Available DVS and historical data are used when risk calculations are performed.
} 
concentrations are screened against the SLs for the protection of groundwater as defined in the Zone 2 ROD (DOE 2005). Based on the screening, site-specific modeling may be conducted if additional evaluation is required. Consideration of an action is required if modeling results indicate a site may be a potential source of contamination to groundwater. The sitewide ROD evaluates available site data for threats to groundwater. Data generated from the DVS process will be included in this ROD. Groundwater SLs for chemicals and radionuclides analyzed under the DVS are presented in Table 5.

The Zone 2 ROD specifically addresses USTs at ETTP, including those in Zone 1 and Zone 2. State UST regulations are applicable or relevant and appropriate regulations for all ETTP tanks according to the Zone 2 ROD. Therefore, closure will be performed according to State of Tennessee regulations. Tanks that are demonstrated to be clean (i.e., containing no fluids that could adversely effect groundwater) and have no soil contamination present to indicate a leak will be closed in place by filling. Tanks that contain residual fluid and/or where soil contamination indicates a leak will be removed according to state UST regulations.

\subsubsection{Special Data Uses and Considerations}

Circumstances requiring special data uses and considerations during EU action/NFA evaluations fall into three categories: (1) evaluation of Class 3 and Class 4 SUs that may not have any analytical data, (2) area-weighted averages, and (3) chemicals and radionuclides with regulatory limit concentrations less than or similar in value to background concentrations.

Class 3 and Class 4 SU Evaluations. Some EUs have historical information and the Class 3 and Class 4 SU walkover assessments provide sufficient information to support the NFA determination. Class 3 and Class 4 SU walkover assessments include visual observations of the SU acreage, collection of radiological survey data, and selected biased sampling where survey results or observations indicate the presence of impacted soils.

Area-weighted Averages. Area-weighted averaging is accomplished by calculating the fraction of the total area of the EU that contains contaminated soil (called a contaminant area fraction). The remaining area of the EU constitutes a remaining acreage area fraction. The average concentrations of the soil constituents in the area of contamination are calculated and then multiplied by the contaminant area fraction. Average soil concentrations then are calculated for the remaining acreage area of the EU using all available sample results or, if no sample data are available, background concentrations. These average concentrations are multiplied by the remaining acreage area fraction. The area-weighted EU average is then calculated as the sum-of-the-fractions.

Regulatory Limit versus Background Concentrations. The industrial PRGs for arsenic, Cs-137, K-40, Ra-226, Th-228, and Th-232 are less than or similar in value to their respective background concentrations, which results in the industrial PRG exceeding all, or most, instances in where the chemical or radionuclide is detected. The Zone 2 ROD recognizes this issue as it pertains to Ra-226, Th-228, and Th-232 and declares the data for these will not be used for risk calculations. Instead, health hazards associated with the presence of these radionuclides in Zone 2 soils will be evaluated by comparison to the RLs for Ra-226 and Th-232 (which contains Th-228 in its decay chain).

When a risk screen is conducted as part of the Decision Rule 3 evaluation (Sect. 3.3.1), secondary concentration comparisons are made in response to PRG exceedances by arsenic, Cs-137, and K-40 before proceeding with the cumulative effects evaluation, which may lead to performing risk calculations for the EU. The industrial PRG for arsenic $(15.9 \mathrm{mg} / \mathrm{kg})$ is very close in value to the arsenic background concentration $(14.95 \mathrm{mg} / \mathrm{kg})$. Although no local background value exists, the industrial PRG for Cs-137 $(1.13 \mathrm{pCi} / \mathrm{g})$ is low enough that this ubiquitous nuclear fallout radionuclide exceeds its PRG in most instances where it is detected, and the industrial PRG for K-40 $(2.73 \mathrm{pCi} / \mathrm{g})$ is less than the background concentration for K-40 (32.12 pCi/g). Secondary concentration comparisons that are performed include 
arsenic concentrations to the arsenic Zone 2 soils average RL, Cs-137 concentrations to the Cs-137 Zone 2 soils average RL, and K-40 concentrations to the K-40 background value. If any of these secondary concentration comparisons result in an exceedance, then the complete EU dataset is evaluated for cumulative effects as described in Sect. 3.3.1.

Ra/Th Decay Series Calculation. Because the carcinogenic risk associated with the concentrations of radium and thorium isotopes in the natural background at ETTP exceeds the cumulative risk goal of $1 \times 10^{-4}$, RL values for these radionuclides are based on alternative concentration levels rather than risk. The alternative concentration levels of $5 \mathrm{pCi} / \mathrm{g}$ above background (average RL) and $15 \mathrm{pCi} / \mathrm{g}$ above background (maximum RL) were set as low as reasonably achievable under the site-specific conditions. Because site-specific background concentrations of these radionuclides exceed the target risk range, concentrations of these radionuclides and their decay series are not considered in the risk estimates.

The Zone 2 ROD states that average RL and maximum RL exceedances by Ra-226, Th-230, and Th-232 will be evaluated by summing above-background concentrations of the greater of Ra- 226 or Th230 with the above-background concentrations of Th-232 and comparing the results to $5 \mathrm{pCi} / \mathrm{g}$ (average RL) and $15 \mathrm{pCi} / \mathrm{g}$ (maximum RL). The calculations are performed by subtracting the background values of Ra-226, Th-230, and Th-232 from the analytical result. A Ra/Th decay series value then is calculated for each sample by selecting the larger of the Ra-226 or Th-230 value and summing the selected value with the Th-232 value.

$\mathrm{The} \mathrm{Ra} / \mathrm{Th}$ decay series was considered to be analyzed in a sample if one or more of the three radionuclides it comprises were analyzed in the sample. Also, this decay series was considered to be detected in a sample if one or more of the three radionuclides it comprised were detected in a sample. It is possible that a Ra/Th decay series detected value could equal zero.

\subsubsection{Qualitative Risk Screening for Unrestricted Use}

While not required by the Zone $2 \mathrm{ROD}$, a qualitative risk screening for unrestricted use was conducted to determine the possibility for releasing the EUs without institutional controls. These results are provided for information only and do not form the basis for action (see Sect. 11). For this screening, average concentrations were compared to $1 \times 10^{-6}$ residential PRGs and ETTP soils background values from Table 4 in Soil Background Supplemental Data Set for the East Tennessee Technology Park, Oak Ridge, Tennessee (DOE 2003). EPA Region IX residential PRGs $1 \times 10^{-6}$ and ETTP soil background values for the chemicals and radionuclides analyzed under the DVS are presented in Table 5. 


\section{FINAL STATUS ASSESSMENTS}

This section presents results of the DVS evaluations of the 11 exposure units in Zone 2 at ETTP and the final status assessments for each EU made on the basis of those evaluations. Guidelines for the evaluations conducted are presented in Sect. 2, and guidelines for making the final status asses sments are presented in Sect. 3. A high-level summary of the DVS evaluations are presented in Table 7.

The final status assessment conclusions for each EU are presented in Table 8, which is followed by a summary of the evaluation and conclusions. Conclusions presented in Table 8 and the summaries are based on an evaluation of existing information in terms of the four DVS decision rules described in Sect. 3. Table 7 provides the information by EU and includes the EU acreage, Class 1 and Class 2 SU acreage, Class 3 SU acreage, and FFA sites in each EU.

Because all samples within the 010 -ft soil interval are considered equally in the risk assessment, there is no differentiation of the contamination information by depth. Any contamination in the 0-10-ft interval is considered to be equally accessible to an industrial worker. Depth information for discrete interval samples, which include all VOC samples and the majority of the radiological samples, is provided in the accompanying compact disc. Since there is no depth differentiation of the potential impact of contamination, details regarding sample intervals are not included in the EU evaluations presented in the following text.

Details of the material presented in Table s 7 and 8 and the associated summaries are presented in the TMs in Appendixes A through K. Analytical data summary tables for each EU are presented in the EU TMs. The complete set of analytical data used to generate the summary data tables for all EUs are provided on a CD with this PCCR. Data are also available in the OREIS database, which can be accessed by contacting DOE.

Recommendations for the Zone 2 ROD Appendix A FFA sites are summarized in Table 9. Characterization, evaluation, and remediation of these sites will be used as a metric for completion of the closure of ETTP. Some EUs contain one or more FFA sites. However, the final action/NFA decisions are made on an EU basis and are not predicated upon results from any smaller-scale subdivision of the EU. If the evaluation of all available data for an EU supports a NFA determination at the EU level, then all FFA sites within that EU are considered NFA by inclusion. If a limited set of data results in the determination that action is required within an EU, then the final status of the EU and all included FFA sites is deferred until the action is completed and an EU-level NFA determination is made.

Table 7. DVS evaluation summary for the FY 2007 Zone 2 EUs

\begin{tabular}{ll}
\hline Bulk acreage summary & \\
\hline Total acreage in Zone 2 & 819 \\
Acreage included in this PCCR & $195.5^{a}$ \\
Acreage for NFA - no RA & 143.1 \\
Acreage for NFA - post RA ${ }^{b}$ & 58.5 \\
Acreage of RAs conducted & 0.0 acres \\
Acreage of RAs to be conducted & $>1.0$ acres \\
\hline SU classification summary for acreage in the PCCR & \\
\hline Class 1 SU acreage & 0.07 \\
Class 2 SU acreage & 4.8 \\
Class 3 SU acreage & 190.7 \\
Class 4 SU acreage & 0 \\
\hline
\end{tabular}


Table 7. (continued)

\title{
EU summary
}

Number of EUs in Zone 2

44

Number of EUs addressed in this PCCR 11

Number of EUs for NFA

9

Number of EUs for NFA - post RA

2

\section{Characterization summary}

Sample analyses DVS and historical

Metal: 391

PCB: 401

Radionuclide: 515

SVOC: 380

Approximately 2.1 acres (new surveys)

Radiological walkover survey acreage

Geophysical survey acreage

Linear feet of soil core obtained

Class 3 and Class 4 SU walkover assessments
0.0

Approximately $850 \mathrm{ft}$

Assessment point locations: 157

Mid-point locations: 116

Discretionary point locations: 90

Total locations assessed: 363
FFA Sites Addressed - NFA

K-892-J Cooling Tower Basin

K-762 Switchyard Soils

K-762 Valve Vaults 1 and 2

K-879-L Oil Containment Structure

K-879-M Oil Containment Structure

K-33 RCW Lines Leak Site

K-892-G Cooling Tower Basin

FFA Sites - Additional Action

K-1407-C Soil Piles (Rusty's Mountain)
K-892-H Cooling Tower Basin

K-897-A Oil Containment Structure

K-300 Service Station

K-1414 Garage Diesel Tank/Soils

K-1070-C/D Burial Ground

K-1070 Pits Area

K-1070-G Burial Ground
VOC: 361

Other: 191

TCLP SVOC: 40

TCLP Metals: 40

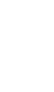

${ }^{\mathrm{a}}$ Excludes 6.0 acres of the active TSCAI.

${ }^{b}$ The need for RA anywhere in an EU means the NFA decision cannot be made for the whole EU until the action is completed. Final status of FFA sites within an EU where an action is planned is contingent upon completion of the RA. "Acreage for NFA-post RA" is the sum of the acreages of all EUs in which a RA is to be conducted. "Acreages of RAs to be conducted" is the sum of acreages of the actions themselves.

DVS = Dynamic Verification Strategy

$\mathrm{EU}=$ exposure unit

FFA = Federal Facility Agreement

$\mathrm{FY}=$ fiscal year

$\mathrm{NFA}=$ no further action

$\mathrm{PCB}=$ polychlorinated biphenyl

PCCR = Phased Construction Completion Report
$\mathrm{RA}=$ remedial action

$\mathrm{RCW}$ = recirculating cooling water

$\mathrm{SU}=$ soil unit

SVOC $=$ semivolatile organic compound

TCLP $=$ toxicity characteristic leaching procedure

TSCAI = Toxic Substances Control Act of 1976 Incinerator

$\mathrm{VOC}=$ volatile organic compound 
Table 8. Final status assessment summary for FY 2007 Zone 2 EUs

\begin{tabular}{|c|c|c|c|c|c|c|c|c|}
\hline $\mathbf{E U}$ & $\begin{array}{r}\text { EU size } \\
\text { (acres) }\end{array}$ & EU Group & $\begin{array}{c}\text { Zone } 2 \text { ROD Appendix A } \\
\text { FFA sites } \\
\end{array}$ & $\begin{array}{c}\text { Class } 1 \\
\text { and } 2 \\
\text { SU area } \\
(\text { acres }) \\
\end{array}$ & $\begin{array}{c}\text { Class } 3 \\
\text { and } 4 \mathrm{SU} \\
\text { area } \\
(\text { acres })\end{array}$ & Risk evaluation & $\begin{array}{c}\text { Decision rule } \\
\text { e valuation }\end{array}$ & $\begin{array}{c}\begin{array}{c}\text { Final status } \\
\text { decision }\end{array} \\
\end{array}$ \\
\hline $\mathrm{Z} 2-01$ & 29.7 & $\mathrm{~K}-31 / 33$ & $\begin{array}{l}\text { K-892-J Cooling Tower } \\
\text { Basin }\end{array}$ & 0.3 & 29.4 & Passes risk screen & $\begin{array}{l}\text { Max RL: NFA } \\
\text { Avg RL: NFA } \\
\text { Risk: NFA } \\
\text { GW: NFA }\end{array}$ & NFA for soils \\
\hline Z2-03 & 14.9 & $\mathrm{~K}-31 / 33$ & $\begin{array}{l}\text { K-762 Switchyard Soils } \\
\text { K-762 Valve Vaults } 1 \text { and } 2 \\
\text { K-879-L Oil Containment } \\
\text { Structure } \\
\text { K-879-M Oil Containment } \\
\text { Structure }\end{array}$ & 0.3 & 14.6 & Passes risk screen & $\begin{array}{l}\text { Max RL: NFA } \\
\text { Avg RL: NFA } \\
\text { Risk: NFA } \\
\text { GW: NFA }\end{array}$ & NFA for soils \\
\hline Z2-08 & 24 & $\mathrm{~K}-31 / 33$ & $\begin{array}{l}\text { K-33 RCW Lines Leak Site } \\
\text { K-892-G Cooling Tower } \\
\text { Basin } \\
\text { K-892-H Cooling Tower } \\
\text { Basin } \\
\text { K-897-A Oil Containment } \\
\text { Structure }\end{array}$ & $<0.1$ & 24.0 & Passes risk screen & $\begin{array}{l}\text { Max RL: NFA } \\
\text { Avg RL: NFA } \\
\text { Risk: NFA } \\
\text { GW: NFA }\end{array}$ & NFA for soils \\
\hline $\mathrm{Z} 2-23$ & 8.5 & $\mathrm{~K}-25$ & K-300 Service Station & 0 & 8.5 & Passes risk screen & $\begin{array}{l}\text { Max RL: NFA } \\
\text { Avg RL: NFA } \\
\text { Risk: NFA } \\
\text { GW: NFA }\end{array}$ & NFA for soils \\
\hline $\mathrm{Z} 2-24$ & 22 & Main Plant & None & 0 & 22 & Passes risk screen & $\begin{array}{l}\text { Max RL: NFA } \\
\text { Avg RL: NFA } \\
\text { Risk: NFA } \\
\text { GW: NFA }\end{array}$ & NFA for soils \\
\hline $\mathrm{Z} 2-28$ & 20.5 & Haul Road & $\begin{array}{l}\text { K-1407-C Soil Piles (Rusty's } \\
\text { Mountain) }\end{array}$ & 2.5 & 18 & Fails risk screen & $\begin{array}{l}\text { Max RL: RA } \\
\text { Avg RL: NFA } \\
\text { Risk: NFA } \\
\text { GW: NFA }\end{array}$ & $\begin{array}{l}\text { RA of Max RL } \\
\text { exceedance soils }\end{array}$ \\
\hline
\end{tabular}


Table 8. (continued)

\begin{tabular}{|c|c|c|c|c|c|c|c|c|}
\hline $\mathbf{E U}$ & $\begin{array}{r}\text { EU size } \\
\text { (acres) }\end{array}$ & EU Group & $\begin{array}{c}\text { Zone } 2 \text { ROD Appendix A } \\
\text { FFA sites } \\
\end{array}$ & $\begin{array}{l}\text { Class } 1 \\
\text { and } 2 \\
\text { SU area } \\
\text { (acres) } \\
\end{array}$ & $\begin{array}{l}\text { Class } 3 \\
\text { and } 4 \mathrm{SU} \\
\text { area } \\
\text { (acres) }\end{array}$ & Risk evaluation & $\begin{array}{c}\begin{array}{c}\text { Decision rule } \\
\text { evaluation }\end{array} \\
\end{array}$ & Final status decision \\
\hline $\mathrm{Z} 2-34$ & 13.2 & South Park & None & 0 & 13.2 & Passes risk screen & $\begin{array}{l}\text { Max RL: NFA } \\
\text { Avg RL: NFA } \\
\text { Risk: NFA } \\
\text { GW: NFA }\end{array}$ & NFA for soils \\
\hline $\mathrm{Z} 2-37$ & 5.9 & K-1070-C/D & $\begin{array}{l}\text { K-1414 Garage Diesel } \\
\text { Tank/Soils }\end{array}$ & 0 & 5.9 & Passes risk screen & $\begin{array}{l}\text { Max RL: NFA } \\
\text { Avg RL: NFA } \\
\text { Risk: NFA } \\
\text { GW: NFA }\end{array}$ & NFA for soils \\
\hline $\mathrm{Z} 2-41$ & 38 & K-1070-C/D & $\begin{array}{l}\text { K-1070-C/D Burial Ground } \\
\text { K-1070 Pits } \\
\text { K-1071 Concrete Pad }\end{array}$ & $>0.1$ & 37.9 & $\begin{array}{l}\text { K-1071 Concrete Pad } \\
\text { RA according to the } \\
\text { Zone } 2 \text { ROD }\end{array}$ & $\begin{array}{l}\text { Max RL: RA } \\
\text { Avg RL: NFA } \\
\text { Risk: NFA } \\
\text { GW: NFA }\end{array}$ & $\begin{array}{l}\text { RA of K-1071 } \\
\text { concrete pad }\end{array}$ \\
\hline $\mathrm{Z} 2-43$ & 8.7 & South Park & None & 1 & 7.7 & Passes risk screen & $\begin{array}{l}\text { Max RL: NFA } \\
\text { Avg RL: NFA } \\
\text { Risk: NFA } \\
\text { GW: NFA }\end{array}$ & NFA for soils \\
\hline $\mathrm{Z} 2-44$ & $16.1^{a}$ & $\begin{array}{l}\text { Mitchell } \\
\text { Branch }\end{array}$ & K-1070-G Burial Ground & 0.6 & 9.5 & Passes risk screen & $\begin{array}{l}\text { Max RL: NFA } \\
\text { Avg RL: NFA } \\
\text { Risk: NFA } \\
\text { GW: NFA }\end{array}$ & NFA for soils \\
\hline
\end{tabular}

${ }^{a}$ Includes 6.0 acres of active TSCAI that are excluded from this PCCR.

Avg $=$ average
$\mathrm{EU}=$ exposure unit

$\mathrm{FY}=$ fiscal year

$\mathrm{GW}=$ groundwate

$\mathrm{Max}=$ maximum

NFA $=$ no further action

PCCR $=$ Phased Const ruction Completion Report
$\mathrm{RA}=$ remedial action

$\mathrm{RCW}$ = recirculating cooling water

$\mathrm{RL}=$ remediation level

ROD $=$ Record of Decision

$\mathrm{SU}=$ soil unit

TSCAI = Toxic Substances Control Act of 1976 Incinerator 
Table 9. Summary of conclusions for FY 2007 EU Zone 2 ROD Appendix A FFA sites

\begin{tabular}{ll}
\hline \multicolumn{1}{c}{ Zone 2 ROD Appendix A FFA Site } & Recommendation \\
\hline K-892-J Cooling Tower Basin & NFA \\
K-762 Switchyard Soils & NFA \\
K-762 Valve Vaults 1 and 2 & NFA \\
K-897-L Oil Containment Structure & NFA \\
K-897-M Oil Containment Structure & NFA \\
K-33 RCW Lines Leak Site & NFA \\
K-892-G Cooling Tower Basin & NFA \\
K-892-H Cooling Tower Basin & NFA \\
K-897-A Oil Containment Structure & NFA \\
K-300 Area Service Station & NFA \\
K-1407-C Soil Piles (Rusty's Mountain) & Action required based on maximum RL exceedances \\
K-1414 Garage Diesel Tank/Soils & NFA \\
K-1070-C/D Burial Ground & NFA \\
K-1070 Pits & NFA \\
K-1071 Concrete Pad & Action required according to the Zone 2 ROD \\
K-1070-G Burial Ground & NFA \\
\hline EU = exposure unit & RFA = Federal Facility Agreement \\
FY = fiscal year & ROD = Record of Decision \\
NFA = no further action &
\end{tabular}

\subsection{EXPOSURE UNIT EVALUATIONS}

The following sections summarize the evaluation and conclusions for each EU. Details of the material presented in Tables 7, 8, and 9, and the following sections, are presented in the appropriate TM appendices.

\subsubsection{Exposure Unit Z2-01}

EU Z2-01 consists of an area of approximately 32.6 acres and occupies the northern extent of Zone 2 that merges directly with the forested Zone 1 EUs 58, 63, and 68 (see Appendix A). Therefore, the northeast portion of this EU is forested (with forest making up approximately $10 \%$ of the EU). The southern portion of the EU, which is cleared and industrialized, contains infrastructure for support of the K-33 building. This EU is generally flat in the southern portion but has a relatively steep grade in the northern portion, which is located on the southern flank of Black Oak Ridge. The EU drains to Poplar Creek on the east and to the K-901-A Holding Pond on the southwest. The K-892-J Cooling Tower Basin is the only FFA site included in this EU.

The site conceptual model for EU Z2-01 is primarily a surface release model and subordinate subsurface release model for the K-892 Cooling Tower Basin. The surface release model presumes activities associated with surface dumping, general work activities, and possible releases of contaminants at other facilities in the EU could have resulted in releases of radiological and/or chemical contaminants to the ground surface. The subsurface release model presumes contaminated soils and building debris would be leached by water infiltrating through the cooling water basins and subsequently released to subsurface soils. 
The Class 2 SU has 0.3 acres and the Class 3 SU has 32.3 acres in EU Z2-01. At the time of DQO scoping, the Cooling Tower Basin was in a Class 3 SU. A four-point composite sample was collected, and the points were spaced to provide maximum coverage of the fill material. Analytical results from the biased sample showed PCB average RL exceedances and the Cooling Tower Basin was reclassified as a Class 2 SU. Four Class 2 SU systematic grid sample locations were identified in the new Class 2 SU. Two discrete samples were collected at each location, one from $06 \mathrm{in}$. deep and the other from 6in. to $2 \mathrm{ft}$ deep, and analyzed for PCBs.

The Class $3 \mathrm{SU}$ was assessed during a Class $3 \mathrm{SU}$ walkover assessment. Prior to the start of fieldwork, 27 APs were identified in this EU and are documented in the DQO Scoping Package. The actual number of APs evaluated corresponds to the number planned. In addition to the APs, the field team made assessments at $22 \mathrm{MP}$ locations and conducted DP surveys at 26 locations (see below). Based on an evaluation of the walkover assessment results, two biased sample locations were selected for sampling.

Nine facilities were identified in EU Z2-01 during DQO scoping. Discretionary field measurements were taken at each facility listed above but no elevated radioactivity or indication of chemical contamination was observed; therefore, no soil samples were collected at these facilities. A four-point composite sample was collected from soil associated with the concrete rubble fill in the K-892-J Cooling Tower Basin.

There were five sample locations in the Class 2 SU of EU Z2-01. One location was a DVS biased sample collected from the K-892-J Cooling Tower Basin FFA site when it was a Class 3 SU. The other four locations were DVS systematic grid locations sampled in response to PCB average RL exceedances in the original K-892-J Cooling Tower Basin biased sample. Sample analyses included DVS samples (2 VOC, 2 SVOC, 10 PCB, 6 metals, and 4 RAD) and historic samples (one SVOC, one PCB, one metal, and eight RAD).

There were a total of 18 sample locations in this EU, which consisted of the following:

- Four DVS systematic grid locations in the Class 2 SUs,

- One biased sample location in the Class 2 SUs,

- Five DVS biased sample locations in the Class 3 SUs, and

- Eight historical sample locations in the Class 3 SUs.

Monitoring well pairs UNW-040/BRW028 and UNW-045/BRW-032 were drilled and completed in 1988. These wells were sampled during 1989-1990 and 1994-1995. Water levels in well pair UNW-040/BRW028 are approximately $12 \mathrm{ft}$ bgs with a very slight downward gradient. Water levels in well pair UNW-045/BRW-032 are approximately $45 \mathrm{ft}$ bgs and also exhibit a downward gradient. Mercury was reported once above MCLs in the two unconsolidated zone wells during 1995, which was the last time the wells were sampled. No other COCs have been reported above MCLs in these wells during any sampling event.

Following is a summary of the data evaluation for EU Z2-01.

\begin{tabular}{cccccc}
\hline EU \# & $\begin{array}{c}\text { Maximum RL } \\
\text { exceeded? }\end{array}$ & $\begin{array}{c}\text { Average RL over } \\
\text { EU exceeded? }\end{array}$ & $\begin{array}{c}\text { Industrial risk } \\
\text { above } \mathbf{1} \times \mathbf{1 0}^{-\mathbf{4}} \boldsymbol{?}\end{array}$ & $\begin{array}{c}\text { Potential source to } \\
\text { groundwater? }\end{array}$ & $\begin{array}{c}\text { Action } \\
\text { required? }\end{array}$ \\
\hline $\mathrm{Z} 2-01$ & No & No & No & No & No \\
\hline EU $=$ exposure unit & & & & & \\
RL $=$ remediation level & & & &
\end{tabular}


Based on historical and DVS sampling information, and results of the walkover assessment, the following statements can be made:

- No Zone 2 COCs were detected at concentrations in excess of maximum RLs.

- No Zone 2 COCs were present with a mean concentration exceeding the average RL across the EU.

- No Zone 2 chemicals or radionuclides were present with average concentrations greater than their industrial PRGs. Therefore, the industrial risk is less than $1 \times 10^{-4}$ and the target organ $\mathrm{HI}$ is $<1$.

- The soils do not pose a threat to groundwater.

- NFA is appropriate to meet industrialland use.

- There is a low probability this EU can be released with no land use restrictions. Numerous residential PRGs are exceeded for metals, radionuclides, PCBs, and SVOCs.

In addition, based on sampling analytical results and an evaluation of the EU-wide contaminant profile, soils in the following Zone 2 ROD Appendix A FFA site in EU Z2-01 do not pose a potential threat to the future industrial worker or groundwater:

- K-892-J Cooling Tower Basin

\subsubsection{Exposure Unit Z2-03}

EU Z2-03 is located in the K-31/K-33 Area EU Group and has an area of approximately 15 acres (see Appendix B). The EU is bounded to the north by EU Z2-02, to the south by Zone 1, to the east by Bldg. K-31 (EU Z2-06) and EU Z2-07, and to the west by Zone 1. All land area in this EU has been impacted by site operations. Impacts to the EU included construction of buildings, roads, and parking lots. The EU is generally flat with very low relief and drains via storm drains to the K-901-A Holding Pond. The K-762 Switchyard Soils, K-762 Valve Vaults 1 and 2, K-897-L Oil containment Structure, and K-897-M Oil containment Structure are Zone 2 ROD Appendix A FFA sites included in this EU.

There are 0.3 acres of Class 2 SUs and 14.6 acres of Class 3 SUs in EU Z2-03.

There are two conceptual site models pertinent to the potential release of contamination for EU Z2-03, a surface release model and shallow-point source release model. The surface release model is representative of releases and spills of oils from transformers in the switchyard and deposition of lead-based paints from facilities and structures in the area. The shallow-point source release model is appropriate for releases of PCB oils in oil skimmers, transformer vaults, and French drain systems within and in proximity to the K-762 switchyard.

The RAD157 Class 2 SU was identified during DQO scoping. This Class 2 SU is centered on historical sample location RAD157, which had a Cs-137 average RL exceedance. This Class 2 SU is located in the northwest quadrant of the EU on the northwest corner of the K-762 Switchyard.

The K-762 Class 2 SU comprises approximately 0.3 acres in the northeast portion of the K-762 Switchyard and was classified as a Class 2 SU based on PCB screening results in the originally unclassified acreage of the Switchyard. The footprint of the K-762 Switchyard defines the boundaries of the K-762 Switchyard Soils FFA site.

The Class 3 SU was assessed during a Class 3 SU walkover assessment. In addition to the multiple anthropogenic features present in the highly industrialized area of this EU, 10 additional anthropogenic features were recognized during the walkover assessment [two of these (K-762 transformer vaults) being representative of 20 transformer vaults in the EU] and include the following:

- Ditch/culvert between road and railroad tracks, 
- Concrete lined ditch west of road,

- Concrete stops for vehicle parking,

- Culvert downgradient of K-1066-K Cylinder Yard,

- Culvert/ditch south end of parking lot,

- Transformer vault located in center of K-762 Switchyard,

- Transformer vault located in the central/southeast portion of the K-762 Switchyard,

- Valve vault at north end of K-762 Switchyard,

- Concrete pits adjacent to railroad tracks (west side), and

- Storm water catch basin.

Each of the 10 anthropogenic features was surveyed for radiation and inspected for visual evidence of chemical contamination. Four of the 10 features that showed visual evidence for potential sources of chemical contamination and were selected for biased sampling include the following:

- Culvert downgradient of the K-1066-K Cylinder Yard,

- Concrete pits adjacent to the railroad tracks, and

- Two K-762 transformer vaults (as representatives for the 20 transformer vaults in the EU).

There were five sample locations in that consisted of twop systematic grid locations in the Class 2 $\mathrm{SU}$, one biased location in the Class $2 \mathrm{SU}$, one PCB confirmatory sample, and one historical sample location. Sample analyses included DVS samples (4 VOC, 8 SVOC, 11 PCB, 6 metals, and 3 RAD) and historic samples (2 VOC, 2 SVOC, 6 PCB, 2 metals, and 12 RAD).

The following is a summary of the data evaluation for EU Z2-07.

\begin{tabular}{cccccc}
\hline EU \# & $\begin{array}{c}\text { Max RL } \\
\text { exceeded? }\end{array}$ & $\begin{array}{c}\text { Average RL over } \\
\text { EU exceeded? }\end{array}$ & $\begin{array}{c}\text { Industrial risk } \\
\text { above } \mathbf{1} \times \mathbf{1 0}^{-4} \boldsymbol{?}\end{array}$ & $\begin{array}{c}\text { Potential source to } \\
\text { groundwater? }\end{array}$ & $\begin{array}{c}\text { Action } \\
\text { Required? }\end{array}$ \\
\hline Z2-07 & No & No & No & No & No \\
\hline EU $=$ exposure unit & & & & & \\
RL $=$ remediation level & & & &
\end{tabular}

Based on historical and DVS sampling information, and results of the walkover assessment, the following statements can be made for EU Z2-07:

- No Zone 2 COCs were detected at concentrations in excess of maximum RLs.

- No Zone 2 COCs were present with a mean concentration exceeding the average RL across the EU.

- No Zone 2 chemicals or radionuclides were present with average concentrations greater than their industrial PRGs. Therefore, the industrial risk is $<1 \times 10^{-4}$ and the target organ $\mathrm{HI}$ is $<1$.

- The soils do not pose a threat to groundwater.

- NFA is necessary to meet industrial land use.

- There is a low probability this EU can be released with no land use restrictions. Numerous residential PRGs are exceeded for metals, radionuclides, PCBs, and SVOCs. 
In addition, based on sampling analytical results and an evaluation of the EU-wide contaminant profile, soils in the following Zone 2 ROD Appendix A FFA sites in EU Z2-03 do not pose a potential threat to the future industrial worker or groundwater:

- K-762 Switchyard Soils,

- K-762 Valve Vaults 1 and 2,

- K-897-L Oil Containment Structure, and

- K-897-M Oil Containment Structure.

\subsubsection{Exposure Unit Z2-08}

EU Z2-08 is located in the K-31/K-33 Area EU Group and has an area of approximately 24 acres (see Appendix C). This EU is bounded by EU Z2-01 to the north, Bldg. K-33 (EUs Z2-04 and Z2-05) to the west, EU Z2-09 to the south, and Poplar Creek to the east. Land area in this EU has been impacted by site operations and contains infrastructure to support K-33 building operations. Impacts to the EU have included construction of buildings, roads, and parking lots. The EU is generally flat and drains to Poplar Creek on the east.

The K-33 RCW Lines Leak Site, K-892-G Cooling Tower Basin, K-892-H Cooling Tower Basin, and K-897-A Oil Containment Structure are Zone 2 ROD Appendix A FFA sites included in this EU.

With the exception of $<0.1$ Class 2 acres, the remaining 24 acres of EU Z2-08 have been classified a Class 3 SU.

The two site conceptual models pertinent in EU Z2-08 include a surface release model appropriate for most of the site facilities and general operations conducted within the EU, and a subsurface release of liquids model appropriate for cooling water basins and containment structures.

The surface release model presumes activities associated with the cooling towers, above-ground fuel tanks, and other facilities in the EU could have resulted in releases of radiological and/or chemical contaminants to the ground surface. The subsurface release model presumes contaminated sediment in cooling water basins and/or containment structures (e.g., valve vaults) would be leached by water to subsurface soils.

The Class $3 \mathrm{SU}$ in this EU was assessed during a Class $3 \mathrm{SU}$ walkover assessment. In addition to the multiple anthropogenic features present in this highly industrialized EU, 20 additional anthropogenic features recognized during the Class $3 \mathrm{SU}$ walkover assessment include the following:

- Pull box station,

- Concrete pad with electrical conduit,

- RCW return lines,

- Inactive valve vault

- Gasoline above-ground storage tank (AST),

- Wood debris pile,

- Large soil/spoil pile,

- Pull box and concrete piers,

- Steel pipe, 
- Air release for fire water system,

- Concrete pedestals,

- Concrete foundation and conduit,

- Air release for sanitary water system,

- Air release for sanitary water system,

- Air release for fire water system,

- Concrete vault with flow control,

- Concrete pad with railroad tracks,

- Diesel AST,

- Large pile of concrete and asphalt rubble, and

- Transformers associated with K-892.

Forty-seven facilities are listed in the DQO Scoping Package as located in EU Z2-08; however, one falls in Z2-09 and is not addressed in this PCCR. Forty-six facilities, including the K-897-A Oil Containment Structure FFA Site, were assessed during the Class 3 SU walkover assessment

There are 18 biased sample locations in the Class 3 SU, and one biased and one historical sample location in the Class 2 SU. Sample analyses included DVS samples (16 VOC, 19 SVOC, 130 PCB, 30 metals, and $41 \mathrm{RAD}$ ) and historic samples (5 VOC, 6 SVOC, 6 PCB, 6 metals, and 32 RAD).

There are two well pairs (UNW-044/BRW031 and UNW083/BRW-063) and one additional bedrock well (BRW-062) in EU Z2-08 located downgradient of the K-892K Cooling Towers and Basins. In each pair, one well is completed in the bedrock (BRW) and one is completed in the unconsolidated zone (UNW). Vertical gradients are generally downward into the bedrock formation. The wells were monitored and sampled from 1989 through 1995. Monitoring at the UNW-044/BRW031 well pair ceased after 1992, but sampling at BRW-031 continued until 1998. Technetium-99 in BRW-031 was reported at concentrations above MCLs in 1992, but by 1998 concentrations had dropped below MCL criteria. Total chromium concentrations were reported in well BRW063 during 1994-1995. Sediments in the cooling water basins were removed from the EU in early 1994. There appears to be a correlation between the detection of total chromium at elevated concentrations in the downgradient well and disturbance of the basin sediments. Chromium concentrations in late 1995 had dropped to levels well below MCLs.

The following is a summary of the data evaluation for EU Z2-08.

\begin{tabular}{lccccc}
\hline EU \# & $\begin{array}{c}\text { Maximum RL } \\
\text { exceeded? }\end{array}$ & $\begin{array}{c}\text { Average RL over } \\
\text { EU exceeded? }\end{array}$ & $\begin{array}{c}\text { Industrial risk } \\
\text { above } \mathbf{1} \times \mathbf{1 0}^{-4}\end{array}$ & $\begin{array}{c}\text { Potential source to } \\
\text { groundwater? }\end{array}$ & $\begin{array}{c}\text { Action } \\
\text { required? }\end{array}$ \\
\hline $\mathrm{Z} 2-08$ & No & No & No & No & No \\
\hline $\begin{array}{l}\mathrm{EU}=\text { exposure unit } \\
\mathrm{RL}=\text { remediation level }\end{array}$ & & & & \\
\end{tabular}

Based on historical and DVS sampling information, and results of the walkover assessment, the following statements can be made for EU 2-08:

- No Zone 2 COCs were detected at concentrations in excess of maximum RLs.

- No Zone 2 COCs were present with a mean concentration exceeding the average RL across the EU.

- No Zone 2 chemicals or radionuclides were present with average concentrations greater than their industrial PRGs. Therefore, the industrial risk is $<1 \times 10^{-4}$ and the target organ $\mathrm{HI}$ is $<1$. 
- The soils do not pose a threat to groundwater.

- $\quad$ NFA is necessary to meet industrial land use.

- There is a low probability this EU can be released with no land use restrictions. Numerous residential PRGs were exceeded for metals, radionuclides, PCBs, and SVOCs.

In addition, based on sampling analytical results and an evaluation of the EU-wide contaminant profile, soils in the following Zone 2 ROD Appendix A FFA sites in this EU do not pose a potential threat to the future industrial worker or to groundwater:

- K-33 RCW Lines Leak Site,

- K-892-G Cooling Tower Basin,

- K-892-H Cooling Tower Basin, and

- K-897-A Oil Containment Structure.

\subsubsection{Exposure Unit Z2-23}

EU Z2-23 is located in the south-central portion of ETTP Zone 2 in the K-25 Area EU Group and has a total land area of 8.5 acres (see Appendix D). This EU lies directly south of the K-25 building and is bounded on the north by EU Z2-22, on the east by EU Z2-26, on the south by EU Z2-24, and on the west by EUs Z2-13 and Z2-14. All land area in the EU has been impacted to some degree by plant activities, but evaluation of historical aerial photographs, plant records, and historical data indicate no activities occurred that resulted in a contaminant release.

The K-300 Area Service Station is the only Zone 2 ROD Appendix A FFA site included in this EU.

The primary conceptual site model for EU Z2-23 is a surface release model There is no evidence of burial or subsurface potential sources of contaminants.

EU Z2-23 has been classified as a Class 3 SU in its entirety. The Class 3 SU was assessed during a Class $3 \mathrm{SU}$ walkover assessment. One anthropogenic feature, RCW line valve vault, was identified during the walkover assessment. Although the RCW line valve vault was surveyed for radiation and inspected for visual evidence of chemical contamination, no significant accumulation of sediment was present. Therefore, the valve vault was not identified for biased sampling.

Thirteen facilities were identified during DQO scoping and 15 facilities were assessed during the Class 3 SU walkover assessment (Table 1). The facility assessments are reported in the Zone 2 EU Survey Summary Report. In summary, no facilities exceeded the radiation survey SL; however, facilities identified as potential contaminant release sources based on visual inspection include the following:

- K-300 Area Service Station (FFA site),

- UST/oil skimmer adjacent to the K-1652 Plant Protection Headquarters, and

- K-1066-C Cylinder Storage Yard.

There were 34 sample locations in EU Z2-23-18 DVS biased sample locations, 1 early characterization sample, and 15 historical sample locations. Sample analyses included DVS samples [7 VOC, 10 SVOC, 16 PCB, 21 metals, $10 \mathrm{RAD}$, and 7 diesel-range organics (DROs)/gasoline range organics (GROs)] and historic samples (21 VOC, 21 SVOC, 19 PCB, 17 metals, and 27 RAD. The following is a summary of the data evaluation for EU Z2-23. 


\begin{tabular}{cccccc}
\hline EU \# & $\begin{array}{c}\text { Maximum RL } \\
\text { exceeded? }\end{array}$ & $\begin{array}{c}\text { Average RL over } \\
\text { EU exceeded? }\end{array}$ & $\begin{array}{c}\text { Industrial risk } \\
\text { above } \mathbf{1} \times \mathbf{1 0}^{-4}\end{array}$ & $\begin{array}{c}\text { Potential source to } \\
\text { groundwater? }\end{array}$ & $\begin{array}{c}\text { Action } \\
\text { required? }\end{array}$ \\
\hline Z2-23 & No & No & No & No & No \\
\hline
\end{tabular}

$\mathrm{EU}=$ exposure unit

$\mathrm{RL}=$ remediation level

Based on historical and DVS sampling information, and results of the walkover assessment, the following statements can be made for EU Z2-23:

- No Zone 2 COCs were detected at concentrations in excess of maximum RLs.

- No Zone 2 COCs were present with a mean concentration exceeding the average RL across the EU.

- No Zone 2 chemicals or radionuclides were present with average concentrations greater than their industrial PRGs. Therefore, the industrial risk is $<1 \times 10^{-4}$ and the target organ $\mathrm{HI}$ is $<1$.

- The soils do not pose a threat to groundwater.

- NFA is necessary to meet industrial land use.

- There is a low probability this EU can be released with no land use restrictions. Numerous Residential PRG exceedances occur for metals, radionuclides, PCBs, and SVOCs.

In addition, based on sampling analytical results and an evaluation of the EU-wide contaminant profile, soils in the following Zone 2 ROD Appendix A FFA site in EU Z2-23 do not pose a potential threat to the future industrial worker or to groundwater:

- K-300 Area Service Station.

\subsubsection{Exposure Unit Z2-24}

EU Z2-24 is located in the Main Plant Group along the southern boundary of Zone 2 and has an area of approximately 22 acres (see Appendix E). All land area in this EU has been impacted by site operations, including the construction of buildings, roads, parking lots, and sidewalks. EU Z2-24 lies at the southern end of the major industrialized portion of ETTP and has several large areas of maintained lawn.

The K-300 Area Service Station Underground Storage Tank FFA site is the only Zone 2 ROD Appendix A FFA site included in this EU. Geophysical evidence and sample data demonstrate that the K-300 Area Service Station FFA site was incorrectly located in EU Z2-24. Instead, it was determined the location of this FFA site was in EU Z2-23.

EU Z2-24 has been classified as a Class 3 SU in its entirety and was assessed during a Class 3 SU walkover assessment. Two anthropogenic features identified during the walkover assessment include an unnumbered mobile security guard shack and a sediment accumulation area southeast of K-1310-HF. The sediment accumulation area was selected for sampling.

Twenty-one facilities were listed in the DQO scoping package as being located in EU Z2-24 (Table 1) and 21 facilities were assessed during the Class 3 SU walkover assessment. With the exception of the K-1650 UST, no facility was identified as a possible source for either chemical or radiological contamination, and no biased sample locations were selected. Biased sampling at the K-1650 UST was defined during DQO scoping.

The primary conceptual site model for EU Z2-24 is a surface release model There is no evidence of burial or subsurface potential sources of contaminants. There were nine DVS and historical sample locations in the EU Z2-24 Class 3 SU. Sample analyses included DVS samples (4 VOC, 6 SVOC, 6 PCB, 
6 metals 2 RAD, and 3 DRO/GRO) and historic samples (2VOC, 2 metals, and 1 RAD). The following is a summary of the data evaluation for EU Z2-24.

\begin{tabular}{lccccc}
\hline EU \# & $\begin{array}{c}\text { Maximum RL } \\
\text { exceeded? }\end{array}$ & $\begin{array}{c}\text { Average RL over } \\
\text { EU exceeded? }\end{array}$ & $\begin{array}{c}\text { Industrial risk } \\
\text { above } \mathbf{1} \times \mathbf{1 0}^{-4}\end{array}$ & $\begin{array}{c}\text { Potential source } \\
\text { to groundwater? }\end{array}$ & $\begin{array}{c}\text { Action } \\
\text { required? }\end{array}$ \\
\hline $\mathrm{Z} 2-24$ & No & No & No & No & No \\
\hline $\begin{array}{l}\mathrm{EU}=\text { exposure unit } \\
\mathrm{RL}=\text { remediation level }\end{array}$ & & & & & \\
\end{tabular}

Based on historical and DVS sampling information, and results of the walkover assessment, the following statements can be made for EU Z2-24:

- No Zone 2 COCs were detected at concentrations in excess of maximum RLs.

- No Zone 2 soils COCs were present with a mean concentration exceeding the average RL across the EU.

- No $1 \times 10^{-5}$ industrial PRGs were exceeded in samples collected. . Therefore, it was concluded the industrial risk for EU Z2-24 was $<1 \times 10^{-4}$ ELCR and the target organ $\mathrm{HI}<1$.

- No chemical or radionuclide exceeded its GW SL in the soil samples. Therefore, it was concluded that the soils do not pose a threat to groundwater.

- NFA is appropriate under the Zone 2 ROD to meet industrial land use for the 22 acres of this EU.

- There is a low probability the acreage could be released with no land use restrictions because of industrial and residential PRG exceedances for metals, radionuclides, PCBs, and SVOCs.

\subsubsection{Exposure Unit Z2 -28}

EU Z2-28 is located in the Haul Road EU Group along the northern boundary of Zone 2 and has an area of approximately 20.5 acres (see Appendix F). The majority of the land area in this EU has been impacted by site operations, including forest clearing and road construction, railroads, parking lots, reorientation of Mitchell Branch, construction of a portion of the Haul Road, and other small facilities. In addition, the site was used for above-ground dumping of soil, building rubble, and debris. The K-1407-C Soil Piles FFA Site (also known as Rusty's Mountain) was the only FFA site listed in Appendix A of the Zone 2 ROD included in this EU.

There are $<0.05$ acres of Class 1 soils and they all occur within the K-1407-C Soil Piles FFA Site, 2.5 acres of Class 2 soils that encompass the boundaries of the K-1407-C Soil Piles FFA Site, and 18 acres of Class 3 soils in this EU. Biased area radiation (BAR) surveys were performed around the five areas with known maximum RL exceedances and around the five areas with known average RL exceedances.

The conceptual site model is a surface release model from historic facilities, material storage, and soil accumulation areas. Surface releases are confined to the K-1407-C Soil Piles (commonly referred to as Rusty's Mountain).

Six facilities listed in the DQO Scoping Package were all assessed during the Class 3 SU walkover assessment (Table 1) and are reported in the Zone 2 EU Survey Summary Report. None of the facilities were identified as a possible source of chemical or radiological contamination. Based on visual assessment of each anthropogenic feature for evidence of possible contamination, radiological surveys at each anthropogenic feature, and extensive historical sampling conducted around these anthropogenic features, it was determined no DVS Class 3 SU biased sampling would be conducted. 
There are a total of 17 DVS and historical sample locations in the Class 3 SUs, 33 DVS and historical sample locations in the Class $2 \mathrm{SU}$, and 19 sample locations in the Class 1 SU. Sample analyses included DVS samples (16 VOC, 19 SVOC, 30 PCB, 30 metals, and 41 RAD) and historic samples (5 VOC, 6 SVOC, 6 PCB, 6 metals, and 32 RAD).

The following is a summary of the data evaluation for EU Z2-27.

\begin{tabular}{lccccc}
\hline EU \# & $\begin{array}{c}\text { Maximum RL } \\
\text { exceeded? }\end{array}$ & $\begin{array}{c}\text { Average RL over } \\
\text { EU exceeded? }\end{array}$ & $\begin{array}{c}\text { Industrial risk } \\
\text { above } \mathbf{1} \times \mathbf{1 0}^{-4}\end{array}$ & $\begin{array}{c}\text { Potential source } \\
\text { to groundwater? }\end{array}$ & $\begin{array}{c}\text { Action } \\
\text { required? }\end{array}$ \\
\hline $\mathrm{Z} 2-28$ & Yes & No & No & No & Yes \\
\hline $\begin{array}{l}\mathrm{EU}=\text { exposure unit } \\
\mathrm{RL}=\text { remediation level }\end{array}$ & & & & \\
\end{tabular}

Based on historical and DVS sampling information, and results of the walkover assessment, the following statements can be made concernin g EU Z2-28:

There were three Zone 2 soil COCs present with verified $\mathrm{Ra} / \mathrm{Th}$ decay series maximum RL exceedances at sample locations RAD 199, RAD 205, and EU Z2-28-204.

- There were no Zone 2 soil COCs with an average concentration that exceeded an average RL.

- No Zone 2 chemicals or radionuclides were present with average concentrations greater than their industrial PRGs across the entire EU Z2-28. Therefore, the industrial risk was $<1 \times 10^{-4}$ and the target organ HI was $<1$.

- Contaminated soils that exceeded Ra/Th decay series maximum RLs at three locations or U-234 and U-238 groundwater SLs at 16 locations in the K-1407-C Soil Piles FFA Site are recommended for removal, which will eliminate any potential threat to local groundwater. Sampling results from the three monitoring wells in the EU do not exhibit similar contaminants, which supports the premise that contaminants are limited to the isolated locations in the K-1407-C Soil Piles FFA Site

- Six areas that include all of the maximum RL and groundwater SL exceedances totaling approximately $600 \mathrm{yd}^{3}$ were identified for focused remedial action.

- There is a low probability this EU can be released with no land use restrictions. Following the proposed remedial action, industrial and residential PRG exceedances in soils left in place will remain.

\subsubsection{Exposure Unit Z2-34}

EU Z2-34 is located in the South Park Area Group in the southeast quadrant of Zone 2 and consists of 13.2 acres (see Appendix G). Site operations have impacted the majority of land in this EU, including construction of buildings, roads, parking lots, and sidewalks. This EU is on the southern boundary of the administrative section of ETTP, which generally housed offices. There are no FFA sites in EU Z2-34 that are listed in Appendix A of the Zone 2 ROD.

The conceptual site model for EU Z2-34 is a surface release model but is limited to very small-volume surface releases to soils. There were no waste handling or storage facilities in the area and no subsurface burial sites in the EU because the area was used for a portion of the administrative complex, including office buildings, parking lots, and office trailers.

This entire EU consists of Class 3 acreage that was assessed during a Class 3 SU walkover assessment. Other than plant facilities and associated constructed features, the Contamination Area/Radioactive Material Area, which consists of a line of hay bales adjacent to the parking area 
established during recent $D \& D$ activities, was the only anthropogenic feature was identified during the Class 3 SU walkover assessment. Based on visual assessment of this anthropogenic feature for evidence of possible contamination, a biased sample location was selected.

In addition, two sediment accumulation area sample locations were identified during the Class $3 \mathrm{SU}$ walkover assessment. One area was located near Assembly Area 2 and the other was located at the footprint of the loading dock for the former K-1001 building. A biased soil sample location also was identified at the radiation background measuring point for the Class $3 \mathrm{SU}$ walkover assessment.

One biased sample location was identified during DQO scoping at the southeast corner of the former K-1001 building near a storm drain catch basin where several pipelines intersect. Rationale for this sample location consisted of anecdotal evidence that some part of K-1001 had been used as a laboratory prior to conversion to an office building. The selected location was considered to be the most likely release point for building drains to release contaminants to surface soil.

There were a total of five sample locations in EU Z2-34, all which were DVS biased samples. Sample analyses included DVS samples (one VOC, three SVOC, four PCB, six metals, and three RAD). There were no historic samples in EU-34.

The following is a summary of the data evaluation for EU Z2-34.

\begin{tabular}{lccccc}
\hline EU \# & $\begin{array}{c}\text { Maximum RL } \\
\text { exceeded? }\end{array}$ & $\begin{array}{c}\text { Average RL over } \\
\text { EU exceeded? }\end{array}$ & $\begin{array}{c}\text { Industrial risk } \\
\text { above 1 x 10 }\end{array}$ & $\begin{array}{c}\text { Potential source to } \\
\text { groundwater? }\end{array}$ & $\begin{array}{c}\text { Action } \\
\text { required? }\end{array}$ \\
\hline $\mathrm{Z} 2-34$ & No & No & No & No & No \\
\hline $\begin{array}{l}\mathrm{EU}=\text { exposure unit } \\
\mathrm{RL}=\text { remediation level }\end{array}$ & & & & \\
\end{tabular}

Based on historical and DVS sampling information, and results of the walkover assessment, the following statements can be made for EU Z2-34:

- No Zone 2 COCs were detected at concentrations in excess of maximum RLs.

- No Zone 2 COCs were present with a mean concentration exceeding the average RL across the EU.

- No Zone 2 chemicals or radionuclides were present with average concentrations greater than their industrial PRGs across the entire EU. Therefore, the industrial risk was $<1 \times 10^{-4}$ and the target organ HI was $<1$.

- The soils do not pose a threat to groundwater.

- NFA is necessary to meet industrial land use.

- There is a low probability this EU can be released with no land use restrictions. Numerous Res PRG exceedances, including Ra/Th decay series, U-238, Cs-137, and arsenic, occur for chemicals and radionuclides. Industrial and residential PRG exceedances occur in the EU. Specific chemicals and radionuclides with criteria exceedances are present in the EU.

\subsubsection{Exposure Unit Z2-37}

EU Z2-37 is located in the K-1070-C/D and Downgradient Area EU Group in the southeast quadrant of Zone 2 and consists of approximately 5.9 acres (see Appendix H). All of the land area in EU Z2-37 has been impacted by site operations. This EU lies at the eastern edge of the industrialized heart of ETTP Zone 2 with the K-1070-C/D Burial Ground to the east in EU Z2-41 and Bldg. K-1401 and support facilities to the west in EUs Z2-31 and Z2-32. There are several buildings and facilities located in the southern portion of the EU that are associated with the K-1414 Garage as well as roads, parking lots, and 
sidewalks. The northeast half of this EU is dominated by a grass-covered hill sloping down from the K-1070-C/D Burial Ground in EU Z2-41 to the east.

The K-1414 Garage Diesel Tank/Soils FFA site was the only FFA site listed in Appendix A of the Zone 2 ROD included in this EU.

The conceptual site model for EU Z2-37 is a subsurface release model based on a known diesel tank leak site in the area. Results of these earlier sampling programs indicated there was diesel contamination in the area where UST \#9 had leaked.

All of EU Z2-37 consists of Class 3 acreage. Because of extensive historical sampling conducted in the Class 3 SU of this EU, it was agreed during DQO scoping that a Class 3 walkover assessment was not necessary. Facility assessments were performed on 10 of the 11 facilities listed in the DQO Scoping Package.

There were 52 DVS and historical sample locations in the Class 3 SU-six DVS and 46 historical sample locations. Of these sample locations, 45 include samples collected within the 0-to-10-ft depth interval-six DVS and 39 historical sample locations. Sample analyses included DVS samples (6 VOC, $6 \mathrm{SVOC}, 6 \mathrm{PCB}, 6$ metals, and $6 \mathrm{RAD}$ ) and historic samples (93 VOA, 74 SVOC, 53 PCB, 53 metals, $59 \mathrm{RAD}$, and $26 \mathrm{DRO} / \mathrm{GRO})$.

A release of contamination into shallow surface soils occurred at this EU in the late 1980s. This release was estimated to be approximately 500-600 gal of diesel fuel from a fill pipe to a UST located north of the K-1414 Garage. The diesel tank was removed in 1987 under state UST regulatory applicable or relevant and appropriate requirements and a limited volume of soil (not quantified in the closure report) also was excavated at the time.

Several monitoring wells in the area historically have reported benzene above MCLs (5 ug/L). Benzene concentrations have declined to levels below regulatory concern in all but two monitoring wells in the area. These data indicate the diesel fuels have been transported to the west-northwest from the release point and are in the groundwater system in bedrock. Samples collected at the tank site above $10 \mathrm{ft}$ depth have no substantially elevated concentrations of DRO or BTEX compounds.

The following is a summary of the data evaluation for EU Z2-37.

\begin{tabular}{lccccc}
\hline EU \# & $\begin{array}{c}\text { Maximum RL } \\
\text { exceeded? }\end{array}$ & $\begin{array}{c}\text { Averge RL over } \\
\text { EU exceeded? }\end{array}$ & $\begin{array}{c}\text { Industrial risk } \\
\text { above } \mathbf{1} \times \mathbf{1 0}^{-4}\end{array}$ & $\begin{array}{c}\text { Potential source } \\
\text { to groundwater? }\end{array}$ & $\begin{array}{c}\text { Action } \\
\text { required? }\end{array}$ \\
\hline $\mathrm{Z} 2-37$ & No & No & No & No & No \\
\hline $\begin{array}{l}\mathrm{EU}=\text { exposure unit } \\
\mathrm{RL}=\text { remediation level }\end{array}$ & & & & \\
\end{tabular}
Z2-37:

Based on historical and DVS sampling information, the following statements can be made for EU

- No Zone 2 COCs were present at concentrations in excess of maximum RLs.

- No Zone 2 soils COCs were present with a mean concentration exceeding the average RL across the EU.

- While chemicals or radionuclides were present in soils, they were at concentrations such that the industrial risk was $<1 \times 10^{-4}$ ELCR and the target organ $\mathrm{HI}<1$.

- Chemicals and radionuclides in the soils were not potential threats to groundwater.

- NFA is appropriate under the Zone 2 ROD to meet industrial land use. 
- There is a low probability the acreage could be released with no land use restrictions. Industrial and residential PRG exceedances for metals, radionuclides, PCBs, SVOCs, and VOCs occur in this EU.

\subsubsection{Exposure Unit Z2 -41}

EU Z2-41 is located in the K-1070-C/D and Downgradient Area Group in the southeastern quadrant of Zone 2 and consists of approximately 38 acres (see Appendix I). All land area in this EU has been impacted by site operations. The EU is situated on a hill at the eastern edge of the industrialized heart of ETTP Zone 2. Historically, the EU was used primarily for burial and disposal of liquid and solid wastes. A drum crusher was located in the K-1071 Concrete Pad FFA site. There are several buildings and other facilities located throughout the EU.

This EU consists of $<0.05$ acres of Class 1 soils, $<0.1$ acres of Class 2 soils, and 38 acres of Class 3 soils (18.9 acres of Class 3 modified and 19 acres of Class 3). The K-1070-C/D Burial Ground FFA site, K-1070 Pits FFA site, and K-1071 Concrete Pad FFA site are the FFA sites listed in Appendix A of the Zone 2 ROD included in this EU.

The primary conceptual model for the area includes historic VOC releases from pits and trenches to underlying bedrock and eventually groundwater. The pits and trenches were excavated into the intensely fractured residual Rome formation bedrock, which readily accepted the liquid materials (e.g., solvents) poured into the trenches. These liquids are thought to have moved vertically downward through the soil into the rock mass where they occupied the interconnected available pore space and microfractures. The organic liquids subsequently were subsumed into the rock mass by matrix diffusion and slowly released into the groundwater over time. Sampling has shown soil is not an ongoing secondary source, whereas groundwater monitoring data suggest the heavily fractured and porous rock mass is an ongoing secondary contaminant source to groundwater.

Two Class 1 SUs were identified in during DQO scoping-Concrete Pad Class 1 SU and RAD91 Class 1 SU. A BAR survey was conducted over the RAD91 Class 1 SU to delineate a RA boundary. A radiological survey was not conducted over the Concrete Pad Class 1 SU because it was already scheduled for RA based on radiological contamination in historic data.

Two Class 2 SUs were identified during DQO scoping-RAD122 Class 2 SU and Z2-EU41DB-208 Class 2 SU. A BAR survey was conducted over the RAD122 Class 2 SU to define the areal extent of the average RL exceedance. A BAR survey was not conducted over the Z2-EU41DB-208 Class 2 SU because early characterization step-out sampling demonstrated the average RL exceedances were confined to the original sample location.

The extensive sampling dataset for EU Z2-41 includes 28 sample locations in the EU Class 1 SUs, 11 sample locations in the Class 2 SU, and 142 DVS and historical sample locations in the Class 3 SU. Sample analyses included DVS (17 VOC, 66 SVOC, 66 PCB, 66 metals, and 26 RAD) and historic samples (154 VOA, 116 SVOC, 116 PCB, 113 metals, 203 RAD and 152 DRO/GRO).

On-site groundwater SLs were exceeded by U-234, U-235, U-238, and the VOCs tetrachloroethene and trichloroethene. The uranium species are effectively immobile in groundwater at ETTP but VOCs are mobile in ETTP soils. The primary original source of VOCs in groundwater is the K-1070 Pits FFA site. However, only methylene chloride is observed in K-1070 Pits FFA site soils to a depth of $10 \mathrm{ft}$ and methylene chloride is not a significant groundwater contaminant in downgradient monitoring wells. The VOCs disposed of in the K-1070 Pits rapidly moved out of the 10-ft-depth interval into bedrock, which is now the source of the VOC plumes observed in downgradient monitoring wells. It is concluded the K-1070 Pits FFA site is not a source for groundwater contamination. There are no organic chemical groundwater plumes associated with the K-1071 Concrete FFA site as a source. Therefore, it is concluded 
that neither the Concrete Pad Class 1 SU nor the K1071 Concrete Pad FFA site poses a threat to groundwater.

The following is a summary of the data evaluation for EU Z2-41.

\begin{tabular}{lccccc}
\hline EU \# & $\begin{array}{c}\text { Maximum RL } \\
\text { exceeded? }\end{array}$ & $\begin{array}{c}\text { Average RL over } \\
\text { EU exceeded? }\end{array}$ & $\begin{array}{c}\text { Industrial risk } \\
\text { above } \mathbf{1} \times \mathbf{1 0}^{-4}\end{array}$ & $\begin{array}{c}\text { Potential source } \\
\text { to groundwater? }\end{array}$ & $\begin{array}{c}\text { Action } \\
\text { required? }\end{array}$ \\
\hline $\mathrm{Z} 2-41$ & Yes & No & No & No & Yes \\
\hline $\begin{array}{l}\mathrm{EU}=\text { exposure unit } \\
\mathrm{RL}=\text { remediation level }\end{array}$ & & & & \\
\end{tabular}
Z2-41:

Based on historical and DVS sampling information, the following statements can be made for EU

- There are U-235 (242.2 pCi/g) and U-238 (15,670 pCi/g) maximum RL exceedances at the RAD47 historical location in the Concrete Pad Class $1 \mathrm{SU}$.

- No chemical or radionuclide exceeds its average RL across the EU, exclusive of the Concrete Pad Class $1 \mathrm{SU}$.

- No chemicals or radionuclides are in the soils at concentrations high enough for the EU to fail the Zone 2 risk limits. Therefore, the industrial risk was $<1 \times 10^{-4}$ ELCR and the target organ HI was $<1$.

- While downgradient monitoring wells exhibit VOC contamination, the K-1070 Pits FFA site is not a source of groundwater contamination. There are no VOC groundwater plumes associated with the K1071 Concrete Pad FFA site as a source, and neither the Concrete Pad Class 1 SU nor the K-1071 Concrete Pad FFA site poses a threat to groundwater.

- Based on a RA requirement in the Zone 2 ROD, and to address the location of a maximum RL exceedance, excavation and removal for the Concrete Pad Class 1 SU in the K-1071 Concrete Pad FFA site is recommended. Approximately $50 \mathrm{yd}^{3}$ of material will be removed.

- Because of the presence of the K-1070-C/D Burial Ground FFA and K-1070 Pits FFA sites, there is a low probability the land area will be available for unrestricted use.

\subsubsection{Exposure Unit Z2 43}

EU Z2-43 is located in the South Park Area Group in the southeast quadrant of Zone 2 and consists of approximately 8.7 acres (see Appendix J). Site operations, including construction of buildings, roads, parking lots, and sidewalks, have impacted the majority of land in EU Z2-43. This EU is on the southeastern boundary of the administrative section of ETTP. There were no FFA sites listed in Appendix A of the Zone 2 ROD included in this EU.

This EU consists of 1 acre of Class 2 soils and 7.7 acres of Class 3 soil. Other than plant facilities and associated constructed features, no anthropogenic features were identified during the Class 3 SU walkover assessment.

The conceptual site model for EU Z2-43 is a surface release model because of soil reworking and a PCB storage yard. PCBs found in shallow soils support the conceptual model.

Three sediment accumulation areas were identified during the Class 3 SU walkover assessment for biased sampling. 
There were two sample locations in the Class 2 SU and seven sampling locations in the Class 3 SU. All sampling performed in the SU was DVS sampling. Sample analyses included DVS (5 SVOC, 5 PCB, and 5 metals). No historic sampling was performed in this EU. The following is a summary of the data evaluation for EU Z2-43.

\begin{tabular}{lccccc}
\hline EU \# & $\begin{array}{c}\text { Maximum RL } \\
\text { exceeded? }\end{array}$ & $\begin{array}{c}\text { Average RL over } \\
\text { EU exceeded? }\end{array}$ & $\begin{array}{c}\text { Industrial risk } \\
\text { above } \mathbf{1} \times \mathbf{1 0}^{-4}\end{array}$ & $\begin{array}{c}\text { Potential source to } \\
\text { groundwater? }\end{array}$ & $\begin{array}{c}\text { Action } \\
\text { required? }\end{array}$ \\
\hline $\mathrm{Z} 2-43$ & No & No & No & No & No \\
\hline $\begin{array}{l}\mathrm{EU}=\text { exposure unit } \\
\mathrm{RL}=\text { remediation level }\end{array}$ & & & & \\
\end{tabular}

Based on historical and DVS sampling information, and results of the walkover assessment, the following statements can be made for EU Z2-43:

- No Zone 2 COCs were detected at concentrations in excess of maximum RLs.

- No Zone 2 COCs were present with a mean concentration exceeding the average RL across the EU.

- Because no average industrial PRGs were exceeded across the EU, the industrial risk was $<1 \times 10^{-4}$ and the target organ HI was $<1$.

- The soils do not pose a threat to groundwater.

- NFA is appropriate to meet industrial land use.

- There is a low probability this EU can be released with no land use restrictions. Industrial and residential PRG exceedances occur for PCBs and metals.

\subsubsection{Exposure Unit Z2 44}

EU Z2-44 is located in the northeast quadrant of Zone 2 in the Mitchell Branch EU Group and consists of approximately 16.1 acres (see Appendix K). Approximately 6 acres of the EU are associated with the still active TSCA Incinerator (TSCAI) and were exempt from characterization in the DQO Scoping Package, which left approximately 10.1 acres to be assessed. All of the land area in this EU has been impacted by site operations. The western two-thirds of the EU includes the K-1070-G Burial Ground, TSCAI, other facilities, roads, parking lots, and other paved surfaces. The eastern one-third of the EU has not been as heavily impacted and includes a stand of second growth forest.

EU Z2-44 consists of 0.6 acres of Class 2 soils that encompass the footprint of the K-1070-G FFA site and 9.5 acres of Class 3 soils. Aside from plant facilities and associated constructed features, no anthropogenic features were identified during the Class 3 SU walkover assessment. Twenty-two facilities are listed in the DQO Scoping Package as located in this EU, and 27 facilities were assessed during the Class 3 SU walkover assessment.

There are two conceptual site models applicable in EU Z2-44: (1) a subsurface release model that applies to the K-1070-G Burial Ground FFA site, and (2) a surface release model that applies to soils in the area of the above-ground storage tanks and to surface soils in proximity to the active TSCAI. 
There were four DVS sample locations and one historical sample location in the Class 2 SU in each of the Class 2 and Class 3 SUs. Sample analyses included DVS (6 VOC, 10 SVOC, 10 PCB, 10 metals, $5 \mathrm{RAD}$, and $6 \mathrm{DRO} / \mathrm{GRO}$ ) and historic samples (2 metals). Following is a summary of the data evaluation for EU Z2-44.

\begin{tabular}{cccccc}
\hline EU \# & $\begin{array}{c}\text { Maximum RL } \\
\text { exceeded? }\end{array}$ & $\begin{array}{c}\text { Average RL over } \\
\text { EU exceeded? }\end{array}$ & $\begin{array}{c}\text { Industrial risk } \\
\text { above } \mathbf{1 \times 1 0} \mathbf{1 0}^{-4}\end{array}$ & $\begin{array}{c}\text { Potential source } \\
\text { to groundwater? }\end{array}$ & $\begin{array}{c}\text { Action } \\
\text { required? }\end{array}$ \\
\hline Z2-44 & No & No & No & No & No \\
\hline $\begin{array}{l}\mathrm{EU}=\text { exposure unit } \\
\mathrm{RL}=\text { remediation level }\end{array}$ & & & & & \\
\end{tabular}

Based on historical and DVS sampling information, and results of the walkover assessment, the following statements can be made for EU Z2-44:

- No Zone 2 COCs were detected at concentrations in excess of maximum RLs.

- No Zone 2 COCs were present with a mean concentration exceeding the average RL across the EU.

- No chemicals or radionuclides in soils at high enough concentrations for the EU to exceed the Zone 2 risk limits and, therefore, the industrial risk was $<1 \times 10^{-4}$ ELCR and the target organ $\mathrm{HI}<1$.

- No groundwater SL exceedances in the soils data and no MCL exceedances in local groundwater monitoring wells downgradient of the EU and upgradient of the K-1420 site to the west along Mitchell Branch were detected. Therefore, it was concluded the soils of do mt pose a threat to groundwater.

- NFA is appropriate under the Zone 2 ROD to meet industrial land use for this EU.

- There is a low probability the acreage could be released with no land use restrictions because of the K-1070-G Burial Ground FFA site.

- Based on sampling analytical results and the recommendation for this EU, DOE recommends NFA as appropriate for the K-1070-G Burial Ground FFA site.

These recommendations do not apply to the 6 acres exempted from assessment that are associated with the active TSCAI.

\subsection{COMPLETED REMEDIAL ACTIONS}

RA was performed in EUs Z2-33, Z2-35, and Z2-36 as follows:

- Concrete slab removal at Bldgs. K-1004-A, K-1004-B, K-1004-C, K-1004-D, and K-1004-L (plus a small area of soil adjacent to K-1004-L) in EU Z2-33;

- Backfilling the K-1407 E\&F Holding Ponds in EU Z2-35; and

- $\quad$ Backfilling the K-1501 basement and adjacent pits in EU Z2-36.

Performance of these RAs does not enable the EUs to meet the risk criteria of the Zone 2 ROD RAO. DVS characterization and/or additional RAs have not been completed. 


\section{REMEDIATION ACTIVITIES}

below.

RAs were performed in EUs Z2-33, Z2-35, and Z2-36 in FY 2007. Those actions are summarized

Removal of the concrete slabs from previously demolished buildings (and a small area of contaminated soil adjacent to the K-1004-L slab) was performed in the Balance of Site (BOS) laboratory area of EU Z2-33. This action was performed to enhance reindustrialization of the area. Slab removal occurred between August 26, 2006 and April 17, 2007, and involved excavating the concrete and loading it into trucks for disposition at the Environmental Management Waste Management Facility (EMWMF). The concrete ( 8555 tons) was removed to the K-25 concrete staging area for use as K-25 building vault backfill, and 18,180 $\mathrm{yd}^{3}$ of clean soil was used to fill the slab depressions.

The K-1407 E\&F Holding Ponds in EU Z2-35 are earthen structures that were used as extra storage capacity for liquid wastes awaiting treatment at the Central Neutralization Facility during periods of water surge. The ponds were backfilled between April 2 and June 28, 2007 because the surge capacity is no longer needed. The ponds were originally backfilled with overburden soil from the K-1070-B burial grounds, which was determined to be unsuitable for use as backfill. Those soils were removed, returned to the K-1070-B burial grounds, and the ponds were rebackfilled with $7575 \mathrm{yd}^{3}$ of more suitable clean soil.

The ETTP Steam Plant, Bldg. K-1501, in EU Z2-36 was demolished. The basement and two small adjacent pits were backfilled with clean soil between March 30 and June 28, 2007 as a best management

practice to keep the excavations from filling with water and eliminate a safety hazard. Backfill consisted of $6990 \mathrm{yd}^{3}$ of clean soil. 


\section{DEVIATIONS FROM THE RECORD OF DECISION}

The Zone 2 ROD divided the Zone 2 area into seven geographic areas and 44 EUs. To facilitate the DQOs, the Zone 2 RDR/RAWP regrouped these 44 EUs into 12 DQO scoping EU groups. These groups facilitated the DQO process by placing similar facilities and their support facilities together and allowed for identification of data gaps.

Calculation of the acreages in this PCCR has resulted in some discrepancies from the acreages reported in the ROD. These discrepancies are due to boundary refinement and an increased level of accuracy. 


\section{COSTS FOR REMEDIAL ACTION(S)}

Costs for performing the RAs are presented in the table below.

\begin{tabular}{|c|c|c|}
\hline$\underline{\mathbf{E U}}$ & Remedial action performed & Cost \\
\hline$\underline{Z 2-33}$ & $\begin{array}{l}\text { Concrete slab removal at Bldgs. K-1004-A, K-1004-B, K-1004-C, K-1004-D, and } \\
\text { K-1004-L (plus a small area of soil adjacent to K-1004-L) }\end{array}$ & $\$ 1,143,329$ \\
\hline$\underline{\mathrm{Z} 2-35}$ & Backfilling the K-1407 E\&F Holding Ponds & $\$ 135,191$ \\
\hline$\underline{\mathrm{Z} 2-36}$ & Backfilling the K-1501 basement and adjacent pits & $\$ 76,391$ \\
\hline & Total & $\$ 1,354,911$ \\
\hline
\end{tabular}

$\underline{\mathrm{EU}}=$ exposure unit

\begin{tabular}{|c|c|c|}
\hline $\mathbf{E U}$ & Remedial action performed & Cost \\
\hline 7233 & $\begin{array}{l}\text { Concrete slab removal at Bldgs. K } 1004 \text { A, K } 1004 \text { B, K } 1004-C, K 1004-D \text {, and } \\
\text { K } 1004 \text { I (plus a small area of soil adjacent to K } 1004 \text { L) }\end{array}$ & $\$ 1,143,329$ \\
\hline 7235 & Backfilling the K 1407 E E Holding Ponds & $\$ 135,194$ \\
\hline $72-36$ & Backfilling the K-1501 basement and adjacent pits & $\$ 76,391$ \\
\hline
\end{tabular}

$\mathrm{EU}=$ expesure unit 


\section{WASTE MANAGEMENT AND TRANSPORTAION ACTIVITIES FOR REMEDIAL ACTION(S)}

This section describes waste volumes generated during the Zone 2 RAs performed, and the waste volumes and types transported and disposed of at EMWMF. The only waste generated from the RAs was concrete from the removal of the BOS Labs building slabs. Waste volumes consisted of $8555 \mathrm{yd}^{3}$ of concrete that was removed to the K-25 concrete staging area for use as backfill of the K-25 vaults. 


\section{OPERATIONS AND MAINTENANCE}

The TSCAI remains an active, complex-wide hazardous waste treatment system in EU Z2-44 that requires ongoing operations and maintenance. No Zone 2 remedial actions are ongoing that require operations and maintenance other than managing investigation-derived waste.

Native grasses, which require no maintenance, were planted at all three RA locations but may fail to grow because of the very dry spring and summer. In that case, domestic grass may be planted that will require mowing. No further maintenance activities are required for the RAs completed. 


\section{MONITORING SCHEDULE AND/OR EXPECTATIONS}

There are no monitoring requirements for the EUs addressed by this PCCR. 


\section{LAND USE CONTROLS}

This section discusses general land use controls for the EUs in ETTP Zone 2. Details of the controls will be presented in one or more land use control implementation plans to be developed later. An assessment of EUs that may be available for possible unrestricted use is presented in Sect. 11.2.

\subsection{LAND USE CONTROLS UNDER ZONE 2 DVS}

DVS characterization of the EUs presented in this PCCR was conducted in accordance with the requirements of the Zone $2 \mathrm{ROD}$ and Zone 2 RDR/RAWP. The goal of characterization was to gather sufficient information to evaluate the EUs against the four decision rules developed in the DVS DQOs (Table 5), and to identify an action/NFA decision for each EU. The decision rule evaluation process used in this PCCR is described in Sect. 3. Consistent with the Zone 2 ROD, a NFA decision means an EU is available for unrestricted industrial use to a depth of $10 \mathrm{ft}$ bgs.

\subsection{POSSIBLE LIFTING OF LAND USE CONTROLS}

As required by the Zone 2 ROD, this section presents an evaluation of the Zone 2 EUs for possible lifting of land use controls. This section will consider the possibility of lifting the following two land use controls:

- Industrial land use controls below $10 \mathrm{ft}$ bgs, and

- Making certain EUs available for unrestricted land use.

Based on the DVS process and the EU DVS status assessments presented in this PCCR, each EU is assigned a high, medium, or low probability of lifting land use controls.

\subsubsection{Definitions}

High probability — This designation indicates there are no identified areas of contaminated soils and there are no significant disposal or landfill operations observed in the EU. DVS evaluations indicate there was no identified impact within the EU and there is a high probability the acreage could be released with no land use controls following appropriate evaluation.

Medium probability - This designation indicates there is an identifiable impact from facility operations to some portion of the acreage in the EU. This impact may be visible rubbish and debris and/or concentrations of several metals and/or radionuclides above background levels and/or the detection of organic compounds in a few samples within the EU. Based on the observations and sample results, the impact appears to be minor and limited in extent. There is a moderate probability the acreage could be released following appropriate evaluation.

Low Probability_-This designation indicates there is a clearly identified impact to substantial portions of the acreage within the EU. Metals and radionuclides are commonly above background levels and organic compounds may be present in several samples within the EU at levels above $1 \times 10^{-6}$ residential PRGs. The probability of unrestricted use of the acreage in the EU is low.

\subsubsection{Industrial Controls at Depth}

An evaluation was performed to determine which EUs would require industrial controls below $10 \mathrm{ft}$ bgs. The DVS program was designed to assure the top $10 \mathrm{ft}$ of soil meet industrial criteria. However, 
sufficient information exists to make reasonable conclusions regarding the need for land use controls below $10 \mathrm{ft}$ of soil. For those EUs where the top $10 \mathrm{ft}$ of soil meets the industrial criteria and it was determined waste was not buried in the EU, there is no mechanism to transport contaminants to depths below $10 \mathrm{ft}$ and, therefore, those EUs can be considered good candidates for lifting industrial controls below $10 \mathrm{ft}$.

For those EUs where waste was buried, sufficient data was gathered to determine the vertical distribution of contaminants. All EUs that have been cleared for industrial use to a depth of $10 \mathrm{ft}$ bgs have a high probability of being cleared for industrial use to all depths, with the exception of EUs Z2-28, Z2-34, Z2-37, Z2-41, and Z2-44. Formerly buried wastes and/or contaminated groundwater are present at depth in all of these EUs. Those EUs with proposed unrestricted/continued restricted use below $10 \mathrm{ft}$ bgs are shown on Table 10.

\subsubsection{Potential Unrestricted Use}

To conduct the evaluation and determine the probability of lifting land use controls, EU analytical data were compared to background concentrations and $1 \times 10^{-6}$ residential PRGs. A qualitative assessment of the applicability of the comparison results to the whole EU then was made. DVS sampling is biased to areas with relatively high probabilities of being contaminated (i.e., DVS systematic sampling is focused on Class 1 and Class 2 SUs and DVS biased sampling is conducted in all SUs based on a determination from visual and screening assessments that there is a likelihood of contamination). As a result, the presence of background or $1 \times 10^{-6}$ residential-use PRG concentration exceedances in the data set for a particular EU does not automatically preclude the EU from the possibility of lifting industrial land use controls. The probability of lifting land use controls for acreage in Zone 2 is generally low. Zone 2 has been extensively impacted by the construction of ETTP facilities, infrastructure, and heavy industrial activities. Sample results consistently indicate impact to area soils above background levels and commonly above industrialuse PRGs. Also, there are many small structures and abandoned infrastructure in many areas of Zone 2. Therefore, unrestricted use of Zone 2 acreage is an unlikely alternative.

Because the DVS process was designed around requirements of the Zone 2 ROD, which specifies an unrestricted industrial land use, further evaluation is recommended before a final conclusion can be drawn concerning lifting industrial land use controls.

To evaluate for unrestricted use, appropriate DQOs should be developed that consider but are not limited to the following:

- Calculated RLs that are consistent with the risk management requirements of an unrestricted land use scenario;

- RLs for chemicals and radionuclides where background concentrations are greater than residential PRGs (i.e., aluminum, arsenic, iron, manganese, K-40, Ra-226, Th-228, and Th-232);

- RL for Cs-137, a ubiquitous fallout radionuclide that does not have a determined background concentration but typically exceeds its residential PRG whenever detected; and

- $\quad$ EU size.

Taking the above into account, results of the evaluation pocess identified EUs that had high, medium, and low probabilities of meeting further considerations for lifting land use restrictions. The evaluations for the 11 EUs discussed in this PCCR are presented in Table 11. 
Table 10. EUs with restricted/unrestricted land use below $10 \mathrm{ft}$ in Zone 2 EUs of the FY 2007 PCCR

\begin{tabular}{clll}
\hline EU & $\begin{array}{c}\text { Proposed restricted/unrestricted } \\
\text { land use below 10 ft }\end{array}$ & EU & $\begin{array}{c}\text { Proposed restricted/unrestricted } \\
\text { land use below 10 ft }\end{array}$ \\
\hline Z2-01 & Unrestricted & $\mathrm{Z} 2-34$ & Restricted \\
$\mathrm{Z} 2-03$ & Unrestricted & $\mathrm{Z} 2-37$ & Restricted \\
$\mathrm{Z} 2-08$ & Unrestricted & $\mathrm{Z} 2-41$ & Restricted \\
$\mathrm{Z} 2-23$ & Unrestricted & $\mathrm{Z} 2-43$ & Unrestricted \\
$\mathrm{Z} 2-24$ & Unrestricted & $\mathrm{Z} 2-44$ & Restricted \\
$\mathrm{Z} 2-28$ & Restricted & & \\
\hline EU = exposure unit & & \\
FY = fiscal year \\
PCCR = Phased Construction Completion Report
\end{tabular}

Table 11. Probability of lifting land-use restrictions from each $\mathbf{E U}^{a}$

\begin{tabular}{|c|c|c|}
\hline $\mathbf{E U}$ & $\begin{array}{l}\text { Probability of lifting } \\
\text { land-use restrictions }\end{array}$ & Rationale/caveats \\
\hline Z2-01 & Low & $\begin{array}{l}\text { Several } 1 \times 10^{-6} \text { residential PRGs are exceeded in this EU by metals, } \\
\text { PCBs, radionuclides, and SVOCs }\end{array}$ \\
\hline Z2-03 & Low & $\begin{array}{l}\text { Several } 1 \times 10^{-6} \text { residential PRGs are exceeded in this EU by metals, } \\
\text { PCBs, radionuclides, and SVOCs }\end{array}$ \\
\hline Z2-08 & Low & $\begin{array}{l}\text { Several } 1 \times 10^{-6} \text { residential PRGs are exceeded in this EU by metals, } \\
\text { PCBs, radionuclides, and SVOCs }\end{array}$ \\
\hline Z2-23 & Low & $\begin{array}{l}\text { Several } 1 \times 10^{-6} \text { residential PRGs are exceeded in this EU by metals, } \\
\text { PCBs, radionuclides, and SVOCs }\end{array}$ \\
\hline $\mathrm{Z} 2-24$ & Low & $\begin{array}{l}\text { Several } 1 \times 10^{-6} \text { residential PRGs are exceeded in this EU by metals, } \\
\text { PCBs, radionuclides, and SVOCs }\end{array}$ \\
\hline $\mathrm{Z} 2-28$ & Low & $\begin{array}{l}\text { Several } 1 \times 10^{-6} \text { residential PRGs are exceeded in this EU by metals, } \\
\text { PCBs, radionuclides, and SVOCs }\end{array}$ \\
\hline $\mathrm{Z} 2-34$ & Low & $\begin{array}{l}\text { Several } 1 \times 10^{-6} \text { residential PRGs are exceeded in this EU by metals, } \\
\text { PCBs, and radionuclides }\end{array}$ \\
\hline Z2-37 & Low & $\begin{array}{l}\text { Several } 1 \times 10^{-6} \text { residential PRGs are exceeded in this EU by metals, } \\
\text { PCBs, radionuclides, VOCs, and SVOCs }\end{array}$ \\
\hline Z2-41 & Low & $\begin{array}{l}\text { Several } 1 \times 10^{-6} \text { residential PRGs are exceeded in this EU by metals, } \\
\text { PCBs, radionuclides, VOCs, and SVOCs }\end{array}$ \\
\hline $\mathrm{Z} 2-43$ & Low & $\begin{array}{l}\text { Several } 1 \times 10^{-6} \text { residential PRGs are exceeded in this EU by metals, } \\
\text { PCBs, and SVOCs }\end{array}$ \\
\hline $\mathrm{Z} 2-44$ & Low & $\begin{array}{l}\text { Several } 1 \times 10^{-6} \text { residential PRGs are exceeded in this EU by metals, } \\
\text { radionuclides, and SVOCs }\end{array}$ \\
\hline
\end{tabular}

\footnotetext{
${ }^{a}$ Only EUs discussed in this PCCR for Zone 2 were considered.

$\mathrm{EU}=$ exposure unit $\quad \mathrm{PRG}=$ preliminary remediation goal

$\mathrm{PCB}=$ polychlorinated biphenyl $\quad$ SVOC $=$ semivolatile organic compound
} 


\section{REMAINING ACTIVITIES}

This section summarizes activities remaining to be completed in Zone 2 The rationale for these activities falls into four categories:

- Remaining activity is an action to be performed,

- Remaining activity awaits a risk management decision,

- Remaining activity is part of a larger infrastructure investigation to be conducted at a later time, or

- Remaining activity awaits D\&D to make soils accessible.

The status of each EU in Zone 2 is presented in Table 12. EUs included in this PCCR and the 2006

Zone 2 PCCR are shown in Fig. 6. As shown in Fig. 6, characterization has been completed in 17 of the 44 Zone 2 EUs.

Table 12. Status of Zone 2 EUs

\begin{tabular}{|c|c|c|c|c|c|c|}
\hline $\mathbf{E U}$ & $\begin{array}{c}\text { Characterization } \\
\text { complete? }\end{array}$ & $\begin{array}{l}\text { NFA on soil } \\
\text { appropriate? }\end{array}$ & $\begin{array}{c}\text { NFA on } \\
\text { infrastructure }^{\text {appropriate? }}\end{array}$ & $\begin{array}{l}\text { Action } \\
\text { required? }\end{array}$ & $\begin{array}{c}\text { Closure } \\
\text { documentation? }\end{array}$ & $\begin{array}{l}\text { Comment/ } \\
\text { Explanation }\end{array}$ \\
\hline$\overline{Z 2-01}$ & $\checkmark$ & $\checkmark$ & $\checkmark$ & & FY 2007 PCCR & \\
\hline Z2-02 & $\checkmark$ & $\checkmark$ & $\checkmark$ & & FY 2006 PCCR & \\
\hline Z2-03 & $\checkmark$ & $\checkmark$ & $\checkmark$ & & FY 2007 PCCR & \\
\hline Z2-04 & & & & & PCCR or Zone 2 RAR & \\
\hline Z2-05 & & & & & PCCR or Zone 2 RAR & \\
\hline Z2-06 & & & & & PCCR or Zone 2 RAR & \\
\hline $\mathrm{Z} 2-07$ & $\checkmark$ & $\checkmark$ & $\checkmark$ & & FY 2006 PCCR & \\
\hline Z2-08 & $\checkmark$ & $\checkmark$ & $\checkmark$ & & FY 2007 PCCR & \\
\hline Z2-09 & $\checkmark$ & $\checkmark$ & $\checkmark$ & & FY 2006 PCCR & \\
\hline $\mathrm{Z} 2-10$ & $\checkmark$ & $\checkmark$ & $\checkmark$ & & FY 2006 PCCR & \\
\hline $\mathrm{Z} 2-11$ & & & & & PCCR or Zone 2 RAR & \\
\hline Z2-12 & & & & & PCCR or Zone 2 RAR & \\
\hline $\mathrm{Z} 2-13$ & & & & & PCCR or Zone 2 RAR & \\
\hline $\mathrm{Z} 2-14$ & & & & & PCCR or Zone 2 RAR & \\
\hline $\mathrm{Z} 2-15$ & & & & & PCCR or Zone 2 RAR & \\
\hline $\mathrm{Z} 2-16$ & & & & & PCCR or Zone 2 RAR & \\
\hline $\mathrm{Z} 2-17$ & & & & & PCCR or Zone 2 RAR & \\
\hline Z2-18 & & & & & PCCR or Zone 2 RAR & \\
\hline Z2-19 & & & & & PCCR or Zone 2 RAR & \\
\hline $\mathrm{Z} 2-20$ & & & & & PCCR or Zone 2 RAR & \\
\hline $\mathrm{Z} 2-21$ & & & & & PCCR or Zone 2 RAR & \\
\hline $\mathrm{Z} 2-22$ & & & & & PCCR or Zone 2 RAR & \\
\hline $\mathrm{Z} 2-23$ & $\checkmark$ & $\checkmark$ & $\checkmark$ & & FY 2007 PCCR & \\
\hline $\mathrm{Z} 2-24$ & $\checkmark$ & $\checkmark$ & $\checkmark$ & & FY 2007 PCCR & \\
\hline $\mathrm{Z} 2-25$ & & & & & PCCR or Zone 2 RAR & \\
\hline $\mathrm{Z} 2-26$ & & & & & PCCR or Zone 2 RAR & \\
\hline
\end{tabular}


Table 12. (continued)

\begin{tabular}{|c|c|c|c|c|c|c|}
\hline $\mathbf{E U}$ & $\begin{array}{c}\text { Characterization } \\
\text { complete? }\end{array}$ & $\begin{array}{l}\text { NFA on soil } \\
\text { appropriate? }\end{array}$ & $\begin{array}{c}\text { NFA on } \\
\text { infrastructure } \\
\text { appropriate? }^{a}\end{array}$ & $\begin{array}{l}\text { Action } \\
\text { required? }\end{array}$ & $\begin{array}{c}\text { Closure } \\
\text { documentation? }\end{array}$ & $\begin{array}{c}\text { Comment/ } \\
\text { Explanation }\end{array}$ \\
\hline $\mathrm{Z} 2-27$ & $\checkmark$ & $\checkmark$ & $\checkmark$ & & FY 2006 PCCR & \\
\hline $\mathrm{Z} 2-28$ & $\checkmark$ & $\checkmark$ & $\checkmark$ & $\checkmark$ & FY 2007 PCCR & \\
\hline Z2-29 & & & & & PCCR or Zone 2 RAR & \\
\hline $\mathrm{Z} 2-30$ & & & & & PCCR or Zone 2 RAR & \\
\hline $\mathrm{Z} 2-31$ & & & & & PCCR or Zone 2 RAR & \\
\hline $\mathrm{Z} 2-32$ & & & & & PCCR or Zone 2 RAR & \\
\hline $\mathrm{Z} 2-33$ & & & & & PCCR or Zone 2 RAR & \\
\hline $\mathrm{Z} 2-34$ & $\checkmark$ & $\checkmark$ & $\checkmark$ & & FY 2007 PCCR & \\
\hline $\mathrm{Z} 2-35$ & & & & & PCCR or Zone 2 RAR & \\
\hline $\mathrm{Z} 2-36$ & & & & & PCCR or Zone 2 RAR & \\
\hline $\mathrm{Z} 2-37$ & $\checkmark$ & $\checkmark$ & $\checkmark$ & & FY 2007 PCCR & \\
\hline Z2-38 & & & & & PCCR or Zone 2 RAR & \\
\hline Z2-39 & & & & & PCCR or Zone 2 RAR & \\
\hline $\mathrm{Z} 2-40$ & & & & & PCCR or Zone 2 RAR & \\
\hline $\mathrm{Z} 2-41$ & $\checkmark$ & $\checkmark$ & $\checkmark$ & $\checkmark$ & FY 2007 PCCR & \\
\hline $\mathrm{Z} 2-42$ & $\checkmark$ & & & $\checkmark$ & FY 2006 PCCR & \\
\hline $\mathrm{Z} 2-43$ & $\checkmark$ & $\checkmark$ & $\checkmark$ & & FY 2007 PCCR & \\
\hline $\mathrm{Z} 2-44$ & $\checkmark$ & $\checkmark$ & $\checkmark$ & & FY 2007 PCCR & \\
\hline
\end{tabular}

${ }^{a}$ The check mark in this column indicates either the infrastructure has been evaluated or there is no infrastructure requiring evaluation.

$\mathrm{EU}=$ exposure unit

$\mathrm{FY}=$ fiscal year

PCCR $=$ Phased Construction Completion Report

$\mathrm{NFA}=$ no further action RAR $=$ Remedial Action Report 


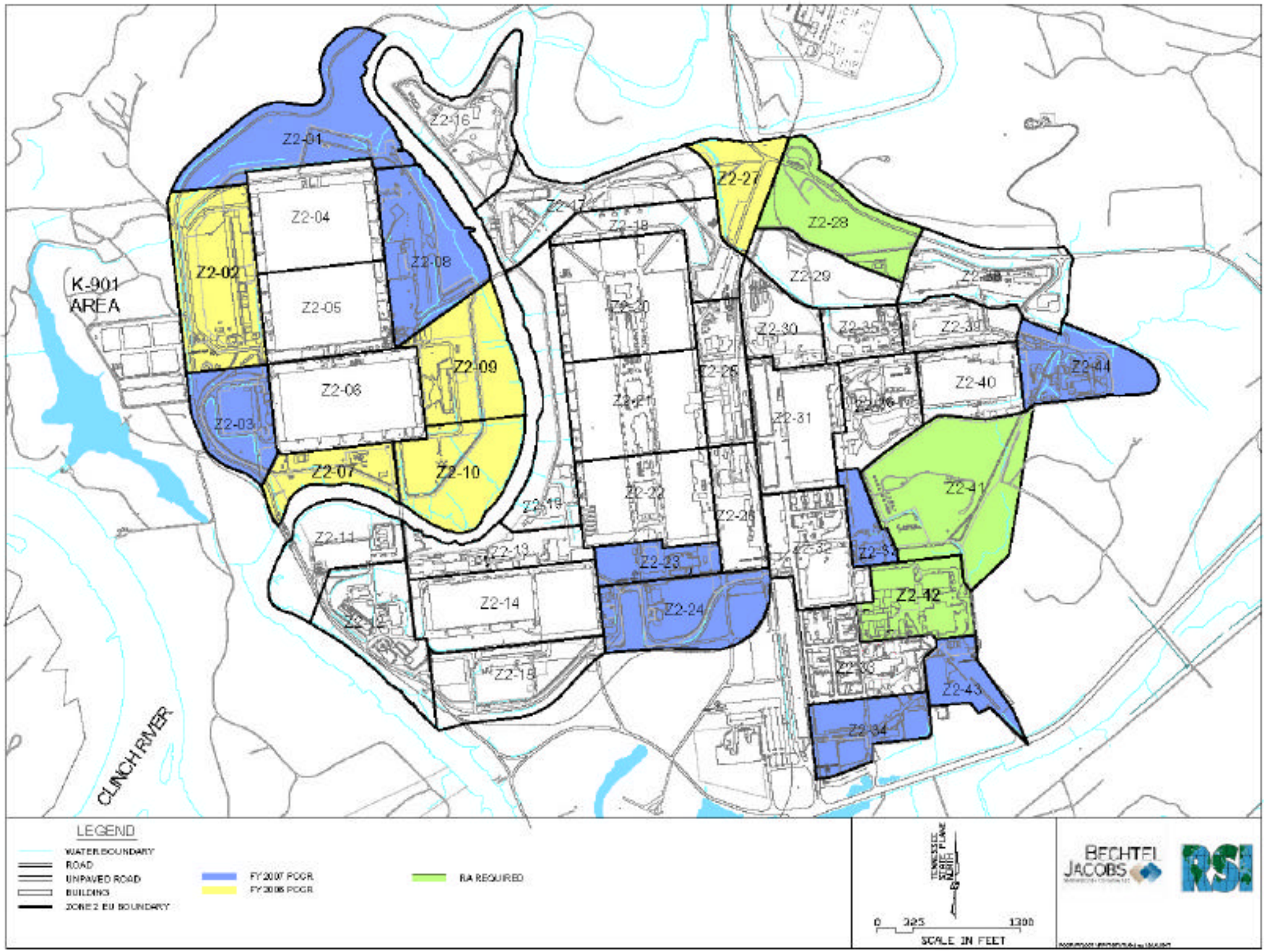

Fig . 6. ETTP Zone 2 EUs included in this and the FY 2006 Zone 2 PCCR 


\section{REFERENCES}

BJC (Bechtel Jacobs Company LLC) 2006. Supporting Documentation for Preliminary Remediation Goals Used in the Dynamic Verification Strategy Sampling Program, East Tennessee Technology Park, Oak Ridge, TN, BJC/OR-2383, Bechtel Jacobs Company LLC, Oak Ridge, TN.

BJC 2007. Zone 2 Dynamic Work Plan, East Tennessee Technology Park, Oak Ridge, Tennessee, BJC/OR-2373/R1.

DOE (U.S. Department of Energy) 1992. Federal Facility Agreement for the Oak Ridge Reservation, DOE/OR-1014, EPA-Region 4, DOE, and TDEC, Washington, D.C.

DOE 1993a. Final Report on the Background Soil Characterization Project at the Oak Ridge Reservation, Oak Ridge, Tennessee, Volume 1 - Results of Field Sampling Program, DOE/OR/01-1175/V1, October.

DOE 1993b. Radiation Protection of the Public and the Environment, DOE O 5400.5, Change 2, U.S. Department of Energy, Washington, D.C.

DOE 2003b. Soil Background Supplemental Data Set for the East Tennessee Technology Park, Oak Ridge, Tennessee, DOE/OR/01-2105\&D1, U.S. Department of Energy, Office of Environmental Management, Oak Ridge, TN.

DOE 2005. Record of Decision for Soil, Buried Waste, and Subsurface Structure Actions in Zone 2, East Tennessee Technology Park, Oak Ridge, Tennessee, DOE/OR/01-2161\&D2, U.S. Department of Energy, Office of Environmental Management, Oak Ridge, TN.

DOE 2007. Remedial Design Report/Remedial Action Work Plan for Zone 2 Soils, Slabs, and Subsurface Structures, East Tennessee Technology Park, Oak Ridge, Tennessee, DOE/OR/01-2224\&D2, U.S. Department of Energy, Office of Environmental Management, Oak Ridge, TN.

EPA (U.S. Environmental Protection Agency) 1989. Risk Assessment for Superfund, Vol. I, Human Health Evaluation Manual (Part A), EPA/540/1-89/002, Washington, D.C.

EPA 2002. Guidance for Comparing Background and Chemical Concentrations in Soil for CERCLA Sites, EPA-540-R-01-003, Washington, D.C.

MMES (Martin Marietta Energy Systems, Inc.) 1994. Cable Insulation PCB Analysis, Internal Correspondence, MMES, February 28, 1994.

ORISE (Oak Ridge Institute for Science and Education) 2000. Polychlorinated Biphenyl and Asbestos Sampling and Analysis Report for the K-762 and K-792 Switchyard Site, East Tennessee Technology Park, Oak Ridge, Tennessee (Draft), ORISE, December 14, 2000. 
Appendix A

K-31/33 EU Group

Exposure Unit Z2-01

Technical Memorandum 


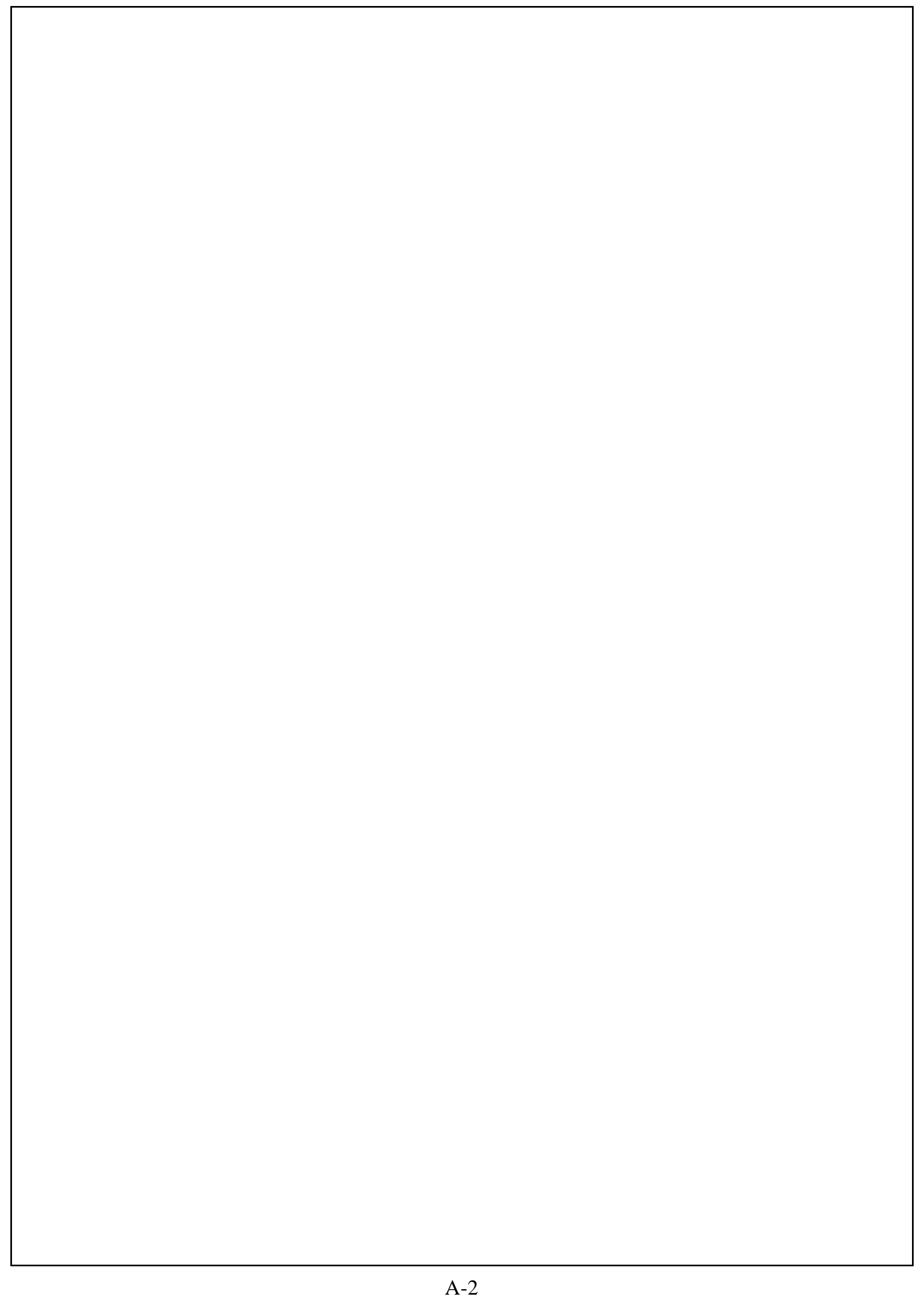




\section{FIGURES}

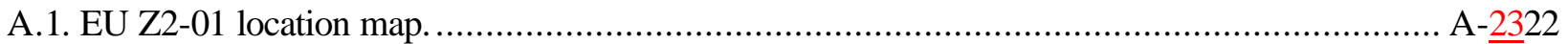

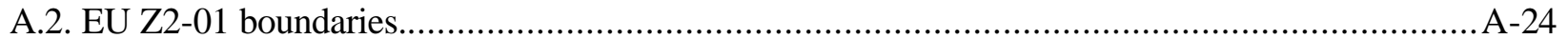

A.3. EU Z2-01 Class 3 and Class 4 SU walkover assessment locations....................................... A-25

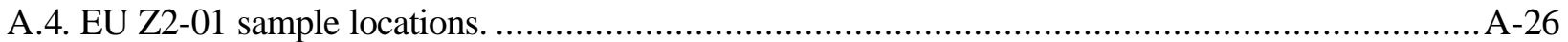

\section{TABLES}

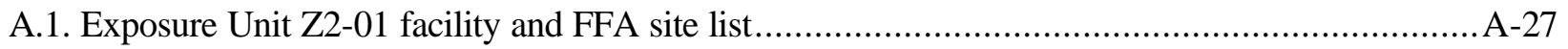

A.2. Exposure Unit Z2-01 sample summary

A.3. Zone 2 EU Z2-01, depth 0-10 ft. 


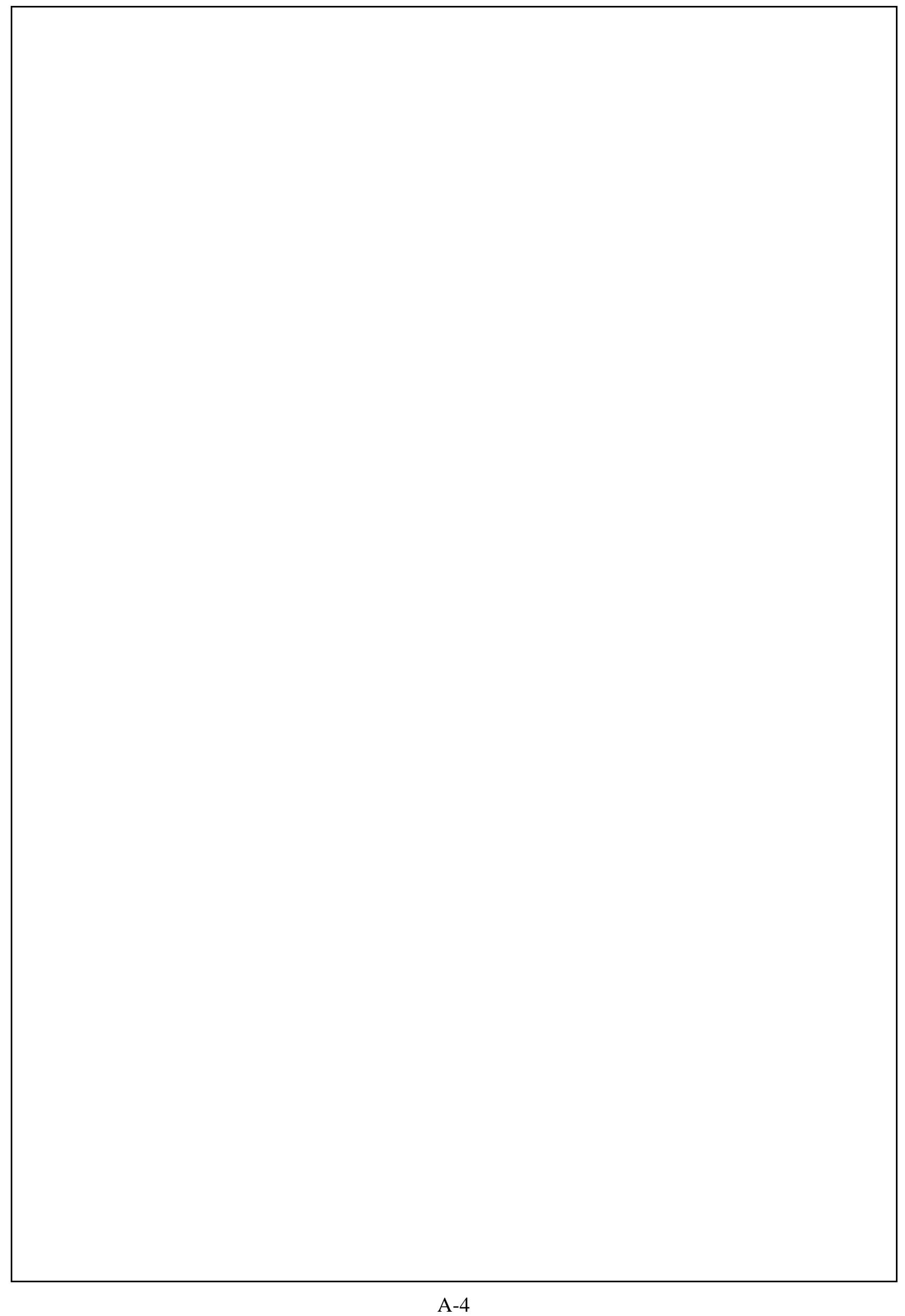




\title{
DYNAMIC VERIFICATION STRATEGY (DVS) TECHNICAL MEMORANDUM (TM)
}

\author{
EXPOSURE UNIT (EU) GROUP: Zone 2 K-31/33 Group EU Z2-01
}

\section{INTRODUCTION}

The purpose of this TM is to document the recommendation for an action/no further action (NFA) decision for EU Z2-01 in the K-31/33 EU Group. The recommendation for this EU is based on existing historical data and DVS soil characterization activities. These data are used to determine the nature and extent of contamination in the EU and to evaluate the need for an action. When it is determined that an action is necessary, the data are also used to calculate soil volumes for the proposed remedial alternative, as identified in the Record of Decision for Soil, Buried Waste, and Subsurface Structure Actions in Zone 2, East Tennessee Technology Park, Oak Ridge, Tennessee (DOE/OR/01-2161\&D2) (Zone 2 ROD).

\begin{tabular}{|l|l|}
\hline 1.0 & BACKGROUND AND EU S UMMARY \\
\hline 1.1 & LOCATIONAT EAST TENNESSEE TECHNOLOGY PARK (ETTP) \\
\hline
\end{tabular}

EU Z2-01 is located along the north boundary of Zone 2 in the K-31/33 EU Group (Fig. A.1). It is bounded by Zone 1 on the north and west; Z2-02, Z2-04 (K-33 building), and Z2-08 on the south; and Poplar Creek on the east.

\section{\begin{tabular}{l|l}
1.2 & EU Z2-28 ACREAGE
\end{tabular}}

EU Z2-01 has an area of approximately 32.6 acres (Fig. A.2).

\section{\begin{tabular}{l|l}
1.3 & SUMMARY DESCRIPTION \\
\hline
\end{tabular}}

EU Z2-01 occupies the northern extent of Zone 2 and merges directly with the forested Zone 1 EUs 58, 63, and 68. Therefore, the northern portion of EU Z2-01 is forested with forest making up approximately $20 \%$ of the EU. The southern, cleared and industrialized portion of the EU contains infrastructure for support of the K-33 Building. The EU is generally flat in the southern, industrialized portion but has a relatively steep gradient in the northern portion, which is located on the southern flank of Black Oak Ridge. The EU drains to Poplar Creek on the east and to the K901-A Holding Pond on the southwest.

The Data Quality Objective (DQO) Scoping Package for the K-31/33 EU Group lists six facilities in EU Z2-01, which is presented in Table A.1.

\section{\begin{tabular}{l|l}
1.4 & SOIL UNITS (SUS)
\end{tabular}}

Class 1 SU: None

Class 2 SU: Originally none; however, 0.3 acres of Class 3 SU comprising the K-892-J Cooling Tower Basin were reclassified as a Class $2 \mathrm{SU}$.

Class 3 SU: 32.3 acres of forest, roads, parking lots, former cooling tower basin, and mowed lawns.

Class 4 SU: None

\begin{tabular}{l|l}
\hline 1.5 & ZONE 2 ROD APPENDIX A FEDERAL FACILITY AGREEMENT (FFA) SITES
\end{tabular}

There is one Zone 2 ROD Appendix A FFA site in EU Z2-01: K-892-J Cooling Tower Basin.

\begin{tabular}{|l|l|}
\hline 2.0 & \multicolumn{1}{|c|}{ DVS INVESTIGATIONS AND RESULTS } \\
\hline 2.1 & DVS FIELD ACTIVITIES \\
\hline
\end{tabular}

DVS activities were conducted in accordance with the Remedial Design Report/Remedial Action Work Plan for Zone 2 Soils, Slabs, and Subsurface Structures, East Tennessee Technology Park, Oak Ridge, Tennessee (DOE/OR/01-2224\&D2) (Zone 2 RDR/RAWP). 
In addition to the APs, the field team made assessments at 22 MP locations (MPs are selected in the field and are points located approximately half way between APs) and conducted DP surveys at 26 locations (see below). Mid-point and DP locations are not specified in planning documents. Based on an evaluation of the walkover assessment results, two biased sample locations were selected for sampling in EU Z2-01.

\begin{tabular}{|c|c|c|c|}
\hline & Number of assessment points & Number of mid-points & $\begin{array}{c}\text { Number of discretionary } \\
\text { points } \\
\end{array}$ \\
\hline EU Z2-01 & 27 & 22 & 17 \\
\hline 2.1.3.1 & CLASS 3 AND CLASS 4 SU RADIO & ICAL SURVEY SUMMARY & \\
\hline
\end{tabular}

Screening level (SL): 3,254 counts per minute.

SL exceedances: No AP, MP, or DP measurements exceeded the SL in EU Z2-01.

\begin{tabular}{|l|l|}
\hline 2.1.3.2 & CLASS 3 AND ClASS 4 SU ANTHROPOGENIC FEATURES \\
\hline
\end{tabular}

Number of identified anthropogenic features: 12

The southern portion of EU Z2-01 consists of facilities and associated constructed features (i.e., roads, parking lots, sidewalks) for support of K-33 building operations. These facilities and constructed features were addressed during the facilities assessment conducted as part of the Class $3 \mathrm{SU}$ walkover assessment (Sect. 2.1.3.3).

Twelve additional anthropogenic features were identified during the Class 3 SU walkover assessment and include:

- PAM Station \#43,

- Air release for fire water line,

- Concrete pad,

- Exposed conduit in ground surface,

- 55-gal drum,

- Soil mounds,

- Steel pipe leading into Poplar Creek,

- Three ends of severed conduit in ground surface,

- Drainage ditch along Perimeter Road,

- Ditch with exposed strip of concrete,

- Access roads (dirt) in woods, and

- Rip-rap-lined drainage ditch.

Each of the 12 anthropogenic features was surveyed for radiation and inspected for visual evidence of chemical contamination. Two of the 12 features (55-gal drum and soil mounds) showed visual evidence for potential sources of chemical contamination and were selected for biased sampling (see Sect. 2.1.3.4). Two additional sediment accumulation areas outside the southwest corner of the EU were also identified. Sediment in these two areas is derived from much of the acreage in EU Z2-01 but is deposited to the south in EU Z2-02. These sample locations and discussion of the sample results are presented in the EU Z2-02 technical memorandum.

\section{\begin{tabular}{|l|l} 
2.1.3.3 & CLASS 3 SU FACILITIES ASSESSMENTS
\end{tabular}}

Six facilities are listed in the DQO Scoping Package as being located in EU Z2-01 (Table A.1). One facility, K-892-X RCW Sludge Tank, is located in EU Z2-08 and is not addressed here. Nine facilities were assessed during the Class $3 \mathrm{SU}$ walkover assessment. The facility assessments are reported in the Assessment Report. In summary, no facility was identified as a possible source for chemical contamination.

\section{\begin{tabular}{|l|l} 
2.1.3.4 & CLASS 3 AND CLASS 4 SU BIASED SAMPLING
\end{tabular}}

Based on visual observation during the Class $3 \mathrm{SU}$ walkover assessment, two locations were selected for biased sampling at anthropogenic features. A four-point composite surface soil sample was collected at a location adjacent to a 55-gal drum and another four-point composite surface soil sample was collected from a soil mound. 
In addition to the biased sampling locations, three sediment accumulation areas were also selected for biased sampling during the Class $3 \mathrm{SU}$ walkover assessment. The areas are located (1) adjacent to the K-893-U Inactive Valve Vault, (2) in a drainage ditch east of the valve vault, and (3) in a ditch west of the valve vault. These accumulation areas receive run-off from areas in proximity to the identified anthropogenic features listed above.

A biased sample location in the K-892-J Cooling Tower Basin FFA site was specified during DQO scoping. A four-point composite surface sample was collected.

Details of Class 3 SU sampling in EU Z2-01 are presented in Table A.2.

\section{2}

\section{DVS AND HISTORICAL SAMPLE RESULTS}

This section presents a summary of analytical results for the DVS and historical samples collected in EU Z2-01. The summary begins with a tabulation of SUs (Sects. 2.2.1 through 2.2.4) and concludes with focused investigation and EU data summaries (Sect. 2.2.5) and FFA site data summaries (Sect. 2.2.6). The combined EU DVS and historical data are summarized in Table A.3. A compact disc containing electronic files for the historical and DVS analytical data used to generate the data tables is provided with this Phased Construction Completion Report (PCCR).

\begin{tabular}{|l|l|}
\hline 2.2.1 & CLASS 1 SUS \\
\hline None & \multicolumn{2}{|l|}{} \\
\hline 2.2.2 & CLASS 2 SUS \\
\hline
\end{tabular}

There are five sample locations in the Class 2 SU of EU Z2-01. One location is a DVS biased sample location collected from the K-892-J Cooling Tower Basin FFA site when it was a Class 3 SU. The other four locations are DVS systematic grid locations sampled in response to PCB average RL exceedances in the original K-892-J Cooling Tower Basin biased sample.

\begin{tabular}{clc}
\hline EU & \multicolumn{1}{c}{ DVS sample locations } & \multicolumn{1}{c}{ Historic sample locations } \\
\hline \multirow{2}{*}{ Z2-01 } & Systematic grid locations: & None \\
& Z2-EU01-201, Z2-EU01-202, Z2-EU01-203, & \\
& Z2-EU01-204 & \\
& Biased sample locations: & \\
& Z2-EU1B-306 & \\
\hline
\end{tabular}

${ }^{a}$ Location Z2-EU1B-306 was identified when the K-892-J Cooling Tower Basin was in a Class 3 SU. Following reclassification, the location is currently in the Class $2 \mathrm{SU}$.

DVS $=$ dynamic verification strategy

$\mathrm{EU}=$ exposure unit

The number of samples collected, sampling intervals, and chemicals and radionuclides analyzed for varied at each location. This information is presented in the EU sampling summary in Table A.2. The data are summarized as part of the EU data summary in Table A.3, and are evaluated by area of interest and EU in Sect. 2.2.4 and by FFA site in Sect. 2.2.5. The number of analyses conducted in the Class $2 \mathrm{SU}$ is presented below by analyte group.

\begin{tabular}{ccc}
\hline Metals & PCBs & Radionuclides \\
\hline 1 & 9 & 1 \\
\hline
\end{tabular}

\section{\begin{tabular}{|l|l|}
\hline 2.2.3 & CLASS 3 AND CLASS 4 SUS
\end{tabular}}

There are 13 DVS and historical sample locations in the EU Z2-01 Class 3 SU. The five DVS sample locations are biased locations associated with anthropogenic features and sediment accumulation areas identified during the Class 3 SU walkover assessment (Sect. 2.1.3.4). One DVS biased sampling location originally in the Class 3 SU became a Class 2 SU sample location when the K-892-J Cooling Tower Basin footprint was reclassified. Eight historic samples were collected as part of the site-wide remedial investigation (RI) and 1994 radiological walkover survey. Sample locations are shown on Fig. A.4 and summarized below. 


\begin{tabular}{cll}
\hline EU & \multicolumn{1}{c}{ DVS sample l ocations } & \multicolumn{1}{c}{ Historic sample locations } \\
\hline \multirow{2}{*}{ Z2-01 } & Z2-EU1B-301, Z2-EU1B-302, Z2-EU1B-303, & PCC-SS6, RAD300, RAD303, RAD304, \\
& Z2-EU1B-304, Z2-EU1B-305 & RAD305, RAD306, RAD308, RAD309 \\
\hline
\end{tabular}

DVS = dynamic verification strategy

$\mathrm{EU}=$ exposure unit

The numbers of samples collected, sampling intervals, and chemicals and radionuclides analyzed for varied at each location by project. Table A.2 describes the details of sampling at each location. The data are summarized in the EU summary on Table A.3 and are evaluated in Sect. 2.2.5. The number of analyses conducted in the Class $3 \mathrm{SU}$ is presented below by analyte group.

\begin{tabular}{ccccc}
\hline Metals & PCBs & Radionuclides & SVOCs & VOCs \\
\hline 6 & 6 & 11 & 3 & 2 \\
\hline PCB = polychlorinated & & & \\
SVOC = semivolatile organic compound \\
VOC = volatile organic compound
\end{tabular}

\section{\begin{tabular}{|l|l}
\hline 2.2.4 & INFRASTRUCTURE \\
\hline
\end{tabular}}

No infrastructure in EU Z2-01 was identified for sampling during DQO scoping. Recirculating cooling water lines present are associated with the Cooling Water Basin; however, the impact to soils from $\mathrm{Cr}^{+6}$ used as a cooling water rust inhibitor is discussed in Investigation of Hexavalent Chromium in Association with the Recirculating Cooling Water System at the East Tennessee Technology Park, Oak Ridge, Tennessee (BJC/OR-2572).

\section{\begin{tabular}{l|l}
$\mathbf{2 . 2 . 5}$ & EU EVALUATION \\
\hline
\end{tabular}}

Characterization data and other information are evaluated for EU Z2-01 in this section. Analytical data is presented by analyte group in the following summaries. The results for a particular analyte group are summarized only if that group was analyzed for in the samples from the unit being summarized. Within each summary, data are evaluated by comparing to certain criteria, including the Zone 2 soils maximum re mediation level (Max RL), Zone 2 soils average remediation level (Avg RL), $1 \times 10^{-5}$ industrial preliminary remediation goal (Ind PRG), ETTP soils background composition (Bkg), Zone 2 groundwater screening levels (GW SL), and $1 \times 10^{-6}$ residential preliminary remediation goal (Res PRG). If a particular criterion does not apply to any member of an analyte group, it is not tabulated for that analyte group. If a particular analyte criterion does not apply to all analytes within an analyte group, those analytes to which it does not apply are notated with NA (not applicable). Metals and radionuclides, which are naturally occurring, are reported in the summaries only if one or more criterion is exceeded. Organic chemicals, which are not naturally occurring, are reported if they are detected even if no criteria are exceeded. The Max RL, Avg RL, Ind PRG, Bkg, GW SL, and Res PRG criteria values, as they pertain to the analytes listed in Appendix A of the RDR/RAWP (i.e., the QAPP), are presented in Sect. 3.1 of this PCCR.

Because the carcinogenic risk associated with the concentration of radium and thorium isotopes in the natural background at ETTP exceeds the cumulative risk goal of $1 \times 10^{-4}$, RL values for these radionuclides are based on alternative concentration levels rather than risk. The alternative concentration levels of $5 \mathrm{pCi} / \mathrm{g}$ above background (Avg RL) and $15 \mathrm{pCi} / \mathrm{g}$ above background (Max RL) were set as low as reasonably achievable (ALARA) under the site-specific conditions. Because site-specific background concentrations of these radionuclides exceed the target risk range, residual concentrations of these radionuclides and their decay series are not considered in estimates of residual risk following any remedial actions.

The Zone 2 ROD states that Avg RL and Max RL exceedances by Ra-226, Th-230, and Th-232 will be evaluated by summing above-background concentrations of the greater of Ra-226 or Th-230 with the above-background concentrations of Th-232 and comparing the results to $5 \mathrm{pCi} / \mathrm{g}$ (Avg RL) and $15 \mathrm{pCi} / \mathrm{g}$ (Max RL). Average and maximum RL exceedances for these radionuclides, if any, are reported in the data summaries below and in Tables A.2 through A.4 as "Ra/Th decay series", and individual RL exceedances by Ra-226, Th-230, and Th-232 are reported as NA. The Ra/Th decay series data are summarized in the following sections only if an average or maximum RL has been exceeded, consistent with the description in the preceding paragraph for reporting radionuclides. Discussion of the $\mathrm{Ra} / \mathrm{Th}$ decay series calculation, including the manner in which the calculation is performed, is presented in Sect. 3.3 of this PCCR. 


\section{Conceptual Site Model (CSM)}

The entire EU was originally classified as a Class 3 SU because no facility records or other information indicated contaminated materials had been stored or disposed of in the area. The K-892-J Cooling Tower Basin had been evaluated and sediment was removed from this basin as part of the Cooling Tower Decontamination and Decommissioning Program conducted for all K-31/K-33 basins in 1994. Subsequent disposal of soil and building rubble in the open basin occurred between 2001-2003, partially filling the structure.

Class 3 acreage is presumed to be uncontaminated. Any impact to soils in the area is assumed to be surface releases from plant activities. Surface dumping ofr rubble ${ }_{2}$ debris, and trash was identified in the northern portion of the EU in a small wooded area along Perimeter Road. A rusted drum and seral-mounds of soil containing debris were identified sampled. Other anthropogenic features included concrete slabs and run-off control ditches. These features are consistent with the surface release model for Class 3 acreage.

The surface release model presumes activities associated with surface dumping, general work activities, and possible releases of contaminants at other facilities in the EU could have resulted in releases of radiological and/or chemical contaminants to the ground surface. Soils in the area have a high percentage of clay and organics, which tend to retard the movement of radiological and organic compounds in the natural environment. Historic radiological walkover surveys and historic and DVS sampling indicate there have been no significant contaminant releases to surface soils within the EU.

The potential for redistribution of surface-released contamination by air is considered low to moderate. Small volume spills will have limited impact to area soil by redistribution through airborne transport.

The potential for redistribution of surface-released contamination by surface water is considered moderate. Topographic relief in the area is minimal and there are few developed drainage pathways. Redistribution would occur by overland flow to sediment accumulation areas. Samples were collected at a sediment accumulation area in the southwestern portion of EU Z2-01.

The potential for redistribution of surface-released contamination to groundwater is considered low. Composition of the soils and the limited volume of potential releases would not pose a threat to local groundwater.

Sampling at the K-892 Cooling Tower Basin was performed as required under the DQO base program requirements. The biased sample reported PCBs above Avg RL; no other COCs were identified. The conceptual model for the reclassified acreage was a surface-filled concrete structure with PCBs being the only COC. Intermedia transfer and transport from this structure is not anticipated. Subsequent sampling indicated soils in the Cooling Tower Basin are contaminated with PCBs above Zone 2 Avg RLs but below Max RLs.

The appropriate CSM for the filled cooling water basin is a subsurface release model that presumes contaminated soils and building debris would be leached by water infiltrating through the cooling water basins and subsequently released to subsurface soils. Sediments accumulated in the cooling water basins were removed in the mid-1990s as part of the demolition of the cooling towers. Contaminant releases to underlying soils may have occurred prior to the removal of the sediment and would have impacted local groundwater. An evaluation of the local groundwater is provided in the following discussion. Subsequent disposal of contaminated soils and building debris in the basins has a potential to release PCBs to the subsurface environment.

The potential for redistribution by air of contamination released in the subsurface is considered very low.

The potential for redistribution by surface water of contamination release in the subsurface is considered very low.

The potential for redistribution by groundwater of PCBs release in the subsurface is considered low because of the very low solubility of the compounds.

\section{Groundwater Evaluation}

Monitoring well pairs UNW-040/BRW028 and UNW-045/BRW-032 were drilled and completed in 1988. These wells were sampled during 1989-1990 and 1994-1995. Water levels in well pair UNW-040/BRW028 are approximately $12 \mathrm{ft}$ bgs with a very slight downward gradient. Water levels in well pair UNW-045/BRW-032 are approximately $45 \mathrm{ft}$ bgs and also exhibit a downward gradient. Mercury was reported once above MCLs in the two unconsolidated zone wells during 1995 and none of the wells have been sampled since. No other COCs have been reported above MCLs in these wells during any sampling event. 


\section{EU Z2-01}

Originally, all of the 32.6 acres of land in EU Z2-01 was classified as a Class 3 SU. However, analytical results from a A four-point composite biased sample (Z2-EU01-306) was collected from backfill soils that had been placed in the K-892-J Cooling Tower Basin (originally part of the Class $3 \mathrm{SU}$ ). Analytical results for this composite sample

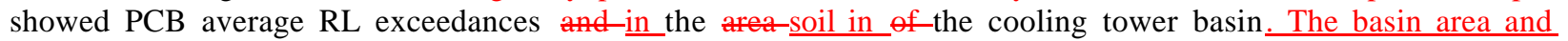
specifically the backfill soils in the basin wereas reclassified as a Class 2 SU. The remainder of BU Z2-01 was evaluated during a Class 3 SU walkover assessment. Twelve anthropogenic features, other than facilities and associated constructed features, were identified during the walkover assessment. Two anthropogenic features were selected for biased sampling based on the conclusion from-visual assessments. that the two - One feares was contained in a rusted drum and the other feature had visible rubble and debris, which could be a potential sources of chemical contamination. One of these samples was is-associated with soils in proximity to a 55-gal drum and the other was is a composite sample of a soil mound that contained visible debris. The remaining small soil mounds identified in the area contained no visible debris and were associated with an old road scar in the forested portion of the EU. These mounds were created by clearing the old roads and were not selected for sampling. In addition, three sediment accumulation areas were identified during the Class $3 \mathrm{SU}$ walkover assessment and a biased sample location was selected in each. These areas receive run-off from most of the other identified anthropogenic features. The radiological SL was not exceeded during the Class $3 \mathrm{SU}$ walkover assessment and no biased sampling was performed based on radiological field characterization. Nine facilities were assessed as part of the Class 3 SU walkover assessment. None was selected for biased sampling.

The majority of the K-892-J Cooling Tower Basin footprint was reclassified as a Class 2 SU based on analytical sample results from the biased sample collected in the basin. Four systematic sample locations were selected in the new Class 2 SU.

There are eight historical sample locations in the Class 3 SU of EU Z2-01. Seven of the sample locations are from the 1994 Radiological walkover survey and are located around the K-892-J Cooling Tower Basin. The eighth sample was collected during the Site-Wide RI and is located along the bank of Poplar Creek.

Following is a summary of the sampling results for EU Z2-01. The summary begins with summary presentations of the analytical results for the focused sampling efforts in the EU and concludes with an overall summary for EU Z2-01. The EU Z2-01 summary includes both data summary tables and a written description of the nature and extent of chemicals and radionuclides observed in the EU. EU-wide data are evaluated against the Zone 2 ROD RAO in Sect. 3.3. Details of the sampling conducted in EU Z2-01 are presented in Table A.2. The data for the entire EU Z2-01 are summarized in Table A.3, and sample locations are shown on Fig. A.4.

DVS Class 2 SU and K-892-J Cooling Tower Basin FFA site Sampling: A four-point composite surface soil sample (Z2-EU1B-306) was collected at the K-892-J Cooling Tower Basin FFA site and analyzed for metals, PCBs, and radionuclides. Analytical results showed PCB Avg RL exceedances and the footprint of the cooling tower basin was reclassified as a Class 2 SU. Four systematic sample locations were identified in the Class 2 SU (Z2-EU01-201, Z2-EU01-202, Z2-EU01-203, and Z2-EU01-204). Two discrete intervals (0-0.5 ft and 0.5-2.0 ft) were sampled and analyzed for PCBs at each location. Analytical results from all five locations show PCB-1254 and total PCB Avg RL exceedances, radionuclide industrial PRG exceedances, and metal and radionuclide background exceedances (see summary below).

EU Z2-01 Class 2 SU and K-892-J FFA site metals with background, PRG, GW SL, and/or RL exceedances (mg/kg)

\begin{tabular}{|c|c|c|c|c|c|c|c|c|c|c|c|}
\hline \multirow[b]{2}{*}{ Analyte } & \multirow[b]{2}{*}{$\begin{array}{c}\text { Detect } \\
\text { frequency }\end{array}$} & \multirow[b]{2}{*}{$\underset{\text { detect }}{\text { Minimum }}$} & \multirow[b]{2}{*}{$\underset{\text { detect }}{\text { Maximum }}$} & \multirow{2}{*}{$\begin{array}{c}\text { Location(s) of } \\
\text { maximum } \\
\text { detect }\end{array}$} & \multirow{2}{*}{$\begin{array}{c}\text { Avg } \\
\text { detected } \\
\text { result }\end{array}$} & \multicolumn{6}{|c|}{ Number of analyses exceeding criteria } \\
\hline & & & & & & $\begin{array}{c}\text { Max } \\
\text { RL }\end{array}$ & $\begin{array}{l}\text { Avg } \\
\text { RL }\end{array}$ & $\begin{array}{l}\text { Ind } \\
\text { PRG }\end{array}$ & Bkg & $\begin{array}{l}\text { GW } \\
\text { SL }\end{array}$ & $\begin{array}{l}\text { Res } \\
\text { PRG }\end{array}$ \\
\hline Aluminum & $1 / 1$ & 14,400 & 14,400 & Z2-EU1B-306 & 14,400 & NA & NA & 0 & 0 & NA & 1 \\
\hline Arsenic & $1 / 1$ & 5.3 & 5.3 & Z2-EU1B-306 & 5.3 & 0 & 0 & 0 & 0 & 0 & 1 \\
\hline Barium & $1 / 1$ & $212 J$ & $212 \mathrm{~J}$ & Z2-EU1B-306 & 212 & NA & NA & 0 & 1 & 0 & 0 \\
\hline Beryllium & $1 / 1$ & $2.9 \mathrm{~J}$ & $2.9 \mathrm{~J}$ & Z2-EU1B-306 & 2.9 & 0 & 0 & 0 & 1 & NA & 0 \\
\hline Cadmium & $1 / 1$ & 2.4 & 2.4 & Z2-EU1B-306 & 2.4 & NA & NA & 0 & 1 & NA & 0 \\
\hline Calcium & $1 / 1$ & 137,000 & 137,000 & Z2-EU1B-306 & 137,000 & NA & NA & NA & 1 & NA & NA \\
\hline Chromium & $1 / 1$ & 57.8 & 57.8 & Z2-EU1B-306 & 57.8 & NA & NA & 0 & 1 & 0 & 1 \\
\hline Copper & $1 / 1$ & $38.7 \mathrm{~J}$ & $38.7 \mathrm{~J}$ & Z2-EU1B-306 & 38.7 & NA & NA & 0 & 1 & NA & 0 \\
\hline Lead & $1 / 1$ & $331 \mathrm{~J}$ & $331 \mathrm{~J}$ & Z2-EU1B-306 & 331 & NA & NA & 0 & 1 & 0 & 0 \\
\hline
\end{tabular}


EU Z2-01 Class 2 SU and K-892-J FFA site metals with background, PRG, GW SL, and/or RL exceedances (mg/kg) (continued)

\begin{tabular}{|c|c|c|c|c|c|c|c|c|c|c|c|}
\hline \multirow[b]{2}{*}{ Analyte } & \multirow[b]{2}{*}{$\begin{array}{c}\text { Detect } \\
\text { frequency }\end{array}$} & \multirow[b]{2}{*}{$\begin{array}{c}\text { Minimum } \\
\text { detect }\end{array}$} & \multirow[b]{2}{*}{$\begin{array}{c}\text { Maximum } \\
\text { detect }\end{array}$} & \multirow{2}{*}{$\begin{array}{c}\text { Location(s) of } \\
\text { maximum } \\
\text { detect }\end{array}$} & \multirow{2}{*}{$\begin{array}{c}\text { Avg } \\
\text { detected } \\
\text { result }\end{array}$} & \multicolumn{6}{|c|}{ Number of analyses exceeding criteria } \\
\hline & & & & & & $\begin{array}{l}\text { Max } \\
\text { RL }\end{array}$ & $\begin{array}{l}\text { Avg } \\
\text { RL }\end{array}$ & $\begin{array}{l}\text { Ind } \\
\text { PRG }\end{array}$ & Bkg & $\begin{array}{l}\text { GW } \\
\text { SL }\end{array}$ & $\begin{array}{c}\text { Res } \\
\text { PRG }\end{array}$ \\
\hline Magnesium & $1 / 1$ & 20,700 & 20,700 & Z2-EU1B-306 & 20,700 & NA & NA & NA & 1 & NA & NA \\
\hline Manganese & $1 / 1$ & 794J & 794J & Z2-EU1B-306 & 794 & NA & NA & 0 & 0 & NA & 1 \\
\hline Thallium & $1 / 1$ & $0.49 \mathrm{~J}$ & $0.49 \mathrm{~J}$ & Z2-EU1B-306 & 0.49 & NA & NA & 0 & 1 & 0 & 0 \\
\hline Uranium & $1 / 1$ & 40.6 & 40.6 & Z2-EU1B-306 & 40.6 & NA & NA & 0 & NA & NA & 1 \\
\hline Vanadium & $1 / 1$ & $13.9 \mathrm{~J}$ & $13.9 \mathrm{~J}$ & Z2-EU1B-306 & 13.9 & NA & NA & 0 & 0 & NA & 1 \\
\hline Zinc & $1 / 1$ & $590 \mathrm{~J}$ & $590 \mathrm{~J}$ & Z2-EU1B-306 & 590 & NA & NA & 0 & 1 & NA & 0 \\
\hline \multicolumn{4}{|c|}{$\overline{\mathrm{Avg}}=$ average } & \multicolumn{8}{|c|}{ NA = not applicable } \\
\hline \multicolumn{4}{|c|}{$\mathrm{Bkg}=$ background } & \multicolumn{8}{|c|}{$\mathrm{PRG}=$ preliminary remediation goal } \\
\hline \multicolumn{4}{|c|}{$\mathrm{EU}=$ exposure unit } & \multicolumn{8}{|c|}{ Res $=$ residential } \\
\hline \multicolumn{4}{|c|}{$\begin{array}{l}\text { FFA }=\text { Federal Facility Agreement } \\
\text { GW }=\text { groundwater }\end{array}$} & \multicolumn{8}{|c|}{$\mathrm{RL}=$ remediation level } \\
\hline \multicolumn{4}{|c|}{$\mathrm{GW}=$ groundwater } & \multicolumn{8}{|c|}{$\mathrm{SL}=$ screening level } \\
\hline \multicolumn{4}{|c|}{ Ind $=$ industrial } & \multicolumn{8}{|c|}{$\mathrm{SU}=$ soil unit } \\
\hline Max $=$ maxim & & & & & & & & & & & \\
\hline
\end{tabular}

EU Z2-01 Class 2 SU and K-892-J FFA Site PCB detects (ug/kg)

\begin{tabular}{|c|c|c|c|c|c|c|c|c|c|}
\hline \multirow[b]{2}{*}{ Analyte } & \multirow[b]{2}{*}{$\begin{array}{c}\text { Detect } \\
\text { frequency }\end{array}$} & \multirow[b]{2}{*}{$\begin{array}{c}\text { Minimum } \\
\text { detect }\end{array}$} & \multirow[b]{2}{*}{$\begin{array}{c}\text { Maximum } \\
\text { detect }\end{array}$} & \multirow{2}{*}{$\begin{array}{l}\text { Location(s) of } \\
\text { maximum } \\
\text { detect }\end{array}$} & \multirow{2}{*}{$\begin{array}{c}\text { Avg } \\
\text { detected } \\
\text { result }\end{array}$} & \multicolumn{4}{|c|}{$\begin{array}{c}\text { Number of analyses } \\
\text { exceeding criteria }\end{array}$} \\
\hline & & & & & & $\begin{array}{c}\text { Max } \\
\text { RL }\end{array}$ & $\begin{array}{l}\text { Avg } \\
\text { RL }\end{array}$ & $\begin{array}{l}\text { Ind } \\
\text { PRG }\end{array}$ & $\begin{array}{l}\text { Res } \\
\text { PRG }\end{array}$ \\
\hline PCB-1254 & $9 / 9$ & 5600 & 35,000 & Z2-EU01-203 & 23,289 & 0 & 8 & 8 & 9 \\
\hline PCB & $9 / 9$ & 5600 & 35,000 & Z2-EU01-203 & 23,289 & 0 & 8 & 8 & 9 \\
\hline
\end{tabular}

Avg $=$ average

$\mathrm{EU}=$ exposure unit

FFA $=$ Federal Facility Agreement

$\mathrm{PCB}=$ polychlorinated biphenyl

Ind $=$ industrial

$\mathrm{PRG}=$ preliminary remediation goal

Max $=$ maximum

Res $=$ residential

$\mathrm{RL}=$ remediation level

$\mathrm{SU}=$ soil unit

EU Z2-01 Class 2 SU and K-892-J FFA Site radionuclides with background, PRG, and/or RL exceedances (pCi/g)

\begin{tabular}{|c|c|c|c|c|c|c|c|c|c|c|c|}
\hline \multirow[b]{2}{*}{ Analyte } & \multirow[b]{2}{*}{$\begin{array}{c}\text { Detect } \\
\text { frequency }\end{array}$} & \multirow[b]{2}{*}{$\begin{array}{c}\text { Minimum } \\
\text { detect }\end{array}$} & \multirow[b]{2}{*}{$\begin{array}{l}\text { Maximum } \\
\text { dete ct }\end{array}$} & \multirow[b]{2}{*}{$\begin{array}{l}\text { Location(s) of } \\
\text { maximum detect }\end{array}$} & \multirow{2}{*}{$\begin{array}{c}\text { Avg } \\
\text { detected } \\
\text { result }\end{array}$} & \multicolumn{6}{|c|}{ Number of analyses exceeding criteria } \\
\hline & & & & & & $\underset{\text { RL }}{\operatorname{Max}}$ & $\begin{array}{l}\text { Avg } \\
\text { RL }\end{array}$ & $\begin{array}{l}\text { Ind } \\
\text { PRG }\end{array}$ & Bkg & $\begin{array}{l}\text { GW } \\
\text { SL }\end{array}$ & $\begin{array}{c}\text { Res } \\
\text { PRG }\end{array}$ \\
\hline Potassium-40 & $1 / 1$ & 4.1 & 4.1 & Z2-EU1B-306 & 4.1 & NA & NA & 1 & 0 & NA & 1 \\
\hline Radium-226 & $1 / 1$ & 0.95 & 0.95 & Z2-EU1B-306 & 0.95 & NA & NA & 1 & 0 & NA & 1 \\
\hline Technetium-99 & $1 / 1$ & 2.63 & 2.63 & Z2-EU1B-306 & 2.63 & NA & NA & 0 & NA & NA & 1 \\
\hline Thorium -228 & $1 / 1$ & 0.76 & 0.76 & Z2-EU1B-306 & 0.76 & NA & NA & 1 & 0 & NA & 1 \\
\hline Thorium -230 & $1 / 1$ & 1.73 & 1.73 & Z2-EU1B-306 & 1.73 & NA & NA & 0 & 1 & NA & 0 \\
\hline Thorium -232 & $1 / 1$ & 0.84 & 0.84 & Z2-EU1B-306 & 0.84 & NA & NA & 1 & 0 & NA & 1 \\
\hline Uranium-233/234 & $1 / 1$ & 12.6 & 12.6 & Z2-EU1B-306 & 12.6 & 0 & 0 & 0 & NA & 0 & 1 \\
\hline Uranium-235/236 & $1 / 1$ & 0.82 & 0.82 & Z2-EU1B-306 & 0.82 & 0 & 0 & 0 & NA & 0 & 1 \\
\hline Uranium-238 & $1 / 1$ & 12.5 & 12.5 & Z2-EU1B-306 & 12.5 & 0 & 0 & 0 & 1 & 0 & 1 \\
\hline
\end{tabular}

\section{Avg $=$ average}

$\mathrm{Bkg}=$ background

$\mathrm{EU}=$ exposure unit

FFA $=$ Federal Facility Agreement

$\mathrm{GW}=$ groundwater

Ind $=$ industrial

Max $=$ maximum

$\mathrm{NA}=$ not applicable

$\mathrm{PRG}=$ preliminary remediation goal

Res $=$ residential

$\mathrm{RL}=$ remediation level

$\mathrm{SL}=$ screening level

$\mathrm{SU}=$ soil unit

DVS Class 3 SU Biased Sample at the 55-Gal Drum Location: One sample location was identified during the Class 3 SU walkover assessment at a 55-gal drum A 0-1 ft sample was collected at Z2-EU1B-301 and analyzed for metals, PCBs, radionuclides, and SVOCs (see summary below). 
EU Z2-01 Class 3 SU 55-gal drum location metal with background,

PRG, GW SL, and/or RL exceedances (mg/kg)

\begin{tabular}{|c|c|c|c|c|c|c|c|c|c|c|c|}
\hline \multirow[b]{2}{*}{ Analyte } & \multirow[b]{2}{*}{$\begin{array}{c}\text { Detect } \\
\text { frequency }\end{array}$} & \multirow[b]{2}{*}{$\begin{array}{c}\text { Minimum } \\
\text { detect }\end{array}$} & \multirow[b]{2}{*}{$\begin{array}{c}\text { Maximum } \\
\text { detect }\end{array}$} & \multirow{2}{*}{$\begin{array}{c}\text { Location(s) of } \\
\text { maximum } \\
\text { detect }\end{array}$} & \multirow{2}{*}{$\begin{array}{c}\text { Avg } \\
\text { detected } \\
\text { result }\end{array}$} & \multicolumn{6}{|c|}{ Number of analyses exceeding criteria } \\
\hline & & & & & & $\begin{array}{l}\text { Max } \\
\text { RL }\end{array}$ & $\begin{array}{l}\text { Avg } \\
\text { RL }\end{array}$ & $\begin{array}{l}\text { Ind } \\
\text { PRG }\end{array}$ & Bkg & $\begin{array}{l}\text { GW } \\
\text { SL }\end{array}$ & $\begin{array}{c}\text { Res } \\
\text { PRG }\end{array}$ \\
\hline Arsenic & $1 / 1$ & 5.5 & 5.5 & Z2-EU1B-301 & 5.5 & 0 & 0 & 0 & 0 & 0 & 1 \\
\hline Manganese & $1 / 1$ & $291 \mathrm{~J}$ & $291 \mathrm{~J}$ & Z2-EU1B-301 & 291 & NA & NA & 0 & 0 & NA & 1 \\
\hline Vanadium & $1 / 1$ & 23.7 & 23.7 & Z2-EU1B-301 & 23.7 & NA & NA & 0 & 0 & NA & 1 \\
\hline $\begin{array}{l}\text { Avg = avera } \\
\text { Bkg = backg } \\
\text { EU = exposu } \\
\text { GW = groun } \\
\text { Ind = indust } \\
\text { Max = maxin }\end{array}$ & $\begin{array}{l}\text { ound } \\
\text { unit } \\
\text { water } \\
\text { am }\end{array}$ & & & $\begin{array}{l}\mathrm{NA}=\text { not applic } \\
\mathrm{PRG}=\text { prelimin } \\
\text { Res }=\text { residentia } \\
\mathrm{RL}=\text { remediatio } \\
\mathrm{SL}=\text { screening } \\
\mathrm{SU}=\text { soil unit }\end{array}$ & $\begin{array}{l}\text { able } \\
\text { ary remedic } \\
\text { on level } \\
\text { level }\end{array}$ & tion go & & & & & \\
\hline
\end{tabular}

PCBs were analyzed for in the sample but were not detected.

EU Z2-01 Class 3 SU 55-gal drum location radionuclides with background, PRG, and/or RL exceedances (pCi/g)

\begin{tabular}{|c|c|c|c|c|c|c|c|c|c|c|c|}
\hline \multirow[b]{2}{*}{ Analyte } & \multirow[b]{2}{*}{$\begin{array}{c}\text { Detect } \\
\text { frequency }\end{array}$} & \multirow[b]{2}{*}{$\begin{array}{c}\text { Minimum } \\
\text { detect }\end{array}$} & \multirow[b]{2}{*}{$\begin{array}{l}\text { Maximum } \\
\text { detect }\end{array}$} & \multirow[b]{2}{*}{$\begin{array}{l}\text { Location(s) of } \\
\text { maximum detect }\end{array}$} & \multirow{2}{*}{$\begin{array}{c}\text { Avg } \\
\text { detected } \\
\text { result }\end{array}$} & \multicolumn{6}{|c|}{ Number of analyses exceeding criteria } \\
\hline & & & & & & $\begin{array}{c}\text { Max } \\
\text { RL }\end{array}$ & $\begin{array}{l}\text { Avg } \\
\text { RL }\end{array}$ & $\begin{array}{c}\text { Ind } \\
\text { PRG }\end{array}$ & Bkg & $\begin{array}{l}\text { GW } \\
\text { SL }\end{array}$ & $\begin{array}{r}\text { Res } \\
\text { PRG }\end{array}$ \\
\hline Potassium-40 & $1 / 1$ & 1.9 & 1.9 & Z2-EU1B-301 & 1.9 & NA & NA & 0 & 0 & NA & 1 \\
\hline Radium-226 & $1 / 1$ & 0.6 & 0.6 & Z2-EU1B-301 & 0.6 & NA & NA & 1 & 0 & NA & 1 \\
\hline Thorium -228 & $1 / 1$ & 0.97 & 0.97 & Z2-EU1B-301 & 0.97 & NA & NA & 1 & 0 & NA & 1 \\
\hline Thorium -232 & $1 / 1$ & 0.86 & 0.86 & Z2-EU1B-301 & 0.86 & NA & NA & 1 & 0 & NA & 1 \\
\hline Uranium-238 & $1 / 1$ & 0.78 & 0.78 & Z2-EU1B-301 & 0.78 & 0 & 0 & 0 & 0 & 0 & 1 \\
\hline
\end{tabular}

\begin{tabular}{ll}
\hline $\mathrm{Avg}=$ average & $\mathrm{NA}=$ not applicable \\
$\mathrm{Bkg}=$ background & $\mathrm{PRG}=$ preliminary remediation goal \\
$\mathrm{EU}=$ exposure unit & $\mathrm{Res}=$ residential \\
$\mathrm{GW}=$ groundwater & $\mathrm{RL}=$ remediation level \\
Ind = industrial & $\mathrm{SL}=$ screening level \\
Max = maximum & $\mathrm{SU}=$ soil unit
\end{tabular}

EU Z2-01 Class 3 SU 55-gal drum locationSVOC detects (ug/kg)

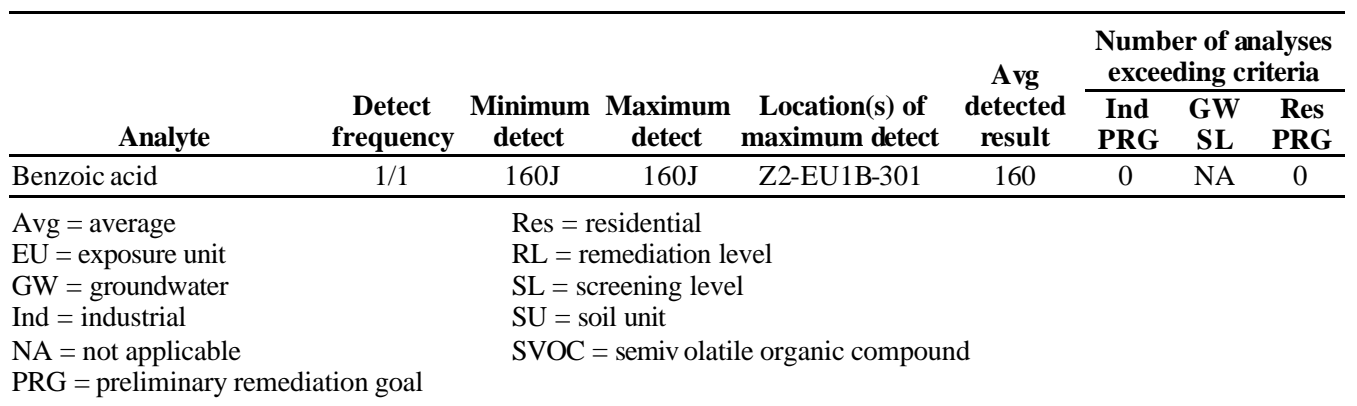

DVS Class 3 SU Sampling at the Soil Mound Location: Biased sample location Z2-EU1B-305 was identified at a soil mound in EU Z2-01 during the Class 3 SU walkover assessment. A four-point composite surface soil sample was collected and analyzed for metals, PCBs, radionuclides, SVOCs, and VOCs (see summary below). 
EU Z2-01 Class 3 SU soil mound location metal with background,

PRG, GW SL, and/or RL exceedances (mg/kg)

\begin{tabular}{|c|c|c|c|c|c|c|c|c|c|c|c|}
\hline \multirow[b]{2}{*}{ Analyte } & \multirow[b]{2}{*}{$\begin{array}{c}\text { Detect } \\
\text { frequency }\end{array}$} & \multirow[b]{2}{*}{$\begin{array}{c}\text { Minimum } \\
\text { detect }\end{array}$} & \multirow[b]{2}{*}{$\begin{array}{c}\text { Maximum } \\
\text { detect }\end{array}$} & \multirow{2}{*}{$\begin{array}{l}\operatorname{Location}(s) \text { of } \\
\text { maximum } \\
\text { detect }\end{array}$} & \multirow{2}{*}{$\begin{array}{c}\text { Avg } \\
\text { detected } \\
\text { result }\end{array}$} & \multicolumn{6}{|c|}{ Number of analyses exceeding criteria } \\
\hline & & & & & & $\begin{array}{c}\text { Max } \\
\text { RL }\end{array}$ & $\begin{array}{l}\text { Avg } \\
\text { RL }\end{array}$ & $\begin{array}{l}\text { Ind } \\
\text { PRG }\end{array}$ & Bkg & $\begin{array}{c}\text { GW } \\
\text { SL }\end{array}$ & $\begin{array}{l}\text { Res } \\
\text { PRG }\end{array}$ \\
\hline Arsenic & $1 / 1$ & 7.1 & 7.1 & Z2-EU1B-305 & 7.1 & 0 & 0 & 0 & 0 & 0 & 1 \\
\hline Manganese & $1 / 1$ & $1020 \mathrm{~J}$ & $1020 \mathrm{~J}$ & Z2-EU1B-305 & 1020 & NA & NA & 0 & 0 & NA & 1 \\
\hline Vanadium & $1 / 1$ & 25 & 25 & Z2-EU1B-305 & 25 & NA & NA & 0 & 0 & NA & 1 \\
\hline
\end{tabular}

Avg $=$ average

$\mathrm{EU}=$ exposure unit

$\mathrm{GW}=$ groundwater

$\mathrm{PRG}=$ preliminary remediation goal

Ind $=$ industrial

Max $=$ maximum

$\mathrm{NA}=$ not applicable

Res $=$ residential

$\mathrm{RL}=$ remediation level

$\mathrm{SL}=$ screening level

$\mathrm{SU}=$ soil unit

PCBs were analyzed for in the sample but were not detected.

EU Z2-01 Class 3 SU soil mound locationradionuclides

with background, PRG, and/or RL exceedances (pCi/g)

\begin{tabular}{|c|c|c|c|c|c|c|c|c|c|c|c|}
\hline \multirow[b]{2}{*}{ Analyte } & \multirow[b]{2}{*}{$\begin{array}{c}\text { Detect } \\
\text { frequency }\end{array}$} & \multirow[b]{2}{*}{$\begin{array}{c}\text { Minimum } \\
\text { detect }\end{array}$} & \multirow[b]{2}{*}{$\underset{\text { detect }}{\text { Maximum }}$} & \multirow[b]{2}{*}{$\begin{array}{l}\text { Location(s) of } \\
\text { maximum detect }\end{array}$} & \multirow{2}{*}{$\begin{array}{c}\text { Avg } \\
\text { detected } \\
\text { result }\end{array}$} & \multicolumn{6}{|c|}{ Number of analyses exceeding criteria } \\
\hline & & & & & & $\begin{array}{l}\text { Max } \\
\text { RL }\end{array}$ & $\begin{array}{l}\text { Avg } \\
\text { RL }\end{array}$ & $\begin{array}{l}\text { Ind } \\
\text { PRG }\end{array}$ & Bkg & $\begin{array}{l}\text { GW } \\
\text { SL }\end{array}$ & $\begin{array}{r}\text { Res } \\
\text { PRG }\end{array}$ \\
\hline Cesium-137 & $1 / 1$ & 0.24 & 0.24 & Z2-EU1B-305 & 0.24 & 0 & 0 & 0 & NA & NA & 1 \\
\hline Radium-226 & $1 / 1$ & 0.79 & 0.79 & Z2-EU1B-305 & 0.79 & NA & NA & 1 & 0 & NA & 1 \\
\hline Thorium -228 & $1 / 1$ & 0.74 & 0.74 & Z2-EU1B-305 & 0.74 & NA & NA & 1 & 0 & NA & 1 \\
\hline Thorium -232 & $1 / 1$ & 0.49 & 0.49 & Z2-EU1B-305 & 0.49 & NA & NA & 1 & 0 & NA & 1 \\
\hline Uranium-238 & $1 / 1$ & 1.05 & 1.05 & Z2-EU1B-305 & 1.05 & 0 & 0 & 0 & 0 & 0 & 1 \\
\hline
\end{tabular}

Avg $=$ average

$\mathrm{Bkg}=$ background

$\mathrm{EU}=$ exposure unit

$\mathrm{GW}=$ groundwater

Ind $=$ industrial

Max = maximum

$\mathrm{NA}=$ not applicable

$\mathrm{PRG}=$ preliminary remediation goal

Res $=$ residential

$\mathrm{RL}=$ remediation level

$\mathrm{SL}=$ screening level

$\mathrm{SU}=$ soil unit

SVOCs were analyzed for in the sample but were not detected.

EU Z2-01 Class 3 SU soil mound location VOC detects (ug/kg)

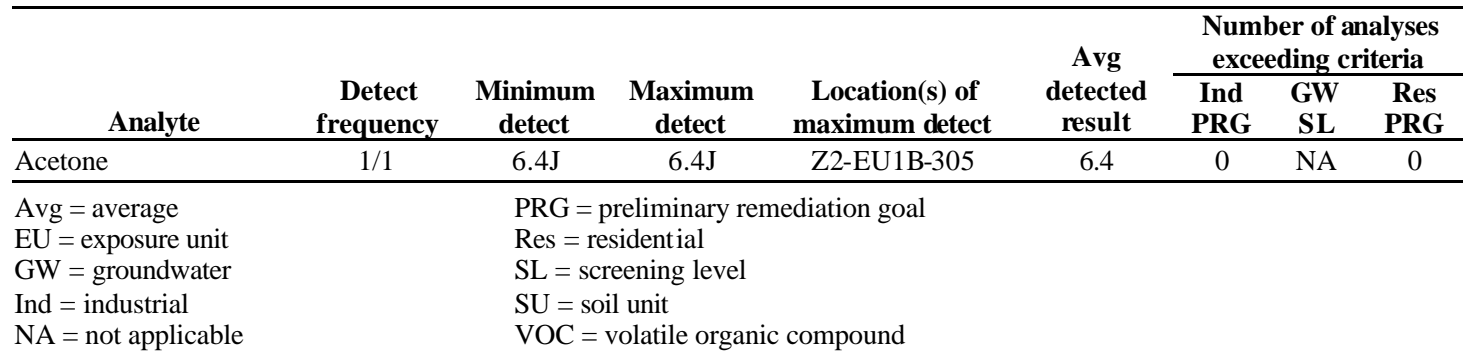

DVS Class 3 SU Sediment Accumulation Areas Sampling: Three sample locations (Z2-EU1B-302, Z2-EU1B-303, Z2-EU1B-304) were identified in three different sediment accumulation areas during the Class $3 \mathrm{SU}$ walkover assessment. Location Z2-EU1B-302 is associated with sediment accumulated above the K-893-U Inactive Valve Vault; a four-point composite surface soil sample was collected and analyzed for metals, PCBs, and radionuclides Location Z2-EU1B-303 is in a drainage ditch to the east of the K-873 Inactive Valve Vault; a five-point composite surface soil sample was collected and analyzed for metals, PCBs, and VOCs. Location Z2-EU1B-304 is in a drainage ditch to the west of the K-873 Inactive Valve Vault; a four-point composite surface soil sample was collected and analyzed for metals and PCBs. Analytical results show radionuclide and one metal industrial PRG exceedance, a chromium groundwater SL exceedance at Z2-EU1B-302, metal and one radionuclide background exceedance, and PCB detections (see summary below). 
EU Z2-01 Class 3 SU sediment accumulation areas metals with background, PRG, GW SL, and/or RL exceedances (mg/kg)

\begin{tabular}{|c|c|c|c|c|c|c|c|c|c|c|c|}
\hline \multirow[b]{2}{*}{ Analyte } & \multirow[b]{2}{*}{$\begin{array}{c}\text { Detect } \\
\text { frequency }\end{array}$} & \multirow[b]{2}{*}{$\begin{array}{c}\text { Minimum } \\
\text { detect }\end{array}$} & \multirow[b]{2}{*}{$\begin{array}{c}\text { Maximum } \\
\text { detect }\end{array}$} & \multirow{2}{*}{$\begin{array}{c}\text { Location(s) of } \\
\text { maximum } \\
\text { detect }\end{array}$} & \multirow{2}{*}{$\begin{array}{c}\text { Avg } \\
\text { detected } \\
\text { result }\end{array}$} & \multicolumn{6}{|c|}{ Number of analyses exceeding criteria } \\
\hline & & & & & & $\begin{array}{l}\text { Max } \\
\text { RL }\end{array}$ & $\begin{array}{l}\text { Avg } \\
\text { RL }\end{array}$ & $\begin{array}{l}\text { Ind } \\
\text { PRG }\end{array}$ & Bkg & $\begin{array}{c}\text { GW } \\
\text { SL }\end{array}$ & $\begin{array}{c}\text { Res } \\
\text { PRG }\end{array}$ \\
\hline Aluminum & $3 / 3$ & $8,330 \mathrm{~J}$ & $9,640 \mathrm{~J}$ & Z2-EU1B-303 & 8,797 & NA & NA & 0 & 0 & NA & 3 \\
\hline Arsenic & $3 / 3$ & 7 & 18.2 & Z2-EU1B-302 & 11.1 & 0 & 0 & 1 & 1 & 0 & 3 \\
\hline Calcium & $3 / 3$ & $30,900 \mathrm{~J}$ & $43,900 \mathrm{~J}$ & Z2-EU1B-303 & 35,633 & NA & NA & NA & 3 & NA & NA \\
\hline Chromium & $3 / 3$ & $11.6 \mathrm{~J}$ & $190 \mathrm{~J}$ & Z2-EU1B-302 & 72.4 & NA & NA & 0 & 1 & 1 & 1 \\
\hline Copper & $3 / 3$ & 7.8 & 31.1 & Z2-EU1B-302 & 15.8 & NA & NA & 0 & 1 & NA & 0 \\
\hline Magnesium & $3 / 3$ & $4,150 \mathrm{~J}$ & $8,800 \mathrm{~J}$ & Z2-EU1B-302 & 5,857 & NA & NA & NA & 3 & NA & NA \\
\hline Manganese & $3 / 3$ & $204 \mathrm{~J}$ & $417 \mathrm{~J}$ & Z2-EU1B-302 & 301 & NA & NA & 0 & 0 & NA & 3 \\
\hline Uranium & $3 / 3$ & 0.91 & 9 & Z2-EU1B-302 & 3.70 & NA & NA & 0 & NA & NA & 1 \\
\hline Vanadium & $3 / 3$ & 18.9 & $25.4 \mathrm{~J}$ & Z2-EU1B-303 & 22.2 & NA & NA & 0 & 0 & NA & 3 \\
\hline Zinc & $3 / 3$ & $34.8 \mathrm{~J}$ & $361 \mathrm{~J}$ & Z2-EU1B-302 & 147 & NA & NA & 0 & 1 & NA & 0 \\
\hline
\end{tabular}

Avg $=$ average

$\mathrm{Bkg}=$ background

$\mathrm{EU}=$ exposure unit

$\mathrm{GW}=$ groundwater

Ind $=$ industrial

$\mathrm{NA}=$ not applicable

$\mathrm{PRG}=$ preliminary remediation goal

Res $=$ residential

Max = maximum

$\mathrm{RL}=$ remediation level

$\mathrm{SL}=$ screening level

$\mathrm{SU}=$ soil unit

EU Z2-01 Class 3 SU sediment accumulation areas PCB detects (ug/kg)

\begin{tabular}{|c|c|c|c|c|c|c|c|c|c|}
\hline \multirow[b]{2}{*}{ Analyte } & \multirow[b]{2}{*}{$\begin{array}{c}\text { Detect } \\
\text { frequency }\end{array}$} & \multirow[b]{2}{*}{$\begin{array}{c}\text { Minimum } \\
\text { detect }\end{array}$} & \multirow[b]{2}{*}{$\begin{array}{c}\text { Maximum } \\
\text { detect }\end{array}$} & \multirow{2}{*}{$\begin{array}{c}\text { Location(s) of } \\
\text { maximum } \\
\text { detect }\end{array}$} & \multirow{2}{*}{$\begin{array}{c}\text { Avg } \\
\text { detected } \\
\text { result }\end{array}$} & \multicolumn{4}{|c|}{$\begin{array}{l}\text { Number of analyses } \\
\text { exceeding criteria }\end{array}$} \\
\hline & & & & & & $\begin{array}{c}\text { Max } \\
\text { RL }\end{array}$ & $\begin{array}{l}\text { Avg } \\
\text { RL }\end{array}$ & $\begin{array}{l}\text { Ind } \\
\text { PRG }\end{array}$ & $\begin{array}{l}\text { Res } \\
\text { PRG }\end{array}$ \\
\hline PCB-1260 & $2 / 3$ & $55 \mathrm{~J}$ & $820 \mathrm{~J}$ & Z2-EU1B-303 & 438 & 0 & 0 & 0 & 1 \\
\hline PCB & $2 / 3$ & $55 \mathrm{~J}$ & $820 \mathrm{~J}$ & Z2-EU1B-303 & 438 & 0 & 0 & 0 & 1 \\
\hline
\end{tabular}

Avg $=$ average

$\mathrm{EU}=$ exposure unit

$\mathrm{PRG}=$ preliminary remediation goal

Ind $=$ industrial

Res $=$ residential

Max $=$ maximum

$\mathrm{PCB}=$ polychlorinated biphenyl

$\mathrm{RL}=$ remediation level

$\mathrm{SU}=$ soil unit

EU Z2-01 Class 3 SU sediment accumulation areas radionuclides with background, PRG, and/or RL exceedances (pCi/g)

\begin{tabular}{|c|c|c|c|c|c|c|c|c|c|c|c|}
\hline \multirow[b]{2}{*}{ Analyte } & \multirow[b]{2}{*}{$\begin{array}{c}\text { Detect } \\
\text { frequency }\end{array}$} & \multirow[b]{2}{*}{$\begin{array}{c}\text { Minimum } \\
\text { detect }\end{array}$} & \multirow[b]{2}{*}{$\begin{array}{c}\text { Maximum } \\
\text { detect }\end{array}$} & \multirow{2}{*}{$\begin{array}{c}\text { Location(s) } \\
\text { of maximum } \\
\text { detect }\end{array}$} & \multirow{2}{*}{$\begin{array}{c}\text { Avg } \\
\text { detected } \\
\text { result }\end{array}$} & \multicolumn{6}{|c|}{ Number of analyses exceeding criteria } \\
\hline & & & & & & $\begin{array}{c}\text { Max } \\
\text { RL } \\
\end{array}$ & $\begin{array}{l}\text { Avg } \\
\text { RL }\end{array}$ & $\begin{array}{c}\text { Ind } \\
\text { PRG }\end{array}$ & Bkg & $\begin{array}{c}\text { GW } \\
\text { SL }\end{array}$ & $\begin{array}{c}\text { Res } \\
\text { PRG }\end{array}$ \\
\hline$\overline{\text { Potassium-40 }}$ & $1 / 1$ & 11 & 11 & Z2-EU1B-302 & 11 & NA & NA & 1 & 0 & NA & 1 \\
\hline Radium-226 & $1 / 1$ & 0.65 & 0.65 & Z2-EU1B-302 & 0.65 & NA & NA & 1 & 0 & NA & 1 \\
\hline Thorium -228 & $1 / 1$ & 0.84 & 0.84 & Z2-EU1B-302 & 0.84 & NA & NA & 1 & 0 & NA & 1 \\
\hline Thorium -232 & $1 / 1$ & 0.63 & 0.63 & Z2-EU1B-302 & 0.63 & NA & NA & 1 & 0 & NA & 1 \\
\hline Uranium-238 & $1 / 1$ & 2.4 & 2.4 & Z2-EU1B-302 & 2.4 & 0 & 0 & 0 & 1 & 0 & 1 \\
\hline
\end{tabular}

Avg $=$ average $\quad \mathrm{NA}=$ not applicable

$\mathrm{Bkg}=$ background $\quad \mathrm{PRG}=$ preliminary remediation goal

$\mathrm{EU}=$ exposure unit $\quad$ Res $=$ residential

$\mathrm{GW}=$ groundwater $\quad \mathrm{RL}=$ remediation level

Ind $=$ industrial $\quad \mathrm{SL}=$ screening level

Max $=$ maximum $\quad \mathrm{SU}=$ soil unit

VOCs were analyzed for in the sample from Z2-EU1B-303 but were not detected.

Class 3 SU Historical Sampling: All eight historical sample locations in EU Z2-01 are in the Class 3 SU. Location PCC-SS6 is a site-wide RI location, and a sample from this location was analyzed for metals, PCBs, radionuclides, and SVOCs. Locations RAD300, RAD303, RAD304, RAD305, RAD306, RAD308, and RAD309 are 1994 radiological walkover survey locations that were analyzed for radionuclides. Analytical results show radionuclide 
industrial PRG exceedances, metal and radionuclide background exceedances, and detection of one SVOC (see summary below).

EU Z2-01 Class 3 SU historical metals with background, PRG, GW SL, and/or RL exceedances (mg/kg)

\begin{tabular}{|c|c|c|c|c|c|c|c|c|c|c|c|}
\hline \multirow[b]{2}{*}{ Analyte } & \multirow[b]{2}{*}{$\begin{array}{c}\text { Detect } \\
\text { frequency }\end{array}$} & \multirow[b]{2}{*}{$\begin{array}{c}\text { Minimum } \\
\text { detect }\end{array}$} & \multirow[b]{2}{*}{$\begin{array}{c}\text { Maximum } \\
\text { detect }\end{array}$} & \multirow{2}{*}{$\begin{array}{c}\text { Location(s) of } \\
\text { maximum } \\
\text { detect }\end{array}$} & \multirow{2}{*}{$\begin{array}{c}\text { Avg } \\
\text { detected } \\
\text { result }\end{array}$} & \multicolumn{6}{|c|}{ Number of analyses exceeding criteria } \\
\hline & & & & & & $\begin{array}{c}\text { Max } \\
\text { RL }\end{array}$ & $\begin{array}{l}\text { Avg } \\
\text { RL }\end{array}$ & $\begin{array}{l}\text { Ind } \\
\text { PRG }\end{array}$ & Bkg & $\begin{array}{c}\text { GW } \\
\text { SL }\end{array}$ & $\begin{array}{c}\text { Res } \\
\text { PRG }\end{array}$ \\
\hline Arsenic & $1 / 1$ & 4.7 & 4.7 & PCC-SS6 & 4.7 & 0 & 0 & 0 & 0 & 0 & 1 \\
\hline Cadmium & $1 / 1$ & 0.42 & 0.42 & PCC-SS6 & 0.42 & NA & NA & 0 & 1 & NA & 0 \\
\hline Calcium & $1 / 1$ & $29,700 \mathrm{~J}$ & $29,700 \mathrm{~J}$ & PCC-SS6 & 29,700 & NA & NA & NA & 1 & NA & NA \\
\hline Magnesium & $1 / 1$ & $3,700 \mathrm{~J}$ & $3,700 \mathrm{~J}$ & PCC-SS6 & 3,700 & NA & NA & NA & 1 & NA & NA \\
\hline Manganese & $1 / 1$ & 399 & 399 & PCC-SS6 & 399 & NA & NA & 0 & 0 & NA & 1 \\
\hline Mercury & $1 / 1$ & 26.9 & 26.9 & PCC-SS6 & 26.9 & 0 & 0 & 0 & 1 & NA & 1 \\
\hline Uranium & $1 / 1$ & 2.5 & 2.5 & PCC-SS6 & 2.5 & NA & NA & 0 & NA & NA & 1 \\
\hline Vanadium & $1 / 1$ & 16.9 & 16.9 & PCC-SS6 & 16.9 & NA & NA & 0 & 0 & NA & 1 \\
\hline
\end{tabular}

\begin{tabular}{ll}
\hline $\mathrm{Avg}=$ average & $\mathrm{NA}=$ not applicable \\
$\mathrm{Bkg}=$ background & $\mathrm{PRG}=$ preliminary remediation goal \\
$\mathrm{EU}=$ exposure unit & $\mathrm{Res}=$ residential \\
$\mathrm{GW}=$ groundwater & $\mathrm{RL}=$ remediation level \\
$\mathrm{Ind}=$ industrial & $\mathrm{SL}=$ screening level \\
$\mathrm{Max}=$ maximum & $\mathrm{SU}=$ soil unit
\end{tabular}

PCBs were analyzed for in the sample from PCC-SS6 but were not detected.

EU Z2-01 Class 3 SU historical radionuclides with background, PRG, and/or RL exceedances (pCi/g)

\begin{tabular}{|c|c|c|c|c|c|c|c|c|c|c|c|}
\hline \multirow[b]{2}{*}{ Analyte } & \multirow[b]{2}{*}{$\begin{array}{c}\text { Detect } \\
\text { frequency }\end{array}$} & \multirow[b]{2}{*}{$\begin{array}{c}\text { Minimum } \\
\text { detect }\end{array}$} & \multirow[b]{2}{*}{$\begin{array}{l}\text { Maximum } \\
\text { detect }\end{array}$} & \multirow[b]{2}{*}{$\begin{array}{l}\text { Location(s) of } \\
\text { maximum detect }\end{array}$} & \multirow{2}{*}{$\begin{array}{c}\text { Avg } \\
\text { detected } \\
\text { result }\end{array}$} & \multicolumn{6}{|c|}{ Number of analyses exceeding criteria } \\
\hline & & & & & & $\begin{array}{c}\text { Max } \\
\text { RL }\end{array}$ & $\begin{array}{l}\text { Avg } \\
\text { RL }\end{array}$ & $\begin{array}{l}\text { Ind } \\
\text { PRG }\end{array}$ & Bkg & $\begin{array}{l}\text { GW } \\
\text { SL }\end{array}$ & $\begin{array}{l}\text { Res } \\
\text { PRG }\end{array}$ \\
\hline Cesium-137 & $8 / 8$ & 0.016 & 0.85 & RAD309 & 0.210 & 0 & 0 & 0 & NA & NA & 3 \\
\hline Cobalt -60 & $7 / 7$ & 0.009 & 0.118 & RAD309 & 0.028 & NA & NA & 0 & NA & NA & 1 \\
\hline Neptunium-237 & $7 / 8$ & 0.02 & 0.47 & RAD300 & 0.254 & 0 & 0 & 0 & NA & NA & 6 \\
\hline Potassium-40 & $7 / 7$ & 10.3 & 17.7 & RAD305 & 15.2 & NA & NA & 7 & 0 & NA & 7 \\
\hline Radium-226 & $6 / 7$ & 0.04 & 2.69 & RAD300 & 1.48 & NA & NA & 5 & 4 & NA & 6 \\
\hline Technetium-99 & $5 / 8$ & 0.05 & 0.79 & RAD309 & 0.248 & NA & NA & 0 & NA & NA & 2 \\
\hline Thorium -228 & $8 / 8$ & 1 & 1.53 & $\begin{array}{l}\text { RAD303 } \\
\text { RAD304 }\end{array}$ & 1.32 & NA & NA & 8 & 0 & NA & 8 \\
\hline Thorium -230 & $8 / 8$ & 1.06 & 1.9 & PCC-SS6 & 1.37 & NA & NA & 0 & 6 & NA & 0 \\
\hline Thorium -232 & $8 / 8$ & 0.95 & 1.46 & RAD304 & 1.27 & NA & NA & 8 & 0 & NA & 8 \\
\hline Uranium-233/234 & $8 / 8$ & 1.02 & 4.04 & RAD300 & 1.63 & 0 & 0 & 0 & NA & 0 & 1 \\
\hline Uranium-235 & $7 / 7$ & 0.062 & 0.48 & RAD309 & 0.236 & 0 & 0 & 0 & NA & 0 & 3 \\
\hline Uranium-238 & $8 / 8$ & 0.97 & 2.72 & RAD300 & 1.37 & 0 & 0 & 0 & 1 & 0 & 8 \\
\hline
\end{tabular}

\begin{tabular}{ll}
\hline Avg $=$ average & NA = not applicable \\
Bkg = background & PRG = preliminary remediation goal \\
EU = exposure unit & Res = residential \\
GW = groundwater & RL = remediation level \\
Ind = industrial & $\mathrm{SL}=$ screening level \\
Max = maximum & $\mathrm{SU}=$ soil unit
\end{tabular}

EU Z2-01 Class 3 SU historical SVOC detects (ug/kg)

\begin{tabular}{|c|c|c|c|c|c|c|c|c|}
\hline \multirow[b]{2}{*}{ Analyte } & \multirow[b]{2}{*}{$\begin{array}{c}\text { Detect } \\
\text { frequency }\end{array}$} & \multirow[b]{2}{*}{$\begin{array}{l}\text { Minimum } \\
\text { detect }\end{array}$} & \multirow[b]{2}{*}{$\begin{array}{c}\text { Maximum } \\
\text { detect }\end{array}$} & \multirow[b]{2}{*}{$\begin{array}{c}\text { Location(s) of } \\
\text { maximum detect }\end{array}$} & \multirow{2}{*}{$\begin{array}{c}\text { Avg } \\
\text { detected } \\
\text { result }\end{array}$} & \multicolumn{3}{|c|}{$\begin{array}{l}\text { Number of analyses } \\
\text { exceeding criteria }\end{array}$} \\
\hline & & & & & & $\begin{array}{l}\text { Ind } \\
\text { PRG }\end{array}$ & $\begin{array}{l}\text { GW } \\
\text { SL }\end{array}$ & $\begin{array}{l}\text { Res } \\
\text { PRG }\end{array}$ \\
\hline Fluoranthene & $1 / 1$ & $97 \mathrm{~J}$ & $97 \mathrm{~J}$ & PCC-SS6 & 97 & 0 & NA & 0 \\
\hline $\begin{array}{l}\text { Avg }=\text { average } \\
\text { EU = exposure unit } \\
\text { Ind = industrial } \\
\text { PRG = preliminary re }\end{array}$ & tion goal & $\begin{array}{l}\text { Res }=r \\
\text { SL }=\mathrm{sc} \\
\text { SU }=\mathrm{so} \\
\text { SVOC }\end{array}$ & $\begin{array}{l}\text { esidential } \\
\text { reening level } \\
\text { il unit } \\
=\text { semivolatils }\end{array}$ & le organic compoun & & & & \\
\hline
\end{tabular}


EU Z2-01 Summary: The bulk of EU Z2-01 was addressed by a Class 3 SU walkover assessment because 32.3 acres of the EU is predominantly a Class $3 \mathrm{SU}$, with approximately 035 acres in a single Class $2 \mathrm{SU}$. During the walkover, 12 anthropogenic features were identified and five facilities were assessed. Two anthropogenic features (55-gal drum and soil mound) were selected for biased sampling; no facility was selected for this sampling. Three Class 3 SU sediment accumulation areas were also identified during the Class 3 SU walkover assessment, and a sample location was selected in each.

Originally, there was no Class $2 \mathrm{SU}$ in EU Z2-01. However, a four-point, composite biased surface soil sample in the K-892-J Cooling Tower Basin showed PCB Avg RL exceedances. In response, the footprint of the cooling tower basin was reclassified as a Class $2 \mathrm{SU}$ and four systematic grid sample locations were identified and sampled.

There are a total of 18 DVS and historical sample locations in EU Z2-01 (see Sects. 2.2.2 and 2.2.3). The following data summaries for EU Z2-01 are compilations of the focused investigation summaries discussed in this section and the FFA site summaries located in Sect. 2.2.6. Analytical results for EU Z2-01 show average RL exceedances for PCB-1254 and total PCBs; industrial PRG exceedances for one metal (arsenic), PCBs, and several radionuclides; a groundwater SL exceedance for chromium background exceedances for metals and radionuclides; and two SVOC and one VOC detections (see summary below). The PCB Avg RL exceedances occur in all five samples from the Class 2 SU/K-892-J Cooling Tower Basin FFA site (see above). The chromium GW SL exceedance occurs in a sediment accumulation area sample (see above). Evaluation of EU Z2-01 chemicals and radionuclides against the Zone 2 ROD RAO is discussed in Sect. 3.3.

EU Z2-01 metals with background, PRG, GW SL, and/or RL exceedances (mg/kg)

\begin{tabular}{|c|c|c|c|c|c|c|c|c|c|c|c|}
\hline \multirow[b]{2}{*}{ Analyte } & \multirow[b]{2}{*}{$\begin{array}{c}\text { Detect } \\
\text { frequency }\end{array}$} & \multirow[b]{2}{*}{$\begin{array}{c}\text { Minimum } \\
\text { detect }\end{array}$} & \multirow[b]{2}{*}{$\begin{array}{c}\text { Maximum } \\
\text { detect }\end{array}$} & \multirow{2}{*}{$\begin{array}{c}\text { Location(s) of } \\
\text { maximum } \\
\text { detect }\end{array}$} & \multirow{2}{*}{$\begin{array}{c}\text { Avg } \\
\text { detected } \\
\text { result }\end{array}$} & \multicolumn{6}{|c|}{ Number of analyses exceeding criteria } \\
\hline & & & & & & $\begin{array}{l}\text { Max } \\
\text { RL } \\
\end{array}$ & $\begin{array}{l}\text { Avg } \\
\text { RL }\end{array}$ & $\begin{array}{l}\text { Ind } \\
\text { PRG }\end{array}$ & Bkg & $\begin{array}{l}\text { GW } \\
\text { SL }\end{array}$ & $\begin{array}{l}\text { Res } \\
\text { PRG }\end{array}$ \\
\hline Aluminum & $7 / 7$ & $5,940 \mathrm{~J}$ & 14,400 & Z2-EU1B-306 & 8,580 & NA & NA & 0 & 0 & NA & 4 \\
\hline Arsenic & $7 / 7$ & 4.7 & 18.2 & Z2-EU1B-302 & 7.97 & 0 & 0 & 1 & 1 & 0 & 7 \\
\hline Barium & $7 / 7$ & $34.4 \mathrm{~J}$ & $212 \mathrm{~J}$ & Z2-EU1B-306 & 66.8 & NA & NA & 0 & 1 & 0 & 0 \\
\hline Beryllium & $7 / 7$ & 0.33 & $2.9 \mathrm{~J}$ & Z2-EU1B-306 & 0.779 & 0 & 0 & 0 & 1 & NA & 0 \\
\hline Cadmium & $7 / 7$ & $0.048 \mathrm{~J}$ & 2.4 & Z2-EU1B-306 & 0.478 & NA & NA & 0 & 2 & NA & 0 \\
\hline Calcium & $7 / 7$ & $190 \mathrm{~J}$ & 137,000 & Z2-EU1B-306 & 39,238 & NA & NA & NA & 5 & NA & NA \\
\hline Chromium & $7 / 7$ & $11.5 \mathrm{~J}$ & $190 \mathrm{~J}$ & Z2-EU1B-302 & 45.8 & NA & NA & 0 & 2 & 1 & 2 \\
\hline Copper & $7 / 7$ & 0.63 & $38.7 \mathrm{~J}$ & Z2-EU1B-306 & 14.3 & NA & NA & 0 & 2 & NA & 0 \\
\hline Lead & $7 / 7$ & $9.7 \mathrm{~J}$ & $331 \mathrm{~J}$ & Z2-EU1B-306 & 60.6 & NA & NA & 0 & 1 & 0 & 0 \\
\hline Magnesium & $7 / 7$ & $200 \mathrm{~J}$ & 20,700 & Z2-EU1B-306 & 6127 & NA & NA & NA & 5 & NA & NA \\
\hline Manganese & $7 / 7$ & $204 \mathrm{~J}$ & $1,020 \mathrm{~J}$ & Z2-EU1B-305 & 487 & NA & NA & 0 & 0 & NA & 7 \\
\hline Mercury & $4 / 7$ & $0.06 \mathrm{~J}$ & 26.9 & PCC-SS6 & 6.79 & 0 & 0 & 0 & 1 & NA & 1 \\
\hline Thallium & $2 / 7$ & $0.11 \mathrm{~J}$ & $0.49 \mathrm{~J}$ & Z2-EU1B-306 & 0.3 & NA & NA & 0 & 1 & 0 & 0 \\
\hline Uranium & $7 / 7$ & 0.53 & 40.6 & Z2-EU1B-306 & 7.93 & NA & NA & 0 & NA & NA & 3 \\
\hline Vanadium & $7 / 7$ & $13.9 \mathrm{~J}$ & $25.4 \mathrm{~J}$ & Z2-EU1B-303 & 20.9 & NA & NA & 0 & 0 & NA & 7 \\
\hline Zinc & $7 / 7$ & $12.3 \mathrm{~J}$ & $590 \mathrm{~J}$ & Z2-EU1B-306 & 156 & NA & NA & 0 & 2 & NA & 0 \\
\hline
\end{tabular}

Avg $=$ average

$\mathrm{Bkg}=$ background

$\mathrm{EU}=$ exposure unit

$\mathrm{GW}=$ groundwater

Ind $=$ industrial

$\mathrm{NA}=$ not applicable

$\mathrm{PRG}=$ preliminary remediation goal

Res $=$ residential

Max = maximum

$\mathrm{RL}=$ remediation level

$\mathrm{SL}=$ screening level

EU Z2-01 PCB detects (ug/kg)

\begin{tabular}{lccccccccc}
\hline & & & & & \multicolumn{4}{c}{ Location(s) of } & \multicolumn{4}{c}{ Avg } & \multicolumn{2}{c}{ exceeding crite ria } \\
& Detect & Minimum & Maximum & maximum & detected & Max & Avg & Ind & Res \\
\multicolumn{1}{c|}{ Analyte } & frequency & detect & detect & detect & result & RL & RL & PRG PRG \\
\hline PCB-1254 & $9 / 15$ & 5,600 & 35,000 & Z2-EU1-203 & 23,289 & 0 & 8 & 8 & 9 \\
PCB-1260 & $2 / 15$ & $55 \mathrm{~J}$ & $820 \mathrm{~J}$ & Z2-EU1B-303 & 438 & 0 & 0 & 0 & 1 \\
PCB & $11 / 14$ & $55 \mathrm{~J}$ & 35,000 & Z2-EU1-203 & 19,134 & 0 & 8 & 8 & 10 \\
\hline
\end{tabular}

Avg $=$ average

$\mathrm{EU}=$ exposure unit

$\mathrm{PRG}=$ preliminary remediation goal

Ind $=$ industrial

Res $=$ residential

Max $=$ maximum

$\mathrm{RL}=$ remediation level 
EU Z2-01 radionuclides with background, PRG, and/or RL exceedances (pCi/g)

\begin{tabular}{|c|c|c|c|c|c|c|c|c|c|c|c|}
\hline \multirow[b]{2}{*}{ Analyte } & \multirow[b]{2}{*}{$\begin{array}{c}\text { Detect } \\
\text { frequency }\end{array}$} & \multirow[b]{2}{*}{$\begin{array}{c}\text { Minimum } \\
\text { detect }\end{array}$} & \multirow[b]{2}{*}{$\begin{array}{c}\text { Maximum } \\
\text { detect }\end{array}$} & \multirow[b]{2}{*}{$\begin{array}{l}\text { Location(s) of } \\
\text { maximum detect }\end{array}$} & \multirow{2}{*}{$\begin{array}{c}\text { Avg } \\
\text { detected } \\
\text { result }\end{array}$} & \multicolumn{6}{|c|}{ Number of analyses exceeding criteria } \\
\hline & & & & & & $\begin{array}{c}\text { Max } \\
\text { RL }\end{array}$ & $\begin{array}{l}\text { Avg } \\
\text { RL }\end{array}$ & $\begin{array}{c}\text { Ind } \\
\text { PRG }\end{array}$ & Bkg & $\begin{array}{l}\text { GW } \\
\text { SL }\end{array}$ & $\begin{array}{c}\text { Res } \\
\text { PRG }\end{array}$ \\
\hline Cesium-137 & $9 / 12$ & 0.016 & 0.85 & RAD309 & 0.213 & 0 & 0 & 0 & NA & NA & 4 \\
\hline Cobalt -60 & $7 / 11$ & 0.009 & 0.118 & RAD309 & 0.028 & NA & NA & 0 & NA & NA & 1 \\
\hline Neptunium-237 & $7 / 12$ & 0.02 & 0.47 & RAD300 & 0.254 & 0 & 0 & 0 & NA & NA & 6 \\
\hline Potassium-40 & $10 / 11$ & 1.9 & 17.7 & RAD305 & 12.3 & NA & NA & 9 & 0 & NA & 10 \\
\hline Radium-226 & $10 / 11$ & 0.04 & 2.69 & RAD300 & 1.19 & NA & NA & 9 & 4 & NA & 10 \\
\hline Technetium-99 & $6 / 12$ & 0.05 & 2.63 & Z2-EU1B-306 & 0.645 & NA & NA & 0 & NA & NA & 3 \\
\hline Thorium -228 & $12 / 12$ & 0.74 & 1.53 & $\begin{array}{l}\text { RAD303 } \\
\text { RAD304 }\end{array}$ & 1.15 & NA & NA & 12 & 0 & NA & 12 \\
\hline Thorium -230 & $12 / 12$ & 0.73 & 1.9 & PCC-SS6 & 1.24 & NA & NA & 0 & 7 & NA & 0 \\
\hline Thorium -232 & $12 / 12$ & 0.49 & 1.46 & RAD304 & 1.08 & NA & NA & 12 & 0 & NA & 12 \\
\hline Uranium-233/234 & $12 / 12$ & 0.77 & 12.6 & Z2-EU1B-306 & 2.49 & 0 & 0 & 0 & NA & 0 & 2 \\
\hline Uranium-235 & $7 / 7$ & 0.062 & 0.48 & RAD309 & 0.236 & 0 & 0 & 0 & NA & 0 & 3 \\
\hline Uranium-235/236 & $5 / 5$ & 0.053 & 0.82 & Z2-EU1B-306 & 0.244 & 0 & 0 & 0 & NA & 0 & 1 \\
\hline Uranium-238 & $12 / 12$ & 0.78 & 12.5 & Z2-EU1B-306 & 2.31 & 0 & 0 & 0 & 3 & 0 & 12 \\
\hline
\end{tabular}

\section{Avg $=$ average}

$\mathrm{Bkg}=$ background

$\mathrm{EU}=$ exposure unit

$\mathrm{GW}=$ groundwater

Max $=$ maximum

$\mathrm{NA}=$ not applicable

$\mathrm{PRG}=$ preliminary remediation goal

Ind $=$ industrial

Res $=$ residential

$\mathrm{RL}=$ remediation level

EU Z2-01 SVOC detects (ug/kg)

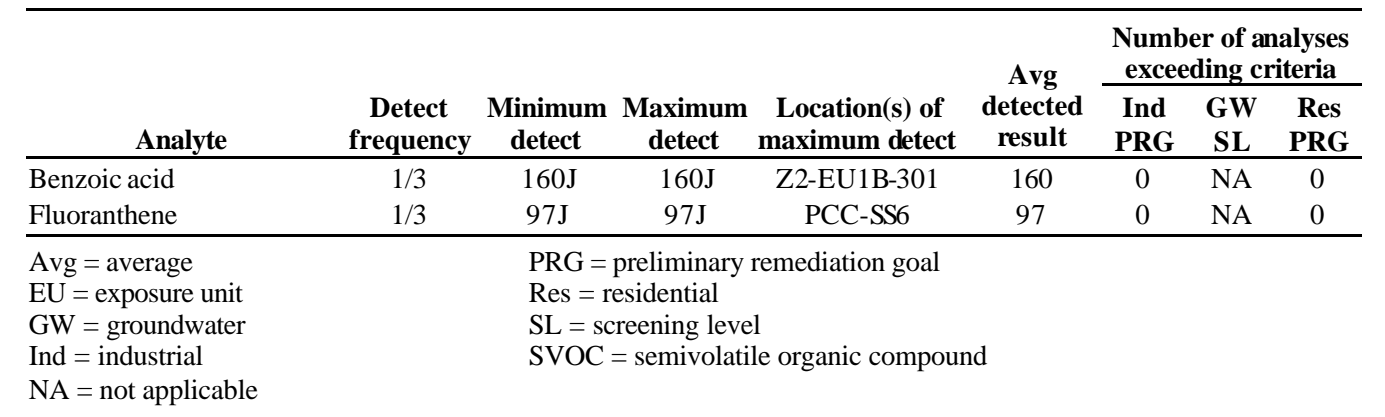

EU Z2-01 VOC detects (ug/kg)

\begin{tabular}{|c|c|c|c|c|c|c|c|c|}
\hline \multirow[b]{2}{*}{ Analyte } & \multirow[b]{2}{*}{$\begin{array}{c}\text { Detect } \\
\text { frequency }\end{array}$} & \multirow[b]{2}{*}{$\begin{array}{c}\text { Minimum } \\
\text { detect }\end{array}$} & \multirow[b]{2}{*}{$\begin{array}{c}\text { Maximum } \\
\text { detect }\end{array}$} & \multirow[b]{2}{*}{$\begin{array}{c}\text { Location(s) of } \\
\text { maximum detect }\end{array}$} & \multirow{2}{*}{$\begin{array}{c}\text { Avg } \\
\text { detected } \\
\text { result }\end{array}$} & \multicolumn{3}{|c|}{$\begin{array}{l}\text { Number of analyses } \\
\text { exceeding criteria }\end{array}$} \\
\hline & & & & & & $\begin{array}{l}\text { Ind } \\
\text { PRG }\end{array}$ & $\begin{array}{l}\text { GW } \\
\text { SL }\end{array}$ & $\begin{array}{c}\text { Res } \\
\text { PRG }\end{array}$ \\
\hline Acetone & $1 / 2$ & $6.4 \mathrm{~J}$ & $6.4 \mathrm{~J}$ & Z2-EU1B-305 & 6.4 & 0 & NA & 0 \\
\hline $\begin{array}{l}\text { Avg }=\text { average } \\
\text { EU = exposure unit } \\
\text { GW = groundwater } \\
\text { Ind }=\text { industrial } \\
\text { NA }=\text { not applicable }\end{array}$ & & $\begin{array}{l}\mathrm{PRG}=\mathrm{p} \\
\mathrm{Res}=\mathrm{re} \\
\mathrm{SL}=\mathrm{scr} \\
\mathrm{VOC}=\end{array}$ & $\begin{array}{l}\text { eliminary rer } \\
\text { idential } \\
\text { ening level } \\
\text { olatile organi }\end{array}$ & $\begin{array}{l}\text { ediation goal } \\
\text { compound }\end{array}$ & & & & \\
\hline
\end{tabular}

\section{\begin{tabular}{|l|l|}
\hline 2.2.6 & ZONE 2 ROD APPENDIX A FFA SITES EVALUATION \\
\hline
\end{tabular}}

K-892-J Cooling Tower Basin FFA Site: The footprint of the K-892-J Cooling Tower Basin FFA site was defined as a Class 2 SU during the course of EU Z2-01 characterization. The FFA site was sampled as described for the Class 2 $\mathrm{SU}$ in Sect. 2.1.2.3. The sample data are presented in Sect. 2.2.5 under the subheading "DVS Class $2 \mathrm{SU}$ and K-892-J Cooling Tower Basin FFA Site Sampling”. 


\begin{tabular}{|l|l|}
\hline & \\
\hline 3.0 & RISK EVALUATION AND ACTION/NO FURTHER ACTION DECISION \\
\hline 3.1 & INTRODUCTION \\
\hline
\end{tabular}

In this section, data are evaluated in terms of the four decision rules presented in the Zone 2 RDR/RAWP. The decision rules are:

- Does the concentration of any Zone 2 COC exceed its maximum RL?

- Does the mean concentration of any Zone 2 COC exceed its Avg RL across the EU?

- Does the EU pose a risk exceeding an industrial $1 \times 10^{-4}$ excess lifetime cancer risk (ELCR) or target organ hazard index (HI) of 1 ?

- Does the site pose a threat to groundwater based on MCL exceedances or soil RLs for protection of groundwater?

Table A.3 presents the results from comparing the data to the Zone 2 soils RLs, industrial PRGs (set at an ELCR of $1 \times 10^{-5}$ or a $\mathrm{HI}$ of 1), and background levels. In addition, the EU summary in Sect. 2.2.5 presents an evaluation of the EU data by analyte group. The following table summarizes the conclusions for EU Z2-01.

\begin{tabular}{lccccc}
\hline EU \# & $\begin{array}{c}\text { Max RL } \\
\text { exceeded? }\end{array}$ & $\begin{array}{c}\text { Average RL over } \\
\text { EU exceeded? }\end{array}$ & $\begin{array}{c}\text { Industrial risk } \\
\text { above } \mathbf{1} \times \mathbf{1 0}^{-4} \text { ? }\end{array}$ & $\begin{array}{c}\text { Potential source } \\
\text { to groundwater? }\end{array}$ & $\begin{array}{c}\text { Action } \\
\text { required? }\end{array}$ \\
\hline $\mathrm{Z} 2-01$ & No & No & No & No & No \\
\hline $\begin{array}{l}\mathrm{EU}=\text { exposure unit } \\
\mathrm{RL}=\text { remediation level }\end{array}$ & & & & \\
\end{tabular}

\section{\begin{tabular}{l|l}
3.2 & DATA EVALUATION FOR THE ACTION /NO FURTHER ACTION DECISION \\
\hline
\end{tabular}}

Requirements for determining NFA in the Zone 2 EUs are stated in the protection goals of the Zone 2 ROD remedial action objective (RAO). Four decision (see Sect. 3.2) rules were developed in the DVS DQOs that state the specific criteria against which each EU must be compared to make the NFA decision. Methods for conducting the decision rule evaluations and the special data handling requirements are discussed in Sect. 3.3 of this PCCR. In summary, the decision rule criteria for NFA are that each EU must meet each of the following compositional constraints:

- Zone 2 soils maximum RLs - maximum allowable concentrations of the Zone 2 soils COCs. Zone 2 soils maximum RLs are presented in the Zone 2 ROD and in Table 5 of this PCCR.

- Zone 2 soils average RLs - limit on the allowable average concentrations of the Zone 2 soils COCs across an EU. Zone 2 soils average RLs are presented in the Zone 2 ROD and in Table 5 of this PCCR.

- Cumulative risk across the EU-cumulative risk across an EU cannot exceed $1 \times 10^{-4}$ ELCR or HI of 1. A stepwise evaluation of cumulative risk is performed by first comparing EU data to $1 \times 10^{-5}$ industrial PRGs. The $1 \times 10^{-5}$ Ind PRGs for analytes required by the RDR/RAWP are presented in Table 5 of this PCCR.

- Groundwater protection goals - compositions of Zone 2 soils cannot pose a threat to groundwater. This evaluation is conducted by assessing local groundwater monitoring results and comparing soils compositions to calculated SLs. The values for the GW SLs are presented in Table 5 of this PCCR.

\begin{tabular}{|l|l|}
\hline 3.3 & SUMMARY AND CONCLUSIONS \\
\hline
\end{tabular}

EU Z2-01

Maximum RL screening. Based on historical and DVS sampling information and results of the Class 3 walkover assessment, no Zone 2 COCs were detected at concentrations in excess of maximum RLs.

Average RL screening. PCB-1254 and total PCB average RLs are exceeded at all five sample locations in the Class 2 SU (the K-892-J Cooling Tower Basin FFA site). The first step in determining whether an average RL has been exceeded across an EU is to determine whether the noted individual average RL exceedances cause EU average detected concentrations to exceed an average RL without area weighting. In the case of EU Z2-01 the PCB-1254 and total PCB average detected concentrations $(23,289 \mathrm{ug} / \mathrm{kg}$ and $19,134 \mathrm{ug} / \mathrm{kg}$, respectively) both exceed their average RL $(10,000 \mathrm{ug} / \mathrm{kg})$. 
The second step in determining whether an average RL has been exceeded across an EU is to calculate the weighted average concentration of those chemicals and radionuclides whose average detected concentration exceeds an average RL and compare the weighted average concentration to the average RL. The weighted average calculation is described in Sect. 3.3 of this PCCR. For PCB-1254, the weighted average concentration is $240 \mathrm{ug} / \mathrm{kg}$, which is less than the average RL of $10,000 \mathrm{ug} / \mathrm{kg}$ and for total PCBs. The weighted average concentration is $563 \mathrm{ug} / \mathrm{kg}$, which also is less than the average RL of $10,000 \mathrm{ug} / \mathrm{kg}$.

In conclusion, based on historical and DVS sampling information and results of the Class 3 SU walkover assessment, no Zone 2 COCs are present with a mean concentration exceeding the average RL across EU Z2-01.

Risk evaluation. The first step in the risk evaluation is to evaluate $1 \times 10^{-5}$ industrial PRG exceedances in order to determine which chemicals and radionuclides are likely to exceed the $1 \times 10^{-4}$ ELCR or target organ HI of 1 . In EU Z2-01, the $1 \times 10^{-5}$ Ind PRG was exceeded in one or more samples by arsenic (1), PCB-1254 (8), total PCBs (8), K-40 (9), Ra-226 (9), Th-228 (12), and Th-232 (12). As explained in Sect. 3.3 of this PCCR, K-40 is further evaluated for risk only if its average concentration exceeds its background value, risk from arsenic is evaluated by comparison of its average concentration to its Zone 2 soils COC average RL, and Ra-226, and Th-232 are evaluated by summing their concentrations ( $\mathrm{Ra} / \mathrm{Th}$ decay series) and comparing the result to their mutual Zone 2 soils $\mathrm{COC}$ average RL (this evaluation includes Th-228 as part of the Th-232 decay chain). The average detected K-40 concentration $(12.3 \mathrm{pCi} / \mathrm{g})$ does not exceed the $\mathrm{K} 40$ background value $(32.12 \mathrm{pCi} / \mathrm{g})$, the average detected concentration of arsenic $(7.97 \mathrm{mg} / \mathrm{kg}$ ) does not exceed the arsenic average $\mathrm{RL}(300 \mathrm{mg} / \mathrm{kg})$, and there are no occurrences of the $\mathrm{Ra} / \mathrm{Th}$ decay series exceeding the average $\mathrm{RLs}(5 \mathrm{pCi} / \mathrm{g})$.

The second step in the risk evaluation is to determine if the average detected concentration of any of the remaining chemicals or radionuclides exceeds a $1 \times 10^{-5}$ Ind PRG. For EU Z2-01 the remaining chemicals and radionuclides with individual $1 \times 10^{-5}$ Ind PRG exceedances are PCB-1254 and total PCBs. The average detected concentrations of both PCB-1254 and total PCBs $\left(23,289 \mathrm{ug} / \mathrm{kg}\right.$ and $19,134 \mathrm{ug} / \mathrm{kg}$, respectively) are both greater than the $1 \times 10^{-5}$ Ind PRG $(7,436 \mathrm{ug} / \mathrm{kg})$.

The third step in the risk evaluation is to calculate the weighted average concentration of those chemicals and radionuclides whose average detected concentration exceeds the $1 \times 10^{-5}$ Ind PRG and compare the weighted average concentration to the $1 \times 10^{-5}$ Ind PRG. The weighted average calculation is described in Sect. 3.3 of this PCCR. The weighted average concentration for PCB-1254 in EU Z2-01 is $240 \mathrm{ug} / \mathrm{kg}$ and for total PCBs it is $600 \mathrm{ug} / \mathrm{kg}$. Both of these values are less than the $1 \times 10^{-5}$ Ind PRG of 7,436 ug/ $\mathrm{kg}$.

In conclusion, there are no chemicals or radionuclides in EU Z2-01 with average concentrations greater than their $1 \times 10^{-5}$ Ind PRGs or that exceed the risk evaluation criteria described in Sect. 3.3 of this PCCR. Therefore, the industrial risk for EU Z2-01 is less than $1 \times 10^{-4}$ ELCR and target organ HI of 1 .

Threat to groundwater. The chromium concentration (190J $\mathrm{mg} / \mathrm{kg}$ ) in a sediment accumulation area sample (Z2-EU1B-302) exceeds the GW SL for chromium $(172 \mathrm{mg} / \mathrm{kg})$. The sediment accumulation area is sediment accumulated above the K-893-U Inactive Valve Vault. The valve vault structure itself is a concrete lined pit so that leaching of chromium to groundwater will not occur. Additionally, there are no chromium MCL exceedances in area groundwater monitoring wells. It is concluded that chromium in accumulated sediments at the K-893-U Inactive Valve Vault does not pose a threat to groundwater.

In conclusion, based on the results of the Class $3 \mathrm{SU}$ walkover assessment and associated samples, and on the results of historical sampling, the soils in EU Z2-01 do not pose a threat to groundwater.

Qualitative risk screening for unrestricted use. There is a low probability that this acreage could be released with no land use restrictions. PCB average RL exceedances in the Class 2 SU and numerous Ind PRG and Res PRG exceedances for metals, radionuclides, PCBs, and SVOCs occur in EU Z2-01. Specific chemicals and radionuclides with criteria exceedances are presented in the EU Z2-01 summary in Sect. 2.2.5. An appropriate evaluation of residential risk should be conducted to make a definitive conclusion.

\section{FFA Sites}

Based on analytical results (Sect. 2.2.6) and evaluation of the EU -wide contaminant profile (above), soils in the following Zone 2 ROD Appendix A FFA sites in EU Z2-01 do not pose a potential threat to the future industrial worker or to groundwater: K-892-J Cooling Tower Basin. 


\begin{tabular}{|c|c|}
\hline 4.0 & RECOMMENDATION FOR ACTION/NO FURTHER ACTION \\
\hline 4.1 & DECISION AND REMEDIATION ACTIVITIES \\
\hline
\end{tabular}

EU Z2-01: Based on results of the Class 3 walkover assessment, and the analytical results of historical and DVS samples collected in EU Z2-01, the U.S. Department of Energy (DOE) recommends that NFA is appropriate under the Zone 2 ROD to meet industrial land use the 32.6 acres of ETTP, Zone 2, EU Z2-01.

FFA Sites: Based on analytical results and recommendations for all EU Z2-01, the DOE recommends that NFA is appropriate for the following FFA sites: K-892-J Cooling Tower Basin.

\begin{tabular}{|l|l|}
\hline 4.2 & EXCAVATION ACTIVITIES/CONFIRMATION SAMPLING \\
\hline
\end{tabular}

None 


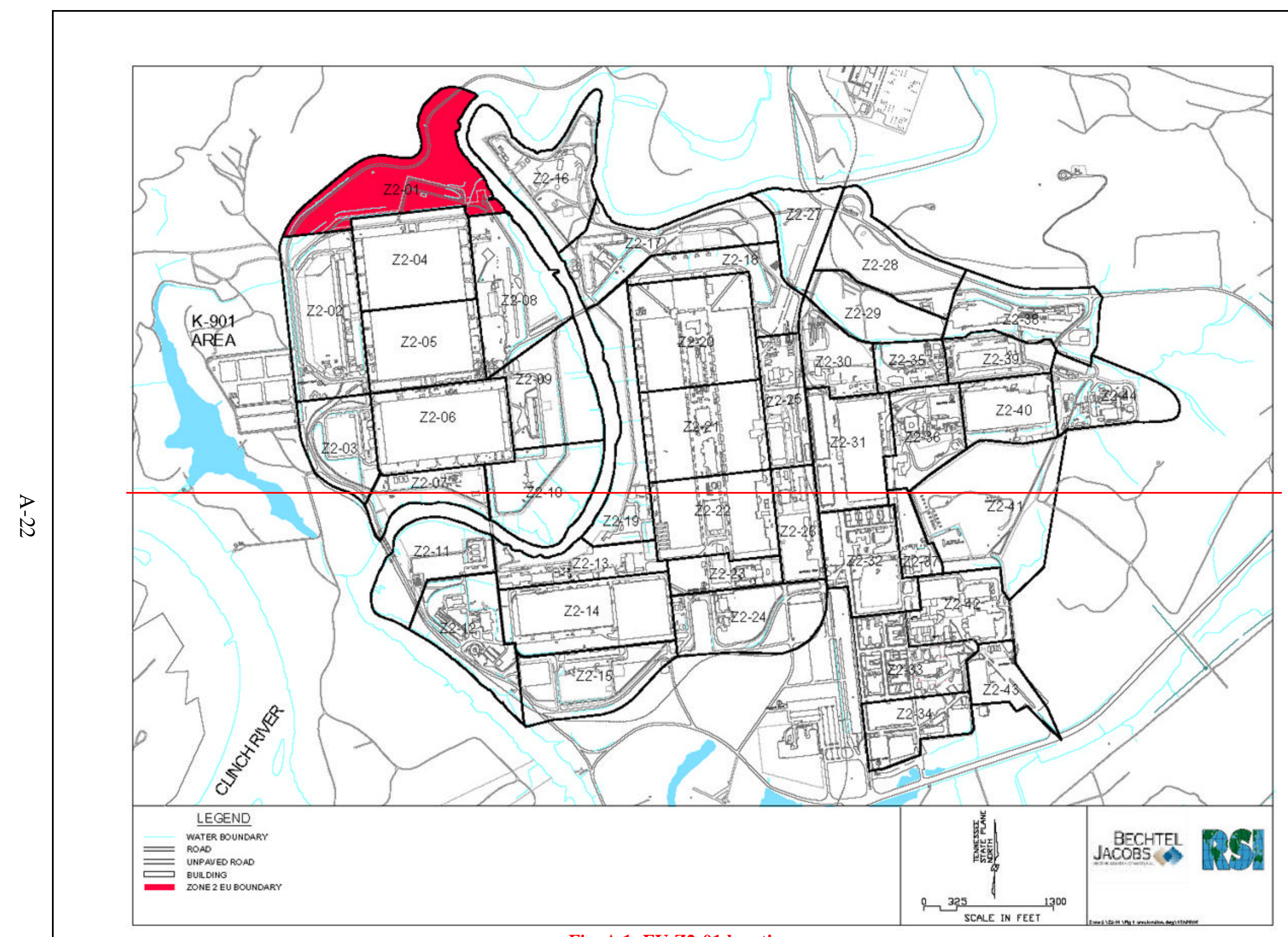

Fig. A.1. EU Z2-01 location map. 


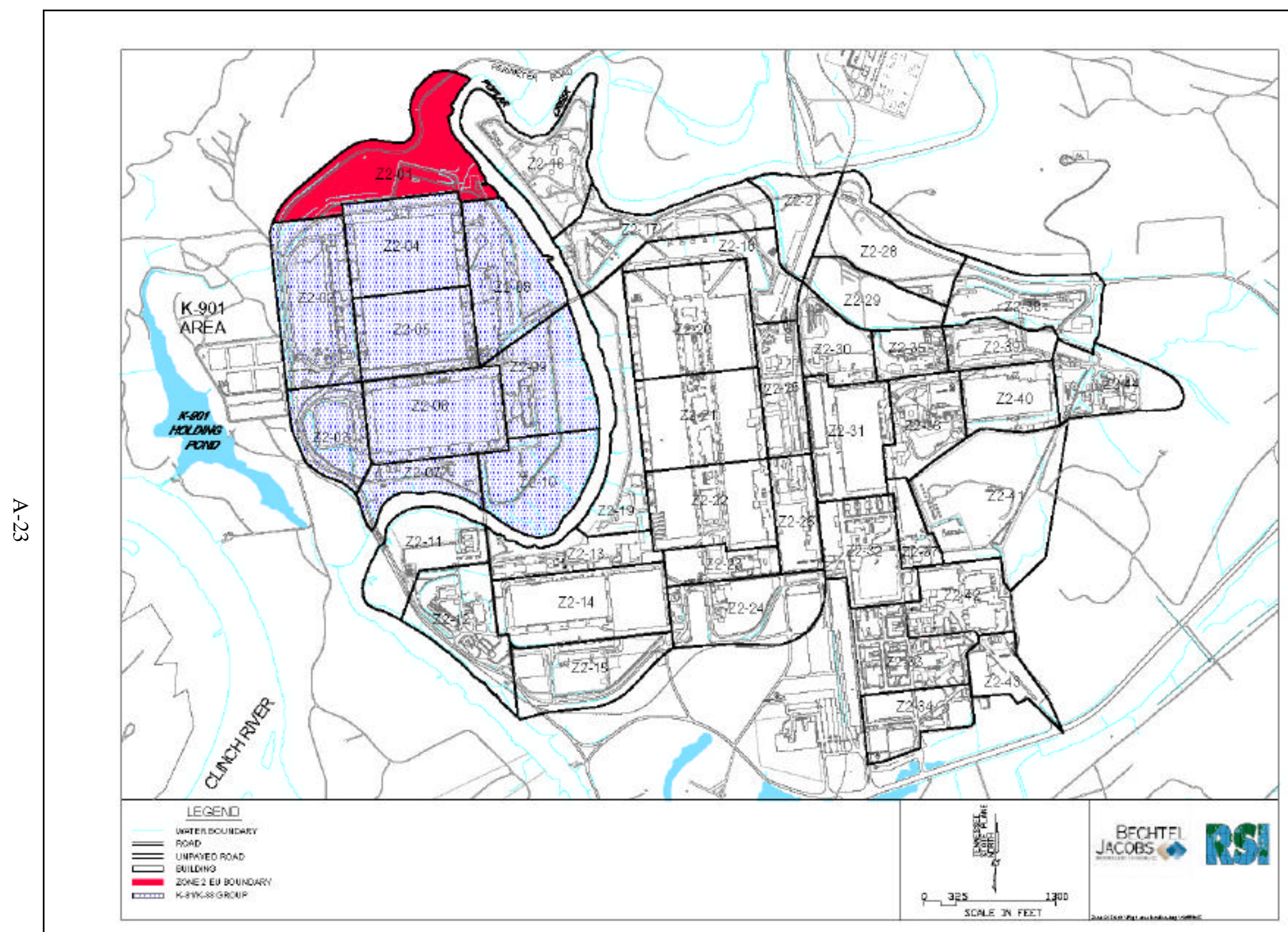

Fig. A.1. EU Z2-01 location map. 


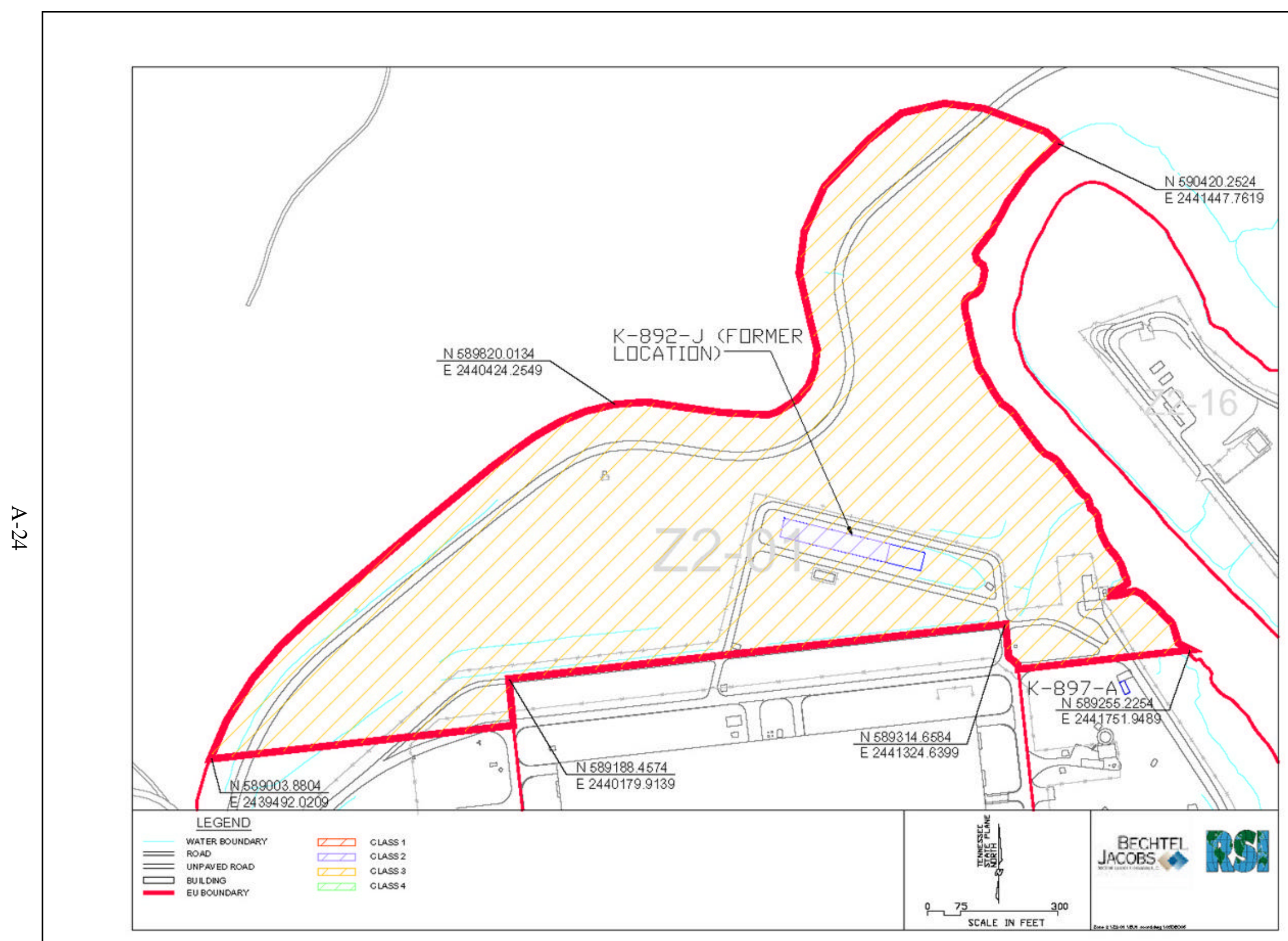

Fig. A.1. EU Z2-01 boundaries. 


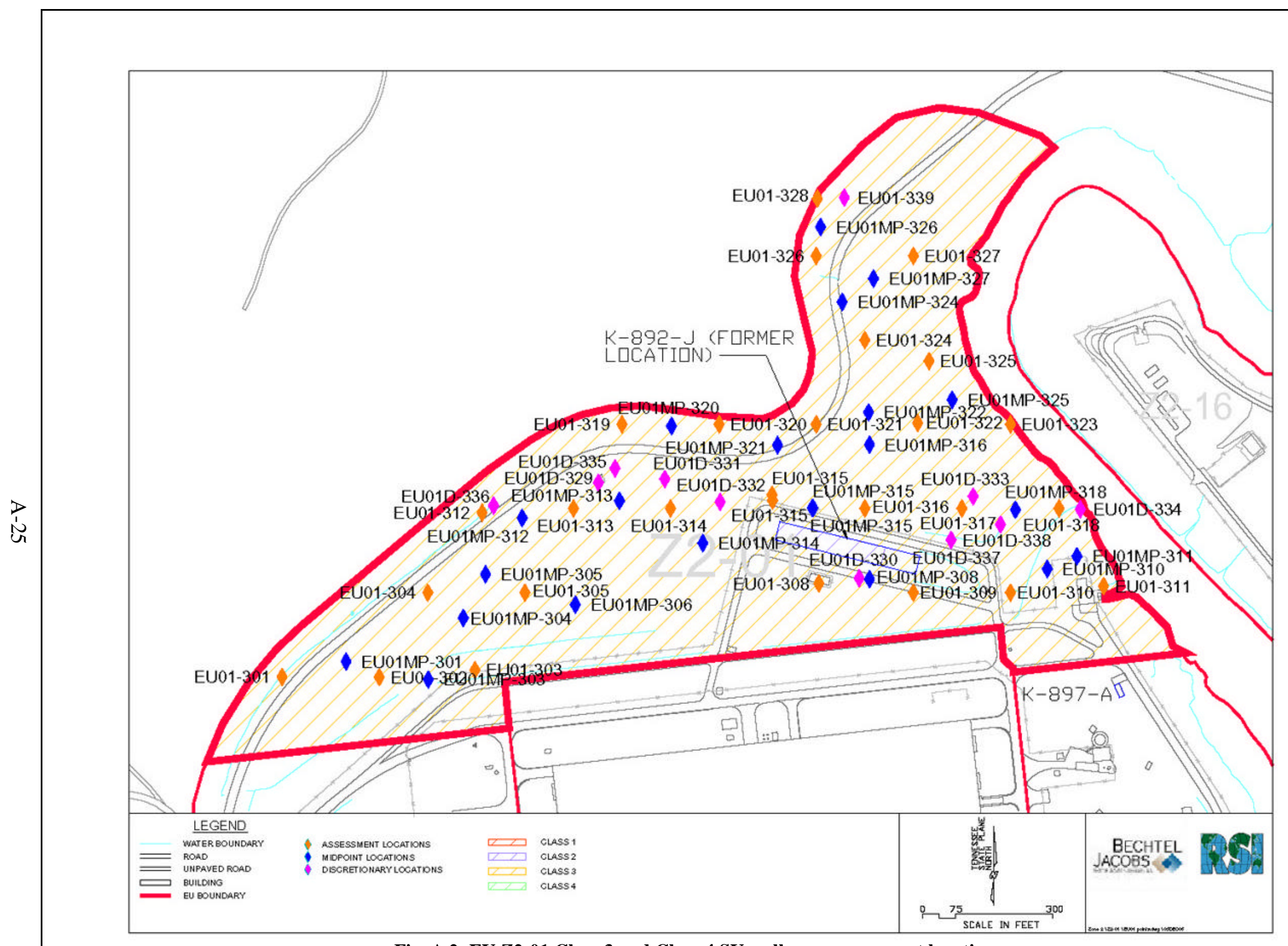

Fig. A.2. EU Z2-01 Class 3 and Class 4 SU walkover assessment locations. 


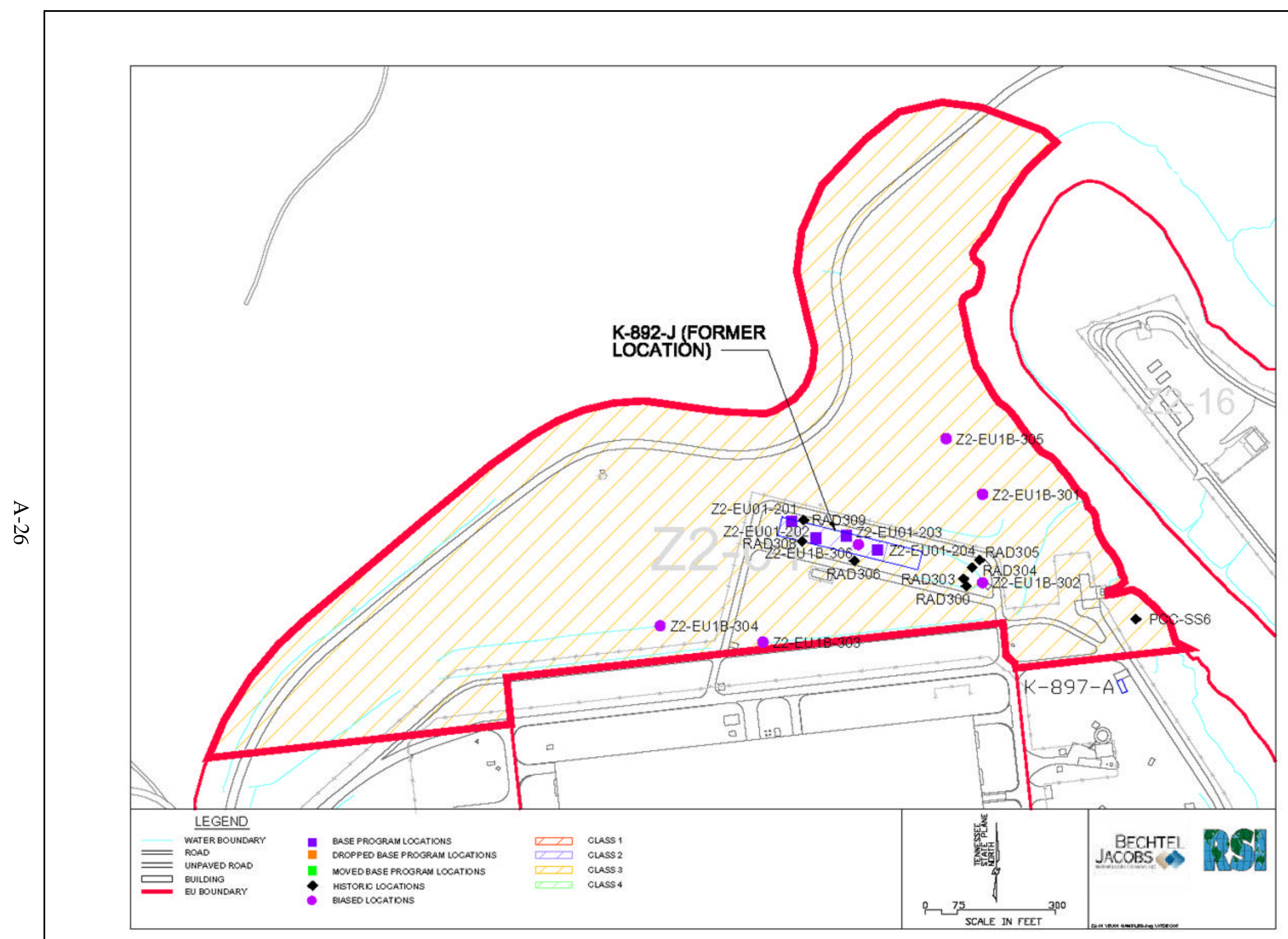

Fig. A.3. EU Z2-01 sample locations. 
Table A.1. Exposure Unit Z2-01 facility and FFA site list

\begin{tabular}{|c|c|c|c|c|}
\hline \multirow[b]{2}{*}{ Facility name DQO scoping } & \multirow[b]{2}{*}{ Facility name } & \multicolumn{2}{|c|}{ Facility assessed? } & \multirow[b]{2}{*}{ Comments } \\
\hline & & Yes & No & \\
\hline K-873 RCW Valve Vault & K-873 Inactive Valve Vault & $\mathrm{X}$ & & \\
\hline K-891 Raw Water Pumphouse & K-891 Former Raw Water Pumphouse & $\mathrm{X}$ & & Demolished; only concrete foundation remains \\
\hline K-892-U Valve House and Electrical Panels & K-892-U Former Valve House and Electrical Panels & $\mathrm{X}$ & & $\begin{array}{l}\text { Demolished; only concrete foundation remains } \\
\text { with conduit protruding through floor }\end{array}$ \\
\hline K-892-W Valve House & K-892-W Former Valve House & $\mathrm{X}$ & & $\begin{array}{l}\text { Demolished; only concrete foundation remains } \\
\text { with one valve }\end{array}$ \\
\hline K-892-X RCW Sludge Tank & & $\mathrm{X}$ & & Facility is in Z2-08 and is not addressed here \\
\hline 892-J Cooling Tower Basin (cooling towers removed) & & $\mathrm{X}$ & & FFA site; only basement foundation remains \\
\hline \multirow[t]{4}{*}{ Facilities not in DQO Scoping } & K-892-V Former Valve House & $\mathrm{X}$ & & $\begin{array}{l}\text { Demolished; only concrete foundation remains } \\
\text { with one valve }\end{array}$ \\
\hline & K-893-L Inactive Valve Vault & $\mathrm{X}$ & & \\
\hline & K-892-U Former Valve House & $\bar{X}$ & & Demolished; only concrete foundation remains \\
\hline & K-893-U Inactive Valve Vault & $\mathrm{X}$ & & \\
\hline
\end{tabular}

$\mathrm{DQO}=$ data quality objective

FFA = Federal Facility Agreemen 
Table A.2. Exposure Unit Z2-01 sample summary

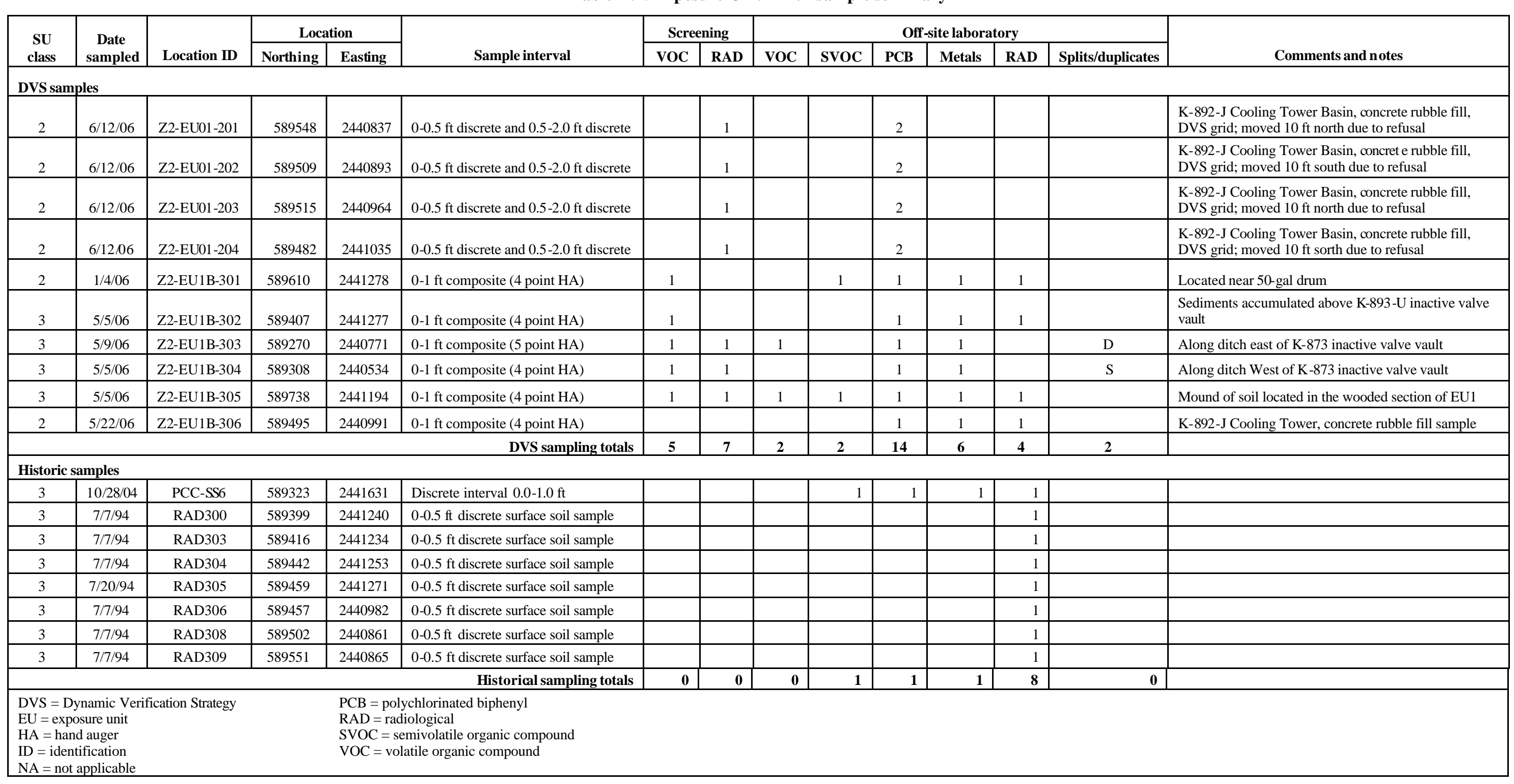


Table A.3. Zone 2 EU Z2-01, depth 0-10 ft

\begin{tabular}{|c|c|c|c|c|c|c|c|c|c|c|c|c|c|}
\hline Analyte & $\begin{array}{c}\text { Frequency } \\
\text { of detect }\end{array}$ & $\begin{array}{c}\text { Minimum } \\
\text { detect }\end{array}$ & $\begin{array}{c}\text { Maximum } \\
\text { detect }\end{array}$ & $\begin{array}{c}\text { Location(s) of } \\
\text { maximum } \\
\text { detected result }\end{array}$ & $\begin{array}{c}\text { Average } \\
\text { detected } \\
\text { result }\end{array}$ & $\begin{array}{c}\text { Maximum } \\
\text { RL } \\
\end{array}$ & $\begin{array}{c}\text { Frequency } \\
\text { of detects } \\
\text { exceeding } \\
\text { maximum RL }\end{array}$ & $\begin{array}{c}\text { Average } \\
\text { RL }\end{array}$ & $\begin{array}{c}\text { Frequency of } \\
\text { detects exceeding } \\
\text { average RL }\end{array}$ & $\begin{array}{r}\text { PRG limit } \\
\left(10^{-5} \text { or } 1\right)\end{array}$ & $\begin{array}{l}\text { Frequency } \\
\text { of detects } \\
\text { exceeding } \\
\text { PRGlimit } \\
\end{array}$ & $\begin{array}{c}\text { Background } \\
\text { concentration }\end{array}$ & $\begin{array}{c}\text { Frequency } \\
\text { of detects } \\
\text { exceeding } \\
\text { background }\end{array}$ \\
\hline \multicolumn{14}{|l|}{ Inorganics $(\mathrm{mg} / \mathbf{k g})$} \\
\hline Aluminum & $7 / 7$ & $5940 \mathrm{~J}$ & 14400 & Z2-EU1B-306 & 8580 & & NA & & NA & $1.0 \mathrm{E}+05$ & $0 / 7$ & 40300 & $0 / 7$ \\
\hline Antimony & $6 / 7$ & $0.14 \mathrm{~J}$ & $0.46 \mathrm{~J}$ & Z2-EU1B-306 & 0.25 & & NA & & NA & $4.1 \mathrm{E}+02$ & $0 / 7$ & 1.52 & $0 / 7$ \\
\hline Arsenic & $7 / 7$ & 4.7 & 18.2 & Z2-EU1B-302 & 7.97 & 900 & $0 / 7$ & 300 & $0 / 7$ & $1.6 \mathrm{E}+01$ & $1 / 7$ & 14.95 & $1 / 7$ \\
\hline Barium & $7 / 7$ & $34.4 \mathrm{~J}$ & $212 \mathrm{~J}$ & Z2-EU1B-306 & 66.76 & & NA & & NA & $6.7 \mathrm{E}+04$ & $0 / 7$ & 124.93 & $1 / 7$ \\
\hline Beryllium & $7 / 7$ & 0.33 & $2.9 \mathrm{~J}$ & Z2-EU1B-306 & 0.78 & 6000 & $0 / 7$ & 2000 & $0 / 7$ & $1.9 \mathrm{E}+03$ & $0 / 7$ & 2.2 & $1 / 7$ \\
\hline Boron & $4 / 7$ & $3.5 \mathrm{~J}$ & $22.2 \mathrm{~J}$ & Z2-EU1B-306 & 10.55 & & NA & & NA & $1.0 \mathrm{E}+05$ & $0 / 7$ & & NA \\
\hline Cadmium & $7 / 7$ & $0.048 \mathrm{~J}$ & 2.4 & Z2-EU1B-306 & 0.48 & & NA & & NA & $4.5 \mathrm{E}+02$ & $0 / 7$ & $0.22 \mathrm{U}$ & $2 / 7$ \\
\hline Calcium & $7 / 7$ & $190 \mathrm{~J}$ & 137000 & Z2-EU1B-306 & 39238 & & NA & & NA & & NA & 2400 & $5 / 7$ \\
\hline Chromium & $7 / 7$ & $11.5 \mathrm{~J}$ & $190 \mathrm{~J}$ & Z2-EU1B-302 & 45.79 & & $\mathrm{NA}$ & & NA & $6.4 \mathrm{E}+02$ & $0 / 7$ & 44.88 & $2 / 7$ \\
\hline Cobalt & $7 / 7$ & $4.6 \mathrm{~J}$ & $11.9 \mathrm{~J}$ & Z2-EU1B-305 & 7.2 & & NA & & NA & $1.3 \mathrm{E}+04$ & $0 / 7$ & 42 & $0 / 7$ \\
\hline Copper & $7 / 7$ & \begin{tabular}{l|l}
0.63 \\
\end{tabular} & $38.7 \mathrm{~J}$ & Z2-EU1B-306 & 14.3 & & NA & & NA & $4.1 \mathrm{E}+04$ & $0 / 7$ & 22.48 & $2 / 7$ \\
\hline Iron & $7 / 7$ & $11900 \mathrm{~J}$ & 21600 & Z2-EU1B-306 & 15914.29 & & $\mathrm{NA}$ & & NA & $1.0 \mathrm{E}+05$ & $0 / 7$ & 58600 & $0 / 7$ \\
\hline Lead & $7 / 7$ & $9.7 \mathrm{~J}$ & $331 \mathrm{~J}$ & Z2-EU1B-306 & 60.64 & & $\mathrm{NA}$ & & NA & $8.0 \mathrm{E}+02$ & $0 / 7$ & 37.91 & $1 / 7$ \\
\hline Lithium & $7 / 7$ & 4.4 & 23.5 & Z2-EU1B-303 & 13.81 & & $\mathrm{NA}$ & & NA & $2.0 \mathrm{E}+04$ & $0 / 7$ & 48.94 & $0 / 7$ \\
\hline Magnesium & $7 / 7$ & $200 \mathrm{~J}$ & 20700 & Z2-EU1B-306 & 6126.57 & & NA & & NA & & NA & 3300 & $5 / 7$ \\
\hline Manganese & $7 / 7$ & $204 \mathrm{~J}$ & $1020 \mathrm{~J}$ & Z2-EU1B-305 & 486.71 & & $\mathrm{NA}$ & & NA & $1.9 \mathrm{E}+04$ & $0 / 7$ & 2200 & $0 / 7$ \\
\hline Mercury & $4 / 7$ & $0.06 \mathrm{~J}$ & 26.9 & PCC-SS6 & 6.79 & 1800 & $0 / 7$ & 600 & $0 / 7$ & $3.1 \mathrm{E}+02$ & $0 / 7$ & 0.17 & $1 / 7$ \\
\hline Molybdenum & $7 / 7$ & $0.52 \mathrm{~J}$ & 9.2 & Z2-EU1B-306 & 1.92 & & NA & & NA & $5.1 \mathrm{E}+03$ & $0 / 7$ & & NA \\
\hline Nickel & $7 / 7$ & 6.7 & $24.5 \mathrm{~J}$ & Z2-EU1B-306 & 12.87 & & $\mathrm{NA}$ & & NA & $2.0 \mathrm{E}+04$ & $0 / 7$ & 26.07 & $0 / 7$ \\
\hline Potassium & $7 / 7$ & $164 \mathrm{~J}$ & $2200 \mathrm{~J}$ & Z2-EU1B-306 & 971.57 & & $\mathrm{NA}$ & & NA & & NA & 5074.69 & $0 / 7$ \\
\hline Selenium & $3 / 7$ & $0.15 \mathrm{~J}$ & $0.46 \mathrm{~J}$ & Z2-EU1B-302 & 0.31 & & $\mathrm{NA}$ & & $\mathrm{NA}$ & $5.1 \mathrm{E}+03$ & $0 / 7$ & 1.47 & $0 / 7$ \\
\hline Silver & $6 / 7$ & $0.057 \mathrm{~J}$ & $0.5 \mathrm{~J}$ & PCC-SS6 & 0.22 & & $\mathrm{NA}$ & & $\mathrm{NA}$ & $5.1 \mathrm{E}+03$ & $0 / 7$ & $0.6 \mathrm{U}$ & $0 / 7$ \\
\hline Sodium & $2 / 7$ & 20.5 & $315 \mathrm{~J}$ & Z2-EU1B-306 & 167.75 & & NA & & NA & & NA & 497 & $0 / 7$ \\
\hline Strontium & $1 / 1$ & $24.3 \mathrm{~J}$ & $24.3 \mathrm{~J}$ & PCC-SS6 & 24.3 & & $\mathrm{NA}$ & & NA & $1.0 \mathrm{E}+05$ & $0 / 1$ & 87.05 & $0 / 1$ \\
\hline Thallium & $2 / 7$ & $0.11 \mathrm{~J}$ & $0.49 \mathrm{~J}$ & Z2-EU1B-306 & 0.3 & & $\mathrm{NA}$ & & NA & $6.7 \mathrm{E}+01$ & $0 / 7$ & $0.4 \mathrm{U}$ & $1 / 7$ \\
\hline Uranium & $7 / 7$ & 0.53 & 40.6 & Z2-EU1B-306 & 7.93 & & NA & & NA & $2.0 \mathrm{E}+02$ & $0 / 7$ & & NA \\
\hline Vanadium & $7 / 7$ & $13.9 \mathrm{~J}$ & $25.4 \mathrm{~J}$ & Z2-EU1B-303 & 20.87 & & $\mathrm{NA}$ & & $\mathrm{NA}$ & $1.0 \mathrm{E}+03$ & $0 / 7$ & 65.47 & $0 / 7$ \\
\hline Zinc & $7 / 7$ & $12.3 \mathrm{~J}$ & $590 \mathrm{~J}$ & Z2-EU1B-306 & 155.5 & & $\mathrm{NA}$ & & NA & $1.0 \mathrm{E}+05$ & $0 / 7$ & 89.7 & $2 / 7$ \\
\hline \multicolumn{14}{|c|}{ Radionuclides (pCi/g) } \\
\hline Actinium-228 & $7 / 7$ & 0.91 & 1.49 & RAD303 & 1.23 & & $\mathrm{NA}$ & & NA & $1.2 \mathrm{E}+04$ & $0 / 7$ & & NA \\
\hline Alpha activity & $5 / 5$ & 23.4 & 66 & Z2-EU1B-306 & 41.54 & & NA & & NA & & NA & & NA \\
\hline Beta activity & $5 / 5$ & 8.9 & 59.7 & Z2-EU1B-306 & 37.22 & & $\mathrm{NA}$ & & NA & & NA & & NA \\
\hline Bismuth-214 & $7 / 7$ & 0.547 & 0.76 & RAD305 & 0.68 & & $\mathrm{NA}$ & & NA & $1.3 \mathrm{E}+05$ & $0 / 7$ & & NA \\
\hline Cesium-134 & $4 / 7$ & 0.004 & 0.015 & RAD304 & 0.01 & & NA & & NA & $2.6 \mathrm{E}+00$ & $0 / 7$ & & NA \\
\hline Cesium 137 & $9 / 12$ & 0.016 & 0.85 & RAD309 & 0.21 & 20 & $0 / 12$ & 2 & $0 / 12$ & $1.1 \mathrm{E}+00$ & $0 / 12$ & & $\mathrm{NA}$ \\
\hline Cobalt-57 & $2 / 7$ & 0.01 & 0.068 & RAD309 & 0.04 & & NA & & NA & $1.4 \mathrm{E}+02$ & $0 / 7$ & & NA \\
\hline Cobalt-60 & $7 / 11$ & \begin{tabular}{l|l|}
0.009 \\
\end{tabular} & 0.118 & RAD309 & 0.03 & & NA & & $\mathrm{NA}$ & $6.0 \mathrm{E}-01$ & $0 / 11$ & & NA \\
\hline Lead-212 & $7 / 7$ & 0.858 & 1.62 & RAD305 & 1.24 & & NA & & NA & $6.1 \mathrm{E}+04$ & $0 / 7$ & & NA \\
\hline Lead-214 & $7 / 7$ & 0.708 & 1.11 & RAD305 & 0.9 & & NA & & NA & $7.5 \mathrm{E}+05$ & $0 / 7$ & & NA \\
\hline Neptunium-237 & $7 / 12$ & 0.02 & 0.47 & RAD300 & 0.25 & 50 & $0 / 12$ & 5 & $0 / 12$ & $2.7 \mathrm{E}+00$ & $0 / 12$ & & NA \\
\hline Plutonium 238 & $6 / 8$ & 0.002 & 0.0126 & RAD306 & 0.01 & & NA & & NA & $1.7 \mathrm{E}+02$ & $0 / 8$ & & NA \\
\hline Plutonium 239 & $7 / 8$ & $\begin{array}{ll}0.013 \\
\end{array}$ & 0.105 & RAD300 & 0.07 & & $\mathrm{NA}$ & & $\mathrm{NA}$ & $1.5 \mathrm{E}+02$ & $0 / 8$ & & NA \\
\hline Plutonium 241 & $1 / 1$ & 1.37 & 1.37 & PCC-SS6 & 1.37 & & $\mathrm{NA}$ & & $\mathrm{NA}$ & $1.7 \mathrm{E}+04$ & $0 / 1$ & & NA \\
\hline Plutonium 242 & $0 / 1$ & ND & ND & & ND & & $\mathrm{NA}$ & & NA & $1.5 \mathrm{E}+02$ & $0 / 1$ & & NA \\
\hline Plutonium 244 & $0 / 1$ & $\mathrm{ND}$ & $\mathrm{ND}$ & & $\mathrm{ND}$ & & $\mathrm{NA}$ & & $\mathrm{NA}$ & $1.4 \mathrm{E}+00$ & $0 / 1$ & & $\mathrm{NA}$ \\
\hline Potassium-40 & $10 / 11$ & 1.9 & 17.7 & RAD305 & 12.33 & & $\mathrm{NA}$ & & NA & $2.7 \mathrm{E}+00$ & $9 / 11$ & 32.12 & $0 / 11$ \\
\hline $\mathrm{Ra} / \mathrm{Th}$ decay series & $12 / 12$ & 0 & 1.44 & RAD300 & 0.41 & 15 & $0 / 12$ & 5 & $0 / 12$ & & NA & & $\mathrm{NA}$ \\
\hline
\end{tabular}




\begin{tabular}{|c|c|c|c|c|c|c|c|c|c|c|c|c|c|}
\hline Analyte & $\begin{array}{c}\text { Frequency } \\
\text { of detect }\end{array}$ & $\begin{array}{c}\text { Minimum } \\
\text { detect }\end{array}$ & $\underset{\text { detect }}{\text { Maximum }}$ & $\begin{array}{l}\text { Location(s) of } \\
\text { maximum } \\
\text { detected result }\end{array}$ & $\begin{array}{l}\text { Average } \\
\text { detected } \\
\text { result }\end{array}$ & $\underset{\text { RL }}{\text { Maximum }}$ & $\begin{array}{c}\text { Frequency } \\
\text { of detects } \\
\text { exceeding } \\
\text { maximum RL }\end{array}$ & $\begin{array}{c}\text { Average } \\
\text { RL }\end{array}$ & $\begin{array}{c}\text { Frequency of } \\
\text { detects exceeding } \\
\text { average RL }\end{array}$ & $\begin{array}{l}\text { PRG limit } \\
\left(10^{-5} \text { or } 1\right)\end{array}$ & $\begin{array}{l}\text { Frequency } \\
\text { of detects } \\
\text { exceeding } \\
\text { PRG limit }\end{array}$ & $\begin{array}{l}\text { Background } \\
\text { concentration }\end{array}$ & $\begin{array}{c}\text { Frequency } \\
\text { of detects } \\
\text { exceeding } \\
\text { background }\end{array}$ \\
\hline Radium-226 & $10 / 11$ & 0.04 & 2.69 & RAD300 & 1.19 & 15 & $\mathrm{NA}^{a}$ & 5 & $\mathrm{NA}^{a}$ & $2.6 \mathrm{E}-01$ & $9 / 11$ & 1.25 & $4 / 11$ \\
\hline Technetium-99 & $6 / 12$ & 0.05 & 2.63 & Z2-EU1B-306 & 0.65 & & NA & & NA & $8.9 \mathrm{E}+03$ & $0 / 12$ & & NA \\
\hline Thallium-208 & $7 / 7$ & 0.282 & 0.464 & RAD305 & 0.37 & & $\mathrm{NA}$ & & $\mathrm{NA}$ & $3.7 \mathrm{E}+05$ & $0 / 7$ & & NA \\
\hline Thorium-228 & $12 / 12$ & 0.74 & 1.53 & $\begin{array}{l}\text { RAD303 } \\
\text { RAD304 }\end{array}$ & 1.15 & & $\mathrm{NA}$ & & $\mathrm{NA}$ & $1.7 \mathrm{E}-01$ & $12 / 12^{b}$ & 1.86 & $0 / 12$ \\
\hline Thorium 229 & $0 / 1$ & ND & $\mathrm{ND}$ & & $\mathrm{ND}$ & & $\mathrm{NA}$ & & $\mathrm{NA}$ & $1.8 \mathrm{E}+00$ & $0 / 1$ & & $\mathrm{NA}$ \\
\hline Thorium 230 & $12 / 12$ & 0.73 & 1.9 & PCC-SS6 & 1.24 & 15 & $\mathrm{NA}^{a}$ & 5 & $\mathrm{NA}^{a}$ & $2.1 \mathrm{E}+02$ & $0 / 12$ & 1.2 & $7 / 12$ \\
\hline Thorium 232 & $12 / 12$ & 0.49 & 1.46 & RAD304 & 1.08 & 15 & $\mathrm{NA}^{a}$ & 5 & $\mathrm{NA}^{a}$ & $1.7 \mathrm{E}-01$ & $12 / 12^{b}$ & 1.95 & $0 / 12$ \\
\hline Thorium-234 & $11 / 12$ & 1.1 & 9.32 & RAD309 & 2.9 & & NA & & $\mathrm{NA}$ & $3.3 \mathrm{E}+04$ & $0 / 12$ & & NA \\
\hline Uranium-232 & $1 / 1$ & 0.162 & 0.162 & PCC-SS6 & 0.16 & & NA & & NA & $8.0 \mathrm{E}+01$ & $0 / 1$ & & NA \\
\hline Uranium-234 & $12 / 12$ & 0.77 & 12.6 & Z2-EU1B-306 & 2.49 & 7000 & $0 / 12$ & 700 & $0 / 12$ & $3.3 \mathrm{E}+02$ & $0 / 12$ & & NA \\
\hline Uranium-235 & $12 / 12$ & 0.053 & 0.82 & Z2-EU1B-306 & 0.24 & 80 & $0 / 12$ & 8 & $0 / 12$ & $3.9 \mathrm{E}+00$ & $0 / 12$ & & $\mathrm{NA}$ \\
\hline Uranium-238 & $12 / 12$ & 0.78 & 12.5 & Z2-EU1B-306 & 2.31 & 500 & $0 / 12$ & 50 & $0 / 12$ & $1.8 \mathrm{E}+01$ & $0 / 12$ & 1.47 & $3 / 12$ \\
\hline \multicolumn{14}{|c|}{ Organics, pesticides, and PCBs (ug/kg) } \\
\hline PCB-1016 & $0 / 15$ & $\mathrm{ND}$ & ND & & $\mathrm{ND}$ & 100000 & $0 / 15$ & 10000 & $0 / 15$ & $3.7 \mathrm{E}+04$ & $0 / 15$ & & NA \\
\hline PCB-1221 & $0 / 15$ & ND & ND & & ND & 100000 & $0 / 15$ & 10000 & $0 / 15$ & $7.4 \mathrm{E}+03$ & $0 / 15$ & & NA \\
\hline PCB-1232 & $0 / 15$ & ND & $\mathrm{ND}$ & & $\mathrm{ND}$ & 100000 & $0 / 15$ & 10000 & $0 / 15$ & $7.4 \mathrm{E}+03$ & $0 / 15$ & & $\mathrm{NA}$ \\
\hline PCB-1242 & $0 / 15$ & ND & ND & & $\mathrm{ND}$ & 100000 & $0 / 15$ & 10000 & $0 / 15$ & $7.4 \mathrm{E}+03$ & $0 / 15$ & & NA \\
\hline PCB-1248 & $0 / 15$ & ND & ND & & ND & 100000 & $0 / 15$ & 10000 & $0 / 15$ & $7.4 \mathrm{E}+03$ & $0 / 15$ & & $\mathrm{NA}$ \\
\hline PCB-1254 & $9 / 15$ & 5600 & 35000 & Z2-EU01-203 & 23288.89 & 100000 & $0 / 15$ & 10000 & $8 / 15$ & $7.4 \mathrm{E}+03$ & $8 / 15$ & & NA \\
\hline PCB-1260 & $2 / 15$ & $55 \mathrm{~J}$ & $820 \mathrm{~J}$ & Z2-EU1B-303 & 437.5 & 100000 & $0 / 15$ & 10000 & $0 / 15$ & $7.4 \mathrm{E}+03$ & $0 / 15$ & & NA \\
\hline Polychlorinated biphenyl & $11 / 14$ & $55 \mathrm{~J}$ & 35000 & Z2-EU01-203 & 19134.09 & 100000 & $0 / 14$ & 10000 & $8 / 14$ & $7.4 \mathrm{E}+03$ & $8 / 14$ & & $\mathrm{NA}$ \\
\hline \multicolumn{14}{|l|}{ Semivolatile organics $(\mathbf{u g} / \mathbf{k g})$} \\
\hline 1,2,4 Trichlorobenzene & $0 / 2$ & $\mathrm{ND}$ & $\mathrm{ND}$ & & $\mathrm{ND}$ & & $\mathrm{NA}$ & & NA & $2.2 \mathrm{E}+05$ & $0 / 2$ & & $\mathrm{NA}$ \\
\hline 1,2-Dichlorobenzene & $0 / 2$ & ND & $\mathrm{ND}$ & & $\mathrm{ND}$ & & NA & & NA & $6.0 \mathrm{E}+05$ & $0 / 2$ & & NA \\
\hline 1,3-Dichlorobenzene & $0 / 2$ & ND & ND & & ND & & NA & & $\mathrm{NA}$ & $6.0 \mathrm{E}+05$ & $0 / 2$ & & NA \\
\hline 1,4-Dichlorobenzene & $0 / 2$ & ND & ND & & $\mathrm{ND}$ & & $\mathrm{NA}$ & & $\mathrm{NA}$ & $7.9 \mathrm{E}+04$ & $0 / 2$ & & $\mathrm{NA}$ \\
\hline 2,3,4,6-Tetrachlorophenol & $0 / 2$ & $\mathrm{ND}$ & $\mathrm{ND}$ & & $\mathrm{ND}$ & & NA & & NA & $1.8 \mathrm{E}+07$ & $0 / 2$ & & NA \\
\hline 2,4,5-Trichlorophenol & $0 / 3$ & $\mathrm{ND}$ & ND & & ND & & NA & & NA & $6.2 \mathrm{E}+07$ & $0 / 3$ & & NA \\
\hline 2,4,6-Trichlorophenol & $0 / 3$ & ND & $\mathrm{ND}$ & & $\mathrm{ND}$ & & $\mathrm{NA}$ & & $\mathrm{NA}$ & $6.2 \mathrm{E}+04$ & $0 / 3$ & & $\mathrm{NA}$ \\
\hline 2,4-Dichlorophenol & $0 / 3$ & ND & ND & & ND & & NA & & NA & $1.8 \mathrm{E}+06$ & $0 / 3$ & & NA \\
\hline 2,4-Dimethylphenol & $0 / 3$ & $\mathrm{ND}$ & ND & & $\mathrm{ND}$ & & $\mathrm{NA}$ & & $\mathrm{NA}$ & $1.2 \mathrm{E}+07$ & $0 / 3$ & & $\mathrm{NA}$ \\
\hline 2,4-Dinitrophenol & $0 / 3$ & ND & ND & & ND & & $\mathrm{NA}$ & & $\mathrm{NA}$ & $1.2 \mathrm{E}+06$ & $0 / 3$ & & $\mathrm{NA}$ \\
\hline 2,4-Dinitrotoluene & $0 / 3$ & ND & ND & & ND & & NA & & NA & $2.5 \mathrm{E}+04$ & $0 / 3$ & & NA \\
\hline 2,6-Dinitrotoluene & $0 / 3$ & $\mathrm{ND}$ & $\mathrm{ND}$ & & $\mathrm{ND}$ & & $\mathrm{NA}$ & & $\mathrm{NA}$ & $2.5 \mathrm{E}+04$ & $0 / 3$ & & $\mathrm{NA}$ \\
\hline 2-Chloronaphthalene & $0 / 3$ & ND & ND & & ND & & NA & & NA & $2.3 \mathrm{E}+07$ & $0 / 3$ & & NA \\
\hline 2-Chlorophenol & $0 / 3$ & ND & ND & & $\mathrm{ND}$ & & $\mathrm{NA}$ & & $\mathrm{NA}$ & $2.4 \mathrm{E}+05$ & $0 / 3$ & & $\mathrm{NA}$ \\
\hline 2-Methyl-4,6-dinitrophenol & $0 / 3$ & ND & $\mathrm{ND}$ & & $\mathrm{ND}$ & & $\mathrm{NA}$ & & $\mathrm{NA}$ & $6.2 \mathrm{E}+04$ & $0 / 3$ & & $\mathrm{NA}$ \\
\hline 2-Methylnaphthalene & $0 / 3$ & ND & ND & & ND & & NA & & $\mathrm{NA}$ & $1.9 \mathrm{E}+05$ & $0 / 3$ & & NA \\
\hline 2-Methylphenol & $0 / 3$ & ND & $\mathrm{ND}$ & & $\mathrm{ND}$ & & NA & & $\mathrm{NA}$ & $3.1 \mathrm{E}+07$ & $0 / 3$ & & $\mathrm{NA}$ \\
\hline 2-Nitrobenzenamine & $0 / 3$ & ND & ND & & $\mathrm{ND}$ & & $\mathrm{NA}$ & & $\mathrm{NA}$ & $1.8 \mathrm{E}+06$ & $0 / 3$ & & $\mathrm{NA}$ \\
\hline 2-Nitrophenol & $0 / 3$ & ND & ND & & ND & & $\mathrm{NA}$ & & $\mathrm{NA}$ & & $\mathrm{NA}$ & & $\mathrm{NA}$ \\
\hline 3,3'-Dichlorobenzidine & $0 / 3$ & ND & ND & & ND & & NA & & NA & $3.8 \mathrm{E}+04$ & $0 / 3$ & & NA \\
\hline 3-Nitrobenzenamine & $0 / 3$ & ND & ND & & ND & & NA & & NA & $1.8 \mathrm{E}+05$ & $0 / 3$ & & NA \\
\hline 4-Bromophenyl phenyl ether & $0 / 3$ & ND & ND & & $\mathrm{ND}$ & & $\mathrm{NA}$ & & $\mathrm{NA}$ & & $\mathrm{NA}$ & & $\mathrm{NA}$ \\
\hline 4-Chloro-3-methylphenol & $0 / 3$ & ND & ND & & ND & & $\mathrm{NA}$ & & NA & & NA & & NA \\
\hline 4-Chlorobenzenamine & $0 / 3$ & ND & ND & & ND & & $\mathrm{NA}$ & & NA & $2.5 \mathrm{E}+06$ & $0 / 3$ & & NA \\
\hline 4-Chlorophenyl phenyl ether & $0 / 3$ & ND & ND & & ND & & NA & & NA & & NA & & NA \\
\hline 4-Methylphenol & $0 / 2$ & ND & ND & & ND & & NA & & NA & $3.1 \mathrm{E}+06$ & $0 / 2$ & & NA \\
\hline 4-Nitrobenzenamine & $0 / 3$ & ND & ND & & ND & & $\mathrm{NA}$ & & NA & $8.2 \mathrm{E}+05$ & $0 / 3$ & & $\mathrm{NA}$ \\
\hline
\end{tabular}




\begin{tabular}{|c|c|c|c|c|c|c|c|c|c|c|c|c|c|}
\hline Analyte & $\begin{array}{r}\text { Frequency } \\
\text { of detect }\end{array}$ & $\begin{array}{c}\text { Minimum } \\
\text { detect }\end{array}$ & $\begin{array}{c}\text { Maximum } \\
\text { detect }\end{array}$ & $\begin{array}{c}\begin{array}{c}\text { Location(s) of } \\
\text { maximum } \\
\text { detected result }\end{array} \\
\end{array}$ & $\begin{array}{c}\text { Average } \\
\text { detected } \\
\text { result } \\
\end{array}$ & $\begin{array}{c}\text { Maximum } \\
\text { RL }\end{array}$ & $\begin{array}{c}\text { Frequency } \\
\text { of detects } \\
\text { exceeding } \\
\text { maximum RL }\end{array}$ & $\begin{array}{c}\text { Average } \\
\text { RL }\end{array}$ & $\begin{array}{c}\begin{array}{c}\text { Frequency of } \\
\text { detects exceeding } \\
\text { average RL }\end{array} \\
\end{array}$ & $\begin{array}{r}\text { PRG limit } \\
\left(\mathbf{1 0}^{-5} \text { or } 1\right)\end{array}$ & $\begin{array}{c}\begin{array}{c}\text { Frequency } \\
\text { of detects } \\
\text { exceeding } \\
\text { PRGlimit }\end{array} \\
\end{array}$ & $\begin{array}{c}\text { Background } \\
\text { concentration }\end{array}$ & $\begin{array}{c}\text { Frequency } \\
\text { of detects } \\
\text { exceeding } \\
\text { background }\end{array}$ \\
\hline 4-Nitrophenol & $0 / 3$ & ND & ND & & $\mathrm{ND}$ & & NA & & NA & & NA & & NA \\
\hline Acenaphthene & $0 / 3$ & ND & ND & & ND & & NA & & $\mathrm{NA}$ & $2.9 \mathrm{E}+07$ & $0 / 3$ & & NA \\
\hline Acenaphthylene & $0 / 3$ & $\mathrm{ND}$ & ND & & ND & & $\mathrm{NA}$ & & $\mathrm{NA}$ & $2.9 \mathrm{E}+07$ & $0 / 3$ & & NA \\
\hline Aniline & $0 / 2$ & $\mathrm{ND}$ & $\mathrm{ND}$ & & $\mathrm{ND}$ & & $\mathrm{NA}$ & & $\mathrm{NA}$ & $3.0 \mathrm{E}+06$ & $0 / 2$ & & NA \\
\hline Anthracene & $0 / 3$ & ND & ND & & $\mathrm{ND}$ & & NA & & NA & $1.0 \mathrm{E}+08$ & $0 / 3$ & & NA \\
\hline Benz(a)anthracene & $0 / 3$ & $\mathrm{ND}$ & $\mathrm{ND}$ & & $\mathrm{ND}$ & & NA & & $\mathrm{NA}$ & $2.1 \mathrm{E}+04$ & $0 / 3$ & & $\mathrm{NA}$ \\
\hline Benzenemethanol & $0 / 3$ & ND & ND & & ND & & NA & & $\mathrm{NA}$ & $1.0 \mathrm{E}+08$ & $0 / 3$ & & NA \\
\hline Benzo(a)pyrene & $0 / 3$ & ND & ND & & ND & & NA & & $\mathrm{NA}$ & $2.1 \mathrm{E}+03$ & $0 / 3$ & & NA \\
\hline Benzo(b)fluoranthene & $0 / 3$ & $\mathrm{ND}$ & $\mathrm{ND}$ & & ND & & NA & & $\mathrm{NA}$ & $2.1 \mathrm{E}+04$ & $0 / 3$ & & NA \\
\hline Benzo(ghi)perylene & $0 / 3$ & ND & ND & & $\mathrm{ND}$ & & $\mathrm{NA}$ & & $\mathrm{NA}$ & $2.9 \mathrm{E}+07$ & $0 / 3$ & & NA \\
\hline Benzo(k)fluoranthene & $0 / 3$ & ND & ND & & $\mathrm{ND}$ & & NA & & NA & $2.1 \mathrm{E}+05$ & $0 / 3$ & & NA \\
\hline Benzoic acid & $1 / 3$ & $160 \mathrm{~J}$ & $160 \mathrm{~J}$ & Z2-EU1B-301 & 160 & & NA & & $\mathrm{NA}$ & $1.0 \mathrm{E}+08$ & $0 / 3$ & & NA \\
\hline Bis(2-chloroethoxy)methane & $0 / 3$ & $\mathrm{ND}$ & $\mathrm{ND}$ & & ND & & $\mathrm{NA}$ & & $\mathrm{NA}$ & & NA & & $\mathrm{NA}$ \\
\hline Bis(2-chloroethyl) ether & $0 / 3$ & ND & $\mathrm{ND}$ & & ND & & NA & & $\mathrm{NA}$ & $5.8 \mathrm{E}+03$ & $0 / 3$ & & NA \\
\hline Bis(2-chloroisopropyl) ether & $0 / 3$ & ND & $\mathrm{ND}$ & & $\mathrm{ND}$ & & NA & & NA & $7.4 \mathrm{E}+04$ & $0 / 3$ & & NA \\
\hline Bis(2-ethylhexyl)phthalate & $0 / 3$ & ND & ND & & $\mathrm{ND}$ & & NA & & $\mathrm{NA}$ & $1.2 \mathrm{E}+06$ & $0 / 3$ & & NA \\
\hline Butyl benzyl phthalate & $0 / 3$ & ND & ND & & ND & & $\mathrm{NA}$ & & NA & $1.0 \mathrm{E}+08$ & $0 / 3$ & & $\mathrm{NA}$ \\
\hline Carbazole & $0 / 3$ & ND & $\mathrm{ND}$ & & $\mathrm{ND}$ & & $\mathrm{NA}$ & & NA & $8.6 \mathrm{E}+05$ & $0 / 3$ & & $\mathrm{NA}$ \\
\hline Chrysene & $0 / 3$ & ND & $\mathrm{ND}$ & & $\mathrm{ND}$ & & $\mathrm{NA}$ & & $\mathrm{NA}$ & $2.1 \mathrm{E}+06$ & $0 / 3$ & & $\mathrm{NA}$ \\
\hline Di-n-butyl phthalate & $0 / 1$ & ND & ND & & $\mathrm{ND}$ & & NA & & NA & $6.2 \mathrm{E}+07$ & $0 / 1$ & & NA \\
\hline Di-n-octylphthalate & $0 / 3$ & $\mathrm{ND}$ & $\mathrm{ND}$ & & ND & & NA & & NA & $2.5 \mathrm{E}+07$ & $0 / 3$ & & NA \\
\hline Dibenz(a,h)anthracene & $0 / 3$ & ND & $\mathrm{ND}$ & & $\mathrm{ND}$ & & $\mathrm{NA}$ & & $\mathrm{NA}$ & $2.1 \mathrm{E}+03$ & $0 / 3$ & & $\mathrm{NA}$ \\
\hline Dibenzofuran & $0 / 3$ & ND & $\mathrm{ND}$ & & $\mathrm{ND}$ & & NA & & $\mathrm{NA}$ & $1.6 \mathrm{E}+06$ & $0 / 3$ & & NA \\
\hline Diethyl phthalate & $0 / 3$ & ND & $\mathrm{ND}$ & & $\mathrm{ND}$ & & NA & & NA & $1.0 \mathrm{E}+08$ & $0 / 3$ & & NA \\
\hline Dimethyl phthalate & $0 / 3$ & ND & $\mathrm{ND}$ & & $\mathrm{ND}$ & & $\mathrm{NA}$ & & NA & $1.0 \mathrm{E}+08$ & $0 / 3$ & & NA \\
\hline Fluoranthene & $1 / 3$ & $97 \mathrm{~J}$ & $97 \mathrm{~J}$ & $\begin{array}{l}\text { PCC-SS6 } \\
\end{array}$ & 97 & & $\mathrm{NA}$ & & $\mathrm{NA}$ & $2.2 \mathrm{E}+07$ & $0 / 3$ & & NA \\
\hline Fluorene & $0 / 3$ & $\mathrm{ND}$ & $\mathrm{ND}$ & & $\mathrm{ND}$ & & $\mathrm{NA}$ & & NA & $2.6 \mathrm{E}+07$ & $0 / 3$ & & NA \\
\hline Hexachlorobenzene & $0 / 3$ & ND & $\mathrm{ND}$ & & $\mathrm{ND}$ & & NA & & NA & $1.1 \mathrm{E}+04$ & $0 / 3$ & & $\mathrm{NA}$ \\
\hline Hexachlorobutadiene & $0 / 2$ & ND & $\mathrm{ND}$ & & ND & & $\mathrm{NA}$ & & NA & $1.8 \mathrm{E}+05$ & $0 / 2$ & & NA \\
\hline Hexachlorocyclopentadiene & $0 / 3$ & ND & $\mathrm{ND}$ & & $\mathrm{ND}$ & & $\mathrm{NA}$ & & $\mathrm{NA}$ & $3.7 \mathrm{E}+06$ & $0 / 3$ & & NA \\
\hline Hexachloroethane & $0 / 3$ & $\mathrm{ND}$ & $\mathrm{ND}$ & & $\mathrm{ND}$ & & $\mathrm{NA}$ & & $\mathrm{NA}$ & $6.2 \mathrm{E}+05$ & $0 / 3$ & & $\mathrm{NA}$ \\
\hline Indeno(1,2,3-cd)pyrene & $0 / 3$ & ND & $\mathrm{ND}$ & & ND & & NA & & $\mathrm{NA}$ & $2.1 \mathrm{E}+04$ & $0 / 3$ & & NA \\
\hline Isophorone & $0 / 3$ & ND & $\mathrm{ND}$ & & $\mathrm{ND}$ & & NA & & $\mathrm{NA}$ & $5.1 \mathrm{E}+06$ & $0 / 3$ & & NA \\
\hline N-Nitroso-di-n-propylamine & $0 / 3$ & $\mathrm{ND}$ & $\mathrm{ND}$ & & ND & & $\mathrm{NA}$ & & $\mathrm{NA}$ & $2.5 \mathrm{E}+03$ & $0 / 3$ & & $\mathrm{NA}$ \\
\hline N-Nitrosodiphenylamine & $0 / 3$ & ND & ND & & $\mathrm{ND}$ & & $\mathrm{NA}$ & & NA & $3.5 \mathrm{E}+06$ & $0 / 3$ & & $\mathrm{NA}$ \\
\hline Naphthalene & $0 / 3$ & ND & $\mathrm{ND}$ & & $\mathrm{ND}$ & & $\mathrm{NA}$ & & NA & $1.9 \mathrm{E}+05$ & $0 / 3$ & & $\mathrm{NA}$ \\
\hline Nitrobenzene & $0 / 3$ & $\mathrm{ND}$ & $\mathrm{ND}$ & & $\mathrm{ND}$ & & $\mathrm{NA}$ & & $\mathrm{NA}$ & $1.0 \mathrm{E}+05$ & $0 / 3$ & & $\mathrm{NA}$ \\
\hline Pentachlorophenol & $0 / 3$ & ND & ND & & $\mathrm{ND}$ & & $\mathrm{NA}$ & & $\mathrm{NA}$ & $9.0 \mathrm{E}+04$ & $0 / 3$ & & NA \\
\hline Phenanthrene & $0 / 3$ & $\mathrm{ND}$ & $\mathrm{ND}$ & & ND & & $\mathrm{NA}$ & & NA & $2.9 \mathrm{E}+07$ & $0 / 3$ & & NA \\
\hline Phenol & $0 / 3$ & ND & $\mathrm{ND}$ & & $\mathrm{ND}$ & & $\mathrm{NA}$ & & $\mathrm{NA}$ & $1.0 \mathrm{E}+08$ & $0 / 3$ & & $\mathrm{NA}$ \\
\hline Pyrene & $0 / 3$ & ND & $\mathrm{ND}$ & & ND & & $\mathrm{NA}$ & & $\mathrm{NA}$ & $2.9 \mathrm{E}+07$ & $0 / 3$ & & NA \\
\hline Pyridine & $0 / 2$ & $\mathrm{ND}$ & $\mathrm{ND}$ & & $\mathrm{ND}$ & & $\mathrm{NA}$ & & $\mathrm{NA}$ & $6.2 \mathrm{E}+05$ & $0 / 2$ & & NA \\
\hline M+P methylphenol & $0 / 1$ & ND & $\mathrm{ND}$ & & $\mathrm{ND}$ & & $\mathrm{NA}$ & & $\mathrm{NA}$ & & $\mathrm{NA}$ & & $\mathrm{NA}$ \\
\hline \multicolumn{14}{|l|}{ Volatile organics (ug/kg) } \\
\hline 1,1,1-Trichloroethane & $0 / 2$ & $\mathrm{ND}$ & $\mathrm{ND}$ & & $\mathrm{ND}$ & & $\mathrm{NA}$ & & $\mathrm{NA}$ & $1.2 \mathrm{E}+06$ & $0 / 2$ & & NA \\
\hline 1,1,2,2-Tetrachloroethane & $0 / 2$ & ND & $\mathrm{ND}$ & & $\mathrm{ND}$ & & $\mathrm{NA}$ & & $\mathrm{NA}$ & $9.3 \mathrm{E}+03$ & $0 / 2$ & & $\mathrm{NA}$ \\
\hline 1,1,2-Trichloroethane & $0 / 2$ & ND & $\mathrm{ND}$ & & ND & & $\mathrm{NA}$ & & $\mathrm{NA}$ & $1.6 \mathrm{E}+04$ & $0 / 2$ & & $\mathrm{NA}$ \\
\hline 1,1-Dichloroethane & $0 / 2$ & $\mathrm{ND}$ & $\mathrm{ND}$ & & $\mathrm{ND}$ & & NA & & $\mathrm{NA}$ & $1.7 \mathrm{E}+06$ & $0 / 2$ & & NA \\
\hline 1,1-Dichloroethene & $0 / 2$ & ND & $\mathrm{ND}$ & & $\mathrm{ND}$ & & $\mathrm{NA}$ & & $\mathrm{NA}$ & $4.1 \mathrm{E}+05$ & $0 / 2$ & & $\mathrm{NA}$ \\
\hline 1,2-Dichloroethane & $0 / 2$ & ND & ND & & ND & & $\mathrm{NA}$ & & $\mathrm{NA}$ & $6.0 \mathrm{E}+03$ & $0 / 2$ & & $\mathrm{NA}$ \\
\hline
\end{tabular}




\begin{tabular}{|c|c|c|c|c|c|c|c|c|c|c|c|c|c|}
\hline Analyte & $\begin{array}{c}\text { Frequency } \\
\text { of detect }\end{array}$ & $\begin{array}{c}\text { Minimum } \\
\text { detect }\end{array}$ & $\begin{array}{c}\text { Maximum } \\
\text { detect }\end{array}$ & $\begin{array}{c}\begin{array}{c}\text { Location(s) of } \\
\text { maximum } \\
\text { detected result }\end{array} \\
\end{array}$ & $\begin{array}{c}\text { Average } \\
\text { detected } \\
\text { result }\end{array}$ & $\begin{array}{c}\text { Maximum } \\
\text { RL } \\
\end{array}$ & $\begin{array}{c}\text { Frequency } \\
\text { of detects } \\
\text { exceeding } \\
\text { maximum RL }\end{array}$ & $\begin{array}{c}\text { Average } \\
\text { RL }\end{array}$ & $\begin{array}{c}\text { Frequency of } \\
\text { detects exceeding } \\
\text { average RL }\end{array}$ & $\begin{array}{r}\text { PRG limit } \\
\left(10^{-5} \text { or } 1\right)\end{array}$ & $\begin{array}{c}\text { Frequency } \\
\text { of detects } \\
\text { exceeding } \\
\text { PRGlimit }\end{array}$ & $\begin{array}{c}\text { Background } \\
\text { concentration }\end{array}$ & $\begin{array}{c}\text { Frequency } \\
\text { of detects } \\
\text { exceeding } \\
\text { background }\end{array}$ \\
\hline 1,2-Dichloropropane & $0 / 2$ & ND & ND & & $\mathrm{ND}$ & & NA & & NA & $7.4 \mathrm{E}+03$ & $0 / 2$ & & NA \\
\hline 2-Butanone & $0 / 2$ & ND & ND & & ND & & $\mathrm{NA}$ & & $\mathrm{NA}$ & $1.0 \mathrm{E}+08$ & $0 / 2$ & & NA \\
\hline 2-Hexanone & $0 / 2$ & ND & ND & & $\mathrm{ND}$ & & $\mathrm{NA}$ & & NA & & NA & & NA \\
\hline 4-Methyl-2-pentanone & $0 / 2$ & ND & ND & & $\mathrm{ND}$ & & $\mathrm{NA}$ & & NA & $4.7 \mathrm{E}+07$ & $0 / 2$ & & NA \\
\hline Acetone & $1 / 2$ & $6.4 \mathrm{~J}$ & $6.4 \mathrm{~J}$ & Z2-EU1B-305 & 6.4 & & NA & & NA & $5.4 \mathrm{E}+07$ & $0 / 2$ & & NA \\
\hline Benzene & $0 / 2$ & ND & ND & & $\mathrm{ND}$ & & $\mathrm{NA}$ & & NA & $1.4 \mathrm{E}+04$ & $0 / 2$ & & NA \\
\hline Bromodichloromethane & $0 / 2$ & $\mathrm{ND}$ & ND & & $\mathrm{ND}$ & & $\mathrm{NA}$ & & $\mathrm{NA}$ & $1.8 \mathrm{E}+04$ & $0 / 2$ & & NA \\
\hline Bromoform & $0 / 2$ & $\mathrm{ND}$ & $\mathrm{ND}$ & & $\mathrm{ND}$ & & NA & & NA & $2.2 \mathrm{E}+06$ & $0 / 2$ & & NA \\
\hline Bromomethane & $0 / 2$ & ND & $\mathrm{ND}$ & & ND & & $\mathrm{NA}$ & & NA & $1.3 \mathrm{E}+04$ & $0 / 2$ & & NA \\
\hline Carbon disulfide & $0 / 2$ & $\mathrm{ND}$ & $\mathrm{ND}$ & & $\mathrm{ND}$ & & $\mathrm{NA}$ & & NA & $7.2 \mathrm{E}+05$ & $0 / 2$ & & NA \\
\hline Carbon tetrachloride & $0 / 2$ & $\mathrm{ND}$ & ND & & $\mathrm{ND}$ & & $\mathrm{NA}$ & & NA & $5.5 \mathrm{E}+03$ & $0 / 2$ & & NA \\
\hline Chlorobenzene & $0 / 2$ & $\mathrm{ND}$ & ND & & $\mathrm{ND}$ & & $\mathrm{NA}$ & & NA & $5.3 \mathrm{E}+05$ & $0 / 2$ & & NA \\
\hline Chloroethane & $0 / 2$ & ND & $\mathrm{ND}$ & & $\mathrm{ND}$ & & $\mathrm{NA}$ & & NA & $6.5 \mathrm{E}+04$ & $0 / 2$ & & NA \\
\hline Chloroform & $0 / 2$ & ND & ND & & ND & & $\mathrm{NA}$ & & NA & $4.7 \mathrm{E}+03$ & $0 / 2$ & & NA \\
\hline Chloromethane & $0 / 2$ & ND & $\mathrm{ND}$ & & $\mathrm{ND}$ & & $\mathrm{NA}$ & & NA & $1.6 \mathrm{E}+05$ & $0 / 2$ & & NA \\
\hline Dibromochloromethane & $0 / 2$ & ND & $\mathrm{ND}$ & & $\mathrm{ND}$ & & $\mathrm{NA}$ & & NA & $2.6 \mathrm{E}+04$ & $0 / 2$ & & NA \\
\hline Ethylbenzene & $0 / 2$ & ND & ND & & $\mathrm{ND}$ & & NA & & NA & $4.0 \mathrm{E}+05$ & $0 / 2$ & & NA \\
\hline Methylene chloride & $0 / 2$ & ND & $\mathrm{ND}$ & & ND & & $\mathrm{NA}$ & & NA & $2.1 \mathrm{E}+05$ & $0 / 2$ & & NA \\
\hline Styrene & $0 / 2$ & ND & $\mathrm{ND}$ & & $\mathrm{ND}$ & & $\mathrm{NA}$ & & $\mathrm{NA}$ & $1.7 \mathrm{E}+06$ & $0 / 2$ & & NA \\
\hline Tetrachloroethene & $0 / 2$ & ND & ND & & $\mathrm{ND}$ & & $\mathrm{NA}$ & & NA & $1.3 \mathrm{E}+04$ & $0 / 2$ & & NA \\
\hline Toluene & $0 / 2$ & $\mathrm{ND}$ & ND & & $\mathrm{ND}$ & & $\mathrm{NA}$ & & NA & $5.2 \mathrm{E}+05$ & $0 / 2$ & & NA \\
\hline Total xylene & $0 / 2$ & ND & ND & & ND & & $\mathrm{NA}$ & & NA & $4.2 \mathrm{E}+05$ & $0 / 2$ & & NA \\
\hline Trichloroethene & $0 / 2$ & ND & $\mathrm{ND}$ & & $\mathrm{ND}$ & & $\mathrm{NA}$ & & NA & $1.1 \mathrm{E}+03$ & $0 / 2$ & & NA \\
\hline Vinyl chloride & $0 / 2$ & ND & $\mathrm{ND}$ & & $\mathrm{ND}$ & & $\mathrm{NA}$ & & NA & $7.5 \mathrm{E}+03$ & $0 / 2$ & & NA \\
\hline cis-1,2-Dichloroethene & $0 / 2$ & $\mathrm{ND}$ & $\mathrm{ND}$ & & $\mathrm{ND}$ & & $\mathrm{NA}$ & & NA & $1.5 \mathrm{E}+05$ & $0 / 2$ & & NA \\
\hline cis-1,3-Dichloropropene & $0 / 2$ & ND & ND & & ND & & $\mathrm{NA}$ & & NA & $1.8 \mathrm{E}+04$ & $0 / 2$ & & NA \\
\hline trans-1,2-Dichloroethene & $0 / 2$ & ND & $\mathrm{ND}$ & & $\mathrm{ND}$ & & $\mathrm{NA}$ & & NA & $2.3 \mathrm{E}+05$ & $0 / 2$ & & NA \\
\hline trans-1,3-Dichloropropene & $0 / 2$ & ND & $\mathrm{ND}$ & & $\mathrm{ND}$ & & $\mathrm{NA}$ & & $\mathrm{NA}$ & $1.8 \mathrm{E}+04$ & $0 / 2$ & & NA \\
\hline \multicolumn{14}{|c|}{${ }^{a}$ Radionuclide is evaluated as part of Ra/Th decay series as discussed in the Zone 2 ROD. } \\
\hline \multicolumn{14}{|c|}{ 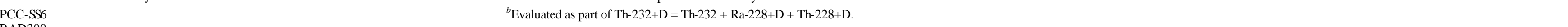 } \\
\hline $\begin{array}{l}\text { RAD300 } \\
\text { RAD303 }\end{array}$ & & & & \multirow{6}{*}{\multicolumn{10}{|c|}{$\begin{array}{l}\text { EU = exposure unit } \\
J=\text { analyte was positively identified and result is the approximate con } \\
\mathrm{NA}=\text { not applicable } \\
\mathrm{ND}=\text { not detected } \\
\mathrm{PCB}=\text { polychloride biphenyl } \\
\mathrm{PRG}=\text { preliminary remediation goal } \\
\mathrm{RL}=\text { remediation level }\end{array}$}} \\
\hline $\begin{array}{l}\text { RAD3030 } \\
\text { RAD04 }\end{array}$ & & & & & & & & & & & & & \\
\hline RAD305 & & & & & & & & & & & & & \\
\hline RAD306 & & & & & & & & & & & & & \\
\hline RAD308 & & & & & & & & & & & & & \\
\hline $\begin{array}{l}\text { RAD309 } 201 \\
\text { Z2-EU01-201 }\end{array}$ & & & & & & & & & & & & & \\
\hline Z2-EU01-202 & & & & $\mathrm{U}=$ analyte was $\mathrm{n}$ & detected above $\mathrm{t}$ & ported samp & quantitation limit & & & & & & \\
\hline
\end{tabular}




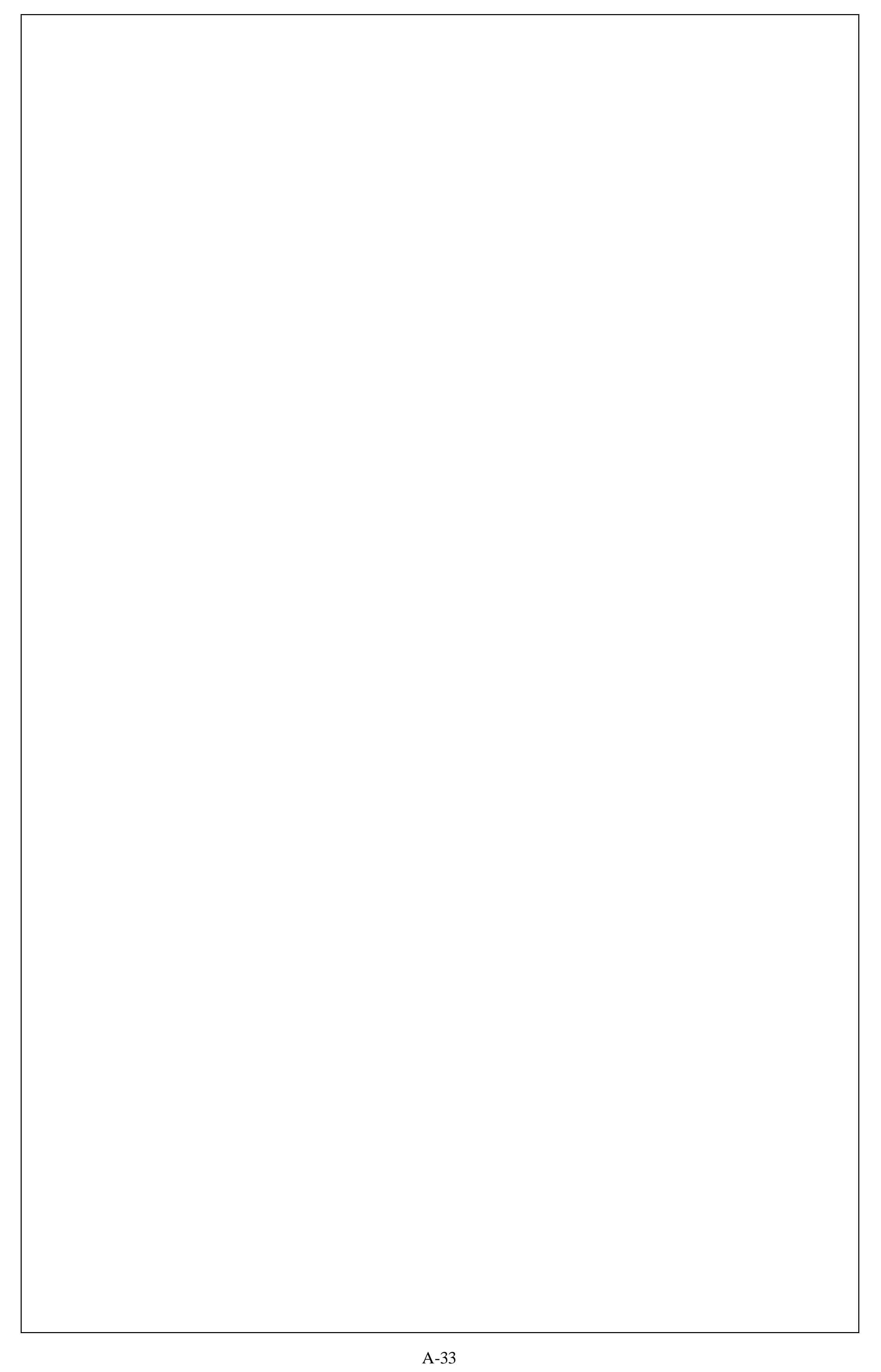




\section{Appendix B}

\section{K-31/K-33 Group}

Exposure Unit Z2-03

Technical Memorandum 


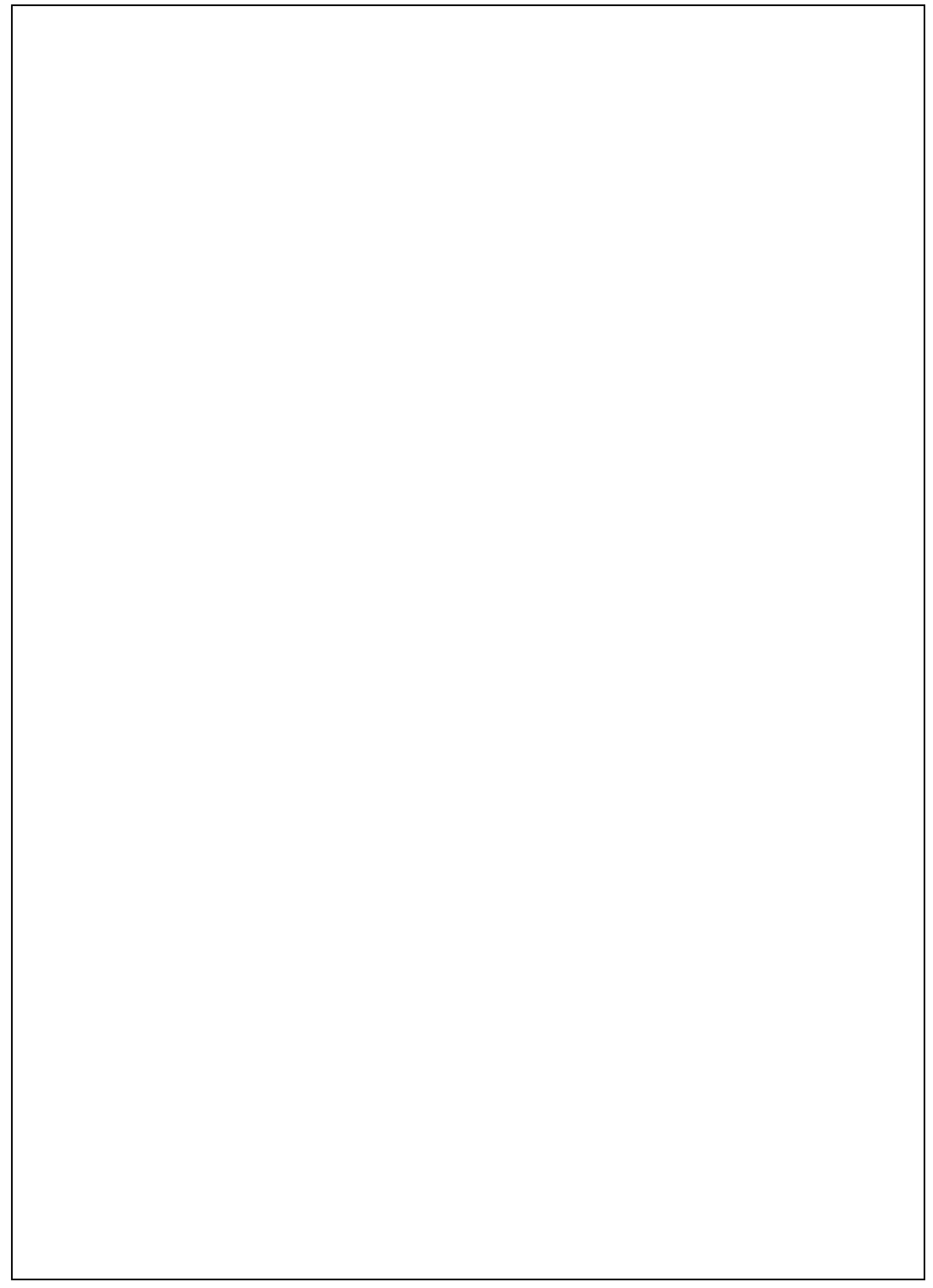

B-2 


\section{FIGURES}

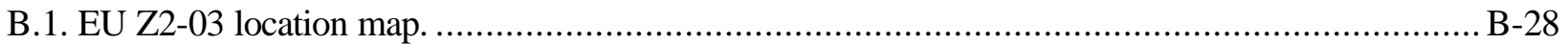

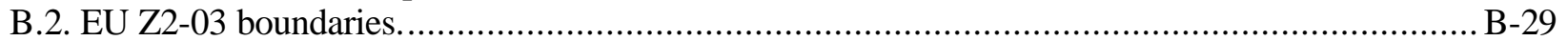

B.3. EU Z2-03 BAR survey results of RAD157 Class 2 SU......................................................

B.4. EU Z2-03 Class 3 SU walkover assessment locations..................................................... B-31

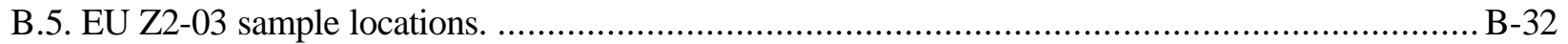

\section{TABLES}

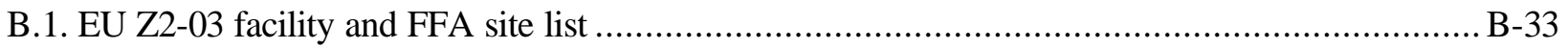

B.2. K-31/K-33 Group EU Z2-03 sample summary ..................................................................

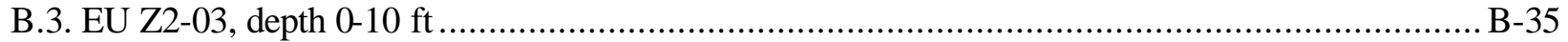




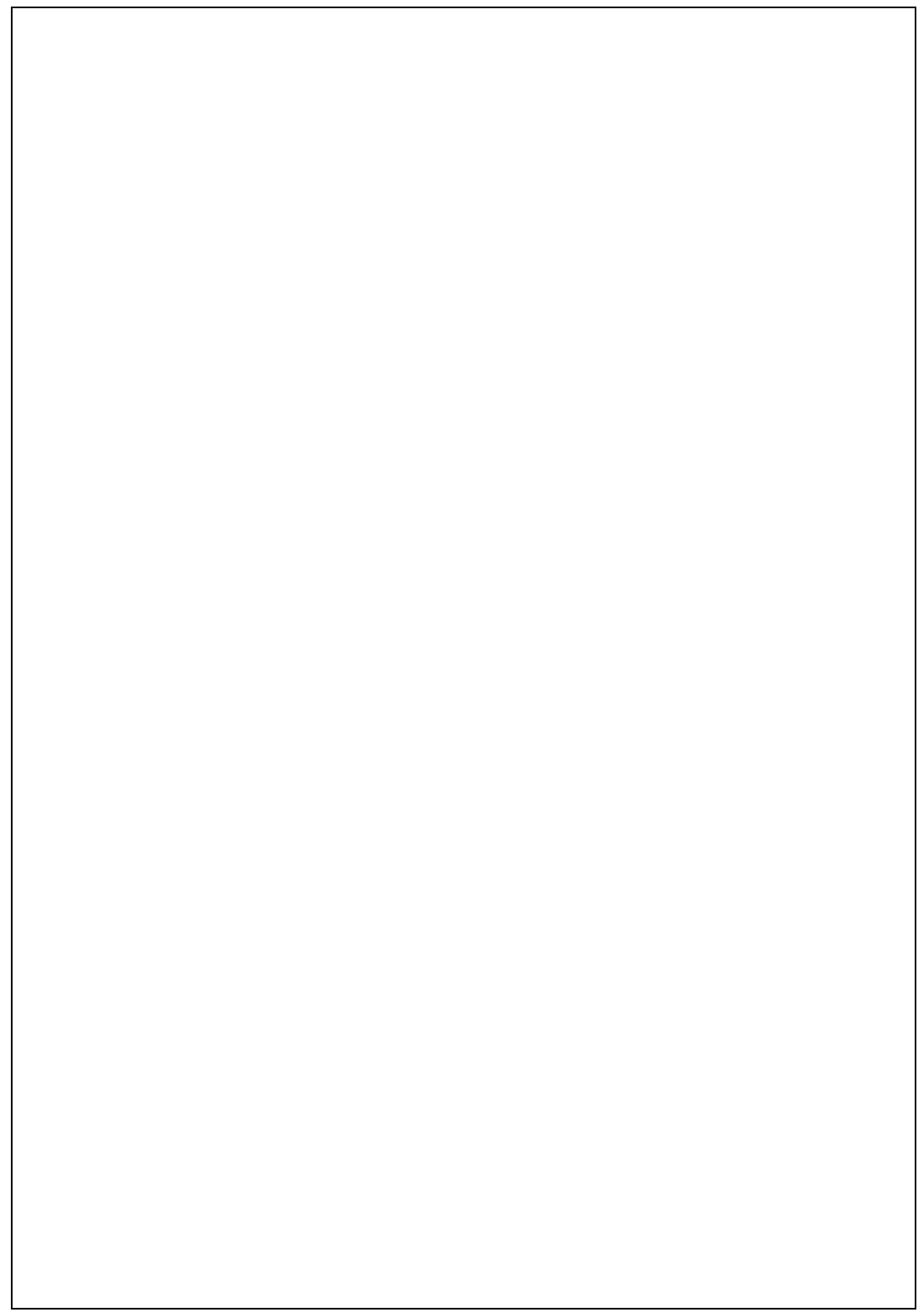

B-4 


\section{DYNAMIC VERIFICATION STRATEGY (DVS) TECHNICAL MEMORANDUM (TM)}

EXPOSURE UNIT (EU) GROUP: Zone 2 K-31/K-33 Group EU Z2-03

\section{INTRODUCTION}

The purpose of this TM is to document the recommendation for an action/no further action (NFA) decision for EU Z2-03 in the K-31/K-33 EU Group. The recommendation for this EU is based on existing historical data and DVS characterization activities. These data are used to determine the nature and extent of contamination in the EU and evaluate the need for an action. When it is determined an action is necessary, the data are also used to calculate soil volumes for the proposed remedial alternative as identified in the Record of Decision for Soil, Buried Waste, and Subsurface Structure Actions in Zone 2, East Tennessee Technology Park, Oak Ridge, Tennessee (DOE/OR/01-2161\&D2) (Zone 2 ROD).

\begin{tabular}{|l|l|}
\hline 1.0 & BACKGROUND AND EU SUMMARY \\
\hline 1.1 & LOCATIO NAT EAST TENNESSEE TECHNOLOGY PARK (ETTP) \\
\hline
\end{tabular}

EU Z2-03 is bound on the north by EU Z2-02, on the south by Zone 1, on the east by the K-31 building (EU Z2-06) and EU Z2-07, and on the west by Zone 1 (Fig. B.1).

\begin{tabular}{|l|l|}
\hline 1.2 & EU Z2-03 ACREAGE \\
\hline
\end{tabular}

EU Z2-03 has an area of approximately 15 acres (Fig. B.2).

\begin{tabular}{|l|l|}
1.3 & SUMMARY DESCRIPTION \\
\hline
\end{tabular}

All of the land area in EU Z2-03 has been impacted by site operations, including construction of buildings, roads, and parking lots. The EU is generally flat-lying ground with very low relief and drains via storm drains to the K-901-A Holding Pond.

The Data Quality Objective (DQO) Scoping Package for the K-31/K-33 EU Group lists 12 facilities in EU Z2-03 (see Table B.1).

\section{\begin{tabular}{l|l}
1.4 & SOIL UNITS (SUS) \\
\hline
\end{tabular}}

Class 1 SU: None

Class 2 SU: 0.34 acres, including a small area used for determining the areal extent of a historical average remediation level (RL) exceedance, which was listed as unclassified acreage in the DQO Scoping Package but was reclassified as Class $2 \mathrm{SU}$ (see Sect. 2.1.2 for explanation).

Class 3 SU: 14.59 acres, including buildings, roads, parking lots, and vegetation-covered land sloping to Poplar Creek.

Class 4 SU: None

Unclassified: The footprint of the K-762 Switchyard is coincident with the K-762 Switchyard Soils Federal Facility Agreement (FFA) site that was not classified into soil units for DQO scoping. A real-time characterization project was performed to provide data to aid in classification.

\section{\begin{tabular}{l|l}
1.5 & ZONE 2 ROD APPENDIX A FEDERAL FACILITY AGREEMENT (FFA) SITES
\end{tabular}}

There are four FFA sites in EU Z2-03 that are listed in Appendix A of the Zone 2 ROD:

- K-762 Switchyard Soils FFA site;

- K-762 Valve Vaults 1 and 2 FFA site;

- K-897-L Oil Containment Structure FFA site; and

- $\quad$ K-897-M Oil Containment Structure FFA site. 


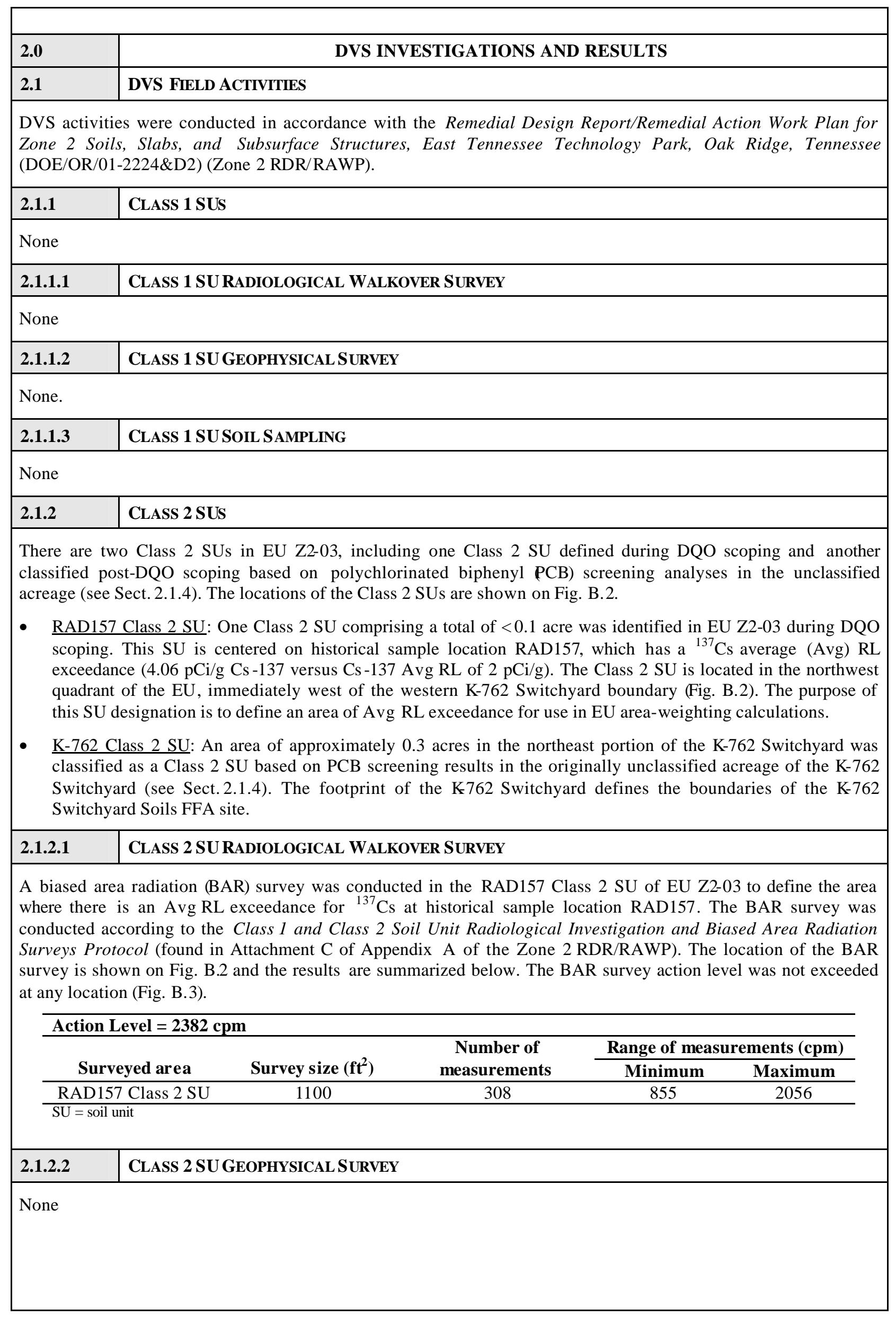


RAD157 Class $2 \mathrm{SU}$ : A biased soil sample location was identified in the Class 2 SU at historical sample location RAD157 to confirm the historical Cs -137 average RL exceedance. Because an action level exceedance area could not be defined during the BAR survey (see Sect. 2.1.2.1), there was no boundary to define the sampling point locations for the four-point composite sample, and this sample was not collected.

K-762 Class 2 SU: There are three DVS sample locations in the K762 Class 2 SU. One PCB screening confirmation sample location was identified in the Class 2 SU (see Sect. 2.1.4), and two systematic grid sample locations were identified in the Class 2 SU based on the results of PCB screening.

\section{\begin{tabular}{|l|l} 
2.1.3 & Class 3 AND ClaSs 4 SU WALKOVER ASSESSMENT
\end{tabular}}

The protocol for addressing the Class 3 and Class 4 SUs in EU Z2-03 is the Class 3 and Class 4 Soil Unit Walkover Inspection Protocol (found in Attachment $\mathrm{C}$ of Appendix A in the Zone 2 RDR/RAWP). Because there are no Class 4 SUs in this EU, only Class 3 SUs are addressed. The purpose of the Class 3 SU walkover assessment is to systematically inspect Class 3 SUs by visual observation along transects to established grid assessment locations, map observed features, collect radiological screening data at grid and discretionary locations, and visually inspect and perform radiological screening surveys on the plant facilities. Details of the walkover assessment results for EU Z2-03 are presented in Walkover Inspections and Radiological Surveys for FY 2007 Exposure Units in Zones 1 and 2, East Tennessee Technology Park, Oak Ridge, Tennessee (BJC/OR-2691). The report results are summarized below in Sects. 2.1.3.1 and 2.1.3.2. The assessment point (AP), mid-point (MP), and discretionary point (DP) locations are shown in Fig. B.4.

Eleven APs were identified in this EU prior to the start of fieldwork and are documented in the DQO Scoping Package. There were 14 APs evaluated in EU Z2-03.

In addition to the APs, the field team made assessments at 14 MP locations (MPs are selected in the field and are points located approximately half way between APs) and conducted discretionary surveys at nine locations. MP and DP locations are not specified in planning documents.

\begin{tabular}{lccc}
\hline & Number of APs & Number of MPs & Number of DPs \\
\hline EU Z2-03 & 14 & 14 & 9 \\
\hline $\mathrm{AP}=$ assessment point & $\mathrm{EU}=$ exposure unit & \\
$\mathrm{DP}=$ discretionary point & $\mathrm{MP}=$ mid-point &
\end{tabular}

\section{\begin{tabular}{|l|l} 
2.1.3.1 & ClaSS 3 AND ClASS 4 SU RADIOLOGICAL SURVEY SUMMARY
\end{tabular}}

Screening level (SL): $3254 \mathrm{cpm}$

SL exceedances: No AP, MP, or DP measurements exceeded the SL in EU Z2-03.

\section{\begin{tabular}{l|l} 
2.1.3.2 & CLASS 3 AND ClASS 4 SU ANTHROPOGENIC FEATURES \\
\hline
\end{tabular}}

Number of identified anthropogenic features: 9

EU Z2-03 is located in a highly industrialized portion of the East Tennessee Technology Park (ETTP). As such, there are numerous anthropogenic features that consist of facilities and associated constructed features such as roads, sidewalks, and paved areas. Plant facilities and their associated constructed features are assessed as part of the Class 3 and Class 4 SU walkover assessment protocol (Sect. 2.1.3.3).

Nine additional anthropogenic features were recognized during the Class 3 SU walkover assessment. One of these features, the K-762 transformer vault, is representative of approximately 20 transformer vaults in the EU, which includes the following:

1) Ditch/culvert between road and railroad tracks,

2) Concrete-lined ditch west of road,

3) Concrete stops for vehicle parking,

4) Culvert downgradient of K-1066-K Cylinder Yard,

5) Culvert/ditch south end of parking lot,

6) Transformer vault located in center of K-762 Switchyard, 
7) Valve vault at north end of K-762 Switchyard,

8) Concrete pits adjacent to railroad tracks (west side), and

9) Storm water catch basin.

Each of the nine anthropogenic features was surveyed for radiation and inspected for visual evidence of chemical contamination. Four locations that showed visual evidence for potential sources of chemical contamination and were selected for biased sampling include the culvert downgradient of the K1066-K Cylinder Yard, concrete pits adjacent to the railroad tracks, and two of the K762 transformer vaults as representatives of approximately 20 transformer vaults in the EU.

\section{\begin{tabular}{|l|l} 
2.1.3.3 & CLASS 3 SU FACILITIES ASSESSMENTS \\
\hline
\end{tabular}}

Twelve facilities are listed in the DQO scoping package as being located in EU Z2-03 (Table B.1). Seven facilities, including the K-897-L and K-897-M Oil Containment Structure FFA sites and the K-762 Valve Vaults 1 and 2 FFA site (Sect. 2.2.6), were assessed during the Class $3 \mathrm{SU}$ walkover assessment. An accounting of facilities in the EU is presented in Table B.1. The facility assessments are reported in the Zone 2 EU Summary Report. In summary, no facilities were identified for biased sampling based on visual observation that the facilities were potential sources of chemical contamination or on radiation screening. The K-897-L and K-897-M Oil Containment Structures are Zone 2 ROD Appendix A FFA sites, and biased sampling locations were designated at these sites during DQO scoping. The valve vaults in the K-762 Valve Vaults 1 and 2 FFA site were inspected with the intent of collecting accumulated sediment for analysis. However, insufficient sediment existed in the valve vaults for sampling.

\section{\begin{tabular}{|l|l} 
2.1.3.4 & CLASS 3 AND CLASS 4 SU BIASED SAMPLING
\end{tabular}}

There are eight DVS biased sample locations in the EU Z2-03 Class 3 SU.

Based on visual observation during the Class 3 SU walkover assessment, four locations were selected for biased sampling at anthropogenic features:

- One location at the concrete pits adjacent to the railroad tracks,

- Two locations at transformer vaults, and

- One location at the culvert leading downgradient of the K-1066-K Cylinder Yard.

Two locations were selected during DQO scoping at the following Zone 2 ROD Appendix A FFA sites:

- K-897-L Oil Containment Structure and

- $\quad$ K-897-M Oil Containment Structure.

Two PCB immunoassay test kit confirmation sample locations (Sect. 2.1.4) were selected in the Class 3 SU portion of the K-762 Switchyard Soils FFA site.

\section{\begin{tabular}{|l|l} 
2.1.4 & UNCLASSIFIED ACREAGE \\
\hline
\end{tabular}}

The footprint of the K-762 Switchyard is coincident with the boundaries of the K-762 Switchyard Soils FFA site that was not classified into SUs for DQO scoping. The rationale was that PCBs are the most likely contaminants in the switchyard, but very little PCB data are available. To properly classify the switchyard acreage into SUs, 22 systematic grid locations were identified during DQO scoping for surface soil PCB testing with PCB immunoassay test kits. The following decision rules were specified during DQO scoping:

- Areas of the K-762 Switchyard will be classified as Class 2 SUs if PCB test kits indicate PCB concentrations $=10,000 \mathrm{ug} / \mathrm{kg}$. Samples $>10,000 \mathrm{ug} / \mathrm{kg}$ will be sent for laboratory analysis.

- Class 2 SUs will be sampled according to the Class 2 SU sampling requirements specified in the DQOs, including $20 \%$ of the samples will receive full suite analysis and sampling plans will require RA Core Team concurrence.

- Areas of the K-762 Switchyard will be classified as Class 3 SUs and will require NFA if the PCB test kits indicate that PCB concentrations are $<10,000 \mathrm{ug} / \mathrm{kg}$.

- Class 1 SUs will not be defined based on PCB test kit results. 
In addition to reclassification and concomitant sampling, the plan required a confirmatory sample be collected from every location where the PCB immunoassay test kit results exceeded 10,000 ug/kg PCBs. One immunoassay test kit result exceeded 10,000 ug/kg PCBs. Based on these results, three confirmatory samples were collected (two were collected even though the test kit results were less than 10,000 ug/kg), one Class 2 SU was defined (see Sect. 2.1.2), and a sampling plan was developed (summarized in Sect. 2.1.2.3). The RA Core Team concurred on the SU classifications and sampling plan on December 12, 2005.

\section{\begin{tabular}{l|l}
\hline 2.2 & DVS AND HISTORICAL SAMPLE RESULTS
\end{tabular}}

Sample data for EU Z2-03 are presented in the data summary table (Table B.3). The following presentation of sample results summarizes subsets of Table B.3 data by presenting pertinent results for focused characterization within the EU. A compact disc containing electronic files for the historical and DVS analytical data used to generate the data tables is provided with this Phased Construction Completion Report (PCCR).

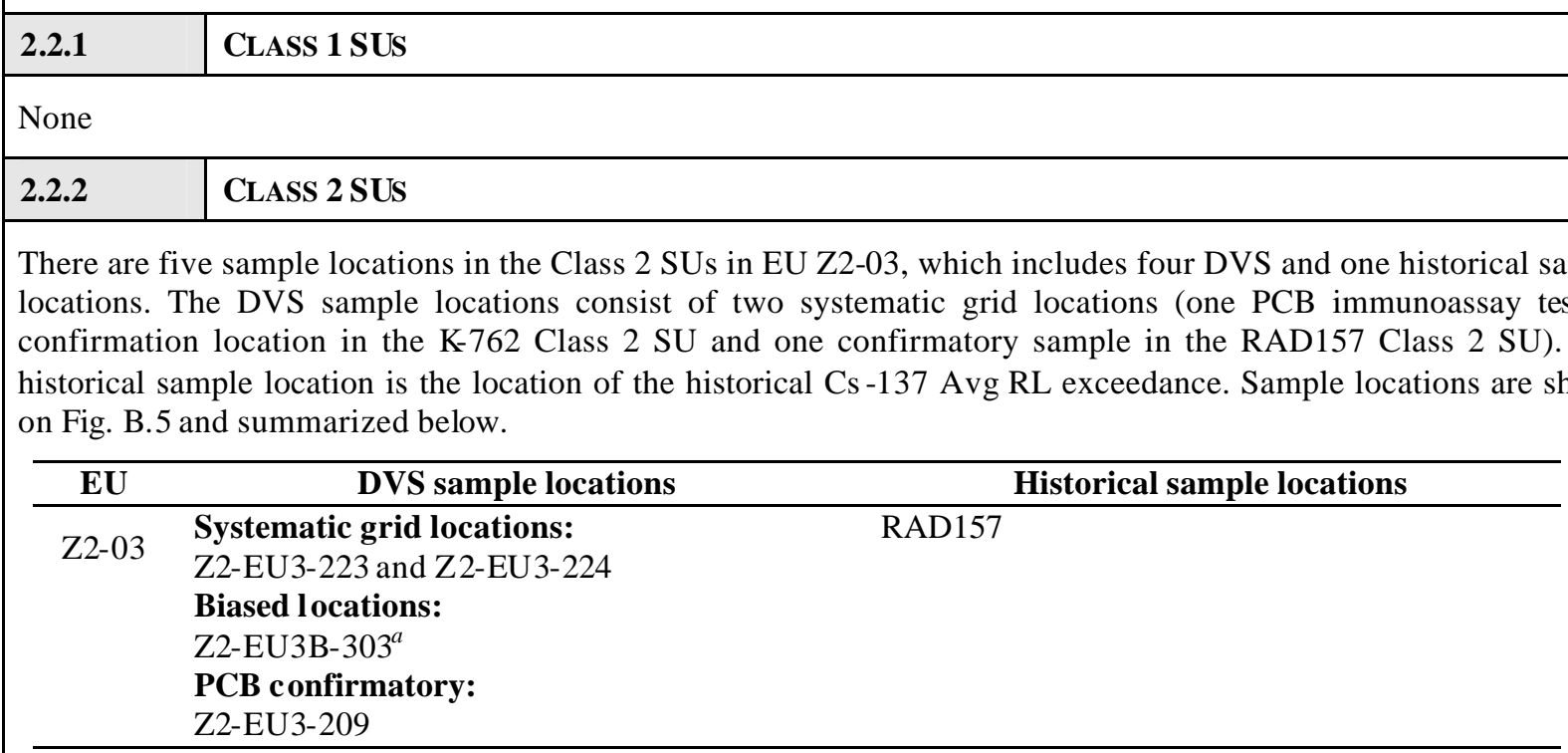

${ }^{a}$ The biased location has a Class 3 SU numeric designation but was collected in the RAD157 Class 2 SU.

DVS $=$ Dynamic Verification Strategy

$\mathrm{EU}=$ exposure unit

$\mathrm{PCB}=$ polychlorinated biphenyl

The number of samples collected and sampling intervals varied at each location as did the chemicals and radionuclides analyzed (Table B.2). The data are summarized as parts of the EU data summary in Table B.3, and data are evaluated by are of interest and EU in Sect. 2.2.4 and by FFA site in Sect. 2.2.5. The number of analyses conducted in the Class $2 \mathrm{SU}$ is presented below by analyte group.

\begin{tabular}{|c|c|c|c|c|}
\hline Metals & PCBs & Radionuclides & SVOCs & VOCs \\
\hline 2 & 3 & 3 & 3 & 2 \\
\hline
\end{tabular}

\section{\begin{tabular}{|l|l|}
\hline 2.2.3 & CLASS 3 AND CLASS 4 SUS \\
\hline
\end{tabular}}

There are 22 sample locations in the EU Z2-03 Class 3 SU-eight DVS sample locations and 14 historical sample locations. Six of the DVS locations are biased locations described in Sect. 2.1.3.4. The remaining two DVS Class 3 SU sample locations are for PCB immunoassay test kit result confirmatory sampling. Historical sample locations are from the 1994 and 1995 radiological walkover surveys, the $1999 \mathrm{draft}$ Sitewide RI, and the 2000 railroad right-of-way investigation. 


\begin{tabular}{|c|c|c|}
\hline $\mathbf{E U}$ & DVS sample locations & Historical sample locations \\
\hline Z2-03 & $\begin{array}{l}\text { Biased locations: } \\
\text { Z2-EU3B-301, Z2-EU3B-302, Z2-EU3B-304, } \\
\text { Z2-EU3B-305, Z2-EU3B-306, Z2-EU3B-307 } \\
\text { PCB confirmatory locations: } \\
\text { Z2-EU3-206, Z2-EU3-219 }\end{array}$ & $\begin{array}{l}\text { 144, 145, 236, 236, KA36155001-21, } \\
\text { KA36155001-22, KAA-SS-S11, RAD138, } \\
\text { RAD141, RAD154, RAD156, RAD167, } \\
\text { RR-S13, RR-S14 }, \text { RR-SS14 }\end{array}$ \\
\hline
\end{tabular}

${ }^{a} \mathrm{PCB}$ confirmatory locations have Class $2 \mathrm{SU}$ numeric designations but were collected in the Class $3 \mathrm{SU}$. Soil unit boundaries were defined based on results of the PCB field screening activities. The field screening location carried a Class 2 SU location ID, but many of these locations subsequently were in the Class $3 \mathrm{SU}$ because no indication of contamination was reported in the field screening test kits.

${ }^{b}$ RR-S14 and RR-SS14 are discrete depth samples collected at the same location.

DVS $=$ Dynamic Verification Strategy

$\mathrm{EU}=$ exposure unit

$\mathrm{PCB}=$ polychlorinated biphenyl

The number of samples collected at each location and sampling intervals varied at each location as did the chemicals and radionuclides analyzed (Table B.2). The data are summarized as parts of the EU data summary in Table B.3, and data are evaluated by area of interest and EU in Sect. 2.2.4 and by FFA site in Sect. 2.2.5. The number of analyses conducted in the Class $3 \mathrm{SU}$ is presented below by analyte group.

\begin{tabular}{ccccc}
\hline Metals & PCBs & Radionuclides & SVOCs & VOCs \\
\hline 6 & 14 & 12 & 7 & 4 \\
\hline PCB = polychlorinated biphenyl & & & \\
SVOC = semivolatile organic compound \\
VOC = volatile organic compound
\end{tabular}

\section{\begin{tabular}{|l|l|} 
2.2.4 & INFRASTRUCTURE \\
\hline
\end{tabular}}

A sample of accumulated sediment was collected from the K-897-L Oil Containment Structure and K-897-M Oil Containment Structure (Sect. 2.1.3.4). The analytical results for these structures, Zone 2 ROD Appendix A FFA sites, are presented in Sect. 2.2.6. Sediment samples from two K-762 transformer vaults were collected as part of the Class 3 SU walkover assessment (Sect. 2.1.3.4). The two transformer vaults were selected as representative of the 20 transformer vaults in EU Z2-03. These vaults were accessible and had accumulated sediment for sampling. The remaining vaults either had no sediment or were inaccessible or both. Analytical data are presented in Sect. 2.2.5.

\section{\begin{tabular}{|l|l|}
\hline 2.2.5 & EU EVALUATION \\
\hline
\end{tabular}}

Characterization data and other information are evaluated for EU Z2-03 in this section. The analytical data in the following summaries are presented by analyte group. Results for a particular analyte group are summarized only if that group was analyzed in samples from the unit being summarized. Within each summary, the data are evaluated by comparing to certain criteria, which include the Zone 2 soils maximum remediation level (Max RL), Zone 2 soils Avg RL, $1 \times 10^{-5}$ industrial preliminary remediation goal (Ind PRG), ETTP soils background composition (Bkg), Zone 2 groundwater screening levels (GW SL), and $1 \times 10^{-6}$ residential preliminary remediation goal (Res PRG). If a particular criterion does not apply to any member of an analyte group, it is not tabulated for that analyte group; if a particular criterion does not apply to all analytes within an analyte group, those analytes to which it does not apply are notated with not applicable (NA). Individual netals and radionuclides, which are naturally occurring, are reported in the summaries only if one or more criterion is exceeded. Organic chemicals, which are not naturally occurring, are reported if detected, even if no criteria are exceeded. The Max RL, Avg RL, Ind PRG, Bkg, GW SL, and Res PRG criteria values, as they pertain to the analytes listed in Appendix A of the RDR/RAWP (i.e., Quality Assurance Project Plan), are presented in Table 5 of this PCCR.

Because the carcinogenic risk associated with the concentrations of radium and thorium isotopes in the natural background at ETTP exceeds the cumulative risk goal of $1 \times 10^{-4}$, RL values for these radionuclides are based on alternative concentration levels rather than risk. The alternative concentration levels of $5 \mathrm{pCi} / \mathrm{g}$ above background (Avg RL) and $15 \mathrm{pCi} / \mathrm{g}$ above background (Max RL) were set as low a reasonably achievable under the site-specific conditions. Because site-specific background concentrations of these radionuclides exceed the target risk range, residual concentrations of these radionuclides and their decay series are not considered in estimates of residual risk following any remedial actions. 
The Zone 2 ROD states that Avg and Max RL exceedances by Ra-226, Th-230, and Th-232 will be evaluated by summing above-background concentrations of the greater of Ra-226 or Th-230 with the above-background concentrations of Th-232, and comparing the results to $5 \mathrm{pCi} / \mathrm{g}$ (Avg RL) and $15 \mathrm{pCi} / \mathrm{g}$ (Max RL). The required calculations have been performed. Avg and Max RL exceedances for these radionuclides, if any, are reported in the TM data summaries below and in Table B.3 as "Ra/Th decay series", and individual RL exceedances by Ra-226, Th-230, and Th-232 are reported as NA. The Ra/Th decay series data are summarized in the following sections only if an Avg or Max RL has been exceeded, consistent with the description in the preceding paragraph for reporting radionuclides. Discussion of the $\mathrm{Ra} / \mathrm{Th}$ decay series calculation, including the manner in which the calculation is performed, is presented in Sect. 3.3 of this PCCR.

\section{Conceptual Site Model (CSM)}

There are two conceptual site models pertinent to the potential release of contamination for EU Z2-03, a surface release model and a shallow-point source release model. The surface release model is representative of releases and spills of oils from transformers in the switchyard and deposition of lead-based paints from facilities and structures in the area. The shallow-point source release model is appropriate for releases of PCB oils in oil skimmers, transformer vaults, and French drain systems within and in proximity to the K-762 switchyard.

Surface release model intermedia transfer potential

Surface releases of PCB oils have a low probability of being transported by air because the oils tend to seep into the ground surface and adhere to soils. PCB and other waste oils were commonly used for dust suppression.

There is a low to moderate probability for redistribution of surface release PCB oils by surface water transport due to the tendency of the oils to adhere to soil and immobilize the fine soil fraction.

Redistribution of PCB to groundwater has a low probability of transport because PCB oils adhere to soil particles and are generally immobile in the subsurface environment.

$\underline{\text { Shallow subsurface release model intermedia transfer potential }}$

There is a very low potential for redistribution of subsurface contaminants by airborne transport.

The potential for redistribution of subsurface contaminants by surface water is low.

Redistribution of subsurface releases of contamination by groundwater has moderate potential. Contaminants in EU Z2-03 are predominantly PCB oils, which tend to remain at or very near the release point or accumulate in oil skimmers and containment structures.

\section{Groundwater Evaluation}

No groundwater monitoring wells exist in EU Z2-03. There are three wells to the north in EU Z2-02 where surface conditions and usage of the acreage are very similar to EU Z2-03.

All three wells in EU Z2-02 are located east of the switchyard along the road west of the K-31 building. These wells are in proximity to the transformer vaults and collection sumps from the K-792 switchyard. Depth to groundwater in the unconsolidated zone is $8-13 \mathrm{ft}$ bgs, and in the bedrock formations is 15-22 $\mathrm{ft}$ bgs. Vertical gradients are consistently downward toward the bedrock section. All of the wells were installed in 1989 and were regularly monitored from 1989-1995. Monitoring of the unconsolidated zone well ceased after 1995 but continued in both bedrock wells through 1998. Lead was detected in the unconsolidated zone well at a concentration of $130 \mathrm{ug} / \mathrm{lin}$ 1989. Lead has not been detected above MCLs in any well since this one occasion. Bedrock well BRW -027 had ${ }^{99}$ Tc detected on one occasion in 1992 at a concentration of 947 pCi/L. Since this one detection, ${ }^{99} \mathrm{Tc}$ has not been detected in any other well above MCLs. Because soil and potential contaminant release conditions in EU Z2-03 are very similar to those in EU Z2-02, it is concluded that impacts to surface soils and local groundwater would also be comparable.

Potential sources may have been from oil skimmers and oil containment structures. However, recent samples from these structures have not reported detections of volatile organic compounds (VOCs) or semivolatile organic compounds (SVOCs) above groundwater protection screening criteria in containment structure sediments or soil samples within the EU. There is no identified contaminant mass in EU Z2-03 that would pose a threat to local groundwater. 


\section{EU Z2-03 Sampling Results}

The 15 acres of EU Z2-03 have been classified into 0.3 acres of Class 2 SU and 14.63 acres of Class 3 SU. Currently, the bulk of the EU is covered by buildings and paved areas such as sidewalks, roads, and parking lots. The K-762 Switchyard area is gravel covered.

A Class 3 SU walkover assessment was conducted over the Class 3 SU. Because EU Z2-03 is located in a highly industrialized portion of ETTP, anthropogenic features are common. However, most of the anthropogenic features are facilities, and seven facilities were evaluated as part of the Class $3 \mathrm{SU}$ walkover assessment; no facilities were selected for biased sampling. Ten additional anthropogenic features were identified in the EU. Four of these features were selected for biased sampling based on visual evaluations that indicated the potential for chemical contamination (Sect. 2.1.3.4). No locations in the Class 3 SU exceeded the radiological screening level (SL), and no biased sampling was conducted. Also, there are two PCB confirmatory sample locations (Sect. 2.1.4) and eight historical sample locations in the Class 3 SU of EU Z2-03. Four of the historical sample locations were storm drain sediment locations. Two of the historical sample locations were from French drain locations and two were from test pit sediment locations.

In addition to the Class 3 SU biased sampling based on the Class 3 SU walkover assessment results and PCB field analytical results, two DVS Class $3 \mathrm{SU}$ biased samples locations were identified during DQO scoping-one location at each of the K-897-L and K-897-M Oil Containment Structures (FFA sites).

There are two Class 2 SUs in EU Z2-03. As described in Sects. 2.1.2 and 2.1.4, one Class 2 SU was defined during classification of unclassified acreage based on PCB immunoassay test kit results, while the other was defined during DQO scoping to evaluate the extent of Avg RL exceedances at historical sample location RAD157.

Following is a summary of the sampling results for EU Z2-03. The summary begins with a presentation of the analytical results for the focused sampling efforts and concludes with a review for the entire EU. This EU summary includes both data tables and a written description of the nature and extent of chemicals and radionuclides observed in the EU. Sample summaries for the Zone 2 ROD FFA sites in EU Z2-03 are presented in Sect. 2.2.6, and the data from those sites are included in the summary at the end of this section. EU-wide data are evaluated against the Zone 2 ROD RAO in Sect. 3.3. Details of the sampling conducted in EU Z2-03 are presented in Table B.2, data for the entire EU are summarized in Table B.3, and sample locations are shown on Fig. B.5.

Sampling at the RAD157 Class 2 SU: The RAD157 Class 2 SU encompasses historical sampling location RAD157, which had a Cs-137 average RL exceedance (Sect. 2.1.2). A BAR survey was conducted but failed to detect radiation in excess of two times the background value (Sect. 2.1.2.1). Confirmation sample location Z2-EU3B-303 was identified at the coordinates of RAD157 and a surface soil sample was collected (Sect. 2.1.2.3) and analyzed for radionuclides. Analytical data for the RAD157 and Z2-EU3B-303 samples are summarized below. Analytical results summarized below show the original Cs-137 Avg RL exceedance in the historical sample from RAD157 but demonstrate that the sample from Z2-EU3B-303 failed to confirm the exceedance. The summary below also shows radionuclide Ind PRG exceedances in the RAD157 Class 2 SU. The Cs -137 Ind PRG exceedance noted below also occurs in the historical sample from the RAD157 location but the exceedance was not duplicated in the confirmation sample.

EU Z2-03 RAD157 CLASS 2 SU RADIONUCLIDES WITH BACKGROUND, PRG, AND/OR RL EXCEEDANCES (pCi/g)

\begin{tabular}{|c|c|c|c|c|c|c|c|c|c|c|c|}
\hline \multirow[b]{2}{*}{ Analyte } & \multirow[b]{2}{*}{$\begin{array}{c}\text { Detect } \\
\text { frequency }\end{array}$} & \multirow[b]{2}{*}{$\begin{array}{c}\text { Minimum } \\
\text { detect }\end{array}$} & \multirow[b]{2}{*}{$\begin{array}{c}\text { Maximum } \\
\text { detect }\end{array}$} & \multirow[b]{2}{*}{$\begin{array}{l}\text { Location(s) of } \\
\text { maximum detect }\end{array}$} & \multirow{2}{*}{$\begin{array}{c}\text { Average } \\
\text { detected } \\
\text { result }\end{array}$} & \multicolumn{6}{|c|}{ Number of analyses exceeding criteria } \\
\hline & & & & & & $\begin{array}{c}\text { Max } \\
\text { RL }\end{array}$ & $\begin{array}{l}\text { Avg } \\
\text { RL }\end{array}$ & $\begin{array}{l}\text { Ind } \\
\text { PRG }\end{array}$ & Bkg & $\begin{array}{l}\text { GW } \\
\text { SL }\end{array}$ & $\begin{array}{c}\text { Res } \\
\text { PRG }\end{array}$ \\
\hline Cesium-137 & $2 / 2$ & 0.65 & 4.06 & RAD157 & 2.36 & 0 & 1 & 1 & NA & NA & 2 \\
\hline Potassium-40 & $2 / 2$ & 10.9 & 13.9 & Z2-EU3B-303 & 12.4 & NA & NA & 2 & 0 & NA & 2 \\
\hline Radium-226 & $2 / 2$ & 0.75 & 1.1 & RAD157 & 0.925 & NA & NA & 2 & 0 & NA & 2 \\
\hline Technetium-99 & $2 / 2$ & 0.12 & 0.38 & Z2-EU3B-303 & 0.25 & NA & NA & 0 & NA & NA & 1 \\
\hline Thorium -228 & $2 / 2$ & 0.78 & 0.95 & Z2-EU3B-303 & 0.865 & NA & NA & 2 & 0 & NA & 2 \\
\hline Thorium -232 & $2 / 2$ & $0.62 \mathrm{~J}$ & 0.98 & Z2-EU3B-303 & 0.8 & NA & NA & 2 & 0 & NA & 2 \\
\hline Uranium-238 & $2 / 2$ & 0.85 & 0.92 & Z2-EU3B-303 & 0.885 & 0 & 0 & 0 & 0 & 0 & 2 \\
\hline$\overline{\mathrm{Avg}}=$ average & & $\mathrm{NA}=$ not ap & $\overline{\text { pplicable }}$ & & & & & & & & \\
\hline $\mathrm{Bkg}=$ background & & & iminary res & ediation goal & & & & & & & \\
\hline $\mathrm{EU}=$ exposure unit & & Res $=$ resid & lential & & & & & & & & \\
\hline $\mathrm{GW}=$ groundwater & & $\mathrm{RL}=$ remed & diation level & & & & & & & & \\
\hline Ind $=$ industrial & & $\mathrm{SL}=$ screen & ning level & & & & & & & & \\
\hline Max $=$ maximum & & $\mathrm{SU}=$ soil ur & & & & & & & & & \\
\hline
\end{tabular}


DVS Sampling at the K-762 Class 2 SU: The K-762 Class 2 SU was defined post-DQO scoping based on results from PCB immunoassay test kits (Sects. 2.1.2 and 2.1.4). The Class 2 SU has three DVS sample locations that consist of one PCB confirmation sample (Z2-EU3-209) and two systematic grid locations (Z2-EU3-223 and Z2-EU3-224). Samples collected from Z2-EU3-223 were analyzed for metals, PCBs, and SVOCs, and samples collected from Z2-EU3B-224 were analyzed for metals, PCBs, SVOCs, VOCs, and radionuclides. Both locations were field screened for radionuclides and VOCs (Table B.2). Analytical results summarized below show radionuclide industrial PRG exceedances, metal background exceedances, and SVOC detections.

EU Z2-03 K-762 CLASS 2 SU METALS WITH BACKGROUND,

PRG, GW SL, AND/OR RL EXCEEDANCES (mg/kg)

\begin{tabular}{|c|c|c|c|c|c|c|c|c|c|c|c|}
\hline \multirow[b]{2}{*}{ Analyte } & \multirow[b]{2}{*}{$\begin{array}{c}\text { Detect } \\
\text { frequency }\end{array}$} & \multirow[b]{2}{*}{$\begin{array}{c}\text { Minimum } \\
\text { detect }\end{array}$} & \multirow[b]{2}{*}{$\begin{array}{c}\text { Maximum } \\
\text { detect }\end{array}$} & \multirow{2}{*}{$\begin{array}{c}\text { Location(s) of } \\
\text { maximum } \\
\text { detect }\end{array}$} & \multirow{2}{*}{$\begin{array}{c}\text { Average } \\
\text { detected } \\
\text { result }\end{array}$} & \multicolumn{6}{|c|}{ Number of analyses exceeding criteria } \\
\hline & & & & & & $\begin{array}{c}\text { Max } \\
\text { RL }\end{array}$ & $\begin{array}{l}\text { Avg } \\
\text { RL }\end{array}$ & $\begin{array}{c}\text { Ind } \\
\text { PRG }\end{array}$ & Bkg & $\begin{array}{l}\text { GW } \\
\text { SL }\end{array}$ & $\begin{array}{r}\text { Res } \\
\text { PRG }\end{array}$ \\
\hline Arsenic & $1 / 2$ & $0.61 \mathrm{~J}$ & $0.61 \mathrm{~J}$ & Z2-EU3-223 & 0.61 & 0 & 0 & 0 & 0 & 0 & 1 \\
\hline Calcium & $2 / 2$ & $298,000 \mathrm{~J}$ & $301,000 \mathrm{~J}$ & Z2-EU3-223 & 299,500 & NA & NA & NA & 2 & NA & NA \\
\hline Magnesium & $2 / 2$ & $28,900 \mathrm{~J}$ & $53,800 \mathrm{~J}$ & Z2-EU3-224 & 41,350 & NA & NA & NA & 2 & NA & NA \\
\hline Manganese & $2 / 2$ & 202 & 746 & Z2-EU3-223 & 474 & NA & NA & 0 & 0 & NA & 2 \\
\hline Vanadium & $2 / 2$ & 5.7 & 12.4 & Z2-EU3-223 & 9.05 & NA & NA & 0 & 0 & NA & 1 \\
\hline
\end{tabular}

$\mathrm{Bkg}=$ background $\quad \mathrm{PRG}=$ preliminary remediation goal

$\mathrm{EU}=$ exposure unit $\quad$ Res $=$ residential

$\mathrm{GW}=$ groundwater $\quad \mathrm{RL}=$ remediation level

Ind $=$ industrial $\quad \mathrm{SL}=$ screening level

Max = maximum $\quad \mathrm{SU}=$ soil unit

PCBs were analyzed for in all three samples but were not detected.

EU Z2-03 K-762 CLASS 2 SU RADIONUCLIDES WITH BACKGROUND, PRG, AND/OR RL EXCEEDANCES (pCi/g)

\begin{tabular}{|c|c|c|c|c|c|c|c|c|c|c|c|}
\hline \multirow[b]{2}{*}{ Analyte } & \multirow[b]{2}{*}{$\begin{array}{c}\text { Detect } \\
\text { frequency }\end{array}$} & \multirow[b]{2}{*}{$\begin{array}{c}\text { Minimum } \\
\text { detect }\end{array}$} & \multirow[b]{2}{*}{$\begin{array}{l}\text { Maximum } \\
\text { detect }\end{array}$} & \multirow[b]{2}{*}{$\begin{array}{l}\text { Location(s) of } \\
\text { maximum detect }\end{array}$} & \multirow{2}{*}{$\begin{array}{c}\text { Average } \\
\text { detected } \\
\text { result }\end{array}$} & \multicolumn{6}{|c|}{ Number of analyses exceeding criteria } \\
\hline & & & & & & $\begin{array}{c}\text { Max } \\
\text { RL }\end{array}$ & $\begin{array}{l}\text { Avg } \\
\text { RL } \\
\end{array}$ & $\begin{array}{c}\text { Ind } \\
\text { PRG } \\
\end{array}$ & Bkg & $\begin{array}{c}\text { GW } \\
\text { SL } \\
\end{array}$ & $\begin{array}{r}\text { Res } \\
\text { PRG }\end{array}$ \\
\hline Potassium-40 & $1 / 1$ & 11.8 & 11.8 & Z2-EU3-224 & 11.8 & NA & NA & 1 & 0 & NA & 1 \\
\hline Radium-226 & $1 / 1$ & 0.78 & 0.78 & Z2-EU3-224 & 0.78 & NA & NA & 1 & 0 & NA & 1 \\
\hline Thorium -228 & $1 / 1$ & 0.75 & 0.75 & Z2-EU3-224 & 0.75 & NA & NA & 1 & 0 & NA & 1 \\
\hline Thorium -232 & $1 / 1$ & 0.87 & 0.87 & Z2-EU3-224 & 0.87 & NA & NA & 1 & 0 & NA & 1 \\
\hline
\end{tabular}

Avg = average

NA $=$ not applicable

$\mathrm{Bkg}=$ background $\quad \mathrm{PRG}=$ preliminary remediation goal

$\mathrm{EU}=$ exposure unit $\quad$ Res $=$ residential

$\mathrm{GW}=$ groundwater $\quad \mathrm{RL}=$ remediation level

Ind $=$ industrial $\quad \mathrm{SL}=$ screening level

Max $=$ maximum $\quad \mathrm{SU}=$ soil unit

EU Z2-03 K-762 CLASS 2 SUSVOC DETECTS (ug/kg)

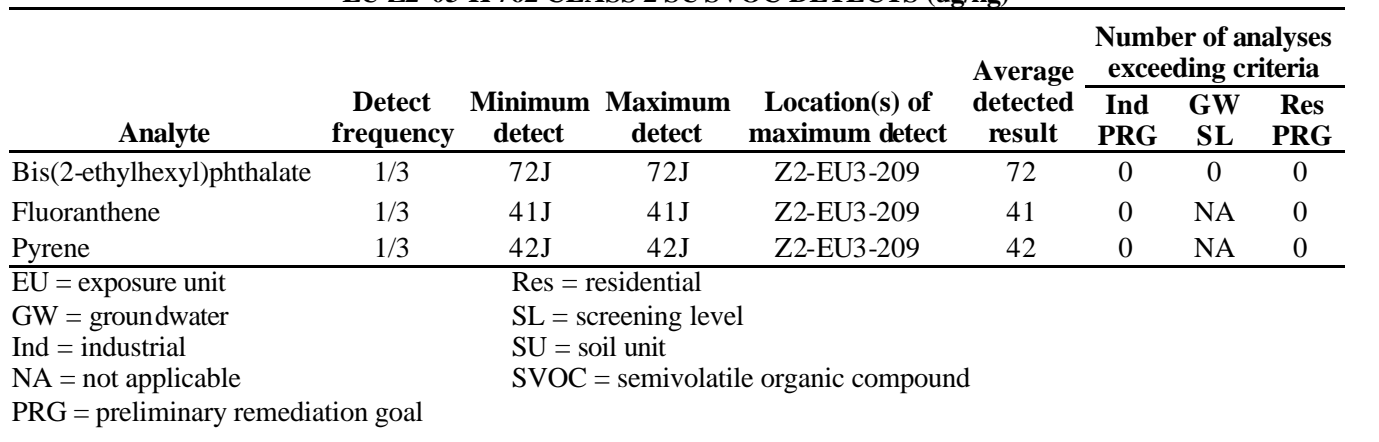

VOCs were analyzed for in the samples from Z2-EU3-209 and Z2-EU3-224 but were not detected.

DVS Biased Sampling at the Class 3 SU Concrete Pit: A concrete pit adjacent to the railroad tracks in the Class 3 SU was selected for biased sampling based on visual observations made during the Class $3 \mathrm{SU}$ walkover assessment. 
Sample location Z2-EU3B-304 was identified inside the concrete pit, and a sample of sediment was collected from the pit and field screened for VOCs and analyzed for metals, PCBs, and SVOCs. The volume of sediment in the pits was minimal and contained within the concrete structure. Analytical results summarized below show arsenic, iron, and lead Ind PRG exceedances; antimony, chromium, and lead GW SL exceedances; several metal background exceedances; and PCB and SVOC detections.

EU Z2-03 CLASS 3 SU CONCRETE PIT METALS WITH BACKGROUND, PRG, GW SL, AND/OR RL EXCEEDANCES (mg/kg)

\begin{tabular}{|c|c|c|c|c|c|c|c|c|c|c|c|}
\hline \multirow[b]{2}{*}{ Analyte } & \multirow[b]{2}{*}{$\begin{array}{c}\text { Detect } \\
\text { frequency }\end{array}$} & \multirow[b]{2}{*}{$\begin{array}{c}\text { Minimum } \\
\text { detect }\end{array}$} & \multirow[b]{2}{*}{$\begin{array}{c}\text { Maximum } \\
\text { detect }\end{array}$} & \multirow{2}{*}{$\begin{array}{c}\text { Location(s) of } \\
\text { maximum } \\
\text { detect }\end{array}$} & \multirow{2}{*}{$\begin{array}{c}\begin{array}{c}\text { Average } \\
\text { detected } \\
\text { result }\end{array} \\
\end{array}$} & \multicolumn{6}{|c|}{ Number of analyses exceeding criteria } \\
\hline & & & & & & $\begin{array}{c}\text { Max } \\
\text { RL }\end{array}$ & $\begin{array}{c}\text { Avg } \\
\text { RL }\end{array}$ & $\begin{array}{l}\text { Ind } \\
\text { PRG }\end{array}$ & Bkg & $\begin{array}{c}\text { GW } \\
\text { SL }\end{array}$ & $\begin{array}{c}\text { Res } \\
\text { PRG }\end{array}$ \\
\hline Aluminum & $1 / 1$ & $12,900 \mathrm{~J}$ & $12,900 \mathrm{~J}$ & Z2-EU3B-304 & 12,900 & NA & NA & 0 & 0 & NA & 1 \\
\hline Antimony & $1 / 1$ & $260 \mathrm{~J}$ & $260 \mathrm{~J}$ & Z2-EU3B-304 & 260 & NA & NA & 0 & 1 & 1 & 1 \\
\hline Arsenic & $1 / 1$ & 24.9 & 24.9 & Z2-EU3B-304 & 24.9 & 0 & 0 & 1 & 1 & 0 & 1 \\
\hline Barium & $1 / 1$ & 169 & 169 & Z2-EU3B-304 & 169 & NA & NA & 0 & 1 & 0 & 0 \\
\hline Cadmium & $1 / 1$ & $76.4 \mathrm{~J}$ & $76.4 \mathrm{~J}$ & Z2-EU3B-304 & 76.4 & NA & NA & 0 & 1 & NA & 1 \\
\hline Calcium & $1 / 1$ & $43,300 \mathrm{~J}$ & $43,300 \mathrm{~J}$ & Z2-EU3B-304 & 43,300 & NA & NA & NA & 1 & NA & NA \\
\hline Chromium & $1 / 1$ & 227J & $227 \mathrm{~J}$ & Z2-EU3B-304 & 227 & NA & NA & 0 & 1 & 1 & 1 \\
\hline Copper & $1 / 1$ & 11,900 & 11,900 & Z2-EU3B-304 & 11,900 & NA & NA & 0 & 1 & NA & 1 \\
\hline Iron & $1 / 1$ & $109,000 \mathrm{~J}$ & $109,000 \mathrm{~J}$ & Z2-EU3B-304 & 109,000 & NA & NA & 1 & 1 & NA & 1 \\
\hline Lead & $1 / 1$ & 9,560 & 9,560 & Z2-EU3B-304 & 9,560 & NA & NA & 1 & 1 & 1 & 1 \\
\hline Magnesium & $1 / 1$ & $4,580 \mathrm{~J}$ & $4,580 \mathrm{~J}$ & Z2-EU3B-304 & 4,580 & NA & NA & NA & 1 & NA & NA \\
\hline Manganese & $1 / 1$ & $477 \mathrm{~J}$ & $477 \mathrm{~J}$ & Z2-EU3B-304 & 477 & NA & NA & 0 & 0 & NA & 1 \\
\hline Mercury & $1 / 1$ & $1.3 \mathrm{~J}$ & $1.3 \mathrm{~J}$ & Z2-EU3B-304 & 1.3 & 0 & 0 & 0 & 1 & NA & 0 \\
\hline Nickel & $1 / 1$ & $137 \mathrm{~J}$ & $137 \mathrm{~J}$ & Z2-EU3B-304 & 137 & NA & NA & 0 & 1 & NA & 0 \\
\hline Silver & $1 / 1$ & 4.1 & 4.1 & Z2-EU3B-304 & 4.1 & NA & NA & 0 & 1 & NA & 0 \\
\hline Uranium & $1 / 1$ & 5.9 & 5.9 & Z2-EU3B-304 & 5.9 & NA & NA & 0 & NA & NA & 1 \\
\hline Vanadium & $1 / 1$ & 22.4 & 22.4 & Z2-EU3B-304 & 22.4 & NA & NA & 0 & 0 & NA & 1 \\
\hline Zinc & $1 / 1$ & $3,180 \mathrm{~J}$ & $3,180 \mathrm{~J}$ & Z2-EU3B-304 & 3,180 & NA & NA & 0 & 1 & NA & 1 \\
\hline \multicolumn{2}{|c|}{$\overline{\mathrm{Avg}}=$ average } & \multicolumn{2}{|c|}{ NA $=$ not applicable } & & & & & & & & \\
\hline \multicolumn{2}{|c|}{$\mathrm{Bkg}=$ background } & \multirow{2}{*}{\multicolumn{3}{|c|}{$\mathrm{PRG}=$ preliminary remediation goal }} & & & & & & & \\
\hline \multicolumn{2}{|c|}{$\mathrm{EU}=$ exposure unit } & & & & & & & & & & \\
\hline \multicolumn{2}{|c|}{$\mathrm{GW}=$ groundwater } & \multicolumn{3}{|c|}{ Res $=$ residential } & & & & & & & \\
\hline \multicolumn{2}{|c|}{ Ind $=$ industrial } & \multirow{2}{*}{\multicolumn{3}{|c|}{$\mathrm{SL}=$ screening level }} & & & & & & & \\
\hline \multicolumn{2}{|c|}{ Max $=$ maximum } & $\mathrm{SU}=\mathrm{sC}$ & & & & & & & & & \\
\hline
\end{tabular}

EU Z2-03 CLASS 3 SU CONCRETEPIT PCB DETECTS (ug/kg)

\begin{tabular}{lccccccccc}
\hline & & & & & \multicolumn{4}{c}{$\begin{array}{c}\text { Number of analyses } \\
\text { exceeding criteria }\end{array}$} \\
\hline Analyte & $\begin{array}{c}\text { Detect } \\
\text { frequency }\end{array}$ & $\begin{array}{c}\text { Minimum } \\
\text { detect }\end{array}$ & $\begin{array}{c}\text { Maximum } \\
\text { detect }\end{array}$ & $\begin{array}{c}\text { Location(s) of } \\
\text { maximum } \\
\text { detect }\end{array}$ & $\begin{array}{c}\text { Average } \\
\text { detected } \\
\text { result }\end{array}$ & $\begin{array}{c}\text { Max } \\
\text { RL }\end{array}$ & $\begin{array}{c}\text { Avg } \\
\text { RL }\end{array}$ & $\begin{array}{c}\text { Ind } \\
\text { PRG PRG }\end{array}$ \\
\hline PCB 1254 & $1 / 1$ & $330 \mathrm{~J}$ & $330 \mathrm{~J}$ & Z2-EU3B-304 & 330 & 0 & 0 & 0 & 1 \\
PCB & $1 / 1$ & $330 \mathrm{~J}$ & 330J & Z2-EU3B-304 & 330 & 0 & 0 & 0 & 1 \\
\hline
\end{tabular}

Avg = average $\quad$ PRG $=$ preliminary remediation goal

$\mathrm{EU}=$ exposure unit $\quad$ Res $=$ residential

Ind $=$ industrial $\quad$ RL $=$ remediation level

$\mathrm{Max}=$ maximum $\quad \mathrm{SU}=$ soil unit

$\mathrm{PCB}=$ polychlorinated biphenyl

EU Z2-03 CLASS 3 SU CONCRETE PIT SVOC DETECTS (ug/kg)

\begin{tabular}{lcccccccc}
\hline & & & & & \multicolumn{4}{c}{$\begin{array}{c}\text { Number of analyses } \\
\text { exceeding criteria }\end{array}$} \\
\cline { 6 - 10 } \multicolumn{1}{c}{ Analyte } & $\begin{array}{c}\text { Detect } \\
\text { frequency }\end{array}$ & $\begin{array}{c}\text { Minimum } \\
\text { detect }\end{array}$ & $\begin{array}{c}\text { Maximum } \\
\text { detect }\end{array}$ & $\begin{array}{c}\text { Location(s) of } \\
\text { maximum detect }\end{array}$ & $\begin{array}{c}\text { Average } \\
\text { detected } \\
\text { result }\end{array}$ & $\begin{array}{c}\text { Ind } \\
\text { PRG }\end{array}$ & $\begin{array}{c}\text { GW } \\
\text { SL }\end{array}$ & $\begin{array}{c}\text { Res } \\
\text { PRG }\end{array}$ \\
\hline 2-Methylphenol & $1 / 1$ & 1,800 & 1,800 & Z2-EU3B-304 & 1,800 & 0 & NA & 0 \\
Acenaphthene & $1 / 1$ & $210 \mathrm{~J}$ & $210 \mathrm{~J}$ & Z2-EU3B-304 & 210 & 0 & NA & 0 \\
Anthracene & $1 / 1$ & $200 \mathrm{~J}$ & $200 \mathrm{~J}$ & Z2-EU3B-304 & 200 & 0 & NA & 0 \\
Benz(a)anthracene & $1 / 1$ & 1,300 & 1,300 & Z2-EU3B-304 & 1,300 & 0 & NA & 1 \\
Benzo(a)pyrene & $1 / 1$ & $1,100 \mathrm{~J}$ & $1,100 \mathrm{~J}$ & Z2-EU3B-304 & 1,100 & 0 & NA & 1 \\
Benzo(b)fluoranthene & $1 / 1$ & 1,300 & 1,300 & Z2-EU3B-304 & 1,300 & 0 & NA & 1 \\
\hline
\end{tabular}


EU Z2-03 CLASS 3 SU CONCRETE PIT SVOC DETECTS (ug/kg) (continued)

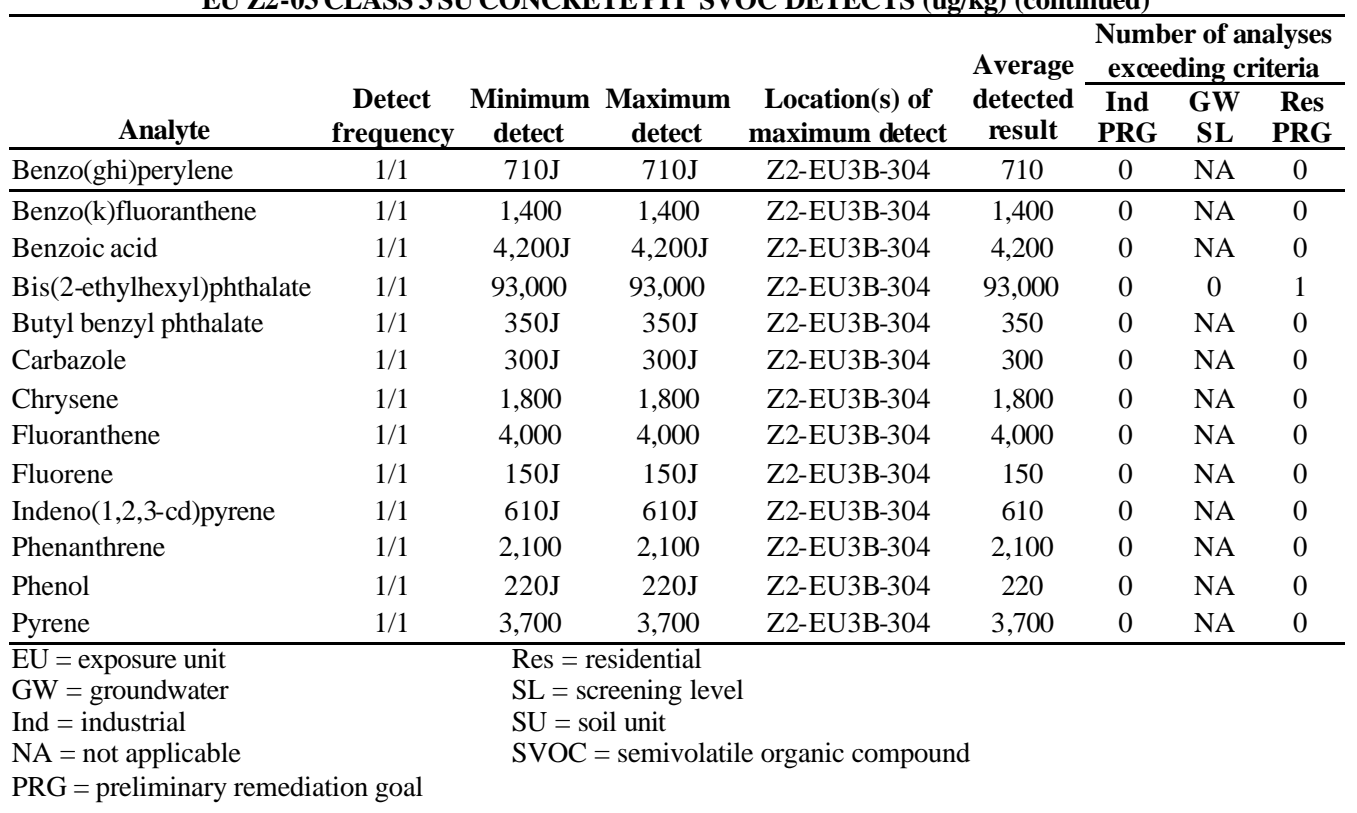

DVS Biased Sampling at the Class 3 SU Culvert: A biased sample location (Z2-EU3B-307) was selected in a culvert leading from the K-1066-K Cylinder Yard based on visual observations made during the Class 3 SU walkover assessment. A discrete surface soil sample was collected and screened for VOCs and analyzed for metals, PCBs, and radionuclides. Analytical results summarized below show radionuclide industrial PRG and background exceedances.

EU Z2-03 CLASS 3 SU CULVERT METALS WITH BACKGROUND, PRG, GW SL, AND/OR RL EXCEEDANCES (mg/kg)

\begin{tabular}{|c|c|c|c|c|c|c|c|c|c|c|c|}
\hline \multirow[b]{2}{*}{ Analyte } & \multirow[b]{2}{*}{$\begin{array}{c}\text { Detect } \\
\text { frequency }\end{array}$} & \multirow[b]{2}{*}{$\begin{array}{c}\text { Minimum } \\
\text { detect }\end{array}$} & \multirow[b]{2}{*}{$\begin{array}{c}\text { Maximum } \\
\text { detect }\end{array}$} & \multirow{2}{*}{$\begin{array}{c}\operatorname{Location}(\mathbf{s}) \text { of } \\
\text { maximum } \\
\text { detect }\end{array}$} & \multirow{2}{*}{$\begin{array}{c}\text { Average } \\
\text { detected } \\
\text { result }\end{array}$} & \multicolumn{6}{|c|}{ Number of analyses exceeding criteria } \\
\hline & & & & & & $\begin{array}{c}\text { Max } \\
\text { RL }\end{array}$ & $\begin{array}{l}\text { Avg } \\
\text { RL }\end{array}$ & $\begin{array}{l}\text { Ind } \\
\text { PRG }\end{array}$ & Bkg & $\begin{array}{c}\text { GW } \\
\text { SL }\end{array}$ & $\begin{array}{c}\text { Res } \\
\text { PRG }\end{array}$ \\
\hline Aluminum & $1 / 1$ & $8,600 \mathrm{~J}$ & $8,600 \mathrm{~J}$ & Z2-EU3B-307 & 8,600 & NA & NA & 0 & 0 & NA & 1 \\
\hline Arsenic & $1 / 1$ & 5.1 & 5.1 & Z2-EU3B-307 & 5.1 & 0 & 0 & 0 & 0 & 0 & 1 \\
\hline Iron & $1 / 1$ & $18,600 \mathrm{~J}$ & $18,600 \mathrm{~J}$ & Z2-EU3B-307 & 18,600 & NA & NA & 0 & 0 & NA & 1 \\
\hline Uranium & $1 / 1$ & 3.6 & 3.6 & Z2-EU3B-307 & 3.6 & NA & NA & 0 & NA & NA & 1 \\
\hline Vanadium & $1 / 1$ & 19.9 & 19.9 & Z2-EU3B-307 & 19.9 & NA & NA & 0 & 0 & NA & 1 \\
\hline
\end{tabular}

\begin{tabular}{ll}
\hline $\mathrm{Avg}=$ average & $\mathrm{NA}=$ not applicable \\
$\mathrm{Bkg}=$ background & $\mathrm{PRG}=$ preliminary remediation goal
\end{tabular}

$\mathrm{EU}=$ exposure unit $\quad$ Res $=$ residential

$\mathrm{GW}=$ groundwater $\quad \mathrm{RL}=$ remediation level

Ind $=$ industrial $\quad \mathrm{SL}=$ screening level

Max $=$ maximum $\quad \mathrm{SU}=$ soil unit

PCBs were analyzed for in the sample but were not detected.

EU Z2-03 CLASS 3 SU CULVERT RADIONUCLIDES WITH BACKGROUND, PRG, AND/OR RL EXCEEDANCES (pCi/g)

\begin{tabular}{|c|c|c|c|c|c|c|c|c|c|c|c|}
\hline \multirow[b]{2}{*}{ Analyte } & \multirow[b]{2}{*}{$\begin{array}{c}\text { Detect } \\
\text { frequency }\end{array}$} & \multirow[b]{2}{*}{$\begin{array}{c}\text { Minimum } \\
\text { detect }\end{array}$} & \multirow[b]{2}{*}{$\begin{array}{c}\text { Maximum } \\
\text { detect }\end{array}$} & \multirow[b]{2}{*}{$\begin{array}{c}\text { Location(s) of } \\
\text { maximum detect }\end{array}$} & \multirow{2}{*}{$\begin{array}{c}\text { Average } \\
\text { detected } \\
\text { result } \\
\end{array}$} & \multicolumn{6}{|c|}{ Number of analyses exceeding criteria } \\
\hline & & & & & & $\begin{array}{c}\text { Max } \\
\text { RL }\end{array}$ & $\begin{array}{l}\text { Avg } \\
\text { RL }\end{array}$ & $\begin{array}{l}\text { Ind } \\
\text { PRG }\end{array}$ & Bkg & $\begin{array}{l}\text { GW } \\
\text { SL }\end{array}$ & $\begin{array}{l}\text { Res } \\
\text { PRG }\end{array}$ \\
\hline Potassium-40 & $1 / 1$ & 10.5 & 10.5 & Z2-EU3B-307 & 10.5 & NA & NA & 1 & 0 & NA & 1 \\
\hline Radium-226 & $1 / 1$ & 0.94 & 0.94 & Z2-EU3B-307 & 0.94 & NA & NA & 1 & 0 & NA & 1 \\
\hline Thorium -228 & $1 / 1$ & 1.2 & 1.2 & Z2-EU3B-307 & 1.2 & NA & NA & 1 & 0 & NA & 1 \\
\hline Thorium -230 & $1 / 1$ & 1.33 & 1.33 & Z2-EU3B-307 & 1.33 & NA & NA & 0 & 1 & NA & 0 \\
\hline
\end{tabular}


EU Z2-03 CLASS 3 SU CULVERT RADIONUCLIDES WITH BACKGROUND, PRG, AND/OR RL EXCEEDANCES (pCi/g) (continued)

\begin{tabular}{|c|c|c|c|c|c|c|c|c|c|c|c|}
\hline \multirow[b]{2}{*}{ A-nalyte } & \multirow[b]{2}{*}{$\begin{array}{c}\text { Detect } \\
\text { frequency }\end{array}$} & \multirow[b]{2}{*}{$\begin{array}{c}\text { Minimum } \\
\text { detect }\end{array}$} & \multirow[b]{2}{*}{$\begin{array}{c}\text { Maximum } \\
\text { detect }\end{array}$} & \multirow[b]{2}{*}{$\begin{array}{c}\text { Location(s) of } \\
\text { maximum detect }\end{array}$} & \multirow{2}{*}{$\begin{array}{c}\text { Average } \\
\text { detected } \\
\text { result }\end{array}$} & \multicolumn{6}{|c|}{ Number of analyses exceeding criteria } \\
\hline & & & & & & $\begin{array}{c}\text { Max } \\
\text { RL }\end{array}$ & $\begin{array}{l}\text { Avg } \\
\text { RL } \\
\end{array}$ & $\begin{array}{c}\text { Ind } \\
\text { PRG } \\
\end{array}$ & Bkg & $\begin{array}{c}\text { GW } \\
\text { SL } \\
\end{array}$ & $\begin{array}{r}\text { Res } \\
\text { PRG } \\
\end{array}$ \\
\hline Thorium -232 & $1 / 1$ & 1.27 & 1.27 & Z2-EU3B-307 & 1.27 & $\mathrm{NA}$ & NA & 1 & 0 & $\mathrm{NA}$ & 1 \\
\hline Uranium-238 & $1 / 1$ & 1.24 & 1.24 & Z2-EU3B-307 & 1.24 & 0 & 0 & 0 & 0 & 0 & 1 \\
\hline Avg = average & & $\mathrm{NA}=$ not ap & pplicable & & & & & & & & \\
\hline $\mathrm{Bkg}=$ background & & $\mathrm{PRG}=$ preli & iminary reme & ediation goal & & & & & & & \\
\hline $\mathrm{EU}=$ exposure unit & & Res $=$ reside & ential & & & & & & & & \\
\hline $\mathrm{GW}=$ groundwater & & $\mathrm{RL}=$ remed & diation level & & & & & & & & \\
\hline Ind $=$ industrial & & $\mathrm{SL}=$ screen & ing level & & & & & & & & \\
\hline Max $=$ maximum & & $\mathrm{SU}=$ soil un & & & & & & & & & \\
\hline
\end{tabular}

DVS Biased Sampling at the Class 3 SU Transformer Vaults: Two K-762 transformer vaults were selected for biased sampling during the Class $3 \mathrm{SU}$ walkover assessment. The two vaults selected for sampling are representative of 20 transformer vaults in this EU. A sediment sample was collected at a transformer vault located in the central portion of the EU at location Z2-EU3B-305. Another sediment sample was collected at a transformer vault located in the southeast/central portion of the EU at location Z2-EU3B-306. Both samples were field screened for radionuclides and VOCs and analyzed for metals, PCBs, and SVOCs. Analytical results summarized below show an arsenic Ind PRG exceedance, lead Ind PRG exceedances in both samples, GW SL exceedances by antimony and lead, several metal background exceedances, and PCB and SVOC detections.

EU Z2-03 CLASS 3 SU K-897 TRANSFORMER VAULTS METALS WITH BACKGROUND, PRG, GW SL, AND/OR RL EXCEEDANCES (mg/kg)

\begin{tabular}{|c|c|c|c|c|c|c|c|c|c|c|c|}
\hline \multirow[b]{2}{*}{ Analyte } & \multirow[b]{2}{*}{$\begin{array}{c}\text { Detect } \\
\text { frequency }\end{array}$} & \multirow[b]{2}{*}{$\begin{array}{c}\text { Minimum } \\
\text { detect }\end{array}$} & \multirow[b]{2}{*}{$\begin{array}{c}\text { Maximum } \\
\text { detect }\end{array}$} & \multirow{2}{*}{$\begin{array}{c}\operatorname{Location}(\mathbf{s}) \text { of } \\
\text { maximum } \\
\text { detect }\end{array}$} & \multirow{2}{*}{$\begin{array}{c}\text { Average } \\
\text { detected } \\
\text { result }\end{array}$} & \multicolumn{6}{|c|}{ Number of analyses exceeding criteria } \\
\hline & & & & & & $\begin{array}{l}\text { Max } \\
\text { RL }\end{array}$ & $\begin{array}{l}\text { Avg } \\
\text { RL }\end{array}$ & $\begin{array}{l}\text { Ind } \\
\text { PRG }\end{array}$ & Bkg & $\begin{array}{c}\text { GW } \\
\text { SL }\end{array}$ & $\begin{array}{c}\text { Res } \\
\text { PRG }\end{array}$ \\
\hline Aluminum & $2 / 2$ & $11,600 \mathrm{~J}$ & $15,000 \mathrm{~J}$ & Z2-EU3B-306 & 13,300 & NA & NA & 0 & 0 & NA & 2 \\
\hline Antimony & $2 / 2$ & $16.4 \mathrm{~J}$ & $208 \mathrm{~J}$ & Z2-EU3B-306 & 112 & NA & NA & 0 & 2 & 1 & 2 \\
\hline Arsenic & $2 / 2$ & 12.9 & 19.3 & Z2-EU3B-306 & 16.1 & 0 & 0 & 1 & 1 & 0 & 2 \\
\hline Cadmium & $2 / 2$ & $19.9 \mathrm{~J}$ & $36.5 \mathrm{~J}$ & Z2-EU3B-305 & 28.2 & NA & NA & 0 & 2 & NA & 2 \\
\hline Calcium & $2 / 2$ & $54,200 \mathrm{~J}$ & $104,000 \mathrm{~J}$ & Z2-EU3B-305 & 79,100 & NA & NA & NA & 2 & NA & NA \\
\hline Chromium & $2 / 2$ & $79.3 \mathrm{~J}$ & $96.5 \mathrm{~J}$ & Z2-EU3B-306 & 87.9 & NA & NA & 0 & 2 & 0 & 2 \\
\hline Copper & $2 / 2$ & 167 & 309 & Z2-EU3B-306 & 238 & NA & NA & 0 & 2 & NA & 0 \\
\hline Iron & $2 / 2$ & $20,900 \mathrm{~J}$ & $24,200 \mathrm{~J}$ & Z2-EU3B-305 & 22,550 & NA & NA & 0 & 0 & NA & 2 \\
\hline Lead & $2 / 2$ & 1,970 & 5,990 & Z2-EU3B-306 & 3,980 & NA & NA & 2 & 2 & 1 & 2 \\
\hline Magnesium & $2 / 2$ & $5,340 \mathrm{~J}$ & $7,640 \mathrm{~J}$ & Z2-EU3B-306 & 6,490 & NA & NA & NA & 2 & NA & NA \\
\hline Manganese & $2 / 2$ & $217 \mathrm{~J}$ & $222 \mathrm{~J}$ & Z2-EU3B-306 & 220 & NA & NA & 0 & 0 & NA & 2 \\
\hline Mercury & $2 / 2$ & $1.5 \mathrm{~J}$ & $2.3 \mathrm{~J}$ & Z2-EU3B-305 & 1.9 & 0 & 0 & 0 & 2 & NA & 0 \\
\hline Nickel & $2 / 2$ & $137 \mathrm{~J}$ & $269 \mathrm{~J}$ & Z2-EU3B-306 & 203 & NA & NA & 0 & 2 & NA & 1 \\
\hline Selenium & $2 / 2$ & $1 \mathrm{~J}$ & 2 & Z2-EU3B-306 & 1.5 & NA & NA & 0 & 1 & NA & 0 \\
\hline Silver & $2 / 2$ & $1.6 \mathrm{~J}$ & 4.8 & Z2-EU3B-306 & 3.2 & NA & NA & 0 & 2 & NA & 0 \\
\hline Uranium & $2 / 2$ & 7.2 & 7.5 & Z2-EU3B-305 & 7.35 & NA & NA & 0 & NA & NA & 2 \\
\hline Vanadium & $2 / 2$ & 20.6 & 20.7 & Z2-EU3B-305 & 20.7 & NA & NA & 0 & 0 & NA & 2 \\
\hline Zinc & $2 / 2$ & $8,490 \mathrm{~J}$ & $14,800 \mathrm{~J}$ & Z2-EU3B-306 & 11,645 & NA & NA & 0 & 2 & NA & 2 \\
\hline \multicolumn{2}{|c|}{ Avg = average } & $\mathrm{NA}=\mathrm{n}$ & t applicable & & & & & & & & \\
\hline \multicolumn{2}{|c|}{$\mathrm{Bkg}=$ background } & & . & mediation goal & & & & & & & \\
\hline \multirow{2}{*}{\multicolumn{2}{|c|}{$\begin{array}{l}\mathrm{EU}=\text { exposure unit } \\
\mathrm{GW}=\text { groundwater }\end{array}$}} & $\operatorname{Res}=1$ & sidential & & & & & & & & \\
\hline & & $\mathrm{RL}=\mathrm{r}$ & mediation le & & & & & & & & \\
\hline \multicolumn{2}{|c|}{$\begin{array}{l}\mathrm{GW}=\text { groundwater } \\
\text { Ind = industrial }\end{array}$} & $\mathrm{SL}=\mathrm{s}$ & eening level & & & & & & & & \\
\hline \multicolumn{2}{|c|}{ Max = maximum } & $\mathrm{SU}=\mathrm{so}$ & il unit & & & & & & & & \\
\hline
\end{tabular}




\begin{tabular}{|c|c|c|c|c|c|c|c|c|c|}
\hline \multirow[b]{2}{*}{ Analyte } & \multirow[b]{2}{*}{$\begin{array}{c}\text { Detect } \\
\text { frequency }\end{array}$} & \multirow[b]{2}{*}{$\begin{array}{c}\text { Minimum } \\
\text { detect }\end{array}$} & \multirow[b]{2}{*}{$\begin{array}{l}\text { Maximum } \\
\text { detect }\end{array}$} & \multirow{2}{*}{$\begin{array}{c}\text { Location(s) of } \\
\text { maximum } \\
\text { detect }\end{array}$} & \multirow{2}{*}{$\begin{array}{c}\text { Average } \\
\text { detected } \\
\text { result }\end{array}$} & \multicolumn{4}{|c|}{$\begin{array}{c}\text { Number of analyses } \\
\text { exceeding criteria }\end{array}$} \\
\hline & & & & & & $\begin{array}{c}\text { Max } \\
\text { RL } \\
\end{array}$ & $\begin{array}{l}\text { Avg } \\
\text { RL }\end{array}$ & $\begin{array}{c}\text { Ind } \\
\text { PRG } \\
\end{array}$ & $\begin{array}{c}\text { Res } \\
\text { PRG } \\
\end{array}$ \\
\hline PCB-1254 & $1 / 2$ & $150 \mathrm{~J}$ & $150 \mathrm{~J}$ & Z2-EU3B-305 & 150 & 0 & 0 & 0 & 1 \\
\hline PCB-1260 & $2 / 2$ & $270 \mathrm{~J}$ & $330 \mathrm{~J}$ & Z2-EU3B-305 & 300 & 0 & 0 & 0 & 2 \\
\hline PCB & $2 / 2$ & $270 \mathrm{~J}$ & $480 \mathrm{~J}$ & Z2-EU3B-305 & 375 & 0 & 0 & 0 & 2 \\
\hline
\end{tabular}

Avg = average

$\mathrm{EU}=$ exposure unit $\quad$ Res $=$ residential

Ind $=$ industrial $\quad \mathrm{RL}=$ remediation level

Max = maximum

$\mathrm{PCB}=$ polychlorinated biphenyl

$\mathrm{SU}=$ soil unit

EU Z2-03 CLASS 3 SU K-897 TRANSFORMER VAULTSSVOC DETECTS (ug/kg)

\begin{tabular}{|c|c|c|c|c|c|c|c|c|}
\hline \multirow[b]{2}{*}{ Analyte } & \multirow[b]{2}{*}{$\begin{array}{c}\text { Detect } \\
\text { frequency }\end{array}$} & \multirow[b]{2}{*}{$\begin{array}{c}\text { Minimum } \\
\text { detect }\end{array}$} & \multirow[b]{2}{*}{$\begin{array}{c}\text { Maximum } \\
\text { detect }\end{array}$} & \multirow[b]{2}{*}{$\begin{array}{c}\text { Location(s) of } \\
\text { maximum detect }\end{array}$} & \multirow{2}{*}{$\begin{array}{c}\text { Average } \\
\text { detected } \\
\text { result }\end{array}$} & \multicolumn{3}{|c|}{$\begin{array}{c}\text { Number of analyses } \\
\text { exceeding criteria }\end{array}$} \\
\hline & & & & & & $\begin{array}{l}\text { Ind } \\
\text { PRG } \\
\end{array}$ & $\begin{array}{l}\text { GW } \\
\text { SL } \\
\end{array}$ & $\begin{array}{c}\text { Res } \\
\text { PRG } \\
\end{array}$ \\
\hline Acenaphthene & $2 / 2$ & $100 \mathrm{~J}$ & $130 \mathrm{~J}$ & Z2-EU3B-306 & 115 & 0 & NA & 0 \\
\hline Acenaphthylene & $1 / 2$ & $140 \mathrm{~J}$ & $140 \mathrm{~J}$ & Z2-EU3B-305 & 140 & 0 & NA & 0 \\
\hline Anthracene & $2 / 2$ & $270 \mathrm{~J}$ & $270 \mathrm{~J}$ & $\begin{array}{l}\text { Z2-EU3B-305 } \\
\text { Z2-EU3B-306 }\end{array}$ & 270 & 0 & NA & 0 \\
\hline Benz(a)anthracene & $2 / 2$ & 970 & 1,300 & Z2-EU3B-306 & 1,135 & 0 & NA & 2 \\
\hline Benzo(a)pyrene & $2 / 2$ & 950 & 1200 & Z2-EU3B-306 & 1,075 & 0 & NA & 2 \\
\hline Benzo(b)fluoranthene & $2 / 2$ & 1,200 & 1,500 & Z2-EU3B-306 & 1,350 & 0 & NA & 2 \\
\hline Benzo(ghi)perylene & $2 / 2$ & $610 \mathrm{~J}$ & $770 \mathrm{~J}$ & Z2-EU3B-306 & 690 & 0 & NA & 0 \\
\hline Benzo(k)fluoranthene & $2 / 2$ & 1,100 & 1,200 & Z2-EU3B-306 & 1,150 & 0 & NA & 0 \\
\hline Bis(2-ethylhexyl)phthalate & $2 / 2$ & $500 \mathrm{~J}$ & $830 \mathrm{~J}$ & Z2-EU3B-306 & 665 & 0 & 0 & 0 \\
\hline Carbazole & $2 / 2$ & $210 \mathrm{~J}$ & $340 \mathrm{~J}$ & Z2-EU3B-306 & 275 & 0 & NA & 0 \\
\hline Chrysene & $2 / 2$ & 1,200 & 1,500 & Z2-EU3B-306 & 1,350 & 0 & NA & 0 \\
\hline Dibenz(a,h)anthracene & $1 / 2$ & $260 \mathrm{~J}$ & $260 \mathrm{~J}$ & Z2-EU3B-306 & 260 & 0 & NA & 1 \\
\hline Fluoranthene & $2 / 2$ & 2,300 & 3,600 & Z2-EU3B-306 & 2,950 & 0 & NA & 0 \\
\hline Fluorene & $1 / 2$ & $110 \mathrm{~J}$ & $110 \mathrm{~J}$ & Z2-EU3B-306 & 110 & 0 & NA & 0 \\
\hline Indeno(1,2,3-cd)pyrene & $2 / 2$ & $550 \mathrm{~J}$ & $690 \mathrm{~J}$ & Z2-EU3B-306 & 620 & 0 & NA & 1 \\
\hline Phenanthrene & $2 / 2$ & 980 & 1,800 & Z2-EU3B-306 & 1,390 & 0 & NA & 0 \\
\hline Pyrene & $2 / 2$ & 2,000 & 2,700 & Z2-EU3B-306 & 2,350 & 0 & NA & 0 \\
\hline $\mathrm{EU}=$ exposure unit & & Res $=r$ & esidential & & & & & \\
\hline $\mathrm{GW}=$ groundwater & & $\mathrm{SL}=\mathrm{sc}$ & creening level & & & & & \\
\hline Ind $=$ industrial & & $\mathrm{SU}=\mathrm{sc}$ & oil unit & & & & & \\
\hline $\begin{array}{l}\text { NA }=\text { not applicable } \\
\text { PRG = preliminary remedia }\end{array}$ & on & SVOC & $=$ semivolatil & le organic compoun & & & & \\
\hline
\end{tabular}

Historical Storm Drain Sediment Sampling in the Class 3 SU: Four storm drain sediment sample locations were identified for the draft 1999 Sitewide RI (locations 144, 145, 235, and 236). The samples were analyzed for PCB. Analytical results summarized below show detections of PCB-1260 at two locations.

EU Z2-03 CLASS 3 HISTORICAL STORM DRAIN SEDIMENT PCB DETECTS (ug/kg)

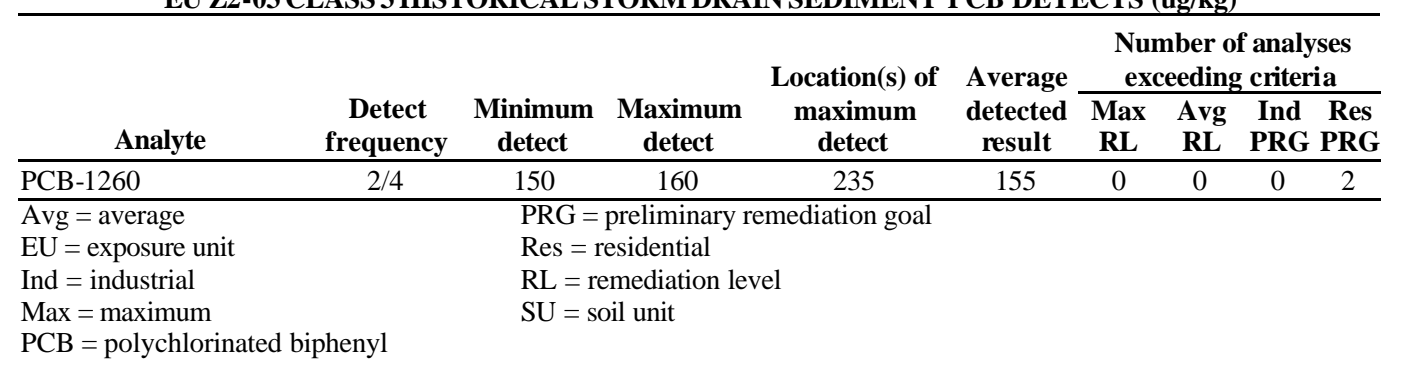

Historical Sampling in the Class 3 SU: Other than the historical French drain and tests pit sediment sample locations (see above), there are 10 historical sample locations in the BU Z2-03 Class 3 SU (see Sect. 2.2.3 for sample 
locations). Sampling was conducted under three different projects with overall sample analyses including metals, PCBs, radionuclides, SVOCs, and VOCs (see Table B.2 for sampling and analysis details). When the Class 3 SU historical data are combined with the DVS Class $3 \mathrm{SU}$ biased sampling results described in the preceding text and results for the Class 3 SU PCB confirmatory sample locations that are described below, all of the Class 3 SU analytical results will have been described. Analytical results for the Class 3 SU historical samples summarized below show one metal (arsenic) and several radionuclide industrial PRG exceedances; metal and radionuclide background exceedances; and PCB, SVOC, and VOC detections.

EU Z2-03 CLASS 3 SU HISTORICAL METALS WITH BACKGROUND, PRG, GW SL, AND/OR RL EXCEEDANCES (mg/kg)

\begin{tabular}{|c|c|c|c|c|c|c|c|c|c|c|c|}
\hline \multirow[b]{2}{*}{ Analyte } & \multirow[b]{2}{*}{$\begin{array}{c}\text { Detect } \\
\text { frequency }\end{array}$} & \multirow[b]{2}{*}{$\begin{array}{c}\text { Minimum } \\
\text { detect }\end{array}$} & \multirow[b]{2}{*}{$\begin{array}{c}\text { Maximum } \\
\text { detect }\end{array}$} & \multirow{2}{*}{$\begin{array}{l}\text { Location(s) of } \\
\text { maximum } \\
\text { detect }\end{array}$} & \multirow{2}{*}{$\begin{array}{c}\text { Average } \\
\text { detected } \\
\text { result }\end{array}$} & \multicolumn{6}{|c|}{ Number of analyses exceeding criteria } \\
\hline & & & & & & $\begin{array}{c}\text { Max } \\
\text { RL }\end{array}$ & $\begin{array}{l}\text { Avg } \\
\text { RL }\end{array}$ & $\begin{array}{l}\text { Ind } \\
\text { PRG }\end{array}$ & Bkg & $\begin{array}{c}\text { GW } \\
\text { SL }\end{array}$ & $\begin{array}{c}\text { Res } \\
\text { PRG }\end{array}$ \\
\hline Aluminum & $2 / 2$ & 23,000 & 52,000 & RR-S14 & 37,500 & NA & NA & 0 & 1 & NA & 2 \\
\hline Arsenic & $2 / 2$ & $15.9 \mathrm{~J}$ & $17.4 \mathrm{~J}$ & RR-SS14 & 16.65 & 0 & 0 & 1 & 2 & 0 & 2 \\
\hline Cadmium & $1 / 2$ & $1.85 \mathrm{~J}$ & $1.85 \mathrm{~J}$ & RR-S14 & 1.85 & NA & NA & 0 & 1 & NA & 0 \\
\hline Chromium & $2 / 2$ & 35.9 & $63.1 \mathrm{~J}$ & RR-S14 & 49.5 & NA & NA & 0 & 1 & 0 & 2 \\
\hline Iron & $2 / 2$ & $34,000 \mathrm{~J}$ & 42,200 & RR-S14 & 38,100 & NA & NA & 0 & 0 & NA & 2 \\
\hline Manganese & $2 / 2$ & $158 \mathrm{~J}$ & 215 & RR-S14 & 186.5 & NA & NA & 0 & 0 & NA & 1 \\
\hline Selenium & $1 / 2$ & $7.14 \mathrm{~J}$ & $7.14 \mathrm{~J}$ & RR-S14 & 7.14 & NA & NA & 0 & 1 & NA & 0 \\
\hline Vanadium & $2 / 2$ & 46.1 & 78.7 & RR-S14 & 62.4 & NA & NA & 0 & 1 & NA & 2 \\
\hline Zinc & $2 / 2$ & $57.1 \mathrm{~J}$ & $117 \mathrm{~J}$ & RR-S14 & 87.05 & NA & NA & 0 & 1 & NA & 0 \\
\hline
\end{tabular}

Avg = average NA = not applicable

$\mathrm{Bkg}=$ background $\quad \mathrm{PRG}=$ preliminary remediation goal

$\mathrm{EU}=$ exposure unit $\quad$ Res $=$ residential

$\mathrm{GW}=$ groundwater $\quad \mathrm{RL}=$ remediation level

Ind $=$ industrial $\quad \mathrm{SL}=$ screening level

Max $=$ maximum $\quad \mathrm{SU}=$ soil unit

EU Z2-03 CLASS 3 SU HISTORICAL PCB DETECTS (ug/kg)

\begin{tabular}{|c|c|c|c|c|c|c|c|c|c|}
\hline \multirow[b]{2}{*}{ Analyte } & \multirow[b]{2}{*}{$\begin{array}{c}\text { Detect } \\
\text { frequency }\end{array}$} & \multirow[b]{2}{*}{$\begin{array}{c}\text { Minimum } \\
\text { detect }\end{array}$} & \multirow[b]{2}{*}{$\begin{array}{c}\text { Maximum } \\
\text { detect }\end{array}$} & \multirow{2}{*}{$\begin{array}{c}\text { Location(s) of } \\
\text { maximum } \\
\text { detect }\end{array}$} & \multirow{2}{*}{$\begin{array}{c}\text { Average } \\
\text { detected } \\
\text { result }\end{array}$} & \multicolumn{4}{|c|}{$\begin{array}{l}\text { Number of analyses } \\
\text { exceeding criteria }\end{array}$} \\
\hline & & & & & & $\begin{array}{c}\text { Max } \\
\text { RL }\end{array}$ & $\begin{array}{c}\text { Avg } \\
\text { RL }\end{array}$ & $\begin{array}{l}\text { Ind } \\
\text { PRG }\end{array}$ & $\begin{array}{l}\text { Res } \\
\text { PRG } \\
\end{array}$ \\
\hline PCB-1016 & $1 / 2$ & $0.024 \mathrm{~J}$ & $0.024 \mathrm{~J}$ & RR-S14 & 0.024 & 0 & 0 & 0 & 0 \\
\hline $\begin{array}{l}\mathrm{Avg}=\text { average } \\
\mathrm{EU}=\text { exposure unit } \\
\text { Ind = industrial } \\
\mathrm{Max}=\text { maximum } \\
\mathrm{PCB}=\text { polychlorina }\end{array}$ & henyl & $\begin{array}{l}\mathrm{PRG}= \\
\mathrm{Res}=\mathrm{r} \\
\mathrm{RL}=\mathrm{re} \\
\mathrm{SU}=\mathrm{sc}\end{array}$ & $\begin{array}{l}\text { preliminary } \mathrm{r} \\
\text { esidential } \\
\text { emediation le } \\
\text { oil unit }\end{array}$ & $\begin{array}{l}\text { emediation goal } \\
\text { el }\end{array}$ & & & & & \\
\hline
\end{tabular}

EU Z2-03 CLASS 3 SU HISTORICAL RADIONUCLIDES WITH BACKGROUND, PRG, AND/OR RL EXCEEDANCES (pCi/g)

\begin{tabular}{|c|c|c|c|c|c|c|c|c|c|c|c|}
\hline \multirow[b]{2}{*}{ Analyte } & \multirow[b]{2}{*}{$\begin{array}{c}\text { Detect } \\
\text { frequency }\end{array}$} & \multirow[b]{2}{*}{$\begin{array}{c}\text { Minimum } \\
\text { detect }\end{array}$} & \multirow[b]{2}{*}{$\begin{array}{c}\text { Maximum } \\
\text { detect }\end{array}$} & \multirow[b]{2}{*}{$\begin{array}{l}\text { Location(s) of } \\
\text { maximum detect }\end{array}$} & \multirow{2}{*}{$\begin{array}{c}\text { Average } \\
\text { detected } \\
\text { result } \\
\end{array}$} & \multicolumn{6}{|c|}{ Number of analyses exceeding criteria } \\
\hline & & & & & & $\begin{array}{l}\text { Max } \\
\text { RL }\end{array}$ & $\begin{array}{l}\text { Avg } \\
\text { RL }\end{array}$ & $\begin{array}{l}\text { Ind } \\
\text { PRG }\end{array}$ & Bkg & $\begin{array}{l}\text { GW } \\
\text { SL }\end{array}$ & $\begin{array}{l}\text { Res } \\
\text { PRG }\end{array}$ \\
\hline Cesium-137 & $9 / 11$ & $0.04 \mathrm{~J}$ & $1.07 \mathrm{~J}$ & RAD156 & 0.486 & 0 & 0 & 0 & NA & NA & 8 \\
\hline Cobalt -60 & $6 / 11$ & 0.007 & 0.31 & KAA-SS-S11 & 0.066 & NA & NA & 0 & NA & NA & 1 \\
\hline Potassium-40 & $7 / 7$ & 5.82 & $16.1 \mathrm{~J}$ & RAD156 & 11.3 & NA & NA & 7 & 0 & NA & 7 \\
\hline Radium-226 & $2 / 5$ & 0.8 & $2.24 \mathrm{~J}$ & RAD156 & 1.52 & NA & NA & 2 & 1 & NA & 2 \\
\hline Thorium -228 & $9 / 9$ & $0.01 \mathrm{~J}$ & 1.01 & RAD156 & 0.443 & NA & NA & 6 & 0 & NA & 8 \\
\hline Thorium -230 & $7 / 9$ & $0.02 \mathrm{~J}$ & 1.58 & RAD167 & 0.604 & NA & NA & 0 & 1 & NA & 0 \\
\hline Thorium -232 & $9 / 9$ & $0.01 \mathrm{~J}$ & $0.95 \mathrm{~J}$ & RAD156 & 0.459 & NA & NA & 6 & 0 & NA & 8 \\
\hline Uranium-235 & $9 / 11$ & $0.01 \mathrm{~J}$ & $0.26 \mathrm{~J}$ & KA36155001-21 & 0.087 & 0 & 0 & 0 & NA & 0 & 1 \\
\hline Uranium-238 & $11 / 11$ & $0.09 \mathrm{~J}$ & 1.01 & RAD156 & 0.675 & 0 & 0 & 0 & 0 & 0 & 5 \\
\hline $\begin{array}{l}\text { Avg = average } \\
\text { Bkg = background } \\
\mathrm{EU}=\text { exposure unit } \\
\mathrm{GW}=\text { groundwater } \\
\text { Ind = industrial } \\
\text { Max = maximum }\end{array}$ & & $\begin{array}{l}\mathrm{NA}=\text { not ap } \\
\mathrm{PRG}=\text { preli } \\
\text { Res }=\text { reside } \\
\mathrm{RL}=\text { remed } \\
\mathrm{SL}=\text { screen } \\
\mathrm{SU}=\text { soil un }\end{array}$ & $\begin{array}{l}\text { pplicable } \\
\text { iminary reme } \\
\text { ential } \\
\text { diation level } \\
\text { ing level } \\
\text { nit }\end{array}$ & ediation goal & & & & & & & \\
\hline
\end{tabular}




\begin{tabular}{|c|c|c|c|c|c|c|c|c|}
\hline \multirow[b]{2}{*}{ Analyte } & \multirow[b]{2}{*}{$\begin{array}{c}\text { Detect } \\
\text { frequency }\end{array}$} & \multirow[b]{2}{*}{$\begin{array}{c}\text { Minimum } \\
\text { detect }\end{array}$} & \multirow[b]{2}{*}{$\begin{array}{c}\text { Maximum } \\
\text { detect }\end{array}$} & \multirow[b]{2}{*}{$\begin{array}{c}\text { Location(s) of } \\
\text { maximum detect }\end{array}$} & \multirow{2}{*}{$\begin{array}{c}\text { Average } \\
\text { detected } \\
\text { result }\end{array}$} & \multicolumn{3}{|c|}{$\begin{array}{l}\text { Number of analyses } \\
\text { exceeding criteria }\end{array}$} \\
\hline & & & & & & $\begin{array}{l}\text { Ind } \\
\text { PRG }\end{array}$ & $\begin{array}{c}\text { GW } \\
\text { SL }\end{array}$ & $\begin{array}{r}\text { Res } \\
\text { PRG }\end{array}$ \\
\hline Pyrene & $1 / 2$ & $0.064 \mathrm{~J}$ & $0.064 \mathrm{~J}$ & RR-S14 & 0.064 & 0 & $\mathrm{NA}$ & 0 \\
\hline EU $=$ exposure unit & & Res $=r$ & esidential & & & & & \\
\hline $\mathrm{GW}=$ groundwater & & $\mathrm{SL}=\mathrm{SC}$ & creening leve & & & & & \\
\hline Ind $=$ industrial & & $\mathrm{SU}=\mathrm{sc}$ & oil unit & & & & & \\
\hline $\mathrm{NA}=$ not applicable & & SVOC & $=$ semivolatil & le organic compour & & & & \\
\hline
\end{tabular}

EU Z2-03 CLASS 3 SU HISTORICAL VOC DETECTS (ug/kg)

\begin{tabular}{|c|c|c|c|c|c|c|c|c|}
\hline \multirow[b]{2}{*}{ Analyte } & \multirow[b]{2}{*}{$\begin{array}{c}\text { Detect } \\
\text { frequency }\end{array}$} & \multirow[b]{2}{*}{$\underset{\text { detect }}{\text { Minimum }}$} & \multirow[b]{2}{*}{$\begin{array}{c}\text { Maximum } \\
\text { detect }\end{array}$} & \multirow[b]{2}{*}{$\begin{array}{c}\text { Location(s) of } \\
\text { maximum detect }\end{array}$} & \multirow{2}{*}{$\begin{array}{c}\text { Average } \\
\text { detected } \\
\text { result }\end{array}$} & \multicolumn{3}{|c|}{$\begin{array}{l}\text { Number of analyses } \\
\text { exceeding criteria }\end{array}$} \\
\hline & & & & & & $\begin{array}{c}\text { Ind } \\
\text { PRG }\end{array}$ & $\begin{array}{l}\text { GW } \\
\text { SL }\end{array}$ & $\begin{array}{c}\text { Res } \\
\text { PRG }\end{array}$ \\
\hline Acetone & $1 / 1$ & $0.252 \mathrm{~J}$ & $0.252 \mathrm{~J}$ & RR-SS14 & 0.252 & 0 & NA & 0 \\
\hline$\overline{\mathrm{EU}}=$ exposure unit & & Res $=\mathrm{r}$ & idential & & & & & \\
\hline $\mathrm{GW}=$ groundwater & & $\mathrm{SL}=\mathrm{sc}$ & eening level & & & & & \\
\hline Ind $=$ industrial & & $\mathrm{SU}=\mathrm{so}$ & unit & & & & & \\
\hline NA $=$ not applicable & . & $\mathrm{VOC}=$ & olatile organi & compound & & & & \\
\hline
\end{tabular}

PCB Immunoassay Test Kit Confirmation Samples: PCB immunoassay test kits were used to define Class 2 SU boundaries in previously unclassified acreage as described in Sect. 2.1.4. There were 22 locations tested and one test kit result from Z2-EU3-209 exceeded the Avg RL of 10,000 ug/kg for PCBs. Soil samples were collected from location Z2-EU3-209 and two other randomly selected locations (Z2-EU3-206 and Z2-EU3-219) whose test kit results did not exceed the Avg RL and sent to a laboratory for PCB confirmation analysis. Sample location Z2-EU3209 is in the K-762 Class 2 SU and its analytical results are included in the K-762 Class 2 SU summary above. The two remaining PCB confirmatory locations, Z2-EU3-206 and Z2-EU3-219, are in the Class 3 SU. The sample from Z2-EU3-209 was analyzed for SVOCs, VOCs, and PCBs. Analytical results summarized below show SVOC detections in the sample from Z2-EU3-209. Causes for the false positive results for the test kit from Z2-EU3-209 include sensitivity to organic compounds and certain SVOCs. The causes were not pursued further because the results were treated as indicators of contamination and the location was sampled.

PCBs were analyzed for in all three samples but were not detected.

EU Z2-03 PCB TEST KIT CONFIRMATORY SAMPLESSVOC DETECTS (ug/kg)

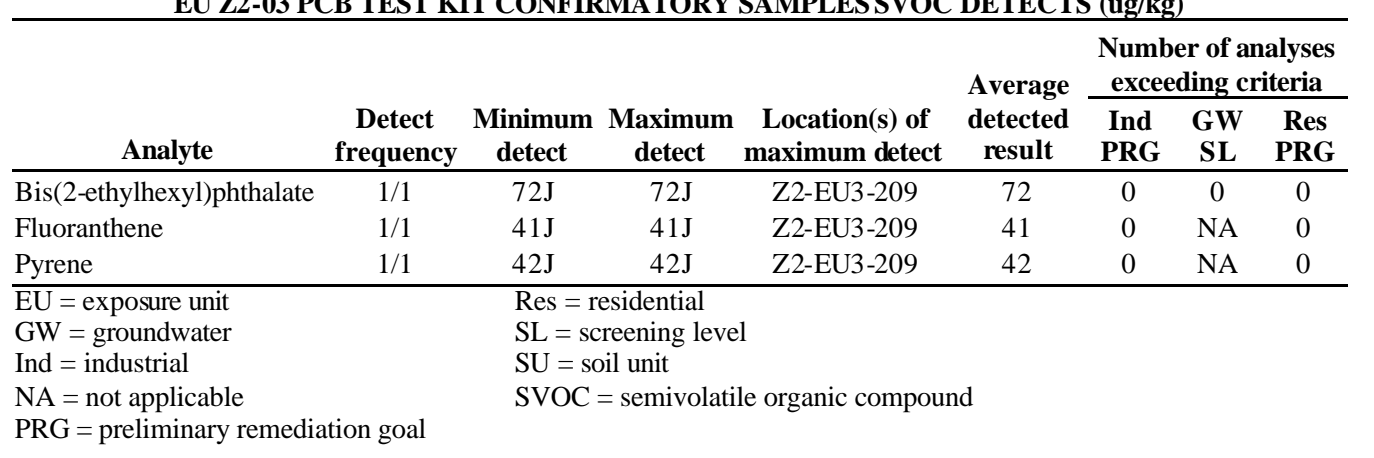

VOCs were analyzed for in the sample from Z2-EU3-209 but were not detected.

EU Z2-03 Summary: There are 28 DVS and historical sample locations in EU Z2-03 (locations identified as RR-S14 and RR-SS14 actually represent only one sample location). EU sample locations are presented in Sects. 2.2.2 and 2.2.3 and are shown on Fig. B.5. Sampling and analytical details for each location are presented in Table B.2. The following data summaries are compilations of the focused investigation summaries shown above and the FFA site 
summaries described in Sect. 2.2.6. Analytical results for EU Z2-03 summarized below show a Cs -137 Avg RL and Ind PRG exceedance; several other radionuclide and metal PRG exceedances; GW SL exceedances by antimony (2), chromium (1), and lead (2); several metal and radionuclide background exceedances; and PCB, SVOC, and VOC detections.

The Cs-137 Avg RL and Ind PRG exceedances occur at the RAD157 historical sample location and are presented above in the RAD157 Class 2 SU summary. Neither exceedance was duplicated in confirmation sample Z2-EU3B-303. The remaining radionuclide Ind PRG exceedances are ubiquitous and are recognized as such in the Zone 2 ROD (Sect. 3.3). The metal Ind PRG exceedances, except one, occur at sediment sample locations Z2-EU3B-304, Z2-EU3B-305, and Z2-EU3B-306, which are in the Class 3 SU K762 transformer vaults and concrete pit (see pertinent summaries above). One metal Ind PRG exceedance (for arsenic) occurs in historical sample RR-SS14. All of the GW SL exceedances occur at sediment sample locations Z2-EU3B-304 and Z2-EU3B-306, which are in the Class 3 SU K-762 transformer vault and concrete pit (see pertinent summaries above). These two samples represent very small sediment volumes and are contained in concrete structures.

EU Z2-03 METALS WITH BACKGROUND, PRG, GW SL, AND/OR RL EXCEEDANCES (mg/kg)

\begin{tabular}{|c|c|c|c|c|c|c|c|c|c|c|c|}
\hline \multirow[b]{2}{*}{ Analyte } & \multirow[b]{2}{*}{$\begin{array}{c}\text { Detect } \\
\text { frequency }\end{array}$} & \multirow[b]{2}{*}{$\begin{array}{c}\text { Minimum } \\
\text { detect }\end{array}$} & \multirow[b]{2}{*}{$\begin{array}{c}\text { Maximum } \\
\text { detect }\end{array}$} & \multirow{2}{*}{$\begin{array}{c}\text { Location(s) of } \\
\text { maximum } \\
\text { detect }\end{array}$} & \multirow{2}{*}{$\begin{array}{c}\text { Average } \\
\text { detected } \\
\text { result }\end{array}$} & \multicolumn{6}{|c|}{ Number of analyses exceeding criteria } \\
\hline & & & & & & $\underset{\text { RL }}{\operatorname{Max}}$ & $\begin{array}{l}\text { Avg } \\
\text { RL }\end{array}$ & $\begin{array}{l}\text { Ind } \\
\text { PRG }\end{array}$ & Bkg & $\begin{array}{c}\text { GW } \\
\text { SL }\end{array}$ & $\begin{array}{c}\text { Res } \\
\text { PRG }\end{array}$ \\
\hline Aluminum & $8 / 8$ & 2,490 & 52,000 & RR-S14 & 16,413 & NA & NA & 0 & 1 & NA & 6 \\
\hline Antimony & $6 / 8$ & $0.059 \mathrm{~J}$ & $260 \mathrm{~J}$ & Z2-EU3B-304 & 80.8 & NA & NA & 0 & 3 & 2 & 3 \\
\hline Arsenic & $7 / 8$ & $0.61 \mathrm{~J}$ & 24.9 & Z2-EU3B-304 & 13.7 & 0 & 0 & 3 & 4 & 0 & 7 \\
\hline Barium & $8 / 8$ & 28.1 & 169 & Z2-EU3B-304 & 78.5 & NA & NA & 0 & 1 & 0 & 0 \\
\hline Cadmium & $7 / 8$ & $0.019 \mathrm{~J}$ & $76.4 \mathrm{~J}$ & Z2-EU3B-304 & 19.3 & NA & NA & 0 & 4 & NA & 3 \\
\hline Calcium & $8 / 8$ & 673 & $301,000 \mathrm{~J}$ & Z2-EU3-223 & 100,557 & NA & NA & NA & 5 & NA & NA \\
\hline Chromium & $8 / 8$ & $5.3 \mathrm{~J}$ & $227 \mathrm{~J}$ & Z2-EU3B-304 & 66.0 & NA & NA & 0 & 4 & 1 & 5 \\
\hline Copper & $8 / 8$ & 3.4 & 11,900 & Z2-EU3B-304 & 1,553 & NA & NA & 0 & 3 & NA & 1 \\
\hline Iron & $8 / 8$ & 4,310 & $109,000 \mathrm{~J}$ & Z2-EU3B-304 & 32,673 & NA & NA & 1 & 1 & NA & 8 \\
\hline Lead & $8 / 8$ & 9.1 & 9,560 & Z2-EU3B-304 & 2,199 & NA & NA & 3 & 3 & 2 & 3 \\
\hline Magnesium & $8 / 8$ & $490 \mathrm{~J}$ & $53,800 \mathrm{~J}$ & Z2-EU3-224 & 13,048 & NA & NA & NA & 5 & NA & NA \\
\hline Manganese & $8 / 8$ & $114 \mathrm{~J}$ & 746 & Z2-EU3-223 & 294 & NA & NA & 0 & 0 & NA & 6 \\
\hline Mercury & $8 / 8$ & $0.021 \mathrm{~J}$ & $2.3 \mathrm{~J}$ & Z2-EU3B-305 & 0.688 & 0 & 0 & 0 & 3 & NA & 0 \\
\hline Nickel & $8 / 8$ & $4.5 \mathrm{~J}$ & $269 \mathrm{~J}$ & Z2-EU3B-306 & 75.0 & NA & NA & 0 & 3 & NA & 1 \\
\hline Selenium & $4 / 8$ & $0.83 \mathrm{~J}$ & $7.14 \mathrm{~J}$ & RR-S14 & 2.74 & NA & NA & 0 & 2 & NA & 0 \\
\hline Silver & $6 / 8$ & $0.021 \mathrm{~J}$ & 4.8 & Z2-EU3B-306 & 1.78 & NA & NA & 0 & 3 & NA & 0 \\
\hline Uranium & $6 / 6$ & 0.33 & 7.5 & Z2-EU3B-305 & 4.16 & NA & NA & 0 & NA & NA & 4 \\
\hline Vanadium & $8 / 8$ & 5.7 & 78.7 & RR-S14 & 28.3 & NA & NA & 0 & 1 & NA & 7 \\
\hline Zinc & $8 / 8$ & $14.2 \mathrm{~J}$ & $14,800 \mathrm{~J}$ & Z2-EU3B-306 & 3,339 & NA & NA & 0 & 4 & NA & 3 \\
\hline \multicolumn{2}{|c|}{$\overline{\text { Avg }=\text { average }}$} & \multicolumn{2}{|c|}{ NA = not applicable } & & & & & & & & \\
\hline \multirow{2}{*}{\multicolumn{2}{|c|}{$\mathrm{Bkg}=$ background }} & \multirow{2}{*}{\multicolumn{3}{|c|}{$\mathrm{PRG}=$ preliminary remediation goal }} & & & & & & & \\
\hline & & & & & & & & & & & \\
\hline \multicolumn{2}{|c|}{$\mathrm{GW}=$ groundwater } & \multicolumn{3}{|c|}{$\mathrm{RL}=$ remediation level } & & & & & & & \\
\hline \multicolumn{2}{|c|}{ Ind $=$ industrial } & $\mathrm{SL}=\mathrm{sc}$ & eening level & & & & & & & & \\
\hline \multicolumn{2}{|c|}{ Max $=$ maximum } & $\mathrm{SU}=\mathrm{sC}$ & il unit & & & & & & & & \\
\hline
\end{tabular}

EU Z2-03 PCB DETECTS (ug/kg)

\begin{tabular}{|c|c|c|c|c|c|c|c|c|c|}
\hline \multirow[b]{2}{*}{ Analyte } & \multirow[b]{2}{*}{$\begin{array}{c}\text { Detect } \\
\text { frequency }\end{array}$} & \multirow[b]{2}{*}{$\begin{array}{c}\text { Minimum } \\
\text { detect }\end{array}$} & \multirow[b]{2}{*}{$\begin{array}{c}\text { Maximum } \\
\text { detect }\end{array}$} & \multirow{2}{*}{$\begin{array}{l}\text { Location(s) of } \\
\text { maximum } \\
\text { detect }\end{array}$} & \multirow{2}{*}{$\begin{array}{c}\text { Average } \\
\text { detected } \\
\text { result }\end{array}$} & \multicolumn{4}{|c|}{$\begin{array}{l}\text { Number of analyses } \\
\text { exceeding criteria }\end{array}$} \\
\hline & & & & & & $\begin{array}{l}\text { Max } \\
\text { RL }\end{array}$ & $\begin{array}{l}\text { Avg } \\
\text { RL }\end{array}$ & $\begin{array}{l}\text { Ind } \\
\text { PRG }\end{array}$ & $\begin{array}{l}\text { Res } \\
\text { PRG }\end{array}$ \\
\hline PCB-1016 & $1 / 17$ & $24 \mathrm{~J}$ & $24 \mathrm{~J}$ & RR-S14 & 24 & 0 & 0 & 0 & 0 \\
\hline PCB-1254 & $3 / 17$ & $150 \mathrm{~J}$ & 1,200 & Z2-EU3B-301 & 560 & 0 & 0 & 0 & 3 \\
\hline PCB-1260 & $5 / 17$ & $84 \mathrm{~J}$ & $330 \mathrm{~J}$ & Z2-EU3B-305 & 199 & 0 & 0 & 0 & 4 \\
\hline PCB & $5 / 11$ & $84 \mathrm{~J}$ & 1,200 & Z2-EU3B-301 & 473 & 0 & 0 & 0 & 4 \\
\hline
\end{tabular}

Avg = average $\quad$ PCB = polychlorinated biphenyl

$\mathrm{EU}=$ exposure unit $\quad \mathrm{PRG}=$ preliminary remediation goal

Ind $=$ in dustrial $\quad$ Res $=$ residential

Max = maximum $\quad \mathrm{RL}=$ remediation level 
EU Z2-03 RADIONUCLIDES WITH BACKGROUND, PRG, AND/OR RL EXCEEDANCES (pCi/g)

\begin{tabular}{|c|c|c|c|c|c|c|c|c|c|c|c|}
\hline \multirow[b]{2}{*}{ Analyte } & \multirow[b]{2}{*}{$\begin{array}{c}\text { Detect } \\
\text { frequency }\end{array}$} & \multirow[b]{2}{*}{$\begin{array}{c}\text { Minimum } \\
\text { detect }\end{array}$} & \multirow[b]{2}{*}{$\begin{array}{c}\text { Maximum } \\
\text { detect }\end{array}$} & \multirow[b]{2}{*}{$\begin{array}{c}\text { Location(s) of } \\
\text { maximum detect }\end{array}$} & \multirow{2}{*}{$\begin{array}{c}\text { Average } \\
\text { detected } \\
\text { result }\end{array}$} & \multicolumn{6}{|c|}{ Number of analyses exceeding criteria } \\
\hline & & & & & & $\begin{array}{c}\text { Max } \\
\text { RL }\end{array}$ & $\begin{array}{l}\text { Avg } \\
\text { RL }\end{array}$ & $\begin{array}{l}\text { Ind } \\
\text { PRG }\end{array}$ & Bkg & $\begin{array}{l}\text { GW } \\
\text { SL }\end{array}$ & $\begin{array}{l}\text { Res } \\
\text { PRG }\end{array}$ \\
\hline Cesium-137 & $11 / 15$ & $0.04 \mathrm{~J}$ & 4.06 & RAD157 & 0.826 & 0 & 1 & 1 & NA & NA & 10 \\
\hline Cobalt -60 & $6 / 15$ & 0.007 & 0.31 & KAA-SS-S11 & 0.066 & NA & NA & 0 & NA & NA & 1 \\
\hline Potassium-40 & $11 / 11$ & 5.82 & $16.1 \mathrm{~J}$ & RAD156 & 11.5 & NA & NA & 11 & 0 & NA & 11 \\
\hline Radium-226 & $6 / 9$ & 0.75 & $2.24 \mathrm{~J}$ & RAD156 & 1.10 & NA & NA & 6 & 1 & NA & 6 \\
\hline Technetium-99 & $4 / 15$ & 0.02 & 0.38 & Z2-EU3B-303 & 0.16 & NA & NA & 0 & NA & NA & 1 \\
\hline Thorium -228 & $13 / 13$ & $0.01 \mathrm{~J}$ & 1.2 & Z2-EU3B-307 & 0.590 & NA & NA & 10 & 0 & NA & 12 \\
\hline Thorium -230 & $10 / 13$ & $0.02 \mathrm{~J}$ & 1.58 & RAD167 & 0.732 & NA & NA & 0 & 2 & NA & 0 \\
\hline Thorium -232 & $13 / 13$ & $0.01 \mathrm{~J}$ & 1.27 & Z2-EU3B-307 & 0.605 & NA & NA & 10 & 0 & NA & 12 \\
\hline Uranium-235 & $12 / 15$ & $0.01 \mathrm{~J}$ & $0.26 \mathrm{~J}$ & KA36155001-21 & 0.086 & 0 & 0 & 0 & NA & 0 & 1 \\
\hline Uranium-238 & $15 / 15$ & $0.09 \mathrm{~J}$ & 1.24 & Z2-EU3B-307 & 0.744 & 0 & 0 & 0 & 0 & 0 & 8 \\
\hline Avg = average & & $\mathrm{NA}=$ not & plicable & & & & & & & & \\
\hline $\mathrm{Bkg}=$ background & & $\mathrm{PRG}=\mathrm{pr}$ & im inary reme & ediation goal & & & & & & & \\
\hline $\mathrm{EU}=$ exposure unit & & Res $=$ resid & ential & & & & & & & & \\
\hline $\mathrm{GW}=$ groundwater & & $\mathrm{RL}=$ remec & diation level & & & & & & & & \\
\hline Ind = industrial & & $\mathrm{SL}=$ screen & ning level & & & & & & & & \\
\hline Max $=$ maximum & & $\mathrm{SU}=$ soil $\mathrm{u}_{\mathrm{I}}$ & & & & & & & & & \\
\hline
\end{tabular}

EU Z2-03 SVOC DETECTS (ug/kg)

\begin{tabular}{|c|c|c|c|c|c|c|c|c|}
\hline \multirow[b]{2}{*}{ Analyte } & \multirow[b]{2}{*}{$\begin{array}{c}\text { Detect } \\
\text { frequency }\end{array}$} & \multirow[b]{2}{*}{$\begin{array}{c}\text { Minimum } \\
\text { detect }\end{array}$} & \multirow[b]{2}{*}{$\begin{array}{c}\text { Maximum } \\
\text { dete ct }\end{array}$} & \multirow{2}{*}{$\begin{array}{c}\text { Location(s) of } \\
\text { maximum detect }\end{array}$} & \multirow{2}{*}{$\begin{array}{c}\text { Average } \\
\text { detected } \\
\text { result }\end{array}$} & \multicolumn{3}{|c|}{$\begin{array}{l}\text { Number of analyses } \\
\text { exceeding criteria }\end{array}$} \\
\hline & & & & & & $\begin{array}{l}\text { Ind } \\
\text { PRG }\end{array}$ & $\begin{array}{l}\text { GW } \\
\text { SL }\end{array}$ & $\begin{array}{l}\text { Res } \\
\text { PRG }\end{array}$ \\
\hline 2-Methylphenol & $1 / 10$ & 1,800 & 1,800 & Z2-EU3B-304 & 1,800 & 0 & NA & 0 \\
\hline Acenaphthene & $3 / 10$ & $100 \mathrm{~J}$ & $210 \mathrm{~J}$ & Z2-EU3B-304 & 147 & 0 & NA & 0 \\
\hline Acenaphthylene & $1 / 10$ & $140 \mathrm{~J}$ & $140 \mathrm{~J}$ & Z2-EU3B-305 & 140 & 0 & NA & 0 \\
\hline Anthracene & $3 / 10$ & $200 \mathrm{~J}$ & $270 \mathrm{~J}$ & $\begin{array}{l}\text { Z2-EU3B-305 } \\
\text { Z2-EU3B-306 }\end{array}$ & 247 & 0 & NA & 0 \\
\hline Benz(a)anthracene & $4 / 10$ & $220 \mathrm{~J}$ & 1,300 & $\begin{array}{l}\text { Z2-EU3B-304 } \\
\text { Z2-EU3B-306 }\end{array}$ & 948 & 0 & NA & 3 \\
\hline Benzo(a)pyrene & $3 / 10$ & 950 & 1,200 & Z2-EU3B-306 & 1,083 & 0 & NA & 3 \\
\hline Benzo(b)fluoranthene & $4 / 10$ & $340 \mathrm{~J}$ & 1,500 & Z2-EU3B-306 & 1,085 & 0 & NA & 3 \\
\hline Benzo(ghi)perylene & $3 / 10$ & $610 \mathrm{~J}$ & $770 \mathrm{~J}$ & Z2-EU3B-306 & 697 & 0 & NA & 0 \\
\hline Benzo(k)fluoranthene & $3 / 10$ & 1,100 & 1,400 & Z2-EU3B-304 & 1,233 & 0 & NA & 0 \\
\hline Benzoic acid & $1 / 8$ & $4,200 \mathrm{~J}$ & $4,200 \mathrm{~J}$ & Z2-EU3B-304 & 4,200 & 0 & NA & 0 \\
\hline Bis(2-ethylhexyl)phthalate & $5 / 10$ & $72 \mathrm{~J}$ & 93,000 & Z2-EU3B-304 & 19,120 & 0 & 0 & 1 \\
\hline Butyl benzyl phthalate & $3 / 10$ & $350 \mathrm{~J}$ & 8,700 & Z2-EU3B-302 & 3,450 & 0 & NA & 0 \\
\hline Carbazole & $3 / 10$ & $210 \mathrm{~J}$ & $340 \mathrm{~J}$ & Z2-EU3B-306 & 283 & 0 & NA & 0 \\
\hline Chrysene & $4 / 10$ & $730 \mathrm{~J}$ & 1,800 & Z2-EU3B-304 & 1,308 & 0 & NA & 0 \\
\hline $\operatorname{Dibenz}(\mathrm{a}, \mathrm{h})$ anthracene & $1 / 10$ & $260 \mathrm{~J}$ & $260 \mathrm{~J}$ & Z2-EU3B-306 & 260 & 0 & NA & 1 \\
\hline Fluoranthene & $6 / 10$ & $41 \mathrm{~J}$ & 4,000 & Z2-EU3B-304 & 1,847 & 0 & NA & 0 \\
\hline Fluorene & $2 / 10$ & $110 \mathrm{~J}$ & $150 \mathrm{~J}$ & Z2-EU3B-304 & 130 & 0 & NA & 0 \\
\hline Indeno(1,2,3-cd)pyrene & $3 / 10$ & $550 \mathrm{~J}$ & $690 \mathrm{~J}$ & Z2-EU3B-306 & 617 & 0 & NA & 1 \\
\hline Phenanthrene & $4 / 10$ & $190 \mathrm{~J}$ & 2,100 & Z2-EU3B-304 & 1,268 & 0 & NA & 0 \\
\hline Phenol & $1 / 10$ & $220 \mathrm{~J}$ & $220 \mathrm{~J}$ & Z2-EU3B-304 & 220 & 0 & NA & 0 \\
\hline Pyrene & $7 / 10$ & $42 \mathrm{~J}$ & 3,700 & Z2-EU3B-304 & 1,349 & 0 & NA & 0 \\
\hline $\begin{array}{l}\text { EU = exposure unit } \\
\text { GW = groundwater } \\
\text { Ind = industrial } \\
\text { NA = not applicable } \\
\text { PRG = prelimin ary remedia }\end{array}$ & tion goal & $\begin{array}{l}\text { Res }=\mathrm{re} \\
\mathrm{SL}=\mathrm{sc} \\
\mathrm{SU}=\mathrm{so} \\
\mathrm{SVOC}=\end{array}$ & $\begin{array}{l}\text { esidential } \\
\text { creening level } \\
\text { oil unit } \\
=\text { semivolatil }\end{array}$ & le organic compoun & & & & \\
\hline
\end{tabular}




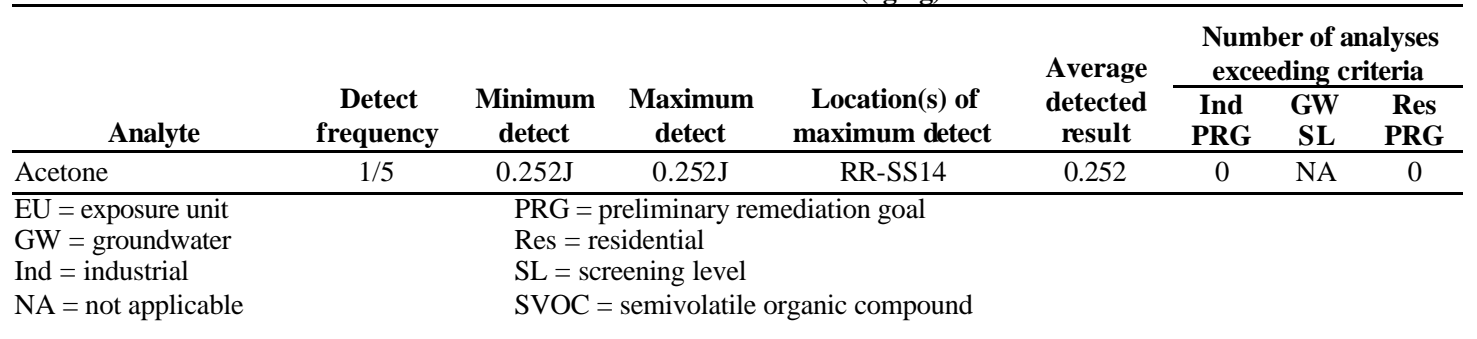

2.2.6

ZONE 2 ROD APPENDIX A FFA SITES EVALUATION

Following is a summary of the analytical results for samples collected to characterize the Zone 2 ROD Appendix A FFA sites located in EU Z2-03. The data summary presentations for the FFA sites follow the guidelines described in the introduction to Sect.2.2.5. Analytical results for the Zone 2 ROD Appendix A FFA sites are included in the EU Z2-03 summary in Sect. 2.2.5.

K-762 Switchyard Soils FFA Site: The K-762 Switchyard Soils FFA site was evaluated with PCB immunoassay test kits (see Sect. 2.1.4), DVS PCB confirmatory sampling (see Sect.2.1.4), DVS sampling in the K-762 Class 2 SU (see Sect. 2.2.2), and Class 3 SU historical sampling (see Sect. 2.2.3). Results of the PCB immunoassay test kits are described in Sect.2.1.4 and are not reiterated here. Also, analytical results for sediment samples from the K-762 transformer vaults are not included here even though the transformer vaults are located within the boundaries of the FFA site. The transformer vault samples represent sediment accumulated within enclosed infrastructure and do not reflect soil compositions of the K762 Switchyard Soils FFA site. Transformer vault data are presented in Sect. 2.2.5, and the transformer vaults are evaluated as part of the EU Z2-03 evaluation in Sect. 3.3.

There are eight DVS and historical sample locations in the K-762 Switchyard Soils FFA site, including two K-762 Class 2 SU systematic sample locations (Z2-EU3-223 and Z2-EU3-224), three PCB confirmatory sample locations (Z2-EU3-206, Z2-EU3-209, and Z2-EU3-219), and three historical sample locations (RAD138, RAD141, and RAD154). Sample locations are shown on Fig. B.5, and sampling and analytical details for each location, are presented in Table B.2. Analytical results summarized below show radionuclide industrial PRG exceedances, metal background exceedances, and detections of SVOCs.

EU Z2-03 K-762 SWITCHYARD SOILS FFA SITE METALS WITH BACKGROUND, PRG, GW SL, AND/OR RL EXCEEDANCES (mg/kg)

\begin{tabular}{|c|c|c|c|c|c|c|c|c|c|c|c|}
\hline \multirow[b]{2}{*}{ Analyte } & \multirow[b]{2}{*}{$\begin{array}{c}\text { Detect } \\
\text { frequency }\end{array}$} & \multirow[b]{2}{*}{$\begin{array}{c}\text { Minimum } \\
\text { detect }\end{array}$} & \multirow[b]{2}{*}{$\begin{array}{c}\text { Maximum } \\
\text { detect }\end{array}$} & \multirow{2}{*}{$\begin{array}{c}\text { Location(s) of } \\
\text { maximum } \\
\text { detect }\end{array}$} & \multirow{2}{*}{$\begin{array}{c}\text { Average } \\
\text { detected } \\
\text { result }\end{array}$} & \multicolumn{6}{|c|}{ Number of analyses exceeding criteria } \\
\hline & & & & & & $\begin{array}{c}\text { Max } \\
\text { RL }\end{array}$ & $\begin{array}{l}\text { Avg } \\
\text { RL }\end{array}$ & $\begin{array}{l}\text { Ind } \\
\text { PRG }\end{array}$ & Bkg & $\begin{array}{l}\text { GW } \\
\text { SL }\end{array}$ & $\begin{array}{l}\text { Res } \\
\text { PRG }\end{array}$ \\
\hline Arsenic & $1 / 2$ & $0.61 \mathrm{~J}$ & $0.61 \mathrm{~J}$ & Z2-EU3-223 & 0.61 & 0 & 0 & 0 & 0 & 0 & 1 \\
\hline Calcium & $2 / 2$ & $298,000 \mathrm{~J}$ & $301,000 \mathrm{~J}$ & Z2-EU3-223 & 299,500 & NA & NA & NA & 2 & NA & NA \\
\hline Magnesium & $2 / 2$ & $28,900 \mathrm{~J}$ & $53,800 \mathrm{~J}$ & Z2-EU3-224 & 41,350 & NA & NA & NA & 2 & NA & NA \\
\hline Manganese & $2 / 2$ & 202 & 746 & Z2-EU3-223 & 474 & NA & NA & 0 & 0 & NA & 2 \\
\hline Vanadium & $2 / 2$ & 5.7 & 12.4 & Z2-EU3-223 & 9.05 & NA & NA & 0 & 0 & NA & 1 \\
\hline \multicolumn{3}{|c|}{$\overline{\mathrm{Avg}}=$ average } & \multicolumn{3}{|c|}{ Max = maximum } & & & & & & \\
\hline \multicolumn{3}{|c|}{$\mathrm{Bkg}=$ background } & \multicolumn{3}{|c|}{ NA = not applicable } & & & & & & \\
\hline \multicolumn{3}{|c|}{$\mathrm{EU}=$ exposure unit } & \multicolumn{3}{|c|}{$\mathrm{PRG}=$ preliminary remediation goal } & & & & & & \\
\hline \multicolumn{3}{|c|}{ FFA $=$ Federal Facility Agreement } & \multicolumn{3}{|c|}{ Res $=$ residential } & & & & & & \\
\hline \multicolumn{3}{|c|}{$\mathrm{GW}=$ groundwater } & \multirow{2}{*}{\multicolumn{3}{|c|}{$\begin{array}{l}\mathrm{RL}=\text { remediation level } \\
\mathrm{SL}=\text { screening level }\end{array}$}} & & & & & & \\
\hline \multicolumn{3}{|c|}{ Ind $=$ industrial } & & & & & & & & & \\
\hline
\end{tabular}

PCBs were analyzed for in five samples but were not detected. 


\begin{tabular}{lcccccccccccc}
\hline \multicolumn{1}{c}{ EU Z2-03 K-762 SWITCHYARD SOILS FFA SITE RADIONUCLIDES WITH } \\
BACKGROUND, PRG, AND/OR RL EXCEEDANCES (pCi/g)
\end{tabular}

EU Z2-03 K-762 SWITCHYARD SOILS FFA SITE SVOC DETECTS (ug/kg)

\begin{tabular}{|c|c|c|c|c|c|c|c|c|}
\hline \multirow[b]{2}{*}{ Analyte } & \multirow[b]{2}{*}{$\begin{array}{c}\text { Detect } \\
\text { frequency }\end{array}$} & \multirow[b]{2}{*}{$\begin{array}{c}\text { Minimum } \\
\text { detect }\end{array}$} & \multirow[b]{2}{*}{$\begin{array}{c}\text { Maximum } \\
\text { detect }\end{array}$} & \multirow[b]{2}{*}{$\begin{array}{l}\text { Location(s) of } \\
\text { maximum detect }\end{array}$} & \multirow{2}{*}{$\begin{array}{c}\begin{array}{c}\text { Average } \\
\text { detected } \\
\text { result }\end{array} \\
\end{array}$} & \multicolumn{3}{|c|}{$\begin{array}{c}\text { Number of analyses } \\
\text { exceeding criteria }\end{array}$} \\
\hline & & & & & & $\begin{array}{l}\text { Ind } \\
\text { PRG } \\
\end{array}$ & $\begin{array}{c}\text { GW } \\
\text { SL } \\
\end{array}$ & $\begin{array}{c}\text { Res } \\
\text { PRG }\end{array}$ \\
\hline Bis(2-ethylhexyl)phthalate & $1 / 3$ & $72 \mathrm{~J}$ & $72 \mathrm{~J}$ & Z2-EU3-209 & 72 & 0 & 0 & 0 \\
\hline Fluoranthene & $1 / 3$ & $41 \mathrm{~J}$ & $41 \mathrm{~J}$ & Z2-EU3-209 & 41 & 0 & NA & 0 \\
\hline Pyrene & $1 / 3$ & $42 \mathrm{~J}$ & $42 \mathrm{~J}$ & Z2-EU3-209 & 42 & 0 & NA & 0 \\
\hline
\end{tabular}

EU = exposure unit $\quad \mathrm{PRG}=$ preliminary remediation goal

FFA $=$ Federal Facility Agreement $\quad$ Res $=$ residential

$\mathrm{GW}=$ groundwater $\quad \mathrm{SL}=$ screening level

Ind = industrial $\quad$ SVOC $=$ semivolatile organic compound

$\mathrm{NA}=$ not applicable

VOCs were analyzed for in two samples but were not detected.

K-762 Valve Vaults 1 and 2 FFA Site: Valve vaults in the K-762 Valve Vaults 1 and 2 FFA site were inspected for the presence of accumulated sediment during the Class $3 \mathrm{SU}$ walkover assessment. It was determined that there is insufficient sediment in the valve vaults to comprise a sample. Therefore, there is insufficient sediment mass within the valve vaults for them to create a hazard to an industrial worker or to be a threat to groundwater.

K-897-L Oil Containment Structure FFA Site: The two oil containment structures in EU Z2-03 listed as Zone 2 ROD Appendix A FFA Sites include the K-897-L Oil Containment Structure and K897-M Oil Containment Structure. Both sites are evaluated together. A DVS sediment sample location was identified inside each structure. Both sample locations, Z2-EU3B-301 and Z2-EU3B-302 (K-897-L Oil Containment Structure and K-897-M Oil Containment Structure, respectively), were field screened for radionuclides and VOCs and analyzed for PCBs, SVOCs, and VOCs. Analytical results summarized below show PCB and SVOC detections.

EU Z2-03 K-897-L AND K-897-M OIL CONTAINMENT STRUCTURE FFA SITES PCB DETECTS (ug/kg)

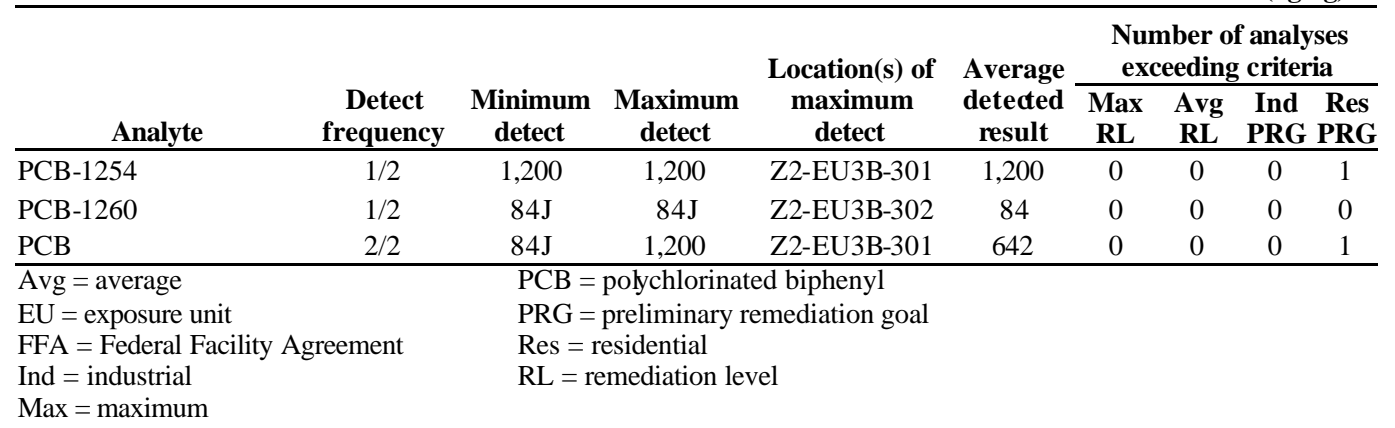




\begin{tabular}{|c|c|c|c|c|c|c|c|c|}
\hline \multirow[b]{2}{*}{ Analyte } & \multirow[b]{2}{*}{$\begin{array}{c}\text { Detect } \\
\text { frequency }\end{array}$} & \multirow[b]{2}{*}{$\begin{array}{c}\text { Minimum } \\
\text { detect }\end{array}$} & \multirow[b]{2}{*}{$\begin{array}{c}\text { Maximum } \\
\text { detect }\end{array}$} & \multirow[b]{2}{*}{$\begin{array}{c}\text { Location(s) of } \\
\text { maximum detect }\end{array}$} & \multirow{2}{*}{$\begin{array}{c}\text { Average } \\
\text { detected } \\
\text { result }\end{array}$} & \multicolumn{3}{|c|}{$\begin{array}{l}\text { Number of analyses } \\
\text { exceeding criteria }\end{array}$} \\
\hline & & & & & & $\begin{array}{l}\text { Ind } \\
\text { PRG }\end{array}$ & $\begin{array}{l}\text { GW } \\
\text { SL }\end{array}$ & $\begin{array}{c}\text { Res } \\
\text { PRG }\end{array}$ \\
\hline Benz(a)anthracene & $1 / 2$ & $220 \mathrm{~J}$ & $220 \mathrm{~J}$ & Z2-EU3B-301 & 220 & 0 & NA & 0 \\
\hline Benzo(b)fluoranthene & $1 / 2$ & $340 \mathrm{~J}$ & $340 \mathrm{~J}$ & Z2-EU3B-301 & 340 & 0 & NA & 0 \\
\hline Bis(2-ethylhexyl)phthalate & $1 / 2$ & $1,200 \mathrm{~J}$ & $1,200 \mathrm{~J}$ & Z2-EU3B-301 & 1,200 & 0 & 0 & 0 \\
\hline Butyl benzyl phthalate & $2 / 2$ & $1,300 \mathrm{~J}$ & 8,700 & Z2-EU3B-302 & 5,000 & 0 & NA & 0 \\
\hline Chrysene & $1 / 2$ & $730 \mathrm{~J}$ & $730 \mathrm{~J}$ & Z2-EU3B-301 & 730 & 0 & NA & 0 \\
\hline Fluoranthene & $2 / 2$ & $550 \mathrm{~J}$ & $590 \mathrm{~J}$ & Z2-EU3B-302 & 570 & 0 & NA & 0 \\
\hline Phenanthrene & $1 / 2$ & $190 \mathrm{~J}$ & $190 \mathrm{~J}$ & Z2-EU3B-301 & 190 & 0 & NA & 0 \\
\hline Pyrene & $2 / 2$ & $440 \mathrm{~J}$ & $500 \mathrm{~J}$ & Z2-EU3B-302 & 470 & 0 & $\mathrm{NA}$ & 0 \\
\hline \multicolumn{5}{|c|}{ PRG = preliminary remediation goal } & & & & \\
\hline \multicolumn{2}{|c|}{ FFA $=$ Federal Facility Agreement } & \multicolumn{3}{|c|}{ Res $=$ residential } & & & & \\
\hline \multicolumn{2}{|c|}{$\mathrm{GW}=$ groundwater } & \multicolumn{3}{|c|}{$\mathrm{SL}=$ screening level } & & & & \\
\hline \multicolumn{2}{|l|}{$\mathrm{NA}=$ not applicable } & SVOC & $=$ semivolati & le organic compou & & & & \\
\hline
\end{tabular}

VOCs were analyzed for in both samples but were not detected.

K-897-M Oil Containment Structure FFA Site: The K-897-M Oil Containment Structure FFA site is evaluated in the preceding evaluation of the K-897-L Oil Containment Structure FFA site.

\begin{tabular}{|l|l|}
\hline 3.0 & \multicolumn{1}{|c|}{ RISK EVALUATION AND ACTION/NO FURTHER ACTION DECISION } \\
\hline 3.1 & INTRODUCTION \\
\hline
\end{tabular}

In this section, data are evaluated in terms of the four decision rules presented in the Zone 2 RDR/RAWP, which include the following:

- Does the concentration of any Zone 2 contaminant of concern (COC) exceed its maximum RL?

- Does the mean concentration of any Zone 2 COC exceed its average RL across the EU?

- Does the EU pose a risk exceeding an industrial $1 \times 10^{-4}$ excess lifetime cancer risk (ELCR) or target organ hazard index (HI) of 1 ?

- Does the site pose a threat to GW based on MCL exceedances or soil RLs for protection of GW?

Table B. 3 presents the results from comparing the data to Zone 2 soils RLs, Ind PRGs (set at an ELCR of $1 \times 10^{-5}$ or a $\mathrm{HI}$ of 1), and background levels. In addition, the EU summary in Sect. 2.2.5 presents an evaluation of the EU data by analyte group. The following table summarizes the conclusions for EU Z2-03.

\begin{tabular}{|c|c|c|c|c|c|}
\hline EU \# & $\begin{array}{r}\text { Max RL } \\
\text { exceeded? }\end{array}$ & $\begin{array}{l}\text { Average RL over } \\
\text { EU exceeded? }\end{array}$ & $\begin{array}{r}\text { Industrial risk } \\
\text { above } 1 \times 10^{-4} ?\end{array}$ & $\begin{array}{l}\text { Potential source } \\
\text { to groundwater? }\end{array}$ & $\begin{array}{c}\text { Action } \\
\text { required? }\end{array}$ \\
\hline $\mathrm{Z} 2-03$ & No & No & No & No & No \\
\hline
\end{tabular}

\section{\begin{tabular}{|l|l}
\hline 3.2 & DATA EVALUATION FOR THE ACTION /NO FURTHER ACTION DECISION
\end{tabular}}

The requirements for determining NFA in the Zone 2 EUs are stated in the protection goals of the Zone 2 ROD remedial action objective (RAO). Four decision rules developed in the DVS DQOs state the specific criteria against which each EU must be compared to make the NFA decision. The four decision rules are presented in Sect. 3.2 of this PCCR, and the manner in which the decision rule evaluations are conducted and special data handling requirements are discussed in Sect. 3.3 of this PCCR. In summary, the decision rule criteria for NFA are that each EU must meet each of the following compositional constraints:

- Zone 2 soils Max RLs - maximum allowable concentrations of Zone 2 soils COCs. Zone 2 soils Max RLs are presented in the Zone 2 ROD and Table 5 of this PCCR. 
- Zone 2 soils Avg RLs - limit on the allowable average concentration of Zone 2 soils COCs across an EU. Zone 2 soils Avg RLs are presented in the Zone 2 ROD and Table 5 of this PCCR.

- Cumulative risk across the EU - cumulative risk across an EU cannot exceed $1 \times 10^{-4}$ ELCR or HI of 1. A stepwise evaluation of cumulative risk is performed by first comparing EU data to $1 \times 10^{-5}$ Ind PRGs. The $1 \times 10^{-5}$ Ind PRGs for analytes required by the RDR/RAWP are presented in Table 5 of this PCCR.

- Groundwater protection goals - composition of Zone 2 soils cannot pose a threat to groundwater. This evaluation is conducted by evaluating local groundwater monitoring results and comparing soils compositions to calculated SLs. Groundwater SLs are presented in Table 5 of this PCCR.

\begin{tabular}{|l|l|}
\hline 3.3 & SUMMARY AND CONCLUSIONS \\
\hline
\end{tabular}

\section{EU Z2-03}

Max RL screening. Based on DVS and historical sampling analytical results and results of the Class 3 walkover assessment, no Zone 2 COCs were detected in EU Z2-03 at concentrations in excess of Max RLs.

Avg RL screening. The Cs -137 average RL was exceeded at historical location RAD157 in the RAD157 Class 2 SU. A BAR survey was conducted in the RAD157 Class 2 SU but failed to identify any action level exceedance, therefore, the areal extent of the historical exceedance could not be defined. Confirmation sample location Z2-EU3B-303 was collected at the RAD157 location but failed to confirm the Cs -137 Avg RL exceedance.

Based on the DVS BAR survey and confirmation sample, it is concluded there is no Cs -137 Avg RL exceedance at location RAD157. In addition, based on other DVS and historical analytical results and results of the Class 3 SU walkover assessment, there are no other chemicals or radionuclides in EU Z2-03 whose average concentration exceeds an Avg RL across the EU.

Risk evaluation. The first step in the risk evaluation is to assess $1 \times 10^{-5}$ Ind PRG exceedances to determine which chemicals and radionuclides are likely to exceed the $1 \times 10^{-4}$ ELCR or target organ HI of 1 . As stated in the evaluation in Sect. 2.2.5, the $1 \times 10^{-5}$ Ind PRG was exceeded in one or more samples by arsenic (3), iron (1), lead (3), Cs-137 (1), K-40 (11), Ra-226 (6), Th-228 (10), and Th-232 (10). As explained in Sect. 3.3 of this PCCR, K-40 is further evaluated for risk only if its average concentration exceeds its background value and Ra-226, Th230 , and Th-232 are evaluated by summing their concentrations ( $\mathrm{Ra} / \mathrm{Th}$ decay series) and comparing the result to their mutual Zone 2 soils COC average RL (this evaluation includes Th-228 as part of the Th-232 decay chain). The average detected $\mathrm{K}-40$ concentration $(11.5 \mathrm{pCi} / \mathrm{g})$ does not exceed the $\mathrm{K}-40$ background value $(32.12 \mathrm{pCi} / \mathrm{g})$ and there are no occurrences of the Ra/Th decay series exceeding the average RL ( $5 \mathrm{pCi} / \mathrm{g})$. In addition, the Cs -137 $1 \times 10-{ }^{5}$ Ind PRG exceedance occurs at historical location RAD157. The DVS confirmation sample at this location (Z2-EU3B-303) failed to confirm the presence of a $1 \times 10^{-5}$ Ind PRG exceedance.

The second step in the risk evaluation is to determine if the average detected concentration of any of the remaining chemicals or radionuclides exceeds a $1 \times 10^{-5}$ Ind PRG. For EU Z2-03, the remaining chemicals and radionuclides with individual $1 \times 10^{-5}$ Ind PRG exceedances are arsenic, iron, and lead. However, all of the $1 \times 10^{-5}$ Ind PRG exceedances for these metals occur within the infrastructure-Class 3 SU K-762 transformer vaults and concrete pit (see Sect. 2.2.5). Zone 2 soils DQOs (Zone 2 RDR/RAWP, Appendix C) require that the infrastructure be evaluated for risk based on Max RL exceedances only because the infrastructure can comprise a vanishingly small proportion of the volume of an EU (i.e., EU area $\times 10-\mathrm{ft}$ depth). Because there is no Max RL for either iron or lead, the potential risk associated with the observed elevated concentrations of arsenic, iron, and lead are further evaluated. Note that the following evaluation ultimately takes the conservative approach of comparing to area-based averages instead of volume-based averages.

The average detected concentration of arsenic $(13.7 \mathrm{mg} / \mathrm{kg})$ is less than the $1 \times 10^{-5}$ Ind PRG $(15.9 \mathrm{mg} / \mathrm{kg})$ and the average detected concentration of iron $(32,673 \mathrm{mg} / \mathrm{kg})$ is also less than the $1 \times 10^{-5}$ Ind PRG $(100,000 \mathrm{mg} / \mathrm{kg})$. Only the average detected concentration of lead $(2,199 \mathrm{mg} / \mathrm{kg})$ is greater than the $1 \times 10^{-5}$ Ind PRG $(800 \mathrm{mg} / \mathrm{kg})$.

The third step in the risk evaluation is to calculate the weighted average concentration of those chemicals and radionuclides whose average detected concentration exceeds the $1 \times 10^{-5}$ Ind PRG, and compare the weighted average concentration to the $1 \times 10^{-5}$ Ind PRG. The weighted average calculation is described in Sect. 3.3 of this PCCR. For EU Z2-03, only lead is evaluated in this third step. The following assumptions were used for the calculation:

- There are 21 transformer vaults and concrete pits in the EU; 
- $\quad$ Each vault or pit is a $10-\mathrm{ft} \times 10$-ft structure;

- Lead concentration in each vault or pit is the maximum observed concentration ;

- Lead concentration outside the vaults and pit is the average of all EU Z2-03 samples, exclusive of the vaults and pit samples; and

- $\quad$ Total area of EU Z2-03 is 14.93 acres.

The weighted average calculation shows the following:

- Vaults and pits occupy 0.048 acres or $0.32 \%$ of the total EU acreage and have a lead concentration of $9560 \mathrm{mg} / \mathrm{kg}$,

- $\quad$ Remaining EU area is 14.882 acres or $99.68 \%$ of the total EU acreage and has an average lead concentration of $13.8 \mathrm{mg} / \mathrm{kg}$, and

- Weighted average lead concentration in the EU is $44.35 \mathrm{mg} / \mathrm{kg}$, which is less than the $1 \times 10^{-5}$ Ind PRG $(800 \mathrm{mg} / \mathrm{kg})$.

In conclusion, there are no chemicals or radionuclides in EU Z2-03 with average concentrations greater than their $1 \times 10^{-5}$ Ind PRGs or that exceed the risk evaluation criteria described in Sect. 3.3 of this PCCR. Therefore, the industrial risk for EU Z2-03 is less than $1 \times 10^{-4}$ ELCR and target organ HI of 1 .

Threat to GW. GW SLs are exceeded in EU Z2-03 by antimony (2), chromium (1), and lead (2). All of the GW SL exceedances occur at sample locations Z2-EU3B-304 and Z2-EU3B-306, which are inside a Class 3 SU transformer vault and concrete pit. These structures are concrete-lined voids and, as such, do not provide access to groundwater. Additionally, there are no antimony, chromium, or lead MCL exceedances in area groundwater monitoring wells. Therefore, the available mass of these metals is too small to pose a threat to groundwater. It is concluded that EU Z2-03 meets the groundwater protection goal of the Zone 2 ROD RAO.

Qualitative risk screening for unrestricted use. There is a low probability that this acreage could be released with no land use restrictions. Numerous Ind and Res PRG exceedances occur in this EU for metals, radionuclides, PCBs, and SVOCs. Specific chemicals and radionuclides with Ind and Res PRG exceedances are presented in the EU Z2-03 summary in Sect. 2.2.5. An appropriate evaluation of residential risk should be conducted to make a definitive conclusion.

\section{FFA Sites}

Based on analytical results (Sect. 2.2.6), the Class 3 SU walkover assessment (Sect. 2.1.3), and an evaluation of the EU-wide contaminant profile (above), soils in the following Zone 2 ROD Appendix A FFA sites in EU Z2-03 do not pose a potential threat to the future industrial worker or to groundwater:

- K-762 Switchyard Soils,

- $\mathrm{K}-762$ Valve Vaults 1 and 2,

- K-897-L Oil Containment Structure, and

- $\quad$ K-897-M Oil Containment Structure.

\begin{tabular}{|l|l|}
\hline 4.0 & RECOMMENDATION FOR ACTION/NO FURTHER ACTION \\
\hline 4.1 & DECISION AND REMEDIATION ACTIVITIES \\
\hline
\end{tabular}

EU Z2-03: Based on results of the Class 3 walkover assessment and analytical results of the DVS and historical samples collected in EU Z2-03, the U.S. Department of Energy (DOE) recommends that NFA is appropriate under the Zone 2 ROD to meet industrial land use for the approximately 15 acres of ETTP Zone 2 EU Z2-03.

FFA Sites: Based on analytical results, the Class $3 \mathrm{SU}$ walkover assessment, and the recommendation for all of EU Z2-03, DOE recommends that NFA is appropriate for the following FFA sites:

- K-762 Switchyard Soils,

- K-762 Valve Vaults 1 and 2,

- K-897-L Oil Containment Structure, and

- K-897-M Oil Containment Structure. 
4.2

EXCAVATION ACTIVITIES/CONFIRMATIONSAMPLING

None 


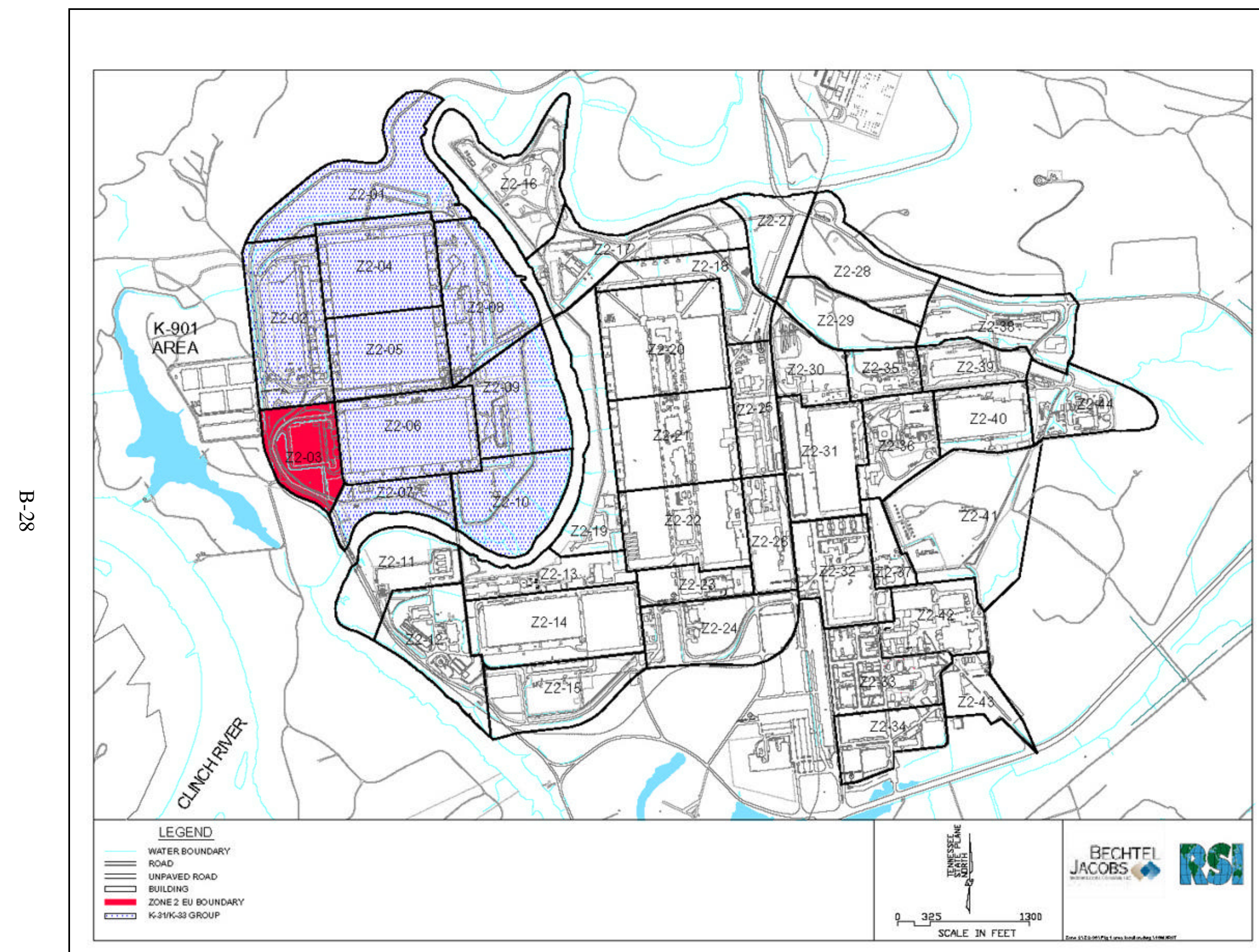

Fig. B.1. EU Z2 -03 location map. 


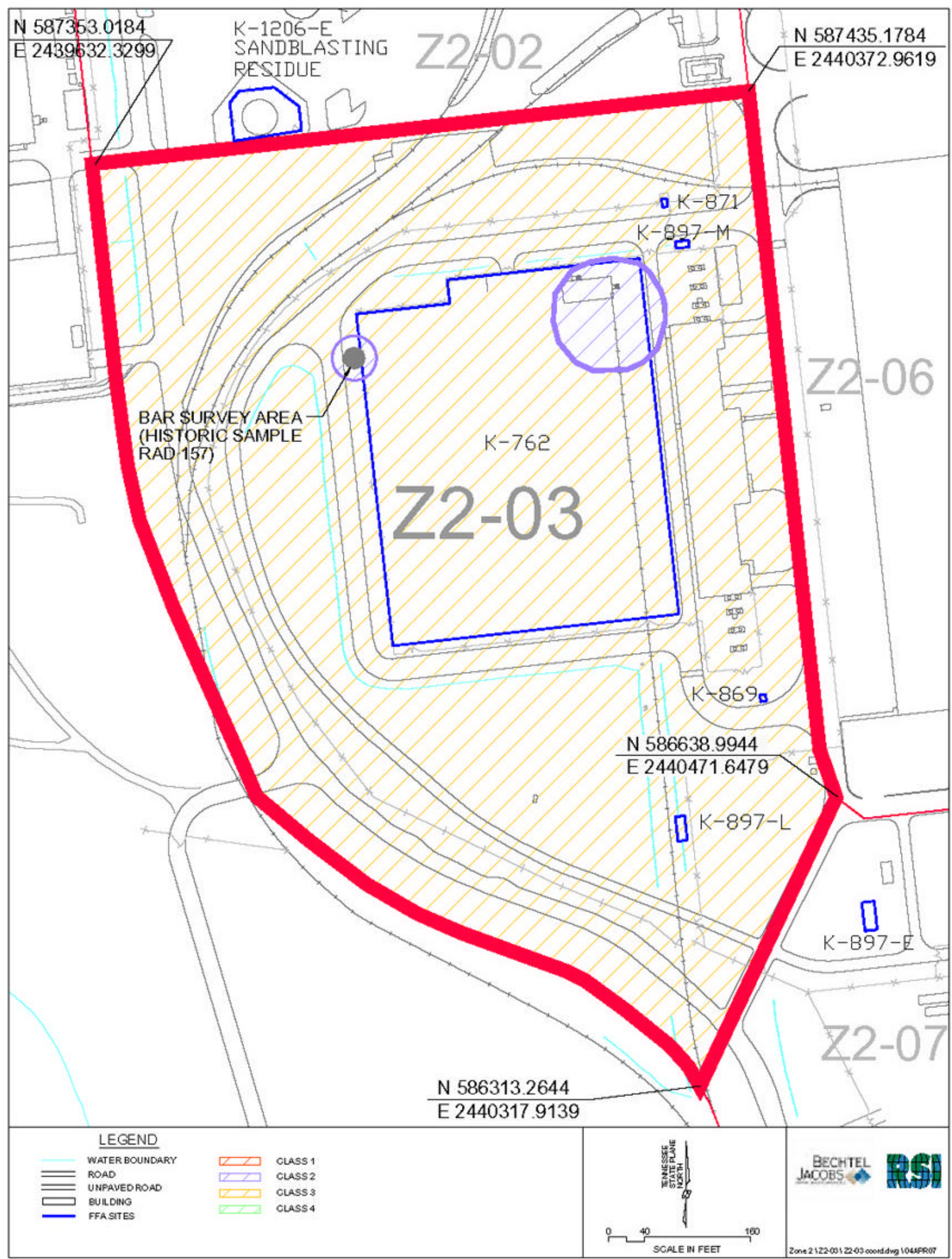

Fig. B.2. EU Z2-03 boundaries. 


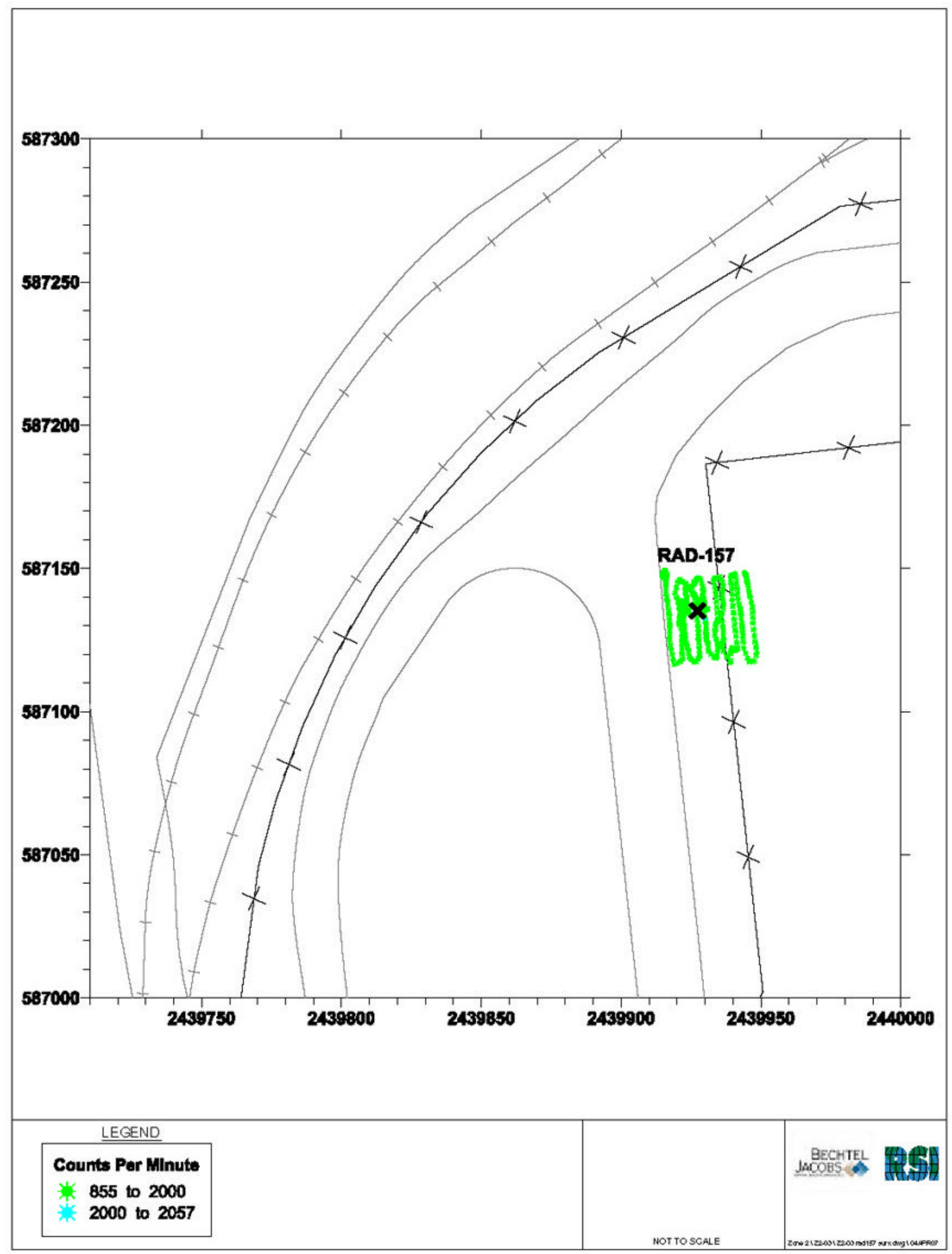

Fig. B.3. EU Z2-03 BAR survey results of RAD157 Class 2 SU. 


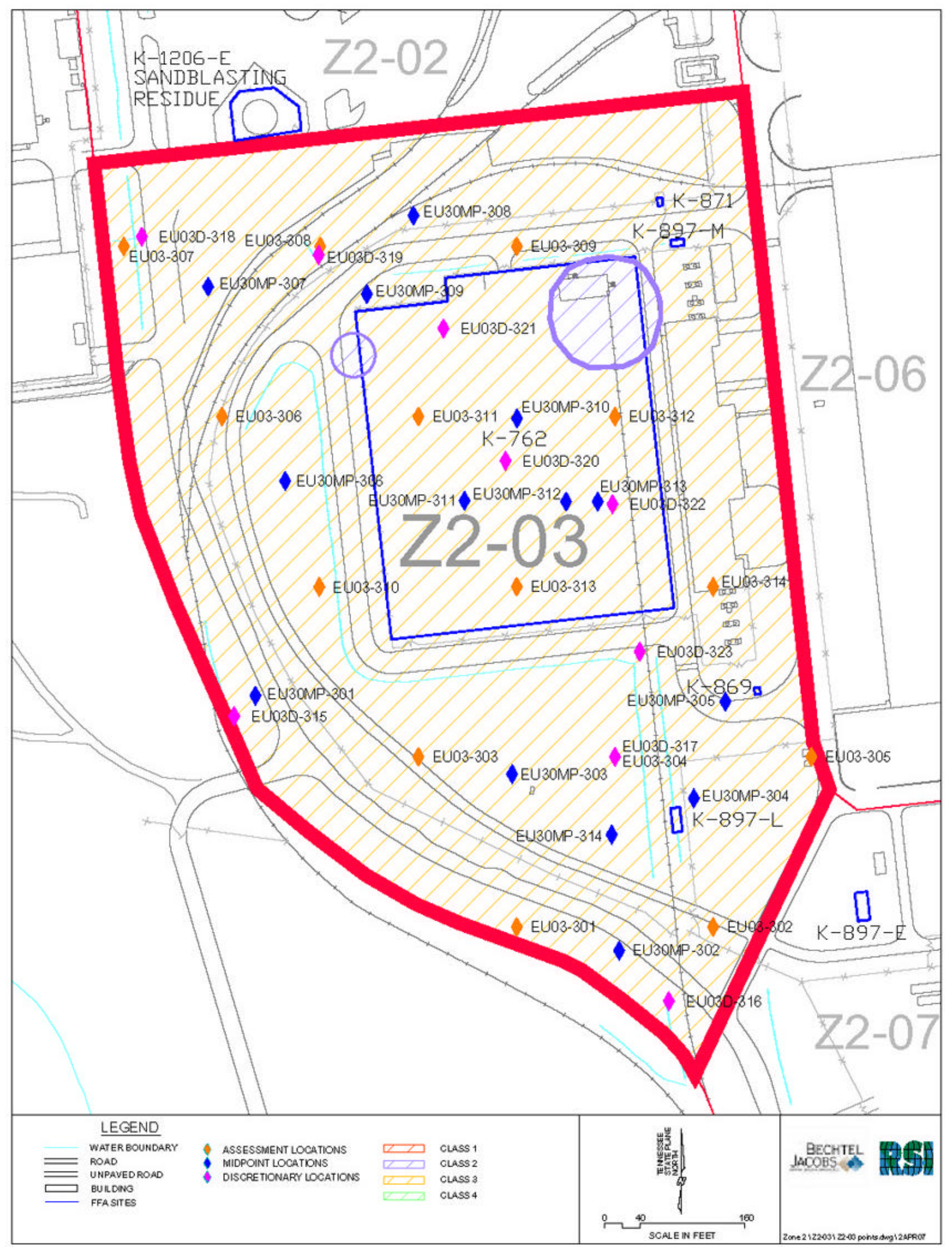

Fig. B.4. EU Z2 -03 Class 3 SU walkover assessment locations. 


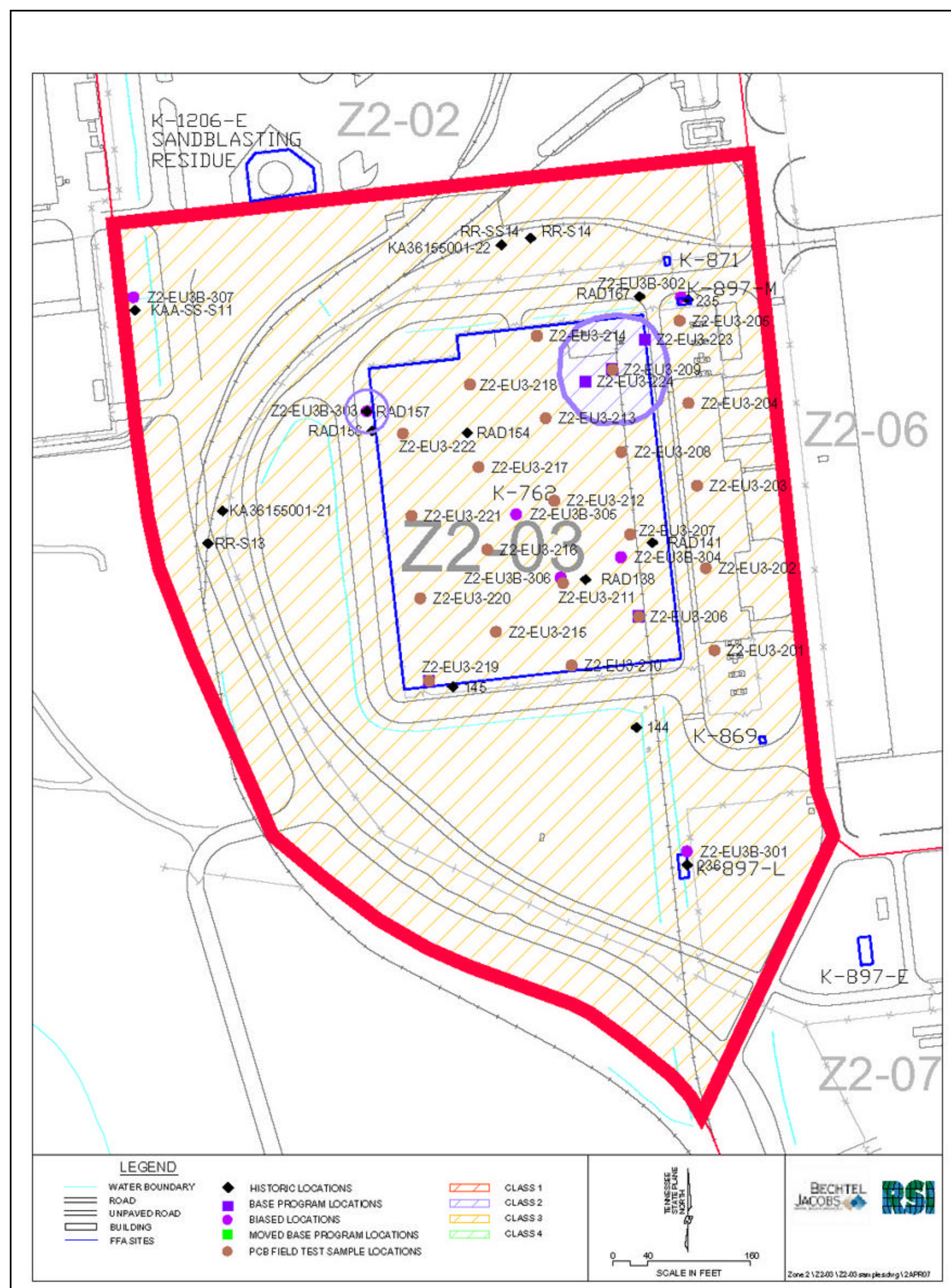

Fig. B.5. EU Z2 -03 sample locations. 
Table B.1. EU Z2-03 facility and FFA site list

\begin{tabular}{|c|c|c|c|c|}
\hline \multirow[b]{2}{*}{ Facility name DQO scoping } & \multirow[b]{2}{*}{ Facility name } & \multicolumn{2}{|c|}{ Facility assessed? } & \multirow[b]{2}{*}{ Comments } \\
\hline & & Yes & No & \\
\hline K-761 Switch House (Characterization Area-Group II EE/CA) & & $\mathrm{X}$ & & \\
\hline K-762 Switchyard Soils (Characterization Area-Future Decisions) & K-762 Switchyard (former) & $\mathrm{X}$ & & $\begin{array}{l}\text { FFA site; covered with } \\
\text { gravel }\end{array}$ \\
\hline K-762 Valve Vaults 1 and 2 (Characterization Area-Future Decisions) & & & $\mathrm{X}$ & FFA site ${ }^{a}$ \\
\hline K-869 Valve Vault & K-869 Inactive Valve Vault & $\mathrm{X}$ & & \\
\hline K-871 Valve Vault & K-871 Inactive Valve Vault & $\mathrm{X}$ & & \\
\hline K-897-L Oil Containment Structure (Characterization Area-Future Decisions) & K-897-L Oil Skimmer & $\mathrm{X}$ & & FFA site \\
\hline K-897-M Oil Containment Structure (Characterization Area-Future Decisions) & K-897-M Oil Skimmer & $\mathrm{X}$ & & FFA site \\
\hline K-899-G Blow Down Valve Vault & & & $\mathrm{X}$ & Located in EU Z2-04 \\
\hline K-1022-1 Air Sampling Monitor & & & $\mathrm{X}$ & Facility no longer exists \\
\hline K-1028-62 Guard Portal (Characterization Area-Group II EE/CA) & & & $\mathrm{X}$ & Facility no longer exists \\
\hline K-1310-GR Training Trailer & & & $\mathrm{X}$ & Facility no longer exists \\
\hline K-1310-GT Human Resources Trailer & & & $\mathrm{X}$ & Facility no longer exists \\
\hline \multicolumn{5}{|l|}{$\begin{array}{ll}\text { Facilities not in DQO Scoping } \\
\end{array}$} \\
\hline K-1310-FL Office Trailer & & $\mathrm{X}$ & & \\
\hline
\end{tabular}

${ }^{a} \mathrm{~K}-762$ valve vaults 1 and 2 are K-869 and K-871 per K-31/K-33 Group DQO scoping package.

$\mathrm{DQO}=$ data quality objective

$\mathrm{EU}=$ exposure unit

$\mathrm{EE} / \mathrm{CA}=$ engineering evaluation/cost analysis $\quad$ FFA $=$ Federal Facility Agreement 
Table B.2. K-31/K-33 Group EU Z2-03 sample summary

\begin{tabular}{|c|c|c|c|c|c|c|c|c|c|c|c|c|c|}
\hline \multirow[b]{2}{*}{$\begin{array}{c}\text { Date } \\
\text { sampled }\end{array}$} & \multirow[b]{2}{*}{ Sample ID } & \multicolumn{2}{|c|}{ Location } & \multirow[b]{2}{*}{ Sample interval } & \multicolumn{2}{|c|}{ Screening } & \multicolumn{6}{|c|}{ Off-site laboratory } & \multirow[b]{2}{*}{ Comments and notes } \\
\hline & & Northing & Easting & & VOC & RAD & VOC & SVOC & PCB & Metals & RAD & $\begin{array}{l}\text { Splits/ } \\
\text { Dups }\end{array}$ & \\
\hline $02 / 01 / 06$ & Z2-EU3-206 & 586895 & 2440245 & 0-3.7 ft discrete sample & & & & & 1 & & & $\mathrm{D}$ & Confirmation to be sent to lab; <10 ppm \\
\hline $02 / 02 / 06$ & Z2-EU3-209 & 587183 & 2440214 & $0-3.7 \mathrm{ft}$ discrete sample & & & 1 & 1 & 1 & & & & $10-50 \mathrm{ppm}$ results, sent to lab \\
\hline $02 / 03 / 06$ & Z2-EU3-219 & 586820 & 2440000 & $0-3.7 \mathrm{ft}$ discrete sample & & & & & 1 & & & & Confirmation to be sent to lab; <10 ppm \\
\hline $04 / 20 / 06$ & Z2-EU3-223 & 587218 & 2440252 & 0 -12ft 3-interval composite & 1 & 1 & & 1 & 1 & 1 & & & \\
\hline $04 / 20 / 06$ & Z2-EU3-224 & 587169 & 2440183 & 0-3.7 ft composite sample & 1 & 1 & 1 & 1 & 1 & 1 & 1 & & Linked to rinsate (K31K33-FCOC251) \\
\hline $11 / 16 / 05$ & Z2-EU3B-301 & 586621 & 2440301 & Grab sample (sediment) & 1 & 1 & 1 & 1 & 1 & & & & K-897-L Oil Skimmer \\
\hline $11 / 16 / 05$ & Z2-EU3B-302 & 587267 & 2440294 & Grab sample (sediment) & 1 & 1 & 1 & 1 & 1 & & & & K-897-M Oil Skimmer \\
\hline $05 / 17 / 06$ & Z2-EU3B-303 & 587134 & 2439928 & 0-1 ft composite (1-point HA) & & & & & & & 1 & & $\begin{array}{l}\text { Confirmation sample from historical sample } \\
\text { exceedance location Rad } 157\end{array}$ \\
\hline $05 / 24 / 06$ & Z2-EU3B-304 & 586964 & 2440224 & Grab sample (sediment) & 1 & & & 1 & 1 & 1 & & & Concrete pits adjacent to railroad tracks (west side) \\
\hline $05 / 24 / 06$ & Z2-EU3B-305 & 587014 & 2440102 & Grab sample (sediment) & 1 & 1 & & 1 & 1 & 1 & & $\mathrm{~S}$ & $\begin{array}{l}\text { K-762 Transformer Vault, sediment from central } \\
\text { location in switchyard }\end{array}$ \\
\hline $05 / 24 / 06$ & Z2-EU3B-306 & 586940 & 2440154 & Grab sample (sediment) & 1 & 1 & & 1 & 1 & 1 & & & $\begin{array}{l}\text { K-762 Transformer Vault, sediment from } \\
\text { southeast/central location in switchyard }\end{array}$ \\
\hline & Z2-EU3B-307 & 587267 & 2439656 & 0-1 ft composite (1-point HA) & 1 & & & & 1 & 1 & 1 & & $\begin{array}{l}\text { 12-in. corrugated metal pipe that drains surface from } \\
\text { K-1066-K }\end{array}$ \\
\hline 05/25/06 & & & & $\begin{array}{r}\text { Total DVS samples } \\
\end{array}$ & 8 & 6 & 4 & 8 & 11 & 6 & 3 & & \\
\hline \multicolumn{14}{|c|}{ Historic soil samples } \\
\hline $01 / 13 / 99$ & KA36155001-21 & 587018 & 2439760 & Surface soil sample $0.0-0.5 \mathrm{ft}$ & & & & & & & 1 & & \\
\hline $01 / 13 / 99$ & KA36155001-22 & 587328 & 2440085 & Surface soil sample $0.0-0.5 \mathrm{ft}$ & & & & & & & 1 & & \\
\hline $08 / 07 / 95$ & KAA-SS-S11 & 587252 & 2439658 & Surface soil sample $0.0-0.5 \mathrm{ft}$ & & & & & & & 1 & & \\
\hline $07 / 19 / 94$ & RAD138 & 586938 & 2440183 & Surface soil sample $0.0-0.5 \mathrm{ft}$ & & & & & & & 1 & & \\
\hline $07 / 19 / 94$ & RAD141 & 586981 & 2440261 & Surface soil sample $0.0-0.5 \mathrm{ft}$ & & & & & & & 1 & & \\
\hline $07 / 19 / 94$ & RAD154 & 587109 & 2440045 & Surface soil sample $0.0-0.5 \mathrm{ft}$ & & & & & & & 1 & & \\
\hline $07 / 19 / 94$ & RAD156 & 587111 & 2439934 & Surface soil sample $0.0-0.5 \mathrm{ft}$ & & & & & & & 1 & & \\
\hline $07 / 19 / 94$ & RAD157 & 587134 & 2439928 & Surface soil sample $0.0-0.5 \mathrm{ft}$ & & & & & & & 1 & & \\
\hline $07 / 19 / 94$ & RAD167 & 587268 & 2440246 & Surface soil sample $0.0-0.5 \mathrm{ft}$ & & & & & & & 1 & & \\
\hline $11 / 23 / 99$ & RR-S13 & 586980 & 2439743 & Surface soil sample $0.0-0.5 \mathrm{ft}$ & & & & & & & 1 & & \\
\hline $11 / 23 / 99$ & RR-S14 & 587336 & 2440119 & Surface soil sample $0.0-0.5 \mathrm{ft}$ & & & 1 & 1 & 1 & 1 & 1 & & \\
\hline $01 / 26 / 00$ & RR-SS14 & 587336 & 2440119 & Subsurface soil sample $0.5-2.0 \mathrm{ft}$ & & & 1 & 1 & 1 & 1 & 1 & & \\
\hline $03 / 10 / 98$ & 144 & 586766 & 2440242 & Grab sample (sediment) French drain & & & & & 1 & & & & \\
\hline $03 / 10 / 98$ & 145 & 586813 & 2440029 & Grab sample (sediment) French drain & & & & & 1 & & & & \\
\hline $03 / 10 / 98$ & 235 & 587264 & 2440303 & Grab sample (sediment) test pit & & & & & 1 & & & & \\
\hline $3 / 10 / 1998$ & 236 & 586605 & 2440301 & Grab Sample (sediment) test pit & & & & & 1 & & & & \\
\hline \multicolumn{5}{|r|}{ Total historic samples } & & 0 & 2 & 2 & 6 & 2 & 12 & & \\
\hline
\end{tabular}

DVS = Dynamic Verification Strategy

$\mathrm{EU}=$ exposure unit

$\mathrm{HA}=$ hand auger

ID $=$ identification
$\mathrm{PCB}=$ polychlorinated biphenyl

$\mathrm{RAD}=$ radiological

VOC $=$ volatile organic compound

$\mathrm{SVOC}=$ semivolatile organic compound 
Table B.3. EU Z2-03, depth 0-10 ft

\begin{tabular}{|c|c|c|c|c|c|c|c|c|c|c|c|c|c|}
\hline Analyte & $\begin{array}{c}\text { Frequency } \\
\text { of detect }\end{array}$ & $\begin{array}{c}\text { Minimum } \\
\text { detect }\end{array}$ & $\underset{\text { detect }}{\text { Maximum }}$ & $\begin{array}{c}\text { Location(s) } \\
\text { of maximum } \\
\text { detected result }\end{array}$ & $\begin{array}{l}\text { Average } \\
\text { detected } \\
\text { result }\end{array}$ & $\begin{array}{c}\text { Max } \\
\text { RL }\end{array}$ & $\begin{array}{l}\text { Frequency of detects } \\
\text { exceeding Max RL }\end{array}$ & Avg RL & $\begin{array}{c}\text { Frequency of } \\
\text { detects exceeding } \\
\text { Avg RL }\end{array}$ & $\begin{array}{l}\text { PRG limit } \\
\left(10^{-5} \text { or } 1\right)\end{array}$ & $\begin{array}{l}\text { Frequency of detects } \\
\text { exceeding PRG limit }\end{array}$ & $\begin{array}{c}\text { Background } \\
\text { concentration }\end{array}$ & $\begin{array}{l}\text { Frequency of detects } \\
\text { exceeding background }\end{array}$ \\
\hline \multicolumn{14}{|l|}{ Inorganics $(\mathrm{mg} / \mathrm{kg})$} \\
\hline Aluminum & $8 / 8$ & 2490 & 52,000 & RR-S14 & $16,412.5$ & & $\mathrm{NA}$ & & NA & $1.0 \mathrm{E}+05$ & $0 / 8$ & 40300 & $1 / 8$ \\
\hline Antimony & $6 / 8$ & $0.059 \mathrm{~J}$ & $260 \mathrm{~J}$ & Z2-EU3B-304 & 80.77 & & NA & & NA & 4.1E+02 & $0 / 8$ & 1.52 & $3 / 8$ \\
\hline Arsenic & $7 / 8$ & $0.61 \mathrm{~J}$ & 24.9 & Z2-EU3B-304 & 13.73 & 900 & $0 / 8$ & 300 & $0 / 8$ & $1.6 \mathrm{E}+01$ & $3 / 8$ & 14.95 & $4 / 8$ \\
\hline Barium & $8 / 8$ & 28.1 & 169 & Z2-EU3B-304 & 78.51 & & NA & & NA & $6.7 \mathrm{E}+04$ & $0 / 8$ & 124.93 & $1 / 8$ \\
\hline Beryllium & $7 / 8$ & $0.17 \mathrm{~J}$ & $1 \mathrm{~J}$ & Z2-EU3B-306 & 0.52 & 6,000 & $0 / 8$ & 2,000 & $0 / 8$ & $1.9 \mathrm{E}+03$ & $0 / 8$ & 2.2 & $0 / 8$ \\
\hline Boron & $3 / 6$ & $7 \mathrm{~J}$ & 31.7 & Z2-EU3B-304 & 17.17 & & NA & & NA & $1.0 \mathrm{E}+05$ & $0 / 6$ & & NA \\
\hline Cadmium & $7 / 8$ & $0.019 \mathrm{~J}$ & $76.4 \mathrm{~J}$ & Z2-EU3B-304 & 19.27 & & NA & & NA & $4.5 \mathrm{E}+02$ & $0 / 8$ & $0.22 \mathrm{U}$ & $4 / 8$ \\
\hline Calcium & $8 / 8$ & 673 & $301,000 \mathrm{~J}$ & Z2-EU3-223 & $100,556.6$ & & NA & & NA & & NA & 2400 & $5 / 8$ \\
\hline Chromium & $8 / 8$ & $5.3 \mathrm{~J}$ & $227 \mathrm{~J}$ & Z2-EU3B-304 & 65.95 & & NA & & NA & $6.4 \mathrm{E}+02$ & $0 / 8$ & 44.88 & $4 / 8$ \\
\hline Cobalt & $8 / 8$ & 2 & $24.6 \mathrm{~J}$ & Z2-EU3B-304 & 9.77 & & NA & & NA & $1.3 \mathrm{E}+04$ & $0 / 8$ & 42 & $0 / 8$ \\
\hline Copper & $8 / 8$ & 3.4 & 11,900 & Z2-EU3B-304 & $1,552.69$ & & NA & & NA & $4.1 \mathrm{E}+04$ & $0 / 8$ & 22.48 & $3 / 8$ \\
\hline Iron & $8 / 8$ & 4310 & $109,000 \mathrm{~J}$ & Z2-EU3B-304 & $32,672.5$ & & NA & & NA & $1.0 \mathrm{E}+05$ & $1 / 8$ & 58600 & $1 / 8$ \\
\hline Lead & $8 / 8$ & 9.1 & 9,560 & Z2-EU3B-304 & $2,198.63$ & & NA & & NA & $8.0 \mathrm{E}+02$ & $3 / 8$ & 37.91 & $3 / 8$ \\
\hline Lithium & $5 / 6$ & $7.2 \mathrm{~J}$ & $20 \mathrm{~J}$ & Z2-EU3B-304 & 11.8 & & NA & & NA & $2.0 \mathrm{E}+04$ & $0 / 6$ & 48.94 & $0 / 6$ \\
\hline Magnesium & $8 / 8$ & $490 \mathrm{~J}$ & $53,800 \mathrm{~J}$ & Z2-EU3-224 & $13,047.5$ & & NA & & NA & & NA & 3300 & $5 / 8$ \\
\hline Manganese & $8 / 8$ & $114 \mathrm{~J}$ & 746 & Z2-EU3-223 & 293.88 & & NA & & NA & $1.9 \mathrm{E}+04$ & $0 / 8$ & 2200 & $0 / 8$ \\
\hline Mercury & $8 / 8$ & $0.021 \mathrm{~J}$ & $2.3 \mathrm{~J}$ & Z2-EU3B-305 & 0.69 & 1,800 & $0 / 8$ & 600 & $0 / 8$ & $3.1 \mathrm{E}+02$ & $0 / 8$ & 0.17 & $3 / 8$ \\
\hline Molybdenum & $4 / 6$ & $0.69 \mathrm{~J}$ & 11.2 & Z2-EU3B-304 & 3.82 & & NA & 000 & NA & $5.1 \mathrm{E}+03$ & $0 / 6$ & 0.11 & NA \\
\hline Nickel & $8 / 8$ & $4.5 \mathrm{~J}$ & $269 \mathrm{~J}$ & Z2-EU3B-306 & 75.03 & & NA & & NA & $2.0 \mathrm{E}+04$ & $0 / 8$ & 26.07 & $3 / 8$ \\
\hline Potassium & $8 / 8$ & $370 \mathrm{~J}$ & 4,030 & RR-S14 & $1,396.5$ & & NA & & NA & & NA & 5074.69 & $0 / 8$ \\
\hline Selenium & $4 / 8$ & $0.83 \mathrm{~J}$ & $7.14 \mathrm{~J}$ & RR-S14 & 2.74 & & NA & & NA & $5.1 \mathrm{E}+03$ & $0 / 8$ & 1.47 & $2 / 8$ \\
\hline Silver & $6 / 8$ & $0.021 \mathrm{~J}$ & 4.8 & Z2-EU3B-306 & 1.78 & & NA & & NA & $5.1 \mathrm{E}+03$ & $0 / 8$ & $0.6 \mathrm{U}$ & $3 / 8$ \\
\hline Sodium & $8 / 8$ & 17.6 & $116 \mathrm{~J}$ & $\begin{array}{c}\text { RR-S14 } \\
\text { Z2-EU3B-304 }\end{array}$ & 80.89 & & NA & & NA & & NA & 497 & $0 / 8$ \\
\hline Thallium & $0 / 8$ & ND & ND & & ND & & NA & & NA & $6.7 \mathrm{E}+01$ & $0 / 8$ & $0.4 \mathrm{U}$ & $0 / 8$ \\
\hline Uranium & $6 / 6$ & 0.33 & 7.5 & Z2-EU3B-305 & 4.16 & & NA & & NA & $2.0 \mathrm{E}+02$ & $0 / 6$ & & NA \\
\hline Vanadium & $8 / 8$ & 5.7 & 78.7 & RR-S14 & 28.31 & & NA & & NA & $1.0 \mathrm{E}+03$ & $0 / 8$ & 65.47 & $1 / 8$ \\
\hline Zinc & $8 / 8$ & $14.2 \mathrm{~J}$ & $14,800 \mathrm{~J}$ & Z2-EU3B-306 & $3,338.63$ & & NA & & NA & $1.0 \mathrm{E}+05$ & $0 / 8$ & 89.7 & $4 / 8$ \\
\hline \multicolumn{14}{|l|}{ Radionuclides (pCi/g) } \\
\hline Actinium-228 & $6 / 6$ & 0.4 & $1.26 \mathrm{~J}$ & RAD156 & 0.77 & & NA & & $\mathrm{NA}$ & $1.2 \mathrm{E}+04$ & $0 / 6$ & & NA \\
\hline Alpha activity & $3 / 3$ & 21.3 & 30.4 & Z2-EU3B-303 & 27.33 & & NA & & NA & & NA & & NA \\
\hline Beta activity & $3 / 3$ & 25.9 & $\begin{array}{l}50.4 \\
35.2 \mathrm{~J}\end{array}$ & Z2-EU3B-303 & 31.17 & & NA & & NA & & NA & & NA \\
\hline Bismuth-214 & $6 / 6$ & 0.312 & $0.7 \mathrm{~J}$ & RAD156 & 0.51 & & NA & & NA & $1.3 \mathrm{E}+05$ & $0 / 6$ & & NA \\
\hline Cesium 134 & $4 / 6$ & 0.001 & 0.029 & RAD157 & 0.01 & & $\mathrm{NA}$ & & NA & $2.6 \mathrm{E}+00$ & $0 / 6$ & & NA \\
\hline Cesium-137 & $11 / 15$ & $0.04 \mathrm{~J}$ & 4.06 & RAD157 & 0.83 & 20 & $0 / 15$ & 2 & $1 / 15$ & $1.1 \mathrm{E}+00$ & $1 / 15$ & & NA \\
\hline Cobalt-57 & $4 / 6$ & 0.001 & 0.011 & RAD141 & 0.01 & & NA & & NA & 1.4E+02 & $0 / 6$ & & NA \\
\hline Cobalt-60 & $6 / 15$ & 0.007 & 0.31 & KAA-SS-S11 & 0.07 & & NA & & NA & $6.0 \mathrm{E}-01$ & $0 / 15$ & & NA \\
\hline Lead-212 & $6 / 6$ & 0.315 & $1.13 \mathrm{~J}$ & RAD156 & 0.75 & & NA & & NA & $6.1 \mathrm{E}+04$ & $0 / 6$ & & NA \\
\hline Lead-214 & $6 / 6$ & 0.363 & $0.896 \mathrm{~J}$ & RAD156 & 0.63 & & NA & & $\mathrm{NA}$ & $7.5 \mathrm{E}+05$ & $0 / 6$ & & NA \\
\hline Neptunium-237 & $4 / 10$ & 0.003 & 0.038 & RAD156 & 0.02 & 50 & $0 / 10$ & 5 & $0 / 10$ & $2.7 \mathrm{E}+00$ & $0 / 10$ & & NA \\
\hline $\begin{array}{l}\text { Plutonium-238 } \\
\text { Plut }\end{array}$ & $3 / 7$ & 0.004 & 0.098 & KAA-SS-S11 & 0.04 & & NA & & NA & $1.7 \mathrm{E}+02$ & $0 / 7$ & & NA \\
\hline Plutonium 239 & $4 / 7$ & 0.004 & 0.032 & RAD141 & 0.02 & & NA & & NA & $1.5 \mathrm{E}+02$ & $0 / 7$ & & NA \\
\hline Potassium-40 & $11 / 11$ & 5.82 & $16.1 \mathrm{~J}$ & RAD156 & 11.5 & & NA & & NA & $2.7 \mathrm{E}+00$ & $11 / 11$ & 32.12 & $0 / 11$ \\
\hline Protactinium $234 \mathrm{~m}$ & $0 / 1$ & ND & ND & & ND & & NA & & NA & $2.5 \mathrm{E}+08$ & $0 / 1$ & & $\mathrm{NA}$ \\
\hline $\mathrm{Ra} / \mathrm{Th}$ decay series & $13 / 13$ & 0 & 0.99 & RAD156 & 0.12 & 15 & $0 / 13$ & 5 & $0 / 13$ & & NA & & NA \\
\hline Radium-226 & $6 / 9$ & 0.75 & $2.24 \mathrm{~J}$ & RAD156 & 1.1 & 15 & $\mathrm{NA}^{\mathrm{a}}$ & 5 & $\mathrm{NA}^{a}$ & $2.6 \mathrm{E}-01$ & $6 / 9$ & 1.25 & $1 / 9$ \\
\hline Technetium-99 & $4 / 15$ & 0.02 & 0.38 & Z2-EU3B-303 & 0.16 & & $\mathrm{NA}$ & & NA & $8.9 \mathrm{E}+03$ & $0 / 15$ & & NA \\
\hline Thallium 208 & $6 / 6$ & 0.1 & $0.365 \mathrm{~J}$ & RAD156 & 0.23 & & NA & & NA & $3.7 \mathrm{E}+05$ & $0 / 6$ & & NA \\
\hline Thorium-228 & $13 / 13$ & $0.01 \mathrm{~J}$ & 1.2 & Z2-EU3B-307 & 0.59 & & $\mathrm{NA}$ & & NA & $1.7 \mathrm{E}-01$ & $10 / 13^{b}$ & 1.86 & $0 / 13$ \\
\hline Thorium-230 & $10 / 13$ & $0.02 \mathrm{~J}$ & 1.58 & RAD167 & 0.73 & 15 & $\mathrm{NA}^{\mathrm{a}}$ & 5 & $\mathrm{NA}^{a}$ & $2.1 \mathrm{E}+02$ & $0 / 13$ & 1.2 & $2 / 13$ \\
\hline Thorium 232 & $13 / 13$ & $0.01 \mathrm{~J}$ & $\begin{array}{l}1.00 \\
1.27\end{array}$ & Z2-EU3B-307 & 0.61 & 15 & $\mathrm{NA}^{\mathrm{a}}$ & 5 & $\mathrm{NA}^{a}$ & $1.7 \mathrm{E}-01$ & $10 / 13^{b}$ & $\begin{array}{l}1.2 \\
1.95\end{array}$ & $0 / 13$ \\
\hline Thorium 234 & $8 / 10$ & 0.64 & $2.38 \mathrm{~J}$ & RR-SS14 & 1.46 & & NA & & NA & $3.3 \mathrm{E}+04$ & $0 / 10$ & & NA \\
\hline Total Activity & $\begin{array}{l}1 / 1 \\
1 / 1\end{array}$ & $9.97 \mathrm{~J}$ & $9.97 \mathrm{~J}$ & RR-SS14 & $\begin{array}{l}1.40 \\
9.97\end{array}$ & & NA & & NA & J.JL+V4 & NA & & NA \\
\hline
\end{tabular}


Table B.3. (continued)

\begin{tabular}{|c|c|c|c|c|c|c|c|c|c|c|c|c|c|}
\hline Analyte & $\begin{array}{r}\begin{array}{r}\text { Frequency } \\
\text { of detect }\end{array} \\
\end{array}$ & $\begin{array}{c}\text { Minimum } \\
\text { detect }\end{array}$ & $\begin{array}{c}\text { Maximum } \\
\text { detect }\end{array}$ & $\begin{array}{c}\text { Location(s) } \\
\text { of maximum } \\
\text { detected result }\end{array}$ & $\begin{array}{c}\text { Average } \\
\text { detected } \\
\text { result }\end{array}$ & $\begin{array}{c}\text { Max } \\
\text { RL }\end{array}$ & $\begin{array}{l}\text { Frequency of detects } \\
\text { exceeding Max RL }\end{array}$ & Avg RL & $\begin{array}{c}\begin{array}{c}\text { Frequency of } \\
\text { detects exceeding } \\
\text { Avg RL }\end{array} \\
\end{array}$ & $\begin{array}{l}\text { PRG limit } \\
\left(10^{-5} \text { or } 1\right)\end{array}$ & $\begin{array}{l}\text { Frequency of detects } \\
\text { exceeding PRG limit }\end{array}$ & $\begin{array}{c}\text { Background } \\
\text { concentration }\end{array}$ & $\begin{array}{l}\text { Frequency of detects } \\
\text { exceeding background }\end{array}$ \\
\hline Uranium-234 & $10 / 15$ & $0.11 \mathrm{~J}$ & 1.46 & Z2-EU3B-307 & 0.8 & 7,000 & $0 / 15$ & 700 & $0 / 15$ & $3.3 \mathrm{E}+02$ & $0 / 15$ & & NA \\
\hline Uranium-235 & $12 / 15$ & $0.01 \mathrm{~J}$ & $0.26 \mathrm{~J}$ & KA36155001-21 & 0.08 & 80 & $0 / 15$ & 8 & $0 / 15$ & $3.9 \mathrm{E}+00$ & $0 / 15$ & & NA \\
\hline Uranium-236 & $0 / 2$ & ND & ND & & ND & & NA & & NA & $3.6 \mathrm{E}+02$ & $0 / 2$ & & NA \\
\hline Uranium-238 & $15 / 15$ & $0.09 \mathrm{~J}$ & 1.24 & Z2-EU3B-307 & 0.74 & 500 & $0 / 15$ & 50 & $0 / 15$ & $1.8 \mathrm{E}+01$ & $0 / 15$ & 1.47 & $0 / 15$ \\
\hline \multicolumn{14}{|c|}{ Organics, Pesticides, and PCBs (ug/kg) } \\
\hline PCB-1016 & $1 / 17$ & $24 \mathrm{~J}$ & $24 \mathrm{~J}$ & RR-S14 & 24 & 100,000 & $0 / 17$ & 10,000 & $0 / 17$ & $3.7 \mathrm{E}+04$ & $0 / 17$ & & NA \\
\hline PCB-1221 & $0 / 17$ & $\mathrm{ND}$ & $\mathrm{ND}$ & & $\mathrm{ND}$ & 100,000 & $0 / 17$ & 10,000 & $0 / 17$ & $7.4 \mathrm{E}+03$ & $0 / 17$ & & NA \\
\hline PCB-1232 & $0 / 17$ & ND & ND & & ND & 100,000 & $0 / 17$ & 10,000 & $0 / 17$ & $7.4 \mathrm{E}+03$ & $0 / 17$ & & NA \\
\hline $\begin{array}{l}\text { PCB-1242 } \\
\text { PCD }\end{array}$ & $0 / 17$ & $\mathrm{ND}$ & $\mathrm{ND}$ & & ND & 100,000 & $0 / 17$ & 10,000 & $0 / 17$ & 7.4E+03 & $0 / 17$ & & NA \\
\hline PCB-1248 & $0 / 17$ & ND & ND & & ND & 100,000 & $0 / 17$ & 10,000 & $0 / 17$ & $7.4 \mathrm{E}+03$ & $0 / 17$ & & NA \\
\hline PCB-1254 & $3 / 17$ & $150 \mathrm{~J}$ & 1,200 & Z2-EU3B-301 & 560 & 100,000 & $0 / 17$ & 10,000 & $0 / 17$ & $7.4 \mathrm{E}+03$ & $0 / 17$ & & NA \\
\hline PCB-1260 & $5 / 17$ & $84 \mathrm{~J}$ & $330 \mathrm{~J}$ & Z2-EU3B-305 & 198.8 & 100,000 & $0 / 17$ & 10,000 & $0 / 17$ & $7.4 \mathrm{E}+03$ & $0 / 17$ & & $\mathrm{NA}$ \\
\hline PCB & $5 / 11$ & $84 \mathrm{~J}$ & 1,200 & Z2-EU3B-301 & 472.8 & 100,000 & $0 / 11$ & 10,000 & $0 / 11$ & $7.4 \mathrm{E}+03$ & $0 / 11$ & & NA \\
\hline \multicolumn{14}{|l|}{ Semivolatile Organics (ug/kg) } \\
\hline $1,2,4$ Trichlorobenzene & $0 / 10$ & $\mathrm{ND}$ & ND & & $\mathrm{ND}$ & & NA & & NA & $2.2 \mathrm{E}+05$ & $0 / 10$ & & $\mathrm{NA}$ \\
\hline 1,2-Dichlorobenzene & $0 / 10$ & $\mathrm{ND}$ & $\mathrm{ND}$ & & ND & & NA & & NA & $6.0 \mathrm{E}+05$ & $0 / 10$ & & NA \\
\hline 1,3-Dichlorobenzene & $0 / 10$ & ND & ND & & ND & & NA & & NA & $6.0 \mathrm{E}+05$ & $0 / 10$ & & NA \\
\hline 1,4-Dichlorobenzene & $0 / 10$ & ND & ND & & ND & & NA & & NA & $7.9 \mathrm{E}+04$ & $0 / 10$ & & NA \\
\hline 2,2'-Dichlorodiisopropyl ether & $0 / 2$ & ND & ND & & ND & & NA & & NA & & NA & & NA \\
\hline 2,3,4,6-Tetrachlorophenol & $0 / 8$ & ND & ND & & ND & & NA & & NA & $1.8 \mathrm{E}+07$ & $0 / 8$ & & NA \\
\hline 2,4,5-Trichlorophenol & $0 / 10$ & $\mathrm{ND}$ & $\mathrm{ND}$ & & $\mathrm{ND}$ & & NA & & NA & $6.2 \mathrm{E}+07$ & $0 / 10$ & & NA \\
\hline 2,4,6-Trichlorophenol & $0 / 10$ & ND & ND & & ND & & NA & & NA & $6.2 \mathrm{E}+04$ & $0 / 10$ & & NA \\
\hline 2,4-Dichlorophenol & $0 / 10$ & ND & ND & & ND & & NA & & NA & $1.8 \mathrm{E}+06$ & $0 / 10$ & & NA \\
\hline 2,4-Dimethylphenol & $0 / 10$ & ND & ND & & ND & & NA & & NA & $1.2 \mathrm{E}+07$ & $0 / 10$ & & NA \\
\hline 2,4-Dinitrophenol & $0 / 10$ & $\mathrm{ND}$ & ND & & ND & & NA & & NA & $1.2 \mathrm{E}+06$ & $0 / 10$ & & NA \\
\hline 2,4-Dinitrotoluene & $0 / 10$ & ND & ND & & ND & & NA & & NA & $2.5 \mathrm{E}+04$ & $0 / 10$ & & NA \\
\hline 2,6-Dinitrotoluene & $0 / 10$ & ND & ND & & ND & & NA & & NA & $2.5 \mathrm{E}+04$ & $0 / 10$ & & NA \\
\hline 2-Chloronaphthalene & $0 / 10$ & ND & ND & & $\mathrm{ND}$ & & NA & & NA & $2.3 \mathrm{E}+07$ & $0 / 10$ & & NA \\
\hline 2-Chlorophenol & $0 / 10$ & $\mathrm{ND}$ & ND & & ND & & NA & & NA & $2.4 \mathrm{E}+05$ & $0 / 10$ & & NA \\
\hline 2-Methyl-4,6-dinitrophenol & $0 / 10$ & $\mathrm{ND}$ & $\mathrm{ND}$ & & $\mathrm{ND}$ & & NA & & NA & $6.2 \mathrm{E}+04$ & $0 / 10$ & & NA \\
\hline 2-Methylnaphthalene & $0 / 10$ & ND & ND & & ND & & NA & & NA & $1.9 \mathrm{E}+05$ & $0 / 10$ & & NA \\
\hline 2-Methylphenol & $1 / 10$ & 1,800 & 1,800 & Z2-EU3B-304 & 1,800 & & NA & & NA & $3.1 \mathrm{E}+07$ & $0 / 10$ & & NA \\
\hline 2-Nitrobenzenamine & $0 / 10$ & ND & ND & & ND & & NA & & NA & $1.8 \mathrm{E}+06$ & $0 / 10$ & & NA \\
\hline 2-Nitrophenol & $0 / 10$ & ND & $\mathrm{ND}$ & & $\mathrm{ND}$ & & NA & & NA & & NA & & NA \\
\hline 3,3'-Dichlorobenzidine & $0 / 10$ & $\mathrm{ND}$ & $\mathrm{ND}$ & & $\mathrm{ND}$ & & NA & & NA & $3.8 \mathrm{E}+04$ & $0 / 10$ & & NA \\
\hline 3-Methylphenol & $0 / 2$ & ND & ND & & ND & & NA & & NA & $3.1 \mathrm{E}+07$ & $0 / 2$ & & NA \\
\hline 3-Nitrobenzenamine & $0 / 10$ & ND & ND & & ND & & NA & & NA & $1.8 \mathrm{E}+05$ & $0 / 10$ & & NA \\
\hline 4-Bromophenyl phenyl ether & $0 / 10$ & ND & ND & & ND & & NA & & NA & & $\mathrm{NA}$ & & NA \\
\hline 4-Chloro-3-methylphenol & $0 / 10$ & ND & ND & & ND & & NA & & NA & & NA & & NA \\
\hline 4-Chlorobenzenamine & $0 / 10$ & ND & ND & & $\mathrm{ND}$ & & NA & & NA & $2.5 \mathrm{E}+06$ & $0 / 10$ & & NA \\
\hline 4-Chlorophenyl phenyl ether & $0 / 10$ & ND & ND & & ND & & NA & & NA & & NA & & NA \\
\hline 4-Methylphenol & $0 / 8$ & $\mathrm{ND}$ & $\mathrm{ND}$ & & ND & & NA & & NA & $3.1 \mathrm{E}+06$ & $0 / 8$ & & NA \\
\hline 4-Nitrobenzenamine & $0 / 10$ & ND & ND & & ND & & NA & & NA & $8.2 \mathrm{E}+05$ & $0 / 10$ & & NA \\
\hline 4-Nitrophenol & $0 / 10$ & $\mathrm{ND}$ & $\mathrm{ND}$ & & $\mathrm{ND}$ & & NA & & NA & & NA & & NA \\
\hline Acenaphthene & $3 / 10$ & $100 \mathrm{~J}$ & $210 \mathrm{~J}$ & Z2-EU3B-304 & 146.67 & & NA & & NA & $2.9 \mathrm{E}+07$ & $0 / 10$ & & NA \\
\hline Acenaphthylene & $1 / 10$ & $140 \mathrm{~J}$ & $140 \mathrm{~J}$ & Z2-EU3B-305 & 140 & & NA & & NA & $2.9 \mathrm{E}+07$ & $0 / 10$ & & NA \\
\hline Aniline & $0 / 8$ & ND & ND & & $\mathrm{ND}$ & & NA & & NA & $3.0 \mathrm{E}+06$ & $0 / 8$ & & NA \\
\hline Anthracene & $3 / 10$ & $200 \mathrm{~J}$ & $270 \mathrm{~J}$ & $\begin{array}{l}\text { Z2-EU3B-305 } \\
\text { Z2-EU3B-306 }\end{array}$ & 246.67 & & NA & & NA & $1.0 \mathrm{E}+08$ & $0 / 10$ & & NA \\
\hline Benz(a)anthracene & $4 / 10$ & $220 \mathrm{~J}$ & 1,300 & $\begin{array}{l}\text { Z2-EU3B-304 } \\
\text { Z2-EU3B-306 }\end{array}$ & 947.5 & & NA & & NA & $2.1 \mathrm{E}+04$ & $0 / 10$ & & NA \\
\hline Benzenemethanol & $0 / 8$ & $\mathrm{ND}$ & ND & & ND & & NA & & NA & $1.0 \mathrm{E}+08$ & $0 / 8$ & & NA \\
\hline Benzo(a)pyrene & $3 / 10$ & 950 & 1,200 & Z2-EU3B-306 & $1,083.33$ & & NA & & NA & $2.1 \mathrm{E}+03$ & $0 / 10$ & & NA \\
\hline Benzo(b)fluoranthene & $4 / 10$ & $340 \mathrm{~J}$ & 1,500 & Z2-EU3B-306 & 1085 & & NA & & NA & $2.1 \mathrm{E}+04$ & $0 / 10$ & & NA \\
\hline Benzo(ghi)perylene & $3 / 10$ & $610 \mathrm{~J}$ & $770 \mathrm{~J}$ & Z2-EU3B-306 & 696.67 & & NA & & NA & $2.9 \mathrm{E}+07$ & $0 / 10$ & & NA \\
\hline Benzo(k)fluoranthene & $3 / 10$ & 1,100 & 1,400 & Z2-EU3B-304 & $1,233.33$ & & NA & & NA & $2.1 \mathrm{E}+05$ & $0 / 10$ & & NA \\
\hline
\end{tabular}


Table B.3. (continued)

\begin{tabular}{|c|c|c|c|c|c|c|c|c|c|c|c|c|c|}
\hline Analyte & $\begin{array}{c}\text { Frequency } \\
\text { of detect }\end{array}$ & $\begin{array}{c}\text { Minimum } \\
\text { detect }\end{array}$ & $\begin{array}{c}\text { Maximum } \\
\text { detect }\end{array}$ & $\begin{array}{c}\text { Location(s) } \\
\text { of maximum } \\
\text { detected result }\end{array}$ & $\begin{array}{l}\text { Average } \\
\text { detected } \\
\text { result }\end{array}$ & $\underset{\mathbf{R L}}{\operatorname{Max}}$ & $\begin{array}{l}\text { Frequency of detects } \\
\text { exceeding Max RL }\end{array}$ & $\operatorname{Avg}$ RL & $\begin{array}{c}\text { Frequency of } \\
\text { detects exceeding } \\
\text { Avg RL }\end{array}$ & $\begin{array}{l}\text { PRG limit } \\
\left(10^{-5} \text { or } 1\right)\end{array}$ & $\begin{array}{l}\text { Frequency of detects } \\
\text { exceeding PRG limit }\end{array}$ & $\begin{array}{c}\text { Background } \\
\text { concentration }\end{array}$ & $\begin{array}{l}\text { Frequency of detects } \\
\text { exceeding background }\end{array}$ \\
\hline Benzoic acid & $1 / 8$ & $4,200 \mathrm{~J}$ & $4,200 \mathrm{~J}$ & Z2-EU3B-304 & 4200 & & NA & & NA & $1.0 \mathrm{E}+08$ & $0 / 8$ & & NA \\
\hline $\operatorname{Bis}(2$-chloroethoxy)methane & $0 / 10$ & $\mathrm{ND}$ & $\mathrm{ND}$ & & ND & & NA & & NA & & NA & & NA \\
\hline Bis(2-chloroethyl) ether & $0 / 10$ & ND & ND & & ND & & NA & & NA & $5.8 \mathrm{E}+03$ & $0 / 10$ & & NA \\
\hline $\begin{array}{l}\mathrm{Bis}(2 \text {-chloroisopropyl) ether }\end{array}$ & $0 / 8$ & $\mathrm{ND}$ & $\mathrm{ND}$ & & $\mathrm{ND}$ & & NA & & NA & $7.4 \mathrm{E}+04$ & $0 / 8$ & & NA \\
\hline $\begin{array}{l}\text { Bis(2-ethylhexyl)phthalate } \\
\text { Dis }\end{array}$ & $5 / 10$ & $72 \mathrm{~J}$ & 93,000 & Z2-EU3B-304 & $19,120.4$ & & NA & & NA & $1.2 \mathrm{E}+06$ & $0 / 10$ & & NA \\
\hline Butyl benzyl phthalate & $3 / 10$ & $350 \mathrm{~J}$ & 8,700 & Z2-EU3B-302 & 3,450 & & NA & & NA & $1.0 \mathrm{E}+08$ & $0 / 10$ & & NA \\
\hline Carbazole & $3 / 10$ & $210 \mathrm{~J}$ & $340 \mathrm{~J}$ & Z2-EU3B-306 & 283.33 & & $\mathrm{NA}$ & & NA & $8.6 \mathrm{E}+05$ & $0 / 10$ & & NA \\
\hline Chrysene & $4 / 10$ & $730 \mathrm{~J}$ & 1,800 & Z2-EU3B-304 & 1307.5 & & NA & & NA & $2.1 \mathrm{E}+06$ & $0 / 10$ & & NA \\
\hline Di-n-butyl phthalate & $2 / 4$ & $290 \mathrm{~J}$ & $450 \mathrm{~J}$ & Z2-EU3B-302 & 370 & & NA & & NA & $6.2 \mathrm{E}+07$ & $0 / 4$ & & NA \\
\hline Di-n-octylphthalate & $0 / 10$ & ND & $\mathrm{ND}$ & & $\mathrm{ND}$ & & NA & & NA & $2.5 \mathrm{E}+07$ & $0 / 10$ & & NA \\
\hline Dibenz $(\mathrm{a}, \mathrm{h})$ anthracene & $1 / 10$ & $260 \mathrm{~J}$ & $260 \mathrm{~J}$ & Z2-EU3B-306 & 260 & & NA & & NA & $2.1 \mathrm{E}+03$ & $0 / 10$ & & NA \\
\hline Dibenzofuran & $0 / 10$ & $\mathrm{ND}$ & ND & & ND & & NA & & NA & $1.6 \mathrm{E}+06$ & $0 / 10$ & & NA \\
\hline Diethyl phthalate & $0 / 10$ & ND & ND & & ND & & NA & & NA & $1.0 \mathrm{E}+08$ & $0 / 10$ & & NA \\
\hline Dimethyl phthalate & $0 / 10$ & ND & ND & & ND & & NA & & NA & $1.0 \mathrm{E}+08$ & $0 / 10$ & & NA \\
\hline Diphenylamine & $0 / 2$ & ND & ND & & ND & & NA & & NA & $1.5 \mathrm{E}+07$ & $0 / 2$ & & NA \\
\hline Diphenyldiazene & $0 / 2$ & ND & $\mathrm{ND}$ & & ND & & NA & & NA & $1.6 \mathrm{E}+05$ & $0 / 2$ & & NA \\
\hline Fluoranthene & $6 / 10$ & $41 \mathrm{~J}$ & 4,000 & Z2-EU3B-304 & $1,846.83$ & & NA & & NA & $2.2 \mathrm{E}+07$ & $0 / 10$ & & NA \\
\hline Fluorene & $2 / 10$ & $110 \mathrm{~J}$ & $150 \mathrm{~J}$ & Z2-EU3B-304 & 130 & & NA & & NA & $2.6 \mathrm{E}+07$ & $0 / 10$ & & NA \\
\hline Hexachlorobenzene & $0 / 10$ & $\mathrm{ND}$ & ND & LL-EUDD-JU4 & $\mathrm{ND}$ & & NA & & NA & $1.1 \mathrm{E}+04$ & $0 / 10$ & & NA \\
\hline Hexachlorobutadiene & $0 / 10$ & $\mathrm{ND}$ & $\mathrm{ND}$ & & ND & & NA & & NA & $1.8 \mathrm{E}+05$ & $0 / 10$ & & NA \\
\hline Hexachlorocyclopentadiene & $0 / 10$ & ND & ND & & ND & & NA & & NA & $3.7 \mathrm{E}+06$ & $0 / 10$ & & NA \\
\hline Hexachloroethane & $0 / 10$ & ND & ND & & ND & & NA & & NA & $6.2 \mathrm{E}+05$ & $0 / 10$ & & NA \\
\hline Indeno( $(1,2,3$-cd $)$ pyrene & $3 / 10$ & $550 \mathrm{~J}$ & $690 \mathrm{~J}$ & Z2-EU3B-306 & 616.67 & & NA & & NA & $2.1 \mathrm{E}+04$ & $0 / 10$ & & NA \\
\hline Isophorone & $0 / 10$ & ND & ND & & ND & & NA & & NA & $5.1 \mathrm{E}+06$ & $0 / 10$ & & NA \\
\hline N-Nitroso-di-n-propylamine & $0 / 10$ & ND & ND & & ND & & NA & & NA & $2.5 \mathrm{E}+03$ & $0 / 10$ & & NA \\
\hline N-Nitrosodimethylamine & $0 / 2$ & $\mathrm{ND}$ & $\mathrm{ND}$ & & $\mathrm{ND}$ & & NA & & NA & $3.4 \mathrm{E}+02$ & $0 / 2$ & & NA \\
\hline N-Nitrosodiphenylamine & $0 / 8$ & ND & ND & & ND & & NA & & NA & $3.5 \mathrm{E}+06$ & $0 / 8$ & & NA \\
\hline Naphthalene & $0 / 10$ & $\mathrm{ND}$ & $\mathrm{ND}$ & & ND & & NA & & NA & $1.9 \mathrm{E}+05$ & $0 / 10$ & & NA \\
\hline Nitrobenzene & $0 / 10$ & $\mathrm{ND}$ & $\mathrm{ND}$ & & ND & & NA & & NA & $1.0 \mathrm{E}+05$ & $0 / 10$ & & NA \\
\hline Pentachlorophenol & $0 / 10$ & ND & ND & & ND & & NA & & NA & $9.0 \mathrm{E}+04$ & $0 / 10$ & & NA \\
\hline Phenanthrene & $4 / 10$ & $190 \mathrm{~J}$ & 2,100 & Z2-EU3B-304 & $1,267.5$ & & NA & & NA & $2.9 \mathrm{E}+07$ & $0 / 10$ & & NA \\
\hline Phenol & $1 / 10$ & $220 \mathrm{~J}$ & $220 \mathrm{~J}$ & Z2-EU3B-304 & 220 & & NA & & NA & $1.0 \mathrm{E}+08$ & $0 / 10$ & & NA \\
\hline $\begin{array}{l}\text { Pyrene } \\
\text { Pron }\end{array}$ & $7 / 10$ & $42 \mathrm{~J}$ & 3700 & Z2-EU3B-304 & $1,349.43$ & & NA & & NA & $2.9 \mathrm{E}+07$ & $0 / 10$ & & NA \\
\hline \multirow{2}{*}{\multicolumn{14}{|c|}{$\begin{array}{l}\text { Pyridine } \\
\text { Volatile Organics }(u g / k g)\end{array}$}} \\
\hline & & & & & & & & & & & & & \\
\hline (1,1-Dimethylethyl)benzene & $0 / 2$ & $\mathrm{ND}$ & ND & & $\mathrm{ND}$ & & NA & & NA & $3.9 \mathrm{E}+05$ & $0 / 2$ & & NA \\
\hline (1-Methylpropyl)benzene & $0 / 2$ & $\mathrm{ND}$ & $\mathrm{ND}$ & & ND & & NA & & NA & $2.2 \mathrm{E}+05$ & $0 / 2$ & & NA \\
\hline $1,1,1,2$-Tetrachloroethane & $0 / 2$ & ND & ND & & ND & & NA & & NA & $7.3 \mathrm{E}+04$ & $0 / 2$ & & NA \\
\hline $\begin{array}{l}1,1,1 \text {-Trichloroethane } \\
\text { lo }\end{array}$ & $0 / 6$ & $\mathrm{ND}$ & $\mathrm{ND}$ & & $\mathrm{ND}$ & & NA & & NA & $1.2 \mathrm{E}+06$ & $0 / 6$ & & NA \\
\hline $1,1,2,2$-Tetrachloroethane & $0 / 6$ & $\mathrm{ND}$ & ND & & ND & & NA & & NA & $9.3 \mathrm{E}+03$ & $0 / 6$ & & NA \\
\hline 1,1,2-Trichloro-1,2,2-trifluoroethane & $0 / 2$ & ND & ND & & ND & & NA & & NA & $5.6 \mathrm{E}+06$ & $0 / 2$ & & NA \\
\hline $\begin{array}{l}1,1,2 \text {-Trichloroethane } \\
\text { latile }\end{array}$ & $0 / 6$ & $\mathrm{ND}$ & $\mathrm{ND}$ & & ND & & NA & & NA & $1.6 \mathrm{E}+04$ & $0 / 6$ & & NA \\
\hline 1,1-Dichloroethane & $0 / 6$ & ND & ND & & ND & & NA & & NA & $1.7 \mathrm{E}+06$ & $0 / 6$ & & NA \\
\hline 1,1-Dichloroethene & $0 / 6$ & ND & ND & & ND & & NA & & NA & 4.1E+05 & $0 / 6$ & & NA \\
\hline 1,1-Dichloropropene & $0 / 2$ & ND & ND & & ND & & NA & & NA & & NA & & NA \\
\hline $1,2,3$-Trichlorobenzene & $0 / 2$ & $\mathrm{ND}$ & ND & & ND & & NA & & NA & & NA & & NA \\
\hline 1,2,3-Trichloropropane & $0 / 2$ & ND & ND & & ND & & NA & & NA & $7.6 \mathrm{E}+02$ & $0 / 2$ & & NA \\
\hline $1,2,4$-Trimethylbenzene & $0 / 2$ & ND & ND & & ND & & NA & & NA & $1.7 \mathrm{E}+05$ & $0 / 2$ & & NA \\
\hline 1,2-Dibromo-3-chloropropane & $0 / 2$ & $\mathrm{ND}$ & $\mathrm{ND}$ & & $\mathrm{ND}$ & & NA & & NA & $1.1 \mathrm{E}+04$ & $0 / 2$ & & NA \\
\hline 1,2-Dibromoethane & $0 / 2$ & ND & ND & & ND & & NA & & NA & $6.3 \mathrm{E}+02$ & $0 / 2$ & & NA \\
\hline 1,2-Dichloroethane & $0 / 6$ & $\mathrm{ND}$ & $\mathrm{ND}$ & & ND & & NA & & NA & $6.0 \mathrm{E}+03$ & $0 / 6$ & & NA \\
\hline 1,2-Dichloropropane & $0 / 6$ & $\mathrm{ND}$ & ND & & $\mathrm{ND}$ & & NA & & NA & $7.4 \mathrm{E}+03$ & $0 / 6$ & & NA \\
\hline 1,2-Dimethylbenzene & $0 / 4$ & ND & ND & & ND & & NA & & NA & 4.2E+05 & $0 / 4$ & & NA \\
\hline 1,3,5-Trimethylbenzene & $0 / 2$ & ND & ND & & ND & & NA & & NA & $7.0 \mathrm{E}+04$ & $0 / 2$ & & NA \\
\hline 1,3-Dichloropropane & $0 / 2$ & ND & ND & & ND & & NA & & NA & $3.6 \mathrm{E}+05$ & $0 / 2$ & & NA \\
\hline 1-Chloro-4-methylbenzene & $0 / 2$ & ND & ND & & ND & & NA & & NA & & NA & & NA \\
\hline
\end{tabular}


Table B.3. (continued)

\begin{tabular}{|c|c|c|c|c|c|c|c|c|c|c|c|c|c|}
\hline $\begin{array}{l}\text { Analyte } \\
\end{array}$ & $\begin{array}{l}\text { Frequency } \\
\text { of detect }\end{array}$ & $\begin{array}{c}\text { Minimum } \\
\text { detect }\end{array}$ & $\begin{array}{c}\text { Maximum } \\
\text { detect }\end{array}$ & $\begin{array}{c}\text { Location(s) } \\
\text { of maximum } \\
\text { detected result }\end{array}$ & $\begin{array}{c}\text { Average } \\
\text { detected } \\
\text { result }\end{array}$ & $\begin{array}{c}\text { Max } \\
\text { RL }\end{array}$ & $\begin{array}{l}\text { Frequency of detects } \\
\text { exceeding Max RL }\end{array}$ & Avg RL & $\begin{array}{c}\begin{array}{c}\text { Frequency of } \\
\text { detects exceeding } \\
\text { Avg RL }\end{array} \\
\end{array}$ & $\begin{array}{l}\text { PRG limit } \\
\left(10^{-5} \text { or } 1\right)\end{array}$ & $\begin{array}{l}\text { Frequency of detects } \\
\text { exceeding PRG limit }\end{array}$ & $\begin{array}{l}\text { Background } \\
\text { concentration }\end{array}$ & $\begin{array}{l}\text { Frequency of detects } \\
\text { exceeding background }\end{array}$ \\
\hline 1-Methyl-4-(1-methylethyl)benzene & $0 / 2$ & $\mathrm{ND}$ & ND & & $\mathrm{ND}$ & & NA & & NA & & NA & & NA \\
\hline 1-chlorohexane & $0 / 2$ & ND & ND & & ND & & NA & & NA & & NA & & NA \\
\hline 2,2-Dichloropropane & $0 / 2$ & ND & ND & & ND & & NA & & NA & & NA & & NA \\
\hline 2-Butanone & $0 / 5$ & ND & ND & & $\mathrm{ND}$ & & NA & & NA & $1.0 \mathrm{E}+08$ & $0 / 5$ & & NA \\
\hline 2-Hexanone & $0 / 5$ & ND & ND & & ND & & NA & & NA & & NA & & NA \\
\hline 2-Methoxy-2-methylpropane & $0 / 2$ & ND & ND & & ND & & NA & & NA & $3.6 \mathrm{E}+05$ & $0 / 2$ & & NA \\
\hline 4-Methyl-2-pentanone & $0 / 6$ & ND & ND & & ND & & NA & & NA & $4.7 \mathrm{E}+07$ & $0 / 6$ & & NA \\
\hline Acetone & $1 / 5$ & $252 \mathrm{~J}$ & $252 \mathrm{~J}$ & RR-SS14 & 252 & & NA & & NA & $5.4 \mathrm{E}+07$ & $0 / 5$ & & NA \\
\hline Benzene & $0 / 6$ & ND & ND & & ND & & NA & & NA & $1.4 \mathrm{E}+04$ & $0 / 6$ & & NA \\
\hline Bromobenzene & $0 / 2$ & ND & ND & & ND & & NA & & NA & $9.2 \mathrm{E}+04$ & $0 / 2$ & & NA \\
\hline Bromochloromethane & $0 / 4$ & $\mathrm{ND}$ & $\mathrm{ND}$ & & ND & & NA & & NA & & NA & & NA \\
\hline Bromodichloromethane & $0 / 6$ & ND & ND & & ND & & NA & & NA & $1.8 \mathrm{E}+04$ & $0 / 6$ & & NA \\
\hline Bromoform & $0 / 6$ & ND & ND & & ND & & NA & & NA & $2.2 \mathrm{E}+06$ & $0 / 6$ & & NA \\
\hline Bromomethane & $0 / 6$ & ND & ND & & ND & & NA & & NA & $1.3 \mathrm{E}+04$ & $0 / 6$ & & NA \\
\hline Butylbenzene & $0 / 2$ & $\mathrm{ND}$ & ND & & ND & & NA & & NA & $2.4 \mathrm{E}+05$ & $0 / 2$ & & NA \\
\hline Carbon disulfide & $0 / 6$ & ND & ND & & ND & & NA & & NA & 7.2E+05 & $0 / 6$ & & NA \\
\hline Carbon tetrachloride & $0 / 6$ & ND & ND & & ND & & NA & & NA & $5.5 \mathrm{E}+03$ & $0 / 6$ & & NA \\
\hline Chlorobenzene & $0 / 6$ & ND & ND & & $\mathrm{ND}$ & & NA & & NA & $5.3 \mathrm{E}+05$ & $0 / 6$ & & NA \\
\hline Chloroethane & $0 / 6$ & ND & ND & & ND & & NA & & NA & $6.5 \mathrm{E}+04$ & $0 / 6$ & & NA \\
\hline Chloroform & $0 / 6$ & $\mathrm{ND}$ & $\mathrm{ND}$ & & $\mathrm{ND}$ & & NA & & NA & $4.7 \mathrm{E}+03$ & $0 / 6$ & & NA \\
\hline Chloromethane & $0 / 6$ & ND & ND & & ND & & NA & & NA & $1.6 \mathrm{E}+05$ & $0 / 6$ & & NA \\
\hline Cumene & $0 / 2$ & ND & ND & & ND & & NA & & NA & $5.2 \mathrm{E}+05$ & $0 / 2$ & & NA \\
\hline Dibromochloromethane & $0 / 6$ & $\mathrm{ND}$ & ND & & ND & & NA & & NA & $2.6 \mathrm{E}+04$ & $0 / 6$ & & NA \\
\hline Dibromomethane & $0 / 2$ & ND & ND & & ND & & NA & & NA & $2.3 \mathrm{E}+05$ & $0 / 2$ & & NA \\
\hline Dichlorodifluoromethane & $0 / 2$ & $\mathrm{ND}$ & $\mathrm{ND}$ & & ND & & NA & & NA & $3.1 \mathrm{E}+05$ & $0 / 2$ & & NA \\
\hline Ethylbenzene & $0 / 6$ & ND & ND & & ND & & NA & & NA & $4.0 \mathrm{E}+05$ & $0 / 6$ & & NA \\
\hline Iodomethane & $0 / 2$ & ND & ND & & ND & & NA & & NA & & NA & & NA \\
\hline M + P Xylene & $0 / 2$ & ND & ND & & ND & & NA & & NA & $4.2 \mathrm{E}+05$ & $0 / 2$ & & NA \\
\hline Methylene chloride & $0 / 6$ & ND & ND & & ND & & NA & & NA & $2.1 \mathrm{E}+05$ & $0 / 6$ & & NA \\
\hline Propylbenzene & $0 / 2$ & ND & ND & & ND & & NA & & NA & $2.4 \mathrm{E}+05$ & $0 / 2$ & & NA \\
\hline Styrene & $0 / 6$ & ND & ND & & ND & & NA & & NA & $1.7 \mathrm{E}+06$ & $0 / 6$ & & NA \\
\hline Tetrachloroethene & $0 / 6$ & $\mathrm{ND}$ & $\mathrm{ND}$ & & $\mathrm{ND}$ & & NA & & NA & $1.3 \mathrm{E}+04$ & $0 / 6$ & & NA \\
\hline Toluene & $0 / 6$ & ND & ND & & ND & & NA & & NA & $5.2 \mathrm{E}+05$ & $0 / 6$ & & NA \\
\hline Total Xylene & $0 / 4$ & ND & ND & & ND & & NA & & NA & $4.2 \mathrm{E}+05$ & $0 / 4$ & & NA \\
\hline Trichloroethene & $0 / 6$ & ND & ND & & ND & & NA & & NA & $1.1 \mathrm{E}+03$ & $0 / 6$ & & NA \\
\hline Trichlorofluoromethane & $0 / 2$ & ND & ND & & ND & & NA & & NA & $1.3 \mathrm{E}+06$ & $0 / 2$ & & NA \\
\hline Vinyl acetate & $0 / 2$ & ND & ND & & ND & & NA & & NA & $1.4 \mathrm{E}+06$ & $0 / 2$ & & NA \\
\hline Vinyl chloride & $0 / 6$ & $\mathrm{ND}$ & ND & & ND & & NA & & NA & $7.5 \mathrm{E}+03$ & $0 / 6$ & & NA \\
\hline cis-1,2-Dichloroethene & $0 / 6$ & $\mathrm{ND}$ & ND & & ND & & NA & & NA & $1.5 \mathrm{E}+05$ & $0 / 6$ & & NA \\
\hline cis-1,3-Dichloropropene & $0 / 6$ & ND & ND & & ND & & NA & & NA & $1.8 \mathrm{E}+04$ & $0 / 6$ & & NA \\
\hline o-Chlorotoluene & $0 / 2$ & ND & ND & & ND & & NA & & NA & $5.6 \mathrm{E}+05$ & $0 / 2$ & & NA \\
\hline trans-1,2-Dichloroethene & $0 / 6$ & ND & ND & & ND & & NA & & NA & $2.3 \mathrm{E}+05$ & $0 / 6$ & & NA \\
\hline trans-1,3-Dichloropropene & $0 / 6$ & ND & ND & & ND & & NA & & NA & $1.8 \mathrm{E}+04$ & $0 / 6$ & & NA \\
\hline
\end{tabular}

${ }^{a}$ Radionuclide is evaluated as part of Ra/Th decay series as discussed in the Zone 2 ROD
${ }^{b}$.

Definition of validation qualifiers include: $J$ = analyte was positively identified and result is approximate concentration of analyte in sample, and $U=$ analyte was not detected above the reported sample quantitation limit.

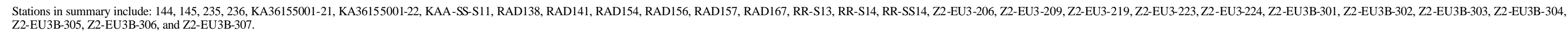

$\begin{array}{ll}\text { Avg }=\text { average } & \mathrm{ND}=\text { not detected } \\ \mathrm{EU}=\text { exposure unit } & \mathrm{PB}=\text { = polychlorinated biphenyl } \\ \text { Max }=\text { maximum } & \mathrm{PRG}=\text { preliminary remediation goal } \\ \mathrm{NA}=\text { not available } & \mathrm{RL}=\text { remediation level }\end{array}$ 
Appendix C

K-31/K-33 Exposure Unit Group Z2-08

Technical Memorandum 


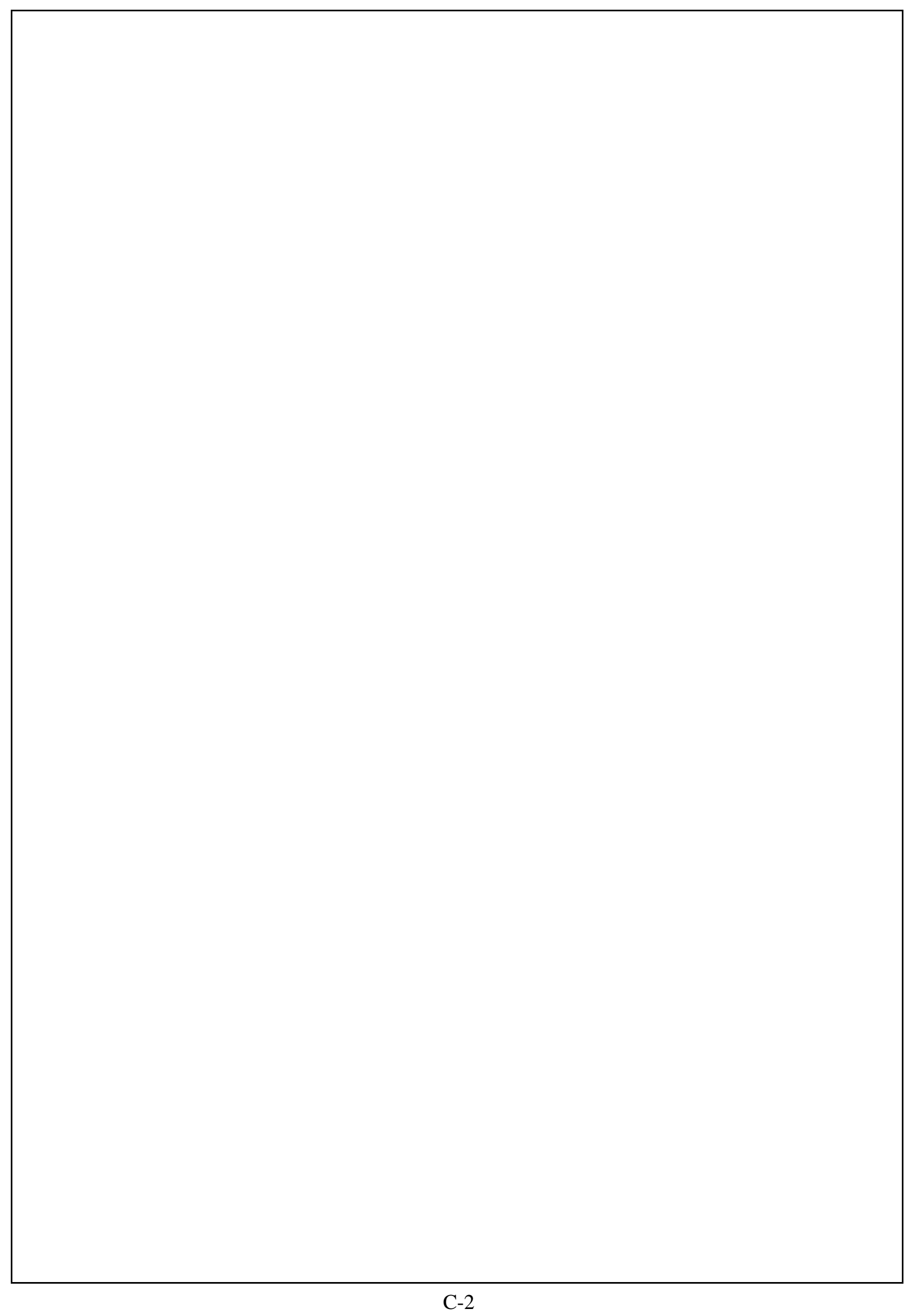




\section{FIGURES}

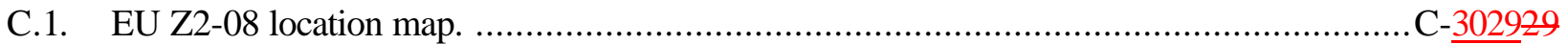

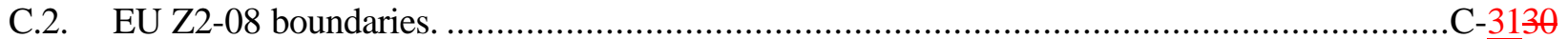

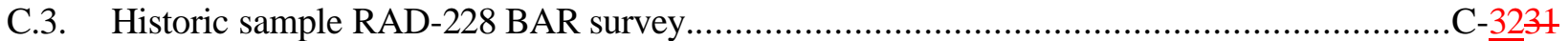

C.4. Class 3 and Class 4 SU walkover assessment locations. ...........................................

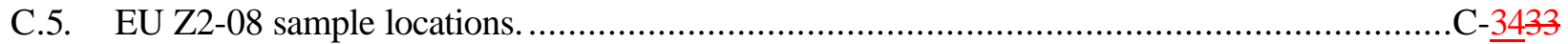

\section{TABLES}

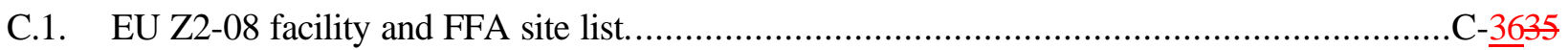

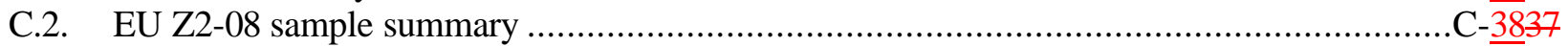

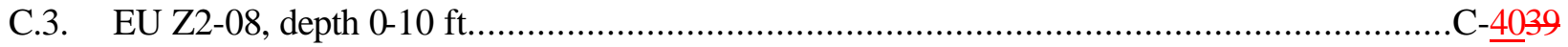

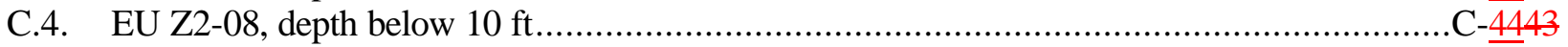




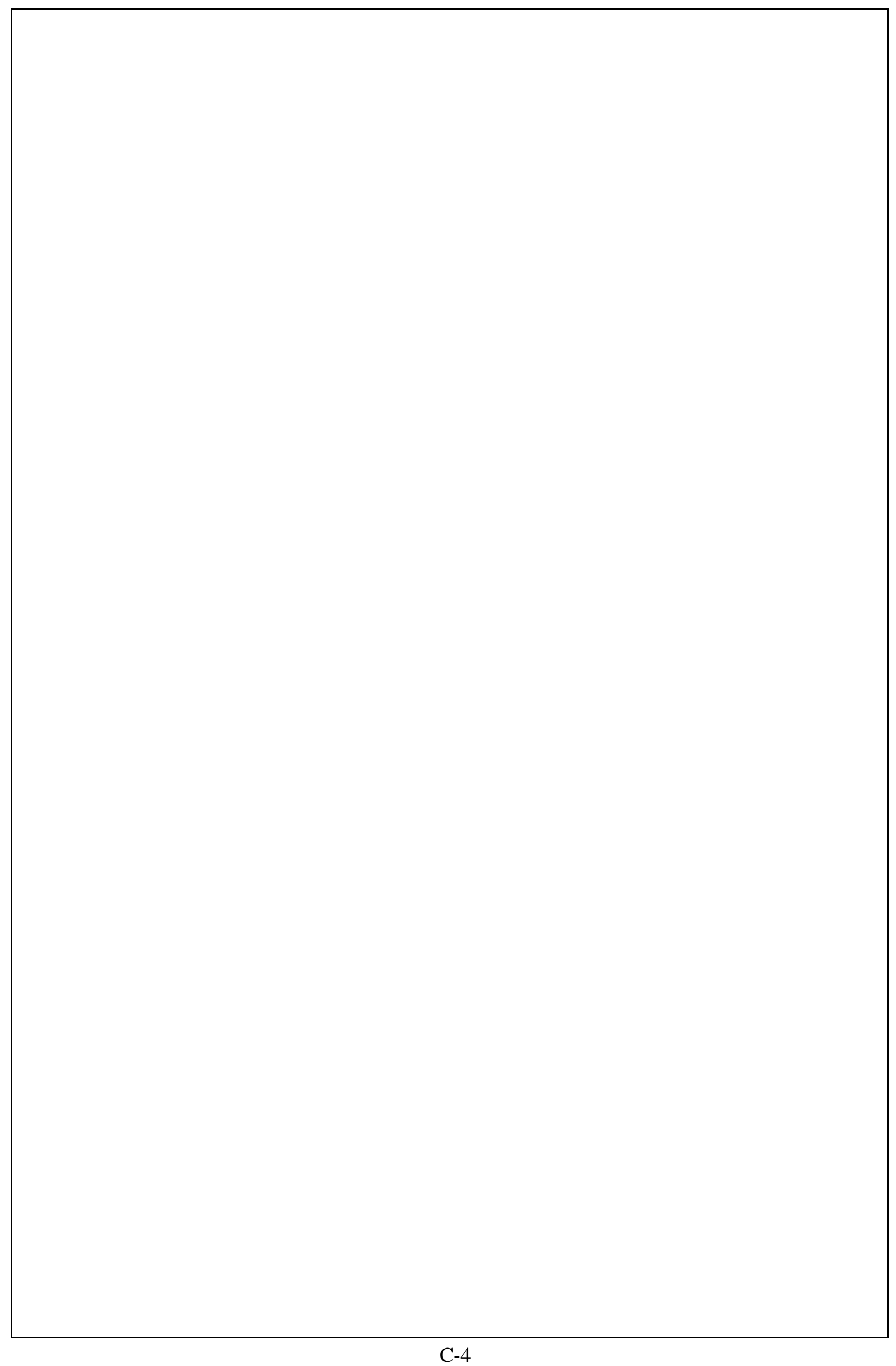




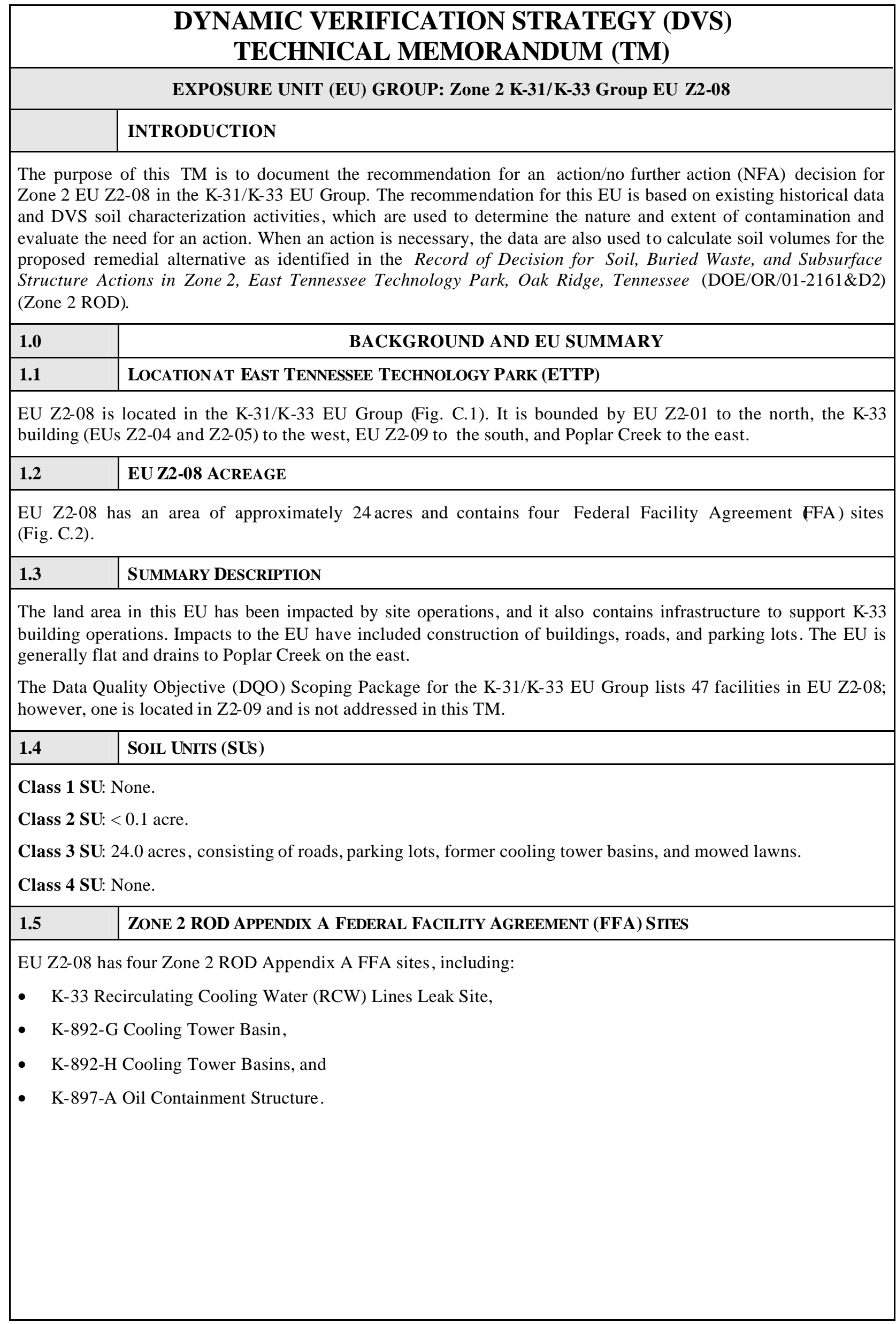




\begin{tabular}{|c|c|}
\hline 2.0 & DVS INVESTIGATIONS AND RESULTS \\
\hline 2.1 & DVS FIELD ACTIVITIES \\
\hline \multicolumn{2}{|c|}{$\begin{array}{l}\text { DVS activities were conducted in accordance with the Remedial Design Report/Remedial Action Work Plan for } \\
\text { Zone } 2 \text { Soils, Slabs, and Infrastructure, East Tennessee Technology Park, Oak Ridge, Tennessee } \\
\text { (DOE/OR/01-2224\&D2) (Zone } 2 \text { RDR/RAWP). }\end{array}$} \\
\hline 2.1.1 & Class 1 SUs \\
\hline \multicolumn{2}{|l|}{ None. } \\
\hline 2.1.1.1 & CLASS 1 SU RADIOLOGICAL WALKOVER SURVEY \\
\hline \multicolumn{2}{|l|}{ None. } \\
\hline 2.1.1.2 & CLASS 1 SU GEOPHYSICAL SURVEY \\
\hline \multicolumn{2}{|l|}{ None. } \\
\hline 2.1.1.3 & CLASS 1 SU SOIL SAMPLING \\
\hline \multicolumn{2}{|l|}{ None. } \\
\hline 2.1.2 & Class 2 SUs \\
\hline \multicolumn{2}{|c|}{$\begin{array}{l}\text { There is one Class } 2 \mathrm{SU} \text { in EU Z2-08 that was defined during DQO scoping to quantify the extent of a U } 238 \\
\text { average (Avg) remediation-level (RL) exceedance at historical location RAD228. The SU is centered on the sample } \\
\text { point and is approximately } 0.1 \text { acre in size. }\end{array}$} \\
\hline 2.1.2.1 & CLASS 2 SU RADIOLOGICAL WALKOVER SURVEY \\
\hline \multicolumn{2}{|c|}{$\begin{array}{l}\text { A biased area radiation (BAR) survey was conducted around historical sample location RAD228 according to the } \\
\text { Class } 1 \text { and Class } 2 \text { Soil Unit Radiological Investigation and Biased Area Radiation Survey Protocol (found in } \\
\text { Attachment C to Appendix A of the Zone } 2 \text { RDR/RAWP). Results of the BAR survey are presented in the Walkover } \\
\text { Inspections and Radiological Surveys for FY } 2007 \text { Exposure Units in Zones } 1 \text { and 2, East Tennessee Technology } \\
\text { Park, Oak Ridge, Tennessee (BJC/OR-2691). According to the survey protocol, the areas of radionuclide Avg RL } \\
\text { exceedances are areas where radiation measurements exceed the screening level (two times background } \\
\text { measurement). A screening level (SL) of } 2382 \text { was determined according to the protocol and an area of } 3700 \mathrm{ft}^{2} \text { was } \\
\text { surveyed. Radiation readings ranged from } 1252 \text { to } 2585 \mathrm{cpm} \text {. The BAR survey action level was exceeded at several } \\
\text { discrete points. However, an area could not be defined. The BAR survey results at historic location RAD228 are } \\
\text { shown on Fig. C-3. }\end{array}$} \\
\hline 2.1.2.2 & CLASS 2 SU GEOPHYSICAL SURVEY \\
\hline \multicolumn{2}{|l|}{ None. } \\
\hline 2.1.2.3 & CLASS 2 SU SOIL SAMPLING \\
\hline \multicolumn{2}{|c|}{$\begin{array}{l}\text { A confirmation sample was collected at historical location RAD228. Step-out sampling was not conducted because } \\
\text { the BAR survey for this location did not identify an area of action-level exceedances (Sect. 2.1.2.1). }\end{array}$} \\
\hline 2.1.3 & CLASS 3 AND CLASS 4 SU WALKOVER ASSESSMENT \\
\hline \multicolumn{2}{|c|}{$\begin{array}{l}\text { The protocol used for addressing the Class } 3 \text { and Class } 4 \text { SUs in EU Z2-08 is found in the Class } 3 \text { and Class } 4 \text { Soil } \\
\text { Unit Walkover Inspection Protocol, Rev. } 1 \text { (found in Attachment C of Appendix A in the Zone } 2 \text { RDR/RAWP). The } \\
\text { purpose of the Class } 3 \text { SU walkover assessments is to systematically inspect Class } 3 \text { SUs by visual observation } \\
\text { along transects to established grid assessment locations, map observed features, and collect radiological screening } \\
\text { data at grid and discretionary locations. Details of the walkover assessment results are presented in the Walkover } \\
\text { Inspections and Radiological Surveys for FY } 2007 \text { Exposure Units in Zones } 1 \text { and 2, East Tennessee Technology }\end{array}$} \\
\hline
\end{tabular}


Park, Oak Ridge, Tennessee (BJC/OR-2691). A summary of the report results is presented in Sects.2.1.3.1 and 2.1.3.2. Fig. C.4 shows the assessment point (AP), mid-point (MP), and discretionary point (DP) locations.

Twenty-three APs were identified in this EU prior to the start of fieldwork and are documented in the DQO Scoping Package. The actual number of APs evaluated in EU Z2-08 corresponds to the number planned.

In addition to the APs, the field team made assessments at 19 MPs, which are selected in the field and are located approximately half way between APs, and conducted discretionary surveys at 20 locations (see below). MP and DP locations are not specified in planning documents.

As described in the survey description, a very small spot $\left(<1 \mathrm{ft}^{2}\right.$ in extent) was defined in proximity to historic sample location RAD 228. This was the only spot that exceeded survey screening levels. A biased sample was collected at this spot that did not report elevated radioactive contamination.

\begin{tabular}{cccc}
\hline EU & Number of APs & Number of MPs & Number of DPs \\
\hline Z2-08 & 23 & 19 & 20 \\
\hline $\mathrm{AP}=$ assessment point & $\mathrm{MP}=$ mid-points & & \\
$\mathrm{DP}=$ discretionary points & & &
\end{tabular}

\section{\begin{tabular}{l|l} 
2.1.3.1 & CLASS 3 AND CLASS 4 SU RADIOLOGICAL SURVEY SUMMARY
\end{tabular}}

SL: $2382 \mathrm{cpm}$.

SL exceedances: No AP, MP, or DP measurements exceeded the SL in EU Z2-08.

\section{\begin{tabular}{|l|l} 
2.1.3.2 & CLASS 3 AND ClASS 4 SU ANTHROPOGENIC FEATURES
\end{tabular}}

\section{Number of identified anthropogenic features: 20}

EU Z2-08 is located in a heavily industrialized portion of Zone 2 As such, it contains numerous facilities and associated constructed features (i.e., roads, parking lots, sidewalks) for support of K-33 building operations. These facilities and constructed features were addressed during the facilities asses sment conducted as part of the Class 3 SU walkover assessment (Sect. 2.1.3.3).

Twenty additional anthropogenic features identified during the Class 3 SU walkover assessment include the following:

1) Pull box station,

2) Concrete pad with electrical conduit,

3) RCW return lines,

4) Inactive valve vault

5) Gasoline above-ground storage tank (AST),

6) Wood debris pile,

7) Large soil/spoil pile,

8) Pull box and concrete piers,

9) Steel pipe,

10) Air release for fire water system,

11) Concrete pedestals,

12) Concrete foundation and conduit,

13) Air release for sanitary water system,

14) Air release for sanitary water system,

15) Air release for fire water system,

16) Concrete vault with flow control,

17) Concrete pad with railroad tracks,

18) Diesel AST,

19) Large pile of concrete and asphalt rubble, and

20) Transformers associated with K-892.

Each anthropogenic feature was surveyed for radiation and inspected for visual evidence of chemical contamination. Four of the features (gasoline AST, wood debris pile, diesel AST, and transformers associated with K-892) showed visual evidence for potential sources of chemical contamination and were selected for biased sampling. 


\subsubsection{3}

CLASS 3 SU FACILITIES ASSESSMENTS

Forty-seven facilities are listed in the DQO Scoping Package as being located in EU Z2-08; however, one falls in Z2-09 and is not addressed in this TM. Forty-one facilities, including the K-897-A Oil Containment Structure FFA Site (Sect. 1.5), were assessed during the Class $3 \mathrm{SU}$ walkover assessment (Table C.1). The facility assessments are reported in the Walkover Inspections and Radiological Surveys for FY 2007 Exposure Units in Zones 1 and 2, East Tennessee Technology Park, Oak Ridge, Tennessee (BJC/OR-2691). In summary, five facilities were identified for biased sampling based on visual observation that the facilities were potential sources of chemical contamination. The K-893-DD, K-893-Q, K-893-V, and K-899-M inactive valve vaults were selected for sampling as representative of 25 inactive valve vaults in this EU (Table C.1). The fifth biased location sample is the K-897-A Oil Containment Structure FFA Site (Sect. 1.5), which was planned during DQO scoping.

\section{\begin{tabular}{l|ll} 
2.1.3.4 & CLASS 3 AND CLASS 4 SU RADIOLOGICAL WALKOVER SURVEY
\end{tabular}}

During the initial phase of DQO scoping for EU Z2-08, several historical sample locations prefixed with "CB" were identified in the southwest corner of the EU. The locations were eventually identified as waste characterization samples for sludge removed from the cooling tower basins. The sludge has since been removed and, with Core Team concurrence, the sample locations were removed from the data set. However, two BAR surveys were conducted over two areas (referred to as "CB" and "892H") in the southwest corner of the EU where the sludge had been stored to investigate potential radionuclide releases during storage. The BAR surveys were conducted according to the Class 1 and Class 2 Soil Unit Radiological Investigation and Biased Area Radiation Survey Protocol (found in Attachment C of Appendix A in the Zone 2 RDR/RAWP). The BAR survey results are summarized below and illustrate the action level was exceeded in the CB survey area.

\begin{tabular}{ccccc}
\hline Action level $=\mathbf{2 3 8 2} \mathbf{~ c p m ~}$ & & & \\
\hline & & Number of & \multicolumn{2}{c}{ Range of measurements (cpm) } \\
\cline { 3 - 5 } Surveyed area name & Survey size $\left(\mathbf{f t}^{2}\right)$ & measurements & Minimum & Maximum \\
\hline $892 \mathrm{H}$ & 1590 & 490 & 1360 & 1944 \\
CB & 1260 & 532 & 1529 & 2494 \\
\hline
\end{tabular}

$\mathrm{cpm}=$ counts per minute

\section{\begin{tabular}{l|l} 
2.1.3.5 & ClaSS 3 AND ClaSS 4 SU BIASED SAMPLING
\end{tabular}}

There are 18 biased sample locations in the EU Z2-08 Class 3 SU.

Based on visual observation during the Class 3 SU walkover assessment, seven locations were selected for biased sampling at anthropogenic features and include the following:

- One sample location at the wood/debris pile;

- Two sample locations at the diesel AST - one location below the overflow pipe and the another location at the base of the slope leading up to the tank;

- Three sample locations at the gasoline AST — one location at the east, south, and west sides of the concrete pad; and

- $\quad$ One sample location at the K-892 transformer housing.

One biased sample location was identified based on elevated radiation observed during the BAR survey, which was conducted at the former location of sludge waste storage in the southwest corner of the EU (Sect. 2.1.3.4).

Four biased sample locations identified during facility assessments conducted as part of the Class $3 \mathrm{SU}$ walkover assessment include the following:

- One location at the K-893-DD inactive valve vault,

- One location at the K-893-Q inactive valve vault,

- $\quad$ One location at the K-893-V inactive valve vault, and

- One location at the K-899-M inactive valve vault. 
Six Class 3 SU biased sample locations were selected during DQO scoping at four FFA sites, including the following:

- $\quad$ One location at the K-897-A Oil Containment Structure FFA Site,

- Two locations at the K-892-G Cooling Tower Basin FFA Site,

- $\quad$ One location at the K-892-H Cooling Tower Basin FFA Site, and

- $\quad$ Two locations at the K-33 RCW Lines Leak Site FFA Site.

Details of the actual sampling and analysis in the Class 3 SU, including sample depths, analytes, and deviations from planned sampling, are presented in Table C.2. Analytical data for the Class 3 SU samples are summarized in Sects. 2.2.5 and 2.2.6, and the results are evaluated in terms of the Zone 2 ROD remedial action objective (RAO) in Sect. 3 .

\section{\begin{tabular}{|l|l}
\hline 2.2 & DVS AND HISTORICAL SAMPLE RESULTS \\
\hline
\end{tabular}}

This section presents a summary of analytical results for the DVS and historical samples collected in EU Z2-28. The summary begins with a tabulation of SU and infrastructure sample locations (Sects. 2.2.1 through 2.2.4) and concludes with focused investigation and EU data summaries (Sect.2.2.5) and FFA site data summaries (Sect. 2.2.6). The combined EU DVS and historical data are summarized in Tables C.3 and C.4. A compact disc containing electronic files for the historical and DVS analytical data used to generate the data tables is provided with this Phased Construction Completion Report (PCCR).

\section{\begin{tabular}{|l|l|} 
2.2.1 & CLASS 1 SUS \\
\hline
\end{tabular}}

None.

\begin{tabular}{|l|l} 
2.2.2 & CLASS 2 SUS \\
\hline
\end{tabular}

There is one DVS and one historical sample location in the EU Z2-08 Class 2 SU. The DVS sample location was selected as a confirmation sample to verify the average RL exceedance observed at historical sample location RAD228. Sample locations are shown on Fig. C.4 and summarized below.

\begin{tabular}{lrc}
\hline EU & DVS sample location & Historic sample location \\
\hline Z2-08 & Z2-EU8B-320 & RAD228 \\
\hline \multicolumn{2}{l}{ DVS = Dynamic Verification Strategy } \\
EU = exposure unit
\end{tabular}

Details of sampling and analysis are presented in Table C.2. The data are summarized in Tables C.3 and C.4 and evaluated in Sect. 2.2.5. The number of analyses conducted in the Class $2 \mathrm{SU}$ is presented below by analyte group.

\begin{tabular}{cccccc}
\hline Metals & PCBs & Radionuclides & SVOCs & VOCs & Other organics \\
\hline 0 & 0 & 2 & 0 & 0 & 0 \\
\hline $\begin{array}{l}\text { PCB = polychlorinated biphenyl } \\
\text { SVOC = semivolatile organic compound } \\
\text { VOC = volatile organic compound }\end{array}$ & & & & \\
\end{tabular}

\section{\begin{tabular}{|l|l|l}
2.2 .3 & CLASS 3 AND CLASS 4 SUS \\
\hline
\end{tabular}}

There are 43 DVS and historical sample locations in the EU Z2-08 Class 3 SU, including 18 DVS biased sample locations associated with anthropogenic features, facilities, and FFA sites; 17 historical samples collected as part of the 1994 radiological walkover survey; and 8 samples collected at a historic RCW line leak site to support a geochemical hexavalent chromium evaluation in the local environment. The sample locations are shown on Fig. C.4 and summarized below. 


\begin{tabular}{cll}
\hline EU & \multicolumn{1}{c}{ DVS sample locations } & \multicolumn{1}{c}{ Historic sample locations } \\
\hline \multirow{2}{*}{ Z2-08 } & Biased Locations: & RCW Leak Line Characterization: \\
& Z2-EU8B-301, Z2-EU8B-302, Z2-EU8B-303, & K33RCW01, K33RCW02, K33RCW03, \\
Z2-EU8B-304, Z2-EU8B-305, Z2-EU8B-306, & K33RCW04, K33RCW05, K33RCW06, \\
Z2-EU8B-307, Z2-EU8B-308, Z2-EU8B-309, & K33RCW07, K33RCW08, \\
Z2-EU8B-310, Z2-EU8B-311, Z2-EU8B-312, & \\
Z2-EU8B-313, Z2-EU8B-314, Z2-EU8B-315, & 1994 Radiological Walkover Survey: \\
Z2-EU8B-317, Z2-EU8B-318, Z2-EU8B-319 & RAD211, RAD221, RAD224, RAD225, \\
& & RAD229, RAD239, RAD240, RAD248, \\
& & RAD249, RAD254, RAD263, RAD268, \\
& & RAD269, RAD271, RAD274, RAD278, \\
& & \\
\hline
\end{tabular}

DVS = Dynamic Verification Strategy

$\mathrm{EU}=$ exposure unit

The number of samples collected, sampling intervals, and chemicals and radionuclides analyzed varied at each location. Details of sampling and analysis at each location are presented in Table C.2. The data are summarized in Table C.3 and evaluated in Sects. 2.2.5 and 2.2.6. The number of analyses conducted in the Class 3 SU is presented below by analyte group.

\begin{tabular}{cccccc}
\hline Metals $^{\boldsymbol{a}}$ & PCBs & Radionuclides & SVOCs & VOCs & Other organics $^{b}$ \\
\hline 28 & 8 & 43 & 24 & 3 & 5 \\
\hline
\end{tabular}

${ }^{a}$ Metals analyzed at the following sample locations include hexavalent chromium: Z2-EU8B-302, Z2-EU8B-303, Z2-EU8B-304, Z2-EU8B-305, Z2-EU8B-306, K33RCW01, K33RCW02, K33RCW03, K33RCW04, K33RCW05, K33RCW06, K33RCW07, and K33RCW08.

${ }^{b}$ Includes hydrocarbons as diesel, diesel-range organics, hydrocarbons as gasoline, and gasoline-range organics.

$\mathrm{PCB}=$ polychlorinated biphenyl

$\mathrm{SVOC}=$ semivolatile organic compound

$\mathrm{VOC}=$ volatile organic compound

\section{\begin{tabular}{l|l} 
2.2.4 & INFRASTRUCTURE \\
\hline
\end{tabular}}

No infrastructure in this EU was identified for sampling during DQO scoping. Valve vaults and other surface infrastructure features were inspected and biased sampling was conducted where accumulated sediment was sufficient to meet required sample volumes.

\section{\begin{tabular}{l|l} 
2.2.5 & EU EVALUATION \\
\hline
\end{tabular}}

Characterization data and other information evaluated for EU Z2-08 are discussed in this section. The analytical data in the following summaries are presented by analyte group. The results for a particular analyte group are summarized only if that group was analyzed in the samples from the unit being summarized. Within each summary, the data are evaluated by comparing to certain criteria, which include the Zone 2 soils maximum RL (Max RL), Zone 2 soils average RL (Avg RL), $1 \times 10^{-5}$ industrial preliminary remediation goal (Ind PRG), ETTP soils background composition (Bkg), Zone 2 groundwater (GW) SLs (GW SL), and $1 \times 10^{-6}$ residential preliminary remediation goal (Res PRG). If a particular criterion does not apply to any member of an analyte group, it is not tabulated for that analyte group; if a particular criterion does not apply to all analytes within an analyte group, those analytes to which it does not apply are notated with NA (not applicable). Individual metals and radionuclides, which are naturally occurring, are reported in the summaries only if one or more criterion is exceeded. Organic chemicals, which are not naturally occurring, are reported if detected, even if no criteria are exceeded. The Max RL, Avg RL, Ind PRG, Bkg, GW SL, and Res PRG criteria values pertaining to the analytes listed in Appendix A of the Zone 2 RDR/RAWP (i.e., the Quality Assurance Project Plan) are presented in Sect. 3.1 of this PCCR.

Because the carcinogenic risk associated with the concentration of radium and thorium isotopes in the natural background at ETTP exceeds the cumulative risk goal of $1 \times 10^{-4}$, RL values for these radionuclides are based on alternative concentration levels rather than risk. The alternative concentration levels of $5 \mathrm{pCi} / \mathrm{g}$ above background (Avg RL) and $15 \mathrm{pCi} / \mathrm{g}$ above background (Max RL) were set as low as reasonably achievable under the site-specific conditions. Because site-specific background concentrations of these radionuclides exceed the target 
risk range, residual concentrations of these radionuclides and their decay series are not considered in estimates of residual risk following any remedial action.

The Zone 2 ROD states that Avg RL and Max RL exceedances by Ra-226, Th-230, and Th-232 will be evaluated by summing above-background concentrations of the greater of Ra-226 or Th-230 with the above-background concentrations of Th-232 and comparing the results to $5 \mathrm{pCi} / \mathrm{g}$ (Avg RL) and $15 \mathrm{pCi} / \mathrm{g}$ (Max RL). Average and maximum RL exceedances for these radionuclides, if any, are reported in the data summaries below and in Tables C. 2 through C. 4 as "Ra/Th decay series", and individual RL exceedances by Ra-226, Th-230, and Th-232 are reported as NA. The Ra/Th decay series data are summarized in the following sections only if an Avg or Max RL has been exceeded, consistent with the description in the preceding paragraph for reporting radionuclides. Discussion of the Ra/Th decay series calculation, including the manner in which the calculation is performed, is presented in Sect. 3.3 of this PCCR.

\section{Conceptual Site Model (CSM)}

Two CSMs pertinent in EU Z2-08 include the following:

- a surface release model appropriate for most of the site facilities and general operations conducted within the $\mathrm{EU}$, and

- a subsurface release of liquids model appropriate for the cooling water basins and containment structures.

The surface release model presumes activities associated with the cooling towers, above-ground fuel tanks, and other facilities in the EU could have resulted in releases of radiological and/or chemical contaminants to the ground surface. Soils in the area have a high percentage of clay and organics that tend to retard the movement of radiological and organic compounds in the natural environment. Historic radiological walkover surveys and historic and DVS sampling indicate there have been no significant contaminant releases to surface soils within the EU. One area less than $10 \mathrm{ft} \times 10 \mathrm{ft}$ was identified in the southwestern portion of the EU where radioactivity was higher than the area background. Biased sampling in this area had concentrations above background levels, but all radioisotope concentrations were below their respective Zone 2 RLs.

The potential for redistribution of surface-released contamination by air is considered to be low to moderate. Small volume spills will have limited impact to area soil by airborne transport.

The potential for redistribution of surface-released contamination by surface water is considered to be moderate. The topographic relief in the area is minimal and there are few developed drainage pathways. Redistribution would occur by overland flow to Poplar Creek. No sediment accumulation areas were identified in EU Z2-08 during the Class 3 SU walkover assessment.

The potential for redistribution of surface-released contamination to groundwater is considered to be low. Composition of the soils and limited volume of potential releases would not pose a threat to local groundwater.

The subsurface release model presumes contaminated sediment in cooling water basins and/or containment structures (e.g., valve vaults) would be leached by water to subsurface soils. Sediments accumulated in the cooling water basins were removed in the mid-1990s as part of the demolition of the cooling towers. Contaminant releases to underlying soils may have occurred prior to the removal of the sediment and would have impacted local groundwater. An evaluation of the local groundwater is provided in the following discussions. Sediments in the oil containment structure and valve vaults represent very small-volume potential releases. Samples of accumulated sediments were collected to determine if the structure could pose a threat as subsurface release points.

The potential for redistribution by air of contamination released in the subsurface is considered to be very low. The potential for redistribution by surface water of contamination released in the subsurface also is considered to be very low.

The potential for redistribution by groundwater of contamination released in the subsurface is considered to be moderate. Movement of radiological and organic contaminants through the subsurface soil is retarded by the high clay percentage and total organic carbon content of the site soils.

\section{Groundwater Evaluation}

There are two well pairs (UNW-044/BRW031 and UNW083/BRW-063) and one additional bedrock well (BRW-062) in EU Z2-08 located downgradient of the K-892K Cooling Towers and Basins. In each pair, one well is completed in the bedrock (BRW) and one is completed in the unconsolidated zone (UNW). Water levels in the area 
are $22-28 \mathrm{ft}$ bgs in UNW and 12-44 ft bgs in BRW. Vertical gradients are generally downward into the bedrock formation. Depth to rock ranges from 5-42 ft bgs over the area. These wells were monitored and sampled from 1989 through 1995. Monitoring at the UNW-044/BRW031 well pair ceased after 1992, but sampling at BRW-031 continued until 1998. Technetium-99 in BRW-031 was reported at concentrations above maximum concentration levels (MCLs) in 1992, but BY 1998 concentrations had dropped below MCL criteria. Total chromium concentrations were reported in well BRW063 during 1994-1995. Sediments in the cooling water basins were removed from the EU in early 1994 . There appears to be a correlation between the detection of total chromium at elevated concentrations in the downgradient well and disturbance of the basin sediments. Chromium concentrations in late 1995 had dropped to levels well below MCLs.

\section{EU Z2-08 Sampling Results}

Except for a small Class $2 \mathrm{SU}\left(\sim 500 \mathrm{ft}^{2}\right)$, this EU was classified as a Class $3 \mathrm{SU}$ during DQO scoping. Thus, the entire 24 acres of the EU were evaluated during the Class $3 \mathrm{SU}$ walkover assessment.

The Class 2 SU in EU Z2-08 was defined during DQO scoping to quantify the extent of a historical U-238 Avg RL exceedance at historical location RAD228. A confirmation sample location was identified and a BAR survey (Sect. 2.1.2.1) was conducted at RAD228. No step-out sampling was conducted because the BAR survey did not identify an area of action-level exceedances

Twenty anthropogenic features, other than facilities and associated constructed features, were identified during the Class 3 SU walkover assessment. Four anthropogenic features were selected for DVS biased sampling based on visual assessments that the features were potential sources of chemical contamination (Sect.2.1.3.5). The radiological SL was not exceeded during the Class $3 \mathrm{SU}$ walkover assessment and no biased sampling was performed based on radiological field characterization. Forty-one facilities were assessed as part of the Class $3 \mathrm{SU}$ walkover assessment and four inactive valve vaults were selected for DVS biased sampling (Sect. 2.1.3.5) as representative of 25 inactive valve vaults in the EU. Although most of the vaults contained standing water, only four had enough sediment to sample. Therefore, these four vaults were considered to be the worst case condition and representative of the limited potential for these structures to act as sediment accumulation areas and potential sources of contamination. The four valve vaults containing sediments were selected for sampling based on visual assessment as potential sources of chemical contamination, but none of the valve vaults exceeded the radiological SL during the facilities assessments.

In addition to the Class $3 \mathrm{SU}$ anthropogenic feature- and facilities-related biased samples, a DVS Class 3 SU biased sample was collected at the location of elevated radiation identified during the BAR survey conducted over an area where cooling basin sludge waste had been stored.

EU Z2-08 has 25 historical sample locations in the Class 3 SU. Seventeen of the sample locations are from the 1994 radiological walkover survey with the remainder from a RCW line characterization performed to collect physical and chemical data at a known RCW line leak site. These data were used to support preparation of a hexavalent chromium geochemical model for the site.

The following paragraphs summarize the EU Z2-08 sampling results. Each summary begins with a presentation of analytical results for the focused sampling efforts in the EU and concludes with an overall summary for EU Z2-08. The EU summary includes both data summary tables and a written description of the nature and extent of chemicals and radionuclides observed in the EU. Sample summaries for the Zone 2 ROD FFA sites in EU Z2-08 are presented in Sect. 2.2.6, and data from those sites are included in the EU Z2-08 summary below. EU-wide data are evaluated against the Zone 2 ROD RAO in Sect. 3.3. Details of sampling conducted in EU Z2-08 are presented in Table C.2, data for EU Z2-08 are summarized in Table C.3, and sample locations are shown in Fig. C.5

DVS Class 2 SU Sampling: The Class 2 SU has one historical sample location (RAD228) and one DVS confirmation sample location (Z2-EU8B-320). Step-out sampling was not conducted because the BAR survey did not identify an area of action-level exceedances (Sect. 2.1.2.1). Analytical results summarized below show the original U-238 Avg RL exceedance; a U-234 GW SL exceedance; several Bkg exceedances; and Cs-137, U-235, and U-238 Ind PRG exceedances in the sample from RAD228 (other radionuclide Ind PRG exceedances are not highlighted here but are discussed in Sect.3.3). In contrast, analytical results from the DVS confirmation sample show only Ind PRG exceedances and a U-238 Bkg exceedance. 
EU Z2-08 CLASS 2 SU RADIONUCLIDES WITH BACKGROUND, PRG, AND/OR RL EXCEEDANCES (pCi/g)

\begin{tabular}{|c|c|c|c|c|c|c|c|c|c|c|c|}
\hline \multirow[b]{2}{*}{ Analyte } & \multirow[b]{2}{*}{$\begin{array}{c}\text { Detect } \\
\text { frequency }\end{array}$} & \multirow[b]{2}{*}{$\begin{array}{c}\text { Minimum } \\
\text { detect }\end{array}$} & \multirow[b]{2}{*}{$\begin{array}{c}\text { Maximum } \\
\text { detect }\end{array}$} & \multirow[b]{2}{*}{$\begin{array}{l}\text { Location(s) of } \\
\text { maximum detect }\end{array}$} & \multirow{2}{*}{$\begin{array}{c}\text { Average } \\
\text { detected } \\
\text { result }\end{array}$} & \multicolumn{6}{|c|}{ Number of analyses exceeding criteria } \\
\hline & & & & & & $\begin{array}{c}\text { Max } \\
\text { RL }\end{array}$ & $\begin{array}{l}\text { Avg } \\
\text { RL }\end{array}$ & $\begin{array}{l}\text { Ind } \\
\text { PRG }\end{array}$ & Bkg & $\begin{array}{l}\text { GW } \\
\text { SL }\end{array}$ & $\begin{array}{c}\text { Res } \\
\text { PRG }\end{array}$ \\
\hline Cesium-137 & $2 / 2$ & 0.276 & 1.94 & RAD228 & 1.11 & 0 & 0 & 1 & NA & NA & 2 \\
\hline Neptunium-237 & $1 / 2$ & 0.29 & 0.29 & RAD228 & 0.29 & 0 & 0 & 0 & NA & NA & 1 \\
\hline Potassium-40 & $2 / 2$ & 7.3 & 7.5 & Z2-EU8B-320 & 7.4 & NA & NA & 2 & 0 & NA & 2 \\
\hline Radium-226 & $2 / 2$ & 0.78 & 4.6 & RAD228 & 2.69 & NA & NA & 2 & 1 & NA & 2 \\
\hline Technetium-99 & $1 / 2$ & 2.53 & 2.53 & RAD228 & 2.53 & NA & NA & 0 & NA & NA & 1 \\
\hline Thorium -228 & $2 / 2$ & 0.923 & 1.08 & Z2-EU8B-320 & 1.00 & NA & NA & 2 & 0 & NA & 2 \\
\hline Thorium -230 & $2 / 2$ & 1.16 & 2.23 & RAD228 & 1.70 & NA & NA & 0 & 1 & NA & 0 \\
\hline Thorium -232 & $2 / 2$ & 1.083 & 1.11 & Z2-EU8B-320 & 1.10 & NA & NA & 2 & 0 & NA & 2 \\
\hline Uranium-233/234 & 1.1 & 72.1 & 72.1 & RAD228 & 72.1 & 0 & 0 & 0 & NA & 1 & 1 \\
\hline Uranium-234 & $1 / 1$ & 21.4 & 21.4 & Z2-EU8B-320 & 21.4 & 0 & 0 & 0 & NA & 0 & 1 \\
\hline Uranium-235 & $2 / 2$ & 1.26 & 4.23 & RAD228 & 2.75 & 0 & 0 & 1 & NA & 0 & 2 \\
\hline Uranium-238 & $2 / 2$ & 15.4 & 58 & RAD228 & 36.7 & 0 & 1 & 1 & 2 & 0 & 2 \\
\hline $\begin{array}{l}\mathrm{Avg}=\text { average } \\
\mathrm{Bkg}=\text { background } \\
\mathrm{EU}=\text { exposure unit } \\
\mathrm{GW}=\text { groundwater } \\
\mathrm{Ind}=\text { industrial } \\
\mathrm{Max}=\text { maximum }\end{array}$ & & $\begin{array}{l}\mathrm{NA}=\text { not ap } \\
\mathrm{PRG}=\text { preli } \\
\text { Res }=\text { reside } \\
\mathrm{RL}=\text { remed } \\
\mathrm{SL}=\text { screen } \\
\mathrm{SU}=\text { soil un }\end{array}$ & $\begin{array}{l}\text { pplicable } \\
\text { liminary reme } \\
\text { lential } \\
\text { diation level } \\
\text { ning level } \\
\text { nit }\end{array}$ & ediation goal & & & & & & & \\
\hline
\end{tabular}

DVS Class 3 SU Biased Sampling at the Wood/Debris Pile: Biased sample location Z2-EU8B-308 was identified at a pile of wood and debris during the Class $3 \mathrm{SU}$ walkover assessment. A five-point surface soil sample was collected and analyzed. Analytical results summarized below show radionuclide Ind PRG exceedances, metal and radionuclide $\mathrm{Bkg}$ exceedances, and detections of polychlorinated biphenyls (PCBs), semivolatile organic compounds (SVOCs), and volatile organic compounds (VOCs).

EU Z2-08 CLASS 3 SU WOOD/DEBRIS PILE METALS WITH BACKGROUND, PRG, GW SL, AND/OR RL EXCEEDANCES (mg/kg)

\begin{tabular}{|c|c|c|c|c|c|c|c|c|c|c|c|}
\hline \multirow[b]{2}{*}{ Analyte } & \multirow[b]{2}{*}{$\begin{array}{c}\text { Detect } \\
\text { frequency }\end{array}$} & \multirow[b]{2}{*}{$\begin{array}{c}\text { Minimum } \\
\text { detect }\end{array}$} & \multirow[b]{2}{*}{$\begin{array}{c}\text { Maximum } \\
\text { detect }\end{array}$} & \multirow{2}{*}{$\begin{array}{l}\operatorname{Location}(\mathbf{s}) \text { of } \\
\text { maximum } \\
\text { detect }\end{array}$} & \multirow{2}{*}{$\begin{array}{c}\text { Average } \\
\text { detected } \\
\text { result }\end{array}$} & \multicolumn{6}{|c|}{ Number of analyses exceeding criteria } \\
\hline & & & & & & $\begin{array}{c}\text { Max } \\
\text { RL }\end{array}$ & $\begin{array}{l}\text { Avg } \\
\text { RL }\end{array}$ & $\begin{array}{c}\text { Ind } \\
\text { PRG }\end{array}$ & Bkg & $\begin{array}{c}\text { GW } \\
\text { SL }\end{array}$ & $\begin{array}{c}\text { Res } \\
\text { PRG }\end{array}$ \\
\hline Aluminum & $1 / 1$ & 12600 & 12600 & Z2-EU8B-308 & 12600 & NA & NA & 0 & 0 & NA & 1 \\
\hline Arsenic & $1 / 1$ & 5.7 & 5.7 & Z2-EU8B-308 & 5.7 & 0 & 0 & 0 & 0 & 0 & 1 \\
\hline Calcium & $1 / 1$ & 30300 & 30300 & Z2-EU8B-308 & 30300 & NA & NA & NA & 1 & NA & NA \\
\hline Magnesium & $1 / 1$ & 13300 & 13300 & Z2-EU8B-308 & 13300 & NA & NA & NA & 1 & NA & NA \\
\hline Manganese & $1 / 1$ & $539 \mathrm{~J}$ & $539 \mathrm{~J}$ & Z2-EU8B-308 & 539 & NA & NA & 0 & 0 & NA & 1 \\
\hline Uranium & $1 / 1$ & 2.4 & 2.4 & Z2-EU8B-308 & 2.4 & NA & NA & 0 & NA & NA & 1 \\
\hline Vanadium & $1 / 1$ & $25.9 \mathrm{~J}$ & $25.9 \mathrm{~J}$ & Z2-EU8B-308 & 25.9 & NA & NA & 0 & 0 & NA & 1 \\
\hline
\end{tabular}

\begin{tabular}{ll}
\hline Avg $=$ average & NA $=$ not applicable \\
Bkg $=$ background & PRG $=$ preliminary remediation goal \\
EU $=$ exposure unit & Res $=$ residential \\
GW = groundwater & RL = remediation level \\
Ind $=$ industrial & SL $=$ screening level \\
Max = maximum & SU = soil unit
\end{tabular}

EU Z2-08 CLASS 3 SU WOOD/DEBRIS PILE PCB DETECTS (ug/kg)

\begin{tabular}{|c|c|c|c|c|c|c|c|c|c|}
\hline \multirow[b]{2}{*}{ Analyte } & \multirow[b]{2}{*}{$\begin{array}{c}\text { Detect } \\
\text { frequency }\end{array}$} & \multirow[b]{2}{*}{$\begin{array}{c}\text { Minimum } \\
\text { detect }\end{array}$} & \multirow[b]{2}{*}{$\begin{array}{l}\text { Maximum } \\
\text { detect }\end{array}$} & \multirow{2}{*}{$\begin{array}{c}\text { Location(s) of } \\
\text { maximum } \\
\text { detect }\end{array}$} & \multirow{2}{*}{$\begin{array}{c}\text { Average } \\
\text { detected } \\
\text { result }\end{array}$} & \multicolumn{4}{|c|}{$\begin{array}{l}\text { Number of analyses } \\
\text { exceeding criteria }\end{array}$} \\
\hline & & & & & & $\begin{array}{l}\text { Max } \\
\text { RL }\end{array}$ & $\begin{array}{l}\text { Avg } \\
\text { RL }\end{array}$ & $\begin{array}{l}\text { Ind } \\
\text { PRG }\end{array}$ & $\begin{array}{l}\text { Res } \\
\text { PRG }\end{array}$ \\
\hline PCB-1260 & $1 / 1$ & 53 & 53 & Z2-EU8B-308 & 53 & 0 & 0 & 0 & 0 \\
\hline PCB & $1 / 1$ & 53 & 53 & Z2-EU8B-308 & 53 & 0 & 0 & 0 & 0 \\
\hline
\end{tabular}

Avg $=$ average

$\mathrm{EU}=$ exposure unit

Ind $=$ industrial

Max = maximum

$\mathrm{PCB}=$ polychlorinated biphenyl
$\mathrm{PRG}=$ preliminary remediation goal

Res $=$ residential

$\mathrm{RL}=$ remediation level

$\mathrm{SU}=$ soil unit 
EU Z2-08 CLASS 3 SU DEBRIS PILE RADIONUCLIDES WITH BACKGROUND, PRG, AND/OR RL EXCEEDANCES (pCi/g)

\begin{tabular}{|c|c|c|c|c|c|c|c|c|c|c|c|}
\hline \multirow[b]{2}{*}{ Analyte } & \multirow[b]{2}{*}{$\begin{array}{c}\text { Detect } \\
\text { frequency }\end{array}$} & \multirow[b]{2}{*}{$\begin{array}{c}\text { Minimum } \\
\text { detect }\end{array}$} & \multirow[b]{2}{*}{$\begin{array}{c}\text { Maximum } \\
\text { detect }\end{array}$} & \multirow[b]{2}{*}{$\begin{array}{l}\text { Location(s) of } \\
\text { maximum detect }\end{array}$} & \multirow{2}{*}{$\begin{array}{c}\text { Average } \\
\text { detected } \\
\text { result }\end{array}$} & \multicolumn{6}{|c|}{ Number of analyses exceeding criteria } \\
\hline & & & & & & $\begin{array}{c}\text { Max } \\
\text { RL }\end{array}$ & $\begin{array}{l}\text { Avg } \\
\text { RL }\end{array}$ & $\begin{array}{l}\text { Ind } \\
\text { PRG }\end{array}$ & Bkg & $\begin{array}{l}\text { GW } \\
\text { SL }\end{array}$ & $\begin{array}{l}\text { Res } \\
\text { PRG }\end{array}$ \\
\hline Potassium-40 & $1 / 1$ & 14 & 14 & Z2-EU8B-308 & 14 & NA & NA & 1 & 0 & NA & 1 \\
\hline Radium-226 & $1 / 1$ & 1.02 & 1.02 & Z2-EU8B-308 & 1.02 & NA & NA & 1 & 0 & NA & 1 \\
\hline Thorium -228 & $1 / 1$ & 1.31 & 1.31 & Z2-EU8B-308 & 1.31 & NA & NA & 1 & 0 & NA & 1 \\
\hline Thorium - 230 & $1 / 1$ & 1.72 & 1.72 & Z2-EU8B-308 & 1.72 & NA & NA & 0 & 1 & NA & 0 \\
\hline Thorium -232 & $1 / 1$ & 1.55 & 1.55 & Z2-EU8B-308 & 1.55 & NA & NA & 1 & 0 & NA & 1 \\
\hline Uranium-238 & $1 / 1$ & 1.52 & 1.52 & Z2-EU8B-308 & 1.52 & 0 & 0 & 0 & 1 & 0 & 1 \\
\hline Avg $=$ average & & \multicolumn{10}{|c|}{$\mathrm{NA}=$ not applicable } \\
\hline $\mathrm{Bkg}=$ background & & \multicolumn{10}{|c|}{$\mathrm{PRG}=$ preliminary remediation goal } \\
\hline$E U=$ exposure unit & & \multicolumn{10}{|c|}{ Res $=$ residential } \\
\hline $\mathrm{GW}=$ groundwater & & \multicolumn{10}{|c|}{$\mathrm{RL}=$ remediation level } \\
\hline Ind $=$ industrial & & \multicolumn{10}{|c|}{$\mathrm{SL}=$ screening level } \\
\hline Max $=$ maximum & & \multicolumn{10}{|c|}{ SU $=$ soil unit } \\
\hline
\end{tabular}

EU Z2-08 CLASS 3 SU WOOD/DEBRIS PILE SVOC DETECTS (ug/kg)

\begin{tabular}{|c|c|c|c|c|c|c|c|c|}
\hline \multirow[b]{2}{*}{ Analyte } & \multirow[b]{2}{*}{$\begin{array}{c}\text { Detect } \\
\text { frequency }\end{array}$} & \multirow[b]{2}{*}{$\begin{array}{c}\text { Minimum } \\
\text { detect }\end{array}$} & \multirow[b]{2}{*}{$\begin{array}{c}\text { Maximum } \\
\text { detect }\end{array}$} & \multirow[b]{2}{*}{$\begin{array}{c}\text { Location(s) of } \\
\text { maximum detect }\end{array}$} & \multirow{2}{*}{$\begin{array}{c}\text { Average } \\
\text { detected } \\
\text { result }\end{array}$} & \multicolumn{3}{|c|}{$\begin{array}{l}\text { Number of analyses } \\
\text { exceeding criteria }\end{array}$} \\
\hline & & & & & & $\begin{array}{l}\text { Ind } \\
\text { PRG }\end{array}$ & $\begin{array}{l}\text { GW } \\
\text { SL }\end{array}$ & $\begin{array}{l}\text { Res } \\
\text { PRG }\end{array}$ \\
\hline Benz(a)anthracene & $1 / 1$ & $81 \mathrm{~J}$ & $81 \mathrm{~J}$ & Z2-EU8B-308 & 81 & 0 & NA & 0 \\
\hline Benzo(a)pyrene & $1 / 1$ & $110 \mathrm{~J}$ & $110 \mathrm{~J}$ & Z2-EU8B-308 & 110 & 0 & NA & 1 \\
\hline Benzo(b)fluoranthene & $1 / 1$ & $100 \mathrm{~J}$ & $100 \mathrm{~J}$ & Z2-EU8B-308 & 100 & 0 & NA & 0 \\
\hline Benzo(ghi)perylene & $1 / 1$ & $99 \mathrm{~J}$ & $99 \mathrm{~J}$ & Z2-EU8B-308 & 99 & 0 & NA & 0 \\
\hline Benzo(k)fluoranthene & $1 / 1$ & $99 \mathrm{~J}$ & $99 \mathrm{~J}$ & Z2-EU8B-308 & 99 & 0 & NA & 0 \\
\hline Chrysene & $1 / 1$ & $100 \mathrm{~J}$ & $100 \mathrm{~J}$ & Z2-EU8B-308 & 100 & 0 & NA & 0 \\
\hline Fluoranthene & $1 / 1$ & $120 \mathrm{~J}$ & $120 \mathrm{~J}$ & Z2-EU8B-308 & 120 & 0 & NA & 0 \\
\hline Indeno(1,2,3-cd)pyrene & $1 / 1$ & $83 \mathrm{~J}$ & $83 \mathrm{~J}$ & Z2-EU8B-308 & 83 & 0 & NA & 0 \\
\hline Phenanthrene & $1 / 1$ & $62 \mathrm{~J}$ & $62 \mathrm{~J}$ & Z2-EU8B-308 & 62 & 0 & NA & 0 \\
\hline Pyrene & $1 / 1$ & $140 \mathrm{~J}$ & $140 \mathrm{~J}$ & Z2-EU8B-308 & 140 & 0 & NA & 0 \\
\hline
\end{tabular}

$\mathrm{EU}=$ exposure unit $\quad \mathrm{PRG}=$ preliminary remediation goal

Ind = industrial $\quad$ Res = residential

$\mathrm{NA}=$ not applicable $\quad \mathrm{SU}=$ soil unit

EU Z2-08 CLASS 3 SU WOOD/DEBRIS PILE VOC DETECTS (ug/kg)

\begin{tabular}{|c|c|c|c|c|c|c|c|c|}
\hline \multirow[b]{2}{*}{ Analyte } & \multirow[b]{2}{*}{$\begin{array}{c}\text { Detect } \\
\text { Frequency }\end{array}$} & \multirow[b]{2}{*}{$\begin{array}{l}\text { Minimum } \\
\text { Detect }\end{array}$} & \multirow[b]{2}{*}{$\begin{array}{c}\text { Maximum } \\
\text { Detect }\end{array}$} & \multirow[b]{2}{*}{$\begin{array}{c}\text { Location(s) of } \\
\text { Maximum Detect }\end{array}$} & \multirow[b]{2}{*}{$\begin{array}{c}\text { Average } \\
\text { Detected } \\
\text { Result }\end{array}$} & \multicolumn{3}{|c|}{$\begin{array}{l}\text { Number of Analyses } \\
\text { Exceeding Criteria }\end{array}$} \\
\hline & & & & & & $\begin{array}{l}\text { Ind } \\
\text { PRG }\end{array}$ & GW SL & $\begin{array}{l}\text { Res } \\
\text { PRG }\end{array}$ \\
\hline Acetone & $1 / 1$ & $7.2 \mathrm{~J}$ & $7.2 \mathrm{~J}$ & Z2-EU8B-308 & 7.2 & 0 & NA & 0 \\
\hline $\begin{array}{l}\text { EU = exposure unit } \\
\text { GW = groundwater } \\
\text { Ind = industrial } \\
\text { NA = not applicable } \\
\text { PRG = preliminary re }\end{array}$ & ation goal & \multicolumn{7}{|c|}{$\begin{array}{l}\text { Res }=\text { residential } \\
\text { SL }=\text { screening level } \\
\text { SU }=\text { soil unit } \\
\text { VOC }=\text { volatile organic compound }\end{array}$} \\
\hline
\end{tabular}

DVS Class 3 SU Biased Sampling at the Diesel AST: Biased sample locations Z2-EU8B-309 and Z2-EU8B-310 were selected at a diesel AST observed during the Class 3 SU walkover assessment. A discrete surface soil sample was collected at Z2-EU8B-309, which was located beneath the tank's overflow pipe, while another discrete surface soil sample was collected at Z2-EU8B-310, which was located at the base of the slope leading to the tank. Analytical results summarized below show detections of SVOCs. 


\begin{tabular}{|c|c|c|c|c|c|c|c|c|}
\hline \multirow[b]{2}{*}{ Analyte } & \multirow[b]{2}{*}{$\begin{array}{c}\text { Detect } \\
\text { frequency }\end{array}$} & \multirow[b]{2}{*}{$\begin{array}{c}\text { Minimum } \\
\text { detect }\end{array}$} & \multirow[b]{2}{*}{$\begin{array}{c}\text { Maximum } \\
\text { detect }\end{array}$} & \multirow[b]{2}{*}{$\begin{array}{l}\text { Location(s) of } \\
\text { maximum detect }\end{array}$} & \multirow{2}{*}{$\begin{array}{c}\text { Average } \\
\text { detected } \\
\text { result }\end{array}$} & \multicolumn{3}{|c|}{$\begin{array}{l}\text { Number of analyses } \\
\text { exceeding criteria }\end{array}$} \\
\hline & & & & & & $\begin{array}{l}\text { Ind } \\
\text { PRG }\end{array}$ & $\begin{array}{c}\text { GW } \\
\text { SL }\end{array}$ & $\begin{array}{l}\text { Res } \\
\text { PRG }\end{array}$ \\
\hline Anthracene & $1 / 2$ & $38 \mathrm{~J}$ & $38 \mathrm{~J}$ & Z2-EU8B-309 & 38 & 0 & NA & 0 \\
\hline Benz(a)anthracene & $2 / 2$ & $75 \mathrm{~J}$ & $110 \mathrm{~J}$ & Z2-EU8B-309 & 92.5 & 0 & NA & 0 \\
\hline Benzo(a)pyrene & $2 / 2$ & $73 \mathrm{~J}$ & $90 \mathrm{~J}$ & Z2-EU8B-309 & 81.5 & 0 & NA & 2 \\
\hline Benzo(b)fluoranthene & $2 / 2$ & $71 \mathrm{~J}$ & $92 J$ & Z2-EU8B-309 & 81.5 & 0 & NA & 0 \\
\hline Benzo(ghi)perylene & $2 / 2$ & $54 \mathrm{~J}$ & $58 \mathrm{~J}$ & Z2-EU8B-310 & 56 & 0 & NA & 0 \\
\hline Benzo(k)fluoranthene & $2 / 2$ & $64 \mathrm{~J}$ & $96 \mathrm{~J}$ & Z2-EU8B-309 & 80 & 0 & NA & 0 \\
\hline Bis(2-ethylhexyl)phthalate & $1 / 2$ & $110 \mathrm{~J}$ & $110 \mathrm{~J}$ & Z2-EU8B-310 & 110 & 0 & 0 & 0 \\
\hline Chrysene & $2 / 2$ & $88 \mathrm{~J}$ & $110 \mathrm{~J}$ & Z2-EU8B-309 & 99 & 0 & NA & 0 \\
\hline Fluoranthene & $2 / 2$ & $170 \mathrm{~J}$ & $220 \mathrm{~J}$ & Z2-EU8B-309 & 195 & 0 & NA & 0 \\
\hline Indeno(1,2,3-cd)pyrene & $2 / 2$ & $47 \mathrm{~J}$ & $55 \mathrm{~J}$ & Z2-EU8B-309 & 51 & 0 & NA & 0 \\
\hline Phenanthrene & $2 / 2$ & $110 \mathrm{~J}$ & $190 \mathrm{~J}$ & Z2-EU8B-309 & 150 & 0 & NA & 0 \\
\hline Pyrene & $2 / 2$ & $120 \mathrm{~J}$ & $180 \mathrm{~J}$ & Z2-EU8B-309 & 150 & 0 & NA & 0 \\
\hline $\begin{array}{l}\text { EU = exposure unit } \\
\mathrm{GW}=\text { groundwater } \\
\text { Ind = industrial } \\
\mathrm{NA}=\text { not applicable } \\
\text { PRG = preliminary remedi }\end{array}$ & on goal & $\begin{array}{l}\text { Res }=\text { resic } \\
\text { SL }=\text { scree } \\
\text { SU }=\text { soil u } \\
\text { SVOC }=\text { se }\end{array}$ & $\begin{array}{l}\text { dential } \\
\text { ning level } \\
\text { anit } \\
\text { emivolatile o }\end{array}$ & rganic compound & & & & \\
\hline
\end{tabular}

Both samples were analyzed for DRO and GRO but were not detected.

DVS Class 3 SU Biased Sampling at the Gasoline AST: Three biased sample locations were selected at a gasoline AST observed during the Class $3 \mathrm{SU}$ walkover assessment. A discrete surface soil sample was collected at each location and analyzed. Sample location Z2-EU8B-311 was located on the east side of the concrete pad on which the tank sits, Z2-EU8B-312 was located on the south side of the concrete pad, and Z2-EU8B-313 was located on the west side of the concrete pad. Analytical results summarized below show SVOC detections.

EU Z2-08 CLASS 3 SU GAS ASTSVOC DETECTS (ug/kg)

\begin{tabular}{|c|c|c|c|c|c|c|c|c|}
\hline \multirow[b]{2}{*}{ Analyte } & \multirow[b]{2}{*}{$\begin{array}{c}\text { Detect } \\
\text { frequency }\end{array}$} & \multirow[b]{2}{*}{$\begin{array}{c}\text { Minimum } \\
\text { detect }\end{array}$} & \multirow[b]{2}{*}{$\begin{array}{c}\text { Maximum } \\
\text { detect }\end{array}$} & \multirow[b]{2}{*}{$\begin{array}{c}\text { Location(s) of } \\
\text { maximum detect }\end{array}$} & \multirow{2}{*}{$\begin{array}{c}\text { Average } \\
\text { detected } \\
\text { result }\end{array}$} & \multicolumn{3}{|c|}{$\begin{array}{c}\text { Number of analyses } \\
\text { exceeding criteria }\end{array}$} \\
\hline & & & & & & $\begin{array}{l}\text { Ind } \\
\text { PRG }\end{array}$ & $\begin{array}{c}\text { GW } \\
\text { SL }\end{array}$ & $\begin{array}{c}\text { Res } \\
\text { PRG }\end{array}$ \\
\hline 2-Methylnaphthalene & $1 / 3$ & $39 \mathrm{~J}$ & $39 \mathrm{~J}$ & Z2-EU8B-311 & 39 & 0 & NA & $\mathrm{NA}$ \\
\hline Acenaphthene & $1 / 3$ & $300 \mathrm{~J}$ & $300 \mathrm{~J}$ & Z2-EU8B-311 & 300 & 0 & NA & 0 \\
\hline Anthracene & $1 / 3$ & 480 & 480 & Z2-EU8B-311 & 480 & 0 & NA & 0 \\
\hline Benz(a)anthracene & $2 / 3$ & $110 \mathrm{~J}$ & 1300 & Z2-EU8B-311 & 705 & 0 & NA & 1 \\
\hline Benzo(a)pyrene & $2 / 3$ & $100 \mathrm{~J}$ & 1100 & Z2-EU8B-311 & 600 & 0 & NA & 2 \\
\hline Benzo(b)fluoranthene & $2 / 3$ & $90 \mathrm{~J}$ & 1000 & Z2-EU8B-311 & 545 & 0 & NA & 1 \\
\hline Benzo(ghi)perylene & $2 / 3$ & $74 \mathrm{~J}$ & 520 & Z2-EU8B-311 & 297 & 0 & NA & 0 \\
\hline Benzo(k)fluoranthene & $2 / 3$ & $92 \mathrm{~J}$ & 1000 & Z2-EU8B-311 & 546 & 0 & NA & 0 \\
\hline Bis(2-ethylhexyl)phthalate & $1 / 3$ & $39 \mathrm{~J}$ & $39 \mathrm{~J}$ & Z2-EU8B-311 & 39 & 0 & 0 & 0 \\
\hline Carbazole & $1 / 3$ & $250 \mathrm{~J}$ & $250 \mathrm{~J}$ & Z2-EU8B-311 & 250 & 0 & NA & 0 \\
\hline Chrysene & $2 / 3$ & $100 \mathrm{~J}$ & 1300 & Z2-EU8B-311 & 700 & 0 & NA & 0 \\
\hline Dibenz(a,h)anthracene & $1 / 3$ & $240 \mathrm{~J}$ & $240 \mathrm{~J}$ & Z2-EU8B-311 & 240 & 0 & NA & 1 \\
\hline Dibenzofuran & $1 / 3$ & $87 \mathrm{~J}$ & $87 \mathrm{~J}$ & Z2-EU8B-311 & 87 & 0 & NA & 0 \\
\hline Fluoranthene & $3 / 3$ & $40 \mathrm{~J}$ & 2600 & Z2-EU8B-311 & 943 & 0 & NA & 0 \\
\hline Fluorene & $1 / 3$ & $260 \mathrm{~J}$ & $260 \mathrm{~J}$ & Z2-EU8B-311 & 260 & 0 & NA & 0 \\
\hline Indeno(1,2,3-cd)pyrene & $2 / 3$ & $71 \mathrm{~J}$ & 560 & Z2-EU8B-311 & 315.5 & 0 & NA & 0 \\
\hline Phenanthrene & $2 / 3$ & $110 \mathrm{~J}$ & 1700 & Z2-EU8B-311 & 905 & 0 & NA & 0 \\
\hline Pyrene & $2 / 3$ & $150 \mathrm{~J}$ & 1800 & Z2-EU8B-311 & 975 & 0 & NA & 0 \\
\hline $\begin{array}{l}\text { EU = exposure unit } \\
\text { GW = groundwater } \\
\text { Ind = industrial } \\
\text { NA = not applicable } \\
\text { PRG = preliminary remedi }\end{array}$ & ngoal & $\begin{array}{l}\text { Res }=\text { resid } \\
\text { SL }=\text { scree } \\
\text { SU }=\text { soil u } \\
\text { SVOC }=\text { se }\end{array}$ & $\begin{array}{l}\text { ential } \\
\text { ning level } \\
\text { nit } \\
\text { mivolatile or }\end{array}$ & rganic compound & & & & \\
\hline
\end{tabular}


GRO were also analyzed for in the three samples but was not detected.

DVS Class 3 SU Biased Sampling at the K-892 Transformer: Biased sample location Z2-EU8B-317 was selected at the K-892 transformer, which was visually identified during the Class 3 SU walkover assessment as a potential source of chemical contamination. A five-point composite surface soil sample was collected and analyzed. Analytical results summarized below show metal background exceedances and SVOC detections.

EU Z2-08 K-892 TRANSFORMER METALS WITH BACKGROUND, PRG, GW SL, AND/OR RL EXCEEDANCES (mg/kg)

\begin{tabular}{|c|c|c|c|c|c|c|c|c|c|c|c|}
\hline \multirow[b]{2}{*}{ Analyte } & \multirow[b]{2}{*}{$\begin{array}{c}\text { Detect } \\
\text { frequency }\end{array}$} & \multirow[b]{2}{*}{$\begin{array}{c}\text { Minimum } \\
\text { detect }\end{array}$} & \multirow[b]{2}{*}{$\begin{array}{c}\text { Maximum } \\
\text { detect }\end{array}$} & \multirow{2}{*}{$\begin{array}{l}\text { Location(s) of } \\
\text { maximum } \\
\text { detect }\end{array}$} & \multirow{2}{*}{$\begin{array}{c}\text { Average } \\
\text { detected } \\
\text { result }\end{array}$} & \multicolumn{6}{|c|}{ Number of analyses exceeding criteria } \\
\hline & & & & & & $\begin{array}{c}\text { Max } \\
\text { RL }\end{array}$ & $\begin{array}{l}\text { Avg } \\
\text { RL }\end{array}$ & $\begin{array}{l}\text { Ind } \\
\text { PRG }\end{array}$ & Bkg & $\begin{array}{c}\text { GW } \\
\text { SL }\end{array}$ & $\begin{array}{l}\text { Res } \\
\text { PRG }\end{array}$ \\
\hline Arsenic & $1 / 1$ & 1.4 & 1.4 & Z2-EU8B-317 & 1.4 & 0 & 0 & 0 & 0 & 0 & 1 \\
\hline Calcium & $1 / 1$ & $291000 \mathrm{~J}$ & $291000 \mathrm{~J}$ & Z2-EU8B-317 & 291000 & NA & NA & NA & 1 & NA & NA \\
\hline Chromium & $1 / 1$ & $27.7 \mathrm{~J}$ & $27.7 \mathrm{~J}$ & Z2-EU8B-317 & 27.7 & NA & NA & 0 & 0 & 0 & 1 \\
\hline Magnesium & $1 / 1$ & $47700 \mathrm{~J}$ & $47700 \mathrm{~J}$ & Z2-EU8B-317 & 47700 & NA & NA & NA & 1 & NA & NA \\
\hline Zinc & $1 / 1$ & $145 \mathrm{~J}$ & $145 \mathrm{~J}$ & Z2-EU8B-317 & 145 & NA & NA & 0 & 1 & NA & 0 \\
\hline
\end{tabular}

\begin{tabular}{ll}
\hline Avg $=$ average & NA $=$ not applicable \\
Bkg $=$ background & PRG = preliminary remediation goal \\
EU $=$ exposure unit & Res $=$ residential \\
GW = groundwater & RL = remediation level \\
Ind $=$ industrial & SL = screening level \\
Max = maximum & SU = soil unit
\end{tabular}

PCBs were analyzed for in the sample but were not detected.

EU Z2-08 K-892 TRANSFORMER SVOC DETECTS (ug/kg)

\begin{tabular}{|c|c|c|c|c|c|c|c|c|}
\hline \multirow[b]{2}{*}{ Analyte } & \multirow[b]{2}{*}{$\begin{array}{l}\text { Detect } \\
\text { frequency }\end{array}$} & \multirow[b]{2}{*}{$\begin{array}{c}\text { Minimum } \\
\text { detect }\end{array}$} & \multirow[b]{2}{*}{$\begin{array}{c}\text { Maximum } \\
\text { detect }\end{array}$} & \multirow[b]{2}{*}{$\begin{array}{c}\text { Location(s) of } \\
\text { maximum detect }\end{array}$} & \multirow{2}{*}{$\begin{array}{c}\text { Average } \\
\text { detected } \\
\text { result }\end{array}$} & \multicolumn{3}{|c|}{$\begin{array}{l}\text { Number of analyses } \\
\text { exceeding criteria }\end{array}$} \\
\hline & & & & & & $\begin{array}{l}\text { Ind } \\
\text { PRG }\end{array}$ & $\begin{array}{l}\text { GW } \\
\text { SL }\end{array}$ & $\begin{array}{l}\text { Res } \\
\text { PRG }\end{array}$ \\
\hline Acenaphthene & $1 / 1$ & $53 \mathrm{~J}$ & $53 \mathrm{~J}$ & Z2-EU8B-317 & 53 & 0 & NA & 0 \\
\hline Anthracene & $1 / 1$ & $83 \mathrm{~J}$ & $83 \mathrm{~J}$ & Z2-EU8B-317 & 83 & 0 & NA & 0 \\
\hline Benz(a)anthracene & $1 / 1$ & $330 \mathrm{~J}$ & $330 \mathrm{~J}$ & Z2-EU8B-317 & 330 & 0 & NA & 0 \\
\hline Benzo(a)pyrene & $1 / 1$ & $300 \mathrm{~J}$ & $300 \mathrm{~J}$ & Z2-EU8B-317 & 300 & 0 & NA & 1 \\
\hline Benzo(b)fluoranthene & $1 / 1$ & $320 \mathrm{~J}$ & $320 \mathrm{~J}$ & Z2-EU8B-317 & 320 & 0 & NA & 0 \\
\hline Benzo(ghi)perylene & $1 / 1$ & $180 \mathrm{~J}$ & $180 \mathrm{~J}$ & Z2-EU8B-317 & 180 & 0 & NA & 0 \\
\hline Benzo(k)fluoranthene & $1 / 1$ & $300 \mathrm{~J}$ & $300 \mathrm{~J}$ & Z2-EU8B-317 & 300 & 0 & NA & 0 \\
\hline Carbazole & $1 / 1$ & $85 \mathrm{~J}$ & $85 \mathrm{~J}$ & Z2-EU8B-317 & 85 & 0 & NA & 0 \\
\hline Chrysene & $1 / 1$ & 360 & 360 & Z2-EU8B-317 & 360 & 0 & NA & 0 \\
\hline Fluoranthene & $1 / 1$ & 800 & 800 & Z2-EU8B-317 & 800 & 0 & NA & 0 \\
\hline Indeno(1,2,3-cd)pyrene & $1 / 1$ & $170 \mathrm{~J}$ & $170 \mathrm{~J}$ & Z2-EU8B-317 & 170 & 0 & NA & 0 \\
\hline Phenanthrene & $1 / 1$ & 460 & 460 & Z2-EU8B-317 & 460 & 0 & NA & 0 \\
\hline Pyrene & $1 / 1$ & 670 & 670 & Z2-EU8B-317 & 670 & 0 & NA & 0 \\
\hline $\begin{array}{l}\mathrm{EU}=\text { exposure unit } \\
\mathrm{GW}=\text { groundwater } \\
\mathrm{Ind}=\text { industrial } \\
\mathrm{NA}=\text { not applicable }\end{array}$ & & $\begin{array}{l}\text { PRG }=\text { prel } \\
\text { Res }=\text { resid } \\
\text { SL }=\text { screel } \\
\text { SVOC }=\text { se }\end{array}$ & $\begin{array}{l}\text { liminary rem } \\
\text { lential } \\
\text { ning level } \\
\text { mivolatile or }\end{array}$ & rganic compound & & & & \\
\hline
\end{tabular}

DVS Class 3 SU Biased Sampling at the Elevated Radiation Location: Biased sample location Z2-EU8B-307 was selected based on elevated radiation readings observed during the BAR survey at the former cooling basin sludge waste storage location. A discrete surface soil sample was collected and analyzed for radionuclides. Analytical results summarized below show radionuclide industrial PRG and background exceedances 
EU Z2-08 ELEVATED RAD RADIONUCLIDES WITH BACKGROUND, PRG, AND/OR RL EXCEEDANCES (pCi/g)

\begin{tabular}{|c|c|c|c|c|c|c|c|c|c|c|c|}
\hline \multirow[b]{2}{*}{ Analyte } & \multirow[b]{2}{*}{$\begin{array}{c}\text { Detect } \\
\text { frequency }\end{array}$} & \multirow[b]{2}{*}{$\begin{array}{c}\text { Minimum } \\
\text { detect }\end{array}$} & \multirow[b]{2}{*}{$\begin{array}{l}\text { Maximum } \\
\text { detect }\end{array}$} & \multirow[b]{2}{*}{$\begin{array}{c}\text { Location(s) of } \\
\text { maximum detect }\end{array}$} & \multirow{2}{*}{$\begin{array}{c}\text { Average } \\
\text { detected } \\
\text { result }\end{array}$} & \multicolumn{6}{|c|}{ Number of analyses exceeding criteria } \\
\hline & & & & & & $\begin{array}{c}\text { Max } \\
\text { RL }\end{array}$ & $\begin{array}{l}\text { Avg } \\
\text { RL }\end{array}$ & $\begin{array}{c}\text { Ind } \\
\text { PRG }\end{array}$ & Bkg & $\begin{array}{c}\text { GW } \\
\text { SL }\end{array}$ & $\begin{array}{c}\text { Res } \\
\text { PRG }\end{array}$ \\
\hline Cesium-137 & $1 / 1$ & 0.48 & 0.48 & Z2-EU8B-307 & 0.48 & 0 & 0 & 0 & NA & NA & 1 \\
\hline Potassium-40 & $1 / 1$ & 9.8 & 9.8 & Z2-EU8B-307 & 9.8 & NA & NA & 1 & 0 & NA & 1 \\
\hline Radium-226 & $1 / 1$ & 0.65 & 0.65 & Z2-EU8B-307 & 0.65 & NA & NA & 1 & 0 & NA & 1 \\
\hline Technetium-99 & $1 / 1$ & 0.41 & 0.41 & Z2-EU8B-307 & 0.41 & NA & NA & 0 & NA & NA & 1 \\
\hline Thorium -228 & $1 / 1$ & 0.76 & 0.76 & Z2-EU8B-307 & 0.76 & NA & NA & 1 & 0 & NA & 1 \\
\hline Thorium -230 & $1 / 1$ & 1.38 & 1.38 & Z2-EU8B-307 & 1.38 & NA & NA & 0 & 1 & NA & 0 \\
\hline Thorium -232 & $1 / 1$ & 0.77 & 0.77 & Z2-EU8B-307 & 0.77 & NA & NA & 1 & 0 & NA & 1 \\
\hline Uranium-233/234 & $1 / 1$ & 27 & 27 & Z2-EU8B-307 & 27 & 0 & 0 & 0 & NA & 0 & 1 \\
\hline Uranium-235/236 & $1 / 1$ & 1.55 & 1.55 & Z2-EU8B-307 & 1.55 & 0 & 0 & 0 & NA & 0 & 1 \\
\hline Uranium-238 & $1 / 1$ & 21 & 21 & Z2-EU8B-307 & 21 & 0 & 0 & 1 & 1 & 0 & 1 \\
\hline
\end{tabular}

\begin{tabular}{ll}
\hline Avg $=$ average & PRG $=$ preliminary remediation goal \\
$\mathrm{Bkg}=$ background & RAD $=$ radiological \\
$\mathrm{EU}=$ exposure unit & Res $=$ residential \\
$\mathrm{GW}=$ groundwater & $\mathrm{RL}=$ remediation level \\
Ind $=$ industrial & $\mathrm{SL}=$ screening level \\
Max $=$ maximum & $\mathrm{SU}=$ soil unit \\
$\mathrm{NA}=$ not applicable &
\end{tabular}

DVS Class 3 SU Biased Sampling at Inactive Valve Vaults: Four inactive valve vaults were selected for biased sampling during the facilities assessment of the Class $3 \mathrm{SU}$ walkover assessment. The four facilities [K-893-V Inactive Valve Vault (sample location Z2-EU8B-315), K-899-M Inactive Valve Vault (sample location Z2-EU8B-314), K-893-DD Inactive Valve Vault (sample location Z2-EU8B-318), and K-893-Q Inactive Valve Vault (sample location Z2-EU8B-319)] were selected to represent the potential for 25 inactive valve vaults in the EU to be contaminant sources. A sample of accumulated sediment from inside the valve vaults was collected at each location and analyzed. Analytical results summarized below show a Cs-137 Avg RL and a chromium GW SL exceedance at location Z2-EU8B-314, one metal and several radionuclide Ind PRG exceedances, metal and radionuclide Bkg exceedances, and PCB detections in one sample (Z2-EU8B-314).

EU Z2-08 CLASS 3 SU INACTIVE VALVE VAULTS METALS WITH BACKGROUND, PRG, GW SL, AND/OR RL EXCEEDANCES (mg/kg)

\begin{tabular}{|c|c|c|c|c|c|c|c|c|c|c|c|}
\hline \multirow[b]{2}{*}{ Analyte } & \multirow[b]{2}{*}{$\begin{array}{c}\text { Detect } \\
\text { frequency }\end{array}$} & \multirow[b]{2}{*}{$\begin{array}{c}\text { Minimum } \\
\text { detect }\end{array}$} & \multirow[b]{2}{*}{$\begin{array}{c}\text { Maximum } \\
\text { detect }\end{array}$} & \multirow{2}{*}{$\begin{array}{l}\text { Location(s) of } \\
\text { maximum } \\
\text { detect }\end{array}$} & \multirow{2}{*}{$\begin{array}{c}\begin{array}{c}\text { Average } \\
\text { detected } \\
\text { result }\end{array} \\
\end{array}$} & \multicolumn{6}{|c|}{ Number of analyses exceeding criteria } \\
\hline & & & & & & $\begin{array}{c}\text { Max } \\
\text { RL }\end{array}$ & $\begin{array}{l}\text { Avg } \\
\text { RL }\end{array}$ & $\begin{array}{l}\text { Ind } \\
\text { PRG }\end{array}$ & Bkg & $\begin{array}{l}\text { GW } \\
\text { SL }\end{array}$ & $\begin{array}{c}\text { Res } \\
\text { PRG }\end{array}$ \\
\hline Aluminum & $4 / 4$ & $2020 \mathrm{~J}$ & $9500 \mathrm{~J}$ & Z2-EU8B-314 & 4250 & NA & NA & 0 & 0 & NA & 1 \\
\hline Arsenic & $4 / 4$ & 2.7 & 27.3 & Z2-EU8B-314 & 12.1 & 0 & 0 & 1 & 2 & 0 & 4 \\
\hline Cadmium & $4 / 4$ & $0.15 \mathrm{~J}$ & $1.7 \mathrm{~J}$ & Z2-EU8B-315 & 1.14 & NA & NA & 0 & 3 & NA & 0 \\
\hline Calcium & $4 / 4$ & $3620 \mathrm{~J}$ & $23300 \mathrm{~J}$ & Z2-EU8B-315 & 10170 & NA & NA & NA & 4 & NA & NA \\
\hline Chromium & $4 / 4$ & $22.1 \mathrm{~J}$ & $446 \mathrm{~J}$ & Z2-EU8B-314 & 132 & NA & NA & 0 & 1 & 1 & 3 \\
\hline Copper & $4 / 4$ & $15.1 \mathrm{~J}$ & 83.3 & Z2-EU8B-314 & 46.7 & NA & NA & 0 & 3 & NA & 0 \\
\hline Iron & $4 / 4$ & $16600 \mathrm{~J}$ & $65000 \mathrm{~J}$ & Z2-EU8B-315 & 36875 & NA & NA & 0 & 1 & NA & 0 \\
\hline Lead & $4 / 4$ & 6.1 & 505 & Z2-EU8B-314 & 191 & NA & NA & 0 & 2 & 0 & 1 \\
\hline Manganese & $4 / 4$ & $94.9 \mathrm{~J}$ & $1410 \mathrm{~J}$ & Z2-EU8B-314 & 480 & NA & NA & 0 & 0 & NA & 2 \\
\hline Mercury & $4 / 4$ & $0.011 \mathrm{~J}$ & $0.93 \mathrm{~J}$ & Z2-EU8B-314 & 0.305 & 0 & 0 & 0 & 2 & NA & 0 \\
\hline Nickel & $4 / 4$ & $8.5 \mathrm{~J}$ & $57.5 \mathrm{~J}$ & Z2-EU8B-314 & 24.55 & NA & NA & 0 & 1 & NA & 0 \\
\hline Uranium & $4 / 4$ & 0.19 & 2.5 & Z2-EU8B-314 & 0.875 & NA & NA & 0 & NA & NA & 1 \\
\hline Vanadium & $4 / 4$ & 3.7 & 21.8 & Z2-EU8B-314 & 9.33 & NA & NA & 0 & 0 & NA & 1 \\
\hline Zinc & $4 / 4$ & $61.1 \mathrm{~J}$ & $1140 \mathrm{~J}$ & Z2-EU8B-314 & 449 & NA & NA & 0 & 3 & $\mathrm{NA}$ & 0 \\
\hline
\end{tabular}

Avg $=$ average

$\mathrm{NA}=$ not applicable

$\mathrm{Bkg}=$ background

$\mathrm{EU}=$ exposure unit

$\mathrm{PRG}=$ preliminary remediation goal

$\mathrm{GW}=$ groundwater

Ind $=$ industrial

Res $=$ residential

$\mathrm{RL}=$ remediation level

$\mathrm{SL}=$ screening level

Max $=$ maximum $\quad \mathrm{SU}=$ soil unit 


\section{EU Z2-08 CLASS 3 SU INACTIVE VALVE VAULTS PCB DETECTS (ug/kg)}

\begin{tabular}{|c|c|c|c|c|c|c|c|c|c|}
\hline \multirow[b]{2}{*}{ Analyte } & \multirow[b]{2}{*}{$\begin{array}{c}\text { Detect } \\
\text { frequency }\end{array}$} & \multirow[b]{2}{*}{$\underset{\text { detect }}{\text { Minimum }}$} & \multirow[b]{2}{*}{$\begin{array}{c}\text { Maximum } \\
\text { detect }\end{array}$} & \multirow{2}{*}{$\begin{array}{c}\text { Location(s) of } \\
\text { maximum } \\
\text { detect }\end{array}$} & \multirow{2}{*}{$\begin{array}{c}\text { Average } \\
\text { detected } \\
\text { result }\end{array}$} & \multicolumn{4}{|c|}{$\begin{array}{l}\text { Number of analyses } \\
\text { exceeding criteria }\end{array}$} \\
\hline & & & & & & $\begin{array}{c}\text { Max } \\
\text { RL }\end{array}$ & $\begin{array}{l}\text { Avg } \\
\text { RL }\end{array}$ & $\begin{array}{l}\text { Ind } \\
\text { PRG }\end{array}$ & $\begin{array}{l}\text { Res } \\
\text { PRG }\end{array}$ \\
\hline-1254 & $1 / 4$ & 160 & 160 & Z2-EU8B-314 & 160 & 0 & 0 & 0 & 1 \\
\hline PCB & $1 / 4$ & $160 \mathrm{~J}$ & $160 \mathrm{~J}$ & Z2-EU8B-314 & 160 & 0 & 0 & 0 & 1 \\
\hline
\end{tabular}

Avg $=$ average

$\mathrm{EU}=$ exposure unit

Ind $=$ industrial

Max $=$ maximum

$\mathrm{PCB}=$ polychlorinated biphenyl
$\mathrm{PRG}=$ preliminary remediation goal

Res $=$ residential

$\mathrm{RL}=$ remediation level

$\mathrm{SU}=$ soil unit

EU Z2-08 CLASS 3 SU INACTIVE VALVE VAULTS RADIONUCLIDES WITH

BAC KGROUND, PRG, AND/OR RL EXCEEDANCES (pCi/g)

\begin{tabular}{|c|c|c|c|c|c|c|c|c|c|c|c|}
\hline \multirow[b]{2}{*}{ Analyte } & \multirow[b]{2}{*}{$\begin{array}{c}\text { Detect } \\
\text { frequency }\end{array}$} & \multirow[b]{2}{*}{$\begin{array}{c}\text { Minimum } \\
\text { detect }\end{array}$} & \multirow[b]{2}{*}{$\begin{array}{c}\text { Maximum } \\
\text { detect }\end{array}$} & \multirow[b]{2}{*}{$\begin{array}{l}\text { Location(s) of } \\
\text { maximum detect }\end{array}$} & \multirow{2}{*}{$\begin{array}{c}\text { Average } \\
\text { detected } \\
\text { result }\end{array}$} & \multicolumn{6}{|c|}{ Number of analyses exceeding criteria } \\
\hline & & & & & & $\begin{array}{l}\text { Max } \\
\text { RL }\end{array}$ & $\begin{array}{c}\text { Avg } \\
\text { RL }\end{array}$ & $\begin{array}{c}\text { Ind } \\
\text { PRG }\end{array}$ & Bkg & $\begin{array}{c}\text { GW } \\
\text { SL }\end{array}$ & $\begin{array}{l}\text { Res } \\
\text { PRG }\end{array}$ \\
\hline Cesium-137 & $2 / 4$ & 0.259 & 2.61 & Z2-EU8B-314 & 1.43 & 0 & 1 & 1 & NA & NA & 2 \\
\hline Potassium-40 & $4 / 4$ & 3.21 & 16.3 & Z2-EU8B-319 & 8.70 & NA & NA & 4 & 0 & NA & 4 \\
\hline Radium-226 & $3 / 4$ & 0.51 & 2.39 & Z2-EU8B-319 & 1.23 & NA & NA & 3 & 1 & NA & 3 \\
\hline Technetium-99 & $1 / 4$ & 0.98 & 0.98 & Z2-EU8B-314 & 0.98 & NA & NA & 0 & NA & NA & 1 \\
\hline Thorium -228 & $4 / 4$ & 0.28 & 2.04 & Z2-EU8B-319 & 0.98 & NA & NA & 4 & 1 & NA & 4 \\
\hline Thorium -230 & $3 / 4$ & 0.51 & 3.04 & Z2-EU8B-319 & 1.6 & NA & NA & 0 & 2 & NA & 0 \\
\hline Thorium -232 & $4 / 4$ & 0.19 & 1.51 & Z2-EU8B-319 & 0.753 & NA & NA & 4 & 0 & NA & 4 \\
\hline Uranium-238 & $4 / 4$ & 0.188 & 2.55 & Z2-EU8B-319 & 1.21 & 0 & 0 & 0 & 2 & 0 & 2 \\
\hline
\end{tabular}

Avg $=$ average NA $=$ not applicable

$\mathrm{Bkg}=$ background $\quad \mathrm{PRG}=$ preliminary remediation goal

$\mathrm{EU}=$ exposure unit $\quad$ Res $=$ residential

$\mathrm{GW}=$ groundwater $\quad \mathrm{RL}=$ remediation level

Ind = industrial $\quad \mathrm{SL}=$ screening level

Max $=$ maximum $\quad \mathrm{SU}=$ soil unit

Historical Sampling in the EU Z2-08 Class 3 SU: Eight of the 25 historical sample locations in this EU are part of a characterization of a RCW leak site conducted in 2004 (location identifiers K33RCW\#\#). The remaining 17 historical sample locations are part of the 1994 radiological walkover survey (location identifiers RAD\#\#\#). The location identifiers for the historical locations are presented in Sect. 2.2.3 and shown on Error! Reference source not found. Historical sample location RAD228 was assigned to the Class 2 SU during DQO scoping and is not included in the following summary. Analytical results summarized below show one metal (arsenic) with three industrial PRG exceedances and several radionuclide industrial PRG exceedances; GW SL exceedances by arsenic (1) and chromium (2); and several metal and radionuclide background exceedances and SVOC detections.

EU Z2-08 HISTORICAL METALS WITH BACKGROUND, PRG, GW SL, AND/OR RL EXCEEDANCES (mg/kg)

\begin{tabular}{|c|c|c|c|c|c|c|c|c|c|c|c|}
\hline \multirow[b]{2}{*}{ Analyte } & \multirow[b]{2}{*}{$\begin{array}{c}\text { Detect } \\
\text { frequency }\end{array}$} & \multirow[b]{2}{*}{$\begin{array}{c}\text { Minimum } \\
\text { detect }\end{array}$} & \multirow[b]{2}{*}{$\begin{array}{c}\text { Maximum } \\
\text { detect }\end{array}$} & \multirow{2}{*}{$\begin{array}{c}\text { Location(s) of } \\
\text { maximum } \\
\text { detect }\end{array}$} & \multirow{2}{*}{$\begin{array}{c}\text { Average } \\
\text { detected } \\
\text { result }\end{array}$} & \multicolumn{6}{|c|}{ Number of analyses exceeding criteria } \\
\hline & & & & & & $\begin{array}{l}\text { Max } \\
\text { RL }\end{array}$ & $\begin{array}{l}\text { Avg } \\
\text { RL }\end{array}$ & $\begin{array}{l}\text { Ind } \\
\text { PRG }\end{array}$ & Bkg & $\begin{array}{l}\text { GW } \\
\text { SL }\end{array}$ & $\begin{array}{l}\text { Res } \\
\text { PRG }\end{array}$ \\
\hline Aluminum & $17 / 17$ & 230 & 21,800 & K33RCW02 & 13,299 & NA & NA & 0 & 0 & NA & 14 \\
\hline Antimony & $4 / 17$ & $0.33 \mathrm{~J}$ & $1.8 \mathrm{~J}$ & K33RCW04 & 1.02 & NA & NA & 0 & 1 & 0 & 0 \\
\hline Arsenic & $17 / 17$ & $0.91 \mathrm{~J}$ & $66.5 \mathrm{~J}$ & K33RCW04 & 13.1 & 0 & 0 & 3 & 3 & 1 & 17 \\
\hline Calcium & $17 / 17$ & 1200 & 305,000 & K33RCW03 & 93,569 & NA & NA & NA & 16 & NA & NA \\
\hline Chromium & $17 / 17$ & $1.9 \mathrm{~J}$ & 261 & K33RCW04 & 58.4 & NA & NA & 0 & 5 & 2 & 10 \\
\hline $\begin{array}{l}\text { Chromium, } \\
\text { hexavalent }^{a}\end{array}$ & $2 / 17$ & $0.76 \mathrm{~J}$ & 0.93 & K33RCW02 & 0.845 & NA & NA & NA & NA & NA & NA \\
\hline Copper & $17 / 17$ & $2.2 \mathrm{~J}$ & $27.6 \mathrm{~J}$ & K33RCW04 & 14.3 & NA & NA & 0 & 3 & NA & 0 \\
\hline Magnesium & $17 / 17$ & $571 \mathrm{~J}$ & 61,700 & K33RCW03 & 10,538 & NA & NA & NA & 9 & NA & NA \\
\hline Manganese & $17 / 17$ & $65.7 \mathrm{~J}$ & $1,040 \mathrm{~J}$ & K33RCW05 & 327.9 & NA & NA & 0 & 0 & NA & 13 \\
\hline Mercury & $14 / 17$ & $0.019 \mathrm{~J}$ & 1.1 & K33RCW05 & 0.148 & 0 & 0 & 0 & 2 & NA & 0 \\
\hline Nickel & $17 / 17$ & $1.6 \mathrm{~J}$ & 32.9 & K33RCW08 & 14.3 & NA & NA & 0 & 1 & NA & 0 \\
\hline Strontium & 17/17 & $4.8 \mathrm{~J}$ & 278 & K33RCW07 & 82.8 & NA & NA & 0 & 6 & NA & 0 \\
\hline Thallium & $1 / 17$ & $0.54 \mathrm{~J}$ & $0.54 \mathrm{~J}$ & K33RCW03 & 0.54 & NA & NA & 0 & 1 & 0 & 1 \\
\hline
\end{tabular}


EU Z2-08 HISTORICAL METALS WITH BACKGROUND,

PRG, GW SL, AND/OR RL EXCEEDANCES (mg/kg) (continued)

\begin{tabular}{|c|c|c|c|c|c|c|c|c|c|c|c|}
\hline \multirow[b]{2}{*}{ Analyte } & \multirow[b]{2}{*}{$\begin{array}{c}\text { Detect } \\
\text { frequency }\end{array}$} & \multirow[b]{2}{*}{$\begin{array}{c}\text { Minimum } \\
\text { detect }\end{array}$} & \multirow[b]{2}{*}{$\begin{array}{c}\text { Maximum } \\
\text { detect }\end{array}$} & \multirow{2}{*}{$\begin{array}{c}\text { Location(s) of } \\
\text { maximum } \\
\text { detect }\end{array}$} & \multirow{2}{*}{$\begin{array}{c}\text { Average } \\
\text { detected } \\
\text { result }\end{array}$} & \multicolumn{6}{|c|}{ Number of analyses exceeding criteria } \\
\hline & & & & & & $\begin{array}{c}\text { Max } \\
\text { RL }\end{array}$ & $\begin{array}{l}\text { Avg } \\
\text { RL }\end{array}$ & $\begin{array}{l}\text { Ind } \\
\text { PRG }\end{array}$ & Bkg & $\begin{array}{l}\text { GW } \\
\text { SL }\end{array}$ & $\begin{array}{c}\text { Res } \\
\text { PRG }\end{array}$ \\
\hline Vanadium & $17 / 17$ & $2.6 \mathrm{~J}$ & 47.8 & K33RCW02 & 23.1 & NA & NA & 0 & 0 & NA & 16 \\
\hline Zinc & $17 / 17$ & 15.2 & 525 & K33RCW04 & 105 & NA & NA & 0 & 4 & NA & 0 \\
\hline
\end{tabular}

${ }^{a}$ Hexavalent chromium is reported for informational purposes even though no evaluation criteria are exceeded.

$\begin{array}{ll}\text { Avg = average } & \mathrm{NA}=\text { not applicable } \\ \mathrm{Bkg}=\text { background } & \mathrm{PRG}=\text { preliminary remediation goal } \\ \mathrm{EU}=\text { exposure unit } & \text { Res = residential } \\ \mathrm{GW}=\text { groundwater } & \mathrm{RL}=\text { remediation level } \\ \text { Ind = industrial } & \mathrm{SL}=\text { screening level } \\ \text { Max = maximum } & \end{array}$

Max = maximum

EU Z2-08 HISTORICAL RADIONUCLIDES WITH BACKGROUND, PRG, AND/OR RL EXCEEDANCES (pCi/g)

\begin{tabular}{|c|c|c|c|c|c|c|c|c|c|c|c|}
\hline \multirow[b]{2}{*}{ Analyte } & \multirow[b]{2}{*}{$\begin{array}{c}\text { Detect } \\
\text { frequency }\end{array}$} & \multirow[b]{2}{*}{$\begin{array}{c}\text { Minimum } \\
\text { detect }\end{array}$} & \multirow[b]{2}{*}{$\begin{array}{l}\text { Maximum } \\
\text { detect }\end{array}$} & \multirow[b]{2}{*}{$\begin{array}{l}\text { Location(s) of } \\
\text { maximum detect }\end{array}$} & \multirow{2}{*}{$\begin{array}{c}\text { Average } \\
\text { detected } \\
\text { result }\end{array}$} & \multicolumn{6}{|c|}{ Number of analyses exceeding criteria } \\
\hline & & & & & & $\begin{array}{l}\text { Max } \\
\text { RL }\end{array}$ & $\begin{array}{l}\text { Avg } \\
\text { RL }\end{array}$ & $\begin{array}{l}\text { Ind } \\
\text { PRG }\end{array}$ & Bkg & $\begin{array}{c}\text { GW } \\
\text { SL }\end{array}$ & $\begin{array}{c}\text { Res } \\
\text { PRG }\end{array}$ \\
\hline Cesium-137 & $17 / 17$ & 0.141 & 1.32 & RAD224 & 0.697 & 0 & 0 & 5 & NA & $\mathrm{NA}$ & 17 \\
\hline Cobalt -60 & $16 / 17$ & 0.006 & 0.095 & RAD239 & 0.026 & NA & NA & 0 & NA & NA & 2 \\
\hline Neptunium-237 & $16 / 17$ & 0.02 & 0.32 & RAD249 & 0.127 & 0 & 0 & 0 & NA & NA & 5 \\
\hline Potassium-40 & $17 / 17$ & 4.65 & 23.9 & RAD274 & 11.0 & NA & NA & 17 & 0 & NA & 17 \\
\hline Radium-226 & $14 / 17$ & 0.14 & 3.8 & RAD225 & 1.53 & NA & NA & 13 & 8 & NA & 14 \\
\hline Technetium-99 & $15 / 17$ & 0 & 1.35 & RAD224 & 0.423 & NA & NA & 0 & NA & NA & 10 \\
\hline Thorium -228 & $17 / 17$ & 0.705 & 1.6 & RAD271 & 1.15 & NA & NA & 17 & 0 & NA & 17 \\
\hline Thorium -230 & $17 / 17$ & 0.75 & 2.27 & RAD271 & 1.38 & NA & NA & 0 & 14 & NA & 0 \\
\hline Thorium -232 & $17 / 17$ & 0.634 & 1.53 & RAD271 & 1.13 & NA & NA & 17 & 0 & NA & 17 \\
\hline Uranium-233/234 & $34 / 34$ & 0.199 & 18.9 & RAD224 & 3.26 & 0 & 0 & 0 & NA & 0 & 6 \\
\hline Uranium-235 & $17 / 17$ & 0.114 & 1.41 & RAD224 & 0.429 & 0 & 0 & 0 & NA & 0 & 7 \\
\hline Uranium-238 & $34 / 34$ & 0.034 & 15 & RAD224 & 2.67 & 0 & 0 & 0 & 12 & 0 & 29 \\
\hline
\end{tabular}

Avg = average NA = not applicable

$\mathrm{Bkg}=$ background $\quad \mathrm{PRG}=$ preliminary remediation goal

$\mathrm{EU}=$ exposure unit $\quad$ Res $=$ residential

$\mathrm{GW}=$ groundwater $\quad \mathrm{RL}=$ remediation level

Ind $=$ industrial $\quad \mathrm{SL}=$ screening level

Max $=$ maximum

EU Z2-08 HISTORICAL SVOC DETECTS (ug/kg)

\begin{tabular}{|c|c|c|c|c|c|c|c|c|}
\hline \multirow[b]{2}{*}{ Analyte } & \multirow[b]{2}{*}{$\begin{array}{c}\text { Detect } \\
\text { frequency }\end{array}$} & \multirow[b]{2}{*}{$\begin{array}{c}\text { Minimum } \\
\text { detect }\end{array}$} & \multirow[b]{2}{*}{$\begin{array}{c}\text { Maximum } \\
\text { detect }\end{array}$} & \multirow[b]{2}{*}{$\begin{array}{c}\text { Location(s) of } \\
\text { maximum detect }\end{array}$} & \multirow{2}{*}{$\begin{array}{c}\text { Average } \\
\text { detected } \\
\text { result }\end{array}$} & \multicolumn{3}{|c|}{$\begin{array}{l}\text { Number of analyses } \\
\text { exceeding criteria }\end{array}$} \\
\hline & & & & & & $\begin{array}{l}\text { Ind } \\
\text { PRG }\end{array}$ & $\begin{array}{l}\text { GW } \\
\text { SL }\end{array}$ & $\begin{array}{l}\text { Res } \\
\text { PRG }\end{array}$ \\
\hline Benz(a)anthracene & $3 / 15$ & $120 \mathrm{~J}$ & $320 \mathrm{~J}$ & K33RCW02 & 190 & 0 & NA & 0 \\
\hline Benzo(a)pyrene & $2 / 15$ & $130 \mathrm{~J}$ & $220 \mathrm{~J}$ & K33RCW02 & 175 & 0 & NA & 2 \\
\hline Benzo(b)fluoranthene & $3 / 15$ & $99 \mathrm{~J}$ & $240 \mathrm{~J}$ & K33RCW02 & 156 & 0 & NA & 0 \\
\hline Benzo(k)fluoranthene & $3 / 15$ & $93 \mathrm{~J}$ & $290 \mathrm{~J}$ & K33RCW02 & 171 & 0 & NA & 0 \\
\hline Chrysene & $4 / 15$ & $88 \mathrm{~J}$ & $390 \mathrm{~J}$ & K33RCW02 & 205 & 0 & NA & 0 \\
\hline Fluoranthene & $4 / 15$ & $73 \mathrm{~J}$ & 470 & K33RCW05 & 286 & 0 & NA & 0 \\
\hline Indeno(1,2,3-cd)pyrene & $2 / 15$ & $100 \mathrm{~J}$ & $110 \mathrm{~J}$ & K33RCW02 & 105 & 0 & NA & 0 \\
\hline Phenanthrene & $1 / 15$ & $380 \mathrm{~J}$ & $380 \mathrm{~J}$ & K33RCW05 & 380 & 0 & NA & 0 \\
\hline Pyrene & $3 / 15$ & $150 \mathrm{~J}$ & 460 & K33RCW02 & 310 & 0 & NA & 0 \\
\hline
\end{tabular}

EU = exposure unit $\quad$ PRG = preliminary remediation goal

$\mathrm{GW}=$ groundwater $\quad$ Res $=$ residential

Ind $=$ industrial $\quad \mathrm{SL}=$ screening level

$\mathrm{NA}=$ not applicable $\quad \mathrm{SVOC}=$ semivolatile organic compound

EU Z2-08 Summary: Except for the approximately $500 \mathrm{ft}^{2}$ Class $2 \mathrm{SU}$, the entire 24 acres of EU Z2-08 is a Class 3 SU. Therefore, the entire EU was addressed by a Class $3 \mathrm{SU}$ walkover assessment. Twenty anthropogenic features 
were identified and 41 facilities were assessed during the walkover assessment. Four anthropogenic features (wood/debris pile, diesel AST, gasoline AST, and transformer) were selected for DVS biased sampling. Four facilities (K-893-Q, K-893-V, K-893-DD, and K-899-M Inactive Valve Vaults) were selected for DVS biased sampling. Six Class 3 SU DVS biased sample locations were identified during the DQO scoping (two locations at the K-33 RCW Lines Leak Site FFA Site, two locations at the K-892-G Cooling Tower Basin FFA Site, one location at the K-892-H Cooling Tower Basin FFA Site, and one location at the K-897-A Oil Containment Structure. A DVS biased sample location was identified based on elevated radiation detected during a BAR survey in an area previously used for storage of cooling basin sludge. In addition, there are 25 historical sample locations in the Class 3 SU.

A Class 2 SU was defined in EU Z2-08 during DQO scoping to quantify the extent of the U-238 average RL exceedance at historical sample location RAD228. A DVS confirmation sample was collected and a BAR survey was conducted. However, the BAR survey did not identify radiation in excess of the AL and step-out sampling was not conducted.

There are 45 DVS and historical sample locations in EU Z2-08. EU sample locations are presented in Sect. 2.2.3. The following data summaries are compilations of the focused investigation summaries in this section and the FFA site summaries in Sect. 2.2.6. Analytical results summarized below show a Cs-137 and a U-238 Avg RL exceedance; one arsenic, three chromium, and one U-234 GW SL exceedances; four arsenic and several radionuclide Ind PRG exceedances; metal and radionuclide Bkg exceedances; and detections of PCBs, SVOCs, and VOCs. As described in the focused investigation summaries above, the Cs-137 Avg RL exceedance occurred in a sediment sample collected from an inactive valve vault; the U-238 Avg RL and U-234 GW SL exceedances occur at historical location RAD228 but was not confirmed by DVS confirmation sampling; one chromium GW SL exceedance occur in a sediment sample from a valve vault; the arsenic and two of the chromium GW SL exceedances occur in historical samples; and Ind PRG exceedances are fairly widespread, especially for radionuclides. The chemicals and radionuclides in EU Z2-08 are evaluated against the Zone 2 ROD RAO in Sect. 3.3.

EU Z2-08 METALS WITH BACKGROUND, PRG, GW SL, AND/OR RL EXCEEDANCES (mg/kg)

\begin{tabular}{|c|c|c|c|c|c|c|c|c|c|c|c|}
\hline \multirow{3}{*}{ Analyte } & \multirow{3}{*}{$\begin{array}{c}\text { Detect } \\
\text { frequency }\end{array}$} & \multirow{3}{*}{$\begin{array}{c}\text { Minimum } \\
\text { detect }\end{array}$} & \multirow{3}{*}{$\begin{array}{c}\text { Maximum } \\
\text { detect }\end{array}$} & \multirow{3}{*}{$\begin{array}{c}\text { Location(s) of } \\
\text { maximum } \\
\text { detect }\end{array}$} & \multirow{3}{*}{$\begin{array}{c}\text { Average } \\
\text { detected } \\
\text { result }\end{array}$} & \multicolumn{6}{|c|}{ Number of analyses exceeding criteria } \\
\hline & & & & & & Max & Avg & Ind & & GW & Res \\
\hline & & & & & & RL & $\mathbf{R L}$ & PRG & Bkg & SL & PRG \\
\hline Aluminum & $27 / 27$ & 230 & 21,800 & K33RCW02 & 11,100 & NA & NA & 0 & 0 & NA & 20 \\
\hline Antimony & $13 / 27$ & $0.083 \mathrm{~J}$ & $1.8 \mathrm{~J}$ & K33RCW04 & 0.528 & NA & NA & 0 & 1 & 0 & 0 \\
\hline Arsenic & $27 / 27$ & $0.57 \mathrm{~J}$ & $66.5 \mathrm{~J}$ & K33RCW04 & 11.2 & 0 & 0 & 4 & 5 & 1 & 27 \\
\hline Cadmium & $11 / 27$ & $0.019 \mathrm{~J}$ & $1.7 \mathrm{~J}$ & Z2-EU8B-315 & 0.472 & NA & NA & 0 & 3 & NA & 0 \\
\hline Calcium & $27 / 27$ & $727 \mathrm{~J}$ & 305,000 & K33RCW03 & 76,117 & NA & NA & NA & 23 & NA & NA \\
\hline Chromium & $27 / 27$ & $1.9 \mathrm{~J}$ & $446 \mathrm{~J}$ & Z2-EU8B-314 & 64.87 & NA & NA & 0 & 8 & 3 & 17 \\
\hline $\begin{array}{l}\text { Chromium } \\
\text { hexavalent }{ }^{a}\end{array}$ & $4 / 21$ & $0.76 \mathrm{~J}$ & 1.8 & Z2-EU8B-305 & 1.12 & NA & NA & NA & NA & NA & NA \\
\hline Copper & $27 / 27$ & $2.2 \mathrm{~J}$ & 83.3 & Z2-EU8B-314 & 18.21 & NA & NA & 0 & 7 & NA & 0 \\
\hline Iron & $27 / 27$ & $1,750 \mathrm{~J}$ & $65,000 \mathrm{~J}$ & Z2-EU8B-315 & 25,011 & NA & NA & 0 & 1 & NA & 27 \\
\hline Lead & $27 / 27$ & 4.7 & 505 & Z2-EU8B-314 & 40.01 & NA & NA & 0 & 2 & 0 & 1 \\
\hline Magnesium & $27 / 27$ & $338 \mathrm{~J}$ & 61,700 & K33RCW03 & $9,238.3$ & NA & NA & NA & 11 & NA & NA \\
\hline Manganese & $27 / 27$ & $65.7 \mathrm{~J}$ & $1,410 \mathrm{~J}$ & Z2-EU8B-314 & 352.5 & NA & NA & 0 & 0 & NA & 19 \\
\hline Mercury & $23 / 27$ & $0.01 \mathrm{~J}$ & 1.1 & K33RCW05 & 0.16 & 0 & 0 & 0 & 4 & NA & 0 \\
\hline Nickel & $27 / 27$ & $1.6 \mathrm{~J}$ & $57.5 \mathrm{~J}$ & Z2-EU8B-314 & 15.18 & NA & NA & 0 & 2 & NA & 0 \\
\hline Strontium & $16 / 16$ & $4.8 \mathrm{~J}$ & 278 & K33RCW07 & 87.2 & NA & NA & 0 & 6 & NA & 0 \\
\hline Thallium & $4 / 27$ & $0.11 \mathrm{~J}$ & $0.54 \mathrm{~J}$ & K33RCW03 & 0.26 & NA & NA & 0 & 1 & 0 & 1 \\
\hline Uranium & $11 / 11$ & 0.19 & 2.5 & Z2-EU8B-314 & 1.14 & NA & NA & 0 & NA & NA & 3 \\
\hline Vanadium & $27 / 27$ & $2.6 \mathrm{~J}$ & 47.8 & K33RCW02 & 20.72 & NA & NA & 0 & 0 & NA & 23 \\
\hline Zinc & $27 / 27$ & $14.4 \mathrm{~J}$ & $1,140 \mathrm{~J}$ & Z2-EU8B-314 & 141.66 & NA & NA & 0 & 8 & NA & 0 \\
\hline
\end{tabular}

${ }^{a}$ Hexavalent chromium is reported for informational purposes even though no evaluation criteria are exceeded.

Avg $=$ average $\mathrm{Bkg}=$ background $\mathrm{EU}=$ exposure unit $\mathrm{GW}=$ groundwater Ind $=$ industrial Max $=$ maximum
$\mathrm{NA}=$ not applicable

$\mathrm{PRG}=$ preliminary remediation goal

Res $=$ residential

$\mathrm{RL}=$ remediation level

$\mathrm{SL}=$ screening level 
EU Z2-08 PCB DETECTS (ug/kg)

\begin{tabular}{|c|c|c|c|c|c|c|c|c|c|}
\hline \multirow[b]{2}{*}{ Analyte } & \multirow[b]{2}{*}{$\begin{array}{c}\text { Detect } \\
\text { frequency }\end{array}$} & \multirow[b]{2}{*}{$\begin{array}{l}\text { Minimum } \\
\text { detect }\end{array}$} & \multirow[b]{2}{*}{$\begin{array}{c}\text { Maximum } \\
\text { detect }\end{array}$} & \multirow{2}{*}{$\begin{array}{c}\text { Location(s) of } \\
\text { maximum } \\
\text { detect }\end{array}$} & \multirow{2}{*}{$\begin{array}{c}\text { Average } \\
\text { detected } \\
\text { result }\end{array}$} & \multicolumn{4}{|c|}{$\begin{array}{c}\text { Number of analyses } \\
\text { exceeding criteria }\end{array}$} \\
\hline & & & & & & $\begin{array}{c}\text { Max } \\
\text { RL }\end{array}$ & $\begin{array}{c}\text { Avg } \\
\text { RL }\end{array}$ & $\begin{array}{l}\text { Ind } \\
\text { PRG }\end{array}$ & $\begin{array}{l}\text { Res } \\
\text { PRG }\end{array}$ \\
\hline PCB-1254 & $2 / 8$ & 160 & $580 \mathrm{~J}$ & Z2-EU8B-301 & 370 & 0 & 0 & 0 & 2 \\
\hline PCB-1260 & $1 / 8$ & 53 & 53 & Z2-EU8B-308 & 53 & 0 & 0 & 0 & 0 \\
\hline PCB & $3 / 8$ & 53 & $580 \mathrm{~J}$ & Z2-EU8B-301 & 264 & 0 & 0 & 0 & 2 \\
\hline
\end{tabular}

Avg = average

$\mathrm{EU}=$ exposure unit

Ind $=$ industrial

Max $=$ maximum
$\mathrm{PCB}=$ polychlorinated biphenyl

$\mathrm{PRG}=$ preliminary remediation goal

Res $=$ residential

$\mathrm{RL}=$ remediation level

EU Z2-08 RADIONUCLIDES WITH BACKGROUND, PRG, AND/OR RL EXCEEDANCES (pCi/g)

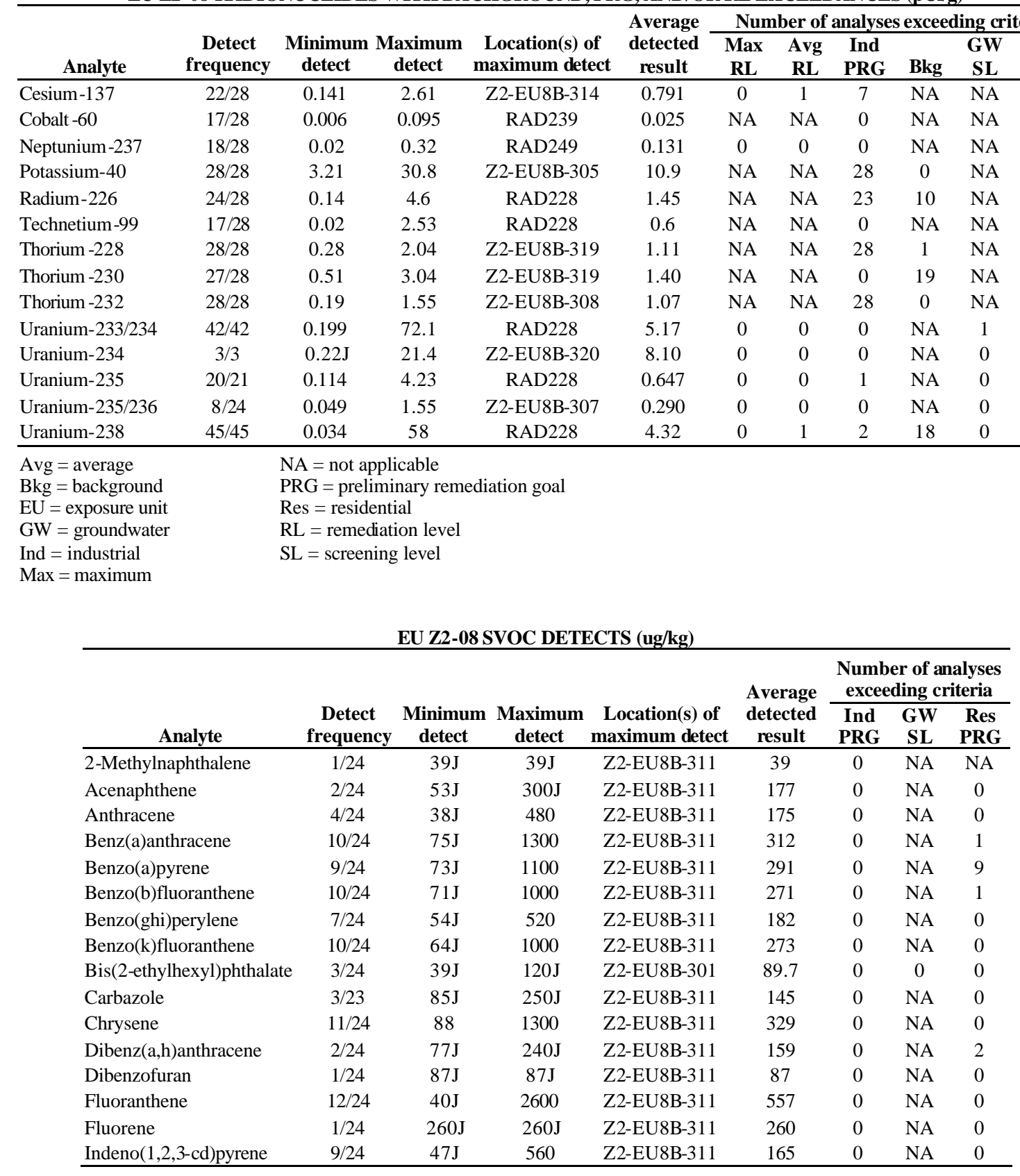


EU Z2-08 SVOC DETECTS (ug/kg) (continued)

\begin{tabular}{|c|c|c|c|c|c|c|c|c|}
\hline \multirow[b]{2}{*}{ Analyte } & \multirow[b]{2}{*}{$\begin{array}{c}\text { Detect } \\
\text { frequency }\end{array}$} & \multirow[b]{2}{*}{$\begin{array}{c}\text { Minimum } \\
\text { detect }\end{array}$} & \multirow[b]{2}{*}{$\begin{array}{c}\text { Maximum } \\
\text { detect }\end{array}$} & \multirow[b]{2}{*}{$\begin{array}{l}\text { Location(s) of } \\
\text { maximum detect }\end{array}$} & \multirow{2}{*}{$\begin{array}{c}\text { Average } \\
\text { detected } \\
\text { result }\end{array}$} & \multicolumn{3}{|c|}{$\begin{array}{c}\text { Number of analyses } \\
\text { exceeding criteria }\end{array}$} \\
\hline & & & & & & $\begin{array}{l}\text { Ind } \\
\text { PRG }\end{array}$ & $\begin{array}{l}\widetilde{G W} \\
\text { SL }\end{array}$ & $\begin{array}{l}\text { Res } \\
\text { PRG }\end{array}$ \\
\hline Phenanthrene & $8 / 24$ & $62 \mathrm{~J}$ & 1700 & Z2-EU8B-311 & 457 & 0 & NA & 0 \\
\hline Pyrene & $10 / 24$ & $120 \mathrm{~J}$ & 1800 & Z2-EU8B-311 & 509 & 0 & NA & 0 \\
\hline
\end{tabular}

$\mathrm{EU}=$ exposure unit $\quad \mathrm{PRG}=$ preliminary remediation goal

$\mathrm{GW}=$ groundwater $\quad$ Res $=$ residential

Ind $=$ industrial $\quad \mathrm{SL}=$ screening level

$\mathrm{NA}=$ not applicable $\quad \mathrm{SVOC}=$ semivolatile organic compound

EU Z2-08 VOC DETECTS (ug/kg)

\begin{tabular}{|c|c|c|c|c|c|c|c|c|}
\hline \multirow[b]{2}{*}{ Analyte } & \multirow[b]{2}{*}{$\begin{array}{c}\text { Detect } \\
\text { frequency }\end{array}$} & \multirow[b]{2}{*}{$\begin{array}{c}\text { Minimum } \\
\text { detect }\end{array}$} & \multirow[b]{2}{*}{$\begin{array}{c}\text { Maximum } \\
\text { detect }\end{array}$} & \multirow[b]{2}{*}{$\begin{array}{c}\text { Location(s) of } \\
\text { maximum detect }\end{array}$} & \multirow{2}{*}{$\begin{array}{c}\text { Average } \\
\text { detected } \\
\text { result }\end{array}$} & \multicolumn{3}{|c|}{$\begin{array}{l}\text { Number of analyses } \\
\text { exceeding criteria }\end{array}$} \\
\hline & & & & & & $\begin{array}{l}\text { Ind } \\
\text { PRG }\end{array}$ & GW SL & $\begin{array}{c}\text { Res } \\
\text { PRG }\end{array}$ \\
\hline 2-Butanone & $1 / 3$ & $8.1 \mathrm{~J}$ & $8.1 \mathrm{~J}$ & Z2-EU8B-301 & 8.1 & 0 & NA & 0 \\
\hline Acetone & $2 / 3$ & $7.2 \mathrm{~J}$ & $24 \mathrm{~J}$ & Z2-EU8B-301 & 15.6 & 0 & NA & 0 \\
\hline
\end{tabular}

$\mathrm{EU}=$ exposure unit $\quad \mathrm{PRG}=$ preliminary remediation goal

$\mathrm{GW}=$ groundwater $\quad$ Res $=$ residential

Ind $=$ industrial $\quad \mathrm{SL}=$ screening level

$\mathrm{NA}=$ not applicable $\quad \mathrm{VOC}=$ volatile organic compound

Samples were analyzed for DRO and GRO but were not detected.

\section{\begin{tabular}{|l|l|}
\hline 2.2.6 & ZONE 2 ROD APPENDIX A FFA SITES EVALUATION
\end{tabular}}

The following is a summary of analytical results for samples collected to characterize the Zone 2 ROD Appendix A FFA sites located in EU Z2-08. The data summary presentations follow the guidelines described in Sect. 2.2.5 and the data described below are included in the EU Z2-08 summary in Sect. 2.2.5. Details of sampling and analysis at the FFA site sample locations are presented in Table C.2.

K-33 RCW Lines Leak Site FFA Site: Two biased sample locations were selected for the K-33 RCW Lines Leak Site FFA Site during DQO scoping. Surface soil samples were collected at Z2-EU8B-302 and Z2-EU8B-304 and analyzed for metals, including hexavalent chromium, and radionuclides. Analytical results summarized below show radionuclide industrial PRG exceedances and one metal background exceedance.

EU Z2-08 K-33 RCW LINES LEAK SITE FFA SITE METALS WITH

BACKGROUND, PRG, GW SL, AND/OR RL EXCEEDANCES (mg/kg)

\begin{tabular}{|c|c|c|c|c|c|c|c|c|c|c|c|}
\hline \multirow[b]{2}{*}{ Analyte } & \multirow[b]{2}{*}{$\begin{array}{c}\text { Detect } \\
\text { frequency }\end{array}$} & \multirow[b]{2}{*}{$\begin{array}{c}\text { Minimum } \\
\text { detect }\end{array}$} & \multirow[b]{2}{*}{$\begin{array}{c}\text { Maximum } \\
\text { detect }\end{array}$} & \multirow{2}{*}{$\begin{array}{l}\text { Location(s) of } \\
\text { maximum } \\
\text { detect }\end{array}$} & \multirow{2}{*}{$\begin{array}{c}\text { Average } \\
\text { detected } \\
\text { result }\end{array}$} & \multicolumn{6}{|c|}{ Number of analyses exceeding criteria } \\
\hline & & & & & & $\begin{array}{c}\text { Max } \\
\text { RL }\end{array}$ & $\begin{array}{l}\text { Avg } \\
\text { RL }\end{array}$ & $\begin{array}{l}\text { Ind } \\
\text { PRG }\end{array}$ & Bkg & $\begin{array}{c}\text { GW } \\
\text { SL }\end{array}$ & $\begin{array}{c}\text { Res } \\
\text { PRG }\end{array}$ \\
\hline Aluminum & $2 / 2$ & $7,360 \mathrm{~J}$ & $12,900 \mathrm{~J}$ & Z2-EU8B-304 & 10,130 & NA & NA & 0 & 0 & NA & 1 \\
\hline Arsenic & $2 / 2$ & 5.1 & 12.6 & Z2-EU8B-304 & 8.85 & 0 & 0 & 0 & 0 & 0 & 2 \\
\hline Chromium & $2 / 2$ & $11.3 \mathrm{~J}$ & $40.4 \mathrm{~J}$ & Z2-EU8B-304 & 25.85 & NA & NA & 0 & 0 & 0 & 1 \\
\hline $\begin{array}{l}\text { Chromium, } \\
\text { hexavalent }^{a}\end{array}$ & $0 / 2$ & ND & ND & ND & ND & NA & NA & NA & NA & NA & NA \\
\hline Copper & $2 / 2$ & $6.7 \mathrm{~J}$ & $23.9 \mathrm{~J}$ & Z2-EU8B-304 & 15.3 & NA & NA & 0 & 1 & NA & 0 \\
\hline Manganese & $2 / 2$ & $136 \mathrm{~J}$ & $351 \mathrm{~J}$ & Z2-EU8B-304 & 243.5 & NA & NA & 0 & 0 & NA & 1 \\
\hline Uranium & $2 / 2$ & 1.1 & 2.1 & Z2-EU8B-304 & 1.6 & NA & NA & 0 & NA & NA & 1 \\
\hline Vanadium & $2 / 2$ & 17.1 & 33.6 & Z2-EU8B-304 & 25.35 & NA & NA & 0 & 0 & NA & 2 \\
\hline
\end{tabular}

${ }^{a}$ Hexavalent chromium is reported for informational purposes even though it was detected.

\footnotetext{
Avg $=$ average

$\mathrm{Bkg}=$ background

$\mathrm{EU}=$ exposure unit

FFA $=$ Federal Facility Agreement

$\mathrm{GW}=$ groundwater

Ind $=$ industrial

Max = maximum
}

$\mathrm{NA}=$ not applicable

$\mathrm{ND}=$ not detected

$\mathrm{PRG}=$ preliminary remediation goal

$\mathrm{RCW}=$ recirculating cooling water

Res $=$ residential

$\mathrm{RL}=$ remediation level

$\mathrm{SL}=$ screening level 
EU Z2-08 K-33 RCW LINES LEAK SITE FFA SITE RADIONUCLIDES WITH

BACKGROUND, PRG, AND/OR RL EXCEEDANCES (pCi/g)

\begin{tabular}{|c|c|c|c|c|c|c|c|c|c|c|c|}
\hline \multirow[b]{2}{*}{ Analyte } & \multirow[b]{2}{*}{$\begin{array}{c}\text { Detect } \\
\text { frequency }\end{array}$} & \multirow[b]{2}{*}{$\begin{array}{c}\text { Minimum } \\
\text { detect }\end{array}$} & \multirow[b]{2}{*}{$\begin{array}{c}\text { Maximum } \\
\text { detect }\end{array}$} & \multirow[b]{2}{*}{$\begin{array}{c}\text { Location(s) of } \\
\text { maximum detect }\end{array}$} & \multirow{2}{*}{$\begin{array}{c}\text { Average } \\
\text { detected } \\
\text { result }\end{array}$} & \multicolumn{6}{|c|}{ Number of analyses exceeding criteria } \\
\hline & & & & & & $\begin{array}{c}\text { Max } \\
\text { RL }\end{array}$ & $\begin{array}{c}\text { Avg } \\
\text { RL }\end{array}$ & $\begin{array}{c}\text { Ind } \\
\text { PRG }\end{array}$ & Bkg & $\begin{array}{c}\text { GW } \\
\text { SL }\end{array}$ & $\begin{array}{l}\text { Res } \\
\text { PRG }\end{array}$ \\
\hline Potassium-40 & $1 / 1$ & 8.2 & 8.2 & Z2-EU8B-304 & 8.2 & NA & NA & 1 & 0 & NA & 1 \\
\hline Radium-226 & $1 / 1$ & 0.81 & 0.81 & Z2-EU8B-304 & 0.81 & NA & NA & 1 & 0 & NA & 1 \\
\hline Thorium -228 & $1 / 1$ & 1.26 & 1.26 & Z2-EU8B-304 & 1.26 & NA & NA & 1 & 0 & NA & 1 \\
\hline Thorium -232 & $1 / 1$ & 1.23 & 1.23 & Z2-EU8B-304 & 1.23 & NA & NA & 1 & 0 & NA & 1 \\
\hline Uranium-238 & $1 / 1$ & 1.13 & 1.13 & Z2-EU8B-304 & 1.13 & 0 & 0 & 0 & 0 & 0 & 1 \\
\hline
\end{tabular}

Avg $=$ average

$\mathrm{Bkg}=$ background

$\mathrm{EU}=$ exposure unit

FFA = Federal Facility Agreement

$\mathrm{GW}=$ groundwater

Ind $=$ industrial

Max = maximum

$\mathrm{NA}=$ not applicable

$\mathrm{PRG}=$ preliminary remediation goal

$\mathrm{RCW}=$ recirculating cooling water

Res $=$ residential

$\mathrm{RL}=$ remediation level

$\mathrm{SL}=$ screening level

K-892-G Cooling Tower Basin FFA Site: Two biased sample locations were selected for the K-892-G Cooling Tower Basin FFA Site during DQO scoping. A surface soil sample was collected at Z2-EU8B-303 and analyzed for metals, including hexavalent chromium Another surface soil sample was collected at Z2-EU8B-305 and analyzed for metals (including hexavalent chromium), PCBs, radionuclides, SVOCs, and VOCs. Both samples were field screened for radionuclides and VOCs. Analytical results summarized below show radionuclide industrial PRG exceedances and metal background exceedances.

EU Z2-08 K-892-G COOLING TOWER BASIN FFA SITE METALS WITH

BACKGROUND, PRG, GW SL, AND/OR RL EXCEEDANCES (mg/kg)

\begin{tabular}{|c|c|c|c|c|c|c|c|c|c|c|c|}
\hline \multirow[b]{2}{*}{ Analyte } & \multirow[b]{2}{*}{$\begin{array}{c}\text { Detect } \\
\text { frequency }\end{array}$} & \multirow[b]{2}{*}{$\begin{array}{c}\text { Minimum } \\
\text { detect }\end{array}$} & \multirow[b]{2}{*}{$\begin{array}{c}\text { Maximum } \\
\text { detect }\end{array}$} & \multirow[b]{2}{*}{$\begin{array}{l}\text { Location(s) of } \\
\text { maximum } \\
\text { detect }\end{array}$} & \multirow[b]{2}{*}{$\begin{array}{c}\text { Average } \\
\text { detected } \\
\text { result }\end{array}$} & \multicolumn{6}{|c|}{ Number of analyses exceeding criteria } \\
\hline & & & & & & $\begin{array}{c}\text { Max } \\
\text { RL }\end{array}$ & $\begin{array}{c}\text { Avg } \\
\text { RL }\end{array}$ & $\begin{array}{l}\text { Ind } \\
\text { PRG }\end{array}$ & Bkg & $\begin{array}{c}\text { GW } \\
\text { SL }\end{array}$ & $\begin{array}{c}\text { Res } \\
\text { PRG }\end{array}$ \\
\hline Aluminum & $2 / 2$ & $13,600 \mathrm{~J}$ & $16,800 \mathrm{~J}$ & Z2-EU8B-305 & 15,200 & NA & NA & 0 & 0 & NA & 2 \\
\hline Arsenic & $2 / 2$ & $0.57 \mathrm{~J}$ & 5.9 & Z2-EU8B-303 & 3.235 & 0 & 0 & 0 & 0 & 0 & 2 \\
\hline Chromium & $2 / 2$ & $69.6 \mathrm{~J}$ & $77.6 \mathrm{~J}$ & Z2-EU8B-305 & 73.6 & NA & NA & 0 & 2 & 0 & 2 \\
\hline $\begin{array}{l}\text { Chromium } \\
\text { hexavalent }^{a}\end{array}$ & $2 / 2$ & 1 & 1.8 & Z2-EU8B-305 & 1.4 & NA & NA & NA & NA & NA & NA \\
\hline Manganese & $2 / 2$ & $129 \mathrm{~J}$ & $829 \mathrm{~J}$ & Z2-EU8B-305 & 479 & NA & NA & 0 & 0 & NA & 1 \\
\hline Vanadium & $2 / 2$ & 14.8 & 33 & Z2-EU8B-303 & 23.9 & NA & NA & 0 & 0 & NA & 2 \\
\hline
\end{tabular}

Avg $=$ average

$\mathrm{Bkg}=$ background

$\mathrm{EU}=$ exposure unit

FFA $=$ Federal Facility Agreement

$\mathrm{GW}=$ groundwater

Ind $=$ industrial
Max $=$ maximum

$\mathrm{NA}=$ not applicable

PRG $=$ preliminary remediation goal

Res $=$ residential

$\mathrm{RL}=$ remediation level

$\mathrm{SL}=$ screening level

PCBs were analyzed for in the sample from Z2-EU8B-305 but were not detected.

EU Z2-08 K-892-G COOLING TOWER BASIN FFA SITE RADIONUCLIDES WITH BACKGROUND, PRG, AND/OR RL EXCEEDANCES (pCi/g)

\begin{tabular}{|c|c|c|c|c|c|c|c|c|c|c|c|}
\hline \multirow[b]{2}{*}{ Analyte } & \multirow[b]{2}{*}{$\begin{array}{c}\text { Detect } \\
\text { frequency }\end{array}$} & \multirow[b]{2}{*}{$\begin{array}{c}\text { Minimum } \\
\text { detect }\end{array}$} & \multirow[b]{2}{*}{$\begin{array}{c}\text { Maximum } \\
\text { detect }\end{array}$} & \multirow[b]{2}{*}{$\begin{array}{c}\text { Location(s) of } \\
\text { maximum detect }\end{array}$} & \multirow{2}{*}{$\begin{array}{c}\text { Average } \\
\text { detected } \\
\text { result }\end{array}$} & \multicolumn{6}{|c|}{ Number of analyses exceeding criteria } \\
\hline & & & & & & $\begin{array}{c}\text { Max } \\
\text { RL }\end{array}$ & $\begin{array}{l}\text { Avg } \\
\text { RL } \\
\end{array}$ & $\begin{array}{l}\text { Ind } \\
\text { PRG }\end{array}$ & Bkg & $\begin{array}{c}\text { GW } \\
\text { SL }\end{array}$ & $\begin{array}{r}\text { Res } \\
\text { PRG }\end{array}$ \\
\hline Potassium-40 & $1 / 1$ & 30.8 & 30.8 & Z2-EU8B-305 & 30.8 & NA & NA & 1 & 0 & NA & 1 \\
\hline Radium-226 & $1 / 1$ & $0.8 \mathrm{~J}$ & $0.8 \mathrm{~J}$ & Z2-EU8B-305 & 0.8 & NA & NA & 1 & 0 & NA & 1 \\
\hline Thorium -228 & $1 / 1$ & 1.52 & 1.52 & Z2-EU8B-305 & 1.52 & NA & NA & 1 & 0 & NA & 1 \\
\hline
\end{tabular}


EU Z2-08 K-892-G COOLING TOWER BASIN FFA SITE RADIONUCLIDES WITH

BACKGROUND, PRG, AND/OR RL EXCEEDANCES (pCi/g) (continued)

\begin{tabular}{|c|c|c|c|c|c|c|c|c|c|c|c|}
\hline \multirow[b]{2}{*}{ Analyte } & \multirow[b]{2}{*}{$\begin{array}{c}\text { Detect } \\
\text { frequency }\end{array}$} & \multirow[b]{2}{*}{$\underset{\text { detect }}{\text { Minimum }}$} & \multirow[b]{2}{*}{$\begin{array}{c}\text { Maximum } \\
\text { detect }\end{array}$} & \multirow[b]{2}{*}{$\begin{array}{l}\text { Location(s) of } \\
\text { maximum detect }\end{array}$} & \multirow{2}{*}{$\begin{array}{c}\text { Average } \\
\text { detected } \\
\text { result }\end{array}$} & \multicolumn{6}{|c|}{ Number of analyses exceeding criteria } \\
\hline & & & & & & $\begin{array}{c}\text { Max } \\
\text { RL }\end{array}$ & $\begin{array}{l}\text { Avg } \\
\text { RL }\end{array}$ & $\begin{array}{l}\text { Ind } \\
\text { PRG }\end{array}$ & Bkg & $\begin{array}{l}\text { GW } \\
\text { SL } \\
\end{array}$ & $\begin{array}{r}\text { Res } \\
\text { PRG } \\
\end{array}$ \\
\hline Thorium -232 & $1 / 1$ & 1.33 & 1.33 & Z2-EU8B-305 & 1.33 & NA & NA & 1 & 0 & NA & 1 \\
\hline Uranium-238 & $1 / 1$ & 1.03 & 1.03 & Z2-EU8B-305 & 1.03 & 0 & 0 & 0 & 0 & 0 & 1 \\
\hline
\end{tabular}

\begin{tabular}{ll}
\hline Avg $=$ average & Max = maximum \\
Bkg = background & NA = not applicable \\
EU = exposure unit & PRG = preliminary remediation goal \\
FFA = Federal Facility Agreement & Res = residential \\
GW = groundwater & RL = remediation level \\
Ind = industrial & SL = screening level
\end{tabular}

SVOCs and VOCs were analyzed for in the sample from Z2-EU8B-305 but were not detected.

K-892-H Cooling Tower Basin FFA Site: One sample location was selected for the K-892-H Cooling Tower Basin FFA Site during DQO scoping. A surface soil sample was collected at Z2-EU8B-306 and analyzed for metals, including hexavalent chromium, and radionuclides. Analytical results summarized below show radionuclide industrial PRG exceedances and a metal background exceedance.

EU Z2-08 K-892-H COOLING TOWER BASIN FFA SITE METALS WITH

BACKGROUND, PRG, GW SL, AND/OR RL EXCEEDANCES (mg/kg)

\begin{tabular}{|c|c|c|c|c|c|c|c|c|c|c|c|}
\hline \multirow[b]{2}{*}{ Analyte } & \multirow[b]{2}{*}{$\begin{array}{c}\text { Detect } \\
\text { frequency }\end{array}$} & \multirow[b]{2}{*}{$\begin{array}{c}\text { Minimum } \\
\text { detect }\end{array}$} & \multirow[b]{2}{*}{$\begin{array}{c}\text { Maximum } \\
\text { detect }\end{array}$} & \multirow[b]{2}{*}{$\begin{array}{l}\text { Location (s) of } \\
\text { maximum detect }\end{array}$} & \multirow{2}{*}{$\begin{array}{c}\text { Average } \\
\text { detected } \\
\text { result }\end{array}$} & \multicolumn{6}{|c|}{ Number of analyses exceeding criteria } \\
\hline & & & & & & $\begin{array}{c}\text { Max } \\
\text { RL }\end{array}$ & $\begin{array}{c}\text { Avg } \\
\text { RL }\end{array}$ & $\begin{array}{l}\text { Ind } \\
\text { PRG }\end{array}$ & Bkg & $\begin{array}{c}\text { GW } \\
\text { SL }\end{array}$ & Res PRG \\
\hline Aluminum & $1 / 1$ & $11,500 \mathrm{~J}$ & $11,500 \mathrm{~J}$ & Z2-EU8B-306 & 11,500 & NA & NA & 0 & 0 & NA & 1 \\
\hline Arsenic & $1 / 1$ & $4.3 \mathrm{~J}$ & $4.3 \mathrm{~J}$ & Z2-EU8B-306 & 4.3 & 0 & 0 & 0 & 0 & 0 & 1 \\
\hline Calcium & $1 / 1$ & $103,000 \mathrm{~J}$ & $103,000 \mathrm{~J}$ & Z2-EU8B-306 & 103,000 & NA & NA & NA & 1 & NA & NA \\
\hline $\begin{array}{l}\text { Chromium } \\
\text { hexavalent }^{a}\end{array}$ & $0 / 1$ & ND & ND & ND & ND & NA & NA & NA & NA & NA & NA \\
\hline Manganese & $1 / 1$ & $597 \mathrm{~J}$ & $597 \mathrm{~J}$ & Z2-EU8B-306 & 597 & NA & NA & 0 & 0 & NA & 1 \\
\hline Vanadium & $1 / 1$ & 27.6 & 27.6 & Z2-EU8B-306 & 27.6 & NA & NA & 0 & 0 & NA & 1 \\
\hline
\end{tabular}

${ }^{a}$ Hexavalent chromium is reported for informational purposes even though none was detected.

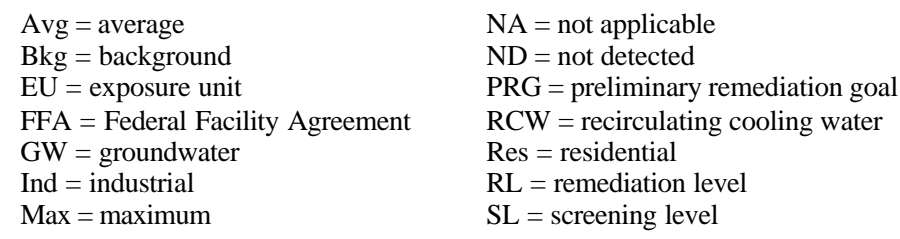

EU Z2-08 K-892-H COOLING TOWER BASIN FFA SITE RADIONUCLIDES WITH BACKGROUND, PRG, AND/OR RL EXCEEDANCES (pCi/g)

\begin{tabular}{|c|c|c|c|c|c|c|c|c|c|c|c|}
\hline \multirow[b]{2}{*}{ Analyte } & \multirow[b]{2}{*}{$\begin{array}{c}\text { Detect } \\
\text { frequency }\end{array}$} & \multirow[b]{2}{*}{$\begin{array}{c}\text { Minimum } \\
\text { detect }\end{array}$} & \multirow[b]{2}{*}{$\begin{array}{l}\text { Maximum } \\
\text { detect }\end{array}$} & \multirow[b]{2}{*}{$\begin{array}{c}\text { Location(s) of } \\
\text { maximum detect }\end{array}$} & \multirow{2}{*}{$\begin{array}{c}\text { Average } \\
\text { detected } \\
\text { result }\end{array}$} & \multicolumn{6}{|c|}{ Number of analyses exceeding criteria } \\
\hline & & & & & & $\begin{array}{l}\text { Max } \\
\text { RL }\end{array}$ & $\begin{array}{l}\text { Avg } \\
\text { RL }\end{array}$ & $\begin{array}{l}\text { Ind } \\
\text { PRG }\end{array}$ & Bkg & $\begin{array}{l}\text { GW } \\
\text { SL }\end{array}$ & $\begin{array}{c}\text { Res } \\
\text { PRG }\end{array}$ \\
\hline Potassium-40 & $1 / 1$ & 7.4 & 7.4 & Z2-EU8B-306 & 7.4 & NA & NA & 1 & 0 & NA & 1 \\
\hline Radium-226 & $1 / 1$ & 1 & 1 & Z2-EU8B-306 & 1 & NA & NA & 1 & 0 & NA & 1 \\
\hline Thorium -228 & $1 / 1$ & 0.75 & 0.75 & Z2-EU8B-306 & 0.75 & NA & NA & 1 & 0 & NA & 1 \\
\hline Thorium -232 & $1 / 1$ & 0.76 & 0.76 & Z2-EU8B-306 & 0.76 & NA & NA & 1 & 0 & NA & 1 \\
\hline
\end{tabular}

Avg $=$ average

$\mathrm{Bkg}=$ background

$\mathrm{EU}=$ exposure unit

FFA $=$ Federal Facility Agreement

$\mathrm{GW}=$ groundwater

Ind $=$ industrial
Max $=$ maximum

$\mathrm{NA}=$ not applicable

PRG $=$ preliminary remediation goal

Res $=$ residential

$\mathrm{RL}=$ remediation level

$\mathrm{SL}=$ screening level 
K-897-A Oil Containment Structure FFA Site: One biased sample location was selected for this site during DQO scoping. A sample of sediment from inside the structure was collected at Z2-EU8B-301 and analyzed. Analytical results summarized below show PCB, SVOC, and VOC detections.

EU Z2-08 K-897-A OIL CONTAINMENT STRUCTURE FFA SITE PCB DETECTS (ug/kg)

\begin{tabular}{|c|c|c|c|c|c|c|c|c|c|}
\hline \multirow[b]{2}{*}{ Analyte } & \multirow[b]{2}{*}{$\begin{array}{c}\text { Detect } \\
\text { frequency }\end{array}$} & \multirow[b]{2}{*}{$\underset{\text { detect }}{\text { Minimum }}$} & \multirow[b]{2}{*}{$\begin{array}{l}\text { Maximum } \\
\text { detect }\end{array}$} & \multirow{2}{*}{$\begin{array}{l}\text { Location(s) of } \\
\text { maximum } \\
\text { detect }\end{array}$} & \multirow{2}{*}{$\begin{array}{c}\text { Average } \\
\text { detected } \\
\text { result }\end{array}$} & \multicolumn{4}{|c|}{$\begin{array}{l}\text { Number of analyses } \\
\text { exceeding criteria }\end{array}$} \\
\hline & & & & & & $\begin{array}{c}\text { Max } \\
\text { RL }\end{array}$ & $\begin{array}{l}\text { Avg } \\
\text { RL }\end{array}$ & $\begin{array}{l}\text { Ind } \\
\text { PRG }\end{array}$ & $\begin{array}{c}\text { Res } \\
\text { PRG }\end{array}$ \\
\hline PCB-1254 & $1 / 1$ & $580 \mathrm{~J}$ & $580 \mathrm{~J}$ & Z2-EU8B-301 & 580 & 0 & 0 & 0 & 1 \\
\hline PCB & $1 / 1$ & $580 \mathrm{~J}$ & $580 \mathrm{~J}$ & Z2-EU8B-301 & 580 & 0 & 0 & 0 & 1 \\
\hline
\end{tabular}

Avg $=$ average

$\mathrm{EU}=$ exposure unit

FFA $=$ Federal Facility Agreement

$\mathrm{PCB}=$ polychlorinated biphenyl

Ind $=$ industrial

$\mathrm{PRG}=$ preliminary remediation goal

Max $=$ maximum

Res $=$ residential

$\mathrm{RL}=$ remediation level

EU Z2-08 K-897-A OIL CONTAINMENT STRUCTURE FFA SITE SVOC DETECTS (ug/kg)

\begin{tabular}{|c|c|c|c|c|c|c|c|c|}
\hline \multirow[b]{2}{*}{ Analyte } & \multirow[b]{2}{*}{$\begin{array}{c}\text { Detect } \\
\text { frequency }\end{array}$} & \multirow[b]{2}{*}{$\begin{array}{c}\text { Minimum } \\
\text { detect }\end{array}$} & \multirow[b]{2}{*}{$\begin{array}{c}\text { Maximum } \\
\text { detect }\end{array}$} & \multirow[b]{2}{*}{$\begin{array}{l}\text { Location(s) of } \\
\text { maximum detect }\end{array}$} & \multirow{2}{*}{$\begin{array}{c}\text { Average } \\
\text { detected } \\
\text { result }\end{array}$} & \multicolumn{3}{|c|}{$\begin{array}{l}\text { Number of analyses } \\
\text { exceeding criteria }\end{array}$} \\
\hline & & & & & & $\begin{array}{c}\text { Ind } \\
\text { PRG }\end{array}$ & $\begin{array}{l}\text { GW } \\
\text { SL }\end{array}$ & $\begin{array}{l}\text { Res } \\
\text { PRG }\end{array}$ \\
\hline Anthracene & $1 / 1$ & $97 \mathrm{~J}$ & $97 \mathrm{~J}$ & Z2-EU8B-301 & 97 & 0 & NA & 0 \\
\hline Benz(a)anthracene & $1 / 1$ & $540 \mathrm{~J}$ & $540 \mathrm{~J}$ & Z2-EU8B-301 & 540 & 0 & NA & 0 \\
\hline Benzo(a)pyrene & $1 / 1$ & $500 \mathrm{~J}$ & $500 \mathrm{~J}$ & Z2-EU8B-301 & 500 & 0 & NA & 1 \\
\hline Benzo(b)fluoranthene & $1 / 1$ & $570 \mathrm{~J}$ & $570 \mathrm{~J}$ & Z2-EU8B-301 & 570 & 0 & NA & 0 \\
\hline Benzo(ghi)perylene & $1 / 1$ & $290 \mathrm{~J}$ & $290 \mathrm{~J}$ & Z2-EU8B-301 & 290 & 0 & NA & 0 \\
\hline Benzo(k)fluoranthene & $1 / 1$ & $570 \mathrm{~J}$ & $570 \mathrm{~J}$ & Z2-EU8B-301 & 570 & 0 & NA & 0 \\
\hline Bis(2-ethylhexyl)phthalate & $1 / 1$ & $120 \mathrm{~J}$ & $120 \mathrm{~J}$ & Z2-EU8B-301 & 120 & 0 & 0 & 0 \\
\hline Carbazole & $1 / 1$ & $100 \mathrm{~J}$ & $100 \mathrm{~J}$ & Z2-EU8B-301 & 100 & 0 & NA & 0 \\
\hline Chrysene & $1 / 1$ & 740 & 740 & Z2-EU8B-301 & 740 & 0 & NA & 0 \\
\hline $\operatorname{Dibenz}(\mathrm{a}, \mathrm{h})$ anthracene & $1 / 1$ & $77 \mathrm{~J}$ & $77 \mathrm{~J}$ & Z2-EU8B-301 & 77 & 0 & NA & 1 \\
\hline Fluoranthene & $1 / 1$ & 1400 & 1400 & Z2-EU8B-301 & 1400 & 0 & NA & 0 \\
\hline Indeno(1,2,3-cd)pyrene & $1 / 1$ & $290 \mathrm{~J}$ & $290 \mathrm{~J}$ & Z2-EU8B-301 & 290 & 0 & NA & 0 \\
\hline Phenanthrene & $1 / 1$ & $640 \mathrm{~J}$ & $640 \mathrm{~J}$ & Z2-EU8B-301 & 640 & 0 & NA & 0 \\
\hline Pyrene & $1 / 1$ & 1100 & 1100 & Z2-EU8B-301 & 1100 & 0 & NA & 0 \\
\hline \multicolumn{9}{|c|}{ Avg $=$ average } \\
\hline \multirow{3}{*}{\multicolumn{9}{|c|}{$\begin{array}{l}\text { EU }=\text { exposure unit } \\
\text { FFA = Federal Facility Agreement } \\
\text { GW = groundwater }\end{array}$}} \\
\hline & & & & & & & & \\
\hline & & & & & & & & \\
\hline \multicolumn{2}{|c|}{ Ind $=$ industrial } & $\mathrm{SVOC}=\mathrm{se}$ & emivolatile or & rganic compound & & & & \\
\hline
\end{tabular}

EU Z2-08 K-897-A OIL CONTAINMENT STRUCTURE FFA SITE VOC DETECTS (ug/kg)

\begin{tabular}{|c|c|c|c|c|c|c|c|c|}
\hline \multirow[b]{2}{*}{ Analyte } & \multirow[b]{2}{*}{$\begin{array}{c}\text { Detect } \\
\text { frequency }\end{array}$} & \multirow[b]{2}{*}{$\begin{array}{c}\text { Minimum } \\
\text { detect }\end{array}$} & \multirow[b]{2}{*}{$\underset{\text { detect }}{\text { Maximum }}$} & \multirow[b]{2}{*}{$\begin{array}{c}\text { Location(s) of } \\
\text { maximum detect }\end{array}$} & \multirow{2}{*}{$\begin{array}{c}\text { Average } \\
\text { detected } \\
\text { result }\end{array}$} & \multicolumn{3}{|c|}{$\begin{array}{c}\text { Number of analyses } \\
\text { exceeding criteria }\end{array}$} \\
\hline & & & & & & $\begin{array}{c}\text { Ind } \\
\text { PRG }\end{array}$ & $\begin{array}{c}\text { GW } \\
\text { SL }\end{array}$ & $\begin{array}{l}\text { Res } \\
\text { PRG }\end{array}$ \\
\hline 2-Butanone & $1 / 1$ & $8.1 \mathrm{~J}$ & $8.1 \mathrm{~J}$ & Z2-EU8B-301 & 8.1 & 0 & NA & 0 \\
\hline Acetone & $1 / 1$ & $24 \mathrm{~J}$ & $24 \mathrm{~J}$ & Z2-EU8B-301 & 24 & 0 & NA & 0 \\
\hline
\end{tabular}

$\mathrm{EU}=$ exposure unit

$\mathrm{PRG}=$ preliminary remediation goal

FFA $=$ Federal Facility Agreement

Res $=$ residential

$\mathrm{GW}=$ groundwater $\quad \mathrm{SL}=$ screening level

Ind $=$ industrial $\quad$ VOC $=$ volatile organic compound

$\mathrm{NA}=$ not applicable 


\begin{tabular}{|l|l|}
\hline & \\
\hline 3.0 & RISK EVALUATION AND ACTION/NO FURTHER ACTION DECISION \\
\hline 3.1 & INTRODUCTION \\
\hline
\end{tabular}

This section presents data evaluated in terms of the four decision rules presented in the Zone 2 RDR/RAWP, which include:

- Does the concentration of any Zone 2 contaminant of concern (COC) exceed its maximum RL?

- Does the mean concentration of any Zone 2 COC exceed its average RL across the EU?

- Does the EU pose a risk exceeding an industrial $1 \times 10^{-4}$ excess lifetime cancer risk (ELCR) or target organ hazard index (HI) of 1 ?

- Does the site pose a threat to groundwater based on MCL exceedances or soil RLs for protection of groundwater?

Table C. 3 presents results from comparison of the data to Zone 2 soils RLs, Ind PRGs (set at an ELCR of $1 \times 10^{-5}$ or a $\mathrm{HI}$ of 1), and background levels. In addition, the EU summary in Sect. 2.2.5 presents an evaluation of the EU data by analyte group. The following table summarizes the conclusions for EU Z2-08.

\begin{tabular}{lccccc}
\hline EU \# & $\begin{array}{c}\text { Max RL } \\
\text { exceeded? }\end{array}$ & $\begin{array}{c}\text { Average RL over } \\
\text { EU exceeded? }\end{array}$ & $\begin{array}{c}\text { Industrial risk } \\
\text { above } \mathbf{1} \times \mathbf{1 0}^{-4}\end{array}$ & $\begin{array}{c}\text { Potential source } \\
\text { to groundwater? }\end{array}$ & $\begin{array}{c}\text { Action } \\
\text { required? }\end{array}$ \\
\hline $\mathrm{Z} 2-08$ & No & No & No & No & No \\
\hline $\begin{array}{l}\mathrm{EU}=\text { exposure unit } \\
\mathrm{RL}=\text { remediation level }\end{array}$ & & & & \\
\end{tabular}

3.2

DATA EVALUATION FOR THE ACTION /NO FURTHER ACTION DECISION

Requirements for determining NFA in the Zone 2 EUs are stated in the protection goals of the Zone 2 ROD RAO. Four decision rules were developed in the DVS DQOs that stated the specific criteria against which each EU must be compared to make the NFA decision. The four decision rules are presented in Sect. 3.2 of this PCCR and the manner in which the decision rule evaluations are conducted and any special data handling requirements are discussed in Sect.3.3. In summary, the decision rule criteria for NFA are that each EU must meet each of the following compositional constraints:

- Zone 2 soils maximum RLs - maximum allowable concentrations of the Zone 2 soils COCs. Zone 2 soils maximum RLs are presented in the Zone 2 ROD and Table 5 of this PCCR.

- Zone 2 soils average RLs - limit on the allowable average concentrations of the Zone 2 soils COCs across an EU. Zone 2 soils average RLs are presented in the Zone 2 ROD and Table 5 of this PCCR.

- Cumulative risk across the EU-cumulative risk across an EU cannot exceed $1 \times 10^{-4}$ ELCR or HI of 1. An evaluation of cumulative risk is performed by first comparing EU data to $1 \times 10^{-5}$ industrial PRGs. The $1 \times 10^{-5}$ Ind PRGs for the analy tes required by the RDR/RAWP are presented in Table 5 of this PCCR.

- Groundwater protection goals - compositions of Zone 2 soils cannot pose a threat to groundwater. This evaluation is conducted by evaluating local groundwater monitoring results and comparing soils compositions to calculated SLs. The values for the GW SLs are presented in Table 5 of this PCCR.

\begin{tabular}{|l|l}
\hline 3.3 & SUMMARY AND CONCLUSIONS \\
\hline
\end{tabular}

\section{EU Z2-08}

Max RL screening. Based on historical and DVS sampling information and results of the Class 3 walkover assessment, no Zone 2 COCs were detected at concentrations in excess of maximum RLs.

Avg RL screening. The Cs-137 average RL was exceeded in the DVS sample from Z2-EU8B-314 and the U-238 average RL was exceeded in the sample from historical sample location RAD228. The DVS confirmation sample at RAD228 did not detect U-238 in excess of the average RL, therefore, only the average RL exceedance at Z2-EU8B-314 will be further evaluated. 
The first step in determining whether the Cs -137 Avg RL was exceeded across EU Z2-08 is to establish if the observed Avg RL exceedance causes the EU average detected Cs -137 concentration to exceed its average RL without area weighting. The average detected concentration of Cs -137 in $\mathrm{EU} Z 2-08$ is $0.79 \mathrm{pCi} / \mathrm{g}$, which is less than the Cs -137 average RL ( $2 \mathrm{pCi} / \mathrm{g}$ ). Based on historical and DVS sampling information, and results of the Class $3 \mathrm{SU}$ walkover assessment, it is concluded no Zone $2 \mathrm{COCs}$ are present with a mean concentration exceeding the average RL across EU Z2-08.

Risk evaluation. The first step in the risk evaluation is to evaluate the $1 \times 10^{-5}$ Ind PRG exceedances to determine which chemicals and radionuclides are likely to exceed the $1 \times 10^{-4}$ ELCR or target organ HI of 1 . In EU Z2-08, the $1 \times 10^{-5}$ Ind PRG was exceeded in one or more samples by arsenic (4), Cs-137 (7), K-40 (28), Ra-226 (23), Th-228 (28), Th-232 (28), U-235 (1), and U-238 (2). As explained in Sect. 3.3, K-40 is evaluated further for risk only if its average concentration exceeds its background value, risk from arsenic is evaluated by comparing its average concentration to its Zone 2 soils Avg RL, and Ra-226 and Th-232 are evaluated by summing their concentrations (Ra/Th decay series) and comparing the result to their mutual Zone 2 soils COC Avg RL (this evaluation includes Th-228 as part of the Th-232 decay chain). The average detected K-40 concentration $(10.9 \mathrm{pCi} / \mathrm{g})$ does not exceed the $\mathrm{K}-40$ background value $(32.12 \mathrm{pCi} / \mathrm{g})$, the average detected concentration of arsenic $(11.2 \mathrm{mg} / \mathrm{kg}$ ) does not exceed the arsenic Avg RL (300 mg/kg), and there are no occurrences of the Ra/Th decay series exceeding the Avg RL (5 pCi/g). In addition, the U-235 Ind PRG exceedance and one U-238 Ind PRG exceedance occurred in the historical sample from location RAD228; DVS confirmation sampling at RAD228 did not detect either of these Ind PRG exceedances. Therefore, arsenic, K-40, Ra-226, Th-228, Th-232, and U-235 will not be carried forward in the risk evaluation.

The second step in the risk evaluation is to determine the average detected concentration of any of the remaining chemicals or radionuclides exceeding a $1 \times 10^{-5}$ Ind PRG. For EU Z2-08, the remaining chemicals or radionuclides with individual $1 \times 10^{-5}$ Ind PRG exceedances are Cs -137 and U-238. The average detected concentration of Cs -137 is $0.79 \mathrm{pCi} / \mathrm{g}$ and for $\mathrm{U}-238$ is $4.3 \mathrm{pCi} / \mathrm{g}$, which are less than the respective Ind $\mathrm{PRG}$ values of $1.13 \mathrm{pCi} / \mathrm{g}$ and $18 \mathrm{pCi} / \mathrm{g}$. Therefore, neither Cs -137 nor U-238 will be carried forward in the risk evaluation.

In conclusion, there are no chemicals or radionuclides in EU Z2-08 with average concentrations greater than their $1 \times 10^{-5}$ Ind PRGs or that exceed the risk evaluation criteria described in Sect. 3.3. Therefore, the industrial risk for EU Z2-08 is less than $1 \times 10^{-4}$ ELCR and target organ HI of 1 .

Threat to groundwater. The arsenic concentration at historical location K33RCW04 (66.5J mg/kg) exceeds its GW SL of $66 \mathrm{mg} / \mathrm{kg}$. Chromium concentrations exceed its GW SL $(172 \mathrm{mg} / \mathrm{kg})$ at one DVS and historical sample locations Z2-EU8B-314 (446J mg/kg), K33RCW04 (261 mg/kg), and K33RCW05 (246J mg/kg). The U-234 concentration at historical location RAD228 (72.1 pCi/g) exceeded the U-234 GW SL of $61.1 \mathrm{pCi} / \mathrm{g}$.

Groundwater samples collected from local groundwater monitoring wells show chromium MCL exceedances in the bedrock well located in the southern portion of EU Z2-08 (BRW-033). These elevated conditions occurred following sludge removal from the cooling water basins. Similar conditions were observed in EU Z2-09 to the south with chromium concentrations showing a spike after removal actions at the cooling water basins and a return to near background levels within a year of RA completion. There are no MCL exceedances for either arsenic or U-234 in the groundwater data.

The arsenic GW SL exceedance occurs at a historical soil sample location (K33RCW04) associated with the K-892-G Cooling Tower Basin. Elevated arsenic at this location originated from wood in the cooling tower that had been treated with arsenic as a preservative. There are numerous DVS and historical sample locations in the vicinity of K33RCW04 that were analyzed for arsenic, but only the K33RCW04 sample has an arsenic GW SL exceedance. Based on this observation, it is concluded the extent of the arsenic GW SL exceedance at K33RCW04 is too small to provide sufficient mass for groundwater contamination.

The three GW SL exceedances define two isolated areas. One area, in the northern part of the EU at the northeast corner of the K-892-G Cooling Tower Basin, is defined by the exeedances at historical sample locations K33RCW04 and K33RCW05 (associated with a known RCW line leak site), which are essentially coincident (Fig. C.4). Other samples have been collected from the vicinity of these two historical locations with no chromium GW SL exceedance. The second area with a chromium GW SL exceedance is the DVS sample location in the K-899-M Valve Vault located in the southern portion of the EU. The valve vault is an isolated, subsurface enclosure where sediment has accumulated. The footprint of the valve vault is approximately $10 \mathrm{ft} \times 10 \mathrm{ft}$, and the sediment in the valve vault is approximately 2 in. thick. In both cases, it is concluded the volume of chromium-contaminated soil and sediment are too small for there to be sufficient mass of chromium that could threaten the groundwater. In 
addition, it has been demonstrated that hexavalent chromium (toxic form of chromium) is not stable in ETTP soils [Investigation of Hexavalent Chromium in Association with the Recirculating Cooling Water System at the East Tennessee Technology Park, Oak Ridge, Tennessee (BJC/OR-2572)]. This conclusion is supported by the hexavalent chromium analytical results reported in the EU Z2-08 summary in Sect. 2.2.5.

The U-234 GW SL exceedance at historical location RAD228 was not confirmed by the DVS confirmation sample collected at Z2-EU8B-320.

In conclusion, based on results of the Class $3 \mathrm{SU}$ walkover assessment and results of DVS and historical sampling, the soils in EU Z2-08 do not pose a threat to groundwater.

Qualitative risk screening for unrestricted use. There is a low probability that the acreage in EU Z2-08 could be released with no land use restrictions. Average RL exceedances, Ind PRG, and Res PRG exceedances occur in EU Z2-08. Specific chemicals and radionuclides with criteria exceedances are presented in the EU Z2-08 summary in Sect. 2.2.5. An appropriate evaluation of residential risk should be conducted to make a definitive conclusion.

\section{FFA Sites}

Based on sampling analytical results (Sect. 2.2.6) and an evaluation of the EU-wide contaminant profile, soils in the following Zone 2 ROD Appendix A FFA Sites in EU Z2-08 do not pose a potential threat to the future industrial worker or to groundwater:

- $\quad$ K-33 RCW Lines Leak Site FFA Site,

- K-892-G Cooling Tower Basin FFA Site,

- $\quad$ K-892-H Cooling Tower Basin FFA Site, and

- K-897-A Oil Containment Structure FFA Site.

\begin{tabular}{|l|l|}
\hline 4.0 & \multicolumn{1}{|c|}{ RECOMMENDATION FOR ACTION/NO FURTHER ACTION } \\
\hline 4.1 & DECISION AND REMEDIATION ACTIVITIES \\
\hline
\end{tabular}

EU Z2 -08: Based on results of the Class 3 and Class 4 SU walkover assessment, analytical results of the DVS and historical samples collected in EU Z2-08, the U.S. Department of Energy (DOE) recommends NFA under the Zone 2 ROD to meet industrial land use for the 24 acres of ETTP Zone 2 EU Z2-08. DOE also recommends that use restrictions below $10 \mathrm{ft}$ be lifted.

FFA Sites: Based on analytical results and the recommendation for EU Z2-08, DOE recommends NFA for the following FFA sites:

- $\quad$ K-33 RCW Lines Leak Site FFA Site,

- K-892-G Cooling Tower Basin FFA Site,

- K-892-H Cooling Tower Basin FFA Site, and

- $\quad$ K-897-A Oil Containment Structure FFA Site.

\section{\begin{tabular}{|l|l}
4.2 & EXCAVATION ACTIVITIES/CONFIRMATION SAMPLING \\
\hline
\end{tabular}}

None. 


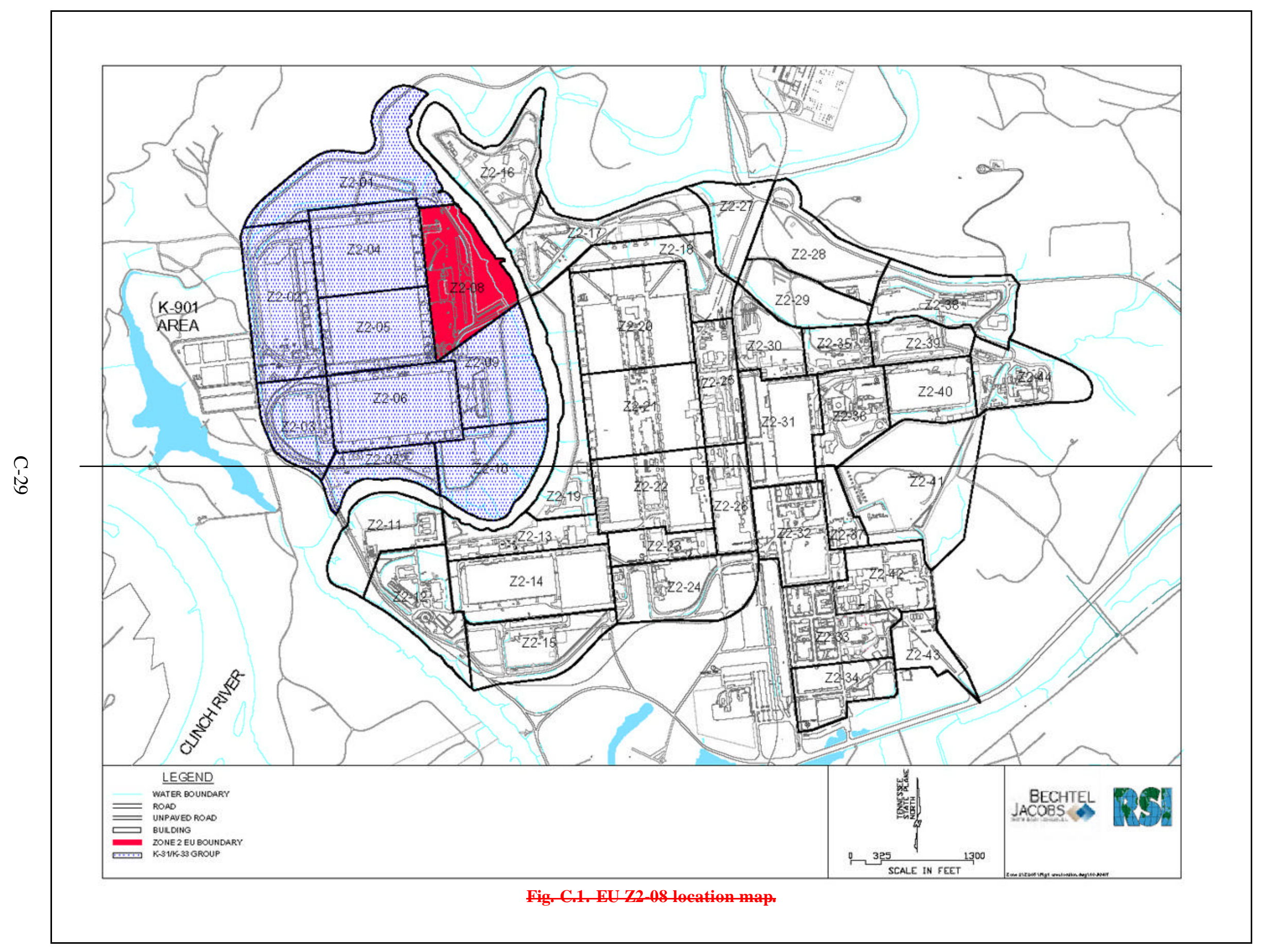




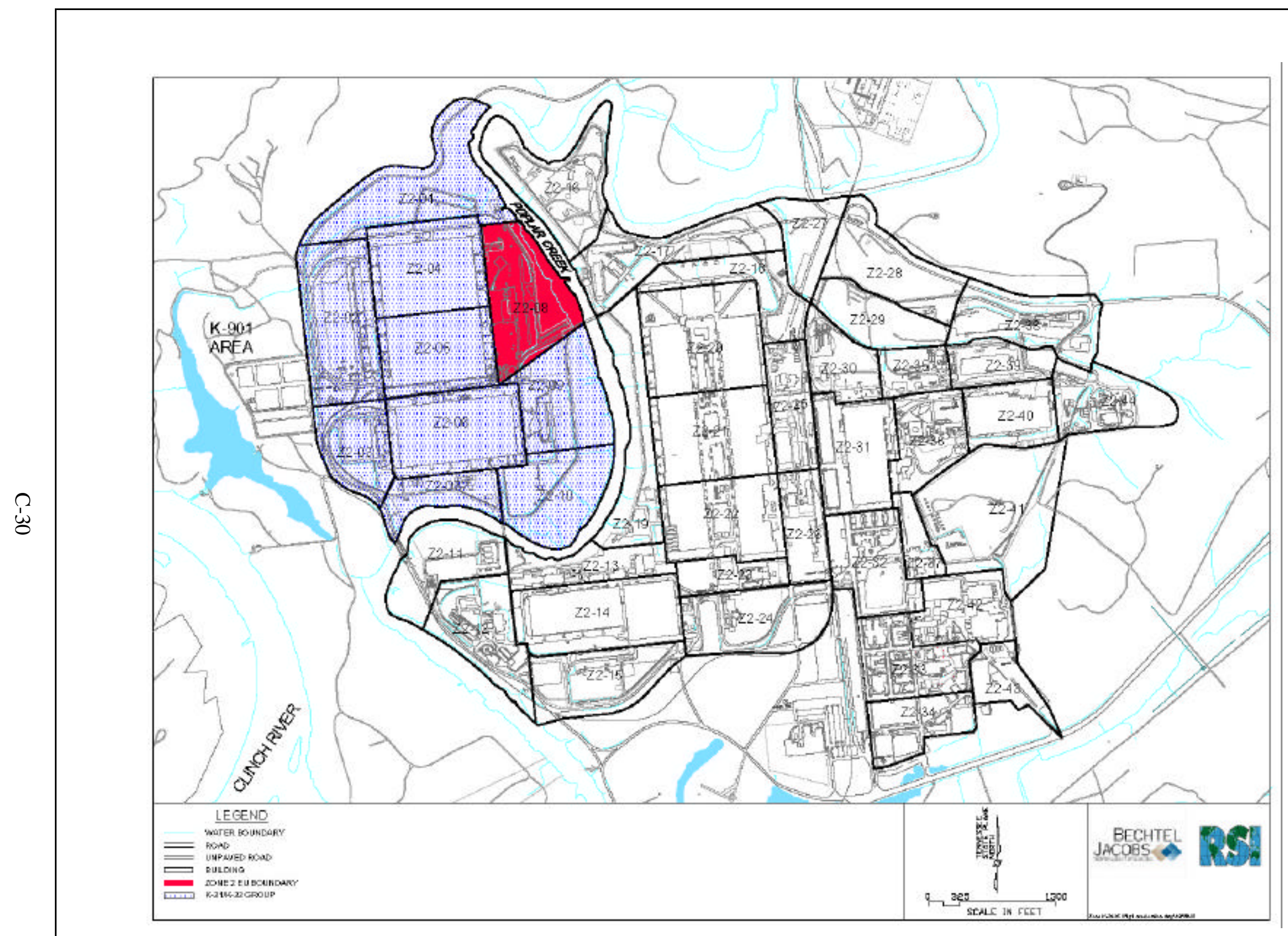

Fig. C.1. EU Z2-08 location map. 


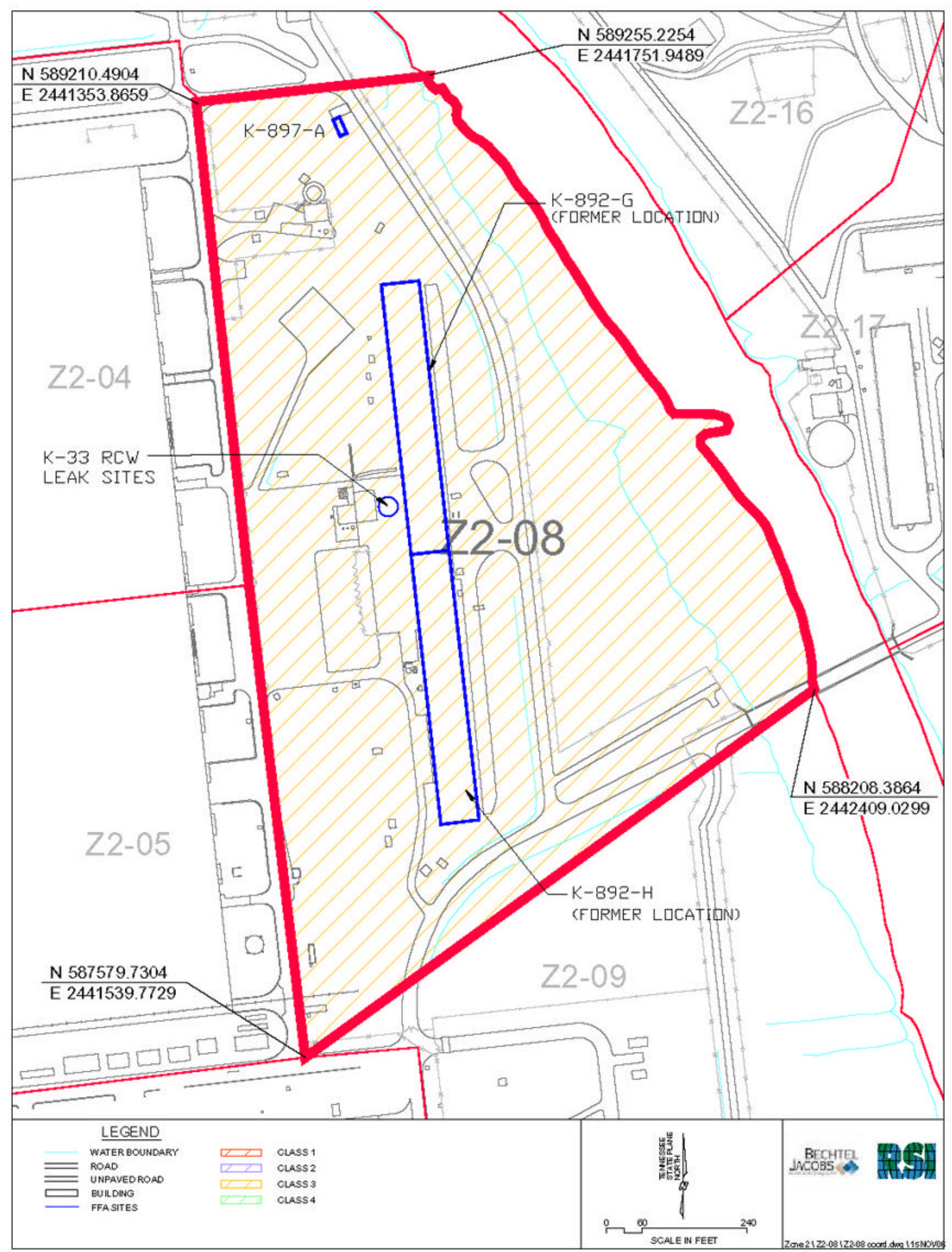

Fig. C.1로. EU Z2-08 boundaries. 


\section{Survey Dates: 08130106 \& 09106/06}

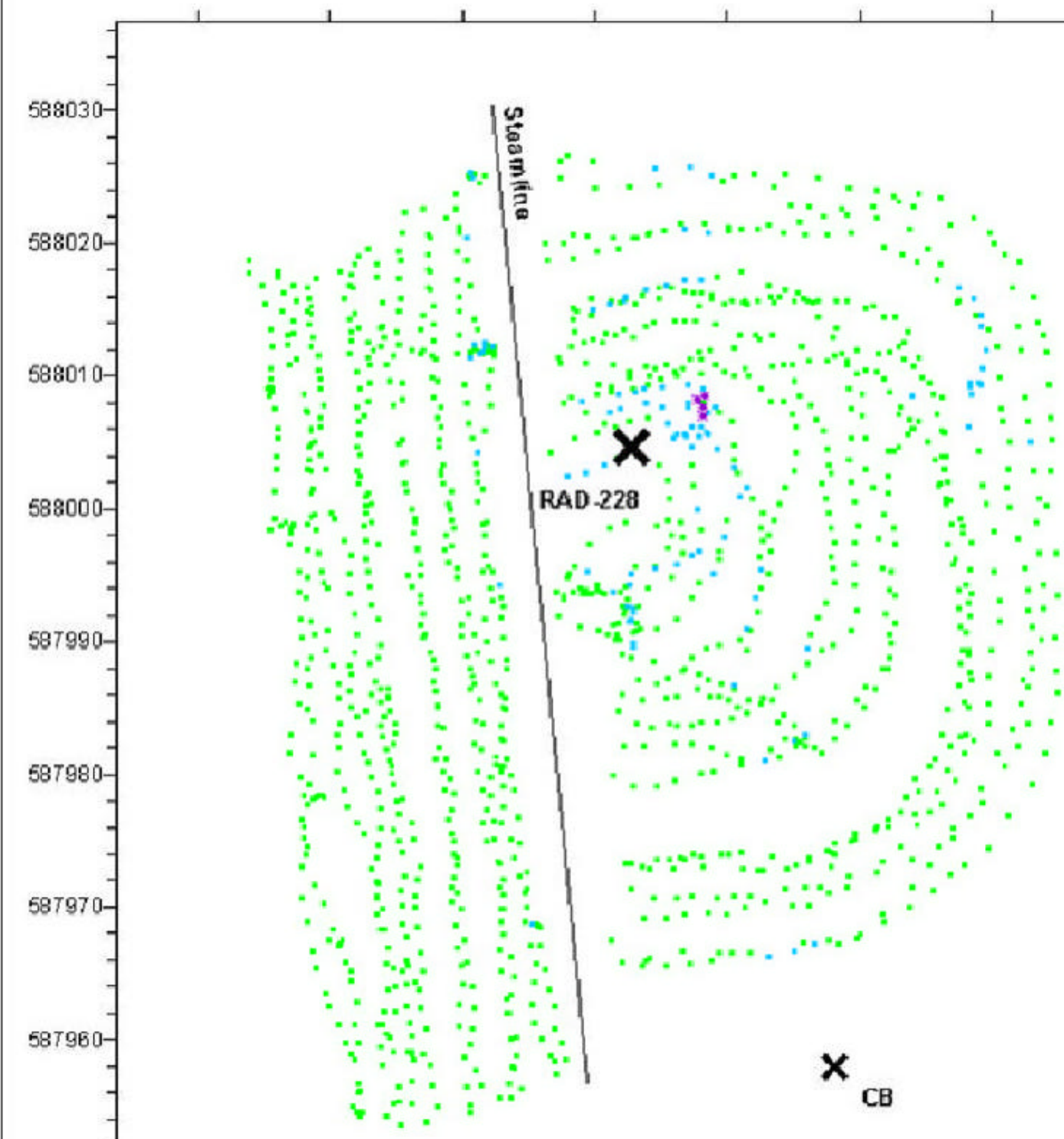

RAD 228 (244 $1594 \mathrm{E}, 588000 \mathrm{~N})$

587950

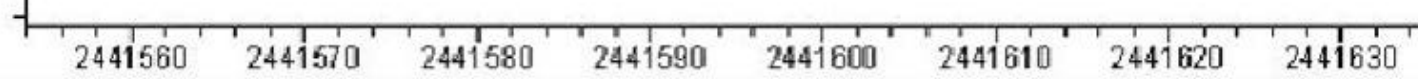

Fig. C.233. Historic sample RAD-228 BAR survey. 


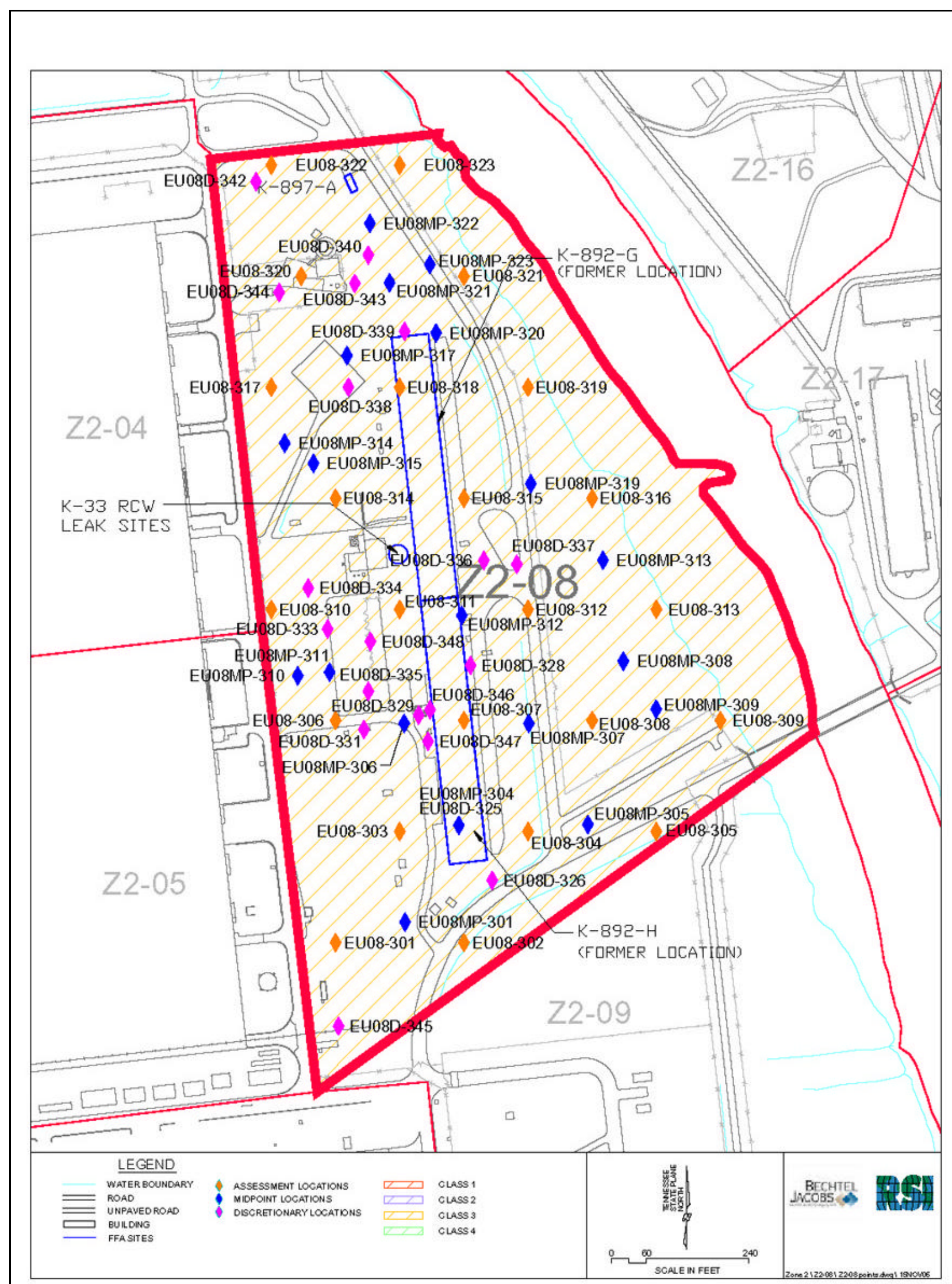

Fig. C. 34 . Class 3 and Class 4 SU walkover assessment locations. 


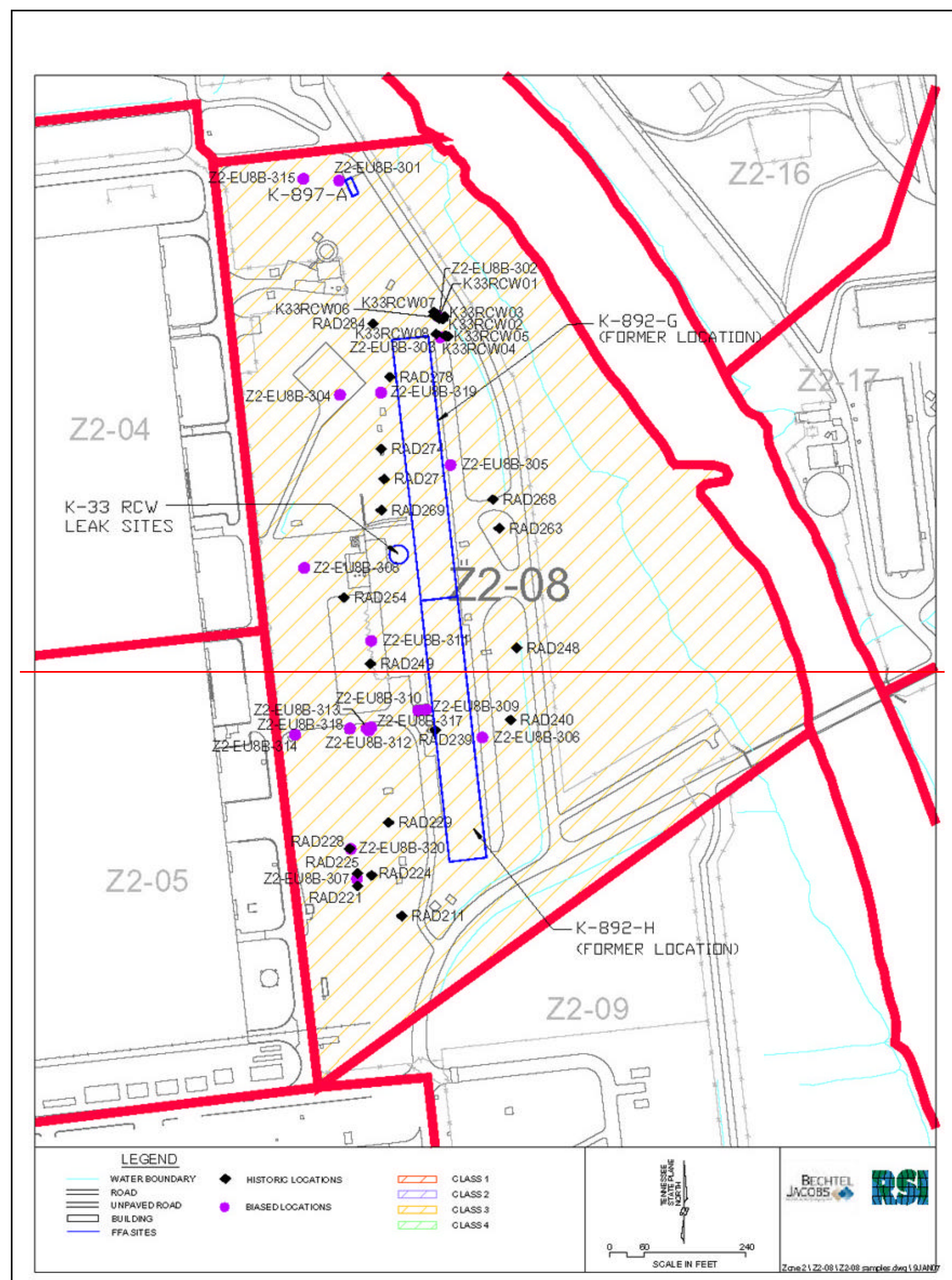

Fig. C.5. EU Z2-08 sample locations. 


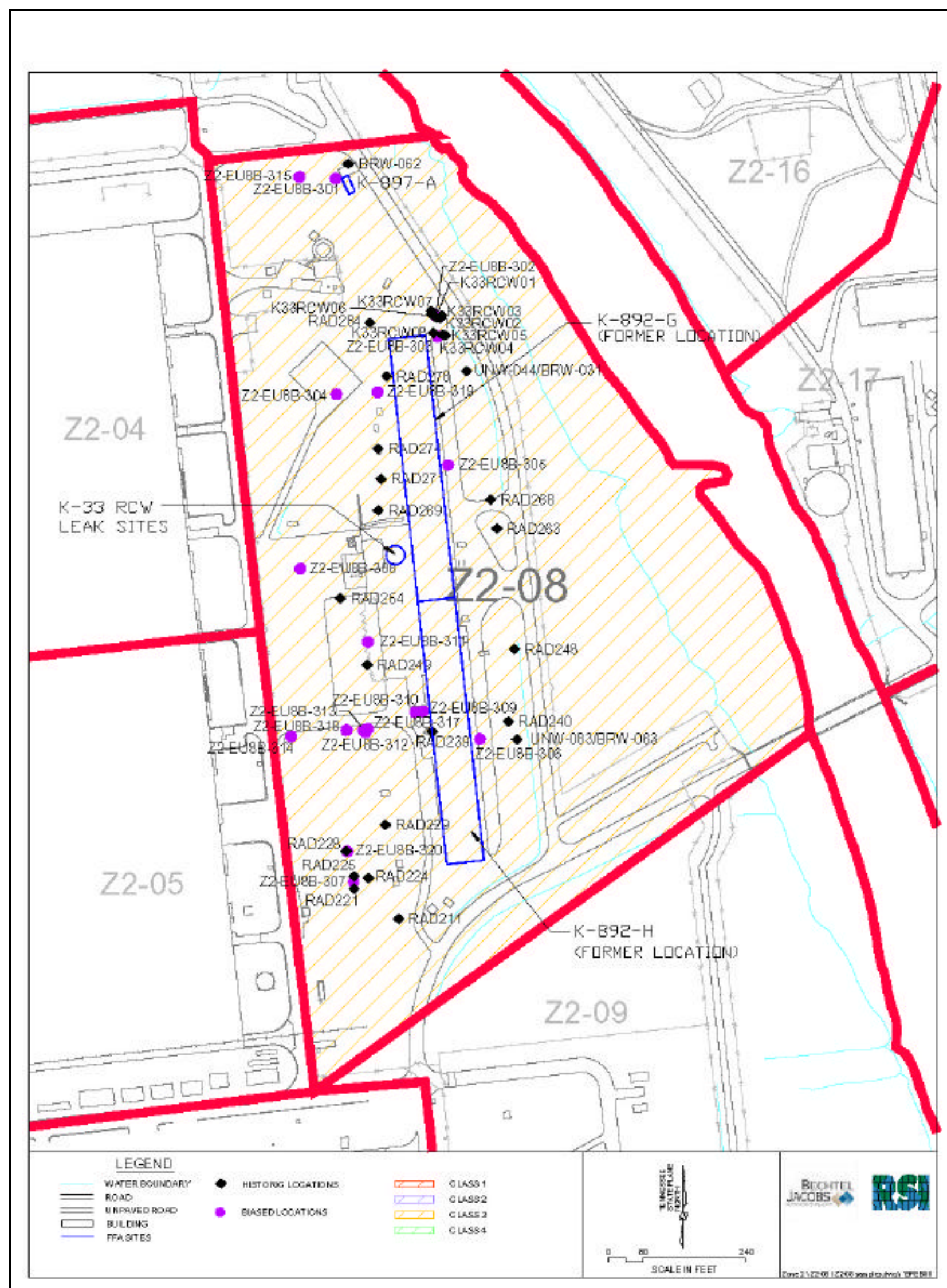

Fig. C.5. EU Z2-08 sample locations. 
Table C.1. EU Z2-08 facility and FFA site list.

\begin{tabular}{|c|c|c|c|c|}
\hline \multirow[b]{2}{*}{ Facility name DQO scoping } & \multirow[b]{2}{*}{ Facility name } & \multicolumn{2}{|c|}{ Facility assessed? } & \multirow[b]{2}{*}{ Comments } \\
\hline & & Yes & No & \\
\hline \multicolumn{5}{|l|}{ K-892 Fire and Raw Cooling Water } \\
\hline Pumphouse & & $\mathrm{X}$ & & \\
\hline K-892 Pumphouse & & $\mathrm{X}$ & & \\
\hline K-892-A Clarifier & K-892-A Former Clarifier (concrete foundation) & $\mathrm{X}$ & & \\
\hline K-892-B Clarifier & K-892-B Former Clarifier (concrete foundation) & $\mathrm{X}$ & & \\
\hline K-892-C Clarifier & K-892-C Former Clarifier (concrete foundation) & $\mathrm{X}$ & & \\
\hline K-892 Center Basin & & & $\mathrm{X}$ & Facility no longer exists \\
\hline K-892-D Valve House & & & $\mathrm{X}$ & Facility no longer exists \\
\hline K-892-E Valve House & & & $\mathrm{X}$ & Facility no longer exists \\
\hline K-892-G Cooling Tower Basin & & & $\mathrm{X}$ & FFA Site; partial wall remains \\
\hline K-892-H Cooling Tower Basin & & & $\mathrm{X}$ & FFA Site; partial wall remains \\
\hline K-892-K Valve House & K-892-K Former Valve House (concrete pad) & $\mathrm{X}$ & & \\
\hline K-892-M Valve House & K-892-M Former Valve House (concrete pad) & $X$ & & \\
\hline K-892-N HCl Pump House & & & $\mathrm{X}$ & Facility no longer exists \\
\hline K-892-P Valve House & K-892-P Former Valve House (concrete pad) & $\mathrm{X}$ & & \\
\hline K-892-Q HCl Storage Tank & & & $\mathrm{X}$ & Facility no longer exists \\
\hline K-892-R Zinc Storage Tank & & & $\mathrm{X}$ & Facility no longer exists \\
\hline K-892-S Chromate Storage Tank & & & $\mathrm{X}$ & Facility no longer exists \\
\hline K-892-T Phosphate Storage Tank & & & $\mathrm{X}$ & Facility no longer exists \\
\hline K-892-AA Clarifier A Valve Vault & K-892-AA Inactive Valve Vault & & $\mathrm{X}$ & Facility no longer exists \\
\hline K-892-Y RCW Sludge Softener Facility & $\begin{array}{l}\text { K-892-Y Maintenance Shop (RCW Sludge } \\
\text { Softener Facility) }\end{array}$ & $\mathrm{X}$ & & \\
\hline K-892-BB Clarifier B Valve Vault & K-892-BB Inactive Valve Vault & $\mathrm{X}$ & & \\
\hline K-893-A RCW Valve Vault & K-893-A Inactive Valve Vault & $\mathrm{X}$ & & \\
\hline K-893-B RCW Valve Vault & K-893-B Inactive Valve Vault & $\mathrm{X}$ & & \\
\hline K-893-C RCW Valve Vault & K-893-C Inactive Valve Vault & $\mathrm{X}$ & & \\
\hline K-893-E RCW Valve Vault & K-893-E Inactive Valve Vault & $X$ & & \\
\hline K-893-F RCW Valve Vault & K-893-F Inactive Va lve Vault & $\mathrm{X}$ & & \\
\hline K-893-G RCW Valve Vault & K-893-G Inactive Valve Vault & $\mathrm{X}$ & & \\
\hline K-893-H RCW Valve Vault & K-893-H Inactive Valve Vault & $\mathrm{X}$ & & \\
\hline K-893-J RCW Valve Vault & K-893-J Inactive Valve Vault & $\mathrm{X}$ & & \\
\hline K-893-V RCW Valve Vault & K-893-V Inactive Valve Vault & $\mathrm{X}$ & & \\
\hline
\end{tabular}


Table C.1. (continued)

\begin{tabular}{|c|c|c|c|c|}
\hline \multirow[b]{2}{*}{ Facility name DQO scoping } & \multirow[b]{2}{*}{ Facility name } & \multicolumn{2}{|c|}{ Facility assessed? } & \multirow[b]{2}{*}{ Comments } \\
\hline & & Yes & No & \\
\hline K-893-W RCW Valve Vault & K-893-W Inactive Valve Vault & $\mathrm{X}$ & & \\
\hline K-893-X RCW Valve Vault & K-893-X Inactive Valve Vault & $\mathrm{X}$ & & \\
\hline K-893-Y RCW Valve Vault & K-893-Y Inactive Valve Vault & $\mathrm{X}$ & & \\
\hline K-893-Z RCW Valve Vault & K-893-Z Inactive Valve Vault & $\mathrm{X}$ & & \\
\hline K-893-AA RCW Valve Vault & K-893-AA Inactive Valve Vault & $\mathrm{X}$ & & \\
\hline K-893-BB RCW Valve Vault & K-893-BB Inactive Valve Vault & $\mathrm{X}$ & & \\
\hline K-893-CC RCW Valve Vault & K-893-CC Inactive Valve Vault & $\mathrm{X}$ & & \\
\hline K-893-DD RCW Valve Vault & K-893-DD Inactive Valve Vault & $\mathrm{X}$ & & \\
\hline K-894 Acid Unloading Station & K-894 Former Acid Unloading Station & $\mathrm{X}$ & & \\
\hline K-894-A Rail Transfer Station & & & $\mathrm{X}$ & Facility no longer exists \\
\hline K-894-B Acid Containment Tank & & $\mathrm{X}$ & & \\
\hline K-896 Recycle Blowdown Facility & K-896 Former Recycle Blowdown Facility & $\mathrm{X}$ & & \\
\hline K-896-A Clarifier Tank & K-896-A Former Clarifier (concrete foundation) & $\mathrm{X}$ & & \\
\hline K-896-B Clarifier Tank & K-896-B Former Clarifier (concrete foundation) & $\mathrm{X}$ & & \\
\hline K-896-C Pump House & & & $\mathrm{X}$ & Facility no longer exists \\
\hline K-897-A Oil Containment Structure & K-897-A Oil Skimmer & $\mathrm{X}$ & & $\begin{array}{l}\text { FFA Site } \\
\text { Listed in DQO Scoping Document in } \\
\text { EU-08; facility falls in EU Z2-09 and } \\
\text { is not evaluated here }\end{array}$ \\
\hline K-33 RCW Lines Leak Sites & & & & $\begin{array}{l}\text { FFA Site; listed in DQO Scoping } \\
\text { Document in EUs Z2-04 and Z2-05 }\end{array}$ \\
\hline \multicolumn{5}{|l|}{ Facilities not in DQO Scoping } \\
\hline K-892-X Former RCW Sludge Tank & & $\mathrm{X}$ & & \\
\hline K-893-D Inactive Valve Vault & & $\mathrm{X}$ & & \\
\hline K-893-EE RCW Valve Vault & & & $\mathrm{X}$ & Facility no longer exists \\
\hline K-893-FF RCW Valve Vault & & & $\mathrm{X}$ & Facility no longer exists \\
\hline K-893-K Inactive Valve Vault & & $\mathrm{X}$ & & \\
\hline K-893-M Inactive Valve Vault & & $\mathrm{X}$ & & \\
\hline K-893-P Inactive Valve Vault & & $\mathrm{X}$ & & \\
\hline K-893-Q Inactive Valve Vault & & $\mathrm{X}$ & & \\
\hline K-899-L Inactive Valve Vault & & $\mathrm{X}$ & & \\
\hline K-899-M Inactive Valve Vault & & $\mathrm{X}$ & & \\
\hline $\begin{array}{l}\mathrm{EU}=\text { exposure unit } \\
\mathrm{DQO}=\text { data quality objective }\end{array}$ & $\begin{array}{l}\text { ederal Facility Agreement } \\
\text { recirculating cooling water }\end{array}$ & & & \\
\hline
\end{tabular}


Table C.2. EU Z2-08 sample summary

\begin{tabular}{|c|c|c|c|c|c|c|c|c|c|c|c|c|c|c|c|}
\hline \multirow[b]{2}{*}{$\begin{array}{l}\text { SU } \\
\text { class }\end{array}$} & \multirow[b]{2}{*}{$\begin{array}{c}\text { Date } \\
\text { sampled }\end{array}$} & \multirow[b]{2}{*}{ Sample ID } & \multicolumn{2}{|c|}{ Location } & \multirow[b]{2}{*}{ Sample interval } & \multicolumn{2}{|c|}{ Screening } & \multicolumn{7}{|c|}{ Off-site laboratory } & \multirow[b]{2}{*}{ Comments and notes } \\
\hline & & & Northing & Easting & & VOC & RAD & VOC & SVOC & PCB & Metals & RAD & $\begin{array}{l}\text { DRO/ } \\
\text { GRO }\end{array}$ & QA & \\
\hline 3 & $2 / 20 / 06$ & Z2-EU8B-301 & 589179 & 2441576 & Grab sample (sediment) & 1 & & 1 & 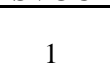 & 1 & & & & $\mathrm{D}$ & $\begin{array}{l}\text { K-897-A Oil } \\
\text { Containment Structure }\end{array}$ \\
\hline 3 & $3 / 13 / 06$ & Z2-EU8B-302 & 588942 & 2441749 & Composite adjacent to pipe & 1 & 1 & & & & 1 & & & & RCW lines leak site \\
\hline 3 & $3 / 13 / 06$ & Z2-EU8B-303 & 588903 & 2441755 & Composite adjacent to pipe & 1 & 1 & & & & 1 & & & & $\begin{array}{l}\text { K-892-G Cooling } \\
\text { Tower Basin }\end{array}$ \\
\hline 3 & $3 / 13 / 06$ & Z2-EU8B-304 & 588801 & 2441578 & Composite adjacent to pipe & 1 & 1 & & & & 1 & 1 & & & RCW lines leak site \\
\hline 3 & $3 / 13 / 06$ & Z2-EU8B-305 & 588678 & 2441773 & Composite adjacent to pipe & 1 & 1 & 1 & 1 & 1 & 1 & 1 & & & $\begin{array}{l}\text { K-892-G Cooling } \\
\text { Tower Basin }\end{array}$ \\
\hline 3 & $3 / 13 / 06$ & Z2-EU8B-306 & 588197 & 2441829 & Composite adjacent to pipe & 1 & 1 & & & & 1 & 1 & & & $\begin{array}{l}\text { K-892-H Cooling } \\
\text { Tower Basin } \\
\end{array}$ \\
\hline 3 & $5 / 17 / 06$ & Z2-EU8B-307 & 587948 & 2441608 & 0-1 ft composite (1-point HA) & 1 & 1 & & & & & 1 & & & $\begin{array}{l}\text { Biased based on } \\
\text { radiological walkover } \\
\text { ralon }\end{array}$ \\
\hline 3 & $5 / 22 / 06$ & Z2-EU8B-308 & 588496 & 2441515 & 0-1 ft composite (5-point HA) & 1 & 1 & 1 & 1 & 1 & 1 & 1 & & & $\begin{array}{l}\text { Wood/debris pile, west } \\
\text { of K-892 }\end{array}$ \\
\hline 3 & $5 / 23 / 06$ & Z2-EU8B-309 & 588246 & 2441730 & 0.5-1 ft composite (1-point HA) & & 1 & & 1 & & & & 1 & & $\begin{array}{l}\text { Diesel tank, sample } \\
\text { below overflow pipe }\end{array}$ \\
\hline 3 & $5 / 23 / 06$ & Z2-EU8B-310 & 588244 & 2441716 & $0.5-1 \mathrm{ft}$ composite (1-point $\mathrm{HA}$ ) & & 1 & & 1 & & & & 1 & & $\begin{array}{l}\text { Diesel tank, sample at } \\
\text { base of slope }\end{array}$ \\
\hline 3 & $5 / 23 / 06$ & Z2-EU8B-311 & 588214 & 2441633 & $0.5-1 \mathrm{ft}$ composite (1-point HA) & & 1 & & 1 & & & & 1 & & $\begin{array}{l}\text { Gas tank, east side of } \\
\text { pad }\end{array}$ \\
\hline 3 & $5 / 23 / 06$ & Z2-EU8B-312 & 588210 & 2441629 & $0.5-1 \mathrm{ft}$ composite (1-point HA) & & 1 & & 1 & & & & 1 & & $\begin{array}{l}\text { Gas tank, south side of } \\
\text { pad }\end{array}$ \\
\hline 3 & $5 / 23 / 06$ & Z2-EU8B-313 & 588213 & 2441625 & 0.5-1 ft composite (1-point $\mathrm{HA}$ ) & & 1 & & 1 & & & & 1 & & $\begin{array}{l}\text { Gas tank, west side of } \\
\text { pad }\end{array}$ \\
\hline 3 & $5 / 25 / 06$ & Z2-EU8B-314 & 588202 & 2441499 & 0-1 ft composite (1-point HA) & 1 & & & & 1 & 1 & 1 & & & $\begin{array}{l}\text { K-899M RCW valve } \\
\text { vault -sediment }\end{array}$ \\
\hline 3 & $5 / 25 / 06$ & Z2-EU8B-315 & 589183 & 2441513 & 0-1 ft composite (1-point HA) & 1 & & & & 1 & 1 & 1 & & & $\begin{array}{l}\text { K-893V RCW valve } \\
\text { vault-sediment }\end{array}$ \\
\hline 3 & & Z2-EU8B-316 & 589039 & 2441626 & $0-1 \mathrm{ft}$ composite (1-point HA) & & & & & & & & & & Dropped \\
\hline 3 & $5 / 24 / 06$ & Z2-EU8B-317 & 588367 & 2441633 & 0-1 ft composite (5-point HA) & 1 & 1 & & 1 & 1 & 1 & & & & K-892 Transformer \\
\hline 3 & $9 / 21 / 07$ & Z2-EU8B-318 & 588213 & 2441596 & Grab sample (sediment) & 1 & & & & 1 & 1 & 1 & & & $\begin{array}{l}\text { Inactive valve vault } \\
\text { K-893-DD } \\
\end{array}$ \\
\hline 3 & $9 / 21 / 07$ & Z2-EU8B-319 & 588805 & 2441650 & Grab Sample (sediment) & 1 & & & & 1 & 1 & 1 & & & $\begin{array}{l}\text { Inactive valve vault } \\
\mathrm{K}-893-\mathrm{Q}\end{array}$ \\
\hline 2 & 9/21/07 & Z2-EU8B-320 & 588000 & 2441597 & $0-1 \mathrm{ft}$ composite ( 1 point HA) & 1 & 1 & & & & & 1 & & & $\begin{array}{l}\text { Confirmation sample at } \\
\text { RAD228 location } \\
\end{array}$ \\
\hline & & & & & Total DVS samples & 14 & 14 & 3 & 9 & 8 & 11 & 10 & 5 & & \\
\hline Histo & c samples & & & & & & & & & & & & & & \\
\hline 3 & $8 / 26 / 04$ & K33RCW01 & 588936 & 2441753 & Discrete interval $5.0-9.0 \mathrm{ft}$ & & & & 1 & & 1 & 1 & & & \\
\hline 3 & $8 / 26 / 04$ & K33RCW02 & 588935 & 2441760 & $\begin{array}{l}\text { Two interval } 0.0-5.0 \mathrm{ft} \text { and } \\
5.0-9.0 \mathrm{ft}\end{array}$ & & & & 2 & & 2 & 2 & & & \\
\hline
\end{tabular}




\section{Table C.2. (continued)}

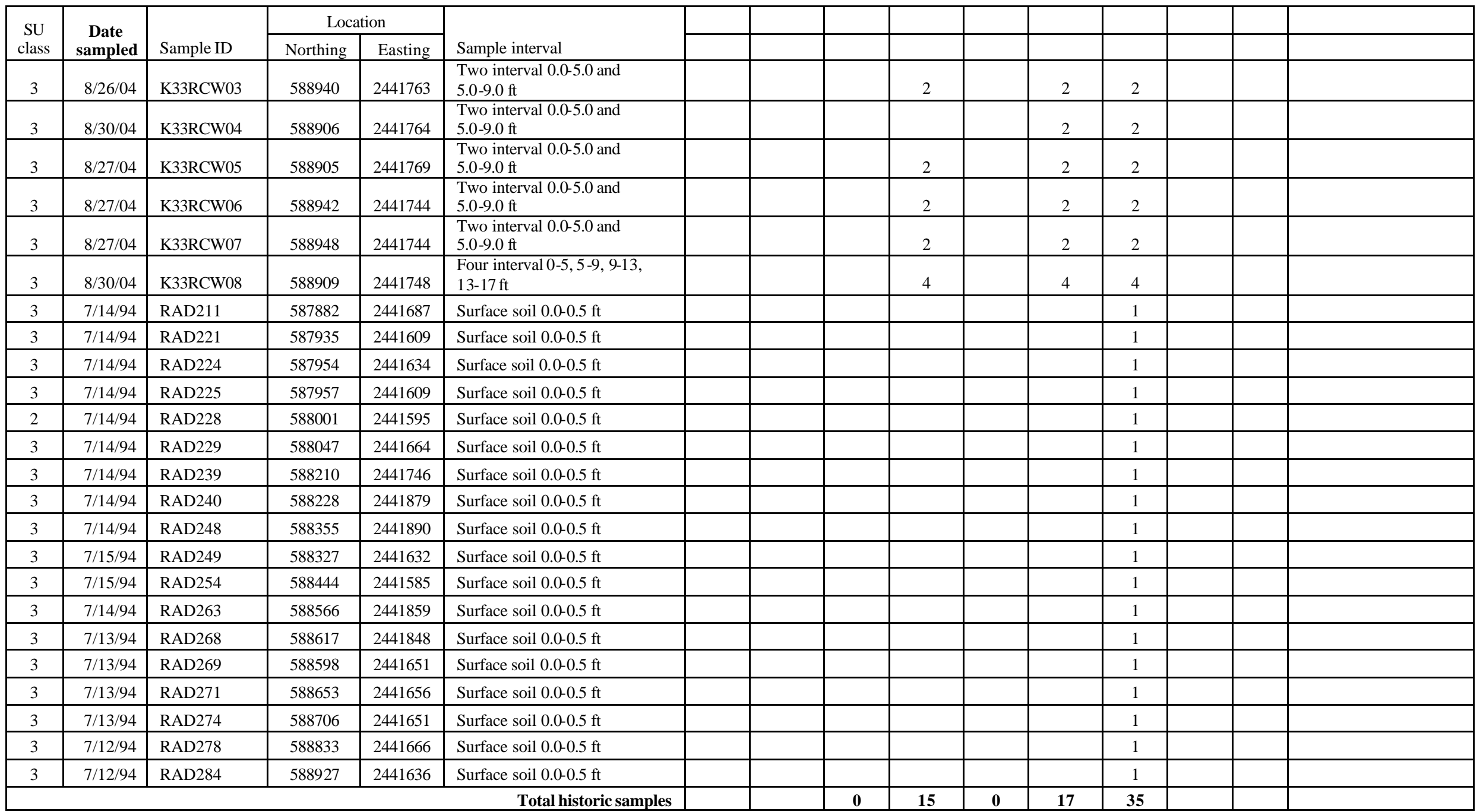

DRO = diesel-range organic

DVS $=$ Dynamic Verification Strategy

GRO = gasoline-range organic

$\mathrm{HA}=$ hand auger

PCB = polychlorinated biphenyl
$\mathrm{QA}=$ quality assurance

$\mathrm{RAD}=$ radiological

$\mathrm{RCW}=$ recirculating cooling water

$\mathrm{SU}=$ soil unit

SVOC $=$ semivolatile organic compound

$\mathrm{VOC}=$ volatile organic compound 
Table C.3. EU Z2-08, depth 0-10 ft

\begin{tabular}{|c|c|c|c|c|c|c|c|c|c|c|c|c|c|}
\hline $\begin{array}{r}\text { Analyte } \\
\end{array}$ & $\begin{array}{r}\text { Frequency } \\
\text { of detect }\end{array}$ & $\begin{array}{c}\text { Minimum } \\
\text { detect }\end{array}$ & $\begin{array}{c}\text { Maximum } \\
\text { detect }\end{array}$ & $\begin{array}{c}\text { Location(s) of } \\
\text { maximum } \\
\text { detected result }\end{array}$ & $\begin{array}{c}\text { Average } \\
\text { detected result }\end{array}$ & $\operatorname{Max}$ RL & $\begin{array}{c}\text { Frequency of } \\
\text { detects exceeding } \\
\text { Max RL } \\
\end{array}$ & Avg RL & $\begin{array}{c}\text { Frequency } \\
\text { of detects } \\
\text { exceeding } \\
\text { Avg RL } \\
\end{array}$ & $\begin{array}{l}\text { PRG limit } \\
\left(10^{-5} \text { or } 1\right) \\
\end{array}$ & 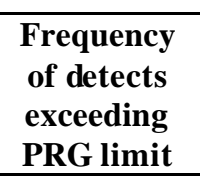 & $\begin{array}{c}\text { Background } \\
\text { concentration }\end{array}$ & $\begin{array}{c}\text { Frequency of } \\
\text { detects exceeding } \\
\text { background }\end{array}$ \\
\hline \multicolumn{14}{|l|}{ Inorganics (mg/kg) } \\
\hline Aluminum & $27 / 27$ & 230 & 21,800 & K33RCW02 & $11,099.63$ & & $\mathrm{NA}$ & & $\mathrm{NA}$ & $1.00 \mathrm{E}+05$ & 0 & 40,300 & $0 / 27$ \\
\hline Antimony & $13 / 27$ & $0.083 \mathrm{~J}$ & $1.8 \mathrm{~J}$ & K33RCW04 & 0.53 & & NA & & NA & $4.10 \mathrm{E}+02$ & $0 / 27$ & 1.52 & $1 / 27$ \\
\hline Arsenic & $27 / 27$ & $0.57 \mathrm{~J}$ & $66.5 \mathrm{~J}$ & K33RCW04 & 11.23 & 900 & $0 / 27$ & 300 & $0 / 27$ & $1.60 \mathrm{E}+01$ & $4 / 27$ & 14.95 & $5 / 27$ \\
\hline Barium & $27 / 27$ & $2.9 \mathrm{~J}$ & $110 \mathrm{~J}$ & Z2-EU8B-308 & 41.42 & & NA & & NA & $6.70 \mathrm{E}+04$ & $0 / 27$ & 124.93 & $0 / 27$ \\
\hline Beryllium & $27 / 27$ & $0.091 \mathrm{~J}$ & 0.93 & K33RCW03 & 0.45 & 6,000 & $0 / 27$ & 2,000 & $0 / 27$ & $1.90 \mathrm{E}+03$ & $0 / 27$ & 2.2 & $0 / 27$ \\
\hline Boron & $18 / 27$ & $2.7 \mathrm{~J}$ & 17.9 & K33RCW03 & 9.83 & & NA & & NA & $1.00 \mathrm{E}+05$ & $0 / 27$ & & NA \\
\hline Cadmium & $11 / 27$ & $0.019 \mathrm{~J}$ & $1.7 \mathrm{~J}$ & Z2-EU8B-315 & 0.47 & & NA & & NA & $4.50 \mathrm{E}+02$ & $0 / 27$ & $0.22 \mathrm{U}$ & 3/27 \\
\hline Calcium & $27 / 27$ & $727 \mathrm{~J}$ & 305,000 & K33RCW03 & $76,116.96$ & & NA & & NA & & NA & 2400 & $22 / 27$ \\
\hline Chromium & $27 / 27$ & $1.9 \mathrm{~J}$ & $446 \mathrm{~J}$ & Z2-EU8B-314 & 64.89 & & NA & & NA & $6.40 \mathrm{E}+02$ & $0 / 27$ & 44.88 & $8 / 27$ \\
\hline Chromium, hexavalent & $4 / 21$ & $0.76 \mathrm{~J}$ & 1.8 & Z2-EU8B-305 & 1.12 & & NA & & NA & $6.40 \mathrm{E}+02$ & $0 / 21$ & & NA \\
\hline Cobalt & $26 / 27$ & $2.2 \mathrm{~J}$ & $17.2 \mathrm{~J}$ & K33RCW08 & 6.7 & & NA & & NA & $1.30 \mathrm{E}+04$ & $0 / 27$ & 42 & $0 / 27$ \\
\hline Copper & $27 / 27$ & $2.2 \mathrm{~J}$ & 83.3 & Z2-EU8B-314 & 18.21 & & NA & & NA & $4.10 \mathrm{E}+04$ & $0 / 27$ & 22.48 & $7 / 27$ \\
\hline Iron & $27 / 27$ & $1750 \mathrm{~J}$ & $65,000 \mathrm{~J}$ & Z2-EU8B-315 & $25,011.11$ & & NA & & NA & $1.00 \mathrm{E}+05$ & $0 / 27$ & 58,600 & $1 / 27$ \\
\hline Lead & $27 / 27$ & 4.7 & 505 & Z2-EU8B-314 & 40.01 & & NA & & NA & $8.00 \mathrm{E}+02$ & $0 / 27$ & 37.91 & $2 / 27$ \\
\hline Lithium & $4 / 10$ & $12.5 \mathrm{~J}$ & 35.2 & Z2-EU8B-305 & 22.03 & & $\mathrm{NA}$ & & $\mathrm{NA}$ & $2.00 \mathrm{E}+04$ & $0 / 10$ & 48.94 & $0 / 10$ \\
\hline Magnesium & $27 / 27$ & $338 \mathrm{~J}$ & 61,700 & K33RCW03 & $9,238.26$ & & NA & & NA & & NA & 3,300 & $11 / 27$ \\
\hline Manganese & $27 / 27$ & $65.7 \mathrm{~J}$ & $1,410 \mathrm{~J}$ & Z2-EU8B-314 & 352.5 & & NA & & NA & $1.90 \mathrm{E}+04$ & $0 / 27$ & 2,200 & $0 / 27$ \\
\hline Mercury & $23 / 27$ & $0.01 \mathrm{~J}$ & 1.1 & K33RCW05 & 0.16 & 1,800 & $0 / 27$ & 600 & $0 / 27$ & $3.10 \mathrm{E}+02$ & $0 / 27$ & 0.17 & $4 / 27$ \\
\hline Molybdenum & $11 / 11$ & $0.093 \mathrm{~J}$ & 2.7 & Z2-EU8B-314 & 1.12 & & NA & & NA & $5.10 \mathrm{E}+03$ & $0 / 11$ & & NA \\
\hline Nickel & $27 / 27$ & $1.6 \mathrm{~J}$ & $57.5 \mathrm{~J}$ & Z2-EU8B-314 & 15.18 & & $\mathrm{NA}$ & & $\mathrm{NA}$ & $2.00 \mathrm{E}+04$ & $0 / 27$ & 26.07 & $1 / 27$ \\
\hline Potassium & $25 / 27$ & $277 \mathrm{~J}$ & $2,890 \mathrm{~J}$ & Z2-EU8B-305 & $1,439.72$ & & NA & & NA & & NA & $5,074.69$ & $0 / 27$ \\
\hline Selenium & $5 / 27$ & $0.15 \mathrm{~J}$ & $0.46 \mathrm{~J}$ & $\begin{array}{c}\text { K33RCW01 } \\
\text { Z2-EU8B-314 }\end{array}$ & 0.29 & & $\mathrm{NA}$ & & $\mathrm{NA}$ & $5.10 \mathrm{E}+03$ & $0 / 27$ & 1.47 & $0 / 27$ \\
\hline Silver & $10 / 27$ & $0.024 \mathrm{~J}$ & $0.32 \mathrm{~J}$ & Z2-EU8B-314 & 0.11 & & NA & & NA & $5.10 \mathrm{E}+03$ & $0 / 27$ & $0.6 \mathrm{U}$ & $0 / 27$ \\
\hline Sodium & $21 / 27$ & $18.8 \mathrm{~J}$ & 475 & Z2-EU8B-319 & 87.2 & & NA & & NA & & NA & 497 & $0 / 27$ \\
\hline Strontium & $16 / 16$ & $4.8 \mathrm{~J}$ & 278 & K33RCW07 & 87.49 & & NA & & NA & $1.00 \mathrm{E}+05$ & $0 / 16$ & 87.05 & $6 / 16$ \\
\hline Thallium & $4 / 27$ & $0.11 \mathrm{~J}$ & $0.54 \mathrm{~J}$ & K33RCW03 & 0.26 & & $\mathrm{NA}$ & & $\mathrm{NA}$ & $6.70 \mathrm{E}+01$ & $0 / 27$ & $0.4 \mathrm{U}$ & $1 / 27$ \\
\hline Tin & $0 / 16$ & ND & ND & & ND & & NA & & NA & $1.00 \mathrm{E}+05$ & $0 / 16$ & & NA \\
\hline Uranium & $11 / 11$ & 0.19 & 2.5 & Z2-EU8B-314 & 1.14 & & NA & & NA & $2.00 \mathrm{E}+02$ & $0 / 11$ & & NA \\
\hline Vanadium & $27 / 27$ & $2.6 \mathrm{~J}$ & 47.8 & K33RCW02 & 20.72 & & NA & & NA & $1.00 \mathrm{E}+03$ & $0 / 27$ & 65.47 & $0 / 27$ \\
\hline Zinc & $27 / 27$ & $14.4 \mathrm{~J}$ & $1,140 \mathrm{~J}$ & Z2-EU8B-314 & 141.66 & & NA & & NA & $1.00 \mathrm{E}+05$ & $0 / 27$ & 89.7 & $8 / 27$ \\
\hline \multicolumn{14}{|l|}{ Radionuclides (pCi/g) } \\
\hline Actinium-228 & $18 / 18$ & 0.54 & 1.54 & RAD271 & 1.09 & & $\mathrm{NA}$ & & $\mathrm{NA}$ & $1.20 \mathrm{E}+04$ & $0 / 18$ & & NA \\
\hline Alpha activity & $25 / 26$ & 5.5 & 67 & Z2-EU8B-307 & 23.08 & & NA & & NA & & NA & & NA \\
\hline Beta activity & $26 / 26$ & 7.6 & $56.1 \mathrm{~J}$ & Z2-EU8B-307 & 30.27 & & NA & & NA & & NA & & NA \\
\hline Bismuth-214 & $18 / 18$ & 0.238 & 1.77 & RAD271 & 0.83 & & NA & & NA & $1.30 \mathrm{E}+05$ & $0 / 18$ & & NA \\
\hline Cesium 134 & $8 / 18$ & 0.005 & 0.05 & RAD278 & 0.02 & & NA & & NA & $2.60 \mathrm{E}+00$ & $0 / 18$ & & NA \\
\hline Cesium 137 & $22 / 28$ & 0.141 & 2.61 & Z2-EU8B-314 & 0.79 & 20 & $0 / 28$ & 2 & $1 / 28$ & $1.10 \mathrm{E}+00$ & $7 / 28$ & & NA \\
\hline Cobalt-57 & $11 / 18$ & 0.001 & 0.016 & RAD229 & 0.01 & & NA & & NA & $1.40 \mathrm{E}+02$ & $0 / 18$ & & NA \\
\hline Cobalt-60 & $17 / 28$ & 0.006 & 0.095 & RAD239 & 0.03 & & NA & & NA & $6.00 \mathrm{E}-01$ & $0 / 28$ & & NA \\
\hline Lead-212 & $18 / 18$ & 0.512 & 1.68 & RAD248 & 1.07 & & NA & & NA & $6.10 \mathrm{E}+04$ & $0 / 18$ & & NA \\
\hline Lead-214 & $18 / 18$ & 0.354 & 2.13 & RAD271 & 1.05 & & NA & & NA & $7.50 \mathrm{E}+05$ & $0 / 18$ & & NA \\
\hline Neptunium-237 & $18 / 28$ & 0.02 & 0.32 & RAD249 & 0.13 & 50 & $0 / 28$ & 5 & $0 / 28$ & $2.70 \mathrm{E}+00$ & $0 / 28$ & & NA \\
\hline Plutonium-238 & $12 / 18$ & 0.0019 & 0.016 & RAD271 & 0.01 & & NA & & NA & $1.70 \mathrm{E}+02$ & $0 / 18$ & & $\mathrm{NA}$ \\
\hline $\begin{array}{l}\text { Plutonium } 239 \\
\text { Plo }\end{array}$ & $\begin{array}{l}12710 \\
16 / 18\end{array}$ & 0.0048 & 0.287 & RAD228 & 0.07 & & NA & & NA & $1.50 \mathrm{E}+02$ & $0 / 18$ & & NA \\
\hline Potassium-40 & $28 / 28$ & 3.21 & 30.8 & Z2-EU8B-305 & 10.93 & & NA & & NA & $2.70 \mathrm{E}+00$ & $28 / 28$ & 32.12 & $0 / 28$ \\
\hline $\mathrm{Ra} / \mathrm{Th}$ decay series & $28 / 28$ & 0 & 3.35 & RAD228 & 0.58 & 15 & $0 / 28$ & 5 & $0 / 28$ & & NA & & NA \\
\hline Radium-226 & $24 / 28$ & 0.14 & 4.6 & RAD228 & 1.45 & 15 & $\mathrm{NA}^{a}$ & 5 & $\mathrm{NA}^{a}$ & $2.60 \mathrm{E}-01$ & $23 / 28$ & 1.25 & $10 / 28$ \\
\hline
\end{tabular}




\begin{tabular}{|c|c|c|c|c|c|c|c|c|c|c|c|c|c|}
\hline Analyte & $\begin{array}{c}\begin{array}{c}\text { Frequency } \\
\text { of detect }\end{array} \\
\end{array}$ & $\begin{array}{c}\text { Minimum } \\
\text { detect }\end{array}$ & $\begin{array}{c}\text { Maximum } \\
\text { detect }\end{array}$ & $\begin{array}{c}\text { Location(s) of } \\
\text { maximum } \\
\text { detected result }\end{array}$ & $\begin{array}{c}\text { Average } \\
\text { detected result }\end{array}$ & Max RL & $\begin{array}{c}\text { Frequency of } \\
\text { detects exceeding } \\
\text { Max RL }\end{array}$ & Avg RL & $\begin{array}{c}\text { Frequency } \\
\text { of detects } \\
\text { exceeding } \\
\text { Avg RL }\end{array}$ & $\begin{array}{c}\mathrm{PRG}_{5} \text { limit } \\
\text { or } 1)\end{array}$ & $\begin{array}{c}\text { Frequency of } \\
\text { detects } \\
\text { exceeding } \\
\text { PRG limit } \\
\end{array}$ & $\begin{array}{c}\text { Background } \\
\text { concentration }\end{array}$ & $\begin{array}{c}\begin{array}{c}\text { Frequency of } \\
\text { detects exceeding } \\
\text { background }\end{array} \\
\end{array}$ \\
\hline Technetium-99 & $17 / 28$ & 0.02 & 2.53 & RAD228 & 0.6 & & NA & & NA & $8.90 \mathrm{E}+03$ & $0 / 28$ & & NA \\
\hline Thallium-208 & $18 / 18$ & 0.141 & 0.58 & RAD278 & 0.33 & & NA & & NA & $3.70 \mathrm{E}+05$ & $0 / 18$ & & NA \\
\hline Thorium 228 & $28 / 28$ & 0.28 & 2.04 & Z2-EU8B-319 & 1.11 & & NA & & NA & $1.70 \mathrm{E}-01$ & $28 / 28^{b}$ & 1.86 & $1 / 28$ \\
\hline Thorium 230 & $27 / 28$ & 0.51 & 3.04 & Z2-EU8B-319 & 1.4 & 15 & $\mathrm{NA}^{a}$ & 5 & $\mathrm{NA}^{a}$ & $2.10 \mathrm{E}+02$ & $0 / 28$ & 1.2 & $19 / 28$ \\
\hline Thorium 232 & $28 / 28$ & 0.19 & 1.55 & Z2-EU8B-308 & 1.07 & 15 & $\mathrm{NA}^{a}$ & 5 & $\mathrm{NA}^{a}$ & $1.70 \mathrm{E}-01$ & $28 / 28^{b}$ & 1.95 & $0 / 28$ \\
\hline Thorium 234 & $22 / 28$ & 1.29 & 48.3 & RAD228 & 7.38 & & NA & & NA & $3.30 \mathrm{E}+04$ & $0 / 28$ & & NA \\
\hline Uranium-234 & $44 / 44$ & 0.199 & 72.1 & RAD228 & 5.47 & 7,000 & $0 / 44$ & 700 & $0 / 44$ & $3.30 \mathrm{E}+02$ & $0 / 44$ & & NA \\
\hline Uranium-235 & $28 / 44$ & 0.049 & 4.23 & RAD228 & 0.54 & 80 & $0 / 44$ & 8 & $0 / 44$ & $3.90 \mathrm{E}+00$ & $1 / 44$ & & NA \\
\hline Uranium-238 & $44 / 44$ & 0.034 & 58 & RAD228 & 4.39 & 500 & $0 / 44$ & 50 & $1 / 44$ & $1.80 \mathrm{E}+01$ & $2 / 44$ & 1.47 & $18 / 44$ \\
\hline \multicolumn{14}{|c|}{ Organics, Pesticides, and PCBs (ug/kg) } \\
\hline PCB-1016 & $0 / 8$ & ND & ND & & ND & 100,000 & $0 / 8$ & 10,000 & $0 / 8$ & $3.70 \mathrm{E}+04$ & $0 / 8$ & & NA \\
\hline PCB-1221 & $0 / 8$ & ND & ND & & ND & 100,000 & $0 / 8$ & 1,0000 & $0 / 8$ & $7.40 \mathrm{E}+03$ & $0 / 8$ & & NA \\
\hline PCB-1232 & $0 / 8$ & ND & ND & & $\mathrm{ND}$ & 100,000 & $0 / 8$ & 10,000 & $0 / 8$ & $7.40 \mathrm{E}+03$ & $0 / 8$ & & NA \\
\hline PCB-1242 & $0 / 8$ & ND & ND & & ND & 100,000 & $0 / 8$ & 10,000 & $0 / 8$ & $7.40 \mathrm{E}+03$ & $0 / 8$ & & NA \\
\hline PCB-1248 & $0 / 8$ & ND & ND & & ND & 100,000 & $0 / 8$ & 10,000 & $0 / 8$ & $7.40 \mathrm{E}+03$ & $0 / 8$ & & NA \\
\hline PCB-1254 & $2 / 8$ & 160 & $580 \mathrm{~J}$ & Z2-EU8B-301 & 370 & 100,000 & $0 / 8$ & 10,000 & $0 / 8$ & $7.40 \mathrm{E}+03$ & $0 / 8$ & & NA \\
\hline PCB-1260 & $1 / 8$ & 53 & 53 & Z2-EU8B-308 & 53 & 100,000 & $0 / 8$ & 10,000 & $0 / 8$ & $7.40 \mathrm{E}+03$ & $0 / 8$ & & NA \\
\hline Polychlorinated biphenyl & $3 / 8$ & 53 & $580 \mathrm{~J}$ & Z2-EU8B-301 & 264.33 & 100,000 & $0 / 8$ & 10,000 & $0 / 8$ & $7.40 \mathrm{E}+03$ & $0 / 8$ & & NA \\
\hline \multicolumn{14}{|l|}{ Semivolatile Organics (ug/kg) } \\
\hline 1,2,4-Trichlorobenzene & $0 / 23$ & ND & ND & & ND & & NA & & NA & $2.20 \mathrm{E}+05$ & $0 / 23$ & & NA \\
\hline 1,2-Dichlorobenzene & $0 / 23$ & ND & $\mathrm{ND}$ & & ND & & NA & & NA & $6.00 \mathrm{E}+05$ & $0 / 23$ & & NA \\
\hline 1,3-Dichlorobenzene & $0 / 23$ & ND & ND & & ND & & NA & & NA & $6.00 \mathrm{E}+05$ & $0 / 23$ & & $\mathrm{NA}$ \\
\hline 1,4-Dichlorobenzene & $0 / 23$ & $\mathrm{ND}$ & $\mathrm{ND}$ & & ND & & NA & & NA & $7.90 \mathrm{E}+04$ & $0 / 23$ & & NA \\
\hline 2,3,4,6-Tetrachlorophenol & $0 / 9$ & $\mathrm{ND}$ & ND & & $\mathrm{ND}$ & & NA & & NA & $1.80 \mathrm{E}+07$ & 0/9 & & NA \\
\hline 2,4,5-Trichlorophenol & $0 / 23$ & ND & ND & & ND & & NA & & NA & $6.20 \mathrm{E}+07$ & $0 / 23$ & & NA \\
\hline 2,4,6-Trichlorophenol & $0 / 23$ & ND & ND & & ND & & NA & & NA & $6.20 \mathrm{E}+04$ & $0 / 23$ & & NA \\
\hline 2,4-Dichlorophenol & $0 / 23$ & ND & ND & & ND & & NA & & NA & $1.80 \mathrm{E}+06$ & $0 / 23$ & & NA \\
\hline 2,4-Dimethylphenol & $0 / 23$ & ND & ND & & ND & & NA & & $\mathrm{NA}$ & $1.20 \mathrm{E}+07$ & $0 / 23$ & & NA \\
\hline 2,4-Dinitrophenol & $0 / 23$ & ND & ND & & ND & & NA & & NA & $1.20 \mathrm{E}+06$ & $0 / 23$ & & NA \\
\hline 2,4-Dinitrotoluene & $0 / 23$ & ND & ND & & ND & & NA & & NA & $2.50 \mathrm{E}+04$ & $0 / 23$ & & NA \\
\hline 2,6-Dinitrotoluene & $0 / 23$ & ND & ND & & ND & & NA & & NA & $2.50 \mathrm{E}+04$ & $0 / 23$ & & NA \\
\hline 2-Chloronaphthalene & $0 / 23$ & $\mathrm{ND}$ & ND & & ND & & NA & & NA & $2.30 \mathrm{E}+07$ & $0 / 23$ & & NA \\
\hline 2-Chlorophenol & $0 / 23$ & ND & ND & & ND & & NA & & NA & $2.40 \mathrm{E}+05$ & $0 / 23$ & & NA \\
\hline 2-Methyl-4,6-dinitrophenol & $0 / 23$ & ND & $\mathrm{ND}$ & & $\mathrm{ND}$ & & NA & & NA & $6.20 \mathrm{E}+04$ & $0 / 23$ & & NA \\
\hline 2-Methylnaphthalene & $1 / 23$ & $39 \mathrm{~J}$ & $39 \mathrm{~J}$ & Z2-EU8B-311 & 39 & & NA & & NA & $1.90 \mathrm{E}+05$ & $0 / 23$ & & NA \\
\hline 2-Methylphenol & $0 / 23$ & ND & $\mathrm{ND}$ & & ND & & NA & & NA & $3.10 \mathrm{E}+07$ & $0 / 23$ & & NA \\
\hline 2-Nitrobenzenamine & $0 / 23$ & ND & ND & & ND & & NA & & NA & $1.80 \mathrm{E}+06$ & $0 / 23$ & & NA \\
\hline 2-Nitrophenol & $0 / 23$ & $\mathrm{ND}$ & ND & & ND & & NA & & NA & & NA & & NA \\
\hline 3,3'-Dichlorobenzidine & $0 / 23$ & ND & ND & & ND & & NA & & NA & $3.80 \mathrm{E}+04$ & $0 / 23$ & & NA \\
\hline 3-Nitrobenzenamine & $0 / 23$ & ND & $\mathrm{ND}$ & & ND & & NA & & NA & $1.80 \mathrm{E}+05$ & $0 / 23$ & & NA \\
\hline 4-Bromophenyl phenyl ether & $0 / 23$ & ND & ND & & ND & & NA & & NA & & NA & & NA \\
\hline 4-Chloro-3-methylphenol & $0 / 23$ & $\mathrm{ND}$ & ND & & ND & & NA & & NA & & NA & & NA \\
\hline 4-Chlorobenzenamine & $0 / 23$ & ND & ND & & ND & & NA & & NA & $2.50 \mathrm{E}+06$ & $0 / 23$ & & NA \\
\hline 4-Chlorophenyl phenyl ether & $0 / 23$ & ND & ND & & ND & & NA & & NA & & NA & & NA \\
\hline 4-Methylphenol & $0 / 23$ & ND & ND & & ND & & NA & & NA & $3.10 \mathrm{E}+06$ & $0 / 23$ & & NA \\
\hline 4-Nitrobenzenamine & $0 / 23$ & $\mathrm{ND}$ & $\mathrm{ND}$ & & $\mathrm{ND}$ & & NA & & NA & $8.20 \mathrm{E}+05$ & $0 / 23$ & & $\mathrm{NA}$ \\
\hline 4-Nitrophenol & $0 / 23$ & $\mathrm{ND}$ & $\mathrm{ND}$ & & ND & & NA & & NA & & NA & & NA \\
\hline Acenaphthene & $2 / 23$ & $53 \mathrm{~J}$ & $300 \mathrm{~J}$ & Z2-EU8B-311 & 176.5 & & NA & & NA & $2.90 \mathrm{E}+07$ & $0 / 23$ & & NA \\
\hline Acenaphthylene & $0 / 23$ & ND & ND & & ND & & NA & & NA & $2.90 \mathrm{E}+07$ & $0 / 23$ & & NA \\
\hline Aniline & $0 / 9$ & $\mathrm{ND}$ & $\mathrm{ND}$ & & ND & & NA & & NA & $3.00 \mathrm{E}+06$ & 0/9 & & NA \\
\hline Anthracene & $4 / 23$ & $38 \mathrm{~J}$ & 480 & Z2-EU8B-311 & 174.5 & & NA & & NA & $1.00 \mathrm{E}+08$ & $0 / 23$ & & NA \\
\hline Benz(a)anthracene & $10 / 23$ & $75 \mathrm{~J}$ & 1,300 & Z2-EU8B-311 & 311.6 & & NA & & NA & $2.10 \mathrm{E}+04$ & $0 / 23$ & & $\mathrm{NA}$ \\
\hline Benzenemethanol & $0 / 9$ & $\mathrm{ND}$ & ND & & ND & & NA & & NA & $1.00 \mathrm{E}+08$ & $0 / 9$ & & NA \\
\hline
\end{tabular}




\begin{tabular}{|c|c|c|c|c|c|c|c|c|c|c|c|c|c|}
\hline Analyte & $\begin{array}{c}\text { Frequency } \\
\text { of detect }\end{array}$ & $\begin{array}{c}\text { Minimum } \\
\text { detect }\end{array}$ & $\begin{array}{c}\text { Maximum } \\
\text { detect }\end{array}$ & $\begin{array}{c}\text { Location(s) of } \\
\text { maximum } \\
\text { detected result }\end{array}$ & $\begin{array}{c}\text { Average } \\
\text { detected result }\end{array}$ & $\operatorname{Max}$ RL & $\begin{array}{c}\text { Frequency of } \\
\text { detects exceeding } \\
\text { Max RL } \\
\end{array}$ & Avg RL & $\begin{array}{c}\text { Frequency } \\
\text { of detects } \\
\text { exceeding } \\
\text { Avg RL } \\
\end{array}$ & $\begin{array}{l}\mathrm{PRG}_{5} \text { limit }\left(10^{-}\right. \\
\text {or } 1)\end{array}$ & $\begin{array}{c}\text { Frequency of } \\
\text { detects } \\
\text { exceeding } \\
\text { PRG limit } \\
\end{array}$ & $\begin{array}{l}\text { Background } \\
\text { concentration }\end{array}$ & $\begin{array}{c}\text { Frequency of } \\
\text { detects exceeding } \\
\text { background }\end{array}$ \\
\hline Benzo(a)pyrene & $9 / 23$ & $73 \mathrm{~J}$ & 1,100 & Z2-EU8B-311 & 291.44 & & NA & & NA & $2.10 \mathrm{E}+03$ & $0 / 23$ & & NA \\
\hline Benzo(b)fluoranthene & $10 / 23$ & $71 \mathrm{~J}$ & 1,000 & Z2-EU8B-311 & 271.2 & & NA & & NA & $2.10 \mathrm{E}+04$ & $0 / 23$ & & NA \\
\hline Benzo(ghi)perylene & $7 / 23$ & $54 \mathrm{~J}$ & 520 & Z2-EU8B-311 & 182.14 & & $\mathrm{NA}$ & & $\mathrm{NA}$ & $2.90 \mathrm{E}+07$ & $0 / 23$ & & $\mathrm{NA}$ \\
\hline Benzo(k)fluoranthene & $10 / 23$ & $64 \mathrm{~J}$ & 1,000 & Z2-EU8B-311 & 273.4 & & NA & & NA & $2.10 \mathrm{E}+05$ & $0 / 23$ & & NA \\
\hline Benzoic acid & $0 / 9$ & ND & ND & & ND & & NA & & NA & $1.00 \mathrm{E}+08$ & $0 / 9$ & & NA \\
\hline $\operatorname{Bis}(2$-chloroethoxy)methane & $0 / 23$ & ND & ND & & $\mathrm{ND}$ & & $\mathrm{NA}$ & & NA & & NA & & $\mathrm{NA}$ \\
\hline Bis(2-chloroethyl) ether & $0 / 23$ & ND & ND & & ND & & NA & & NA & $5.80 \mathrm{E}+03$ & $0 / 23$ & & NA \\
\hline Bis(2-chloroisopropyl) ether & $0 / 9$ & ND & ND & & $\mathrm{ND}$ & & NA & & NA & $7.40 \mathrm{E}+04$ & $0 / 9$ & & NA \\
\hline Bis(2-ethylhexyl)phthalate & $3 / 23$ & $39 \mathrm{~J}$ & $120 \mathrm{~J}$ & Z2-EU8B-301 & 89.67 & & NA & & NA & $1.20 \mathrm{E}+06$ & $0 / 23$ & & NA \\
\hline Butyl benzyl phthalate & $0 / 23$ & ND & $\mathrm{ND}$ & & $\mathrm{ND}$ & & $\mathrm{NA}$ & & NA & $1.00 \mathrm{E}+08$ & $0 / 23$ & & NA \\
\hline Carbazole & $3 / 22$ & $85 \mathrm{~J}$ & $250 \mathrm{~J}$ & Z2-EU8B-311 & 145 & & NA & & NA & $8.60 \mathrm{E}+05$ & $0 / 22$ & & NA \\
\hline Chrysene & $11 / 23$ & $88 \mathrm{~J}$ & 1300 & Z2-EU8B-311 & 328.73 & & NA & & $\mathrm{NA}$ & $2.10 \mathrm{E}+06$ & $0 / 23$ & & $\mathrm{NA}$ \\
\hline Di-n-butyl phthalate & $0 / 14$ & ND & ND & & ND & & NA & & NA & $6.20 \mathrm{E}+07$ & $0 / 14$ & & NA \\
\hline Di-n-octylphthalate & $0 / 23$ & ND & ND & & ND & & NA & & NA & $2.50 \mathrm{E}+07$ & $0 / 23$ & & NA \\
\hline Dibenz $(a, h)$ anthracene & $2 / 23$ & $77 \mathrm{~J}$ & $240 \mathrm{~J}$ & Z2-EU8B-311 & 158.5 & & $\mathrm{NA}$ & & $\mathrm{NA}$ & $2.10 \mathrm{E}+03$ & $0 / 23$ & & $\mathrm{NA}$ \\
\hline Dibenzofuran & $1 / 23$ & $87 \mathrm{~J}$ & $87 \mathrm{~J}$ & Z2-EU8B-311 & 87 & & NA & & NA & $1.60 \mathrm{E}+06$ & $0 / 23$ & & NA \\
\hline Diethyl phthalate & $0 / 23$ & ND & ND & & $\mathrm{ND}$ & & $\mathrm{NA}$ & & $\mathrm{NA}$ & $1.00 \mathrm{E}+08$ & $0 / 23$ & & $\mathrm{NA}$ \\
\hline Dimethyl phthalate & $0 / 22$ & ND & ND & & ND & & NA & & $\mathrm{NA}$ & $1.00 \mathrm{E}+08$ & $0 / 22$ & & NA \\
\hline Fluoranthene & $12 / 23$ & $40 \mathrm{~J}$ & 2,600 & Z2-EU8B-311 & 556.92 & & $\mathrm{NA}$ & & NA & $2.20 \mathrm{E}+07$ & $0 / 23$ & & $\mathrm{NA}$ \\
\hline Fluorene & $1 / 23$ & $260 \mathrm{~J}$ & $260 \mathrm{~J}$ & Z2-EU8B-311 & 260 & & NA & & NA & $2.60 \mathrm{E}+07$ & $0 / 23$ & & NA \\
\hline Hexachlorobenzene & $0 / 23$ & ND & ND & & ND & & NA & & NA & $1.10 \mathrm{E}+04$ & $0 / 23$ & & NA \\
\hline Hexachlorobutadiene & $0 / 9$ & ND & ND & & ND & & $\mathrm{NA}$ & & NA & $1.80 \mathrm{E}+05$ & $0 / 9$ & & NA \\
\hline Hexachlorocyclopentadiene & $0 / 23$ & ND & ND & & ND & & $\mathrm{NA}$ & & NA & $3.70 \mathrm{E}+06$ & $0 / 23$ & & NA \\
\hline Hexachloroethane & $0 / 23$ & ND & ND & & ND & & $\mathrm{NA}$ & & $\mathrm{NA}$ & $6.20 \mathrm{E}+05$ & $0 / 23$ & & NA \\
\hline Indeno(1,2,3-cd)pyrene & 9/23 & $47 \mathrm{~J}$ & 560 & Z2-EU8B-311 & 165.11 & & NA & & NA & $2.10 \mathrm{E}+04$ & $0 / 23$ & & NA \\
\hline Isophorone & $0 / 23$ & ND & ND & & ND & & $\mathrm{NA}$ & & $\mathrm{NA}$ & $5.10 \mathrm{E}+06$ & $0 / 23$ & & $\mathrm{NA}$ \\
\hline N-Nitroso-di-n-propylamine & $0 / 23$ & ND & ND & & ND & & NA & & NA & $2.50 \mathrm{E}+03$ & $0 / 23$ & & NA \\
\hline N-Nitrosodiphenylamine & $0 / 23$ & ND & ND & & ND & & NA & & NA & $3.50 \mathrm{E}+06$ & $0 / 23$ & & NA \\
\hline Naphthalene & $0 / 23$ & ND & ND & & $\mathrm{ND}$ & & NA & & NA & $1.90 \mathrm{E}+05$ & $0 / 23$ & & NA \\
\hline Nitrobenzene & $0 / 23$ & $\mathrm{ND}$ & ND & & $\mathrm{ND}$ & & NA & & NA & $1.00 \mathrm{E}+05$ & $0 / 23$ & & $\mathrm{NA}$ \\
\hline Pentachlorophenol & $0 / 23$ & ND & ND & & ND & & $\mathrm{NA}$ & & NA & $9.00 \mathrm{E}+04$ & $0 / 23$ & & $\mathrm{NA}$ \\
\hline Phenanthrene & $8 / 23$ & $62 \mathrm{~J}$ & 1,700 & Z2-EU8B-311 & 456.5 & & NA & & NA & $2.90 \mathrm{E}+07$ & $0 / 23$ & & NA \\
\hline Phenol & $0 / 23$ & ND & ND & & ND & & NA & & NA & $1.00 \mathrm{E}+08$ & $0 / 23$ & & NA \\
\hline Pyrene & $10 / 23$ & $120 \mathrm{~J}$ & 1,800 & Z2-EU8B-311 & 509 & & NA & & NA & $2.90 \mathrm{E}+07$ & $0 / 23$ & & NA \\
\hline Pyridine & $0 / 9$ & ND & $\mathrm{ND}$ & E2LOD J & $\mathrm{ND}$ & & NA & & NA & $6.20 \mathrm{E}+05$ & $0 / 9$ & & NA \\
\hline \multicolumn{14}{|l|}{ Volatile Organics (ug/kg) } \\
\hline 1,1,1-Trichloroethane & $0 / 3$ & ND & ND & & $\mathrm{ND}$ & & $\mathrm{NA}$ & & NA & $1.20 \mathrm{E}+06$ & $0 / 3$ & & $\mathrm{NA}$ \\
\hline 1,1,2,2-Tetrachloroethane & $0 / 3$ & ND & ND & & ND & & NA & & NA & $9.30 \mathrm{E}+03$ & $0 / 3$ & & $\mathrm{NA}$ \\
\hline 1,1,2-Trichloroethane & $0 / 3$ & ND & ND & & ND & & NA & & NA & $1.60 \mathrm{E}+04$ & $0 / 3$ & & NA \\
\hline 1,1-Dichloroethane & $0 / 3$ & $\mathrm{ND}$ & ND & & $\mathrm{ND}$ & & $\mathrm{NA}$ & & $\mathrm{NA}$ & $1.70 \mathrm{E}+06$ & $0 / 3$ & & $\mathrm{NA}$ \\
\hline 1,1-Dichloroethene & $0 / 3$ & ND & ND & & $\mathrm{ND}$ & & NA & & NA & $4.10 \mathrm{E}+05$ & $0 / 3$ & & $\mathrm{NA}$ \\
\hline 1,2-Dichloroethane & $0 / 3$ & $\mathrm{ND}$ & ND & & ND & & $\mathrm{NA}$ & & NA & $6.00 \mathrm{E}+03$ & $0 / 3$ & & $\mathrm{NA}$ \\
\hline 1,2-Dichloropropane & $0 / 3$ & ND & ND & & $\mathrm{ND}$ & & NA & & NA & $7.40 \mathrm{E}+03$ & $0 / 3$ & & NA \\
\hline 2-Butanone & $1 / 3$ & $8.1 \mathrm{~J}$ & $8.1 \mathrm{~J}$ & Z2-EU8B-301 & 8.1 & & $\mathrm{NA}$ & & $\mathrm{NA}$ & $1.00 \mathrm{E}+08$ & $0 / 3$ & & NA \\
\hline 2-Hexanone & $0 / 3$ & ND & ND & & ND & & NA & & NA & & NA & & NA \\
\hline 4-Methyl-2-pentanone & $0 / 3$ & ND & ND & & ND & & $\mathrm{NA}$ & & NA & $4.70 \mathrm{E}+07$ & $0 / 3$ & & NA \\
\hline Acetone & $2 / 3$ & $7.2 \mathrm{~J}$ & $24 \mathrm{~J}$ & Z2-EU8B-301 & 15.6 & & NA & & NA & $5.40 \mathrm{E}+07$ & $0 / 3$ & & NA \\
\hline Benzene & $0 / 3$ & ND & ND & & ND & & NA & & NA & $1.40 \mathrm{E}+04$ & $0 / 3$ & & NA \\
\hline Bromodichloromethane & $0 / 3$ & ND & ND & & ND & & NA & & NA & $1.80 \mathrm{E}+04$ & $0 / 3$ & & NA \\
\hline Bromoform & $0 / 3$ & ND & ND & & ND & & NA & & NA & $2.20 \mathrm{E}+06$ & $0 / 3$ & & NA \\
\hline Bromomethane & $0 / 3$ & ND & ND & & ND & & NA & & NA & $1.30 \mathrm{E}+04$ & $0 / 3$ & & NA \\
\hline Carbon disulfide & $0 / 3$ & ND & ND & & ND & & NA & & NA & $7.20 \mathrm{E}+05$ & $0 / 3$ & & NA \\
\hline Carbon tetrachloride & $0 / 3$ & $\mathrm{ND}$ & $\mathrm{ND}$ & & $\mathrm{ND}$ & & $\mathrm{NA}$ & & $\mathrm{NA}$ & $5.50 \mathrm{E}+03$ & $0 / 3$ & & $\mathrm{NA}$ \\
\hline
\end{tabular}




\begin{tabular}{|c|c|c|c|c|c|c|c|c|c|c|c|c|c|}
\hline Analyte & $\begin{array}{c}\text { Frequency } \\
\text { of detect }\end{array}$ & $\begin{array}{c}\text { Minimum } \\
\text { detect }\end{array}$ & $\begin{array}{c}\text { Maximum } \\
\text { detect }\end{array}$ & $\begin{array}{c}\text { Location(s) of } \\
\text { maximum } \\
\text { detected result }\end{array}$ & $\begin{array}{c}\text { Average } \\
\text { detected result }\end{array}$ & Max RL & $\begin{array}{c}\text { Frequency of } \\
\text { detects exceeding } \\
\text { Max RL }\end{array}$ & Avg RL & $\begin{array}{c}\text { Frequency } \\
\text { of detects } \\
\text { exceeding } \\
\text { Avg RL } \\
\end{array}$ & $\begin{array}{l}\text { PRG limit (10 } \\
5 \text { or } 1)\end{array}$ & $\begin{array}{c}\text { Frequency of } \\
\text { detects } \\
\text { exceeding } \\
\text { PRG limit } \\
\end{array}$ & $\begin{array}{l}\text { Background } \\
\text { concentration }\end{array}$ & $\begin{array}{c}\text { Frequency of } \\
\text { detects exceeding } \\
\text { background }\end{array}$ \\
\hline Chlorobenzene & $0 / 3$ & $\mathrm{ND}$ & $\mathrm{ND}$ & & ND & & NA & & NA & $5.30 \mathrm{E}+05$ & $0 / 3$ & & NA \\
\hline Chloroethane & $0 / 3$ & ND & ND & & $\mathrm{ND}$ & & NA & & NA & $6.50 \mathrm{E}+04$ & $0 / 3$ & & NA \\
\hline Chloroform & $0 / 3$ & ND & ND & & ND & & NA & & $\mathrm{NA}$ & $4.70 \mathrm{E}+03$ & $0 / 3$ & & NA \\
\hline Chloromethane & $0 / 3$ & ND & ND & & ND & & NA & & NA & $1.60 \mathrm{E}+05$ & $0 / 3$ & & NA \\
\hline Dibromochloromethane & $0 / 3$ & ND & ND & & ND & & $\mathrm{NA}$ & & $\mathrm{NA}$ & $2.60 \mathrm{E}+04$ & $0 / 3$ & & $\mathrm{NA}$ \\
\hline Ethylbenzene & $0 / 3$ & $\mathrm{ND}$ & ND & & $\mathrm{ND}$ & & $\mathrm{NA}$ & & $\mathrm{NA}$ & $4.00 \mathrm{E}+05$ & $0 / 3$ & & NA \\
\hline Methylene chloride & $0 / 3$ & ND & ND & & ND & & NA & & NA & $2.10 \mathrm{E}+05$ & $0 / 3$ & & NA \\
\hline Styrene & $0 / 3$ & ND & $\mathrm{ND}$ & & $\mathrm{ND}$ & & NA & & $\mathrm{NA}$ & $1.70 \mathrm{E}+06$ & $0 / 3$ & & NA \\
\hline Tetrachloroethene & $0 / 3$ & ND & ND & & $\mathrm{ND}$ & & NA & & NA & $1.30 \mathrm{E}+04$ & $0 / 3$ & & NA \\
\hline Toluene & $0 / 3$ & $\mathrm{ND}$ & ND & & ND & & NA & & NA & $5.20 \mathrm{E}+05$ & $0 / 3$ & & NA \\
\hline Total xylene & $0 / 3$ & ND & ND & & ND & & NA & & NA & $4.20 \mathrm{E}+05$ & $0 / 3$ & & NA \\
\hline Trichloroethene & $0 / 3$ & ND & ND & & ND & & NA & & NA & $1.10 \mathrm{E}+03$ & $0 / 3$ & & NA \\
\hline Vinyl chloride & $0 / 3$ & $\mathrm{ND}$ & ND & & $\mathrm{ND}$ & & $\mathrm{NA}$ & & $\mathrm{NA}$ & $7.50 \mathrm{E}+03$ & $0 / 3$ & & NA \\
\hline cis-1,2-Dichloroethene & $0 / 3$ & ND & ND & & $\mathrm{ND}$ & & NA & & NA & $1.50 \mathrm{E}+05$ & $0 / 3$ & & NA \\
\hline cis-1,3-Dichloropropene & $0 / 3$ & ND & ND & & $\mathrm{ND}$ & & NA & & NA & $1.80 \mathrm{E}+04$ & $0 / 3$ & & NA \\
\hline trans-1,2-Dichloroethene & $0 / 3$ & ND & ND & & ND & & NA & & NA & $2.30 \mathrm{E}+05$ & $0 / 3$ & & NA \\
\hline trans-1,3-Dichloropropene & $0 / 3$ & ND & ND & & ND & & NA & & $\mathrm{NA}$ & $1.80 \mathrm{E}+04$ & $0 / 3$ & & NA \\
\hline \multicolumn{14}{|l|}{ Other Organics (ug/kg) } \\
\hline Gasoline Range Organics & $0 / 2$ & $\mathrm{ND}$ & $\mathrm{ND}$ & & $\mathrm{ND}$ & & NA & & $\mathrm{NA}$ & & $\mathrm{NA}$ & & $\mathrm{NA}$ \\
\hline Hydrocarbons as Diesel Fuel & $0 / 2$ & ND & ND & & ND & & NA & & NA & & NA & & NA \\
\hline Hydrocarbons as Gasoline & $0 / 3$ & ND & ND & & ND & & NA & & NA & & NA & & NA \\
\hline Total Organic Carbon (TOC) & $0 / 2$ & ND & ND & & ND & & NA & & NA & & NA & & NA \\
\hline
\end{tabular}

${ }^{a}$ Radionuclide is evaluated as part of Ra/Th decay series as discussed in the Zone 2 ROD.

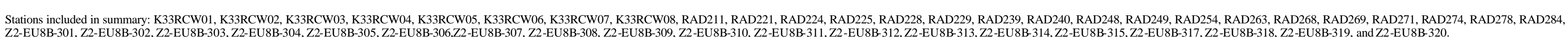

$\mathrm{J}=$ analyte was positively identified and result is the approximate concentration of the analyte in the sample.
$\mathrm{U}=$ analyte was not detected above the reported sample quantitation limit.
Avg $=$ average
$\mathrm{EU}=$ exposure un
$\mathrm{ND}=$ not detected
PCB $=$ polychlorinated biphenyl
PRG = preliminary remediation
Max = maximum
$\mathrm{PRG}=$ remediatiation leve 
Table C.3. (continued)

Table C.4. EU Z2-08, depth below $10 \mathrm{ft}$

\begin{tabular}{|c|c|c|c|c|c|c|c|c|c|c|c|c|c|}
\hline $\begin{array}{l}\text { Analyte } \\
\end{array}$ & $\begin{array}{c}\text { Frequency } \\
\text { of detect }\end{array}$ & $\begin{array}{c}\text { Minimum } \\
\text { detect }\end{array}$ & $\begin{array}{c}\text { Maximum } \\
\text { detect }\end{array}$ & $\begin{array}{c}\text { Location(s) } \\
\text { of maximum } \\
\text { detected result }\end{array}$ & $\begin{array}{l}\text { Average } \\
\text { detected } \\
\text { result }\end{array}$ & Max RL & $\begin{array}{c}\text { Frequency } \\
\text { of detects } \\
\text { exceeding } \\
\text { Max RL }\end{array}$ & $\begin{array}{l}\text { Avg } \\
\text { RL }\end{array}$ & $\begin{array}{c}\text { Frequency } \\
\text { of detects } \\
\text { exceeding } \\
\text { Avg RL }\end{array}$ & $\begin{array}{l}\text { PRG limit } \\
\left(10^{-5} \text { or } 1\right)\end{array}$ & $\begin{array}{l}\text { Frequency } \\
\text { of detects } \\
\text { exceeding } \\
\text { PRG limit }\end{array}$ & $\begin{array}{l}\text { Background } \\
\text { concentration }\end{array}$ & $\begin{array}{l}\text { Frequency of detects } \\
\text { exceeding background }\end{array}$ \\
\hline \multicolumn{14}{|l|}{ Inorganics (mg/kg) } \\
\hline Aluminum & $1 / 1$ & 19,200 & 19,200 & K33RCW08 & 19,200 & & $\mathrm{NA}$ & & NA & $1.00 \mathrm{E}+05$ & $0 / 1$ & 40,300 & $0 / 1$ \\
\hline Antimony & $0 / 1$ & ND & ND & & ND & & NA & & NA & 4.10E+02 & $0 / 1$ & 1.52 & $0 / 1$ \\
\hline Arsenic & $1 / 1$ & $3.6 \mathrm{~J}$ & $3.6 \mathrm{~J}$ & K33RCW08 & 3.6 & 900 & $0 / 1$ & 300 & $0 / 1$ & $1.60 \mathrm{E}+01$ & $0 / 1$ & 14.95 & $0 / 1$ \\
\hline Barium & $1 / 1$ & 38.7 & 38.7 & K33RCW08 & 38.7 & & NA & & NA & $6.70 \mathrm{E}+04$ & $0 / 1$ & 124.93 & $0 / 1$ \\
\hline Beryllium & $1 / 1$ & 1.4 & 1.4 & K33RCW08 & 1.4 & 6,000 & $0 / 1$ & 2,000 & $0 / 1$ & $1.90 \mathrm{E}+03$ & $0 / 1$ & 2.2 & $0 / 1$ \\
\hline $\begin{array}{l}\text { Boron } \\
\text { Bon }\end{array}$ & $1 / 1$ & 18.3 & 18.3 & K33RCW08 & 18.3 & & NA & & NA & $1.00 \mathrm{E}+05$ & $0 / 1$ & & NA \\
\hline Cadmium & $0 / 1$ & ND & ND & & $\mathrm{ND}$ & & $\mathrm{NA}$ & & NA & $4.50 \mathrm{E}+02$ & $0 / 1$ & $0.22 \mathrm{U}$ & $0 / 1$ \\
\hline Calcium & $1 / 1$ & 5,550 & 5,550 & K33RCW08 & 5,550 & & NA & & NA & & NA & 2,400 & $1 / 1$ \\
\hline Chromium & $1 / 1$ & $19.7 \mathrm{~J}$ & $19.7 \mathrm{~J}$ & K33RCW08 & 19.7 & & $\mathrm{NA}$ & & $\mathrm{NA}$ & $6.40 \mathrm{E}+02$ & $0 / 1$ & 44.88 & $0 / 1$ \\
\hline Chromium, hexavalent & $0 / 1$ & ND & ND & & ND & & NA & & NA & $6.40 \mathrm{E}+02$ & $0 / 1$ & & NA \\
\hline Cobalt & $1 / 1$ & $20 \mathrm{~J}$ & $20 \mathrm{~J}$ & K33RCW08 & 20 & & $\mathrm{NA}$ & & NA & $1.30 \mathrm{E}+04$ & $0 / 1$ & 42 & $0 / 1$ \\
\hline Copper & $1 / 1$ & $15.6 \mathrm{~J}$ & $15.6 \mathrm{~J}$ & K33RCW08 & 15.6 & & $\mathrm{NA}$ & & NA & $4.10 \mathrm{E}+04$ & $0 / 1$ & 22.48 & $0 / 1$ \\
\hline Iron & $1 / 1$ & 35,600 & 35,600 & K33RCW08 & 35,600 & & NA & & NA & $1.00 \mathrm{E}+05$ & $0 / 1$ & 58,600 & $0 / 1$ \\
\hline Lead & $1 / 1$ & $13.4 \mathrm{~J}$ & $13.4 \mathrm{~J}$ & K33RCW08 & 13.4 & & NA & & NA & $8.00 \mathrm{E}+02$ & $0 / 1$ & 37.91 & $0 / 1$ \\
\hline Magnesium & $1 / 1$ & $2,400 \mathrm{~J}$ & $2,400 \mathrm{~J}$ & K33RCW08 & 2,400 & & $\mathrm{NA}$ & & NA & & $\mathrm{NA}$ & 3,300 & $0 / 1$ \\
\hline Manganese & $1 / 1$ & $654 \mathrm{~J}$ & $654 \mathrm{~J}$ & K33RCW08 & 654 & & NA & & NA & $1.90 \mathrm{E}+04$ & $0 / 1$ & 2,200 & $0 / 1$ \\
\hline Mercury & $1 / 1$ & $0.042 \mathrm{~J}$ & $0.042 \mathrm{~J}$ & K33RCW08 & 0.04 & 1800 & $0 / 1$ & 600 & $0 / 1$ & $3.10 \mathrm{E}+02$ & $0 / 1$ & 0.17 & $0 / 1$ \\
\hline Nickel & $1 / 1$ & 32.9 & 32.9 & K33RCW08 & 32.9 & & NA & & NA & $2.00 \mathrm{E}+04$ & $0 / 1$ & 26.07 & $1 / 1$ \\
\hline Potassium & $1 / 1$ & $2,750 \mathrm{~J}$ & $2,750 \mathrm{~J}$ & K33RCW08 & 2,750 & & $\mathrm{NA}$ & & NA & & NA & $5,074.69$ & $0 / 1$ \\
\hline Selenium & $0 / 1$ & ND & ND & & ND & & $\mathrm{NA}$ & & NA & $5.10 \mathrm{E}+03$ & $0 / 1$ & $\begin{array}{l}1.47 \\
1.07\end{array}$ & $0 / 1$ \\
\hline Silver & $0 / 1$ & ND & ND & & ND & & NA & & NA & $5.10 \mathrm{E}+03$ & $0 / 1$ & $0.6 \mathrm{U}$ & $0 / 1$ \\
\hline Sodium & $1 / 1$ & $134 \mathrm{~J}$ & $134 \mathrm{~J}$ & K33RCW08 & 134 & & NA & & NA & & NA & 497 & $0 / 1$ \\
\hline Strontium & $1 / 1$ & $8.6 \mathrm{~J}$ & $8.6 \mathrm{~J}$ & K33RCW08 & 8.6 & & $\mathrm{NA}$ & & $\mathrm{NA}$ & $1.00 \mathrm{E}+05$ & $0 / 1$ & 87.05 & $0 / 1$ \\
\hline Thallium & $0 / 1$ & ND & ND & & $\mathrm{ND}$ & & NA & & NA & $6.70 \mathrm{E}+01$ & $0 / 1$ & $0.4 \mathrm{U}$ & $0 / 1$ \\
\hline Tin & $0 / 1$ & ND & $\mathrm{ND}$ & & $\mathrm{ND}$ & & $\mathrm{NA}$ & & NA & $1.00 \mathrm{E}+05$ & $0 / 1$ & & NA \\
\hline Vanadium & $1 / 1$ & $27 \mathrm{~J}$ & $27 \mathrm{~J}$ & K33RCW08 & 27 & & $\mathrm{NA}$ & & NA & $1.00 \mathrm{E}+03$ & $0 / 1$ & 65.47 & $0 / 1$ \\
\hline Zinc & $1 / 1$ & 77.6 & 77.6 & K33RCW08 & 77.6 & & NA & & NA & $1.00 \mathrm{E}+05$ & $0 / 1$ & 89.7 & $0 / 1$ \\
\hline \multicolumn{14}{|l|}{ Radionuclides (pCi/g) } \\
\hline Alpha activity & $1 / 1$ & 22.3 & 22.3 & K33RCW08 & 22.3 & & $\mathrm{NA}$ & & NA & & NA & & NA \\
\hline Beta activity & $1 / 1$ & 30.6 & 30.6 & K33RCW08 & 30.6 & & NA & & NA & & NA & & NA \\
\hline Uranium-234 & $1 / 1$ & $0.77 \mathrm{~J}$ & $0.77 \mathrm{~J}$ & K33RCW08 & 0.77 & 7,000 & $0 / 1$ & 700 & $0 / 1$ & $3.30 \mathrm{E}+02$ & $0 / 1$ & & NA \\
\hline Uranium-235 & $0 / 1$ & $\mathrm{ND}$ & ND & & ND & 80 & $0 / 1$ & 8 & $0 / 1$ & $3.90 \mathrm{E}+00$ & $0 / 1$ & & NA \\
\hline Uranium-238 & $1 / 1$ & $0.95 \mathrm{~J}$ & $0.95 \mathrm{~J}$ & K33RCW08 & 0.95 & 500 & $0 / 1$ & 50 & $0 / 1$ & $1.80 \mathrm{E}+01$ & $0 / 1$ & 1.47 & $0 / 1$ \\
\hline \multicolumn{14}{|c|}{ Semi volatile Organics (ug/kg) } \\
\hline 1,2,4-Trichlorobenzene & $0 / 1$ & $\mathrm{ND}$ & $\mathrm{ND}$ & & $\mathrm{ND}$ & & $\mathrm{NA}$ & & $\mathrm{NA}$ & $2.20 \mathrm{E}+05$ & $0 / 1$ & & $\mathrm{NA}$ \\
\hline 1,2-Dichlorobenzene & $0 / 1$ & $\mathrm{ND}$ & $\mathrm{ND}$ & & ND & & $\mathrm{NA}$ & & $\mathrm{NA}$ & $6.00 \mathrm{E}+05$ & $0 / 1$ & & $\mathrm{NA}$ \\
\hline 1,3-Dichlorobenzene & $0 / 1$ & $\mathrm{ND}$ & $\mathrm{ND}$ & & ND & & NA & & NA & $6.00 \mathrm{E}+05$ & $0 / 1$ & & NA \\
\hline 1,4-Dichlorobenzene & $0 / 1$ & ND & ND & & ND & & NA & & NA & $7.90 \mathrm{E}+04$ & $0 / 1$ & & NA \\
\hline 2,4,5-Trichlorophenol & $0 / 1$ & $\mathrm{ND}$ & ND & & ND & & NA & & NA & $6.20 \mathrm{E}+07$ & $0 / 1$ & & NA \\
\hline 2,4,6-Trichlorophenol & $0 / 1$ & ND & ND & & ND & & NA & & NA & $6.20 \mathrm{E}+04$ & $0 / 1$ & & NA \\
\hline 2,4-Dichlorophenol & $0 / 1$ & $\mathrm{ND}$ & ND & & $\mathrm{ND}$ & & $\mathrm{NA}$ & & $\mathrm{NA}$ & $1.80 \mathrm{E}+06$ & $0 / 1$ & & $\mathrm{NA}$ \\
\hline 2,4-Dimethylphenol & $0 / 1$ & ND & $\mathrm{ND}$ & & $\mathrm{ND}$ & & NA & & NA & $1.20 \mathrm{E}+07$ & $0 / 1$ & & NA \\
\hline 2,4-Dinitrophenol & $0 / 1$ & $\mathrm{ND}$ & $\mathrm{ND}$ & & $\mathrm{ND}$ & & NA & & NA & $1.20 \mathrm{E}+06$ & $0 / 1$ & & NA \\
\hline 2,4-Dinitrotoluene & $0 / 1$ & ND & ND & & ND & & NA & & NA & $2.50 \mathrm{E}+04$ & $0 / 1$ & & NA \\
\hline 2,6-Dinitrotoluene & $0 / 1$ & $\mathrm{ND}$ & $\mathrm{ND}$ & & ND & & $\mathrm{NA}$ & & $\mathrm{NA}$ & $2.50 \mathrm{E}+04$ & $0 / 1$ & & $\mathrm{NA}$ \\
\hline 2-Chloronaphthalene & $0 / 1$ & $\mathrm{ND}$ & $\mathrm{ND}$ & & $\mathrm{ND}$ & & $\mathrm{NA}$ & & NA & $2.30 \mathrm{E}+07$ & $0 / 1$ & & $\mathrm{NA}$ \\
\hline 2-Chlorophenol & $0 / 1$ & $\mathrm{ND}$ & $\mathrm{ND}$ & & $\mathrm{ND}$ & & $\mathrm{NA}$ & & NA & $2.40 \mathrm{E}+05$ & $0 / 1$ & & $\mathrm{NA}$ \\
\hline 2-Methyl-4,6-dinitrophenol & $0 / 1$ & $\mathrm{ND}$ & $\mathrm{ND}$ & & ND & & $\mathrm{NA}$ & & NA & $6.20 \mathrm{E}+04$ & $0 / 1$ & & $\mathrm{NA}$ \\
\hline 2-Methylnaphthalene & $0 / 1$ & $\mathrm{ND}$ & ND & & ND & & $\mathrm{NA}$ & & NA & $1.90 \mathrm{E}+05$ & $0 / 1$ & & NA \\
\hline
\end{tabular}


Table C.3. (continued)

\begin{tabular}{|c|c|c|c|c|c|c|c|c|c|c|c|c|c|}
\hline Analyte & $\begin{array}{r}\text { Frequency } \\
\text { of detect }\end{array}$ & $\begin{array}{c}\text { Minimum } \\
\text { detect }\end{array}$ & $\begin{array}{c}\text { Maximum } \\
\text { detect }\end{array}$ & $\begin{array}{c}\text { Location(s) } \\
\text { of maximum } \\
\text { detected result }\end{array}$ & $\begin{array}{c}\text { Average } \\
\text { detected } \\
\text { result }\end{array}$ & $\operatorname{Max}$ RL & $\begin{array}{c}\text { Frequency } \\
\text { of detects } \\
\text { exceeding } \\
\text { Max RL }\end{array}$ & $\begin{array}{l}\text { Avg } \\
\text { RL }\end{array}$ & $\begin{array}{c}\text { Frequency } \\
\text { of detects } \\
\text { exceeding } \\
\text { Avg RL }\end{array}$ & $\begin{array}{l}\text { PRG limit } \\
\left(10^{-5} \text { or } 1\right)\end{array}$ & $\begin{array}{c}\text { Frequency } \\
\text { of detects } \\
\text { exceeding } \\
\text { PRG limit }\end{array}$ & $\begin{array}{c}\text { Background } \\
\text { concentration }\end{array}$ & $\begin{array}{c}\text { Frequency of detects } \\
\text { exceeding background }\end{array}$ \\
\hline 2-Methylphenol & $0 / 1$ & ND & ND & & ND & & NA & & NA & $3.10 \mathrm{E}+07$ & $0 / 1$ & & NA \\
\hline 2-Nitrobenzenamine & $0 / 1$ & ND & ND & & ND & & NA & & NA & $1.80 \mathrm{E}+06$ & $0 / 1$ & & NA \\
\hline 2-Nitrophenol & $0 / 1$ & $\mathrm{ND}$ & $\mathrm{ND}$ & & $\mathrm{ND}$ & & $\mathrm{NA}$ & & $\mathrm{NA}$ & & NA & & NA \\
\hline 3,3'-Dichlorobenzidine & $0 / 1$ & ND & $\mathrm{ND}$ & & $\mathrm{ND}$ & & NA & & NA & $3.80 \mathrm{E}+04$ & $0 / 1$ & & NA \\
\hline 3-Nitrobenzenamine & $0 / 1$ & $\mathrm{ND}$ & $\mathrm{ND}$ & & $\mathrm{ND}$ & & NA & & NA & $1.80 \mathrm{E}+05$ & $0 / 1$ & & NA \\
\hline 4-Bromophenyl phenyl ether & $0 / 1$ & ND & ND & & ND & & NA & & NA & & NA & & NA \\
\hline 4-Chloro-3-methylphenol & $0 / 1$ & ND & ND & & ND & & NA & & NA & & NA & & NA \\
\hline 4-Chlorobenzenamine & $0 / 1$ & $\mathrm{ND}$ & $\mathrm{ND}$ & & $\mathrm{ND}$ & & NA & & NA & $2.50 \mathrm{E}+06$ & $0 / 1$ & & NA \\
\hline 4-Chlorophenyl phenyl ether & $0 / 1$ & ND & ND & & ND & & NA & & NA & & NA & & NA \\
\hline 4-Methylphenol & $0 / 1$ & $\mathrm{ND}$ & $\mathrm{ND}$ & & $\mathrm{ND}$ & & $\mathrm{NA}$ & & NA & $3.10 \mathrm{E}+06$ & $0 / 1$ & & NA \\
\hline 4-Nitrobenzenamine & $0 / 1$ & ND & ND & & ND & & NA & & NA & $8.20 \mathrm{E}+05$ & $0 / 1$ & & NA \\
\hline 4-Nitrophenol & $0 / 1$ & $\mathrm{ND}$ & ND & & ND & & NA & & NA & & NA & & NA \\
\hline Acenaphthene & $0 / 1$ & $\mathrm{ND}$ & $\mathrm{ND}$ & & $\mathrm{ND}$ & & NA & & NA & $2.90 \mathrm{E}+07$ & $0 / 1$ & & NA \\
\hline Acenaphthylene & $0 / 1$ & ND & ND & & ND & & NA & & NA & $2.90 \mathrm{E}+07$ & $0 / 1$ & & NA \\
\hline Anthracene & $0 / 1$ & $\mathrm{ND}$ & $\mathrm{ND}$ & & $\mathrm{ND}$ & & $\mathrm{NA}$ & & NA & $1.00 \mathrm{E}+08$ & $0 / 1$ & & NA \\
\hline Benz(a)anthracene & $0 / 1$ & ND & ND & & ND & & NA & & NA & $2.10 \mathrm{E}+04$ & $0 / 1$ & & NA \\
\hline $\begin{array}{l}\text { Benzo(a)pyrene } \\
\text { a }\end{array}$ & $0 / 1$ & ND & ND & & $\mathrm{ND}$ & & NA & & NA & $2.10 \mathrm{E}+03$ & $0 / 1$ & & NA \\
\hline Benzo(b)fluoranthene & $0 / 1$ & $\mathrm{ND}$ & ND & & $\mathrm{ND}$ & & NA & & NA & $2.10 \mathrm{E}+04$ & $0 / 1$ & & NA \\
\hline Benzo(ghi)perylene & $0 / 1$ & ND & ND & & ND & & NA & & NA & $2.90 \mathrm{E}+07$ & $0 / 1$ & & NA \\
\hline Benzo(k)fluoranthene & $0 / 1$ & ND & ND & & $\mathrm{ND}$ & & NA & & NA & $2.10 \mathrm{E}+05$ & $0 / 1$ & & NA \\
\hline Bis(2-chloroethoxy)methane & $0 / 1$ & ND & ND & & ND & & NA & & NA & & NA & & NA \\
\hline $\begin{array}{l}\text { Bis(2-chloroethyl) ether } \\
\text { Sisher }\end{array}$ & $0 / 1$ & ND & ND & & ND & & NA & & NA & $5.80 \mathrm{E}+03$ & $0 / 1$ & & NA \\
\hline Bis(2-ethylhexyl)phthalate & $0 / 1$ & ND & ND & & ND & & NA & & NA & $1.20 \mathrm{E}+06$ & $0 / 1$ & & NA \\
\hline Butyl benzyl phthalate & $0 / 1$ & ND & $\mathrm{ND}$ & & $\mathrm{ND}$ & & NA & & NA & $1.00 \mathrm{E}+08$ & $0 / 1$ & & NA \\
\hline Carbazole & $0 / 1$ & ND & ND & & ND & & NA & & NA & $8.60 \mathrm{E}+05$ & $0 / 1$ & & NA \\
\hline Chrysene & $0 / 1$ & ND & ND & & ND & & NA & & NA & $2.10 \mathrm{E}+06$ & $0 / 1$ & & NA \\
\hline Di-n-butyl phthalate & $0 / 1$ & ND & ND & & ND & & NA & & NA & $6.20 \mathrm{E}+07$ & $0 / 1$ & & NA \\
\hline Di-n-octylphthalate & $0 / 1$ & ND & ND & & ND & & NA & & NA & $2.50 \mathrm{E}+07$ & $0 / 1$ & & NA \\
\hline Dibenz(a,h)anthracene & $0 / 1$ & ND & ND & & ND & & NA & & NA & $2.10 \mathrm{E}+03$ & $0 / 1$ & & NA \\
\hline Dibenzofuran & $0 / 1$ & ND & ND & & $\mathrm{ND}$ & & NA & & NA & $1.60 \mathrm{E}+06$ & $0 / 1$ & & NA \\
\hline Diethyl phthalate & $0 / 1$ & ND & ND & & ND & & NA & & NA & $1.00 \mathrm{E}+08$ & $0 / 1$ & & NA \\
\hline Dimethyl phthalate & $0 / 1$ & ND & $\mathrm{ND}$ & & $\mathrm{ND}$ & & NA & & NA & $1.00 \mathrm{E}+08$ & $0 / 1$ & & NA \\
\hline Fluoranthene & $0 / 1$ & ND & ND & & ND & & NA & & NA & $2.20 \mathrm{E}+07$ & $0 / 1$ & & NA \\
\hline Fluorene & $0 / 1$ & $\mathrm{ND}$ & $\mathrm{ND}$ & & $\mathrm{ND}$ & & $\mathrm{NA}$ & & $\mathrm{NA}$ & $2.60 \mathrm{E}+07$ & $0 / 1$ & & $\mathrm{NA}$ \\
\hline Hexachlorobenzene & $0 / 1$ & ND & ND & & ND & & NA & & NA & $1.10 \mathrm{E}+04$ & $0 / 1$ & & NA \\
\hline Hexachlorocyclopentadiene & $0 / 1$ & ND & ND & & $\mathrm{ND}$ & & NA & & NA & $3.70 \mathrm{E}+06$ & $0 / 1$ & & NA \\
\hline Hexachloroethane & $0 / 1$ & $\mathrm{ND}$ & $\mathrm{ND}$ & & $\mathrm{ND}$ & & NA & & NA & $6.20 \mathrm{E}+05$ & $0 / 1$ & & NA \\
\hline Indeno(1,2,3-cd)pyrene & $0 / 1$ & ND & ND & & ND & & NA & & NA & $2.10 \mathrm{E}+04$ & $0 / 1$ & & NA \\
\hline Isophorone & $0 / 1$ & $\mathrm{ND}$ & $\mathrm{ND}$ & & $\mathrm{ND}$ & & NA & & NA & $5.10 \mathrm{E}+06$ & $0 / 1$ & & NA \\
\hline N-Nitroso-di-n-propylamine & $0 / 1$ & ND & ND & & ND & & NA & & NA & $2.50 \mathrm{E}+03$ & $0 / 1$ & & NA \\
\hline $\begin{array}{l}\text { N-Nitrosodiphenylamine } \\
\text { laten }\end{array}$ & $0 / 1$ & ND & ND & & ND & & NA & & NA & $3.50 \mathrm{E}+06$ & $0 / 1$ & & NA \\
\hline Naphthalene & $0 / 1$ & ND & ND & & ND & & NA & & NA & $1.90 \mathrm{E}+05$ & $0 / 1$ & & NA \\
\hline Nitrobenzene & $0 / 1$ & $\mathrm{ND}$ & ND & & $\mathrm{ND}$ & & NA & & NA & $1.00 \mathrm{E}+05$ & $0 / 1$ & & NA \\
\hline Pentachlorophenol & $0 / 1$ & $\mathrm{ND}$ & ND & & $\mathrm{ND}$ & & NA & & NA & $9.00 \mathrm{E}+04$ & $0 / 1$ & & NA \\
\hline Phenanthrene & $0 / 1$ & ND & ND & & ND & & NA & & NA & $2.90 \mathrm{E}+07$ & $0 / 1$ & & NA \\
\hline $\begin{array}{l}\text { Phenol } \\
\text { Phere }\end{array}$ & $0 / 1$ & ND & ND & & ND & & NA & & NA & $1.00 \mathrm{E}+08$ & $0 / 1$ & & NA \\
\hline Pyrene & $0 / 1$ & ND & ND & & ND & & NA & & NA & $2.90 \mathrm{E}+07$ & $0 / 1$ & & NA \\
\hline
\end{tabular}




\begin{tabular}{|c|c|c|}
\hline Analyte & $\begin{array}{c}\text { Frequency } \\
\text { of detect }\end{array}$ & $\underset{\text { detect }}{\text { Minimum }}$ \\
\hline \multicolumn{3}{|c|}{$\begin{array}{l}J=\text { analyte was positively identified and result is approximate concentration of an } \\
\mathrm{U}=\text { analyte was not detected above the reported sample quantitation limit }\end{array}$} \\
\hline $\begin{array}{l}\text { Avg = average } \\
\text { EU = exposure unit } \\
\text { Max = maximum } \\
\mathrm{NA}=\text { not applicable }\end{array}$ & $\begin{array}{l}\mathrm{ND}=\text { not deter } \\
\mathrm{PRG}=\text { prelimi } \\
\mathrm{RL}=\text { remediat }\end{array}$ & $\begin{array}{l}\text { remediation goal } \\
\text { level }\end{array}$ \\
\hline
\end{tabular}

Station included in summary: K33RCW08. 
Appendix D

K-25 Exposure Unit Group Z2-23

Technical Memorandum 


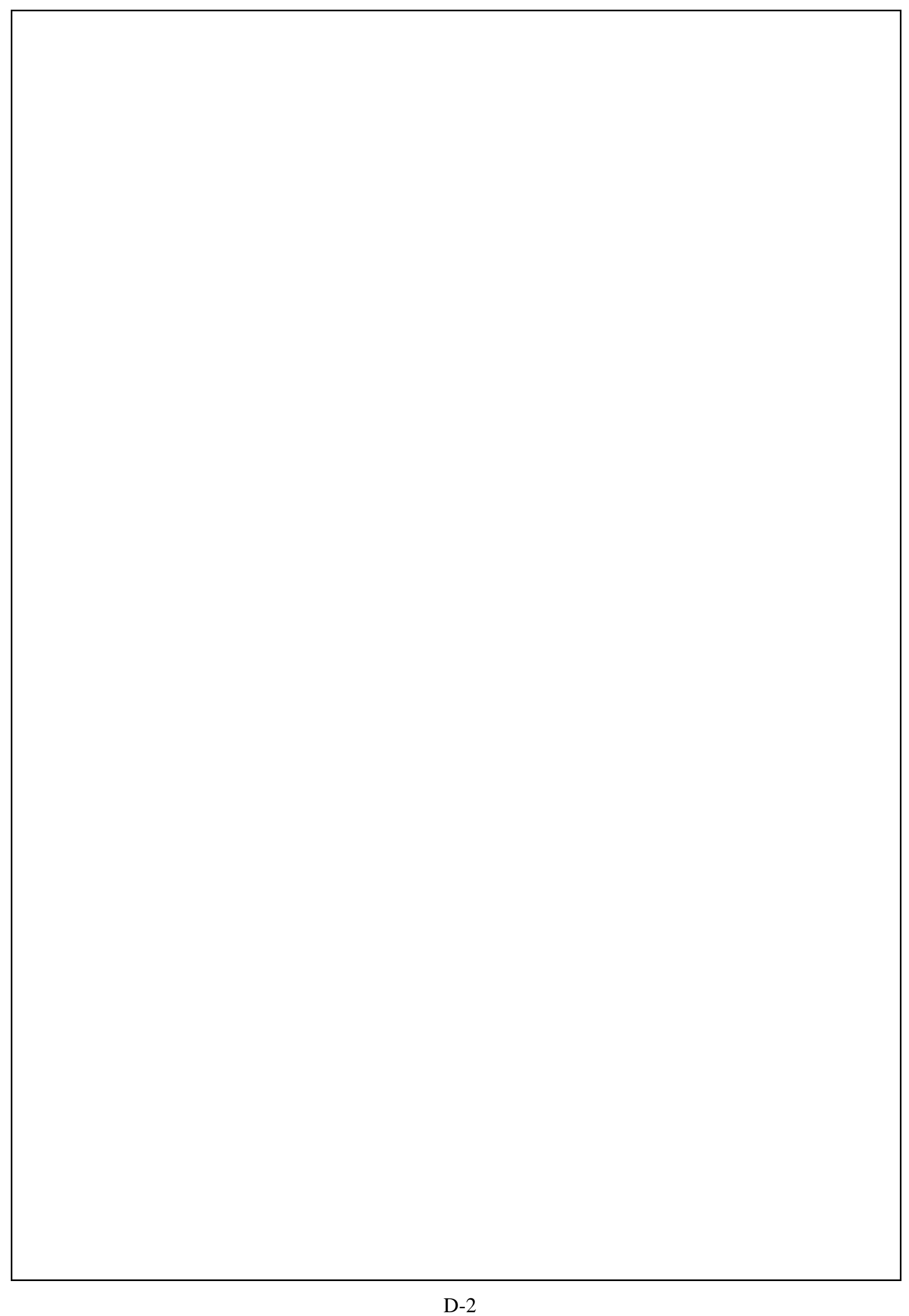




\section{FIGURES}

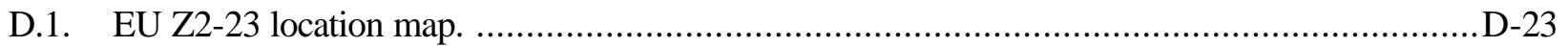

D.2. $\quad$ EU Z2-23 boundaries and FFA site..............................................................................

D.3. EU Z2-23 Class 3 and Class 4 SU walkover assessment locations. .................................... -25

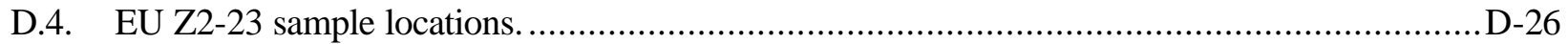

\section{TABLES}

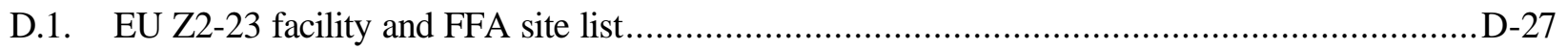

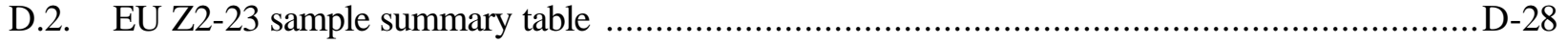

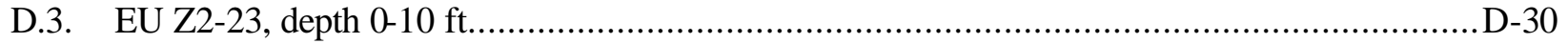




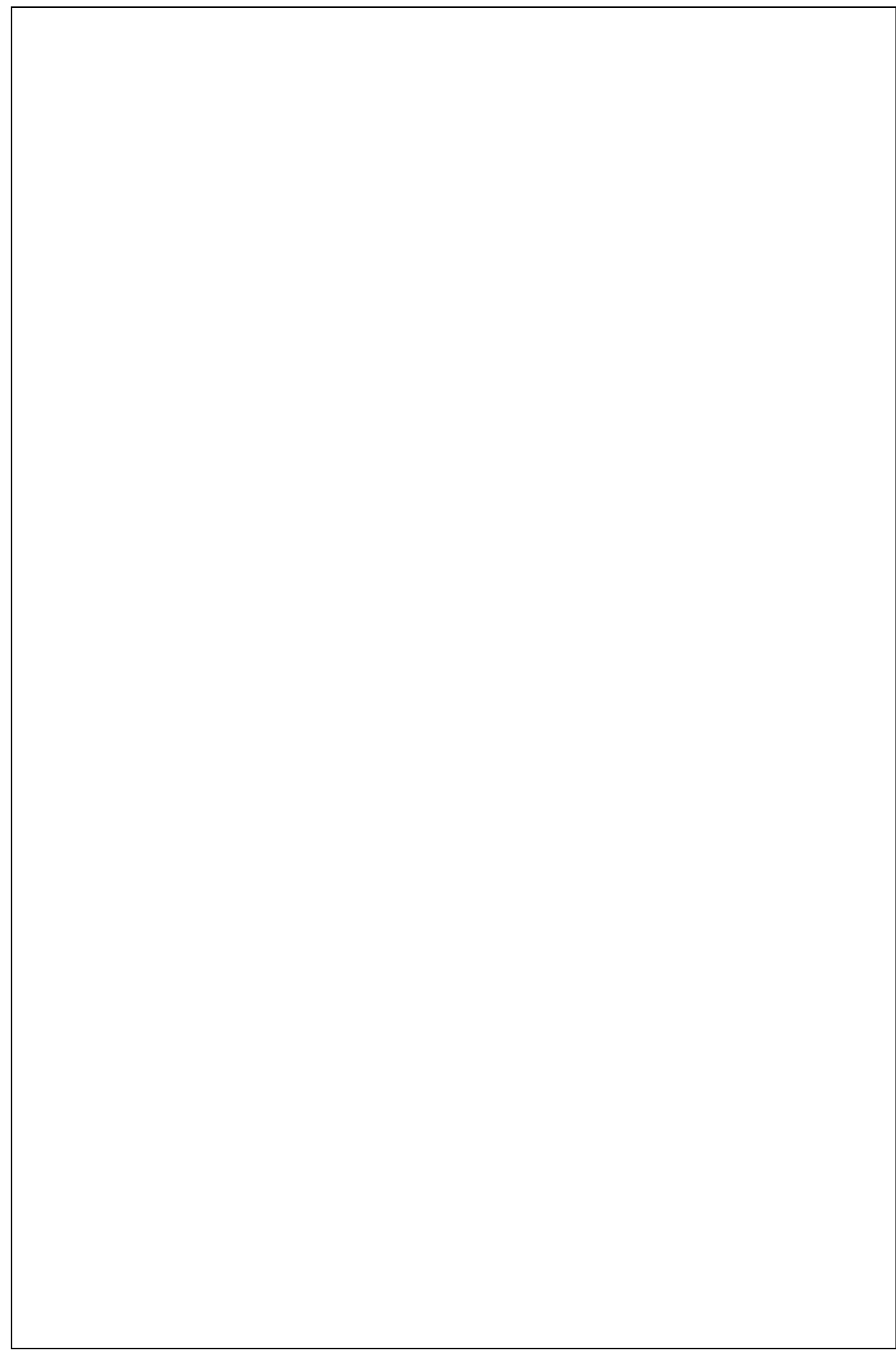

D-4 


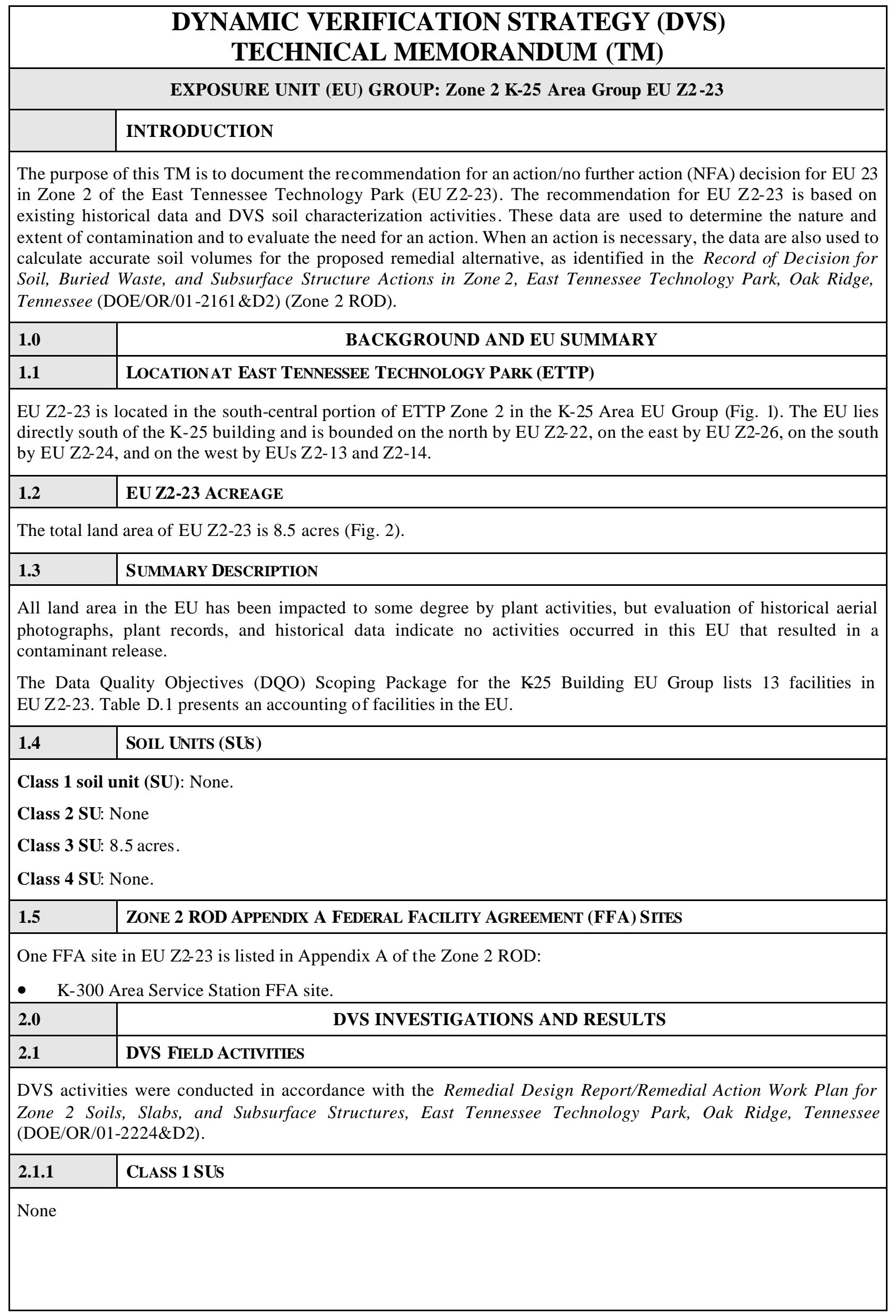




\begin{tabular}{|l|l|}
\hline 2.1.1.1 & CLASS 1 SU RADIOLOGICAL WALKOVER SURVEY \\
\hline None & \multicolumn{2}{|l}{} \\
\hline 2.1.1.2 & CLASS 1 SU GEOPHYSICAL SURVEY \\
\hline None \\
\hline $\mathbf{2 . 1 . 1 . 3}$ & CLASS 1 SU SOIL SAMPLING \\
\hline None & \\
\hline 2.1.2 & CLASS 2 SUS \\
\hline None & \\
\hline 2.12 .1 &
\end{tabular}

\begin{tabular}{|l|l|}
\hline 2.1.2.1 & CLASS 2 SU RADIOLOGICAL WALKOVER SURVEY \\
\hline
\end{tabular}

None

\begin{tabular}{|l|l} 
2.1.2.2 & CLASS 2 SU GEOPHYSICAL SURVEY
\end{tabular}

None

\begin{tabular}{|l|l} 
2.1.2.3 & CLASS 2 SU SOIL SAMPLING \\
\hline
\end{tabular}

None

\begin{tabular}{|l|l} 
2.1.3 & CLASS 3 AND CLASS 4 SU WALKOVER ASSESSMENT \\
\hline
\end{tabular}

The protocol for addressing the Class 3 and Class 4 SUs in EU Z2-23 is the Class 3 and Class 4 Soil Unit Walkover Inspection Protocol (found in Attachment C of Appendix A in the Zone 2 RDR/RAWP). The purpose of the Class 3 SU walkover assessments is to systematically inspect Class 3 SUs by visual observation along transects to established grid assessment locations and map-observed features, and to collect radiological screening data at grid and discretionary locations. Details of the walkover assessment results for EU Z2-23 are presented in the Walkover Inspections and Radiological Survey, Exposure Units in Zones 1 and 2, East Tennessee Technology Park, Oak Ridge, Tennessee (BJC/OR-2691). The report results are summarized below in Sect. 2.1.3.1 and 2.1.3.2. The assessment point (AP), mid-point (MP), and discretionary point (DP) locations are shown in Fig. 3.

Eight APs were identified in the Class 3 SU of EU Z2-23 prior to the start of field work and documented in the DQO Scoping Package. In addition to the APs, the field team made assessments at seven MP locations, which are selected in the field and are located approximately half way between APs, and conducted DPs at one location. MP and DP locations are not specified in planning documents.

\begin{tabular}{cccc}
\hline EU & Number of APs & Number of MPs & Number of DPs \\
\hline Z2-23 & 8 & 7 & 1 \\
\hline $\mathrm{AP}=$ assessment point & EU = exposure unit & \\
$\mathrm{DP}=$ discretionary point & mid-point &
\end{tabular}

\section{\begin{tabular}{|l|l} 
2.1.3.1 & CLASS 3 AND ClASS 4 SU RADIOLOGICAL SURVEY SUMMARY
\end{tabular}}

Screening level (SL): $4046 \mathrm{cpm}$.

SL exceedances: No AP, MP, or DP locations exceeded the SL in EU Z2-23.

\section{\begin{tabular}{|l|l|}
\hline 2.1.3.2 & CLASS 3 AND CLASS 4 SU ANTHROPOGENIC FEATURES
\end{tabular}}

Number of identified anthropogenic features: 1

EU Z2-23 is located in an industrialized portion of ETTP. As such, there are numerous anthropogenic features that consist of facilities and associated constructed features such as roads, sidewalks, and paved areas. Plant facilities and 
their associated constructed features are assessed as part of the Class 3 and Class 4 SU walkover assessment protocol (Sect. 2.1.3.3).

One anthropogenic feature, a recirculating cooling water $(\mathrm{RCW})$ line valve vault, was identified during the Class 3 SU walkover assessment. The RCW line valve vault was surveyed for radiation and inspected for visual evidence of chemical contamination. The radiological survey value was slightly less than background. No significant accumulation of sediment was present. Therefore, the valve vault was not identified for biased sampling.

\section{\begin{tabular}{|l|l} 
2.1.3.3 & CLASS 3 SU FACILITIES ASSESSMENTS
\end{tabular}}

Thirteen facilities were identified during DQO scoping and 15 facilities were assessed during the Class 3 SU walkover assessment (Table D.1). The facility assessments are reported in the Zone 2 EU Survey Summary Report. In summary, no facilit ies exceeded the radiation survey SL; however, facilities identified as potential contaminant release sources based on visual inspection include the following:

- K-300 Area Service Station (FFA site),

- Underground storage tank (UST)/oil skimmer adjacent to the K-1652 Plant Protection Headquarters, and

- $\quad$ K-1066-C Cylinder Storage Yard.

\section{\begin{tabular}{|l|l} 
2.1.3.4 & CLASS 3 SU GEOPHYSICAL SURVEY
\end{tabular}}

A geophysical survey was conducted at the K-300 Area Service Station FFA site because of the possible existence of an UST at the site. Survey results showed a weak electromagnetic (EM) response that is indicative of either the presence of an UST or disturbed soil, but soil sampling at this location (Sect. 2.1.3.5) did not encounter a UST. It was concluded that the UST had been removed and the EM signal response was associated with backfill soil.

\section{\begin{tabular}{l|l} 
2.1.3.5 & CLASS 3 AND CLASS 4 SU BIASED SAMPLING
\end{tabular}}

The following Class 3 SU biased sample locations were identified based on the Class 3 SU walkover assessment, including associated facilities assessments:

- Five surface soil sample locations and one surface/subsurface sample location were identified in a sediment accumulation area near the northeast corner of the K-1066-C Cylinder Storage Yard. Initially, one discrete surface sample was collected in the sediment accumulation area. Analytical results for the initial sample showed elevated polychlorinated biphenyl (PCB) concentrations (Sect.2.2.5) and four discrete step-out sample locations were identified for surface soil sampling (one each $12.5 \mathrm{ft}$ to the north, east, south, and west of the original sediment accumulation area sample location). The surface/subsurface sample location is a confirmation sample located at the original sediment accumulation area sample location to determine depth of contamination.

- Two sample locations were identified along the perimeter fence of the K-1066-C Cylinder Storage Yard. One four-point composite surface sample was collected from the west side of the fence and one four-point composite surface sample was collected from the east side of the fence.

- Three sample locations associated with the geophysical anomaly at the K-300 Area Service Station FFA site (Sect. 2.1.3.4) were identified for subsurface sampling. One location was placed at the geophysical anomaly and the other two locations were placed downgradient (to the west and southwest) of the anomaly.

In addition, several Class 3 SU biased sample locations identified during DQO scoping include the following:

- Four biased sample locations were identified around the UST on the east side of the K-1652 Plant Protection Headquarters, and

- Three biased sample locations were identified along the length of an above-ground process tie line that was used to transport process gases from Bldg. K-25 to Bldg. K-29.

A storm drain sediment sample identified during DQO sampling was collected during the EU Z2-23 investigation but the location of the sample is in EU Z2-14. The sample will be reported in EU Z2-14 TM.

Details of actual sampling and analysis in the Class 3 SU, including sample depths and analytes are presented in Table D.2. Analytical results are summarized in Sects. 2.2.5 and 2.2.6. 
This section presents a summary of analytical results for the DVS and historical samples collected in EU Z2-23. The summary begins with a tabulation of SU and infrastructure sample locations (Sects.2.2.1 through 2.2.4) and concludes with focused investigation and EU data summaries (Sect.2.2.5) and FFA site data summaries (Sect. 2.2.6). The combined EU DVS and historical data are summarized in Table D.3. A compact disc containing electronic files for the historical and DVS analytical data used to generate the data tables is provided with this Phased Construction Completion Report (PCCR).

\begin{tabular}{|c|c|c|}
\hline 2.2.1 & \multicolumn{2}{|l|}{ CLASS 1 SUS } \\
\hline \multicolumn{3}{|l|}{ None } \\
\hline 2.2 .2 & \multicolumn{2}{|l|}{ Class 2 SUS } \\
\hline \multicolumn{3}{|l|}{ None } \\
\hline 2.2 .3 & \multicolumn{2}{|l|}{ Class 3 AND ClaSS 4 SUS } \\
\hline \multicolumn{3}{|c|}{$\begin{array}{l}\text { There are } 34 \text { DVS and historical sample locations in the Class } 3 \text { SU of EU Z2-23. Historical sampling in the Clas } \\
\text { SUs was conducted in the mid-1990s as part of the radiological survey program by reindustrialization for assessm } \\
\text { of the K-1652 facility transfer and by the early characterization program. DVS and historical sample locations } \\
\text { shown on Fig. } 2 \text { and summarized below. }\end{array}$} \\
\hline $\mathbf{E U}$ & DVS sample locations & \begin{tabular}{|c|} 
Historic sample locations \\
\end{tabular} \\
\hline $\mathrm{Z} 2-23$ & $\begin{array}{l}\text { Biased locations: } \\
\text { Z2-EU23B-301, Z2-EU23B-302, } \\
\text { Z2-EU23B-303, Z2-EU23B-304, } \\
\text { Z2-EU23B-305, Z2-EU23B-306, } \\
\text { Z2-EU23B-307, Z2-EU23B-308, } \\
\text { Z2-EU23B-309, Z2-EU23B-310, } \\
\text { Z2-EU23B-311, Z2-EU23B-312, } \\
\text { Z2-EU23B-313, Z2-EU23B-314, } \\
\text { Z2-EU23B-317, Z2-EU23B-318, } \\
\text { Z2-EU23B-319, Z2-EU23B-320 }\end{array}$ & $\begin{array}{l}\text { Early characterization: } \\
\text { Z2-EU22-035 } \\
\text { Other: } \\
\text { 1652-RAD-001, 1652-RAD-002, 1652-RAD-003, } \\
\text { AU-01-01-1652, AU-03-01-1652, AU-04-01-1652, } \\
\text { AU-05-01-1652, AU-06-01-1652, AU-07-01-1652, } \\
\text { AU-10-01-1652, AU-A 2-01-1652, AU-I1-01-1652, } \\
\text { AU-I2-01-1652, AU-I3-01-1652, AU-I4-01-1652, }\end{array}$ \\
\hline
\end{tabular}

DVS = Dynamic Verification Strategy

$\mathrm{EU}=$ exposure unit

The number of samples collected, sampling intervals, and chemicals and radionuclides analyzed varied at each location. The data are summarized as parts of the EU summary in Table D.3, by area of interest and EU in Sect. 2.2.5, and by FFA site in Sect. 2.2.6. The number of analyses conducted in the Class 3 SUs is presented below by analyte group.

\begin{tabular}{ccccccc}
\hline Anions $^{\boldsymbol{a}}$ & Metals $^{\boldsymbol{b}}$ & PCBs & Radionuclides $^{\boldsymbol{c}}$ & SVOCs & VOCs & Other organics $^{\boldsymbol{a}}$ \\
\hline 3 & 39 & 32 & 39 & 31 & 31 & 7 \\
\hline
\end{tabular}

${ }^{a}$ Includes three fluoride analyses at location Z2-EU22-035.

${ }^{b}$ Includes three hexavalent chromium analyses at location Z2-EU22-035.

${ }^{c} \mathrm{U}-235$ results summarized in this Technical Memorandum are from the U-isotopic method (reported as U-235/236 in some samples) when two results are reported.

${ }^{d}$ Includes diesel range and gasoline range organics.

PCB = polychlorinated biphenyl

SVOC = semivolatile organic

$\mathrm{VOC}=$ volatile organic

\section{\begin{tabular}{l|l} 
2.2.4 & INFRASTRUCTURE \\
\hline
\end{tabular}}

Soil associated with above-ground process lines basin was sampled during DVS Class 3 SU biased sampling. 
In this section, characterization data and other information are evaluated for EU Z2-23. Analytical data in the following summaries are presented by analyte group. Results for a particular analyte group are summarized only if that group was analyzed in the samples from the unit being summarized. Within each summary, data are evaluated by comparing to certain criteria, including the Zone 2 soils Max RL, Zone 2 soils Avg RL), $1 \times 10^{-5}$ Ind PRG, ETTP Bkg, Zone 2 GW SLs, and $1 \times 10^{-6}$ residential (Res) PRG. If a particular criterion does not apply to any member of an analyte group, it is not tabulated for that analyte group; if a particular criterion does not apply to all analytes within an analyte group, those analytes to which it does not apply are notated with a NA (not applicable). Individual metals and radionuclides, which are naturally occurring, are reported in the summaries only if one or more criterion is exceeded. Organic chemicals, which are not naturally occurring, are reported if detected, even if no criteria are exceeded. The Max RL, Avg RL, Ind PRG, Bkg, GW SL, and Res PRG criteria values as they pertain to the analytes listed in Appendix A of the RDR/RAWP (i.e., the QAPP) are presented in Sect. 3.1 of this PCCR.

Because the carcinogenic risk associated with the concentration of radium and thorium isotopes in the natural background at ETTP exceeds the cumulative risk goal of $1 \times 10^{-4}$, RL values for these radionuclides are based on alternative concentration levels rather than risk. The alternative concentration levels of $5 \mathrm{pCi} / \mathrm{g}$ above background (Avg RL) and $15 \mathrm{pCi} / \mathrm{g}$ above background (Max RL) were set as low as reasonably achievable (ALARA) under the site-specific conditions. Because site-specific background concentrations of these radionuclides exceed the target risk range, residual concentrations of these radionuclides and their decay series are not considered in estimates of residual risk following any remedial actions.

The Zone 2 ROD states that Avg RL and Max RL exceedances by Ra-226, Th-230, and Th-232 will be evaluated by summing above-background concentrations of the greater of Ra-226 or Th-230 with the above-background concentrations of Th-232 and comparing the results to $5 \mathrm{pCi} / \mathrm{g}$ (average RL) and $15 \mathrm{pCi} / \mathrm{g}$ (maximum RL). Average and maximum RL exceedances for these radionuclides, if any, are reported in the data summaries below and in Tables D.2 through D.4 as "Ra/Th decay series", and individual RL exceedances by Ra-226, Th-230, and Th-232 are reported as NA. The Ra/Th decay series data are summarized in the following sections only if an average or maximum RL has been exceeded, consistent with the description in the preceding paragraph for reporting radionuclides. Discussion of the $\mathrm{Ra} / \mathrm{Th}$ decay series calculation, including the manner in which the calculation is performed, is presented in Sect. 3.3 of this PCCR.

\section{EU Z2-23 Conceptual Site Model}

The entire area of EU Z2-23 was classified as a Class 3 SU in the DQO package based on available facility records and historic sample results. The conceptual site model for Class 3 SU is a surface release model. There is no evidence of burial or subsurface potential sources of contaminants in EU Z2-23. Following development of the DQO package, a set of site drawings for the area, including EU Z2-23, was obtained that showed the K-300 Area Service station in EU Z2-23, while another set of drawings showed the tank in EU Z2-24. Both sites were surveyed using geophysical methods to resolve the discrepancy. While the geophysical survey indicated a subtle anomaly at the EU Z2-23 location, there was no indication of any disturbance of buried objects at the EU Z2-24 location. A UST conceptual model applies to the K-300 Area Service Station FFA site. Releases from a UST at the identified location would move south and west through the subsurface toward an area approximately $10 \mathrm{ft}$ lower in topographic elevation. Biased sampling locations within EU Z2-23 confirm there were minor surface releases of PCB from the $\mathrm{K}-1066-\mathrm{C}$ Cylinder Yard that were detected in samples from a sediment accumulation area. Offset sampling bounded the extent of the area (less than $10 \times 10 \mathrm{ft}$ ) and PCB concentration above Avg RLs, but below Max RLs were reported in laboratory results. Samples at the UST site confirmed the tank was removed and the subtle geophysical anomaly was associated with backfill soil. Numerous volatile organic aromatic detections using a photoionization detector were reported at one downgradient location. Laboratory results for soil samples collected at this location had numerous tentatively identified organic compounds (TICs), which indicates highly degraded fuels . No significant concentrations of identifiable diesel or gasoline range organics were reported.

\section{EU Z2-23 Groundwater Evaluation}

No groundwater monitoring wells are located in EU Z2-23. The closest wells are to the west around the K-27 building and along Poplar Creek. Site-wide water-level data shows the EU Z2-23 area near a groundwater divide. Groundwater flow is to the south from infiltration points east of the K-1652 building and to the west toward the K27 building across the central and western portions of the EU. There is no significant mass of contaminated soils in 
the EU. Three samples at the sediment accumulation area in the north-central portion of the EU did have U-234 concentrations above groundwater SLs, but the impact at this location is limited to an area less than $10 \times 10 \mathrm{ft}$. The contaminants present are in a small isolated surface depression, and infiltration does occur at this location. The mass of contaminants present is minimal and would not pose a threat to local groundwater. Based on the water-level map and recently updated plume map presented in the Draft Site-Wide RI, groundwater flows away from the EU Z2-23 area and contaminated groundwater is not present beneath EU Z2-23.

\section{EU Z2-23 Sampling Results}

EU Z2-23 encompasses a highly industrialized portion of ETTP, including buildings, other facilities, asphalt, and concrete, with very little open area. As a result, the Class 3 SU walkover assessment only identified one anthropogenic feature that was not already addressed by the facility inspection portion of the walkover protocol. No visual evidence for chemical contaminant releases or field screening evidence for radiological contaminant releases were observed at the anthropogenic feature, and no biased sampling was conducted. One sediment accumulation area was identified during the Class $3 \mathrm{SU}$ walkover assessment and DVS biased sampling was conducted.

Facility assessments conducted as part of the Class 3 SU walkover assessment identified three facilities for DVS biased sampling (Sect. 2.1.3.5). The facilities were selected for biased sampling based on visual assessment that indicated the facilities were potential sources of chemical contaminant releases. No facility in EU Z2-23 exceeded the radiological SL during radiological screening, so it was concluded they were not a potential source of radiological contamination. One facility identified for biased sampling was the K-300 Area Service Station FFA site. The data summary for this site is presented in Sect. 2.2.6.

Other DVS biased sample locations were identified during DQO scoping (Sect. 2.1.3.5) including sampling along an above-ground process line. Because the storm drain sample location is in EU Z2-14, the analytical results will be presented in the TM for that EU.

In addition to DVS sampling, there are numerous historical sample locations in EU Z2-23 (Table D.2). All of the historical locations, except one, are around the K-1652 Plant Protection Headquarters. The one exception is early characterization sample location Z2-EU22-035, which was identified during early characterization of EU Z2-22 but is inside EU Z2-23.

Analytical data are summarized below for each of the focused investigations, including historical investigations, in EU Z2-23. The focused investigation at the K-300 Area Service Station FFA site is summarized in Sect. 2.2.6. The focused investigation summaries are followed by a data summary for all of EU Z2-23, including data from the K-300 Area Service Station FFA site. Details of sampling and analysis at each sample location, including the number of samples, sample depths, and analytes, are presented in Table D.2. All analytical data for EU Z2-23 are summarized in Table D.3, and sample locations are shown on Fig. 4. Analytical data summarized below are evaluated in terms of the Zone 2 ROD remedial action objective (RAO) in Sect. 3.

Class 3 SU DVS Biased Sampling in the Sediment Accumulation Area. DVS biased sample location Z2-EU23B-306 was identified in the sediment accumulation area northeast of the K-1066-C Cylinder Storage Yard during the Class 3 SU walkover assessment. A surface soil sample was collected and analyzed for metals and PCBs. Analytical results (included in the following data summary) showed an exceedance of the PCB-1254 average RL. In response, four step-out sample locations were identified (Z2-EU23B-307 to the north, Z2-EU23B-308 to the east, Z2-EU23B-309 to the south, and Z2-EU23B-310 to the west of the original location) and a surface soil sample was collected at each location. In addition, a confirmation sample (Z2-EU23B-311) was placed at the original location and one surface and three subsurface samples were collected to ascertain the depth of the average RL exceedance. Analytical results summarized below illustrate PCB-1254 and total PCB average RL exceedances in the original sample location (Z2-EU23B-306) and one of the step-out locations (Z2-EU23B-310) but not in samples from the confirmation sample location (Z2-EU23B-311). Also, analytical results illustrate Cs -137 average RL exceedances in a step-out sample (Z2-EU23B-310) and in the surface sample and a subsurface sample from the confirmation sample location (Z2-EU23B-311); U-234 GW SL exceedances at two step-out sample locations (Z2-EU23B-307 and Z2-EU23B-310) and in the surface sample and one subsurface sample at the confirmation sample location (Z2-EU23B-311); metal, PCB, and radionuclide Ind PRG exceedances; and metal and radionuclide background exceedances. (Note: U-235 concentrations in the DVS samples were determined by two different analytical methods. Analytical results from the U-isotopic method were selected for data analysis because it is a more accurate method. The selected U-235 result for the surface interval sample at Z2-EU23B-311 was 6.37 pCi/g; however, the $\mathrm{U}-235$ result for the same sample determined by the alternate method was $8.92 \mathrm{pCi} / \mathrm{g}$, which exceeded the U-235 average $\mathrm{RL}$ of $8 \mathrm{pCi} / \mathrm{g})$. 
EU Z2-23 SEDIMENT ACCUMULATION AREA METALS WITH BACKGROUND,

PRG, GW SL, AND/OR RL EXCEEDANCES (mg/kg)

\begin{tabular}{|c|c|c|c|c|c|c|c|c|c|c|c|}
\hline \multirow[b]{2}{*}{ Analyte } & \multirow[b]{2}{*}{$\begin{array}{c}\text { Detect } \\
\text { frequency }\end{array}$} & \multirow[b]{2}{*}{$\underset{\text { detect }}{\text { Minimum }}$} & \multirow[b]{2}{*}{$\underset{\text { detect }}{\text { Maximum }}$} & \multirow{2}{*}{$\begin{array}{c}\text { Location(s) of } \\
\text { maximum } \\
\text { detect }\end{array}$} & \multirow{2}{*}{$\begin{array}{c}\text { Average } \\
\text { detected } \\
\text { result }\end{array}$} & \multicolumn{6}{|c|}{ Number of analyses exceeding criteria } \\
\hline & & & & & & $\begin{array}{c}\text { Max } \\
\text { RL }\end{array}$ & $\begin{array}{l}\text { Avg } \\
\text { RL }\end{array}$ & $\begin{array}{l}\text { Ind } \\
\text { PRG }\end{array}$ & Bkg & $\begin{array}{l}\text { GW } \\
\text { SL }\end{array}$ & $\begin{array}{r}\text { Res } \\
\text { PRG }\end{array}$ \\
\hline Aluminum & $5 / 5$ & 5400 & 21000 & Z2-EU23B-309 & 11480 & NA & NA & 0 & 0 & NA & 3 \\
\hline Antimony & $5 / 5$ & $0.14 \mathrm{~J}$ & 6.8 & Z2-EU23B-306 & 1.64 & NA & NA & 0 & 1 & 0 & 1 \\
\hline Arsenic & $5 / 5$ & 5.1 & 18 & Z2-EU23B-306 & 9.18 & 0 & 0 & 1 & 1 & 0 & 5 \\
\hline Barium & $5 / 5$ & $61 \mathrm{~J}$ & 150 & Z2-EU23B-306 & 106 & NA & NA & 0 & 1 & 0 & 0 \\
\hline Cadmium & $5 / 5$ & 0.33 & 16 & Z2-EU23B-306 & 6.37 & NA & NA & 0 & 5 & NA & 2 \\
\hline Calcium & $5 / 5$ & $2100 \mathrm{~J}$ & $71000 \mathrm{~J}$ & Z2-EU23B-307 & 34620 & NA & NA & NA & 4 & NA & NA \\
\hline Chromium & $5 / 5$ & 12 & 110 & Z2-EU23B-306 & 36.4 & NA & NA & 0 & 1 & 0 & 2 \\
\hline Cobalt & $5 / 5$ & $7 \mathrm{~J}$ & $47 \mathrm{~J}$ & Z2-EU23B-310 & 21.2 & NA & NA & 0 & 1 & NA & 0 \\
\hline Copper & $5 / 5$ & $25 \mathrm{~J}$ & 170 & Z2-EU23B-306 & 63.8 & NA & NA & 0 & 5 & NA & 0 \\
\hline Iron & $5 / 5$ & 14000 & 50000 & Z2-EU23B-309 & 31000 & NA & NA & 0 & 0 & NA & 5 \\
\hline Lead & $5 / 5$ & 33 & 450 & Z2-EU23B-306 & 137 & NA & NA & 0 & 4 & 0 & 1 \\
\hline Magnesium & $5 / 5$ & $1500 \mathrm{~J}$ & $29000 \mathrm{~J}$ & Z2-EU23B-307 & 10780 & NA & NA & NA & 4 & NA & NA \\
\hline Manganese & $5 / 5$ & 270 & 1600 & Z2-EU23B-309 & 842 & NA & NA & 0 & 0 & NA & 5 \\
\hline Mercury & $5 / 5$ & 0.072 & 1.3 & Z2-EU23B-306 & 0.353 & 0 & 0 & 0 & 1 & NA & 0 \\
\hline Nickel & $5 / 5$ & 32 & 580 & Z2-EU23B-306 & 178 & NA & NA & 0 & 5 & NA & 2 \\
\hline Selenium & $3 / 5$ & 0.72 & 1.9 & Z2-EU23B-310 & 1.18 & NA & NA & 0 & 1 & NA & 0 \\
\hline Uranium & $5 / 5$ & 3.4 & 74 & Z2-EU23B-306 & 30.9 & NA & NA & 0 & NA & NA & 5 \\
\hline Vanadium & $5 / 5$ & 12 & 50 & Z2-EU23B-309 & 27.8 & NA & NA & 0 & 0 & NA & 5 \\
\hline Zinc & $5 / 5$ & $74 \mathrm{~J}$ & 720 & Z2-EU23B-306 & 267 & NA & NA & 0 & 4 & NA & 0 \\
\hline
\end{tabular}

Avg $=$ average NA $=$ not applicable

$\mathrm{Bkg}=$ background $\quad \mathrm{PRG}=$ preliminary remediation goal

$\mathrm{EU}=$ exposure unit $\quad$ Res $=$ residential

$\mathrm{GW}=$ groundwater $\quad \mathrm{RL}=$ remediation level

Ind $=$ industrial $\quad$ SL $=$ screening level

Max $=$ maximum

EU Z2-23 SEDIMENT ACCUMULATION AREA PCB DETECTS (ug/kg)

\begin{tabular}{|c|c|c|c|c|c|c|c|c|c|}
\hline \multirow[b]{2}{*}{ Analyte } & \multirow[b]{2}{*}{$\begin{array}{c}\text { Detect } \\
\text { frequency }\end{array}$} & \multirow[b]{2}{*}{$\begin{array}{c}\text { Minimum } \\
\text { detect }\end{array}$} & \multirow[b]{2}{*}{$\begin{array}{c}\text { Maximum } \\
\text { detect }\end{array}$} & \multirow[b]{2}{*}{$\begin{array}{c}\text { Location(s) of } \\
\text { maximum detect }\end{array}$} & \multirow{2}{*}{$\begin{array}{c}\text { Average } \\
\text { detected } \\
\text { result }\end{array}$} & \multicolumn{4}{|c|}{$\begin{array}{l}\text { Number of analyses } \\
\text { exceeding criteria }\end{array}$} \\
\hline & & & & & & $\begin{array}{l}\text { Max } \\
\text { RL }\end{array}$ & $\begin{array}{l}\text { Avg } \\
\text { RL }\end{array}$ & $\begin{array}{l}\text { Ind } \\
\text { PRG }\end{array}$ & $\begin{array}{l}\text { Res } \\
\text { PRG }\end{array}$ \\
\hline PCB-1254 & $7 / 7$ & 140 & 55000 & Z2-EU23B-306 & 12336 & 0 & 2 & 2 & 7 \\
\hline PCB-1260 & $5 / 7$ & 170 & $7300 \mathrm{~J}$ & Z2-EU23B-310 & 1990 & 0 & 0 & 0 & 5 \\
\hline PCB & $7 / 7$ & 140 & 55000 & Z2-EU23B-306 & 13757 & 0 & 2 & 2 & 7 \\
\hline
\end{tabular}

\begin{tabular}{ll}
\hline Avg $=$ average & PCB $=$ polychlorinated biphenyl \\
$\mathrm{EU}=$ exposure unit & $\mathrm{PRG}=$ preliminary remediation goal \\
$\mathrm{Ind}=$ industrial & $\mathrm{RL}=$ remediation level
\end{tabular}

Max = maximum

EU Z2-23 SEDIMENT ACCUMULATION AREA RADIONUCLIDES WITH BACKGROUND, PRG, AND/OR RL EXCEEDANCES (pCi/g)

\begin{tabular}{|c|c|c|c|c|c|c|c|c|c|c|c|}
\hline \multirow[b]{2}{*}{ Analyte } & \multirow[b]{2}{*}{$\begin{array}{c}\text { Detect } \\
\text { frequency }\end{array}$} & \multirow[b]{2}{*}{$\begin{array}{c}\text { Minimum } \\
\text { detect }\end{array}$} & \multirow[b]{2}{*}{$\begin{array}{c}\text { Maximum } \\
\text { detect }\end{array}$} & \multirow{2}{*}{$\begin{array}{l}\text { Location(s) of } \\
\text { maximum } \\
\text { detect }\end{array}$} & \multirow{2}{*}{$\begin{array}{c}\text { Average } \\
\text { detected } \\
\text { result }\end{array}$} & \multicolumn{6}{|c|}{ Number of analyses exceeding criteria } \\
\hline & & & & & & $\begin{array}{c}\text { Max } \\
\text { RL }\end{array}$ & $\begin{array}{l}\text { Avg } \\
\text { RL }\end{array}$ & $\begin{array}{l}\text { Ind } \\
\text { PRG }\end{array}$ & Bkg & $\begin{array}{l}\text { GW } \\
\text { SL }\end{array}$ & $\begin{array}{l}\text { Res } \\
\text { PRG }\end{array}$ \\
\hline $\begin{array}{l}\text { Cesium-137 } \\
\text { - } 137\end{array}$ & $5 / 6$ & 0.438 & $5.76 \mathrm{~J}$ & Z2-EU23B-311 & 3.06 & 0 & 3 & 3 & NA & NA & 5 \\
\hline Neptunium-237 & $4 / 7$ & 0.539 & 1.67 & Z2-EU23B-311 & 1.16 & 0 & 0 & 0 & NA & NA & 4 \\
\hline Potassium-40 & $6 / 6$ & 10.6 & 13.6 & Z2-EU23B-309 & 12.5 & NA & NA & 6 & 0 & NA & 6 \\
\hline Radium-226 & $7 / 7$ & 0.878 & 1.54 & Z2-EU23B-311 & 1.13 & NA & NA & 7 & 3 & NA & 7 \\
\hline Technetium-99 & $7 / 7$ & 7.14 & 250 & Z2-EU23B-311 & 119 & NA & NA & 0 & NA & NA & 7 \\
\hline Thorium - 228 & $4 / 7$ & 1.18 & 1.91 & $\begin{array}{l}\text { Z2-EU23B-309 } \\
\text { Z2-EU23B-311 }\end{array}$ & 1.55 & NA & NA & 4 & 2 & NA & 4 \\
\hline Thorium -230 & $5 / 7$ & 1.71 & 3.36 & Z2-EU23B-311 & 2.73 & NA & NA & 0 & 5 & NA & 0 \\
\hline Thorium -232 & $7 / 7$ & 0.74 & 1.6 & Z2-EU23B-311 & 1.09 & NA & NA & 7 & 0 & NA & 7 \\
\hline Uranium-234 & $7 / 7$ & 8.67 & 149 & Z2-EU23B-311 & 79.3 & 0 & 0 & 0 & NA & 4 & 7 \\
\hline
\end{tabular}


BACKGROUND, PRG, AND/OR RL EXCEEDANCES (pCi/g) (continued)

\begin{tabular}{|c|c|c|c|c|c|c|c|c|c|c|c|}
\hline \multirow[b]{2}{*}{ Analyte } & \multirow[b]{2}{*}{$\begin{array}{c}\text { Detect } \\
\text { frequency }\end{array}$} & \multirow[b]{2}{*}{$\begin{array}{c}\text { Minimum } \\
\text { detect }\end{array}$} & \multirow[b]{2}{*}{$\begin{array}{c}\text { Maximum } \\
\text { detect }\end{array}$} & \multirow{2}{*}{$\begin{array}{c}\text { Location(s) of } \\
\text { maximum } \\
\text { detect }\end{array}$} & \multirow{2}{*}{$\begin{array}{c}\text { Average } \\
\text { detected } \\
\text { result }\end{array}$} & \multicolumn{6}{|c|}{ Number of analyses exceeding criteria } \\
\hline & & & & & & $\begin{array}{c}\text { Max } \\
\text { RL }\end{array}$ & $\begin{array}{l}\text { Avg } \\
\text { RL }\end{array}$ & $\begin{array}{l}\text { Ind } \\
\text { PRG }\end{array}$ & Bkg & $\begin{array}{c}\text { GW } \\
\text { SL }\end{array}$ & $\begin{array}{c}\text { Res } \\
\text { PRG }\end{array}$ \\
\hline Uranium-235 & $7 / 7$ & 0.334 & 6.37 & Z2-EU23B-311 & 3.37 & 0 & 0 & 4 & NA & 0 & 7 \\
\hline Uranium-238 & $7 / 7$ & 3.18 & 20.5 & Z2-EU23B-311 & 10.1 & 0 & 0 & 1 & 7 & 0 & 7 \\
\hline $\begin{array}{l}\mathrm{Avg}=\text { average } \\
\mathrm{Bkg}=\text { background } \\
\mathrm{EU}=\text { exposure unit } \\
\mathrm{GW}=\text { groundwater } \\
\text { Ind = industrial } \\
\text { Max = maximum }\end{array}$ & & $\begin{array}{l}\text { N/A }=\text { not } \\
\text { PRG = pre } \\
\text { Res = resic } \\
\text { RL = reme } \\
\text { SL }=\text { scree }\end{array}$ & $\begin{array}{l}\text { applicable } \\
\text { liminary rem } \\
\text { dential } \\
\text { ediation level } \\
\text { ning level }\end{array}$ & ediation goal & & & & & & & \\
\hline
\end{tabular}

Class 3 SU DVS Biased Samples from the Perimeter of the K-1066-C Cylinder Storage Yard. Two surface soil sample locations were identified outside the fence around the K-1066-C Cylinder Storage Yard. One location is on the east side of the cylinder storage yard (Z2-EU23B-305) and the other location is on the west side of the cylinder storage yard (Z2-EU23B-304). Analytical results summarized below show metal background exceedances and detections of PCBs.

EU Z2-23 K-1066-C CYLINDER STORAGE YARD PERIMETER METALS WITH BACKGROUND, PRG, GW SL, AND/OR RL EXCEEDANCES (mg/kg)

\begin{tabular}{|c|c|c|c|c|c|c|c|c|c|c|c|}
\hline \multirow[b]{2}{*}{ Analyte } & \multirow[b]{2}{*}{$\begin{array}{c}\text { Detect } \\
\text { frequency }\end{array}$} & \multirow[b]{2}{*}{$\begin{array}{c}\text { Minimum } \\
\text { detect }\end{array}$} & \multirow[b]{2}{*}{$\underset{\text { detect }}{\text { Maximum }}$} & \multirow{2}{*}{$\begin{array}{l}\text { Location(s) of } \\
\text { maximum } \\
\text { detect }\end{array}$} & \multirow{2}{*}{$\begin{array}{c}\text { Average } \\
\text { detected } \\
\text { result }\end{array}$} & \multicolumn{6}{|c|}{ Number of analyses exceeding criteria } \\
\hline & & & & & & $\begin{array}{c}\text { Max } \\
\text { RL }\end{array}$ & $\begin{array}{l}\text { Avg } \\
\text { RL }\end{array}$ & $\begin{array}{l}\text { Ind } \\
\text { PRG }\end{array}$ & Bkg & $\begin{array}{l}\text { GW } \\
\text { SL }\end{array}$ & $\begin{array}{l}\text { Res } \\
\text { PRG }\end{array}$ \\
\hline Aluminum & $2 / 2$ & 7500 & 14000 & Z2-EU23B-305 & 10750 & NA & NA & 0 & 0 & NA & 1 \\
\hline Antimony & $2 / 2$ & $0.26 \mathrm{~J}$ & 2.4 & Z2-EU23B-305 & 1.33 & NA & NA & 0 & 1 & 0 & 0 \\
\hline Arsenic & $2 / 2$ & 5.2 & 7.7 & Z2-EU23B-304 & 6.45 & 0 & 0 & 0 & 0 & 0 & 2 \\
\hline Cadmium & $2 / 2$ & $0.78 \mathrm{~J}$ & 0.83 & Z2-EU23B-305 & 0.805 & NA & NA & 0 & 2 & NA & 0 \\
\hline Calcium & $2 / 2$ & 17000 & $77000 \mathrm{~J}$ & Z2-EU23B-304 & 47000 & NA & NA & NA & 2 & NA & NA \\
\hline Chromium & $2 / 2$ & 22 & $36 \mathrm{~J}$ & Z2-EU23B-304 & 29 & NA & NA & 0 & 0 & 0 & 1 \\
\hline Copper & $2 / 2$ & $28 \mathrm{~J}$ & 39 & Z2-EU23B-305 & 33.5 & NA & NA & 0 & 2 & NA & 0 \\
\hline Lead & $2 / 2$ & 57 & 77 & Z2-EU23B-304 & 67 & NA & NA & 0 & 2 & 0 & 0 \\
\hline Magnesium & $2 / 2$ & $2900 \mathrm{~J}$ & 10000 & Z2-EU23B-305 & 6450 & NA & NA & NA & 1 & NA & NA \\
\hline Manganese & $2 / 2$ & 780 & 1700 & Z2-EU23B-304 & 1240 & NA & NA & 0 & 0 & NA & 2 \\
\hline Nickel & $2 / 2$ & 48 & $69 \mathrm{~J}$ & Z2-EU23B-304 & 58.5 & NA & NA & 0 & 2 & NA & 0 \\
\hline Uranium & $2 / 2$ & 4.8 & 24 & Z2-EU23B-304 & 14.4 & NA & NA & 0 & NA & NA & 2 \\
\hline Vanadium & $2 / 2$ & 18 & 33 & Z2-EU23B-305 & 25.5 & NA & NA & 0 & 0 & NA & 2 \\
\hline Zinc & $2 / 2$ & $100 \mathrm{~J}$ & 240 & Z2-EU23B-305 & 170 & NA & NA & 0 & 2 & NA & 0 \\
\hline
\end{tabular}

Avg $=$ average $\quad \mathrm{NA}=$ not applicable

$\mathrm{Bkg}=$ background $\quad \mathrm{PRG}=$ preliminary remediation goal

$\mathrm{EU}=$ exposure unit $\quad$ Res $=$ residential

$\mathrm{GW}=$ groundwater $\quad \mathrm{RL}=$ remediation level

Ind $=$ industrial $\quad \mathrm{SL}=$ screening level

Max $=$ maximum

EU Z2-23 K-1066-C CYLINDER STORAGE YARD PERIMETER PCBs DETECTS (ug/kg)

\begin{tabular}{|c|c|c|c|c|c|c|c|c|c|}
\hline \multirow[b]{2}{*}{ Analyte } & \multirow[b]{2}{*}{$\begin{array}{c}\text { Detect } \\
\text { frequency }\end{array}$} & \multirow[b]{2}{*}{$\underset{\text { detect }}{\text { Minimum }}$} & \multirow[b]{2}{*}{$\underset{\text { detect }}{\text { Maximum }}$} & \multirow[b]{2}{*}{$\begin{array}{l}\text { Location(s) of } \\
\text { maximum detect }\end{array}$} & \multirow{2}{*}{$\begin{array}{c}\text { Average } \\
\text { detected } \\
\text { result }\end{array}$} & \multicolumn{4}{|c|}{$\begin{array}{c}\begin{array}{c}\text { Number of analyses } \\
\text { exceeding criteria }\end{array} \\
\end{array}$} \\
\hline & & & & & & $\begin{array}{c}\text { Max } \\
\text { RL }\end{array}$ & $\begin{array}{c}\text { Avg } \\
\text { RL }\end{array}$ & $\begin{array}{l}\text { Ind } \\
\text { PRG }\end{array}$ & $\begin{array}{l}\text { Res } \\
\text { PRG }\end{array}$ \\
\hline PCB-1254 & $1 / 2$ & 210 & 210 & Z2-EU23B-304 & 210 & 0 & 0 & 0 & 1 \\
\hline PCB-1260 & $1 / 2$ & 240 & 240 & Z2-EU23B-304 & 240 & 0 & 0 & 0 & 1 \\
\hline PCB & $1 / 2$ & 450 & 450 & Z2-EU23B-304 & 450 & 0 & 0 & 0 & 1 \\
\hline
\end{tabular}

Avg $=$ average

$\mathrm{EU}=$ exposure unit

Ind $=$ industrial

Max $=$ maximum
$\mathrm{PCB}=$ polychlorinated biphenyl

$\mathrm{PRG}=$ preliminary remediation goal

Res $=$ residential

$\mathrm{RL}=$ remediation level 
Class 3 SU DVS Biased Sampling at K-1652 UST. Four sample locations were identified during the Class 3 SU facility assessment around the K1652 UST. Subsurface samples were collected from locations on the north (Z2-EU23B-317), east (Z2-EU23B-318), south (Z2-EU23B-319), and west (Z2-EU23B-320) sides of the UST. Analytical results summarized below show metal background exceedances and semivolatile organic compound (SVOC) detections.

Diesel-range organics (DROs) and gasoline-range organics (GROs) were analyzed in all four samples but were not detected.

EU Z2-23 K-1652 UST METALS WITH BACKGROUND, PRG, GW SL, AND/OR RL EXCEEDANCES (mg/kg)

\begin{tabular}{|c|c|c|c|c|c|c|c|c|c|c|c|}
\hline \multirow[b]{2}{*}{ Analyte } & \multirow[b]{2}{*}{$\begin{array}{l}\text { Detect } \\
\text { frequency }\end{array}$} & \multirow[b]{2}{*}{$\begin{array}{c}\text { Minimum } \\
\text { detect }\end{array}$} & \multirow[b]{2}{*}{$\begin{array}{c}\text { Maximum } \\
\text { detect }\end{array}$} & \multirow{2}{*}{$\begin{array}{c}\text { Location(s) of } \\
\text { maximum } \\
\text { detect }\end{array}$} & \multirow{2}{*}{$\begin{array}{c}\text { Average } \\
\text { detected } \\
\text { result }\end{array}$} & \multicolumn{6}{|c|}{ Number of analyses exceeding criteria } \\
\hline & & & & & & $\begin{array}{l}\text { Max } \\
\text { RL }\end{array}$ & $\begin{array}{l}\text { Avg } \\
\text { RL }\end{array}$ & $\begin{array}{l}\text { Ind } \\
\text { PRG }\end{array}$ & Bkg & $\begin{array}{l}\text { GW } \\
\text { SL }\end{array}$ & $\begin{array}{c}\text { Res } \\
\text { PRG }\end{array}$ \\
\hline Aluminum & $4 / 4$ & 15000 & 19000 & Z2-EU23B-318 & 17250 & NA & NA & 0 & 0 & NA & 4 \\
\hline Arsenic & $4 / 4$ & 1.9 & 9 & Z2-EU23B-318 & 4.1 & 0 & 0 & 0 & 0 & 0 & 4 \\
\hline Calcium & $4 / 4$ & 390 & 52000 & Z2-EU23B-318 & 13560 & NA & NA & NA & 1 & NA & NA \\
\hline Copper & $4 / 4$ & 8.2 & 38 & Z2-EU23B-318 & 19.3 & NA & NA & 0 & 1 & NA & 0 \\
\hline Lithium & $4 / 4$ & 27 & 51 & Z2-EU23B-318 & 38 & NA & NA & 0 & 1 & NA & 0 \\
\hline Magnesium & $4 / 4$ & 3100 & 20000 & Z2-EU23B-318 & 7775 & NA & NA & NA & 3 & NA & NA \\
\hline Manganese & $4 / 4$ & 450 & 770 & Z2-EU23B-317 & 593 & NA & NA & 0 & 0 & NA & 4 \\
\hline Uranium & $4 / 4$ & 1.7 & 2.1 & $\begin{array}{l}\text { Z2-EU23B-319 } \\
\text { Z2-EU23B-320 }\end{array}$ & 1.98 & NA & NA & 0 & NA & NA & 4 \\
\hline Vanadium & $4 / 4$ & 26 & 50 & Z2-EU23B-318 & 35.3 & NA & NA & 0 & 0 & NA & 4 \\
\hline
\end{tabular}

Avg $=$ average $\quad \mathrm{NA}=$ not applicable

$\mathrm{Bkg}=$ background $\quad \mathrm{PRG}=$ preliminary remediation goal

$\mathrm{EU}=$ exposure unit $\quad$ Res $=$ residential

$\mathrm{GW}=$ groundwater $\quad \mathrm{RL}=$ remediation level

Ind $=$ industrial $\quad \mathrm{SL}=$ screening level

Max $=$ maximum

EU Z2-23 K-1652 UST SVOC DETECTS (ug/kg)

\begin{tabular}{|c|c|c|c|c|c|c|c|c|}
\hline \multirow[b]{2}{*}{ Analyte } & \multirow{2}{*}{$\begin{array}{c}\text { Detect } \\
\text { frequency }\end{array}$} & \multirow{2}{*}{$\begin{array}{c}\text { Minimum } \\
\text { detect }\end{array}$} & \multirow{2}{*}{$\begin{array}{c}\text { Maximum } \\
\text { detect }\end{array}$} & \multirow{2}{*}{$\begin{array}{c}\text { Location(s) } \\
\text { of maximum } \\
\text { detect }\end{array}$} & \multirow{2}{*}{$\begin{array}{c}\text { Average } \\
\text { detected } \\
\text { result }\end{array}$} & \multicolumn{3}{|c|}{$\begin{array}{c}\text { Number of analyses } \\
\text { exceeding criteria }\end{array}$} \\
\hline & & & & & & Ind PRG & GW SL & Res PRG \\
\hline Benzo(b)fluoranthene & $1 / 4$ & $91 \mathrm{~J}$ & $91 \mathrm{~J}$ & Z2-EU23B-319 & 91 & 0 & NA & 0 \\
\hline Benzo(k)fluoranthene & $1 / 4$ & $110 \mathrm{~J}$ & $110 \mathrm{~J}$ & Z2-EU23B-319 & 110 & 0 & NA & 0 \\
\hline
\end{tabular}

$\mathrm{G}=$ preliminary remediation goal

$\mathrm{RL}=$ remediation level

Ind $=$ industrial $\quad$ SVOC $=$ semivolatile organic compound

$\mathrm{NA}=$ not applicable $\quad$ UST $=$ underground storage tank

Volatile organic compounds (VOCs) were analyzed for in all four samples but were not detected.

Class 3 SU DVS Biased Samples Along the Above-Ground Process Line. Three surface soil sample locations along the above-ground process line in EU Z2-23 were identified during DQO scoping (Z2-EU23B-301, Z2-EU23B-302, and Z2-EU23B-303). Analytical results summarized below show radionuclide Ind PRG exceedances, metal and radionuclide background exceedances, and PCB detections.

EU Z2-23 PROCESS LINES METALS WITH BACKGROUND,

PRG, GW SL, AND/OR RL EXCEEDANCES (mg/kg)

\begin{tabular}{|c|c|c|c|c|c|c|c|c|c|c|c|}
\hline \multirow[b]{2}{*}{ Analyte } & \multirow[b]{2}{*}{$\begin{array}{c}\text { Detect } \\
\text { frequency }\end{array}$} & \multirow[b]{2}{*}{$\begin{array}{c}\text { Minimum } \\
\text { detect }\end{array}$} & \multirow[b]{2}{*}{$\begin{array}{c}\text { Maximum } \\
\text { detect }\end{array}$} & \multirow{2}{*}{$\begin{array}{l}\text { Location(s) of } \\
\text { maximum } \\
\text { detect }\end{array}$} & \multirow{2}{*}{$\begin{array}{c}\text { Average } \\
\text { detected } \\
\text { result }\end{array}$} & \multicolumn{6}{|c|}{ Number of analyses exceeding criteria } \\
\hline & & & & & & $\begin{array}{c}\text { Max } \\
\text { RL }\end{array}$ & $\begin{array}{l}\text { Avg } \\
\text { RL }\end{array}$ & $\begin{array}{l}\text { Ind } \\
\text { PRG }\end{array}$ & Bkg & $\begin{array}{l}\text { GW } \\
\text { SL }\end{array}$ & $\begin{array}{l}\text { Res } \\
\text { PRG }\end{array}$ \\
\hline Aluminum & $3 / 3$ & 7100 & 8600 & Z2-EU23B-301 & 7800 & NA & NA & 0 & 0 & NA & 2 \\
\hline Arsenic & $3 / 3$ & 8.7 & 13 & Z2-EU23B-302 & 10.2 & 0 & 0 & 0 & 0 & 0 & 3 \\
\hline Cadmium & $3 / 3$ & 0.96 & 1.7 & Z2-EU23B-302 & 1.29 & NA & NA & 0 & 3 & NA & 0 \\
\hline Calcium & $3 / 3$ & $3600 \mathrm{~J}$ & 29000 & Z2-EU23B-302 & 13567 & NA & NA & NA & 3 & NA & NA \\
\hline Copper & $3 / 3$ & 21 & 45 & Z2-EU23B-303 & 32.3 & NA & NA & 0 & 2 & NA & 0 \\
\hline Lead & $3 / 3$ & 29 & 140 & Z2-EU23B-303 & 73.7 & NA & NA & 0 & 2 & 0 & 0 \\
\hline Magnesium & $3 / 3$ & 1200 & 15000 & Z2-EU23B-302 & 6233 & NA & NA & NA & 1 & NA & NA \\
\hline
\end{tabular}


EU Z2-23 PROCESS LINES METALS WITH BACKGROUND,

PRG, GW SL, AND/OR RL EXCEEDANCES (mg/kg) (continued)

\begin{tabular}{|c|c|c|c|c|c|c|c|c|c|c|c|}
\hline \multirow[b]{2}{*}{ Analyte } & \multirow[b]{2}{*}{$\begin{array}{c}\text { Detect } \\
\text { frequency }\end{array}$} & \multirow[b]{2}{*}{$\begin{array}{c}\text { Minimum } \\
\text { detect }\end{array}$} & \multirow[b]{2}{*}{$\begin{array}{c}\text { Maximum } \\
\text { detect }\end{array}$} & \multirow{2}{*}{$\begin{array}{c}\text { Location(s) of } \\
\text { maximum } \\
\text { detect }\end{array}$} & \multirow{2}{*}{$\begin{array}{c}\text { Average } \\
\text { detected } \\
\text { result }\end{array}$} & \multicolumn{6}{|c|}{ Number of analyses exceeding criteria } \\
\hline & & & & & & $\begin{array}{c}\text { Max } \\
\text { RL }\end{array}$ & $\begin{array}{c}\text { Avg } \\
\text { RL }\end{array}$ & $\begin{array}{l}\text { Ind } \\
\text { PRG }\end{array}$ & Bkg & $\begin{array}{c}\text { GW } \\
\text { SL }\end{array}$ & $\begin{array}{r}\text { Res } \\
\text { PRG }\end{array}$ \\
\hline Manganese & $3 / 3$ & 1000 & 1500 & Z2-EU23B-302 & 1267 & NA & NA & 0 & 0 & NA & 3 \\
\hline Mercury & $3 / 3$ & 0.071 & 0.19 & Z2-EU23B-303 & 0.127 & 0 & 0 & 0 & 1 & NA & 0 \\
\hline Nickel & $3 / 3$ & 58 & 120 & Z2-EU23B-303 & 82 & NA & NA & 0 & 3 & NA & 0 \\
\hline Uranium & $3 / 3$ & 9.4 & 21 & Z2-EU23B-303 & 14.5 & NA & NA & 0 & NA & NA & 3 \\
\hline Vanadium & $3 / 3$ & 20 & 22 & Z2-EU23B-301 & 21 & NA & NA & 0 & 0 & NA & 3 \\
\hline Zinc & $3 / 3$ & 69 & 140 & Z2-EU23B-303 & 110 & NA & NA & 0 & 2 & NA & 0 \\
\hline
\end{tabular}

Avg $=$ average $\quad$ NA $=$ not applicable

$\mathrm{Bkg}=$ background $\quad \mathrm{PRG}=$ preliminary remediation goal

$\mathrm{EU}=$ exposure unit $\quad$ Res $=$ residential

$\mathrm{GW}=$ groundwater $\quad \mathrm{RL}=$ remediation level

Ind $=$ industrial $\quad \mathrm{SL}=$ screening level

Max $=$ maximum

EU Z2-23 PROCESS LINES PCB DETECTS (ug/kg)

\begin{tabular}{lccccccccc}
\hline & & & & & \multicolumn{3}{c}{$\begin{array}{c}\text { Number of analyses } \\
\text { exceeding criteria }\end{array}$} \\
\cline { 5 - 10 } & Analyte & $\begin{array}{c}\text { Detect } \\
\text { frequency }\end{array}$ & $\begin{array}{c}\text { Minimum } \\
\text { detect }\end{array}$ & $\begin{array}{c}\text { Maximum } \\
\text { detect }\end{array}$ & $\begin{array}{c}\text { Location(s) of } \\
\text { maximum detect }\end{array}$ & $\begin{array}{c}\text { Average } \\
\text { detected } \\
\text { result }\end{array}$ & $\begin{array}{c}\text { Max Avg } \\
\text { RL }\end{array}$ & $\begin{array}{c}\text { Ind } \\
\text { RRG }\end{array}$ & $\begin{array}{c}\text { Res } \\
\text { PRG }\end{array}$ \\
\hline PCB-1254 & $2 / 3$ & 39 & 190 & Z2-EU23B-303 & 115 & 0 & 0 & 0 & 1 \\
PCB-1260 & $2 / 3$ & 67 & 120 & Z2-EU23B-303 & 93.5 & 0 & 0 & 0 & 1 \\
PCB & $2 / 3$ & 110 & 300 & Z2-EU23B-303 & 205 & 0 & 0 & 0 & 1 \\
\hline
\end{tabular}

Avg $=$ average $\quad$ PCB $=$ polychlorinated biphenyl

$\mathrm{EU}=$ exposure unit $\quad \mathrm{PRG}=$ preliminary remediation goal

Ind $=$ industrial $\quad$ Res $=$ residential

Max = maximum $\quad \mathrm{RL}=$ remediation level

EU Z2-23 PROCESS LINES RADIONUCLIDES WITH BACKGROUND, PRG, AND/OR RL EXCEEDANCES (pCi/g)

\begin{tabular}{|c|c|c|c|c|c|c|c|c|c|c|c|}
\hline \multirow[b]{2}{*}{ Analyte } & \multirow[b]{2}{*}{$\begin{array}{c}\text { Detect } \\
\text { frequency }\end{array}$} & \multirow[b]{2}{*}{$\begin{array}{c}\text { Minimum } \\
\text { detect }\end{array}$} & \multirow[b]{2}{*}{$\begin{array}{c}\text { Maximum } \\
\text { detect }\end{array}$} & \multirow{2}{*}{$\begin{array}{c}\text { Location(s) of } \\
\text { maximum } \\
\text { detect }\end{array}$} & \multirow{2}{*}{$\begin{array}{l}\text { Average } \\
\text { detected } \\
\text { result }\end{array}$} & \multicolumn{6}{|c|}{ Number of analyses exceeding criteria } \\
\hline & & & & & & $\begin{array}{c}\text { Max } \\
\text { RL }\end{array}$ & $\begin{array}{c}\text { Avg } \\
\text { RL } \\
\end{array}$ & $\begin{array}{c}\text { Ind } \\
\text { PRG }\end{array}$ & Bkg & $\begin{array}{c}\text { GW } \\
\text { SL }\end{array}$ & $\begin{array}{c}\text { Res } \\
\text { PRG } \\
\end{array}$ \\
\hline Cesium-137 & $2 / 3$ & 0.449 & $0.991 \mathrm{~J}$ & Z2-EU23B-303 & 0.72 & 0 & 0 & 0 & NA & NA & 2 \\
\hline Potassium-40 & $3 / 3$ & $8.54 \mathrm{~J}$ & 13.3 & Z2-EU23B-301 & 11.1 & NA & NA & 3 & 0 & NA & 3 \\
\hline Radium-226 & $3 / 3$ & $0.613 \mathrm{~J}$ & $0.988 J$ & Z2-EU23B-301 & 0.808 & NA & NA & 3 & 0 & NA & 3 \\
\hline Technetium-99 & $3 / 3$ & $6.52 \mathrm{~J}$ & $57.9 \mathrm{~J}$ & Z2-EU23B-303 & 24.1 & NA & NA & 0 & NA & NA & 3 \\
\hline Thorium -228 & $3 / 3$ & 0.961 & 1.19 & Z2-EU23B-301 & 1.08 & NA & NA & 3 & 0 & NA & 3 \\
\hline Thorium -230 & $3 / 3$ & $0.921 \mathrm{~J}$ & $1.63 \mathrm{~J}$ & Z2-EU23B-302 & 1.21 & NA & NA & 0 & 1 & NA & 0 \\
\hline Thorium -232 & $3 / 3$ & 0.806 & 1.2 & Z2-EU23B-303 & 1.04 & NA & NA & 3 & 0 & NA & 3 \\
\hline Uranium-234 & $3 / 3$ & 10.2 & 41 & Z2-EU23B-303 & 21.1 & 0 & 0 & 0 & NA & 0 & 3 \\
\hline Uranium-235 & $3 / 3$ & $0.47 \mathrm{~J}$ & $1.8 \mathrm{~J}$ & Z2-EU23B-303 & 1.06 & 0 & 0 & 0 & NA & 0 & 3 \\
\hline Uranium-238 & $3 / 3$ & 3.44 & 7.84 & Z2-EU23B-303 & 5.70 & 0 & 0 & 0 & 3 & 0 & 3 \\
\hline
\end{tabular}

Avg = average

$\mathrm{NA}=$ not applicable

$\mathrm{Bkg}=$ background $\quad \mathrm{PRG}=$ preliminary remediation goal

$\mathrm{EU}=$ exposure unit $\quad$ Res $=$ residential

$\mathrm{GW}=$ groundwater $\quad \mathrm{RL}=$ remediation level

Ind $=$ industrial $\quad \mathrm{SL}=$ screening level

Max $=$ maximum

Class 3 SU Historical Samples. There are 16 historical sample locations in EU Z2-23 (see Sect. 2.2.3 for historical sample location identifiers). All historical sample locations, except the early characterization location, are from around the K-1652 Plant Protection Headquarters. Additional characterization activities at K-1652 were conducted during DVS characterization at the K-1652 UST (summarized above). Analytical results from the historical samples summarized below show radionuclide Ind PRG exceedances; metal and radionuclide Bkg exceedances; and detections of anions, PCBs, SVOCs, and VOCs. 
EU Z2-23 CLASS 3 SU HISTORICAL ANION ANALYSIS RESULTS (mg/kg)

\begin{tabular}{lccccc}
\hline \multicolumn{1}{c}{ Analyte } & $\begin{array}{c}\text { Detect } \\
\text { frequency }\end{array}$ & $\begin{array}{c}\text { Minimum } \\
\text { detect }\end{array}$ & $\begin{array}{c}\text { Maximum } \\
\text { detect }\end{array}$ & $\begin{array}{c}\text { Location(s) of } \\
\text { maximum detect }\end{array}$ & $\begin{array}{c}\text { Average } \\
\text { detected result }\end{array}$ \\
\hline Fluoride & $2 / 3$ & 6.8 & $10 \mathrm{~J}$ & Z2-EU22-035 & 8.4 \\
\hline $\mathrm{EU}=$ exposure unit & & & & & \\
$\mathrm{SU}=$ soil unit & & & & &
\end{tabular}

EU Z2-23 CLASS 3 SU HISTORICAL METALS ${ }^{a}$ WITH BACKGROUND, PRG, GW SL, AND/OR RL EXCEEDANCES (mg/kg)

\begin{tabular}{|c|c|c|c|c|c|c|c|c|c|c|c|}
\hline \multirow[b]{2}{*}{ Analyte } & \multirow[b]{2}{*}{$\begin{array}{c}\text { Detect } \\
\text { frequency }\end{array}$} & \multirow[b]{2}{*}{$\begin{array}{c}\text { Minimum } \\
\text { detect }\end{array}$} & \multirow[b]{2}{*}{$\underset{\text { detect }}{\text { Maximum }}$} & \multirow{2}{*}{$\begin{array}{c}\text { Location(s) of } \\
\text { maximum } \\
\text { detect }\end{array}$} & \multirow{2}{*}{$\begin{array}{c}\text { Average } \\
\text { detected } \\
\text { result }\end{array}$} & \multicolumn{6}{|c|}{ Number of analyses exceeding criteria } \\
\hline & & & & & & $\begin{array}{l}\text { Max } \\
\text { RL }\end{array}$ & $\begin{array}{l}\text { Avg } \\
\text { RL }\end{array}$ & $\begin{array}{l}\text { Ind } \\
\text { PRG }\end{array}$ & Bkg & $\begin{array}{l}\mathbf{G W} \\
\text { SL }\end{array}$ & $\begin{array}{r}\text { Res } \\
\text { PRG }\end{array}$ \\
\hline Aluminum & $22 / 22$ & $7,628.26 \mathrm{~J}$ & 30,000 & AU-I1-01-1652 & 20,483 & NA & NA & 0 & 0 & NA & 22 \\
\hline Arsenic & $22 / 22$ & 0.91 & 15 & Z2-EU22-035 & 3.82 & 0 & 0 & 0 & 1 & 0 & 22 \\
\hline Barium & $22 / 22$ & 30 & 180 & AU-03-01-1652 & 84.9 & NA & NA & 0 & 1 & 0 & 0 \\
\hline Beryllium & $22 / 22$ & 0.3109 & 2.7 & AU-06-01-1652 & 1.28 & 0 & 0 & 0 & 2 & NA & 0 \\
\hline Cadmium & $21 / 22$ & $0.063 \mathrm{~J}$ & 0.75 & Z2-EU22-035 & 0.254 & NA & NA & 0 & 9 & NA & 0 \\
\hline Calcium & $21 / 21$ & $270 \mathrm{~J}$ & 58,000 & AU-I3-01-1652 & 12,291 & NA & NA & NA & 16 & NA & NA \\
\hline Chromium & $22 / 22$ & $9.6176 \mathrm{~J}$ & 30 & Z2-EU22-035 & 17.9 & NA & NA & 0 & 0 & 0 & 3 \\
\hline Copper & $22 / 22$ & 8.4 & 34 & Z2-EU22-035 & 19.1 & NA & NA & 0 & 8 & NA & 0 \\
\hline Lead & $22 / 22$ & 3.1 & 66 & AU-01-01-1652 & 18.6 & NA & NA & 0 & 3 & 0 & 0 \\
\hline Magnesium & $21 / 21$ & 1800 & $25,000 \mathrm{~J}$ & AU-05-01-1652 & 7,143 & NA & NA & NA & 15 & NA & NA \\
\hline Manganese & $22 / 22$ & $260 \mathrm{~J}$ & 3,900 & AU-03-01-1652 & 844 & NA & NA & 0 & 1 & NA & 22 \\
\hline Nickel & $22 / 22$ & $7.0377 \mathrm{~J}$ & 71 & AU-07-01-1652 & 27.7 & NA & NA & 0 & 10 & NA & 0 \\
\hline Potassium & $21 / 21$ & 1,100 & 7,500 & $\begin{array}{l}\text { AU-I2-01-1652 } \\
\text { AU-06-01-1552 }\end{array}$ & 4,319 & NA & NA & NA & 11 & NA & NA \\
\hline Selenium & $21 / 22$ & 0.57 & $1.8 \mathrm{~J}$ & AU-06-01-1652 & 0.970 & NA & NA & 0 & 1 & NA & 0 \\
\hline Uranium & $4 / 4$ & 0.0477 & 1.9 & Z2-EU22-035 & 1.31 & NA & NA & 0 & NA & NA & 3 \\
\hline Vanadium & $22 / 22$ & $16.8432 \mathrm{~J}$ & 55 & Z2-EU22-035 & 28.3 & NA & NA & 0 & 0 & NA & 22 \\
\hline Zinc & $22 / 22$ & 38 & 90 & AU-01-01-1652 & 55.9 & NA & NA & 0 & 1 & NA & 0 \\
\hline
\end{tabular}

${ }^{a}$ Hexavalent chromium was analyzed in three samples from location Z2-EU22-035 but none was detected.

$\begin{array}{ll}\text { Avg = average } & \mathrm{NA}=\text { not applicable } \\ \mathrm{Bkg}=\text { backgroun } \mathrm{d} & \mathrm{PRG}=\text { preliminary remediation goal } \\ \mathrm{EU}=\text { exposure unit } & \text { Res = residential } \\ \mathrm{GW}=\text { groundwater } & \mathrm{RL}=\text { remediation level } \\ \mathrm{Ind}=\text { industrial } & \mathrm{SL}=\text { screening level } \\ \mathrm{Max}=\text { maximum } & \end{array}$

EU Z2-23 CLASS 3 SU HISTORICAL PCB DETECTS (ug/kg)

\begin{tabular}{|c|c|c|c|c|c|c|c|c|c|}
\hline \multirow[b]{2}{*}{ Analyte } & \multirow[b]{2}{*}{$\begin{array}{c}\text { Detect } \\
\text { frequency }\end{array}$} & \multirow[b]{2}{*}{$\begin{array}{c}\text { Minimum } \\
\text { detect }\end{array}$} & \multirow[b]{2}{*}{$\begin{array}{c}\text { Maximum } \\
\text { detect }\end{array}$} & \multirow[b]{2}{*}{$\begin{array}{l}\text { Location(s) of } \\
\text { maximum detect }\end{array}$} & \multirow{2}{*}{$\begin{array}{c}\text { Average } \\
\text { detected } \\
\text { result }\end{array}$} & \multicolumn{4}{|c|}{$\begin{array}{c}\text { Number of analyses } \\
\text { exceeding criteria }\end{array}$} \\
\hline & & & & & & $\begin{array}{c}\text { Max } \\
\text { RL }\end{array}$ & $\begin{array}{c}\text { Avg } \\
\text { RL }\end{array}$ & $\begin{array}{l}\text { Ind } \\
\text { PRG }\end{array}$ & $\begin{array}{c}\text { Res } \\
\text { PRG }\end{array}$ \\
\hline PCB-1254 & $1 / 20$ & 2.4072 & 2.4072 & 1652-RAD-002 & 2.41 & 0 & 0 & 0 & 0 \\
\hline PCB-1260 & $3 / 20$ & 19J & 51 & Z2-EU22-035 & 35.3 & 0 & 0 & 0 & 0 \\
\hline PCB & $2 / 3$ & $19 \mathrm{~J}$ & 51 & Z2-EU22-035 & 35 & 0 & 0 & 0 & 0 \\
\hline
\end{tabular}

\begin{tabular}{ll}
\hline Avg $=$ average & PCB $=$ polychlorinated biphenyl \\
EU $=$ exposure unit & PRG $=$ preliminary remediation goal \\
Ind $=$ industrial & Res $=$ residential
\end{tabular}

Max = maximum $\quad$ RL $=$ remediation level

EU Z2-23 CLASS 3 SU HISTORICAL RADIONUCLIDES WITH BACKGROUND, PRG, AND/OR RL EXCEEDANCES (pCi/g)

\begin{tabular}{|c|c|c|c|c|c|c|c|c|c|c|c|}
\hline \multirow[b]{2}{*}{ Analyte } & \multirow[b]{2}{*}{$\begin{array}{c}\text { Detect } \\
\text { frequency }\end{array}$} & \multirow[b]{2}{*}{$\begin{array}{c}\text { Minimum } \\
\text { detect }\end{array}$} & \multirow[b]{2}{*}{$\begin{array}{c}\text { Maximum } \\
\text { detect }\end{array}$} & \multirow{2}{*}{$\begin{array}{c}\text { Location(s) of } \\
\text { maximum } \\
\text { detect }\end{array}$} & \multirow{2}{*}{$\begin{array}{c}\text { Average } \\
\text { detected } \\
\text { result }\end{array}$} & \multicolumn{6}{|c|}{ Number of analyses exceeding criteria } \\
\hline & & & & & & $\begin{array}{c}\text { Max } \\
\text { RL }\end{array}$ & $\begin{array}{l}\text { Avg } \\
\text { RL }\end{array}$ & $\begin{array}{l}\text { Ind } \\
\text { PRG }\end{array}$ & Bkg & $\begin{array}{l}\text { GW } \\
\text { SL }\end{array}$ & $\begin{array}{c}\text { Res } \\
\text { PRG }\end{array}$ \\
\hline 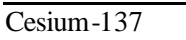 & $11 / 30$ & 0.04 & 0.42 & AU-04-01-1652 & 0.243 & 0 & 0 & 0 & NA & NA & 10 \\
\hline Neptunium-237 & $2 / 11$ & 0.06 & $0.35 \mathrm{~J}$ & 1652-RAD-003 & 0.205 & 0 & 0 & 0 & NA & NA & 1 \\
\hline Potassium-40 & $6 / 6$ & 5.06 & 19.2 & Z2-EU22-035 & 12.8 & NA & NA & 6 & 0 & NA & 6 \\
\hline Radium-226 & $3 / 3$ & $1.18 \mathrm{~J}$ & $1.64 \mathrm{~J}$ & Z2-EU22-035 & 1.48 & NA & NA & 3 & 2 & NA & 3 \\
\hline Technetium-99 & $17 / 30$ & $0.08 \mathrm{~J}$ & 20.4 & AU-07-01-1652 & 7.73 & NA & NA & 0 & NA & NA & 16 \\
\hline
\end{tabular}


EU Z2-23 CLASS 3 SU HISTORICAL RADIONUCLIDES WITH BACKGROUND,

PRG, AND/OR RL EXCEEDANCES (pCi/g) (continued)

\begin{tabular}{|c|c|c|c|c|c|c|c|c|c|c|c|}
\hline \multirow[b]{2}{*}{ Analyte } & \multirow[b]{2}{*}{$\begin{array}{c}\text { Detect } \\
\text { frequency }\end{array}$} & \multirow[b]{2}{*}{$\begin{array}{c}\text { Minimum } \\
\text { detect }\end{array}$} & \multirow[b]{2}{*}{$\begin{array}{c}\text { Maximum } \\
\text { detect }\end{array}$} & \multirow{2}{*}{$\begin{array}{c}\text { Location(s) of } \\
\text { maximum } \\
\text { detect }\end{array}$} & \multirow{2}{*}{$\begin{array}{c}\text { Average } \\
\text { detected } \\
\text { result }\end{array}$} & \multicolumn{6}{|c|}{ Number of analyses exceeding criteria } \\
\hline & & & & & & $\begin{array}{l}\text { Max } \\
\text { RL }\end{array}$ & $\begin{array}{l}\text { Avg } \\
\text { RL }\end{array}$ & $\begin{array}{l}\text { Ind } \\
\text { PRG }\end{array}$ & Bkg & $\begin{array}{l}\text { GW } \\
\text { SL }\end{array}$ & $\begin{array}{c}\text { Res } \\
\text { PRG }\end{array}$ \\
\hline Thorium -228 & $10 / 10$ & 0.46 & 2.3 & Z2-EU22-035 & 1.26 & NA & NA & 9 & 1 & NA & 9 \\
\hline Thorium -230 & 9/9 & $0.51 \mathrm{~J}$ & 2.33 & Z2-EU22-035 & 1.41 & NA & NA & 0 & 8 & NA & 0 \\
\hline Thorium -232 & $10 / 10$ & 0.38 & 2.28 & Z2-EU22-035 & 1.27 & NA & NA & 10 & 1 & NA & 10 \\
\hline Uranium-233/234 & $27 / 27$ & $1.15 \mathrm{~J}$ & $20.8 \mathrm{~J}$ & AU-07-01-1652 & 5.94 & 0 & 0 & 0 & NA & 0 & 10 \\
\hline Uranium-235 & $3 / 6$ & 0.154 & 0.64 & 1652-RAD-001 & 0.471 & 0 & 0 & 0 & NA & 0 & 2 \\
\hline Uranium-235/236 & $24 / 24$ & 0.04 & $0.9 \mathrm{~J}$ & AU-07-01-1652 & 0.208 & 0 & 0 & 0 & NA & 0 & 8 \\
\hline Uranium-238 & $30 / 30$ & 0.898 & $5.41 \mathrm{~J}$ & AU-01-01-1652 & 2.34 & 0 & 0 & 0 & 21 & 0 & 30 \\
\hline \multicolumn{2}{|l|}{$\overline{\text { Avg }=\text { average }}$} & \multicolumn{10}{|c|}{ NA $=$ not applicable } \\
\hline \multirow{2}{*}{\multicolumn{2}{|c|}{$\mathrm{Bkg}=$ background }} & \multirow{2}{*}{\multicolumn{10}{|c|}{$\mathrm{PRG}=$ preliminary remediation goal }} \\
\hline & & & & & & & & & & & \\
\hline EU = exposure unit & & \multicolumn{10}{|c|}{ Res $=$ residential } \\
\hline Ind = industrial & & \multicolumn{2}{|c|}{$\begin{array}{l}\mathrm{RL}=\text { remediation level } \\
\mathrm{SL}=\text { screenin } \mathrm{g} \text { level }\end{array}$} & & & & & & & & \\
\hline \multicolumn{2}{|l|}{ Max $=$ maximum } & & & & & & & & & & \\
\hline
\end{tabular}

EU Z2-23 CLASS 3 SU HISTORICAL SVOC DETECTS (ug/kg)

\begin{tabular}{|c|c|c|c|c|c|c|c|c|}
\hline \multirow[b]{2}{*}{ Analyte } & \multirow[b]{2}{*}{$\begin{array}{c}\text { Detect } \\
\text { frequency }\end{array}$} & \multirow[b]{2}{*}{$\begin{array}{c}\text { Minimum } \\
\text { detect }\end{array}$} & \multirow[b]{2}{*}{$\begin{array}{c}\text { Maximum } \\
\text { detect }\end{array}$} & \multirow{2}{*}{$\begin{array}{c}\text { Location(s) of } \\
\text { maximum } \\
\text { detect }\end{array}$} & \multirow{2}{*}{$\begin{array}{c}\text { Average } \\
\text { detected } \\
\text { result }\end{array}$} & \multicolumn{3}{|c|}{$\begin{array}{c}\text { Number of analyses } \\
\text { exceeding criteria }\end{array}$} \\
\hline & & & & & & $\begin{array}{l}\text { Ind } \\
\text { PRG }\end{array}$ & $\begin{array}{c}\text { GW } \\
\text { SL }\end{array}$ & $\begin{array}{c}\text { Res } \\
\text { PRG }\end{array}$ \\
\hline 2-Methylnaphthalene & $1 / 24$ & $370 \mathrm{~J}$ & $370 \mathrm{~J}$ & AU-03-01-1652 & 2370 & 0 & NA & NA \\
\hline Acenaphthene & $2 / 24$ & $44 \mathrm{~J}$ & 1000 & AU-03-01-1652 & 522 & 0 & NA & 0 \\
\hline Anthracene & $4 / 24$ & $53 \mathrm{~J}$ & 1700 & AU-03-01-1652 & 492 & 0 & NA & 0 \\
\hline Benz(a)anthracene & $6 / 24$ & $67 \mathrm{~J}$ & 2400 & AU-03-01-1652 & 519 & 0 & NA & 1 \\
\hline Benzo(a)pyrene & $5 / 24$ & 82.0945 & 1700 & AU-03-01-1652 & 466 & 0 & NA & 5 \\
\hline Benzo(b)fluoranthene & $5 / 24$ & $130 \mathrm{~J}$ & 1600 & AU-03-01-1652 & 459 & 0 & NA & 1 \\
\hline Benzo(ghi)perylene & $3 / 24$ & $130 \mathrm{~J}$ & 1000 & AU-03-01-1652 & 443 & 0 & NA & 0 \\
\hline Benzo(k)fluoranthene & $5 / 24$ & 96.312 & 1700 & AU-03-01-1652 & 455 & 0 & NA & 0 \\
\hline Bis(2-ethylhexyl)phthalate & $2 / 24$ & $57 \mathrm{~J}$ & 98.7498 & 1652-RAD-003 & 77.9 & 0 & 0 & 0 \\
\hline Carbazole & $1 / 21$ & 1300 & 1300 & AU-03-01-1652 & 1300 & 0 & NA & 0 \\
\hline Chrysene & $6 / 24$ & $65 \mathrm{~J}$ & 2400 & AU-03-01-1652 & 530 & 0 & NA & 0 \\
\hline Dibenz(a,h)anthracene & $2 / 24$ & $56 \mathrm{~J}$ & 600 & AU-03-01-1652 & 328 & 0 & NA & 1 \\
\hline Dibenzofuran & $1 / 24$ & 580 & 580 & AU-03-01-1652 & 580 & 0 & NA & 0 \\
\hline Diethyl phthalate & $1 / 24$ & $150 \mathrm{~J}$ & $150 \mathrm{~J}$ & AU-I3-01-1652 & 150 & 0 & NA & 0 \\
\hline Fluoranthene & $7 / 24$ & 94.9697 & 5800 & AU-03-01-1652 & 1048 & 0 & NA & 0 \\
\hline Fluorene & $1 / 24$ & 1000 & 1000 & AU-03-01-1652 & 1000 & 0 & NA & 0 \\
\hline Indeno(1,2,3-cd)pyrene & $3 / 24$ & $120 \mathrm{~J}$ & 1000 & AU-03-01-1652 & 427 & 0 & NA & 1 \\
\hline Naphthalene & $1 / 30$ & 880 & 880 & AU-03-01-1652 & 880 & 0 & NA & 0 \\
\hline Phenanthrene & $6 / 24$ & $39 \mathrm{~J}$ & 6100 & AU-03-01-1652 & 1167 & 0 & NA & 0 \\
\hline Phenol & $1 / 24$ & $49 \mathrm{~J}$ & $49 \mathrm{~J}$ & AU-03-01-1652 & 49 & 0 & NA & 0 \\
\hline Pyrene & $7 / 24$ & 77.4501 & 4800 & AU-03-01-1652 & 883 & 0 & NA & 0 \\
\hline \multicolumn{2}{|c|}{$\begin{array}{l}\text { EU = exposure unit } \\
\text { GW = groundwater } \\
\text { Ind = industrial } \\
\text { NA = not applicable } \\
\text { PRG = preliminary remediation goal }\end{array}$} & \multicolumn{3}{|c|}{$\begin{array}{l}\text { RL = remediation level } \\
\text { SL = screening level } \\
\text { SU = soil unit } \\
\text { SVOC = semivolatile organic compound }\end{array}$} & & & & \\
\hline
\end{tabular}




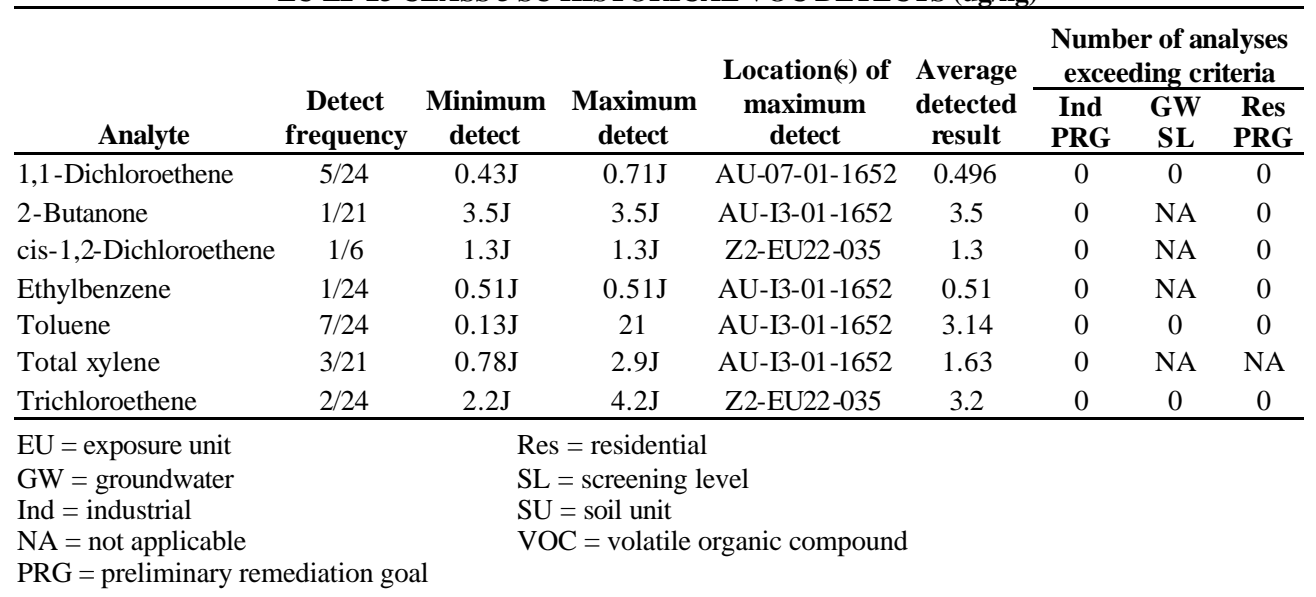

EU Z2-23 Summary. A summary of all DVS and historical analytical results from EU Z2-23, including analytical results for the K-300 Area Service Station FFA site, is shown below (Sect. 2.2.6). There are 34 sample locations in EU Z2-23. Analytical results from samples collected at these locations present PCB-1254, total PCB, Cs-137 Avg RL exceedances, U-234 GW SL exceedances, metal and radionuclide Ind PRG and Bkg exceedances, and detections of PCBs, SVOCs, and VOCs. All Avg RL and GW SL exceedances occur in samples at the sediment accumulation area located northeast of the K-1066-C Cylinder Storage Yard. The remainder of the EU has minimal impact in terms of the evaluation criteria, including the K-1652 Plant Protection Headquarters and surrounding land.

\begin{tabular}{lcccccc}
\hline \multicolumn{1}{c}{ EU Z2-23 ANION ANALYSIS RESULTS $(\mathrm{mg} / \mathrm{kg})$} \\
\hline Analyte & $\begin{array}{c}\text { Detect } \\
\text { frequency }\end{array}$ & $\begin{array}{c}\text { Minimum } \\
\text { detect }\end{array}$ & $\begin{array}{c}\text { Maximum } \\
\text { detect }\end{array}$ & $\begin{array}{c}\text { Location(s) of } \\
\text { maximum } \\
\text { detect }\end{array}$ & $\begin{array}{c}\text { Average } \\
\text { detected } \\
\text { result }\end{array}$ \\
\hline Fluoride & $2 / 3$ & 6.8 & $10 \mathrm{~J}$ & Z2-EU22-035 & 8.4 \\
\hline $\mathrm{EU}=$ exposure unit & & & & &
\end{tabular}

DRO and GRO were analyzed for in seven samples but were not detected.

EU Z2-23 METALS WITH BACKGROUND, PRG, GW SL, AND/OR RL EXCEEDANCES (mg/kg)

\begin{tabular}{|c|c|c|c|c|c|c|c|c|c|c|c|}
\hline \multirow[b]{2}{*}{ Analyte } & \multirow[b]{2}{*}{$\begin{array}{c}\text { Detect } \\
\text { frequency }\end{array}$} & \multirow[b]{2}{*}{$\underset{\text { detect }}{\text { Minimum }}$} & \multirow[b]{2}{*}{$\underset{\text { detect }}{\text { Maximum }}$} & \multirow{2}{*}{$\begin{array}{c}\text { Location(s) } \\
\text { of maximum } \\
\text { detect }\end{array}$} & \multirow{2}{*}{$\begin{array}{c}\text { Average } \\
\text { detected } \\
\text { result }\end{array}$} & \multicolumn{6}{|c|}{ Number of analyses exceeding criteria } \\
\hline & & & & & & $\begin{array}{l}\text { Max } \\
\text { RL }\end{array}$ & $\begin{array}{c}\text { Avg } \\
\text { RL }\end{array}$ & $\begin{array}{l}\text { Ind } \\
\text { PRG }\end{array}$ & Bkg & $\begin{array}{l}\text { GW } \\
\text { SL }\end{array}$ & $\begin{array}{c}\text { Res } \\
\text { PRG }\end{array}$ \\
\hline Aluminum & $39 / 39$ & 5,400 & 30,000 & AU-I1-01-1652 & 17,434 & $\mathrm{NA}$ & NA & 0 & 0 & NA & 35 \\
\hline Antimony & $39 / 39$ & 0.01 & 6.8 & Z2-EU23B-306 & 0.398 & NA & NA & 0 & 2 & 0 & 1 \\
\hline Arsenic & $39 / 39$ & 0.91 & 18 & Z2-EU23B-306 & 5.20 & 0 & 0 & 1 & 2 & 0 & 39 \\
\hline Barium & $39 / 39$ & 30 & 180 & AU-03-01-1652 & 81.4 & NA & NA & 0 & 2 & 0 & 0 \\
\hline Beryllium & $39 / 39$ & 0.31 & 2.7 & AU-06-01-1652 & 1.34 & 0 & 0 & 0 & 2 & NA & 0 \\
\hline Cadmium & $38 / 39$ & $0.06 \mathrm{~J}$ & 16 & Z2-EU23B-306 & 1.12 & NA & NA & 0 & 19 & NA & 2 \\
\hline Calcium & $38 / 38$ & $270 \mathrm{~J}$ & $77,000 \mathrm{~J}$ & Z2-EU23B-304 & 16,459 & NA & NA & NA & 26 & NA & NA \\
\hline Chromium & $39 / 39$ & $9.62 \mathrm{~J}$ & 110 & Z2-EU23B-306 & 20.6 & NA & NA & 0 & 1 & 0 & 6 \\
\hline Cobalt & $39 / 39$ & $4.19 \mathrm{~J}$ & $47 \mathrm{~J}$ & Z2-EU23B-310 & 14.6 & NA & NA & 0 & 1 & NA & 0 \\
\hline Copper & $39 / 39$ & 8.2 & 170 & Z2-EU23B-306 & 27.2 & NA & NA & 0 & 20 & NA & 0 \\
\hline Lead & $39 / 39$ & 3.1 & 450 & Z2-EU23B-306 & 39.6 & NA & NA & 0 & 11 & 0 & 1 \\
\hline Lithium & $20 / 20$ & 5.8 & 51 & Z2-EU23B-318 & 17.8 & NA & NA & 0 & 1 & NA & 0 \\
\hline Magnesium & $38 / 38$ & 1,200 & $29,000 \mathrm{~J}$ & Z2-EU23B-307 & 7,213 & NA & NA & NA & 25 & NA & NA \\
\hline Manganese & $39 / 39$ & $260 \mathrm{~J}$ & 3,900 & AU-03-01-1652 & 870 & NA & NA & 0 & 1 & NA & 39 \\
\hline Mercury & $39 / 39$ & $0.0053 \mathrm{~J}$ & 1.3 & Z2-EU23B-306 & 0.092 & 0 & 0 & 0 & 2 & NA & 0 \\
\hline Nickel & $39 / 39$ & $7.04 \mathrm{~J}$ & 580 & Z2-EU23B-306 & 52.03 & NA & NA & 0 & 21 & NA & 2 \\
\hline
\end{tabular}


EU Z2-23 METALS WITH BACKGROUND, PRG,

GW SL, AND/OR RL EXCEEDANCES (mg/kg) (continued)

\begin{tabular}{|c|c|c|c|c|c|c|c|c|c|c|c|}
\hline \multirow[b]{2}{*}{ Analyte } & \multirow[b]{2}{*}{$\begin{array}{c}\text { Detect } \\
\text { frequency }\end{array}$} & \multirow[b]{2}{*}{$\begin{array}{c}\text { Minimum } \\
\text { detect }\end{array}$} & \multirow[b]{2}{*}{$\begin{array}{c}\text { Maximum } \\
\text { detect }\end{array}$} & \multirow{2}{*}{$\begin{array}{c}\text { Location(s) } \\
\text { of maximum } \\
\text { detect }\end{array}$} & \multirow{2}{*}{$\begin{array}{c}\text { Average } \\
\text { detected } \\
\text { result }\end{array}$} & \multicolumn{6}{|c|}{ Number of analyses exceeding criteria } \\
\hline & & & & & & $\begin{array}{c}\text { Max } \\
\text { RL }\end{array}$ & $\begin{array}{l}\text { Avg } \\
\text { RL }\end{array}$ & $\begin{array}{l}\text { Ind } \\
\text { PRG }\end{array}$ & Bkg & $\begin{array}{l}\text { GW } \\
\text { SL }\end{array}$ & $\begin{array}{l}\text { Res } \\
\text { PRG }\end{array}$ \\
\hline Potassium & $38 / 38$ & 630 & 7500 & $\begin{array}{l}\text { AU-06-01-1652 } \\
\text { AU-I2-01-1652 }\end{array}$ & 3109 & NA & NA & NA & 11 & NA & NA \\
\hline Selenium & $26 / 39$ & 0.57 & 1.9 & Z2-EU23B-310 & 1.01 & NA & NA & 0 & 2 & NA & 0 \\
\hline Uranium & $21 / 21$ & 0.05 & 74 & Z2-EU23B-306 & 11.64 & NA & NA & 0 & NA & NA & 21 \\
\hline Vanadium & $39 / 39$ & 12 & 55 & Z2-EU22-035 & 28.8 & NA & NA & 0 & 0 & NA & 39 \\
\hline Zinc & $39 / 39$ & 38 & 720 & Z2-EU23B-306 & 93.5 & NA & NA & 0 & 9 & NA & 0 \\
\hline
\end{tabular}

Avg $=$ average $\quad$ NA $=$ not applicable

$\mathrm{Bkg}=$ background $\quad \mathrm{PRG}=$ preliminary remediation goal

$\mathrm{EU}=$ exposure unit $\quad$ Res $=$ residential

$\mathrm{GW}=$ groundwater $\quad \mathrm{RL}=$ remediation level

Ind $=$ industrial $\quad \mathrm{SL}=$ screening level

Max $=$ maximum

EU Z2-23 PCB DETECTS (ug/kg)

\begin{tabular}{lccccccccc}
\hline & & & & & \multicolumn{3}{c}{$\begin{array}{c}\text { Number of analyses } \\
\text { exceeding criteria }\end{array}$} \\
\cline { 6 - 11 } & Analyte & $\begin{array}{c}\text { Detect } \\
\text { frequency }\end{array}$ & $\begin{array}{c}\text { Minimum } \\
\text { detect }\end{array}$ & $\begin{array}{c}\text { Maximum } \\
\text { detect }\end{array}$ & $\begin{array}{c}\text { Location(s) of } \\
\text { maximum detect }\end{array}$ & $\begin{array}{c}\text { Average } \\
\text { detected } \\
\text { result }\end{array}$ & $\begin{array}{c}\text { Max Avg } \\
\text { RL }\end{array}$ & $\begin{array}{c}\text { Ind } \\
\text { PRG }\end{array}$ & $\begin{array}{c}\text { Res } \\
\text { PRG }\end{array}$ \\
\hline PCB-1254 & $11 / 32$ & 2.41 & 55000 & Z2-EU23B-306 & 7890 & 0 & 2 & 2 & 9 \\
PCB-1260 & $11 / 32$ & $19 \mathrm{~J}$ & $7300 \mathrm{~J}$ & Z2-EU23B-310 & 953 & 0 & 0 & 0 & 7 \\
PCB & $12 / 15$ & $19 \mathrm{~J}$ & 55000 & Z2-EU23B-306 & 8102 & 0 & 2 & 2 & 9 \\
\hline
\end{tabular}

Avg $=$ average

$\mathrm{EU}=$ exposure unit

Ind $=$ industrial

$\mathrm{PCB}=$ polychlorinated biphenyl

$\mathrm{PRG}=$ preliminary remediation goal

Max = maximum

$\mathrm{RL}=$ remediation level

EU Z2-23 RADIONUCLIDES WITH BACKGROUND,

PRG, AND/OR RL EXCEEDANCES (pCi/g)

\begin{tabular}{|c|c|c|c|c|c|c|c|c|c|c|c|}
\hline \multirow[b]{2}{*}{ Analyte } & \multirow[b]{2}{*}{$\begin{array}{c}\text { Detect } \\
\text { frequency }\end{array}$} & \multirow[b]{2}{*}{$\begin{array}{c}\text { Minimum } \\
\text { detect }\end{array}$} & \multirow[b]{2}{*}{$\begin{array}{c}\text { Maximum } \\
\text { detect }\end{array}$} & \multirow{2}{*}{$\begin{array}{l}\text { Location(s) of } \\
\text { maximum } \\
\text { detect }\end{array}$} & \multirow{2}{*}{$\begin{array}{c}\text { Average } \\
\text { detected } \\
\text { result }\end{array}$} & \multicolumn{6}{|c|}{ Number of analyses exceeding criteria } \\
\hline & & & & & & $\begin{array}{c}\text { Max } \\
\text { RL }\end{array}$ & $\begin{array}{c}\text { Avg } \\
\text { RL }\end{array}$ & $\begin{array}{l}\text { Ind } \\
\text { PRG }\end{array}$ & Bkg & $\begin{array}{l}\text { GW } \\
\text { SL }\end{array}$ & $\begin{array}{r}\text { Res } \\
\text { PRG }\end{array}$ \\
\hline Cesium-137 & $18 / 39$ & 0.04 & $5.76 \mathrm{~J}$ & Z2-EU23B-311 & 1.08 & 0 & 3 & 3 & NA & NA & 17 \\
\hline Neptunium-237 & $6 / 21$ & 0.06 & 1.67 & Z2-EU23B-311 & 0.84 & 0 & 0 & 0 & NA & NA & 5 \\
\hline Potassium-40 & $15 / 15$ & 5.06 & 19.2 & Z2-EU22-035 & 12.4 & NA & NA & 15 & 0 & NA & 15 \\
\hline Radium-226 & $13 / 13$ & $0.613 \mathrm{~J}$ & $1.64 \mathrm{~J}$ & Z2-EU22-035 & 1.14 & NA & NA & 13 & 5 & NA & 13 \\
\hline Technetium-99 & $27 / 40$ & $0.08 \mathrm{~J}$ & 250 & Z2-EU23B-311 & 38.4 & NA & NA & 0 & NA & NA & 25 \\
\hline Thorium -228 & $17 / 20$ & 0.46 & 2.3 & Z2-EU22-035 & 1.32 & NA & NA & 17 & 3 & NA & 17 \\
\hline Thorium -230 & $18 / 20$ & $0.51 \mathrm{~J}$ & 3.36 & Z2-EU23B-311 & 1.74 & NA & NA & 0 & 14 & NA & 0 \\
\hline Thorium -232 & $20 / 20$ & 0.38 & 2.28 & Z2-EU22-035 & 1.17 & NA & NA & 20 & 1 & NA & 20 \\
\hline Uranium-233/234 & $27 / 27$ & $1.15 \mathrm{~J}$ & $20.8 \mathrm{~J}$ & AU-07-01-1652 & 5.94 & 0 & 0 & 0 & NA & 0 & 10 \\
\hline Uranium-234 & $13 / 13$ & 1.64 & 149 & Z2-EU23B-311 & 50.7 & 0 & 0 & 0 & NA & 4 & 10 \\
\hline Uranium-235 & $12 / 15$ & 0.154 & 6.37 & Z2-EU23B-311 & 2.27 & 0 & 0 & 4 & NA & 0 & 11 \\
\hline Uranium-235/236 & $25 / 25$ & 0.04 & $0.9 \mathrm{~J}$ & AU-07-01-1652 & 0.208 & 0 & 0 & 0 & NA & 0 & 9 \\
\hline Uranium-238 & $40 / 40$ & 0.898 & 20.5 & Z2-EU23B-311 & 4.0 & 0 & 0 & 1 & 31 & 0 & 40 \\
\hline
\end{tabular}

Avg = average

$\mathrm{Bkg}=$ background

$\mathrm{EU}=$ exposure unit

$\mathrm{GW}=$ groundwater

$\mathrm{NA}=$ not applicable

$\mathrm{PRG}=$ preliminary remediation goal

Ind $=$ industrial

Res $=$ residential

$\mathrm{RL}=$ remediation level

Max $=$ maximum

$\mathrm{SL}=$ screening level 
EU Z2-23 HISTORICAL SVOC DETECTS (ug/kg)

\begin{tabular}{|c|c|c|c|c|c|c|c|c|}
\hline \multirow[b]{2}{*}{ Analyte } & \multirow[b]{2}{*}{$\begin{array}{c}\text { Detect } \\
\text { frequency }\end{array}$} & \multirow[b]{2}{*}{$\begin{array}{c}\text { Minimum } \\
\text { detect }\end{array}$} & \multirow[b]{2}{*}{$\underset{\text { detect }}{\text { Maximum }}$} & \multirow{2}{*}{$\begin{array}{c}\text { Location(s) of } \\
\text { maximum } \\
\text { detect }\end{array}$} & \multirow{2}{*}{$\begin{array}{c}\text { Average } \\
\text { detected } \\
\text { result }\end{array}$} & \multicolumn{3}{|c|}{$\begin{array}{l}\text { Number of analyses } \\
\text { exceeding criteria }\end{array}$} \\
\hline & & & & & & $\begin{array}{l}\text { Ind } \\
\text { PRG }\end{array}$ & $\begin{array}{l}\text { GW } \\
\text { SL }\end{array}$ & $\begin{array}{l}\text { Res } \\
\text { PRG }\end{array}$ \\
\hline 2-Methylnaphthalene & $1 / 31$ & $370 \mathrm{~J}$ & $370 \mathrm{~J}$ & AU-03-01-1652 & 370 & 0 & NA & NA \\
\hline Acenaphthene & $2 / 31$ & $44 \mathrm{~J}$ & 1000 & AU-03-01-1652 & 522 & 0 & NA & 0 \\
\hline Anthracene & $4 / 31$ & $53 \mathrm{~J}$ & 1700 & AU-03-01-1652 & 492 & 0 & NA & 0 \\
\hline Benz(a)anthracene & $6 / 31$ & $67 \mathrm{~J}$ & 2400 & AU-03-01-1652 & 519 & 0 & NA & 1 \\
\hline Benzo(a)pyrene & $5 / 31$ & 82.09 & 1700 & AU-03-01-1652 & 466 & 0 & NA & 5 \\
\hline Benzo(b)fluoranthene & $7 / 31$ & $91 \mathrm{~J}$ & 1600 & AU-03-01-1652 & 355 & 0 & NA & 1 \\
\hline Benzo(ghi)perylene & $3 / 31$ & $130 \mathrm{~J}$ & 1000 & AU-03-01-1652 & 443 & 0 & NA & 0 \\
\hline Benzo(k)fluoranthene & $7 / 31$ & 96.31 & 1700 & AU-03-01-1652 & 357 & 0 & NA & 0 \\
\hline Bis(2-ethylhexyl)phthalate & $2 / 31$ & $57 \mathrm{~J}$ & 98.75 & 1652-RAD-003 & 77.9 & 0 & 0 & 0 \\
\hline Carbazole & $1 / 28$ & 1300 & 1300 & AU-03-01-1652 & 1300 & 0 & NA & 0 \\
\hline Chrysene & $6 / 31$ & $65 \mathrm{~J}$ & 2400 & AU-03-01-1652 & 530 & 0 & NA & 0 \\
\hline Dibenz(a,h)anthracene & $2 / 31$ & $56 \mathrm{~J}$ & 600 & AU-03-01-1652 & 328 & 0 & NA & 1 \\
\hline Dibenzofuran & $1 / 31$ & 580 & 580 & AU-03-01-1652 & 580 & 0 & NA & 0 \\
\hline Diethyl phthalate & $1 / 31$ & $150 \mathrm{~J}$ & $150 \mathrm{~J}$ & AU-I3-01-1652 & 150 & 0 & NA & 0 \\
\hline Fluoranthene & $7 / 31$ & 94.97 & 5800 & AU-03-01-1652 & 1048 & 0 & NA & 0 \\
\hline Fluorene & $1 / 31$ & 1000 & 1000 & AU-03-01-1652 & 1000 & 0 & NA & 0 \\
\hline Indeno(1,2,3-cd)pyrene & $3 / 31$ & $120 \mathrm{~J}$ & 1000 & AU-03-01-1652 & 427 & 0 & NA & 1 \\
\hline Naphthalene & $1 / 41$ & 880 & 880 & AU-03-01-1652 & 880 & 0 & NA & 0 \\
\hline Phenanthrene & $6 / 31$ & $39 \mathrm{~J}$ & 6100 & AU-03-01-1652 & 1167 & 0 & NA & 0 \\
\hline Phenol & $1 / 31$ & $49 \mathrm{~J}$ & $49 \mathrm{~J}$ & AU-03-01-1652 & 49 & 0 & NA & 0 \\
\hline Pyrene & $7 / 31$ & 77.45 & 4800 & AU-03-01-1652 & 883 & 0 & NA & 0 \\
\hline $\begin{array}{l}\text { EU = exposure unit } \\
\text { GW = groundwater } \\
\text { Ind = industrial } \\
\text { NA = not applicable }\end{array}$ & $\begin{array}{l}\text { PRG }=1 \\
\text { Res }=r e \\
\text { SL }=s c \\
\text { SVOC }\end{array}$ & $\begin{array}{l}\text { reliminary } \mathrm{r} \\
\text { sidential } \\
\text { eening level } \\
=\text { semivolatil }\end{array}$ & e organic co & npound & & & & \\
\hline
\end{tabular}

EU Z2-23 VOC DETECTS (ug/kg)

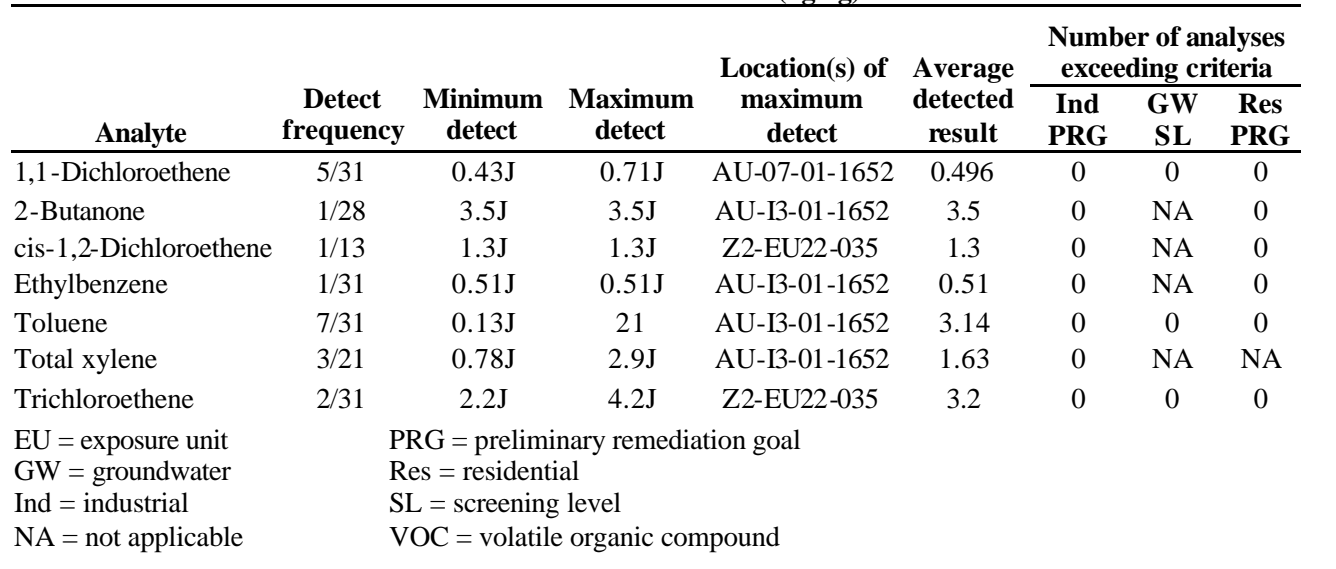

2.2.6

ZONE 2 ROD APPENDIX A FFA SITES EVALUATION

\section{Area Service Station FFA Site}

The K-300 Area Service Station is the only FFA site in EU Z2-23. A DVS investigation was performed to determine the chemical impact of service station activities to EU soils . A geophysical investigation (Sect. 2.1.3.4) indicated the possible presence of a UST, but soil sampling at the anomaly indicated the UST had been removed. Subsurface samples were collected at the geophysical anomaly (Z2-EU23B-312), west of the anomaly (Z2-EU23B-313), and southwest of the anomaly (Z2-EU23B-314). Sampling and analytical details are presented in Table D.2, and sample locations are shown on Fig. 4. Analytical results summarized below show metal background exceedances and detections of SVOCs. Numerous TICs were also reported, which indicated highly degraded fuels had a limited impact on subsurface soils. 
Samples from all three locations were analyzed for DRO and GRO but were not detected.

EU Z2-23 300 AREA SERVICE STATION FFA SITE METALS WITH BACKGROUND, PRG, GW SL, AND/OR RL EXCEEDANCES (mg/kg)

\begin{tabular}{|c|c|c|c|c|c|c|c|c|c|c|c|}
\hline \multirow[b]{2}{*}{ Analyte } & \multirow[b]{2}{*}{$\begin{array}{c}\text { Detect } \\
\text { frequency }\end{array}$} & \multirow[b]{2}{*}{$\begin{array}{c}\text { Minimum } \\
\text { detect }\end{array}$} & \multirow[b]{2}{*}{$\underset{\text { detect }}{\text { Maximum }}$} & \multirow{2}{*}{$\begin{array}{c}\text { Location(s) of } \\
\text { maximum } \\
\text { detect }\end{array}$} & \multirow{2}{*}{$\begin{array}{c}\text { Average } \\
\text { detected } \\
\text { result }\end{array}$} & \multicolumn{6}{|c|}{ Number of analyses exceeding criteria } \\
\hline & & & & & & $\begin{array}{l}\text { Max } \\
\text { RL }\end{array}$ & $\begin{array}{l}\text { Avg } \\
\text { RL }\end{array}$ & $\begin{array}{l}\text { Ind } \\
\text { PRG }\end{array}$ & Bkg & $\begin{array}{c}\text { GW } \\
\text { SL }\end{array}$ & $\begin{array}{c}\text { Res } \\
\text { PRG }\end{array}$ \\
\hline Aluminum & $3 / 3$ & 15000 & 24000 & Z2-EU23B-312 & 19333 & NA & NA & 0 & 0 & NA & 3 \\
\hline Arsenic & $3 / 3$ & 3.4 & 5.8 & Z2-EU23B-313 & 4.33 & 0 & 0 & 0 & 0 & 0 & 3 \\
\hline Copper & $3 / 3$ & 22 & 31 & Z2-EU23B-313 & 27.3 & NA & NA & 0 & 2 & NA & 0 \\
\hline Iron & $3 / 3$ & 32000 & 37000 & Z2-EU23B-313 & 35000 & NA & NA & 0 & 0 & NA & 3 \\
\hline Magnesium & $3 / 3$ & 1400 & 3500 & Z2-EU23B-314 & 2500 & NA & NA & NA & 1 & NA & NA \\
\hline Manganese & $3 / 3$ & 550 & 1200 & Z2-EU23B-313 & 840 & NA & NA & 0 & 0 & NA & 3 \\
\hline Nickel & $3 / 3$ & 18 & 35 & Z2-EU23B-313 & 25.3 & NA & NA & 0 & 1 & NA & 0 \\
\hline Uranium & $3 / 3$ & 1.4 & 1.8 & Z2-EU23B-313 & 1.6 & NA & NA & 0 & NA & NA & 2 \\
\hline Vanadium & $3 / 3$ & 28 & 44 & Z2-EU23B-313 & 36.3 & NA & NA & 0 & 0 & NA & 3 \\
\hline
\end{tabular}

Avg = average $\quad \mathrm{NA}=$ not applicable

Bkg $=$ background $\quad$ PRG $=$ preliminary remediation goal

$\mathrm{EU}=$ exposure unit $\quad$ Res $=$ residential

$\mathrm{GW}=$ groundwater $\quad \mathrm{RL}=$ remediation level

Ind $=$ industrial $\quad \mathrm{SL}=$ screening level

Max = maximum

EU Z2-23 300 AREA SERVICE STATION FFA SITE SVOC DETECTS (ug/kg)

\begin{tabular}{|c|c|c|c|c|c|c|c|c|}
\hline \multirow[b]{2}{*}{ Analyte } & \multirow[b]{2}{*}{$\begin{array}{c}\text { Detect } \\
\text { frequency }\end{array}$} & \multirow[b]{2}{*}{$\begin{array}{c}\text { Minimum } \\
\text { detect }\end{array}$} & \multirow[b]{2}{*}{$\begin{array}{c}\text { Maximum } \\
\text { detect }\end{array}$} & \multirow[b]{2}{*}{$\begin{array}{c}\text { Location(s) of } \\
\text { maximum } \\
\text { dete ct }\end{array}$} & \multirow[b]{2}{*}{$\begin{array}{c}\text { Average } \\
\text { detected } \\
\text { result }\end{array}$} & \multicolumn{3}{|c|}{$\begin{array}{c}\text { Number of analyses } \\
\text { exceeding criteria }\end{array}$} \\
\hline & & & & & & $\begin{array}{l}\text { Ind } \\
\text { PRG }\end{array}$ & $\begin{array}{c}\text { GW } \\
\text { SL }\end{array}$ & $\begin{array}{c}\text { Res } \\
\text { PRG }\end{array}$ \\
\hline Benzo(b)fluoranthene & $1 / 3$ & $97 \mathrm{~J}$ & $97 \mathrm{~J}$ & Z2-EU23B-314 & 97 & 0 & NA & 0 \\
\hline Benzo(k)fluoranthene & $1 / 3$ & $110 \mathrm{~J}$ & $110 \mathrm{~J}$ & Z2-EU23B-314 & 110 & 0 & NA & 0 \\
\hline
\end{tabular}

$\mathrm{EU}=$ exposure unit $\quad \mathrm{PRG}=$ preliminary remediation goal

$\mathrm{GW}=$ groundwater $\quad$ Res $=$ residential

Ind $=$ industrial $\quad \mathrm{SL}=$ screening level

$\mathrm{NA}=$ not applicable $\quad \mathrm{SVOC}=$ semivolatile organic compound

Samples from all three locations were analyzed for VOCs but were not detected.

\begin{tabular}{|l|l|}
\hline 3.0 & \multicolumn{1}{|c|}{ RISK EVALUATION AND ACTION/NO FURTHER ACTION DECISION } \\
\hline 3.1 & INTRODUCTION \\
\hline
\end{tabular}

In this section, data are evaluated in terms of the four decision rules presented in the Zone 2 RDR/RAWP.

- Does the concentration of any Zone 2 contaminant of concern (COC) exceed its maximum RL?

- Does the mean concentration of any Zone $2 \mathrm{COC}$ exceed its average RL across the EU?

- Does the EU pose a risk exceeding an industrial $1 \times 10^{-4}$ excess lifetime cancer risk (ELCR) or target organ hazard index (HI) of 1 ?

- Does the site pose a threat to groundwater based on maximum contaminant level (MCL) exceedances or soil RLs for protection of groundwater?

Table D. 3 presents the results from comparison of the data to Zone 2 soils RLs, to industrial PRGs (set at an ELCR of $1 \times 10^{-5}$ or a HI of 1), and to background levels. The following table summarizes the results for EU Z2-23.

\begin{tabular}{lccccc}
\hline EU \# & $\begin{array}{c}\text { Max RL } \\
\text { exceeded? }\end{array}$ & $\begin{array}{c}\text { Average RL } \\
\text { over EU } \\
\text { exceeded? }\end{array}$ & $\begin{array}{c}\text { Industrial risk } \\
\text { above 1 } \mathbf{1 0} \text { ? }\end{array}$ & $\begin{array}{c}\text { Potential source } \\
\text { to groundwater? }\end{array}$ & $\begin{array}{c}\text { Action } \\
\text { required? }\end{array}$ \\
\hline $\mathrm{Z} 2-23$ & No & No & No & No & No \\
\hline $\mathrm{EU}=$ exposure unit & & & & \\
$\mathrm{RL}=$ remediation level & & & \\
\end{tabular}




\section{\begin{tabular}{|l|l}
3.2 & DATA EVALUATION FOR THE ACTION /NO FURTHER ACTION DECISION \\
\hline
\end{tabular}}

Requirements for determining NFA in the Zone 2 EUs are stated in the protection goals of the Zone 2 ROD RAO. Four decision rules developed in the DVS DQOs state the specific criteria again st which each EU must be compared to make the NFA decision. These rules are presented in Sect.3.1, and the manner in which the decision rule evaluations are conducted and special data handling requirements are discussed in Sect. 3.3. In summary, the decis ion rule criteria for NFA are that each EU must meet each of the following compositional constraints:

- Zone 2 soils Max RLs - maximum allowable concentrations of the Zone 2 soils COCs. Zone 2 soils Max RLs are presented in the Zone 2 ROD and in Table 5 of this PCCR.

- Zone 2 soils Avg RLs - limit on allowable average concentrations of the Zone 2 soils COCs across an EU. Zone 2 soils Avg RLs are presented in the Zone 2 ROD and in Table 5 of this PCCR.

- Cumulative risk across the EU-cumulative risk across an EU cannot exceed $1 \times 10^{-4}$ ELCR or HI =1. A stepwise evaluation of cumulative risk is performed by first comparing EU data to $1 \times 10^{-5}$ Ind PRGs. The $1 \times 10^{-5}$ Ind PRGs for the analytes required by the RDR/RAWP are presented in Table 5 of this PCCR.

- Groundwater protection goals - composition of Zone 1 soils cannot pose a threat to groundwater. This evaluation is conducted by evaluating local groundwater monitoring results and comparing soils compositions to calculated SLs. The values for the GW SLs are presented in Table 5 of this PCCR.

\section{\begin{tabular}{|l|l}
\hline 3.3 & SUMMARY AND CONCLUSIONS \\
\hline
\end{tabular}}

\section{$\underline{\text { EU Z2-23 }}$}

Max RL screening. Based on DVS and historical sampling and results of the Class 3 walkover assessment, no Zone 2 soils COCs were detected at concentrations in excess of Max RLs.

Avg RL screening. Average RLs for PCB-1254 and total PCB are exceeded at sample locations Z2-EU23B-306 and Z2-EU23B-310. Average RLs are also exceeded for Cs-137 at sample locations Z2-EU23B-310 and Z2-EU23B-311 (surface and subsurface sample from this location). All three sample locations with Avg RL exceedances occur in the sediment accumulation area located northeast of the K-1066-C Cylinder Storage Yard.

The first step in evaluating if an Avg RL has been exceeded across an EU is to determine if an EU average detected concentration exceeds the Avg RL. The EU average concentrations for PCB-1254, total PCBs, and Cs-137 are $7890 \mathrm{ug} / \mathrm{kg}, 8102 \mathrm{ug} / \mathrm{kg}$, and $1.08 \mathrm{pCi} / \mathrm{g}$, respectively (Sect. 2.2.5). The values of these concentrations are all less than the respective Avg RLs of $10,000 \mathrm{ug} / \mathrm{kg}, 10,000 \mathrm{ug} / \mathrm{kg}$, and $2 \mathrm{pCi} / \mathrm{g}$. Therefore, it is concluded that PCB-1254, total PCBs, and Cs -137 concentrations do not exc eed their Avg RLs across EU Z2-23.

Based on analytical results from DVS biased sampling and historical sampling in EU Z2-23, and results of the Class 3 SU walkover assessment, no Zone 2 soils COCs have a mean concentration exceeding the Avg RL across the EU.

Risk evaluation. The first step in the risk evaluation is to evaluate $1 \times 10^{-5}$ Ind PRG exceedances in order to determine which chemicals and radionuclides are likely to exceed the $1 \times 10^{-4}$ ELCR or target organ HI of 1 . In EU Z2-23, the $1 \times 10^{-5}$ Ind PRG was exceeded in one or more samples by arsenic (1), PCB-1254 (2), total PCBs (2), Cs-137 (3), K-40 (15), Ra-226 (13), Th-228 (17), Th-232 (20), U-235 (4), and U-238 (1). As discussed in Sect. 3.3 of this PCCR, risk from arsenic is further evaluated by comparison of its concentration to its Zone 2 soils COC average RL; K-40 is evaluated for risk only if its average concentration exceeds its background value; and Ra-226, Th-230, and Th-232 are evaluated by summing their concentrations ( $\mathrm{Ra} / \mathrm{Th}$ decay series) and comparing the result to their mutual Zone 2 soils COC average RL (this evaluation includes Th-228 as part of the Th-232 decay chain). There are no arsenic average RL exceedances. The average detected $\mathrm{K}-40$ concentration $(12.36 \mathrm{pCi} / \mathrm{g})$ does not exceed the $\mathrm{K}-40$ background value $(32.12 \mathrm{pCi} / \mathrm{g})$, and the $\mathrm{Ra} / \mathrm{Th}$ decay series concentration $(0.57 \mathrm{pCi} / \mathrm{g}) \mathrm{does}$ not exceed the average $\mathrm{RL}(5 \mathrm{pCi} / \mathrm{g})$.

For the remaining chemicals and radionuclides with $1 \times 10^{-5}$ Ind PRG exceedances, the average detected concentrations of Cs $-137(1.08 \mathrm{pCi} / \mathrm{g}), \mathrm{U}-235(0.89 \mathrm{pCi} / \mathrm{g})$, and U-238 $(3.95 \mathrm{pCi} / \mathrm{g})$ are all less than their $1 \times 10^{-5}$ Ind PRG values $(1.1 \mathrm{pCi} / \mathrm{g}, 4 \mathrm{pCi} / \mathrm{g}$, and $18 \mathrm{pCi} / \mathrm{g}$, respectively. An average EU concentration was calculated for PCB-1254 and total PCBs by using concentration values equaling one-half the non-detect value. The average 
PCB-1254 concentration $(2,724 \mathrm{ug} / \mathrm{kg})$ and the average total PCB concentration $(6,486 \mathrm{ug} / \mathrm{kg})$ are less than the $1 \times 10^{-5}$ Ind PRG $(7,436 \mathrm{ug} / \mathrm{kg})$.

The industrial risk for EU Z2-23 is less than $1 \times 10^{-4}$ ELCR and target organ HI of 1 .

Threat to groundwater. The groundwater SL for U-234 is exceeded in the sediment accumulation area surface soil samples at locations Z2-EU23B-307, Z2-EU23B-310, and Z2-EU23B-311, and in a subsurface sample at location Z2-EU23B-311. However, there are no U-234 MCL exceedances in area groundwater wells. Therefore, it is concluded U-234 does not pose a threat to groundwater because of its relative immobility ef U 234-in ETTP soils due to a combination of adsorption, complexation, and ion-exchange reactions with the soils, and the small area impacted at the accumulation area.

Qualitative risk for hypothetical unrestricted use. There is a low probability that this acreage could be released with no land use restrictions. Numerous Residential PRG exceedances occur for metals, radionuclides, PCBs, and SVOCs. Specific chemicals and radionuclides with Res PRG exceedances are presented in the EU-Z2-23 summary in Section 2.2.5. An appropriate evaluation of residential risk should be conducted to make a definitive conclusion.

\section{FFA Sites}

Based on sampling analytical results (Sect. 2.2.6) and an evaluation of the EU-wide contaminant profile described above, soils in the following Zone 2 ROD Appendix A FFA site in EU Z2-23 does not pose a potential threat to the future industrial worker or to groundwater:

- K-300 Area Service Station site.

\begin{tabular}{|l|l|}
\hline 4.0 & RECOMMENDATION FOR ACTION/NO FURTHER ACTION \\
\hline 4.1 & DECISION AND REMEDIATION ACTIVITIES \\
\hline
\end{tabular}

EU Z2-23: Based on results of the Class 3 SU walkover assessment and analytical results of the DVS and historical samples collected in EU Z2-23, the U.S. Department of Energy (DOE) recommends that NFA is appropriate under the Zone 2 ROD to meet industrial land use for the 8.5 acres at EU Z2-23. Soil samples from the EU indicate minor impact in a localized sediment accumulation area and a very old leak from a former UST site where TICs were present in subsurface soils. This data supports lifting the restriction on the depth of use to $10 \mathrm{ft}$ bgs. DOE recommends no restrictions on the depth of use in EU Z2-23.

FFA Sites: Based on analytical results and the recommendation for all of EU Z2-23, DOE recommends that NFA is appropriate for the following FFA site:

- K-300 Area Service Station.

\begin{tabular}{|l|l}
\hline 4.2 & EXCAVATION ACTIVITIES/CONFIRMATIONSAMPLING
\end{tabular}

None 


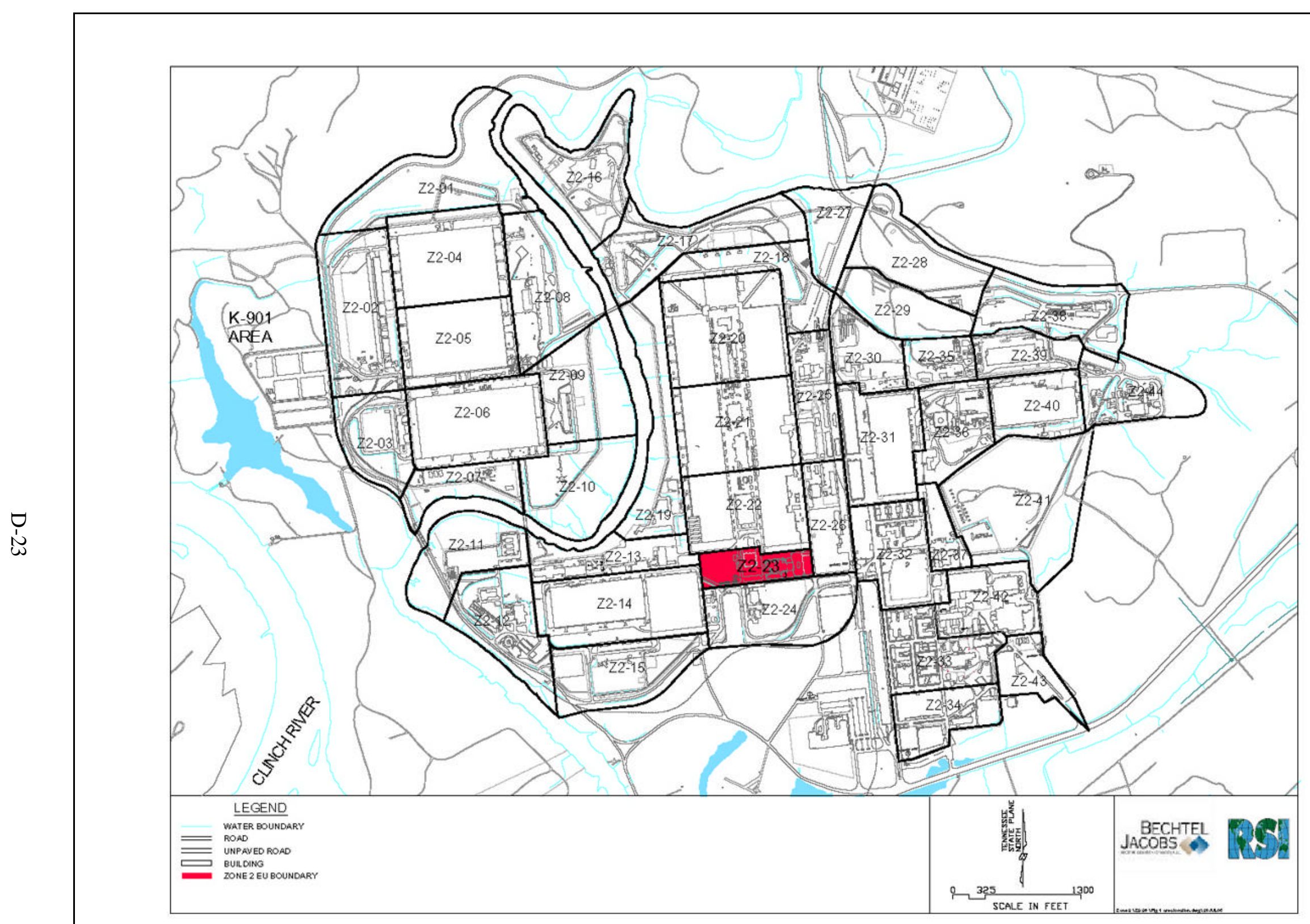

Fig. D.1. EU Z2-23 location map. 


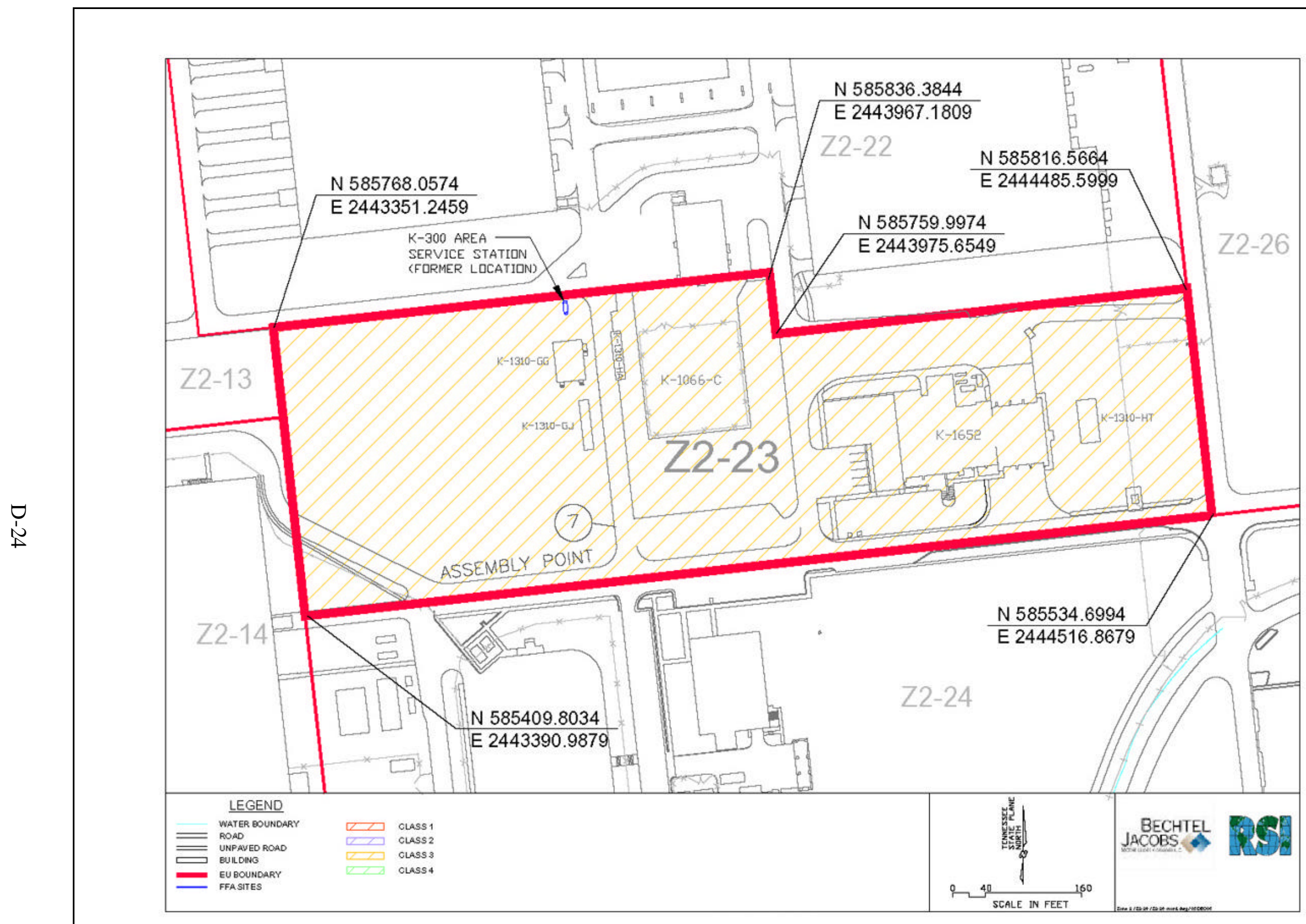

Fig. D.227. EU Z2-23 boundaries and FFA site. 


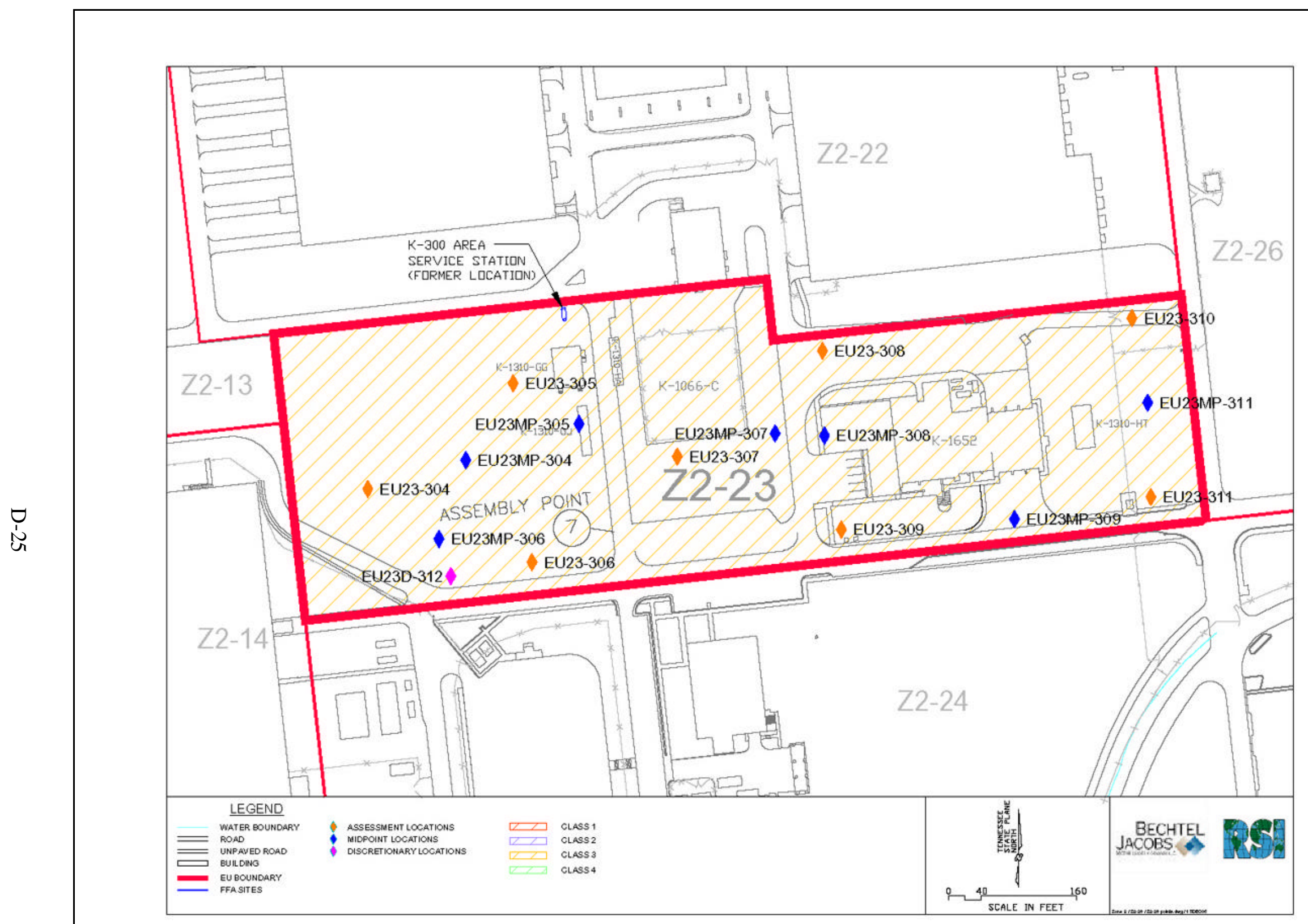

Fig. D.3. EU Z2-23 Class 3 and Class 4 SU walkover assessment locations. 


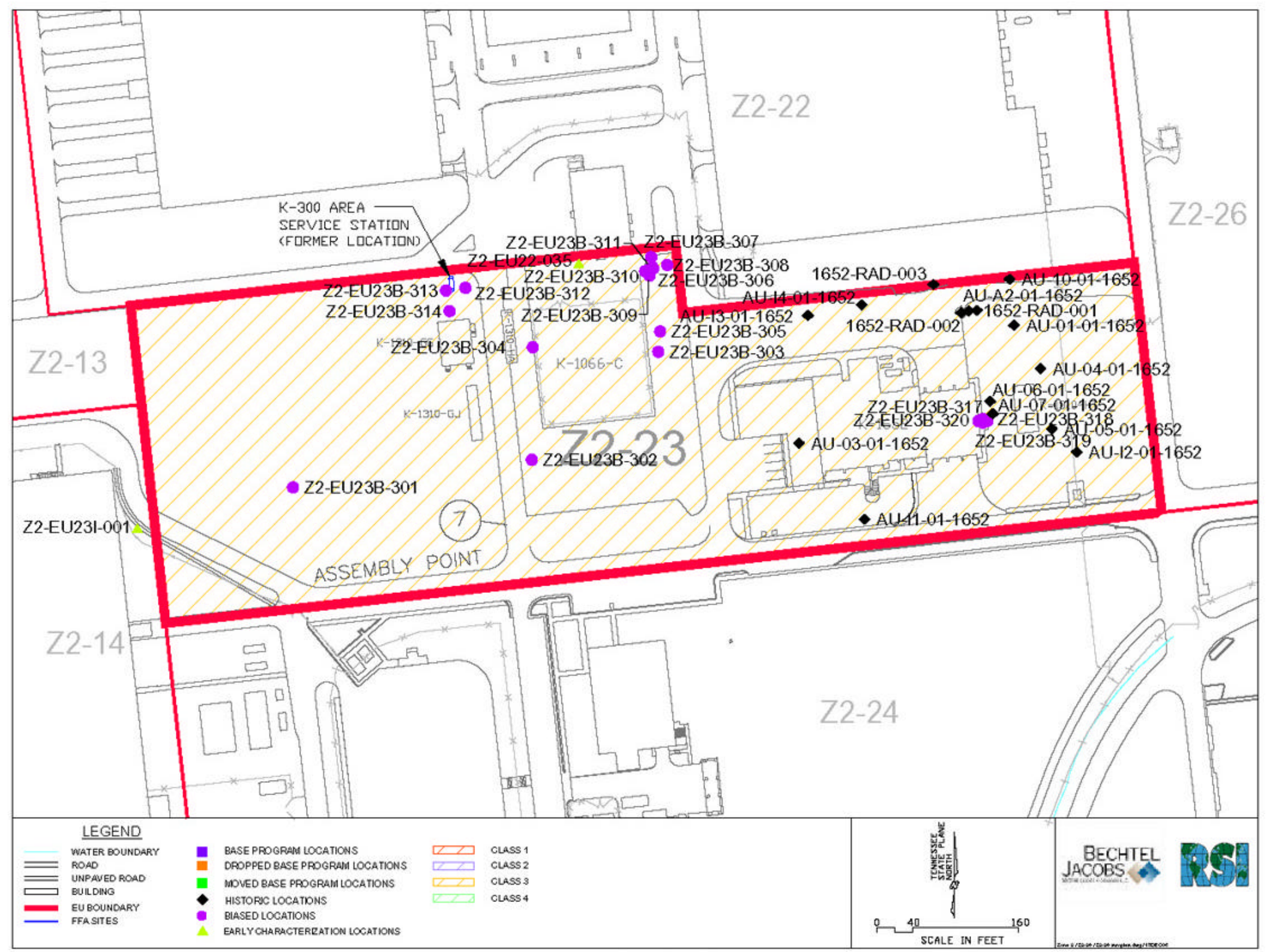

Fig. D.4. EU Z2-23 sample locations. 
Table D.1. EU Z2-23 facility and FFA site list

\begin{tabular}{|c|c|c|c|c|}
\hline \multirow[b]{2}{*}{ Facility name DQO scoping } & \multirow[b]{2}{*}{ Facility name } & \multicolumn{2}{|c|}{$\begin{array}{c}\text { Facility } \\
\text { Assessed? }\end{array}$} & \multirow[b]{2}{*}{ Comments } \\
\hline & & Yes & No & \\
\hline K-300 Area Service Station & K-300 Area Service Station & $\mathrm{X}$ & & FFA site \\
\hline K-700-A-69 Substation & K-700-A-69 Substation & $\mathrm{X}$ & & \\
\hline K-1028-72 Guard Portal & K-1028-72 Guard Portal & $\mathrm{X}$ & & \\
\hline K-1652 Plant Protection Headquarters & K-1652 Plant Protection Headquarters & $\mathrm{X}$ & & \\
\hline K-1066-C Cylinder Storage Yard & K-1066-C Cylinder Storage Yard & $\mathrm{X}$ & & \\
\hline K-1310-GG Construction Trailer & K-1310-GG Construction Trailer & $\mathrm{X}$ & & \\
\hline K-1310-GJ Construction Trailer & K-1310-GJ Construction Trailer & & $\mathrm{X}$ & Facility no longer exists \\
\hline K-1310-HA Construction Trailer & K-1310-HA Construction Trailer & & $\mathrm{X}$ & Facility no longer exists \\
\hline K-1310-HT Trailer & K-1310-HT Trailer & $\mathrm{X}$ & & \\
\hline K-2527-AD Construction Trailer & K-2527-AD Construction Trailer & $\mathrm{X}$ & & \\
\hline K-2527-AE Construction Trailer & K-2527-AE Construction Trailer & $\mathrm{X}$ & & \\
\hline K-2527-AF Construction Trailer & K-2527-AF Construction Trailer & $\mathrm{X}$ & & \\
\hline K-2527-AJ Construction Trailer & K-2527-AJ Construction Trailer & $\mathrm{X}$ & & \\
\hline \multirow[t]{4}{*}{ Facilities not in DQO Scoping } & K-1310-LH Construction Trailer & $\mathrm{X}$ & & \\
\hline & K-1310-LU Construction Trailer & $\mathrm{X}$ & & \\
\hline & K-1310-LW Construction Trailer & $\mathrm{X}$ & & \\
\hline & K-1310-LX Construction Trailer & $\mathrm{X}$ & & \\
\hline
\end{tabular}

DQO = data quality objective

FFA $=$ Federal Facility Agreement 
Table D.2. EU Z2-23 sample summary table

\begin{tabular}{|c|c|c|c|c|c|c|c|c|c|c|c|c|c|c|}
\hline \multirow[b]{2}{*}{$\begin{array}{c}\text { Date } \\
\text { sampled }\end{array}$} & \multirow[b]{2}{*}{$\begin{array}{c}\text { Sample } \\
\text { ID }\end{array}$} & \multicolumn{2}{|c|}{ Location } & \multirow[b]{2}{*}{ Sample interval } & \multicolumn{2}{|c|}{ Screen } & \multicolumn{7}{|c|}{ Off-site laboratory } & \multirow[t]{2}{*}{ Comments and Notes } \\
\hline & & Northing & Easting & & VOC & RAD & VOC & SVOC & Metals & PCB & RAD & $\begin{array}{l}\text { GRO/ } \\
\text { DRO }\end{array}$ & QC & \\
\hline $9 / 1 / 05$ & Z2-EU22-035 & 585814 & 2443858 & 3 discrete intervals & & & 3 & 3 & 3 & 3 & 3 & & & $\begin{array}{l}\text { Early characterization sample associated with EU } 22 \text { falls in } \\
\text { EU } 23 \text {; includes } 3 \text { fluoride and } 3 \text { hexavalent chromium } \\
\text { analyses }\end{array}$ \\
\hline $3 / 20 / 06$ & Z2-EU23B-301 & 585563 & 2443535 & $\begin{array}{l}0-0.5 \mathrm{ft}, 5 \text {-point composite surface soil in grassy } \\
\text { area }\end{array}$ & & & & & 1 & 1 & 1 & & $\mathrm{~S}$ & DQO biased samples along tie lines \\
\hline $3 / 20 / 06$ & Z2-EU23B-302 & 585594 & 2443805 & $\begin{array}{l}0-0.5 \mathrm{ft}, 5 \text {-point composite surface soil in grassy } \\
\text { area }\end{array}$ & & & & & 1 & 1 & 1 & & & DQO biased samples along tie lines \\
\hline $3 / 20 / 06$ & Z2-EU23B-303 & 585716 & 2443948 & $\begin{array}{l}0-0.5 \mathrm{ft}, 5 \text {-point composite surface soil in grassy } \\
\text { area }\end{array}$ & & & & & 1 & 1 & 1 & & & DQO biased samples along tie lines \\
\hline $4 / 24 / 06$ & Z2-EU23B-304 & 585721 & 2443806 & 0 -1 ft, 4-point composite surface soil in grassy area & & & & & 1 & 1 & & & & $\begin{array}{l}\text { Class } 3 \text { selected biased location, along west side of fence at } \\
\mathrm{K}-1066 \mathrm{C}\end{array}$ \\
\hline $4 / 24 / 06$ & Z2-EU23B-305 & 585739 & 2443950 & $0-1 \mathrm{ft}, 4$-point composite surface soil in grassy area & & & & & 1 & 1 & & & & $\begin{array}{l}\text { Class } 3 \text { selected biased location, along east side of fence at } \\
\mathrm{K}-1066 \mathrm{C} \text {, next to west side of tie line }\end{array}$ \\
\hline $4 / 24 / 06$ & Z2-EU23B-306 & 585810 & 2443942 & $0-1 \mathrm{ft}$, single-point surface soil in grassy area. & & & & & 1 & 1 & & & & $\begin{array}{l}\text { Class } 3 \text { selected biased location, in low spot of runoff area in } \\
\text { the northeast corner of K-1066 }\end{array}$ \\
\hline $5 / 26 / 06$ & Z2-EU23B-307 & 585823 & 2443940 & $\begin{array}{l}0-1 \mathrm{ft} \text {, single-point surface soil in grassy area; } \\
\text { VOCs are conditional on PID field screening }\end{array}$ & & 1 & & & 1 & 1 & 1 & & & Z2-EU23B-306 step out, $12.5 \mathrm{ft}$ to the north \\
\hline $5 / 26 / 06$ & Z2-EU23B-308 & 585814 & 2443958 & $\begin{array}{l}0-1 \mathrm{ft} \text {, single-point surface soil in grassy area; } \\
\text { VOCs are conditional on P ID field screening }\end{array}$ & & 1 & & & 1 & 1 & 1 & & & Z2-EU23B-306 step out, $12.5 \mathrm{ft}$ to the east \\
\hline $5 / 26 / 06$ & Z2-EU23B-309 & 585802 & 2443938 & $\begin{array}{l}0-1 \mathrm{ft} \text {, single-point surface soil in grassy area; } \\
\text { VOCs are conditional on PID field screening }\end{array}$ & & 1 & & & 1 & 1 & 1 & & & Z2-EU23B-306 step out, $12.5 \mathrm{ft}$ to the south \\
\hline $5 / 26 / 06$ & Z2-EU23B-310 & 585807 & 2443933 & $\begin{array}{l}0-1 \mathrm{ft} \text {, single-point surface soil in grassy area; } \\
\text { VOCs are conditional on PID field screening }\end{array}$ & & 1 & & & 1 & 1 & 1 & & & Z2-EU23B-306 step out, $12.5 \mathrm{ft}$ to the west \\
\hline 09/19/06 & Z2-EU23B-311 & 585812 & 2443941 & $\begin{array}{l}0-10 \mathrm{ft}, \mathrm{t} \text { wo discrete intervals: } 0.5-2.0 \mathrm{ft} ; \\
6.25-7.0 \mathrm{ft} \text {; and } 8.0-8.75 \mathrm{ft} \text { t three RAD samples } \\
\text { collected from intervals: } 0-0.5 \mathrm{ft}, 0.5-2.0 \mathrm{ft} \text {, and } \\
7.5-8.0 \mathrm{ft}\end{array}$ & 1 & 1 & & & & 2 & 2 & & & $\begin{array}{l}\text { Confirmation sampling performed at former Z2-EU23B-306 } \\
\text { location. RAD hit at } 0.25 \mathrm{ftof} 246 \mathrm{cpm} \text { and at } 7.7 \mathrm{ft} \text { of } \\
283 \mathrm{cpm} .\end{array}$ \\
\hline 09/19/06 & Z2-EU23B-312 & 585788 & 2443730 & $\begin{array}{l}0-15 \mathrm{ft} \text {, one discrete sample interval from } \\
8.3-9.8 \mathrm{ft} ; \text { VOCs and GRO collected from } \\
10.0-10.3 \mathrm{ft}\end{array}$ & 1 & 1 & 1 & 1 & 1 & & & 1 & & Location in the middle of geophysical anomaly/possible UST \\
\hline 09/19/06 & Z2-EU23B-313 & 585785 & 2443708 & $\begin{array}{l}0-15 \mathrm{ft} \text {, one point composite sample interval from } \\
8.2-9.2 \mathrm{ft} \text { and } 11.1-11.6 \mathrm{ft} \text { VOCs and GRO } \\
\text { collected from } 9.2-9.65 \mathrm{ft}\end{array}$ & 1 & 1 & 1 & 1 & 1 & & & 1 & & $\begin{array}{l}\text { Location is downgradient (west) of possible UST ; sample } \\
\text { location based on geophysical data }\end{array}$ \\
\hline 09/20/06 & Z2-EU23B-314 & 585762 & 2443712 & $\begin{array}{l}0-15 \mathrm{ft} \text {, one discrete sample interval from } 0-15 \mathrm{ft} \text { at } \\
\text { the discretion of the geologist }\end{array}$ & 1 & 1 & 1 & 1 & 1 & & & 1 & $\mathrm{D}$ & $\begin{array}{l}\text { Location is downgradient (southwest) of possible UST; sample } \\
\text { location based on geophysical data; high PID hit of } 309 \mathrm{ppm} \text { at } \\
10.0 \mathrm{ft}\end{array}$ \\
\hline 09/15/06 & Z2-EU23B-317 & 585640 & 2444315 & $\begin{array}{l}\text { 6.0-7.0 ft and 9.0-9.5 ft, one discrete sample } \\
\text { interval for SVOCs and metals/Hg; DRO/GRO } \\
\text { collected from 5.1-5.7 ff; VOCs collected from } \\
8.3-8.9 \mathrm{ft}\end{array}$ & 1 & 1 & 1 & 1 & 1 & & & 1 & & $\begin{array}{l}\text { Location is on north side of existing 120-gal UST on east side } \\
\text { of K-1652 }\end{array}$ \\
\hline
\end{tabular}


Table D.2. (continued)

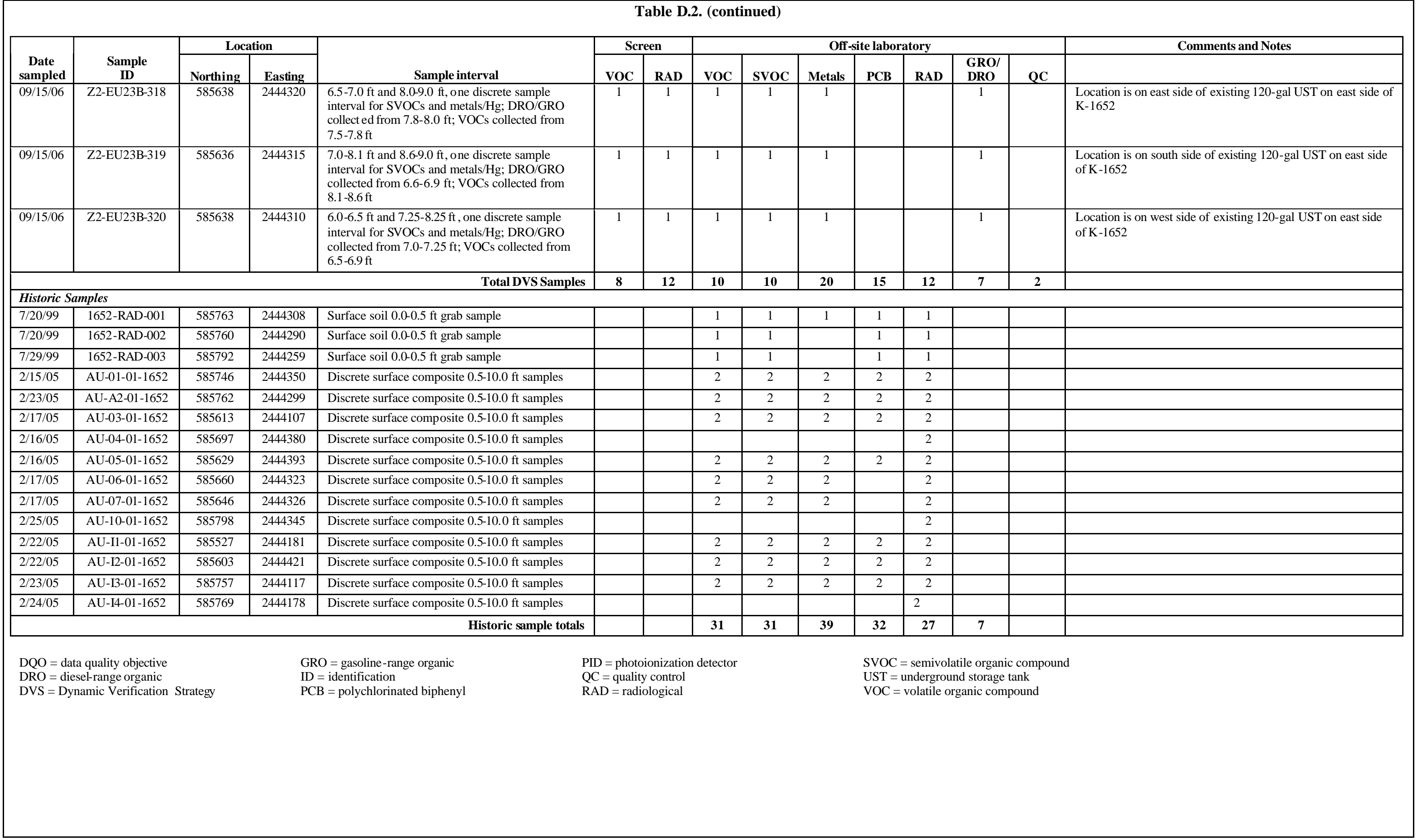




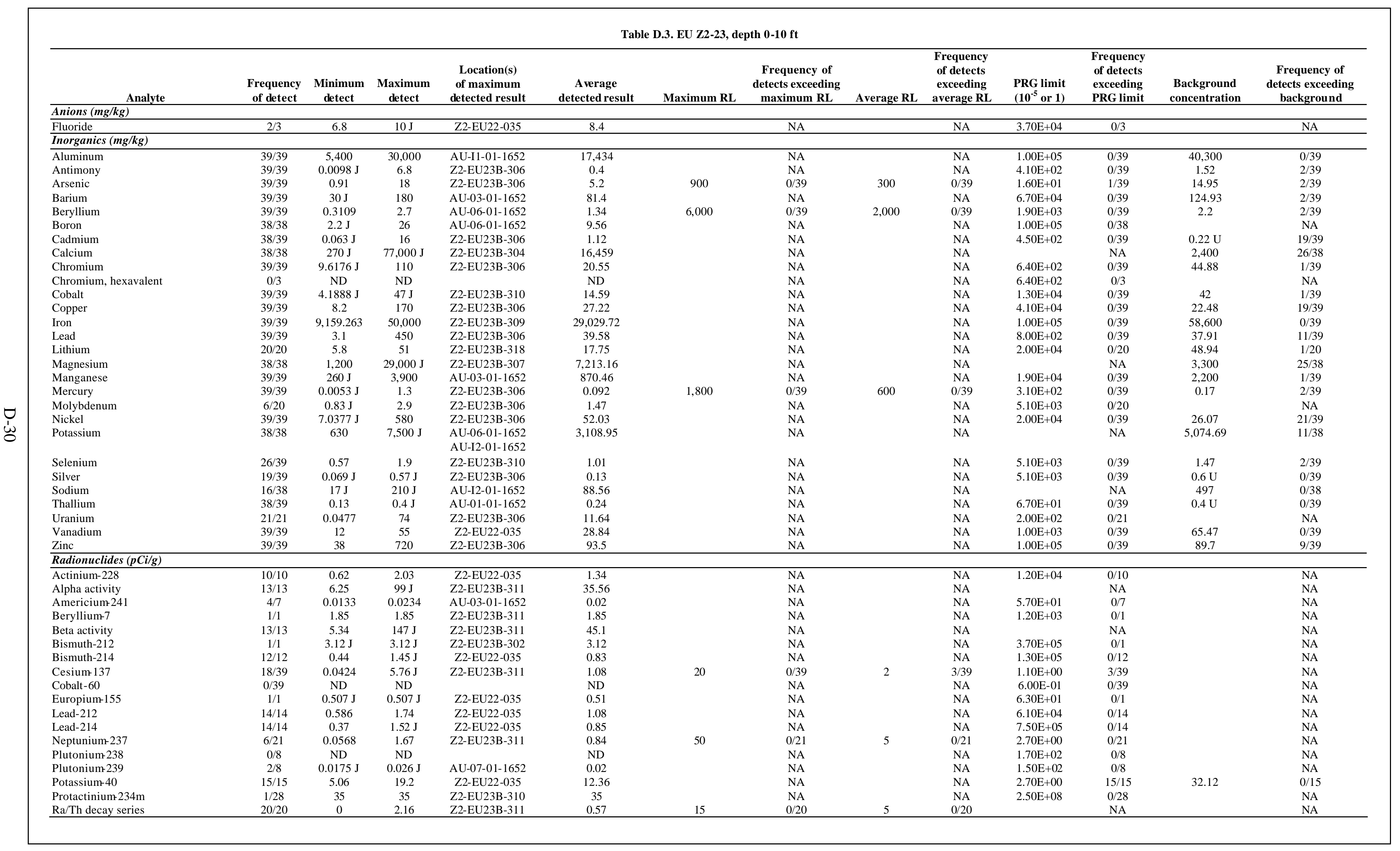


Table D.3. (continued)

\begin{tabular}{|c|c|c|c|c|c|c|c|c|c|c|c|c|c|}
\hline \multicolumn{14}{|c|}{ Table D.3. (continued) } \\
\hline Analyte & $\begin{array}{c}\text { Frequency } \\
\text { of detect }\end{array}$ & $\begin{array}{c}\text { Minimum } \\
\text { detect }\end{array}$ & $\underset{\text { detect }}{\text { Maximum }}$ & $\begin{array}{c}\text { Location(s) } \\
\text { of maximum } \\
\text { detected result }\end{array}$ & $\begin{array}{c}\text { Average } \\
\text { detected result }\end{array}$ & Maximum RL & $\begin{array}{c}\text { Frequency of } \\
\text { detects exceeding } \\
\text { maximum RL }\end{array}$ & Average RL & $\begin{array}{c}\text { Frequency } \\
\text { of detects } \\
\text { exceeding } \\
\text { average RL }\end{array}$ & $\begin{array}{l}\text { PRG limit } \\
\left(1^{-5} \text { or } 1\right)\end{array}$ & $\begin{array}{l}\text { Frequency } \\
\text { of detects } \\
\text { exceeding } \\
\text { PRG limit }\end{array}$ & $\begin{array}{l}\text { Background } \\
\text { concentration }\end{array}$ & $\begin{array}{l}\text { Frequency of } \\
\text { detects exceeding } \\
\text { background }\end{array}$ \\
\hline Radium-226 & $13 / 13$ & $0.613 \mathrm{~J}$ & $1.64 \mathrm{~J}$ & Z2-EU22-035 & 1.14 & 15 & $\mathrm{NA}^{a}$ & 5 & $\mathrm{NA}^{a}$ & $2.60 \mathrm{E}-01$ & $13 / 13$ & 1.25 & $5 / 13$ \\
\hline Technetium-99 & $27 / 40$ & $0.08 \mathrm{~J}$ & 250 & Z2-EU23B-311 & 38.36 & & NA & & NA & $8.90 \mathrm{E}+03$ & $0 / 40$ & & NA \\
\hline Thallium 208 & $11 / 11$ & 0.332 & 0.66 & 1652-RAD-002 & 0.45 & & $\mathrm{NA}$ & & $\mathrm{NA}$ & $3.70 \mathrm{E}+05$ & $0 / 11$ & & NA \\
\hline Thorium 228 & $17 / 20$ & 0.459 & 2.3 & Z2-EU22-035 & 1.32 & & $\mathrm{NA}$ & & NA & $1.70 \mathrm{E}-01$ & $17 / 20^{b}$ & 1.86 & $3 / 20$ \\
\hline Thorium-230 & $18 / 20$ & $0.511 \mathrm{~J}$ & 3.36 & Z2-EU23B-311 & 1.74 & 15 & $\mathrm{NA}^{a}$ & 5 & $\mathrm{NA}^{a}$ & $2.10 \mathrm{E}+02$ & $0 / 20$ & 1.2 & $14 / 20$ \\
\hline Thorium 232 & $20 / 20$ & 0.375 & 2.28 & Z2-EU22-035 & 1.17 & 15 & $\mathrm{NA}^{a}$ & 5 & $\mathrm{NA}^{a}$ & $1.70 \mathrm{E}-01$ & $20 / 20^{b}$ & 1.95 & $1 / 20$ \\
\hline Thorium-234 & $16 / 39$ & 1.18 & 19.8 & Z2-EU23B-311 & 6.03 & & NA & & NA & $3.30 \mathrm{E}+04$ & $0 / 39$ & & NA \\
\hline Uranium-234 & $40 / 40$ & $1.15 \mathrm{~J}$ & 149 & Z2-EU23B-311 & 19.61 & 7000 & $0 / 40$ & 700 & $0 / 40$ & $3.30 \mathrm{E}+02$ & $0 / 40$ & & NA \\
\hline Uranium-235 & $37 / 40$ & $0.0376 \mathrm{~J}$ & 6.37 & Z2-EU23B-311 & 0.89 & 80 & $0 / 40$ & 8 & $0 / 40$ & $3.90 \mathrm{E}+00$ & $4 / 40$ & & NA \\
\hline Uranium-238 & $40 / 40$ & 0.898 & 20.5 & Z2-EU23B-311 & 3.95 & 500 & $0 / 40$ & 50 & $0 / 40$ & $1.80 \mathrm{E}+01$ & $1 / 40$ & 1.47 & $31 / 40$ \\
\hline \multicolumn{14}{|l|}{ Other Organics (ug/kg) } \\
\hline Diesel Range Organics & $0 / 7$ & ND & $\mathrm{ND}$ & & ND & & $\mathrm{NA}$ & & $\mathrm{NA}$ & & $\mathrm{NA}$ & & $\mathrm{NA}$ \\
\hline Gasoline Range Organics & $0 / 7$ & $\mathrm{ND}$ & $\mathrm{ND}$ & & $\mathrm{ND}$ & & NA & & $\mathrm{NA}$ & & NA & & NA \\
\hline \multicolumn{14}{|c|}{ Organics, Pesticides, and PCBs $(\mathrm{ug} / \mathrm{kg})$} \\
\hline PCB-1016 & $0 / 32$ & ND & $\mathrm{ND}$ & & $\mathrm{ND}$ & 100,000 & $0 / 32$ & 10,000 & $0 / 32$ & $3.70 \mathrm{E}+04$ & $0 / 32$ & & NA \\
\hline PCB-1221 & $0 / 32$ & ND & ND & & ND & 100,000 & $0 / 32$ & 10,000 & $0 / 32$ & $7.40 \mathrm{E}+03$ & $0 / 32$ & & NA \\
\hline PCB-1232 & $0 / 32$ & $\mathrm{ND}$ & $\mathrm{ND}$ & & $\mathrm{ND}$ & 100,000 & $0 / 32$ & 10,000 & $0 / 32$ & $7.40 \mathrm{E}+03$ & $0 / 32$ & & $\mathrm{NA}$ \\
\hline PCB-1242 & $0 / 32$ & $\mathrm{ND}$ & ND & & ND & 100,000 & $0 / 32$ & 10,000 & $0 / 32$ & $7.40 \mathrm{E}+03$ & $0 / 32$ & & NA \\
\hline PCB-1248 & 0/32 & ND & ND & & ND & 100,000 & $0 / 32$ & 10,000 & $0 / 32$ & $7.40 \mathrm{E}+03$ & $0 / 32$ & & $\mathrm{NA}$ \\
\hline PCB-1262 & $0 / 3$ & ND & ND & & $\mathrm{ND}$ & 100,000 & $0 / 3$ & 10,000 & $0 / 3$ & $7.40 \mathrm{E}+03$ & $0 / 3$ & & $\mathrm{NA}$ \\
\hline PCB-1268 & $0 / 3$ & $\mathrm{ND}$ & ND & & $\mathrm{ND}$ & 100,000 & $0 / 3$ & 10,000 & $0 / 3$ & $7.40 \mathrm{E}+03$ & $0 / 3$ & & NA \\
\hline Polychlorinated biphenyl & $12 / 15$ & $19 \mathrm{~J}$ & 55,000 & Z2-EU23B-306 & $8,102.5$ & 100,000 & $0 / 15$ & 10,000 & $2 / 15$ & $7.40 \mathrm{E}+03$ & $2 / 15$ & & NA \\
\hline \multicolumn{14}{|l|}{ Semivolatile Organics (ug/kg) } \\
\hline 1,2,4 Trichlorobenzene & $0 / 41$ & ND & $\mathrm{ND}$ & & $\mathrm{ND}$ & & NA & & NA & $2.20 \mathrm{E}+05$ & $0 / 41$ & & $\mathrm{NA}$ \\
\hline 1,2 -Dichlorobenzene & $0 / 41$ & ND & ND & & ND & & NA & & NA & $6.00 \mathrm{E}+05$ & $0 / 41$ & & NA \\
\hline 1,3-Dichlorobenzene & $0 / 41$ & $\mathrm{ND}$ & $\mathrm{ND}$ & & $\mathrm{ND}$ & & $\mathrm{NA}$ & & NA & $6.00 \mathrm{E}+05$ & $0 / 41$ & & $\mathrm{NA}$ \\
\hline 1,4-Dichlorobenzene & $0 / 41$ & ND & ND & & ND & & NA & & NA & $7.90 \mathrm{E}+04$ & $0 / 41$ & & NA \\
\hline 2,3,4,6-Tetrachlorophenol & $0 / 10$ & ND & $\mathrm{ND}$ & & $\mathrm{ND}$ & & NA & & NA & $1.80 \mathrm{E}+07$ & $0 / 10$ & & $\mathrm{NA}$ \\
\hline 2,4,5-Trichlorophenol & $0 / 31$ & $\mathrm{ND}$ & $\mathrm{ND}$ & & $\mathrm{ND}$ & & $\mathrm{NA}$ & & NA & $6.20 \mathrm{E}+07$ & $0 / 31$ & & $\mathrm{NA}$ \\
\hline 2,4,6-Trichlorophenol & $0 / 31$ & ND & $\mathrm{ND}$ & & $\mathrm{ND}$ & & NA & & NA & $6.20 \mathrm{E}+04$ & $0 / 31$ & & NA \\
\hline 2,4-Dichlorophenol & $0 / 31$ & $\mathrm{ND}$ & $\mathrm{ND}$ & & $\mathrm{ND}$ & & $\mathrm{NA}$ & & NA & $1.80 \mathrm{E}+06$ & $0 / 31$ & & $\mathrm{NA}$ \\
\hline 2,4-Dimethylphenol & $0 / 31$ & ND & ND & & ND & & NA & & NA & $1.20 \mathrm{E}+07$ & $0 / 31$ & & NA \\
\hline 2,4-Dinitrophenol & $0 / 31$ & $\mathrm{ND}$ & ND & & ND & & NA & & NA & $1.20 \mathrm{E}+06$ & $0 / 31$ & & NA \\
\hline 2,4-Dinitrotoluene & $0 / 31$ & $\mathrm{ND}$ & ND & & ND & & NA & & NA & $2.50 \mathrm{E}+04$ & $0 / 31$ & & NA \\
\hline 2,6-Dinitrotoluene & $0 / 31$ & ND & ND & & ND & & NA & & NA & $2.50 \mathrm{E}+04$ & $0 / 31$ & & NA \\
\hline 2-Chloronaphthalene & $0 / 31$ & $\mathrm{ND}$ & $\mathrm{ND}$ & & $\mathrm{ND}$ & & $\mathrm{NA}$ & & NA & $2.30 \mathrm{E}+07$ & $0 / 31$ & & $\mathrm{NA}$ \\
\hline 2-Chlorophenol & $0 / 31$ & ND & ND & & ND & & NA & & NA & $2.40 \mathrm{E}+05$ & $0 / 31$ & & NA \\
\hline 2-Methyl-4,6-dinitrophenol & $0 / 31$ & $\mathrm{ND}$ & $\mathrm{ND}$ & & $\mathrm{ND}$ & & $\mathrm{NA}$ & & $\mathrm{NA}$ & $6.20 \mathrm{E}+04$ & $0 / 31$ & & $\mathrm{NA}$ \\
\hline 2-Methylnaphthalene & $1 / 31$ & $370 \mathrm{~J}$ & $370 \mathrm{~J}$ & AU-03-01-1652 & 370 & & NA & & NA & $1.90 \mathrm{E}+05$ & $0 / 31$ & & NA \\
\hline 2-Methylphenol & $0 / 31$ & ND & ND & & ND & & $\mathrm{NA}$ & & NA & $3.10 \mathrm{E}+07$ & $0 / 31$ & & $\mathrm{NA}$ \\
\hline 2-Nitrobenzenamine & $0 / 31$ & $\mathrm{ND}$ & $\mathrm{ND}$ & & $\mathrm{ND}$ & & $\mathrm{NA}$ & & NA & $1.80 \mathrm{E}+06$ & $0 / 31$ & & $\mathrm{NA}$ \\
\hline 2-Nitrophenol & $0 / 31$ & ND & ND & & ND & & NA & & NA & & NA & & NA \\
\hline 3,3'-Dichlorobenzidine & $0 / 31$ & $\mathrm{ND}$ & $\mathrm{ND}$ & & $\mathrm{ND}$ & & $\mathrm{NA}$ & & NA & $3.80 \mathrm{E}+04$ & $0 / 31$ & & $\mathrm{NA}$ \\
\hline 3-Methylphenol & $0 / 10$ & $\mathrm{ND}$ & ND & & ND & & NA & & NA & $3.10 \mathrm{E}+07$ & $0 / 10$ & & NA \\
\hline 3-Nitrobenzenamine & $0 / 31$ & ND & ND & & ND & & NA & & NA & $1.80 \mathrm{E}+05$ & $0 / 31$ & & NA \\
\hline
\end{tabular}


Table D.3. (continued)

\begin{tabular}{|c|c|c|c|c|c|c|c|c|c|c|c|c|c|}
\hline \multicolumn{14}{|c|}{ Table D.3. (continued) } \\
\hline $\begin{array}{c}\text { Analyte } \\
\end{array}$ & $\begin{array}{r}\text { Frequency } \\
\text { of detect }\end{array}$ & $\begin{array}{c}\text { Minimum } \\
\text { detect }\end{array}$ & $\begin{array}{c}\text { Maximum } \\
\text { detect }\end{array}$ & $\begin{array}{c}\text { Location(s) } \\
\text { of maximum } \\
\text { detected result }\end{array}$ & $\begin{array}{c}\text { Average } \\
\text { detected result }\end{array}$ & Maximum RL & $\begin{array}{c}\text { Frequency of } \\
\text { detects exceeding } \\
\text { maximum RL }\end{array}$ & Average RL & $\begin{array}{c}\text { Frequency } \\
\text { of detects } \\
\text { exceeding } \\
\text { average RL }\end{array}$ & $\begin{array}{l}\text { PRG limit } \\
\left(10^{-5} \text { or } 1\right)\end{array}$ & $\begin{array}{l}\text { Frequency } \\
\text { of detects } \\
\text { exceeding } \\
\text { PRG limit }\end{array}$ & $\begin{array}{c}\text { Background } \\
\text { concentration }\end{array}$ & $\begin{array}{c}\text { Frequency of } \\
\text { detects exceeding } \\
\text { background }\end{array}$ \\
\hline 4-Chlorophenyl phenyl ether & $0 / 31$ & $\mathrm{ND}$ & ND & & $\mathrm{ND}$ & & NA & & NA & & NA & & NA \\
\hline 4-Methylphenol & $0 / 21$ & ND & ND & & $\mathrm{ND}$ & & NA & & NA & $3.10 \mathrm{E}+06$ & $0 / 21$ & & NA \\
\hline 4-Nitrobenzenamine & $0 / 31$ & ND & ND & & ND & & NA & & NA & $8.20 \mathrm{E}+05$ & $0 / 31$ & & NA \\
\hline 4-Nitrophenol & $0 / 31$ & $\mathrm{ND}$ & ND & & $\mathrm{ND}$ & & NA & & NA & & NA & & NA \\
\hline Acenaphthene & $2 / 31$ & $44 \mathrm{~J}$ & 1000 & AU-03-01-1652 & 522 & & NA & & NA & $2.90 \mathrm{E}+07$ & $0 / 31$ & & NA \\
\hline Acenaphthylene & $0 / 31$ & ND & ND & & ND & & NA & & NA & $2.90 \mathrm{E}+07$ & $0 / 31$ & & NA \\
\hline Aniline & $0 / 10$ & ND & ND & & ND & & NA & & NA & $3.00 \mathrm{E}+06$ & $0 / 10$ & & NA \\
\hline Anthracene & $4 / 31$ & $53 \mathrm{~J}$ & 1,700 & AU-03-01-1652 & 492.42 & & NA & & NA & $1.00 \mathrm{E}+08$ & $0 / 31$ & & NA \\
\hline Benz(a)anthracene & $6 / 31$ & $67 \mathrm{~J}$ & 2,400 & AU-03-01-1652 & 519.4 & & NA & & NA & $2.10 \mathrm{E}+04$ & $0 / 31$ & & NA \\
\hline Benzenemethanol & $0 / 13$ & $\mathrm{ND}$ & ND & & ND & & NA & & NA & $1.00 \mathrm{E}+08$ & $0 / 13$ & & NA \\
\hline Benzidine & $0 / 3$ & ND & $\mathrm{ND}$ & & $\mathrm{ND}$ & & NA & & NA & $7.50 \mathrm{E}+01$ & $0 / 3$ & & NA \\
\hline Benzo(a)pyrene & $5 / 31$ & 82.0945 & 1,700 & AU-03-01-1652 & 466.42 & & NA & & NA & $2.10 \mathrm{E}+03$ & $0 / 31$ & & NA \\
\hline Benzo(b)fluoranthene & $7 / 31$ & $91 \mathrm{~J}$ & 1,600 & AU-03-01-1652 & 355.03 & & NA & & NA & $2.10 \mathrm{E}+04$ & $0 / 31$ & & NA \\
\hline Benzo(ghi)perylene & $3 / 31$ & $130 \mathrm{~J}$ & 1,000 & AU-03-01-1652 & 443.33 & & NA & & NA & $2.90 \mathrm{E}+07$ & $0 / 31$ & & NA \\
\hline Benzo(k)fluoranthene & $7 / 31$ & 96.312 & 1,700 & AU-03-01-1652 & 356.62 & & NA & & NA & $2.10 \mathrm{E}+05$ & $0 / 31$ & & NA \\
\hline Benzoic acid & $0 / 13$ & ND & ND & & ND & & NA & & NA & $1.00 \mathrm{E}+08$ & $0 / 13$ & & NA \\
\hline Bis(2-chloroethoxy)methane & $0 / 31$ & $\mathrm{ND}$ & $\mathrm{ND}$ & & ND & & NA & & NA & & NA & & NA \\
\hline Bis(2-chloroethyl) ether & $0 / 31$ & ND & ND & & ND & & NA & & NA & $5.80 \mathrm{E}+03$ & $0 / 31$ & & NA \\
\hline Bis(2-chloroisopropyl) ether & $0 / 31$ & ND & ND & & ND & & NA & & NA & $7.40 \mathrm{E}+04$ & $0 / 31$ & & NA \\
\hline Bis(2-ethylhexyl)phthalate & $2 / 31$ & $57 \mathrm{~J}$ & 98.7498 & 1652-RAD-003 & 77.87 & & NA & & NA & $1.20 \mathrm{E}+06$ & $0 / 31$ & & NA \\
\hline Butyl benzyl phthalate & $0 / 31$ & $\mathrm{ND}$ & ND & & ND & & NA & & NA & $1.00 \mathrm{E}+08$ & $0 / 31$ & & NA \\
\hline 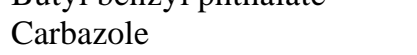 & $1 / 28$ & 1300 & 1300 & AU-03-01-1652 & 1300 & & NA & & NA & $8.60 \mathrm{E}+05$ & $0 / 28$ & & NA \\
\hline Chrysene & $6 / 31$ & $65 \mathrm{~J}$ & 2,400 & AU-03-01-1652 & 529.93 & & NA & & NA & $2.10 \mathrm{E}+06$ & $0 / 31$ & & NA \\
\hline Di-n-butyl phthalate & $0 / 31$ & ND & ND & & ND & & NA & & NA & $6.20 \mathrm{E}+07$ & $0 / 31$ & & NA \\
\hline Di-n-octylphthalate & $0 / 31$ & ND & ND & & ND & & NA & & NA & $2.50 \mathrm{E}+07$ & $0 / 31$ & & NA \\
\hline Dibenz $(a, h)$ anthracene & $2 / 31$ & $56 \mathrm{~J}$ & 600 & AU-03-01-1652 & 328 & & NA & & NA & $2.10 \mathrm{E}+03$ & $0 / 31$ & & NA \\
\hline Dibenzofuran & $1 / 31$ & 580 & 580 & AU-03-01-1652 & 580 & & NA & & NA & $1.60 \mathrm{E}+06$ & $0 / 31$ & & NA \\
\hline Diethyl phthalate & $1 / 31$ & $150 \mathrm{~J}$ & $150 \mathrm{~J}$ & AU-I3-01-1652 & 150 & & NA & & NA & $1.00 \mathrm{E}+08$ & $0 / 31$ & & NA \\
\hline Dimethyl phthalate & $0 / 31$ & ND & ND & & ND & & NA & & NA & $1.00 \mathrm{E}+08$ & $0 / 31$ & & NA \\
\hline Diphenyldiazene & $0 / 10$ & ND & ND & & ND & & NA & & NA & $1.60 \mathrm{E}+05$ & $0 / 10$ & & NA \\
\hline Fluoranthene & $7 / 31$ & 94.9697 & 5,800 & AU-03-01-1652 & $1,048.42$ & & NA & & NA & $2.20 \mathrm{E}+07$ & $0 / 31$ & & NA \\
\hline Fluorene & $1 / 31$ & 1000 & 1,000 & AU-03-01-1652 & 1000 & & NA & & NA & $2.60 \mathrm{E}+07$ & $0 / 31$ & & NA \\
\hline Hexachlorobenzene & $0 / 31$ & $\mathrm{ND}$ & ND & & ND & & NA & & NA & $1.10 \mathrm{E}+04$ & $0 / 31$ & & NA \\
\hline Hexachlorobutadiene & $0 / 41$ & ND & ND & & ND & & NA & & NA & $1.80 \mathrm{E}+05$ & $0 / 41$ & & NA \\
\hline Hexachlorocyclopentadiene & $0 / 31$ & ND & ND & & ND & & NA & & NA & $3.70 \mathrm{E}+06$ & $0 / 31$ & & NA \\
\hline Hexachloroethane & $0 / 31$ & ND & ND & & ND & & NA & & NA & $6.20 \mathrm{E}+05$ & $0 / 31$ & & NA \\
\hline Indeno(1,2,3-cd)pyrene & $3 / 31$ & $120 \mathrm{~J}$ & 1,000 & AU-03-01-1652 & 426.67 & & NA & & NA & $2.10 \mathrm{E}+04$ & $0 / 31$ & & NA \\
\hline Isophorone & $0 / 31$ & $\mathrm{ND}$ & $\mathrm{ND}$ & & $\mathrm{ND}$ & & NA & & NA & $5.10 \mathrm{E}+06$ & $0 / 31$ & & NA \\
\hline N-Nitroso-di-n-propylamine & $0 / 31$ & ND & $\mathrm{ND}$ & & ND & & NA & & NA & $2.50 \mathrm{E}+03$ & $0 / 31$ & & NA \\
\hline N-Nitrosodimethylamine & $0 / 10$ & ND & ND & & ND & & NA & & NA & $3.40 \mathrm{E}+02$ & $0 / 10$ & & NA \\
\hline N-Nitrosodiphenylamine & $0 / 31$ & ND & ND & & ND & & NA & & NA & $3.50 \mathrm{E}+06$ & $0 / 31$ & & NA \\
\hline Naphthalene & $1 / 41$ & 880 & 880 & AU-03-01-1652 & 880 & & NA & & NA & $1.90 \mathrm{E}+05$ & $0 / 41$ & & NA \\
\hline Nitrobenzene & $0 / 31$ & $\mathrm{ND}$ & $\mathrm{ND}$ & & $\mathrm{ND}$ & & NA & & NA & $1.00 \mathrm{E}+05$ & $0 / 31$ & & NA \\
\hline Pentachlorophenol & $0 / 31$ & ND & ND & & ND & & NA & & NA & $9.00 \mathrm{E}+04$ & $0 / 31$ & & NA \\
\hline Phenanthrene & $6 / 31$ & $39 \mathrm{~J}$ & 6,100 & AU-03-01-1652 & $1,166.92$ & & NA & & NA & $2.90 \mathrm{E}+07$ & $0 / 31$ & & NA \\
\hline Phenol & $1 / 31$ & $49 \mathrm{~J}$ & $49 \mathrm{~J}$ & AU-03-01-1652 & 49 & & NA & & NA & $1.00 \mathrm{E}+08$ & $0 / 31$ & & NA \\
\hline Pyrene & $7 / 31$ & 77.4501 & 4,800 & AU-03-01-1652 & 882.95 & & NA & & NA & $2.90 \mathrm{E}+07$ & $0 / 31$ & & NA \\
\hline Pyridine & $0 / 10$ & ND & ND & & $\mathrm{ND}$ & & NA & & NA & $6.20 \mathrm{E}+05$ & $0 / 10$ & & NA \\
\hline \multicolumn{14}{|l|}{ Volatile Organics $(\mathrm{ug} / \mathrm{kg})$} \\
\hline (1,1-Dimethylethyl)benzene & $0 / 13$ & $\mathrm{ND}$ & ND & & ND & & $\mathrm{NA}$ & & NA & $3.90 \mathrm{E}+05$ & $0 / 13$ & & NA \\
\hline (1-Methylpropyl)benzene & $0 / 13$ & ND & ND & & ND & & NA & & NA & $2.20 \mathrm{E}+05$ & $0 / 13$ & & NA \\
\hline 1,1,1,2-Tetrachloroethane & $0 / 13$ & ND & ND & & ND & & NA & & NA & $7.30 \mathrm{E}+04$ & $0 / 13$ & & NA \\
\hline 1,1,1-Trichloroethane & $0 / 31$ & $\mathrm{ND}$ & ND & & ND & & NA & & NA & $1.20 \mathrm{E}+06$ & $0 / 31$ & & NA \\
\hline
\end{tabular}


Table D.3. (continued)

\begin{tabular}{|c|c|c|c|c|c|c|c|c|c|c|c|c|c|}
\hline Analyte & $\begin{array}{c}\text { Frequency } \\
\text { of detect }\end{array}$ & $\begin{array}{c}\text { Minimum } \\
\text { detect }\end{array}$ & $\begin{array}{c}\text { Maximum } \\
\text { detect }\end{array}$ & $\begin{array}{c}\text { Location(s) } \\
\text { of maximum } \\
\text { detected result }\end{array}$ & $\begin{array}{c}\text { Average } \\
\text { detected result }\end{array}$ & Maximum RL & $\begin{array}{c}\text { Frequency of } \\
\text { detects exceeding } \\
\text { maximum RL }\end{array}$ & Average RL & $\begin{array}{c}\text { Frequency } \\
\text { of detects } \\
\text { exceeding } \\
\text { average RL }\end{array}$ & $\begin{array}{l}\text { PRG limit } \\
\left(10^{-5} \text { or } 1\right)\end{array}$ & $\begin{array}{l}\text { Frequency } \\
\text { of detects } \\
\text { exceeding } \\
\text { PRG limit }\end{array}$ & $\begin{array}{c}\text { Background } \\
\text { concentration }\end{array}$ & $\begin{array}{c}\text { Frequency of } \\
\text { detects exceeding } \\
\text { background }\end{array}$ \\
\hline 1,1,2,2-Tetrachloroethane & $0 / 31$ & ND & ND & & $\mathrm{ND}$ & & NA & & NA & $9.30 \mathrm{E}+03$ & $0 / 31$ & & NA \\
\hline 1,1,2-Trichloro-1,2,2-trifluoroethane & $0 / 28$ & ND & ND & & ND & & NA & & NA & $5.60 \mathrm{E}+06$ & $0 / 28$ & & NA \\
\hline 1,1,2-Trichloroethane & $0 / 31$ & ND & ND & & ND & & $\mathrm{NA}$ & & NA & $1.60 \mathrm{E}+04$ & $0 / 31$ & & NA \\
\hline $\begin{array}{l}1,1 \text {-Dichloroethane } \\
\text { late }\end{array}$ & $0 / 31$ & ND & $\mathrm{ND}$ & & ND & & NA & & NA & $1.70 \mathrm{E}+06$ & $0 / 31$ & & NA \\
\hline 1,1 -Dichloroethene & $5 / 31$ & $0.43 \mathrm{~J}$ & $0.71 \mathrm{~J}$ & AU-07-01-1652 & 0.5 & & NA & & NA & $4.10 \mathrm{E}+05$ & $0 / 31$ & & NA \\
\hline 1,1-Dichloropropene & $0 / 13$ & ND & $\mathrm{ND}$ & & ND & & $\mathrm{NA}$ & & NA & & NA & & NA \\
\hline 1,2,3-Trichlorobenzene & $0 / 13$ & ND & ND & & ND & & NA & & NA & & NA & & NA \\
\hline 1,2,3-Trichloropropane & $0 / 13$ & ND & ND & & ND & & NA & & NA & $7.60 \mathrm{E}+02$ & $0 / 13$ & & $\mathrm{NA}$ \\
\hline $1,2,4$ Trimethylbenzene & $0 / 13$ & ND & ND & & ND & & NA & & NA & $1.70 \mathrm{E}+05$ & $0 / 13$ & & NA \\
\hline 1,2-Dibromo-3-chloropropane & $0 / 13$ & $\mathrm{ND}$ & $\mathrm{ND}$ & & $\mathrm{ND}$ & & $\mathrm{NA}$ & & $\mathrm{NA}$ & $1.10 \mathrm{E}+04$ & $0 / 13$ & & $\mathrm{NA}$ \\
\hline 1,2-Dibromoethane & $0 / 13$ & ND & $\mathrm{ND}$ & & $\mathrm{ND}$ & & NA & & NA & $6.30 \mathrm{E}+02$ & $0 / 13$ & & NA \\
\hline 1,2-Dichloroethane & $0 / 31$ & ND & ND & & ND & & NA & & NA & $6.00 \mathrm{E}+03$ & $0 / 31$ & & $\mathrm{NA}$ \\
\hline 1,2-Dichloroethene & $\begin{array}{l}0 / 18 \\
0 / 18\end{array}$ & ND & ND & & ND & & NA & & NA & $\begin{array}{l}0.0 \mathrm{C}+0 \mathrm{~S} \\
1.50 \mathrm{E}+05\end{array}$ & $0 / 18$ & & NA \\
\hline 1,2 -Dichloropropane & $0 / 31$ & ND & ND & & ND & & NA & & NA & $7.40 \mathrm{E}+03$ & $0 / 31$ & & NA \\
\hline 1,2-Dimethylbenzene & $0 / 10$ & ND & ND & & ND & & NA & & NA & 4.20E+05 & $0 / 10$ & & NA \\
\hline 1,3,5-Trimethylbenzene & $0 / 13$ & ND & ND & & ND & & $\mathrm{NA}$ & & NA & $7.00 \mathrm{E}+04$ & $0 / 13$ & & NA \\
\hline 1,3-Dichloropropane & $0 / 13$ & ND & ND & & ND & & NA & & NA & $3.60 \mathrm{E}+05$ & $0 / 13$ & & NA \\
\hline 1-Chloro-4-methylbenzene & $0 / 13$ & ND & ND & & ND & & $\mathrm{NA}$ & & NA & & NA & & NA \\
\hline 1-Methyl-4-(1-methylethyl)benzene & $0 / 13$ & ND & ND & & $\mathrm{ND}$ & & NA & & NA & & NA & & NA \\
\hline 1-chlorohexane & $0 / 10$ & ND & $\mathrm{ND}$ & & $\mathrm{ND}$ & & $\mathrm{NA}$ & & $\mathrm{NA}$ & & $\mathrm{NA}$ & & $\mathrm{NA}$ \\
\hline 2,2-Dichloropropane & $0 / 13$ & ND & ND & & ND & & NA & & NA & & NA & & NA \\
\hline 2-Butanone & $1 / 28$ & $3.5 \mathrm{~J}$ & $3.5 \mathrm{~J}$ & AU-I3-01-1652 & 3.5 & & NA & & NA & $1.00 \mathrm{E}+08$ & $0 / 28$ & & NA \\
\hline 2-Hexanone & $0 / 28$ & ND & ND & & $\mathrm{ND}$ & & NA & & NA & & NA & & NA \\
\hline 2-Methoxy-2-methylpropane & $0 / 10$ & ND & ND & & ND & & $\mathrm{NA}$ & & NA & $3.60 \mathrm{E}+05$ & $0 / 10$ & & NA \\
\hline 4-Methyl-2-pentanone & $0 / 28$ & ND & ND & & $\mathrm{ND}$ & & $\mathrm{NA}$ & & $\mathrm{NA}$ & $4.70 \mathrm{E}+07$ & $0 / 28$ & & NA \\
\hline Acetone & $0 / 28$ & ND & ND & & ND & & NA & & NA & $5.40 \mathrm{E}+07$ & $0 / 28$ & & NA \\
\hline $\begin{array}{l}\text { Benzene } \\
\text { Bentive }\end{array}$ & $0 / 31$ & ND & ND & & ND & & NA & & NA & $1.40 \mathrm{E}+04$ & $0 / 31$ & & NA \\
\hline Bromobenzene & $0 / 13$ & ND & ND & & ND & & $\mathrm{NA}$ & & NA & $9.20 \mathrm{E}+04$ & $0 / 13$ & & NA \\
\hline Bromochloromethane & $0 / 13$ & ND & ND & & ND & & NA & & NA & & NA & & NA \\
\hline Bromodichloromethane & $0 / 31$ & ND & ND & & ND & & NA & & NA & $1.80 \mathrm{E}+04$ & $0 / 31$ & & NA \\
\hline Bromoform & $0 / 31$ & ND & ND & & ND & & NA & & NA & $2.20 \mathrm{E}+06$ & $0 / 31$ & & NA \\
\hline $\begin{array}{l}\text { Bromomethane } \\
\text { Bromoling }\end{array}$ & $0 / 31$ & ND & ND & & ND & & NA & & NA & $1.30 \mathrm{E}+04$ & $0 / 31$ & & NA \\
\hline Butylbenzene & $0 / 13$ & ND & ND & & ND & & NA & & NA & $2.40 \mathrm{E}+05$ & $0 / 13$ & & NA \\
\hline Carbon disulfide & $0 / 28$ & ND & ND & & ND & & NA & & NA & $7.20 \mathrm{E}+05$ & $0 / 28$ & & NA \\
\hline Carbon tetrachloride & $0 / 31$ & ND & ND & & ND & & NA & & NA & $5.50 \mathrm{E}+03$ & $0 / 31$ & & NA \\
\hline Chlorobenzene & $0 / 31$ & ND & ND & & $\mathrm{ND}$ & & $\mathrm{NA}$ & & NA & $5.30 \mathrm{E}+05$ & $0 / 31$ & & NA \\
\hline Chloroethane & $0 / 31$ & ND & ND & & $\mathrm{ND}$ & & $\mathrm{NA}$ & & NA & $6.50 \mathrm{E}+04$ & $0 / 31$ & & NA \\
\hline Chloroform & $0 / 31$ & ND & ND & & ND & & NA & & NA & $4.70 \mathrm{E}+03$ & $0 / 31$ & & NA \\
\hline Chloromethane & $0 / 31$ & $\mathrm{ND}$ & $\mathrm{ND}$ & & ND & & $\mathrm{NA}$ & & NA & $1.60 \mathrm{E}+05$ & $0 / 31$ & & NA \\
\hline Cumene & $0 / 13$ & $\mathrm{ND}$ & ND & & $\mathrm{ND}$ & & NA & & NA & $5.20 \mathrm{E}+05$ & $0 / 13$ & & NA \\
\hline Dibromochloromethane & $0 / 31$ & ND & ND & & ND & & NA & & NA & $2.60 \mathrm{E}+04$ & $0 / 31$ & & NA \\
\hline Dibromomethane & $0 / 13$ & ND & $\mathrm{ND}$ & & ND & & NA & & NA & $2.30 \mathrm{E}+05$ & $0 / 13$ & & NA \\
\hline Dichlorodifluoromethane & $0 / 13$ & $\mathrm{ND}$ & $\mathrm{ND}$ & & $\mathrm{ND}$ & & NA & & NA & $3.10 \mathrm{E}+05$ & $0 / 13$ & & NA \\
\hline $\begin{array}{l}\text { Ethylbenzene } \\
\text { Elline }\end{array}$ & $1 / 31$ & $0.51 \mathrm{~J}$ & $0.51 \mathrm{~J}$ & AU-I3-01-1652 & 0.51 & & NA & & NA & $\begin{array}{l}3.10 \mathrm{C}+03 \\
4.00 \mathrm{E}+05\end{array}$ & $0 / 31$ & & NA \\
\hline Iodomethane & $0 / 10$ & ND & $\mathrm{ND}$ & & ND & & NA & & NA & & NA & & NA \\
\hline M + P xylene & $0 / 10$ & ND & ND & & ND & & NA & & NA & $4.20 \mathrm{E}+05$ & $0 / 10$ & & NA \\
\hline Methylene chloride & $0 / 31$ & ND & $\mathrm{ND}$ & & $\mathrm{ND}$ & & NA & & NA & $2.10 \mathrm{E}+05$ & $0 / 31$ & & NA \\
\hline $\begin{array}{l}\text { Propylbenzene } \\
\text { P }\end{array}$ & $0 / 13$ & ND & $\mathrm{ND}$ & & $\mathrm{ND}$ & & $\mathrm{NA}$ & & NA & $2.40 \mathrm{E}+05$ & $0 / 13$ & & NA \\
\hline Styrene & $0 / 31$ & $\mathrm{ND}$ & ND & & $\mathrm{ND}$ & & NA & & $\mathrm{NA}$ & $1.70 \mathrm{E}+06$ & $0 / 31$ & & NA \\
\hline Tetrachloroethene & $0 / 31$ & $\mathrm{ND}$ & $\mathrm{ND}$ & & ND & & NA & & NA & $1.30 \mathrm{E}+04$ & $0 / 31$ & & NA \\
\hline Toluene & $7 / 31$ & $0.13 \mathrm{~J}$ & 21 & AU-I3-01-1652 & 3.14 & & NA & & NA & $5.20 \mathrm{E}+05$ & $0 / 31$ & & NA \\
\hline Total xylene & $3 / 21$ & $0.78 \mathrm{~J}$ & $2.9 \mathrm{~J}$ & AU-I3-01-1652 & 1.63 & & NA & & NA & $4.20 \mathrm{E}+05$ & $0 / 21$ & & NA \\
\hline Trichloroethene & $2 / 31$ & $2.2 \mathrm{~J}$ & $4.2 \mathrm{~J}$ & Z2-EU22-035 & 3.2 & & NA & & NA & $1.10 \mathrm{E}+03$ & $0 / 31$ & & NA \\
\hline
\end{tabular}




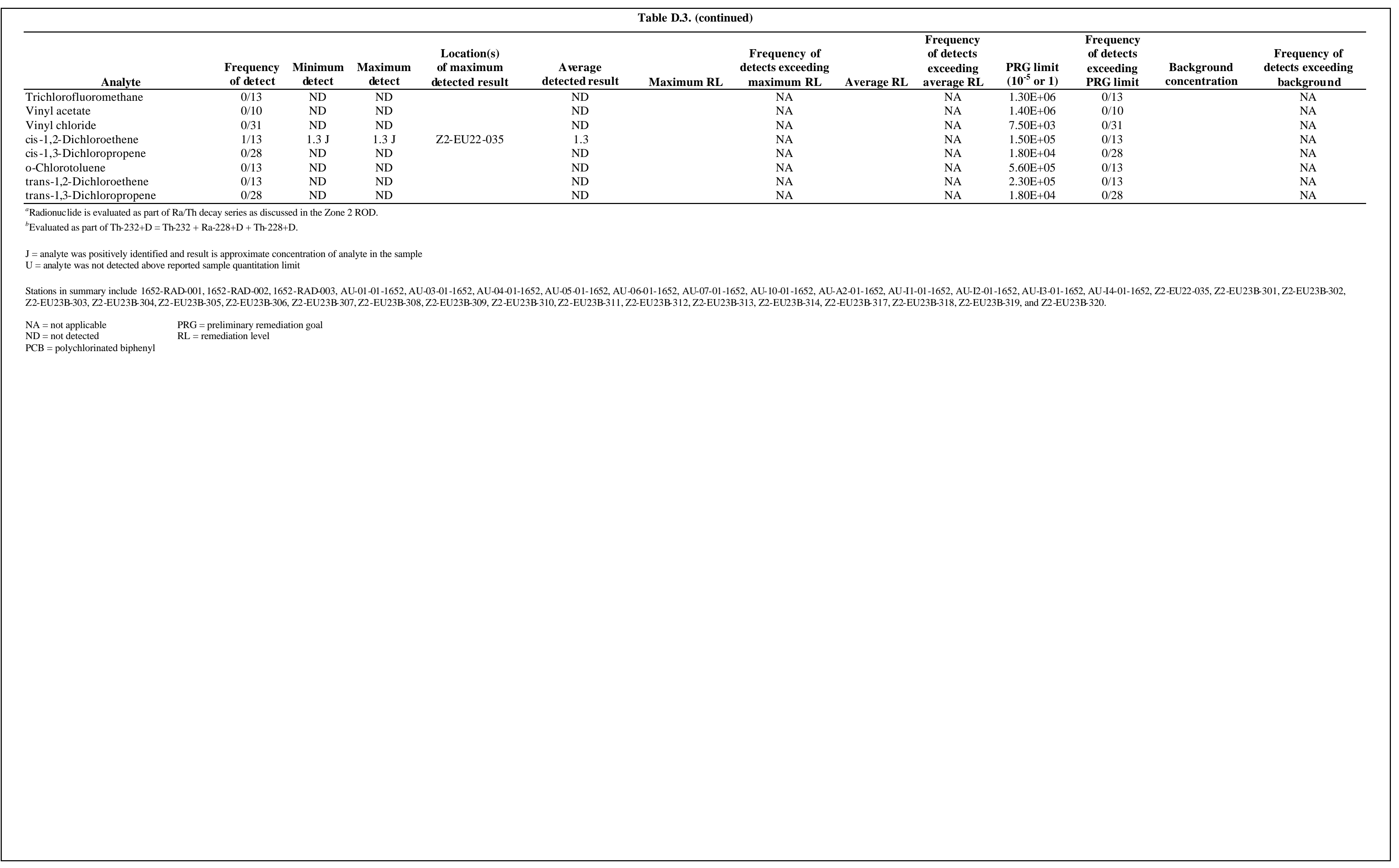


Appendix E

Main Plant Group Exposure Unit Z2-24

Technical Memorandum 


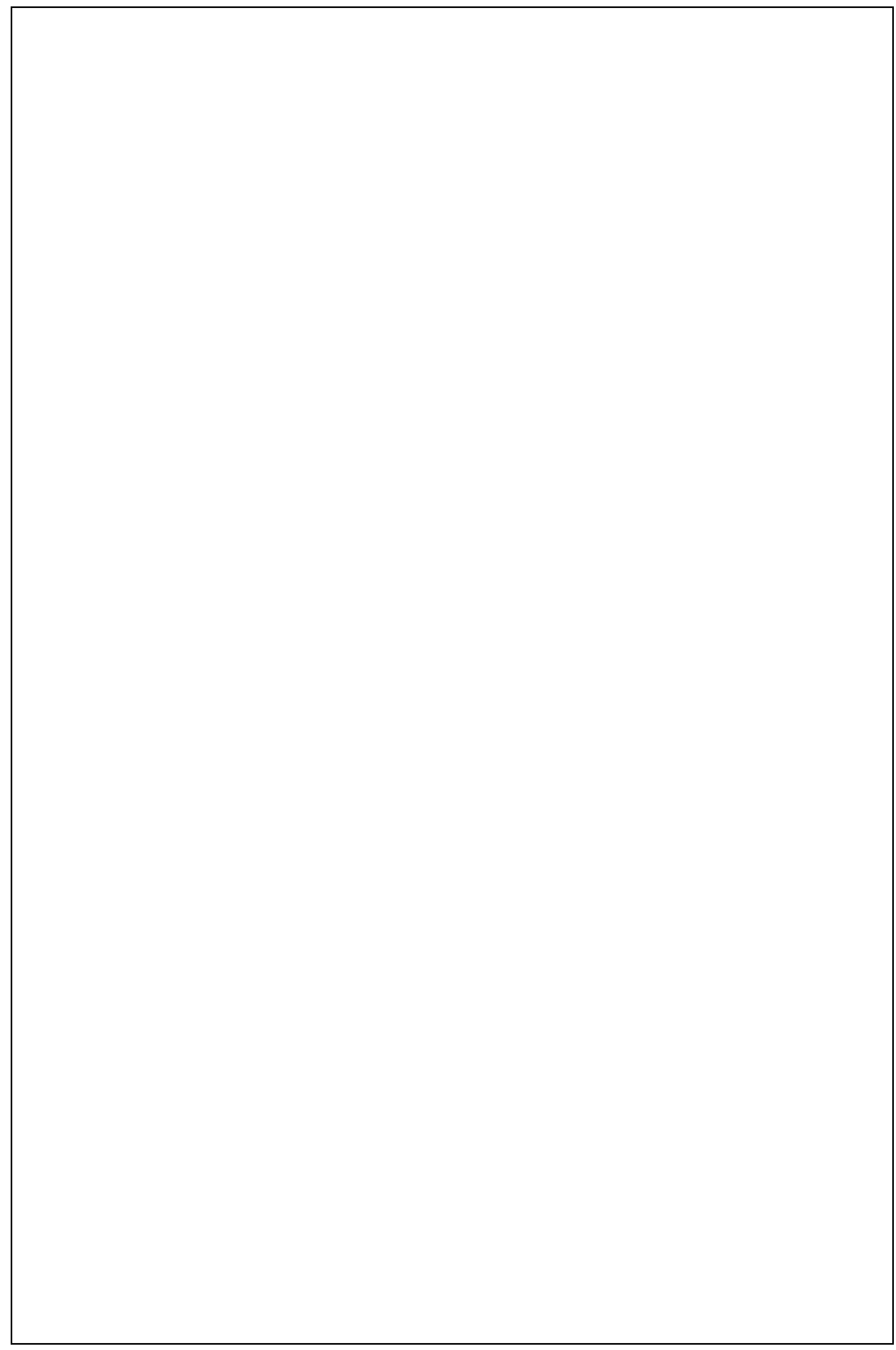

E-2 


\section{FIGURES}

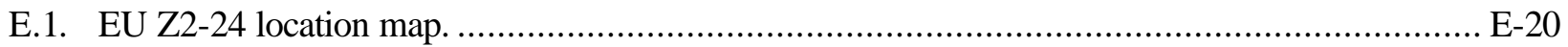

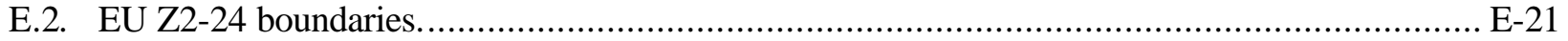

E.3. EU Z2-24 Class 3 and 4 SU walkover assessment locations............................................... E-22

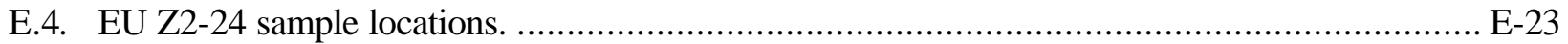

\section{TABLES}

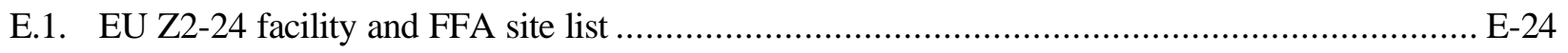

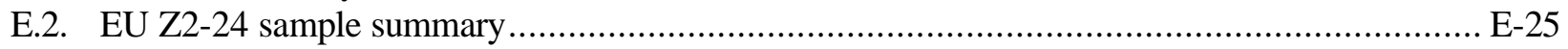

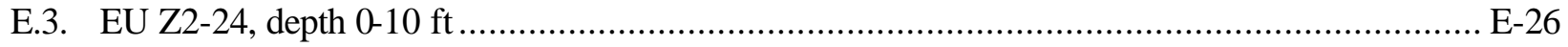

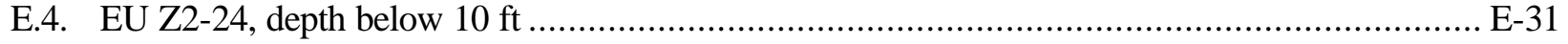




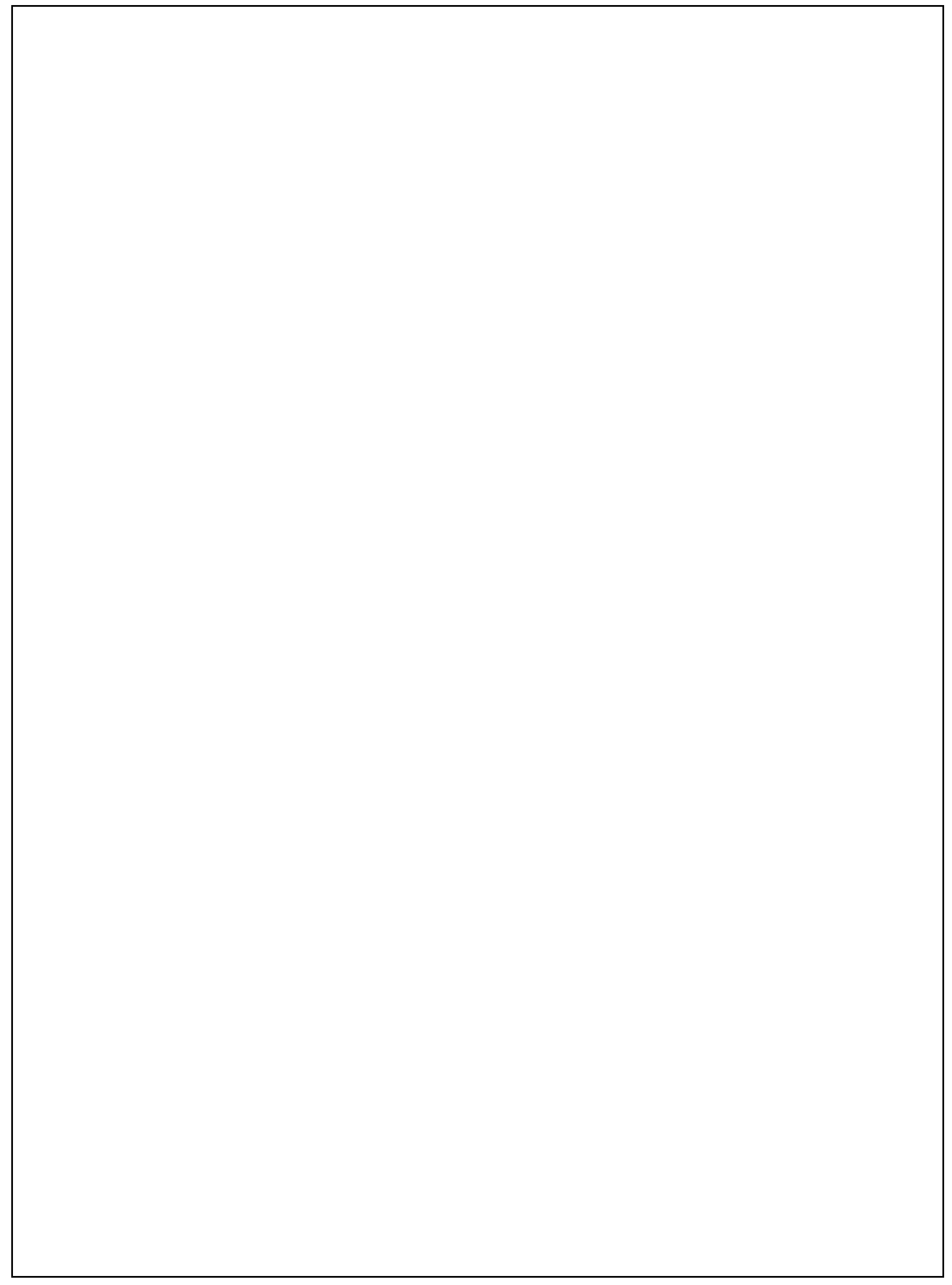




\section{DYNAMIC VERIFICATION STRATEGY (DVS) TECHNICAL MEMORANDUM (TM)}

EXPOSURE UNIT (EU) GROUP: Zone 2 Main Plant Group EU Z2-24

\section{INTRODUCTION}

The purpose of this TM is to document the recommendation for an action/no further action (NFA) decision for Zone 2 EU Z2-24 in the Main Plant EU Group. The recommendation for this EU is based on existing historical data and DVS soil characterization activities. These data are used to determine the nature and extent of contamination in the EU and evaluate the need for an action. When it is determined that an action is necessary, the data are also used to calculate soil volumes for the proposed remedial alternative as identified in the Record of Decision for Soil, Buried Waste, and Subsurface Structure Actions in Zone 2, East Tennessee Technology Park, Oak Ridge, Tennessee (DOE/OR/01-2161\&D2) (Zone 2 ROD).

\begin{tabular}{|l|l|}
\hline 1.0 & BACKGROUND AND EU SUMMARY \\
\hline 1.1 & LOCATIONAT EAST TENNESSEE TECHNOLOGY PARK (ETTP) \\
\hline
\end{tabular}

EU Z2-24 is located along the south boundary of Zone 2 in the Main Plant EU Group (Fig. E. 1). It is bounded on the north by EU Z2-23, on the east by EU Z2-32 and Zone 1, on the south by Zone 1, and on the west by EU Z2-14 and EU Z2-15.

\section{\begin{tabular}{l|l}
1.2 & EU Z2-24 ACREAGE \\
\hline
\end{tabular}}

EU Z2-24 has an area of approximately 22 acres (Fig. E.2).

\section{\begin{tabular}{|l|l|}
\hline 1.3 & SUMMARY DESCRIPTION \\
\hline
\end{tabular}}

All land area in EU Z2-24 has been impacted by site operations, including the construction of buildings, roads, parking lots, and sidewalks. EU Z2-24 lies at the southern end of the major industrialized portion of ETTP and has several large areas of maintained lawn.

The Data Quality Objective (DQO) Scoping Package for the Main Plant EU Group lists 21 facilities in EU Z2-24. Table E. 1 presents an accounting of facilities in the EU.

\begin{tabular}{l|l}
1.4 & SOIL UNITS (SUS) \\
\hline
\end{tabular}

Class 1 soil unit (SU): None

Class 2 SU: None

Class 3 SU: 22 acres

Class 4 SU: None

\section{\begin{tabular}{l|l}
1.5 & ZONE 2 ROD APPENDIX A FEDERAL FACILITY AGREEMENT (FFA) SITES
\end{tabular}}

There is one FFA site originally believed to be in EU Z2-24 that is listed in Appendix A of the Zone 2 ROD:

- K-300 Area Service Station.

Geophysical evidence (Sect. 2.1.3.4) and sample data demonstrate that the K300 Area Service Station was incorrectly located in EU Z2-24. Instead, it has been determined that the location of this FFA site is in EU Z2-23 at the intersection of Avenue $\mathrm{L}$ and $8^{\text {th }}$ Street. The FFA site is not discussed in this TM but is included in the EU Z2-23 TM. 


\begin{tabular}{cccc}
\hline & $\begin{array}{c}\text { Number of } \\
\text { assessment points }\end{array}$ & $\begin{array}{c}\text { Number of } \\
\text { mi d-points }\end{array}$ & $\begin{array}{c}\text { Number of } \\
\text { discretionary points }\end{array}$ \\
\hline EU Z2-24 & 23 & 20 & 2 \\
\hline
\end{tabular}

\section{\begin{tabular}{|l|l} 
2.1.3.1 & CLASS 3 AND CLASS 4 SU RADIOLOGICAL SURVEY SUMMARY
\end{tabular}}

Screening level (SL): $4082 \mathrm{cpm}$.

SL exceedances: None.

\begin{tabular}{|l|l} 
2.1.3.2 & CLASS 3 AND CLASS 4 SU ANTHROPOGENIC FEATURES \\
\hline
\end{tabular}

Number of identified anthropogenic features: 2

EU Z2-24 is located in an industrialized portion of ETTP. As such, there are numerous anthropogenic features, including facilities and associated constructed features such as roads, sidewalks, and paved areas. Plant facilities and their associated constructed features are assessed as part of the Class 3 and Class 4 SU walkover assessment protocol (Sect. 2.1.3.3). Two anthropogenic features identified during the walkover assessment include an unnumbered mobile security guard shack and a sediment accumulation area southeast of K-1310-HF. The sediment accumulation area was selected for sampling.

\section{\begin{tabular}{|l|l} 
2.1.3.3 & CLASS 3 SU FACILITIES ASSESSMENTS
\end{tabular}}

Twenty-one facilities are listed in the DQO soping package as being located in EU Z2-24 (Table E.1) and 21 facilities were assessed during the Class 3 SU walkover assessment, including the K-1650 UST. The facility assessments are reported in the Zone 2 EU Summary Report. With the exception of the K-1650 UST, no facility was identified as a possible source for either chemical or radiological contamination, and no biased sample locations were selected. Biased sampling at the K-1650 UST was defined during DQO scoping.

\section{\begin{tabular}{|l|l} 
2.1.3.4 & CLASS 3 AND CLASS 4 SU BIASED SAMPLING \\
\hline
\end{tabular}}

A geophysical survey was conducted in EU Z2-24 at the location indicated in plant records as the site of the former K-300 Area Service Station. Results of the geophysical survey did not show the presence of any buried metallic objects such as an UST. Other plant drawings indicate the location of the K-300 Area Service Station is to the north of EU Z2-24 in EU Z2-23. A geophysical survey was conducted at the location identified on the site drawing in EU Z2-23 and the results of that survey show the possible presence of a UST. It is concluded that the location of the K-300 Area Service Station FFA site is in EU Z2-23. The geophysical report was issued as a separate document and will be included in the Administrative Record for EU Z2-24.

\section{\begin{tabular}{|l|l} 
2.1.3.5 & CLASS 3 AND CLASS 4 SU BIASED SAMPLING
\end{tabular}}

A sediment accumulation area was identified during the Class $3 \mathrm{SU}$ walkover assessment, and a biased sample location was selected at this point.

Four DVS Class 3 SU biased sample locations were identified in EU Z2-24 during DQO scoping - two locations at the presumed K-300 Area Service Station and two locations at the K-1650 UST. A fifth sample location was added during field work at the K-1650 UST, bringing the total number of sample locations based on DQO scoping to five.

Details of actual sampling and analysis in the Class $3 \mathrm{SU}$, including sample depths and analytes, are presented in Table E.2.

\section{\begin{tabular}{|l|l}
\hline 2.2 & DVS AND HISTORICAL SAMPLE RESULTS \\
\hline
\end{tabular}}

This section presents a summary of analytical results for DVS and historical samples collected in EU Z2-24. The summary begins with a tabulation of SU and infrastructure sample locations (Sects.2.2.1 through 2.2.4) and concludes with a focused investigation, EU data summaries (Sect.2.2.5), and FFA site data summaries (Sect. 2.2.6). The combined EU DVS and historical data are summarized in Tables E.3 and E.4. A compact disc containing electronic files for the historical and DVS analytical data used to generate the data tables is provided with this Phased Construction Completion Report (PCCR). 


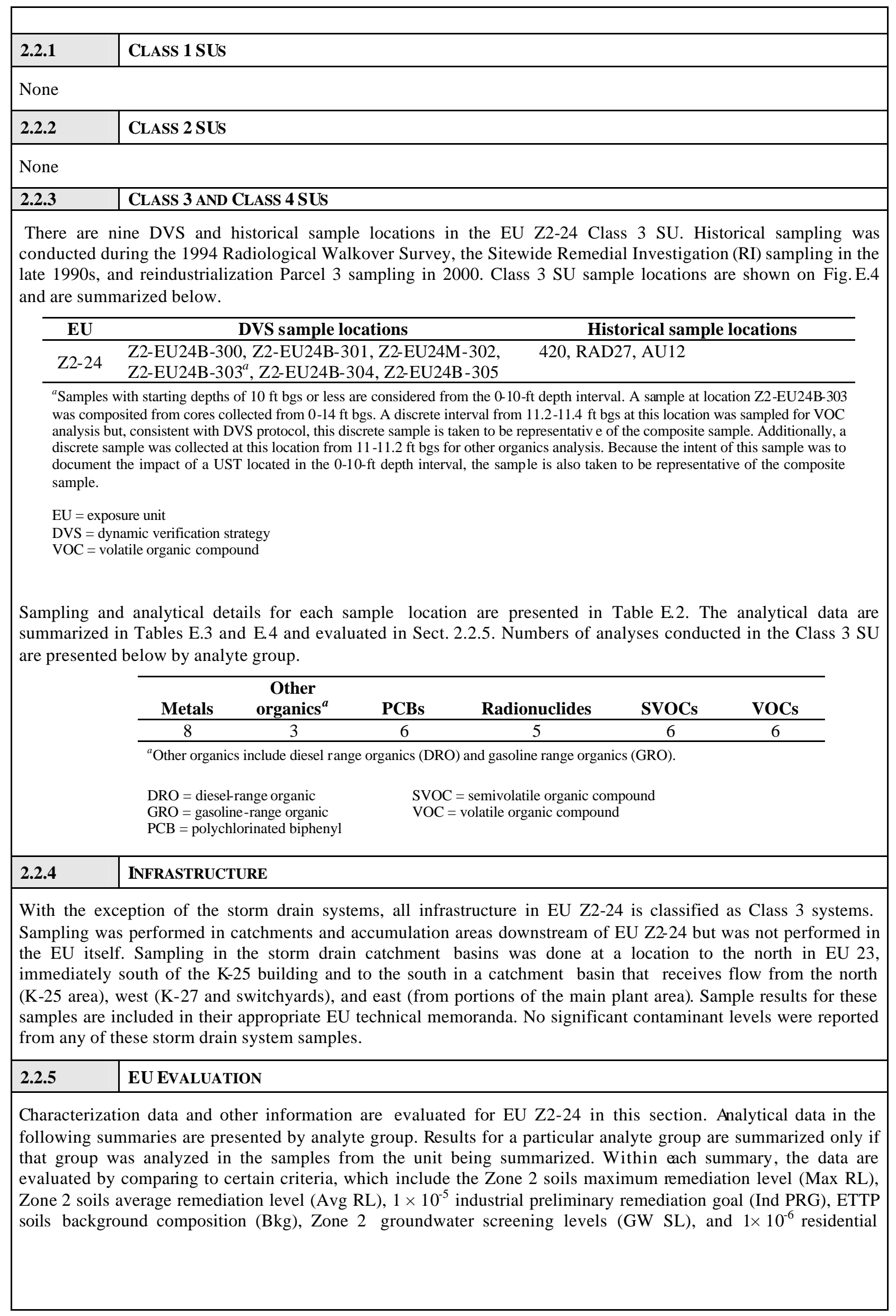


preliminary remediation goal (Res PRG). If a particular criterion does not apply to any member of an analyte group, it is not tabulated for that analyte group; if a particular criterion does not apply to all analytes within an analyte group, those analytes to which it does not apply are notated with not applicable (NA). Individual netals and radionuclides, which are naturally occurring, are reported in the summaries only if one or more criterion is exceeded. Organic chemicals, which are not naturally occurring, are reported if detected, even if no criteria are exceeded. The Max RL, Avg RL, Ind PRG, Bkg, GW SL, and Res PRG criteria values, as they pertain to he analytes listed in Appendix A of the RDR/RAWP (i.e., Quality Assurance Project Plan), are presented in Table E.4 of this PCCR.

Because the carcinogenic risk associated with the concentrations of radium and thorium isotopes in the natural background at ETTP exceeds the cumulative risk goal of $1 \times 10^{-4}$, RL values for these radionuclides are based on alternative concentration levels rather than risk. The alternative concentration levels of $5 \mathrm{pCi} / \mathrm{g}$ above background (Avg RL) and $15 \mathrm{pCi} / \mathrm{g}$ above background (Max RL) were set as low a reasonably achievable under the site-specific conditions. Because site-specific background concentrations of these radionuclides exceed the target risk range, residual concentrations of these radionuclides and their decay series are not considered in estimates of residual risk following any remedial actions.

The Zone 2 ROD states that Avg and Max RL exceedances by Ra-226, Th-230, and Th-232 will be evaluated by summing above-background concentrations of the greater of Ra-226 or Th-230 with the above-background concentrations of Th-232, and comparing the results to $5 \mathrm{pCi} / \mathrm{g}$ (Avg RL) and $15 \mathrm{pCi} / \mathrm{g}$ (Max RL). These required calculations have been performed. Avg and Max RL exceedances for these radionuclides, if any, are reported in the TM data summaries below and in Table E.3 as "Ra/Th decay series", and individual RL exceedances by Ra-226, Th-230, and Th-232 are reported as NA. The Ra/Th decay series data are summarized in the following sections only if an Avg or Max RL has been exceeded, consistent with the description in the preceding paragraph for reporting radionuclides. Discussion of the $\mathrm{Ra} / \mathrm{Th}$ decay series calculation, including the manner in which the calculation is performed, is presented in Sect. 3.3 of this PCCR.

\section{EU Z2-24 Conceptual Site Model (CSM)}

The conceptual site model for the Class $3 \mathrm{SU}$ is a surface release model. There was no evidence of burial or subsurface potential sources of contaminants. Following development of the DQO package, a set of site drawings for the area, including EU Z2-24, was obtained that showed the location of the 300 Area Service Station in EU Z2-23 and another set of drawings showed the service station in EU Z2-24. Both sites were surveyed using geophysical methods in an attempt to resolve the discrepancy. The geophysical survey indicated a subtle anomaly at the EU Z2-23 location. There was no indication of any disturbance or buried objects at the EU Z2-24 location. Two biased samples were collected in EU Z2-24 in the area shown on the site drawing as the location of the K-300 Area Service Station even though the geophysical survey had negative results. No significant contaminant concentrations were reported in these samples. Additional biased samples were collected at the K-1650 site and in a sediment accumulation area. The Class 3 SU walkover assessment of the EU and limited biased sampling support the proposed CSM and indicate there is no significant contamination in the EU.

\section{EU Z2-24 Groundwater Evaluation}

There are no groundwater monitoring wells in EU Z2-24. The closest wells are to the west around the K-27 building and along Poplar Creek. Site-wide water-level data show the EU Z2-24 area is south of a groundwater divide. Groundwater flow is to the south toward the K-1007 Ponds. There is no significant mass of contaminated soils in the EU that would pose a threat to local groundwater. Based on the water-level map and recently updated plume map presented in the Draft Sitewide RI, groundwater flows south from the EU Z2-24 area and contaminated groundwater is not present beneath EU Z2-24.

\section{EU Z2-24 Sampling Results}

The entire 22 acres of EU Z2-24 have been classified as a Class 3 SU. The Class 3 SU walkover assessment did not identify any anthropogenic features that were not accounted for in the facility assessment. Based on a visual inspection for chemical contamination and radiological surveys for radiological contamination, no facility was identified for biased sampling. One sediment accumulation area was identified during the Class $3 \mathrm{SU}$ walkover assessment and a biased sample location was selected.

In addition to the sediment accumulation area sample location identified during the Class $3 \mathrm{SU}$ walkover assessment, four biased sample locations were selected during DQO scoping-two locations at the K-300 Area Service Station and two locations at the K-1650 UST; a fifth biased location was selected at the K-1650 UST during 
field work. Geophysical investigations demonstrated that the K-300 Area Service Station is not located in EU Z2-24. Instead, the location of the site is in EU Z2-23 (Sect. 2.1.3.4). However, sampling was conducted at the two locations in EU Z2-24 that were selected during DQO scoping.

The three historical sample locations in EU Z2-24 include one historical location from the 1994 Radiological Walkover Survey, the Sitewide RI work done in the late 1990s, and another location from the ReindustrializationParcel 3 sampling done in 2000.

The following is a summary of sampling results for EU Z2-24. The summary begins with the presentation of analytical results for the focused sampling efforts in the EU and concludes with an overall discussion for EU Z2-24. The summary includes both data tables and a written description of the nature and extent of the chemicals and radionuclides observed in the EU. A summary of all EU Z2-24 data is presented in Tables E.3 and E.4. Sample locations are shown on Fig. E.4. Data summarized in this section are evaluated in terms of the Zone 2 ROD remedial action objective (RAO) shown in Sect. 3.3.

DVS Biased Sampling at the Sediment Accumulation Area: A surface sample was collected at location Z2-EU24B-305 in a sediment accumu lation area located in the west-central quadrant of EU Z2-24. Analytical results summarized below show radionuclide Ind PRG exceedances, metal and radionuclide Bkg exceedances, and detections of PCBs and SVOCs.

EU Z2-24 SEDIMENT ACCUMULATION AREA METALS WITH BACKGROUND, PRG, GW SL, AND/OR RL EXCEEDANCES (mg/kg)

\begin{tabular}{|c|c|c|c|c|c|c|c|c|c|c|c|}
\hline \multirow[b]{2}{*}{ Analyte } & \multirow[b]{2}{*}{$\begin{array}{c}\text { Detect } \\
\text { frequency }\end{array}$} & \multirow[b]{2}{*}{$\begin{array}{c}\text { Minimum } \\
\text { detect }\end{array}$} & \multirow[b]{2}{*}{$\begin{array}{c}\text { Maximum } \\
\text { detect }\end{array}$} & \multirow{2}{*}{$\begin{array}{c}\text { Location(s) of } \\
\text { maximum } \\
\text { detect }\end{array}$} & \multirow{2}{*}{$\begin{array}{c}\text { Average } \\
\text { detected } \\
\text { result }\end{array}$} & \multicolumn{6}{|c|}{ Number of analyses exceeding criteria } \\
\hline & & & & & & $\begin{array}{c}\text { Max } \\
\text { RL }\end{array}$ & $\begin{array}{l}\text { Avg } \\
\text { RL }\end{array}$ & $\begin{array}{l}\text { Ind } \\
\text { PRG }\end{array}$ & Bkg & $\begin{array}{c}\text { GW } \\
\text { SL }\end{array}$ & $\begin{array}{c}\text { Res } \\
\text { PRG }\end{array}$ \\
\hline Arsenic & $1 / 1$ & 3.7 & 3.7 & Z2-EU24B-305 & 3.7 & 0 & 0 & 0 & 0 & 0 & 1 \\
\hline Calcium & $1 / 1$ & 250,000 & 250,000 & Z2-EU24B-305 & 250,000 & NA & NA & NA & 1 & NA & NA \\
\hline Magnesium & $1 / 1$ & $21,000 \mathrm{~J}$ & $21,000 \mathrm{~J}$ & Z2-EU24B-305 & 21,000 & NA & NA & NA & 1 & NA & NA \\
\hline Manganese & $1 / 1$ & $310 \mathrm{~J}$ & $310 \mathrm{~J}$ & Z2-EU24B-305 & 310 & NA & NA & 0 & 0 & NA & 1 \\
\hline Vanadium & $1 / 1$ & 8.6 & 8.6 & Z2-EU24B-305 & 8.6 & NA & NA & 0 & 0 & NA & 1 \\
\hline Zinc & $1 / 1$ & $120 \mathrm{~J}$ & $120 \mathrm{~J}$ & Z2-EU24B-305 & 120 & NA & NA & 0 & 1 & NA & 0 \\
\hline
\end{tabular}

Avg $=$ average $\quad \mathrm{NA}=$ not applicable

$\mathrm{Bkg}=$ background $\quad \mathrm{PRG}=$ preliminary remediation goal

$\mathrm{EU}=$ exposure unit $\quad$ Res $=$ residential

$\mathrm{GW}=$ groundwater $\quad \mathrm{RL}=$ remediation level

Ind $=$ industrial $\quad \mathrm{SL}=$ screening level

Max $=$ maximum

EU Z2-24 SEDIMENT ACCUMULATION AREA PCB DETECTS (ug/kg)

\begin{tabular}{|c|c|c|c|c|c|c|c|c|c|}
\hline \multirow[b]{2}{*}{ Analyte } & \multirow[b]{2}{*}{$\begin{array}{c}\text { Detect } \\
\text { frequency }\end{array}$} & \multirow[b]{2}{*}{$\begin{array}{c}\text { Minimum } \\
\text { detect }\end{array}$} & \multirow[b]{2}{*}{$\begin{array}{c}\text { Maximum } \\
\text { detect }\end{array}$} & \multirow[b]{2}{*}{$\begin{array}{l}\text { Location(s) of } \\
\text { maximum detect }\end{array}$} & \multirow{2}{*}{$\begin{array}{c}\text { Average } \\
\text { detected } \\
\text { result }\end{array}$} & \multicolumn{4}{|c|}{ Number of analyses exceeding criteria } \\
\hline & & & & & & Max RL & $\operatorname{Avg}$ RL & Ind PRG & Res PRG \\
\hline PCB-1254 & $1 / 1$ & 210 & 210 & Z2-EU24B-305 & 210 & 0 & 0 & 0 & 1 \\
\hline PCB & $1 / 1$ & 210 & 210 & Z2-EU24B-305 & 210 & 0 & 0 & 0 & 1 \\
\hline
\end{tabular}

Avg = average

$\mathrm{EU}=$ exposure unit

Ind $=$ industrial

Max = maximum
$\mathrm{PCB}=$ polychlorinated biphenyl

$\mathrm{PRG}=$ preliminary remediation goal

Res $=$ residential

$\mathrm{RL}=$ remediation level

EU Z2-24 SEDIMENT ACCUMULATION AREA RADIONUCLIDES WITH BACKGROUND, PRG, AND/OR RL EXCEEDANCES (pCi/g)

\begin{tabular}{|c|c|c|c|c|c|c|c|c|c|c|c|}
\hline \multirow[b]{2}{*}{ Analyte } & \multirow[b]{2}{*}{$\begin{array}{c}\text { Detect } \\
\text { frequency }\end{array}$} & \multirow[b]{2}{*}{$\underset{\text { detect }}{\text { Minimum }}$} & \multirow[b]{2}{*}{$\underset{\text { detect }}{\text { Maximum }}$} & \multirow[b]{2}{*}{$\begin{array}{c}\text { Location(s) of } \\
\text { maximum detect }\end{array}$} & \multirow{2}{*}{$\begin{array}{c}\text { Average } \\
\text { detected } \\
\text { result }\end{array}$} & \multicolumn{6}{|c|}{ Number of analyses exceeding criteria } \\
\hline & & & & & & $\begin{array}{l}\text { Max } \\
\text { RL }\end{array}$ & $\begin{array}{l}\text { Avg } \\
\text { RL }\end{array}$ & $\begin{array}{l}\text { Ind } \\
\text { PRG }\end{array}$ & Bkg & $\begin{array}{l}\text { GW } \\
\text { SL }\end{array}$ & $\begin{array}{l}\text { Res } \\
\text { PRG }\end{array}$ \\
\hline Potassium-40 & $1 / 1$ & 5.99 & 5.99 & Z2-EU24B-305 & 5.99 & NA & NA & 1 & 0 & NA & 1 \\
\hline Radium-226 & $1 / 1$ & 0.334 & 0.334 & Z2-EU24B-305 & 0.334 & NA & NA & 1 & 0 & NA & 1 \\
\hline Thorium -228 & $1 / 1$ & 1.01 & 1.01 & Z2-EU24B-305 & 1.01 & NA & NA & 1 & 0 & NA & 1 \\
\hline
\end{tabular}


EU Z2-24 SEDIMENT ACCUMULATION AREA RADIONUCLIDES WITH BACKGROUND,

PRG, AND/OR RL EXCEEDANCES (pCi/g) (continued)

\begin{tabular}{|c|c|c|c|c|c|c|c|c|c|c|c|}
\hline \multirow[b]{2}{*}{ Analyte } & \multirow[b]{2}{*}{$\begin{array}{c}\text { Detect } \\
\text { frequency }\end{array}$} & \multirow[b]{2}{*}{$\begin{array}{c}\text { Minimum } \\
\text { detect }\end{array}$} & \multirow[b]{2}{*}{$\begin{array}{c}\text { Maximum } \\
\text { detect }\end{array}$} & \multirow[b]{2}{*}{$\begin{array}{c}\text { Location(s) of } \\
\text { maximum detect }\end{array}$} & \multirow{2}{*}{$\begin{array}{c}\text { Average } \\
\text { detected } \\
\text { result }\end{array}$} & \multicolumn{6}{|c|}{ Number of analyses exceeding criteria } \\
\hline & & & & & & $\begin{array}{c}\text { Max } \\
\text { RL }\end{array}$ & $\begin{array}{l}\text { Avg } \\
\text { RL }\end{array}$ & $\begin{array}{l}\text { Ind } \\
\text { PRG }\end{array}$ & Bkg & $\begin{array}{l}\text { GW } \\
\text { SL }\end{array}$ & $\begin{array}{l}\text { Res } \\
\text { PRG }\end{array}$ \\
\hline Thorium -230 & $1 / 1$ & 1.35 & 1.35 & Z2-EU24B-305 & 1.35 & NA & NA & 0 & 1 & NA & 0 \\
\hline Thorium -232 & $1 / 1$ & 1.06 & 1.06 & Z2-EU24B-305 & 1.06 & NA & NA & 1 & 0 & NA & 1 \\
\hline $\begin{array}{l}\text { Avg = average } \\
\text { Bkg = background } \\
\mathrm{EU}=\text { exposure unit } \\
\mathrm{GW}=\text { groundwater } \\
\text { Ind = industrial } \\
\mathrm{Max}=\text { maximum }\end{array}$ & & $\begin{array}{l}\text { NA }=\text { not ap } \\
\text { PRG }=\text { preli } \\
\text { Res }=\text { reside } \\
\text { RL }=\text { remed } \\
\text { SL }=\text { screen }\end{array}$ & $\begin{array}{l}\text { pplicable } \\
\text { iminary reme } \\
\text { lential } \\
\text { diation level } \\
\text { ning level }\end{array}$ & ediation goal & & & & & & & \\
\hline
\end{tabular}

EU Z2-24 SEDIMENT ACCUMULATION AREA SVOC DETECTS (ug/kg)

\begin{tabular}{|c|c|c|c|c|c|c|c|c|}
\hline \multirow[b]{2}{*}{ Analyte } & \multirow[b]{2}{*}{$\begin{array}{l}\text { Detect } \\
\text { frequency }\end{array}$} & \multirow[b]{2}{*}{$\begin{array}{c}\text { Minimum } \\
\text { detect }\end{array}$} & \multirow[b]{2}{*}{$\begin{array}{c}\text { Maximum } \\
\text { detect }\end{array}$} & \multirow[b]{2}{*}{$\begin{array}{c}\text { Location(s) of } \\
\text { maximum detect }\end{array}$} & \multirow{2}{*}{$\begin{array}{c}\text { Average } \\
\text { detected } \\
\text { result }\end{array}$} & \multicolumn{3}{|c|}{$\begin{array}{l}\text { Number of analyses } \\
\text { exceeding criteria }\end{array}$} \\
\hline & & & & & & $\begin{array}{l}\text { Ind } \\
\text { PRG }\end{array}$ & $\begin{array}{c}\text { GW } \\
\text { SL }\end{array}$ & $\begin{array}{c}\text { Res } \\
\text { PRG }\end{array}$ \\
\hline Benz(a)anthracene & $1 / 1$ & $290 \mathrm{~J}$ & $290 \mathrm{~J}$ & Z2-EU24B-305 & 290 & 0 & NA & 0 \\
\hline Benzo(a)pyrene & $1 / 1$ & $320 \mathrm{~J}$ & $320 \mathrm{~J}$ & Z2-EU24B-305 & 320 & 0 & NA & 1 \\
\hline Benzo(b)fluoranthene & $1 / 1$ & $470 \mathrm{~J}$ & $470 \mathrm{~J}$ & Z2-EU24B-305 & 470 & 0 & NA & 0 \\
\hline Benzo(ghi)perylene & $1 / 1$ & $410 \mathrm{~J}$ & $410 \mathrm{~J}$ & Z2-EU24B-305 & 410 & 0 & NA & 0 \\
\hline Benzo(k)fluoranthene & $1 / 1$ & $160 \mathrm{~J}$ & $160 \mathrm{~J}$ & Z2-EU24B-305 & 160 & 0 & NA & 0 \\
\hline Bis(2-ethylhexyl)phthalate & $1 / 1$ & $680 \mathrm{~J}$ & $680 \mathrm{~J}$ & Z2-EU24B-305 & 680 & 0 & 0 & 0 \\
\hline Chrysene & $1 / 1$ & $340 \mathrm{~J}$ & $340 \mathrm{~J}$ & Z2-EU24B-305 & 340 & 0 & NA & 0 \\
\hline Fluoranthene & $1 / 1$ & $530 \mathrm{~J}$ & $530 \mathrm{~J}$ & Z2-EU24B-305 & 530 & 0 & NA & 0 \\
\hline Indeno(1,2,3-cd)pyrene & $1 / 1$ & $330 \mathrm{~J}$ & $330 \mathrm{~J}$ & Z2-EU24B-305 & 330 & 0 & NA & 0 \\
\hline Phenanthrene & $1 / 1$ & $390 \mathrm{~J}$ & $390 \mathrm{~J}$ & Z2-EU24B-305 & 390 & 0 & NA & 0 \\
\hline Pyrene & $1 / 1$ & $2,000 \mathrm{~J}$ & $2,000 \mathrm{~J}$ & Z2-EU24B-305 & 2,000 & 0 & NA & 0 \\
\hline $\begin{array}{l}\mathrm{EU}=\text { exposure unit } \\
\mathrm{GW}=\text { groundwater } \\
\text { Ind = industrial } \\
\mathrm{PRG}=\text { preliminary remedia }\end{array}$ & tion goal & $\begin{array}{l}\text { Res }=r \\
\text { RL }=r e \\
\text { SL }=s c \\
\text { SVOC }\end{array}$ & $\begin{array}{l}\text { esidential } \\
\text { emediation le } \\
\text { reening level } \\
=\text { semivolatil }\end{array}$ & $\begin{array}{l}\text { evel } \\
\text { ile organic compoun }\end{array}$ & & & & \\
\hline
\end{tabular}

VOCs were analyzed for in the sample but were not detected.

DVS Sampling at the Presumed Site of the K-300 Area Service Station: The former location of the K-300 Area Service Station and, therefore, the location of the K-300 Area Service Station FFA site was identified in EU Z2-24 during DQO scoping. A geophysical survey at the location did not produce results indicative of the presence of an UST, concluding the FFA site is located in EU Z2-23 (Sect. 2.1.3.4). Biased locations Z2-EU24B-300 and Z2-EU24B-301 identified during DQO scoping were sampled and analyzed as described in Table E.2. Analytical results summarized below show metal background exceedances and detections of PCBs and SVOCs.

PRESUMED EU Z2-24 K-300 AREA SERVICE STATION SITE METALS WITH BACKGROUND, PRG, GW SL, AND/OR RL EXCEEDANCES (mg/kg)

\begin{tabular}{|c|c|c|c|c|c|c|c|c|c|c|c|}
\hline \multirow[b]{2}{*}{ Analyte } & \multirow[b]{2}{*}{$\begin{array}{c}\text { Detect } \\
\text { frequency }\end{array}$} & \multirow[b]{2}{*}{$\begin{array}{c}\text { Minimum } \\
\text { detect }\end{array}$} & \multirow[b]{2}{*}{$\begin{array}{c}\text { Maximum } \\
\text { detect }\end{array}$} & \multirow{2}{*}{$\begin{array}{c}\text { Location(s) of } \\
\text { maximum } \\
\text { detect }\end{array}$} & \multirow{2}{*}{$\begin{array}{c}\text { Average } \\
\text { detected } \\
\text { result }\end{array}$} & \multicolumn{6}{|c|}{ Number of analyses exceeding criteria } \\
\hline & & & & & & $\begin{array}{c}\text { Max } \\
\text { RL }\end{array}$ & $\begin{array}{c}\text { Avg } \\
\text { RL }\end{array}$ & $\begin{array}{c}\text { Ind } \\
\text { PRG }\end{array}$ & Bkg & $\begin{array}{c}\text { GW } \\
\text { SL }\end{array}$ & $\begin{array}{r}\text { Res } \\
\text { PRG }\end{array}$ \\
\hline Aluminum & $2 / 2$ & 7,700 & 18,000 & Z2-EU24B-301 & 12,850 & NA & NA & 0 & 0 & NA & 2 \\
\hline Arsenic & $2 / 2$ & 3.7 & 5.5 & Z2-EU24B-300 & 4.6 & 0 & 0 & 0 & 0 & 0 & 2 \\
\hline Calcium & $2 / 2$ & $6,400 \mathrm{~J}$ & $22,000 \mathrm{~J}$ & Z2-EU24B-300 & 14,200 & NA & NA & NA & 2 & NA & NA \\
\hline Copper & $2 / 2$ & 17 & 25 & Z2-EU24B-301 & 21 & NA & NA & 0 & 1 & NA & 0 \\
\hline Magnesium & $2 / 2$ & $3,700 \mathrm{~J}$ & $6,600 \mathrm{~J}$ & Z2-EU24B-300 & 5,150 & NA & NA & NA & 2 & NA & NA \\
\hline Manganese & $2 / 2$ & $350 \mathrm{~J}$ & $740 \mathrm{~J}$ & Z2-EU24B-301 & 545 & NA & NA & 0 & 0 & NA & 2 \\
\hline
\end{tabular}


BACKGROUND, PRG, GW SL, AND/OR RL EXCEEDANCES (mg/kg) (continued)

\begin{tabular}{|c|c|c|c|c|c|c|c|c|c|c|c|}
\hline \multirow[b]{2}{*}{ Analyte } & \multirow[b]{2}{*}{$\begin{array}{c}\text { Detect } \\
\text { frequency }\end{array}$} & \multirow[b]{2}{*}{$\begin{array}{c}\text { Minimum } \\
\text { detect }\end{array}$} & \multirow[b]{2}{*}{$\begin{array}{c}\text { Maximum } \\
\text { detect }\end{array}$} & \multirow{2}{*}{$\begin{array}{l}\text { Location(s) of } \\
\text { maximum } \\
\text { detect }\end{array}$} & \multirow{2}{*}{$\begin{array}{c}\text { Average } \\
\text { detected } \\
\text { result }\end{array}$} & \multicolumn{6}{|c|}{ Number of analyses exceeding criteria } \\
\hline & & & & & & $\begin{array}{c}\text { Max } \\
\text { RL }\end{array}$ & $\begin{array}{c}\text { Avg } \\
\text { RL }\end{array}$ & $\begin{array}{l}\text { Ind } \\
\text { PRG }\end{array}$ & Bkg & $\begin{array}{c}\text { GW } \\
\text { SL }\end{array}$ & $\begin{array}{c}\text { Res } \\
\text { PRG } \\
\end{array}$ \\
\hline Uranium & $2 / 2$ & $1.9 \mathrm{~J}$ & $2.1 \mathrm{~J}$ & Z2-EU24B-301 & 2 & NA & NA & 0 & NA & NA & 2 \\
\hline Vanadium & $2 / 2$ & 22 & 36 & Z2-EU24B-301 & 29 & NA & NA & 0 & 0 & NA & 2 \\
\hline
\end{tabular}

Avg $=$ average $\quad$ NA $=$ not applicable

$\mathrm{Bkg}=$ background $\quad \mathrm{PRG}=$ preliminary remediation goal

$\mathrm{EU}=$ exposure unit $\quad$ Res $=$ residential

$\mathrm{GW}=$ groundwater $\quad \mathrm{RL}=$ remediation level

Ind $=$ industrial $\quad \mathrm{SL}=$ screening level

Max $=$ maximum

PRESUMED EU Z2-24 K-300 AREA SERVICE STATION SITE PCB DETECTS (ug/kg)

\begin{tabular}{|c|c|c|c|c|c|c|c|c|c|}
\hline \multirow[b]{2}{*}{ Analyte } & \multirow[b]{2}{*}{$\begin{array}{c}\text { Detect } \\
\text { frequency }\end{array}$} & \multirow[b]{2}{*}{$\begin{array}{c}\text { Minimum } \\
\text { detect }\end{array}$} & \multirow[b]{2}{*}{$\begin{array}{c}\text { Maximum } \\
\text { detect }\end{array}$} & \multirow[b]{2}{*}{$\begin{array}{c}\text { Location(s) of } \\
\text { maximum detect }\end{array}$} & \multirow{2}{*}{$\begin{array}{c}\text { Average } \\
\text { detected } \\
\text { result }\end{array}$} & \multicolumn{4}{|c|}{ Number of analyses exceeding criteria } \\
\hline & & & & & & $\begin{array}{l}\text { Max } \\
\text { RL }\end{array}$ & $\begin{array}{l}\text { Avg } \\
\text { RL }\end{array}$ & $\begin{array}{l}\text { Ind } \\
\text { PRG }\end{array}$ & $\begin{array}{l}\text { Res } \\
\text { PRG }\end{array}$ \\
\hline PCB-1254 & $1 / 2$ & 89 & 89 & Z2-EU24B-300 & 89 & 0 & 0 & 0 & 0 \\
\hline PCB & $1 / 2$ & 89 & 89 & Z2-EU24B-300 & 89 & 0 & 0 & 0 & 0 \\
\hline
\end{tabular}

Avg = average

Ind $=$ industrial $\quad$ PRG $=$ preliminary remediation goal

Max $=$ maximum $\quad \mathrm{RL}=$ remediation level

PRESUMED EU Z2-24 K-300 AREA SERVICE STATION SITE SVOC DETECTS (ug/kg)

\begin{tabular}{|c|c|c|c|c|c|c|c|c|}
\hline \multirow[b]{2}{*}{ Analyte } & \multirow[b]{2}{*}{$\begin{array}{l}\text { Detect } \\
\text { frequency }\end{array}$} & \multirow[b]{2}{*}{$\underset{\text { detect }}{\text { Minimum }}$} & \multirow[b]{2}{*}{$\begin{array}{c}\text { Maximum } \\
\text { detect }\end{array}$} & \multirow[b]{2}{*}{$\begin{array}{c}\text { Location(s) of } \\
\text { maximum detect }\end{array}$} & \multirow{2}{*}{$\begin{array}{c}\text { Average } \\
\text { detected } \\
\text { result }\end{array}$} & \multicolumn{3}{|c|}{$\begin{array}{l}\text { Number of Analyses } \\
\text { Exceeding Criteria }\end{array}$} \\
\hline & & & & & & $\begin{array}{l}\text { Ind } \\
\text { PRG }\end{array}$ & $\begin{array}{l}\text { GW } \\
\text { SL }\end{array}$ & $\begin{array}{l}\text { Res } \\
\text { PRG }\end{array}$ \\
\hline Benz(a)anthracene & $1 / 2$ & $40 \mathrm{~J}$ & $40 \mathrm{~J}$ & Z2-EU24B-300 & 40 & 0 & NA & 0 \\
\hline Benzo(a)pyrene & $1 / 2$ & $66 \mathrm{~J}$ & $66 \mathrm{~J}$ & Z2-EU24B-300 & 66 & 0 & NA & 1 \\
\hline Benzo(b)fluoranthene & $1 / 2$ & $72 \mathrm{~J}$ & $72 \mathrm{~J}$ & Z2-EU24B-300 & 72 & 0 & NA & 0 \\
\hline Benzo(ghi)perylene & $1 / 2$ & $120 \mathrm{~J}$ & $120 \mathrm{~J}$ & Z2-EU24B-300 & 120 & 0 & NA & 0 \\
\hline Benzo(k)fluoranthene & $1 / 2$ & $45 \mathrm{~J}$ & $45 \mathrm{~J}$ & Z2-EU24B-300 & 45 & 0 & NA & 0 \\
\hline Chrysene & $1 / 2$ & $35 \mathrm{~J}$ & $35 \mathrm{~J}$ & Z2-EU24B-300 & 35 & 0 & NA & 0 \\
\hline Fluoranthene & $1 / 2$ & $79 \mathrm{~J}$ & $79 \mathrm{~J}$ & Z2-EU24B-300 & 79 & 0 & NA & 0 \\
\hline Indeno(1,2,3-cd)pyrene & $1 / 2$ & $45 \mathrm{~J}$ & $45 \mathrm{~J}$ & Z2-EU24B-300 & 45 & 0 & NA & 0 \\
\hline Pyrene & $1 / 2$ & $70 \mathrm{~J}$ & $70 \mathrm{~J}$ & Z2-EU24B-300 & 70 & 0 & NA & 0 \\
\hline $\begin{array}{l}\mathrm{EU}=\text { exposure unit } \\
\mathrm{GW}=\text { groundwater } \\
\text { Ind = industrial } \\
\mathrm{NA}=\text { not applicable }\end{array}$ & $\begin{array}{l}\text { PRG = } \\
\text { Res }=1 \\
\text { SL }=\text { s } \\
\text { SVOC }\end{array}$ & $\begin{array}{l}\text { preliminary } \\
\text { residential } \\
\text { creening leve } \\
=\text { semivolat }\end{array}$ & $\begin{array}{l}\text { el } \\
\text { tile organic c }\end{array}$ & compound & & & & \\
\hline
\end{tabular}

DVS Biased Sampling at the K-1650 UST: Biased sample locations Z2-EU24M-302, Z2-EU24B-303, and Z2-EU24B-304) were identified at the K-1650 UST. Two of the locations were originally identified during DQO scoping and the third location was added during field work. Sampling and analytical details are described in Table E. 2 [note that the discrete sample for diesel-range organics (DROs) and gasoline-range organics (GROs) analyses at Z2-EU24B-303 was collected at a depth greater than $10 \mathrm{ft}$ bgs]. Analytical results summarized below show radionuclide Ind PRG exceedances, metal and radionuclide Bkg exceedances, and detections of DRO, SVOCs, and VOCs. 
EU Z2-24 K-1650 UST METALS WITH BACKGROUND, PRG, GW SL, AND/OR RL EXCEEDANCES (mg/kg)

\begin{tabular}{|c|c|c|c|c|c|c|c|c|c|c|c|}
\hline \multirow[b]{2}{*}{ Analyte } & \multirow[b]{2}{*}{$\begin{array}{c}\text { Detect } \\
\text { frequency }\end{array}$} & \multirow[b]{2}{*}{$\begin{array}{c}\text { Minimum } \\
\text { detect }\end{array}$} & \multirow[b]{2}{*}{$\begin{array}{c}\text { Maximum } \\
\text { detect }\end{array}$} & \multirow{2}{*}{$\begin{array}{l}\text { Location(s) of } \\
\text { maximum } \\
\text { detect }\end{array}$} & \multirow{2}{*}{$\begin{array}{c}\text { Average } \\
\text { detected } \\
\text { result }\end{array}$} & \multicolumn{6}{|c|}{ Number of analyses exceeding criteria } \\
\hline & & & & & & $\begin{array}{c}\text { Max } \\
\text { RL }\end{array}$ & $\begin{array}{l}\text { Avg } \\
\text { RL }\end{array}$ & $\begin{array}{l}\text { Ind } \\
\text { PRG }\end{array}$ & Bkg & $\begin{array}{c}\text { GW } \\
\text { SL }\end{array}$ & $\begin{array}{l}\text { Res } \\
\text { PRG }\end{array}$ \\
\hline Aluminum & $3 / 3$ & 16,000 & 18,000 & Z2-EU24B-303 & 17,000 & NA & NA & 0 & 0 & NA & 3 \\
\hline Arsenic & $3 / 3$ & 3.4 & 9.2 & Z2-EU24M-302 & 6.8 & 0 & 0 & 0 & 0 & 0 & 3 \\
\hline Cadmium & $3 / 3$ & 0.093 & 0.23 & Z2-EU24B-303 & 0.171 & NA & NA & 0 & 1 & NA & 0 \\
\hline Calcium & $3 / 3$ & 11,000 & 36,000 & Z2-EU24B-304 & 22,333 & NA & NA & NA & 3 & NA & NA \\
\hline Cobalt & $3 / 3$ & 6.4 & 120 & Z2-EU24B-303 & 46.1 & NA & NA & 0 & 1 & NA & 0 \\
\hline Copper & $3 / 3$ & 17 & 37 & Z2-EU24B-303 & 28.7 & NA & NA & 0 & 2 & NA & 0 \\
\hline Lead & $3 / 3$ & 19 & 68 & Z2-EU24B-303 & 40 & NA & NA & 0 & 1 & 0 & 0 \\
\hline Magnesium & $3 / 3$ & $4,000 \mathrm{~J}$ & $11,000 \mathrm{~J}$ & $\begin{array}{l}\text { Z2-EU24M-302 } \\
\text { Z2-EU24B-304 }\end{array}$ & 8,667 & NA & NA & NA & 3 & NA & NA \\
\hline Manganese & $3 / 3$ & $300 \mathrm{~J}$ & $3,100 \mathrm{~J}$ & Z2-EU24B-303 & 1,317 & NA & NA & 0 & 1 & NA & 3 \\
\hline Mercury & $3 / 3$ & $0.087 \mathrm{~J}$ & $0.3 \mathrm{~J}$ & Z2-EU24B-304 & 0.159 & 0 & 0 & 0 & 1 & NA & 0 \\
\hline Nickel & $3 / 3$ & 9.8 & 95 & Z2-EU24B-303 & 41.6 & NA & NA & 0 & 1 & NA & 0 \\
\hline Thallium & $3 / 3$ & 0.21 & 0.42 & Z2-EU24B-303 & 0.297 & NA & NA & 0 & 1 & 0 & 0 \\
\hline Uranium & $3 / 3$ & 1.5 & 3.1 & Z2-EU24B-303 & 2.23 & NA & NA & 0 & NA & NA & 2 \\
\hline Vanadium & $3 / 3$ & 33 & 59 & Z2-EU24B-303 & 45.7 & NA & NA & 0 & 0 & NA & 3 \\
\hline Zinc & $3 / 3$ & $32 \mathrm{~J}$ & $110 \mathrm{~J}$ & Z2-EU24B-303 & 68.3 & NA & NA & 0 & 1 & NA & 0 \\
\hline
\end{tabular}

\begin{tabular}{ll}
\hline Avg $=$ average & NA $=$ not applicable \\
$\mathrm{Bkg}=$ background & $\mathrm{PRG}=$ preliminary remediation goal \\
$\mathrm{EU}=$ exposure unit & $\mathrm{Res}=$ residential \\
$\mathrm{GW}=$ groundwater & $\mathrm{RL}=$ remediation level \\
$\mathrm{Ind}=$ industrial & $\mathrm{SL}=$ screening level \\
$\mathrm{Max}=$ maximum &
\end{tabular}

EU Z2-24 K-1650UST OTHER ORGANICS DETECTS (mg/kg)

\begin{tabular}{lcccccc}
\hline Analyte & $\begin{array}{c}\text { Detect } \\
\text { frequency }\end{array}$ & $\begin{array}{c}\text { Minimum } \\
\text { detect }\end{array}$ & $\begin{array}{c}\text { Maximum } \\
\text { detect }\end{array}$ & $\begin{array}{c}\text { Location(s) of } \\
\text { maximum detect }\end{array}$ & $\begin{array}{c}\text { Average } \\
\text { detected } \\
\text { result }\end{array}$ \\
\hline DROs & $1 / 3$ & 7.8 & 7.8 & Z2-EU24M-302 & 7.8 \\
\hline
\end{tabular}

DRO $=$ diesel-range organic

$\mathrm{EU}=$ exposure unit

UST $=$ underground storage tank

PCBs were analyzed for in the three samples but were not detected.

EU Z2-24 K-1650 UST RADIONUCLIDES WITH BACKGROUND, PRG, AND/OR RL EXCEEDANCES (pCi/g)

\begin{tabular}{|c|c|c|c|c|c|c|c|c|c|c|c|}
\hline \multirow[b]{2}{*}{ Analyte } & \multirow[b]{2}{*}{$\begin{array}{c}\text { Detect } \\
\text { frequency }\end{array}$} & \multirow[b]{2}{*}{$\begin{array}{c}\text { Minimum } \\
\text { detect }\end{array}$} & \multirow[b]{2}{*}{$\begin{array}{c}\text { Maximum } \\
\text { detect }\end{array}$} & \multirow[b]{2}{*}{$\begin{array}{l}\text { Location(s) of } \\
\text { maximum detect }\end{array}$} & \multirow{2}{*}{$\begin{array}{c}\text { Ave rage } \\
\text { detected } \\
\text { result }\end{array}$} & \multicolumn{6}{|c|}{ Number of analyses exceeding criteria } \\
\hline & & & & & & $\begin{array}{l}\text { Max } \\
\text { RL }\end{array}$ & $\begin{array}{l}\text { Avg } \\
\text { RL }\end{array}$ & $\begin{array}{l}\text { Ind } \\
\text { PRG }\end{array}$ & Bkg & $\begin{array}{l}\text { GW } \\
\text { SL }\end{array}$ & $\begin{array}{r}\text { Res } \\
\text { PRG }\end{array}$ \\
\hline Potassium-40 & $1 / 1$ & 25.4 & 25.4 & Z2-EU24M-302 & 25.4 & NA & NA & 1 & 0 & NA & 1 \\
\hline Radium-226 & $1 / 1$ & $1.46 \mathrm{~J}$ & $1.46 \mathrm{~J}$ & Z2-EU24M-302 & 1.46 & NA & NA & 1 & 1 & NA & 1 \\
\hline Thorium -228 & $1 / 1$ & 1.34 & 1.34 & Z2-EU24M-302 & 1.34 & NA & NA & 1 & 0 & NA & 1 \\
\hline Thorium -230 & $1 / 1$ & 1.67 & 1.67 & Z2-EU24M-302 & 1.67 & NA & NA & 0 & 1 & NA & 0 \\
\hline Thorium -232 & $1 / 1$ & 1.56 & 1.56 & Z2-EU24M-302 & 1.56 & NA & NA & 1 & 0 & NA & 1 \\
\hline Uranium-238 & $1 / 1$ & 2.22 & 2.22 & Z2-EU24M-302 & 2.22 & 0 & 0 & 0 & 1 & 0 & 1 \\
\hline
\end{tabular}

Avg $=$ average NA $=$ not applicable

$\mathrm{Bkg}=$ background $\quad \mathrm{PRG}=$ preliminary remediation goal

$\mathrm{EU}=$ exposure unit $\quad$ Res $=$ residential

$\mathrm{GW}=$ groundwater $\quad \mathrm{RL}=$ remediation level

Ind $=$ industrial $\quad \mathrm{SL}=$ screening level

Max = maximum 


\begin{tabular}{|c|c|c|c|c|c|c|c|c|}
\hline \multirow[b]{2}{*}{ Analyte } & \multirow[b]{2}{*}{$\begin{array}{c}\text { Detect } \\
\text { frequency }\end{array}$} & \multirow[b]{2}{*}{$\begin{array}{c}\text { Minimum } \\
\text { detect }\end{array}$} & \multirow[b]{2}{*}{$\begin{array}{c}\text { Maximum } \\
\text { detect }\end{array}$} & \multirow[b]{2}{*}{$\begin{array}{c}\text { Location(s) of } \\
\text { maximum detect }\end{array}$} & \multirow{2}{*}{$\begin{array}{c}\text { Average } \\
\text { detected } \\
\text { result }\end{array}$} & \multicolumn{3}{|c|}{$\begin{array}{l}\text { Number of analyses } \\
\text { exceeding criteria }\end{array}$} \\
\hline & & & & & & $\begin{array}{l}\text { Ind } \\
\text { PRG }\end{array}$ & $\begin{array}{l}\text { GW } \\
\text { SL }\end{array}$ & $\begin{array}{l}\text { Res } \\
\text { PRG }\end{array}$ \\
\hline Acenaphthene & $3 / 3$ & $61 \mathrm{~J}$ & $310 \mathrm{~J}$ & Z2-EU24B-304 & 170 & 0 & NA & 0 \\
\hline Anthracene & $2 / 3$ & $96 \mathrm{~J}$ & 860 & Z2-EU24B-304 & 478 & 0 & NA & 0 \\
\hline Benz(a)anthracene & $3 / 3$ & $73 \mathrm{~J}$ & 1,500 & Z2-EU24B-304 & 588 & 0 & NA & 1 \\
\hline Benzo(a)pyrene & $3 / 3$ & $81 \mathrm{~J}$ & $1,100 \mathrm{~J}$ & Z2-EU24B-304 & 450 & 0 & NA & 3 \\
\hline Benzo(b)fluoranthene & $3 / 3$ & $98 \mathrm{~J}$ & $1,300 \mathrm{~J}$ & Z2-EU24B-304 & 539 & 0 & NA & 1 \\
\hline Benzo(ghi)perylene & $3 / 3$ & $99 \mathrm{~J}$ & $550 \mathrm{~J}$ & Z2-EU24B-304 & 256 & 0 & NA & 0 \\
\hline Benzo(k)fluoranthene & $3 / 3$ & 37 & 630 & Z2-EU24B-304 & 255 & 0 & NA & 0 \\
\hline Carbazole & $1 / 3$ & $65 \mathrm{~J}$ & $65 \mathrm{~J}$ & Z2-EU24B-304 & 65 & 0 & NA & 0 \\
\hline Chrysene & $3 / 3$ & $55 \mathrm{~J}$ & 1,100 & Z2-EU24B-304 & 438 & 0 & NA & 0 \\
\hline $\operatorname{Dibenz}(\mathrm{a}, \mathrm{h})$ anthracene & $1 / 3$ & $190 \mathrm{~J}$ & $190 \mathrm{~J}$ & Z2-EU24B-304 & 190 & 0 & NA & 1 \\
\hline Dibenzofuran & $2 / 3$ & $130 \mathrm{~J}$ & $220 \mathrm{~J}$ & Z2-EU24B-304 & 175 & 0 & NA & 0 \\
\hline Fluoranthene & $3 / 3$ & $140 \mathrm{~J}$ & 3,800 & Z2-EU24B-304 & 1,463 & 0 & NA & 0 \\
\hline Fluorene & $3 / 3$ & $50 \mathrm{~J}$ & $340 \mathrm{~J}$ & Z2-EU24B-304 & 167 & 0 & NA & 0 \\
\hline Indeno(1,2,3-cd)pyrene & $3 / 3$ & $37 \mathrm{~J}$ & 570 & Z2-EU24B-304 & 228 & 0 & NA & 0 \\
\hline Naphthalene & $1 / 6$ & 9.8 & 9.8 & Z2-EU24M-302 & 9.8 & 0 & NA & 0 \\
\hline Phenanthrene & $3 / 3$ & $210 \mathrm{~J}$ & 2,900 & Z2-EU24B-304 & 1,150 & 0 & NA & 0 \\
\hline Pyrene & $3 / 3$ & $120 \mathrm{~J}$ & $2,800 \mathrm{~J}$ & Z2-EU24B-304 & 1,073 & 0 & NA & 0 \\
\hline
\end{tabular}

$\mathrm{EU}=$ exposure unit

$\mathrm{GW}=$ groundwater

Res $=$ residential

Ind $=$ industrial

$\mathrm{SL}=$ screening level

NA $=$ not applicable

SVOC $=$ semivolatile organic compound

$\mathrm{PRG}=$ preliminary remediation goal

UST $=$ underground storage $\mathrm{t}$ ank

EU Z2-24 K-1650 UST VOC DETECTS (ug/kg)

\begin{tabular}{|c|c|c|c|c|c|c|c|c|}
\hline \multirow[b]{2}{*}{ Analyte } & \multirow[b]{2}{*}{$\begin{array}{c}\text { Detect } \\
\text { frequency }\end{array}$} & \multirow[b]{2}{*}{$\begin{array}{l}\text { Minimum } \\
\text { detect }\end{array}$} & \multirow[b]{2}{*}{$\begin{array}{c}\text { Maximum } \\
\text { detect }\end{array}$} & \multirow[b]{2}{*}{$\begin{array}{c}\text { Location(s) of } \\
\text { maximum detect }\end{array}$} & \multirow{2}{*}{$\begin{array}{c}\text { Average } \\
\text { detected } \\
\text { result }\end{array}$} & \multicolumn{3}{|c|}{$\begin{array}{l}\text { Number of analyses } \\
\text { exceeding criteria }\end{array}$} \\
\hline & & & & & & $\begin{array}{l}\text { Ind } \\
\text { PRG }\end{array}$ & $\begin{array}{c}\text { GW } \\
\text { SL }\end{array}$ & $\begin{array}{l}\text { Res } \\
\text { PRG }\end{array}$ \\
\hline Acetone & $1 / 3$ & 13 & 13 & Z2-EU24M-302 & 13 & 0 & NA & 0 \\
\hline$\overline{\mathrm{EU}}=$ exposure unit & & Res $=\mathrm{re}$ & idential & & & & & \\
\hline $\mathrm{GW}=$ groundwater & & $\mathrm{SL}=\mathrm{sc}$ & ening level & & & & & \\
\hline Ind $=$ industrial & & $\mathrm{UST}=\mathrm{l}$ & derground st & rage tank & & & & \\
\hline $\mathrm{NA}=$ not applicable & & $\mathrm{VOC}=$ & olatile organi & compound & & & & \\
\hline
\end{tabular}

Class 3 SU Historical Sampling: Historical sample locations 420, AU12, and RAD27 are located in EU Z2-24 Class 3 SU. Sampling and analytical details are presented in Table E. 2. Analytical results summarized below show radionuclide Ind PRG exceedances, metal and radionuclide Bkg exceedances, and VOC detections.

EU Z2-24 HISTORICAL METALS WITH BACKGROUND, PRG, GW SL, AND/OR RL EXCEEDANCES (mg/kg)

\begin{tabular}{|c|c|c|c|c|c|c|c|c|c|c|c|}
\hline \multirow[b]{2}{*}{ Analyte } & \multirow[b]{2}{*}{$\begin{array}{c}\text { Detect } \\
\text { frequency }\end{array}$} & \multirow[b]{2}{*}{$\begin{array}{c}\text { Minimum } \\
\text { detect }\end{array}$} & \multirow[b]{2}{*}{$\begin{array}{c}\text { Maximum } \\
\text { detect }\end{array}$} & \multirow{2}{*}{$\begin{array}{c}\text { Location(s) of } \\
\text { maximum } \\
\text { detect }\end{array}$} & \multirow{2}{*}{$\begin{array}{c}\text { Average } \\
\text { detected } \\
\text { result }\end{array}$} & \multicolumn{6}{|c|}{ Number of analyses exceeding criteria } \\
\hline & & & & & & $\begin{array}{c}\text { Max } \\
\text { RL }\end{array}$ & $\begin{array}{c}\text { Avg } \\
\text { RL }\end{array}$ & $\begin{array}{l}\text { Ind } \\
\text { PRG }\end{array}$ & Bkg & $\begin{array}{l}\text { GW } \\
\text { SL }\end{array}$ & $\begin{array}{c}\text { Res } \\
\text { PRG }\end{array}$ \\
\hline Aluminum & $2 / 2$ & 5,930 & 8,030 & 420 & 6,980 & NA & NA & 0 & 0 & NA & 1 \\
\hline Arsenic & $2 / 2$ & 3.9 & 4 & 420 & 3.95 & 0 & 0 & 0 & 0 & 0 & 2 \\
\hline Lead & $2 / 2$ & $22.2 \mathrm{~J}$ & $50.4 \mathrm{~J}$ & 420 & 36.3 & NA & NA & 0 & 1 & 0 & 0 \\
\hline Manganese & $2 / 2$ & 426 & 2,120 & 420 & 1,273 & NA & NA & 0 & 0 & NA & 2 \\
\hline Thallium & $1 / 2$ & 0.8 & 0.8 & 420 & 0.8 & NA & NA & 0 & 1 & 0 & 1 \\
\hline Vanadium & $2 / 2$ & 27.6 & 36.8 & 420 & 32.2 & NA & NA & 0 & 0 & NA & 2 \\
\hline
\end{tabular}

Avg $=$ average $\quad \mathrm{NA}=$ not applicable

$\mathrm{Bkg}=$ background $\quad \mathrm{PRG}=$ preliminary remediation goal

$\mathrm{EU}=$ exposure unit $\quad$ Res $=$ residential

$\mathrm{GW}=$ groundwater $\quad \mathrm{RL}=$ remediation level

Ind $=$ industrial $\quad \mathrm{SL}=$ screening level

Max = maximum 
EU Z2-24 HISTORICAL RADIONUCLIDES WITH BACKGROUND, PRG, AND/OR RL EXCEEDANCES (pCi/g)

\begin{tabular}{|c|c|c|c|c|c|c|c|c|c|c|c|}
\hline \multirow[b]{2}{*}{ Analyte } & \multirow[b]{2}{*}{$\begin{array}{c}\text { Detect } \\
\text { frequency }\end{array}$} & \multirow[b]{2}{*}{$\begin{array}{c}\text { Minimum } \\
\text { detect }\end{array}$} & \multirow[b]{2}{*}{$\begin{array}{c}\text { Maximum } \\
\text { detect }\end{array}$} & \multirow[b]{2}{*}{$\begin{array}{l}\text { Location(s) of } \\
\text { maximum detect }\end{array}$} & \multirow{2}{*}{$\begin{array}{c}\text { Average } \\
\text { detected } \\
\text { result }\end{array}$} & \multicolumn{6}{|c|}{ Number of analyses exceeding criteria } \\
\hline & & & & & & $\begin{array}{c}\text { Max } \\
\text { RL }\end{array}$ & $\begin{array}{l}\text { Avg } \\
\text { RL }\end{array}$ & $\begin{array}{l}\text { Ind } \\
\text { PRG }\end{array}$ & Bkg & $\begin{array}{c}\text { GW } \\
\text { SL }\end{array}$ & $\begin{array}{l}\text { Res } \\
\text { PRG }\end{array}$ \\
\hline Potassium-40 & $1 / 1$ & 12.3 & 12.3 & RAD27 & 12.3 & NA & NA & 1 & 0 & NA & 1 \\
\hline Technetium-99 & $1 / 1$ & 5.11 & 5.11 & RAD27 & 5.11 & NA & NA & 0 & NA & NA & 1 \\
\hline Thorium -228 & $3 / 3$ & 0.92 & 1.22 & AU12 & 1.08 & NA & NA & 1 & 0 & NA & 1 \\
\hline $\begin{array}{l}\text { Thorium -232 } \\
\text { Uranium- }\end{array}$ & $3 / 3$ & 0.91 & 1.24 & AU12 & 1.05 & NA & NA & 1 & 0 & NA & 1 \\
\hline $233 / 234$ & $3 / 3$ & 1.28 & 7.89 & AU12 & 3.49 & 0 & 0 & 0 & NA & 0 & 1 \\
\hline Uranium-235 & $3 / 3$ & 0.0 .094 & 0.79 & RAD27 & 0.35 & 0 & 0 & 0 & NA & 0 & 1 \\
\hline Uranium-238 & $3 / 3$ & 0.89 & 4.62 & RAD27 & 2.19 & 0 & 0 & 0 & 1 & 0 & 1 \\
\hline
\end{tabular}

\section{Avg $=$ average $\quad \mathrm{NA}=$ not applicable}

$\mathrm{Bkg}=$ background $\quad \mathrm{PRG}=$ preliminary remediation goal

$\mathrm{EU}=$ exposure unit $\quad$ Res $=$ residential

$\mathrm{GW}=$ groundwater $\quad \mathrm{RL}=$ remediation level

Ind $=$ industrial $\quad \mathrm{SL}=$ screening level

Max = maximum

\section{EU Z2-24 HISTORICAL VOC DETECTS (ug/kg)}

\begin{tabular}{|c|c|c|c|c|c|c|c|c|}
\hline \multirow[b]{2}{*}{ Analyte } & \multirow[b]{2}{*}{$\begin{array}{c}\text { Detect } \\
\text { frequency }\end{array}$} & \multirow[b]{2}{*}{$\begin{array}{c}\text { Minimum } \\
\text { detect }\end{array}$} & \multirow[b]{2}{*}{$\begin{array}{c}\text { Maximum } \\
\text { detect }\end{array}$} & \multirow[b]{2}{*}{$\begin{array}{c}\text { Location(s) of } \\
\text { maximum detect }\end{array}$} & \multirow{2}{*}{$\begin{array}{c}\text { Average } \\
\text { detected } \\
\text { result }\end{array}$} & \multicolumn{3}{|c|}{$\begin{array}{l}\text { Number of analyses } \\
\text { exceeding criteria }\end{array}$} \\
\hline & & & & & & $\begin{array}{l}\text { Ind } \\
\text { PRG }\end{array}$ & $\begin{array}{c}\text { GW } \\
\text { SL }\end{array}$ & $\begin{array}{l}\text { Res } \\
\text { PRG }\end{array}$ \\
\hline Acetone & $2 / 2$ & $420 \mathrm{~J}$ & $870 \mathrm{~J}$ & 420 & 645 & 0 & NA & 0 \\
\hline Toluene & $2 / 2$ & $12 \mathrm{~J}$ & $47 \mathrm{~J}$ & 420 & 29.5 & 0 & 0 & 0 \\
\hline$\overline{\mathrm{EU}}=\mathrm{exposure}$ unit & & $\mathrm{PRG}=$ & reliminary re & ediation goal & & & & \\
\hline $\mathrm{GW}=$ groundwater & & Res $=r$ & idential & & & & & \\
\hline Ind $=$ industrial & & $\mathrm{SL}=\mathrm{sc}$ & ening level & & & & & \\
\hline NA $=$ not applicable & & $\mathrm{VOC}=$ & olatile organ & compound & & & & \\
\hline
\end{tabular}

EU Z2-24 Summary: This section presents a summary of the nature and extent of contamination in EU Z2-24 by combining all analytical data for the EU that are presented in the focused investigation summaries above. There are nine sample locations in EU Z2-24 that include three historical sample locations and six DVS sample locations. DVS sampling was performed at the K-1650 UST, sediment accumulation area, and the presumed location of the K-300 Area Service Station. Details of sampling and analysis in this EU are presented in Table E. 2 and sample locations are shown on Fig. E.4. Analytical results for all of the samples summarized below show radionuclide Ind PRG exceedances; metal and radionuclide Bkg exceedances; and detections of DRO, PCBs, SVOCs, and VOCs.

EU Z2-24 METALS WITH BACKGROUND, PRG, GW SL, AND/OR RL EXCEEDANCES (mg/kg)

\begin{tabular}{|c|c|c|c|c|c|c|c|c|c|c|c|}
\hline \multirow[b]{2}{*}{ Analyte } & \multirow[b]{2}{*}{$\begin{array}{l}\text { Detect } \\
\text { frequency }\end{array}$} & \multirow[b]{2}{*}{$\begin{array}{c}\text { Minimum } \\
\text { detect }\end{array}$} & \multirow[b]{2}{*}{$\begin{array}{c}\text { Maximum } \\
\text { detect }\end{array}$} & \multirow[b]{2}{*}{$\begin{array}{l}\text { Location(s) of } \\
\text { maximum detect }\end{array}$} & \multirow[b]{2}{*}{$\begin{array}{c}\text { Average } \\
\text { detected } \\
\text { result }\end{array}$} & \multicolumn{6}{|c|}{ Number of analyses exceeding criteria } \\
\hline & & & & & & $\begin{array}{c}\text { Max } \\
\text { RL }\end{array}$ & $\begin{array}{c}\text { Avg } \\
\text { RL }\end{array}$ & $\begin{array}{l}\text { Ind } \\
\text { PRG }\end{array}$ & Bkg & $\begin{array}{c}\text { GW } \\
\text { SL }\end{array}$ & $\begin{array}{l}\text { Res } \\
\text { PRG }\end{array}$ \\
\hline Aluminum & $8 / 8$ & 2,900 & 18,000 & $\begin{array}{l}\text { Z2-EU24B-301 } \\
\text { Z2-EU24B-303 }\end{array}$ & 11,695 & NA & NA & 0 & 0 & NA & 6 \\
\hline Arsenic & $8 / 8$ & 3.4 & 9.2 & Z2-EU24M-302 & 5.15 & 0 & 0 & 0 & 0 & 0 & 8 \\
\hline Cadmium & $6 / 8$ & 0.093 & 0.23 & Z2-EU24B-303 & 0.166 & NA & NA & 0 & 1 & NA & 0 \\
\hline Calcium & $8 / 8$ & 338 & $250,000 \mathrm{~J}$ & Z2-EU24B-305 & 43,307 & NA & NA & NA & 6 & NA & NA \\
\hline Cobalt & $8 / 8$ & 3.8 & 120 & Z2-EU24B-303 & 25.3 & NA & NA & 0 & 1 & NA & 0 \\
\hline Copper & $8 / 8$ & 12 & 37 & Z2-EU24B-303 & 22.6 & NA & $\mathrm{NA}$ & 0 & 3 & NA & 0 \\
\hline Lead & $8 / 8$ & 16 & 68 & Z2-EU24B-303 & 31.7 & NA & NA & 0 & 2 & 0 & 0 \\
\hline Magnesium & $8 / 8$ & 197 & $21,000 \mathrm{~J}$ & Z2-EU24B-305 & 7,227 & NA & NA & NA & 6 & NA & NA \\
\hline Manganese & $8 / 8$ & $300 \mathrm{~J}$ & $3,100 \mathrm{~J}$ & Z2-EU24B-303 & 987 & NA & $\mathrm{NA}$ & 0 & 1 & NA & 8 \\
\hline Mercury & $8 / 8$ & 0.012 & 0.3 & Z2-EU24B-304 & 0.086 & 0 & 0 & 0 & 1 & NA & 0 \\
\hline Nickel & $8 / 8$ & 9.2 & 95 & Z2-EU24B-303 & 26.5 & NA & NA & 0 & 1 & NA & 0 \\
\hline Thallium & $7 / 8$ & 0.1 & 0.8 & 420 & 0.316 & NA & NA & 0 & 2 & 0 & 1 \\
\hline Uranium & $6 / 6$ & $1.1 \mathrm{~J}$ & $3.1 \mathrm{~J}$ & Z2-EU24B-303 & 1.97 & NA & NA & 0 & NA & NA & 4 \\
\hline
\end{tabular}


EU Z2-24 METALS WITH BACKGROUND, PRG, GW SL, AND/OR RL EXCEEDANCES (mg/kg) (cont'd)

\begin{tabular}{|c|c|c|c|c|c|c|c|c|c|c|c|}
\hline \multirow[b]{2}{*}{ Analyte } & \multirow[b]{2}{*}{$\begin{array}{c}\text { Detect } \\
\text { frequency }\end{array}$} & \multirow[b]{2}{*}{$\begin{array}{c}\text { Minimum } \\
\text { detect }\end{array}$} & \multirow[b]{2}{*}{$\begin{array}{c}\text { Maximum } \\
\text { detect }\end{array}$} & \multirow[b]{2}{*}{$\begin{array}{c}\text { Location(s) of } \\
\text { maximum detect }\end{array}$} & \multirow{2}{*}{$\begin{array}{c}\text { Average } \\
\text { detected } \\
\text { result }\end{array}$} & \multicolumn{6}{|c|}{ Number of analyses exceeding criteria } \\
\hline & & & & & & $\begin{array}{c}\text { Max } \\
\text { RL }\end{array}$ & $\begin{array}{l}\text { Avg } \\
\text { RL }\end{array}$ & $\begin{array}{c}\text { Ind } \\
\text { PRG }\end{array}$ & Bkg & $\begin{array}{c}\text { GW } \\
\text { SL }\end{array}$ & $\begin{array}{c}\text { Res } \\
\text { PRG }\end{array}$ \\
\hline$\overline{\text { Vanadium }}$ & $8 / 8$ & 8.6 & 59 & Z2-EU24B-303 & 33.5 & NA & NA & 0 & 0 & NA & 8 \\
\hline Zinc & $8 / 8$ & $32 \mathrm{~J}$ & $120 \mathrm{~J}$ & Z2-EU24B-305 & 69.4 & NA & NA & 0 & 2 & NA & 0 \\
\hline
\end{tabular}

Avg = average

$\mathrm{NA}=$ not applicable

$\mathrm{Bkg}=$ background $\quad \mathrm{PRG}=$ preliminary remediation goal

$\mathrm{EU}=$ exposure unit $\quad$ Res $=$ residential

$\mathrm{GW}=$ groundwater $\quad \mathrm{RL}=$ remediation level

Ind $=$ industrial $\quad \mathrm{SL}=$ screening level

Max $=$ maximum

EU Z2-24 OTHER ORGANICS DETECTS (mg/kg)

\begin{tabular}{lccccc}
\hline \multicolumn{1}{c}{ Analyte } & $\begin{array}{c}\text { Detect } \\
\text { frequency }\end{array}$ & $\begin{array}{c}\text { Minimum } \\
\text { detect }\end{array}$ & $\begin{array}{c}\text { Maximum } \\
\text { detect }\end{array}$ & $\begin{array}{c}\text { Location(s) of } \\
\text { maximum detect }\end{array}$ & $\begin{array}{c}\text { Average } \\
\text { detected } \\
\text { result }\end{array}$ \\
\hline DROs & $1 / 3$ & 7.8 & 7.8 & Z2-EU24M-302 & 7.8 \\
\hline $\begin{array}{l}\text { DRO = diesel-range organic } \\
\text { EU }=\text { exposure unit }\end{array}$ & & & & \\
\hline
\end{tabular}

EU Z2-24 PCB DETECTS (ug/kg)

\begin{tabular}{|c|c|c|c|c|c|c|c|c|c|}
\hline \multirow[b]{2}{*}{ Analyte } & \multirow[b]{2}{*}{$\begin{array}{c}\text { Detect } \\
\text { frequency }\end{array}$} & \multirow[b]{2}{*}{$\begin{array}{c}\text { Minimum } \\
\text { detect }\end{array}$} & \multirow[b]{2}{*}{$\begin{array}{c}\text { Maximum } \\
\text { detect }\end{array}$} & \multirow{2}{*}{$\begin{array}{c}\text { Location(s) of } \\
\text { maximum } \\
\text { detect }\end{array}$} & \multirow{2}{*}{$\begin{array}{c}\text { Average } \\
\text { detected } \\
\text { result }\end{array}$} & \multicolumn{4}{|c|}{$\begin{array}{c}\text { Number of analyses } \\
\text { exceeding criteria }\end{array}$} \\
\hline & & & & & & $\begin{array}{c}\text { Max } \\
\text { RL }\end{array}$ & $\begin{array}{l}\text { Avg } \\
\text { RL }\end{array}$ & $\begin{array}{c}\text { Ind } \\
\text { PRG }\end{array}$ & $\begin{array}{l}\text { Res } \\
\text { PRG } \\
\end{array}$ \\
\hline PCB-1254 & $2 / 6$ & 89 & 210 & Z2-EU24B-305 & 150 & 0 & 0 & 0 & 1 \\
\hline PCB & $2 / 6$ & 89 & 210 & Z2-EU24B-305 & 150 & 0 & 0 & 0 & 1 \\
\hline
\end{tabular}

Avg = average

$\mathrm{EU}=$ exposure unit

Ind $=$ industrial

Max $=$ maximum
$\mathrm{PCB}=$ polychlorinated biphenyl

$\mathrm{PRG}=$ preliminary remediation goal

Res $=$ residential

$\mathrm{RL}=$ remediation level

EU Z2-24 RADIONUCLIDES WITH BACKGROUND, PRG, AND/OR RL EXCEEDANCES (pCi/g)

\begin{tabular}{|c|c|c|c|c|c|c|c|c|c|c|c|}
\hline \multirow[b]{2}{*}{ Analyte } & \multirow[b]{2}{*}{$\begin{array}{c}\text { Detect } \\
\text { frequency }\end{array}$} & \multirow[b]{2}{*}{$\begin{array}{c}\text { Minimum } \\
\text { detect }\end{array}$} & \multirow[b]{2}{*}{$\begin{array}{c}\text { Maximum } \\
\text { detect }\end{array}$} & \multirow[b]{2}{*}{$\begin{array}{c}\text { Location(s) of } \\
\text { maximum detect }\end{array}$} & \multirow{2}{*}{$\begin{array}{c}\text { Average } \\
\text { detected } \\
\text { result }\end{array}$} & \multicolumn{6}{|c|}{ Number of analyses exceeding criteria } \\
\hline & & & & & & $\begin{array}{c}\text { Max } \\
\text { RL }\end{array}$ & $\begin{array}{l}\text { Avg } \\
\text { RL }\end{array}$ & $\begin{array}{c}\text { Ind } \\
\text { PRG }\end{array}$ & Bkg & $\begin{array}{l}\text { GW } \\
\text { SL }\end{array}$ & $\begin{array}{c}\text { Res } \\
\text { PRG }\end{array}$ \\
\hline Potassium-40 & $3 / 3$ & 5.99 & 25.4 & Z2-EU24M-302 & 14.6 & NA & NA & 3 & 0 & NA & 3 \\
\hline Radium-226 & $2 / 3$ & 0.334 & $1.46 \mathrm{~J}$ & Z2-EU24M-302 & 0.897 & NA & NA & 2 & 1 & NA & 2 \\
\hline Technetium-99 & $1 / 5$ & 5.11 & 5.11 & RAD27 & 5.11 & NA & NA & 0 & NA & NA & 1 \\
\hline Thorium -228 & $5 / 5$ & 0.92 & 1.34 & Z2-EU24M-302 & 1.12 & NA & NA & 5 & 0 & NA & 5 \\
\hline Thorium -230 & $5 / 5$ & $1.09 \mathrm{~J}$ & 1.67 & Z2-EU24M-302 & 1.41 & NA & NA & 0 & 2 & NA & 0 \\
\hline Thorium -232 & $5 / 5$ & 0.91 & 1.56 & Z2-EU24M-302 & 1.16 & NA & NA & 5 & 0 & NA & 5 \\
\hline Uranium-234 & $5 / 5$ & 1.23 & 7.89 & RAD27 & 2.69 & 0 & 0 & 0 & NA & 0 & 1 \\
\hline Uranium-235 & $3 / 5$ & 0.79 & 0.79 & RAD27 & 0.35 & 0 & 0 & 0 & NA & 0 & 1 \\
\hline Uranium-238 & $5 / 5$ & 0.722 & 4.62 & RAD27 & 1.9 & 0 & 0 & 0 & 2 & 0 & 2 \\
\hline
\end{tabular}

Avg = average $\quad$ NA $=$ not applicable

$\mathrm{Bkg}=$ background $\quad \mathrm{PRG}=$ preliminary remediation goal

$\mathrm{EU}=$ exposure unit $\quad$ Res $=$ residential

$\mathrm{GW}=$ groundwater $\quad \mathrm{RL}=$ remediation level

Ind $=$ industrial $\quad \mathrm{SL}=$ screening level

Max = maximum 
EU Z2-24 SVOC DETECTS (ug/kg)

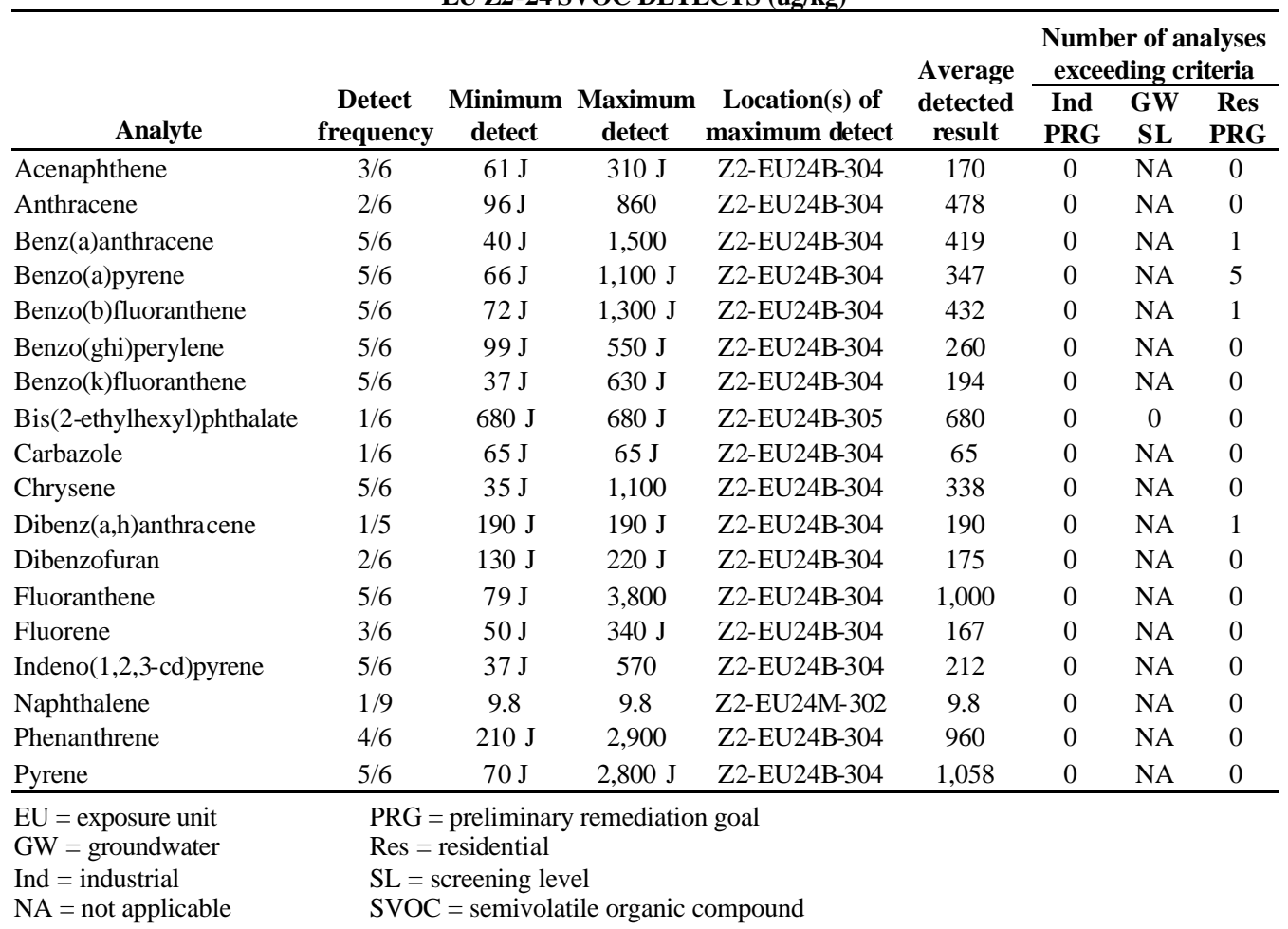

EU Z2-24 VOC DETECTS (ug/kg)

\begin{tabular}{|c|c|c|c|c|c|c|c|c|}
\hline \multirow[b]{2}{*}{ Analyte } & \multirow[b]{2}{*}{$\begin{array}{c}\text { Detect } \\
\text { frequency }\end{array}$} & \multirow[b]{2}{*}{$\underset{\text { detect }}{\text { Minimum }}$} & \multirow[b]{2}{*}{$\begin{array}{c}\text { Maximum } \\
\text { detect }\end{array}$} & \multirow[b]{2}{*}{$\begin{array}{c}\text { Location(s) of } \\
\text { maximum detect }\end{array}$} & \multirow{2}{*}{$\begin{array}{c}\text { Average } \\
\text { detected } \\
\text { result }\end{array}$} & \multicolumn{3}{|c|}{$\begin{array}{l}\text { Number of analyses } \\
\text { exceeding criteria }\end{array}$} \\
\hline & & & & & & $\begin{array}{l}\text { Ind } \\
\text { PRG }\end{array}$ & GW & $\begin{array}{c}\text { Res } \\
\text { PRG }\end{array}$ \\
\hline Acetone & $3 / 6$ & $13 \mathrm{~J}$ & $870 \mathrm{~J}$ & 420 & 434 & 0 & NA & 0 \\
\hline Toluene & $2 / 6$ & $12 \mathrm{~J}$ & $47 \mathrm{~J}$ & 420 & 29.5 & 0 & 0 & 0 \\
\hline
\end{tabular}

EU $=$ exposure unit $\quad$ PRG $=$ preliminary remediation goal

$\mathrm{GW}=$ groundwater $\quad$ Res $=$ residential

Ind $=$ industrial $\quad \mathrm{SL}=$ screening level

$\mathrm{NA}=$ not applicable $\quad \mathrm{VOC}=$ volatile organic compound

\subsection{6 \\ ZONE 2 ROD APPENDIX A FFA SITES EVALUATION}

The location of the K-300 Area Service Station FFA site was identified during DQO scoping as being in EU Z2-24. However, based on geophysical survey results (Sect. 2.1.3.4) and re-evaluation of plant records, it was determined the FFA site is located in EU Z2-23. The K-300 Area Service Station FFA site is evaluated in the EU Z2-23 TM.

\begin{tabular}{|l|l|}
\hline 3.0 & \multicolumn{1}{|c|}{ RISK EVALUATION AND ACTION/NO FURTHER ACTION DECISION } \\
\hline 3.1 & INTRODUCTION \\
\hline
\end{tabular}

In this section, data are evaluated in terms of the four decision rules presented in the Zone 2 RDR/RAWP, which include:

- Does the concentration of any Zone 2 contaminant of concern (COC) exceed its maximum RL?

- Does the mean concentration of any Zone 2 COC exceed its average RL across the EU?

- Does the EU pose a risk exceeding an industrial $1 \times 10^{-4}$ excess lifetime cancer risk (ELCR) or target organ hazard index $(\mathrm{HI})$ of 1 ?

- Does the site pose a threat to groundwater based on MCL exceedances or soil RLs for protection of groundwater? 
Table E. 3 presents the results from comparing the data to Zone 2 soils RLs, industrial PRGs (set at an ELCR of $1 \times 10^{-5}$ or a HI of 1), and background levels. In addition, the EU summary in Sect. 2.2.5 presents an evaluation of the EU data by analyte group. The following table summarizes the conclusions for EU Z2-24.

\begin{tabular}{lccccc}
\hline EU \# & $\begin{array}{c}\text { Max RL } \\
\text { exceeded? }\end{array}$ & $\begin{array}{c}\text { Average RL over } \\
\text { EU exceeded? }\end{array}$ & $\begin{array}{c}\text { Industrial risk } \\
\text { above } \mathbf{1} \times \mathbf{1 0}^{-\mathbf{4}} \text { ? }\end{array}$ & $\begin{array}{c}\text { Potential source } \\
\text { to groundwater? }\end{array}$ & $\begin{array}{c}\text { Action } \\
\text { required? }\end{array}$ \\
\hline $\mathrm{Z} 2-24$ & No & No & No & No & No \\
\hline $\begin{array}{l}\mathrm{EU}=\text { exposure unit } \\
\mathrm{RL}=\text { remediation level }\end{array}$ & & & & & \\
\end{tabular}

\section{\begin{tabular}{l|l}
3.2 & DATA EVALUATION FOR THE ACTION /NO FURTHER ACTION DECISION
\end{tabular}}

Requirements for determining NFA in the Zone 2 EUs are stated in the protection goals of the Zone 2 ROD remedial action objective (RAO). Four decision rules were developed in the DVS DQOs that state the specific criteria against which each EU must be compared to make the NFA decision. The four decision rules are presented in Sect. 3.2 of this PCCR. The approach used in conducting the decision rule evaluations and special data handling requirements are discussed in Sect. 3.3 of this PCCR. In summary, the decision rule criteria for NFA are that each EU must meet each of the following compositional constraints:

- Zone 2 soils maximum RLs - maximum allowable concentrations of the Zone 2 soils COCs. Zone 2 soils maximum RLs are presented in the Zone 1 ROD and Table 5 of this PCCR.

- Zone 2 soils average RLs - limit on the allowable average concentrations of the Zone 2 soils COCs across an EU. Zone 2 soils average RLs are presented in the Zone 1 ROD and Table 5 of this PCCR.

- Cumulative risk across the EU-cumulative risk across an EU cannot exceed $1 \times 10^{-4}$ ELCR or HI of 1 . A stepwise evaluation of cumulative risk is performed by first comparing EU data to $1 \times 10^{-5}$ industrial PRGs. The $1 \times 10^{-5}$ Ind PRGs for the analytes required by the RDR/RAWP are presented in Table 5 of this PCCR.

- Groundwater protection goals - compositions of Zone 2 soils cannot pose a threat to groundwater. This evaluation is conducted by evaluating local groundwater monitoring results and comparing soils compositions to calculated SLs. Groundwater SLs are presented in Table 5 of this PCCR.

\begin{tabular}{|l|l|}
\hline 3.3 & SUMMARY AND CONCLUSIONS \\
\hline
\end{tabular}

$\underline{\text { EU Z2-24 }}$

Maximum RL screening. Based on historical and DVS sampling information and results of the Class 3 walkover assessment, no Zone 2 COCs were detected at concentrations in excess of maximum RLs.

Average RL screening. Based on analytical results from DVS biased sampling and historical sampling in EU Z2-24 and results of the Class 3 walkover assessment, no Zone 2 soils COCs are present with a mean concentration exceeding the average RL across the EU.

Risk evaluation. No $1 \times 10^{-5}$ industrial PRGs are exceeded in samples collected in EU Z2-24, except for K-40, Ra-226, Th-228, and Th-232 (see PCCR Sect.3.3.2 for a description on how these radionuclides were evaluated). Therefore, it is concluded the industrial risk for EU Z2-24 is less than $1 \times 10^{-4}$ ELCR and target organ HI of 1.

Threat to groundwater. Evaluation of ETTP groundwater shows there is no contaminated groundwater in EU Z2-24. Analytical data show no chemical or radionuclide exceeds its GW SL in EU Z2-24 soil samples. Therefore, it is concluded that EU Z2-24 soils do not pose a threat to groundwater.

Qualitative risk screening for unrestricted use. There is a low probability that the EU Z2-24 acreage could be released with no land use restrictions. Ind and Res PRG exceedances for metals, radionuclides, PCBs, and SVOCs occur in EU Z2-24. Specific chemicals and radionuclides with criteria exceedances are presented in the EU Z2-24 summary in Sect. 2.2.5. An appropriate evaluation of residential risk should be conducted to make a definitive conclusion. 


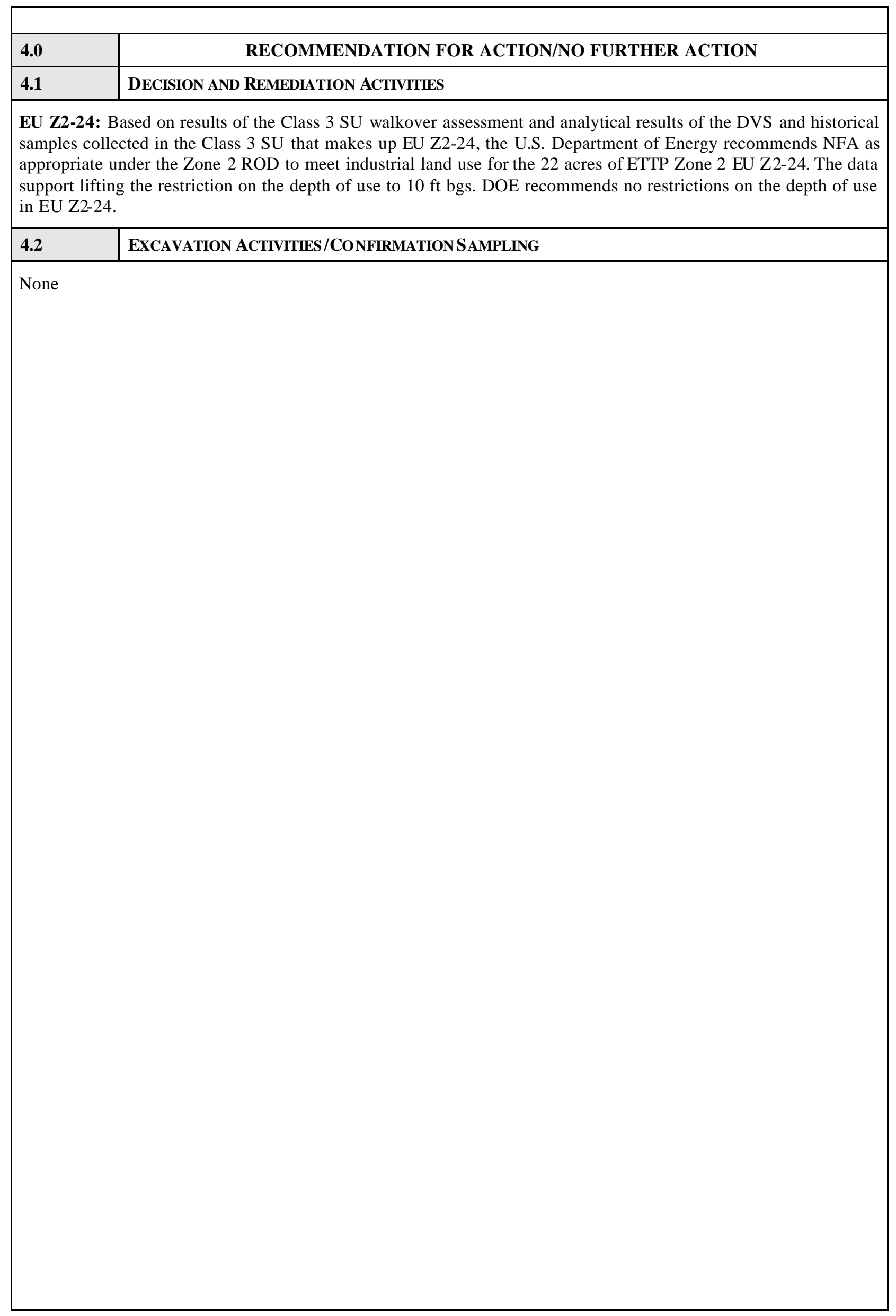




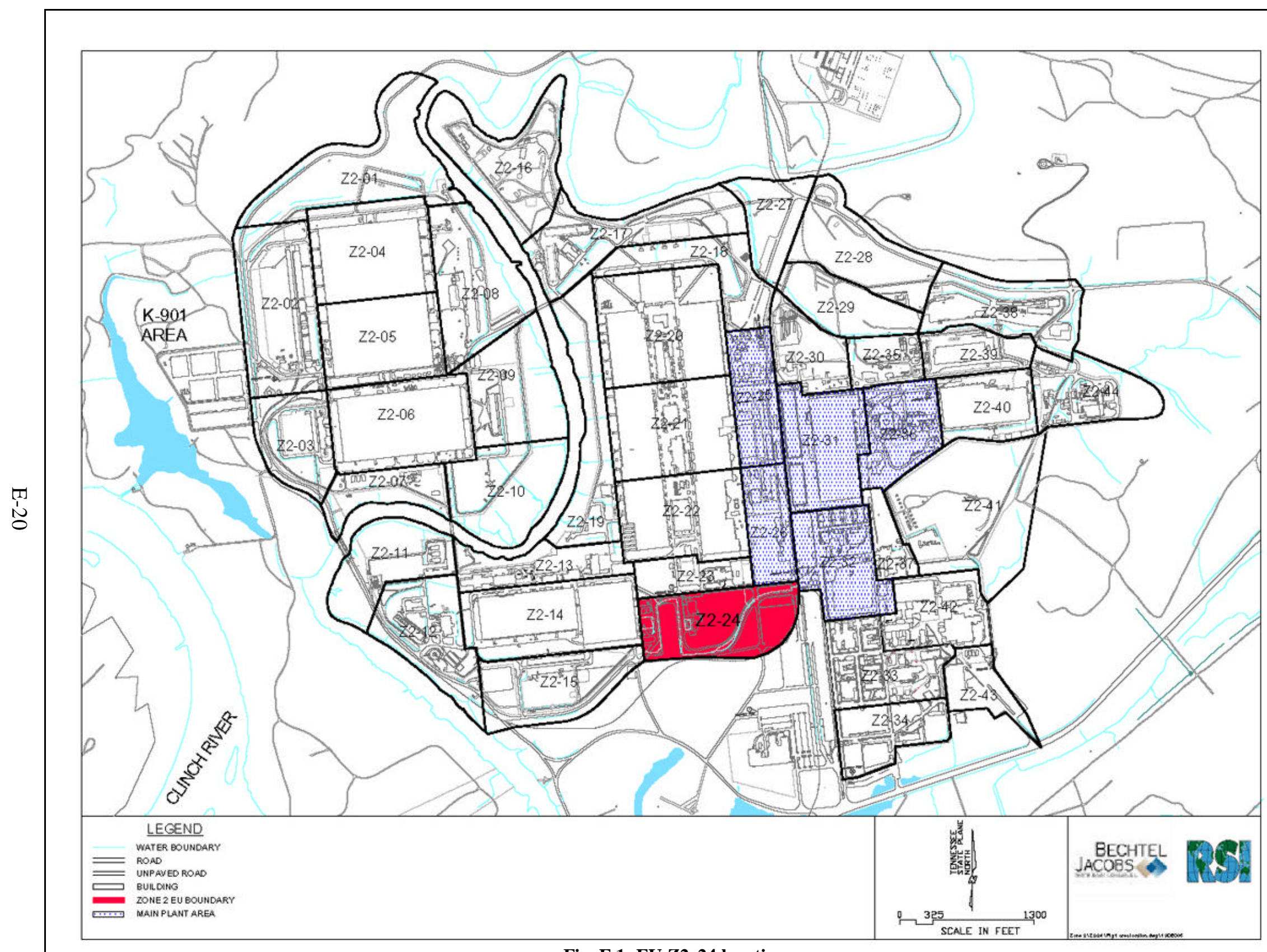

Fig. E.1. EU Z2 -24 location map. 


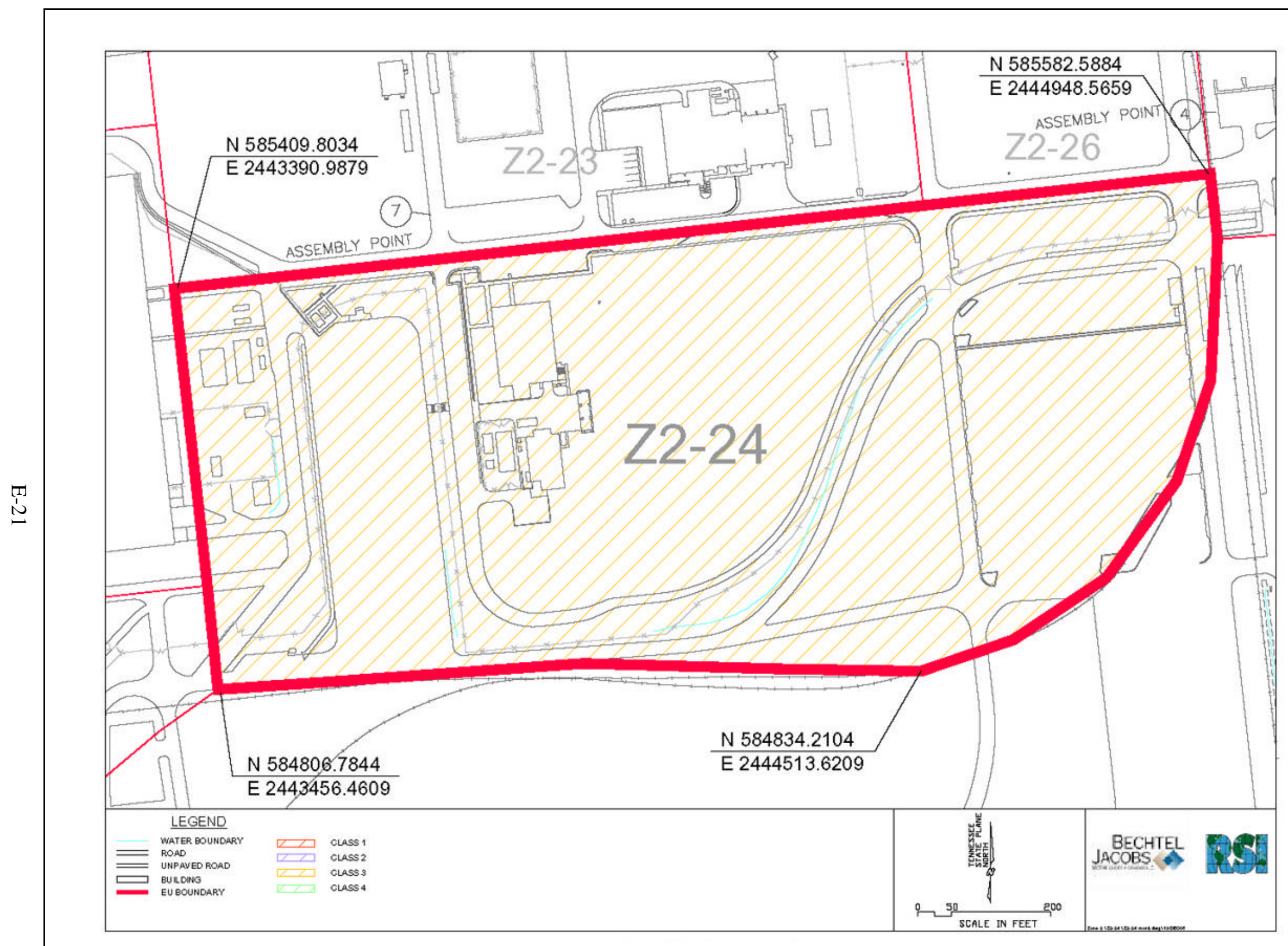

Fig. E.2. EU Z2-24 boundaries. 


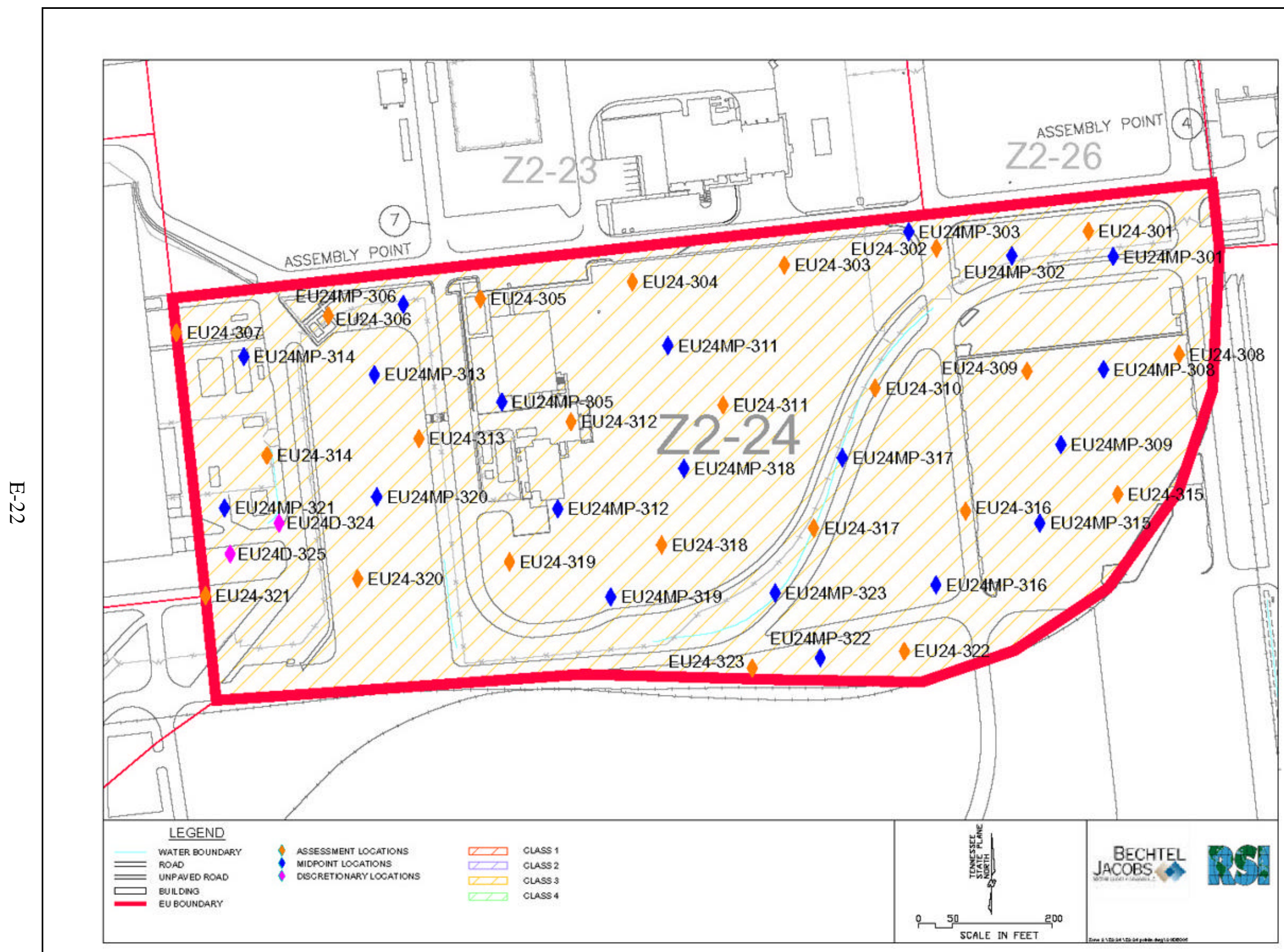

Fig. E.3. EU Z2-24 Class 3 and 4 SU walkover assessment locations. 


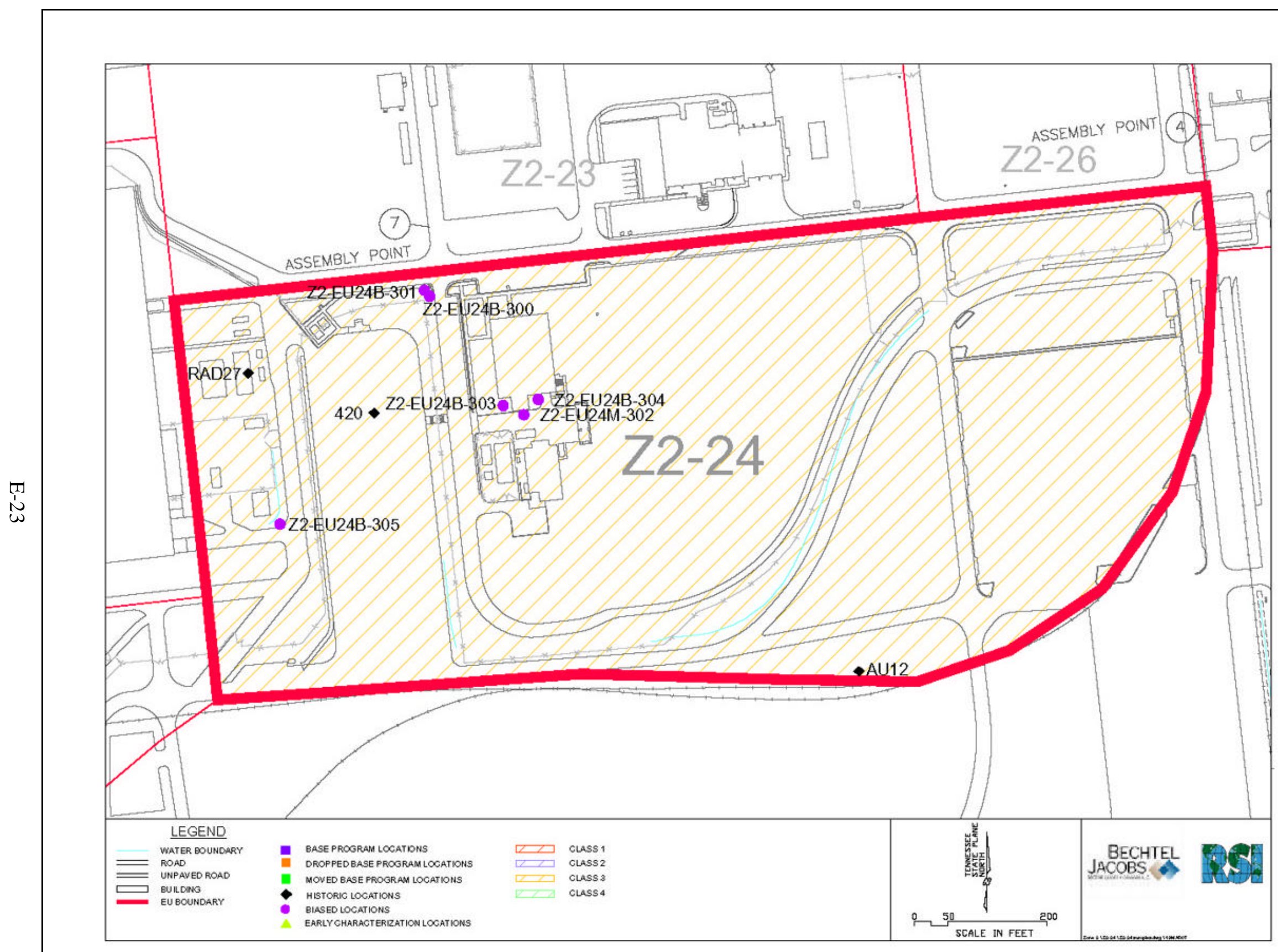

Fig. E.4. EU Z2 -24 sample locations. 
Table E.1. EU Z2-24 facility and FFA site list

\begin{tabular}{|c|c|c|c|c|}
\hline \multirow[b]{2}{*}{ Facility name DQO scoping } & \multirow[b]{2}{*}{ Facility name } & \multicolumn{2}{|c|}{$\begin{array}{c}\text { Facility } \\
\text { assessed? }\end{array}$} & \multirow[b]{2}{*}{ Comments } \\
\hline & & Yes & No & \\
\hline K-300 Area Service Station (Historical) & K-300 Area Service Station & $\mathrm{X}$ & & $\begin{array}{l}\text { FFA site; originally in } \\
\text { EU Z2-24 but falls in } \\
\text { EU Z2-23 }\end{array}$ \\
\hline K-1019-4A Bus Shelter (Characterization Area-Group II EE/CA) & & $\mathrm{X}$ & & \\
\hline K-1019-7A Bus Shelter (Characterization Area-Group II EE/CA) & & $\mathrm{X}$ & & \\
\hline K-1019-7B Bus Shelter (Characterization Area-Group II EE/CA) & & $\mathrm{X}$ & & \\
\hline K-1028-55 Gate House at Portal 7 (Characterization Area- & & & & \\
\hline Group II EE/CA) & & $\mathrm{X}$ & & \\
\hline K-1034-A Plant Record Vault Building (Characterization Area- & & & & \\
\hline Group II EE/CA) & & $\mathrm{X}$ & & \\
\hline K-1240-4B Parking Lot at Portal 4W & & $\mathrm{X}$ & & \\
\hline K-1240-7A Parking Lot at Portal 7 & & $\mathrm{X}$ & & \\
\hline K-1310-EJ (Characterization Area-Group II EE/CA) & & & $\mathrm{X}$ & Facility no longer exists \\
\hline K-1310-GA & K-1310-GA Changehouse & $\mathrm{X}$ & & \\
\hline K-1310-GX & & & $\mathrm{X}$ & Facility no longer exists \\
\hline K-1310-GY & & & $\mathrm{X}$ & Facility no longer exists \\
\hline K-1310-HF & K-1310-HF Break Room Trailer & $\mathrm{X}$ & & \\
\hline K-1310-HH & & & $\mathrm{X}$ & Facility no longer exists \\
\hline K-1314-A (Characterization Area-Group II EE/CA) & K-1314-A Prefab Storage Building & $\mathrm{X}$ & & \\
\hline K-1314-E (Characterization Area-Group II EE/CA) & K-1314-E Prefab Storage Building & $\mathrm{X}$ & & \\
\hline $\mathrm{K}-1314-\mathrm{F}$ & K-1314-F Storage Yard & $\mathrm{X}$ & & \\
\hline $\begin{array}{l}\text { K-1550-L } \\
\text { K-1650 Central Control Facility (Characterization Area-Group II }\end{array}$ & & & $\mathrm{X}$ & Facility no longer exists \\
\hline $\mathrm{EE} / \mathrm{CA})$ & & $\mathrm{X}$ & & \\
\hline K-1650 UST & & $\mathrm{X}$ & & \\
\hline K-1650-B Steam Boiler & & $\mathrm{X}$ & & \\
\hline \multicolumn{5}{|l|}{ Facilities not in DQO s coping } \\
\hline K-1310-KU Sealand Office Trailer & & $\mathrm{X}$ & & \\
\hline K-1310-KV Sealand Office Trailer & & $\mathrm{X}$ & & \\
\hline K-1310-MG Sealand Office Trailer & & $\mathrm{X}$ & & \\
\hline K-1310-MY Sealand Office Trailer & & $\mathrm{X}$ & & \\
\hline K-1650-C Air Compressor Enclosure & & $\mathrm{X}$ & & \\
\hline
\end{tabular}

$\begin{array}{ll}\mathrm{CA}=\text { cost analysis } & \mathrm{EE}=\text { engineering evaluation } \\ \mathrm{DQO}=\text { data quality objective } & \mathrm{UST}=\text { underground storage tank }\end{array}$


Table E.2. EU Z2-24 sample summary

\begin{tabular}{|c|c|c|c|c|c|c|c|c|c|c|c|c|c|c|c|}
\hline \multirow[b]{2}{*}{$\begin{array}{c}\text { SU } \\
\text { Class }\end{array}$} & \multirow[b]{2}{*}{$\begin{array}{c}\text { Date } \\
\text { sampled }\end{array}$} & \multirow[b]{2}{*}{ Location ID $^{a}$} & \multicolumn{2}{|c|}{ Location $^{b}$} & \multirow[b]{2}{*}{ Sample interval } & \multicolumn{2}{|c|}{ Screen } & \multicolumn{7}{|c|}{ Off-Site Laboratory $^{c}$} & \multirow[b]{2}{*}{$\begin{array}{l}\text { Comments } \\
\text { and Notes }\end{array}$} \\
\hline & & & Easting & Northing & & VOC & RAD & VOC & SVOC & MET & PCB & $\mathbf{R A D}^{d}$ & $\begin{array}{l}\text { GRO/ } \\
\text { DRO }\end{array}$ & $\begin{array}{l}\text { Splits/ } \\
\text { Dups }\end{array}$ & \\
\hline 3 & $9 / 27 / 06$ & Z2-EU24B-300 & 2443777 & 585416 & $0-10 \mathrm{ft}$, three interval composite & 1 & 1 & & 1 & 1 & 1 & & & & $\begin{array}{l}\text { K-300 Area } \\
\text { Service } \\
\text { Station }^{e}\end{array}$ \\
\hline 3 & $9 / 27 / 06$ & Z2-EU24B-301 & 2443769 & 585425 & $0-10 \mathrm{ft}$, three interval composite & 1 & 1 & & 1 & 1 & 1 & & & & $\begin{array}{l}\text { K-300 Area } \\
\text { Service } \\
\text { Station }^{e}\end{array}$ \\
\hline 3 & $9 / 28 / 06$ & Z2-EU24M-302 & 2443919 & 585237 & $0-14 \mathrm{ft}$, three interval composite & 1 & 1 & 1 & 1 & 1 & 1 & 1 & 1 & $\mathrm{~S}$ & $\begin{array}{l}\text { K-1650 Diesel } \\
\text { Tank }\end{array}$ \\
\hline 3 & $9 / 28 / 06$ & Z2-EU24B-303 & 2443888 & 585251 & $0-14 \mathrm{ft}$, three interval composite & 1 & 1 & 1 & 1 & 1 & 1 & & 1 & & $\begin{array}{l}\text { K-1650 Diesel } \\
\text { Tank }\end{array}$ \\
\hline 3 & $9 / 28 / 06$ & Z2-EU24B-304 & 2443941 & 585260 & $0-14 \mathrm{ft}$, three interval composite & 1 & 1 & 1 & 1 & 1 & 1 & & 1 & & $\begin{array}{l}\text { K-1650 Diesel } \\
\text { Tank }\end{array}$ \\
\hline 3 & $9 / 28 / 06$ & Z2-EU24B-305 & 2443551 & 585072 & Grab sample (sediment) & 1 & 1 & 1 & 1 & 1 & 1 & 1 & & & $\begin{array}{l}\text { Sediment } \\
\text { Accumulation } \\
\text { Area }\end{array}$ \\
\hline & & & & & Total DVS samples & 6 & 6 & 4 & 6 & 6 & 6 & 2 & 3 & 1 & \\
\hline \multicolumn{16}{|c|}{ Historical samples } \\
\hline 3 & $3 / 15 / 98$ & 420 & 2443693 & 585240 & Two discrete intervals $6-8 \mathrm{ft}$ and $8-10 \mathrm{ft}$ & & & 2 & & 2 & & & & & \\
\hline 3 & $9 / 26 / 94$ & RAD27 & 2443503 & 585300 & One discrete interval $0-0.5 \mathrm{ft}$ & & & & & & & 1 & & & \\
\hline 3 & $\begin{array}{c}3 / 21 / 00 \\
5 / 9 / 00\end{array}$ & AU12 & 2444251 & 584850 & Two discrete intervals $0-0.5$ and $0.5-2 \mathrm{ft}$ & & & & & & & 2 & & & \\
\hline & & & & & Total historical samples & & & 2 & & 2 & & 3 & & & \\
\hline
\end{tabular}

${ }^{a c}$ B" in sample number indicates a biased sample.

Coordinates listed number Location column are the adjusted coordinates.

${ }^{c}$ Note the following requirements for soil samples collected under this DWP:

\begin{tabular}{|l|c|c|l|c|}
\hline Analyte & SW846 Method & Holding time in days & Containers & Quantity \\
\hline Metals & $6010 \mathrm{~B} / 7471 \mathrm{~A}$ & $180 / 28$ & 4-oz wide mouthed glass jar with Teflon-lined cap (or approved equivalent) & $10-50 \mathrm{~g}$ \\
\hline PCBs & 8082 & 14 & 4-oz wide mouthed glass jar with Teflon-lined cap (or approved equivalent) & $30 \mathrm{~g}$ \\
\hline RAD & HASL-3000 & 180 & 8-oz amber glass (or approved equivalent) & $100-500 \mathrm{~g}$ \\
\hline SVOCs & 8270 & 14 & 4-oz wide mouthed glass jar with Teflon-lined cap (or approved equivalent) & $30 \mathrm{~g}$ \\
\hline VOCs & $8260 \mathrm{~B}$ & 14 & 4-oz wide mouthed glass jar with septum, Teflon-lined cap (or approved equivalent) & $15 \mathrm{~g}$ \\
\hline DRO/GRO & $8015 \mathrm{M}$ & 14 & 4-oz wide mouthed glass jar with septum, Teflon-lined cap (or approved equivalent) & $30 \mathrm{~g}$ \\
\hline
\end{tabular}

${ }^{d}$ Standard radiological analysis includes alpha spec, gamma spec, and technetium-99.

${ }^{e}$ Presumed site.

$\mathrm{EU}=$ exposure unit

列

$\mathrm{DRO}=$ diesel-range organic

$\mathrm{GRO}=$ gasoline-range organic

ID = identification

$\mathrm{RAD}=$ radiological

SU $=$ soil unit

MET $=$ metal

= semivolatile organic compound

$\mathrm{VOC}=$ volatile organic compound 
Table E.3. EU Z2-24, depth 0-10 ft

\begin{tabular}{|c|c|c|c|c|c|c|c|c|c|c|c|c|c|}
\hline Analyte & $\begin{array}{c}\text { Frequency } \\
\text { of detect }\end{array}$ & $\begin{array}{c}\text { Minimum } \\
\text { detect }\end{array}$ & $\begin{array}{c}\text { Maximum } \\
\text { detect }\end{array}$ & $\begin{array}{c}\text { Location(s) of } \\
\text { maximum } \\
\text { detected result }\end{array}$ & $\begin{array}{c}\text { Average } \\
\text { detected } \\
\text { result }\end{array}$ & $\begin{array}{c}\text { Max } \\
\text { RL }\end{array}$ & $\begin{array}{c}\text { Frequency } \\
\text { of detects } \\
\text { exceeding } \\
\text { Max RL } \\
\end{array}$ & $\begin{array}{l}\text { Avg } \\
\text { RL }\end{array}$ & $\begin{array}{c}\text { Frequency } \\
\text { of detects } \\
\text { exceeding } \\
\text { Avg RL }\end{array}$ & $\begin{array}{c}\text { PRG } \\
\text { limit } \\
\left(10^{-5} \text { or } 1\right)\end{array}$ & $\begin{array}{c}\text { Frequency } \\
\text { of detects } \\
\text { exceeding } \\
\text { PRG limit } \\
\end{array}$ & $\begin{array}{c}\text { Background } \\
\text { concentration }\end{array}$ & $\begin{array}{c}\text { Frequency } \\
\text { of detects } \\
\text { exceeding } \\
\text { background }\end{array}$ \\
\hline \multicolumn{14}{|l|}{ Inorganics $(\mathrm{mg} / \mathrm{kg})$} \\
\hline Aluminum & $8 / 8$ & 2,900 & 18,000 & $\begin{array}{l}\text { Z2-EU24B-301 } \\
\text { Z2-EU24B-303 }\end{array}$ & 11,695 & & NA & & NA & $1.00 \mathrm{E}+05$ & $0 / 8$ & 40,300 & $0 / 8$ \\
\hline Antimony & $8 / 8$ & $0.074 \mathrm{~J}$ & $0.93 \mathrm{~J}$ & 420 & 0.38 & & NA & & NA & $4.10 \mathrm{E}+02$ & $0 / 8$ & 1.52 & $0 / 8$ \\
\hline Arsenic & $8 / 8$ & 3.4 & 9.2 & Z2-EU24M-302 & 5.15 & 900 & $0 / 8$ & 300 & $0 / 8$ & $1.60 \mathrm{E}+01$ & $0 / 8$ & 14.95 & $0 / 8$ \\
\hline Barium & $8 / 8$ & 18.7 & 77 & Z2-EU24B-303 & 48.48 & & NA & & NA & $6.70 \mathrm{E}+04$ & $0 / 8$ & 124.93 & $0 / 8$ \\
\hline Beryllium & $8 / 8$ & $0.28 \mathrm{~J}$ & $1.4 \mathrm{~J}$ & Z2-EU24B-301 & 0.75 & 6,000 & $0 / 8$ & 2000 & $0 / 8$ & $1.90 \mathrm{E}+03$ & $0 / 8$ & 2.2 & $0 / 8$ \\
\hline Boron & $6 / 6$ & $1.4 \mathrm{~J}$ & 5.7 & Z2-EU24B-305 & 2.98 & & NA & & NA & $1.00 \mathrm{E}+05$ & $0 / 6$ & & NA \\
\hline Cadmium & $6 / 8$ & 0.093 & 0.23 & Z2-EU24B-303 & 0.17 & & NA & & NA & $4.50 \mathrm{E}+02$ & $0 / 8$ & $0.22 \mathrm{U}$ & $1 / 8$ \\
\hline Calcium & $8 / 8$ & 338 & $250,000 \mathrm{~J}$ & Z2-EU24B-305 & $43,307.38$ & & NA & & NA & & NA & 2400 & $6 / 8$ \\
\hline Chromium & $8 / 8$ & 5.4 & 19 & Z2-EU24B-303 & 12.35 & & NA & & NA & $6.40 \mathrm{E}+02$ & $0 / 8$ & 44.88 & $0 / 8$ \\
\hline Cobalt & $8 / 8$ & 3.8 & 120 & Z2-EU24B-303 & 25.31 & & NA & & NA & $1.30 \mathrm{E}+04$ & $0 / 8$ & 42 & $1 / 8$ \\
\hline Copper & $8 / 8$ & 12 & 37 & Z2-EU24B-303 & 22.59 & & NA & & NA & $4.10 \mathrm{E}+04$ & $0 / 8$ & 22.48 & $3 / 8$ \\
\hline Iron & $8 / 8$ & 8,300 & 50,000 & Z2-EU24B-303 & 29375 & & NA & & NA & $1.00 \mathrm{E}+05$ & $0 / 8$ & 58,600 & $0 / 8$ \\
\hline Lead & $8 / 8$ & 16 & 68 & Z2-EU24B-303 & 31.7 & & NA & & NA & $8.00 \mathrm{E}+02$ & $0 / 8$ & 37.91 & $2 / 8$ \\
\hline Lithium & $6 / 6$ & $6.5 \mathrm{~J}$ & $36 \mathrm{~J}$ & Z2-EU24B-303 & 15.5 & & NA & & NA & $2.00 \mathrm{E}+04$ & $0 / 6$ & 48.94 & $0 / 6$ \\
\hline Magnesium & $8 / 8$ & 197 & $21,000 \mathrm{~J}$ & Z2-EU24B-305 & 7226.5 & & NA & & NA & & NA & 3,300 & $6 / 8$ \\
\hline Manganese & $8 / 8$ & $300 \mathrm{~J}$ & $3,100 \mathrm{~J}$ & Z2-EU24B-303 & 987 & & NA & & NA & $1.90 \mathrm{E}+04$ & $0 / 8$ & 2,200 & $1 / 8$ \\
\hline Mercury & $8 / 8$ & $0.012 \mathrm{~J}$ & $0.3 \mathrm{~J}$ & Z2-EU24B-304 & 0.09 & 1,800 & $0 / 8$ & 600 & $0 / 8$ & $3.10 \mathrm{E}+02$ & $0 / 8$ & 0.17 & $1 / 8$ \\
\hline Molybdenum & $4 / 6$ & $0.68 \mathrm{~J}$ & 1.6 & Z2-EU24B-303 & 1.06 & & NA & & NA & $5.10 \mathrm{E}+03$ & $0 / 6$ & & NA \\
\hline Nickel & $8 / 8$ & 9.2 & 95 & Z2-EU24B-303 & 26.51 & & NA & & NA & $2.00 \mathrm{E}+04$ & $0 / 8$ & 26.07 & $1 / 8$ \\
\hline Potassium & $8 / 8$ & $523 \mathrm{~J}$ & 2,000 & Z2-EU24B-301 & $1,134.75$ & & NA & & NA & & NA & $5,074.69$ & $0 / 8$ \\
\hline Selenium & $2 / 8$ & 0.41 & 0.84 & 420 & 0.63 & & NA & & NA & $5.10 \mathrm{E}+03$ & $0 / 8$ & 1.47 & $0 / 8$ \\
\hline Silver & $0 / 8$ & ND & ND & & ND & & NA & & NA & $5.10 \mathrm{E}+03$ & $0 / 8$ & $0.6 \mathrm{U}$ & $0 / 8$ \\
\hline Sodium & $8 / 8$ & $33 \mathrm{~J}$ & 180 & Z2-EU24B-305 & 68.76 & & NA & & NA & & NA & 497 & $0 / 8$ \\
\hline Thallium & $7 / 8$ & 0.1 & 0.8 & 420 & 0.32 & & NA & & NA & $6.70 \mathrm{E}+01$ & $0 / 8$ & $0.4 \mathrm{U}$ & $2 / 8$ \\
\hline Uranium & $6 / 6$ & $1.1 \mathrm{~J}$ & $3.1 \mathrm{~J}$ & Z2-EU24B-303 & 1.97 & & NA & & NA & $2.00 \mathrm{E}+02$ & $0 / 6$ & & NA \\
\hline Vanadium & $8 / 8$ & 8.6 & 59 & Z2-EU24B-303 & 33.5 & & NA & & NA & $1.00 \mathrm{E}+03$ & $0 / 8$ & 65.47 & $0 / 8$ \\
\hline Zinc & $8 / 8$ & $32 \mathrm{~J}$ & $120 \mathrm{~J}$ & Z2-EU24B-305 & 69.44 & & NA & & NA & $1.00 \mathrm{E}+05$ & $0 / 8$ & 89.7 & $2 / 8$ \\
\hline \multicolumn{14}{|l|}{ Radionuclides (pCi/g) } \\
\hline Actinium-228 & $3 / 3$ & 0.28 & 1.88 & Z2-EU24M-302 & 0.98 & & NA & & NA & $1.20 \mathrm{E}+04$ & $0 / 3$ & & NA \\
\hline Alpha activity & $2 / 2$ & 4.49 & 4.7 & Z2-EU24B-305 & 4.6 & & NA & & NA & & NA & & NA \\
\hline Americium 241 & $1 / 2$ & $0.0386 \mathrm{~J}$ & $0.0386 \mathrm{~J}$ & AU12 & 0.04 & & NA & & NA & $5.70 \mathrm{E}+01$ & $0 / 2$ & & NA \\
\hline Beta activity & $2 / 2$ & 4.02 & 4.84 & Z2-EU24B-305 & 4.43 & & NA & & NA & & NA & & NA \\
\hline Bismuth-214 & $2 / 2$ & 0.46 & 1.16 & Z2-EU24M-302 & 0.81 & & NA & & NA & $1.30 \mathrm{E}+05$ & $0 / 2$ & & NA \\
\hline Cesium-134 & $0 / 1$ & ND & ND & & ND & & NA & & NA & $2.60 \mathrm{E}+00$ & $0 / 1$ & & NA \\
\hline Cesium-137 & $2 / 5$ & 0.0879 & 0.107 & AU12 & 0.1 & 20 & $0 / 5$ & 2 & $0 / 5$ & $1.10 \mathrm{E}+00$ & $0 / 5$ & & NA \\
\hline Cobalt-57 & $1 / 1$ & 0.001 & 0.001 & RAD27 & 0 & & NA & & NA & $1.40 \mathrm{E}+02$ & $0 / 1$ & & NA \\
\hline Cobalt-60 & $0 / 5$ & ND & ND & & ND & & NA & & NA & 6.00E-01 & $0 / 5$ & & NA \\
\hline Lead-212 & $2 / 2$ & 0.279 & 1.93 & Z2-EU24M-302 & 1.1 & & NA & & NA & $6.10 \mathrm{E}+04$ & $0 / 2$ & & NA \\
\hline Lead-214 & $3 / 3$ & 0.383 & 1.48 & Z2-EU24M-302 & 0.8 & & NA & & NA & $7.50 \mathrm{E}+05$ & $0 / 3$ & & NA \\
\hline Neptunium-237 & $1 / 5$ & 0.011 & 0.011 & RAD27 & 0.01 & 50 & $0 / 5$ & 5 & $0 / 5$ & $2.70 \mathrm{E}+00$ & $0 / 5$ & & NA \\
\hline Plutonium 238 & $0 / 3$ & ND & ND & & ND & & NA & & NA & $1.70 \mathrm{E}+02$ & $0 / 3$ & & NA \\
\hline Plutonium-239 & $1 / 3$ & 0.052 & 0.052 & RAD27 & 0.05 & & NA & & NA & $1.50 \mathrm{E}+02$ & $0 / 3$ & & NA \\
\hline Potassium-40 & $3 / 3$ & 5.99 & 25.4 & Z2-EU24M-302 & 14.56 & & NA & & NA & $2.70 \mathrm{E}+00$ & $3 / 3$ & 32.12 & $0 / 3$ \\
\hline Protactinium $234 \mathrm{~m}$ & $1 / 2$ & 1.84 & 1.84 & AU12 & 1.84 & & NA & & NA & $2.50 \mathrm{E}+08$ & $0 / 2$ & & NA \\
\hline $\mathrm{Ra} / \mathrm{Th}$ decay series & $5 / 5$ & 0 & 0.47 & Z2-EU24M-302 & 0.12 & 15 & $0 / 5$ & 5 & $0 / 5$ & & NA & & NA \\
\hline Radium-226 & $2 / 3$ & 0.334 & $1.46 \mathrm{~J}$ & Z2-EU24M-302 & 0.9 & 15 & $\mathrm{NA}^{a}$ & 5 & NA1 & $2.60 \mathrm{E}-01$ & $2 / 3$ & 1.25 & $1 / 3$ \\
\hline
\end{tabular}




\begin{tabular}{|c|c|c|c|c|c|c|c|c|c|c|c|c|c|}
\hline $\begin{array}{r}\text { Analyte } \\
\end{array}$ & $\begin{array}{r}\text { Frequency } \\
\text { of detect }\end{array}$ & $\begin{array}{c}\text { Minimum } \\
\text { detect }\end{array}$ & $\begin{array}{c}\text { Maximum } \\
\text { detect }\end{array}$ & $\begin{array}{c}\text { Location(s) of } \\
\text { maximum } \\
\text { detected result }\end{array}$ & $\begin{array}{c}\text { Average } \\
\text { detected } \\
\text { result }\end{array}$ & $\begin{array}{l}\text { Max } \\
\text { RL }\end{array}$ & $\begin{array}{c}\text { Frequency } \\
\text { of detects } \\
\text { exceeding } \\
\text { Max RL } \\
\end{array}$ & $\begin{array}{l}\text { Avg } \\
\text { RL }\end{array}$ & $\begin{array}{c}\text { Frequency } \\
\text { of detects } \\
\text { exceeding } \\
\text { Avg RL } \\
\end{array}$ & $\begin{array}{c}\text { PRG } \\
\text { limit } \\
\left(10^{-5} \text { or } 1\right) \\
\end{array}$ & $\begin{array}{c}\text { Frequency } \\
\text { of detects } \\
\text { exceeding } \\
\text { PRG limit } \\
\end{array}$ & $\begin{array}{c}\text { Background } \\
\text { concentration }\end{array}$ & $\begin{array}{c}\text { Frequency } \\
\text { of detects } \\
\text { exceeding } \\
\text { background }\end{array}$ \\
\hline Strontium-90 & $0 / 2$ & ND & ND & & ND & & NA & & NA & $1.10 \mathrm{E}+02$ & $0 / 2$ & & NA \\
\hline Technetium-99 & $1 / 5$ & 5.11 & 5.11 & RAD27 & 5.11 & & NA & & NA & $8.90 \mathrm{E}+03$ & $0 / 5$ & & $\mathrm{NA}$ \\
\hline Thallium 208 & $2 / 2$ & 0.049 & 0.516 & Z2-EU24M-302 & 0.28 & & NA & & NA & $3.70 \mathrm{E}+05$ & $0 / 2$ & & NA \\
\hline Thorium-228 & $5 / 5$ & 0.92 & 1.34 & Z2-EU24M-302 & 1.12 & & NA & & NA & $1.70 \mathrm{E}-01$ & $5 / 5^{b}$ & 1.86 & $0 / 5$ \\
\hline Thorium-230 & $5 / 5$ & $1.09 \mathrm{~J}$ & 1.67 & Z2-EU24M -302 & 1.3 & 15 & $\mathrm{NA}^{a}$ & 5 & $\mathrm{NA}^{a}$ & $2.10 \mathrm{E}+02$ & $0 / 5$ & 1.2 & $2 / 5$ \\
\hline Thorium-232 & $5 / 5$ & 0.91 & 1.56 & Z2-EU24M-302 & 1.16 & 15 & $\mathrm{NA}^{a}$ & 5 & $\mathrm{NA}^{a}$ & $1.70 \mathrm{E}-01$ & $5 / 5^{b}$ & 1.95 & $0 / 5$ \\
\hline Thorium-234 & $3 / 5$ & 0.684 & 0.984 & AU12 & 0.87 & & NA & & NA & $3.30 \mathrm{E}+04$ & $0 / 5$ & & NA \\
\hline Total Activity & $0 / 2$ & ND & ND & & ND & & NA & & NA & & NA & & NA \\
\hline Uranium-234 & $5 / 5$ & 1.23 & 7.89 & RAD27 & 2.69 & 7,000 & $0 / 5$ & 700 & $0 / 5$ & $3.30 \mathrm{E}+02$ & $0 / 5$ & & NA \\
\hline Uranium-235 & $3 / 5$ & 0.0943 & 0.79 & RAD27 & 0.35 & 80 & $0 / 5$ & 8 & $0 / 5$ & $3.90 \mathrm{E}+00$ & $0 / 5$ & & NA \\
\hline Uranium-238 & $5 / 5$ & 0.722 & 4.62 & RAD27 & 1.9 & 500 & $0 / 5$ & 50 & $0 / 5$ & $1.80 \mathrm{E}+01$ & $0 / 5$ & 1.47 & $2 / 5$ \\
\hline \multicolumn{14}{|l|}{ Other organics $(u g / k g)$} \\
\hline DROs & $1 / 3$ & 7800 & 7800 & Z2-EU24M-302 & 7800 & & NA & & NA & & NA & & NA \\
\hline GROs & $0 / 3$ & ND & $\mathrm{ND}$ & & $\mathrm{ND}$ & & NA & & NA & & NA & & NA \\
\hline \multicolumn{14}{|c|}{ Organics, pesticides, and PCBs $(\mathrm{ug} / \mathrm{kg})$} \\
\hline PCB-1016 & $0 / 6$ & $\mathrm{ND}$ & ND & & $\mathrm{ND}$ & 100,000 & $0 / 6$ & 10,000 & $0 / 6$ & $3.70 \mathrm{E}+04$ & $0 / 6$ & & NA \\
\hline PCB-1221 & $0 / 6$ & ND & ND & & ND & 100,000 & $0 / 6$ & 10,000 & $0 / 6$ & $7.40 \mathrm{E}+03$ & $0 / 6$ & & NA \\
\hline PCB-1232 & $0 / 6$ & ND & ND & & ND & 100,000 & $0 / 6$ & 10,000 & $0 / 6$ & $7.40 \mathrm{E}+03$ & $0 / 6$ & & NA \\
\hline PCB-1242 & $0 / 6$ & ND & ND & & ND & 100,000 & $0 / 6$ & 10,000 & $0 / 6$ & $7.40 \mathrm{E}+03$ & $0 / 6$ & & NA \\
\hline PCB-1248 & $0 / 6$ & ND & $\mathrm{ND}$ & & $\mathrm{ND}$ & 100,000 & $0 / 6$ & 10,000 & $0 / 6$ & $7.40 \mathrm{E}+03$ & $0 / 6$ & & NA \\
\hline PCB-1254 & $2 / 6$ & 89 & 210 & Z2-EU24B-305 & 149.5 & 100,000 & $0 / 6$ & 10,000 & $0 / 6$ & $7.40 \mathrm{E}+03$ & $0 / 6$ & & NA \\
\hline PCB-1260 & $0 / 6$ & ND & ND & & ND & 100,000 & $0 / 6$ & 10,000 & $0 / 6$ & $7.40 \mathrm{E}+03$ & $0 / 6$ & & NA \\
\hline Polychlorinated biphenyl & $2 / 6$ & 89 & 210 & Z2-EU24B-305 & 149.5 & 100,000 & $0 / 6$ & 10,000 & $0 / 6$ & $7.40 \mathrm{E}+03$ & $0 / 6$ & & $\mathrm{NA}$ \\
\hline \multicolumn{14}{|l|}{ Semivolatile organics (ug/kg) } \\
\hline $1,2,4$ Trichlorobenzene & $0 / 8$ & ND & $\mathrm{ND}$ & & ND & & NA & & NA & $2.20 \mathrm{E}+05$ & $0 / 8$ & & NA \\
\hline 1,2-Dichlorobenzene & $0 / 8$ & ND & ND & & ND & & NA & & NA & $6.00 \mathrm{E}+05$ & $0 / 8$ & & NA \\
\hline 1,3-Dichlorobenzene & $0 / 8$ & $\mathrm{ND}$ & $\mathrm{ND}$ & & $\mathrm{ND}$ & & NA & & $\mathrm{NA}$ & $6.00 \mathrm{E}+05$ & $0 / 8$ & & $\mathrm{NA}$ \\
\hline 1,4-Dichlorobenzene & $0 / 8$ & ND & ND & & ND & & NA & & NA & $7.90 \mathrm{E}+04$ & $0 / 8$ & & NA \\
\hline 2,3,4,6-Tetrachlorophenol & $0 / 6$ & $\mathrm{ND}$ & $\mathrm{ND}$ & & $\mathrm{ND}$ & & NA & & $\mathrm{NA}$ & $1.80 \mathrm{E}+07$ & $0 / 6$ & & $\mathrm{NA}$ \\
\hline 2,4,5-Trichlorophenol & $0 / 6$ & $\mathrm{ND}$ & $\mathrm{ND}$ & & ND & & NA & & NA & $6.20 \mathrm{E}+07$ & $0 / 6$ & & NA \\
\hline 2,4,6-Trichlorophenol & $0 / 6$ & ND & ND & & $\mathrm{ND}$ & & NA & & NA & $6.20 \mathrm{E}+04$ & $0 / 6$ & & NA \\
\hline 2,4-Dichlorophenol & $0 / 6$ & ND & ND & & ND & & NA & & NA & $1.80 \mathrm{E}+06$ & $0 / 6$ & & NA \\
\hline 2,4-Dimethylphenol & $0 / 6$ & ND & ND & & ND & & NA & & NA & $1.20 \mathrm{E}+07$ & $0 / 6$ & & NA \\
\hline 2,4-Dinitrophenol & $0 / 6$ & ND & ND & & ND & & NA & & NA & $1.20 \mathrm{E}+06$ & $0 / 6$ & & NA \\
\hline 2,4-Dinitrotoluene & $0 / 6$ & ND & $\mathrm{ND}$ & & ND & & NA & & NA & $2.50 \mathrm{E}+04$ & $0 / 6$ & & NA \\
\hline 2,6-Dinitrotoluene & $0 / 6$ & ND & $\mathrm{ND}$ & & $\mathrm{ND}$ & & NA & & NA & $2.50 \mathrm{E}+04$ & $0 / 6$ & & $\mathrm{NA}$ \\
\hline 2-Chloronaphthalene & $0 / 6$ & ND & $\mathrm{ND}$ & & ND & & NA & & NA & $2.30 \mathrm{E}+07$ & $0 / 6$ & & NA \\
\hline 2-Chlorophenol & $0 / 6$ & ND & $\mathrm{ND}$ & & ND & & NA & & NA & $2.40 \mathrm{E}+05$ & $0 / 6$ & & NA \\
\hline 2-Methyl-4,6-dinitrophenol & $0 / 6$ & $\mathrm{ND}$ & $\mathrm{ND}$ & & $\mathrm{ND}$ & & NA & & $\mathrm{NA}$ & $6.20 \mathrm{E}+04$ & $0 / 6$ & & $\mathrm{NA}$ \\
\hline 2-Methylnaphthalene & $0 / 6$ & ND & ND & & ND & & NA & & NA & $1.90 \mathrm{E}+05$ & $0 / 6$ & & NA \\
\hline 2-Methylphenol & $0 / 6$ & ND & $\mathrm{ND}$ & & ND & & NA & & NA & $3.10 \mathrm{E}+07$ & $0 / 6$ & & NA \\
\hline 2-Nitrobenzenamine & $0 / 6$ & ND & ND & & $\mathrm{ND}$ & & NA & & NA & $1.80 \mathrm{E}+06$ & $0 / 6$ & & NA \\
\hline 2-Nitrophenol & $0 / 6$ & ND & $\mathrm{ND}$ & & ND & & NA & & NA & & NA & & NA \\
\hline 3,3'-Dichlorobenzidine & $0 / 5$ & ND & ND & & ND & & NA & & NA & $3.80 \mathrm{E}+04$ & $0 / 5$ & & NA \\
\hline 3-Methylphenol & $0 / 6$ & ND & ND & & ND & & NA & & NA & $3.10 \mathrm{E}+07$ & $0 / 6$ & & NA \\
\hline 3-Nitrobenzenamine & $0 / 6$ & ND & ND & & ND & & NA & & NA & $1.80 \mathrm{E}+05$ & $0 / 6$ & & NA \\
\hline 4-Bromophenyl phenyl ether & $0 / 6$ & ND & ND & & ND & & NA & & NA & & NA & & NA \\
\hline 4-Chloro-3-methylphenol & $0 / 6$ & ND & $\mathrm{ND}$ & & $\mathrm{ND}$ & & $\mathrm{NA}$ & & NA & & $\mathrm{NA}$ & & $\mathrm{NA}$ \\
\hline 4-Chlorobenzenamine & $0 / 6$ & ND & ND & & ND & & NA & & NA & $2.50 \mathrm{E}+06$ & $0 / 6$ & & NA \\
\hline 4-Chlorophenyl phenyl ether & $0 / 6$ & $\mathrm{ND}$ & $\mathrm{ND}$ & & ND & & NA & & NA & & NA & & NA \\
\hline 4-Nitrobenzenamine & $0 / 6$ & $\mathrm{ND}$ & $\mathrm{ND}$ & & $\mathrm{ND}$ & & NA & & NA & $8.20 \mathrm{E}+05$ & $0 / 6$ & & NA \\
\hline
\end{tabular}


Table E.3. (continued)

\begin{tabular}{|c|c|c|c|c|c|c|c|c|c|c|c|c|c|}
\hline $\begin{array}{r}\text { Analyte } \\
\end{array}$ & $\begin{array}{c}\text { Frequency } \\
\text { of detect }\end{array}$ & $\begin{array}{c}\text { Minimum } \\
\text { detect }\end{array}$ & $\begin{array}{c}\text { Maximum } \\
\text { detect }\end{array}$ & $\begin{array}{c}\text { Location(s) of } \\
\text { maximum } \\
\text { detected result }\end{array}$ & $\begin{array}{c}\text { Average } \\
\text { detected } \\
\text { result }\end{array}$ & $\begin{array}{l}\text { Max } \\
\text { RL }\end{array}$ & $\begin{array}{c}\text { Frequency } \\
\text { of detects } \\
\text { exceeding } \\
\text { Max RL } \\
\end{array}$ & $\begin{array}{l}\text { Avg } \\
\text { RL }\end{array}$ & $\begin{array}{c}\text { Frequency } \\
\text { of detects } \\
\text { exceeding } \\
\text { Avg RL } \\
\end{array}$ & $\begin{array}{c}\text { PRG } \\
\text { limit } \\
\left(10^{-5} \text { or } 1\right) \\
\end{array}$ & 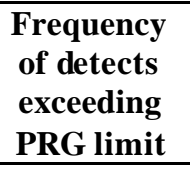 & $\begin{array}{c}\text { Background } \\
\text { concentration }\end{array}$ & $\begin{array}{c}\text { Frequency } \\
\text { of detects } \\
\text { exceeding } \\
\text { background }\end{array}$ \\
\hline 4-Nitrophenol & $0 / 6$ & ND & ND & & ND & & NA & & $\mathrm{NA}$ & & NA & & NA \\
\hline Acenaphthene & $3 / 6$ & $61 \mathrm{~J}$ & $310 \mathrm{~J}$ & Z2-EU24B-304 & 170.33 & & NA & & NA & $2.90 \mathrm{E}+07$ & $0 / 6$ & & NA \\
\hline Acenaphthylene & $0 / 6$ & ND & ND & & ND & & NA & & $\mathrm{NA}$ & $2.90 \mathrm{E}+07$ & $0 / 6$ & & NA \\
\hline Aniline & $0 / 6$ & ND & ND & & ND & & NA & & NA & $3.00 \mathrm{E}+06$ & $0 / 6$ & & NA \\
\hline Anthracene & $2 / 6$ & $96 \mathrm{~J}$ & 860 & Z2-EU24B-304 & 478 & & NA & & NA & $1.00 \mathrm{E}+08$ & $0 / 6$ & & NA \\
\hline Benz(a)anthracene & $5 / 6$ & $40 \mathrm{~J}$ & 1,500 & Z2-EU24B-304 & 418.6 & & NA & & NA & $2.10 \mathrm{E}+04$ & $0 / 6$ & & NA \\
\hline Benzenemethanol & $0 / 6$ & ND & ND & & ND & & NA & & NA & $1.00 \mathrm{E}+08$ & $0 / 6$ & & NA \\
\hline Benzo(a)pyrene & $5 / 6$ & $66 \mathrm{~J}$ & $1,100 \mathrm{~J}$ & Z2-EU24B-304 & 347.4 & & NA & & $\mathrm{NA}$ & $2.10 \mathrm{E}+03$ & $0 / 6$ & & $\mathrm{NA}$ \\
\hline Benzo(b)fluoranthene & $5 / 6$ & $72 \mathrm{~J}$ & $1,300 \mathrm{~J}$ & Z2-EU24B-304 & 432 & & NA & & NA & $2.10 \mathrm{E}+04$ & $0 / 6$ & & NA \\
\hline Benzo(ghi)perylene & $5 / 6$ & $99 \mathrm{~J}$ & $550 \mathrm{~J}$ & Z2-EU24B-304 & 259.8 & & NA & & NA & $2.90 \mathrm{E}+07$ & $0 / 6$ & & NA \\
\hline Benzo(k)fluoranthene & $5 / 6$ & $37 \mathrm{~J}$ & $630 \mathrm{~J}$ & Z2-EU24B-304 & 193.8 & & NA & & NA & $2.10 \mathrm{E}+05$ & $0 / 6$ & & NA \\
\hline Benzoic acid & $0 / 6$ & ND & $\mathrm{ND}$ & & ND & & NA & & NA & $1.00 \mathrm{E}+08$ & $0 / 6$ & & NA \\
\hline Bis(2-chloroethoxy)methane & $0 / 6$ & ND & ND & & ND & & NA & & $\mathrm{NA}$ & & NA & & NA \\
\hline Bis(2-chloroethyl) ether & $0 / 6$ & ND & ND & & ND & & NA & & NA & $5.80 \mathrm{E}+03$ & $0 / 6$ & & NA \\
\hline Bis(2-chloroisopropyl) ether & $0 / 6$ & ND & ND & & ND & & NA & & $\mathrm{NA}$ & $7.40 \mathrm{E}+04$ & $0 / 6$ & & NA \\
\hline Bis(2-ethylhexyl)phthalate & $1 / 6$ & $680 \mathrm{~J}$ & $680 \mathrm{~J}$ & Z2-EU24B-305 & 680 & & NA & & NA & $1.20 \mathrm{E}+06$ & $0 / 6$ & & NA \\
\hline Butyl benzyl phthalate & $0 / 5$ & ND & $\mathrm{ND}$ & & ND & & NA & & NA & $1.00 \mathrm{E}+08$ & $0 / 5$ & & NA \\
\hline Carbazole & $1 / 6$ & $65 \mathrm{~J}$ & $65 \mathrm{~J}$ & Z2-EU24B-304 & 65 & & NA & & NA & $8.60 \mathrm{E}+05$ & $0 / 6$ & & NA \\
\hline Chrysene & $5 / 6$ & $35 \mathrm{~J}$ & 1100 & Z2-EU24B-304 & 338 & & NA & & NA & $2.10 \mathrm{E}+06$ & $0 / 6$ & & NA \\
\hline Di-n-butyl phthalate & $0 / 6$ & $\mathrm{ND}$ & $\mathrm{ND}$ & & $\mathrm{ND}$ & & NA & & $\mathrm{NA}$ & $6.20 \mathrm{E}+07$ & $0 / 6$ & & $\mathrm{NA}$ \\
\hline Di-n-octylphthalate & $0 / 5$ & ND & ND & & ND & & NA & & $\mathrm{NA}$ & $2.50 \mathrm{E}+07$ & $0 / 5$ & & NA \\
\hline Dibenz $(a, h)$ anthracene & $1 / 5$ & $190 \mathrm{~J}$ & $190 \mathrm{~J}$ & Z2-EU24B-304 & 190 & & NA & & $\mathrm{NA}$ & $2.10 \mathrm{E}+03$ & $0 / 5$ & & NA \\
\hline Dibenzofuran & $2 / 6$ & $130 \mathrm{~J}$ & $220 \mathrm{~J}$ & Z2-EU24B-304 & 175 & & NA & & NA & $1.60 \mathrm{E}+06$ & $0 / 6$ & & $\mathrm{NA}$ \\
\hline Diethyl phthalate & $0 / 6$ & ND & ND & & ND & & NA & & NA & $1.00 \mathrm{E}+08$ & $0 / 6$ & & NA \\
\hline Dimethyl phthalate & $0 / 6$ & $\mathrm{ND}$ & $\mathrm{ND}$ & & ND & & NA & & NA & $1.00 \mathrm{E}+08$ & $0 / 6$ & & NA \\
\hline Diphenyldiazene & $0 / 6$ & ND & $\mathrm{ND}$ & & ND & & NA & & NA & $1.60 \mathrm{E}+05$ & $0 / 6$ & & NA \\
\hline Fluoranthene & $5 / 6$ & $79 \mathrm{~J}$ & 3800 & Z2-EU24B-304 & 999.8 & & NA & & NA & $2.20 \mathrm{E}+07$ & $0 / 6$ & & NA \\
\hline Fluorene & $3 / 6$ & $50 \mathrm{~J}$ & $340 \mathrm{~J}$ & Z2-EU24B-304 & 166.67 & & NA & & NA & $2.60 \mathrm{E}+07$ & $0 / 6$ & & NA \\
\hline Hexachlorobenzene & $0 / 6$ & ND & $\mathrm{ND}$ & & ND & & NA & & NA & $1.10 \mathrm{E}+04$ & $0 / 6$ & & NA \\
\hline Hexachlorobutadiene & $0 / 8$ & $\mathrm{ND}$ & $\mathrm{ND}$ & & ND & & NA & & NA & $1.80 \mathrm{E}+05$ & $0 / 8$ & & NA \\
\hline Hexachlorocyclopentadiene & $0 / 6$ & ND & ND & & ND & & NA & & $\mathrm{NA}$ & $3.70 \mathrm{E}+06$ & $0 / 6$ & & NA \\
\hline Hexachloroethane & $0 / 6$ & ND & $\mathrm{ND}$ & & ND & & $\mathrm{NA}$ & & $\mathrm{NA}$ & $6.20 \mathrm{E}+05$ & $0 / 6$ & & NA \\
\hline Indeno(1,2,3-cd)pyrene & $5 / 6$ & $37 \mathrm{~J}$ & 570 & Z2-EU24B-304 & 211.6 & & NA & & NA & $2.10 \mathrm{E}+04$ & $0 / 6$ & & NA \\
\hline Isophorone & $0 / 6$ & ND & ND & & $\mathrm{ND}$ & & $\mathrm{NA}$ & & NA & $5.10 \mathrm{E}+06$ & $0 / 6$ & & NA \\
\hline N-Nitroso-di-n-propylamine & $0 / 6$ & ND & ND & & ND & & NA & & NA & $2.50 \mathrm{E}+03$ & $0 / 6$ & & NA \\
\hline N-Nitrosodimethylamine & $0 / 6$ & ND & ND & & ND & & NA & & NA & $3.40 \mathrm{E}+02$ & $0 / 6$ & & NA \\
\hline N-Nitrosodiphenylamine & $0 / 6$ & ND & $\mathrm{ND}$ & & ND & & NA & & NA & $3.50 \mathrm{E}+06$ & $0 / 6$ & & NA \\
\hline Naphthalene & $1 / 8$ & 9.8 & 9.8 & Z2-EU24M-302 & 9.8 & & NA & & NA & $1.90 \mathrm{E}+05$ & $0 / 8$ & & NA \\
\hline Nitrobenzene & $0 / 6$ & ND & ND & & ND & & NA & & NA & $1.00 \mathrm{E}+05$ & $0 / 6$ & & NA \\
\hline Pentachlorophenol & $0 / 6$ & ND & ND & & ND & & NA & & NA & $9.00 \mathrm{E}+04$ & $0 / 6$ & & NA \\
\hline Phenanthrene & $4 / 6$ & $210 \mathrm{~J}$ & 2900 & Z2-EU24B-304 & 960 & & NA & & NA & $2.90 \mathrm{E}+07$ & $0 / 6$ & & NA \\
\hline Phenol & $0 / 6$ & ND & ND & & ND & & NA & & NA & $1.00 \mathrm{E}+08$ & $0 / 6$ & & NA \\
\hline Pyrene & $5 / 6$ & $70 \mathrm{~J}$ & $2800 \mathrm{~J}$ & Z2-EU24B-304 & 1058 & & NA & & NA & $2.90 \mathrm{E}+07$ & $0 / 6$ & & NA \\
\hline Pyridine & $0 / 6$ & $\mathrm{ND}$ & ND & & ND & & NA & & $\mathrm{NA}$ & $6.20 \mathrm{E}+05$ & $0 / 6$ & & NA \\
\hline \multicolumn{14}{|l|}{ Volatile Organics $(u g / k g)$} \\
\hline (1,1-Dimethylethyl)benzene & $0 / 3$ & ND & ND & & ND & & NA & & NA & $3.90 \mathrm{E}+05$ & $0 / 3$ & & NA \\
\hline (1-Methylpropyl)benzene & $0 / 3$ & ND & ND & & ND & & NA & & NA & $2.20 \mathrm{E}+05$ & $0 / 3$ & & NA \\
\hline 1,1,1,2-Tetrachloroethane & $0 / 3$ & ND & ND & & ND & & NA & & NA & $7.30 \mathrm{E}+04$ & $0 / 3$ & & NA \\
\hline 1,1,1-Trichloroethane & $0 / 5$ & ND & ND & & ND & & NA & & NA & $1.20 \mathrm{E}+06$ & $0 / 5$ & & NA \\
\hline 1,1,2,2-Tetrachloroethane & $0 / 5$ & ND & ND & & ND & & NA & & NA & $9.30 \mathrm{E}+03$ & $0 / 5$ & & NA \\
\hline 1,1,2-Trichloro-1,2,2-trifluoroethane & $0 / 5$ & ND & ND & & ND & & NA & & NA & $5.60 \mathrm{E}+06$ & $0 / 5$ & & NA \\
\hline 1,1,2-Trichloroethane & $0 / 5$ & ND & ND & & $\mathrm{ND}$ & & NA & & NA & $1.60 \mathrm{E}+04$ & $0 / 5$ & & NA \\
\hline
\end{tabular}


Table E.3. (continued)

\begin{tabular}{|c|c|c|c|c|c|c|c|c|c|c|c|c|c|}
\hline $\begin{array}{r}\text { Analyte } \\
\end{array}$ & $\begin{array}{r}\text { Frequency } \\
\text { of detect }\end{array}$ & $\begin{array}{c}\text { Minimum } \\
\text { detect }\end{array}$ & $\begin{array}{c}\text { Maximum } \\
\text { detect }\end{array}$ & $\begin{array}{c}\text { Location(s) of } \\
\text { maximum } \\
\text { detected result }\end{array}$ & $\begin{array}{c}\text { Average } \\
\text { detected } \\
\text { result }\end{array}$ & $\begin{array}{c}\text { Max } \\
\text { RL } \\
\end{array}$ & $\begin{array}{c}\text { Frequency } \\
\text { of detects } \\
\text { exceeding } \\
\text { Max RL } \\
\end{array}$ & $\begin{array}{l}\text { Avg } \\
\text { RL }\end{array}$ & $\begin{array}{c}\text { Frequency } \\
\text { of detects } \\
\text { exceeding } \\
\text { Avg RL } \\
\end{array}$ & $\begin{array}{c}\text { PRG } \\
\text { limit } \\
\left(10^{-5} \text { or } 1\right) \\
\end{array}$ & 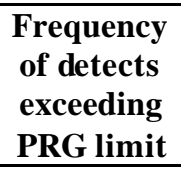 & $\begin{array}{c}\text { Background } \\
\text { concentration }\end{array}$ & $\begin{array}{c}\text { Frequency } \\
\text { of detects } \\
\text { exceeding } \\
\text { background }\end{array}$ \\
\hline 1,1-Dichloroethane & $0 / 5$ & ND & $\mathrm{ND}$ & & $\mathrm{ND}$ & & NA & & NA & $1.70 \mathrm{E}+06$ & $0 / 5$ & & NA \\
\hline 1,1-Dichloroethene & $0 / 5$ & $\mathrm{ND}$ & $\mathrm{ND}$ & & $\mathrm{ND}$ & & $\mathrm{NA}$ & & $\mathrm{NA}$ & $4.10 \mathrm{E}+05$ & $0 / 5$ & & $\mathrm{NA}$ \\
\hline 1,1-Dichloropropene & $0 / 3$ & ND & ND & & ND & & NA & & NA & & NA & & NA \\
\hline 1,2,3-Trichlorobenzene & $0 / 3$ & $\mathrm{ND}$ & ND & & ND & & NA & & NA & & NA & & $\mathrm{NA}$ \\
\hline 1,2,3-Trichloropropane & $0 / 3$ & ND & ND & & $\mathrm{ND}$ & & NA & & NA & $7.60 \mathrm{E}+02$ & $0 / 3$ & & NA \\
\hline 1,2,4Trimethylbenzene & $0 / 3$ & ND & $\mathrm{ND}$ & & $\mathrm{ND}$ & & NA & & NA & $1.70 \mathrm{E}+05$ & $0 / 3$ & & NA \\
\hline 1,2-Dibromo-3-chloropropane & $0 / 3$ & ND & $\mathrm{ND}$ & & ND & & NA & & NA & $1.10 \mathrm{E}+04$ & $0 / 3$ & & NA \\
\hline 1,2-Dibromoethane & $0 / 3$ & $\mathrm{ND}$ & $\mathrm{ND}$ & & ND & & NA & & NA & $6.30 \mathrm{E}+02$ & $0 / 3$ & & $\mathrm{NA}$ \\
\hline 1,2-Dichloroethane & $0 / 5$ & $\mathrm{ND}$ & ND & & $\mathrm{ND}$ & & NA & & NA & $6.00 \mathrm{E}+03$ & $0 / 5$ & & NA \\
\hline 1,2-Dichloroethene & $0 / 2$ & ND & ND & & ND & & NA & & $\mathrm{NA}$ & $1.50 \mathrm{E}+05$ & $0 / 2$ & & NA \\
\hline 1,2-Dichloropropane & $0 / 5$ & ND & ND & & $\mathrm{ND}$ & & NA & & NA & $7.40 \mathrm{E}+03$ & $0 / 5$ & & NA \\
\hline 1,2-Dimethylbenzene & $0 / 3$ & $\mathrm{ND}$ & ND & & ND & & NA & & NA & $4.20 \mathrm{E}+05$ & $0 / 3$ & & NA \\
\hline 1,3,5-Trimethylbenzene & $0 / 3$ & ND & ND & & ND & & NA & & NA & $7.00 \mathrm{E}+04$ & $0 / 3$ & & NA \\
\hline 1,3-Dichloropropane & $0 / 3$ & ND & ND & & ND & & NA & & NA & $3.60 \mathrm{E}+05$ & $0 / 3$ & & NA \\
\hline 1-Chloro-4-methylbenzene & $0 / 3$ & ND & ND & & ND & & NA & & NA & & NA & & NA \\
\hline 1-Methyl-4-(1-methylethyl)benzene & $0 / 3$ & ND & ND & & ND & & NA & & NA & & NA & & NA \\
\hline 1-chlorohexane & $0 / 3$ & ND & $\mathrm{ND}$ & & ND & & NA & & NA & & NA & & NA \\
\hline 2,2-Dichloropropane & $0 / 3$ & $\mathrm{ND}$ & $\mathrm{ND}$ & & $\mathrm{ND}$ & & NA & & NA & & NA & & NA \\
\hline 2-Butanone & $0 / 5$ & ND & $\mathrm{ND}$ & & $\mathrm{ND}$ & & NA & & NA & $1.00 \mathrm{E}+08$ & $0 / 5$ & & NA \\
\hline 2-Hexanone & $0 / 5$ & $\mathrm{ND}$ & ND & & ND & & NA & & NA & & NA & & NA \\
\hline 2-Methoxy-2-methylpropane & $0 / 3$ & ND & ND & & ND & & NA & & NA & $3.60 \mathrm{E}+05$ & $0 / 3$ & & NA \\
\hline 4-Methyl-2-pentanone & $0 / 5$ & ND & ND & & ND & & NA & & NA & $4.70 \mathrm{E}+07$ & $0 / 5$ & & NA \\
\hline 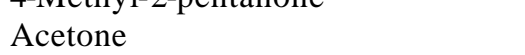 & $3 / 5$ & $13 \mathrm{~J}$ & $870 \mathrm{~J}$ & 420 & 434.33 & & NA & & NA & $5.40 \mathrm{E}+07$ & $0 / 5$ & & NA \\
\hline Benzene & $0 / 5$ & ND & ND & & ND & & NA & & NA & $1.40 \mathrm{E}+04$ & $0 / 5$ & & NA \\
\hline Bromobenzene & $0 / 3$ & ND & ND & & ND & & NA & & NA & $9.20 \mathrm{E}+04$ & $0 / 3$ & & NA \\
\hline Bromochloromethane & $0 / 3$ & ND & ND & & ND & & NA & & NA & & NA & & NA \\
\hline Bromodichloromethane & $0 / 5$ & ND & ND & & ND & & NA & & $\mathrm{NA}$ & $1.80 \mathrm{E}+04$ & $0 / 5$ & & NA \\
\hline $\begin{array}{l}\text { Bromoform } \\
\text { B. }\end{array}$ & $0 / 5$ & $\mathrm{ND}$ & $\mathrm{ND}$ & & $\mathrm{ND}$ & & $\mathrm{NA}$ & & NA & $2.20 \mathrm{E}+06$ & $0 / 5$ & & NA \\
\hline Bromomethane & $0 / 5$ & ND & $\mathrm{ND}$ & & $\mathrm{ND}$ & & NA & & NA & $1.30 \mathrm{E}+04$ & $0 / 5$ & & NA \\
\hline Butylbenzene & $0 / 3$ & ND & ND & & $\mathrm{ND}$ & & NA & & NA & $2.40 \mathrm{E}+05$ & $0 / 3$ & & NA \\
\hline Carbon disulfide & $0 / 5$ & $\mathrm{ND}$ & $\mathrm{ND}$ & & $\mathrm{ND}$ & & $\mathrm{NA}$ & & NA & $7.20 \mathrm{E}+05$ & $0 / 5$ & & NA \\
\hline Carbon tetrachloride & $0 / 5$ & ND & ND & & ND & & NA & & NA & $5.50 \mathrm{E}+03$ & $0 / 5$ & & NA \\
\hline Chlorobenzene & $0 / 5$ & ND & ND & & ND & & $\mathrm{NA}$ & & $\mathrm{NA}$ & $5.30 \mathrm{E}+05$ & $0 / 5$ & & NA \\
\hline Chloroethane & $0 / 5$ & ND & ND & & ND & & NA & & NA & $6.50 \mathrm{E}+04$ & $0 / 5$ & & NA \\
\hline Chloroform & $0 / 5$ & $\mathrm{ND}$ & ND & & ND & & NA & & NA & $4.70 \mathrm{E}+03$ & $0 / 5$ & & NA \\
\hline Chloromethane & $0 / 5$ & ND & $\mathrm{ND}$ & & $\mathrm{ND}$ & & NA & & NA & $1.60 \mathrm{E}+05$ & $0 / 5$ & & NA \\
\hline Cumene & $0 / 3$ & ND & ND & & ND & & NA & & NA & $5.20 \mathrm{E}+05$ & $0 / 3$ & & NA \\
\hline Dibromochloromethane & $0 / 5$ & $\mathrm{ND}$ & $\mathrm{ND}$ & & $\mathrm{ND}$ & & $\mathrm{NA}$ & & $\mathrm{NA}$ & $2.60 \mathrm{E}+04$ & $0 / 5$ & & $\mathrm{NA}$ \\
\hline Dibromomethane & $0 / 3$ & ND & ND & & ND & & NA & & NA & $2.30 \mathrm{E}+05$ & $0 / 3$ & & NA \\
\hline Dichlorodifluoromethane & $0 / 3$ & ND & ND & & ND & & NA & & NA & $3.10 \mathrm{E}+05$ & $0 / 3$ & & NA \\
\hline Ethylbenzene & $0 / 5$ & ND & ND & & ND & & $\mathrm{NA}$ & & NA & $4.00 \mathrm{E}+05$ & $0 / 5$ & & NA \\
\hline Iodomethane & $0 / 3$ & ND & ND & & $\mathrm{ND}$ & & NA & & NA & & NA & & NA \\
\hline M + P Xylene & $0 / 5$ & ND & ND & & ND & & NA & & NA & $4.20 \mathrm{E}+05$ & $0 / 5$ & & NA \\
\hline Methylene chloride & $0 / 5$ & ND & ND & & ND & & NA & & NA & $2.10 \mathrm{E}+05$ & $0 / 5$ & & NA \\
\hline Propylbenzene & $0 / 3$ & $\mathrm{ND}$ & $\mathrm{ND}$ & & ND & & NA & & NA & $2.40 \mathrm{E}+05$ & $0 / 3$ & & NA \\
\hline Styrene & $0 / 5$ & ND & ND & & ND & & NA & & NA & $1.70 \mathrm{E}+06$ & $0 / 5$ & & NA \\
\hline Tetrachloroethene & $0 / 5$ & ND & ND & & ND & & NA & & $\mathrm{NA}$ & $1.30 \mathrm{E}+04$ & $0 / 5$ & & NA \\
\hline Toluene & $2 / 5$ & $12 \mathrm{~J}$ & $47 \mathrm{~J}$ & 420 & 29.5 & & NA & & NA & $5.20 \mathrm{E}+05$ & $0 / 5$ & & NA \\
\hline Trichloroethene & $0 / 5$ & ND & $\mathrm{ND}$ & & ND & & NA & & NA & $1.10 \mathrm{E}+03$ & $0 / 5$ & & NA \\
\hline Trichlorofluoromethane & $0 / 3$ & ND & $\mathrm{ND}$ & & $\mathrm{ND}$ & & $\mathrm{NA}$ & & NA & $1.30 \mathrm{E}+06$ & $0 / 3$ & & $\mathrm{NA}$ \\
\hline Vinyl acetate & $0 / 3$ & ND & ND & & ND & & NA & & NA & $1.40 \mathrm{E}+06$ & $0 / 3$ & & NA \\
\hline Vinyl chloride & $0 / 5$ & ND & ND & & ND & & NA & & NA & $7.50 \mathrm{E}+03$ & $0 / 5$ & & NA \\
\hline
\end{tabular}


Table E.3. (continued)

\begin{tabular}{|c|c|c|c|c|c|c|c|c|c|c|c|c|c|}
\hline Analyte & $\begin{array}{c}\text { Frequency } \\
\text { of detect }\end{array}$ & $\begin{array}{c}\text { Minimum } \\
\text { detect }\end{array}$ & $\begin{array}{c}\text { Maximum } \\
\text { detect }\end{array}$ & $\begin{array}{c}\text { Location(s) of } \\
\text { maximum } \\
\text { detected result }\end{array}$ & $\begin{array}{c}\text { Average } \\
\text { detected } \\
\text { result }\end{array}$ & $\begin{array}{c}\text { Max } \\
\text { RL }\end{array}$ & $\begin{array}{c}\text { Frequency } \\
\text { of detects } \\
\text { exceeding } \\
\text { Max RL }\end{array}$ & $\begin{array}{l}\text { Avg } \\
\text { RL }\end{array}$ & $\begin{array}{l}\text { Frequency } \\
\text { of detects } \\
\text { exceeding } \\
\text { Avg RL } \\
\end{array}$ & $\begin{array}{c}\text { PRG } \\
\text { limit } \\
\left(10^{-5} \text { or } 1\right)\end{array}$ & $\begin{array}{c}\text { Frequency } \\
\text { of detects } \\
\text { exceeding } \\
\text { PRG limit }\end{array}$ & $\begin{array}{l}\text { Background } \\
\text { concentration }\end{array}$ & $\begin{array}{c}\text { Frequency } \\
\text { of detects } \\
\text { exceeding } \\
\text { background }\end{array}$ \\
\hline cis-1,2-Dichloroethene & $0 / 3$ & $\mathrm{ND}$ & $\mathrm{ND}$ & & ND & & NA & & NA & $1.50 \mathrm{E}+05$ & $0 / 3$ & & NA \\
\hline cis-1,3-Dichloropropene & $0 / 5$ & ND & $\mathrm{ND}$ & & ND & & NA & & NA & $1.80 \mathrm{E}+04$ & $0 / 5$ & & NA \\
\hline o-Chlorotoluene & $0 / 3$ & ND & ND & & ND & & NA & & NA & $5.60 \mathrm{E}+05$ & $0 / 3$ & & NA \\
\hline trans-1,2-Dichloroethene & $0 / 3$ & ND & ND & & ND & & NA & & NA & $2.30 \mathrm{E}+05$ & $0 / 3$ & & NA \\
\hline trans-13-Dichloropropene & $0 / 5$ & ND & ND & & ND & & $\mathrm{NA}$ & & $\mathrm{NA}$ & $180 \mathrm{E}+04$ & $0 / 5$ & & NA \\
\hline
\end{tabular}

Stations in summary include 420, AU12, RAD27, Z2-EU24B-300, Z2-EU24B-301, Z2-EU24B-303, Z2-EU24B-304, Z2-EU24B-305, and Z2-EU24M-302.

Definition of validation qualifiers: $\mathrm{J}=$ analyte positively identified and result is approximate concentration of analyte in sample, and $\mathrm{U}=$ analyte was not detected above reported sample quantitation limit

${ }^{a}$ Radionuclide is evaluated as part of Ra/Th decay series as discussed in the Zone 2 ROD.
${ }^{b}$ Evaluated as part of Th-232+D $=$ Th- $232+$ Ra-228+D + Th-228+D

$\mathrm{Avg}=$ average
$\mathrm{DRO}=$ diesel-ragec

$\mathrm{GRO}=$ gasoline-range organic $\quad \mathrm{PRG}=$ preliminary remediation goal 
Table E.4. EU Z2-24, depth below $10 \mathrm{ft}$

\begin{tabular}{|c|c|c|c|c|c|c|c|c|c|c|c|c|c|}
\hline Analyte & $\begin{array}{r}\text { Frequency } \\
\text { of detect }\end{array}$ & $\begin{array}{c}\text { Minimum } \\
\text { detect }\end{array}$ & $\begin{array}{c}\text { Maximum } \\
\text { detect }\end{array}$ & $\begin{array}{c}\text { Location(s) } \\
\text { of } \\
\text { maximum } \\
\text { detected } \\
\text { result }\end{array}$ & $\begin{array}{c}\text { Average } \\
\text { detected } \\
\text { result }\end{array}$ & $\begin{array}{c}\text { Maximum } \\
\text { RL }\end{array}$ & $\begin{array}{c}\text { Frequency } \\
\text { of detects } \\
\text { exceeding } \\
\text { Max RL }\end{array}$ & $\begin{array}{c}\text { Average } \\
\text { RL }\end{array}$ & $\begin{array}{c}\text { Frequency } \\
\text { of detects } \\
\text { exceeding } \\
\text { Avg RL }\end{array}$ & $\begin{array}{l}\text { PRG limit } \\
\left(10^{-5} \text { or } 1\right)\end{array}$ & $\begin{array}{l}\text { Frequency } \\
\text { of detects } \\
\text { exceeding } \\
\text { PRG limit }\end{array}$ & $\begin{array}{l}\text { Background } \\
\text { concentration }\end{array}$ & $\begin{array}{c}\text { Frequency } \\
\text { of detects } \\
\text { exceeding } \\
\text { background }\end{array}$ \\
\hline \multicolumn{14}{|l|}{ Other organics $(u g / k g)$} \\
\hline DROs & $0 / 1$ & $\mathrm{ND}$ & $\mathrm{ND}$ & & $\mathrm{ND}$ & & $\mathrm{NA}$ & & $\mathrm{NA}$ & & $\mathrm{NA}$ & & $\mathrm{NA}$ \\
\hline GROs & $0 / 1$ & ND & $\mathrm{ND}$ & & ND & & $\mathrm{NA}$ & & NA & & NA & & NA \\
\hline \multicolumn{14}{|l|}{ Semivolatile organics $(u g / k g)$} \\
\hline 1,2,4-Trichlorobenzene & $0 / 1$ & $\mathrm{ND}$ & $\mathrm{ND}$ & & $\mathrm{ND}$ & & $\mathrm{NA}$ & & $\mathrm{NA}$ & $2.20 \mathrm{E}+05$ & $0 / 1$ & & $\mathrm{NA}$ \\
\hline 1,2-Dichlorobenzene & $0 / 1$ & ND & ND & & ND & & NA & & NA & $6.00 \mathrm{E}+05$ & $0 / 1$ & & NA \\
\hline 1,3-Dichlorobenzene & $0 / 1$ & $\mathrm{ND}$ & $\mathrm{ND}$ & & $\mathrm{ND}$ & & $\mathrm{NA}$ & & $\mathrm{NA}$ & $6.00 \mathrm{E}+05$ & $0 / 1$ & & $\mathrm{NA}$ \\
\hline 1,4-Dichlorobenzene & $0 / 1$ & $\mathrm{ND}$ & ND & & ND & & NA & & NA & $7.90 \mathrm{E}+04$ & $0 / 1$ & & NA \\
\hline Hexachlorobutadiene & $0 / 1$ & $\mathrm{ND}$ & $\mathrm{ND}$ & & ND & & NA & & NA & $1.80 \mathrm{E}+05$ & $0 / 1$ & & NA \\
\hline Naphthalene & $0 / 1$ & $\mathrm{ND}$ & $\mathrm{ND}$ & & $\mathrm{ND}$ & & $\mathrm{NA}$ & & $\mathrm{NA}$ & $1.90 \mathrm{E}+05$ & $0 / 1$ & & $\mathrm{NA}$ \\
\hline \multicolumn{14}{|l|}{ Volatile organics $(\mathrm{ug} / \mathrm{kg})$} \\
\hline (1,1-Dimethylethyl)benzene & $0 / 1$ & $\mathrm{ND}$ & $\mathrm{ND}$ & & $\mathrm{ND}$ & & NA & & $\mathrm{NA}$ & $3.90 \mathrm{E}+05$ & $0 / 1$ & & $\mathrm{NA}$ \\
\hline (1-Methylpropyl)benzene & $0 / 1$ & ND & ND & & $\mathrm{ND}$ & & NA & & $\mathrm{NA}$ & $2.20 \mathrm{E}+05$ & $0 / 1$ & & $\mathrm{NA}$ \\
\hline 1,1,1,2-Tetrachloroethane & $0 / 1$ & ND & ND & & ND & & NA & & NA & $7.30 \mathrm{E}+04$ & $0 / 1$ & & NA \\
\hline $\begin{array}{l}1,1,1 \text {-Trichloroethane } \\
\text { lo }\end{array}$ & $0 / 1$ & ND & ND & & $\mathrm{ND}$ & & NA & & NA & $1.20 \mathrm{E}+06$ & $0 / 1$ & & $\mathrm{NA}$ \\
\hline $1,1,2,2$-Tetrachloroethane & $0 / 1$ & $\mathrm{ND}$ & ND & & ND & & NA & & $\mathrm{NA}$ & $9.30 \mathrm{E}+03$ & $0 / 1$ & & $\mathrm{NA}$ \\
\hline 1,1,2-Trichloro-1,2,2-trifluoroethane & $0 / 1$ & ND & ND & & ND & & NA & & NA & $5.60 \mathrm{E}+06$ & $0 / 1$ & & NA \\
\hline 1,1,2-Trichloroethane & $0 / 1$ & ND & ND & & ND & & NA & & NA & $1.60 \mathrm{E}+04$ & $0 / 1$ & & NA \\
\hline 1,1-Dichloroethane & $0 / 1$ & ND & ND & & ND & & NA & & NA & $1.70 \mathrm{E}+06$ & $0 / 1$ & & NA \\
\hline 1,1 -Dichloroethene & $0 / 1$ & $\mathrm{ND}$ & ND & & ND & & NA & & NA & $4.10 \mathrm{E}+05$ & $0 / 1$ & & NA \\
\hline 1,1-Dichloropropene & $0 / 1$ & ND & ND & & ND & & NA & & NA & & NA & & NA \\
\hline 1,2,3-Trichlorobenzene & $0 / 1$ & ND & ND & & ND & & NA & & NA & & NA & & NA \\
\hline 1,2,3-Trichloropropane & $0 / 1$ & ND & $\mathrm{ND}$ & & ND & & NA & & NA & $7.60 \mathrm{E}+02$ & $\begin{array}{l}\text { NA } \\
0 / 1\end{array}$ & & NA \\
\hline $1,2,4$-Trimethylbenzene & $0 / 1$ & ND & ND & & ND & & NA & & NA & $1.70 \mathrm{E}+05$ & $0 / 1$ & & NA \\
\hline 1,2-Dibromo-3-chloropropane & $0 / 1$ & $\mathrm{ND}$ & $\mathrm{ND}$ & & $\mathrm{ND}$ & & $\mathrm{NA}$ & & $\mathrm{NA}$ & $1.10 \mathrm{E}+04$ & $0 / 1$ & & $\mathrm{NA}$ \\
\hline 1,2-Dibromoethane & $0 / 1$ & ND & ND & & ND & & NA & & NA & $6.30 \mathrm{E}+02$ & $0 / 1$ & & NA \\
\hline 1,2-Dichloroethane & $0 / 1$ & ND & ND & & $\mathrm{ND}$ & & NA & & NA & $6.00 \mathrm{E}+03$ & $0 / 1$ & & $\mathrm{NA}$ \\
\hline 1,2-Dichloropropane & $0 / 1$ & $\mathrm{ND}$ & $\mathrm{ND}$ & & ND & & NA & & NA & 7.40E+03 & $0 / 1$ & & NA \\
\hline 1,2-Dimethylbenzene & $0 / 1$ & $\mathrm{ND}$ & ND & & ND & & NA & & NA & $4.20 \mathrm{E}+05$ & $0 / 1$ & & NA \\
\hline 1,3,5-Trimethylbenzene & $0 / 1$ & ND & $\mathrm{ND}$ & & $\mathrm{ND}$ & & NA & & NA & $7.00 \mathrm{E}+04$ & $0 / 1$ & & $\mathrm{NA}$ \\
\hline 1,3 -Dichloropropane & $0 / 1$ & ND & ND & & ND & & NA & & NA & $3.60 \mathrm{E}+05$ & $0 / 1$ & & NA \\
\hline 1 -Chloro-4-methylbenzene & $0 / 1$ & $\mathrm{ND}$ & ND & & ND & & NA & & NA & & NA & & NA \\
\hline 1-Methyl-4-(1-methylethyl)benzene & $0 / 1$ & $\mathrm{ND}$ & $\mathrm{ND}$ & & $\mathrm{ND}$ & & NA & & NA & & NA & & NA \\
\hline 1-chlorohexane & $0 / 1$ & $\mathrm{ND}$ & ND & & ND & & NA & & NA & & NA & & NA \\
\hline 2,2-Dichloropropane & $0 / 1$ & $\mathrm{ND}$ & $\mathrm{ND}$ & & ND & & $\mathrm{NA}$ & & $\mathrm{NA}$ & & NA & & $\mathrm{NA}$ \\
\hline 2-Butanone & $0 / 1$ & ND & ND & & ND & & NA & & NA & $1.00 \mathrm{E}+08$ & $0 / 1$ & & NA \\
\hline 2-Hexanone & $0 / 1$ & $\mathrm{ND}$ & $\mathrm{ND}$ & & ND & & NA & & NA & $1.00 \mathrm{E}+00$ & NA & & NA \\
\hline 2-Methoxy-2-methylpropane & $0 / 1$ & ND & ND & & ND & & NA & & NA & $3.60 \mathrm{E}+05$ & $0 / 1$ & & NA \\
\hline 4-Methyl-2-pentanone & $0 / 1$ & ND & $\mathrm{ND}$ & & ND & & NA & & NA & $4.70 \mathrm{E}+07$ & $0 / 1$ & & $\mathrm{NA}$ \\
\hline Acetone & $0 / 1$ & $\mathrm{ND}$ & ND & & $\mathrm{ND}$ & & NA & & NA & $5.40 \mathrm{E}+07$ & $0 / 1$ & & $\mathrm{NA}$ \\
\hline Benzene & $0 / 1$ & ND & ND & & ND & & NA & & NA & $1.40 \mathrm{E}+04$ & $0 / 1$ & & NA \\
\hline Bromobenzene & $0 / 1$ & ND & ND & & ND & & NA & & NA & $9.20 \mathrm{E}+04$ & $0 / 1$ & & NA \\
\hline Bromochloromethane & $0 / 1$ & ND & ND & & ND & & NA & & NA & & NA & & NA \\
\hline Bromodichloromethane & $0 / 1$ & $\mathrm{ND}$ & $\mathrm{ND}$ & & ND & & NA & & NA & $1.80 \mathrm{E}+04$ & $0 / 1$ & & NA \\
\hline Bromoform & $0 / 1$ & ND & ND & & ND & & NA & & NA & $2.20 \mathrm{E}+06$ & $0 / 1$ & & NA \\
\hline Bromomethane & $0 / 1$ & $\mathrm{ND}$ & $\mathrm{ND}$ & & $\mathrm{ND}$ & & NA & & NA & $1.30 \mathrm{E}+04$ & $0 / 1$ & & NA \\
\hline Butylbenzene & $0 / 1$ & $\mathrm{ND}$ & ND & & ND & & NA & & NA & $2.40 \mathrm{E}+05$ & $0 / 1$ & & NA \\
\hline Carbon disulfide & $0 / 1$ & ND & ND & & $\mathrm{ND}$ & & NA & & $\mathrm{NA}$ & $7.20 \mathrm{E}+05$ & $0 / 1$ & & NA \\
\hline Carbon tetrachloride & $0 / 1$ & $\mathrm{ND}$ & ND & & ND & & NA & & NA & $\begin{array}{l}7.20 \mathrm{E}+\mathrm{US} \\
5.50 \mathrm{E}+03\end{array}$ & $0 / 1$ & & NA \\
\hline Chlorobenzene & $0 / 1$ & ND & ND & & ND & & NA & & NA & $5.30 \mathrm{E}+05$ & $0 / 1$ & & NA \\
\hline
\end{tabular}


Table E.4. (continued)

\begin{tabular}{|c|c|c|c|c|c|c|c|c|c|c|c|c|c|}
\hline $\begin{array}{r}\text { Analyte } \\
\end{array}$ & $\begin{array}{r}\text { Frequency } \\
\text { of detect }\end{array}$ & $\begin{array}{c}\text { Minimum } \\
\text { detect }\end{array}$ & $\begin{array}{c}\text { Maximum } \\
\text { detect }\end{array}$ & $\begin{array}{c}\text { Location(s) } \\
\text { of } \\
\text { maximum } \\
\text { detected } \\
\text { result }\end{array}$ & $\begin{array}{c}\text { Average } \\
\text { detected } \\
\text { result }\end{array}$ & $\operatorname{Max}$ RL & $\begin{array}{c}\text { Frequency } \\
\text { of detects } \\
\text { exceeding } \\
\text { Max RL }\end{array}$ & Avg RL & $\begin{array}{c}\text { Frequency } \\
\text { of detects } \\
\text { exceeding } \\
\text { Avg RL }\end{array}$ & $\begin{array}{l}\text { PRG limit } \\
\left(10^{-5} \text { or } 1\right)\end{array}$ & $\begin{array}{l}\text { Frequency } \\
\text { of detects } \\
\text { exceeding } \\
\text { PRG limit }\end{array}$ & $\begin{array}{l}\text { Background } \\
\text { concentration }\end{array}$ & $\begin{array}{c}\text { Frequency } \\
\text { of detects } \\
\text { exceeding } \\
\text { background }\end{array}$ \\
\hline Chloroethane & $0 / 1$ & $\mathrm{ND}$ & ND & & ND & & NA & & NA & $6.50 \mathrm{E}+04$ & $0 / 1$ & & NA \\
\hline Chloroform & $0 / 1$ & ND & ND & & ND & & NA & & NA & $4.70 \mathrm{E}+03$ & $0 / 1$ & & NA \\
\hline Chloromethane & $0 / 1$ & $\mathrm{ND}$ & ND & & ND & & NA & & NA & $1.60 \mathrm{E}+05$ & $0 / 1$ & & NA \\
\hline Cumene & $0 / 1$ & ND & ND & & ND & & NA & & NA & $5.20 \mathrm{E}+05$ & $0 / 1$ & & NA \\
\hline Dibromochloromethane & $0 / 1$ & ND & $\mathrm{ND}$ & & ND & & NA & & NA & $2.60 \mathrm{E}+04$ & $0 / 1$ & & NA \\
\hline Dibromomethane & $0 / 1$ & ND & ND & & ND & & NA & & NA & $2.30 \mathrm{E}+05$ & $0 / 1$ & & NA \\
\hline Dichlorodifluoromethane & $0 / 1$ & $\mathrm{ND}$ & ND & & ND & & NA & & NA & $3.10 \mathrm{E}+05$ & $0 / 1$ & & NA \\
\hline Ethylbenzene & $0 / 1$ & ND & ND & & ND & & NA & & NA & $4.00 \mathrm{E}+05$ & $0 / 1$ & & NA \\
\hline Iodomethane & $0 / 1$ & $\mathrm{ND}$ & $\mathrm{ND}$ & & $\mathrm{ND}$ & & NA & & NA & & NA & & $\mathrm{NA}$ \\
\hline M + P Xylene & $0 / 1$ & $\mathrm{ND}$ & $\mathrm{ND}$ & & $\mathrm{ND}$ & & NA & & NA & 4.20E+05 & $0 / 1$ & & NA \\
\hline Methylene chloride & $0 / 1$ & $\mathrm{ND}$ & ND & & ND & & NA & & NA & $2.10 \mathrm{E}+05$ & $0 / 1$ & & NA \\
\hline Propylbenzene & $0 / 1$ & $\mathrm{ND}$ & $\mathrm{ND}$ & & $\mathrm{ND}$ & & $\mathrm{NA}$ & & NA & $2.40 \mathrm{E}+05$ & $0 / 1$ & & $\mathrm{NA}$ \\
\hline Styrene & $0 / 1$ & ND & ND & & ND & & NA & & NA & $1.70 \mathrm{E}+06$ & $0 / 1$ & & NA \\
\hline Tetrachloroethene & $0 / 1$ & $\mathrm{ND}$ & ND & & ND & & NA & & NA & $1.30 \mathrm{E}+04$ & $0 / 1$ & & NA \\
\hline Toluene & $0 / 1$ & ND & ND & & ND & & NA & & NA & $5.20 \mathrm{E}+05$ & $0 / 1$ & & NA \\
\hline Trichloroethene & $0 / 1$ & $\mathrm{ND}$ & $\mathrm{ND}$ & & ND & & NA & & NA & $1.10 \mathrm{E}+03$ & $0 / 1$ & & NA \\
\hline Trichlorofluoromethane & $0 / 1$ & $\mathrm{ND}$ & $\mathrm{ND}$ & & $\mathrm{ND}$ & & $\mathrm{NA}$ & & $\mathrm{NA}$ & $1.30 \mathrm{E}+06$ & $0 / 1$ & & $\mathrm{NA}$ \\
\hline Vinyl acetate & $0 / 1$ & ND & $\mathrm{ND}$ & & ND & & NA & & NA & $1.40 \mathrm{E}+06$ & $0 / 1$ & & NA \\
\hline Vinyl chloride & $0 / 1$ & $\mathrm{ND}$ & $\mathrm{ND}$ & & $\mathrm{ND}$ & & $\mathrm{NA}$ & & $\mathrm{NA}$ & $7.50 \mathrm{E}+03$ & $0 / 1$ & & $\mathrm{NA}$ \\
\hline cis-1,2-Dichloroethene & $0 / 1$ & ND & ND & & ND & & NA & & NA & $1.50 \mathrm{E}+05$ & $0 / 1$ & & NA \\
\hline cis-1,3-Dichloropropene & $0 / 1$ & ND & ND & & ND & & NA & & NA & $1.80 \mathrm{E}+04$ & $0 / 1$ & & $\mathrm{NA}$ \\
\hline o-Chlorotoluene & $0 / 1$ & ND & $\mathrm{ND}$ & & ND & & NA & & NA & $5.60 \mathrm{E}+05$ & $0 / 1$ & & NA \\
\hline trans-1,2-Dichloroethene & $0 / 1$ & ND & $\mathrm{ND}$ & & ND & & NA & & NA & $2.30 \mathrm{E}+05$ & $0 / 1$ & & NA \\
\hline trans-1,3-Dichloropropene & $0 / 1$ & ND & $\mathrm{ND}$ & & ND & & NA & & NA & $1.80 \mathrm{E}+04$ & $0 / 1$ & & $\mathrm{NA}$ \\
\hline
\end{tabular}

Definition of validation qualifiers: $\mathrm{J}=$ analyte was positively identified and result is approximate concentration of analyte in sample, and $\mathrm{U}=$ analyte not detected above reported sample quantitation limi

$\begin{array}{ll}\text { Avg }=\text { average } & \mathrm{NA}=\text { not applicable } \\ \mathrm{DRO}=\text { diesel-range organic } & \mathrm{ND}=\text { not detected }\end{array}$

$\begin{array}{ll}\mathrm{GRO}=\text { gasoline-range organic } & \mathrm{ND}=\text { not detected } \\ \mathrm{Max}=\text { maximum } & \mathrm{PL}=\text { preliminary remediation goal } \\ \mathrm{RL}=\text { remediation level }\end{array}$ 


\section{Appendix F \\ Haul Road Exposure Unit Group Z2-28}

Technical Memorandum 


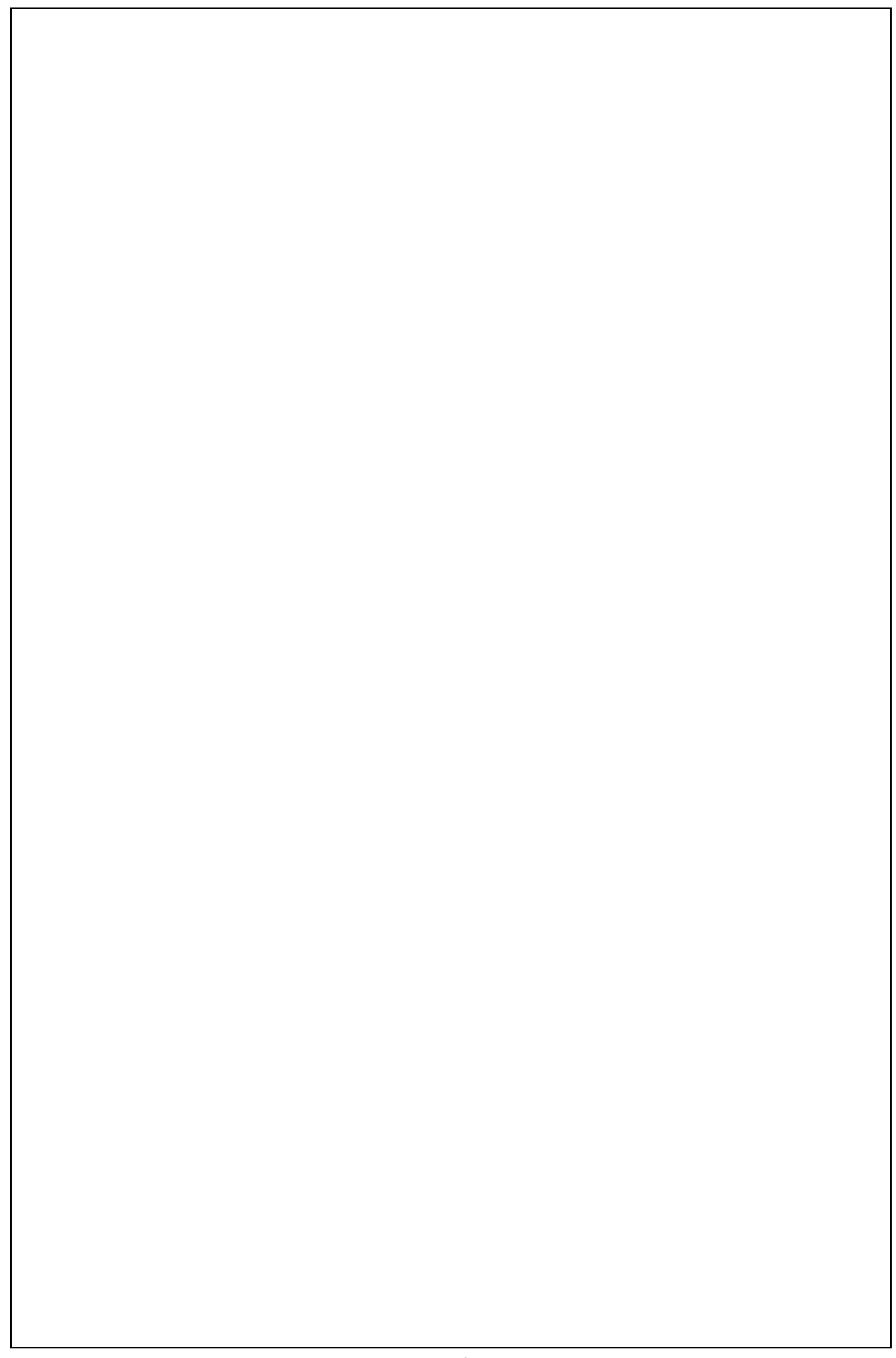

F-2 


\section{FIGURES}

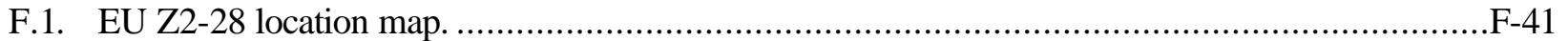

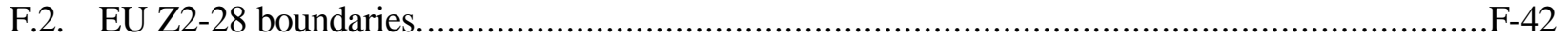

F.3. EU Z2-28 BAR survey at K-1407-C Soil Piles and locations of historical samples...................F-43

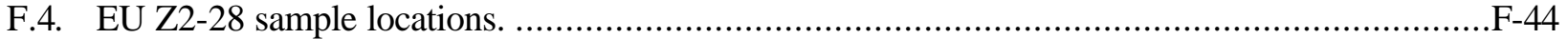

F.5. EU Z2-28 detail sample locations at K-1407-C Soil Piles.............................................. 45

F.6. EU Z2-28 Class 3 and Class 4 SU walkover assessment locations. ......................................46

\section{TABLES}

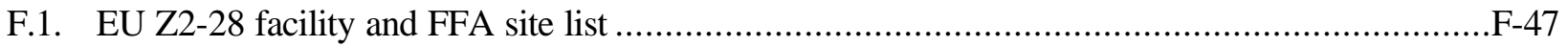

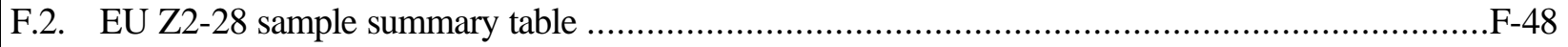

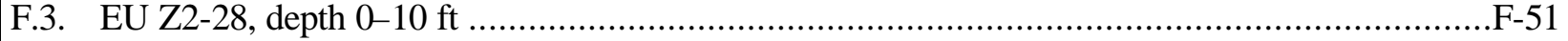

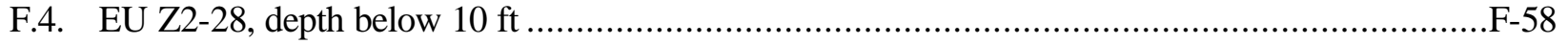




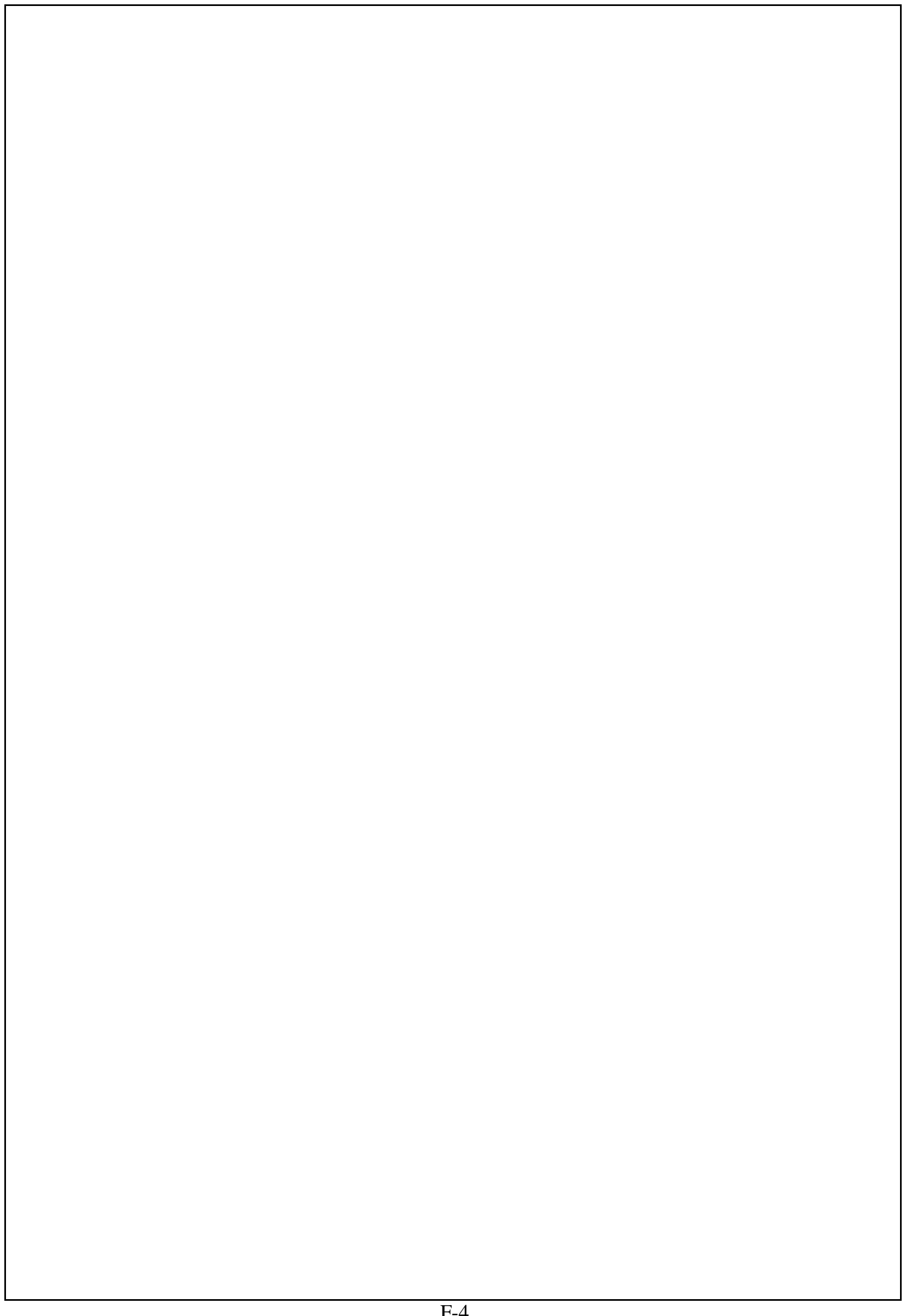




\section{DYNAMIC VERIFICATION STRATEGY (DVS) TECHNICAL MEMORANDUM (TM)}

EXPOSURE UNIT (EU) GROUP: Zone 2 Haul Road Group EU Z2-28

\section{INTRODUCTION}

The purpose of this Technical Memorandum is to document the recommendation for an action/no further action (NFA) decision for EU Z2-28 in the Haul Road EU Group. The recommendation for this EU is based on existing historical data and DVS soil characterization activities. These data are used to determine the nature and extent of contamination in the EU and to evaluate the need for an action. When it is determined an action is necessary, the data are also used to calculate soil volumes for the proposed remedial alternative as identified in the Record of Decision for Soil, Buried Waste, and Subsurface Structure Actions in Zone 2, East Tennessee Technology Park, Oak Ridge, Tennessee (DOE/OR/01-2161\&D2) (Zone 2 ROD).

\begin{tabular}{|l|l|}
\hline 1.0 & BACKGROUND AND EU SUMMARY \\
\hline 1.1 & LOCATIONAT EAST TENNESSEE TECHNOLOGY PARK (ETTP) \\
\hline
\end{tabular}

EU Z2-28 is located along the northern boundary of Zone 2 in the Haul Road EU Group (Fig. F.1).

\begin{tabular}{|l|l|}
\hline 1.2 & EU Z2-28 ACREAGE \\
\hline
\end{tabular}

EU Z2-28 has an area of approximately 20.5 acres.

\begin{tabular}{|l|l|l}
\hline 1.3 & SUMMARY DESCRIPTION \\
\hline
\end{tabular}

The majority of the land area in EU Z2-28 has been impacted by site operations, including forest clearing and road construction, railroads, parking lots, reorientation of Mitchell Branch, construction of a portion of the Haul Road, and other small facilities. In addition, the site (see Sect. 1.5) was used for above-ground dumping of soil, building rubble, and debris.

The data quality objective (DQO) scoping package for the Haul Road EU Group lists six facilities in EU Z2-28. An accounting of facilities in the EU is presented in Table F.1.

\section{\begin{tabular}{l|l}
1.4 & SOIL UNITS (SUS) \\
\hline
\end{tabular}}

Class 1 soil unit $(\mathbf{S U}):<0.05$ acre

Class 2 SU: 2.5 acres

Class 3 SU: 18.0 acres

Class 4 SU: None

The EU Z2-28 soil unit boundaries are shown on Fig. F.2.

\section{\begin{tabular}{l|l} 
1.5 & ZONE 2 ROD APPENDIX A FEDERAL FACILITY AGREEMENT (FFA) SITES \\
\hline
\end{tabular}}

There is one FFA site in EU Z2-28 that is listed in Appendix A of the Zone 2 ROD:

The K-1407-C Soil Piles FFA Site (also known as Rusty's Mountain) is the only FFA site in EU Z2-28 listed in Appendix A of the Zone 2 ROD.

\begin{tabular}{|l|l|}
\hline 2.0 & \multicolumn{1}{|c|}{ DVS INVESTIGATIONS AND RESULTS } \\
\hline 2.1 & DVS FIELD ACTIVITIES \\
\hline
\end{tabular}

DVS activities were conducted in accordance with the Remedial Design Report/Remedial Action Work Plan for Zone 2 Soils, Slabs, and Infrastructure, East Tennessee Technology Park, Oak Ridge, Tennessee (DOE/OR/01-2224\&D2) (Zone 2 RDR/RAWP). 


\subsection{1}

CLASS 1 SUS

The purpose of Class 1 SUs in EU Z2-28 is to define remedial action boundaries (RABs) around areas with known maximum remediation level (RL) exceedances. As such, four Class 1 SUs were identified during DQO scoping. One additional area was added based on the results of early characterization sampling following approval of the DQO package. In the following descriptions, the SUs addressed by the Class $1 \mathrm{SU}$ RAB definition will be referred to either by the historical sample location name with the maximum RL exceedance or, in the case of more than one historical maximum RL exceedance at locations in proximity to one another, by the historical sample location name with the greatest relative maximum RL exceedance. All Class 1 SUs in EU Z2-28 occur in the K-1407-C Soil Piles FFA Site.

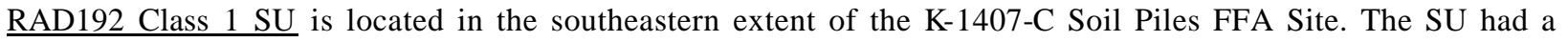
maximum RL exceedance for the Ra/Th decay series and average RL exceedances for Cs -137 and the Ra/Th decay series at historic al sample location RAD192.

RAD199 Class $1 \mathrm{SU}$ is located roughly midway along the southern boundary of the K-1407-C Soil Piles FFA Site. The SU had maximum RL exceedances for Cs -137 and the Ra/Th decay series and average RL exceedances for Cs-137, the Ra/Th decay series, U-235, and U-238 at historical sample location RAD199.

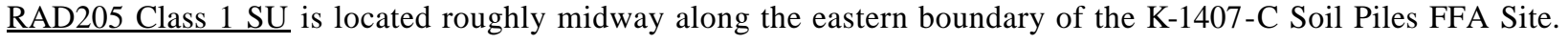
The SU had maximum RL exceedances for the Ra/Th decay series and average RL exceedances for Cs -137 , the $\mathrm{Ra}$ Th decay series, U235, and U-238 at historical sample locations RAD204, RAD205, and RAD206, and maximum and average RL exceedances for the Ra/Th decay series at historical sample location RAD207.

RAD218 Class $1 \mathrm{SU}$ is located in the west/central portion of the K-1407-C Soil Piles FFA Site. The SU had a maximum RL exceedance for the Ra/Th decay series and average RL exceedances for the Ra/Th decay series, U-235, and U-238 at historical sample location RAD218.

Z2-EU28-204 Class 1 SU is located in the west/central portion of the K-1407-C Soil Piles FFA Site. The SU had a maximum RL exceedance for the Ra/Th decay series at early characterization sample location Z2-EU28-204. This early characterization sampling location was identified as having a maximum RL exceedance subsequent to DQO scoping and sampling is not described in the DQO scoping package for the Haul Road Group of EUs.

\section{\begin{tabular}{|l|l} 
2.1.1.1 & CLASS 1 SU RADIOLOGICAL WALKOVER SURVEY
\end{tabular}}

Biased area radiation (BAR) surveys were conducted in the Class 1 SUs in EU Z2-28 according to the project protocol for radiation surveys. BAR surveys are radiological walkover surveys with a high density of radiation measurement points whose purpose, in Class 1 SUs, is to define RABs around locations with known maximum RL exceedances. BAR surveys were conducted at five Class 1 SUs (see Sect. 2.1.1 for Class 1 SU naming conventions). Locations of the BAR surveys are shown on Fig. F.3 and details are presented in the Zone 2 EU Survey Summary Report. The RAB for Class 1 SUs is defined by the two times background boundary as determined by the BAR survey. For EU Z2-28 Class 1 SUs, two times the background was $3496 \mathrm{cpm}$.

\begin{tabular}{|c|c|c|c|c|}
\hline \multirow[b]{2}{*}{ Class $1 \mathrm{SU}$} & \multicolumn{3}{|c|}{$\begin{array}{l}\text { Range of radiation readings } \\
(\mathbf{c p m})\end{array}$} & \multirow{2}{*}{$\underset{\left(\mathrm{ft}^{2}\right)}{\text { Area within }} \mathrm{RAB}$} \\
\hline & $\left(\mathbf{f t}^{2}\right)$ & Minimum & Maximum & \\
\hline RAD192 & 210 & 1,321 & 3,089 & None \\
\hline RAD199 & 240 & 1,072 & 8,652 & 20 \\
\hline RAD205 & 336 & 1,762 & 48,974 & 200 \\
\hline RAD218 & 340 & 225 & 6,190 & 50 \\
\hline Z2-EU28-204 & 8,000 & 1,511 & 8,082 & 50 \\
\hline
\end{tabular}

$\mathrm{BAR}=$ biased radiation area

$\mathrm{RAB}=$ remedial action boundaries

$\mathrm{SU}=$ soil unit

\section{\begin{tabular}{|l|l} 
2.1.1.2 & CLASS 1 SU GEOPHYSICAL SURVEY \\
\hline
\end{tabular}}

None. 


\section{\begin{tabular}{|l|l} 
2.1.1.3 & CLASS 1 SU SOIL S AMPLING \\
\hline
\end{tabular}}

DVS Class 1 SU soil sampling in EU Z2-28 was conducted for RAB confirmation around historical maximum RL exceedances. The Class $1 \mathrm{SU}$ areas are described above in Sect. 2.1.1. All EU Z2-28 sample locations are shown on Fig. F.4. a subset of the sample locations focusing on the K-1407-C Soil Piles FFA Site is shown in Fig. F.5. Detail survey plats are provided in the Zone 2 EU Survey Summary Report.

RAD192 Class 1 SU: DVS sampling consisted of collecting a four-point composite step-out sample (Z2-EU28B-117) from around the location of historical sample RAD192. The location for Z2-EU28B-117 (shown in Fig. F.5) is actually the location of only one of four sampling points for the step-out sample. The sampling points for the step-out sample saturated the area and a confirmation sample at the location of historical sample RAD192 was not collected. No radiation measurements exceeded two times background during the BAR survey at the RAD192 Class $1 \mathrm{SU}$ (Sect. 2.1.1.1), so a two times background boundary could not be delineated.

RAD199 Class 1 SU: DVS sampling consisted of collecting a confirmation sample (Z2-EU28B-118) from the area of highest radiation, and a four-point composite step-out sample (Z2-EU28B-119) from within the elevated radioactivity boundary delineated during the BAR survey of this SU (Sect. 2.1.1.1). Sample locations in this Class 1 SU are shown on Fig. F.5.

RAD205 Class 1 SU: DVS sampling consisted of collecting a confirmation sample (Z2-EU28B-114) and two composite step-out samples [Z2-EU28B-115 and Z2-EU28B-116 (see Fig. F.5)]. The confirmation sample location was at the point of highest elevated radioactivity as determined by the BAR survey (Sect. 2.1.1.1), which is in proximity to historic sample locations RAD205 and RAD206. A 45-point composite sample was collected inside the two times background radiation boundary and analyzed for a full suite of analytes to provide EMWMF WAC acceptance data for the remedial action. The second step-out sample, a 4-point composite sample from outside the boundary, was collected and analyzed for RAD only to confirm the defined boundary. Sample locations are shown on Fig. F.5.

RAD218 Class $1 \mathrm{SU}$ : The BAR survey of RAD218 Class 1 SU identified an area of elevated radioactivity a few feet south of the historical sample location (see Fig. F.3). Two sample locations (Z2-EU28B-123 and Z2-EU23B-124) were identified in the area of elevated radioactivity and discrete samples were collected to quantify the radionuclide concentrations in this area (see Fig. F.5).

Z2-EU28-204 Class 1 SU: The BAR survey in Z2-EU28-204 Class 1 SU defined a relatively small RAB (see Sect. 2.1.1.1) that was not amenable to four-point composite step-out sampling. DVS sampling in Z2-EU28-204 Class $1 \mathrm{SU}$ consisted of collecting a discrete interval sample at location Z2-EU28B-125, which is in proximity to the Z2-EU28-204 early characterization location.

\section{\begin{tabular}{|l|l|l}
\hline 2.1.2 & CLASS 2 SUS \\
\hline
\end{tabular}}

Approximately 2.5 acres in the southeast corner of EU Z2-28, which encompasses the boundaries of the K-1407-C Soil Piles FFA Site, was classified as a Class 2 SU during DQO scoping. Uncertainty in the compositional nature of soils in this area relative to the Zone 2 ROD remedial action objective (RAO) arises from maximum and average RL exceedances in several historical samples. Class 1 SUs were established to define RABs around the maximum RL exceedances (Sect.2.1.1). To define the areal extent of the average RL exceedances, four locations for area definition were established during DQO scoping that lie within the Class 2 SU and encompass locations of the historical average RL exceedances. Two additional areas were added for area definition following DQO scoping. In the following descriptions, the locations for area definition will be referred to either by the historical sample location name with the average RL exceedance or, in the case of more than one historical average RL exceedance at locations in proximity to one another, by the historical sample location name with the greatest relative average RL exceedance.

- Area definition location RAD197 was added to the EU Z2-28 characterization program after DQO scoping. This historical location is located in the eastern portion of the K-1407-C Soil Piles FFA Site and had a Ra/Th decay series average RL exceedance.

- Area definition location RAD203 is located in the east/central portion of the K-1407-C Soil Piles FFA Site. This location was identified for area definition during DQO scoping because of elevated Ra-226 (5.3 pCi/g), which exceeded the Ra-226 average RL at this location. However, the Zone 2 ROD specifies that Ra-226 will be evaluated as part of the $\mathrm{Ra} / \mathrm{Th}$ decay series. Calculation of $\mathrm{Ra} / \mathrm{Th}$ decay series concentrations is described in 
Sect. 3.3 of this Phased Construction Completion Report (PCCR). The Ra/Th decay series concentration is $4.05 \mathrm{pCi} / \mathrm{g}$ when the calculation is performed for this historical sample location, which is less than the average $\mathrm{RL}$ for the $\mathrm{Ra} / \mathrm{Th}$ decay series $(5 \mathrm{pCi} / \mathrm{g})$.

- Area definition location RAD209 is located in the central portion of the K-1407-C Soil Piles FFA Site. This area was identified for area definition during DQO scoping because of an average RL exceedance for U-238 at historical sample location RAD209. In the DQO scoping package, DVS sampling at this location was to include historical locations RAD210, RAD212, and RAD214. However, it was decided based on the BAR survey of this area (Sect.2.1.2.1) that samples would be collected to characterize the area around RAD 209 independently from the area around the other historical samples.

- Area definition location RAD212 is located in the central portion of the K-1407-C Soil Piles FFA Site. This area was identified for area definition during DQO scoping because of an average RL exceedance for U-238 at historical sample location RAD210, average RL exceedances for the Ra/Th decay series, U-235, and U-238 at historical sample location RAD212, and an average RL exceedance for U-238 at historical sample location RAD214. In the DQO package, DVS sampling at this group of historical locations includes historical location RAD209. However, it was decided that the location of RAD 209 would be investigated independently of the other locations based on the BAR survey results (Sect. 2.1.2.1).

- Area definition location RAD219 is located in the western portion of the K-1407-C Soil Piles FFA Site. This area was identified for area definition during DQO scoping because of average RL exceedances for the Ra/Th decay series, U-235, and U-238 at historical sample location RAD219.

Area definition location Z2-EU28M-102 was added to the EU Z2-28 characterization program after DQO scoping. Early characterization location Z2-EU28M-102 is located in the eastern portion of the K-1407-C Soil Piles FFA Site. This location had a Ra/Th decay series average RL exceedance.

2.1.2.1

ClaSS 2 SU RADIOLOGICAL WALKOVER SURVEY

BAR surveys were conducted at area definition locations in the Class $2 \mathrm{SU}$ to define the areal extent of average RL exceedances so that an area term is available for calculating if the EU average concentration of a Zone 2 soils contaminant of concern (COC) exceeds its average RL. If an average RL exceedance is confirmed by DVS sampling, the areal extent of the exceedance is determined to be the area exceeding two times background as determined by the BAR survey. For EU Z2-28, two times background radiation was determined to be $3496 \mathrm{cpm}$. BAR surveys were conducted at three area definition locations in the Class 2 SU of EU Z2-28 (see Sect. 2.1.2 for the Class 2 SU naming convention). Locations of the BAR surveys are shown on Fig. F.3 and details of the BAR surveys are presented in the Zone 2 EU Survey Summary Report.

\begin{tabular}{|c|c|c|c|c|}
\hline \multirow{2}{*}{$\begin{array}{c}\text { Class } 2 \text { SU area } \\
\text { definition location }\end{array}$} & \multirow{2}{*}{$\underset{\left(\mathrm{ft}^{2}\right)}{\text { Area of BAR survey }}$} & \multicolumn{2}{|c|}{$\begin{array}{l}\text { Range of radiation readings } \\
(\mathbf{c p m})\end{array}$} & \multirow{2}{*}{$\begin{array}{c}\text { Area of } 2 \mathbf{x} \text { background } \\
\text { radiation } \\
\left(\mathbf{f t}^{2}\right)\end{array}$} \\
\hline & & Minimum & Maximum & \\
\hline RAD203 & None & None & None & None \\
\hline RAD209/212 & 510 & 2239 & 5724 & $200 / 80$ \\
\hline RAD219 & 120 & 2852 & 4318 & None \\
\hline RAD197 & 8000 & 1104 & 1678 & None \\
\hline Z2-EU28M-102 & 8000 & 1249 & 2488 & None \\
\hline
\end{tabular}

$\mathrm{BAR}=$ biased area radiation

$\mathrm{SU}=$ soil unit

A BAR survey was not conducted at RAD203 because DVS confirmation sample Z2-EU28B-126 did not verify the historic average RL exceedance. The BAR survey at RAD209 and RAD212 locations delineated two distinct areas that exceed two times background. Although some readings exceeded the action level during the RAD219 location BAR survey, a distinct area of elevated radioactivity could not be discerned in the vicinity of RAD219. Instead, an area of elevated radioactivity was observed to the south of the RAD219 location. This area is the same area discussed above as being to the south of the RAD218 Class $1 \mathrm{SU}$ (see Sect.2.1.1.3). No radiation reading exceeded the two times background action level during BAR surveys at RAD197 and Z2-EU28M-102 locations. 


\section{\begin{tabular}{|l|l} 
2.1.2.2 & CLASS 2 SU GEOPHYSICAL SURVEY
\end{tabular}}

None.

\subsubsection{3}

CLASS 2 SUSOIL SAMPLING

DVS Class 2 SU soil sampling in EU Z2-28 was conducted for area definition around historical average RL exceedances (see area definition locations described in Sect. 2.1.2 above). The historical sample and area definition locations are shown on Fig. F.5.

RAD203 area definition location: Confirmation sample location Z2-EU28B-126 was selected at the location of RAD203.

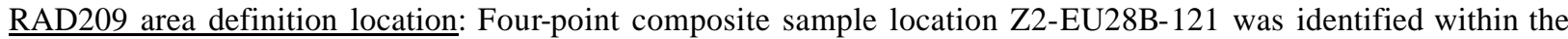
two times background radiation boundary in the RAD209 area definition location.

RAD212 area definition location: Four-point composite sample location Z2-EU28B-122 was identified within the two times background radiation boundary in the RAD212 area definition location.

RAD219 area definition location: As described in Sect. 2.1.2.1, the BAR survey of RAD219 area definition location failed to identify elevated radioactivity in the vicinity of historical sample location RAD219. Instead, an area of elevated radioactivity was identified to the south. Because of the proximity of RAD219 area definition location and the RAD218 Class $1 \mathrm{SU}$, this area was sampled to quantify radionuclide concentrations associated with the RAD218 Class 1 SU as described above in Sect. 2.1.1.3.

RAD197 area definition location: As described in Sect. 2.1.2.1 the BAR survey of RAD197 area definition location failed to detect radiation in excess of two times background. No DVS sampling was conducted at this location.

Z2-EU28M-102 area definition location: As described in Sect.2.1.2.1, the BAR survey of Z2-EU28M-102 area definition location failed to detect radiation in excess of two times background. No DVS sampling was conducted at this location.

\section{\begin{tabular}{|l|l} 
2.1.3 & CLASS 3 AND CLASS 4 SU WALKOVER ASSESSMENT
\end{tabular}}

The protocol for addressing the Class 3 and Class 4 SUs in EU Z2-28 is the Class 3 and Class 4 Soil Unit Walkover Inspection Protocol (found in Attachment C of Appendix A in the Zone 2 RDR/RAWP). The purpose of the Class 3 SU walkover assessments is to systematically inspect Class 3 SUs by visual observation along transects to established grid assessment locations and map-observed features, and to collect radiological screening data at grid and discretionary locations. Details of the walkover assessment results for EU Z2-28 are presented in the Walkover Inspections and Radiological Surveys for FY 2007 Exposure Units in Zones 1 and 2, East Tennessee Technology Park, Oak Ridge, Tennessee (BJC/OR-2691). The report results are summarized below in Sect. 2.1.3.1 and 2.1.3.2. The assessment point (AP), mid-point (MP), and discretionary point (DP) locations are shown in Fig. F.3.

Prior to the start of field work, 15 APs were identified in EU Z2-28 and are documented in the DQO scoping package. The actual number of APs evaluated in EU Z2-28 corresponds to the number planned.

In addition to APs, the field team made assessments at $14 \mathrm{MP}$ locations, which are selected in the field and are points located approximately half way between APs, and conducted discretionary surveys at seven locations (see below). MP and DP locations are not specified in planning documents.

\begin{tabular}{cccc}
\hline & $\begin{array}{c}\text { Number of } \\
\text { assessment points }\end{array}$ & $\begin{array}{c}\text { Number of } \\
\text { mi d-points }\end{array}$ & $\begin{array}{c}\text { Number of } \\
\text { discretionary points }\end{array}$ \\
\hline EU Z2-28 & 15 & 14 & 2 \\
\hline
\end{tabular}

\subsubsection{1}

\section{CLASS 3 AND CLASS 4 SU RADIOLOGICAL SURVEY SUMMARY}

Screening level (SL): $3068 \mathrm{cpm}$.

SL exceedances: No AP, MP, or DP measurements exceeded the SL in EU Z2-28. 
2.1.3.2 ClASS 3 AND ClASS 4 SU ANTHROPOGENIC FEATURES

\section{Number of identified anthropogenic features: 5}

Five anthropogenic features were identified during the Class $3 \mathrm{SU}$ walkover assessment and include:

- Grassy knoll east of the Ellis Cemetery ,

- Fence line and drainage ditch north of Blair Road,

- Soil mounds in wooded area,

- Low grassy area north of the Scale House and marked by posts, and

- Concrete-lined ditch.

\section{\begin{tabular}{|l|l|l|l|l} 
2.1.3.3 & CLASS 3 SU FACILITIES ASSESSMENTS \\
\hline
\end{tabular}}

Six facilities are listed in the DQO scoping package and all were assessed during the Class 3 SU walkover assessment (Table F.1). The facility assessments are reported in the Zone 2 EU Survey Summary Report. None of the facilities were identified as a possible source of chemical or radiologicalcontamination.

\section{\begin{tabular}{|l|l} 
2.1.3.4 & CLASS 3 AND CLASS 4 SU BIASED SAMPLING \\
\hline
\end{tabular}}

Based on visual assessment of each anthropogenic feature for evidence of possible contamination, radiological surveys at each anthropogenic feature, and taking into consideration the extensive historical sampling conducted around these anthropogenic features, it was decided that no DVS Class 3 SU biased sampling would be conducted.

\section{\begin{tabular}{|l|l|}
\hline 2.2 & DVS AND HISTORICAL SAMPLE RESULTS
\end{tabular}}

This section presents a summary of analytical results for the DVS and his torical samples collected in EU Z2-28. The summary begins with a tabulation of SU and infrastructure sample locations (Sects. 2.2.1 through 2.2.4) and concludes with focused investigation and EU data summaries (Sect.2.2.5) and FFA site data summaries (Sect. 2.2.6). The combined EU DVS and historical data are summarized in Tables F.3 and F.4. A compact disc containing electronic files for the historical and DVS analytical data used to generate the data tables is provided with this PCCR.

\section{\begin{tabular}{l|l} 
2.2.1 & CLASS 1 SUS
\end{tabular}}

There are a total of 17 DVS and historical sample locations in the Class 1 SUs of EU Z2-28. The Class 1 SUs were set up during DQO scoping to define the RABs around historical sample locations, or clusters of locations, with maximum RL exceedances. Because the Class $1 \mathrm{SU}$ sampling is for RAB definition, multiple samples that include historical samples, confirmation samples, and four-point composite samp les may be reported for each Class $1 \mathrm{SU}$.

\begin{tabular}{|c|c|c|}
\hline Historical sample(s) & Confirmation sample(s) & Step-out composite sample(s) \\
\hline$\overline{R A D 192 \text { Class } 1 \mathrm{SU}}$ & & \\
\hline RAD192 & None & Z2-EU28B-117 \\
\hline RAD199 Class $1 \mathrm{SU}$ & & \\
\hline RAD199 & Z2-EU28B-118 & Z2-EU28B-119 \\
\hline RAD205 Class $1 \mathrm{SU}$ & & \\
\hline $\begin{array}{l}\text { RAD204, RAD205, } \\
\text { RAD206, RAD207 }\end{array}$ & Z2-EU28B-114 & Z2-EU28B-115, Z2-EU28B-116 \\
\hline RAD218 Class $1 \mathrm{SU}$ & & \\
\hline RAD218 & Z2-EU28B-123, Z2-EU28B-124 & \\
\hline$\overline{Z 2-E U 28-204 \text { Class } 1 \mathrm{SU}}$ & & \\
\hline Z2-EU28-204 & Z2-EU28B-125 & \\
\hline
\end{tabular}

The number of samples collected, sampling intervals, and chemicals and radionuclides analyzed at each location varied. Sampling and analytical details for each sample location are presented in Table F.2. The analytical data are 
summarized in Tables F.3 and F.4 and evaluated in Sect. 2.2.5. The number of analyses conducted by analyte group in the Class $1 \mathrm{SU}$ is presented below.

\begin{tabular}{lcccc}
\hline Metals & PCBs & Radionuclides & SVOCs & VOCs \\
\hline 3 & 3 & 17 & 2 & 2 \\
\hline PCB = polychlorinated biphenyl & & & \\
SVOC = semivolatile organic compound & & \\
VOC = volatile organic compound & & &
\end{tabular}

\section{\begin{tabular}{l|l} 
2.2.2 & CLASS 2 SUS \\
\hline
\end{tabular}}

There are 33 DVS and historical sample locations in the Class 2 SU of EU Z2-28. The Class 2 SU is a relatively large area in the southeastern corner of EU Z2-28. This area was classified as Class 2 because it was uncertain if soils would exceed the compositional limits imposed by the Zone 2 ROD RAO. It was decided during the DQO scoping process that sufficient early characterization and other historical sample locations existed to fully characterize this Class $2 \mathrm{SU}$, so no DVS samples were required except as needed to quantify the areal extent of historical average RL exceedances. As a result, area definition investigations of EU Z2-28 were set up during DQO scoping to define the areal extent of historical average RL exceedances so that an area term would be available when calculating whether an average Zone 2 COC concentration exceeded its average RL. BAR surveys were conducted at these area definition locations, except as explained in Sect. 2.1.2.1, and the areas were sampled. DVS and historical sampling within the Class $2 \mathrm{SU}$, including the area definition locations, are shown in the following two tables.

Class 2 SU sampling other than area definition sampling

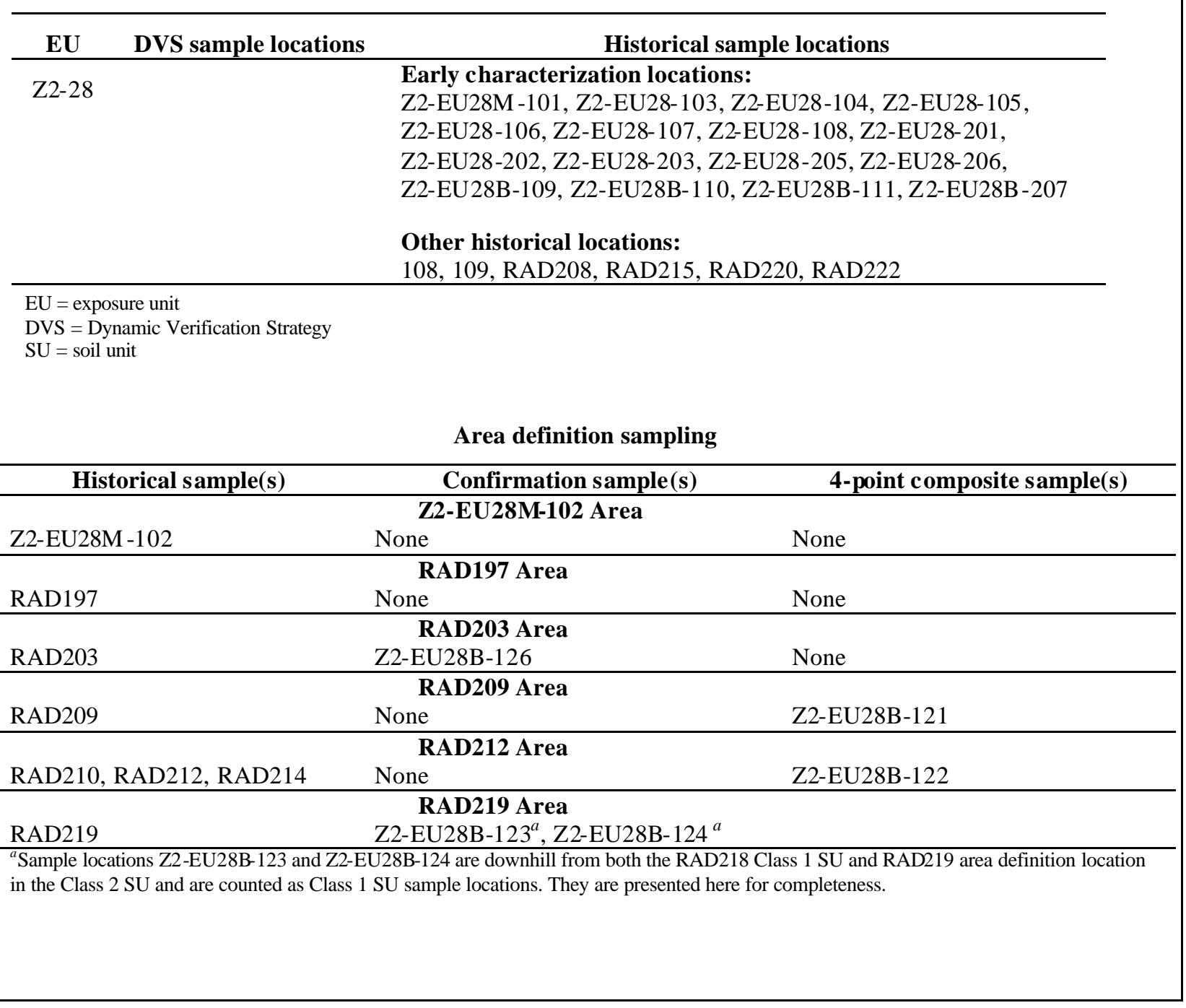


The number of samples collected, sampling intervals, and chemicals and radionuclides analyzed at each location varied by project. Sampling and analytical details for each sample location are presented in Table F.2. The analytical data are summarized in Table F.3 and evaluated in Sect. 2.2.5. Numbers of analyses conducted in the Class 2 SU are presented below by analyte group. Analytes from Z2-EU28B-123 and Z2-EU28B-124 are not included below but are tabulated for Class 1 SU sampling in Sect. 2.2.1.

\begin{tabular}{lcccc}
\hline Metals & PCBs & Radionuclides & SVOCs & VOCs \\
\hline 20 & 20 & 36 & 10 & 11 \\
\hline $\begin{array}{l}\text { PCB }=\text { polychlorinated biphenyl } \\
\text { SVOC = semivolatile organic compound } \\
\text { VOC = volatile organic compound }\end{array}$ & & &
\end{tabular}

\section{\begin{tabular}{|l|l|}
\hline 2.2.3 & CLASS 3 AND CLASS 4 SUS \\
\hline
\end{tabular}}

There are a total of 19 sample locations in EU Z2-28 Class 3 SU and all sampling performed is historical. Sampling in the Class 3 SU was conducted during compliance sampling in 1994, Haul Road characterization in 2002, and early characterization sampling in 2005. Class 3 SU sample locations are shown on Fig. F. 3 and summarized below.

\begin{tabular}{|c|c|c|}
\hline $\mathbf{E U}$ & DVS sample locations & Historical sample locations \\
\hline $\mathrm{Z} 2-28$ & & $\begin{array}{l}\text { Compliance locations: S4 } \\
\text { Haul Road characterization locations: BLRD01R1, BLRD02R1, } \\
\text { BLRD03R1, BLRD04R1, BLRD05R1, BLRD06R1, BLRD07R1, } \\
\text { BLRD08R1, BLRD09R1, BLRD10R1, BLRD11R1 }\end{array}$ \\
\hline & & $\begin{array}{l}\text { Early characterization locations: } \\
\text { Z2-EU28B-317, Z2-EU28B-318, Z2-EU28B-319, Z2-EU28B-320, } \\
\text { Z2-EU28B-321, Z2-EU28B-322, Z2-EU28B-323 }\end{array}$ \\
\hline
\end{tabular}

The number of samples collected, sampling intervals, and chemicals and radionuclides analyzed at each location varied by project. Sampling and analytical details for each sample location are presented in Table F.2. The analytical data are summarized in Table F.3 and evaluated in Sect. 2.2.5. The number of analyses conducted in the Class 3 SU are presented below by analyte group.

\begin{tabular}{|c|c|c|c|c|}
\hline Metals $^{a}$ & PPCBs & Radionuclides & SVOCs & VOCs \\
\hline 13 & 13 & 21 & 13 & 8 \\
\hline \multicolumn{5}{|c|}{$\begin{array}{l}{ }^{a} \text { Compliance location S4 was sampled on three different dates. The metals suite analyzed } \\
\text { during those sampling events consisted of a select group of metals (cadmium, lead, mercury, } \\
\text { nickel, selenium, silver, and uranium). Uranium was analyzed during all three sampling events } \\
\text { but the remaining six metals were analyzed during only one sampling event. The metals tally } \\
\text { presented here includes only the one sampling event at S4 during which all seven metals were } \\
\text { analyzed. }\end{array}$} \\
\hline $\begin{array}{l}\mathrm{PPCB}=\text { pest } \\
\text { SVOC = sem } \\
\text { VOC }=\text { volat }\end{array}$ & $\begin{array}{l}\text { and polychl } \\
\text { tile organic } \\
\text { ganic compe }\end{array}$ & $\begin{array}{l}\text { ed biphenyl } \\
\text { ound }\end{array}$ & & \\
\hline
\end{tabular}

\section{\begin{tabular}{|l|l|} 
2.2.4 & INFRASTRUCTURE \\
\hline
\end{tabular}}

No infrastructure sampling was performed in EU Z2-28.

\section{\begin{tabular}{l|l} 
2.2.5 & EU EVALUATION \\
\hline
\end{tabular}}

Characterization data and other information are evaluated for EU Z2-28 in this section. Analytical data in the following summaries are presented by analyte group, which are summarized only if that group was analyzed in the 
samples from the unit being summarized. Within each summary, the data are evaluated by comparing to certain criteria that includes the Zone 2 soils maximum remediation level (Max RL), Zone 2 soils average remediation level (Avg RL), the $1 \times 10^{-5}$ industrial preliminary remediation goal (Ind PRG), the ETTP soils background composition (Bkg), Zone 2 groundwater screening levels (GW SL), and the $1 \times 10^{-6}$ residential preliminary remediation goal (Res PRG). If a particular criterion does not apply to any member of an analyte group, it is not tabulated for that analyte group; if a particular criterion does not apply to all analytes within an analyte group, those analytes to which it does not apply are notated with NA (not applicable). Individual metals and radionuclides, which are naturally occurring, are reported in the summaries only if one or more criterion is exceeded. Organic chemicals, which are not naturally occurring, are reported if they are detected even if no criteria are exceeded. Table F.4 of this PCCR presented the Max RL, Avg RL, Ind PRG, Bkg, GW SL, and Res PRG criteria values as they pertain to the analytes listed in Appendix A of the RDR/RAWP (i.e., the QAPP).

Because the carcinogenic risk associated with the concentration of radium and thorium isotopes in the natural background at ETTP exceeds the cumulative risk goal of $1 \times 10^{-4}$, RL values for these radionuclides are based on alternative concentration levels rather than risk. The alternative concentration levels of $5 \mathrm{pCi} / \mathrm{g}$ above background (Avg RL) and $15 \mathrm{pCi} / \mathrm{g}$ above background (Max RL) were set as low as reasonably achievable (ALARA) under the site-specific conditions. Because site-specific background concentrations of these radionuclides exceed the target risk range, residual concentrations of these radionuclides and their decay series are not considered in estimates of residual risk following any remedial actions.

The Zone 2 ROD states that Avg RL and Max RL exceedances by Ra-226, Th-230, and Th-232 will be evaluated by summing above-background concentrations of the greater of Ra-226 or Th-230 with the above-background concentrations of Th-232 and comparing the results to $5 \mathrm{pCi} / \mathrm{g}$ (average RL) and $15 \mathrm{pCi} / \mathrm{g}$ (maximum RL). Average and maximum RL exceedances for these radionuclides, if any, are reported in the data summaries below and in Tables F.2 through F.4 as "Ra/Th decay series", and individual RL exceedances by Ra-226, Th-230, and Th-232 are reported as NA. The Ra/Th decay series data are summarized in the following sections only if an average or maximum RL has been exceeded, consistent with the description in the preceding paragraph for reporting radionuclides. Discussion of the $\mathrm{Ra} / \mathrm{Th}$ decay series calculation, including the manner in which the calculation is performed, is presented in Sect. 3.3 of this PCCR.

\section{Conceptual Site Model}

The 21-acre EU Z2-28 is located along the northern boundary of Zone 2 in the Haul Road EU Group. The entire northern portion of the EU was initially a Class $3 \mathrm{SU}$. The southeastern portion of the EU associated with the K-1407-C Soil Piles FFA Site was classified as Class 1 and Class 2 SUs. There is one FFA site in EU Z2-28, the K-1407-C Soil Piles (commonly referred to as Rusty's Mountain). There are six facilities in the EU and a former asphalt plant that has been demolished.

A Class 3 walkover assessment was conducted in the EU. Five anthropogenic features were identified, and six facilities were inspected and evaluated as potential contaminant release sites. Historical sampling in the Class $3 \mathrm{SU}$ resulted in collection of soil samples along the Haul Road corridor prior to road construction, and a sampling program in the central portion of the EU in the area of the former asphalt plant footprint had acquired several samples where anomalous features were identified. Based on the results of these previous investigations, no additional biased sampling was conducted under the DVS as a result of the Class 3 assessments.

In the Class 3 SUs, which includes all acreage in the northern portion of the EU, the conceptual site model lists the potential for release of contaminants on the ground surface, which was the site of the Blair Road Asphalt Plant. There was a borrow area where very limited excavation occurred, and there was a scale house along Blair Road where roll-off boxes were occasionally staged prior to entering the site. Releases in these areas would have impacted surface soils and a full suite of chemicals and radionuclides would be potential contaminants.

At the K-1407-C Soil Piles FFA Site, soils excavated from the northern portion of the site have been accumulated in an approximately 2 -acre area. These soils are predominantly impacted by contamination fromprevious operations in the northern portion of the plant. Soils were placed in the area if they exhibited elevated radioactivity or as a matter of convenience rather than hauling off site. Surface contamination of soil with radiological COCs is known in the area. Several very small areas, several cubic yards in volume, have been identified with radiological COCs above Zone 2 maximum RLs. These small volumes represent less than $1 \%$ of the total surface area of the site. Subsurface conditions probably reflect a similar pattern with small isolated volumes of radioactive contamination distributed through the total soil mass. The small size of the isolated contamination generally corresponds to individual mounds 
(i.e., dump truck load) of material. It is not feasible to identify all these small volumes in the subsurface with drilling and sampling techniques. To date, subsurface sampling has not reported any radiological contamination above Zone 2 maximum RLs from the K-1407-C Soil Piles FFA Site.

\section{Intermedia Transfer Potential}

- Soil to air-There is a low probability that soil and solid waste particulates would be transported by air from the areas identified as potential sources of contamination because the area has an existing well that is established and maintained and grass vegetative cover.

- Soil to surface water and sediment-Impacts to surface water from the areas identified as potential sources of contamination is moderate to high. Remobilization of sediments along Mitchell Branch could occur during flood conditions with discharge to Poplar Creek. Infiltration of precipitation through debris and rubble in the fill area south of Poplar Creek is probable. The infiltrating water would discharge to Poplar Creek.

- Soil to groundwater-The potential for impact to groundwater in this EU is low. Any radiological contamination would be preferentially adsorbed to shallow subsurface soil, but there is potential for contaminant migration by particulate and colloidal transport. The entire area is in proximity to surface water bodies and would be the primary receiving waters from any contamination in the EU .

\section{Groundwater Evaluation}

There are three groundwater monitoring wells in EU Z2-28 - one unconsolidated zone well (UNW-006) located on the east end of the K-1407-C Soils Pile FFA Site (Rusty's Mountain), and a well pair [one bedrock well and one unconsolidated zone well (BRW-013 and UNW-011, respectively)] located on the western boundary of Rusty's Mountain. These monitoring wells provide data on the impact to local groundwater from soils deposited in Rusty's Mountain and are the baseline wells (upgradient) for the K-1407-C Pond Closure Site, which is in EU Z2-28 and downgradient of Rusty's Mountain.

These three monitoring wells were constructed in the late 1980s prior to closure of the K-1407 Ponds. The unconsolidated zone wells were constructed in October 1985 to top of bedrock (approximately $30 \mathrm{ft}$ bgs), and the present water levels are above top of rock (approximately $23 \mathrm{ft} \mathrm{bgs}$ ). The bedrock well was constructed in 1987 to a total depth of $165 \mathrm{ft}$ bgs. These water-level relationships indicate there is a single aquifer, and the unconsolidated zone and bedrock formations locally are well connected and act as a single hydrologic unit.

Groundwater data have been collected since the wells were first constructed until the mid 1990s. Several rounds of sampling in 1994 and 1995 represent the most comprehensive set of groundwater samples from these wells. Laboratory analyses of samples collected from the three wells show sporadic detection of a few metals at greater than MCL concentrations (arsenic, cadmium, lead, thallium, and uranium). Detections of radionuclides at above MCL concentrations is restricted to one occurrence for alpha activity in UNW-011. Review of the historic data for UNW-011 identified the single alpha exceedance as a statistical outlier which is not considered to be representative of the local groundwater conditions. A wide range of variability in the analytical results for other radionuclides was also noted in the data set, often for the same sampling event. Since there is no QA/QC information available, these data are considered to be suspect.

The primary contaminants at Rusty's Mountain are radionuclides in surface soils (predominantly Cs -137 and scattered detections of U-234 and U-238). Regardless of radiological SL values, radionuclides should be immobile in clay-rich soil at Rusty's Mountain. Nonetheless, contaminated soils that exceed maximum RLs or groundwater SLs are recommended for removal, which will eliminate any potential threat to local groundwater.

\section{Sampling Results}

The EU Z2-28 ( 21 acres) has been classified into five Class 1 SUs with a total area of $<0.05$ acres, a single Class 2 SU of 2.5 acres, and the remaining 18 acres classified as a Class 3 SU. The EU lies in a relatively unindustrialized portion of Zone 2 and, compared to the more industrialized interior of Zone 2, is sparsely populated by buildings and paved areas such as sidewalks, roads, and parking lots. The remainder of the EU is covered by trees, shrubs, and maintained lawns.

The dominant feature and area of concern in EU Z2-28 is the K-1407-C Soils Pile FFA Site (Rusty's Mountain), whose boundaries coincide with the Class 2 SU. The Class 1 SUs are all located within the K-1407-C Soil Piles FFA Site and, therefore, lie within the boundaries of the Class 2 SU. The Class 1 SUs were set up to have focused 
characterization define the extent of Zone 2 soils COCs maximum RL exceedances. Six area definition locations were also set up within the Class $2 \mathrm{SU}$ of EU Z2-28. The area definition locations focus characterization to define the areal extent of Zone 2 soils COCs average RL exceedances. All DVS Class 2 SU sampling occurred in the area definition locations. The remainder of the Class 2 SU has been thoroughly addressed by early characterization and other historical sampling.

A Class 3 SU walkover assessment was conducted over the Class 3 SU. Because EU Z2-28 is located in an industrialized portion of ETTP, anthropogenic features are common. However, many of the anthropogenic features are facilities, and six facilities were evaluated as part of the Class $3 \mathrm{SU}$ walkover assessment (Sect. 2.1.3.3); no biased sampling around facilities was conducted based on assessment conclusions that the facilities were not potential sources of contamination. Five additional anthropogenic features were identified in the EU (Sect. 2.1.3.2). No anthropogenic features were selected for biased sampling based on radiation survey results, visual evaluations, or the extensive historical sampling in the Class $3 \mathrm{SU}$ (Sect. 2.1.3.4).

A summary of sampling results for EU Z2-28 is shown in the following tables. The summary begins with summary presentations of analytical results for focused sampling efforts in the EU and concludes with an overall summary for EU Z2-28. Focused sampling efforts summarized below included the Class 1 SUs, Class 2 SU area definition locations, Class $2 \mathrm{SU}$ historical sampling outside the area definition locations, and historical sampling in the Class 3 SU. Because of the importance of the Class $1 \mathrm{SU}$ and area definition location sampling results to the decision for EU Z2-28, the sampling results and conclusions drawn are summarized in Table F.5. The summary for EU Z2-28 includes both data summary tables and a written description of the nature and extent of chemicals and radionuclides observed. Tables F.3 and F.4 provide a summary of all EU Z2-28 data while sample locations are shown on Fig. F.4.

DVS Sampling in RAD192 Class 1 SU: Four-point composite step-out sample Z2-EU28B-117 was collected from within the RAB defined by the BAR survey at historical sample RAD192. The four sampling points for the composite sample saturated the small RAB area defined by the BAR survey, consequently, a confirmation sample was not collected. Historical sample RAD192 was analyzed for radionuclides and had a maximum RL exceedance for the $\mathrm{Ra} / \mathrm{Th}$ decay series, average RL exceedances for $\mathrm{Cs}-137$ and the Ra/Th decay series, and several radionuclide industrial PRG and background exceedances. The step-out sample was analyzed for radionuclides. Analytical results illustrate there are several radionuclide industrial PRG exceedances but no RL exceedances within the RAB (see summary table below).

EU Z2-28 RAD192 Class 1 SU historical radionuclides with background, PRG, and/or RL exceedances (pCi/g)

\begin{tabular}{|c|c|c|c|c|c|c|c|c|c|c|c|}
\hline \multirow[b]{2}{*}{ Analyte } & \multirow[b]{2}{*}{$\begin{array}{c}\text { Detect } \\
\text { frequency }\end{array}$} & \multirow[b]{2}{*}{$\begin{array}{c}\text { Minimum } \\
\text { detect }\end{array}$} & \multirow[b]{2}{*}{$\begin{array}{c}\text { Maximum } \\
\text { detect }\end{array}$} & \multirow[b]{2}{*}{$\begin{array}{c}\text { Location(s) of } \\
\text { maximum detect }\end{array}$} & \multirow{2}{*}{$\begin{array}{c}\text { Avg } \\
\text { detected } \\
\text { result }\end{array}$} & \multicolumn{6}{|c|}{ Number of analyses exceeding criteria } \\
\hline & & & & & & $\begin{array}{c}\text { Max } \\
\text { RL }\end{array}$ & $\begin{array}{l}\text { Avg } \\
\text { RL }\end{array}$ & $\begin{array}{l}\text { Ind } \\
\text { PRG }\end{array}$ & Bkg & $\begin{array}{l}\text { GW } \\
\text { SL }\end{array}$ & $\begin{array}{l}\text { Res } \\
\text { PRG }\end{array}$ \\
\hline Cesium-137 & $1 / 1$ & 4.71 & 4.71 & RAD192 & 4.71 & 0 & 1 & 1 & NA & NA & 1 \\
\hline Neptunium-237 & $1 / 1$ & 1.74 & 1.74 & RAD192 & 1.74 & 0 & 0 & 0 & NA & NA & 1 \\
\hline Potassium-40 & $1 / 1$ & 5.85 & 5.85 & RAD192 & 5.85 & NA & NA & 1 & 0 & NA & 1 \\
\hline Radium-226 & $1 / 1$ & 11.9 & 11.9 & RAD192 & 11.9 & NA & NA & 1 & 1 & NA & 1 \\
\hline Technetium-99 & $1 / 1$ & 137.9 & 137.9 & RAD192 & 137.9 & NA & NA & 0 & NA & NA & 1 \\
\hline Thorium-228 & $1 / 1$ & 1.24 & 1.24 & RAD192 & 1.24 & NA & NA & 1 & 0 & NA & 1 \\
\hline Thorium -230 & $1 / 1$ & 28 & 28 & RAD192 & 28 & NA & NA & 0 & 1 & NA & 1 \\
\hline Thorium-232 & $1 / 1$ & 1.18 & 1.18 & RAD192 & 1.18 & NA & NA & 1 & 0 & NA & 1 \\
\hline $\mathrm{Ra} / \mathrm{Th}$ decay series & $1 / 1$ & 26.8 & 26.8 & RAD192 & 26.8 & 1 & 1 & $\mathrm{NA}$ & NA & NA & NA \\
\hline Uranium-233/234 & $1 / 1$ & 51.3 & 51.3 & RAD192 & 51.3 & 0 & 0 & 0 & NA & 0 & 1 \\
\hline Uranium-235 & $2 / 2$ & 2.43 & 6.37 & RAD192 & 4.4 & 0 & 0 & 1 & NA & 0 & 2 \\
\hline Uranium-238 & $1 / 1$ & 28.8 & 28.8 & RAD192 & 28.8 & 0 & 0 & 1 & 1 & 0 & 1 \\
\hline Avg $=$ average & \multicolumn{11}{|c|}{$\mathrm{NA}=$ not applicable } \\
\hline $\mathrm{Bkg}=$ background & & & inary remedi & ion goal & & & & & & & \\
\hline $\mathrm{EU}=$ exposure unit & & Res $=$ resider & tial & & & & & & & & \\
\hline $\mathrm{GW}=$ groundwater & \multirow{2}{*}{\multicolumn{11}{|c|}{$\begin{array}{l}\mathrm{RL}=\text { remediation level } \\
\mathrm{SL}=\text { screening level }\end{array}$}} \\
\hline Ind = industrial & & & & & & & & & & & \\
\hline Max $=$ maximum & \multicolumn{11}{|c|}{$\mathrm{SU}=$ soil unit } \\
\hline
\end{tabular}


EU Z2-28 RAD192 Class 1 SU four-point composite sample radionuclides with background, PRG, and/or RL exceedances (pCi/g)

\begin{tabular}{|c|c|c|c|c|c|c|c|c|c|c|c|}
\hline \multirow[b]{2}{*}{ Analyte } & \multirow[b]{2}{*}{$\begin{array}{c}\text { Detect } \\
\text { frequency }\end{array}$} & \multirow[b]{2}{*}{$\begin{array}{c}\text { Minimum } \\
\text { detect }\end{array}$} & \multirow[b]{2}{*}{$\underset{\text { detect }}{\text { Maximum }}$} & \multirow[b]{2}{*}{$\begin{array}{c}\text { Location(s) of } \\
\text { maximum detect }\end{array}$} & \multirow{2}{*}{$\begin{array}{c}\text { Avg } \\
\text { detected } \\
\text { result }\end{array}$} & \multicolumn{6}{|c|}{ Number of analyses exceeding criteria } \\
\hline & & & & & & $\begin{array}{c}\text { Max } \\
\text { RL }\end{array}$ & $\begin{array}{l}\text { Avg } \\
\text { RL }\end{array}$ & $\begin{array}{l}\text { Ind } \\
\text { PRG }\end{array}$ & Bkg & $\begin{array}{l}\text { GW } \\
\text { SL }\end{array}$ & $\begin{array}{r}\text { Res } \\
\text { PRG }\end{array}$ \\
\hline Potassium-40 & $1 / 1$ & 7.08 & 7.08 & Z2-EU28B-117 & 7.08 & NA & NA & 1 & 0 & NA & 1 \\
\hline Radium-226 & $1 / 1$ & 1.5 & 1.5 & Z2-EU28B-117 & 1.5 & NA & NA & 1 & 1 & NA & 1 \\
\hline Technetium-99 & $1 / 1$ & 12.1 & 12.1 & Z2-EU28B-117 & 12.1 & NA & NA & 0 & NA & NA & 1 \\
\hline Thorium -228 & $1 / 1$ & 2.36 & 2.36 & Z2-EU28B-117 & 2.36 & NA & NA & 1 & 1 & NA & 1 \\
\hline Thorium -230 & $1 / 1$ & 3.47 & 3.47 & Z2-EU28B-117 & 3.47 & NA & NA & 0 & 1 & NA & 0 \\
\hline Thorium -232 & $1 / 1$ & 2 & 2 & Z2-EU28B-117 & 2 & NA & NA & 1 & 1 & NA & 1 \\
\hline Uranium-234 & $1 / 1$ & 10.5 & 10.5 & Z2-EU28B-117 & 10.5 & 0 & 0 & 0 & NA & 0 & 1 \\
\hline Uranium-235 & $1 / 1$ & 0.433 & 0.433 & Z2-EU28B-117 & 0.433 & 0 & 0 & 0 & NA & 0 & 1 \\
\hline Uranium-238 & $1 / 1$ & 5.53 & 5.53 & Z2-EU28B-117 & 5.53 & 0 & 0 & 0 & 1 & 0 & 1 \\
\hline
\end{tabular}

\begin{tabular}{ll}
\hline Avg = average & NA = not applicable \\
Bkg = background & PRG = preliminary remediation goal \\
EU = exposure unit & Res = residential \\
GW = groundwater & RL = remediation level \\
Ind = industrial & SL = screening level \\
Max = maximum & SU = soil unit
\end{tabular}

DVS Sampling in RAD199 Class 1 SU: The sample from historical location RAD199 had maximum RL exceedances for Cs -137 and the Ra/Th decay series; average RL exceedances for Cs -137 , the Ra/Th decay series, U-235, and U-238; groundwater SL exceedances for U-234 and U-238; and several radionuclide industrial PRG and background exceedances (see summary below).

EU Z2-28 RAD199 Class 1 SU historical radionuclides with background, PRG, and/or RL exceedances (pCi/g)

\begin{tabular}{|c|c|c|c|c|c|c|c|c|c|c|c|}
\hline \multirow[b]{2}{*}{ Analyte } & \multirow[b]{2}{*}{$\begin{array}{c}\text { Detect } \\
\text { frequency }\end{array}$} & \multirow[b]{2}{*}{$\begin{array}{c}\text { Minimum } \\
\text { detect }\end{array}$} & \multirow[b]{2}{*}{$\begin{array}{c}\text { Maximum } \\
\text { detect }\end{array}$} & \multirow[b]{2}{*}{$\begin{array}{c}\text { Location(s) of } \\
\text { maximum detect }\end{array}$} & \multirow{2}{*}{$\begin{array}{c}\text { Avg } \\
\text { detected } \\
\text { result }\end{array}$} & \multicolumn{6}{|c|}{ Number of analyses exceeding criteria } \\
\hline & & & & & & $\begin{array}{c}\text { Max } \\
\text { RL }\end{array}$ & $\begin{array}{l}\text { Avg } \\
\text { RL }\end{array}$ & $\begin{array}{c}\text { Ind } \\
\text { PRG } \\
\end{array}$ & Bkg & $\begin{array}{l}\text { GW } \\
\text { SL }\end{array}$ & $\begin{array}{r}\text { Res } \\
\text { PRG }\end{array}$ \\
\hline Cesium-137 & $1 / 1$ & 48 & 48 & RAD199 & 48 & 1 & 1 & 1 & NA & NA & 1 \\
\hline Neptunium-237 & $1 / 1$ & 4.26 & 4.26 & RAD199 & 4.26 & 0 & 0 & 1 & NA & NA & 1 \\
\hline Potassium-40 & $1 / 1$ & 6.8 & 6.8 & RAD199 & 6.8 & NA & NA & 1 & 0 & NA & 1 \\
\hline Radium-226 & $1 / 1$ & 35.8 & 35.8 & RAD199 & 35.8 & NA & NA & 1 & 1 & NA & 1 \\
\hline Technet ium-99 & $1 / 1$ & 663.7 & 663.7 & RAD199 & 663.7 & NA & NA & 0 & NA & NA & 1 \\
\hline Thorium -228 & $1 / 1$ & 3.69 & 3.69 & RAD199 & 3.69 & NA & NA & 1 & 1 & NA & 1 \\
\hline Thorium -230 & $1 / 1$ & 186.7 & 186.7 & RAD199 & 186.7 & NA & NA & 0 & 1 & NA & 1 \\
\hline Thorium -232 & $1 / 1$ & 2.51 & 2.51 & RAD199 & 2.51 & NA & NA & 1 & 1 & NA & 1 \\
\hline $\mathrm{Ra} / \mathrm{Th}$ decay series & $1 / 1$ & 186.06 & 186.06 & RAD199 & 186.06 & 1 & 1 & NA & NA & NA & NA \\
\hline Uranium-233/234 & $1 / 1$ & 449 & 449 & RAD199 & 449 & 0 & 0 & 1 & NA & 1 & 1 \\
\hline Uranium-235 & $1 / 1$ & 22.4 & 22.4 & RAD199 & 22.4 & 0 & 1 & 1 & NA & 0 & 1 \\
\hline Uranium-238 & $1 / 1$ & 203 & 203 & RAD199 & 203 & 0 & 1 & 1 & 1 & 1 & 1 \\
\hline $\begin{array}{l}\text { Avg = average } \\
\mathrm{Bkg}=\text { background } \\
\mathrm{EU}=\text { exposure unit } \\
\mathrm{GW}=\text { groundwater } \\
\text { Ind = industrial } \\
\text { Max = maximum }\end{array}$ & & $\begin{array}{l}\mathrm{NA}=\text { not a } \\
\mathrm{PRG}=\text { prel } \\
\text { Res }=\text { resid } \\
\mathrm{RL}=\text { reme } \\
\mathrm{SL}=\text { scree } \\
\mathrm{SU}=\text { soil } \mathrm{u}\end{array}$ & $\begin{array}{l}\text { pplicable } \\
\text { iminary reme } \\
\text { ential } \\
\text { diation level } \\
\text { ing level } \\
\text { nit }\end{array}$ & ation goal & & & & & & & \\
\hline
\end{tabular}

A confirmation sample was collected at Z2-EU28B-118 in proximity to historical sample location RAD199. The confirmation sample was analyzed for metals, PCBs, radionuclides, SVOCs, and VOCs and analytical results confirmed the $\mathrm{Ra} / \mathrm{Th}$ decay series maximum RL exceedance but did not confirm the Cs-137 maximum RL exceedance (see summary below).

Analy tical results for the RAD 199 Class 1 SU confirmation sample show a maximum RL exceedance for the Ra/Th decay series; average RL exceedances for Cs -137 , Np-237, Ra/Th decay series, U-235, and U-238; groundwater SL 
exceedances for U-234 and U-238; industrial PRG exceedances for several radionuclides; background exceedances for several metals and radionuclides; and PCB and SVOC detections.

EU Z2-28 RAD199 Class 1 SU confirmation sample radionuclides with background, PRG, and/or RL exceedances (pCi/g)

\begin{tabular}{|c|c|c|c|c|c|c|c|c|c|c|c|}
\hline \multirow[b]{2}{*}{ Analyte } & \multirow[b]{2}{*}{$\begin{array}{c}\text { Detect } \\
\text { frequency }\end{array}$} & \multirow[b]{2}{*}{$\begin{array}{c}\text { Minimum } \\
\text { detect }\end{array}$} & \multirow[b]{2}{*}{$\begin{array}{c}\text { Maximum } \\
\text { detect }\end{array}$} & \multirow[b]{2}{*}{$\begin{array}{l}\text { Location(s) of } \\
\text { maximum detect }\end{array}$} & \multirow{2}{*}{$\begin{array}{c}\text { Avg } \\
\text { detected } \\
\text { result }\end{array}$} & \multicolumn{6}{|c|}{ Number of analyses exceeding criteria } \\
\hline & & & & & & $\begin{array}{c}\text { Max } \\
\text { RL } \\
\end{array}$ & $\begin{array}{l}\text { Avg } \\
\text { RL }\end{array}$ & $\begin{array}{c}\text { Ind } \\
\text { PRG } \\
\end{array}$ & Bkg & $\begin{array}{c}\text { GW } \\
\text { SL } \\
\end{array}$ & $\begin{array}{r}\text { Res } \\
\text { PRG }\end{array}$ \\
\hline Cesium-137 & $1 / 1$ & 13.8 & 13.8 & Z2-EU28B-118 & 13.8 & 0 & 1 & 1 & NA & NA & 1 \\
\hline Neptunium-237 & $1 / 1$ & 15.6 & 15.6 & Z2-EU28B-118 & 15.6 & 0 & 1 & 1 & NA & NA & 1 \\
\hline Radium-226 & $1 / 1$ & 1.84 & 1.84 & Z2-EU28B-118 & 1.84 & NA & NA & 1 & 1 & NA & 1 \\
\hline Technetium-99 & $1 / 1$ & 723 & 723 & Z2-EU28B-118 & 723 & NA & NA & 0 & NA & NA & 1 \\
\hline Thorium -228 & $1 / 1$ & 1.07 & 1.07 & Z2-EU28B-118 & 1.07 & NA & NA & 1 & 0 & NA & 1 \\
\hline Thorium -230 & $1 / 1$ & 94.4 & 94.4 & Z2-EU28B-118 & 94.4 & NA & NA & 0 & 1 & NA & 1 \\
\hline Thorium -232 & $1 / 1$ & 1.32 & 1.32 & Z2-EU28B-118 & 1.32 & NA & NA & 1 & 0 & NA & 1 \\
\hline $\mathrm{Ra} / \mathrm{Th}$ decay series & $1 / 1$ & 93.2 & 93.2 & Z2-EU28B-118 & 93.2 & 1 & 1 & NA & NA & NA & NA \\
\hline Uranium-234 & $1 / 1$ & 163 & 163 & Z2-EU28B-118 & 163 & 0 & 0 & 0 & NA & 1 & 1 \\
\hline Uranium-235 & $1 / 1$ & 10.5 & 10.5 & Z2-EU28B-118 & 10.5 & 0 & 1 & 1 & NA & 0 & 1 \\
\hline Uranium-238 & $1 / 1$ & 82.9 & 82.9 & Z2-EU28B-118 & 82.9 & 0 & 1 & 1 & 1 & 1 & 1 \\
\hline Avg $=$ average & & & \multicolumn{9}{|c|}{ NA = not applicable } \\
\hline $\mathrm{Bkg}=$ background & & & \multirow{2}{*}{\multicolumn{9}{|c|}{$\begin{array}{l}\mathrm{PRG}=\text { preliminary remediation goal } \\
\text { Res = residential }\end{array}$}} \\
\hline $\mathrm{EU}=$ exposure unit & & & & & & & & & & & \\
\hline $\mathrm{GW}=$ groundwater & & & \multicolumn{9}{|c|}{$\mathrm{RL}=$ remediation level } \\
\hline Ind $=$ industrial & & & \multicolumn{9}{|c|}{$\mathrm{SL}=$ screening level } \\
\hline Max $=$ maximum & & & \multicolumn{9}{|c|}{$\mathrm{SU}=$ soil unit } \\
\hline
\end{tabular}

EU Z2-28 RAD199 Class 1 SU confirmation sample metals with background, PRG, GW SL, and/or RL exceedances (mg/kg)

\begin{tabular}{|c|c|c|c|c|c|c|c|c|c|c|c|}
\hline \multirow[b]{2}{*}{ Analyte } & \multirow[b]{2}{*}{$\begin{array}{c}\text { Detect } \\
\text { frequency }\end{array}$} & \multirow[b]{2}{*}{$\begin{array}{c}\text { Minimum } \\
\text { detect }\end{array}$} & \multirow[b]{2}{*}{$\begin{array}{c}\text { Maximum } \\
\text { detect }\end{array}$} & \multirow{2}{*}{$\begin{array}{c}\text { Location(s) of } \\
\text { maximum } \\
\text { detect }\end{array}$} & \multirow{2}{*}{$\begin{array}{c}\text { Avg } \\
\text { detected } \\
\text { result }\end{array}$} & \multicolumn{6}{|c|}{ Number of analyses exceeding criteria } \\
\hline & & & & & & $\begin{array}{c}\text { Max } \\
\text { RL }\end{array}$ & $\begin{array}{c}\text { Avg } \\
\text { RL }\end{array}$ & $\begin{array}{c}\text { Ind } \\
\text { PRG }\end{array}$ & Bkg & $\begin{array}{l}\text { GW } \\
\text { SL }\end{array}$ & $\begin{array}{c}\text { Res } \\
\text { PRG }\end{array}$ \\
\hline Aluminum & $1 / 1$ & 9,700 & 9,700 & Z2-EU28B-118 & 9,700 & NA & NA & 0 & 0 & NA & 1 \\
\hline Arsenic & $1 / 1$ & 8.2 & 8.2 & Z2-EU28B-118 & 8.2 & 0 & 0 & 0 & 0 & 0 & 1 \\
\hline Cadmium & $1 / 1$ & $0.92 \mathrm{~J}$ & $0.92 \mathrm{~J}$ & Z2-EU28B-1 18 & 0.92 & NA & NA & 0 & 1 & NA & 0 \\
\hline Calcium & $1 / 1$ & $290,000 \mathrm{~J}$ & $290,000 \mathrm{~J}$ & Z2-EU28B-118 & 290,000 & NA & NA & NA & 1 & NA & NA \\
\hline Chromium & $1 / 1$ & $44 \mathrm{~J}$ & $44 \mathrm{~J}$ & Z2-EU28B-118 & 44 & NA & NA & 0 & 0 & 0 & 1 \\
\hline Copper & $1 / 1$ & $69 \mathrm{~J}$ & $69 \mathrm{~J}$ & Z2-EU28B-118 & 69 & NA & NA & 0 & 1 & NA & 0 \\
\hline Magnesium & $1 / 1$ & $23,000 \mathrm{~J}$ & $23,000 \mathrm{~J}$ & Z2-EU28B-118 & 23,000 & NA & NA & NA & 1 & NA & NA \\
\hline Manganese & $1 / 1$ & $250 \mathrm{~J}$ & $250 \mathrm{~J}$ & Z2-EU28B-118 & 250 & NA & NA & 0 & 0 & NA & 1 \\
\hline Mercury & $1 / 1$ & 36 & 36 & Z2-EU28B-118 & 36 & 0 & 0 & 0 & 1 & NA & 1 \\
\hline Nickel & $1 / 1$ & $310 \mathrm{~J}$ & $310 \mathrm{~J}$ & Z2-EU28B-118 & 310 & NA & NA & 0 & 1 & NA & 1 \\
\hline Uranium & $1 / 1$ & $78 \mathrm{~J}$ & $78 \mathrm{~J}$ & Z2-EU28B-118 & 78 & NA & NA & 0 & NA & NA & 1 \\
\hline Vanadium & $1 / 1$ & $14 \mathrm{~J}$ & $14 \mathrm{~J}$ & Z2-EU28B-118 & 14 & NA & NA & 0 & 0 & NA & 1 \\
\hline
\end{tabular}

Avg = average NA = not applicable

$\mathrm{Bkg}=$ background $\quad \mathrm{PRG}=$ preliminary remediation goal

$\mathrm{EU}=$ exposure unit $\quad$ Res $=$ residential

$\mathrm{GW}=$ groundwater $\quad \mathrm{RL}=$ remediation level

Ind $=$ industrial $\quad \mathrm{SL}=$ screening level

Max $=$ maximum $\quad \mathrm{SU}=$ soil unit 
EU Z2-28 RAD199 Class 1 SU confirmation sample PCB detects (ug/kg)

\begin{tabular}{|c|c|c|c|c|c|c|c|c|c|}
\hline \multirow[b]{2}{*}{ Analyte } & \multirow[b]{2}{*}{$\begin{array}{c}\text { Detect } \\
\text { frequency }\end{array}$} & \multirow[b]{2}{*}{$\begin{array}{l}\text { Minimum } \\
\text { detect }\end{array}$} & \multirow[b]{2}{*}{$\begin{array}{c}\text { Maximum } \\
\text { detect }\end{array}$} & \multirow{2}{*}{$\begin{array}{l}\text { Location(s) of } \\
\text { maximum } \\
\text { detect }\end{array}$} & \multirow{2}{*}{$\begin{array}{c}\text { Avg } \\
\text { detected } \\
\text { result }\end{array}$} & \multicolumn{4}{|c|}{$\begin{array}{l}\text { Number of analyses } \\
\text { exceeding criteria }\end{array}$} \\
\hline & & & & & & $\begin{array}{l}\text { Max } \\
\text { RL }\end{array}$ & $\begin{array}{l}\text { Avg } \\
\text { RL }\end{array}$ & $\begin{array}{l}\text { Ind } \\
\text { PRG }\end{array}$ & $\begin{array}{l}\text { Res } \\
\text { PRG }\end{array}$ \\
\hline PCB-1260 & $1 / 1$ & 1,400 & 1,400 & Z2-EU28B-118 & 1,400 & 0 & 0 & 0 & 1 \\
\hline PCB & $1 / 1$ & 1,400 & 1,400 & Z2-EU28B-118 & 1,400 & 0 & 0 & 0 & 1 \\
\hline
\end{tabular}

Avg = average

$\mathrm{EU}=$ exposure unit

$\mathrm{PRG}=$ preliminary remediation goal

Ind $=$ industrial

Res $=$ residentia

Max = maximum

$\mathrm{RL}=$ remediation level

$\mathrm{PCB}=$ polychlorinated biphenyl

$\mathrm{SU}=$ soil unit

EU Z2-28 RAD199 Class 1 SU confirmation sample SVOC detects (ug/kg)

\begin{tabular}{|c|c|c|c|c|c|c|c|c|}
\hline \multirow[b]{2}{*}{ Analyte } & \multirow[b]{2}{*}{$\begin{array}{c}\text { Detect } \\
\text { frequency }\end{array}$} & \multirow[b]{2}{*}{$\begin{array}{c}\text { Minimum } \\
\text { detect }\end{array}$} & \multirow[b]{2}{*}{$\begin{array}{c}\text { Maximum } \\
\text { detect }\end{array}$} & \multirow{2}{*}{$\begin{array}{c}\text { Location(s) of } \\
\text { maximum } \\
\text { detect }\end{array}$} & \multirow{2}{*}{$\begin{array}{c}\text { Avg } \\
\text { detected } \\
\text { result }\end{array}$} & \multicolumn{3}{|c|}{$\begin{array}{l}\text { Number of analyses } \\
\text { exceeding criteria }\end{array}$} \\
\hline & & & & & & $\begin{array}{c}\text { Ind } \\
\text { PRG }\end{array}$ & $\begin{array}{c}\text { GW } \\
\text { SL }\end{array}$ & $\begin{array}{c}\text { Res } \\
\text { PRG }\end{array}$ \\
\hline Benzo(b)fluoranthene & $1 / 1$ & $35 \mathrm{~J}$ & $35 \mathrm{~J}$ & Z2-EU28B-118 & 35 & 0 & NA & 0 \\
\hline Chrysene & $1 / 1$ & $19 \mathrm{~J}$ & $19 \mathrm{~J}$ & Z2-EU28B-118 & 19 & 0 & NA & 0 \\
\hline Pyrene & $1 / 1$ & $38 \mathrm{~J}$ & $38 \mathrm{~J}$ & Z2-EU28B-118 & 38 & 0 & NA & 0 \\
\hline
\end{tabular}

Avg $=$ average

$\mathrm{EU}=$ exposure unit

$\mathrm{GW}=$ groundwater

$\mathrm{PRG}=$ preliminary remediation goal

Ind $=$ industrial

$\mathrm{NA}=$ not applicable

Res $=$ residential

$\mathrm{SL}=$ screening level

$\mathrm{SU}=$ soil unit

SVOC $=$ semivolatile organic compound

VOCs were analyzed for in the sample from Z2-EU28B-118 but were not detected.

Four-point composite step-out sample Z2-EU28B-119 was collected from within the RAB and defined by the BAR survey around RAD199. The step-out sample was analyzed for radionuclides. Analytical results for the RAD199 Class 1 SU four-point composite step-out sample show industrial PRG and background exc eedances for several radionuclides within the RAB but no radionuclide RL exceedances (see summary table below).

EU Z2-28 RAD199 Class 1 SU four-point composite step-out sample radionuclides with background, PRG, and/or RL exceedances (pCi/g)

\begin{tabular}{|c|c|c|c|c|c|c|c|c|c|c|c|}
\hline \multirow[b]{2}{*}{ Analyte } & \multirow[b]{2}{*}{$\begin{array}{c}\text { Detect } \\
\text { frequency }\end{array}$} & \multirow[b]{2}{*}{$\begin{array}{c}\text { Minimum } \\
\text { detect }\end{array}$} & \multirow[b]{2}{*}{$\begin{array}{c}\text { Maximum } \\
\text { detect }\end{array}$} & \multirow[b]{2}{*}{$\begin{array}{l}\text { Location(s) of } \\
\text { maximum detect }\end{array}$} & \multirow{2}{*}{$\begin{array}{c}\text { Avg } \\
\text { detected } \\
\text { result }\end{array}$} & \multicolumn{6}{|c|}{ Number of analyses exceeding criteria } \\
\hline & & & & & & $\begin{array}{c}\text { Max } \\
\text { RL } \\
\end{array}$ & $\begin{array}{c}\text { Avg } \\
\text { RL }\end{array}$ & $\begin{array}{l}\text { Ind } \\
\text { PRG } \\
\end{array}$ & Bkg & $\begin{array}{l}\text { GW } \\
\text { SL } \\
\end{array}$ & $\begin{array}{r}\text { Res } \\
\text { PRG } \\
\end{array}$ \\
\hline Cesium-137 & $1 / 1$ & 0.357 & 0.357 & Z2-EU28B-119 & 0.357 & 0 & 0 & 0 & NA & NA & 1 \\
\hline Neptunium-237 & $1 / 1$ & 0.571 & 0.571 & Z2-EU28B-119 & 0.571 & 0 & 0 & 0 & NA & NA & 1 \\
\hline Potassium-40 & $1 / 1$ & 13.1 & 13.1 & Z2-EU28B-119 & 13.1 & NA & NA & 1 & 0 & NA & 1 \\
\hline Radium-226 & $1 / 1$ & 1.29 & 1.29 & Z2-EU28B-119 & 1.29 & NA & NA & 1 & 1 & NA & 1 \\
\hline Technetium-99 & $1 / 1$ & 16.4 & 16.4 & Z2-EU28B-119 & 16.4 & NA & NA & 0 & NA & NA & 1 \\
\hline Thorium -228 & $1 / 1$ & 1.72 & 1.72 & Z2-EU28B-119 & 1.72 & NA & NA & 1 & 0 & NA & 1 \\
\hline Thorium -230 & $1 / 1$ & 4.25 & 4.25 & Z2-EU28B-119 & 4.25 & NA & NA & 0 & 1 & NA & 1 \\
\hline Thorium -232 & $1 / 1$ & 1.6 & 1.6 & Z2-EU28B-119 & 1.6 & NA & NA & 1 & 0 & NA & 1 \\
\hline Uranium-234 & $1 / 1$ & 11.1 & 11.1 & Z2-EU28B-119 & 11.1 & 0 & 0 & 0 & NA & 0 & 1 \\
\hline Uranium-235 & $1 / 1$ & 0.537 & 0.537 & Z2-EU28B-119 & 0.537 & 0 & 0 & 0 & NA & 0 & 1 \\
\hline Uranium-238 & $1 / 1$ & 6.62 & 6.62 & Z2-EU28B-119 & 6.62 & 0 & 0 & 0 & 1 & 0 & 1 \\
\hline
\end{tabular}

Avg = average NA $=$ not applicable

$\mathrm{Bkg}=$ background $\quad \mathrm{PRG}=$ preliminary remediation goal

$\mathrm{EU}=$ exposure unit $\quad$ Res $=$ residential

$\mathrm{GW}=$ groundwater $\quad \mathrm{RL}=$ remediation level

Ind $=$ industrial $\quad \mathrm{SL}=$ screening level

Max $=$ maximum $\quad \mathrm{SU}=$ soil unit 
DVS Sampling in RAD205 Class 1 SU: Historically, RAD205 Class 1 SU, which encompasses historical sample locations RAD204, RAD205, RAD206, and RAD207, had maximum RL exceedances for the Ra/Th decay series; average RL exceedances for Cs -137 , the Ra/Th decay series, U-235, and U-238; groundwater SL exceedances for U-234 and U-238; and several radionuclide industrial PRG and background exceedances.

EU Z2-28 RAD205 Class 1 SU historical radionuclides with background, PRG, and/or RL exceedances (pCi/g)

\begin{tabular}{|c|c|c|c|c|c|c|c|c|c|c|c|}
\hline \multirow[b]{2}{*}{ Analyte } & \multirow[b]{2}{*}{$\begin{array}{c}\text { Detect } \\
\text { frequency }\end{array}$} & \multirow[b]{2}{*}{$\begin{array}{c}\text { Minimum } \\
\text { detect }\end{array}$} & \multirow[b]{2}{*}{$\begin{array}{c}\text { Maximum } \\
\text { detect }\end{array}$} & \multirow[b]{2}{*}{$\begin{array}{c}\text { Location(s) of } \\
\text { maximum detect }\end{array}$} & \multirow{2}{*}{$\begin{array}{c}\text { Avg } \\
\text { detected } \\
\text { result }\end{array}$} & \multicolumn{6}{|c|}{ Number of analyses exceeding criteria } \\
\hline & & & & & & $\begin{array}{c}\text { Max } \\
\text { RL }\end{array}$ & $\begin{array}{l}\text { Avg } \\
\text { RL }\end{array}$ & $\begin{array}{l}\text { Ind } \\
\text { PRG }\end{array}$ & Bkg & $\begin{array}{c}\text { GW } \\
\text { SL }\end{array}$ & $\begin{array}{r}\text { Res } \\
\text { PRG }\end{array}$ \\
\hline Cesium-137 & $4 / 4$ & 0.021 & 15.9 & RAD205 & 8.42 & 0 & 3 & 3 & NA & $\mathrm{NA}$ & 3 \\
\hline Neptunium-237 & $3 / 4$ & 0.62 & 4 & RAD205 & 2.84 & 0 & 0 & 2 & NA & NA & 3 \\
\hline Potassium-40 & $4 / 4$ & 10.8 & 20.8 & RAD204 & 16.1 & NA & NA & 4 & 0 & NA & 4 \\
\hline Radium-226 & $3 / 4$ & 0.14 & 12.2 & RAD205 & 6.61 & NA & NA & 2 & 2 & NA & 3 \\
\hline Technetium-99 & $4 / 4$ & $540.5 \mathrm{~J}$ & 2,085 & RAD207 & 1,066 & NA & NA & 0 & NA & NA & 4 \\
\hline Thorium -228 & $4 / 4$ & 4.7 & 54 & RAD205 & 19.8 & NA & NA & 4 & 4 & NA & 4 \\
\hline Thorium -230 & $4 / 4$ & 77.4 & 204 & RAD205 & 153 & NA & NA & 1 & 4 & NA & 4 \\
\hline Thorium -232 & $4 / 4$ & $5.4 \mathrm{~J}$ & $20.5 \mathrm{~J}$ & RAD206 & 11.4 & NA & NA & 4 & 4 & NA & 4 \\
\hline $\mathrm{Ra} / \mathrm{Th}$ decay series & $4 / 4$ & 79.65 & 221.35 & RAD205 & 161 & 4 & 4 & NA & NA & NA & NA \\
\hline Uranium-233/234 & $4 / 4$ & 52.3 & 490 & RAD204 & 325 & 0 & 0 & 2 & NA & 3 & 4 \\
\hline Uranium-235 & $4 / 4$ & 3.41 & 32 & RAD205 & 20.3 & 0 & 3 & 3 & NA & 0 & 4 \\
\hline Uranium-238 & $4 / 4$ & 28.5 & 219 & RAD204 & 134 & 0 & 3 & 4 & 4 & 3 & 4 \\
\hline
\end{tabular}

Avg = average NA $=$ not applicable

$\mathrm{Bkg}=$ background $\quad \mathrm{PRG}=$ preliminary remediation goal

$\mathrm{EU}=$ exposure unit $\quad$ Res $=$ residential

$\mathrm{GW}=$ groundwater $\quad \mathrm{RL}=$ remediation level

Ind $=$ industrial $\quad$ SL $=$ screening level

Max = maximum $\quad \mathrm{SU}=$ soil unit

A confirmation sample was collected at Z2-EU28B-114 from the point of highest radioactivity, as determined by the BAR survey, and analyzed for radionuclides. Analytical results confirmed the maximum RL exceedance for the $\mathrm{Ra} / \mathrm{Th}$ decay series; average RL exceedances for Cs -137, Ra/Th decay series, U-234, U-235, and U-238; and GW SL exceedances for U-234 and U-238 (see summary below).

EU Z2-28 RAD205 Class 1 SU confirmation sample radionuclides with background, PRG, and/or RL exceedances ( $\mathrm{pCi} / \mathrm{g}$ )

\begin{tabular}{|c|c|c|c|c|c|c|c|c|c|c|c|}
\hline \multirow[b]{2}{*}{ Analyte } & \multirow[b]{2}{*}{$\begin{array}{c}\text { Detect } \\
\text { frequency }\end{array}$} & \multirow[b]{2}{*}{$\begin{array}{c}\text { Minimum } \\
\text { detect }\end{array}$} & \multirow[b]{2}{*}{$\begin{array}{c}\text { Maximum } \\
\text { detect }\end{array}$} & \multirow[b]{2}{*}{$\begin{array}{l}\text { Location(s) of } \\
\text { maximum detect }\end{array}$} & \multirow{2}{*}{$\begin{array}{c}\text { Avg } \\
\text { detected } \\
\text { result }\end{array}$} & \multicolumn{6}{|c|}{ Number of analyses exceeding criteria } \\
\hline & & & & & & $\begin{array}{c}\text { Max } \\
\text { RL }\end{array}$ & $\begin{array}{l}\text { Avg } \\
\text { RL }\end{array}$ & $\begin{array}{l}\text { Ind } \\
\text { PRG }\end{array}$ & Bkg & $\begin{array}{c}\text { GW } \\
\text { SL }\end{array}$ & $\begin{array}{r}\text { Res } \\
\text { PRG }\end{array}$ \\
\hline Cesium-137 & $1 / 1$ & 6.5 & 6.5 & Z2-EU28B-114 & 6.5 & 0 & 1 & 1 & NA & NA & 1 \\
\hline Neptunium-237 & $1 / 1$ & 1.2 & 1.2 & Z2-EU28B-114 & 1.2 & 0 & 0 & 0 & NA & NA & 1 \\
\hline Potassium-40 & $1 / 1$ & 16.8 & 16.8 & Z2-EU28B-114 & 16.8 & NA & NA & 1 & 0 & NA & 1 \\
\hline Radium-226 & $1 / 1$ & 1.58 & 1.58 & Z2-EU28B-114 & 1.58 & NA & NA & 1 & 1 & NA & 1 \\
\hline Technetium-99 & $1 / 1$ & 1,410 & 1,410 & Z2-EU28B-114 & 1,410 & NA & NA & 0 & NA & NA & 1 \\
\hline Thorium -228 & $1 / 1$ & 3.49 & 3.49 & Z2-EU28B-114 & 3.49 & NA & NA & 1 & 1 & NA & 1 \\
\hline Thorium -230 & $1 / 1$ & 96.3 & 96.3 & Z2-EU28B-114 & 96.3 & NA & NA & 0 & 1 & NA & 1 \\
\hline Thorium -232 & $1 / 1$ & 2.38 & 2.38 & Z2-EU28B-114 & 2.38 & NA & NA & 1 & 1 & NA & 1 \\
\hline $\mathrm{Ra} / \mathrm{Th}$ decay series & $1 / 1$ & 95.53 & 95.53 & Z2-EU28B-114 & 95.53 & 1 & 1 & NA & NA & NA & NA \\
\hline Uranium-234 & $1 / 1$ & 842 & 842 & Z2-EU28B-114 & 842 & 0 & 1 & 1 & NA & 1 & 1 \\
\hline Uranium-235 & $1 / 1$ & 54.9 & 54.9 & Z2-EU28B-114 & 54.9 & 0 & 1 & 1 & NA & 0 & 1 \\
\hline Uranium-238 & $1 / 1$ & 421 & 421 & Z2-EU28B-114 & 421 & 0 & 1 & 1 & 1 & 1 & 1 \\
\hline
\end{tabular}

\begin{tabular}{ll}
\hline Avg = average & NA = not applicable \\
Bkg = background & PRG = preliminary remediation goal \\
EU = exposure unit & Res = residential \\
GW = groundwater & RL = remediation level \\
Ind = industrial & $\mathrm{SL}=$ screening level \\
Max = maximum & $\mathrm{SU}=$ soil unit
\end{tabular}


Two step-out samples, one four-point and one five-point, were collected from within the RAB as defined by the BAR survey, Z2-EU28B-115 and Z2-EU28B-116, respectively. The five sampling points for step-out sample Z2-EU28B-115 are proximal to the historical and confirmation sample locations. This proximal step-out sample was analyzed for metals, PCBs, radionuclides, SVOCs, and VOCs. The five-four sampling points for step-out sample Z2-EU28B-116 was more distal from the historical and confirmation sample locations. This distal step-out sample was analyzed for radionuclides. Both step-out samples have Ra/Th decay series maximum RL exceedances but the $\mathrm{Ra} / \mathrm{Th}$ decay series concentrations decrease with distance from the historical and confirmation sample locations (see summary below).

Analytical results for the proximal step-out sample show a maximum RL exceedance for the Ra/Th decay series; average RL exceedances for Cs -137 , the Ra/Th decay series, U-235, and U-238; groundwater SL exceedances for U-234 and U-238; industrial PRG exceedances for radionuclides; background exceedances for radionuclides; and PCB and SVOC detections (see summary below).

EU Z2-28 RAD205 Class 1 SU proximal step-out sample metals with background, PRG, GW SL, and/or RL exceedances (mg/kg)

\begin{tabular}{|c|c|c|c|c|c|c|c|c|c|c|c|}
\hline \multirow[b]{2}{*}{ Analyte } & \multirow[b]{2}{*}{$\begin{array}{c}\text { Detect } \\
\text { frequency }\end{array}$} & \multirow[b]{2}{*}{$\underset{\text { detect }}{\text { Minimum }}$} & \multirow[b]{2}{*}{$\begin{array}{c}\text { Maximum } \\
\text { detect }\end{array}$} & \multirow{2}{*}{$\begin{array}{l}\text { Location(s) of } \\
\text { maximum } \\
\text { detect }\end{array}$} & \multirow{2}{*}{$\begin{array}{c}\text { Avg } \\
\text { detected } \\
\text { result }\end{array}$} & \multicolumn{6}{|c|}{ Number of analyses exceeding criteria } \\
\hline & & & & & & $\begin{array}{l}\text { Max } \\
\text { RL }\end{array}$ & $\begin{array}{l}\text { Avg } \\
\text { RL }\end{array}$ & $\begin{array}{c}\text { Ind } \\
\text { PRG }\end{array}$ & Bkg & $\begin{array}{l}\text { GW } \\
\text { SL }\end{array}$ & $\begin{array}{l}\text { Res } \\
\text { PRG }\end{array}$ \\
\hline Aluminum & $1 / 1$ & 12,000 & 12,000 & Z2-EU28B-115 & 12,000 & NA & $\mathrm{NA}$ & 0 & 0 & NA & 1 \\
\hline Arsenic & $1 / 1$ & 5.5 & 5.5 & Z2-EU28B-115 & 5.5 & 0 & 0 & 0 & 0 & 0 & 1 \\
\hline Cadmium & $1 / 1$ & $0.93 \mathrm{~J}$ & $0.93 \mathrm{~J}$ & Z2-EU28B-115 & 0.93 & NA & NA & 0 & 1 & NA & 0 \\
\hline Calcium & $1 / 1$ & $50,000 \mathrm{~J}$ & $50,000 \mathrm{~J}$ & Z2-EU28B-115 & 50,000 & NA & NA & NA & 1 & NA & NA \\
\hline Chromium & $1 / 1$ & $34 \mathrm{~J}$ & $34 \mathrm{~J}$ & Z2-EU28B-115 & 34 & NA & NA & 0 & 0 & 0 & 1 \\
\hline Copper & $1 / 1$ & $42 \mathrm{~J}$ & $42 \mathrm{~J}$ & Z2-EU28B-115 & 42 & NA & NA & 0 & 1 & NA & 0 \\
\hline Magnesium & $1 / 1$ & $12,000 \mathrm{~J}$ & $12,000 \mathrm{~J}$ & Z2-EU28B-115 & 12,000 & NA & NA & NA & 1 & NA & NA \\
\hline Manganese & $1 / 1$ & 490J & $490 \mathrm{~J}$ & Z2-EU28B-115 & 490 & NA & NA & 0 & 0 & NA & 1 \\
\hline Mercury & $1 / 1$ & 86 & 86 & Z2-EU28B-115 & 86 & 0 & 0 & 0 & 1 & NA & 1 \\
\hline Nickel & $1 / 1$ & $170 \mathrm{~J}$ & $170 \mathrm{~J}$ & Z2-EU28B-115 & 170 & NA & NA & 0 & 1 & NA & 1 \\
\hline Uranium & $1 / 1$ & $94 \mathrm{~J}$ & $94 \mathrm{~J}$ & Z2-EU28B-115 & 94 & NA & NA & 0 & NA & NA & 1 \\
\hline Vanadium & $1 / 1$ & $25 \mathrm{~J}$ & $25 \mathrm{~J}$ & Z2-EU28B-115 & 25 & NA & NA & 0 & 0 & NA & 1 \\
\hline
\end{tabular}

Avg $=$ average

$\mathrm{NA}=$ not applicable

$\mathrm{Bkg}=$ background $\quad \mathrm{PRG}=$ preliminary remediation goal

$\mathrm{EU}=$ exposure unit $\quad$ Res $=$ residential

$\mathrm{GW}=$ groundwater $\quad \mathrm{RL}=$ remediation level

Ind $=$ industrial $\quad$ SL $=$ screening level

Max $=$ maximum $\quad \mathrm{SU}=$ soil unit

EU Z2-28 RAD205 Class 1 SU proximal step-out sample PCB detects (ug/kg)

\begin{tabular}{|c|c|c|c|c|c|c|c|c|c|}
\hline \multirow[b]{2}{*}{ Analyte } & \multirow[b]{2}{*}{$\begin{array}{c}\text { Detect } \\
\text { frequency }\end{array}$} & \multirow[b]{2}{*}{$\begin{array}{c}\text { Minimum } \\
\text { detect }\end{array}$} & \multirow[b]{2}{*}{$\begin{array}{c}\text { Maximum } \\
\text { detect }\end{array}$} & \multirow{2}{*}{$\begin{array}{c}\text { Location(s) of } \\
\text { maximum } \\
\text { detect }\end{array}$} & \multirow{2}{*}{$\begin{array}{c}\text { Avg } \\
\text { detected } \\
\text { result } \\
\end{array}$} & \multicolumn{4}{|c|}{$\begin{array}{c}\text { Number of analyses } \\
\text { exceeding criteria }\end{array}$} \\
\hline & & & & & & $\begin{array}{c}\text { Max } \\
\text { RL }\end{array}$ & $\begin{array}{l}\text { Avg } \\
\text { RL }\end{array}$ & $\begin{array}{c}\text { Ind } \\
\text { PRG }\end{array}$ & $\begin{array}{l}\text { Res } \\
\text { PRG }\end{array}$ \\
\hline PCB-1260 & $1 / 1$ & 4,200 & 4,200 & Z2-EU28B-115 & 4,200 & 0 & 0 & 0 & 1 \\
\hline PCB & $1 / 1$ & 4,200 & 4,200 & Z2-EU28B-115 & 4,200 & 0 & 0 & 0 & 1 \\
\hline
\end{tabular}

Avg $=$ average

$\mathrm{EU}=$ exposure unit

Ind $=$ industrial

Max = maximum

$\mathrm{PCB}=$ polychlorinated biphenyl
$\mathrm{PRG}=$ preliminary remediation goal

Res $=$ residential

$\mathrm{RL}=$ remediation level

$\mathrm{SU}=$ soil unit 
EU Z2-28 RAD205 Class 1 SU proximal step-out sample radionuclides with background, PRG, and/or RL exceedances (pCi/g)

\begin{tabular}{|c|c|c|c|c|c|c|c|c|c|c|c|}
\hline \multirow[b]{2}{*}{ Analyte } & \multirow[b]{2}{*}{$\begin{array}{c}\text { Detect } \\
\text { frequency }\end{array}$} & \multirow[b]{2}{*}{$\begin{array}{c}\text { Minimum } \\
\text { detect }\end{array}$} & \multirow[b]{2}{*}{$\begin{array}{c}\text { Maximum } \\
\text { detect }\end{array}$} & \multirow[b]{2}{*}{$\begin{array}{c}\text { Location(s) of } \\
\text { maximum detect }\end{array}$} & \multirow{2}{*}{$\begin{array}{c}\text { Avg } \\
\text { detected } \\
\text { result }\end{array}$} & \multicolumn{6}{|c|}{ Number of analyses exceeding criteria } \\
\hline & & & & & & $\begin{array}{c}\text { Max } \\
\text { RL }\end{array}$ & $\begin{array}{l}\text { Avg } \\
\text { RL }\end{array}$ & $\begin{array}{c}\text { Ind } \\
\text { PRG }\end{array}$ & Bkg & $\begin{array}{l}\text { GW } \\
\text { SL } \\
\end{array}$ & $\begin{array}{r}\text { Res } \\
\text { PRG }\end{array}$ \\
\hline Cesium-137 & $1 / 1$ & 2.33 & 2.33 & Z2-EU28B-115 & 2.33 & 0 & 1 & 1 & NA & NA & 1 \\
\hline Neptunium-237 & $1 / 1$ & 2.41 & 2.41 & Z2-EU28B-115 & 2.41 & 0 & 0 & 0 & NA & NA & 1 \\
\hline Potassium-40 & $1 / 1$ & 18.6 & 18.6 & Z2-EU28B-115 & 18.6 & NA & NA & 1 & 0 & NA & 1 \\
\hline Radium-226 & $1 / 1$ & 1.54 & 1.54 & Z2-EU28B-115 & 1.54 & NA & NA & 1 & 1 & NA & 1 \\
\hline Technetium-99 & $1 / 1$ & 2,550 & 2,550 & Z2-EU28B-115 & 2,550 & NA & NA & 0 & NA & NA & 1 \\
\hline Thorium -228 & $1 / 1$ & 4.4 & 4.4 & Z2-EU28B-115 & 4.4 & NA & NA & 1 & 1 & NA & 1 \\
\hline Thorium -230 & $1 / 1$ & 47.9 & 47.9 & Z2-EU28B-115 & 47.9 & NA & NA & 0 & 1 & NA & 1 \\
\hline Thorium -232 & $1 / 1$ & 2.35 & 2.35 & Z2-EU28B-115 & 2.35 & NA & NA & 1 & 1 & NA & 1 \\
\hline $\mathrm{Ra} / \mathrm{Th}$ decay series & $1 / 1$ & 47.1 & 47.1 & Z2-EU28B-115 & 47.1 & 1 & 1 & NA & NA & NA & NA \\
\hline Uranium-234 & $1 / 1$ & 173 & 173 & Z2-EU28B-115 & 173 & 0 & 0 & 0 & NA & 1 & 1 \\
\hline Uranium-235 & $1 / 1$ & 9.06 & 9.06 & Z2-EU28B-1 15 & 9.06 & 0 & 1 & 1 & NA & 0 & 1 \\
\hline Uranium-238 & $1 / 1$ & 83.7 & 83.7 & Z2-EU28B-115 & 83.7 & 0 & 1 & 1 & 1 & 1 & 1 \\
\hline
\end{tabular}

Avg = average

$\mathrm{Bkg}=$ background

$\mathrm{EU}=$ exposure unit $\quad$ Res $=$ residential

NA $=$ not applicable

$\mathrm{GW}=$ groundwater $\quad \mathrm{RL}=$ remediation level

Ind = industrial $\quad \mathrm{SL}=$ screening level

Max $=$ maximum $\quad \mathrm{SU}=$ soil unit

EU Z2-28 RAD205 Class 1 SU proximal step-out sample SVOC detects (ug/kg)

\begin{tabular}{|c|c|c|c|c|c|c|c|c|}
\hline \multirow[b]{2}{*}{ Analyte } & \multirow[b]{2}{*}{$\begin{array}{c}\text { Detect } \\
\text { frequency }\end{array}$} & \multirow[b]{2}{*}{$\begin{array}{l}\text { Minimum } \\
\text { detect }\end{array}$} & \multirow[b]{2}{*}{$\begin{array}{c}\text { Maximum } \\
\text { detect }\end{array}$} & \multirow[b]{2}{*}{$\begin{array}{l}\text { Location(s) of } \\
\text { maximum detect }\end{array}$} & \multirow{2}{*}{$\begin{array}{c}\text { Avg } \\
\text { detected } \\
\text { result }\end{array}$} & \multicolumn{3}{|c|}{$\begin{array}{c}\text { Number of analyses } \\
\text { exceeding criteria }\end{array}$} \\
\hline & & & & & & $\begin{array}{c}\text { Ind } \\
\text { PRG }\end{array}$ & $\begin{array}{l}\text { GW } \\
\text { SL }\end{array}$ & $\begin{array}{c}\text { Res } \\
\text { PRG }\end{array}$ \\
\hline Anthracene & $1 / 1$ & $120 \mathrm{~J}$ & $120 \mathrm{~J}$ & Z2-EU28B-115 & 120 & 0 & NA & 0 \\
\hline Benz(a)anthracene & $1 / 1$ & 830 & 830 & Z2-EU28B-115 & 830 & 0 & NA & 1 \\
\hline Benzo(a)pyrene & $1 / 1$ & $830 \mathrm{~J}$ & $830 \mathrm{~J}$ & Z2-EU28B-115 & 830 & 0 & NA & 1 \\
\hline Benzo(b)fluoranthene & $1 / 1$ & $970 \mathrm{~J}$ & $970 \mathrm{~J}$ & Z2-EU28B-1 15 & 970 & 0 & NA & 1 \\
\hline Benzo(ghi)perylene & $1 / 1$ & $960 \mathrm{~J}$ & $960 \mathrm{~J}$ & Z2-EU28B-115 & 960 & 0 & NA & 0 \\
\hline Benzo(k)fluoranthene & $1 / 1$ & $430 \mathrm{~J}$ & $430 \mathrm{~J}$ & Z2-EU28B-115 & 430 & 0 & NA & 0 \\
\hline Chrysene & $1 / 1$ & 630 & 630 & Z2-EU28B-115 & 630 & 0 & NA & 0 \\
\hline Dibenz(a,h)anthracene & $1 / 1$ & $150 \mathrm{~J}$ & $150 \mathrm{~J}$ & Z2-EU28B-115 & 150 & 0 & NA & 1 \\
\hline Fluoranthene & $1 / 1$ & 1,100 & 1,100 & Z2-EU28B-115 & 1,100 & 0 & NA & 0 \\
\hline Hexachlorobenzene & $1 / 1$ & $320 \mathrm{~J}$ & $320 \mathrm{~J}$ & Z2-EU28B-115 & 320 & 0 & NA & 1 \\
\hline Indeno(1,2,3-cd)pyrene & $1 / 1$ & 760 & 760 & Z2-EU28B-115 & 760 & 0 & NA & 1 \\
\hline Phenanthrene & $1 / 1$ & $200 \mathrm{~J}$ & $200 \mathrm{~J}$ & Z2-EU28B-115 & 200 & 0 & NA & 0 \\
\hline Pyrene & $1 / 1$ & 1,900 & 1,900 & Z2-EU28B-115 & 1,900 & 0 & NA & 0 \\
\hline
\end{tabular}

$\begin{array}{ll}\text { Avg }=\text { average } & \text { PRG = preliminary remediation goal } \\ \text { EU = exposure unit } & \text { Res = residential } \\ \text { GW = groundwater } & \text { SL = screening level } \\ \text { Ind = industrial } & \text { SU = soil unit } \\ \text { NA = not applicable } & \text { SVOC = semivolatile organic compound }\end{array}$

VOCs were analyzed in the sample for Z2-EU28B-115 but were not detected.

Analytical results for the distal step-out sample show a maximum RL exceedance for the Ra/Th decay series, an average RL exceedance for the $\mathrm{Ra} / \mathrm{Th}$ decay series, and several radionuclide industrial PRG and background exceedances (see summary below). Sampling points for the distal step-out sample were spaced farther from the confirmation sampling location and closer to the RAB than sampling points for the proximal step-out sample. Comparison of the distal step-out sample analytical results to the proximal step-out sample shows decreasing radionuclide concentrations toward the $\mathrm{RAB}$. 
EU Z2-28 RAD205 Class 1 SU distal step-out sample radionuclides with background, PRG, and/or RL exceedances (pCi/g)

\begin{tabular}{|c|c|c|c|c|c|c|c|c|c|c|c|}
\hline \multirow[b]{2}{*}{ Analyte } & \multirow[b]{2}{*}{$\begin{array}{c}\text { Detect } \\
\text { fre quency }\end{array}$} & \multirow[b]{2}{*}{$\begin{array}{c}\text { Minimum } \\
\text { detect }\end{array}$} & \multirow[b]{2}{*}{$\begin{array}{c}\text { Maximum } \\
\text { detect }\end{array}$} & \multirow[b]{2}{*}{$\begin{array}{c}\text { Location(s) of } \\
\text { maximum detect }\end{array}$} & \multirow{2}{*}{$\begin{array}{c}\text { Avg } \\
\text { detected } \\
\text { result }\end{array}$} & \multicolumn{6}{|c|}{ Number of analyses exceeding criteria } \\
\hline & & & & & & $\begin{array}{c}\text { Max } \\
\text { RL }\end{array}$ & $\begin{array}{l}\text { Avg } \\
\text { RL }\end{array}$ & $\begin{array}{l}\text { Ind } \\
\text { PRG }\end{array}$ & Bkg & $\begin{array}{c}\mathbf{G W} \\
\text { SL }\end{array}$ & $\begin{array}{r}\text { Res } \\
\text { PRG }\end{array}$ \\
\hline Potassium-40 & $1 / 1$ & 17.6 & 17.6 & Z2-EU28B-116 & 17.6 & NA & NA & 1 & 0 & NA & 1 \\
\hline Radium-226 & $1 / 1$ & 0.998 & 0.998 & Z2-EU28B-116 & 0.998 & NA & NA & 1 & 0 & NA & 1 \\
\hline Technetium-99 & $1 / 1$ & 268 & 268 & Z2-EU28B-116 & 268 & NA & NA & 0 & NA & NA & 1 \\
\hline Thorium -228 & $1 / 1$ & 1.71 & 1.71 & Z2-EU28B-116 & 1.71 & NA & NA & 1 & 0 & NA & 1 \\
\hline Thorium -230 & $1 / 1$ & 22 & 22 & Z2-EU28B-116 & 22 & NA & NA & 0 & 1 & NA & 1 \\
\hline Thorium -232 & $1 / 1$ & 1.39 & 1.39 & Z2-EU28B-116 & 1.39 & NA & NA & 1 & 0 & NA & 1 \\
\hline $\mathrm{Ra} / \mathrm{Th}$ decay series & $1 / 1$ & 20.8 & 20.8 & Z2-EU28B-116 & 20.8 & 1 & 1 & NA & NA & NA & NA \\
\hline Uranium-234 & $1 / 1$ & 25.2 & 25.2 & Z2-EU28B-116 & 25.2 & 0 & 0 & 0 & NA & 0 & 1 \\
\hline
\end{tabular}

Avg $=$ average

$\mathrm{Bkg}=$ background

$\mathrm{EU}=$ exposure unit

$\mathrm{GW}=$ groundwater

Ind $=$ industrial

Max $=$ maximum
$\mathrm{NA}=$ not applicable

$\mathrm{PRG}=$ preliminary remediation goal

Res $=$ residential

$\mathrm{RL}=$ remediation level

$\mathrm{SL}=$ screening level

$\mathrm{SU}=$ soil unit

EU Z2-28 RAD205 Class 1 SU distal step-out sample radionuclides with background, PRG, and/or RL exceedances (pCi/g) (continued)

\begin{tabular}{|c|c|c|c|c|c|c|c|c|c|c|c|}
\hline \multirow[b]{2}{*}{ Analyte } & \multirow[b]{2}{*}{$\begin{array}{c}\text { Detect } \\
\text { frequency }\end{array}$} & \multirow[b]{2}{*}{$\begin{array}{c}\text { Minimum } \\
\text { detect }\end{array}$} & \multirow[b]{2}{*}{$\begin{array}{c}\text { Maximum } \\
\text { detect }\end{array}$} & \multirow[b]{2}{*}{$\begin{array}{c}\text { Location(s) of } \\
\text { maximum detect }\end{array}$} & \multirow{2}{*}{$\begin{array}{c}\text { Avg } \\
\text { detected } \\
\text { result }\end{array}$} & \multicolumn{6}{|c|}{ Number of analyses exceeding criteria } \\
\hline & & & & & & $\begin{array}{c}\text { Max } \\
\text { RL }\end{array}$ & $\begin{array}{l}\text { Avg } \\
\text { RL }\end{array}$ & $\begin{array}{l}\text { Ind } \\
\text { PRG }\end{array}$ & Bkg & $\begin{array}{c}\text { GW } \\
\text { SL }\end{array}$ & $\begin{array}{r}\text { Res } \\
\text { PRG }\end{array}$ \\
\hline Uranium-235 & $1 / 1$ & 1.5 & 1.5 & Z2-EU28B-116 & 1.5 & 0 & 0 & 0 & NA & 0 & 1 \\
\hline Uranium-238 & $1 / 1$ & 14.1 & 14.1 & Z2-EU28B-116 & 14.1 & 0 & 0 & 0 & 1 & 0 & 1 \\
\hline
\end{tabular}

\begin{tabular}{ll}
\hline Avg $=$ average & NA $=$ not applicable \\
Bkg $=$ background & PRG $=$ preliminary remediation goal \\
EU $=$ exposure unit & Res $=$ residential \\
GW $=$ groundwater & RL $=$ remediation level \\
Ind $=$ industrial & SL $=$ screening level \\
Max = maximum & SU = soil unit
\end{tabular}

DVS Sampling Associated with RAD218 Class 1 SU: Historical sample location RAD218 had a maximum RL exceedance for the Ra/Th decay series; average RL exceedances for the Ra/Th decay series, U-235, and U-238; groundwater SL exceedances for $\mathrm{U} 234$ and $\mathrm{U} 238$; and several radionuclide industrial PRG and background exceedances (see summary below).

EU Z2-28 RAD218 Class 1 SU historical radionuclides with background, PRG, and/or RL exceedances (pCi/g)

\begin{tabular}{|c|c|c|c|c|c|c|c|c|c|c|c|}
\hline \multirow[b]{2}{*}{ Analyte } & \multirow[b]{2}{*}{$\begin{array}{c}\text { Detect } \\
\text { frequency }\end{array}$} & \multirow[b]{2}{*}{$\begin{array}{c}\text { Minimum } \\
\text { detect }\end{array}$} & \multirow[b]{2}{*}{$\begin{array}{c}\text { Maximum } \\
\text { detect }\end{array}$} & \multirow[b]{2}{*}{$\begin{array}{c}\text { Location(s) of } \\
\text { maximum detect }\end{array}$} & \multirow{2}{*}{$\begin{array}{c}\text { Avg } \\
\text { detected } \\
\text { result }\end{array}$} & \multicolumn{6}{|c|}{ Number of analyses exceeding criteria } \\
\hline & & & & & & $\begin{array}{l}\text { Max } \\
\text { RL }\end{array}$ & $\begin{array}{l}\text { Avg } \\
\text { RL }\end{array}$ & $\begin{array}{c}\text { Ind } \\
\text { PRG }\end{array}$ & Bkg & $\begin{array}{l}\text { GW } \\
\text { SL }\end{array}$ & $\begin{array}{l}\text { Res } \\
\text { PRG }\end{array}$ \\
\hline Cesium-137 & $1 / 1$ & 0.13 & 0.13 & RAD218 & 0.13 & 0 & 0 & 0 & NA & NA & 1 \\
\hline Neptunium-237 & $1 / 1$ & 0.15 & 0.15 & RAD218 & 0.15 & 0 & 0 & 0 & NA & NA & 1 \\
\hline Potassium-40 & $1 / 1$ & 21.7 & 21.7 & RAD218 & 21.7 & NA & NA & 1 & 0 & NA & 1 \\
\hline Radium-226 & $1 / 1$ & 16.9 & 16.9 & RAD218 & 16.9 & NA & NA & 1 & 1 & NA & 1 \\
\hline Technetium-99 & $1 / 1$ & 24.3 & 24.3 & RAD218 & 24.3 & NA & NA & 0 & NA & NA & 1 \\
\hline Thorium -228 & $1 / 1$ & 1.14 & 1.14 & RAD218 & 1.14 & NA & NA & 1 & 0 & NA & 1 \\
\hline Thorium -230 & $1 / 1$ & 1.87 & 1.87 & RAD218 & 1.87 & NA & NA & 0 & 1 & NA & 0 \\
\hline Thorium -232 & $1 / 1$ & 0.86 & 0.86 & RAD218 & 0.86 & NA & NA & 1 & 0 & NA & 1 \\
\hline $\mathrm{Ra} / \mathrm{Th}$ decay series & $1 / 1$ & 15.65 & 15.65 & RAD218 & 15.65 & 1 & 1 & NA & NA & NA & NA \\
\hline Uranium-233/234 & $1 / 1$ & 218 & 218 & RAD218 & 218 & 0 & 0 & 0 & NA & 1 & 1 \\
\hline
\end{tabular}


EU Z2-28 RAD218 Class 1 SU historical radionuclides with background, PRG, and/or RL exceedances (pCi/g) (continued)

\begin{tabular}{|c|c|c|c|c|c|c|c|c|c|c|c|}
\hline \multirow[b]{2}{*}{ Analyte } & \multirow[b]{2}{*}{$\begin{array}{c}\text { Detect } \\
\text { frequency }\end{array}$} & \multirow[b]{2}{*}{$\begin{array}{c}\text { Minimum } \\
\text { detect }\end{array}$} & \multirow[b]{2}{*}{$\begin{array}{c}\text { Maximum } \\
\text { detect }\end{array}$} & \multirow[b]{2}{*}{$\begin{array}{c}\text { Location(s) of } \\
\text { maximum detect }\end{array}$} & \multirow{2}{*}{$\begin{array}{c}\text { Avg } \\
\text { detected } \\
\text { result }\end{array}$} & \multicolumn{6}{|c|}{ Number of analyses exceeding criteria } \\
\hline & & & & & & $\begin{array}{l}\text { Max } \\
\text { RL }\end{array}$ & $\begin{array}{l}\text { Avg } \\
\text { RL }\end{array}$ & $\begin{array}{l}\text { Ind } \\
\text { PRG }\end{array}$ & Bkg & $\begin{array}{c}\text { GW } \\
\text { SL }\end{array}$ & $\begin{array}{l}\text { Res } \\
\text { PRG }\end{array}$ \\
\hline Uranium-235 & $1 / 1$ & 16.2 & 16.2 & RAD218 & 16.2 & 0 & 1 & 1 & NA & 0 & 1 \\
\hline Uranium-238 & $1 / 1$ & 228 & 228 & RAD218 & 228 & 0 & 1 & 1 & 1 & 1 & 1 \\
\hline Avg $=$ average & & \multicolumn{10}{|c|}{ NA $=$ not applicable } \\
\hline $\mathrm{Bkg}=$ background & & \multirow{2}{*}{\multicolumn{10}{|c|}{ PRG = preliminary remediation goal }} \\
\hline $\mathrm{EU}=$ exposure unit & & \multicolumn{8}{|c|}{ Res $=$ residential } & & \\
\hline $\mathrm{GW}=$ groundwater & & \multicolumn{10}{|c|}{$\mathrm{RL}=$ remediation level } \\
\hline Ind $=$ industrial & & \multicolumn{10}{|c|}{$\mathrm{SL}=$ screening level } \\
\hline Max $=$ maximum & & \multicolumn{10}{|c|}{$\mathrm{SU}=$ soil unit } \\
\hline
\end{tabular}

As described in Sects. 2.1.1.1 and 2.1.1.3, the BAR survey identified an area of elevated radioactivity a few feet south of the historical sample location. Discrete sample locations Z2-EU28B-123 and Z2-EU28B-124 were selected at points of elevated radiation as defined by the BAR survey. Samples were collected and analyzed for radionuclides. BAR survey results and DVS sampling results for the RAD218 Class 1 SU also apply to the RAD219 Class 2 SU. DVS samples associated with the RAD218 Class 1 SU failed to confirm a maximum RL exceedance although each sample had an average RL exceedance (see summary below).

Analytical results for the combined discrete samples associated with the RAD218 Class 1 SU show average RL exceedances for U-238 in both samples, groundwater SL exceedances for U-234 and U-238 in both samples, and several radionuclide industrial PRG and background exceedances (see summary below). There are no maximum RL exceedances in either sample.

EU Z2-28 RAD218 Class 1 SU discrete samples radionuclides with background, PRG, and/or RL exceedances (pCi/g)

\begin{tabular}{|c|c|c|c|c|c|c|c|c|c|c|c|}
\hline \multirow[b]{2}{*}{ Analyte } & \multirow[b]{2}{*}{$\begin{array}{c}\text { Detect } \\
\text { frequency }\end{array}$} & \multirow[b]{2}{*}{$\begin{array}{c}\text { Minimum } \\
\text { detect }\end{array}$} & \multirow[b]{2}{*}{$\begin{array}{c}\text { Maximum } \\
\text { detect }\end{array}$} & \multirow[b]{2}{*}{$\begin{array}{l}\text { Location(s) of } \\
\text { maximum detect }\end{array}$} & \multirow{2}{*}{$\begin{array}{c}\text { Avg } \\
\text { detected } \\
\text { result }\end{array}$} & \multicolumn{6}{|c|}{ Number of analyses exceeding criteria } \\
\hline & & & & & & $\begin{array}{l}\text { Max } \\
\text { RL }\end{array}$ & $\begin{array}{l}\text { Avg } \\
\text { RL }\end{array}$ & $\begin{array}{l}\text { Ind } \\
\text { PRG }\end{array}$ & Bkg & $\begin{array}{l}\text { GW } \\
\text { SL }\end{array}$ & $\begin{array}{l}\text { Res } \\
\text { PRG }\end{array}$ \\
\hline Neptunium-237 & $1 / 2$ & 0.696 & 0.696 & Z2-EU28B-124 & 0.696 & 0 & 0 & 0 & NA & NA & 1 \\
\hline Potassium-40 & $2 / 2$ & 22.7 & 22.8 & Z2-EU28B-123 & 22.75 & NA & NA & 2 & 0 & NA & 2 \\
\hline Radium-226 & $2 / 2$ & 0.811 & 0.974 & Z2-EU28B-124 & 0.8925 & NA & NA & 2 & 0 & NA & 2 \\
\hline Thorium -228 & $2 / 2$ & 1.33 & 1.74 & Z2-EU28B-123 & 1.535 & NA & NA & 2 & 0 & NA & 2 \\
\hline Thorium -232 & $2 / 2$ & 1.34 & 1.63 & Z2-EU28B-123 & 1.485 & NA & NA & 2 & 0 & NA & 2 \\
\hline Uranium-234 & $2 / 2$ & 63.6 & 92.1 & Z2-EU28B-124 & 77.85 & 0 & 0 & 0 & NA & 2 & 2 \\
\hline Uranium-235 & $2 / 2$ & 4.16 & 5.29 & Z2-EU28B-124 & 4.725 & 0 & 0 & 2 & NA & 0 & 2 \\
\hline Uranium-238 & $2 / 2$ & 66.2 & 99.3 & Z2-EU28B-124 & 82.75 & 0 & 2 & 2 & 2 & 2 & 2 \\
\hline
\end{tabular}

\begin{tabular}{ll}
\hline Avg $=$ average & NA $=$ not applicable \\
Bkg $=$ background & PRG $=$ preliminary remediation goal \\
EU $=$ exposure unit & Res $=$ residential \\
GW $=$ groundwater & RL $=$ remediation level \\
Ind $=$ industrial & SL $=$ screening level \\
Max = maximum & SU $=$ soil unit
\end{tabular}

DVS Sampling in Z2-EU28-204 Class 1 SU: Analytical results from early characterization sample location Z2-EU28-204 show maximum and average RL exceedances for the Ra/Th decay series; several radionuclide industrial PRG exceedances; several metal and radionuclide background exceedances; and a detection of PCB-1254 (see summary below). 
EU Z2-28-204 Class 1 SU historical metals with background, PRG, GW SL, and/or RL exceedances (mg/kg)

\begin{tabular}{|c|c|c|c|c|c|c|c|c|c|c|c|}
\hline \multirow[b]{2}{*}{ Analyte } & \multirow[b]{2}{*}{$\begin{array}{l}\text { Detect } \\
\text { frequency }\end{array}$} & \multirow[b]{2}{*}{$\underset{\text { detect }}{\text { Minimum }}$} & \multirow[b]{2}{*}{$\underset{\text { detect }}{\text { Maximum }}$} & \multirow{2}{*}{$\begin{array}{c}\text { Location(s) of } \\
\text { maximum } \\
\text { detect }\end{array}$} & \multirow{2}{*}{$\begin{array}{c}\text { Avg } \\
\text { detected } \\
\text { result }\end{array}$} & \multicolumn{6}{|c|}{ Number of analyses exceeding criteria } \\
\hline & & & & & & $\begin{array}{l}\text { Max } \\
\text { RL }\end{array}$ & $\begin{array}{l}\text { Avg } \\
\text { RL }\end{array}$ & $\begin{array}{l}\text { Ind } \\
\text { PRG }\end{array}$ & Bkg & $\begin{array}{l}\text { GW } \\
\text { SL }\end{array}$ & $\begin{array}{c}\text { Res } \\
\text { PRG }\end{array}$ \\
\hline Aluminum & $1 / 1$ & 24,000 & 24,000 & Z2-EU28-204 & 24,000 & NA & NA & 0 & 0 & NA & 1 \\
\hline Arsenic & $1 / 1$ & 13.5 & 13.5 & Z2-EU28-204 & 13.5 & 0 & 0 & 0 & 0 & 0 & 1 \\
\hline Calcium & $1 / 1$ & $12,400 \mathrm{~J}$ & $12,400 \mathrm{~J}$ & Z2-EU28-204 & 12,400 & NA & NA & NA & 1 & NA & NA \\
\hline Chromium & $1 / 1$ & 37 & 37 & Z2-EU28-204 & 37 & NA & NA & 0 & 0 & 0 & 1 \\
\hline Lead & $1 / 1$ & $44.1 \mathrm{~J}$ & $44.1 \mathrm{~J}$ & Z2-EU28-204 & 44.1 & NA & NA & 0 & 1 & 0 & 0 \\
\hline Manganese & $1 / 1$ & $1,160 \mathrm{~J}$ & $1,160 \mathrm{~J}$ & Z2-EU28-204 & 1,160 & NA & NA & 0 & 0 & NA & 1 \\
\hline Mercury & $1 / 1$ & $0.29 \mathrm{~J}$ & $0.29 \mathrm{~J}$ & Z2-EU28-204 & 0.29 & 0 & 0 & 0 & 1 & NA & 0 \\
\hline Selenium & $1 / 1$ & $1.6 \mathrm{~J}$ & $1.6 \mathrm{~J}$ & Z2-EU28-204 & 1.6 & NA & NA & 0 & 1 & NA & 0 \\
\hline Uranium & $1 / 1$ & $2.5 \mathrm{~J}$ & $2.5 \mathrm{~J}$ & Z2-EU28-204 & 2.5 & NA & NA & 0 & NA & NA & 1 \\
\hline Vanadium & $1 / 1$ & 72.7 & 72.7 & Z2-EU28-204 & 72.7 & NA & NA & 0 & 1 & NA & 1 \\
\hline
\end{tabular}

Avg $=$ average $\quad$ PRG $=$ preliminary remediation goal

$\mathrm{Bkg}=$ background $\quad$ Res $=$ residential

$\mathrm{GW}=$ groundwater $\quad \mathrm{RL}=$ remediation level

Ind $=$ industrial $\quad \mathrm{SL}=$ screening level

Max $=$ maximum $\quad \mathrm{SU}=$ soil unit

$\mathrm{NA}=$ not applicable

EU Z2-28-204 Class 1 SU historical PCB detects (ug/kg)

\begin{tabular}{|c|c|c|c|c|c|c|c|c|c|}
\hline \multirow[b]{2}{*}{ Analyte } & \multirow[b]{2}{*}{$\begin{array}{c}\text { Detect } \\
\text { frequency }\end{array}$} & \multirow[b]{2}{*}{$\begin{array}{l}\text { Minimum } \\
\text { dete ct }\end{array}$} & \multirow[b]{2}{*}{$\begin{array}{c}\text { Maximum } \\
\text { detect }\end{array}$} & \multirow{2}{*}{$\begin{array}{c}\text { Location(s) of } \\
\text { maximum } \\
\text { detect }\end{array}$} & \multirow{2}{*}{$\begin{array}{c}\text { Avg } \\
\text { detected } \\
\text { result }\end{array}$} & \multicolumn{4}{|c|}{$\begin{array}{l}\text { Number of analyses } \\
\text { exceeding criteria }\end{array}$} \\
\hline & & & & & & $\begin{array}{c}\text { Max } \\
\text { RL }\end{array}$ & $\begin{array}{l}\text { Avg } \\
\text { RL } \\
\end{array}$ & $\begin{array}{l}\text { Ind } \\
\text { PRG }\end{array}$ & $\begin{array}{r}\text { Res } \\
\text { PRG }\end{array}$ \\
\hline PCB-1254 & $1 / 1$ & $7.8 \mathrm{~J}$ & $7.8 \mathrm{~J}$ & Z2-EU28-204 & 7.8 & 0 & 0 & 0 & 0 \\
\hline Avg $=$ average & PRC & $=$ preliminar & remediation & goal & & & & & \\
\hline Ind = industrial & Res & $=$ residential & & & & & & & \\
\hline Max $=$ maximum & RL & $=$ remediation & evel & & & & & & \\
\hline $\mathrm{PCB}=$ polychlorinated biphenyls & SU & = soil unit & & & & & & & \\
\hline
\end{tabular}

EU Z2-28-204 Class 1 SU historical radionuclides with background, PRG, and/or RL exceedances (pCi/g)

\begin{tabular}{|c|c|c|c|c|c|c|c|c|c|c|c|}
\hline \multirow[b]{2}{*}{ Analyte } & \multirow[b]{2}{*}{$\begin{array}{c}\text { Detect } \\
\text { frequency }\end{array}$} & \multirow[b]{2}{*}{$\begin{array}{c}\text { Minimum } \\
\text { detect }\end{array}$} & \multirow[b]{2}{*}{$\begin{array}{c}\text { Maximum } \\
\text { detect }\end{array}$} & \multirow[b]{2}{*}{$\begin{array}{c}\text { Location(s) of } \\
\text { maximum detect }\end{array}$} & \multirow{2}{*}{$\begin{array}{c}\text { Avg } \\
\text { detected } \\
\text { result }\end{array}$} & \multicolumn{6}{|c|}{ Number of analyses exceeding criteria } \\
\hline & & & & & & $\begin{array}{c}\text { Max } \\
\text { RL }\end{array}$ & $\begin{array}{l}\text { Avg } \\
\text { RL }\end{array}$ & $\begin{array}{l}\text { Ind } \\
\text { PRG }\end{array}$ & Bkg & $\begin{array}{l}\text { GW } \\
\text { SL }\end{array}$ & $\begin{array}{r}\text { Res } \\
\text { PRG }\end{array}$ \\
\hline Cesium-137 & $1 / 1$ & 1.91 & 1.91 & Z2-EU28-204 & 1.91 & 0 & 0 & 1 & NA & NA & 1 \\
\hline Neptunium-237 & $1 / 1$ & 2.65 & 2.65 & Z2-EU28-204 & 2.65 & 0 & 0 & 0 & NA & NA & 1 \\
\hline Potassium-40 & $1 / 1$ & 12.1 & 12.1 & Z2-EU28-204 & 12.1 & NA & NA & 1 & 0 & NA & 1 \\
\hline Radium-226 & $1 / 1$ & $1.33 \mathrm{~J}$ & $1.33 \mathrm{~J}$ & Z2-EU28-204 & 1.33 & NA & NA & 1 & 1 & NA & 1 \\
\hline Technetium-99 & $1 / 1$ & 72 & 72 & Z2-EU28-204 & 72 & NA & NA & 0 & NA & NA & 1 \\
\hline Thorium -228 & $1 / 1$ & 1.23 & 1.23 & Z2-EU28-204 & 1.23 & NA & NA & 1 & 0 & NA & 1 \\
\hline Thorium -230 & $1 / 1$ & 16.6 & 16.6 & Z2-EU28-204 & 16.6 & NA & NA & 0 & 1 & NA & 1 \\
\hline Thorium -232 & $1 / 1$ & 0.984 & 0.984 & Z2-EU28-204 & 0.984 & NA & NA & 1 & 0 & NA & 1 \\
\hline $\mathrm{Ra} / \mathrm{Th}$ decay series & $1 / 1$ & 15.4 & 15.4 & Z2-EU28-204 & 15.4 & 1 & 1 & NA & NA & NA & NA \\
\hline Uranium-233/234 & $1 / 1$ & $28.2 \mathrm{~J}$ & $28.2 \mathrm{~J}$ & Z2-EU28-204 & 28.2 & 0 & 0 & 0 & NA & 0 & 1 \\
\hline Uranium-235 & $1 / 1$ & 1.19 & 1.19 & Z2-EU28-204 & 1.19 & 0 & 0 & 0 & NA & 0 & 1 \\
\hline Uranium-235/236 & $1 / 1$ & 2.32 & 2.32 & Z2-EU28-204 & 2.32 & 0 & 0 & 0 & NA & 0 & 1 \\
\hline Uranium-238 & $1 / 1$ & $16.8 \mathrm{~J}$ & $16.8 \mathrm{~J}$ & Z2-EU28-204 & 16.8 & 0 & 0 & 0 & 1 & 0 & 1 \\
\hline
\end{tabular}

Avg = average

$\mathrm{Bkg}=$ background

$\mathrm{GW}=$ groundwater

$\mathrm{PRG}=$ preliminary remediation goal

Ind $=$ industrial

Res $=$ residential

$\mathrm{RL}=$ remediation level

Max = maximum

$\mathrm{NA}=$ not applicable

$\mathrm{SL}=$ screening level

$\mathrm{SU}=$ soil unit 
Discrete DVS sample location Z2-EU28B-125 was selected in proximity to the Z2-EU28-204 location and was analyzed for radionuclides. Analytical results for the DVS sample show no maximum RL exceedances, average RL exceedances by $\mathrm{Cs}-137$ and the $\mathrm{Ra} / \mathrm{Th}$ decay series, and several radionuclide industrial PRG and background exceedances.

EU Z2-28-204 Class 1 SU DVS sample radionuclides with background, PRG, and/or RL exceedances (pCi/g)

\begin{tabular}{|c|c|c|c|c|c|c|c|c|c|c|c|}
\hline \multirow[b]{2}{*}{ Analyte } & \multirow[b]{2}{*}{$\begin{array}{c}\text { Detect } \\
\text { frequency }\end{array}$} & \multirow[b]{2}{*}{$\begin{array}{c}\text { Minimum } \\
\text { detect }\end{array}$} & \multirow[b]{2}{*}{$\begin{array}{c}\text { Maximum } \\
\text { detect }\end{array}$} & \multirow[b]{2}{*}{$\begin{array}{c}\text { Location(s) of } \\
\text { maximum detect }\end{array}$} & \multirow{2}{*}{$\begin{array}{c}\text { Avg } \\
\text { detected } \\
\text { result }\end{array}$} & \multicolumn{6}{|c|}{ Number of analyses exceeding criteria } \\
\hline & & & & & & $\begin{array}{c}\text { Max } \\
\text { RL }\end{array}$ & $\begin{array}{l}\text { Avg } \\
\text { RL }\end{array}$ & $\begin{array}{c}\text { Ind } \\
\text { PRG }\end{array}$ & Bkg & $\begin{array}{l}\text { GW } \\
\text { SL }\end{array}$ & $\begin{array}{r}\text { Res } \\
\text { PRG }\end{array}$ \\
\hline Cesium-137 & $1 / 1$ & 2.32 & 2.32 & Z2-EU28B-125 & 2.32 & 0 & 1 & 1 & $\overrightarrow{\mathrm{NA}}$ & NA & 1 \\
\hline Neptunium-237 & $1 / 1$ & 3.35 & 3.35 & Z2-EU28B-125 & 3.35 & 0 & 0 & 1 & NA & NA & 1 \\
\hline Potassium-40 & $1 / 1$ & 7.78 & 7.78 & Z2-EU28B-125 & 7.78 & NA & NA & 1 & 0 & NA & 1 \\
\hline Radium-226 & $1 / 1$ & 0.914 & 0.914 & Z2-EU28B-125 & 0.914 & NA & NA & 1 & 0 & NA & 1 \\
\hline Technetium-99 & $1 / 1$ & 110 & 110 & Z2-EU28B-125 & 110 & NA & NA & 0 & NA & NA & 1 \\
\hline Thorium -228 & $1 / 1$ & 1.21 & 1.21 & Z2-EU28B-125 & 1.21 & NA & NA & 1 & 0 & NA & 1 \\
\hline Thorium -230 & $1 / 1$ & 15 & 15 & Z2-EU28B-125 & 15 & NA & NA & 0 & 1 & NA & 1 \\
\hline Thorium -232 & $1 / 1$ & 1.35 & 1.35 & Z2-EU28B-125 & 1.35 & NA & NA & 1 & 0 & NA & 1 \\
\hline $\mathrm{Ra} / \mathrm{Th}$ decay series & $1 / 1$ & 13.8 & 13.8 & Z2-EU28B-125 & 13.8 & 0 & 1 & NA & NA & NA & NA \\
\hline Uranium-234 & $1 / 1$ & 24.6 & 24.6 & Z2-EU28B-125 & 24.6 & 0 & 0 & 0 & NA & 0 & 1 \\
\hline Uranium-235 & $1 / 1$ & 1.24 & 1.24 & Z2-EU28B-125 & 1.24 & 0 & 0 & 0 & NA & 0 & 1 \\
\hline Uranium-238 & $1 / 1$ & 13.6 & 13.6 & Z2-EU28B-125 & 13.6 & 0 & 0 & 0 & 1 & 0 & 1 \\
\hline
\end{tabular}

Avg $=$ average

$\mathrm{Bkg}=$ background

NA $=$ not applicable

DVS $=$ Dynamic Verification Strategy

$\mathrm{PRG}=$ preliminary remediation goal

$\mathrm{GW}=$ groundwater

Ind $=$ industrial

Res $=$ residential

$\mathrm{RL}=$ remediation level

$\mathrm{SL}=$ screening level

Max $=$ maximum

$\mathrm{SU}=$ soil unit

DVS Area Definition Sampling in RAD203 Class 2 SU: DVS sampling was conducted to define the extent of the average RL exceedance at historical sample location RAD203. Confirmation sample Z2-EU28B-126 was collected. The historical sample had a Ra-226 average RL exceedance ( $5.3 \mathrm{pCi} / \mathrm{g}$ in the sample versus $5 \mathrm{pCi} / \mathrm{g}$ average $\mathrm{RL}$ ), however, the $\mathrm{Ra} / \mathrm{Th}$ decay series concentration $(4.03 \mathrm{pCi} / \mathrm{g})$ did not exceed the $\mathrm{Ra} / \mathrm{Th}$ decay series average $\mathrm{RL}$ $(5 \mathrm{pCi} / \mathrm{g})$. Analytical results for the historical sample illustrate radionuclide industrial PRG and background exceedances (see summary below).

EU Z2-28-RAD203 Class 2 SU historical radionuclides with background, PRG, and/or RL exceedances (pCi/g)

\begin{tabular}{|c|c|c|c|c|c|c|c|c|c|c|c|}
\hline \multirow[b]{2}{*}{ Analyte } & \multirow[b]{2}{*}{$\begin{array}{c}\text { Detect } \\
\text { frequency }\end{array}$} & \multirow[b]{2}{*}{$\begin{array}{c}\text { Minimum } \\
\text { detect }\end{array}$} & \multirow[b]{2}{*}{$\begin{array}{l}\text { Maximum } \\
\text { detect }\end{array}$} & \multirow[b]{2}{*}{$\begin{array}{l}\text { Location(s) of } \\
\text { maximum detect }\end{array}$} & \multirow{2}{*}{$\begin{array}{c}\text { Average } \\
\text { detected } \\
\text { result }\end{array}$} & \multicolumn{6}{|c|}{ Number of analyses exceeding criteria } \\
\hline & & & & & & $\begin{array}{c}\text { Max } \\
\text { RL }\end{array}$ & $\begin{array}{l}\text { Avg } \\
\text { RL }\end{array}$ & $\begin{array}{l}\text { Ind } \\
\text { PRG }\end{array}$ & Bkg & $\begin{array}{c}\text { GW } \\
\text { SL }\end{array}$ & $\begin{array}{c}\text { Res } \\
\text { PRG }\end{array}$ \\
\hline Cesium-137 & $1 / 1$ & 0.076 & 0.076 & RAD203 & 0.076 & 0 & 0 & 0 & NA & NA & 1 \\
\hline Neptunium-237 & $1 / 1$ & 0.67 & 0.67 & RAD203 & 0.67 & 0 & 0 & 0 & NA & NA & 1 \\
\hline Potassium-40 & $1 / 1$ & 11.2 & 11.2 & RAD203 & 11.2 & NA & NA & 1 & 0 & NA & 1 \\
\hline Radium-226 & $1 / 1$ & 5.3 & 5.3 & RAD203 & 5.3 & NA & NA & 1 & 1 & NA & 1 \\
\hline Technetium-99 & $1 / 1$ & 0.81 & 0.81 & RAD203 & 0.81 & NA & NA & 0 & NA & NA & 1 \\
\hline Thorium -228 & $1 / 1$ & 2.1 & 2.1 & RAD203 & 2.1 & NA & NA & 1 & 1 & NA & 1 \\
\hline Thorium -230 & $1 / 1$ & 1.68 & 1.68 & RAD203 & 1.68 & NA & NA & 0 & 1 & NA & 0 \\
\hline Thorium -232 & $1 / 1$ & 1.55 & 1.55 & RAD203 & 1.55 & NA & NA & 1 & 0 & NA & 1 \\
\hline Uranium-235 & $1 / 1$ & 0.35 & 0.35 & RAD203 & 0.35 & 0 & 0 & 0 & NA & 0 & 1 \\
\hline Uranium-238 & $1 / 1$ & 3.54 & 3.54 & RAD203 & 3.54 & 0 & 0 & 0 & 1 & 0 & 1 \\
\hline $\begin{array}{l}\text { Avg }=\text { average } \\
\mathrm{Bkg}=\text { background } \\
\mathrm{EU}=\text { exposure unit } \\
\mathrm{GW}=\text { groundwater } \\
\text { Ind = industrial } \\
\mathrm{Max}=\text { maximum }\end{array}$ & & $\begin{array}{l}\mathrm{NA}=\text { not al } \\
\mathrm{PRG}=\text { prel } \\
\text { Res }=\text { resid } \\
\mathrm{RL}=\text { remec } \\
\mathrm{SL}=\text { screen } \\
\mathrm{SU}=\text { soil ur }\end{array}$ & $\begin{array}{l}\text { oplicable } \\
\text { minary remed } \\
\text { ential } \\
\text { iation level } \\
\text { ing level } \\
\text { it }\end{array}$ & ation goal & & & & & & & \\
\hline
\end{tabular}


A BAR survey was not conducted at this location because confirmation sample analytical results failed to confirm any average RL exceedance. The confirmation sample was analyzed for radionuclides. Analytical results from the confirmation sample show several radionuclide industrial PRG and background exceedances but no maximum or average RL or groundwater SL exceedances (see summary below).

EU Z2-28 RAD203 Class 2 SU confirmation sample radionuclides with background, PRG, and/or RL exceedances (pCi/g)

\begin{tabular}{|c|c|c|c|c|c|c|c|c|c|c|c|}
\hline \multirow[b]{2}{*}{ Analyte } & \multirow[b]{2}{*}{$\begin{array}{c}\text { Detect } \\
\text { frequency }\end{array}$} & \multirow[b]{2}{*}{$\begin{array}{c}\text { Minimum } \\
\text { detect }\end{array}$} & \multirow[b]{2}{*}{$\begin{array}{c}\text { Maximum } \\
\text { detect }\end{array}$} & \multirow[b]{2}{*}{$\begin{array}{c}\text { Location(s) of } \\
\text { maximum detect }\end{array}$} & \multirow{2}{*}{$\begin{array}{c}\text { Average } \\
\text { detected } \\
\text { result }\end{array}$} & \multicolumn{6}{|c|}{ Number of analyses exceeding criteria } \\
\hline & & & & & & $\begin{array}{c}\text { Max } \\
\text { RL }\end{array}$ & $\begin{array}{l}\text { Avg } \\
\text { RL }\end{array}$ & $\begin{array}{l}\text { Ind } \\
\text { PRG }\end{array}$ & Bkg & $\begin{array}{c}\text { GW } \\
\text { SL }\end{array}$ & $\begin{array}{r}\text { Res } \\
\text { PRG }\end{array}$ \\
\hline Potassium-40 & $1 / 1$ & 7.76 & 7.76 & Z2-EU28B-126 & 7.76 & NA & NA & 1 & 0 & NA & 1 \\
\hline Radium-226 & $1 / 1$ & 1.3 & 1.3 & Z2-EU28B-126 & 1.3 & NA & NA & 1 & 1 & NA & 1 \\
\hline Thorium -228 & $1 / 1$ & 1.65 & 1.65 & Z2-EU28B-126 & 1.65 & NA & NA & 1 & 0 & NA & 1 \\
\hline Thorium -230 & $1 / 1$ & 1.59 & 1.59 & Z2-EU28B-126 & 1.59 & NA & NA & 0 & 1 & NA & 0 \\
\hline Thorium -232 & $1 / 1$ & 1.35 & 1.35 & Z2-EU28B-126 & 1.35 & NA & NA & 1 & 0 & NA & 1 \\
\hline Uranium-238 & $1 / 1$ & 2.69 & 2.69 & Z2-EU28B-126 & 2.69 & 0 & 0 & 0 & 1 & 0 & 1 \\
\hline
\end{tabular}

Avg $=$ average

$\mathrm{Bkg}=$ background

$\mathrm{NA}=$ not applicable

$\mathrm{EU}=$ exposure unit

$\mathrm{GW}=$ groundwater

Ind $=$ industrial

$\mathrm{PRG}=$ preliminary remediation goal

Res $=$ residential

$\mathrm{RL}=$ remediation level

Max $=$ maximum

$\mathrm{SU}=$ soil unit

DVS Class 2 SU Area Definition Sampling at RAD209: The RAD209 historical sample had a U-238 average RL exceedance, groundwater SL exceedances for U-234 and U-238, and several radionuclide industrial PRG and background exceedances (see summary below).

EU Z2-28 RAD209 Class 2 SU historical radionuclides with background, PRG, and/or RL exceedances (pCi/g)

\begin{tabular}{|c|c|c|c|c|c|c|c|c|c|c|c|}
\hline \multirow[b]{2}{*}{ Analyte } & \multirow[b]{2}{*}{$\begin{array}{c}\text { Detect } \\
\text { frequency }\end{array}$} & \multirow[b]{2}{*}{$\begin{array}{c}\text { Minimum } \\
\text { detect }\end{array}$} & \multirow[b]{2}{*}{$\begin{array}{c}\text { Maximum } \\
\text { detect }\end{array}$} & \multirow[b]{2}{*}{$\begin{array}{l}\text { Location(s) of } \\
\text { maximum detect }\end{array}$} & \multirow{2}{*}{$\begin{array}{c}\text { Average } \\
\text { detected } \\
\text { result }\end{array}$} & \multicolumn{6}{|c|}{ Number of analyses exceeding criteria } \\
\hline & & & & & & $\begin{array}{c}\text { Max } \\
\text { RL }\end{array}$ & $\begin{array}{l}\text { Avg } \\
\text { RL }\end{array}$ & $\begin{array}{l}\text { Ind } \\
\text { PRG }\end{array}$ & Bkg & $\begin{array}{l}\text { GW } \\
\text { SL }\end{array}$ & $\begin{array}{l}\text { Res } \\
\text { PRG }\end{array}$ \\
\hline Potassium-40 & $1 / 1$ & 20.4 & 20.4 & RAD209 & 20.4 & NA & NA & 1 & 0 & NA & 1 \\
\hline Technetium-99 & $1 / 1$ & 7.4 & 7.4 & RAD209 & 7.4 & NA & NA & 0 & NA & NA & 1 \\
\hline Thorium -228 & $1 / 1$ & 1.54 & 1.54 & RAD209 & 1.54 & NA & NA & 1 & 0 & NA & 1 \\
\hline Thorium-232 & $1 / 1$ & 1.51 & 1.51 & RAD209 & 1.51 & NA & NA & 1 & 0 & NA & 1 \\
\hline Uranium-233/234 & $1 / 1$ & 76.6 & 76.6 & RAD209 & 76.6 & 0 & 0 & 0 & NA & 1 & 1 \\
\hline Uranium-235 & $1 / 1$ & 4.72 & 4.72 & RAD209 & 4.72 & 0 & 0 & 1 & NA & 0 & 1 \\
\hline Uranium-238 & $1 / 1$ & 82.9 & 82.9 & RAD209 & 82.9 & 0 & 1 & 1 & 1 & 1 & 1 \\
\hline
\end{tabular}

\begin{tabular}{ll}
\hline Avg = average & NA = not applicable \\
Bkg = background & PRG = preliminary remediation goal \\
EU = exposure unit & Res = residential \\
GW = groundwater & RL = remediation level \\
Ind = industrial & SU = soil unit \\
Max = maximum &
\end{tabular}

DVS sampling was conducted at historical sample location RAD209 to define the extent of the average RL exceedance. Four-point composite step-out sample Z2-EU28B-121 was collected from within the BAR survey two times the background boundary around historical sample location RAD209. The DVS step-out sample was analyzed for radionuclides and the analytical results show average RL and background exceedances for U-238, groundwater SL exceedances for U-234 and U-238, and several industrial PRG exceedances (see summary below). The step-out sample analytical results confirm the U-238 average RL exceedance. 


\section{EU Z2-28 RAD209 Class 2 SU DVS step-out sample radionuclides with background, PRG, and/or RL exceedances (pCi/g)}

\begin{tabular}{|c|c|c|c|c|c|c|c|c|c|c|c|}
\hline \multirow[b]{2}{*}{ Analyte } & \multirow[b]{2}{*}{$\begin{array}{c}\text { Detect } \\
\text { frequency }\end{array}$} & \multirow[b]{2}{*}{$\begin{array}{c}\text { Minimum } \\
\text { detect }\end{array}$} & \multirow[b]{2}{*}{$\begin{array}{c}\text { Maximum } \\
\text { detect }\end{array}$} & \multirow[b]{2}{*}{$\begin{array}{c}\text { Location(s) of } \\
\text { maximum detect }\end{array}$} & \multirow{2}{*}{$\begin{array}{c}\text { Avg } \\
\text { detected } \\
\text { result }\end{array}$} & \multicolumn{6}{|c|}{ Number of analyses exceeding criteria } \\
\hline & & & & & & $\begin{array}{c}\text { Max } \\
\text { RL }\end{array}$ & $\begin{array}{l}\text { Avg } \\
\text { RL }\end{array}$ & $\begin{array}{l}\text { Ind } \\
\text { PRG }\end{array}$ & Bkg & $\begin{array}{c}\text { GW } \\
\text { SL }\end{array}$ & $\begin{array}{r}\text { Res } \\
\text { PRG }\end{array}$ \\
\hline Neptunium-237 & $1 / 1$ & 0.355 & 0.355 & Z2-EU28B-121 & 0.355 & 0 & 0 & 0 & $\mathrm{NA}$ & NA & 1 \\
\hline Potassium-40 & $1 / 1$ & 17.7 & 17.7 & Z2-EU28B-121 & 17.7 & NA & NA & 1 & 0 & NA & 1 \\
\hline Radium-226 & $1 / 1$ & 0.537 & 0.537 & Z2-EU28B-121 & 0.537 & NA & NA & 1 & 0 & NA & 1 \\
\hline Thorium-228 & $1 / 1$ & 1.49 & 1.49 & Z2-EU28B-121 & 1.49 & NA & NA & 1 & 0 & NA & 1 \\
\hline Thorium -232 & $1 / 1$ & 1.15 & 1.15 & Z2-EU28B-121 & 1.15 & NA & NA & 1 & 0 & NA & 1 \\
\hline Uranium-234 & $1 / 1$ & 66.2 & 66.2 & Z2-EU28B-121 & 66.2 & 0 & 0 & 0 & NA & 1 & 1 \\
\hline Uranium-235 & $1 / 1$ & 4.09 & 4.09 & Z2-EU28B-121 & 4.09 & 0 & 0 & 1 & NA & 0 & 1 \\
\hline Uranium-238 & $1 / 1$ & 68.6 & 68.6 & Z2-EU28B-121 & 68.6 & 0 & 1 & 1 & 1 & 1 & 1 \\
\hline
\end{tabular}

\begin{tabular}{ll}
\hline Avg $=$ average & Max = maximum \\
Bkg = background & NA = not applicable \\
DVS = Dynamic Verification Strategy & PRG = preliminary remediation goal \\
EU = exposure unit & Res = residential \\
GW = groundwater & RL = remediation level \\
Ind = industrial & SU = soil unit
\end{tabular}

DVS Class 2 SU Area Definition Sampling at RAD212: Historical samples in the RAD212 area had average RL exceedances for Ra/Th decay series, U-235, and U-238; GW SL exceedances for U-234 and U-238; and several radionuclide industrial PRG and background exceedances.

EU Z2-28 RAD212 Class 2 SU historical radionuclides with background, PRG, and/or RL exceedances (pCi/g)

\begin{tabular}{|c|c|c|c|c|c|c|c|c|c|c|c|}
\hline \multirow[b]{2}{*}{ Analyte } & \multirow[b]{2}{*}{$\begin{array}{c}\text { Detect } \\
\text { frequency }\end{array}$} & \multirow[b]{2}{*}{$\begin{array}{c}\text { Minimum } \\
\text { detect }\end{array}$} & \multirow[b]{2}{*}{$\begin{array}{c}\text { Maximum } \\
\text { detect }\end{array}$} & \multirow[b]{2}{*}{$\begin{array}{l}\text { Location(s) of } \\
\text { maximum detect }\end{array}$} & \multirow{2}{*}{$\begin{array}{c}\text { Avg } \\
\text { detected } \\
\text { result }\end{array}$} & \multicolumn{6}{|c|}{ Number of analyses exceeding criteria } \\
\hline & & & & & & $\begin{array}{l}\text { Max } \\
\text { RL }\end{array}$ & $\begin{array}{l}\text { Avg } \\
\text { RL }\end{array}$ & $\begin{array}{l}\text { Ind } \\
\text { PRG }\end{array}$ & Bkg & $\begin{array}{l}\text { GW } \\
\text { SL }\end{array}$ & $\begin{array}{r}\text { Res } \\
\text { PRG }\end{array}$ \\
\hline Cesium-137 & $3 / 3$ & 0.04 & 0.096 & RAD212 & 0.066 & 0 & 0 & 0 & NA & NA & 2 \\
\hline Potassium-40 & $3 / 3$ & 21 & 23.1 & RAD214 & 21.9 & NA & NA & 3 & 0 & NA & 3 \\
\hline Radium-226 & $3 / 3$ & 0.8 & 9.9 & RAD212 & 4.97 & NA & NA & 3 & 2 & NA & 3 \\
\hline Technetium-99 & $3 / 3$ & 3.55 & 26.2 & RAD210 & 11.5 & NA & NA & 0 & NA & NA & 3 \\
\hline Thorium -228 & $3 / 3$ & 1.53 & 2.16 & RAD212 & 1.90 & NA & NA & 3 & 2 & NA & 3 \\
\hline Thorium -230 & $3 / 3$ & 1.25 & 1.77 & RAD212 & 1.51 & NA & NA & 0 & 3 & NA & 0 \\
\hline Thorium -232 & $3 / 3$ & 1.21 & 1.72 & RAD212 & 1.48 & NA & NA & 3 & 0 & NA & 3 \\
\hline $\mathrm{Ra} / \mathrm{Th}$ decay series & $3 / 3$ & 0.32 & 8.65 & RAD212 & 3.87 & 0 & 1 & NA & NA & NA & NA \\
\hline Uranium-233/234 & $3 / 3$ & 52.2 & 168 & RAD212 & 114 & 0 & 0 & 0 & NA & 2 & 3 \\
\hline Uranium-235 & $3 / 3$ & 3.8 & 9.7 & RAD212 & 6.83 & 0 & 1 & 2 & NA & 0 & 3 \\
\hline Uranium-238 & $3 / 3$ & 54.8 & 174 & RAD212 & 119 & 0 & 3 & 3 & 3 & 2 & 3 \\
\hline
\end{tabular}

\begin{tabular}{ll}
\hline Avg $=$ average & $\mathrm{NA}=$ not applicable \\
$\mathrm{Bkg}=$ background & $\mathrm{PRG}=$ preliminary remediation goal \\
$\mathrm{EU}=$ exposure unit & Res $=$ residential \\
$\mathrm{GW}=$ groundwater & $\mathrm{RL}=$ remediation level \\
Ind = industrial & $\mathrm{SU}=$ soil unit \\
Max = maximum &
\end{tabular}

DVS sampling was conducted to define the extent of the average RL exceedances at historical sample location RAD212. Four-point composite step-out sample Z2-EU28B-122 was collected from within the BAR survey two times the background boundary in the vicinity of historical sample locations RAD210, RAD212, and RAD214. The DVS step-out sample was analyzed for radionuclides and the analytical results show average RL and background exceedances for U-238, groundwater SL exceedances for U-234 and U-238, and industrial PRG exceedances for several radionuclides (see summary below). The DVS step-out sample confirmed the U-238 average RL and U-234 and U-238 GW SL exceedances. 


\section{EU Z2-28 RAD212 Class 2 SU DVS step-out sample radionuclides with background, PRG, and/or RL exceedances (pCi/g)}

\begin{tabular}{|c|c|c|c|c|c|c|c|c|c|c|c|}
\hline \multirow[b]{2}{*}{ Analyte } & \multirow[b]{2}{*}{$\begin{array}{c}\text { Detect } \\
\text { frequency }\end{array}$} & \multirow[b]{2}{*}{$\begin{array}{c}\text { Minimum } \\
\text { detect }\end{array}$} & \multirow[b]{2}{*}{$\begin{array}{c}\text { Maximum } \\
\text { detect }\end{array}$} & \multirow[b]{2}{*}{$\begin{array}{l}\text { Location(s) of } \\
\text { maximum detect }\end{array}$} & \multirow{2}{*}{$\begin{array}{c}\text { Avg } \\
\text { detected } \\
\text { result }\end{array}$} & \multicolumn{6}{|c|}{ Number of analyses exceeding criteria } \\
\hline & & & & & & $\underset{\text { RL }}{\operatorname{Max}}$ & $\begin{array}{l}\text { Avg } \\
\text { RL }\end{array}$ & $\begin{array}{l}\text { Ind } \\
\text { PRG }\end{array}$ & Bkg & $\begin{array}{l}\mathbf{G W} \\
\text { SL }\end{array}$ & $\begin{array}{c}\text { Res } \\
\text { PRG }\end{array}$ \\
\hline Potassium-40 & $1 / 1$ & 21.9 & 21.9 & Z2-EU28B-122 & 21.9 & NA & NA & 1 & 0 & NA & 1 \\
\hline Radium-226 & $1 / 1$ & 0.573 & 0.573 & Z2-EU28B-122 & 0.573 & NA & NA & 1 & 0 & NA & 1 \\
\hline Technetium-99 & $1 / 1$ & 4.08 & 4.08 & Z2-EU28B-122 & 4.08 & NA & NA & 0 & NA & NA & 1 \\
\hline Thorium -228 & $1 / 1$ & 1.76 & 1.76 & Z2-EU28B-122 & 1.76 & NA & NA & 1 & 0 & NA & 1 \\
\hline Thorium -232 & $1 / 1$ & 1.28 & 1.28 & Z2-EU28B-122 & 1.28 & NA & NA & 1 & 0 & NA & 1 \\
\hline Uranium-234 & $1 / 1$ & 74.8 & 74.8 & Z2-EU28B-122 & 74.8 & 0 & 0 & 0 & NA & 1 & 1 \\
\hline Uranium-235 & $1 / 1$ & 4.08 & 4.08 & Z2-EU28B-122 & 4.08 & 0 & 0 & 1 & NA & 0 & 1 \\
\hline Uranium-238 & $1 / 1$ & 79.1 & 79.1 & Z2-EU28B-122 & 79.1 & 0 & 1 & 1 & 1 & 1 & 1 \\
\hline
\end{tabular}

\begin{tabular}{ll}
\hline Avg $=$ average & Max = maximum \\
Bkg = background & NA = not applicable \\
DVS = Dynamic Verification Strategy & PRG = preliminary remediation goal \\
EU = exposure unit & Res = residential \\
GW = groundwater & RL = remediation level \\
Ind = industrial & SU = soil unit
\end{tabular}

DVS Class 2 SU Area Definition Sampling at RAD219: Historical sample location RAD219 had average RL exceedances for the Ra/Th decay series, U-235, and U-238; groundwater SL exceedances for U-234 and U-238; and several radionuclide industrial PRG and background exceedances (see summary below).

EU Z2-28 RAD219 Class 2 SU historical radionuclides with background, PRG, and/or RL exceedances (pCi/g)

\begin{tabular}{|c|c|c|c|c|c|c|c|c|c|c|c|}
\hline \multirow[b]{2}{*}{ Analyte } & \multirow[b]{2}{*}{$\begin{array}{c}\text { Detect } \\
\text { frequency }\end{array}$} & \multirow[b]{2}{*}{$\begin{array}{c}\text { Minimum } \\
\text { detect }\end{array}$} & \multirow[b]{2}{*}{$\begin{array}{c}\text { Maximum } \\
\text { detect }\end{array}$} & \multirow[b]{2}{*}{$\begin{array}{l}\text { Location(s) of } \\
\text { maximum detect }\end{array}$} & \multirow{2}{*}{$\begin{array}{c}\text { Avg } \\
\text { detected } \\
\text { result }\end{array}$} & \multicolumn{6}{|c|}{ Number of analyses exceeding criteria } \\
\hline & & & & & & $\begin{array}{l}\text { Max } \\
\text { RL }\end{array}$ & $\begin{array}{l}\text { Avg } \\
\text { RL }\end{array}$ & $\begin{array}{l}\text { Ind } \\
\text { PRG }\end{array}$ & Bkg & $\begin{array}{l}\text { GW } \\
\text { SL }\end{array}$ & $\begin{array}{r}\text { Res } \\
\text { PRG }\end{array}$ \\
\hline Cesium-137 & $1 / 1$ & 0.123 & 0.123 & RAD219 & 0.123 & 0 & 0 & 0 & NA & NA & 1 \\
\hline Potassium-40 & $1 / 1$ & 22.3 & 22.3 & RAD219 & 22.3 & NA & NA & 1 & 0 & NA & 1 \\
\hline Radium-226 & $1 / 1$ & 12.4 & 12.4 & RAD219 & 12.4 & NA & NA & 1 & 1 & NA & 1 \\
\hline Technetium-99 & $1 / 1$ & 7.65 & 7.65 & RAD219 & 7.65 & NA & NA & 0 & NA & NA & 1 \\
\hline Thorium -228 & $1 / 1$ & 2.12 & 2.12 & RAD219 & 2.12 & NA & NA & 1 & 1 & NA & 1 \\
\hline Thorium -230 & $1 / 1$ & 1.26 & 1.26 & RAD219 & 1.26 & NA & NA & 0 & 1 & NA & 0 \\
\hline Thorium -232 & $1 / 1$ & 1.36 & 1.36 & RAD219 & 1.36 & NA & NA & 1 & 0 & NA & 1 \\
\hline $\mathrm{Ra} / \mathrm{Th}$ decay series & $1 / 1$ & 11.15 & 11.15 & RAD219 & 11.15 & 0 & 1 & NA & NA & NA & NA \\
\hline Uranium-233/234 & $1 / 1$ & 172 & 172 & RAD219 & 172 & 0 & 0 & 0 & NA & 1 & 1 \\
\hline Uranium-235 & $1 / 1$ & 11.2 & 11.2 & RAD219 & 11.2 & 0 & 1 & 1 & NA & 0 & 1 \\
\hline Uranium-238 & $1 / 1$ & 184 & 184 & RAD219 & 184 & 0 & 1 & 1 & 1 & 1 & 1 \\
\hline
\end{tabular}

Avg = average

$\mathrm{Bkg}=$ background

$\mathrm{EU}=$ exposure unit

$\mathrm{GW}=$ groundwater

Ind $=$ industrial

Max $=$ maximum
$\mathrm{NA}=$ not applicable

$\mathrm{PRG}=$ preliminary remediation goal

Res $=$ residential

$\mathrm{RL}=$ remediation level

$\mathrm{SU}=$ soil unit

DVS sampling was conducted to define the extent of the average RL exceedance at historical sampling location RAD219. Two discrete samples, Z2-EU28B-123 and Z2-EU28B-124, were collected from within the BAR survey two times the background boundary associated with the RAD219 area definition location. DVS samples for the RAD219 area are also associated with the RAD218 Class 1 SU and analytical results are evaluated above as part of the RAD218 Class 1 SU evaluation. In summary, DVS sample results show average RL exceedances for U-238 in both samples, groundwater SL exceedances for U234 and U238 in both samples, and several radionuclide industrial PRG and background exceedances (see RAD218 Class 1 SU summary above). 
Historical Sampling in Class 2 SU Outside Areas with Average RL Exceedances: There are 24 historical sample locations in the EU Z2-28 Class 2 SU not included with the area definition locations summarized in the preceding sections (see Sect.2.2.2 for a listing of historical sample locations). Overall, the historical samples were analyzed for a full suite of analytes, including metals, PCBs, radionuclides, SVOCs, and VOCs. Location-specific sampling and analysis details are presented in Table F.2. Analytical results for Class 2 SU historical samples outside the area definition locations show industrial PRG exceedances for arsenic and several radionuclides, background exceedances for several metals and radionuclides, and detection of PCBs, SVOCs, and VOCs (see summary below).

EU Z2-28 Class 2 SU historical metals

with background, PRG, GW SL, and/or RL exceedances (mg/kg)

\begin{tabular}{|c|c|c|c|c|c|c|c|c|c|c|c|}
\hline \multirow[b]{2}{*}{ Analyte } & \multirow[b]{2}{*}{$\begin{array}{l}\text { Detect } \\
\text { frequency }\end{array}$} & \multirow[b]{2}{*}{$\underset{\text { detect }}{\text { Minimum }}$} & \multirow[b]{2}{*}{$\begin{array}{c}\text { Maximum } \\
\text { detect }\end{array}$} & \multirow{2}{*}{$\begin{array}{l}\text { Location(s) of } \\
\text { maximum } \\
\text { detect }\end{array}$} & \multirow{2}{*}{$\begin{array}{c}\text { Avg } \\
\text { detected } \\
\text { result }\end{array}$} & \multicolumn{6}{|c|}{ Number of analyses exceeding criteria } \\
\hline & & & & & & $\begin{array}{l}\text { Max } \\
\text { RL }\end{array}$ & $\begin{array}{l}\text { Avg } \\
\text { RL }\end{array}$ & $\begin{array}{l}\text { Ind } \\
\text { PRG }\end{array}$ & Bkg & $\begin{array}{l}\text { GW } \\
\text { SL }\end{array}$ & Res PRG \\
\hline Aluminum & $19 / 19$ & 14,700 & $49,000 \mathrm{~J}$ & Z2-EU28-203 & 25,932 & NA & NA & 0 & 2 & NA & 19 \\
\hline Arsenic & $19 / 19$ & $3.9 \mathrm{~J}$ & $53.8 \mathrm{~J}$ & Z2-EU28B-207 & 14.3 & 0 & 0 & 5 & 6 & 0 & 19 \\
\hline Barium & $19 / 19$ & $36.6 \mathrm{~J}$ & 242 & Z2-EU28B-207 & 88.5 & NA & NA & 0 & 4 & 0 & 0 \\
\hline Beryllium & $19 / 19$ & $0.58 \mathrm{~J}$ & 4.3 & Z2-EU28B-110 & 1.40 & 0 & 0 & 0 & 3 & NA & 0 \\
\hline Cadmium & $19 / 19$ & $0.088 \mathrm{~J}$ & 0.88 & Z2-EU28-205 & 0.354 & NA & NA & 0 & 13 & NA & 0 \\
\hline Calcium & $19 / 19$ & $298 \mathrm{~J}$ & $46,100 \mathrm{~J}$ & Z2-EU28-202 & 12,902 & NA & NA & NA & 16 & NA & NA \\
\hline Chromium & $19 / 19$ & 21.1 & $128 \mathrm{~J}$ & Z2-EU28B-207 & 40.7 & NA & NA & 0 & 3 & 0 & 18 \\
\hline Cobalt & $19 / 19$ & $3.1 \mathrm{~J}$ & $45.4 \mathrm{~J}$ & Z2-EU28B-111 & 15.5 & NA & NA & 0 & 1 & NA & 0 \\
\hline Copper & $19 / 19$ & 17.1 & $65.6 \mathrm{~J}$ & Z2-EU28-202 & 29.3 & NA & NA & 0 & 13 & NA & 0 \\
\hline Iron & $19 / 19$ & 23,000 & 78,300 & Z2-EU28-203 & 38,474 & NA & NA & 0 & 2 & NA & 0 \\
\hline Lead & $19 / 19$ & $11.4 \mathrm{~J}$ & $114 \mathrm{~J}$ & Z2-EU28B-207 & 43.5 & NA & NA & 0 & 9 & 0 & 0 \\
\hline Magnesium & $19 / 19$ & $1,540 \mathrm{~J}$ & 11,100 & Z2-EU28-104 & 4,778 & NA & NA & NA & 11 & NA & NA \\
\hline Manganese & $19 / 19$ & $241 \mathrm{~J}$ & $3,620 \mathrm{~J}$ & Z2-EU28B-111 & 931 & NA & NA & 0 & 2 & NA & 19 \\
\hline Nickel & $19 / 19$ & 17 & $118 \mathrm{~J}$ & Z2-EU28B-111 & 35.8 & NA & NA & 0 & 12 & NA & 0 \\
\hline Selenium & $12 / 15$ & 0.9 & $3.4 \mathrm{~J}$ & Z2-EU28-203 & 1.73 & NA & NA & 0 & 6 & NA & 0 \\
\hline Silver & $3 / 19$ & 0.91 & 1 & Z2-EU28-104 & 0.947 & NA & NA & 0 & 3 & NA & 0 \\
\hline Thallium & $19 / 19$ & $0.18 \mathrm{~J}$ & $1.1 \mathrm{~J}$ & Z2-EU28-201 & 0.403 & NA & NA & 0 & 7 & 0 & 3 \\
\hline Uranium & $19 / 19$ & $0.7 \mathrm{~J}$ & $8.9 \mathrm{~J}$ & $\begin{array}{l}\text { Z2-EU28-205 } \\
\text { Z2-EU28-202 }\end{array}$ & 3.16 & NA & NA & 0 & NA & NA & 14 \\
\hline Vanadium & $19 / 19$ & 29.3 & $135 \mathrm{~J}$ & Z2-EU28B-207 & 61.4 & NA & NA & 0 & 4 & NA & 19 \\
\hline Zinc & $19 / 19$ & $39.5 \mathrm{~J}$ & $301 \mathrm{~J}$ & Z2-EU28B-111 & 90.2 & NA & NA & 0 & 5 & NA & 0 \\
\hline
\end{tabular}

Avg $=$ average

$\mathrm{Bkg}=$ background

$\mathrm{EU}=$ exposure unit

$\mathrm{GW}=$ groundwater

Ind $=$ industrial

Max $=$ maximum

$\mathrm{NA}=$ not applicable

$\mathrm{PRG}=$ preliminary remediation goal

Res $=$ residential

$\mathrm{RL}=$ remediation level

$\mathrm{SL}=$ screening level

$\mathrm{SU}=$ soil unit

EU Z2-28 Class 2 SU historical PCB detects (ug/kg)

\begin{tabular}{|c|c|c|c|c|c|c|c|c|c|}
\hline \multirow[b]{2}{*}{ Analyte } & \multirow[b]{2}{*}{$\begin{array}{c}\text { Detect } \\
\text { frequency }\end{array}$} & \multirow[b]{2}{*}{$\begin{array}{c}\text { Minimum } \\
\text { detect }\end{array}$} & \multirow[b]{2}{*}{$\begin{array}{c}\text { Maximum } \\
\text { detect }\end{array}$} & \multirow{2}{*}{$\begin{array}{c}\text { Location(s) of } \\
\text { maximum } \\
\text { detect }\end{array}$} & \multirow{2}{*}{$\begin{array}{c}\text { Avg } \\
\text { detected } \\
\text { result }\end{array}$} & \multicolumn{4}{|c|}{$\begin{array}{c}\text { Number of analyses } \\
\text { exceeding criteria }\end{array}$} \\
\hline & & & & & & $\begin{array}{c}\text { Max } \\
\text { RL }\end{array}$ & $\begin{array}{l}\text { Avg } \\
\text { RL } \\
\end{array}$ & $\begin{array}{c}\text { Ind } \\
\text { PRG } \\
\end{array}$ & $\begin{array}{r}\text { Res } \\
\text { PRG } \\
\end{array}$ \\
\hline PCB-1254 & $10 / 19$ & 5.1 & 33.3 & Z2-EU28-107 & 13.1 & 0 & 0 & 0 & 0 \\
\hline PCB-1260 & $7 / 19$ & $1.8 \mathrm{~J}$ & 36.2 & Z2-EU28-107 & 8.11 & 0 & 0 & 0 & 0 \\
\hline
\end{tabular}

Avg $=$ average

$\mathrm{EU}=$ exposure unit

Ind $=$ industrial

Max = maximum

$\mathrm{PCB}=$ polychlorinated biphenyls
$\mathrm{PRG}=$ preliminary remediation goal

Res $=$ residential

$\mathrm{RL}=$ remediation level

$\mathrm{SU}=$ soil unit 
EU Z2-28 Class 2 SU historical radionuclides with background, PRG, and/or RL exceedances (pCi/g)

\begin{tabular}{|c|c|c|c|c|c|c|c|c|c|c|c|}
\hline \multirow[b]{2}{*}{ Analyte } & \multirow[b]{2}{*}{$\begin{array}{l}\text { Detect } \\
\text { frequency }\end{array}$} & \multirow[b]{2}{*}{$\begin{array}{c}\text { Minimum } \\
\text { detect }\end{array}$} & \multirow[b]{2}{*}{$\begin{array}{c}\text { Maximum } \\
\text { detect }\end{array}$} & \multirow[b]{2}{*}{$\begin{array}{l}\text { Location(s) of } \\
\text { maximum detect }\end{array}$} & \multirow{2}{*}{$\begin{array}{c}\text { Avg } \\
\text { detected } \\
\text { result }\end{array}$} & \multicolumn{6}{|c|}{ Number of analyses exceeding criteria } \\
\hline & & & & & & $\begin{array}{c}\text { Max } \\
\text { RL }\end{array}$ & $\begin{array}{l}\text { Avg } \\
\text { RL }\end{array}$ & $\begin{array}{l}\text { Ind } \\
\text { PRG }\end{array}$ & Bkg & $\begin{array}{l}\text { GW } \\
\text { SL }\end{array}$ & $\begin{array}{r}\text { Res } \\
\text { PRG }\end{array}$ \\
\hline Cesium-137 & $5 / 25$ & 0.007 & $0.102 \mathrm{~J}$ & Z2-EU28-107 & 0.067 & 0 & 0 & 0 & NA & NA & 3 \\
\hline Neptunium-237 & $4 / 25$ & 0 & 0.16 & RAD222 & 0.081 & 0 & 0 & 0 & NA & NA & 1 \\
\hline Potassium-40 & $23 / 23$ & 7.57 & 29.8 & Z2-EU28B-109 & 15.0 & NA & NA & 23 & 0 & NA & 23 \\
\hline Radium-226 & $23 / 23$ & 0 & 3.2 & RAD220 & 1.59 & NA & NA & 22 & 13 & NA & 22 \\
\hline Technetium-99 & $7 / 25$ & 0 & 25.2 & RAD222 & 8.43 & NA & NA & 0 & NA & NA & 6 \\
\hline Thorium -228 & $25 / 25$ & 1.05 & 3.13 & Z2-EU28-203 & 1.75 & NA & NA & 25 & 9 & NA & 25 \\
\hline Thorium -230 & $25 / 25$ & 0.505 & 2.97 & Z2-EU28-202 & 1.72 & NA & NA & 0 & 20 & NA & 0 \\
\hline Thorium -232 & $25 / 25$ & 0.687 & 2.66 & Z2-EU28-202 & 1.48 & NA & NA & 25 & 4 & NA & 25 \\
\hline Uranium-233/234 & $23 / 23$ & 0.836 & 10.77 & RAD215 & 2.38 & 0 & 0 & 0 & NA & 0 & 1 \\
\hline Uranium-234 & $2 / 2$ & 12.9 & 14 & 109 & 13.5 & 0 & 0 & 0 & NA & 0 & 2 \\
\hline Uranium-235 & $11 / 29$ & 0.1 & 0.97 & RAD208 & 0.433 & 0 & 0 & 0 & NA & 0 & 8 \\
\hline Uranium-235/236 & $9 / 19$ & 0.12 & 0.549 & Z2-EU28-205 & 0.232 & 0 & 0 & 0 & NA & 0 & 4 \\
\hline Uranium-238 & $25 / 25$ & 0.878 & 7.71 & 109 & 2.27 & 0 & 0 & 0 & 18 & 0 & 25 \\
\hline $\begin{array}{l}\mathrm{Avg}=\text { average } \\
\mathrm{Bkg}=\text { background } \\
\mathrm{EU}=\text { exposure unit } \\
\mathrm{GW}=\text { groundwater }\end{array}$ & & $\begin{array}{l}\text { Ind }=\text { indus } \\
\text { Max = max } \\
\text { NA = not a } \\
\text { PRG = prel }\end{array}$ & $\begin{array}{l}\text { trial } \\
\text { imum } \\
\text { oplicable } \\
\text { iminary remec }\end{array}$ & ation goal & $\begin{array}{l}\text { S }=\text { resident } \\
=\text { remediat } \\
=\text { screenin } \\
=\text { soil unit }\end{array}$ & $\begin{array}{l}\text { ial } \\
\text { ion lev } \\
\text { level }\end{array}$ & & & & & \\
\hline
\end{tabular}

EU Z2-28 Class 2 SU historical SVOC detects (ug/kg)

\begin{tabular}{|c|c|c|c|c|c|c|c|c|}
\hline \multirow[b]{2}{*}{ Analyte } & \multirow{2}{*}{$\begin{array}{c}\text { Detect } \\
\text { frequency }\end{array}$} & \multirow{2}{*}{$\begin{array}{c}\text { Minimum } \\
\text { detect }\end{array}$} & \multirow{2}{*}{$\begin{array}{c}\text { Maximum } \\
\text { detect }\end{array}$} & \multirow{2}{*}{$\begin{array}{l}\text { Location(s) of } \\
\text { maximum detect }\end{array}$} & \multirow{2}{*}{$\begin{array}{c}\text { Avg } \\
\text { detected } \\
\text { result }\end{array}$} & \multicolumn{3}{|c|}{$\begin{array}{c}\text { Number of analyses } \\
\text { exceeding criteria }\end{array}$} \\
\hline & & & & & & Ind PRG & GW SL & Res PRG \\
\hline Benzo(a)pyrene & $2 / 10$ & 45.6 & 63 & Z2-EU28-106 & 54.3 & 0 & NA & 1 \\
\hline Benzo(b)fluoranthene & $1 / 10$ & 44.2 & 44.2 & Z2-EU28-106 & 44.2 & 0 & NA & 0 \\
\hline Benzo(ghi)perylene & $1 / 10$ & 136 & 136 & Z2-EU28-106 & 136 & 0 & NA & 0 \\
\hline Benzo(k)fluoranthene & $1 / 10$ & $22.8 \mathrm{~J}$ & $22.8 \mathrm{~J}$ & Z2-EU28-103 & 22.8 & 0 & NA & 0 \\
\hline Bis(2-ethylhexyl)phthalate & $1 / 10$ & $105 \mathrm{~J}$ & $105 \mathrm{~J}$ & Z2-EU28B-111 & 105 & 0 & 0 & 0 \\
\hline Chrysene & $1 / 10$ & $22.7 \mathrm{~J}$ & $22.7 \mathrm{~J}$ & Z2-EU28-106 & 22.7 & 0 & NA & 0 \\
\hline Fluoranthene & $3 / 10$ & $15.6 \mathrm{~J}$ & $384 J$ & Z2-EU28-205 & 144 & 0 & NA & 0 \\
\hline Indeno(1,2,3-cd)pyrene & $1 / 10$ & 152 & 152 & Z2-EU28-106 & 152 & 0 & NA & 0 \\
\hline Pyrene & $4 / 10$ & $8.2 \mathrm{~J}$ & $38.4 \mathrm{~J}$ & Z2-EU28-106 & 17.9 & 0 & NA & 0 \\
\hline
\end{tabular}

Avg $=$ average $\quad \mathrm{NA}=$ not applicable $\quad \mathrm{SL}=$ screening level

$\mathrm{EU}=$ exposure unit $\quad \mathrm{PRG}=$ preliminary remediation goal $\quad \mathrm{SU}=$ soil unit

$\mathrm{GW}=$ groundwater $\quad$ Res $=$ residential $\quad$ SVOC $=$ semivolatile organic compound

Ind = industrial

EU Z2-28 Class 2 SU historical VOC detects (ug/kg)

\begin{tabular}{|c|c|c|c|c|c|c|c|c|}
\hline \multirow[b]{2}{*}{ Analyte } & \multirow{2}{*}{$\begin{array}{c}\text { Detect } \\
\text { frequency }\end{array}$} & \multirow{2}{*}{$\begin{array}{c}\text { Minimum } \\
\text { detect }\end{array}$} & \multirow{2}{*}{$\begin{array}{c}\text { Maximum } \\
\text { detect }\end{array}$} & \multirow{2}{*}{$\begin{array}{c}\text { Location(s) of } \\
\text { maximum detect }\end{array}$} & \multirow{2}{*}{$\begin{array}{c}\text { Avg } \\
\text { detected } \\
\text { result }\end{array}$} & \multicolumn{3}{|c|}{$\begin{array}{c}\text { Number of analyses } \\
\text { exceeding crite ria }\end{array}$} \\
\hline & & & & & & Ind PRG & GW SL & Res PRG \\
\hline 2-Butanone & $2 / 12$ & $5.9 \mathrm{~J}$ & 7.6 & Z2-EU28B-111 & 6.75 & 0 & NA & 0 \\
\hline Acetone & $9 / 12$ & 6.5 & 105 & Z2-EU28-105 & 40.4 & 0 & NA & 0 \\
\hline Carbon disulfide & $1 / 12$ & $5.7 \mathrm{~J}$ & $5.7 \mathrm{~J}$ & Z2-EU28B-111 & 5.7 & 0 & NA & 0 \\
\hline Ethylbenzene & $1 / 12$ & $13 \mathrm{~J}$ & $13 \mathrm{~J}$ & Z2-EU28-105 & 13 & 0 & NA & 0 \\
\hline Methylene chloride & $2 / 12$ & $2.5 \mathrm{~J}$ & $3 \mathrm{~J}$ & Z2-EU28-105 & 2.75 & 0 & 0 & 0 \\
\hline Tetrachloroethene & $1 / 12$ & $0.54 \mathrm{~J}$ & $0.54 \mathrm{~J}$ & Z2-EU28-205 & 0.54 & 0 & 0 & 0 \\
\hline Toluene & $8 / 12$ & $0.59 \mathrm{~J}$ & 8.9 & Z2-EU28-105 & 2.64 & 0 & 0 & 0 \\
\hline
\end{tabular}

Avg = average $\quad$ Ind $=$ industrial $\quad$ Res = residential

$\mathrm{EU}=$ exposure unit $\quad \mathrm{NA}=$ not applicable $\quad \mathrm{SU}=$ soil unit

$\mathrm{GW}=$ groundwater $\quad \mathrm{PRG}=$ preliminary remediation goal $\quad$ VOC = volatile organic compound 
Historical Sampling in Class $3 \mathrm{SU}$ : There are 19 historical sample locations in EU Z2-28 Class 3 SU (see Sect. 2.2.3 for a listing of sample locations). Overall, samples were analyzed for metals, PCBs/pesticides, radionuclides, SVOCs, and PCBs. Location-specific sampling and analysis details are presented in Table F.2. Analytical data show industrial PRG and background exceedances for metals and radionuclides, and detection of PCBs, SVOCs, and VOCs (see summary below).

EU Z2-28 Class 3 SU metals with background, PRG, GW SL, and/or RL exceedances (mg/kg)

\begin{tabular}{|c|c|c|c|c|c|c|c|c|c|c|c|}
\hline \multirow[b]{2}{*}{ Analyte } & \multirow[b]{2}{*}{$\begin{array}{c}\text { Detect } \\
\text { frequency }\end{array}$} & \multirow[b]{2}{*}{$\begin{array}{l}\text { Minimum } \\
\text { detect }\end{array}$} & \multirow[b]{2}{*}{$\begin{array}{c}\text { Maximum } \\
\text { detect }\end{array}$} & \multirow[b]{2}{*}{$\begin{array}{c}\text { Location(s) of } \\
\text { maximum detect }\end{array}$} & \multirow{2}{*}{$\begin{array}{c}\text { Avg } \\
\text { detected } \\
\text { result }\end{array}$} & \multicolumn{6}{|c|}{ Number of analyses exceeding criteria } \\
\hline & & & & & & $\begin{array}{c}\text { Max } \\
\text { RL }\end{array}$ & $\begin{array}{l}\text { Avg } \\
\text { RL }\end{array}$ & $\begin{array}{c}\text { Ind } \\
\text { PRG }\end{array}$ & Bkg & $\begin{array}{l}\text { GW } \\
\text { SL }\end{array}$ & $\begin{array}{r}\text { Res } \\
\text { PRG } \\
\end{array}$ \\
\hline Aluminum & $12 / 12$ & $5,990 \mathrm{~J}$ & 45,600 & BLRD10R1 & 20,703 & NA & NA & 0 & 1 & NA & 11 \\
\hline Arsenic & $12 / 12$ & 4 & 17.8 & BLRD10R1 & 9.7 & 0 & 0 & 1 & 2 & 0 & 12 \\
\hline Cadmium & $13 / 13$ & $0.2 \mathrm{~J}$ & 15.6 & BLRD08R1 & 1.58 & NA & NA & 0 & 11 & NA & 1 \\
\hline Calcium & $12 / 12$ & $1,460 \mathrm{~J}$ & 205,000 & Z2-EU28B-323 & 73,879 & NA & NA & NA & 10 & NA & NA \\
\hline Chromium & $12 / 12$ & 8.9 & $44.7 \mathrm{~J}$ & BLRD10R1 & 23.6 & NA & NA & 0 & 0 & 0 & 5 \\
\hline Copper & $12 / 12$ & $9.4 \mathrm{~J}$ & $55.2 \mathrm{~J}$ & BLRD11R1 & 23.2 & NA & NA & 0 & 4 & NA & 0 \\
\hline Lead & $13 / 13$ & $18 \mathrm{~J}$ & 52.3 & BLRD02R1 & 34.6 & NA & NA & 0 & 5 & 0 & 0 \\
\hline Lithium & $7 / 7$ & $8 \mathrm{~J}$ & $93.3 \mathrm{~J}$ & Z2-EU28B-320 & 24.5 & NA & NA & 0 & 1 & NA & 0 \\
\hline Magnesium & $12 / 12$ & 2,200 & 102,000 & Z2-EU28B-322 & 23,118 & NA & NA & NA & 10 & NA & NA \\
\hline Manganese & $12 / 12$ & $228 \mathrm{~J}$ & 1,690 & Z2-EU28B-321 & 717 & NA & NA & 0 & 0 & NA & 12 \\
\hline Nickel & $13 / 13$ & 12.3 & $161 \mathrm{~J}$ & BLRD11R1 & 36.9 & NA & NA & 0 & 6 & NA & 1 \\
\hline Selenium & $8 / 13$ & 0.6 & 1.8 & Z2-EU28B-317 & 1.34 & NA & NA & 0 & 5 & NA & 0 \\
\hline Silver & $7 / 13$ & 0.077 & 1.1 & Z2-EU28B-321 & 0.441 & NA & NA & 0 & 2 & NA & 0 \\
\hline
\end{tabular}

EU Z2-28 Class 3 SU metals with background, PRG, GW SL, and/or RL exceedances $(\mathrm{mg} / \mathrm{kg})$ (continued)

\begin{tabular}{|c|c|c|c|c|c|c|c|c|c|c|c|}
\hline \multirow[b]{2}{*}{ Analyte } & \multirow[b]{2}{*}{$\begin{array}{c}\text { Detect } \\
\text { frequency }\end{array}$} & \multirow[b]{2}{*}{$\begin{array}{c}\text { Minimum } \\
\text { detect }\end{array}$} & \multirow[b]{2}{*}{$\begin{array}{c}\text { Maximum } \\
\text { detect }\end{array}$} & \multirow[b]{2}{*}{$\begin{array}{c}\text { Location(s) of } \\
\text { maximum detect }\end{array}$} & \multirow{2}{*}{$\begin{array}{c}\text { Avg } \\
\text { detected } \\
\text { result }\end{array}$} & \multicolumn{6}{|c|}{ Number of analyses exceeding criteria } \\
\hline & & & & & & $\begin{array}{l}\text { Max } \\
\text { RL }\end{array}$ & $\begin{array}{l}\text { Avg } \\
\text { RL }\end{array}$ & $\begin{array}{l}\text { Ind } \\
\text { PRG }\end{array}$ & Bkg & $\begin{array}{c}\text { GW } \\
\text { SL }\end{array}$ & $\begin{array}{c}\text { Res } \\
\text { PRG } \\
\end{array}$ \\
\hline Strontium & $7 / 7$ & $3.4 \mathrm{~J}$ & 207 & Z2-EU28B-323 & 79.3 & NA & NA & 0 & 2 & NA & 0 \\
\hline Thallium & $12 / 12$ & $0.14 \mathrm{~J}$ & 0.63 & Z2-EU28B-320 & 0.324 & NA & NA & 0 & 4 & 0 & 2 \\
\hline Uranium & $9 / 10$ & $0.78 \mathrm{~J}$ & $10.3 \mathrm{~J}$ & Z2-EU28B-317 & 2.58 & NA & NA & 0 & NA & NA & 4 \\
\hline Vanadium & $12 / 12$ & $14.8 \mathrm{~J}$ & $77.5 \mathrm{~J}$ & BLRD10R1 & 37.6 & NA & NA & 0 & 2 & NA & 12 \\
\hline Zinc & $12 / 12$ & $27.9 \mathrm{~J}$ & $99.6 \mathrm{~J}$ & BLRD02R1 & 59.9 & NA & NA & 0 & 1 & NA & 0 \\
\hline
\end{tabular}

Avg $=$ average

Bkg $=$ background

$\mathrm{EU}=$ exposure unit

$\mathrm{NA}=$ not applicable

$\mathrm{PRG}=$ preliminary remediation goal

$\mathrm{GW}=$ groundwater

Res $=$ residential

$\mathrm{RL}=$ remediation level

Ind $=$ industrial $\quad \mathrm{SL}=$ screening level

Max $=$ maximum $\quad \mathrm{SU}=$ soil unit

EU Z2-28 Class 3 SU PCB detects (ug/kg)

\begin{tabular}{|c|c|c|c|c|c|c|c|c|c|}
\hline \multirow[b]{2}{*}{ Analyte } & \multirow[b]{2}{*}{$\begin{array}{c}\text { Detect } \\
\text { frequency }\end{array}$} & \multirow[b]{2}{*}{$\begin{array}{c}\text { Minimum } \\
\text { detect }\end{array}$} & \multirow[b]{2}{*}{$\begin{array}{c}\text { Maximum } \\
\text { detect }\end{array}$} & \multirow{2}{*}{$\begin{array}{c}\text { Location(s) of } \\
\text { maximum } \\
\text { detect }\end{array}$} & \multirow{2}{*}{$\begin{array}{c}\text { Avg } \\
\text { detected } \\
\text { result }\end{array}$} & \multicolumn{4}{|c|}{$\begin{array}{c}\text { Number of analyses } \\
\text { exceeding criteria }\end{array}$} \\
\hline & & & & & & $\begin{array}{c}\text { Max } \\
\text { RL }\end{array}$ & $\begin{array}{l}\text { Avg } \\
\text { RL }\end{array}$ & $\begin{array}{c}\text { Ind } \\
\text { PRG }\end{array}$ & $\begin{array}{c}\text { Res } \\
\text { PRG } \\
\end{array}$ \\
\hline PCB-1254 & $6 / 13$ & $24 \mathrm{~J}$ & $690 \mathrm{~J}$ & BLRD07R1 & 230 & 0 & 0 & 0 & 2 \\
\hline PCB-1260 & $6 / 13$ & $13.5 \mathrm{~J}$ & $490 \mathrm{~J}$ & BLRD07R1 & 174 & 0 & 0 & 0 & 3 \\
\hline
\end{tabular}

Avg $=$ average

$\mathrm{EU}=$ exposure unit

$\mathrm{PRG}=$ preliminary remediation goal

Ind $=$ industrial

Res $=$ residential

Max = maximum

$\mathrm{PCB}=$ polychlorinated biphenyl

$\mathrm{RL}=$ remediation level

$\mathrm{SU}=$ soil unit

Pesticides were analyzed for in a sample from S4 but were not detected. 
EU Z2-28 Class 3 SU radionuclides with background, PRG, and/or RL exceedances (pCi/g)

\begin{tabular}{|c|c|c|c|c|c|c|c|c|c|c|c|}
\hline \multirow[b]{2}{*}{ Analyte } & \multirow[b]{2}{*}{$\begin{array}{c}\text { Detect } \\
\text { frequency }\end{array}$} & \multirow[b]{2}{*}{$\underset{\text { detect }}{\text { Minimum }}$} & \multirow[b]{2}{*}{$\begin{array}{c}\text { Maximum } \\
\text { detect }\end{array}$} & \multirow[b]{2}{*}{$\begin{array}{l}\text { Location(s) of } \\
\text { maximum detect }\end{array}$} & \multirow{2}{*}{$\begin{array}{c}\text { Avg } \\
\text { detected } \\
\text { result }\end{array}$} & \multicolumn{6}{|c|}{ Number of analyses exceeding criteria } \\
\hline & & & & & & $\begin{array}{l}\text { Max } \\
\text { RL }\end{array}$ & $\begin{array}{l}\text { Avg } \\
\text { RL }\end{array}$ & $\begin{array}{l}\text { Ind } \\
\text { PRG }\end{array}$ & Bkg & $\begin{array}{l}\text { GW } \\
\text { SL }\end{array}$ & $\begin{array}{r}\text { Res } \\
\text { PRG }\end{array}$ \\
\hline Cesium-137 & $15 / 21$ & 0.0216 & 1.05 & BLRD11R1 & 0.283 & 0 & 0 & 0 & NA & NA & 13 \\
\hline Neptunium-237 & $2 / 10$ & 0 & 0.629 & $\mathrm{~S} 4$ & 0.315 & 0 & 0 & 0 & NA & NA & 1 \\
\hline Potassium-40 & $8 / 8$ & 4.86 & 22.4 & Z2-EU28B-320 & 11.9 & NA & NA & 8 & 0 & NA & 8 \\
\hline Radium-226 & $7 / 7$ & $1.02 \mathrm{~J}$ & $1.45 \mathrm{~J}$ & Z2-EU28B-317 & 1.22 & NA & NA & 7 & 3 & NA & 7 \\
\hline Technetium-99 & $1 / 21$ & 36.6 & 36.6 & S4 & 36.6 & NA & NA & 0 & NA & NA & 1 \\
\hline Thorium -228 & $18 / 18$ & $0.536 \mathrm{~J}$ & 2.09 & Z2-EU28B-318 & 1.08 & NA & NA & 18 & 1 & NA & 18 \\
\hline Thorium -230 & $18 / 18$ & $0.671 \mathrm{~J}$ & 1.87 & Z2-EU28B-320 & 1.16 & NA & NA & 0 & 9 & NA & 0 \\
\hline Thorium -232 & $18 / 18$ & $0.388 \mathrm{~J}$ & 2.05 & Z2-EU28B-318 & 1.05 & NA & NA & 18 & 2 & NA & 18 \\
\hline Uranium-233/234 & $18 / 18$ & $0.833 \mathrm{~J}$ & 4.59 & BLRD11R1 & 1.98 & 0 & 0 & 0 & NA & 0 & 1 \\
\hline Uranium-235 & $1 / 9$ & 0.207 & 0.207 & S4 & 0.207 & 0 & 0 & 0 & NA & 0 & 1 \\
\hline Uranium-238 & $23 / 28$ & 0.233 & 4.22 & Z2-EU28B-321 & 1.62 & 0 & 0 & 0 & 11 & 0 & 20 \\
\hline
\end{tabular}

Avg = average

Bkg $=$ background

$\mathrm{EU}=$ exposure unit

$\mathrm{GW}=$ groundwater

$\mathrm{NA}=$ not applicable

$\mathrm{PRG}=$ preliminary remediation goal

Res $=$ residential

$\mathrm{RL}=$ remediation level

Ind $=$ industrial

$\mathrm{SL}=$ screening level

Max $=$ maximum

$\mathrm{SU}=$ soil unit

EU Z2-28 Class 3 SU SVOC detects (ug/kg)

\begin{tabular}{|c|c|c|c|c|c|c|c|c|}
\hline \multirow[b]{2}{*}{ Analyte } & \multirow[b]{2}{*}{$\begin{array}{c}\text { Detect } \\
\text { frequency }\end{array}$} & \multirow[b]{2}{*}{$\begin{array}{c}\text { Minimum } \\
\text { detect }\end{array}$} & \multirow[b]{2}{*}{$\begin{array}{c}\text { Maximum } \\
\text { detect }\end{array}$} & \multirow[b]{2}{*}{$\begin{array}{c}\text { Location(s) of } \\
\text { maximum detect }\end{array}$} & \multirow{2}{*}{$\begin{array}{c}\text { Avg } \\
\text { detected } \\
\text { result }\end{array}$} & \multicolumn{3}{|c|}{$\begin{array}{l}\text { Number of analyses } \\
\text { exceeding criteria }\end{array}$} \\
\hline & & & & & & $\begin{array}{c}\text { Ind } \\
\text { PRG }\end{array}$ & $\begin{array}{l}\text { GW } \\
\text { SL }\end{array}$ & $\begin{array}{c}\text { Res } \\
\text { PRG }\end{array}$ \\
\hline 2-Methylnaphthalene & $1 / 13$ & $25 \mathrm{~J}$ & $25 \mathrm{~J}$ & Z2-EU28B-317 & 25 & 0 & NA & NA \\
\hline Acenaphthene & $1 / 13$ & $9.8 \mathrm{~J}$ & $9.8 \mathrm{~J}$ & Z2-EU28B-318 & 9.8 & 0 & NA & 0 \\
\hline Acenaphthylene & $2 / 13$ & $20.6 \mathrm{~J}$ & 273 & Z2-EU28B-317 & 147 & 0 & NA & 0 \\
\hline Anthracene & $2 / 13$ & 74.3 & 85.3 & Z2-EU28B-317 & 79.8 & 0 & NA & 0 \\
\hline Benz(a)anthracene & $4 / 13$ & $99 \mathrm{~J}$ & 761 & Z2-EU28B-318 & 407 & 0 & NA & 1 \\
\hline Benzo(a)pyrene & $6 / 13$ & $150 \mathrm{~J}$ & 982 & Z2-EU28B-317 & 419 & 0 & NA & 6 \\
\hline Benzo(b)fluoranthene & $7 / 13$ & $86.3 \mathrm{~J}$ & 1,610 & Z2-EU28B-317 & 485 & 0 & NA & 2 \\
\hline Benzo(ghi)perylene & $4 / 13$ & 120 & 824 & Z2-EU28B-317 & 378 & 0 & NA & 0 \\
\hline Benzo(k)fluoranthene & $2 / 13$ & $140 \mathrm{~J}$ & $170 \mathrm{~J}$ & BLRD11R1 & 155 & 0 & NA & 0 \\
\hline Chrysene & $5 / 13$ & $120 \mathrm{~J}$ & 748 & Z2-EU28B-318 & 360 & 0 & NA & 0 \\
\hline Dibenz(a,h)anthracene & $2 / 13$ & 175 & 210 & Z2-EU28B-317 & 193 & 0 & NA & 2 \\
\hline Fluoranthene & $6 / 13$ & $92.2 \mathrm{~J}$ & 1,200 & Z2-EU28B-318 & 486 & 0 & NA & 0 \\
\hline Fluorene & $2 / 13$ & $29.9 \mathrm{~J}$ & $33.8 \mathrm{~J}$ & Z2-EU28B-318 & 31.9 & 0 & NA & 0 \\
\hline Indeno(1,2,3-cd)pyrene & $6 / 13$ & 100 & 654 & Z2-EU28B-317 & 412 & 0 & NA & 1 \\
\hline Naphthalene & $1 / 13$ & $30.1 \mathrm{~J}$ & $30.1 \mathrm{~J}$ & Z2-EU28B-317 & 30.1 & 0 & NA & 0 \\
\hline Phenanthrene & $5 / 13$ & $53 \mathrm{~J}$ & 605 & Z2-EU28B-318 & 277 & 0 & NA & 0 \\
\hline Pyrene & $7 / 13$ & $155 \mathrm{~J}$ & 1,390 & Z2-EU28B-318 & 497 & 0 & NA & 0 \\
\hline
\end{tabular}

Avg $=$ average

$\mathrm{Bkg}=$ background

$\mathrm{EU}=$ exposure unit

$\mathrm{GW}=$ groundwater

Ind $=$ industrial

Max $=$ maximum

$\mathrm{NA}=$ not applicable

$\mathrm{PRG}=$ preliminary remediation goal

Res $=$ residential

$\mathrm{RL}=$ remediation level

$\mathrm{SL}=$ screening level

$\mathrm{SU}=$ soil unit

SVOC $=$ semivolatile organic compound 
EU Z2-28 Class 3 SU VOC detects (ug/kg)

\begin{tabular}{|c|c|c|c|c|c|c|c|c|}
\hline \multirow[b]{2}{*}{ Analyte } & \multirow{2}{*}{$\begin{array}{c}\text { Detect } \\
\text { frequency }\end{array}$} & \multirow{2}{*}{$\begin{array}{c}\text { Minimum } \\
\text { detect }\end{array}$} & \multirow{2}{*}{$\begin{array}{c}\text { Maximum } \\
\text { detect }\end{array}$} & \multirow{2}{*}{$\begin{array}{c}\text { Location(s) of } \\
\text { maximum detect }\end{array}$} & \multirow{2}{*}{$\begin{array}{c}\text { Avg } \\
\text { detected } \\
\text { result }\end{array}$} & \multicolumn{3}{|c|}{$\begin{array}{c}\text { Number of analyses } \\
\text { exceeding criteria }\end{array}$} \\
\hline & & & & & & Ind PRG & GW SL & Res PRG \\
\hline 1,1-Dichloroethene & $1 / 9$ & $0.84 \mathrm{~J}$ & $0.84 \mathrm{~J}$ & Z2-EU28B-319 & 0.84 & 0 & 0 & 0 \\
\hline 2-Butanone & $1 / 9$ & $23.1 \mathrm{~J}$ & $23.1 \mathrm{~J}$ & Z2-EU28B-319 & 23.1 & 0 & NA & 0 \\
\hline Acetone & $3 / 9$ & $7.2 \mathrm{~J}$ & $92.7 \mathrm{~J}$ & Z2-EU28B-319 & 36.1 & 0 & NA & 0 \\
\hline Methylene chloride & $6 / 9$ & $1.5 \mathrm{~J}$ & $4.6 \mathrm{~J}$ & BLRD02R1 & 2.7 & 0 & 0 & 0 \\
\hline Toluene & $2 / 9$ & $0.48 \mathrm{~J}$ & 5.3 & Z2-EU28B-322 & 2.89 & 0 & 0 & 0 \\
\hline
\end{tabular}

Avg $=$ average

$\mathrm{EU}=$ exposure unit

$\mathrm{PRG}=$ preliminary remediation goal

$\mathrm{GW}=$ groundwater

Ind $=$ industrial

Res $=$ residential

$\mathrm{SL}=$ screening level

$\mathrm{SU}=$ soil unit

$\mathrm{NA}=$ not applicable

VOC $=$ volatile organic compound

EU Z2-28 Summary: This section presents a summary of the nature and extent of contamination in EU Z2-28 by combining all of the analytical data presented in the focused investigation summaries above. There are 69 sample locations in EU Z2-28. Details of sampling and analysis in this EU are presented in Table F.2, and the sample locations are shown in Fig. F.4. Analytical results for all the samples show maximum RL exceedances for Cs -137 (1) and the Ra/Th decay series (12); average RL exceedances for Cs-137 (9), Np-237 (1), the Ra/Th decay series (17), U-234 (1), U-235 (10), and U-238 (17); arsenic (7) and numerous radionuclide industrial PRG exceedances; radionuclide GW SL exceedances; metal and radionuclide background exceedances; and detections of PCBs, SVOCs, and VOCs (see summary below). Radionuclide RL and GW SL exceedances all occur at the Class 1 SUs and Class 2 SU area definition locations in the K1407-C Soil Piles FFA Site (Rusty's Mountain) (see data summaries above).

EU Z2-28 radionuclides with background, PRG, and/or RL exceedances (pCi/g)

\begin{tabular}{|c|c|c|c|c|c|c|c|c|c|c|c|}
\hline \multirow[b]{2}{*}{ Analyte } & \multirow[b]{2}{*}{$\begin{array}{c}\text { Detect } \\
\text { frequency }\end{array}$} & \multirow[b]{2}{*}{$\begin{array}{c}\text { Minimum } \\
\text { detect }\end{array}$} & \multirow[b]{2}{*}{$\begin{array}{c}\text { Maximum } \\
\text { detect }\end{array}$} & \multirow[b]{2}{*}{$\begin{array}{l}\text { Location(s) of } \\
\text { maximum detect }\end{array}$} & \multirow{2}{*}{$\begin{array}{c}\text { Avg } \\
\text { detected } \\
\text { result }\end{array}$} & \multicolumn{6}{|c|}{ Number of analyses exceeding criteria } \\
\hline & & & & & & $\begin{array}{c}\text { Max } \\
\text { RL }\end{array}$ & $\begin{array}{c}\text { Avg } \\
\text { RL }\end{array}$ & $\begin{array}{l}\text { Ind } \\
\text { PRG }\end{array}$ & Bkg & $\begin{array}{c}\text { GW } \\
\text { SL }\end{array}$ & $\begin{array}{r}\text { Res } \\
\text { PRG }\end{array}$ \\
\hline Cesium-137 & $39 / 74$ & 0.007 & 48 & RAD199 & 2.98 & 1 & 9 & 10 & NA & NA & 33 \\
\hline Neptunium-237 & $24 / 63$ & 0.011 & 15.6 & Z2-EU28B-118 & 1.61 & 0 & 1 & 5 & NA & NA & 17 \\
\hline Potassium-40 & $58 / 59$ & 4.86 & 29.8 & Z2-EU28B-109 & 15.1 & NA & NA & 58 & 0 & NA & 58 \\
\hline Radium-226 & $56 / 58$ & 0 & 35.8 & RAD199 & 3.33 & NA & NA & 54 & 34 & NA & 55 \\
\hline Technetium-99 & $31 / 74$ & 0 & 2,550 & Z2-EU28B-115 & 336 & NA & $\mathrm{NA}$ & 0 & NA & NA & 30 \\
\hline Thorium -228 & $71 / 71$ & $0.536 \mathrm{~J}$ & 54 & RAD205 & 2.67 & NA & NA & 71 & 23 & NA & 71 \\
\hline Thorium -230 & $71 / 71$ & 0.505 & 204 & RAD205 & 17.3 & NA & NA & 1 & 53 & NA & 14 \\
\hline Thorium -232 & $71 / 71$ & $0.388 \mathrm{~J}$ & $20.5 \mathrm{~J}$ & RAD206 & 1.98 & NA & $\mathrm{NA}$ & 71 & 15 & NA & 71 \\
\hline $\mathrm{Ra} / \mathrm{Th}$ decay series & $71 / 71$ & 0 & 213.95 & RAD205 & 17.3 & 12 & 17 & NA & NA & NA & NA \\
\hline Uranium-233/234 & $57 / 57$ & $0.833 \mathrm{~J}$ & 490 & RAD204 & 48.6 & 0 & 0 & 3 & NA & 9 & 17 \\
\hline Uranium-234 & $17 / 17$ & 0.233 & 842 & Z2-EU28B-114 & 92.8 & 0 & 1 & 1 & NA & 7 & 13 \\
\hline Uranium-235 & $40 / 67$ & 0.1 & 54.9 & Z2-EU28B-114 & 6.75 & 0 & 10 & 17 & NA & 0 & 36 \\
\hline Uranium-235/236 & $22 / 39$ & 0.0379 & 2.32 & Z2-EU28-204 & 0.255 & 0 & 0 & 0 & NA & 0 & 5 \\
\hline Uranium-238 & $74 / 74$ & 0.233 & 421 & Z2-EU28B-114 & 36.5 & 0 & 17 & 20 & 55 & 16 & 71 \\
\hline
\end{tabular}

Avg $=$ average

$\mathrm{Bkg}=$ background

$\mathrm{EU}=$ exposure unit

$\mathrm{PRG}=$ preliminary remediation goal

$\mathrm{GW}=$ groundwater

Ind $=$ industrial

Res $=$ residential

$\mathrm{RL}=$ remediation level

$\mathrm{SL}=$ screening level

$\mathrm{NA}=$ not applicable

$\mathrm{SU}=$ soil unit 
EU Z2-28 metals with background, PRG, GW SL, and/or RL exceeda nces (mg/kg)

\begin{tabular}{|c|c|c|c|c|c|c|c|c|c|c|c|}
\hline \multirow[b]{2}{*}{ Analyte } & \multirow[b]{2}{*}{$\begin{array}{c}\text { Detect } \\
\text { frequency }\end{array}$} & \multirow[b]{2}{*}{$\begin{array}{c}\text { Minimum } \\
\text { detect }\end{array}$} & \multirow[b]{2}{*}{$\begin{array}{c}\text { Maximum } \\
\text { detect }\end{array}$} & \multirow[b]{2}{*}{$\begin{array}{c}\text { Location(s) of } \\
\text { maximum detect }\end{array}$} & \multirow{2}{*}{$\begin{array}{c}\text { Avg } \\
\text { detected } \\
\text { result }\end{array}$} & \multicolumn{6}{|c|}{ Number of analyses exceeding criteria } \\
\hline & & & & & & $\begin{array}{l}\text { Max } \\
\text { RL }\end{array}$ & $\begin{array}{l}\text { Avg } \\
\text { RL }\end{array}$ & $\begin{array}{l}\text { Ind } \\
\text { PRG }\end{array}$ & Bkg & $\begin{array}{l}\text { GW } \\
\text { SL }\end{array}$ & $\begin{array}{l}\text { Res } \\
\text { PRG }\end{array}$ \\
\hline Aluminum & $35 / 35$ & $5,990 \mathrm{~J}$ & $49,000 \mathrm{~J}$ & Z2-EU28-203 & 23,618 & NA & NA & 0 & 3 & NA & 34 \\
\hline Arsenic & $35 / 35$ & $3.9 \mathrm{~J}$ & $53.8 \mathrm{~J}$ & Z2-EU28B-207 & 12.4 & 0 & 0 & 7 & 9 & 0 & 35 \\
\hline Barium & $35 / 35$ & $25 \mathrm{~J}$ & 242 & Z2-EU28B-207 & 78.5 & NA & NA & 0 & 3 & 0 & 0 \\
\hline Beryllium & $35 / 35$ & $0.22 \mathrm{~J}$ & 4.3 & Z2-EU28B-110 & 1.07 & 0 & 0 & 0 & 3 & NA & 0 \\
\hline Cadmium & $36 / 36$ & $0.088 \mathrm{~J}$ & 15.6 & BLRD08R1 & 0.84 & NA & NA & 0 & 27 & NA & 1 \\
\hline Calcium & $35 / 35$ & $298 \mathrm{~J}$ & $290,000 \mathrm{~J}$ & Z2-EU28B-118 & 42,848 & NA & NA & NA & 30 & NA & NA \\
\hline Chromium & $35 / 35$ & 8.9 & $128 \mathrm{~J}$ & Z2-EU28B-207 & 34.6 & NA & NA & 0 & 3 & 0 & 27 \\
\hline Cobalt & $35 / 35$ & $3.1 \mathrm{~J}$ & $45.4 \mathrm{~J}$ & Z2-EU28B-111 & 13.9 & NA & NA & 0 & 1 & NA & 0 \\
\hline Copper & $35 / 35$ & $9.4 \mathrm{~J}$ & $69 \mathrm{~J}$ & Z2-EU28B-118 & 28.7 & NA & NA & 0 & 20 & NA & 0 \\
\hline Iron & $35 / 35$ & 6,690 & 78,300 & Z2-EU28-203 & 31,288 & NA & NA & 0 & 2 & NA & 0 \\
\hline Lead & $36 / 36$ & $11.4 \mathrm{~J}$ & $114 \mathrm{~J}$ & Z2-EU28B-207 & 38.7 & NA & NA & 0 & 16 & 0 & 0 \\
\hline Lithium & $30 / 30$ & $8 \mathrm{~J}$ & $93.3 \mathrm{~J}$ & Z2-EU28B-320 & 17.5 & NA & NA & 0 & 1 & NA & 0 \\
\hline Magnesium & $35 / 35$ & $1,540 \mathrm{~J}$ & 102,000 & Z2-EU28B-322 & 11,856 & NA & NA & NA & 24 & NA & NA \\
\hline Manganese & $35 / 35$ & $228 \mathrm{~J}$ & $3,620 \mathrm{~J}$ & Z2-EU28B-111 & 821 & NA & NA & 0 & 2 & NA & 35 \\
\hline Mercury & $36 / 36$ & $0.0052 \mathrm{~J}$ & 86 & Z2-EU28B-115 & 3.57 & 0 & 0 & 0 & 3 & NA & 2 \\
\hline Nickel & $36 / 36$ & 12.3 & $310 \mathrm{~J}$ & Z2-EU28B-118 & 47.9 & NA & NA & 0 & 21 & NA & 3 \\
\hline Selenium & $21 / 32$ & 0.6 & $3.4 \mathrm{~J}$ & Z2-EU28-203 & 1.58 & NA & NA & 0 & 12 & NA & 0 \\
\hline Silver & $11 / 36$ & 0.17 & 1.1 & Z2-EU28B-321 & 0.56 & NA & NA & 0 & 5 & NA & 0 \\
\hline Strontium & $28 / 28$ & $3.4 \mathrm{~J}$ & 207 & Z2-EU28B-323 & 32.14 & NA & NA & 0 & 2 & NA & 0 \\
\hline Thallium & $35 / 35$ & 0.13 & $1.1 \mathrm{~J}$ & Z2-EU28-201 & 0.359 & NA & NA & 0 & 11 & 0 & 5 \\
\hline Uranium & $32 / 33$ & $0.7 \mathrm{~J}$ & $94 \mathrm{~J}$ & $\begin{array}{l}\text { Z2-EU28B-115 } \\
\text { Z2-EU28-202 }\end{array}$ & 8.55 & NA & NA & 0 & NA & NA & 22 \\
\hline Vanadium & $35 / 35$ & $14 \mathrm{~J}$ & $135 \mathrm{~J}$ & Z2-EU28B-207 & 51.4 & NA & NA & 0 & 8 & NA & 35 \\
\hline Zinc & $35 / 35$ & $27.9 \mathrm{~J}$ & $301 \mathrm{~J}$ & Z2-EU28B-111 & 76.9 & NA & NA & 0 & 6 & NA & 0 \\
\hline
\end{tabular}

Avg $=$ average

$\mathrm{Bkg}=$ background

$\mathrm{EU}=$ exposure unit

$\mathrm{GW}=$ groundwater

Ind $=$ industrial

$\mathrm{NA}=$ not applicable

PRG = preliminary remediation goal

Res $=$ residential

$\mathrm{RL}=$ remediation level

$\mathrm{SL}=$ screening level

$\mathrm{SU}=$ soil unit

EU Z2-28 PCB detects (ug/kg)

\begin{tabular}{|c|c|c|c|c|c|c|c|c|c|}
\hline \multirow[b]{2}{*}{ Analyte } & \multirow[b]{2}{*}{$\begin{array}{c}\text { Detect } \\
\text { frequency }\end{array}$} & \multirow[b]{2}{*}{$\begin{array}{c}\text { Minimum } \\
\text { detect }\end{array}$} & \multirow[b]{2}{*}{$\begin{array}{c}\text { Maximum } \\
\text { detect }\end{array}$} & \multirow{2}{*}{$\begin{array}{l}\text { Location(s) of } \\
\text { maximum } \\
\text { detect }\end{array}$} & \multirow{2}{*}{$\begin{array}{c}\text { Avg } \\
\text { detected } \\
\text { result }\end{array}$} & \multicolumn{4}{|c|}{$\begin{array}{l}\text { Number of analyses } \\
\text { exceeding criteria }\end{array}$} \\
\hline & & & & & & $\begin{array}{c}\text { Max } \\
\text { RL }\end{array}$ & $\begin{array}{l}\text { Avg } \\
\text { RL }\end{array}$ & $\begin{array}{c}\text { Ind } \\
\text { PRG }\end{array}$ & $\begin{array}{l}\text { Res } \\
\text { PRG }\end{array}$ \\
\hline PCB-1254 & $18 / 36$ & 5.1 & $690 \mathrm{~J}$ & BLRD07R1 & 86.3 & 0 & 0 & 0 & 2 \\
\hline PCB-1260 & $16 / 36$ & $1.8 \mathrm{~J}$ & 4,200 & Z2-EU28B-115 & 419 & 0 & 0 & 0 & 5 \\
\hline PCB & $2 / 2$ & 1,400 & 4,200 & Z2-EU28B-115 & 2,800 & 0 & 0 & 0 & 2 \\
\hline
\end{tabular}

Avg $=$ average

$\mathrm{EU}=$ exposure unit

Ind $=$ industrial

$\mathrm{PCB}=$ polychlorinated biphenyl

PRG $=$ preliminary remediation goal

Res $=$ residential

Max = maximum $\quad \mathrm{RL}=$ remediation level

Pesticides were analyzed for in a sample from S4 but were not detected. 
EU Z2-28 SVOC detects (ug/kg)

\begin{tabular}{|c|c|c|c|c|c|c|c|c|}
\hline \multirow[b]{2}{*}{ Analyte } & \multirow[b]{2}{*}{$\begin{array}{l}\text { Detect } \\
\text { frequency }\end{array}$} & \multirow[b]{2}{*}{$\begin{array}{c}\text { Minimum } \\
\text { detect }\end{array}$} & \multirow[b]{2}{*}{$\begin{array}{c}\text { Maximum } \\
\text { detect }\end{array}$} & \multirow{2}{*}{$\begin{array}{c}\text { Location(s) of } \\
\text { maximum } \\
\text { detect }\end{array}$} & \multirow{2}{*}{$\begin{array}{c}\text { Avg } \\
\text { detected } \\
\text { result }\end{array}$} & \multicolumn{3}{|c|}{$\begin{array}{l}\text { Number of analyses } \\
\text { exceeding criteria }\end{array}$} \\
\hline & & & & & & $\begin{array}{c}\text { Ind } \\
\text { PRG }\end{array}$ & $\begin{array}{l}\text { GW } \\
\text { SL }\end{array}$ & $\begin{array}{r}\text { Res } \\
\text { PRG }\end{array}$ \\
\hline 2-Methylnaphthalene & $1 / 25$ & $25 \mathrm{~J}$ & $25 \mathrm{~J}$ & Z2-EU28B-317 & 25 & 0 & NA & NA \\
\hline Acenaphthene & $1 / 25$ & $9.8 \mathrm{~J}$ & $9.8 \mathrm{~J}$ & Z2-EU28B-318 & 9.8 & 0 & NA & 0 \\
\hline Acenaphthylene & $2 / 25$ & $20.6 \mathrm{~J}$ & 273 & Z2-EU28B-317 & 147 & 0 & NA & 0 \\
\hline Anthracene & $3 / 25$ & 74.3 & $120 \mathrm{~J}$ & Z2-EU28B-115 & 93.2 & 0 & NA & 0 \\
\hline Benz(a)anthracene & $5 / 25$ & $99 \mathrm{~J}$ & 830 & Z2-EU28B-115 & 492 & 0 & NA & 2 \\
\hline Benzo(a)pyrene & $9 / 25$ & 45.6 & 982 & Z2-EU28B-317 & 384 & 0 & NA & 8 \\
\hline Benzo(b)fluoranthene & $10 / 25$ & $35 \mathrm{~J}$ & 1,610 & Z2-EU28B-317 & 445 & 0 & NA & 3 \\
\hline Benzo(ghi)perylene & $6 / 25$ & 120 & $960 \mathrm{~J}$ & Z2-EU28B-115 & 434 & 0 & NA & 0 \\
\hline Benzo(k)fluoranthene & $4 / 25$ & $22.8 \mathrm{~J}$ & $430 \mathrm{~J}$ & Z2-EU28B-115 & 191 & 0 & NA & 0 \\
\hline Bis(2-ethylhexyl)phthalate & $1 / 25$ & $105 \mathrm{~J}$ & $105 \mathrm{~J}$ & Z2-EU28B-111 & 105 & 0 & 0 & 0 \\
\hline Chrysene & $8 / 25$ & $19 \mathrm{~J}$ & 748 & Z2-EU28B-318 & 309 & 0 & NA & 0 \\
\hline Dibenz(a,h)anthracene & $3 / 25$ & $150 \mathrm{~J}$ & 210 & Z2-EU28B-317 & 178 & 0 & NA & 3 \\
\hline Fluoranthene & $10 / 25$ & $15.6 \mathrm{~J}$ & 1,200 & Z2-EU28B-318 & 445 & 0 & NA & 0 \\
\hline Fluorene & $2 / 25$ & $29.9 \mathrm{~J}$ & $33.8 \mathrm{~J}$ & Z2-EU28B-318 & 31.9 & 0 & NA & 0 \\
\hline Hexachlorobenzene & $1 / 25$ & $320 \mathrm{~J}$ & $320 \mathrm{~J}$ & Z2-EU28B-115 & 320 & 0 & NA & 1 \\
\hline Indeno(1,2,3-cd)pyrene & $8 / 25$ & $100 \mathrm{~J}$ & 760 & Z2-EU28B-115 & 423 & 0 & NA & 2 \\
\hline Naphthalene & $1 / 25$ & $30.1 \mathrm{~J}$ & $30.1 \mathrm{~J}$ & Z2-EU28B-317 & 30.1 & 0 & NA & 0 \\
\hline Phenanthrene & $6 / 25$ & $53 \mathrm{~J}$ & 605 & Z2-EU28B-318 & 264 & 0 & NA & 0 \\
\hline Pyrene & $14 / 25$ & $8.2 \mathrm{~J}$ & 1,900 & Z2-EU28B-115 & 422 & 0 & NA & 0 \\
\hline
\end{tabular}

\section{Avg $=$ average}

$\mathrm{EU}=$ exposure unit

$\mathrm{GW}=$ groundwater

Ind $=$ industrial

$\mathrm{NA}=$ not applicable

$\mathrm{PRG}=$ preliminary remediation goal

Res $=$ residential

$\mathrm{SL}=$ screening level

SVOC $=$ semivolatile organic compound

EU Z2-28 VOC detects (ug/kg)

\begin{tabular}{lcccccccc}
\hline & & & & & \multicolumn{2}{c}{$\begin{array}{c}\text { Number of analyses } \\
\text { exceeding criteria }\end{array}$} \\
\cline { 5 - 8 } \multicolumn{1}{c}{ Analyte } & Detect & Minimum & Maximum & Location(s) of & $\begin{array}{c}\text { Avg } \\
\text { detected } \\
\text { result }\end{array}$ & $\begin{array}{c}\text { Ind } \\
\text { PRG }\end{array}$ & $\begin{array}{c}\text { GW } \\
\text { SL }\end{array}$ & $\begin{array}{c}\text { Res } \\
\text { PRG }\end{array}$ \\
\hline 1,1-Dichloroethene & $1 / 23$ & $0.84 \mathrm{~J}$ & $0.84 \mathrm{~J}$ & Z2-EU28B-319 & 0.84 & 0 & 0 & 0 \\
2-Butanone & $3 / 23$ & $5.9 \mathrm{~J}$ & $23.1 \mathrm{~J}$ & Z2-EU28B-319 & 12.2 & 0 & NA & 0 \\
Acetone & $12 / 23$ & 6.5 & 105 & Z2-EU28-105 & 39.3 & 0 & NA & 0 \\
Carbon disulfide & $1 / 23$ & $5.7 \mathrm{~J}$ & $5.7 \mathrm{~J}$ & Z2-EU28B-111 & 5.7 & 0 & NA & 0 \\
Ethylbenzene & $1 / 23$ & $13 \mathrm{~J}$ & $13 \mathrm{~J}$ & Z2-EU28-105 & 13 & 0 & NA & 0 \\
Methylene chloride & $8 / 23$ & $1.5 \mathrm{~J}$ & $4.6 \mathrm{~J}$ & BLRD02R1 & 2.71 & 0 & 0 & 0 \\
Tetrachloroethene & $1 / 23$ & $0.54 \mathrm{~J}$ & $0.54 \mathrm{~J}$ & Z2-EU28-205 & 0.54 & 0 & 0 & 0 \\
Toluene & $10 / 23$ & $0.48 \mathrm{~J}$ & 8.9 & Z2-EU28-105 & 2.69 & 0 & 0 & 0 \\
\hline
\end{tabular}

Avg $=$ average $\quad \mathrm{PRG}=$ preliminary remediation goal

$\mathrm{EU}=$ exposure unit $\quad$ Res $=$ residential

$\mathrm{GW}=$ groundwater $\quad \mathrm{SL}=$ screening level

Ind $=$ industrial $\quad$ VOC $=$ volatile organic compound

$\mathrm{NA}=$ not applicable

\section{\begin{tabular}{|l|l} 
2.2.6 & ZONE 2 ROD APPENDIX A FFA SITES EVALUATION
\end{tabular}}

The K-1407-C Soil Piles Site is the only FFA site located in EU Z2-28. All Class 1 and Class 2 SUs in the EU are located within the boundaries of the FFA site. Therefore, the FFA site has been sampled extensively. Analytical results for sampling at the FFA site are presented in the Class 1 and Class 2 SU summaries in Sect. 2.2.5. 


\begin{tabular}{|l|l|}
\hline 3.0 & \multicolumn{1}{|c|}{ RISK EVALUATION AND ACTION/NO FURTHER ACTION DECISION } \\
\hline 3.1 & INTRODUCTION \\
\hline
\end{tabular}

In this section, data are evaluated in terms of the four decision rules presented in the Zone 2 RAWP. The decision rules include:

- Does the concentration of any Zone 2 COC exceed its maximum RL?

- Does the mean concentration of any Zone 2 COC exceed its average RL across the EU?

- Does the EU pose a risk exceeding an industrial $1 \times 10^{-4}$ excess lifetime cancer risk (ELCR) or target organ hazard index $(\mathrm{HI})$ of 1 ?

- Does the site pose a threat to groundwater based on MCL exceedances or soil RLs for protection of groundwater?

Results from comparing the data to Zone 2 soils RLs, Ind PRGs (set at an ELCR of $1 \times 10^{-5}$ or a HI of 1), and Bkg levels is presented in Table F.3. In addition, Sect. 2.2.5 presents an evaluation of the EU data by analyte group. The following table summarizes the conclusions for EU Z2-28.

\begin{tabular}{lccccc}
\hline EU \# & $\begin{array}{c}\text { Max RL } \\
\text { exceeded? }\end{array}$ & $\begin{array}{c}\text { Average RL over } \\
\text { EU exceeded? }\end{array}$ & $\begin{array}{c}\text { Industrial risk } \\
\text { above } \mathbf{1} \times \mathbf{1 0}^{-4} \text { ? }\end{array}$ & $\begin{array}{c}\text { Potential source } \\
\text { to groundwater? }\end{array}$ & $\begin{array}{c}\text { Action } \\
\text { required? }\end{array}$ \\
\hline $\mathrm{Z} 2-28$ & Yes & No & No & No & Yes \\
\hline $\begin{array}{l}\mathrm{EU}=\text { exposure unit } \\
\mathrm{RL}=\text { remediation level }\end{array}$ & & & & \\
\hline 3.2 & DATA EVALUATION FOR THE ACTION /NO FURTHER ACTION DECISION & \\
\hline
\end{tabular}

Requirements for determining NFA in the Zone 2 EUs are stated in the protection goals of the Zone 2 ROD. To make the NFA decision, four decision rules (PCCR, Sect. 3.2) were developed in the DVS DQOs that state the specific criteria against which each EU must be compared. The manner in which decision rule evaluations are conducted and any special data handling requirements are discussed in Sect.3.3 of this PCCR. In summary, NFA decision rule criteria states every EU must meet each of the following compositional constraints:

- Zone 2 soils maximum RLs (maximum allowable concentrations of the Zone 2 soils COCs). Zone 2 soils Max RLs are presented in the Zone 2 ROD and Table 5 of this PCCR.

- Zone 2 soils average RLs (limit on allowable average concentrations of the Zone 2 soils COCs across an EU). Zone 2 soils Avg RLs are presented in the Zone 2 ROD and Table 5 of this PCCR.

- Cumulative risk across the EU (cumulative risk across an EU cannot exceed $1 \times 10^{-4}$ ELCR or HI of 1). A step-wise evaluation of cumulative risk is performed by first comparing EU data to $1 \times 10^{-5}$ Ind PRGs. The $1 \times 10^{-5}$ Ind PRGs for the analytes required by the RDR/RAWP are presented in Table 5 of this PCCR.

Groundwater protection goals (compositions of Zone 2 soils cannot pose a threat to groundwater). This evaluation is conducted by evaluating local groundwater monitoring results and comparing soils compositions to calculated SLs. Values for the GW SLs are presented in Table 5 of this PCCR.

\begin{tabular}{|l|l|}
\hline 3.3 & SUMMARY AND CONCLUSIONS \\
\hline
\end{tabular}

EU Z2-28

Maximum RL screening: There are several locations in Class 1 SUs located in EU Z2-28 where RLs for Zone 2 soils radiological COCs are exceeded in historical samples, DVS samples, or both. DVS confirmation sampling is conducted to verify historical sampling results because of uncertain quality control in historical sampling and analysis (other than early characterization sampling and analysis). A historical sample is verified if it has a maximum RL exceedance and the DVS sample has a maximum or average RL exceedance for the same chemical or radionuclide. Otherwise, a historical result is overridden by a DVS result. Results of such an analysis for each of the five Class 1 SUs are presented in Table F.5 and summarized below: 
- Class 1 SUs and their corresponding radionuclides with maximum RL exceedances are: RAD199 Class 1 SU (Cs-137 and Ra/Th decay series), RAD205 Class 1 SU (Ra/Th decay series), and EU Z2-28-204 Class 1 SU (Ra/Th decay series).

- $\quad$ No maximum RL exceedances occurred in Class 1 SUs RAD192 or RAD218.

In conclusion, there are three locations in EU Z2-28 with verified maximum RL exceedances. In accordance with the Zone 2 ROD, a remedial action is required in EU Z2-28 (see Sect. 4.1 of this TM).

Average RL screening: Radionuclide average RLs are exceeded in DVS and historical samples at several Class 1 SUs (see Sect. 2.1.1 of this document) and Class $2 \mathrm{SU}$ area definition locations (see Sect. 2.2.1 of this document) in EU Z2-28. DVS confirmation sampling is conducted to verify historical sampling results because of uncertain quality control in historical sampling and analysis. A historical result is overridden by a DVS result if the historical sample average RL exceedance (other than an early characterization exceedance) cannot be verified by DVS sampling. Results of the analysis for each of the five Class 1 SUs and six area definition locations are presented in Table F.4 and summarized below:

- Average RL exceedances occur in the following SUs and area definition locations within the boundaries of the K-1407-C Soils Pile FFA Site (Rusty's Mountain):

- Class 1 SU RAD199 (Cs -137, Np-237, Ra/Th decay series, U-235, and U-238), RAD205 (Cs-137, Ra/Th decay series, U-234, U-235, and U-238), RAD218 (U-238), and Z2-EU28-204 (Cs-137 and Ra/Th decay series).

- Area definition locations RAD209 (U-238), RAD212 (U-238), RAD219 (U-238), and Z2-EU28M-102 ( $\mathrm{Ra} / \mathrm{Th}$ decay series).

- $\quad$ No average RL exceedances occurred in Class 1 SU RAD192 or area definition locations RAD203 or RAD197.

There are two steps in determining if an average RL has been exceeded across an EU. First, identify those chemicals and radionuclides whose average detected concentration exceeds an average RL. Second, determine if those chemicals or radionuclides also have a weighted EU average concentration that exceeds an average RL. The weighted average calculation is described in Sect. 3.3 of this PCCR.

Only average detected concentrations of Cs -137 (2.98 pCi/g) and the Ra/Th decay series (17.3 pCi/g) in EU Z2-28 exceeded their average RLs [2 pCi/g and $5 \mathrm{pCi} / \mathrm{g}$, respectively (see EU Z2-28 summary in Sect. 2.2.5 of this PCCR)] Thus, only Cs-137 and the $\mathrm{Ra} / \mathrm{Th}$ decay series should be carried into the next step of the weighted average calculation. It is important to note, at this point in the average RL screening, that all Cs -137 and all but one $\mathrm{Ra} / \mathrm{Th}$ decay series average RL exceedances occur at locations requiring remedial actions because of maximum RL exceedances. The single exception is the Ra/Th decay series average RL exceedance at early characterization location Z2-EU28M-102. As described in Table F.4, the average RL exceedance at this location is the product of point source contamination and, as such, makes a negligible contribution to the EU's average composition.

In conclusion, remedial action is required in EU Z2-28 because of maximum RL exceedances. The action will address all average RL exceedances that have a definable area. Following the action, there will be no Zone 2 soils COC in EU Z2-28 with an average concentration that exceeds an average RL.

Risk Evaluation. Comparing the EU average concentrations to $1 \times 10^{-5}$ industrial PRGs is the first step in evaluating if any chemical or radionuclide exceeds the $1 \times 10^{-4}$ ELCR limit of the Zone 2 ROD. The EU Z2-28 summary in Sect. 2.2.5 states that one metal and several radionuclides have one or more $1 \times 10^{-5}$ industrial PRG exceedances. Of metal and radionuclides with $1 \times 10^{-5}$ industrial PRG exceedances, the following have EU average concentrations that exceed the $1 \times 10^{-5}$ industrial PRG: Cs $-137(2.98 \mathrm{pCi} / \mathrm{g}$ average versus $1.1 \mathrm{pCi} / \mathrm{g}$ industrial PRG), U-235 (7.27 pCi/g average versus $4 \mathrm{pCi} / \mathrm{g}$ industrial PRG), and U-238 (36.5 pCi/g average versus $18 \mathrm{pCi} / \mathrm{g}$ industrial PRG). The average concentration of Ra-226 and Th-232 also exceeds their respective $1 \times 10^{-5}$ industrial PRG but are not included in Zone 2 soils risk calculations (Zone 2 ROD).

A quantitative human health risk assessment (HHRA) was conducted based on the magnitude of $1 \times 10^{-5}$ industrial PRG exceedances (see Sect. 2.2.5). Soils exceeding industrial PRGs are the same soils in the K-1407-C Soil Piles FFA Site that require an action in response to several maximum RL exceedances. Locations with confirmed maximum RL exceedances, and nearby locations with average RL exceedances, were excluded from the data set prior to evaluating risk. The HHRA was conducted to evaluate residual risk to an industrial worker and to determine if the risk criteria established in the Zone 2 ROD were met. The calculated industrial risk is $3.2 \times 10^{-5}$ and the HI is 0.19 . 
In conclusion, there are no chemicals or radionuclides in EU Z2-28 that exceed the risk evaluation criteria described in this PCCR, Sect. 3.3. The industrial risk is less than $1 \times 10^{-4}$ ELCR and target organ HI of 1 .

Threat to groundwater: Groundwater SLs for U-234 (including U-233/234 analyses) and U-238 are exceeded in 16 samples. All the sample locations are located in the K-1407-C Soil Piles FFA Site and fall into six Class 1 SUs and area definition locations:

- $\quad$ Class 1 SU RAD199 (2 samples), RAD205 (5 samples), and RAD218 (3 samples).

- Area definition location RAD209 (2 samples), RAD212 (3 samples), and RAD219 (1 sample).

All GW SL exceedances observed in historical samples are confirmed by DVS sampling (DVS confirmation of historical results at RAD219 is the same as historical sample location RAD218).

The primary contaminants at Rusty's Mountain are radionuclides in surface soils (predominantly Cs - 137 and scattered detections of U-234 and U-238). Regardless of radiological SL values, radionuclides should be immobile in clay-rich soil at Rusty's Mountain. Nonetheless, contaminated soils that exceed maximum RLs or groundwater SLs are recommended for removal, which will eliminate any potential threat to local groundwater.

Qualitative risk screening for unrestricted use: There is a low probability that the land area of EU Z2-28 will be available for unrestricted use. There are maximum and average RL exceedances, industrial and residential PRG exceedances, and GW SL exceedances in the Class 1 and Class 2 SUs (see Sect. 2.2.5). Following the remedial action proposed in Sect.4, there still will be industrial and residential PRG exceedances in soils left in place. An evaluation using the appropriate land use assumptions is necessary to make a final determination.

\section{FFA Sites}

The K-1407-C Soil Piles FFA Site contains all of the criteria exceedances in EU Z2-28 and, therefore, is evaluated in the preceding EU evaluation.

\begin{tabular}{|l|l|}
\hline 4.0 & \multicolumn{1}{|c|}{ RECOMMENDATION FOR ACTION/NO FURTHER ACTION } \\
\hline 4.1 & DECISION AND REMEDIATION ACTIVITIES \\
\hline 4.1.1 & REMEDIAL ACTION RECOMMENDATIONS FOR Z2-EU28 \\
\hline
\end{tabular}

Several areas identified based on the results of historic sampling where contaminant concentrations exceeded either average or maximum remediation levels include Class 1 SUs RAD192, RAD199, RAD205, RAD218, Z2-EU28-204; and Class 2 SU RAD209. BAR surveys were conducted at each of these areas to define surface contamination boundaries and assist in defining the extent of the required remedial action excavation limits. Results of the surveys, additional DVS sampling, and remedial action recommendation for each area are presented below.

RAD192 Class 1 SU is an isolated point along the southern edge of Rusty's Mountain. A 20- $\times 25$-ft BAR survey of the area centered on the historic location did not identify surface soil contamination. All radiological measurements within the BAR survey area were less than two times the background levels. A soil sample was collected at the location of the historic sample and radiological contaminants were present (Tc-99 at $12.1 \mathrm{pCi} / \mathrm{g}, \mathrm{U}-234$ at $10.5 \mathrm{pCi} / \mathrm{g}$, and $\mathrm{U}-238$ and $5.53 \mathrm{pCi} / \mathrm{g}$ ). However, these results are below all Zone 2 remedial action criteria. Neither the BAR survey nor the additional soil sample confirm the historic RL exceedance, and no contamination boundary could be defined. The U.S. Department of Energy (DOE) recommends an area approximately $3 \mathrm{ft} \times 3 \mathrm{ft} \times 0.5$-ft thick be scraped from the historic location as a precaution to remove any soils that may exceed Zone 2 maximum $\mathrm{RL}$ in the immediate area of the historic sample.

RAD199 Class 1 SU is an isolated point south of the propane tank on the south side of Rusty's Mountain. A $20-\times 20$-ft BAR survey centered on the historic location clearly defined an area of substantially elevated radioactivity in surface soils (less than approximately $5 \times 5 \mathrm{ft}$ in extent). A confirmatory soil sample was collected within the defined boundary and confirmed the presence of $\mathrm{Ra} / \mathrm{Th}$ decay series at concentrations above maximum RLs. DOE recommends an area of soil approximately $5 \mathrm{ft} \times 5 \mathrm{ft} \times 0.5-\mathrm{ft}$ thick be removed from the area to remediate this location.

RAD205 Class 1 SU is an area of contaminated soil located along the eastern boundary of Rusty's Mountain. There are four historic samples in the area that have reported elevated concentrations of thorium (either Th-230 or Th-232). A 35- $\times 45-\mathrm{ft} \mathrm{BAR} \mathrm{survey} \mathrm{was} \mathrm{performed} \mathrm{over} \mathrm{an} \mathrm{area} \mathrm{approximately} \mathrm{centered} \mathrm{on} \mathrm{the} \mathrm{RAD} 207$ sample location. The survey defined an area approximately $20 \times 30 \mathrm{ft}$ in extent that exhibited elevated radioactivity in excess of twice the local background levels. Within the defined area, several mounds of soil (clearly dump truck 
loads of mixed debris and soils) were associated with the elevated radioactivity. Confirmation and waste acceptance criteria samples were collected inside and outside the defined boundary. Results of the survey and sampling defined an area with radiological contamination in excess of Zone 2 Maximum RLs. DOE recommends a volume of soil approximately $35 \mathrm{ft} \times 25 \mathrm{ft}$ and $3-\mathrm{ft}$ deep (approximately $100 \mathrm{yd}^{3}$ of soil ) be removed from this location.

RAD218 Class 1 SU is an isolated point near the west-central section of Rusty's Mountain. Results of the historic sample indicated concentrations of Ra/Th decay series above maximum RLs. A BAR survey performed in the area did not define a boundary that isolated the RAD218 location. Topographic relief in the immediate area is extremely variable with small isolated soil mounds and narrow, deep (10-15 ft) holes between the small mounds and ridges that make up the large waste soil disposal area. Isolated locations of elevated radioactivity were identified along a narrow ridge where the RAD218 sample point was located. Confirmation samples did have significantly elevated U-238 concentrations above average RL but did not report thorium at elevated levels. This location is associated with a larger area of contaminated soils. As described in the RAD-209/210 discussion below, a remedial action is recommended for the larger site.

Z2-EU28-204 Class $1 \mathrm{SU}$ is an isolated point near the west end of Rusty's Mountain that was collected as part of the early characterization systematic grid samples. The sample reported elevated $\mathrm{Ra} / \mathrm{Th}$ decay series concentrations. A BAR survey in the area did not define a surface contamination boundary; however, the confirmation area composite exhibited elevated Th-230 above its Zone 2 average RL. DOE recommends a soil removal action of an area approximately $7 \times 7 \mathrm{ft}$ and 3-ft deep (approximately $5 \mathrm{yd}^{3}$ ) at the Z2-EU28-204 sample location.

RAD209 area definition location Class 2 SU is an area of small dump truck loads of debris and soil near the west-central portion of Rusty's Mountain. Several historic samples in this area (RAD209, RAD210, RAD212, RAD214, RAD218, and RAD 219) have radioactive soil contamination above the Zone 2 average RLs. Radiological surveys in this area were over small mounds and isolated piles of soil. Radioactivity above twice the background levels was observed in several locations centered near the historic RAD209 location, near the RAD210 location, and along the lower slope below the RAD218 and RAD219 locations. Soil contamination is present in the area distributed within the soil and debris mound over the local sample location cluster. DVS sampling confirmed several radiological COCs are present above Zone 2 average RL and above soil screening levels for protection of groundwater. DOE recommends a soil removal action of an area approximately $60 \mathrm{ft} \times 60 \mathrm{ft}$ and 3-ft deep (approximately $400 \mathrm{yd}^{3}$ ).

The total volume of contaminated soil to be removed from the Zone 2 EU 28 at the Rusty's Mountain site is approximately $600 \mathrm{yd}^{3}$.

Other Class 2 area definition locations in Zone 2 EU 28 associated with Rusty's Mountain are limited in extent and have no contaminant concentrations above maximum RLs. Beyond the K-1407-C Soil Piles FFA Site (Rusty's Mountain), the remainder of the EU is Class 3 acreage that has been assessed and sampled, and has no apparent contaminated soils. DOE recommends a NFA determination for the remainder of the EU.

\section{\begin{tabular}{|l|l}
4.2 & EXCAVATION ACTIVITIES/CONFIRMATION SAMPLING
\end{tabular}}

Several locations are present in Z2-28 with concentrations that exceed maximum RLs established in the Zone 2 ROD. Therefore, an action is required. The proposed action is excavation.

The proposed area of excavation consists of locations with concentrations exceeding a maximum RL and areas within a circular area $50 \mathrm{ft}$ in diameter centered on each location, including RAD192, RAD197, RAD199, RAD203, RAD204, RAD205, RAD206, RAD207, RAD218, Z2-EU28-204, Z2-EU28B-114, Z2-EU28B-115, Z2-EU28B-116, Z2-EU28B-118, Z2-EU28B-119, and Z2-EU28B-125.

Removal of contaminated soils will be determined in the field using hand-held radioactivity field meters. Once the area of excavation is below twice the background levels, four-point composite soil samples will be collected to confirm contamination has been removed over the base of the excavation.

Removal of soils exceeding maximum RLs and soils in the vicinity of RL exceedances results in acceptable risk and hazard levels for EU Z2-28. Thus, the proposed excavation meets the risk criteria established in the ROD for ETTP Zone 2 Soils as follows:

- All individual concentrations are less than the maximum RLs established for ETTP soils;

- All average concentrations are less than the average RLs established for ETTP soils; 
- Total cancer risk across all contaminants and pathways for the industrial worker is less than $1 \times 10^{-4}$; and

- Total HI across all contaminants and pathways for the industrial worker is less than 1.0. 


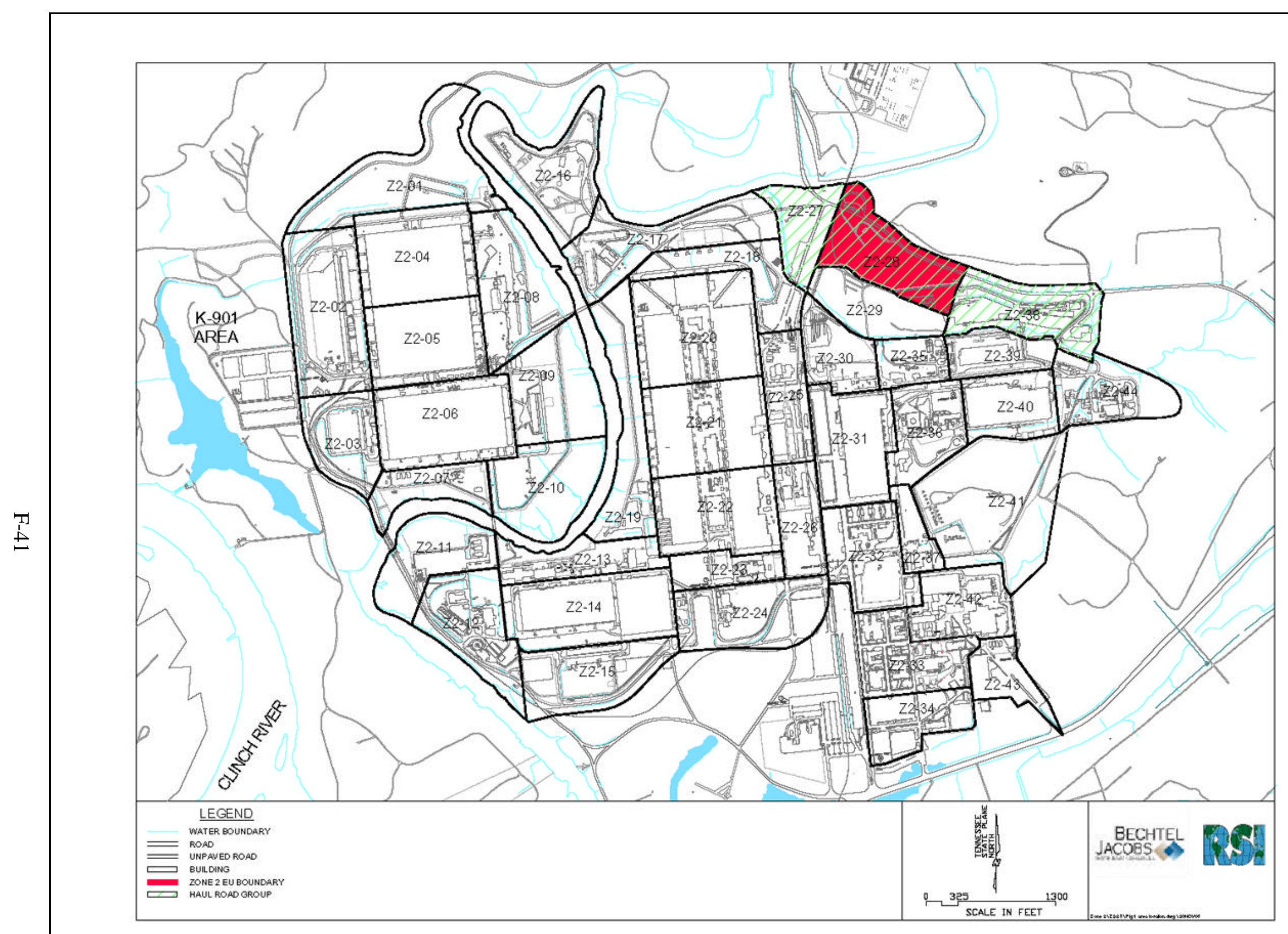

Fig. F.1. EU Z2-28 location map. 


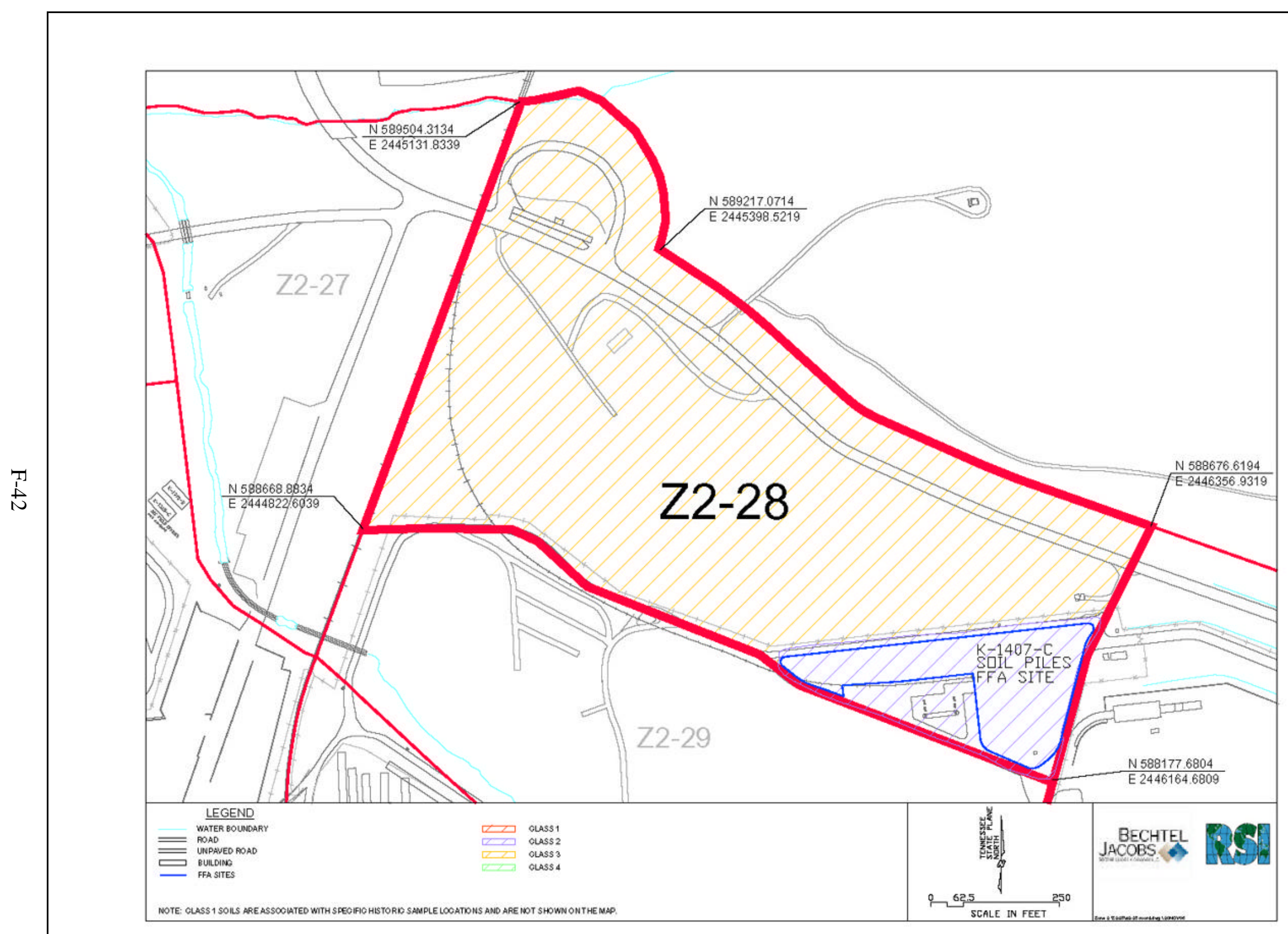

Fig. F.2. EU Z2-28 boundaries. 


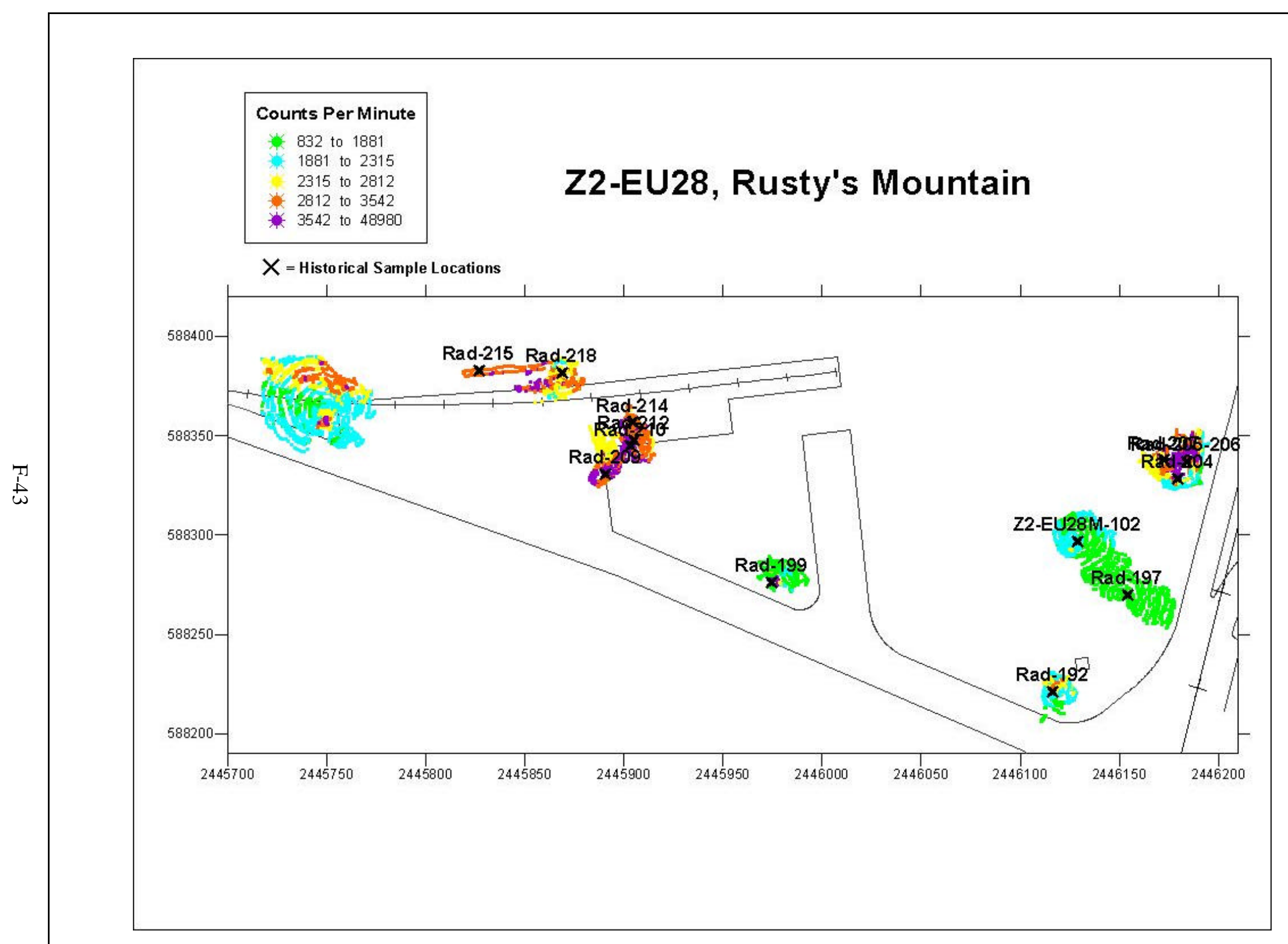

Fig. F.3. EU Z2-28 BAR survey at K-1407-C Soil Piles and locations of historical samples. 


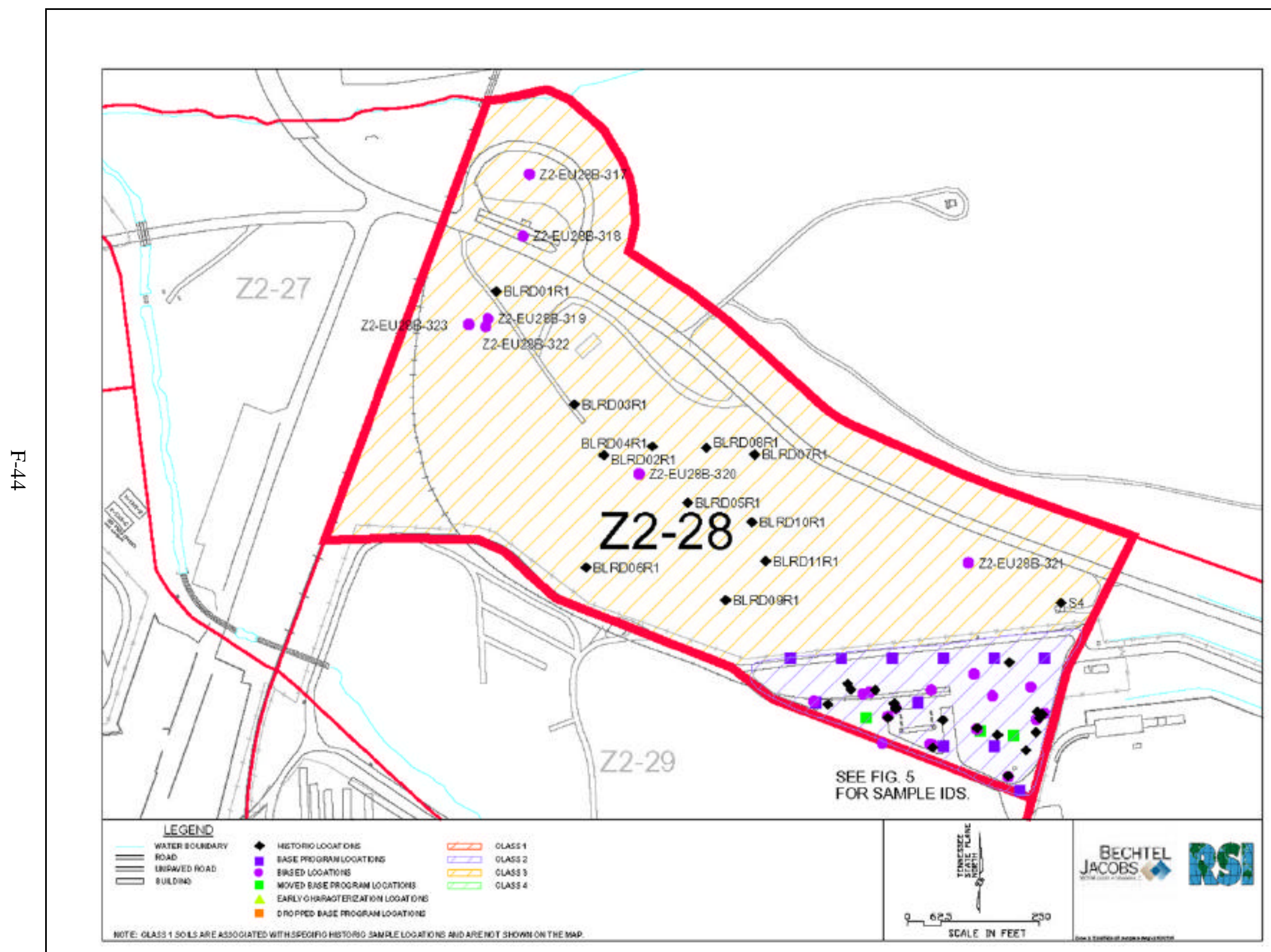

Fig. F.4. EU Z2-28 sample locations. 


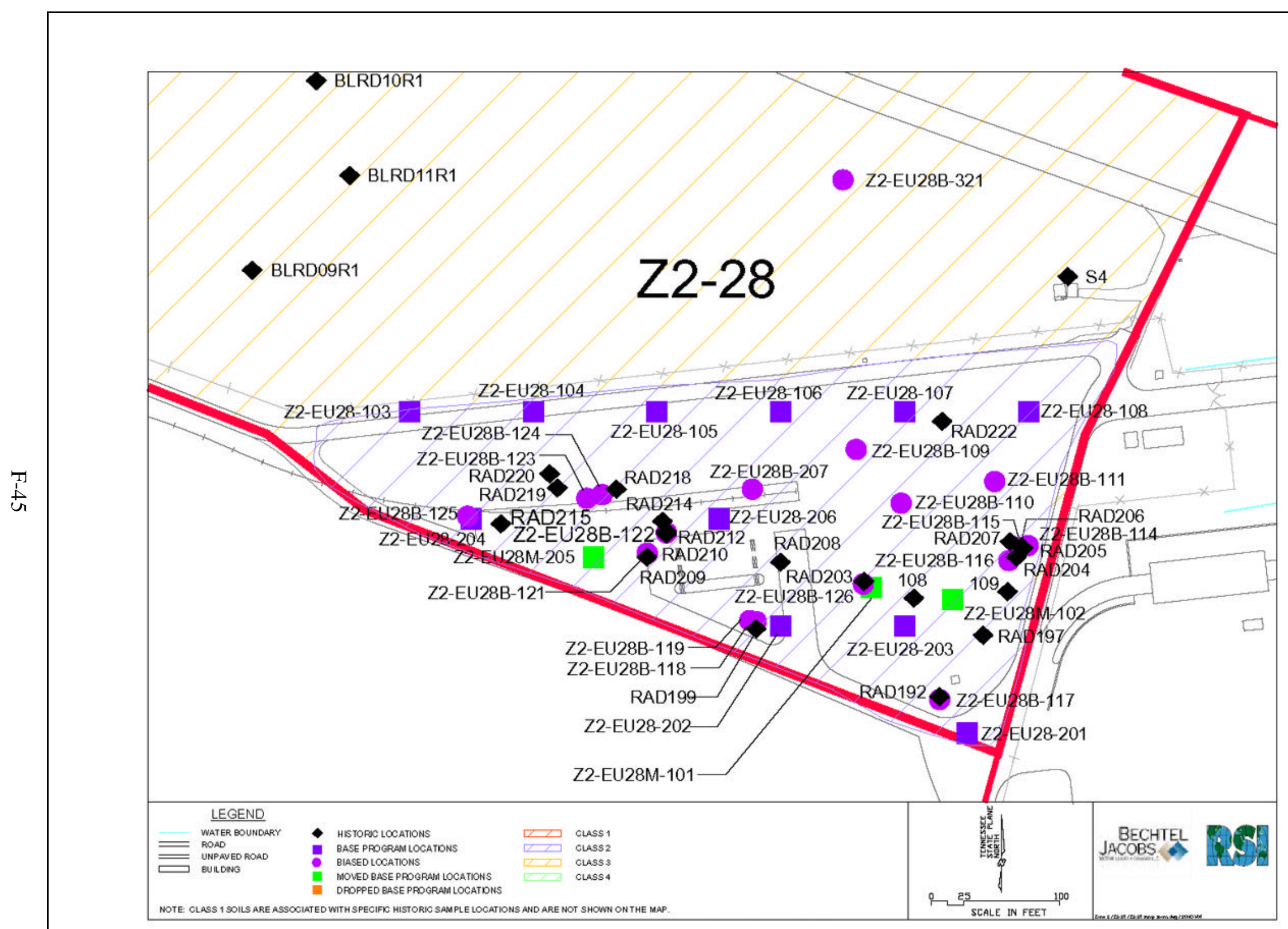

Fig. F.5. EU Z2-28 detail sample locations at K-1407-C Soil Piles. 


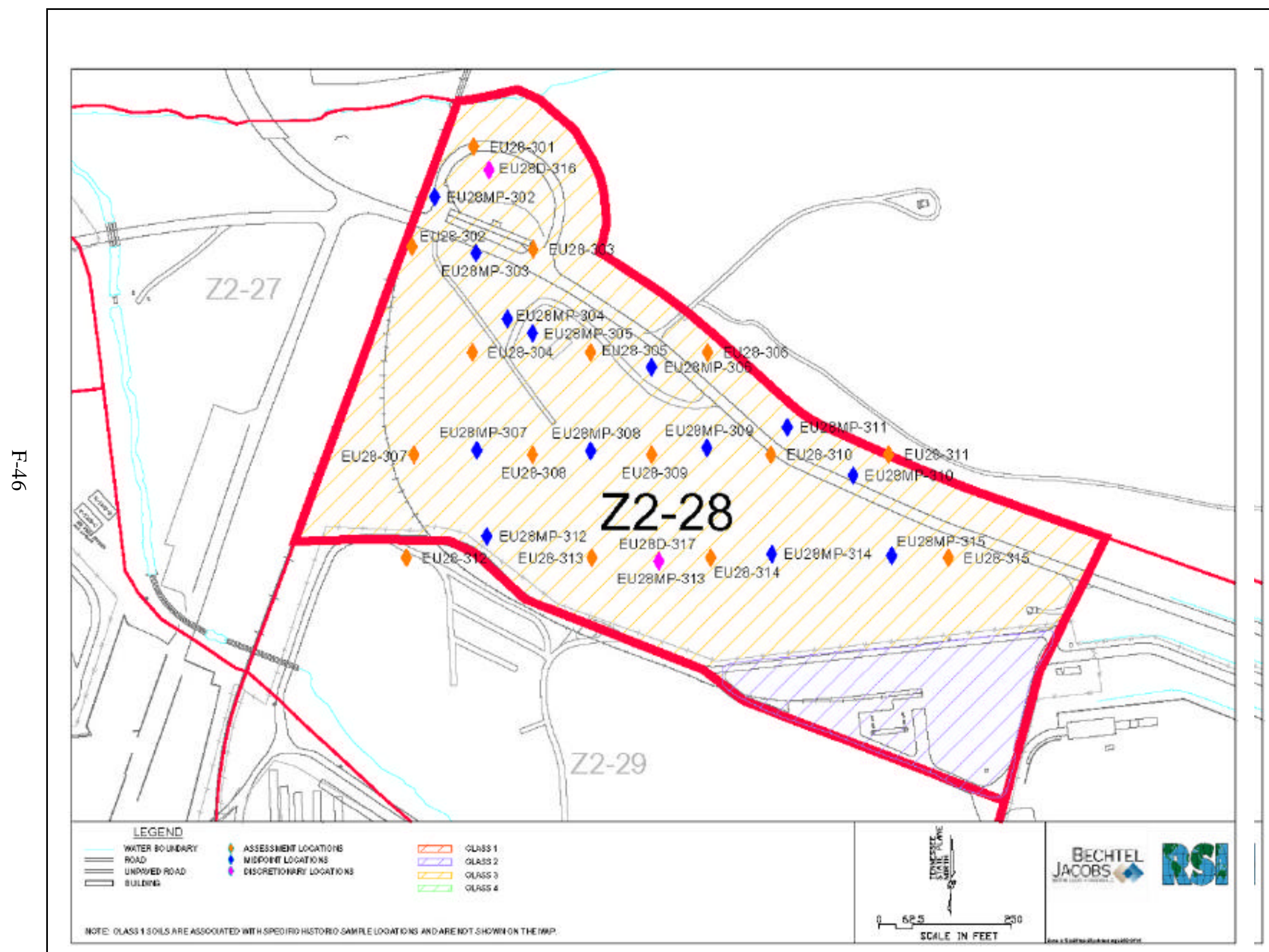

Fig. F.6. EU Z2-28 Class 3 and Class 4 SU walkover assessment locations. 
Table F.1. EU Z2 -28 facility and FFA site list

\begin{tabular}{lccr}
\hline \multicolumn{1}{c}{ Facility name DQO scoping } & Facility assessed? & Comments \\
\cline { 2 - 3 } K-1022-4 Air Sampling Monitoring Station & $\mathrm{X}$ & No & \\
K-1022-10 Air Sampling Monitoring Station & $\mathrm{X}$ & \\
K-1216 Scale House & $\mathrm{X}$ & \\
K-1234 Propane Storage Tank & $\mathrm{X}$ & \\
K-1234-A Valve House & $\mathrm{X}$ & FFA Site also known as Rusty's \\
K-1407-C Soil Piles & $\mathrm{X}$ & Mountain \\
& & \\
DQO $=$ data quality objectives & & \\
EU $=$ exposure unit & & \\
FFA $=$ Federal Facility Agreement & &
\end{tabular}




\begin{tabular}{|c|c|c|c|c|c|c|c|c|c|c|c|c|c|c|}
\hline \multirow{2}{*}{$\begin{array}{l}\text { SU } \\
\text { class }\end{array}$} & \multirow{2}{*}{$\begin{array}{l}\text { Date } \\
\text { sampled }\end{array}$} & \multirow[b]{2}{*}{ Sample ID } & \multicolumn{2}{|c|}{ Location } & \multirow[b]{2}{*}{ Sample interval } & \multicolumn{2}{|c|}{ Screening } & \multicolumn{6}{|c|}{ Off-site laboratory } & \multirow[b]{2}{*}{ Comments and notes } \\
\hline & & & Northing & Easting & & VOC & RAD & VOC & SVOC & PCB & Metals & RAD & Splits & \\
\hline 2 & $3 / 21 / 05$ & Z2-EU28M-101 & 588307 & 2446066 & 3 -interval composite $0-10 \mathrm{ft}$ & 1 & 1 & & & 1 & 1 & 1 & & \\
\hline 2 & $3 / 22 / 05$ & Z2-EU28M-102 & 588298 & 2446129 & 3 -interval composite $0-10 \mathrm{ft}$ & 1 & 1 & & & 1 & 1 & 1 & & \\
\hline 2 & $3 / 17 / 05$ & Z2-EU28-103 & 588444 & 2445706 & 3 -interval composite $0-10 \mathrm{ft}$ & 1 & 1 & 1 & 1 & 1 & 1 & 1 & & Discrete interval VOA \\
\hline 2 & $3 / 17 / 05$ & Z2-EU28-104 & 588444 & 2445802 & 3 -interval composite $0-10 \mathrm{f}$. & 1 & 1 & & & 1 & 1 & 1 & & \\
\hline 2 & $3 / 18 / 05$ & Z2-EU28-105 & 588444 & 2445899 & 3 -interval composite $0-10 \mathrm{ft}$ & 1 & 1 & 1 & & 1 & 1 & 1 & & Discrete interval VOA \\
\hline 2 & $3 / 18 / 05$ & Z2-EU28-106 & 588444 & 2445995 & 3 -interval composite $0-10 \mathrm{ft}$ & 1 & 1 & 1 & 1 & 1 & 1 & 1 & $\mathrm{D}$ & Discrete interval VOA \\
\hline 2 & $3 / 18 / 05$ & Z2-EU28-107 & 588444 & 2446092 & 3 -interval composite $0-10 \mathrm{ft}$ & 1 & 1 & & & 1 & 1 & 1 & & \\
\hline 2 & $3 / 18 / 05$ & Z2-EU28-108 & 588444 & 2446189 & 3 -interval composite $0-10 \mathrm{ft}$ & 1 & 1 & & & 1 & 1 & 1 & & \\
\hline 2 & $3 / 23 / 05$ & Z2-EU28B-109 & 588415 & 2446054 & 2 discrete intervals & 1 & 1 & 2 & 2 & 2 & 2 & 2 & & $17-19,21-23.9 \mathrm{ft}$ intervals \\
\hline 2 & $3 / 23 / 05$ & Z2-EU28B-110 & 588373 & 2446089 & 2 discrete intervals & 1 & 1 & 2 & 2 & 2 & 2 & 2 & & $25-28,29-33 \mathrm{ft}$ intervals \\
\hline 2 & $3 / 24 / 05$ & Z2-EU28B-111 & 588390 & 2446162 & 2 discrete intervals & 1 & 1 & 2 & 2 & 2 & 2 & 2 & & $18-21,21-24.5 \mathrm{ft}$ intervals \\
\hline 1 & $2 / 16 / 06$ & Z2-EU28B-114 & 588340 & 2446188 & Single point $0-1 \mathrm{ft}$ & 1 & 1 & & & & & 1 & & $\begin{array}{l}\text { Confirmation of location } \\
\text { RAD205 }\end{array}$ \\
\hline 1 & $2 / 15 / 06$ & Z2-EU28B-115 & 588339 & 2446181 & 5-point composite $0-1 \mathrm{ft}$ & 1 & 1 & 1 & 1 & 1 & 1 & 1 & $\mathrm{D}$ & Step out of RAD203 \\
\hline 1 & $2 / 16 / 06$ & Z2-EU28B-116 & 588328 & 2446173 & 4-point composite 0 - $1 \mathrm{ft}$ & 1 & 1 & & & & & 1 & & Step out of RAD203 \\
\hline 1 & $2 / 16 / 06$ & Z2-EU28B-117 & 588220 & 2446119 & 4-point composite 0 - $1 \mathrm{ft}$ & 1 & 1 & & & & & 1 & & Affiliated with RAD192 \\
\hline 1 & $2 / 16 / 06$ & Z2-EU28B-118 & 588281 & 2445976 & Single point $0-1 \mathrm{ft}$ & 1 & 1 & 1 & 1 & 1 & 1 & 1 & & $\begin{array}{l}\text { Confirmation of location } \\
\text { RAD199 }\end{array}$ \\
\hline 1 & $2 / 16 / 06$ & Z2-EU28B-119 & 588281 & 2445971 & 4-point composite 0-1 ft & 1 & 1 & & & & & 1 & & \\
\hline 2 & $2 / 16 / 06$ & Z2-EU28B-121 & 588334 & 2445891 & 4-point composite $0-1 \mathrm{ft}$ & 1 & 1 & & & & & 1 & & Affiliated with RAD2097 \\
\hline 2 & $2 / 16 / 06$ & Z2-EU28B-122 & 588350 & 2445906 & 4-point composite 0 - $1 \mathrm{ft}$ & 1 & 1 & & & & & 1 & & Affiliated with RAD212 \\
\hline 1 & $2 / 16 / 06$ & Z2-EU28B-123 & 588377 & 2445844 & Single point $0-1 \mathrm{ft}$ & 1 & 1 & & & & & 1 & $\mathrm{~S}$ & RAD218 confirmation \\
\hline 1 & $2 / 16 / 06$ & Z2-EU28B-124 & 588380 & 2445856 & Single point $0-1 \mathrm{ft}$ & 1 & 1 & & & & & 1 & & Confirmation of RAD218 \\
\hline 1 & $2 / 16 / 06$ & Z2-EU28B-125 & 588363 & 2445751 & Single point $0-1 \mathrm{ft}$ & 1 & 1 & & & & & 1 & $\mathrm{D}$ & $\begin{array}{l}\text { Confirmation of } \\
\text { Z2-EU28-204 }\end{array}$ \\
\hline 2 & $4 / 2506$ & Z2-EU28B-126 & 588310 & 2446060 & Single point $0-1 \mathrm{ft}$ & 1 & 1 & & & & & 1 & & $\begin{array}{l}\text { Confirmation of location } \\
\text { RAD203 }\end{array}$ \\
\hline 2 & $3 / 22 / 05$ & Z2-EU28-201 & 588194 & 2446140 & 3 -interval composite $0-10 \mathrm{ft}$ & 1 & 1 & & & 1 & 1 & 1 & $\mathrm{~S}$ & \\
\hline 2 & $3 / 22 / 05$ & Z2-EU28-202 & 588277 & 2445995 & 3 -interval composite $0-10 \mathrm{ft}$ & 1 & 1 & & & 1 & 1 & 1 & & \\
\hline 2 & $3 / 22 / 05$ & Z2-EU28-203 & 588277 & 2446092 & 3 -interval composite $0-10 \mathrm{ft}$ & 1 & 1 & & & 1 & 1 & 1 & & \\
\hline 1 & $3 / 21 / 05$ & Z2-EU28-204 & 588361 & 2445754 & 3 -interval composite $0-10 \mathrm{ft}$ & 1 & 1 & & & 1 & 1 & 1 & & \\
\hline 2 & $3 / 21 / 05$ & Z2-EU28-205 & 588331 & 2445849 & 3 -interval composite $0-10 \mathrm{ft}$ & 1 & 1 & 1 & 1 & 1 & 1 & 1 & & Discrete interval VOA \\
\hline 2 & $3 / 21 / 05$ & Z2-EU28-206 & 588361 & 2445947 & 3 -interval composite $0-10 \mathrm{ft}$ & 1 & 1 & & & 1 & 1 & 1 & & \\
\hline
\end{tabular}




\begin{tabular}{|c|c|c|c|c|c|c|c|c|c|c|c|c|c|c|}
\hline \multicolumn{15}{|c|}{ Table F.2. (continued) } \\
\hline \multirow{2}{*}{$\begin{array}{l}\text { SU } \\
\text { class }\end{array}$} & \multirow{2}{*}{$\begin{array}{c}\text { Date } \\
\text { sampled }\end{array}$} & \multirow[b]{2}{*}{ Sample ID } & \multicolumn{2}{|c|}{ Location } & \multirow[b]{2}{*}{ Sample interval } & \multicolumn{2}{|c|}{ Screening } & \multicolumn{6}{|c|}{ Off-site laboratory } & \multirow{3}{*}{$\begin{array}{l}\text { Comments and notes } \\
315 \mathrm{cpm} \text { at } 8.2 \mathrm{ft} ; \text { discrete } \\
\text { RAD sample collected } \\
\text { from } 8.1-8.6 \mathrm{ft} \text {; discrete } \\
\text { interval VOA }\end{array}$} \\
\hline & & & Northing & Easting & & VOC & RAD & VOC & SVOC & PCB & Metals & RAD & Splits & \\
\hline 2 & $3 / 24 / 05$ & Z2-EU28B-207 & 588384 & 2445973 & 3 -ft composite $18-21 \mathrm{ft}$ & 1 & 1 & 1 & 1 & 1 & 1 & 1 & & \\
\hline \multicolumn{15}{|c|}{ Zone 2 EU 28 biased haul road corridor Class 3 biased } \\
\hline 3 & $3 / 9 / 05$ & Z2-EU28B-317 & 589364 & 2445211 & 3 -interval composite $0-10 \mathrm{ft}$ & 1 & 1 & & 1 & 1 & 1 & 1 & & \\
\hline 3 & 3/9/05 & Z2-EU28B-318 & 589246 & 2445199 & 3 -interval composite $0-10 \mathrm{ft}$ & 1 & 1 & & 1 & 1 & 1 & 1 & & \\
\hline 3 & 3/8/05 & Z2-EU28B-319 & 589089 & 2445132 & 3 -interval composite $0-10 \mathrm{ft}$ & 1 & 1 & & 1 & 1 & 1 & 1 & $\mathrm{D}$ & $\begin{array}{l}15.9 \mathrm{ft} \mathrm{ppm} \text { at } 2.8 \mathrm{ft} ; \\
244 \mathrm{cpm} \text { detected at } 7.7 \mathrm{ft}\end{array}$ \\
\hline 3 & 3/9/05 & Z2-EU28B-320 & 588795 & 2445419 & 3 -interval composite $0-10 \mathrm{ft}$ & 1 & 1 & & 1 & 1 & 1 & 1 & & \\
\hline 3 & $3 / 9 / 05$ & Z2-EU28B-321 & 588626 & 2446044 & 3 -interval composite $0-10 \mathrm{ft}$ & 1 & 1 & 1 & 1 & 1 & 1 & 1 & & Discrete interval VOA \\
\hline 3 & $3 / 11 / 05$ & Z2-EU28B-322 & 589074 & 2445128 & Interval composite $0-1 \mathrm{ft}$ & 1 & 1 & 1 & 1 & 1 & 1 & 1 & & Discrete interval VOA \\
\hline 3 & $3 / 11 / 05$ & Z2-EU28B-323 & 589078 & 2445096 & Interval composite $0-1 \mathrm{ft}$ & 1 & 1 & 1 & 1 & 1 & 1 & 1 & & $\begin{array}{l}\text { Refusal at } 0.2 \mathrm{ft} \text {; moved } \\
10 \mathrm{ft}\end{array}$ \\
\hline \multicolumn{6}{|c|}{ Total DVS and early characterization samples EU 28} & 38 & 38 & 11 & 15 & 27 & 27 & 22 & 6 & \\
\hline \multicolumn{15}{|c|}{ Historic samples EU-28 } \\
\hline 2 & $3 / 4 / 98$ & 108 & 588299 & 2446099 & 1 composite interval $0-2.0 \mathrm{ft}$ & & & & & & & 1 & & \\
\hline 2 & $3 / 4 / 98$ & 109 & 588304 & 2446172 & 1 composite interval $0-2.0 \mathrm{ft}$ & & & & & & & 1 & & \\
\hline 3 & $1 / 28 / 02$ & BLRD01R1 & 589141 & 2445148 & Surface soil $0-0.5 \mathrm{ft}$ & & & & & & 1 & 1 & & \\
\hline 3 & $1 / 28 / 02$ & BLRD02R1 & 588830 & 2445352 & Surface soil $0-0.5 \mathrm{ft}$ & & & 1 & 1 & 1 & 1 & 1 & & \\
\hline 3 & $1 / 28 / 02$ & BLRD03R1 & 588927 & 2445296 & Surface soil $0-0.5 \mathrm{ft}$ & & & & 1 & & & 1 & & \\
\hline 3 & $1 / 28 / 02$ & BLRD04R1 & 588847 & 2445444 & Surface soil $0-0.5 \mathrm{ft}$ & & & 1 & & & & 1 & & \\
\hline 3 & $1 / 28 / 02$ & BLRD05R1 & 588740 & 2445511 & Surface soil $0-0.5 \mathrm{ft}$ & & & & 1 & & & 1 & & \\
\hline 3 & $1 / 28 / 02$ & BLRD06R1 & 588617 & 2445318 & Surface soil $0-0.5 \mathrm{ft}$ & & & 1 & & & & 1 & & \\
\hline 3 & $1 / 28 / 02$ & BLRD07R1 & 588831 & 2445638 & Surface soil $0-0.5 \mathrm{ft}$ & & & & & 1 & & 1 & & \\
\hline 3 & $1 / 28 / 02$ & BLRD08R1 & 588844 & 2445547 & Surface soil $0-0.5 \mathrm{ft}$ & & & 1 & 1 & 1 & 1 & 1 & & \\
\hline 3 & $1 / 28 / 02$ & BLRD09R1 & 588555 & 2445583 & Surface soil $0-0.5 \mathrm{ft}$ & & & & & 1 & & 1 & & \\
\hline 3 & $1 / 28 / 02$ & BLRD10R1 & 588703 & 2445633 & Surface soil $0-0.5 \mathrm{ft}$ & & & & & & 1 & 1 & & \\
\hline 3 & $1 / 28 / 02$ & BLRD11R1 & 588629 & 2445659 & Surface soil $0-0.5 \mathrm{ft}$ & & & 1 & 1 & 1 & 1 & 1 & & \\
\hline 1 & $8 / 30 / 94$ & RAD192 & 588222 & 2446119 & Surface soil $0-0.5 \mathrm{ft}$ & & & & & & & 1 & & \\
\hline 2 & 9/30/94 & RAD197 & 588270 & 2446153 & Surface soil $0-0.5 \mathrm{ft}$ & & & & & & & 1 & & \\
\hline 1 & $9 / 7 / 94$ & RAD199 & 588275 & 2445976 & Surface soil $0-0.5 \mathrm{ft}$ & & & & & & & 1 & & \\
\hline 2 & $8 / 30 / 94$ & RAD203 & 588312 & 2446060 & Surface soil $0-0.5 \mathrm{ft}$ & & & & & & & 1 & & \\
\hline 1 & $8 / 30 / 94$ & RAD204 & 588331 & 2446179 & Surface soil $0-0.5 \mathrm{ft}$ & & & & & & & 1 & & \\
\hline 1 & $8 / 30 / 94$ & RAD205 & 588338 & 2446184 & Surface soil $0-0.5 \mathrm{ft}$ & & & & & & & 1 & & \\
\hline
\end{tabular}




\begin{tabular}{|c|c|c|c|c|c|c|c|c|c|c|c|c|c|c|}
\hline \multicolumn{15}{|c|}{ Table F.2. (continued) } \\
\hline \multirow{2}{*}{$\begin{array}{c}\text { SU } \\
\text { class }\end{array}$} & \multirow{2}{*}{$\begin{array}{c}\text { Date } \\
\text { sampled }\end{array}$} & \multirow[b]{2}{*}{ Sample ID } & \multicolumn{2}{|c|}{ Location } & \multirow[b]{2}{*}{ Sample interval } & \multicolumn{3}{|c|}{ Screening } & \multicolumn{4}{|c|}{ Off-site laboratory } & \multirow[b]{2}{*}{ Splits } & \multirow[b]{2}{*}{ Comments and notes } \\
\hline & & & Northing & Easting & & VOC & RAD & VOC & SVOC & PCB & Metals & RAD & & \\
\hline 1 & $8 / 30 / 94$ & RAD206 & 588339 & 2446183 & Surface soil $0-0.5 \mathrm{ft}$ & & & & & & & 1 & & \\
\hline 1 & $8 / 30 / 94$ & RAD207 & 588343 & 2446174 & Surface soil $0-0.5 \mathrm{ft}$ & & & & & & & 1 & & \\
\hline 2 & 9/7/94 & RAD208 & 588327 & 2445995 & Surface soil $0-0.5 \mathrm{ft}$ & & & & & & & 1 & & \\
\hline 2 & 9/30/94 & RAD209 & 588331 & 2445891 & Surface soil $0-0.5 \mathrm{ft}$ & & & & & & & 1 & & \\
\hline 2 & 9/30/94 & RAD210 & 588349 & 2445906 & Surface soil $0-0.5 \mathrm{ft}$ & & & & & & & 1 & & \\
\hline 2 & 9/30/94 & RAD212 & 588351 & 2445906 & Surface soil $0-0.5 \mathrm{ft}$ & & & & & & & 1 & & \\
\hline 2 & $9 / 30 / 94$ & RAD214 & 588359 & 2445903 & Surface soil $0-0.5 \mathrm{ft}$ & & & & & & & 1 & & \\
\hline 2 & $9 / 30 / 94$ & RAD215 & 588357 & 2445777 & Surface soil $0-0.5 \mathrm{ft}$ & & & & & & & 1 & & \\
\hline 1 & 9/7/94 & RAD218 & 588384 & 2445867 & Surface soil $0-0.5 \mathrm{ft}$ & & & & & & & 1 & & \\
\hline 2 & $9 / 30 / 94$ & RAD219 & 588385 & 2445821 & Surface soil $0-0.5 \mathrm{ft}$ & & & & & & & 1 & & \\
\hline 2 & 9/7/94 & RAD220 & 588396 & 2445815 & Surface soil $0-0.5 \mathrm{ft}$ & & & & & & & 1 & & \\
\hline 2 & $8 / 31 / 94$ & RAD222 & 588437 & 2446121 & Surface soil $0-0.5 \mathrm{ft}$ & & & & & & & 1 & & \\
\hline \multirow[t]{2}{*}{3} & $12 / 15 / 94$ & S4 & 588550 & 2446219 & Interval unknown & & & & 1 & 1 & 1 & 1 & & \\
\hline & & & & & Total historic sa & les in $Z$ & EU-28 & 5 & 6 & 6 & 6 & 35 & & \\
\hline \multicolumn{3}{|c|}{$\begin{array}{l}\text { DVS = Dynamic Verification Strategy } \\
\text { EU = exposure unit } \\
\text { ID = identification } \\
\text { PCB = polychlorinated biphenyl }\end{array}$} & \multicolumn{3}{|c|}{$\begin{array}{l}\text { SU = soil unit } \\
\text { RAD = radiological } \\
\text { SVOC = semivolatile organic compound } \\
\text { VOC = volatile organic compound }\end{array}$} & & & & & & & & & \\
\hline
\end{tabular}




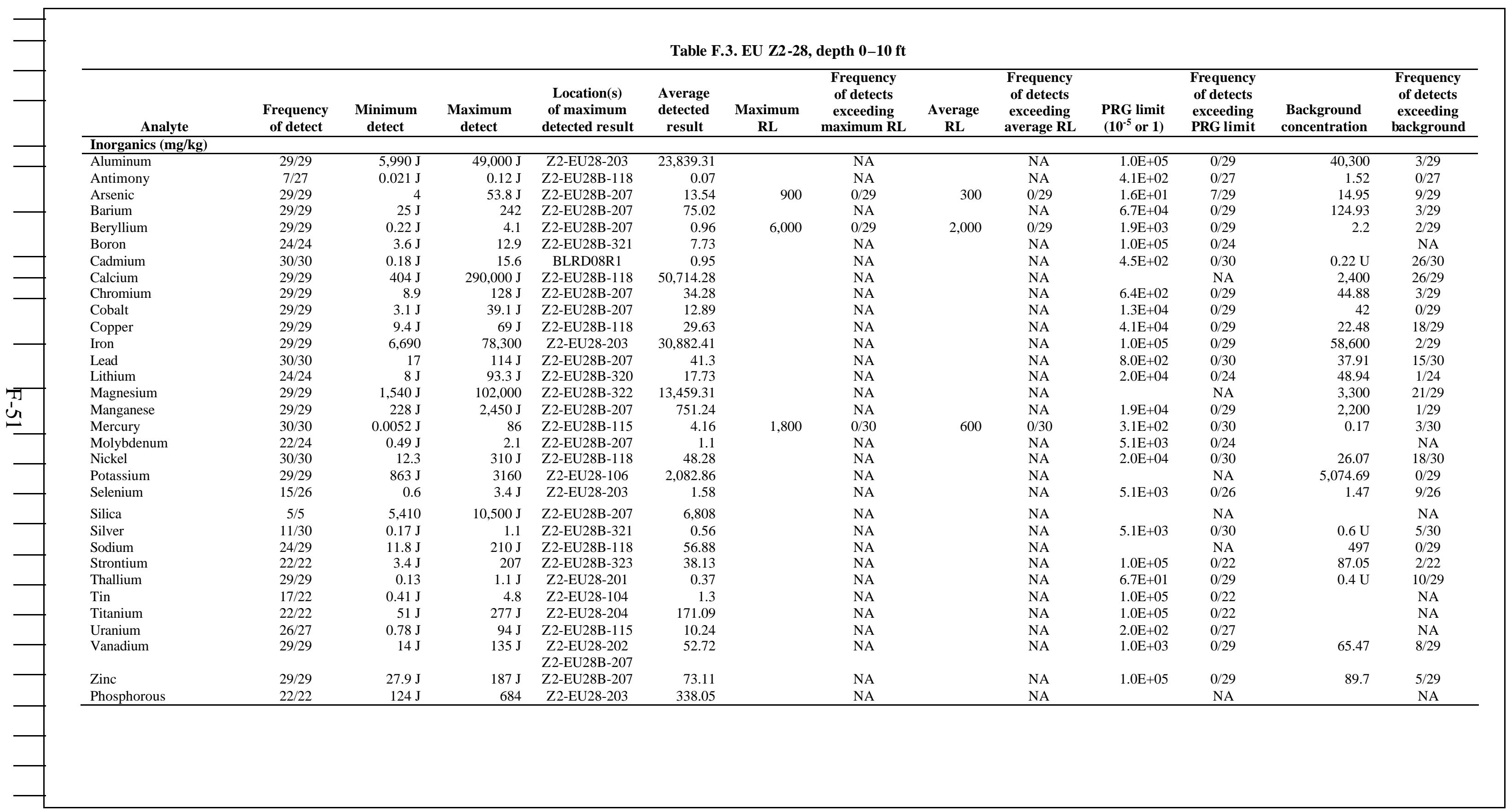


Table F.3. (continued)

\begin{tabular}{|c|c|c|c|c|c|c|c|c|c|c|c|c|c|}
\hline Analyte & $\begin{array}{c}\text { Frequency } \\
\text { of detect }\end{array}$ & $\begin{array}{c}\text { Minimum } \\
\text { detect }\end{array}$ & $\begin{array}{c}\text { Maximum } \\
\text { detect }\end{array}$ & $\begin{array}{l}\text { Location(s) of } \\
\text { maximum } \\
\text { detected result }\end{array}$ & $\begin{array}{l}\text { Average } \\
\text { detected } \\
\text { result }\end{array}$ & $\begin{array}{c}\text { Maximum } \\
\text { RL }\end{array}$ & $\begin{array}{c}\text { Frequency } \\
\text { of detects } \\
\text { exceeding } \\
\text { maximum } \\
\text { RL }\end{array}$ & $\begin{array}{c}\text { Average } \\
\text { RL }\end{array}$ & $\begin{array}{c}\text { Frequency } \\
\text { of detects } \\
\text { exceeding } \\
\text { average RL }\end{array}$ & $\begin{array}{l}\text { PRG limit } \\
\left(10^{-5} \text { or } 1\right)\end{array}$ & $\begin{array}{c}\text { Frequency } \\
\text { of detects } \\
\text { exceeding } \\
\text { PRG limit }\end{array}$ & $\begin{array}{l}\text { Background } \\
\text { concentration }\end{array}$ & $\begin{array}{l}\text { Frequency } \\
\text { of detects } \\
\text { exceeding } \\
\text { background }\end{array}$ \\
\hline \multicolumn{14}{|c|}{ Radionuclides (pCi/g) } \\
\hline Actinium-228 & $26 / 28$ & 0.15 & 3.1 & RAD205 & 1.48 & & NA & & NA & $1.2 \mathrm{E}+04$ & $0 / 28$ & & NA \\
\hline Alpha activity & $24 / 26$ & 4.07 & 805 & Z2-EU28B-114 & 75.77 & & NA & & NA & & NA & & NA \\
\hline Beta activity & $24 / 26$ & $7.63 \mathrm{~J}$ & 1,110 & Z2-EU28B-114 & 142.18 & & NA & & NA & & NA & & NA \\
\hline Bismuth-212 & $1 / 1$ & 4.07 & 4.07 & Z2-EU28B-124 & 4.07 & & NA & & NA & $3.7 \mathrm{E}+05$ & $0 / 1$ & & NA \\
\hline Bismuth-214 & $29 / 29$ & 0.332 & 2.04 & RAD205 & 1.03 & & NA & & NA & $1.3 \mathrm{E}+05$ & $0 / 29$ & & NA \\
\hline Cesium-134 & $8 / 18$ & 0.006 & 0.042 & RAD219 & 0.02 & & NA & & NA & $2.6 \mathrm{E}+00$ & $0 / 18$ & & NA \\
\hline Cesium-137 & $39 / 68$ & 0.007 & 48 & RAD199 & 3.05 & 20 & $1 / 68$ & 2 & $9 / 68$ & $1.1 \mathrm{E}+00$ & $10 / 68$ & & NA \\
\hline Cobalt-57 & $9 / 18$ & 0.003 & 0.085 & RAD204 & 0.03 & & NA & & NA & $1.4 \mathrm{E}+02$ & $0 / 18$ & & NA \\
\hline Cobalt -60 & $9 / 65$ & 0.00448 & 0.03 & RAD208 & 0.01 & & NA & & NA & $6.0 \mathrm{E}-01$ & $0 / 65$ & & NA \\
\hline Lead-212 & $30 / 30$ & 0.242 & 55.8 & RAD205 & 3.82 & & NA & & NA & $6.1 \mathrm{E}+04$ & $0 / 30$ & & NA \\
\hline Lead-214 & $30 / 30$ & 0.421 & 2.48 & RAD205 & 1.2 & & NA & & NA & $7.5 \mathrm{E}+05$ & $0 / 30$ & & NA \\
\hline Neptunium-237 & $24 / 57$ & 0.011 & 15.6 & Z2-EU28B-118 & 1.78 & 50 & $0 / 57$ & 5 & $1 / 57$ & $2.7 \mathrm{E}+00$ & $5 / 57$ & & NA \\
\hline Plutonium-238 & $13 / 23$ & 0.003 & 1 & RAD205 & 0.19 & & NA & & NA & $1.7 \mathrm{E}+02$ & $0 / 23$ & & NA \\
\hline $\begin{array}{l}\text { Plutonium-239 } \\
\text { Paus }\end{array}$ & $17 / 23$ & 0.0021 & 47.2 & RAD199 & 6.08 & & NA & & NA & $1.5 \mathrm{E}+02$ & $0 / 23$ & & NA \\
\hline Potassium-40 & $52 / 53$ & 4.86 & 25.8 & Z2-EU28-205 & 14.66 & & NA & & NA & $2.7 \mathrm{E}+00$ & $52 / 53$ & 32.12 & $0 / 53$ \\
\hline Protactinium-234m & $7 / 10$ & 64.4 & 524 & Z2-EU28B-114 & 156.2 & & NA & & NA & $2.5 \mathrm{E}+08$ & $0 / 10$ & & NA \\
\hline $\mathrm{Ra} / \mathrm{Th}$ decay series & $65 / 65$ & 0 & 213.95 & RAD205 & 18.81 & 15 & $12 / 65$ & 5 & $17 / 65$ & & NA & & NA \\
\hline Radium-226 & $49 / 52$ & 0.14 & 35.8 & RAD199 & 3.64 & 15 & $\mathrm{NA}^{b}$ & 5 & $\mathrm{NA}^{b}$ & $2.6 \mathrm{E}-01$ & $48 / 52$ & 1.25 & $31 / 52$ \\
\hline Technetium-99 & $29 / 68$ & 0.81 & 2,550 & Z2-EU28B-115 & 357.86 & & NA & & NA & $8.9 \mathrm{E}+03$ & $0 / 68$ & & NA \\
\hline Thallium-208 & $28 / 28$ & 0.071 & 17.3 & RAD205 & 1.25 & & NA & & NA & $3.7 \mathrm{E}+05$ & $0 / 28$ & & NA \\
\hline Thorium-228 & $65 / 65$ & $0.536 \mathrm{~J}$ & 54 & RAD205 & 2.78 & & NA & & NA & $1.7 \mathrm{E}-01$ & $65 / 65^{a}$ & 1.86 & $23 / 65$ \\
\hline Thorium-230 & $65 / 65$ & 0.505 & 204 & RAD205 & 18.56 & 15 & $\mathrm{NA}^{b}$ & 5 & $\mathrm{NA}^{b}$ & $2.1 \mathrm{E}+02$ & $0 / 65$ & 1.2 & $50 / 65$ \\
\hline Thorium-232 & $65 / 65$ & $0.388 \mathrm{~J}$ & $20.5 \mathrm{~J}$ & RAD206 & 2.04 & 15 & $\mathrm{NA}^{b}$ & 5 & $\mathrm{NA}^{b}$ & $1.7 \mathrm{E}-01$ & $65 / 65^{a}$ & 1.95 & $15 / 65$ \\
\hline Thorium-234 & $38 / 53$ & 0.44 & 288 & Z2-EU28B-114 & 61.88 & & NA & & NA & $3.3 \mathrm{E}+04$ & $0 / 53$ & & NA \\
\hline Uranium-234 & $67 / 68$ & 0.6 & 842 & Z2-EU28B-114 & 64.77 & 7,000 & $0 / 68$ & 700 & $1 / 68$ & $3.3 \mathrm{E}+02$ & $4 / 68$ & & NA \\
\hline Uranium-235 & $53 / 67$ & 0.0379 & 54.9 & Z2-EU28B-114 & 5.1 & 80 & $0 / 67$ & 8 & $10 / 67$ & $3.9 \mathrm{E}+00$ & $17 / 67$ & & NA \\
\hline Uranium-236 & $0 / 1$ & ND & ND & & ND & & NA & & NA & $3.6 \mathrm{E}+02$ & $0 / 1$ & & NA \\
\hline Uranium-238 & $66 / 68$ & 0.527 & 421 & Z2-EU28B-114 & 40.79 & 500 & $0 / 68$ & 50 & $17 / 68$ & $1.8 \mathrm{E}+01$ & $20 / 68$ & 1.47 & $52 / 68$ \\
\hline \multicolumn{14}{|c|}{ Organics, pesticides, and PCBs (ug/kg) } \\
\hline 4,4'-DDD & $0 / 1$ & ND & ND & & ND & & NA & & NA & $1.0 \mathrm{E}+05$ & $0 / 1$ & & NA \\
\hline 4,4-DDE & $0 / 1$ & ND & ND & & $\mathrm{ND}$ & & NA & & NA & $7.0 \mathrm{E}+04$ & $0 / 1$ & & NA \\
\hline 4,4'-DDT & $0 / 1$ & ND & ND & & ND & & NA & & NA & $7.0 \mathrm{E}+04$ & $0 / 1$ & & NA \\
\hline Aldrin & $0 / 1$ & ND & ND & & ND & & NA & & NA & $1.0 \mathrm{E}+03$ & $0 / 1$ & & NA \\
\hline Dieldrin & $0 / 1$ & ND & ND & & ND & & NA & & NA & $1.1 \mathrm{E}+03$ & $0 / 1$ & & NA \\
\hline Endosulfan I & $0 / 1$ & ND & ND & & ND & & NA & & NA & $3.7 \mathrm{E}+06$ & $0 / 1$ & & NA \\
\hline Endosulfan II & $0 / 1$ & ND & ND & & ND & & NA & & NA & $3.7 \mathrm{E}+06$ & $0 / 1$ & & NA \\
\hline Endosulfan sulfate & $0 / 1$ & ND & ND & & ND & & NA & & NA & $3.7 \mathrm{E}+06$ & $0 / 1$ & & NA \\
\hline Endrin & $0 / 1$ & ND & ND & & ND & & NA & & NA & $1.8 \mathrm{E}+05$ & $0 / 1$ & & NA \\
\hline Endrin ketone & $0 / 1$ & ND & ND & & ND & & NA & & NA & $1.8 \mathrm{E}+05$ & $0 / 1$ & & NA \\
\hline Heptachlor & $0 / 1$ & ND & ND & & ND & & NA & & NA & $3.8 \mathrm{E}+03$ & $0 / 1$ & & NA \\
\hline
\end{tabular}


Table F.3. (continued) 
Table F.3. (continued)

\begin{tabular}{|c|c|c|c|c|c|c|c|c|c|c|c|c|c|}
\hline Analyte & $\begin{array}{c}\text { Frequency } \\
\text { of detect }\end{array}$ & $\begin{array}{c}\text { Minimum } \\
\text { detect }\end{array}$ & $\begin{array}{c}\text { Maximum } \\
\text { detect }\end{array}$ & $\begin{array}{c}\text { Location(s) of } \\
\text { maximum } \\
\text { detected result }\end{array}$ & $\begin{array}{c}\text { Average } \\
\text { detected } \\
\text { result }\end{array}$ & $\begin{array}{c}\text { Maximum } \\
\text { RL }\end{array}$ & $\begin{array}{c}\text { Frequency } \\
\text { of detects } \\
\text { exceeding } \\
\text { maximum } \\
\text { RL } \\
\end{array}$ & $\begin{array}{c}\text { Average } \\
\text { RL }\end{array}$ & $\begin{array}{c}\text { Frequency } \\
\text { of detects } \\
\text { exceeding } \\
\text { average RL } \\
\end{array}$ & $\begin{array}{c}\text { PRG limit } \\
\left(10^{-5} \text { or } 1\right)\end{array}$ & $\begin{array}{c}\text { Frequency } \\
\text { of detects } \\
\text { exceeding } \\
\text { PRG limit }\end{array}$ & $\begin{array}{c}\text { Background } \\
\text { concentration }\end{array}$ & $\begin{array}{c}\text { Frequency } \\
\text { of detects } \\
\text { exceeding } \\
\text { background }\end{array}$ \\
\hline 4-Bromophenyl phenyl ether & $0 / 19$ & $\mathrm{ND}$ & ND & & $\mathrm{ND}$ & & NA & & NA & & NA & & NA \\
\hline 4-Chloro-3-methylphenol & $0 / 19$ & ND & $\mathrm{ND}$ & & $\mathrm{ND}$ & & NA & & NA & & NA & & NA \\
\hline 4-Chlorobenzenamine & $0 / 19$ & ND & ND & & ND & & NA & & NA & $2.5 \mathrm{E}+06$ & $0 / 19$ & & NA \\
\hline 4-Chlorophenyl phenyl ether & $0 / 19$ & ND & ND & & ND & & NA & & NA & & NA & & NA \\
\hline 4-Methylphenol & $0 / 17$ & ND & ND & & ND & & NA & & NA & $3.1 \mathrm{E}+06$ & $0 / 17$ & & NA \\
\hline 4-Nitrobenzenamine & $0 / 8$ & ND & ND & & ND & & NA & & NA & $8.2 \mathrm{E}+05$ & $0 / 8$ & & NA \\
\hline 4-Nitrophenol & $0 / 19$ & $\mathrm{ND}$ & ND & & $\mathrm{ND}$ & & NA & & NA & & NA & & NA \\
\hline Acenaphthene & $1 / 19$ & $9.8 \mathrm{~J}$ & $9.8 \mathrm{~J}$ & Z2-EU28B-318 & 9.8 & & NA & & NA & $2.9 \mathrm{E}+07$ & $0 / 19$ & & NA \\
\hline Acenaphthylene & $2 / 19$ & $20.6 \mathrm{~J}$ & 273 & Z2-EU28B-317 & 146.8 & & NA & & NA & $2.9 \mathrm{E}+07$ & $0 / 19$ & & NA \\
\hline Aniline & $0 / 3$ & ND & ND & & ND & & NA & & NA & $3.0 \mathrm{E}+06$ & $0 / 3$ & & NA \\
\hline Anthracene & $3 / 19$ & 74.3 & $120 \mathrm{~J}$ & Z2-EU28B-115 & 93.2 & & NA & & NA & $1.0 \mathrm{E}+08$ & $0 / 19$ & & NA \\
\hline Benz(a)anthracene & $5 / 19$ & $99 \mathrm{~J}$ & 830 & Z2-EU28B-115 & 491.8 & & NA & & NA & $2.1 \mathrm{E}+04$ & $0 / 19$ & & NA \\
\hline Benzenemethanol & $0 / 14$ & ND & ND & & ND & & NA & & NA & $1.0 \mathrm{E}+08$ & $0 / 14$ & & NA \\
\hline Benzo(a)pyrene & $9 / 19$ & 45.6 & 982 & Z2-EU28B-317 & 383.62 & & NA & & NA & $2.1 \mathrm{E}+03$ & $0 / 19$ & & NA \\
\hline Benzo(b)fluoranthene & $10 / 19$ & $35 \mathrm{~J}$ & 1610 & Z2-EU28B-317 & 444.65 & & NA & & NA & $2.1 \mathrm{E}+04$ & $0 / 19$ & & NA \\
\hline Benzo(ghi)perylene & $6 / 19$ & $120 \mathrm{~J}$ & $960 \mathrm{~J}$ & Z2-EU28B-115 & 434.33 & & NA & & NA & $2.9 \mathrm{E}+07$ & $0 / 19$ & & NA \\
\hline Benzo(k)fluoranthene & $4 / 19$ & $22.8 \mathrm{~J}$ & $430 \mathrm{~J}$ & Z2-EU28B-115 & 190.7 & & NA & & NA & $2.1 \mathrm{E}+05$ & $0 / 19$ & & NA \\
\hline Benzoic acid & $0 / 13$ & ND & ND & & ND & & NA & & NA & $1.0 \mathrm{E}+08$ & $0 / 13$ & & NA \\
\hline Bis(2-chloroethoxy)methane & $0 / 19$ & ND & ND & & ND & & NA & & NA & & NA & & NA \\
\hline Bis(2-chloroethyl)ether & $0 / 19$ & ND & ND & & ND & & NA & & NA & $5.8 \mathrm{E}+03$ & $0 / 19$ & & NA \\
\hline Bis(2-chloroisopropyl)ether & $0 / 19$ & ND & ND & & ND & & NA & & NA & 7.4E+04 & $0 / 19$ & & NA \\
\hline Bis(2-ethylhexyl)phthalate & $0 / 19$ & ND & $\mathrm{ND}$ & & ND & & NA & & NA & $1.2 \mathrm{E}+06$ & $0 / 19$ & & NA \\
\hline Butyl benzyl phthalate & $0 / 19$ & ND & ND & & ND & & NA & & NA & $1.0 \mathrm{E}+08$ & $0 / 19$ & & NA \\
\hline Carbazole & $0 / 8$ & ND & ND & & ND & & NA & & NA & $8.6 \mathrm{E}+05$ & $0 / 8$ & & NA \\
\hline Chrysene & $8 / 19$ & $19 \mathrm{~J}$ & 748 & Z2-EU28B-318 & 308.71 & & NA & & NA & $2.1 \mathrm{E}+06$ & $0 / 19$ & & NA \\
\hline Di-n-butyl phthalate & $0 / 8$ & ND & ND & & ND & & NA & & NA & $6.2 \mathrm{E}+07$ & $0 / 8$ & & NA \\
\hline Di-n-octylphthalate & $1 / 19$ & $38 \mathrm{~J}$ & $38 \mathrm{~J}$ & Z2-EU28B-118 & 38 & & NA & & NA & $2.5 \mathrm{E}+07$ & $0 / 19$ & & NA \\
\hline Dibenz(a,h)anthracene & $3 / 19$ & $150 \mathrm{~J}$ & 210 & Z2-EU28B-317 & 178.33 & & NA & & NA & $2.1 \mathrm{E}+03$ & $0 / 19$ & & NA \\
\hline Dibenzofuran & $0 / 19$ & ND & ND & & ND & & NA & & NA & $1.6 \mathrm{E}+06$ & $0 / 19$ & & NA \\
\hline Diethyl phthalate & $0 / 19$ & ND & ND & & ND & & NA & & NA & $1.0 \mathrm{E}+08$ & $0 / 19$ & & NA \\
\hline Dimethyl phthalate & $0 / 19$ & ND & ND & & ND & & NA & & NA & $1.0 \mathrm{E}+08$ & $0 / 19$ & & NA \\
\hline Dipheny lamine & $0 / 11$ & ND & ND & & ND & & NA & & NA & $1.5 \mathrm{E}+07$ & $0 / 11$ & & NA \\
\hline Diphenyldiazene & $0 / 2$ & ND & ND & & ND & & NA & & NA & $1.6 \mathrm{E}+05$ & $0 / 2$ & & NA \\
\hline Fluoranthene & 9/19 & $32.6 \mathrm{~J}$ & 1200 & Z2-EU28B-318 & 492.64 & & NA & & NA & $2.2 \mathrm{E}+07$ & $0 / 19$ & & NA \\
\hline Fluorene & $2 / 19$ & $29.9 \mathrm{~J}$ & $33.8 \mathrm{~J}$ & Z2-EU28B-318 & 31.85 & & NA & & NA & $2.6 \mathrm{E}+07$ & $0 / 19$ & & NA \\
\hline Hexachlorobenzene & $1 / 19$ & $320 \mathrm{~J}$ & $320 \mathrm{~J}$ & Z2-EU28B-115 & 320 & & NA & & NA & $1.1 \mathrm{E}+04$ & $0 / 19$ & & NA \\
\hline Hexachlorobutadiene & $0 / 19$ & ND & ND & & ND & & NA & & NA & $1.8 \mathrm{E}+05$ & $0 / 19$ & & NA \\
\hline Hexachlorocyclopentadiene & $0 / 19$ & ND & ND & & ND & & NA & & NA & $3.7 \mathrm{E}+06$ & $0 / 19$ & & NA \\
\hline Hexachloroethane & $0 / 19$ & ND & ND & & ND & & NA & & NA & $6.2 \mathrm{E}+05$ & $0 / 19$ & & NA \\
\hline Indeno(1,2,3-cd)pyrene & $8 / 19$ & $100 \mathrm{~J}$ & 760 & Z2-EU28B-115 & 422.88 & & NA & & NA & $2.1 \mathrm{E}+04$ & $0 / 19$ & & NA \\
\hline Isophorone & $0 / 19$ & ND & $\mathrm{ND}$ & & ND & & NA & & NA & $5.1 \mathrm{E}+06$ & $0 / 19$ & & NA \\
\hline
\end{tabular}


Table F.3. (continued) 
Table F.3. (continued)

\begin{tabular}{|c|c|c|c|c|c|c|c|c|c|c|c|c|c|}
\hline $\begin{array}{r}\text { Analyte } \\
\end{array}$ & $\begin{array}{c}\text { Frequency } \\
\text { of detect }\end{array}$ & $\begin{array}{c}\text { Minimum } \\
\text { detect }\end{array}$ & $\begin{array}{c}\text { Maximum } \\
\text { detect }\end{array}$ & $\begin{array}{c}\text { Location(s) of } \\
\text { maximum } \\
\text { detected result }\end{array}$ & $\begin{array}{c}\text { Average } \\
\text { detected } \\
\text { result }\end{array}$ & $\begin{array}{c}\text { Maximum } \\
\text { RL }\end{array}$ & $\begin{array}{c}\text { Frequency } \\
\text { of detects } \\
\text { exceeding } \\
\text { maximum } \\
\text { RL } \\
\end{array}$ & $\begin{array}{c}\text { Average } \\
\text { RL }\end{array}$ & $\begin{array}{c}\text { Frequency } \\
\text { of detects } \\
\text { exceeding } \\
\text { average RL } \\
\end{array}$ & $\begin{array}{l}\text { PRG limit } \\
\left(10^{-5} \text { or } 1\right)\end{array}$ & $\begin{array}{c}\text { Frequency } \\
\text { of detects } \\
\text { exceeding } \\
\text { PRG limit }\end{array}$ & $\begin{array}{c}\text { Background } \\
\text { concentration }\end{array}$ & $\begin{array}{c}\text { Frequency } \\
\text { of detects } \\
\text { exceeding } \\
\text { background }\end{array}$ \\
\hline 4-Methyl-2-pentanone & $0 / 17$ & ND & ND & & $\mathrm{ND}$ & & NA & & NA & $4.7 \mathrm{E}+07$ & $0 / 17$ & & NA \\
\hline Acetone & $6 / 17$ & 6.5 & 105 & Z2-EU28-105 & 38.18 & & NA & & NA & $5.4 \mathrm{E}+07$ & $0 / 17$ & & NA \\
\hline Benzene & $0 / 17$ & ND & ND & & ND & & NA & & NA & $1.4 \mathrm{E}+04$ & $0 / 17$ & & NA \\
\hline Bromobenzene & $0 / 2$ & ND & ND & & ND & & NA & & NA & $9.2 \mathrm{E}+04$ & $0 / 2$ & & NA \\
\hline Bromochloromethane & $0 / 2$ & ND & ND & & ND & & NA & & NA & & NA & & NA \\
\hline Bromodichloromethane & $0 / 17$ & ND & ND & & ND & & NA & & NA & $1.8 \mathrm{E}+04$ & $0 / 17$ & & NA \\
\hline Bromoform & $0 / 17$ & ND & ND & & ND & & NA & & NA & $2.2 \mathrm{E}+06$ & $0 / 17$ & & NA \\
\hline Bromomethane & $0 / 17$ & ND & ND & & ND & & NA & & NA & $1.3 \mathrm{E}+04$ & $0 / 17$ & & NA \\
\hline Butylbenzene & $0 / 2$ & ND & ND & & ND & & NA & & NA & $2.4 \mathrm{E}+05$ & $0 / 2$ & & NA \\
\hline Carbon disulfide & $0 / 17$ & ND & ND & & ND & & NA & & NA & $7.2 \mathrm{E}+05$ & $0 / 17$ & & NA \\
\hline Carbon tetrachloride & $0 / 17$ & ND & ND & & ND & & NA & & NA & $5.5 \mathrm{E}+03$ & $0 / 17$ & & NA \\
\hline Chlorobenzene & $0 / 17$ & ND & $\mathrm{ND}$ & & ND & & NA & & NA & $5.3 \mathrm{E}+05$ & $0 / 17$ & & NA \\
\hline Chloroethane & $0 / 17$ & ND & ND & & ND & & NA & & NA & $6.5 \mathrm{E}+04$ & $0 / 17$ & & NA \\
\hline Chloroform & $0 / 17$ & ND & ND & & ND & & NA & & NA & $4.7 \mathrm{E}+03$ & $0 / 17$ & & NA \\
\hline Chloromethane & $0 / 17$ & ND & ND & & ND & & NA & & NA & $1.6 \mathrm{E}+05$ & $0 / 17$ & & NA \\
\hline Cumene & $0 / 2$ & ND & ND & & ND & & NA & & NA & $5.2 \mathrm{E}+05$ & $0 / 2$ & & NA \\
\hline Dibromochloromethane & $0 / 17$ & ND & $\mathrm{ND}$ & & ND & & NA & & NA & $2.6 \mathrm{E}+04$ & $0 / 17$ & & NA \\
\hline Dibromomethane & $0 / 2$ & ND & ND & & ND & & NA & & NA & $2.3 \mathrm{E}+05$ & $0 / 2$ & & NA \\
\hline Dichlorodifluoromethane & $0 / 2$ & ND & ND & & ND & & NA & & NA & $3.1 \mathrm{E}+05$ & $0 / 2$ & & NA \\
\hline Ethylbenzene & $1 / 17$ & $13 \mathrm{~J}$ & $13 \mathrm{~J}$ & Z2-EU28-105 & 13 & & NA & & NA & $4.0 \mathrm{E}+05$ & $0 / 17$ & & NA \\
\hline Iodomethane & $0 / 2$ & ND & ND & & ND & & NA & & NA & & NA & & NA \\
\hline $\mathrm{M}+\mathrm{P}$ xylene & $0 / 2$ & ND & $\mathrm{ND}$ & & ND & & NA & & NA & $4.2 \mathrm{E}+05$ & $0 / 2$ & & NA \\
\hline Methylene chloride & $7 / 17$ & $1.5 \mathrm{~J}$ & $4.6 \mathrm{~J}$ & BLRD02R1 & 2.74 & & NA & & NA & $2.1 \mathrm{E}+05$ & $0 / 17$ & & NA \\
\hline Propylbenzene & $0 / 2$ & ND & ND & & ND & & NA & & NA & $2.4 \mathrm{E}+05$ & $0 / 2$ & & NA \\
\hline Styrene & $0 / 17$ & ND & ND & & ND & & NA & & NA & $1.7 \mathrm{E}+06$ & $0 / 17$ & & NA \\
\hline Tetrachloroethene & $1 / 17$ & $0.54 \mathrm{~J}$ & $0.54 \mathrm{~J}$ & Z2-EU28-205 & 0.54 & & NA & & NA & $1.3 \mathrm{E}+04$ & $0 / 17$ & & NA \\
\hline Toluene & $4 / 17$ & $0.48 \mathrm{~J}$ & 8.9 & Z2-EU28-105 & 3.86 & & NA & & NA & $5.2 \mathrm{E}+05$ & $0 / 17$ & & NA \\
\hline Total xylene & $0 / 15$ & ND & ND & & ND & & NA & & NA & $4.2 \mathrm{E}+05$ & $0 / 15$ & & NA \\
\hline Trichloroethene & $0 / 17$ & ND & ND & & ND & & NA & & NA & $1.1 \mathrm{E}+03$ & $0 / 17$ & & NA \\
\hline Trichlorofluoromethane & $0 / 2$ & ND & ND & & ND & & NA & & NA & $1.3 \mathrm{E}+06$ & $0 / 2$ & & NA \\
\hline Vinyl acetate & $0 / 2$ & ND & ND & & ND & & NA & & NA & $1.4 \mathrm{E}+06$ & $0 / 2$ & & NA \\
\hline Vinyl chloride & $0 / 17$ & ND & ND & & ND & & NA & & NA & $7.5 \mathrm{E}+03$ & $0 / 17$ & & NA \\
\hline cis-1,2-Dichloroethene & $0 / 12$ & ND & ND & & ND & & NA & & NA & $1.5 \mathrm{E}+05$ & $0 / 12$ & & NA \\
\hline cis-1,3-Dichloropropene & $0 / 17$ & ND & $\mathrm{ND}$ & & ND & & NA & & NA & $1.8 \mathrm{E}+04$ & $0 / 17$ & & NA \\
\hline o-Chlorotoluene & $0 / 2$ & ND & ND & & ND & & NA & & NA & $5.6 \mathrm{E}+05$ & $0 / 2$ & & NA \\
\hline trans-1,2-Dichloroethene & $0 / 12$ & ND & ND & & ND & & NA & & NA & $2.3 \mathrm{E}+05$ & $0 / 12$ & & NA \\
\hline trans-1,3-Dichloropropene & $0 / 17$ & ND & ND & & ND & & NA & & NA & $1.8 \mathrm{E}+04$ & $0 / 17$ & & NA \\
\hline
\end{tabular}


Table F.3. (continued)

\begin{tabular}{|c|c|c|c|c|c|c|c|c|c|c|c|c|c|}
\hline Analyte & $\begin{array}{c}\text { Frequency } \\
\text { of detect }\end{array}$ & $\begin{array}{c}\text { Minimum } \\
\text { detect }\end{array}$ & $\underset{\text { detect }}{\text { Maximum }}$ & $\begin{array}{l}\text { Location(s) of } \\
\text { maximum } \\
\text { detected result }\end{array}$ & $\begin{array}{c}\text { Average } \\
\text { detected } \\
\text { result }\end{array}$ & $\underset{\text { RL }}{\text { Maximum }}$ & $\begin{array}{c}\text { Frequency } \\
\text { of detects } \\
\text { exceeding } \\
\text { maximum } \\
\text { RL }\end{array}$ & $\begin{array}{c}\text { Average } \\
\text { RL }\end{array}$ & $\begin{array}{l}\text { Frequency } \\
\text { of detects } \\
\text { exceeding } \\
\text { average RL }\end{array}$ & $\begin{array}{l}\text { PRG limit } \\
\left(10^{-5} \text { or } 1\right)\end{array}$ & $\begin{array}{c}\text { Frequency } \\
\text { of detects } \\
\text { exceeding } \\
\text { PRG limit }\end{array}$ & $\begin{array}{l}\text { Background } \\
\text { concentration }\end{array}$ & $\begin{array}{c}\text { Frequency } \\
\text { of detects } \\
\text { exceeding } \\
\text { background }\end{array}$ \\
\hline
\end{tabular}

thated as part of Th-232+D $=$ Th-232 $+\mathrm{Ra}-228+\mathrm{D}+\mathrm{Th}-228+\mathrm{D}$

$\mathrm{EU}=$ exposure unit

$\mathrm{J}=$ analyte was positively identified and result is the approximate concentratio $\mathrm{n}$ of the analyte in the sample

$\mathrm{NA}=$ not applicable
$\mathrm{ND}=$ not detected

$\mathrm{ND}=$ not detected
$\mathrm{PCB}=$ polychloride biphenyl

$\mathrm{PRG}=$ preliminary remediation

$\mathrm{RL}=$ remediation level

$\mathrm{U}=$ analyte was not detected above the reported sample quantitation limi 
Table F.4. EU Z2-28, depth below $10 \mathrm{ft}$

\begin{tabular}{|c|c|c|c|c|c|c|c|c|c|c|c|c|c|}
\hline Analyte & $\begin{array}{c}\text { Frequency } \\
\text { of detect }\end{array}$ & $\begin{array}{c}\text { Minimum } \\
\text { detect }\end{array}$ & $\begin{array}{c}\text { Maximum } \\
\text { detect }\end{array}$ & $\begin{array}{c}\text { Location(s) of } \\
\text { maximum } \\
\text { detected result }\end{array}$ & $\begin{array}{c}\text { Average } \\
\text { detected } \\
\text { result } \\
\end{array}$ & $\begin{array}{c}\text { Maximum } \\
\text { RL } \\
\end{array}$ & $\begin{array}{c}\text { Frequency } \\
\text { of detects } \\
\text { exceeding } \\
\text { maximum } \\
\text { RL } \\
\end{array}$ & $\begin{array}{c}\text { Average } \\
\text { RL }\end{array}$ & $\begin{array}{c}\text { Frequency } \\
\text { of detects } \\
\text { exceeding } \\
\text { average RL } \\
\end{array}$ & $\begin{array}{l}\text { PRG limit } \\
\left(10^{-5} \text { or } 1\right)\end{array}$ & $\begin{array}{c}\text { Frequency } \\
\text { of detects } \\
\text { exceeding } \\
\text { PRG limit } \\
\end{array}$ & $\begin{array}{c}\text { Background } \\
\text { concentration }\end{array}$ & $\begin{array}{c}\text { Frequency } \\
\text { of detects } \\
\text { exceeding } \\
\text { background }\end{array}$ \\
\hline \multicolumn{14}{|c|}{ Inorganics (mg/kg) } \\
\hline Aluminum & $6 / 6$ & 17,400 & 31,600 & Z2-EU28B-111 & 22,550 & & NA & & NA & $1.0 \mathrm{E}+05$ & $0 / 6$ & 40,300 & $0 / 6$ \\
\hline Antimony & $0 / 6$ & ND & ND & & ND & & NA & & NA & $4.1 \mathrm{E}+02$ & $0 / 6$ & 1.52 & $0 / 6$ \\
\hline Arsenic & $6 / 6$ & $3.9 \mathrm{~J}$ & $10.7 \mathrm{~J}$ & Z2-EU28B-111 & 6.83 & 900 & $0 / 6$ & 300 & $0 / 6$ & $1.6 \mathrm{E}+01$ & $0 / 6$ & 14.95 & $0 / 6$ \\
\hline Barium & $6 / 6$ & 52 & 126 & Z2-EU28B-109 & 95.17 & & NA & & NA & $6.7 \mathrm{E}+04$ & $0 / 6$ & 124.93 & $2 / 6$ \\
\hline Beryllium & $6 / 6$ & $0.59 \mathrm{~J}$ & 4.3 & Z2-EU28B-110 & 1.57 & 6,000 & $0 / 6$ & 2,000 & $0 / 6$ & $1.9 \mathrm{E}+03$ & $0 / 6$ & 2.2 & $1 / 6$ \\
\hline Boron & $6 / 6$ & 7.2 & 16.6 & Z2-EU28B-109 & 11.57 & & NA & & NA & $1.0 \mathrm{E}+05$ & $0 / 6$ & & NA \\
\hline Cadmium & $6 / 6$ & $0.088 \mathrm{~J}$ & 0.64 & Z2-EU28B-110 & 0.21 & & NA & & NA & $4.5 \mathrm{E}+02$ & $0 / 6$ & $0.22 \mathrm{U}$ & $1 / 6$ \\
\hline Calcium & $6 / 6$ & $298 \mathrm{~J}$ & $8,250 \mathrm{~J}$ & Z2-EU28B-111 & $4,829.67$ & & NA & & NA & & NA & 2,400 & $4 / 6$ \\
\hline Chromium & $6 / 6$ & $32.3 \mathrm{~J}$ & $43.3 \mathrm{~J}$ & Z2-EU28B-109 & 36.07 & & NA & & NA & $6.4 \mathrm{E}+02$ & $0 / 6$ & 44.88 & $0 / 6$ \\
\hline Cobalt & $6 / 6$ & $7.4 \mathrm{~J}$ & $45.4 \mathrm{~J}$ & Z2-EU28B-111 & 18.95 & & NA & & NA & $1.3 \mathrm{E}+04$ & $0 / 6$ & 42 & $1 / 6$ \\
\hline Copper & $6 / 6$ & $17.1 \mathrm{~J}$ & $47.9 \mathrm{~J}$ & Z2-EU28B-111 & 24.33 & & NA & & NA & $4.1 \mathrm{E}+04$ & $0 / 6$ & 22.48 & $2 / 6$ \\
\hline Iron & $6 / 6$ & $23,500 \mathrm{~J}$ & $43,200 \mathrm{~J}$ & Z2-EU28B-111 & 33,250 & & NA & & NA & $1.0 \mathrm{E}+05$ & $0 / 6$ & 58,600 & $0 / 6$ \\
\hline Lead & $6 / 6$ & $11.4 \mathrm{~J}$ & $65.9 \mathrm{~J}$ & Z2-EU28B-111 & 26.33 & & NA & & NA & $8.0 \mathrm{E}+02$ & $0 / 6$ & 37.91 & $1 / 6$ \\
\hline Lithium & $6 / 6$ & 11 & 19.5 & Z2-EU28B-111 & 16.63 & & NA & & NA & $2.0 \mathrm{E}+04$ & $0 / 6$ & 48.94 & $0 / 6$ \\
\hline Magnesium & $6 / 6$ & $1,560 \mathrm{~J}$ & $7,000 \mathrm{~J}$ & Z2-EU28B-111 & $4,108.33$ & & NA & & NA & & NA & 3,300 & $3 / 6$ \\
\hline Manganese & $6 / 6$ & $307 \mathrm{~J}$ & $3,620 \mathrm{~J}$ & Z2-EU28B-111 & $1,159.17$ & & NA & & NA & $1.9 \mathrm{E}+04$ & $0 / 6$ & 2,200 & $1 / 6$ \\
\hline Mercury & $6 / 6$ & 0.019 & 0.13 & Z2-EU28B-110 & 0.07 & 1,800 & $0 / 6$ & 600 & $0 / 6$ & $3.1 \mathrm{E}+02$ & $0 / 6$ & 0.17 & $0 / 6$ \\
\hline Molybdenum & $4 / 6$ & $0.48 \mathrm{~J}$ & $1 \mathrm{~J}$ & Z2-EU28B-109 & 0.75 & & NA & & NA & $5.1 \mathrm{E}+03$ & $0 / 6$ & & NA \\
\hline Nickel & $6 / 6$ & $18.7 \mathrm{~J}$ & $118 \mathrm{~J}$ & Z2-EU28B-111 & 43.92 & & NA & & NA & $2.0 \mathrm{E}+04$ & $0 / 6$ & 26.07 & $3 / 6$ \\
\hline Potassium & $6 / 6$ & 2110 & 4,910 & Z2-EU28B-109 & 3410 & & NA & & NA & & NA & $5,074.69$ & $0 / 6$ \\
\hline Selenium & $6 / 6$ & 0.9 & $3.1 \mathrm{~J}$ & Z2-EU28B-111 & 1.58 & & NA & & NA & $5.1 \mathrm{E}+03$ & $0 / 6$ & 1.47 & $3 / 6$ \\
\hline Silica & $6 / 6$ & $7,270 \mathrm{~J}$ & $10,600 \mathrm{~J}$ & Z2-EU28B-111 & 9,020 & & NA & & NA & & NA & & NA \\
\hline Silver & $0 / 6$ & ND & ND & & ND & & NA & & NA & $5.1 \mathrm{E}+03$ & $0 / 6$ & $0.6 \mathrm{U}$ & $0 / 6$ \\
\hline Sodium & $6 / 6$ & $13.8 \mathrm{~J}$ & $63.1 \mathrm{~J}$ & Z2-EU28B-109 & 38.47 & & NA & & NA & & NA & 497 & $0 / 6$ \\
\hline Strontium & $6 / 6$ & $3.8 \mathrm{~J}$ & $16.6 \mathrm{~J}$ & Z2-EU28B-109 & 10.18 & & NA & & NA & $1.0 \mathrm{E}+05$ & $0 / 6$ & 87.05 & $0 / 6$ \\
\hline Thallium & $6 / 6$ & $0.2 \mathrm{~J}$ & 0.53 & Z2-EU28B-111 & 0.32 & & NA & & NA & $6.7 \mathrm{E}+01$ & $0 / 6$ & $0.4 \mathrm{U}$ & $1 / 6$ \\
\hline Tin & $6 / 6$ & $0.75 \mathrm{~J}$ & 1.4 & Z2-EU28B-111 & 0.95 & & NA & & NA & $1.0 \mathrm{E}+05$ & $0 / 6$ & & NA \\
\hline Titanium & $6 / 6$ & 144 & 306 & Z2-EU28B-109 & 232.83 & & NA & & NA & $1.0 \mathrm{E}+05$ & $0 / 6$ & & NA \\
\hline Uranium & $6 / 6$ & $0.7 \mathrm{~J}$ & $2 \mathrm{~J}$ & Z2-EU28B-110 & 1.25 & & NA & & NA & $2.0 \mathrm{E}+02$ & $0 / 6$ & & NA \\
\hline Vanadium & $6 / 6$ & 29.3 & 64.5 & Z2-EU28B-109 & 44.77 & & NA & & NA & $1.0 \mathrm{E}+03$ & $0 / 6$ & 65.47 & $0 / 6$ \\
\hline Zinc & $6 / 6$ & $43.4 \mathrm{~J}$ & $301 \mathrm{~J}$ & Z2-EU28B-111 & 94.95 & & NA & & NA & $1.0 \mathrm{E}+05$ & $0 / 6$ & 89.7 & $1 / 6$ \\
\hline Phosphorous & $6 / 6$ & $270 \mathrm{~J}$ & $388 \mathrm{~J}$ & Z2-EU28B-111 & 332.33 & & NA & & NA & & NA & & NA \\
\hline
\end{tabular}


Table F.4. (continued)

\begin{tabular}{|c|c|c|c|c|c|c|c|c|c|c|c|c|c|}
\hline \multicolumn{14}{|c|}{ Table F.4. (continued) } \\
\hline Analyte & $\begin{array}{c}\text { Frequency } \\
\text { of detect }\end{array}$ & $\begin{array}{c}\text { Minimum } \\
\text { detect }\end{array}$ & $\begin{array}{c}\text { Maximum } \\
\text { detect }\end{array}$ & $\begin{array}{l}\text { Location(s) of } \\
\text { maximum } \\
\text { detected result }\end{array}$ & $\begin{array}{c}\text { Average } \\
\text { detected } \\
\text { result }\end{array}$ & $\begin{array}{c}\text { Maximum } \\
\text { RL }\end{array}$ & $\begin{array}{c}\text { Frequency } \\
\text { of detects } \\
\text { exceeding } \\
\text { maximum } \\
\text { RL } \\
\end{array}$ & $\begin{array}{c}\text { Average } \\
\text { RL }\end{array}$ & $\begin{array}{c}\text { Frequency } \\
\text { of detects } \\
\text { exceeding } \\
\text { average } R L\end{array}$ & $\begin{array}{l}\text { PRG limit } \\
\left(10^{-5} \text { or } 1\right)\end{array}$ & $\begin{array}{c}\text { Frequency } \\
\text { of detects } \\
\text { exceeding } \\
\text { PRG limit }\end{array}$ & $\begin{array}{c}\text { Background } \\
\text { concentration }\end{array}$ & $\begin{array}{c}\text { Frequency } \\
\text { of detects } \\
\text { exceeding } \\
\text { background }\end{array}$ \\
\hline \multicolumn{14}{|l|}{ Radionuclides (pCi/g) } \\
\hline Cesium 137 & $0 / 6$ & ND & ND & & ND & 20 & $0 / 6$ & 2 & $0 / 6$ & $1.1 \mathrm{E}+00$ & $0 / 6$ & & NA \\
\hline Cobalt-60 & $0 / 6$ & ND & ND & & ND & & NA & & NA & $6.0 \mathrm{E}-01$ & $0 / 6$ & & NA \\
\hline Neptunium-237 & $0 / 6$ & ND & ND & & ND & 50 & $0 / 6$ & 5 & $0 / 6$ & $2.7 \mathrm{E}+00$ & $0 / 6$ & & NA \\
\hline Potassium-40 & $6 / 6$ & 7.57 & 29.8 & Z2-EU28B-109 & 18.8 & & NA & & NA & $2.7 \mathrm{E}+00$ & $6 / 6$ & 32.12 & $0 / 6$ \\
\hline $\mathrm{Ra} / \mathrm{Th}$ decay series & $6 / 6$ & 0 & 0.86 & Z2-EU28B-109 & 0.29 & 15 & $0 / 6$ & 5 & $0 / 6$ & & NA & & NA \\
\hline Radium-226 & $6 / 6$ & 1.03 & 2.09 & Z2-EU28B-109 & 1.39 & 15 & $\mathrm{NA}^{a}$ & 5 & $\mathrm{NA}^{a}$ & $2.6 \mathrm{E}-01$ & $6 / 6$ & 1.25 & $3 / 6$ \\
\hline Technetium-99 & $0 / 6$ & ND & ND & & ND & & NA & & NA & $8.9 \mathrm{E}+03$ & $0 / 6$ & & NA \\
\hline Thorium 228 & $6 / 6$ & 1.05 & 1.72 & Z2-EU28B-109 & 1.43 & & NA & & NA & $1.7 \mathrm{E}-01$ & $6 / 6^{b}$ & 1.86 & $0 / 6$ \\
\hline Thorium-230 & $6 / 6$ & 0.657 & 2.06 & Z2-EU28B-109 & 1.25 & 15 & $\mathrm{NA}^{a}$ & 5 & $\mathrm{NA}^{a}$ & $2.1 \mathrm{E}+02$ & $0 / 6$ & 1.2 & $3 / 6$ \\
\hline Thorium 232 & $6 / 6$ & 0.985 & 1.47 & Z2-EU28B-111 & 1.27 & 15 & $\mathrm{NA}^{a}$ & 5 & $\mathrm{NA}^{a}$ & $1.7 \mathrm{E}-01$ & $6 / 6^{b}$ & 1.95 & $0 / 6$ \\
\hline Thorium-234 & $2 / 6$ & $1.84 \mathrm{~J}$ & $1.88 \mathrm{~J}$ & Z2-EU28B-109 & 1.86 & & NA & & NA & $3.3 \mathrm{E}+04$ & $0 / 6$ & & NA \\
\hline Uranium-234 & $6 / 6$ & 0.836 & 2.98 & Z2-EU28B-110 & 1.62 & 7,000 & $0 / 6$ & 700 & $0 / 6$ & $3.3 \mathrm{E}+02$ & $0 / 6$ & & NA \\
\hline Uranium-235 & $2 / 6$ & 0.181 & $0.195 \mathrm{~J}$ & Z2-EU28B-110 & 0.19 & 80 & $0 / 6$ & 8 & $0 / 6$ & $3.9 \mathrm{E}+00$ & $0 / 6$ & & NA \\
\hline Uranium-238 & $6 / 6$ & 0.878 & 1.86 & Z2-EU28B-109 & 1.37 & 500 & $0 / 6$ & 50 & $0 / 6$ & $1.8 \mathrm{E}+01$ & $0 / 6$ & 1.47 & $3 / 6$ \\
\hline \multicolumn{14}{|c|}{ Organics, pesticides, and PCBs (ug/kg) } \\
\hline PCB-1016 & $0 / 6$ & ND & ND & & ND & 100,000 & $0 / 6$ & 10,000 & $0 / 6$ & $3.7 \mathrm{E}+04$ & $0 / 6$ & & NA \\
\hline PCB-1221 & $0 / 6$ & ND & ND & & ND & 100,000 & $0 / 6$ & 10,000 & $0 / 6$ & 7.4E+03 & $0 / 6$ & & NA \\
\hline PCB-1232 & $0 / 6$ & ND & ND & & ND & 100,000 & $0 / 6$ & 10,000 & $0 / 6$ & $7.4 \mathrm{E}+03$ & $0 / 6$ & & NA \\
\hline PCB-1242 & $0 / 6$ & ND & ND & & ND & 100,000 & $0 / 6$ & 10,000 & $0 / 6$ & $7.4 \mathrm{E}+03$ & $0 / 6$ & & NA \\
\hline PCB-1248 & $0 / 6$ & ND & ND & & ND & 100,000 & $0 / 6$ & 10,000 & $0 / 6$ & $7.4 \mathrm{E}+03$ & $0 / 6$ & & NA \\
\hline PCB-1254 & $2 / 6$ & 5.1 & 7 & Z2-EU28B-109 & 6.05 & 100,000 & $0 / 6$ & 10,000 & $0 / 6$ & $7.4 \mathrm{E}+03$ & $0 / 6$ & & NA \\
\hline PCB-1260 & $2 / 6$ & $1.8 \mathrm{~J}$ & $3.6 \mathrm{~J}$ & Z2-EU28B-109 & 2.7 & 100,000 & $0 / 6$ & 10,000 & $0 / 6$ & $7.4 \mathrm{E}+03$ & $0 / 6$ & & NA \\
\hline \multicolumn{14}{|c|}{ Semivolatile organics (ug/kg) } \\
\hline 1,2,4-Trichlorobenzene & $0 / 6$ & ND & ND & & ND & & NA & & NA & $2.2 \mathrm{E}+05$ & $0 / 6$ & & NA \\
\hline 1,2-Dichlorobenzene & $0 / 6$ & ND & ND & & ND & & NA & & NA & $6.0 \mathrm{E}+05$ & $0 / 6$ & & NA \\
\hline 1,3-Dichlorobenzene & $0 / 6$ & ND & ND & & ND & & NA & & NA & $6.0 \mathrm{E}+05$ & $0 / 6$ & & NA \\
\hline 1,4-Dichlorobenzene & $0 / 6$ & ND & ND & & ND & & NA & & NA & $7.9 \mathrm{E}+04$ & $0 / 6$ & & NA \\
\hline 2,4,5-Trichlorophenol & $0 / 6$ & ND & ND & & ND & & NA & & NA & $6.2 \mathrm{E}+07$ & $0 / 6$ & & NA \\
\hline 2,4,6-Trichlorophenol & $0 / 6$ & ND & ND & & ND & & NA & & NA & $6.2 \mathrm{E}+04$ & $0 / 6$ & & NA \\
\hline 2,4-Dichlorophenol & $0 / 6$ & ND & ND & & ND & & NA & & NA & $1.8 \mathrm{E}+06$ & $0 / 6$ & & NA \\
\hline 2,4-Dimethylphenol & $0 / 6$ & ND & ND & & ND & & NA & & NA & $1.2 \mathrm{E}+07$ & $0 / 6$ & & NA \\
\hline 2,4-Dinitrophenol & $0 / 6$ & ND & ND & & ND & & NA & & NA & $1.2 \mathrm{E}+06$ & $0 / 6$ & & NA \\
\hline 2,4-Dinitrotoluene & $0 / 6$ & ND & ND & & ND & & NA & & NA & $2.5 \mathrm{E}+04$ & $0 / 6$ & & NA \\
\hline 2,6-Dinitrotoluene & $0 / 6$ & ND & ND & & ND & & NA & & NA & $2.5 \mathrm{E}+04$ & $0 / 6$ & & NA \\
\hline
\end{tabular}


Table F.4. (continued)

\begin{tabular}{|c|c|c|c|c|c|c|c|c|c|c|c|c|c|}
\hline \multicolumn{14}{|c|}{ Table F.4. (continued) } \\
\hline Analyte & $\begin{array}{c}\text { Frequency } \\
\text { of detect }\end{array}$ & $\begin{array}{c}\text { Minimum } \\
\text { detect }\end{array}$ & $\begin{array}{c}\text { Maximum } \\
\text { detect }\end{array}$ & $\begin{array}{l}\text { Location(s) of } \\
\text { maximum } \\
\text { detected result }\end{array}$ & $\begin{array}{c}\text { Average } \\
\text { detected } \\
\text { result }\end{array}$ & $\begin{array}{c}\text { Maximum } \\
\text { RL }\end{array}$ & $\begin{array}{c}\text { Frequency } \\
\text { of detects } \\
\text { exceeding } \\
\text { maximum } \\
\text { RL } \\
\end{array}$ & $\begin{array}{c}\text { Average } \\
\text { RL }\end{array}$ & $\begin{array}{c}\text { Frequency } \\
\text { of detects } \\
\text { exceeding } \\
\text { average RL }\end{array}$ & $\begin{array}{l}\text { PRG limit } \\
\left(10^{-5} \text { or } 1\right)\end{array}$ & $\begin{array}{l}\text { Frequency } \\
\text { of detects } \\
\text { exceeding } \\
\text { PRG limit }\end{array}$ & $\begin{array}{c}\text { Background } \\
\text { concentration }\end{array}$ & $\begin{array}{c}\text { Frequency } \\
\text { of detects } \\
\text { exceeding } \\
\text { background }\end{array}$ \\
\hline 2-Chloronaphthalene & $0 / 6$ & $\mathrm{ND}$ & $\mathrm{ND}$ & & $\mathrm{ND}$ & & NA & & NA & $2.3 \mathrm{E}+07$ & $0 / 6$ & & NA \\
\hline 2-Chlorophenol & $0 / 6$ & ND & ND & & ND & & NA & & NA & $2.4 \mathrm{E}+05$ & $0 / 6$ & & NA \\
\hline 2-Methyl-4,6-dinitrophenol & $0 / 6$ & ND & ND & & ND & & NA & & NA & $6.2 \mathrm{E}+04$ & $0 / 6$ & & NA \\
\hline 2-Methylnaphthalene & $0 / 6$ & ND & ND & & ND & & NA & & NA & $1.9 \mathrm{E}+05$ & $0 / 6$ & & NA \\
\hline 2-Methylphenol & $0 / 6$ & ND & ND & & ND & & NA & & NA & $3.1 \mathrm{E}+07$ & $0 / 6$ & & NA \\
\hline 2-Nitrobenzenamine & $0 / 6$ & ND & ND & & ND & & NA & & NA & $1.8 \mathrm{E}+06$ & $0 / 6$ & & NA \\
\hline 2-Nitrophenol & $0 / 6$ & ND & ND & & ND & & NA & & NA & & NA & & NA \\
\hline 3,3'-Dichlorobenzidine & $0 / 6$ & ND & ND & & ND & & NA & & NA & $3.8 \mathrm{E}+04$ & $0 / 6$ & & NA \\
\hline 3-Nitrobenzenamine & $0 / 6$ & ND & ND & & ND & & NA & & NA & $1.8 \mathrm{E}+05$ & $0 / 6$ & & NA \\
\hline 4-Bromophenyl phenyl & & & & & & & & & & & & & \\
\hline ether & $0 / 6$ & ND & ND & & ND & & NA & & NA & & NA & & NA \\
\hline 4-Chloro-3-methylphenol & $0 / 6$ & ND & ND & & ND & & NA & & NA & & NA & & NA \\
\hline 4-Chlorobenzenamine & $0 / 6$ & ND & ND & & ND & & NA & & NA & $2.5 \mathrm{E}+06$ & $0 / 6$ & & NA \\
\hline 4-Chlorophenyl phenyl & & & & & & & & & & & & & \\
\hline ether & $0 / 6$ & ND & ND & & ND & & NA & & NA & & NA & & NA \\
\hline 4-Methylphenol & $0 / 6$ & ND & ND & & ND & & NA & & NA & $3.1 \mathrm{E}+06$ & $0 / 6$ & & NA \\
\hline 4-Nitrophenol & $0 / 6$ & ND & ND & & ND & & NA & & NA & & NA & & NA \\
\hline Acenaphthene & $0 / 6$ & ND & ND & & ND & & NA & & NA & $2.9 \mathrm{E}+07$ & $0 / 6$ & & NA \\
\hline Acenaphthylene & $0 / 6$ & ND & ND & & ND & & NA & & NA & $2.9 \mathrm{E}+07$ & $0 / 6$ & & NA \\
\hline Anthracene & $0 / 6$ & ND & ND & & ND & & NA & & NA & $1.0 \mathrm{E}+08$ & $0 / 6$ & & NA \\
\hline Benz(a)anthracene & $0 / 6$ & ND & ND & & ND & & NA & & NA & $2.1 \mathrm{E}+04$ & $0 / 6$ & & NA \\
\hline Benzenemethanol & $0 / 6$ & ND & ND & & ND & & NA & & NA & $1.0 \mathrm{E}+08$ & $0 / 6$ & & NA \\
\hline Benzo(a)pyrene & $0 / 6$ & ND & ND & & ND & & NA & & NA & $2.1 \mathrm{E}+03$ & $0 / 6$ & & NA \\
\hline Benzo(b)fluoranthene & $0 / 6$ & ND & ND & & ND & & NA & & NA & $2.1 \mathrm{E}+04$ & $0 / 6$ & & NA \\
\hline Benzo(ghi)perylene & $0 / 6$ & ND & ND & & ND & & NA & & NA & $2.9 \mathrm{E}+07$ & $0 / 6$ & & NA \\
\hline Benzo(k)fluoranthene & $0 / 6$ & ND & ND & & ND & & NA & & NA & $2.1 \mathrm{E}+05$ & $0 / 6$ & & NA \\
\hline Bis(2-chloroethoxy) & & & & & & & & & & & & & \\
\hline methane & $0 / 6$ & ND & ND & & ND & & NA & & NA & & NA & & NA \\
\hline Bis(2-chloroethyl)ether & $0 / 6$ & ND & ND & & ND & & NA & & NA & $5.8 \mathrm{E}+03$ & $0 / 6$ & & NA \\
\hline Bis(2-chloroisopropyl) & & & & & & & & & & & & & \\
\hline ether & $0 / 6$ & ND & ND & & ND & & NA & & NA & $7.4 \mathrm{E}+04$ & $0 / 6$ & & NA \\
\hline Bis(2-ethylhexyl)phthalate & $1 / 6$ & $105 \mathrm{~J}$ & $105 \mathrm{~J}$ & Z2-EU28B-111 & 105 & & NA & & NA & $1.2 \mathrm{E}+06$ & $0 / 6$ & & NA \\
\hline Butyl benzyl phthalate & $0 / 6$ & ND & ND & & ND & & NA & & NA & $1.0 \mathrm{E}+08$ & $0 / 6$ & & NA \\
\hline Chrysene & $0 / 6$ & ND & ND & & ND & & NA & & NA & $2.1 \mathrm{E}+06$ & $0 / 6$ & & NA \\
\hline Di-n-octylphthalate & $0 / 6$ & ND & ND & & ND & & NA & & NA & $2.5 \mathrm{E}+07$ & $0 / 6$ & & NA \\
\hline
\end{tabular}


Table F.4. (continued)

\begin{tabular}{|c|c|c|c|c|c|c|c|c|c|c|c|c|c|}
\hline Analyte & $\begin{array}{l}\text { Frequency } \\
\text { of detect }\end{array}$ & $\begin{array}{c}\text { Minimum } \\
\text { detect }\end{array}$ & $\begin{array}{c}\text { Maximum } \\
\text { detect }\end{array}$ & $\begin{array}{l}\text { Location(s) of } \\
\text { maximum } \\
\text { detected result }\end{array}$ & $\begin{array}{c}\text { Average } \\
\text { detected } \\
\text { result }\end{array}$ & $\begin{array}{c}\text { Maximum } \\
\text { RL }\end{array}$ & $\begin{array}{c}\text { Frequency } \\
\text { of detects } \\
\text { exceeding } \\
\text { maximum } \\
\text { RL }\end{array}$ & $\begin{array}{c}\text { Average } \\
\text { RL }\end{array}$ & $\begin{array}{l}\text { Frequency } \\
\text { of detects } \\
\text { exceeding } \\
\text { average RL }\end{array}$ & $\begin{array}{l}\text { PRG limit } \\
\left(10^{-5} \text { or } 1\right)\end{array}$ & $\begin{array}{l}\text { Frequency } \\
\text { of detects } \\
\text { exceeding } \\
\text { PRG limit }\end{array}$ & $\begin{array}{l}\text { Background } \\
\text { concentration }\end{array}$ & $\begin{array}{l}\text { Frequency } \\
\text { of detects } \\
\text { exceeding } \\
\text { background }\end{array}$ \\
\hline Dibenz(a,h)anthracene & $0 / 6$ & ND & $\mathrm{ND}$ & & $\mathrm{ND}$ & & NA & & NA & $2.1 \mathrm{E}+03$ & $0 / 6$ & & NA \\
\hline Dibenzofuran & $0 / 6$ & ND & ND & & ND & & NA & & NA & $1.6 \mathrm{E}+06$ & $0 / 6$ & & NA \\
\hline Diethyl phthalate & $0 / 6$ & ND & ND & & ND & & NA & & NA & $1.0 \mathrm{E}+08$ & $0 / 6$ & & NA \\
\hline Dimethyl phthalate & $0 / 6$ & ND & ND & & ND & & NA & & NA & $1.0 \mathrm{E}+08$ & $0 / 6$ & & NA \\
\hline Diphenylamine & $0 / 6$ & ND & ND & & ND & & NA & & NA & $1.5 \mathrm{E}+07$ & $0 / 6$ & & NA \\
\hline Fluoranthene & $1 / 6$ & $15.6 \mathrm{~J}$ & $15.6 \mathrm{~J}$ & Z2-EU28B-111 & 15.6 & & NA & & NA & $2.2 \mathrm{E}+07$ & $0 / 6$ & & NA \\
\hline Fluorene & $0 / 6$ & ND & ND & & ND & & NA & & NA & $2.6 \mathrm{E}+07$ & $0 / 6$ & & NA \\
\hline Hexachlorobenzene & $0 / 6$ & ND & ND & & ND & & NA & & NA & $1.1 \mathrm{E}+04$ & $0 / 6$ & & NA \\
\hline Hexachlorobutadiene & $0 / 6$ & ND & ND & & ND & & NA & & NA & $1.8 \mathrm{E}+05$ & $0 / 6$ & & NA \\
\hline Hexachlorocyclopentadiene & $0 / 6$ & ND & ND & & ND & & NA & & NA & $3.7 \mathrm{E}+06$ & $0 / 6$ & & NA \\
\hline Hexachloroethane & $0 / 6$ & ND & ND & & ND & & NA & & NA & $6.2 \mathrm{E}+05$ & $0 / 6$ & & NA \\
\hline Indeno(1,2,3-cd)pyrene & $0 / 6$ & ND & ND & & ND & & NA & & NA & $2.1 \mathrm{E}+04$ & $0 / 6$ & & NA \\
\hline Isophorone & $0 / 6$ & ND & ND & & ND & & NA & & NA & $5.1 \mathrm{E}+06$ & $0 / 6$ & & NA \\
\hline N-Nitroso-di-n- & $0 / 6$ & ND & $\mathrm{ND}$ & & $\mathrm{ND}$ & & NA & & NA & $25 \mathrm{E}+03$ & $0 / 6$ & & $\mathrm{NA}$ \\
\hline Naphthalene & $0 / 6$ & ND & ND & & ND & & NA & & NA & $1.9 \mathrm{E}+05$ & $0 / 6$ & & NA \\
\hline Nitrobenzene & $0 / 6$ & ND & ND & & ND & & NA & & NA & $1.0 \mathrm{E}+05$ & $0 / 6$ & & NA \\
\hline Pentachlorophenol & $0 / 6$ & ND & ND & & ND & & NA & & NA & $9.0 \mathrm{E}+04$ & $0 / 6$ & & NA \\
\hline Phenanthrene & $0 / 6$ & ND & ND & & ND & & NA & & NA & $2.9 \mathrm{E}+07$ & $0 / 6$ & & NA \\
\hline Phenol & $0 / 6$ & ND & ND & & ND & & NA & & NA & $1.0 \mathrm{E}+08$ & $0 / 6$ & & NA \\
\hline Pyrene & $2 / 6$ & $8.2 \mathrm{~J}$ & $15.8 \mathrm{~J}$ & Z2-EU28B-111 & 12 & & NA & & NA & $2.9 \mathrm{E}+07$ & $0 / 6$ & & NA \\
\hline \multicolumn{14}{|l|}{ Volatile organics (ug/kg) } \\
\hline 1,1,1-Trichloroethane & $0 / 6$ & ND & ND & & ND & & NA & & NA & $1.2 \mathrm{E}+06$ & $0 / 6$ & & NA \\
\hline $1,1,2,2$-Tetrachloroethane & $0 / 6$ & ND & ND & & ND & & NA & & NA & $9.3 \mathrm{E}+03$ & $0 / 6$ & & NA \\
\hline 1,1,2-Trichloroethane & $0 / 6$ & ND & ND & & ND & & NA & & NA & $1.6 \mathrm{E}+04$ & $0 / 6$ & & NA \\
\hline 1,1-Dichloroethane & $0 / 6$ & ND & ND & & ND & & NA & & NA & $1.7 \mathrm{E}+06$ & $0 / 6$ & & NA \\
\hline 1,1-Dichloroethene & $0 / 6$ & ND & ND & & ND & & NA & & NA & $4.1 \mathrm{E}+05$ & $0 / 6$ & & NA \\
\hline 1,2-Dichloroethane & $0 / 6$ & ND & ND & & ND & & NA & & NA & $6.0 \mathrm{E}+03$ & $0 / 6$ & & NA \\
\hline 1,2-Dichloropropane & $0 / 6$ & ND & ND & & ND & & NA & & NA & $7.4 \mathrm{E}+03$ & $0 / 6$ & & NA \\
\hline 2-Butanone & $2 / 6$ & $5.9 \mathrm{~J}$ & 7.6 & Z2-EU28B-111 & 6.75 & & NA & & NA & $1.0 \mathrm{E}+08$ & $0 / 6$ & & NA \\
\hline 2-Hexanone & $0 / 6$ & ND & ND & & ND & & NA & & NA & & NA & & NA \\
\hline 4-Methyl-2-pentanone & $0 / 6$ & ND & ND & & ND & & NA & & NA & $4.7 \mathrm{E}+07$ & $0 / 6$ & & NA \\
\hline Acetone & $6 / 6$ & 7.6 & 90.2 & Z2-EU28B-110 & 40.48 & & NA & & NA & $5.4 \mathrm{E}+07$ & $0 / 6$ & & NA \\
\hline Benzene & $0 / 6$ & ND & ND & & ND & & NA & & NA & $1.4 \mathrm{E}+04$ & $0 / 6$ & & NA \\
\hline Bromodichloromethane & $0 / 6$ & ND & ND & & ND & & NA & & NA & $1.8 \mathrm{E}+04$ & $0 / 6$ & & NA \\
\hline
\end{tabular}


Table F.4. (continued)

\begin{tabular}{|c|c|c|c|c|c|c|c|c|c|c|c|c|c|}
\hline \multicolumn{14}{|c|}{ Table F.4. (continued) } \\
\hline Analyte & $\begin{array}{l}\text { Frequency } \\
\text { of detect }\end{array}$ & $\begin{array}{c}\text { Minimum } \\
\text { detect }\end{array}$ & $\begin{array}{c}\text { Maximum } \\
\text { detect }\end{array}$ & $\begin{array}{l}\text { Location(s) of } \\
\text { maximum } \\
\text { detected result }\end{array}$ & $\begin{array}{c}\text { Average } \\
\text { detected } \\
\text { result }\end{array}$ & $\begin{array}{c}\text { Maximum } \\
\text { RL }\end{array}$ & $\begin{array}{c}\text { Frequency } \\
\text { of detects } \\
\text { exceeding } \\
\text { maximum } \\
\text { RL }\end{array}$ & $\begin{array}{c}\text { Average } \\
\text { RL }\end{array}$ & $\begin{array}{l}\text { Frequency } \\
\text { of detects } \\
\text { exceeding } \\
\text { average } R L\end{array}$ & $\begin{array}{l}\text { PRG limit } \\
\left(10^{-5} \text { or } 1\right)\end{array}$ & $\begin{array}{c}\text { Frequency } \\
\text { of detects } \\
\text { exceeding } \\
\text { PRG limit }\end{array}$ & $\begin{array}{l}\text { Background } \\
\text { concentration }\end{array}$ & $\begin{array}{l}\text { Frequency } \\
\text { of detects } \\
\text { exceeding } \\
\text { background }\end{array}$ \\
\hline Bromoform & $0 / 6$ & ND & ND & & $\mathrm{ND}$ & & NA & & NA & $2.2 \mathrm{E}+06$ & $0 / 6$ & & NA \\
\hline Bromomethane & $0 / 6$ & ND & ND & & ND & & NA & & NA & $1.3 \mathrm{E}+04$ & $0 / 6$ & & NA \\
\hline Carbon disulfide & $1 / 6$ & $5.7 \mathrm{~J}$ & $5.7 \mathrm{~J}$ & Z2-EU28B-111 & 5.7 & & NA & & NA & $7.2 \mathrm{E}+05$ & $0 / 6$ & & NA \\
\hline Carbon tetrachloride & $0 / 6$ & ND & ND & & ND & & NA & & NA & $5.5 \mathrm{E}+03$ & $0 / 6$ & & NA \\
\hline Chlorobenzene & $0 / 6$ & ND & ND & & ND & & NA & & NA & $5.3 \mathrm{E}+05$ & $0 / 6$ & & NA \\
\hline Chloroethane & $0 / 6$ & ND & ND & & ND & & NA & & NA & $6.5 \mathrm{E}+04$ & $0 / 6$ & & NA \\
\hline Chloroform & $0 / 6$ & ND & ND & & ND & & NA & & NA & $4.7 \mathrm{E}+03$ & $0 / 6$ & & NA \\
\hline Chloromethane & $0 / 6$ & ND & ND & & ND & & NA & & NA & $1.6 \mathrm{E}+05$ & $0 / 6$ & & NA \\
\hline Dibromochloromethane & $0 / 6$ & ND & ND & & ND & & NA & & NA & $2.6 \mathrm{E}+04$ & $0 / 6$ & & NA \\
\hline Ethylbenzene & $0 / 6$ & ND & ND & & ND & & NA & & NA & $4.0 \mathrm{E}+05$ & $0 / 6$ & & NA \\
\hline Methylene chloride & $1 / 6$ & $2.5 \mathrm{~J}$ & $2.5 \mathrm{~J}$ & Z2-EU28B-110 & 2.5 & & NA & & NA & $2.1 \mathrm{E}+05$ & $0 / 6$ & & NA \\
\hline Styrene & $0 / 6$ & ND & ND & & ND & & NA & & NA & $1.7 \mathrm{E}+06$ & $0 / 6$ & & NA \\
\hline Tetrachloroethene & $0 / 6$ & ND & ND & & ND & & NA & & NA & $1.3 \mathrm{E}+04$ & $0 / 6$ & & NA \\
\hline Toluene & $6 / 6$ & $0.59 \mathrm{~J}$ & 3.8 & Z2-EU28B-110 & 1.9 & & NA & & NA & $5.2 \mathrm{E}+05$ & $0 / 6$ & & NA \\
\hline Total xylene & $0 / 6$ & ND & ND & & ND & & NA & & NA & $4.2 \mathrm{E}+05$ & $0 / 6$ & & NA \\
\hline Trichloroethene & $0 / 6$ & ND & ND & & ND & & NA & & NA & $1.1 \mathrm{E}+03$ & $0 / 6$ & & NA \\
\hline Vinyl chloride & $0 / 6$ & ND & ND & & ND & & NA & & NA & $7.5 \mathrm{E}+03$ & $0 / 6$ & & NA \\
\hline cis-1,2-Dichloroethene & $0 / 6$ & ND & ND & & ND & & NA & & NA & $1.5 \mathrm{E}+05$ & $0 / 6$ & & NA \\
\hline cis-1,3-Dichloropropene & $0 / 6$ & ND & ND & & ND & & NA & & NA & $1.8 \mathrm{E}+04$ & $0 / 6$ & & NA \\
\hline trans-1,2-Dichloroethene & $0 / 6$ & ND & ND & & ND & & NA & & NA & $2.3 \mathrm{E}+05$ & $0 / 6$ & & NA \\
\hline trans-1,3-Dichloropropene & $0 / 6$ & ND & ND & & ND & & NA & & NA & $1.8 \mathrm{E}+04$ & $0 / 6$ & & NA \\
\hline
\end{tabular}

${ }^{a}$ Evaluated as part of $\mathrm{Th}-232+\mathrm{D}=\mathrm{Th}-232+\mathrm{Ra}-228+\mathrm{D}+\mathrm{Th}-228+\mathrm{D}$

Radionuclide is evaluated as part of Ra/Th decay series as discussed in the Zone $2 \mathrm{ROD}$.

$\mathrm{EU}=$ exposure unit

$\mathrm{J}=$ analyte was positively identified and result is the approximate concentratio $\mathrm{n}$ of the analyte in the sample

$\mathrm{ND}=$ not detected

$\mathrm{PCB}=$ polychloride biphenyl

$\mathrm{PRG}=$ preliminary remediation goa

$\mathrm{U}=$ analyte was not detected above the reported sample quantitation limit 
Table 1. Summary and conclusions for the Class 1 SUs and area definition locations

\begin{tabular}{|c|c|c|c|}
\hline Area/location name & Sample locations & Results summary & Conclusions \\
\hline \multicolumn{4}{|l|}{ Class $1 \mathrm{SUs}$} \\
\hline RAD 192 & $\begin{array}{l}\text { RAD192 } \\
\text { Z2-EU28B-117 }\end{array}$ & $\begin{array}{l}\text { BAR survey failed to identify RAB; no } \\
\text { RL exceedances in confirmation sample }\end{array}$ & No RL exceedances in this Class $1 \mathrm{SU}$ \\
\hline RAD 199 & $\begin{array}{l}\text { RAD199 } \\
\text { Z2-EU28B-118 } \\
\text { Z2-EU28B-119 }\end{array}$ & $\begin{array}{l}\text { BAR survey identified } 20 \mathrm{ft}^{2} \mathrm{RAB} \text {; } \\
\text { maximum and average } \mathrm{RL} \text { exceedances } \\
\text { in confirmation sample; no RL } \\
\text { exceedances outside RAB }\end{array}$ & $\begin{array}{l}\mathrm{Ra} / \mathrm{Th} \text { decay series maximum } \mathrm{RL} \text { exceedance and } \\
\mathrm{Cs}-137, \mathrm{~Np}-237, \mathrm{Ra} / \mathrm{Th} \text { decay series, } \mathrm{U}-235 \text {, and } \\
\mathrm{U}-239 \text { average } \mathrm{RL} \text { exceedances over an area of } \\
25 \mathrm{ft}^{2}\end{array}$ \\
\hline RAD 205 & $\begin{array}{l}\text { RAD204 } \\
\text { RAD205 } \\
\text { RAD206 } \\
\text { RAD207 } \\
\text { Z2-EU28B-114 } \\
\text { Z2-EU28B-115 } \\
\text { Z2-EU28B-116 }\end{array}$ & $\begin{array}{l}\text { BAR survey identified } 200 \mathrm{ft}^{2} \mathrm{RAB} \text {; } \\
\text { maximum and average } \mathrm{RL} \text { exceedances } \\
\text { in confirmation sample and in two } \\
\text { step-out samples from within RAB }\end{array}$ & $\begin{array}{l}\mathrm{Ra} / \mathrm{Th} \text { decay series maximum RL exceedance and } \\
\mathrm{Cs}-137, \mathrm{Ra} / \mathrm{Th} \text { decay series, } \mathrm{U}-234, \mathrm{U}-235 \text {, and } \\
\mathrm{U}-238 \text { average RL exceedances over an area of } \\
600 \mathrm{ft}^{2}\end{array}$ \\
\hline RAD 218 & $\begin{array}{l}\text { RAD218 } \\
\text { Z2-EU28B-123 } \\
\text { Z2-EU28B-124 }\end{array}$ & $\begin{array}{l}\text { BAR survey identified } 50 \mathrm{ft}^{2} \mathrm{RAB} \text { but } \\
\text { not at RAD } 218 \text { location; } 2 \text { discrete } \\
\text { samples from inside } \mathrm{RAB} \text { with average } \\
\text { RL exceedances }\end{array}$ & $\begin{array}{l}\text { No maximum RL exceedances; nearby } 50 \mathrm{ft}^{2} \text { area } \\
\text { identified with U-238 average RL exceedance }\end{array}$ \\
\hline Z2-EU28-204 & $\begin{array}{l}\text { Z2-EU28-204 } \\
\text { Z2-EU28B-125 }\end{array}$ & $\begin{array}{l}\text { BAR survey identified } 50 \mathrm{ft}^{2} \mathrm{RAB} \text {; only } \\
\text { average RL exceedances in confirmation } \\
\text { sample }\end{array}$ & $\begin{array}{l}\text { Although DVS sampling failed to confirm early } \\
\text { characterization Ra/Th decay series maximum RL } \\
\text { exceedance, early characterization results are } \\
\text { conclusive. There are Ra/Th maximum RL and } \\
\text { Cs- } 137 \text { and } \mathrm{Ra} / \mathrm{Th} \text { decay series average } \mathrm{RL} \\
\text { exceedances over an assumed area of } 50 \mathrm{ft}^{2}\end{array}$ \\
\hline \multicolumn{4}{|c|}{ Area definition locations } \\
\hline RAD203 & $\begin{array}{l}\text { RAD203 } \\
\text { Z2-EU28B-126 }\end{array}$ & $\begin{array}{l}\text { No BAR survey; no RL exceedances in } \\
\text { confirmation sample }\end{array}$ & No average RL exceedances in RAD203 area \\
\hline RAD209 & $\begin{array}{l}\text { RAD209 } \\
\text { Z2-EU28B-121 }\end{array}$ & $\begin{array}{l}\text { BAR survey identified } 200 \mathrm{ft}^{2} \text { with action } \\
\text { level exceedance; } \mathrm{U}-238 \text { average } \mathrm{RL} \\
\text { exceedance confirmed in confirmation } \\
\text { sample }\end{array}$ & U-238 average RL exceedance over $200 \mathrm{ft}^{2}$ area \\
\hline RAD212 & $\begin{array}{l}\text { RAD210 } \\
\text { RAD212 } \\
\text { RAD214 } \\
\text { Z2-EU28B-122 }\end{array}$ & $\begin{array}{l}\text { BAR survey identified } 80 \mathrm{ft}^{2} \text { with action } \\
\text { level exceedance; } \mathrm{U}-238 \text { average } \mathrm{RL} \\
\text { exceedance confirmed in confirmation } \\
\text { sample }\end{array}$ & $\mathrm{U}-238$ average $\mathrm{RL}$ exceedance over $80 \mathrm{ft}^{2}$ area \\
\hline RAD219 & $\begin{array}{l}\text { RAD219 } \\
\text { Z2-EU28B-123 } \\
\text { Z2-EU28B-124 }\end{array}$ & $\begin{array}{l}\text { BAR survey identified } 50 \text { sq } \mathrm{ft} \text { RAB but } \\
\text { not at RAD } 219 \text { location; } 2 \text { discrete } \\
\text { samples from inside RAB had U- } 238 \\
\text { average RL exceedances }\end{array}$ & $\mathrm{U}-238$ average $\mathrm{RL}$ exceedance $50 \mathrm{ft}^{2}$ area \\
\hline RAD197 & RAD197 & $\begin{array}{l}\text { BAR survey failed to identify action level } \\
\text { exceedances; no confirmation sampling }\end{array}$ & No average RL exceedances at RAD157 area \\
\hline Z2-EU28M-101 & Z2-EU28M-101 & $\begin{array}{l}\text { BAR survey failed to identify action level } \\
\text { exceedances }\end{array}$ & $\begin{array}{l}\text { Point source } \mathrm{Ra} / \mathrm{Th} \text { decay series average } \mathrm{RL} \\
\text { exceedance }\end{array}$ \\
\hline \multicolumn{4}{|c|}{$\begin{array}{l}{ }^{a} \text { Discrete DVS sample locations Z2-EU28B-123 and Z2-EU28B-124 are in an area of BAR survey action-level exceedance downhill from both } \\
\text { the RA218 Class } 1 \text { SU and the RAD218 area definition location. }\end{array}$} \\
\hline
\end{tabular}




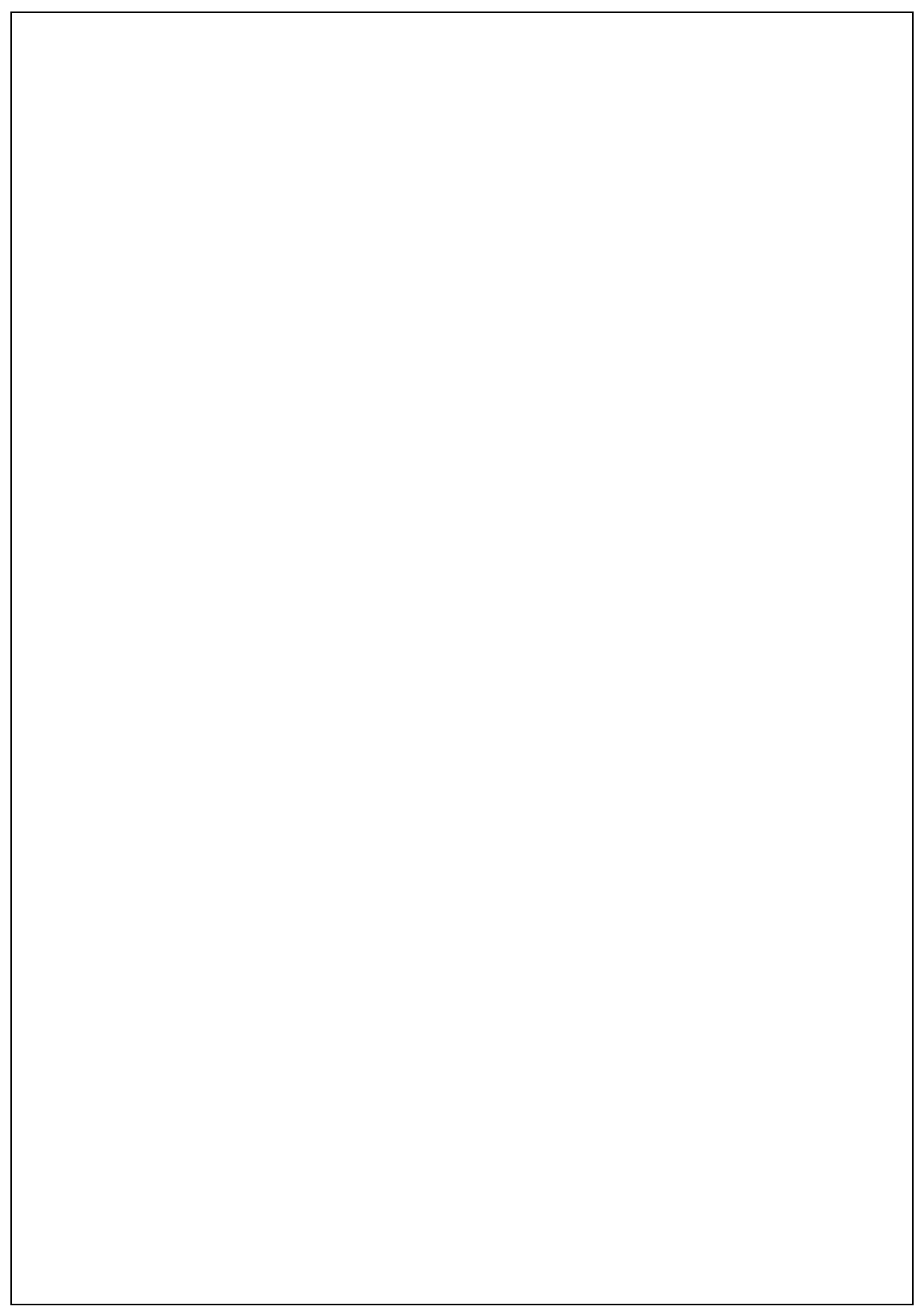

F-64 
Appendix G

South Park Area Exposure Unit Group EU Z2-34

Technical Memorandum 


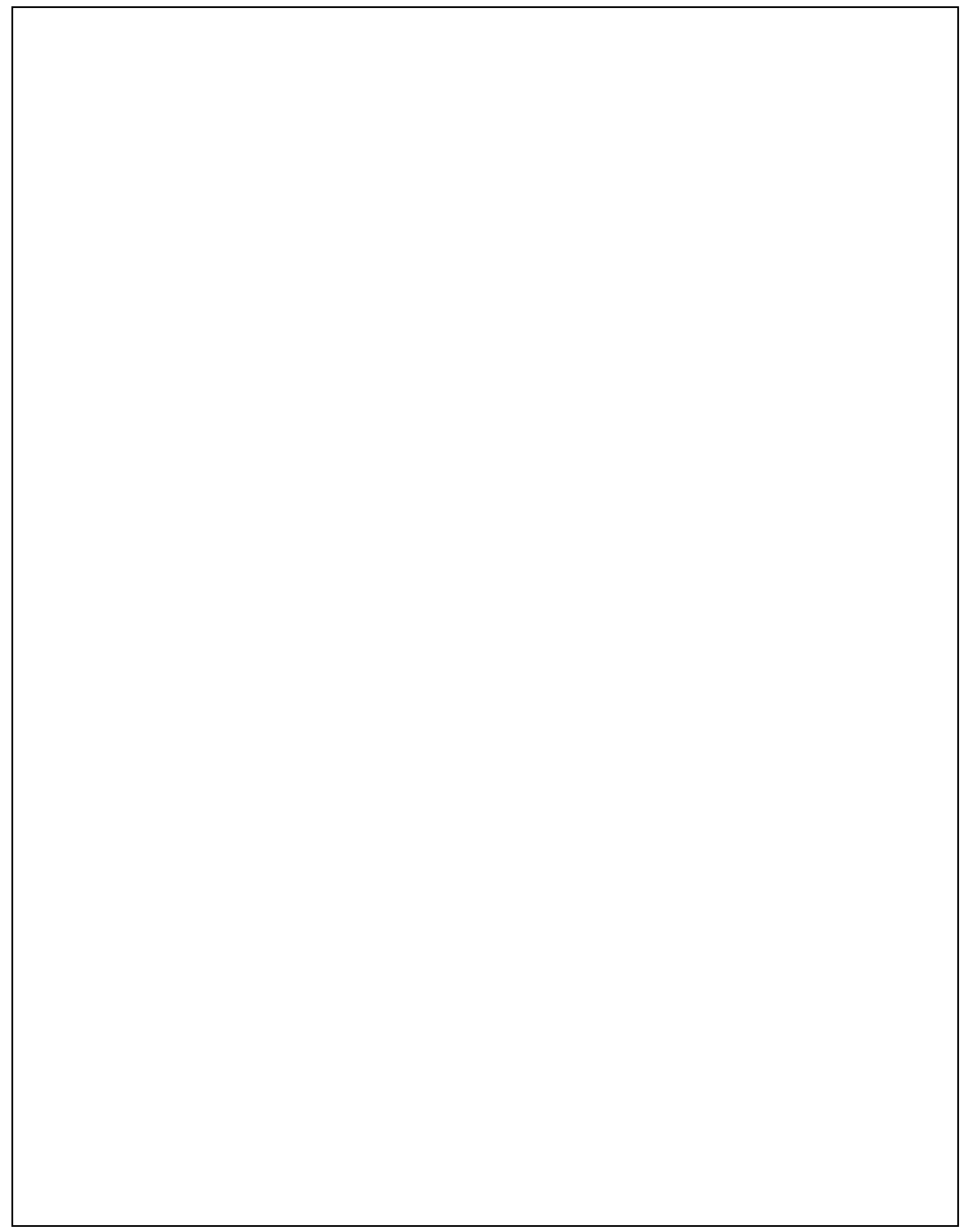

G-2 


\section{FIGURES}

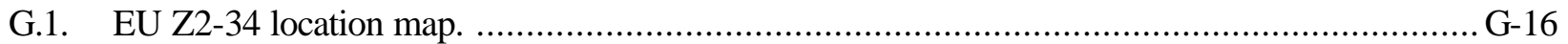

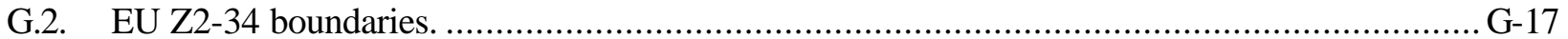

G.3. EU Z2-34 Class 3 and 4 SU walkover assessment locations. ......................................... G-18

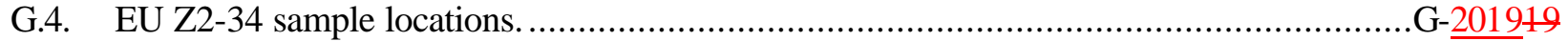

\section{TABLES}

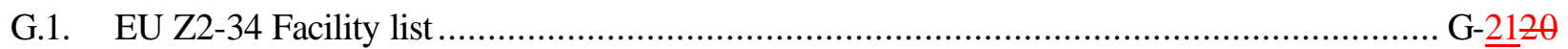

G.2. EU Z2-34 sample summary .................................................................... G-22 21

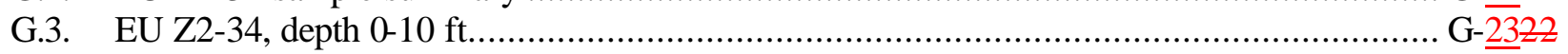




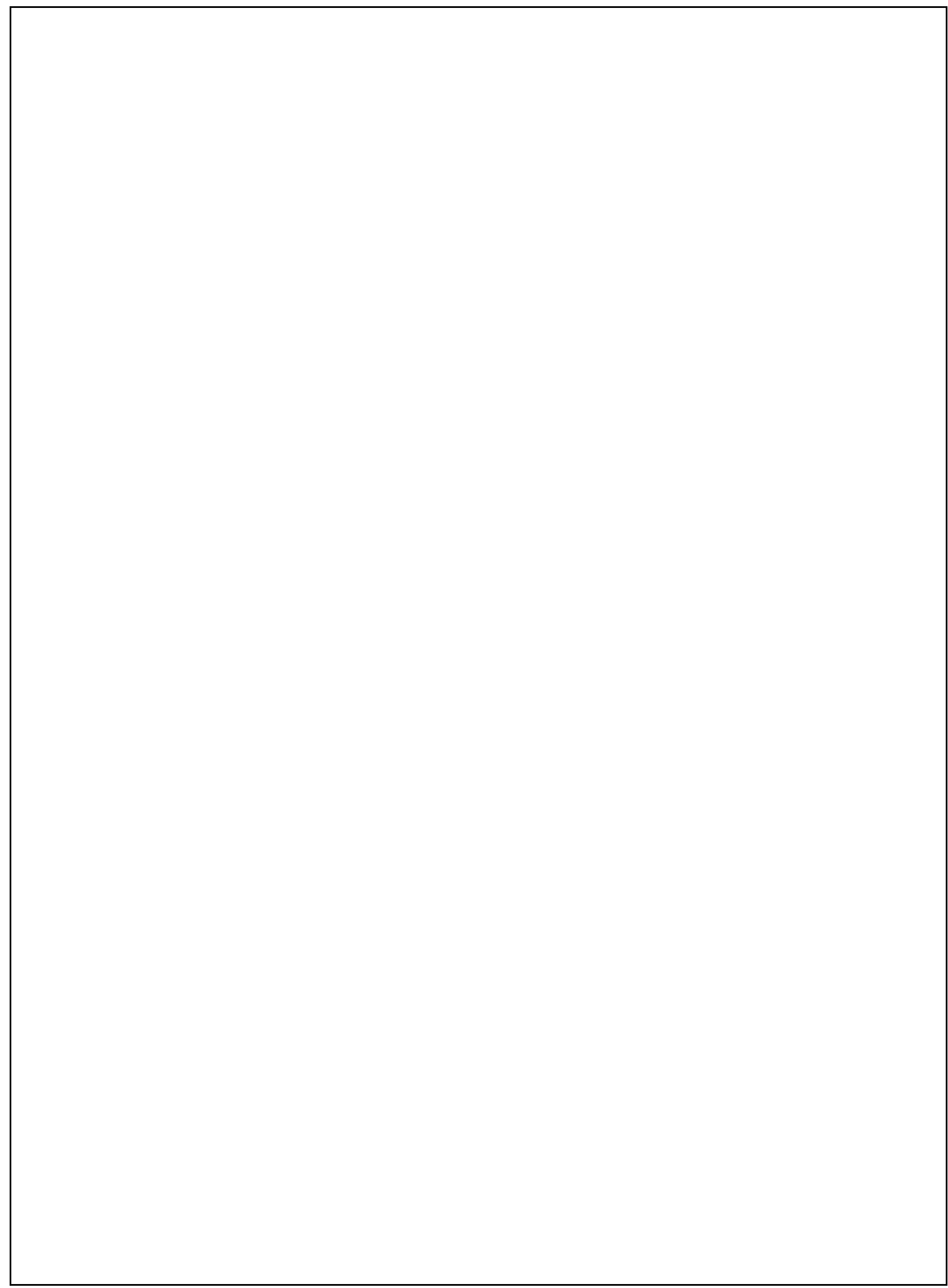

G-4 


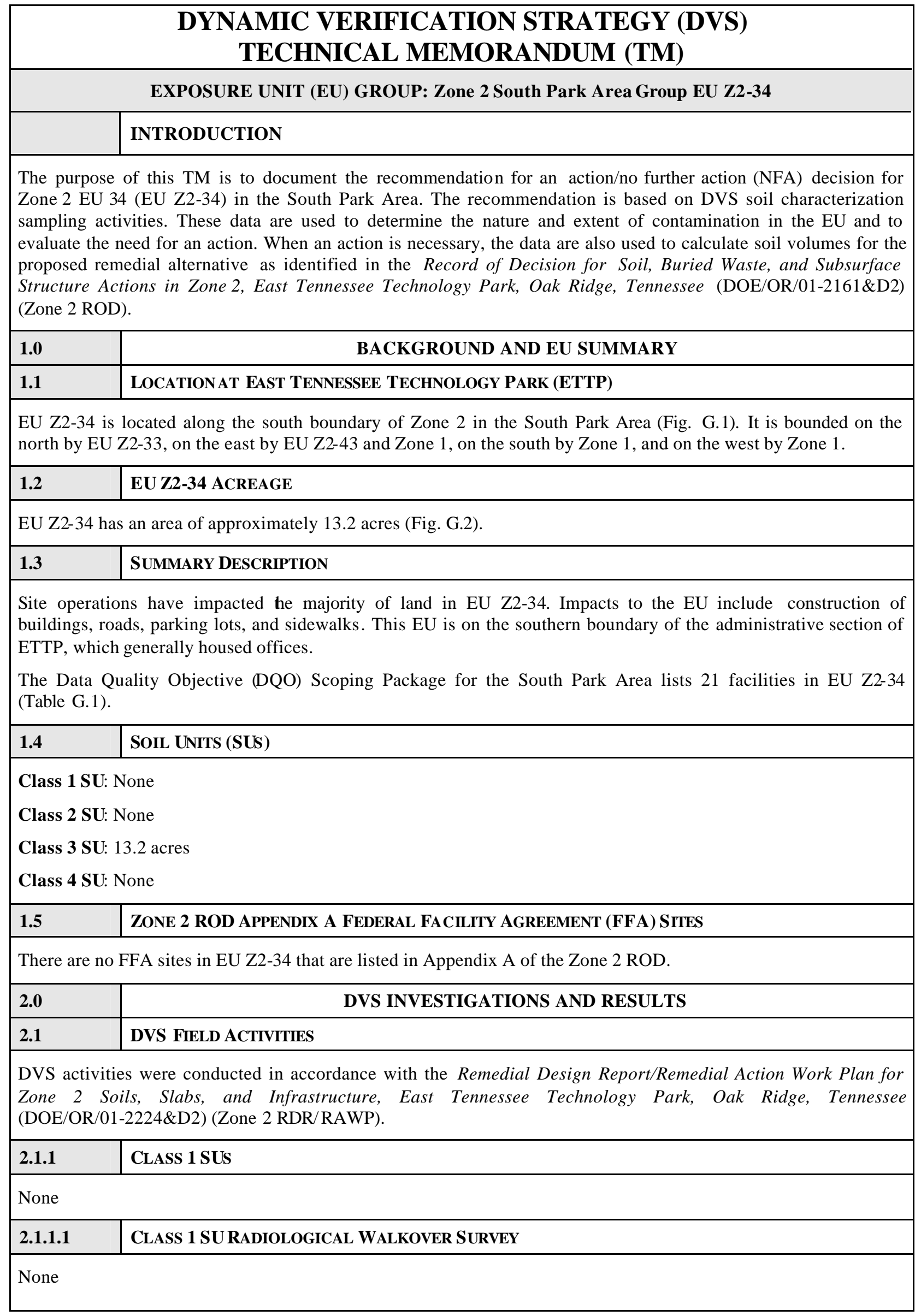




\section{\begin{tabular}{|l|l|l|l}
\hline 2.1.1.2 & CLASS 1 SU GEOPHYSICAL SURVEY \\
\hline
\end{tabular}}

None

\begin{tabular}{|l|l|}
\hline 2.1.1.3 & CLASS 1 SUSOIL SAMPLING \\
\hline
\end{tabular}

None

\begin{tabular}{|l|l}
\hline 2.1.2 & Class 2 SUS \\
\hline
\end{tabular}

None

\section{\begin{tabular}{l|l} 
2.1.2.1 & ClASS 2 SU RADIOLOGICAL WALKOVER SURVEY
\end{tabular}}

None

\begin{tabular}{|l|l} 
2.1.2.2 & CLASS 2 SU GEOPHYSICAL SURVEY
\end{tabular}

None

2.1.2.3

ClASS 2 SUSOIL SAMPLING

None

\section{\begin{tabular}{|l|ll} 
2.1.3 & ClaSs 3 AND ClaSs 4 SU WALKOVER ASSESSMENT
\end{tabular}}

The protocol for addressing Class 3 and Class 4 SUs in EU Z2-34 is the Class 3 and Class 4 Soil Unit Walkover Inspection Protocol Rev 01 (found in Attachment C of Appendix A in the Zone 2 RDR/RAWP). Only Class 3 SUs are addressed because no Class 4 SUs exist in EU Z2-34. The purpose of the Class 3 SU walkover assessments is to systematically inspect Class 3 SUs by visual observation along transects to established grid assessment locations and map-observed features, and to collect radiological screening data at grid and discretionary locations. Details of the walkover assessment results are presented in Walkover Inspections and Radiological Surveys for FY 2007 Exposure Units in Zones 1 and 2, East Tennessee Technology Park, Oak Ridge, Tennessee (BJC/OR-2691). A summary of report results is presented below in Sects. 2.1.3.1 and 2.1.3.2. Fig. G.3 shows the assessment point (AP), mid-point (MP), and discretionary point (DP) locations.

Twelve APs were identified in this EU prior to the start of fieldwork and are documented in the DQO Scoping Package. The actual number of APs evaluated in corresponds to the number planned.

In addition to the APs, the field team made assessments at seven MP locations (MPs are selected in the field and are points bcated approximately halfway between APs) and conducted a discretionary survey at one location (see below). MPs and DPs are not specified in planning documents.

\begin{tabular}{cccc}
\hline & $\begin{array}{c}\text { Number of } \\
\text { assessment points }\end{array}$ & $\begin{array}{c}\text { Number of } \\
\text { mi d-points }\end{array}$ & $\begin{array}{c}\text { Number of } \\
\text { discretionary points }\end{array}$ \\
\hline EU Z2-34 & 12 & 7 & 1 \\
\hline EU = exposure unit & & &
\end{tabular}

\section{\begin{tabular}{|l|l} 
2.1.3.1 & ClASS 3 AND ClaSS 4 SU RADIOLOGICAL SURVEY SUMMARY
\end{tabular}}

Screening level (SL): $4046 \mathrm{cpm}$

SL exceedances : None.

\section{\begin{tabular}{|l|l} 
2.1.3.2 & CLASS 3 AND CLASS 4 SU ANTHROPOGENIC FEATURES \\
\hline
\end{tabular}}

Number of identified anthropogenic features: 1

EU Z2-34 is located in an industrialized portion of ETTP. As such, there are numerous anthropogenic features that consist of facilities and associated constructed features such as roads, sidewalks, and paved areas. Plant facilities and their associated constructed features are assessed as part of the Class 3 and Class 4 SU walkover assessment protocol (Sect. 2.1.3.3). Other than plant facilities and associated constructed features, one anthropogenic feature 
was identified in EU Z2-34 during the Class 3 SU walkover assessment. The anthropogenic feature identified in EU Z2-34 during the Class $3 \mathrm{SU}$ assessment is:

- Contamination Area/Radioactive Material Area (CA/RMA), which consists of a line of hay bales adjacent to the parking area established during recent decontamination and decommissioning (D\&D) activities.

\section{\begin{tabular}{l|l} 
2.1.3.3 & CLASS 3 SU FACILITIES ASSESSMENTS \\
\hline
\end{tabular}}

The DQO Scoping Package lists 21 facilities that are located in EU Z2-34 (Table G.1). Only nine facilities were assessed during the Class $3 \mathrm{SU}$ walkover assessment because 12 facilities have been removed by D\&D activites (Table G.1). The facility assessments are reported in the Zone 2 EU Summary Report. No facility was identified as a possible source for either chemical or radiological contamination.

\section{\begin{tabular}{|l|l} 
2.1.3.4 & CLASS 3 AND CLASS 4 SU BIASED SAMPLING \\
\hline
\end{tabular}}

Based on visual assessment of the single anthropogenic feature for evidence of possible contamination, a biased sample location was selected.

In addition, two sediment accumulation area sample locations were identified during the Class 3 SU walkover assessment. One area is located near Assembly Area 2 and the other is located at the footprint of the loading dock for the former K-1001 building. A biased soil sample location was also identified at the radiation background measuring point for the Class $3 \mathrm{SU}$ walkover assessment.

One biased sample location was identified during DQO scoping at the southeast corner of the former K-1001 building near a storm drain catch basin where several pipelines intersect. Rationale for this sample location consisted of anecdotal evidence that some part of K-1001 had been used as a laboratory prior to conversion to an office building. The selected location was considered to be the most likely release point for building drains to release contaminants to surface soil.

The details of actual sampling and analysis in the Class $3 \mathrm{SU}$, including sample depths and analytes, are presented in Table G.2.

\section{\begin{tabular}{|l|l}
\hline 2.2 & DVS AND HISTORICAL SAMPLE RESULTS
\end{tabular}}

This section presents a summary of analytical results for the DVS samples collected in EU Z2-34 (see Table G.3); there are no historical sample locations. The summary begins with a tabulation of SU and infrastructure sample locations (Sects. 2.2.1 through 2.2.4) and concludes with focused investigation and EU data summaries (Sect. 2.2.5). A compact disc containing electronic files for the historical and DVS analytical data used to generate the data tables is provided with this Phased Construction Completion Report (PCCR).

\begin{tabular}{|l|l|}
\hline 2.2.1 & CLASS 1 SUS \\
\hline None \\
\hline $\mathbf{2 . 2 . 2}$ & CLASS 2 SUS \\
\hline None \\
\hline $\mathbf{2 . 2 . 3}$ & CLASS 3 AND CLASS 4 SUS \\
\hline
\end{tabular}

The five DVS sample locations in the Class 3 SU were biased sampled. Class 3 SU sample locations are shown on Fig. G.3 and summarized below.

\begin{tabular}{clc}
\hline EU & \multicolumn{1}{c}{ DVS sample locations } & Historical sample locations \\
\hline Z2-34 & Biased locations: & None \\
& Z2-EU34B-301, Z2-EU34B-302, Z2-EU34B-303, & \\
& Z2-EU34B-304, Z2-EU34B-305 & \\
\hline
\end{tabular}

DVS $=$ Dynamic Verification Strategy

$\mathrm{EU}=$ exposure unit

Sampling and analytical details for each sample location are presented in Table G.2. The analytical data are summarized in Table G.3 and evaluated in Sect. 2.2.5. The number of analyses conducted in the Class $3 \mathrm{SU}$ is presented below by analyte group. 


\begin{tabular}{lcccc}
\hline Metals & PCBs & Radionuclides & SVOCs & VOCs \\
\hline 4 & 3 & 3 & 3 & 1 \\
\hline PCB $=$ polychlorinated biphenyl & & & \\
SVOC = semivolatile organic & & & \\
VOC = volatile organic & & &
\end{tabular}

\section{\begin{tabular}{l|l} 
2.2.4 & INFRASTRUCTURE \\
\hline
\end{tabular}}

A soil sample location was identified during DQO scoping adjacent to the storm drain at the southeast corner of the former K-1001 building. The sample location is tabulated with the other DVS sample locations in Sect. 2.2.3 and the analytical data are evaluated below in Sect. 2.2.5.

\section{\begin{tabular}{|l|l|}
\hline 2.2.5 & EU EVALUATION \\
\hline
\end{tabular}}

Characterization data and other information are evaluated for EU Z2-34 in this section. The analytical data in the following summaries are presented by analyte group. Results for a particular analyte group are summarized only if that group was analyzed in the samples from the unit being summarized. Within each summary, the data are evaluated by comparing to certain criteria that include the Zone 2 soils maximum remediation level (Max RL), Zone 2 soils average remediation level (Avg RL), $1 \times 10^{-5}$ industrial preliminary remediation goal (Ind PRG), ETTP soils background composition (Bkg), Zone 2 groundwater screening levels (GW SL), and $1 \times 10^{-6}$ residential preliminary remediation goal (Res PRG). If a particular criterion does not apply to any member of an analyte group, it is not tabulated for that analyte group; if a particular criterion does not apply to all analytes within an analyte group, those analytes to which it does not apply are notated with not applicable (NA). Individual netals and radionuclides, which are naturally occurring, are reported in the summaries only if one or more criterion is exceeded. Organic chemicals, which are not naturally occurring, are reported if detected, even if no criteria are exceeded. The Max RL, Avg RL, Ind PRG, Bkg, GW SL, and Res PRG criteria values, as they pertain to the analytes listed in Appendix A of the RDR/RAWP (i.e., Quality Assurance Project Plan), are presented in Table G.4 of this PCCR.

Because the carcinogenic risk associated with the concentrations of radium and thorium isotopes in the natural background at ETTP exceeds the cumulative risk goal of $1 \times 10^{-4}$, RL values for these radionuclides are based on alternative concentration levels rather than risk. The alternative concentration levels of $5 \mathrm{pCi} / \mathrm{g}$ above background (Avg RL) and $15 \mathrm{pCi} / \mathrm{g}$ above background (Max RL) were set as low a reasonably achievable under the site-specific conditions. Because site-specific background concentrations of these radionuclides exceed the target risk range, residual concentrations of these radionuclides and their decay series are not considered in estimates of residual risk following any remedial actions.

The Zone 2 ROD states that Avg and Max RL exceedances by Ra-226, Th-230, and Th-232 will be evaluated by summing above-background concentrations of the greater of Ra-226 or Th-230 with the above-background concentrations of Th-232, and comparing the results to $5 \mathrm{pCi} / \mathrm{g}$ (Avg RL) and $15 \mathrm{pCi} / \mathrm{g}$ (Max RL). These required calculations have been performed. Avg and Max RL exceedances for these radionuclides, if any, are reported in the TM data summaries below and in Table G.2 as "Ra/Th decay series", and individual RL exceedances by Ra-226, Th-230, and Th-232 are reported as NA. The Ra/Th decay series data are summarized in following sections only if an Avg or Max RL has been exceeded, consistent with the description in the preceding paragraph for reporting radionuclides. Discussion of the $\mathrm{Ra} / \mathrm{Th}$ decay series calculation, including the manner in which the calculation is performed, is presented in Sect. 3.3 of this PCCR.

\section{EU Z2-34 Conceptual Site Model (CSM)}

All acreage in EU Z2-34 is classified as a single Class 3 SU. The area was used for a portion of the administrative complex, including office buildings, parking lots, and office trailers. Any contamination in the EU would have been very small volume surface releases to soils. There were no waste handling or storage facilities in the area, no subsurface burial sites in the EU, and no Class 2 infrastructure in the EU (laboratory drain lines are west of the western EU boundary). The CSM supporting the Class 3 SU classification concludes there is a high probability of no contamination in the area. Facility records, visual inspections, field measurements, and selected biased sampling support and confirm the Class 3 SU classification for EU Z2-34. 


\section{EU Z2-34 Groundwater Evaluation}

The two groundwater monitoring wells in EU Z2-34, BRW-113 and BRW-114, are located in the north portion of the EU. These two wells were installed in February 2004 as part of the site-wide remedial investigation program. Both wells are completed in the Chickamauga Bedrock formation at depths of $67-87 \mathrm{ft}$ and $32-42 \mathrm{ft} b g s$, respectively. Samples were collected from these wells in March 2004 after they were installed and developed. TCE was reported in BRW-113 at $6.3 \mathrm{ppb}$, and PCE was reported in both wells at 14 and $12 \mathrm{ppb}$, respectively. These results are greater than the TCE and PCE $5 \mathrm{mg} / \mathrm{L}$ maximum contaminant level (MCL) values. The bedrock is shallow and vapors from volatile organic compound (VOC)-contaminated groundwater could migrate into overlying soils .

No contaminated soil was identified within the EU Z2-34 boundary. However, there are several potential sources of PCE and TCE contamination to the north in EU Z2-33. There are six acid neutralization pits associated with the former K-1004 laboratory complex in EU Z2-33 that had very high levels of PCBs and VOCs at parts per thousand concentrations in accumulated sediments. Minor releases from these sumps may be the source of very low concentrations of dissolved phase TCE and PCE in the two wells. Biased samples will be obtained from these potential sources during EU Z2-33 DVS characterization.

Groundwater flow in the area is generally to the south/southwest, and the acid pits potential sources are upgradient from the two wells located in EU Z2-34. Facility records, visual inspections, and selected biased sampling have not identified a substantial mass of contaminated soil in EU Z2-34 that would pose a threat to local groundwater.

\section{EU Z2-34 Sampling Results}

EU Z2-34 lies at the southern extent of the industrialized part of ETTP Zone 2. The EU contains office buildings and associated infrastructure (parking lots, sidewalks) and several large grassy areas. The entire 13.2 acres have been classified a Class $3 \mathrm{SU}$. As a result, the entire EU was addressed by the Class $3 \mathrm{SU}$ walkover assessment. Twenty-one facilities were identified in this EU during DQO scoping and nine facilities were assessed during the Class $3 \mathrm{SU}$ walkover assessment. Twelve facilities had been removed by D\&D operations (mostly office trailers). No facility was identified for sampling. An accounting of facilities in this EU is presented in Table G.1. Other than facilities, a CA/RMA (anthropogenic feature) was identified during the Class $3 \mathrm{SU}$ walkover assessment and a biased sample location was selected. In addition, two sediment accumulation areas were identified for biased sampling, and the location used for the Class $3 \mathrm{SU}$ walkover assessment background radiation determination was also sampled. Finally, one biased sampling location, soil surrounding a storm drain at the southeast corner of the former K-1001 building, was identified during DQO scoping.

The following summarizes the sampling results for EU Z2-34, which begins with summary presentations of analytical results for the focused sampling efforts in the EU and concludes with an overall summary for EU Z2-34. The focused sampling efforts summarized below include the anthropogenic feature, sediment accumulation areas, Class $3 \mathrm{SU}$ walkover assessment background radiation location, and the storm drain at the former K-1001 building. The summary includes both data summary tables and a written description of the nature and extent of chemicals and radionuclides observed in the EU. A summary of all EU Z2-34 data is presented in Table G.3. EU-wide data are evaluated in terms of the Zone 2 ROD remedial action objective (RAO) in Sect. 3.3.

DVS Biased Sampling at the CA/RMA Anthropogenic Feature: Biased sample location Z2-EU34B-304 was identified at the CA/RMA anthropogenic feature during the Class 3 SU walkover assessment. Sampling and analytical details are presented in Table G.2. Analytical results summarized below show radionuclide Ind PRG and Bkg exceedances.

EU Z2-34 CA/RMA RADIONUCLIDES WITH BACKGROUND, PRG, AND/OR RL EXCEEDANCES (pCi/g)

\begin{tabular}{|c|c|c|c|c|c|c|c|c|c|c|c|}
\hline \multirow[b]{2}{*}{ Analyte } & \multirow[b]{2}{*}{$\begin{array}{c}\text { Detect } \\
\text { frequency }\end{array}$} & \multirow[b]{2}{*}{$\begin{array}{c}\text { Minimum } \\
\text { detect }\end{array}$} & \multirow[b]{2}{*}{$\begin{array}{c}\text { Maximum } \\
\text { detect }\end{array}$} & \multirow[b]{2}{*}{$\begin{array}{c}\text { Location(s) of } \\
\text { maximum detect }\end{array}$} & \multirow{2}{*}{$\begin{array}{c}\text { Average } \\
\text { detected } \\
\text { result }\end{array}$} & \multicolumn{6}{|c|}{ Number of analyses exceeding criteria } \\
\hline & & & & & & $\begin{array}{c}\text { Max } \\
\text { RL }\end{array}$ & $\begin{array}{l}\text { Avg } \\
\text { RL }\end{array}$ & $\begin{array}{l}\text { Ind } \\
\text { PRG }\end{array}$ & Bkg & $\begin{array}{l}\text { GW } \\
\text { SL }\end{array}$ & $\begin{array}{l}\text { Res } \\
\text { PRG }\end{array}$ \\
\hline Cesium-137 & $1 / 1$ & 0.233 & 0.233 & Z2-EU34B-304 & 0.233 & 0 & 0 & 0 & NA & NA & 1 \\
\hline Potassium- 40 & $1 / 1$ & 5.6 & 5.6 & Z2-EU34B-304 & 5.6 & NA & NA & 1 & 0 & NA & 1 \\
\hline Radium-226 & $1 / 1$ & 0.85 & 0.85 & Z2-EU34B-304 & 0.85 & NA & NA & 1 & 0 & NA & 1 \\
\hline Thorium -228 & $1 / 1$ & 1.21 & 1.21 & Z2-EU34B-304 & 1.21 & NA & NA & 1 & 0 & NA & 1 \\
\hline Thorium -230 & $1 / 1$ & 1.55 & 1.55 & Z2-EU34B-304 & 1.55 & NA & NA & 0 & 1 & NA & 0 \\
\hline
\end{tabular}


EU Z2-34 CA/RMA RADIONUCLIDES WITH BACKGROUND, PRG, AND/OR RL EXCEEDANCES (pCi/g) (continued)

\begin{tabular}{|c|c|c|c|c|c|c|c|c|c|c|c|}
\hline \multirow[b]{2}{*}{ Analyte } & \multirow[b]{2}{*}{$\begin{array}{c}\text { Detect } \\
\text { frequency }\end{array}$} & \multirow[b]{2}{*}{$\begin{array}{c}\text { Minimum } \\
\text { detect }\end{array}$} & \multirow[b]{2}{*}{$\begin{array}{c}\text { Maximum } \\
\text { detect }\end{array}$} & \multirow[b]{2}{*}{$\begin{array}{c}\text { Location(s) of } \\
\text { maximum detect }\end{array}$} & \multirow{2}{*}{$\begin{array}{c}\text { Average } \\
\text { detected } \\
\text { result }\end{array}$} & \multicolumn{6}{|c|}{ Number of analyses exceeding criteria } \\
\hline & & & & & & $\begin{array}{c}\text { Max } \\
\text { RL }\end{array}$ & $\begin{array}{c}\text { Avg } \\
\text { RL }\end{array}$ & $\begin{array}{c}\text { Ind } \\
\text { PRG }\end{array}$ & Bkg & $\begin{array}{l}\text { GW } \\
\text { SL }\end{array}$ & $\begin{array}{l}\text { Res } \\
\text { PRG }\end{array}$ \\
\hline Thorium -232 & $1 / 1$ & 1.04 & 1.04 & Z2-EU34B-304 & 1.04 & NA & NA & 1 & 0 & NA & 1 \\
\hline Uranium-238 & $1 / 1$ & 1.31 & 1.31 & Z2-EU34B-304 & 1.31 & 0 & 0 & 0 & 0 & 0 & 1 \\
\hline \multicolumn{3}{|l|}{$\overline{\text { Avg }=\text { average }}$} & \multicolumn{9}{|c|}{ NA = not applicable } \\
\hline \multicolumn{3}{|c|}{$\mathrm{Bkg}=$ background } & \multicolumn{9}{|c|}{$\mathrm{PRG}=$ preliminary remediation goal } \\
\hline \multicolumn{3}{|c|}{$\mathrm{CA}=$ Contamination Area } & \multicolumn{9}{|c|}{ Res $=$ residential } \\
\hline \multicolumn{3}{|c|}{ EU $=$ exposure unit } & \multicolumn{9}{|c|}{$\mathrm{RL}=$ remediation level } \\
\hline \multicolumn{3}{|c|}{$\mathrm{GW}=$ groundwater } & \multicolumn{9}{|c|}{ RMA $=$ Radioactive Material Area } \\
\hline \multicolumn{3}{|c|}{ Ind = industrial } & \multicolumn{9}{|c|}{$\mathrm{SL}=$ screening level } \\
\hline
\end{tabular}

DVS Sediment Accumulation Areas Biased Samples: There are two DVS biased sample locations in sediment the accumulation areas. Sample Z2-EU34B-303 is located in the sediment accumulation area near Assembly Area 2 and sample Z2-EU34B-305 is located in the sediment accumulation area at he loading dock of the former K-1001 building. Sampling and analytical details are presented in Table G.2. Analytical results summarized below show metal Bkg exceedances and several SVOC detections.

EU Z2-34 SEDIMENT ACCUMULATION AREAS METALS WITH BACKGROUND, PRG, GW SL, AND/OR RL EXCEEDANCES (mg/kg)

\begin{tabular}{|c|c|c|c|c|c|c|c|c|c|c|c|}
\hline \multirow[b]{2}{*}{ Analyte } & \multirow[b]{2}{*}{$\begin{array}{c}\text { Detect } \\
\text { frequency }\end{array}$} & \multirow[b]{2}{*}{$\underset{\text { detect }}{\text { Minimum }}$} & \multirow[b]{2}{*}{$\begin{array}{c}\text { Maximum } \\
\text { detect }\end{array}$} & \multirow{2}{*}{$\begin{array}{l}\text { Location(s) of } \\
\text { maximum } \\
\text { detect }\end{array}$} & \multirow{2}{*}{$\begin{array}{c}\text { Average } \\
\text { detected } \\
\text { result }\end{array}$} & \multicolumn{6}{|c|}{ Number of analyses exceeding criteria } \\
\hline & & & & & & $\begin{array}{c}\text { Max } \\
\text { RL }\end{array}$ & $\begin{array}{l}\text { Avg } \\
\text { RL } \\
\end{array}$ & $\begin{array}{l}\text { Ind } \\
\text { PRG }\end{array}$ & Bkg & $\begin{array}{c}\text { GW } \\
\text { SL }\end{array}$ & $\begin{array}{c}\text { Res } \\
\text { PRG }\end{array}$ \\
\hline Aluminum & $2 / 2$ & $9,040 \mathrm{~J}$ & $11,100 \mathrm{~J}$ & Z2-EU34B-303 & 10,070 & $\mathrm{NA}$ & NA & 0 & 0 & NA & 2 \\
\hline Arsenic & $2 / 2$ & $3.1 \mathrm{~J}$ & $6.5 \mathrm{~J}$ & Z2-EU34B-303 & 4.8 & 0 & 0 & 0 & 0 & 0 & 2 \\
\hline Calcium & $2 / 2$ & $1,670 \mathrm{~J}$ & $14,000 \mathrm{~J}$ & Z2-EU34B-303 & 7,835 & NA & NA & NA & 1 & NA & NA \\
\hline Magnesium & $2 / 2$ & $673 \mathrm{~J}$ & $7,190 \mathrm{~J}$ & Z2-EU34B-303 & 3,932 & NA & NA & NA & 1 & NA & NA \\
\hline Manganese & $2 / 2$ & 1,010 & 1,710 & Z2-EU34B-303 & 1,360 & NA & NA & 0 & 0 & NA & 2 \\
\hline Vanadium & $2 / 2$ & $16.9 \mathrm{~J}$ & $26.1 \mathrm{~J}$ & Z2-EU34B-303 & 21.5 & NA & NA & 0 & 0 & NA & 2 \\
\hline $\begin{array}{l}\text { Avg = averag } \\
\mathrm{Bkg}=\text { backg } \\
\mathrm{EU}=\text { exposur } \\
\mathrm{GW}=\text { grounc } \\
\text { Ind = industr } \\
\mathrm{Max}=\text { maxim }\end{array}$ & $\begin{array}{l}\text { und } \\
\text { un it } \\
\text { vater } \\
\text { ll } \\
\text { im }\end{array}$ & & $\begin{array}{l}\text { NA }=\text { not } \\
\text { PRG = pre } \\
\text { Res = resi } \\
\text { RL = reme } \\
\text { SL }=\text { scree }\end{array}$ & $\begin{array}{l}\text { applicable } \\
\text { liminary remediat } \\
\text { dential } \\
\text { ediation level } \\
\text { ning level }\end{array}$ & tion goal & & & & & & \\
\hline
\end{tabular}

PCBs were analyzed for in both samples but were not detected.

EU Z2-34 SEDIMENT ACCUMULATION AREASSVOC DETECTS (ug/kg)

\begin{tabular}{|c|c|c|c|c|c|c|c|c|}
\hline \multirow[b]{2}{*}{ Analyte } & \multirow[b]{2}{*}{$\begin{array}{l}\text { Detect } \\
\text { frequency }\end{array}$} & \multirow[b]{2}{*}{$\begin{array}{c}\text { Minimum } \\
\text { detect }\end{array}$} & \multirow[b]{2}{*}{$\begin{array}{l}\text { Maximum } \\
\text { detect }\end{array}$} & \multirow[b]{2}{*}{$\begin{array}{l}\text { Location(s) of } \\
\text { maximum detect }\end{array}$} & \multirow{2}{*}{$\begin{array}{c}\text { Average } \\
\text { detected } \\
\text { result }\end{array}$} & \multicolumn{3}{|c|}{$\begin{array}{l}\text { Number of analyses } \\
\text { exceeding criteria }\end{array}$} \\
\hline & & & & & & $\begin{array}{l}\text { Ind } \\
\text { PRG }\end{array}$ & $\begin{array}{l}\text { GW } \\
\text { SL }\end{array}$ & $\begin{array}{l}\text { Res } \\
\text { PRG }\end{array}$ \\
\hline Benz(a)anthracene & $2 / 2$ & $56 \mathrm{~J}$ & $59 \mathrm{~J}$ & Z2-EU34B-303 & 57.5 & 0 & NA & 0 \\
\hline Benzo(a)pyrene & $2 / 2$ & $56 \mathrm{~J}$ & $60 \mathrm{~J}$ & Z2-EU34B-305 & 58 & 0 & NA & 0 \\
\hline Benzo(b)fluoranthene & $2 / 2$ & $49 \mathrm{~J}$ & $55 \mathrm{~J}$ & Z2-EU34B-305 & 52 & 0 & NA & 0 \\
\hline Benzo(ghi)perylene & $2 / 2$ & $37 \mathrm{~J}$ & $45 \mathrm{~J}$ & Z2-EU34B-305 & 41 & 0 & NA & 0 \\
\hline Benzo(k)fluoranthene & $2 / 2$ & $55 \mathrm{~J}$ & $59 \mathrm{~J}$ & Z2-EU34B-303 & 57 & 0 & NA & 0 \\
\hline Chrysene & $2 / 2$ & $60 \mathrm{~J}$ & $61 \mathrm{~J}$ & Z2-EU34B-303 & 60.5 & 0 & NA & 0 \\
\hline Fluoranthene & $2 / 2$ & $98 \mathrm{~J}$ & $110 \mathrm{~J}$ & Z2-EU34B-303 & 104 & 0 & NA & 0 \\
\hline
\end{tabular}




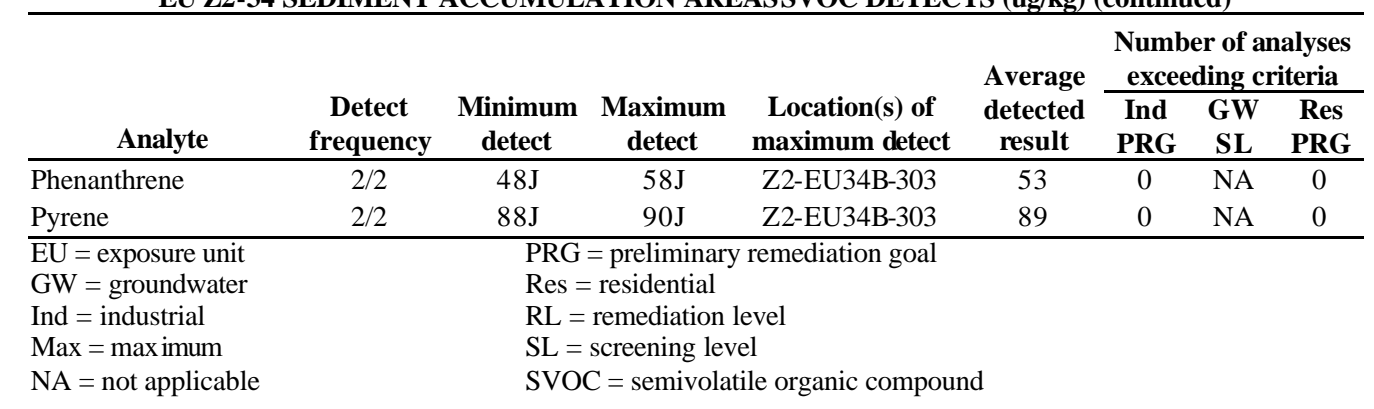

DVS Biased Sampling at the Radiological Background Location: Soil sample location Z2-EU34B-302 was identified during field work at the location used to determine the Class 3 SU walkover assessment radiological background. Sampling and analytical details are presented in Table G.2. Analytical results summarized below show radionuclide Ind PRG exceedances and metal and radionuclide Bkg exceedances.

EU Z2-34 BACKGROUND LOCATION METALS WITH BACKGROUND, PRG, GW SL, AND/OR RL EXCEEDANCES (mg/kg)

\begin{tabular}{|c|c|c|c|c|c|c|c|c|c|c|c|}
\hline \multirow[b]{2}{*}{ Analyte } & \multirow[b]{2}{*}{$\begin{array}{c}\text { Detect } \\
\text { frequency }\end{array}$} & \multirow[b]{2}{*}{$\begin{array}{c}\text { Minimum } \\
\text { detect }\end{array}$} & \multirow[b]{2}{*}{$\begin{array}{c}\text { Maximum } \\
\text { detect }\end{array}$} & \multirow[b]{2}{*}{$\begin{array}{c}\text { Location(s) of } \\
\text { maximum detect }\end{array}$} & \multirow{2}{*}{$\begin{array}{c}\text { Average } \\
\text { detected } \\
\text { result }\end{array}$} & \multicolumn{6}{|c|}{ Number of analyses exceeding criteria } \\
\hline & & & & & & $\begin{array}{c}\text { Max } \\
\text { RL }\end{array}$ & $\begin{array}{l}\text { Avg } \\
\text { RL }\end{array}$ & $\begin{array}{c}\text { Ind } \\
\text { PRG }\end{array}$ & Bkg & $\begin{array}{c}\text { GW } \\
\text { SL }\end{array}$ & $\begin{array}{c}\text { Res } \\
\text { PRG }\end{array}$ \\
\hline$\overline{\text { Aluminum }}$ & $1 / 1$ & $11,200 \mathrm{~J}$ & $11,200 \mathrm{~J}$ & Z2-EU34B-302 & 11,200 & NA & NA & 0 & 0 & NA & 1 \\
\hline Arsenic & $1 / 1$ & $6.1 \mathrm{~J}$ & $6.1 \mathrm{~J}$ & Z2-EU34B-302 & 6.1 & 0 & 0 & 0 & 0 & 0 & 1 \\
\hline Calcium & $1 / 1$ & $10,400 \mathrm{~J}$ & $10,400 \mathrm{~J}$ & Z2-EU34B-302 & 10,400 & NA & NA & NA & 1 & NA & NA \\
\hline Lead & $1 / 1$ & $41.9 \mathrm{~J}$ & $41.9 \mathrm{~J}$ & Z2-EU34B-302 & 41.9 & NA & NA & 0 & 1 & 0 & 0 \\
\hline Magnesium & $1 / 1$ & $5,150 \mathrm{~J}$ & $5,150 \mathrm{~J}$ & Z2-EU34B-302 & 5,150 & NA & NA & NA & 1 & NA & NA \\
\hline Manganese & $1 / 1$ & 1,490 & 1,490 & Z2-EU34B-302 & 1,490 & NA & NA & 0 & 0 & NA & 1 \\
\hline Nickel & $1 / 1$ & 27.9 & 27.9 & Z2-EU34B-302 & 27.9 & NA & NA & 0 & 1 & NA & 0 \\
\hline Uranium & $1 / 1$ & 1.9 & 1.9 & Z2-EU34B-302 & 1.9 & NA & NA & 0 & NA & NA & 1 \\
\hline Vanadium & $1 / 1$ & $25.1 \mathrm{~J}$ & $25.1 \mathrm{~J}$ & Z2-EU34B-302 & 25.1 & NA & NA & 0 & 0 & NA & 1 \\
\hline \multicolumn{3}{|c|}{$\overline{\mathrm{Avg}}=$ average } & $\mathrm{NA}=1$ & applicable & & & & & & & \\
\hline \multicolumn{3}{|c|}{$\mathrm{Bkg}=$ background } & $\mathrm{PRG}=\mathrm{p}$ & oreliminary remedia & tion goal & & & & & & \\
\hline \multicolumn{3}{|c|}{$\mathrm{EU}=$ exposure unit } & Res $=$ re & sidential & & & & & & & \\
\hline \multicolumn{3}{|c|}{$\mathrm{GW}=$ groundwater } & $\mathrm{RL}=\mathrm{re}$ & mediation level & & & & & & & \\
\hline \multicolumn{3}{|c|}{ Ind $=$ industrial } & $\mathrm{SL}=\mathrm{scl}$ & reening level & & & & & & & \\
\hline \multicolumn{3}{|c|}{ Max = maximum } & & & & & & & & & \\
\hline
\end{tabular}

EU Z2-34 BACKGROUND LOCATION RADIONUCLIDES WITH BACKGROUND, PRG, AND/OR RL EXCEEDANCES (pCi/g)

\begin{tabular}{|c|c|c|c|c|c|c|c|c|c|c|c|}
\hline \multirow[b]{2}{*}{ Analyte } & \multirow[b]{2}{*}{$\begin{array}{l}\text { Detect } \\
\text { frequency }\end{array}$} & \multirow[b]{2}{*}{$\begin{array}{c}\text { Minimum } \\
\text { detect }\end{array}$} & \multirow[b]{2}{*}{$\begin{array}{c}\text { Maximum } \\
\text { detect }\end{array}$} & \multirow[b]{2}{*}{$\begin{array}{l}\text { Location(s) of } \\
\text { maximum detect }\end{array}$} & \multirow{2}{*}{$\begin{array}{c}\text { Average } \\
\text { detected } \\
\text { result }\end{array}$} & \multicolumn{6}{|c|}{ Number of analyses exceeding criteria } \\
\hline & & & & & & $\begin{array}{c}\text { Max } \\
\text { RL }\end{array}$ & $\begin{array}{l}\text { Avg } \\
\text { RL }\end{array}$ & $\begin{array}{l}\text { Ind } \\
\text { PRG }\end{array}$ & Bkg & $\begin{array}{l}\text { GW } \\
\text { SL }\end{array}$ & $\begin{array}{c}\text { Res } \\
\text { PRG }\end{array}$ \\
\hline Cesium-137 & $1 / 1$ & 0.162 & 0.162 & Z2-EU34B-302 & 0.162 & 0 & 0 & 0 & NA & NA & 1 \\
\hline Potassium-40 & $1 / 1$ & 17.4 & 17.4 & Z2-EU34B-302 & 17.4 & NA & NA & 1 & 0 & NA & 1 \\
\hline Radium-226 & $1 / 1$ & 0.9 & 0.9 & Z2-EU34B-302 & 0.9 & NA & NA & 1 & 0 & NA & 1 \\
\hline Technetium-99 & $1 / 1$ & 1.26 & 1.26 & Z2-EU34B-302 & 1.26 & NA & NA & 0 & NA & NA & 1 \\
\hline Thorium -228 & $1 / 1$ & 1.39 & 1.39 & Z2-EU34B-302 & 1.39 & NA & NA & 1 & 0 & NA & 1 \\
\hline Thorium -230 & $1 / 1$ & 1.47 & 1.47 & Z2-EU34B-302 & 1.47 & NA & NA & 0 & 1 & NA & 0 \\
\hline Thorium -232 & $1 / 1$ & 1.51 & 1.51 & Z2-EU34B-302 & 1.51 & NA & NA & 1 & 0 & NA & 1 \\
\hline Uranium-235 & $1 / 1$ & 0.24 & 0.24 & Z2-EU34B-302 & 0.24 & 0 & 0 & 0 & NA & 0 & 1 \\
\hline Uranium-238 & $1 / 1$ & 2.4 & 2.4 & Z2-EU34B-302 & 2.4 & 0 & 0 & 0 & 1 & 0 & 1 \\
\hline $\begin{array}{l}\text { Avg = average } \\
\text { Bkg = background } \\
\text { EU = exposure unit } \\
\text { GW = groundwater } \\
\text { Ind = industrial } \\
\text { Max = maximum }\end{array}$ & & $\begin{array}{l}\mathrm{N} \\
\mathrm{F} \\
\mathrm{F} \\
\mathrm{F} \\
\mathrm{S}\end{array}$ & $\begin{array}{l}\text { NA }=\text { not app } \\
\text { PRG }=\text { prelim } \\
\text { Res }=\text { residen } \\
\text { RL }=\text { remedia } \\
\text { SL }=\text { screenin }\end{array}$ & $\begin{array}{l}\text { licable } \\
\text { ninary remediation } \\
\text { tial } \\
\text { ation level } \\
\text { ag level }\end{array}$ & soal & & & & & & \\
\hline
\end{tabular}


and analytical details are presented in Table G.2. Analytical results summarized below show radionuclide Ind PRG exceedances and metal and radionuclide Bkg exceedances.

EU Z2-34 K-1001 STORM DRAIN LOCATION METALS WITH BACKGROUND, PRG, GW SL, AND/OR RL EXCEEDANCES (mg/kg)

\begin{tabular}{|c|c|c|c|c|c|c|c|c|c|c|c|}
\hline \multirow[b]{2}{*}{ Analyte } & \multirow[b]{2}{*}{$\begin{array}{c}\text { Detect } \\
\text { frequency }\end{array}$} & \multirow[b]{2}{*}{$\begin{array}{c}\text { Minimum } \\
\text { detect }\end{array}$} & \multirow[b]{2}{*}{$\begin{array}{c}\text { Maximum } \\
\text { detect }\end{array}$} & \multirow{2}{*}{$\begin{array}{c}\text { Location(s) of } \\
\text { maximum } \\
\text { detect }\end{array}$} & \multirow{2}{*}{$\begin{array}{c}\text { Average } \\
\text { detected } \\
\text { result }\end{array}$} & \multicolumn{6}{|c|}{ Number of analyses exceeding criteria } \\
\hline & & & & & & $\begin{array}{c}\text { Max } \\
\text { RL } \\
\end{array}$ & $\begin{array}{c}\text { Avg } \\
\text { RL }\end{array}$ & $\begin{array}{c}\text { Ind } \\
\text { PRG } \\
\end{array}$ & Bkg & $\begin{array}{c}\text { GW } \\
\text { SL } \\
\end{array}$ & $\begin{array}{c}\text { Res } \\
\text { PRG } \\
\end{array}$ \\
\hline Aluminum & $1 / 1$ & $13,300 \mathrm{~J}$ & $13,300 \mathrm{~J}$ & Z2-EU34B-301 & 13,300 & NA & NA & 0 & 0 & NA & 1 \\
\hline Arsenic & $1 / 1$ & $4.3 \mathrm{~J}$ & $4.3 \mathrm{~J}$ & Z2-EU34B-301 & 4.3 & 0 & 0 & 0 & 0 & 0 & 1 \\
\hline Calcium & $1 / 1$ & $9,150 \mathrm{~J}$ & $9,150 \mathrm{~J}$ & Z2-EU34B-301 & 9,150 & NA & NA & NA & 1 & NA & NA \\
\hline Manganese & $1 / 1$ & 1,470 & 1,470 & Z2-EU34B-301 & 1,470 & NA & NA & 0 & 0 & NA & 1 \\
\hline Nickel & $1 / 1$ & 27.5 & 27.5 & Z2-EU34B-301 & 27.5 & NA & NA & 0 & 1 & NA & 0 \\
\hline Vanadium & $1 / 1$ & $23 \mathrm{~J}$ & $23 \mathrm{~J}$ & Z2-EU34B-301 & 23 & NA & NA & 0 & 0 & NA & 1 \\
\hline \multicolumn{3}{|c|}{ Avg = average } & \multicolumn{3}{|c|}{$\mathrm{NA}=$ not applicable } & & & & & & \\
\hline \multicolumn{3}{|c|}{$\mathrm{Bkg}=$ background } & \multicolumn{3}{|c|}{$\mathrm{PRG}=$ preliminary remediation goal } & & & & & & \\
\hline \multicolumn{3}{|c|}{$\mathrm{EU}=$ exposure unit } & \multicolumn{3}{|c|}{ Res $=$ residential } & & & & & & \\
\hline \multicolumn{3}{|c|}{$\mathrm{GW}=$ groundwater } & \multicolumn{3}{|c|}{$\mathrm{RL}=$ remediation level } & & & & & & \\
\hline \multicolumn{3}{|c|}{ Ind = industrial } & $\mathrm{SL}=$ scree & ning level & & & & & & & \\
\hline
\end{tabular}

PCBs were analyzed for but were not detected.

EU Z2-34 K-1001 STORM DRAIN LOCATION RADIONUCLIDES WITH BACKGROUND, PRG, AND/OR RL EXCEEDANCES (pCi/g)

\begin{tabular}{|c|c|c|c|c|c|c|c|c|c|c|c|}
\hline \multirow[b]{2}{*}{ Analyte } & \multirow[b]{2}{*}{$\begin{array}{c}\text { Detect } \\
\text { frequency }\end{array}$} & \multirow[b]{2}{*}{$\begin{array}{c}\text { Minimum } \\
\text { detect }\end{array}$} & \multirow[b]{2}{*}{$\begin{array}{l}\text { Maximum } \\
\text { detect }\end{array}$} & \multirow[b]{2}{*}{$\begin{array}{c}\text { Location(s) of } \\
\text { maximum detect }\end{array}$} & \multirow{2}{*}{$\begin{array}{c}\text { Average } \\
\text { detected } \\
\text { result }\end{array}$} & \multicolumn{6}{|c|}{ Number of analyses exceeding criteria } \\
\hline & & & & & & $\underset{\text { RL }}{\text { Max }}$ & $\begin{array}{l}\text { Avg } \\
\text { RL }\end{array}$ & $\begin{array}{c}\text { Ind } \\
\text { PRG }\end{array}$ & Bkg & $\begin{array}{l}\text { GW } \\
\text { SL }\end{array}$ & $\begin{array}{c}\text { Res } \\
\text { PRG }\end{array}$ \\
\hline Potassium-40 & $1 / 1$ & 21 & 21 & Z2-EU34B-301 & 21 & NA & NA & 1 & 0 & NA & 1 \\
\hline Radium-226 & $1 / 1$ & 1.33 & 1.33 & Z2-EU34B-301 & 1.33 & NA & NA & 1 & 1 & NA & 1 \\
\hline Thorium -228 & $1 / 1$ & 1.52 & 1.52 & Z2-EU34B-301 & 1.52 & NA & NA & 1 & 0 & NA & 1 \\
\hline Thorium -230 & $1 / 1$ & 1.23 & 1.23 & Z2-EU34B-301 & 1.23 & NA & NA & 0 & 1 & NA & 0 \\
\hline Thorium -232 & $1 / 1$ & 1.53 & 1.53 & Z2-EU34B-301 & 1.53 & NA & NA & 1 & 0 & NA & 1 \\
\hline Uranium-238 & $1 / 1$ & 1.04 & 1.04 & Z2-EU34B-301 & 1.04 & 0 & 0 & 0 & 0 & 0 & 1 \\
\hline Avg = average & \multicolumn{11}{|c|}{ NA $=$ not applicable } \\
\hline $\mathrm{Bkg}=$ background & \multicolumn{11}{|c|}{$\mathrm{PRG}=$ preliminary remediation goal } \\
\hline $\mathrm{EU}=$ exposure unit & \multicolumn{11}{|c|}{ Res $=$ residential } \\
\hline $\mathrm{GW}=$ groundwater & \multicolumn{11}{|c|}{$\mathrm{RL}=$ remediation level } \\
\hline Ind $=$ industrial & \multirow{2}{*}{\multicolumn{11}{|c|}{$\mathrm{SL}=$ screening level }} \\
\hline Max $=$ maximum & & & & & & & & & & & \\
\hline
\end{tabular}

SVOCs and VOCs were analyzed for but were not detected.

EU Z2-34 Summary: The entire EU is a Class 3 SU. Therefore, the whole EU was addressed by a Class 3 SU walkover assessment. One anthropogenic feature, a CA/RMA, and two sediment accumulation areas were identified during the assessment and selected for DVS biased sampling. Nine facilities were assessed but none were selected for sampling. In addition, the location used to determine radiation background was also selected for biased sampling. Soil surrounding the storm drain at the southeast corner of the former K-1001 building was identified as a Class 3 SU DVS biased sample location during DQO scoping. There were no historical sample locations in EU Z2-34.

This section presents a summary of the nature and extent of contamination by combining all analytical data presented in the focused investigation summaries above. There were five sample locations in this EU. The details of sampling and analysis are presented in Table G.2. Analytical results for all samples summarized below show radionuclide Ind PRG exceedances, metal and radionuclide Bkg exceedances, and detections of SVOCs. 
EU Z2-34 METALS WITH BACKGROUND, PRG, GW SL, AND/OR RL EXCEEDANCES (mg/kg)

\begin{tabular}{|c|c|c|c|c|c|c|c|c|c|c|c|}
\hline \multirow[b]{2}{*}{ Analyte } & \multirow[b]{2}{*}{$\begin{array}{c}\text { Detect } \\
\text { frequency }\end{array}$} & \multirow[b]{2}{*}{$\begin{array}{c}\text { Minimum } \\
\text { detect }\end{array}$} & \multirow[b]{2}{*}{$\begin{array}{c}\text { Maximum } \\
\text { detect }\end{array}$} & \multirow[b]{2}{*}{$\begin{array}{l}\text { Location(s) of } \\
\text { maximum detect }\end{array}$} & \multirow{2}{*}{$\begin{array}{c}\text { Average } \\
\text { detected } \\
\text { result }\end{array}$} & \multicolumn{6}{|c|}{ Number of analyses exceeding criteria } \\
\hline & & & & & & $\begin{array}{c}\text { Max } \\
\text { RL }\end{array}$ & $\begin{array}{c}\text { Avg } \\
\text { RL }\end{array}$ & $\begin{array}{l}\text { Ind } \\
\text { PRG }\end{array}$ & Bkg & $\begin{array}{c}\text { GW } \\
\text { SL }\end{array}$ & $\begin{array}{r}\text { Res } \\
\text { PRG }\end{array}$ \\
\hline Aluminum & $4 / 4$ & $9,040 \mathrm{~J}$ & $13,300 \mathrm{~J}$ & Z2-EU34B-301 & 11,160 & NA & NA & 0 & 0 & NA & 4 \\
\hline Arsenic & $4 / 4$ & $3.1 \mathrm{~J}$ & $6.5 \mathrm{~J}$ & Z2-EU34B-303 & 5 & 0 & 0 & 0 & 0 & 0 & 4 \\
\hline Calcium & $4 / 4$ & $1,670 \mathrm{~J}$ & $14,000 \mathrm{~J}$ & Z2-EU34B-303 & 8,805 & NA & NA & NA & 3 & NA & NA \\
\hline Lead & $4 / 4$ & $17.4 \mathrm{~J}$ & $41.9 \mathrm{~J}$ & Z2-EU34B-302 & 32.7 & NA & NA & 0 & 1 & 0 & 0 \\
\hline Magnesium & $4 / 4$ & $673 \mathrm{~J}$ & $7,190 \mathrm{~J}$ & Z2-EU34B-303 & 3,786 & NA & NA & NA & 2 & NA & NA \\
\hline Manganese & $4 / 4$ & 1,010 & 1,710 & Z2-EU34B-303 & 1,420 & NA & NA & 0 & 0 & NA & 4 \\
\hline Nickel & $4 / 4$ & 6.3 & 27.9 & Z2-EU34B-302 & 18.4 & NA & NA & 0 & 2 & NA & 0 \\
\hline Uranium & $4 / 4$ & 0.59 & 1.9 & Z2-EU34B-302 & 1.15 & NA & NA & 0 & NA & NA & 1 \\
\hline Vanadium & $4 / 4$ & $16.9 \mathrm{~J}$ & $26.1 \mathrm{~J}$ & Z2-EU34B-303 & 22.8 & NA & NA & 0 & 0 & NA & 4 \\
\hline
\end{tabular}

Avg = average NA $=$ not applicable

$\mathrm{Bkg}=$ background $\quad \mathrm{PRG}=$ preliminary remediation goal

$\mathrm{EU}=$ exposure unit $\quad$ Res $=$ residential

$\mathrm{GW}=$ groundwater $\quad \mathrm{RL}=$ remediation level

Ind $=$ industrial $\quad \mathrm{SL}=$ screening level

Max = maximum

PCBs were analyzed for in three samples but were not detected.

EU Z2-34 RADIONUCLIDES WITH BACKGROUND, PRG, AND/OR RL EXCEEDANCES (pCi/g)

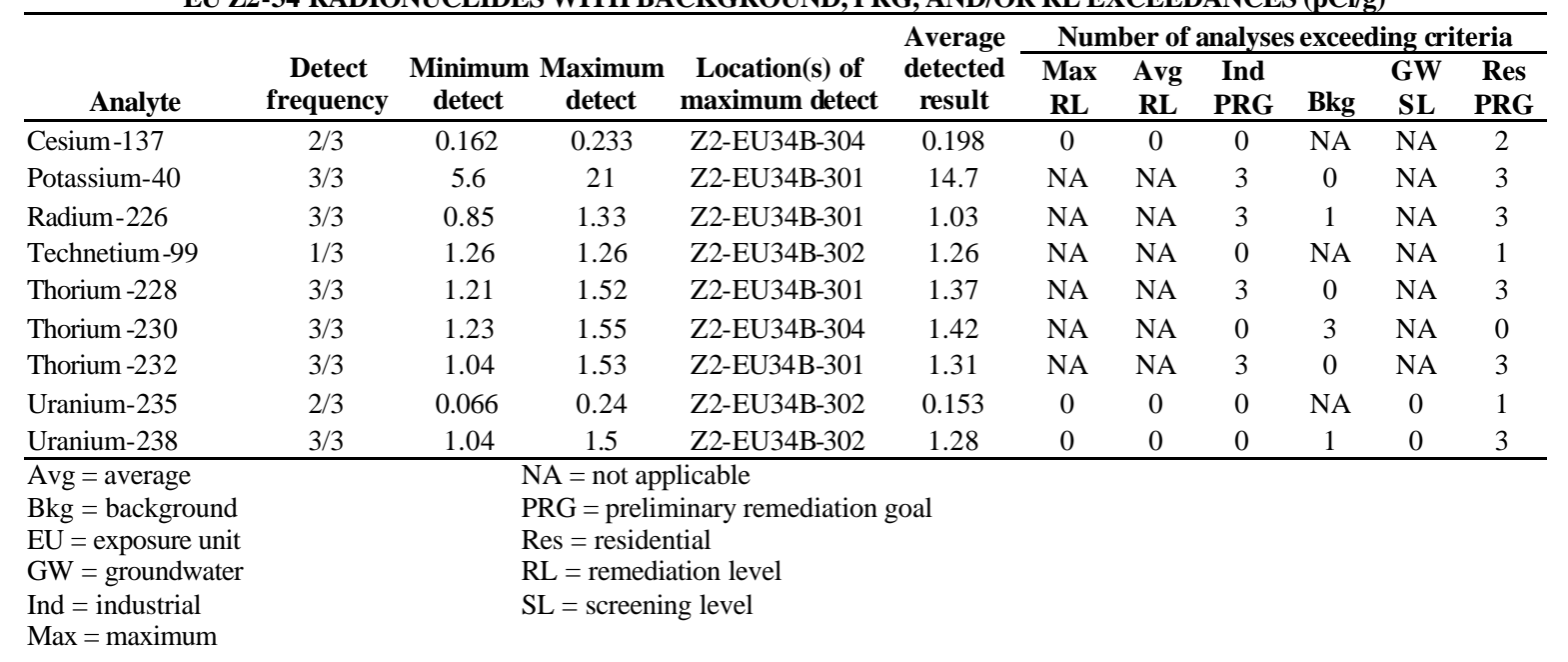

EU Z2-34 SVOC DETECTS (ug/kg)

\begin{tabular}{|c|c|c|c|c|c|c|c|c|}
\hline \multirow[b]{2}{*}{ Analyte } & \multirow[b]{2}{*}{$\begin{array}{c}\text { Detect } \\
\text { frequency }\end{array}$} & \multirow[b]{2}{*}{$\begin{array}{c}\text { Minimum } \\
\text { detect }\end{array}$} & \multirow[b]{2}{*}{$\begin{array}{c}\text { Maximum } \\
\text { detect }\end{array}$} & \multirow[b]{2}{*}{$\begin{array}{l}\text { Location(s) of } \\
\text { maximum detect }\end{array}$} & \multirow{2}{*}{$\begin{array}{c}\text { Average } \\
\text { detected } \\
\text { result }\end{array}$} & \multicolumn{3}{|c|}{$\begin{array}{c}\text { Number of analyses } \\
\text { exceeding criteria }\end{array}$} \\
\hline & & & & & & $\begin{array}{l}\text { Ind } \\
\text { PRG }\end{array}$ & $\begin{array}{l}\text { GW } \\
\text { SL }\end{array}$ & $\begin{array}{r}\text { Res } \\
\text { PRG }\end{array}$ \\
\hline Benz(a)anthracene & $2 / 3$ & $56 \mathrm{~J}$ & $59 \mathrm{~J}$ & Z2-EU34B-303 & 57.5 & 0 & NA & 0 \\
\hline Benzo(a)pyrene & $2 / 3$ & $56 \mathrm{~J}$ & $60 \mathrm{~J}$ & Z2-EU34B-305 & 58 & 0 & NA & 0 \\
\hline Benzo(b)fluoranthene & $2 / 3$ & $49 \mathrm{~J}$ & $55 \mathrm{~J}$ & Z2-EU34B-305 & 52 & 0 & NA & 0 \\
\hline Benzo(ghi)perylene & $2 / 3$ & $37 \mathrm{~J}$ & $45 \mathrm{~J}$ & Z2-EU34B-305 & 41 & 0 & NA & 0 \\
\hline Benzo(k)fluoranthene & $2 / 3$ & $55 \mathrm{~J}$ & $59 \mathrm{~J}$ & Z2-EU34B-303 & 57 & 0 & NA & 0 \\
\hline Chrysene & $2 / 3$ & $60 \mathrm{~J}$ & $61 \mathrm{~J}$ & Z2-EU34B-303 & 60.5 & 0 & NA & 0 \\
\hline Fluoranthene & $2 / 3$ & $98 \mathrm{~J}$ & $110 \mathrm{~J}$ & Z2-EU34B-303 & 104 & 0 & NA & 0 \\
\hline Phenanthrene & $2 / 3$ & $48 \mathrm{~J}$ & $58 \mathrm{~J}$ & Z2-EU34B-303 & 53 & 0 & NA & 0 \\
\hline Pyrene & $2 / 3$ & $88 \mathrm{~J}$ & $90 \mathrm{~J}$ & Z2-EU34B-303 & 89 & 0 & NA & 0 \\
\hline
\end{tabular}

$\mathrm{EU}=$ exposure unit $\quad \mathrm{PRG}=$ preliminary remediation goal

$\mathrm{GW}=$ groundwater $\quad$ Res $=$ residential

Ind $=$ industrial $\quad \mathrm{SL}=$ screening level

$\mathrm{NA}=$ not applicable $\quad \mathrm{SVOC}=$ semivolatile organic 
VOCs were analyzed for in one sample but were not detected.

\section{\begin{tabular}{|l|l} 
2.2.6 & ZONE 2 ROD APPENDIX A FFA SITES EVALUATION \\
\hline
\end{tabular}}

None

\begin{tabular}{|l|l|}
\hline 3.0 & \multicolumn{1}{|c}{ RISK EVALUATION AND ACTION/NO FURTHER ACTION DECISION } \\
\hline 3.1 & INTRODUCTION \\
\hline
\end{tabular}

In this section, data are evaluated in terms of the four decision rules presented in the Zone 2 RDR/RAWP, which include:

- Does the concentration of any Zone 2 contaminant of concern (COC) exceed its maximum RL?

- Does the mean concentration of any Zone 2 COC exceed its average RL across the EU?

- Does the EU pose a risk exceeding an industrial $1 \times 10^{-4}$ excess lifetime cancer risk (ELCR) or target organ hazard index (HI) of 1 ?

- Does the site pose a threat to groundwater based on MCL exceedances or soil RLs for protection of groundwater?

Table G.3 presents the results of comparing the data to Zone 2 soils RLs, Ind PRGs (set at an ELCR of $1 \times 10^{-5}$ or a HI of 1), and background levels. In addition, the EU summary in Sect. 2.2.5 presents an evaluation of the EU data by analyte group. The following table summarizes the conclusions for EU Z2-34.

\begin{tabular}{lccccc}
\hline EU \# & $\begin{array}{c}\text { Max RL } \\
\text { exceeded? }\end{array}$ & $\begin{array}{c}\text { Average RL over } \\
\text { EU exceeded? }\end{array}$ & $\begin{array}{c}\text { Industrial risk } \\
\text { above } \mathbf{1 \times 1 0 ^ { - 4 }} \boldsymbol{?}\end{array}$ & $\begin{array}{c}\text { Potential source } \\
\text { to groundwater? }\end{array}$ & $\begin{array}{c}\text { Action } \\
\text { required? }\end{array}$ \\
\hline $\mathrm{Z} 2-34$ & No & No & No & No & No \\
\hline $\begin{array}{l}\mathrm{EU}=\text { exposure unit } \\
\mathrm{RL}=\text { remediation level }\end{array}$ & & & & & \\
\end{tabular}

\section{\begin{tabular}{|l|l}
3.2 & DATA EVALUATION FOR THE ACTION /NO FURTHER ACTION DECISION
\end{tabular}}

Requirements for determining NFA in the Zone 2 EUs are stated in the protection goals of the Zone 2 ROD RAO. Four decision rules developed in the DVS DQOs state the specific criteria against which each EU must be compared to make the NFA decision. The four decision rules are presented in Sect. 3.2 of this PCCR and the manner in which the decision rule evaluations are conducted and special data handling requirements are discussed in Sect. 3.3 of this PCCR. In summary, the decision rule criteria for NFA are that each EU must meet each of the following compositional constraints:

- Zone 2 soils Max RLs - maximum allowable concentrations of the Zone 2 soils COCs. Zone 2 soils Max RLs are presented in the Zone 2 ROD and Table 5 of this PCCR.

- Zone 2 soils Avg RLs-limit on the allowable average concentrations of the Zone 2 soils COCs across an EU. Zone 2 soils Avg RLs are presented in the Zone 2 ROD and Table 5 of this PCCR.

- Cumulative risk across the EU - cumulative risk across an EU cannot exceed $1 \times 10^{-4}$ ELCR or HI of 1 . A stepwise evaluation of cumulative risk is performed by first comparing EU data to $1 \times 10^{-5}$ Ind PRGs. The $1 \times 10^{-5}$ Ind PRGs for the analytes required by the RDR/RAWP are presented in Table 5 of this PCCR.

- Groundwater protection goals - compositions of Zone 2 soils cannot pose a threat to groundwater. This evaluation is conducted by evaluating local groundwater monitoring results and comparing soils compositions to calculated SLs. Groundwater SLs are presented in Table 5 of this PCCR.

\section{\begin{tabular}{l|l} 
3.3 & SUMMARY AND CONCLUSIONS
\end{tabular}}

EU Z2-34

Max RL screening. Based on DVS sampling information and results of the Class 3 walkover assessment, no Zone 2 COCs were detected at concentrations in excess of maximum RLs. 
Avg RL screening. Based on analytical results from DVS biased sampling in EU Z2-34 and results of the Class 3 walkover assessment, no Zone 2 soils COCs are present with a mean concentration exceeding the Avg RL across the EU.

Risk evaluation. No $1 \times 10^{-5}$ industrial PRGs are exceeded in the biased samples except those for K-40, Ra-226, Th-228, and Th-232 (see PCCR Sect. 3.3.2 for a description of how these radionuclides are evaluated).

The industrial risk for EU Z2-34 is less than $1 \times 10^{-4}$ ELCR and target organ HI of 1 .

Threat to groundwater. There are no GW SL exceedances in EU Z2-34 soils and VOC MCL exceedances in local groundwater wells are attributed to sources derived from upgradient sources. Therefore, it is concluded there are no threats to groundwater from EU Z2-34 soils.

Qualitative risk screening for unrestricted use. There is a low probability that the acreage in EU Z2-34 could be released with no land use restrictions. Ind and Res PRG exceedances occur in the EU. Specific chemicals and radionuclides with criteria exceedances are presented in the EU summary in Sect. 2.2.5. An appropriate evaluation of residential risk should be conducted to make a definitive conclusion.

\begin{tabular}{|l|l|}
\hline 4.0 & \multicolumn{1}{|c|}{ RECOMMENDATION FOR ACTION/NO FURTHER ACTION } \\
\hline 4.1. & DECISION AND REMEDIATION ACTIVITIES \\
\hline
\end{tabular}

EU Z2-34: Based on results of the Class $3 \mathrm{SU}$ walkover assessment and analytical results of the DVS samples collected, the U.S. Department of Energy (DOE) recommends that No Further Action is appropriate under the Zone 2 ROD to meet industrial land use for the 13.2 acres of ETTP Zone 2 EU Z2-34. Because of the potential for encountering VOC vapors in soil from VOC-contaminated groundwater, DOE believes retaining the land use restriction below $10 \mathrm{ft}$ depth is warranted.

\begin{tabular}{|l|l|}
\hline 4.2 & EXCAVATION ACTIVITIES/CONFIRMATIONSAMPLING \\
\hline None
\end{tabular}

None 


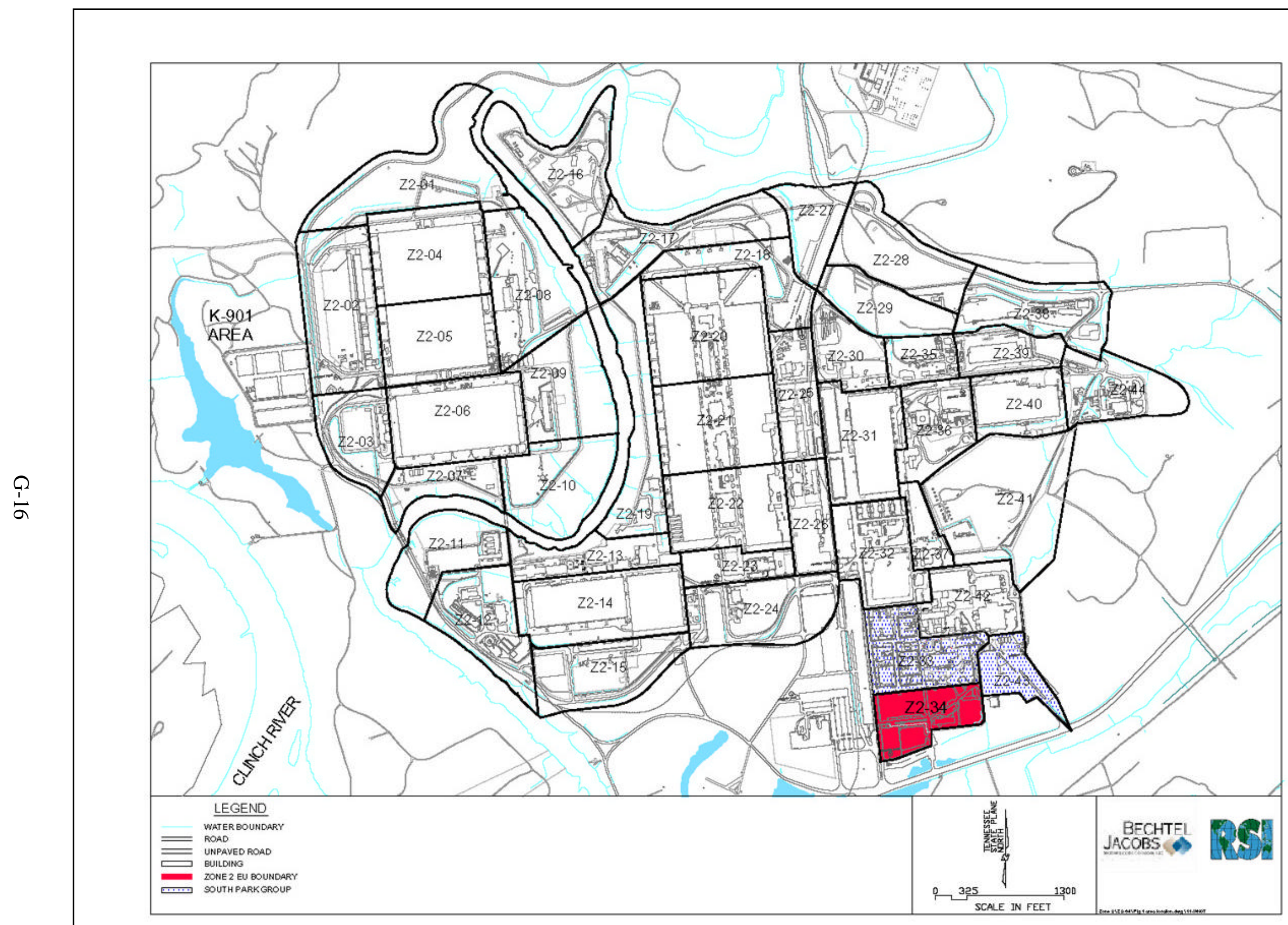

Fig. G.1. EU Z2-34 location map. 


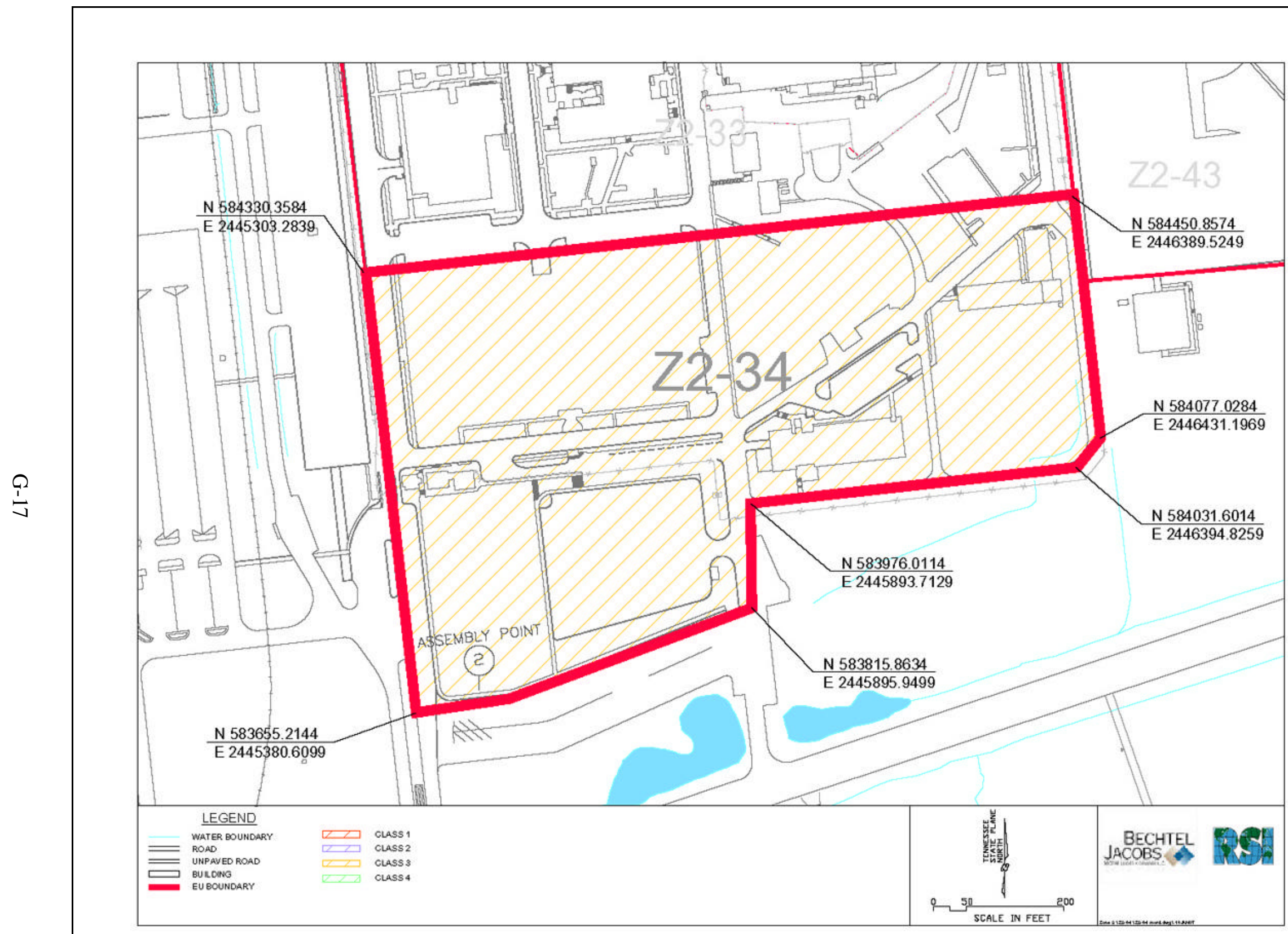

Fig. G.2. EU Z2-34 boundaries. 


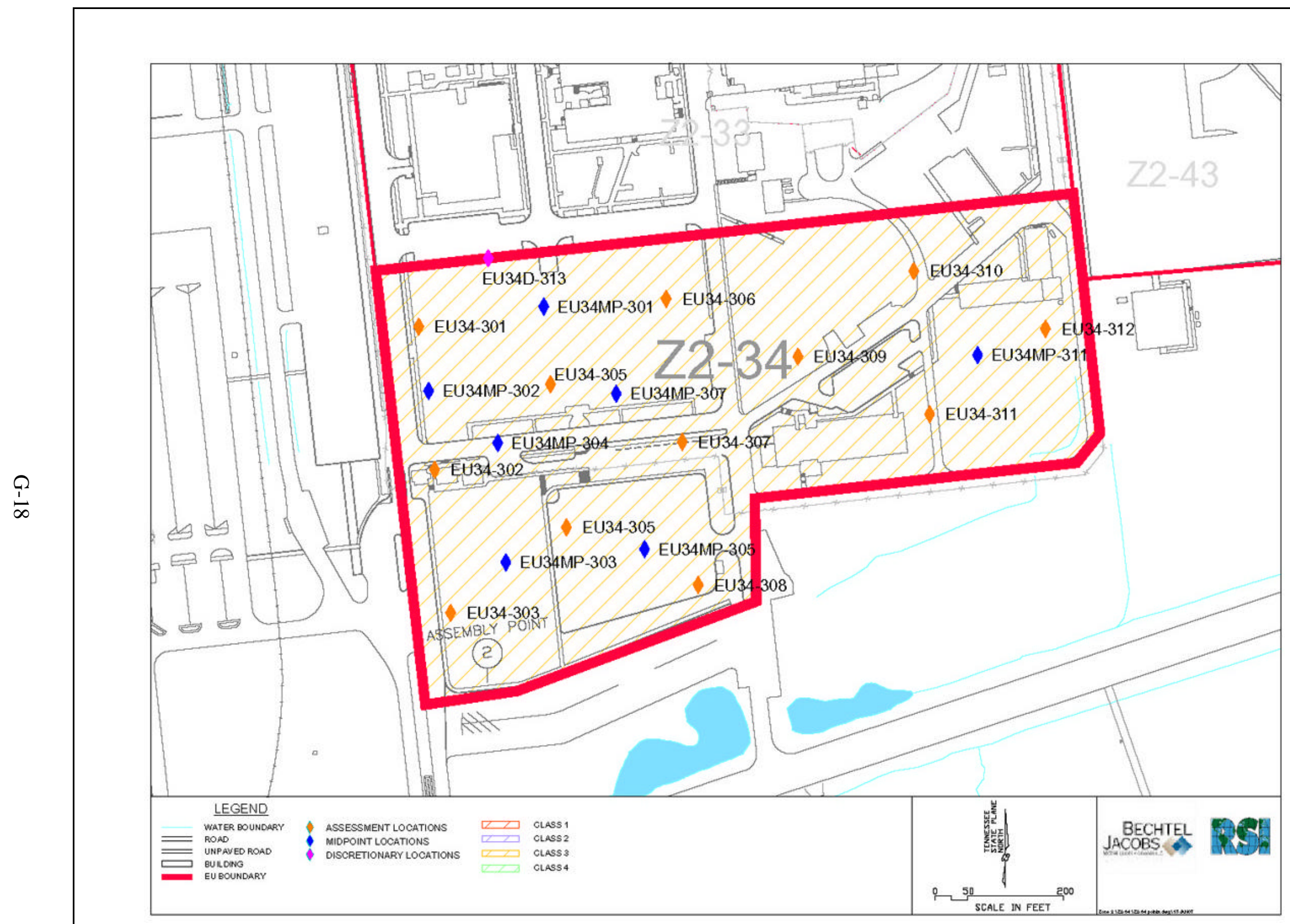

Fig. G.3. EU Z2-34 Class 3 and 4 SU walkover assessment locations. 


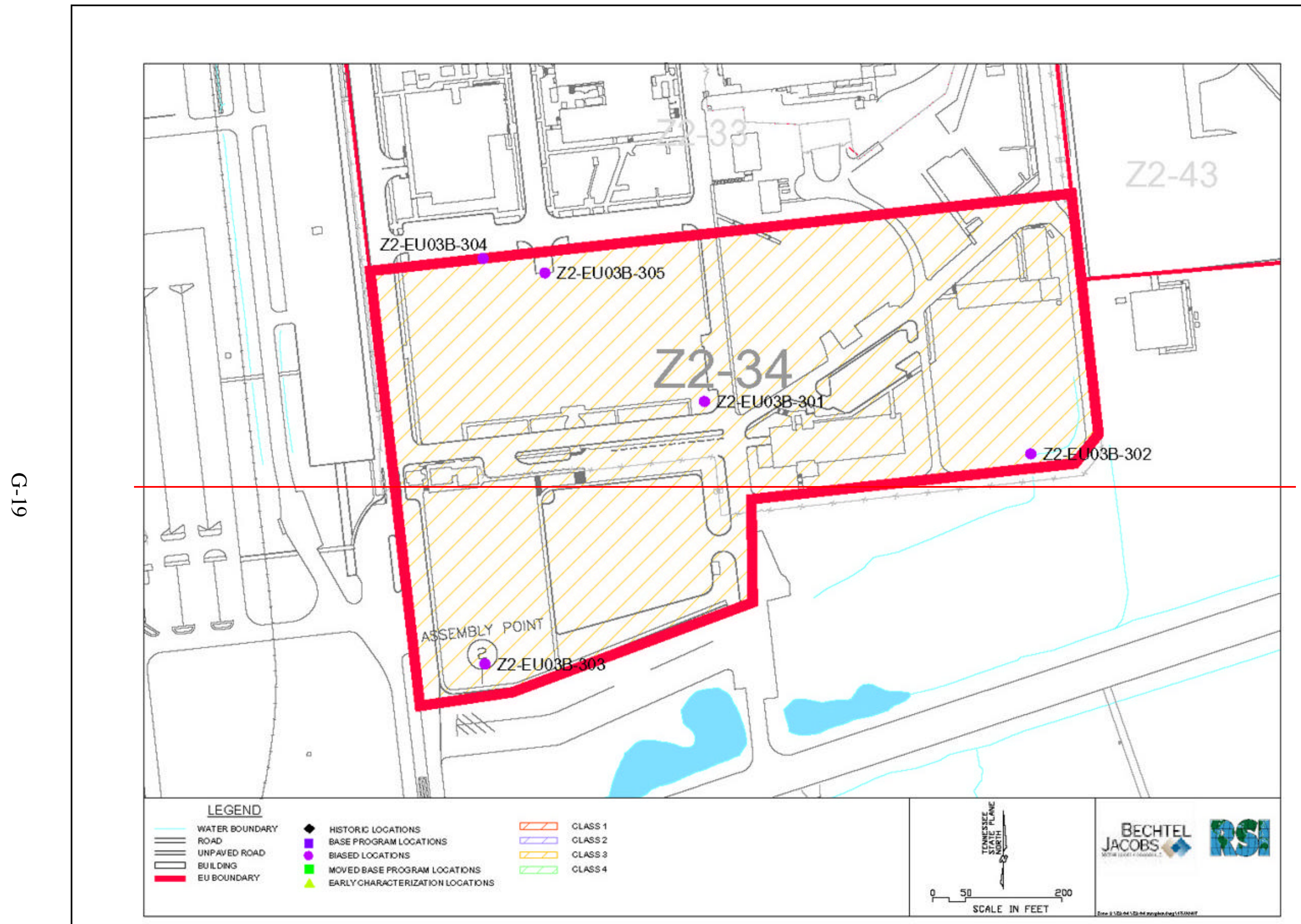

Fig. G.4. EU Z2-34 sample locations. 


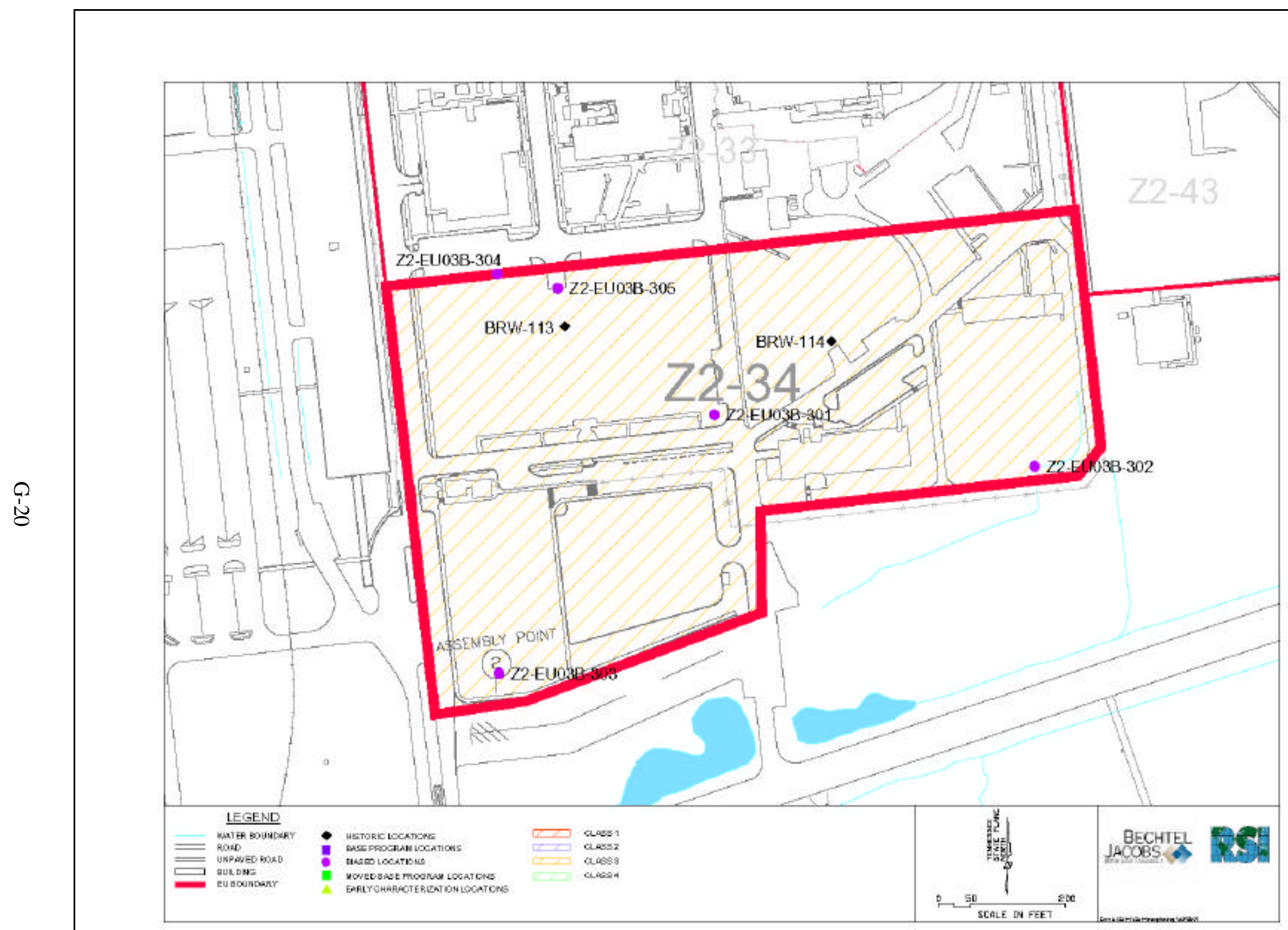

Fig. G.4. EU Z2-34 sample locations. 
Table G.1. EU Z2-34 Facility list

\begin{tabular}{lcc}
\hline \multicolumn{1}{c}{ Facility name DQO scoping } & Facility name & \multicolumn{2}{c}{ Facility assessed? } \\
\cline { 2 - 3 } K-1000 Visitors Center & $\mathrm{X}$ & No \\
K-1001 Administration Building & & $\mathrm{X}$ \\
K-1019-21 Bus Shelter & $\mathrm{X}$ & $\mathrm{X}$ \\
K-1028-57 Guard Portal & $\mathrm{X}$ & \\
K-1028-59 Guard Portal & $\mathrm{X}$ \\
K-1240-2C Parking Area & $\mathrm{X}$ & \\
K-1240-2D Parking Area & & $\mathrm{X}$ \\
K-1310-BY Storage Trailer & & \\
K-1320 Engineering Expansion Office & $\mathrm{X}$ & \\
Building & $\mathrm{X}$ & \\
K-1320-A Office Building & $\mathrm{X}$ & $\mathrm{X}$ \\
K-1543 Sanitary Water Meter & & $\mathrm{X}$ \\
K-1550-A Engineering Office Trailer & & $\mathrm{X}$ \\
K-1550-B Engineering Office Trailer & & $\mathrm{X}$ \\
K-1550-C Engineering Office Trailer & & $\mathrm{X}$ \\
K-1550-D Engineering Office Trailer & & $\mathrm{X}$ \\
K-1550-E Engineering Office Trailer & & $\mathrm{X}$ \\
K-1550-F Engineering Office Trailer & & $\mathrm{X}$ \\
K-1550-G Engineering Office Trailer & & $\mathrm{X}$ \\
K-1550-H Engineering Office Trailer & & \\
K-1550-I Engineering Office Trailer & & $\mathrm{X}$ \\
K-1580 Engineering Office Building & & \\
\hline
\end{tabular}

DQO = data quality objective

$\mathrm{EU}=$ exposure unit

FFA $=$ Federal Facility Agreement 
Table G.2. EU Z2-34 sample summary

\begin{tabular}{|c|c|c|c|c|c|c|c|c|c|c|c|c|c|c|}
\hline \multirow{2}{*}{$\begin{array}{l}\text { SU } \\
\text { class }\end{array}$} & \multirow[b]{2}{*}{ Location ID } & \multirow[b]{2}{*}{ Date sampled } & \multicolumn{2}{|c|}{ Location } & \multirow[b]{2}{*}{ Sample interval } & \multicolumn{3}{|c|}{ Screen } & \multicolumn{4}{|c|}{ Off-Site Laboratory } & \multirow{2}{*}{$\begin{array}{l}\text { Splits/ } \\
\text { Dups }\end{array}$} & \multirow[b]{2}{*}{ Comments and notes } \\
\hline & & & Northing & Easting & & RAD & VOC & Metals & PCB & RAD & SVOC & VOC & & \\
\hline 3 & Z2-EU34B-301 & $7 / 17 / 2006$ & 584127.8 & 2445821.1 & $\begin{array}{l}0-10 \mathrm{ft} \text {. Three-interval composite soil } 0-0.5,0-0.5,0-0.5,0.5-2 \text {, } \\
7.1-7.6 \text { and } 9.0-10.0 \mathrm{ft} \text {. }\end{array}$ & 1 & 1 & 1 & 1 & 1 & 1 & 1 & $\mathrm{D}$ & $\begin{array}{l}\text { Class } 3 \text { biased sample point; } \\
\text { RAD hit of } 229.4 \mathrm{cpm} \text { at } 8.25 \mathrm{ft}\end{array}$ \\
\hline 3 & Z2-EU34B-302 & 7/17/2006 & 584046.4 & 2446326.5 & 0-1 ft. One-point composite soil sample & & 1 & 1 & & 1 & & & & $\begin{array}{l}\text { Collect in low spot considered } \\
\text { to be the background location } \\
\text { south of K-1320 }\end{array}$ \\
\hline 3 & Z2-EU34B-303 & 7/17/2006 & 583720.0 & 2445481.3 & 0-1 ft. One-point composite sediment sample & & 1 & 1 & 1 & & 1 & & & $\begin{array}{l}\text { Collect in sediments in low spot } \\
\text { near Assembly Point } 2\end{array}$ \\
\hline 3 & Z2-EU34B-304 & 9/5/2006 & 584349.7 & 2445478.5 & $0-1 \mathrm{ft}$. Five-point composite soil sample & & 1 & & & 1 & & & & $\begin{array}{l}\text { Collect adjacent to straw bales } \\
\text { marked as RMA south of K- } \\
1006\end{array}$ \\
\hline 3 & Z2-EU34B-305 & 7/17/2006 & 584327.4 & 2445574.0 & $0-1 \mathrm{ft}$. One-point composite sediment sample & 1 & 1 & 1 & 1 & & 1 & & & $\begin{array}{l}\text { Collect in sediments } \\
\text { north-central portion of original } \\
\text { building footprint near the } \\
\text { former loading dock of K-1001 }\end{array}$ \\
\hline
\end{tabular}

\begin{tabular}{ll}
\hline DVS $=$ =ynnamic Verification Strategy & RMA $=$ Radioactive Material Area \\
EU $=$ exposure unit & SU $=$ soil unit \\
ID $=$ identification & SVOC $=$ semivolatile organic compound \\
PCB $=$ polychlorinated biphenyl & VOC $=$ volatile organic compound
\end{tabular}

DVS SAMPLING TOTALS

(1) " $\mathrm{B}$ " in sample number indicates a biased sample; " $\mathrm{M}$ " in sample number indicates moved more than $5 \mathrm{ft}$. from the original location

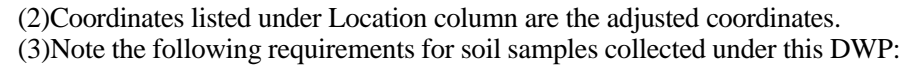

\begin{tabular}{|c|c|c|c|c|}
\hline Analyte & SW846 Method & Holding time in days & Containers & $\begin{array}{l}\text { Quantity } \\
\end{array}$ \\
\hline Metals & $6010 \mathrm{~B} / 7471 \mathrm{~A}$ & $180 / 28$ & 4-Oz wide-mouthed amber glass jar with Teflon-lined cap (or approved equivalent) & 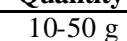 \\
\hline PCBs & 8082 & 14 & 4-oz wide-mouthed amber glass jar with Tefflon-lined cap (or approved equivalent) & $30 \mathrm{~g}$ \\
\hline RAD & HASL-3000 & 180 & 8-oz amber glass (or approved equivalent) & $100-500 \mathrm{~g}$ \\
\hline $\begin{array}{l}\text { SVOCs } \\
\text { vors }\end{array}$ & $\begin{array}{l}8270 \\
820 \mathrm{~B}\end{array}$ & 14 & 4-oz wide-mouthed glass jar with Teflon-lined cap (or approved equivalent) & $30 \mathrm{~g}$ \\
\hline VOCs & & & 4-oz wide-mouthed glass jar with septum, Teflon-lined cap (or approved equivalent) & $15 \mathrm{~g}$ \\
\hline
\end{tabular}

(4)Standard radiological analysis includes alpha spec, gamma spec, and technetium-99. 
Table G.3. EU Z2-34, depth 0-10 ft

\begin{tabular}{|c|c|c|c|c|c|c|c|c|c|c|c|c|c|}
\hline Analyte & $\begin{array}{r}\text { Frequency } \\
\text { of detect }\end{array}$ & $\begin{array}{c}\text { Minimum } \\
\text { detect }\end{array}$ & $\begin{array}{c}\text { Maximum } \\
\text { detect }\end{array}$ & $\begin{array}{c}\text { Location(s) } \\
\text { of maximum } \\
\text { detected result }\end{array}$ & $\begin{array}{c}\text { Average } \\
\text { detected } \\
\text { result }\end{array}$ & $\begin{array}{c}\text { Max } \\
\text { RL }\end{array}$ & $\begin{array}{c}\text { Frequency } \\
\text { of detects } \\
\text { exceeding } \\
\text { Max RL }\end{array}$ & $\begin{array}{l}\text { Avg } \\
\text { RL }\end{array}$ & $\begin{array}{c}\text { Frequency } \\
\text { of detects } \\
\text { exceeding } \\
\text { Avg RL } \\
\end{array}$ & $\begin{array}{l}\text { PRG limit } \\
\left(10^{-5} \text { or } 1\right)\end{array}$ & $\begin{array}{c}\text { Frequency } \\
\text { of detects } \\
\text { exceeding } \\
\text { PRG limit } \\
\end{array}$ & $\begin{array}{c}\text { Background } \\
\text { concentration }\end{array}$ & $\begin{array}{c}\text { Frequency } \\
\text { of detects } \\
\text { exceeding } \\
\text { background }\end{array}$ \\
\hline \multicolumn{14}{|l|}{ Inorganics $(\mathrm{mg} / \mathbf{k g})$} \\
\hline Aluminum & $4 / 4$ & $9,040 \mathrm{~J}$ & $13,300 \mathrm{~J}$ & Z2-EU34B-301 & 11,160 & & NA & & NA & $1.00 \mathrm{E}+05$ & $0 / 4$ & 40,300 & $0 / 4$ \\
\hline Antimony & $2 / 4$ & $0.2 \mathrm{~J}$ & $0.2 \mathrm{~J}$ & $\begin{array}{l}\text { Z2-EU34B-302 } \\
\text { Z2-EU34B-303 }\end{array}$ & 0.2 & & NA & & NA & $4.10 \mathrm{E}+02$ & $0 / 4$ & 1.52 & $0 / 4$ \\
\hline Arsenic & $4 / 4$ & $3.1 \mathrm{~J}$ & $6.5 \mathrm{~J}$ & Z2-EU34B-303 & 5 & 900 & $0 / 4$ & 300 & $0 / 4$ & $1.60 \mathrm{E}+01$ & $0 / 4$ & 14.95 & $0 / 4$ \\
\hline Barium & $4 / 4$ & 82.1 & 117 & Z2-EU34B-303 & 102.75 & & NA & & NA & $6.70 \mathrm{E}+04$ & $0 / 4$ & 124.93 & $0 / 4$ \\
\hline Beryllium & $4 / 4$ & 0.58 & 1.7 & Z2-EU34B-301 & 0.98 & 6,000 & $0 / 4$ & 2,000 & $0 / 4$ & $1.90 \mathrm{E}+03$ & $0 / 4$ & 2.2 & $0 / 4$ \\
\hline Boron & $0 / 4$ & ND & ND & & ND & & NA & & NA & $1.00 \mathrm{E}+05$ & $0 / 4$ & & NA \\
\hline Cadmium & $4 / 4$ & $0.082 \mathrm{~J}$ & 0.19 & Z2-EU34B-303 & 0.15 & & NA & & NA & $4.50 \mathrm{E}+02$ & $0 / 4$ & $0.22 \mathrm{U}$ & $0 / 4$ \\
\hline Calcium & $4 / 4$ & $1670 \mathrm{~J}$ & $14,000 \mathrm{~J}$ & Z2-EU34B-303 & 8,805 & & NA & & NA & & NA & 2400 & $3 / 4$ \\
\hline Chromium & $4 / 4$ & $10.4 \mathrm{~J}$ & $20.8 \mathrm{~J}$ & Z2-EU34B-301 & 17.18 & & NA & & NA & $6.40 \mathrm{E}+02$ & $0 / 4$ & 44.88 & $0 / 4$ \\
\hline Cobalt & $4 / 4$ & $7.6 \mathrm{~J}$ & $36.7 \mathrm{~J}$ & Z2-EU34B-301 & 20.68 & & NA & & NA & $1.30 \mathrm{E}+04$ & $0 / 4$ & 42 & $0 / 4$ \\
\hline Copper & $4 / 4$ & $4.8 \mathrm{~J}$ & $15.3 \mathrm{~J}$ & Z2-EU34B-302 & 11.68 & & NA & & NA & $4.10 \mathrm{E}+04$ & $0 / 4$ & 22.48 & $0 / 4$ \\
\hline Iron & $4 / 4$ & 10,900 & 30,800 & Z2-EU34B-301 & 22,700 & & NA & & NA & $1.00 \mathrm{E}+05$ & $0 / 4$ & 58,600 & $0 / 4$ \\
\hline Lead & $4 / 4$ & $17.4 \mathrm{~J}$ & $41.9 \mathrm{~J}$ & Z2-EU34B-302 & 32.7 & & NA & & NA & $8.00 \mathrm{E}+02$ & $0 / 4$ & 37.91 & $1 / 4$ \\
\hline Lithium & $4 / 4$ & $5.1 \mathrm{~J}$ & 19.6 & Z2-EU34B-301 & 12 & & NA & & NA & $2.00 \mathrm{E}+04$ & $0 / 4$ & 48.94 & $0 / 4$ \\
\hline Magnesium & $4 / 4$ & $673 \mathrm{~J}$ & $7190 \mathrm{~J}$ & Z2-EU34B-303 & $3,785.75$ & & NA & & NA & & NA & 3,300 & $2 / 4$ \\
\hline Manganese & $4 / 4$ & 1,010 & 1710 & Z2-EU34B-303 & 1420 & & NA & & NA & $1.90 \mathrm{E}+04$ & $0 / 4$ & 2,200 & $0 / 4$ \\
\hline Mercury & $1 / 4$ & 0.098 & 0.098 & Z2-EU34B-302 & 0.1 & 1,800 & $0 / 4$ & 600 & $0 / 4$ & $3.10 \mathrm{E}+02$ & $0 / 4$ & 0.17 & $0 / 4$ \\
\hline Molybdenum & $4 / 4$ & $0.54 \mathrm{~J}$ & $1.1 \mathrm{~J}$ & Z2-EU34B-303 & 0.78 & & NA & & NA & $5.10 \mathrm{E}+03$ & $0 / 4$ & & NA \\
\hline Nickel & $4 / 4$ & 6.3 & 27.9 & Z2-EU34B-302 & 18.38 & & NA & & NA & $2.00 \mathrm{E}+04$ & $0 / 4$ & 26.07 & $2 / 4$ \\
\hline Potassium & $4 / 4$ & 822 & 1350 & Z2-EU34B-301 & $1,089.25$ & & NA & & NA & & NA & $5,074.69$ & $0 / 4$ \\
\hline Selenium & $0 / 4$ & ND & ND & & ND & & NA & & NA & $5.10 \mathrm{E}+03$ & $0 / 4$ & 1.47 & $0 / 4$ \\
\hline Silver & $4 / 4$ & $0.057 \mathrm{~J}$ & $0.14 \mathrm{~J}$ & Z2-EU34B-302 & 0.11 & & NA & & NA & $5.10 \mathrm{E}+03$ & $0 / 4$ & $0.6 \mathrm{U}$ & $0 / 4$ \\
\hline Sodium & $3 / 4$ & 41.3 & 48.9 & Z2-EU34B-301 & 45.4 & & NA & & NA & & NA & 497 & $0 / 4$ \\
\hline Thallium & $0 / 4$ & ND & ND & & ND & & NA & & NA & $6.70 \mathrm{E}+01$ & $0 / 4$ & $0.4 \mathrm{U}$ & $0 / 4$ \\
\hline Uranium & $4 / 4$ & 0.59 & 1.9 & Z2-EU34B-302 & 1.15 & & NA & & NA & $2.00 \mathrm{E}+02$ & $0 / 4$ & & NA \\
\hline Vanadium & $4 / 4$ & $16.9 \mathrm{~J}$ & $26.1 \mathrm{~J}$ & Z2-EU34B-303 & 22.78 & & NA & & NA & $1.00 \mathrm{E}+03$ & $0 / 4$ & 65.47 & $0 / 4$ \\
\hline Zinc & $4 / 4$ & $31 \mathrm{~J}$ & $46.3 \mathrm{~J}$ & Z2-EU34B-301 & 41.2 & & NA & & NA & $1.00 \mathrm{E}+05$ & $0 / 4$ & 89.7 & $0 / 4$ \\
\hline
\end{tabular}




\begin{tabular}{|c|c|c|c|c|c|c|c|c|c|c|c|c|}
\hline \multicolumn{13}{|c|}{ Table G.3. (continued) } \\
\hline $\begin{array}{c}\text { Frequency } \\
\text { of detect }\end{array}$ & $\begin{array}{c}\text { Minimum } \\
\text { detect }\end{array}$ & $\begin{array}{c}\text { Maximum } \\
\text { detect }\end{array}$ & $\begin{array}{c}\text { Location(s) } \\
\text { of maximum } \\
\text { detected result }\end{array}$ & $\begin{array}{c}\text { Average } \\
\text { detected } \\
\text { result }\end{array}$ & $\begin{array}{c}\text { Max } \\
\text { RL }\end{array}$ & $\begin{array}{c}\text { Frequency } \\
\text { of detects } \\
\text { exceeding } \\
\text { Max RL } \\
\end{array}$ & $\begin{array}{l}\text { Avg } \\
\text { RL }\end{array}$ & $\begin{array}{c}\text { Frequency } \\
\text { of detects } \\
\text { exceeding } \\
\text { Avg RL } \\
\end{array}$ & $\begin{array}{l}\text { PRG limit } \\
\left(10^{-5} \text { or } 1\right)\end{array}$ & 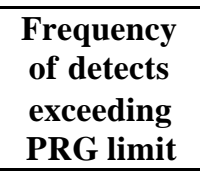 & $\begin{array}{c}\text { Background } \\
\text { concentration }\end{array}$ & $\begin{array}{c}\text { Frequency } \\
\text { of detects } \\
\text { exceeding } \\
\text { background }\end{array}$ \\
\hline $3 / 3$ & 12.4 & 33 & Z2-EU34B-302 & 21.8 & & $\mathrm{NA}$ & & $\mathrm{NA}$ & & NA & & NA \\
\hline $3 / 3$ & 18.4 & 37.7 & Z2-EU34B-302 & 27.73 & & NA & & NA & & $\mathrm{NA}$ & & NA \\
\hline $2 / 3$ & 0.162 & 0.233 & Z2-EU34B-304 & 0.2 & 20 & $0 / 3$ & 2 & $0 / 3$ & $1.10 \mathrm{E}+00$ & $0 / 3$ & & NA \\
\hline $0 / 3$ & $\mathrm{ND}$ & $\mathrm{ND}$ & & $\mathrm{ND}$ & & $\mathrm{NA}$ & & $\mathrm{NA}$ & $6.00 \mathrm{E}-01$ & $0 / 3$ & & $\mathrm{NA}$ \\
\hline $0 / 3$ & $\mathrm{ND}$ & $\mathrm{ND}$ & & $\mathrm{ND}$ & 50 & $0 / 3$ & 5 & $0 / 3$ & $2.70 \mathrm{E}+00$ & $0 / 3$ & & $\mathrm{NA}$ \\
\hline $3 / 3$ & 5.6 & 21 & Z2-EU34B-301 & 14.67 & & NA & & NA & $2.70 \mathrm{E}+00$ & $3 / 3$ & 32.12 & $0 / 3$ \\
\hline $3 / 3$ & 0.08 & 0.35 & Z2-EU34B-304 & 0.23 & 15 & $0 / 3$ & 5 & $0 / 3$ & & NA & & NA \\
\hline $3 / 3$ & 0.85 & 1.33 & Z2-EU34B-301 & 1.03 & 15 & $\mathrm{NA}^{a}$ & 5 & $\mathrm{NA}^{a}$ & $2.60 \mathrm{E}-01$ & $3 / 3$ & 1.25 & $1 / 3$ \\
\hline $1 / 3$ & 1.26 & 1.26 & Z2-EU34B-302 & 1.26 & & NA & & NA & $8.90 \mathrm{E}+03$ & $0 / 3$ & & NA \\
\hline $3 / 3$ & 1.21 & 1.52 & Z2-EU34B-301 & 1.37 & & $\mathrm{NA}$ & & $\mathrm{NA}$ & $1.70 \mathrm{E}-01$ & $3 / 3^{b}$ & 1.86 & $0 / 3$ \\
\hline $3 / 3$ & 1.23 & 1.55 & Z2-EU34B-304 & 1.42 & 15 & $\mathrm{NA}^{a}$ & 5 & $\mathrm{NA}^{a}$ & $2.10 \mathrm{E}+02$ & $0 / 3$ & 1.2 & $3 / 3$ \\
\hline $3 / 3$ & 1.04 & 1.51 & Z2-EU34B-302 & 1.31 & 15 & $\mathrm{NA}^{a}$ & 5 & $\mathrm{NA}^{a}$ & $1.70 \mathrm{E}-01$ & $3 / 3^{b}$ & 1.95 & $0 / 3$ \\
\hline $3 / 3$ & 1.09 & 2.31 & Z2-EU34B-302 & 1.87 & 7,000 & $0 / 3$ & 700 & $0 / 3$ & $3.30 \mathrm{E}+02$ & $0 / 3$ & & NA \\
\hline $2 / 3$ & 0.066 & 0.24 & Z2-EU34B-302 & 0.15 & 80 & $0 / 3$ & 8 & $0 / 3$ & $3.90 \mathrm{E}+00$ & $0 / 3$ & & $\mathrm{NA}$ \\
\hline $3 / 3$ & 1.04 & 1.5 & Z2-EU34B-302 & 1.28 & 500 & $0 / 3$ & 50 & $0 / 3$ & $1.80 \mathrm{E}+01$ & $0 / 3$ & 1.47 & $1 / 3$ \\
\hline \multicolumn{13}{|c|}{ Organics, Pesticides, and PCBs (ug/kg) } \\
\hline $0 / 3$ & $\mathrm{ND}$ & ND & & ND & 100,000 & $0 / 3$ & 10,000 & $0 / 3$ & $3.70 \mathrm{E}+04$ & $0 / 3$ & & NA \\
\hline $0 / 3$ & ND & ND & & ND & 100,000 & $0 / 3$ & 10,000 & $0 / 3$ & $7.40 \mathrm{E}+03$ & $0 / 3$ & & NA \\
\hline $0 / 3$ & $\mathrm{ND}$ & $\mathrm{ND}$ & & ND & 100,000 & $0 / 3$ & 10,000 & $0 / 3$ & $7.40 \mathrm{E}+03$ & $0 / 3$ & & $\mathrm{NA}$ \\
\hline $0 / 3$ & ND & ND & & ND & 100,000 & $0 / 3$ & 10,000 & $0 / 3$ & $7.40 \mathrm{E}+03$ & $0 / 3$ & & NA \\
\hline $0 / 3$ & $\mathrm{ND}$ & $\mathrm{ND}$ & & ND & 100,000 & $0 / 3$ & 10,000 & $0 / 3$ & $7.40 \mathrm{E}+03$ & $0 / 3$ & & NA \\
\hline $0 / 3$ & $\mathrm{ND}$ & $\mathrm{ND}$ & & $\mathrm{ND}$ & 100,000 & $0 / 3$ & 10,000 & $0 / 3$ & $7.40 \mathrm{E}+03$ & $0 / 3$ & & NA \\
\hline $0 / 3$ & ND & $\mathrm{ND}$ & & ND & 100,000 & $0 / 3$ & 10,000 & $0 / 3$ & $7.40 \mathrm{E}+03$ & $0 / 3$ & & NA \\
\hline $0 / 3$ & ND & ND & & ND & 100,000 & $0 / 3$ & 10,000 & $0 / 3$ & $7.40 \mathrm{E}+03$ & $0 / 3$ & & $\mathrm{NA}$ \\
\hline \multicolumn{13}{|c|}{ Semivolatile Organics (ug/kg) } \\
\hline $0 / 3$ & ND & ND & & ND & & NA & & NA & $2.20 \mathrm{E}+05$ & $0 / 3$ & & NA \\
\hline $0 / 3$ & ND & $\mathrm{ND}$ & & $\mathrm{ND}$ & & $\mathrm{NA}$ & & $\mathrm{NA}$ & $6.00 \mathrm{E}+05$ & $0 / 3$ & & $\mathrm{NA}$ \\
\hline $0 / 3$ & ND & ND & & ND & & $\mathrm{NA}$ & & NA & $6.00 \mathrm{E}+05$ & $0 / 3$ & & $\mathrm{NA}$ \\
\hline
\end{tabular}




\begin{tabular}{|c|c|c|c|c|c|c|c|c|c|c|c|c|c|}
\hline \multicolumn{14}{|c|}{ Table G.3. (continued) } \\
\hline Analyte & $\begin{array}{c}\text { Frequency } \\
\text { of detect }\end{array}$ & $\begin{array}{c}\text { Minimum } \\
\text { detect }\end{array}$ & $\begin{array}{c}\text { Maximum } \\
\text { detect }\end{array}$ & $\begin{array}{c}\text { Location(s) } \\
\text { of maximum } \\
\text { detected result }\end{array}$ & $\begin{array}{c}\text { Average } \\
\text { detected } \\
\text { result }\end{array}$ & $\begin{array}{c}\text { Max } \\
\text { RL }\end{array}$ & $\begin{array}{c}\text { Frequency } \\
\text { of detects } \\
\text { exceeding } \\
\text { Max RL } \\
\end{array}$ & $\begin{array}{l}\text { Avg } \\
\text { RL }\end{array}$ & 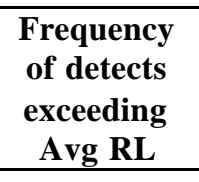 & $\begin{array}{l}\text { PRG limit } \\
\left(10^{-5} \text { or } 1\right)\end{array}$ & 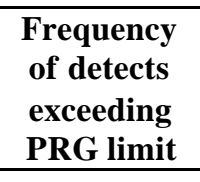 & $\begin{array}{c}\text { Background } \\
\text { concentration }\end{array}$ & $\begin{array}{c}\text { Frequency } \\
\text { of detects } \\
\text { exceeding } \\
\text { background }\end{array}$ \\
\hline 2,4,5-Trichlorophenol & $0 / 3$ & $\mathrm{ND}$ & $\mathrm{ND}$ & & $\mathrm{ND}$ & & $\mathrm{NA}$ & & $\mathrm{NA}$ & $6.20 \mathrm{E}+07$ & $0 / 3$ & & $\mathrm{NA}$ \\
\hline 2,4,6-Trichlorophenol & $0 / 3$ & ND & $\mathrm{ND}$ & & ND & & NA & & NA & $6.20 \mathrm{E}+04$ & $0 / 3$ & & NA \\
\hline 2,4-Dichlorophenol & $0 / 3$ & $\mathrm{ND}$ & $\mathrm{ND}$ & & ND & & NA & & NA & $1.80 \mathrm{E}+06$ & $0 / 3$ & & NA \\
\hline 2,4-Dimethylphenol & $0 / 3$ & $\mathrm{ND}$ & $\mathrm{ND}$ & & $\mathrm{ND}$ & & $\mathrm{NA}$ & & $\mathrm{NA}$ & $1.20 \mathrm{E}+07$ & $0 / 3$ & & $\mathrm{NA}$ \\
\hline 2,4-Dinitrotoluene & $0 / 3$ & $\mathrm{ND}$ & $\mathrm{ND}$ & & $\mathrm{ND}$ & & $\mathrm{NA}$ & & $\mathrm{NA}$ & $2.50 \mathrm{E}+04$ & $0 / 3$ & & $\mathrm{NA}$ \\
\hline 2,6-Dinitrotoluene & $0 / 3$ & $\mathrm{ND}$ & ND & & $\mathrm{ND}$ & & NA & & NA & $2.50 \mathrm{E}+04$ & $0 / 3$ & & NA \\
\hline 2-Chloronaphthalene & $0 / 3$ & ND & $\mathrm{ND}$ & & ND & & NA & & NA & $2.30 \mathrm{E}+07$ & $0 / 3$ & & NA \\
\hline 2-Chlorophenol & $0 / 3$ & $\mathrm{ND}$ & $\mathrm{ND}$ & & $\mathrm{ND}$ & & $\mathrm{NA}$ & & $\mathrm{NA}$ & $2.40 \mathrm{E}+05$ & $0 / 3$ & & $\mathrm{NA}$ \\
\hline 2-Methyl-4,6-dinitrophenol & $0 / 3$ & $\mathrm{ND}$ & $\mathrm{ND}$ & & $\mathrm{ND}$ & & $\mathrm{NA}$ & & NA & $6.20 \mathrm{E}+04$ & $0 / 3$ & & $\mathrm{NA}$ \\
\hline 2-Methylnaphthalene & $0 / 3$ & $\mathrm{ND}$ & $\mathrm{ND}$ & & $\mathrm{ND}$ & & $\mathrm{NA}$ & & $\mathrm{NA}$ & $1.90 \mathrm{E}+05$ & $0 / 3$ & & $\mathrm{NA}$ \\
\hline 2-Methylphenol & $0 / 3$ & ND & $\mathrm{ND}$ & & $\mathrm{ND}$ & & $\mathrm{NA}$ & & $\mathrm{NA}$ & $3.10 \mathrm{E}+07$ & $0 / 3$ & & $\mathrm{NA}$ \\
\hline 2-Nitrobenzenamine & $0 / 3$ & $\mathrm{ND}$ & $\mathrm{ND}$ & & ND & & $\mathrm{NA}$ & & $\mathrm{NA}$ & $1.80 \mathrm{E}+06$ & $0 / 3$ & & $\mathrm{NA}$ \\
\hline 3,3'-Dichlorobenzidine & $0 / 3$ & $\mathrm{ND}$ & $\mathrm{ND}$ & & $\mathrm{ND}$ & & NA & & NA & $3.80 \mathrm{E}+04$ & $0 / 3$ & & NA \\
\hline 3-Nitrobenzenamine & $0 / 3$ & $\mathrm{ND}$ & $\mathrm{ND}$ & & $\mathrm{ND}$ & & $\mathrm{NA}$ & & $\mathrm{NA}$ & $1.80 \mathrm{E}+05$ & $0 / 3$ & & $\mathrm{NA}$ \\
\hline 4-Bromophenyl phenyl ether & $0 / 3$ & ND & $\mathrm{ND}$ & & $\mathrm{ND}$ & & NA & & NA & & NA & & NA \\
\hline 4-Chloro-3-methylphenol & $0 / 3$ & $\mathrm{ND}$ & $\mathrm{ND}$ & & $\mathrm{ND}$ & & $\mathrm{NA}$ & & $\mathrm{NA}$ & & NA & & NA \\
\hline 4-Chlorobenzenamine & $0 / 3$ & ND & ND & & $\mathrm{ND}$ & & NA & & NA & $2.50 \mathrm{E}+06$ & $0 / 3$ & & NA \\
\hline 4-Chlorophenyl phenyl ether & $0 / 3$ & $\mathrm{ND}$ & ND & & ND & & NA & & NA & & NA & & NA \\
\hline 4-Methylphenol & $0 / 3$ & $\mathrm{ND}$ & $\mathrm{ND}$ & & $\mathrm{ND}$ & & $\mathrm{NA}$ & & $\mathrm{NA}$ & $3.10 \mathrm{E}+06$ & $0 / 3$ & & $\mathrm{NA}$ \\
\hline 4-Nitrobenzenamine & $0 / 3$ & ND & $\mathrm{ND}$ & & ND & & NA & & NA & $8.20 \mathrm{E}+05$ & $0 / 3$ & & NA \\
\hline 4-Nitrophenol & $0 / 3$ & $\mathrm{ND}$ & $\mathrm{ND}$ & & $\mathrm{ND}$ & & $\mathrm{NA}$ & & $\mathrm{NA}$ & & $\mathrm{NA}$ & & NA \\
\hline Acenaphthene & $0 / 3$ & ND & $\mathrm{ND}$ & & ND & & NA & & NA & $2.90 \mathrm{E}+07$ & $0 / 3$ & & NA \\
\hline Acenaphthylene & $0 / 3$ & ND & $\mathrm{ND}$ & & ND & & NA & & NA & $2.90 \mathrm{E}+07$ & $0 / 3$ & & NA \\
\hline Aniline & $0 / 3$ & $\mathrm{ND}$ & $\mathrm{ND}$ & & ND & & $\mathrm{NA}$ & & $\mathrm{NA}$ & $3.00 \mathrm{E}+06$ & $0 / 3$ & & $\mathrm{NA}$ \\
\hline Anthracene & $0 / 3$ & ND & ND & & $\mathrm{ND}$ & & NA & & NA & $1.00 \mathrm{E}+08$ & $0 / 3$ & & NA \\
\hline Benz(a)anthracene & $2 / 3$ & $56 \mathrm{~J}$ & $59 \mathrm{~J}$ & Z2-EU34B-303 & 57.5 & & $\mathrm{NA}$ & & $\mathrm{NA}$ & $2.10 \mathrm{E}+04$ & $0 / 3$ & & $\mathrm{NA}$ \\
\hline Benzenemethanol & $0 / 3$ & ND & $\mathrm{ND}$ & & $\mathrm{ND}$ & & NA & & NA & $1.00 \mathrm{E}+08$ & $0 / 3$ & & NA \\
\hline Benzo(a)pyrene & $2 / 3$ & $56 \mathrm{~J}$ & $60 \mathrm{~J}$ & Z2-EU34B-305 & 58 & & $\mathrm{NA}$ & & NA & $2.10 \mathrm{E}+03$ & $0 / 3$ & & $\mathrm{NA}$ \\
\hline
\end{tabular}




\begin{tabular}{|c|c|c|c|c|c|c|c|c|c|c|c|c|c|}
\hline \multicolumn{14}{|c|}{ Table G.3. (continued) } \\
\hline Analyte & $\begin{array}{c}\text { Frequency } \\
\text { of detect }\end{array}$ & $\begin{array}{c}\text { Minimum } \\
\text { detect }\end{array}$ & $\begin{array}{c}\text { Maximum } \\
\text { detect }\end{array}$ & $\begin{array}{c}\text { Location(s) } \\
\text { of maximum } \\
\text { detected result }\end{array}$ & $\begin{array}{c}\text { Average } \\
\text { detected } \\
\text { result }\end{array}$ & $\begin{array}{c}\text { Max } \\
\text { RL }\end{array}$ & $\begin{array}{c}\text { Frequency } \\
\text { of detects } \\
\text { exceeding } \\
\text { Max RL } \\
\end{array}$ & $\begin{array}{l}\text { Avg } \\
\text { RL }\end{array}$ & 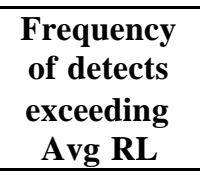 & $\begin{array}{l}\text { PRG limit } \\
\left(10^{-5} \text { or } 1\right)\end{array}$ & 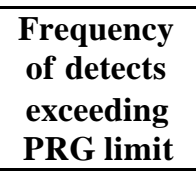 & $\begin{array}{c}\text { Background } \\
\text { concentration }\end{array}$ & $\begin{array}{c}\text { Frequency } \\
\text { of detects } \\
\text { exceeding } \\
\text { background }\end{array}$ \\
\hline Benzo(k)fluoranthene & $2 / 3$ & $55 \mathrm{~J}$ & $59 \mathrm{~J}$ & Z2-EU34B-303 & 57 & & $\mathrm{NA}$ & & $\mathrm{NA}$ & $2.10 \mathrm{E}+05$ & $0 / 3$ & & $\mathrm{NA}$ \\
\hline Benzoic acid & $0 / 3$ & $\mathrm{ND}$ & $\mathrm{ND}$ & & $\mathrm{ND}$ & & NA & & $\mathrm{NA}$ & $1.00 \mathrm{E}+08$ & $0 / 3$ & & $\mathrm{NA}$ \\
\hline Bis(2-chloroethoxy)methane & $0 / 3$ & $\mathrm{ND}$ & ND & & ND & & NA & & NA & & NA & & NA \\
\hline Bis(2-chloroethyl) ether & $0 / 3$ & $\mathrm{ND}$ & $\mathrm{ND}$ & & $\mathrm{ND}$ & & $\mathrm{NA}$ & & $\mathrm{NA}$ & $5.80 \mathrm{E}+03$ & $0 / 3$ & & $\mathrm{NA}$ \\
\hline Bis(2-chloroisopropyl) ether & $0 / 3$ & $\mathrm{ND}$ & ND & & $\mathrm{ND}$ & & NA & & NA & $7.40 \mathrm{E}+04$ & $0 / 3$ & & NA \\
\hline Bis(2-ethylhexyl)phthalate & $0 / 3$ & $\mathrm{ND}$ & $\mathrm{ND}$ & & $\mathrm{ND}$ & & NA & & NA & $1.20 \mathrm{E}+06$ & $0 / 3$ & & NA \\
\hline Butyl benzyl phthalate & $0 / 3$ & $\mathrm{ND}$ & $\mathrm{ND}$ & & $\mathrm{ND}$ & & $\mathrm{NA}$ & & $\mathrm{NA}$ & $1.00 \mathrm{E}+08$ & $0 / 3$ & & $\mathrm{NA}$ \\
\hline Carbazole & $0 / 3$ & ND & ND & & ND & & $\mathrm{NA}$ & & $\mathrm{NA}$ & $8.60 \mathrm{E}+05$ & $0 / 3$ & & $\mathrm{NA}$ \\
\hline Chrysene & $2 / 3$ & $60 \mathrm{~J}$ & $61 \mathrm{~J}$ & Z2-EU34B-303 & 60.5 & & $\mathrm{NA}$ & & $\mathrm{NA}$ & $2.10 \mathrm{E}+06$ & $0 / 3$ & & $\mathrm{NA}$ \\
\hline Di-n-butyl phthalate & $0 / 3$ & ND & ND & & $\mathrm{ND}$ & & $\mathrm{NA}$ & & $\mathrm{NA}$ & $6.20 \mathrm{E}+07$ & $0 / 3$ & & $\mathrm{NA}$ \\
\hline Di-n-octylphthalate & $0 / 3$ & $\mathrm{ND}$ & $\mathrm{ND}$ & & $\mathrm{ND}$ & & $\mathrm{NA}$ & & NA & $2.50 \mathrm{E}+07$ & $0 / 3$ & & NA \\
\hline Dibenz(a,h)anthracene & $0 / 3$ & $\mathrm{ND}$ & $\mathrm{ND}$ & & $\mathrm{ND}$ & & NA & & NA & $2.10 \mathrm{E}+03$ & $0 / 3$ & & NA \\
\hline Diethyl phthalate & $0 / 3$ & $\mathrm{ND}$ & $\mathrm{ND}$ & & $\mathrm{ND}$ & & NA & & NA & $1.00 \mathrm{E}+08$ & $0 / 3$ & & NA \\
\hline Dimethyl phthalate & $0 / 3$ & $\mathrm{ND}$ & $\mathrm{ND}$ & & $\mathrm{ND}$ & & $\mathrm{NA}$ & & $\mathrm{NA}$ & $1.00 \mathrm{E}+08$ & $0 / 3$ & & $\mathrm{NA}$ \\
\hline Diphenyldiazene & $0 / 3$ & $\mathrm{ND}$ & ND & & $\mathrm{ND}$ & & NA & & NA & $1.60 \mathrm{E}+05$ & $0 / 3$ & & NA \\
\hline Fluoranthene & $2 / 3$ & $98 \mathrm{~J}$ & $110 \mathrm{~J}$ & Z2-EU34B-303 & 104 & & NA & & NA & $2.20 \mathrm{E}+07$ & $0 / 3$ & & NA \\
\hline Fluorene & $0 / 3$ & $\mathrm{ND}$ & $\mathrm{ND}$ & & ND & & NA & & NA & $2.60 \mathrm{E}+07$ & $0 / 3$ & & NA \\
\hline Hexachlorobenzene & $0 / 3$ & $\mathrm{ND}$ & $\mathrm{ND}$ & & $\mathrm{ND}$ & & NA & & NA & $1.10 \mathrm{E}+04$ & $0 / 3$ & & NA \\
\hline Hexachlorobutadiene & $0 / 3$ & $\mathrm{ND}$ & $\mathrm{ND}$ & & $\mathrm{ND}$ & & $\mathrm{NA}$ & & $\mathrm{NA}$ & $1.80 \mathrm{E}+05$ & $0 / 3$ & & $\mathrm{NA}$ \\
\hline Hexachlorocyclopentadiene & $0 / 3$ & $\mathrm{ND}$ & $\mathrm{ND}$ & & $\mathrm{ND}$ & & NA & & NA & $3.70 \mathrm{E}+06$ & $0 / 3$ & & NA \\
\hline Hexachloroethane & $0 / 3$ & $\mathrm{ND}$ & $\mathrm{ND}$ & & $\mathrm{ND}$ & & $\mathrm{NA}$ & & $\mathrm{NA}$ & $6.20 \mathrm{E}+05$ & $0 / 3$ & & $\mathrm{NA}$ \\
\hline Indeno(1,2,3-cd)pyrene & $0 / 3$ & $\mathrm{ND}$ & $\mathrm{ND}$ & & ND & & NA & & NA & $2.10 \mathrm{E}+04$ & $0 / 3$ & & NA \\
\hline Isophorone & $0 / 3$ & $\mathrm{ND}$ & $\mathrm{ND}$ & & $\mathrm{ND}$ & & NA & & NA & $5.10 \mathrm{E}+06$ & $0 / 3$ & & $\mathrm{NA}$ \\
\hline N-Nitroso-di-n-propylamine & $0 / 3$ & $\mathrm{ND}$ & ND & & $\mathrm{ND}$ & & NA & & $\mathrm{NA}$ & $2.50 \mathrm{E}+03$ & $0 / 3$ & & $\mathrm{NA}$ \\
\hline N-Nitrosodimethylamine & $0 / 3$ & ND & $\mathrm{ND}$ & & ND & & NA & & NA & $3.40 \mathrm{E}+02$ & $0 / 3$ & & NA \\
\hline $\mathrm{N}$-Nitrosodiphenylamine & $0 / 3$ & $\mathrm{ND}$ & $\mathrm{ND}$ & & $\mathrm{ND}$ & & $\mathrm{NA}$ & & $\mathrm{NA}$ & $3.50 \mathrm{E}+06$ & $0 / 3$ & & $\mathrm{NA}$ \\
\hline Naphthalene & $0 / 3$ & $\mathrm{ND}$ & $\mathrm{ND}$ & & $\mathrm{ND}$ & & NA & & NA & $1.90 \mathrm{E}+05$ & $0 / 3$ & & NA \\
\hline Nitrobenzene & $0 / 3$ & $\mathrm{ND}$ & ND & & $\mathrm{ND}$ & & $\mathrm{NA}$ & & NA & $1.00 \mathrm{E}+05$ & $0 / 3$ & & $\mathrm{NA}$ \\
\hline
\end{tabular}




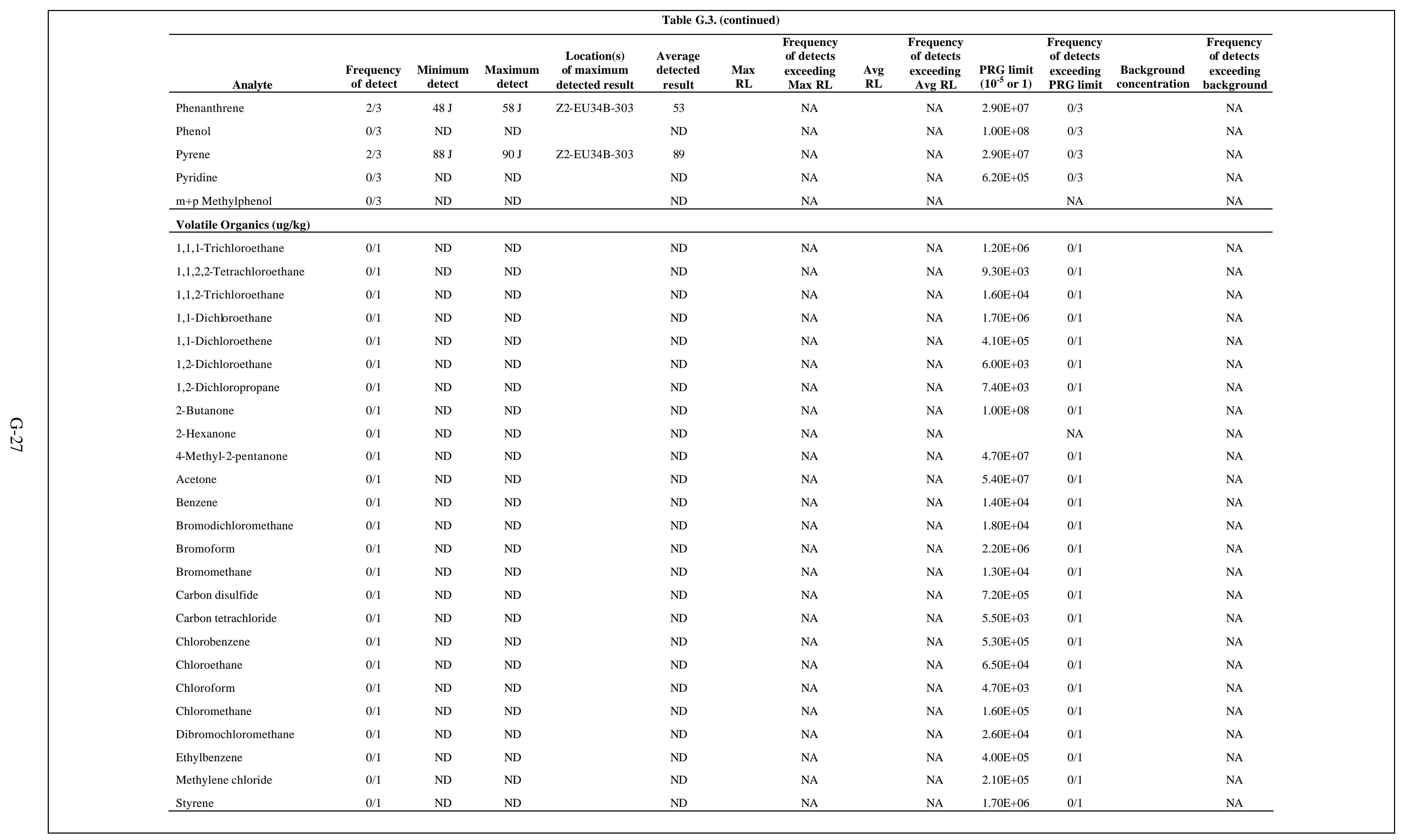


Table G.3. (continued)

\begin{tabular}{|c|c|c|c|c|c|c|c|c|c|c|c|c|c|}
\hline Analyte & $\begin{array}{c}\text { Frequency } \\
\text { of detect }\end{array}$ & $\begin{array}{c}\text { Minimum } \\
\text { detect }\end{array}$ & $\begin{array}{c}\text { Maximum } \\
\text { detect }\end{array}$ & $\begin{array}{c}\text { Location(s) } \\
\text { of maximum } \\
\text { detected result }\end{array}$ & $\begin{array}{c}\text { Average } \\
\text { detected } \\
\text { result }\end{array}$ & $\begin{array}{c}\text { Max } \\
\text { RL }\end{array}$ & $\begin{array}{c}\text { Frequency } \\
\text { of detects } \\
\text { exceeding } \\
\text { Max RL }\end{array}$ & $\begin{array}{l}\text { Avg } \\
\text { RL }\end{array}$ & $\begin{array}{c}\text { Frequency } \\
\text { of detects } \\
\text { exceeding } \\
\text { Avg RL }\end{array}$ & $\begin{array}{l}\text { PRG limit } \\
\left(10^{-5} \text { or } 1\right)\end{array}$ & $\begin{array}{l}\text { Frequency } \\
\text { of detects } \\
\text { exceeding } \\
\text { PRG limit }\end{array}$ & $\begin{array}{l}\text { Background } \\
\text { concentration }\end{array}$ & $\begin{array}{c}\text { Frequency } \\
\text { of detects } \\
\text { exceeding } \\
\text { background }\end{array}$ \\
\hline Tetrachloroethene & $0 / 1$ & ND & ND & & ND & & NA & & NA & $1.30 \mathrm{E}+04$ & $0 / 1$ & & NA \\
\hline Toluene & $0 / 1$ & ND & $\mathrm{ND}$ & & ND & & NA & & NA & $5.20 \mathrm{E}+05$ & $0 / 1$ & & NA \\
\hline Total xylene & $0 / 1$ & ND & ND & & ND & & NA & & NA & $4.20 \mathrm{E}+05$ & $0 / 1$ & & NA \\
\hline Trichloroethene & $0 / 1$ & ND & ND & & ND & & NA & & NA & $1.10 \mathrm{E}+03$ & $0 / 1$ & & NA \\
\hline Vinyl chloride & $0 / 1$ & ND & ND & & ND & & NA & & NA & $7.50 \mathrm{E}+03$ & $0 / 1$ & & NA \\
\hline cis-1,2-Dichloroethene & $0 / 1$ & ND & ND & & ND & & NA & & NA & $1.50 \mathrm{E}+05$ & $0 / 1$ & & NA \\
\hline cis-1,3-Dichloropropene & $0 / 1$ & ND & ND & & ND & & NA & & NA & $1.80 \mathrm{E}+04$ & $0 / 1$ & & NA \\
\hline trans-1,2-Dichloroethene & $0 / 1$ & ND & ND & & ND & & NA & & NA & $2.30 \mathrm{E}+05$ & $0 / 1$ & & NA \\
\hline trans-1,3-Dichloropropene & $0 / 1$ & ND & ND & & $\mathrm{ND}$ & & NA & & NA & $1.80 \mathrm{E}+04$ & $0 / 1$ & & NA \\
\hline
\end{tabular}

${ }^{a}$ Radionuclide is evaluated as part of Ra/Th decay series as discussed in the Zone 2 ROD
${ }^{b}$ Evaluated a part of Th-232 $+\mathrm{D}=$ Th-232 + Ra-228+D + Th-2228+D.

Definition of validation qualifiers included: $J=$ analyte was positively identified and result is approximate concentration of analyte in the sample, and $\mathrm{U}=$ analyte was not detected above reported sample quantitation limi

Stations in summary include Z2-EU34B-301, Z2-EU34B-302, Z2-EU34B-303, Z2-EU34B-304, and Z2-EU34B-305.

$\begin{array}{ll}\mathrm{Avg}=\text { average } & \mathrm{ND}=\text { not detected } \\ \mathrm{EU}=\text { exposure unit } & \mathrm{PCB}=\text { = }\end{array}$

$\begin{array}{ll}\mathrm{EU}=\text { exposure } & \mathrm{PCB}=\text { polychlorinated biphenyl } \\ \mathrm{Max}=\text { maximum } & \mathrm{PRG}=\text { preliminary remediation }\end{array}$

$\begin{array}{ll}\mathrm{Max}=\text { maximum } & \mathrm{PRG}=\text { preliminary remediation goal } \\ \mathrm{NA}=\text { not applicable } & \mathrm{RL}=\text { remediation level }\end{array}$ 


\section{Appendix H}

K-1070-C/D and Downgradient Area Group

Exposure Unit Z2-37

Technical Memorandum 


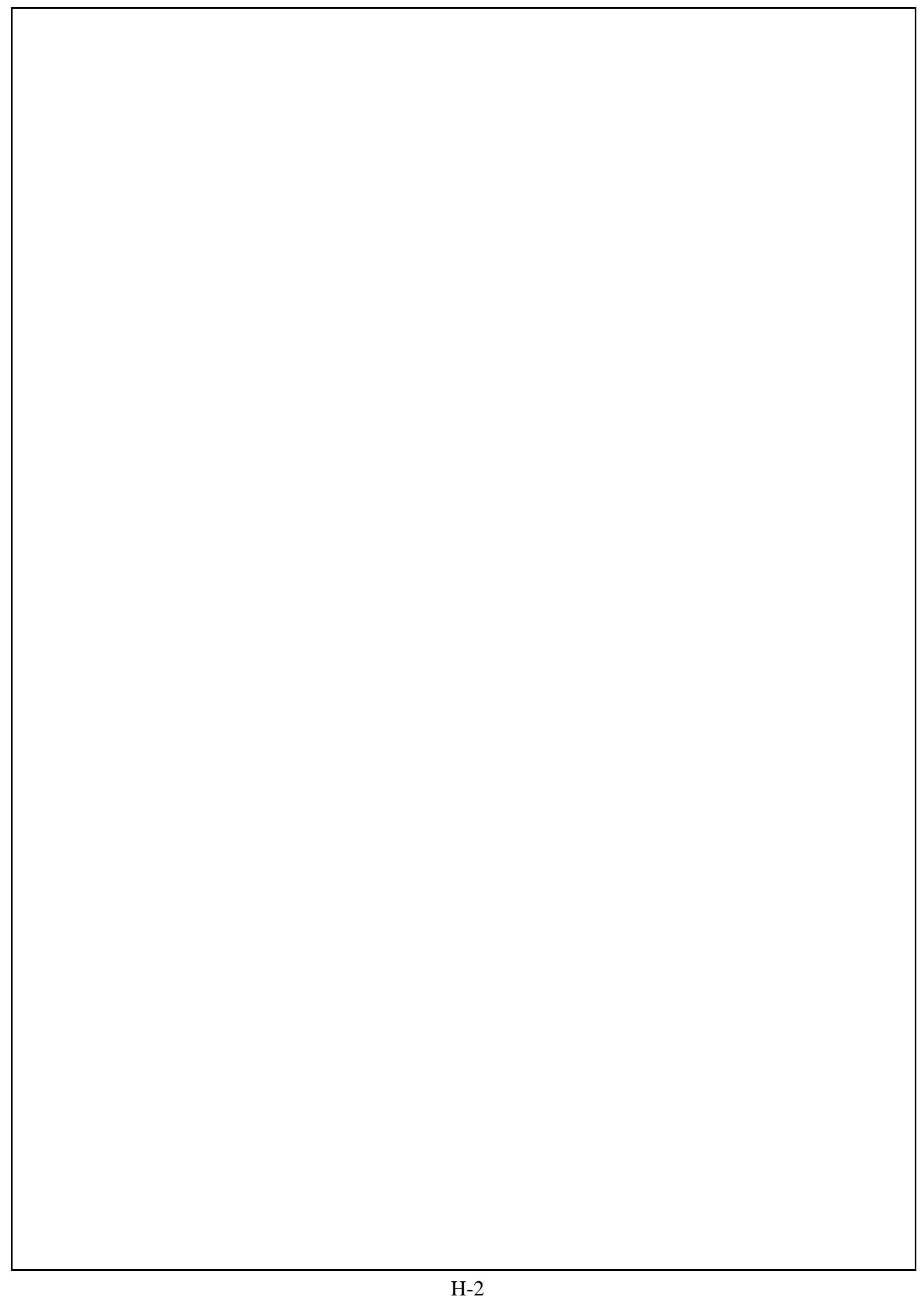

H-2 


\section{FIGURES}

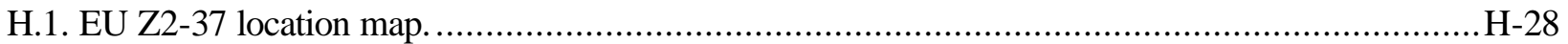

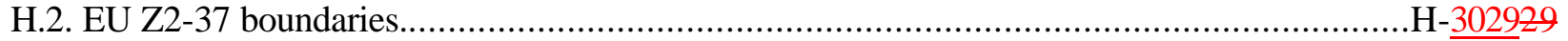

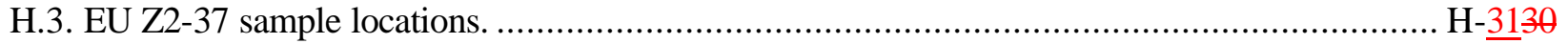

\section{TABLES}

H.1. EU Z2-37 facility and FFA site list ................................................................. H-

H.2. EU Z2-37 sample summary................................................................... H-

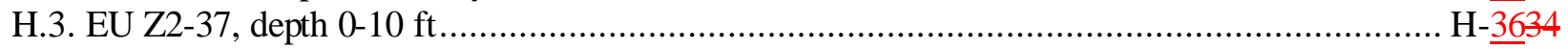

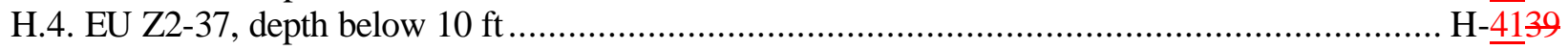




\section{DYNAMIC VERIFICATION STRATEGY (DVS) TECHNICAL MEMORANDUM (TM)}

EXPOSURE UNIT (EU) GROUP: Zone 2 K-1070-C/D and Downgradient Area Group EU Z2-37

\section{INTRODUCTION}

The purpose of this TM is to document the recommendation for an action/no further action (NFA) decision for Zone 2 exposure unit 37 (EU Z2-37) in the K-1070-C/D and Downgradient Area EU Group. The recommendation for this EU is based on existing historical data and DVS soil characterization activities. These data are used to determine the nature and extent of contamination in the EU and evaluate the need for an action. When it is determined that an action is necessary, the data also are used to calculate soil volumes for the proposed remedial alternative as identified in the Record of Decision for Soil, Buried Waste, and Subsurface Structure Actions in Zone 2, East Tennessee Technology Park, Oak Ridge, Tennessee (DOE/OR/01-2161\&D2) (Zone 2 ROD).

\begin{tabular}{|l|r|}
\hline H.1.0 & BACKGROUND AND EU SUMMARY \\
\hline H.1.1 & LOCATIONAT EAST TENNESSEE TECHNOLOGY PARK (ETTP) \\
\hline
\end{tabular}

EU Z2-37 is located in the east-central portion of Zone 2 in the K-1070-C/D and Downgradient Area EU Group (Fig. H.1). This EU is bounded on the north by EU Z2-36, on the east by EU Z2-41, on the south by EUs Z2-32 and Z2-42, and on the west by EUs Z2-31 and Z2-32.

\section{\begin{tabular}{l|l} 
H.1.2 & EU Z2-37 ACREAGE \\
\hline
\end{tabular}}

EU Z2-37 has an area of approximately 5.9 acres (Fig. H.2).

\section{\begin{tabular}{l|l} 
H.1.3 & SUMMARY DESCRIPTION \\
\hline
\end{tabular}}

All of the land area in EU Z2-37 has been impacted by site operations. This EU lies at the eastern edge of the industrialized heart of ETTP Zone 2 with the K-1070-C/D Burial Ground to the east in EU Z2-41 and Bldg. K-1401 and support facilities to the west in EUs Z2-31 and Z2-32. There are several buildings and facilities located in the southern portion of the EU that are associated with the K-1414 Garage as well as roads, parking lots, and sidewalks. The northeast half of this EU is dominated by a grass-covered hill sloping down from the K-1070-C/D Burial Ground in EU Z2-41 to the east.

Six underground storage tanks (USTs) existed at the K-1414 Garage. Two USTs, one for diesel fuel and one for unleaded gasoline, were installed in 1992 and are currently active. These two tanks are located west of K-1414 in EU Z2-32. The other four USTs, which have been in place since 1949 when the K-1414 garage began operations, include a waste oil storage tank [underground storage tank (UST) \#6], unleaded gasoline tank (UST \#7) that underwent a clean closure-in-place in 1994, diesel tank (UST \#8) that was removed in 1987 and received a clean closure, and another diesel tank (UST\#9) that was removed in 1987. The tank closures were performed in accordance with UST rules of the Tennessee Department of Environment and Conservation (TDEC) Chap. 1200-1-15-06(7)(e)(4). A diesel fuel leak from piping associated with UST \#9 was discovered in 1987. The site of this former UST and the surrounding soils constitute the K-1414 Garage Diesel Tank/Soils FFA site.

The DQO Scoping Package for the K-1070-C/D and Downgradient Area EU Group lists 11 facilities in EU Z2-37. Table H.1 presents an accounting of facilities in the EU.

\section{\begin{tabular}{l|l} 
H.1.4 & SOIL UNITS (SUS) \\
\hline
\end{tabular}}

Class 1 SU: None

Class 2 SU: None

Class 3 SU: 5.9 acres

Class 4 SU: None

The EU Z2-37 soil unit boundaries are shown on Fig. H.2. 
There is one FFA site in EU Z2-37 that is listed in Appendix A of the Zone 2 ROD:

- $\quad$ K-1414 Garage Diesel Tank/Soils FFA site

\begin{tabular}{|l|l|}
\hline H.2.0 & \multicolumn{1}{|c}{ DVS INVESTIGATIONS AND RESULTS } \\
\hline H.2.1 & DVS FIELD ACTIVITIES \\
\hline
\end{tabular}

DVS activities were conducted in accordance with the Remedial Design Report/Remedial Action Work Plan for Zone 2 Soils, Slabs, and Infrastructure, East Tennessee Technology Park, Oak Ridge, Tennessee (DOE/OR/01-2224\&D2) (Zone 2 RDR/RAWP).

\begin{tabular}{|c|c|}
\hline H.2.1.1 & CLASS 1 SUS \\
\hline \multicolumn{2}{|l|}{ None } \\
\hline H.2.1.1.1 & CLASS 1 SU RADIOLOGICAL WALKOVER SURVEY \\
\hline \multicolumn{2}{|l|}{ None } \\
\hline H.2.1.1.2 & CLASS 1 SU GEOPHYSICAL SURVEY \\
\hline \multicolumn{2}{|l|}{ None } \\
\hline H.2.1.1.3 & CLASS 1 SU SOIL SAMPLING \\
\hline \multicolumn{2}{|l|}{ None } \\
\hline H.2.1.2 & Class 2 SUS \\
\hline \multicolumn{2}{|l|}{ None } \\
\hline H.2.1.2.1 & CLASS 2 SU RADIOLOGICAL WALKOVER SURVEY \\
\hline \multicolumn{2}{|l|}{ None } \\
\hline H.2.1.2.2 & CLASS 2 SU GEOPHYSICAL SURVEY \\
\hline \multicolumn{2}{|l|}{ None } \\
\hline H.2.1.2.3 & Class 2 SU SOIL SAMPLING \\
\hline \multicolumn{2}{|l|}{ None } \\
\hline H.2.1.3 & Class 3 AND ClaSS 4 SU WALKOVER ASSESSMENT \\
\hline \multicolumn{2}{|c|}{$\begin{array}{l}\text { Because of extensive historical sampling conducted in the Class } 3 \text { SU of EU Z2-37, it was agreed during DQO } \\
\text { scoping that a Class } 3 \text { walkover assessment was not necessary. }\end{array}$} \\
\hline H.2.1.3.1 & CLASS 3 AND CLASS 4 SU RADIOLOGICAL SURVEY SUMMARY \\
\hline \multicolumn{2}{|c|}{$\begin{array}{l}\text { Screening level (SL): None } \\
\text { SL exceedances: None }\end{array}$} \\
\hline H.2.1.3.2 & CLASS 3 AND CLASS 4 SU ANTHROPOGENIC FEATURES \\
\hline \multicolumn{2}{|c|}{ Number of identified anthropogenic features: None } \\
\hline
\end{tabular}




\section{H.2.1.3.3 $\quad$ CLASS 3 SU FACILITIES ASSESSMENTS}

Eleven facilities are listed in the DQO Scoping Package as being located in EU Z-37, and 10 facilities were assessed (Table H.1). The facility assessments are reported in the Walkover Inspections and Radiological Surveys for FY2007 Exposure Units in Zones 1 and 2, East Tennessee Technology Park, Oak Ridge, Tennessee (BJC/OR2691). In summary, no facility was identified as a possible source for either chemical or radiological contamination.

\section{H.2.1.3.4 $\quad$ CLASS 3 AND CLASS 4 SU BIASED SAMPLING}

Class 3 SU biased sample locations associated with storm drains were identified during DQO scoping. During field work, two biased sediment sample locations were selected in the storm drain along Avenue D and a biased soil sample location was selected in a utility corridor. In addition, as a best management practice, three biased sample locations associated with the SW-31 spring were selected during field work-one location is in the ditch near the spring, another is in the ditch uphill from the spring, and the third is in the ditch downhill from the spring.

Details of actual sampling and analysis in the Class $3 \mathrm{SU}$, including sample depths, analytes, and deviations from planned sampling, are presented in Table H.2.

\section{\begin{tabular}{|l|l|l} 
H.2.2 & DVS AND HISTORICAL SAMPLE RESULTS \\
\hline
\end{tabular}}

The full data set for EU Z2-37 contains several samples collected from depths $>10 \mathrm{ft}$ bgs. Consistent with the requirements of the Zone 2 ROD, this TM evaluates only samples collected from the 0 - to 10 -ft-bgs interval (i.e., any sample whose starting depth is < $10 \mathrm{ft} \mathrm{bgs})$. Results for the $\theta$ to $10-\mathrm{ft}-\mathrm{bgs}$ samples are summarized in Table H.3. Subsets of Table H.3 are discussed in Sects. H.2.2.5 and H.2.2.6 as focused characterization summaries and the EU Z2-37 summary. Results for samples from > $10 \mathrm{ft}$ bgs are summarized in Table H.4. A compact disc containing electronic files for the historical and DVS analytical data used to generate Tables H.3 and H.4 is provided with this Phased Construction Completion Report (PCCR).

\begin{tabular}{|l|l|}
\hline 2.2.1 & \multicolumn{1}{l|}{ CLASS 1 SUS } \\
\hline None \\
\hline $\mathbf{2 . 2 . 2}$ & CLASS 2 SUS \\
\hline None \\
\hline $\mathbf{2 . 2 . 3}$ & CLASS 3 AND CLASS 4 SUS \\
\hline
\end{tabular}

There are 52 DVS and historical sample locations in this EU Class 3 SU-six DVS sample locations and 46 historical sample locations. Of these 52 sample locations, 42 include samples collected within the 0 to $10 \mathrm{ft}$ depth interval-six DVS sample locations and 36 historical sample locations. Three of the historical sample locations (SB120, SB122, and SB123) are not discussed in this TM and are not listed in the following table. Samples from these locations were analyzed only for alpha activity and beta/gamma activity with results reported in $\mathrm{cpm}$ which are quasi-quantitative measures that cannot be converted to quantitative values for use in a risk assessment. The DVS sample locations consist of biased sample locations identified during DQO scoping and other biased locations added during field work. Historical sampling in the Class 3 SU was conducted during the K-25 Radiation Survey, K-25 Radiological Survey Phase II, K-1414 Diesel UST investigation, K-1070-C/D Phase 2 Remedial Investigation (RI), ETTP Release Project, and ETTP Site-Wide Residual Contamination Project. Five historical sample locations are in or around the K-1414 Garage Diesel Tank/Soil FFA site or downgradient from it and were selected as representative sample locations for the FFA site. Thirty-three samples from the $\theta$ to 10 -ft-depth interval at 18 sample locations were analyzed using the field gas chromatograph (GC) method. The field GC analytical results are not evaluated in this TM because field analytical methods lack the quality controls obtained by laboratory methods. Field GC sample locations are listed separately in the following table and field GC analytical results are summarized separately at the end of Sect. H.2.2.5. Samples from some field GC sample locations also were collected for laboratory analysis, therefore, certain sample locations fall under more than the field GC headings in the following table. Class $3 \mathrm{SU}$ sample locations are shown on Fig. H.3 and summarized below. 


\begin{tabular}{|c|c|c|}
\hline $\mathbf{E U}$ & DVS sample locations & Historical sample locations \\
\hline \multicolumn{3}{|c|}{ Locations with samples from 0 to $10 \mathrm{ft}$ bgs } \\
\hline \multirow[t]{3}{*}{ Z2-37 } & $\begin{array}{l}\text { Z2-EU37B-301, Z2-EU37B-302, } \\
\text { Z2-EU37B-303, Z2-EU37B-304, } \\
\text { Z2-EU37B-305, Z2-EU37B-306 }\end{array}$ & $\begin{array}{l}\text { K-1414 Garage Diesel Tank/Soil FFA Site: BH005, } \\
\text { BH006, ETTP-REL12, ETTP-REL13, SB088 }\end{array}$ \\
\hline & & $\begin{array}{l}\text { Other Historical Locations: BH002, BH004, BH007, } \\
\text { BH008, BH011, BH0012, BH013, RAD69, RAD78, RAD85, } \\
\text { RAD90, SB078, SB079, SB080, SB081, SB082, SB083, } \\
\text { SB087, SB089, SB090, SB091, SB092, SB093, SB099 }\end{array}$ \\
\hline & & $\begin{array}{l}\text { Field GC Locations: SB078, SB079, SB080, SB081,SB082, } \\
\text { SB083, SB087, SB088, SB089, SB090, SB091, SB092, } \\
\text { SB093, SB099, SB103, SB109, SB110, SB111 }\end{array}$ \\
\hline \multicolumn{3}{|c|}{ Locations with samples from $>10 \mathrm{ft}$ bgs } \\
\hline \multirow[t]{3}{*}{ Z2-37 } & & $\begin{array}{l}\text { K-1414 Garage Diesel Tank/Soil FFA Site: BH004, } \\
\text { BH005, SB088 }\end{array}$ \\
\hline & & $\begin{array}{l}\text { Other Historical Locations: BH001, BH002, BH003, } \\
\text { BH004, BH007, BH011, K1070CD-DPT-04, } \\
\text { K1070CD-DPT-05, K1070CD-DPT-06, K1200-DPT-01, } \\
\text { K1200-DPT-02, SB047, SB048, SB049, SB078, SB079, } \\
\text { SB080, SB081, SB082, SB083, SB087, SB090, SB091, } \\
\text { SB109 }\end{array}$ \\
\hline & & $\begin{array}{l}\text { Field GC Locations: SB078, SB079, SB080, SB081, } \\
\text { SB082, SB083, SB087, SB088, SB090, SB091, SB103, } \\
\text { SB109 }\end{array}$ \\
\hline
\end{tabular}

DVS = dynamic verification strategy $\quad$ FFA $=$ Federal Facility Agreement

$\mathrm{EU}=$ exposure unit $\quad \mathrm{GC}=$ gas chromatograph

The number of samples collected and sampling intervals at each location varied as well as the chemicals and radionuclides analyzed for (Table H.2). Data for samples collected from the 0 to 10 - $\mathrm{ft}$ bgs depth interval are summarized in Table H.3, evaluated by area of interest and EU in Sect. H.2.2.5, and by FFA site in Sect. H.2.2.6. Data for samples collected from $>10 \mathrm{ft}$ bgs are summarized in Table H.4. The numbers of analyses conducted in the Class $3 \mathrm{SU}$ for samples collected from the 0 to $10-\mathrm{ft}$-bgs depth interval are presented below by analyte group. Analyses conducted by the field GC method are not included in the following tables.

\begin{tabular}{cccccc}
\hline Metals & $\begin{array}{c}\text { Other } \\
\text { organics }^{\boldsymbol{a}}\end{array}$ & PPCBs $^{\boldsymbol{b}}$ & Radionuclides $^{\boldsymbol{c}}$ & SVOCs & VOCs $^{\boldsymbol{d}}$ \\
\hline 23 & 14 & 23 & 28 & 35 & 35 \\
\hline
\end{tabular}

${ }^{a}$ This group includes diesel range and gasoline range organics.

${ }^{b}$ The tally for PPCBs is based on PCB analyses. PCBs were reported each time the PPCB analyte group was analyzed. Pesticides were reported for 17 PPCB analyte group analyses in historical samples.

${ }^{\circ}$ The tally for radionuclides is based on counts of U-235 and U-238 analyses. Some samples were analyzed for radionuclide or gross activity suites that did not include these two radionuclides.

${ }^{d}$ VOC analytical suites differed by project. The tally for VOCs is based on a count of chlorinated solvents.

$\mathrm{PCB}=$ polychlorinated biphenyl

SVOC $=$ semivolatile organic compound

PPCB = pesticides and polychlorinated biphenyl

$\mathrm{VOC}=$ volatile organic compound

\section{\begin{tabular}{|l|l|}
\hline 2.2.4 & INFRASTRUCTURE \\
\hline
\end{tabular}}

Biased sampling locations were identified during DQO scoping at storm drains and utility corridors. Sample results are described in Sect. H.2.2.5. 
In this section, characterization data and other information are evaluated for EU Z2-37. The analytical data in the following summaries are presented by analyte group. The results for a particular analyte group are summarized only if that group was analyzed in the samples from the unit being summarized. Within each summary, the data are evaluated by comparing to certain criteria, which include the Zone 2 soils maximum remediation level (Max RL), Zone 2 soils average remediation level (Avg RL), the $1 \times 10^{-5}$ industrial preliminary remediation goal (Ind PRG), the ETTP soils background composition (Bkg), Zone 2 groundwater screening levels (GW SL), and the $1 \times 10^{-6}$ residential preliminary remediation goal (Res PRG). If a particular criterion does not apply to any member of an analyte group, it is not tabulated for that analyte group; if a particular criterion does not apply to all analytes within an analyte group, those analytes to which it does not apply are notated with NA (not applicable). Individual metals and radionuclides, which are naturally occurring, are reported in the summaries only if one or more criterion is exceeded. Organic chemicals, which are not naturally occurring, are reported if detected, even if no criteria are exceeded. The Max RL, Avg RL, Ind PRG, Bkg, GW SL, and Res PRG criteria values, as they pertain to the analytes listed in Appendix A of the RDR/RAWP (i.e., Quality Assurance Program Plan), are presented in Sect. H.3.1 of this PCCR.

Because the carcinogenic risk associated with concentrations of radium and thorium isotopes in the natural background at ETTP exceeds the cumulative risk goal of $1 \times 10^{-4}$, RL values for these radionuclides are based on alternative concentration levels rather than risk. The alternative concentration levels of $5 \mathrm{pCi} / \mathrm{g}$ above background (Avg RL) and $15 \mathrm{pCi} / \mathrm{g}$ above background (Max RL) were set as low as reasonably achievable under the site-specific conditions. Because site-specific background concentrations of these radionuclides exceed the target risk range, residual concentrations of these radionuclides and their decay series are not considered in estimates of residual risk following any remedial action.

The Zone 2 ROD states that Avg RL and Max RL exceedances by Ra-226, Th-230, and Th-232 will be evaluated by summing above-background concentrations of the greater of Ra-226 or Th-230 with the above-background concentrations of Th-232 and comparing the results to $5 \mathrm{pCi} / \mathrm{g}$ (Avg RL) and $15 \mathrm{pCi} / \mathrm{g}$ (Max RL). The required calculations have been performed. Average and maximum RL exceedances for these radionuclides, if any, are reported in the TM data summaries below and in Table H.2 as "Ra/Th decay series"; individual RL exceedances by Ra-226, Th-230, and Th-232 are reported as NA. The Ra/Th decay series data are summarized in the sections that follow only if an Avg or Max RL has been exceeded, consistent with the description in the preceding paragraph for reporting radionuclides. Discussion of the $\mathrm{Ra} / \mathrm{Th}$ decay series calculation, including the manner in which the calculation is performed, is presented in Sect. H.3.3 of this PCCR.

\section{Conceptual Site Model (CSM)}

EU Z2-37 is located in the east-central portion of Zone 2 in the K-1070C/D and Downgradient Area EU Group. The entire EU was classified as a Class 3 SU. The K-1414 Garage and its five associated tanks are located in the southern half of the EU. The K-1414 area was planned to be classified as a Class 1 SU based on a known diesel tank leak site in the area, and a Class 2 SU covering all of the other tank locations and the grounds adjacent to the shop was also planned. Prior to work under the DVS program, extensive sampling had been done in the K-1414 area and across the western slope of the K-1070-C/D Burial Ground, which is located in the northern portion of the EU to determine the nature and extent of both soil and groundwater impacts. Results of these earlier sampling programs indicated there was diesel contamination in the area where UST \#9 had leaked. The tank and soils in proximity to the tank were removed in the mid-1990s.

Samples collected in the down-slope position from the K-1070-C/D Burial Ground did not indicate contamination in the 0 to $10-\mathrm{ft}$ interval. As a result of this prior sampling, essentially all of EU Z2-37 was classified in the DQO package as a modified Class $3 \mathrm{SU}$; walkover assessments for the central area were not required since extensive soil sampling had already been performed. Because so much work had been performed and documented in the K-1070-C/D Phase 2 RI, both the nature and extent of contamination and the CSM are fairly we 11 understood

There is a groundwater volatile organic compound (VOC) release point located east of EU Z2-37 that is associated with the G pit located in the K-1070 Pits FFA Site in EU Z2-41. This source area is associated with a soil contamination area that begins at a depth of approximately $10 \mathrm{ft}$ below bgs and extends to depths in excess of $40 \mathrm{ft}$ bgs. The soil impact extends into this EU but at depths $>10 \mathrm{ft}$. Sampling in the area east of the pits has shown no significant VOC contamination in the top $10 \mathrm{ft}$ of soil down slope of the release point. 


\section{Groundwater Evaluation}

Geologic setting-A topographic high is located in and generally encompassed by EU Z2-41. This high ground is bounded to the east by a perennial drainage and a second slightly higher area further to the east. The K-25 thrust fault bounds the topographic high ground, which is located on the hanging wall of the thrust. The trace of the fault in the Zone 2 area is shown on Fig. H.1. The fault trace defines a small splinter thrust block approximately one-half mile wide and several miles in length that has a synclinal form. The western edge of this splinter thrust block is what underlies the eastern portions of ETTP Zone 2 and EUs Z2-37 and Z2-41. The geologic section of rock units in the area beneath this EU is Rome Formation of Cambrian age. This section of rock is comprised of thin interbedded sandstone and shale, with minor beds of chert and limestone in the upper section. Because of the extensive deformation that occurred during thrust faulting, the rock is shattered into very small fragments. The presence of extensive microfractures results in a porous and permeable overall rock mass.

Soils and hydrology - A surface residual soil covers most of the high ground and is up to $20 \mathrm{ft}$ thick in some areas. These surface soils are composed predominantly of clay and cover the slopes where the soil cover thins to a few feet in thickness. Rome formation outcrops are observed at isolated locations along perennial drainages and infiltration through the surface clay-rich residuum is low to moderate. Surface water and groundwater flow generally occur in a radial pattern from the top of the knoll underlying the K-1070-C/D Burial Ground. Tracer tests conducted by the site-wide program have shown gradients and the transport rate as high, with some locations along the western flank of the K-1070-C/D Burial Ground recording $5 \mathrm{ft} /$ day.

Source areas-A release of contamination into shallow surface soils occurred at this EU in the late 1980s. This release was estimated to be approximately 500-600 gal of diesel fuel from a fill pipe to a UST located north of the K-1414 Garage. The diesel tank was removed in 1987 under state UST regulatory ARARS and a limited volume of soil (not quantified in the closure report) also was excavated at the time. Several soil samples from the area reported diesel-range organics (DRO) above the former regulatory criteria of $100 \mathrm{mg} / \mathrm{kg}$. Soil borings SB-087, BH004, and BH005, all located approximately 100-130 ft west of the tank location, reported high concentrations of DRO and substantially elevated concentrations of BTEX compounds in SB087 soils from sample intervals below $6 \mathrm{ft}$ bgs. Soil samples collected in immediate proximity to the tank locations did not report significantly elevated concentrations of DRO or BTEX compounds.

Several monitoring wells in the area historically have reported benzene above maximum contaminant levels (MCLs) $(5 \mathrm{ug} / \mathrm{L})$. Benzene concentrations have declined to levels below regulatory concern in all but two monitoring wells in the area. One temporary drive point detected benzene approximately $200 \mathrm{ft}$ northeast of the tank location. It is not clear if this result is related to the diesel tank or the G-pit plume that crosses through EU Z2-37 in that area. Soil samples with elevated DRO and BTEX compounds were collected at depths of $6-15 \mathrm{ft}$ bgs. The water table in monitoring wells in proximity to the sample points ranges from 6-16 ft bgs. These data indicate the diesel fuels have been transported to the west-northwest from the release point and are in the groundwater system. Samples collected at the tank site have no substantially elevated concentrations of DRO or BTEX compounds.

These data indicate the primary source of diesel fuel contamination was removed with the tank removal action and that both an immiscible diesel fuel component of the release and associated dissolved phase BTEX compounds are present in the local groundwater. Concentrations of these compounds in unconsolidated zone wells exhibit a clear declining trend over the last 12 years. There does not appear to be a substantial source of diesel and BTEX compounds in the area. There is no removal action required in this EU to remove contaminated soils for the protection of groundwater.

\section{Sampling Results}

All of the 5.9 acres of EU Z2-37 have been classified as a Class 3 SU. However, because of extensive historical sampling, it was determined during DQO scoping that a Class $3 \mathrm{SU}$ walkover assessment was not necessary.

DVS sampling was conducted at two locations in storm drains, one location in a utility corridor, and three locations around the SW31 spring. As described in Sect.H.2.2.3, historical sampling in the EU has been extensive. The historical samples have been divided into two groups for evaluation purposes. The first group includes six sample locations that are used to evaluate the K-1414 Garage Diesel Tank/Soils FFA site (Sect. H.2.2.6). The second group consists of the remaining historical locations.

Following is a summary of the sampling results for samples collected from the 0- to 10-ft-depth interval in this EU. The summary begins with summary presentations of the analytical results for the focused sampling efforts in the EU and concludes with an overall EU summary. The EU summary includes both data summary tables and a written 
description of the nature and extent of chemicals and radionuclides observed in the EU, including data from the samples collected in the K-1414 Garage Diesel Tank/Soils FFA site (Sect. H.2.2.6). A summary of the soils data collected from 0 to $10 \mathrm{ft}$ bgs is presented in Table H.3, data for samples collected from > $10 \mathrm{ft}$ bgs are summarized in Table H.4, and all sample locations are shown on Fig. H.3. Data summarized in this section are evaluated in terms of the Zone 2 ROD remedial action objective (RAO) in Sect. H.3.3.

DVS Storm Drain Sediment Sampling: Two storm drain sediment sample locations were selected in the storm drain along Avenue D. Location Z2-EU37B-302 is south of K-1310-DD and location Z2-EU37B-305 is downhill from the SW31 spring. Analytical results summarized below show several radionuclide, one metal, and one semivolatile organic compound (SVOC) Ind PRG exceedances; metal and radionuclide Bkg exceedances; and detections of PCBs and SVOCs.

EU Z2-37 STORM DRAIN SEDIMENT METALS WITH BACKGROUND,

PRG, GW SL, AND/OR RL EXCEEDANCES (mg/kg) 0-10 ft

\begin{tabular}{|c|c|c|c|c|c|c|c|c|c|c|c|}
\hline \multirow[b]{2}{*}{ Analyte } & \multirow[b]{2}{*}{$\begin{array}{c}\text { Detect } \\
\text { frequency }\end{array}$} & \multirow[b]{2}{*}{$\begin{array}{c}\text { Minimum } \\
\text { detect }\end{array}$} & \multirow[b]{2}{*}{$\begin{array}{c}\text { Maximum } \\
\text { detect }\end{array}$} & \multirow{2}{*}{$\begin{array}{c}\text { Location(s) of } \\
\text { maximum } \\
\text { detect }\end{array}$} & \multirow{2}{*}{$\begin{array}{c}\text { Average } \\
\text { detected } \\
\text { result }\end{array}$} & \multicolumn{6}{|c|}{ Number of analyses exceeding criteria } \\
\hline & & & & & & $\begin{array}{c}\text { Max } \\
\text { RL }\end{array}$ & $\begin{array}{c}\text { Avg } \\
\text { RL }\end{array}$ & $\begin{array}{l}\text { Ind } \\
\text { PRG }\end{array}$ & Bkg & $\begin{array}{l}\text { GW } \\
\text { SL }\end{array}$ & $\begin{array}{c}\text { Res } \\
\text { PRG }\end{array}$ \\
\hline Arsenic & $2 / 2$ & 6.9 & 18 & Z2-EU37B-305 & 12.5 & 0 & 0 & 1 & 1 & 0 & 2 \\
\hline Barium & $2 / 2$ & 250 & 520 & Z2-EU37B-302 & 385 & NA & NA & 0 & 2 & 0 & 0 \\
\hline Cadmium & $2 / 2$ & $0.13 \mathrm{~J}$ & $0.27 \mathrm{~J}$ & Z2-EU37B-305 & 0.2 & NA & NA & 0 & 1 & NA & 0 \\
\hline Calcium & $2 / 2$ & 160,000 & 240,000 & Z2-EU37B-305 & 200,000 & NA & NA & NA & 2 & NA & NA \\
\hline Lead & $2 / 2$ & 15 & 41 & Z2-EU37B-305 & 28 & NA & NA & 0 & 1 & 0 & 0 \\
\hline Magnesium & $2 / 2$ & 23,000 & 41,000 & Z2-EU37B-302 & 32,000 & NA & NA & NA & 2 & NA & NA \\
\hline Manganese & $2 / 2$ & 12,000 & 16,000 & Z2-EU37B-305 & 14,000 & NA & NA & 0 & 2 & NA & 2 \\
\hline Vanadium & $2 / 2$ & 9.4 & 13 & Z2-EU37B-302 & 11.2 & NA & NA & 0 & 0 & NA & 2 \\
\hline Zinc & $2 / 2$ & $69 \mathrm{~J}$ & $160 \mathrm{~J}$ & Z2-EU37B-305 & 115 & NA & NA & 0 & 1 & NA & 0 \\
\hline
\end{tabular}

Avg = average NA = not applicable

$\mathrm{Bkg}=$ background $\quad \mathrm{PRG}=$ preliminary remediation goal

$\mathrm{EU}=$ exposure unit $\quad$ Res $=$ residential

$\mathrm{GW}=$ groundwater $\quad \mathrm{RL}=$ remediation level

Ind $=$ industrial $\quad \mathrm{SL}=$ screening level

Max = maximum $\quad$ SU $=$ soil unit

EU Z2-37 S TORM DRAIN SEDIMENT PCB DETECTS (ug/kg) 0-10 ft

\begin{tabular}{|c|c|c|c|c|c|c|c|c|c|}
\hline \multirow[b]{2}{*}{ Analyte } & \multirow[b]{2}{*}{$\begin{array}{c}\text { Detect } \\
\text { frequency }\end{array}$} & \multirow[b]{2}{*}{$\underset{\text { detect }}{\text { Minimum }}$} & \multirow[b]{2}{*}{$\underset{\text { detect }}{\text { Maximum }}$} & \multirow{2}{*}{$\begin{array}{c}\text { Location(s) of } \\
\text { maximum } \\
\text { detect }\end{array}$} & \multirow{2}{*}{$\begin{array}{c}\text { Average } \\
\text { detected } \\
\text { result }\end{array}$} & \multicolumn{4}{|c|}{$\begin{array}{l}\text { Number of analyses } \\
\text { exceeding criteria }\end{array}$} \\
\hline & & & & & & $\begin{array}{l}\text { Max } \\
\text { RL }\end{array}$ & $\begin{array}{l}\text { Avg } \\
\text { RL }\end{array}$ & $\begin{array}{l}\text { Ind } \\
\text { PRG }\end{array}$ & $\begin{array}{c}\text { Res } \\
\text { PRG }\end{array}$ \\
\hline PCB-1254 & $2 / 2$ & 120 & 2,600 & Z2-EU37B-305 & 1,360 & 0 & 0 & 0 & 2 \\
\hline Polychlorinated biphenyl & $2 / 2$ & 120 & 2,600 & Z2-EU37B-305 & 1,360 & 0 & 0 & 0 & 2 \\
\hline
\end{tabular}

Avg $=$ average $\quad$ PCB $=$ polychlorinated biphenyl

$\mathrm{EU}=$ exposure unit $\quad \mathrm{PRG}=$ preliminary remediation goal

Ind $=$ industrial $\quad$ Res $=$ residential

Max $=$ maximum $\quad \mathrm{RL}=$ remediation level 
EU Z2-37 STORM DRAIN SEDIMENT RADIONUCLIDES WITH BACKGROUND,

PRG, AND/OR RL EXCEEDANCES (pCi/g) 0-10 ft

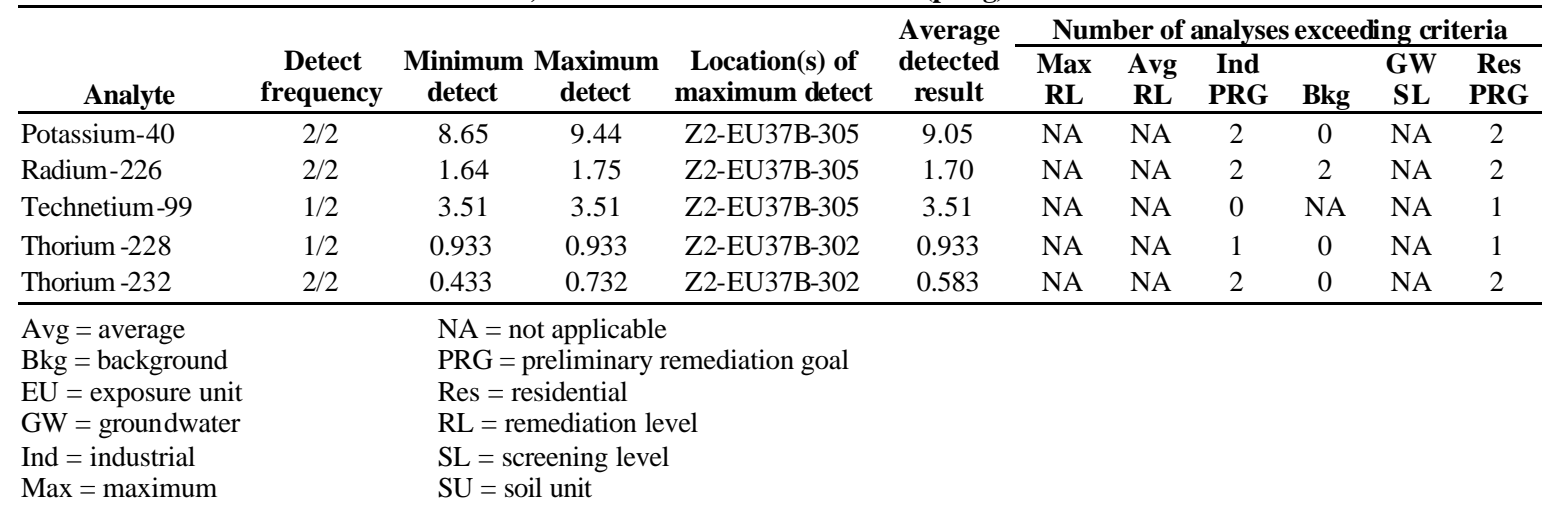

EU Z2-37 STORM DRAIN SEDIMENT SVOC DETECTS (ug/kg) 0-10 ft

\begin{tabular}{|c|c|c|c|c|c|c|c|c|}
\hline \multirow[b]{2}{*}{ Analyte } & \multirow[b]{2}{*}{$\begin{array}{c}\text { Detect } \\
\text { frequency }\end{array}$} & \multirow[b]{2}{*}{$\begin{array}{c}\text { Minimum } \\
\text { detect }\end{array}$} & \multirow[b]{2}{*}{$\begin{array}{c}\text { Maximum } \\
\text { detect }\end{array}$} & \multirow[b]{2}{*}{$\begin{array}{c}\text { Location(s) of } \\
\text { maximum detect }\end{array}$} & \multirow{2}{*}{$\begin{array}{c}\text { Average } \\
\text { detected } \\
\text { result }\end{array}$} & \multicolumn{3}{|c|}{$\begin{array}{l}\text { Number of analyses } \\
\text { exceeding criteria }\end{array}$} \\
\hline & & & & & & $\begin{array}{l}\text { Ind } \\
\text { PRG }\end{array}$ & $\begin{array}{l}\text { GW } \\
\text { SL }\end{array}$ & $\begin{array}{l}\text { Res } \\
\text { PRG }\end{array}$ \\
\hline Acenaphthene & $1 / 2$ & $170 \mathrm{~J}$ & $170 \mathrm{~J}$ & Z2-EU37B-302 & 170 & 0 & NA & 0 \\
\hline Anthracene & $1 / 2$ & $400 \mathrm{~J}$ & $400 \mathrm{~J}$ & Z2-EU37B-302 & 400 & 0 & NA & 0 \\
\hline Benz(a)anthracene & $2 / 2$ & $410 \mathrm{~J}$ & 2,400 & Z2-EU37B-302 & 1,405 & 0 & NA & 1 \\
\hline Benzo(a)pyrene & $2 / 2$ & $560 \mathrm{~J}$ & $2,200 \mathrm{~J}$ & Z2-EU37B-302 & 1,380 & 1 & NA & 2 \\
\hline Benzo(b)fluoranthene & $2 / 2$ & $1,000 \mathrm{~J}$ & $3,800 \mathrm{~J}$ & Z2-EU37B-302 & 2,400 & 0 & NA & 2 \\
\hline Benzo(ghi)perylene & $2 / 2$ & $370 \mathrm{~J}$ & $1,100 \mathrm{~J}$ & Z2-EU37B-302 & 735 & 0 & NA & 0 \\
\hline Benzo(k)fluoranthene & $2 / 2$ & $360 \mathrm{~J}$ & $1,500 \mathrm{~J}$ & Z2-EU37B-302 & 930 & 0 & NA & 0 \\
\hline Bis(2-ethylh exyl)phthalate & $2 / 2$ & $210 \mathrm{~J}$ & 4,400 & Z2-EU37B-305 & 2,305 & 0 & 0 & 0 \\
\hline Butyl benzyl phthalate & $1 / 2$ & $170 \mathrm{~J}$ & $170 \mathrm{~J}$ & Z2-EU37B-305 & 170 & 0 & NA & 0 \\
\hline Carbazole & $1 / 2$ & 650 & 650 & Z2-EU37B-302 & 650 & 0 & NA & 0 \\
\hline Chrysene & $2 / 2$ & $530 \mathrm{~J}$ & 2,500 & Z2-EU37B-302 & 1,515 & 0 & NA & 0 \\
\hline Dibenz(a,h)anthracene & $1 / 2$ & $300 \mathrm{~J}$ & $300 \mathrm{~J}$ & Z2-EU37B-302 & 300 & 0 & NA & 1 \\
\hline Dibenzofuran & $1 / 2$ & $72 \mathrm{~J}$ & $72 \mathrm{~J}$ & Z2-EU37B-302 & 72 & 0 & NA & 0 \\
\hline Fluoranthene & $2 / 2$ & $870 \mathrm{~J}$ & 5,700 & Z2-EU37B-302 & 3,285 & 0 & NA & 0 \\
\hline Fluorene & $1 / 2$ & $160 \mathrm{~J}$ & $160 \mathrm{~J}$ & Z2-EU37B-302 & 160 & 0 & NA & 0 \\
\hline Indeno(1,2,3-cd)pyrene & $2 / 2$ & $370 \mathrm{~J}$ & 1,100 & Z2-EU37B-302 & 735 & 0 & NA & 1 \\
\hline Phenanthrene & $2 / 2$ & $240 \mathrm{~J}$ & 2,900 & Z2-EU37B-302 & 1,570 & 0 & NA & 0 \\
\hline Pyrene & $2 / 2$ & $850 \mathrm{~J}$ & 4,600 & Z2-EU37B-302 & 2,725 & 0 & NA & 0 \\
\hline
\end{tabular}

\begin{tabular}{ll}
\hline EU $=$ exposure unit & PRG = preliminary remediation goal \\
$\mathrm{GW}=$ groundwater & Res = residential \\
Ind = industrial & SL $=$ screening level \\
NA = not applicable & SVOC = semivohtile organic compound
\end{tabular}

VOCs were analyzed for in both samples but were not detected.

DVS Utility Corridor Sampling: One biased soil sample location, Z2-EU37B-301, was identified in the utility corridor that runs along Avenue D. Analytical results summarized below show radionuclide Ind PRG exceedances, metal Bkg exceedances, and polychlorinated biphenyl (PCB) and SVOC detections. 
EU Z2-37 UTILITY CORRIDOR SOILS METALS WITH BACKGROUND,

PRG, GW SL, AND/OR RL EXCEEDANCES (mg/kg) 0-10 ft

\begin{tabular}{|c|c|c|c|c|c|c|c|c|c|c|c|}
\hline \multirow[b]{2}{*}{ Analyte } & \multirow[b]{2}{*}{$\begin{array}{c}\text { Detect } \\
\text { frequency }\end{array}$} & \multirow[b]{2}{*}{$\begin{array}{c}\text { Minimum } \\
\text { detect }\end{array}$} & \multirow[b]{2}{*}{$\underset{\text { detect }}{\text { Maximum }}$} & \multirow{2}{*}{$\begin{array}{c}\text { Location(s) of } \\
\text { maximum } \\
\text { detect }\end{array}$} & \multirow{2}{*}{$\begin{array}{c}\text { Average } \\
\text { detected } \\
\text { result }\end{array}$} & \multicolumn{6}{|c|}{ Number of analyses exceeding criteria } \\
\hline & & & & & & $\begin{array}{c}\text { Max } \\
\text { RL }\end{array}$ & $\begin{array}{l}\text { Avg } \\
\text { RL }\end{array}$ & $\begin{array}{l}\text { Ind } \\
\text { PRG }\end{array}$ & Bkg & $\begin{array}{c}\text { GW } \\
\text { SL }\end{array}$ & $\begin{array}{c}\text { Res } \\
\text { PRG }\end{array}$ \\
\hline Arsenic & $1 / 1$ & 7.3 & 7.3 & Z2-EU37B-301 & 7.3 & 0 & 0 & 0 & 0 & 0 & 1 \\
\hline Cadmium & $1 / 1$ & $0.34 \mathrm{~J}$ & $0.34 \mathrm{~J}$ & Z2-EU37B-301 & 0.34 & NA & NA & 0 & 1 & NA & 0 \\
\hline Chromium & $1 / 1$ & 38 & 38 & Z2-EU37B-301 & 38 & NA & NA & 0 & 0 & 0 & 1 \\
\hline Copper & $1 / 1$ & $54 \mathrm{~J}$ & $54 \mathrm{~J}$ & Z2-EU37B-301 & 54 & NA & NA & 0 & 1 & NA & 0 \\
\hline Lead & $1 / 1$ & 45 & 45 & Z2-EU37B-301 & 45 & NA & NA & 0 & 1 & 0 & 0 \\
\hline Magnesium & $1 / 1$ & 19,000 & 19,000 & Z2-EU37B-301 & 19,000 & NA & NA & NA & 1 & NA & NA \\
\hline Manganese & $1 / 1$ & 640 & 640 & Z2-EU37B-301 & 640 & NA & NA & 0 & 0 & NA & 1 \\
\hline Nickel & $1 / 1$ & 100 & 100 & Z2-EU37B-301 & 100 & NA & NA & 0 & 1 & NA & 0 \\
\hline Uranium & $1 / 1$ & 1.9 & 1.9 & Z2-EU37B-301 & 1.9 & NA & NA & 0 & NA & NA & 1 \\
\hline Vanadium & $1 / 1$ & 26 & 26 & Z2-EU37B-301 & 26 & NA & NA & 0 & 0 & NA & 1 \\
\hline
\end{tabular}

Avg = average $\quad \mathrm{NA}=$ not applicable

$\mathrm{Bkg}=$ background $\quad \mathrm{PRG}=$ preliminary remediation goal

$\mathrm{EU}=$ exposure unit $\quad$ Res $=$ residential

$\mathrm{GW}=$ groundwater $\quad \mathrm{RL}=$ remediation level

Ind $=$ industrial $\quad \mathrm{SL}=$ screening level

Max = maximum $\quad \mathrm{SU}=$ soil unit

EU Z2-37 UTILITY CORRIDOR SOILSPCB DETECTS (ug/kg) 0-10 ft

\begin{tabular}{|c|c|c|c|c|c|c|c|c|c|}
\hline \multirow[b]{2}{*}{ Analyte } & \multirow[b]{2}{*}{$\begin{array}{c}\text { Detect } \\
\text { frequency }\end{array}$} & \multirow[b]{2}{*}{$\begin{array}{c}\text { Minimum } \\
\text { detect }\end{array}$} & \multirow[b]{2}{*}{$\begin{array}{c}\text { Maximum } \\
\text { detect }\end{array}$} & \multirow{2}{*}{$\begin{array}{c}\text { Location(s) of } \\
\text { maximum } \\
\text { detect }\end{array}$} & \multirow{2}{*}{$\begin{array}{c}\text { Average } \\
\text { detected } \\
\text { result }\end{array}$} & \multicolumn{4}{|c|}{$\begin{array}{c}\text { Number of analyses } \\
\text { exceeding criteria }\end{array}$} \\
\hline & & & & & & $\begin{array}{l}\text { Max } \\
\text { RL }\end{array}$ & $\begin{array}{l}\text { Avg } \\
\text { RL }\end{array}$ & $\begin{array}{l}\text { Ind } \\
\text { PRG }\end{array}$ & $\begin{array}{c}\text { Res } \\
\text { PRG }\end{array}$ \\
\hline PCB-1254 & $1 / 1$ & 190 & 190 & Z2-EU37B-301 & 190 & 0 & 0 & 0 & 1 \\
\hline PCB-1260 & $1 / 1$ & 200 & 200 & Z2-EU37B-301 & 200 & 0 & 0 & 0 & 1 \\
\hline Polychlorinated biphenyl & $1 / 1$ & 390 & 390 & Z2-EU37B-301 & 390 & 0 & 0 & 0 & 1 \\
\hline
\end{tabular}

Avg $=$ average $\quad \mathrm{PCB}=$ polychlorinated biphenyl

$\mathrm{EU}=$ exposure unit $\quad \mathrm{PRG}=$ preliminary remediation goal

Ind $=$ industrial $\quad$ Res $=$ residential

Max $=$ maximum $\quad \mathrm{RL}=$ remediation level

EU Z2-37 UTILITY CORRIDOR SOILSRADIONUCLIDES WITH BACKGROUND, PRG, AND/OR RL EXCEEDANCES (pCi/g) 0-10 ft

\begin{tabular}{|c|c|c|c|c|c|c|c|c|c|c|c|}
\hline \multirow[b]{2}{*}{ Analyte } & \multirow[b]{2}{*}{$\begin{array}{c}\text { Detect } \\
\text { frequency }\end{array}$} & \multirow[b]{2}{*}{$\begin{array}{c}\text { Minimum } \\
\text { detect }\end{array}$} & \multirow[b]{2}{*}{$\begin{array}{c}\text { Maximum } \\
\text { detect }\end{array}$} & \multirow[b]{2}{*}{$\begin{array}{l}\text { Location(s) of } \\
\text { maximum detect }\end{array}$} & \multirow{2}{*}{$\begin{array}{c}\text { Average } \\
\text { detected } \\
\text { result }\end{array}$} & \multicolumn{6}{|c|}{ Number of analyses exceeding criteri a } \\
\hline & & & & & & $\begin{array}{c}\text { Max } \\
\text { RL }\end{array}$ & $\begin{array}{l}\text { Avg } \\
\text { RL }\end{array}$ & $\begin{array}{l}\text { Ind } \\
\text { PRG }\end{array}$ & Bkg & $\begin{array}{c}\text { GW } \\
\text { SL }\end{array}$ & $\begin{array}{l}\text { Res } \\
\text { PRG }\end{array}$ \\
\hline Potassium-40 & $1 / 1$ & 22.2 & 22.2 & Z2-EU37B-301 & 22.2 & NA & NA & 1 & 0 & NA & 1 \\
\hline Radium-226 & $1 / 1$ & 0.473 & 0.473 & Z2-EU37B-301 & 0.473 & NA & NA & 1 & 0 & NA & 1 \\
\hline Thorium -228 & $1 / 1$ & 1.19 & 1.19 & Z2-EU37B-301 & 1.19 & NA & NA & 1 & 0 & NA & 1 \\
\hline Thorium - 232 & $1 / 1$ & 1.59 & 1.59 & Z2-EU37B-301 & 1.59 & NA & NA & 1 & 0 & NA & 1 \\
\hline Uranium-238 & $1 / 1$ & 1.37 & 1.37 & Z2-EU37B-301 & 1.37 & 0 & 0 & 0 & 0 & 0 & 1 \\
\hline
\end{tabular}

Avg $=$ average

$\mathrm{Bkg}=$ background

$\mathrm{EU}=$ exposure unit

$\mathrm{GW}=$ groundwater

Ind $=$ industrial

Max $=$ maximum
$\mathrm{NA}=$ not applicable

$\mathrm{PRG}=$ preliminary remediation goal

Res $=$ residential

$\mathrm{RL}=$ remediation level

$\mathrm{SL}=$ screening level

$\mathrm{SU}=$ soil unit 


\begin{tabular}{|c|c|c|c|c|c|c|c|c|}
\hline \multirow[b]{2}{*}{ Analyte } & \multirow[b]{2}{*}{$\begin{array}{c}\text { Detect } \\
\text { frequency }\end{array}$} & \multirow[b]{2}{*}{$\begin{array}{c}\text { Minimum } \\
\text { detect }\end{array}$} & \multirow[b]{2}{*}{$\begin{array}{c}\text { Maximum } \\
\text { detect }\end{array}$} & \multirow[b]{2}{*}{$\begin{array}{c}\text { Location(s) of } \\
\text { maximum detect }\end{array}$} & \multirow{2}{*}{$\begin{array}{c}\text { Average } \\
\text { detected } \\
\text { result }\end{array}$} & \multicolumn{3}{|c|}{$\begin{array}{c}\text { Number of analyses } \\
\text { exceeding criteria }\end{array}$} \\
\hline & & & & & & $\begin{array}{c}\text { Ind } \\
\text { PRG }\end{array}$ & GW & $\begin{array}{c}\text { Res } \\
\text { PRG }\end{array}$ \\
\hline 2-Methylnaphthalene & $1 / 1$ & $180 \mathrm{~J}$ & $180 \mathrm{~J}$ & Z2-EU37B-301 & 180 & 0 & NA & NA \\
\hline Anthracene & $1 / 1$ & $99 \mathrm{~J}$ & $99 \mathrm{~J}$ & Z2-EU37B-301 & 99 & 0 & NA & 0 \\
\hline Benz(a)anthracene & $1 / 1$ & 1,100 & 1,100 & Z2-EU37B-301 & 1,100 & 0 & NA & 1 \\
\hline Benzo(a)pyrene & $1 / 1$ & 1,300 & 1,300 & Z2-EU37B-301 & 1,300 & 0 & NA & 1 \\
\hline Benzo(b)fluoranthene & $1 / 1$ & 2,100 & 2,100 & Z2-EU37B-301 & 2,100 & 0 & NA & 1 \\
\hline Benzo(ghi)perylene & $1 / 1$ & 680 & 680 & Z2-EU37B-301 & 680 & 0 & NA & 0 \\
\hline Benzo(k)fluoranthene & $1 / 1$ & 770 & 770 & Z2-EU37B-301 & 770 & 0 & NA & 0 \\
\hline Chrysene & $1 / 1$ & 1,100 & 1,100 & Z2-EU37B-301 & 1.100 & 0 & NA & 0 \\
\hline Dibenz(a,h)anthracene & $1 / 1$ & $180 \mathrm{~J}$ & $180 \mathrm{~J}$ & Z2-EU37B-301 & 180 & 0 & NA & 1 \\
\hline Fluoranthene & $1 / 1$ & 1,500 & 1,500 & Z2-EU37B-301 & 1,500 & 0 & NA & 0 \\
\hline Indeno(1,2,3-cd)pyrene & $1 / 1$ & 630 & 630 & Z2-EU37B-301 & 630 & 0 & NA & 1 \\
\hline Naphthalene & $1 / 1$ & $140 \mathrm{~J}$ & $140 \mathrm{~J}$ & Z2-EU37B-301 & 140 & 0 & NA & 0 \\
\hline Phenanthrene & $1 / 1$ & $330 \mathrm{~J}$ & $330 \mathrm{~J}$ & Z2-EU37B-301 & 330 & 0 & NA & 0 \\
\hline Pyrene & $1 / 1$ & 1,500 & 1,500 & Z2-EU37B-301 & 1,500 & 0 & NA & 0 \\
\hline $\mathrm{EU}=$ exposure unit & \multicolumn{8}{|c|}{$\mathrm{PRG}=$ preliminary remediation goal } \\
\hline $\mathrm{GW}=$ groundwater & \multicolumn{8}{|c|}{ Res $=$ residential } \\
\hline Ind $=$ industrial & \multicolumn{8}{|c|}{$\mathrm{SL}=$ screening level } \\
\hline NA $=$ not applicable & \multicolumn{8}{|c|}{ SVOC $=$ semivolatile organic compound } \\
\hline
\end{tabular}

VOCs were analyzed for but were not detected.

DVS Soil Sampling Associated with the SW31 Spring: Three biased sample locations were selected to-for investigation of possible soil contamination resulting from overflow of the SW-31 Spring sump any lingering effects ef the SW31 Spring on nearby soils. Location Z2-EU37B-303 is in the adjacent ditch uphill from the spring, location Z2-EU37B-304 is in the adjacent ditch downhill from the spring, and location Z2-EU37B-306 is in the adjacent ditch next to the spring. Analytical results summarized below show radionuclide and SVOC Ind PRG exceedances; metal and radionuclide Bkg exceedances; and PCB, SVOC, and VOC detections.

EU Z2-37 SW 31 SOILS METALS WITH BACKGROUND,PRG, GW SL, AND/OR RL EXCEEDANCES (mg/kg) 0-10 ft

\begin{tabular}{|c|c|c|c|c|c|c|c|c|c|c|c|}
\hline \multirow[b]{2}{*}{ Analyte } & \multirow[b]{2}{*}{$\begin{array}{c}\text { Detect } \\
\text { frequency }\end{array}$} & \multirow[b]{2}{*}{$\begin{array}{c}\text { Minimum } \\
\text { detect }\end{array}$} & \multirow[b]{2}{*}{$\underset{\text { detect }}{\text { Maximum }}$} & \multirow{2}{*}{$\begin{array}{c}\text { Location(s) of } \\
\text { maximum } \\
\text { detect }\end{array}$} & \multirow{2}{*}{$\begin{array}{c}\text { Average } \\
\text { detected } \\
\text { result }\end{array}$} & \multicolumn{6}{|c|}{ Number of analyses exceeding criteria } \\
\hline & & & & & & $\begin{array}{c}\text { Max } \\
\text { RL }\end{array}$ & $\begin{array}{l}\text { Avg } \\
\text { RL }\end{array}$ & $\begin{array}{l}\text { Ind } \\
\text { PRG }\end{array}$ & Bkg & $\begin{array}{l}\text { GW } \\
\text { SL }\end{array}$ & $\begin{array}{c}\text { Res } \\
\text { PRG }\end{array}$ \\
\hline Aluminum & $3 / 3$ & 6,600 & 10,000 & Z2-EU37B-306 & 8,800 & NA & NA & 0 & 0 & NA & 2 \\
\hline Arsenic & $3 / 3$ & 6.7 & 13 & Z2-EU37B-303 & 9.03 & 0 & 0 & 0 & 0 & 0 & 3 \\
\hline Barium & $3 / 3$ & 71 & 390 & Z2-EU37B-306 & 190 & NA & NA & 0 & 1 & 0 & 0 \\
\hline Cadmium & $3 / 3$ & $0.12 \mathrm{~J}$ & $0.56 \mathrm{~J}$ & Z2-EU37B-304 & 0.273 & NA & NA & 0 & 1 & NA & 0 \\
\hline Calcium & $3 / 3$ & 14,000 & 93,000 & Z2-EU37B-303 & 52,000 & NA & NA & NA & 3 & NA & NA \\
\hline Copper & $3 / 3$ & 20J & $51 \mathrm{~J}$ & Z2-EU37B-304 & 33.7 & NA & NA & 0 & 2 & NA & 0 \\
\hline Lead & $3 / 3$ & 17 & 52 & Z2-EU37B-304 & 33 & NA & NA & 0 & 1 & 0 & 0 \\
\hline Magnesium & $3 / 3$ & 3,500 & 9,400 & Z2-EU37B-303 & 7,000 & NA & NA & NA & 3 & NA & NA \\
\hline Manganese & $3 / 3$ & 220 & 10,000 & Z2-EU37B-306 & 3,807 & NA & NA & 0 & 1 & NA & 3 \\
\hline Mercury & $3 / 3$ & 0.069 & 0.25 & Z2-EU37B-304 & 0.150 & 0 & 0 & 0 & 1 & NA & 0 \\
\hline Nickel & $3 / 3$ & 14 & 91 & Z2-EU37B-304 & 47 & NA & NA & 0 & 2 & NA & 0 \\
\hline Uranium & $3 / 3$ & 1.1 & 2 & Z2-EU37B-304 & 1.47 & NA & NA & 0 & NA & NA & 1 \\
\hline Vanadium & $3 / 3$ & 23 & 26 & Z2-EU37B-306 & 24.3 & NA & NA & 0 & 0 & NA & 3 \\
\hline Zinc & $3 / 3$ & $44 \mathrm{~J}$ & $92 \mathrm{~J}$ & Z2-EU37B-303 & 71.7 & NA & NA & 0 & 1 & NA & 0 \\
\hline
\end{tabular}

Avg $=$ average $\quad \mathrm{NA}=$ not applicable

$\mathrm{Bkg}=$ background $\quad \mathrm{PRG}=$ preliminary remediation goal

$\mathrm{EU}=$ exposure unit $\quad$ Res $=$ residential

$\mathrm{GW}=$ groundwater $\quad \mathrm{RL}=$ remediation level

Ind $=$ industrial $\quad \mathrm{SL}=$ screening level

Max = maximum $\quad \mathrm{SU}=$ soil unit 
EU Z2-37 SW 31 SOILSPCB DETECTS (ug/kg) 0-10 ft

\begin{tabular}{|c|c|c|c|c|c|c|c|c|c|}
\hline \multirow[b]{2}{*}{ Analyte } & \multirow[b]{2}{*}{$\begin{array}{c}\text { Detect } \\
\text { frequency }\end{array}$} & \multirow[b]{2}{*}{$\begin{array}{c}\text { Minimum } \\
\text { detect }\end{array}$} & \multirow[b]{2}{*}{$\begin{array}{c}\text { Maximum } \\
\text { detect }\end{array}$} & \multirow{2}{*}{$\begin{array}{l}\text { Location(s) of } \\
\text { maximum } \\
\text { detect }\end{array}$} & \multirow{2}{*}{$\begin{array}{c}\text { Average } \\
\text { detected } \\
\text { result }\end{array}$} & \multicolumn{4}{|c|}{$\begin{array}{l}\text { Number of analyses } \\
\text { exceeding criteria }\end{array}$} \\
\hline & & & & & & $\begin{array}{c}\text { Max } \\
\text { RL }\end{array}$ & $\begin{array}{l}\text { Avg } \\
\text { RL }\end{array}$ & $\begin{array}{c}\text { Ind } \\
\text { PRG }\end{array}$ & $\begin{array}{l}\text { Res } \\
\text { PRG }\end{array}$ \\
\hline PCB-1254 & $2 / 3$ & 26 & 220 & Z2-EU37B-304 & 123 & 0 & 0 & 0 & 11 \\
\hline PCB-1260 & $1 / 3$ & $120 \mathrm{~J}$ & $120 \mathrm{~J}$ & Z2-EU37B-306 & 120 & 0 & 0 & 0 & 1 \\
\hline Polychlorinated biphenyl & $3 / 3$ & 26 & 220 & Z2-EU37B-304 & 122 & 0 & 0 & 0 & 2 \\
\hline
\end{tabular}

Avg $=$ average $\quad \mathrm{PCB}=$ polychlorinated biphenyl

$\mathrm{EU}=$ exposure unit $\quad \mathrm{PRG}=$ preliminary remediation goal

Ind $=$ industrial $\quad$ Res $=$ residential

Max $=$ maximum $\quad \mathrm{RL}=$ remediation level

EU Z2-37 SW 31 SOILSRADIONUCLIDES WITH BACKGROUND, PRG, AND/OR RL EXCEEDANCES (pCi/g) 0-10 ft

\begin{tabular}{|c|c|c|c|c|c|c|c|c|c|c|c|}
\hline \multirow[b]{2}{*}{ Analyte } & \multirow[b]{2}{*}{$\begin{array}{c}\text { Detect } \\
\text { frequency }\end{array}$} & \multirow[b]{2}{*}{$\begin{array}{c}\text { Minimum } \\
\text { detect }\end{array}$} & \multirow[b]{2}{*}{$\begin{array}{c}\text { Maximum } \\
\text { detect }\end{array}$} & \multirow[b]{2}{*}{$\begin{array}{c}\text { Location(s) of } \\
\text { maximum detect }\end{array}$} & \multirow{2}{*}{$\begin{array}{c}\text { Average } \\
\text { detected } \\
\text { result }\end{array}$} & \multicolumn{6}{|c|}{ Number of analyses exceeding criteria } \\
\hline & & & & & & $\underset{\text { RL }}{\operatorname{Max}}$ & $\begin{array}{l}\text { Avg } \\
\text { RL }\end{array}$ & $\begin{array}{l}\text { Ind } \\
\text { PRG }\end{array}$ & Bkg & $\begin{array}{c}\text { GW } \\
\text { SL }\end{array}$ & $\begin{array}{l}\text { Res } \\
\text { PRG }\end{array}$ \\
\hline 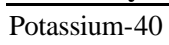 & $3 / 3$ & 19.9 & 31.7 & Z2-EU37B-306 & 24.7 & NA & NA & 3 & 0 & NA & 3 \\
\hline Radium-226 & $3 / 3$ & 0.923 & 1.63 & Z2-EU37B-306 & 1.19 & NA & NA & 3 & 1 & NA & 3 \\
\hline Thorium -228 & $3 / 3$ & 0.991 & 1.41 & Z2-EU37B-306 & 1.14 & NA & NA & 3 & 0 & NA & 3 \\
\hline Thorium-230 & $3 / 3$ & 1.19 & 1.84 & Z2-EU37B-303 & 1.46 & NA & NA & 0 & 2 & NA & 0 \\
\hline Thorium -232 & $3 / 3$ & 0.886 & 1.6 & Z2-EU37B-306 & 1.32 & NA & NA & 3 & 0 & NA & 3 \\
\hline Uranium-235 & $2 / 3$ & 0.113 & 0.206 & Z2-EU37B-306 & 0.160 & 0 & 0 & 0 & NA & 0 & 1 \\
\hline Uranium-238 & $3 / 3$ & 1.29 & 1.41 & Z2-EU37B-303 & 1.36 & 0 & 0 & 0 & 0 & 0 & 3 \\
\hline
\end{tabular}

Avg = average

$\mathrm{Bkg}=$ background

$\mathrm{EU}=$ exposure unit

$\mathrm{NA}=$ not applicable

$\mathrm{GW}=$ groundwater

$\mathrm{PRG}=$ preliminary remediation goal

Res $=$ residential

$\mathrm{RL}=$ remediation level

Ind $=$ industrial

$\mathrm{SL}=$ screening level

Max = maximum $\quad \mathrm{SU}=$ soil unit

EU Z2-37 SW31 SOILSSVOC DETECTS (ug/kg) 0-10 ft

\begin{tabular}{|c|c|c|c|c|c|c|c|c|}
\hline \multirow[b]{2}{*}{ Analyte } & \multirow[b]{2}{*}{$\begin{array}{c}\text { Detect } \\
\text { frequency }\end{array}$} & \multirow[b]{2}{*}{$\begin{array}{c}\text { Minimum } \\
\text { detect }\end{array}$} & \multirow[b]{2}{*}{$\begin{array}{c}\text { Maximum } \\
\text { detect }\end{array}$} & \multirow[b]{2}{*}{$\begin{array}{c}\text { Location(s) of } \\
\text { maximum detect }\end{array}$} & \multirow{2}{*}{$\begin{array}{c}\text { Average } \\
\text { detected } \\
\text { result }\end{array}$} & \multicolumn{3}{|c|}{$\begin{array}{l}\text { Number of analyses } \\
\text { exceeding criteria }\end{array}$} \\
\hline & & & & & & $\begin{array}{l}\text { Ind } \\
\text { PRG }\end{array}$ & $\begin{array}{c}\text { GW } \\
\text { SL }\end{array}$ & $\begin{array}{l}\text { Res } \\
\text { PRG }\end{array}$ \\
\hline 2-Methylnaphthalene & $1 / 3$ & $120 \mathrm{~J}$ & $120 \mathrm{~J}$ & Z2-EU37B-306 & 120 & 0 & NA & NA \\
\hline Acenaphthene & $1 / 3$ & $280 \mathrm{~J}$ & $280 \mathrm{~J}$ & Z2-EU37B-306 & 280 & 0 & NA & 0 \\
\hline Anthracene & $1 / 3$ & 1,400 & 1,400 & Z2-EU37B-306 & 1,400 & 0 & NA & 0 \\
\hline Benz(a)anthracene & $3 / 3$ & $140 \mathrm{~J}$ & 5,400 & Z2-EU37B-306 & 1,930 & 0 & NA & 1 \\
\hline Benzo(a)pyrene & $3 / 3$ & $150 \mathrm{~J}$ & 4,900 & Z2-EU37B-306 & 1,783 & 1 & NA & 3 \\
\hline Benzo(b)fluoranthene & $3 / 3$ & $240 \mathrm{~J}$ & 6,600 & Z2-EU37B-306 & 2,420 & 0 & NA & 1 \\
\hline Benzo(ghi)perylene & $3 / 3$ & $61 \mathrm{~J}$ & 1,800 & Z2-EU37B-306 & 657 & 0 & NA & 0 \\
\hline Benzo(k)fluoranthene & $3 / 3$ & $96 \mathrm{~J}$ & 2,800 & Z2-EU37B-306 & 1,029 & 0 & NA & 0 \\
\hline Carbazole & $1 / 3$ & 660 & 660 & Z2-EU37B-306 & 660 & 0 & NA & 0 \\
\hline Chrysene & $3 / 3$ & $150 \mathrm{~J}$ & 4,900 & Z2-EU37B-306 & 1,777 & 0 & NA & 0 \\
\hline $\operatorname{Dibenz}(\mathrm{a}, \mathrm{h})$ anthracene & $1 / 3$ & 530 & 530 & Z2-EU37B-306 & 530 & 0 & NA & 1 \\
\hline Dibenzofuran & $1 / 3$ & $100 \mathrm{~J}$ & $100 \mathrm{~J}$ & Z2-EU37B-306 & 100 & 0 & NA & 0 \\
\hline Fluoranthene & $3 / 3$ & $270 \mathrm{~J}$ & 12,000 & Z2-EU37B-306 & 4,240 & 0 & NA & 0 \\
\hline Fluorene & $1 / 3$ & $320 \mathrm{~J}$ & $320 \mathrm{~J}$ & Z2-EU37B-306 & 320 & 0 & NA & 0 \\
\hline Indeno(1,2,3-cd)pyrene & $3 / 3$ & $66 \mathrm{~J}$ & 1,800 & Z2-EU37B-306 & 665 & 0 & NA & 1 \\
\hline Phenanthrene & $3 / 3$ & $56 \mathrm{~J}$ & 5,100 & Z2-EU37B-306 & 1,759 & 0 & NA & 0 \\
\hline Pyrene & $3 / 3$ & $220 \mathrm{~J}$ & 8,100 & Z2-EU37B-306 & 2,893 & 0 & NA & 0 \\
\hline $\begin{array}{l}\mathrm{EU}=\text { exposure unit } \\
\mathrm{GW}=\text { groundwater } \\
\text { Ind = industrial } \\
\mathrm{NA}=\text { not applicable }\end{array}$ & $\begin{array}{l}\mathrm{PRG}=\text { prel } \\
\text { Res }=\text { resid } \\
\mathrm{SL}=\text { screer } \\
\text { SVOC }=\text { se }\end{array}$ & $\begin{array}{l}\text { liminary rem } \\
\text { lential } \\
\text { ning level } \\
\text { emivolatile o }\end{array}$ & $\begin{array}{l}\text { nediation goa } \\
\text { organic comp }\end{array}$ & pound & & & & \\
\hline
\end{tabular}




\begin{tabular}{|c|c|c|c|c|c|c|c|c|}
\hline \multirow[b]{2}{*}{ Analyte } & \multirow[b]{2}{*}{$\begin{array}{c}\text { Detect } \\
\text { frequency }\end{array}$} & \multirow[b]{2}{*}{$\begin{array}{c}\text { Minimum } \\
\text { detect }\end{array}$} & \multirow[b]{2}{*}{$\begin{array}{c}\text { Maximum } \\
\text { detect }\end{array}$} & \multirow[b]{2}{*}{$\begin{array}{c}\text { Location(s) of } \\
\text { maximum detect }\end{array}$} & \multirow{2}{*}{$\begin{array}{c}\text { Average } \\
\text { detected } \\
\text { result }\end{array}$} & \multicolumn{3}{|c|}{$\begin{array}{c}\text { Number of analyses } \\
\text { exceeding criteria }\end{array}$} \\
\hline & & & & & & $\begin{array}{c}\text { Ind } \\
\text { PRG } \\
\end{array}$ & $\begin{array}{l}\text { GW } \\
\text { SL } \\
\end{array}$ & $\begin{array}{l}\text { Res } \\
\text { PRG }\end{array}$ \\
\hline 1,1,1-Trichloroethane & $1 / 3$ & 7.1 & 7.1 & Z2-EU37B-304 & 7.1 & 0 & 0 & 0 \\
\hline 1,1-Dichloroethane & $2 / 3$ & $1.1 \mathrm{~J}$ & $1.5 \mathrm{~J}$ & Z2-EU37B-304 & 1.3 & 0 & NA & 0 \\
\hline 1,1-Dichloroethene & $1 / 3$ & $1.3 \mathrm{~J}$ & $1.3 \mathrm{~J}$ & Z2-EU37B-304 & 1.3 & 0 & 0 & 0 \\
\hline $\mathrm{EU}=$ exposure unit & \multicolumn{8}{|c|}{$\mathrm{PRG}=$ preliminary remediation goal } \\
\hline $\mathrm{GW}=$ groundwater & \multicolumn{8}{|c|}{ Res $=$ residential } \\
\hline Ind $=$ industrial & \multicolumn{8}{|c|}{$\mathrm{SL}=$ screening level } \\
\hline $\mathrm{NA}=$ not applicable & \multicolumn{8}{|c|}{ VOC $=$ volatile organic compound } \\
\hline
\end{tabular}

Historical Sampling in EU Z2-37: There are 24 historical samp le locations in this EU, with samples collected from 0- to 10-ft bgs that are not included as part of the K-1414 Garage Diesel Tank/Soil FFA site characterization (Sect. H.2.2.6). Sample locations are identified in Sect. H.2.2.3. Analytical results summarized below show one manganese and several radionuclide Ind PRG exceedances; several metal and radionuclide Bkg exceedances; and detections of DRO, gasoline-range organic (GRO), PCBs, one pesticide (methoxychlor), SVOCs, and VOCs. The DRO and GRO detections occur at sample location BH004, which is downgradient of the K-1414 Garage Diesel Tank/Soil FFA site.

EU Z2-37 HISTORICAL METALS WITH BACKGROUND, PRG, GW SL, AND/OR RL EXCEEDANCES (mg/kg) 0-10 ft

\begin{tabular}{|c|c|c|c|c|c|c|c|c|c|c|c|}
\hline \multirow[b]{2}{*}{ Analyte } & \multirow[b]{2}{*}{$\begin{array}{c}\text { Detect } \\
\text { frequency }\end{array}$} & \multirow[b]{2}{*}{$\begin{array}{c}\text { Minimum } \\
\text { detect }\end{array}$} & \multirow[b]{2}{*}{$\begin{array}{c}\text { Maximum } \\
\text { detect }\end{array}$} & \multirow{2}{*}{$\begin{array}{l}\text { Location(s) of } \\
\text { maximum } \\
\text { detect }\end{array}$} & \multirow{2}{*}{$\begin{array}{c}\text { Average } \\
\text { detected } \\
\text { result }\end{array}$} & \multicolumn{6}{|c|}{ Number of analyses exceeding criteria } \\
\hline & & & & & & $\begin{array}{c}\text { Max } \\
\text { RL }\end{array}$ & $\begin{array}{l}\text { Avg } \\
\text { RL }\end{array}$ & $\begin{array}{c}\text { Ind } \\
\text { PRG }\end{array}$ & Bkg & $\begin{array}{c}\text { GW } \\
\text { SL }\end{array}$ & $\begin{array}{c}\text { Res } \\
\text { PRG }\end{array}$ \\
\hline Aluminum & $16 / 16$ & 8,790 & 20,400 & SB080 & 14,505 & NA & NA & 0 & 0 & NA & 16 \\
\hline Arsenic & $16 / 16$ & $1.4 \mathrm{~J}$ & $13.8 \mathrm{~J}$ & SB080 & 5.47 & 0 & 0 & 0 & 0 & 0 & 16 \\
\hline Barium & $16 / 16$ & 43 & 1,420 & SB089 & 170 & NA & NA & 0 & 4 & 0 & 1 \\
\hline Beryllium & $16 / 16$ & 0.23 & 6.3 & BH012 & 1.11 & 0 & 0 & 0 & 1 & NA & 0 \\
\hline Cadmium & $3 / 16$ & 0.25 & 0.37 & SB099 & 0.32 & NA & NA & 0 & 3 & NA & 0 \\
\hline Calcium & $16 / 16$ & 177 & 40,800 & SB079 & 7,381 & NA & NA & NA & 6 & NA & NA \\
\hline Chromium & $16 / 16$ & $11 \mathrm{~J}$ & 36.9 & SB099 & 21.6 & NA & NA & 0 & 0 & 0 & 5 \\
\hline Cobalt & $16 / 16$ & 3.9 & 52.7 & SB080 & 18.5 & NA & NA & 0 & 1 & NA & 0 \\
\hline Copper & $15 / 16$ & 8.2 & 59.6 & SB083 & 25.6 & NA & NA & 0 & 7 & NA & 0 \\
\hline Iron & $16 / 16$ & 13,300 & 36,600 & SB080 & 26,456 & NA & NA & 0 & 0 & NA & 16 \\
\hline Lead & $16 / 16$ & 13.9 & 45.2 & BH012 & 23.4 & NA & NA & 0 & 2 & 0 & 0 \\
\hline Magnesium & $16 / 16$ & 470 & 22,400 & SB079 & 3,756 & NA & NA & NA & 4 & NA & NA \\
\hline Manganese & $16 / 16$ & 142 & 20,600 & SB089 & 1,977 & NA & NA & 1 & 1 & NA & 15 \\
\hline Nickel & $16 / 16$ & $6.8 \mathrm{~J}$ & 65.3 & SB078 & 28.1 & NA & NA & 0 & 7 & NA & 0 \\
\hline Selenium & $7 / 10$ & $0.35 \mathrm{~J}$ & $2.4 \mathrm{~J}$ & SB082 & 1.48 & NA & NA & 0 & 3 & NA & 0 \\
\hline Silver & $15 / 16$ & 1.1 & $3.3 \mathrm{~J}$ & SB089 & 1.97 & NA & NA & 0 & 15 & NA & 0 \\
\hline Thallium & $6 / 16$ & 0.14 & 0.56 & BH012 & 0.397 & NA & NA & 0 & 3 & 0 & 3 \\
\hline Vanadium & $16 / 16$ & 15.2 & 42.6 & SB092 & 28.7 & NA & NA & 0 & 0 & NA & 16 \\
\hline Zinc & $16 / 16$ & $20.7 \mathrm{~J}$ & $152 \mathrm{~J}$ & BH012 & 56.6 & NA & NA & 0 & 2 & NA & 0 \\
\hline
\end{tabular}

Avg $=$ average

$\mathrm{Bkg}=$ background

$\mathrm{EU}=$ exposure unit

$\mathrm{GW}=$ groundwater

Ind $=$ industrial

Max $=$ maximum
$\mathrm{NA}=$ not applicable

$\mathrm{PRG}=$ preliminary remediation goal

Res $=$ residential

$\mathrm{RL}=$ remediation level

$\mathrm{SL}=$ screening level

$\mathrm{SU}=$ soil unit 
EU Z2-37 HISTORICAL OTHER ORGANICS DETECTS (mg/kg) 0-10 ft

\begin{tabular}{lccccc}
\hline \multicolumn{1}{c}{ Analyte } & $\begin{array}{c}\text { Detect } \\
\text { frequency }\end{array}$ & $\begin{array}{c}\text { Minimum } \\
\text { detect }\end{array}$ & $\begin{array}{c}\text { Maximum } \\
\text { detect }\end{array}$ & $\begin{array}{c}\text { Location(s) of } \\
\text { maximum } \\
\text { detect }\end{array}$ & $\begin{array}{c}\text { Average } \\
\text { detected } \\
\text { result }\end{array}$ \\
\hline Diesel Range Organics & $1 / 11$ & $329 \mathrm{~J}$ & $329 \mathrm{~J}$ & BH004 & 329 \\
Gasoline Range Organics & $1 / 11$ & 88.5 & 88.5 & BH004 & 88.5 \\
\hline
\end{tabular}

$\mathrm{EU}=$ exposure unit

EU Z2-37 HISTORICAL PPCB DETECTS (ug/kg) 0-10 ft

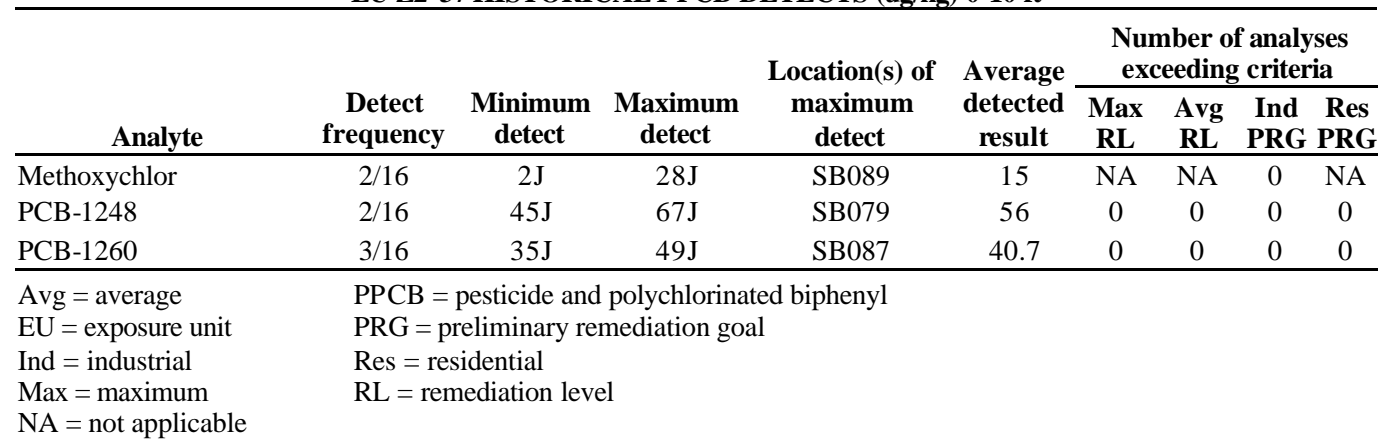

EU Z2-37 HISTORICAL RADIONUCLIDES WITH BACKGROUND, PRG, AND/OR RL EXCEEDANCES (pCi/g) 0-10 ft

\begin{tabular}{|c|c|c|c|c|c|c|c|c|c|c|c|}
\hline \multirow[b]{2}{*}{ Analyte } & \multirow[b]{2}{*}{$\begin{array}{c}\text { Detect } \\
\text { frequency }\end{array}$} & \multirow[b]{2}{*}{$\begin{array}{c}\text { Minimum } \\
\text { detect }\end{array}$} & \multirow[b]{2}{*}{$\begin{array}{c}\text { Maximum } \\
\text { detect }\end{array}$} & \multirow[b]{2}{*}{$\begin{array}{l}\text { Location(s) of } \\
\text { maximum detect }\end{array}$} & \multirow{2}{*}{$\begin{array}{c}\text { Average } \\
\text { detected } \\
\text { result }\end{array}$} & \multicolumn{6}{|c|}{ Number of analyses exceeding criteria } \\
\hline & & & & & & $\begin{array}{l}\text { Max } \\
\text { RL }\end{array}$ & $\begin{array}{c}\text { Avg } \\
\text { RL }\end{array}$ & $\begin{array}{l}\text { Ind } \\
\text { PRG }\end{array}$ & Bkg & $\begin{array}{c}\text { GW } \\
\text { SL }\end{array}$ & $\begin{array}{c}\text { Res } \\
\text { PRG }\end{array}$ \\
\hline Cesium-137 & $4 / 18$ & 0.66 & 0.99 & RAD90 & 0.798 & 0 & 0 & 0 & NA & NA & 4 \\
\hline Potassium-40 & $6 / 6$ & 9.2 & 35.6 & BH012 & 15.6 & NA & NA & 6 & 1 & NA & 6 \\
\hline Radium-226 & $4 / 4$ & 1.4 & 4.5 & RAD85 & 3.45 & NA & NA & 4 & 4 & NA & 4 \\
\hline Technetium-99 & $14 / 20$ & $0.32 \mathrm{~J}$ & $3.47 \mathrm{~J}$ & RAD85 & 1.35 & NA & NA & 0 & NA & NA & 14 \\
\hline Thorium -228 & $5 / 6$ & 1.47 & $1.97 \mathrm{~J}$ & BH012 & 1.60 & NA & NA & 5 & 1 & NA & 5 \\
\hline Thorium -230 & $6 / 6$ & $1.07 \mathrm{~J}$ & 1.48 & RAD69 & 1.32 & NA & NA & 0 & 4 & NA & 0 \\
\hline Thorium -232 & $6 / 6$ & $0.9 \mathrm{~J}$ & 1.49 & RAD69 & 1.22 & NA & NA & 6 & 0 & NA & 6 \\
\hline Uranium-235 & $17 / 19$ & 0.02 & 0.33 & RAD85 & 0.109 & 0 & 0 & 0 & NA & 0 & 3 \\
\hline Uranium-238 & $19 / 19$ & 0.72 & 2.42 & RAD90 & 1.45 & 0 & 0 & 0 & 7 & 0 & 18 \\
\hline
\end{tabular}

Avg $=$ average $\quad$ NA $=$ not applicable

$\mathrm{Bkg}=$ background $\quad \mathrm{PRG}=$ preliminary remediation goal

$\mathrm{EU}=$ exposure unit $\quad$ Res $=$ residential

$\mathrm{GW}=$ groundwater $\quad \mathrm{RL}=$ remediation level

Ind $=$ industrial $\quad \mathrm{SL}=$ screening level

Max = maximum $\quad$ SU $=$ soil unit

EU Z2-37 HISTORICAL SVOC DETECTS (ug/kg) 0-10 ft

\begin{tabular}{|c|c|c|c|c|c|c|c|c|}
\hline \multirow[b]{2}{*}{ Analyte } & \multirow[b]{2}{*}{$\begin{array}{c}\text { Detect } \\
\text { frequency }\end{array}$} & \multirow[b]{2}{*}{$\begin{array}{c}\text { Minimum } \\
\text { detect }\end{array}$} & \multirow[b]{2}{*}{$\begin{array}{c}\text { Maximum } \\
\text { detect }\end{array}$} & \multirow[b]{2}{*}{$\begin{array}{c}\text { Location(s) of } \\
\text { maximum detect }\end{array}$} & \multirow{2}{*}{$\begin{array}{c}\text { Average } \\
\text { detected } \\
\text { result }\end{array}$} & \multicolumn{3}{|c|}{$\begin{array}{l}\text { Number of analyses } \\
\text { exceeding criteria }\end{array}$} \\
\hline & & & & & & $\begin{array}{c}\text { Ind } \\
\text { PRG }\end{array}$ & $\begin{array}{l}\text { GW } \\
\text { SL }\end{array}$ & $\begin{array}{l}\text { Res } \\
\text { PRG }\end{array}$ \\
\hline 2-Methylnaphthalene & $1 / 24$ & $220 \mathrm{~J}$ & $220 \mathrm{~J}$ & BH004 & 220 & 0 & NA & NA \\
\hline Acenaphthene & $2 / 23$ & $43 \mathrm{~J}$ & $160 \mathrm{~J}$ & SB093 & 102 & 0 & NA & 0 \\
\hline Acenaphthylene & $1 / 24$ & $99 \mathrm{~J}$ & $99 \mathrm{~J}$ & BH007 & 99 & 0 & NA & 0 \\
\hline Anthracene & $2 / 24$ & $96 \mathrm{~J}$ & $260 \mathrm{~J}$ & SB093 & 178 & 0 & NA & 0 \\
\hline Benz(a)anthracene & $4 / 25$ & $54 \mathrm{~J}$ & 550 & SB093 & 224 & 0 & NA & 0 \\
\hline Benzo(a)pyrene & $4 / 25$ & $93 \mathrm{~J}$ & 580 & SB093 & 243 & 0 & NA & 4 \\
\hline Benzo(b)fluoranthene & $4 / 25$ & $86 \mathrm{~J}$ & 740 & SB093 & 284 & 0 & NA & 1 \\
\hline Benzo(ghi)perylene & $4 / 25$ & $78 \mathrm{~J}$ & $330 \mathrm{~J}$ & SB093 & 190 & 0 & NA & 0 \\
\hline Benzo(k)fluoranthene & $4 / 25$ & $99 \mathrm{~J}$ & 560 & SB093 & 242 & 0 & NA & 0 \\
\hline Bis(2-ethylhexyl)phthalate & $6 / 25$ & $45 \mathrm{~J}$ & $82 \mathrm{~J}$ & SB099 & 61.7 & 0 & 0 & 0 \\
\hline Carbazole & $1 / 24$ & $59 \mathrm{~J}$ & $59 \mathrm{~J}$ & SB093 & 59 & 0 & NA & 0 \\
\hline Chrysene & $4 / 25$ & $67 \mathrm{~J}$ & 680 & SB093 & 257 & 0 & NA & 0 \\
\hline
\end{tabular}




\begin{tabular}{|c|c|c|c|c|c|c|c|c|}
\hline \multirow[b]{2}{*}{ Analyte } & \multirow[b]{2}{*}{$\begin{array}{c}\text { Detect } \\
\text { frequency }\end{array}$} & \multirow[b]{2}{*}{$\begin{array}{c}\text { Minimum } \\
\text { detect }\end{array}$} & \multirow[b]{2}{*}{$\begin{array}{c}\text { Maximum } \\
\text { detect }\end{array}$} & \multirow[b]{2}{*}{$\begin{array}{l}\text { Location(s) of } \\
\text { maximum detect }\end{array}$} & \multirow{2}{*}{$\begin{array}{c}\text { Average } \\
\text { detected } \\
\text { result }\end{array}$} & \multicolumn{3}{|c|}{$\begin{array}{l}\text { Number of analyses } \\
\text { exceeding criteria }\end{array}$} \\
\hline & & & & & & $\begin{array}{l}\text { Ind } \\
\text { PRG }\end{array}$ & $\begin{array}{l}\text { GW } \\
\text { SL }\end{array}$ & $\begin{array}{l}\text { Res } \\
\text { PRG }\end{array}$ \\
\hline Dibenz(a,h)anthracene & $2 / 24$ & $89 \mathrm{~J}$ & $140 \mathrm{~J}$ & SB093 & 115 & 0 & NA & 2 \\
\hline Dibenzofuran & $1 / 24$ & $60 \mathrm{~J}$ & $60 \mathrm{~J}$ & SB093 & 60 & 0 & NA & 0 \\
\hline Dimethyl phthalate & $3 / 24$ & $52 \mathrm{~J}$ & $400 \mathrm{~J}$ & BH004 & 182 & 0 & NA & 0 \\
\hline Di-n-butyl phthalate & $2 / 25$ & $240 \mathrm{~J}$ & 2,500 & BH004 & 1,370 & 0 & NA & 0 \\
\hline Fluoranthene & $5 / 25$ & $53 \mathrm{~J}$ & 1,500 & SB093 & 473 & 0 & NA & 0 \\
\hline Fluorene & $2 / 24$ & $120 \mathrm{~J}$ & $140 \mathrm{~J}$ & SB093 & 130 & 0 & NA & 0 \\
\hline Indeno(1,2,3-cd)pyrene & $4 / 25$ & $72 \mathrm{~J}$ & $270 \mathrm{~J}$ & SB093 & 150 & 0 & NA & 0 \\
\hline Naphthalene & $3 / 25$ & $50 \mathrm{~J}$ & $100 \mathrm{~J}$ & SB089 & 72.7 & 0 & NA & 0 \\
\hline Phenanthrene & $5 / 25$ & $50 \mathrm{~J}$ & 1,200 & SB093 & 366 & 0 & NA & 0 \\
\hline Pyrene & $7 / 24$ & $46 \mathrm{~J}$ & 1,300 & SB093 & 331 & 0 & NA & 0 \\
\hline
\end{tabular}

$\mathrm{EU}=$ exposure unit $\quad \mathrm{PRG}=$ preliminary remediation goal

$\mathrm{GW}=$ groundwater $\quad$ Res $=$ residential

Ind $=$ industrial $\quad \mathrm{SL}=$ screening level

$\mathrm{NA}=$ not applicable $\quad \mathrm{SVOC}=$ semivolatile organic compound

EU Z2-37 HISTORICAL VOC DETECTS (ug/kg) 0-10 ft

\begin{tabular}{|c|c|c|c|c|c|c|c|c|}
\hline \multirow[b]{2}{*}{ Analyte } & \multirow[b]{2}{*}{$\begin{array}{c}\text { Detect } \\
\text { frequency }\end{array}$} & \multirow[b]{2}{*}{$\underset{\text { detect }}{\text { Minimum }}$} & \multirow[b]{2}{*}{$\begin{array}{c}\text { Maximum } \\
\text { detect }\end{array}$} & \multirow[b]{2}{*}{$\begin{array}{c}\text { Location(s) of } \\
\text { maximum detect }\end{array}$} & \multirow{2}{*}{$\begin{array}{c}\text { Average } \\
\text { detected } \\
\text { result }\end{array}$} & \multicolumn{3}{|c|}{$\begin{array}{l}\text { Number of analyses } \\
\text { exceeding criteria }\end{array}$} \\
\hline & & & & & & $\begin{array}{c}\text { Ind } \\
\text { PRG }\end{array}$ & $\begin{array}{l}\text { GW } \\
\text { SL }\end{array}$ & $\begin{array}{c}\text { Res } \\
\text { PRG }\end{array}$ \\
\hline 1,1,1-Trichloroethane & $1 / 25$ & $2 \mathrm{~J}$ & $2 \mathrm{~J}$ & SB092 & 2 & 0 & 0 & 0 \\
\hline $\begin{array}{l}\text { 1,1,2-Trichloro-1,2,2- } \\
\text { trifluoroethane }\end{array}$ & $3 / 25$ & 4 & $940 \mathrm{~J}$ & BH004 & 316 & 0 & NA & 0 \\
\hline 1,1-Dichloroethane & $4 / 25$ & 1 & $5 \mathrm{~J}$ & SB092 & 2.25 & 0 & NA & 0 \\
\hline 1,2-Dichloroethene & $3 / 25$ & $3 \mathrm{~J}$ & 23 & SB089 & 10 & 0 & NA & NA \\
\hline 2-Butanone & $1 / 25$ & $25 \mathrm{~J}$ & $25 \mathrm{~J}$ & BH007 & 25 & 0 & NA & 0 \\
\hline 4-Methyl2-pentanone & $2 / 25$ & $1 \mathrm{~J}$ & $2 \mathrm{~J}$ & BH011 & 1.5 & 0 & NA & 0 \\
\hline Acetone & $13 / 25$ & $41 \mathrm{~J}$ & 910 & BH004 & 205 & 0 & NA & 0 \\
\hline Ethylbenzene & $2 / 25$ & $1 \mathrm{~J}$ & 2900 & BH004 & 1451 & 0 & NA & 0 \\
\hline Methylene chloride & $11 / 25$ & 13 & 110 & SB087 & 38.5 & 0 & 0 & 0 \\
\hline Tetrachloroethene & $5 / 25$ & 2 & $5 \mathrm{~J}$ & BH012 & 2.8 & 0 & 0 & 0 \\
\hline Total Xylene & $1 / 25$ & 2100 & 2100 & BH004 & 2100 & 0 & NA & NA \\
\hline Trichloroethene & $2 / 25$ & $3 \mathrm{~J}$ & $4 \mathrm{~J}$ & SB089 & 3.5 & 0 & 0 & 0 \\
\hline
\end{tabular}

\begin{tabular}{ll}
\hline EU $=$ exposure unit & PRG = preliminary remediation goal \\
GW = groundwater & Res = residential \\
Ind $=$ industrial & SL $=$ screening level \\
NA = not applicable & VOC = volatile organic compound
\end{tabular}

EU Z2-37 Summary: This section presents a summary of the nature and extent of contamination from 0 to $10 \mathrm{ft}$ bgs in EU Z2-37 by combining all the analytical data presented in the focused investigation summaries above. The summary that follows also includes FFA site data summarized in Sect. H.2.2.6. There are six DVS and 29 historical sample locations with soil samples collected from the 0 to $10-\mathrm{ft}$-bgs depth interval in this EU. Details of the sampling and analysis are presented in Table H.2 and sample locations are shown in Fig. H.3. Analytical results for all the samples, which are summarized below, show Ind PRG exceedances by arsenic (1), manganese (1), several radionuclides, and benzo(a)pyrene (2); several metal and radionuclide Bkg exceedances; and DRO, GRO, pesticide and polychlorinated biphenyl, SVOC, and VOC detections.

The arsenic Ind PRG exceedance occurs at DVS storm drain sediment location Z2-EU37B-305. The manganese Ind PRG exceedance occurs at historical sample location SB089, which is located in the southeast portion of the EU close to the K-1414 Garage. The radionuclide Ind PRG exceedances all occur for a group of radionuclides that requires special data evaluation as discussed in Sect. H.3.3. 
Bkg exceedances are fairly widespread. Sixteen different metals exceed their Bkg criteria and the number of times each metal exceeds its Bkg criterion ranges from 1 to 16. Six different radionuclides exceed their Bkg criteria and the number of times each radionuclides exceeds $\mathrm{Bkg}$ ranges from one to eight times.

DRO and GRO were detected at historical locations BH004 and BH005, which are associated with or in proximity to the K-1414 Garage Diesel Tank/Soils FFA Site (Fig. H.4). The presence of DRO and GRO represents residual contamination from the diesel fuel tank leak discovered in 1987. The pesticide methoxychlor was detected at two historical sample locations (SB083 in the north/central portion of the EU and SB089 in the southeast quadrant of the EU). PCB-1248, PCB-1254, PCB-1260, and total PCBs were detected at five historical locations (SB078, SB079, SB087, SB091, and SB092) and all six DVS locations (see Sect.H.2.2.3). Except for SB091, the historical locations with PCB detections occur in the northern two-thirds of the EU. The six DVS sample locations all represent either storm drain sediments or drainage ditch soils. SVOC detections are fairly widespread over the EU, with a total of 23 different SVOCs detected at all 6DVS and 18 historical sample locations. VOC detections were also widespread, with 17 different VOCs detected at two DVS and 20 historical locations. Two DVS sample locations, Z2-EU37B-303 and Z2-EU37B-304, are ditch sample locations associated with the SW31 spring.

EU Z2-37 METALS WITH BACKGROUND, PRG, GW SL, AND/OR RL EXCEEDANCES (mg/kg) 0-10 ft

\begin{tabular}{|c|c|c|c|c|c|c|c|c|c|c|c|}
\hline \multirow[b]{2}{*}{ Analyte } & \multirow[b]{2}{*}{$\begin{array}{c}\text { Detect } \\
\text { frequency }\end{array}$} & \multirow[b]{2}{*}{$\begin{array}{c}\text { Minimum } \\
\text { detect }\end{array}$} & \multirow[b]{2}{*}{$\begin{array}{c}\text { Maximum } \\
\text { detect }\end{array}$} & \multirow{2}{*}{$\begin{array}{l}\text { Location(s) of } \\
\text { maximum } \\
\text { detect }\end{array}$} & \multirow{2}{*}{$\begin{array}{c}\text { Average } \\
\text { detected } \\
\text { result }\end{array}$} & \multicolumn{6}{|c|}{ Number of analyses exceeding criteria } \\
\hline & & & & & & $\begin{array}{l}\text { Max } \\
\text { RL }\end{array}$ & $\begin{array}{l}\text { Avg } \\
\text { RL }\end{array}$ & $\begin{array}{c}\text { Ind } \\
\text { PRG }\end{array}$ & Bkg & $\begin{array}{c}\text { GW } \\
\text { SL }\end{array}$ & $\begin{array}{l}\text { Res } \\
\text { PRG }\end{array}$ \\
\hline Aluminum & $23 / 23$ & 2,400 & 20,400 & SB080 & 12,938 & NA & NA & 0 & 0 & NA & 20 \\
\hline Arsenic & $23 / 23$ & $1.4 \mathrm{~J}$ & 18 & Z2-EU37B-305 & 7.06 & 0 & 0 & 1 & 2 & 0 & 23 \\
\hline Barium & $23 / 23$ & 43 & 1,420 & SB089 & 185 & NA & NA & 0 & 8 & 0 & 1 \\
\hline Beryllium & $23 / 23$ & 0.23 & 6.3 & BH012 & 1.03 & 0 & 0 & 0 & 1 & NA & 0 \\
\hline Cadmium & $10 / 23$ & $0.12 \mathrm{~J}$ & $0.56 \mathrm{~J}$ & Z2-EU37B-304 & 0.29 & NA & NA & 0 & 7 & NA & 0 \\
\hline Calcium & $23 / 23$ & 177 & 240,000 & Z2-EU37B-305 & 31,814 & NA & NA & NA & 12 & NA & NA \\
\hline Chromium & $23 / 23$ & 10 & 38 & Z2-EU37B-301 & 20.9 & NA & NA & 0 & 0 & 0 & 6 \\
\hline Cobalt & $23 / 23$ & 3.9 & 52.7 & SB080 & 18.7 & NA & NA & 0 & 1 & NA & 0 \\
\hline Copper & $22 / 23$ & 8.2 & 80.7 & SB088 & 29.3 & NA & NA & 0 & 11 & NA & 0 \\
\hline Iron & $23 / 23$ & 13,300 & 50,000 & Z2-EU37B-306 & 28,365 & NA & NA & 0 & 0 & NA & 23 \\
\hline Lead & $23 / 23$ & 13.9 & 52 & Z2-EU37B-304 & 26.4 & NA & NA & 0 & 5 & 0 & 0 \\
\hline Magnesium & $23 / 23$ & 470 & 41,000 & Z2-EU37B-302 & 7,207 & NA & NA & NA & 10 & NA & NA \\
\hline Manganese & $23 / 23$ & 142 & 20,600 & SB089 & 3,196 & NA & NA & 1 & 4 & NA & 22 \\
\hline Mercury & $16 / 23$ & $0.023 \mathrm{~J}$ & 0.25 & Z2-EU37B-304 & 0.101 & 0 & 0 & 0 & 1 & NA & 0 \\
\hline Nickel & $23 / 23$ & $6.8 \mathrm{~J}$ & 100 & Z2-EU37B-301 & 33.5 & NA & NA & 0 & 11 & NA & 0 \\
\hline Selenium & $7 / 16$ & $0.35 \mathrm{~J}$ & $2.4 \mathrm{~J}$ & SB082 & 1.48 & NA & NA & 0 & 3 & NA & 0 \\
\hline Silver & $16 / 23$ & 1.1 & $3.3 \mathrm{~J}$ & SB089 & 2.04 & NA & NA & 0 & 16 & NA & 0 \\
\hline Thallium & $12 / 23$ & 0.052 & 0.56 & BH012 & 0.291 & NA & NA & 0 & 3 & 0 & 3 \\
\hline Uranium & $6 / 6$ & 0.64 & 2 & Z2-EU37B-304 & 1.28 & NA & NA & 0 & NA & NA & 2 \\
\hline Vanadium & $23 / 23$ & 9.4 & 42.6 & SB092 & 26.8 & NA & NA & 0 & 0 & NA & 23 \\
\hline Zinc & $23 / 23$ & $20.7 \mathrm{~J}$ & $160 \mathrm{~J}$ & Z2-EU37B-305 & 66.2 & NA & NA & 0 & 4 & NA & 0 \\
\hline
\end{tabular}

\begin{tabular}{ll}
\hline Avg $=$ average & NA = not applicable \\
Bkg = background & PRG = preliminary remediation goal \\
EU = exposure unit & Res = residential \\
GW = groundwater & RL = remediation level \\
Ind = industrial & SL = screening level \\
Max = maximum & SU = soil unit
\end{tabular}

EU Z2-37 OTHER ORGANICS DETECTS (mg/kg) 0-10 ft

\begin{tabular}{lccccc}
\hline \multicolumn{1}{c}{ Analyte } & $\begin{array}{c}\text { Detect } \\
\text { frequency }\end{array}$ & $\begin{array}{c}\text { Minimum } \\
\text { detect }\end{array}$ & $\begin{array}{c}\text { Maximum } \\
\text { detect }\end{array}$ & $\begin{array}{c}\text { Location(s) of } \\
\text { maximum } \\
\text { detect }\end{array}$ & $\begin{array}{c}\text { Average } \\
\text { detected } \\
\text { result }\end{array}$ \\
\hline Diesel Range Organics & $2 / 14$ & $190 \mathrm{~J}$ & $329 \mathrm{~J}$ & BH004 & 260 \\
Gasoline Range Organics & $2 / 14$ & $7.5 \mathrm{~J}$ & 88.5 & BH004 & 48 \\
\hline
\end{tabular}

$\mathrm{EU}=$ exposure unit 
EU Z2-37 PPCB DETECTS (ug/kg) 0-10 ft

\begin{tabular}{|c|c|c|c|c|c|c|c|c|c|}
\hline \multirow[b]{2}{*}{ Analyte } & \multirow[b]{2}{*}{$\begin{array}{c}\text { Detect } \\
\text { frequency }\end{array}$} & \multirow[b]{2}{*}{$\begin{array}{c}\text { Minimum } \\
\text { detect }\end{array}$} & \multirow[b]{2}{*}{$\begin{array}{c}\text { Maximum } \\
\text { detect }\end{array}$} & \multirow{2}{*}{$\begin{array}{l}\text { Location(s) of } \\
\text { maximum } \\
\text { detect }\end{array}$} & \multirow{2}{*}{$\begin{array}{c}\text { Average } \\
\text { detected } \\
\text { result }\end{array}$} & \multicolumn{4}{|c|}{$\begin{array}{l}\text { Number of analyses } \\
\text { exceeding criteria }\end{array}$} \\
\hline & & & & & & $\begin{array}{c}\text { Max } \\
\text { RL }\end{array}$ & $\begin{array}{l}\text { Avg } \\
\text { RL }\end{array}$ & $\begin{array}{l}\text { Ind } \\
\text { PRG }\end{array}$ & $\begin{array}{l}\text { Res } \\
\text { PRG }\end{array}$ \\
\hline Methoxychlor & $2 / 17$ & $2 \mathrm{~J}$ & $28 \mathrm{~J}$ & SB089 & 15 & NA & NA & 0 & NA \\
\hline PCB-1248 & $2 / 23$ & $45 \mathrm{~J}$ & $67 \mathrm{~J}$ & SB079 & 56 & 0 & 0 & 0 & 0 \\
\hline PCB-1254 & $5 / 23$ & 26 & 2,600 & Z2-EU37B-305 & 631 & 0 & 0 & 0 & 4 \\
\hline PCB-1260 & $5 / 23$ & $35 \mathrm{~J}$ & 200 & Z2-EU37B-301 & 88.4 & 0 & 0 & 0 & 2 \\
\hline Polychlorinated Biphenyl & $6 / 6$ & 26 & 2,600 & Z2-EU37B-305 & 579 & 0 & 0 & 0 & 5 \\
\hline
\end{tabular}

Avg = average

$\mathrm{EU}=$ exposure unit

Ind $=$ industrial

PPCB = pesticide and polychlorinated biphenyl

Max $=$ maximum

$\mathrm{PRG}=$ preliminary remediation goal

$\mathrm{NA}=$ not applicable

$\mathrm{RL}=$ remediation level

EU Z2-37 RADIONUCLIDES WITH BACKGROUND, PRG, AND/OR RL EXCEEDANCES (pCi/g) 0-10 ft

\begin{tabular}{|c|c|c|c|c|c|c|c|c|c|c|c|}
\hline \multirow[b]{2}{*}{ Analyte } & \multirow[b]{2}{*}{$\begin{array}{c}\text { Detect } \\
\text { frequency }\end{array}$} & \multirow[b]{2}{*}{$\begin{array}{c}\text { Minimum } \\
\text { detect }\end{array}$} & \multirow[b]{2}{*}{$\begin{array}{c}\text { Maximum } \\
\text { detect }\end{array}$} & \multirow[b]{2}{*}{$\begin{array}{c}\text { Location(s) of } \\
\text { maximum detect }\end{array}$} & \multirow{2}{*}{$\begin{array}{c}\text { Average } \\
\text { detected } \\
\text { result }\end{array}$} & \multicolumn{6}{|c|}{ Number of analyses exceeding criteria } \\
\hline & & & & & & $\begin{array}{c}\text { Max } \\
\text { RL }\end{array}$ & $\begin{array}{l}\text { Avg } \\
\text { RL }\end{array}$ & $\begin{array}{l}\text { Ind } \\
\text { PRG }\end{array}$ & Bkg & $\begin{array}{c}\text { GW } \\
\text { SL }\end{array}$ & $\begin{array}{c}\text { Res } \\
\text { PRG } \\
\end{array}$ \\
\hline Cesium-137 & $6 / 27$ & 0.223 & 1.01 & ETTP-REL12 & 0.737 & 0 & 0 & 0 & NA & NA & 6 \\
\hline Potassium-40 & $14 / 14$ & 8.65 & 45.7 & ETTP-REL13 & 21.3 & NA & NA & 14 & 3 & NA & 14 \\
\hline Radium-226 & $11 / 12$ & 0.473 & 4.5 & RAD85 & 2.05 & NA & NA & 11 & 8 & NA & 11 \\
\hline Technetium-99 & $18 / 29$ & $0.23 \mathrm{~J}$ & 3.51 & Z2-EU37B-305 & 1.36 & NA & NA & 0 & NA & NA & 17 \\
\hline Thorium -228 & $12 / 14$ & 0.892 & $1.97 \mathrm{~J}$ & BH012 & 1.29 & NA & NA & 12 & 1 & NA & 12 \\
\hline Thorium -230 & $12 / 14$ & 0.688 & 1.84 & Z2-EU37B-303 & 1.23 & NA & NA & 0 & 6 & NA & 0 \\
\hline Thorium -232 & $14 / 14$ & 0.433 & 1.97 & ETTP-REL13 & 1.28 & NA & NA & 14 & 1 & NA & 14 \\
\hline Uranium-234 & $28 / 28$ & $0.6 \mathrm{~J}$ & 7.94 & ETTP-REL12 & 1.85 & 0 & 0 & 0 & NA & 0 & 1 \\
\hline Uranium-235 & $22 / 28$ & 0.02 & $0.482 \mathrm{~J}$ & ETTP-REL12 & 0.127 & 0 & 0 & 0 & NA & 0 & 5 \\
\hline Uranium-238 & $28 / 28$ & 0.701 & 4.26 & ETTP-REL12 & 1.47 & 0 & 0 & 0 & 8 & 0 & 25 \\
\hline $\begin{array}{l}\text { Avg = average } \\
\mathrm{Bkg}=\text { background } \\
\mathrm{EU}=\text { exposure unit } \\
\mathrm{GW}=\text { groundwater } \\
\text { Ind = industrial } \\
\mathrm{Max}=\text { maximum }\end{array}$ & & $\begin{array}{l}\text { NA }=\text { not ap } \\
\text { PRG }=\text { preli } \\
\text { Res }=\text { reside } \\
\text { RL }=\text { remed } \\
\text { SL }=\text { screen } \\
\text { SU }=\text { soil un }\end{array}$ & $\begin{array}{l}\text { pplicable } \\
\text { iminary reme } \\
\text { ential } \\
\text { liation level } \\
\text { ling level } \\
\text { hit }\end{array}$ & ediation goal & & & & & & & \\
\hline
\end{tabular}

EU Z2-37 SVOC DETECTS (ug/kg) 0-10 ft

\begin{tabular}{|c|c|c|c|c|c|c|c|c|}
\hline \multirow[b]{2}{*}{ Analyte } & \multirow[b]{2}{*}{$\begin{array}{l}\text { Detect } \\
\text { frequency }\end{array}$} & \multirow[b]{2}{*}{$\begin{array}{c}\text { Minimum } \\
\text { detect }\end{array}$} & \multirow[b]{2}{*}{$\begin{array}{c}\text { Maximum } \\
\text { detect }\end{array}$} & \multirow[b]{2}{*}{$\begin{array}{l}\text { Location(s) of } \\
\text { maximum detect }\end{array}$} & \multirow{2}{*}{$\begin{array}{c}\text { Average } \\
\text { detected } \\
\text { result }\end{array}$} & \multicolumn{3}{|c|}{$\begin{array}{l}\text { Number of analyses } \\
\text { exceeding criteria }\end{array}$} \\
\hline & & & & & & $\begin{array}{l}\text { Ind } \\
\text { PRG }\end{array}$ & $\begin{array}{l}\text { GW } \\
\text { SL }\end{array}$ & $\begin{array}{c}\text { Res } \\
\text { PRG }\end{array}$ \\
\hline 2-Methylnaphthalene & $4 / 34$ & $120 \mathrm{~J}$ & 2,200 & SB088 & 680 & 0 & NA & NA \\
\hline Acenaphthene & $5 / 33$ & $43 \mathrm{~J}$ & $280 \mathrm{~J}$ & Z2-EU37B-306 & 157 & 0 & NA & 0 \\
\hline Acenaphthylene & $1 / 34$ & $99 \mathrm{~J}$ & $99 \mathrm{~J}$ & BH007 & 99 & 0 & NA & 0 \\
\hline Anthracene & $5 / 34$ & $96 \mathrm{~J}$ & 1,400 & Z2-EU37B-306 & 451 & 0 & NA & 0 \\
\hline Benz(a)anthracene & $10 / 35$ & $54 \mathrm{~J}$ & 5,400 & Z2-EU37B-306 & 1,059 & 0 & NA & 3 \\
\hline Benzo(a)pyrene & $10 / 35$ & $93 \mathrm{~J}$ & 4,900 & Z2-EU37B-306 & 1,038 & 2 & NA & 10 \\
\hline Benzo(b)fluoranthene & $10 / 35$ & $86 \mathrm{~J}$ & 6,600 & Z2-EU37B-306 & 1,530 & 0 & NA & 5 \\
\hline Benzo(ghi)perylene & $10 / 35$ & $61 \mathrm{~J}$ & 1,800 & Z2-EU37B-306 & 488 & 0 & NA & 0 \\
\hline Benzo(k)fluoranthene & $10 / 35$ & $96 \mathrm{~J}$ & 2,800 & Z2-EU37B-306 & 669 & 0 & NA & 0 \\
\hline Bis(2-ethylhexyl)phthalate & $8 / 35$ & $45 \mathrm{~J}$ & 4,400 & Z2-EU37B-305 & 623 & 0 & 0 & 0 \\
\hline Butyl benzyl phthalate & $1 / 34$ & $170 \mathrm{~J}$ & $170 \mathrm{~J}$ & Z2-EU37B-305 & 170 & 0 & NA & 0 \\
\hline Carbazole & $3 / 34$ & $59 \mathrm{~J}$ & 660 & Z2-EU37B-306 & 456 & 0 & NA & 0 \\
\hline Chrysene & $10 / 35$ & $67 \mathrm{~J}$ & 4,900 & Z2-EU37B-306 & 1,049 & 0 & NA & 0 \\
\hline Dibenz(a,h)anthracene & $5 / 34$ & $89 \mathrm{~J}$ & 530 & Z2-EU37B-306 & 248 & 0 & NA & 5 \\
\hline Dibenzofuran & $3 / 34$ & $60 \mathrm{~J}$ & $100 \mathrm{~J}$ & Z2-EU37B-306 & 77.3 & 0 & NA & 0 \\
\hline Dimethyl phthalate & $3 / 34$ & $52 \mathrm{~J}$ & $400 \mathrm{~J}$ & BH004 & 182 & 0 & NA & 0 \\
\hline Di-n-butyl phthalate & $2 / 35$ & $240 \mathrm{~J}$ & 2500 & BH004 & 1,370 & 0 & NA & 0 \\
\hline Fluoranthene & $12 / 35$ & $40 \mathrm{~J}$ & 12,000 & Z2-EU37B-306 & 1,933 & 0 & NA & 0 \\
\hline
\end{tabular}




\begin{tabular}{|c|c|c|c|c|c|c|c|c|}
\hline \multirow[b]{2}{*}{ Analyte } & \multirow[b]{2}{*}{$\begin{array}{c}\text { Detect } \\
\text { frequency }\end{array}$} & \multirow[b]{2}{*}{$\begin{array}{c}\text { Minimum } \\
\text { detect }\end{array}$} & \multirow[b]{2}{*}{$\begin{array}{c}\text { Maximum } \\
\text { detect }\end{array}$} & \multirow[b]{2}{*}{$\begin{array}{c}\text { Location(s) of } \\
\text { maximum detect }\end{array}$} & \multirow{2}{*}{$\begin{array}{c}\text { Average } \\
\text { detected } \\
\text { result }\end{array}$} & \multicolumn{3}{|c|}{$\begin{array}{c}\text { Number of analyses } \\
\text { exceeding criteria }\end{array}$} \\
\hline & & & & & & $\begin{array}{l}\text { Ind } \\
\text { PRG }\end{array}$ & $\begin{array}{c}\text { GW } \\
\text { SL }\end{array}$ & $\begin{array}{c}\text { Res } \\
\text { PRG }\end{array}$ \\
\hline Fluorene & $5 / 34$ & $120 \mathrm{~J}$ & 320 & $\begin{array}{c}\text { SB088 Z2-37B- } \\
306\end{array}$ & 212 & 0 & NA & 0 \\
\hline Indeno(1,2,3-cd)pyrene & $10 / 35$ & $66 \mathrm{~J}$ & 1,800 & Z2-EU37B-306 & 470 & 0 & NA & 3 \\
\hline Naphthalene & $5 / 41$ & $50 \mathrm{~J}$ & $330 \mathrm{~J}$ & SB088 & 138 & 0 & NA & 0 \\
\hline Phenanthrene & $13 / 35$ & $50 \mathrm{~J}$ & 5,100 & Z2-EU37B-306 & 884 & 0 & NA & 0 \\
\hline Pyrene & $15 / 34$ & $40 \mathrm{~J}$ & 8,100 & Z2-EU37B-306 & 1,208 & 0 & NA & 0 \\
\hline
\end{tabular}

$\mathrm{EU}=$ exposure unit $\quad \mathrm{PRG}=$ preliminary remediation goal

$\mathrm{GW}=$ groundwater $\quad$ Res $=$ residential

Ind $=$ industrial $\quad \mathrm{SL}=$ screening level

$\mathrm{NA}=$ not applicable $\quad \mathrm{SVOC}=$ semivolatile organic compound

EU Z2-37 VOC DETECTS (ug/kg) 0-10 ft

\begin{tabular}{|c|c|c|c|c|c|c|c|c|}
\hline \multirow[b]{2}{*}{ Analyte } & \multirow[b]{2}{*}{$\begin{array}{c}\text { Detect } \\
\text { frequency }\end{array}$} & \multirow[b]{2}{*}{$\begin{array}{c}\text { Minimum } \\
\text { detect }\end{array}$} & \multirow[b]{2}{*}{$\begin{array}{c}\text { Maximum } \\
\text { detect }\end{array}$} & \multirow[b]{2}{*}{$\begin{array}{c}\text { Location(s) of } \\
\text { maximum detect }\end{array}$} & \multirow{2}{*}{$\begin{array}{c}\text { Average } \\
\text { detected } \\
\text { result }\end{array}$} & \multicolumn{3}{|c|}{$\begin{array}{l}\text { Number of analyses } \\
\text { exceeding criteria }\end{array}$} \\
\hline & & & & & & $\begin{array}{c}\text { Ind } \\
\text { PRG }\end{array}$ & $\begin{array}{c}\text { GW } \\
\text { SL }\end{array}$ & $\begin{array}{l}\text { Res } \\
\text { PRG }\end{array}$ \\
\hline 1,1,1-Trichloroethane & $3 / 35$ & $2 \mathrm{~J}$ & 8 & SB088 & 5.7 & 0 & 0 & 0 \\
\hline $\begin{array}{l}\text { 1,1,2-Trichloro-1,2,2- } \\
\text { trifluoroethane }\end{array}$ & $4 / 35$ & 4 & $940 \mathrm{~J}$ & BH004 & 238 & 0 & NA & 0 \\
\hline 1,1-Dichloroethane & $7 / 35$ & 1 & 18 & SB088 & 4.23 & 0 & NA & 0 \\
\hline 1,1-Dichloroethene & $2 / 35$ & $1.3 \mathrm{~J}$ & $6 \mathrm{~J}$ & BH005 & 3.65 & 0 & 0 & 0 \\
\hline 1,2-Dichloroethene & $3 / 29$ & $3 \mathrm{~J}$ & 23 & SB089 & 10 & 0 & NA & NA \\
\hline 2-Butanone & $2 / 35$ & $25 \mathrm{~J}$ & $52 \mathrm{~J}$ & BH005 & 38.5 & 0 & NA & 0 \\
\hline 4-Methyl2-pentanone & $2 / 35$ & $1 \mathrm{~J}$ & $2 \mathrm{~J}$ & BH011 & 1.5 & 0 & NA & 0 \\
\hline Acetone & $15 / 35$ & $41 \mathrm{~J}$ & 6,600 & BH006 & 653 & 0 & NA & 0 \\
\hline Benzene & $2 / 35$ & $26 \mathrm{~J}$ & 44 & SB088 & 35 & 0 & 0 & 0 \\
\hline Carbon disulfide & $1 / 35$ & $5 \mathrm{~J}$ & $5 \mathrm{~J}$ & SB088 & 5 & 0 & NA & 0 \\
\hline cis-1,2-Dichloroethene & $1 / 6$ & $1.5 \mathrm{~J}$ & $1.5 \mathrm{~J}$ & Z2-EU37B-304 & 1.5 & 0 & NA & 0 \\
\hline Ethylbenzene & $5 / 35$ & $1 \mathrm{~J}$ & $4,300 \mathrm{~J}$ & SB088 & 1,470 & 0 & NA & 0 \\
\hline Methylene chloride & $13 / 35$ & 13 & 110 & SB087 & 37.6 & 0 & 0 & 0 \\
\hline Tetrachloroethene & $9 / 35$ & 2 & $14 \mathrm{~J}$ & SB088 & 5.56 & 0 & 0 & 0 \\
\hline Toluene & $3 / 35$ & $19 \mathrm{~J}$ & $200 \mathrm{~J}$ & BH005 & 81.3 & 0 & 0 & 0 \\
\hline Total Xylene & $4 / 29$ & $5 \mathrm{~J}$ & $5,000 \mathrm{~J}$ & SB088 & 1,821 & 0 & NA & NA \\
\hline Trichloroethene & $2 / 35$ & $3 \mathrm{~J}$ & $4 \mathrm{~J}$ & SB089 & 3.5 & 0 & 0 & 0 \\
\hline
\end{tabular}

$\mathrm{EU}=$ exposure unit $\quad \mathrm{PRG}=$ preliminary remediation goal

$\mathrm{GW}=$ groundwater $\quad$ Res $=$ residential

Ind $=$ industrial $\quad \mathrm{SL}=$ screening level

$\mathrm{NA}=$ not applicable $\quad \mathrm{VOC}=$ volatile organic compound

Samples collected from the 0- to 10-ft-depth interval at 18 historical sample locations (Sect. H.2.2.3) were analyzed by the field GC method. Most of the field GC analyses were for VOCs, and many of the samples analyzed for VOCs by field GC had duplicate analyses conducted at an off-site laboratory. Analytical results from these duplicate analyses are included in the foregoing summaries. However, the database also reports that metals, PPCBs, radionuclides, and SVOCs were analyzed for by field GC in samples from four locations (SB103, SB109, SB110, and SB111). It is impossible to verify and correct the database because these analyses were conducted too far in the past (1993). As a result, metals, PPCBs, radionuclides, and SVOCs designated as field GC analytes in the database are not included in the foregoing data summaries, instead they are summarized below. Following are summaries of all EU Z2-37 data designated in the database as being analyzed for by field GC. 
EU Z2-37 FIELD GC METALS WITH BACKGROUND, PRG,

GW SL, AND/OR RL EXCEEDANCES (mg/kg) 0-10 ft

\begin{tabular}{|c|c|c|c|c|c|c|c|c|c|c|c|}
\hline \multirow[b]{2}{*}{ Analyte } & \multirow[b]{2}{*}{$\begin{array}{c}\text { Detect } \\
\text { frequency }\end{array}$} & \multirow[b]{2}{*}{$\begin{array}{c}\text { Minimum } \\
\text { detect }\end{array}$} & \multirow[b]{2}{*}{$\begin{array}{c}\text { Maximum } \\
\text { detect }\end{array}$} & \multirow{2}{*}{$\begin{array}{c}\text { Location(s) of } \\
\text { maximum } \\
\text { detect }\end{array}$} & \multirow{2}{*}{$\begin{array}{c}\text { Average } \\
\text { detected } \\
\text { result }\end{array}$} & \multicolumn{6}{|c|}{ Number of analyses exceeding criteria } \\
\hline & & & & & & $\begin{array}{l}\text { Max } \\
\text { RL }\end{array}$ & $\begin{array}{l}\text { Avg } \\
\text { RL }\end{array}$ & $\begin{array}{c}\text { Ind } \\
\text { PRG }\end{array}$ & Bkg & $\begin{array}{l}\text { GW } \\
\text { SL }\end{array}$ & $\begin{array}{c}\text { Res } \\
\text { PRG }\end{array}$ \\
\hline Aluminum & $5 / 5$ & 10,900 & 20,100 & SB103 & 15,840 & $\mathrm{NA}$ & NA & 0 & 0 & NA & 5 \\
\hline Arsenic & $5 / 5$ & $6.3 \mathrm{~J}$ & $21 \mathrm{~J}$ & SB111 & 10.6 & 0 & 0 & 1 & 1 & 0 & 5 \\
\hline Barium & $5 / 5$ & 38.6 & 245 & SB111 & 134 & NA & NA & 0 & 2 & 0 & 0 \\
\hline Beryllium & $5 / 5$ & $0.36 \mathrm{~J}$ & $5.7 \mathrm{~J}$ & SB111 & 2.05 & 0 & 0 & 0 & 1 & NA & 0 \\
\hline Cadmium & $4 / 5$ & 0.22 & 0.99 & SB111 & 0.498 & NA & NA & 0 & 3 & NA & 0 \\
\hline Calcium & $5 / 5$ & 2,140 & $6,600 \mathrm{~J}$ & SB110 & 3,326 & NA & NA & NA & 4 & NA & NA \\
\hline Chromium & $5 / 5$ & 18.8 & 39.9 & SB109 & 27.5 & NA & NA & 0 & 0 & 0 & 2 \\
\hline Cobalt & $5 / 5$ & $4.8 \mathrm{~J}$ & $134 \mathrm{~J}$ & SB111 & 41.8 & NA & NA & 0 & 1 & NA & 0 \\
\hline Copper & $5 / 5$ & 22.4 & 207 & SB111 & 71.9 & NA & NA & 0 & 4 & NA & 0 \\
\hline Iron & $5 / 5$ & 22,700 & 38,200 & SB111 & 30,060 & NA & NA & 0 & 0 & NA & 5 \\
\hline Lead & $5 / 5$ & 14.6 & $51.5 \mathrm{~J}$ & SB111 & 23.6 & NA & NA & 0 & 1 & 0 & 0 \\
\hline Magnesium & $5 / 5$ & 1,090 & 5,230 & SB103 & 3450 & NA & NA & NA & 3 & NA & NA \\
\hline Manganese & $5 / 5$ & 260 & 4,310 & SB111 & 1471 & NA & NA & 0 & 1 & NA & 5 \\
\hline Mercury & $4 / 5$ & 0.07 & 0.22 & SB111 & 0.16 & 0 & 0 & 0 & 2 & NA & 0 \\
\hline Nickel & $5 / 5$ & $18.2 \mathrm{~J}$ & $95 \mathrm{~J}$ & SB111 & 43.2 & NA & NA & 0 & 4 & NA & 0 \\
\hline Silver & $5 / 5$ & 0.98 & 2 & SB103 & 1.54 & NA & NA & 0 & 5 & NA & 0 \\
\hline Thallium & $4 / 5$ & 0.34 & 0.99 & SB111 & 0.533 & NA & NA & 0 & 2 & 0 & 1 \\
\hline Vanadium & $5 / 5$ & 23.7 & 47.3 & SB109 & 32.6 & NA & NA & 0 & 0 & NA & 5 \\
\hline Zinc & $5 / 5$ & $40.8 \mathrm{~J}$ & $186 \mathrm{~J}$ & SB111 & 92.7 & NA & NA & 0 & 1 & NA & 0 \\
\hline
\end{tabular}

Avg $=$ average $\quad$ Max $=$ maximum

$\mathrm{Bkg}=$ background $\quad \mathrm{NA}=$ not applicable

$\mathrm{EU}=$ exposure unit $\quad \mathrm{PRG}=$ preliminary remediation goal

$\mathrm{GC}=$ gas chromatograph $\quad$ Res $=$ residential

$\mathrm{GW}=$ groundwater $\quad \mathrm{RL}=$ remediation level

Ind $=$ industrial $\quad \mathrm{SL}=$ screening level

EU Z2-37 FIELD GCPPCB DETECTS (ug/kg) 0-10 ft

\begin{tabular}{|c|c|c|c|c|c|c|c|c|c|}
\hline \multirow[b]{2}{*}{ Analyte } & \multirow[b]{2}{*}{$\begin{array}{c}\text { Detect } \\
\text { frequency }\end{array}$} & \multirow[b]{2}{*}{$\begin{array}{c}\text { Minimum } \\
\text { detect }\end{array}$} & \multirow[b]{2}{*}{$\begin{array}{l}\text { Maximum } \\
\text { detect }\end{array}$} & \multirow{2}{*}{$\begin{array}{c}\text { Location(s) of } \\
\text { maximum } \\
\text { detect }\end{array}$} & \multirow{2}{*}{$\begin{array}{c}\text { Average } \\
\text { detected } \\
\text { result }\end{array}$} & \multicolumn{4}{|c|}{$\begin{array}{l}\text { Number of analyses } \\
\text { exceeding criteria }\end{array}$} \\
\hline & & & & & & $\begin{array}{c}\text { Max } \\
\text { RL }\end{array}$ & $\begin{array}{c}\text { Avg } \\
\text { RL }\end{array}$ & $\begin{array}{l}\text { Ind } \\
\text { PRG }\end{array}$ & $\begin{array}{l}\text { Res } \\
\text { PRG }\end{array}$ \\
\hline PCB-1248 & $1 / 5$ & $440 \mathrm{~J}$ & $440 \mathrm{~J}$ & SB110 & 440 & 0 & 0 & 0 & 1 \\
\hline $\begin{array}{l}\text { Avg }=\text { average } \\
\text { EU }=\text { exposure unit } \\
\text { GC }=\text { gas chromatograph } \\
\text { Ind }=\text { industrial } \\
\text { Max }=\text { maximum }\end{array}$ & $\begin{array}{l}\mathrm{PPCB}= \\
\mathrm{PRG}= \\
\mathrm{Res}=\mathrm{r} \\
\mathrm{RL}=\mathrm{re}\end{array}$ & $\begin{array}{l}\text { pesticide and } \\
\text { reliminary re } \\
\text { sidential } \\
\text { nediation leve }\end{array}$ & $\begin{array}{l}\text { polychlorinat } \\
\text { mediation goa }\end{array}$ & $\begin{array}{l}\text { ed biphenyl } \\
1\end{array}$ & & & & & \\
\hline
\end{tabular}

EU Z2-37 FIELD GC RADIONUCLIDES WITH BACKGROUND, PRG, AND/OR RL EXCEEDANCES (pCi/g) 0-10 ft

\begin{tabular}{|c|c|c|c|c|c|c|c|c|c|c|c|}
\hline \multirow[b]{2}{*}{ Analyte } & \multirow[b]{2}{*}{$\begin{array}{c}\text { Detect } \\
\text { frequency }\end{array}$} & \multirow[b]{2}{*}{$\begin{array}{c}\text { Minimum } \\
\text { detect }\end{array}$} & \multirow[b]{2}{*}{$\begin{array}{c}\text { Maximum } \\
\text { detect }\end{array}$} & \multirow[b]{2}{*}{$\begin{array}{l}\text { Location(s) of } \\
\text { maximum detect }\end{array}$} & \multirow{2}{*}{$\begin{array}{c}\text { Average } \\
\text { detected } \\
\text { result }\end{array}$} & \multicolumn{6}{|c|}{ Number of analyses exceeding criteria } \\
\hline & & & & & & $\begin{array}{c}\text { Max } \\
\text { RL }\end{array}$ & $\begin{array}{l}\text { Avg } \\
\text { RL }\end{array}$ & $\begin{array}{l}\text { Ind } \\
\text { PRG }\end{array}$ & Bkg & $\begin{array}{l}\text { GW } \\
\text { SL }\end{array}$ & $\begin{array}{l}\text { Res } \\
\text { PRG }\end{array}$ \\
\hline Technetium-99 & $3 / 5$ & 0.52 & 0.63 & SB110 & 0.57 & NA & NA & 0 & NA & NA & 3 \\
\hline Uranium-234 & $5 / 5$ & $0.79 \mathrm{~J}$ & 2.7 & SB111 & 1.51 & 0 & 0 & 0 & NA & 0 & 0 \\
\hline Uranium-235 & $5 / 5$ & $0.06 \mathrm{~J}$ & 0.22 & SB111 & 0.142 & 0 & 0 & 0 & NA & 0 & 1 \\
\hline Uranium-238 & $5 / 5$ & $1 \mathrm{~J}$ & 2.8 & SB111 & 1.76 & 0 & 0 & 0 & 3 & 0 & 5 \\
\hline
\end{tabular}

Avg $=$ average $\quad$ Max $=$ maximum

$\mathrm{Bkg}=$ background $\quad \mathrm{NA}=$ not applicable

$\mathrm{EU}=$ exposure unit $\quad \mathrm{PRG}=$ preliminary remediation goal

$\mathrm{GC}=$ gas chromatograph $\quad$ Res $=$ residential

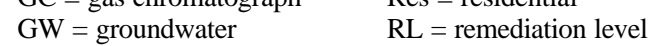

Ind $=$ industrial $\quad \mathrm{SL}=$ screening level 


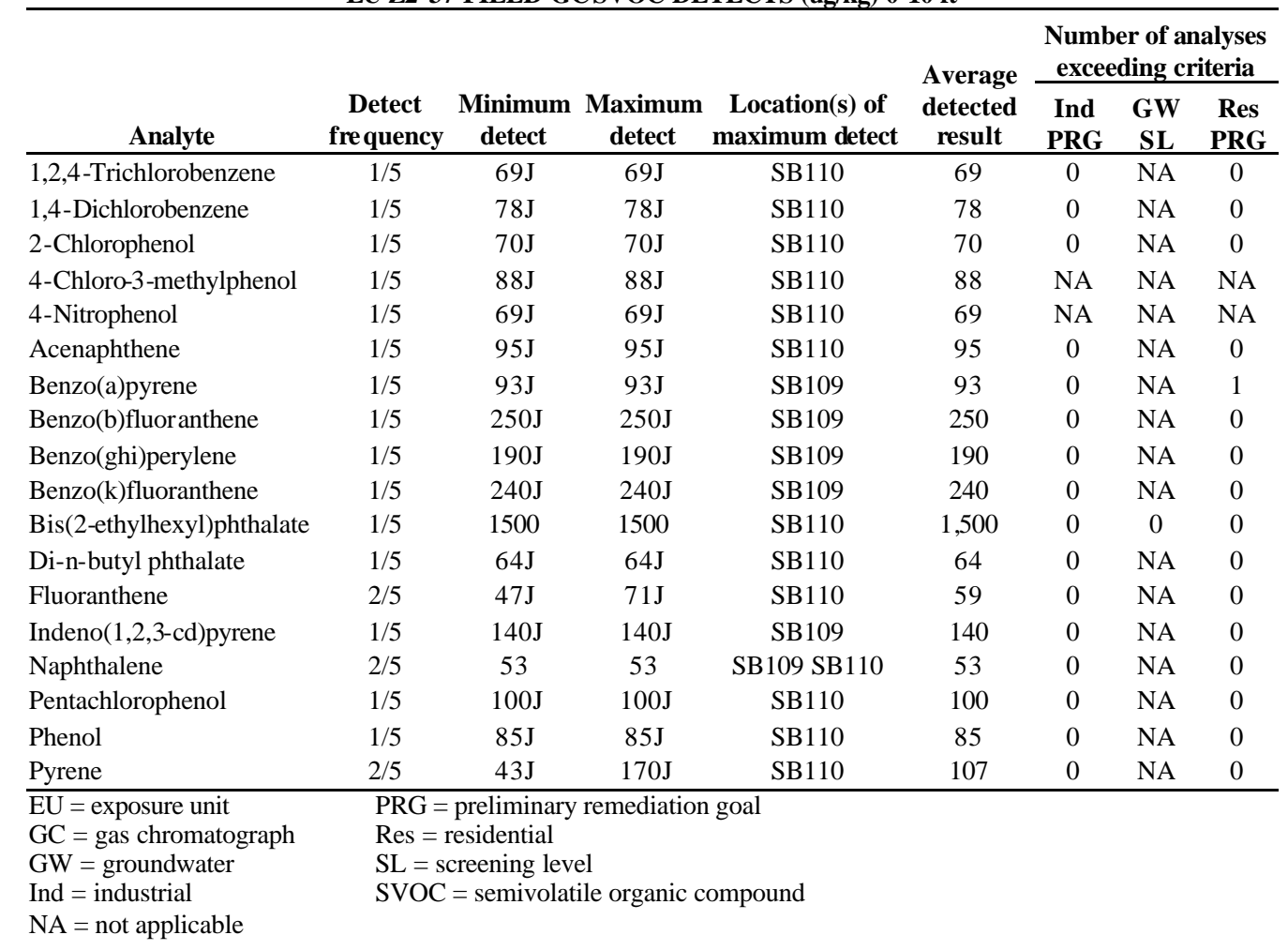

EU Z2-37 FIELD GC VOC DETECTS (ug/kg) 0-10 ft

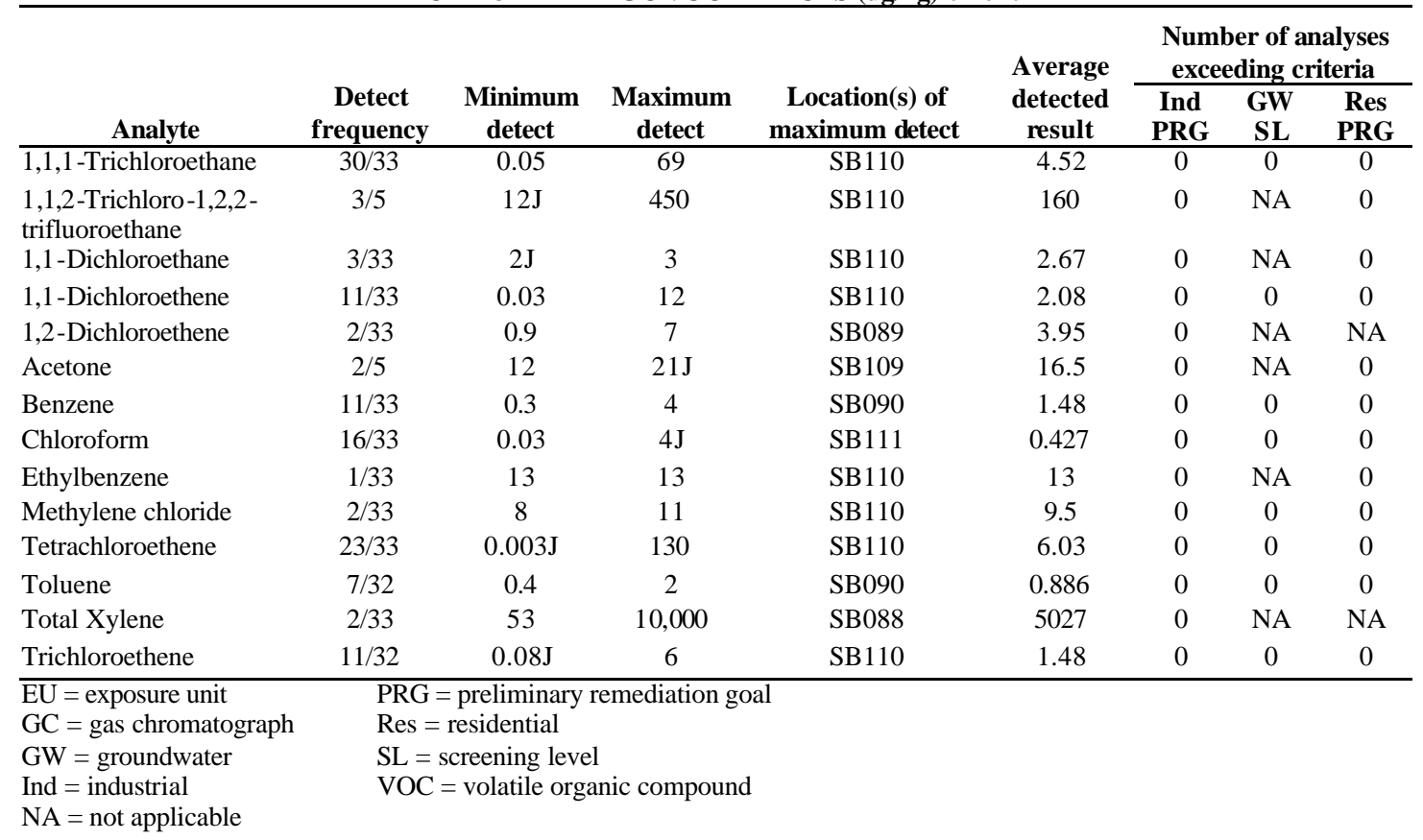

\section{\begin{tabular}{|l|l} 
2.2.6 & ZONE 2 ROD APPENDIX A FFA SITES EVALUATION
\end{tabular}}

There is one FFA site located in this EU that is identified in Appendix A of the Zone 2 ROD-the K-1414 Garage Diesel Tank/Soil FFA Site. A fuel leak from piping associated with the diesel tank was discovered in 1987 and is 
documented in the K-1070-C/D Phase 2 RI. Five historical sample locations were selected for this TM to represent soil that would have been impacted by the fuel leak as described in Sect. H.2.2.3. Sample locations are presented in Sect. H.2.2.3 and shown in Fig. H.3. Analytical results summarized below for samples collected from 0 to $10 \mathrm{ft}$ at these five locations show radionuclide Ind PRG exceedances; metal and radionuclide Bkg exceedances; and detections of DRO, GRO, SVOCs, and VOCs. Unlike the SVOCs, and VOCs, there are no Zone 2 ROD criteria against which to evaluate the DRO and GRO detections. DRO and GRO were both detected in one sample at location BH005, 190J $\mathrm{mg} / \mathrm{kg}$ and $7.5 \mathrm{~J} \mathrm{mg} / \mathrm{kg}$, respectively.

EU Z2-37 K-1414 GARAGE DIESEL TANK/SOILS FFA SITE METALS WITH

BACKGROUND, PRG, GW SL, AND/OR RL EXCEEDANCES (mg/kg) 0-10 ft

\begin{tabular}{|c|c|c|c|c|c|c|c|c|c|c|c|}
\hline \multirow[b]{2}{*}{ Analyte } & \multirow[b]{2}{*}{$\begin{array}{l}\text { Detect } \\
\text { frequency }\end{array}$} & \multirow[b]{2}{*}{$\begin{array}{c}\text { Minimum } \\
\text { detect }\end{array}$} & \multirow[b]{2}{*}{$\begin{array}{c}\text { Maximum } \\
\text { detect }\end{array}$} & \multirow{2}{*}{$\begin{array}{c}\text { Location(s) of } \\
\text { maximum } \\
\text { detect }\end{array}$} & \multirow{2}{*}{$\begin{array}{c}\text { Average } \\
\text { detected } \\
\text { result }\end{array}$} & \multicolumn{6}{|c|}{ Number of analyses exceeding criteria } \\
\hline & & & & & & $\underset{\text { RL }}{\operatorname{Max}}$ & $\begin{array}{l}\text { Avg } \\
\text { RL }\end{array}$ & $\begin{array}{l}\text { Ind } \\
\text { PRG }\end{array}$ & Bkg & $\begin{array}{c}\text { GW } \\
\text { SL }\end{array}$ & $\begin{array}{c}\text { Res } \\
\text { PRG }\end{array}$ \\
\hline Aluminum & $1 / 1$ & 18,500 & 18,500 & SB088 & 18,500 & NA & NA & 0 & 0 & NA & 1 \\
\hline Arsenic & $1 / 1$ & $15.5 \mathrm{~J}$ & $15.5 \mathrm{~J}$ & SB088 & 15.5 & 0 & 0 & 0 & 1 & 0 & 1 \\
\hline Barium & $1 / 1$ & 138 & 138 & SB088 & 138 & NA & NA & 0 & 1 & 0 & 0 \\
\hline Cadmium & $1 / 1$ & 0.38 & 0.38 & SB088 & 0.38 & NA & NA & 0 & 1 & NA & 0 \\
\hline Copper & $1 / 1$ & 80.7 & 80.7 & SB088 & 80.7 & NA & NA & 0 & 1 & NA & 0 \\
\hline Iron & $1 / 1$ & 37,100 & 37,100 & SB088 & 37,100 & NA & NA & 0 & 0 & NA & 1 \\
\hline Manganese & $1 / 1$ & 1,820 & 1,820 & SB088 & 1,820 & NA & NA & 0 & 0 & NA & 1 \\
\hline Nickel & $1 / 1$ & 34.1 & 34.1 & SB088 & 34.1 & NA & NA & 0 & 1 & NA & 0 \\
\hline Silver & $1 / 1$ & 3 & 3 & SB088 & 3 & NA & NA & 0 & 1 & NA & 0 \\
\hline Vanadium & $1 / 1$ & 35.8 & 35.8 & SB088 & 35.8 & NA & NA & 0 & 0 & NA & 1 \\
\hline
\end{tabular}

Avg = average $\quad$ Max $=$ maximum

$\mathrm{Bkg}=$ background $\quad \mathrm{NA}=$ not applicable

$\mathrm{EU}=$ exposure unit $\quad \mathrm{PRG}=$ preliminary remediation goal

FFA $=$ Federal Facility Agreement $\quad$ Res $=$ residential

$\mathrm{GW}=$ groundwater $\quad \mathrm{RL}=$ remediation level

Ind $=$ industrial $\quad \mathrm{SL}=$ screening level

EU Z2-37 K-1414 GARAGE DIESEL TANK/SOILS FFA

SITE OTHER ORGANICS DETECTS (mg/kg) 0-10 ft

\begin{tabular}{lccccc}
\hline \multicolumn{1}{c}{ Analyte } & $\begin{array}{c}\text { Detect } \\
\text { frequency }\end{array}$ & $\begin{array}{c}\text { Minimum } \\
\text { detect }\end{array}$ & $\begin{array}{c}\text { Maximum } \\
\text { detect }\end{array}$ & $\begin{array}{c}\text { Location(s) of } \\
\text { maximum } \\
\text { detect }\end{array}$ & $\begin{array}{c}\text { Average } \\
\text { detected } \\
\text { result }\end{array}$ \\
\hline Diesel Range Organics & $1 / 3$ & $190 \mathrm{~J}$ & $190 \mathrm{~J}$ & BH005 & 190 \\
Gasoline Range Organics & $1 / 3$ & $7.5 \mathrm{~J}$ & $7.5 \mathrm{~J}$ & BH005 & 7.5 \\
\hline
\end{tabular}

$\mathrm{EU}=$ exposure unit

$\mathrm{FFA}=$ Federal Facility Agreement

PCBs were analyzed for in one sample but were not detected.

EU Z2-37 K-1414 GARAGE DIESEL TANK/SOILS FFA SITE RADIONUCLIDES WITH BACKGROUND, PRG, AND/OR RL EXCEEDANCES (pCi/g) 0-10 ft

\begin{tabular}{|c|c|c|c|c|c|c|c|c|c|c|c|}
\hline \multirow[b]{2}{*}{ Analyte } & \multirow[b]{2}{*}{$\begin{array}{c}\text { Detect } \\
\text { frequency }\end{array}$} & \multirow[b]{2}{*}{$\begin{array}{c}\text { Minimum } \\
\text { detect }\end{array}$} & \multirow[b]{2}{*}{$\begin{array}{c}\text { Maximum } \\
\text { detect }\end{array}$} & \multirow[b]{2}{*}{$\begin{array}{c}\text { Location(s) of } \\
\text { maximum detect }\end{array}$} & \multirow{2}{*}{$\begin{array}{c}\text { Average } \\
\text { detected } \\
\text { result }\end{array}$} & \multicolumn{6}{|c|}{ Number of analyses exceeding criteria } \\
\hline & & & & & & $\begin{array}{c}\text { Max } \\
\text { RL }\end{array}$ & $\begin{array}{l}\text { Avg } \\
\text { RL }\end{array}$ & $\begin{array}{c}\text { Ind } \\
\text { PRG }\end{array}$ & Bkg & $\begin{array}{l}\text { GW } \\
\text { SL }\end{array}$ & $\begin{array}{c}\text { Res } \\
\text { PRG }\end{array}$ \\
\hline Cesium-137 & $2 / 3$ & 0.223 & 1.01 & ETTP-REL12 & 0.617 & 0 & 0 & 0 & NA & NA & 2 \\
\hline Potassium-40 & $2 / 2$ & 44.2 & 45.7 & ETTP-REL13 & 45.0 & NA & NA & 2 & 2 & NA & 2 \\
\hline Radium-226 & $1 / 2$ & 1.28 & 1.28 & ETTP-REL12 & 1.28 & NA & NA & 1 & 1 & NA & 1 \\
\hline Technetium-99 & $3 / 3$ & $0.23 \mathrm{~J}$ & $1.18 \mathrm{~J}$ & ETTP-REL12 & 0.667 & NA & NA & 0 & NA & NA & 2 \\
\hline Thorium -228 & $2 / 2$ & 0.892 & 1.08 & ETTP-REL13 & 0.986 & NA & NA & 2 & 0 & NA & 2 \\
\hline Thorium -232 & $2 / 2$ & 1.95 & 1.97 & ETTP-REL13 & 1.96 & NA & NA & 2 & 1 & NA & 2 \\
\hline Uranium-234 & $3 / 3$ & 1.96 & 7.94 & ETTP-REL12 & 3.97 & 0 & 0 & 0 & NA & 0 & 1 \\
\hline
\end{tabular}




\begin{tabular}{|c|c|c|c|c|c|c|c|c|c|c|}
\hline \multicolumn{11}{|c|}{$\begin{array}{l}\text { EU Z2-37 K-1414 GARAGE DIESEL TANK/SOILS FFA SITE RADIO NUCLIDES } \\
\text { WITH BACKGROUND, PRG, AND/OR RL EXCEEDANCES (pCi/g) 0-10 ft (cont'd) }\end{array}$} \\
\hline \multirow[b]{2}{*}{ Analyte } & \multirow[b]{2}{*}{$\begin{array}{c}\text { Minimum } \\
\text { detect }\end{array}$} & \multirow[b]{2}{*}{$\begin{array}{l}\text { Maximum } \\
\text { detect }\end{array}$} & \multirow[b]{2}{*}{$\begin{array}{l}\text { Location(s) of } \\
\text { maximum detect }\end{array}$} & \multirow{2}{*}{$\begin{array}{c}\text { Average } \\
\text { detected } \\
\text { result }\end{array}$} & \multicolumn{6}{|c|}{ Number of analyses exceeding criteria } \\
\hline & & & & & $\begin{array}{l}\text { Max } \\
\text { RL }\end{array}$ & Avg & $\begin{array}{l}\text { Ind } \\
\text { PRG }\end{array}$ & Bkg & $\begin{array}{l}\text { GW } \\
\text { SL }\end{array}$ & $\begin{array}{c}\text { Res } \\
\text { PRG }\end{array}$ \\
\hline Uranium-235 & $0.0479 \mathrm{~J}$ & $0.482 \mathrm{~J}$ & ETTP-REL12 & 0.213 & 0 & 0 & 0 & NA & 0 & 1 \\
\hline Uranium-238 & 0.917 & 4.26 & ETTP-REL12 & 2.19 & 0 & 0 & 0 & 1 & 0 & 3 \\
\hline $\begin{array}{l}\text { Avg = average } \\
\text { Bkg = background } \\
\text { EU = exposure unit } \\
\text { FFA = Federal Facility Agreement } \\
\text { GW = groundwater } \\
\text { Ind = industrial }\end{array}$ & $\begin{array}{l}\text { Max }=\mathrm{n} \\
\mathrm{NA}=\mathrm{n} \\
\mathrm{PRG}=\mathrm{r} \\
\mathrm{Res}=\mathrm{re} \\
\mathrm{RL}=\mathrm{re} \\
\mathrm{SL}=\mathrm{sc}\end{array}$ & $\begin{array}{l}\text { naximum } \\
\text { ot applicable } \\
\text { preliminary r } \\
\text { esidential } \\
\text { mediation le } \\
\text { reening level }\end{array}$ & $\begin{array}{l}\text { remediation goal } \\
\text { vel }\end{array}$ & & & & & & & \\
\hline
\end{tabular}

EU Z2-37 K-1414 GARAGE DIESEL TANK/SOILS FFA SITE SVOC DETECTS (ug/kg) 0-10 ft

\begin{tabular}{|c|c|c|c|c|c|c|c|c|}
\hline \multirow[b]{2}{*}{ Analyte } & \multirow[b]{2}{*}{$\begin{array}{c}\text { Detect } \\
\text { frequency }\end{array}$} & \multirow[b]{2}{*}{$\begin{array}{l}\text { Minimum } \\
\text { dete ct }\end{array}$} & \multirow[b]{2}{*}{$\begin{array}{c}\text { Maximum } \\
\text { detect }\end{array}$} & \multirow[b]{2}{*}{$\begin{array}{c}\text { Location(s) of } \\
\text { maximum detect }\end{array}$} & \multirow{2}{*}{$\begin{array}{c}\text { Average } \\
\text { detected } \\
\text { result }\end{array}$} & \multicolumn{3}{|c|}{$\begin{array}{c}\text { Number of analyses } \\
\text { exceeding criteria }\end{array}$} \\
\hline & & & & & & $\begin{array}{l}\text { Ind } \\
\text { PRG }\end{array}$ & $\begin{array}{l}\text { GW } \\
\text { SL }\end{array}$ & $\begin{array}{l}\text { Res } \\
\text { PRG }\end{array}$ \\
\hline 2-Methylnaphthalene & $1 / 4$ & 2200 & 2200 & SB088 & 2200 & 0 & NA & NA \\
\hline Acenaphthene & $1 / 4$ & $130 \mathrm{~J}$ & $130 \mathrm{~J}$ & SB088 & 130 & 0 & NA & 0 \\
\hline Fluoranthene & $1 / 4$ & $40 \mathrm{~J}$ & $40 \mathrm{~J}$ & BH006 & 40 & 0 & NA & 0 \\
\hline Fluorene & $1 / 4$ & $320 \mathrm{~J}$ & $320 \mathrm{~J}$ & SB088 & 320 & 0 & NA & 0 \\
\hline Naphthalene & $1 / 4$ & $330 \mathrm{~J}$ & $330 \mathrm{~J}$ & SB088 & 330 & 0 & NA & 0 \\
\hline Phenanthrene & $2 / 4$ & $130 \mathrm{~J}$ & 790 & SB088 & 460 & 0 & NA & 0 \\
\hline Pyrene & $2 / 4$ & $40 \mathrm{~J}$ & $130 \mathrm{~J}$ & SB088 & 85 & 0 & NA & 0 \\
\hline
\end{tabular}

EU = exposure unit $\quad$ PRG = preliminary remediation goal

FFA $=$ Federal Facility Agreement $\quad$ Res $=$ residential

$\mathrm{GW}=$ groundwater $\quad \mathrm{SL}=$ screening level

Ind $=$ industrial $\quad$ SVOC $=$ semivolatile organic compound

$\mathrm{NA}=$ not applicable

EU Z2-37 K-1414 GARAGE DIESEL TANK/SOILS FFA SITE VOC DETECTS (ug/kg) 0-10 ft

\begin{tabular}{|c|c|c|c|c|c|c|c|c|}
\hline \multirow[b]{2}{*}{ Analyte } & \multirow[b]{2}{*}{$\begin{array}{c}\text { Detect } \\
\text { frequency }\end{array}$} & \multirow[b]{2}{*}{$\begin{array}{l}\text { Minimum } \\
\text { detect }\end{array}$} & \multirow[b]{2}{*}{$\begin{array}{l}\text { Maximum } \\
\text { detect }\end{array}$} & \multirow[b]{2}{*}{$\begin{array}{c}\text { Location(s) of } \\
\text { maximum detect }\end{array}$} & \multirow{2}{*}{$\begin{array}{c}\text { Average } \\
\text { detected } \\
\text { result }\end{array}$} & \multicolumn{3}{|c|}{$\begin{array}{c}\text { Number of analyses } \\
\text { exceeding criteria }\end{array}$} \\
\hline & & & & & & $\begin{array}{l}\text { Ind } \\
\text { PRG }\end{array}$ & $\begin{array}{l}\text { GW } \\
\text { SL }\end{array}$ & $\begin{array}{c}\text { Res } \\
\text { PRG }\end{array}$ \\
\hline 1,1,1-Trichloroethane & $1 / 4$ & 8 & 8 & SB088 & 8 & 0 & 0 & 0 \\
\hline $\begin{array}{l}\text { 1,1,2-Trichloro-1,2,2- } \\
\text { trifluoroethane }\end{array}$ & $1 / 4$ & $5 \mathrm{~J}$ & $5 \mathrm{~J}$ & SB088 & 5 & 0 & NA & 0 \\
\hline 1,1-Dichloroethane & $1 / 4$ & 18 & 18 & SB088 & 18 & 0 & NA & 0 \\
\hline 1,1-Dichloroethene & $1 / 4$ & $6 \mathrm{~J}$ & $6 \mathrm{~J}$ & BH005 & 6 & 0 & 0 & 0 \\
\hline 2-Butanone & $1 / 4$ & $52 \mathrm{~J}$ & $52 \mathrm{~J}$ & BH005 & 52 & 0 & NA & 0 \\
\hline Acetone & $2 / 4$ & $530 \mathrm{~J}$ & 6600 & BH006 & 3565 & 0 & NA & 0 \\
\hline Benzene & $2 / 4$ & $26 \mathrm{~J}$ & 44 & SB088 & 35 & 0 & 0 & 0 \\
\hline Carbon disulfide & $1 / 4$ & $5 \mathrm{~J}$ & $5 \mathrm{~J}$ & SB088 & 5 & 0 & NA & 0 \\
\hline Ethylbenzene & $3 / 4$ & 11 & $4300 \mathrm{~J}$ & SB088 & 1484 & 0 & NA & 0 \\
\hline Methylene chloride & $1 / 4$ & $29 \mathrm{~J}$ & $29 \mathrm{~J}$ & BH005 & 29 & 0 & 0 & 0 \\
\hline Tetrachloroethene & $4 / 4$ & $5 \mathrm{~J}$ & $14 \mathrm{~J}$ & SB088 & 9 & 0 & 0 & 0 \\
\hline Toluene & $4 / 5$ & $6 \mathrm{~J}$ & $200 \mathrm{~J}$ & BH005 & 62.5 & 0 & 0 & 0 \\
\hline Total Xylene & $3 / 4$ & $5 \mathrm{~J}$ & $5000 \mathrm{~J}$ & SB088 & 1728 & 0 & NA & NA \\
\hline $\begin{array}{l}\text { EU = exposure unit } \\
\text { FFA = Federal Facility } \\
\text { GW = groundwater } \\
\text { Ind = industrial } \\
\text { NA = not applicable }\end{array}$ & greement & \multicolumn{3}{|c|}{$\begin{array}{l}\text { PRG = preliminary remediation goal } \\
\text { Res = residential } \\
\text { SL = screening level } \\
\text { VOC = volatile organic compound }\end{array}$} & & & & \\
\hline
\end{tabular}




\begin{tabular}{|l|l|}
\hline & \\
\hline 3.0 & RISK EVALUATION AND ACTION/NO FURTHER ACTION DECISION \\
\hline 3.1 & INTRODUCTION \\
\hline
\end{tabular}

In this section, data are evaluated in terms of the four decision rules presented in the Zone 2 RAWP. The decision rules are:

- Does the concentration of any Zone 2 contaminant of concern (COC) exceed its maximum RL?

- Does the mean concentration of any Zone 2 COC exceed its average RL across the EU?

- Does the EU pose a risk exceeding an industrial $1 \times 10^{-4}$ excess lifetime cancer risk (ELCR) or target organ hazard index (HI) of 1 ?

- Does the site pose a threat to groundwater based on MCL exceedances or soil RLs for protection of groundwater?

Table H.3 presents the results from comparison of the data to Zone 2 soils RLs, industrial PRGs (set at an ELCR of $1 \times 10^{-5}$ or a HI of 1), and background levels. In addition, the EU summary in Sect. H.2.2.5 presents an evaluation of the EU data by analyte group. The following table summarizes the conclusions for EU Z2-37.

\begin{tabular}{cccccc}
\hline EU \# & $\begin{array}{c}\text { Max RL } \\
\text { exceeded? }\end{array}$ & $\begin{array}{c}\text { Avg RL over } \\
\text { EU exceeded? }\end{array}$ & $\begin{array}{c}\text { Industrial risk } \\
\text { above } \mathbf{1} \times \mathbf{1 0}^{-4} \text { ? }\end{array}$ & $\begin{array}{c}\text { Potential source } \\
\text { to groundwater? }\end{array}$ & $\begin{array}{c}\text { Action } \\
\text { required? }\end{array}$ \\
\hline $\mathrm{Z} 2-37$ & No & No & No & No & No \\
\hline $\begin{array}{l}\mathrm{EU}=\text { exposure unit } \\
\mathrm{RL}=\text { remediation level }\end{array}$ & & & & \\
\end{tabular}

\begin{tabular}{l|l}
3.2 & DATA EVALUATION FOR THE ACTION /NO FURTHER ACTION DECISION
\end{tabular}

The requirements for determining NFA in the Zone 2 EUs are stated in the protection goals of the Zone 2 ROD RAO. Four decision rules were developed in the DVS DQOs that state the specific criteria against which each EU must be compared to make the NFA decision. The four decision rules are presented in Sect. H.3.2 of this PCCR and the manner in which the decision rule evaluations are conducted and special data handling requirements are discussed in Sect. H.3.3 of the PCCR. In summary, the decision rule criteria for NFA are that each EU must meet each of the following compositional constraints:

- Zone 2 soils Max RLs - maximum allowable concentrations of the Zone 2 soils COCs. Zone 2 soils Max RLs are presented in the Zone 1 ROD and Table 5 of this PCCR.

- Zone 2 soils Avg RLs - limit on the allowable average concentrations of the Zone 2 soils COCs across an EU. Zone 2 soils Avg RLs are presented in the Zone 1 ROD and Table 5 of this PCCR.

- Cumulative risk across the EU - cumulative risk across an EU cannot exceed $1 \times 10^{-4}$ ELCR or HI of 1. A stepwise evaluation of cumulative risk is performed by comparing the EU data to $1 \times 10^{-5}$ industrial PRGs. The $1 \times 10^{-5}$ Ind PRGs for the analytes required by the RDR/RAWP are presented in Table 5 of this PCCR.

Groundwater protection goals - the composition of Zone 2 soils cannot pose a threat to groundwater. This evaluation is conducted by evaluating local groundwater monitoring results and comparing soil compositions to calculated SLs. Groundwater SLs are presented in Table 5 of this PCCR.

\section{\begin{tabular}{|l|l}
\hline 3.3 & SUMMARY AND CONCLUSIONS \\
\hline
\end{tabular}}

$\underline{\text { EU Z2-37 }}$

Max RL screening. Based on analytical results from DVS biased and historical sampling in EU Z2-37, no Zone 2 COCs are present at concentrations in excess of Max RLs.

Avg RL screening. Based on analytical results from DVS biased sampling and historical sampling in EU Z2-37, no Zone 2 soils COCs are present with a mean concentration exceeding the Avg RL across the EU.

Risk evaluation. The first step in the risk evaluation is to evaluate $1 \times 10^{-5}$ Ind PRG exceedances to determine which chemicals and radionuclides are likely to exceed the $1 \times 10^{-4}$ ELCR or target organ HI of 1 . As discussed in Sect. H.2.2.5, the $1 \times 10^{-5}$ Ind PRG was exceeded in one or more samples by arsenic (1), manganese (1), K-40 (14), Ra-226 (11), Th-228 (12), Th-232 (14), and benzo(a)pyrene (2). As explained in Sect. H.3.3 of this PCCR, K-40 is 
evaluated further for risk only if its average concentration exceeds its background value and Ra-226, Th-230, and Th-232 are evaluated by summing their concentrations ( $\mathrm{Ra} / \mathrm{Th}$ decay series) and comparing the result to their mutual Zone 2 soils COC average RL (this evaluation includes Th-228 as part of the Th-232 decay chain). The average detected $\mathrm{K}-40$ concentration $(21.3 \mathrm{pCi} / \mathrm{g})$ does not exceed the $\mathrm{K}-40$ background value $(32.12 \mathrm{pCi} / \mathrm{g})$ and there are no occurrences of the Ra/Th decay series exceeding the Avg RL (5 pCi/g). Therefore, K-40, Ra-226, Th-228, and Th-232 will not be carried forward in the risk evaluation.

The second step in the risk evaluation is to determine if the average detected concentration of any of the remaining chemicals or radionuclides exceeds a $1 \times 10^{-5}$ Ind PRG. For EU Z2-37, the remaining chemicals and radionuclides with individual $1 \times 10^{-5}$ Ind PRG exceedances are arsenic, manganese, and benzo(a)pyrene. The average detected concentration of arsenic $\left(7.06 \mathrm{mg} / \mathrm{kg}\right.$ ) is less than the $1 \times 10^{-5}$ Ind PRG $(15.9 \mathrm{mg} / \mathrm{kg})$, the average detected concentration of manganese $(3196 \mathrm{mg} / \mathrm{kg})$ is also less than the $1 \times 10^{-5}$ Ind PRG $(19,458 \mathrm{mg} / \mathrm{kg})$, and the average detected concentration of benzo(a)pyrene $(1038 \mathrm{ug} / \mathrm{kg})$ is also less than the $1 \times 10^{-5}$ Ind PRG $(2110 \mathrm{ug} / \mathrm{kg})$. It is concluded there are no chemicals or radionuclides in soils of this EU at concentrations high enough for the EU to fail the Zone 2 risk limits. Therefore, the industrial risk for EU Z2-37 is less than $1 \times 10^{-4}$ ELCR and target organ HI of 1 .

\section{Threat to groundwater.}

One or more groundwater VOC plumes are known to occur beneath EU Z2-37. However, the sources of these plumes are either upgradient in EU Z2-41 or are in deep bedrock beneath the EU (see CSM in Sect. H.2.2.5). Because there are no GW SL exceedances in soil samples collected from the 0-to 10-ft-depth interval in this EU, there are no potential sources for groundwater VOC contamination in that depth interval.

Both DRO and GRO have been detected in area groundwater monitoring wells and were detected in two samples from two his torical sampling locations. There are no site-specific or action-specific criteria in the Zone 2 ROD that pertain to USTs. However, according to UST Rules of the TDEC Chap. 1200-1-15-06(7)(e)(4), site-specific, risk-based cleanup levels may be utilized where appropriate.

It is concluded that chemicals and radionuclides in the soils of EU Z2-37 are not potential threats to groundwater.

Qualitative risk screening for unrestricted use. There is a low probability that the EU Z2-37 acreage could be released with no land use restrictions. Ind and Res PRG exceedances for metals, radionuclides, PCBs, SVOCs, and VOCs occur in this EU. Specific chemicals and radionuclides with criteria exceedances are presented in Sect. H.2.2.5. An appropriate evaluation of residential risk should be conducted to make a definitive conclusion.

\section{FFA Sites}

Based on sampling analytical results (Sect. H.2.2.6) and an evaluation of the EU-wide contaminant profile (above), soils in the K-1414 Diesel Tank/Soils Zone 2 ROD Appendix A FFA Site in EU Z2-37 do not pose a potential threat to the future industrial worker or to groundwater.

\begin{tabular}{|l|l|}
\hline 4.0 & RECOMMENDATION FOR ACTION/NO FURTHER ACTION \\
\hline 4.1 & DECISION AND REMEDIATION ACTIVITIES \\
\hline
\end{tabular}

EU Z2-37: Based on results of the Class 3 SU walkover assessment and analytical results of the DVS and historical samples collected in EU Z2-37, the U.S. Department of Energy recommends that NFA is appropriate under the Zone 2 ROD to meet industrial land use for the 5.9 acres of ETTP Zone 2 EU37.

There are 27 historical sample locations in EU Z2-37 with samples from > $10 \mathrm{ft}$ bgs. Analytical results summarized in Table H.4 show metal, radionuclide, and VOC Ind PRG exceedances; VOC GW SL exceedances; numerous metal and radionuclide Bkg exceedances; metal, radionuclide, PCB, and VOC Res PRG exceedances; DRO and GRO exceedances of the Tennessee groundwater protection criterion; and detections of DRO, GRO, pesticides, PCBs, SVOCs, and VOCs that do not exceed any criteria. Based on this data evaluation and the fact that one or more groundwater contaminant plumes occur under portions of this EU, DOE does not recommend that the 10 -ft-depth use restriction be lifted.

FFA Sites: Based on sampling analytical results and the recommendation for EU Z2-37, DOE recommends NFA as appropriate for the K-1414 Diesel Tank/Soils FFA Site. 
4.2

EXCAVATION ACTIVITIES/CONFIRMATIONSAMPLING

None 


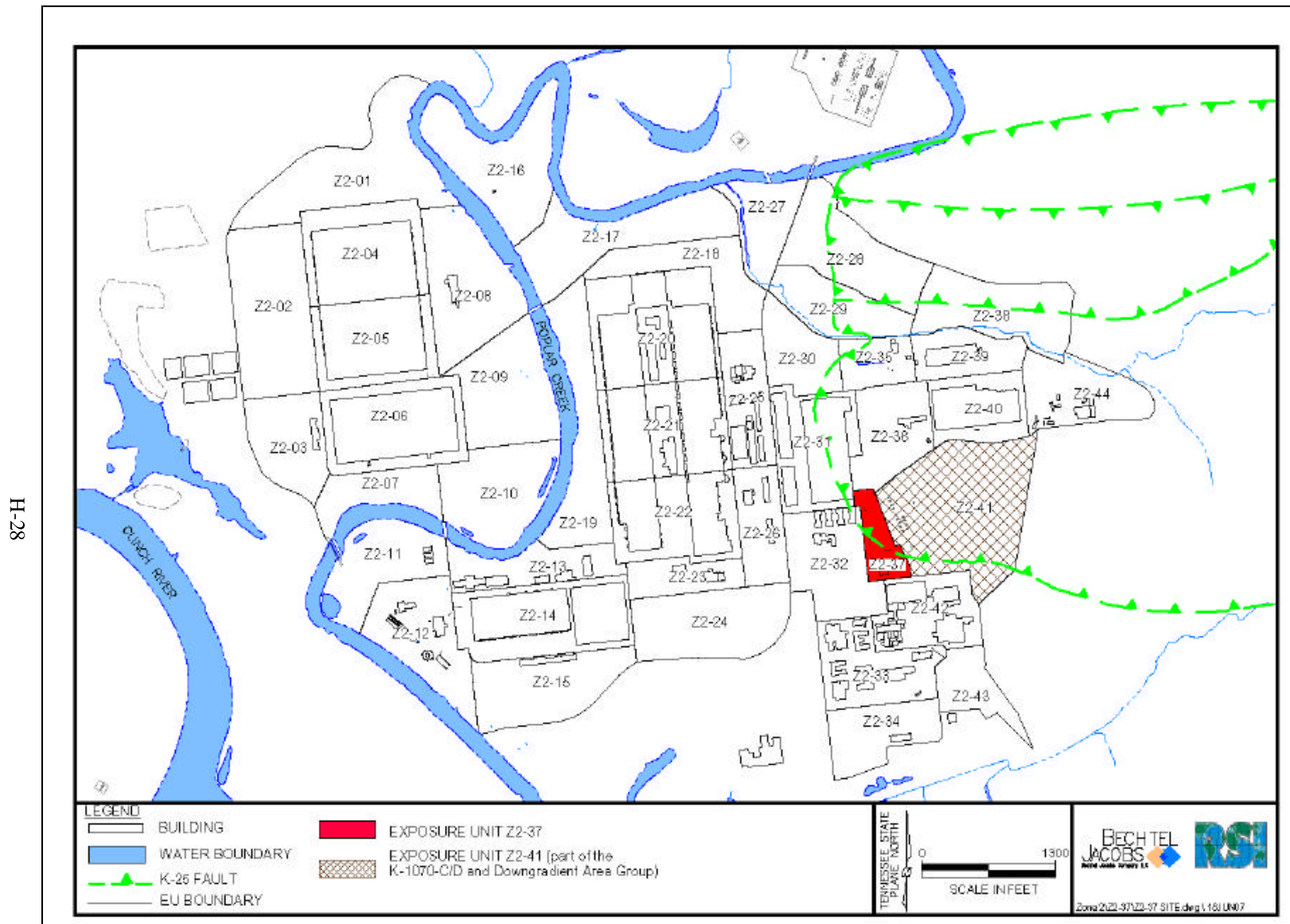

Fig. H.1. EU Z2-37 location map. 


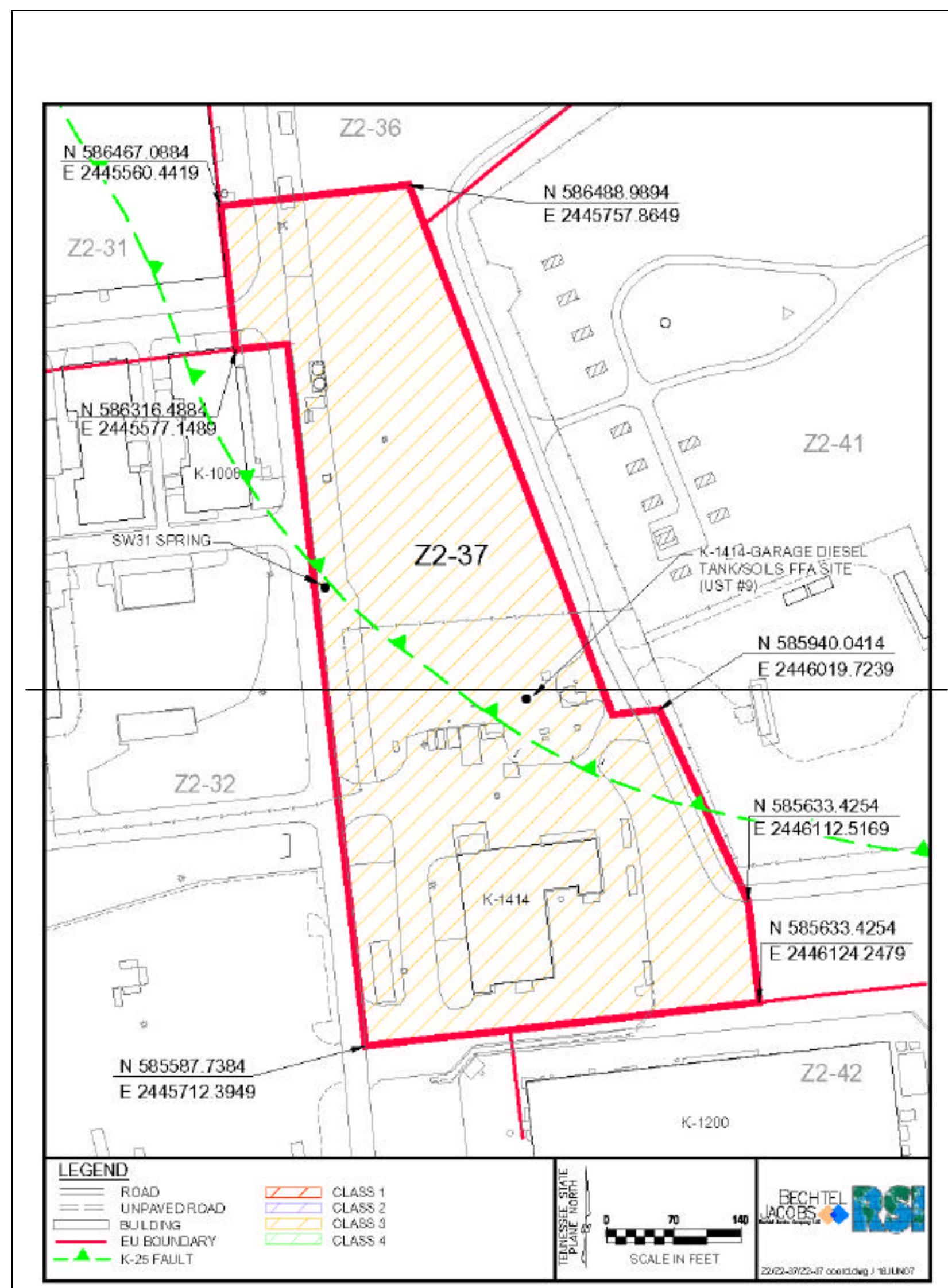

Fig. H.2, EU Z2-37 boundaries. 


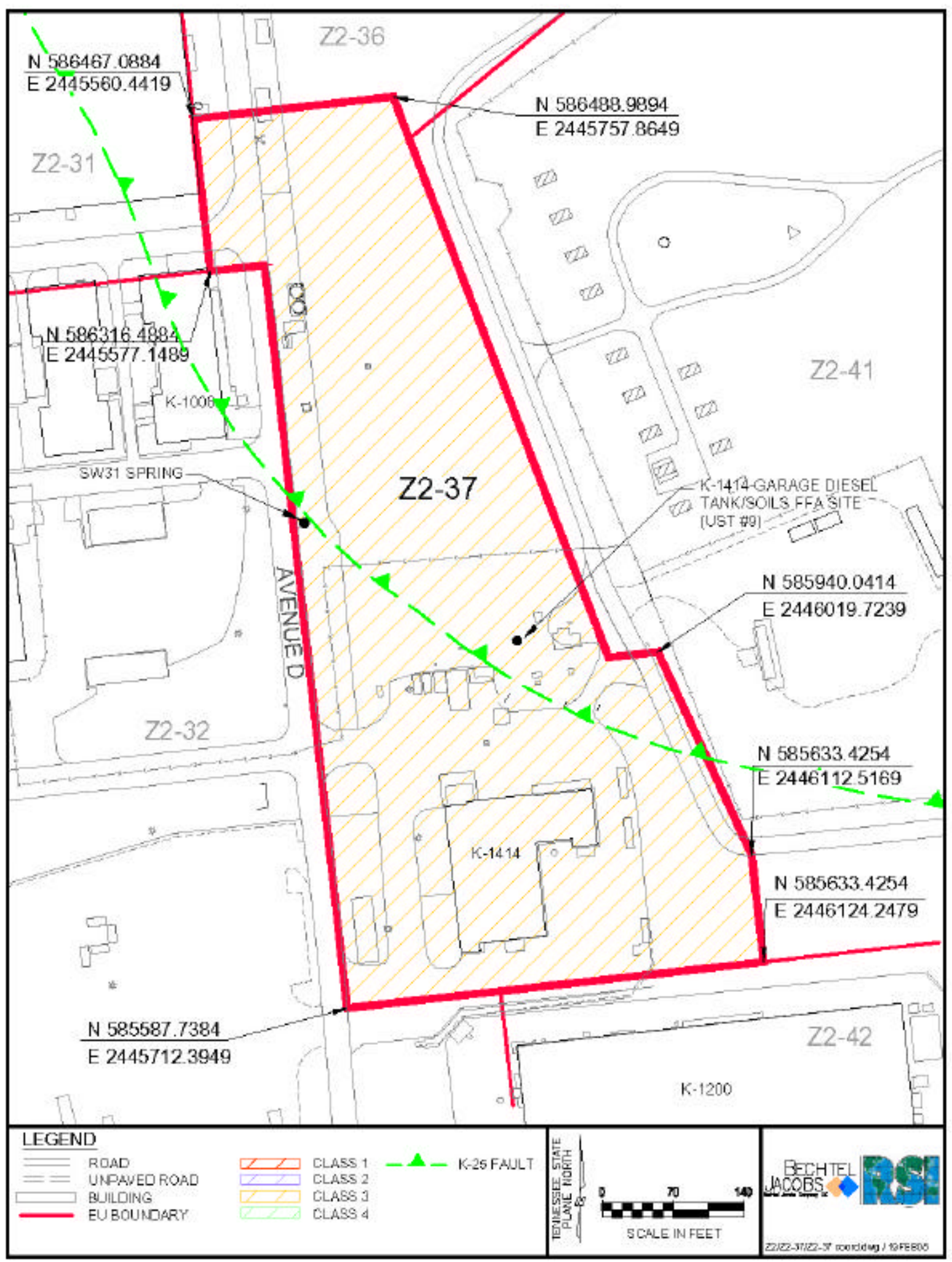

Fig. H.2. EU Z2-37 boundaries. 


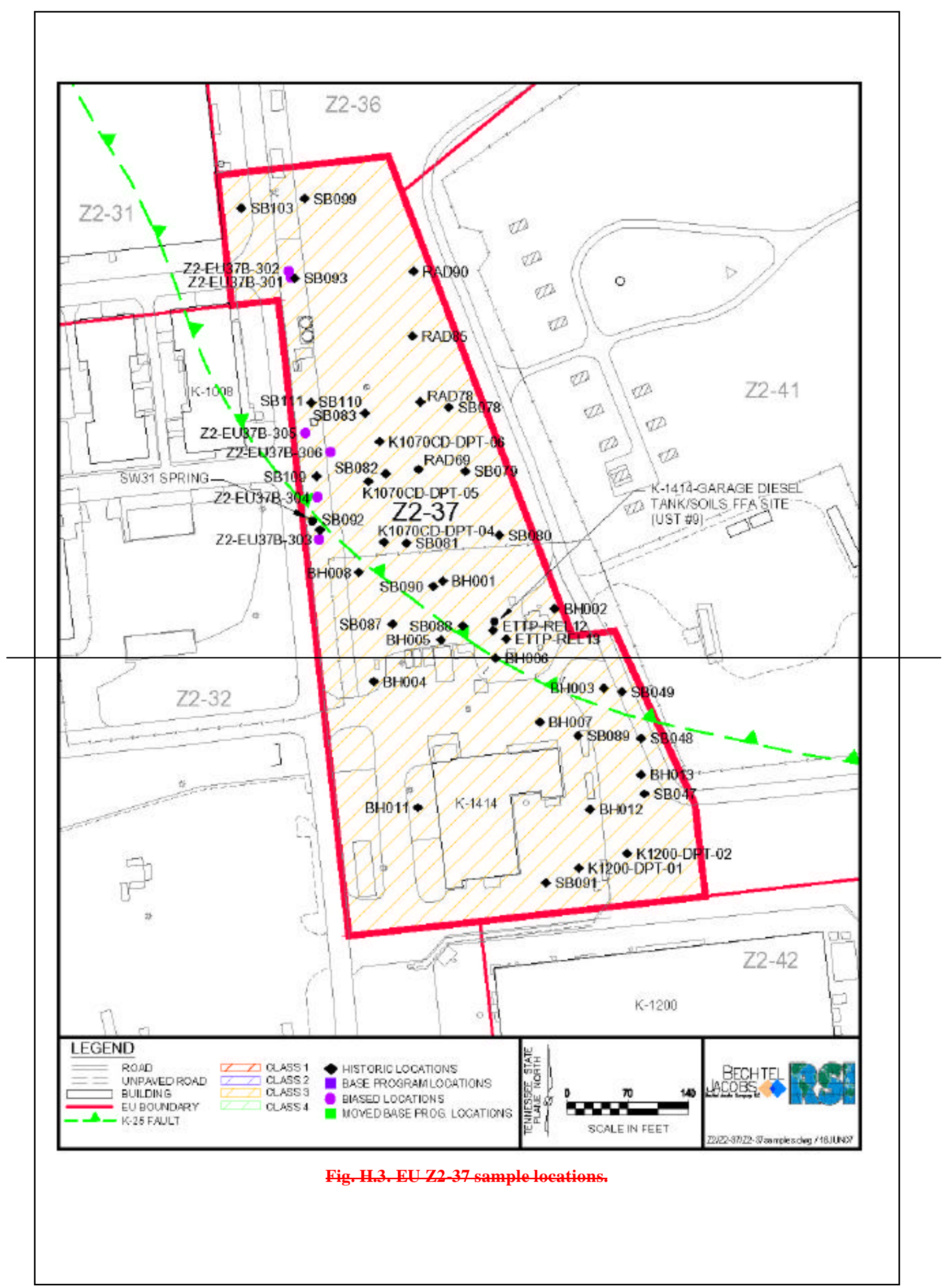




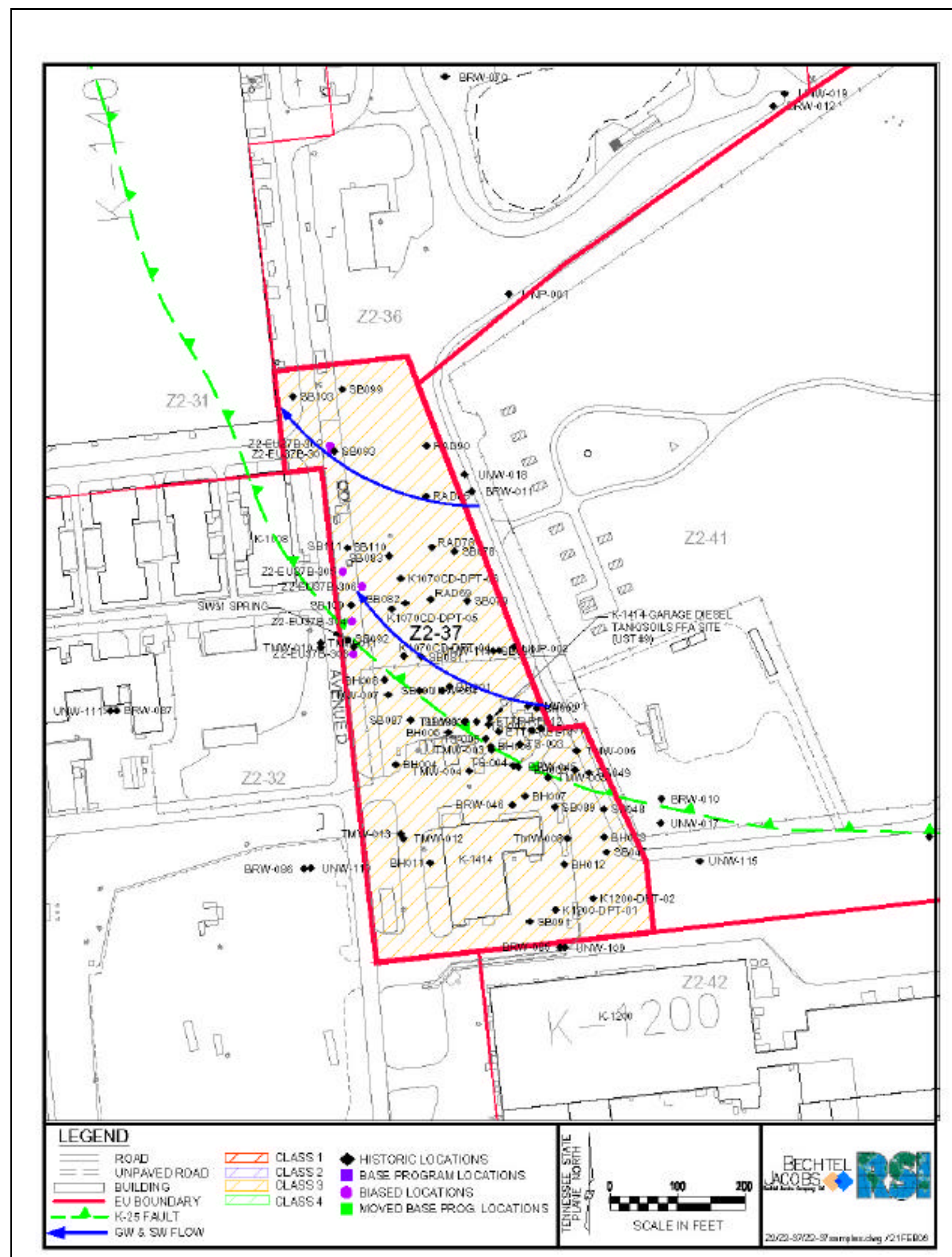

Fig. H.3. EU Z2 -37 sample locations. 
Table H.1. EU Z2-37 facility and FFA site list

\begin{tabular}{|c|c|c|c|c|}
\hline \multirow[b]{2}{*}{ Facility name DQO scoping } & \multirow[b]{2}{*}{ Facility name } & \multicolumn{2}{|c|}{ Facility assessed? } & \multirow[b]{2}{*}{ Comments } \\
\hline & & Yes & No & \\
\hline K-700-A-2 Substation & & $\mathrm{X}$ & & \\
\hline K-1310-CD Storage Shed & & $\mathrm{X}$ & & \\
\hline K-1310-DD Office Trailer & & $\mathrm{X}$ & & \\
\hline K-1414 Garage Diesel Tank/Soils & & $\mathrm{X}$ & & FFA site \\
\hline K-1414 Underground Storage Tank (UST \#8) & & & $\mathrm{X}$ & $\begin{array}{l}\text { Tank removed in 1997; received clean } \\
\text { closure }\end{array}$ \\
\hline K-1414 Unleaded Gasoline Underground Storage Tank (UST \#7) & & & $\mathrm{X}$ & Clean closure-in-place 1994 \\
\hline K-1414 Waste Oil Underground Storage Tank (UST \#6) & & $\mathrm{X}$ & & \\
\hline K-1414-B Vehicle Wash Facility & & $\mathrm{X}$ & & \\
\hline K-1414-C Storage Shed & & $\mathrm{X}$ & & \\
\hline K-1414-D Backflow Preventer & & $\mathrm{X}$ & & \\
\hline SW31 Spring (ROD signed 9/30/92) & & $\mathrm{X}$ & & \\
\hline \multicolumn{5}{|l|}{ Facilities not in DQO scoping } \\
\hline K-720-A Storage Building & & $\mathrm{X}$ & & \\
\hline
\end{tabular}


Table H.2. EU Z2-37 sample summary

\begin{tabular}{|c|c|c|c|c|c|c|c|c|c|c|c|c|c|c|c|c|}
\hline \multirow[b]{2}{*}{$\begin{array}{c}\text { Su } \\
\text { class }\end{array}$} & \multirow[b]{2}{*}{$\begin{array}{c}\text { Date } \\
\text { sampled }\end{array}$} & \multirow[b]{2}{*}{ EU } & \multirow[b]{2}{*}{ Location ID } & \multicolumn{2}{|c|}{ Location } & \multirow[b]{2}{*}{ Sample interval } & \multicolumn{2}{|c|}{ Screening } & \multicolumn{7}{|c|}{ Off-site laboratory } & \multirow[b]{2}{*}{ Comments and notes } \\
\hline & & & & Northing & Easting & & voC & RAD & VOC & svoc & PCB & Metals & RAD & $\begin{array}{l}\begin{array}{l}\text { GRO/ } \\
\text { DRO }\end{array} \\
\end{array}$ & $\begin{array}{c}\text { Splits/ } \\
\text { duplicates }\end{array}$ & \\
\hline \multicolumn{17}{|c|}{ DVS samples } \\
\hline 3 & $9 / 11 / 06$ & $\mathrm{Z2}-37$ & Z2-EU37B-301 & 586349 & 2445645 & $\begin{array}{l}\text { Surface to water table; three-interval } \\
\text { composite soil } 0-0.5,0.5-2,1.5 \mathrm{ft} \\
\text { within } 2 \mathrm{ft} \text { to water table }\end{array}$ & 1 & 1 & 1 & 1 & 1 & 1 & 1 & & $\mathrm{D}$ & $\begin{array}{l}\text { Sample along utility corridor (storm drain, fire water, } \\
\text { sanitary sewerr) naar Avenue D. Sample located in grassy } \\
\text { area of utility corridor south of K-1310-DD. RAD and } \\
\text { VOC analyses conditional upon field screening results. }\end{array}$ \\
\hline 3 & 9/11/06 & Z2-37 & Z2-EU37B-302 & 586356 & 2445643 & 0 to $1.0 \mathrm{ft}$ single-point sediment sample & 1 & 1 & & 1 & 1 & 1 & 1 & & $\mathrm{~s}$ & $\begin{array}{l}\text { Sediment sample from within the storm drain located in the } \\
\text { utility corridor (south of K-1310-DD). }\end{array}$ \\
\hline 3 & 9/11/06 & $\mathrm{Z} 2-37$ & Z2-EU37B-303 & 586046 & 2445678 & $\begin{array}{l}0-10 \mathrm{ft} \text { t three-interval composite soil } \\
0.5,0.5-2,1.5 \mathrm{ft} \text { within } 2-10 \mathrm{ft}\end{array}$ & 1 & 1 & 1 & 1 & 1 & 1 & 1 & & & Sample located upstream of the SW31 Spring. \\
\hline 3 & 9/11/06 & Z2-37 & Z2-EU37B-304 & 586094 & 2445676 & $\begin{array}{l}0-10 \mathrm{ft} \text { t three-interval composite soil } \\
0-0.5,0.5-2,1.5 \mathrm{ft} \text { within } 2-10 \mathrm{ft}\end{array}$ & 1 & 1 & & 1 & 1 & 1 & 1 & & & Sample located downstream of the SW31 Spring. \\
\hline 3 & 9/12/06 & Z2-37 & Z2-EU37B-305 & 586169 & 2445662 & 0 - to 1-ft single-point sediment sample & 1 & 1 & 1 & 1 & 1 & 1 & 1 & & & $\begin{array}{l}\text { Sediment sample from within the storm drain located } \\
\text { downstream of SW31. }\end{array}$ \\
\hline \multirow[t]{2}{*}{3} & 9/12/06 & Z2-37 & Z2-EU37B-306 & 586147 & 2445691 & $\begin{array}{l}\text { Four-point composite sediment sample, } \\
0 \text { to } 1 \mathrm{ft}\end{array}$ & 1 & 1 & 1 & 1 & 1 & 1 & 1 & & & Sediment sample from within the ditch area eastof SW31. \\
\hline & & & & & & DVS sampling total & 6 & 6 & 6 & 6 & 6 & 6 & 6 & & 2 & \\
\hline \multicolumn{17}{|c|}{ Historical samples } \\
\hline 3 & $10 / 5 / 93$ & Z2-37 & BH001 & 585998 & 2445821 & Borehole 2 samples to $16 \mathrm{ft}$ & & & 2 & 2 & 1 & 1 & 1 & 2 & & \\
\hline 3 & $10 / 5 / 93$ & Z2-37 & BH002 & 585966 & 2445950 & Borehole 3 samples to $17 \mathrm{ft}$ & & & 3 & 3 & 1 & 1 & 1 & 3 & & \\
\hline 3 & $10 / 5 / 93$ & Z2-37 & ВH003 & 585874 & 2446007 & Borehole sample at $12 \mathrm{ft}$ & & & 1 & 1 & 1 & 1 & 1 & 1 & & \\
\hline 3 & 10/5/93 & Z2-37 & ВH004 & 585882 & 2445741 & Borehole 3 samples to $14 \mathrm{ft}$ & & & 3 & 3 & 1 & 1 & 1 & 3 & & \\
\hline 3 & 10/13/93 & Z2-37 & ВH005 & 585930 & 2445819 & Borehole 3 samples to $14 \mathrm{ft}$ & & & 3 & 3 & 1 & 1 & 1 & 3 & & \\
\hline 3 & 10/12/93 & Z2-37 & ВH006 & 585909 & 2445882 & Borehole 3 samples to $12 \mathrm{ft}$ & & & 3 & 3 & 1 & 1 & 1 & 3 & & \\
\hline 3 & 10/11/93 & Z2-37 & BH007 & 585835 & 2445933 & Borehole 3 samples to $13.5 \mathrm{ft}$ & & & 3 & 3 & 1 & 1 & 1 & 3 & & \\
\hline 3 & $10 / 5 / 93$ & Z2-37 & BH008 & 586008 & 2445724 & Borehole sample at $8 \mathrm{ft}$ & & & 1 & 1 & 1 & 1 & 1 & 1 & & \\
\hline 3 & 10/11/93 & Z2-37 & BH011 & 585736 & 2445792 & Borehole 4 samples to $18 \mathrm{ft}$ & & & 4 & 4 & 1 & 1 & 1 & 4 & & \\
\hline 3 & $10 / 8 / 93$ & Z2-37 & BH012 & 585734 & 2445991 & Borehole 2 samples to $11.5 \mathrm{ft}$ & & & 2 & 2 & 1 & 1 & 1 & 2 & & \\
\hline 3 & $10 / 8 / 93$ & Z2-37 & BH013 & 585774 & 2446050 & Borehole sample at $3 \mathrm{ft}$ & & & 1 & 1 & & & & 1 & & \\
\hline 3 & $6 / 28 / 01$ & Z2-37 & ETTP-REL12 & 585941 & 2445879 & Surface soil sample & & & & & & & 1 & & & \\
\hline 3 & $6 / 28 / 01$ & Z2-37 & ETTP-REL13 & 585931 & 2445894 & Surface soil sample & & & & & & & 1 & & & \\
\hline 3 & $2 / 10 / 05$ & $\mathrm{Z} 2-37$ & K1070CD-DPT-04 & 586043 & 2445753 & Borehole sample at $18 \mathrm{ft}$ & & & 1 & 1 & & & & & & \\
\hline 3 & $2 / 14 / 05$ & Z2-37 & K1070CD-DPT-05 & 586113 & 2445735 & Borehole sample at $21 \mathrm{ft}$ & & & 1 & 1 & & & & & & \\
\hline 3 & $2 / 14 / 05$ & Z2-37 & K1070CD-DPT-06 & 586159 & 2445748 & Borehole sample at $26 \mathrm{ft}$ & & & 1 & 1 & & & & & & \\
\hline 3 & $2 / 16 / 05$ & Z2-37 & K1200-DPT-01 & 585666 & 2445978 & Borehole sample at $23 \mathrm{ft}$ & & & 1 & 1 & & & & & & \\
\hline 3 & $2 / 16 / 05$ & Z2-37 & K1200-DPT-02 & 585683 & 2446034 & Borehole sample at $21 \mathrm{ft}$ & & & 1 & 1 & & & & & & \\
\hline 3 & 9/7/94 & Z2-37 & RAD69 & 586127 & 2445793 & Surface soil sample & & & & & & & 1 & & & \\
\hline 3 & 9/7/94 & Z2-37 & RAD78 & 586205 & 2445795 & Surface soil sample & & & & & & & 1 & & & \\
\hline 3 & 9/8/94 & Z2-37 & RAD85 & 586281 & 2445786 & Surface soil sample & & & & & & & 1 & & & \\
\hline 3 & 9/8/94 & Z2-37 & RAD90 & 586356 & 2445787 & Surface soil sample & & & & & & & 1 & & & \\
\hline 3 & $9 / 3 / 93$ & Z2-37 & SB047 & 585752 & 2446054 & Borehole 2 samples to $27 \mathrm{ft}$ & & & 2 & 2 & 2 & 2 & 2 & & & \\
\hline 3 & 9/7/93 & Z2-37 & SB048 & 585816 & 2446050 & Borehole sample at $15 \mathrm{ft}$ & & & 1 & 1 & 1 & 1 & 1 & & & \\
\hline 3 & 9/7/93 & Z2-37 & SB049 & 585870 & 2446028 & Borehole sample at $15 \mathrm{ft}$ & & & 1 & 1 & 1 & 1 & 1 & & & \\
\hline 3 & 10/21/93 & Z2-37 & SB078 & 586199 & 2445828 & Borehole 8 samples to $20 \mathrm{ft}$ & & & 8 & 3 & 3 & 3 & 3 & & & Includes 5 field GC samples \\
\hline 3 & 10/20/93 & Z2-37 & SB079 & 586125 & 2445847 & Borehole 7 samples to $23 \mathrm{ft}$ & & & 7 & 3 & 3 & 3 & 3 & & & Includes 4 field GC samples \\
\hline 3 & 10/20/93 & Z2-37 & SB080 & 586051 & 2445886 & Borehole 7 samples to $16 \mathrm{ft}$ & & & 7 & 3 & 3 & 3 & 3 & & & Includes 4 field GC samples \\
\hline 3 & 10/22/93 & Z2-37 & SB081 & 586042 & 2445779 & Borehole 7 samples to $19 \mathrm{ft}$ & & & 7 & 3 & 3 & 3 & 3 & & & Includes 4 field GC samples \\
\hline 3 & 10/25/93 & $\mathrm{Z} 2-37$ & SB082 & 586122 & 2445755 & Borehole 8 samples to $25 \mathrm{ft}$ & & & 8 & 3 & 3 & 3 & 3 & & & Includes 5 field GC samples \\
\hline 3 & 10/25/93 & Z2-37 & SB083 & 586192 & 2445731 & Borehole 6 samples to $20 \mathrm{ft}$ & & & 6 & 2 & 2 & 2 & 2 & & & Includes 4 field GC samples \\
\hline
\end{tabular}


Table H.2. (continued)

\begin{tabular}{|c|c|c|c|c|c|c|c|c|c|c|c|c|c|c|c|}
\hline \multirow{2}{*}{$\begin{array}{l}\text { SU } \\
\text { class }\end{array}$} & \multirow{2}{*}{$\begin{array}{c}\text { Date } \\
\text { sampled }\end{array}$} & \multirow[b]{2}{*}{ EU } & \multirow[b]{2}{*}{ Location ID } & \multicolumn{2}{|c|}{ Location } & \multirow[b]{2}{*}{ Sample interval } & \multicolumn{4}{|c|}{ Screening } & \multicolumn{3}{|c|}{ Off-site laboratory } & \multirow[b]{2}{*}{ 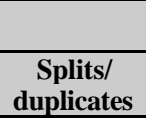 } & \multirow[b]{2}{*}{ Comments and notes } \\
\hline & & & & Northing & Easting & & VOC & RAD & VOC & SVOC & PCB & Metals & RAD & & \\
\hline 3 & $11 / 3 / 93$ & Z2-37 & SB087 & 585948 & 2445763 & Borehole 7 samples to $18 \mathrm{ft}$ & & & 7 & 3 & 3 & 3 & 3 & & Includes 4 field GC samples \\
\hline 3 & $11 / 4 / 93$ & Z2-37 & SB088 & 585946 & 2445844 & Borehole 5 samples to $15 \mathrm{ft}$ & & & 5 & 2 & 2 & 2 & 2 & & Includes 3 field GC samples \\
\hline 3 & $11 / 5 / 93$ & Z2-37 & SB089 & 585819 & 2445977 & Borehole 4 samples to $6 \mathrm{ft}$ & & & 4 & 2 & 2 & 2 & 2 & & Includes 2 field GC samples \\
\hline 3 & $11 / 8 / 93$ & Z2-37 & SB090 & 585992 & 2445810 & Borehole 5 samples to $15 \mathrm{ft}$ & & & 5 & 2 & 2 & 2 & 2 & & Includes 3 field GC samples \\
\hline 3 & $11 / 9 / 93$ & Z2-37 & SB091 & 585649 & 2445940 & Borehole 7 samples to $23 \mathrm{ft}$ & & & 7 & 2 & 2 & 2 & 2 & & Includes 5 field GC samples \\
\hline 3 & $11 / 11 / 93$ & Z2-37 & SB092 & 586057 & 2445679 & Borehole s2 samples to $5 \mathrm{ft}$ & & & 2 & 1 & 1 & 1 & 1 & & Includes 1 field GC sample \\
\hline 3 & $11 / 11 / 93$ & Z2-37 & SB093 & 586348 & 2445650 & Borehole 2 samples to $5 \mathrm{ft}$ & & & 2 & 1 & 1 & 1 & 1 & & Includes 1 field GC sample \\
\hline 3 & $11 / 11 / 93$ & Z2-37 & SB099 & 586440 & 2445661 & Borehole 2 samples to $5 \mathrm{ft}$ & & & 2 & 1 & 1 & 1 & 1 & & Includes 1 field GC sample \\
\hline 3 & $11 / 22 / 93$ & Z2-37 & SB103 & 586429 & 2445588 & Borehole 5 samples to $15 \mathrm{ft}$ & & & 5 & 2 & 2 & 2 & 2 & & Includes 5 field GC samples \\
\hline 3 & $12 / 1 / 93$ & Z2-37 & SB109 & 586119 & 2445675 & Borehole 10 samples to $35 \mathrm{ft}$ & & & 10 & 3 & 3 & 3 & 3 & & Includes 9 field GC samples \\
\hline 3 & 12/2/93 & Z2-37 & SB110 & 586204 & 2445669 & Borehole 4 samples to $8 \mathrm{ft}$ & & & 4 & 2 & 2 & 2 & 2 & & Includes 4 field GC samples \\
\hline \multirow[t]{2}{*}{3} & 12/2/93 & Z2-37 & SB111 & 586204 & 2445669 & Borehole 2 samples to $5 \mathrm{ft}$ & & & 2 & 1 & 1 & 1 & 1 & & Includes 2 field GC sample \\
\hline & & & & & & Historical sampling total & & & 133 & 74 & 53 & 53 & 59 & 26 & \\
\hline
\end{tabular}

$\mathrm{D}=$ duplicate
$\mathrm{D}$

$\mathrm{PCB}=$ polychlorinated bipheny 1
$\mathrm{RAD}=$ radidorian

DVS = Dynamic Verification Strategy
D

$\mathrm{EU}=$ exposure unit
$\mathrm{GC}=$ gas chromatogr

$\begin{array}{ll}\mathrm{GC}=\text { gas chromatograph } & \mathrm{SVOC}=\text { semivolatile organic compound } \\ \mathrm{GRO}=\text { gasoline range organic } & \text { VOC }=\text { volatile organic compound }\end{array}$

$\mathrm{S}=$ split
$\mathrm{SU}=$ soil 
Table H.3. EU Z2-37, depth 0-10 ft

\begin{tabular}{|c|c|c|c|c|c|c|c|c|c|c|c|c|c|}
\hline $\begin{array}{r}\text { Analyte } \\
\end{array}$ & $\begin{array}{c}\text { Frequency } \\
\text { of detect }\end{array}$ & $\begin{array}{c}\text { Minimum } \\
\text { detect }\end{array}$ & $\begin{array}{c}\text { Maximum } \\
\text { detect }\end{array}$ & $\begin{array}{c}\text { Location(s) } \\
\text { of maximum } \\
\text { detected result }\end{array}$ & $\begin{array}{c}\text { Average } \\
\text { detected result }\end{array}$ & $\begin{array}{c}\text { Maximum } \\
\text { RL }\end{array}$ & $\begin{array}{c}\text { Frequency } \\
\text { of detects } \\
\text { exceeding } \\
\text { maximum RL }\end{array}$ & $\begin{array}{c}\text { Average } \\
\text { RL }\end{array}$ & $\begin{array}{r}\text { Frequency } \\
\text { of detects } \\
\text { exceeding } \\
\text { a verage RL } \\
\end{array}$ & $\begin{array}{l}\text { PRG limit } \\
\left(10^{-5} \text { or } 1\right)\end{array}$ & $\begin{array}{c}\text { Frequency } \\
\text { of detects } \\
\text { exceeding } \\
\text { PRG limit }\end{array}$ & $\begin{array}{c}\text { Background } \\
\text { concentration }\end{array}$ & $\begin{array}{c}\text { Frequency } \\
\text { of detects } \\
\text { exceeding } \\
\text { background }\end{array}$ \\
\hline \multicolumn{14}{|l|}{ Inorganics (mg/kg) } \\
\hline Aluminum & $23 / 23$ & 2,400 & 20,400 & SB080 & 12,938 & & NA & & NA & $1.00 \mathrm{E}+05$ & $0 / 23$ & 40,300 & $0 / 23$ \\
\hline Antimony & $9 / 11$ & $0.096 \mathrm{~J}$ & $1.4 \mathrm{~J}$ & Z2-EU37B-302 & 0.415 & & NA & & NA & $4.10 \mathrm{E}+02$ & $0 / 11$ & 1.52 & $0 / 11$ \\
\hline Arsenic & $23 / 23$ & $1.4 \mathrm{~J}$ & 18 & Z2-EU37B-305 & 7.06 & 900 & $0 / 23$ & 300 & $0 / 23$ & $1.60 \mathrm{E}+01$ & $1 / 23$ & 14.95 & $2 / 23$ \\
\hline Barium & $23 / 23$ & 43 & 1420 & SB089 & 185 & & NA & & NA & $6.70 \mathrm{E}+04$ & $0 / 23$ & 124.93 & $8 / 23$ \\
\hline Beryllium & $23 / 23$ & 0.23 & 6.3 & BH012 & 1.03 & 6,000 & $0 / 23$ & 2,000 & $0 / 23$ & $1.90 \mathrm{E}+03$ & $0 / 23$ & 2.2 & $1 / 23$ \\
\hline Boron & $3 / 6$ & $2.2 \mathrm{~J}$ & 8.5 & Z2-EU37B-301 & 5.13 & & NA & & NA & $1.00 \mathrm{E}+05$ & $0 / 6$ & & NA \\
\hline Cadmium & $10 / 23$ & $0.12 \mathrm{~J}$ & $0.56 \mathrm{~J}$ & Z2-EU37B-304 & 0.29 & & NA & & NA & $4.50 \mathrm{E}+02$ & $0 / 23$ & $0.22 \mathrm{U}$ & $7 / 23$ \\
\hline Calcium & $23 / 23$ & 177 & 240,000 & Z2-EU37B-305 & 31,814 & & NA & & NA & & NA & 2,400 & $12 / 23$ \\
\hline Chromium & $23 / 23$ & 10 & 38 & Z2-EU37B-301 & 20.9 & & NA & & NA & $6.40 \mathrm{E}+02$ & $0 / 23$ & 44.88 & $0 / 23$ \\
\hline Cobalt & $23 / 23$ & 3.9 & 52.7 & SB080 & 18.7 & & NA & & NA & $1.30 \mathrm{E}+04$ & $0 / 23$ & 42 & $1 / 23$ \\
\hline Copper & $22 / 23$ & 8.2 & 80.7 & SB088 & 29.3 & & NA & & NA & $4.10 \mathrm{E}+04$ & $0 / 23$ & 22.48 & $11 / 23$ \\
\hline Cyanide & $0 / 15$ & ND & $\mathrm{ND}$ & & $\mathrm{ND}$ & & NA & & NA & $1.20 \mathrm{E}+04$ & $0 / 15$ & $0.6 \mathrm{U}$ & $0 / 15$ \\
\hline Iron & $23 / 23$ & 13,300 & 50,000 & Z2-EU37B-306 & 28,365 & & NA & & NA & $1.00 \mathrm{E}+05$ & $0 / 23$ & 58,600 & $0 / 23$ \\
\hline Lead & $23 / 23$ & 13.9 & 52 & Z2-EU37B-304 & 26.4 & & NA & & NA & $8.00 \mathrm{E}+02$ & $0 / 23$ & 37.91 & $5 / 23$ \\
\hline Lithium & $6 / 6$ & 9.9 & 45 & Z2-EU37B-301 & 19.7 & & NA & & NA & $2.00 \mathrm{E}+04$ & $0 / 6$ & 48.94 & $0 / 6$ \\
\hline Magnesium & $23 / 23$ & 470 & 41,000 & Z2-EU37B-302 & 7,207 & & NA & & NA & & NA & 3,300 & $10 / 23$ \\
\hline Manganese & $23 / 23$ & 142 & 20,600 & SB089 & 3,196 & & NA & & NA & $1.90 \mathrm{E}+04$ & $1 / 23$ & 2,200 & $4 / 23$ \\
\hline Mercury & $16 / 23$ & $0.023 \mathrm{~J}$ & 0.25 & Z2-EU37B-304 & 0.101 & 1,800 & $0 / 23$ & 600 & $0 / 23$ & $3.10 \mathrm{E}+02$ & $0 / 23$ & 0.17 & $1 / 23$ \\
\hline Molybdenum & $7 / 23$ & 0.55 & $7.9 \mathrm{~J}$ & SB092 & 5.32 & & NA & & NA & $5.10 \mathrm{E}+03$ & $0 / 23$ & & $\mathrm{NA}$ \\
\hline Nickel & $23 / 23$ & $6.8 \mathrm{~J}$ & 100 & Z2-EU37B-301 & 33.5 & & NA & & NA & $2.00 \mathrm{E}+04$ & $0 / 23$ & 26.07 & $11 / 23$ \\
\hline Potassium & $23 / 23$ & 639 & 3270 & SB099 & 1528 & & $\mathrm{NA}$ & & NA & & NA & 5074.69 & $0 / 23$ \\
\hline Selenium & $7 / 16$ & $0.35 \mathrm{~J}$ & $2.4 \mathrm{~J}$ & SB082 & 1.48 & & NA & & NA & $5.10 \mathrm{E}+03$ & $0 / 16$ & 1.47 & $3 / 16$ \\
\hline Silver & $16 / 23$ & 1.1 & $3.3 \mathrm{~J}$ & SB089 & 2.04 & & NA & & NA & $5.10 \mathrm{E}+03$ & $0 / 23$ & $0.6 \mathrm{U}$ & $16 / 23$ \\
\hline Sodium & $16 / 23$ & 28.3 & 167 & SB093 & 79.1 & & NA & & NA & & NA & 497 & $0 / 23$ \\
\hline Thallium & $12 / 23$ & 0.052 & 0.56 & BH012 & 0.291 & & NA & & NA & $6.70 \mathrm{E}+01$ & $0 / 23$ & $0.4 \mathrm{U}$ & $3 / 23$ \\
\hline Tin & $9 / 17$ & 2.2 & $9 \mathrm{~J}$ & SB080, SB093 & 6.69 & & NA & & NA & $1.00 \mathrm{E}+05$ & $0 / 17$ & & NA \\
\hline Uranium & $6 / 6$ & 0.64 & 2 & Z2-EU37B-304 & 1.28 & & NA & & NA & $2.00 \mathrm{E}+02$ & $0 / 6$ & & $\mathrm{NA}$ \\
\hline Vanadium & $23 / 23$ & 9.4 & 42.6 & SB092 & 26.8 & & NA & & NA & $1.00 \mathrm{E}+03$ & $0 / 23$ & 65.47 & $0 / 23$ \\
\hline Zinc & $23 / 23$ & $20.7 \mathrm{~J}$ & $160 \mathrm{~J}$ & Z2-EU37B-305 & 66.2 & & NA & & NA & $1.00 \mathrm{E}+05$ & $0 / 23$ & 89.7 & $4 / 23$ \\
\hline \multicolumn{14}{|l|}{ Other organics (mg/kg) } \\
\hline Diesel Range Organics & $2 / 14$ & $190 \mathrm{~J}$ & $329 \mathrm{~J}$ & BH004 & 260 & & $\mathrm{NA}$ & & $\mathrm{NA}$ & & NA & & NA \\
\hline Gasoline Range Organics & $2 / 14$ & $7.5 \mathrm{~J}$ & 88.5 & BH004 & 48 & & NA & & NA & & NA & & NA \\
\hline \multicolumn{14}{|c|}{ Organics, pesticides, and PCBs (ug/kg) } \\
\hline $4,4^{\prime}-\mathrm{DDD}$ & $0 / 17$ & $\mathrm{ND}$ & ND & & ND & & NA & & NA & $1.00 \mathrm{E}+05$ & $0 / 17$ & & NA \\
\hline 4,4'-DDE & $0 / 17$ & ND & ND & & ND & & NA & & NA & $7.00 \mathrm{E}+04$ & $0 / 17$ & & NA \\
\hline $4,4^{\prime}-\mathrm{DDT}$ & $0 / 17$ & ND & ND & & ND & & NA & & NA & $7.00 \mathrm{E}+04$ & $0 / 17$ & & NA \\
\hline Aldrin & $0 / 17$ & ND & ND & & $\mathrm{ND}$ & & NA & & NA & $1.00 \mathrm{E}+03$ & $0 / 17$ & & NA \\
\hline Dieldrin & $0 / 17$ & ND & ND & & ND & & NA & & NA & $1.10 \mathrm{E}+03$ & $0 / 17$ & & NA \\
\hline Endosulfan I & $0 / 17$ & ND & ND & & $\mathrm{ND}$ & & NA & & NA & $3.70 \mathrm{E}+06$ & $0 / 17$ & & NA \\
\hline Endosulfan II & $0 / 17$ & ND & ND & & ND & & NA & & NA & $3.70 \mathrm{E}+06$ & $0 / 17$ & & NA \\
\hline Endosulfan sulfate & $0 / 17$ & ND & ND & & ND & & NA & & NA & $3.70 \mathrm{E}+06$ & $0 / 17$ & & NA \\
\hline Endrin & $0 / 17$ & $\mathrm{ND}$ & ND & & ND & & NA & & NA & $1.80 \mathrm{E}+05$ & $0 / 17$ & & NA \\
\hline Endrin aldehyde & $0 / 17$ & ND & ND & & ND & & NA & & NA & $1.80 \mathrm{E}+05$ & $0 / 17$ & & NA \\
\hline Endrin ketone & $0 / 17$ & ND & ND & & ND & & NA & & NA & $1.80 \mathrm{E}+05$ & $0 / 17$ & & NA \\
\hline Heptachlor & $0 / 17$ & ND & ND & & ND & & NA & & NA & $3.80 \mathrm{E}+03$ & $0 / 17$ & & NA \\
\hline Heptachlor epoxide & $0 / 17$ & $\mathrm{ND}$ & ND & & ND & & NA & & NA & $1.90 \mathrm{E}+03$ & $0 / 17$ & & NA \\
\hline Lindane & $0 / 17$ & ND & $\mathrm{ND}$ & & ND & & NA & & NA & $1.70 \mathrm{E}+04$ & $0 / 17$ & & NA \\
\hline Methoxychlor & $2 / 17$ & $2 \mathrm{~J}$ & $28 \mathrm{~J}$ & SB089 & 15 & & NA & & NA & $3.10 \mathrm{E}+06$ & $0 / 17$ & & NA \\
\hline PCB-1016 & $0 / 23$ & ND & $\mathrm{ND}$ & & $\mathrm{ND}$ & 100,000 & $0 / 23$ & 10,000 & $0 / 23$ & $3.70 \mathrm{E}+04$ & $0 / 23$ & & NA \\
\hline PCB-1221 & $0 / 23$ & ND & ND & & ND & 100,000 & $0 / 23$ & 10,000 & $0 / 28$ & $7.40 \mathrm{E}+03$ & $0 / 23$ & & $\mathrm{NA}$ \\
\hline
\end{tabular}


Table H.3. (continued)

\begin{tabular}{|c|c|c|c|c|c|c|c|c|c|c|c|c|c|}
\hline $\begin{array}{r}\text { Analyte } \\
\end{array}$ & $\begin{array}{r}\text { Frequency } \\
\text { of detect }\end{array}$ & $\begin{array}{c}\text { Minimum } \\
\text { detect }\end{array}$ & $\begin{array}{c}\text { Maximum } \\
\text { detect }\end{array}$ & $\begin{array}{c}\text { Location(s) } \\
\text { of maximum } \\
\text { detected result }\end{array}$ & $\begin{array}{c}\text { Average } \\
\text { detected result }\end{array}$ & $\begin{array}{c}\text { Maximum } \\
\text { RL }\end{array}$ & $\begin{array}{c}\text { Frequency } \\
\text { of detects } \\
\text { exceeding } \\
\text { maximum RL }\end{array}$ & $\begin{array}{c}\text { Average } \\
\text { RL }\end{array}$ & $\begin{array}{c}\text { Frequency } \\
\text { of detects } \\
\text { exceeding } \\
\text { average RL } \\
\end{array}$ & $\begin{array}{l}\text { PRG limit } \\
\left(10^{-5} \text { or } 1\right)\end{array}$ & $\begin{array}{l}\text { Frequency } \\
\text { of detects } \\
\text { exceeding } \\
\text { PRG limit }\end{array}$ & $\begin{array}{l}\text { Background } \\
\text { concentration }\end{array}$ & $\begin{array}{c}\text { Frequency } \\
\text { of detects } \\
\text { exceeding } \\
\text { background }\end{array}$ \\
\hline PCB-1232 & $0 / 23$ & $\mathrm{ND}$ & ND & & $\mathrm{ND}$ & 100,000 & $0 / 23$ & 10,000 & $0 / 28$ & $7.40 \mathrm{E}+03$ & $0 / 23$ & & NA \\
\hline PCB-1242 & $0 / 23$ & $\mathrm{ND}$ & ND & & $\mathrm{ND}$ & 100,000 & $0 / 23$ & 10,000 & $0 / 28$ & $7.40 \mathrm{E}+03$ & $0 / 23$ & & NA \\
\hline PCB-1248 & $2 / 23$ & $45 \mathrm{~J}$ & $67 \mathrm{~J}$ & SB079 & 56 & 100,000 & $0 / 23$ & 10,000 & $0 / 28$ & $7.40 \mathrm{E}+03$ & $0 / 23$ & & NA \\
\hline PCB-1254 & $5 / 23$ & 26 & 2,600 & Z2-EU37B-305 & 631 & 100,000 & $0 / 23$ & 10,000 & $0 / 28$ & $7.40 \mathrm{E}+03$ & $0 / 23$ & & NA \\
\hline PCB-1260 & $5 / 23$ & $35 \mathrm{~J}$ & 200 & Z2-EU37B-301 & 88.4 & 100,000 & $0 / 23$ & 10,000 & $0 / 28$ & $7.40 \mathrm{E}+03$ & $0 / 23$ & & NA \\
\hline Polychlorinated biphenyl & $6 / 6$ & 26 & 2,600 & Z2-EU37B-305 & 579 & 100,000 & $0 / 6$ & 10,000 & $0 / 6$ & $7.40 \mathrm{E}+03$ & $0 / 6$ & & NA \\
\hline Toxaphene & $0 / 17$ & $\mathrm{ND}$ & ND & & ND & & NA & & NA & $1.60 \mathrm{E}+04$ & $0 / 17$ & & NA \\
\hline alpha-BHC & $0 / 17$ & $\mathrm{ND}$ & ND & & ND & & NA & & NA & $3.60 \mathrm{E}+03$ & $0 / 17$ & & NA \\
\hline alpha-Chlordane & $0 / 17$ & $\mathrm{ND}$ & ND & & ND & & NA & & NA & $6.50 \mathrm{E}+04$ & $0 / 17$ & & NA \\
\hline beta-BHC & $0 / 17$ & ND & ND & & ND & & NA & & NA & $1.30 \mathrm{E}+04$ & $0 / 17$ & & NA \\
\hline delta-BHC & $0 / 17$ & ND & ND & & ND & & NA & & NA & & NA & & NA \\
\hline gamma-Chlordane & $0 / 17$ & ND & ND & & ND & & NA & & NA & $6.50 \mathrm{E}+04$ & $0 / 17$ & & NA \\
\hline \multicolumn{14}{|l|}{ Radionuclides (pCi/g) } \\
\hline Actinium-228 & $9 / 9$ & 0.94 & 2.19 & Z2-EU37B-306 & 1.36 & & NA & & NA & $1.20 \mathrm{E}+04$ & $0 / 9$ & & NA \\
\hline Alpha activity & $23 / 23$ & 4.19 & 60.96 & SB088 & 23 & & NA & & NA & & NA & & NA \\
\hline Americium 241 & $0 / 2$ & $\mathrm{ND}$ & ND & & $\mathrm{ND}$ & & NA & & NA & $5.70 \mathrm{E}+01$ & $0 / 2$ & & NA \\
\hline Beta activity & $23 / 23$ & 2.69 & 60.96 & SB088 & 26.1 & & $\mathrm{NA}$ & & NA & & $\mathrm{NA}$ & & NA \\
\hline Bismuth-214 & $10 / 10$ & 0.642 & 1.18 & RAD78 & 0.86 & & NA & & NA & $1.30 \mathrm{E}+05$ & $0 / 10$ & & NA \\
\hline Cesium 134 & $4 / 4$ & 0.016 & 0.028 & RAD69 & 0.022 & & NA & & NA & $2.60 \mathrm{E}+00$ & $0 / 4$ & & NA \\
\hline Cesium 137 & $6 / 27$ & 0.223 & 1.01 & ETTP-REL12 & 0.737 & 20 & $0 / 27$ & 2 & $0 / 27$ & $1.10 \mathrm{E}+00$ & $0 / 27$ & & NA \\
\hline Cobalt -57 & $1 / 4$ & 0.019 & 0.019 & $\begin{array}{l}\text { RAD69 } \\
\text { RAd }\end{array}$ & 0.019 & & NA & & NA & $1.40 \mathrm{E}+02$ & $0 / 4$ & & NA \\
\hline \multirow[t]{2}{*}{ Cobalt- 60} & $4 / 25$ & 0.014 & 0.018 & RAD78 & 0.016 & & $\mathrm{NA}$ & & $\mathrm{NA}$ & $6.00 \mathrm{E}-01$ & $0 / 25$ & & NA \\
\hline & $12 / 12$ & 0.34 & 1.81 & $\begin{array}{l}\text { RAD85 } \\
\text { BH012 }\end{array}$ & 1.22 & & NA & & NA & $6.10 \mathrm{E}+04$ & $0 / 12$ & & NA \\
\hline Lead-214 & $10 / 10$ & 0.675 & 1.3 & RAD78 & 0.985 & & NA & & NA & $\begin{array}{l}0.10+04 \\
7.50 \mathrm{E}+05\end{array}$ & $0 / 10$ & & $\begin{array}{l}\text { NA } \\
\text { NA }\end{array}$ \\
\hline Neptunium-237 & $3 / 12$ & 0.03 & 0.12 & RAD78 & 0.063 & 50 & $0 / 12$ & 5 & $0 / 12$ & $2.70 \mathrm{E}+00$ & $0 / 12$ & & NA \\
\hline Plutonium 238 & $3 / 8$ & 0.005 & 0.016 & RAD69 & 0.01 & & $\mathrm{NA}$ & & NA & $1.70 \mathrm{E}+02$ & $0 / 8$ & & NA \\
\hline Plutonium 239 & $2 / 8$ & 0.013 & 0.053 & RAD78 & 0.033 & & NA & & NA & $1.50 \mathrm{E}+02$ & $0 / 8$ & & NA \\
\hline Potassium-40 & $14 / 14$ & 8.65 & 45.7 & ETTP-REL13 & 21.3 & & NA & & NA & $2.70 \mathrm{E}+00$ & $14 / 14$ & 32.12 & $3 / 14$ \\
\hline $\mathrm{Ra} / \mathrm{Th}$ decay series & $14 / 14$ & 0 & 3.25 & RAD85 & 0.804 & 15 & $0 / 14$ & 5 & $0 / 14$ & & NA & & NA \\
\hline Radium-226 & $11 / 12$ & 0.473 & 4.5 & RAD85 & 2.05 & 15 & $\mathrm{NA}^{a}$ & 5 & $\mathrm{NA}^{a}$ & $2.60 \mathrm{E}-01$ & $11 / 12$ & 1.25 & $8 / 12$ \\
\hline Strontium-90 & $13 / 19$ & $0.04 \mathrm{~J}$ & $1.77 \mathrm{~J}$ & BH012 & 0.566 & & NA & & NA & $1.10 \mathrm{E}+02$ & $0 / 19$ & & NA \\
\hline Technetium-99 & $18 / 29$ & $0.23 \mathrm{~J}$ & 3.51 & Z2-EU37B-305 & 1.36 & & NA & & NA & $8.90 \mathrm{E}+03$ & $0 / 29$ & & NA \\
\hline Thallium 208 & $8 / 8$ & 0.259 & 0.56 & BH012 & 0.404 & & $\mathrm{NA}$ & & $\mathrm{NA}$ & $3.70 \mathrm{E}+05$ & $0 / 8$ & & $\mathrm{NA}$ \\
\hline Thorium-228 & $12 / 14$ & 0.892 & $1.97 \mathrm{~J}$ & BH012 & 1.29 & & NA & & NA & $1.70 \mathrm{E}-01$ & $12 / 14^{b}$ & 1.86 & $1 / 14$ \\
\hline Thorium 230 & $12 / 14$ & 0.688 & 1.84 & Z2-EU37B-303 & 1.23 & 15 & $\mathrm{NA}^{a}$ & 5 & $\mathrm{NA}^{a}$ & $2.10 \mathrm{E}+02$ & $0 / 14$ & 1.2 & $6 / 14$ \\
\hline Thorium-232 & $14 / 14$ & 0.433 & 1.97 & ETTP-REL13 & 1.28 & 15 & $\mathrm{NA}^{a}$ & 5 & $\mathrm{NA}^{a}$ & $1.70 \mathrm{E}-01$ & $14 / 14^{b}$ & 1.95 & $1 / 14$ \\
\hline Thorium 234 & $4 / 10$ & 2.81 & 3.27 & RAD78 & 3.06 & & NA & & NA & $3.30 \mathrm{E}+04$ & $0 / 10$ & & NA \\
\hline Uranium-234 & $28 / 28$ & $0.6 \mathrm{~J}$ & 7.94 & ETTP-REL12 & 1.85 & 7,000 & $0 / 28$ & 700 & $0 / 28$ & $3.30 \mathrm{E}+02$ & $0 / 28$ & & NA \\
\hline Uranium-235 & $22 / 28$ & 0.02 & $0.482 \mathrm{~J}$ & ETTP-REL12 & 0.127 & 80 & $0 / 28$ & 8 & $0 / 28$ & $3.90 \mathrm{E}+00$ & $0 / 28$ & & NA \\
\hline Uranium-238 & $28 / 28$ & 0.701 & 4.26 & ETTP-REL12 & 1.47 & 500 & $0 / 28$ & 50 & $0 / 28$ & $1.80 \mathrm{E}+01$ & $0 / 28$ & 1.47 & $8 / 28$ \\
\hline \multicolumn{14}{|c|}{ Semivolatile organics (ug/kg) } \\
\hline 1,2,4-Trichlorobenzene & $0 / 36$ & $\mathrm{ND}$ & ND & & ND & & NA & & NA & $2.20 \mathrm{E}+05$ & $0 / 36$ & & NA \\
\hline 1,2-Dichlorobenzene & $0 / 37$ & ND & $\mathrm{ND}$ & & ND & & NA & & NA & $6.00 \mathrm{E}+05$ & $0 / 37$ & & NA \\
\hline 1,3-Dichlorobenzene & $0 / 37$ & ND & ND & & ND & & NA & & NA & $6.00 \mathrm{E}+05$ & $0 / 37$ & & NA \\
\hline 1,4-Dichlorobenzene & $0 / 36$ & ND & ND & & ND & & NA & & NA & $7.90 \mathrm{E}+04$ & $0 / 36$ & & NA \\
\hline 2,3,4,6-Tetrachlorophenol & $0 / 6$ & $\mathrm{ND}$ & $\mathrm{ND}$ & & $\mathrm{ND}$ & & NA & & NA & $1.80 \mathrm{E}+07$ & $0 / 6$ & & NA \\
\hline 2,4,5-Trichlorophenol & $0 / 34$ & $\mathrm{ND}$ & ND & & ND & & NA & & NA & $6.20 \mathrm{E}+07$ & $0 / 34$ & & NA \\
\hline 2,4,6-Trichlorophenol & $0 / 34$ & ND & $\mathrm{ND}$ & & ND & & NA & & NA & $6.20 \mathrm{E}+04$ & $0 / 34$ & & NA \\
\hline 2,4-Dichlorophenol & $0 / 34$ & $\mathrm{ND}$ & ND & & ND & & NA & & NA & $1.80 \mathrm{E}+06$ & $0 / 34$ & & NA \\
\hline 2,4-Dimethylphenol & $0 / 34$ & $\mathrm{ND}$ & $\mathrm{ND}$ & & $\mathrm{ND}$ & & NA & & NA & $1.20 \mathrm{E}+07$ & $0 / 34$ & & NA \\
\hline 2,4-Dinitrophenol & $0 / 34$ & $\mathrm{ND}$ & ND & & ND & & NA & & NA & $1.20 \mathrm{E}+06$ & $0 / 34$ & & NA \\
\hline 2,4-Dinitrotoluene & $0 / 33$ & ND & ND & & ND & & NA & & NA & $2.50 \mathrm{E}+04$ & $0 / 33$ & & NA \\
\hline
\end{tabular}


Table H.3. (continued)

\begin{tabular}{|c|c|c|c|c|c|c|c|c|c|c|c|c|c|}
\hline Analyte & $\begin{array}{c}\text { Frequency } \\
\text { of detect }\end{array}$ & $\begin{array}{c}\text { Minimum } \\
\text { detect }\end{array}$ & $\begin{array}{c}\text { Maximum } \\
\text { detect }\end{array}$ & $\begin{array}{c}\text { Location(s) } \\
\text { of maximum } \\
\text { detected result }\end{array}$ & $\begin{array}{c}\text { Average } \\
\text { detected result }\end{array}$ & $\begin{array}{c}\text { Maximum } \\
\text { RL }\end{array}$ & $\begin{array}{c}\text { Frequency } \\
\text { of detects } \\
\text { exceeding } \\
\text { maximum RL }\end{array}$ & $\begin{array}{c}\text { Average } \\
\text { RL }\end{array}$ & $\begin{array}{c}\text { Frequency } \\
\text { of detects } \\
\text { exceeding } \\
\text { average RL } \\
\end{array}$ & $\begin{array}{l}\text { PRG limit } \\
\left(10^{-5} \text { or } 1\right)\end{array}$ & $\begin{array}{l}\text { Frequency } \\
\text { of detects } \\
\text { exceeding } \\
\text { PRG limit }\end{array}$ & $\begin{array}{c}\text { Background } \\
\text { concentration }\end{array}$ & $\begin{array}{c}\text { Frequency } \\
\text { of detects } \\
\text { exceeding } \\
\text { background }\end{array}$ \\
\hline 2,6-Dinitrotoluene & $0 / 34$ & ND & ND & & $\mathrm{ND}$ & & NA & & NA & $2.50 \mathrm{E}+04$ & $0 / 34$ & & NA \\
\hline 2-Chloronaphthalene & $0 / 34$ & ND & $\mathrm{ND}$ & & ND & & NA & & NA & $2.30 \mathrm{E}+07$ & $0 / 34$ & & NA \\
\hline 2-Chlorophenol & $0 / 34$ & ND & ND & & ND & & NA & & NA & $2.40 \mathrm{E}+05$ & $0 / 34$ & & NA \\
\hline 2-Methyl-4,6-dinitrophenol & $0 / 34$ & $\mathrm{ND}$ & $\mathrm{ND}$ & & $\mathrm{ND}$ & & NA & & NA & $6.20 \mathrm{E}+04$ & $0 / 34$ & & NA \\
\hline 2-Methylnaphthalene & $4 / 34$ & $120 \mathrm{~J}$ & 2,200 & SB088 & 680 & & NA & & NA & $1.90 \mathrm{E}+05$ & $0 / 34$ & & NA \\
\hline 2-Methylphenol & $0 / 34$ & ND & ND & & ND & & NA & & NA & $3.10 \mathrm{E}+07$ & $0 / 34$ & & NA \\
\hline 2-Nitrobenzenamine & $0 / 34$ & ND & ND & & ND & & NA & & NA & $1.80 \mathrm{E}+06$ & $0 / 34$ & & NA \\
\hline 2-Nitrophenol & $0 / 34$ & ND & $\mathrm{ND}$ & & ND & & NA & & NA & & NA & & NA \\
\hline 3,3'-Dichlorobenzidine & $0 / 34$ & ND & ND & & ND & & NA & & NA & $3.80 \mathrm{E}+04$ & $0 / 34$ & & NA \\
\hline 3-Methylphenol & $0 / 6$ & ND & ND & & ND & & NA & & NA & $3.10 \mathrm{E}+07$ & $0 / 6$ & & NA \\
\hline 3-Nitrobenzenamine & $0 / 34$ & ND & ND & & ND & & NA & & NA & $1.80 \mathrm{E}+05$ & $0 / 34$ & & NA \\
\hline 4-Bromophenyl phenyl ether & $0 / 34$ & ND & ND & & ND & & NA & & NA & & NA & & NA \\
\hline 4-Chloro-3-methylphenol & $0 / 34$ & ND & ND & & ND & & NA & & NA & & NA & & NA \\
\hline 4-Chlorobenzenamine & $0 / 34$ & ND & $\mathrm{ND}$ & & ND & & NA & & NA & $2.50 \mathrm{E}+06$ & $0 / 34$ & & NA \\
\hline 4-Chlorophenyl phenyl ether & $0 / 34$ & ND & ND & & ND & & NA & & NA & & NA & & NA \\
\hline 4-Methylphenol & $0 / 28$ & ND & ND & & ND & & NA & & NA & $3.10 \mathrm{E}+06$ & $0 / 28$ & & NA \\
\hline 4-Nitrobenzenamine & $0 / 34$ & ND & ND & & ND & & NA & & NA & $8.20 \mathrm{E}+05$ & $0 / 34$ & & NA \\
\hline 4-Nitrophenol & $0 / 34$ & ND & ND & & $\mathrm{ND}$ & & NA & & NA & & NA & & NA \\
\hline Acenaphthene & $5 / 33$ & $43 \mathrm{~J}$ & $280 \mathrm{~J}$ & Z2-EU37B-306 & 157 & & NA & & NA & $2.90 \mathrm{E}+07$ & $0 / 33$ & & NA \\
\hline Acenaphthylene & $1 / 34$ & $99 \mathrm{~J}$ & $99 \mathrm{~J}$ & BH007 & 99 & & NA & & NA & $2.90 \mathrm{E}+07$ & $0 / 34$ & & NA \\
\hline Aniline & $0 / 6$ & ND & ND & & ND & & NA & & NA & $3.00 \mathrm{E}+06$ & $0 / 6$ & & NA \\
\hline Anthracene & $5 / 34$ & $96 \mathrm{~J}$ & 1,400 & Z2-EU37B-306 & 451 & & NA & & NA & $1.00 \mathrm{E}+08$ & $0 / 34$ & & NA \\
\hline Benz(a)anthracene & $10 / 35$ & $54 \mathrm{~J}$ & 5,400 & Z2-EU37B-306 & 1,059 & & NA & & NA & $2.10 \mathrm{E}+04$ & $0 / 35$ & & NA \\
\hline Benzenemethanol & $0 / 6$ & $\mathrm{ND}$ & ND & & ND & & NA & & NA & $1.00 \mathrm{E}+08$ & $0 / 6$ & & NA \\
\hline Benzo(a)pyrene & $10 / 35$ & $93 \mathrm{~J}$ & 4,900 & Z2-EU37B-306 & 1,038 & & NA & & NA & $2.10 \mathrm{E}+03$ & $2 / 35$ & & NA \\
\hline Benzo(b)fluoranthene & $10 / 35$ & $86 \mathrm{~J}$ & 6,600 & Z2-EU37B-306 & 1,530 & & NA & & NA & $2.10 \mathrm{E}+04$ & $0 / 35$ & & NA \\
\hline Benzo(ghi)perylene & $10 / 35$ & $61 \mathrm{~J}$ & 1,800 & Z2-EU37B-306 & 488 & & NA & & NA & $2.90 \mathrm{E}+07$ & $0 / 35$ & & NA \\
\hline Benzo(k)fluoranthene & $10 / 35$ & $96 \mathrm{~J}$ & 2,800 & Z2-EU37B-306 & 669 & & $\mathrm{NA}$ & & NA & $2.10 \mathrm{E}+05$ & $0 / 35$ & & NA \\
\hline Benzoic acid & $0 / 6$ & ND & ND & & $\mathrm{ND}$ & & NA & & NA & $1.00 \mathrm{E}+08$ & $0 / 6$ & & NA \\
\hline Bis(2-chloroethoxy)methane & $0 / 34$ & ND & ND & & ND & & NA & & NA & & NA & & NA \\
\hline Bis(2-chloroethyl) ether & $0 / 34$ & ND & ND & & ND & & NA & & NA & $5.80 \mathrm{E}+03$ & $0 / 34$ & & NA \\
\hline $\operatorname{Bis}(2$-chloroisopropyl) ether & $0 / 34$ & ND & ND & & $\mathrm{ND}$ & & NA & & NA & $7.40 \mathrm{E}+04$ & $0 / 34$ & & NA \\
\hline Bis(2-ethylhexyl)phthalate & $8 / 35$ & $45 \mathrm{~J}$ & 4,400 & Z2-EU37B-305 & 623 & & NA & & NA & $1.20 \mathrm{E}+06$ & $0 / 35$ & & NA \\
\hline Butyl benzyl phthalate & $1 / 34$ & $170 \mathrm{~J}$ & $170 \mathrm{~J}$ & Z2-EU37B-305 & 170 & & NA & & NA & $1.00 \mathrm{E}+08$ & $0 / 34$ & & NA \\
\hline Carbazole & $3 / 34$ & $59 \mathrm{~J}$ & 660 & Z2-EU37B-306 & 456 & & NA & & NA & $8.60 \mathrm{E}+05$ & $0 / 34$ & & NA \\
\hline Chrysene & $10 / 35$ & $67 \mathrm{~J}$ & 4,900 & Z2-EU37B-306 & 1,049 & & NA & & NA & $2.10 \mathrm{E}+06$ & $0 / 35$ & & NA \\
\hline Di-n-butyl phthalate & $2 / 35$ & $240 \mathrm{~J}$ & 2,500 & BH004 & 1,370 & & NA & & $\mathrm{NA}$ & $6.20 \mathrm{E}+07$ & $0 / 35$ & & NA \\
\hline Di-n-octylphthalate & $0 / 34$ & ND & ND & & $\mathrm{ND}$ & & NA & & NA & $2.50 \mathrm{E}+07$ & $0 / 34$ & & NA \\
\hline Dibenz(a,h)anthracene & $5 / 34$ & $89 \mathrm{~J}$ & 530 & Z2-EU37B-306 & 248 & & NA & & NA & $2.10 \mathrm{E}+03$ & $0 / 34$ & & NA \\
\hline Dibenzofuran & $3 / 34$ & $60 \mathrm{~J}$ & $100 \mathrm{~J}$ & Z2-EU37B-306 & 77.3 & & NA & & NA & $1.60 \mathrm{E}+06$ & $0 / 34$ & & NA \\
\hline Diethyl phthalate & $0 / 34$ & ND & ND & & ND & & NA & & NA & $1.00 \mathrm{E}+08$ & $0 / 34$ & & NA \\
\hline Dimethyl phthalate & $3 / 34$ & $52 \mathrm{~J}$ & $400 \mathrm{~J}$ & BH004 & 182 & & NA & & NA & $1.00 \mathrm{E}+08$ & $0 / 34$ & & NA \\
\hline Diphenyldiazene & $0 / 6$ & ND & $\mathrm{ND}$ & & ND & & NA & & NA & $1.60 \mathrm{E}+05$ & $0 / 6$ & & NA \\
\hline Fluoranthene & $12 / 35$ & $40 \mathrm{~J}$ & 12,000 & Z2-EU37B-306 & 1,933 & & NA & & NA & $2.20 \mathrm{E}+07$ & $0 / 35$ & & NA \\
\hline Fluorene & $5 / 34$ & $120 \mathrm{~J}$ & $320 \mathrm{~J}$ & $\begin{array}{c}\text { SB088 } \\
\text { Z2-EU37B-306 }\end{array}$ & 212 & & NA & & NA & $2.60 \mathrm{E}+07$ & $0 / 34$ & & NA \\
\hline Hexachlorobenzene & $0 / 34$ & ND & ND & & $\mathrm{ND}$ & & NA & & NA & $1.10 \mathrm{E}+04$ & $0 / 34$ & & NA \\
\hline Hexachlorobutadiene & $0 / 37$ & ND & ND & & ND & & NA & & NA & $1.80 \mathrm{E}+05$ & $0 / 37$ & & NA \\
\hline Hexachlorocyclopentadiene & $0 / 34$ & ND & ND & & ND & & NA & & NA & $3.70 \mathrm{E}+06$ & $0 / 34$ & & NA \\
\hline Hexachloroethane & $0 / 34$ & ND & ND & & ND & & NA & & NA & $6.20 \mathrm{E}+05$ & $0 / 34$ & & NA \\
\hline Indeno(1,2,3-cd)pyrene & $10 / 35$ & $66 \mathrm{~J}$ & 1,800 & Z2-EU37B-306 & 470 & & NA & & NA & $2.10 \mathrm{E}+04$ & $0 / 35$ & & NA \\
\hline Isophorone & $0 / 34$ & ND & ND & & ND & & NA & & NA & $5.10 \mathrm{E}+06$ & $0 / 34$ & & NA \\
\hline N-Nitroso-di-n-propylamine & $0 / 33$ & ND & ND & & ND & & NA & & NA & $2.50 \mathrm{E}+03$ & $0 / 33$ & & NA \\
\hline
\end{tabular}


Table H.3. (continued)

\begin{tabular}{|c|c|c|c|c|c|c|c|c|c|c|c|c|c|}
\hline Analyte & $\begin{array}{c}\text { Frequency } \\
\text { of detect }\end{array}$ & $\begin{array}{c}\text { Minimum } \\
\text { detect }\end{array}$ & $\begin{array}{c}\text { Maximum } \\
\text { detect }\end{array}$ & $\begin{array}{c}\text { Location(s) } \\
\text { of maximum } \\
\text { detected result }\end{array}$ & $\begin{array}{c}\text { Average } \\
\text { detected result }\end{array}$ & $\begin{array}{c}\text { Maximum } \\
\text { RL }\end{array}$ & $\begin{array}{c}\text { Frequency } \\
\text { of detects } \\
\text { exceeding } \\
\text { maximum RL }\end{array}$ & $\begin{array}{c}\text { Average } \\
\text { RL }\end{array}$ & $\begin{array}{c}\text { Frequency } \\
\text { of detects } \\
\text { exceeding } \\
\text { average RL }\end{array}$ & $\begin{array}{l}\text { PRG limit } \\
\left(10^{-5} \text { or } 1\right)\end{array}$ & $\begin{array}{c}\text { Frequency } \\
\text { of detects } \\
\text { exceeding } \\
\text { PRG limit }\end{array}$ & $\begin{array}{l}\text { Background } \\
\text { concentration }\end{array}$ & $\begin{array}{c}\text { Frequency } \\
\text { of detects } \\
\text { exceeding } \\
\text { background }\end{array}$ \\
\hline N-Nitrosodimethylamine & $0 / 6$ & ND & ND & & ND & & NA & & NA & $3.40 \mathrm{E}+02$ & $0 / 6$ & & NA \\
\hline $\mathrm{N}$-Nitrosodiphenylamine & $0 / 34$ & ND & ND & & ND & & NA & & NA & $3.50 \mathrm{E}+06$ & $0 / 34$ & & NA \\
\hline Naphthalene & $5 / 38$ & $50 \mathrm{~J}$ & $330 \mathrm{~J}$ & SB088 & 138 & & NA & & NA & $1.90 \mathrm{E}+05$ & $0 / 38$ & & NA \\
\hline Nitrobenzene & $0 / 34$ & ND & ND & & ND & & NA & & NA & $1.00 \mathrm{E}+05$ & $0 / 34$ & & NA \\
\hline Pentachlorophenol & $0 / 34$ & ND & ND & & ND & & NA & & NA & $9.00 \mathrm{E}+04$ & $0 / 34$ & & NA \\
\hline Phenanthrene & $13 / 35$ & $50 \mathrm{~J}$ & 5,100 & Z2-EU37B-306 & 884 & & NA & & NA & $2.90 \mathrm{E}+07$ & $0 / 35$ & & NA \\
\hline Phenol & $0 / 34$ & $\mathrm{ND}$ & ND & & ND & & NA & & NA & $1.00 \mathrm{E}+08$ & $0 / 34$ & & NA \\
\hline Pyrene & $15 / 34$ & $40 \mathrm{~J}$ & 8,100 & Z2-EU37B-306 & 1,208 & & NA & & NA & $2.90 \mathrm{E}+07$ & $0 / 34$ & & NA \\
\hline Pyridine & $0 / 6$ & ND & $\mathrm{ND}$ & & $\mathrm{ND}$ & & NA & & NA & $6.20 \mathrm{E}+05$ & $0 / 6$ & & NA \\
\hline \multicolumn{14}{|l|}{ Volatile organics (ug/kg) } \\
\hline (1,1-Dimethylethyl)benzene & $0 / 6$ & $\mathrm{ND}$ & $\mathrm{ND}$ & & $\mathrm{ND}$ & & NA & & NA & $3.90 \mathrm{E}+05$ & $0 / 6$ & & $\mathrm{NA}$ \\
\hline (1-Methylpropyl)benzene & $0 / 6$ & $\mathrm{ND}$ & $\mathrm{ND}$ & & $\mathrm{ND}$ & & $\mathrm{NA}$ & & NA & $2.20 \mathrm{E}+05$ & $0 / 6$ & & NA \\
\hline 1,1,1,2-Tetrachloroethane & $0 / 6$ & ND & ND & & ND & & NA & & NA & $7.30 \mathrm{E}+04$ & $0 / 6$ & & NA \\
\hline 1,1,1-Trichloroethane & 3/35 & $2 \mathrm{~J}$ & 8 & SB088 & 5.7 & & NA & & NA & $1.20 \mathrm{E}+06$ & $0 / 35$ & & NA \\
\hline 1,1,2,2-Tetrachloroethane & $0 / 35$ & $\mathrm{ND}$ & ND & & $\mathrm{ND}$ & & NA & & NA & $9.30 \mathrm{E}+03$ & $0 / 35$ & & NA \\
\hline $\begin{array}{l}\text { 1,1,2-Trichloro-1,2,2- } \\
\text { trifluoroethane }\end{array}$ & $4 / 35$ & $4 \mathrm{~J}$ & $940 \mathrm{~J}$ & BH004 & 238 & & NA & & NA & $5.60 \mathrm{E}+06$ & $0 / 35$ & & NA \\
\hline 1,1,2-Trichloroethane & $0 / 35$ & ND & ND & & ND & & NA & & NA & $1.60 \mathrm{E}+04$ & $0 / 35$ & & NA \\
\hline 1,1-Dichloroethane & $7 / 35$ & $1 \mathrm{~J}$ & 18 & SB088 & 4.23 & & NA & & NA & $1.70 \mathrm{E}+06$ & $0 / 35$ & & NA \\
\hline 1,1-Dichloroethene & $2 / 35$ & $1.3 \mathrm{~J}$ & 6 & BH005 & 3.65 & & NA & & NA & $4.10 \mathrm{E}+05$ & $0 / 35$ & & NA \\
\hline 1,1-Dichloropropene & $0 / 6$ & ND & $\mathrm{ND}$ & & $\mathrm{ND}$ & & NA & & NA & & NA & & NA \\
\hline 1,2,3-Trichlorobenzene & $0 / 6$ & ND & ND & & ND & & NA & & NA & & NA & & NA \\
\hline $1,2,3$-Trichloropropane & $0 / 6$ & ND & $\mathrm{ND}$ & & ND & & NA & & NA & $7.60 \mathrm{E}+02$ & $0 / 6$ & & NA \\
\hline $1,2,4$ Trimethylbenzene & $0 / 6$ & $\mathrm{ND}$ & $\mathrm{ND}$ & & $\mathrm{ND}$ & & NA & & NA & $1.70 \mathrm{E}+05$ & $0 / 6$ & & NA \\
\hline 1,2-Dibromo-3-chloropropane & $0 / 6$ & ND & ND & & ND & & NA & & NA & $1.10 \mathrm{E}+04$ & $0 / 6$ & & NA \\
\hline 1,2-Dibromoethane & $0 / 6$ & ND & ND & & ND & & NA & & NA & $6.30 \mathrm{E}+02$ & $0 / 6$ & & NA \\
\hline 1,2-Dichloroethane & $0 / 35$ & $\mathrm{ND}$ & $\mathrm{ND}$ & & ND & & NA & & NA & $6.00 \mathrm{E}+03$ & $0 / 35$ & & NA \\
\hline 1,2-Dichloroethene & $3 / 29$ & $3 \mathrm{~J}$ & 23 & SB089 & 10 & & NA & & NA & $1.50 \mathrm{E}+05$ & $0 / 29$ & & NA \\
\hline 1,2-Dichloropropane & $0 / 35$ & $\mathrm{ND}$ & $\mathrm{ND}$ & & ND & & NA & & NA & $7.40 \mathrm{E}+03$ & $0 / 35$ & & NA \\
\hline 1,2-Dimethylbenzene & $0 / 6$ & ND & ND & & ND & & NA & & NA & $4.20 \mathrm{E}+05$ & $0 / 6$ & & NA \\
\hline 1,3,5-Trimethylbenzene & $0 / 6$ & ND & ND & & ND & & NA & & NA & $7.00 \mathrm{E}+04$ & $0 / 6$ & & NA \\
\hline 1,3-Dichloropropane & $0 / 6$ & $\mathrm{ND}$ & $\mathrm{ND}$ & & ND & & NA & & NA & $3.60 \mathrm{E}+05$ & $0 / 6$ & & NA \\
\hline 1-Chloro-4-methylbenzene & $0 / 6$ & ND & ND & & ND & & NA & & NA & & NA & & NA \\
\hline $\begin{array}{l}\text { 1-Methyl-4-(1-methylethyl) } \\
\text { benzene }\end{array}$ & $0 / 6$ & $\mathrm{ND}$ & $\mathrm{ND}$ & & ND & & NA & & NA & & NA & & NA \\
\hline 1-chlorohexane & $0 / 6$ & ND & ND & & ND & & NA & & NA & & NA & & NA \\
\hline 2,2-Dichloropropane & $0 / 6$ & ND & ND & & ND & & NA & & NA & & NA & & NA \\
\hline 2-Butanone & $2 / 35$ & $25 \mathrm{~J}$ & $52 \mathrm{~J}$ & BH005 & 38.5 & & NA & & NA & $1.00 \mathrm{E}+08$ & $0 / 35$ & & NA \\
\hline 2-Hexanone & $0 / 35$ & ND & ND & & ND & & NA & & NA & & NA & & NA \\
\hline 2-Methoxy -2-methylpropane & $0 / 6$ & ND & ND & & ND & & NA & & NA & $3.60 \mathrm{E}+05$ & $0 / 6$ & & NA \\
\hline 4-Methyl-2-pentanone & $2 / 35$ & $1 \mathrm{~J}$ & $2 \mathrm{~J}$ & BH011 & 1.5 & & NA & & NA & $4.70 \mathrm{E}+07$ & $0 / 35$ & & NA \\
\hline Acetone & $15 / 35$ & $41 \mathrm{~J}$ & 6,600 & BHOO6 & 653 & & NA & & NA & $5.40 \mathrm{E}+07$ & $0 / 35$ & & NA \\
\hline Benzene & $2 / 35$ & $26 \mathrm{~J}$ & 44 & SB088 & 35 & & NA & & NA & $1.40 \mathrm{E}+04$ & $0 / 35$ & & NA \\
\hline Bromobenzene & $0 / 6$ & ND & ND & & ND & & NA & & NA & $9.20 \mathrm{E}+04$ & $0 / 6$ & & NA \\
\hline Bromochloromethane & $0 / 6$ & $\mathrm{ND}$ & ND & & ND & & NA & & NA & & NA & & NA \\
\hline Bromodichloromethane & $0 / 35$ & ND & ND & & $\mathrm{ND}$ & & NA & & NA & $1.80 \mathrm{E}+04$ & $0 / 35$ & & NA \\
\hline Bromoform & $0 / 35$ & ND & ND & & ND & & NA & & NA & $2.20 \mathrm{E}+06$ & $0 / 35$ & & NA \\
\hline Bromomethane & $0 / 35$ & $\mathrm{ND}$ & ND & & ND & & NA & & NA & $1.30 \mathrm{E}+04$ & $0 / 35$ & & NA \\
\hline Butylbenzene & $0 / 6$ & ND & ND & & ND & & NA & & NA & $2.40 \mathrm{E}+05$ & $0 / 6$ & & NA \\
\hline Carbon disulfide & $1 / 35$ & $5 \mathrm{~J}$ & $5 \mathrm{~J}$ & SB088 & 5 & & NA & & NA & $7.20 \mathrm{E}+05$ & $0 / 35$ & & NA \\
\hline Carbon tetrachloride & $0 / 35$ & $\mathrm{ND}$ & $\mathrm{ND}$ & & $\mathrm{ND}$ & & NA & & NA & $5.50 \mathrm{E}+03$ & $0 / 35$ & & NA \\
\hline Chlorobenzene & $0 / 35$ & ND & ND & & ND & & NA & & NA & $5.30 \mathrm{E}+05$ & $0 / 35$ & & NA \\
\hline Chloroethane & $0 / 35$ & ND & ND & & ND & & NA & & NA & $6.50 \mathrm{E}+04$ & $0 / 35$ & & NA \\
\hline
\end{tabular}


Table H.3. (continued)

\begin{tabular}{|c|c|c|c|c|c|c|c|c|c|c|c|c|c|}
\hline Analyte & $\begin{array}{r}\text { Frequency } \\
\text { of detect }\end{array}$ & $\begin{array}{c}\text { Minimum } \\
\text { detect }\end{array}$ & $\begin{array}{c}\text { Maximum } \\
\text { detect }\end{array}$ & $\begin{array}{c}\begin{array}{c}\text { Location(s) } \\
\text { of maximum } \\
\text { detected result }\end{array} \\
\text { 中. }\end{array}$ & $\begin{array}{c}\text { Average } \\
\text { detected result }\end{array}$ & $\begin{array}{c}\text { Maximum } \\
\text { RL }\end{array}$ & $\begin{array}{c}\text { Frequency } \\
\text { of detects } \\
\text { exceeding } \\
\text { maximum RL }\end{array}$ & $\begin{array}{c}\text { Average } \\
\text { RL }\end{array}$ & $\begin{array}{c}\text { Frequency } \\
\text { of detects } \\
\text { exceeding } \\
\text { average RL } \\
\end{array}$ & $\begin{array}{l}\text { PRG limit } \\
\left(10^{-5} \text { or } 1\right)\end{array}$ & $\begin{array}{c}\text { Frequency } \\
\text { of detects } \\
\text { exceeding } \\
\text { PRG limit }\end{array}$ & $\begin{array}{c}\text { Background } \\
\text { concentration }\end{array}$ & $\begin{array}{c}\text { Frequency } \\
\text { of detects } \\
\text { exceeding } \\
\text { background }\end{array}$ \\
\hline Chloroform & $0 / 35$ & $\mathrm{ND}$ & $\mathrm{ND}$ & & $\mathrm{ND}$ & & NA & & NA & $4.70 \mathrm{E}+03$ & $0 / 35$ & & NA \\
\hline Chloromethane & $0 / 35$ & $\mathrm{ND}$ & $\mathrm{ND}$ & & $\mathrm{ND}$ & & NA & & NA & $1.60 \mathrm{E}+05$ & $0 / 35$ & & NA \\
\hline Cumene & $0 / 6$ & ND & ND & & $\mathrm{ND}$ & & NA & & NA & $5.20 \mathrm{E}+05$ & $0 / 6$ & & NA \\
\hline Dibromochloromethane & $0 / 35$ & ND & ND & & ND & & NA & & NA & $2.60 \mathrm{E}+04$ & $0 / 35$ & & NA \\
\hline Dibromomethane & $0 / 6$ & $\mathrm{ND}$ & $\mathrm{ND}$ & & ND & & NA & & NA & $2.30 \mathrm{E}+05$ & $0 / 6$ & & NA \\
\hline Dichlorodifluoromethane & $0 / 6$ & $\mathrm{ND}$ & $\mathrm{ND}$ & & $\mathrm{ND}$ & & NA & & NA & $3.10 \mathrm{E}+05$ & $0 / 6$ & & NA \\
\hline Ethylbenzene & $5 / 35$ & $1 \mathrm{~J}$ & $4,300 \mathrm{~J}$ & SB088 & 1,470 & & NA & & NA & $4.00 \mathrm{E}+05$ & $0 / 35$ & & $\mathrm{NA}$ \\
\hline Iodomethane & $0 / 6$ & ND & ND & & ND & & NA & & NA & & NA & & NA \\
\hline M + P Xylene & $0 / 6$ & ND & ND & & ND & & NA & & NA & $4.20 \mathrm{E}+05$ & $0 / 6$ & & NA \\
\hline Methylene chloride & $13 / 35$ & 13 & 110 & SB087 & 37.6 & & NA & & NA & $2.10 \mathrm{E}+05$ & $0 / 35$ & & NA \\
\hline Propylbenzene & $0 / 6$ & $\mathrm{ND}$ & ND & & ND & & NA & & NA & $2.40 \mathrm{E}+05$ & $0 / 6$ & & NA \\
\hline Styrene & $0 / 35$ & $\mathrm{ND}$ & $\mathrm{ND}$ & & $\mathrm{ND}$ & & NA & & NA & $1.70 \mathrm{E}+06$ & $0 / 35$ & & NA \\
\hline Tetrachloroethene & 9/35 & $2 \mathrm{~J}$ & $14 \mathrm{~J}$ & SB088 & 5.56 & & NA & & NA & $1.30 \mathrm{E}+04$ & $0 / 35$ & & NA \\
\hline Toluene & $3 / 35$ & $19 \mathrm{~J}$ & $200 \mathrm{~J}$ & BH005 & 81.3 & & NA & & NA & $5.20 \mathrm{E}+05$ & $0 / 35$ & & NA \\
\hline Total Xylene & $4 / 29$ & $5 \mathrm{~J}$ & $5,000 \mathrm{~J}$ & SB088 & 1,821 & & NA & & NA & $4.20 \mathrm{E}+05$ & $0 / 29$ & & NA \\
\hline Trichloroethene & $2 / 35$ & $3 \mathrm{~J}$ & $4 \mathrm{~J}$ & SB089 & 3.5 & & NA & & NA & $1.10 \mathrm{E}+03$ & $0 / 35$ & & NA \\
\hline Trichlorofluoromethane & $0 / 6$ & $\mathrm{ND}$ & ND & & $\mathrm{ND}$ & & NA & & NA & $1.30 \mathrm{E}+06$ & $0 / 6$ & & NA \\
\hline Vinyl acetate & $0 / 6$ & ND & ND & & ND & & NA & & NA & $1.40 \mathrm{E}+06$ & $0 / 6$ & & NA \\
\hline Vinyl chloride & $0 / 35$ & ND & ND & & $\mathrm{ND}$ & & $\mathrm{NA}$ & & NA & $7.50 \mathrm{E}+03$ & $0 / 35$ & & $\mathrm{NA}$ \\
\hline cis-1,2-Dichloroethene & $1 / 6$ & $1.5 \mathrm{~J}$ & $1.5 \mathrm{~J}$ & Z2-EU37B-304 & 1.5 & & NA & & NA & $1.50 \mathrm{E}+05$ & $0 / 6$ & & NA \\
\hline cis-1,3-Dichloropropene & $0 / 35$ & ND & $\mathrm{ND}$ & & $\mathrm{ND}$ & & NA & & NA & $1.80 \mathrm{E}+04$ & $0 / 35$ & & $\mathrm{NA}$ \\
\hline $\mathrm{o}$-Chlorotoluene & $0 / 6$ & $\mathrm{ND}$ & $\mathrm{ND}$ & & ND & & NA & & NA & $5.60 \mathrm{E}+05$ & $0 / 6$ & & NA \\
\hline trans-1,2-Dichloroethene & $0 / 6$ & ND & ND & & ND & & NA & & NA & $2.30 \mathrm{E}+05$ & $0 / 6$ & & NA \\
\hline trans-1,3-Dichloropropene & $0 / 35$ & $\mathrm{ND}$ & ND & & ND & & NA & & NA & $1.80 \mathrm{E}+04$ & $0 / 35$ & & NA \\
\hline
\end{tabular}

${ }^{b}$ Evalionucted as part of $\mathrm{Th}-232+\mathrm{D}=\mathrm{Th}-232+\mathrm{Ra}-228+\mathrm{D}+\mathrm{Th}-228+\mathrm{D}$.

Stations in summary included BH002, BH004, BH005, BH006, BH007, BH008, BH011, BH012, BH013, ETTP-REL12, ETTP-REL13, RAD69, RAD78, RAD85, RAD90, SB078, SB079, SB080, SB081, SB082, SB083, SB087, SB088, SB089, SB090, SB091, SB092, SB093, SB099, Z2-EU37B-301, Z2-EU378
302, 22-EU37B-303, Z2-EU7304, ,

$\mathrm{EU}=$ exposure unit
$\mathrm{J}=$ analyte was positively identified and result is approximate concentration of analyte in sample $\mathrm{NA}=$ not applicable

$\mathrm{ND}=$ not detected
$\mathrm{PCB}=$ polychlorinated biphenyl
PRG = preliminary remediation goal

$\mathrm{RL}=$ remediation level
$\mathrm{ROD}=$ record of decision

$=$ analyte was not detected above reported sample quantitation limi 
Table H.4. EU Z2-37, depth below $10 \mathrm{ft}$

\begin{tabular}{|c|c|c|c|c|c|c|c|c|c|c|c|c|c|}
\hline Analyte & $\begin{array}{c}\text { Frequency } \\
\text { of detect }\end{array}$ & $\begin{array}{c}\text { Minimum } \\
\text { detect }\end{array}$ & $\begin{array}{c}\text { Maximum } \\
\text { detect }\end{array}$ & $\begin{array}{c}\text { Location(s) } \\
\text { of maximum } \\
\text { detected result }\end{array}$ & $\begin{array}{c}\text { Average } \\
\text { detected } \\
\text { result }\end{array}$ & $\underset{\text { RL }}{\text { Maximum }}$ & $\begin{array}{c}\text { Frequency } \\
\text { of detects } \\
\text { exceeding } \\
\text { maximum RL }\end{array}$ & $\begin{array}{l}\text { Average } \\
\text { RL }\end{array}$ & $\begin{array}{l}\text { Frequency } \\
\text { of detects } \\
\text { exceeding } \\
\text { average RL }\end{array}$ & $\begin{array}{l}\text { PRG limit } \\
\left(10^{-5} \text { or } 1\right)\end{array}$ & $\begin{array}{l}\text { Frequency } \\
\text { of detects } \\
\text { exceeding } \\
\text { PRG limit }\end{array}$ & $\begin{array}{l}\text { Background } \\
\text { concentration }\end{array}$ & $\begin{array}{l}\text { Frequency } \\
\text { of detects } \\
\text { exceeding } \\
\text { background }\end{array}$ \\
\hline \multicolumn{14}{|l|}{ Inorganics $(\mathrm{mg} / \mathrm{kg})$} \\
\hline Aluminum & $29 / 29$ & 10,400 & 31,000 & SB048 & 17,776 & & NA & & NA & $1.00 \mathrm{E}+05$ & $0 / 29$ & 40,300 & $0 / 29$ \\
\hline Antimony & $6 / 13$ & $0.28 \mathrm{~J}$ & $0.59 \mathrm{~J}$ & SB079 & 0.383 & & NA & & NA & $4.10 \mathrm{E}+02$ & $0 / 13$ & 1.52 & $0 / 13$ \\
\hline Arsenic & $28 / 28$ & $2.5 \mathrm{~J}$ & $28.8 \mathrm{~J}$ & SB078 & 9.33 & 900 & $0 / 28$ & 300 & $0 / 28$ & $1.60 \mathrm{E}+01$ & $2 / 28$ & 14.95 & $2 / 28$ \\
\hline Barium & $29 / 29$ & $36.7 \mathrm{~J}$ & $417 \mathrm{~J}$ & SB083 & 161 & & NA & & NA & $6.70 \mathrm{E}+04$ & $0 / 29$ & 124.93 & $13 / 29$ \\
\hline Beryllium & $28 / 29$ & $0.58 \mathrm{~J}$ & $5.5 \mathrm{~J}$ & SB109 & 2.02 & 6,000 & $0 / 29$ & 2,000 & $0 / 29$ & $1.90 \mathrm{E}+03$ & $0 / 29$ & 2.2 & $7 / 29$ \\
\hline Cadmium & $5 / 29$ & 0.31 & 1.2 & SB109 & 0.632 & & NA & & NA & $4.50 \mathrm{E}+02$ & $0 / 29$ & $0.22 \mathrm{U}$ & $5 / 29$ \\
\hline Calcium & $29 / 29$ & 325 & $45,200 \mathrm{~J}$ & SB091 & 4116 & & NA & & NA & & NA & 2400 & $7 / 29$ \\
\hline Chromium & $29 / 29$ & 11.9 & 39 & SB083 & 22.2 & & NA & & NA & $6.40 \mathrm{E}+02$ & $0 / 29$ & 44.88 & $0 / 29$ \\
\hline Cobalt & $29 / 29$ & $8.5 \mathrm{~J}$ & 178 & SB079 & 37.1 & & NA & & NA & $1.30 \mathrm{E}+04$ & $0 / 29$ & 42 & $6 / 29$ \\
\hline Copper & $27 / 29$ & 9.5 & 114 & SB081 & 34.8 & & NA & & NA & $4.10 \mathrm{E}+04$ & $0 / 29$ & 22.48 & $17 / 9$ \\
\hline Cyanide & $0 / 21$ & ND & $\mathrm{ND}$ & & $\mathrm{ND}$ & & NA & & NA & $1.20 \mathrm{E}+04$ & $0 / 21$ & $0.6 \mathrm{U}$ & $0 / 21$ \\
\hline Iron & $29 / 29$ & 18,700 & 40,400 & ВH003 & 29,759 & & NA & & NA & $1.00 \mathrm{E}+05$ & $0 / 29$ & 58,600 & $0 / 29$ \\
\hline Lead & $29 / 29$ & $5.7 \mathrm{~J}$ & $159 \mathrm{~J}$ & SB048 & 34.2 & & $\mathrm{NA}$ & & $\mathrm{NA}$ & $8.00 \mathrm{E}+02$ & $0 / 29$ & 37.91 & $9 / 29$ \\
\hline Magnesium & $29 / 29$ & 593 & 12,500 & BHOO1 & 2,936 & & NA & & NA & & NA & 3,300 & $8 / 29$ \\
\hline Manganese & $29 / 29$ & $119 \mathrm{~J}$ & $4,100 \mathrm{~J}$ & SB079 & 1,396 & & $\mathrm{NA}$ & & $\mathrm{NA}$ & $1.90 \mathrm{E}+04$ & $0 / 29$ & 2,200 & $7 / 29$ \\
\hline Mercury & $12 / 29$ & 0.05 & 0.47 & SB109 & 0.137 & 1,800 & $0 / 29$ & 600 & $0 / 29$ & $3.10 \mathrm{E}+02$ & $0 / 29$ & 0.17 & $2 / 29$ \\
\hline Molybdenum & $8 / 29$ & 0.7 & $8.7 \mathrm{~J}$ & SB087 & 3.65 & & NA & & NA & $5.10 \mathrm{E}+03$ & $0 / 29$ & & NA \\
\hline Nickel & $29 / 29$ & 10.7 & $84.2 \mathrm{~J}$ & BHO05 & 39.5 & & NA & & NA & $2.00 \mathrm{E}+04$ & $0 / 29$ & 26.07 & $24 / 29$ \\
\hline Potassium & $29 / 29$ & 1,240 & 5,310 & SB083 & 2,136 & & NA & & NA & & NA & $5,074.69$ & $1 / 29$ \\
\hline Selenium & $7 / 20$ & $0.34 \mathrm{~J}$ & $2.2 \mathrm{~J}$ & SB079 & 0.917 & & NA & & NA & $5.10 \mathrm{E}+03$ & $0 / 20$ & 1.47 & $1 / 20$ \\
\hline Silver & $29 / 29$ & 0.69 & 3.3 & SB087 & 1.92 & & NA & & NA & $5.10 \mathrm{E}+03$ & $0 / 29$ & $0.6 \mathrm{U}$ & $29 / 29$ \\
\hline Sodium & $22 / 29$ & 37.5 & 364 & SB047 & 118 & & NA & & NA & & NA & 497 & $0 / 29$ \\
\hline Thallium & $13 / 29$ & 0.18 & 1.6 & SB079 & 0.702 & & NA & & NA & $6.70 \mathrm{E}+01$ & $0 / 29$ & $0.4 \mathrm{U}$ & $10 / 29$ \\
\hline Tin & $21 / 29$ & 2 & $10 \mathrm{~J}$ & SB079 & 5.7 & & NA & & NA & $1.00 \mathrm{E}+05$ & $0 / 29$ & & $\mathrm{NA}$ \\
\hline Vanadium & $29 / 29$ & 14.8 & 43.7 & SB081 & 25.9 & & NA & & NA & $1.00 \mathrm{E}+03$ & $0 / 29$ & 65.47 & $0 / 29$ \\
\hline Zinc & $29 / 29$ & $24.4 \mathrm{~J}$ & 248 & SB048 & 97.5 & & NA & & NA & $1.00 \mathrm{E}+05$ & $0 / 29$ & 89.7 & $16 / 29$ \\
\hline \multicolumn{14}{|l|}{ Other organics (mg/kg) } \\
\hline Diesel Range Organics & $7 / 12$ & $8.9 \mathrm{~J}$ & 530 & BH005 & 151 & & NA & & NA & & NA & & NA \\
\hline Gasoline Range Organics & $8 / 12$ & 2.694 & 610 & BH004 & 185 & & NA & & $\mathrm{NA}$ & & $\mathrm{NA}$ & & NA \\
\hline \multicolumn{14}{|c|}{ Organics, pesticides, and PCBs (ug/kg) } \\
\hline $4,4^{\prime}-$ DDD & $0 / 25$ & $\mathrm{ND}$ & $\mathrm{ND}$ & & $\mathrm{ND}$ & & NA & & NA & $1.00 \mathrm{E}+05$ & $0 / 25$ & & NA \\
\hline $4,4^{\prime}-\mathrm{DDE}$ & $0 / 25$ & ND & ND & & ND & & NA & & NA & $7.00 \mathrm{E}+04$ & $0 / 25$ & & NA \\
\hline $4,4^{\prime}-\mathrm{DDT}$ & $1 / 25$ & $0.4 \mathrm{~J}$ & $0.4 \mathrm{~J}$ & SB082 & 0.4 & & NA & & NA & $7.00 \mathrm{E}+04$ & $0 / 25$ & & NA \\
\hline Aldrin & $0 / 25$ & ND & ND & & $\mathrm{ND}$ & & NA & & NA & $1.00 \mathrm{E}+03$ & $0 / 25$ & & NA \\
\hline Dieldrin & $0 / 25$ & ND & ND & & ND & & NA & & NA & $1.10 \mathrm{E}+03$ & $0 / 25$ & & NA \\
\hline Endosulfan I & $0 / 25$ & ND & ND & & ND & & NA & & NA & $3.70 \mathrm{E}+06$ & $0 / 25$ & & NA \\
\hline Endosulfan II & $0 / 25$ & $\mathrm{ND}$ & $\mathrm{ND}$ & & ND & & NA & & NA & $3.70 \mathrm{E}+06$ & $0 / 25$ & & NA \\
\hline Endosulfan sulfate & $0 / 25$ & $\mathrm{ND}$ & $\mathrm{ND}$ & & $\mathrm{ND}$ & & NA & & NA & $3.70 \mathrm{E}+06$ & $0 / 25$ & & NA \\
\hline Endrin & $0 / 25$ & ND & ND & & ND & & NA & & NA & $1.80 \mathrm{E}+05$ & $0 / 25$ & & NA \\
\hline Endrin aldehyde & $0 / 25$ & $\mathrm{ND}$ & $\mathrm{ND}$ & & $\mathrm{ND}$ & & NA & & $\mathrm{NA}$ & $1.80 \mathrm{E}+05$ & $0 / 25$ & & NA \\
\hline Endrin ketone & $0 / 25$ & ND & ND & & ND & & NA & & NA & $1.80 \mathrm{E}+05$ & $0 / 25$ & & NA \\
\hline Heptachlor & $0 / 25$ & $\mathrm{ND}$ & ND & & $\mathrm{ND}$ & & NA & & NA & $3.80 \mathrm{E}+03$ & $0 / 25$ & & NA \\
\hline Heptachlor epoxide & $0 / 25$ & ND & ND & & ND & & NA & & NA & $1.90 \mathrm{E}+03$ & $0 / 25$ & & NA \\
\hline Lindane & $0 / 25$ & ND & $\mathrm{ND}$ & & $\mathrm{ND}$ & & NA & & NA & $1.70 \mathrm{E}+04$ & $0 / 25$ & & NA \\
\hline Methoxychlor & $3 / 25$ & $1.6 \mathrm{~J}$ & $24 \mathrm{~J}$ & SB081 & 13.9 & & NA & & NA & $3.10 \mathrm{E}+06$ & $0 / 25$ & & NA \\
\hline PCB-1016 & $0 / 29$ & ND & ND & & ND & 100,000 & $0 / 29$ & 10,000 & $0 / 29$ & $3.70 \mathrm{E}+04$ & $0 / 29$ & & NA \\
\hline PCB-1221 & $0 / 29$ & $\mathrm{ND}$ & $\mathrm{ND}$ & & $\mathrm{ND}$ & 100,000 & $0 / 29$ & 10,000 & $0 / 29$ & $7.40 \mathrm{E}+03$ & $0 / 29$ & & NA \\
\hline PCB-1232 & $0 / 29$ & ND & ND & & ND & 100,000 & $0 / 29$ & 10,000 & $0 / 29$ & $7.40 \mathrm{E}+03$ & $0 / 29$ & & NA \\
\hline $\begin{array}{l}\text { PCB-1242 } \\
\text { PCD }\end{array}$ & $0 / 29$ & $\mathrm{ND}$ & $\mathrm{ND}$ & & ND & 100,000 & $0 / 29$ & 10,000 & $0 / 29$ & 7.40E+03 & $0 / 29$ & & NA \\
\hline PCB-1248 & $2 / 29$ & $100 \mathrm{~J}$ & $1,200 \mathrm{~J}$ & SB080 & 650 & 100,000 & $0 / 29$ & 10,000 & $0 / 29$ & 7.40E+03 & $0 / 29$ & & NA \\
\hline
\end{tabular}


Table H.4. (continued)

\begin{tabular}{|c|c|c|c|c|c|c|c|c|c|c|c|c|c|}
\hline Analyte & $\begin{array}{c}\text { Frequency } \\
\text { of detect }\end{array}$ & $\begin{array}{c}\text { Minimum } \\
\text { detect }\end{array}$ & $\begin{array}{c}\text { Maximum } \\
\text { detect }\end{array}$ & $\begin{array}{c}\text { Location(s) } \\
\text { of maximum } \\
\text { detected result }\end{array}$ & $\begin{array}{c}\text { Average } \\
\text { detected } \\
\text { result }\end{array}$ & $\begin{array}{c}\text { Maximum } \\
\text { RL }\end{array}$ & $\begin{array}{c}\text { Frequency } \\
\text { of detects } \\
\text { exceeding } \\
\text { maximum RL }\end{array}$ & $\begin{array}{c}\text { Average } \\
\text { RL }\end{array}$ & $\begin{array}{c}\text { Frequency } \\
\text { of detects } \\
\text { exceeding } \\
\text { average RL } \\
\end{array}$ & $\begin{array}{l}\text { PRG limit } \\
\left(10^{-5} \text { or } 1\right)\end{array}$ & $\begin{array}{l}\text { Frequency } \\
\text { of detects } \\
\text { exceeding } \\
\text { PRG limit } \\
\end{array}$ & $\begin{array}{c}\text { Background } \\
\text { concentration }\end{array}$ & $\begin{array}{c}\text { Frequency } \\
\text { of detects } \\
\text { exceeding } \\
\text { background }\end{array}$ \\
\hline PCB-1254 & $0 / 29$ & ND & ND & & ND & 100,000 & $0 / 29$ & 10,000 & $0 / 29$ & $7.40 \mathrm{E}+03$ & $0 / 29$ & & NA \\
\hline PCB-1260 & $2 / 29$ & $15 \mathrm{~J}$ & $32 \mathrm{~J}$ & SB087 & 23.5 & 100,000 & $0 / 29$ & 10,000 & $0 / 29$ & $7.40 \mathrm{E}+03$ & $0 / 29$ & & NA \\
\hline Toxaphene & $0 / 25$ & $\mathrm{ND}$ & $\mathrm{ND}$ & & ND & & NA & & NA & $1.60 \mathrm{E}+04$ & $0 / 25$ & & NA \\
\hline alpha-BHC & $0 / 25$ & ND & ND & & ND & & NA & & NA & $3.60 \mathrm{E}+03$ & $0 / 25$ & & NA \\
\hline alpha-Chlordane & $0 / 25$ & ND & $\mathrm{ND}$ & & $\mathrm{ND}$ & & NA & & NA & $6.50 \mathrm{E}+04$ & $0 / 25$ & & NA \\
\hline beta-BHC & $0 / 25$ & ND & ND & & ND & & NA & & NA & $1.30 \mathrm{E}+04$ & $0 / 25$ & & NA \\
\hline delta-BHC & $0 / 25$ & ND & ND & & ND & & NA & & NA & & NA & & NA \\
\hline gamma-Chlordane & $0 / 25$ & $\mathrm{ND}$ & $\mathrm{ND}$ & & $\mathrm{ND}$ & & NA & & NA & $6.50 \mathrm{E}+04$ & $0 / 25$ & & NA \\
\hline \multicolumn{14}{|l|}{ Radionuclides (pCi/g) } \\
\hline Actinium-228 & $1 / 1$ & 1.41 & 1.41 & BH006 & 1.41 & & NA & & NA & $1.20 \mathrm{E}+04$ & $0 / 1$ & & NA \\
\hline Alpha activity & $27 / 27$ & 5.22 & 52.92 & SB081 & 24.7 & & NA & & NA & & NA & & NA \\
\hline Americium 241 & $3 / 11$ & $0.06 \mathrm{~J}$ & $0.37 \mathrm{~J}$ & SB049 & 0.26 & & NA & & NA & $5.70 \mathrm{E}+01$ & $0 / 11$ & & NA \\
\hline Beta activity & $29 / 29$ & 2.77 & 65.02 & SB087 & 36.2 & & NA & & NA & & NA & & NA \\
\hline Bismuth-214 & $4 / 4$ & 0.92 & 1.26 & BH011 & 1.07 & & NA & & NA & $1.30 \mathrm{E}+05$ & $0 / 4$ & & NA \\
\hline Cesium-137 & $0 / 21$ & ND & ND & & ND & 20 & $0 / 21$ & 2 & $0 / 21$ & $1.10 \mathrm{E}+00$ & $0 / 21$ & & NA \\
\hline Cobalt-60 & $0 / 21$ & ND & $\mathrm{ND}$ & & ND & & NA & & NA & $6.00 \mathrm{E}-01$ & $0 / 21$ & & NA \\
\hline Lead-212 & $6 / 6$ & 0.22 & 1.88 & BH002 & 1.28 & & NA & & NA & $6.10 \mathrm{E}+04$ & $0 / 6$ & & NA \\
\hline Lead-214 & $4 / 4$ & 0.87 & 1.17 & BH005 & 0.95 & & NA & & NA & $7.50 \mathrm{E}+05$ & $0 / 4$ & & NA \\
\hline Neptunium-237 & $2 / 12$ & $0.02 \mathrm{~J}$ & $0.06 \mathrm{~J}$ & SB049 & 0.04 & 50 & $0 / 12$ & 5 & $0 / 12$ & $2.70 \mathrm{E}+00$ & $0 / 12$ & & NA \\
\hline Plutonium-238 & $3 / 12$ & $0.87 \mathrm{~J}$ & 1.6 & SB047 & 1.34 & & NA & & NA & $1.70 \mathrm{E}+02$ & $0 / 12$ & & NA \\
\hline Plutonium 239 & $1 / 12$ & 0.11 & 0.11 & SB047 & 0.11 & & NA & & NA & $1.50 \mathrm{E}+02$ & $0 / 12$ & & NA \\
\hline Potassium-40 & $8 / 8$ & 24.18 & 39.4 & BHO02 & 29.1 & & NA & & NA & $2.70 \mathrm{E}+00$ & $8 / 8$ & 32.12 & $2 / 8$ \\
\hline $\mathrm{Ra} / \mathrm{Th}$ decay series & $12 / 12$ & 0 & 3.24 & BH005 & 0.53 & 15 & $0 / 12$ & 5 & $0 / 12$ & & NA & & NA \\
\hline Strontium-90 & $16 / 28$ & $0.23 \mathrm{~J}$ & $4.83 \mathrm{~J}$ & BHO01 & 1.55 & & NA & & NA & $1.10 \mathrm{E}+02$ & $0 / 28$ & & NA \\
\hline Technetium-99 & $19 / 29$ & $0.1 \mathrm{~J}$ & $3.03 \mathrm{~J}$ & SB047 & 1.44 & & NA & & NA & $8.90 \mathrm{E}+03$ & $0 / 29$ & & NA \\
\hline Thallium 208 & $3 / 3$ & 0.52 & 0.62 & BHO11 & 0.57 & & NA & & NA & $3.70 \mathrm{E}+05$ & $0 / 3$ & & NA \\
\hline Thorium-228 & $12 / 12$ & 0.97 & $1.97 \mathrm{~J}$ & BHO05 & 1.55 & & NA & & NA & $1.70 \mathrm{E}-01$ & $12 / 12^{a}$ & 1.86 & $1 / 12$ \\
\hline Thorium 230 & $12 / 12$ & $0.73 \mathrm{~J}$ & $4.44 \mathrm{~J}$ & BH005 & 1.6 & 15 & $\mathrm{NA}^{b}$ & 5 & $\mathrm{NA}^{b}$ & $2.10 \mathrm{E}+02$ & $0 / 12$ & 1.2 & $5 / 12$ \\
\hline Thorium-232 & $12 / 12$ & $0.86 \mathrm{~J}$ & $1.63 \mathrm{~J}$ & BHO05 & 1.21 & 15 & $\mathrm{NA}^{b}$ & 5 & $\mathrm{NA}^{b}$ & $1.70 \mathrm{E}-01$ & $12 / 12^{a}$ & 1.95 & $0 / 12$ \\
\hline Uranium-234 & $27 / 28$ & 0.46 & 2.7 & SB079 & 1.21 & 7,000 & $0 / 28$ & 700 & $0 / 28$ & $3.30 \mathrm{E}+02$ & $0 / 28$ & & $\mathrm{NA}$ \\
\hline Uranium-235 & $19 / 28$ & 0.01 & 0.23 & SB079 & 0.07 & 80 & $0 / 28$ & 8 & $0 / 28$ & $3.90 \mathrm{E}+00$ & $0 / 28$ & & $\mathrm{NA}$ \\
\hline Uranium-238 & $28 / 28$ & 0.44 & 2.6 & SB079 & 1.16 & 500 & $0 / 28$ & 50 & $0 / 28$ & $1.80 \mathrm{E}+01$ & $0 / 28$ & 1.47 & $6 / 28$ \\
\hline \multicolumn{14}{|c|}{ Semivolatile organics (ug/kg) } \\
\hline 1,2,4-Trichlorobenzene & $0 / 36$ & $\mathrm{ND}$ & $\mathrm{ND}$ & & $\mathrm{ND}$ & & NA & & NA & $2.20 \mathrm{E}+05$ & $0 / 36$ & & NA \\
\hline 1,2-Dichlorobenzene & $0 / 38$ & ND & ND & & ND & & NA & & NA & $6.00 \mathrm{E}+05$ & $0 / 38$ & & NA \\
\hline 1,3-Dichlorobenzene & $0 / 38$ & ND & ND & & ND & & NA & & NA & $6.00 \mathrm{E}+05$ & $0 / 38$ & & NA \\
\hline 1,4-Dichlorobenzene & $0 / 36$ & $\mathrm{ND}$ & ND & & $\mathrm{ND}$ & & NA & & $\mathrm{NA}$ & $7.90 \mathrm{E}+04$ & $0 / 36$ & & NA \\
\hline 2,4,5-Trichlorophenol & $0 / 33$ & ND & ND & & ND & & NA & & NA & $6.20 \mathrm{E}+07$ & $0 / 33$ & & NA \\
\hline 2,4,6-Trichlorophenol & $0 / 33$ & ND & ND & & ND & & NA & & NA & $6.20 \mathrm{E}+04$ & $0 / 33$ & & NA \\
\hline 2,4-Dichlorophenol & $0 / 33$ & ND & ND & & ND & & NA & & NA & $1.80 \mathrm{E}+06$ & $0 / 33$ & & NA \\
\hline 2,4-Dimethylphenol & $0 / 33$ & ND & ND & & $\mathrm{ND}$ & & NA & & NA & $1.20 \mathrm{E}+07$ & $0 / 33$ & & NA \\
\hline 2,4-Dinitrophenol & $0 / 33$ & $\mathrm{ND}$ & $\mathrm{ND}$ & & $\mathrm{ND}$ & & NA & & $\mathrm{NA}$ & $1.20 \mathrm{E}+06$ & $0 / 33$ & & NA \\
\hline 2,4-Dinitrotoluene & $0 / 31$ & ND & $\mathrm{ND}$ & & $\mathrm{ND}$ & & NA & & NA & $2.50 \mathrm{E}+04$ & $0 / 31$ & & NA \\
\hline 2,6-Dinitrotoluene & $0 / 33$ & ND & ND & & ND & & NA & & $\mathrm{NA}$ & $2.50 \mathrm{E}+04$ & $0 / 33$ & & NA \\
\hline 2-Chloronaphthalene & $0 / 33$ & ND & ND & & ND & & NA & & NA & $2.30 \mathrm{E}+07$ & $0 / 33$ & & NA \\
\hline 2-Chlorophenol & $0 / 33$ & $\mathrm{ND}$ & $\mathrm{ND}$ & & ND & & NA & & NA & $2.40 \mathrm{E}+05$ & $0 / 33$ & & NA \\
\hline 2-Methyl-4,6-dinitrophenol & $0 / 33$ & ND & $\mathrm{ND}$ & & ND & & NA & & NA & $6.20 \mathrm{E}+04$ & $0 / 33$ & & NA \\
\hline 2-Methylnaphthalene & 9/33 & $100 \mathrm{~J}$ & 1,600 & BHO04 & 1019 & & NA & & NA & $1.90 \mathrm{E}+05$ & $0 / 33$ & & NA \\
\hline 2-Methylphenol & $0 / 33$ & $\mathrm{ND}$ & $\mathrm{ND}$ & & ND & & NA & & NA & $3.10 \mathrm{E}+07$ & $0 / 33$ & & NA \\
\hline 2-Nitrobenzenamine & $0 / 33$ & $\mathrm{ND}$ & ND & & ND & & NA & & NA & $1.80 \mathrm{E}+06$ & $0 / 33$ & & NA \\
\hline 2-Nitrophenol & $0 / 33$ & $\mathrm{ND}$ & $\mathrm{ND}$ & & $\mathrm{ND}$ & & $\mathrm{NA}$ & & $\mathrm{NA}$ & & NA & & NA \\
\hline 3,3'-Dichlorobenzidine & $0 / 33$ & ND & ND & & ND & & NA & & NA & $3.80 \mathrm{E}+04$ & $0 / 33$ & & NA \\
\hline 3-Nitrobenzenamine & $0 / 33$ & ND & ND & & $\mathrm{ND}$ & & $\mathrm{NA}$ & & NA & $1.80 \mathrm{E}+05$ & $0 / 33$ & & NA \\
\hline
\end{tabular}


Table H.4. (continued)

\begin{tabular}{|c|c|c|c|c|c|c|c|c|c|c|c|c|c|}
\hline $\begin{array}{c}\text { Analyte } \\
\end{array}$ & $\begin{array}{r}\text { Frequency } \\
\text { of detect }\end{array}$ & $\begin{array}{c}\text { Minimum } \\
\text { detect }\end{array}$ & $\begin{array}{c}\text { Maximum } \\
\text { detect }\end{array}$ & $\begin{array}{c}\text { Location(s) } \\
\text { of maximum } \\
\text { detected result }\end{array}$ & $\begin{array}{c}\text { Average } \\
\text { detected } \\
\text { result }\end{array}$ & $\begin{array}{c}\text { Maximum } \\
\text { RL }\end{array}$ & $\begin{array}{c}\text { Frequency } \\
\text { of detects } \\
\text { exceeding } \\
\text { maximum RL }\end{array}$ & $\begin{array}{c}\text { Average } \\
\text { RL }\end{array}$ & $\begin{array}{c}\text { Frequency } \\
\text { of detects } \\
\text { exceeding } \\
\text { average RL } \\
\end{array}$ & $\begin{array}{l}\text { PRG limit } \\
\left(10^{-5} \text { or } 1\right)\end{array}$ & $\begin{array}{c}\text { Frequency } \\
\text { of detects } \\
\text { exceeding } \\
\text { PRG limit }\end{array}$ & $\begin{array}{c}\text { Background } \\
\text { concentration }\end{array}$ & $\begin{array}{c}\text { Frequency } \\
\text { of detects } \\
\text { exceeding } \\
\text { background }\end{array}$ \\
\hline 4-Bromophenyl phenyl ether & $0 / 33$ & ND & ND & & ND & & NA & & NA & & NA & & NA \\
\hline 4-Chloro-3-methylphenol & $0 / 33$ & ND & ND & & ND & & NA & & NA & & NA & & NA \\
\hline 4-Chlorobenzenamine & $0 / 33$ & ND & ND & & ND & & NA & & NA & $2.50 \mathrm{E}+06$ & $0 / 33$ & & NA \\
\hline 4-Chlorophenyl phenyl ether & $0 / 33$ & $\mathrm{ND}$ & $\mathrm{ND}$ & & ND & & NA & & NA & & NA & & NA \\
\hline 4-Methylphenol & $0 / 33$ & ND & ND & & ND & & NA & & NA & $3.10 \mathrm{E}+06$ & $0 / 33$ & & NA \\
\hline 4-Nitrobenzenamine & $0 / 33$ & ND & ND & & ND & & NA & & NA & $8.20 \mathrm{E}+05$ & $0 / 33$ & & NA \\
\hline 4-Nitrophenol & $0 / 33$ & ND & ND & & ND & & NA & & NA & . & NA & & NA \\
\hline Acenaphthene & $4 / 31$ & $62 \mathrm{~J}$ & $130 \mathrm{~J}$ & BH001 & 91.8 & & NA & & NA & $2.90 \mathrm{E}+07$ & $0 / 31$ & & NA \\
\hline Acenaphthylene & $0 / 33$ & $\mathrm{ND}$ & $\mathrm{ND}$ & & ND & & NA & & NA & $2.90 \mathrm{E}+07$ & $0 / 33$ & & NA \\
\hline Anthracene & $0 / 33$ & ND & ND & & ND & & NA & & NA & $1.00 \mathrm{E}+08$ & $0 / 33$ & & NA \\
\hline Benz(a)anthracene & $0 / 33$ & $\mathrm{ND}$ & ND & & $\mathrm{ND}$ & & NA & & NA & $2.10 \mathrm{E}+04$ & $0 / 33$ & & NA \\
\hline $\begin{array}{l}\text { Benzo(a)pyrene } \\
\text { Baren }\end{array}$ & $0 / 33$ & ND & ND & & ND & & NA & & NA & $2.10 \mathrm{E}+03$ & $0 / 33$ & & NA \\
\hline Benzo(b)fluoranthene & $0 / 33$ & ND & $\mathrm{ND}$ & & ND & & NA & & NA & $2.10 \mathrm{E}+04$ & $0 / 33$ & & NA \\
\hline Benzo(ghi)perylene & $0 / 33$ & ND & ND & & ND & & NA & & NA & $2.90 \mathrm{E}+07$ & $0 / 33$ & & NA \\
\hline Benzo(k)fluoranthene & $0 / 33$ & ND & ND & & ND & & NA & & NA & $2.10 \mathrm{E}+05$ & $0 / 33$ & & NA \\
\hline $\operatorname{Bis}(2$-chloroethoxy)methane & $0 / 33$ & ND & ND & & ND & & NA & & NA & & NA & & NA \\
\hline Bis(2-chloroethyl) ether & $0 / 33$ & ND & ND & & ND & & NA & & NA & $5.80 \mathrm{E}+03$ & $0 / 33$ & & NA \\
\hline Bis(2-chloroisopropyl) ether & $0 / 33$ & ND & ND & & ND & & NA & & NA & $7.40 \mathrm{E}+04$ & $0 / 33$ & & NA \\
\hline Bis(2-ethylhexyl)phthalate & $6 / 33$ & $32 \mathrm{~J}$ & 5,100 & SB080 & 1,053 & & NA & & NA & $1.20 \mathrm{E}+06$ & $0 / 33$ & & NA \\
\hline Butyl benzyl phthalate & $1 / 33$ & $11 \mathrm{~J}$ & $11 \mathrm{~J}$ & BH002 & 11 & & NA & & NA & $1.00 \mathrm{E}+08$ & $0 / 33$ & & NA \\
\hline Carbazole & $1 / 33$ & $46 \mathrm{~J}$ & $46 \mathrm{~J}$ & SB088 & 46 & & NA & & NA & $8.60 \mathrm{E}+05$ & $0 / 33$ & & NA \\
\hline Chrysene & $0 / 33$ & ND & ND & & ND & & NA & & NA & $2.10 \mathrm{E}+06$ & $0 / 33$ & & NA \\
\hline Di-n-butyl phthalate & $0 / 33$ & ND & ND & & $\mathrm{ND}$ & & NA & & NA & $6.20 \mathrm{E}+07$ & $0 / 33$ & & NA \\
\hline Di-n-octylphthalate & $1 / 33$ & $5 \mathrm{~J}$ & $5 \mathrm{~J}$ & BH002 & 5 & & NA & & NA & $2.50 \mathrm{E}+07$ & $0 / 33$ & & NA \\
\hline Dibenz $(\mathrm{a}, \mathrm{h})$ anthracene & $0 / 33$ & $\mathrm{ND}$ & ND & & ND & & NA & & $\mathrm{NA}$ & $2.10 \mathrm{E}+03$ & $0 / 33$ & & NA \\
\hline Dibenzofuran & $0 / 33$ & ND & ND & & ND & & NA & & NA & $1.60 \mathrm{E}+06$ & $0 / 33$ & & NA \\
\hline Diethyl phthalate & $1 / 33$ & $6 \mathrm{~J}$ & $6 \mathrm{~J}$ & BH002 & 6 & & NA & & NA & $1.00 \mathrm{E}+08$ & $0 / 33$ & & NA \\
\hline Dimethyl phthalate & $8 / 33$ & $59 \mathrm{~J}$ & $250 \mathrm{~J}$ & BH004 & 126 & & NA & & NA & $1.00 \mathrm{E}+08$ & $0 / 33$ & & NA \\
\hline Fluoranthene & $0 / 33$ & ND & ND & & ND & & NA & & NA & $2.20 \mathrm{E}+07$ & $0 / 33$ & & NA \\
\hline Fluorene & $2 / 33$ & $190 \mathrm{~J}$ & $250 \mathrm{~J}$ & BH005 & 220 & & NA & & NA & $2.60 \mathrm{E}+07$ & $0 / 33$ & & NA \\
\hline Hexachlorobenzene & $0 / 33$ & ND & ND & Dow & $\mathrm{ND}$ & & NA & & NA & $1.10 \mathrm{E}+04$ & $0 / 33$ & & NA \\
\hline Hexachlorobutadiene & $0 / 38$ & ND & ND & & ND & & NA & & NA & $1.80 \mathrm{E}+05$ & $0 / 38$ & & NA \\
\hline Hexachlorocyclopentadiene & $0 / 33$ & ND & ND & & ND & & NA & & NA & $3.70 \mathrm{E}+06$ & $0 / 33$ & & NA \\
\hline Hexachloroethane & $0 / 33$ & ND & ND & & ND & & NA & & NA & $6.20 \mathrm{E}+05$ & $0 / 33$ & & NA \\
\hline Indeno(1,2,3-cd)pyrene & $0 / 33$ & ND & ND & & ND & & NA & & NA & $2.10 \mathrm{E}+04$ & $0 / 33$ & & NA \\
\hline Isophorone & $0 / 33$ & ND & ND & & ND & & NA & & NA & $5.10 \mathrm{E}+06$ & $0 / 33$ & & NA \\
\hline N-Nitroso-di-n-propylamine & $0 / 31$ & $\mathrm{ND}$ & $\mathrm{ND}$ & & $\mathrm{ND}$ & & NA & & NA & $2.50 \mathrm{E}+03$ & $0 / 31$ & & NA \\
\hline N-Nitrosodiphenylamine & $0 / 33$ & ND & ND & & ND & & NA & & NA & $3.50 \mathrm{E}+06$ & $0 / 33$ & & NA \\
\hline Naphthalene & $8 / 33$ & $40 \mathrm{~J}$ & $320 \mathrm{~J}$ & $\begin{array}{l}\text { BH004 } \\
\text { BH006 }\end{array}$ & 221 & & NA & & NA & $1.90 \mathrm{E}+05$ & $0 / 33$ & & NA \\
\hline Nitrobenzene & $0 / 33$ & ND & ND & & ND & & NA & & NA & $1.00 \mathrm{E}+05$ & $0 / 33$ & & NA \\
\hline Pentachlorophenol & $0 / 33$ & ND & ND & & ND & & NA & & NA & $9.00 \mathrm{E}+04$ & $0 / 33$ & & NA \\
\hline Phenanthrene & $11 / 33$ & $38 \mathrm{~J}$ & 1,100 & BH001 & 452 & & NA & & NA & $2.90 \mathrm{E}+07$ & $0 / 33$ & & NA \\
\hline Phenol & $0 / 33$ & ND & ND & & ND & & NA & & NA & $1.00 \mathrm{E}+08$ & $0 / 33$ & & NA \\
\hline Pyrene & $6 / 31$ & $48 \mathrm{~J}$ & $130 \mathrm{~J}$ & BH001 & 88 & & NA & & NA & $2.90 \mathrm{E}+07$ & $0 / 31$ & & NA \\
\hline \multicolumn{14}{|l|}{ Volatile organics (ug/kg) } \\
\hline 1,1,1-Trichloroethane & $13 / 38$ & $2 \mathrm{~J}$ & 20,000 & K1070CD-DPT-05 & 1587 & & NA & & $\mathrm{NA}$ & $1.20 \mathrm{E}+06$ & $0 / 38$ & & NA \\
\hline 1,1,2,2-Tetrachloroethane & $1 / 38$ & $8 \mathrm{~J}$ & $8 \mathrm{~J}$ & SB080 & 8 & & NA & & NA & $9.30 \mathrm{E}+03$ & $0 / 38$ & & NA \\
\hline $\begin{array}{l}\text { 1,1,2-Trichloro-1,2,2- } \\
\text { trifluoreethane }\end{array}$ & $13 / 33$ & $2 \mathrm{~J}$ & 2,700 & BH001 & 392 & & NA & & NA & $5.60 \mathrm{E}+06$ & $0 / 33$ & & NA \\
\hline 1,1,2-Trichloroethane & $4 / 38$ & $6 \mathrm{~J}$ & 42 & SB080 & 22.3 & & NA & & NA & $1.60 \mathrm{E}+04$ & $0 / 38$ & & NA \\
\hline 1,1-Dichloroethane & $13 / 38$ & $3 \mathrm{~J}$ & 75 & SB079 & 24.5 & & NA & & NA & $1.70 \mathrm{E}+06$ & $0 / 38$ & & NA \\
\hline 1,1-Dichloroethene & $4 / 38$ & 20 & 5,700 & K1070CD-DPT-05 & 1,443 & & NA & & NA & $4.10 \mathrm{E}+05$ & $0 / 38$ & & NA \\
\hline
\end{tabular}




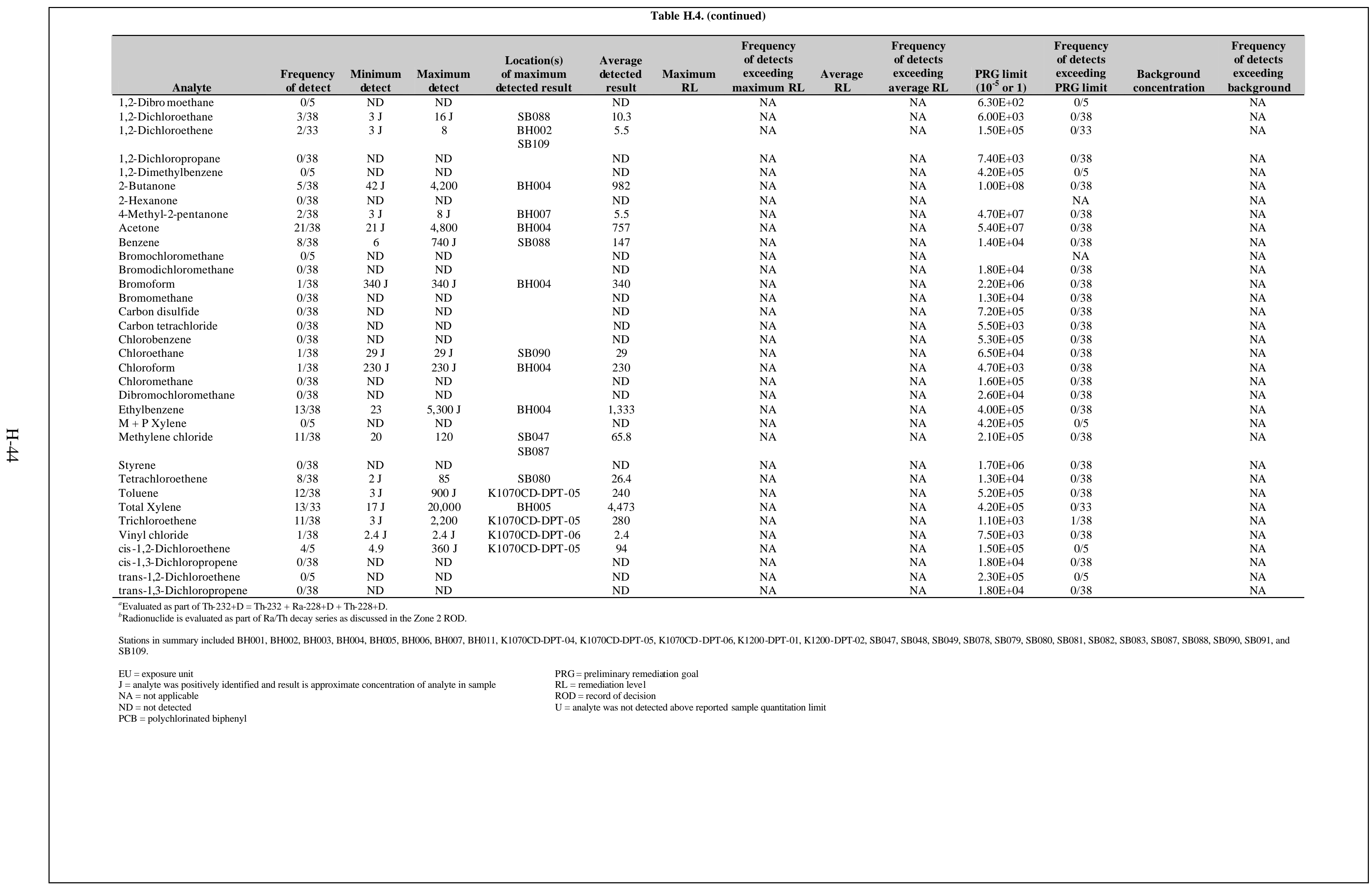


Appendix G

South Park Area Exposure Unit Group EU Z2-34

Technical Memorandum 


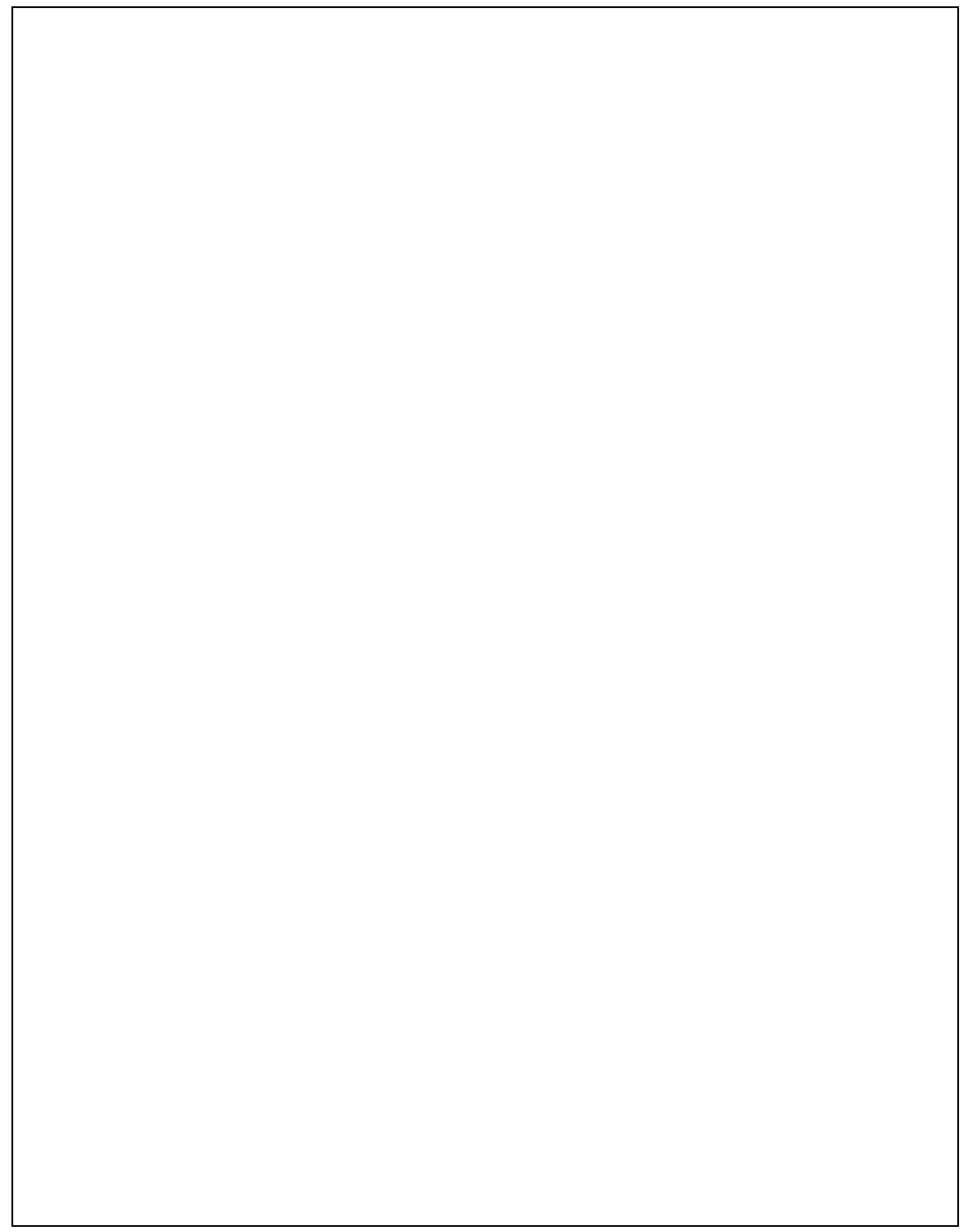

G-2 


\section{FIGURES}

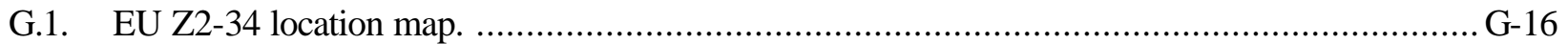

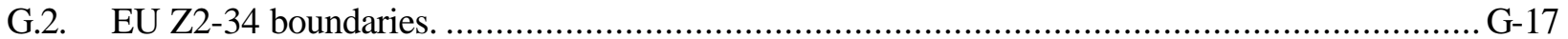

G.3. EU Z2-34 Class 3 and 4 SU walkover assessment locations. ......................................... G-18

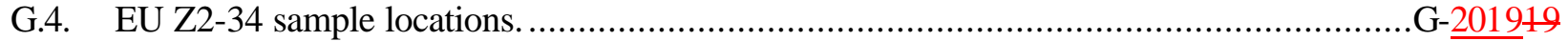

\section{TABLES}

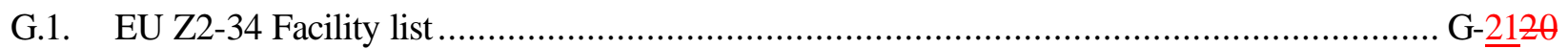

G.2. EU Z2-34 sample summary .................................................................... G-22 21

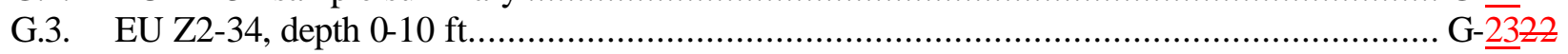




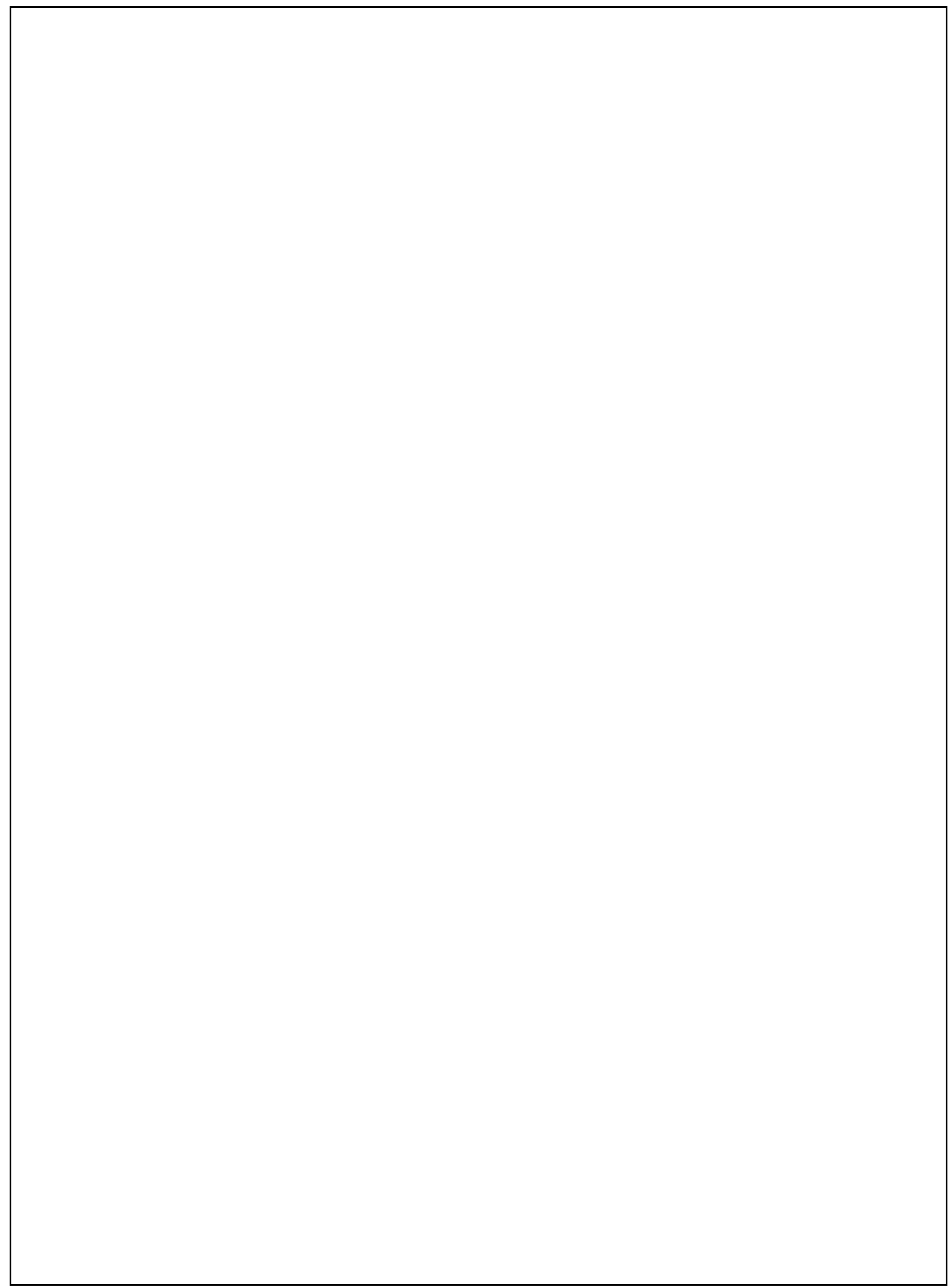

G-4 


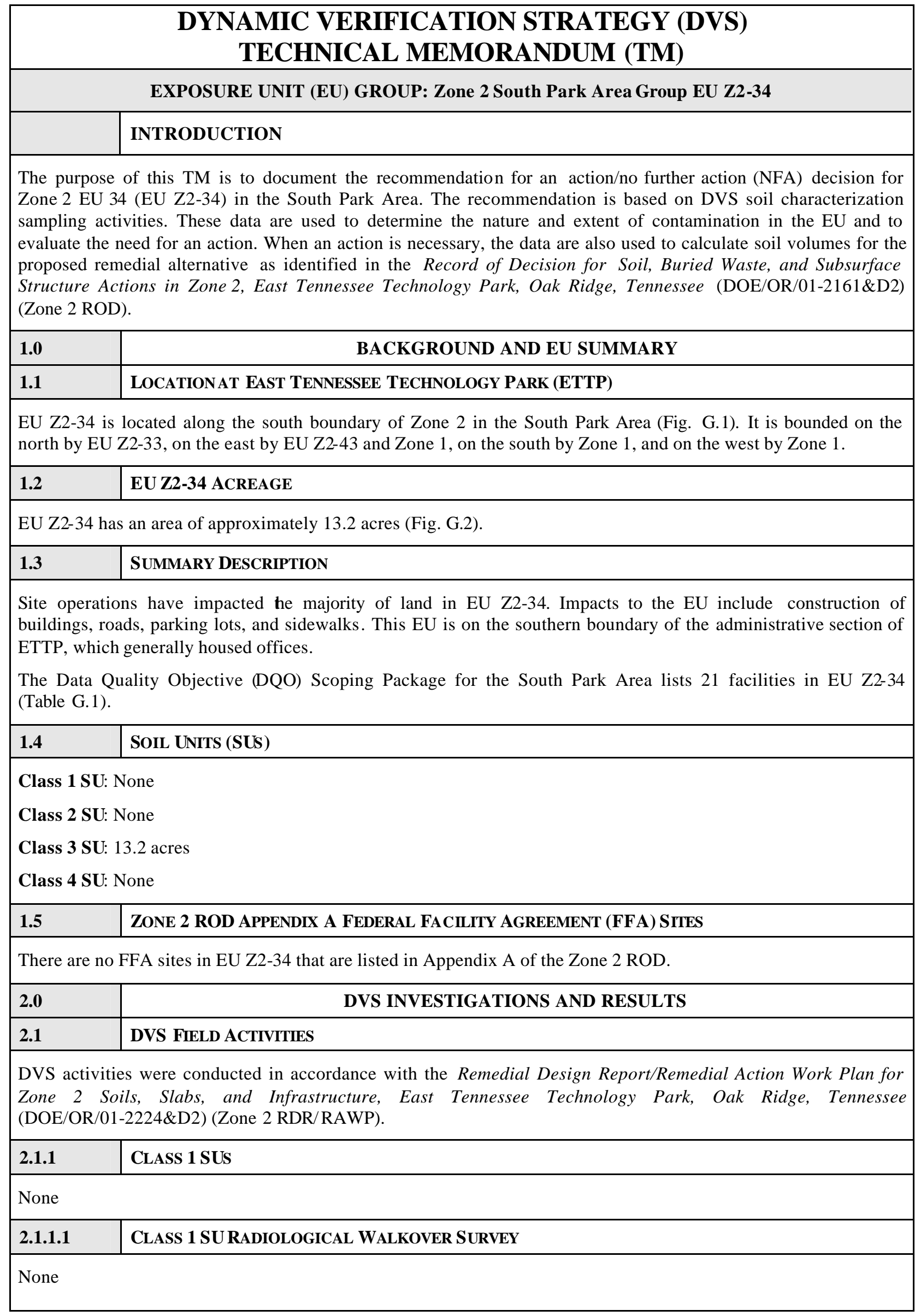




\section{\begin{tabular}{|l|l|l|l}
\hline 2.1.1.2 & CLASS 1 SU GEOPHYSICAL SURVEY \\
\hline
\end{tabular}}

None

\begin{tabular}{|l|l|}
\hline 2.1.1.3 & CLASS 1 SUSOIL SAMPLING \\
\hline
\end{tabular}

None

\begin{tabular}{|l|l}
\hline 2.1.2 & Class 2 SUS \\
\hline
\end{tabular}

None

\section{\begin{tabular}{l|l} 
2.1.2.1 & ClASS 2 SU RADIOLOGICAL WALKOVER SURVEY
\end{tabular}}

None

\begin{tabular}{|l|l} 
2.1.2.2 & CLASS 2 SU GEOPHYSICAL SURVEY
\end{tabular}

None

2.1.2.3

ClASS 2 SUSOIL SAMPLING

None

\section{\begin{tabular}{|l|ll} 
2.1.3 & ClaSs 3 AND ClaSs 4 SU WALKOVER ASSESSMENT
\end{tabular}}

The protocol for addressing Class 3 and Class 4 SUs in EU Z2-34 is the Class 3 and Class 4 Soil Unit Walkover Inspection Protocol Rev 01 (found in Attachment C of Appendix A in the Zone 2 RDR/RAWP). Only Class 3 SUs are addressed because no Class 4 SUs exist in EU Z2-34. The purpose of the Class 3 SU walkover assessments is to systematically inspect Class 3 SUs by visual observation along transects to established grid assessment locations and map-observed features, and to collect radiological screening data at grid and discretionary locations. Details of the walkover assessment results are presented in Walkover Inspections and Radiological Surveys for FY 2007 Exposure Units in Zones 1 and 2, East Tennessee Technology Park, Oak Ridge, Tennessee (BJC/OR-2691). A summary of report results is presented below in Sects. 2.1.3.1 and 2.1.3.2. Fig. G.3 shows the assessment point (AP), mid-point (MP), and discretionary point (DP) locations.

Twelve APs were identified in this EU prior to the start of fieldwork and are documented in the DQO Scoping Package. The actual number of APs evaluated in corresponds to the number planned.

In addition to the APs, the field team made assessments at seven MP locations (MPs are selected in the field and are points bcated approximately halfway between APs) and conducted a discretionary survey at one location (see below). MPs and DPs are not specified in planning documents.

\begin{tabular}{cccc}
\hline & $\begin{array}{c}\text { Number of } \\
\text { assessment points }\end{array}$ & $\begin{array}{c}\text { Number of } \\
\text { mi d-points }\end{array}$ & $\begin{array}{c}\text { Number of } \\
\text { discretionary points }\end{array}$ \\
\hline EU Z2-34 & 12 & 7 & 1 \\
\hline EU = exposure unit & & &
\end{tabular}

\section{\begin{tabular}{|l|l} 
2.1.3.1 & ClASS 3 AND ClaSS 4 SU RADIOLOGICAL SURVEY SUMMARY
\end{tabular}}

Screening level (SL): $4046 \mathrm{cpm}$

SL exceedances : None.

\section{\begin{tabular}{|l|l} 
2.1.3.2 & CLASS 3 AND CLASS 4 SU ANTHROPOGENIC FEATURES \\
\hline
\end{tabular}}

Number of identified anthropogenic features: 1

EU Z2-34 is located in an industrialized portion of ETTP. As such, there are numerous anthropogenic features that consist of facilities and associated constructed features such as roads, sidewalks, and paved areas. Plant facilities and their associated constructed features are assessed as part of the Class 3 and Class 4 SU walkover assessment protocol (Sect. 2.1.3.3). Other than plant facilities and associated constructed features, one anthropogenic feature 
was identified in EU Z2-34 during the Class 3 SU walkover assessment. The anthropogenic feature identified in EU Z2-34 during the Class $3 \mathrm{SU}$ assessment is:

- Contamination Area/Radioactive Material Area (CA/RMA), which consists of a line of hay bales adjacent to the parking area established during recent decontamination and decommissioning (D\&D) activities.

\section{\begin{tabular}{l|l} 
2.1.3.3 & CLASS 3 SU FACILITIES ASSESSMENTS \\
\hline
\end{tabular}}

The DQO Scoping Package lists 21 facilities that are located in EU Z2-34 (Table G.1). Only nine facilities were assessed during the Class $3 \mathrm{SU}$ walkover assessment because 12 facilities have been removed by D\&D activites (Table G.1). The facility assessments are reported in the Zone 2 EU Summary Report. No facility was identified as a possible source for either chemical or radiological contamination.

\section{\begin{tabular}{|l|l} 
2.1.3.4 & CLASS 3 AND CLASS 4 SU BIASED SAMPLING \\
\hline
\end{tabular}}

Based on visual assessment of the single anthropogenic feature for evidence of possible contamination, a biased sample location was selected.

In addition, two sediment accumulation area sample locations were identified during the Class 3 SU walkover assessment. One area is located near Assembly Area 2 and the other is located at the footprint of the loading dock for the former K-1001 building. A biased soil sample location was also identified at the radiation background measuring point for the Class $3 \mathrm{SU}$ walkover assessment.

One biased sample location was identified during DQO scoping at the southeast corner of the former K-1001 building near a storm drain catch basin where several pipelines intersect. Rationale for this sample location consisted of anecdotal evidence that some part of K-1001 had been used as a laboratory prior to conversion to an office building. The selected location was considered to be the most likely release point for building drains to release contaminants to surface soil.

The details of actual sampling and analysis in the Class $3 \mathrm{SU}$, including sample depths and analytes, are presented in Table G.2.

\section{\begin{tabular}{|l|l}
\hline 2.2 & DVS AND HISTORICAL SAMPLE RESULTS
\end{tabular}}

This section presents a summary of analytical results for the DVS samples collected in EU Z2-34 (see Table G.3); there are no historical sample locations. The summary begins with a tabulation of SU and infrastructure sample locations (Sects. 2.2.1 through 2.2.4) and concludes with focused investigation and EU data summaries (Sect. 2.2.5). A compact disc containing electronic files for the historical and DVS analytical data used to generate the data tables is provided with this Phased Construction Completion Report (PCCR).

\begin{tabular}{|l|l|}
\hline 2.2.1 & CLASS 1 SUS \\
\hline None \\
\hline $\mathbf{2 . 2 . 2}$ & CLASS 2 SUS \\
\hline None \\
\hline $\mathbf{2 . 2 . 3}$ & CLASS 3 AND CLASS 4 SUS \\
\hline
\end{tabular}

The five DVS sample locations in the Class 3 SU were biased sampled. Class 3 SU sample locations are shown on Fig. G.3 and summarized below.

\begin{tabular}{clc}
\hline EU & \multicolumn{1}{c}{ DVS sample locations } & Historical sample locations \\
\hline Z2-34 & Biased locations: & None \\
& Z2-EU34B-301, Z2-EU34B-302, Z2-EU34B-303, & \\
& Z2-EU34B-304, Z2-EU34B-305 & \\
\hline
\end{tabular}

DVS $=$ Dynamic Verification Strategy

$\mathrm{EU}=$ exposure unit

Sampling and analytical details for each sample location are presented in Table G.2. The analytical data are summarized in Table G.3 and evaluated in Sect. 2.2.5. The number of analyses conducted in the Class $3 \mathrm{SU}$ is presented below by analyte group. 


\begin{tabular}{lcccc}
\hline Metals & PCBs & Radionuclides & SVOCs & VOCs \\
\hline 4 & 3 & 3 & 3 & 1 \\
\hline PCB $=$ polychlorinated biphenyl & & & \\
SVOC = semivolatile organic & & & \\
VOC = volatile organic & & &
\end{tabular}

\section{\begin{tabular}{l|l} 
2.2.4 & INFRASTRUCTURE \\
\hline
\end{tabular}}

A soil sample location was identified during DQO scoping adjacent to the storm drain at the southeast corner of the former K-1001 building. The sample location is tabulated with the other DVS sample locations in Sect. 2.2.3 and the analytical data are evaluated below in Sect. 2.2.5.

\section{\begin{tabular}{|l|l|}
\hline 2.2.5 & EU EVALUATION \\
\hline
\end{tabular}}

Characterization data and other information are evaluated for EU Z2-34 in this section. The analytical data in the following summaries are presented by analyte group. Results for a particular analyte group are summarized only if that group was analyzed in the samples from the unit being summarized. Within each summary, the data are evaluated by comparing to certain criteria that include the Zone 2 soils maximum remediation level (Max RL), Zone 2 soils average remediation level (Avg RL), $1 \times 10^{-5}$ industrial preliminary remediation goal (Ind PRG), ETTP soils background composition (Bkg), Zone 2 groundwater screening levels (GW SL), and $1 \times 10^{-6}$ residential preliminary remediation goal (Res PRG). If a particular criterion does not apply to any member of an analyte group, it is not tabulated for that analyte group; if a particular criterion does not apply to all analytes within an analyte group, those analytes to which it does not apply are notated with not applicable (NA). Individual netals and radionuclides, which are naturally occurring, are reported in the summaries only if one or more criterion is exceeded. Organic chemicals, which are not naturally occurring, are reported if detected, even if no criteria are exceeded. The Max RL, Avg RL, Ind PRG, Bkg, GW SL, and Res PRG criteria values, as they pertain to the analytes listed in Appendix A of the RDR/RAWP (i.e., Quality Assurance Project Plan), are presented in Table G.4 of this PCCR.

Because the carcinogenic risk associated with the concentrations of radium and thorium isotopes in the natural background at ETTP exceeds the cumulative risk goal of $1 \times 10^{-4}$, RL values for these radionuclides are based on alternative concentration levels rather than risk. The alternative concentration levels of $5 \mathrm{pCi} / \mathrm{g}$ above background (Avg RL) and $15 \mathrm{pCi} / \mathrm{g}$ above background (Max RL) were set as low a reasonably achievable under the site-specific conditions. Because site-specific background concentrations of these radionuclides exceed the target risk range, residual concentrations of these radionuclides and their decay series are not considered in estimates of residual risk following any remedial actions.

The Zone 2 ROD states that Avg and Max RL exceedances by Ra-226, Th-230, and Th-232 will be evaluated by summing above-background concentrations of the greater of Ra-226 or Th-230 with the above-background concentrations of Th-232, and comparing the results to $5 \mathrm{pCi} / \mathrm{g}$ (Avg RL) and $15 \mathrm{pCi} / \mathrm{g}$ (Max RL). These required calculations have been performed. Avg and Max RL exceedances for these radionuclides, if any, are reported in the TM data summaries below and in Table G.2 as "Ra/Th decay series", and individual RL exceedances by Ra-226, Th-230, and Th-232 are reported as NA. The Ra/Th decay series data are summarized in following sections only if an Avg or Max RL has been exceeded, consistent with the description in the preceding paragraph for reporting radionuclides. Discussion of the $\mathrm{Ra} / \mathrm{Th}$ decay series calculation, including the manner in which the calculation is performed, is presented in Sect. 3.3 of this PCCR.

\section{EU Z2-34 Conceptual Site Model (CSM)}

All acreage in EU Z2-34 is classified as a single Class 3 SU. The area was used for a portion of the administrative complex, including office buildings, parking lots, and office trailers. Any contamination in the EU would have been very small volume surface releases to soils. There were no waste handling or storage facilities in the area, no subsurface burial sites in the EU, and no Class 2 infrastructure in the EU (laboratory drain lines are west of the western EU boundary). The CSM supporting the Class 3 SU classification concludes there is a high probability of no contamination in the area. Facility records, visual inspections, field measurements, and selected biased sampling support and confirm the Class 3 SU classification for EU Z2-34. 


\section{EU Z2-34 Groundwater Evaluation}

The two groundwater monitoring wells in EU Z2-34, BRW-113 and BRW-114, are located in the north portion of the EU. These two wells were installed in February 2004 as part of the site-wide remedial investigation program. Both wells are completed in the Chickamauga Bedrock formation at depths of $67-87 \mathrm{ft}$ and $32-42 \mathrm{ft} b g s$, respectively. Samples were collected from these wells in March 2004 after they were installed and developed. TCE was reported in BRW-113 at $6.3 \mathrm{ppb}$, and PCE was reported in both wells at 14 and $12 \mathrm{ppb}$, respectively. These results are greater than the TCE and PCE $5 \mathrm{mg} / \mathrm{L}$ maximum contaminant level (MCL) values. The bedrock is shallow and vapors from volatile organic compound (VOC)-contaminated groundwater could migrate into overlying soils .

No contaminated soil was identified within the EU Z2-34 boundary. However, there are several potential sources of PCE and TCE contamination to the north in EU Z2-33. There are six acid neutralization pits associated with the former K-1004 laboratory complex in EU Z2-33 that had very high levels of PCBs and VOCs at parts per thousand concentrations in accumulated sediments. Minor releases from these sumps may be the source of very low concentrations of dissolved phase TCE and PCE in the two wells. Biased samples will be obtained from these potential sources during EU Z2-33 DVS characterization.

Groundwater flow in the area is generally to the south/southwest, and the acid pits potential sources are upgradient from the two wells located in EU Z2-34. Facility records, visual inspections, and selected biased sampling have not identified a substantial mass of contaminated soil in EU Z2-34 that would pose a threat to local groundwater.

\section{EU Z2-34 Sampling Results}

EU Z2-34 lies at the southern extent of the industrialized part of ETTP Zone 2. The EU contains office buildings and associated infrastructure (parking lots, sidewalks) and several large grassy areas. The entire 13.2 acres have been classified a Class $3 \mathrm{SU}$. As a result, the entire EU was addressed by the Class $3 \mathrm{SU}$ walkover assessment. Twenty-one facilities were identified in this EU during DQO scoping and nine facilities were assessed during the Class $3 \mathrm{SU}$ walkover assessment. Twelve facilities had been removed by D\&D operations (mostly office trailers). No facility was identified for sampling. An accounting of facilities in this EU is presented in Table G.1. Other than facilities, a CA/RMA (anthropogenic feature) was identified during the Class $3 \mathrm{SU}$ walkover assessment and a biased sample location was selected. In addition, two sediment accumulation areas were identified for biased sampling, and the location used for the Class $3 \mathrm{SU}$ walkover assessment background radiation determination was also sampled. Finally, one biased sampling location, soil surrounding a storm drain at the southeast corner of the former K-1001 building, was identified during DQO scoping.

The following summarizes the sampling results for EU Z2-34, which begins with summary presentations of analytical results for the focused sampling efforts in the EU and concludes with an overall summary for EU Z2-34. The focused sampling efforts summarized below include the anthropogenic feature, sediment accumulation areas, Class $3 \mathrm{SU}$ walkover assessment background radiation location, and the storm drain at the former K-1001 building. The summary includes both data summary tables and a written description of the nature and extent of chemicals and radionuclides observed in the EU. A summary of all EU Z2-34 data is presented in Table G.3. EU-wide data are evaluated in terms of the Zone 2 ROD remedial action objective (RAO) in Sect. 3.3.

DVS Biased Sampling at the CA/RMA Anthropogenic Feature: Biased sample location Z2-EU34B-304 was identified at the CA/RMA anthropogenic feature during the Class 3 SU walkover assessment. Sampling and analytical details are presented in Table G.2. Analytical results summarized below show radionuclide Ind PRG and Bkg exceedances.

EU Z2-34 CA/RMA RADIONUCLIDES WITH BACKGROUND, PRG, AND/OR RL EXCEEDANCES (pCi/g)

\begin{tabular}{|c|c|c|c|c|c|c|c|c|c|c|c|}
\hline \multirow[b]{2}{*}{ Analyte } & \multirow[b]{2}{*}{$\begin{array}{c}\text { Detect } \\
\text { frequency }\end{array}$} & \multirow[b]{2}{*}{$\begin{array}{c}\text { Minimum } \\
\text { detect }\end{array}$} & \multirow[b]{2}{*}{$\begin{array}{c}\text { Maximum } \\
\text { detect }\end{array}$} & \multirow[b]{2}{*}{$\begin{array}{c}\text { Location(s) of } \\
\text { maximum detect }\end{array}$} & \multirow{2}{*}{$\begin{array}{c}\text { Average } \\
\text { detected } \\
\text { result }\end{array}$} & \multicolumn{6}{|c|}{ Number of analyses exceeding criteria } \\
\hline & & & & & & $\begin{array}{c}\text { Max } \\
\text { RL }\end{array}$ & $\begin{array}{l}\text { Avg } \\
\text { RL }\end{array}$ & $\begin{array}{l}\text { Ind } \\
\text { PRG }\end{array}$ & Bkg & $\begin{array}{l}\text { GW } \\
\text { SL }\end{array}$ & $\begin{array}{l}\text { Res } \\
\text { PRG }\end{array}$ \\
\hline Cesium-137 & $1 / 1$ & 0.233 & 0.233 & Z2-EU34B-304 & 0.233 & 0 & 0 & 0 & NA & NA & 1 \\
\hline Potassium- 40 & $1 / 1$ & 5.6 & 5.6 & Z2-EU34B-304 & 5.6 & NA & NA & 1 & 0 & NA & 1 \\
\hline Radium-226 & $1 / 1$ & 0.85 & 0.85 & Z2-EU34B-304 & 0.85 & NA & NA & 1 & 0 & NA & 1 \\
\hline Thorium -228 & $1 / 1$ & 1.21 & 1.21 & Z2-EU34B-304 & 1.21 & NA & NA & 1 & 0 & NA & 1 \\
\hline Thorium -230 & $1 / 1$ & 1.55 & 1.55 & Z2-EU34B-304 & 1.55 & NA & NA & 0 & 1 & NA & 0 \\
\hline
\end{tabular}


EU Z2-34 CA/RMA RADIONUCLIDES WITH BACKGROUND, PRG, AND/OR RL EXCEEDANCES (pCi/g) (continued)

\begin{tabular}{|c|c|c|c|c|c|c|c|c|c|c|c|}
\hline \multirow[b]{2}{*}{ Analyte } & \multirow[b]{2}{*}{$\begin{array}{c}\text { Detect } \\
\text { frequency }\end{array}$} & \multirow[b]{2}{*}{$\begin{array}{c}\text { Minimum } \\
\text { detect }\end{array}$} & \multirow[b]{2}{*}{$\begin{array}{c}\text { Maximum } \\
\text { detect }\end{array}$} & \multirow[b]{2}{*}{$\begin{array}{c}\text { Location(s) of } \\
\text { maximum detect }\end{array}$} & \multirow{2}{*}{$\begin{array}{c}\text { Average } \\
\text { detected } \\
\text { result }\end{array}$} & \multicolumn{6}{|c|}{ Number of analyses exceeding criteria } \\
\hline & & & & & & $\begin{array}{c}\text { Max } \\
\text { RL }\end{array}$ & $\begin{array}{c}\text { Avg } \\
\text { RL }\end{array}$ & $\begin{array}{c}\text { Ind } \\
\text { PRG }\end{array}$ & Bkg & $\begin{array}{l}\text { GW } \\
\text { SL }\end{array}$ & $\begin{array}{l}\text { Res } \\
\text { PRG }\end{array}$ \\
\hline Thorium -232 & $1 / 1$ & 1.04 & 1.04 & Z2-EU34B-304 & 1.04 & NA & NA & 1 & 0 & NA & 1 \\
\hline Uranium-238 & $1 / 1$ & 1.31 & 1.31 & Z2-EU34B-304 & 1.31 & 0 & 0 & 0 & 0 & 0 & 1 \\
\hline \multicolumn{3}{|l|}{$\overline{\text { Avg }=\text { average }}$} & \multicolumn{9}{|c|}{ NA = not applicable } \\
\hline \multicolumn{3}{|c|}{$\mathrm{Bkg}=$ background } & \multicolumn{9}{|c|}{$\mathrm{PRG}=$ preliminary remediation goal } \\
\hline \multicolumn{3}{|c|}{$\mathrm{CA}=$ Contamination Area } & \multicolumn{9}{|c|}{ Res $=$ residential } \\
\hline \multicolumn{3}{|c|}{ EU $=$ exposure unit } & \multicolumn{9}{|c|}{$\mathrm{RL}=$ remediation level } \\
\hline \multicolumn{3}{|c|}{$\mathrm{GW}=$ groundwater } & \multicolumn{9}{|c|}{ RMA $=$ Radioactive Material Area } \\
\hline \multicolumn{3}{|c|}{ Ind = industrial } & \multicolumn{9}{|c|}{$\mathrm{SL}=$ screening level } \\
\hline
\end{tabular}

DVS Sediment Accumulation Areas Biased Samples: There are two DVS biased sample locations in sediment the accumulation areas. Sample Z2-EU34B-303 is located in the sediment accumulation area near Assembly Area 2 and sample Z2-EU34B-305 is located in the sediment accumulation area at he loading dock of the former K-1001 building. Sampling and analytical details are presented in Table G.2. Analytical results summarized below show metal Bkg exceedances and several SVOC detections.

EU Z2-34 SEDIMENT ACCUMULATION AREAS METALS WITH BACKGROUND, PRG, GW SL, AND/OR RL EXCEEDANCES (mg/kg)

\begin{tabular}{|c|c|c|c|c|c|c|c|c|c|c|c|}
\hline \multirow[b]{2}{*}{ Analyte } & \multirow[b]{2}{*}{$\begin{array}{c}\text { Detect } \\
\text { frequency }\end{array}$} & \multirow[b]{2}{*}{$\underset{\text { detect }}{\text { Minimum }}$} & \multirow[b]{2}{*}{$\begin{array}{c}\text { Maximum } \\
\text { detect }\end{array}$} & \multirow{2}{*}{$\begin{array}{l}\text { Location(s) of } \\
\text { maximum } \\
\text { detect }\end{array}$} & \multirow{2}{*}{$\begin{array}{c}\text { Average } \\
\text { detected } \\
\text { result }\end{array}$} & \multicolumn{6}{|c|}{ Number of analyses exceeding criteria } \\
\hline & & & & & & $\begin{array}{c}\text { Max } \\
\text { RL }\end{array}$ & $\begin{array}{l}\text { Avg } \\
\text { RL } \\
\end{array}$ & $\begin{array}{l}\text { Ind } \\
\text { PRG }\end{array}$ & Bkg & $\begin{array}{c}\text { GW } \\
\text { SL }\end{array}$ & $\begin{array}{c}\text { Res } \\
\text { PRG }\end{array}$ \\
\hline Aluminum & $2 / 2$ & $9,040 \mathrm{~J}$ & $11,100 \mathrm{~J}$ & Z2-EU34B-303 & 10,070 & $\mathrm{NA}$ & NA & 0 & 0 & NA & 2 \\
\hline Arsenic & $2 / 2$ & $3.1 \mathrm{~J}$ & $6.5 \mathrm{~J}$ & Z2-EU34B-303 & 4.8 & 0 & 0 & 0 & 0 & 0 & 2 \\
\hline Calcium & $2 / 2$ & $1,670 \mathrm{~J}$ & $14,000 \mathrm{~J}$ & Z2-EU34B-303 & 7,835 & NA & NA & NA & 1 & NA & NA \\
\hline Magnesium & $2 / 2$ & $673 \mathrm{~J}$ & $7,190 \mathrm{~J}$ & Z2-EU34B-303 & 3,932 & NA & NA & NA & 1 & NA & NA \\
\hline Manganese & $2 / 2$ & 1,010 & 1,710 & Z2-EU34B-303 & 1,360 & NA & NA & 0 & 0 & NA & 2 \\
\hline Vanadium & $2 / 2$ & $16.9 \mathrm{~J}$ & $26.1 \mathrm{~J}$ & Z2-EU34B-303 & 21.5 & NA & NA & 0 & 0 & NA & 2 \\
\hline $\begin{array}{l}\text { Avg = averag } \\
\mathrm{Bkg}=\text { backg } \\
\mathrm{EU}=\text { exposur } \\
\mathrm{GW}=\text { grounc } \\
\text { Ind = industr } \\
\mathrm{Max}=\text { maxim }\end{array}$ & $\begin{array}{l}\text { und } \\
\text { un it } \\
\text { vater } \\
\text { ll } \\
\text { im }\end{array}$ & & $\begin{array}{l}\text { NA }=\text { not } \\
\text { PRG = pre } \\
\text { Res = resi } \\
\text { RL = reme } \\
\text { SL }=\text { scree }\end{array}$ & $\begin{array}{l}\text { applicable } \\
\text { liminary remediat } \\
\text { dential } \\
\text { ediation level } \\
\text { ning level }\end{array}$ & tion goal & & & & & & \\
\hline
\end{tabular}

PCBs were analyzed for in both samples but were not detected.

EU Z2-34 SEDIMENT ACCUMULATION AREASSVOC DETECTS (ug/kg)

\begin{tabular}{|c|c|c|c|c|c|c|c|c|}
\hline \multirow[b]{2}{*}{ Analyte } & \multirow[b]{2}{*}{$\begin{array}{l}\text { Detect } \\
\text { frequency }\end{array}$} & \multirow[b]{2}{*}{$\begin{array}{c}\text { Minimum } \\
\text { detect }\end{array}$} & \multirow[b]{2}{*}{$\begin{array}{l}\text { Maximum } \\
\text { detect }\end{array}$} & \multirow[b]{2}{*}{$\begin{array}{l}\text { Location(s) of } \\
\text { maximum detect }\end{array}$} & \multirow{2}{*}{$\begin{array}{c}\text { Average } \\
\text { detected } \\
\text { result }\end{array}$} & \multicolumn{3}{|c|}{$\begin{array}{l}\text { Number of analyses } \\
\text { exceeding criteria }\end{array}$} \\
\hline & & & & & & $\begin{array}{l}\text { Ind } \\
\text { PRG }\end{array}$ & $\begin{array}{l}\text { GW } \\
\text { SL }\end{array}$ & $\begin{array}{l}\text { Res } \\
\text { PRG }\end{array}$ \\
\hline Benz(a)anthracene & $2 / 2$ & $56 \mathrm{~J}$ & $59 \mathrm{~J}$ & Z2-EU34B-303 & 57.5 & 0 & NA & 0 \\
\hline Benzo(a)pyrene & $2 / 2$ & $56 \mathrm{~J}$ & $60 \mathrm{~J}$ & Z2-EU34B-305 & 58 & 0 & NA & 0 \\
\hline Benzo(b)fluoranthene & $2 / 2$ & $49 \mathrm{~J}$ & $55 \mathrm{~J}$ & Z2-EU34B-305 & 52 & 0 & NA & 0 \\
\hline Benzo(ghi)perylene & $2 / 2$ & $37 \mathrm{~J}$ & $45 \mathrm{~J}$ & Z2-EU34B-305 & 41 & 0 & NA & 0 \\
\hline Benzo(k)fluoranthene & $2 / 2$ & $55 \mathrm{~J}$ & $59 \mathrm{~J}$ & Z2-EU34B-303 & 57 & 0 & NA & 0 \\
\hline Chrysene & $2 / 2$ & $60 \mathrm{~J}$ & $61 \mathrm{~J}$ & Z2-EU34B-303 & 60.5 & 0 & NA & 0 \\
\hline Fluoranthene & $2 / 2$ & $98 \mathrm{~J}$ & $110 \mathrm{~J}$ & Z2-EU34B-303 & 104 & 0 & NA & 0 \\
\hline
\end{tabular}




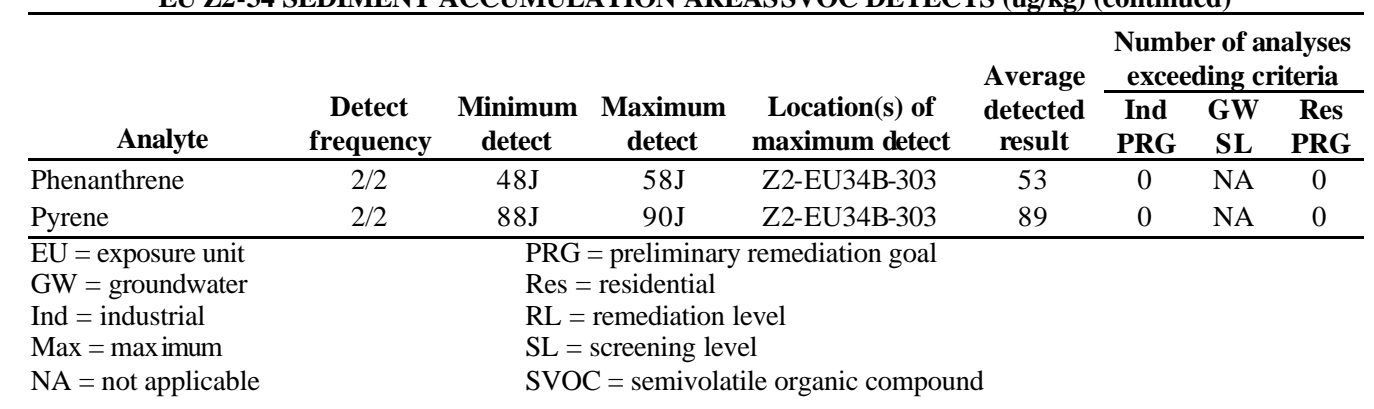

DVS Biased Sampling at the Radiological Background Location: Soil sample location Z2-EU34B-302 was identified during field work at the location used to determine the Class 3 SU walkover assessment radiological background. Sampling and analytical details are presented in Table G.2. Analytical results summarized below show radionuclide Ind PRG exceedances and metal and radionuclide Bkg exceedances.

EU Z2-34 BACKGROUND LOCATION METALS WITH BACKGROUND, PRG, GW SL, AND/OR RL EXCEEDANCES (mg/kg)

\begin{tabular}{|c|c|c|c|c|c|c|c|c|c|c|c|}
\hline \multirow[b]{2}{*}{ Analyte } & \multirow[b]{2}{*}{$\begin{array}{c}\text { Detect } \\
\text { frequency }\end{array}$} & \multirow[b]{2}{*}{$\begin{array}{c}\text { Minimum } \\
\text { detect }\end{array}$} & \multirow[b]{2}{*}{$\begin{array}{c}\text { Maximum } \\
\text { detect }\end{array}$} & \multirow[b]{2}{*}{$\begin{array}{c}\text { Location(s) of } \\
\text { maximum detect }\end{array}$} & \multirow{2}{*}{$\begin{array}{c}\text { Average } \\
\text { detected } \\
\text { result }\end{array}$} & \multicolumn{6}{|c|}{ Number of analyses exceeding criteria } \\
\hline & & & & & & $\begin{array}{c}\text { Max } \\
\text { RL }\end{array}$ & $\begin{array}{l}\text { Avg } \\
\text { RL }\end{array}$ & $\begin{array}{c}\text { Ind } \\
\text { PRG }\end{array}$ & Bkg & $\begin{array}{c}\text { GW } \\
\text { SL }\end{array}$ & $\begin{array}{c}\text { Res } \\
\text { PRG }\end{array}$ \\
\hline$\overline{\text { Aluminum }}$ & $1 / 1$ & $11,200 \mathrm{~J}$ & $11,200 \mathrm{~J}$ & Z2-EU34B-302 & 11,200 & NA & NA & 0 & 0 & NA & 1 \\
\hline Arsenic & $1 / 1$ & $6.1 \mathrm{~J}$ & $6.1 \mathrm{~J}$ & Z2-EU34B-302 & 6.1 & 0 & 0 & 0 & 0 & 0 & 1 \\
\hline Calcium & $1 / 1$ & $10,400 \mathrm{~J}$ & $10,400 \mathrm{~J}$ & Z2-EU34B-302 & 10,400 & NA & NA & NA & 1 & NA & NA \\
\hline Lead & $1 / 1$ & $41.9 \mathrm{~J}$ & $41.9 \mathrm{~J}$ & Z2-EU34B-302 & 41.9 & NA & NA & 0 & 1 & 0 & 0 \\
\hline Magnesium & $1 / 1$ & $5,150 \mathrm{~J}$ & $5,150 \mathrm{~J}$ & Z2-EU34B-302 & 5,150 & NA & NA & NA & 1 & NA & NA \\
\hline Manganese & $1 / 1$ & 1,490 & 1,490 & Z2-EU34B-302 & 1,490 & NA & NA & 0 & 0 & NA & 1 \\
\hline Nickel & $1 / 1$ & 27.9 & 27.9 & Z2-EU34B-302 & 27.9 & NA & NA & 0 & 1 & NA & 0 \\
\hline Uranium & $1 / 1$ & 1.9 & 1.9 & Z2-EU34B-302 & 1.9 & NA & NA & 0 & NA & NA & 1 \\
\hline Vanadium & $1 / 1$ & $25.1 \mathrm{~J}$ & $25.1 \mathrm{~J}$ & Z2-EU34B-302 & 25.1 & NA & NA & 0 & 0 & NA & 1 \\
\hline \multicolumn{3}{|c|}{$\overline{\mathrm{Avg}}=$ average } & $\mathrm{NA}=1$ & applicable & & & & & & & \\
\hline \multicolumn{3}{|c|}{$\mathrm{Bkg}=$ background } & $\mathrm{PRG}=\mathrm{p}$ & oreliminary remedia & tion goal & & & & & & \\
\hline \multicolumn{3}{|c|}{$\mathrm{EU}=$ exposure unit } & Res $=$ re & sidential & & & & & & & \\
\hline \multicolumn{3}{|c|}{$\mathrm{GW}=$ groundwater } & $\mathrm{RL}=\mathrm{re}$ & mediation level & & & & & & & \\
\hline \multicolumn{3}{|c|}{ Ind $=$ industrial } & $\mathrm{SL}=\mathrm{scl}$ & reening level & & & & & & & \\
\hline \multicolumn{3}{|c|}{ Max = maximum } & & & & & & & & & \\
\hline
\end{tabular}

EU Z2-34 BACKGROUND LOCATION RADIONUCLIDES WITH BACKGROUND, PRG, AND/OR RL EXCEEDANCES (pCi/g)

\begin{tabular}{|c|c|c|c|c|c|c|c|c|c|c|c|}
\hline \multirow[b]{2}{*}{ Analyte } & \multirow[b]{2}{*}{$\begin{array}{l}\text { Detect } \\
\text { frequency }\end{array}$} & \multirow[b]{2}{*}{$\begin{array}{c}\text { Minimum } \\
\text { detect }\end{array}$} & \multirow[b]{2}{*}{$\begin{array}{c}\text { Maximum } \\
\text { detect }\end{array}$} & \multirow[b]{2}{*}{$\begin{array}{l}\text { Location(s) of } \\
\text { maximum detect }\end{array}$} & \multirow{2}{*}{$\begin{array}{c}\text { Average } \\
\text { detected } \\
\text { result }\end{array}$} & \multicolumn{6}{|c|}{ Number of analyses exceeding criteria } \\
\hline & & & & & & $\begin{array}{c}\text { Max } \\
\text { RL }\end{array}$ & $\begin{array}{l}\text { Avg } \\
\text { RL }\end{array}$ & $\begin{array}{l}\text { Ind } \\
\text { PRG }\end{array}$ & Bkg & $\begin{array}{l}\text { GW } \\
\text { SL }\end{array}$ & $\begin{array}{c}\text { Res } \\
\text { PRG }\end{array}$ \\
\hline Cesium-137 & $1 / 1$ & 0.162 & 0.162 & Z2-EU34B-302 & 0.162 & 0 & 0 & 0 & NA & NA & 1 \\
\hline Potassium-40 & $1 / 1$ & 17.4 & 17.4 & Z2-EU34B-302 & 17.4 & NA & NA & 1 & 0 & NA & 1 \\
\hline Radium-226 & $1 / 1$ & 0.9 & 0.9 & Z2-EU34B-302 & 0.9 & NA & NA & 1 & 0 & NA & 1 \\
\hline Technetium-99 & $1 / 1$ & 1.26 & 1.26 & Z2-EU34B-302 & 1.26 & NA & NA & 0 & NA & NA & 1 \\
\hline Thorium -228 & $1 / 1$ & 1.39 & 1.39 & Z2-EU34B-302 & 1.39 & NA & NA & 1 & 0 & NA & 1 \\
\hline Thorium -230 & $1 / 1$ & 1.47 & 1.47 & Z2-EU34B-302 & 1.47 & NA & NA & 0 & 1 & NA & 0 \\
\hline Thorium -232 & $1 / 1$ & 1.51 & 1.51 & Z2-EU34B-302 & 1.51 & NA & NA & 1 & 0 & NA & 1 \\
\hline Uranium-235 & $1 / 1$ & 0.24 & 0.24 & Z2-EU34B-302 & 0.24 & 0 & 0 & 0 & NA & 0 & 1 \\
\hline Uranium-238 & $1 / 1$ & 2.4 & 2.4 & Z2-EU34B-302 & 2.4 & 0 & 0 & 0 & 1 & 0 & 1 \\
\hline $\begin{array}{l}\text { Avg = average } \\
\text { Bkg = background } \\
\text { EU = exposure unit } \\
\text { GW = groundwater } \\
\text { Ind = industrial } \\
\text { Max = maximum }\end{array}$ & & $\begin{array}{l}\mathrm{N} \\
\mathrm{F} \\
\mathrm{F} \\
\mathrm{F} \\
\mathrm{S}\end{array}$ & $\begin{array}{l}\text { NA }=\text { not app } \\
\text { PRG }=\text { prelim } \\
\text { Res }=\text { residen } \\
\text { RL }=\text { remedia } \\
\text { SL }=\text { screenin }\end{array}$ & $\begin{array}{l}\text { licable } \\
\text { ninary remediation } \\
\text { tial } \\
\text { ation level } \\
\text { ag level }\end{array}$ & soal & & & & & & \\
\hline
\end{tabular}


and analytical details are presented in Table G.2. Analytical results summarized below show radionuclide Ind PRG exceedances and metal and radionuclide Bkg exceedances.

EU Z2-34 K-1001 STORM DRAIN LOCATION METALS WITH BACKGROUND, PRG, GW SL, AND/OR RL EXCEEDANCES (mg/kg)

\begin{tabular}{|c|c|c|c|c|c|c|c|c|c|c|c|}
\hline \multirow[b]{2}{*}{ Analyte } & \multirow[b]{2}{*}{$\begin{array}{c}\text { Detect } \\
\text { frequency }\end{array}$} & \multirow[b]{2}{*}{$\begin{array}{c}\text { Minimum } \\
\text { detect }\end{array}$} & \multirow[b]{2}{*}{$\begin{array}{c}\text { Maximum } \\
\text { detect }\end{array}$} & \multirow{2}{*}{$\begin{array}{c}\text { Location(s) of } \\
\text { maximum } \\
\text { detect }\end{array}$} & \multirow{2}{*}{$\begin{array}{c}\text { Average } \\
\text { detected } \\
\text { result }\end{array}$} & \multicolumn{6}{|c|}{ Number of analyses exceeding criteria } \\
\hline & & & & & & $\begin{array}{c}\text { Max } \\
\text { RL } \\
\end{array}$ & $\begin{array}{c}\text { Avg } \\
\text { RL }\end{array}$ & $\begin{array}{c}\text { Ind } \\
\text { PRG } \\
\end{array}$ & Bkg & $\begin{array}{c}\text { GW } \\
\text { SL } \\
\end{array}$ & $\begin{array}{c}\text { Res } \\
\text { PRG } \\
\end{array}$ \\
\hline Aluminum & $1 / 1$ & $13,300 \mathrm{~J}$ & $13,300 \mathrm{~J}$ & Z2-EU34B-301 & 13,300 & NA & NA & 0 & 0 & NA & 1 \\
\hline Arsenic & $1 / 1$ & $4.3 \mathrm{~J}$ & $4.3 \mathrm{~J}$ & Z2-EU34B-301 & 4.3 & 0 & 0 & 0 & 0 & 0 & 1 \\
\hline Calcium & $1 / 1$ & $9,150 \mathrm{~J}$ & $9,150 \mathrm{~J}$ & Z2-EU34B-301 & 9,150 & NA & NA & NA & 1 & NA & NA \\
\hline Manganese & $1 / 1$ & 1,470 & 1,470 & Z2-EU34B-301 & 1,470 & NA & NA & 0 & 0 & NA & 1 \\
\hline Nickel & $1 / 1$ & 27.5 & 27.5 & Z2-EU34B-301 & 27.5 & NA & NA & 0 & 1 & NA & 0 \\
\hline Vanadium & $1 / 1$ & $23 \mathrm{~J}$ & $23 \mathrm{~J}$ & Z2-EU34B-301 & 23 & NA & NA & 0 & 0 & NA & 1 \\
\hline \multicolumn{3}{|c|}{ Avg = average } & \multicolumn{3}{|c|}{$\mathrm{NA}=$ not applicable } & & & & & & \\
\hline \multicolumn{3}{|c|}{$\mathrm{Bkg}=$ background } & \multicolumn{3}{|c|}{$\mathrm{PRG}=$ preliminary remediation goal } & & & & & & \\
\hline \multicolumn{3}{|c|}{$\mathrm{EU}=$ exposure unit } & \multicolumn{3}{|c|}{ Res $=$ residential } & & & & & & \\
\hline \multicolumn{3}{|c|}{$\mathrm{GW}=$ groundwater } & \multicolumn{3}{|c|}{$\mathrm{RL}=$ remediation level } & & & & & & \\
\hline \multicolumn{3}{|c|}{ Ind = industrial } & $\mathrm{SL}=$ scree & ning level & & & & & & & \\
\hline
\end{tabular}

PCBs were analyzed for but were not detected.

EU Z2-34 K-1001 STORM DRAIN LOCATION RADIONUCLIDES WITH BACKGROUND, PRG, AND/OR RL EXCEEDANCES (pCi/g)

\begin{tabular}{|c|c|c|c|c|c|c|c|c|c|c|c|}
\hline \multirow[b]{2}{*}{ Analyte } & \multirow[b]{2}{*}{$\begin{array}{c}\text { Detect } \\
\text { frequency }\end{array}$} & \multirow[b]{2}{*}{$\begin{array}{c}\text { Minimum } \\
\text { detect }\end{array}$} & \multirow[b]{2}{*}{$\begin{array}{l}\text { Maximum } \\
\text { detect }\end{array}$} & \multirow[b]{2}{*}{$\begin{array}{c}\text { Location(s) of } \\
\text { maximum detect }\end{array}$} & \multirow{2}{*}{$\begin{array}{c}\text { Average } \\
\text { detected } \\
\text { result }\end{array}$} & \multicolumn{6}{|c|}{ Number of analyses exceeding criteria } \\
\hline & & & & & & $\underset{\text { RL }}{\text { Max }}$ & $\begin{array}{l}\text { Avg } \\
\text { RL }\end{array}$ & $\begin{array}{c}\text { Ind } \\
\text { PRG }\end{array}$ & Bkg & $\begin{array}{l}\text { GW } \\
\text { SL }\end{array}$ & $\begin{array}{c}\text { Res } \\
\text { PRG }\end{array}$ \\
\hline Potassium-40 & $1 / 1$ & 21 & 21 & Z2-EU34B-301 & 21 & NA & NA & 1 & 0 & NA & 1 \\
\hline Radium-226 & $1 / 1$ & 1.33 & 1.33 & Z2-EU34B-301 & 1.33 & NA & NA & 1 & 1 & NA & 1 \\
\hline Thorium -228 & $1 / 1$ & 1.52 & 1.52 & Z2-EU34B-301 & 1.52 & NA & NA & 1 & 0 & NA & 1 \\
\hline Thorium -230 & $1 / 1$ & 1.23 & 1.23 & Z2-EU34B-301 & 1.23 & NA & NA & 0 & 1 & NA & 0 \\
\hline Thorium -232 & $1 / 1$ & 1.53 & 1.53 & Z2-EU34B-301 & 1.53 & NA & NA & 1 & 0 & NA & 1 \\
\hline Uranium-238 & $1 / 1$ & 1.04 & 1.04 & Z2-EU34B-301 & 1.04 & 0 & 0 & 0 & 0 & 0 & 1 \\
\hline Avg = average & \multicolumn{11}{|c|}{ NA $=$ not applicable } \\
\hline $\mathrm{Bkg}=$ background & \multicolumn{11}{|c|}{$\mathrm{PRG}=$ preliminary remediation goal } \\
\hline $\mathrm{EU}=$ exposure unit & \multicolumn{11}{|c|}{ Res $=$ residential } \\
\hline $\mathrm{GW}=$ groundwater & \multicolumn{11}{|c|}{$\mathrm{RL}=$ remediation level } \\
\hline Ind $=$ industrial & \multirow{2}{*}{\multicolumn{11}{|c|}{$\mathrm{SL}=$ screening level }} \\
\hline Max $=$ maximum & & & & & & & & & & & \\
\hline
\end{tabular}

SVOCs and VOCs were analyzed for but were not detected.

EU Z2-34 Summary: The entire EU is a Class 3 SU. Therefore, the whole EU was addressed by a Class 3 SU walkover assessment. One anthropogenic feature, a CA/RMA, and two sediment accumulation areas were identified during the assessment and selected for DVS biased sampling. Nine facilities were assessed but none were selected for sampling. In addition, the location used to determine radiation background was also selected for biased sampling. Soil surrounding the storm drain at the southeast corner of the former K-1001 building was identified as a Class 3 SU DVS biased sample location during DQO scoping. There were no historical sample locations in EU Z2-34.

This section presents a summary of the nature and extent of contamination by combining all analytical data presented in the focused investigation summaries above. There were five sample locations in this EU. The details of sampling and analysis are presented in Table G.2. Analytical results for all samples summarized below show radionuclide Ind PRG exceedances, metal and radionuclide Bkg exceedances, and detections of SVOCs. 
EU Z2-34 METALS WITH BACKGROUND, PRG, GW SL, AND/OR RL EXCEEDANCES (mg/kg)

\begin{tabular}{|c|c|c|c|c|c|c|c|c|c|c|c|}
\hline \multirow[b]{2}{*}{ Analyte } & \multirow[b]{2}{*}{$\begin{array}{c}\text { Detect } \\
\text { frequency }\end{array}$} & \multirow[b]{2}{*}{$\begin{array}{c}\text { Minimum } \\
\text { detect }\end{array}$} & \multirow[b]{2}{*}{$\begin{array}{c}\text { Maximum } \\
\text { detect }\end{array}$} & \multirow[b]{2}{*}{$\begin{array}{l}\text { Location(s) of } \\
\text { maximum detect }\end{array}$} & \multirow{2}{*}{$\begin{array}{c}\text { Average } \\
\text { detected } \\
\text { result }\end{array}$} & \multicolumn{6}{|c|}{ Number of analyses exceeding criteria } \\
\hline & & & & & & $\begin{array}{c}\text { Max } \\
\text { RL }\end{array}$ & $\begin{array}{c}\text { Avg } \\
\text { RL }\end{array}$ & $\begin{array}{l}\text { Ind } \\
\text { PRG }\end{array}$ & Bkg & $\begin{array}{c}\text { GW } \\
\text { SL }\end{array}$ & $\begin{array}{r}\text { Res } \\
\text { PRG }\end{array}$ \\
\hline Aluminum & $4 / 4$ & $9,040 \mathrm{~J}$ & $13,300 \mathrm{~J}$ & Z2-EU34B-301 & 11,160 & NA & NA & 0 & 0 & NA & 4 \\
\hline Arsenic & $4 / 4$ & $3.1 \mathrm{~J}$ & $6.5 \mathrm{~J}$ & Z2-EU34B-303 & 5 & 0 & 0 & 0 & 0 & 0 & 4 \\
\hline Calcium & $4 / 4$ & $1,670 \mathrm{~J}$ & $14,000 \mathrm{~J}$ & Z2-EU34B-303 & 8,805 & NA & NA & NA & 3 & NA & NA \\
\hline Lead & $4 / 4$ & $17.4 \mathrm{~J}$ & $41.9 \mathrm{~J}$ & Z2-EU34B-302 & 32.7 & NA & NA & 0 & 1 & 0 & 0 \\
\hline Magnesium & $4 / 4$ & $673 \mathrm{~J}$ & $7,190 \mathrm{~J}$ & Z2-EU34B-303 & 3,786 & NA & NA & NA & 2 & NA & NA \\
\hline Manganese & $4 / 4$ & 1,010 & 1,710 & Z2-EU34B-303 & 1,420 & NA & NA & 0 & 0 & NA & 4 \\
\hline Nickel & $4 / 4$ & 6.3 & 27.9 & Z2-EU34B-302 & 18.4 & NA & NA & 0 & 2 & NA & 0 \\
\hline Uranium & $4 / 4$ & 0.59 & 1.9 & Z2-EU34B-302 & 1.15 & NA & NA & 0 & NA & NA & 1 \\
\hline Vanadium & $4 / 4$ & $16.9 \mathrm{~J}$ & $26.1 \mathrm{~J}$ & Z2-EU34B-303 & 22.8 & NA & NA & 0 & 0 & NA & 4 \\
\hline
\end{tabular}

Avg = average NA $=$ not applicable

$\mathrm{Bkg}=$ background $\quad \mathrm{PRG}=$ preliminary remediation goal

$\mathrm{EU}=$ exposure unit $\quad$ Res $=$ residential

$\mathrm{GW}=$ groundwater $\quad \mathrm{RL}=$ remediation level

Ind $=$ industrial $\quad \mathrm{SL}=$ screening level

Max = maximum

PCBs were analyzed for in three samples but were not detected.

EU Z2-34 RADIONUCLIDES WITH BACKGROUND, PRG, AND/OR RL EXCEEDANCES (pCi/g)

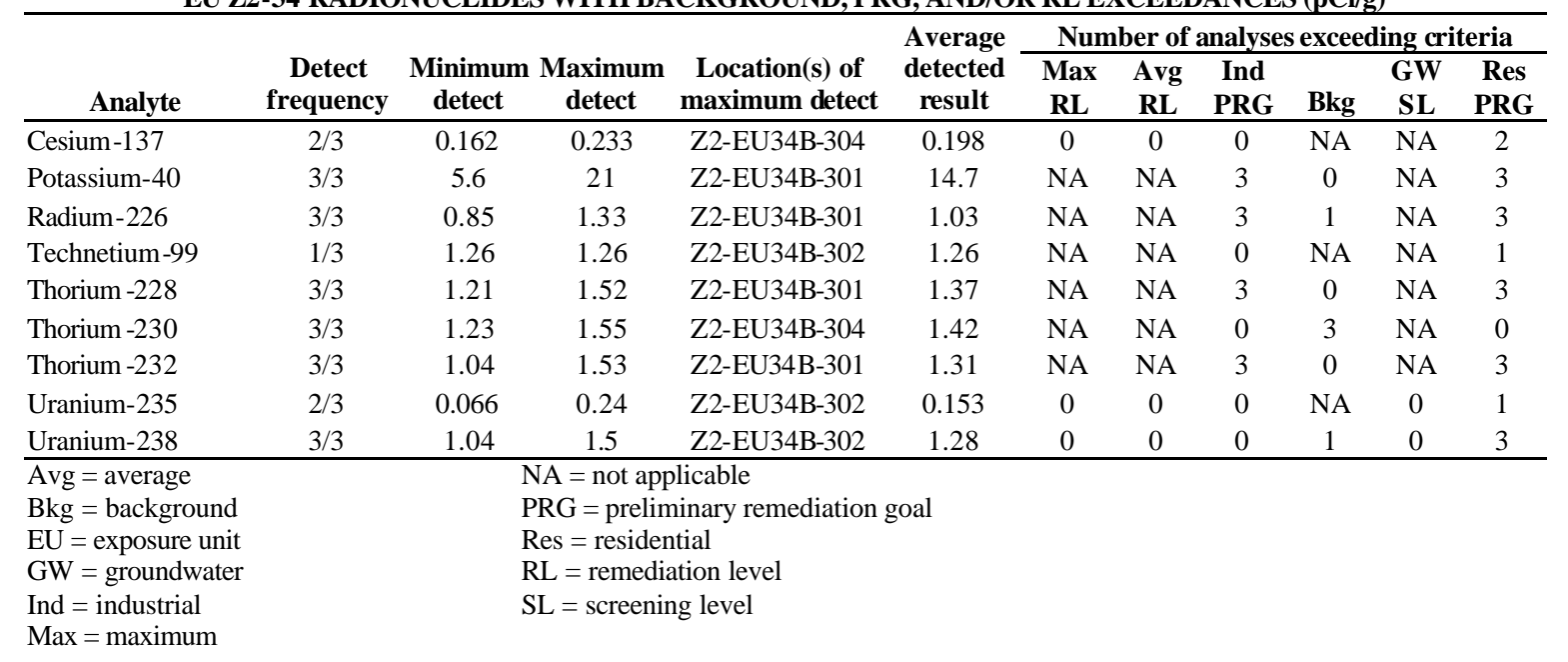

EU Z2-34 SVOC DETECTS (ug/kg)

\begin{tabular}{|c|c|c|c|c|c|c|c|c|}
\hline \multirow[b]{2}{*}{ Analyte } & \multirow[b]{2}{*}{$\begin{array}{c}\text { Detect } \\
\text { frequency }\end{array}$} & \multirow[b]{2}{*}{$\begin{array}{c}\text { Minimum } \\
\text { detect }\end{array}$} & \multirow[b]{2}{*}{$\begin{array}{c}\text { Maximum } \\
\text { detect }\end{array}$} & \multirow[b]{2}{*}{$\begin{array}{l}\text { Location(s) of } \\
\text { maximum detect }\end{array}$} & \multirow{2}{*}{$\begin{array}{c}\text { Average } \\
\text { detected } \\
\text { result }\end{array}$} & \multicolumn{3}{|c|}{$\begin{array}{c}\text { Number of analyses } \\
\text { exceeding criteria }\end{array}$} \\
\hline & & & & & & $\begin{array}{l}\text { Ind } \\
\text { PRG }\end{array}$ & $\begin{array}{l}\text { GW } \\
\text { SL }\end{array}$ & $\begin{array}{r}\text { Res } \\
\text { PRG }\end{array}$ \\
\hline Benz(a)anthracene & $2 / 3$ & $56 \mathrm{~J}$ & $59 \mathrm{~J}$ & Z2-EU34B-303 & 57.5 & 0 & NA & 0 \\
\hline Benzo(a)pyrene & $2 / 3$ & $56 \mathrm{~J}$ & $60 \mathrm{~J}$ & Z2-EU34B-305 & 58 & 0 & NA & 0 \\
\hline Benzo(b)fluoranthene & $2 / 3$ & $49 \mathrm{~J}$ & $55 \mathrm{~J}$ & Z2-EU34B-305 & 52 & 0 & NA & 0 \\
\hline Benzo(ghi)perylene & $2 / 3$ & $37 \mathrm{~J}$ & $45 \mathrm{~J}$ & Z2-EU34B-305 & 41 & 0 & NA & 0 \\
\hline Benzo(k)fluoranthene & $2 / 3$ & $55 \mathrm{~J}$ & $59 \mathrm{~J}$ & Z2-EU34B-303 & 57 & 0 & NA & 0 \\
\hline Chrysene & $2 / 3$ & $60 \mathrm{~J}$ & $61 \mathrm{~J}$ & Z2-EU34B-303 & 60.5 & 0 & NA & 0 \\
\hline Fluoranthene & $2 / 3$ & $98 \mathrm{~J}$ & $110 \mathrm{~J}$ & Z2-EU34B-303 & 104 & 0 & NA & 0 \\
\hline Phenanthrene & $2 / 3$ & $48 \mathrm{~J}$ & $58 \mathrm{~J}$ & Z2-EU34B-303 & 53 & 0 & NA & 0 \\
\hline Pyrene & $2 / 3$ & $88 \mathrm{~J}$ & $90 \mathrm{~J}$ & Z2-EU34B-303 & 89 & 0 & NA & 0 \\
\hline
\end{tabular}

$\mathrm{EU}=$ exposure unit $\quad \mathrm{PRG}=$ preliminary remediation goal

$\mathrm{GW}=$ groundwater $\quad$ Res $=$ residential

Ind $=$ industrial $\quad \mathrm{SL}=$ screening level

$\mathrm{NA}=$ not applicable $\quad \mathrm{SVOC}=$ semivolatile organic 
VOCs were analyzed for in one sample but were not detected.

\section{\begin{tabular}{|l|l} 
2.2.6 & ZONE 2 ROD APPENDIX A FFA SITES EVALUATION \\
\hline
\end{tabular}}

None

\begin{tabular}{|l|l|}
\hline 3.0 & \multicolumn{1}{|c}{ RISK EVALUATION AND ACTION/NO FURTHER ACTION DECISION } \\
\hline 3.1 & INTRODUCTION \\
\hline
\end{tabular}

In this section, data are evaluated in terms of the four decision rules presented in the Zone 2 RDR/RAWP, which include:

- Does the concentration of any Zone 2 contaminant of concern (COC) exceed its maximum RL?

- Does the mean concentration of any Zone 2 COC exceed its average RL across the EU?

- Does the EU pose a risk exceeding an industrial $1 \times 10^{-4}$ excess lifetime cancer risk (ELCR) or target organ hazard index (HI) of 1 ?

- Does the site pose a threat to groundwater based on MCL exceedances or soil RLs for protection of groundwater?

Table G.3 presents the results of comparing the data to Zone 2 soils RLs, Ind PRGs (set at an ELCR of $1 \times 10^{-5}$ or a HI of 1), and background levels. In addition, the EU summary in Sect. 2.2.5 presents an evaluation of the EU data by analyte group. The following table summarizes the conclusions for EU Z2-34.

\begin{tabular}{lccccc}
\hline EU \# & $\begin{array}{c}\text { Max RL } \\
\text { exceeded? }\end{array}$ & $\begin{array}{c}\text { Average RL over } \\
\text { EU exceeded? }\end{array}$ & $\begin{array}{c}\text { Industrial risk } \\
\text { above } \mathbf{1 \times 1 0 ^ { - 4 }} \boldsymbol{?}\end{array}$ & $\begin{array}{c}\text { Potential source } \\
\text { to groundwater? }\end{array}$ & $\begin{array}{c}\text { Action } \\
\text { required? }\end{array}$ \\
\hline $\mathrm{Z} 2-34$ & No & No & No & No & No \\
\hline $\begin{array}{l}\mathrm{EU}=\text { exposure unit } \\
\mathrm{RL}=\text { remediation level }\end{array}$ & & & & & \\
\end{tabular}

\section{\begin{tabular}{|l|l}
3.2 & DATA EVALUATION FOR THE ACTION /NO FURTHER ACTION DECISION
\end{tabular}}

Requirements for determining NFA in the Zone 2 EUs are stated in the protection goals of the Zone 2 ROD RAO. Four decision rules developed in the DVS DQOs state the specific criteria against which each EU must be compared to make the NFA decision. The four decision rules are presented in Sect. 3.2 of this PCCR and the manner in which the decision rule evaluations are conducted and special data handling requirements are discussed in Sect. 3.3 of this PCCR. In summary, the decision rule criteria for NFA are that each EU must meet each of the following compositional constraints:

- Zone 2 soils Max RLs - maximum allowable concentrations of the Zone 2 soils COCs. Zone 2 soils Max RLs are presented in the Zone 2 ROD and Table 5 of this PCCR.

- Zone 2 soils Avg RLs-limit on the allowable average concentrations of the Zone 2 soils COCs across an EU. Zone 2 soils Avg RLs are presented in the Zone 2 ROD and Table 5 of this PCCR.

- Cumulative risk across the EU - cumulative risk across an EU cannot exceed $1 \times 10^{-4}$ ELCR or HI of 1 . A stepwise evaluation of cumulative risk is performed by first comparing EU data to $1 \times 10^{-5}$ Ind PRGs. The $1 \times 10^{-5}$ Ind PRGs for the analytes required by the RDR/RAWP are presented in Table 5 of this PCCR.

- Groundwater protection goals - compositions of Zone 2 soils cannot pose a threat to groundwater. This evaluation is conducted by evaluating local groundwater monitoring results and comparing soils compositions to calculated SLs. Groundwater SLs are presented in Table 5 of this PCCR.

\section{\begin{tabular}{l|l} 
3.3 & SUMMARY AND CONCLUSIONS
\end{tabular}}

EU Z2-34

Max RL screening. Based on DVS sampling information and results of the Class 3 walkover assessment, no Zone 2 COCs were detected at concentrations in excess of maximum RLs. 
Avg RL screening. Based on analytical results from DVS biased sampling in EU Z2-34 and results of the Class 3 walkover assessment, no Zone 2 soils COCs are present with a mean concentration exceeding the Avg RL across the EU.

Risk evaluation. No $1 \times 10^{-5}$ industrial PRGs are exceeded in the biased samples except those for K-40, Ra-226, Th-228, and Th-232 (see PCCR Sect. 3.3.2 for a description of how these radionuclides are evaluated).

The industrial risk for EU Z2-34 is less than $1 \times 10^{-4}$ ELCR and target organ HI of 1 .

Threat to groundwater. There are no GW SL exceedances in EU Z2-34 soils and VOC MCL exceedances in local groundwater wells are attributed to sources derived from upgradient sources. Therefore, it is concluded there are no threats to groundwater from EU Z2-34 soils.

Qualitative risk screening for unrestricted use. There is a low probability that the acreage in EU Z2-34 could be released with no land use restrictions. Ind and Res PRG exceedances occur in the EU. Specific chemicals and radionuclides with criteria exceedances are presented in the EU summary in Sect. 2.2.5. An appropriate evaluation of residential risk should be conducted to make a definitive conclusion.

\begin{tabular}{|l|l|}
\hline 4.0 & \multicolumn{1}{|c|}{ RECOMMENDATION FOR ACTION/NO FURTHER ACTION } \\
\hline 4.1. & DECISION AND REMEDIATION ACTIVITIES \\
\hline
\end{tabular}

EU Z2-34: Based on results of the Class $3 \mathrm{SU}$ walkover assessment and analytical results of the DVS samples collected, the U.S. Department of Energy (DOE) recommends that No Further Action is appropriate under the Zone 2 ROD to meet industrial land use for the 13.2 acres of ETTP Zone 2 EU Z2-34. Because of the potential for encountering VOC vapors in soil from VOC-contaminated groundwater, DOE believes retaining the land use restriction below $10 \mathrm{ft}$ depth is warranted.

\begin{tabular}{|l|l|}
\hline 4.2 & EXCAVATION ACTIVITIES/CONFIRMATIONSAMPLING \\
\hline None
\end{tabular}

None 


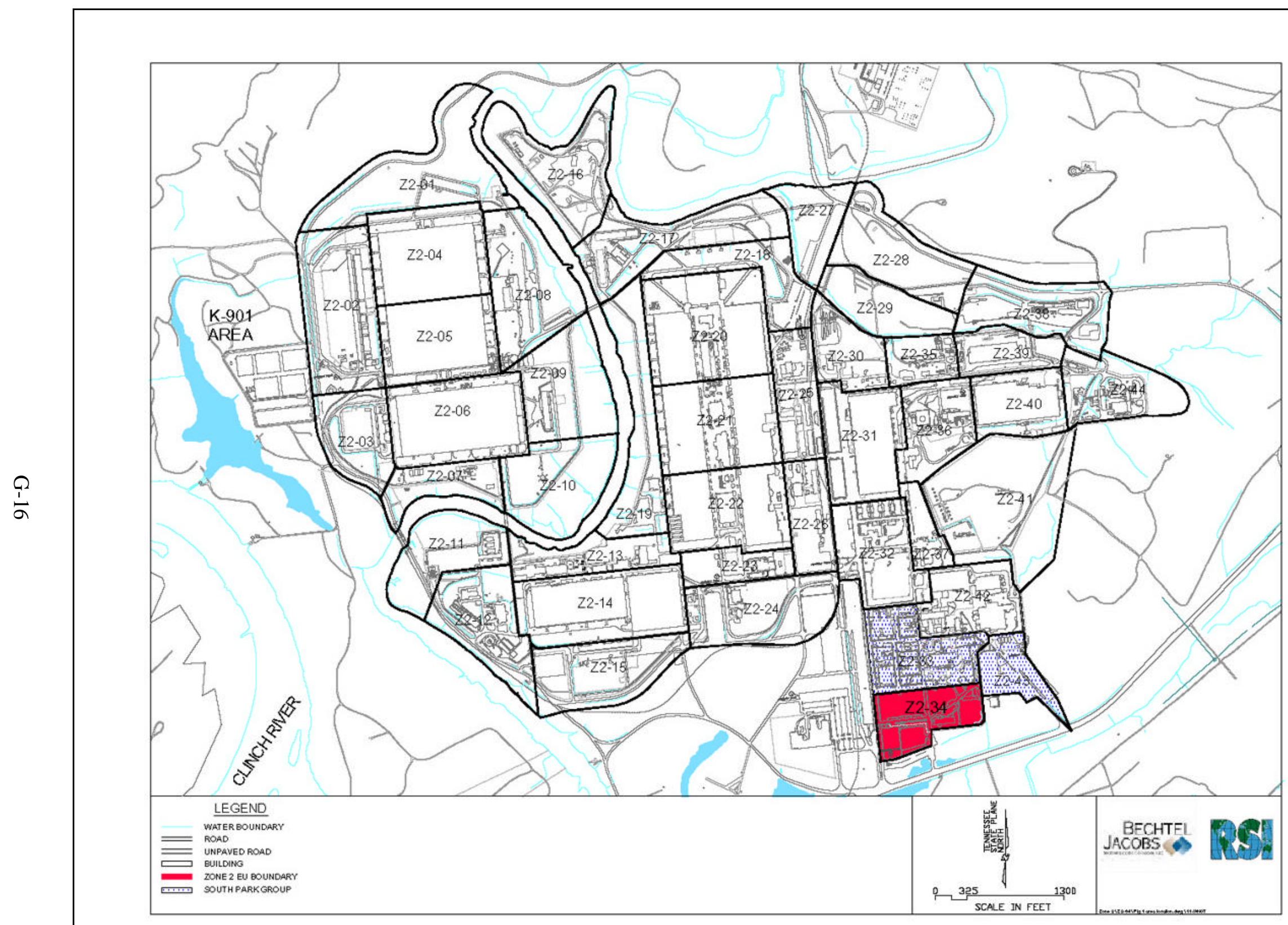

Fig. G.1. EU Z2-34 location map. 


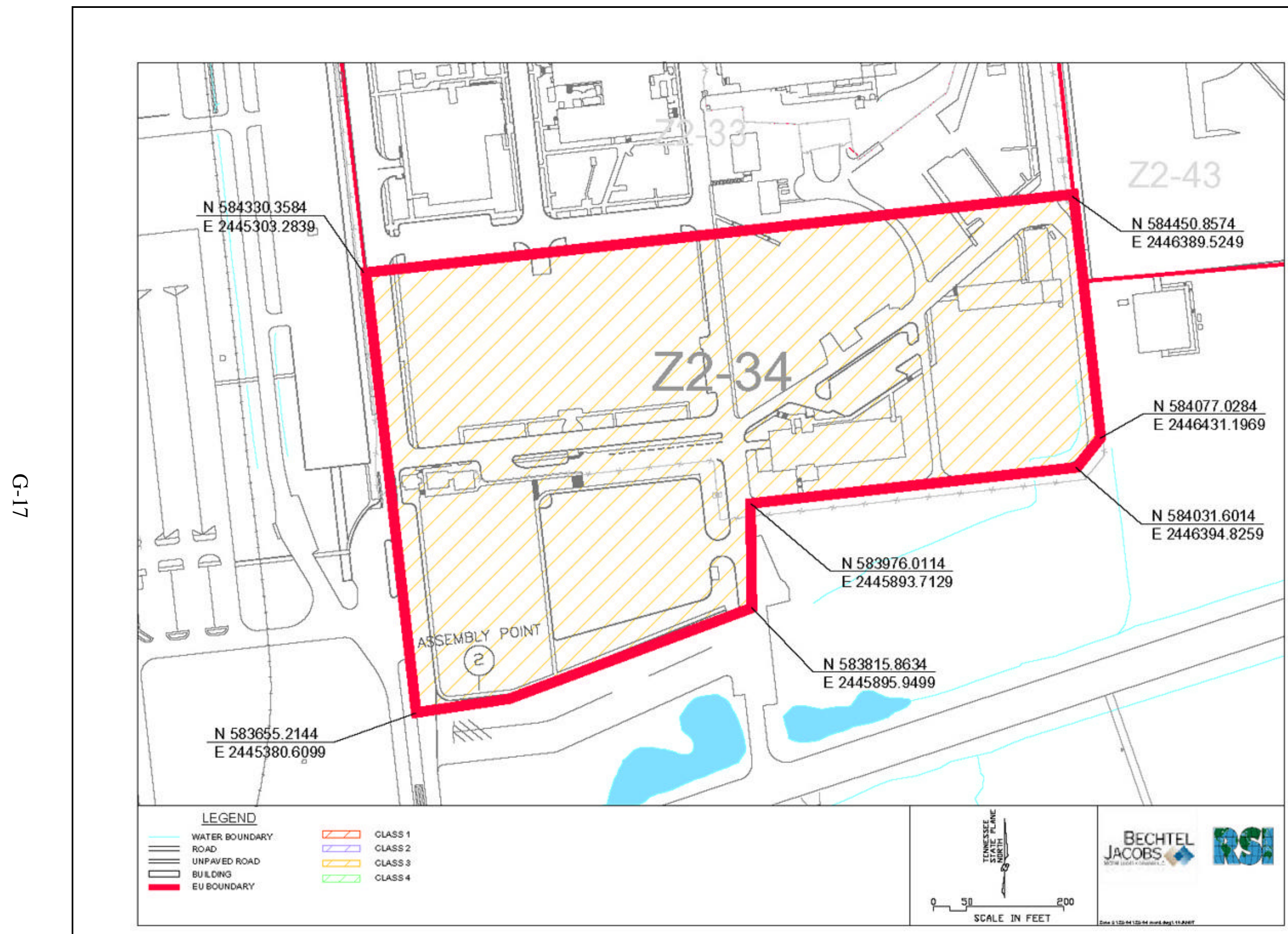

Fig. G.2. EU Z2-34 boundaries. 


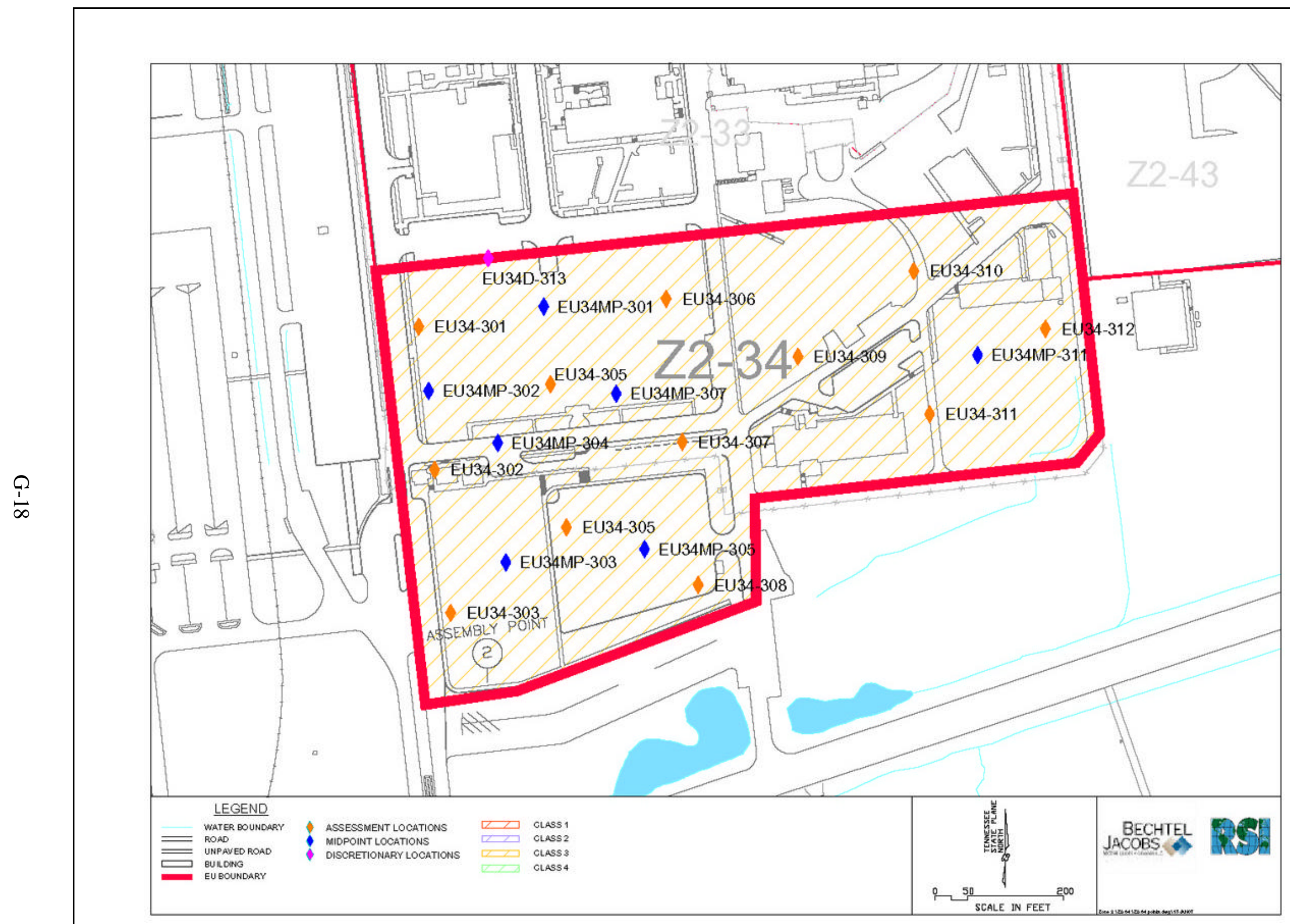

Fig. G.3. EU Z2-34 Class 3 and 4 SU walkover assessment locations. 


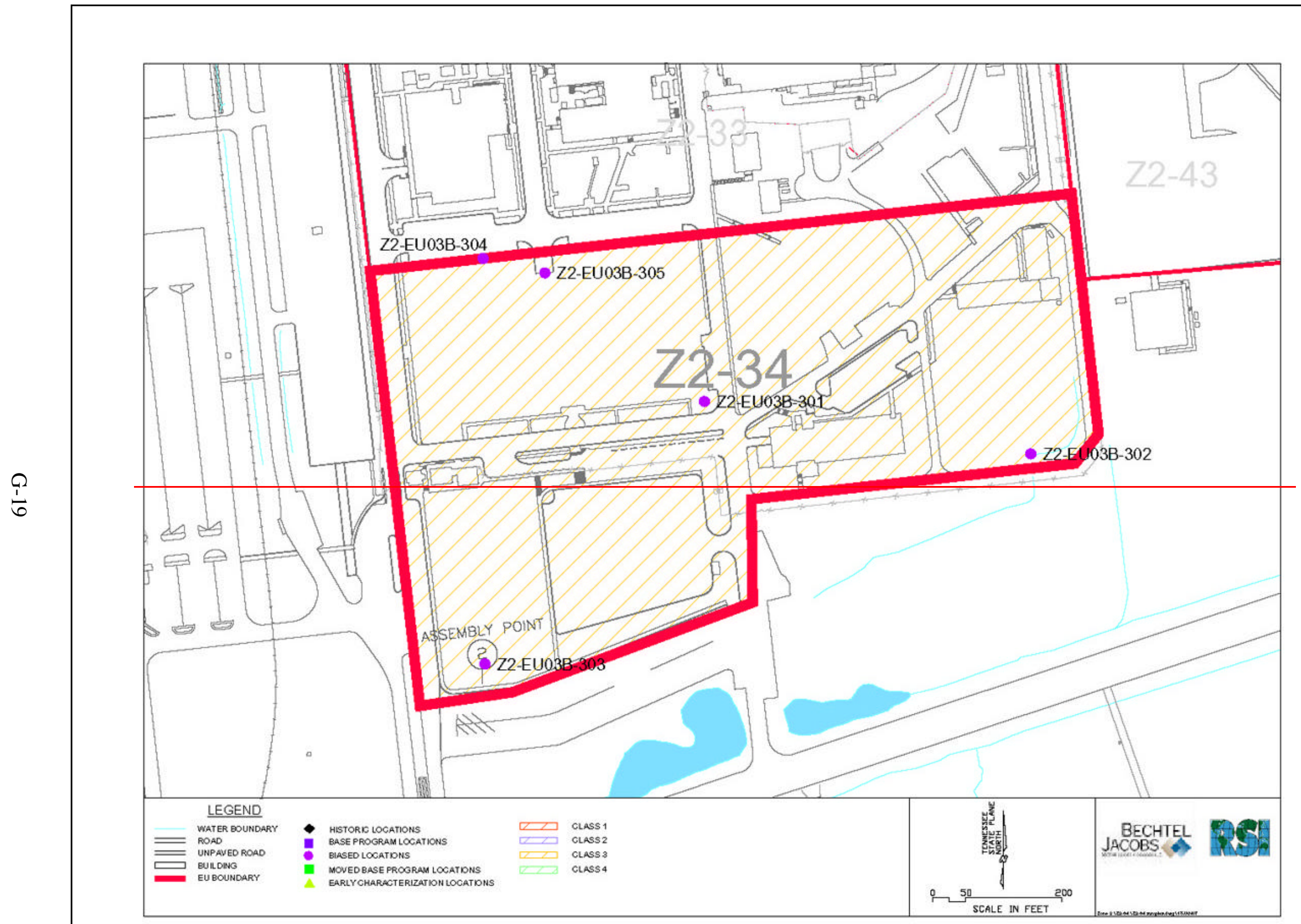

Fig. G.4. EU Z2-34 sample locations. 


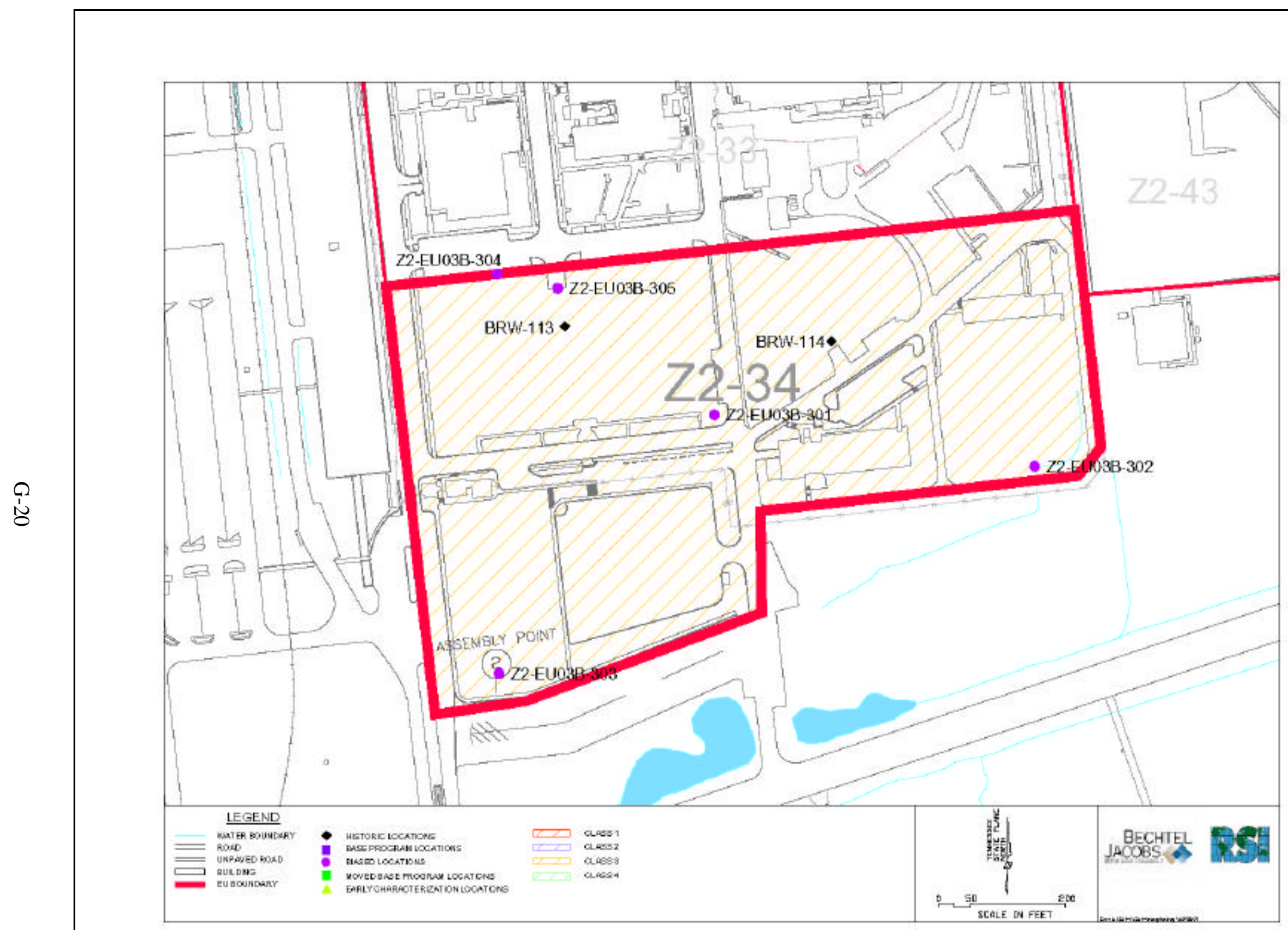

Fig. G.4. EU Z2-34 sample locations. 
Table G.1. EU Z2-34 Facility list

\begin{tabular}{lcc}
\hline \multicolumn{1}{c}{ Facility name DQO scoping } & Facility name & \multicolumn{2}{c}{ Facility assessed? } \\
\cline { 2 - 3 } K-1000 Visitors Center & $\mathrm{X}$ & No \\
K-1001 Administration Building & & $\mathrm{X}$ \\
K-1019-21 Bus Shelter & $\mathrm{X}$ & $\mathrm{X}$ \\
K-1028-57 Guard Portal & $\mathrm{X}$ & \\
K-1028-59 Guard Portal & $\mathrm{X}$ \\
K-1240-2C Parking Area & $\mathrm{X}$ & \\
K-1240-2D Parking Area & & $\mathrm{X}$ \\
K-1310-BY Storage Trailer & & \\
K-1320 Engineering Expansion Office & $\mathrm{X}$ & \\
Building & $\mathrm{X}$ & \\
K-1320-A Office Building & $\mathrm{X}$ & $\mathrm{X}$ \\
K-1543 Sanitary Water Meter & & $\mathrm{X}$ \\
K-1550-A Engineering Office Trailer & & $\mathrm{X}$ \\
K-1550-B Engineering Office Trailer & & $\mathrm{X}$ \\
K-1550-C Engineering Office Trailer & & $\mathrm{X}$ \\
K-1550-D Engineering Office Trailer & & $\mathrm{X}$ \\
K-1550-E Engineering Office Trailer & & $\mathrm{X}$ \\
K-1550-F Engineering Office Trailer & & $\mathrm{X}$ \\
K-1550-G Engineering Office Trailer & & $\mathrm{X}$ \\
K-1550-H Engineering Office Trailer & & \\
K-1550-I Engineering Office Trailer & & $\mathrm{X}$ \\
K-1580 Engineering Office Building & & \\
\hline
\end{tabular}

DQO = data quality objective

$\mathrm{EU}=$ exposure unit

FFA $=$ Federal Facility Agreement 
Table G.2. EU Z2-34 sample summary

\begin{tabular}{|c|c|c|c|c|c|c|c|c|c|c|c|c|c|c|}
\hline \multirow{2}{*}{$\begin{array}{l}\text { SU } \\
\text { class }\end{array}$} & \multirow[b]{2}{*}{ Location ID } & \multirow[b]{2}{*}{ Date sampled } & \multicolumn{2}{|c|}{ Location } & \multirow[b]{2}{*}{ Sample interval } & \multicolumn{3}{|c|}{ Screen } & \multicolumn{4}{|c|}{ Off-Site Laboratory } & \multirow{2}{*}{$\begin{array}{l}\text { Splits/ } \\
\text { Dups }\end{array}$} & \multirow[b]{2}{*}{ Comments and notes } \\
\hline & & & Northing & Easting & & RAD & VOC & Metals & PCB & RAD & SVOC & VOC & & \\
\hline 3 & Z2-EU34B-301 & $7 / 17 / 2006$ & 584127.8 & 2445821.1 & $\begin{array}{l}0-10 \mathrm{ft} \text {. Three-interval composite soil } 0-0.5,0-0.5,0-0.5,0.5-2 \text {, } \\
7.1-7.6 \text { and } 9.0-10.0 \mathrm{ft} \text {. }\end{array}$ & 1 & 1 & 1 & 1 & 1 & 1 & 1 & $\mathrm{D}$ & $\begin{array}{l}\text { Class } 3 \text { biased sample point; } \\
\text { RAD hit of } 229.4 \mathrm{cpm} \text { at } 8.25 \mathrm{ft}\end{array}$ \\
\hline 3 & Z2-EU34B-302 & 7/17/2006 & 584046.4 & 2446326.5 & 0-1 ft. One-point composite soil sample & & 1 & 1 & & 1 & & & & $\begin{array}{l}\text { Collect in low spot considered } \\
\text { to be the background location } \\
\text { south of K-1320 }\end{array}$ \\
\hline 3 & Z2-EU34B-303 & 7/17/2006 & 583720.0 & 2445481.3 & 0-1 ft. One-point composite sediment sample & & 1 & 1 & 1 & & 1 & & & $\begin{array}{l}\text { Collect in sediments in low spot } \\
\text { near Assembly Point } 2\end{array}$ \\
\hline 3 & Z2-EU34B-304 & 9/5/2006 & 584349.7 & 2445478.5 & $0-1 \mathrm{ft}$. Five-point composite soil sample & & 1 & & & 1 & & & & $\begin{array}{l}\text { Collect adjacent to straw bales } \\
\text { marked as RMA south of K- } \\
1006\end{array}$ \\
\hline 3 & Z2-EU34B-305 & 7/17/2006 & 584327.4 & 2445574.0 & $0-1 \mathrm{ft}$. One-point composite sediment sample & 1 & 1 & 1 & 1 & & 1 & & & $\begin{array}{l}\text { Collect in sediments } \\
\text { north-central portion of original } \\
\text { building footprint near the } \\
\text { former loading dock of K-1001 }\end{array}$ \\
\hline
\end{tabular}

\begin{tabular}{ll}
\hline DVS $=$ =ynnamic Verification Strategy & RMA $=$ Radioactive Material Area \\
EU $=$ exposure unit & SU $=$ soil unit \\
ID $=$ identification & SVOC $=$ semivolatile organic compound \\
PCB $=$ polychlorinated biphenyl & VOC $=$ volatile organic compound
\end{tabular}

DVS SAMPLING TOTALS

(1) " $\mathrm{B}$ " in sample number indicates a biased sample; " $\mathrm{M}$ " in sample number indicates moved more than $5 \mathrm{ft}$. from the original location

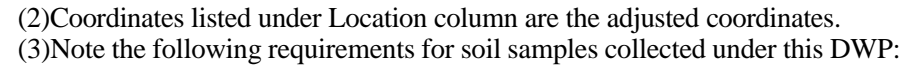

\begin{tabular}{|c|c|c|c|c|}
\hline Analyte & SW846 Method & Holding time in days & Containers & $\begin{array}{l}\text { Quantity } \\
\end{array}$ \\
\hline Metals & $6010 \mathrm{~B} / 7471 \mathrm{~A}$ & $180 / 28$ & 4-Oz wide-mouthed amber glass jar with Teflon-lined cap (or approved equivalent) & 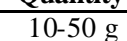 \\
\hline PCBs & 8082 & 14 & 4-oz wide-mouthed amber glass jar with Tefflon-lined cap (or approved equivalent) & $30 \mathrm{~g}$ \\
\hline RAD & HASL-3000 & 180 & 8-oz amber glass (or approved equivalent) & $100-500 \mathrm{~g}$ \\
\hline $\begin{array}{l}\text { SVOCs } \\
\text { vors }\end{array}$ & $\begin{array}{l}8270 \\
820 \mathrm{~B}\end{array}$ & 14 & 4-oz wide-mouthed glass jar with Teflon-lined cap (or approved equivalent) & $30 \mathrm{~g}$ \\
\hline VOCs & & & 4-oz wide-mouthed glass jar with septum, Teflon-lined cap (or approved equivalent) & $15 \mathrm{~g}$ \\
\hline
\end{tabular}

(4)Standard radiological analysis includes alpha spec, gamma spec, and technetium-99. 
Table G.3. EU Z2-34, depth 0-10 ft

\begin{tabular}{|c|c|c|c|c|c|c|c|c|c|c|c|c|c|}
\hline Analyte & $\begin{array}{r}\text { Frequency } \\
\text { of detect }\end{array}$ & $\begin{array}{c}\text { Minimum } \\
\text { detect }\end{array}$ & $\begin{array}{c}\text { Maximum } \\
\text { detect }\end{array}$ & $\begin{array}{c}\text { Location(s) } \\
\text { of maximum } \\
\text { detected result }\end{array}$ & $\begin{array}{c}\text { Average } \\
\text { detected } \\
\text { result }\end{array}$ & $\begin{array}{c}\text { Max } \\
\text { RL }\end{array}$ & $\begin{array}{c}\text { Frequency } \\
\text { of detects } \\
\text { exceeding } \\
\text { Max RL }\end{array}$ & $\begin{array}{l}\text { Avg } \\
\text { RL }\end{array}$ & $\begin{array}{c}\text { Frequency } \\
\text { of detects } \\
\text { exceeding } \\
\text { Avg RL } \\
\end{array}$ & $\begin{array}{l}\text { PRG limit } \\
\left(10^{-5} \text { or } 1\right)\end{array}$ & $\begin{array}{c}\text { Frequency } \\
\text { of detects } \\
\text { exceeding } \\
\text { PRG limit } \\
\end{array}$ & $\begin{array}{c}\text { Background } \\
\text { concentration }\end{array}$ & $\begin{array}{c}\text { Frequency } \\
\text { of detects } \\
\text { exceeding } \\
\text { background }\end{array}$ \\
\hline \multicolumn{14}{|l|}{ Inorganics $(\mathrm{mg} / \mathbf{k g})$} \\
\hline Aluminum & $4 / 4$ & $9,040 \mathrm{~J}$ & $13,300 \mathrm{~J}$ & Z2-EU34B-301 & 11,160 & & NA & & NA & $1.00 \mathrm{E}+05$ & $0 / 4$ & 40,300 & $0 / 4$ \\
\hline Antimony & $2 / 4$ & $0.2 \mathrm{~J}$ & $0.2 \mathrm{~J}$ & $\begin{array}{l}\text { Z2-EU34B-302 } \\
\text { Z2-EU34B-303 }\end{array}$ & 0.2 & & NA & & NA & $4.10 \mathrm{E}+02$ & $0 / 4$ & 1.52 & $0 / 4$ \\
\hline Arsenic & $4 / 4$ & $3.1 \mathrm{~J}$ & $6.5 \mathrm{~J}$ & Z2-EU34B-303 & 5 & 900 & $0 / 4$ & 300 & $0 / 4$ & $1.60 \mathrm{E}+01$ & $0 / 4$ & 14.95 & $0 / 4$ \\
\hline Barium & $4 / 4$ & 82.1 & 117 & Z2-EU34B-303 & 102.75 & & NA & & NA & $6.70 \mathrm{E}+04$ & $0 / 4$ & 124.93 & $0 / 4$ \\
\hline Beryllium & $4 / 4$ & 0.58 & 1.7 & Z2-EU34B-301 & 0.98 & 6,000 & $0 / 4$ & 2,000 & $0 / 4$ & $1.90 \mathrm{E}+03$ & $0 / 4$ & 2.2 & $0 / 4$ \\
\hline Boron & $0 / 4$ & ND & ND & & ND & & NA & & NA & $1.00 \mathrm{E}+05$ & $0 / 4$ & & NA \\
\hline Cadmium & $4 / 4$ & $0.082 \mathrm{~J}$ & 0.19 & Z2-EU34B-303 & 0.15 & & NA & & NA & $4.50 \mathrm{E}+02$ & $0 / 4$ & $0.22 \mathrm{U}$ & $0 / 4$ \\
\hline Calcium & $4 / 4$ & $1670 \mathrm{~J}$ & $14,000 \mathrm{~J}$ & Z2-EU34B-303 & 8,805 & & NA & & NA & & NA & 2400 & $3 / 4$ \\
\hline Chromium & $4 / 4$ & $10.4 \mathrm{~J}$ & $20.8 \mathrm{~J}$ & Z2-EU34B-301 & 17.18 & & NA & & NA & $6.40 \mathrm{E}+02$ & $0 / 4$ & 44.88 & $0 / 4$ \\
\hline Cobalt & $4 / 4$ & $7.6 \mathrm{~J}$ & $36.7 \mathrm{~J}$ & Z2-EU34B-301 & 20.68 & & NA & & NA & $1.30 \mathrm{E}+04$ & $0 / 4$ & 42 & $0 / 4$ \\
\hline Copper & $4 / 4$ & $4.8 \mathrm{~J}$ & $15.3 \mathrm{~J}$ & Z2-EU34B-302 & 11.68 & & NA & & NA & $4.10 \mathrm{E}+04$ & $0 / 4$ & 22.48 & $0 / 4$ \\
\hline Iron & $4 / 4$ & 10,900 & 30,800 & Z2-EU34B-301 & 22,700 & & NA & & NA & $1.00 \mathrm{E}+05$ & $0 / 4$ & 58,600 & $0 / 4$ \\
\hline Lead & $4 / 4$ & $17.4 \mathrm{~J}$ & $41.9 \mathrm{~J}$ & Z2-EU34B-302 & 32.7 & & NA & & NA & $8.00 \mathrm{E}+02$ & $0 / 4$ & 37.91 & $1 / 4$ \\
\hline Lithium & $4 / 4$ & $5.1 \mathrm{~J}$ & 19.6 & Z2-EU34B-301 & 12 & & NA & & NA & $2.00 \mathrm{E}+04$ & $0 / 4$ & 48.94 & $0 / 4$ \\
\hline Magnesium & $4 / 4$ & $673 \mathrm{~J}$ & $7190 \mathrm{~J}$ & Z2-EU34B-303 & $3,785.75$ & & NA & & NA & & NA & 3,300 & $2 / 4$ \\
\hline Manganese & $4 / 4$ & 1,010 & 1710 & Z2-EU34B-303 & 1420 & & NA & & NA & $1.90 \mathrm{E}+04$ & $0 / 4$ & 2,200 & $0 / 4$ \\
\hline Mercury & $1 / 4$ & 0.098 & 0.098 & Z2-EU34B-302 & 0.1 & 1,800 & $0 / 4$ & 600 & $0 / 4$ & $3.10 \mathrm{E}+02$ & $0 / 4$ & 0.17 & $0 / 4$ \\
\hline Molybdenum & $4 / 4$ & $0.54 \mathrm{~J}$ & $1.1 \mathrm{~J}$ & Z2-EU34B-303 & 0.78 & & NA & & NA & $5.10 \mathrm{E}+03$ & $0 / 4$ & & NA \\
\hline Nickel & $4 / 4$ & 6.3 & 27.9 & Z2-EU34B-302 & 18.38 & & NA & & NA & $2.00 \mathrm{E}+04$ & $0 / 4$ & 26.07 & $2 / 4$ \\
\hline Potassium & $4 / 4$ & 822 & 1350 & Z2-EU34B-301 & $1,089.25$ & & NA & & NA & & NA & $5,074.69$ & $0 / 4$ \\
\hline Selenium & $0 / 4$ & ND & ND & & ND & & NA & & NA & $5.10 \mathrm{E}+03$ & $0 / 4$ & 1.47 & $0 / 4$ \\
\hline Silver & $4 / 4$ & $0.057 \mathrm{~J}$ & $0.14 \mathrm{~J}$ & Z2-EU34B-302 & 0.11 & & NA & & NA & $5.10 \mathrm{E}+03$ & $0 / 4$ & $0.6 \mathrm{U}$ & $0 / 4$ \\
\hline Sodium & $3 / 4$ & 41.3 & 48.9 & Z2-EU34B-301 & 45.4 & & NA & & NA & & NA & 497 & $0 / 4$ \\
\hline Thallium & $0 / 4$ & ND & ND & & ND & & NA & & NA & $6.70 \mathrm{E}+01$ & $0 / 4$ & $0.4 \mathrm{U}$ & $0 / 4$ \\
\hline Uranium & $4 / 4$ & 0.59 & 1.9 & Z2-EU34B-302 & 1.15 & & NA & & NA & $2.00 \mathrm{E}+02$ & $0 / 4$ & & NA \\
\hline Vanadium & $4 / 4$ & $16.9 \mathrm{~J}$ & $26.1 \mathrm{~J}$ & Z2-EU34B-303 & 22.78 & & NA & & NA & $1.00 \mathrm{E}+03$ & $0 / 4$ & 65.47 & $0 / 4$ \\
\hline Zinc & $4 / 4$ & $31 \mathrm{~J}$ & $46.3 \mathrm{~J}$ & Z2-EU34B-301 & 41.2 & & NA & & NA & $1.00 \mathrm{E}+05$ & $0 / 4$ & 89.7 & $0 / 4$ \\
\hline
\end{tabular}




\begin{tabular}{|c|c|c|c|c|c|c|c|c|c|c|c|c|}
\hline \multicolumn{13}{|c|}{ Table G.3. (continued) } \\
\hline $\begin{array}{c}\text { Frequency } \\
\text { of detect }\end{array}$ & $\begin{array}{c}\text { Minimum } \\
\text { detect }\end{array}$ & $\begin{array}{c}\text { Maximum } \\
\text { detect }\end{array}$ & $\begin{array}{c}\text { Location(s) } \\
\text { of maximum } \\
\text { detected result }\end{array}$ & $\begin{array}{c}\text { Average } \\
\text { detected } \\
\text { result }\end{array}$ & $\begin{array}{c}\text { Max } \\
\text { RL }\end{array}$ & $\begin{array}{c}\text { Frequency } \\
\text { of detects } \\
\text { exceeding } \\
\text { Max RL } \\
\end{array}$ & $\begin{array}{l}\text { Avg } \\
\text { RL }\end{array}$ & $\begin{array}{c}\text { Frequency } \\
\text { of detects } \\
\text { exceeding } \\
\text { Avg RL } \\
\end{array}$ & $\begin{array}{l}\text { PRG limit } \\
\left(10^{-5} \text { or } 1\right)\end{array}$ & 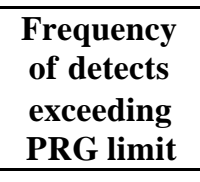 & $\begin{array}{c}\text { Background } \\
\text { concentration }\end{array}$ & $\begin{array}{c}\text { Frequency } \\
\text { of detects } \\
\text { exceeding } \\
\text { background }\end{array}$ \\
\hline $3 / 3$ & 12.4 & 33 & Z2-EU34B-302 & 21.8 & & $\mathrm{NA}$ & & $\mathrm{NA}$ & & NA & & NA \\
\hline $3 / 3$ & 18.4 & 37.7 & Z2-EU34B-302 & 27.73 & & NA & & NA & & $\mathrm{NA}$ & & NA \\
\hline $2 / 3$ & 0.162 & 0.233 & Z2-EU34B-304 & 0.2 & 20 & $0 / 3$ & 2 & $0 / 3$ & $1.10 \mathrm{E}+00$ & $0 / 3$ & & NA \\
\hline $0 / 3$ & $\mathrm{ND}$ & $\mathrm{ND}$ & & $\mathrm{ND}$ & & $\mathrm{NA}$ & & $\mathrm{NA}$ & $6.00 \mathrm{E}-01$ & $0 / 3$ & & $\mathrm{NA}$ \\
\hline $0 / 3$ & $\mathrm{ND}$ & $\mathrm{ND}$ & & $\mathrm{ND}$ & 50 & $0 / 3$ & 5 & $0 / 3$ & $2.70 \mathrm{E}+00$ & $0 / 3$ & & $\mathrm{NA}$ \\
\hline $3 / 3$ & 5.6 & 21 & Z2-EU34B-301 & 14.67 & & NA & & NA & $2.70 \mathrm{E}+00$ & $3 / 3$ & 32.12 & $0 / 3$ \\
\hline $3 / 3$ & 0.08 & 0.35 & Z2-EU34B-304 & 0.23 & 15 & $0 / 3$ & 5 & $0 / 3$ & & NA & & NA \\
\hline $3 / 3$ & 0.85 & 1.33 & Z2-EU34B-301 & 1.03 & 15 & $\mathrm{NA}^{a}$ & 5 & $\mathrm{NA}^{a}$ & $2.60 \mathrm{E}-01$ & $3 / 3$ & 1.25 & $1 / 3$ \\
\hline $1 / 3$ & 1.26 & 1.26 & Z2-EU34B-302 & 1.26 & & NA & & NA & $8.90 \mathrm{E}+03$ & $0 / 3$ & & NA \\
\hline $3 / 3$ & 1.21 & 1.52 & Z2-EU34B-301 & 1.37 & & $\mathrm{NA}$ & & $\mathrm{NA}$ & $1.70 \mathrm{E}-01$ & $3 / 3^{b}$ & 1.86 & $0 / 3$ \\
\hline $3 / 3$ & 1.23 & 1.55 & Z2-EU34B-304 & 1.42 & 15 & $\mathrm{NA}^{a}$ & 5 & $\mathrm{NA}^{a}$ & $2.10 \mathrm{E}+02$ & $0 / 3$ & 1.2 & $3 / 3$ \\
\hline $3 / 3$ & 1.04 & 1.51 & Z2-EU34B-302 & 1.31 & 15 & $\mathrm{NA}^{a}$ & 5 & $\mathrm{NA}^{a}$ & $1.70 \mathrm{E}-01$ & $3 / 3^{b}$ & 1.95 & $0 / 3$ \\
\hline $3 / 3$ & 1.09 & 2.31 & Z2-EU34B-302 & 1.87 & 7,000 & $0 / 3$ & 700 & $0 / 3$ & $3.30 \mathrm{E}+02$ & $0 / 3$ & & NA \\
\hline $2 / 3$ & 0.066 & 0.24 & Z2-EU34B-302 & 0.15 & 80 & $0 / 3$ & 8 & $0 / 3$ & $3.90 \mathrm{E}+00$ & $0 / 3$ & & $\mathrm{NA}$ \\
\hline $3 / 3$ & 1.04 & 1.5 & Z2-EU34B-302 & 1.28 & 500 & $0 / 3$ & 50 & $0 / 3$ & $1.80 \mathrm{E}+01$ & $0 / 3$ & 1.47 & $1 / 3$ \\
\hline \multicolumn{13}{|c|}{ Organics, Pesticides, and PCBs (ug/kg) } \\
\hline $0 / 3$ & $\mathrm{ND}$ & ND & & ND & 100,000 & $0 / 3$ & 10,000 & $0 / 3$ & $3.70 \mathrm{E}+04$ & $0 / 3$ & & NA \\
\hline $0 / 3$ & ND & ND & & ND & 100,000 & $0 / 3$ & 10,000 & $0 / 3$ & $7.40 \mathrm{E}+03$ & $0 / 3$ & & NA \\
\hline $0 / 3$ & $\mathrm{ND}$ & $\mathrm{ND}$ & & ND & 100,000 & $0 / 3$ & 10,000 & $0 / 3$ & $7.40 \mathrm{E}+03$ & $0 / 3$ & & $\mathrm{NA}$ \\
\hline $0 / 3$ & ND & ND & & ND & 100,000 & $0 / 3$ & 10,000 & $0 / 3$ & $7.40 \mathrm{E}+03$ & $0 / 3$ & & NA \\
\hline $0 / 3$ & $\mathrm{ND}$ & $\mathrm{ND}$ & & ND & 100,000 & $0 / 3$ & 10,000 & $0 / 3$ & $7.40 \mathrm{E}+03$ & $0 / 3$ & & NA \\
\hline $0 / 3$ & $\mathrm{ND}$ & $\mathrm{ND}$ & & $\mathrm{ND}$ & 100,000 & $0 / 3$ & 10,000 & $0 / 3$ & $7.40 \mathrm{E}+03$ & $0 / 3$ & & NA \\
\hline $0 / 3$ & ND & $\mathrm{ND}$ & & ND & 100,000 & $0 / 3$ & 10,000 & $0 / 3$ & $7.40 \mathrm{E}+03$ & $0 / 3$ & & NA \\
\hline $0 / 3$ & ND & ND & & ND & 100,000 & $0 / 3$ & 10,000 & $0 / 3$ & $7.40 \mathrm{E}+03$ & $0 / 3$ & & $\mathrm{NA}$ \\
\hline \multicolumn{13}{|c|}{ Semivolatile Organics (ug/kg) } \\
\hline $0 / 3$ & ND & ND & & ND & & NA & & NA & $2.20 \mathrm{E}+05$ & $0 / 3$ & & NA \\
\hline $0 / 3$ & ND & $\mathrm{ND}$ & & $\mathrm{ND}$ & & $\mathrm{NA}$ & & $\mathrm{NA}$ & $6.00 \mathrm{E}+05$ & $0 / 3$ & & $\mathrm{NA}$ \\
\hline $0 / 3$ & ND & ND & & ND & & $\mathrm{NA}$ & & NA & $6.00 \mathrm{E}+05$ & $0 / 3$ & & $\mathrm{NA}$ \\
\hline
\end{tabular}




\begin{tabular}{|c|c|c|c|c|c|c|c|c|c|c|c|c|c|}
\hline \multicolumn{14}{|c|}{ Table G.3. (continued) } \\
\hline Analyte & $\begin{array}{c}\text { Frequency } \\
\text { of detect }\end{array}$ & $\begin{array}{c}\text { Minimum } \\
\text { detect }\end{array}$ & $\begin{array}{c}\text { Maximum } \\
\text { detect }\end{array}$ & $\begin{array}{c}\text { Location(s) } \\
\text { of maximum } \\
\text { detected result }\end{array}$ & $\begin{array}{c}\text { Average } \\
\text { detected } \\
\text { result }\end{array}$ & $\begin{array}{c}\text { Max } \\
\text { RL }\end{array}$ & $\begin{array}{c}\text { Frequency } \\
\text { of detects } \\
\text { exceeding } \\
\text { Max RL } \\
\end{array}$ & $\begin{array}{l}\text { Avg } \\
\text { RL }\end{array}$ & 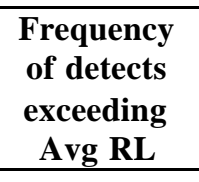 & $\begin{array}{l}\text { PRG limit } \\
\left(10^{-5} \text { or } 1\right)\end{array}$ & 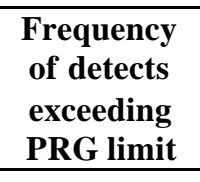 & $\begin{array}{c}\text { Background } \\
\text { concentration }\end{array}$ & $\begin{array}{c}\text { Frequency } \\
\text { of detects } \\
\text { exceeding } \\
\text { background }\end{array}$ \\
\hline 2,4,5-Trichlorophenol & $0 / 3$ & $\mathrm{ND}$ & $\mathrm{ND}$ & & $\mathrm{ND}$ & & $\mathrm{NA}$ & & $\mathrm{NA}$ & $6.20 \mathrm{E}+07$ & $0 / 3$ & & $\mathrm{NA}$ \\
\hline 2,4,6-Trichlorophenol & $0 / 3$ & ND & $\mathrm{ND}$ & & ND & & NA & & NA & $6.20 \mathrm{E}+04$ & $0 / 3$ & & NA \\
\hline 2,4-Dichlorophenol & $0 / 3$ & $\mathrm{ND}$ & $\mathrm{ND}$ & & ND & & NA & & NA & $1.80 \mathrm{E}+06$ & $0 / 3$ & & NA \\
\hline 2,4-Dimethylphenol & $0 / 3$ & $\mathrm{ND}$ & $\mathrm{ND}$ & & $\mathrm{ND}$ & & $\mathrm{NA}$ & & $\mathrm{NA}$ & $1.20 \mathrm{E}+07$ & $0 / 3$ & & $\mathrm{NA}$ \\
\hline 2,4-Dinitrotoluene & $0 / 3$ & $\mathrm{ND}$ & $\mathrm{ND}$ & & $\mathrm{ND}$ & & $\mathrm{NA}$ & & $\mathrm{NA}$ & $2.50 \mathrm{E}+04$ & $0 / 3$ & & $\mathrm{NA}$ \\
\hline 2,6-Dinitrotoluene & $0 / 3$ & $\mathrm{ND}$ & ND & & $\mathrm{ND}$ & & NA & & NA & $2.50 \mathrm{E}+04$ & $0 / 3$ & & NA \\
\hline 2-Chloronaphthalene & $0 / 3$ & ND & $\mathrm{ND}$ & & ND & & NA & & NA & $2.30 \mathrm{E}+07$ & $0 / 3$ & & NA \\
\hline 2-Chlorophenol & $0 / 3$ & $\mathrm{ND}$ & $\mathrm{ND}$ & & $\mathrm{ND}$ & & $\mathrm{NA}$ & & $\mathrm{NA}$ & $2.40 \mathrm{E}+05$ & $0 / 3$ & & $\mathrm{NA}$ \\
\hline 2-Methyl-4,6-dinitrophenol & $0 / 3$ & $\mathrm{ND}$ & $\mathrm{ND}$ & & $\mathrm{ND}$ & & $\mathrm{NA}$ & & NA & $6.20 \mathrm{E}+04$ & $0 / 3$ & & $\mathrm{NA}$ \\
\hline 2-Methylnaphthalene & $0 / 3$ & $\mathrm{ND}$ & $\mathrm{ND}$ & & $\mathrm{ND}$ & & $\mathrm{NA}$ & & $\mathrm{NA}$ & $1.90 \mathrm{E}+05$ & $0 / 3$ & & $\mathrm{NA}$ \\
\hline 2-Methylphenol & $0 / 3$ & ND & $\mathrm{ND}$ & & $\mathrm{ND}$ & & $\mathrm{NA}$ & & $\mathrm{NA}$ & $3.10 \mathrm{E}+07$ & $0 / 3$ & & $\mathrm{NA}$ \\
\hline 2-Nitrobenzenamine & $0 / 3$ & $\mathrm{ND}$ & $\mathrm{ND}$ & & ND & & $\mathrm{NA}$ & & $\mathrm{NA}$ & $1.80 \mathrm{E}+06$ & $0 / 3$ & & $\mathrm{NA}$ \\
\hline 3,3'-Dichlorobenzidine & $0 / 3$ & $\mathrm{ND}$ & $\mathrm{ND}$ & & $\mathrm{ND}$ & & NA & & NA & $3.80 \mathrm{E}+04$ & $0 / 3$ & & NA \\
\hline 3-Nitrobenzenamine & $0 / 3$ & $\mathrm{ND}$ & $\mathrm{ND}$ & & $\mathrm{ND}$ & & $\mathrm{NA}$ & & $\mathrm{NA}$ & $1.80 \mathrm{E}+05$ & $0 / 3$ & & $\mathrm{NA}$ \\
\hline 4-Bromophenyl phenyl ether & $0 / 3$ & ND & $\mathrm{ND}$ & & $\mathrm{ND}$ & & NA & & NA & & NA & & NA \\
\hline 4-Chloro-3-methylphenol & $0 / 3$ & $\mathrm{ND}$ & $\mathrm{ND}$ & & $\mathrm{ND}$ & & $\mathrm{NA}$ & & $\mathrm{NA}$ & & NA & & NA \\
\hline 4-Chlorobenzenamine & $0 / 3$ & ND & ND & & $\mathrm{ND}$ & & NA & & NA & $2.50 \mathrm{E}+06$ & $0 / 3$ & & NA \\
\hline 4-Chlorophenyl phenyl ether & $0 / 3$ & $\mathrm{ND}$ & ND & & ND & & NA & & NA & & NA & & NA \\
\hline 4-Methylphenol & $0 / 3$ & $\mathrm{ND}$ & $\mathrm{ND}$ & & $\mathrm{ND}$ & & $\mathrm{NA}$ & & $\mathrm{NA}$ & $3.10 \mathrm{E}+06$ & $0 / 3$ & & $\mathrm{NA}$ \\
\hline 4-Nitrobenzenamine & $0 / 3$ & ND & $\mathrm{ND}$ & & ND & & NA & & NA & $8.20 \mathrm{E}+05$ & $0 / 3$ & & NA \\
\hline 4-Nitrophenol & $0 / 3$ & $\mathrm{ND}$ & $\mathrm{ND}$ & & $\mathrm{ND}$ & & $\mathrm{NA}$ & & $\mathrm{NA}$ & & $\mathrm{NA}$ & & NA \\
\hline Acenaphthene & $0 / 3$ & ND & $\mathrm{ND}$ & & ND & & NA & & NA & $2.90 \mathrm{E}+07$ & $0 / 3$ & & NA \\
\hline Acenaphthylene & $0 / 3$ & ND & $\mathrm{ND}$ & & ND & & NA & & NA & $2.90 \mathrm{E}+07$ & $0 / 3$ & & NA \\
\hline Aniline & $0 / 3$ & $\mathrm{ND}$ & $\mathrm{ND}$ & & ND & & $\mathrm{NA}$ & & $\mathrm{NA}$ & $3.00 \mathrm{E}+06$ & $0 / 3$ & & $\mathrm{NA}$ \\
\hline Anthracene & $0 / 3$ & ND & ND & & $\mathrm{ND}$ & & NA & & NA & $1.00 \mathrm{E}+08$ & $0 / 3$ & & NA \\
\hline Benz(a)anthracene & $2 / 3$ & $56 \mathrm{~J}$ & $59 \mathrm{~J}$ & Z2-EU34B-303 & 57.5 & & $\mathrm{NA}$ & & $\mathrm{NA}$ & $2.10 \mathrm{E}+04$ & $0 / 3$ & & $\mathrm{NA}$ \\
\hline Benzenemethanol & $0 / 3$ & ND & $\mathrm{ND}$ & & $\mathrm{ND}$ & & NA & & NA & $1.00 \mathrm{E}+08$ & $0 / 3$ & & NA \\
\hline Benzo(a)pyrene & $2 / 3$ & $56 \mathrm{~J}$ & $60 \mathrm{~J}$ & Z2-EU34B-305 & 58 & & $\mathrm{NA}$ & & NA & $2.10 \mathrm{E}+03$ & $0 / 3$ & & $\mathrm{NA}$ \\
\hline
\end{tabular}




\begin{tabular}{|c|c|c|c|c|c|c|c|c|c|c|c|c|c|}
\hline \multicolumn{14}{|c|}{ Table G.3. (continued) } \\
\hline Analyte & $\begin{array}{c}\text { Frequency } \\
\text { of detect }\end{array}$ & $\begin{array}{c}\text { Minimum } \\
\text { detect }\end{array}$ & $\begin{array}{c}\text { Maximum } \\
\text { detect }\end{array}$ & $\begin{array}{c}\text { Location(s) } \\
\text { of maximum } \\
\text { detected result }\end{array}$ & $\begin{array}{c}\text { Average } \\
\text { detected } \\
\text { result }\end{array}$ & $\begin{array}{c}\text { Max } \\
\text { RL }\end{array}$ & $\begin{array}{c}\text { Frequency } \\
\text { of detects } \\
\text { exceeding } \\
\text { Max RL } \\
\end{array}$ & $\begin{array}{l}\text { Avg } \\
\text { RL }\end{array}$ & 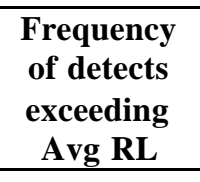 & $\begin{array}{l}\text { PRG limit } \\
\left(10^{-5} \text { or } 1\right)\end{array}$ & 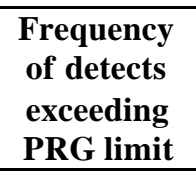 & $\begin{array}{c}\text { Background } \\
\text { concentration }\end{array}$ & $\begin{array}{c}\text { Frequency } \\
\text { of detects } \\
\text { exceeding } \\
\text { background }\end{array}$ \\
\hline Benzo(k)fluoranthene & $2 / 3$ & $55 \mathrm{~J}$ & $59 \mathrm{~J}$ & Z2-EU34B-303 & 57 & & $\mathrm{NA}$ & & $\mathrm{NA}$ & $2.10 \mathrm{E}+05$ & $0 / 3$ & & $\mathrm{NA}$ \\
\hline Benzoic acid & $0 / 3$ & $\mathrm{ND}$ & $\mathrm{ND}$ & & $\mathrm{ND}$ & & NA & & $\mathrm{NA}$ & $1.00 \mathrm{E}+08$ & $0 / 3$ & & $\mathrm{NA}$ \\
\hline Bis(2-chloroethoxy)methane & $0 / 3$ & $\mathrm{ND}$ & ND & & ND & & NA & & NA & & NA & & NA \\
\hline Bis(2-chloroethyl) ether & $0 / 3$ & $\mathrm{ND}$ & $\mathrm{ND}$ & & $\mathrm{ND}$ & & $\mathrm{NA}$ & & $\mathrm{NA}$ & $5.80 \mathrm{E}+03$ & $0 / 3$ & & $\mathrm{NA}$ \\
\hline Bis(2-chloroisopropyl) ether & $0 / 3$ & $\mathrm{ND}$ & ND & & $\mathrm{ND}$ & & NA & & NA & $7.40 \mathrm{E}+04$ & $0 / 3$ & & NA \\
\hline Bis(2-ethylhexyl)phthalate & $0 / 3$ & $\mathrm{ND}$ & $\mathrm{ND}$ & & $\mathrm{ND}$ & & NA & & NA & $1.20 \mathrm{E}+06$ & $0 / 3$ & & NA \\
\hline Butyl benzyl phthalate & $0 / 3$ & $\mathrm{ND}$ & $\mathrm{ND}$ & & $\mathrm{ND}$ & & $\mathrm{NA}$ & & $\mathrm{NA}$ & $1.00 \mathrm{E}+08$ & $0 / 3$ & & $\mathrm{NA}$ \\
\hline Carbazole & $0 / 3$ & ND & ND & & ND & & $\mathrm{NA}$ & & $\mathrm{NA}$ & $8.60 \mathrm{E}+05$ & $0 / 3$ & & $\mathrm{NA}$ \\
\hline Chrysene & $2 / 3$ & $60 \mathrm{~J}$ & $61 \mathrm{~J}$ & Z2-EU34B-303 & 60.5 & & $\mathrm{NA}$ & & $\mathrm{NA}$ & $2.10 \mathrm{E}+06$ & $0 / 3$ & & $\mathrm{NA}$ \\
\hline Di-n-butyl phthalate & $0 / 3$ & ND & ND & & $\mathrm{ND}$ & & $\mathrm{NA}$ & & $\mathrm{NA}$ & $6.20 \mathrm{E}+07$ & $0 / 3$ & & $\mathrm{NA}$ \\
\hline Di-n-octylphthalate & $0 / 3$ & $\mathrm{ND}$ & $\mathrm{ND}$ & & $\mathrm{ND}$ & & $\mathrm{NA}$ & & NA & $2.50 \mathrm{E}+07$ & $0 / 3$ & & NA \\
\hline Dibenz(a,h)anthracene & $0 / 3$ & $\mathrm{ND}$ & $\mathrm{ND}$ & & $\mathrm{ND}$ & & NA & & NA & $2.10 \mathrm{E}+03$ & $0 / 3$ & & NA \\
\hline Diethyl phthalate & $0 / 3$ & $\mathrm{ND}$ & $\mathrm{ND}$ & & $\mathrm{ND}$ & & NA & & NA & $1.00 \mathrm{E}+08$ & $0 / 3$ & & NA \\
\hline Dimethyl phthalate & $0 / 3$ & $\mathrm{ND}$ & $\mathrm{ND}$ & & $\mathrm{ND}$ & & $\mathrm{NA}$ & & $\mathrm{NA}$ & $1.00 \mathrm{E}+08$ & $0 / 3$ & & $\mathrm{NA}$ \\
\hline Diphenyldiazene & $0 / 3$ & $\mathrm{ND}$ & ND & & $\mathrm{ND}$ & & NA & & NA & $1.60 \mathrm{E}+05$ & $0 / 3$ & & NA \\
\hline Fluoranthene & $2 / 3$ & $98 \mathrm{~J}$ & $110 \mathrm{~J}$ & Z2-EU34B-303 & 104 & & NA & & NA & $2.20 \mathrm{E}+07$ & $0 / 3$ & & NA \\
\hline Fluorene & $0 / 3$ & $\mathrm{ND}$ & $\mathrm{ND}$ & & ND & & NA & & NA & $2.60 \mathrm{E}+07$ & $0 / 3$ & & NA \\
\hline Hexachlorobenzene & $0 / 3$ & $\mathrm{ND}$ & $\mathrm{ND}$ & & $\mathrm{ND}$ & & NA & & NA & $1.10 \mathrm{E}+04$ & $0 / 3$ & & NA \\
\hline Hexachlorobutadiene & $0 / 3$ & $\mathrm{ND}$ & $\mathrm{ND}$ & & $\mathrm{ND}$ & & $\mathrm{NA}$ & & $\mathrm{NA}$ & $1.80 \mathrm{E}+05$ & $0 / 3$ & & $\mathrm{NA}$ \\
\hline Hexachlorocyclopentadiene & $0 / 3$ & $\mathrm{ND}$ & $\mathrm{ND}$ & & $\mathrm{ND}$ & & NA & & NA & $3.70 \mathrm{E}+06$ & $0 / 3$ & & NA \\
\hline Hexachloroethane & $0 / 3$ & $\mathrm{ND}$ & $\mathrm{ND}$ & & $\mathrm{ND}$ & & $\mathrm{NA}$ & & $\mathrm{NA}$ & $6.20 \mathrm{E}+05$ & $0 / 3$ & & $\mathrm{NA}$ \\
\hline Indeno(1,2,3-cd)pyrene & $0 / 3$ & $\mathrm{ND}$ & $\mathrm{ND}$ & & ND & & NA & & NA & $2.10 \mathrm{E}+04$ & $0 / 3$ & & NA \\
\hline Isophorone & $0 / 3$ & $\mathrm{ND}$ & $\mathrm{ND}$ & & $\mathrm{ND}$ & & NA & & NA & $5.10 \mathrm{E}+06$ & $0 / 3$ & & $\mathrm{NA}$ \\
\hline N-Nitroso-di-n-propylamine & $0 / 3$ & $\mathrm{ND}$ & ND & & $\mathrm{ND}$ & & NA & & $\mathrm{NA}$ & $2.50 \mathrm{E}+03$ & $0 / 3$ & & $\mathrm{NA}$ \\
\hline N-Nitrosodimethylamine & $0 / 3$ & ND & $\mathrm{ND}$ & & ND & & NA & & NA & $3.40 \mathrm{E}+02$ & $0 / 3$ & & NA \\
\hline $\mathrm{N}$-Nitrosodiphenylamine & $0 / 3$ & $\mathrm{ND}$ & $\mathrm{ND}$ & & $\mathrm{ND}$ & & $\mathrm{NA}$ & & $\mathrm{NA}$ & $3.50 \mathrm{E}+06$ & $0 / 3$ & & $\mathrm{NA}$ \\
\hline Naphthalene & $0 / 3$ & $\mathrm{ND}$ & $\mathrm{ND}$ & & $\mathrm{ND}$ & & NA & & NA & $1.90 \mathrm{E}+05$ & $0 / 3$ & & NA \\
\hline Nitrobenzene & $0 / 3$ & $\mathrm{ND}$ & ND & & $\mathrm{ND}$ & & $\mathrm{NA}$ & & NA & $1.00 \mathrm{E}+05$ & $0 / 3$ & & $\mathrm{NA}$ \\
\hline
\end{tabular}




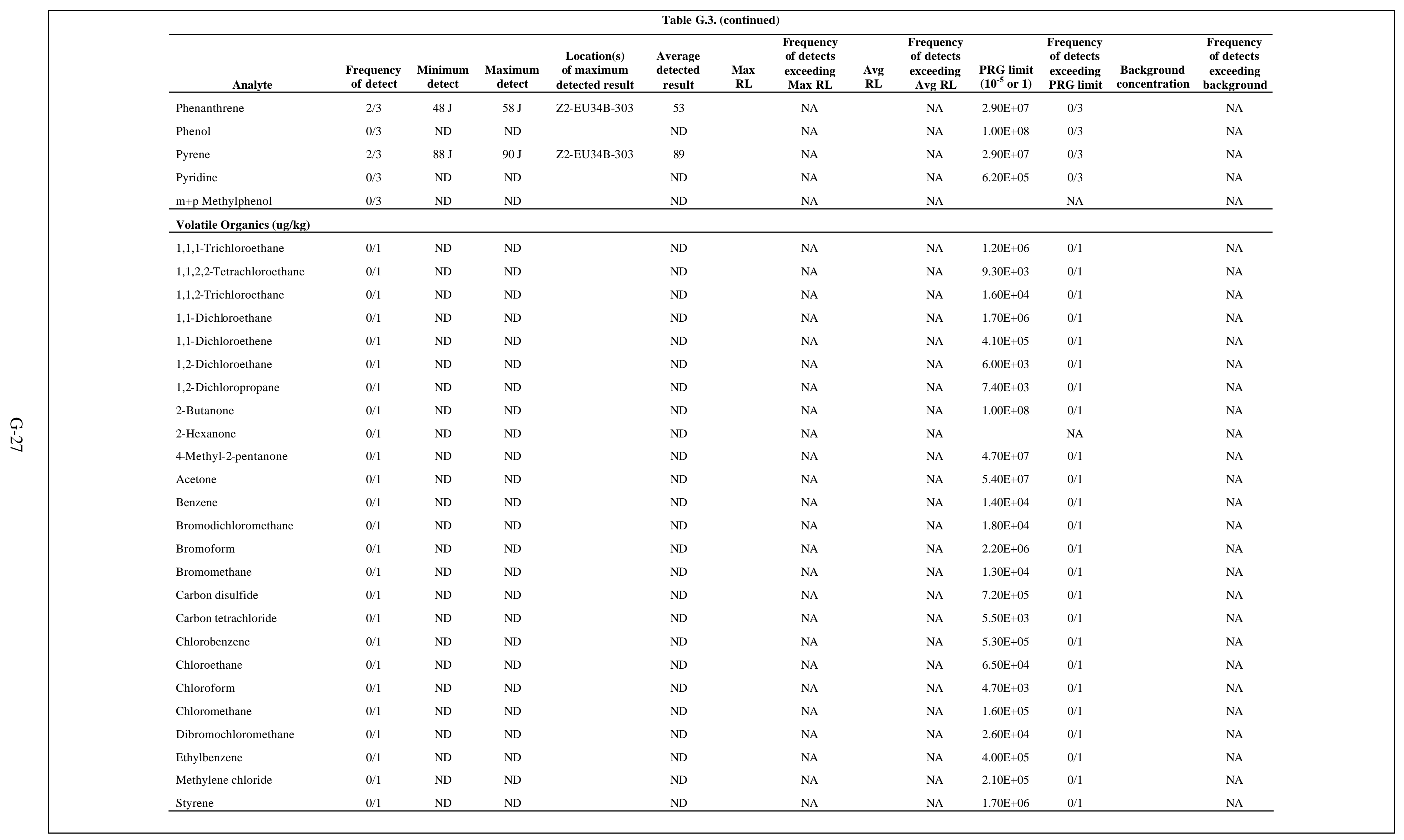


Table G.3. (continued)

\begin{tabular}{|c|c|c|c|c|c|c|c|c|c|c|c|c|c|}
\hline Analyte & $\begin{array}{c}\text { Frequency } \\
\text { of detect }\end{array}$ & $\begin{array}{c}\text { Minimum } \\
\text { detect }\end{array}$ & $\begin{array}{c}\text { Maximum } \\
\text { detect }\end{array}$ & $\begin{array}{c}\text { Location(s) } \\
\text { of maximum } \\
\text { detected result }\end{array}$ & $\begin{array}{c}\text { Average } \\
\text { detected } \\
\text { result }\end{array}$ & $\begin{array}{c}\text { Max } \\
\text { RL }\end{array}$ & $\begin{array}{c}\text { Frequency } \\
\text { of detects } \\
\text { exceeding } \\
\text { Max RL }\end{array}$ & $\begin{array}{l}\text { Avg } \\
\text { RL }\end{array}$ & $\begin{array}{c}\text { Frequency } \\
\text { of detects } \\
\text { exceeding } \\
\text { Avg RL }\end{array}$ & $\begin{array}{l}\text { PRG limit } \\
\left(10^{-5} \text { or } 1\right)\end{array}$ & $\begin{array}{l}\text { Frequency } \\
\text { of detects } \\
\text { exceeding } \\
\text { PRG limit }\end{array}$ & $\begin{array}{l}\text { Background } \\
\text { concentration }\end{array}$ & $\begin{array}{c}\text { Frequency } \\
\text { of detects } \\
\text { exceeding } \\
\text { background }\end{array}$ \\
\hline Tetrachloroethene & $0 / 1$ & ND & ND & & ND & & NA & & NA & $1.30 \mathrm{E}+04$ & $0 / 1$ & & NA \\
\hline Toluene & $0 / 1$ & ND & $\mathrm{ND}$ & & ND & & NA & & NA & $5.20 \mathrm{E}+05$ & $0 / 1$ & & NA \\
\hline Total xylene & $0 / 1$ & ND & ND & & ND & & NA & & NA & $4.20 \mathrm{E}+05$ & $0 / 1$ & & NA \\
\hline Trichloroethene & $0 / 1$ & ND & ND & & ND & & NA & & NA & $1.10 \mathrm{E}+03$ & $0 / 1$ & & NA \\
\hline Vinyl chloride & $0 / 1$ & ND & ND & & ND & & NA & & NA & $7.50 \mathrm{E}+03$ & $0 / 1$ & & NA \\
\hline cis-1,2-Dichloroethene & $0 / 1$ & ND & ND & & ND & & NA & & NA & $1.50 \mathrm{E}+05$ & $0 / 1$ & & NA \\
\hline cis-1,3-Dichloropropene & $0 / 1$ & ND & ND & & ND & & NA & & NA & $1.80 \mathrm{E}+04$ & $0 / 1$ & & NA \\
\hline trans-1,2-Dichloroethene & $0 / 1$ & ND & ND & & ND & & NA & & NA & $2.30 \mathrm{E}+05$ & $0 / 1$ & & NA \\
\hline trans-1,3-Dichloropropene & $0 / 1$ & ND & ND & & $\mathrm{ND}$ & & NA & & NA & $1.80 \mathrm{E}+04$ & $0 / 1$ & & NA \\
\hline
\end{tabular}

${ }^{a}$ Radionuclide is evaluated as part of Ra/Th decay series as discussed in the Zone 2 ROD
${ }^{b}$ Evaluated a part of Th-232 $+\mathrm{D}=$ Th-232 + Ra-228+D + Th-2228+D.

Definition of validation qualifiers included: $J=$ analyte was positively identified and result is approximate concentration of analyte in the sample, and $\mathrm{U}=$ analyte was not detected above reported sample quantitation limi

Stations in summary include Z2-EU34B-301, Z2-EU34B-302, Z2-EU34B-303, Z2-EU34B-304, and Z2-EU34B-305.

$\begin{array}{ll}\mathrm{Avg}=\text { average } & \mathrm{ND}=\text { not detected } \\ \mathrm{EU}=\text { exposure unit } & \mathrm{PCB}=\text { = }\end{array}$

$\begin{array}{ll}\mathrm{EU}=\text { exposure } & \mathrm{PCB}=\text { polychlorinated biphenyl } \\ \mathrm{Max}=\text { maximum } & \mathrm{PRG}=\text { preliminary remediation }\end{array}$

$\begin{array}{ll}\mathrm{Max}=\text { maximum } & \mathrm{PRG}=\text { preliminary remediation goal } \\ \mathrm{NA}=\text { not applicable } & \mathrm{RL}=\text { remediation level }\end{array}$ 


\section{Appendix H}

K-1070-C/D and Downgradient Area Group

Exposure Unit Z2-37

Technical Memorandum 


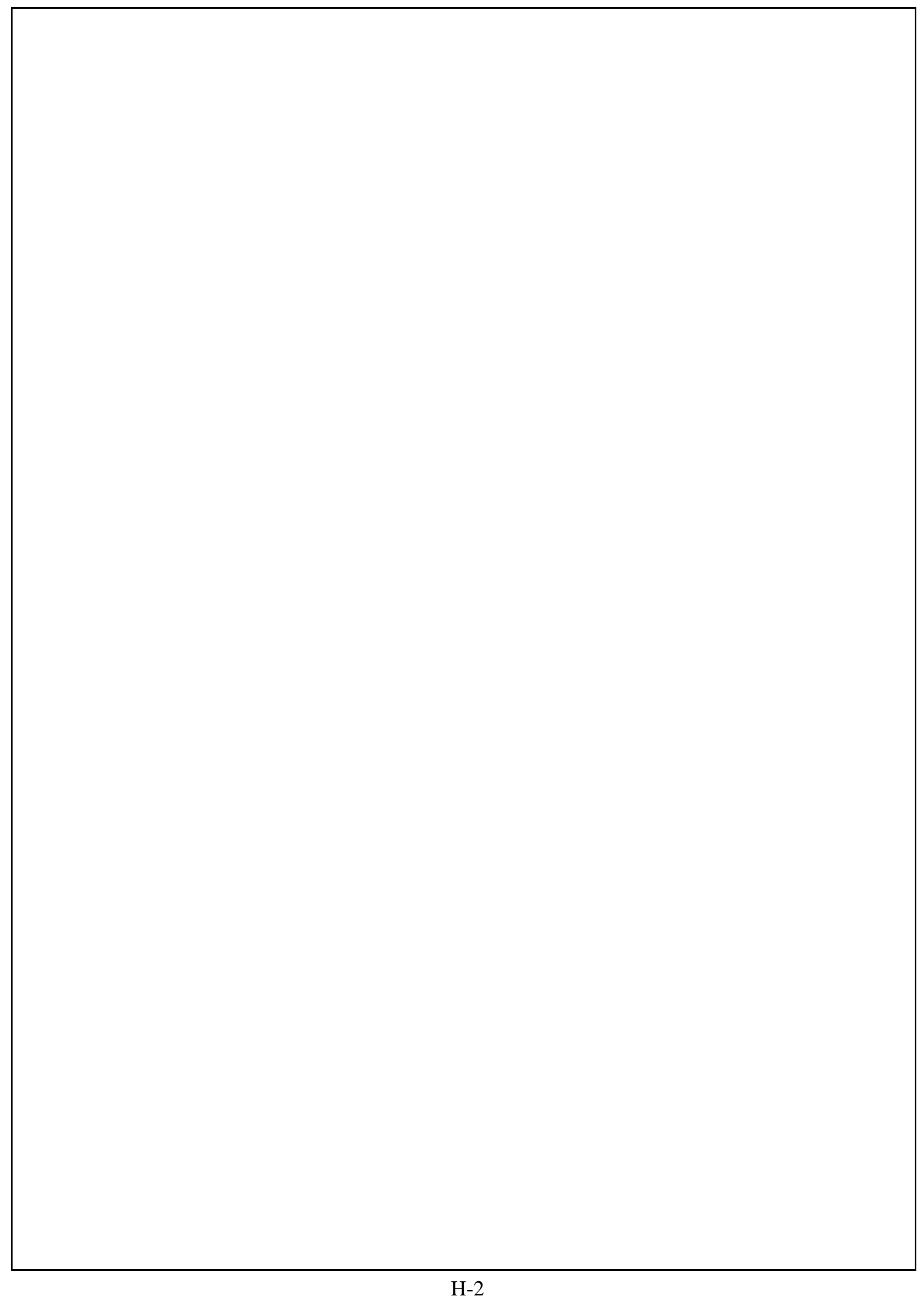

H-2 


\section{FIGURES}

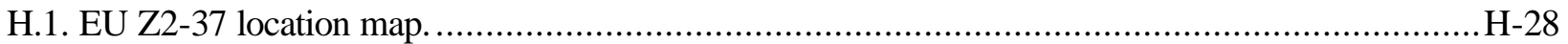

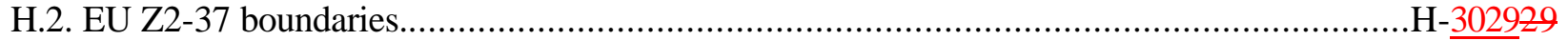

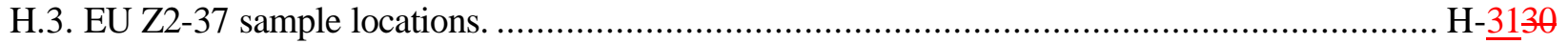

\section{TABLES}

H.1. EU Z2-37 facility and FFA site list ................................................................. H-

H.2. EU Z2-37 sample summary................................................................... H-

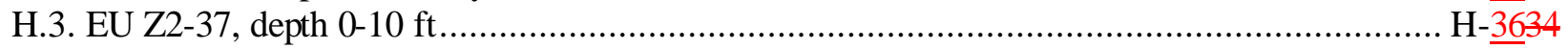

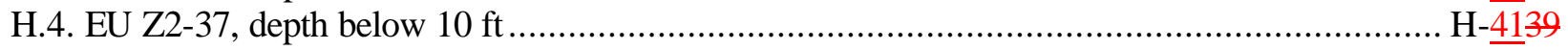




\section{DYNAMIC VERIFICATION STRATEGY (DVS) TECHNICAL MEMORANDUM (TM)}

EXPOSURE UNIT (EU) GROUP: Zone 2 K-1070-C/D and Downgradient Area Group EU Z2-37

\section{INTRODUCTION}

The purpose of this TM is to document the recommendation for an action/no further action (NFA) decision for Zone 2 exposure unit 37 (EU Z2-37) in the K-1070-C/D and Downgradient Area EU Group. The recommendation for this EU is based on existing historical data and DVS soil characterization activities. These data are used to determine the nature and extent of contamination in the EU and evaluate the need for an action. When it is determined that an action is necessary, the data also are used to calculate soil volumes for the proposed remedial alternative as identified in the Record of Decision for Soil, Buried Waste, and Subsurface Structure Actions in Zone 2, East Tennessee Technology Park, Oak Ridge, Tennessee (DOE/OR/01-2161\&D2) (Zone 2 ROD).

\begin{tabular}{|l|r|}
\hline H.1.0 & BACKGROUND AND EU SUMMARY \\
\hline H.1.1 & LOCATIONAT EAST TENNESSEE TECHNOLOGY PARK (ETTP) \\
\hline
\end{tabular}

EU Z2-37 is located in the east-central portion of Zone 2 in the K-1070-C/D and Downgradient Area EU Group (Fig. H.1). This EU is bounded on the north by EU Z2-36, on the east by EU Z2-41, on the south by EUs Z2-32 and Z2-42, and on the west by EUs Z2-31 and Z2-32.

\section{\begin{tabular}{l|l} 
H.1.2 & EU Z2-37 ACREAGE \\
\hline
\end{tabular}}

EU Z2-37 has an area of approximately 5.9 acres (Fig. H.2).

\section{\begin{tabular}{l|l} 
H.1.3 & SUMMARY DESCRIPTION \\
\hline
\end{tabular}}

All of the land area in EU Z2-37 has been impacted by site operations. This EU lies at the eastern edge of the industrialized heart of ETTP Zone 2 with the K-1070-C/D Burial Ground to the east in EU Z2-41 and Bldg. K-1401 and support facilities to the west in EUs Z2-31 and Z2-32. There are several buildings and facilities located in the southern portion of the EU that are associated with the K-1414 Garage as well as roads, parking lots, and sidewalks. The northeast half of this EU is dominated by a grass-covered hill sloping down from the K-1070-C/D Burial Ground in EU Z2-41 to the east.

Six underground storage tanks (USTs) existed at the K-1414 Garage. Two USTs, one for diesel fuel and one for unleaded gasoline, were installed in 1992 and are currently active. These two tanks are located west of K-1414 in EU Z2-32. The other four USTs, which have been in place since 1949 when the K-1414 garage began operations, include a waste oil storage tank [underground storage tank (UST) \#6], unleaded gasoline tank (UST \#7) that underwent a clean closure-in-place in 1994, diesel tank (UST \#8) that was removed in 1987 and received a clean closure, and another diesel tank (UST\#9) that was removed in 1987. The tank closures were performed in accordance with UST rules of the Tennessee Department of Environment and Conservation (TDEC) Chap. 1200-1-15-06(7)(e)(4). A diesel fuel leak from piping associated with UST \#9 was discovered in 1987. The site of this former UST and the surrounding soils constitute the K-1414 Garage Diesel Tank/Soils FFA site.

The DQO Scoping Package for the K-1070-C/D and Downgradient Area EU Group lists 11 facilities in EU Z2-37. Table H.1 presents an accounting of facilities in the EU.

\section{\begin{tabular}{l|l} 
H.1.4 & SOIL UNITS (SUS) \\
\hline
\end{tabular}}

Class 1 SU: None

Class 2 SU: None

Class 3 SU: 5.9 acres

Class 4 SU: None

The EU Z2-37 soil unit boundaries are shown on Fig. H.2. 
There is one FFA site in EU Z2-37 that is listed in Appendix A of the Zone 2 ROD:

- $\quad$ K-1414 Garage Diesel Tank/Soils FFA site

\begin{tabular}{|l|l|}
\hline H.2.0 & \multicolumn{1}{|c}{ DVS INVESTIGATIONS AND RESULTS } \\
\hline H.2.1 & DVS FIELD ACTIVITIES \\
\hline
\end{tabular}

DVS activities were conducted in accordance with the Remedial Design Report/Remedial Action Work Plan for Zone 2 Soils, Slabs, and Infrastructure, East Tennessee Technology Park, Oak Ridge, Tennessee (DOE/OR/01-2224\&D2) (Zone 2 RDR/RAWP).

\begin{tabular}{|c|c|}
\hline H.2.1.1 & CLASS 1 SUS \\
\hline \multicolumn{2}{|l|}{ None } \\
\hline H.2.1.1.1 & CLASS 1 SU RADIOLOGICAL WALKOVER SURVEY \\
\hline \multicolumn{2}{|l|}{ None } \\
\hline H.2.1.1.2 & CLASS 1 SU GEOPHYSICAL SURVEY \\
\hline \multicolumn{2}{|l|}{ None } \\
\hline H.2.1.1.3 & CLASS 1 SU SOIL SAMPLING \\
\hline \multicolumn{2}{|l|}{ None } \\
\hline H.2.1.2 & Class 2 SUS \\
\hline \multicolumn{2}{|l|}{ None } \\
\hline H.2.1.2.1 & CLASS 2 SU RADIOLOGICAL WALKOVER SURVEY \\
\hline \multicolumn{2}{|l|}{ None } \\
\hline H.2.1.2.2 & CLASS 2 SU GEOPHYSICAL SURVEY \\
\hline \multicolumn{2}{|l|}{ None } \\
\hline H.2.1.2.3 & Class 2 SU SOIL SAMPLING \\
\hline \multicolumn{2}{|l|}{ None } \\
\hline H.2.1.3 & Class 3 AND ClaSS 4 SU WALKOVER ASSESSMENT \\
\hline \multicolumn{2}{|c|}{$\begin{array}{l}\text { Because of extensive historical sampling conducted in the Class } 3 \text { SU of EU Z2-37, it was agreed during DQO } \\
\text { scoping that a Class } 3 \text { walkover assessment was not necessary. }\end{array}$} \\
\hline H.2.1.3.1 & CLASS 3 AND CLASS 4 SU RADIOLOGICAL SURVEY SUMMARY \\
\hline \multicolumn{2}{|c|}{$\begin{array}{l}\text { Screening level (SL): None } \\
\text { SL exceedances: None }\end{array}$} \\
\hline H.2.1.3.2 & CLASS 3 AND CLASS 4 SU ANTHROPOGENIC FEATURES \\
\hline \multicolumn{2}{|c|}{ Number of identified anthropogenic features: None } \\
\hline
\end{tabular}




\section{H.2.1.3.3 $\quad$ CLASS 3 SU FACILITIES ASSESSMENTS}

Eleven facilities are listed in the DQO Scoping Package as being located in EU Z-37, and 10 facilities were assessed (Table H.1). The facility assessments are reported in the Walkover Inspections and Radiological Surveys for FY2007 Exposure Units in Zones 1 and 2, East Tennessee Technology Park, Oak Ridge, Tennessee (BJC/OR2691). In summary, no facility was identified as a possible source for either chemical or radiological contamination.

\section{H.2.1.3.4 $\quad$ CLASS 3 AND CLASS 4 SU BIASED SAMPLING}

Class 3 SU biased sample locations associated with storm drains were identified during DQO scoping. During field work, two biased sediment sample locations were selected in the storm drain along Avenue D and a biased soil sample location was selected in a utility corridor. In addition, as a best management practice, three biased sample locations associated with the SW-31 spring were selected during field work-one location is in the ditch near the spring, another is in the ditch uphill from the spring, and the third is in the ditch downhill from the spring.

Details of actual sampling and analysis in the Class $3 \mathrm{SU}$, including sample depths, analytes, and deviations from planned sampling, are presented in Table H.2.

\section{\begin{tabular}{|l|l|l} 
H.2.2 & DVS AND HISTORICAL SAMPLE RESULTS \\
\hline
\end{tabular}}

The full data set for EU Z2-37 contains several samples collected from depths $>10 \mathrm{ft}$ bgs. Consistent with the requirements of the Zone 2 ROD, this TM evaluates only samples collected from the 0 - to 10 -ft-bgs interval (i.e., any sample whose starting depth is < $10 \mathrm{ft} \mathrm{bgs})$. Results for the $\theta$ to $10-\mathrm{ft}-\mathrm{bgs}$ samples are summarized in Table H.3. Subsets of Table H.3 are discussed in Sects. H.2.2.5 and H.2.2.6 as focused characterization summaries and the EU Z2-37 summary. Results for samples from > $10 \mathrm{ft}$ bgs are summarized in Table H.4. A compact disc containing electronic files for the historical and DVS analytical data used to generate Tables H.3 and H.4 is provided with this Phased Construction Completion Report (PCCR).

\begin{tabular}{|l|l|}
\hline 2.2.1 & \multicolumn{1}{l|}{ CLASS 1 SUS } \\
\hline None \\
\hline $\mathbf{2 . 2 . 2}$ & CLASS 2 SUS \\
\hline None \\
\hline $\mathbf{2 . 2 . 3}$ & CLASS 3 AND CLASS 4 SUS \\
\hline
\end{tabular}

There are 52 DVS and historical sample locations in this EU Class 3 SU-six DVS sample locations and 46 historical sample locations. Of these 52 sample locations, 42 include samples collected within the 0 to $10 \mathrm{ft}$ depth interval-six DVS sample locations and 36 historical sample locations. Three of the historical sample locations (SB120, SB122, and SB123) are not discussed in this TM and are not listed in the following table. Samples from these locations were analyzed only for alpha activity and beta/gamma activity with results reported in $\mathrm{cpm}$ which are quasi-quantitative measures that cannot be converted to quantitative values for use in a risk assessment. The DVS sample locations consist of biased sample locations identified during DQO scoping and other biased locations added during field work. Historical sampling in the Class 3 SU was conducted during the K-25 Radiation Survey, K-25 Radiological Survey Phase II, K-1414 Diesel UST investigation, K-1070-C/D Phase 2 Remedial Investigation (RI), ETTP Release Project, and ETTP Site-Wide Residual Contamination Project. Five historical sample locations are in or around the K-1414 Garage Diesel Tank/Soil FFA site or downgradient from it and were selected as representative sample locations for the FFA site. Thirty-three samples from the $\theta$ to 10 -ft-depth interval at 18 sample locations were analyzed using the field gas chromatograph (GC) method. The field GC analytical results are not evaluated in this TM because field analytical methods lack the quality controls obtained by laboratory methods. Field GC sample locations are listed separately in the following table and field GC analytical results are summarized separately at the end of Sect. H.2.2.5. Samples from some field GC sample locations also were collected for laboratory analysis, therefore, certain sample locations fall under more than the field GC headings in the following table. Class $3 \mathrm{SU}$ sample locations are shown on Fig. H.3 and summarized below. 


\begin{tabular}{|c|c|c|}
\hline $\mathbf{E U}$ & DVS sample locations & Historical sample locations \\
\hline \multicolumn{3}{|c|}{ Locations with samples from 0 to $10 \mathrm{ft}$ bgs } \\
\hline \multirow[t]{3}{*}{ Z2-37 } & $\begin{array}{l}\text { Z2-EU37B-301, Z2-EU37B-302, } \\
\text { Z2-EU37B-303, Z2-EU37B-304, } \\
\text { Z2-EU37B-305, Z2-EU37B-306 }\end{array}$ & $\begin{array}{l}\text { K-1414 Garage Diesel Tank/Soil FFA Site: BH005, } \\
\text { BH006, ETTP-REL12, ETTP-REL13, SB088 }\end{array}$ \\
\hline & & $\begin{array}{l}\text { Other Historical Locations: BH002, BH004, BH007, } \\
\text { BH008, BH011, BH0012, BH013, RAD69, RAD78, RAD85, } \\
\text { RAD90, SB078, SB079, SB080, SB081, SB082, SB083, } \\
\text { SB087, SB089, SB090, SB091, SB092, SB093, SB099 }\end{array}$ \\
\hline & & $\begin{array}{l}\text { Field GC Locations: SB078, SB079, SB080, SB081,SB082, } \\
\text { SB083, SB087, SB088, SB089, SB090, SB091, SB092, } \\
\text { SB093, SB099, SB103, SB109, SB110, SB111 }\end{array}$ \\
\hline \multicolumn{3}{|c|}{ Locations with samples from $>10 \mathrm{ft}$ bgs } \\
\hline \multirow[t]{3}{*}{ Z2-37 } & & $\begin{array}{l}\text { K-1414 Garage Diesel Tank/Soil FFA Site: BH004, } \\
\text { BH005, SB088 }\end{array}$ \\
\hline & & $\begin{array}{l}\text { Other Historical Locations: BH001, BH002, BH003, } \\
\text { BH004, BH007, BH011, K1070CD-DPT-04, } \\
\text { K1070CD-DPT-05, K1070CD-DPT-06, K1200-DPT-01, } \\
\text { K1200-DPT-02, SB047, SB048, SB049, SB078, SB079, } \\
\text { SB080, SB081, SB082, SB083, SB087, SB090, SB091, } \\
\text { SB109 }\end{array}$ \\
\hline & & $\begin{array}{l}\text { Field GC Locations: SB078, SB079, SB080, SB081, } \\
\text { SB082, SB083, SB087, SB088, SB090, SB091, SB103, } \\
\text { SB109 }\end{array}$ \\
\hline
\end{tabular}

DVS = dynamic verification strategy $\quad$ FFA $=$ Federal Facility Agreement

$\mathrm{EU}=$ exposure unit $\quad \mathrm{GC}=$ gas chromatograph

The number of samples collected and sampling intervals at each location varied as well as the chemicals and radionuclides analyzed for (Table H.2). Data for samples collected from the 0 to 10 - $\mathrm{ft}$ bgs depth interval are summarized in Table H.3, evaluated by area of interest and EU in Sect. H.2.2.5, and by FFA site in Sect. H.2.2.6. Data for samples collected from $>10 \mathrm{ft}$ bgs are summarized in Table H.4. The numbers of analyses conducted in the Class $3 \mathrm{SU}$ for samples collected from the 0 to $10-\mathrm{ft}$-bgs depth interval are presented below by analyte group. Analyses conducted by the field GC method are not included in the following tables.

\begin{tabular}{cccccc}
\hline Metals & $\begin{array}{c}\text { Other } \\
\text { organics }^{\boldsymbol{a}}\end{array}$ & PPCBs $^{\boldsymbol{b}}$ & Radionuclides $^{\boldsymbol{c}}$ & SVOCs & VOCs $^{\boldsymbol{d}}$ \\
\hline 23 & 14 & 23 & 28 & 35 & 35 \\
\hline
\end{tabular}

${ }^{a}$ This group includes diesel range and gasoline range organics.

${ }^{b}$ The tally for PPCBs is based on PCB analyses. PCBs were reported each time the PPCB analyte group was analyzed. Pesticides were reported for 17 PPCB analyte group analyses in historical samples.

${ }^{\circ}$ The tally for radionuclides is based on counts of U-235 and U-238 analyses. Some samples were analyzed for radionuclide or gross activity suites that did not include these two radionuclides.

${ }^{d}$ VOC analytical suites differed by project. The tally for VOCs is based on a count of chlorinated solvents.

$\mathrm{PCB}=$ polychlorinated biphenyl

SVOC $=$ semivolatile organic compound

PPCB = pesticides and polychlorinated biphenyl

$\mathrm{VOC}=$ volatile organic compound

\section{\begin{tabular}{|l|l|}
\hline 2.2.4 & INFRASTRUCTURE \\
\hline
\end{tabular}}

Biased sampling locations were identified during DQO scoping at storm drains and utility corridors. Sample results are described in Sect. H.2.2.5. 
In this section, characterization data and other information are evaluated for EU Z2-37. The analytical data in the following summaries are presented by analyte group. The results for a particular analyte group are summarized only if that group was analyzed in the samples from the unit being summarized. Within each summary, the data are evaluated by comparing to certain criteria, which include the Zone 2 soils maximum remediation level (Max RL), Zone 2 soils average remediation level (Avg RL), the $1 \times 10^{-5}$ industrial preliminary remediation goal (Ind PRG), the ETTP soils background composition (Bkg), Zone 2 groundwater screening levels (GW SL), and the $1 \times 10^{-6}$ residential preliminary remediation goal (Res PRG). If a particular criterion does not apply to any member of an analyte group, it is not tabulated for that analyte group; if a particular criterion does not apply to all analytes within an analyte group, those analytes to which it does not apply are notated with NA (not applicable). Individual metals and radionuclides, which are naturally occurring, are reported in the summaries only if one or more criterion is exceeded. Organic chemicals, which are not naturally occurring, are reported if detected, even if no criteria are exceeded. The Max RL, Avg RL, Ind PRG, Bkg, GW SL, and Res PRG criteria values, as they pertain to the analytes listed in Appendix A of the RDR/RAWP (i.e., Quality Assurance Program Plan), are presented in Sect. H.3.1 of this PCCR.

Because the carcinogenic risk associated with concentrations of radium and thorium isotopes in the natural background at ETTP exceeds the cumulative risk goal of $1 \times 10^{-4}$, RL values for these radionuclides are based on alternative concentration levels rather than risk. The alternative concentration levels of $5 \mathrm{pCi} / \mathrm{g}$ above background (Avg RL) and $15 \mathrm{pCi} / \mathrm{g}$ above background (Max RL) were set as low as reasonably achievable under the site-specific conditions. Because site-specific background concentrations of these radionuclides exceed the target risk range, residual concentrations of these radionuclides and their decay series are not considered in estimates of residual risk following any remedial action.

The Zone 2 ROD states that Avg RL and Max RL exceedances by Ra-226, Th-230, and Th-232 will be evaluated by summing above-background concentrations of the greater of Ra-226 or Th-230 with the above-background concentrations of Th-232 and comparing the results to $5 \mathrm{pCi} / \mathrm{g}$ (Avg RL) and $15 \mathrm{pCi} / \mathrm{g}$ (Max RL). The required calculations have been performed. Average and maximum RL exceedances for these radionuclides, if any, are reported in the TM data summaries below and in Table H.2 as "Ra/Th decay series"; individual RL exceedances by Ra-226, Th-230, and Th-232 are reported as NA. The Ra/Th decay series data are summarized in the sections that follow only if an Avg or Max RL has been exceeded, consistent with the description in the preceding paragraph for reporting radionuclides. Discussion of the $\mathrm{Ra} / \mathrm{Th}$ decay series calculation, including the manner in which the calculation is performed, is presented in Sect. H.3.3 of this PCCR.

\section{Conceptual Site Model (CSM)}

EU Z2-37 is located in the east-central portion of Zone 2 in the K-1070C/D and Downgradient Area EU Group. The entire EU was classified as a Class 3 SU. The K-1414 Garage and its five associated tanks are located in the southern half of the EU. The K-1414 area was planned to be classified as a Class 1 SU based on a known diesel tank leak site in the area, and a Class 2 SU covering all of the other tank locations and the grounds adjacent to the shop was also planned. Prior to work under the DVS program, extensive sampling had been done in the K-1414 area and across the western slope of the K-1070-C/D Burial Ground, which is located in the northern portion of the EU to determine the nature and extent of both soil and groundwater impacts. Results of these earlier sampling programs indicated there was diesel contamination in the area where UST \#9 had leaked. The tank and soils in proximity to the tank were removed in the mid-1990s.

Samples collected in the down-slope position from the K-1070-C/D Burial Ground did not indicate contamination in the 0 to $10-\mathrm{ft}$ interval. As a result of this prior sampling, essentially all of EU Z2-37 was classified in the DQO package as a modified Class $3 \mathrm{SU}$; walkover assessments for the central area were not required since extensive soil sampling had already been performed. Because so much work had been performed and documented in the K-1070-C/D Phase 2 RI, both the nature and extent of contamination and the CSM are fairly we 11 understood

There is a groundwater volatile organic compound (VOC) release point located east of EU Z2-37 that is associated with the G pit located in the K-1070 Pits FFA Site in EU Z2-41. This source area is associated with a soil contamination area that begins at a depth of approximately $10 \mathrm{ft}$ below bgs and extends to depths in excess of $40 \mathrm{ft}$ bgs. The soil impact extends into this EU but at depths $>10 \mathrm{ft}$. Sampling in the area east of the pits has shown no significant VOC contamination in the top $10 \mathrm{ft}$ of soil down slope of the release point. 


\section{Groundwater Evaluation}

Geologic setting-A topographic high is located in and generally encompassed by EU Z2-41. This high ground is bounded to the east by a perennial drainage and a second slightly higher area further to the east. The K-25 thrust fault bounds the topographic high ground, which is located on the hanging wall of the thrust. The trace of the fault in the Zone 2 area is shown on Fig. H.1. The fault trace defines a small splinter thrust block approximately one-half mile wide and several miles in length that has a synclinal form. The western edge of this splinter thrust block is what underlies the eastern portions of ETTP Zone 2 and EUs Z2-37 and Z2-41. The geologic section of rock units in the area beneath this EU is Rome Formation of Cambrian age. This section of rock is comprised of thin interbedded sandstone and shale, with minor beds of chert and limestone in the upper section. Because of the extensive deformation that occurred during thrust faulting, the rock is shattered into very small fragments. The presence of extensive microfractures results in a porous and permeable overall rock mass.

Soils and hydrology - A surface residual soil covers most of the high ground and is up to $20 \mathrm{ft}$ thick in some areas. These surface soils are composed predominantly of clay and cover the slopes where the soil cover thins to a few feet in thickness. Rome formation outcrops are observed at isolated locations along perennial drainages and infiltration through the surface clay-rich residuum is low to moderate. Surface water and groundwater flow generally occur in a radial pattern from the top of the knoll underlying the K-1070-C/D Burial Ground. Tracer tests conducted by the site-wide program have shown gradients and the transport rate as high, with some locations along the western flank of the K-1070-C/D Burial Ground recording $5 \mathrm{ft} /$ day.

Source areas-A release of contamination into shallow surface soils occurred at this EU in the late 1980s. This release was estimated to be approximately 500-600 gal of diesel fuel from a fill pipe to a UST located north of the K-1414 Garage. The diesel tank was removed in 1987 under state UST regulatory ARARS and a limited volume of soil (not quantified in the closure report) also was excavated at the time. Several soil samples from the area reported diesel-range organics (DRO) above the former regulatory criteria of $100 \mathrm{mg} / \mathrm{kg}$. Soil borings SB-087, BH004, and BH005, all located approximately 100-130 ft west of the tank location, reported high concentrations of DRO and substantially elevated concentrations of BTEX compounds in SB087 soils from sample intervals below $6 \mathrm{ft}$ bgs. Soil samples collected in immediate proximity to the tank locations did not report significantly elevated concentrations of DRO or BTEX compounds.

Several monitoring wells in the area historically have reported benzene above maximum contaminant levels (MCLs) $(5 \mathrm{ug} / \mathrm{L})$. Benzene concentrations have declined to levels below regulatory concern in all but two monitoring wells in the area. One temporary drive point detected benzene approximately $200 \mathrm{ft}$ northeast of the tank location. It is not clear if this result is related to the diesel tank or the G-pit plume that crosses through EU Z2-37 in that area. Soil samples with elevated DRO and BTEX compounds were collected at depths of $6-15 \mathrm{ft}$ bgs. The water table in monitoring wells in proximity to the sample points ranges from 6-16 ft bgs. These data indicate the diesel fuels have been transported to the west-northwest from the release point and are in the groundwater system. Samples collected at the tank site have no substantially elevated concentrations of DRO or BTEX compounds.

These data indicate the primary source of diesel fuel contamination was removed with the tank removal action and that both an immiscible diesel fuel component of the release and associated dissolved phase BTEX compounds are present in the local groundwater. Concentrations of these compounds in unconsolidated zone wells exhibit a clear declining trend over the last 12 years. There does not appear to be a substantial source of diesel and BTEX compounds in the area. There is no removal action required in this EU to remove contaminated soils for the protection of groundwater.

\section{Sampling Results}

All of the 5.9 acres of EU Z2-37 have been classified as a Class 3 SU. However, because of extensive historical sampling, it was determined during DQO scoping that a Class $3 \mathrm{SU}$ walkover assessment was not necessary.

DVS sampling was conducted at two locations in storm drains, one location in a utility corridor, and three locations around the SW31 spring. As described in Sect.H.2.2.3, historical sampling in the EU has been extensive. The historical samples have been divided into two groups for evaluation purposes. The first group includes six sample locations that are used to evaluate the K-1414 Garage Diesel Tank/Soils FFA site (Sect. H.2.2.6). The second group consists of the remaining historical locations.

Following is a summary of the sampling results for samples collected from the 0- to 10-ft-depth interval in this EU. The summary begins with summary presentations of the analytical results for the focused sampling efforts in the EU and concludes with an overall EU summary. The EU summary includes both data summary tables and a written 
description of the nature and extent of chemicals and radionuclides observed in the EU, including data from the samples collected in the K-1414 Garage Diesel Tank/Soils FFA site (Sect. H.2.2.6). A summary of the soils data collected from 0 to $10 \mathrm{ft}$ bgs is presented in Table H.3, data for samples collected from > $10 \mathrm{ft}$ bgs are summarized in Table H.4, and all sample locations are shown on Fig. H.3. Data summarized in this section are evaluated in terms of the Zone 2 ROD remedial action objective (RAO) in Sect. H.3.3.

DVS Storm Drain Sediment Sampling: Two storm drain sediment sample locations were selected in the storm drain along Avenue D. Location Z2-EU37B-302 is south of K-1310-DD and location Z2-EU37B-305 is downhill from the SW31 spring. Analytical results summarized below show several radionuclide, one metal, and one semivolatile organic compound (SVOC) Ind PRG exceedances; metal and radionuclide Bkg exceedances; and detections of PCBs and SVOCs.

EU Z2-37 STORM DRAIN SEDIMENT METALS WITH BACKGROUND,

PRG, GW SL, AND/OR RL EXCEEDANCES (mg/kg) 0-10 ft

\begin{tabular}{|c|c|c|c|c|c|c|c|c|c|c|c|}
\hline \multirow[b]{2}{*}{ Analyte } & \multirow[b]{2}{*}{$\begin{array}{c}\text { Detect } \\
\text { frequency }\end{array}$} & \multirow[b]{2}{*}{$\begin{array}{c}\text { Minimum } \\
\text { detect }\end{array}$} & \multirow[b]{2}{*}{$\begin{array}{c}\text { Maximum } \\
\text { detect }\end{array}$} & \multirow{2}{*}{$\begin{array}{c}\text { Location(s) of } \\
\text { maximum } \\
\text { detect }\end{array}$} & \multirow{2}{*}{$\begin{array}{c}\text { Average } \\
\text { detected } \\
\text { result }\end{array}$} & \multicolumn{6}{|c|}{ Number of analyses exceeding criteria } \\
\hline & & & & & & $\begin{array}{c}\text { Max } \\
\text { RL }\end{array}$ & $\begin{array}{c}\text { Avg } \\
\text { RL }\end{array}$ & $\begin{array}{l}\text { Ind } \\
\text { PRG }\end{array}$ & Bkg & $\begin{array}{l}\text { GW } \\
\text { SL }\end{array}$ & $\begin{array}{c}\text { Res } \\
\text { PRG }\end{array}$ \\
\hline Arsenic & $2 / 2$ & 6.9 & 18 & Z2-EU37B-305 & 12.5 & 0 & 0 & 1 & 1 & 0 & 2 \\
\hline Barium & $2 / 2$ & 250 & 520 & Z2-EU37B-302 & 385 & NA & NA & 0 & 2 & 0 & 0 \\
\hline Cadmium & $2 / 2$ & $0.13 \mathrm{~J}$ & $0.27 \mathrm{~J}$ & Z2-EU37B-305 & 0.2 & NA & NA & 0 & 1 & NA & 0 \\
\hline Calcium & $2 / 2$ & 160,000 & 240,000 & Z2-EU37B-305 & 200,000 & NA & NA & NA & 2 & NA & NA \\
\hline Lead & $2 / 2$ & 15 & 41 & Z2-EU37B-305 & 28 & NA & NA & 0 & 1 & 0 & 0 \\
\hline Magnesium & $2 / 2$ & 23,000 & 41,000 & Z2-EU37B-302 & 32,000 & NA & NA & NA & 2 & NA & NA \\
\hline Manganese & $2 / 2$ & 12,000 & 16,000 & Z2-EU37B-305 & 14,000 & NA & NA & 0 & 2 & NA & 2 \\
\hline Vanadium & $2 / 2$ & 9.4 & 13 & Z2-EU37B-302 & 11.2 & NA & NA & 0 & 0 & NA & 2 \\
\hline Zinc & $2 / 2$ & $69 \mathrm{~J}$ & $160 \mathrm{~J}$ & Z2-EU37B-305 & 115 & NA & NA & 0 & 1 & NA & 0 \\
\hline
\end{tabular}

Avg = average NA = not applicable

$\mathrm{Bkg}=$ background $\quad \mathrm{PRG}=$ preliminary remediation goal

$\mathrm{EU}=$ exposure unit $\quad$ Res $=$ residential

$\mathrm{GW}=$ groundwater $\quad \mathrm{RL}=$ remediation level

Ind $=$ industrial $\quad \mathrm{SL}=$ screening level

Max = maximum $\quad$ SU $=$ soil unit

EU Z2-37 S TORM DRAIN SEDIMENT PCB DETECTS (ug/kg) 0-10 ft

\begin{tabular}{|c|c|c|c|c|c|c|c|c|c|}
\hline \multirow[b]{2}{*}{ Analyte } & \multirow[b]{2}{*}{$\begin{array}{c}\text { Detect } \\
\text { frequency }\end{array}$} & \multirow[b]{2}{*}{$\underset{\text { detect }}{\text { Minimum }}$} & \multirow[b]{2}{*}{$\underset{\text { detect }}{\text { Maximum }}$} & \multirow{2}{*}{$\begin{array}{c}\text { Location(s) of } \\
\text { maximum } \\
\text { detect }\end{array}$} & \multirow{2}{*}{$\begin{array}{c}\text { Average } \\
\text { detected } \\
\text { result }\end{array}$} & \multicolumn{4}{|c|}{$\begin{array}{l}\text { Number of analyses } \\
\text { exceeding criteria }\end{array}$} \\
\hline & & & & & & $\begin{array}{l}\text { Max } \\
\text { RL }\end{array}$ & $\begin{array}{l}\text { Avg } \\
\text { RL }\end{array}$ & $\begin{array}{l}\text { Ind } \\
\text { PRG }\end{array}$ & $\begin{array}{c}\text { Res } \\
\text { PRG }\end{array}$ \\
\hline PCB-1254 & $2 / 2$ & 120 & 2,600 & Z2-EU37B-305 & 1,360 & 0 & 0 & 0 & 2 \\
\hline Polychlorinated biphenyl & $2 / 2$ & 120 & 2,600 & Z2-EU37B-305 & 1,360 & 0 & 0 & 0 & 2 \\
\hline
\end{tabular}

Avg $=$ average $\quad$ PCB $=$ polychlorinated biphenyl

$\mathrm{EU}=$ exposure unit $\quad \mathrm{PRG}=$ preliminary remediation goal

Ind $=$ industrial $\quad$ Res $=$ residential

Max $=$ maximum $\quad \mathrm{RL}=$ remediation level 
EU Z2-37 STORM DRAIN SEDIMENT RADIONUCLIDES WITH BACKGROUND,

PRG, AND/OR RL EXCEEDANCES (pCi/g) 0-10 ft

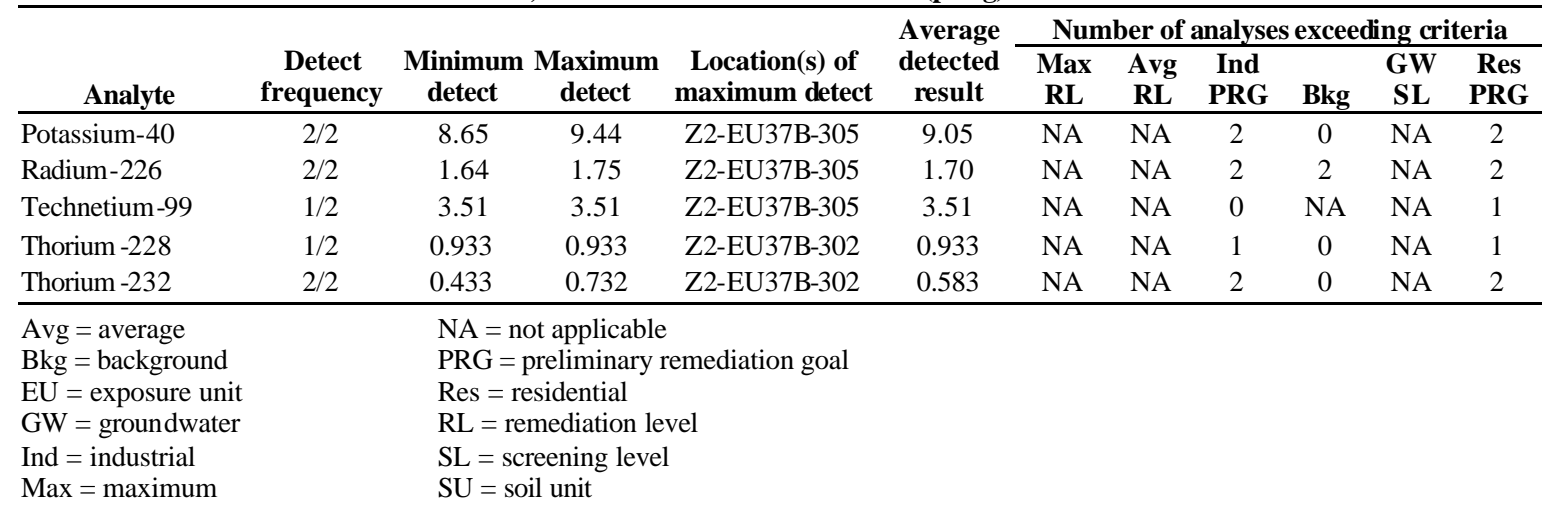

EU Z2-37 STORM DRAIN SEDIMENT SVOC DETECTS (ug/kg) 0-10 ft

\begin{tabular}{|c|c|c|c|c|c|c|c|c|}
\hline \multirow[b]{2}{*}{ Analyte } & \multirow[b]{2}{*}{$\begin{array}{c}\text { Detect } \\
\text { frequency }\end{array}$} & \multirow[b]{2}{*}{$\begin{array}{c}\text { Minimum } \\
\text { detect }\end{array}$} & \multirow[b]{2}{*}{$\begin{array}{c}\text { Maximum } \\
\text { detect }\end{array}$} & \multirow[b]{2}{*}{$\begin{array}{c}\text { Location(s) of } \\
\text { maximum detect }\end{array}$} & \multirow{2}{*}{$\begin{array}{c}\text { Average } \\
\text { detected } \\
\text { result }\end{array}$} & \multicolumn{3}{|c|}{$\begin{array}{l}\text { Number of analyses } \\
\text { exceeding criteria }\end{array}$} \\
\hline & & & & & & $\begin{array}{l}\text { Ind } \\
\text { PRG }\end{array}$ & $\begin{array}{l}\text { GW } \\
\text { SL }\end{array}$ & $\begin{array}{l}\text { Res } \\
\text { PRG }\end{array}$ \\
\hline Acenaphthene & $1 / 2$ & $170 \mathrm{~J}$ & $170 \mathrm{~J}$ & Z2-EU37B-302 & 170 & 0 & NA & 0 \\
\hline Anthracene & $1 / 2$ & $400 \mathrm{~J}$ & $400 \mathrm{~J}$ & Z2-EU37B-302 & 400 & 0 & NA & 0 \\
\hline Benz(a)anthracene & $2 / 2$ & $410 \mathrm{~J}$ & 2,400 & Z2-EU37B-302 & 1,405 & 0 & NA & 1 \\
\hline Benzo(a)pyrene & $2 / 2$ & $560 \mathrm{~J}$ & $2,200 \mathrm{~J}$ & Z2-EU37B-302 & 1,380 & 1 & NA & 2 \\
\hline Benzo(b)fluoranthene & $2 / 2$ & $1,000 \mathrm{~J}$ & $3,800 \mathrm{~J}$ & Z2-EU37B-302 & 2,400 & 0 & NA & 2 \\
\hline Benzo(ghi)perylene & $2 / 2$ & $370 \mathrm{~J}$ & $1,100 \mathrm{~J}$ & Z2-EU37B-302 & 735 & 0 & NA & 0 \\
\hline Benzo(k)fluoranthene & $2 / 2$ & $360 \mathrm{~J}$ & $1,500 \mathrm{~J}$ & Z2-EU37B-302 & 930 & 0 & NA & 0 \\
\hline Bis(2-ethylh exyl)phthalate & $2 / 2$ & $210 \mathrm{~J}$ & 4,400 & Z2-EU37B-305 & 2,305 & 0 & 0 & 0 \\
\hline Butyl benzyl phthalate & $1 / 2$ & $170 \mathrm{~J}$ & $170 \mathrm{~J}$ & Z2-EU37B-305 & 170 & 0 & NA & 0 \\
\hline Carbazole & $1 / 2$ & 650 & 650 & Z2-EU37B-302 & 650 & 0 & NA & 0 \\
\hline Chrysene & $2 / 2$ & $530 \mathrm{~J}$ & 2,500 & Z2-EU37B-302 & 1,515 & 0 & NA & 0 \\
\hline Dibenz(a,h)anthracene & $1 / 2$ & $300 \mathrm{~J}$ & $300 \mathrm{~J}$ & Z2-EU37B-302 & 300 & 0 & NA & 1 \\
\hline Dibenzofuran & $1 / 2$ & $72 \mathrm{~J}$ & $72 \mathrm{~J}$ & Z2-EU37B-302 & 72 & 0 & NA & 0 \\
\hline Fluoranthene & $2 / 2$ & $870 \mathrm{~J}$ & 5,700 & Z2-EU37B-302 & 3,285 & 0 & NA & 0 \\
\hline Fluorene & $1 / 2$ & $160 \mathrm{~J}$ & $160 \mathrm{~J}$ & Z2-EU37B-302 & 160 & 0 & NA & 0 \\
\hline Indeno(1,2,3-cd)pyrene & $2 / 2$ & $370 \mathrm{~J}$ & 1,100 & Z2-EU37B-302 & 735 & 0 & NA & 1 \\
\hline Phenanthrene & $2 / 2$ & $240 \mathrm{~J}$ & 2,900 & Z2-EU37B-302 & 1,570 & 0 & NA & 0 \\
\hline Pyrene & $2 / 2$ & $850 \mathrm{~J}$ & 4,600 & Z2-EU37B-302 & 2,725 & 0 & NA & 0 \\
\hline
\end{tabular}

\begin{tabular}{ll}
\hline EU $=$ exposure unit & PRG = preliminary remediation goal \\
$\mathrm{GW}=$ groundwater & Res = residential \\
Ind = industrial & SL $=$ screening level \\
NA = not applicable & SVOC = semivohtile organic compound
\end{tabular}

VOCs were analyzed for in both samples but were not detected.

DVS Utility Corridor Sampling: One biased soil sample location, Z2-EU37B-301, was identified in the utility corridor that runs along Avenue D. Analytical results summarized below show radionuclide Ind PRG exceedances, metal Bkg exceedances, and polychlorinated biphenyl (PCB) and SVOC detections. 
EU Z2-37 UTILITY CORRIDOR SOILS METALS WITH BACKGROUND,

PRG, GW SL, AND/OR RL EXCEEDANCES (mg/kg) 0-10 ft

\begin{tabular}{|c|c|c|c|c|c|c|c|c|c|c|c|}
\hline \multirow[b]{2}{*}{ Analyte } & \multirow[b]{2}{*}{$\begin{array}{c}\text { Detect } \\
\text { frequency }\end{array}$} & \multirow[b]{2}{*}{$\begin{array}{c}\text { Minimum } \\
\text { detect }\end{array}$} & \multirow[b]{2}{*}{$\underset{\text { detect }}{\text { Maximum }}$} & \multirow{2}{*}{$\begin{array}{c}\text { Location(s) of } \\
\text { maximum } \\
\text { detect }\end{array}$} & \multirow{2}{*}{$\begin{array}{c}\text { Average } \\
\text { detected } \\
\text { result }\end{array}$} & \multicolumn{6}{|c|}{ Number of analyses exceeding criteria } \\
\hline & & & & & & $\begin{array}{c}\text { Max } \\
\text { RL }\end{array}$ & $\begin{array}{l}\text { Avg } \\
\text { RL }\end{array}$ & $\begin{array}{l}\text { Ind } \\
\text { PRG }\end{array}$ & Bkg & $\begin{array}{c}\text { GW } \\
\text { SL }\end{array}$ & $\begin{array}{c}\text { Res } \\
\text { PRG }\end{array}$ \\
\hline Arsenic & $1 / 1$ & 7.3 & 7.3 & Z2-EU37B-301 & 7.3 & 0 & 0 & 0 & 0 & 0 & 1 \\
\hline Cadmium & $1 / 1$ & $0.34 \mathrm{~J}$ & $0.34 \mathrm{~J}$ & Z2-EU37B-301 & 0.34 & NA & NA & 0 & 1 & NA & 0 \\
\hline Chromium & $1 / 1$ & 38 & 38 & Z2-EU37B-301 & 38 & NA & NA & 0 & 0 & 0 & 1 \\
\hline Copper & $1 / 1$ & $54 \mathrm{~J}$ & $54 \mathrm{~J}$ & Z2-EU37B-301 & 54 & NA & NA & 0 & 1 & NA & 0 \\
\hline Lead & $1 / 1$ & 45 & 45 & Z2-EU37B-301 & 45 & NA & NA & 0 & 1 & 0 & 0 \\
\hline Magnesium & $1 / 1$ & 19,000 & 19,000 & Z2-EU37B-301 & 19,000 & NA & NA & NA & 1 & NA & NA \\
\hline Manganese & $1 / 1$ & 640 & 640 & Z2-EU37B-301 & 640 & NA & NA & 0 & 0 & NA & 1 \\
\hline Nickel & $1 / 1$ & 100 & 100 & Z2-EU37B-301 & 100 & NA & NA & 0 & 1 & NA & 0 \\
\hline Uranium & $1 / 1$ & 1.9 & 1.9 & Z2-EU37B-301 & 1.9 & NA & NA & 0 & NA & NA & 1 \\
\hline Vanadium & $1 / 1$ & 26 & 26 & Z2-EU37B-301 & 26 & NA & NA & 0 & 0 & NA & 1 \\
\hline
\end{tabular}

Avg = average $\quad \mathrm{NA}=$ not applicable

$\mathrm{Bkg}=$ background $\quad \mathrm{PRG}=$ preliminary remediation goal

$\mathrm{EU}=$ exposure unit $\quad$ Res $=$ residential

$\mathrm{GW}=$ groundwater $\quad \mathrm{RL}=$ remediation level

Ind $=$ industrial $\quad \mathrm{SL}=$ screening level

Max = maximum $\quad \mathrm{SU}=$ soil unit

EU Z2-37 UTILITY CORRIDOR SOILSPCB DETECTS (ug/kg) 0-10 ft

\begin{tabular}{|c|c|c|c|c|c|c|c|c|c|}
\hline \multirow[b]{2}{*}{ Analyte } & \multirow[b]{2}{*}{$\begin{array}{c}\text { Detect } \\
\text { frequency }\end{array}$} & \multirow[b]{2}{*}{$\begin{array}{c}\text { Minimum } \\
\text { detect }\end{array}$} & \multirow[b]{2}{*}{$\begin{array}{c}\text { Maximum } \\
\text { detect }\end{array}$} & \multirow{2}{*}{$\begin{array}{c}\text { Location(s) of } \\
\text { maximum } \\
\text { detect }\end{array}$} & \multirow{2}{*}{$\begin{array}{c}\text { Average } \\
\text { detected } \\
\text { result }\end{array}$} & \multicolumn{4}{|c|}{$\begin{array}{c}\text { Number of analyses } \\
\text { exceeding criteria }\end{array}$} \\
\hline & & & & & & $\begin{array}{l}\text { Max } \\
\text { RL }\end{array}$ & $\begin{array}{l}\text { Avg } \\
\text { RL }\end{array}$ & $\begin{array}{l}\text { Ind } \\
\text { PRG }\end{array}$ & $\begin{array}{c}\text { Res } \\
\text { PRG }\end{array}$ \\
\hline PCB-1254 & $1 / 1$ & 190 & 190 & Z2-EU37B-301 & 190 & 0 & 0 & 0 & 1 \\
\hline PCB-1260 & $1 / 1$ & 200 & 200 & Z2-EU37B-301 & 200 & 0 & 0 & 0 & 1 \\
\hline Polychlorinated biphenyl & $1 / 1$ & 390 & 390 & Z2-EU37B-301 & 390 & 0 & 0 & 0 & 1 \\
\hline
\end{tabular}

Avg $=$ average $\quad \mathrm{PCB}=$ polychlorinated biphenyl

$\mathrm{EU}=$ exposure unit $\quad \mathrm{PRG}=$ preliminary remediation goal

Ind $=$ industrial $\quad$ Res $=$ residential

Max $=$ maximum $\quad \mathrm{RL}=$ remediation level

EU Z2-37 UTILITY CORRIDOR SOILSRADIONUCLIDES WITH BACKGROUND, PRG, AND/OR RL EXCEEDANCES (pCi/g) 0-10 ft

\begin{tabular}{|c|c|c|c|c|c|c|c|c|c|c|c|}
\hline \multirow[b]{2}{*}{ Analyte } & \multirow[b]{2}{*}{$\begin{array}{c}\text { Detect } \\
\text { frequency }\end{array}$} & \multirow[b]{2}{*}{$\begin{array}{c}\text { Minimum } \\
\text { detect }\end{array}$} & \multirow[b]{2}{*}{$\begin{array}{c}\text { Maximum } \\
\text { detect }\end{array}$} & \multirow[b]{2}{*}{$\begin{array}{l}\text { Location(s) of } \\
\text { maximum detect }\end{array}$} & \multirow{2}{*}{$\begin{array}{c}\text { Average } \\
\text { detected } \\
\text { result }\end{array}$} & \multicolumn{6}{|c|}{ Number of analyses exceeding criteri a } \\
\hline & & & & & & $\begin{array}{c}\text { Max } \\
\text { RL }\end{array}$ & $\begin{array}{l}\text { Avg } \\
\text { RL }\end{array}$ & $\begin{array}{l}\text { Ind } \\
\text { PRG }\end{array}$ & Bkg & $\begin{array}{c}\text { GW } \\
\text { SL }\end{array}$ & $\begin{array}{l}\text { Res } \\
\text { PRG }\end{array}$ \\
\hline Potassium-40 & $1 / 1$ & 22.2 & 22.2 & Z2-EU37B-301 & 22.2 & NA & NA & 1 & 0 & NA & 1 \\
\hline Radium-226 & $1 / 1$ & 0.473 & 0.473 & Z2-EU37B-301 & 0.473 & NA & NA & 1 & 0 & NA & 1 \\
\hline Thorium -228 & $1 / 1$ & 1.19 & 1.19 & Z2-EU37B-301 & 1.19 & NA & NA & 1 & 0 & NA & 1 \\
\hline Thorium - 232 & $1 / 1$ & 1.59 & 1.59 & Z2-EU37B-301 & 1.59 & NA & NA & 1 & 0 & NA & 1 \\
\hline Uranium-238 & $1 / 1$ & 1.37 & 1.37 & Z2-EU37B-301 & 1.37 & 0 & 0 & 0 & 0 & 0 & 1 \\
\hline
\end{tabular}

Avg $=$ average

$\mathrm{Bkg}=$ background

$\mathrm{EU}=$ exposure unit

$\mathrm{GW}=$ groundwater

Ind $=$ industrial

Max $=$ maximum
$\mathrm{NA}=$ not applicable

$\mathrm{PRG}=$ preliminary remediation goal

Res $=$ residential

$\mathrm{RL}=$ remediation level

$\mathrm{SL}=$ screening level

$\mathrm{SU}=$ soil unit 


\begin{tabular}{|c|c|c|c|c|c|c|c|c|}
\hline \multirow[b]{2}{*}{ Analyte } & \multirow[b]{2}{*}{$\begin{array}{c}\text { Detect } \\
\text { frequency }\end{array}$} & \multirow[b]{2}{*}{$\begin{array}{c}\text { Minimum } \\
\text { detect }\end{array}$} & \multirow[b]{2}{*}{$\begin{array}{c}\text { Maximum } \\
\text { detect }\end{array}$} & \multirow[b]{2}{*}{$\begin{array}{c}\text { Location(s) of } \\
\text { maximum detect }\end{array}$} & \multirow{2}{*}{$\begin{array}{c}\text { Average } \\
\text { detected } \\
\text { result }\end{array}$} & \multicolumn{3}{|c|}{$\begin{array}{c}\text { Number of analyses } \\
\text { exceeding criteria }\end{array}$} \\
\hline & & & & & & $\begin{array}{c}\text { Ind } \\
\text { PRG }\end{array}$ & GW & $\begin{array}{c}\text { Res } \\
\text { PRG }\end{array}$ \\
\hline 2-Methylnaphthalene & $1 / 1$ & $180 \mathrm{~J}$ & $180 \mathrm{~J}$ & Z2-EU37B-301 & 180 & 0 & NA & NA \\
\hline Anthracene & $1 / 1$ & $99 \mathrm{~J}$ & $99 \mathrm{~J}$ & Z2-EU37B-301 & 99 & 0 & NA & 0 \\
\hline Benz(a)anthracene & $1 / 1$ & 1,100 & 1,100 & Z2-EU37B-301 & 1,100 & 0 & NA & 1 \\
\hline Benzo(a)pyrene & $1 / 1$ & 1,300 & 1,300 & Z2-EU37B-301 & 1,300 & 0 & NA & 1 \\
\hline Benzo(b)fluoranthene & $1 / 1$ & 2,100 & 2,100 & Z2-EU37B-301 & 2,100 & 0 & NA & 1 \\
\hline Benzo(ghi)perylene & $1 / 1$ & 680 & 680 & Z2-EU37B-301 & 680 & 0 & NA & 0 \\
\hline Benzo(k)fluoranthene & $1 / 1$ & 770 & 770 & Z2-EU37B-301 & 770 & 0 & NA & 0 \\
\hline Chrysene & $1 / 1$ & 1,100 & 1,100 & Z2-EU37B-301 & 1.100 & 0 & NA & 0 \\
\hline Dibenz(a,h)anthracene & $1 / 1$ & $180 \mathrm{~J}$ & $180 \mathrm{~J}$ & Z2-EU37B-301 & 180 & 0 & NA & 1 \\
\hline Fluoranthene & $1 / 1$ & 1,500 & 1,500 & Z2-EU37B-301 & 1,500 & 0 & NA & 0 \\
\hline Indeno(1,2,3-cd)pyrene & $1 / 1$ & 630 & 630 & Z2-EU37B-301 & 630 & 0 & NA & 1 \\
\hline Naphthalene & $1 / 1$ & $140 \mathrm{~J}$ & $140 \mathrm{~J}$ & Z2-EU37B-301 & 140 & 0 & NA & 0 \\
\hline Phenanthrene & $1 / 1$ & $330 \mathrm{~J}$ & $330 \mathrm{~J}$ & Z2-EU37B-301 & 330 & 0 & NA & 0 \\
\hline Pyrene & $1 / 1$ & 1,500 & 1,500 & Z2-EU37B-301 & 1,500 & 0 & NA & 0 \\
\hline $\mathrm{EU}=$ exposure unit & \multicolumn{8}{|c|}{$\mathrm{PRG}=$ preliminary remediation goal } \\
\hline $\mathrm{GW}=$ groundwater & \multicolumn{8}{|c|}{ Res $=$ residential } \\
\hline Ind $=$ industrial & \multicolumn{8}{|c|}{$\mathrm{SL}=$ screening level } \\
\hline NA $=$ not applicable & \multicolumn{8}{|c|}{ SVOC $=$ semivolatile organic compound } \\
\hline
\end{tabular}

VOCs were analyzed for but were not detected.

DVS Soil Sampling Associated with the SW31 Spring: Three biased sample locations were selected to-for investigation of possible soil contamination resulting from overflow of the SW-31 Spring sump any lingering effects ef the SW31 Spring on nearby soils. Location Z2-EU37B-303 is in the adjacent ditch uphill from the spring, location Z2-EU37B-304 is in the adjacent ditch downhill from the spring, and location Z2-EU37B-306 is in the adjacent ditch next to the spring. Analytical results summarized below show radionuclide and SVOC Ind PRG exceedances; metal and radionuclide Bkg exceedances; and PCB, SVOC, and VOC detections.

EU Z2-37 SW 31 SOILS METALS WITH BACKGROUND,PRG, GW SL, AND/OR RL EXCEEDANCES (mg/kg) 0-10 ft

\begin{tabular}{|c|c|c|c|c|c|c|c|c|c|c|c|}
\hline \multirow[b]{2}{*}{ Analyte } & \multirow[b]{2}{*}{$\begin{array}{c}\text { Detect } \\
\text { frequency }\end{array}$} & \multirow[b]{2}{*}{$\begin{array}{c}\text { Minimum } \\
\text { detect }\end{array}$} & \multirow[b]{2}{*}{$\underset{\text { detect }}{\text { Maximum }}$} & \multirow{2}{*}{$\begin{array}{c}\text { Location(s) of } \\
\text { maximum } \\
\text { detect }\end{array}$} & \multirow{2}{*}{$\begin{array}{c}\text { Average } \\
\text { detected } \\
\text { result }\end{array}$} & \multicolumn{6}{|c|}{ Number of analyses exceeding criteria } \\
\hline & & & & & & $\begin{array}{c}\text { Max } \\
\text { RL }\end{array}$ & $\begin{array}{l}\text { Avg } \\
\text { RL }\end{array}$ & $\begin{array}{l}\text { Ind } \\
\text { PRG }\end{array}$ & Bkg & $\begin{array}{l}\text { GW } \\
\text { SL }\end{array}$ & $\begin{array}{c}\text { Res } \\
\text { PRG }\end{array}$ \\
\hline Aluminum & $3 / 3$ & 6,600 & 10,000 & Z2-EU37B-306 & 8,800 & NA & NA & 0 & 0 & NA & 2 \\
\hline Arsenic & $3 / 3$ & 6.7 & 13 & Z2-EU37B-303 & 9.03 & 0 & 0 & 0 & 0 & 0 & 3 \\
\hline Barium & $3 / 3$ & 71 & 390 & Z2-EU37B-306 & 190 & NA & NA & 0 & 1 & 0 & 0 \\
\hline Cadmium & $3 / 3$ & $0.12 \mathrm{~J}$ & $0.56 \mathrm{~J}$ & Z2-EU37B-304 & 0.273 & NA & NA & 0 & 1 & NA & 0 \\
\hline Calcium & $3 / 3$ & 14,000 & 93,000 & Z2-EU37B-303 & 52,000 & NA & NA & NA & 3 & NA & NA \\
\hline Copper & $3 / 3$ & 20J & $51 \mathrm{~J}$ & Z2-EU37B-304 & 33.7 & NA & NA & 0 & 2 & NA & 0 \\
\hline Lead & $3 / 3$ & 17 & 52 & Z2-EU37B-304 & 33 & NA & NA & 0 & 1 & 0 & 0 \\
\hline Magnesium & $3 / 3$ & 3,500 & 9,400 & Z2-EU37B-303 & 7,000 & NA & NA & NA & 3 & NA & NA \\
\hline Manganese & $3 / 3$ & 220 & 10,000 & Z2-EU37B-306 & 3,807 & NA & NA & 0 & 1 & NA & 3 \\
\hline Mercury & $3 / 3$ & 0.069 & 0.25 & Z2-EU37B-304 & 0.150 & 0 & 0 & 0 & 1 & NA & 0 \\
\hline Nickel & $3 / 3$ & 14 & 91 & Z2-EU37B-304 & 47 & NA & NA & 0 & 2 & NA & 0 \\
\hline Uranium & $3 / 3$ & 1.1 & 2 & Z2-EU37B-304 & 1.47 & NA & NA & 0 & NA & NA & 1 \\
\hline Vanadium & $3 / 3$ & 23 & 26 & Z2-EU37B-306 & 24.3 & NA & NA & 0 & 0 & NA & 3 \\
\hline Zinc & $3 / 3$ & $44 \mathrm{~J}$ & $92 \mathrm{~J}$ & Z2-EU37B-303 & 71.7 & NA & NA & 0 & 1 & NA & 0 \\
\hline
\end{tabular}

Avg $=$ average $\quad \mathrm{NA}=$ not applicable

$\mathrm{Bkg}=$ background $\quad \mathrm{PRG}=$ preliminary remediation goal

$\mathrm{EU}=$ exposure unit $\quad$ Res $=$ residential

$\mathrm{GW}=$ groundwater $\quad \mathrm{RL}=$ remediation level

Ind $=$ industrial $\quad \mathrm{SL}=$ screening level

Max = maximum $\quad \mathrm{SU}=$ soil unit 
EU Z2-37 SW 31 SOILSPCB DETECTS (ug/kg) 0-10 ft

\begin{tabular}{|c|c|c|c|c|c|c|c|c|c|}
\hline \multirow[b]{2}{*}{ Analyte } & \multirow[b]{2}{*}{$\begin{array}{c}\text { Detect } \\
\text { frequency }\end{array}$} & \multirow[b]{2}{*}{$\begin{array}{c}\text { Minimum } \\
\text { detect }\end{array}$} & \multirow[b]{2}{*}{$\begin{array}{c}\text { Maximum } \\
\text { detect }\end{array}$} & \multirow{2}{*}{$\begin{array}{l}\text { Location(s) of } \\
\text { maximum } \\
\text { detect }\end{array}$} & \multirow{2}{*}{$\begin{array}{c}\text { Average } \\
\text { detected } \\
\text { result }\end{array}$} & \multicolumn{4}{|c|}{$\begin{array}{l}\text { Number of analyses } \\
\text { exceeding criteria }\end{array}$} \\
\hline & & & & & & $\begin{array}{c}\text { Max } \\
\text { RL }\end{array}$ & $\begin{array}{l}\text { Avg } \\
\text { RL }\end{array}$ & $\begin{array}{c}\text { Ind } \\
\text { PRG }\end{array}$ & $\begin{array}{l}\text { Res } \\
\text { PRG }\end{array}$ \\
\hline PCB-1254 & $2 / 3$ & 26 & 220 & Z2-EU37B-304 & 123 & 0 & 0 & 0 & 11 \\
\hline PCB-1260 & $1 / 3$ & $120 \mathrm{~J}$ & $120 \mathrm{~J}$ & Z2-EU37B-306 & 120 & 0 & 0 & 0 & 1 \\
\hline Polychlorinated biphenyl & $3 / 3$ & 26 & 220 & Z2-EU37B-304 & 122 & 0 & 0 & 0 & 2 \\
\hline
\end{tabular}

Avg $=$ average $\quad \mathrm{PCB}=$ polychlorinated biphenyl

$\mathrm{EU}=$ exposure unit $\quad \mathrm{PRG}=$ preliminary remediation goal

Ind $=$ industrial $\quad$ Res $=$ residential

Max $=$ maximum $\quad \mathrm{RL}=$ remediation level

EU Z2-37 SW 31 SOILSRADIONUCLIDES WITH BACKGROUND, PRG, AND/OR RL EXCEEDANCES (pCi/g) 0-10 ft

\begin{tabular}{|c|c|c|c|c|c|c|c|c|c|c|c|}
\hline \multirow[b]{2}{*}{ Analyte } & \multirow[b]{2}{*}{$\begin{array}{c}\text { Detect } \\
\text { frequency }\end{array}$} & \multirow[b]{2}{*}{$\begin{array}{c}\text { Minimum } \\
\text { detect }\end{array}$} & \multirow[b]{2}{*}{$\begin{array}{c}\text { Maximum } \\
\text { detect }\end{array}$} & \multirow[b]{2}{*}{$\begin{array}{c}\text { Location(s) of } \\
\text { maximum detect }\end{array}$} & \multirow{2}{*}{$\begin{array}{c}\text { Average } \\
\text { detected } \\
\text { result }\end{array}$} & \multicolumn{6}{|c|}{ Number of analyses exceeding criteria } \\
\hline & & & & & & $\underset{\text { RL }}{\operatorname{Max}}$ & $\begin{array}{l}\text { Avg } \\
\text { RL }\end{array}$ & $\begin{array}{l}\text { Ind } \\
\text { PRG }\end{array}$ & Bkg & $\begin{array}{c}\text { GW } \\
\text { SL }\end{array}$ & $\begin{array}{l}\text { Res } \\
\text { PRG }\end{array}$ \\
\hline 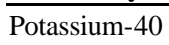 & $3 / 3$ & 19.9 & 31.7 & Z2-EU37B-306 & 24.7 & NA & NA & 3 & 0 & NA & 3 \\
\hline Radium-226 & $3 / 3$ & 0.923 & 1.63 & Z2-EU37B-306 & 1.19 & NA & NA & 3 & 1 & NA & 3 \\
\hline Thorium -228 & $3 / 3$ & 0.991 & 1.41 & Z2-EU37B-306 & 1.14 & NA & NA & 3 & 0 & NA & 3 \\
\hline Thorium-230 & $3 / 3$ & 1.19 & 1.84 & Z2-EU37B-303 & 1.46 & NA & NA & 0 & 2 & NA & 0 \\
\hline Thorium -232 & $3 / 3$ & 0.886 & 1.6 & Z2-EU37B-306 & 1.32 & NA & NA & 3 & 0 & NA & 3 \\
\hline Uranium-235 & $2 / 3$ & 0.113 & 0.206 & Z2-EU37B-306 & 0.160 & 0 & 0 & 0 & NA & 0 & 1 \\
\hline Uranium-238 & $3 / 3$ & 1.29 & 1.41 & Z2-EU37B-303 & 1.36 & 0 & 0 & 0 & 0 & 0 & 3 \\
\hline
\end{tabular}

Avg = average

$\mathrm{Bkg}=$ background

$\mathrm{EU}=$ exposure unit

$\mathrm{NA}=$ not applicable

$\mathrm{GW}=$ groundwater

$\mathrm{PRG}=$ preliminary remediation goal

Res $=$ residential

$\mathrm{RL}=$ remediation level

Ind $=$ industrial

$\mathrm{SL}=$ screening level

Max = maximum $\quad \mathrm{SU}=$ soil unit

EU Z2-37 SW31 SOILSSVOC DETECTS (ug/kg) 0-10 ft

\begin{tabular}{|c|c|c|c|c|c|c|c|c|}
\hline \multirow[b]{2}{*}{ Analyte } & \multirow[b]{2}{*}{$\begin{array}{c}\text { Detect } \\
\text { frequency }\end{array}$} & \multirow[b]{2}{*}{$\begin{array}{c}\text { Minimum } \\
\text { detect }\end{array}$} & \multirow[b]{2}{*}{$\begin{array}{c}\text { Maximum } \\
\text { detect }\end{array}$} & \multirow[b]{2}{*}{$\begin{array}{c}\text { Location(s) of } \\
\text { maximum detect }\end{array}$} & \multirow{2}{*}{$\begin{array}{c}\text { Average } \\
\text { detected } \\
\text { result }\end{array}$} & \multicolumn{3}{|c|}{$\begin{array}{l}\text { Number of analyses } \\
\text { exceeding criteria }\end{array}$} \\
\hline & & & & & & $\begin{array}{l}\text { Ind } \\
\text { PRG }\end{array}$ & $\begin{array}{c}\text { GW } \\
\text { SL }\end{array}$ & $\begin{array}{l}\text { Res } \\
\text { PRG }\end{array}$ \\
\hline 2-Methylnaphthalene & $1 / 3$ & $120 \mathrm{~J}$ & $120 \mathrm{~J}$ & Z2-EU37B-306 & 120 & 0 & NA & NA \\
\hline Acenaphthene & $1 / 3$ & $280 \mathrm{~J}$ & $280 \mathrm{~J}$ & Z2-EU37B-306 & 280 & 0 & NA & 0 \\
\hline Anthracene & $1 / 3$ & 1,400 & 1,400 & Z2-EU37B-306 & 1,400 & 0 & NA & 0 \\
\hline Benz(a)anthracene & $3 / 3$ & $140 \mathrm{~J}$ & 5,400 & Z2-EU37B-306 & 1,930 & 0 & NA & 1 \\
\hline Benzo(a)pyrene & $3 / 3$ & $150 \mathrm{~J}$ & 4,900 & Z2-EU37B-306 & 1,783 & 1 & NA & 3 \\
\hline Benzo(b)fluoranthene & $3 / 3$ & $240 \mathrm{~J}$ & 6,600 & Z2-EU37B-306 & 2,420 & 0 & NA & 1 \\
\hline Benzo(ghi)perylene & $3 / 3$ & $61 \mathrm{~J}$ & 1,800 & Z2-EU37B-306 & 657 & 0 & NA & 0 \\
\hline Benzo(k)fluoranthene & $3 / 3$ & $96 \mathrm{~J}$ & 2,800 & Z2-EU37B-306 & 1,029 & 0 & NA & 0 \\
\hline Carbazole & $1 / 3$ & 660 & 660 & Z2-EU37B-306 & 660 & 0 & NA & 0 \\
\hline Chrysene & $3 / 3$ & $150 \mathrm{~J}$ & 4,900 & Z2-EU37B-306 & 1,777 & 0 & NA & 0 \\
\hline $\operatorname{Dibenz}(\mathrm{a}, \mathrm{h})$ anthracene & $1 / 3$ & 530 & 530 & Z2-EU37B-306 & 530 & 0 & NA & 1 \\
\hline Dibenzofuran & $1 / 3$ & $100 \mathrm{~J}$ & $100 \mathrm{~J}$ & Z2-EU37B-306 & 100 & 0 & NA & 0 \\
\hline Fluoranthene & $3 / 3$ & $270 \mathrm{~J}$ & 12,000 & Z2-EU37B-306 & 4,240 & 0 & NA & 0 \\
\hline Fluorene & $1 / 3$ & $320 \mathrm{~J}$ & $320 \mathrm{~J}$ & Z2-EU37B-306 & 320 & 0 & NA & 0 \\
\hline Indeno(1,2,3-cd)pyrene & $3 / 3$ & $66 \mathrm{~J}$ & 1,800 & Z2-EU37B-306 & 665 & 0 & NA & 1 \\
\hline Phenanthrene & $3 / 3$ & $56 \mathrm{~J}$ & 5,100 & Z2-EU37B-306 & 1,759 & 0 & NA & 0 \\
\hline Pyrene & $3 / 3$ & $220 \mathrm{~J}$ & 8,100 & Z2-EU37B-306 & 2,893 & 0 & NA & 0 \\
\hline $\begin{array}{l}\mathrm{EU}=\text { exposure unit } \\
\mathrm{GW}=\text { groundwater } \\
\text { Ind = industrial } \\
\mathrm{NA}=\text { not applicable }\end{array}$ & $\begin{array}{l}\mathrm{PRG}=\text { prel } \\
\text { Res }=\text { resid } \\
\mathrm{SL}=\text { screer } \\
\text { SVOC }=\text { se }\end{array}$ & $\begin{array}{l}\text { liminary rem } \\
\text { lential } \\
\text { ning level } \\
\text { emivolatile o }\end{array}$ & $\begin{array}{l}\text { nediation goa } \\
\text { organic comp }\end{array}$ & pound & & & & \\
\hline
\end{tabular}




\begin{tabular}{|c|c|c|c|c|c|c|c|c|}
\hline \multirow[b]{2}{*}{ Analyte } & \multirow[b]{2}{*}{$\begin{array}{c}\text { Detect } \\
\text { frequency }\end{array}$} & \multirow[b]{2}{*}{$\begin{array}{c}\text { Minimum } \\
\text { detect }\end{array}$} & \multirow[b]{2}{*}{$\begin{array}{c}\text { Maximum } \\
\text { detect }\end{array}$} & \multirow[b]{2}{*}{$\begin{array}{c}\text { Location(s) of } \\
\text { maximum detect }\end{array}$} & \multirow{2}{*}{$\begin{array}{c}\text { Average } \\
\text { detected } \\
\text { result }\end{array}$} & \multicolumn{3}{|c|}{$\begin{array}{c}\text { Number of analyses } \\
\text { exceeding criteria }\end{array}$} \\
\hline & & & & & & $\begin{array}{c}\text { Ind } \\
\text { PRG } \\
\end{array}$ & $\begin{array}{l}\text { GW } \\
\text { SL } \\
\end{array}$ & $\begin{array}{l}\text { Res } \\
\text { PRG }\end{array}$ \\
\hline 1,1,1-Trichloroethane & $1 / 3$ & 7.1 & 7.1 & Z2-EU37B-304 & 7.1 & 0 & 0 & 0 \\
\hline 1,1-Dichloroethane & $2 / 3$ & $1.1 \mathrm{~J}$ & $1.5 \mathrm{~J}$ & Z2-EU37B-304 & 1.3 & 0 & NA & 0 \\
\hline 1,1-Dichloroethene & $1 / 3$ & $1.3 \mathrm{~J}$ & $1.3 \mathrm{~J}$ & Z2-EU37B-304 & 1.3 & 0 & 0 & 0 \\
\hline $\mathrm{EU}=$ exposure unit & \multicolumn{8}{|c|}{$\mathrm{PRG}=$ preliminary remediation goal } \\
\hline $\mathrm{GW}=$ groundwater & \multicolumn{8}{|c|}{ Res $=$ residential } \\
\hline Ind $=$ industrial & \multicolumn{8}{|c|}{$\mathrm{SL}=$ screening level } \\
\hline $\mathrm{NA}=$ not applicable & \multicolumn{8}{|c|}{ VOC $=$ volatile organic compound } \\
\hline
\end{tabular}

Historical Sampling in EU Z2-37: There are 24 historical samp le locations in this EU, with samples collected from 0- to 10-ft bgs that are not included as part of the K-1414 Garage Diesel Tank/Soil FFA site characterization (Sect. H.2.2.6). Sample locations are identified in Sect. H.2.2.3. Analytical results summarized below show one manganese and several radionuclide Ind PRG exceedances; several metal and radionuclide Bkg exceedances; and detections of DRO, gasoline-range organic (GRO), PCBs, one pesticide (methoxychlor), SVOCs, and VOCs. The DRO and GRO detections occur at sample location BH004, which is downgradient of the K-1414 Garage Diesel Tank/Soil FFA site.

EU Z2-37 HISTORICAL METALS WITH BACKGROUND, PRG, GW SL, AND/OR RL EXCEEDANCES (mg/kg) 0-10 ft

\begin{tabular}{|c|c|c|c|c|c|c|c|c|c|c|c|}
\hline \multirow[b]{2}{*}{ Analyte } & \multirow[b]{2}{*}{$\begin{array}{c}\text { Detect } \\
\text { frequency }\end{array}$} & \multirow[b]{2}{*}{$\begin{array}{c}\text { Minimum } \\
\text { detect }\end{array}$} & \multirow[b]{2}{*}{$\begin{array}{c}\text { Maximum } \\
\text { detect }\end{array}$} & \multirow{2}{*}{$\begin{array}{l}\text { Location(s) of } \\
\text { maximum } \\
\text { detect }\end{array}$} & \multirow{2}{*}{$\begin{array}{c}\text { Average } \\
\text { detected } \\
\text { result }\end{array}$} & \multicolumn{6}{|c|}{ Number of analyses exceeding criteria } \\
\hline & & & & & & $\begin{array}{c}\text { Max } \\
\text { RL }\end{array}$ & $\begin{array}{l}\text { Avg } \\
\text { RL }\end{array}$ & $\begin{array}{c}\text { Ind } \\
\text { PRG }\end{array}$ & Bkg & $\begin{array}{c}\text { GW } \\
\text { SL }\end{array}$ & $\begin{array}{c}\text { Res } \\
\text { PRG }\end{array}$ \\
\hline Aluminum & $16 / 16$ & 8,790 & 20,400 & SB080 & 14,505 & NA & NA & 0 & 0 & NA & 16 \\
\hline Arsenic & $16 / 16$ & $1.4 \mathrm{~J}$ & $13.8 \mathrm{~J}$ & SB080 & 5.47 & 0 & 0 & 0 & 0 & 0 & 16 \\
\hline Barium & $16 / 16$ & 43 & 1,420 & SB089 & 170 & NA & NA & 0 & 4 & 0 & 1 \\
\hline Beryllium & $16 / 16$ & 0.23 & 6.3 & BH012 & 1.11 & 0 & 0 & 0 & 1 & NA & 0 \\
\hline Cadmium & $3 / 16$ & 0.25 & 0.37 & SB099 & 0.32 & NA & NA & 0 & 3 & NA & 0 \\
\hline Calcium & $16 / 16$ & 177 & 40,800 & SB079 & 7,381 & NA & NA & NA & 6 & NA & NA \\
\hline Chromium & $16 / 16$ & $11 \mathrm{~J}$ & 36.9 & SB099 & 21.6 & NA & NA & 0 & 0 & 0 & 5 \\
\hline Cobalt & $16 / 16$ & 3.9 & 52.7 & SB080 & 18.5 & NA & NA & 0 & 1 & NA & 0 \\
\hline Copper & $15 / 16$ & 8.2 & 59.6 & SB083 & 25.6 & NA & NA & 0 & 7 & NA & 0 \\
\hline Iron & $16 / 16$ & 13,300 & 36,600 & SB080 & 26,456 & NA & NA & 0 & 0 & NA & 16 \\
\hline Lead & $16 / 16$ & 13.9 & 45.2 & BH012 & 23.4 & NA & NA & 0 & 2 & 0 & 0 \\
\hline Magnesium & $16 / 16$ & 470 & 22,400 & SB079 & 3,756 & NA & NA & NA & 4 & NA & NA \\
\hline Manganese & $16 / 16$ & 142 & 20,600 & SB089 & 1,977 & NA & NA & 1 & 1 & NA & 15 \\
\hline Nickel & $16 / 16$ & $6.8 \mathrm{~J}$ & 65.3 & SB078 & 28.1 & NA & NA & 0 & 7 & NA & 0 \\
\hline Selenium & $7 / 10$ & $0.35 \mathrm{~J}$ & $2.4 \mathrm{~J}$ & SB082 & 1.48 & NA & NA & 0 & 3 & NA & 0 \\
\hline Silver & $15 / 16$ & 1.1 & $3.3 \mathrm{~J}$ & SB089 & 1.97 & NA & NA & 0 & 15 & NA & 0 \\
\hline Thallium & $6 / 16$ & 0.14 & 0.56 & BH012 & 0.397 & NA & NA & 0 & 3 & 0 & 3 \\
\hline Vanadium & $16 / 16$ & 15.2 & 42.6 & SB092 & 28.7 & NA & NA & 0 & 0 & NA & 16 \\
\hline Zinc & $16 / 16$ & $20.7 \mathrm{~J}$ & $152 \mathrm{~J}$ & BH012 & 56.6 & NA & NA & 0 & 2 & NA & 0 \\
\hline
\end{tabular}

Avg $=$ average

$\mathrm{Bkg}=$ background

$\mathrm{EU}=$ exposure unit

$\mathrm{GW}=$ groundwater

Ind $=$ industrial

Max $=$ maximum
$\mathrm{NA}=$ not applicable

$\mathrm{PRG}=$ preliminary remediation goal

Res $=$ residential

$\mathrm{RL}=$ remediation level

$\mathrm{SL}=$ screening level

$\mathrm{SU}=$ soil unit 
EU Z2-37 HISTORICAL OTHER ORGANICS DETECTS (mg/kg) 0-10 ft

\begin{tabular}{lccccc}
\hline \multicolumn{1}{c}{ Analyte } & $\begin{array}{c}\text { Detect } \\
\text { frequency }\end{array}$ & $\begin{array}{c}\text { Minimum } \\
\text { detect }\end{array}$ & $\begin{array}{c}\text { Maximum } \\
\text { detect }\end{array}$ & $\begin{array}{c}\text { Location(s) of } \\
\text { maximum } \\
\text { detect }\end{array}$ & $\begin{array}{c}\text { Average } \\
\text { detected } \\
\text { result }\end{array}$ \\
\hline Diesel Range Organics & $1 / 11$ & $329 \mathrm{~J}$ & $329 \mathrm{~J}$ & BH004 & 329 \\
Gasoline Range Organics & $1 / 11$ & 88.5 & 88.5 & BH004 & 88.5 \\
\hline
\end{tabular}

$\mathrm{EU}=$ exposure unit

EU Z2-37 HISTORICAL PPCB DETECTS (ug/kg) 0-10 ft

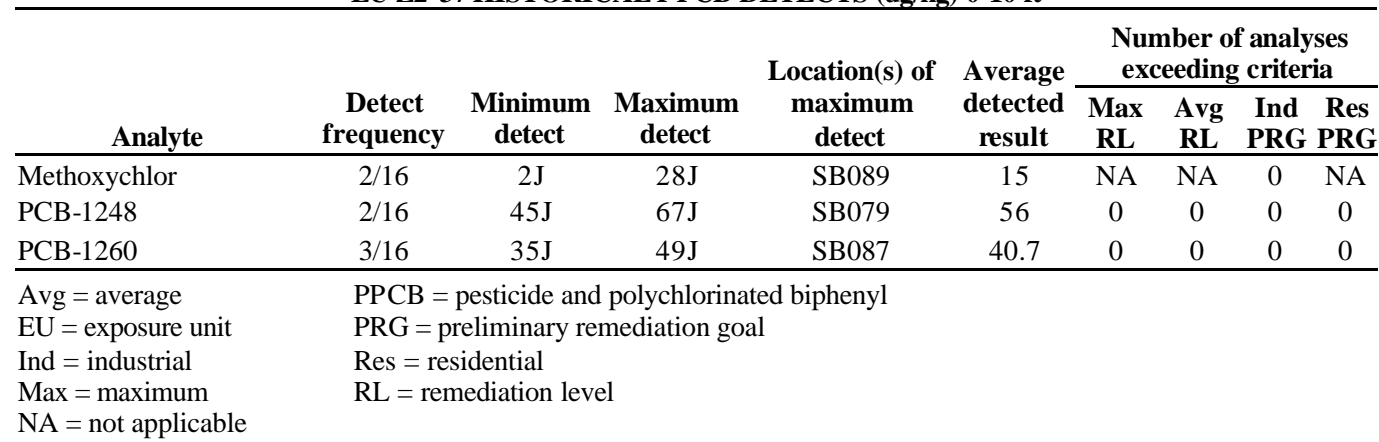

EU Z2-37 HISTORICAL RADIONUCLIDES WITH BACKGROUND, PRG, AND/OR RL EXCEEDANCES (pCi/g) 0-10 ft

\begin{tabular}{|c|c|c|c|c|c|c|c|c|c|c|c|}
\hline \multirow[b]{2}{*}{ Analyte } & \multirow[b]{2}{*}{$\begin{array}{c}\text { Detect } \\
\text { frequency }\end{array}$} & \multirow[b]{2}{*}{$\begin{array}{c}\text { Minimum } \\
\text { detect }\end{array}$} & \multirow[b]{2}{*}{$\begin{array}{c}\text { Maximum } \\
\text { detect }\end{array}$} & \multirow[b]{2}{*}{$\begin{array}{l}\text { Location(s) of } \\
\text { maximum detect }\end{array}$} & \multirow{2}{*}{$\begin{array}{c}\text { Average } \\
\text { detected } \\
\text { result }\end{array}$} & \multicolumn{6}{|c|}{ Number of analyses exceeding criteria } \\
\hline & & & & & & $\begin{array}{l}\text { Max } \\
\text { RL }\end{array}$ & $\begin{array}{c}\text { Avg } \\
\text { RL }\end{array}$ & $\begin{array}{l}\text { Ind } \\
\text { PRG }\end{array}$ & Bkg & $\begin{array}{c}\text { GW } \\
\text { SL }\end{array}$ & $\begin{array}{c}\text { Res } \\
\text { PRG }\end{array}$ \\
\hline Cesium-137 & $4 / 18$ & 0.66 & 0.99 & RAD90 & 0.798 & 0 & 0 & 0 & NA & NA & 4 \\
\hline Potassium-40 & $6 / 6$ & 9.2 & 35.6 & BH012 & 15.6 & NA & NA & 6 & 1 & NA & 6 \\
\hline Radium-226 & $4 / 4$ & 1.4 & 4.5 & RAD85 & 3.45 & NA & NA & 4 & 4 & NA & 4 \\
\hline Technetium-99 & $14 / 20$ & $0.32 \mathrm{~J}$ & $3.47 \mathrm{~J}$ & RAD85 & 1.35 & NA & NA & 0 & NA & NA & 14 \\
\hline Thorium -228 & $5 / 6$ & 1.47 & $1.97 \mathrm{~J}$ & BH012 & 1.60 & NA & NA & 5 & 1 & NA & 5 \\
\hline Thorium -230 & $6 / 6$ & $1.07 \mathrm{~J}$ & 1.48 & RAD69 & 1.32 & NA & NA & 0 & 4 & NA & 0 \\
\hline Thorium -232 & $6 / 6$ & $0.9 \mathrm{~J}$ & 1.49 & RAD69 & 1.22 & NA & NA & 6 & 0 & NA & 6 \\
\hline Uranium-235 & $17 / 19$ & 0.02 & 0.33 & RAD85 & 0.109 & 0 & 0 & 0 & NA & 0 & 3 \\
\hline Uranium-238 & $19 / 19$ & 0.72 & 2.42 & RAD90 & 1.45 & 0 & 0 & 0 & 7 & 0 & 18 \\
\hline
\end{tabular}

Avg $=$ average $\quad$ NA $=$ not applicable

$\mathrm{Bkg}=$ background $\quad \mathrm{PRG}=$ preliminary remediation goal

$\mathrm{EU}=$ exposure unit $\quad$ Res $=$ residential

$\mathrm{GW}=$ groundwater $\quad \mathrm{RL}=$ remediation level

Ind $=$ industrial $\quad \mathrm{SL}=$ screening level

Max = maximum $\quad$ SU $=$ soil unit

EU Z2-37 HISTORICAL SVOC DETECTS (ug/kg) 0-10 ft

\begin{tabular}{|c|c|c|c|c|c|c|c|c|}
\hline \multirow[b]{2}{*}{ Analyte } & \multirow[b]{2}{*}{$\begin{array}{c}\text { Detect } \\
\text { frequency }\end{array}$} & \multirow[b]{2}{*}{$\begin{array}{c}\text { Minimum } \\
\text { detect }\end{array}$} & \multirow[b]{2}{*}{$\begin{array}{c}\text { Maximum } \\
\text { detect }\end{array}$} & \multirow[b]{2}{*}{$\begin{array}{c}\text { Location(s) of } \\
\text { maximum detect }\end{array}$} & \multirow{2}{*}{$\begin{array}{c}\text { Average } \\
\text { detected } \\
\text { result }\end{array}$} & \multicolumn{3}{|c|}{$\begin{array}{l}\text { Number of analyses } \\
\text { exceeding criteria }\end{array}$} \\
\hline & & & & & & $\begin{array}{c}\text { Ind } \\
\text { PRG }\end{array}$ & $\begin{array}{l}\text { GW } \\
\text { SL }\end{array}$ & $\begin{array}{l}\text { Res } \\
\text { PRG }\end{array}$ \\
\hline 2-Methylnaphthalene & $1 / 24$ & $220 \mathrm{~J}$ & $220 \mathrm{~J}$ & BH004 & 220 & 0 & NA & NA \\
\hline Acenaphthene & $2 / 23$ & $43 \mathrm{~J}$ & $160 \mathrm{~J}$ & SB093 & 102 & 0 & NA & 0 \\
\hline Acenaphthylene & $1 / 24$ & $99 \mathrm{~J}$ & $99 \mathrm{~J}$ & BH007 & 99 & 0 & NA & 0 \\
\hline Anthracene & $2 / 24$ & $96 \mathrm{~J}$ & $260 \mathrm{~J}$ & SB093 & 178 & 0 & NA & 0 \\
\hline Benz(a)anthracene & $4 / 25$ & $54 \mathrm{~J}$ & 550 & SB093 & 224 & 0 & NA & 0 \\
\hline Benzo(a)pyrene & $4 / 25$ & $93 \mathrm{~J}$ & 580 & SB093 & 243 & 0 & NA & 4 \\
\hline Benzo(b)fluoranthene & $4 / 25$ & $86 \mathrm{~J}$ & 740 & SB093 & 284 & 0 & NA & 1 \\
\hline Benzo(ghi)perylene & $4 / 25$ & $78 \mathrm{~J}$ & $330 \mathrm{~J}$ & SB093 & 190 & 0 & NA & 0 \\
\hline Benzo(k)fluoranthene & $4 / 25$ & $99 \mathrm{~J}$ & 560 & SB093 & 242 & 0 & NA & 0 \\
\hline Bis(2-ethylhexyl)phthalate & $6 / 25$ & $45 \mathrm{~J}$ & $82 \mathrm{~J}$ & SB099 & 61.7 & 0 & 0 & 0 \\
\hline Carbazole & $1 / 24$ & $59 \mathrm{~J}$ & $59 \mathrm{~J}$ & SB093 & 59 & 0 & NA & 0 \\
\hline Chrysene & $4 / 25$ & $67 \mathrm{~J}$ & 680 & SB093 & 257 & 0 & NA & 0 \\
\hline
\end{tabular}




\begin{tabular}{|c|c|c|c|c|c|c|c|c|}
\hline \multirow[b]{2}{*}{ Analyte } & \multirow[b]{2}{*}{$\begin{array}{c}\text { Detect } \\
\text { frequency }\end{array}$} & \multirow[b]{2}{*}{$\begin{array}{c}\text { Minimum } \\
\text { detect }\end{array}$} & \multirow[b]{2}{*}{$\begin{array}{c}\text { Maximum } \\
\text { detect }\end{array}$} & \multirow[b]{2}{*}{$\begin{array}{l}\text { Location(s) of } \\
\text { maximum detect }\end{array}$} & \multirow{2}{*}{$\begin{array}{c}\text { Average } \\
\text { detected } \\
\text { result }\end{array}$} & \multicolumn{3}{|c|}{$\begin{array}{l}\text { Number of analyses } \\
\text { exceeding criteria }\end{array}$} \\
\hline & & & & & & $\begin{array}{l}\text { Ind } \\
\text { PRG }\end{array}$ & $\begin{array}{l}\text { GW } \\
\text { SL }\end{array}$ & $\begin{array}{l}\text { Res } \\
\text { PRG }\end{array}$ \\
\hline Dibenz(a,h)anthracene & $2 / 24$ & $89 \mathrm{~J}$ & $140 \mathrm{~J}$ & SB093 & 115 & 0 & NA & 2 \\
\hline Dibenzofuran & $1 / 24$ & $60 \mathrm{~J}$ & $60 \mathrm{~J}$ & SB093 & 60 & 0 & NA & 0 \\
\hline Dimethyl phthalate & $3 / 24$ & $52 \mathrm{~J}$ & $400 \mathrm{~J}$ & BH004 & 182 & 0 & NA & 0 \\
\hline Di-n-butyl phthalate & $2 / 25$ & $240 \mathrm{~J}$ & 2,500 & BH004 & 1,370 & 0 & NA & 0 \\
\hline Fluoranthene & $5 / 25$ & $53 \mathrm{~J}$ & 1,500 & SB093 & 473 & 0 & NA & 0 \\
\hline Fluorene & $2 / 24$ & $120 \mathrm{~J}$ & $140 \mathrm{~J}$ & SB093 & 130 & 0 & NA & 0 \\
\hline Indeno(1,2,3-cd)pyrene & $4 / 25$ & $72 \mathrm{~J}$ & $270 \mathrm{~J}$ & SB093 & 150 & 0 & NA & 0 \\
\hline Naphthalene & $3 / 25$ & $50 \mathrm{~J}$ & $100 \mathrm{~J}$ & SB089 & 72.7 & 0 & NA & 0 \\
\hline Phenanthrene & $5 / 25$ & $50 \mathrm{~J}$ & 1,200 & SB093 & 366 & 0 & NA & 0 \\
\hline Pyrene & $7 / 24$ & $46 \mathrm{~J}$ & 1,300 & SB093 & 331 & 0 & NA & 0 \\
\hline
\end{tabular}

$\mathrm{EU}=$ exposure unit $\quad \mathrm{PRG}=$ preliminary remediation goal

$\mathrm{GW}=$ groundwater $\quad$ Res $=$ residential

Ind $=$ industrial $\quad \mathrm{SL}=$ screening level

$\mathrm{NA}=$ not applicable $\quad \mathrm{SVOC}=$ semivolatile organic compound

EU Z2-37 HISTORICAL VOC DETECTS (ug/kg) 0-10 ft

\begin{tabular}{|c|c|c|c|c|c|c|c|c|}
\hline \multirow[b]{2}{*}{ Analyte } & \multirow[b]{2}{*}{$\begin{array}{c}\text { Detect } \\
\text { frequency }\end{array}$} & \multirow[b]{2}{*}{$\underset{\text { detect }}{\text { Minimum }}$} & \multirow[b]{2}{*}{$\begin{array}{c}\text { Maximum } \\
\text { detect }\end{array}$} & \multirow[b]{2}{*}{$\begin{array}{c}\text { Location(s) of } \\
\text { maximum detect }\end{array}$} & \multirow{2}{*}{$\begin{array}{c}\text { Average } \\
\text { detected } \\
\text { result }\end{array}$} & \multicolumn{3}{|c|}{$\begin{array}{l}\text { Number of analyses } \\
\text { exceeding criteria }\end{array}$} \\
\hline & & & & & & $\begin{array}{c}\text { Ind } \\
\text { PRG }\end{array}$ & $\begin{array}{l}\text { GW } \\
\text { SL }\end{array}$ & $\begin{array}{c}\text { Res } \\
\text { PRG }\end{array}$ \\
\hline 1,1,1-Trichloroethane & $1 / 25$ & $2 \mathrm{~J}$ & $2 \mathrm{~J}$ & SB092 & 2 & 0 & 0 & 0 \\
\hline $\begin{array}{l}\text { 1,1,2-Trichloro-1,2,2- } \\
\text { trifluoroethane }\end{array}$ & $3 / 25$ & 4 & $940 \mathrm{~J}$ & BH004 & 316 & 0 & NA & 0 \\
\hline 1,1-Dichloroethane & $4 / 25$ & 1 & $5 \mathrm{~J}$ & SB092 & 2.25 & 0 & NA & 0 \\
\hline 1,2-Dichloroethene & $3 / 25$ & $3 \mathrm{~J}$ & 23 & SB089 & 10 & 0 & NA & NA \\
\hline 2-Butanone & $1 / 25$ & $25 \mathrm{~J}$ & $25 \mathrm{~J}$ & BH007 & 25 & 0 & NA & 0 \\
\hline 4-Methyl2-pentanone & $2 / 25$ & $1 \mathrm{~J}$ & $2 \mathrm{~J}$ & BH011 & 1.5 & 0 & NA & 0 \\
\hline Acetone & $13 / 25$ & $41 \mathrm{~J}$ & 910 & BH004 & 205 & 0 & NA & 0 \\
\hline Ethylbenzene & $2 / 25$ & $1 \mathrm{~J}$ & 2900 & BH004 & 1451 & 0 & NA & 0 \\
\hline Methylene chloride & $11 / 25$ & 13 & 110 & SB087 & 38.5 & 0 & 0 & 0 \\
\hline Tetrachloroethene & $5 / 25$ & 2 & $5 \mathrm{~J}$ & BH012 & 2.8 & 0 & 0 & 0 \\
\hline Total Xylene & $1 / 25$ & 2100 & 2100 & BH004 & 2100 & 0 & NA & NA \\
\hline Trichloroethene & $2 / 25$ & $3 \mathrm{~J}$ & $4 \mathrm{~J}$ & SB089 & 3.5 & 0 & 0 & 0 \\
\hline
\end{tabular}

\begin{tabular}{ll}
\hline EU $=$ exposure unit & PRG = preliminary remediation goal \\
GW = groundwater & Res = residential \\
Ind $=$ industrial & SL $=$ screening level \\
NA = not applicable & VOC = volatile organic compound
\end{tabular}

EU Z2-37 Summary: This section presents a summary of the nature and extent of contamination from 0 to $10 \mathrm{ft}$ bgs in EU Z2-37 by combining all the analytical data presented in the focused investigation summaries above. The summary that follows also includes FFA site data summarized in Sect. H.2.2.6. There are six DVS and 29 historical sample locations with soil samples collected from the 0 to $10-\mathrm{ft}$-bgs depth interval in this EU. Details of the sampling and analysis are presented in Table H.2 and sample locations are shown in Fig. H.3. Analytical results for all the samples, which are summarized below, show Ind PRG exceedances by arsenic (1), manganese (1), several radionuclides, and benzo(a)pyrene (2); several metal and radionuclide Bkg exceedances; and DRO, GRO, pesticide and polychlorinated biphenyl, SVOC, and VOC detections.

The arsenic Ind PRG exceedance occurs at DVS storm drain sediment location Z2-EU37B-305. The manganese Ind PRG exceedance occurs at historical sample location SB089, which is located in the southeast portion of the EU close to the K-1414 Garage. The radionuclide Ind PRG exceedances all occur for a group of radionuclides that requires special data evaluation as discussed in Sect. H.3.3. 
Bkg exceedances are fairly widespread. Sixteen different metals exceed their Bkg criteria and the number of times each metal exceeds its Bkg criterion ranges from 1 to 16. Six different radionuclides exceed their Bkg criteria and the number of times each radionuclides exceeds $\mathrm{Bkg}$ ranges from one to eight times.

DRO and GRO were detected at historical locations BH004 and BH005, which are associated with or in proximity to the K-1414 Garage Diesel Tank/Soils FFA Site (Fig. H.4). The presence of DRO and GRO represents residual contamination from the diesel fuel tank leak discovered in 1987. The pesticide methoxychlor was detected at two historical sample locations (SB083 in the north/central portion of the EU and SB089 in the southeast quadrant of the EU). PCB-1248, PCB-1254, PCB-1260, and total PCBs were detected at five historical locations (SB078, SB079, SB087, SB091, and SB092) and all six DVS locations (see Sect.H.2.2.3). Except for SB091, the historical locations with PCB detections occur in the northern two-thirds of the EU. The six DVS sample locations all represent either storm drain sediments or drainage ditch soils. SVOC detections are fairly widespread over the EU, with a total of 23 different SVOCs detected at all 6DVS and 18 historical sample locations. VOC detections were also widespread, with 17 different VOCs detected at two DVS and 20 historical locations. Two DVS sample locations, Z2-EU37B-303 and Z2-EU37B-304, are ditch sample locations associated with the SW31 spring.

EU Z2-37 METALS WITH BACKGROUND, PRG, GW SL, AND/OR RL EXCEEDANCES (mg/kg) 0-10 ft

\begin{tabular}{|c|c|c|c|c|c|c|c|c|c|c|c|}
\hline \multirow[b]{2}{*}{ Analyte } & \multirow[b]{2}{*}{$\begin{array}{c}\text { Detect } \\
\text { frequency }\end{array}$} & \multirow[b]{2}{*}{$\begin{array}{c}\text { Minimum } \\
\text { detect }\end{array}$} & \multirow[b]{2}{*}{$\begin{array}{c}\text { Maximum } \\
\text { detect }\end{array}$} & \multirow{2}{*}{$\begin{array}{l}\text { Location(s) of } \\
\text { maximum } \\
\text { detect }\end{array}$} & \multirow{2}{*}{$\begin{array}{c}\text { Average } \\
\text { detected } \\
\text { result }\end{array}$} & \multicolumn{6}{|c|}{ Number of analyses exceeding criteria } \\
\hline & & & & & & $\begin{array}{l}\text { Max } \\
\text { RL }\end{array}$ & $\begin{array}{l}\text { Avg } \\
\text { RL }\end{array}$ & $\begin{array}{c}\text { Ind } \\
\text { PRG }\end{array}$ & Bkg & $\begin{array}{c}\text { GW } \\
\text { SL }\end{array}$ & $\begin{array}{l}\text { Res } \\
\text { PRG }\end{array}$ \\
\hline Aluminum & $23 / 23$ & 2,400 & 20,400 & SB080 & 12,938 & NA & NA & 0 & 0 & NA & 20 \\
\hline Arsenic & $23 / 23$ & $1.4 \mathrm{~J}$ & 18 & Z2-EU37B-305 & 7.06 & 0 & 0 & 1 & 2 & 0 & 23 \\
\hline Barium & $23 / 23$ & 43 & 1,420 & SB089 & 185 & NA & NA & 0 & 8 & 0 & 1 \\
\hline Beryllium & $23 / 23$ & 0.23 & 6.3 & BH012 & 1.03 & 0 & 0 & 0 & 1 & NA & 0 \\
\hline Cadmium & $10 / 23$ & $0.12 \mathrm{~J}$ & $0.56 \mathrm{~J}$ & Z2-EU37B-304 & 0.29 & NA & NA & 0 & 7 & NA & 0 \\
\hline Calcium & $23 / 23$ & 177 & 240,000 & Z2-EU37B-305 & 31,814 & NA & NA & NA & 12 & NA & NA \\
\hline Chromium & $23 / 23$ & 10 & 38 & Z2-EU37B-301 & 20.9 & NA & NA & 0 & 0 & 0 & 6 \\
\hline Cobalt & $23 / 23$ & 3.9 & 52.7 & SB080 & 18.7 & NA & NA & 0 & 1 & NA & 0 \\
\hline Copper & $22 / 23$ & 8.2 & 80.7 & SB088 & 29.3 & NA & NA & 0 & 11 & NA & 0 \\
\hline Iron & $23 / 23$ & 13,300 & 50,000 & Z2-EU37B-306 & 28,365 & NA & NA & 0 & 0 & NA & 23 \\
\hline Lead & $23 / 23$ & 13.9 & 52 & Z2-EU37B-304 & 26.4 & NA & NA & 0 & 5 & 0 & 0 \\
\hline Magnesium & $23 / 23$ & 470 & 41,000 & Z2-EU37B-302 & 7,207 & NA & NA & NA & 10 & NA & NA \\
\hline Manganese & $23 / 23$ & 142 & 20,600 & SB089 & 3,196 & NA & NA & 1 & 4 & NA & 22 \\
\hline Mercury & $16 / 23$ & $0.023 \mathrm{~J}$ & 0.25 & Z2-EU37B-304 & 0.101 & 0 & 0 & 0 & 1 & NA & 0 \\
\hline Nickel & $23 / 23$ & $6.8 \mathrm{~J}$ & 100 & Z2-EU37B-301 & 33.5 & NA & NA & 0 & 11 & NA & 0 \\
\hline Selenium & $7 / 16$ & $0.35 \mathrm{~J}$ & $2.4 \mathrm{~J}$ & SB082 & 1.48 & NA & NA & 0 & 3 & NA & 0 \\
\hline Silver & $16 / 23$ & 1.1 & $3.3 \mathrm{~J}$ & SB089 & 2.04 & NA & NA & 0 & 16 & NA & 0 \\
\hline Thallium & $12 / 23$ & 0.052 & 0.56 & BH012 & 0.291 & NA & NA & 0 & 3 & 0 & 3 \\
\hline Uranium & $6 / 6$ & 0.64 & 2 & Z2-EU37B-304 & 1.28 & NA & NA & 0 & NA & NA & 2 \\
\hline Vanadium & $23 / 23$ & 9.4 & 42.6 & SB092 & 26.8 & NA & NA & 0 & 0 & NA & 23 \\
\hline Zinc & $23 / 23$ & $20.7 \mathrm{~J}$ & $160 \mathrm{~J}$ & Z2-EU37B-305 & 66.2 & NA & NA & 0 & 4 & NA & 0 \\
\hline
\end{tabular}

\begin{tabular}{ll}
\hline Avg $=$ average & NA = not applicable \\
Bkg = background & PRG = preliminary remediation goal \\
EU = exposure unit & Res = residential \\
GW = groundwater & RL = remediation level \\
Ind = industrial & SL = screening level \\
Max = maximum & SU = soil unit
\end{tabular}

EU Z2-37 OTHER ORGANICS DETECTS (mg/kg) 0-10 ft

\begin{tabular}{lccccc}
\hline \multicolumn{1}{c}{ Analyte } & $\begin{array}{c}\text { Detect } \\
\text { frequency }\end{array}$ & $\begin{array}{c}\text { Minimum } \\
\text { detect }\end{array}$ & $\begin{array}{c}\text { Maximum } \\
\text { detect }\end{array}$ & $\begin{array}{c}\text { Location(s) of } \\
\text { maximum } \\
\text { detect }\end{array}$ & $\begin{array}{c}\text { Average } \\
\text { detected } \\
\text { result }\end{array}$ \\
\hline Diesel Range Organics & $2 / 14$ & $190 \mathrm{~J}$ & $329 \mathrm{~J}$ & BH004 & 260 \\
Gasoline Range Organics & $2 / 14$ & $7.5 \mathrm{~J}$ & 88.5 & BH004 & 48 \\
\hline
\end{tabular}

$\mathrm{EU}=$ exposure unit 
EU Z2-37 PPCB DETECTS (ug/kg) 0-10 ft

\begin{tabular}{|c|c|c|c|c|c|c|c|c|c|}
\hline \multirow[b]{2}{*}{ Analyte } & \multirow[b]{2}{*}{$\begin{array}{c}\text { Detect } \\
\text { frequency }\end{array}$} & \multirow[b]{2}{*}{$\begin{array}{c}\text { Minimum } \\
\text { detect }\end{array}$} & \multirow[b]{2}{*}{$\begin{array}{c}\text { Maximum } \\
\text { detect }\end{array}$} & \multirow{2}{*}{$\begin{array}{l}\text { Location(s) of } \\
\text { maximum } \\
\text { detect }\end{array}$} & \multirow{2}{*}{$\begin{array}{c}\text { Average } \\
\text { detected } \\
\text { result }\end{array}$} & \multicolumn{4}{|c|}{$\begin{array}{l}\text { Number of analyses } \\
\text { exceeding criteria }\end{array}$} \\
\hline & & & & & & $\begin{array}{c}\text { Max } \\
\text { RL }\end{array}$ & $\begin{array}{l}\text { Avg } \\
\text { RL }\end{array}$ & $\begin{array}{l}\text { Ind } \\
\text { PRG }\end{array}$ & $\begin{array}{l}\text { Res } \\
\text { PRG }\end{array}$ \\
\hline Methoxychlor & $2 / 17$ & $2 \mathrm{~J}$ & $28 \mathrm{~J}$ & SB089 & 15 & NA & NA & 0 & NA \\
\hline PCB-1248 & $2 / 23$ & $45 \mathrm{~J}$ & $67 \mathrm{~J}$ & SB079 & 56 & 0 & 0 & 0 & 0 \\
\hline PCB-1254 & $5 / 23$ & 26 & 2,600 & Z2-EU37B-305 & 631 & 0 & 0 & 0 & 4 \\
\hline PCB-1260 & $5 / 23$ & $35 \mathrm{~J}$ & 200 & Z2-EU37B-301 & 88.4 & 0 & 0 & 0 & 2 \\
\hline Polychlorinated Biphenyl & $6 / 6$ & 26 & 2,600 & Z2-EU37B-305 & 579 & 0 & 0 & 0 & 5 \\
\hline
\end{tabular}

Avg = average

$\mathrm{EU}=$ exposure unit

Ind $=$ industrial

PPCB = pesticide and polychlorinated biphenyl

Max $=$ maximum

$\mathrm{PRG}=$ preliminary remediation goal

$\mathrm{NA}=$ not applicable

$\mathrm{RL}=$ remediation level

EU Z2-37 RADIONUCLIDES WITH BACKGROUND, PRG, AND/OR RL EXCEEDANCES (pCi/g) 0-10 ft

\begin{tabular}{|c|c|c|c|c|c|c|c|c|c|c|c|}
\hline \multirow[b]{2}{*}{ Analyte } & \multirow[b]{2}{*}{$\begin{array}{c}\text { Detect } \\
\text { frequency }\end{array}$} & \multirow[b]{2}{*}{$\begin{array}{c}\text { Minimum } \\
\text { detect }\end{array}$} & \multirow[b]{2}{*}{$\begin{array}{c}\text { Maximum } \\
\text { detect }\end{array}$} & \multirow[b]{2}{*}{$\begin{array}{c}\text { Location(s) of } \\
\text { maximum detect }\end{array}$} & \multirow{2}{*}{$\begin{array}{c}\text { Average } \\
\text { detected } \\
\text { result }\end{array}$} & \multicolumn{6}{|c|}{ Number of analyses exceeding criteria } \\
\hline & & & & & & $\begin{array}{c}\text { Max } \\
\text { RL }\end{array}$ & $\begin{array}{l}\text { Avg } \\
\text { RL }\end{array}$ & $\begin{array}{l}\text { Ind } \\
\text { PRG }\end{array}$ & Bkg & $\begin{array}{c}\text { GW } \\
\text { SL }\end{array}$ & $\begin{array}{c}\text { Res } \\
\text { PRG } \\
\end{array}$ \\
\hline Cesium-137 & $6 / 27$ & 0.223 & 1.01 & ETTP-REL12 & 0.737 & 0 & 0 & 0 & NA & NA & 6 \\
\hline Potassium-40 & $14 / 14$ & 8.65 & 45.7 & ETTP-REL13 & 21.3 & NA & NA & 14 & 3 & NA & 14 \\
\hline Radium-226 & $11 / 12$ & 0.473 & 4.5 & RAD85 & 2.05 & NA & NA & 11 & 8 & NA & 11 \\
\hline Technetium-99 & $18 / 29$ & $0.23 \mathrm{~J}$ & 3.51 & Z2-EU37B-305 & 1.36 & NA & NA & 0 & NA & NA & 17 \\
\hline Thorium -228 & $12 / 14$ & 0.892 & $1.97 \mathrm{~J}$ & BH012 & 1.29 & NA & NA & 12 & 1 & NA & 12 \\
\hline Thorium -230 & $12 / 14$ & 0.688 & 1.84 & Z2-EU37B-303 & 1.23 & NA & NA & 0 & 6 & NA & 0 \\
\hline Thorium -232 & $14 / 14$ & 0.433 & 1.97 & ETTP-REL13 & 1.28 & NA & NA & 14 & 1 & NA & 14 \\
\hline Uranium-234 & $28 / 28$ & $0.6 \mathrm{~J}$ & 7.94 & ETTP-REL12 & 1.85 & 0 & 0 & 0 & NA & 0 & 1 \\
\hline Uranium-235 & $22 / 28$ & 0.02 & $0.482 \mathrm{~J}$ & ETTP-REL12 & 0.127 & 0 & 0 & 0 & NA & 0 & 5 \\
\hline Uranium-238 & $28 / 28$ & 0.701 & 4.26 & ETTP-REL12 & 1.47 & 0 & 0 & 0 & 8 & 0 & 25 \\
\hline $\begin{array}{l}\text { Avg = average } \\
\mathrm{Bkg}=\text { background } \\
\mathrm{EU}=\text { exposure unit } \\
\mathrm{GW}=\text { groundwater } \\
\text { Ind = industrial } \\
\mathrm{Max}=\text { maximum }\end{array}$ & & $\begin{array}{l}\text { NA }=\text { not ap } \\
\text { PRG }=\text { preli } \\
\text { Res }=\text { reside } \\
\text { RL }=\text { remed } \\
\text { SL }=\text { screen } \\
\text { SU }=\text { soil un }\end{array}$ & $\begin{array}{l}\text { pplicable } \\
\text { iminary reme } \\
\text { ential } \\
\text { liation level } \\
\text { ling level } \\
\text { hit }\end{array}$ & ediation goal & & & & & & & \\
\hline
\end{tabular}

EU Z2-37 SVOC DETECTS (ug/kg) 0-10 ft

\begin{tabular}{|c|c|c|c|c|c|c|c|c|}
\hline \multirow[b]{2}{*}{ Analyte } & \multirow[b]{2}{*}{$\begin{array}{l}\text { Detect } \\
\text { frequency }\end{array}$} & \multirow[b]{2}{*}{$\begin{array}{c}\text { Minimum } \\
\text { detect }\end{array}$} & \multirow[b]{2}{*}{$\begin{array}{c}\text { Maximum } \\
\text { detect }\end{array}$} & \multirow[b]{2}{*}{$\begin{array}{l}\text { Location(s) of } \\
\text { maximum detect }\end{array}$} & \multirow{2}{*}{$\begin{array}{c}\text { Average } \\
\text { detected } \\
\text { result }\end{array}$} & \multicolumn{3}{|c|}{$\begin{array}{l}\text { Number of analyses } \\
\text { exceeding criteria }\end{array}$} \\
\hline & & & & & & $\begin{array}{l}\text { Ind } \\
\text { PRG }\end{array}$ & $\begin{array}{l}\text { GW } \\
\text { SL }\end{array}$ & $\begin{array}{c}\text { Res } \\
\text { PRG }\end{array}$ \\
\hline 2-Methylnaphthalene & $4 / 34$ & $120 \mathrm{~J}$ & 2,200 & SB088 & 680 & 0 & NA & NA \\
\hline Acenaphthene & $5 / 33$ & $43 \mathrm{~J}$ & $280 \mathrm{~J}$ & Z2-EU37B-306 & 157 & 0 & NA & 0 \\
\hline Acenaphthylene & $1 / 34$ & $99 \mathrm{~J}$ & $99 \mathrm{~J}$ & BH007 & 99 & 0 & NA & 0 \\
\hline Anthracene & $5 / 34$ & $96 \mathrm{~J}$ & 1,400 & Z2-EU37B-306 & 451 & 0 & NA & 0 \\
\hline Benz(a)anthracene & $10 / 35$ & $54 \mathrm{~J}$ & 5,400 & Z2-EU37B-306 & 1,059 & 0 & NA & 3 \\
\hline Benzo(a)pyrene & $10 / 35$ & $93 \mathrm{~J}$ & 4,900 & Z2-EU37B-306 & 1,038 & 2 & NA & 10 \\
\hline Benzo(b)fluoranthene & $10 / 35$ & $86 \mathrm{~J}$ & 6,600 & Z2-EU37B-306 & 1,530 & 0 & NA & 5 \\
\hline Benzo(ghi)perylene & $10 / 35$ & $61 \mathrm{~J}$ & 1,800 & Z2-EU37B-306 & 488 & 0 & NA & 0 \\
\hline Benzo(k)fluoranthene & $10 / 35$ & $96 \mathrm{~J}$ & 2,800 & Z2-EU37B-306 & 669 & 0 & NA & 0 \\
\hline Bis(2-ethylhexyl)phthalate & $8 / 35$ & $45 \mathrm{~J}$ & 4,400 & Z2-EU37B-305 & 623 & 0 & 0 & 0 \\
\hline Butyl benzyl phthalate & $1 / 34$ & $170 \mathrm{~J}$ & $170 \mathrm{~J}$ & Z2-EU37B-305 & 170 & 0 & NA & 0 \\
\hline Carbazole & $3 / 34$ & $59 \mathrm{~J}$ & 660 & Z2-EU37B-306 & 456 & 0 & NA & 0 \\
\hline Chrysene & $10 / 35$ & $67 \mathrm{~J}$ & 4,900 & Z2-EU37B-306 & 1,049 & 0 & NA & 0 \\
\hline Dibenz(a,h)anthracene & $5 / 34$ & $89 \mathrm{~J}$ & 530 & Z2-EU37B-306 & 248 & 0 & NA & 5 \\
\hline Dibenzofuran & $3 / 34$ & $60 \mathrm{~J}$ & $100 \mathrm{~J}$ & Z2-EU37B-306 & 77.3 & 0 & NA & 0 \\
\hline Dimethyl phthalate & $3 / 34$ & $52 \mathrm{~J}$ & $400 \mathrm{~J}$ & BH004 & 182 & 0 & NA & 0 \\
\hline Di-n-butyl phthalate & $2 / 35$ & $240 \mathrm{~J}$ & 2500 & BH004 & 1,370 & 0 & NA & 0 \\
\hline Fluoranthene & $12 / 35$ & $40 \mathrm{~J}$ & 12,000 & Z2-EU37B-306 & 1,933 & 0 & NA & 0 \\
\hline
\end{tabular}




\begin{tabular}{|c|c|c|c|c|c|c|c|c|}
\hline \multirow[b]{2}{*}{ Analyte } & \multirow[b]{2}{*}{$\begin{array}{c}\text { Detect } \\
\text { frequency }\end{array}$} & \multirow[b]{2}{*}{$\begin{array}{c}\text { Minimum } \\
\text { detect }\end{array}$} & \multirow[b]{2}{*}{$\begin{array}{c}\text { Maximum } \\
\text { detect }\end{array}$} & \multirow[b]{2}{*}{$\begin{array}{c}\text { Location(s) of } \\
\text { maximum detect }\end{array}$} & \multirow{2}{*}{$\begin{array}{c}\text { Average } \\
\text { detected } \\
\text { result }\end{array}$} & \multicolumn{3}{|c|}{$\begin{array}{c}\text { Number of analyses } \\
\text { exceeding criteria }\end{array}$} \\
\hline & & & & & & $\begin{array}{l}\text { Ind } \\
\text { PRG }\end{array}$ & $\begin{array}{c}\text { GW } \\
\text { SL }\end{array}$ & $\begin{array}{c}\text { Res } \\
\text { PRG }\end{array}$ \\
\hline Fluorene & $5 / 34$ & $120 \mathrm{~J}$ & 320 & $\begin{array}{c}\text { SB088 Z2-37B- } \\
306\end{array}$ & 212 & 0 & NA & 0 \\
\hline Indeno(1,2,3-cd)pyrene & $10 / 35$ & $66 \mathrm{~J}$ & 1,800 & Z2-EU37B-306 & 470 & 0 & NA & 3 \\
\hline Naphthalene & $5 / 41$ & $50 \mathrm{~J}$ & $330 \mathrm{~J}$ & SB088 & 138 & 0 & NA & 0 \\
\hline Phenanthrene & $13 / 35$ & $50 \mathrm{~J}$ & 5,100 & Z2-EU37B-306 & 884 & 0 & NA & 0 \\
\hline Pyrene & $15 / 34$ & $40 \mathrm{~J}$ & 8,100 & Z2-EU37B-306 & 1,208 & 0 & NA & 0 \\
\hline
\end{tabular}

$\mathrm{EU}=$ exposure unit $\quad \mathrm{PRG}=$ preliminary remediation goal

$\mathrm{GW}=$ groundwater $\quad$ Res $=$ residential

Ind $=$ industrial $\quad \mathrm{SL}=$ screening level

$\mathrm{NA}=$ not applicable $\quad \mathrm{SVOC}=$ semivolatile organic compound

EU Z2-37 VOC DETECTS (ug/kg) 0-10 ft

\begin{tabular}{|c|c|c|c|c|c|c|c|c|}
\hline \multirow[b]{2}{*}{ Analyte } & \multirow[b]{2}{*}{$\begin{array}{c}\text { Detect } \\
\text { frequency }\end{array}$} & \multirow[b]{2}{*}{$\begin{array}{c}\text { Minimum } \\
\text { detect }\end{array}$} & \multirow[b]{2}{*}{$\begin{array}{c}\text { Maximum } \\
\text { detect }\end{array}$} & \multirow[b]{2}{*}{$\begin{array}{c}\text { Location(s) of } \\
\text { maximum detect }\end{array}$} & \multirow{2}{*}{$\begin{array}{c}\text { Average } \\
\text { detected } \\
\text { result }\end{array}$} & \multicolumn{3}{|c|}{$\begin{array}{l}\text { Number of analyses } \\
\text { exceeding criteria }\end{array}$} \\
\hline & & & & & & $\begin{array}{c}\text { Ind } \\
\text { PRG }\end{array}$ & $\begin{array}{c}\text { GW } \\
\text { SL }\end{array}$ & $\begin{array}{l}\text { Res } \\
\text { PRG }\end{array}$ \\
\hline 1,1,1-Trichloroethane & $3 / 35$ & $2 \mathrm{~J}$ & 8 & SB088 & 5.7 & 0 & 0 & 0 \\
\hline $\begin{array}{l}\text { 1,1,2-Trichloro-1,2,2- } \\
\text { trifluoroethane }\end{array}$ & $4 / 35$ & 4 & $940 \mathrm{~J}$ & BH004 & 238 & 0 & NA & 0 \\
\hline 1,1-Dichloroethane & $7 / 35$ & 1 & 18 & SB088 & 4.23 & 0 & NA & 0 \\
\hline 1,1-Dichloroethene & $2 / 35$ & $1.3 \mathrm{~J}$ & $6 \mathrm{~J}$ & BH005 & 3.65 & 0 & 0 & 0 \\
\hline 1,2-Dichloroethene & $3 / 29$ & $3 \mathrm{~J}$ & 23 & SB089 & 10 & 0 & NA & NA \\
\hline 2-Butanone & $2 / 35$ & $25 \mathrm{~J}$ & $52 \mathrm{~J}$ & BH005 & 38.5 & 0 & NA & 0 \\
\hline 4-Methyl2-pentanone & $2 / 35$ & $1 \mathrm{~J}$ & $2 \mathrm{~J}$ & BH011 & 1.5 & 0 & NA & 0 \\
\hline Acetone & $15 / 35$ & $41 \mathrm{~J}$ & 6,600 & BH006 & 653 & 0 & NA & 0 \\
\hline Benzene & $2 / 35$ & $26 \mathrm{~J}$ & 44 & SB088 & 35 & 0 & 0 & 0 \\
\hline Carbon disulfide & $1 / 35$ & $5 \mathrm{~J}$ & $5 \mathrm{~J}$ & SB088 & 5 & 0 & NA & 0 \\
\hline cis-1,2-Dichloroethene & $1 / 6$ & $1.5 \mathrm{~J}$ & $1.5 \mathrm{~J}$ & Z2-EU37B-304 & 1.5 & 0 & NA & 0 \\
\hline Ethylbenzene & $5 / 35$ & $1 \mathrm{~J}$ & $4,300 \mathrm{~J}$ & SB088 & 1,470 & 0 & NA & 0 \\
\hline Methylene chloride & $13 / 35$ & 13 & 110 & SB087 & 37.6 & 0 & 0 & 0 \\
\hline Tetrachloroethene & $9 / 35$ & 2 & $14 \mathrm{~J}$ & SB088 & 5.56 & 0 & 0 & 0 \\
\hline Toluene & $3 / 35$ & $19 \mathrm{~J}$ & $200 \mathrm{~J}$ & BH005 & 81.3 & 0 & 0 & 0 \\
\hline Total Xylene & $4 / 29$ & $5 \mathrm{~J}$ & $5,000 \mathrm{~J}$ & SB088 & 1,821 & 0 & NA & NA \\
\hline Trichloroethene & $2 / 35$ & $3 \mathrm{~J}$ & $4 \mathrm{~J}$ & SB089 & 3.5 & 0 & 0 & 0 \\
\hline
\end{tabular}

$\mathrm{EU}=$ exposure unit $\quad \mathrm{PRG}=$ preliminary remediation goal

$\mathrm{GW}=$ groundwater $\quad$ Res $=$ residential

Ind $=$ industrial $\quad \mathrm{SL}=$ screening level

$\mathrm{NA}=$ not applicable $\quad \mathrm{VOC}=$ volatile organic compound

Samples collected from the 0- to 10-ft-depth interval at 18 historical sample locations (Sect. H.2.2.3) were analyzed by the field GC method. Most of the field GC analyses were for VOCs, and many of the samples analyzed for VOCs by field GC had duplicate analyses conducted at an off-site laboratory. Analytical results from these duplicate analyses are included in the foregoing summaries. However, the database also reports that metals, PPCBs, radionuclides, and SVOCs were analyzed for by field GC in samples from four locations (SB103, SB109, SB110, and SB111). It is impossible to verify and correct the database because these analyses were conducted too far in the past (1993). As a result, metals, PPCBs, radionuclides, and SVOCs designated as field GC analytes in the database are not included in the foregoing data summaries, instead they are summarized below. Following are summaries of all EU Z2-37 data designated in the database as being analyzed for by field GC. 
EU Z2-37 FIELD GC METALS WITH BACKGROUND, PRG,

GW SL, AND/OR RL EXCEEDANCES (mg/kg) 0-10 ft

\begin{tabular}{|c|c|c|c|c|c|c|c|c|c|c|c|}
\hline \multirow[b]{2}{*}{ Analyte } & \multirow[b]{2}{*}{$\begin{array}{c}\text { Detect } \\
\text { frequency }\end{array}$} & \multirow[b]{2}{*}{$\begin{array}{c}\text { Minimum } \\
\text { detect }\end{array}$} & \multirow[b]{2}{*}{$\begin{array}{c}\text { Maximum } \\
\text { detect }\end{array}$} & \multirow{2}{*}{$\begin{array}{c}\text { Location(s) of } \\
\text { maximum } \\
\text { detect }\end{array}$} & \multirow{2}{*}{$\begin{array}{c}\text { Average } \\
\text { detected } \\
\text { result }\end{array}$} & \multicolumn{6}{|c|}{ Number of analyses exceeding criteria } \\
\hline & & & & & & $\begin{array}{l}\text { Max } \\
\text { RL }\end{array}$ & $\begin{array}{l}\text { Avg } \\
\text { RL }\end{array}$ & $\begin{array}{c}\text { Ind } \\
\text { PRG }\end{array}$ & Bkg & $\begin{array}{l}\text { GW } \\
\text { SL }\end{array}$ & $\begin{array}{c}\text { Res } \\
\text { PRG }\end{array}$ \\
\hline Aluminum & $5 / 5$ & 10,900 & 20,100 & SB103 & 15,840 & $\mathrm{NA}$ & NA & 0 & 0 & NA & 5 \\
\hline Arsenic & $5 / 5$ & $6.3 \mathrm{~J}$ & $21 \mathrm{~J}$ & SB111 & 10.6 & 0 & 0 & 1 & 1 & 0 & 5 \\
\hline Barium & $5 / 5$ & 38.6 & 245 & SB111 & 134 & NA & NA & 0 & 2 & 0 & 0 \\
\hline Beryllium & $5 / 5$ & $0.36 \mathrm{~J}$ & $5.7 \mathrm{~J}$ & SB111 & 2.05 & 0 & 0 & 0 & 1 & NA & 0 \\
\hline Cadmium & $4 / 5$ & 0.22 & 0.99 & SB111 & 0.498 & NA & NA & 0 & 3 & NA & 0 \\
\hline Calcium & $5 / 5$ & 2,140 & $6,600 \mathrm{~J}$ & SB110 & 3,326 & NA & NA & NA & 4 & NA & NA \\
\hline Chromium & $5 / 5$ & 18.8 & 39.9 & SB109 & 27.5 & NA & NA & 0 & 0 & 0 & 2 \\
\hline Cobalt & $5 / 5$ & $4.8 \mathrm{~J}$ & $134 \mathrm{~J}$ & SB111 & 41.8 & NA & NA & 0 & 1 & NA & 0 \\
\hline Copper & $5 / 5$ & 22.4 & 207 & SB111 & 71.9 & NA & NA & 0 & 4 & NA & 0 \\
\hline Iron & $5 / 5$ & 22,700 & 38,200 & SB111 & 30,060 & NA & NA & 0 & 0 & NA & 5 \\
\hline Lead & $5 / 5$ & 14.6 & $51.5 \mathrm{~J}$ & SB111 & 23.6 & NA & NA & 0 & 1 & 0 & 0 \\
\hline Magnesium & $5 / 5$ & 1,090 & 5,230 & SB103 & 3450 & NA & NA & NA & 3 & NA & NA \\
\hline Manganese & $5 / 5$ & 260 & 4,310 & SB111 & 1471 & NA & NA & 0 & 1 & NA & 5 \\
\hline Mercury & $4 / 5$ & 0.07 & 0.22 & SB111 & 0.16 & 0 & 0 & 0 & 2 & NA & 0 \\
\hline Nickel & $5 / 5$ & $18.2 \mathrm{~J}$ & $95 \mathrm{~J}$ & SB111 & 43.2 & NA & NA & 0 & 4 & NA & 0 \\
\hline Silver & $5 / 5$ & 0.98 & 2 & SB103 & 1.54 & NA & NA & 0 & 5 & NA & 0 \\
\hline Thallium & $4 / 5$ & 0.34 & 0.99 & SB111 & 0.533 & NA & NA & 0 & 2 & 0 & 1 \\
\hline Vanadium & $5 / 5$ & 23.7 & 47.3 & SB109 & 32.6 & NA & NA & 0 & 0 & NA & 5 \\
\hline Zinc & $5 / 5$ & $40.8 \mathrm{~J}$ & $186 \mathrm{~J}$ & SB111 & 92.7 & NA & NA & 0 & 1 & NA & 0 \\
\hline
\end{tabular}

Avg $=$ average $\quad$ Max $=$ maximum

$\mathrm{Bkg}=$ background $\quad \mathrm{NA}=$ not applicable

$\mathrm{EU}=$ exposure unit $\quad \mathrm{PRG}=$ preliminary remediation goal

$\mathrm{GC}=$ gas chromatograph $\quad$ Res $=$ residential

$\mathrm{GW}=$ groundwater $\quad \mathrm{RL}=$ remediation level

Ind $=$ industrial $\quad \mathrm{SL}=$ screening level

EU Z2-37 FIELD GCPPCB DETECTS (ug/kg) 0-10 ft

\begin{tabular}{|c|c|c|c|c|c|c|c|c|c|}
\hline \multirow[b]{2}{*}{ Analyte } & \multirow[b]{2}{*}{$\begin{array}{c}\text { Detect } \\
\text { frequency }\end{array}$} & \multirow[b]{2}{*}{$\begin{array}{c}\text { Minimum } \\
\text { detect }\end{array}$} & \multirow[b]{2}{*}{$\begin{array}{l}\text { Maximum } \\
\text { detect }\end{array}$} & \multirow{2}{*}{$\begin{array}{c}\text { Location(s) of } \\
\text { maximum } \\
\text { detect }\end{array}$} & \multirow{2}{*}{$\begin{array}{c}\text { Average } \\
\text { detected } \\
\text { result }\end{array}$} & \multicolumn{4}{|c|}{$\begin{array}{l}\text { Number of analyses } \\
\text { exceeding criteria }\end{array}$} \\
\hline & & & & & & $\begin{array}{c}\text { Max } \\
\text { RL }\end{array}$ & $\begin{array}{c}\text { Avg } \\
\text { RL }\end{array}$ & $\begin{array}{l}\text { Ind } \\
\text { PRG }\end{array}$ & $\begin{array}{l}\text { Res } \\
\text { PRG }\end{array}$ \\
\hline PCB-1248 & $1 / 5$ & $440 \mathrm{~J}$ & $440 \mathrm{~J}$ & SB110 & 440 & 0 & 0 & 0 & 1 \\
\hline $\begin{array}{l}\text { Avg }=\text { average } \\
\text { EU }=\text { exposure unit } \\
\text { GC }=\text { gas chromatograph } \\
\text { Ind }=\text { industrial } \\
\text { Max }=\text { maximum }\end{array}$ & $\begin{array}{l}\mathrm{PPCB}= \\
\mathrm{PRG}= \\
\mathrm{Res}=\mathrm{r} \\
\mathrm{RL}=\mathrm{re}\end{array}$ & $\begin{array}{l}\text { pesticide and } \\
\text { reliminary re } \\
\text { sidential } \\
\text { nediation leve }\end{array}$ & $\begin{array}{l}\text { polychlorinat } \\
\text { mediation goa }\end{array}$ & $\begin{array}{l}\text { ed biphenyl } \\
1\end{array}$ & & & & & \\
\hline
\end{tabular}

EU Z2-37 FIELD GC RADIONUCLIDES WITH BACKGROUND, PRG, AND/OR RL EXCEEDANCES (pCi/g) 0-10 ft

\begin{tabular}{|c|c|c|c|c|c|c|c|c|c|c|c|}
\hline \multirow[b]{2}{*}{ Analyte } & \multirow[b]{2}{*}{$\begin{array}{c}\text { Detect } \\
\text { frequency }\end{array}$} & \multirow[b]{2}{*}{$\begin{array}{c}\text { Minimum } \\
\text { detect }\end{array}$} & \multirow[b]{2}{*}{$\begin{array}{c}\text { Maximum } \\
\text { detect }\end{array}$} & \multirow[b]{2}{*}{$\begin{array}{l}\text { Location(s) of } \\
\text { maximum detect }\end{array}$} & \multirow{2}{*}{$\begin{array}{c}\text { Average } \\
\text { detected } \\
\text { result }\end{array}$} & \multicolumn{6}{|c|}{ Number of analyses exceeding criteria } \\
\hline & & & & & & $\begin{array}{c}\text { Max } \\
\text { RL }\end{array}$ & $\begin{array}{l}\text { Avg } \\
\text { RL }\end{array}$ & $\begin{array}{l}\text { Ind } \\
\text { PRG }\end{array}$ & Bkg & $\begin{array}{l}\text { GW } \\
\text { SL }\end{array}$ & $\begin{array}{l}\text { Res } \\
\text { PRG }\end{array}$ \\
\hline Technetium-99 & $3 / 5$ & 0.52 & 0.63 & SB110 & 0.57 & NA & NA & 0 & NA & NA & 3 \\
\hline Uranium-234 & $5 / 5$ & $0.79 \mathrm{~J}$ & 2.7 & SB111 & 1.51 & 0 & 0 & 0 & NA & 0 & 0 \\
\hline Uranium-235 & $5 / 5$ & $0.06 \mathrm{~J}$ & 0.22 & SB111 & 0.142 & 0 & 0 & 0 & NA & 0 & 1 \\
\hline Uranium-238 & $5 / 5$ & $1 \mathrm{~J}$ & 2.8 & SB111 & 1.76 & 0 & 0 & 0 & 3 & 0 & 5 \\
\hline
\end{tabular}

Avg $=$ average $\quad$ Max $=$ maximum

$\mathrm{Bkg}=$ background $\quad \mathrm{NA}=$ not applicable

$\mathrm{EU}=$ exposure unit $\quad \mathrm{PRG}=$ preliminary remediation goal

$\mathrm{GC}=$ gas chromatograph $\quad$ Res $=$ residential

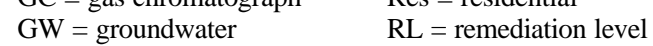

Ind $=$ industrial $\quad \mathrm{SL}=$ screening level 


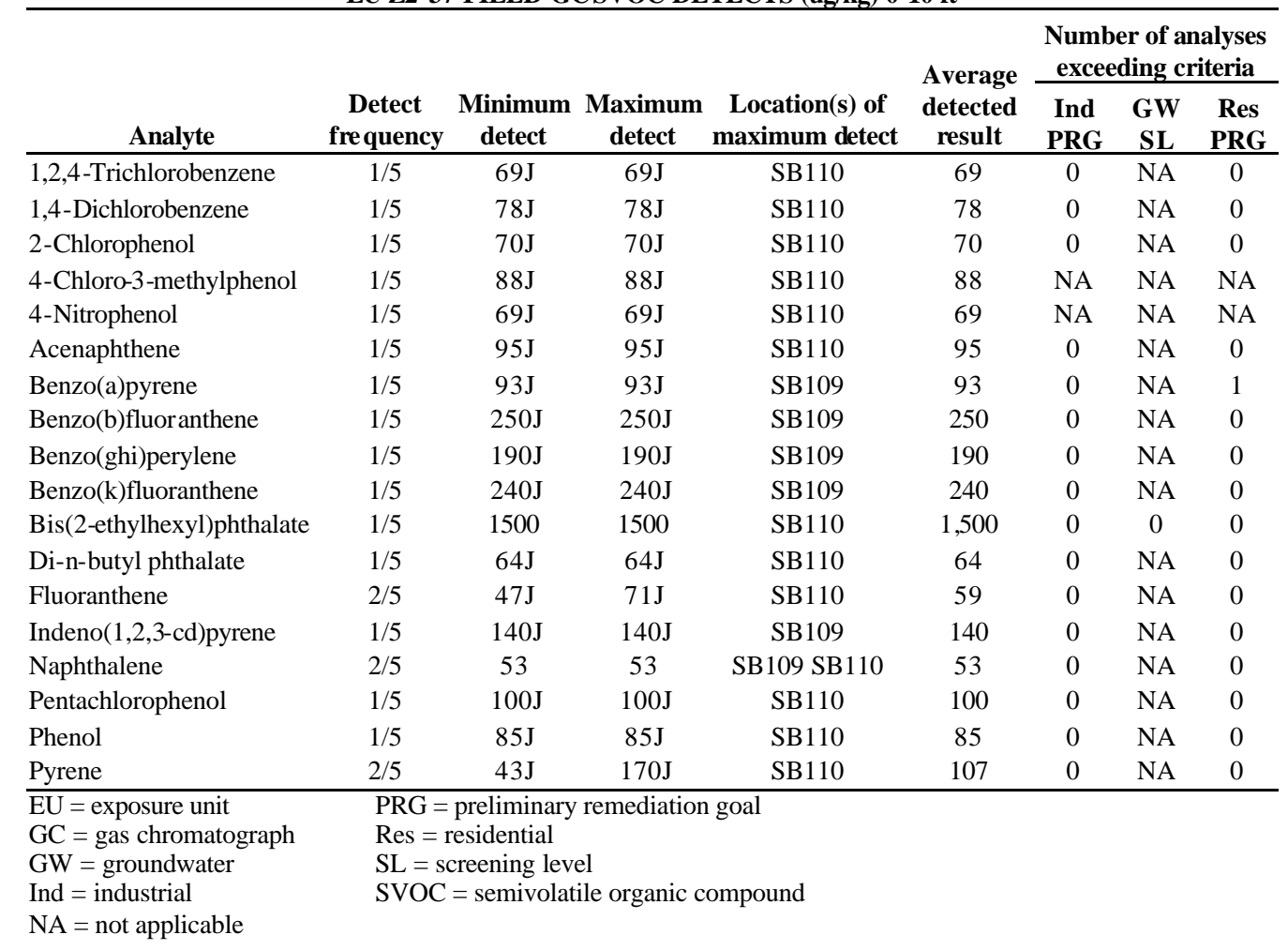

EU Z2-37 FIELD GC VOC DETECTS (ug/kg) 0-10 ft

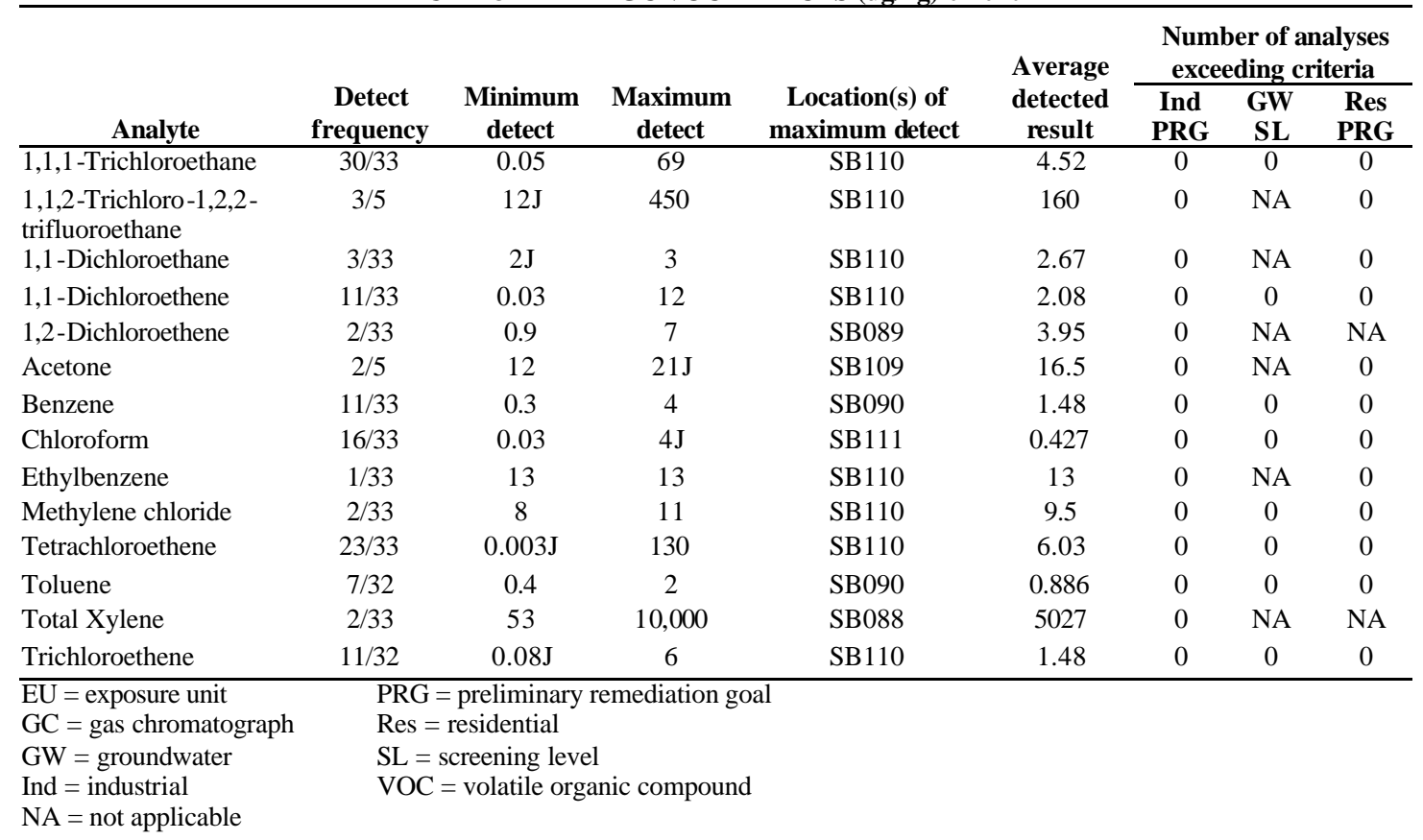

\section{\begin{tabular}{|l|l} 
2.2.6 & ZONE 2 ROD APPENDIX A FFA SITES EVALUATION
\end{tabular}}

There is one FFA site located in this EU that is identified in Appendix A of the Zone 2 ROD-the K-1414 Garage Diesel Tank/Soil FFA Site. A fuel leak from piping associated with the diesel tank was discovered in 1987 and is 
documented in the K-1070-C/D Phase 2 RI. Five historical sample locations were selected for this TM to represent soil that would have been impacted by the fuel leak as described in Sect. H.2.2.3. Sample locations are presented in Sect. H.2.2.3 and shown in Fig. H.3. Analytical results summarized below for samples collected from 0 to $10 \mathrm{ft}$ at these five locations show radionuclide Ind PRG exceedances; metal and radionuclide Bkg exceedances; and detections of DRO, GRO, SVOCs, and VOCs. Unlike the SVOCs, and VOCs, there are no Zone 2 ROD criteria against which to evaluate the DRO and GRO detections. DRO and GRO were both detected in one sample at location BH005, 190J $\mathrm{mg} / \mathrm{kg}$ and $7.5 \mathrm{~J} \mathrm{mg} / \mathrm{kg}$, respectively.

EU Z2-37 K-1414 GARAGE DIESEL TANK/SOILS FFA SITE METALS WITH

BACKGROUND, PRG, GW SL, AND/OR RL EXCEEDANCES (mg/kg) 0-10 ft

\begin{tabular}{|c|c|c|c|c|c|c|c|c|c|c|c|}
\hline \multirow[b]{2}{*}{ Analyte } & \multirow[b]{2}{*}{$\begin{array}{l}\text { Detect } \\
\text { frequency }\end{array}$} & \multirow[b]{2}{*}{$\begin{array}{c}\text { Minimum } \\
\text { detect }\end{array}$} & \multirow[b]{2}{*}{$\begin{array}{c}\text { Maximum } \\
\text { detect }\end{array}$} & \multirow{2}{*}{$\begin{array}{c}\text { Location(s) of } \\
\text { maximum } \\
\text { detect }\end{array}$} & \multirow{2}{*}{$\begin{array}{c}\text { Average } \\
\text { detected } \\
\text { result }\end{array}$} & \multicolumn{6}{|c|}{ Number of analyses exceeding criteria } \\
\hline & & & & & & $\underset{\text { RL }}{\operatorname{Max}}$ & $\begin{array}{l}\text { Avg } \\
\text { RL }\end{array}$ & $\begin{array}{l}\text { Ind } \\
\text { PRG }\end{array}$ & Bkg & $\begin{array}{c}\text { GW } \\
\text { SL }\end{array}$ & $\begin{array}{c}\text { Res } \\
\text { PRG }\end{array}$ \\
\hline Aluminum & $1 / 1$ & 18,500 & 18,500 & SB088 & 18,500 & NA & NA & 0 & 0 & NA & 1 \\
\hline Arsenic & $1 / 1$ & $15.5 \mathrm{~J}$ & $15.5 \mathrm{~J}$ & SB088 & 15.5 & 0 & 0 & 0 & 1 & 0 & 1 \\
\hline Barium & $1 / 1$ & 138 & 138 & SB088 & 138 & NA & NA & 0 & 1 & 0 & 0 \\
\hline Cadmium & $1 / 1$ & 0.38 & 0.38 & SB088 & 0.38 & NA & NA & 0 & 1 & NA & 0 \\
\hline Copper & $1 / 1$ & 80.7 & 80.7 & SB088 & 80.7 & NA & NA & 0 & 1 & NA & 0 \\
\hline Iron & $1 / 1$ & 37,100 & 37,100 & SB088 & 37,100 & NA & NA & 0 & 0 & NA & 1 \\
\hline Manganese & $1 / 1$ & 1,820 & 1,820 & SB088 & 1,820 & NA & NA & 0 & 0 & NA & 1 \\
\hline Nickel & $1 / 1$ & 34.1 & 34.1 & SB088 & 34.1 & NA & NA & 0 & 1 & NA & 0 \\
\hline Silver & $1 / 1$ & 3 & 3 & SB088 & 3 & NA & NA & 0 & 1 & NA & 0 \\
\hline Vanadium & $1 / 1$ & 35.8 & 35.8 & SB088 & 35.8 & NA & NA & 0 & 0 & NA & 1 \\
\hline
\end{tabular}

Avg = average $\quad$ Max $=$ maximum

$\mathrm{Bkg}=$ background $\quad \mathrm{NA}=$ not applicable

$\mathrm{EU}=$ exposure unit $\quad \mathrm{PRG}=$ preliminary remediation goal

FFA $=$ Federal Facility Agreement $\quad$ Res $=$ residential

$\mathrm{GW}=$ groundwater $\quad \mathrm{RL}=$ remediation level

Ind $=$ industrial $\quad \mathrm{SL}=$ screening level

EU Z2-37 K-1414 GARAGE DIESEL TANK/SOILS FFA

SITE OTHER ORGANICS DETECTS (mg/kg) 0-10 ft

\begin{tabular}{lccccc}
\hline \multicolumn{1}{c}{ Analyte } & $\begin{array}{c}\text { Detect } \\
\text { frequency }\end{array}$ & $\begin{array}{c}\text { Minimum } \\
\text { detect }\end{array}$ & $\begin{array}{c}\text { Maximum } \\
\text { detect }\end{array}$ & $\begin{array}{c}\text { Location(s) of } \\
\text { maximum } \\
\text { detect }\end{array}$ & $\begin{array}{c}\text { Average } \\
\text { detected } \\
\text { result }\end{array}$ \\
\hline Diesel Range Organics & $1 / 3$ & $190 \mathrm{~J}$ & $190 \mathrm{~J}$ & BH005 & 190 \\
Gasoline Range Organics & $1 / 3$ & $7.5 \mathrm{~J}$ & $7.5 \mathrm{~J}$ & BH005 & 7.5 \\
\hline
\end{tabular}

$\mathrm{EU}=$ exposure unit

$\mathrm{FFA}=$ Federal Facility Agreement

PCBs were analyzed for in one sample but were not detected.

EU Z2-37 K-1414 GARAGE DIESEL TANK/SOILS FFA SITE RADIONUCLIDES WITH BACKGROUND, PRG, AND/OR RL EXCEEDANCES (pCi/g) 0-10 ft

\begin{tabular}{|c|c|c|c|c|c|c|c|c|c|c|c|}
\hline \multirow[b]{2}{*}{ Analyte } & \multirow[b]{2}{*}{$\begin{array}{c}\text { Detect } \\
\text { frequency }\end{array}$} & \multirow[b]{2}{*}{$\begin{array}{c}\text { Minimum } \\
\text { detect }\end{array}$} & \multirow[b]{2}{*}{$\begin{array}{c}\text { Maximum } \\
\text { detect }\end{array}$} & \multirow[b]{2}{*}{$\begin{array}{c}\text { Location(s) of } \\
\text { maximum detect }\end{array}$} & \multirow{2}{*}{$\begin{array}{c}\text { Average } \\
\text { detected } \\
\text { result }\end{array}$} & \multicolumn{6}{|c|}{ Number of analyses exceeding criteria } \\
\hline & & & & & & $\begin{array}{c}\text { Max } \\
\text { RL }\end{array}$ & $\begin{array}{l}\text { Avg } \\
\text { RL }\end{array}$ & $\begin{array}{c}\text { Ind } \\
\text { PRG }\end{array}$ & Bkg & $\begin{array}{l}\text { GW } \\
\text { SL }\end{array}$ & $\begin{array}{c}\text { Res } \\
\text { PRG }\end{array}$ \\
\hline Cesium-137 & $2 / 3$ & 0.223 & 1.01 & ETTP-REL12 & 0.617 & 0 & 0 & 0 & NA & NA & 2 \\
\hline Potassium-40 & $2 / 2$ & 44.2 & 45.7 & ETTP-REL13 & 45.0 & NA & NA & 2 & 2 & NA & 2 \\
\hline Radium-226 & $1 / 2$ & 1.28 & 1.28 & ETTP-REL12 & 1.28 & NA & NA & 1 & 1 & NA & 1 \\
\hline Technetium-99 & $3 / 3$ & $0.23 \mathrm{~J}$ & $1.18 \mathrm{~J}$ & ETTP-REL12 & 0.667 & NA & NA & 0 & NA & NA & 2 \\
\hline Thorium -228 & $2 / 2$ & 0.892 & 1.08 & ETTP-REL13 & 0.986 & NA & NA & 2 & 0 & NA & 2 \\
\hline Thorium -232 & $2 / 2$ & 1.95 & 1.97 & ETTP-REL13 & 1.96 & NA & NA & 2 & 1 & NA & 2 \\
\hline Uranium-234 & $3 / 3$ & 1.96 & 7.94 & ETTP-REL12 & 3.97 & 0 & 0 & 0 & NA & 0 & 1 \\
\hline
\end{tabular}




\begin{tabular}{|c|c|c|c|c|c|c|c|c|c|c|}
\hline \multicolumn{11}{|c|}{$\begin{array}{l}\text { EU Z2-37 K-1414 GARAGE DIESEL TANK/SOILS FFA SITE RADIO NUCLIDES } \\
\text { WITH BACKGROUND, PRG, AND/OR RL EXCEEDANCES (pCi/g) 0-10 ft (cont'd) }\end{array}$} \\
\hline \multirow[b]{2}{*}{ Analyte } & \multirow[b]{2}{*}{$\begin{array}{c}\text { Minimum } \\
\text { detect }\end{array}$} & \multirow[b]{2}{*}{$\begin{array}{l}\text { Maximum } \\
\text { detect }\end{array}$} & \multirow[b]{2}{*}{$\begin{array}{l}\text { Location(s) of } \\
\text { maximum detect }\end{array}$} & \multirow{2}{*}{$\begin{array}{c}\text { Average } \\
\text { detected } \\
\text { result }\end{array}$} & \multicolumn{6}{|c|}{ Number of analyses exceeding criteria } \\
\hline & & & & & $\begin{array}{l}\text { Max } \\
\text { RL }\end{array}$ & Avg & $\begin{array}{l}\text { Ind } \\
\text { PRG }\end{array}$ & Bkg & $\begin{array}{l}\text { GW } \\
\text { SL }\end{array}$ & $\begin{array}{c}\text { Res } \\
\text { PRG }\end{array}$ \\
\hline Uranium-235 & $0.0479 \mathrm{~J}$ & $0.482 \mathrm{~J}$ & ETTP-REL12 & 0.213 & 0 & 0 & 0 & NA & 0 & 1 \\
\hline Uranium-238 & 0.917 & 4.26 & ETTP-REL12 & 2.19 & 0 & 0 & 0 & 1 & 0 & 3 \\
\hline $\begin{array}{l}\text { Avg = average } \\
\text { Bkg = background } \\
\text { EU = exposure unit } \\
\text { FFA = Federal Facility Agreement } \\
\text { GW = groundwater } \\
\text { Ind = industrial }\end{array}$ & $\begin{array}{l}\text { Max }=\mathrm{n} \\
\mathrm{NA}=\mathrm{n} \\
\mathrm{PRG}=\mathrm{r} \\
\mathrm{Res}=\mathrm{re} \\
\mathrm{RL}=\mathrm{re} \\
\mathrm{SL}=\mathrm{sc}\end{array}$ & $\begin{array}{l}\text { naximum } \\
\text { ot applicable } \\
\text { preliminary r } \\
\text { esidential } \\
\text { mediation le } \\
\text { reening level }\end{array}$ & $\begin{array}{l}\text { remediation goal } \\
\text { vel }\end{array}$ & & & & & & & \\
\hline
\end{tabular}

EU Z2-37 K-1414 GARAGE DIESEL TANK/SOILS FFA SITE SVOC DETECTS (ug/kg) 0-10 ft

\begin{tabular}{|c|c|c|c|c|c|c|c|c|}
\hline \multirow[b]{2}{*}{ Analyte } & \multirow[b]{2}{*}{$\begin{array}{c}\text { Detect } \\
\text { frequency }\end{array}$} & \multirow[b]{2}{*}{$\begin{array}{l}\text { Minimum } \\
\text { dete ct }\end{array}$} & \multirow[b]{2}{*}{$\begin{array}{c}\text { Maximum } \\
\text { detect }\end{array}$} & \multirow[b]{2}{*}{$\begin{array}{c}\text { Location(s) of } \\
\text { maximum detect }\end{array}$} & \multirow{2}{*}{$\begin{array}{c}\text { Average } \\
\text { detected } \\
\text { result }\end{array}$} & \multicolumn{3}{|c|}{$\begin{array}{c}\text { Number of analyses } \\
\text { exceeding criteria }\end{array}$} \\
\hline & & & & & & $\begin{array}{l}\text { Ind } \\
\text { PRG }\end{array}$ & $\begin{array}{l}\text { GW } \\
\text { SL }\end{array}$ & $\begin{array}{l}\text { Res } \\
\text { PRG }\end{array}$ \\
\hline 2-Methylnaphthalene & $1 / 4$ & 2200 & 2200 & SB088 & 2200 & 0 & NA & NA \\
\hline Acenaphthene & $1 / 4$ & $130 \mathrm{~J}$ & $130 \mathrm{~J}$ & SB088 & 130 & 0 & NA & 0 \\
\hline Fluoranthene & $1 / 4$ & $40 \mathrm{~J}$ & $40 \mathrm{~J}$ & BH006 & 40 & 0 & NA & 0 \\
\hline Fluorene & $1 / 4$ & $320 \mathrm{~J}$ & $320 \mathrm{~J}$ & SB088 & 320 & 0 & NA & 0 \\
\hline Naphthalene & $1 / 4$ & $330 \mathrm{~J}$ & $330 \mathrm{~J}$ & SB088 & 330 & 0 & NA & 0 \\
\hline Phenanthrene & $2 / 4$ & $130 \mathrm{~J}$ & 790 & SB088 & 460 & 0 & NA & 0 \\
\hline Pyrene & $2 / 4$ & $40 \mathrm{~J}$ & $130 \mathrm{~J}$ & SB088 & 85 & 0 & NA & 0 \\
\hline
\end{tabular}

EU = exposure unit $\quad$ PRG = preliminary remediation goal

FFA $=$ Federal Facility Agreement $\quad$ Res $=$ residential

$\mathrm{GW}=$ groundwater $\quad \mathrm{SL}=$ screening level

Ind $=$ industrial $\quad$ SVOC $=$ semivolatile organic compound

$\mathrm{NA}=$ not applicable

EU Z2-37 K-1414 GARAGE DIESEL TANK/SOILS FFA SITE VOC DETECTS (ug/kg) 0-10 ft

\begin{tabular}{|c|c|c|c|c|c|c|c|c|}
\hline \multirow[b]{2}{*}{ Analyte } & \multirow[b]{2}{*}{$\begin{array}{c}\text { Detect } \\
\text { frequency }\end{array}$} & \multirow[b]{2}{*}{$\begin{array}{l}\text { Minimum } \\
\text { detect }\end{array}$} & \multirow[b]{2}{*}{$\begin{array}{l}\text { Maximum } \\
\text { detect }\end{array}$} & \multirow[b]{2}{*}{$\begin{array}{c}\text { Location(s) of } \\
\text { maximum detect }\end{array}$} & \multirow{2}{*}{$\begin{array}{c}\text { Average } \\
\text { detected } \\
\text { result }\end{array}$} & \multicolumn{3}{|c|}{$\begin{array}{c}\text { Number of analyses } \\
\text { exceeding criteria }\end{array}$} \\
\hline & & & & & & $\begin{array}{l}\text { Ind } \\
\text { PRG }\end{array}$ & $\begin{array}{l}\text { GW } \\
\text { SL }\end{array}$ & $\begin{array}{c}\text { Res } \\
\text { PRG }\end{array}$ \\
\hline 1,1,1-Trichloroethane & $1 / 4$ & 8 & 8 & SB088 & 8 & 0 & 0 & 0 \\
\hline $\begin{array}{l}\text { 1,1,2-Trichloro-1,2,2- } \\
\text { trifluoroethane }\end{array}$ & $1 / 4$ & $5 \mathrm{~J}$ & $5 \mathrm{~J}$ & SB088 & 5 & 0 & NA & 0 \\
\hline 1,1-Dichloroethane & $1 / 4$ & 18 & 18 & SB088 & 18 & 0 & NA & 0 \\
\hline 1,1-Dichloroethene & $1 / 4$ & $6 \mathrm{~J}$ & $6 \mathrm{~J}$ & BH005 & 6 & 0 & 0 & 0 \\
\hline 2-Butanone & $1 / 4$ & $52 \mathrm{~J}$ & $52 \mathrm{~J}$ & BH005 & 52 & 0 & NA & 0 \\
\hline Acetone & $2 / 4$ & $530 \mathrm{~J}$ & 6600 & BH006 & 3565 & 0 & NA & 0 \\
\hline Benzene & $2 / 4$ & $26 \mathrm{~J}$ & 44 & SB088 & 35 & 0 & 0 & 0 \\
\hline Carbon disulfide & $1 / 4$ & $5 \mathrm{~J}$ & $5 \mathrm{~J}$ & SB088 & 5 & 0 & NA & 0 \\
\hline Ethylbenzene & $3 / 4$ & 11 & $4300 \mathrm{~J}$ & SB088 & 1484 & 0 & NA & 0 \\
\hline Methylene chloride & $1 / 4$ & $29 \mathrm{~J}$ & $29 \mathrm{~J}$ & BH005 & 29 & 0 & 0 & 0 \\
\hline Tetrachloroethene & $4 / 4$ & $5 \mathrm{~J}$ & $14 \mathrm{~J}$ & SB088 & 9 & 0 & 0 & 0 \\
\hline Toluene & $4 / 5$ & $6 \mathrm{~J}$ & $200 \mathrm{~J}$ & BH005 & 62.5 & 0 & 0 & 0 \\
\hline Total Xylene & $3 / 4$ & $5 \mathrm{~J}$ & $5000 \mathrm{~J}$ & SB088 & 1728 & 0 & NA & NA \\
\hline $\begin{array}{l}\text { EU = exposure unit } \\
\text { FFA = Federal Facility } \\
\text { GW = groundwater } \\
\text { Ind = industrial } \\
\text { NA = not applicable }\end{array}$ & greement & \multicolumn{3}{|c|}{$\begin{array}{l}\text { PRG = preliminary remediation goal } \\
\text { Res = residential } \\
\text { SL = screening level } \\
\text { VOC = volatile organic compound }\end{array}$} & & & & \\
\hline
\end{tabular}




\begin{tabular}{|l|l|}
\hline & \\
\hline 3.0 & RISK EVALUATION AND ACTION/NO FURTHER ACTION DECISION \\
\hline 3.1 & INTRODUCTION \\
\hline
\end{tabular}

In this section, data are evaluated in terms of the four decision rules presented in the Zone 2 RAWP. The decision rules are:

- Does the concentration of any Zone 2 contaminant of concern (COC) exceed its maximum RL?

- Does the mean concentration of any Zone 2 COC exceed its average RL across the EU?

- Does the EU pose a risk exceeding an industrial $1 \times 10^{-4}$ excess lifetime cancer risk (ELCR) or target organ hazard index (HI) of 1 ?

- Does the site pose a threat to groundwater based on MCL exceedances or soil RLs for protection of groundwater?

Table H.3 presents the results from comparison of the data to Zone 2 soils RLs, industrial PRGs (set at an ELCR of $1 \times 10^{-5}$ or a HI of 1), and background levels. In addition, the EU summary in Sect. H.2.2.5 presents an evaluation of the EU data by analyte group. The following table summarizes the conclusions for EU Z2-37.

\begin{tabular}{cccccc}
\hline EU \# & $\begin{array}{c}\text { Max RL } \\
\text { exceeded? }\end{array}$ & $\begin{array}{c}\text { Avg RL over } \\
\text { EU exceeded? }\end{array}$ & $\begin{array}{c}\text { Industrial risk } \\
\text { above } \mathbf{1} \times \mathbf{1 0}^{-4} \text { ? }\end{array}$ & $\begin{array}{c}\text { Potential source } \\
\text { to groundwater? }\end{array}$ & $\begin{array}{c}\text { Action } \\
\text { required? }\end{array}$ \\
\hline $\mathrm{Z} 2-37$ & No & No & No & No & No \\
\hline $\begin{array}{l}\mathrm{EU}=\text { exposure unit } \\
\mathrm{RL}=\text { remediation level }\end{array}$ & & & & \\
\end{tabular}

\begin{tabular}{l|l}
3.2 & DATA EVALUATION FOR THE ACTION /NO FURTHER ACTION DECISION
\end{tabular}

The requirements for determining NFA in the Zone 2 EUs are stated in the protection goals of the Zone 2 ROD RAO. Four decision rules were developed in the DVS DQOs that state the specific criteria against which each EU must be compared to make the NFA decision. The four decision rules are presented in Sect. H.3.2 of this PCCR and the manner in which the decision rule evaluations are conducted and special data handling requirements are discussed in Sect. H.3.3 of the PCCR. In summary, the decision rule criteria for NFA are that each EU must meet each of the following compositional constraints:

- Zone 2 soils Max RLs - maximum allowable concentrations of the Zone 2 soils COCs. Zone 2 soils Max RLs are presented in the Zone 1 ROD and Table 5 of this PCCR.

- Zone 2 soils Avg RLs - limit on the allowable average concentrations of the Zone 2 soils COCs across an EU. Zone 2 soils Avg RLs are presented in the Zone 1 ROD and Table 5 of this PCCR.

- Cumulative risk across the EU - cumulative risk across an EU cannot exceed $1 \times 10^{-4}$ ELCR or HI of 1. A stepwise evaluation of cumulative risk is performed by comparing the EU data to $1 \times 10^{-5}$ industrial PRGs. The $1 \times 10^{-5}$ Ind PRGs for the analytes required by the RDR/RAWP are presented in Table 5 of this PCCR.

Groundwater protection goals - the composition of Zone 2 soils cannot pose a threat to groundwater. This evaluation is conducted by evaluating local groundwater monitoring results and comparing soil compositions to calculated SLs. Groundwater SLs are presented in Table 5 of this PCCR.

\section{\begin{tabular}{|l|l}
\hline 3.3 & SUMMARY AND CONCLUSIONS \\
\hline
\end{tabular}}

$\underline{\text { EU Z2-37 }}$

Max RL screening. Based on analytical results from DVS biased and historical sampling in EU Z2-37, no Zone 2 COCs are present at concentrations in excess of Max RLs.

Avg RL screening. Based on analytical results from DVS biased sampling and historical sampling in EU Z2-37, no Zone 2 soils COCs are present with a mean concentration exceeding the Avg RL across the EU.

Risk evaluation. The first step in the risk evaluation is to evaluate $1 \times 10^{-5}$ Ind PRG exceedances to determine which chemicals and radionuclides are likely to exceed the $1 \times 10^{-4}$ ELCR or target organ HI of 1 . As discussed in Sect. H.2.2.5, the $1 \times 10^{-5}$ Ind PRG was exceeded in one or more samples by arsenic (1), manganese (1), K-40 (14), Ra-226 (11), Th-228 (12), Th-232 (14), and benzo(a)pyrene (2). As explained in Sect. H.3.3 of this PCCR, K-40 is 
evaluated further for risk only if its average concentration exceeds its background value and Ra-226, Th-230, and Th-232 are evaluated by summing their concentrations ( $\mathrm{Ra} / \mathrm{Th}$ decay series) and comparing the result to their mutual Zone 2 soils COC average RL (this evaluation includes Th-228 as part of the Th-232 decay chain). The average detected $\mathrm{K}-40$ concentration $(21.3 \mathrm{pCi} / \mathrm{g})$ does not exceed the $\mathrm{K}-40$ background value $(32.12 \mathrm{pCi} / \mathrm{g})$ and there are no occurrences of the Ra/Th decay series exceeding the Avg RL (5 pCi/g). Therefore, K-40, Ra-226, Th-228, and Th-232 will not be carried forward in the risk evaluation.

The second step in the risk evaluation is to determine if the average detected concentration of any of the remaining chemicals or radionuclides exceeds a $1 \times 10^{-5}$ Ind PRG. For EU Z2-37, the remaining chemicals and radionuclides with individual $1 \times 10^{-5}$ Ind PRG exceedances are arsenic, manganese, and benzo(a)pyrene. The average detected concentration of arsenic $\left(7.06 \mathrm{mg} / \mathrm{kg}\right.$ ) is less than the $1 \times 10^{-5}$ Ind PRG $(15.9 \mathrm{mg} / \mathrm{kg})$, the average detected concentration of manganese $(3196 \mathrm{mg} / \mathrm{kg})$ is also less than the $1 \times 10^{-5}$ Ind PRG $(19,458 \mathrm{mg} / \mathrm{kg})$, and the average detected concentration of benzo(a)pyrene $(1038 \mathrm{ug} / \mathrm{kg})$ is also less than the $1 \times 10^{-5}$ Ind PRG $(2110 \mathrm{ug} / \mathrm{kg})$. It is concluded there are no chemicals or radionuclides in soils of this EU at concentrations high enough for the EU to fail the Zone 2 risk limits. Therefore, the industrial risk for EU Z2-37 is less than $1 \times 10^{-4}$ ELCR and target organ HI of 1 .

\section{Threat to groundwater.}

One or more groundwater VOC plumes are known to occur beneath EU Z2-37. However, the sources of these plumes are either upgradient in EU Z2-41 or are in deep bedrock beneath the EU (see CSM in Sect. H.2.2.5). Because there are no GW SL exceedances in soil samples collected from the 0-to 10-ft-depth interval in this EU, there are no potential sources for groundwater VOC contamination in that depth interval.

Both DRO and GRO have been detected in area groundwater monitoring wells and were detected in two samples from two his torical sampling locations. There are no site-specific or action-specific criteria in the Zone 2 ROD that pertain to USTs. However, according to UST Rules of the TDEC Chap. 1200-1-15-06(7)(e)(4), site-specific, risk-based cleanup levels may be utilized where appropriate.

It is concluded that chemicals and radionuclides in the soils of EU Z2-37 are not potential threats to groundwater.

Qualitative risk screening for unrestricted use. There is a low probability that the EU Z2-37 acreage could be released with no land use restrictions. Ind and Res PRG exceedances for metals, radionuclides, PCBs, SVOCs, and VOCs occur in this EU. Specific chemicals and radionuclides with criteria exceedances are presented in Sect. H.2.2.5. An appropriate evaluation of residential risk should be conducted to make a definitive conclusion.

\section{FFA Sites}

Based on sampling analytical results (Sect. H.2.2.6) and an evaluation of the EU-wide contaminant profile (above), soils in the K-1414 Diesel Tank/Soils Zone 2 ROD Appendix A FFA Site in EU Z2-37 do not pose a potential threat to the future industrial worker or to groundwater.

\begin{tabular}{|l|l|}
\hline 4.0 & RECOMMENDATION FOR ACTION/NO FURTHER ACTION \\
\hline 4.1 & DECISION AND REMEDIATION ACTIVITIES \\
\hline
\end{tabular}

EU Z2-37: Based on results of the Class 3 SU walkover assessment and analytical results of the DVS and historical samples collected in EU Z2-37, the U.S. Department of Energy recommends that NFA is appropriate under the Zone 2 ROD to meet industrial land use for the 5.9 acres of ETTP Zone 2 EU37.

There are 27 historical sample locations in EU Z2-37 with samples from > $10 \mathrm{ft}$ bgs. Analytical results summarized in Table H.4 show metal, radionuclide, and VOC Ind PRG exceedances; VOC GW SL exceedances; numerous metal and radionuclide Bkg exceedances; metal, radionuclide, PCB, and VOC Res PRG exceedances; DRO and GRO exceedances of the Tennessee groundwater protection criterion; and detections of DRO, GRO, pesticides, PCBs, SVOCs, and VOCs that do not exceed any criteria. Based on this data evaluation and the fact that one or more groundwater contaminant plumes occur under portions of this EU, DOE does not recommend that the 10 -ft-depth use restriction be lifted.

FFA Sites: Based on sampling analytical results and the recommendation for EU Z2-37, DOE recommends NFA as appropriate for the K-1414 Diesel Tank/Soils FFA Site. 
4.2

EXCAVATION ACTIVITIES/CONFIRMATIONSAMPLING

None 


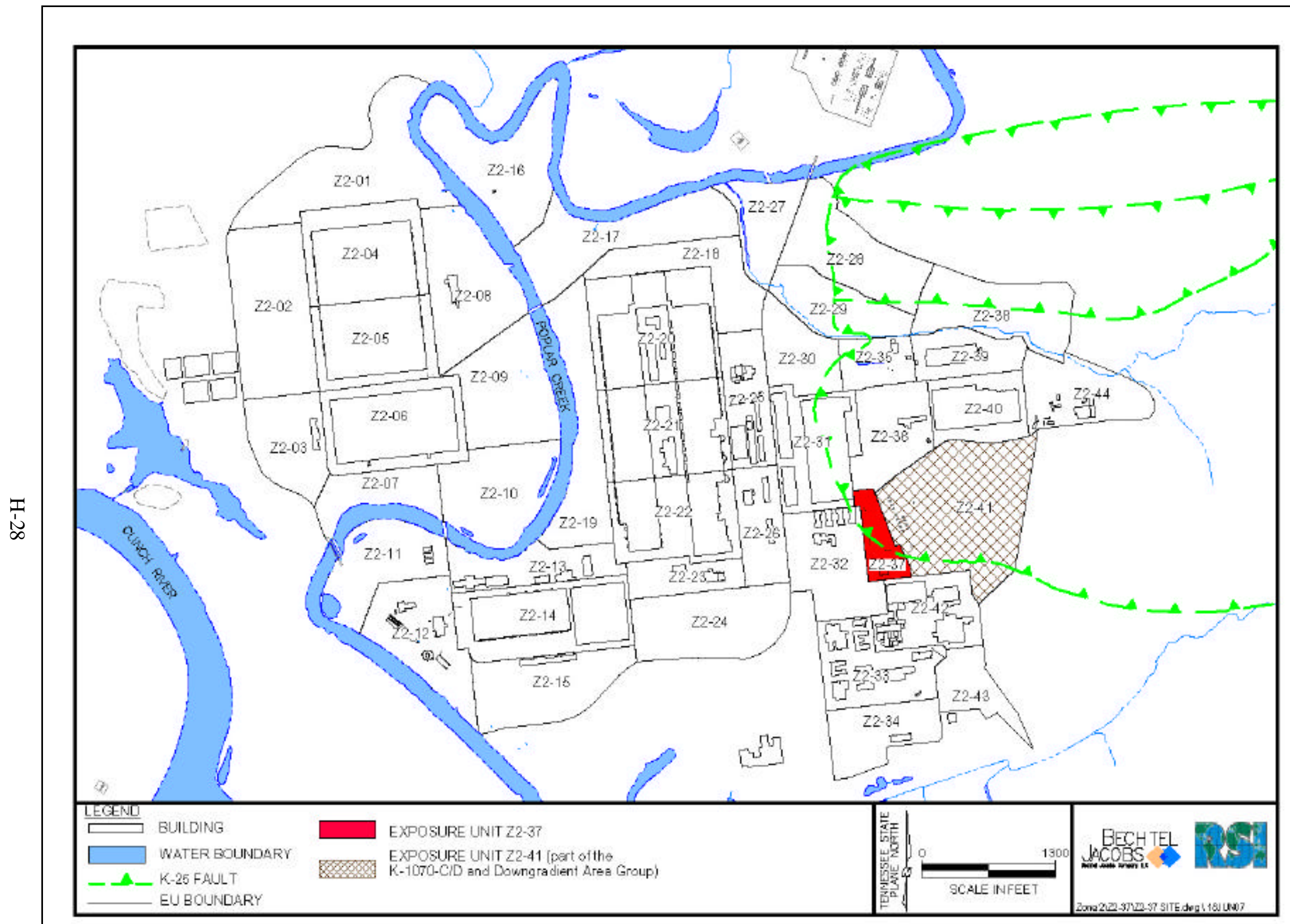

Fig. H.1. EU Z2-37 location map. 


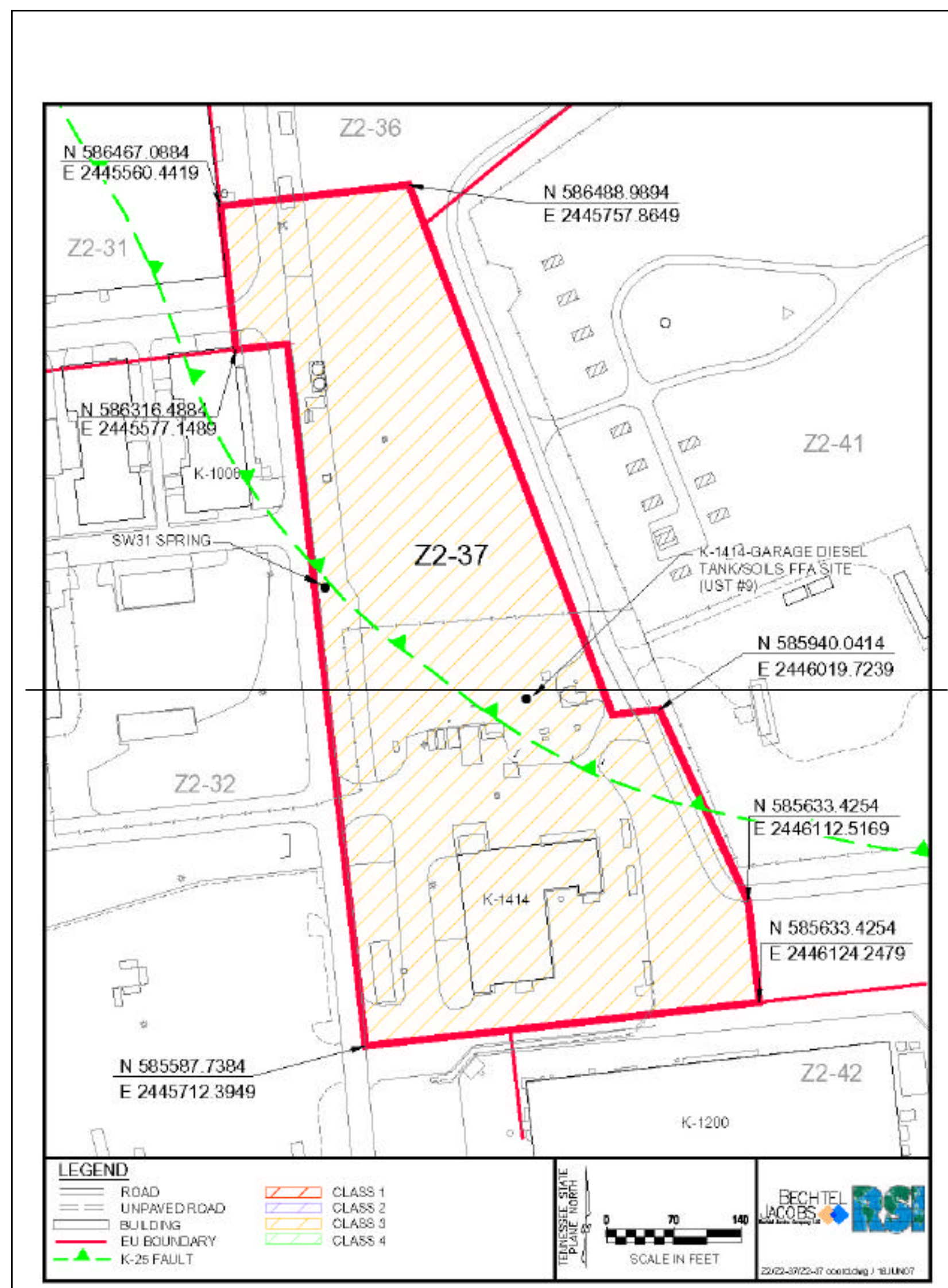

Fig. H.2, EU Z2-37 boundaries. 


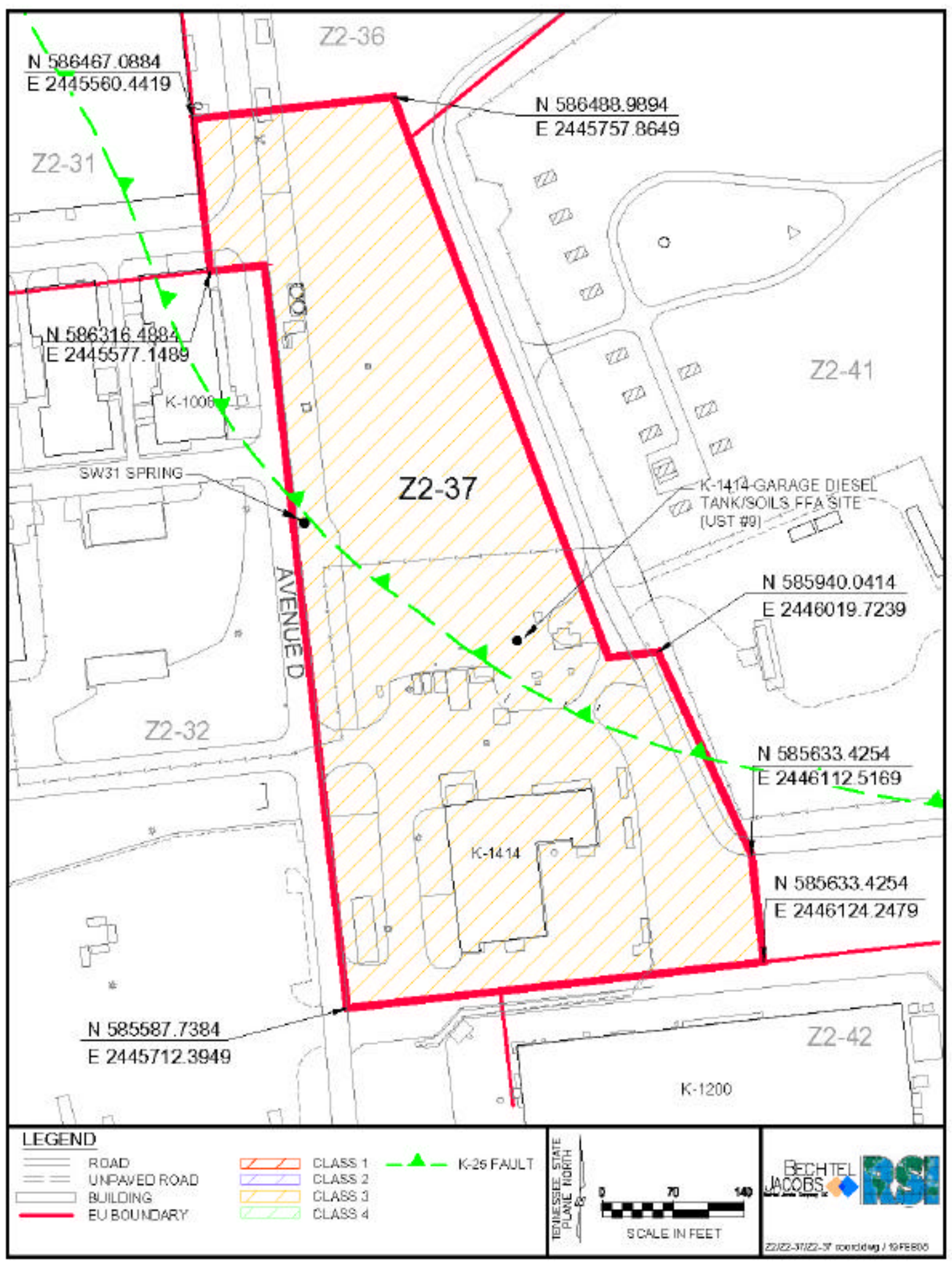

Fig. H.2. EU Z2-37 boundaries. 


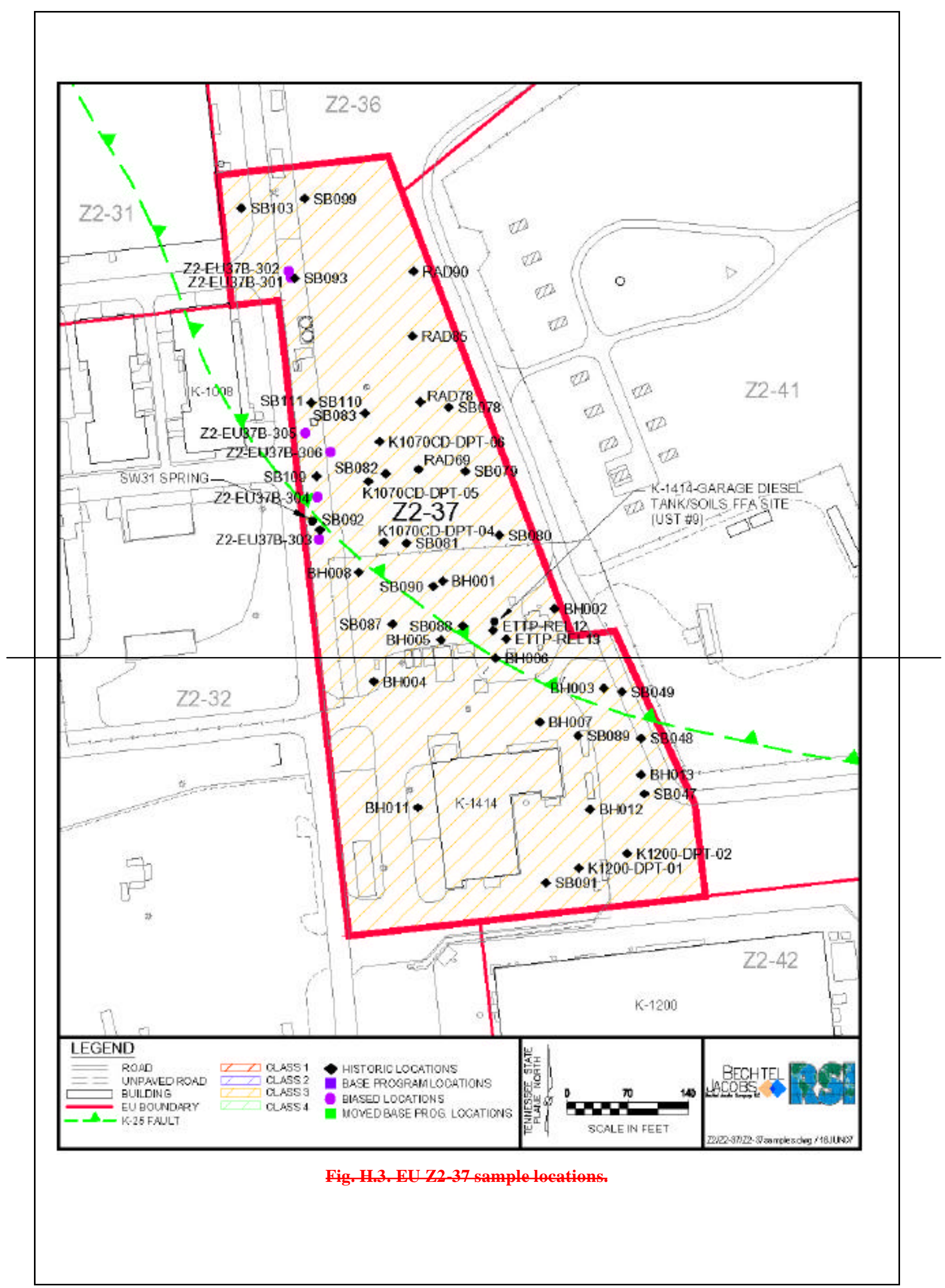




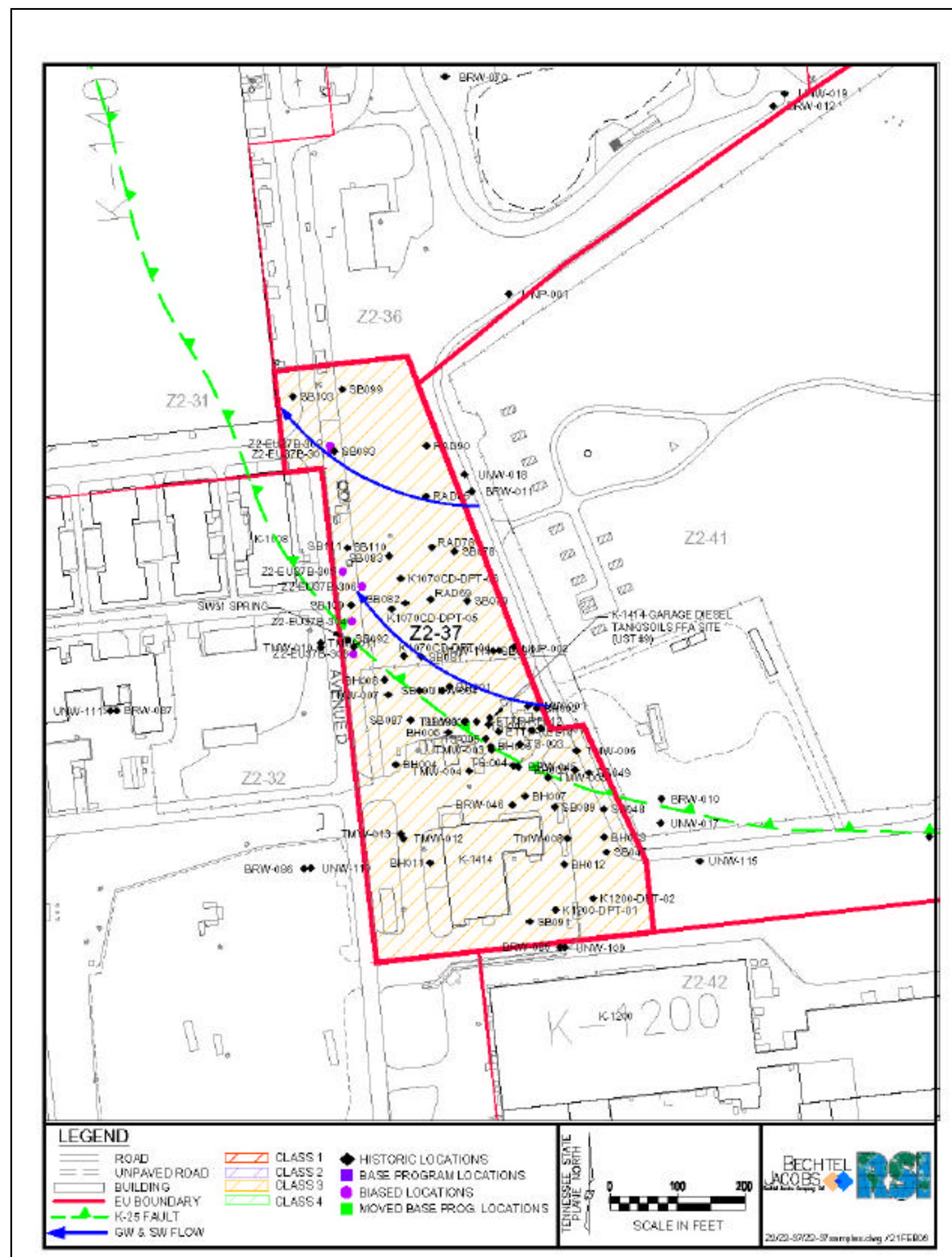

Fig. H.3. EU Z2 -37 sample locations. 
Table H.1. EU Z2-37 facility and FFA site list

\begin{tabular}{|c|c|c|c|c|}
\hline \multirow[b]{2}{*}{ Facility name DQO scoping } & \multirow[b]{2}{*}{ Facility name } & \multicolumn{2}{|c|}{ Facility assessed? } & \multirow[b]{2}{*}{ Comments } \\
\hline & & Yes & No & \\
\hline K-700-A-2 Substation & & $\mathrm{X}$ & & \\
\hline K-1310-CD Storage Shed & & $\mathrm{X}$ & & \\
\hline K-1310-DD Office Trailer & & $\mathrm{X}$ & & \\
\hline K-1414 Garage Diesel Tank/Soils & & $\mathrm{X}$ & & FFA site \\
\hline K-1414 Underground Storage Tank (UST \#8) & & & $\mathrm{X}$ & $\begin{array}{l}\text { Tank removed in 1997; received clean } \\
\text { closure }\end{array}$ \\
\hline K-1414 Unleaded Gasoline Underground Storage Tank (UST \#7) & & & $\mathrm{X}$ & Clean closure-in-place 1994 \\
\hline K-1414 Waste Oil Underground Storage Tank (UST \#6) & & $\mathrm{X}$ & & \\
\hline K-1414-B Vehicle Wash Facility & & $\mathrm{X}$ & & \\
\hline K-1414-C Storage Shed & & $\mathrm{X}$ & & \\
\hline K-1414-D Backflow Preventer & & $\mathrm{X}$ & & \\
\hline SW31 Spring (ROD signed 9/30/92) & & $\mathrm{X}$ & & \\
\hline \multicolumn{5}{|l|}{ Facilities not in DQO scoping } \\
\hline K-720-A Storage Building & & $\mathrm{X}$ & & \\
\hline
\end{tabular}


Table H.2. EU Z2-37 sample summary

\begin{tabular}{|c|c|c|c|c|c|c|c|c|c|c|c|c|c|c|c|c|}
\hline \multirow[b]{2}{*}{$\begin{array}{c}\text { Su } \\
\text { class }\end{array}$} & \multirow[b]{2}{*}{$\begin{array}{c}\text { Date } \\
\text { sampled }\end{array}$} & \multirow[b]{2}{*}{ EU } & \multirow[b]{2}{*}{ Location ID } & \multicolumn{2}{|c|}{ Location } & \multirow[b]{2}{*}{ Sample interval } & \multicolumn{2}{|c|}{ Screening } & \multicolumn{7}{|c|}{ Off-site laboratory } & \multirow[b]{2}{*}{ Comments and notes } \\
\hline & & & & Northing & Easting & & voC & RAD & VOC & svoc & PCB & Metals & RAD & $\begin{array}{l}\begin{array}{l}\text { GRO/ } \\
\text { DRO }\end{array} \\
\end{array}$ & $\begin{array}{c}\text { Splits/ } \\
\text { duplicates }\end{array}$ & \\
\hline \multicolumn{17}{|c|}{ DVS samples } \\
\hline 3 & $9 / 11 / 06$ & $\mathrm{Z2}-37$ & Z2-EU37B-301 & 586349 & 2445645 & $\begin{array}{l}\text { Surface to water table; three-interval } \\
\text { composite soil } 0-0.5,0.5-2,1.5 \mathrm{ft} \\
\text { within } 2 \mathrm{ft} \text { to water table }\end{array}$ & 1 & 1 & 1 & 1 & 1 & 1 & 1 & & $\mathrm{D}$ & $\begin{array}{l}\text { Sample along utility corridor (storm drain, fire water, } \\
\text { sanitary sewerr) naar Avenue D. Sample located in grassy } \\
\text { area of utility corridor south of K-1310-DD. RAD and } \\
\text { VOC analyses conditional upon field screening results. }\end{array}$ \\
\hline 3 & 9/11/06 & Z2-37 & Z2-EU37B-302 & 586356 & 2445643 & 0 to $1.0 \mathrm{ft}$ single-point sediment sample & 1 & 1 & & 1 & 1 & 1 & 1 & & $\mathrm{~s}$ & $\begin{array}{l}\text { Sediment sample from within the storm drain located in the } \\
\text { utility corridor (south of K-1310-DD). }\end{array}$ \\
\hline 3 & 9/11/06 & $\mathrm{Z} 2-37$ & Z2-EU37B-303 & 586046 & 2445678 & $\begin{array}{l}0-10 \mathrm{ft} \text { t three-interval composite soil } \\
0.5,0.5-2,1.5 \mathrm{ft} \text { within } 2-10 \mathrm{ft}\end{array}$ & 1 & 1 & 1 & 1 & 1 & 1 & 1 & & & Sample located upstream of the SW31 Spring. \\
\hline 3 & 9/11/06 & Z2-37 & Z2-EU37B-304 & 586094 & 2445676 & $\begin{array}{l}0-10 \mathrm{ft} \text { t three-interval composite soil } \\
0-0.5,0.5-2,1.5 \mathrm{ft} \text { within } 2-10 \mathrm{ft}\end{array}$ & 1 & 1 & & 1 & 1 & 1 & 1 & & & Sample located downstream of the SW31 Spring. \\
\hline 3 & 9/12/06 & Z2-37 & Z2-EU37B-305 & 586169 & 2445662 & 0 - to 1-ft single-point sediment sample & 1 & 1 & 1 & 1 & 1 & 1 & 1 & & & $\begin{array}{l}\text { Sediment sample from within the storm drain located } \\
\text { downstream of SW31. }\end{array}$ \\
\hline \multirow[t]{2}{*}{3} & 9/12/06 & Z2-37 & Z2-EU37B-306 & 586147 & 2445691 & $\begin{array}{l}\text { Four-point composite sediment sample, } \\
0 \text { to } 1 \mathrm{ft}\end{array}$ & 1 & 1 & 1 & 1 & 1 & 1 & 1 & & & Sediment sample from within the ditch area eastof SW31. \\
\hline & & & & & & DVS sampling total & 6 & 6 & 6 & 6 & 6 & 6 & 6 & & 2 & \\
\hline \multicolumn{17}{|c|}{ Historical samples } \\
\hline 3 & $10 / 5 / 93$ & Z2-37 & BH001 & 585998 & 2445821 & Borehole 2 samples to $16 \mathrm{ft}$ & & & 2 & 2 & 1 & 1 & 1 & 2 & & \\
\hline 3 & $10 / 5 / 93$ & Z2-37 & BH002 & 585966 & 2445950 & Borehole 3 samples to $17 \mathrm{ft}$ & & & 3 & 3 & 1 & 1 & 1 & 3 & & \\
\hline 3 & $10 / 5 / 93$ & Z2-37 & ВH003 & 585874 & 2446007 & Borehole sample at $12 \mathrm{ft}$ & & & 1 & 1 & 1 & 1 & 1 & 1 & & \\
\hline 3 & 10/5/93 & Z2-37 & ВH004 & 585882 & 2445741 & Borehole 3 samples to $14 \mathrm{ft}$ & & & 3 & 3 & 1 & 1 & 1 & 3 & & \\
\hline 3 & 10/13/93 & Z2-37 & ВH005 & 585930 & 2445819 & Borehole 3 samples to $14 \mathrm{ft}$ & & & 3 & 3 & 1 & 1 & 1 & 3 & & \\
\hline 3 & 10/12/93 & Z2-37 & ВH006 & 585909 & 2445882 & Borehole 3 samples to $12 \mathrm{ft}$ & & & 3 & 3 & 1 & 1 & 1 & 3 & & \\
\hline 3 & 10/11/93 & Z2-37 & BH007 & 585835 & 2445933 & Borehole 3 samples to $13.5 \mathrm{ft}$ & & & 3 & 3 & 1 & 1 & 1 & 3 & & \\
\hline 3 & $10 / 5 / 93$ & Z2-37 & BH008 & 586008 & 2445724 & Borehole sample at $8 \mathrm{ft}$ & & & 1 & 1 & 1 & 1 & 1 & 1 & & \\
\hline 3 & 10/11/93 & Z2-37 & BH011 & 585736 & 2445792 & Borehole 4 samples to $18 \mathrm{ft}$ & & & 4 & 4 & 1 & 1 & 1 & 4 & & \\
\hline 3 & $10 / 8 / 93$ & Z2-37 & BH012 & 585734 & 2445991 & Borehole 2 samples to $11.5 \mathrm{ft}$ & & & 2 & 2 & 1 & 1 & 1 & 2 & & \\
\hline 3 & $10 / 8 / 93$ & Z2-37 & BH013 & 585774 & 2446050 & Borehole sample at $3 \mathrm{ft}$ & & & 1 & 1 & & & & 1 & & \\
\hline 3 & $6 / 28 / 01$ & Z2-37 & ETTP-REL12 & 585941 & 2445879 & Surface soil sample & & & & & & & 1 & & & \\
\hline 3 & $6 / 28 / 01$ & Z2-37 & ETTP-REL13 & 585931 & 2445894 & Surface soil sample & & & & & & & 1 & & & \\
\hline 3 & $2 / 10 / 05$ & $\mathrm{Z} 2-37$ & K1070CD-DPT-04 & 586043 & 2445753 & Borehole sample at $18 \mathrm{ft}$ & & & 1 & 1 & & & & & & \\
\hline 3 & $2 / 14 / 05$ & Z2-37 & K1070CD-DPT-05 & 586113 & 2445735 & Borehole sample at $21 \mathrm{ft}$ & & & 1 & 1 & & & & & & \\
\hline 3 & $2 / 14 / 05$ & Z2-37 & K1070CD-DPT-06 & 586159 & 2445748 & Borehole sample at $26 \mathrm{ft}$ & & & 1 & 1 & & & & & & \\
\hline 3 & $2 / 16 / 05$ & Z2-37 & K1200-DPT-01 & 585666 & 2445978 & Borehole sample at $23 \mathrm{ft}$ & & & 1 & 1 & & & & & & \\
\hline 3 & $2 / 16 / 05$ & Z2-37 & K1200-DPT-02 & 585683 & 2446034 & Borehole sample at $21 \mathrm{ft}$ & & & 1 & 1 & & & & & & \\
\hline 3 & 9/7/94 & Z2-37 & RAD69 & 586127 & 2445793 & Surface soil sample & & & & & & & 1 & & & \\
\hline 3 & 9/7/94 & Z2-37 & RAD78 & 586205 & 2445795 & Surface soil sample & & & & & & & 1 & & & \\
\hline 3 & 9/8/94 & Z2-37 & RAD85 & 586281 & 2445786 & Surface soil sample & & & & & & & 1 & & & \\
\hline 3 & 9/8/94 & Z2-37 & RAD90 & 586356 & 2445787 & Surface soil sample & & & & & & & 1 & & & \\
\hline 3 & $9 / 3 / 93$ & Z2-37 & SB047 & 585752 & 2446054 & Borehole 2 samples to $27 \mathrm{ft}$ & & & 2 & 2 & 2 & 2 & 2 & & & \\
\hline 3 & 9/7/93 & Z2-37 & SB048 & 585816 & 2446050 & Borehole sample at $15 \mathrm{ft}$ & & & 1 & 1 & 1 & 1 & 1 & & & \\
\hline 3 & 9/7/93 & Z2-37 & SB049 & 585870 & 2446028 & Borehole sample at $15 \mathrm{ft}$ & & & 1 & 1 & 1 & 1 & 1 & & & \\
\hline 3 & 10/21/93 & Z2-37 & SB078 & 586199 & 2445828 & Borehole 8 samples to $20 \mathrm{ft}$ & & & 8 & 3 & 3 & 3 & 3 & & & Includes 5 field GC samples \\
\hline 3 & 10/20/93 & Z2-37 & SB079 & 586125 & 2445847 & Borehole 7 samples to $23 \mathrm{ft}$ & & & 7 & 3 & 3 & 3 & 3 & & & Includes 4 field GC samples \\
\hline 3 & 10/20/93 & Z2-37 & SB080 & 586051 & 2445886 & Borehole 7 samples to $16 \mathrm{ft}$ & & & 7 & 3 & 3 & 3 & 3 & & & Includes 4 field GC samples \\
\hline 3 & 10/22/93 & Z2-37 & SB081 & 586042 & 2445779 & Borehole 7 samples to $19 \mathrm{ft}$ & & & 7 & 3 & 3 & 3 & 3 & & & Includes 4 field GC samples \\
\hline 3 & 10/25/93 & $\mathrm{Z} 2-37$ & SB082 & 586122 & 2445755 & Borehole 8 samples to $25 \mathrm{ft}$ & & & 8 & 3 & 3 & 3 & 3 & & & Includes 5 field GC samples \\
\hline 3 & 10/25/93 & Z2-37 & SB083 & 586192 & 2445731 & Borehole 6 samples to $20 \mathrm{ft}$ & & & 6 & 2 & 2 & 2 & 2 & & & Includes 4 field GC samples \\
\hline
\end{tabular}


Table H.2. (continued)

\begin{tabular}{|c|c|c|c|c|c|c|c|c|c|c|c|c|c|c|c|}
\hline \multirow{2}{*}{$\begin{array}{l}\text { SU } \\
\text { class }\end{array}$} & \multirow{2}{*}{$\begin{array}{c}\text { Date } \\
\text { sampled }\end{array}$} & \multirow[b]{2}{*}{ EU } & \multirow[b]{2}{*}{ Location ID } & \multicolumn{2}{|c|}{ Location } & \multirow[b]{2}{*}{ Sample interval } & \multicolumn{4}{|c|}{ Screening } & \multicolumn{3}{|c|}{ Off-site laboratory } & \multirow[b]{2}{*}{ 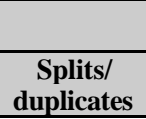 } & \multirow[b]{2}{*}{ Comments and notes } \\
\hline & & & & Northing & Easting & & VOC & RAD & VOC & SVOC & PCB & Metals & RAD & & \\
\hline 3 & $11 / 3 / 93$ & Z2-37 & SB087 & 585948 & 2445763 & Borehole 7 samples to $18 \mathrm{ft}$ & & & 7 & 3 & 3 & 3 & 3 & & Includes 4 field GC samples \\
\hline 3 & $11 / 4 / 93$ & Z2-37 & SB088 & 585946 & 2445844 & Borehole 5 samples to $15 \mathrm{ft}$ & & & 5 & 2 & 2 & 2 & 2 & & Includes 3 field GC samples \\
\hline 3 & $11 / 5 / 93$ & Z2-37 & SB089 & 585819 & 2445977 & Borehole 4 samples to $6 \mathrm{ft}$ & & & 4 & 2 & 2 & 2 & 2 & & Includes 2 field GC samples \\
\hline 3 & $11 / 8 / 93$ & Z2-37 & SB090 & 585992 & 2445810 & Borehole 5 samples to $15 \mathrm{ft}$ & & & 5 & 2 & 2 & 2 & 2 & & Includes 3 field GC samples \\
\hline 3 & $11 / 9 / 93$ & Z2-37 & SB091 & 585649 & 2445940 & Borehole 7 samples to $23 \mathrm{ft}$ & & & 7 & 2 & 2 & 2 & 2 & & Includes 5 field GC samples \\
\hline 3 & $11 / 11 / 93$ & Z2-37 & SB092 & 586057 & 2445679 & Borehole s2 samples to $5 \mathrm{ft}$ & & & 2 & 1 & 1 & 1 & 1 & & Includes 1 field GC sample \\
\hline 3 & $11 / 11 / 93$ & Z2-37 & SB093 & 586348 & 2445650 & Borehole 2 samples to $5 \mathrm{ft}$ & & & 2 & 1 & 1 & 1 & 1 & & Includes 1 field GC sample \\
\hline 3 & $11 / 11 / 93$ & Z2-37 & SB099 & 586440 & 2445661 & Borehole 2 samples to $5 \mathrm{ft}$ & & & 2 & 1 & 1 & 1 & 1 & & Includes 1 field GC sample \\
\hline 3 & $11 / 22 / 93$ & Z2-37 & SB103 & 586429 & 2445588 & Borehole 5 samples to $15 \mathrm{ft}$ & & & 5 & 2 & 2 & 2 & 2 & & Includes 5 field GC samples \\
\hline 3 & $12 / 1 / 93$ & Z2-37 & SB109 & 586119 & 2445675 & Borehole 10 samples to $35 \mathrm{ft}$ & & & 10 & 3 & 3 & 3 & 3 & & Includes 9 field GC samples \\
\hline 3 & 12/2/93 & Z2-37 & SB110 & 586204 & 2445669 & Borehole 4 samples to $8 \mathrm{ft}$ & & & 4 & 2 & 2 & 2 & 2 & & Includes 4 field GC samples \\
\hline \multirow[t]{2}{*}{3} & 12/2/93 & Z2-37 & SB111 & 586204 & 2445669 & Borehole 2 samples to $5 \mathrm{ft}$ & & & 2 & 1 & 1 & 1 & 1 & & Includes 2 field GC sample \\
\hline & & & & & & Historical sampling total & & & 133 & 74 & 53 & 53 & 59 & 26 & \\
\hline
\end{tabular}

$\mathrm{D}=$ duplicate
$\mathrm{D}$

$\mathrm{PCB}=$ polychlorinated bipheny 1
$\mathrm{RAD}=$ radidorian

DVS = Dynamic Verification Strategy
D

$\mathrm{EU}=$ exposure unit
$\mathrm{GC}=$ gas chromatogr

$\begin{array}{ll}\mathrm{GC}=\text { gas chromatograph } & \mathrm{SVOC}=\text { semivolatile organic compound } \\ \mathrm{GRO}=\text { gasoline range organic } & \text { VOC }=\text { volatile organic compound }\end{array}$

$\mathrm{S}=$ split
$\mathrm{SU}=$ soil 
Table H.3. EU Z2-37, depth 0-10 ft

\begin{tabular}{|c|c|c|c|c|c|c|c|c|c|c|c|c|c|}
\hline $\begin{array}{r}\text { Analyte } \\
\end{array}$ & $\begin{array}{c}\text { Frequency } \\
\text { of detect }\end{array}$ & $\begin{array}{c}\text { Minimum } \\
\text { detect }\end{array}$ & $\begin{array}{c}\text { Maximum } \\
\text { detect }\end{array}$ & $\begin{array}{c}\text { Location(s) } \\
\text { of maximum } \\
\text { detected result }\end{array}$ & $\begin{array}{c}\text { Average } \\
\text { detected result }\end{array}$ & $\begin{array}{c}\text { Maximum } \\
\text { RL }\end{array}$ & $\begin{array}{c}\text { Frequency } \\
\text { of detects } \\
\text { exceeding } \\
\text { maximum RL }\end{array}$ & $\begin{array}{c}\text { Average } \\
\text { RL }\end{array}$ & $\begin{array}{r}\text { Frequency } \\
\text { of detects } \\
\text { exceeding } \\
\text { a verage RL } \\
\end{array}$ & $\begin{array}{l}\text { PRG limit } \\
\left(10^{-5} \text { or } 1\right)\end{array}$ & $\begin{array}{c}\text { Frequency } \\
\text { of detects } \\
\text { exceeding } \\
\text { PRG limit }\end{array}$ & $\begin{array}{c}\text { Background } \\
\text { concentration }\end{array}$ & $\begin{array}{c}\text { Frequency } \\
\text { of detects } \\
\text { exceeding } \\
\text { background }\end{array}$ \\
\hline \multicolumn{14}{|l|}{ Inorganics (mg/kg) } \\
\hline Aluminum & $23 / 23$ & 2,400 & 20,400 & SB080 & 12,938 & & NA & & NA & $1.00 \mathrm{E}+05$ & $0 / 23$ & 40,300 & $0 / 23$ \\
\hline Antimony & $9 / 11$ & $0.096 \mathrm{~J}$ & $1.4 \mathrm{~J}$ & Z2-EU37B-302 & 0.415 & & NA & & NA & $4.10 \mathrm{E}+02$ & $0 / 11$ & 1.52 & $0 / 11$ \\
\hline Arsenic & $23 / 23$ & $1.4 \mathrm{~J}$ & 18 & Z2-EU37B-305 & 7.06 & 900 & $0 / 23$ & 300 & $0 / 23$ & $1.60 \mathrm{E}+01$ & $1 / 23$ & 14.95 & $2 / 23$ \\
\hline Barium & $23 / 23$ & 43 & 1420 & SB089 & 185 & & NA & & NA & $6.70 \mathrm{E}+04$ & $0 / 23$ & 124.93 & $8 / 23$ \\
\hline Beryllium & $23 / 23$ & 0.23 & 6.3 & BH012 & 1.03 & 6,000 & $0 / 23$ & 2,000 & $0 / 23$ & $1.90 \mathrm{E}+03$ & $0 / 23$ & 2.2 & $1 / 23$ \\
\hline Boron & $3 / 6$ & $2.2 \mathrm{~J}$ & 8.5 & Z2-EU37B-301 & 5.13 & & NA & & NA & $1.00 \mathrm{E}+05$ & $0 / 6$ & & NA \\
\hline Cadmium & $10 / 23$ & $0.12 \mathrm{~J}$ & $0.56 \mathrm{~J}$ & Z2-EU37B-304 & 0.29 & & NA & & NA & $4.50 \mathrm{E}+02$ & $0 / 23$ & $0.22 \mathrm{U}$ & $7 / 23$ \\
\hline Calcium & $23 / 23$ & 177 & 240,000 & Z2-EU37B-305 & 31,814 & & NA & & NA & & NA & 2,400 & $12 / 23$ \\
\hline Chromium & $23 / 23$ & 10 & 38 & Z2-EU37B-301 & 20.9 & & NA & & NA & $6.40 \mathrm{E}+02$ & $0 / 23$ & 44.88 & $0 / 23$ \\
\hline Cobalt & $23 / 23$ & 3.9 & 52.7 & SB080 & 18.7 & & NA & & NA & $1.30 \mathrm{E}+04$ & $0 / 23$ & 42 & $1 / 23$ \\
\hline Copper & $22 / 23$ & 8.2 & 80.7 & SB088 & 29.3 & & NA & & NA & $4.10 \mathrm{E}+04$ & $0 / 23$ & 22.48 & $11 / 23$ \\
\hline Cyanide & $0 / 15$ & ND & $\mathrm{ND}$ & & $\mathrm{ND}$ & & NA & & NA & $1.20 \mathrm{E}+04$ & $0 / 15$ & $0.6 \mathrm{U}$ & $0 / 15$ \\
\hline Iron & $23 / 23$ & 13,300 & 50,000 & Z2-EU37B-306 & 28,365 & & NA & & NA & $1.00 \mathrm{E}+05$ & $0 / 23$ & 58,600 & $0 / 23$ \\
\hline Lead & $23 / 23$ & 13.9 & 52 & Z2-EU37B-304 & 26.4 & & NA & & NA & $8.00 \mathrm{E}+02$ & $0 / 23$ & 37.91 & $5 / 23$ \\
\hline Lithium & $6 / 6$ & 9.9 & 45 & Z2-EU37B-301 & 19.7 & & NA & & NA & $2.00 \mathrm{E}+04$ & $0 / 6$ & 48.94 & $0 / 6$ \\
\hline Magnesium & $23 / 23$ & 470 & 41,000 & Z2-EU37B-302 & 7,207 & & NA & & NA & & NA & 3,300 & $10 / 23$ \\
\hline Manganese & $23 / 23$ & 142 & 20,600 & SB089 & 3,196 & & NA & & NA & $1.90 \mathrm{E}+04$ & $1 / 23$ & 2,200 & $4 / 23$ \\
\hline Mercury & $16 / 23$ & $0.023 \mathrm{~J}$ & 0.25 & Z2-EU37B-304 & 0.101 & 1,800 & $0 / 23$ & 600 & $0 / 23$ & $3.10 \mathrm{E}+02$ & $0 / 23$ & 0.17 & $1 / 23$ \\
\hline Molybdenum & $7 / 23$ & 0.55 & $7.9 \mathrm{~J}$ & SB092 & 5.32 & & NA & & NA & $5.10 \mathrm{E}+03$ & $0 / 23$ & & $\mathrm{NA}$ \\
\hline Nickel & $23 / 23$ & $6.8 \mathrm{~J}$ & 100 & Z2-EU37B-301 & 33.5 & & NA & & NA & $2.00 \mathrm{E}+04$ & $0 / 23$ & 26.07 & $11 / 23$ \\
\hline Potassium & $23 / 23$ & 639 & 3270 & SB099 & 1528 & & $\mathrm{NA}$ & & NA & & NA & 5074.69 & $0 / 23$ \\
\hline Selenium & $7 / 16$ & $0.35 \mathrm{~J}$ & $2.4 \mathrm{~J}$ & SB082 & 1.48 & & NA & & NA & $5.10 \mathrm{E}+03$ & $0 / 16$ & 1.47 & $3 / 16$ \\
\hline Silver & $16 / 23$ & 1.1 & $3.3 \mathrm{~J}$ & SB089 & 2.04 & & NA & & NA & $5.10 \mathrm{E}+03$ & $0 / 23$ & $0.6 \mathrm{U}$ & $16 / 23$ \\
\hline Sodium & $16 / 23$ & 28.3 & 167 & SB093 & 79.1 & & NA & & NA & & NA & 497 & $0 / 23$ \\
\hline Thallium & $12 / 23$ & 0.052 & 0.56 & BH012 & 0.291 & & NA & & NA & $6.70 \mathrm{E}+01$ & $0 / 23$ & $0.4 \mathrm{U}$ & $3 / 23$ \\
\hline Tin & $9 / 17$ & 2.2 & $9 \mathrm{~J}$ & SB080, SB093 & 6.69 & & NA & & NA & $1.00 \mathrm{E}+05$ & $0 / 17$ & & NA \\
\hline Uranium & $6 / 6$ & 0.64 & 2 & Z2-EU37B-304 & 1.28 & & NA & & NA & $2.00 \mathrm{E}+02$ & $0 / 6$ & & $\mathrm{NA}$ \\
\hline Vanadium & $23 / 23$ & 9.4 & 42.6 & SB092 & 26.8 & & NA & & NA & $1.00 \mathrm{E}+03$ & $0 / 23$ & 65.47 & $0 / 23$ \\
\hline Zinc & $23 / 23$ & $20.7 \mathrm{~J}$ & $160 \mathrm{~J}$ & Z2-EU37B-305 & 66.2 & & NA & & NA & $1.00 \mathrm{E}+05$ & $0 / 23$ & 89.7 & $4 / 23$ \\
\hline \multicolumn{14}{|l|}{ Other organics (mg/kg) } \\
\hline Diesel Range Organics & $2 / 14$ & $190 \mathrm{~J}$ & $329 \mathrm{~J}$ & BH004 & 260 & & $\mathrm{NA}$ & & $\mathrm{NA}$ & & NA & & NA \\
\hline Gasoline Range Organics & $2 / 14$ & $7.5 \mathrm{~J}$ & 88.5 & BH004 & 48 & & NA & & NA & & NA & & NA \\
\hline \multicolumn{14}{|c|}{ Organics, pesticides, and PCBs (ug/kg) } \\
\hline $4,4^{\prime}-\mathrm{DDD}$ & $0 / 17$ & $\mathrm{ND}$ & ND & & ND & & NA & & NA & $1.00 \mathrm{E}+05$ & $0 / 17$ & & NA \\
\hline 4,4'-DDE & $0 / 17$ & ND & ND & & ND & & NA & & NA & $7.00 \mathrm{E}+04$ & $0 / 17$ & & NA \\
\hline $4,4^{\prime}-\mathrm{DDT}$ & $0 / 17$ & ND & ND & & ND & & NA & & NA & $7.00 \mathrm{E}+04$ & $0 / 17$ & & NA \\
\hline Aldrin & $0 / 17$ & ND & ND & & $\mathrm{ND}$ & & NA & & NA & $1.00 \mathrm{E}+03$ & $0 / 17$ & & NA \\
\hline Dieldrin & $0 / 17$ & ND & ND & & ND & & NA & & NA & $1.10 \mathrm{E}+03$ & $0 / 17$ & & NA \\
\hline Endosulfan I & $0 / 17$ & ND & ND & & $\mathrm{ND}$ & & NA & & NA & $3.70 \mathrm{E}+06$ & $0 / 17$ & & NA \\
\hline Endosulfan II & $0 / 17$ & ND & ND & & ND & & NA & & NA & $3.70 \mathrm{E}+06$ & $0 / 17$ & & NA \\
\hline Endosulfan sulfate & $0 / 17$ & ND & ND & & ND & & NA & & NA & $3.70 \mathrm{E}+06$ & $0 / 17$ & & NA \\
\hline Endrin & $0 / 17$ & $\mathrm{ND}$ & ND & & ND & & NA & & NA & $1.80 \mathrm{E}+05$ & $0 / 17$ & & NA \\
\hline Endrin aldehyde & $0 / 17$ & ND & ND & & ND & & NA & & NA & $1.80 \mathrm{E}+05$ & $0 / 17$ & & NA \\
\hline Endrin ketone & $0 / 17$ & ND & ND & & ND & & NA & & NA & $1.80 \mathrm{E}+05$ & $0 / 17$ & & NA \\
\hline Heptachlor & $0 / 17$ & ND & ND & & ND & & NA & & NA & $3.80 \mathrm{E}+03$ & $0 / 17$ & & NA \\
\hline Heptachlor epoxide & $0 / 17$ & $\mathrm{ND}$ & ND & & ND & & NA & & NA & $1.90 \mathrm{E}+03$ & $0 / 17$ & & NA \\
\hline Lindane & $0 / 17$ & ND & $\mathrm{ND}$ & & ND & & NA & & NA & $1.70 \mathrm{E}+04$ & $0 / 17$ & & NA \\
\hline Methoxychlor & $2 / 17$ & $2 \mathrm{~J}$ & $28 \mathrm{~J}$ & SB089 & 15 & & NA & & NA & $3.10 \mathrm{E}+06$ & $0 / 17$ & & NA \\
\hline PCB-1016 & $0 / 23$ & ND & $\mathrm{ND}$ & & $\mathrm{ND}$ & 100,000 & $0 / 23$ & 10,000 & $0 / 23$ & $3.70 \mathrm{E}+04$ & $0 / 23$ & & NA \\
\hline PCB-1221 & $0 / 23$ & ND & ND & & ND & 100,000 & $0 / 23$ & 10,000 & $0 / 28$ & $7.40 \mathrm{E}+03$ & $0 / 23$ & & $\mathrm{NA}$ \\
\hline
\end{tabular}


Table H.3. (continued)

\begin{tabular}{|c|c|c|c|c|c|c|c|c|c|c|c|c|c|}
\hline $\begin{array}{r}\text { Analyte } \\
\end{array}$ & $\begin{array}{r}\text { Frequency } \\
\text { of detect }\end{array}$ & $\begin{array}{c}\text { Minimum } \\
\text { detect }\end{array}$ & $\begin{array}{c}\text { Maximum } \\
\text { detect }\end{array}$ & $\begin{array}{c}\text { Location(s) } \\
\text { of maximum } \\
\text { detected result }\end{array}$ & $\begin{array}{c}\text { Average } \\
\text { detected result }\end{array}$ & $\begin{array}{c}\text { Maximum } \\
\text { RL }\end{array}$ & $\begin{array}{c}\text { Frequency } \\
\text { of detects } \\
\text { exceeding } \\
\text { maximum RL }\end{array}$ & $\begin{array}{c}\text { Average } \\
\text { RL }\end{array}$ & $\begin{array}{c}\text { Frequency } \\
\text { of detects } \\
\text { exceeding } \\
\text { average RL } \\
\end{array}$ & $\begin{array}{l}\text { PRG limit } \\
\left(10^{-5} \text { or } 1\right)\end{array}$ & $\begin{array}{l}\text { Frequency } \\
\text { of detects } \\
\text { exceeding } \\
\text { PRG limit }\end{array}$ & $\begin{array}{l}\text { Background } \\
\text { concentration }\end{array}$ & $\begin{array}{c}\text { Frequency } \\
\text { of detects } \\
\text { exceeding } \\
\text { background }\end{array}$ \\
\hline PCB-1232 & $0 / 23$ & $\mathrm{ND}$ & ND & & $\mathrm{ND}$ & 100,000 & $0 / 23$ & 10,000 & $0 / 28$ & $7.40 \mathrm{E}+03$ & $0 / 23$ & & NA \\
\hline PCB-1242 & $0 / 23$ & $\mathrm{ND}$ & ND & & $\mathrm{ND}$ & 100,000 & $0 / 23$ & 10,000 & $0 / 28$ & $7.40 \mathrm{E}+03$ & $0 / 23$ & & NA \\
\hline PCB-1248 & $2 / 23$ & $45 \mathrm{~J}$ & $67 \mathrm{~J}$ & SB079 & 56 & 100,000 & $0 / 23$ & 10,000 & $0 / 28$ & $7.40 \mathrm{E}+03$ & $0 / 23$ & & NA \\
\hline PCB-1254 & $5 / 23$ & 26 & 2,600 & Z2-EU37B-305 & 631 & 100,000 & $0 / 23$ & 10,000 & $0 / 28$ & $7.40 \mathrm{E}+03$ & $0 / 23$ & & NA \\
\hline PCB-1260 & $5 / 23$ & $35 \mathrm{~J}$ & 200 & Z2-EU37B-301 & 88.4 & 100,000 & $0 / 23$ & 10,000 & $0 / 28$ & $7.40 \mathrm{E}+03$ & $0 / 23$ & & NA \\
\hline Polychlorinated biphenyl & $6 / 6$ & 26 & 2,600 & Z2-EU37B-305 & 579 & 100,000 & $0 / 6$ & 10,000 & $0 / 6$ & $7.40 \mathrm{E}+03$ & $0 / 6$ & & NA \\
\hline Toxaphene & $0 / 17$ & $\mathrm{ND}$ & ND & & ND & & NA & & NA & $1.60 \mathrm{E}+04$ & $0 / 17$ & & NA \\
\hline alpha-BHC & $0 / 17$ & $\mathrm{ND}$ & ND & & ND & & NA & & NA & $3.60 \mathrm{E}+03$ & $0 / 17$ & & NA \\
\hline alpha-Chlordane & $0 / 17$ & $\mathrm{ND}$ & ND & & ND & & NA & & NA & $6.50 \mathrm{E}+04$ & $0 / 17$ & & NA \\
\hline beta-BHC & $0 / 17$ & ND & ND & & ND & & NA & & NA & $1.30 \mathrm{E}+04$ & $0 / 17$ & & NA \\
\hline delta-BHC & $0 / 17$ & ND & ND & & ND & & NA & & NA & & NA & & NA \\
\hline gamma-Chlordane & $0 / 17$ & ND & ND & & ND & & NA & & NA & $6.50 \mathrm{E}+04$ & $0 / 17$ & & NA \\
\hline \multicolumn{14}{|l|}{ Radionuclides (pCi/g) } \\
\hline Actinium-228 & $9 / 9$ & 0.94 & 2.19 & Z2-EU37B-306 & 1.36 & & NA & & NA & $1.20 \mathrm{E}+04$ & $0 / 9$ & & NA \\
\hline Alpha activity & $23 / 23$ & 4.19 & 60.96 & SB088 & 23 & & NA & & NA & & NA & & NA \\
\hline Americium 241 & $0 / 2$ & $\mathrm{ND}$ & ND & & $\mathrm{ND}$ & & NA & & NA & $5.70 \mathrm{E}+01$ & $0 / 2$ & & NA \\
\hline Beta activity & $23 / 23$ & 2.69 & 60.96 & SB088 & 26.1 & & $\mathrm{NA}$ & & NA & & $\mathrm{NA}$ & & NA \\
\hline Bismuth-214 & $10 / 10$ & 0.642 & 1.18 & RAD78 & 0.86 & & NA & & NA & $1.30 \mathrm{E}+05$ & $0 / 10$ & & NA \\
\hline Cesium 134 & $4 / 4$ & 0.016 & 0.028 & RAD69 & 0.022 & & NA & & NA & $2.60 \mathrm{E}+00$ & $0 / 4$ & & NA \\
\hline Cesium 137 & $6 / 27$ & 0.223 & 1.01 & ETTP-REL12 & 0.737 & 20 & $0 / 27$ & 2 & $0 / 27$ & $1.10 \mathrm{E}+00$ & $0 / 27$ & & NA \\
\hline Cobalt -57 & $1 / 4$ & 0.019 & 0.019 & $\begin{array}{l}\text { RAD69 } \\
\text { RAd }\end{array}$ & 0.019 & & NA & & NA & $1.40 \mathrm{E}+02$ & $0 / 4$ & & NA \\
\hline \multirow[t]{2}{*}{ Cobalt- 60} & $4 / 25$ & 0.014 & 0.018 & RAD78 & 0.016 & & $\mathrm{NA}$ & & $\mathrm{NA}$ & $6.00 \mathrm{E}-01$ & $0 / 25$ & & NA \\
\hline & $12 / 12$ & 0.34 & 1.81 & $\begin{array}{l}\text { RAD85 } \\
\text { BH012 }\end{array}$ & 1.22 & & NA & & NA & $6.10 \mathrm{E}+04$ & $0 / 12$ & & NA \\
\hline Lead-214 & $10 / 10$ & 0.675 & 1.3 & RAD78 & 0.985 & & NA & & NA & $\begin{array}{l}0.10+04 \\
7.50 \mathrm{E}+05\end{array}$ & $0 / 10$ & & $\begin{array}{l}\text { NA } \\
\text { NA }\end{array}$ \\
\hline Neptunium-237 & $3 / 12$ & 0.03 & 0.12 & RAD78 & 0.063 & 50 & $0 / 12$ & 5 & $0 / 12$ & $2.70 \mathrm{E}+00$ & $0 / 12$ & & NA \\
\hline Plutonium 238 & $3 / 8$ & 0.005 & 0.016 & RAD69 & 0.01 & & $\mathrm{NA}$ & & NA & $1.70 \mathrm{E}+02$ & $0 / 8$ & & NA \\
\hline Plutonium 239 & $2 / 8$ & 0.013 & 0.053 & RAD78 & 0.033 & & NA & & NA & $1.50 \mathrm{E}+02$ & $0 / 8$ & & NA \\
\hline Potassium-40 & $14 / 14$ & 8.65 & 45.7 & ETTP-REL13 & 21.3 & & NA & & NA & $2.70 \mathrm{E}+00$ & $14 / 14$ & 32.12 & $3 / 14$ \\
\hline $\mathrm{Ra} / \mathrm{Th}$ decay series & $14 / 14$ & 0 & 3.25 & RAD85 & 0.804 & 15 & $0 / 14$ & 5 & $0 / 14$ & & NA & & NA \\
\hline Radium-226 & $11 / 12$ & 0.473 & 4.5 & RAD85 & 2.05 & 15 & $\mathrm{NA}^{a}$ & 5 & $\mathrm{NA}^{a}$ & $2.60 \mathrm{E}-01$ & $11 / 12$ & 1.25 & $8 / 12$ \\
\hline Strontium-90 & $13 / 19$ & $0.04 \mathrm{~J}$ & $1.77 \mathrm{~J}$ & BH012 & 0.566 & & NA & & NA & $1.10 \mathrm{E}+02$ & $0 / 19$ & & NA \\
\hline Technetium-99 & $18 / 29$ & $0.23 \mathrm{~J}$ & 3.51 & Z2-EU37B-305 & 1.36 & & NA & & NA & $8.90 \mathrm{E}+03$ & $0 / 29$ & & NA \\
\hline Thallium 208 & $8 / 8$ & 0.259 & 0.56 & BH012 & 0.404 & & $\mathrm{NA}$ & & $\mathrm{NA}$ & $3.70 \mathrm{E}+05$ & $0 / 8$ & & $\mathrm{NA}$ \\
\hline Thorium-228 & $12 / 14$ & 0.892 & $1.97 \mathrm{~J}$ & BH012 & 1.29 & & NA & & NA & $1.70 \mathrm{E}-01$ & $12 / 14^{b}$ & 1.86 & $1 / 14$ \\
\hline Thorium 230 & $12 / 14$ & 0.688 & 1.84 & Z2-EU37B-303 & 1.23 & 15 & $\mathrm{NA}^{a}$ & 5 & $\mathrm{NA}^{a}$ & $2.10 \mathrm{E}+02$ & $0 / 14$ & 1.2 & $6 / 14$ \\
\hline Thorium-232 & $14 / 14$ & 0.433 & 1.97 & ETTP-REL13 & 1.28 & 15 & $\mathrm{NA}^{a}$ & 5 & $\mathrm{NA}^{a}$ & $1.70 \mathrm{E}-01$ & $14 / 14^{b}$ & 1.95 & $1 / 14$ \\
\hline Thorium 234 & $4 / 10$ & 2.81 & 3.27 & RAD78 & 3.06 & & NA & & NA & $3.30 \mathrm{E}+04$ & $0 / 10$ & & NA \\
\hline Uranium-234 & $28 / 28$ & $0.6 \mathrm{~J}$ & 7.94 & ETTP-REL12 & 1.85 & 7,000 & $0 / 28$ & 700 & $0 / 28$ & $3.30 \mathrm{E}+02$ & $0 / 28$ & & NA \\
\hline Uranium-235 & $22 / 28$ & 0.02 & $0.482 \mathrm{~J}$ & ETTP-REL12 & 0.127 & 80 & $0 / 28$ & 8 & $0 / 28$ & $3.90 \mathrm{E}+00$ & $0 / 28$ & & NA \\
\hline Uranium-238 & $28 / 28$ & 0.701 & 4.26 & ETTP-REL12 & 1.47 & 500 & $0 / 28$ & 50 & $0 / 28$ & $1.80 \mathrm{E}+01$ & $0 / 28$ & 1.47 & $8 / 28$ \\
\hline \multicolumn{14}{|c|}{ Semivolatile organics (ug/kg) } \\
\hline 1,2,4-Trichlorobenzene & $0 / 36$ & $\mathrm{ND}$ & ND & & ND & & NA & & NA & $2.20 \mathrm{E}+05$ & $0 / 36$ & & NA \\
\hline 1,2-Dichlorobenzene & $0 / 37$ & ND & $\mathrm{ND}$ & & ND & & NA & & NA & $6.00 \mathrm{E}+05$ & $0 / 37$ & & NA \\
\hline 1,3-Dichlorobenzene & $0 / 37$ & ND & ND & & ND & & NA & & NA & $6.00 \mathrm{E}+05$ & $0 / 37$ & & NA \\
\hline 1,4-Dichlorobenzene & $0 / 36$ & ND & ND & & ND & & NA & & NA & $7.90 \mathrm{E}+04$ & $0 / 36$ & & NA \\
\hline 2,3,4,6-Tetrachlorophenol & $0 / 6$ & $\mathrm{ND}$ & $\mathrm{ND}$ & & $\mathrm{ND}$ & & NA & & NA & $1.80 \mathrm{E}+07$ & $0 / 6$ & & NA \\
\hline 2,4,5-Trichlorophenol & $0 / 34$ & $\mathrm{ND}$ & ND & & ND & & NA & & NA & $6.20 \mathrm{E}+07$ & $0 / 34$ & & NA \\
\hline 2,4,6-Trichlorophenol & $0 / 34$ & ND & $\mathrm{ND}$ & & ND & & NA & & NA & $6.20 \mathrm{E}+04$ & $0 / 34$ & & NA \\
\hline 2,4-Dichlorophenol & $0 / 34$ & $\mathrm{ND}$ & ND & & ND & & NA & & NA & $1.80 \mathrm{E}+06$ & $0 / 34$ & & NA \\
\hline 2,4-Dimethylphenol & $0 / 34$ & $\mathrm{ND}$ & $\mathrm{ND}$ & & $\mathrm{ND}$ & & NA & & NA & $1.20 \mathrm{E}+07$ & $0 / 34$ & & NA \\
\hline 2,4-Dinitrophenol & $0 / 34$ & $\mathrm{ND}$ & ND & & ND & & NA & & NA & $1.20 \mathrm{E}+06$ & $0 / 34$ & & NA \\
\hline 2,4-Dinitrotoluene & $0 / 33$ & ND & ND & & ND & & NA & & NA & $2.50 \mathrm{E}+04$ & $0 / 33$ & & NA \\
\hline
\end{tabular}


Table H.3. (continued)

\begin{tabular}{|c|c|c|c|c|c|c|c|c|c|c|c|c|c|}
\hline Analyte & $\begin{array}{c}\text { Frequency } \\
\text { of detect }\end{array}$ & $\begin{array}{c}\text { Minimum } \\
\text { detect }\end{array}$ & $\begin{array}{c}\text { Maximum } \\
\text { detect }\end{array}$ & $\begin{array}{c}\text { Location(s) } \\
\text { of maximum } \\
\text { detected result }\end{array}$ & $\begin{array}{c}\text { Average } \\
\text { detected result }\end{array}$ & $\begin{array}{c}\text { Maximum } \\
\text { RL }\end{array}$ & $\begin{array}{c}\text { Frequency } \\
\text { of detects } \\
\text { exceeding } \\
\text { maximum RL }\end{array}$ & $\begin{array}{c}\text { Average } \\
\text { RL }\end{array}$ & $\begin{array}{c}\text { Frequency } \\
\text { of detects } \\
\text { exceeding } \\
\text { average RL } \\
\end{array}$ & $\begin{array}{l}\text { PRG limit } \\
\left(10^{-5} \text { or } 1\right)\end{array}$ & $\begin{array}{l}\text { Frequency } \\
\text { of detects } \\
\text { exceeding } \\
\text { PRG limit }\end{array}$ & $\begin{array}{c}\text { Background } \\
\text { concentration }\end{array}$ & $\begin{array}{c}\text { Frequency } \\
\text { of detects } \\
\text { exceeding } \\
\text { background }\end{array}$ \\
\hline 2,6-Dinitrotoluene & $0 / 34$ & ND & ND & & $\mathrm{ND}$ & & NA & & NA & $2.50 \mathrm{E}+04$ & $0 / 34$ & & NA \\
\hline 2-Chloronaphthalene & $0 / 34$ & ND & $\mathrm{ND}$ & & ND & & NA & & NA & $2.30 \mathrm{E}+07$ & $0 / 34$ & & NA \\
\hline 2-Chlorophenol & $0 / 34$ & ND & ND & & ND & & NA & & NA & $2.40 \mathrm{E}+05$ & $0 / 34$ & & NA \\
\hline 2-Methyl-4,6-dinitrophenol & $0 / 34$ & $\mathrm{ND}$ & $\mathrm{ND}$ & & $\mathrm{ND}$ & & NA & & NA & $6.20 \mathrm{E}+04$ & $0 / 34$ & & NA \\
\hline 2-Methylnaphthalene & $4 / 34$ & $120 \mathrm{~J}$ & 2,200 & SB088 & 680 & & NA & & NA & $1.90 \mathrm{E}+05$ & $0 / 34$ & & NA \\
\hline 2-Methylphenol & $0 / 34$ & ND & ND & & ND & & NA & & NA & $3.10 \mathrm{E}+07$ & $0 / 34$ & & NA \\
\hline 2-Nitrobenzenamine & $0 / 34$ & ND & ND & & ND & & NA & & NA & $1.80 \mathrm{E}+06$ & $0 / 34$ & & NA \\
\hline 2-Nitrophenol & $0 / 34$ & ND & $\mathrm{ND}$ & & ND & & NA & & NA & & NA & & NA \\
\hline 3,3'-Dichlorobenzidine & $0 / 34$ & ND & ND & & ND & & NA & & NA & $3.80 \mathrm{E}+04$ & $0 / 34$ & & NA \\
\hline 3-Methylphenol & $0 / 6$ & ND & ND & & ND & & NA & & NA & $3.10 \mathrm{E}+07$ & $0 / 6$ & & NA \\
\hline 3-Nitrobenzenamine & $0 / 34$ & ND & ND & & ND & & NA & & NA & $1.80 \mathrm{E}+05$ & $0 / 34$ & & NA \\
\hline 4-Bromophenyl phenyl ether & $0 / 34$ & ND & ND & & ND & & NA & & NA & & NA & & NA \\
\hline 4-Chloro-3-methylphenol & $0 / 34$ & ND & ND & & ND & & NA & & NA & & NA & & NA \\
\hline 4-Chlorobenzenamine & $0 / 34$ & ND & $\mathrm{ND}$ & & ND & & NA & & NA & $2.50 \mathrm{E}+06$ & $0 / 34$ & & NA \\
\hline 4-Chlorophenyl phenyl ether & $0 / 34$ & ND & ND & & ND & & NA & & NA & & NA & & NA \\
\hline 4-Methylphenol & $0 / 28$ & ND & ND & & ND & & NA & & NA & $3.10 \mathrm{E}+06$ & $0 / 28$ & & NA \\
\hline 4-Nitrobenzenamine & $0 / 34$ & ND & ND & & ND & & NA & & NA & $8.20 \mathrm{E}+05$ & $0 / 34$ & & NA \\
\hline 4-Nitrophenol & $0 / 34$ & ND & ND & & $\mathrm{ND}$ & & NA & & NA & & NA & & NA \\
\hline Acenaphthene & $5 / 33$ & $43 \mathrm{~J}$ & $280 \mathrm{~J}$ & Z2-EU37B-306 & 157 & & NA & & NA & $2.90 \mathrm{E}+07$ & $0 / 33$ & & NA \\
\hline Acenaphthylene & $1 / 34$ & $99 \mathrm{~J}$ & $99 \mathrm{~J}$ & BH007 & 99 & & NA & & NA & $2.90 \mathrm{E}+07$ & $0 / 34$ & & NA \\
\hline Aniline & $0 / 6$ & ND & ND & & ND & & NA & & NA & $3.00 \mathrm{E}+06$ & $0 / 6$ & & NA \\
\hline Anthracene & $5 / 34$ & $96 \mathrm{~J}$ & 1,400 & Z2-EU37B-306 & 451 & & NA & & NA & $1.00 \mathrm{E}+08$ & $0 / 34$ & & NA \\
\hline Benz(a)anthracene & $10 / 35$ & $54 \mathrm{~J}$ & 5,400 & Z2-EU37B-306 & 1,059 & & NA & & NA & $2.10 \mathrm{E}+04$ & $0 / 35$ & & NA \\
\hline Benzenemethanol & $0 / 6$ & $\mathrm{ND}$ & ND & & ND & & NA & & NA & $1.00 \mathrm{E}+08$ & $0 / 6$ & & NA \\
\hline Benzo(a)pyrene & $10 / 35$ & $93 \mathrm{~J}$ & 4,900 & Z2-EU37B-306 & 1,038 & & NA & & NA & $2.10 \mathrm{E}+03$ & $2 / 35$ & & NA \\
\hline Benzo(b)fluoranthene & $10 / 35$ & $86 \mathrm{~J}$ & 6,600 & Z2-EU37B-306 & 1,530 & & NA & & NA & $2.10 \mathrm{E}+04$ & $0 / 35$ & & NA \\
\hline Benzo(ghi)perylene & $10 / 35$ & $61 \mathrm{~J}$ & 1,800 & Z2-EU37B-306 & 488 & & NA & & NA & $2.90 \mathrm{E}+07$ & $0 / 35$ & & NA \\
\hline Benzo(k)fluoranthene & $10 / 35$ & $96 \mathrm{~J}$ & 2,800 & Z2-EU37B-306 & 669 & & $\mathrm{NA}$ & & NA & $2.10 \mathrm{E}+05$ & $0 / 35$ & & NA \\
\hline Benzoic acid & $0 / 6$ & ND & ND & & $\mathrm{ND}$ & & NA & & NA & $1.00 \mathrm{E}+08$ & $0 / 6$ & & NA \\
\hline Bis(2-chloroethoxy)methane & $0 / 34$ & ND & ND & & ND & & NA & & NA & & NA & & NA \\
\hline Bis(2-chloroethyl) ether & $0 / 34$ & ND & ND & & ND & & NA & & NA & $5.80 \mathrm{E}+03$ & $0 / 34$ & & NA \\
\hline $\operatorname{Bis}(2$-chloroisopropyl) ether & $0 / 34$ & ND & ND & & $\mathrm{ND}$ & & NA & & NA & $7.40 \mathrm{E}+04$ & $0 / 34$ & & NA \\
\hline Bis(2-ethylhexyl)phthalate & $8 / 35$ & $45 \mathrm{~J}$ & 4,400 & Z2-EU37B-305 & 623 & & NA & & NA & $1.20 \mathrm{E}+06$ & $0 / 35$ & & NA \\
\hline Butyl benzyl phthalate & $1 / 34$ & $170 \mathrm{~J}$ & $170 \mathrm{~J}$ & Z2-EU37B-305 & 170 & & NA & & NA & $1.00 \mathrm{E}+08$ & $0 / 34$ & & NA \\
\hline Carbazole & $3 / 34$ & $59 \mathrm{~J}$ & 660 & Z2-EU37B-306 & 456 & & NA & & NA & $8.60 \mathrm{E}+05$ & $0 / 34$ & & NA \\
\hline Chrysene & $10 / 35$ & $67 \mathrm{~J}$ & 4,900 & Z2-EU37B-306 & 1,049 & & NA & & NA & $2.10 \mathrm{E}+06$ & $0 / 35$ & & NA \\
\hline Di-n-butyl phthalate & $2 / 35$ & $240 \mathrm{~J}$ & 2,500 & BH004 & 1,370 & & NA & & $\mathrm{NA}$ & $6.20 \mathrm{E}+07$ & $0 / 35$ & & NA \\
\hline Di-n-octylphthalate & $0 / 34$ & ND & ND & & $\mathrm{ND}$ & & NA & & NA & $2.50 \mathrm{E}+07$ & $0 / 34$ & & NA \\
\hline Dibenz(a,h)anthracene & $5 / 34$ & $89 \mathrm{~J}$ & 530 & Z2-EU37B-306 & 248 & & NA & & NA & $2.10 \mathrm{E}+03$ & $0 / 34$ & & NA \\
\hline Dibenzofuran & $3 / 34$ & $60 \mathrm{~J}$ & $100 \mathrm{~J}$ & Z2-EU37B-306 & 77.3 & & NA & & NA & $1.60 \mathrm{E}+06$ & $0 / 34$ & & NA \\
\hline Diethyl phthalate & $0 / 34$ & ND & ND & & ND & & NA & & NA & $1.00 \mathrm{E}+08$ & $0 / 34$ & & NA \\
\hline Dimethyl phthalate & $3 / 34$ & $52 \mathrm{~J}$ & $400 \mathrm{~J}$ & BH004 & 182 & & NA & & NA & $1.00 \mathrm{E}+08$ & $0 / 34$ & & NA \\
\hline Diphenyldiazene & $0 / 6$ & ND & $\mathrm{ND}$ & & ND & & NA & & NA & $1.60 \mathrm{E}+05$ & $0 / 6$ & & NA \\
\hline Fluoranthene & $12 / 35$ & $40 \mathrm{~J}$ & 12,000 & Z2-EU37B-306 & 1,933 & & NA & & NA & $2.20 \mathrm{E}+07$ & $0 / 35$ & & NA \\
\hline Fluorene & $5 / 34$ & $120 \mathrm{~J}$ & $320 \mathrm{~J}$ & $\begin{array}{c}\text { SB088 } \\
\text { Z2-EU37B-306 }\end{array}$ & 212 & & NA & & NA & $2.60 \mathrm{E}+07$ & $0 / 34$ & & NA \\
\hline Hexachlorobenzene & $0 / 34$ & ND & ND & & $\mathrm{ND}$ & & NA & & NA & $1.10 \mathrm{E}+04$ & $0 / 34$ & & NA \\
\hline Hexachlorobutadiene & $0 / 37$ & ND & ND & & ND & & NA & & NA & $1.80 \mathrm{E}+05$ & $0 / 37$ & & NA \\
\hline Hexachlorocyclopentadiene & $0 / 34$ & ND & ND & & ND & & NA & & NA & $3.70 \mathrm{E}+06$ & $0 / 34$ & & NA \\
\hline Hexachloroethane & $0 / 34$ & ND & ND & & ND & & NA & & NA & $6.20 \mathrm{E}+05$ & $0 / 34$ & & NA \\
\hline Indeno(1,2,3-cd)pyrene & $10 / 35$ & $66 \mathrm{~J}$ & 1,800 & Z2-EU37B-306 & 470 & & NA & & NA & $2.10 \mathrm{E}+04$ & $0 / 35$ & & NA \\
\hline Isophorone & $0 / 34$ & ND & ND & & ND & & NA & & NA & $5.10 \mathrm{E}+06$ & $0 / 34$ & & NA \\
\hline N-Nitroso-di-n-propylamine & $0 / 33$ & ND & ND & & ND & & NA & & NA & $2.50 \mathrm{E}+03$ & $0 / 33$ & & NA \\
\hline
\end{tabular}


Table H.3. (continued)

\begin{tabular}{|c|c|c|c|c|c|c|c|c|c|c|c|c|c|}
\hline Analyte & $\begin{array}{c}\text { Frequency } \\
\text { of detect }\end{array}$ & $\begin{array}{c}\text { Minimum } \\
\text { detect }\end{array}$ & $\begin{array}{c}\text { Maximum } \\
\text { detect }\end{array}$ & $\begin{array}{c}\text { Location(s) } \\
\text { of maximum } \\
\text { detected result }\end{array}$ & $\begin{array}{c}\text { Average } \\
\text { detected result }\end{array}$ & $\begin{array}{c}\text { Maximum } \\
\text { RL }\end{array}$ & $\begin{array}{c}\text { Frequency } \\
\text { of detects } \\
\text { exceeding } \\
\text { maximum RL }\end{array}$ & $\begin{array}{c}\text { Average } \\
\text { RL }\end{array}$ & $\begin{array}{c}\text { Frequency } \\
\text { of detects } \\
\text { exceeding } \\
\text { average RL }\end{array}$ & $\begin{array}{l}\text { PRG limit } \\
\left(10^{-5} \text { or } 1\right)\end{array}$ & $\begin{array}{c}\text { Frequency } \\
\text { of detects } \\
\text { exceeding } \\
\text { PRG limit }\end{array}$ & $\begin{array}{l}\text { Background } \\
\text { concentration }\end{array}$ & $\begin{array}{c}\text { Frequency } \\
\text { of detects } \\
\text { exceeding } \\
\text { background }\end{array}$ \\
\hline N-Nitrosodimethylamine & $0 / 6$ & ND & ND & & ND & & NA & & NA & $3.40 \mathrm{E}+02$ & $0 / 6$ & & NA \\
\hline $\mathrm{N}$-Nitrosodiphenylamine & $0 / 34$ & ND & ND & & ND & & NA & & NA & $3.50 \mathrm{E}+06$ & $0 / 34$ & & NA \\
\hline Naphthalene & $5 / 38$ & $50 \mathrm{~J}$ & $330 \mathrm{~J}$ & SB088 & 138 & & NA & & NA & $1.90 \mathrm{E}+05$ & $0 / 38$ & & NA \\
\hline Nitrobenzene & $0 / 34$ & ND & ND & & ND & & NA & & NA & $1.00 \mathrm{E}+05$ & $0 / 34$ & & NA \\
\hline Pentachlorophenol & $0 / 34$ & ND & ND & & ND & & NA & & NA & $9.00 \mathrm{E}+04$ & $0 / 34$ & & NA \\
\hline Phenanthrene & $13 / 35$ & $50 \mathrm{~J}$ & 5,100 & Z2-EU37B-306 & 884 & & NA & & NA & $2.90 \mathrm{E}+07$ & $0 / 35$ & & NA \\
\hline Phenol & $0 / 34$ & $\mathrm{ND}$ & ND & & ND & & NA & & NA & $1.00 \mathrm{E}+08$ & $0 / 34$ & & NA \\
\hline Pyrene & $15 / 34$ & $40 \mathrm{~J}$ & 8,100 & Z2-EU37B-306 & 1,208 & & NA & & NA & $2.90 \mathrm{E}+07$ & $0 / 34$ & & NA \\
\hline Pyridine & $0 / 6$ & ND & $\mathrm{ND}$ & & $\mathrm{ND}$ & & NA & & NA & $6.20 \mathrm{E}+05$ & $0 / 6$ & & NA \\
\hline \multicolumn{14}{|l|}{ Volatile organics (ug/kg) } \\
\hline (1,1-Dimethylethyl)benzene & $0 / 6$ & $\mathrm{ND}$ & $\mathrm{ND}$ & & $\mathrm{ND}$ & & NA & & NA & $3.90 \mathrm{E}+05$ & $0 / 6$ & & $\mathrm{NA}$ \\
\hline (1-Methylpropyl)benzene & $0 / 6$ & $\mathrm{ND}$ & $\mathrm{ND}$ & & $\mathrm{ND}$ & & $\mathrm{NA}$ & & NA & $2.20 \mathrm{E}+05$ & $0 / 6$ & & NA \\
\hline 1,1,1,2-Tetrachloroethane & $0 / 6$ & ND & ND & & ND & & NA & & NA & $7.30 \mathrm{E}+04$ & $0 / 6$ & & NA \\
\hline 1,1,1-Trichloroethane & 3/35 & $2 \mathrm{~J}$ & 8 & SB088 & 5.7 & & NA & & NA & $1.20 \mathrm{E}+06$ & $0 / 35$ & & NA \\
\hline 1,1,2,2-Tetrachloroethane & $0 / 35$ & $\mathrm{ND}$ & ND & & $\mathrm{ND}$ & & NA & & NA & $9.30 \mathrm{E}+03$ & $0 / 35$ & & NA \\
\hline $\begin{array}{l}\text { 1,1,2-Trichloro-1,2,2- } \\
\text { trifluoroethane }\end{array}$ & $4 / 35$ & $4 \mathrm{~J}$ & $940 \mathrm{~J}$ & BH004 & 238 & & NA & & NA & $5.60 \mathrm{E}+06$ & $0 / 35$ & & NA \\
\hline 1,1,2-Trichloroethane & $0 / 35$ & ND & ND & & ND & & NA & & NA & $1.60 \mathrm{E}+04$ & $0 / 35$ & & NA \\
\hline 1,1-Dichloroethane & $7 / 35$ & $1 \mathrm{~J}$ & 18 & SB088 & 4.23 & & NA & & NA & $1.70 \mathrm{E}+06$ & $0 / 35$ & & NA \\
\hline 1,1-Dichloroethene & $2 / 35$ & $1.3 \mathrm{~J}$ & 6 & BH005 & 3.65 & & NA & & NA & $4.10 \mathrm{E}+05$ & $0 / 35$ & & NA \\
\hline 1,1-Dichloropropene & $0 / 6$ & ND & $\mathrm{ND}$ & & $\mathrm{ND}$ & & NA & & NA & & NA & & NA \\
\hline 1,2,3-Trichlorobenzene & $0 / 6$ & ND & ND & & ND & & NA & & NA & & NA & & NA \\
\hline $1,2,3$-Trichloropropane & $0 / 6$ & ND & $\mathrm{ND}$ & & ND & & NA & & NA & $7.60 \mathrm{E}+02$ & $0 / 6$ & & NA \\
\hline $1,2,4$ Trimethylbenzene & $0 / 6$ & $\mathrm{ND}$ & $\mathrm{ND}$ & & $\mathrm{ND}$ & & NA & & NA & $1.70 \mathrm{E}+05$ & $0 / 6$ & & NA \\
\hline 1,2-Dibromo-3-chloropropane & $0 / 6$ & ND & ND & & ND & & NA & & NA & $1.10 \mathrm{E}+04$ & $0 / 6$ & & NA \\
\hline 1,2-Dibromoethane & $0 / 6$ & ND & ND & & ND & & NA & & NA & $6.30 \mathrm{E}+02$ & $0 / 6$ & & NA \\
\hline 1,2-Dichloroethane & $0 / 35$ & $\mathrm{ND}$ & $\mathrm{ND}$ & & ND & & NA & & NA & $6.00 \mathrm{E}+03$ & $0 / 35$ & & NA \\
\hline 1,2-Dichloroethene & $3 / 29$ & $3 \mathrm{~J}$ & 23 & SB089 & 10 & & NA & & NA & $1.50 \mathrm{E}+05$ & $0 / 29$ & & NA \\
\hline 1,2-Dichloropropane & $0 / 35$ & $\mathrm{ND}$ & $\mathrm{ND}$ & & ND & & NA & & NA & $7.40 \mathrm{E}+03$ & $0 / 35$ & & NA \\
\hline 1,2-Dimethylbenzene & $0 / 6$ & ND & ND & & ND & & NA & & NA & $4.20 \mathrm{E}+05$ & $0 / 6$ & & NA \\
\hline 1,3,5-Trimethylbenzene & $0 / 6$ & ND & ND & & ND & & NA & & NA & $7.00 \mathrm{E}+04$ & $0 / 6$ & & NA \\
\hline 1,3-Dichloropropane & $0 / 6$ & $\mathrm{ND}$ & $\mathrm{ND}$ & & ND & & NA & & NA & $3.60 \mathrm{E}+05$ & $0 / 6$ & & NA \\
\hline 1-Chloro-4-methylbenzene & $0 / 6$ & ND & ND & & ND & & NA & & NA & & NA & & NA \\
\hline $\begin{array}{l}\text { 1-Methyl-4-(1-methylethyl) } \\
\text { benzene }\end{array}$ & $0 / 6$ & $\mathrm{ND}$ & $\mathrm{ND}$ & & ND & & NA & & NA & & NA & & NA \\
\hline 1-chlorohexane & $0 / 6$ & ND & ND & & ND & & NA & & NA & & NA & & NA \\
\hline 2,2-Dichloropropane & $0 / 6$ & ND & ND & & ND & & NA & & NA & & NA & & NA \\
\hline 2-Butanone & $2 / 35$ & $25 \mathrm{~J}$ & $52 \mathrm{~J}$ & BH005 & 38.5 & & NA & & NA & $1.00 \mathrm{E}+08$ & $0 / 35$ & & NA \\
\hline 2-Hexanone & $0 / 35$ & ND & ND & & ND & & NA & & NA & & NA & & NA \\
\hline 2-Methoxy -2-methylpropane & $0 / 6$ & ND & ND & & ND & & NA & & NA & $3.60 \mathrm{E}+05$ & $0 / 6$ & & NA \\
\hline 4-Methyl-2-pentanone & $2 / 35$ & $1 \mathrm{~J}$ & $2 \mathrm{~J}$ & BH011 & 1.5 & & NA & & NA & $4.70 \mathrm{E}+07$ & $0 / 35$ & & NA \\
\hline Acetone & $15 / 35$ & $41 \mathrm{~J}$ & 6,600 & BHOO6 & 653 & & NA & & NA & $5.40 \mathrm{E}+07$ & $0 / 35$ & & NA \\
\hline Benzene & $2 / 35$ & $26 \mathrm{~J}$ & 44 & SB088 & 35 & & NA & & NA & $1.40 \mathrm{E}+04$ & $0 / 35$ & & NA \\
\hline Bromobenzene & $0 / 6$ & ND & ND & & ND & & NA & & NA & $9.20 \mathrm{E}+04$ & $0 / 6$ & & NA \\
\hline Bromochloromethane & $0 / 6$ & $\mathrm{ND}$ & ND & & ND & & NA & & NA & & NA & & NA \\
\hline Bromodichloromethane & $0 / 35$ & ND & ND & & $\mathrm{ND}$ & & NA & & NA & $1.80 \mathrm{E}+04$ & $0 / 35$ & & NA \\
\hline Bromoform & $0 / 35$ & ND & ND & & ND & & NA & & NA & $2.20 \mathrm{E}+06$ & $0 / 35$ & & NA \\
\hline Bromomethane & $0 / 35$ & $\mathrm{ND}$ & ND & & ND & & NA & & NA & $1.30 \mathrm{E}+04$ & $0 / 35$ & & NA \\
\hline Butylbenzene & $0 / 6$ & ND & ND & & ND & & NA & & NA & $2.40 \mathrm{E}+05$ & $0 / 6$ & & NA \\
\hline Carbon disulfide & $1 / 35$ & $5 \mathrm{~J}$ & $5 \mathrm{~J}$ & SB088 & 5 & & NA & & NA & $7.20 \mathrm{E}+05$ & $0 / 35$ & & NA \\
\hline Carbon tetrachloride & $0 / 35$ & $\mathrm{ND}$ & $\mathrm{ND}$ & & $\mathrm{ND}$ & & NA & & NA & $5.50 \mathrm{E}+03$ & $0 / 35$ & & NA \\
\hline Chlorobenzene & $0 / 35$ & ND & ND & & ND & & NA & & NA & $5.30 \mathrm{E}+05$ & $0 / 35$ & & NA \\
\hline Chloroethane & $0 / 35$ & ND & ND & & ND & & NA & & NA & $6.50 \mathrm{E}+04$ & $0 / 35$ & & NA \\
\hline
\end{tabular}


Table H.3. (continued)

\begin{tabular}{|c|c|c|c|c|c|c|c|c|c|c|c|c|c|}
\hline Analyte & $\begin{array}{r}\text { Frequency } \\
\text { of detect }\end{array}$ & $\begin{array}{c}\text { Minimum } \\
\text { detect }\end{array}$ & $\begin{array}{c}\text { Maximum } \\
\text { detect }\end{array}$ & $\begin{array}{c}\begin{array}{c}\text { Location(s) } \\
\text { of maximum } \\
\text { detected result }\end{array} \\
\text { 中. }\end{array}$ & $\begin{array}{c}\text { Average } \\
\text { detected result }\end{array}$ & $\begin{array}{c}\text { Maximum } \\
\text { RL }\end{array}$ & $\begin{array}{c}\text { Frequency } \\
\text { of detects } \\
\text { exceeding } \\
\text { maximum RL }\end{array}$ & $\begin{array}{c}\text { Average } \\
\text { RL }\end{array}$ & $\begin{array}{c}\text { Frequency } \\
\text { of detects } \\
\text { exceeding } \\
\text { average RL } \\
\end{array}$ & $\begin{array}{l}\text { PRG limit } \\
\left(10^{-5} \text { or } 1\right)\end{array}$ & $\begin{array}{c}\text { Frequency } \\
\text { of detects } \\
\text { exceeding } \\
\text { PRG limit }\end{array}$ & $\begin{array}{c}\text { Background } \\
\text { concentration }\end{array}$ & $\begin{array}{c}\text { Frequency } \\
\text { of detects } \\
\text { exceeding } \\
\text { background }\end{array}$ \\
\hline Chloroform & $0 / 35$ & $\mathrm{ND}$ & $\mathrm{ND}$ & & $\mathrm{ND}$ & & NA & & NA & $4.70 \mathrm{E}+03$ & $0 / 35$ & & NA \\
\hline Chloromethane & $0 / 35$ & $\mathrm{ND}$ & $\mathrm{ND}$ & & $\mathrm{ND}$ & & NA & & NA & $1.60 \mathrm{E}+05$ & $0 / 35$ & & NA \\
\hline Cumene & $0 / 6$ & ND & ND & & $\mathrm{ND}$ & & NA & & NA & $5.20 \mathrm{E}+05$ & $0 / 6$ & & NA \\
\hline Dibromochloromethane & $0 / 35$ & ND & ND & & ND & & NA & & NA & $2.60 \mathrm{E}+04$ & $0 / 35$ & & NA \\
\hline Dibromomethane & $0 / 6$ & $\mathrm{ND}$ & $\mathrm{ND}$ & & ND & & NA & & NA & $2.30 \mathrm{E}+05$ & $0 / 6$ & & NA \\
\hline Dichlorodifluoromethane & $0 / 6$ & $\mathrm{ND}$ & $\mathrm{ND}$ & & $\mathrm{ND}$ & & NA & & NA & $3.10 \mathrm{E}+05$ & $0 / 6$ & & NA \\
\hline Ethylbenzene & $5 / 35$ & $1 \mathrm{~J}$ & $4,300 \mathrm{~J}$ & SB088 & 1,470 & & NA & & NA & $4.00 \mathrm{E}+05$ & $0 / 35$ & & $\mathrm{NA}$ \\
\hline Iodomethane & $0 / 6$ & ND & ND & & ND & & NA & & NA & & NA & & NA \\
\hline M + P Xylene & $0 / 6$ & ND & ND & & ND & & NA & & NA & $4.20 \mathrm{E}+05$ & $0 / 6$ & & NA \\
\hline Methylene chloride & $13 / 35$ & 13 & 110 & SB087 & 37.6 & & NA & & NA & $2.10 \mathrm{E}+05$ & $0 / 35$ & & NA \\
\hline Propylbenzene & $0 / 6$ & $\mathrm{ND}$ & ND & & ND & & NA & & NA & $2.40 \mathrm{E}+05$ & $0 / 6$ & & NA \\
\hline Styrene & $0 / 35$ & $\mathrm{ND}$ & $\mathrm{ND}$ & & $\mathrm{ND}$ & & NA & & NA & $1.70 \mathrm{E}+06$ & $0 / 35$ & & NA \\
\hline Tetrachloroethene & 9/35 & $2 \mathrm{~J}$ & $14 \mathrm{~J}$ & SB088 & 5.56 & & NA & & NA & $1.30 \mathrm{E}+04$ & $0 / 35$ & & NA \\
\hline Toluene & $3 / 35$ & $19 \mathrm{~J}$ & $200 \mathrm{~J}$ & BH005 & 81.3 & & NA & & NA & $5.20 \mathrm{E}+05$ & $0 / 35$ & & NA \\
\hline Total Xylene & $4 / 29$ & $5 \mathrm{~J}$ & $5,000 \mathrm{~J}$ & SB088 & 1,821 & & NA & & NA & $4.20 \mathrm{E}+05$ & $0 / 29$ & & NA \\
\hline Trichloroethene & $2 / 35$ & $3 \mathrm{~J}$ & $4 \mathrm{~J}$ & SB089 & 3.5 & & NA & & NA & $1.10 \mathrm{E}+03$ & $0 / 35$ & & NA \\
\hline Trichlorofluoromethane & $0 / 6$ & $\mathrm{ND}$ & ND & & $\mathrm{ND}$ & & NA & & NA & $1.30 \mathrm{E}+06$ & $0 / 6$ & & NA \\
\hline Vinyl acetate & $0 / 6$ & ND & ND & & ND & & NA & & NA & $1.40 \mathrm{E}+06$ & $0 / 6$ & & NA \\
\hline Vinyl chloride & $0 / 35$ & ND & ND & & $\mathrm{ND}$ & & $\mathrm{NA}$ & & NA & $7.50 \mathrm{E}+03$ & $0 / 35$ & & $\mathrm{NA}$ \\
\hline cis-1,2-Dichloroethene & $1 / 6$ & $1.5 \mathrm{~J}$ & $1.5 \mathrm{~J}$ & Z2-EU37B-304 & 1.5 & & NA & & NA & $1.50 \mathrm{E}+05$ & $0 / 6$ & & NA \\
\hline cis-1,3-Dichloropropene & $0 / 35$ & ND & $\mathrm{ND}$ & & $\mathrm{ND}$ & & NA & & NA & $1.80 \mathrm{E}+04$ & $0 / 35$ & & $\mathrm{NA}$ \\
\hline $\mathrm{o}$-Chlorotoluene & $0 / 6$ & $\mathrm{ND}$ & $\mathrm{ND}$ & & ND & & NA & & NA & $5.60 \mathrm{E}+05$ & $0 / 6$ & & NA \\
\hline trans-1,2-Dichloroethene & $0 / 6$ & ND & ND & & ND & & NA & & NA & $2.30 \mathrm{E}+05$ & $0 / 6$ & & NA \\
\hline trans-1,3-Dichloropropene & $0 / 35$ & $\mathrm{ND}$ & ND & & ND & & NA & & NA & $1.80 \mathrm{E}+04$ & $0 / 35$ & & NA \\
\hline
\end{tabular}

${ }^{b}$ Evalionucted as part of $\mathrm{Th}-232+\mathrm{D}=\mathrm{Th}-232+\mathrm{Ra}-228+\mathrm{D}+\mathrm{Th}-228+\mathrm{D}$.

Stations in summary included BH002, BH004, BH005, BH006, BH007, BH008, BH011, BH012, BH013, ETTP-REL12, ETTP-REL13, RAD69, RAD78, RAD85, RAD90, SB078, SB079, SB080, SB081, SB082, SB083, SB087, SB088, SB089, SB090, SB091, SB092, SB093, SB099, Z2-EU37B-301, Z2-EU378
302, 22-EU37B-303, Z2-EU7304, ,

$\mathrm{EU}=$ exposure unit
$\mathrm{J}=$ analyte was positively identified and result is approximate concentration of analyte in sample $\mathrm{NA}=$ not applicable

$\mathrm{ND}=$ not detected
$\mathrm{PCB}=$ polychlorinated biphenyl
PRG = preliminary remediation goal

$\mathrm{RL}=$ remediation level
$\mathrm{ROD}=$ record of decision

$=$ analyte was not detected above reported sample quantitation limi 
Table H.4. EU Z2-37, depth below $10 \mathrm{ft}$

\begin{tabular}{|c|c|c|c|c|c|c|c|c|c|c|c|c|c|}
\hline Analyte & $\begin{array}{c}\text { Frequency } \\
\text { of detect }\end{array}$ & $\begin{array}{c}\text { Minimum } \\
\text { detect }\end{array}$ & $\begin{array}{c}\text { Maximum } \\
\text { detect }\end{array}$ & $\begin{array}{c}\text { Location(s) } \\
\text { of maximum } \\
\text { detected result }\end{array}$ & $\begin{array}{c}\text { Average } \\
\text { detected } \\
\text { result }\end{array}$ & $\underset{\text { RL }}{\text { Maximum }}$ & $\begin{array}{c}\text { Frequency } \\
\text { of detects } \\
\text { exceeding } \\
\text { maximum RL }\end{array}$ & $\begin{array}{l}\text { Average } \\
\text { RL }\end{array}$ & $\begin{array}{l}\text { Frequency } \\
\text { of detects } \\
\text { exceeding } \\
\text { average RL }\end{array}$ & $\begin{array}{l}\text { PRG limit } \\
\left(10^{-5} \text { or } 1\right)\end{array}$ & $\begin{array}{l}\text { Frequency } \\
\text { of detects } \\
\text { exceeding } \\
\text { PRG limit }\end{array}$ & $\begin{array}{l}\text { Background } \\
\text { concentration }\end{array}$ & $\begin{array}{l}\text { Frequency } \\
\text { of detects } \\
\text { exceeding } \\
\text { background }\end{array}$ \\
\hline \multicolumn{14}{|l|}{ Inorganics $(\mathrm{mg} / \mathrm{kg})$} \\
\hline Aluminum & $29 / 29$ & 10,400 & 31,000 & SB048 & 17,776 & & NA & & NA & $1.00 \mathrm{E}+05$ & $0 / 29$ & 40,300 & $0 / 29$ \\
\hline Antimony & $6 / 13$ & $0.28 \mathrm{~J}$ & $0.59 \mathrm{~J}$ & SB079 & 0.383 & & NA & & NA & $4.10 \mathrm{E}+02$ & $0 / 13$ & 1.52 & $0 / 13$ \\
\hline Arsenic & $28 / 28$ & $2.5 \mathrm{~J}$ & $28.8 \mathrm{~J}$ & SB078 & 9.33 & 900 & $0 / 28$ & 300 & $0 / 28$ & $1.60 \mathrm{E}+01$ & $2 / 28$ & 14.95 & $2 / 28$ \\
\hline Barium & $29 / 29$ & $36.7 \mathrm{~J}$ & $417 \mathrm{~J}$ & SB083 & 161 & & NA & & NA & $6.70 \mathrm{E}+04$ & $0 / 29$ & 124.93 & $13 / 29$ \\
\hline Beryllium & $28 / 29$ & $0.58 \mathrm{~J}$ & $5.5 \mathrm{~J}$ & SB109 & 2.02 & 6,000 & $0 / 29$ & 2,000 & $0 / 29$ & $1.90 \mathrm{E}+03$ & $0 / 29$ & 2.2 & $7 / 29$ \\
\hline Cadmium & $5 / 29$ & 0.31 & 1.2 & SB109 & 0.632 & & NA & & NA & $4.50 \mathrm{E}+02$ & $0 / 29$ & $0.22 \mathrm{U}$ & $5 / 29$ \\
\hline Calcium & $29 / 29$ & 325 & $45,200 \mathrm{~J}$ & SB091 & 4116 & & NA & & NA & & NA & 2400 & $7 / 29$ \\
\hline Chromium & $29 / 29$ & 11.9 & 39 & SB083 & 22.2 & & NA & & NA & $6.40 \mathrm{E}+02$ & $0 / 29$ & 44.88 & $0 / 29$ \\
\hline Cobalt & $29 / 29$ & $8.5 \mathrm{~J}$ & 178 & SB079 & 37.1 & & NA & & NA & $1.30 \mathrm{E}+04$ & $0 / 29$ & 42 & $6 / 29$ \\
\hline Copper & $27 / 29$ & 9.5 & 114 & SB081 & 34.8 & & NA & & NA & $4.10 \mathrm{E}+04$ & $0 / 29$ & 22.48 & $17 / 9$ \\
\hline Cyanide & $0 / 21$ & ND & $\mathrm{ND}$ & & $\mathrm{ND}$ & & NA & & NA & $1.20 \mathrm{E}+04$ & $0 / 21$ & $0.6 \mathrm{U}$ & $0 / 21$ \\
\hline Iron & $29 / 29$ & 18,700 & 40,400 & ВH003 & 29,759 & & NA & & NA & $1.00 \mathrm{E}+05$ & $0 / 29$ & 58,600 & $0 / 29$ \\
\hline Lead & $29 / 29$ & $5.7 \mathrm{~J}$ & $159 \mathrm{~J}$ & SB048 & 34.2 & & $\mathrm{NA}$ & & $\mathrm{NA}$ & $8.00 \mathrm{E}+02$ & $0 / 29$ & 37.91 & $9 / 29$ \\
\hline Magnesium & $29 / 29$ & 593 & 12,500 & BHOO1 & 2,936 & & NA & & NA & & NA & 3,300 & $8 / 29$ \\
\hline Manganese & $29 / 29$ & $119 \mathrm{~J}$ & $4,100 \mathrm{~J}$ & SB079 & 1,396 & & $\mathrm{NA}$ & & $\mathrm{NA}$ & $1.90 \mathrm{E}+04$ & $0 / 29$ & 2,200 & $7 / 29$ \\
\hline Mercury & $12 / 29$ & 0.05 & 0.47 & SB109 & 0.137 & 1,800 & $0 / 29$ & 600 & $0 / 29$ & $3.10 \mathrm{E}+02$ & $0 / 29$ & 0.17 & $2 / 29$ \\
\hline Molybdenum & $8 / 29$ & 0.7 & $8.7 \mathrm{~J}$ & SB087 & 3.65 & & NA & & NA & $5.10 \mathrm{E}+03$ & $0 / 29$ & & NA \\
\hline Nickel & $29 / 29$ & 10.7 & $84.2 \mathrm{~J}$ & BHO05 & 39.5 & & NA & & NA & $2.00 \mathrm{E}+04$ & $0 / 29$ & 26.07 & $24 / 29$ \\
\hline Potassium & $29 / 29$ & 1,240 & 5,310 & SB083 & 2,136 & & NA & & NA & & NA & $5,074.69$ & $1 / 29$ \\
\hline Selenium & $7 / 20$ & $0.34 \mathrm{~J}$ & $2.2 \mathrm{~J}$ & SB079 & 0.917 & & NA & & NA & $5.10 \mathrm{E}+03$ & $0 / 20$ & 1.47 & $1 / 20$ \\
\hline Silver & $29 / 29$ & 0.69 & 3.3 & SB087 & 1.92 & & NA & & NA & $5.10 \mathrm{E}+03$ & $0 / 29$ & $0.6 \mathrm{U}$ & $29 / 29$ \\
\hline Sodium & $22 / 29$ & 37.5 & 364 & SB047 & 118 & & NA & & NA & & NA & 497 & $0 / 29$ \\
\hline Thallium & $13 / 29$ & 0.18 & 1.6 & SB079 & 0.702 & & NA & & NA & $6.70 \mathrm{E}+01$ & $0 / 29$ & $0.4 \mathrm{U}$ & $10 / 29$ \\
\hline Tin & $21 / 29$ & 2 & $10 \mathrm{~J}$ & SB079 & 5.7 & & NA & & NA & $1.00 \mathrm{E}+05$ & $0 / 29$ & & $\mathrm{NA}$ \\
\hline Vanadium & $29 / 29$ & 14.8 & 43.7 & SB081 & 25.9 & & NA & & NA & $1.00 \mathrm{E}+03$ & $0 / 29$ & 65.47 & $0 / 29$ \\
\hline Zinc & $29 / 29$ & $24.4 \mathrm{~J}$ & 248 & SB048 & 97.5 & & NA & & NA & $1.00 \mathrm{E}+05$ & $0 / 29$ & 89.7 & $16 / 29$ \\
\hline \multicolumn{14}{|l|}{ Other organics (mg/kg) } \\
\hline Diesel Range Organics & $7 / 12$ & $8.9 \mathrm{~J}$ & 530 & BH005 & 151 & & NA & & NA & & NA & & NA \\
\hline Gasoline Range Organics & $8 / 12$ & 2.694 & 610 & BH004 & 185 & & NA & & $\mathrm{NA}$ & & $\mathrm{NA}$ & & NA \\
\hline \multicolumn{14}{|c|}{ Organics, pesticides, and PCBs (ug/kg) } \\
\hline $4,4^{\prime}-$ DDD & $0 / 25$ & $\mathrm{ND}$ & $\mathrm{ND}$ & & $\mathrm{ND}$ & & NA & & NA & $1.00 \mathrm{E}+05$ & $0 / 25$ & & NA \\
\hline $4,4^{\prime}-\mathrm{DDE}$ & $0 / 25$ & ND & ND & & ND & & NA & & NA & $7.00 \mathrm{E}+04$ & $0 / 25$ & & NA \\
\hline $4,4^{\prime}-\mathrm{DDT}$ & $1 / 25$ & $0.4 \mathrm{~J}$ & $0.4 \mathrm{~J}$ & SB082 & 0.4 & & NA & & NA & $7.00 \mathrm{E}+04$ & $0 / 25$ & & NA \\
\hline Aldrin & $0 / 25$ & ND & ND & & $\mathrm{ND}$ & & NA & & NA & $1.00 \mathrm{E}+03$ & $0 / 25$ & & NA \\
\hline Dieldrin & $0 / 25$ & ND & ND & & ND & & NA & & NA & $1.10 \mathrm{E}+03$ & $0 / 25$ & & NA \\
\hline Endosulfan I & $0 / 25$ & ND & ND & & ND & & NA & & NA & $3.70 \mathrm{E}+06$ & $0 / 25$ & & NA \\
\hline Endosulfan II & $0 / 25$ & $\mathrm{ND}$ & $\mathrm{ND}$ & & ND & & NA & & NA & $3.70 \mathrm{E}+06$ & $0 / 25$ & & NA \\
\hline Endosulfan sulfate & $0 / 25$ & $\mathrm{ND}$ & $\mathrm{ND}$ & & $\mathrm{ND}$ & & NA & & NA & $3.70 \mathrm{E}+06$ & $0 / 25$ & & NA \\
\hline Endrin & $0 / 25$ & ND & ND & & ND & & NA & & NA & $1.80 \mathrm{E}+05$ & $0 / 25$ & & NA \\
\hline Endrin aldehyde & $0 / 25$ & $\mathrm{ND}$ & $\mathrm{ND}$ & & $\mathrm{ND}$ & & NA & & $\mathrm{NA}$ & $1.80 \mathrm{E}+05$ & $0 / 25$ & & NA \\
\hline Endrin ketone & $0 / 25$ & ND & ND & & ND & & NA & & NA & $1.80 \mathrm{E}+05$ & $0 / 25$ & & NA \\
\hline Heptachlor & $0 / 25$ & $\mathrm{ND}$ & ND & & $\mathrm{ND}$ & & NA & & NA & $3.80 \mathrm{E}+03$ & $0 / 25$ & & NA \\
\hline Heptachlor epoxide & $0 / 25$ & ND & ND & & ND & & NA & & NA & $1.90 \mathrm{E}+03$ & $0 / 25$ & & NA \\
\hline Lindane & $0 / 25$ & ND & $\mathrm{ND}$ & & $\mathrm{ND}$ & & NA & & NA & $1.70 \mathrm{E}+04$ & $0 / 25$ & & NA \\
\hline Methoxychlor & $3 / 25$ & $1.6 \mathrm{~J}$ & $24 \mathrm{~J}$ & SB081 & 13.9 & & NA & & NA & $3.10 \mathrm{E}+06$ & $0 / 25$ & & NA \\
\hline PCB-1016 & $0 / 29$ & ND & ND & & ND & 100,000 & $0 / 29$ & 10,000 & $0 / 29$ & $3.70 \mathrm{E}+04$ & $0 / 29$ & & NA \\
\hline PCB-1221 & $0 / 29$ & $\mathrm{ND}$ & $\mathrm{ND}$ & & $\mathrm{ND}$ & 100,000 & $0 / 29$ & 10,000 & $0 / 29$ & $7.40 \mathrm{E}+03$ & $0 / 29$ & & NA \\
\hline PCB-1232 & $0 / 29$ & ND & ND & & ND & 100,000 & $0 / 29$ & 10,000 & $0 / 29$ & $7.40 \mathrm{E}+03$ & $0 / 29$ & & NA \\
\hline $\begin{array}{l}\text { PCB-1242 } \\
\text { PCD }\end{array}$ & $0 / 29$ & $\mathrm{ND}$ & $\mathrm{ND}$ & & ND & 100,000 & $0 / 29$ & 10,000 & $0 / 29$ & 7.40E+03 & $0 / 29$ & & NA \\
\hline PCB-1248 & $2 / 29$ & $100 \mathrm{~J}$ & $1,200 \mathrm{~J}$ & SB080 & 650 & 100,000 & $0 / 29$ & 10,000 & $0 / 29$ & 7.40E+03 & $0 / 29$ & & NA \\
\hline
\end{tabular}


Table H.4. (continued)

\begin{tabular}{|c|c|c|c|c|c|c|c|c|c|c|c|c|c|}
\hline Analyte & $\begin{array}{c}\text { Frequency } \\
\text { of detect }\end{array}$ & $\begin{array}{c}\text { Minimum } \\
\text { detect }\end{array}$ & $\begin{array}{c}\text { Maximum } \\
\text { detect }\end{array}$ & $\begin{array}{c}\text { Location(s) } \\
\text { of maximum } \\
\text { detected result }\end{array}$ & $\begin{array}{c}\text { Average } \\
\text { detected } \\
\text { result }\end{array}$ & $\begin{array}{c}\text { Maximum } \\
\text { RL }\end{array}$ & $\begin{array}{c}\text { Frequency } \\
\text { of detects } \\
\text { exceeding } \\
\text { maximum RL }\end{array}$ & $\begin{array}{c}\text { Average } \\
\text { RL }\end{array}$ & $\begin{array}{c}\text { Frequency } \\
\text { of detects } \\
\text { exceeding } \\
\text { average RL } \\
\end{array}$ & $\begin{array}{l}\text { PRG limit } \\
\left(10^{-5} \text { or } 1\right)\end{array}$ & $\begin{array}{l}\text { Frequency } \\
\text { of detects } \\
\text { exceeding } \\
\text { PRG limit } \\
\end{array}$ & $\begin{array}{c}\text { Background } \\
\text { concentration }\end{array}$ & $\begin{array}{c}\text { Frequency } \\
\text { of detects } \\
\text { exceeding } \\
\text { background }\end{array}$ \\
\hline PCB-1254 & $0 / 29$ & ND & ND & & ND & 100,000 & $0 / 29$ & 10,000 & $0 / 29$ & $7.40 \mathrm{E}+03$ & $0 / 29$ & & NA \\
\hline PCB-1260 & $2 / 29$ & $15 \mathrm{~J}$ & $32 \mathrm{~J}$ & SB087 & 23.5 & 100,000 & $0 / 29$ & 10,000 & $0 / 29$ & $7.40 \mathrm{E}+03$ & $0 / 29$ & & NA \\
\hline Toxaphene & $0 / 25$ & $\mathrm{ND}$ & $\mathrm{ND}$ & & ND & & NA & & NA & $1.60 \mathrm{E}+04$ & $0 / 25$ & & NA \\
\hline alpha-BHC & $0 / 25$ & ND & ND & & ND & & NA & & NA & $3.60 \mathrm{E}+03$ & $0 / 25$ & & NA \\
\hline alpha-Chlordane & $0 / 25$ & ND & $\mathrm{ND}$ & & $\mathrm{ND}$ & & NA & & NA & $6.50 \mathrm{E}+04$ & $0 / 25$ & & NA \\
\hline beta-BHC & $0 / 25$ & ND & ND & & ND & & NA & & NA & $1.30 \mathrm{E}+04$ & $0 / 25$ & & NA \\
\hline delta-BHC & $0 / 25$ & ND & ND & & ND & & NA & & NA & & NA & & NA \\
\hline gamma-Chlordane & $0 / 25$ & $\mathrm{ND}$ & $\mathrm{ND}$ & & $\mathrm{ND}$ & & NA & & NA & $6.50 \mathrm{E}+04$ & $0 / 25$ & & NA \\
\hline \multicolumn{14}{|l|}{ Radionuclides (pCi/g) } \\
\hline Actinium-228 & $1 / 1$ & 1.41 & 1.41 & BH006 & 1.41 & & NA & & NA & $1.20 \mathrm{E}+04$ & $0 / 1$ & & NA \\
\hline Alpha activity & $27 / 27$ & 5.22 & 52.92 & SB081 & 24.7 & & NA & & NA & & NA & & NA \\
\hline Americium 241 & $3 / 11$ & $0.06 \mathrm{~J}$ & $0.37 \mathrm{~J}$ & SB049 & 0.26 & & NA & & NA & $5.70 \mathrm{E}+01$ & $0 / 11$ & & NA \\
\hline Beta activity & $29 / 29$ & 2.77 & 65.02 & SB087 & 36.2 & & NA & & NA & & NA & & NA \\
\hline Bismuth-214 & $4 / 4$ & 0.92 & 1.26 & BH011 & 1.07 & & NA & & NA & $1.30 \mathrm{E}+05$ & $0 / 4$ & & NA \\
\hline Cesium-137 & $0 / 21$ & ND & ND & & ND & 20 & $0 / 21$ & 2 & $0 / 21$ & $1.10 \mathrm{E}+00$ & $0 / 21$ & & NA \\
\hline Cobalt-60 & $0 / 21$ & ND & $\mathrm{ND}$ & & ND & & NA & & NA & $6.00 \mathrm{E}-01$ & $0 / 21$ & & NA \\
\hline Lead-212 & $6 / 6$ & 0.22 & 1.88 & BH002 & 1.28 & & NA & & NA & $6.10 \mathrm{E}+04$ & $0 / 6$ & & NA \\
\hline Lead-214 & $4 / 4$ & 0.87 & 1.17 & BH005 & 0.95 & & NA & & NA & $7.50 \mathrm{E}+05$ & $0 / 4$ & & NA \\
\hline Neptunium-237 & $2 / 12$ & $0.02 \mathrm{~J}$ & $0.06 \mathrm{~J}$ & SB049 & 0.04 & 50 & $0 / 12$ & 5 & $0 / 12$ & $2.70 \mathrm{E}+00$ & $0 / 12$ & & NA \\
\hline Plutonium-238 & $3 / 12$ & $0.87 \mathrm{~J}$ & 1.6 & SB047 & 1.34 & & NA & & NA & $1.70 \mathrm{E}+02$ & $0 / 12$ & & NA \\
\hline Plutonium 239 & $1 / 12$ & 0.11 & 0.11 & SB047 & 0.11 & & NA & & NA & $1.50 \mathrm{E}+02$ & $0 / 12$ & & NA \\
\hline Potassium-40 & $8 / 8$ & 24.18 & 39.4 & BHO02 & 29.1 & & NA & & NA & $2.70 \mathrm{E}+00$ & $8 / 8$ & 32.12 & $2 / 8$ \\
\hline $\mathrm{Ra} / \mathrm{Th}$ decay series & $12 / 12$ & 0 & 3.24 & BH005 & 0.53 & 15 & $0 / 12$ & 5 & $0 / 12$ & & NA & & NA \\
\hline Strontium-90 & $16 / 28$ & $0.23 \mathrm{~J}$ & $4.83 \mathrm{~J}$ & BHO01 & 1.55 & & NA & & NA & $1.10 \mathrm{E}+02$ & $0 / 28$ & & NA \\
\hline Technetium-99 & $19 / 29$ & $0.1 \mathrm{~J}$ & $3.03 \mathrm{~J}$ & SB047 & 1.44 & & NA & & NA & $8.90 \mathrm{E}+03$ & $0 / 29$ & & NA \\
\hline Thallium 208 & $3 / 3$ & 0.52 & 0.62 & BHO11 & 0.57 & & NA & & NA & $3.70 \mathrm{E}+05$ & $0 / 3$ & & NA \\
\hline Thorium-228 & $12 / 12$ & 0.97 & $1.97 \mathrm{~J}$ & BHO05 & 1.55 & & NA & & NA & $1.70 \mathrm{E}-01$ & $12 / 12^{a}$ & 1.86 & $1 / 12$ \\
\hline Thorium 230 & $12 / 12$ & $0.73 \mathrm{~J}$ & $4.44 \mathrm{~J}$ & BH005 & 1.6 & 15 & $\mathrm{NA}^{b}$ & 5 & $\mathrm{NA}^{b}$ & $2.10 \mathrm{E}+02$ & $0 / 12$ & 1.2 & $5 / 12$ \\
\hline Thorium-232 & $12 / 12$ & $0.86 \mathrm{~J}$ & $1.63 \mathrm{~J}$ & BHO05 & 1.21 & 15 & $\mathrm{NA}^{b}$ & 5 & $\mathrm{NA}^{b}$ & $1.70 \mathrm{E}-01$ & $12 / 12^{a}$ & 1.95 & $0 / 12$ \\
\hline Uranium-234 & $27 / 28$ & 0.46 & 2.7 & SB079 & 1.21 & 7,000 & $0 / 28$ & 700 & $0 / 28$ & $3.30 \mathrm{E}+02$ & $0 / 28$ & & $\mathrm{NA}$ \\
\hline Uranium-235 & $19 / 28$ & 0.01 & 0.23 & SB079 & 0.07 & 80 & $0 / 28$ & 8 & $0 / 28$ & $3.90 \mathrm{E}+00$ & $0 / 28$ & & $\mathrm{NA}$ \\
\hline Uranium-238 & $28 / 28$ & 0.44 & 2.6 & SB079 & 1.16 & 500 & $0 / 28$ & 50 & $0 / 28$ & $1.80 \mathrm{E}+01$ & $0 / 28$ & 1.47 & $6 / 28$ \\
\hline \multicolumn{14}{|c|}{ Semivolatile organics (ug/kg) } \\
\hline 1,2,4-Trichlorobenzene & $0 / 36$ & $\mathrm{ND}$ & $\mathrm{ND}$ & & $\mathrm{ND}$ & & NA & & NA & $2.20 \mathrm{E}+05$ & $0 / 36$ & & NA \\
\hline 1,2-Dichlorobenzene & $0 / 38$ & ND & ND & & ND & & NA & & NA & $6.00 \mathrm{E}+05$ & $0 / 38$ & & NA \\
\hline 1,3-Dichlorobenzene & $0 / 38$ & ND & ND & & ND & & NA & & NA & $6.00 \mathrm{E}+05$ & $0 / 38$ & & NA \\
\hline 1,4-Dichlorobenzene & $0 / 36$ & $\mathrm{ND}$ & ND & & $\mathrm{ND}$ & & NA & & $\mathrm{NA}$ & $7.90 \mathrm{E}+04$ & $0 / 36$ & & NA \\
\hline 2,4,5-Trichlorophenol & $0 / 33$ & ND & ND & & ND & & NA & & NA & $6.20 \mathrm{E}+07$ & $0 / 33$ & & NA \\
\hline 2,4,6-Trichlorophenol & $0 / 33$ & ND & ND & & ND & & NA & & NA & $6.20 \mathrm{E}+04$ & $0 / 33$ & & NA \\
\hline 2,4-Dichlorophenol & $0 / 33$ & ND & ND & & ND & & NA & & NA & $1.80 \mathrm{E}+06$ & $0 / 33$ & & NA \\
\hline 2,4-Dimethylphenol & $0 / 33$ & ND & ND & & $\mathrm{ND}$ & & NA & & NA & $1.20 \mathrm{E}+07$ & $0 / 33$ & & NA \\
\hline 2,4-Dinitrophenol & $0 / 33$ & $\mathrm{ND}$ & $\mathrm{ND}$ & & $\mathrm{ND}$ & & NA & & $\mathrm{NA}$ & $1.20 \mathrm{E}+06$ & $0 / 33$ & & NA \\
\hline 2,4-Dinitrotoluene & $0 / 31$ & ND & $\mathrm{ND}$ & & $\mathrm{ND}$ & & NA & & NA & $2.50 \mathrm{E}+04$ & $0 / 31$ & & NA \\
\hline 2,6-Dinitrotoluene & $0 / 33$ & ND & ND & & ND & & NA & & $\mathrm{NA}$ & $2.50 \mathrm{E}+04$ & $0 / 33$ & & NA \\
\hline 2-Chloronaphthalene & $0 / 33$ & ND & ND & & ND & & NA & & NA & $2.30 \mathrm{E}+07$ & $0 / 33$ & & NA \\
\hline 2-Chlorophenol & $0 / 33$ & $\mathrm{ND}$ & $\mathrm{ND}$ & & ND & & NA & & NA & $2.40 \mathrm{E}+05$ & $0 / 33$ & & NA \\
\hline 2-Methyl-4,6-dinitrophenol & $0 / 33$ & ND & $\mathrm{ND}$ & & ND & & NA & & NA & $6.20 \mathrm{E}+04$ & $0 / 33$ & & NA \\
\hline 2-Methylnaphthalene & 9/33 & $100 \mathrm{~J}$ & 1,600 & BHO04 & 1019 & & NA & & NA & $1.90 \mathrm{E}+05$ & $0 / 33$ & & NA \\
\hline 2-Methylphenol & $0 / 33$ & $\mathrm{ND}$ & $\mathrm{ND}$ & & ND & & NA & & NA & $3.10 \mathrm{E}+07$ & $0 / 33$ & & NA \\
\hline 2-Nitrobenzenamine & $0 / 33$ & $\mathrm{ND}$ & ND & & ND & & NA & & NA & $1.80 \mathrm{E}+06$ & $0 / 33$ & & NA \\
\hline 2-Nitrophenol & $0 / 33$ & $\mathrm{ND}$ & $\mathrm{ND}$ & & $\mathrm{ND}$ & & $\mathrm{NA}$ & & $\mathrm{NA}$ & & NA & & NA \\
\hline 3,3'-Dichlorobenzidine & $0 / 33$ & ND & ND & & ND & & NA & & NA & $3.80 \mathrm{E}+04$ & $0 / 33$ & & NA \\
\hline 3-Nitrobenzenamine & $0 / 33$ & ND & ND & & $\mathrm{ND}$ & & $\mathrm{NA}$ & & NA & $1.80 \mathrm{E}+05$ & $0 / 33$ & & NA \\
\hline
\end{tabular}


Table H.4. (continued)

\begin{tabular}{|c|c|c|c|c|c|c|c|c|c|c|c|c|c|}
\hline $\begin{array}{c}\text { Analyte } \\
\end{array}$ & $\begin{array}{r}\text { Frequency } \\
\text { of detect }\end{array}$ & $\begin{array}{c}\text { Minimum } \\
\text { detect }\end{array}$ & $\begin{array}{c}\text { Maximum } \\
\text { detect }\end{array}$ & $\begin{array}{c}\text { Location(s) } \\
\text { of maximum } \\
\text { detected result }\end{array}$ & $\begin{array}{c}\text { Average } \\
\text { detected } \\
\text { result }\end{array}$ & $\begin{array}{c}\text { Maximum } \\
\text { RL }\end{array}$ & $\begin{array}{c}\text { Frequency } \\
\text { of detects } \\
\text { exceeding } \\
\text { maximum RL }\end{array}$ & $\begin{array}{c}\text { Average } \\
\text { RL }\end{array}$ & $\begin{array}{c}\text { Frequency } \\
\text { of detects } \\
\text { exceeding } \\
\text { average RL } \\
\end{array}$ & $\begin{array}{l}\text { PRG limit } \\
\left(10^{-5} \text { or } 1\right)\end{array}$ & $\begin{array}{c}\text { Frequency } \\
\text { of detects } \\
\text { exceeding } \\
\text { PRG limit }\end{array}$ & $\begin{array}{c}\text { Background } \\
\text { concentration }\end{array}$ & $\begin{array}{c}\text { Frequency } \\
\text { of detects } \\
\text { exceeding } \\
\text { background }\end{array}$ \\
\hline 4-Bromophenyl phenyl ether & $0 / 33$ & ND & ND & & ND & & NA & & NA & & NA & & NA \\
\hline 4-Chloro-3-methylphenol & $0 / 33$ & ND & ND & & ND & & NA & & NA & & NA & & NA \\
\hline 4-Chlorobenzenamine & $0 / 33$ & ND & ND & & ND & & NA & & NA & $2.50 \mathrm{E}+06$ & $0 / 33$ & & NA \\
\hline 4-Chlorophenyl phenyl ether & $0 / 33$ & $\mathrm{ND}$ & $\mathrm{ND}$ & & ND & & NA & & NA & & NA & & NA \\
\hline 4-Methylphenol & $0 / 33$ & ND & ND & & ND & & NA & & NA & $3.10 \mathrm{E}+06$ & $0 / 33$ & & NA \\
\hline 4-Nitrobenzenamine & $0 / 33$ & ND & ND & & ND & & NA & & NA & $8.20 \mathrm{E}+05$ & $0 / 33$ & & NA \\
\hline 4-Nitrophenol & $0 / 33$ & ND & ND & & ND & & NA & & NA & . & NA & & NA \\
\hline Acenaphthene & $4 / 31$ & $62 \mathrm{~J}$ & $130 \mathrm{~J}$ & BH001 & 91.8 & & NA & & NA & $2.90 \mathrm{E}+07$ & $0 / 31$ & & NA \\
\hline Acenaphthylene & $0 / 33$ & $\mathrm{ND}$ & $\mathrm{ND}$ & & ND & & NA & & NA & $2.90 \mathrm{E}+07$ & $0 / 33$ & & NA \\
\hline Anthracene & $0 / 33$ & ND & ND & & ND & & NA & & NA & $1.00 \mathrm{E}+08$ & $0 / 33$ & & NA \\
\hline Benz(a)anthracene & $0 / 33$ & $\mathrm{ND}$ & ND & & $\mathrm{ND}$ & & NA & & NA & $2.10 \mathrm{E}+04$ & $0 / 33$ & & NA \\
\hline $\begin{array}{l}\text { Benzo(a)pyrene } \\
\text { Baren }\end{array}$ & $0 / 33$ & ND & ND & & ND & & NA & & NA & $2.10 \mathrm{E}+03$ & $0 / 33$ & & NA \\
\hline Benzo(b)fluoranthene & $0 / 33$ & ND & $\mathrm{ND}$ & & ND & & NA & & NA & $2.10 \mathrm{E}+04$ & $0 / 33$ & & NA \\
\hline Benzo(ghi)perylene & $0 / 33$ & ND & ND & & ND & & NA & & NA & $2.90 \mathrm{E}+07$ & $0 / 33$ & & NA \\
\hline Benzo(k)fluoranthene & $0 / 33$ & ND & ND & & ND & & NA & & NA & $2.10 \mathrm{E}+05$ & $0 / 33$ & & NA \\
\hline $\operatorname{Bis}(2$-chloroethoxy)methane & $0 / 33$ & ND & ND & & ND & & NA & & NA & & NA & & NA \\
\hline Bis(2-chloroethyl) ether & $0 / 33$ & ND & ND & & ND & & NA & & NA & $5.80 \mathrm{E}+03$ & $0 / 33$ & & NA \\
\hline Bis(2-chloroisopropyl) ether & $0 / 33$ & ND & ND & & ND & & NA & & NA & $7.40 \mathrm{E}+04$ & $0 / 33$ & & NA \\
\hline Bis(2-ethylhexyl)phthalate & $6 / 33$ & $32 \mathrm{~J}$ & 5,100 & SB080 & 1,053 & & NA & & NA & $1.20 \mathrm{E}+06$ & $0 / 33$ & & NA \\
\hline Butyl benzyl phthalate & $1 / 33$ & $11 \mathrm{~J}$ & $11 \mathrm{~J}$ & BH002 & 11 & & NA & & NA & $1.00 \mathrm{E}+08$ & $0 / 33$ & & NA \\
\hline Carbazole & $1 / 33$ & $46 \mathrm{~J}$ & $46 \mathrm{~J}$ & SB088 & 46 & & NA & & NA & $8.60 \mathrm{E}+05$ & $0 / 33$ & & NA \\
\hline Chrysene & $0 / 33$ & ND & ND & & ND & & NA & & NA & $2.10 \mathrm{E}+06$ & $0 / 33$ & & NA \\
\hline Di-n-butyl phthalate & $0 / 33$ & ND & ND & & $\mathrm{ND}$ & & NA & & NA & $6.20 \mathrm{E}+07$ & $0 / 33$ & & NA \\
\hline Di-n-octylphthalate & $1 / 33$ & $5 \mathrm{~J}$ & $5 \mathrm{~J}$ & BH002 & 5 & & NA & & NA & $2.50 \mathrm{E}+07$ & $0 / 33$ & & NA \\
\hline Dibenz $(\mathrm{a}, \mathrm{h})$ anthracene & $0 / 33$ & $\mathrm{ND}$ & ND & & ND & & NA & & $\mathrm{NA}$ & $2.10 \mathrm{E}+03$ & $0 / 33$ & & NA \\
\hline Dibenzofuran & $0 / 33$ & ND & ND & & ND & & NA & & NA & $1.60 \mathrm{E}+06$ & $0 / 33$ & & NA \\
\hline Diethyl phthalate & $1 / 33$ & $6 \mathrm{~J}$ & $6 \mathrm{~J}$ & BH002 & 6 & & NA & & NA & $1.00 \mathrm{E}+08$ & $0 / 33$ & & NA \\
\hline Dimethyl phthalate & $8 / 33$ & $59 \mathrm{~J}$ & $250 \mathrm{~J}$ & BH004 & 126 & & NA & & NA & $1.00 \mathrm{E}+08$ & $0 / 33$ & & NA \\
\hline Fluoranthene & $0 / 33$ & ND & ND & & ND & & NA & & NA & $2.20 \mathrm{E}+07$ & $0 / 33$ & & NA \\
\hline Fluorene & $2 / 33$ & $190 \mathrm{~J}$ & $250 \mathrm{~J}$ & BH005 & 220 & & NA & & NA & $2.60 \mathrm{E}+07$ & $0 / 33$ & & NA \\
\hline Hexachlorobenzene & $0 / 33$ & ND & ND & Dow & $\mathrm{ND}$ & & NA & & NA & $1.10 \mathrm{E}+04$ & $0 / 33$ & & NA \\
\hline Hexachlorobutadiene & $0 / 38$ & ND & ND & & ND & & NA & & NA & $1.80 \mathrm{E}+05$ & $0 / 38$ & & NA \\
\hline Hexachlorocyclopentadiene & $0 / 33$ & ND & ND & & ND & & NA & & NA & $3.70 \mathrm{E}+06$ & $0 / 33$ & & NA \\
\hline Hexachloroethane & $0 / 33$ & ND & ND & & ND & & NA & & NA & $6.20 \mathrm{E}+05$ & $0 / 33$ & & NA \\
\hline Indeno(1,2,3-cd)pyrene & $0 / 33$ & ND & ND & & ND & & NA & & NA & $2.10 \mathrm{E}+04$ & $0 / 33$ & & NA \\
\hline Isophorone & $0 / 33$ & ND & ND & & ND & & NA & & NA & $5.10 \mathrm{E}+06$ & $0 / 33$ & & NA \\
\hline N-Nitroso-di-n-propylamine & $0 / 31$ & $\mathrm{ND}$ & $\mathrm{ND}$ & & $\mathrm{ND}$ & & NA & & NA & $2.50 \mathrm{E}+03$ & $0 / 31$ & & NA \\
\hline N-Nitrosodiphenylamine & $0 / 33$ & ND & ND & & ND & & NA & & NA & $3.50 \mathrm{E}+06$ & $0 / 33$ & & NA \\
\hline Naphthalene & $8 / 33$ & $40 \mathrm{~J}$ & $320 \mathrm{~J}$ & $\begin{array}{l}\text { BH004 } \\
\text { BH006 }\end{array}$ & 221 & & NA & & NA & $1.90 \mathrm{E}+05$ & $0 / 33$ & & NA \\
\hline Nitrobenzene & $0 / 33$ & ND & ND & & ND & & NA & & NA & $1.00 \mathrm{E}+05$ & $0 / 33$ & & NA \\
\hline Pentachlorophenol & $0 / 33$ & ND & ND & & ND & & NA & & NA & $9.00 \mathrm{E}+04$ & $0 / 33$ & & NA \\
\hline Phenanthrene & $11 / 33$ & $38 \mathrm{~J}$ & 1,100 & BH001 & 452 & & NA & & NA & $2.90 \mathrm{E}+07$ & $0 / 33$ & & NA \\
\hline Phenol & $0 / 33$ & ND & ND & & ND & & NA & & NA & $1.00 \mathrm{E}+08$ & $0 / 33$ & & NA \\
\hline Pyrene & $6 / 31$ & $48 \mathrm{~J}$ & $130 \mathrm{~J}$ & BH001 & 88 & & NA & & NA & $2.90 \mathrm{E}+07$ & $0 / 31$ & & NA \\
\hline \multicolumn{14}{|l|}{ Volatile organics (ug/kg) } \\
\hline 1,1,1-Trichloroethane & $13 / 38$ & $2 \mathrm{~J}$ & 20,000 & K1070CD-DPT-05 & 1587 & & NA & & $\mathrm{NA}$ & $1.20 \mathrm{E}+06$ & $0 / 38$ & & NA \\
\hline 1,1,2,2-Tetrachloroethane & $1 / 38$ & $8 \mathrm{~J}$ & $8 \mathrm{~J}$ & SB080 & 8 & & NA & & NA & $9.30 \mathrm{E}+03$ & $0 / 38$ & & NA \\
\hline $\begin{array}{l}\text { 1,1,2-Trichloro-1,2,2- } \\
\text { trifluoreethane }\end{array}$ & $13 / 33$ & $2 \mathrm{~J}$ & 2,700 & BH001 & 392 & & NA & & NA & $5.60 \mathrm{E}+06$ & $0 / 33$ & & NA \\
\hline 1,1,2-Trichloroethane & $4 / 38$ & $6 \mathrm{~J}$ & 42 & SB080 & 22.3 & & NA & & NA & $1.60 \mathrm{E}+04$ & $0 / 38$ & & NA \\
\hline 1,1-Dichloroethane & $13 / 38$ & $3 \mathrm{~J}$ & 75 & SB079 & 24.5 & & NA & & NA & $1.70 \mathrm{E}+06$ & $0 / 38$ & & NA \\
\hline 1,1-Dichloroethene & $4 / 38$ & 20 & 5,700 & K1070CD-DPT-05 & 1,443 & & NA & & NA & $4.10 \mathrm{E}+05$ & $0 / 38$ & & NA \\
\hline
\end{tabular}




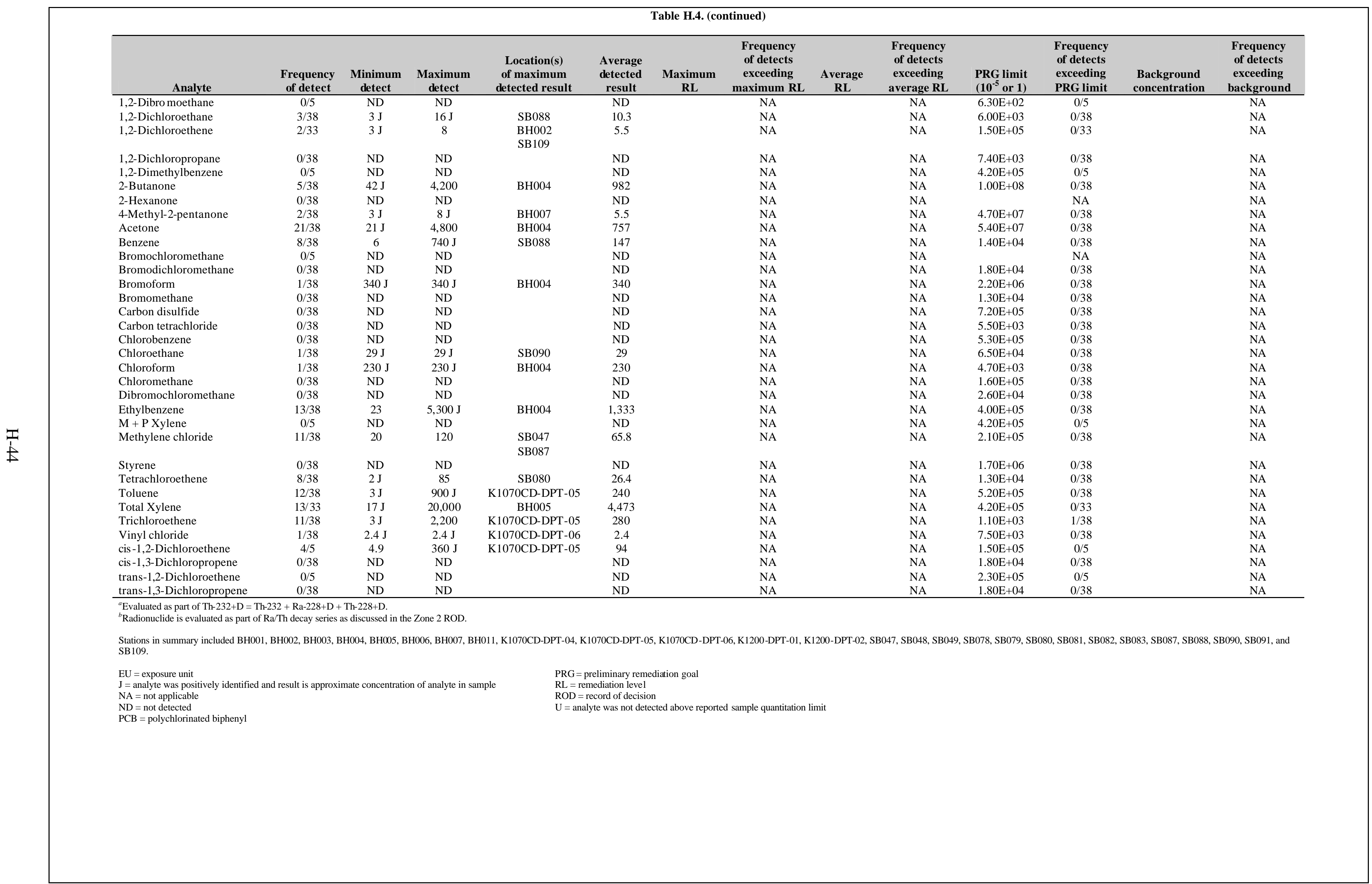




\section{Appendix I}

\section{K-1070-C/D and Downgradient Area}

Exposure Unit Group Z2-41

Technical Memorandum 


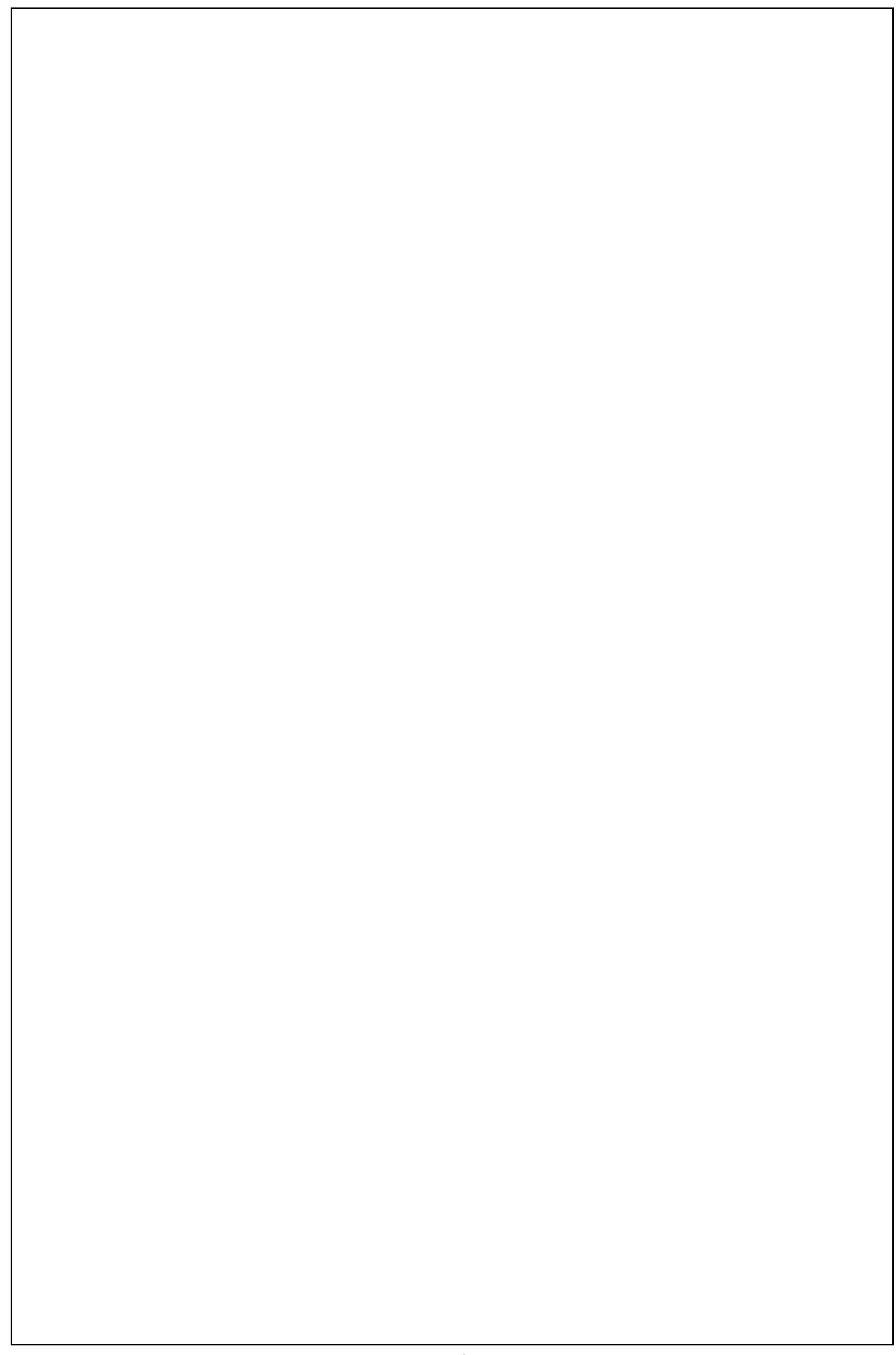




\section{FIGURES}

I.1. EU Z2-41 location map.

I-4544

I.2. EU Z2-41 boundaries with soil units and FFA sites.

I-464645

I.3. EU Z2-41 Class 3 walkover assessment locations. $\mathrm{I}-4846$

I.4. EU Z2-41 sample locations.

$\mathrm{I}-4947$

I.5. EU Z2-41 K-1071 Concrete Pad Class 1 SU sample locations.

I.6. EU Z2-41 K-1070-A pits FFA site.

I.7. EU Z2-41 conceptual site model block diagram.

\section{TABLES}

I.1. EU Z2-41 facilities

I.2. EU Z2-41 sample summary

I.3. EU Z2-41, depth 0-10 ft

I.4. EU Z2-41, depth $>10 \mathrm{ft}$ 


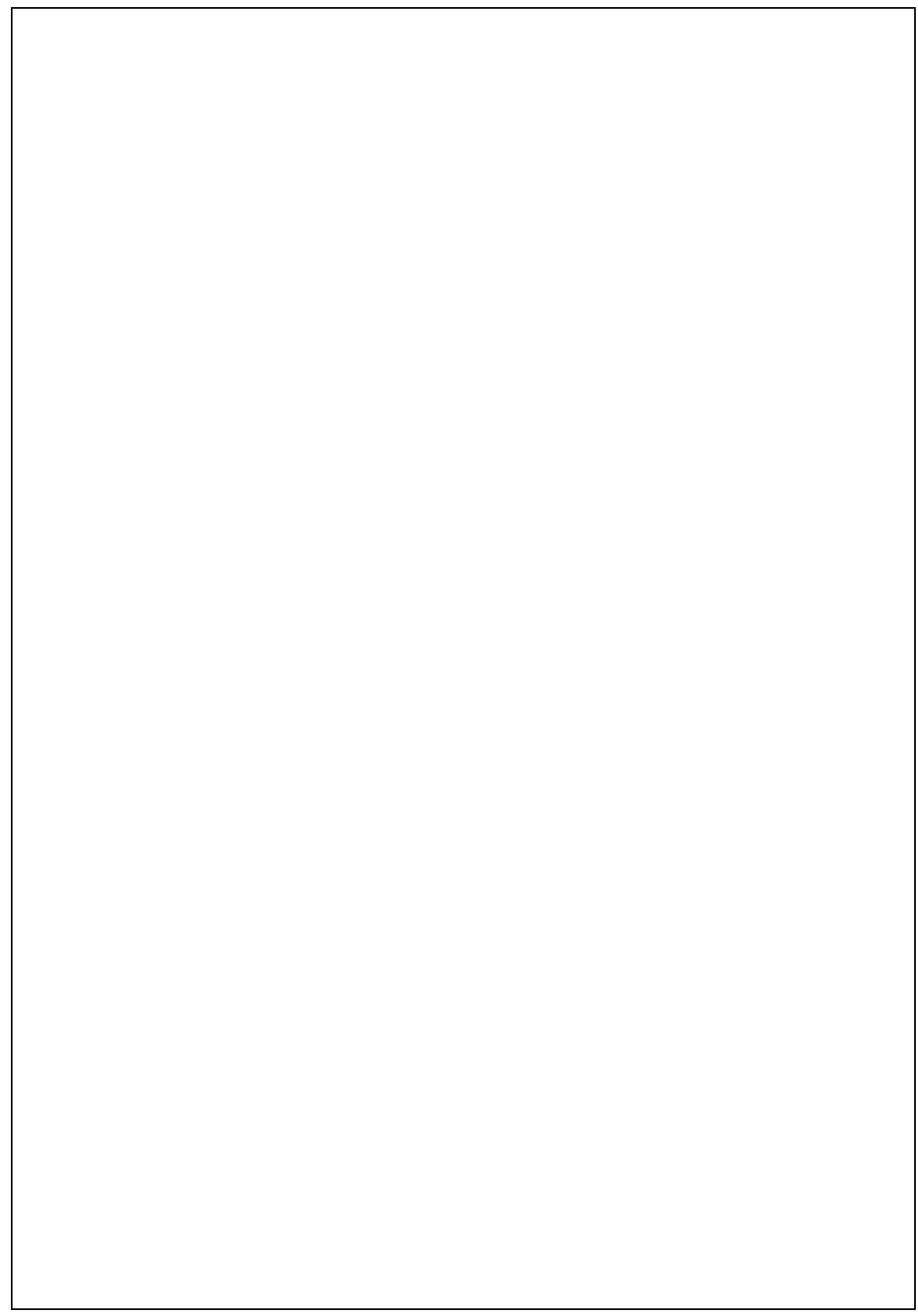




\section{DYNAMIC VERIFICATION STRATEGY (DVS) TECHNICAL MEMORANDUM (TM)}

EXPOSURE UNIT (EU) GROUP: Zone 2 K-1070-C/D and Downgradient Area Group EU Z2-41

\section{INTRODUCTION}

The purpose of this TM is to document the recommendation for an action/no further action (NFA) decision for Zone 2 exposure unit 41 (EU Z2-41) in the K-1070-C/D and Downgradient Area EU Group. The recommendation for this EU is based on existing historical data and DVS soil characterization activities. These data are used to determine the nature and extent of contamination in the EU and evaluate the need for an action. When it is determined that an action is necessary, the data are also used to calculate soil volumes for the proposed remedial alternative as identified in the Record of Decision for Soil, Buried Waste, and Subsurface Structure Actions in Zone 2, East Tennessee Technology Park, Oak Ridge, Tennessee (DOE/OR/01-2161\&D2) (Zone 2 ROD).

\begin{tabular}{|l|l|}
\hline 1.0 & BACKGROUND AND EU SUMMARY \\
\hline 1.1 & LOCATIONAT EAST TENNESSEE TECHNOLOGY PARK (ETTP) \\
\hline
\end{tabular}

EU Z2-41 is located along the eastern boundary of Zone 2 in the K-1070-C/D and Downgradient Area EU Group, and is bounded on the north by EUs Z2-36 and Z2-40, on the east by U.S. Department of Energy (DOE) property, on the south by EU Z2-42, and on the west by EU Z2-37 (Fig. I. 1).

1.2

EU Z2-41 ACREAGE

EU Z2-41 has an area of approximately 38 acres (Fig. I.2).

\begin{tabular}{|l|l}
1.3 & SUMMARY DESCRIPTION \\
\hline
\end{tabular}

All land area in EU Z2-41 has been impacted by site operations. The EU is on a hill at the eastern edge of the industrialized heart of ETTP Zone 2. Historically, the EU was used primarily for burial and disposal of liquid and solid wastes. A drum crusher was located in the K-1071 Concrete Pad Federal Facility Agreement (FFA) site. There are several buildings and other facilities located throughout the EU .

The Data Quality Objective (DQO) scoping package for the K-1070-C/D and Downgradient Area EU Group lists 10 facilities in EU Z2-41. Table I.1 presents an accounting of facilities in the EU.

\begin{tabular}{l|l}
\hline 1.4 & SOIL UNITS (SUS) \\
\hline
\end{tabular}

Class 1 SU: $<0.05$ acres

Class 2 SU: $<0.1$ acres

Class 3 SU: 38 acres (18.9 acres of Class 3 modified, and 19 acres of Class 3)

Class 4 SU: None

\begin{tabular}{|l|l|}
\hline 1.5 & ZONE 2 ROD APPENDIX A FFA SITES \\
\hline
\end{tabular}

There are three FFA sites in EU Z2-41 that are listed in Appendix A of the Zone 2 ROD:

- $\quad$ K-1070-C/D Burial Ground FFA site,

- $\quad$ K-1070 Pits FFA site, and

- $\quad$ K-1071 Concrete Pad FFA site.

FFA sites are consolidated in the Zone 2 ROD but depicted as individual entities in the K-1070-C/D and Downgradient Area Group DQO Scoping Package. For example, the figures show a K-1070-C Burial Ground FFA site and K-1070-D Burial Ground FFA site. These two locations make up the K-1070-C/D Burial Ground FFA site of the Zone 2 ROD. Additionally, the figures in the DQO scoping package show a North K-1070 Pits Area FFA site and South K-1070 Pits Area FFA site. These two locations make up the K-1070 Pits FFA site of the Zone 2 ROD. 


\begin{tabular}{|l|l|}
\hline & \\
\hline 2.0 & DVS INVESTIGATIONS AND RESULTS \\
\hline 2.1 & DVS FIELD ACTIVITIES \\
\hline
\end{tabular}

DVS activities were conducted in accordance with the Remedial Design Report/Remedial Action Work Plan for Zone 2 Soils, Slabs, and Subsurface Structures, East Tennessee Technology Park, Oak Ridge, Tennessee (DOE/OR/01-2224\&D2) (Zone 2 RDR/RAWP).

\section{\begin{tabular}{l|l} 
2.1.1 & CLASS 1 SUS \\
\hline
\end{tabular}}

Two Class 1 SUs were identified in EU Z2-41 during DQO scoping (see DQO scoping package, Fig. 7).

Concrete Pad Class 1 SU: The K-1071 Concrete Pad is located in the K-1071 Concrete Pad FFA site. It is implied in the Zone 2 ROD Sect. 2.95 and Fig. 2.15 that the concrete pad and soils surrounding it will be excavated and removed. The concrete pad and surrounding soil were classified as a Class 1 SU. Historical sample locations within this Class $1 \mathrm{SU}$ (Sect. 2.2.1) include RAD47, where there are U-235 and U-238 maximum (Max) remediation level (RL) exceedances, and early characterization location Z2-EU41DB-218, where there is a U-238 average (Avg) RL exceedance. In addition, the K-1070-C/D Phase 2 Remedial Investigation (RI) reports additional rejected U-235 and U-238 data that exceed average RLs. These rejected historic data clearly indicate elevated concentrations of U-234, $\mathrm{U}-235$ and $\mathrm{U}-238$ in soils around the pad.

Boundaries of the concrete pad are recognizable today by the elevated soil mound that resulted from placement of soil over the pad. The soil was placed there to protect the industrial worker from unnecessary exposure to radiation until the concrete pad is removed.

RAD91 Class 1 SU: This Class 1 SU was defined based on U-235 and U-238 Max RL exceedances at historical sample location RAD91.

\section{\begin{tabular}{l|l} 
2.1.1.1 & CLASS 1 SU RADIOLOGICAL WALKOVER SURVEY
\end{tabular}}

A biased area radiation (BAR) survey was conducted over the RAD91 Class $1 \mathrm{SU}$ to delineate a remedial action boundary. A radiological survey was not conducted over the Concrete Pad Class $1 \mathrm{SU}$ because it is already slated for a remedial action based on radiological contamination. Details of the BAR survey over the RAD91 Class 1 SU are presented in Walkover Inspections and Radiological Surveys for FY2007 Exposure Units in Zones 1 and 2, East Tennessee Technology Park, Oak Ridge, Tennessee (BJC/OR-2691). In summary, the radiation action level was not exceeded at any point during the survey, therefore, a remedial action boundary was not determined and step-out sampling was not conducted.

\section{\begin{tabular}{l|l} 
2.1.1.2 & CLASS 1 SU GEOPHYSICAL SURVEY \\
\hline
\end{tabular}}

None.

\section{\begin{tabular}{|l|l} 
2.1.1.3 & CLASS 1 SU SOIL SAMPLING \\
\hline
\end{tabular}}

DVS biased sampling in the EU Z2-41 Class 1 SUs was conducted as described below.

Concrete Pad Class 1 SU: Four DVS biased sample locations were identified on the concrete pad and a concrete sample was collected at each location for waste acceptance criteria. In addition, one DVS soil sample location was identified to confirm an elevated lead concentration observed at historical location SS007.

RAD91 Class 1 SU: A BAR survey was conducted over the RAD91 Class 1 SU (Sect. 2.1.1.1) and a DVS confirmation sample location was identified at the point of highest radiation. Step-out sampling was not conducted because the action level was not exceeded during the BAR survey.

Details of the actual sampling and analysis in the Class 1 SUs, including sample depths, analytes, and deviations from planned sampling, are presented in Table I.2.

\section{\begin{tabular}{l|l} 
2.1.2 & CLASS 2 SUS \\
\hline
\end{tabular}}

Two Class 2 SUs were identified in EU Z2-41 during DQO scoping (see DQO scoping package, Fig. 7). 
RAD122 Class 2 SU: This SU was defined based on a Cs -137 Avg RL exceedance at historical sample location RAD122.

Z2-EU41DB-208 Class 2 SU: This SU was defined based on U-235 and U-238 Avg RL exceedances at early characterization sample location Z2-EU41DB-208.

\section{\begin{tabular}{l|l} 
2.1.2.1 & CLASS 2 SU RADIOLOGICAL WALKOVER SURVEY
\end{tabular}}

A BAR survey was conducted over the RAD122 Class 2 SU to define the areal extent of the Avg RL exceedance. A BAR survey was not conducted over the Z2-EU41DB-208 Class 2 SU because early characterization step-out sampling demonstrated that the Avg RL exceedances were confined to the original sample location. Details of the BAR survey over the RAD122 Class 2 SU are presented in Walkover Inspections and Radiological Surveys for FY2007 Exposure Units in Zones 1 and 2, East Tennessee Technology Park, Oak Ridge, Tennessee (BJC/OR-2691). It was concluded there was no extent to the Avg RL exceedance, so no step-out sampling was conducted because the radiation action level was not exceeded at any point during the survey.

\section{\begin{tabular}{|l|l|l} 
2.1.2.2 & CLASS 2 SU GEOPHYSICAL SURVEY
\end{tabular}}

None.

\section{\begin{tabular}{|l|l|l|l} 
2.1.2.3 & CLASS 2 SU SOIL S AMPLING \\
\hline
\end{tabular}}

DVS biased sampling was conducted in the EU Z2-41 Class 2 SUs as described below.

RAD122 Class 2 SU: A confirmation sample location was identified at the point of highest radiation. Step-out sampling was not conducted because the action level was not exceeded during the BAR survey.

No DVS sampling was conducted at the Z2-EU41DB-208 Class 2 SU. This SU was addressed by step-out sampling during early characterization. Details of the actual sampling and analysis in the Class 2 SUs, including sample depths, analytes, and deviations from planned sampling, are presented in Table I.2.

\section{\begin{tabular}{l|l} 
2.1.3 & CLASS 3 AND ClASS 4 SU WALKOVER ASSESSMENT
\end{tabular}}

The protocol for addressing Class 3 and Class 4 SUs at ETTP is described in the Class 3 and Class 4 Soil Unit Walkover Inspection Protocol, Rev. 1 (found Attachment C of Appendix A in the Zone 2 RDR/RAWP). Because there are no Class 4 SUs in EU Z2-41, only Class 3 SUs are addressed. The purpose of the Class 3 SU walkover assessments is to systematically inspect Class 3 SUs by visual observation along transects to established grid assessment locations and map-observed features, collect radiological screening data at grid and discretionary locations, and visually inspect and perform radiological screening surveys on the plant facilities. Details of the walkover assessment results for the EU Z2-41 Class $3 \mathrm{SU}$ are presented in the document Walkover Inspections and Radiological Surveys for FY2007 Exposure Units in Zones 1 and 2, East Tennessee Technology Park, Oak Ridge, Tennessee (BJC/OR-2691) (Assessment Report). A summary of the report results is presented below in Sects. 2.1.3.1 and 2.1.3.2. The assessment point (AP), mid-point (MP), and discretionary point (DP) locations are shown on Fig. I.3.

Because of extensive sampling conducted in the Class $3 \mathrm{SU}$ of EU Z2-41 by early characterization and to support the ROD for the K-1070-C/D Operable Unit historical projects, it was agreed during DQO scoping that a Class 3 walkover assessment would be conducted over only 19 acres of EU Z2-41 (see DQO scoping package, Fig. 7). A total of 19 APs were identified in EU Z2-41 prior to the start of fieldwork and are documented in the DQO scoping package. The actual number of APs evaluated in EU Z2-41 was 19.

In addition to the APs, the field team made assessments at one MP location (MPs are selected in the field and are points located approximately half way between APs) and conducted discretionary surveys at 10 locations (see below). The number of MP locations differs from the walkover inspection protocol because of access limitations and the heavy tree canopy obstructing the GPS satellite signal. While hundreds of radiological measurements were obtained in the area, their locations could not be determined but none exceeded the screening level. MP and DP locations are not specified in planning documents. 


\begin{tabular}{lccc}
\hline & Number of APs & Number of MPs & Number of DPs \\
\hline EU Z2-41 & 19 & 1 & 10 \\
\hline AP = assessment point & MP = mid-point & & \\
DP = discretionary point & & & \\
\hline
\end{tabular}

\section{\begin{tabular}{|l|l} 
2.1.3.1 & CLASS 3 AND CLASS 4 SU RADIOLOGICAL SURVEY SUMMARY
\end{tabular}}

Screening level (SL): 3892 counts per minute (cpm)

SL exceedances: No AP, MP, or DP measurements exceeded the SL in EU Z2-41.

\section{\begin{tabular}{|l|l} 
2.1.3.2 & ClaSS 3 AND ClaSS 4 SU ANTHROPOGENIC FEATURES
\end{tabular}}

\section{Number of identified anthropogenic features: 6}

EU Z2-41 is located in an industrialized portion of ETTP. As such, there are numerous anthropogenic features, including facilities and associated constructed features such as roads, sidewalks, and paved areas. Plant facilities and their associated constructed features are assessed as part of the Class 3 and Class 4 SU walkover assessment protocol and summarized in Sect. 2.1.3.3.

Six additional anthropogenic features recognized during the Class $3 \mathrm{SU}$ walkover assessment include the following:

1) Soil mounds containing metal pipes and steel cable,

2) Concrete sump/well with a wood cover,

3) Empty water tank,

4) Vegetated "Contaminated Area",

5) Shed with maintenance equipment and tools, and

6) Open shed used for storage.

In addition to the six anthropogenic features, four sediment accumulation areas were also identified during the Class 3 SU walkover assessment in EU Z2-41.

\section{\begin{tabular}{l|l} 
2.1.3.3 & CLASS 3 SU FACILITIES ASSESSMENTS \\
\hline
\end{tabular}}

Ten facilities are listed in the DQO scoping package as being located in EU Z2-41 and 11 facilities were assessed. The facility assessments are reported in the assessment report with a list of EU Z2-41 facilities is presented in Table I.1. In summary, no facility was identified as a possible source for either chemical or radiological contamination.

\section{\begin{tabular}{|l|l} 
2.1.3.4 & CLASS 3 AND CLASS 4 SU BIASED SAMPLING \\
\hline
\end{tabular}}

Five biased sample locations were identified in EU Z2-41 based on the Class 3 SU walkover assessment. One biased sample location is associated with soil mounds containing steel pipe and cables (anthropogenic features) while the other four biased sample locations are associated with the four sediment accumulation areas. The remaining anthropogenic features identified during the Class 3 SU walkover assessment occur in an area of the EU that has been extensively sampled. Therefore, no additional sampling was conducted. Visual and radiological assessments of facilities in EU Z2-41did not identify any evidence for possible sources of contamination.

Details of the actual sampling and analysis in the Class 3 SU, including sample depths, analytes, and deviations from planned sampling, are presented in Table I.2.

\section{\begin{tabular}{|l|l|}
\hline 2.2 & DVS AND HISTORICAL SAMPLE RESULTS \\
\hline
\end{tabular}}

Sample data for EU Z2-41 are presented in Tables I.3 and I.4. The following presentation of sample results summarizes subsets of Table I.3 by presenting pertinent results for focused characterization within EU Z2-41. The full data set for EU Z2-41 contains numerous samples collected from depths up to $45 \mathrm{ft}$ bgs. Consistent with the requirements of the Zone 2 ROD, this TM evaluates only samples collected from the 0 - to - $10 \mathrm{ft}$ bgs interval (i.e., any sample with a starting depth of $10 \mathrm{ft}$ bgs or less). Results for the 0 - to 10 - $\mathrm{ft}$ bgs samples are summarized in Table I.3 and discussed in Sects. 2.2.5 and 2.2.6. Results for samples greater than $10 \mathrm{ft}$ bgs are summarized in Table I.4. A compact disc containing electronic files for the historical and DVS analytical data used to generate the data tables is provided with this Phased Construction Completion Report (PCCR). 
There are 28 sample locations in the EU Z2-41 Class 1 SUs-6 DVS biased sample locations and 22 historical sample locations. All Class 1 SU samples were collected between 0 and 10 -ft bgs. Historical sampling in the Class 1 SUs was conducted during early characterization, 1999 Site-wide RI, K-25 radiation survey, and K-1070-C/D Phase 2 RI.

\begin{tabular}{cll}
\hline EU & \multicolumn{1}{c}{ DVS sample locations $^{a}$} & \multicolumn{1}{c}{ Historical sample locations $^{a, b}$} \\
\hline \multirow{2}{*}{ Z2-41 } & $\begin{array}{l}\text { Concrete Pad Class 1 SU Concrete Sample } \\
\text { Locations: }\end{array}$ & $\begin{array}{l}\text { Concrete Pad Class 1 SU Historical } \\
\text { Locations: }\end{array}$ \\
& Z2-EU41DCC-101, Z2-EU41DCC-102, & RAD47, RAD50, SS001, SS002, SS003, \\
Z2-EU41DCC-103, Z2-EU41DCC-104 & SS004, SS005, SS006, SS007, SS008, SS009, \\
& SS010, SS011, SS012, SS013, SS014, SS015, \\
& Concrete Pad Class 1 SU Biased Location: & Z2-EU41DB-210, Z2-EU41DB-214, \\
Z2-EU41D-201 & Z2-EU41DB-218, Z2-EU41DB-219 \\
& & \\
& RAD91 Class 1 SU Confirmation Location: & RAD91 Class 1 SU Historical Locations: \\
Z2-EU41D-100 & RAD91 \\
\hline
\end{tabular}

\footnotetext{
${ }^{a}$ All DVS and early characterization sample locations are in a Class $1 \mathrm{SU}$ even though some sample location identifiers indicate otherwise.

${ }^{b}$ Sample location identifiers prefixed with "Z2" are early characterization locations.

$\mathrm{EU}=$ exposure unit

DVS = dynamic verification strategy

$\mathrm{SU}=$ soil unit
}

The number of samples collected at each location and sampling intervals at each location varied as did the chemicals and radionuclides that were analyzed. This information is presented in Table I.2 of the EU sampling summary. The data are summarized in the EU data summary in Tables I.3 and I.4, and data are evaluated by area of interest and EU in Sect. 2.2.5 and by FFA site in Sect.2.2.6. The number of analyses conducted in the Class 1 SUs is presented below by analyte group.

\begin{tabular}{ccccc}
\hline Metals & PPCBs $^{a}$ & Radionuclides $^{a, b, c}$ & SVOCs & VOCs \\
\hline 24 & 23 & 20 & 23 & 16 \\
\hline
\end{tabular}

${ }^{\mathrm{T}} \mathrm{T}$ ally for PPCBs is for PCBs and includes seven pesticide analyses.

${ }^{\mathrm{b}}$ Tally is based on counts of U-235 and U-238 analyses. Sampling for radionuclides at Z2-EU41DB-218 in the Concrete P ad Class 1 SU occurred on two different days; analyses from both sample events are counted here.

${ }^{\mathrm{c} S}$ Some radionuclide analyses for samples from historical locations SS001 through SS007 in the K-1071 Concrete Pad Class I SU were rejected during data validation and are not available in OREIS. The data were collected as part of the K-1070-C/D Phase 2 RI and, although the data were rejected, the RI states the analytical results represent "minimum activities for the samples". The rejected data are not included in the radionuclide tally in this TM. Review of the data quality analyses reported in Appendix I of DOE/OR/01-1297\&D2\&V3, pp. I24-I28 indicates uranium isotopes were present at substantially elevated concentrations in the samples collected in proximity to the concrete pad. However, validation of the data identified several problems with the quantitation of the data and determined these could not be used for calculations of risk and, therefore, rejected the data. Because the data carried an " $R$ " qualifier, these data were not loaded into OREIS and the raw data results are not available.

OREIS = Oak Ridge Environmental Information System

$\mathrm{PCB}=$ polychlorinated biphenyl

PPCB = pesticide and polychlorinated biphenyl

$\mathrm{RI}=$ remedial investigation

$$
\begin{aligned}
& \text { SU = soil unit } \\
& \text { SVOC = semivolatile organic compound } \\
& \text { TM = Technical Memorandum } \\
& \text { VOC = volatile organic compound }
\end{aligned}
$$

\section{\begin{tabular}{|l|l|} 
2.2.2 & CLASS 2 SUS \\
\hline
\end{tabular}}

There are 11 sample locations in the EU Z2-41 Class 2 SU-one DVS and 10 historical locations. All Class 2 SU samples were collected between 0 and $10 \mathrm{ft}$ bgs. Historical sampling in the Class 2 SUs was conducted during early characterization and the $\mathrm{K}-25$ radiation survey. 


\begin{tabular}{cll}
\hline EU & \multicolumn{1}{c}{ DVS sample locations } & \multicolumn{1}{c}{ Historical sample locations } \\
\hline \multirow{2}{*}{ Z2-41 } & RAD122 Class 2 SU Biased Location: & Z2-EU41DB-208 Class 2 SU Early \\
& Z2-EU41D-200 & Characterization Biased Locations: \\
& & Z2-EU41DB-208, Z2-EU41DB-208A, \\
& Z2-EU41DB-208-1, Z2-EU41DB-208-2, \\
& Z2-EU41DB-208-3, Z2-EU41DB-208-4, \\
& Z2-EU41DB-208-7, Z2-EU41DB-208-10, \\
& Z2-EU41DB-208-11 \\
& \\
& RAD122 Class 2 SU Historical Location: \\
& RAD122 \\
\hline
\end{tabular}

$\mathrm{EU}=$ exposure unit

DVS $=$ dynamic verification strategy

$\mathrm{SU}=$ soil unit

The number of samples and sampling intervals collected at each location and chemicals and radionuclides that were analyzed varied (see Table I.2). The data are summarized in Tables I.3 and I.4 and are evaluated by area of interest and EU in Sect. 2.2.5 and by FFA site in Sect. 2.2.6. The number of analyses conducted in the Class 2 SUs is presented below by analyte group.

\begin{tabular}{ccccc}
\hline Metals & PCBs & Radionuclides & SVOCs $^{a}$ & VOCs $^{-}$ \\
\hline 7 & 7 & 11 & 7 & 4 \\
\hline
\end{tabular}

${ }^{a}$ Analytical results for some SVOCs are also reported as part of the VOC analytical suite.

These duplicate results are not included in the tally.

$\mathrm{PCB}=$ polychlorinated biphenyl

SVOC = semivolatile organic compound

$\mathrm{VOC}=$ volatile organic compund

\section{\begin{tabular}{|l|l} 
2.2.3 & CLASS 3 AND ClASS 4 SUS \\
\hline
\end{tabular}}

There are 142 DVS and historical sample locations in the EU Z2-41 Class 3 SU where samples were collected from between 0and $10 \mathrm{ft}$ bgs-5 DVS sample locations and 137 historical sample locations. Three of the historical sample locations (SB119, SB121, and SB124) are not discussed in this TM and are not listed in the following table. Samples from these locations were analyzed only for alpha activity and beta/gamma activity with results reported in cpm. The DVS sample locations are the soil mounds anthropogenic feature location and the four sediment accumulation areas. Historical sampling in the Class $3 \mathrm{SU}$ was conducted by early characterization, K-25 radiation survey, K-25 radiological survey Phase II, K-1070-C/D Phase 2 RI, 1999 Site-wide RI, and ETTP Site-wide Residual Contamination Project. Class 3 SU sample location Z2-EU41-BKG was selected to document the soil composition of the location used for background measurements for soil core radiological screening. This sample location is actually outside of the EU Z2-41 area and is not included here. Finally, volatile organic compounds (VOCs) were analyzed by the field gas chromatograph (GC) method in samples fromthe 0-10-ft-depth interval at 31 of the 137 historical sample locations. Because field analytical methods lack the quality control obtained by laboratory methods, the field GC analytical results are not evaluated in this TM. Samples from all field GC locations also were analyzed for VOCs at a fixed laboratory. Class 3 SU sample locations are shown on Fig. I.4 and presented in the following table. Sample location details at the K-1071 Concrete Pad Class 1 SU and K-1070-A pits FFA site are shown in Figs. I.5 and I.6, respectively. 


\begin{tabular}{|c|c|c|}
\hline $\mathbf{E U}$ & DVS sample locations $^{a}$ & Historical sample locations $^{a, b}$ \\
\hline \multicolumn{3}{|c|}{ Locations with samples between 0 and $10 \mathrm{ft}$ bgs } \\
\hline \multirow{44}{*}{$\mathrm{Z} 2-41$} & Biased Locations $^{c}$ : & K-1070-C/D Burial Ground FFA Site Locations: \\
\hline & Z2-EU41DB-238, Z2-EU41DB-239, & ETTP-REL14, ETTP-REL15, ETTP-REL16, \\
\hline & Z2-EU41DB-240, Z2-EU41DB-241, & KAC-SS-S21, KAC-SS-S41, RAD33, RAD34, RAD35, \\
\hline & Z2-EU41DB-242 & RAD40, RAD41, RAD45, RAD48, RAD57, RAD60, \\
\hline & & RAD62, RAD74, RAD77, RAD80, RAD81, RAD86, \\
\hline & & RAD87, RAD89, RAD96, RAD102, RAD103, RAD123, \\
\hline & & RAD125, SB028, SB029, SB064, SB084, SB085, \\
\hline & & SB086, SB094, SB095, SB096, SB097, SB098, \\
\hline & & Z2-EU41C-201, Z2-EU41C-202, Z2-EU41C-203, \\
\hline & & Z2-EU41C-204, Z2-EU41CM-205, Z2-EU41CM-206, \\
\hline & & Z2-EU41C-207, Z2-EU41C-208, Z2-EU41C-209, \\
\hline & & Z2-EU41C-210, Z2-EU41C-211, Z2-EU41C-212, \\
\hline & & Z2-EU41CB-213, Z2-EU41DB-201, Z2-EU41DB-202, \\
\hline & & Z2-EU41DB-203, Z2-EU41DB-204, Z2-EU41DB-206, \\
\hline & & Z2-EU41DB-207, Z2-EU41DB-209, Z2-EU41DB-211, \\
\hline & & Z2-EU41DB-212, Z2-EU41DB-213, Z2-EU41DB-217, \\
\hline & & Z2-EU41DB-236, Z2-EU41DB-237, \\
\hline & & Z2-EU41DKB-205, Z2-EU41DKB-233, \\
\hline & & Z2-EU41DKB-234, SD011, SD012, SD013, SD014, \\
\hline & & SD015 \\
\hline & & K-1070 Pits FFA Site Locations: \\
\hline & & RAD72, SB050, SB051, SB052, SB053, SB054, SB055, \\
\hline & & SB056, SB057, SB058, SB059, SB060, SB061, SB062, \\
\hline & & SB063, SB065, SB066, SB067, SB068, SB069, SB070, \\
\hline & & SB071, SB072, Z2-EU41DB-220, Z2-EU41DB-221, \\
\hline & & Z2-EU41DB-222, Z2-EU41DB-223, Z2-EU41DB-224, \\
\hline & & Z2-EU41DB-225, Z2-EU41DB-226, Z2-EU41DB-227, \\
\hline & & Z2-EU41DB-228, Z2-EU41DB-229, Z2-EU41DB-230, \\
\hline & & Z2-EU41DB-231, Z2-EU41DB-232 \\
\hline & & K-1071 Concrete Pad FFA Site Historical Locations: \\
\hline & & RAD73, Z2-EU41DB-215 \\
\hline & & Other Historical Locations: \\
\hline & & KAC-SS-S11, KAC-SS-S31, KAC-SS-S32, \\
\hline & & KAC-SS-S51, KAC-SS-S61, KAC-SS-S71, \\
\hline & & KAC-SS-S81, KAC-SS-S91, KAC-SS-S101, \\
\hline & & KAC-SS-S111, SB033, SB034, SB040, SB073, SB074, \\
\hline & & SB075, SB076, SB077, SD001, SD002, SD003, SD004, \\
\hline & & SD005, SD017 \\
\hline & & Field GC Locations: \\
\hline & & SB050, SB051, SB052, SB053, SB054, SB055, SB056, \\
\hline & & SB057, SB058, SB059, SB060, SB061, SB062, SB063, \\
\hline & & SB064, SB065, SB066, SB067, SB068, SB069, SB070, \\
\hline & & SB071, SB072, SB073, SB074, SB075, SB076, SB077, \\
\hline & & SB084, SB085, SB086 \\
\hline
\end{tabular}




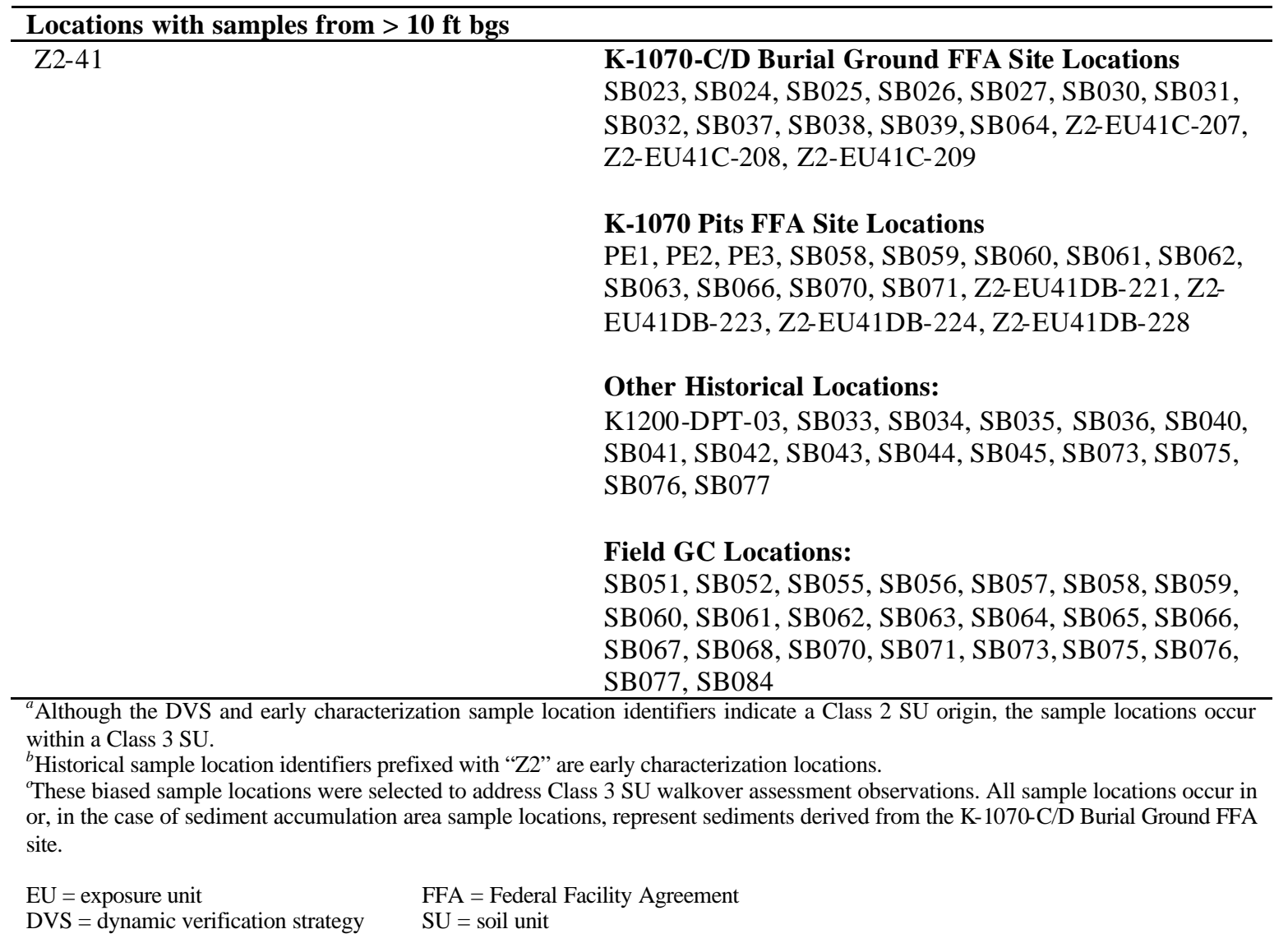

The number of samples collected and sampling intervals at each location varied as did the chemicals and radionuclides that were analyzed for (see Table I.2). The data are summarized in Table I.3, evaluated by area of interest and EU in Sect.2.2.5, and evaluated by FFA site in Sect.2.2.6. The number of analyses conducted in the Class $3 \mathrm{SU}$ is presented below by analyte group.

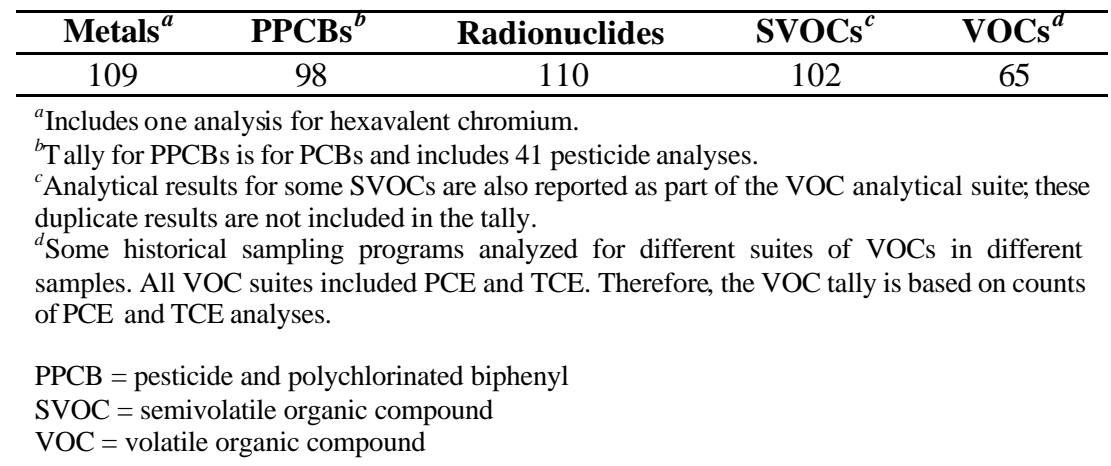

\section{\begin{tabular}{|l|l|} 
2.2.4 & INFRASTRUCTURE \\
\hline
\end{tabular}}

There is no extensive buried infrastructure in Z2-EU-41; therefore, no infrastructure sampling was conducted.

\section{\begin{tabular}{|l|l|}
\hline 2.2.5 & EU EVALUATION \\
\hline
\end{tabular}}

This section evaluates the characterization data and other information for EU Z2-41. Analytical data in the following summaries are presented by analyte group. The results for a particular analyte group are summarized only if that 
group was analyzed for in the samples from the unit being summarized. Within each summary, the data are evaluated by comparing to criteria that includes the Zone 2 soils Max RL, Zone 2 soils Avg RL, $1 \times 10^{-5}$ industrial preliminary remediation goal (Ind PRG), ETTP soils background composition (Bkg), Zone 2 groundwater screening levels (GW SL), and $1 \times 10^{-6}$ residential preliminary remediation goal (Res PRG). If a particular criterion does not apply to any member of an analyte group, it is not tabulated for that group. If a particular criterion does not apply to all analytes within an analyte group, those analytes to which it does not apply are notated with NA (not applicable). Individual metals and radionuclides, which are naturally occurring, are reported in the summaries only if one or more criterion is exceeded. Organic chemicals, which are not naturally occurring, are reported if they are detected even if no criteria are exceeded. The Max RL, Avg RL, Ind PRG, Bkg, GW SL, and Res PRG criteria values, as pertaining to the analytes listed in Appendix A of the RDR/RAWP (i.e., Quality Assurance Project Plan), are presented in Table 5 of this PCCR.

Because the carcinogenic risk associated with concentrations of radium and thorium isotopes in the natural background at ETTP exceeds the cumulative risk goal of $1 \times 10^{-4}$, RL values for these radionuclides are based on alternative concentration levels rather than risk. The alternative concentration levels of $5 \mathrm{pCi} / \mathrm{g}$ above background (Avg RL) and $15 \mathrm{pCi} / \mathrm{g}$ above background (Max RL) were set as low a reasonably achievable under the site-specific conditions. Because site-specific background concentrations of these radionuclides exceed the target risk range, residual concentrations of these radionuclides and their decay series are not considered in estimates of residual risk following any remedial action.

The Zone 2 ROD states that Avg RL and Max RL exceedances by Ra-226, Th-230, and Th-232 will be evaluated by summing above-background concentrations of the greater of Ra-226 or Th-230 with the above-background concentrations of Th-232 and comparing the results to $5 \mathrm{pCi} / \mathrm{g}$ (Avg RL) and $15 \mathrm{pCi} / \mathrm{g}$ (Max RL). The required calculations have been performed. Average and Max RL exceedances for these radionuclides, if any, are reported in the TM data summaries below and Table I.2 as "Ra/Th decay series," and individual RL exceedances by Ra-226, Th-230, and Th-232 are reported as NA. The Ra/Th decay series data are summarized in the sections that follow only if an Avg or Max RL has been exceeded, consistent with the description in the preceding paragraph for reporting radionuclides. Discussion of the $\mathrm{Ra} / \mathrm{Th}$ decay series calculation, including the manner in which the calculation is performed, is presented in Sect. 3.3 of this PCCR.

\section{Conceptual Site Model (CSM)}

EU Z2-41 is located along the east-central boundary of Zone 2 in the K-1070-C/D and Downgradient Area Group. The entire northern portion of the EU has been classified a Class 3 SU. The southeastern portion of the EU encompasses three different disposal areas: the K-1070-D Burial Trenches, K-1070-C Burial Grounds, and K-1070 Pits. These areas initially were planned to be classified as Class 1 and/or Class 2 SUs. Prior to work performed under the DVS Program, extensive sampling had been performed in the area to determine the nature and extent of soil and groundwater contamination. Results of these earlier sampling programs indicated no significant shallow zone (0-10 ft bgs) soil contamination. As a result of this prior sampling, much of the central portion of this EU has been classified in the DQO package as a modified Class 3 SU. The modification was that Class 3 walkover assessments for the central area were not required because extensive soil sampling had already been completed.

A Class 3 walkover assessment was conducted in the northern portion of the EU and biased sampling was performed to verify the historic results in several areas. Because of the volume of work performed and documented in the K-1070-C/D Phase 2 RI, both the nature and extent of contamination and the CSM were fairly well understood. Three interpreted groundwater sources in the EU (see discussions below) included burial trenches beneath the C storage yard, D trenches along the eastern boundary of the EU, and a series of pits along the western slope. DVS and historic sampling in the area of the pits and trenches has shown no significant contamination in the upper $10 \mathrm{ft}$ of soil in the EU.

The primary conceptual model for the area includes historic VOC releases from pits and trenches to underlying bedrock and eventually groundwater. The pits and trenches were excavated into the intensely fractured residual Rome Formation bedrock, which readily accepted the liquid materials (e.g., solvents) poured into the trenches . These liquids are thought to have moved vertically downward through the soil into the rock mass where they occupied the interconnected available pore space and microfractures. The organic liquids subsequently were subsumed into the rock mass by matrix diffusion and slowly released into the groundwater over time. 
Sampling has shown soil is not an ongoing secondary source, whereas groundwater monitoring data suggest the heavily fractured and porous rock mass is an ongoing secondary contaminant source to groundwater. The conceptual model is supported by the following observations:

- VOC contaminants are dense nonaqueous -phase liquids that migrate vertically in the subsurface,

- Contaminant plumes appear to have stabilized, which indicates no continuing migration of the source material and no additional release of contaminant mass,

- Lateral extent of the plumes do not appear to have changed significantly in the last 10-12 years;,

- Concentrations of the primary organic compounds (carbon tetrachloride, PCE, and TCE) are declining in monitoring wells north of K-1200, and

- Ratios of degradation products (DCE and DCA) to parent compounds are increasing with an overall declining total concentration trend.

The secondary conceptual model includes some very limited surface releases of soil contamination around the former K-1071 Concrete Pad and other isolated locations within the EU. Verification sampling confirmed there are two small areas of soil contamination in the EU that fail Max RL criteria. A block diagram illustrating the conceptual site model is shown in Fig. I.7.

Intermedia Transfer Potential

- Soil to air-There is a low probability that soil and solid waste particulates would be transported by air from the areas identified as potential sources of contamination because the area has an existing well-established and maintained grass vegetative cover.

- Soil to surface water and sediment-Impacts to surface water from the areas identified as potential sources of contamination is moderate. Remobilization of sediments could occur during high rain events, however, a temporary cover over the concrete pads and soils at the K-1071 Concrete Pad FFA site precludes significant erosional runoff.

- Soil to Groundwater-There are three interpreted historic sources of contamination to groundwater in EU Z2-41.

\section{EU Z2-41 Groundwater Evaluation}

Geologic setting. A topographic high is located in and generally encompassed by this EU. This high ground is bounded to the east by a perennial drainage and a second slightly higher area further east. The K-25 thrust fault bounds the topographic high ground, which is located on the hanging wall of the thrust. The fault trace in the Zone 2 area is shown on Fig. i.1. The fault trace defines a small splinter thrust block approximately one-half mile wide and several miles in length that has a synclinal form. The western edge of this splinter thrust block underlies the eastern portions of Zone 2 and EUs Z2-37 and Z2-41. The geologic section of rock units in the area beneath EU Z2-41 includes the Rome Formation of Cambrian age. This section of rock is comprised of thin interbedded sandstone and shale, with minor beds of chert and limestone in the upper section. Because of the extensive deformation that occurred during thrust faulting, the rock is shattered into very small fragments. The presence of extensive microfractures results in a porous and permeable overall rock mass.

Soils and Hydrology. A surface residual soil covers most of the high ground and is up to $20 \mathrm{ft}$ thick in some areas. These surface soils are composed predominantly of clay and cover slopes where the soil cover thins to a few feet. Rome formation outcrops are observed at isolated locations along perennial drainages. Infiltration through the surface clay-rich residuum is low to moderate. Surface water and groundwater flow generally occurs in a radial pattern from the top of the knoll underlying the K-1070-C/D Burial Ground. Surface water drainage and groundwater flow directions are shown in Fig. I.3. Gradients and transport rate are high $(5 \mathrm{ft}$ per day at some locations along the western flank of the K-1070-C/D Burial Ground) as measured by tracer tests conducted by the Site-wide Program.

Source Areas. There are three suspected sources of groundwater contamination within EU Z2-41. All of the sources are historic and have associated contaminant plumes that extend beyond the EU Z2-41 boundary. All plumes originating within EU Z2-41 are predominantly volatile organic compound plumes. Each has a slightly different contaminant fingerprint and can, with reasonable reliability, be tied back to the original release point where the contaminant entered the subsurface. 
One historic source area and associated plume is located at the south end of the K-1070-D trenches, with the plume extending to the west from the trenches. a point north of the K 1200 centrifuge building where the flow turns to the south and pools on the north side of the building beneath the patrol road. There is no clearly defined transport path from the area north of $\mathrm{K} 1200$. The source release point appears to be associated with the K-1070-D trenches that were excavated to $40 \mathrm{ft}$ and used to bury waste and materials during the 1970s and 1980s. Releases of organic liquids in these deep trenches appear to have migrated vertically downward into the Rome rock mass.

Assuming the conceptual distribution of free phase organic liquids is directly beneath the release point at the southern end of the K-1070-D trenches, then the source in the rock mass is $40 \mathrm{ft}$ or deeper below the present ground surface. There are several monitoring wells in the $\mathrm{K}-1070-\mathrm{C}$ area that provide information on the concentrations along the plume. There are also numerous geoprobe borings and soil samples that define the flow pathway and support the CSM.

Another historic source area and associated plume is located beneath and west of the former Gpit location. The source area associated with Gpit may have received approximately 30,000 gal of organic liquids in 10-40 gal releases over a 15-year period. This secondary source extends down slope and into the subsurface to depths from $10 \mathrm{ft}$ to $>40 \mathrm{ft}$ bgs. This source area has an associated plume that may extend westward as far as the southwest corner of the K-1401 building. The G-pit was excavated during a removal action in 2000.

There is an indication that a historic release of organic compounds also occurred in the bermed area in the northwest corner of the K-1070-C/D Burial Ground, which also is considered to be a historic source. However, historic and recent DVS soil sampling in the area have not identified any mass of soil contaminated with organic compounds. Monitoring wells downgradient of the former bermed drum storage area have reported organic compound concentrations well above their respective maximum contaminant levels (MCLs). The primary organic compounds TCA and TCE concentrations are declining in wells north and downgradient of the bermed drum storage area (UNP-001 is the only pertinent location). The ratio of degradation products (DCA and DCE) to parent compounds is increasing with an overall declining total concentration trend.

Based on the results of DVS and historical soil sampling in the 0 - to $10-\mathrm{ft}$ depth interval, the previous removal action at the G-Pit, and a conceptual understanding of the behavior of liquid organic chemicals in soils and fractured rock, it is concluded that a source for organic chemical contamination no longer exists above either bedrock or the water table in EU Z2-41.

\section{EU Z2-41 Sampling Results}

The bulk of EU Z2-41 has been classified as a Class 3 SU. The EU contains three FFA sites that are listed in Appendix A of the Zone 2 ROD-K-1070-C/D Burial Ground FFA site, K1070 Pits FFA site, and K1071 Concrete Pad FFA site. An approximately 0.5 acre Class $1 \mathrm{SU}$, the Concrete Pad, was defined in the K-1071 Concrete Pad FFA site. In addition, the RAD91 Class 1 SU was identified to verify a Max RL exceedance and define the boundaries of the exceedance for a possible remedial action. The RAD122 and Z2-EU41DB-208 Class 2 SUs were identified to verify Avg RL exceedances and define the areas of exceedances for Avg RL-weighted calculations. Class 1 and Class 2 SUs are addressed by sampling and BAR surveys. BAR survey results are described in Sect.2.1.1.1 for the Class 1 SUs and Sect.2.1.2.1 for the Class 2 SUs. Sampling results are described below.

A Class 3 SU walkover assessment was conducted over a portion of the EU Z2-41 Class 3 SU (see Sect. 2.1.3 for a description). Six anthropogenic features and four sediment accumulation areas were identified during the Class 3 SU walkover assessment (Sect. 2.1.3.2). In addition, nine facilities were assessed (Sect. 2.1.3.3). Biased sampling was conducted at one anthropogenic feature (soil mounds) and at all four sediment accumulation areas. No facilities were identified as potential sources of contamination and no biased sample locations at the facilities were selected.

Extensive historical sampling was conducted in EU Z2-41 during the K-25 Radiation Survey, K-25 Radiological Survey Phase II, K-1070-C/D Phase 2 RI, 1999 Site-wide RI, ETTP Site-wide Residual Contamination Project, and early characterization. There are 158 historical sample locations in the EU. Another 12 sample locations were added during DVS sampling.

Following is a summary of the sampling results for EU Z2-41, which begins with summary presentations of analytical results for the focused sampling efforts in the EU and concludes with an overall summary for EU Z2-41. The focused sampling efforts include the Class 1 SUs, Class 2 SUs, DVS biased sampling at the soil mounds anthropogenic feature, and DVS biased sampling at the sediment accumulation areas. This section concludes with a summary of all sampling results in EU Z2-41, including data summary tables and a written description of the nature 
and extent of chemicals and radionuclides observed in the EU. Data summaries for the Zone 2 ROD Appendix A FFA sites are presented in Sect.2.2.6, including FFA site sample data. Summaries of all EU Z2-41 data are presented in Tables I.3 and I. 4 and sample locations are shown on Fig. I.4.

EU Z2-41 Concrete Pad Class 1 SU: The Concrete Pad Class 1 SU is located in the K-1071 Concrete Pad FFA site (Sect. 2.2.6). The Zone 2 ROD implies that a remedial action will be conducted in this site. There are five DVS and 21 historical sample locations in this Class 1 SU. Four DVS biased concrete sample locations on the concrete pad were selected during DQO scoping for waste acceptance criteria determination. A DVS soil sample location was identified to confirm an elevated lead concentration at historical sample location SS007. The remaining soil sample locations in this Class $1 \mathrm{SU}$ are all historical locations, including location SS007 (elevated lead concentration), location RAD47 (U-235 and U-238 Max RL exceedances), and early characterization location Z2-EU41DB-218, which is a confirmation location for RAD47 (U-238 Avg RL exceedance). The following summary of results addresses the concrete and soil samples separately.

There are four concrete sample locations on the concrete pad in the Concrete Pad Class 1 SU (Z2-EU41DCC-101, Z2-EU41DCC-102, Z2-EU41DCC-103, and Z2-EU41DCC-104). Analytical results summarized below show exceedances of radionuclide soil Ind PRGs, soil Bkg exceedances by six metals and one radionuclide, and detections of PCBs and SVOCs.

EU Z2-41 CONCRETE PAD CLASS 1 SU CONCRETE METALS WITH BACKGROUND, PRG, GW SL, AND/OR RL EXCEEDANCES (mg/kg) 0-10 ft

\begin{tabular}{|c|c|c|c|c|c|c|c|c|c|c|c|}
\hline \multirow[b]{2}{*}{ Analyte } & \multirow[b]{2}{*}{$\begin{array}{c}\text { Detect } \\
\text { frequency }\end{array}$} & \multirow[b]{2}{*}{$\underset{\text { detect }}{\text { Minimum }}$} & \multirow[b]{2}{*}{$\underset{\text { detect }}{\text { Maximum }}$} & \multirow[b]{2}{*}{$\begin{array}{l}\text { Location(s) of } \\
\text { maximum detect }\end{array}$} & \multirow{2}{*}{$\begin{array}{c}\text { Average } \\
\text { detected } \\
\text { result }\end{array}$} & \multicolumn{6}{|c|}{ Number of analyses exceeding criteria } \\
\hline & & & & & & $\begin{array}{c}\text { Max } \\
\text { RL }\end{array}$ & $\begin{array}{l}\text { Avg } \\
\text { RL }\end{array}$ & $\begin{array}{l}\text { Ind } \\
\text { PRG }\end{array}$ & Bkg & $\begin{array}{l}\text { GW } \\
\text { SL }\end{array}$ & $\begin{array}{l}\text { Res } \\
\text { PRG }\end{array}$ \\
\hline Arsenic & $4 / 4$ & 4.3 & 5.1 & Z2-EU41DCC-103 & 4.7 & 0 & 0 & 0 & 0 & 0 & 4 \\
\hline Barium & $4 / 4$ & 95 & 170 & Z2-EU41DCC-101 & 131 & NA & NA & 0 & 2 & 0 & 0 \\
\hline Cadmium & $4 / 4$ & 0.19 & 0.86 & Z2-EU41DCC-102 & 0.63 & NA & NA & 0 & 3 & NA & 0 \\
\hline Calcium & $4 / 4$ & 240,000 & 300,000 & $\begin{array}{l}\text { Z2-EU41DCC-102 } \\
\text { Z2-EU41DCC-103 }\end{array}$ & 277,500 & NA & NA & NA & 4 & NA & NA \\
\hline Copper & $4 / 4$ & $14 \mathrm{~J}$ & $26 \mathrm{~J}$ & Z2-EU41DCC-101 & 20 & NA & NA & 0 & 2 & NA & 0 \\
\hline Magnesium & $4 / 4$ & $11,000 \mathrm{~J}$ & $19,000 \mathrm{~J}$ & Z2-EU41DCC-104 & 14,750 & NA & NA & NA & 4 & NA & NA \\
\hline Nickel & $4 / 4$ & $9.4 \mathrm{~J}$ & $30 \mathrm{~J}$ & Z2-EU41DCC-101 & 17.9 & NA & NA & 0 & 1 & NA & 0 \\
\hline Uranium & $4 / 4$ & $1.6 \mathrm{~J}$ & $35 \mathrm{~J}$ & Z2-EU41DCC-101 & 14.4 & NA & NA & 0 & NA & NA & 4 \\
\hline Vanadium & $4 / 4$ & 8.8 & 14 & Z2-EU41DCC-104 & 11.0 & NA & NA & 0 & 0 & NA & 4 \\
\hline
\end{tabular}

Avg = average $\quad$ NA $=$ not applicable

$\mathrm{Bkg}=$ background $\quad \mathrm{PRG}=$ preliminary remediation goal

$\mathrm{EU}=$ exposure unit $\quad$ Res $=$ residential

$\mathrm{GW}=$ groundwater $\quad \mathrm{RL}=$ remediation level

Ind = industrial $\quad \mathrm{SL}=$ screening level

Max $=$ maximum $\quad \mathrm{SU}=$ soil unit

EU Z2-41 CONCRETE PAD CLASS 1 SU CONCRETE PPCB DETECTS (ug/kg) 0-10 ft

\begin{tabular}{|c|c|c|c|c|c|c|c|c|c|}
\hline \multirow[b]{2}{*}{ Analyte } & \multirow[b]{2}{*}{$\begin{array}{c}\text { Detect } \\
\text { frequency }\end{array}$} & \multirow[b]{2}{*}{$\begin{array}{c}\text { Minimum } \\
\text { detect }\end{array}$} & \multirow[b]{2}{*}{$\begin{array}{c}\text { Maximum } \\
\text { detect }\end{array}$} & \multirow[b]{2}{*}{$\begin{array}{c}\text { Location(s) of } \\
\text { maximum detect }\end{array}$} & \multirow{2}{*}{$\begin{array}{c}\text { Average } \\
\text { detected } \\
\text { result }\end{array}$} & \multicolumn{4}{|c|}{$\begin{array}{c}\text { Number of analyses } \\
\text { exceeding criteria }\end{array}$} \\
\hline & & & & & & $\begin{array}{c}\text { Max } \\
\text { RL }\end{array}$ & $\begin{array}{l}\text { Avg } \\
\text { RL }\end{array}$ & $\begin{array}{c}\text { Ind } \\
\text { PRG }\end{array}$ & $\begin{array}{l}\text { Res } \\
\text { PRG }\end{array}$ \\
\hline PCB-1254 & $2 / 4$ & 480 & $1600 \mathrm{~J}$ & Z2-EU41DCC-103 & 1040 & 0 & 0 & 0 & 2 \\
\hline Polychlorinated biphenyl & $2 / 4$ & 480 & $1600 \mathrm{~J}$ & Z2-EU41DCC-103 & 1040 & 0 & 0 & 0 & 2 \\
\hline
\end{tabular}

Avg = average

$\mathrm{EU}=$ exposure unit

Ind $=$ industrial

Max $=$ maximum

$\mathrm{PRG}=$ preliminary remediation goal

PPCB = pesticides and polychlorinated biphenyl

Res $=$ residential

$\mathrm{RL}=$ remediation level

$\mathrm{SU}=$ soil unit 
EU Z2-41 CONCRETE PAD CLASS 1 SU CONCRETE RADIONUCLIDES WITH BACKGROUND, PRG, AND/OR RL EXCEEDANCES (pCi/g) 0-10 ft

\begin{tabular}{|c|c|c|c|c|c|c|c|c|c|c|c|}
\hline \multirow[b]{2}{*}{ Analyte } & \multirow[b]{2}{*}{$\begin{array}{c}\text { Detect } \\
\text { frequency }\end{array}$} & \multirow[b]{2}{*}{$\begin{array}{c}\text { Minimum } \\
\text { detect }\end{array}$} & \multirow[b]{2}{*}{$\begin{array}{c}\text { Maximum } \\
\text { detect }\end{array}$} & \multirow[b]{2}{*}{$\begin{array}{c}\text { Location(s) of } \\
\text { maximum detect }\end{array}$} & \multirow{2}{*}{$\begin{array}{c}\text { Average } \\
\text { detected } \\
\text { result }\end{array}$} & \multicolumn{6}{|c|}{ Number of analyses exceeding criteria } \\
\hline & & & & & & $\begin{array}{c}\text { Max } \\
\text { RL } \\
\end{array}$ & $\begin{array}{l}\text { Avg } \\
\text { RL }\end{array}$ & $\begin{array}{c}\text { Ind } \\
\text { PRG }\end{array}$ & Bkg & $\begin{array}{c}\text { GW } \\
\text { SL } \\
\end{array}$ & $\begin{array}{r}\text { Res } \\
\text { PRG } \\
\end{array}$ \\
\hline Radium-226 & $3 / 4$ & 0.274 & 0.544 & Z2-EU41DCC-103 & 0.451 & NA & NA & 3 & 0 & NA & 3 \\
\hline Technetium-99 & $1 / 4$ & 9.64 & 9.64 & Z2-EU41DCC-103 & 9.64 & NA & NA & 0 & NA & NA & 1 \\
\hline Thorium -232 & $2 / 4$ & 0.175 & 0.324 & Z2-EU41DCC-103 & 0.250 & NA & NA & 1 & 0 & NA & 2 \\
\hline Uranium-234 & $4 / 4$ & 0.26 & 16.4 & Z2-EU41DCC-101 & 6.63 & 0 & 0 & 0 & NA & 0 & 2 \\
\hline Uranium-235 & $2 / 4$ & 0.346 & 0.768 & Z2-EU41DCC-101 & 0.557 & 0 & 0 & 0 & NA & 0 & 2 \\
\hline Uranium-238 & $4 / 4$ & 0.358 & 14.1 & Z2-EU41DCC-101 & 5.14 & 0 & 0 & 0 & 2 & 0 & 3 \\
\hline
\end{tabular}

Avg = average

$\mathrm{Bkg}=$ background

$\mathrm{EU}=$ exposure unit

$\mathrm{GW}=$ groundwater

$\mathrm{NA}=$ not applicable

$\mathrm{PRG}=$ preliminary remediation goal

Ind $=$ industrial

Max $=$ maximum

Res $=$ residential

$\mathrm{RL}=$ remediation level

$\mathrm{SL}=$ screening level

$\mathrm{SU}=$ soil unit

EU Z2-41 CONCRETE PAD CLASS 1 SU CONCRETE SVOC DETECTS (ug/kg) 0-10 ft

\begin{tabular}{|c|c|c|c|c|c|c|c|c|}
\hline \multirow[b]{2}{*}{ Analyte } & \multirow[b]{2}{*}{$\begin{array}{c}\text { Detect } \\
\text { frequency }\end{array}$} & \multirow[b]{2}{*}{$\begin{array}{c}\text { Minimum } \\
\text { detect }\end{array}$} & \multirow[b]{2}{*}{$\begin{array}{c}\text { Maximum } \\
\text { detect }\end{array}$} & \multirow[b]{2}{*}{$\begin{array}{c}\text { Location(s) of } \\
\text { maximum detect }\end{array}$} & \multirow{2}{*}{$\begin{array}{c}\text { Average } \\
\text { detected } \\
\text { result }\end{array}$} & \multicolumn{3}{|c|}{$\begin{array}{c}\text { Number of analyses } \\
\text { exceeding criteria }\end{array}$} \\
\hline & & & & & & $\begin{array}{l}\text { Ind } \\
\text { PRG }\end{array}$ & $\begin{array}{l}\text { GW } \\
\text { SL }\end{array}$ & $\begin{array}{c}\text { Res } \\
\text { PRG }\end{array}$ \\
\hline Benzo(a)pyrene & $1 / 4$ & $21 \mathrm{~J}$ & $21 \mathrm{~J}$ & Z2-EU41DCC-104 & 21 & 0 & NA & 0 \\
\hline Benzo(b)fluoranthene & $1 / 4$ & $30 \mathrm{~J}$ & $30 \mathrm{~J}$ & Z2-EU41DCC-104 & 30 & 0 & NA & 0 \\
\hline Bis(2-ethylhexyl)phthalate & $3 / 4$ & $390 \mathrm{~J}$ & $3600 \mathrm{~J}$ & Z2-EU41DCC-101 & 2230 & 0 & 0 & 0 \\
\hline Diethyl phthalate & $1 / 4$ & $50 \mathrm{~J}$ & $50 \mathrm{~J}$ & Z2-EU41DCC-101 & 50 & 0 & NA & 0 \\
\hline Phenanthrene & $1 / 4$ & $69 \mathrm{~J}$ & $69 \mathrm{~J}$ & Z2-EU41DCC-102 & 69 & 0 & NA & 0 \\
\hline Phenol & $1 / 4$ & $430 \mathrm{~J}$ & $430 \mathrm{~J}$ & Z2-EU41DCC-103 & 430 & 0 & NA & 0 \\
\hline $\begin{array}{l}\text { EU = exposure unit } \\
\mathrm{GW}=\text { groundwater } \\
\text { Ind = industrial } \\
\mathrm{NA}=\text { not applicable } \\
\text { PRG = preliminary remedia }\end{array}$ & goal & \multicolumn{7}{|c|}{$\begin{array}{l}\text { Res = residential } \\
\text { SL = screening level } \\
\text { SU = soil unit } \\
\text { SVOC = semivolatile organic compound }\end{array}$} \\
\hline
\end{tabular}

There are 22 historical soil sample locations (see Sect. 2.2.1) and one DVS soil sample location in the Concrete Pad Class 1 SU. DVS sample location Z2-EU41D-201 was selected to confirm an elevated lead concentration observed in a sample from historical location SS007. Analytical results summarized below show U-235 and U-238 Max RL exceedances; U-234, U-235, and U-238 Avg RL exceedances; several radionuclide and two VOCs PCE and TCE with Ind PRG exceedances; GW SL exceedances by U-234, U-235, U-238, methylene chloride, PCE, and TCE; several metal Bkg exceedances and U-238 Bkg exceedances in eight samples; and detections of 1 PCB, 26 SVOCs, and 13 VOCs. The Max RL exceedances occur at sample location RAD47 and the Avg RL exceedances occur at RAD47 and its DVS confirmation sample location Z2-EU41DB-218. Notably, the Max RL exceedances at RAD47 were not confirmed by DVS sampling and a BAR survey was not conducted (Sect. 2.1.1.1). The elevated lead concentration $(230 \mathrm{mg} / \mathrm{kg})$ observed at location SS007 was not confirmed by the DVS confirmation sample $(25 \mathrm{mg} / \mathrm{kg})$.

In addition to the data summarized below, there are additional radionuclide data for historical samples SS001 through SS007 that were rejected during data validation. The data were collected for the K-1070-C/D RI, which states the data represent minimum concentrations. However, the data are not available in OREIS because it does not accept rejected data. Nevertheless, the RI states that among these rejected data, the maximum U-234 concentration is $290 \mathrm{pCi} / \mathrm{g}$ at SS002, the maximum U-235 concentration is $15 \mathrm{pCi} / \mathrm{g}$ at SS002, and the maximum U-238 concentration is $260 \mathrm{pCi} / \mathrm{g}$ at SS002 and SS003. Consistent with the RI interpretation that these rejected data represent minimum concentrations, there are also, at a minimum, U-235 and U-238 Avg RL exceedances and U-234, U-235, and U-238 Ind PRG and GW SL exceedances in Concrete Pad Class 1 SU soils. 
EU Z2-41 CONCRETE PAD CLASS 1 SU SOIL METALS WITH BACKGROUND, PRG, GW SL, AND/OR RL EXCEEDANCES (mg/kg) 0-10 ft

\begin{tabular}{|c|c|c|c|c|c|c|c|c|c|c|c|}
\hline \multirow[b]{2}{*}{ Analyte } & \multirow[b]{2}{*}{$\begin{array}{c}\text { Detect } \\
\text { frequency }\end{array}$} & \multirow[b]{2}{*}{$\begin{array}{c}\text { Minimum } \\
\text { detect }\end{array}$} & \multirow[b]{2}{*}{$\begin{array}{c}\text { Maximum } \\
\text { detect }\end{array}$} & \multirow[b]{2}{*}{$\begin{array}{l}\text { Location(s) of } \\
\text { maximum detect }\end{array}$} & \multirow{2}{*}{$\begin{array}{c}\text { Average } \\
\text { detected } \\
\text { result }\end{array}$} & \multicolumn{6}{|c|}{ Number of analyses exceeding criteria } \\
\hline & & & & & & $\begin{array}{l}\text { Max } \\
\text { RL }\end{array}$ & $\begin{array}{l}\text { Avg } \\
\text { RL }\end{array}$ & $\begin{array}{l}\text { Ind } \\
\text { PRG }\end{array}$ & Bkg & $\begin{array}{l}\text { GW } \\
\text { SL }\end{array}$ & $\begin{array}{l}\text { Res } \\
\text { PRG }\end{array}$ \\
\hline Aluminum & $20 / 20$ & 3680 & 26,000 & Z2-EU41DB-219 & 14,966 & NA & NA & 0 & 0 & NA & 17 \\
\hline Antimony & $9 / 15$ & $0.22 \mathrm{~J}$ & $4.2 \mathrm{~J}$ & SS007 & 0.744 & NA & NA & 0 & 1 & 0 & 1 \\
\hline Arsenic & $19 / 20$ & 1.7 & $11.7 \mathrm{~J}$ & SS005 & 4.41 & 0 & 0 & 0 & 0 & 0 & 19 \\
\hline Cadmium & $8 / 20$ & 0.098 & $3.8 \mathrm{~J}$ & SSO07 & 1.35 & NA & NA & 0 & 6 & NA & 1 \\
\hline Calcium & $20 / 20$ & $1770 \mathrm{~J}$ & 235,000 & SS003 & 68,151 & NA & NA & NA & 18 & NA & NA \\
\hline Chromium & $20 / 20$ & 10 & 156 & SS007 & 34.3 & NA & NA & 0 & 2 & 0 & 14 \\
\hline Copper & $20 / 20$ & $6.7 \mathrm{~J}$ & $1100 \mathrm{~J}$ & SS007 & 129 & NA & NA & 0 & 13 & NA & 2 \\
\hline Lead & $20 / 20$ & 10.2 & 230 & SS007 & 33.0 & NA & NA & 0 & 3 & 0 & 0 \\
\hline Magnesium & $20 / 20$ & $830 \mathrm{~J}$ & $49,000 \mathrm{~J}$ & Z2-EU41DB-210 & 12,012 & NA & NA & NA & 9 & NA & NA \\
\hline Manganese & $20 / 20$ & $112 \mathrm{~J}$ & $1800 \mathrm{~J}$ & Z2-EU41D-201 & 386.3 & NA & NA & 0 & 0 & NA & 14 \\
\hline Mercury & $13 / 19$ & 0.028 & 1.5 & SS007 & 0.308 & 0 & 0 & 0 & 5 & NA & 0 \\
\hline Nickel & $20 / 20$ & $9.1 \mathrm{~J}$ & $938 \mathrm{~J}$ & 5007 & 130 & NA & NA & 0 & 12 & NA & 3 \\
\hline Silver & $3 / 17$ & $0.76 \mathrm{~J}$ & $1.2 \mathrm{~J}$ & SS005 & 0.983 & NA & NA & 0 & 3 & NA & 0 \\
\hline Sodium & $13 / 20$ & $34 \mathrm{~J}$ & 546 & SS013 & 154 & NA & NA & NA & 1 & NA & NA \\
\hline Vanadium & $20 / 20$ & 6.7 & 66.5 & SS005 & 24.8 & NA & NA & 0 & 1 & NA & 18 \\
\hline Zinc & $20 / 20$ & 27 & $420 \mathrm{~J}$ & SS007 & 84.1 & NA & NA & 0 & 7 & NA & 0 \\
\hline
\end{tabular}

Avg $=$ average

$\mathrm{NA}=$ not applicable

$\mathrm{Bkg}=$ background $\quad \mathrm{PRG}=$ preliminary remediation goal

$\mathrm{EU}=$ exposure unit Res $=$ residential

$\mathrm{GW}=$ groundwater $\quad \mathrm{RL}=$ remediation level

Ind $=$ industrial $\quad \mathrm{SL}=$ screening level

Max $=$ maximum $\quad \mathrm{SU}=$ soil unit

EU Z2-41 CONCRETE PAD CLASS 1 SU SOIL PPCB DETECTS (ug/kg) 0-10 ft

\begin{tabular}{|c|c|c|c|c|c|c|c|c|c|}
\hline \multirow[b]{2}{*}{ Analyte } & \multirow[b]{2}{*}{$\begin{array}{c}\text { Detect } \\
\text { frequency }\end{array}$} & \multirow[b]{2}{*}{$\begin{array}{c}\text { Minimum } \\
\text { detect }\end{array}$} & \multirow[b]{2}{*}{$\underset{\text { detect }}{\text { Maximum }}$} & \multirow[b]{2}{*}{$\begin{array}{c}\text { Location(s) of } \\
\text { maximum detect }\end{array}$} & \multirow{2}{*}{$\begin{array}{c}\text { Average } \\
\text { detected } \\
\text { result }\end{array}$} & \multicolumn{4}{|c|}{$\begin{array}{l}\text { Number of analyses } \\
\text { exceeding criteria }\end{array}$} \\
\hline & & & & & & $\begin{array}{l}\text { Max } \\
\text { RL }\end{array}$ & $\begin{array}{l}\text { Avg } \\
\text { RL }\end{array}$ & $\begin{array}{l}\text { Ind } \\
\text { PRG }\end{array}$ & $\begin{array}{c}\text { Res } \\
\text { PRG }\end{array}$ \\
\hline PCB-1254 & $12 / 19$ & $14 \mathrm{~J}$ & 2500 & SS002, SS003 & 800 & 0 & 0 & 0 & 8 \\
\hline $\begin{array}{l}\text { Avg = average } \\
\text { EU = exposure un it } \\
\text { Ind = industrial } \\
\text { Max = maximum }\end{array}$ & & & $\begin{array}{l}\text { PRG }=\text { prelim } \\
\text { Res }=\text { residen } \\
\text { RL }=\text { remedia } \\
\text { SU }=\text { soil unit }\end{array}$ & $\begin{array}{l}\text { nary remediation go } \\
\text { ial } \\
\text { ion level }\end{array}$ & & & & & \\
\hline
\end{tabular}

EU Z2-41 CONCRETE PAD CLASS 1 SU SOIL RADIONUCLIDES WITH

BACKGROUND, PRG, AND/OR RL EXCEEDANCES (pCi/g) 0-10 ft

\begin{tabular}{|c|c|c|c|c|c|c|c|c|c|c|c|}
\hline \multirow[b]{2}{*}{ Analyte } & \multirow[b]{2}{*}{$\begin{array}{c}\text { Detect } \\
\text { frequency }\end{array}$} & \multirow[b]{2}{*}{$\underset{\text { detect }}{\text { Minimum }}$} & \multirow[b]{2}{*}{$\underset{\text { detect }}{\text { Maximum }}$} & \multirow[b]{2}{*}{$\begin{array}{l}\text { Location(s) of } \\
\text { maximum detect }\end{array}$} & \multirow{2}{*}{$\begin{array}{c}\text { Average } \\
\text { detected } \\
\text { result }\end{array}$} & \multicolumn{6}{|c|}{ Number of analyses exceeding criteria } \\
\hline & & & & & & $\begin{array}{c}\text { Max } \\
\text { RL }\end{array}$ & $\begin{array}{l}\text { Avg } \\
\text { RL }\end{array}$ & $\begin{array}{l}\text { Ind } \\
\text { PRG }\end{array}$ & Bkg & $\begin{array}{l}\text { GW } \\
\text { SL }\end{array}$ & $\begin{array}{l}\text { Res } \\
\text { PRG }\end{array}$ \\
\hline Cesium-137 & $2 / 12$ & 0.427 & 1.025 & RAD47 & 0.726 & 0 & 0 & 0 & NA & NA & 2 \\
\hline Neptunium-237 & $2 / 5$ & 0.1577 & 1.554 & RAD47 & 0.856 & 0 & 0 & 0 & NA & NA & 2 \\
\hline Potassium-40 & $1 / 4$ & 1.604 & 1.604 & RAD47 & 1.60 & NA & NA & 0 & 0 & NA & 1 \\
\hline Radium-226 & $1 / 3$ & 0.489 & 0.489 & Z2-EU41DB-218 & 0.489 & NA & NA & 1 & 0 & NA & 1 \\
\hline Technetium-99 & $18 / 20$ & $0.6 \mathrm{~J}$ & 61.81 & SS007 & 14.8 & NA & NA & 0 & NA & NA & 18 \\
\hline Thorium -232 & $1 / 3$ & 0.315 & 0.315 & Z2-EU41DB-218 & 0.315 & NA & NA & 1 & 0 & NA & 1 \\
\hline Thorium -234 & $2 / 4$ & 68.2 & 11,660 & RAD47 & 5864 & NA & NA & 0 & NA & NA & 1 \\
\hline Uranium-234 & $14 / 14$ & 0.831 & 2114 & RAD47 & 156 & 0 & 1 & 1 & NA & 1 & 5 \\
\hline
\end{tabular}


EU Z2-41 CONCRETE PAD CLASS 1 SU SOIL RADIONUCLIDES WITH

BACKGROUND, PRG, AND/OR RL EXCEEDANCES (pCi/g) 0-10 ft (cont'd)

\begin{tabular}{|c|c|c|c|c|c|c|c|c|c|c|c|}
\hline \multirow[b]{2}{*}{ Analyte } & \multirow[b]{2}{*}{$\begin{array}{c}\text { Detect } \\
\text { frequency }\end{array}$} & \multirow[b]{2}{*}{$\begin{array}{c}\text { Minimum } \\
\text { detect }\end{array}$} & \multirow[b]{2}{*}{$\begin{array}{l}\text { Maximum } \\
\text { detect }\end{array}$} & \multirow[b]{2}{*}{$\begin{array}{l}\text { Location(s) of } \\
\text { maximum detect }\end{array}$} & \multirow{2}{*}{$\begin{array}{c}\text { Average } \\
\text { detected } \\
\text { result }\end{array}$} & \multicolumn{6}{|c|}{ Number of analyses exceeding criteria } \\
\hline & & & & & & $\begin{array}{l}\text { Max } \\
\text { RL }\end{array}$ & $\begin{array}{c}\text { Avg } \\
\text { RL }\end{array}$ & $\begin{array}{l}\text { Ind } \\
\text { PRG }\end{array}$ & Bkg & $\begin{array}{c}\text { GW } \\
\text { SL }\end{array}$ & $\begin{array}{c}\text { Res } \\
\text { PRG }\end{array}$ \\
\hline Uranium-235 & $13 / 14$ & 0.01 & 242.2 & RAD47 & 19.0 & 1 & 1 & 1 & NA & 1 & 7 \\
\hline Uranium-238 & $14 / 14$ & $0.24 \mathrm{~J}$ & 15,670 & RAD47 & 1133 & 1 & 2 & 2 & 8 & 2 & 12 \\
\hline
\end{tabular}

\begin{tabular}{ll}
\hline Avg = average & $\mathrm{NA}=$ not applicable \\
$\mathrm{Bkg}=$ background & $\mathrm{PRG}=$ preliminary remediation goal \\
$\mathrm{EU}=$ exposure unit & Res = residential \\
$\mathrm{GW}=$ groundwater & $\mathrm{RL}=$ remediation level \\
$\mathrm{Ind}=$ industrial & $\mathrm{SL}=$ screening level \\
$\mathrm{Max}=$ maximum & $\mathrm{SU}=$ soil unit
\end{tabular}

EU Z2-41 CONCRETE PAD CLASS 1 SU SOIL SVOC DETECTS (ug/kg) 0-10 ft

\begin{tabular}{|c|c|c|c|c|c|c|c|c|}
\hline \multirow[b]{2}{*}{ Analyte } & \multirow[b]{2}{*}{$\begin{array}{c}\text { Detect } \\
\text { frequency }\end{array}$} & \multirow[b]{2}{*}{$\begin{array}{c}\text { Minimum } \\
\text { detect }\end{array}$} & \multirow[b]{2}{*}{$\begin{array}{c}\text { Maximum } \\
\text { detect }\end{array}$} & \multirow[b]{2}{*}{$\begin{array}{l}\text { Location(s) of } \\
\text { maximum detect }\end{array}$} & \multirow{2}{*}{$\begin{array}{c}\text { Average } \\
\text { detected } \\
\text { result }\end{array}$} & \multicolumn{3}{|c|}{$\begin{array}{c}\text { Number of analyses } \\
\text { exceeding criteria }\end{array}$} \\
\hline & & & & & & $\begin{array}{l}\text { Ind } \\
\text { PRG }\end{array}$ & $\begin{array}{l}\text { GW } \\
\text { SL }\end{array}$ & $\begin{array}{l}\text { Res } \\
\text { PRG }\end{array}$ \\
\hline 1,2,4-Trichlorobenzene & $4 / 20$ & 730 & 7300 & SS002 & 2800 & 0 & NA & 1 \\
\hline 1,2-Dichlorobenzene & $1 / 20$ & 720 & 720 & SS002 & 720 & 0 & NA & 0 \\
\hline 2-Methylnaphthalene & $4 / 19$ & $52 \mathrm{~J}$ & $100 \mathrm{~J}$ & SS002 & 76 & 0 & NA & NA \\
\hline 4-Methylphenol & $1 / 15$ & $63 \mathrm{~J}$ & $63 \mathrm{~J}$ & SS013 & 63 & 0 & NA & NA \\
\hline Acenaphthene & $3 / 19$ & $22 \mathrm{~J}$ & $70 \mathrm{~J}$ & SS004 & 44.3 & 0 & NA & 0 \\
\hline Anthracene & $3 / 19$ & $20 \mathrm{~J}$ & $54 \mathrm{~J}$ & SS014 & 42.3 & 0 & NA & 0 \\
\hline Benz(a)anthracene & $5 / 19$ & $42 \mathrm{~J}$ & $170 \mathrm{~J}$ & SS014 & 96 & 0 & NA & 0 \\
\hline Benzo(a)pyrene & $5 / 19$ & $32 \mathrm{~J}$ & $120 \mathrm{~J}$ & Z2-EU41DB-219 & 70.4 & 0 & NA & 2 \\
\hline Benzo(b)fluoranthene & $5 / 19$ & $40 \mathrm{~J}$ & $200 \mathrm{~J}$ & Z2-EU41DB-219 & 105 & 0 & NA & 0 \\
\hline Benzo(ghi)perylene & $2 / 19$ & $86 \mathrm{~J}$ & $120 \mathrm{~J}$ & SS015 & 103 & 0 & NA & 0 \\
\hline Benzo(k)fluoranthene & $4 / 19$ & $35 \mathrm{~J}$ & $140 \mathrm{~J}$ & SS014 & 75.3 & 0 & NA & 0 \\
\hline Bis(2-ethylhexyl)phthalate & $5 / 19$ & $2300 \mathrm{~J}$ & 37,000 & Z2-EU41DB-218 & 10,840 & 0 & 0 & 1 \\
\hline Butyl benzyl phthalate & $1 / 19$ & 680 & 680 & SS015 & 680 & 0 & NA & 0 \\
\hline Carbazole & $1 / 19$ & $34 \mathrm{~J}$ & $34 \mathrm{~J}$ & Z2-EU41DB-219 & 34 & 0 & NA & 0 \\
\hline Chrysene & $6 / 19$ & $33 \mathrm{~J}$ & $180 \mathrm{~J}$ & SS014 & 86.5 & 0 & NA & 0 \\
\hline Dibenzofuran & $1 / 19$ & $20 \mathrm{~J}$ & $20 \mathrm{~J}$ & SS002 & 20 & 0 & NA & 0 \\
\hline Diethyl phthalate & $2 / 19$ & $33 \mathrm{~J}$ & $66 \mathrm{~J}$ & SS015 & 49.5 & 0 & NA & 0 \\
\hline Dimethyl phthalate & $3 / 19$ & $51 \mathrm{~J}$ & $220 \mathrm{~J}$ & SS006 & 108 & 0 & NA & 0 \\
\hline Di-n-butyl phthalate & $1 / 19$ & 780 & 780 & Z2-EU41DB-210 & 780 & 0 & NA & 0 \\
\hline Di-n-octylphthalate & $3 / 19$ & $56 \mathrm{~J}$ & $310 \mathrm{~J}$ & SS004 & 145 & 0 & NA & 0 \\
\hline Fluoranthene & $9 / 19$ & $43 \mathrm{~J}$ & 430 & SS014 & 157 & 0 & NA & 0 \\
\hline Fluorene & $1 / 19$ & $29 \mathrm{~J}$ & $29 \mathrm{~J}$ & Z2-EU41DB-219 & 29 & 0 & NA & 0 \\
\hline Indeno(1,2,3-cd)pyrene & $2 / 19$ & $87 \mathrm{~J}$ & $96 \mathrm{~J}$ & SS015 & 91.5 & 0 & NA & 0 \\
\hline Phenanthrene & $8 / 19$ & $43 \mathrm{~J}$ & $300 \mathrm{~J}$ & SS014 & 126 & 0 & NA & 0 \\
\hline Phenol & $2 / 19$ & $65 \mathrm{~J}$ & $490 \mathrm{~J}$ & SS002 & 278 & 0 & NA & 0 \\
\hline Pyrene & $11 / 19$ & $53 \mathrm{~J}$ & 460 & SS014 & 154 & 0 & NA & 0 \\
\hline
\end{tabular}

$\mathrm{EU}=$ exposure unit $\quad$ Res $=$ residential

$\mathrm{GW}=$ groundwater $\quad \mathrm{SL}=$ screening level

Ind = industrial $\quad \mathrm{SU}=$ soil unit

$\mathrm{NA}=$ not applicable $\quad \mathrm{SVOC}=$ semivolatile organ ic compound

$\mathrm{PRG}=$ preliminary remediation goal

EU Z2-41 CONCRETE PAD CLASS 1 SU SOIL VOC DETECTS (ug/kg) 0-10 ft

\begin{tabular}{|c|c|c|c|c|c|c|c|c|}
\hline \multirow[b]{2}{*}{ Analyte } & \multirow[b]{2}{*}{$\begin{array}{c}\text { Detect } \\
\text { frequency }\end{array}$} & \multirow[b]{2}{*}{$\begin{array}{c}\text { Minimum } \\
\text { detect }\end{array}$} & \multirow[b]{2}{*}{$\begin{array}{c}\text { Maximum } \\
\text { detect }\end{array}$} & \multirow[b]{2}{*}{$\begin{array}{l}\text { Location(s) of } \\
\text { maximum detect }\end{array}$} & \multirow{2}{*}{$\begin{array}{c}\text { Average } \\
\text { detected } \\
\text { result }\end{array}$} & \multicolumn{3}{|c|}{$\begin{array}{c}\text { Number of analyses } \\
\text { exceeding criteria }\end{array}$} \\
\hline & & & & & & $\begin{array}{l}\text { Ind } \\
\text { PRG }\end{array}$ & $\begin{array}{c}\text { GW } \\
\text { SL }\end{array}$ & $\begin{array}{r}\text { Res } \\
\text { PRG }\end{array}$ \\
\hline 1,1,1-Trichloroethane & $1 / 16$ & 59 & 59 & SS007 & 59 & 0 & 0 & 0 \\
\hline $\begin{array}{l}\text { 1,1,2-Trichloro-1,2,2- } \\
\text { trifluoroethane }\end{array}$ & $4 / 16$ & $20 \mathrm{~J}$ & $1100 \mathrm{~J}$ & SS002 & 305 & 0 & NA & 0 \\
\hline 1,1-Dichloroethane & $2 / 16$ & $2 \mathrm{~J}$ & 130 & SS007 & 66 & 0 & NA & 0 \\
\hline 1,2-Dichloroethene & $9 / 15$ & 3 & 36,000 & SS002 & 4543 & 0 & NA & NA \\
\hline
\end{tabular}


EU Z2-41 CONCRETE PAD CLASS 1 SU SOIL VOC DETECTS (ug/kg) 0-10 ft (continued)

\begin{tabular}{ll}
\hline EU = exposure unit & Res = residential \\
GW = groundwater & SL = screening level \\
Ind = industrial & SU = soil unit \\
NA = not applicable & VOC = volatile organic compound \\
PRG = preliminary remediation goal &
\end{tabular}

EU Z2-41 RAD91 Class 1 SU: The RAD91 Class 1 SU is located in the K-1070-C/D Burial Ground FFA site (Sect. 2.2.6). This Class $1 \mathrm{SU}$ was created because of U-235 and U-238 Max RL exceedances as well as a U-234 Avg RL exceedance at historical sample location RAD91. There are two sample locations in the RAD91 Class 1 SU (Sect. 2.2.1), the original historical sample location (RAD91) and a DVS confirmation sample location (Z2-EU41D-100). A BAR survey was conducted (Sect.2.1.1.1) but did not detect radiation in excess of the AL, therefore, step-out sampling was not conducted. Only radiological analyses were performed because radionuclides were the only exceedances in RAD 91. Analytical results summarized below for this SU show that the Max RL, Avg RL, Ind PRG, and GW SL exceedances that occurred at historical location RAD91 were not confirmed by confirmation sampling. This result is consistent with the RAD91 Class 1 SU BAR survey results.

EU Z2-41 RAD91 CLASS 1 SU RADIONUCLIDES WITH BACKGROUND, PRG, AND/OR RL EXCEEDANCES (pCi/g) 0-10 ft

\begin{tabular}{|c|c|c|c|c|c|c|c|c|c|c|c|}
\hline \multirow[b]{2}{*}{ Analyte } & \multirow[b]{2}{*}{$\begin{array}{c}\text { Detect } \\
\text { frequency }\end{array}$} & \multirow[b]{2}{*}{$\begin{array}{c}\text { Minimum } \\
\text { detect }\end{array}$} & \multirow[b]{2}{*}{$\begin{array}{c}\text { Maximum } \\
\text { detect }\end{array}$} & \multirow[b]{2}{*}{$\begin{array}{c}\text { Location(s) of } \\
\text { maximum detect }\end{array}$} & \multirow{2}{*}{$\begin{array}{c}\text { Average } \\
\text { detected } \\
\text { result }\end{array}$} & \multicolumn{6}{|c|}{ Number of analyses exceeding criteria } \\
\hline & & & & & & $\begin{array}{c}\text { Max } \\
\text { RL }\end{array}$ & $\begin{array}{l}\text { Avg } \\
\text { RL }\end{array}$ & $\begin{array}{l}\text { Ind } \\
\text { PRG }\end{array}$ & Bkg & $\begin{array}{c}\text { GW } \\
\text { SL }\end{array}$ & $\begin{array}{c}\text { Res } \\
\text { PRG }\end{array}$ \\
\hline Cesium-137 & $1 / 2$ & 0.923 & 0.923 & RAD91 & 0.923 & 0 & 0 & 0 & NA & $\mathrm{NA}$ & 1 \\
\hline Neptunium-237 & $1 / 2$ & 0.4673 & 0.4673 & RAD91 & 0.467 & 0 & 0 & 0 & NA & NA & 1 \\
\hline Potassium-40 & $2 / 2$ & 7.57 & 48.47 & RAD91 & 28.0 & NA & NA & 2 & 1 & NA & 2 \\
\hline Technetium-99 & $1 / 2$ & 594 & 594 & RAD91 & 594 & NA & NA & 0 & NA & NA & 1 \\
\hline Thorium -234 & $1 / 2$ & 2570 & 2570 & RAD91 & 2570 & NA & NA & 0 & NA & NA & 1 \\
\hline Uranium-234 & $2 / 2$ & 1.13 & 2552 & RAD91 & 1277 & 0 & 1 & 1 & NA & 1 & 1 \\
\hline Uranium-235 & $2 / 2$ & 0.273 & 130.4 & RAD91 & 65.3 & 1 & 1 & 1 & NA & 1 & 2 \\
\hline Uranium-238 & $2 / 2$ & 0.6 & 2851 & RAD91 & 1426 & 1 & 1 & 1 & 1 & 1 & 1 \\
\hline $\begin{array}{l}\mathrm{Avg}=\text { average } \\
\mathrm{Bkg}=\text { background } \\
\mathrm{EU}=\text { exposure unit } \\
\mathrm{GW}=\text { groundwater } \\
\text { Ind = industrial } \\
\mathrm{Max}=\text { maximum }\end{array}$ & & $\begin{array}{l}\mathrm{NA}=\text { not ap } \\
\mathrm{PRG}=\text { preli } \\
\text { Res }=\text { reside } \\
\mathrm{RL}=\text { remed } \\
\mathrm{SL}=\text { screen } \\
\mathrm{SU}=\text { soil un }\end{array}$ & $\begin{array}{l}\text { pplicable } \\
\text { iminary reme } \\
\text { ential } \\
\text { liation level } \\
\text { ing level } \\
\text { nit }\end{array}$ & diation goal & & & & & & & \\
\hline
\end{tabular}

EU Z2-41 RAD122 Class 2 SU: The RAD122 Class 2 SU is located in the K-1070-C/D Burial Ground FFA site (Sect. 2.2.6). This Class 2 SU was created because of a Cs -137 Avg RL exceedance at the RAD122 historical sample location. There are two sample locations in this Class 2 SU (Sect. 2.2.1), the original historical sample location and a DVS confirmation sample location. A BAR survey was conducted (Sect.2.1.1.1) but did not detect radiation in excess of the AL therefore, step-out sampling was not conducted. Analytical results summarized below show the Avg RL exceedance that occurred at historical location RAD122 was not confirmed by confirmation sampling. This result is consistent with the RAD122 Class 2 SU BAR survey results. 
EU Z2-41 RAD122 CLASS 2 SU RADIONUCLIDES WITH BACKGROUND, PRG, AND/OR RL EXCEEDANCES (pCi/g) 0-10 ft

\begin{tabular}{|c|c|c|c|c|c|c|c|c|c|c|c|}
\hline \multirow[b]{2}{*}{ Analyte } & \multirow[b]{2}{*}{$\begin{array}{c}\text { Detect } \\
\text { frequency }\end{array}$} & \multirow[b]{2}{*}{$\begin{array}{c}\text { Minimum } \\
\text { detect }\end{array}$} & \multirow[b]{2}{*}{$\begin{array}{c}\text { Maximum } \\
\text { detect }\end{array}$} & \multirow[b]{2}{*}{$\begin{array}{l}\text { Location(s) of } \\
\text { maximum detect }\end{array}$} & \multirow{2}{*}{$\begin{array}{c}\text { Average } \\
\text { detected } \\
\text { result }\end{array}$} & \multicolumn{6}{|c|}{ Number of analyses exceeding criteria } \\
\hline & & & & & & $\begin{array}{c}\text { Max } \\
\text { RL }\end{array}$ & $\begin{array}{l}\text { Avg } \\
\text { RL }\end{array}$ & $\begin{array}{l}\text { Ind } \\
\text { PRG }\end{array}$ & Bkg & $\begin{array}{l}\text { GW } \\
\text { SL }\end{array}$ & $\begin{array}{l}\text { Res } \\
\text { PRG } \\
\end{array}$ \\
\hline Cesium-137 & $1 / 2$ & 5.87 & 5.87 & RAD122 & 5.87 & 0 & 1 & 1 & NA & NA & 1 \\
\hline Potassium-40 & $1 / 2$ & 2.439 & 2.439 & RAD122 & 2.44 & NA & NA & 0 & 0 & NA & 1 \\
\hline Uranium-235 & $1 / 2$ & 0.2014 & 0.2014 & RAD122 & 0.201 & 0 & 0 & 0 & NA & 0 & 1 \\
\hline Avg = average & & \multicolumn{10}{|c|}{$\mathrm{NA}=$ not applicable } \\
\hline $\mathrm{Bkg}=$ background & & \multirow{2}{*}{\multicolumn{10}{|c|}{ PRG = preliminary remediation goal }} \\
\hline $\mathrm{EU}=$ exposure unit & & \multicolumn{9}{|c|}{ Res $=$ residential } & \\
\hline $\mathrm{GW}=$ groundwater & & \multicolumn{10}{|c|}{$\mathrm{RL}=$ remediation level } \\
\hline Ind $=$ industrial & & \multicolumn{10}{|c|}{$\mathrm{SL}=$ screening level } \\
\hline Max $=$ maximum & & \multicolumn{10}{|c|}{$\mathrm{SU}=$ soil unit } \\
\hline
\end{tabular}

EU Z2-41 Z2-EU41DB-208 Class 2 SU: The Z2-EU41DB-208 Class 2 SU is located in the K-1070-C/D Burial Ground FFA site (Sect. 2.2.6). This Class 2 SU was created because U-235 and U-238 Avg RLs were exceeded at early characterization sample location Z2-EU41DB-208. These exceedances were followed up with eight additional early characterization sample locations that are presented in Sect.2.2.2. One of the additional locations is a few feet from the original Z2-EU41DB-208 location and was assigned the same location identifier. The remaining seven additional locations are step-out locations. A BAR survey was not conducted at this Class $2 \mathrm{SU}$ (Sect. 2.1.2.1). Analytical results summarized below for samples from all nine locations show that the Avg RL exceedances do not occur in any of the additional samples, although the U238 Ind PRG was exceeded at one step-out location (Z2-EU41DB-208-3). In addition to the U-238 Ind PRG exceedance, there are several other radionuclide Ind PRG exceedances; metal and radionuclide Bkg exceedances; and PCB, SVOC, and VOC detections.

EU Z2-41 Z2-EU41DB -208 CLASS 2 SU METALS WITH BACKGROUND, PRG, GW SL, AND/OR RL EXCEEDANCES (mg/kg) 0-10 ft

\begin{tabular}{|c|c|c|c|c|c|c|c|c|c|c|c|}
\hline \multirow[b]{2}{*}{ Analyte } & \multirow[b]{2}{*}{$\begin{array}{c}\text { Detect } \\
\text { frequency }\end{array}$} & \multirow[b]{2}{*}{$\begin{array}{c}\text { Minimum } \\
\text { detect }\end{array}$} & \multirow[b]{2}{*}{$\begin{array}{c}\text { Maximum } \\
\text { detect }\end{array}$} & \multirow[b]{2}{*}{$\begin{array}{c}\text { Location(s) of } \\
\text { maximum detect }\end{array}$} & \multirow{2}{*}{$\begin{array}{c}\text { Average } \\
\text { detected } \\
\text { result }\end{array}$} & \multicolumn{6}{|c|}{ Number of analyses exceeding criteria } \\
\hline & & & & & & $\begin{array}{c}\text { Max } \\
\text { RL }\end{array}$ & $\begin{array}{l}\text { Avg } \\
\text { RL }\end{array}$ & $\begin{array}{l}\text { Ind } \\
\text { PRG }\end{array}$ & Bkg & $\begin{array}{c}\text { GW } \\
\text { SL }\end{array}$ & $\begin{array}{l}\text { Res } \\
\text { PRG }\end{array}$ \\
\hline Aluminum & $7 / 7$ & 3500 & 16,000 & $\begin{array}{c}\text { Z2-EU41DB-208 } \\
\text { Z2-EU41DB-208-10 }\end{array}$ & 12,929 & NA & NA & 0 & 0 & NA & 6 \\
\hline Arsenic & $7 / 7$ & $2 \mathrm{~J}$ & $3.6 \mathrm{~J}$ & Z2EU41DB-208-10 & 2.77 & 0 & 0 & 0 & 0 & 0 & 7 \\
\hline Barium & $7 / 7$ & $30 \mathrm{~J}$ & $160 \mathrm{~J}$ & Z2-EU41DB-208-7 & 108 & NA & NA & 0 & 2 & 0 & 0 \\
\hline Cadmium & $7 / 7$ & 0.071 & $0.94 \mathrm{~J}$ & Z2-EU41DB-208 & 0.346 & NA & NA & 0 & 3 & NA & 0 \\
\hline Calcium & $7 / 7$ & $4100 \mathrm{~J}$ & 260,000 & Z2EU41DB-208-11 & 54,743 & NA & NA & NA & 7 & NA & NA \\
\hline Chromium & $7 / 7$ & $5.2 \mathrm{~J}$ & $44 \mathrm{~J}$ & Z2-EU41DB-208-4 & 30.6 & NA & NA & 0 & 0 & 0 & 6 \\
\hline Lithium & $7 / 7$ & 18 & 51 & Z2-EU41DB-208 & 26.3 & NA & NA & 0 & 1 & NA & 0 \\
\hline Magnesium & $7 / 7$ & $3300 \mathrm{~J}$ & $32,000 \mathrm{~J}$ & Z2EU41DB-208-11 & 9800 & NA & NA & NA & 6 & NA & NA \\
\hline Manganese & $7 / 7$ & $120 \mathrm{~J}$ & 610 & Z2-EU41DB-208-4 & 263 & NA & NA & 0 & 0 & NA & 3 \\
\hline Nickel & $7 / 7$ & $6.8 \mathrm{~J}$ & $41 \mathrm{~J}$ & Z2EU41DB-208-10 & 29.1 & NA & NA & 0 & 5 & NA & 0 \\
\hline Silver & $2 / 2$ & $0.083 \mathrm{~J}$ & $0.82 \mathrm{~J}$ & Z2-EU41DB-208 & 0.452 & NA & NA & 0 & 1 & NA & 0 \\
\hline Uranium & $5 / 5$ & 0.82 & 8 & Z2-EU41DB-208-4 & 5.06 & NA & NA & 0 & NA & NA & 4 \\
\hline Vanadium & $7 / 7$ & $7.4 \mathrm{~J}$ & $26 \mathrm{~J}$ & Z2EU41DB-208-10 & 19.8 & NA & NA & 0 & 0 & NA & 6 \\
\hline Zinc & $7 / 7$ & $21 \mathrm{~J}$ & $110 \mathrm{~J}$ & Z2-EU41DB-208 & 52.6 & NA & NA & 0 & 1 & NA & 0 \\
\hline
\end{tabular}

Avg $=$ average $\mathrm{NA}=$ not applicable

$\mathrm{Bkg}=$ background

$\mathrm{EU}=$ exposure unit

$\mathrm{GW}=$ groundwater

PRG $=$ preliminary remediation goal

Ind $=$ industrial

Res $=$ residential

$\mathrm{RL}=$ remediation level

Max $=$ maximum

$\mathrm{SL}=$ screening level

$\mathrm{SU}=$ soil unit 


\begin{tabular}{|c|c|c|c|c|c|c|c|c|c|}
\hline \multirow[b]{2}{*}{ Analyte } & \multirow[b]{2}{*}{$\begin{array}{c}\text { Detect } \\
\text { frequency }\end{array}$} & \multirow[b]{2}{*}{$\begin{array}{c}\text { Minimum } \\
\text { detect }\end{array}$} & \multirow[b]{2}{*}{$\begin{array}{c}\text { Maximum } \\
\text { detect }\end{array}$} & \multirow[b]{2}{*}{$\begin{array}{c}\text { Location(s) of } \\
\text { maximum detect }\end{array}$} & \multirow{2}{*}{$\begin{array}{c}\text { Average } \\
\text { detected } \\
\text { result }\end{array}$} & \multicolumn{4}{|c|}{$\begin{array}{c}\text { Number of analyses } \\
\text { exceeding criteria }\end{array}$} \\
\hline & & & & & & $\begin{array}{c}\text { Max } \\
\text { RL }\end{array}$ & $\begin{array}{l}\text { Avg } \\
\text { RL }\end{array}$ & $\begin{array}{c}\text { Ind } \\
\text { PRG }\end{array}$ & $\begin{array}{r}\text { Res } \\
\text { PRG } \\
\end{array}$ \\
\hline PCB-1254 & $6 / 7$ & $91 \mathrm{~J}$ & 240 & Z2-EU41DB-208-3 & 135 & 0 & 0 & 0 & 3 \\
\hline PCB-1260 & $1 / 6$ & $77 \mathrm{~J}$ & $77 \mathrm{~J}$ & Z2-EU41DB-208 & 77 & 0 & 0 & 0 & 0 \\
\hline Polychlorinated Biphenyl & $6 / 7$ & $97 \mathrm{~J}$ & 240 & Z2-EU41DB-208-3 & 148 & 0 & 0 & 0 & 4 \\
\hline
\end{tabular}

Avg = average $\quad$ PRG $=$ preliminary remediation goal

$\mathrm{EU}=$ exposure unit $\quad$ Res $=$ residential

Ind = industrial $\quad \mathrm{RL}=$ remediation level

Max = maximum $\quad \mathrm{SU}=$ soil unit

$\mathrm{PCB}=$ polychlorinated biphenyl

EU Z2-41 Z2 -EU41DB -208 CLASS 2 SU RADIONUCLIDES WITH BACKGROUND, PRG, AND/OR RL EXCEEDANCES (pCi/g) 0-10 ft

\begin{tabular}{|c|c|c|c|c|c|c|c|c|c|c|c|}
\hline \multirow[b]{2}{*}{ Analyte } & \multirow[b]{2}{*}{$\begin{array}{c}\text { Detect } \\
\text { frequency }\end{array}$} & \multirow[b]{2}{*}{$\begin{array}{c}\text { Minimum } \\
\text { detect }\end{array}$} & \multirow[b]{2}{*}{$\begin{array}{c}\text { Maximum } \\
\text { detect }\end{array}$} & \multirow[b]{2}{*}{$\begin{array}{c}\text { Location(s) of } \\
\text { maximum detect }\end{array}$} & \multirow{2}{*}{$\begin{array}{c}\text { Average } \\
\text { detected } \\
\text { result }\end{array}$} & \multicolumn{6}{|c|}{ Number of analyses exceeding criteria } \\
\hline & & & & & & $\begin{array}{c}\text { Max } \\
\text { RL }\end{array}$ & $\begin{array}{l}\text { Avg } \\
\text { RL }\end{array}$ & $\begin{array}{c}\text { Ind } \\
\text { PRG }\end{array}$ & Bkg & $\begin{array}{c}\text { GW } \\
\text { SL } \\
\end{array}$ & $\begin{array}{r}\text { Res } \\
\text { PRG } \\
\end{array}$ \\
\hline Radium-226 & $5 / 9$ & $0.215 \mathrm{~J}$ & 0.345 & Z2-EU41DB-208A & 0.282 & NA & NA & 4 & 0 & NA & 5 \\
\hline Thorium -228 & $2 / 9$ & 0.42 & 0.428 & Z2-EU41DB-208-3 & 0.424 & NA & NA & 2 & 0 & NA & 2 \\
\hline Thorium -232 & $5 / 9$ & 0.167 & 0.38 & Z2-EU41DB-208-7 & 0.234 & NA & NA & 4 & 0 & NA & 5 \\
\hline Uranium-234 & $9 / 9$ & 0.565 & $272 J$ & Z2-EU41DB-208 & 36.8 & 0 & 0 & 0 & NA & 1 & 4 \\
\hline Uranium-235 & $5 / 9$ & 0.083 & $11.2 \mathrm{~J}$ & Z2-EU41DB-208 & 2.88 & 0 & 1 & 1 & NA & 0 & 4 \\
\hline Uranium-238 & $9 / 9$ & 0.208 & $284 \mathrm{~J}$ & Z2-EU41DB-208 & 36.4 & 0 & 1 & 2 & 4 & 1 & 7 \\
\hline
\end{tabular}

Avg $=$ average $\quad$ NA $=$ not applicable

$\mathrm{Bkg}=$ background $\quad \mathrm{PRG}=$ preliminary remediation goal

$\mathrm{EU}=$ exposure unit $\quad$ Res $=$ residential

$\mathrm{GW}=$ groundwater $\quad \mathrm{RL}=$ remediation level

Ind $=$ industrial $\quad \mathrm{SL}=$ screening level

Max $=$ maximum $\quad \mathrm{SU}=$ soil unit

EU Z2-41 Z2-EU41DB -208 CLASS 2 SUSVOC DETECTS (ug/kg) 0-10 ft

\begin{tabular}{|c|c|c|c|c|c|c|c|c|}
\hline \multirow[b]{2}{*}{ Analyte } & \multirow[b]{2}{*}{$\begin{array}{c}\text { Detect } \\
\text { frequency }\end{array}$} & \multirow[b]{2}{*}{$\begin{array}{l}\text { Minimum } \\
\text { detect }\end{array}$} & \multirow[b]{2}{*}{$\underset{\text { detect }}{\text { Maximum }}$} & \multirow[b]{2}{*}{$\begin{array}{c}\text { Location(s) of } \\
\text { maximum detect }\end{array}$} & \multirow{2}{*}{$\begin{array}{c}\text { Average } \\
\text { detected } \\
\text { result }\end{array}$} & \multicolumn{3}{|c|}{$\begin{array}{c}\text { Number of analyses } \\
\text { exceeding criteria }\end{array}$} \\
\hline & & & & & & $\begin{array}{c}\text { Ind } \\
\text { PRG }\end{array}$ & $\begin{array}{c}\text { GW } \\
\text { SL }\end{array}$ & $\begin{array}{c}\text { Res } \\
\text { PRG }\end{array}$ \\
\hline$\overline{\text { Benz(a)anthracene }}$ & $3 / 7$ & $22 \mathrm{~J}$ & 36 & $\begin{array}{l}\text { Z2-EU41DB-208-4 } \\
\text { Z2-EU41DB-208-7 }\end{array}$ & 31.3 & 0 & NA & 0 \\
\hline Benzo(a)pyrene & $3 / 7$ & $19 \mathrm{~J}$ & $30 \mathrm{~J}$ & Z2-EU41DB-208-7 & 26 & 0 & NA & 0 \\
\hline Benzo(b)fluoranthene & $2 / 7$ & $36 \mathrm{~J}$ & $40 \mathrm{~J}$ & Z2-EU41DB-208-7 & 38 & 0 & NA & 0 \\
\hline Bis(2-ethylhexyl)phthalate & $1 / 6$ & 470 & 470 & Z2-EU41DB-208-3 & 470 & 0 & 0 & 0 \\
\hline Butyl benzyl phthalate & $2 / 6$ & $22 \mathrm{~J}$ & $62 \mathrm{~J}$ & Z2-EU41DB-208-3 & 42 & 0 & NA & 0 \\
\hline Chrysene & $3 / 7$ & $25 \mathrm{~J}$ & $32 \mathrm{~J}$ & Z2-EU41DB-208-7 & 27.7 & 0 & NA & 0 \\
\hline Di-n-butyl phthalate & $1 / 7$ & $92 \mathrm{~J}$ & $92 \mathrm{~J}$ & Z2-EU41DB-208-3 & 92 & 0 & NA & 0 \\
\hline Fluoranthene & $2 / 7$ & $89 \mathrm{~J}$ & $93 \mathrm{~J}$ & Z2-EU41DB-208-7 & 91 & 0 & NA & 0 \\
\hline Phenanthrene & $2 / 7$ & $49 \mathrm{~J}$ & $86 \mathrm{~J}$ & Z2-EU41DB-208-4 & 67.5 & 0 & NA & 0 \\
\hline Pyrene & $3 / 7$ & 60 & $85 \mathrm{~J}$ & Z2EU41DB-208-11 & 68.3 & 0 & NA & 0 \\
\hline $\begin{array}{l}\text { EU = exposure unit } \\
\text { GW = groundwater } \\
\text { Ind = industrial } \\
\text { NA = not applicable } \\
\text { PRG = preliminary remedia }\end{array}$ & tion goal & \multicolumn{7}{|c|}{$\begin{array}{l}\text { Res = residential } \\
\text { SL = screening level } \\
\text { SU = soil unit } \\
\text { SVOC = semivolatile organic compound }\end{array}$} \\
\hline
\end{tabular}


EU Z2-41 Z2-EU41DB -208 CLASS 2 SU VOC DETECTS (ug/kg) 0-10 ft

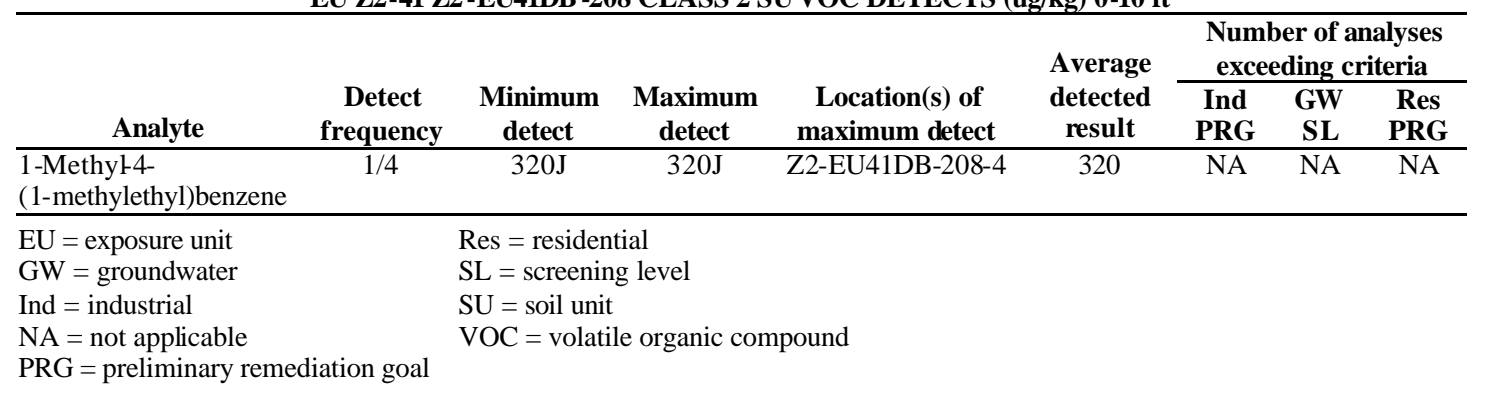

EU Z2-41 DVS Sampling at the Soil Mounds: A DVS biased sample location (Z2-EU41DB-242) was selected at the soil mounds anthropogenic feature identified during the Class $3 \mathrm{SU}$ walkover assessment of EU Z2-41 (Sect. 2.1.3.4). The soil mounds and associated sample location are located in the K-1070-C/D Burial Ground FFA site (Sect. 2.2.6). Analytical results summarized below for the soil mounds sample show one radionuclide Ind PRG exceedance and several metal Bkg exceedances.

EU Z2-41 SOIL MOUNDS SAMPLING METALS WITH BACKGROUND, PRG, GW SL, AND/OR RL EXCEEDANCES (mg/kg) 0-10 ft

\begin{tabular}{|c|c|c|c|c|c|c|c|c|c|c|c|}
\hline \multirow[b]{2}{*}{ Analyte } & \multirow[b]{2}{*}{$\begin{array}{c}\text { Detect } \\
\text { frequency }\end{array}$} & \multirow[b]{2}{*}{$\begin{array}{c}\text { Minimum } \\
\text { detect }\end{array}$} & \multirow[b]{2}{*}{$\begin{array}{c}\text { Maximum } \\
\text { detect }\end{array}$} & \multirow[b]{2}{*}{$\begin{array}{c}\text { Location(s) of } \\
\text { maximum detect }\end{array}$} & \multirow{2}{*}{$\begin{array}{c}\text { Average } \\
\text { detected } \\
\text { result }\end{array}$} & \multicolumn{6}{|c|}{ Number of analyses exceeding criteria } \\
\hline & & & & & & $\begin{array}{l}\text { Max } \\
\text { RL }\end{array}$ & $\begin{array}{l}\text { Avg } \\
\text { RL }\end{array}$ & $\begin{array}{l}\text { Ind } \\
\text { PRG }\end{array}$ & Bkg & $\begin{array}{c}\text { GW } \\
\text { SL }\end{array}$ & $\begin{array}{c}\text { Res } \\
\text { PRG }\end{array}$ \\
\hline Aluminum & $1 / 1$ & 16,000 & 16,000 & Z2-EU41DB-242 & 16,000 & NA & NA & 0 & 0 & NA & 1 \\
\hline Arsenic & $1 / 1$ & 6.6 & 6.6 & Z2-EU41DB-242 & 6.6 & 0 & 0 & 0 & 0 & 0 & 1 \\
\hline Barium & $1 / 1$ & 180 & 180 & Z2-EU41DB-242 & 180 & NA & NA & 0 & 1 & 0 & 0 \\
\hline Chromium & $1 / 1$ & $27 \mathrm{~J}$ & $27 \mathrm{~J}$ & Z2-EU41DB-242 & 27 & NA & NA & 0 & 0 & 0 & 1 \\
\hline Copper & $1 / 1$ & $35 \mathrm{~J}$ & $35 \mathrm{~J}$ & Z2-EU41DB-242 & 35 & NA & NA & 0 & 1 & NA & 0 \\
\hline Manganese & $1 / 1$ & $770 \mathrm{~J}$ & $770 \mathrm{~J}$ & Z2-EU41DB-242 & 770 & NA & NA & 0 & 0 & NA & 1 \\
\hline Nickel & $1 / 1$ & $110 \mathrm{~J}$ & $110 \mathrm{~J}$ & Z2-EU41DB-242 & 110 & NA & NA & 0 & 1 & NA & 0 \\
\hline Vanadium & $1 / 1$ & 30 & 30 & Z2-EU41DB-242 & 30 & NA & NA & 0 & 0 & NA & 1 \\
\hline
\end{tabular}

Avg = average $\quad$ NA $=$ not applicable

$\mathrm{Bkg}=$ background $\quad \mathrm{PRG}=$ preliminary remediation goal

$\mathrm{EU}=$ exposure unit $\quad$ Res $=$ residential

$\mathrm{GW}=$ groundwater $\quad \mathrm{RL}=$ remediation level

Ind = industrial $\quad \mathrm{SL}=$ screening level

Max $=$ maximum $\quad \mathrm{SU}=$ soil unit

PCBs were analyzed for in the sample but were not detected.

EU Z2-41 SOIL MOUNDS SAMPLING RADIONUCLIDES WITH BACKGROUND, PRG, AND/OR RL EXCEEDANCES (pCi/g) 0-10 ft

\begin{tabular}{|c|c|c|c|c|c|c|c|c|c|c|c|}
\hline \multirow[b]{2}{*}{ Analyte } & \multirow[b]{2}{*}{$\begin{array}{l}\text { Detect } \\
\text { frequency }\end{array}$} & \multirow[b]{2}{*}{$\underset{\text { detect }}{\text { Minimum }}$} & \multirow[b]{2}{*}{$\underset{\text { detect }}{\text { Maximum }}$} & \multirow[b]{2}{*}{$\begin{array}{l}\text { Location(s) of } \\
\text { maximum detect }\end{array}$} & \multirow{2}{*}{$\begin{array}{c}\text { Average } \\
\text { detected } \\
\text { result }\end{array}$} & \multicolumn{6}{|c|}{ Number of analyses exceeding criteria } \\
\hline & & & & & & $\begin{array}{c}\text { Max } \\
\text { RL }\end{array}$ & $\begin{array}{l}\text { Avg } \\
\text { RL }\end{array}$ & $\begin{array}{c}\text { Ind } \\
\text { PRG }\end{array}$ & Bkg & $\begin{array}{l}\text { GW } \\
\text { SL }\end{array}$ & $\begin{array}{l}\text { Res } \\
\text { PRG }\end{array}$ \\
\hline Radium-226 & $1 / 1$ & 0.535 & 0.535 & Z2-EU41DB-242 & 0.535 & NA & NA & 1 & 0 & NA & 1 \\
\hline \multicolumn{2}{|l|}{ Avg $=$ average } & \multicolumn{3}{|c|}{ NA $=$ not applicable } & & & & & & & \\
\hline \multicolumn{2}{|c|}{$\mathrm{Bkg}=$ background } & \multicolumn{3}{|c|}{$\mathrm{PRG}=$ preliminary remediation goal } & & & & & & & \\
\hline \multirow{2}{*}{\multicolumn{2}{|c|}{$\begin{array}{l}\mathrm{EU}=\text { exposure unit } \\
\mathrm{GW}=\text { groundwater }\end{array}$}} & \multicolumn{3}{|c|}{ Res $=$ residential } & & & & & & & \\
\hline & & \multicolumn{3}{|c|}{$\mathrm{RL}=$ remediation level } & & & & & & & \\
\hline \multicolumn{2}{|c|}{ Ind $=$ industrial } & $\mathrm{SL}=$ scre & ening level & & & & & & & & \\
\hline \multicolumn{2}{|c|}{ Max $=$ maximum } & $\mathrm{SU}=$ soil & unit & & & & & & & & \\
\hline
\end{tabular}

SVOCs were analyzed for in the sample but were not detected.

EU Z2-41 DVS Sediment Accumulation Area Sampling: Four DVS biased sample locations (Z2-EU41DB-238, Z2-EU41DB-239, Z2-EU41DB-240, and Z2-EU41DB-241) were selected to characterize the four sediment accumulation areas identified during the Class 3 SU walkover assessment of EU Z2-41 (Sect. 2.1.3.4). All four sediment accumulation areas are either located in the K-1070-C/D Burial Ground FFA site (Sect. 2.2.6) or receive 
drainage from the site. Analytical results summarized below for the four sediment accumulation area samples show radionuclide Ind PRG exceedances, metals Bkg exceedances, and SVOC detections.

EU Z2-41 SEDIMENT ACCUMULATION AREAS SAMPLING METALS WITH BACKGROUND, PRG, GW SL, AND/OR RL EXCEEDANCES (mg/kg) 0-10 ft

\begin{tabular}{|c|c|c|c|c|c|c|c|c|c|c|c|}
\hline \multirow[b]{2}{*}{ Analyte } & \multirow[b]{2}{*}{$\begin{array}{c}\text { Detect } \\
\text { frequency }\end{array}$} & \multirow[b]{2}{*}{$\underset{\text { detect }}{\text { Minimum }}$} & \multirow[b]{2}{*}{$\underset{\text { detect }}{\text { Maximum }}$} & \multirow[b]{2}{*}{$\begin{array}{l}\text { Location(s) of } \\
\text { maximum detect }\end{array}$} & \multirow{2}{*}{$\begin{array}{c}\text { Average } \\
\text { detected } \\
\text { result }\end{array}$} & \multicolumn{6}{|c|}{ Number of analyses exceeding criteria } \\
\hline & & & & & & $\begin{array}{c}\text { Max } \\
\text { RL }\end{array}$ & $\begin{array}{c}\text { Avg } \\
\text { RL }\end{array}$ & $\begin{array}{l}\text { Ind } \\
\text { PRG }\end{array}$ & Bkg & $\begin{array}{c}\text { GW } \\
\text { SL }\end{array}$ & $\begin{array}{l}\text { Res } \\
\text { PRG }\end{array}$ \\
\hline Aluminum & $4 / 4$ & 11,000 & 19,000 & Z2-EU41DB-240 & 14,750 & NA & NA & 0 & 0 & NA & 4 \\
\hline Arsenic & $4 / 4$ & 2.9 & 7 & Z2-EU41DB-240 & 4.1 & 0 & 0 & 0 & 0 & 0 & 4 \\
\hline Barium & $4 / 4$ & 62 & 130 & Z2-EU41DB-240 & 89.8 & NA & NA & 0 & 1 & 0 & 0 \\
\hline Calcium & $4 / 4$ & 710 & 40,000 & Z2-EU41DB-238 & 13,900 & NA & NA & NA & 2 & NA & NA \\
\hline Chromium & $4 / 4$ & $17 \mathrm{~J}$ & $34 \mathrm{~J}$ & Z2-EU41DB-240 & 24.8 & NA & NA & 0 & 0 & 0 & 2 \\
\hline Copper & $4 / 4$ & $19 \mathrm{~J}$ & $130 \mathrm{~J}$ & Z2-EU41DB-240 & 49.8 & NA & NA & 0 & 2 & NA & 0 \\
\hline Magnesium & $4 / 4$ & $1700 \mathrm{~J}$ & $5500 \mathrm{~J}$ & Z2-EU41DB-238 & 3625 & NA & NA & NA & 2 & NA & NA \\
\hline Manganese & $4 / 4$ & $310 \mathrm{~J}$ & $810 \mathrm{~J}$ & Z2-EU41DB-240 & 495 & NA & NA & 0 & 0 & NA & 4 \\
\hline Nickel & $4 / 4$ & $25 \mathrm{~J}$ & $210 \mathrm{~J}$ & Z2-EU41DB-240 & 73.5 & NA & NA & 0 & 3 & NA & 1 \\
\hline Uranium & $4 / 4$ & $0.71 \mathrm{~J}$ & $3.8 \mathrm{~J}$ & Z2-EU41DB-239 & 1.94 & NA & NA & 0 & NA & NA & 2 \\
\hline Vanadium & $4 / 4$ & 20 & 28 & Z2-EU41DB-241 & 24 & NA & NA & 0 & 0 & NA & 4 \\
\hline
\end{tabular}

Avg $=$ average NA $=$ not applicable

$\mathrm{Bkg}=$ background $\quad \mathrm{PRG}=$ preliminary remediation goal

$\mathrm{EU}=$ exposure unit $\quad$ Res $=$ residential

$\mathrm{GW}=$ groundwater $\quad \mathrm{RL}=$ remediation level

Ind $=$ industrial $\quad$ SL $=$ screening level

Max $=$ maximum $\quad \mathrm{SU}=$ soil unit

PCBs were analyzed for in the sample but were not detected.

EU Z2-41 SEDIMENT ACCUMULATION AREAS SAMPLING RADIONUCLIDES WITH

BACKGROUND, PRG, AND/OR RL EXCEEDANCES (pCi/g) 0-10 ft

\begin{tabular}{|c|c|c|c|c|c|c|c|c|c|c|c|}
\hline \multirow[b]{2}{*}{ Analyte } & \multirow[b]{2}{*}{$\begin{array}{c}\text { Detect } \\
\text { frequency }\end{array}$} & \multirow[b]{2}{*}{$\begin{array}{c}\text { Minimum } \\
\text { detect }\end{array}$} & \multirow[b]{2}{*}{$\begin{array}{c}\text { Maximum } \\
\text { detect }\end{array}$} & \multirow[b]{2}{*}{$\begin{array}{c}\text { Location(s) of } \\
\text { maximum detect }\end{array}$} & \multirow{2}{*}{$\begin{array}{c}\text { Average } \\
\text { detecte d } \\
\text { result }\end{array}$} & \multicolumn{6}{|c|}{ Number of analyses exceeding criteria } \\
\hline & & & & & & $\begin{array}{c}\text { Max } \\
\text { RL }\end{array}$ & $\begin{array}{c}\text { Avg } \\
\text { RL }\end{array}$ & $\begin{array}{l}\text { Ind } \\
\text { PRG }\end{array}$ & Bkg & $\begin{array}{l}\text { GW } \\
\text { SL }\end{array}$ & $\begin{array}{r}\text { Res } \\
\text { PRG }\end{array}$ \\
\hline Radium-226 & $3 / 4$ & 0.305 & 0.476 & Z2-EU41DB-239 & 0.372 & NA & NA & 3 & 0 & NA & 3 \\
\hline Thorium -232 & $1 / 4$ & 0.254 & 0.254 & Z2-EU41DB-241 & 0.254 & NA & NA & 1 & 0 & NA & 1 \\
\hline Uranium-235 & $1 / 4$ & 0.201 & 0.201 & Z2-EU41DB-240 & 0.201 & 0 & 0 & 0 & NA & 0 & 1 \\
\hline Uranium-238 & $3 / 4$ & 0.35 & 0.769 & Z2-EU41DB-240 & 0.573 & 0 & 0 & 0 & 0 & 0 & 1 \\
\hline
\end{tabular}

Avg $=$ average

$\mathrm{Bkg}=$ background

$\mathrm{EU}=$ exposure unit

$\mathrm{GW}=$ groundwater

Ind $=$ industrial

Max = maximum
$\mathrm{NA}=$ not applicable

$\mathrm{PRG}=$ preliminary remediation goal

Res $=$ residential

$\mathrm{RL}=$ remediation level

$\mathrm{SL}=$ screening level

EU Z2-41 SEDIMENT ACCUMULATION AREAS SAMPLING SVOC DETECTS (ug/kg) 0-10 ft

\begin{tabular}{|c|c|c|c|c|c|c|c|c|}
\hline \multirow[b]{2}{*}{ Analyte } & \multirow[b]{2}{*}{$\begin{array}{c}\text { Detect } \\
\text { frequency }\end{array}$} & \multirow[b]{2}{*}{$\begin{array}{c}\text { Minimum } \\
\text { detect }\end{array}$} & \multirow[b]{2}{*}{$\begin{array}{c}\text { Maximum } \\
\text { detect }\end{array}$} & \multirow[b]{2}{*}{$\begin{array}{c}\text { Location(s) of } \\
\text { maximum detect }\end{array}$} & \multirow{2}{*}{$\begin{array}{c}\text { Average } \\
\text { detected } \\
\text { result }\end{array}$} & \multicolumn{3}{|c|}{$\begin{array}{l}\text { Number of analyses } \\
\text { exceeding criteria }\end{array}$} \\
\hline & & & & & & $\begin{array}{l}\text { Ind } \\
\text { PRG }\end{array}$ & $\begin{array}{l}\text { GW } \\
\text { SL }\end{array}$ & $\begin{array}{l}\text { Res } \\
\text { PRG }\end{array}$ \\
\hline Benz(a)anthracene & $1 / 4$ & $78 \mathrm{~J}$ & $78 \mathrm{~J}$ & Z2-EU41DB-238 & 78 & 0 & NA & 0 \\
\hline Benzo(a)pyrene & $2 / 4$ & $20 \mathrm{~J}$ & $74 \mathrm{~J}$ & Z2-EU41DB-238 & 47 & 0 & NA & 1 \\
\hline Benzo(b)fluoranthene & $2 / 4$ & $30 \mathrm{~J}$ & $110 \mathrm{~J}$ & Z2-EU41DB-238 & 70 & 0 & NA & 0 \\
\hline Benzo(ghi)perylene & $1 / 4$ & $89 \mathrm{~J}$ & $89 \mathrm{~J}$ & Z2-EU41DB-238 & 89 & 0 & NA & 0 \\
\hline Benzo(k)fluoranthene & $1 / 4$ & $35 \mathrm{~J}$ & $35 \mathrm{~J}$ & Z2-EU41DB-238 & 35 & 0 & NA & 0 \\
\hline Bis(2-ethylhexyl)phthalate & $3 / 4$ & 150 & $170 \mathrm{~J}$ & Z2-EU41DB-239 & 157 & 0 & 0 & 0 \\
\hline Butyl benzyl phthalate & $1 / 4$ & $41 \mathrm{~J}$ & $41 \mathrm{~J}$ & Z2-EU41DB-238 & 41 & 0 & NA & 0 \\
\hline Chrysene & $1 / 4$ & $71 \mathrm{~J}$ & $71 \mathrm{~J}$ & Z2-EU41DB-238 & 71 & 0 & NA & 0 \\
\hline Diethyl phthalate & $1 / 4$ & $50 \mathrm{~J}$ & $50 \mathrm{~J}$ & Z2-EU41DB-239 & 50 & 0 & NA & 0 \\
\hline Fluoranthene & $1 / 4$ & $160 \mathrm{~J}$ & $160 \mathrm{~J}$ & Z2-EU41DB-238 & 160 & 0 & NA & 0 \\
\hline
\end{tabular}




\begin{tabular}{|c|c|c|c|c|c|c|c|c|}
\hline \multirow[b]{2}{*}{ Analyte } & \multirow[b]{2}{*}{$\begin{array}{c}\text { Detect } \\
\text { frequency }\end{array}$} & \multirow[b]{2}{*}{$\begin{array}{c}\text { Minimum } \\
\text { detect }\end{array}$} & \multirow[b]{2}{*}{$\begin{array}{c}\text { Maximum } \\
\text { detect }\end{array}$} & \multirow[b]{2}{*}{$\begin{array}{l}\text { Location(s) of } \\
\text { maximum detect }\end{array}$} & \multirow{2}{*}{$\begin{array}{c}\text { Average } \\
\text { detected } \\
\text { result }\end{array}$} & \multicolumn{3}{|c|}{$\begin{array}{l}\text { Number of analyses } \\
\text { exceeding criteria }\end{array}$} \\
\hline & & & & & & $\begin{array}{l}\text { Ind } \\
\text { PRG }\end{array}$ & $\begin{array}{l}\text { GW } \\
\text { SL }\end{array}$ & $\begin{array}{l}\text { Res } \\
\text { PRG }\end{array}$ \\
\hline Indeno(1,2,3-cd)pyrene & $1 / 4$ & $63 \mathrm{~J}$ & $63 \mathrm{~J}$ & Z2-EU41DB-238 & 63 & 0 & NA & 0 \\
\hline Phenanthrene & $1 / 4$ & $68 \mathrm{~J}$ & $68 \mathrm{~J}$ & Z2-EU41DB-238 & 68 & 0 & NA & 0 \\
\hline Pyrene & $1 / 4$ & $330 \mathrm{~J}$ & $330 \mathrm{~J}$ & Z2-EU41DB-238 & 330 & 0 & NA & 0 \\
\hline
\end{tabular}

$\mathrm{EU}=$ exposure unit $\quad \mathrm{PRG}=$ preliminary remediation goal

$\mathrm{GW}=$ groundwater $\quad$ Res $=$ residential

Ind $=$ industrial $\quad$ SL $=$ screening level

$\mathrm{NA}=$ not applicable $\quad \mathrm{SVOC}=$ semivolatile organic compound

EU Z2-41 Other Historical Sampling: There are 24 historical sample locations in EU Z2-41 that are not included in the focused summaries above or the FFA site summaries in Sect. 2.2.6; these locations are presented in Sect. 2.2.3 as "Other Historical Locations". Analytical results summarized below show one metal and several radionuclide Ind PRG exceedances, metal and radionuclide Bkg exceedances, and PCB, SVOC, and VOC detects.

EU Z2-41 OTHER HISTORICAL SAMPLES METALS WITH BACKGROUND, PRG, GW SL, AND/OR RL EXCEEDANCES (mg/kg) 0-10 ft

\begin{tabular}{|c|c|c|c|c|c|c|c|c|c|c|c|}
\hline \multirow[b]{2}{*}{ Analyte } & \multirow[b]{2}{*}{$\begin{array}{c}\text { Detect } \\
\text { frequency }\end{array}$} & \multirow[b]{2}{*}{$\underset{\text { detect }}{\text { Minimum }}$} & \multirow[b]{2}{*}{$\begin{array}{c}\text { Maximum } \\
\text { detect }\end{array}$} & \multirow[b]{2}{*}{$\begin{array}{c}\text { Location(s) of } \\
\text { maximum detect }\end{array}$} & \multirow{2}{*}{$\begin{array}{l}\text { Average } \\
\text { detected } \\
\text { result }\end{array}$} & \multicolumn{6}{|c|}{ Number of analyses exceeding criteria } \\
\hline & & & & & & $\begin{array}{c}\text { Max } \\
\text { RL }\end{array}$ & $\begin{array}{l}\text { Avg } \\
\text { RL }\end{array}$ & $\begin{array}{l}\text { Ind } \\
\text { PRG }\end{array}$ & Bkg & $\begin{array}{l}\text { GW } \\
\text { SL }\end{array}$ & $\begin{array}{l}\text { Res } \\
\text { PRG }\end{array}$ \\
\hline Aluminum & $15 / 15$ & 4790 & 28,000 & SB073 & 15,615 & NA & NA & 0 & 0 & NA & 13 \\
\hline Arsenic & $15 / 15$ & $2.1 \mathrm{~J}$ & $49 \mathrm{~J}$ & SD002 & 9.07 & 0 & 0 & 1 & 1 & 0 & 15 \\
\hline Barium & $15 / 15$ & 38.4 & 224 & SD017 & 110 & NA & NA & 0 & 4 & 0 & 0 \\
\hline Cadmium & $3 / 15$ & 0.24 & 0.61 & SD017 & 0.377 & NA & NA & 0 & 3 & NA & 0 \\
\hline Calcium & $15 / 15$ & 27 & 7300 & SD001 & 1351 & NA & NA & NA & 3 & NA & NA \\
\hline Chromium & $15 / 15$ & 9.7 & 37.3 & SB033 & 21.5 & NA & NA & 0 & 0 & 0 & 6 \\
\hline Copper & $15 / 15$ & 12 & $54.6 \mathrm{~J}$ & SD002 & 25.5 & NA & NA & 0 & 7 & NA & 0 \\
\hline Iron & $15 / 15$ & 6590 & 36,400 & SB077 & 22,799 & NA & NA & 0 & 0 & NA & 15 \\
\hline Lead & $15 / 15$ & $3.3 \mathrm{~J}$ & 64.8 & SB073 & 17.1 & NA & NA & 0 & 1 & 0 & 0 \\
\hline Magnesium & $15 / 15$ & 684 & 4950 & SB073 & 2043 & NA & NA & NA & 3 & NA & NA \\
\hline Manganese & $15 / 15$ & 29.3 & 1490 & SB073 & 391 & NA & NA & 0 & 0 & NA & 8 \\
\hline Nickel & $15 / 15$ & 6.6 & 222 & SD002 & 42.6 & NA & NA & 0 & 6 & NA & 1 \\
\hline Selenium & $9 / 14$ & 0.34 & $3.6 \mathrm{~J}$ & SB033 & 1.5 & NA & NA & 0 & 4 & NA & 0 \\
\hline Silver & $12 / 15$ & 0.57 & 2.1 & SB077 & 1.32 & NA & NA & 0 & 11 & NA & 0 \\
\hline Thallium & $3 / 15$ & 0.3 & 0.43 & SD017 & 0.347 & NA & NA & 0 & 1 & 0 & 0 \\
\hline Vanadium & $15 / 15$ & 11.1 & 47.5 & SB077 & 24.8 & NA & NA & 0 & 0 & NA & 15 \\
\hline Zinc & $15 / 15$ & 12.9 & $147 \mathrm{~J}$ & SB073 & 40.7 & NA & NA & 0 & 1 & NA & 0 \\
\hline
\end{tabular}

Avg $=$ average NA $=$ not applicable

$\mathrm{Bkg}=$ background $\quad \mathrm{PRG}=$ preliminary remediation goal

$\mathrm{EU}=$ exposure unit $\quad$ Res $=$ residential

$\mathrm{GW}=$ groundwater $\quad \mathrm{RL}=$ remediation level

Ind $=$ industrial $\quad \mathrm{SL}=$ screening level

Max $=$ maximum

EU Z2-41 OTHER HISTORICAL SAMPLES PPCB DETECTS (ug/kg) 0-10 ft

\begin{tabular}{|c|c|c|c|c|c|c|c|c|c|}
\hline \multirow[b]{2}{*}{ Analyte } & \multirow[b]{2}{*}{$\begin{array}{c}\text { Detect } \\
\text { frequency }\end{array}$} & \multirow[b]{2}{*}{$\begin{array}{c}\text { Minimum } \\
\text { detect }\end{array}$} & \multirow[b]{2}{*}{$\begin{array}{c}\text { Maximum } \\
\text { detect }\end{array}$} & \multirow[b]{2}{*}{$\begin{array}{c}\text { Location(s) of } \\
\text { maximum detect }\end{array}$} & \multirow{2}{*}{$\begin{array}{c}\text { Average } \\
\text { detected } \\
\text { result }\end{array}$} & \multicolumn{4}{|c|}{$\begin{array}{l}\text { Number of analyses } \\
\text { exceeding criteria }\end{array}$} \\
\hline & & & & & & $\begin{array}{l}\text { Max } \\
\text { RL }\end{array}$ & $\begin{array}{l}\text { Avg } \\
\text { RL }\end{array}$ & $\begin{array}{l}\text { Ind } \\
\text { PRG }\end{array}$ & $\begin{array}{l}\text { Res } \\
\text { PRG }\end{array}$ \\
\hline PCB-1248 & $1 / 9$ & $450 \mathrm{~J}$ & $450 \mathrm{~J}$ & SB074 & 450 & 0 & 0 & 0 & 1 \\
\hline $\begin{array}{l}\text { Avg = average } \\
\text { EU = exposure unit } \\
\text { Ind = industrial } \\
\text { Max = maximum }\end{array}$ & $\begin{array}{l}\mathrm{PPCB}= \\
\mathrm{PRG}=\mathrm{p} \\
\mathrm{Res}=\mathrm{re} \\
\mathrm{RL}=\text { ren }\end{array}$ & $\begin{array}{l}\text { esticides an } \\
\text { eliminary re } \\
\text { idential } \\
\text { ediation leve }\end{array}$ & $\begin{array}{l}\mathrm{d} \text { polychlorin } \\
\text { mediation go }\end{array}$ & ted biphenyl & & & & & \\
\hline
\end{tabular}




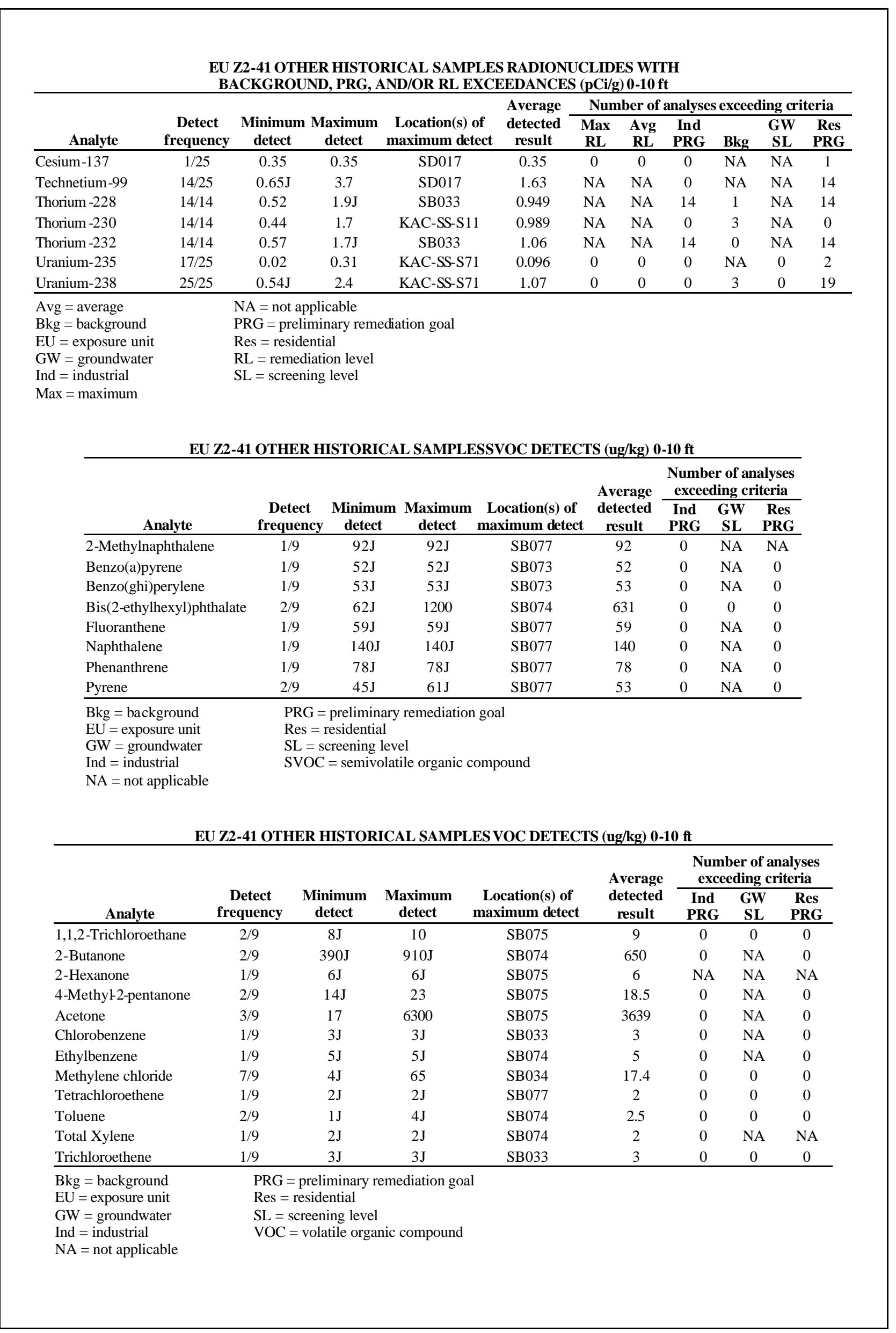


EU Z2-41 Soils Summary: This section presents a summary of the nature and extent of contamination in EU Z2-41 soil by combining all of the analytical data for the EU that are presented in the focused investigation summaries above and the FFA site summaries in Sect. 2.2.6. There are 176 soil sample locations with samples collected from between 0-10 ft bgs in this EU-eight DVS and 168 historical locations. The details of sampling and analysis are presented in Table I.2 and sample locations are shown in Fig. I.4.

During the K-1070-C/D Phase 2 RI, VOCs were analyzed for by means of field gas chromatography (GC) in several samples from sample locations prefixed with "SB". Samples from all of the same sample locations were also sent to a fixed laboratory for VOC analysis. In most cases, samples sent to the fixed laboratory were collected from the same sample depth interval as the samples analyzed by the field GC. Because the field GC analyses were not conducted with the same quality control procedures obtained from a fixed laboratory, the resulting data are not evaluated in this section or in Sect. 3. However, a summary of field GC analytical results for samples collected from between 0-10 ft bgs are presented at the end of this section.

Following is an evaluation of the fixed laboratory data for soil samples collected between $0-10 \mathrm{ft}$ bgs; concrete samples from the Concrete Pad Class $1 \mathrm{SU}$ are not included in the following evaluation. Analytical results summarized below for the soil samples analyzed at the fixed laboratory show U-235 and U-238 Max RL exceedances; Cs-137, U-234, U-235, and U-238 Avg RL exceedances; one metal and several radionuclide, SVOC, and VOC Ind PRG exceedances; radionuclide and VOC GW SL exceedances; metals and radionuclide Bkg exceedances; and PCB, SVOC, and VOC detections.

The radionuclide RL exceedances occur in the following SUs: U-234 Avg RL, U-235 Avg and Max RLs, and U-238 Avg and Max RLs at the RAD47 historical location in the Concrete Pad Class 1 SU; U-234 Avg RL, U-235 Avg and Max RLs, and U-238 Avg and Max RLs at the RAD91 location in the RAD91 Class 1 SU; Cs -137 Avg RL at the RAD122 historical location in the RAD122 Class 2 SU; and U-235 and U-238 Avg RLs at the Z2-EU41DB-208 historical location in the Z2-EU41DB-208 Class 2 SU. Early characterization confirmation sampling at the RAD47 location showed a U-238 Avg RL exceedance, which presumes the Avg and Max RL exceedances at RAD47 are confirmed. The BAR survey conducted in the RAD91 Class 1 SU did not detect an area of radiation in excess of the AL (Sect. 2.1.1.1) and the DVS confirmation sample at the RAD91 location did not show any RL exceedances. It is concluded that the Max and Avg RL exceedances at the RAD91 historical location are not confirmed. The BAR survey conducted in the RAD122 Class 2 SU also did not detect an area of radiation in excess of the AL (Sect. 2.1.2.1) and the DVS confirmation sample at the RAD122 location did not show any RL exceedances. It is likewise concluded that the Avg RL exceedance at the RAD122 historical location is not confirmed. Early characterization step-out sampling was conducted around the Z2-EU41DB-208 location. Step-out locations were spaced $12.5 \mathrm{ft}$ from the original sample location with a second set of step-out locations spaced another $12.5 \mathrm{ft}$ from the first set. There were no RL exceedances in any of the step-out samples and it is concluded that the Avg RL exceedances at the Z2-EU41DB-208 location are of an extent less than the area of a circle with a 12.5-ft radius (approximately $500 \mathrm{ft}^{2}$ ).

Several of the radionuclide Ind PRG exceedances are associated with the Max and Avg RL exceedances and occur in the associated SUs as described in the preceding paragraph. Confirmation sampling did not confirm $U 234$, U-235, and U-238 Ind PRG exceedances at the RAD91 historical location or Cs-137 Ind PRG exceedance at the RAD122 historical location. The bulk of the radionuclide Ind PRG exceedances in EU Z2-41, however, are for K-40 and the radium and thorium isotopes. Risk from these radionuclides is handled with special rules that are described in the introduction to this section and in Sect. 3.3. The remaining radionuclides with Ind PRG exceedances include Cs-137 at RAD74 and RAD102 historical locations, and U-235 and U238 at location Z2-EU41C-212 in the K-1070-C area. SVOC Ind PRG exceedances are restricted to two locations (Z2-EU41C-208 and Z2-EU41C-209) in the K-1070-C area. The VOC Ind PRG exceedances are for PCE and TCE at one historical location (SS002) in the concrete Pad Class 1 SU.

Radionuclide GW SL exceedances occur in SUs with radionuclide RL exceedances that are described above, except for a U-234 GW SL exceedance at location Z2-EU41C-212 in the K-1070-C area. The GW SL exceedances and associated SUs include U-234, U-235, and U-238 in the Concrete Pad Class 1 SU at historical sample location RAD47 and U-238 at its DVS confirmation sample location; U-234, U-235, and U-238 at h istorical location RAD91 in the RAD91 Class $1 \mathrm{SU}$; and U234 and U238 at early characterization bcation Z2-EU41DB-208 in the Z2-EU41DB-208 Class 2 SU. Confirmation sampling confirmed the U-238 GW SL exceedance at the RAD47 location but did not confirm the radionuclide exceedances at the RAD91 location. There are no GW SL exceedances in the early characterization step-out samples in the Z2-EU41DB-208 Class 2 SU that demonstrate the original GW SL exceedances are of limited extent (i.e., less than approximately $500 \mathrm{ft}^{2}$ for the RL exceedances). The VOC GW 
SL exceedances are for methylene chloride, PCE, and TCE. One of the two methylene chloride GW SL exceedances occurs at a historical sample location in the K-1070 Pits FFA site (Sect. 2.2.6). The remaining methylene chloride GW SL exceedance and all of the PCE and TCE GW SL exceedances occur in the Concrete Pad Class 1 SU.

In addition to the $\mathrm{EU}$-wide data summarized below and data summarized in the preceding focused summaries, there are radionuclide data from the Concrete Pad Class $1 \mathrm{SU}$ that were rejected during validation but which the K-1070-C/D RI Report says represent minimum concentrations. Based on this and the data discussion in the K-1070-C/D RI Report, there are also additional U-235 and U-238 Avg RL exceedances and U-234, U-235, and U-238 Ind PRG and GW SL exceedances in the Concrete Pad Class 1 SU.

EU Z2-41 SOILS METALS WITH BACKGROUND, PRG, GW SL, AND/OR RL EXCEEDANCES (mg/kg) 0-10 ft

\begin{tabular}{|c|c|c|c|c|c|c|c|c|c|c|c|}
\hline \multirow[b]{2}{*}{ Analyte } & \multirow[b]{2}{*}{$\begin{array}{c}\text { Detect } \\
\text { frequency }\end{array}$} & \multirow[b]{2}{*}{$\begin{array}{c}\text { Minimum } \\
\text { detect }\end{array}$} & \multirow[b]{2}{*}{$\begin{array}{c}\text { Maximum } \\
\text { detect }\end{array}$} & \multirow[b]{2}{*}{$\begin{array}{l}\text { Location(s) of } \\
\text { maximum detect }\end{array}$} & \multirow{2}{*}{$\begin{array}{c}\text { Average } \\
\text { detected } \\
\text { result }\end{array}$} & \multicolumn{6}{|c|}{ Number of analyses exceeding criteria } \\
\hline & & & & & & $\begin{array}{c}\text { Max } \\
\text { RL }\end{array}$ & $\begin{array}{l}\text { Avg } \\
\text { RL }\end{array}$ & $\begin{array}{l}\text { Ind } \\
\text { PRG }\end{array}$ & Bkg & $\begin{array}{l}\text { GW } \\
\text { SL }\end{array}$ & $\begin{array}{l}\text { Res } \\
\text { PRG }\end{array}$ \\
\hline Aluminum & $136 / 136$ & 3500 & 29,000 & $\begin{array}{l}\text { Z2-EU41C-207 } \\
\text { Z2-EU41C-211 }\end{array}$ & 17,085 & NA & NA & 0 & 0 & NA & 129 \\
\hline Antimony & $37 / 53$ & $0.0028 \mathrm{~J}$ & $4.2 \mathrm{~J}$ & SS007 & 0.330 & NA & NA & 0 & 1 & 0 & 1 \\
\hline Arsenic & $131 / 136$ & $0.98 \mathrm{~J}$ & $49 \mathrm{~J}$ & SD002 & 4.92 & 0 & 0 & 1 & 2 & 0 & 131 \\
\hline Barium & $136 / 136$ & $21.5 \mathrm{~J}$ & $540 \mathrm{~J}$ & Z2-EU41DB-211 & 121 & NA & NA & 0 & 53 & 0 & 1 \\
\hline Beryllium & $136 / 136$ & 0.23 & 2.8 & SB097 & 0.846 & 0 & 0 & 0 & 1 & NA & \\
\hline Cadmium & $68 / 136$ & 0.071 & $3.8 \mathrm{~J}$ & SS007 & 1.10 & NA & NA & 0 & 58 & NA & 1 \\
\hline Calcium & $127 / 135$ & 20.2 & 260,000 & Z2EU41DB-208-11 & 21,766 & NA & NA & NA & 71 & NA & NA \\
\hline Chromium & $136 / 136$ & $5.2 \mathrm{~J}$ & 156 & SS007 & 26.2 & NA & NA & 0 & 5 & 0 & 85 \\
\hline Cobalt & $136 / 136$ & 1.8 & 43 & SB069 & 10.4 & NA & NA & 0 & 1 & NA & 0 \\
\hline Copper & $135 / 136$ & 4.7 & $1100 \mathrm{~J}$ & SS007 & 40.6 & NA & NA & 0 & 52 & NA & 2 \\
\hline Lead & $136 / 136$ & $3.3 \mathrm{~J}$ & 230 & SS007 & 18.0 & NA & NA & 0 & 6 & 0 & 0 \\
\hline Lithium & $63 / 63$ & 5.7 & 51 & Z2-EU41DB-208 & 16.8 & NA & NA & 0 & 1 & NA & 0 \\
\hline Iron & $136 / 136$ & 6590 & 42,400 & SS007 & 25,803 & NA & NA & 0 & 0 & NA & 136 \\
\hline Magnesium & $136 / 136$ & 497 & $56,000 \mathrm{~J}$ & Z2-EU41DB-211 & 4955 & NA & NA & NA & 41 & NA & NA \\
\hline Manganese & $136 / 136$ & 29.3 & $2700 \mathrm{~J}$ & Z2-EU41DB-212 & 373 & NA & NA & 0 & 2 & NA & 84 \\
\hline Mercury & $85 / 135$ & $0.0088 \mathrm{~J}$ & $4.3 \mathrm{~J}$ & Z2-EU41DB-231 & 0.170 & 0 & 0 & 0 & 13 & NA & 1 \\
\hline Nickel & $136 / 136$ & 5.5 & $2100 \mathrm{~J}$ & Z2-EU41C-208 & 69.4 & NA & NA & 0 & 69 & NA & 9 \\
\hline Selenium & $30 / 100$ & 0.34 & $3.6 \mathrm{~J}$ & SB033 & 1.40 & NA & NA & 0 & 9 & NA & 0 \\
\hline Silver & $63 / 93$ & $0.083 \mathrm{~J}$ & 2.7 & SB051 & 1.36 & NA & NA & 0 & 56 & NA & 0 \\
\hline Sodium & $111 / 136$ & 19.8 & $41,000 \mathrm{~J}$ & Z2-EU41C-211 & 461 & NA & NA & NA & 3 & NA & NA \\
\hline Thallium & $82 / 136$ & 0.063 & $0.57 \mathrm{~J}$ & SB050 & 0.219 & NA & NA & 0 & 4 & 0 & 2 \\
\hline Uranium & $11 / 11$ & $0.71 \mathrm{~J}$ & 8 & Z2-EU41DB-208-4 & 3.22 & NA & NA & 0 & NA & NA & 6 \\
\hline Vanadium & $136 / 136$ & 6.7 & 66.5 & SS005 & 23.9 & NA & NA & 0 & 1 & NA & 133 \\
\hline Zinc & $136 / 136$ & 8.1 & $420 \mathrm{~J}$ & SS007 & 45.9 & NA & NA & 0 & 11 & NA & 0 \\
\hline
\end{tabular}

Avg $=$ average $\quad \mathrm{NA}=$ not applicable

$\mathrm{Bkg}=$ background $\quad \mathrm{PRG}=$ preliminary remediation goal

$\mathrm{EU}=$ exposure unit $\quad$ Res $=$ residential

$\mathrm{GW}=$ groundwater $\quad \mathrm{RL}=$ remediation level

Ind $=$ industrial $\quad \mathrm{SL}=$ screening level

Max $=$ maximum 
EU Z2-41 SOILS PPCB DETECTS (ug/kg) 0-10 ft

\begin{tabular}{lccccccccc}
\hline & & & & & \multicolumn{3}{c}{$\begin{array}{c}\text { Number of analyses } \\
\text { exceeding criteria }\end{array}$} \\
\cline { 5 - 9 } \multicolumn{1}{c}{ Analyte } & $\begin{array}{c}\text { Detect } \\
\text { frequency }\end{array}$ & $\begin{array}{c}\text { Minimum } \\
\text { detect }\end{array}$ & $\begin{array}{c}\text { Maximum } \\
\text { detect }\end{array}$ & $\begin{array}{c}\text { Location(s) of } \\
\text { maximum detect }\end{array}$ & $\begin{array}{c}\text { Average } \\
\text { detected } \\
\text { result }\end{array}$ & $\begin{array}{c}\text { Max } \\
\text { RL }\end{array}$ & $\begin{array}{c}\text { Avg } \\
\text { RL }\end{array}$ & $\begin{array}{c}\text { Ind } \\
\text { PRG PRG }\end{array}$ \\
\hline Methoxychlor & $1 / 48$ & $2.2 \mathrm{~J}$ & $2.2 \mathrm{~J}$ & SB069 & 2.2 & NA & NA & 0 & NA \\
PCB-1242 & $1 / 123$ & 71 & 71 & SB064 & 71 & 0 & 0 & 0 & 0 \\
PCB-1248 & $3 / 123$ & $130 \mathrm{~J}$ & 490 & SB071 & 357 & 0 & 0 & 0 & 3 \\
PCB-1254 & $43 / 124$ & $4.7 \mathrm{~J}$ & 2500 & SS002 SS003 & 269 & 0 & 0 & 0 & 13 \\
PCB-1260 & $12 / 123$ & $9.7 \mathrm{~J}$ & 1300 & Z2-EU41DKB-205 & 162 & 0 & 0 & 0 & 3 \\
Polychlorinated Biphenyl & $30 / 61$ & 4.7J & 1300 & Z2-EU41DKB-205 & 113 & 0 & 0 & 0 & 7 \\
\hline
\end{tabular}

Avg $=$ average $\quad$ PPCB $=$ pesticide and polychlorinated biphenyl

$\mathrm{EU}=$ exposure unit $\quad \mathrm{PRG}=$ preliminary remediation goal

Ind $=$ industrial

Max = maximum

Res $=$ residential

$\mathrm{NA}=$ not applicable

$\mathrm{RL}=$ remediation level

EU Z2-41 SOILS RADIONUCLIDES WITH BACKGROUND, PRG, AND/OR RL EXCEEDANCES (pCi/g) 0-10 ft

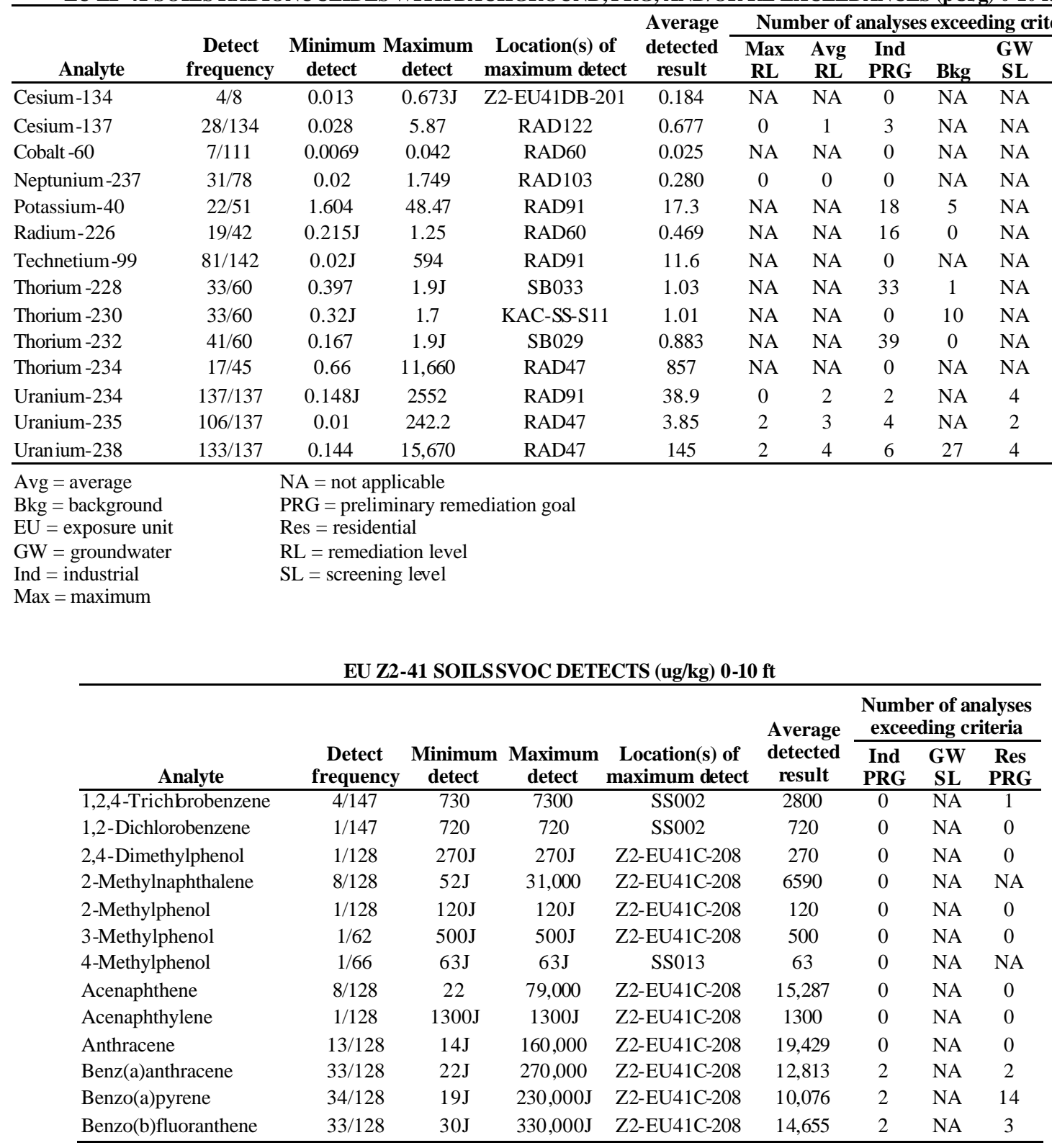


EU Z2-41 SOILSSVOC DETECTS (ug/kg) 0-10 ft (cont'd)

\begin{tabular}{|c|c|c|c|c|c|c|c|c|}
\hline \multirow[b]{2}{*}{ Analyte } & \multirow[b]{2}{*}{$\begin{array}{l}\text { Detect } \\
\text { frequency }\end{array}$} & \multirow[b]{2}{*}{$\begin{array}{l}\text { Minimum } \\
\text { detect }\end{array}$} & \multirow[b]{2}{*}{$\begin{array}{c}\text { Maximum } \\
\text { detect }\end{array}$} & \multirow[b]{2}{*}{$\begin{array}{l}\text { Location(s) of } \\
\text { maximum detect }\end{array}$} & \multirow{2}{*}{$\begin{array}{c}\text { Average } \\
\text { detected } \\
\text { result }\end{array}$} & \multicolumn{3}{|c|}{$\begin{array}{l}\text { Number of analyses } \\
\text { exceeding criteria }\end{array}$} \\
\hline & & & & & & $\begin{array}{l}\text { Ind } \\
\text { PRG }\end{array}$ & $\begin{array}{l}\text { GW } \\
\text { SL }\end{array}$ & $\begin{array}{l}\text { Res } \\
\text { PRG }\end{array}$ \\
\hline$\overline{\text { Benzo(ghi)perylene }}$ & $15 / 128$ & $22 \mathrm{~J}$ & $100,000 \mathrm{~J}$ & Z2-EU41C-208 & 11,816 & 0 & NA & 0 \\
\hline Benzo(k)fluoranthene & $22 / 128$ & $20 \mathrm{~J}$ & $110,000 \mathrm{~J}$ & Z2-EU41C-208 & 8072 & 0 & NA & 2 \\
\hline Bis(2-ethylhexyl)phthalate & $44 / 127$ & $53 \mathrm{~J}$ & 110,000 & $\begin{array}{l}\text { Z2-EU41C-208 } \\
\text { Z2-EU41DB-232 }\end{array}$ & 16,320 & 0 & 0 & 7 \\
\hline Butyl benzyl phthalate & $10 / 127$ & $22 \mathrm{~J}$ & 660,000 & Z2-EU41C-203 & 66,099 & 0 & NA & 0 \\
\hline Carbazole & $6 / 128$ & $34 \mathrm{~J}$ & 120,000 & Z2-EU41C-208 & 31,387 & 0 & NA & 2 \\
\hline Chrysene & $30 / 128$ & $25 \mathrm{~J}$ & 220,000 & Z2-EU41C-208 & 11,085 & 0 & NA & 2 \\
\hline Dibenz(a,h)anthracene & $2 / 127$ & $74 \mathrm{~J}$ & $63,000 \mathrm{~J}$ & Z2-EU41C-208 & 31,537 & 1 & NA & 2 \\
\hline Dibenzofuran & $4 / 128$ & $20 \mathrm{~J}$ & 44,000 & Z2-EU41C-208 & 18,014 & 0 & NA & 2 \\
\hline Diethyl phthalate & $14 / 128$ & 22 & $66 \mathrm{~J}$ & SS015 & 36.3 & 0 & NA & 0 \\
\hline Dimethyl phthalate & $6 / 128$ & $51 \mathrm{~J}$ & $650 \mathrm{~J}$ & SB050 & 183 & 0 & NA & 0 \\
\hline Di-n-butyl phthalate & $11 / 128$ & $25 \mathrm{~J}$ & 780 & Z2-EU41DB-210 & 178 & 0 & NA & 0 \\
\hline Di-n-octylphthalate & $10 / 127$ & 32 & $310 \mathrm{~J}$ & SS004 & 86.8 & 0 & NA & 0 \\
\hline Fluoranthene & $42 / 128$ & $33 \mathrm{~J}$ & 700,000 & Z2-EU41C-208 & 21,832 & 0 & NA & 1 \\
\hline Fluorene & $5 / 128$ & $20 \mathrm{~J}$ & 110,000 & Z2-EU41C-208 & 33,228 & 0 & NA & 0 \\
\hline Indeno(1,2,3-cd)pyrene & $10 / 127$ & $46 \mathrm{~J}$ & 95,000 & Z2-EU41C-208 & 15,394 & 2 & NA & 2 \\
\hline Naphthalene & $8 / 147$ & $15 \mathrm{~J}$ & 110,000 & Z2-EU41C-208 & 24,559 & 0 & NA & 3 \\
\hline Phenanthrene & $35 / 128$ & $28 \mathrm{~J}$ & 630,000 & Z2-EU41C-208 & 24,406 & 0 & NA & 2 \\
\hline Phenol & $3 / 128$ & $65 \mathrm{~J}$ & $490 \mathrm{~J}$ & SS002 & 275 & 0 & NA & 0 \\
\hline Pyrene & $49 / 128$ & $25 \mathrm{~J}$ & 470,000 & Z2-EU41C-208 & 14,829 & 0 & NA & 2 \\
\hline
\end{tabular}

\begin{tabular}{ll}
\hline EU $=$ exposure unit & PRG $=$ preliminary remediation goal \\
GW = groundwater & Res $=$ residential \\
Ind = industrial & SL = screening level \\
NA = not applicable & SVOC = semivolatile organic compound
\end{tabular}

EU Z2-41 SOILS VOC DETECTS (ug/kg) 0-10 ft

\begin{tabular}{|c|c|c|c|c|c|c|c|c|}
\hline \multirow[b]{2}{*}{ Analyte } & \multirow[b]{2}{*}{$\begin{array}{l}\text { Detect } \\
\text { frequency }\end{array}$} & \multirow[b]{2}{*}{$\begin{array}{c}\text { Minimum } \\
\text { detect }\end{array}$} & \multirow[b]{2}{*}{$\begin{array}{l}\text { Maximum } \\
\text { detect }\end{array}$} & \multirow[b]{2}{*}{$\begin{array}{l}\text { Location(s) of } \\
\text { maximum detect }\end{array}$} & \multirow{2}{*}{$\begin{array}{c}\text { Average } \\
\text { detected } \\
\text { result }\end{array}$} & \multicolumn{3}{|c|}{$\begin{array}{c}\text { Number of analyses } \\
\text { exceeding criteria }\end{array}$} \\
\hline & & & & & & $\begin{array}{l}\text { Ind } \\
\text { PRG }\end{array}$ & $\begin{array}{c}\text { GW } \\
\text { SL }\end{array}$ & $\begin{array}{l}\text { Res } \\
\text { PRG }\end{array}$ \\
\hline 1,1,1-Trichloroethane & $3 / 85$ & $23 \mathrm{~J}$ & 59 & SS007 & 37.3 & 0 & 0 & 0 \\
\hline $\begin{array}{l}\text { 1,1,2-Trichloro-1,2,2- } \\
\text { trifluoroethane }\end{array}$ & $16 / 85$ & $1 \mathrm{~J}$ & $1100 \mathrm{~J}$ & SS002 & 79.3 & 0 & NA & 0 \\
\hline 1,1,2-Trichloroethane & $3 / 85$ & $4 \mathrm{~J}$ & 10 & SB075 & 7.33 & 0 & 0 & 0 \\
\hline 1,1-Dichloroethane & $2 / 85$ & $2 \mathrm{~J}$ & 130 & SS007 & 66 & 0 & NA & 0 \\
\hline 1,2-Dichloroethene & $9 / 66$ & 3 & 36,000 & SS002 & 4543 & 0 & NA & NA \\
\hline $\begin{array}{l}\text { 1-Methy-4-(1-methylethyl) } \\
\text { benzene }\end{array}$ & $1 / 19$ & $320 \mathrm{~J}$ & $320 \mathrm{~J}$ & Z2-EU41DB-208-4 & 320 & NA & NA & NA \\
\hline 2-Butanone & $9 / 85$ & $6 \mathrm{~J}$ & $1100 \mathrm{~J}$ & SB071 & 305 & 0 & NA & 0 \\
\hline 2-Hexanone & $2 / 85$ & $6 \mathrm{~J}$ & $11 \mathrm{~J}$ & SB055 & 8.5 & NA & NA & NA \\
\hline 4-Methyl2-pentanone & $3 / 85$ & $3 \mathrm{~J}$ & 23 & SB075 & 13.3 & 0 & NA & 0 \\
\hline Acetone & $24 / 85$ & $10 \mathrm{~J}$ & 6300 & SB075 & 686 & 0 & NA & 0 \\
\hline Carbon disulfide & $2 / 85$ & $2 \mathrm{~J}$ & 5 & SB053 & 3.5 & 0 & NA & 0 \\
\hline Chlorobenzene & $2 / 85$ & 1 & $3 \mathrm{~J}$ & SB033 & 2 & 0 & NA & 0 \\
\hline Ethylbenzene & $5 / 85$ & $2 \mathrm{~J}$ & $180 \mathrm{~J}$ & SB071 & 53.2 & 0 & NA & 0 \\
\hline Methylene chloride & $26 / 85$ & 4 & 1600 & Z2-EU41DB-232 & 120 & 0 & 2 & 0 \\
\hline Tetrachloroethene & $13 / 85$ & $2 \mathrm{~J}$ & 330,000 & SS002 & 26,495 & 1 & 3 & 4 \\
\hline Toluene & $13 / 85$ & $1 \mathrm{~J}$ & 1900J & SS002 & 270 & 0 & 0 & 0 \\
\hline Total Xylene & $10 / 66$ & 2 & 2100 & SS002 & 375 & 0 & NA & NA \\
\hline Trichloroethene & $7 / 85$ & $3 \mathrm{~J}$ & 18,000 & SS002 & 2619 & 1 & 1 & 4 \\
\hline $\begin{array}{l}\text { EU = exposure unit } \\
\text { GW = groundwater } \\
\text { Ind = industrial } \\
\mathrm{NA}=\text { not applicable }\end{array}$ & $\begin{array}{l}\mathrm{PRG}=\mathrm{p} \\
\text { Res }=\mathrm{res} \\
\mathrm{SL}=\mathrm{scr} \\
\mathrm{VOC}=\mathrm{v}\end{array}$ & $\begin{array}{l}\text { liminary rem } \\
\text { dential } \\
\text { ening level } \\
\text { latile organic }\end{array}$ & $\begin{array}{l}\text { ediation goal } \\
\text { compound }\end{array}$ & & & & & \\
\hline
\end{tabular}


Soil samples from within the 0 - to 10-ft-depth interval were analyzed for VOCs by field GC at 31 locations in EU Z2-41. Field GC analysis was conducted as part of the K-1070-C/D Phase 2 RI at the locations presented in Sect. 2.2.3. The analyses were performed at locations where samples also were collected for laboratory VOC analyses and, in most cases, on splits of samples collected for laboratory analyses. Analytical results showed higher VOC concentrations in the majority of samples analyzed compared to the corresponding laboratory analytical results. The K-1070-C/D Phase 2 RI did not differentiate between field GC results and laboratory VOC results in its evaluation of analytical data. A summary of the field GC analytical results follows.

EU Z2-41 FIELD GC VOC DETECTS (ug/kg) 0-10 ft

\begin{tabular}{lcccccccc}
\hline & & & & & & \multicolumn{2}{c}{$\begin{array}{c}\text { Number of analyses } \\
\text { exceeding criteria }\end{array}$} \\
\cline { 5 - 8 } \multicolumn{1}{c}{ Analyte } & $\begin{array}{c}\text { Detect } \\
\text { frequency }\end{array}$ & $\begin{array}{c}\text { Minimum } \\
\text { detect }\end{array}$ & $\begin{array}{c}\text { Maximum } \\
\text { detect }\end{array}$ & $\begin{array}{c}\text { Location(s) of } \\
\text { maximum detect }\end{array}$ & $\begin{array}{c}\text { Average } \\
\text { detected } \\
\text { result }\end{array}$ & $\begin{array}{c}\text { Ind } \\
\text { PRG }\end{array}$ & $\begin{array}{c}\text { GW } \\
\text { SL }\end{array}$ & $\begin{array}{c}\text { Res } \\
\text { PRG }\end{array}$ \\
\hline 1,1,1-Trichloroethane & $61 / 62$ & 0.003 & 1300 & SB071 & 30.3 & 0 & 0 & 0 \\
1,1-Dichloroethane & $8 / 62$ & 2 & 11 & SB057 & 6.5 & 0 & NA & 0 \\
1,1-Dichloroethene & $37 / 62$ & 0.03 & 56 & SB074 & 2.50 & 0 & 0 & 0 \\
1,2-Dichloroethene & $16 / 62$ & 0.2 & 7 & SB059 SB060 & 3.13 & 0 & NA & NA \\
Benzene & $35 / 62$ & 0.1 & 4 & SB058 SB060 SB069 & 1.55 & 0 & 0 & 0 \\
Carbon tetrachloride & $5 / 62$ & 0.009 & $0.3 \mathrm{~J}$ & SB058 & 0.068 & 0 & 0 & 0 \\
Chloroform & $39 / 56$ & $0.04 \mathrm{~J}$ & 6 & SB059 & 0.501 & 0 & 0 & 0 \\
Methylene chloride & $2 / 62$ & $190 \mathrm{~J}$ & $240 \mathrm{~J}$ & SB074 & 215 & 0 & 0 & 0 \\
Tetrachloroethene & $56 / 62$ & 0.004 & 92 & SB071 & 1.97 & 0 & 0 & 0 \\
Toluene & $27 / 62$ & 0.4 & 3800 & SB071 & 143 & 0 & 0 & 0 \\
Total Xylene & $1 / 62$ & 8 & 8 & SB071 & 8 & 0 & NA & NA \\
Trichloroethene & $14 / 62$ & 0.008 & 100 & SB071 & 16.6 & 0 & 0 & 1 \\
\hline
\end{tabular}

$\mathrm{EU}=$ exposure unit $\quad \mathrm{PRG}=$ preliminary remediation goal

$\mathrm{GC}=$ gas chromatograph $\quad$ Res $=$ residential

$\mathrm{GW}=$ groundwater $\quad \mathrm{SL}=$ screening level

Ind $=$ industrial $\quad$ VOC $=$ volatile organic compound

$\mathrm{NA}=$ not applicable

\subsection{6 \\ ZONE 2 ROD APPENDIX A FFA SITES EVALUATION}

There are three FFA sites in EU Z2-41 that are identified in Appendix A of the Zone 2 ROD. Analytical results from the three FFA sites are summarized below and included in the EU Z2-41 summary in Sect. 2.2.5. Sample locations are shown on Fig. I.4. Several of the FFA site sample locations are included in focused sampling effort summaries in Sect. 2.2.5 and noted in the summaries that follow. Note again that samples obtained from the locations described below were obtained from the $0-10 \mathrm{ft}$ depth interval.

K-1070-C/D Burial Ground FFA site: Ninety-one sample locations fall within the boundaries of the K-1070-C/D Burial Ground FFA site-7 DVS locations and 84 historical locations. Sample locations for the K-1070-C/D Burial Ground FFA site include those listed in the table in Sect. 2.2.3. Also there are several sample locations at this FFA site that have been presented in focused sampling effort summaries in Sect. 2.2.5. These include the RAD91 Class 1 SU, RAD122 Class 2 SU, Z2-EU41DB-208 Class 2 SU, soil mound, and sediment accumulation areas sample locations. Analytical results for the site samples summarized below show one U-235 and one U-238 Max RL exceedance; one Cs-137, one U-234, two U235, and two U-238 Avg RL exceedances; radionuclide Ind PRG exceedances (several of which correspond to samples with Max and Avg RL exceedances); five different SVOCs with Ind PRG exceedances in either one or two samples; GW SL exceedances for U-234, U235, and U-238; numerous metal and several radionuclide Bkg exceedances; and PCB, SVOC, and VOC detections.

All Max and Avg RL exceedances at this site occur at focused sampling effort locations that are summarized in Sect. 2.2.5. The U-235 and U-238 Max RL exceedances, their corresponding Avg RL exceedances, and the U-234 Avg RL exceedance occur in the RAD91 Class 1 SU. The remaining U-235 and U-238 Avg RL exceedances occur in the Z2-EU41DB-208 Class 2 SU and the Cs -137 Avg RL exceedance occurs in the RAD122 Class 2 SU.

When the radionuclide industrial PRG exceedances associated with the Max and Avg RL exceedance locations are accounted for, there remain two Cs-137, one U-235, and two U-238 Ind PRG exceedances (K-40, radium and thorium isotopes receive special handling for risk evaluation). The remaining Cs -137 Ind PRG exceedance occurs at RAD74 and RAD102 historical locations, the U-235 exceedances occur at Z2-EU41C-212 early characterization 
location, and two U-238 exceedances occur at Z2-EU41C-212 early characterization location and Z2-EU41DB-208-3 early characterization location, which is in the Z2-EU41DB-208 Class 2 SU.

The SVOC Ind PRG exceedances all occur in the K-1070-C area of the K-1070-C/D Burial Ground FFA site at early characterization sample locations Z2-EU41C-208 and Z2-EU41C-209.

All but one of the GW SL exceedances occurs at locations with corresponding Max and Avg RL exceedances. The exception is a U-234 GW SL exceedance at early characterization location Z2-EU41C-212.

EU Z2-41 K-1070-C/D BURIAL GROUND FFA SITE METALS WITH BACKGROUND, PRG, GW SL, AND/OR RL EXCEEDANCES (mg/kg) 0-10 ft

\begin{tabular}{|c|c|c|c|c|c|c|c|c|c|c|c|}
\hline \multirow[b]{2}{*}{ Analyte } & \multirow[b]{2}{*}{$\begin{array}{c}\text { Detect } \\
\text { frequency }\end{array}$} & \multirow[b]{2}{*}{$\begin{array}{l}\text { Minimum } \\
\text { detect }\end{array}$} & \multirow[b]{2}{*}{$\begin{array}{c}\text { Maximum } \\
\text { detect }\end{array}$} & \multirow[b]{2}{*}{$\begin{array}{c}\text { Location(s) of } \\
\text { maximum detect }\end{array}$} & \multirow{2}{*}{$\begin{array}{c}\text { Average } \\
\text { detected } \\
\text { result }\end{array}$} & \multicolumn{6}{|c|}{ Number of analyses exceeding criteria } \\
\hline & & & & & & $\begin{array}{l}\text { Max } \\
\text { RL }\end{array}$ & $\begin{array}{l}\text { Avg } \\
\text { RL }\end{array}$ & $\begin{array}{c}\text { Ind } \\
\text { PRG }\end{array}$ & Bkg & $\begin{array}{l}\text { GW } \\
\text { SL }\end{array}$ & $\begin{array}{l}\text { Res } \\
\text { PRG }\end{array}$ \\
\hline Aluminum & $60 / 60$ & 3500 & 29,000 & $\begin{array}{l}\text { Z2-EU41C-207 } \\
\text { Z2-EU41C-211 }\end{array}$ & 16,595 & NA & NA & 0 & 0 & NA & 58 \\
\hline Arsenic & $56 / 60$ & 1.5 & 7.7 & Z2-EU41DB-217 & 3.56 & 0 & 0 & 0 & 0 & 0 & 56 \\
\hline Barium & $60 / 60$ & 29 & $540 \mathrm{~J}$ & Z2-EU41DB-211 & 127 & NA & NA & 0 & 25 & 0 & 1 \\
\hline Beryllium & $60 / 60$ & 0.23 & 2.8 & SB097 & 0.880 & 0 & 0 & 0 & 1 & NA & 0 \\
\hline Cadmium & $43 / 60$ & 0.071 & $1.9 \mathrm{~J}$ & $\begin{array}{l}\text { Z2-EU41C-204 } \\
\text { Z2-EU41C-207 }\end{array}$ & 0.937 & NA & NA & 0 & 35 & NA & 0 \\
\hline Calcium & $56 / 59$ & 249 & 260,000 & Z2EU41DB-208-11 & 20,985 & NA & NA & NA & 42 & NA & NA \\
\hline Chromium & $60 / 60$ & $5.2 \mathrm{~J}$ & $48 \mathrm{~J}$ & Z2-EU41DKB-234 & 23.8 & NA & NA & 0 & 2 & 0 & 32 \\
\hline Copper & $59 / 60$ & 4.7 & $180 \mathrm{~J}$ & Z2-EU41C-209 & 29.0 & NA & NA & 0 & 22 & NA & 0 \\
\hline Iron & $60 / 60$ & 6600 & 42,000 & Z2-EU41DB-240 & 25,711 & NA & NA & 0 & 0 & NA & 60 \\
\hline Lithium & $44 / 44$ & 5.7 & 51 & Z2-EU41DB-208 & 17.1 & NA & NA & 0 & 1 & NA & 0 \\
\hline Magnesium & $60 / 60$ & 764 & $56,000 \mathrm{~J}$ & Z2-EU41DB-211 & 5352 & NA & NA & NA & 25 & NA & NA \\
\hline Manganese & $60 / 60$ & $34 \mathrm{~J}$ & $2700 \mathrm{~J}$ & Z2-EU41DB-212 & 443 & NA & NA & 0 & 1 & NA & 42 \\
\hline Mercury & $44 / 60$ & $0.0088 \mathrm{~J}$ & 0.29 & SB094 & 0.064 & 0 & 0 & 0 & 3 & NA & 0 \\
\hline Nickel & $60 / 60$ & 5.7 & $2100 \mathrm{~J}$ & Z2-EU41C-208 & 85.4 & NA & NA & 0 & 35 & NA & 5 \\
\hline Silver & $21 / 33$ & $0.083 \mathrm{~J}$ & 2 & SD015 & 1.04 & NA & NA & 0 & 16 & NA & 0 \\
\hline Sodium & $54 / 60$ & $33 \mathrm{~J}$ & $41,000 \mathrm{~J}$ & Z2-EU41C-211 & 856 & NA & NA & NA & 2 & NA & NA \\
\hline Thallium & $52 / 60$ & 0.063 & 0.53 & SB097 & 0.210 & NA & NA & 0 & 2 & 0 & 1 \\
\hline Uranium & $10 / 10$ & $0.71 \mathrm{~J}$ & 8 & Z2-EU41DB-208-4 & 3.45 & NA & NA & 0 & NA & NA & 6 \\
\hline Vanadium & $60 / 60$ & $7.4 \mathrm{~J}$ & 34.2 & SB064 & 21.1 & NA & NA & 0 & 0 & NA & 59 \\
\hline Zinc & $60 / 60$ & 8.1 & $130 \mathrm{~J}$ & Z2-EU41C-207 & 44.2 & NA & NA & 0 & 3 & NA & 0 \\
\hline
\end{tabular}

Avg $=$ average $\quad$ Max $=$ maximum

$\mathrm{Bkg}=$ background $\quad \mathrm{NA}=$ not applicable

$\mathrm{EU}=$ exposure unit

FFA $=$ Federal Facility Agreement

$\mathrm{PRG}=$ preliminary remediation goal

$\mathrm{GW}=$ groundwater

Res $=$ residential

Ind $=$ industrial $\quad \mathrm{SL}=$ screening level

EU Z2-41 K-1070-C/D BURIAL GROUND FFA SITE PPCB DETECTS (ug/kg) 0-10 ft

\begin{tabular}{|c|c|c|c|c|c|c|c|c|c|}
\hline \multirow[b]{2}{*}{ Analyte } & \multirow[b]{2}{*}{$\begin{array}{c}\text { Detect } \\
\text { frequency }\end{array}$} & \multirow[b]{2}{*}{$\begin{array}{c}\text { Minimum } \\
\text { detect }\end{array}$} & \multirow[b]{2}{*}{$\begin{array}{c}\text { Maximum } \\
\text { detect }\end{array}$} & \multirow[b]{2}{*}{$\begin{array}{c}\text { Location(s) of } \\
\text { maximum detect }\end{array}$} & \multirow{2}{*}{$\begin{array}{c}\text { Average } \\
\text { detected } \\
\text { result }\end{array}$} & \multicolumn{4}{|c|}{$\begin{array}{l}\text { Number of analyses } \\
\text { exceeding criteria }\end{array}$} \\
\hline & & & & & & $\begin{array}{c}\text { Max } \\
\text { RL }\end{array}$ & $\begin{array}{l}\text { Avg } \\
\text { RL }\end{array}$ & $\begin{array}{c}\text { Ind } \\
\text { PRG }\end{array}$ & $\begin{array}{l}\text { Res } \\
\text { PRG }\end{array}$ \\
\hline PCB-1242 & $1 / 54$ & 71 & 71 & SB064 & 71 & 0 & 0 & 0 & 0 \\
\hline PCB-1254 & $26 / 55$ & $4.7 \mathrm{~J}$ & 240 & Z2-EU41DB-208-3 & 59.1 & 0 & 0 & 0 & 4 \\
\hline PCB-1260 & $9 / 54$ & $9.9 \mathrm{~J}$ & 1300 & Z2-EU41DKB-205 & 193 & 0 & 0 & 0 & 2 \\
\hline Polychlorinated Biphenyl & $25 / 44$ & $4.7 \mathrm{~J}$ & 1300 & Z2-EU41DKB-205 & 125 & 0 & 0 & 0 & 6 \\
\hline
\end{tabular}

Avg $=$ average

$\mathrm{PPCB}=$ pesticide and polychlorinated biphenyl

$\mathrm{EU}=$ exposure unit

$\mathrm{PRG}=$ preliminary remediation goal

FFA = Federal Facility Agreement $\quad$ Res $=$ residential

Ind $=$ industrial

$\mathrm{RL}=$ remediation level

Max $=$ maximum 
EU Z2-41 K-1070-C/D BURIAL GROUND FFA SITE RADIONUCLIDES WITH

BACKGROUND, PRG, AND/OR RL EXCEEDANCES (pCi/g) 0-10 ft

\begin{tabular}{|c|c|c|c|c|c|c|c|c|c|c|c|}
\hline \multirow[b]{2}{*}{ Analyte } & \multirow[b]{2}{*}{$\begin{array}{c}\text { Detect } \\
\text { frequency }\end{array}$} & \multirow[b]{2}{*}{$\begin{array}{c}\text { Minimum } \\
\text { detect }\end{array}$} & \multirow[b]{2}{*}{$\begin{array}{c}\text { Maximum } \\
\text { detect }\end{array}$} & \multirow[b]{2}{*}{$\begin{array}{c}\text { Location(s) of } \\
\text { maximum detect }\end{array}$} & \multirow{2}{*}{$\begin{array}{c}\text { Average } \\
\text { detected } \\
\text { result }\end{array}$} & \multicolumn{6}{|c|}{ Number of analyses exceeding criteria } \\
\hline & & & & & & $\begin{array}{c}\text { Max } \\
\text { RL }\end{array}$ & $\begin{array}{l}\text { Avg } \\
\text { RL }\end{array}$ & $\begin{array}{l}\text { Ind } \\
\text { PRG }\end{array}$ & Bkg & $\begin{array}{l}\text { GW } \\
\text { SL }\end{array}$ & $\begin{array}{l}\text { Res } \\
\text { PRG }\end{array}$ \\
\hline Cesium-134 & $4 / 8$ & 0.013 & $0.673 \mathrm{~J}$ & Z2-EU41DB-201 & 0.184 & NA & NA & 0 & NA & NA & 1 \\
\hline Cesium-137 & $23 / 64$ & 0.028 & 5.87 & RAD122 & 0.690 & 0 & 1 & 3 & NA & NA & 16 \\
\hline Cobalt -60 & $7 / 45$ & 0.0069 & 0.042 & RAD60 & 0.025 & NA & NA & 0 & NA & NA & 1 \\
\hline Neptunium-237 & $23 / 53$ & 0.0289 & 1.749 & RAD103 & 0.242 & 0 & 0 & 0 & NA & NA & 9 \\
\hline Potassium-40 & $20 / 42$ & 2.439 & 48.47 & RAD91 & 18.7 & NA & NA & 17 & 5 & NA & 20 \\
\hline Radium-226 & $17 / 35$ & $0.215 \mathrm{~J}$ & 1.25 & RAD60 & 0.478 & NA & NA & 14 & 0 & NA & 17 \\
\hline Technetium-99 & $22 / 64$ & $0.02 \mathrm{~J}$ & 594 & RAD91 & 28.5 & NA & NA & 0 & NA & NA & 18 \\
\hline Thorium -228 & $19 / 39$ & 0.397 & $1.8 \mathrm{~J}$ & SB029 & 1.08 & NA & NA & 19 & 0 & NA & 19 \\
\hline Thorium -230 & $17 / 39$ & $0.32 \mathrm{~J}$ & 1.6 & RAD62 & 1.06 & NA & NA & 0 & 7 & NA & 0 \\
\hline Thorium -232 & $26 / 39$ & 0.167 & $1.9 \mathrm{~J}$ & SB029 & 0.810 & NA & NA & 24 & 0 & NA & 26 \\
\hline Thorium -234 & $14 / 36$ & 0.66 & 2570 & RAD91 & 202 & NA & NA & 0 & NA & NA & 1 \\
\hline Uranium-234 & $65 / 65$ & $0.148 \mathrm{~J}$ & 2552 & RAD91 & 47.2 & 0 & 1 & 1 & NA & 3 & 12 \\
\hline Uranium-235 & $47 / 65$ & 0.02 & 130.4 & RAD91 & 3.34 & 1 & 2 & 3 & NA & 1 & 23 \\
\hline Uranium-238 & $62 / 65$ & 0.1852 & 2851 & RAD91 & 53.4 & 1 & 2 & 4 & 13 & 2 & 31 \\
\hline
\end{tabular}

Avg $=$ average

$\mathrm{Bkg}=$ background

Max $=$ maximum

$\mathrm{EU}=$ exposure unit

FFA $=$ Federal Facility Agreement

NA $=$ not applicable

$\mathrm{PRG}=$ preliminary remediation goal

$\mathrm{GW}=$ groundwater

Res $=$ residential

$\mathrm{RL}=$ remediation level

Ind $=$ industrial

$\mathrm{SL}=$ screening level

EU Z2-41 K-1070-C/D BURIAL GROUND FFA SITE RADIONUCLIDES WITH BACKGROUND, PRG, AND/OR RL EXCEEDANCES (pCi/g) 0-10 ft

\begin{tabular}{|c|c|c|c|c|c|c|c|c|c|c|c|}
\hline \multirow[b]{2}{*}{ Analyte } & \multirow[b]{2}{*}{$\begin{array}{c}\text { Detect } \\
\text { frequency }\end{array}$} & \multirow[b]{2}{*}{$\underset{\text { detect }}{\text { Minimum }}$} & \multirow[b]{2}{*}{$\begin{array}{c}\text { Maximum } \\
\text { detect }\end{array}$} & \multirow[b]{2}{*}{$\begin{array}{c}\text { Location (s) of } \\
\text { maximum detect }\end{array}$} & \multirow{2}{*}{$\begin{array}{c}\text { Average } \\
\text { detected } \\
\text { result }\end{array}$} & \multicolumn{6}{|c|}{ Number of analyses exceeding criteria } \\
\hline & & & & & & $\begin{array}{c}\text { Max } \\
\text { RL }\end{array}$ & $\begin{array}{l}\text { Avg } \\
\text { RL }\end{array}$ & $\begin{array}{c}\text { Ind } \\
\text { PRG }\end{array}$ & Bkg & $\begin{array}{l}\text { GW } \\
\text { SL }\end{array}$ & $\begin{array}{c}\text { Res } \\
\text { PRG }\end{array}$ \\
\hline Cesium-134 & $4 / 8$ & 0.013 & $0.673 \mathrm{~J}$ & Z2-EU41DB-201 & 0.184 & NA & NA & 0 & NA & NA & 1 \\
\hline Cesium-137 & $23 / 64$ & 0.028 & 5.87 & RAD122 & 0.690 & 0 & 1 & 3 & NA & NA & 16 \\
\hline Cobalt -60 & $7 / 45$ & 0.0069 & 0.042 & RAD60 & 0.025 & NA & NA & 0 & NA & NA & 1 \\
\hline Neptunium-237 & $23 / 53$ & 0.0289 & 1.749 & RAD103 & 0.242 & 0 & 0 & 0 & NA & NA & 9 \\
\hline Potassium-40 & $20 / 42$ & 2.439 & 48.47 & RAD91 & 18.7 & NA & NA & 17 & 5 & NA & 20 \\
\hline Radium-226 & $17 / 35$ & $0.215 \mathrm{~J}$ & 1.25 & RAD60 & 0.478 & NA & NA & 14 & 0 & NA & 17 \\
\hline Technetium-99 & $22 / 64$ & $0.02 \mathrm{~J}$ & 594 & RAD91 & 28.5 & NA & NA & 0 & NA & NA & 18 \\
\hline Thorium -228 & $19 / 39$ & 0.397 & $1.8 \mathrm{~J}$ & SB029 & 1.08 & NA & NA & 19 & 0 & NA & 19 \\
\hline Thorium -230 & $17 / 39$ & $0.32 \mathrm{~J}$ & 1.6 & RAD62 & 1.06 & NA & NA & 0 & 7 & NA & 0 \\
\hline Thorium -232 & $26 / 39$ & 0.167 & $1.9 \mathrm{~J}$ & SB029 & 0.810 & NA & NA & 24 & 0 & NA & 26 \\
\hline Thorium -234 & $14 / 36$ & 0.66 & 2570 & RAD91 & 202 & NA & NA & 0 & NA & NA & 1 \\
\hline Uranium-234 & $65 / 65$ & $0.148 \mathrm{~J}$ & 2552 & RAD91 & 47.2 & 0 & 1 & 1 & NA & 3 & 12 \\
\hline Uranium-235 & $47 / 65$ & 0.02 & 130.4 & RAD91 & 3.34 & 1 & 2 & 3 & NA & 1 & 23 \\
\hline Uranium-238 & $62 / 65$ & 0.1852 & 2851 & RAD91 & 53.4 & 1 & 2 & 4 & 13 & 2 & 31 \\
\hline
\end{tabular}

Avg = average

Max $=$ maximum

$\mathrm{Bkg}=$ background

$\mathrm{NA}=$ not applicable

$\mathrm{EU}=$ exposure unit

$\mathrm{PRG}=$ preliminary remediation goal

FFA $=$ Federal Facility Agreement

$\mathrm{GW}=$ groundwater

Res $=$ residential

Ind $=$ industrial

$\mathrm{RL}=$ remediation level

$\mathrm{SL}=$ screening level

EU Z2-41 K-1070-C/D BURIAL GROUND FFA SITE SVOC DETECTS (ug/kg) 0-10 ft

\begin{tabular}{lccccccccc}
\hline & & & & & \multicolumn{3}{c}{$\begin{array}{c}\text { Number of analyses } \\
\text { Anceeding criteria }\end{array}$} \\
\cline { 7 - 10 } \multicolumn{1}{c}{ Analyte } & $\begin{array}{c}\text { Detect } \\
\text { frequency }\end{array}$ & $\begin{array}{c}\text { Minimum } \\
\text { detect }\end{array}$ & $\begin{array}{c}\text { Maximum } \\
\text { detect }\end{array}$ & $\begin{array}{c}\text { Location(s) of } \\
\text { maximum detect }\end{array}$ & $\begin{array}{c}\text { Average } \\
\text { detected } \\
\text { result }\end{array}$ & $\begin{array}{c}\text { Ind } \\
\text { PRG }\end{array}$ & $\begin{array}{c}\text { GW } \\
\text { SL }\end{array}$ & $\begin{array}{c}\text { Res } \\
\text { PRG }\end{array}$ \\
\hline 2,4-Dimethylphenol & $1 / 60$ & 270J & 270J & Z2-EU41C-208 & 270 & 0 & NA & 0 \\
2-Methylnaphthalene & $2 / 60$ & $21,000 \mathrm{~J}$ & 31,000 & Z2-EU41C-208 & 26,000 & 0 & NA & NA \\
2-Methylphenol & $1 / 60$ & $120 \mathrm{~J}$ & $120 \mathrm{~J}$ & Z2-EU41C-208 & 120 & 0 & NA & 0 \\
3-Methylphenol & $1 / 44$ & $500 \mathrm{~J}$ & $500 \mathrm{~J}$ & Z2-EU41C-208 & 500 & 0 & NA & 0 \\
\hline
\end{tabular}




\begin{tabular}{|c|c|c|c|c|c|c|c|c|}
\hline \multirow[b]{2}{*}{ Analyte } & \multirow[b]{2}{*}{$\begin{array}{c}\text { Detect } \\
\text { frequency }\end{array}$} & \multirow[b]{2}{*}{$\begin{array}{c}\text { Minimum } \\
\text { detect }\end{array}$} & \multirow[b]{2}{*}{$\begin{array}{c}\text { Maximum } \\
\text { detect }\end{array}$} & \multirow[b]{2}{*}{$\begin{array}{c}\text { Location(s) of } \\
\text { maximum detect }\end{array}$} & \multirow{2}{*}{$\begin{array}{c}\text { Average } \\
\text { detected } \\
\text { result }\end{array}$} & \multicolumn{3}{|c|}{$\begin{array}{c}\text { Number of analyses } \\
\text { exceeding criteria }\end{array}$} \\
\hline & & & & & & $\begin{array}{c}\text { Ind } \\
\text { PRG } \\
\end{array}$ & $\begin{array}{c}\text { GW } \\
\text { SL } \\
\end{array}$ & $\begin{array}{c}\text { Res } \\
\text { PRG } \\
\end{array}$ \\
\hline Acenaphthene & $4 / 60$ & $22 \mathrm{~J}$ & 79,000 & Z2-EU41C-208 & 30,519 & 0 & NA & 0 \\
\hline Acenaphthylene & $1 / 60$ & $1300 \mathrm{~J}$ & $1300 \mathrm{~J}$ & Z2-EU41C-208 & 1300 & 0 & NA & 0 \\
\hline Anthracene & $9 / 60$ & $14 J$ & 160,000 & Z2-EU41C-208 & 28,026 & 0 & NA & 0 \\
\hline Benz(a)anthracene & $22 / 60$ & $22 \mathrm{~J}$ & 270,000 & Z2-EU41C-208 & 19,154 & 2 & NA & 2 \\
\hline Benzo(a)pyrene & $22 / 60$ & $19 \mathrm{~J}$ & $230,000 \mathrm{~J}$ & Z2-EU41C-208 & 15,507 & 2 & NA & 9 \\
\hline Benzo(b)fluoranthene & $22 / 60$ & $30 \mathrm{~J}$ & $330,000 \mathrm{~J}$ & Z2-EU41C-208 & 21,896 & 2 & NA & 2 \\
\hline Benzo(ghi)perylene & $9 / 60$ & $22 \mathrm{~J}$ & $100,000 \mathrm{~J}$ & Z2-EU41C-208 & 19,614 & 0 & NA & 0 \\
\hline Benzo(k)fluoranthene & $15 / 60$ & $20 \mathrm{~J}$ & $110,000 \mathrm{~J}$ & Z2-EU41C-208 & 11,783 & 0 & NA & 2 \\
\hline Bis(2-ethylhexyl)phthalate & $26 / 59$ & $54 \mathrm{~J}$ & 110,000 & Z2-EU41C-208 & 13,950 & 0 & 0 & 3 \\
\hline Butyl benzylphthalate & $7 / 59$ & $22 \mathrm{~J}$ & 660,000 & Z2-EU41C-203 & 94,318 & 0 & NA & 0 \\
\hline Carbazole & $4 / 60$ & $60 \mathrm{~J}$ & 120,000 & Z2-EU41C-208 & 47,036 & 0 & NA & 2 \\
\hline Chrysene & $21 / 60$ & $25 \mathrm{~J}$ & 220,000 & Z2-EU41C-208 & 15,773 & 0 & NA & 2 \\
\hline Dibenz(a,h)anthracene & $2 / 59$ & $74 \mathrm{~J}$ & $63,000 \mathrm{~J}$ & Z2-EU41C-208 & 31,537 & 1 & NA & 2 \\
\hline Dibenzofuran & $2 / 60$ & 28,000 & 44,000 & Z2-EU41C-208 & 36,000 & 0 & NA & 2 \\
\hline Diethyl phthalate & $8 / 60$ & 22 & $50 \mathrm{~J}$ & Z2-EU41DB-239 & 31.8 & 0 & NA & 0 \\
\hline Di-n-butyl phthalate & $4 / 60$ & $41 \mathrm{~J}$ & 640 & Z2-EU41C-203 & 206 & 0 & NA & 0 \\
\hline Di-n-octylphthalate & $2 / 59$ & $32 \mathrm{~J}$ & $110 \mathrm{~J}$ & Z2-EU41DB-209 & 71 & 0 & NA & 0 \\
\hline Fluoranthene & $26 / 60$ & $33 \mathrm{~J}$ & 700,000 & Z2-EU41C-208 & 35,128 & 0 & NA & 1 \\
\hline Fluorene & $3 / 60$ & $20 \mathrm{~J}$ & 110,000 & Z2-EU41C-208 & 55,340 & 0 & NA & 0 \\
\hline Indeno(1,2,3-cd)pyrene & $6 / 59$ & $46 \mathrm{~J}$ & 95,000 & Z2-EU41C-208 & 25,558 & 2 & NA & 2 \\
\hline Naphthalene & $5 / 77$ & $15 \mathrm{~J}$ & 110,000 & Z2-EU41C-208 & 39,243 & 0 & NA & 3 \\
\hline Phenanthrene & $21 / 60$ & $30 \mathrm{~J}$ & 630,000 & Z2-EU41C-208 & 40,567 & 0 & NA & 2 \\
\hline Phenol & $1 / 60$ & $270 \mathrm{~J}$ & $270 \mathrm{~J}$ & Z2-EU41C-208 & 270 & 0 & NA & 0 \\
\hline Pyrene & $30 / 60$ & $25 \mathrm{~J}$ & 470,000 & Z2-EU41C-208 & 24,102 & 0 & NA & 2 \\
\hline$\overline{\mathrm{EU}}=$ exposure unit & $\mathrm{P}$ & \multicolumn{7}{|c|}{ PRG = preliminary remediation goal } \\
\hline FFA $=$ Federal Facility Agr & eement & \multicolumn{7}{|c|}{ Res $=$ residential } \\
\hline $\mathrm{GW}=$ groundwater & & \multicolumn{7}{|c|}{$\mathrm{SL}=$ screening level } \\
\hline $\begin{array}{l}\text { Ind }=\text { industrial } \\
\text { NA }=\text { not applicable }\end{array}$ & & \multicolumn{7}{|c|}{$\mathrm{SVOC}=$ semivolatile organic compound } \\
\hline
\end{tabular}

EU Z2-41 K-1070-C/D BURIAL GROUND FFA SITE VOC DETECTS (ug/kg) 0-10 ft

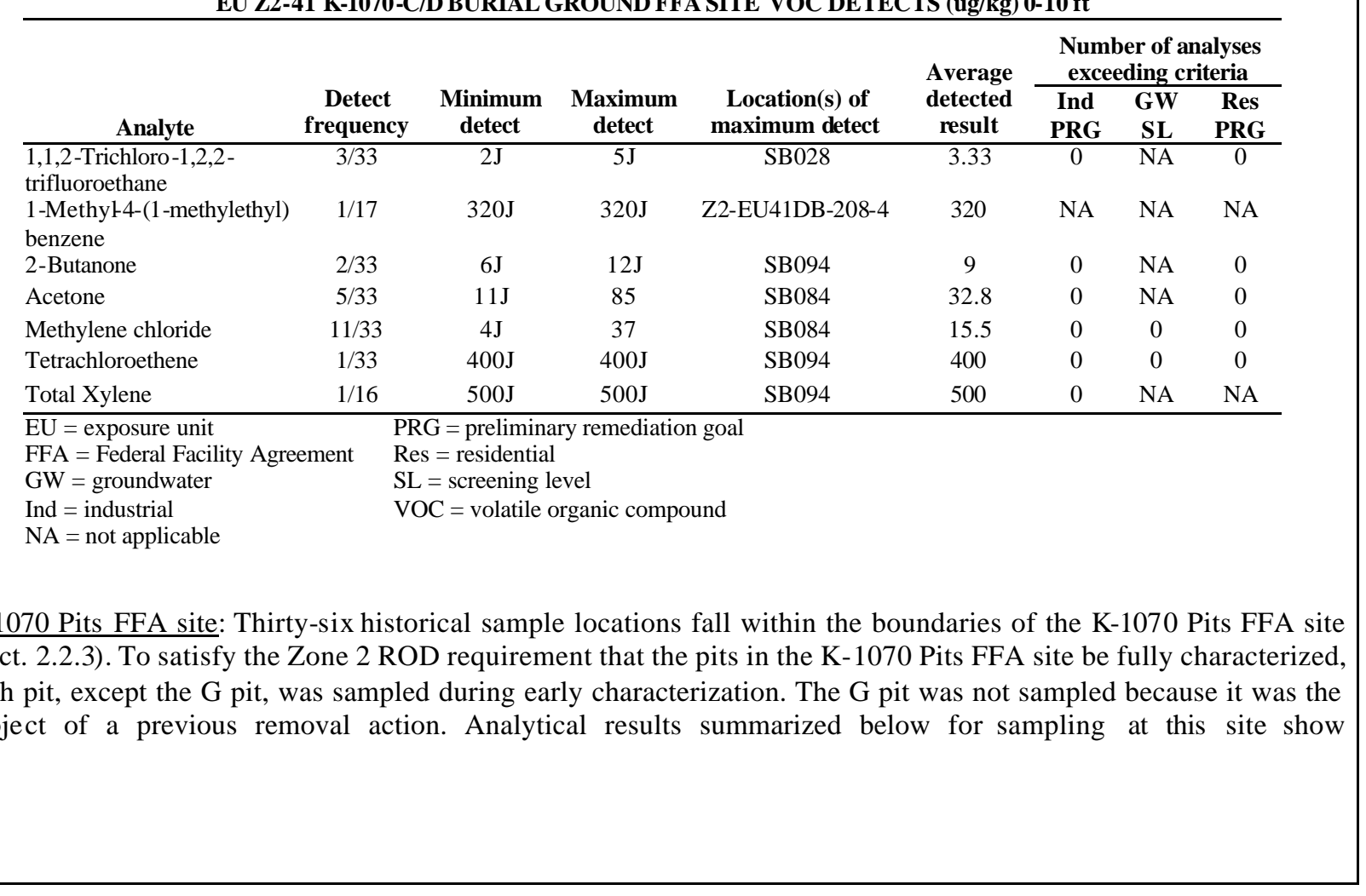


radionuclide Ind PRG exceedances, methylene chloride GW SL exceedance, metal and radionuclide Bkg exceedances, and PCB, SVOC, and VOC detections. The methylene chloride GW SL exceedance occurs at early characterization location Z2-EU41DB-232, which is located at the southeastern-most unnamed pit.

EU Z2-41 K-1070 PITS FFA SITE METALS WITH BACKGROUND, PRG, GW SL, AND/OR RL EXCEEDANCES (mg/kg) 0-10 ft

\begin{tabular}{|c|c|c|c|c|c|c|c|c|c|c|c|}
\hline \multirow[b]{2}{*}{ Analyte } & \multirow[b]{2}{*}{$\begin{array}{c}\text { Detect } \\
\text { frequency }\end{array}$} & \multirow[b]{2}{*}{$\begin{array}{l}\text { Minimum } \\
\text { detect }\end{array}$} & \multirow[b]{2}{*}{$\underset{\text { detect }}{\text { Maximum }}$} & \multirow[b]{2}{*}{$\begin{array}{l}\text { Location(s) of } \\
\text { maximum detect }\end{array}$} & \multirow{2}{*}{$\begin{array}{c}\text { Average } \\
\text { detected } \\
\text { result }\end{array}$} & \multicolumn{6}{|c|}{ Number of analyses exceeding criteria } \\
\hline & & & & & & $\begin{array}{c}\text { Max } \\
\text { RL }\end{array}$ & $\begin{array}{l}\text { Avg } \\
\text { RL }\end{array}$ & $\begin{array}{c}\text { Ind } \\
\text { PRG }\end{array}$ & Bkg & $\begin{array}{l}\text { GW } \\
\text { SL }\end{array}$ & $\begin{array}{c}\text { Res } \\
\text { PRG }\end{array}$ \\
\hline Aluminum & $40 / 40$ & 10,100 & 24,900 & SB053 & 19,485 & NA & NA & 0 & 0 & NA & 40 \\
\hline Arsenic & $40 / 40$ & $0.98 \mathrm{~J}$ & $15.8 \mathrm{~J}$ & SB061 & 5.55 & 0 & 0 & 0 & 1 & 0 & 40 \\
\hline Barium & $40 / 40$ & $21.5 \mathrm{~J}$ & $239 \mathrm{~J}$ & SB072 & 114 & NA & NA & 0 & 13 & 0 & 0 \\
\hline Cadmium & $13 / 40$ & 1.2 & $2.9 \mathrm{~J}$ & Z2-EU41DB-232 & 1.62 & NA & NA & 0 & 13 & NA & 0 \\
\hline Calcium & $35 / 40$ & 20.2 & $87,000 \mathrm{~J}$ & Z2-EU41DB-223 & 5026 & NA & NA & NA & 7 & NA & NA \\
\hline Chromium & $40 / 40$ & 13.2 & 55 & Z2-EU41DB-228 & 27.5 & NA & NA & 0 & 1 & 0 & 32 \\
\hline Cobalt & $40 / 40$ & 1.8 & 43 & SB069 & 8.88 & NA & NA & 0 & 1 & NA & 0 \\
\hline Copper & $40 / 40$ & 8.7 & 40.7 & SB070 & 19.6 & NA & NA & 0 & 9 & NA & 0 \\
\hline Iron & $40 / 40$ & 13,200 & 41,000 & Z2-EU41DB-230 & 28,475 & NA & NA & 0 & 0 & NA & 40 \\
\hline Lead & $40 / 40$ & $6.2 \mathrm{~J}$ & $114 \mathrm{~J}$ & SB061 & 16.1 & NA & NA & 0 & 2 & 0 & 0 \\
\hline Magnesium & $40 / 40$ & 497 & $7900 \mathrm{~J}$ & Z2-EU41DB-223 & 1934 & NA & NA & NA & 3 & NA & NA \\
\hline Manganese & $40 / 40$ & 29.8 & $2210 \mathrm{~J}$ & SB069 & 253 & NA & NA & 0 & 1 & NA & 19 \\
\hline Mercury & $24 / 40$ & $0.024 \mathrm{~J}$ & $4.3 \mathrm{~J}$ & Z2-EU41DB-231 & 0.301 & 0 & 0 & 0 & 5 & NA & 1 \\
\hline Nickel & $40 / 40$ & 5.5 & 108 & SB054 & 24.9 & NA & NA & 0 & 15 & NA & 0 \\
\hline Selenium & $8 / 25$ & $0.97 \mathrm{~J}$ & 2.8 & SB060 SB067 & 1.95 & NA & NA & 0 & 5 & NA & 0 \\
\hline Silver & $27 / 27$ & 0.35 & 2.7 & SB051 & 1.68 & NA & NA & 0 & 26 & NA & 0 \\
\hline Thallium & $15 / 40$ & $0.13 \mathrm{~J}$ & $0.57 \mathrm{~J}$ & SB050 & 0.213 & NA & NA & 0 & 1 & 0 & 1 \\
\hline Vanadium & $40 / 40$ & 15.7 & 46.8 & SB066 & 27.5 & NA & NA & 0 & 0 & NA & 40 \\
\hline
\end{tabular}

Avg $=$ average $\quad$ Max $=$ maximum

$\mathrm{Bkg}=$ background $\quad \mathrm{NA}=$ not applicable

$\mathrm{EU}=$ exposure unit

FFA = Federal Facility Agreement

PRG $=$ preliminary remediation goal

$\mathrm{GW}=$ groundwater

Res $=$ residential

Ind = industrial $\quad \mathrm{SL}=$ screening level

EU Z2-41 K-1070 PITS FFA SITE PPCB DETECTS (ug/kg) 0-10 ft

\begin{tabular}{|c|c|c|c|c|c|c|c|c|c|}
\hline \multirow[b]{2}{*}{ Analyte } & \multirow[b]{2}{*}{$\begin{array}{c}\text { Detect } \\
\text { frequency }\end{array}$} & \multirow[b]{2}{*}{$\begin{array}{c}\text { Minimum } \\
\text { detect }\end{array}$} & \multirow[b]{2}{*}{$\begin{array}{c}\text { Maximum } \\
\text { detect }\end{array}$} & \multirow[b]{2}{*}{$\begin{array}{c}\text { Location(s) of } \\
\text { maximum detect }\end{array}$} & \multirow{2}{*}{$\begin{array}{c}\text { Average } \\
\text { detected } \\
\text { result }\end{array}$} & \multicolumn{4}{|c|}{$\begin{array}{l}\text { Number of analyses } \\
\text { exceeding criteria }\end{array}$} \\
\hline & & & & & & $\begin{array}{c}\text { Max } \\
\text { RL }\end{array}$ & $\begin{array}{l}\text { Avg } \\
\text { RL }\end{array}$ & $\begin{array}{l}\text { Ind } \\
\text { PRG }\end{array}$ & $\begin{array}{l}\text { Res } \\
\text { PRG }\end{array}$ \\
\hline Methoxychlor & $1 / 27$ & $2.2 \mathrm{~J}$ & $2.2 \mathrm{~J}$ & SB069 & 2.2 & NA & NA & 0 & NA \\
\hline PCB-1248 & $2 / 40$ & $130 \mathrm{~J}$ & 490 & SB071 & 310 & 0 & 0 & 0 & 2 \\
\hline PCB-1254 & $5 / 40$ & $8 \mathrm{~J}$ & $350 \mathrm{~J}$ & SB071 & 87.7 & 0 & 0 & 0 & 1 \\
\hline PCB-1260 & $3 / 40$ & $9.7 \mathrm{~J}$ & 170 & Z2-EU41DB-228 & 68.2 & 0 & 0 & 0 & 1 \\
\hline Polychlorinated Biphenyl & $5 / 13$ & $8 \mathrm{~J}$ & 170 & Z2-EU41DB-228 & 52.5 & 0 & 0 & 0 & 1 \\
\hline
\end{tabular}

Avg $=$ average $\quad \mathrm{NA}=$ not applicable

$\mathrm{EU}=$ exposure unit $\quad \mathrm{PPCB}=$ pesticide and polychlorinated biphenyl

FFA $=$ Federal Facility Agreement $\quad P R G=$ preliminary remediation goal

Ind $=$ industrial $\quad$ Res $=$ residential

Max $=$ maximum $\quad \mathrm{RL}=$ remediation level

EU Z2-41 K-1070 PITS FFA SITE RADIONUCLIDES WITH BACKGROUND,

PRG, AND/OR RL EXCEEDANCES (pCi/g) 0-10 ft

\begin{tabular}{|c|c|c|c|c|c|c|c|c|c|c|c|}
\hline \multirow[b]{2}{*}{ Analy te } & \multirow[b]{2}{*}{$\begin{array}{c}\text { Detect } \\
\text { frequency }\end{array}$} & \multirow[b]{2}{*}{$\begin{array}{c}\text { Minimum } \\
\text { detect }\end{array}$} & \multirow[b]{2}{*}{$\begin{array}{c}\text { Maximum } \\
\text { detect }\end{array}$} & \multirow[b]{2}{*}{$\begin{array}{l}\text { Location(s) of } \\
\text { maximum detect }\end{array}$} & \multirow{2}{*}{$\begin{array}{c}\text { Average } \\
\text { detected } \\
\text { result }\end{array}$} & \multicolumn{6}{|c|}{ Number of analyses exceeding criteria } \\
\hline & & & & & & $\begin{array}{c}\text { Max } \\
\text { RL }\end{array}$ & $\begin{array}{l}\text { Avg } \\
\text { RL }\end{array}$ & $\begin{array}{l}\text { Ind } \\
\text { PRG }\end{array}$ & Bkg & $\begin{array}{c}\text { GW } \\
\text { SL }\end{array}$ & $\begin{array}{c}\text { Res } \\
\text { PRG }\end{array}$ \\
\hline Cesium-137 & $1 / 32$ & 0.685 & 0.685 & RAD72 & 0.685 & 0 & 0 & 0 & NA & NA & 1 \\
\hline Neptunium-237 & $3 / 5$ & 0.1068 & 0.43 & Z2-EU41DB-225 & 0.273 & 0 & 0 & 0 & NA & NA & 2 \\
\hline Potassium-40 & $1 / 5$ & 3.226 & 3.226 & RAD72 & 3.23 & NA & NA & 1 & 0 & NA & 1 \\
\hline Radium-226 & $1 / 4$ & $0.295 \mathrm{~J}$ & $0.295 \mathrm{~J}$ & Z2-EU41DB-225 & 0.295 & NA & NA & 1 & 0 & NA & 1 \\
\hline Technetium-99 & $26 / 32$ & 0.03 & 3.8 & RAD72 & 1.05 & NA & NA & 0 & NA & NA & 23 \\
\hline
\end{tabular}


EU Z2-41 K-1070 PITS FFA SITE RADIONUCLIDES WITH BACKGROUND, PRG, AND/OR RL EXCEEDANCES (pCi/g) 0-10 ft (cont'd)

\begin{tabular}{|c|c|c|c|c|c|c|c|c|c|c|c|}
\hline \multirow[b]{2}{*}{ Analyte } & \multirow[b]{2}{*}{$\begin{array}{c}\text { Detect } \\
\text { frequency }\end{array}$} & \multirow[b]{2}{*}{$\begin{array}{c}\text { Minimum } \\
\text { detect }\end{array}$} & \multirow[b]{2}{*}{$\begin{array}{c}\text { Maximum } \\
\text { detect }\end{array}$} & \multirow[b]{2}{*}{$\begin{array}{c}\text { Location(s) of } \\
\text { maximum detect }\end{array}$} & \multirow{2}{*}{$\begin{array}{c}\text { Average } \\
\text { detected } \\
\text { result }\end{array}$} & \multicolumn{6}{|c|}{ Number of analyses exceeding criteria } \\
\hline & & & & & & $\begin{array}{c}\text { Max } \\
\text { RL }\end{array}$ & $\begin{array}{l}\text { Avg } \\
\text { RL }\end{array}$ & $\begin{array}{c}\text { Ind } \\
\text { PRG }\end{array}$ & Bkg & $\begin{array}{l}\text { GW } \\
\text { SL }\end{array}$ & $\begin{array}{c}\text { Res } \\
\text { PRG }\end{array}$ \\
\hline Uranium-234 & $32 / 32$ & 0.234 & 4.984 & RAD72 & 1.21 & 0 & 0 & 0 & NA & 0 & 1 \\
\hline Uranium-238 & $31 / 32$ & 0.144 & 1.9 & SB066 & 0.993 & 0 & 0 & 0 & 3 & 0 & 25 \\
\hline \multicolumn{2}{|c|}{$\begin{array}{l}\text { Avg = average } \\
\text { Bkg = background } \\
\text { EU = exposure unit } \\
\text { FFA = Federal Facility Agreement } \\
\text { GW = groundwater } \\
\text { Ind = industrial }\end{array}$} & $\begin{array}{l}\text { Max = } \\
\text { NA = } \\
\text { PRG = } \\
\text { Res }= \\
\text { RL }=1 \\
\text { SL }=\mathrm{s}\end{array}$ & $\begin{array}{l}\text { maximum } \\
\text { not applicabl } \\
=\text { preliminary } \\
\text { residential } \\
\text { emediation lo } \\
\text { creening leve }\end{array}$ & $\begin{array}{l}\text { le } \\
\text { remediation goal } \\
\text { evel } \\
\text { el }\end{array}$ & & & & & & & \\
\hline
\end{tabular}

EU Z2-41 K-1070 PITS FFA SITE SVOC DETECTS (ug/kg) 0-10 ft

\begin{tabular}{|c|c|c|c|c|c|c|c|c|}
\hline \multirow[b]{2}{*}{ Analyte } & \multirow[b]{2}{*}{$\begin{array}{c}\text { Detect } \\
\text { frequency }\end{array}$} & \multirow[b]{2}{*}{$\begin{array}{c}\text { Minimum } \\
\text { detect }\end{array}$} & \multirow[b]{2}{*}{$\begin{array}{c}\text { Maximum } \\
\text { detect }\end{array}$} & \multirow[b]{2}{*}{$\begin{array}{c}\text { Location(s) of } \\
\text { maximum detect }\end{array}$} & \multirow{2}{*}{$\begin{array}{c}\text { Average } \\
\text { detected } \\
\text { result }\end{array}$} & \multicolumn{3}{|c|}{$\begin{array}{l}\text { Number of analyses } \\
\text { exceeding criteria }\end{array}$} \\
\hline & & & & & & $\begin{array}{c}\text { Ind } \\
\text { PRG }\end{array}$ & $\begin{array}{l}\text { GW } \\
\text { SL }\end{array}$ & $\begin{array}{l}\text { Res } \\
\text { PRG }\end{array}$ \\
\hline 2-Methylnaphthalene & $1 / 39$ & $320 \mathrm{~J}$ & $320 \mathrm{~J}$ & SB071 & 320 & 0 & NA & NA \\
\hline Acenaphthene & $1 / 39$ & $88 \mathrm{~J}$ & $88 \mathrm{~J}$ & Z2-EU41DB-223 & 88 & 0 & NA & 0 \\
\hline Anthracene & $1 / 39$ & $220 \mathrm{~J}$ & $220 \mathrm{~J}$ & Z2-EU41DB-223 & 220 & 0 & NA & 0 \\
\hline Benz(a)anthracene & $5 / 39$ & $25 \mathrm{~J}$ & 590 & Z2-EU41DB-223 & 183 & 0 & NA & 0 \\
\hline Benzo(a)pyrene & $5 / 39$ & $24 \mathrm{~J}$ & 660 & Z2-EU41DB-223 & 196 & 0 & NA & 2 \\
\hline Benzo(b)fluoranthene & $5 / 39$ & $37 \mathrm{~J}$ & 820 & Z2-EU41DB-223 & 260 & 0 & NA & 1 \\
\hline Benzo(ghi)perylene & $2 / 39$ & $97 \mathrm{~J}$ & $320 \mathrm{~J}$ & Z2-EU41DB-223 & 209 & 0 & NA & 0 \\
\hline Benzo(k)fluoranthene & $2 / 39$ & $110 \mathrm{~J}$ & $380 \mathrm{~J}$ & Z2-EU41DB-223 & 245 & 0 & NA & 0 \\
\hline Bis(2-ethylhexyl)phthalate & $11 / 39$ & $53 \mathrm{~J}$ & 110,000 & Z2-EU41DB-232 & 27,265 & 0 & 0 & 3 \\
\hline Butyl benzyl phthalate & $2 / 39$ & $28 \mathrm{~J}$ & $61 \mathrm{~J}$ & SB053 & 44.5 & 0 & NA & 0 \\
\hline Carbazole & $1 / 39$ & $140 \mathrm{~J}$ & $140 \mathrm{~J}$ & Z2-EU41DB-223 & 140 & 0 & NA & 0 \\
\hline Chrysene & $2 / 39$ & $180 \mathrm{~J}$ & 550 & Z2-EU41DB-223 & 365 & 0 & NA & 0 \\
\hline Dibenzofuran & $1 / 39$ & $37 \mathrm{~J}$ & $37 \mathrm{~J}$ & Z2-EU41DB-223 & 37 & 0 & NA & 0 \\
\hline Diethyl phthalate & $4 / 39$ & $27 \mathrm{~J}$ & $49 \mathrm{~J}$ & Z2-EU41DB-232 & 38.8 & 0 & NA & 0 \\
\hline Dimethyl phthalate & $3 / 39$ & 59 & $650 \mathrm{~J}$ & SB050 & 257 & 0 & NA & 0 \\
\hline Di-n-butyl phthalate & $6 / 39$ & $25 \mathrm{~J}$ & $100 \mathrm{~J}$ & Z2-EU41DB-232 & 59.8 & 0 & NA & 0 \\
\hline Di-n-octylphthalate & $5 / 39$ & $32 \mathrm{~J}$ & $99 \mathrm{~J}$ & Z2-EU41DB-232 & 58.2 & 0 & NA & 0 \\
\hline Fluoranthene & $5 / 39$ & $39 \mathrm{~J}$ & 1600 & Z2-EU41DB-223 & 402 & 0 & NA & 0 \\
\hline Fluorene & $1 / 39$ & $91 \mathrm{~J}$ & $91 \mathrm{~J}$ & Z2-EU41DB-223 & 91 & 0 & NA & 0 \\
\hline Indeno(1,2,3-cd)pyrene & $2 / 39$ & $91 \mathrm{~J}$ & $320 \mathrm{~J}$ & Z2-EU41DB-223 & 206 & 0 & NA & 0 \\
\hline Naphthalene & $2 / 40$ & $57 \mathrm{~J}$ & $63 \mathrm{~J}$ & SB071 & 60 & 0 & NA & 0 \\
\hline Phenanthrene & $4 / 39$ & $28 \mathrm{~J}$ & 960 & Z2-EU41DB-223 & 287 & 0 & NA & 0 \\
\hline Pyrene & $5 / 39$ & $31 \mathrm{~J}$ & 1300 & Z2-EU41DB-223 & 333 & 0 & NA & 0 \\
\hline \multicolumn{2}{|l|}{ EU $=$ exposure unit } & \multicolumn{7}{|c|}{ PRG = preliminary remediation goal } \\
\hline \multirow{2}{*}{\multicolumn{2}{|c|}{$\begin{array}{l}\text { FFA }=\text { Federal Facility Agreement } \\
\text { GW = groundwater }\end{array}$}} & \multirow{2}{*}{\multicolumn{7}{|c|}{ Res $=$ residential }} \\
\hline & & & & & & & & \\
\hline Ind = industrial & & \multicolumn{7}{|c|}{$\begin{array}{l}\text { SL }=\text { screening level } \\
\text { SVOC }=\text { semivolatile organic compound }\end{array}$} \\
\hline
\end{tabular}

EU Z2-41 K-1070 PITS FFA SITE VOC DETECTS (ug/kg) 0-10 ft

\begin{tabular}{|c|c|c|c|c|c|c|c|c|}
\hline \multirow[b]{2}{*}{ Analyte } & \multirow[b]{2}{*}{$\begin{array}{c}\text { Detect } \\
\text { frequency }\end{array}$} & \multirow[b]{2}{*}{$\begin{array}{c}\text { Minimum } \\
\text { detect }\end{array}$} & \multirow[b]{2}{*}{$\begin{array}{c}\text { Maximum } \\
\text { detect }\end{array}$} & \multirow[b]{2}{*}{$\begin{array}{c}\text { Location(s) of } \\
\text { maximum detect }\end{array}$} & \multirow{2}{*}{$\begin{array}{c}\text { Average } \\
\text { detected } \\
\text { result }\end{array}$} & \multicolumn{3}{|c|}{$\begin{array}{l}\text { Number of analyses } \\
\text { exceeding criteria }\end{array}$} \\
\hline & & & & & & $\begin{array}{l}\text { Ind } \\
\text { PRG }\end{array}$ & $\begin{array}{c}\text { GW } \\
\text { SL }\end{array}$ & $\begin{array}{l}\text { Res } \\
\text { PRG }\end{array}$ \\
\hline $\begin{array}{l}\text { 1,1,1-Trichloroethane } \\
\text { 1,1,2-Trichloro-1,2,2- }\end{array}$ & $2 / 27$ & $23 \mathrm{~J}$ & 30 & SB056 & 26.5 & 0 & 0 & 0 \\
\hline trifluoroethane & $9 / 27$ & $1 \mathrm{~J}$ & 18 & SB067 & 4.22 & 0 & NA & 0 \\
\hline 1,1,2-Trichloroethane & $1 / 27$ & $4 \mathrm{~J}$ & $4 \mathrm{~J}$ & SB058 & 4 & 0 & 0 & 0 \\
\hline 2-Butanone & $1 / 27$ & $1100 \mathrm{~J}$ & $1100 \mathrm{~J}$ & SB071 & 1100 & 0 & NA & 0 \\
\hline 2-Hexanone & $1 / 27$ & $11 \mathrm{~J}$ & $11 \mathrm{~J}$ & SB055 & 11 & NA & NA & NA \\
\hline
\end{tabular}




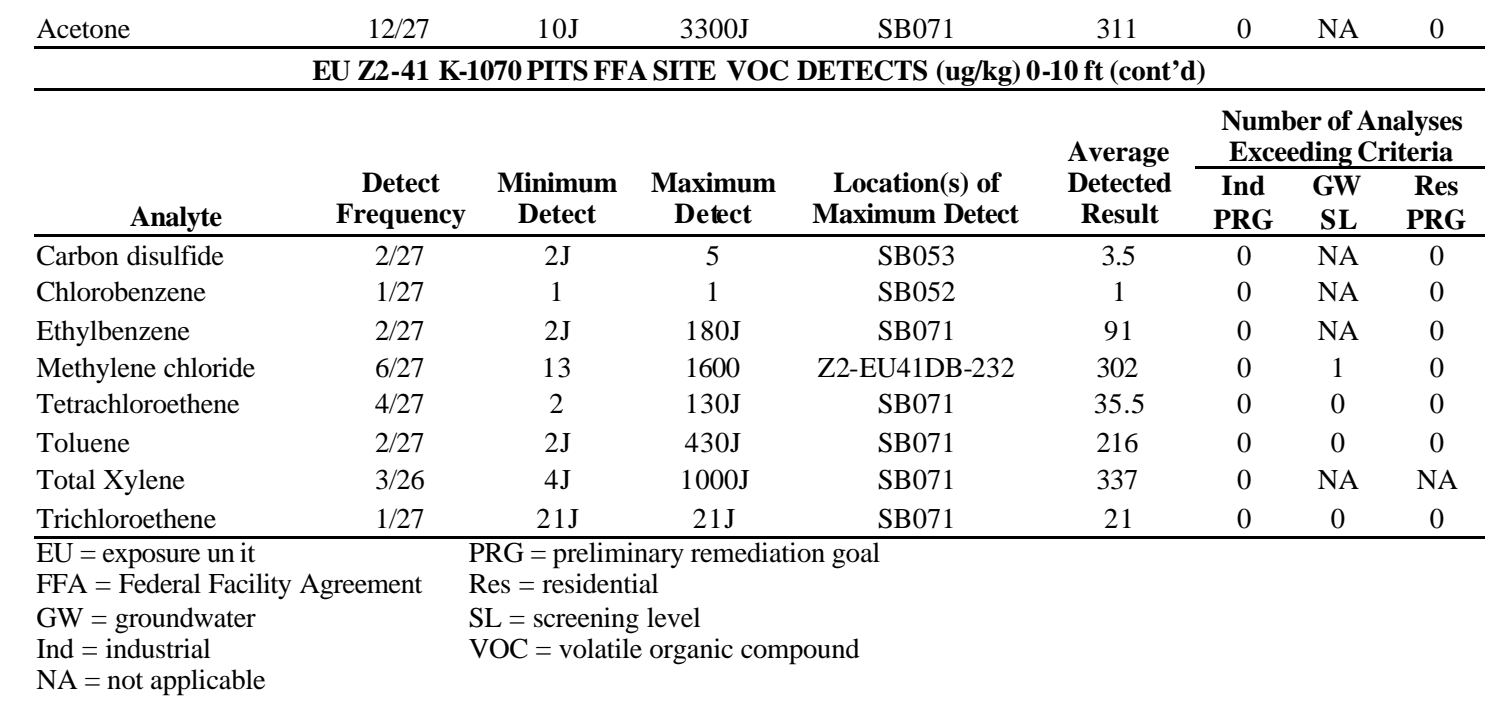

K-1071 Concrete Pad FFA site: Twenty-four soil sample locations fall within the boundaries of the K-1071 Concrete Pad FFA site-one DVS location and 23 historical locations. Sample locations for this site include the Concrete Pad Class $1 \mathrm{SU}$ sample locations plus an additional two locations presented in the table in Sect. 2.2.3. Analytical results summarized here are for soil samples only; the four concrete samples collected from the Concrete Pad Class 1 SU and summarized in Sect. 2.2.5 are not included. Analytical results summarized below are similar to those for the Concrete Pad Class 1 SU (Sect. 2.2.5) because the Concrete Pad Class 1 SU sample locations include the bulk of sample locations for this site. Analytical results show U-235 and U-238 Max and Avg. RL exceedances associated with the historical RAD47 location and its DVS confirmation sample location; radionuclide Ind PRG and GW SL exceedances also associated with the RAD47 and confirmation locations; PCE and TCE Ind PRG exceedances in the Concrete Pad Class $1 \mathrm{SU}$; methylene chloride, PCE, and TCE GW SL exceedances in the Concrete Pad Class 1 SU; metals and radionuclide Bkg exceedances; and PCB, SVOC, and VOC detections. All RL, Ind PRG, and GW SL exceedances at this site occur within the Concrete Pad Class 1 SU (i.e., no exceedances occur at the two sample locations located outside the boundaries of the Class $1 \mathrm{SU}$ ).

In addition, as discussed in Sect. 2.2.5, there are U-234, U-235, and U-238 data that were rejected during validation. Laboratory results indicated the presence of these radioisotopes at significantly elevated concentrations, however, there were problems with the laboratory accurately quantifying the results, which resulted in the data being rejected.

EU Z2-41 K-1071 CONCRETE PAD FFA SITE METALS WITH BACKGROUND, PRG, GW SL, AND/OR RL EXCEEDANCES (mg/kg) 0-10 ft

\begin{tabular}{|c|c|c|c|c|c|c|c|c|c|c|c|}
\hline \multirow[b]{2}{*}{ Analyte } & \multirow[b]{2}{*}{$\begin{array}{c}\text { Detect } \\
\text { frequency }\end{array}$} & \multirow[b]{2}{*}{$\begin{array}{c}\text { Minimum } \\
\text { detect }\end{array}$} & \multirow[b]{2}{*}{$\underset{\text { detect }}{\text { Maximum }}$} & \multirow[b]{2}{*}{$\begin{array}{l}\text { Location(s) of } \\
\text { maximum detect }\end{array}$} & \multirow{2}{*}{$\begin{array}{c}\text { Average } \\
\text { detected } \\
\text { result }\end{array}$} & \multicolumn{6}{|c|}{ Number of analyses exceeding criteria } \\
\hline & & & & & & $\begin{array}{c}\text { Max } \\
\text { RL }\end{array}$ & $\begin{array}{c}\text { Avg } \\
\text { RL }\end{array}$ & $\begin{array}{l}\text { Ind } \\
\text { PRG }\end{array}$ & Bkg & $\begin{array}{c}\text { GW } \\
\text { SL }\end{array}$ & $\begin{array}{r}\text { Res } \\
\text { PRG }\end{array}$ \\
\hline$\overline{\text { Aluminum }}$ & $21 / 21$ & 3680 & 26,000 & Z2-EU41DB-219 & 14,967 & NA & NA & 0 & 0 & NA & 18 \\
\hline Antimony & $9 / 16$ & $0.22 \mathrm{~J}$ & $4.2 \mathrm{~J}$ & SS007 & 0.744 & NA & NA & 0 & 1 & 0 & 1 \\
\hline Arsenic & $20 / 21$ & 1.7 & $11.7 \mathrm{~J}$ & SS005 & 4.38 & 0 & 0 & 0 & 0 & 0 & 20 \\
\hline Barium & $21 / 21$ & 22.7 & 237 & SS007 & 127 & NA & NA & 0 & 11 & 0 & 0 \\
\hline Cadmium & $9 / 21$ & 0.098 & $3.8 \mathrm{~J}$ & SS007 & 1.36 & NA & NA & 0 & 7 & NA & 1 \\
\hline Calcium & $21 / 21$ & $1770 \mathrm{~J}$ & 235,000 & SS003 & 66,334 & NA & NA & NA & 19 & NA & NA \\
\hline Chromium & $21 / 21$ & 10 & 156 & SS007 & 34.0 & NA & NA & 0 & 2 & 0 & 15 \\
\hline Copper & $21 / 21$ & $6.7 \mathrm{~J}$ & $1100 \mathrm{~J}$ & SS007 & 124 & NA & NA & 0 & 14 & NA & 2 \\
\hline Lead & $21 / 21$ & 10.2 & 230 & SS007 & 33.1 & NA & NA & 0 & 3 & 0 & 0 \\
\hline Magnesium & $21 / 21$ & $830 \mathrm{~J}$ & $49,000 \mathrm{~J}$ & Z2-EU41DB-210 & 11,654 & NA & NA & NA & 10 & NA & NA \\
\hline Manganese & $21 / 21$ & $112 \mathrm{~J}$ & $1800 \mathrm{~J}$ & Z2-EU41D-201 & 389 & NA & NA & 0 & 0 & NA & 15 \\
\hline Mercury & $14 / 20$ & 0.028 & 1.5 & SS007 & 0.290 & 0 & 0 & 0 & 5 & NA & 0 \\
\hline Nickel & $21 / 21$ & $9.1 \mathrm{~J}$ & $938 \mathrm{~J}$ & SS007 & 128 & NA & NA & 0 & 13 & NA & 3 \\
\hline Silver & $3 / 18$ & $0.76 \mathrm{~J}$ & $1.2 \mathrm{~J}$ & SS005 & 0.983 & NA & NA & 0 & 3 & NA & 0 \\
\hline Sodium & $14 / 21$ & $34 \mathrm{~J}$ & 546 & SS013 & 149 & NA & NA & NA & 1 & NA & NA \\
\hline
\end{tabular}


EU Z2-41 K-1071 CONCRETE PAD FFA SITE METALS WITH BACKGROUND, PRG, GW SL, AND/OR RL EXCEEDANCES (mg/kg) 0-10 ft (cont'd)

\begin{tabular}{|c|c|c|c|c|c|c|c|c|c|c|c|}
\hline \multirow[b]{2}{*}{ Analyte } & \multirow[b]{2}{*}{$\begin{array}{c}\text { Detect } \\
\text { frequency }\end{array}$} & \multirow[b]{2}{*}{$\begin{array}{c}\text { Minimum } \\
\text { detect }\end{array}$} & \multirow[b]{2}{*}{$\begin{array}{c}\text { Maximum } \\
\text { detect }\end{array}$} & \multirow[b]{2}{*}{$\begin{array}{l}\text { Location(s) of } \\
\text { maximum detect }\end{array}$} & \multirow{2}{*}{$\begin{array}{c}\text { Average } \\
\text { detected } \\
\text { result }\end{array}$} & \multicolumn{6}{|c|}{ Number of analyses exceeding criteria } \\
\hline & & & & & & $\begin{array}{c}\text { Max } \\
\text { RL }\end{array}$ & $\begin{array}{l}\text { Avg } \\
\text { RL }\end{array}$ & $\begin{array}{c}\text { Ind } \\
\text { PRG }\end{array}$ & Bkg & $\begin{array}{c}\text { GW } \\
\text { SL }\end{array}$ & $\begin{array}{l}\text { Res } \\
\text { PRG }\end{array}$ \\
\hline Vanadium & $21 / 21$ & 6.7 & 66.5 & SS005 & 24.7 & NA & NA & 0 & 1 & NA & 19 \\
\hline Zinc & $21 / 21$ & 27 & $420 \mathrm{~J}$ & SS007 & 83.8 & NA & NA & 0 & 7 & NA & 0 \\
\hline
\end{tabular}

Avg $=$ average

$\mathrm{Bkg}=$ background

$\mathrm{EU}=$ exposure unit

FFA $=$ Federal Facility Agreement

$\mathrm{GW}=$ groundwater

Max = maximum

$\mathrm{NA}=$ not applicable

$\mathrm{PRG}=$ preliminary remediation goal

Ind $=$ industrial

Res $=$ residential

$\mathrm{RL}=$ remediation level

$\mathrm{SL}=$ screening level

EU Z2-41 K-1071 CONCRETE PAD FFA SITE PPCB DETECTS (ug/kg) 0-10 ft

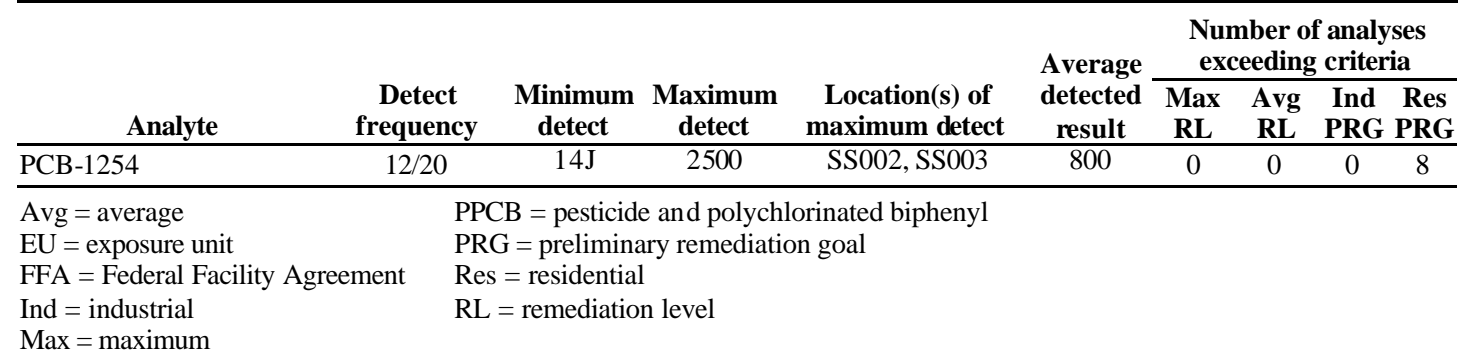

EU Z2-41 K-1071 CONCRETE PAD FFA SITE RADIONUCLIDES WITH BACKGROUND, PRG, AND/OR RL EXCEEDANCES (pCi/g) 0-10 ft

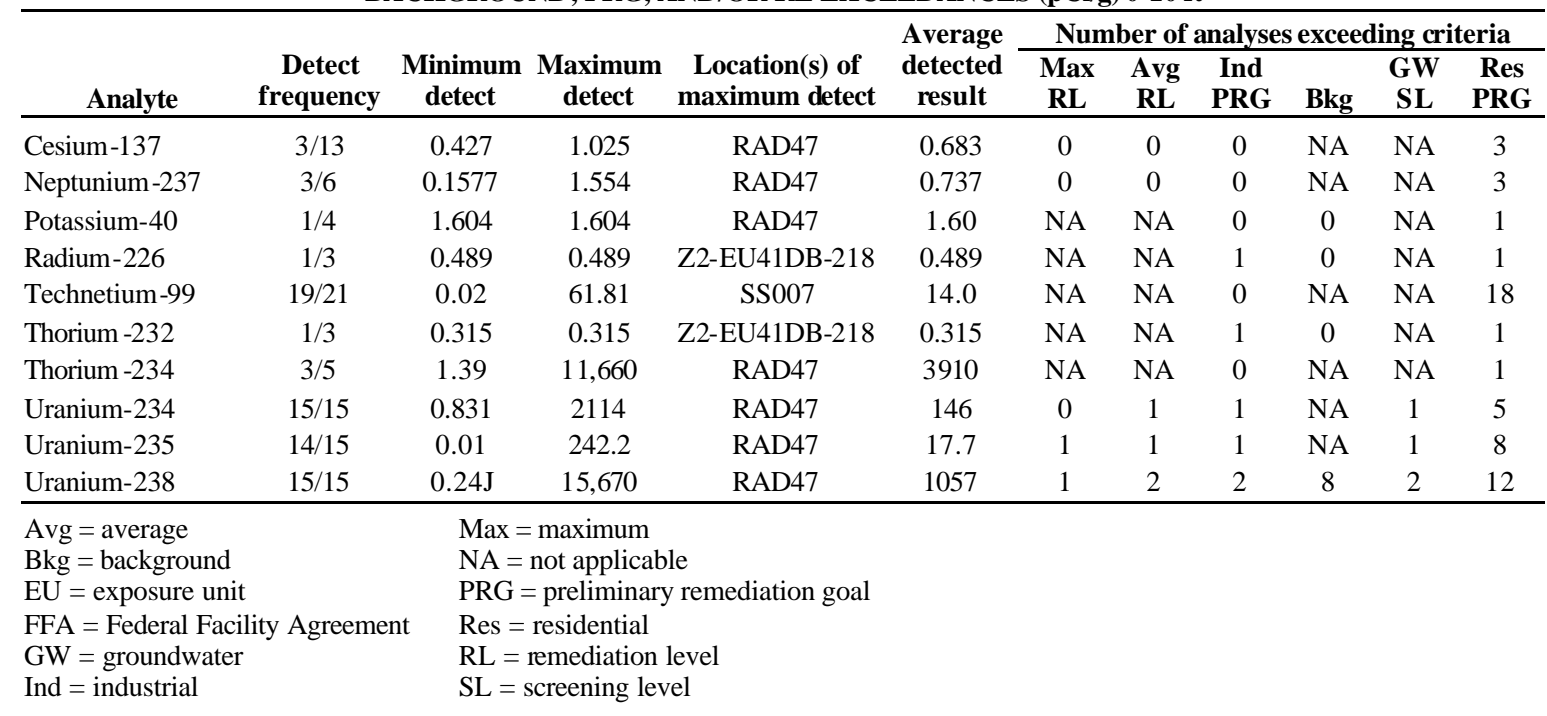

EU Z2-41 K-1071 CONCRETE PAD FFA SITE SVOC DETECTS (ug/kg) 0-10 ft

\begin{tabular}{|c|c|c|c|c|c|c|c|c|}
\hline \multirow[b]{2}{*}{ Analyte } & \multirow[b]{2}{*}{$\begin{array}{c}\text { Detect } \\
\text { frequency }\end{array}$} & \multirow[b]{2}{*}{$\begin{array}{c}\text { Minimum } \\
\text { detect }\end{array}$} & \multirow[b]{2}{*}{$\begin{array}{c}\text { Maximum } \\
\text { detect }\end{array}$} & \multirow[b]{2}{*}{$\begin{array}{c}\text { Location(s) of } \\
\text { maximum detect }\end{array}$} & \multirow{2}{*}{$\begin{array}{c}\text { Average } \\
\text { detected } \\
\text { result }\end{array}$} & \multicolumn{3}{|c|}{$\begin{array}{l}\text { Number of analyses } \\
\text { exceeding criteria }\end{array}$} \\
\hline & & & & & & $\begin{array}{l}\text { Ind } \\
\text { PRG }\end{array}$ & $\begin{array}{l}\text { GW } \\
\text { SL }\end{array}$ & $\begin{array}{l}\text { Res } \\
\text { PRG }\end{array}$ \\
\hline 1,2,4-Trichlorobenzene & $4 / 21$ & 730 & 7300 & SS002 & 2800 & 0 & NA & 1 \\
\hline 1,2-Dichlorobenzene & $1 / 21$ & 720 & 720 & SSO02 & 720 & 0 & NA & 0 \\
\hline 2-Methylnaphthalene & $4 / 20$ & $52 \mathrm{~J}$ & $100 \mathrm{~J}$ & SS002 & 76 & 0 & NA & NA \\
\hline 4-Methylphenol & $1 / 15$ & $63 \mathrm{~J}$ & $63 \mathrm{~J}$ & SS013 & 63 & 0 & NA & NA \\
\hline Acenaphthene & $3 / 20$ & $22 \mathrm{~J}$ & $70 \mathrm{~J}$ & SS004 & 44.3 & 0 & NA & 0 \\
\hline Anthracene & $3 / 20$ & $20 \mathrm{~J}$ & $54 \mathrm{~J}$ & SS014 & 42.3 & 0 & NA & 0 \\
\hline
\end{tabular}




\begin{tabular}{|c|c|c|c|c|c|c|c|c|}
\hline \multirow[b]{2}{*}{ Analyte } & \multirow[b]{2}{*}{$\begin{array}{l}\text { Detect } \\
\text { frequency }\end{array}$} & \multirow[b]{2}{*}{$\begin{array}{c}\text { Minimum } \\
\text { detect }\end{array}$} & \multirow[b]{2}{*}{$\begin{array}{c}\text { Maximum } \\
\text { detect }\end{array}$} & \multirow[b]{2}{*}{$\begin{array}{c}\text { Location(s) of } \\
\text { maximum detect }\end{array}$} & \multirow{2}{*}{$\begin{array}{c}\text { Average } \\
\text { detected } \\
\text { result }\end{array}$} & \multicolumn{3}{|c|}{$\begin{array}{l}\text { Number of analyses } \\
\text { exceeding criteria }\end{array}$} \\
\hline & & & & & & $\begin{array}{l}\text { Ind } \\
\text { PRG }\end{array}$ & $\begin{array}{l}\text { GW } \\
\text { SL }\end{array}$ & $\begin{array}{l}\text { Res } \\
\text { PRG }\end{array}$ \\
\hline Benz(a)anthracene & $6 / 20$ & $42 \mathrm{~J}$ & $170 \mathrm{~J}$ & SS014 & 89.8 & 0 & NA & 0 \\
\hline Benzo(a)pyrene & $6 / 20$ & $32 \mathrm{~J}$ & $120 \mathrm{~J}$ & Z2-EU41DB-219 & 70.7 & 0 & NA & 3 \\
\hline Benzo(b)fluoranthene & $6 / 20$ & $40 \mathrm{~J}$ & $200 \mathrm{~J}$ & Z2-EU41DB-219 & 104 & 0 & NA & 0 \\
\hline Benzo(ghi)perylene & $3 / 20$ & $44 \mathrm{~J}$ & $120 \mathrm{~J}$ & SS015 & 83.3 & 0 & NA & 0 \\
\hline Benzo(k)fluoranthene & $5 / 20$ & $35 \mathrm{~J}$ & $140 \mathrm{~J}$ & SS014 & 68.4 & 0 & NA & 0 \\
\hline Bis(2-ethylhexyl)phthalate & $5 / 20$ & $2300 \mathrm{~J}$ & 37,000 & Z2-EU41DB-218 & 10,840 & 0 & 0 & 1 \\
\hline Butyl benzyl phthalate & $1 / 20$ & 680 & 680 & SS015 & 680 & 0 & NA & 0 \\
\hline Carbazole & $1 / 20$ & $34 \mathrm{~J}$ & $34 \mathrm{~J}$ & Z2-EU41DB-219 & 34 & 0 & NA & 0 \\
\hline Chrysene & $7 / 20$ & $33 \mathrm{~J}$ & $180 \mathrm{~J}$ & SS014 & 81.1 & 0 & NA & 0 \\
\hline Dibenzofuran & $1 / 20$ & $20 \mathrm{~J}$ & $20 \mathrm{~J}$ & SS002 & 20 & 0 & NA & 0 \\
\hline Diethyl phthalate & $2 / 20$ & $33 \mathrm{~J}$ & $66 \mathrm{~J}$ & SS015 & 49.5 & 0 & NA & 0 \\
\hline Dimethyl phthalate & $3 / 20$ & $51 \mathrm{~J}$ & $220 \mathrm{~J}$ & SS006 & 108 & 0 & NA & 0 \\
\hline Di-n-butyl phthalate & $1 / 20$ & 780 & 780 & Z2-EU41DB-210 & 780 & 0 & NA & 0 \\
\hline Di-n-octylphthalate & $3 / 20$ & $56 \mathrm{~J}$ & $310 \mathrm{~J}$ & SS004 & 145 & 0 & NA & 0 \\
\hline Fluoranthene & $10 / 20$ & $43 \mathrm{~J}$ & 430 & SS014 & 154 & 0 & NA & 0 \\
\hline Fluorene & $1 / 20$ & $29 \mathrm{~J}$ & $29 \mathrm{~J}$ & Z2-EU41DB-219 & 29 & 0 & NA & 0 \\
\hline Indeno(1,2,3-cd)pyrene & $2 / 20$ & $87 \mathrm{~J}$ & $96 \mathrm{~J}$ & SS015 & 91.5 & 0 & NA & 0 \\
\hline Phenanthrene & $9 / 20$ & $43 \mathrm{~J}$ & $300 \mathrm{~J}$ & SS014 & 121 & 0 & NA & 0 \\
\hline Phenol & $2 / 20$ & $65 \mathrm{~J}$ & $490 \mathrm{~J}$ & SS002 & 278 & 0 & NA & 0 \\
\hline Pyrene & $12 / 20$ & $53 \mathrm{~J}$ & 460 & SS014 & 149 & 0 & NA & 0 \\
\hline $\begin{array}{l}\text { EU }=\text { exposure unit } \\
\text { FFA = Federal Facility Agr } \\
\text { GW = groundwater } \\
\text { Ind = industrial } \\
\text { NA = not applicable }\end{array}$ & eement & $\begin{array}{l}\text { RG }=\text { prelim } \\
\text { Res = residen } \\
\mathrm{SL}=\text { screenin } \\
\mathrm{SVOC}=\text { semi }\end{array}$ & $\begin{array}{l}\text { linary remed } \\
\text { tial } \\
\text { ig level } \\
\text { ivolatile org }\end{array}$ & anic compound & & & & \\
\hline
\end{tabular}

EU Z2-41 K-1071 CONCRETE PAD FFA SITE VOC DETECTS (ug/kg) 0-10 ft

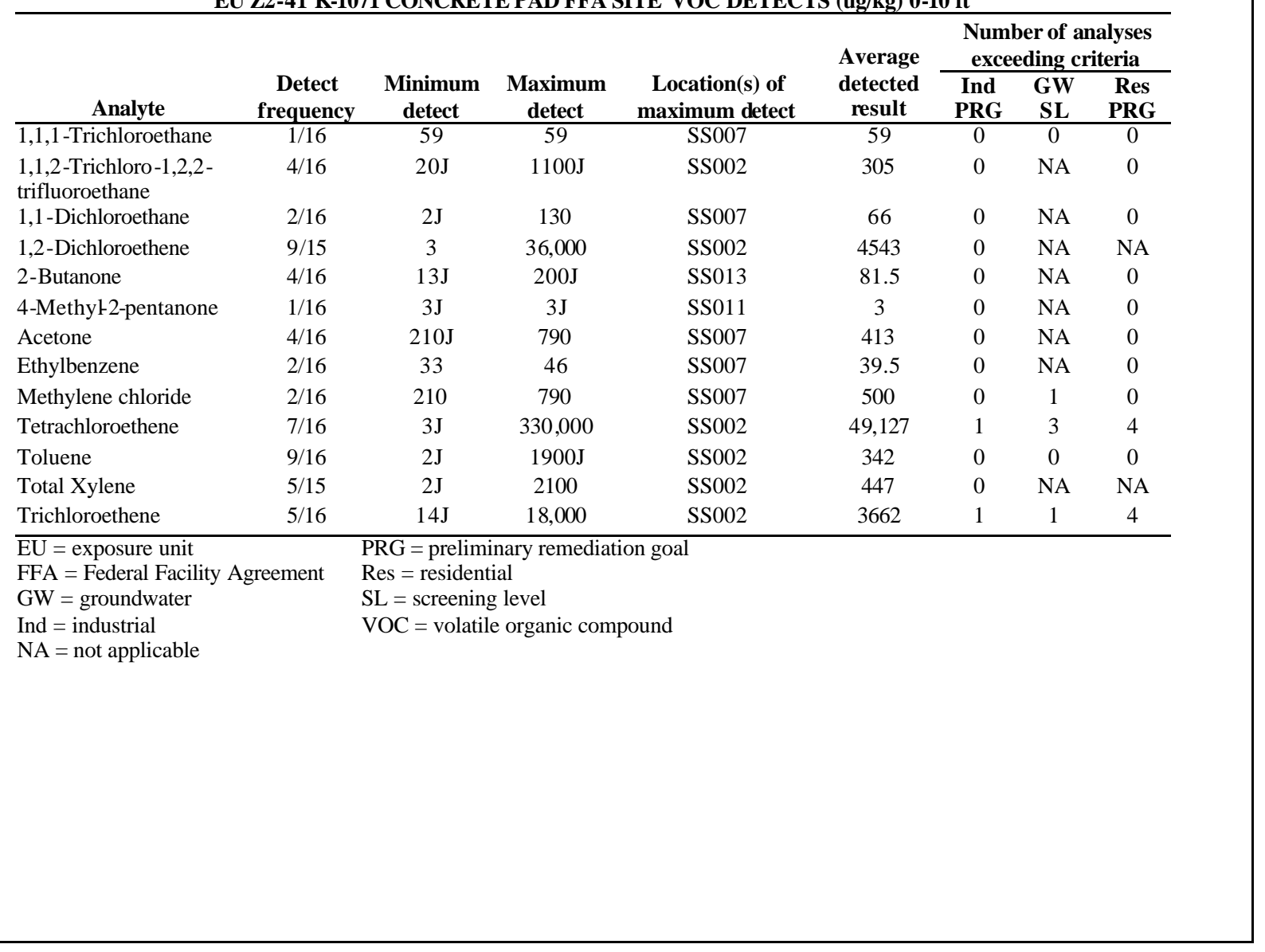




\begin{tabular}{|l|l|}
\hline & \\
\hline 3.0 & RISK EVALUATION AND ACTION/NO FURTHER ACTION DECISION \\
\hline 3.1 & INTRODUCTION \\
\hline
\end{tabular}

In this section, data are evaluated in terms of the four decision rules presented in the Zone 2 RDR/RAWP, which include the following:

- Does the concentration of any Zone 2 contaminant of concern (COC) exceed its Max RL?

- Does the mean concentration of any Zone 2 COC exceed its Avg RL across the EU?

- Does the EU pose a risk exceeding an industrial $1 \times 10^{-4}$ excess lifetime cancer risk (ELCR) or target organ hazard index (HI) of 1 ?

- Does the site pose a threat to groundwater based on MCL exceedances or soil SLs for protection of groundwater?

Table I.3 presents the results from comparison of the data to Zone 2 soils RLs, Ind PRGs (set at an ELCR of $1 \times 10-^{5}$ or a $\mathrm{HI}$ of 1), and to background levels. In addition, the EU summary in Sect. 2.2.5 presents an evaluation of the EU data by analy te group. The following table summarizes the conclusions for EU Z2-41.

\begin{tabular}{lccccc}
\hline EU \# & $\begin{array}{r}\text { Max RL } \\
\text { exceeded? }\end{array}$ & $\begin{array}{c}\text { Avg RL over } \\
\text { EU exceeded? }\end{array}$ & $\begin{array}{c}\text { Industrial risk } \\
\text { above } \mathbf{1} \times \mathbf{1 0}^{\mathbf{4}} \text { ? }\end{array}$ & $\begin{array}{c}\text { Potential source } \\
\text { to groundwater? }\end{array}$ & $\begin{array}{c}\text { Action } \\
\text { required? }\end{array}$ \\
\hline $\mathrm{Z} 2-41$ & Yes & No & No & No & Yes \\
\hline $\begin{array}{l}\mathrm{EU}=\text { exposure unit } \\
\mathrm{RL}=\text { remediation level }\end{array}$ & & & & \\
\end{tabular}

\section{\begin{tabular}{l|l}
3.2 & DATA EVALUATION FOR THE ACTION /NO FURTHER ACTION DECISION
\end{tabular}}

The requirements for determining NFA in the Zone 2 EUs are stated in the protection goals of the Zone 2 ROD remedial action objective (RAO). Four decision rules were developed in the DVS DQOs that state the specific criteria against which each EU must be compared to make the NFA decision. The four decision rules are presented in Sect. 3.2 of this PCCR and the manner in which the decision rule evaluations are conducted and special data handling requirements are discussed in Sect. 3.3. In summary, the decision rule criteria for NFA are that each EU must meet each of the following compositional constraints:

- Zone 2 soils Max RLs - maximu m allowable concentrations of Zone 2 soils COCs. Zone 2 soils Max RLs are presented in the Zone 2 ROD and Table 5 of this PCCR.

- Zone 2 soils Avg RLs - limit on the allowable average concentrations of Zone 2 soils COCs across an EU. Zone 2 soils Avg RLs are presented in the Zone 2 ROD and Table 5 of this PCCR.

- Cumulative risk across the EU-cumulative risk across an EU cannot exceed $1 \times 10^{-4}$ ELCR or HI of 1. A stepwise evaluation of cumulative risk is performed by first comparing EU data to $1 \times 10^{-5}$ Ind PRGs. The $1 \times 10^{-5}$ Ind PRGs for analytes required by the RDR/RAWP are presented in Table 5 of this PCCR.

- Groundwater protection goals - compositions of Zone 2 soils cannot pose a threat to groundwater. This evaluation is conducted by evaluating local groundwater monitoring results and comparing soils compositions to calculated SLs. Groundwater SLs are presented in Table 5 of this PCCR.

\begin{tabular}{|l|l|}
3.3 & SUMMARY AND CONCLUSIONS \\
\hline
\end{tabular}

$\underline{\text { EU Z2-41 }}$

Max RL screening. Based on analytical results from historical sampling, DVS BAR surveying, DVS and early characterization confirmation sampling, and as discussed in Sect.2.2.5, there are U235 and U238 Max RL exceedances at the RAD47 historical location in the Concrete Pad Class 1 SU. A protective interim action was taken in 1993 (covering the pad with soils) and an action to remove the pad and immediately surrounding shallow soil was indicated in the Zone 2 ROD.

Avg RL screening. Based on analytical results from historical sampling, DVS BAR surveying, DVS and early characterization confirmation and step-out sampling, there are U235 and U238 Avg RL exceedances in the Z2-EU41DB-208 Class $2 \mathrm{SU}$ that encompass an area of approximately $500 \mathrm{ft}^{2}$ or $0.03 \%$ of the 38 acres in EU 
Z2-41. In addition, there are U-235 and U-238 Avg RL exceedances in the Concrete Pad Class 1 SU at the RAD47 historical location, including its confirmation sample location, and the U-235 and U-238 Avg RL exceedances among the rejected data for Concrete Pad Class 1 SU sample locations SS001 through SS007. Because an action has already been determined for the Concrete Pad Class $1 \mathrm{SU}$ and rejected data are not included in OREIS and are, therefore, unavailable for evaluation, the Concrete Pad Class $1 \mathrm{SU}$ samples are not evaluated for their contribution to EU-wide Avg RL exceedances (assuming the recommended removal action is performed).

The first step in determining whether the U-235 and U-238 Avg RLs are exceeded across EU Z2-41 is to compare average concentrations to the Avg RLs, $8 \mathrm{pCi} / \mathrm{g}$ and $50 \mathrm{pCi} / \mathrm{g}$, respectively. The average detected concentrations were calculated to exclude the Concrete Pad Class $1 \mathrm{SU}$ data and are, therefore, different from the averages presented in the EU Z2-41 summary in Sect. 2.2.5. The resulting average detected U-235 concentration is $1.8 \mathrm{pCi} / \mathrm{g}$, which is less than the Avg RL, and the resulting average detected U-238 concentration is $19 \mathrm{pCi} / \mathrm{g}$, which is also less than the Avg RL.

Therefore, it is concluded that, no chemical or radionuclide in EU Z2-41 exceeds its Avg RL across the EU, exclusive of the Concrete Pad Class 1 SU.

Risk evaluation. One metal (arsenic) and several radionuclide and SVOC concentrations exceed Ind PRGs in the EU Z2-41 data set (see EU Z2-41 summary in Sect. 2.2.5). Among these are K-40, Ra-226, Th-228, and Th-232. K-40 is evaluated for risk only if it occurs at a concentration that exceeds both its Ind PRG and its background concentration. Review of the EU Z2-41 data shows there are five occurrences of K-40 where both the Ind PRG and background concentration are exceeded. As described in the introduction to Sect. 2.2.5 and in Sect. 3.3 of this PCCR, risk from Ra-226, Th-228, and Th-232 are evaluated by comparing to the Ra/Th decay series Avg and Max RLs. There are no Ra/Th decay series RL exceedances in EU Z2-41 data. Other chemicals and radionuclides with Ind PRG exceedances ae presented in the table below, including K-40. Data from the RAD91 and RAD122 historical locations are not included in the following table because they were not confirmed by DVS and early characterization confirmation sample. Also, data from the Concrete Pad Class $1 \mathrm{SU}$ are excluded for the same reasons as described in the Avg RL screening above.

Average detected concentrations in EU Z2-41 were recalculated to exclude RAD91, RAD122, and Concrete Pad Class $1 \mathrm{SU}$ data and therefore are different from the average concentrations reported in the EU Z2-41 Summary in Section 2.2.5. Comparison of the recalculated average detected concentrations across EU Z2-41 to Ind PRGs in the table below shows that the average detected concentrations of K-40, benzo(a)pyrene, and dibenz(a,h)anthracene exceed their respective Ind PRGs. Although the average detected concentration of K-40 (25.9 pCi/g) exceeds the Ind PRG it does not exceed the K-40 background value (32.1 pCi $/ \mathrm{g})$. Therefore, $\mathrm{K}-40$ will not be evaluated further for risk.

Area weighted average calculations for benzo(a)pyrene and dibenz(a,h)anthracene were conducted using the following concentration and area assumptions.

- Benzo(a)pyrene exceeded its Ind PRG at locations Z2-EU41C-208 and Z2-EU41C-209 with a maximum concentration of $230,000 \mathrm{ug} / \mathrm{kg}$, and benzo(a,h)anthracene exceeded its Ind PRG at location Z2-EU41C-208 with a concentration of $63,000 \mathrm{ug} / \mathrm{kg}$. The area over which exceedances of both chemicals occur is assumed to be oval shaped, encompassing both sample locations, and covering $10,000 \mathrm{ft}^{2}$, which translates to a weighting factor of 0.006 .

- Benzo(a)pyrene, and dibenz(a,h)anthracene concentrations for EU Z2-41, outside the areas with Ind PRG exceedances, are the average concentrations from all other samples. One half of the detection limit was used in the average calculations for non-detects. The weighting factor for the area of EU Z2-41 outside of the areas with Ind PRG exceedances was calculated as 1 -sum of weighting factors for areas with Ind PRG exceedances.

The following table shows that the weighted average concentration of neither benzo(a)pyrene nor dibenz(a,h)anthracene exceeds the Ind PRG. Therefore, a quantitative risk assessment will not be performed. 


\begin{tabular}{lcccc}
\hline \multicolumn{1}{c}{$\begin{array}{c}\text { Chemical or } \\
\text { radionuclide }\end{array}$} & Unit & Ind PRG & $\begin{array}{c}\text { Average } \\
\text { detected } \\
\text { concentration }\end{array}$ & $\begin{array}{c}\text { Weighted average } \\
\text { concentration }\end{array}$ \\
\hline Arsenic & $\mathrm{mg} / \mathrm{kg}$ & 16 & 5.02 & \\
$\mathrm{~K}-40$ & $\mathrm{pCi} / \mathrm{g}$ & 2.7 & 25.9 & \\
$\mathrm{U}-234$ & $\mathrm{pCi} / \mathrm{g}$ & 330 & 4.9 & \\
$\mathrm{U}-235$ & $\mathrm{pCi} / \mathrm{g}$ & 4 & 0.54 & \\
$\mathrm{U}-238$ & $\mathrm{pCi} / \mathrm{g}$ & 18 & 4.1 & \\
Benz(a)anthracene & $\mathrm{ug} / \mathrm{kg}$ & 21,000 & 16,250 & \\
Benzo(a)pyrene & $\mathrm{ug} / \mathrm{kg}$ & 2100 & 11,415 & \\
Benzo(b)fluoranthene & $\mathrm{ug} / \mathrm{kg}$ & 21,000 & 17,259 & \\
Dibenz(a,h)anthracene & $\mathrm{ug} / \mathrm{kg}$ & 2100 & 63,000 & \\
Indeno(1,2,3-cd)pyrene & $\mathrm{ug} / \mathrm{kg}$ & 21,000 & 19,223 & \\
Tetrachloroethene & $\mathrm{ug} / \mathrm{kg}$ & 13,000 & 8.27 & \\
Trichloroethene & $\mathrm{ug} / \mathrm{kg}$ & 1100 & 52.1 & \\
\hline Ind = industrial & & & & \\
PRG = preliminary remediation goal & & & &
\end{tabular}

Threat to groundwater. The ROD-defined GW SLs were exceeded in EU Z2-41 by U-234, U-235, U-238, methylene chloride, tetrachloroethene, and tricholoroethene (see Sect. 2.2.5). Evaluation of these GW SL exceedances in terms of MCL exceedances is complicated by the hydrogeology of the EU (see Sect. 2.2.5). The following discussion does not include results from the RAD91 historical location, where analytical results were not confirmed by confirmation sampling.

The U-234 GW SL was exceeded at RAD47 historical location in the Concrete Pad Class 1 SU, Z2-EU41DB-208 location in the Z2-EU41DB-208 Class 2 SU, and Z2-EU41C-212; the U-235 GW SL was exceeded at the RAD47 location; and the U-238 GW SL was exceeded at the RAD47 location (including its confirmation sample location) and the Z2-EU41DB-208 location. The methylene chloride GW SL was exceeded at the SS007 location in the Concrete Pad Class 1 SU and at the SB071 and Z2-EU41DB-232 locations in the K-1070 Pits FFA site; the tetrachloroethene GW SL was exceeded at the SS002, SS003, and SS004 locations in the Concrete Pad Class 1 SU; and the trichloroethene GW SL was exceeded at the SS002 location.

Thus, of the 14 GW SL exceedances, 9 occur at five locations in the Concrete Pad Class 1 SU, 2 occur at a single location in the Z2-EU41DB-208 Class 2 SU, 2 occur at two locations in the K-1070 Pits FFA site, and 1 occurs at a discrete location.

Because of their physico-chemical properties, site-related radionuclides (except for Tc-99) are immobile in soils . As a result, radionuclide groundwater plumes are unknown at ETTP. Results from downgradient monitoring well samples have no exhibited presence of radionuclides which could potentially have been derived from EU Z2-41. Therefore, based on the foregoing discussion and their small areal extents, the Z2-EU41DB-208 Class 2 SU and location Z2-EU41C-212 are not considered threats to groundwater. Likewise, only the RAD47 location in the Concrete Pad Class $1 \mathrm{SU}$ has documented radionuclide GW SL exceedances. There is an insufficient mass of radionuclides at the RAD47 historical location for this location to be a potential source of groundwater contamination.

VOCs are mobile in ETTP soils. All groundwater plumes at ETTP are VOC plumes and several of them are interpreted to have originated in EU Z2-41. The primary original source of VOCs in groundwater is the K-1070 Pits FFA site. However, as documented in Sects. 2.2.5 and 2.2.6, only methylene chloride is observed in K-1070 Pits FFA site soils to a depth of $10 \mathrm{ft}$ and methylene chloride is not a significant groundwater contaminant in downgradient monitoring wells. As described in the CSM (Sect. 2.2.5), the VOCs disposed of in the K-1070 Pits rapidly moved out of the 10-ft-depth interval into bedrock, which is now the source of the VOC plumes observed in downgradient monitoring wells. It is concluded that the K-1070 Pits FFA site is not a source for groundwater contamination.

Although there are four historical sample locations with VOC groundwater SL exceedances in the Concrete Pad Class $1 \mathrm{SU}$, there are no organic chemical groundwater plumes associated with the SU or the K-1071 Concrete Pad FFA site in general. Additionally, these locations will be removed as part of the recommended remedial action and will no longer pose a potential threat to groundwater. Therefore, it is concluded that neither the Concrete Pad Class 1 SU nor the K-1071 Concrete Pad FFA site poses a threat to groundwater. 
Qualitative risk screening for unrestricted use. There is a low probability that the land area of EU Z2-41 will be available for unrestricted use. This area contains Max and Avg RL exceedances, Ind and Res PRG exceedances, and GW SL exceedances in the Class 1 and Class 2 SUs (see Sect. 2.2.5), and the EU was used for burial and disposal of many different materials and substances. Following the remedial action proposed in Sect. 4, there still will be Ind and Res PRG exceedances in soils left in place. An evaluation using the appropriate land-use assumptions is necessary to make a final determination.

\section{FFA Sites}

The following statements regarding the Zone 2 ROD Appendix A FFA sites in EU Z2-41 are based on sampling analytical results (see Sect.2.2.6) and an evaluation of the EU-wide contaminant profile within the 0-10-ft-depth interval (above):

- $\quad$ K-1070-C/D Burial Ground FFA site-site does not pose a potential threat to the future industrial worker or groundwater.

- K-1070 Pits FFA site—site does not pose a potential threat to the future industrial worker or groundwater.

- $\quad$ K-1071 Concrete Pad FFA site-site poses a potential threat to the future industrial worker but does not pose a threat to groundwater.

\begin{tabular}{|l|l|}
\hline 4.0 & \multicolumn{1}{|c|}{ RECOMMENDATION FOR ACTION/NO FURTHER ACTION } \\
\hline 4.1 & DECISION AND REMEDIATION ACTIVITIES \\
\hline
\end{tabular}

EU Z2-41: Based on a remedial action requirement in the Zone 2 ROD, and to address the location of a Max RL exceedance, DOE recommends a remedial action of excavation and removal for the Concrete Pad Class 1 SU in the K-1071 Concrete Pad FFA site of EU Z2-41. The volume of contaminated material to be removed is estimated to be 50 cubic yards and encompass the concrete pad and immediately surrounding soil to a nominal depth of $2 \mathrm{ft}$. A larger volume of material may be generated to perform the remedial action.

Based on DVS and historical sampling results and a Class 3 SU walkover assessment in EU Z241 DOE recommends NFA for the remaining areas of EU Z2-41. DOE recognizes that the K1070 Pits FFA site was a primary source for groundwater contamination in the past, but presently contaminants have moved out of the FFA site soils and reside in the fractured bedrock at depths from $>10 \mathrm{ft}$ bgs to $>40 \mathrm{ft}$ bgs. In addition, one of the primary sources of contamination, GPit, has been removed. Based on DVS and historical sampling results and a Class 3 SU walkover assessment in EU Z2-41, DOE recommends NFA for the remaining areas of EU Z2-41. DOE recognizes that the K-1070 Pits FFA site (s pecifically G Pit) was a primary source for groundwater contamination in the past, but presently contaminants have moved out of the FFA Site soils and reside in the fractured bedrock at depths from $>10-40 \mathrm{ft}$ bgs. According to the Zone 2 ROD, the soils program has responsibility to assess the impact of contaminated soils as a threat to groundwater where the contamination resides in soils above the saturated zone or in soils overlying bedrock. If the source of GW contaminants is below the water table or in bedrock, the assessment and selection of appropriate actions is beyond the scope of the soils program and will be addressed by the Site-wide RI/FS/ROD Program for ETTP. Determination of the final groundwater protection assessments and actions are beyond the scope of the soils program because VOCs disposed of in G-Pit and in the D trenches at ETTP in EU 41 have entered the bedrock units underlying EU-41. In addition, one of the primary sources of contamination (G-Pit) has been removed. This is consistent with the Zone 2 ROD remedial action objective to remove soil to the water table, bedrock, or acceptable levels of contamination, whichever is shallowest, to protect underlying groundwater to MCLS.

DVS and historical sampling and the Class 3 SU walkover assessment in EU Z2-41 have demonstrated that soils from 0-10 ft bgs meet the Zone 2 ROD requirements for industrial land use except in the K-1071 Concrete Pad FFA site. However, the presence of the K-1070-C/D Burial Ground and K-1070 Pits introduces sufficient uncertainty regarding soil compositions below $10 \mathrm{ft}$ bgs that DOE does not recommend removal of the 10-ft depth use restriction.

FFA Sites: Based on sampling analytical results and the recommendation for all of EU Z2-41, DOE recommends that NFA is appropriate for the following Zone 2 ROD Appendix A FFA sites:

- K-1070-C/D Burial Ground FFA site, and

- $\quad \mathrm{K}-1070$ Pits FFA site. 
DOE is recommending a remedial action in EU Z2-41 that will address risk to the future industrial worker from soils in the K-1071 Concrete Pad FFA site.

Access controls will be put in place around the K-1070-C/D Burial Ground. These access controls will include a fence and daily surveillance.

\section{\begin{tabular}{|l|l}
4.2 & EXCAVATION ACTIVITIES/CONFIRMATION SAMPLING \\
\hline
\end{tabular}}

The Concrete Pad site is shown in detail on Fig. I.2. The area of the soil removal action encompasses the entire concrete pad and the soils around the pad that reported elevated radiological contamination above Zone 2 Avg RLs and/or above groundwater screening SLs. Estimates of the volume to be removed include the following:

- For concrete, the area of the pad $=641 \mathrm{ft}^{2}$ and the pad is assumed to be 6 in. thick, which yields a volume estimate of approximately $12 \mathrm{cy}$ of concrete rubble.

- Soils in the area cover approximately $1600 \mathrm{ft}^{2}$ and the depth of excavation is estimated to be 6 in., which yields a volume estimate of approximately $30 \mathrm{cy}$ of soil.

- The estimate as stated in the recommendation is $50 \mathrm{cy}$, which is a rounding up to allow additional materials to be taken should the area be slightly larger than defined by the Characterization Program.

Confirmation of the remedial action activity will require a radiological survey of $100 \%$ the excavated area to determine that all soils having an elevated radioactivity in excess of 4 times ambient background have been removed. Additional soil will be removed until the radiological survey meets the $4 \mathrm{X}$ criteria. Four (five-point) composite samples (each covering an area approximately $25 \times 25 \mathrm{ft}$ ) will be collected over the area of excavation (approximately $2000 \mathrm{ft}^{2}$ ) and analyzed for radioisotopes, metals, and PCBs to confirm clean-up levels have been achieved. 


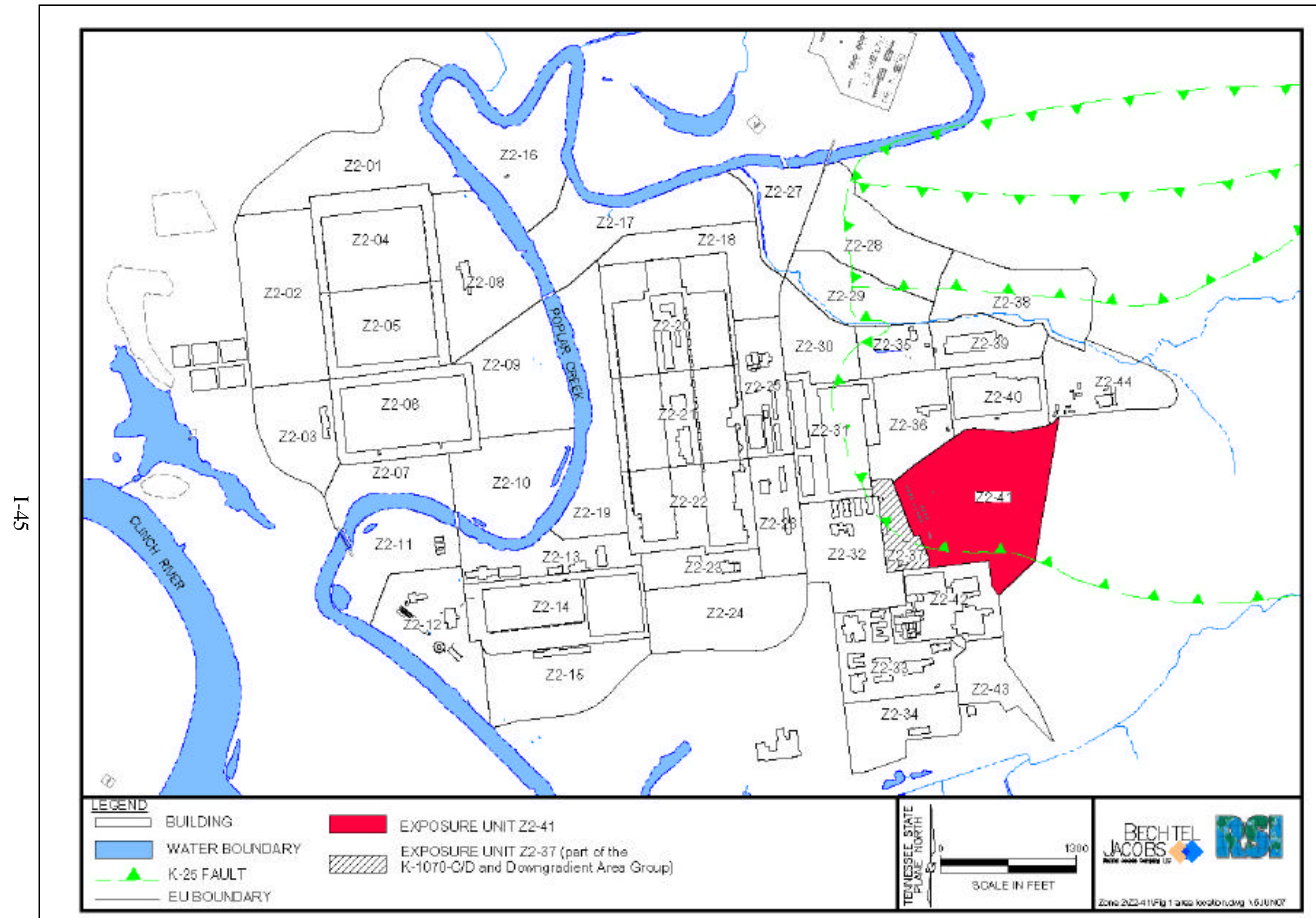

Fig. I.1. EU Z2-41 location map. 


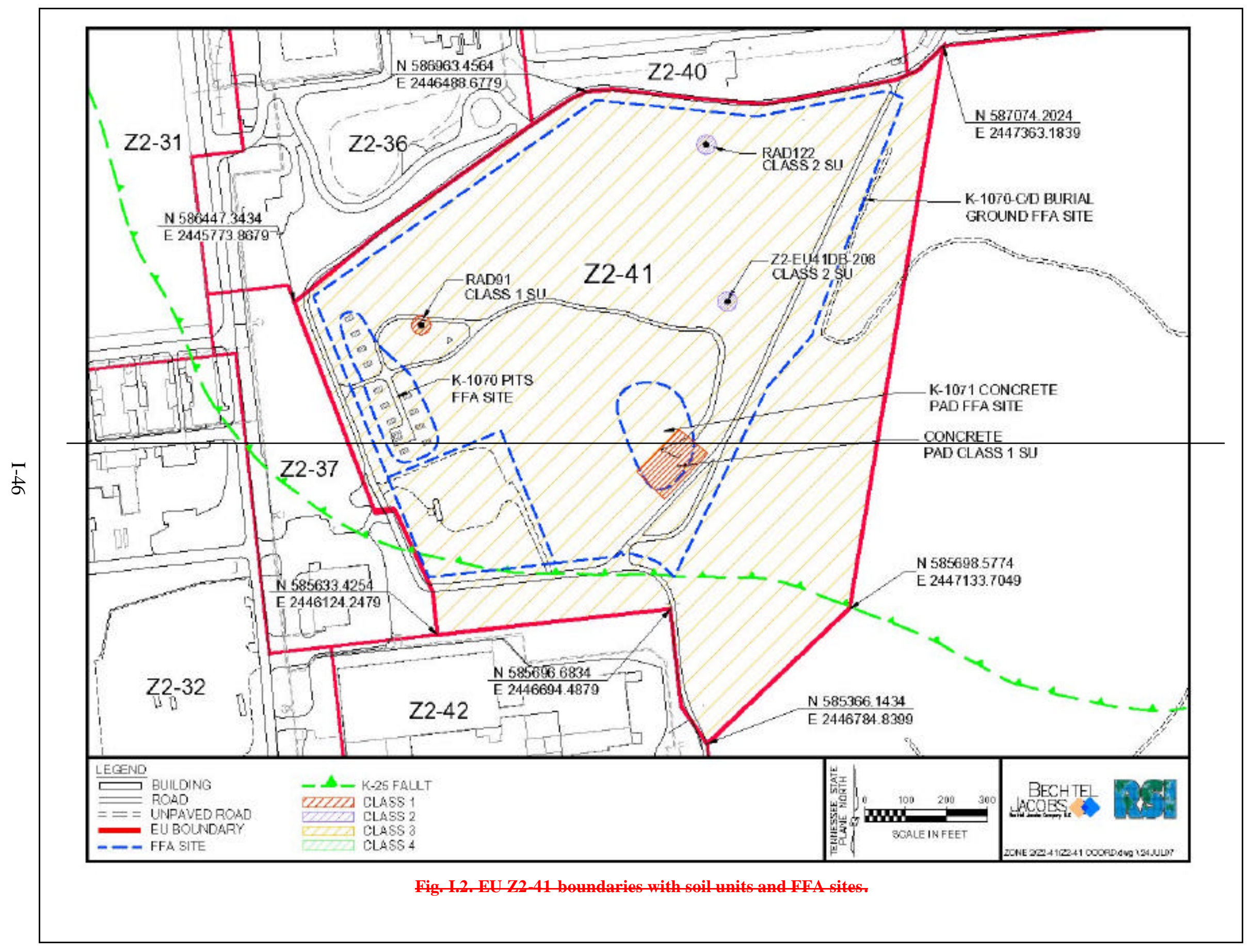




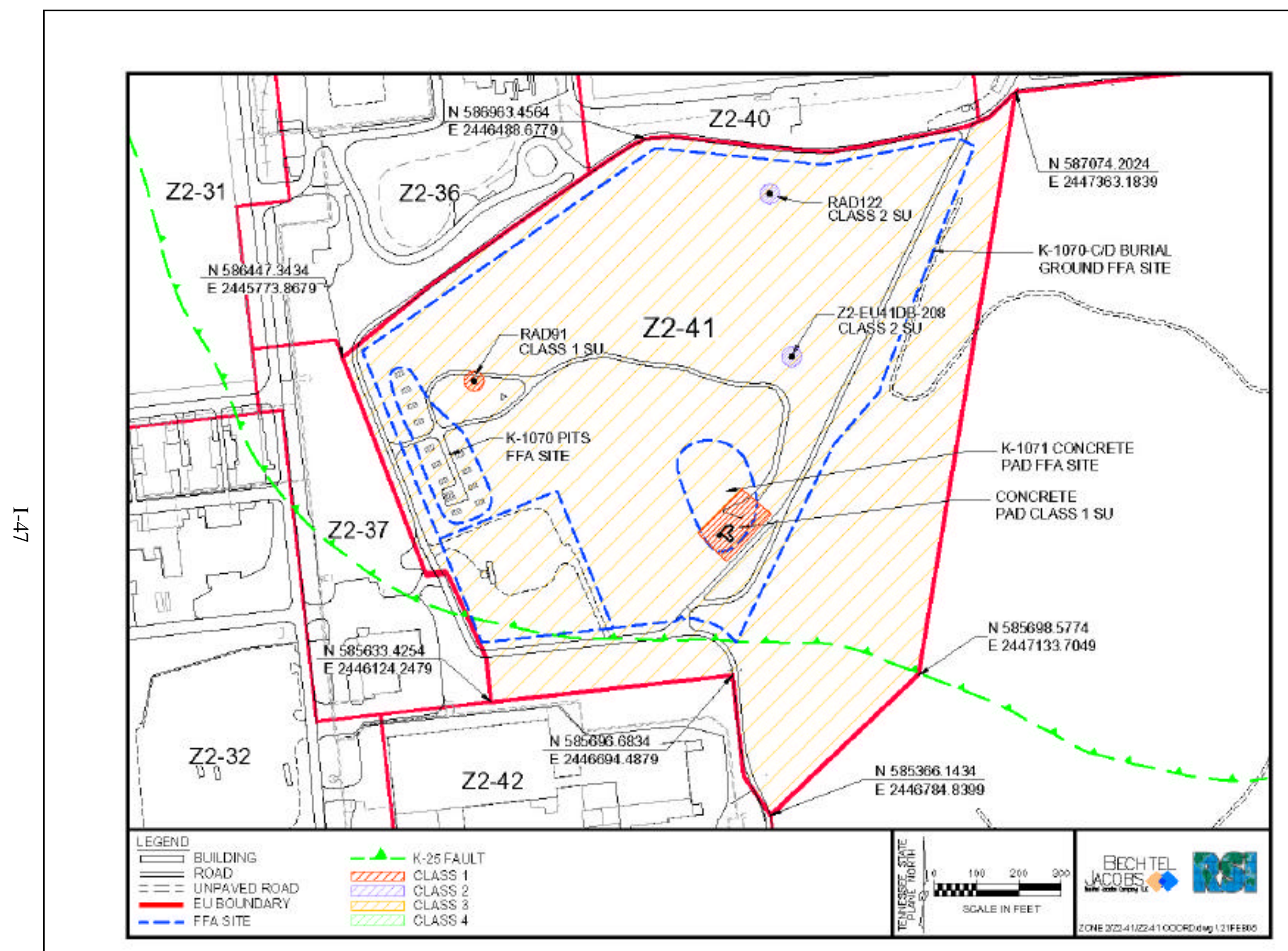

Fig. I.2. EU Z2-41 boundaries with soil units and FFA sites. 


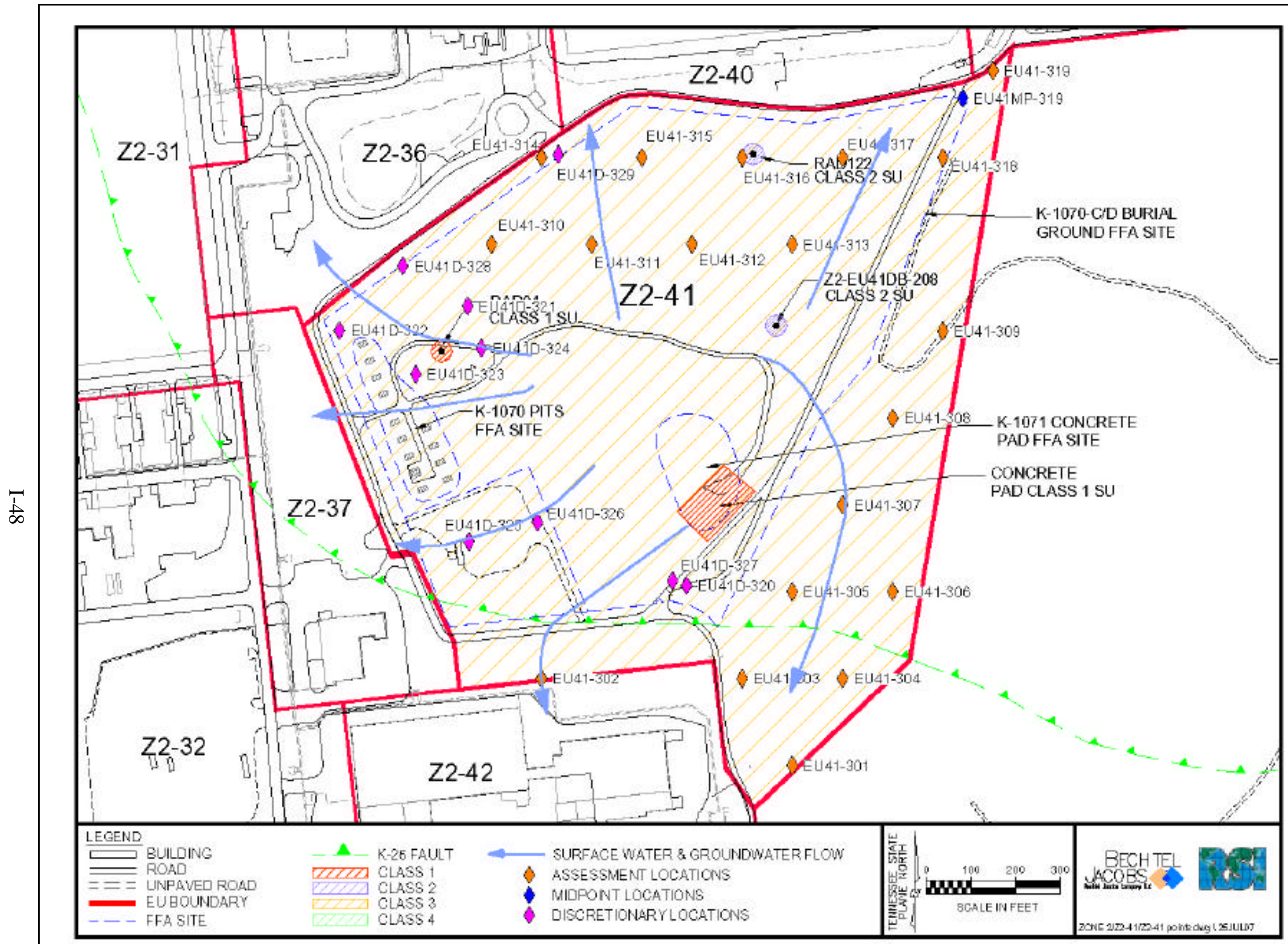

Fig. I.23. EU Z2-41 Class 3 walkover assessment locations. 


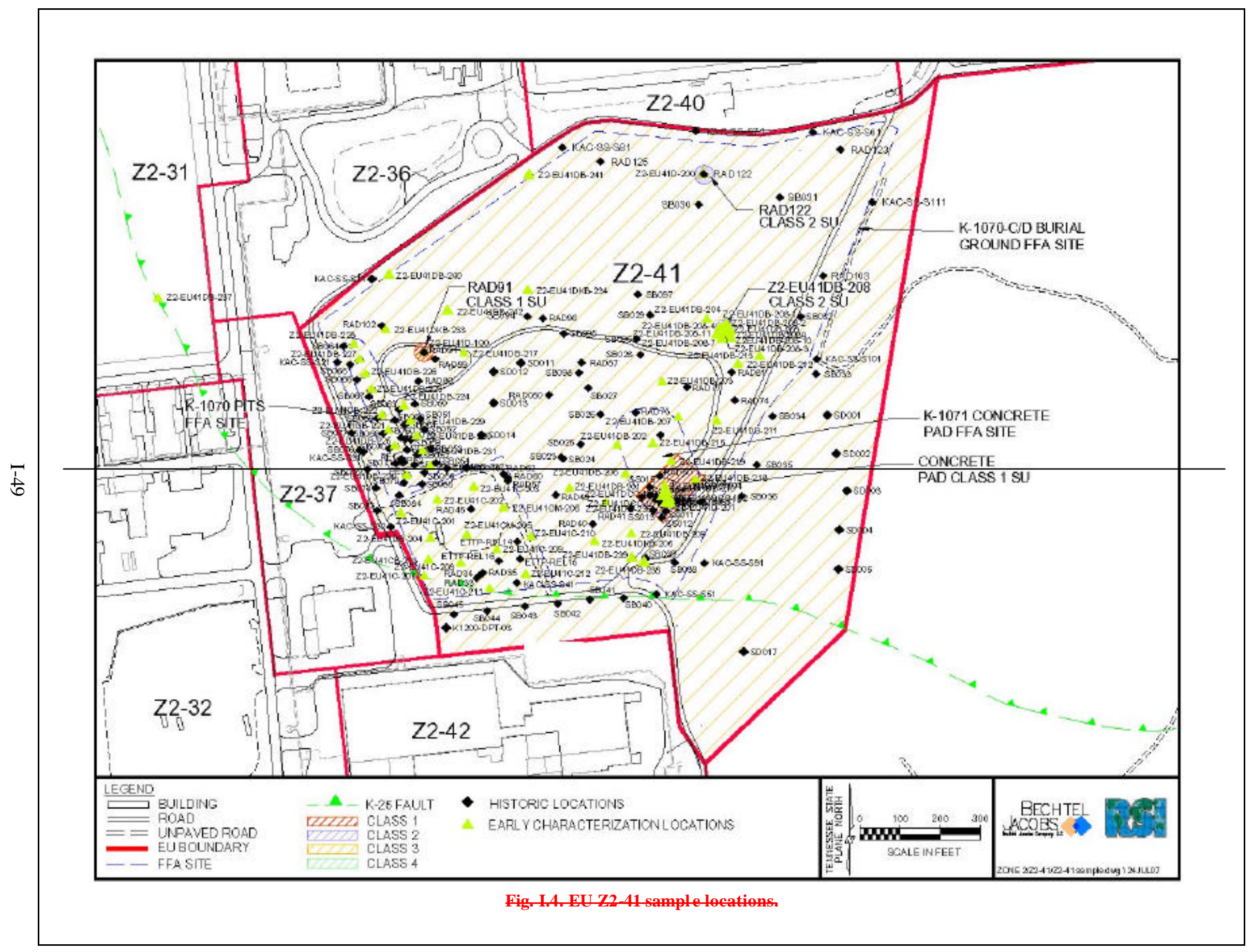




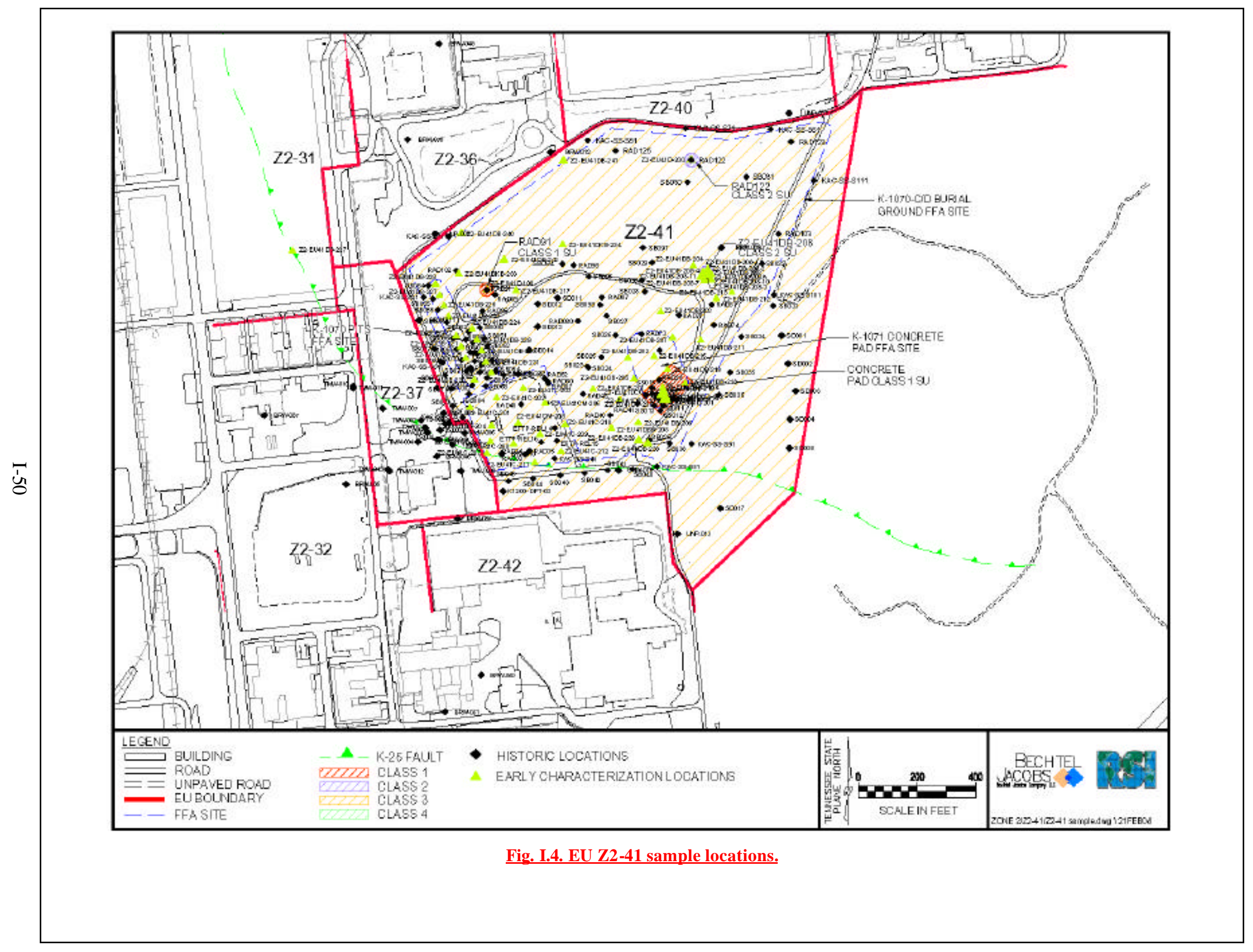




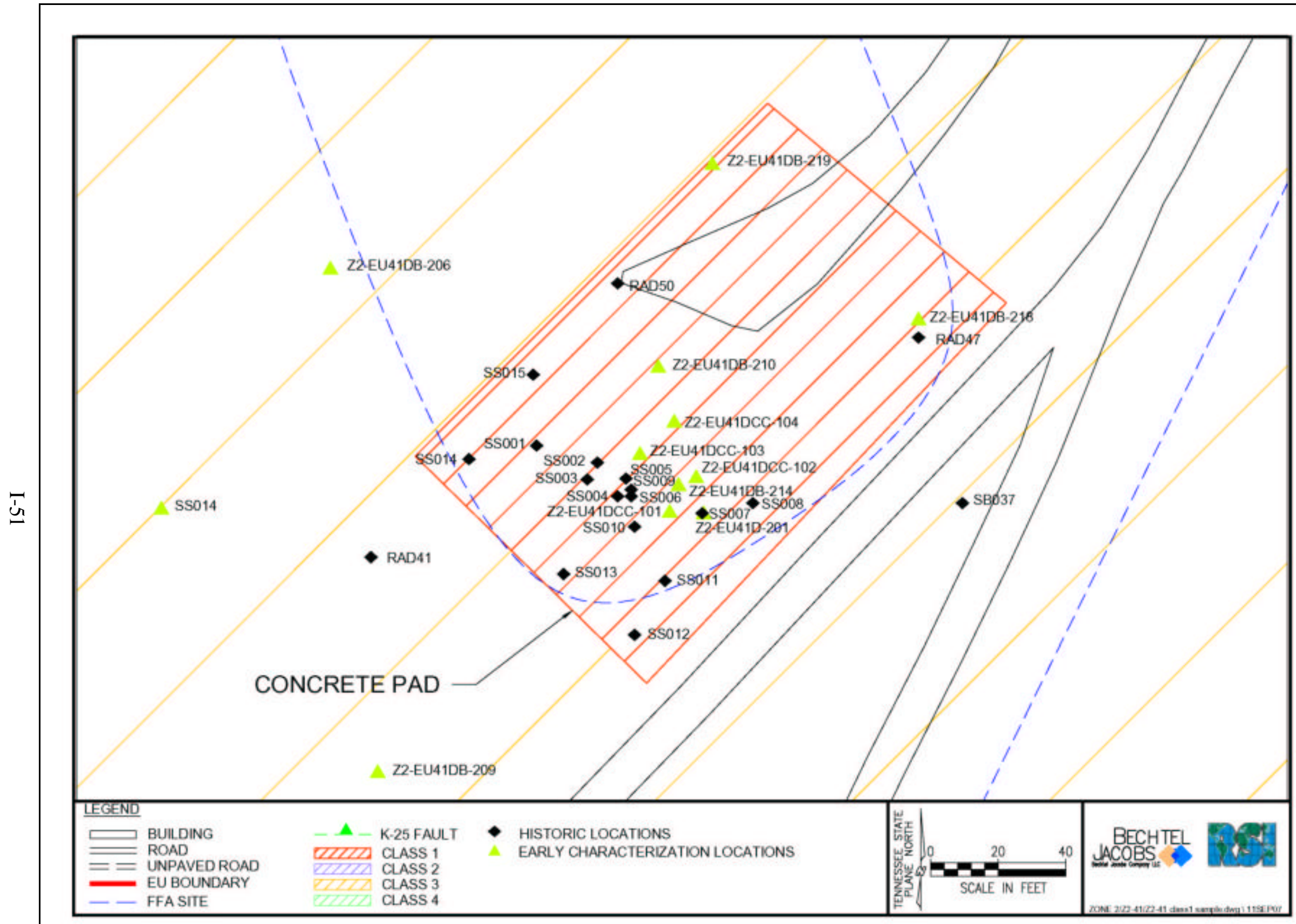

Fig. I. $\underline{3}$. EU Z2 -41 K-1071 Concrete Pad Class 1 SU sample locations. 


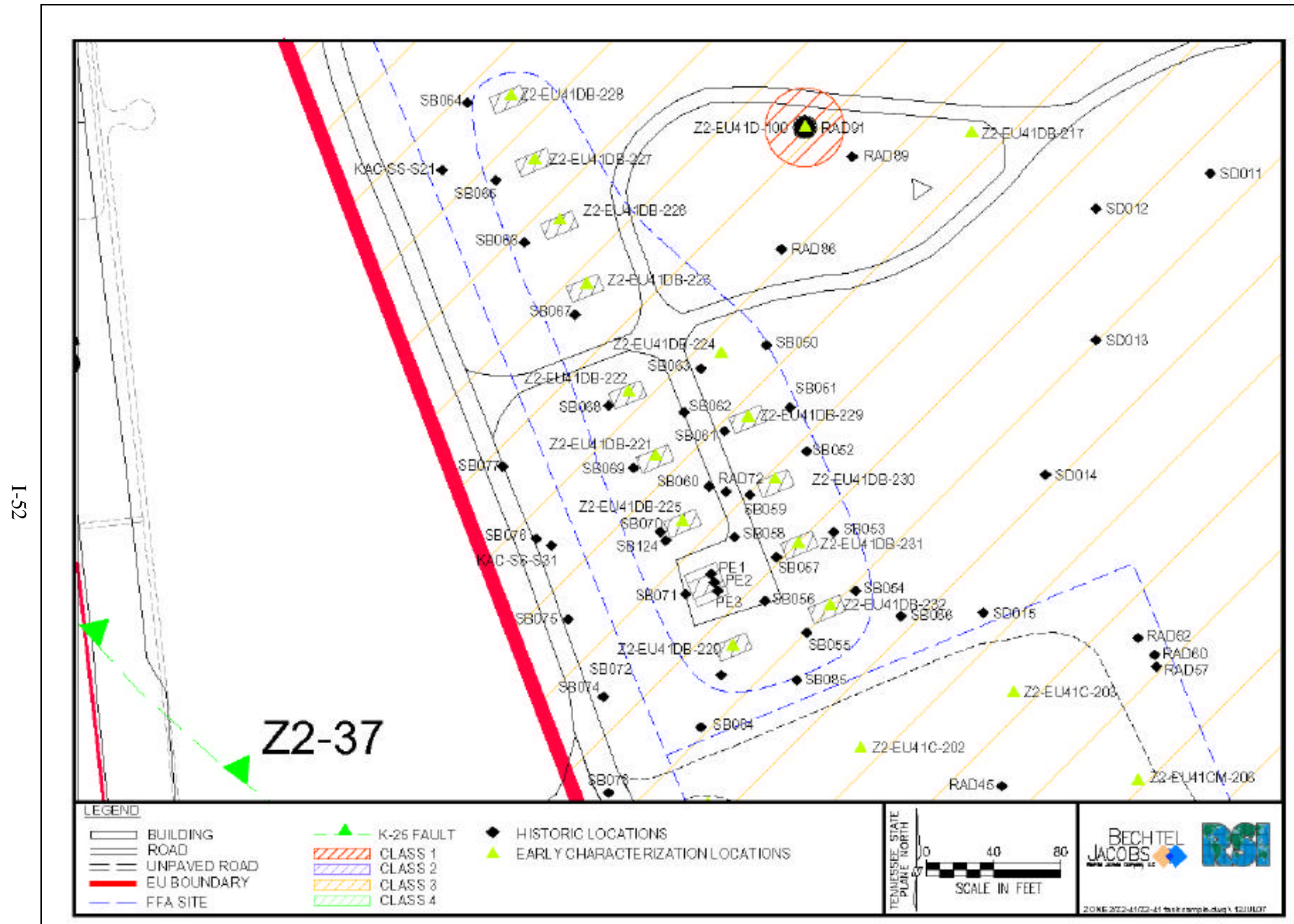

Fig. I.46. EU Z2-41 K-1070-A pits FFA site. 


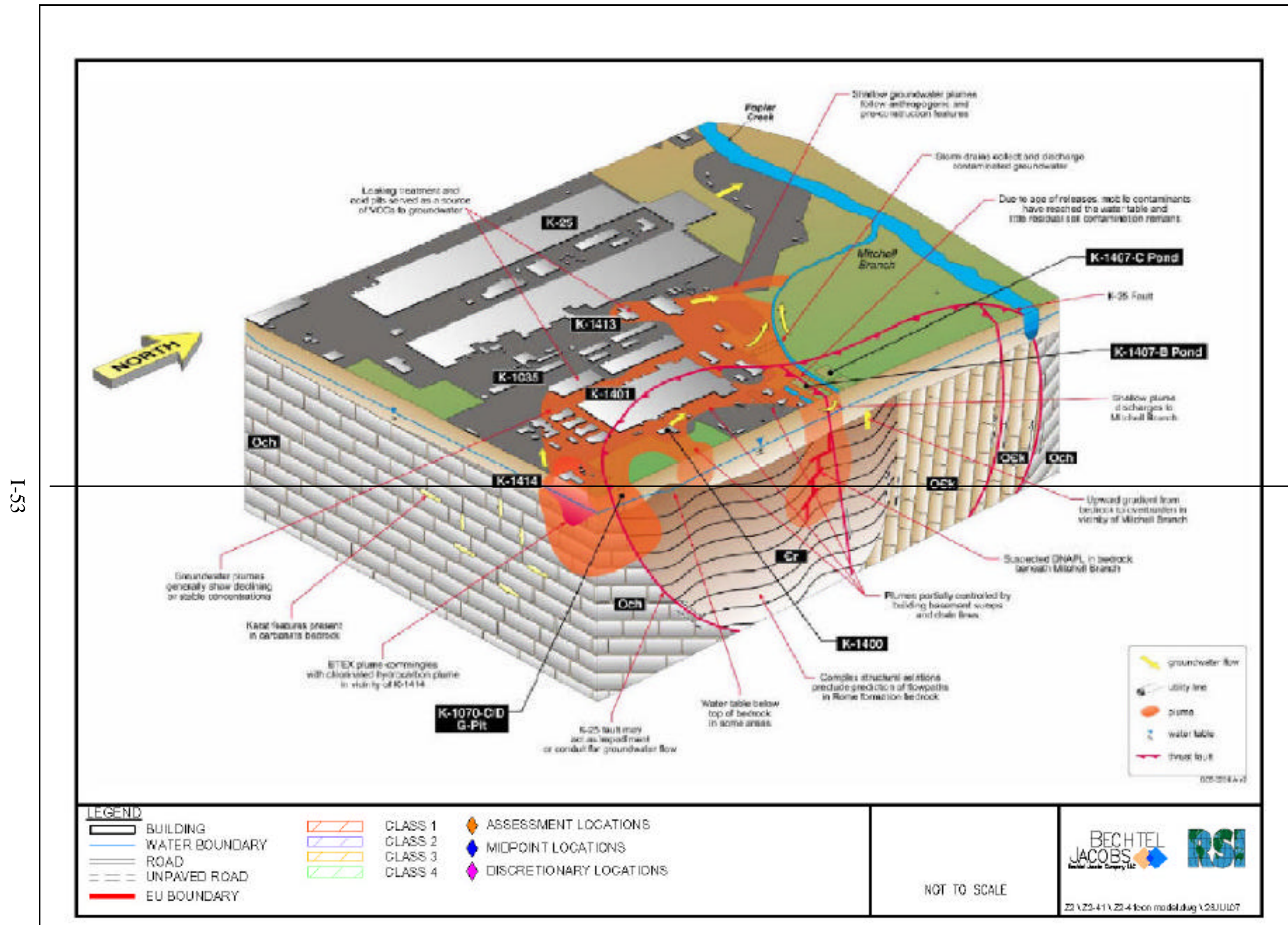

Fig. I.7. EU 72-41 conceptual site model block diagram. 


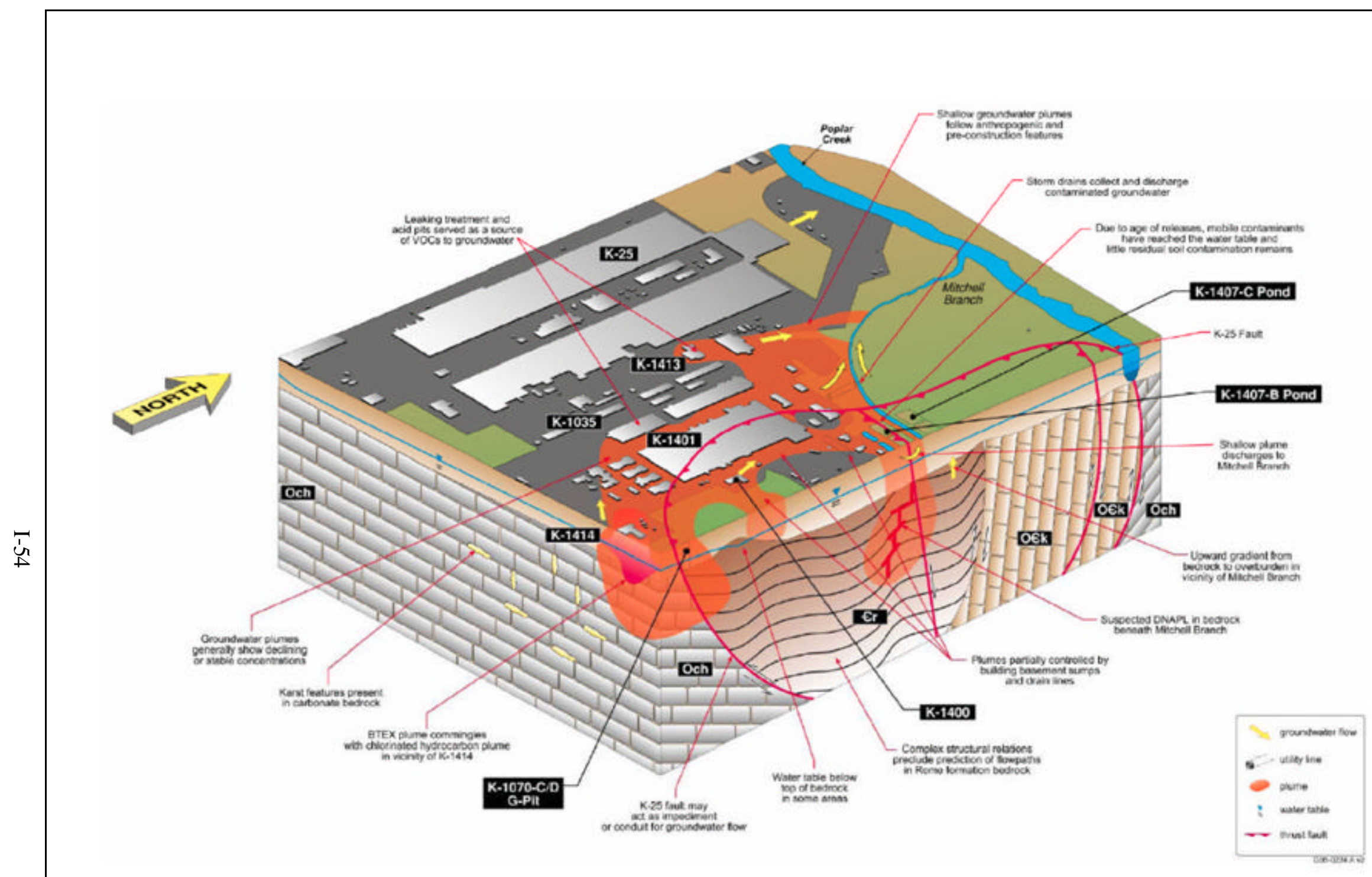

Fig. I.7. EU Z2-41 conceptual site model block diagram. 
Table I.1. EU Z2-41 facilities

\begin{tabular}{|c|c|c|c|c|}
\hline \multirow[b]{2}{*}{ Facility name DQO scoping } & \multirow[b]{2}{*}{ Facility name } & \multicolumn{2}{|c|}{ Facility assessed? } & \multirow[b]{2}{*}{ Comments } \\
\hline & & Yes & No & \\
\hline K-1070-C/D Burial Ground & & $\mathrm{X}$ & & FFA site \\
\hline K-1070-C/D Area Collection Trench & & $\mathrm{X}$ & & \\
\hline K-1070 Pits & & $\mathrm{X}$ & & FFA site \\
\hline K-1070-D1 Storage Dike & K-1070-D1 Former Storage Pad & $\mathrm{X}$ & & \\
\hline K-1070-D2 Storage Dike & K-1070-D2 Former Storage Pad & $\mathrm{X}$ & & \\
\hline K-1070-D3 Storage Dike & K-1070-D3 Former Storage Pad & $\mathrm{X}$ & & \\
\hline K-1071 Concrete Pad & & $\mathrm{X}$ & & FFA site \\
\hline K-1028-60 Guard Portal & & $\mathrm{X}$ & & \\
\hline K-1208 Meteorological Tower & & $\mathrm{X}$ & & \\
\hline K-1310-BK Storage Trailer & & $\mathrm{X}$ & & \\
\hline
\end{tabular}

K-1310-BK Storage Trailer

$\mathrm{EU}=$ exposure unit

FFA $=$ Federal Facility Agreement 
Table I.2. EU Z2-41 sample summar

\begin{tabular}{|c|c|c|c|c|c|c|c|c|c|c|c|c|}
\hline \multirow{2}{*}{$\begin{array}{c}\text { SU } \\
\text { class }\end{array}$} & \multirow{2}{*}{$\begin{array}{c}\text { Date } \\
\text { sampled }\end{array}$} & \multirow[b]{2}{*}{ Sample ID } & \multicolumn{2}{|c|}{ Location } & \multirow[b]{2}{*}{ Sample interval } & \multirow[b]{2}{*}{ VOC } & \multirow{2}{*}{ SVOC } & \multirow{3}{*}{ Metal } & \multirow{3}{*}{ PCB } & \multirow[b]{2}{*}{ RAD } & \multirow{2}{*}{$\begin{array}{l}\text { Splits (S)/ } \\
\text { Dups (D) }\end{array}$} & \multirow[b]{2}{*}{ Comments } \\
\hline & & & North & East & & & & & & & & \\
\hline \multicolumn{11}{|c|}{ Area C } & & \\
\hline 3 & $12 / 13 / 2005$ & Z2-EU41C-201 & 585989 & 2446027 & Three interval composite & 1 & 1 & 1 & 1 & & & $\begin{array}{l}\text { Collected - PID } 5.2 \text { ppm - TB EU410058 } \\
\end{array}$ \\
\hline 3 & $12 / 14 / 2005$ & Z2-EU41C-202 & 586022 & 2446118 & Three interval composite & 1 & 2 & 2 & 2 & 1 & & Collected - PID $7.4 \mathrm{ppm}$ - refusal at $12.9 \mathrm{ft}$ \\
\hline 3 & $12 / 14 / 2005$ & Z2-EU41C-203 & 586055 & 2446209 & Three interval composite, plus a deeper interval sample & & 2 & 2 & 2 & & & Collected - refusal at $15.4 \mathrm{ft}$ \\
\hline 3 & $12 / 16 / 2005$ & Z2-EU41C-204 & 585927 & 2446101 & Three interval composite, plus a deeper interval sample & & 1 & 1 & 1 & & & Collected - rinsates EU410021-EU410025 \\
\hline 3 & $1 / 10 / 2006$ & Z2-EU41CM-205 & 585935 & 2446192 & Three interval composite & 1 & 1 & 1 & 1 & 1 & $\mathrm{~S}$ & Collected - no PID hits \\
\hline 3 & $1 / 10 / 2006$ & Z2-EU41CM-206 & 586003 & 2446283 & Three interval composite & 1 & 1 & 1 & 1 & & & Collected - PID 5.6 ppm \\
\hline 3 & $12 / 20 / 2005$ & Z2-EU41C-207 & 585832 & 2446085 & Three interval composite, plus a deeper interval samp le & & 2 & 2 & 2 & 1 & & Collected - added RAD to SOW \\
\hline 3 & $1 / 11 / 2006$ & Z2-EU41C-208 & 585865 & 2446176 & Three interval composite, plus a deeper interval sample & 1 & 2 & 2 & 2 & & & Collected - rinsates EU410031-EU410035 \\
\hline 3 & $12 / 16 / 2005$ & Z2-EU41C-209 & 585898 & 2446266 & Three interval composite, plus a deeper interval sample & 1 & 2 & 2 & 2 & 1 & $\mathrm{D}$ & Collected - $249 \mathrm{cpm}$ \\
\hline 3 & $12 / 19 / 2005$ & Z2-EU41C-210 & 585931 & 2446352 & Three interval composite & & 1 & 1 & 1 & & & Collected \\
\hline 3 & $12 / 19 / 2005$ & Z2-EU41C-211 & 585800 & 2446248 & Three interval composite & & 1 & 1 & 1 & & & Collected \\
\hline 3 & $12 / 19 / 2005$ & Z2-EU41C-212 & 585837 & 2446338 & Three interval composite & & 1 & 1 & 1 & 1 & & Collected $-282.2 \mathrm{cpm}$ \\
\hline \multicolumn{13}{|c|}{ Biased Locations-Area C } \\
\hline 3 & $1 / 9 / 2006$ & Z2-EU41CB-213 & 585873 & 2446096 & Three interval composite & 1 & 1 & 1 & 1 & & & Collected - no PID hits - TB EU410062 \\
\hline \multicolumn{13}{|c|}{ Trench Areas, B iased Locations-Area D } \\
\hline 3 & 9/26/2006 & Z2-EU41D-201 & 2446697 & 586015 & $0-1 \mathrm{ft}$ surface soil & & & 1 & & & & \\
\hline 3 & $11 / 11 / 2005$ & Z2-EU41DB-201 & 586051 & 2446447 & Three interval composite & & 1 & 1 & 1 & 1 & & \\
\hline 3 & $11 / 14 / 2005$ & Z2-EU41DB-202 & 586158 & 2446566 & Three interval composite & & 1 & 1 & 1 & 1 & & \\
\hline 3 & $11 / 14 / 2005$ & Z2-EU41DB-203 & 586316 & 2446678 & Three interval composite & & 1 & 1 & 1 & & $\mathrm{D}$ & Collected \\
\hline 3 & $11 / 10 / 2005$ & Z2-EU41DB-204 & 586473 & 2446789 & Three interval composite & & 1 & 1 & 1 & 1 & & Collected RAD - $233 \mathrm{cpm}$ \\
\hline 3 & $11 / 15 / 2005$ & Z2-EU41DB-206 & 586087 & 2446587 & Three interval composite & & 1 & 1 & 1 & & & \\
\hline 3 & $11 / 16 / 2005$ & Z2-EU41DB-207 & 586228 & 2446718 & Three interval composite & & 1 & 1 & 1 & & & Collected \\
\hline 2 & $11 / 17 / 2005$ & Z2-EU41DB-208 & 586449 & 2446835 & Two intervals & 2 & 2 & 2 & 2 & 2 & & Collected RAD - 4,374 cpm \\
\hline 3 & $11 / 17 / 2005$ & Z2-EU41DB-209 & 585938 & 2446601 & Three interval composite & & 1 & 1 & 1 & & $\mathrm{~s}$ & Collected \\
\hline 1 & $11 / 18 / 2005$ & Z2-EU41DB-210 & 586058 & 2446684 & Three interval composite & & 1 & 1 & 1 & & & Collected - rinsates EU410006-EU410010 \\
\hline 3 & $11 / 22 / 2005$ & Z2-EU41DB-211 & 586219 & 2446814 & Three interval composite & 1 & 1 & 1 & 1 & & & Collected - PID $14.8 \mathrm{ppm}$ \\
\hline 3 & $11 / 29 / 2005$ & Z2-EU41DB-212 & 586361 & 2446867 & Three interval composite & & 1 & 1 & 1 & 1 & & Collected RAD - $221 \mathrm{cpm}$ \\
\hline 3 & $11 / 29 / 2005$ & Z2-EU41DB-213 & 586381 & 2446921 & Three interval composite & 1 & 1 & 1 & 1 & 1 & & Collected - added RAD to SOW \\
\hline 1 & $11 / 18 / 2005$ & Z2-EU41DB-214 & 586023 & 2446690 & Three interval composite & & 1 & 1 & 1 & & & \\
\hline 3 & $11 / 16 / 2005$ & Z2-EU41DB-215 & 586163 & 2446655 & Three interval composite & & 1 & 1 & 1 & & & \\
\hline 3 & $11 / 15 / 2005$ & Z2-EU41DB-236 & 586016 & 2446537 & Three interval composite & 1 & 1 & 1 & 1 & & & \\
\hline \multicolumn{13}{|c|}{ Elevated RAD Areas } \\
\hline & 9/26/2006 & Z2-EU41D-200 & 586834.5 & 2446780.9 & $0-1 \mathrm{ft}$ surface soil & & & & & 1 & & \\
\hline 3 & $11 / 30 / 2005$ & Z2-EU41DB-217 & 586388 & 2446184 & Three interval composite & 1 & 1 & 1 & 1 & 1 & & Collected VOA and RAD - PID $14.9 \mathrm{ppm}, 239 \mathrm{cpm}$ \\
\hline 1 & $1 / 11 / 2006$ & Z2-EU41DB-218 & 586072 & 2446761 & Three interval composite & 1 & 1 & 1 & 1 & 2 & & Collected RAD- $1278 \mathrm{cpm}$ \\
\hline 1 & $11 / 21 / 2005$ & Z2-EU41DB-219 & 586118 & 2446700 & Three interval composite & & 1 & 1 & 1 & 1 & & Collected - added RAD to SOW \\
\hline \multicolumn{13}{|c|}{ Disposal Pits } \\
\hline 3 & $12 / 9 / 2005$ & Z2-EU41DB-220 & 586083 & 2446042 & Three interval composite, plus a deeper interval sample & & 2 & 2 & 2 & 1 & & Collected RAD- $218 \mathrm{cpm}$ \\
\hline 3 & $12 / 1 / 2005$ & Z2-EU41DB-221 & 586196 & 2445996 & Three interval composite, plus a deeper interval sample & & 2 & 2 & 2 & 1 & & Collected RAD- $198.6 \mathrm{cpm}$ \\
\hline 3 & $12 / 12 / 2005$ & Z2-EU41DB-222 & 586234 & 2445980 & Three interval composite, plus a deeper interval sample & & 2 & 2 & 2 & & $\mathrm{~S}$ & Collected - refusal at $16 \mathrm{ft}$ \\
\hline 3 & $12 / 6 / 2005$ & Z2-EU41DB-223 & 586298 & 2445955 & Three interval composite, plus a deeper interval sample & & 2 & 2 & 2 & 1 & & Collected RAD- $230 \mathrm{cpm}$ \\
\hline 3 & $12 / 7 / 2005$ & Z2-EU41DB-224 & 586257 & 2446035 & Three interval composite, plus a deeper interval sample & & 2 & 2 & 2 & 1 & & Collected RAD - $201 \mathrm{cpm}$ \\
\hline 3 & 12/9/2005 & Z2-EU41DB-225 & 586157 & 2446012 & Three interval composite, plus a deeper interval sample & & 2 & 2 & 2 & 1 & $\mathrm{D}$ & Collected - added RAD to SOW \\
\hline 3 & $12 / 6 / 2005$ & Z2-EU41DB-226 & 586336 & 2445939 & Three interval composite & & 1 & 1 & 1 & 1 & & Collected RAD - $193 \mathrm{cpm}$ \\
\hline
\end{tabular}


Table I.2. (continued)

\begin{tabular}{|c|c|c|c|c|c|c|c|c|c|c|c|c|}
\hline \multirow{2}{*}{$\begin{array}{c}\text { SU } \\
\text { class }\end{array}$} & \multirow{2}{*}{$\begin{array}{c}\text { Date } \\
\text { sampled }\end{array}$} & \multirow[b]{2}{*}{ Sample ID } & \multicolumn{2}{|c|}{ Location } & \multirow[b]{2}{*}{ Sample interval } & \multirow[b]{2}{*}{ VOC } & \multirow[b]{2}{*}{ SVOC } & \multirow[b]{2}{*}{ Metal } & \multirow[b]{2}{*}{ PCB } & \multirow[b]{2}{*}{ RAD } & \multirow{2}{*}{$\begin{array}{l}\text { Splits (S)/ } \\
\text { Dups (D) }\end{array}$} & \multirow[b]{2}{*}{ Comments } \\
\hline & & & North & East & & & & & & & & \\
\hline 3 & $12 / 5 / 2005$ & Z2-EU41DB-227 & 586372 & 2445924 & Three interval composite, plus a deeper interval sample & & 2 & 2 & 2 & 2 & $\mathrm{D}$ & \\
\hline 3 & $12 / 2 / 2005$ & Z2-EU41DB-228 & 586410 & 2445910 & Three interval composite, plus a deeper interval sample & & 2 & 2 & 2 & 1 & & Collected RAD - $194 \mathrm{cpm}$ \\
\hline 3 & $12 / 7 / 2005$ & Z2-EU41DB-229 & 586219 & 2446051 & Surface sample & & 1 & 1 & 1 & & & \\
\hline 3 & $12 / 7 / 2005$ & Z2-EU41DB-230 & 586182 & 2446067 & Surface sample & & 1 & 1 & 1 & & & \\
\hline 3 & $12 / 8 / 2005$ & Z2-EU41DB-231 & 586144 & 2446081 & Three interval composite, plus a deeper interval sample & & 2 & 2 & 2 & & & Collected - not enough sample for $1.5 \mathrm{ft}$ - hard at $15 \mathrm{ft}$ \\
\hline 3 & $12 / 8 / 2005$ & Z2-EU41DB-232 & 586107 & 2446100 & Three interval composite & 1 & 1 & 1 & 1 & & $\mathrm{~S}$ & Collected VOA - PID 15 ppm \\
\hline \multicolumn{13}{|c|}{ Former Dike Areas } \\
\hline 1 & $9 / 26 / 2006$ & Z2-EU41D-100 & 586391 & 2446085 & 0 -1 ft surface soil & & & & & 1 & & \\
\hline 3 & $11 / 30 / 2005$ & Z2-EU41DKB-205 & 585918 & 2446510 & Three interval composite, plus a deeper interval sample & & 2 & 2 & 2 & 1 & & Collected RAD - $191.5 \mathrm{cpm}$ \\
\hline 3 & $12 / 1 / 2005$ & Z2-EU41DKB-233 & 586446 & 2445989 & Surface sample & 1 & 2 & 2 & 2 & & $\mathrm{D}$ & \\
\hline 3 & $12 / 1 / 2005$ & Z2-EU41DKB-234 & 586545 & 2446343 & Three interval composite, plus a deeper interval sample & 1 & 2 & 2 & 2 & & $\mathrm{~S}$ & Collected \\
\hline \multicolumn{13}{|c|}{ Additional Biased Locations } \\
\hline 3 & $11 / 22 / 2005$ & Z2-EU41DB-237 & 586524 & 2445422 & Three interval composite & & 1 & 1 & 1 & & & \\
\hline & & & & & Total samples & 17 & 66 & 67 & 66 & 28 & $\mathbf{0}$ & \\
\hline 3 & $7 / 12 / 2001$ & $\begin{array}{l}\text { ETTP-REL14 } \\
\end{array}$ & 585919 & 2446317 & Surface soil sample & & & & & 1 & & \\
\hline 3 & $7 / 12 / 2001$ & ETTP-REL15 & 585876 & 2446324 & Surface soil sample & & & & & 1 & & \\
\hline 3 & $7 / 12 / 2001$ & ETTP-REL16 & 585871 & 2446271 & Surface soil sample & & & & & 1 & & \\
\hline 3 & 2/17/2005 & K1200-DPT-03 & 585704 & 2446139 & Discrete interval $45-47.5 \mathrm{ft}$ & 1 & 1 & & & & & \\
\hline 3 & $10 / 30 / 1995$ & KAC-SS-S11 & 586574 & 2445955 & Surface soil sample & & & & & 1 & & \\
\hline 3 & 11/3/1995 & KAC-SS-S101 & 586374 & 2447063 & Surface soil sample & & & & & 1 & & \\
\hline 3 & $11 / 3 / 1995$ & KAC-SS-S111 & 586765 & 2447201 & Surface soil sample & & & & & 1 & & \\
\hline 3 & $10 / 30 / 1995$ & KAC-SS-S21 & 586366 & 2445869 & Surface soil sample & & & & & 1 & & \\
\hline 3 & 10/30/1995 & KAC-SS-S31 & 586143 & 2445934 & Surface soil sample & & & & & 1 & & \\
\hline 3 & $10 / 30 / 1995$ & KAC-SS-S32 & 585956 & 2446002 & Surface soil sample & & & & & 1 & & \\
\hline 3 & 10/30/1995 & KAC-SS-S41 & 585816 & 2446316 & Surface soil sample & & & & & 1 & & \\
\hline 3 & 10/30/1995 & KAC-SS-S51 & 585788 & 2446664 & Surface soil sample & & & & & 1 & & \\
\hline 3 & $10 / 30 / 1995$ & KAC-SS-S61 & 586939 & 2447053 & Surface soil sample & & & & & 1 & & \\
\hline 3 & 10/30/1995 & KAC-SS-S71 & 586942 & 2446762 & Surface soil sample & & & & & 1 & & \\
\hline 3 & $10 / 30 / 1995$ & KAC-SS-S81 & 586901 & 2446429 & Surface soil sample & & & & & 1 & & \\
\hline 3 & 11/3/1995 & KAC-SS-S91 & 585866 & 2446783 & Surface soil sample & & & & & 1 & & \\
\hline 3 & $1 / 5 / 2000$ & PE1 & 586126 & 2446029 & Discrete interval $15-15.5 \mathrm{ft}$ & 1 & 1 & & 1 & 1 & & \\
\hline 3 & $1 / 5 / 2000$ & PE2 & 586121 & 2446031 & Discrete interval $15-15.5 \mathrm{ft}$ & 1 & 1 & & 1 & 1 & & \\
\hline 3 & $1 / 5 / 2000$ & PE3 & 586116 & 2446033 & Discrete interval $15-15.5 \mathrm{ft}$ & 1 & 1 & & 1 & 1 & & \\
\hline 3 & $8 / 3 / 1994$ & RAD102 & 586457 & 2445980 & Surface soil samp le & & & & & 1 & & \\
\hline 3 & $8 / 17 / 1994$ & RAD103 & 586582 & 2447079 & Surface soil sample & & & & & 1 & & \\
\hline 3 & $8 / 8 / 1994$ & RAD122 & 586835 & 2446781 & Surface soil sample & & & & & 1 & & \\
\hline 3 & $8 / 2 / 1994$ & RAD123 & 586896 & 2447122 & Surface soil sample & & & & & 1 & & \\
\hline 3 & $8 / 8 / 1994$ & RAD125 & 586866 & 2446524 & Surface soil sample & & & & & 1 & & \\
\hline 3 & $7 / 22 / 1994$ & RAD33 & 585829 & 2446216 & Surface soil sample & & & & & 1 & & \\
\hline 3 & $7 / 22 / 1994$ & RAD34 & 585835 & 2446223 & Surface soil sample & & & & & 1 & & \\
\hline 3 & $7 / 22 / 1994$ & RAD35 & 585842 & 2446231 & Surface soil sample & & & & & 1 & & \\
\hline 3 & $8 / 8 / 1994$ & RAD40 & 585963 & 2446505 & Surface soil sample & & & & & 1 & & \\
\hline 3 & $8 / 10 / 1994$ & RAD41 & 586002 & 2446599 & Surface soil sample & & & & & 1 & & \\
\hline 3 & $7 / 22 / 1994$ & RAD45 & 586000 & 2446202 & Surface soil sample & & & & & 1 & & \\
\hline 1 & 8/17/1994 & RAD47 & 586067 & 2446761 & Surface soil sample & & & & & 1 & & \\
\hline 3 & $8 / 8 / 1994$ & RAD48 & 586036 & 2446413 & Surface soil sample & & & & & 1 & & \\
\hline 1 & $8 / 10 / 1994$ & RAD50 & 586083 & 2446672 & Surface soil sample & & & & & 1 & & \\
\hline 3 & $7 / 20 / 1994$ & RAD57 & 586071 & 2446294 & Surface soil sample & & & & & 1 & & \\
\hline 3 & $7 / 22 / 1994$ & RAD60 & 586078 & 2446293 & Surface soil sample & & & & & 1 & & \\
\hline 3 & $7 / 22 / 1994$ & RAD62 & 586088 & 2446283 & Surface soil sample & & & & & 1 & & \\
\hline
\end{tabular}




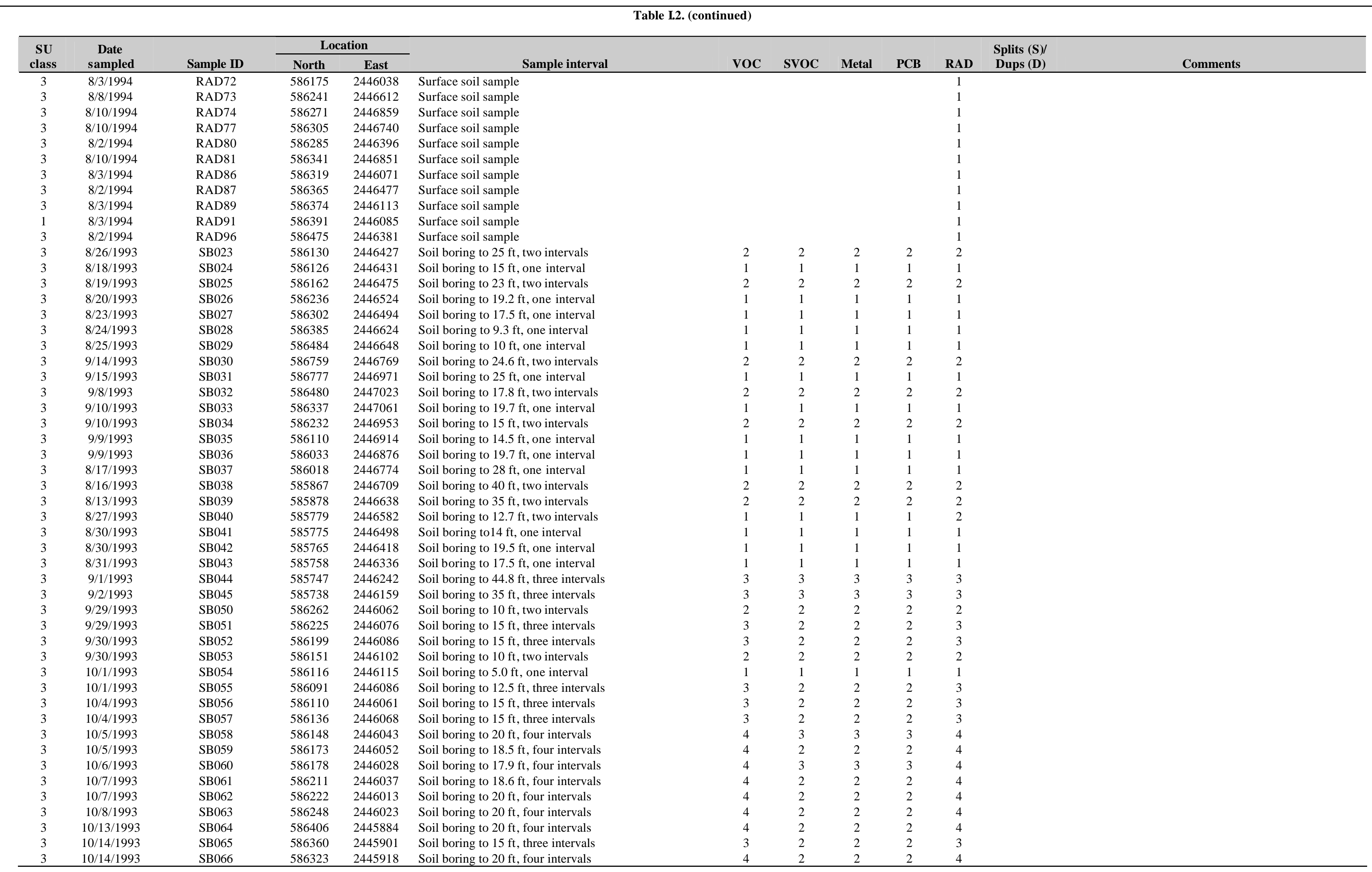


Table I.2. (continued)

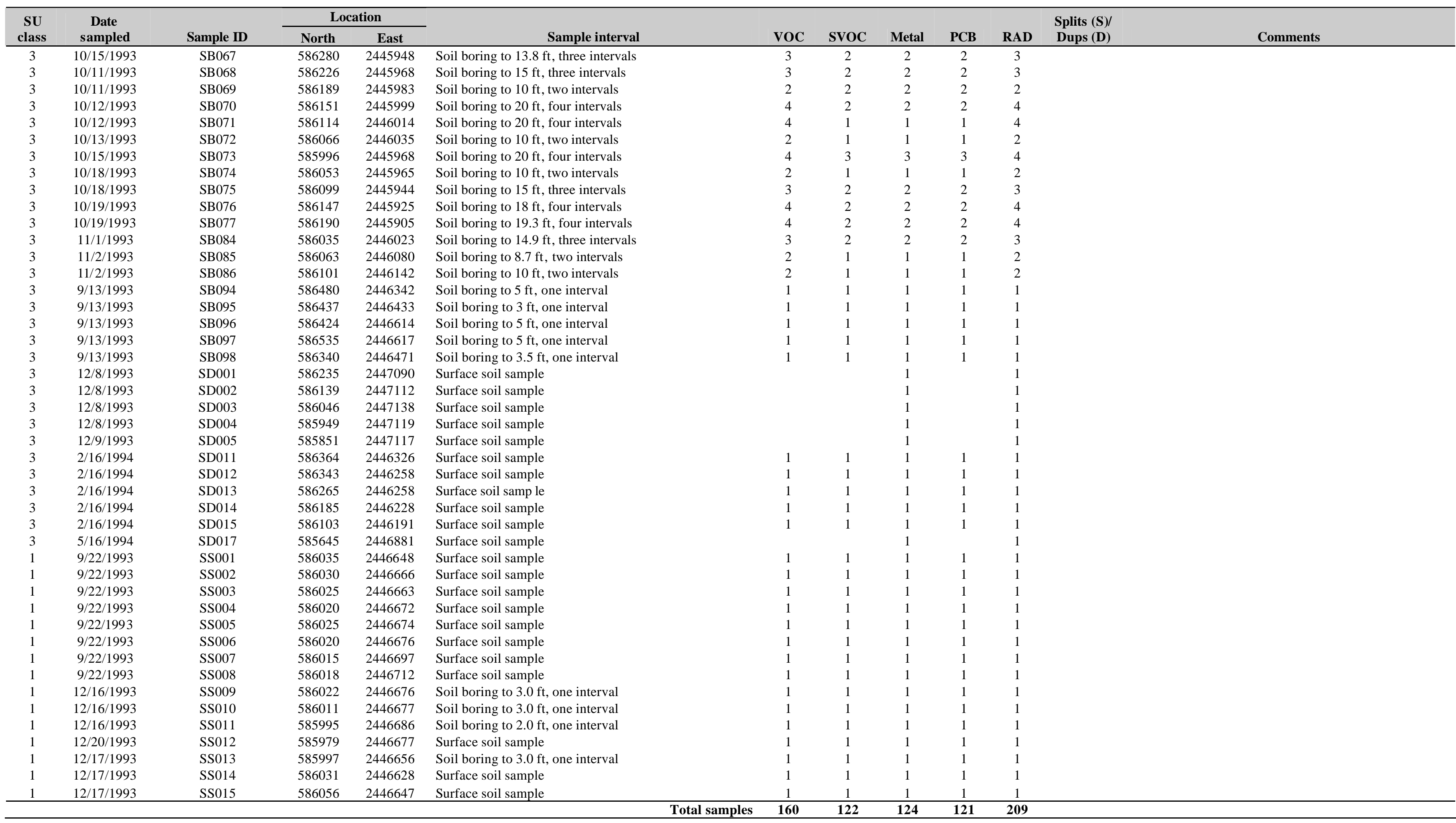




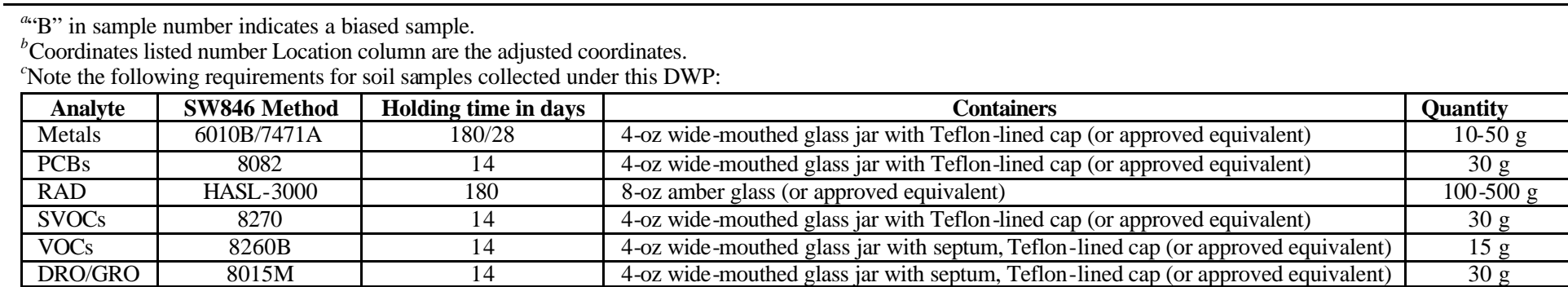

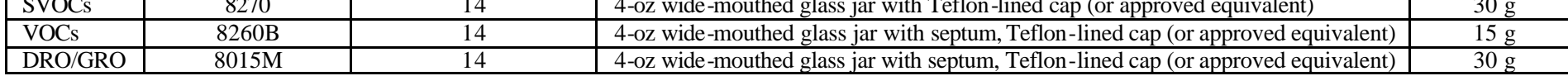

${ }^{d}$ Standard radiological analysis includes alpha spec, gamma spec, and technetium-99.

$\mathrm{EU}=$ exposure unit
$\mathrm{ID}=$ identification

$\mathrm{SOW}=$ statement of work
$\mathrm{SU}=$ soil unit

$\begin{array}{ll}\mathrm{PCB}=\text { polychlorinated biphenyl } & \mathrm{SU}=\text { soil unit } \\ \mathrm{SVOC}=\text { semivolatile organic compound }\end{array}$

$\begin{array}{ll}\mathrm{PID}=\text { photoionization detector } & \text { VOA }=\text { volatile organic aromatic } \\ \mathrm{RAD}=\text { radiological } & \text { VOC }=\text { volatile organic compound }\end{array}$ 
Table I.3. EU Z2-41, depth 0-10 ft

\begin{tabular}{|c|c|c|c|c|c|c|c|c|c|c|c|c|c|}
\hline $\begin{array}{l}\text { Analyte } \\
\end{array}$ & $\begin{array}{c}\text { Frequency } \\
\text { of detect }\end{array}$ & $\begin{array}{c}\text { Minimum } \\
\text { detect }\end{array}$ & $\begin{array}{c}\text { Maximum } \\
\text { detect }\end{array}$ & $\begin{array}{c}\begin{array}{c}\text { Location(s) of } \\
\text { maximum detected } \\
\text { result }\end{array} \\
\end{array}$ & $\begin{array}{c}\text { Average } \\
\text { detected } \\
\text { result }\end{array}$ & $\begin{array}{c}\text { Maximum } \\
\text { RL } \\
\end{array}$ & $\begin{array}{c}\text { Frequency } \\
\text { of detects } \\
\text { exceeding } \\
\text { maximum RL } \\
\end{array}$ & $\begin{array}{c}\text { Average } \\
\text { RL } \\
\end{array}$ & $\begin{array}{c}\text { Frequency } \\
\text { of detects } \\
\text { exceeding } \\
\text { average RL }\end{array}$ & $\begin{array}{c}\text { PRG } \\
\text { limit } \\
\left(10^{-5} \text { or } 1\right) \\
\end{array}$ & $\begin{array}{c}\text { Frequency } \\
\text { of detects } \\
\text { exceeding } \\
\text { PRG limit } \\
\end{array}$ & $\begin{array}{l}\text { Background } \\
\text { concentration }\end{array}$ & $\begin{array}{c}\text { Frequency } \\
\text { of detects } \\
\text { exceeding } \\
\text { background }\end{array}$ \\
\hline \multicolumn{14}{|l|}{ Inorganics (mg/kg) } \\
\hline Aluminum & $135 / 135$ & 3,500 & 29,000 & $\begin{array}{l}\text { Z2-EU41C-207 } \\
\text { Z2-EU41C-211 }\end{array}$ & $17,043.04$ & & NA & & $\mathrm{NA}$ & $1.00 \mathrm{E}+05$ & $0 / 135$ & 40,300 & $0 / 135$ \\
\hline Antimony & $37 / 53$ & $0.0028 \mathrm{~J}$ & $4.2 \mathrm{~J}$ & SS007 & 0.33 & & NA & & NA & $4.10 \mathrm{E}+02$ & $0 / 53$ & 1.52 & $1 / 53$ \\
\hline Arsenic & $131 / 135$ & $0.98 \mathrm{~J}$ & $49 \mathrm{~J}$ & SD002 & 4.89 & 900 & $0 / 135$ & 300 & $0 / 135$ & $1.60 \mathrm{E}+01$ & $1 / 135$ & 14.95 & $2 / 135$ \\
\hline Barium & $135 / 135$ & $21.5 \mathrm{~J}$ & $540 \mathrm{~J}$ & Z2-EU41DB-211 & 120.61 & & NA & & NA & $6.70 \mathrm{E}+04$ & 0/135 & 124.93 & $52 / 135$ \\
\hline Beryllium & $135 / 135$ & 0.23 & 2.8 & SB097 & 0.85 & 6,000 & $0 / 135$ & 2,000 & $0 / 135$ & $1.90 \mathrm{E}+03$ & 0/135 & 2.2 & $1 / 135$ \\
\hline Boron & $63 / 63$ & $0.65 \mathrm{~J}$ & $10 \mathrm{~J}$ & Z2-EU41DB-211 & 2.6 & & NA & & NA & $1.00 \mathrm{E}+05$ & $0 / 63$ & & NA \\
\hline Cadmium & $68 / 135$ & 0.071 & $3.8 \mathrm{~J}$ & SS007 & 1.1 & & NA & & NA & $4.50 \mathrm{E}+02$ & 0/135 & $0.22 \mathrm{U}$ & $58 / 135$ \\
\hline Calcium & $126 / 134$ & 20.2 & 260,000 & Z2EU41DB-208-11 & $21,930.56$ & & $\mathrm{NA}$ & & $\mathrm{NA}$ & & NA & 2,400 & $71 / 134$ \\
\hline Chromium & $135 / 135$ & $5.2 \mathrm{~J}$ & 156 & SS007 & 26.2 & & $\mathrm{NA}$ & & NA & $6.40 \mathrm{E}+02$ & 0/135 & 44.88 & $5 / 135$ \\
\hline Chromium, hexavalent & $0 / 1$ & ND & ND & & ND & & NA & & NA & $6.40 \mathrm{E}+02$ & $0 / 1$ & & NA \\
\hline Cobalt & $135 / 135$ & 1.8 & 43 & SB069 & 10.45 & & NA & & NA & $1.30 \mathrm{E}+04$ & $0 / 135$ & 42 & $1 / 135$ \\
\hline Copper & $134 / 135$ & 4.7 & $1100 \mathrm{~J}$ & SS007 & 40.69 & & NA & & NA & $4.10 \mathrm{E}+04$ & $0 / 135$ & 22.48 & $51 / 135$ \\
\hline Cyanide & $0 / 62$ & $\mathrm{ND}$ & ND & & ND & & $\mathrm{NA}$ & & NA & $1.20 \mathrm{E}+04$ & $0 / 62$ & $0.6 \mathrm{U}$ & $0 / 62$ \\
\hline Iron & $135 / 135$ & 6,590 & 42,400 & SS007 & $25,766.74$ & & NA & & NA & $1.00 \mathrm{E}+05$ & $0 / 135$ & 58,600 & $0 / 135$ \\
\hline Lead & $135 / 135$ & $3.3 \mathrm{~J}$ & 230 & SS007 & 17.96 & & NA & & NA & $8.00 \mathrm{E}+02$ & $0 / 135$ & 37.91 & $6 / 135$ \\
\hline Lithium & $63 / 63$ & 5.7 & 51 & Z2-EU41DB-208 & 16.76 & & NA & & NA & $2.00 \mathrm{E}+04$ & $0 / 63$ & 48.94 & $1 / 63$ \\
\hline Magnesium & $135 / 135$ & 497 & $56,000 \mathrm{~J}$ & Z2-EU41DB-211 & $4,981.04$ & & NA & & NA & & NA & 3,300 & $41 / 135$ \\
\hline Manganese & $135 / 135$ & 29.3 & $2,700 \mathrm{~J}$ & Z2-EU41DB-212 & 373.58 & & NA & & NA & $1.90 \mathrm{E}+04$ & $0 / 135$ & 2,200 & $2 / 135$ \\
\hline Mercury & $84 / 134$ & $0.0088 \mathrm{~J}$ & $4.3 \mathrm{~J}$ & Z2-EU41DB-231 & 0.17 & 1,800 & $0 / 134$ & 600 & $0 / 134$ & $3.10 \mathrm{E}+02$ & $0 / 134$ & 0.17 & $13 / 134$ \\
\hline Molybdenum & $26 / 133$ & $0.089 \mathrm{~J}$ & 11 & SS007 & 1.54 & & NA & & NA & $5.10 \mathrm{E}+03$ & $0 / 133$ & & NA \\
\hline Nickel & $135 / 135$ & 5.5 & $2,100 \mathrm{~J}$ & Z2-EU41C-208 & 69.7 & & NA & & NA & $2.00 \mathrm{E}+04$ & $0 / 135$ & 26.07 & $68 / 135$ \\
\hline Potassium & $135 / 135$ & 444 & 3650 & SB072 & $1,859.39$ & & NA & & NA & & NA & $5,074.69$ & $0 / 135$ \\
\hline Selenium & 29/99 & 0.34 & $3.6 \mathrm{~J}$ & SB033 & 1.35 & & NA & & NA & $5.10 \mathrm{E}+03$ & $0 / 99$ & 1.47 & $8 / 99$ \\
\hline Silver & $62 / 92$ & $0.083 \mathrm{~J}$ & 2.7 & SB051 & 1.36 & & NA & & NA & $5.10 \mathrm{E}+03$ & $0 / 92$ & $0.6 \mathrm{U}$ & $55 / 92$ \\
\hline Sodium & $110 / 135$ & 19.8 & $41,000 \mathrm{~J}$ & Z2-EU41C-211 & 464.27 & & $\mathrm{NA}$ & & NA & & NA & 497 & $3 / 135$ \\
\hline Thallium & $82 / 135$ & 0.063 & $0.57 \mathrm{~J}$ & SB050 & 0.22 & & NA & & NA & $6.70 \mathrm{E}+01$ & $0 / 135$ & $0.4 \mathrm{U}$ & $4 / 135$ \\
\hline Tin & $42 / 72$ & $1.4 \mathrm{~J}$ & $11.9 \mathrm{~J}$ & SS007 & 3.91 & & $\mathrm{NA}$ & & $\mathrm{NA}$ & $1.00 \mathrm{E}+05$ & 0/72 & & $\mathrm{NA}$ \\
\hline Uranium & $11 / 11$ & $0.71 \mathrm{~J}$ & 8 & Z2-EU41DB-208-4 & 3.22 & & NA & & NA & $2.00 \mathrm{E}+02$ & $0 / 11$ & & NA \\
\hline Vanadium & $135 / 135$ & 6.7 & 66.5 & SS005 & 23.89 & & NA & & NA & $1.00 \mathrm{E}+03$ & $0 / 135$ & 65.47 & $1 / 135$ \\
\hline Zinc & $135 / 135$ & 8.1 & $420 \mathrm{~J}$ & SS007 & 45.89 & & NA & & NA & $1.00 \mathrm{E}+05$ & $0 / 135$ & 89.7 & $11 / 135$ \\
\hline \multicolumn{14}{|l|}{ Radionuclides (pCi/g) } \\
\hline Actinium-228 & $7 / 7$ & 0.209 & 1.68 & RAD34 & 1.19 & & NA & & NA & $1.20 \mathrm{E}+04$ & $0 / 7$ & & $\mathrm{NA}$ \\
\hline Alpha activity & $106 / 109$ & 0.509 & 15,700 & RAD47 & 260.92 & & NA & & NA & & NA & & NA \\
\hline Americium 241 & $6 / 6$ & $0.23 \mathrm{~J}$ & $0.48 \mathrm{~J}$ & SB033 & 0.34 & & NA & & NA & $5.70 \mathrm{E}+01$ & $0 / 6$ & & NA \\
\hline Beta activity & $120 / 123$ & 0.833 & 18,100 & RAD47 & 286.24 & & NA & & NA & & NA & & NA \\
\hline Bismuth-212 & $2 / 2$ & 0.931 & $7.59 \mathrm{~J}$ & Z2-EU41DB-219 & 4.26 & & NA & & NA & $3.70 \mathrm{E}+05$ & $0 / 2$ & & NA \\
\hline Bismuth-214 & $19 / 19$ & 0.135 & 5.026 & RAD74 & 0.85 & & NA & & NA & $1.30 \mathrm{E}+05$ & $0 / 19$ & & NA \\
\hline Cadmium 109 & $3 / 3$ & 1.756 & 3.08 & $\begin{array}{l}\text { RAD877 } \\
\text { RAD96 }\end{array}$ & 2.64 & & $\mathrm{NA}$ & & $\mathrm{NA}$ & $3.20 \mathrm{E}+03$ & $0 / 3$ & & $\mathrm{NA}$ \\
\hline Cesium-134 & $4 / 8$ & 0.013 & $0.673 \mathrm{~J}$ & Z2-EU41DB-201 & 0.18 & & NA & & NA & $2.60 \mathrm{E}+00$ & $0 / 8$ & & NA \\
\hline Cesium 137 & $28 / 133$ & 0.028 & 5.87 & RAD122 & 0.68 & 20 & $0 / 133$ & 2 & $1 / 133$ & $1.10 \mathrm{E}+00$ & $3 / 133$ & & NA \\
\hline Cobalt-57 & $4 / 7$ & 0.002 & 0.01 & RAD35 & 0.005 & & NA & & NA & $1.40 \mathrm{E}+02$ & $0 / 7$ & & NA \\
\hline Cobalt-60 & $7 / 110$ & 0.0069 & 0.042 & RAD60 & 0.025 & & NA & & $\mathrm{NA}$ & $6.00 \mathrm{E}-01$ & $0 / 110$ & & NA \\
\hline Lead-212 & $23 / 23$ & 0.0176 & 10.36 & RAD91 & 1.33 & & NA & & NA & $6.10 \mathrm{E}+04$ & $0 / 23$ & & NA \\
\hline Lead-214 & $11 / 11$ & 0.161 & 1.236 & RAD123 & 0.777 & & NA & & NA & $7.50 \mathrm{E}+05$ & $0 / 11$ & & NA \\
\hline Neptunium-237 & $31 / 78$ & 0.02 & 1.749 & RAD103 & 0.28 & 50 & $0 / 78$ & 5 & $0 / 78$ & $2.70 \mathrm{E}+00$ & $0 / 78$ & & NA \\
\hline Plutonium-238 & $24 / 81$ & 0.0019 & 0.184 & RAD86 & 0.054 & & NA & & NA & $1.70 \mathrm{E}+02$ & $0 / 81$ & & NA \\
\hline Plutonium 239 & $21 / 81$ & 0.0028 & 0.1976 & RAD122 & 0.041 & & NA & & NA & $1.50 \mathrm{E}+02$ & $0 / 81$ & & NA \\
\hline
\end{tabular}




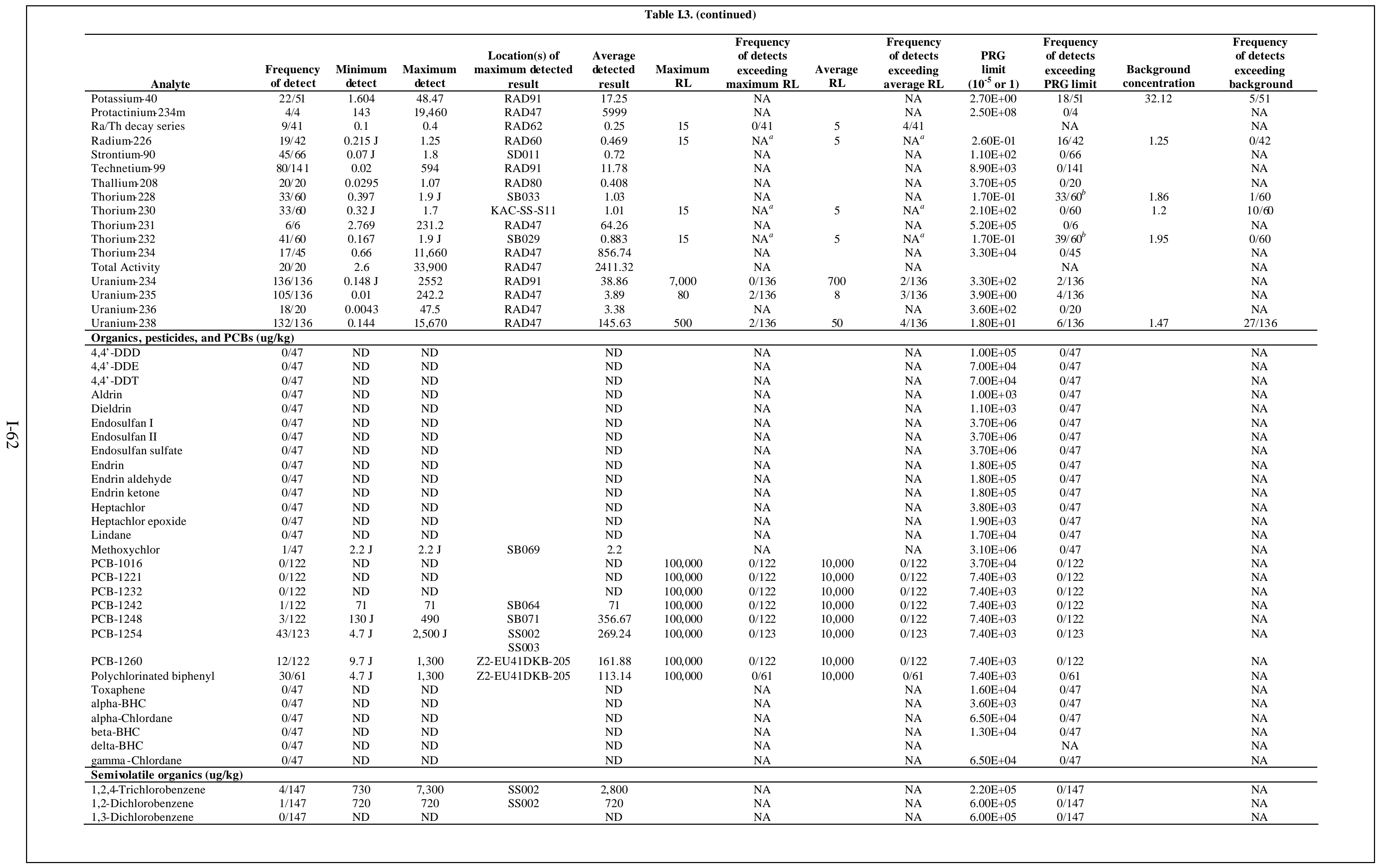




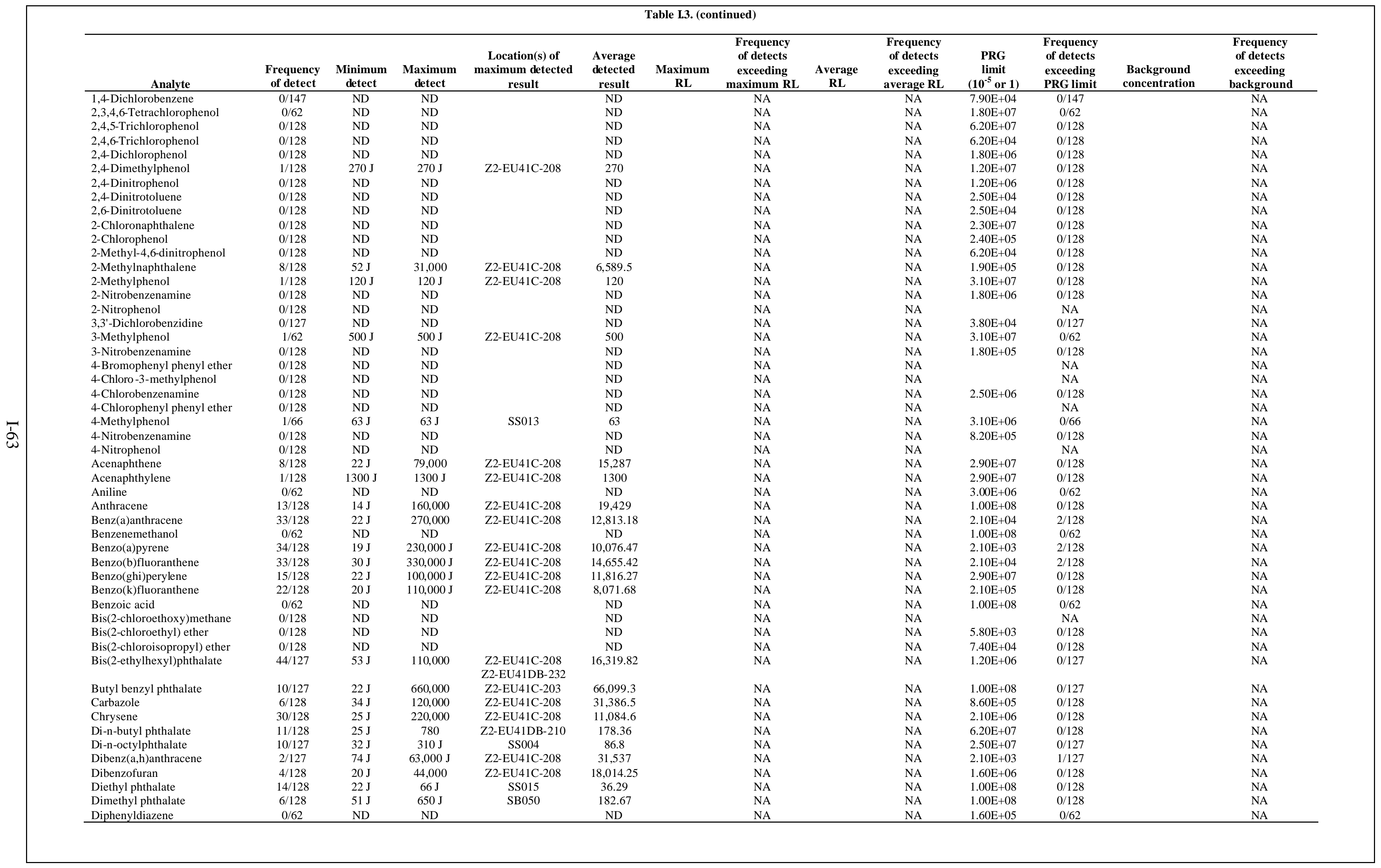




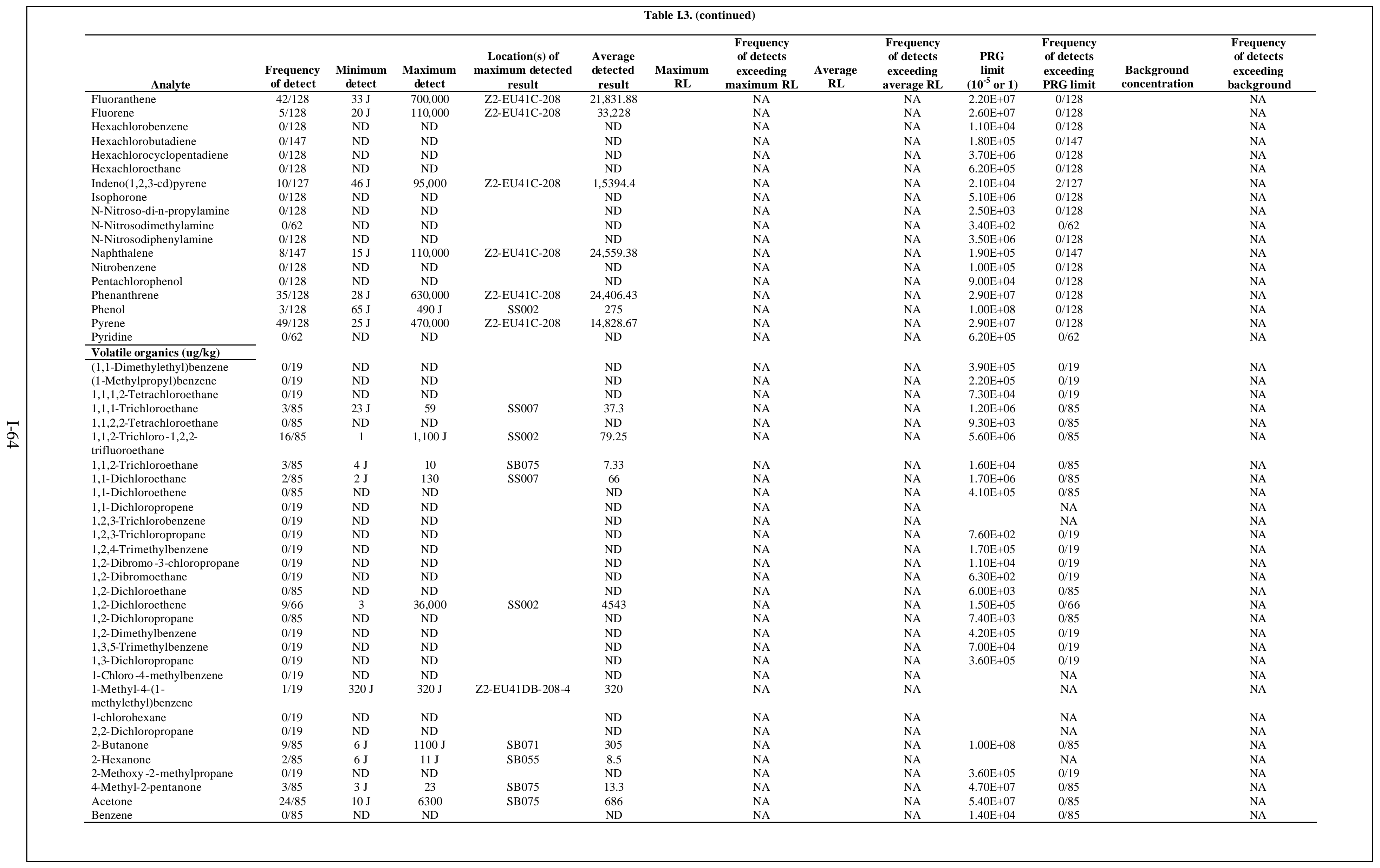




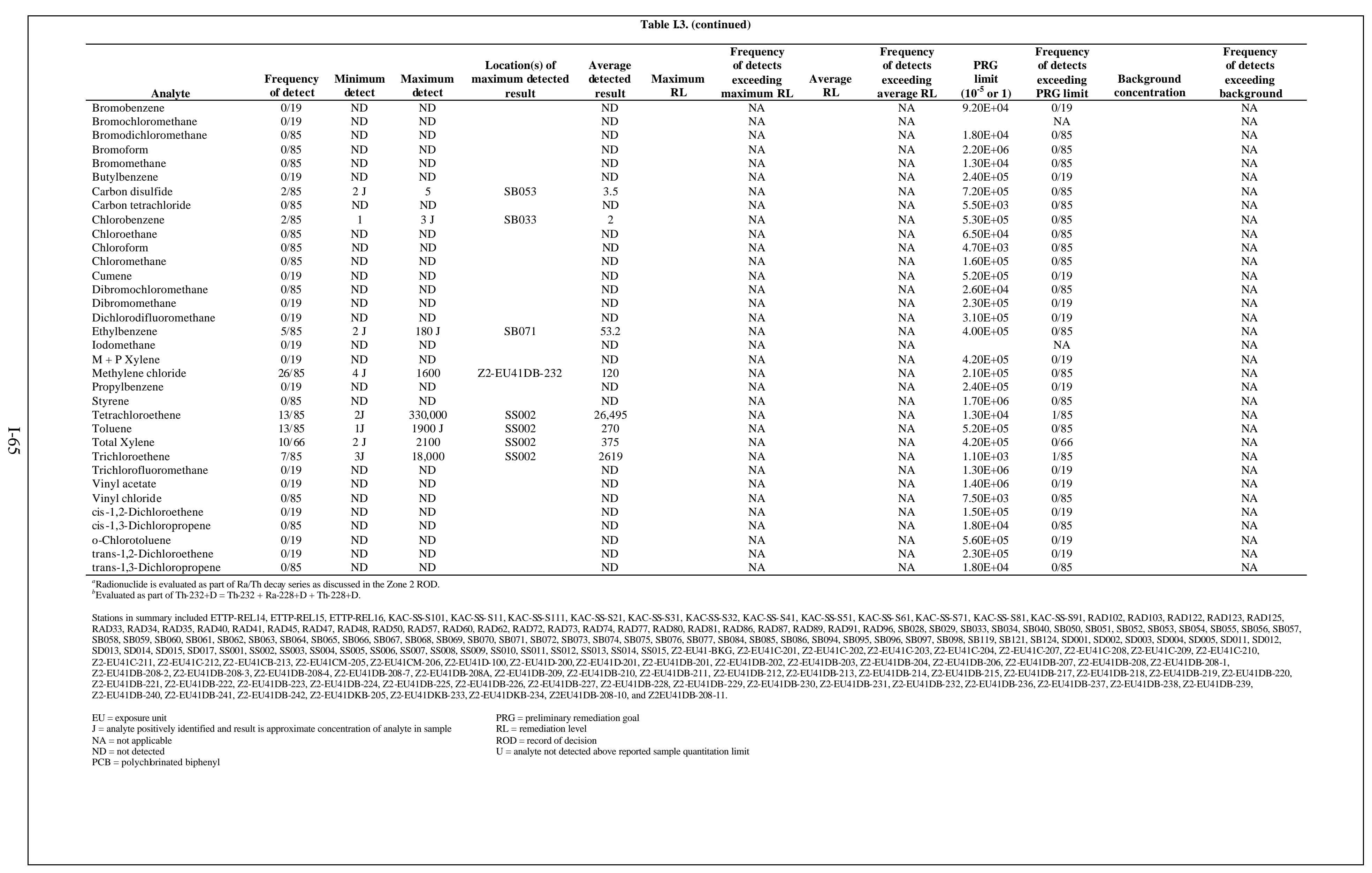


Table I.4. EU Z2-41, depth >10 ft

\begin{tabular}{|c|c|c|c|c|c|c|c|c|c|c|c|c|c|}
\hline $\begin{array}{rr}\text { Analyte } \\
\end{array}$ & $\begin{array}{r}\text { Frequency } \\
\text { of detect }\end{array}$ & $\begin{array}{c}\text { Minimum } \\
\text { detect }\end{array}$ & $\begin{array}{c}\text { Maximum } \\
\text { detect }\end{array}$ & $\begin{array}{c}\text { Location(s) } \\
\text { of maximum } \\
\text { detected result }\end{array}$ & $\begin{array}{c}\text { Average } \\
\text { detected } \\
\text { result }\end{array}$ & $\begin{array}{c}\text { Maximum } \\
\text { RL }\end{array}$ & $\begin{array}{c}\text { Frequency } \\
\text { of detects } \\
\text { exceeding } \\
\text { maximum RL }\end{array}$ & $\begin{array}{c}\text { Average } \\
\text { RL }\end{array}$ & $\begin{array}{c}\text { Frequency } \\
\text { of detects } \\
\text { exceeding } \\
\text { average RL } \\
\end{array}$ & $\begin{array}{l}\text { PRG limit } \\
\left(10^{-5} \text { or } 1\right)\end{array}$ & $\begin{array}{c}\text { Frequency } \\
\text { of detects } \\
\text { exceeding } \\
\text { PRG limit }\end{array}$ & $\begin{array}{c}\text { Background } \\
\text { concentration }\end{array}$ & $\begin{array}{c}\text { Frequency } \\
\text { of detects } \\
\text { exceeding } \\
\text { background }\end{array}$ \\
\hline \multicolumn{14}{|l|}{ Inorganics $(\mathrm{mg} / \mathbf{k g})$} \\
\hline Aluminum & $70 / 70$ & 7,500 & 36,000 & Z2-EU41C-208 & 18,237 & & NA & & NA & $1.00 \mathrm{E}+05$ & $0 / 70$ & 4,0300 & $0 / 70$ \\
\hline Antimony & $10 / 18$ & $0.0019 \mathrm{~J}$ & $0.36 \mathrm{~J}$ & SB052 & 0.14 & & NA & & NA & $4.10 \mathrm{E}+02$ & $0 / 18$ & 1.52 & $0 / 18$ \\
\hline Arsenic & $67 / 70$ & 0.56 & 14 & Z2-EU41C-207 & 4.7 & 900 & 0/70 & 300 & $0 / 70$ & $1.60 \mathrm{E}+01$ & $0 / 70$ & 14.95 & 0/70 \\
\hline Barium & $70 / 70$ & 31.4 & 742 & SB076 & 208 & & NA & & NA & $6.70 \mathrm{E}+04$ & $0 / 70$ & 124.93 & $33 / 70$ \\
\hline Beryllium & $70 / 70$ & 0.37 & 3.9 & SB045 & 1.11 & 6,000 & $0 / 70$ & 2,000 & $0 / 70$ & $1.90 \mathrm{E}+03$ & $0 / 70$ & 2.2 & $3 / 70$ \\
\hline Boron & $14 / 14$ & $1.2 \mathrm{~J}$ & 5.5 & Z2-EU41C-207 & 2.64 & & NA & & NA & $1.00 \mathrm{E}+05$ & $0 / 14$ & & NA \\
\hline Cadmium & $14 / 70$ & $0.83 \mathrm{~J}$ & $8.9 \mathrm{~J}$ & Z2-EU41DB-221 & 2.23 & & NA & & NA & $4.50 \mathrm{E}+02$ & $0 / 70$ & $0.22 \mathrm{U}$ & $14 / 70$ \\
\hline Calcium & $68 / 70$ & $30 \mathrm{~J}$ & $6670 \mathrm{~J}$ & SB024 & 1189 & & NA & & NA & & NA & 2400 & $11 / 70$ \\
\hline Chromium & $70 / 70$ & 7.8 & $49.5 \mathrm{~J}$ & SB063 & 26.2 & & NA & & NA & $6.40 \mathrm{E}+02$ & $0 / 70$ & 44.88 & $4 / 70$ \\
\hline Chromium, hexavalent & $0 / 1$ & $\mathrm{ND}$ & $\mathrm{ND}$ & & $\mathrm{ND}$ & & NA & & NA & $6.40 \mathrm{E}+02$ & $0 / 1$ & & NA \\
\hline Cobalt & $70 / 70$ & 2.2 & $52.5 \mathrm{~J}$ & SB077 & 19.1 & & NA & & NA & $1.30 \mathrm{E}+04$ & $0 / 70$ & 42 & $3 / 70$ \\
\hline Copper & $70 / 70$ & 8.9 & $41 \mathrm{~J}$ & Z2-EU41C-203 & 18.7 & & NA & & NA & $4.10 \mathrm{E}+04$ & $0 / 70$ & 22.48 & $16 / 70$ \\
\hline Cyanide & $2 / 56$ & $4 \mathrm{~J}$ & 10.3 & SB060 & 7.15 & & NA & & NA & $1.20 \mathrm{E}+04$ & $0 / 56$ & $0.6 \mathrm{U}$ & $2 / 56$ \\
\hline Iron & $70 / 70$ & 11,000 & 52,000 & $\begin{array}{l}\text { Z2-EU41DB-223 } \\
\text { Z2-EU41DB-225 }\end{array}$ & 27720 & & NA & & NA & $1.00 \mathrm{E}+05$ & $0 / 70$ & 58,600 & $0 / 70$ \\
\hline Lead & $70 / 70$ & $4.5 \mathrm{~J}$ & 130 & Z2-EU41C-207 & 14.8 & & NA & & NA & $8.00 \mathrm{E}+02$ & $0 / 70$ & 37.91 & $3 / 70$ \\
\hline Lithium & $14 / 14$ & 8.8 & 35 & Z2-EU41DB-227 & 18.6 & & NA & & NA & $2.00 \mathrm{E}+04$ & $0 / 14$ & 48.94 & $0 / 14$ \\
\hline Magnesium & $70 / 70$ & 567 & 7790 & SB063 & 2731 & & NA & & NA & & NA & 3,300 & $20 / 70$ \\
\hline Manganese & $70 / 70$ & 19.9 & 3230 & SB077 & 593 & & NA & & NA & $1.90 \mathrm{E}+04$ & $0 / 70$ & 2,200 & $2 / 70$ \\
\hline Mercury & $19 / 69$ & $0.0024 \mathrm{~J}$ & $3.5 \mathrm{~J}$ & Z2-EU41DB-231 & 0.3 & 1,800 & $0 / 69$ & 600 & $0 / 69$ & $3.10 \mathrm{E}+02$ & $0 / 69$ & 0.17 & $3 / 69$ \\
\hline Molybdenum & $24 / 70$ & $0.091 \mathrm{~J}$ & $6.8 \mathrm{~J}$ & SB084 & 1.59 & & NA & & NA & $5.10 \mathrm{E}+03$ & $0 / 70$ & & NA \\
\hline Nickel & $69 / 70$ & 4.3 & $900 \mathrm{~J}$ & Z2-EU41C-208 & 38.5 & & NA & & NA & $2.00 \mathrm{E}+04$ & $0 / 70$ & 26.07 & $33 / 70$ \\
\hline Potassium & $69 / 70$ & $860 \mathrm{~J}$ & 5110 & SB064 & 2312 & & NA & & NA & & NA & $5,074.69$ & $1 / 70$ \\
\hline Selenium & $18 / 54$ & 0.39 & 2.3 & $\begin{array}{c}\text { SB084 } \\
\text { Z2-EU41DB-225 }\end{array}$ & 1.08 & & NA & & NA & $5.10 \mathrm{E}+03$ & $0 / 54$ & 1.47 & $3 / 54$ \\
\hline Silver & $53 / 56$ & 0.49 & 2.6 & $\begin{array}{l}\text { 22-EU41DB-2LS } \\
\text { SB044 } \\
\text { SB071 }\end{array}$ & 1.48 & & NA & & NA & $5.10 \mathrm{E}+03$ & $0 / 56$ & $0.6 \mathrm{U}$ & $49 / 56$ \\
\hline Sodium & $60 / 70$ & $33 \mathrm{~J}$ & $2100 \mathrm{~J}$ & $\begin{array}{c}\text { SB084 } \\
\text { Z2-EU41C-207 }\end{array}$ & 130 & & NA & & NA & & NA & 497 & $1 / 70$ \\
\hline $\begin{array}{l}\text { Sodium } \\
\text { Thallium }\end{array}$ & $26 / 70$ & 0.068 & 0.5 & $\begin{array}{l}\text { C2-EU4IC-OI } \\
\text { SB035 } \\
\text { SB045 }\end{array}$ & 0.25 & & NA & & NA & $6.70 \mathrm{E}+01$ & $\begin{array}{l}\text { NA } \\
0 / 70\end{array}$ & $0.4 \mathrm{U}$ & $5 / 70$ \\
\hline & & & & Z2-EU41C-207 & & & & & & & & & \\
\hline Tin & $41 / 56$ & 1.9 & $7.6 \mathrm{~J}$ & SB084 & 3.69 & & NA & & NA & $1.00 \mathrm{E}+05$ & $0 / 56$ & & NA \\
\hline Vanadium & $70 / 70$ & 7.5 & 35 & Z2-EU41DB-222 & 22.1 & & NA & & NA & $1.00 \mathrm{E}+03$ & $0 / 70$ & 65.47 & $0 / 70$ \\
\hline & $70 / 70$ & 10.9 & 310 & SB045 & 55.2 & & NA & & NA & $1.00 \mathrm{E}+05$ & $0 / 70$ & 89.7 & $7 / 70$ \\
\hline \multicolumn{14}{|l|}{ Radionuclides (pCi/g) } \\
\hline Alpha activity & $47 / 48$ & 2.03 & $49.34 \mathrm{~J}$ & SB057 & 22 & & NA & & $\mathrm{NA}$ & & $\mathrm{NA}$ & & NA \\
\hline Americium 241 & $31 / 31$ & $0.05 \mathrm{~J}$ & $1.8 \mathrm{~J}$ & SB033 & 0.39 & & NA & & NA & $5.70 \mathrm{E}+01$ & $0 / 31$ & & NA \\
\hline Beta activity & $69 / 69$ & 1.3 & $215.57 \mathrm{~J}$ & SB055 & 37.8 & & NA & & NA & & $\mathrm{NA}$ & & NA \\
\hline Cesium 137 & $0 / 66$ & $\mathrm{ND}$ & ND & & ND & 20 & $0 / 66$ & 2 & $0 / 66$ & $1.10 \mathrm{E}+00$ & $0 / 66$ & & NA \\
\hline Cobalt-60 & $0 / 66$ & $\mathrm{ND}$ & ND & & $\mathrm{ND}$ & & NA & & NA & $6.00 \mathrm{E}-01$ & $0 / 66$ & & NA \\
\hline Neptunium-237 & $23 / 42$ & 0.01 & 0.75 & Z2-EU41DB-224 & 0.08 & 50 & $0 / 42$ & 5 & $0 / 42$ & $2.70 \mathrm{E}+00$ & $0 / 42$ & & NA \\
\hline Plutonium-238 & $15 / 42$ & 0.01 & $0.22 \mathrm{~J}$ & SB035 & 0.07 & & NA & & NA & $1.70 \mathrm{E}+02$ & $0 / 42$ & & NA \\
\hline Plutonium 239 & $12 / 41$ & 0.01 & 0.149 & Z2-EU41DB-228 & 0.04 & & NA & & NA & $1.50 \mathrm{E}+02$ & $0 / 41$ & & NA \\
\hline Potassium-40 & $0 / 9$ & ND & ND & & $\mathrm{ND}$ & & NA & & NA & $2.70 \mathrm{E}+00$ & $0 / 9$ & 32.12 & $0 / 9$ \\
\hline $\mathrm{Ra} / \mathrm{Th}$ decay series & $40 / 40$ & 0 & 1.7 & SB044 & 0.6 & 15 & $0 / 40$ & 5 & $0 / 40$ & & NA & & NA \\
\hline Radium-226 & $5 / 9$ & $0.161 \mathrm{~J}$ & $0.399 \mathrm{~J}$ & Z2-EU41C-207 & 0.27 & 15 & $\mathrm{NA}^{a}$ & 5 & $\mathrm{NA}^{a}$ & $2.60 \mathrm{E}-01$ & $2 / 9$ & 1.25 & $0 / 9$ \\
\hline Strontium-90 & $45 / 52$ & $0.01 \mathrm{~J}$ & $4.8 \mathrm{~J}$ & SB045 & 1.03 & & NA & & NA & $1.10 \mathrm{E}+02$ & $0 / 52$ & & NA \\
\hline Technetium-99 & $50 / 69$ & 0.01 & 31.8 & Z2-EU41DB-223 & 3.18 & & NA & & NA & $8.90 \mathrm{E}+03$ & $0 / 69$ & & NA \\
\hline
\end{tabular}




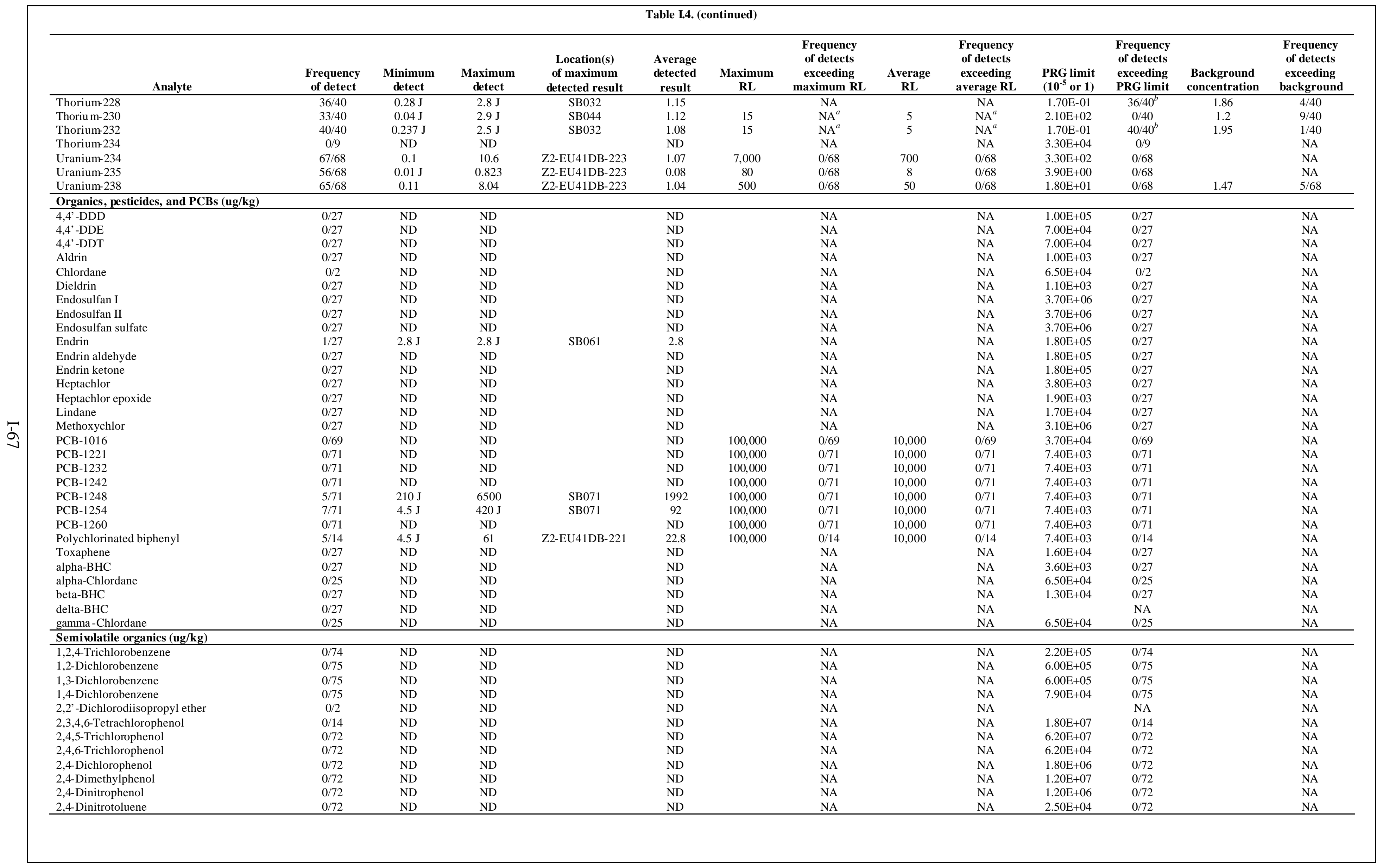




\begin{tabular}{|c|c|c|c|c|c|c|c|c|c|c|c|c|c|}
\hline \multicolumn{14}{|c|}{ Table I.4. (continued) } \\
\hline $\begin{array}{l}\text { Analyte } \\
\end{array}$ & $\begin{array}{r}\text { Frequency } \\
\text { of detect }\end{array}$ & $\begin{array}{c}\text { Minimum } \\
\text { detect }\end{array}$ & $\begin{array}{c}\text { Maximum } \\
\text { detect }\end{array}$ & $\begin{array}{c}\text { Location(s) } \\
\text { of maximum } \\
\text { detected result }\end{array}$ & $\begin{array}{c}\text { Average } \\
\text { detected } \\
\text { result }\end{array}$ & $\begin{array}{c}\text { Maximum } \\
\text { RL }\end{array}$ & $\begin{array}{c}\text { Frequency } \\
\text { of detects } \\
\text { exceeding } \\
\text { maximum RL }\end{array}$ & $\begin{array}{c}\text { Average } \\
\text { RL }\end{array}$ & $\begin{array}{l}\text { Frequency } \\
\text { of detects } \\
\text { exceeding } \\
\text { average RL }\end{array}$ & $\begin{array}{l}\text { PRG limit } \\
\left(10^{-5} \text { or } 1\right)\end{array}$ & $\begin{array}{l}\text { Frequency } \\
\text { of detects } \\
\text { exceeding } \\
\text { PRG limit }\end{array}$ & $\begin{array}{l}\text { Background } \\
\text { concentration }\end{array}$ & $\begin{array}{l}\text { Frequency } \\
\text { of detects } \\
\text { exceeding } \\
\text { background }\end{array}$ \\
\hline 2,6-Dinitrotoluene & $0 / 72$ & $\mathrm{ND}$ & $\mathrm{ND}$ & & ND & & NA & & NA & $2.50 \mathrm{E}+04$ & $0 / 72$ & & NA \\
\hline 2-Chloronaphthalene & $0 / 72$ & $\mathrm{ND}$ & $\mathrm{ND}$ & & $\mathrm{ND}$ & & $\mathrm{NA}$ & & $\mathrm{NA}$ & $2.30 \mathrm{E}+07$ & $0 / 72$ & & $\mathrm{NA}$ \\
\hline 2-Chlorophenol & $0 / 72$ & ND & $\mathrm{ND}$ & & $\mathrm{ND}$ & & $\mathrm{NA}$ & & NA & $2.40 \mathrm{E}+05$ & $0 / 72$ & & NA \\
\hline 2-Methyl-4,6-dinitrophenol & $0 / 72$ & ND & ND & & ND & & NA & & NA & $6.20 \mathrm{E}+04$ & 0/72 & & NA \\
\hline 2-Methylnaphthalene & $3 / 70$ & $32 \mathrm{~J}$ & 770 & SB071 & 377 & & NA & & NA & $1.90 \mathrm{E}+05$ & $0 / 70$ & & NA \\
\hline 2-Methylphenol & $0 / 72$ & ND & ND & TDO & ND & & NA & & NA & $3.10 \mathrm{E}+07$ & $0 / 72$ & & NA \\
\hline 2-Nitrobenzenamine & $0 / 70$ & ND & $\mathrm{ND}$ & & $\mathrm{ND}$ & & $\mathrm{NA}$ & & $\mathrm{NA}$ & $1.80 \mathrm{E}+06$ & $0 / 70$ & & $\mathrm{NA}$ \\
\hline 2-Nitrophenol & $2 / 72$ & $73 \mathrm{~J}$ & $84 \mathrm{~J}$ & SB071 & 78.5 & & NA & & NA & & NA & & NA \\
\hline 3,3'-Dichlorobenzidine & $0 / 70$ & ND & ND & & $\mathrm{ND}$ & & $\mathrm{NA}$ & & $\mathrm{NA}$ & $3.80 \mathrm{E}+04$ & $0 / 70$ & & $\mathrm{NA}$ \\
\hline 3-Methylphenol & $0 / 14$ & $\mathrm{ND}$ & $\mathrm{ND}$ & & $\mathrm{ND}$ & & $\mathrm{NA}$ & & NA & $3.10 \mathrm{E}+07$ & $0 / 14$ & & $\mathrm{NA}$ \\
\hline 3-Nitrobenzenamine & $0 / 70$ & ND & ND & & $\mathrm{ND}$ & & $\mathrm{NA}$ & & NA & $1.80 \mathrm{E}+05$ & $0 / 70$ & & NA \\
\hline 4-Bromophenyl phenyl ether & 0/72 & $\mathrm{ND}$ & $\mathrm{ND}$ & & $\mathrm{ND}$ & & NA & & $\mathrm{NA}$ & & NA & & $\mathrm{NA}$ \\
\hline 4-Chloro-3-methylphenol & $0 / 72$ & ND & ND & & $\mathrm{ND}$ & & NA & & NA & & NA & & NA \\
\hline 4-Chlorobenzenamine & $0 / 70$ & ND & $\mathrm{ND}$ & & $\mathrm{ND}$ & & NA & & $\mathrm{NA}$ & $2.50 \mathrm{E}+06$ & $0 / 70$ & & $\mathrm{NA}$ \\
\hline 4-Chlorophenyl phenyl ether & $0 / 72$ & $\mathrm{ND}$ & $\mathrm{ND}$ & & ND & & NA & & NA & & NA & & NA \\
\hline 4-Methylphenol & $0 / 56$ & ND & $\mathrm{ND}$ & & $\mathrm{ND}$ & & NA & & NA & $3.10 \mathrm{E}+06$ & $0 / 56$ & & NA \\
\hline 4-Nitrobenzenamine & 0/70 & $\mathrm{ND}$ & $\mathrm{ND}$ & & $\mathrm{ND}$ & & NA & & NA & $8.20 \mathrm{E}+05$ & $0 / 70$ & & NA \\
\hline 4-Nitrophenol & $1 / 72$ & $94 \mathrm{~J}$ & $94 \mathrm{~J}$ & SB058 & 94 & & NA & & NA & & NA & & NA \\
\hline Acenaphthene & 2/72 & $27 \mathrm{~J}$ & $94 \mathrm{~J}$ & Z2-EU41C-209 & 61 & & NA & & $\mathrm{NA}$ & $2.90 \mathrm{E}+07$ & $0 / 72$ & & $\mathrm{NA}$ \\
\hline Acenaphthylene & $0 / 72$ & ND & ND & & ND & & NA & & NA & $2.90 \mathrm{E}+07$ & $0 / 72$ & & NA \\
\hline Aniline & $0 / 14$ & $\mathrm{ND}$ & $\mathrm{ND}$ & & ND & & NA & & NA & $3.00 \mathrm{E}+06$ & $0 / 14$ & & NA \\
\hline Anthracene & 2/72 & $58 \mathrm{~J}$ & $260 \mathrm{~J}$ & Z2-EU41C-209 & 159 & & NA & & NA & $1.00 \mathrm{E}+08$ & $0 / 72$ & & NA \\
\hline Benz(a)anthracene & 2/72 & $120 \mathrm{~J}$ & 470 & Z2-EU41C-209 & 295 & & NA & & NA & $2.10 \mathrm{E}+04$ & $0 / 72$ & & NA \\
\hline Benzenemethanol & $0 / 14$ & $\mathrm{ND}$ & $\mathrm{ND}$ & & $\mathrm{ND}$ & & NA & & $\mathrm{NA}$ & $1.00 \mathrm{E}+08$ & $0 / 14$ & & $\mathrm{NA}$ \\
\hline Benzo(a)pyrene & $3 / 72$ & $43 \mathrm{~J}$ & $320 \mathrm{~J}$ & Z2-EU41C-209 & 153 & & NA & & NA & $2.10 \mathrm{E}+03$ & $0 / 72$ & & NA \\
\hline Benzo(b)fluoranthene & $3 / 72$ & $50 \mathrm{~J}$ & 430 & Z2-EU41C-209 & 193 & & NA & & NA & $2.10 \mathrm{E}+04$ & $0 / 72$ & & NA \\
\hline Benzo(ghi)perylene & $2 / 72$ & $67 \mathrm{~J}$ & $190 \mathrm{~J}$ & Z2-EU41C-209 & 129 & & NA & & NA & $2.90 \mathrm{E}+07$ & $0 / 72$ & & NA \\
\hline Benzo(k)fluoranthene & 2/72 & $51 \mathrm{~J}$ & $190 \mathrm{~J}$ & Z2-EU41C-209 & 121 & & NA & & NA & $2.10 \mathrm{E}+05$ & $0 / 72$ & & NA \\
\hline Benzoic acid & $0 / 14$ & ND & ND & & ND & & NA & & NA & $1.00 \mathrm{E}+08$ & $0 / 14$ & & NA \\
\hline Bis(2-chloroethoxy)methane & $0 / 72$ & ND & ND & & ND & & NA & & NA & & NA & & NA \\
\hline Bis(2-chloroethyl) ether & $0 / 72$ & ND & ND & & ND & & NA & & NA & $5.80 \mathrm{E}+03$ & $0 / 72$ & & NA \\
\hline Bis(2-chloroisopropyl) ether & $0 / 70$ & ND & ND & & ND & & NA & & NA & $7.40 \mathrm{E}+04$ & $0 / 70$ & & NA \\
\hline Bis(2-ethylhexyl)phthalate & $23 / 72$ & 37 & 160,000 & Z2-EU41DB-220 & 17,280 & & $\mathrm{NA}$ & & $\mathrm{NA}$ & $1.20 \mathrm{E}+06$ & $0 / 72$ & & $\mathrm{NA}$ \\
\hline Butyl benzyl phthalate & $5 / 72$ & $40 \mathrm{~J}$ & $49 \mathrm{~J}$ & $\begin{array}{l}\text { Z2-EU41C-202 } \\
\text { Z2-EU41DB-231 }\end{array}$ & 45 & & $\mathrm{NA}$ & & $\mathrm{NA}$ & $1.00 \mathrm{E}+08$ & 0/72 & & $\mathrm{NA}$ \\
\hline Carbazole & $2 / 70$ & $190 \mathrm{~J}$ & $200 \mathrm{~J}$ & Z2-EU41C-209 & 195 & & NA & & NA & $8.60 \mathrm{E}+05$ & 0/70 & & NA \\
\hline Chrysene & $2 / 72$ & $93 \mathrm{~J}$ & $370 \mathrm{~J}$ & Z2-EU41C-209 & 232 & & NA & & NA & $2.10 \mathrm{E}+06$ & $0 / 72$ & & NA \\
\hline Di-n-butyl phthalate & $6 / 72$ & $30 \mathrm{~J}$ & 510 (B) & PE2 & 187 & & NA & & NA & $6.20 \mathrm{E}+07$ & $0 / 72$ & & $\mathrm{NA}$ \\
\hline Di-n-octylphthalate & $3 / 72$ & $46 \mathrm{~J}$ & $120 \mathrm{~J}$ & Z2-EU41DB-220 & 71.7 & & NA & & NA & $2.50 \mathrm{E}+07$ & $0 / 72$ & & NA \\
\hline Dibenz $(a, h)$ anthracene & $0 / 72$ & ND & $\mathrm{ND}$ & & ND & & NA & & NA & $2.10 \mathrm{E}+03$ & $0 / 72$ & & NA \\
\hline Dibenzofuran & $2 / 70$ & $25 \mathrm{~J}$ & $68 \mathrm{~J}$ & Z2-EU41C-209 & 46.5 & & NA & & NA & $1.60 \mathrm{E}+06$ & $0 / 70$ & & NA \\
\hline Diethyl phthalate & 2/72 & $24 \mathrm{~J}$ & $57 \mathrm{~J}$ & Z2-EU41DB-220 & 40.5 & & NA & & NA & $1.00 \mathrm{E}+08$ & 0/72 & & NA \\
\hline Dimethyl phthalate & $7 / 72$ & $49 \mathrm{~J}$ & $260 \mathrm{~J}$ & SB058 & 132 & & NA & & NA & $1.00 \mathrm{E}+08$ & $0 / 72$ & & $\mathrm{NA}$ \\
\hline Diphenyldiazene & $0 / 16$ & ND & $\mathrm{ND}$ & & ND & & NA & & NA & $1.60 \mathrm{E}+05$ & $0 / 16$ & & NA \\
\hline Fluoranthene & 3/72 & $76 \mathrm{~J}$ & 1100 & Z2-EU41C-209 & 489 & & $\mathrm{NA}$ & & $\mathrm{NA}$ & $2.20 \mathrm{E}+07$ & $0 / 72$ & & $\mathrm{NA}$ \\
\hline Fluorene & $4 / 72$ & $49 \mathrm{~J}$ & $160 \mathrm{~J}$ & SB071 & 102 & & NA & & NA & $2.60 \mathrm{E}+07$ & $0 / 72$ & & NA \\
\hline Hexachlorobenzene & 0/72 & ND & ND & & $\mathrm{ND}$ & & NA & & NA & $1.10 \mathrm{E}+04$ & $0 / 72$ & & NA \\
\hline Hexachlorobutadiene & $0 / 74$ & $\mathrm{ND}$ & $\mathrm{ND}$ & & $\mathrm{ND}$ & & NA & & NA & $1.80 \mathrm{E}+05$ & $0 / 74$ & & $\mathrm{NA}$ \\
\hline Hexachlorocyclopentadiene & $0 / 72$ & $\mathrm{ND}$ & $\mathrm{ND}$ & & $\mathrm{ND}$ & & NA & & NA & $3.70 \mathrm{E}+06$ & $0 / 72$ & & NA \\
\hline Hexachloroethane & $0 / 72$ & ND & $\mathrm{ND}$ & & $\mathrm{ND}$ & & NA & & NA & $6.20 \mathrm{E}+05$ & $0 / 72$ & & $\mathrm{NA}$ \\
\hline Indeno(1,2,3-cd)pyrene & $1 / 72$ & $170 \mathrm{~J}$ & $170 \mathrm{~J}$ & Z2-EU41C-209 & 170 & & NA & & NA & $2.10 \mathrm{E}+04$ & $0 / 72$ & & NA \\
\hline
\end{tabular}




\begin{tabular}{|c|c|c|c|c|c|c|c|c|c|c|c|c|c|}
\hline \multicolumn{14}{|c|}{ Table I.4. (continued) } \\
\hline Analyte & $\begin{array}{c}\text { Frequency } \\
\text { of detect }\end{array}$ & $\begin{array}{c}\text { Minimum } \\
\text { detect }\end{array}$ & $\begin{array}{c}\text { Maximum } \\
\text { detect }\end{array}$ & $\begin{array}{c}\text { Location(s) } \\
\text { of maximum } \\
\text { detected result }\end{array}$ & $\begin{array}{l}\text { Average } \\
\text { detected } \\
\text { result }\end{array}$ & $\begin{array}{c}\text { Maximum } \\
\text { RL }\end{array}$ & $\begin{array}{l}\text { Frequency } \\
\text { of detects } \\
\text { exceeding } \\
\text { maximum RL }\end{array}$ & $\begin{array}{c}\text { Average } \\
\text { RL }\end{array}$ & $\begin{array}{c}\text { Frequency } \\
\text { of detects } \\
\text { exceeding } \\
\text { average RL }\end{array}$ & $\begin{array}{l}\text { PRG limit } \\
\left(10^{-5} \text { or } 1\right)\end{array}$ & $\begin{array}{l}\text { Frequency } \\
\text { of detects } \\
\text { exceeding } \\
\text { PRG limit }\end{array}$ & $\begin{array}{l}\text { Background } \\
\text { concentration }\end{array}$ & $\begin{array}{c}\text { Frequency } \\
\text { of detects } \\
\text { exceeding } \\
\text { background }\end{array}$ \\
\hline Isophorone & $0 / 72$ & $\mathrm{ND}$ & $\mathrm{ND}$ & & ND & & NA & & NA & $5.10 \mathrm{E}+06$ & $0 / 72$ & & NA \\
\hline N-Nitroso-di-n-propylamine & $0 / 72$ & ND & ND & & ND & & NA & & NA & $2.50 \mathrm{E}+03$ & $0 / 72$ & & NA \\
\hline N-Nitrosodimethylamine & $0 / 16$ & ND & ND & & ND & & NA & & NA & $3.40 \mathrm{E}+02$ & $0 / 16$ & & NA \\
\hline N-Nitrosodiphenylamine & $0 / 72$ & ND & ND & & ND & & NA & & NA & $3.50 \mathrm{E}+06$ & $0 / 72$ & & NA \\
\hline Naphthalene & $4 / 73$ & $70 \mathrm{~J}$ & 430 & Z2-EU41DB-224 & 240 & & NA & & NA & $1.90 \mathrm{E}+05$ & $0 / 73$ & & NA \\
\hline Nitrobenzene & $0 / 72$ & ND & ND & & ND & & NA & & NA & $1.00 \mathrm{E}+05$ & $0 / 72$ & & NA \\
\hline Pentachlorophenol & $1 / 72$ & $92 \mathrm{~J}$ & $92 \mathrm{~J}$ & SB058 & 92 & & NA & & NA & $9.00 \mathrm{E}+04$ & $0 / 72$ & & $\mathrm{NA}$ \\
\hline Phenol & $0 / 72$ & ND & $\mathrm{ND}$ & & $\mathrm{ND}$ & & NA & & $\mathrm{NA}$ & $1.00 \mathrm{E}+08$ & $0 / 72$ & & $\mathrm{NA}$ \\
\hline Pyrene & $4 / 72$ & $70 \mathrm{~J}$ & 820 & Z2-EU41C-209 & 284 & & NA & & NA & $2.90 \mathrm{E}+07$ & $0 / 72$ & & NA \\
\hline Pyridine & $0 / 16$ & $\mathrm{ND}$ & $\mathrm{ND}$ & & $\mathrm{ND}$ & & NA & & NA & $6.20 \mathrm{E}+05$ & $0 / 16$ & & NA \\
\hline \multicolumn{14}{|l|}{ Volatile organics (ug/kg) } \\
\hline (1,1-Dimethylethyl)benzene & $0 / 1$ & $\mathrm{ND}$ & $\mathrm{ND}$ & & $\mathrm{ND}$ & & $\mathrm{NA}$ & & $\mathrm{NA}$ & $3.90 \mathrm{E}+05$ & $0 / 1$ & & $\mathrm{NA}$ \\
\hline (1-Methylpropyl)benzene & $0 / 1$ & ND & ND & & ND & & NA & & NA & $2.20 \mathrm{E}+05$ & $0 / 1$ & & NA \\
\hline $1,1,1,2$-Tetrachloroethane & $0 / 4$ & ND & ND & & ND & & NA & & NA & $7.30 \mathrm{E}+04$ & $0 / 4$ & & NA \\
\hline 1,1,1-Trichloroethane & 9/57 & $1 \mathrm{~J}$ & $600 \mathrm{~J}$ & SB071 & 96.1 & & NA & & NA & $1.20 \mathrm{E}+06$ & $0 / 57$ & & NA \\
\hline $1,1,2,2$-Tetrachloroethane & 2/57 & $5 \mathrm{~J}$ & 12 & SB076 & 8.5 & & NA & & NA & $9.30 \mathrm{E}+03$ & $0 / 57$ & & NA \\
\hline 1,1,2-Trichloro-1,2,2-trifluoroethane & $6 / 56$ & $1 \mathrm{~J}$ & 78 & SB073 & 17.2 & & NA & & NA & $5.60 \mathrm{E}+06$ & $0 / 56$ & & $\mathrm{NA}$ \\
\hline $\begin{array}{l}1,1,2 \text {-Trichloroethane } \\
\text { a }\end{array}$ & $6 / 57$ & $2 \mathrm{~J}$ & $730 \mathrm{~J}$ & SB071 & 145 & & NA & & NA & $1.60 \mathrm{E}+04$ & $0 / 57$ & & NA \\
\hline 1,1-Dichloroethane & 3/57 & 19 & 56 & SB076 & 40.3 & & NA & & $\mathrm{NA}$ & $1.70 \mathrm{E}+06$ & $0 / 57$ & & NA \\
\hline 1,1-Dichloroethene & $1 / 57$ & 68 & 68 & SB073 & 68 & & NA & & NA & $4.10 \mathrm{E}+05$ & $0 / 57$ & & NA \\
\hline 1,2,3-Trichloropropane & $0 / 4$ & $\mathrm{ND}$ & $\mathrm{ND}$ & & $\mathrm{ND}$ & & NA & & NA & $7.60 \mathrm{E}+02$ & $0 / 4$ & & NA \\
\hline 1,2,4-Trimethylbenzene & $2 / 4$ & 97 & 160 & PE2 & 129 & & NA & & NA & $1.70 \mathrm{E}+05$ & $0 / 4$ & & NA \\
\hline 1,2-Dibromo-3-chloropropane & $0 / 4$ & $\mathrm{ND}$ & ND & & ND & & NA & & NA & $1.10 \mathrm{E}+04$ & $0 / 4$ & & NA \\
\hline 1,2-Dibromoethane & $0 / 5$ & $\mathrm{ND}$ & $\mathrm{ND}$ & & $\mathrm{ND}$ & & $\mathrm{NA}$ & & NA & $6.30 \mathrm{E}+02$ & $0 / 5$ & & $\mathrm{NA}$ \\
\hline 1,2-Dichloro-1,1,2,2-tetrafluoroethane & $0 / 3$ & ND & ND & & $\mathrm{ND}$ & & NA & & NA & & $\mathrm{NA}$ & & NA \\
\hline 1,2-Dichloroethane & $3 / 57$ & $5 \mathrm{~J}$ & 26 & SB075 & 12.7 & & NA & & NA & $6.00 \mathrm{E}+03$ & $0 / 57$ & & NA \\
\hline 1,2-Dichloroethene & $5 / 52$ & $3 \mathrm{~J}$ & 29 & SB045 & 14.2 & & NA & & $\mathrm{NA}$ & $1.50 \mathrm{E}+05$ & $0 / 52$ & & $\mathrm{NA}$ \\
\hline 1,2-Dichloropropane & $0 / 57$ & ND & ND & & ND & & NA & & NA & $7.40 \mathrm{E}+03$ & $0 / 57$ & & NA \\
\hline 1,2-Dimethylbenzene & $1 / 5$ & 21 & 21 & PE2 & 21 & & NA & & NA & $4.20 \mathrm{E}+05$ & $0 / 5$ & & NA \\
\hline 1,3,5-Trimethylbenzene & $0 / 1$ & $\mathrm{ND}$ & $\mathrm{ND}$ & & $\mathrm{ND}$ & & NA & & NA & $7.00 \mathrm{E}+04$ & $0 / 1$ & & NA \\
\hline 1,3-Dichloropropane & $0 / 1$ & $\mathrm{ND}$ & $\mathrm{ND}$ & & $\mathrm{ND}$ & & NA & & NA & $3.60 \mathrm{E}+05$ & $0 / 1$ & & NA \\
\hline 1-Butanol & $0 / 3$ & ND & ND & & ND & & NA & & NA & $6.10 \mathrm{E}+07$ & $0 / 3$ & & NA \\
\hline 1-Chloro-4-methylbenzene & $0 / 1$ & ND & ND & & ND & & NA & & $\mathrm{NA}$ & & NA & & NA \\
\hline 1-Methyl-4-(1-methylethyl) benzene & $0 / 1$ & $\mathrm{ND}$ & $\mathrm{ND}$ & & $\mathrm{ND}$ & & $\mathrm{NA}$ & & NA & & $\mathrm{NA}$ & & $\mathrm{NA}$ \\
\hline 1-chlorohexane & $0 / 1$ & $\mathrm{ND}$ & ND & & ND & & NA & & NA & & NA & & NA \\
\hline 2,2-Dichloropropane & $0 / 1$ & $\mathrm{ND}$ & ND & & $\mathrm{ND}$ & & $\mathrm{NA}$ & & $\mathrm{NA}$ & & NA & & $\mathrm{NA}$ \\
\hline 2-Butanone & $9 / 57$ & 12 & 16,000 & SB071 & 2490 & & NA & & NA & $1.00 \mathrm{E}+08$ & $0 / 57$ & & NA \\
\hline 2-Hexanone & 2/57 & $4 \mathrm{~J}$ & 17 & SB038 & 10.5 & & NA & & NA & & $\mathrm{NA}$ & & NA \\
\hline 2-Methoxy-2-methylpropane & $0 / 1$ & $\mathrm{ND}$ & $\mathrm{ND}$ & & ND & & NA & & NA & $3.60 \mathrm{E}+05$ & $0 / 1$ & & NA \\
\hline 2 -Nitropropane & $0 / 3$ & $\mathrm{ND}$ & ND & & ND & & NA & & NA & . & $\mathrm{NA}$ & & $\mathrm{NA}$ \\
\hline 4-Methyl-2-pentanone & $5 / 57$ & $11 \mathrm{~J}$ & $510 \mathrm{~J}$ & SB071 & 199 & & NA & & $\mathrm{NA}$ & $4.70 \mathrm{E}+07$ & $0 / 57$ & & $\mathrm{NA}$ \\
\hline Acetone & $15 / 57$ & $13 \mathrm{~J}$ & 26,000 & SB071 & 4452 & & NA & & NA & $5.40 \mathrm{E}+07$ & $0 / 57$ & & NA \\
\hline Acrylonitrile & $0 / 3$ & $\mathrm{ND}$ & $\mathrm{ND}$ & & $\mathrm{ND}$ & & NA & & $\mathrm{NA}$ & $4.90 \mathrm{E}+03$ & $0 / 3$ & & $\mathrm{NA}$ \\
\hline Benzene & $2 / 57$ & $4 \mathrm{~J}$ & 6 & SB076 & 5 & & NA & & NA & $1.40 \mathrm{E}+04$ & $0 / 57$ & & NA \\
\hline Bromobenzene & $0 / 1$ & ND & ND & & $\mathrm{ND}$ & & NA & & NA & $9.20 \mathrm{E}+04$ & $0 / 1$ & & NA \\
\hline
\end{tabular}




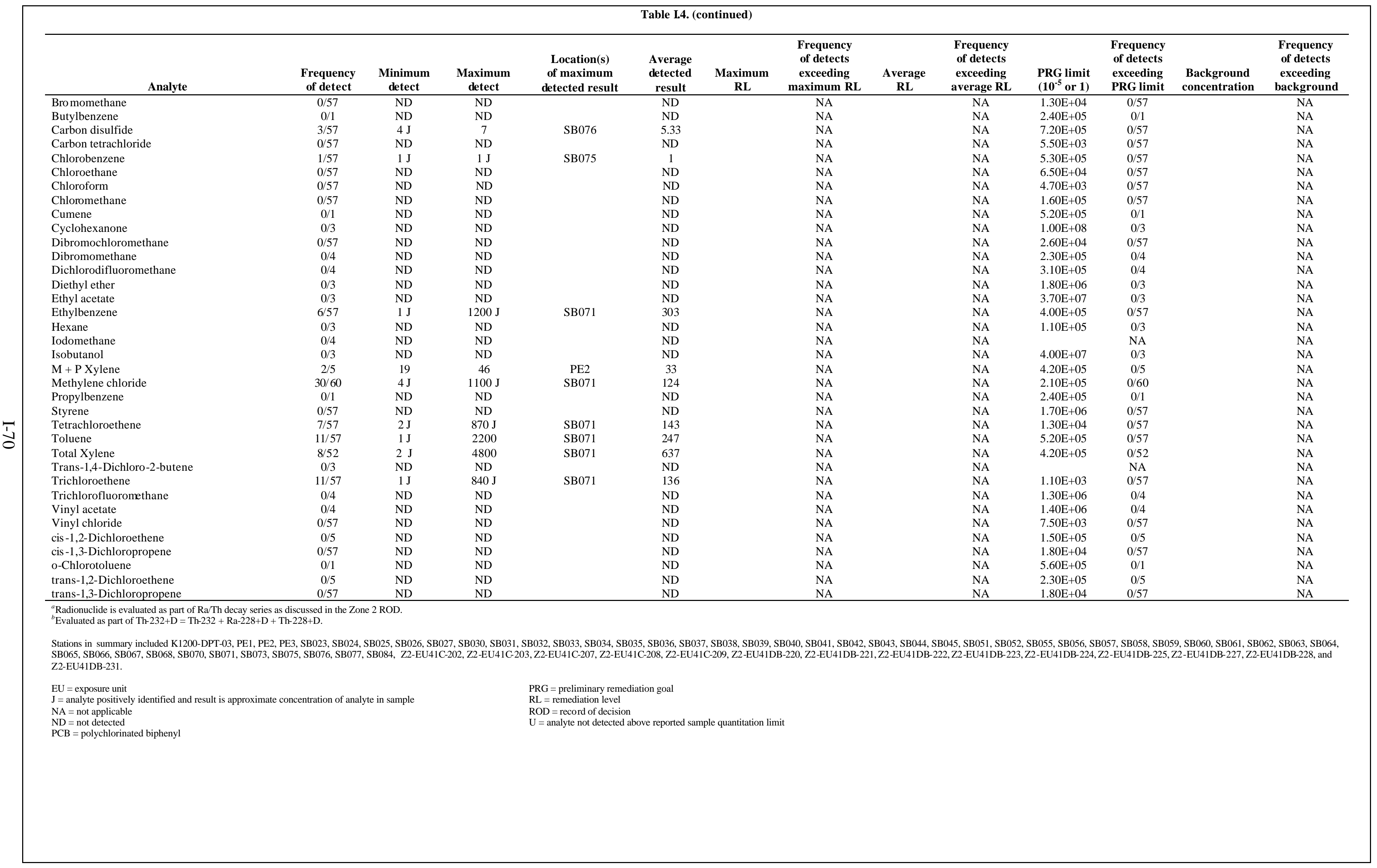




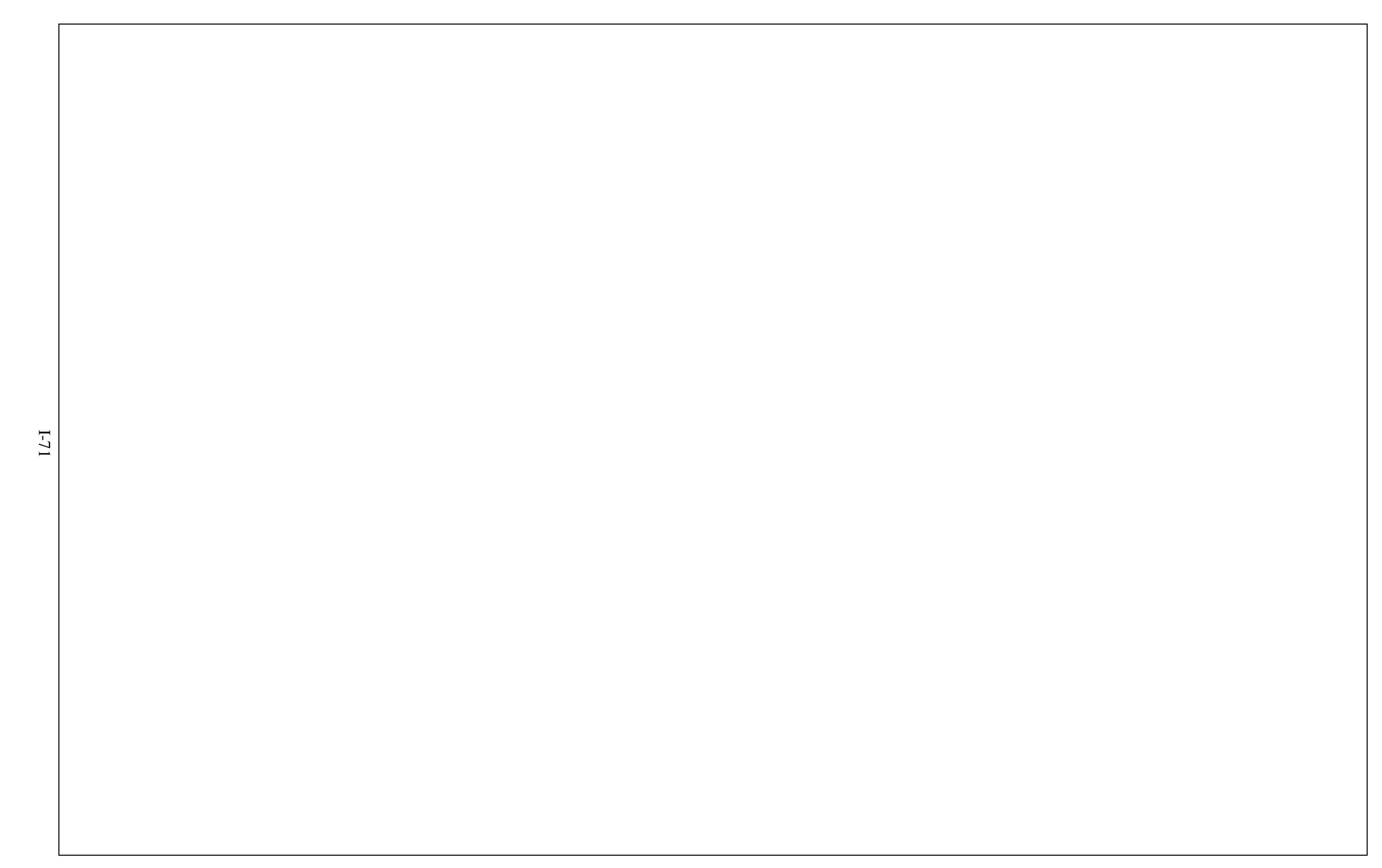


Appendix J

South Park Exposure Unit Group Z2-43

Technical Memorandum 


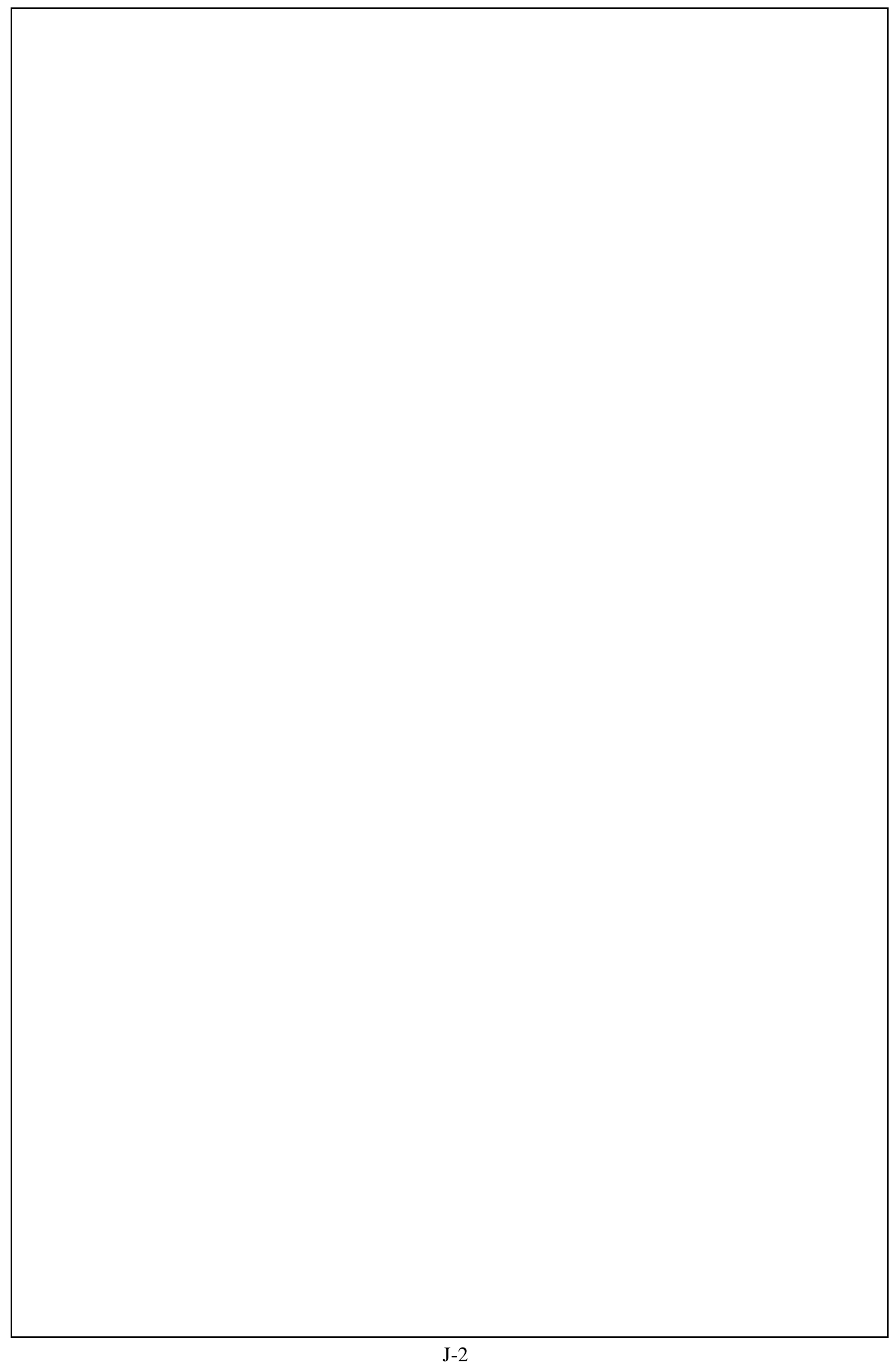




\section{FIGURES}

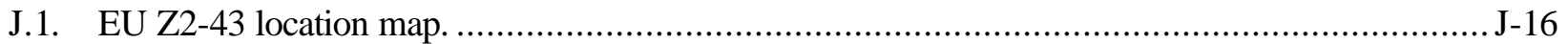

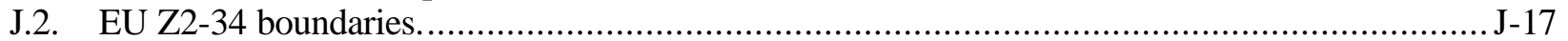

J.3. EU Z2-43 Class 3 and Cla ss 4 SU walkover assessment locations...................................... J-18

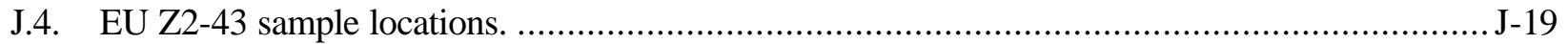

\section{TABLES}

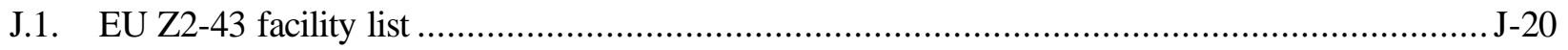

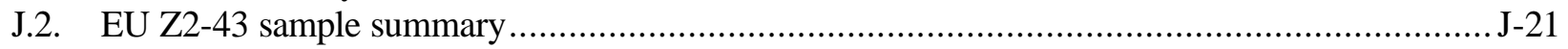

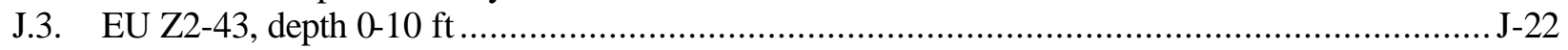




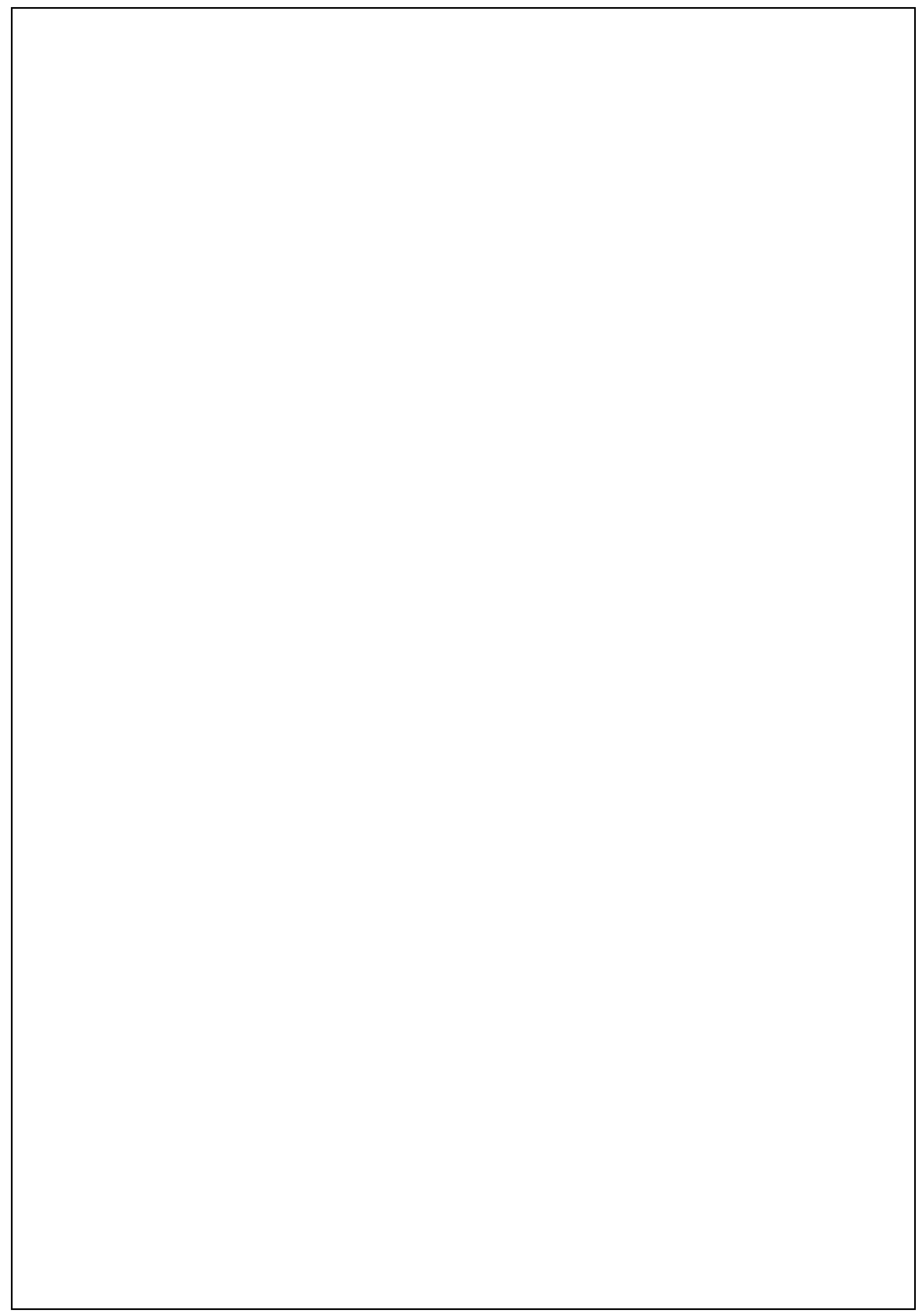

J-4 


\section{DYNAMIC VERIFICATION STRATEGY (DVS) TECHNICAL MEMORANDUM (TM)}

EXPOSURE UNIT (EU) GROUP: Zone 2 South Park Group EU Z2 -43

\section{INTRODUCTION}

The purpose of this TM is to document the recommendation for an action/no further action (NFA) decision for EU Z2-43 in the South Park EU Group. The recommendation for this EU is based on existing historical data and DVS characterization activities. These data are used to determine the nature and extent of contamination in the EU and to evaluate the need for an action. When it is determined an action is necessary, the data are also used to calculate soil volumes for the proposed remedial alternative as identified in the Record of Decision for Soil, Buried Waste, and Subsurface Structure Actions in Zone 2, East Tennessee Technology Park, Oak Ridge, Tennessee (DOE/OR/01-2161\&D2) (Zone 2 ROD).

\begin{tabular}{|l|l|}
\hline 1.0 & BACKGROUND AND EU SUMMARY \\
\hline 1.1 & LOCATIONAT EAST TENNESSEE TECHNOLOGY PARK (ETTP) \\
\hline
\end{tabular}

EU Z2-43 is located along the southern boundary of Zone 2 in the South Park EU Group (Fig. J.1). It is bounded on the north by EU Z2-42, on the east and south by U.S. Department of Energy (DOE) property, and on the west by EU Z2-33 and EU Z2-34.

1.2

EU Z2-43 ACREAGE

EU Z2-43 has an area of approximately 8.7 acres (Fig. J.2).

\begin{tabular}{l|l}
1.3 & SUMMARY DESCRIPTION \\
\hline
\end{tabular}

The majority of land area in EU Z2-43 has been impacted by site operations. Impacts to the EU include construction of buildings, roads, parking lots, and sidewalks. The bulk of EU Z2-43 is covered with parking lots.

The data quality objective (DQO) scoping package for the South Park EU Group lists 10 facilities in EU Z2-43. Table J. 1 presents an accounting of facilities in the EU.

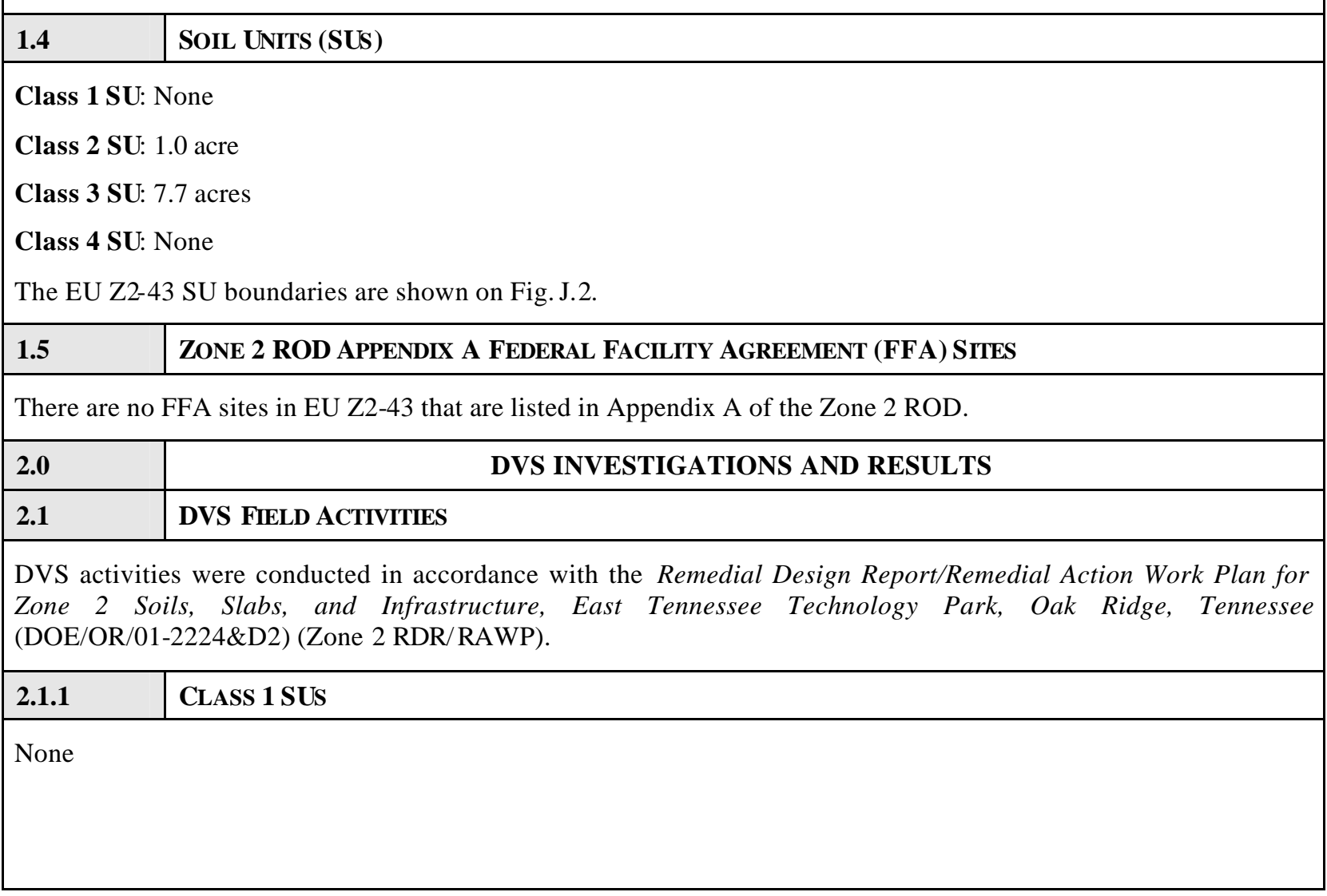


None

2.1.1.2

CLASS 1 SU GEOPHYSICAL SURVEY

None

2.1.1.3

CLASS 1 SU SOIL SAMPLING

None

\begin{tabular}{|l|l|}
\hline 2.1.2 & Class 2 SUS \\
\hline
\end{tabular}

Based on historical aerial photographs that show possible storage and lay down areas, approximately 1 acre at the northeast end of EU Z2-43 has been classified as a Class 2 SU (Fig. J.2).

\section{\begin{tabular}{l|l} 
2.1.2.1 & CLASS 2 SU RADIOLOGICAL WALKOVER SURVEY
\end{tabular}}

No walkover surveys were conducted because the area is paved.

\section{\begin{tabular}{|l|l} 
2.1.2.2 & CLASS 2 SU GEOPHYSICAL SURVEY \\
\hline
\end{tabular}}

None

\section{\begin{tabular}{|l|l} 
2.1.2.3 & CLASS 2 SUSOIL SAMPLING \\
\hline
\end{tabular}}

A systematic sampling grid with two sample locations was set up for the EU Z2-43 Class 2 SU during DQO scoping.

\section{\begin{tabular}{|l|l} 
2.1.3 & Class 3 AND Class 4 SU WALKOVER ASSESSMENT \\
\hline
\end{tabular}}

The protocol for addressing Class 3 and Class 4 SUs in EU Z2-23 is the Class 3 and Class 4 Soil Unit Walkover Inspection Protocol (found in Attachment $\mathrm{C}$ of Appendix A in the Zone 2 RDR/RAWP). The purpose of the Class 3 SU walkover assessments is to systematically inspect Class 3 SUs by visual observation along transects to established grid assessment locations and map-observed features, collect radiological screening data at grid and discretionary locations, and visually inspect and perform radiological screening surveys on the plant facilities. Details of the walkover assessment results for EU Z2-23 are presented in the Walkover Inspections and Radiological Surveys for FY 2007 Exposure Units in Zones 1 and 2, East Tennessee Technology Park, Oak Ridge, Tennessee (BJC/OR-2691). The report results are summarized below in Sects. 2.1.3.1 and 2.1.3.2. The assessment point (AP), mid-point (MP), and discretionary point (DP) locations are shown in Fig. J.3.

Seven APs were identified in EU Z2-43 prior to the start of fieldwork and are documented in the DQO scoping package. Eight APs were evaluated in EU Z2-43.

In addition to APs, the field team made assessments at five MP locations that are selected in the field and are points located approximately halfway between APs and conducted DPs at seven locations. MP and DP locations are not specified in planning documents.

\begin{tabular}{|c|c|c|c|}
\hline EU & Number of APs & Number of MPs & Number of DPs \\
\hline Z2-43 & 8 & 5 & 0 \\
\hline AP = assessment point & EU = exposure unit \\
DP = discretionary point & MP = mid-point
\end{tabular}

\section{\begin{tabular}{l|l} 
2.1.3.1 & CLASS 3 AND CLASS 4 SU RADIOLOGICAL SURVEY SUMMARY \\
\hline
\end{tabular}}

Screening level (SL): $4046 \mathrm{cpm}$

SL exceedances: None 


\section{\begin{tabular}{|l|l} 
2.1.3.2 & CLASS 3 AND CLASS 4 SU ANTHROPOGENIC FEATURES \\
\hline
\end{tabular}}

\section{Number of identified anthropogenic features: 0}

EU Z2-43 is located in an industrialized portion of ETTP. As such, there are numerous anthropogenic features that consist of facilities and associated constructed features such as roads, sidewalks, and paved areas. Plant facilities and their associated constructed features are assessed as part of the Class 3 and Class 4 SU walkover assessment protocol (Sect. 2.1.3.3). Other than plant facilities and associated constructed features, no anthropogenic features were identified in EU Z2-43 during the Class 3 SU walkover assessment.

\section{\begin{tabular}{|l|l} 
2.1.3.3 & CLASS 3 SU FACILITIES ASSESSMENTS \\
\hline
\end{tabular}}

Ten facilities are listed in the DQO scoping package as being located in EU Z2-43 (Table J.1), and seven facilities were assessed during the Class 3 SU walkover assessment (Table J.1). The facility assessments are reported in the Zone 2 EU Survey Summary Report. In summary, no facility was identified as a possible source for either chemical or radiological contamination.

\section{\begin{tabular}{|l|l|} 
2.1.3.4 & CLASS 3 AND CLASS 4 SU BIASED SAMPLING \\
\hline
\end{tabular}}

Three sediment accumulation areas identified in EU Z2-43 during the Class 3 SU walkover assessment include an area in the far southeast portion of the EU, an area west of Portal 3, and an area south of Bldg. K-1220 and east of the former location of MDM Corporation (MDM) trailers. This last sediment accumulation area received runoff from an asphalt wastewater storage area. A four-point composite surface soil sample was collected at each of the sediment accumulation areas.

Polychlorinated biphenyl (PCB) average remediation levels (RLs) were exceeded at the sample location in the sediment accumulation area south of Bldg. K-1220. To delineate the extent of the average RL exceedances, four additional biased sampling locations were identified in the sediment accumulation area-two locations to the northwest of the original location and two locations to the southeast of the original location.

Details of sampling and analysis in EU Z2-43 are presented in Table J.2.

\section{\begin{tabular}{l|l}
2.2 & DVS AND HISTORICAL SAMPLE RESULTS \\
\hline
\end{tabular}}

This section presents a summary of analytical results for the DVS samples collected in EU Z2-43; there were no historical sample locations. The summary begins with a tabulation of SU and infrastructure sample locations (Sects. 2.2.1 through 2.2.4) and concludes with focused investigation and EU data summaries (Sect. 2.2.5). The EU DVS data are summarized in Table J.3. A compact disc containing electronic files for the historical and DVS analytical data used to generate the data tables is provided with this Phased Construction Completion Report (PCCR).

\begin{tabular}{|l|l|}
\hline 2.2.1 & CLASS 1 SUS \\
\hline
\end{tabular}

None

\begin{tabular}{|l|l}
\hline 2.2.2 & CLASS 2 SUS
\end{tabular}

There are two sample locations in the EU Z2-43 Class 2 SU. All sampling performed in the SU was DVS sampling. Class 2 SU sampling locations are shown on Fig. J.4 and are summarized below.

\begin{tabular}{cll}
\hline EU & \multicolumn{1}{c}{ DVS sample locations } & Historical sample locations \\
\hline Z2-43 & Systematic grid locations: & None \\
& Z2-EU43-201, Z2-EU43-202 & \\
\hline
\end{tabular}

DVS $=$ Dynamic Verification Strategy

$\mathrm{EU}=$ exposure unit

Sampling and analytical details for each sample location are presented in Table J.2. The analytical data are summarized in Table J.3 and evaluated in Sect.2.2.5. The number of analyses conducted in the Class 2 SU is presented below by analyte group. 


\begin{tabular}{ccc}
\hline Metals & PCBs & SVOCs \\
\hline 2 & 2 & 2 \\
\hline
\end{tabular}

$\mathrm{PCB}=$ polychlorinated biphenyl

$\mathrm{SVOC}=$ semivolatile organic compound

\section{\begin{tabular}{|l|l|}
\hline 2.2.3 & CLASS 3 AND CLASS 4 SUS \\
\hline
\end{tabular}}

There are seven sample locations in the EU Z2-43 Class 3 SU. All sampling performed in the SU was DVS biased sampling. Class 3 SU sample locations are shown on Fig. J.4 and are summarized below.

\begin{tabular}{cll}
\hline EU & \multicolumn{1}{c}{ DVS sample locations } & Historical sample locations \\
\hline Z2-43 & Biased locations: & None \\
& Z2-EU43B-301, Z2-EU43B-302, Z2-EU43B-303, & \\
& Z2-EU43B-304, Z2-EU43B-305, Z2-EU43B-306, & \\
& Z2-EU43B-307 \\
\hline
\end{tabular}

DVS = Dynamic Verification Strategy

$\mathrm{EU}=$ exposure unit

Sampling and analytical details for each sample location are presented in Table J.2. The analytical data are summarized in Table J.3 and evaluated in Sect.2.2.5. The number of analyses conducted in the Class 3 SU is presented below by analyte group.

\begin{tabular}{ccc}
\hline Metals & PCBs & SVOCs \\
\hline 3 & 7 & 3 \\
\hline \multicolumn{2}{l}{ PCB = polychlorinated biphenyl } \\
SVOC = semivolatile organic compound
\end{tabular}

\section{\begin{tabular}{l|l} 
2.2.4 & INFRASTRUCTURE \\
\hline
\end{tabular}}

No infrastructure sampling was performed in EU Z2-43.

\section{\begin{tabular}{l|l} 
2.2.5 & EU EVALUATION \\
\hline
\end{tabular}}

In this section, characterization data and other information are evaluated for EU Z2-43. The analytical data in the following summaries are presented by analyte group. Results for a particular analyte group are summarized only if that group was analyzed in the samples from the unit being summarized. Within each summary, the data are evaluated by comparing to certain criteria, which include the Zone 2 soils maximum RL (Max RL), Zone 2 soils average RL (Avg RL), $1 \times 10^{-5}$ industrial preliminary remediation goal (Ind PRG), ETTP soils background composition (Bkg), Zone 2 groundwater screening levels (GW SL), and $1 \times 10^{-6}$ residential PRG (Res PRG). If a particular criterion does not apply to any member of an analyte group, it is not tabulated for that analyte group; if a particular criterion does not apply to all analytes within an analyte group, those analytes to which it does not apply are notated with NA (not applicable). Individual netals and radionuclides, which are naturally occurring, are reported in the summaries only if one or more criterion is exceeded. Organic chemicals, which are not naturally occurring, are reported if detected, even if no criteria are exceeded. The Max RL, Avg RL, Ind PRG, Bkg, GW SL, and Res PRG criteria values, as they pertain to the analytes listed in Appendix A of the RDR/RAWP (i.e., Quality Assurance Project Plan), are presented in Table 5 of this PCCR.

Because the carcinogenic risk associated with concentrations of radium and thorium isotopes in the natural background at ETTP exceeds the cumulative risk goal of $1 \times 10^{-4}$, RL values for these radionuclides are based on alternative concentration levels rather than risk. The alternative concentration levels of $5 \mathrm{pCi} / \mathrm{g}$ above background (Avg RL) and $15 \mathrm{pCi} / \mathrm{g}$ above background (Max RL) were set as low a reasonably achievable under the site-specific conditions. Because site-specific background concentrations of these radionuclides exceed the target risk range, residual concentrations of these radionuclides and their decay series are not considered in estimates of residual ris $\mathrm{k}$ following any remedial action.

The Zone 2 ROD states that Avg RL and Max RL exceedances by Ra-226, Th-230, and Th-232 will be evaluated by summing above-background concentrations of the greater of Ra-226 or Th-230 with the above-background concentrations of Th-232 and comparing the results to $5 \mathrm{pCi} / \mathrm{g}$ (average RL) and $15 \mathrm{pCi} / \mathrm{g}$ (maximum RL). The required calculations have been performed. Avg and Max RL exceedances for these radionuclides, if any, are reported in the TM data summaries below and in Table J.2 as "Ra/Th decay series", and individual RL exceedances 
by Ra-226, Th-230, and Th-232 are reported as NA. The Ra/Th decay series data are summarized in the sections that follow only if an Avg or Max RL has been exceeded, consistent with the description in the preceding paragraph for reporting radionuclides. Discussion of the $\mathrm{Ra} / \mathrm{Th}$ decay series calculation, including the manner in which the calculation is performed, is presented in Sect. 3.3 of this PCCR.

\section{EU Z2-43 Conceptual Site Model (CSM)}

Historic aerial photos of the site show an area where materials were staged along the northern portion of the EU. This area is currently an asphalt parking lot. The area was reworked and prepared for paving in 1973. There is a possibility that contaminants may have been released causing the area to be classified as a Class 2 SU. The CSM for this Class $2 \mathrm{SU}$ is a surface release model. Samples from DVS borings in the area had no reported indications of soil contamination. The remainder of the EU is a Class $3 \mathrm{SU}$. A sample in a sediment accumulation area located south of Bldg. K-1220 and east of a former PCB storage yard reported PCBs at concentrations above Zone 2 Avg RLs. Step-out locations associated with this sample location also reported low levels of PCBs in two samples. This is a surface impact that is consistent with the surface release CSM.

\section{EU Z2-43 Groundwater Evaluation}

There are no groundwater wells in EU 43. There are wells to the west in EUs 33 and 34. The following statements are based on data from the wells to the west. Groundwater underlying the EU is estimated at 6-10 ft below ground surface with flow predominantly toward the southwest. There is a topographic high east of the EU associated with the trace of the K-25 fault. The groundwater flow direction is from this high area toward the K-1007 Ponds located to the southwest in Zone 1. Soil sampling in the EU includes two deep borings and seven surface soil biased sample locations selected based on Class $3 \mathrm{SU}$ walkover assessments. The Class $3 \mathrm{SU}$ walkover assessment and subsequent biased sampling did not identify any significant mass of contaminated soil. Based on results of the assessments and sampling, it is concluded that there is no contaminant mass within EU Z2-43 that would pose a threat to local groundwater quality.

\section{EU Z2-43 Sampling Results}

The 8.7 acres of EU Z2-43 has been divided into approximately a 1 acre Class 2 SU and 7.7 acres Class 3 SU. The Class 2 SU was addressed with two systematic grid sample locations. The Class $3 \mathrm{SU}$ was addressed with a Class 3 SU walkover assessment during which seven facilities were assessed and three sediment accumulation areas were identified. Other than facilities and related infrastructure, which are addressed separately during the Class 3 SU walkover assessment, no anthropogenic features were identified. There are nine soil sample locations in EU Z2-43. All soil sampling in the EU was DVS soil sampling; there are no historical sample locations. DVS sampling consisted of the two Class 2 SU systematic grid sample locations and seven Class 3 SU biased sample locations. The Class $3 \mathrm{SU}$ sampling was conducted in three sediment accumulation areas. One area was sampled multiple times to define the extent of PCB contamination.

Following is a summary of the sampling results for EU Z2-43. The summary begins with a presentation of the analytical results for the focused sampling efforts in the EU and concludes with an overall summary for EU Z2-43. The focused sampling efforts included the Class 2 SU sampling, sediment accumulation area sampling, and sampling to delineate the extent of PCB contamination. The EU Z2-43 summary includes both data summary tables and a written description of the nature and extent of chemicals and radionuclides observed. A summary of all data is presented in Table J.3, and sample locations are shown on Fig. J.4. The EU-wide data are evaluated in terms of the Zone 2 ROD remedial action objective (RAO) in Sect. 3.3.

DVS Class 2 SU Systematic Sampling: The Class 2 SU was defined to encompass a possible storage and lay down area located in the northern part of the EU. Class 2 SU systematic grid sample locations Z2-EU43-201 and Z2-EU43-202 were identified during DQO scoping. Sampling and analytical details are presented in Table J.2. Analytical results summarized below show metal background exceedances. 
EU Z2-43 CLASS 2 SU METALS WITH BACKGROUND, PRG, GW SL, AND/OR RL EXCEEDANCES (mg/kg)

\begin{tabular}{|c|c|c|c|c|c|c|c|c|c|c|c|}
\hline \multirow[b]{2}{*}{ Analyte } & \multirow[b]{2}{*}{$\begin{array}{c}\text { Detect } \\
\text { frequency }\end{array}$} & \multirow[b]{2}{*}{$\begin{array}{c}\text { Minimum } \\
\text { detect }\end{array}$} & \multirow[b]{2}{*}{$\begin{array}{c}\text { Maximum } \\
\text { detect }\end{array}$} & \multirow{2}{*}{$\begin{array}{l}\text { Location(s) of } \\
\text { maximum } \\
\text { detect }\end{array}$} & \multirow{2}{*}{$\begin{array}{c}\text { Average } \\
\text { detected } \\
\text { result }\end{array}$} & \multicolumn{6}{|c|}{ Number of analyses exceeding criteria } \\
\hline & & & & & & $\begin{array}{c}\text { Max } \\
\text { RL }\end{array}$ & $\begin{array}{l}\text { Avg } \\
\text { RL }\end{array}$ & $\begin{array}{c}\text { Ind } \\
\text { PRG }\end{array}$ & Bkg & $\begin{array}{c}\text { GW } \\
\text { SL }\end{array}$ & $\begin{array}{c}\text { Res } \\
\text { PRG }\end{array}$ \\
\hline Aluminum & $2 / 2$ & $12,600 \mathrm{~J}$ & $21,000 \mathrm{~J}$ & Z2-EU43-202 & 16,800 & NA & NA & 0 & 0 & NA & 2 \\
\hline Arsenic & $2 / 2$ & $0.89 \mathrm{~J}$ & $2.6 \mathrm{~J}$ & Z2-EU43-202 & 1.745 & 0 & 0 & 0 & 0 & 0 & 2 \\
\hline Barium & $2 / 2$ & $63.4 \mathrm{~J}$ & $280 \mathrm{~J}$ & Z2-EU43-202 & 171.7 & NA & NA & 0 & 1 & 0 & 0 \\
\hline Calcium & $2 / 2$ & $7,070 \mathrm{~J}$ & $12,300 \mathrm{~J}$ & Z2-EU43-201 & 9,685 & NA & NA & NA & 2 & NA & NA \\
\hline Chromium & $2 / 2$ & 17.7 & 28.9 & Z2-EU43-202 & 23.3 & NA & NA & 0 & 0 & 0 & 1 \\
\hline Copper & $2 / 2$ & 17.5 & 28 & Z2-EU43-201 & 22.8 & NA & NA & 0 & 1 & NA & 0 \\
\hline Lead & $2 / 2$ & 22.9 & 48.3 & Z2-EU43-201 & 35.6 & NA & NA & 0 & 1 & 0 & 0 \\
\hline Manganese & $2 / 2$ & $161 \mathrm{~J}$ & $529 \mathrm{~J}$ & Z2-EU43-202 & 345 & NA & NA & 0 & 0 & NA & 1 \\
\hline Vanadium & $2 / 2$ & 22.6 & 23.3 & Z2-EU43-201 & 23 & NA & NA & 0 & 0 & NA & 2 \\
\hline
\end{tabular}

\begin{tabular}{ll}
\hline Avg = average & $\mathrm{NA}=$ not applicable \\
$\mathrm{Bkg}=$ background & $\mathrm{PRG}=$ preliminary remediation goal \\
$\mathrm{EU}=$ exposure unit & Res = residential \\
$\mathrm{GW}=$ groundwater & $\mathrm{RL}=$ remediation level \\
Ind = industrial & $\mathrm{SL}=$ screening level \\
Max = maximum & $\mathrm{SU}=$ soil unit
\end{tabular}

PCBs and semivolatile organic compounds (SVOCs) were analyzed in both samples but were not detected.

DVS Class 3 SU Biased Sampling at Sediment Accumulation Areas: Three biased sampling locations were identified in three sediment accumulation areas during the Class 3 SU walkover assessment. Location Z2-EU43B-301 is associated with the sediment accumulation area in the southeast corner of the EU, location Z2-EU43B-302 is associated with the sediment accumulation area to the south of Bldg. K-1220 and to the east of the MDM trailers, and location Z2-EU43B-303 is associated with the sediment acumulation area west of Portal3. Sampling and analytical details are presented in Table J.2. Analytical results summarized below show PCB-1254 and total PCBs Avg RL exceedances at location Z2-EU43B-302, metal Bkg exceedances, and detections of SVOCs.

EU Z2-43 SEDIMENT ACCUMULATION AREAS METALS WITH BACKGROUND, PRG, GW SL, AND/OR RL EXCEEDANCES (mg/kg)

\begin{tabular}{|c|c|c|c|c|c|c|c|c|c|c|c|}
\hline \multirow[b]{2}{*}{ Analyte } & \multirow[b]{2}{*}{$\begin{array}{c}\text { Detect } \\
\text { frequency }\end{array}$} & \multirow[b]{2}{*}{$\begin{array}{c}\text { Minimum } \\
\text { detect }\end{array}$} & \multirow[b]{2}{*}{$\begin{array}{c}\text { Maximum } \\
\text { detect }\end{array}$} & \multirow{2}{*}{$\begin{array}{l}\text { Location(s) of } \\
\text { maximum } \\
\text { detect }\end{array}$} & \multirow{2}{*}{$\begin{array}{c}\text { Average } \\
\text { detected } \\
\text { result }\end{array}$} & \multicolumn{6}{|c|}{ Number of analyses exceeding criteria } \\
\hline & & & & & & $\begin{array}{c}\text { Max } \\
\text { RL }\end{array}$ & $\begin{array}{l}\text { Avg } \\
\text { RL }\end{array}$ & $\begin{array}{l}\text { Ind } \\
\text { PRG }\end{array}$ & Bkg & $\begin{array}{l}\text { GW } \\
\text { SL }\end{array}$ & $\begin{array}{c}\text { Res } \\
\text { PRG }\end{array}$ \\
\hline Aluminum & $3 / 3$ & $7,410 \mathrm{~J}$ & $9,220 \mathrm{~J}$ & Z2-EU43B-301 & 8,387 & NA & NA & 0 & 0 & NA & 2 \\
\hline Arsenic & $3 / 3$ & $3.9 \mathrm{~J}$ & 6.6 & Z2-EU43B-303 & 5.43 & 0 & 0 & 0 & 0 & 0 & 3 \\
\hline Chromium & $3 / 3$ & 14.3 & 100 & Z2-EU43B-302 & 44.7 & NA & NA & 0 & 1 & 0 & 1 \\
\hline Lead & $3 / 3$ & 56.1 & 414 & Z2-EU43B-302 & 176 & NA & NA & 0 & 3 & 0 & 1 \\
\hline Manganese & $3 / 3$ & $389 \mathrm{~J}$ & $801 \mathrm{~J}$ & Z2-EU43B-303 & 554 & NA & NA & 0 & 0 & NA & 3 \\
\hline Uranium & $3 / 3$ & 1.5 & 2.8 & Z2-EU43B-301 & 1.93 & NA & NA & 0 & NA & NA & 1 \\
\hline Vanadium & $3 / 3$ & 14.6 & 21.8 & Z2-EU43B-301 & 18.4 & NA & NA & 0 & 0 & NA & 3 \\
\hline
\end{tabular}

Avg = average NA $=$ not applicable

$\mathrm{Bkg}=$ background $\quad \mathrm{PRG}=$ preliminary remediation goal

$\mathrm{EU}=$ exposure unit $\quad$ Res $=$ residential

$\mathrm{GW}=$ groundwater $\quad \mathrm{RL}=$ remediation level

Ind $=$ industrial $\quad \mathrm{SL}=$ screening level

Max $=$ maximum 


\begin{tabular}{|c|c|c|c|c|c|c|c|c|c|}
\hline \multirow[b]{2}{*}{ Analyte } & \multirow[b]{2}{*}{$\begin{array}{c}\text { Detect } \\
\text { frequency }\end{array}$} & \multirow[b]{2}{*}{$\begin{array}{c}\text { Minimum } \\
\text { detect }\end{array}$} & \multirow[b]{2}{*}{$\begin{array}{c}\text { Maximum } \\
\text { detect }\end{array}$} & \multirow{2}{*}{$\begin{array}{l}\text { Location(s) of } \\
\text { maximum } \\
\text { detect }\end{array}$} & \multirow{2}{*}{$\begin{array}{c}\text { Average } \\
\text { detected } \\
\text { result }\end{array}$} & \multicolumn{4}{|c|}{$\begin{array}{l}\text { Number of analyses } \\
\text { exceeding criteria }\end{array}$} \\
\hline & & & & & & $\begin{array}{l}\text { Max } \\
\text { RL }\end{array}$ & $\begin{array}{l}\text { Avg } \\
\text { RL }\end{array}$ & $\begin{array}{l}\text { Ind } \\
\text { PRG }\end{array}$ & $\begin{array}{l}\text { Res } \\
\text { PRG } \\
\end{array}$ \\
\hline PCB-1254 & $1 / 3$ & 18,000 & 18,000 & Z2-EU43B-302 & 18,000 & 0 & 1 & 1 & 1 \\
\hline PCB & $1 / 3$ & 18,000 & 18,000 & Z2-EU43B-302 & 18,000 & 0 & 1 & 1 & 1 \\
\hline
\end{tabular}

\begin{tabular}{ll}
\hline Avg $=$ average & PCB $=$ polychlorinated biphenyl \\
EU $=$ exposure unit & PRG $=$ preliminary remediation goal \\
Ind $=$ industrial & Res $=$ residential \\
Max = maximum & RL $=$ remediation level
\end{tabular}

EU Z2-43 SEDIMENT ACCUMULATION AREASSVOC DETECTS (ug/kg)

\begin{tabular}{|c|c|c|c|c|c|c|c|c|}
\hline \multirow[b]{2}{*}{ Analyte } & \multirow[b]{2}{*}{$\begin{array}{c}\text { Detect } \\
\text { frequency }\end{array}$} & \multirow[b]{2}{*}{$\begin{array}{l}\text { Minimum } \\
\text { detect }\end{array}$} & \multirow[b]{2}{*}{$\begin{array}{c}\text { Maximum } \\
\text { detect }\end{array}$} & \multirow[b]{2}{*}{$\begin{array}{l}\text { Location(s) of } \\
\text { maximum detect }\end{array}$} & \multirow{2}{*}{$\begin{array}{c}\text { Average } \\
\text { detected } \\
\text { result }\end{array}$} & \multicolumn{3}{|c|}{$\begin{array}{l}\text { Number of analyses } \\
\text { exceeding criteria }\end{array}$} \\
\hline & & & & & & $\begin{array}{l}\text { Ind } \\
\text { PRG }\end{array}$ & $\begin{array}{l}\text { GW } \\
\text { SL }\end{array}$ & $\begin{array}{l}\text { Res } \\
\text { PRG }\end{array}$ \\
\hline Anthracene & $1 / 3$ & $66 \mathrm{~J}$ & $66 \mathrm{~J}$ & Z2-EU43B-301 & 66 & 0 & NA & 0 \\
\hline Benz(a)anthracene & $2 / 3$ & $130 \mathrm{~J}$ & $390 \mathrm{~J}$ & Z2-EU43B-301 & 260 & 0 & NA & 0 \\
\hline Benzo(a)pyrene & $2 / 3$ & $170 \mathrm{~J}$ & 530 & Z2-EU43B-301 & 350 & 0 & NA & 2 \\
\hline Benzo(b)fluoranthene & $3 / 3$ & $37 \mathrm{~J}$ & 510 & Z2-EU43B-301 & 239 & 0 & NA & 0 \\
\hline Benzo(ghi)perylene & $3 / 3$ & $47 \mathrm{~J}$ & $430 \mathrm{~J}$ & Z2-EU43B-301 & 212 & 0 & NA & 0 \\
\hline Benzo(k)fluoranthene & $2 / 3$ & $170 \mathrm{~J}$ & 520 & Z2-EU43B-301 & 345 & 0 & NA & 0 \\
\hline Bis(2-ethylhexyl)phthalate & $1 / 3$ & $160 \mathrm{~J}$ & $160 \mathrm{~J}$ & Z2-EU43B-302 & 160 & 0 & 0 & 0 \\
\hline Butyl benzyl phthalate & $1 / 3$ & $38 \mathrm{~J}$ & $38 \mathrm{~J}$ & Z2-EU43B-302 & 38 & 0 & NA & 0 \\
\hline Chrysene & $2 / 3$ & $140 \mathrm{~J}$ & $420 \mathrm{~J}$ & Z2-EU43B-301 & 280 & 0 & NA & 0 \\
\hline Dibenz(a,h)anthracene & $2 / 3$ & $39 \mathrm{~J}$ & $78 \mathrm{~J}$ & Z2-EU43B-301 & 58.5 & 0 & NA & 1 \\
\hline Fluoranthene & $3 / 3$ & $45 \mathrm{~J}$ & 740 & Z2-EU43B-301 & 338 & 0 & NA & 0 \\
\hline Indeno(1,2,3-cd)pyrene & $2 / 3$ & $160 \mathrm{~J}$ & $430 \mathrm{~J}$ & Z2-EU43B-301 & 295 & 0 & NA & 0 \\
\hline Phenanthrene & $2 / 3$ & $100 \mathrm{~J}$ & $230 \mathrm{~J}$ & Z2-EU43B-301 & 165 & 0 & NA & 0 \\
\hline Pyrene & $2 / 3$ & $170 \mathrm{~J}$ & 540 & Z2-EU43B-301 & 355 & 0 & NA & 0 \\
\hline $\begin{array}{l}\text { EU = exposure unit } \\
\text { GW = groundwater } \\
\text { Ind = industrial } \\
\text { NA = not applicable }\end{array}$ & & $\begin{array}{l}\text { PRG }=1 \\
\text { Res }=r \\
\text { SL }=\mathrm{sc} \\
\text { SVOC }\end{array}$ & $\begin{array}{l}\text { preliminary } 1 \\
\text { esidential } \\
\text { creening leve } \\
=\text { semivolatil }\end{array}$ & e organic compound & & & & \\
\hline
\end{tabular}

DVS Class 3 SU Biased Sampling for PCB Extent: Four biased sample locations were identified to delineate the extent of the PCB average RL exceedances observed at location Z2-EU43B-302. Locations Z2-EU43B-305 and Z2-EU43B-306 are located northwest of the RL exceedances and locations Z2-EU43B-304 and Z2-EU43B-307 are located to the southeast. Sampling and analytical details are presented in Table J.2. Analytical results summarized below show there are no RL exceedances in the confirmation samples although PCB-1254 and total PCBs were detected in samples Z2-EU43B-304 and Z2-EU43B-306.

EU Z2-43 PCB EXTENT SAMPLES PCB DETECTS (ug/kg)

\begin{tabular}{|c|c|c|c|c|c|c|c|c|c|}
\hline \multirow[b]{2}{*}{ Analyte } & \multirow[b]{2}{*}{$\begin{array}{c}\text { Detect } \\
\text { frequency }\end{array}$} & \multirow[b]{2}{*}{$\begin{array}{c}\text { Minimum } \\
\text { detect }\end{array}$} & \multirow[b]{2}{*}{$\begin{array}{c}\text { Maximum } \\
\text { detect }\end{array}$} & \multirow{2}{*}{$\begin{array}{c}\text { Location(s) of } \\
\text { maximum } \\
\text { detect }\end{array}$} & \multirow{2}{*}{$\begin{array}{c}\text { Average } \\
\text { detected } \\
\text { result }\end{array}$} & \multicolumn{4}{|c|}{$\begin{array}{c}\text { Number of analyses } \\
\text { exceeding criteria }\end{array}$} \\
\hline & & & & & & $\begin{array}{c}\text { Max } \\
\text { RL }\end{array}$ & $\begin{array}{l}\text { Avg } \\
\text { RL }\end{array}$ & $\begin{array}{l}\text { Ind } \\
\text { PRG }\end{array}$ & $\begin{array}{c}\text { Res } \\
\text { PRG }\end{array}$ \\
\hline PCB-1254 & $2 / 4$ & 110 & 560 & Z2-EU43B-304 & 335 & 0 & 0 & 0 & 1 \\
\hline PCB & $2 / 4$ & $110 \mathrm{~J}$ & 560 & Z2-EU43B-304 & 335 & 0 & 0 & 0 & 1 \\
\hline $\begin{array}{l}\text { Avg = average } \\
\text { EU = exposure unit } \\
\text { Ind = industrial } \\
\text { Max = maximum }\end{array}$ & $\begin{array}{l}\mathrm{PCB}= \\
\mathrm{PRG}= \\
\mathrm{Res}= \\
\mathrm{RL}=\end{array}$ & $\begin{array}{l}=\text { polychlorin } \\
=\text { preliminary } \\
\text { residential } \\
\text { remediation l }\end{array}$ & $\begin{array}{l}\text { lated bipheny } \\
\text { remediation } \\
\text { level }\end{array}$ & goal & & & & & \\
\hline
\end{tabular}

EU Z2-43 Summary: This section presents a summary of the nature and extent of contamination in EU Z2-43 by combining all analytical data for the EU that are presented in the focused investigation summaries above. There are 
nine sample locations in EU Z2-43. Details of EU sampling and analysis are presented in Table J.2, and sample locations are shown on Fig. J.4. Analytical results for all samples summarized below show PCB-1254 and total PCBs Avg RL exceedances, PCB Ind PRG exceedances, other PCB detections, metals background exceedances, and SVOC detections. The PCB Avg RL and Ind PRG exceedances all occur in the sediment accumulation area sample at location Z2-EU43B-302. This sediment accumulation area receives runoff from an asphalt storage pad. The other PCB detections occur in samples from locations Z2-EU43B-304 and Z2-EU43B-306, whose purpose was to delineate PCB RL exceedances around location Z2-EU43B-302. Based on these data, it is concluded that PCBs are present in the sediment accumulation area located south of Bldg. K-1220 but the PCB Avg RL and Ind PRG exceedances are restricted to a small area represented by location Z2-EU43B-302.

EU Z2-43 METALS WITH BACKGROUND, PRG, GW SL, AND/OR RL EXCEEDANCES (mg/kg)

\begin{tabular}{|c|c|c|c|c|c|c|c|c|c|c|c|}
\hline \multirow[b]{2}{*}{ Analyte } & \multirow[b]{2}{*}{$\begin{array}{c}\text { Detect } \\
\text { frequency }\end{array}$} & \multirow[b]{2}{*}{$\begin{array}{c}\text { Minimum } \\
\text { detect }\end{array}$} & \multirow[b]{2}{*}{$\underset{\text { detect }}{\text { Maximum }}$} & \multirow{2}{*}{$\begin{array}{c}\text { Location(s) of } \\
\text { maximum } \\
\text { detect }\end{array}$} & \multirow{2}{*}{$\begin{array}{c}\text { Average } \\
\text { detected } \\
\text { result }\end{array}$} & \multicolumn{6}{|c|}{ Number of analyses exceeding criteria } \\
\hline & & & & & & $\begin{array}{c}\text { Max } \\
\text { RL }\end{array}$ & $\begin{array}{l}\text { Avg } \\
\text { RL }\end{array}$ & $\begin{array}{l}\text { Ind } \\
\text { PRG }\end{array}$ & Bkg & $\begin{array}{l}\text { GW } \\
\text { SL }\end{array}$ & $\begin{array}{l}\text { Res } \\
\text { PRG }\end{array}$ \\
\hline Aluminum & $5 / 5$ & $7,410 \mathrm{~J}$ & $21,000 \mathrm{~J}$ & Z2-EU43-202 & 11,752 & NA & NA & 0 & 0 & NA & 4 \\
\hline Arsenic & $5 / 5$ & $0.89 \mathrm{~J}$ & 6.6 & Z2-EU43B-303 & 3.96 & 0 & 0 & 0 & 0 & 0 & 5 \\
\hline Barium & $5 / 5$ & $63.4 \mathrm{~J}$ & $280 \mathrm{~J}$ & Z2-EU43-202 & 129 & NA & NA & 0 & 1 & 0 & 0 \\
\hline Cadmium & $5 / 5$ & 0.067 & 0.74 & Z2-EU43B-302 & 0.316 & NA & NA & 0 & 3 & NA & 0 \\
\hline Calcium & $5 / 5$ & $7,070 \mathrm{~J}$ & $65,200 \mathrm{~J}$ & Z2-EU43B-302 & 22,714 & NA & NA & NA & 5 & NA & NA \\
\hline Chromium & $5 / 5$ & 14.3 & 100 & Z2-EU43B-302 & 36.1 & NA & NA & 0 & 1 & 0 & 2 \\
\hline Copper & $5 / 5$ & 15.1 & 28.2 & Z2-EU43B-302 & 21.3 & NA & NA & 0 & 2 & NA & 0 \\
\hline Lead & $5 / 5$ & 22.9 & 414 & Z2-EU43B-302 & 120 & NA & NA & 0 & 4 & 0 & 1 \\
\hline Manganese & $5 / 5$ & $161 \mathrm{~J}$ & $801 \mathrm{~J}$ & Z2-EU43B-303 & 471 & NA & NA & 0 & 0 & NA & 4 \\
\hline Manganese & $5 / 5$ & 161 & 801 & Z2-EU43B-303 & 471 & NA & NA & 0 & 0 & NA & 4 \\
\hline Mercury & $3 / 5$ & 0.11 & 0.24 & Z2-EU43B-303 & 0.167 & 0 & 0 & 0 & 1 & NA & 0 \\
\hline Nickel & $5 / 5$ & $17.8 \mathrm{~J}$ & $28.3 \mathrm{~J}$ & Z2-EU43B-302 & 23.8 & NA & NA & 0 & 1 & NA & 0 \\
\hline Uranium & $5 / 5$ & 0.33 & 2.8 & Z2-EU43B-301 & 1.31 & NA & NA & 0 & NA & NA & 1 \\
\hline Vanadium & $5 / 5$ & 14.6 & 23.3 & Z2-EU43-201 & 20.2 & NA & NA & 0 & 0 & NA & 5 \\
\hline Zinc & $5 / 5$ & $53.8 \mathrm{~J}$ & $486 \mathrm{~J}$ & Z2-EU43B-301 & 152 & NA & NA & 0 & 1 & NA & 0 \\
\hline
\end{tabular}

Avg $=$ average $\quad$ NA $=$ not applicable

$\mathrm{Bkg}=$ background $\quad \mathrm{PRG}=$ preliminary remediation goal

$\mathrm{EU}=$ exposure unit $\quad$ Res $=$ residential

$\mathrm{GW}=$ groundwater $\quad \mathrm{RL}=$ remediation level

Ind $=$ industrial $\quad \mathrm{SL}=$ screening level

Max $=$ maximum

EU Z2-43 PCB DETECTS (ug/kg)

\begin{tabular}{|c|c|c|c|c|c|c|c|c|c|}
\hline \multirow[b]{2}{*}{ Analyte } & \multirow[b]{2}{*}{$\begin{array}{c}\text { Detect } \\
\text { frequency }\end{array}$} & \multirow[b]{2}{*}{$\begin{array}{c}\text { Minimum } \\
\text { detect }\end{array}$} & \multirow[b]{2}{*}{$\underset{\text { detect }}{\text { Maximum }}$} & \multirow{2}{*}{$\begin{array}{c}\text { Location(s) of } \\
\text { maximum } \\
\text { detect }\end{array}$} & \multirow{2}{*}{$\begin{array}{c}\text { Average } \\
\text { detected } \\
\text { result }\end{array}$} & \multicolumn{4}{|c|}{$\begin{array}{l}\text { Number of analyses } \\
\text { exceeding criteria }\end{array}$} \\
\hline & & & & & & $\begin{array}{c}\text { Max } \\
\text { RL }\end{array}$ & $\begin{array}{l}\text { Avg } \\
\text { RL }\end{array}$ & $\begin{array}{l}\text { Ind } \\
\text { PRG }\end{array}$ & $\begin{array}{l}\text { Res } \\
\text { PRG }\end{array}$ \\
\hline PCB-1254 & $3 / 9$ & 110 & 18,000 & Z2-EU43B-302 & 6,223 & 0 & 1 & 1 & 2 \\
\hline PCB & $3 / 9$ & $110 \mathrm{~J}$ & 18,000 & Z2-EU43B-302 & 6,223 & 0 & 1 & 1 & 2 \\
\hline
\end{tabular}

Avg $=$ average

$\mathrm{EU}=$ exposure unit

Ind $=$ industrial

Max $=$ maximum
$\mathrm{PCB}=$ polychlorinated biphenyl

$\mathrm{PRG}=$ preliminary remediation goal

Res $=$ residential

$\mathrm{RL}=$ remediation level

EU Z2-43 SVOC DETECTS (ug/kg)

\begin{tabular}{|c|c|c|c|c|c|c|c|c|}
\hline \multirow[b]{2}{*}{ Analyte } & \multirow[b]{2}{*}{$\begin{array}{c}\text { Detect } \\
\text { frequency }\end{array}$} & \multirow[b]{2}{*}{$\begin{array}{c}\text { Minimum } \\
\text { detect }\end{array}$} & \multirow[b]{2}{*}{$\begin{array}{c}\text { Maximum } \\
\text { detect }\end{array}$} & \multirow[b]{2}{*}{$\begin{array}{c}\text { Location(s) of } \\
\text { maximum detect }\end{array}$} & \multirow{2}{*}{$\begin{array}{c}\text { Average } \\
\text { detected } \\
\text { result }\end{array}$} & \multicolumn{3}{|c|}{$\begin{array}{l}\text { Number of analyses } \\
\text { exceeding criteria }\end{array}$} \\
\hline & & & & & & $\begin{array}{l}\text { Ind } \\
\text { PRG }\end{array}$ & $\begin{array}{l}\text { GW } \\
\text { SL }\end{array}$ & $\begin{array}{l}\text { Res } \\
\text { PRG }\end{array}$ \\
\hline Anthracene & $1 / 5$ & $66 \mathrm{~J}$ & $66 \mathrm{~J}$ & Z2-EU43B-301 & 66 & 0 & NA & 0 \\
\hline Benz(a)anthracene & $2 / 5$ & $130 \mathrm{~J}$ & $390 \mathrm{~J}$ & Z2-EU43B-301 & 260 & 0 & NA & 0 \\
\hline Benzo(a)pyrene & $2 / 5$ & $170 \mathrm{~J}$ & 530 & Z2-EU43B-301 & 350 & 0 & NA & 2 \\
\hline Benzo(b)fluoranthene & $3 / 5$ & $37 \mathrm{~J}$ & 510 & Z2-EU43B-301 & 239 & 0 & NA & 0 \\
\hline Benzo(ghi)perylene & $3 / 5$ & $47 \mathrm{~J}$ & $430 \mathrm{~J}$ & Z2-EU43B-301 & 212 & 0 & NA & 0 \\
\hline
\end{tabular}


EU Z2-43 SVOC DETECTS (ug/kg) (continued)

\begin{tabular}{|c|c|c|c|c|c|c|c|c|}
\hline \multirow[b]{2}{*}{ Analyte } & \multirow[b]{2}{*}{$\begin{array}{c}\text { Detect } \\
\text { frequency }\end{array}$} & \multirow[b]{2}{*}{$\begin{array}{c}\text { Minimum } \\
\text { detect }\end{array}$} & \multirow[b]{2}{*}{$\begin{array}{c}\text { Maximum } \\
\text { detect }\end{array}$} & \multirow[b]{2}{*}{$\begin{array}{l}\text { Location(s) of } \\
\text { maximum detect }\end{array}$} & \multirow{2}{*}{$\begin{array}{c}\text { Average } \\
\text { detected } \\
\text { result }\end{array}$} & \multicolumn{3}{|c|}{$\begin{array}{l}\text { Number of analyses } \\
\text { exceeding criteria }\end{array}$} \\
\hline & & & & & & $\begin{array}{l}\text { Ind } \\
\text { PRG }\end{array}$ & $\begin{array}{l}\text { GW } \\
\text { SL }\end{array}$ & $\begin{array}{l}\text { Res } \\
\text { PRG }\end{array}$ \\
\hline Benzo(k)fluoranthene & $2 / 5$ & $170 \mathrm{~J}$ & 520 & Z2-EU43B-301 & 345 & 0 & NA & 0 \\
\hline Bis(2-ethylhexyl)phthalate & $1 / 5$ & $160 \mathrm{~J}$ & $160 \mathrm{~J}$ & Z2-EU43B-302 & 160 & 0 & 0 & 0 \\
\hline Butyl benzyl phthalate & $1 / 5$ & $38 \mathrm{~J}$ & $38 \mathrm{~J}$ & Z2-EU43B-302 & 38 & 0 & NA & 0 \\
\hline Chrysene & $2 / 5$ & $140 \mathrm{~J}$ & $420 \mathrm{~J}$ & Z2-EU43B-301 & 280 & 0 & NA & 0 \\
\hline $\operatorname{Dibenz}(\mathrm{a}, \mathrm{h})$ anthracene & $2 / 5$ & $39 \mathrm{~J}$ & $78 \mathrm{~J}$ & Z2-EU43B-301 & 58.5 & 0 & NA & 1 \\
\hline Fluoranthene & $3 / 5$ & $45 \mathrm{~J}$ & 740 & Z2-EU43B-301 & 338 & 0 & NA & 0 \\
\hline Indeno(1,2,3-cd)pyrene & $2 / 5$ & $160 \mathrm{~J}$ & $430 \mathrm{~J}$ & Z2-EU43B-301 & 295 & 0 & NA & 0 \\
\hline Phenanthrene & $2 / 5$ & $100 \mathrm{~J}$ & $230 \mathrm{~J}$ & Z2-EU43B-301 & 165 & 0 & NA & 0 \\
\hline Pyrene & $2 / 5$ & $170 \mathrm{~J}$ & 540 & Z2-EU43B-301 & 355 & 0 & NA & 0 \\
\hline
\end{tabular}

$\mathrm{EU}=$ exposure unit $\quad \mathrm{SL}=$ screening level

$\mathrm{GW}=$ groundwater $\quad$ Res $=$ residential

Ind = industrial $\quad \mathrm{SL}=$ screening level

$\mathrm{NA}=$ not applicable $\quad \mathrm{SVOC}=$ semivolatile organic compound

$\mathrm{PRG}=$ preliminary remediation goal

2.2.6

ZONE 2 ROD APPENDIX A FFA SITES EVALUATION

None.

\begin{tabular}{|l|l|}
\hline 3.0 & \multicolumn{1}{|c}{ RISK EVALUATION AND ACTION/NO FURTHER ACTION DECISION } \\
\hline 3.1 & INTRODUCTION \\
\hline
\end{tabular}

In this section, data are evaluated in terms of the four decision rules presented in the Zone 2 RDR/RAWP, which include the following:

- Does the concentration of any Zone 2 contaminant of concern (COC) exceed its maximum RL?

- Does the mean concentration of any Zone 2 COC exceed its Avg RL across the EU?

- Does the EU pose a risk exceeding an industrial $1 \times 10^{-4}$ excess lifetime cancer risk (ELCR) or target organ hazard index (HI) of 1 ?

- Does the site pose a threat to groundwater based on MCL exceedances or soil RLs for protection of groundwater?

Table J. 3 presents the results from comparison of the data to Zone 2 soils RLs, Ind PRGs (set at an ELCR of $1 \times 10^{-5}$ or a HI of 1), and to background levels. In addition, the EU summary in Sect. 2.2.5 presents an evaluation of the EU data by analyte group. The following table summarizes the conclusions for EU Z2-43.

\begin{tabular}{|c|c|c|c|c|c|}
\hline EU \# & $\begin{array}{c}\text { Max RL } \\
\text { exceeded? }\end{array}$ & $\begin{array}{c}\text { Average RL over } \\
\text { EU exceeded? }\end{array}$ & $\begin{array}{c}\text { Industrial risk } \\
\text { above } \mathbf{1} \times \mathbf{1 0}^{-4}\end{array}$ & $\begin{array}{c}\text { Potential source } \\
\text { to groundwater? }\end{array}$ & $\begin{array}{c}\text { Action } \\
\text { required? }\end{array}$ \\
\hline $\mathrm{Z} 2-43$ & No & No & No & No & No \\
\hline
\end{tabular}

$\mathrm{EU}=$ exposure unit

$\mathrm{RL}=$ remediation level

\section{\begin{tabular}{|l|l}
3.2 & DATA EVALUATION FOR THE ACTION /NO FURTHER ACTION DECISION
\end{tabular}}

The requirements for determining NFA in Zone 2 EUs are stated in the protection goals of the Zone 2 ROD RAO. Four decision rules were developed in the DVS DQOs that state the specific criteria against which each EU must be compared to make the NFA decision. The four decision rules are presented in Sect. 3.2 of this PCCR, and the manner in which the decision rule evaluations are conducted and special data handling requirements are discussed in 
Sect. 3.3 of this PCCR. In summary, the decision rule criteria for NFA are that each EU must meet each of the following compositional constraints:

- Zone 2 soils Max RLs - maximum allowable concentrations of the Zone 2 soils COCs. Zone 2 soils Max RLs are presented in the Zone 2 ROD and Table 5 of this PCCR.

- Zone 2 soils Avg RLs - limit on the allowable average concentrations of the Zone 2 soils COCs across an EU. Zone 2 soils Avg RLs are presented in the Zone 2 ROD and Table 5 of this PCCR.

- Cumu lative risk across the EU - cumulative risk across an EU cannot exceed $1 \times 10^{-4}$ ELCR or HI of 1 . A stepwise evaluation of cumulative risk is performed by first comparing EU data to $1 \times 10^{-5}$ industrial PRGs. The $1 \times 10^{-5}$ Ind PRGs for the analytes required by the RDR/RAWP are presented in Table 5 of this PCCR.

- Groundwater protection goals - compositions of Zone 2 soils cannot pose a threat to groundwater. This evaluation is conducted by evaluating local groundwater monitoring results and comparing soils compositions to calculated SLs. Groundwater SLs are presented in Table 5 of this PCCR.

\section{\begin{tabular}{|l|l} 
3.3 & SUMMARY AND CONCLUSIONS \\
\hline
\end{tabular}}

EU Z2-43

Max RL screening. Based on historical and DVS sampling information and results of the Class 3 walkover assessment, no Zone 2 COCs were detected at concentrations in excess of Max RLs.

Avg RL screening. Avg RLs for PCB-1254 and total PCBs were exceeded in the soil sample collected at sediment accumulation area biased sample location Z2-EU43B-302. This sediment accumulation area receives runoff from an asphalt storage area and the presence of PCBs represents the accumulation of solid, PCB-contaminated particles (e.g., paint chips, rust, soil particles). Four additional samples were collected to delineate the extent of the exceedances around Z2-EU43B-302. Analytical results from the four PCB extent samples showed the presence of PCB-1254 and total PCBs but at concentrations less than their respective Avg RLs. It is concluded that the Avg RL exceedances are confined to the Z2-EU43B-302 location, which represents an area less than $1 \%$ of the EU area and, therefore, will not cause the EU average PCB concentrations to exceed the Avg RL. For example, PCBs were detected in three of the nine samples analyzed for PCBs. The average detected PCB-1254 and total PCBs concentrations are both $6223 \mathrm{ug} / \mathrm{kg}$ (Sect. 2.2.5), which is less than the Avg RL concentration (10,000 ug/ $/ \mathrm{kg}$ ). If the non-detected PCBs in the other six samples were taken into account in the average calculations, the resulting averages would be substantially less than detected average concentrations. Therefore, based on analytical results from the DVS biased sampling and historical sampling in EU Z2-43, and results of the Class 3 walkover assessment, no Zone 2 soils COCs are present with a mean concentration exceeding the Avg RL across the EU.

Risk evaluation. The first step in the risk evaluation is to evaluate $1 \times 10^{-5}$ Ind PRG exceedances to determine which chemicals and radionuclides are likely to exceed the $1 \times 10^{-4}$ ELCR or target organ HI of 1 . PCB-1254 and total PCBs $1 \times 10^{-5}$ Ind PRGs were exceeded in the sediment accumulation area biased sample location Z2-EU43B-302. Four additional biased samples were collected to delineate the extent of PCB contamination but none had a $1 \times 10^{-5}$ Ind PRG exceedance. In addition, the average PCB-1254 and total PCBs concentrations $(6223 \mathrm{ug} / \mathrm{kg}) \mathrm{are}$ less than the $1 \times 10^{-5}$ Ind PRG $(7436 \mathrm{ug} / \mathrm{kg})$.

The industrial risk for EU Z2-43 is less than $1 \times 10^{-4}$ ELCR and target organ HI of 1 .

Threat to groundwater. There are no groundwater monitoring wells in EU 43. Class 3 assessments and biased sampling in the EU did not identify any soil areas that had contaminant concentrations above Zone 2 GW SLs. Therefore, it is concluded there are no threats to groundwater quality in the EU Z2-43 soils.

Qualitative risk screening for unrestricted use. There is a low probability that this acreage could be released with no land use restrictions. Ind and Res PRG exceedances occur in the EU. Specific chemicals and radionuclides with criteria exceedances are presented in the EU Z2-43 summary in Sect. 2.2.5. An appropriate evaluation of residential risk should be conducted to make a definitive conclusion. 


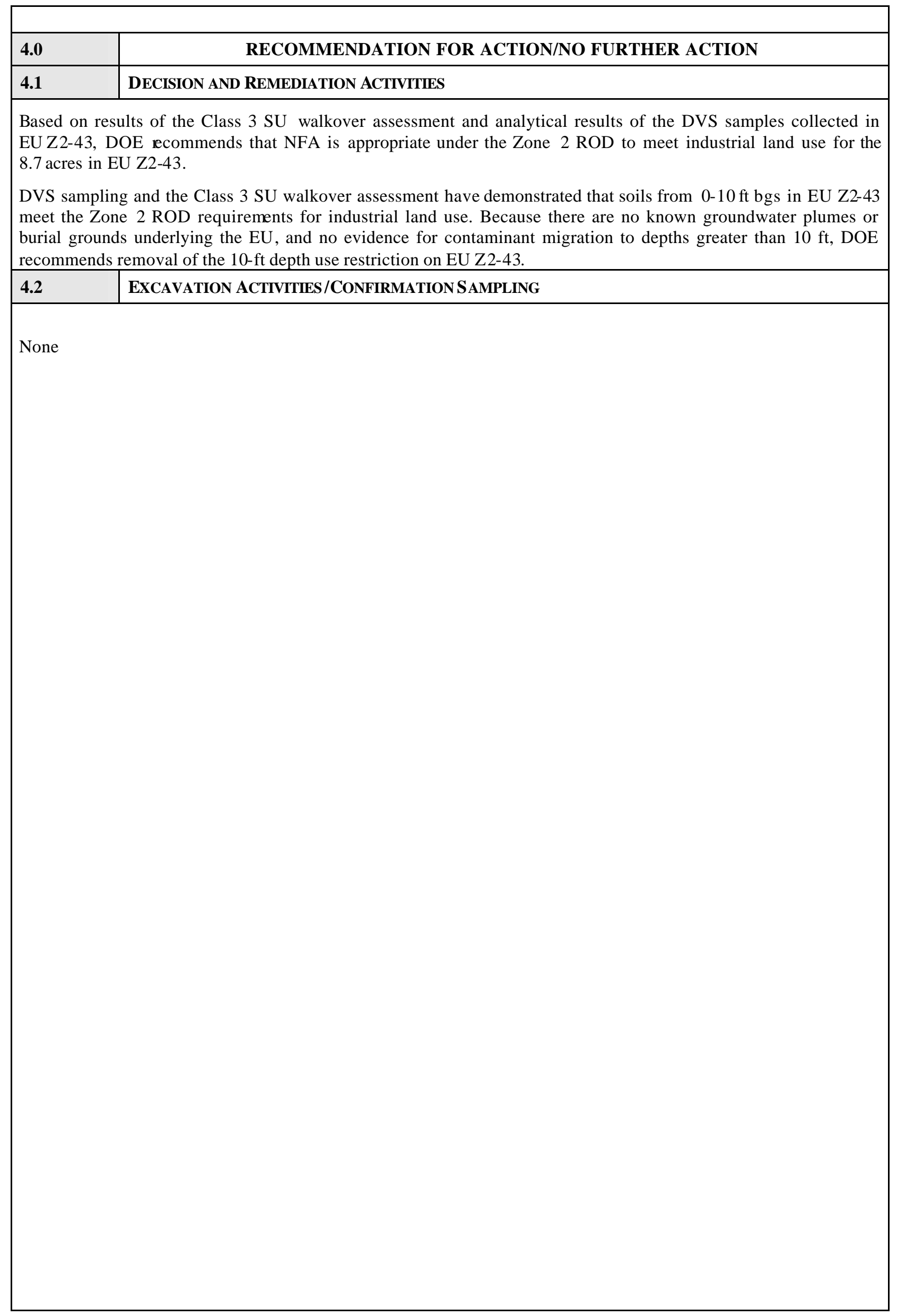




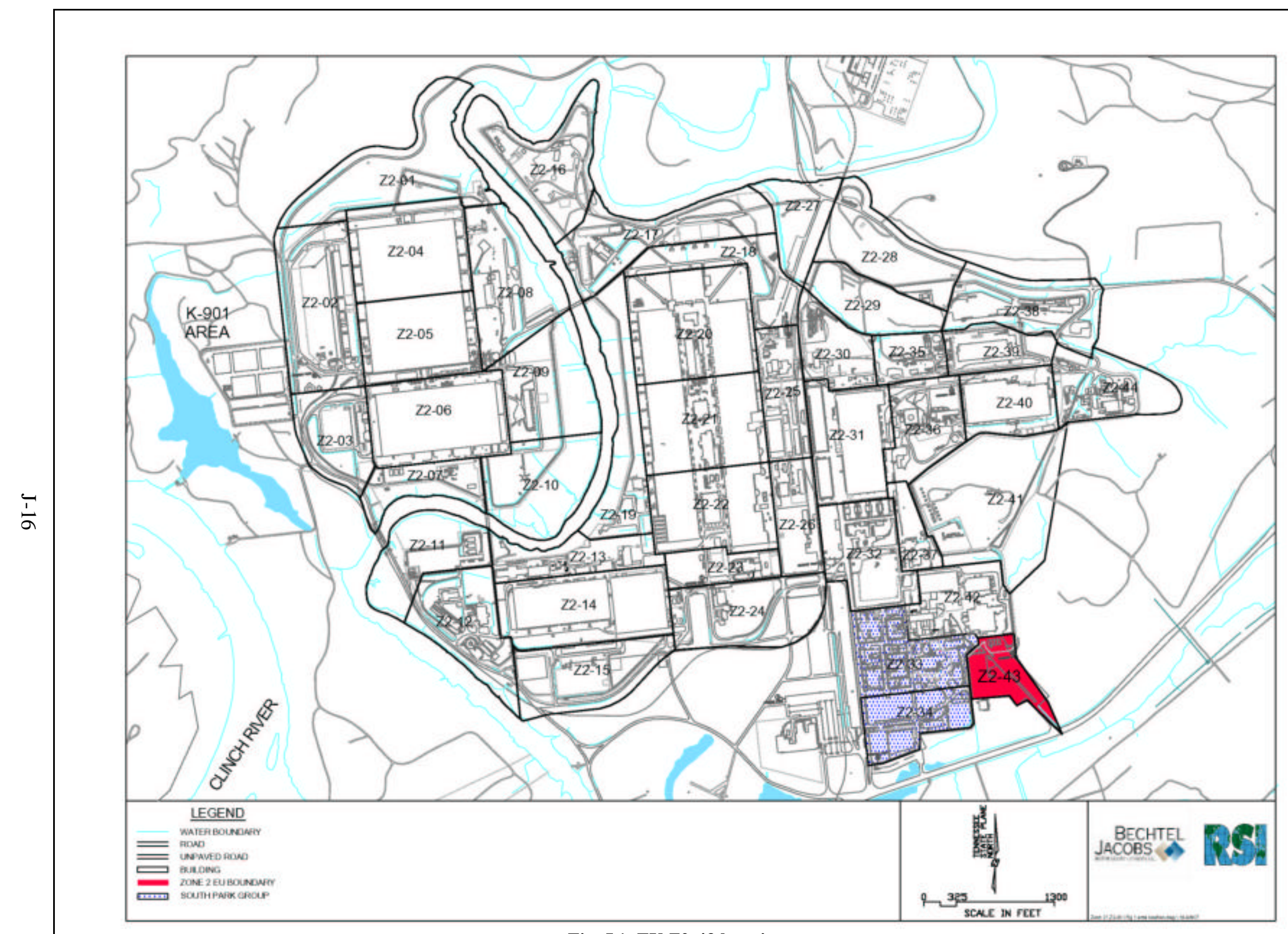

Fig. J.1. EU Z2-43 location map. 


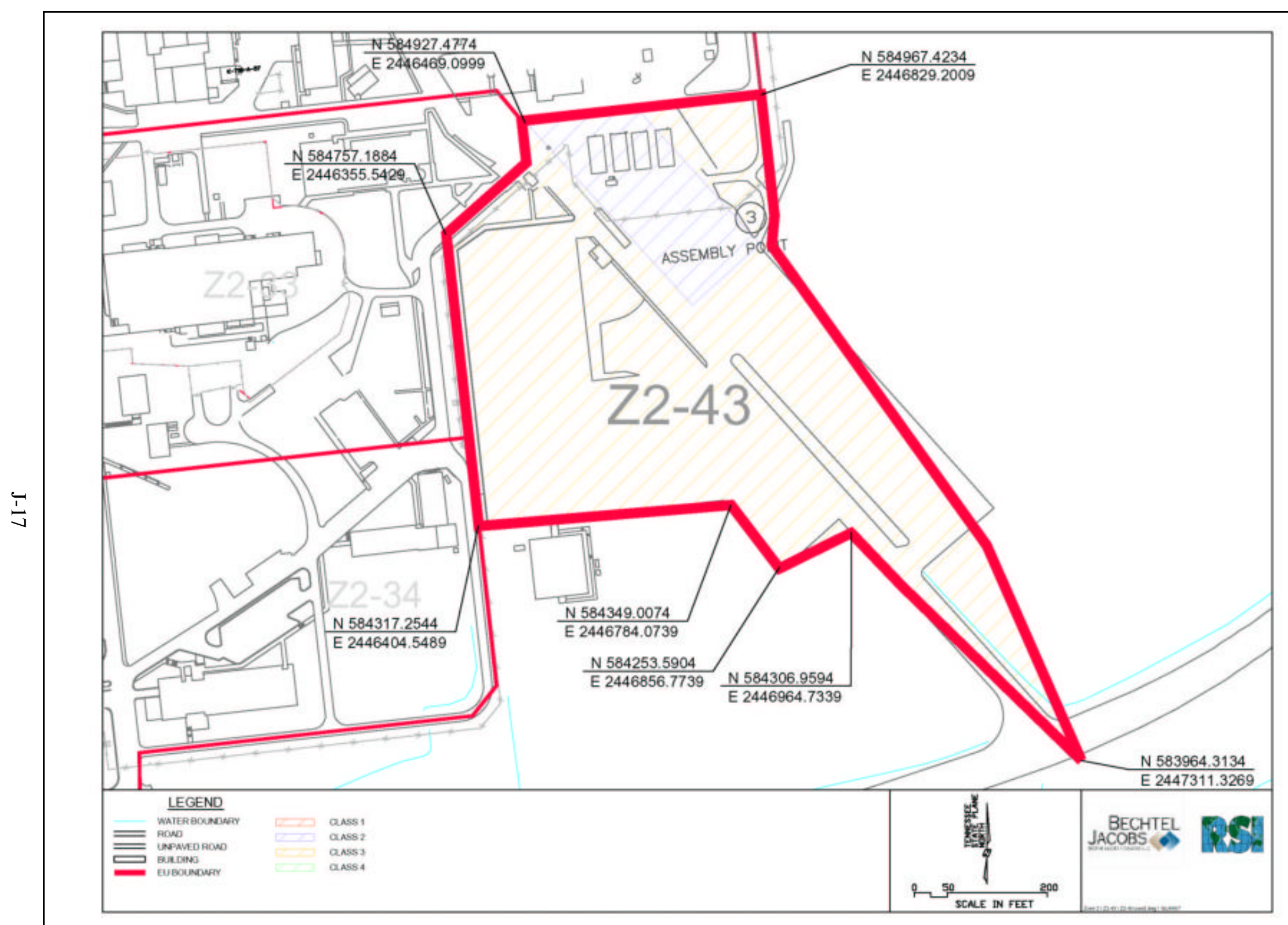

Fig. J.2. EU Z2-34 boundaries. 


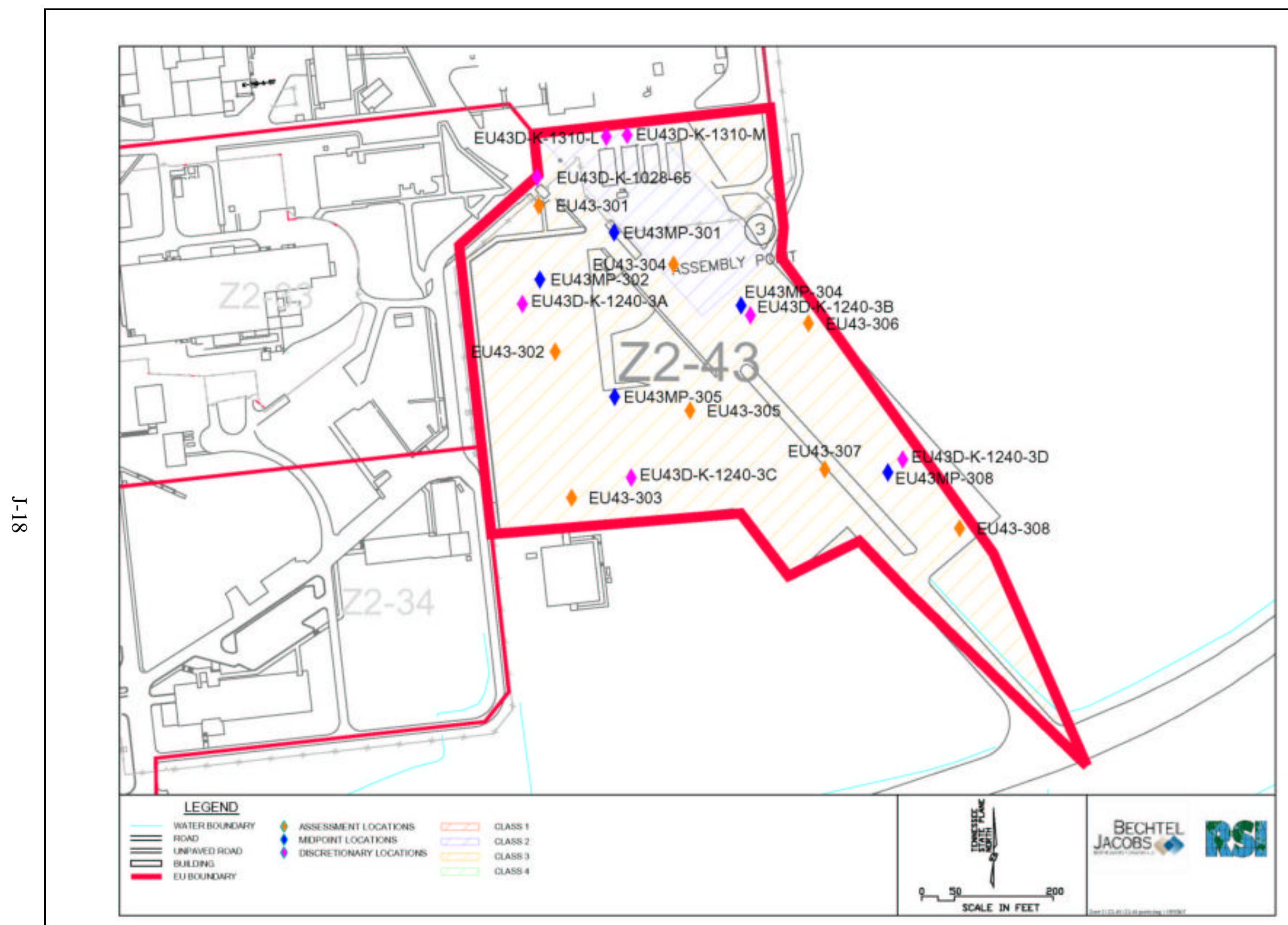

Fig. J.3. EU Z2-43 Class 3 and Class 4 SU walkover assessment locations. 


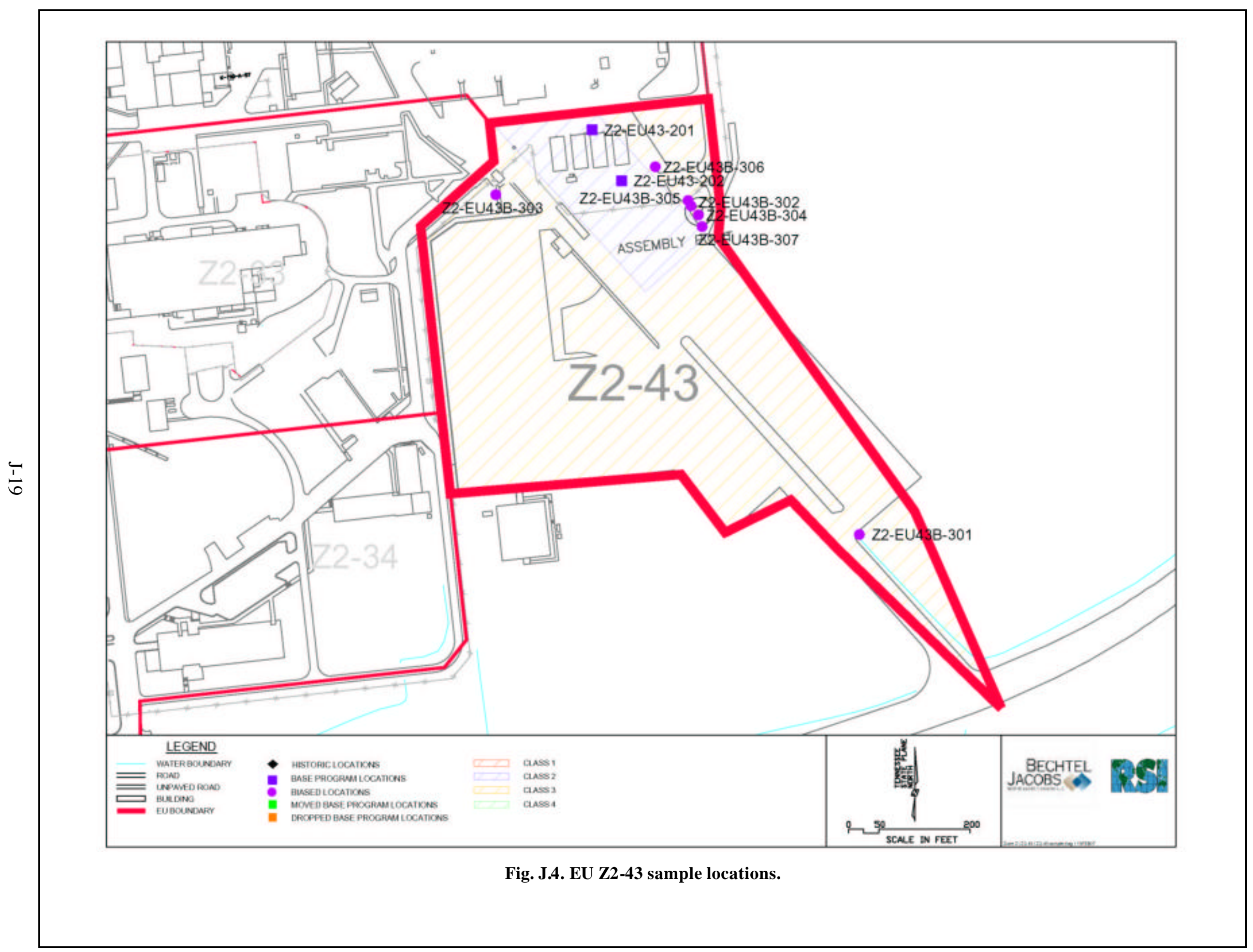


Table J.1. EU Z2-43 facility list

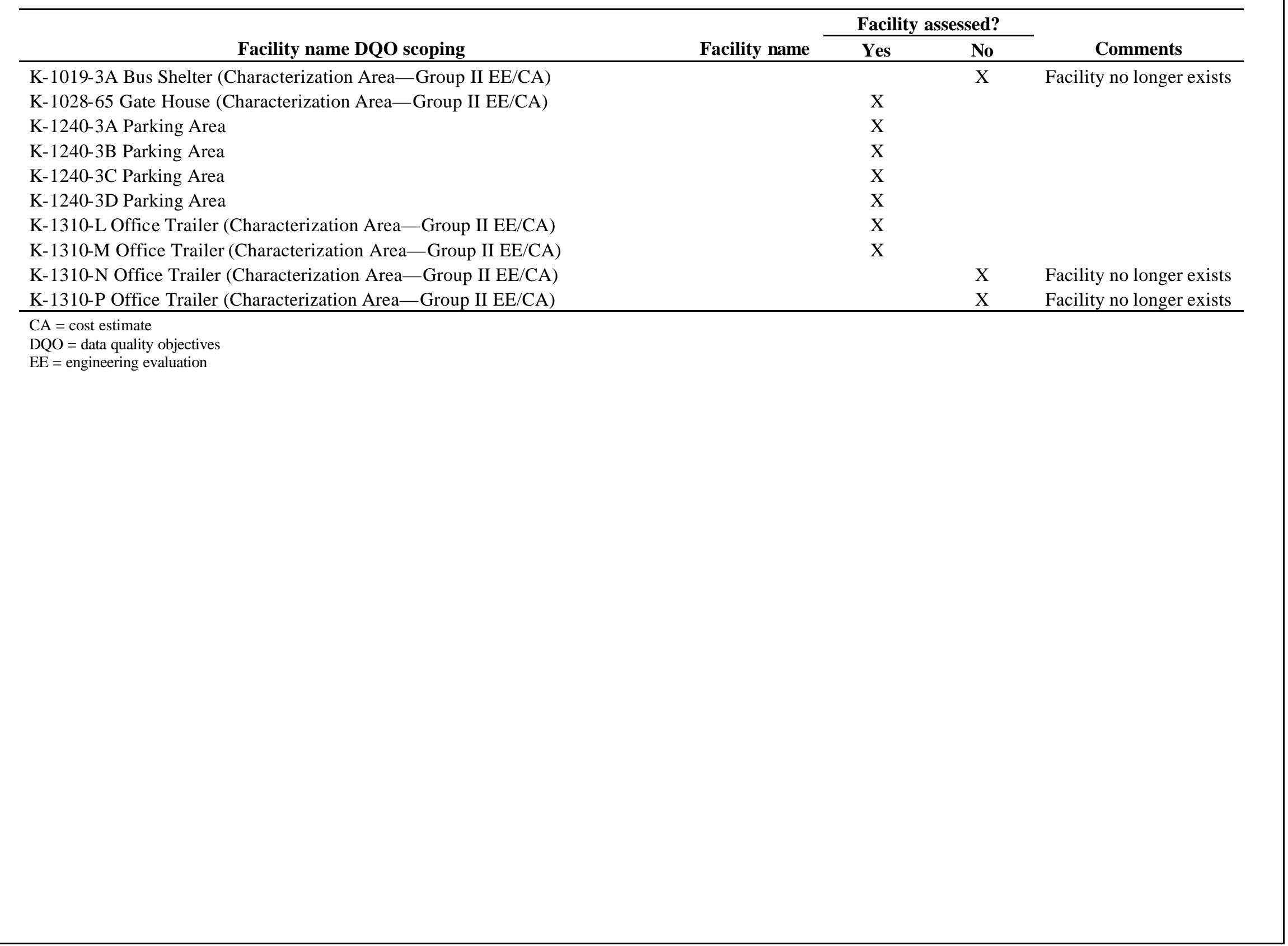




\begin{tabular}{|c|c|c|c|c|c|c|c|c|c|c|c|c|c|}
\hline \multirow[b]{2}{*}{ Location ID ${ }^{a}$} & \multirow[b]{2}{*}{ Date sampled } & \multicolumn{2}{|c|}{ Location $^{b}$} & \multirow[b]{2}{*}{ Sample interval } & \multicolumn{2}{|c|}{ Screen } & \multicolumn{5}{|c|}{ Off-Site laboratory $^{c}$} & \multirow[b]{2}{*}{ Splits/Dups } & \multirow[b]{2}{*}{ Comments and notes } \\
\hline & & Northing & Easting & & RAD & VOC & Metals & PCB & $\mathbf{R A D}^{d}$ & SVOC & VOC & & \\
\hline \multicolumn{14}{|c|}{ Class 2 Sample Points } \\
\hline Z2-EU43-201 & $7 / 18 / 2006$ & 584915.9 & 2446638.3 & $0.6-2.6 \mathrm{ft}$; one-point composite soil sample (asphalt surface 1 in.) & 1 & 1 & 1 & 1 & & 1 & & & Class 2 sample point \\
\hline Z2-EU43-202 & $7 / 18 / 2006$ & 584832.2 & 2446686.6 & $0.55-2.55 \mathrm{ft}$; one-point composite soil sample (asphalt surface 2 in.) & 1 & 1 & 1 & 1 & & 1 & & $\mathrm{~s}$ & Class 2 sample point \\
\hline \multicolumn{14}{|c|}{ Class 3 Biased Sample Points } \\
\hline Z2-EU43B-301 & $7 / 19 / 2006$ & 584250.1 & 2447077.8 & $0-0.5 \mathrm{ft}$, four-point composite sediment sample & & 1 & 1 & 1 & & 1 & & & $\begin{array}{l}\text { Collected sediments in far southeast } \\
\text { section of EU }\end{array}$ \\
\hline Z2-EU43B-302 & $7 / 19 / 2006$ & 584791.0 & 2446800.7 & $0-0.5 \mathrm{ft}$, four-point composite sediment sample & & 1 & 1 & 1 & & 1 & & & $\begin{array}{l}\text { Collected sediments in area south of } \\
\text { Bldg. K-1220 }\end{array}$ \\
\hline Z2-EU43B-303 & $7 / 19 / 2006$ & 584809.3 & 2446479.6 & $0-0.5 \mathrm{ft}$, four-point composite sediment sample & & 1 & 1 & 1 & & 1 & & & Collected sediments west of Portal 3 \\
\hline Z2-EU43B-304 & 9/21/2006 & 584776.0 & 2446813.0 & $0-1 \mathrm{ft}$, one-point composite soil sample & & 1 & & 1 & & & & & $\begin{array}{l}\text { Located downgradient of 4-point } \\
\text { composite location Z2-EU433B-302 } \\
\text { (exceeded Avg RL for PCBs) }\end{array}$ \\
\hline Z2-EU43B-305 & $9 / 21 / 2006$ & 584799.7 & 2446796.0 & $0-1 \mathrm{ft}$, one-point composite soil sample & & 1 & & 1 & & & & & $\begin{array}{l}\text { Located upgradient of 4-point } \\
\text { composite Z2-EU43B-302 (exceeded } \\
\text { Avg RL for PCBs) }\end{array}$ \\
\hline Z2-EU43B-306 & $9 / 21 / 2006$ & 584855.3 & 2446742.0 & $0-1 \mathrm{ft}$, one-point composite soil sample & & 1 & & 1 & & & & & $\begin{array}{l}\text { Located upgradient of 4-point } \\
\text { composite Z2-EU43B-302 (exceeded } \\
\text { Avg RL for PCBs) }\end{array}$ \\
\hline Z2-EU43B-307 & $9 / 21 / 2006$ & 584757.0 & 2446819.0 & $0-1 \mathrm{ft}$, one-point composite soil sample & & 1 & & 1 & & & & & $\begin{array}{l}\text { Located downgr adient of 4-point } \\
\text { composite location Z2-EU43B-302 } \\
\text { (exceeded Avg RL for PCBs) }\end{array}$ \\
\hline & & & & Total DVS samples & 2 & 9 & 5 & 9 & 0 & 2 & 0 & & \\
\hline
\end{tabular}

a.B" in sample number indicates a biased sample

"Coordinates sisted number Location column are the adjusted coordinates.
"Notet the following requirements for soil samples collected under this DW

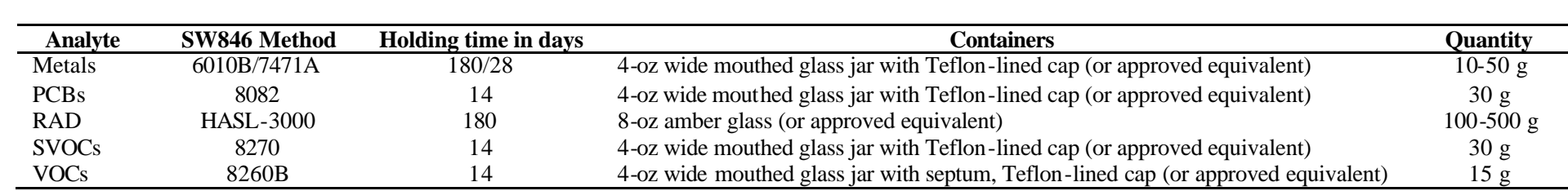

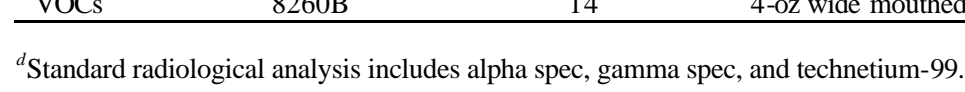

Avg $=$ average
EvU = expousere
ID

$\mathrm{EU}=$ exposure unit
$\mathrm{ID}=$ identification

$\mathrm{RAD}=$ radiological
$\mathrm{RL}=$ remediation level

PCB = polychlorinated bipheny 1

SVOC = semivolatile organic compound
VOC = volatile organic compound 
Table J.3. EU Z2-43, depth 0-10 ft

\begin{tabular}{|c|c|c|c|c|c|c|c|c|c|c|c|c|c|}
\hline Analyte & $\begin{array}{r}\text { Frequency } \\
\text { of detect }\end{array}$ & $\begin{array}{c}\text { Minimum } \\
\text { detect }\end{array}$ & $\begin{array}{c}\text { Maximum } \\
\text { detect }\end{array}$ & $\begin{array}{c}\text { Location(s) } \\
\text { of maximum } \\
\text { detected result }\end{array}$ & $\begin{array}{c}\text { Average } \\
\text { detected result }\end{array}$ & Max RL & $\begin{array}{c}\text { Frequency of } \\
\text { detects } \\
\text { exceeding } \\
\text { Max RL } \\
\end{array}$ & Avg RL & $\begin{array}{c}\text { Frequency } \\
\text { of detects } \\
\text { exceeding Avg RL }\end{array}$ & $\begin{array}{l}\text { PRG limit } \\
\left(10^{-5} \text { or } 1\right)\end{array}$ & $\begin{array}{l}\text { Frequency of detects } \\
\text { exceeding PRG limit }\end{array}$ & $\begin{array}{l}\text { Background } \\
\text { concentration }\end{array}$ & $\begin{array}{l}\text { Frequency of detects } \\
\text { exceeding background }\end{array}$ \\
\hline \multicolumn{14}{|l|}{ Inorganics (mg/kg) } \\
\hline Aluminum & $5 / 5$ & $7410 \mathrm{~J}$ & $21000 \mathrm{~J}$ & Z2-EU43-202 & 11752 & & NA & & $\mathrm{NA}$ & $1.00 \mathrm{E}+05$ & $0 / 5$ & 40300 & $0 / 5$ \\
\hline Antimony & $5 / 5$ & $0.067 \mathrm{~J}$ & $0.31 \mathrm{~J}$ & Z2-EU43B-302 & 0.16 & & NA & & NA & $4.10 \mathrm{E}+02$ & $0 / 5$ & 1.52 & $0 / 5$ \\
\hline Arsenic & $5 / 5$ & $0.89 \mathrm{~J}$ & 6.6 & Z2-EU43B-303 & 3.96 & 900 & $0 / 5$ & 300 & $0 / 5$ & $1.60 \mathrm{E}+01$ & $0 / 5$ & 14.95 & $0 / 5$ \\
\hline Barium & $5 / 5$ & $63.4 \mathrm{~J}$ & $280 \mathrm{~J}$ & Z2-EU43-202 & 128.6 & & NA & & NA & $6.70 \mathrm{E}+04$ & $0 / 5$ & 124.93 & $1 / 5$ \\
\hline Beryllium & $5 / 5$ & 0.59 & 1.8 & Z2-EU43-201 & 1.01 & 6000 & $0 / 5$ & 2000 & $0 / 5$ & $1.90 \mathrm{E}+03$ & $0 / 5$ & 2.2 & $0 / 5$ \\
\hline Boron & $3 / 5$ & $2.9 \mathrm{~J}$ & $6.8 \mathrm{~J}$ & Z2-EU43B-301 & 4.47 & & NA & & NA & $1.00 \mathrm{E}+05$ & $0 / 5$ & & NA \\
\hline Cadmium & $5 / 5$ & 0.067 & 0.74 & Z2-EU43B-302 & 0.32 & & NA & & NA & 4.50E+02 & $0 / 5$ & $0.22 \mathrm{U}$ & $3 / 5$ \\
\hline Calcium & $5 / 5$ & $7070 \mathrm{~J}$ & $65200 \mathrm{~J}$ & Z2-EU43B-302 & 22714 & & NA & & $\mathrm{NA}$ & & $\mathrm{NA}$ & 2400 & $5 / 5$ \\
\hline Chromium & $5 / 5$ & 14.3 & 100 & Z2-EU43B-302 & 36.12 & & NA & & NA & $6.40 \mathrm{E}+02$ & $0 / 5$ & 44.88 & $1 / 5$ \\
\hline Cobalt & $5 / 5$ & $8.7 \mathrm{~J}$ & $30.3 \mathrm{~J}$ & Z2-EU43-201 & 14.82 & & NA & & NA & $1.30 \mathrm{E}+04$ & $0 / 5$ & 42 & $0 / 5$ \\
\hline Copper & $5 / 5$ & 15.1 & 28.2 & Z2-EU43B-302 & $\begin{array}{l}21.02 \\
21.26\end{array}$ & & NA & & NA & $4.10 \mathrm{E}+04$ & $0 / 5$ & 22.48 & $2 / 5$ \\
\hline Iron & $5 / 5$ & $14800 \mathrm{~J}$ & $33500 \mathrm{~J}$ & Z2-EU43B-302 & 23200 & & $\mathrm{NA}$ & & $\mathrm{NA}$ & $1.00 \mathrm{E}+05$ & $0 / 5$ & 58600 & $0 / 5$ \\
\hline Lead & $5 / 5$ & 22.9 & 414 & Z2-EU43B-302 & 119.92 & & NA & & NA & $8.00 \mathrm{E}+02$ & $0 / 5$ & 37.91 & $4 / 5$ \\
\hline Lithium & $5 / 5$ & 13.7 & 25.3 & Z2-EU43-202 & 18.44 & & NA & & $\mathrm{NA}$ & $2.00 \mathrm{E}+04$ & $0 / 5$ & 48.94 & $0 / 5$ \\
\hline Magnesium & $5 / 5$ & 1450 & 9130 & Z2-EU43B-302 & 4812 & & NA & & NA & & NA & 3300 & $3 / 5$ \\
\hline Manganese & $5 / 5$ & $161 \mathrm{~J}$ & $801 \mathrm{~J}$ & Z2-EU43B-303 & 470.6 & & NA & & $\mathrm{NA}$ & $1.90 \mathrm{E}+04$ & $0 / 5$ & 2200 & $0 / 5$ \\
\hline Mercury & $3 / 5$ & 0.11 & 0.24 & Z2-EU43B-303 & 0.17 & 1800 & $0 / 5$ & 600 & $0 / 5$ & $3.10 \mathrm{E}+02$ & $0 / 5$ & 0.17 & $1 / 5$ \\
\hline Molybdenum & $5 / 5$ & $0.1 \mathrm{~J}$ & 1.3 & Z2-EU43B-302 & 0.68 & & NA & & $\mathrm{NA}$ & $5.10 \mathrm{E}+03$ & $0 / 5$ & & $\mathrm{NA}$ \\
\hline Nickel & $5 / 5$ & $17.8 \mathrm{~J}$ & $28.3 \mathrm{~J}$ & Z2-EU43B-302 & 23.84 & & NA & & $\mathrm{NA}$ & $2.00 \mathrm{E}+04$ & $0 / 5$ & 26.07 & $1 / 5$ \\
\hline Potassium & $5 / 5$ & 897 & 1440 & Z2-EU43-201 & 1144.4 & & NA & & $\mathrm{NA}$ & & $\mathrm{NA}$ & 5074.69 & $0 / 5$ \\
\hline Selenium & $4 / 5$ & $0.25 \mathrm{~J}$ & $0.76 \mathrm{~J}$ & Z2-EU43-202 & 0.42 & & NA & & NA & $5.10 \mathrm{E}+03$ & $0 / 5$ & 1.47 & $0 / 5$ \\
\hline Silver & $5 / 5$ & $0.064 \mathrm{~J}$ & $0.19 \mathrm{~J}$ & Z2-EU43B-302 & 0.1 & & NA & & $\mathrm{NA}$ & $5.10 \mathrm{E}+03$ & $0 / 5$ & $0.6 \mathrm{U}$ & $0 / 5$ \\
\hline Sodium & $4 / 5$ & 19.1 & 69.2 & Z2-EU43-202 & 49.83 & & NA & & NA & & NA & 497 & $0 / 5$ \\
\hline Thallium & $0 / 5$ & ND & ND & & ND & & NA & & $\mathrm{NA}$ & $6.70 \mathrm{E}+01$ & $0 / 5$ & $0.4 \mathrm{U}$ & $0 / 5$ \\
\hline Uranium & $5 / 5$ & 0.33 & 2.8 & Z2-EU43B-301 & 1.31 & & NA & & NA & $2.00 \mathrm{E}+02$ & $0 / 5$ & & NA \\
\hline Vanadium & $5 / 5$ & 14.6 & 23.3 & Z2-EU43-201 & 20.24 & & NA & & NA & $1.00 \mathrm{E}+03$ & $0 / 5$ & 65.47 & $0 / 5$ \\
\hline Zinc & $5 / 5$ & $53.8 \mathrm{~J}$ & $486 \mathrm{~J}$ & Z2-EU43B-301 & 151.52 & & $\mathrm{NA}$ & & $\mathrm{NA}$ & $1.00 \mathrm{E}+05$ & $0 / 5$ & 89.7 & $1 / 5$ \\
\hline \multicolumn{14}{|l|}{ Organics, Pesticides, and PCBs (ug/kg) } \\
\hline PCB-1016 & $0 / 9$ & $\mathrm{ND}$ & $\mathrm{ND}$ & & $\mathrm{ND}$ & 100,000 & $0 / 9$ & 10000 & $0 / 9$ & $3.70 \mathrm{E}+04$ & $0 / 9$ & & $\mathrm{NA}$ \\
\hline PCB-1221 & 0/9 & $\mathrm{ND}$ & $\mathrm{ND}$ & & $\mathrm{ND}$ & 100000 & $0 / 9$ & 10000 & $0 / 9$ & $7.40 \mathrm{E}+03$ & $0 / 9$ & & NA \\
\hline PCB-1232 & $0 / 9$ & ND & $\mathrm{ND}$ & & ND & 100000 & $0 / 9$ & 10000 & $0 / 9$ & 7.40E+03 & $0 / 9$ & & NA \\
\hline PCB-1242 & $0 / 9$ & ND & ND & & ND & 100000 & 0/9 & 10000 & 0/9 & $7.40 \mathrm{E}+03$ & 0/9 & & $\mathrm{NA}$ \\
\hline PCB-1248 & 0/9 & $\mathrm{ND}$ & $\mathrm{ND}$ & & $\mathrm{ND}$ & 100000 & $0 / 9$ & 10000 & $0 / 9$ & $7.40 \mathrm{E}+03$ & $0 / 9$ & & $\mathrm{NA}$ \\
\hline PCB-1254 & 3/9 & 110 & 18000 & Z2-EU43B-302 & 6223.33 & 100000 & $0 / 9$ & 10000 & $1 / 9$ & $7.40 \mathrm{E}+03$ & $1 / 9$ & & NA \\
\hline PCB-1260 & $0 / 9$ & ND & $\mathrm{ND}$ & & ND & 100000 & $0 / 9$ & 10000 & 0/9 & $7.40 \mathrm{E}+03$ & $0 / 9$ & & NA \\
\hline Polychlorinated biphenyl & $3 / 9$ & $110 \mathrm{~J}$ & 18000 & Z2-EU43B-302 & 6223.33 & 100000 & $0 / 9$ & 10000 & $1 / 9$ & $7.40 \mathrm{E}+03$ & $1 / 9$ & & NA \\
\hline \multicolumn{14}{|l|}{ Semivolatile Organics (ug/kg) } \\
\hline 1,2,4-Trichlorobenzene & $0 / 5$ & $\mathrm{ND}$ & $\mathrm{ND}$ & & $\mathrm{ND}$ & & $\mathrm{NA}$ & & $\mathrm{NA}$ & $2.20 \mathrm{E}+05$ & $0 / 5$ & & $\mathrm{NA}$ \\
\hline 1,2-Dichlorobenzene & $0 / 5$ & $\mathrm{ND}$ & $\mathrm{ND}$ & & ND & & NA & & NA & $6.00 \mathrm{E}+05$ & $0 / 5$ & & NA \\
\hline 1,3-Dichlorobenzene & $0 / 5$ & $\mathrm{ND}$ & $\mathrm{ND}$ & & ND & & NA & & NA & $6.00 \mathrm{E}+05$ & $0 / 5$ & & NA \\
\hline 1,4-Dichlorobenzene & $0 / 5$ & $\mathrm{ND}$ & $\mathrm{ND}$ & & $\mathrm{ND}$ & & NA & & $\mathrm{NA}$ & $7.90 \mathrm{E}+04$ & $0 / 5$ & & NA \\
\hline 2,3,4,6-Tetrachlorophenol & $0 / 5$ & ND & $\mathrm{ND}$ & & ND & & NA & & NA & $1.80 \mathrm{E}+07$ & $0 / 5$ & & NA \\
\hline 2,4,5-Trichlorophenol & $0 / 5$ & $\mathrm{ND}$ & ND & & $\mathrm{ND}$ & & $\mathrm{NA}$ & & $\mathrm{NA}$ & $6.20 \mathrm{E}+07$ & $0 / 5$ & & NA \\
\hline 2,4,6-Trichlorophenol & $0 / 5$ & $\mathrm{ND}$ & $\mathrm{ND}$ & & $\mathrm{ND}$ & & $\mathrm{NA}$ & & $\mathrm{NA}$ & $6.20 \mathrm{E}+04$ & $0 / 5$ & & $\mathrm{NA}$ \\
\hline 2,4-Dichlorophenol & $0 / 5$ & $\mathrm{ND}$ & $\mathrm{ND}$ & & $\mathrm{ND}$ & & NA & & NA & $1.80 \mathrm{E}+06$ & $0 / 5$ & & $\mathrm{NA}$ \\
\hline 2,4-Dimethylphenol & $0 / 5$ & $\mathrm{ND}$ & $\mathrm{ND}$ & & $\mathrm{ND}$ & & NA & & NA & $1.20 \mathrm{E}+07$ & $0 / 5$ & & NA \\
\hline 2,4-Dinitrophenol & $0 / 5$ & $\mathrm{ND}$ & $\mathrm{ND}$ & & $\mathrm{ND}$ & & NA & & $\mathrm{NA}$ & $1.20 \mathrm{E}+06$ & $0 / 5$ & & $\mathrm{NA}$ \\
\hline 2,4-Dinitrotoluene & $0 / 5$ & ND & $\mathrm{ND}$ & & ND & & NA & & NA & $2.50 \mathrm{E}+04$ & $0 / 5$ & & NA \\
\hline 2,6-Dinitrotoluene & $0 / 5$ & ND & $\mathrm{ND}$ & & $\mathrm{ND}$ & & $\mathrm{NA}$ & & $\mathrm{NA}$ & $2.50 \mathrm{E}+04$ & $0 / 5$ & & $\mathrm{NA}$ \\
\hline 2-Chloronaphthalene & $0 / 5$ & $\mathrm{ND}$ & $\mathrm{ND}$ & & $\mathrm{ND}$ & & $\mathrm{NA}$ & & $\mathrm{NA}$ & $2.30 \mathrm{E}+07$ & $0 / 5$ & & $\mathrm{NA}$ \\
\hline 2-Chlorophenol & $0 / 5$ & $\mathrm{ND}$ & $\mathrm{ND}$ & & $\mathrm{ND}$ & & NA & & NA & $2.40 \mathrm{E}+05$ & $0 / 5$ & & NA \\
\hline
\end{tabular}


Table J.3. (continued)

\begin{tabular}{|c|c|c|c|c|c|c|c|c|c|c|c|c|c|}
\hline $\begin{array}{rr}\text { Analyte } \\
\end{array}$ & $\begin{array}{c}\text { Frequency } \\
\text { of detect }\end{array}$ & $\begin{array}{c}\text { Minimum } \\
\text { detect }\end{array}$ & $\begin{array}{c}\text { Maximum } \\
\text { detect }\end{array}$ & $\begin{array}{c}\text { Location(s) } \\
\text { of maximum } \\
\text { detected result }\end{array}$ & $\begin{array}{c}\text { Average } \\
\text { detected result }\end{array}$ & Max RL & $\begin{array}{c}\text { Frequency of } \\
\text { detects } \\
\text { exceeding } \\
\text { Max RL } \\
\end{array}$ & Avg RL & $\begin{array}{c}\text { Frequency } \\
\text { of detects } \\
\text { exceeding Avg RL }\end{array}$ & $\begin{array}{l}\text { PRG limit } \\
\left(10^{-5} \text { or } 1\right)\end{array}$ & $\begin{array}{l}\text { Frequency of detects } \\
\text { exceeding PRG limit }\end{array}$ & $\begin{array}{c}\text { Background } \\
\text { concentration }\end{array}$ & $\begin{array}{c}\text { Frequency of detects } \\
\text { exceeding background }\end{array}$ \\
\hline 2-Methyl-6-6-dinitrophenol & $0 / 5$ & $\mathrm{ND}$ & $\mathrm{ND}$ & & $\mathrm{ND}$ & & NA & & NA & $6.20 \mathrm{E}+04$ & $0 / 5$ & & NA \\
\hline 2-Methylnaphthalene & $0 / 5$ & ND & ND & & ND & & $\mathrm{NA}$ & & $\mathrm{NA}$ & $1.90 \mathrm{E}+05$ & $0 / 5$ & & $\mathrm{NA}$ \\
\hline 2-Methylphenol & $0 / 5$ & ND & ND & & ND & & NA & & NA & $3.10 \mathrm{E}+07$ & $0 / 5$ & & $\mathrm{NA}$ \\
\hline 2-Nitrobenzenamine & $0 / 5$ & $\mathrm{ND}$ & ND & & $\mathrm{ND}$ & & NA & & NA & $1.80 \mathrm{E}+06$ & $0 / 5$ & & NA \\
\hline 2-Nitrophenol & $0 / 5$ & ND & ND & & ND & & $\mathrm{NA}$ & & NA & & NA & & NA \\
\hline 3,3'-Dichlorobenzidine & $0 / 5$ & ND & ND & & $\mathrm{ND}$ & & $\mathrm{NA}$ & & $\mathrm{NA}$ & $3.80 \mathrm{E}+04$ & $0 / 5$ & & NA \\
\hline 3-Nitrobenzenamine & $0 / 5$ & $\mathrm{ND}$ & ND & & $\mathrm{ND}$ & & $\mathrm{NA}$ & & $\mathrm{NA}$ & $1.80 \mathrm{E}+05$ & $0 / 5$ & & $\mathrm{NA}$ \\
\hline 4-Bromophenyl phenyl ether & $0 / 5$ & ND & ND & & $\mathrm{ND}$ & & NA & & NA & & NA & & $\mathrm{NA}$ \\
\hline 4-Chloro-3-methylphenol & $0 / 5$ & ND & ND & & ND & & NA & & $\mathrm{NA}$ & & NA & & $\mathrm{NA}$ \\
\hline 4-Chlorobenzenamine & $0 / 5$ & ND & ND & & ND & & $\mathrm{NA}$ & & NA & $2.50 \mathrm{E}+06$ & $0 / 5$ & & $\mathrm{NA}$ \\
\hline 4-Chlorophenyl phenyl ether & $0 / 5$ & ND & ND & & $\mathrm{ND}$ & & NA & & $\mathrm{NA}$ & & NA & & NA \\
\hline 4-Methylphenol & $0 / 5$ & ND & ND & & $\mathrm{ND}$ & & NA & & $\mathrm{NA}$ & $3.10 \mathrm{E}+06$ & $0 / 5$ & & NA \\
\hline 4-Nitrobenzenamine & $0 / 5$ & ND & ND & & $\mathrm{ND}$ & & $\mathrm{NA}$ & & $\mathrm{NA}$ & $8.20 \mathrm{E}+05$ & $0 / 5$ & & $\mathrm{NA}$ \\
\hline 4-Nitrophenol & $0 / 5$ & $\mathrm{ND}$ & ND & & $\mathrm{ND}$ & & $\mathrm{NA}$ & & $\mathrm{NA}$ & & NA & & NA \\
\hline Acenaphthene & $0 / 5$ & ND & ND & & ND & & $\mathrm{NA}$ & & $\mathrm{NA}$ & $2.90 \mathrm{E}+07$ & $0 / 5$ & & $\mathrm{NA}$ \\
\hline Acenaphthylene & $0 / 5$ & ND & ND & & ND & & NA & & NA & $2.90 \mathrm{E}+07$ & $0 / 5$ & & NA \\
\hline Aniline & $0 / 5$ & ND & ND & & $\mathrm{ND}$ & & $\mathrm{NA}$ & & NA & $3.00 \mathrm{E}+06$ & $0 / 5$ & & NA \\
\hline Anthracene & $1 / 5$ & $66 \mathrm{~J}$ & $66 \mathrm{~J}$ & Z2-EU43B-301 & 66 & & NA & & NA & $1.00 \mathrm{E}+08$ & $0 / 5$ & & NA \\
\hline Benz(a)anthracene & $2 / 5$ & $130 \mathrm{~J}$ & $390 \mathrm{~J}$ & Z2-EU43B-301 & 260 & & $\mathrm{NA}$ & & $\mathrm{NA}$ & $2.10 \mathrm{E}+04$ & $0 / 5$ & & $\mathrm{NA}$ \\
\hline Benzenemethanol & $0 / 5$ & ND & ND & & $\mathrm{ND}$ & & NA & & $\mathrm{NA}$ & $1.00 \mathrm{E}+08$ & $0 / 5$ & & $\mathrm{NA}$ \\
\hline Benzo(a)pyrene & $2 / 5$ & $170 \mathrm{~J}$ & 530 & Z2-EU43B-301 & 350 & & NA & & NA & $2.10 \mathrm{E}+03$ & $0 / 5$ & & NA \\
\hline Benzo(b)fluoranthene & $3 / 5$ & $37 \mathrm{~J}$ & 510 & Z2-EU43B-301 & 239 & & $\mathrm{NA}$ & & $\mathrm{NA}$ & $2.10 \mathrm{E}+04$ & $0 / 5$ & & $\mathrm{NA}$ \\
\hline Benzo(ghi)perylene & $3 / 5$ & $47 \mathrm{~J}$ & $430 \mathrm{~J}$ & Z2-EU43B-301 & 212.33 & & $\mathrm{NA}$ & & NA & $2.90 \mathrm{E}+07$ & $0 / 5$ & & NA \\
\hline Benzo(k)fluoranthene & $2 / 5$ & $170 \mathrm{~J}$ & 520 & Z2-EU43B-301 & 345 & & NA & & NA & $2.10 \mathrm{E}+05$ & $0 / 5$ & & NA \\
\hline Benzoic acid & $0 / 5$ & ND & $\mathrm{ND}$ & & $\mathrm{ND}$ & & NA & & NA & $1.00 \mathrm{E}+08$ & $0 / 5$ & & NA \\
\hline Bis(2-chloroethoxy)methane & $0 / 5$ & ND & $\mathrm{ND}$ & & $\mathrm{ND}$ & & $\mathrm{NA}$ & & $\mathrm{NA}$ & & $\mathrm{NA}$ & & $\mathrm{NA}$ \\
\hline Bis(2-chloroethyl) ether & $0 / 5$ & ND & ND & & $\mathrm{ND}$ & & NA & & NA & $5.80 \mathrm{E}+03$ & $0 / 5$ & & $\mathrm{NA}$ \\
\hline Bis(2-chloroisopropyl) ether & $0 / 5$ & ND & ND & & ND & & NA & & NA & $7.40 \mathrm{E}+04$ & $0 / 5$ & & $\mathrm{NA}$ \\
\hline Bis(2-ethylhexyl)phthalate & $1 / 5$ & $160 \mathrm{~J}$ & $160 \mathrm{~J}$ & Z2-EU43B-302 & 160 & & NA & & NA & $1.20 \mathrm{E}+06$ & $0 / 5$ & & NA \\
\hline Butyl benzyl phthalate & $1 / 5$ & $38 \mathrm{~J}$ & $38 \mathrm{~J}$ & Z2-EU43B-302 & 38 & & NA & & NA & $1.00 \mathrm{E}+08$ & $0 / 5$ & & NA \\
\hline Carbazole & $0 / 5$ & ND & ND & & ND & & $\mathrm{NA}$ & & $\mathrm{NA}$ & $8.60 \mathrm{E}+05$ & $0 / 5$ & & $\mathrm{NA}$ \\
\hline Chrysene & $2 / 5$ & $140 \mathrm{~J}$ & $420 \mathrm{~J}$ & Z2-EU43B-301 & 280 & & $\mathrm{NA}$ & & $\mathrm{NA}$ & $2.10 \mathrm{E}+06$ & $0 / 5$ & & $\mathrm{NA}$ \\
\hline Di-n-butyl phthalate & $0 / 5$ & ND & ND & & ND & & $\mathrm{NA}$ & & NA & $6.20 \mathrm{E}+07$ & $0 / 5$ & & $\mathrm{NA}$ \\
\hline Di-n-octylphthalate & $0 / 5$ & ND & ND & & ND & & $\mathrm{NA}$ & & $\mathrm{NA}$ & $2.50 \mathrm{E}+07$ & $0 / 5$ & & NA \\
\hline Dibenz(a,h)anthracene & $2 / 5$ & $39 \mathrm{~J}$ & $78 \mathrm{~J}$ & Z2-EU43B-301 & 58.5 & & NA & & NA & $2.10 \mathrm{E}+03$ & $0 / 5$ & & NA \\
\hline Dibenzofuran & $0 / 5$ & ND & ND & & $\mathrm{ND}$ & & $\mathrm{NA}$ & & NA & $1.60 \mathrm{E}+06$ & $0 / 5$ & & NA \\
\hline Diethyl phthalate & $0 / 5$ & $\mathrm{ND}$ & $\mathrm{ND}$ & & $\mathrm{ND}$ & & NA & & $\mathrm{NA}$ & $1.00 \mathrm{E}+08$ & $0 / 5$ & & NA \\
\hline Dimethyl phthalate & $0 / 5$ & $\mathrm{ND}$ & ND & & $\mathrm{ND}$ & & $\mathrm{NA}$ & & $\mathrm{NA}$ & $1.00 \mathrm{E}+08$ & $0 / 5$ & & NA \\
\hline Diphenyldiazene & $0 / 5$ & $\mathrm{ND}$ & ND & & ND & & NA & & NA & $1.60 \mathrm{E}+05$ & $0 / 5$ & & $\mathrm{NA}$ \\
\hline Fluoranthene & $3 / 5$ & $45 \mathrm{~J}$ & 740 & Z2-EU43B-301 & 338.33 & & $\mathrm{NA}$ & & $\mathrm{NA}$ & $2.20 \mathrm{E}+07$ & $0 / 5$ & & $\mathrm{NA}$ \\
\hline Fluorene & $0 / 5$ & $\mathrm{ND}$ & ND & & ND & & NA & & NA & $2.60 \mathrm{E}+07$ & $0 / 5$ & & NA \\
\hline Hexachlorobenzene & $0 / 5$ & $\mathrm{ND}$ & $\mathrm{ND}$ & & $\mathrm{ND}$ & & NA & & NA & $1.10 \mathrm{E}+04$ & $0 / 5$ & & NA \\
\hline Hexachlorobutadiene & $0 / 5$ & ND & ND & & $\mathrm{ND}$ & & NA & & $\mathrm{NA}$ & $1.80 \mathrm{E}+05$ & $0 / 5$ & & NA \\
\hline Hexachlorocyclopentadiene & $0 / 5$ & ND & ND & & $\mathrm{ND}$ & & $\mathrm{NA}$ & & $\mathrm{NA}$ & $3.70 \mathrm{E}+06$ & $0 / 5$ & & $\mathrm{NA}$ \\
\hline Hexachloroethane & $0 / 5$ & $\mathrm{ND}$ & $\mathrm{ND}$ & & $\mathrm{ND}$ & & NA & & NA & $6.20 \mathrm{E}+05$ & $0 / 5$ & & NA \\
\hline Indeno(1,2,3-cd)pyrene & $2 / 5$ & $160 \mathrm{~J}$ & $430 \mathrm{~J}$ & Z2-EU43B-301 & 295 & & $\mathrm{NA}$ & & $\mathrm{NA}$ & $2.10 \mathrm{E}+04$ & $0 / 5$ & & $\mathrm{NA}$ \\
\hline Isophorone & $0 / 5$ & ND & ND & & ND & & NA & & $\mathrm{NA}$ & $5.10 \mathrm{E}+06$ & $0 / 5$ & & $\mathrm{NA}$ \\
\hline N-Nitroso -di-n-propylamine & $0 / 5$ & $\mathrm{ND}$ & $\mathrm{ND}$ & & $\mathrm{ND}$ & & NA & & NA & $2.50 \mathrm{E}+03$ & $0 / 5$ & & $\mathrm{NA}$ \\
\hline N-Nitrosodimethylamine & $0 / 5$ & ND & $\mathrm{ND}$ & & $\mathrm{ND}$ & & $\mathrm{NA}$ & & NA & $3.40 \mathrm{E}+02$ & $0 / 5$ & & NA \\
\hline N-Nitrosodiphenylamine & $0 / 5$ & ND & $\mathrm{ND}$ & & $\mathrm{ND}$ & & $\mathrm{NA}$ & & $\mathrm{NA}$ & $3.50 \mathrm{E}+06$ & $0 / 5$ & & $\mathrm{NA}$ \\
\hline Naphthalene & $0 / 5$ & ND & ND & & $\mathrm{ND}$ & & NA & & NA & $1.90 \mathrm{E}+05$ & $0 / 5$ & & NA \\
\hline Nitrobenzene & $0 / 5$ & ND & $\mathrm{ND}$ & & $\mathrm{ND}$ & & NA & & NA & $1.00 \mathrm{E}+05$ & $0 / 5$ & & NA \\
\hline Pentachlorophenol & $0 / 5$ & ND & ND & & ND & & $\mathrm{NA}$ & & NA & $9.00 \mathrm{E}+04$ & $0 / 5$ & & NA \\
\hline Phenanthrene & $2 / 5$ & $100 \mathrm{~J}$ & $230 \mathrm{~J}$ & Z2-EU43B-301 & 165 & & $\mathrm{NA}$ & & $\mathrm{NA}$ & $2.90 \mathrm{E}+07$ & $0 / 5$ & & NA \\
\hline
\end{tabular}


Table J.3. (continued)

\begin{tabular}{|c|c|c|c|c|c|c|c|c|c|c|c|c|c|}
\hline Analyte & $\begin{array}{c}\text { Frequency } \\
\text { of detect }\end{array}$ & $\begin{array}{c}\text { Minimum } \\
\text { detect }\end{array}$ & $\begin{array}{c}\text { Maximum } \\
\text { detect }\end{array}$ & $\begin{array}{c}\text { Location(s) } \\
\text { of maximum } \\
\text { detected result }\end{array}$ & $\begin{array}{c}\begin{array}{c}\text { Average } \\
\text { detected result }\end{array} \\
\text {. }\end{array}$ & Max RL & 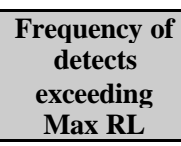 & Avg RL & $\begin{array}{c}\begin{array}{c}\text { Frequency } \\
\text { of detects } \\
\text { exceeding Avg RL }\end{array} \\
\text { exces }\end{array}$ & $\begin{array}{l}\text { PRG limit } \\
\left(10^{-5} \text { or } 1\right)\end{array}$ & $\begin{array}{l}\text { Frequency of detects } \\
\text { exceeding PRG limit }\end{array}$ & $\begin{array}{l}\text { Background } \\
\text { concentration }\end{array}$ & $\begin{array}{l}\text { Frequency of detects } \\
\text { exceeding background }\end{array}$ \\
\hline Phenol & $0 / 5$ & ND & $\mathrm{ND}$ & & $\mathrm{ND}$ & & NA & & NA & $1.00 \mathrm{E}+08$ & $0 / 5$ & & NA \\
\hline Pyrene & $2 / 5$ & $170 \mathrm{~J}$ & 540 & Z2-EU43B-301 & 355 & & NA & & NA & $2.90 \mathrm{E}+07$ & $0 / 5$ & & NA \\
\hline Pyridine & $0 / 5$ & ND & ND & & ND & & NA & & NA & $6.20 \mathrm{E}+05$ & $0 / 5$ & & NA \\
\hline m+p Methylphenol & $0 / 5$ & ND & ND & & ND & & NA & & NA & & NA & & NA \\
\hline
\end{tabular}

Definition of validation qualifiers: $\mathrm{J}=$ analyte positively identified and result is approximate concentration of analyte in sample, and $\mathrm{U}=$ analyte was not detected above reported sample quantitation limit.

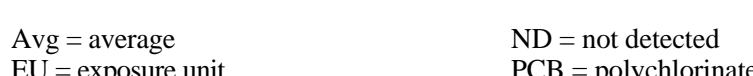

$\begin{array}{ll}\mathrm{EU}=\text { exposure unit } & \mathrm{PCB}=\text { polychlorinated biphenyl } \\ \text { Max = maximum } & \mathrm{PRG}=\text { preliminary remedintion gol }\end{array}$

$\begin{array}{ll}\text { Max }=\text { maximum } & \mathrm{PRG}=\text { polychilininarinated remedianition goal } \\ \mathrm{NA}=\text { not applicable } & \mathrm{RL}=\text { remediation level }\end{array}$ 
Appendix K

Mitchell Branch Exposure Unit Group EU Z2-44

Technical Memorandum 


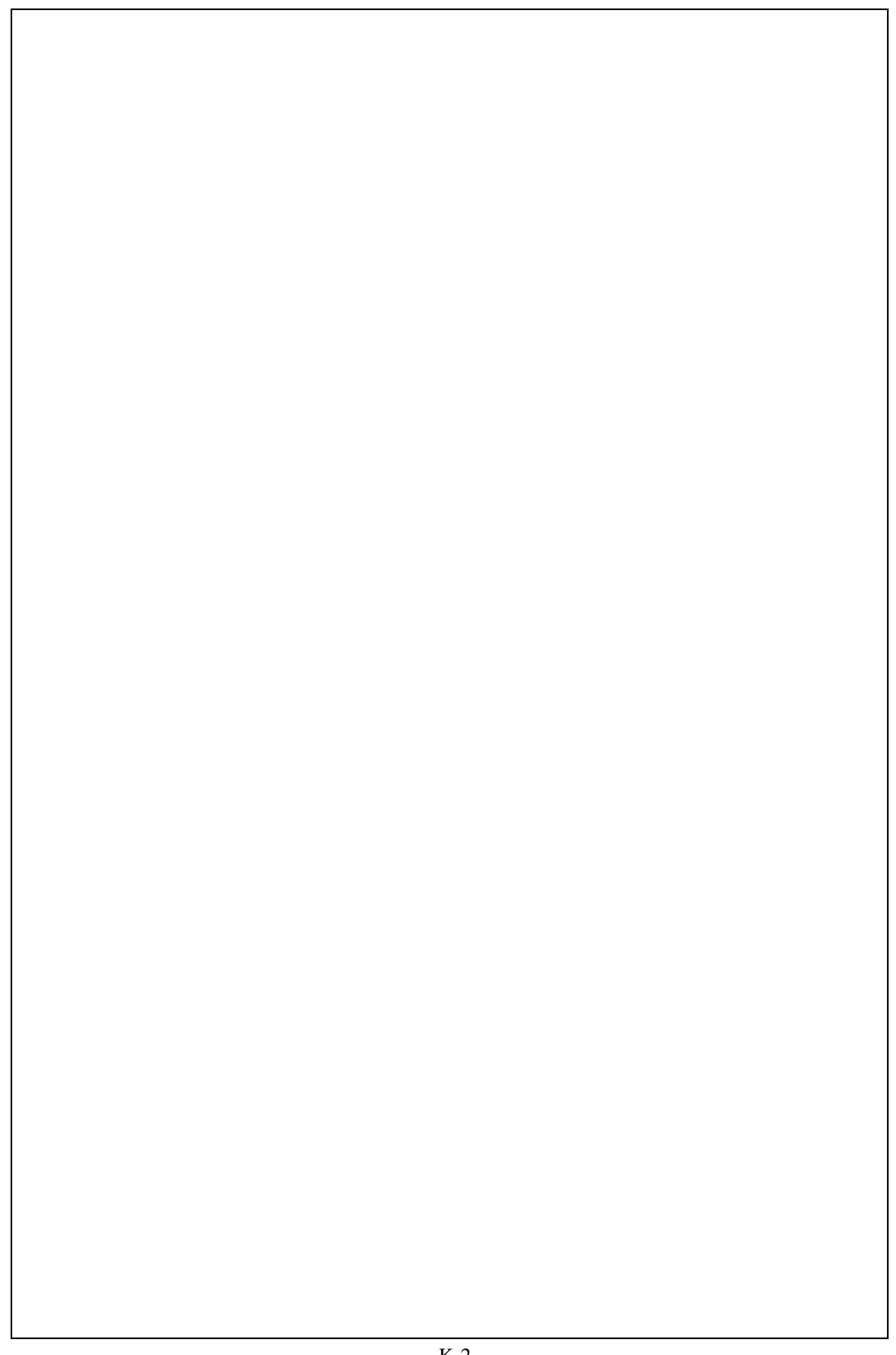

K-2 


\section{FIGURES}

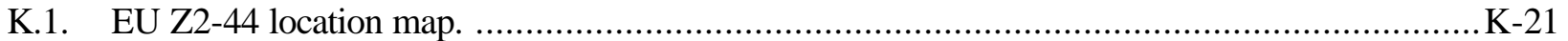

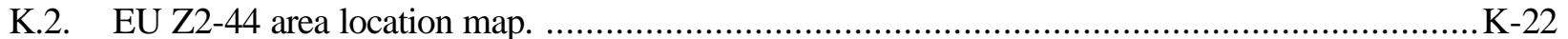

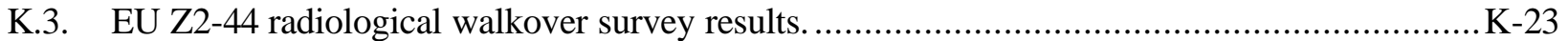

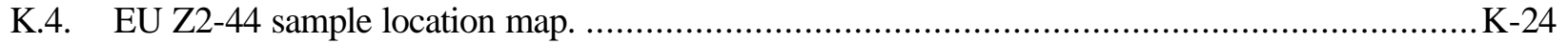

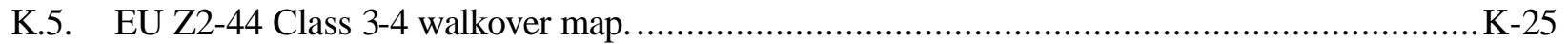

\section{TABLES}

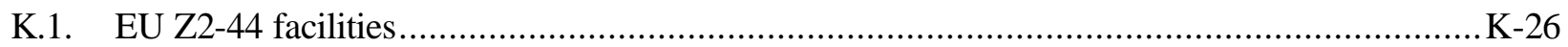

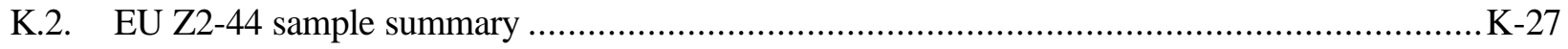

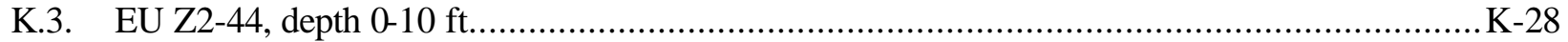




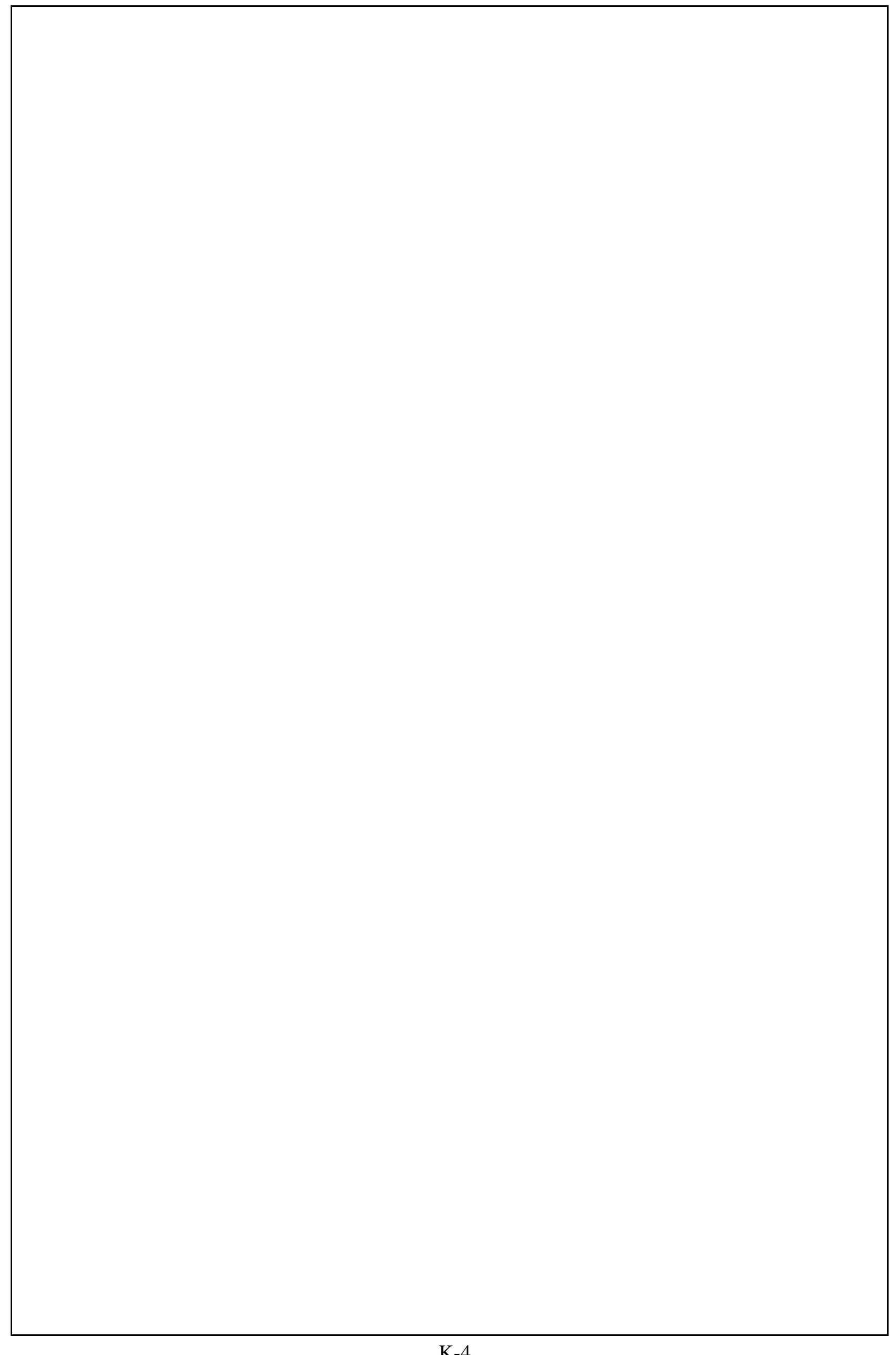

K-4 


\section{DYNAMIC VERIFICATION STRATEGY (DVS) TECHNICAL MEMORANDUM (TM)}

EXPOSURE UNIT (EU) GROUP: Zone 2 Mitchell Branch Group EU 44

\section{INTRODUCTION}

The purpose of this TM is to document the recommendation for an action/no further action (NFA) decision for Zone 2 EU 44 (EU Z2-44) in the Mitchell Branch EU Group. The recommendation for this EU is based on existing historical data and DVS soil characterization activities. These data are used to determine the nature and extent of contamination in the EU and evaluate the need for an action. When an action is determined necessary, the data are also used to calculate soil volumes for the proposed remedial alternative as identified in the Record of Decision for Soil, Buried Waste, and Subsurface Structure Actions in Zone 2, East Tennessee Technology Park, Oak Ridge, Tennessee (DOE/OR/01-2161\&D2) (Zone 2 ROD).

\begin{tabular}{|l|l|}
\hline 1.0 & BACKGROUND AND EU SUMMARY \\
\hline 1.1 & LOCATIONAT EAST TENNESSEE TECHNOLOGY PARK (ETTP) \\
\hline
\end{tabular}

EU Z2-44 is located in the northeast quadrant of Zone 2 in the Mitchell Branch EU Group (Fig. K.1). EU Z2-44 is bounded on the north by the K1700 Stream (Mitchell Branch) and Zone 1, on the east and south by U.S. Department of Energy (DOE) property, and on the west by EU Z2-39 and EU Z2-40.

EU Z2-44 has an area of approximately 16.1 acres (Fig. K.2). Approximately 6 acres of the EU are associated with the still active Toxic Substances Control Act of 1976 (TSCA) incinerator and were exempted from characterization in the Data Quality Objective (DQO) Scoping Package that was approved by the Core Team. The remaining 10.1 acres are addressed in this TM. When the TSCA site is closed (no closure data has been announced as of this writing), the facility and surrounding area exempted from the DVS evaluation will be completed.

\section{\begin{tabular}{l|l}
1.3 & SUMMARY DESCRIPTION \\
\hline
\end{tabular}}

All of the land area in EU Z2-44 has been impacted by site operations. The western two-thirds of the EU includes the K-1070-G Burial Ground, the Toxic Substances Control Act incinerator (TSCAI) and other facilities, roads, parking lots, and paved surfaces. The eastern one-third of the EU has not been as heavily impacted and includes a stand of second-growth forest. The contents of the K-1070-G Burial Ground are unknown but are believed to be construction debris based on materials present on the ground surface.

The DQO Scoping Package for the Mitchell Branch EU Group lists 22 facilities in EU Z2-44 (see Table K.1).

\section{\begin{tabular}{l|l}
1.4 & SOIL UNITS (SUS) \\
\hline
\end{tabular}}

Class 1 SU: None.

Class 2 SU: 0.6 acres covering the K-1070-G Federal Facility Agreement (FFA) site.

Class 3 SU: 9.5 acres consisting of two discrete Class 3 SUs separated by the Class 2 SU and TSCAI.

Class 4 SU: None.

Exempt acreage: Six acres of the active TSCAI facility were exempted from characterization and no sampling was conducted in that area.

EU Z2-44 soil unit boundaries are shown on Fig. K.2.

\section{\begin{tabular}{l|l}
\hline 1.5 & ZONE 2 ROD APPENDIX A FFA SITES \\
\hline
\end{tabular}}

There is one FFA site in EU Z2-44 that is listed in Appendix A of the Zone 2 ROD:

- $\quad$ K-1070-G Burial Ground 


\begin{tabular}{|c|c|}
\hline 2.0 & DVS INVESTIGATIONS AND RESULTS \\
\hline 2.1 & DVS FIELD ACTIVITIES \\
\hline \multicolumn{2}{|c|}{$\begin{array}{l}\text { DVS activities were conducted in accordance with the Remedial Design Report/Remedial Action Work Plan for } \\
\text { Zone } 2 \text { Soils, Slabs, and Infrastructure, East Tennessee Technology Park, Oak Ridge, Tennessee } \\
\text { (DOE/OR/01-2224\&D2) (Zone } 2 \text { RDR/RAWP). }\end{array}$} \\
\hline 2.1.1 & Class 1 SUs \\
\hline \multicolumn{2}{|l|}{ None } \\
\hline 2.1.1.1 & CLASS 1 SU RADIOLOGICAL WALKOVER SURVEY \\
\hline \multicolumn{2}{|l|}{ None } \\
\hline 2.1.1.2 & CLASS 1 SU GEOPHYSICAL SURVEY \\
\hline \multicolumn{2}{|l|}{ None } \\
\hline 2.1.1.3 & CLASS 1 SU SOIL SAMPLING \\
\hline \multicolumn{2}{|l|}{ None } \\
\hline 2.1 .2 & CLASS 2 SUS \\
\hline \multicolumn{2}{|c|}{$\begin{array}{l}\text { The 0.6-acre Class } 2 \text { SU acreage in EU Z2-44 encompasses the footprint of the K-1070-G Burial Ground FFA site. } \\
\text { The location of the Class } 2 \text { SU is shown on Fig. K.2. }\end{array}$} \\
\hline 2.1.2.1 & CLASS 2 SU RADIOLOGICAL WALKOVER SURVEY \\
\hline \multicolumn{2}{|c|}{$\begin{array}{l}\text { A radiological walkover survey was identified during DQO scoping for the Class } 2 \mathrm{SU} \text { in EU Z2-44 (i.e., K-1070-G } \\
\text { Burial Ground). The required survey was conducted on November 8, 2005. The surveyed area was approximately } \\
0.54 \text { acres and had } 2865 \text { discrete radiation measurements taken. Radiation measurements ranged from } 1124 \text { to } \\
2927 \mathrm{cpm} \text { Two individual measurements ( } 2912 \mathrm{cpm} \text { and } 2927 \mathrm{cpm} \text { ) met or exceeded the action level (AL) of } \\
2912 \mathrm{cpm} \text { These measurements exceeding the AL defined two points along the northern boundary of the survey that } \\
\text { were spaced approximately } 70 \mathrm{ft} \text { apart. The two readings correspond to single points and have no appreciable extent. } \\
\text { Because the exceedances were so close to the AL and were single isolated points, no biased samples were collected. } \\
\text { The location of the radiological walkover survey in EU Z2-44 is shown on Fig. K.3 and detailed in Walkover } \\
\text { Inspections and Radiological Surveys for FY2007 Exposure Units in Zones } 1 \text { and 2, East Tennessee Technology } \\
\text { Park, Oak Ridge, Tennessee (BJC/OR-2691) (Assessment Report). }\end{array}$} \\
\hline 2.1.2.2 & CLASS 2 SU GEOPHYSICAL SURVEY \\
\hline \multicolumn{2}{|l|}{ None } \\
\hline 2.1.2.3 & CLASS 2 SU SOIL SAMPLING \\
\hline \multicolumn{2}{|c|}{$\begin{array}{l}\text { The DQO Scoping Package for the Mitchell Branch EU Group called for four systematic grid sample locations in } \\
\text { the EU Z2-44 Class } 2 \text { SU (K-1070-G Burial Ground). All four locations were sampled during the EU investigation. } \\
\text { Sample locations are shown on Fig. K.4 and the details of sampling and analysis at each Class } 2 \text { SU sample location } \\
\text { are presented in Table K.2. }\end{array}$} \\
\hline 2.1 .3 & ClASS 3 AND ClASS 4 SU WALKOVER ASSESSMENT \\
\hline \multicolumn{2}{|c|}{$\begin{array}{l}\text { Protocol for addressing the Class } 3 \text { SUs in EU Z2-44 is discussed in the Class } 3 \text { and Class } 4 \text { Soil Unit Walkover } \\
\text { Inspection Protocol, Rev. } 1 \text { (found in Appendix A of the Zone } 2 \text { RDR/RAWP). Because there are no Class } 4 \text { SUs in } \\
\text { this EU, the walkover assessment will be referred to as a Class } 3 \text { SU walkover assessment. The purpose of Class } 3 \\
\text { SU walkover assessments is to systematically inspect Class } 3 \text { SUs by visual observation along transects to } \\
\text { established grid assessment locations, map observed features, and collect radiological screening data at grid and }\end{array}$} \\
\hline
\end{tabular}


discretionary locations. Details of the walkover assessment results for this EU are presented in the Assessment Report.

A summary of the report results is presented below in Sect. 2.1.3.1 and 2.1.3.2. Fig. K.5 shows the assessment point (AP), mid-point (MP), and discretionary point (DP) locations.

A total of 8 APs were identified in the EU prior to the start of fieldwork and are documented in the DQO Scoping Package. Eight APs were actually assessed during the Class 3 SU walkover assessment.

In addition to the APs, the field team made assessments at seven MP locations (MPs are selected in the field and are located approximately half way between APs) and conducted discretionary surveys at a total of seven locations.

\begin{tabular}{lccc}
\hline & Number of APs & Number of MPs & Number of DP \\
\hline EU Z2-44 & 8 & 7 & 7 \\
\hline AP $=$ assessment point & & & \\
DP = discretionary point & & & \\
MP = mid-point & & & \\
\end{tabular}

\subsubsection{1}

\section{CLASS 3 AND CLASS 4 SU RADIOLOGICAL SURVEY SUMMARY}

Screening level (SL): 2900

SL exceedances: None

\section{\begin{tabular}{|l|l} 
2.1.3.2 & CLASS 3 AND CLASS 4 SU ANTHROPOGENIC FEATURES
\end{tabular}}

\section{Number of identified anthropogenic features: None}

EU Z2-44 is located in an industrialized portion of ETTP. As such, there are numerous anthropogenic features that consist of facilities and associated constructed features such as roads, sidewalks, and paved areas. Plant facilities and their associated constructed features are assessed as part of the Class 3 and Class 4 SU walkover assessment protocol (Sect. 2.1.3.3). Other than plant facilities and associated constructed features, no anthropogenic features were identified in EU Z2-44 during the Class 3 SU walkover assessment.

Seven sediment accumulation areas were identified during the Class $3 \mathrm{SU}$ walkover assessment. Five of the seven are located at storm drain outfalls that have been sampled on previous occasions as part of the surface water and sediment sampling program and, therefore, were not selected for biased sampling. One of the two remaining sediment accumulation areas is located at a storm drain grate behind Bldg. K-1430 and the other is at a storm drain grate behind the northwest corner of Bldg. K-1425. These latter two sediment accumulation areas were selected for biased sampling.

\section{\begin{tabular}{|l|l} 
2.1.3.3 & CLASS 3 SU FACILITIES ASSESSMENTS
\end{tabular}}

Twelve facilities are listed in the DQO Scoping Package as being located in EU Z2-44 and 27 facilities were assessed during the Class $3 \mathrm{SU}$ walkover assessment (Table TABLE K.. 1). The facility assessments are reported in the Assessment Report. No facility was identified as a possible source for either chemical or radiological contamination.

\section{\begin{tabular}{|l|l}
\hline 2.1.3.4 & ClaSS 3 AND ClASS 4 SU BIASED SAMPLING
\end{tabular}}

Two DVS Class 3 SU biased sampling locations were identified during the Class 3 SU walkover assessment-one at the sediment accumulation area behind Bldg. K-1430 and the other at the sediment accumulation area behind Bldg. K-1425.

In addition, four Class $3 \mathrm{SU}$ biased sample locations were identified in during DQO scoping. The four locations are around the K-1425-A through D storage tanks.

Class 3 SU sample locations are shown on Fig. K.4 and sampling and analytical details for each location are presented in Table K.2. 
This section presents a summary of analytical results for DVS and historical samples collected in this EU. The summary begins with a tabulation of SU and infrastructure sample locations (Sects. 2.2.1 through 2.2.4), continues with focused investigation and EU data summaries (Sect. 2.2.5), and concludes with FFA site summaries (Sect. 2.2.6). Data for the samples collected in this EU are summarized in Table K.3. A compact disc containing electronic files for the historical and DVS analytical data used to generate the data tables is provided with this Phased Construction Completion Report (PCCR).

\section{\begin{tabular}{l|l} 
2.2.1 & CLASS 1 SUS
\end{tabular}}

None

\subsection{2}

\section{Class 2 SUS}

There are four DVS and one historical sample locations in the Class 2 SU of EU Z2-44. All of the DVS sample locations are systematic grid locations. The historical sample location is from the 1994 Radiological Walkover Survey. This historical sample location was located in the EU Z2-44 Class 2 SU after DQO scoping. Class 2 SU sample locations are shown on Fig. K.4 and summarized below.

\begin{tabular}{cll}
\hline EU & \multicolumn{1}{c}{ DVS sample locations } & Historical sample locations \\
\hline \multirow{2}{*}{ Z2-44 } & Systematic Grid Locations: & RAD131 \\
& Z2-EU44-200, Z2-EU44-201, Z2-EU44-202, & \\
& Z2-EU44-203 & \\
\hline
\end{tabular}

DVS = Dynamic Verification Strategy

$\mathrm{EU}=$ exposure unit

Sampling and analytical details for each sample location are presented in Table K.2. The analytical data are summarized in Table K.3 and evaluated in Sect. 2.2.5. The numbers of analyses conducted in the Class 2 SU are presented below by analyte group.

\begin{tabular}{ccccc}
\hline Metals & PCBs & Radionuclides & SVOCs & VOCs \\
\hline 4 & 4 & 3 & 4 & 2 \\
\hline PCB = polychlorinated biphenyl & & & \\
SVOC = semivolatile organic compound & & \\
VOC = volatile organic compound & & &
\end{tabular}

\section{\begin{tabular}{|l|l|}
\hline 2.2.3 & CLASS 3 AND ClASS 4 SUS \\
\hline
\end{tabular}}

There are six DVS biased sample locations and one historical sample location in the EU Z2-44 Class 3 SU. The historical sample location from the 1994 Radiological Walkover Survey was not located in the EU Z2-44 Class 3 SU until after DQO scoping. Class 3 SU sample locations are summarized below.

\begin{tabular}{cll}
\hline EU & \multicolumn{1}{c}{ DVS sample locations } & \multicolumn{1}{c}{ Historical sample locations } \\
\hline \multirow{2}{*}{ Z2-44 } & Biased Locations: & RAD133 \\
& Z2-EU44B-300, Z2-EU44B-301, Z2-EU44B-302, & \\
& Z2-EU44B-303, Z2-EU44B-304, Z2-EU44B-305 & \\
\hline
\end{tabular}

DVS = Dynamic Verification Strategy

$\mathrm{EU}=$ exposure unit

Sampling and analytical details fr each sample location are presented in Table K.2. The analytical data are summarized in Table K.3 and evaluated in Sect. 2.2.5. The numbers of analyses conducted in the Class 3 SU are presented below by analyte group. 


\begin{tabular}{cccccc}
\hline Metals & $\begin{array}{c}\text { Other } \\
\text { organics }\end{array}$ & PCBs & Radionuclides & SVOCs $^{b}$ & VOCs \\
\hline 6 & 6 & 6 & 4 & 6 & 4 \\
\hline
\end{tabular}

${ }^{a}$ Other organics $=$ DRO and GRO.

${ }^{b}$ Some SVOCs are analyzed and reported with the VOC suite of chemicals. The number of SVOC analyses reported here refers to the number of SVOC analyses specifically requested from the laboratory.

$\mathrm{DRO}=$ diesel range organic $\quad \mathrm{SVOC}=$ semivolatile organic compound

$\mathrm{GRO}=$ gasoline range organic $\quad \mathrm{VOC}=$ volatile organic compound

$\mathrm{PCB}=$ polychlorinated biphenyl

\section{\begin{tabular}{l|l} 
2.2.4 & INFRASTRUCTURE \\
\hline
\end{tabular}}

No infrastructure sampling was performed in EU Z2-44.

\section{\begin{tabular}{l|l} 
2.2.5 & EU EVALUATION
\end{tabular}}

In this section, characterization data and other information are evaluated for EU Z2-44. Analytical data in the following summaries are presented by analyte group, and results for a particular analyte group are summarized only if that group was analyzed in the samples from the unit being summarized. Within each summary, the data are evaluated by comparing to certain criteria, including the Zone 2 soils maximum remediation level (Max RL), Zone 2 soils average remediation level (Avg RL), the $1 \times 10^{-5}$ industrial preliminary remediation goal (Ind PRG), ETTP soils background composition (Bkg), Zone 2 groundwater screening levels (GW SL), and the $1 \times 10^{-6}$ residential preliminary remediation goal (Res PRG). If a particular criterion does not apply to any member of an analyte group, it is not tabulated for that analyte group; if a particular criterion does not apply to all analytes within an analyte group, those analytes to which it does not apply are notated with NA (not applicable). Individual netals and radionuclides, which are naturally occurring, are reported in the summaries only if one or more criterion is exceeded. Organic chemicals, which are not naturally occurring, are reported if they are detected even if no criteria are exceeded. The Max RL, Avg RL, Ind PRG, Bkg, GW SL, and Res PRG criteria values, as they pertain to the analytes listed in Appendix A of the RDR/RAWP (i.e., QAPP), are presented in Table 5 of this PCCR.

Because the carcinogenic risk associated with concentrations of radium and thorium is otopes in the natural background at ETTP exceeds the cumulative risk goal of $1 \times 10^{-4}$, RL values for these radionuclides are based on alternative concentration levels rather than risk. The alternative concentration levels of $5 \mathrm{pCi} / \mathrm{g}$ above background (Avg RL) and $15 \mathrm{pCi} / \mathrm{g}$ above background (Max RL) were set as low as reasonably achievable under the site-specific conditions. Because site-specific background concentrations of these radionuclides exceed the target risk range, residual concentrations of these radionuclides and their decay series are not considered in estimates of residual risk following any remedial action.

The Zone 2 ROD states that Avg and Max RL exceedances by Ra-226, Th-230, and Th-232 will be evaluated by summing above-background concentrations of the greater of Ra-226 or Th-230 with the above-background concentrations of Th-232 and comparing the results to $5 \mathrm{pCi} / \mathrm{g}$ (Avg RL) and $15 \mathrm{pCi} / \mathrm{g}$ (Max RL). The required calculations have been performed. Avg and Max RL exceedances for these radionuclides, if any, are reported in the TM data summaries below and in Table TABLE K..2 as "Ra/Th decay series", and individual RL exceedances by Ra-226, Th-230, and Th-232 are reported as NA. The Ra/Th decay series data are summarized in the sections that follow only if an Avg or Max RL has been exceeded, consistent with the description in the preceding paragraph for reporting radionuclides. Discussion of the $\mathrm{Ra} / \mathrm{Th}$ decay series calculation, including the manner in which the calculation is performed, is presented in Sect. 3.3 of the PCCR.

\section{EU Z2-44 Conceptual Site Model (CSM)}

The two CSMs applicable to EU Z2-44 are a landfill CSM, which applies to the K-1070-G Burial Ground FFA site, and a surface release model, which applies to soils in the area of the above-ground storage tanks and surface soils in proximity to the active TSCAI.

The landfill CSM was applied to the K-1070-G Burial Ground site, which dictated all four borings be drilled $10 \mathrm{ft}$ deep in that Class $2 \mathrm{SU}$ and the analytical suite include SVOCs. The K-1070-G Burial Ground is in proximity to Mitchell Branch along its north boundary. The site has a 2-ft-thick clay cap over the burial area, and no large debris 
or rubble was encountered during drilling and no obvious waste materials were observed in the soil cores. Some small black particles were noted that were identified as coal fines.

Potential releases of contaminants from the landfill site are considered low to moderate, release to air from buried waste materials is considered low because the waste is buried, release from buried waste materials to surface water is considered low because the site has an intact cover, and release from the waste materials to groundwater is considered moderate. Depth to water in the area is estimated to be below the base of the landfill. Saturated conditions within the landfill materials would occur during flooding conditions, which has occurred on occasion in the past. Subsequent leaching and transport during these conditions is considered to be a minimal potential threat to Mitchell Branch.

Contaminant release to surface soils is the predominant CSM for EU Z2-44. Waste handling operations occur in the area associated with the TSCAI. Also, there is an above-ground storage tank west of the incinerator site that could have been a release site to surface soils. Sampling in the area does not indicate any surface releases have occurred.

\section{EU Z2-44 Groundwater Evaluation}

There are no groundwater wells in EU Z2-44. The closest wells are located to the west and upgradient of the K-1420 building site. These upgradient wells are considered baseline wells for comparison to monitoring wells in proximity to the K-1420 site. Groundwater in the area ranges from approximately $5 \mathrm{ft}$ bgs along the southern boundary of the EU to approximately $15 \mathrm{ft}$ bgs beneath the K-1070 G landfill. A topographic knoll underlain by a Rome formation is immediately south of the EU. The north flank of this knoll was cut during construction of the TSCAI and associated facilities. The local water Table K.is near the ground surface along the southern line of the EU, with flow to the north toward Mitchell Branch. There are no identified sources of soil contamination in the area and there are no areas identified where surface releases of contamination have impacted surface soils. There is no contaminant mass in EU Z2-44 that poses a threat to groundwater.

\section{EU Z2-44 Sampling Results}

The 16 acres of EU Z2-44 have been classified into a Class 2 SU covering 0.6 acres and two Class 3 SUs with a combined land area of 9.5 acres; the 6 acres of the active TSCAI facility were not classified or investigated for reporting in this TM. The Class $2 \mathrm{SU}$ is defined by the footprint of the K-1070-G Burial Ground FFA site. Four DVS systematic grid sample locations were identified in the Class $2 \mathrm{SU}$.

A walkover assessment was conducted over the Class $3 \mathrm{SU}$ in this EU. No anthropogenic features other than facilities were identified. Twenty-seven facilities were assessed during the Class 3 SU walkover assessment (Table K.1). No biased sampling was conducted based on facility assessments. Two biased sample locations were identified in sediment accumulation areas in the Class 3 SU. During DQO scoping, four DVS biased sample locations were identified in the Class 3 SU around the K-1425-A through D storage tanks.

In addition to the DVS systematic grid and biased sampling locations, there are two historical sample locations in this EU (one location is in the Class 2 SU and the other location is in the Class $3 \mathrm{SU}$ ).

A summary of sampling results for EU Z2-44 is discussed below. The summation begins with summary presentations of analytical results for the focused sampling efforts and concludes with an overall summary for this EU. The focused sampling efforts summarized below include the Class 2 SU DVS and historical sampling, Class 3 SU DVS biased sampling around the K-1425-A through D storage tanks, Class 3 SU biased sampling in the sediment accumulation areas, and historical sampling in the Class 3 SU. The EU summary concludes with both data summary tables and a written description of the nature and extent of the chemicals and radionuclides observed. A summary of all EU Z2-44 data is presented in Table K.3 and sample locations are shown on Fig. K.4.

DVS Systematic Grid Sampling in the Class 2 SU: The EU Z2-44 Class 2 SU is located on the footprint of the K-1070-G Burial Ground FFA site (Sect.1.5). There are four DVS systematic grid sample locations and one historical sample location in the Class 2 SU. Sample locations are presented in Sect. 2.2.2. Details of sampling at each sample location are presented in Table K.2. Analytical results summarized below show radionuclide industrial PRG exceedances, background exceedances by five metals and one radionuclide, and detections of SVOCs . 
EU Z2-44 CLASS 2 SU METALS WITH B ACKGROUND, PRG, GW SL, AND/OR RL EXCEEDANCES (mg/kg)

\begin{tabular}{|c|c|c|c|c|c|c|c|c|c|c|c|}
\hline \multirow[b]{2}{*}{ Analyte } & \multirow[b]{2}{*}{$\begin{array}{c}\text { Detect } \\
\text { frequency }\end{array}$} & \multirow[b]{2}{*}{$\begin{array}{c}\text { Minimum } \\
\text { detect }\end{array}$} & \multirow[b]{2}{*}{$\begin{array}{c}\text { Maximum } \\
\text { detect }\end{array}$} & \multirow{2}{*}{$\begin{array}{c}\text { Location(s) of } \\
\text { maximum } \\
\text { detect }\end{array}$} & \multirow{2}{*}{$\begin{array}{c}\text { Average } \\
\text { detected } \\
\text { result }\end{array}$} & \multicolumn{6}{|c|}{ Number of analyses exceeding criteria } \\
\hline & & & & & & $\begin{array}{c}\text { Max } \\
\text { RL }\end{array}$ & $\begin{array}{l}\text { Avg } \\
\text { RL }\end{array}$ & $\begin{array}{l}\text { Ind } \\
\text { PRG }\end{array}$ & Bkg & $\begin{array}{c}\text { GW } \\
\text { SL }\end{array}$ & $\begin{array}{l}\text { Res } \\
\text { PRG }\end{array}$ \\
\hline Aluminum & $4 / 4$ & 15,000 & 18,000 & Z2-EU44-202 & 16,500 & NA & $\overline{\mathrm{NA}}$ & 0 & 0 & $\overline{\mathrm{NA}}$ & 4 \\
\hline Arsenic & $4 / 4$ & 3.5 & 5.6 & Z2-EU44-203 & 4.63 & 0 & 0 & 0 & 0 & 0 & 4 \\
\hline Cadmium & $4 / 4$ & 0.44 & 0.79 & Z2-EU44-200 & 0.615 & NA & NA & 0 & 4 & NA & 0 \\
\hline Calcium & $4 / 4$ & $2,300 \mathrm{~J}$ & $10,000 \mathrm{~J}$ & Z2-EU44-203 & 4,575 & NA & NA & NA & 3 & NA & NA \\
\hline Chromium & $4 / 4$ & $28 \mathrm{~J}$ & $33 \mathrm{~J}$ & $\begin{array}{l}\text { Z2-EU44-200 } \\
\text { Z2-EU44-201 }\end{array}$ & 31.8 & NA & NA & 0 & 0 & 0 & 4 \\
\hline Copper & $4 / 4$ & $24 \mathrm{~J}$ & $38 \mathrm{~J}$ & $\begin{array}{l}\text { Z2-EU44-202 } \\
\text { Z2-EU44-203 }\end{array}$ & 30.5 & NA & NA & 0 & 4 & NA & 0 \\
\hline Magnesium & $4 / 4$ & $3,500 \mathrm{~J}$ & $4,600 \mathrm{~J}$ & $\begin{array}{l}\text { Z2-EU44-201 } \\
\text { Z2-EU44-203 }\end{array}$ & 4,125 & NA & NA & NA & 4 & NA & NA \\
\hline Manganese & $4 / 4$ & 500 & 820 & Z2-EU44-203 & 635 & NA & NA & 0 & 0 & NA & 4 \\
\hline Nickel & $4 / 4$ & $47 \mathrm{~J}$ & $89 \mathrm{~J}$ & Z2-EU44-203 & 58 & NA & NA & 0 & 4 & NA & 0 \\
\hline Uranium & $4 / 4$ & 0.72 & 8.4 & Z2-EU44-200 & 2.74 & NA & NA & 0 & NA & NA & 1 \\
\hline Vanadium & $4 / 4$ & 28 & 32 & Z2-EU44-200 & 30.3 & NA & NA & 0 & 0 & NA & 4 \\
\hline
\end{tabular}

Avg = average NA = not applicable

$\mathrm{Bkg}=$ background $\quad \mathrm{PRG}=$ preliminary remediation goal

$\mathrm{EU}=$ exposure unit $\quad$ Res $=$ residential

$\mathrm{GW}=$ groundwater $\quad \mathrm{RL}=$ remediation level

Ind $=$ industrial $\quad \mathrm{SL}=$ screening level

Max = maximum $\quad$ SU $=$ soil unit

PCBs were analyzed for in all four samples but were not detected.

EU Z2-44 CLASS 2 SU RADIONUCLIDES WITH BACKGROUND, PRG, AND/OR RL EXCEEDANCES (pCi/g)

\begin{tabular}{|c|c|c|c|c|c|c|c|c|c|c|c|}
\hline \multirow[b]{2}{*}{ Analyte } & \multirow[b]{2}{*}{$\begin{array}{c}\text { Detect } \\
\text { frequency }\end{array}$} & \multirow[b]{2}{*}{$\begin{array}{c}\text { Minimum } \\
\text { detect }\end{array}$} & \multirow[b]{2}{*}{$\begin{array}{c}\text { Maximum } \\
\text { detect }\end{array}$} & \multirow[b]{2}{*}{$\begin{array}{c}\text { Location(s) of } \\
\text { maximum detect }\end{array}$} & \multirow{2}{*}{$\begin{array}{c}\text { Average } \\
\text { detected } \\
\text { result }\end{array}$} & \multicolumn{6}{|c|}{ Number of analyses exceeding criteria } \\
\hline & & & & & & $\begin{array}{c}\text { Max } \\
\text { RL }\end{array}$ & $\begin{array}{l}\text { Avg } \\
\text { RL }\end{array}$ & $\begin{array}{l}\text { Ind } \\
\text { PRG }\end{array}$ & Bkg & $\begin{array}{c}\text { GW } \\
\text { SL }\end{array}$ & $\begin{array}{l}\text { Res } \\
\text { PRG }\end{array}$ \\
\hline Cesium-137 & $1 / 3$ & 0.22 & 0.22 & RAD131 & 0.22 & 0 & 0 & 0 & NA & NA & 1 \\
\hline Neptunium-237 & $1 / 3$ & 0.29 & 0.29 & RAD131 & 0.29 & 0 & 0 & 0 & NA & NA & 1 \\
\hline Potassium-40 & $3 / 3$ & 14.6 & 18.9 & RAD131 & 16.5 & NA & NA & 3 & 0 & NA & 3 \\
\hline Radium-226 & $3 / 3$ & 0.6 & 1.31 & Z2-EU44-202 & 0.897 & NA & NA & 3 & 1 & NA & 3 \\
\hline Thorium -228 & $3 / 3$ & 0.88 & 1.6 & Z2-EU44-200 & 1.33 & NA & NA & 3 & 0 & NA & 3 \\
\hline Thorium -232 & $3 / 3$ & 1.12 & 1.41 & RAD131 & 1.27 & NA & NA & 3 & 0 & NA & 3 \\
\hline Uranium-238 & $3 / 3$ & 0.765 & 1.1 & RAD131 & 0.918 & 0 & 0 & 0 & 0 & 0 & 3 \\
\hline
\end{tabular}

Avg = average NA = not applicable

$\mathrm{Bkg}=$ background $\quad \mathrm{PRG}=$ preliminary remediation goal

$\mathrm{EU}=$ exposure unit $\quad$ Res $=$ residential

$\mathrm{GW}=$ groundwater $\quad \mathrm{RL}=$ remediation level

Ind $=$ industrial $\quad \mathrm{SL}=$ screening level

Max = maximum $\quad \mathrm{SU}=$ soil unit 


\begin{tabular}{|c|c|c|c|c|c|c|c|c|}
\hline \multirow[b]{2}{*}{ Analyte } & \multirow[b]{2}{*}{$\begin{array}{c}\text { Detect } \\
\text { frequency }\end{array}$} & \multirow[b]{2}{*}{$\begin{array}{c}\text { Minimum } \\
\text { detect }\end{array}$} & \multirow[b]{2}{*}{$\begin{array}{c}\text { Maximum } \\
\text { detect }\end{array}$} & \multirow{2}{*}{$\begin{array}{c}\text { Location(s) of } \\
\text { maximum } \\
\text { detect }\end{array}$} & \multirow{2}{*}{$\begin{array}{c}\text { Average } \\
\text { detected } \\
\text { result }\end{array}$} & \multicolumn{3}{|c|}{$\begin{array}{c}\text { Number of analyses } \\
\text { exceeding crite ria }\end{array}$} \\
\hline & & & & & & $\begin{array}{l}\text { Ind } \\
\text { PRG }\end{array}$ & $\begin{array}{l}\text { GW } \\
\text { SL }\end{array}$ & $\begin{array}{l}\text { Res } \\
\text { PRG }\end{array}$ \\
\hline 2-Methylnaphthalene & $1 / 4$ & $91 \mathrm{~J}$ & $91 \mathrm{~J}$ & Z2-EU44-202 & 91 & 0 & NA & NA \\
\hline Benz(a)anthracene & $2 / 4$ & $36 \mathrm{~J}$ & $45 \mathrm{~J}$ & Z2-EU44-202 & 40.5 & 0 & NA & 0 \\
\hline Benzo(a)pyrene & $2 / 4$ & $37 \mathrm{~J}$ & $45 \mathrm{~J}$ & Z2-EU44-202 & 41 & 0 & NA & 0 \\
\hline Benzo(b)fluoranthene & $2 / 4$ & $52 \mathrm{~J}$ & $69 \mathrm{~J}$ & Z2-EU44-202 & 60.5 & 0 & NA & 0 \\
\hline Benzo(k)fluoranthene & $2 / 4$ & $26 \mathrm{~J}$ & $27 \mathrm{~J}$ & Z2-EU44-202 & 26.5 & 0 & NA & 0 \\
\hline Chrysene & $2 / 4$ & $35 \mathrm{~J}$ & $38 \mathrm{~J}$ & Z2-EU44-202 & 36.5 & 0 & NA & 0 \\
\hline Fluoranthene & $2 / 4$ & $78 \mathrm{~J}$ & $92 \mathrm{~J}$ & Z2-EU44-202 & 85 & 0 & NA & 0 \\
\hline Phenanthrene & $2 / 4$ & $45 \mathrm{~J}$ & $82 \mathrm{~J}$ & Z2-EU44-202 & 63.5 & 0 & NA & 0 \\
\hline Pyrene & $2 / 4$ & $57 \mathrm{~J}$ & $68 \mathrm{~J}$ & Z2-EU44-202 & 62.5 & 0 & NA & 0 \\
\hline $\begin{array}{l}\text { EU }=\text { exposure unit } \\
\mathrm{GW}=\text { groundwater } \\
\text { Ind }=\text { industrial } \\
\mathrm{NA}=\text { not applicable } \\
\text { PRG = preliminary re }\end{array}$ & ation $\mathrm{g}$ & $\begin{array}{l}\text { Res }=\text { resi } \\
\text { SL }=\text { scre } \\
\text { SU }=\text { soil } \\
\text { SVOC }=\text { s }\end{array}$ & $\begin{array}{l}\text { dential } \\
\text { ening level } \\
\text { unit } \\
\text { semivolatile o }\end{array}$ & rganic compound & & & & \\
\hline
\end{tabular}

VOCs were analyzed for in two samples but were not detected.

DVS Class 3 SU Biased Sampling at the K-1425-A through D Storage Tanks: There are four DVS biased sample locations in the Class $3 \mathrm{SU}$ around the K1425-A through D storage tanks (Z2-EU44B-300, Z2-EU44B-301, Z2-EU44B-302, and Z2-EU44B-303). Details of DVS sampling at each sample location are presented in Table K.2. Analytical results summarized below show one metal (arsenic) and several radionuclide industrial PRG exceedances, background exceedances by 10 metals and 5 radionuclides, and detections of SVOCs .

Diesel-range organics (DROs) and gasoline-range organics were analyzed in all four samples but were not detected.

\section{EU Z2-44 CLASS 3 SU K-1425 STORAGE TANKS METALS WITH BACKGROUND,} PRG, GW SL, AND/OR RL EXCEEDANCES (mg/kg)

\begin{tabular}{|c|c|c|c|c|c|c|c|c|c|c|c|}
\hline \multirow[b]{2}{*}{ Analyte } & \multirow[b]{2}{*}{$\begin{array}{l}\text { Detect } \\
\text { frequency }\end{array}$} & \multirow[b]{2}{*}{$\begin{array}{c}\text { Minimum } \\
\text { detect }\end{array}$} & \multirow[b]{2}{*}{$\begin{array}{c}\text { Maximum } \\
\text { detect }\end{array}$} & \multirow{2}{*}{$\begin{array}{l}\text { Location(s) of } \\
\text { maximum } \\
\text { detect }\end{array}$} & \multirow{2}{*}{$\begin{array}{c}\text { Average } \\
\text { detected } \\
\text { result }\end{array}$} & \multicolumn{6}{|c|}{ Number of analyses exceeding criteria } \\
\hline & & & & & & $\begin{array}{c}\text { Max } \\
\text { RL }\end{array}$ & $\begin{array}{l}\text { Avg } \\
\text { RL }\end{array}$ & $\begin{array}{l}\text { Ind } \\
\text { PRG }\end{array}$ & Bkg & $\begin{array}{l}\text { GW } \\
\text { SL }\end{array}$ & $\begin{array}{r}\text { Res } \\
\text { PRG }\end{array}$ \\
\hline Aluminum & $4 / 4$ & 12,000 & 15,000 & $\begin{array}{l}\text { Z2-EU44B-301 } \\
\text { Z2-EU44B-303 }\end{array}$ & 13,500 & NA & NA & 0 & 0 & NA & 4 \\
\hline Arsenic & $4 / 4$ & 4.5 & 48 & Z2-EU44B-301 & 20.0 & 0 & 0 & 2 & 2 & 0 & 4 \\
\hline Barium & $4 / 4$ & $51 \mathrm{~J}$ & $150 \mathrm{~J}$ & Z2-EU44B-303 & 85.5 & NA & NA & 0 & 1 & 0 & 0 \\
\hline Cadmium & $4 / 4$ & 0.31 & 1.3 & Z2-EU44B-301 & 0.673 & NA & NA & 0 & 4 & NA & 0 \\
\hline Calcium & $4 / 4$ & $520 \mathrm{~J}$ & $56,000 \mathrm{~J}$ & Z2-EU44B-303 & 16,255 & NA & NA & NA & 2 & NA & NA \\
\hline Chromium & $4 / 4$ & $21 \mathrm{~J}$ & 39J & Z2-EU44B-301 & 29 & NA & NA & 0 & 0 & 0 & 3 \\
\hline Copper & $4 / 4$ & $10 \mathrm{~J}$ & $430 \mathrm{~J}$ & Z2-EU44B-301 & 119.5 & NA & NA & 0 & 1 & NA & 1 \\
\hline Lead & $4 / 4$ & $7.8 \mathrm{~J}$ & $70 \mathrm{~J}$ & Z2-EU44B-301 & 31.5 & NA & NA & 0 & 1 & 0 & 0 \\
\hline Magnesium & $4 / 4$ & $1,100 \mathrm{~J}$ & $22,000 \mathrm{~J}$ & Z2-EU44B-303 & 6,725 & NA & NA & NA & 1 & NA & NA \\
\hline Manganese & $4 / 4$ & 420 & 1,000 & Z2-EU44B-301 & 600 & NA & NA & 0 & 0 & NA & 4 \\
\hline Nickel & $4 / 4$ & 23 & 990J & Z2-EU44B-301 & 265 & NA & NA & 0 & 1 & NA & 1 \\
\hline Uranium & $4 / 4$ & 0.72 & 2.5 & Z2-EU44B-301 & 1.37 & NA & NA & 0 & NA & NA & 1 \\
\hline Vanadium & $4 / 4$ & 27 & 90 & Z2-EU44B-301 & 48.3 & NA & NA & 0 & 1 & NA & 4 \\
\hline Zinc & $4 / 4$ & $22 \mathrm{~J}$ & $190 \mathrm{~J}$ & Z2-EU44B-301 & 74.8 & NA & NA & 0 & 1 & NA & 0 \\
\hline
\end{tabular}

Avg = average $\quad$ NA $=$ not applicable

$\mathrm{Bkg}=$ background $\quad \mathrm{PRG}=$ preliminary remediation goal

$\mathrm{EU}=$ exposure unit $\quad$ Res $=$ residential

$\mathrm{GW}=$ groundwater $\quad \mathrm{RL}=$ remediation level

Ind $=$ industrial $\quad \mathrm{SL}=$ screening level

Max = maximum $\quad \mathrm{SU}=$ soil unit

PCBs were analyzed for in all four samples but were not detected. 
EU Z2-44 CLASS 3 SU K-1425 STORAGE TANKS RADIONUCLIDES WITH

BACKGROUND, PRG, AND/OR RL EXCEEDANCES (pCi/g)

\begin{tabular}{|c|c|c|c|c|c|c|c|c|c|c|c|}
\hline \multirow[b]{2}{*}{ Analyte } & \multirow[b]{2}{*}{$\begin{array}{c}\text { Detect } \\
\text { frequency }\end{array}$} & \multirow[b]{2}{*}{$\begin{array}{c}\text { Minimum } \\
\text { detect }\end{array}$} & \multirow[b]{2}{*}{$\begin{array}{c}\text { Maximum } \\
\text { detect }\end{array}$} & \multirow[b]{2}{*}{$\begin{array}{c}\text { Location(s) of } \\
\text { maximum detect }\end{array}$} & \multirow{2}{*}{$\begin{array}{c}\text { Average } \\
\text { detected } \\
\text { result }\end{array}$} & \multicolumn{6}{|c|}{ Number of analyses exceeding criteria } \\
\hline & & & & & & $\begin{array}{c}\text { Max } \\
\text { RL }\end{array}$ & $\begin{array}{l}\text { Avg } \\
\text { RL }\end{array}$ & $\begin{array}{l}\text { Ind } \\
\text { PRG }\end{array}$ & Bkg & $\begin{array}{c}\text { GW } \\
\text { SL }\end{array}$ & $\begin{array}{l}\text { Res } \\
\text { PRG }\end{array}$ \\
\hline Potassium-40 & $2 / 2$ & $4.62 \mathrm{~J}$ & 11.8 & Z2-EU44B-300 & 8.21 & NA & NA & 2 & 0 & NA & 2 \\
\hline Radium-226 & $2 / 2$ & 0.82 & 2.49 & Z2-EU44B-301 & 1.66 & NA & NA & 2 & 1 & NA & 2 \\
\hline Thorium -228 & $2 / 2$ & 1.63 & 1.93 & Z2-EU44B-301 & 1.78 & NA & NA & 2 & 1 & NA & 2 \\
\hline Thorium -230 & $2 / 2$ & 1.63 & 2.7 & Z2-EU44B-301 & 2.17 & NA & NA & 0 & 2 & NA & 0 \\
\hline Thorium -232 & $2 / 2$ & 1.59 & 2.74 & Z2-EU44B-301 & 2.17 & NA & NA & 2 & 1 & NA & 2 \\
\hline Uranium-238 & $2 / 2$ & 1.89 & 2.23 & Z2-EU44B-301 & 2.06 & 0 & 0 & 0 & 2 & 0 & 2 \\
\hline
\end{tabular}

\begin{tabular}{ll}
\hline Avg $=$ average & $\mathrm{NA}=$ not applicable \\
$\mathrm{Bkg}=$ background & $\mathrm{PRG}=$ preliminary remediation goal \\
$\mathrm{EU}=$ exposure unit & Res $=$ residential \\
$\mathrm{GW}=$ groundwater & $\mathrm{RL}=$ remediation level \\
$\mathrm{Ind}=$ industrial & $\mathrm{SL}=$ screening level \\
$\mathrm{Max}=$ maximum & $\mathrm{SU}=$ soil unit
\end{tabular}

EU Z2-44 CLASS 3 SU K-1425 STORAGE TANKSSVOC DETECTS (ug/kg)

\begin{tabular}{|c|c|c|c|c|c|c|c|c|}
\hline \multirow[b]{2}{*}{ Analyte } & \multirow[b]{2}{*}{$\begin{array}{c}\text { Detect } \\
\text { frequency }\end{array}$} & \multirow[b]{2}{*}{$\begin{array}{c}\text { Minimum } \\
\text { detect }\end{array}$} & \multirow[b]{2}{*}{$\begin{array}{c}\text { Maximum } \\
\text { detect }\end{array}$} & \multirow{2}{*}{$\begin{array}{c}\text { Location(s) of } \\
\text { maximum } \\
\text { detect }\end{array}$} & \multirow{2}{*}{$\begin{array}{c}\text { Average } \\
\text { detected } \\
\text { result }\end{array}$} & \multicolumn{3}{|c|}{$\begin{array}{l}\text { Number of analyses } \\
\text { exceeding criteria }\end{array}$} \\
\hline & & & & & & $\begin{array}{l}\text { Ind } \\
\text { PRG }\end{array}$ & $\begin{array}{c}\text { GW } \\
\text { SL }\end{array}$ & $\begin{array}{c}\text { Res } \\
\text { PRG }\end{array}$ \\
\hline Anthracene & $1 / 4$ & $200 \mathrm{~J}$ & $200 \mathrm{~J}$ & Z2-EU44B-303 & 200 & 0 & NA & 0 \\
\hline Benz(a)anthracene & $1 / 4$ & $380 \mathrm{~J}$ & $380 \mathrm{~J}$ & Z2-EU44B-303 & 380 & 0 & NA & 0 \\
\hline Benzo(a)pyrene & $1 / 4$ & $270 \mathrm{~J}$ & $270 \mathrm{~J}$ & Z2-EU44B-303 & 270 & 0 & NA & 1 \\
\hline Benzo(b)fluoranthene & $1 / 4$ & $370 \mathrm{~J}$ & $370 \mathrm{~J}$ & Z2-EU44B-303 & 370 & 0 & NA & 0 \\
\hline Benzo(ghi)perylene & $1 / 4$ & $78 \mathrm{~J}$ & $78 \mathrm{~J}$ & Z2-EU44B-303 & 78 & 0 & NA & 0 \\
\hline Benzo(k)fluoranthene & $1 / 4$ & $190 \mathrm{~J}$ & $190 \mathrm{~J}$ & Z2-EU44B-303 & 190 & 0 & NA & 0 \\
\hline $\begin{array}{l}\text { Bis(2- } \\
\text { ethylhexyl)phthalate }\end{array}$ & $1 / 4$ & $310 \mathrm{~J}$ & $310 \mathrm{~J}$ & Z2-EU44B-302 & 310 & 0 & 0 & 0 \\
\hline Chrysene & $1 / 4$ & $300 \mathrm{~J}$ & $300 \mathrm{~J}$ & Z2-EU44B-303 & 300 & 0 & NA & 0 \\
\hline Fluoranthene & $1 / 4$ & 1,100 & 1,100 & Z2-EU44B-303 & 1,100 & 0 & NA & 0 \\
\hline Fluorene & $1 / 4$ & $53 \mathrm{~J}$ & $53 \mathrm{~J}$ & Z2-EU44B-303 & 53 & 0 & NA & 0 \\
\hline Indeno(1,2,3-cd)pyrene & $1 / 4$ & $83 \mathrm{~J}$ & $83 \mathrm{~J}$ & Z2-EU44B-303 & 83 & 0 & NA & 0 \\
\hline Phenanthrene & $1 / 4$ & 570 & 570 & Z2-EU44B-303 & 570 & 0 & NA & 0 \\
\hline Pyrene & $1 / 4$ & 740 & 740 & Z2-EU44B-303 & 740 & 0 & NA & 0 \\
\hline $\begin{array}{l}\mathrm{EU}=\text { exposure unit } \\
\mathrm{GW}=\text { groundwater } \\
\text { Ind = industrial } \\
\mathrm{NA}=\text { not applicable } \\
\mathrm{PRG}=\text { preliminary rem }\end{array}$ & on goal & $\begin{array}{l}\text { Res = resi } \\
\text { SL = scre } \\
\text { SU = soil } \\
\text { SVOC = s }\end{array}$ & $\begin{array}{l}\text { idential } \\
\text { ening level } \\
\text { unit } \\
\text { semivolatile o }\end{array}$ & organic compound & & & & \\
\hline
\end{tabular}

VOCs were analyzed for in all four samples but were not detected.

DVS Biased Sampling in Class 3 SU Sediment Accumulation Areas: Two biased sample locations were identified in sediment accumulation areas during the Class $3 \mathrm{SU}$ walkover assessment. One sediment accumulation area is located behind Bldg. K-1430 (location Z2-EU44B-304) and the other are is at the sediment accumulation area behind Bldg. K-1425 (location Z2-EU44B-305). Analytical results summarized below show radionuclide Ind PRG exceedances, metal and radionuclide Bkg exceedances, and DRO, polychlorinated biphenyl (PCB), and semivolatile organic compound (SVOC) detections. 
EU Z2-44 CLASS 3 SU SEDIMENT ACCUMULATION AREAS METALS WITH

BACKGROUND, PRG, GW SL, AND/OR RL EXCEEDANCES (mg/kg)

\begin{tabular}{|c|c|c|c|c|c|c|c|c|c|c|c|}
\hline \multirow[b]{2}{*}{ Analyte } & \multirow[b]{2}{*}{$\begin{array}{c}\text { Detect } \\
\text { frequency }\end{array}$} & \multirow[b]{2}{*}{$\begin{array}{c}\text { Minimum } \\
\text { detect }\end{array}$} & \multirow[b]{2}{*}{$\begin{array}{c}\text { Maximum } \\
\text { detect }\end{array}$} & \multirow{2}{*}{$\begin{array}{c}\text { Location(s) of } \\
\text { maximum } \\
\text { detect }\end{array}$} & \multirow{2}{*}{$\begin{array}{c}\text { Average } \\
\text { detected } \\
\text { result }\end{array}$} & \multicolumn{6}{|c|}{ Number of analyses exceeding criteria } \\
\hline & & & & & & $\begin{array}{c}\text { Max } \\
\text { RL }\end{array}$ & $\begin{array}{c}\text { Avg } \\
\text { RL }\end{array}$ & $\begin{array}{l}\text { Ind } \\
\text { PRG }\end{array}$ & Bkg & $\begin{array}{c}\text { GW } \\
\text { SL }\end{array}$ & $\begin{array}{c}\text { Res } \\
\text { PRG }\end{array}$ \\
\hline Aluminum & $2 / 2$ & 1,300 & 9,700 & Z2-EU44B-305 & 5,500 & NA & NA & 0 & 0 & NA & 1 \\
\hline Arsenic & $2 / 2$ & 3.7 & 6.3 & Z2-EU44B-305 & 5 & 0 & 0 & 0 & 0 & 0 & 2 \\
\hline Cadmium & $2 / 2$ & 0.35 & $1.6 \mathrm{~J}$ & Z2-EU44B-304 & 0.975 & NA & NA & 0 & 2 & NA & 0 \\
\hline Calcium & $2 / 2$ & 12,000 & $23,0000 \mathrm{~J}$ & Z2-EU44B-304 & 12,1000 & NA & NA & NA & 2 & NA & NA \\
\hline Chromium & $2 / 2$ & $22 \mathrm{~J}$ & 24 & Z2-EU44B-305 & 23 & NA & NA & 0 & 0 & 0 & 1 \\
\hline Copper & $2 / 2$ & $40 \mathrm{~J}$ & 130 & Z2-EU44B-305 & 85 & NA & NA & 0 & 2 & NA & 0 \\
\hline Iron & $2 / 2$ & $20,000 \mathrm{~J}$ & 38,000 & Z2-EU44B-305 & 29,000 & NA & NA & 0 & 0 & NA & 2 \\
\hline Magnesium & $2 / 2$ & 2,600 & $15,000 \mathrm{~J}$ & Z2-EU44B-304 & 8,800 & NA & NA & NA & 1 & NA & NA \\
\hline Manganese & $2 / 2$ & $140 \mathrm{~J}$ & 360 & Z2-EU44B-305 & 250 & NA & NA & 0 & 0 & NA & 1 \\
\hline Nickel & $2 / 2$ & $38 \mathrm{~J}$ & 310 & Z2-EU44B-305 & 174 & NA & NA & 0 & 2 & NA & 1 \\
\hline Selenium & $2 / 2$ & 0.97 & 3.7 & Z2-EU44B-305 & 2.335 & NA & NA & 0 & 1 & NA & 0 \\
\hline Vanadium & $2 / 2$ & 8 & 27 & Z2-EU44B-305 & 17.5 & NA & NA & 0 & 0 & NA & 2 \\
\hline Zinc & $2 / 2$ & 230 & $560 \mathrm{~J}$ & Z2-EU44B-304 & 395 & NA & NA & 0 & 2 & NA & 0 \\
\hline
\end{tabular}

Avg $=$ average

$\mathrm{Bkg}=$ background

$\mathrm{EU}=$ exposure unit

$\mathrm{GW}=$ groundwater

Ind $=$ industrial

Max = maximum

$\mathrm{NA}=$ not applicable

$\mathrm{PRG}=$ preliminary remediation goal

Res $=$ residential

$\mathrm{RL}=$ remediation level

$\mathrm{SL}=$ screening level

$\mathrm{SU}=$ soil unit

EU Z2-44 CLASS 3 SU SEDIMENT ACCUMULATION AREAS OTHER ORGANICS DETECTS (mg/kg)

\begin{tabular}{lccccc}
\hline \multicolumn{1}{c}{ Analyte } & $\begin{array}{c}\text { Detect } \\
\text { frequency }\end{array}$ & $\begin{array}{c}\text { Minimum } \\
\text { detect }\end{array}$ & $\begin{array}{c}\text { Maximum } \\
\text { detect }\end{array}$ & $\begin{array}{c}\text { Location(s) of } \\
\text { maximum } \\
\text { detect }\end{array}$ & $\begin{array}{c}\text { Average } \\
\text { detected } \\
\text { result }\end{array}$ \\
\hline Diesel Range Organics & $2 / 2$ & $14 \mathrm{~J}$ & $58 \mathrm{~J}$ & Z2-EU44B-304 & 36 \\
\hline $\mathrm{EU}=$ exposure unit & & & & & \\
$\mathrm{SU}=$ soil unit & & & & &
\end{tabular}

EU Z2-44 CLASS 3 SU SEDIMENT ACCUMULATION AREAS PCB DETECTS (ug/kg)

\begin{tabular}{|c|c|c|c|c|c|c|c|c|c|}
\hline \multirow[b]{2}{*}{ Analyte } & \multirow[b]{2}{*}{$\begin{array}{c}\text { Detect } \\
\text { frequency }\end{array}$} & \multirow[b]{2}{*}{$\begin{array}{c}\text { Minimum } \\
\text { detect }\end{array}$} & \multirow[b]{2}{*}{$\begin{array}{c}\text { Maximum } \\
\text { detect }\end{array}$} & \multirow{2}{*}{$\begin{array}{c}\text { Location(s) of } \\
\text { maximum } \\
\text { detect }\end{array}$} & \multirow{2}{*}{$\begin{array}{c}\text { Average } \\
\text { detected } \\
\text { result }\end{array}$} & \multicolumn{4}{|c|}{$\begin{array}{c}\text { Number of analyses } \\
\text { exceeding criteria }\end{array}$} \\
\hline & & & & & & $\begin{array}{c}\text { Max } \\
\text { RL }\end{array}$ & $\begin{array}{l}\text { Avg } \\
\text { RL }\end{array}$ & $\begin{array}{l}\text { Ind } \\
\text { PRG }\end{array}$ & $\begin{array}{l}\text { Res } \\
\text { PRG }\end{array}$ \\
\hline PCB-1254 & $2 / 2$ & 110 & 240 & Z2-EU44B-304 & 175 & 0 & 0 & 0 & 1 \\
\hline Polychlorinated Biphenyl & $2 / 2$ & 110 & 240 & Z2-EU44B-304 & 175 & 0 & 0 & 0 & 1 \\
\hline
\end{tabular}

Avg $=$ average

$\mathrm{EU}=$ exposure unit

Ind $=$ industrial

Max $=$ maximum

$\mathrm{PCB}=$ polychlorinated biphenyl
$\mathrm{PRG}=$ preliminary remediation goal

Res $=$ residential

$\mathrm{RL}=$ remediation level

$\mathrm{SU}=$ soil unit 
EU Z2-44 CLASS 3 SU SEDIMENT ACCUMULATIO N AREAS RADIONUCLIDES

WITH BACKGROUND, PRG, AND/OR RL EXCEEDANCES (pCi/g)

\begin{tabular}{|c|c|c|c|c|c|c|c|c|c|c|c|}
\hline \multirow[b]{2}{*}{ Analyte } & \multirow[b]{2}{*}{$\begin{array}{c}\text { Detect } \\
\text { frequency }\end{array}$} & \multirow[b]{2}{*}{$\begin{array}{c}\text { Minimum } \\
\text { detect }\end{array}$} & \multirow[b]{2}{*}{$\begin{array}{c}\text { Maximum } \\
\text { detect }\end{array}$} & \multirow[b]{2}{*}{$\begin{array}{c}\text { Location(s) of } \\
\text { maximum detect }\end{array}$} & \multirow{2}{*}{$\begin{array}{c}\text { Average } \\
\text { detected } \\
\text { result }\end{array}$} & \multicolumn{6}{|c|}{ Number of analyses exceeding criteria } \\
\hline & & & & & & $\begin{array}{c}\text { Max } \\
\text { RL }\end{array}$ & $\begin{array}{c}\text { Avg } \\
\text { RL }\end{array}$ & $\begin{array}{l}\text { Ind } \\
\text { PRG }\end{array}$ & Bkg & $\begin{array}{l}\text { GW } \\
\text { SL }\end{array}$ & $\begin{array}{l}\text { Res } \\
\text { PRG }\end{array}$ \\
\hline Potassium-40 & $2 / 2$ & 6.34 & 11.3 & Z2-EU44B-305 & 8.82 & NA & NA & 2 & 0 & NA & 2 \\
\hline Radium-226 & $1 / 2$ & 0.823 & 0.823 & Z2-EU44B-305 & 0.823 & NA & NA & 1 & 0 & NA & 1 \\
\hline Thorium -228 & $1 / 2$ & 1.39 & 1.39 & Z2-EU44B-305 & 1.39 & NA & NA & 1 & 0 & NA & 1 \\
\hline Thorium -232 & $2 / 2$ & 0.353 & 1.08 & Z2-EU44B-305 & 0.717 & NA & NA & 2 & 0 & NA & 2 \\
\hline Uranium-238 & $2 / 2$ & 0.457 & 0.845 & Z2-EU44B-305 & 0.651 & 0 & 0 & 0 & 0 & 0 & 1 \\
\hline
\end{tabular}

\begin{tabular}{ll}
\hline Avg $=$ average & NA $=$ not applicable \\
Bkg = background & PRG = preliminary remediation goal \\
EU = exposure unit & Res = residential \\
GW = groundwater & RL = remediation level \\
Ind = industrial & $\mathrm{SL}=$ screening level \\
Max = maximum & $\mathrm{SU}=$ soil unit
\end{tabular}

EU Z2-44 CLASS 3 SU SEDIMENT ACCUMULATION AREASSVOC DETECTS (ug/kg)

\begin{tabular}{|c|c|c|c|c|c|c|c|c|}
\hline \multirow[b]{2}{*}{ Analyte } & \multirow[b]{2}{*}{$\begin{array}{c}\text { Detect } \\
\text { frequency }\end{array}$} & \multirow[b]{2}{*}{$\begin{array}{c}\text { Minimum } \\
\text { detect }\end{array}$} & \multirow[b]{2}{*}{$\begin{array}{c}\text { Maximum } \\
\text { detect }\end{array}$} & \multirow[b]{2}{*}{$\begin{array}{c}\text { Location(s) of } \\
\text { maximum detect }\end{array}$} & \multirow{2}{*}{$\begin{array}{c}\text { Average } \\
\text { detected } \\
\text { result }\end{array}$} & \multicolumn{3}{|c|}{$\begin{array}{c}\text { Number of analyses } \\
\text { exceeding criteria }\end{array}$} \\
\hline & & & & & & $\begin{array}{l}\text { Ind } \\
\text { PRG }\end{array}$ & $\begin{array}{l}\text { GW } \\
\text { SL }\end{array}$ & $\begin{array}{l}\text { Res } \\
\text { PRG }\end{array}$ \\
\hline 2-Methylnaphthalene & $1 / 2$ & $290 \mathrm{~J}$ & $290 \mathrm{~J}$ & Z2-EU44B-304 & 290 & 0 & NA & NA \\
\hline 3-Methylphenol & $1 / 2$ & $810 \mathrm{~J}$ & $810 \mathrm{~J}$ & Z2-EU44B-305 & 810 & 0 & NA & 0 \\
\hline Benz(a)anthracene & $1 / 2$ & $500 \mathrm{~J}$ & $500 \mathrm{~J}$ & Z2-EU44B-304 & 500 & 0 & NA & 0 \\
\hline Benzo(a)pyrene & $1 / 2$ & $410 \mathrm{~J}$ & $410 \mathrm{~J}$ & Z2-EU44B-304 & 410 & 0 & NA & 1 \\
\hline Benzo(b)fluoranthene & $2 / 2$ & $300 \mathrm{~J}$ & 2,700 & Z2-EU44B-304 & 1,500 & 0 & NA & 1 \\
\hline Benzo(k)fluoranthene & $1 / 2$ & $1,100 \mathrm{~J}$ & $1,100 \mathrm{~J}$ & Z2-EU44B-304 & 1,100 & 0 & NA & 0 \\
\hline Benzoic acid & $1 / 2$ & $2,600 \mathrm{~J}$ & $2,600 \mathrm{~J}$ & Z2-EU44B-304 & 2,600 & 0 & NA & 0 \\
\hline Bis(2-ethylhexyl)phthalate & $1 / 2$ & $530 \mathrm{~J}$ & $530 \mathrm{~J}$ & Z2-EU44B-304 & 530 & 0 & 0 & 0 \\
\hline Carbazole & $1 / 2$ & $480 \mathrm{~J}$ & $480 \mathrm{~J}$ & Z2-EU44B-304 & 480 & 0 & NA & 0 \\
\hline Chrysene & $1 / 2$ & 3,300 & 3,300 & Z2-EU44B-304 & 3,300 & 0 & NA & 0 \\
\hline Dibenzofuran & $1 / 2$ & $720 \mathrm{~J}$ & $720 \mathrm{~J}$ & Z2-EU44B-304 & 720 & 0 & NA & 0 \\
\hline Fluoranthene & $2 / 2$ & $290 \mathrm{~J}$ & 14,000 & Z2-EU44B-304 & 7,145 & 0 & NA & 0 \\
\hline Naphthalene & $1 / 2$ & $630 \mathrm{~J}$ & $630 \mathrm{~J}$ & Z2-EU44B-304 & 630 & 0 & NA & 0 \\
\hline Phenanthrene & $1 / 2$ & 11,000 & 11,000 & Z2-EU44B-304 & 11,000 & 0 & NA & 0 \\
\hline Pyrene & $1 / 2$ & $6,700 \mathrm{~J}$ & $6,700 \mathrm{~J}$ & Z2-EU44B-304 & 6,700 & 0 & NA & 0 \\
\hline
\end{tabular}

EU = exposure unit Res $=$ residential

$\mathrm{GW}=$ groundwater $\quad \mathrm{SL}=$ screening level

Ind $=$ industrial

$\mathrm{NA}=$ not applicable

$\mathrm{SU}=$ soil unit
$\mathrm{SVOC}=$ semivolatile organic compound

$\mathrm{PRG}=$ preliminary remediation goal

Historical Sampling in the Class $3 \mathrm{SU}$ : There is one historical sample location in the EU Z2-44 Class 3 SU, which is from the 1994 Radiological Walkover Survey. Analytical results summarized below show radionuclide Ind PRG exceedances. 
EU Z2-44 CLASS 3 SU HISTORICAL RADIONUCLIDES WITH

BACKGROUND, PRG, AND/OR RL EXCEEDANCES (pCi/g)

\begin{tabular}{|c|c|c|c|c|c|c|c|c|c|c|c|}
\hline \multirow[b]{2}{*}{ Analyte } & \multirow[b]{2}{*}{$\begin{array}{c}\text { Detect } \\
\text { frequency }\end{array}$} & \multirow[b]{2}{*}{$\begin{array}{c}\text { Minimum } \\
\text { detect }\end{array}$} & \multirow[b]{2}{*}{$\begin{array}{c}\text { Maximum } \\
\text { detect }\end{array}$} & \multirow[b]{2}{*}{$\begin{array}{c}\text { Location(s) of } \\
\text { maximum detect }\end{array}$} & \multirow{2}{*}{$\begin{array}{c}\text { Average } \\
\text { detected } \\
\text { result }\end{array}$} & \multicolumn{6}{|c|}{ Number of analyses exceeding criteria } \\
\hline & & & & & & $\begin{array}{c}\text { Max } \\
\text { RL }\end{array}$ & $\begin{array}{l}\text { Avg } \\
\text { RL }\end{array}$ & $\begin{array}{l}\text { Ind } \\
\text { PRG }\end{array}$ & Bkg & $\begin{array}{l}\text { GW } \\
\text { SL }\end{array}$ & $\begin{array}{l}\text { Res } \\
\text { PRG }\end{array}$ \\
\hline Cesium-137 & $1 / 1$ & 0.181 & 0.181 & RAD133 & 0.181 & 0 & 0 & 0 & $\mathrm{NA}$ & NA & 1 \\
\hline Potassium-40 & $1 / 1$ & 14.7 & 14.7 & RAD133 & 14.7 & NA & NA & 1 & 0 & NA & 1 \\
\hline Technetium-99 & $1 / 1$ & 0.64 & 0.64 & RAD133 & 0.64 & NA & NA & 0 & NA & NA & 1 \\
\hline Thorium -228 & $1 / 1$ & 1.2 & 1.2 & RAD133 & 1.2 & NA & NA & 1 & 0 & NA & 1 \\
\hline Thorium -230 & $1 / 1$ & 1.33 & 1.33 & RAD133 & 1.33 & NA & NA & 0 & 1 & NA & 0 \\
\hline Thorium -232 & $1 / 1$ & 0.94 & 0.94 & RAD133 & 0.94 & NA & NA & 1 & 0 & NA & 1 \\
\hline Uranium-238 & $1 / 1$ & 1.14 & 1.14 & RAD133 & 1.14 & 0 & 0 & 0 & 0 & 0 & 1 \\
\hline
\end{tabular}

Avg $=$ average

$\mathrm{NA}=$ not applicable

$\mathrm{Bkg}=$ background

$\mathrm{EU}=$ exposure unit

PRG $=$ preliminary remediation goal

$\mathrm{GW}=$ groundwater

Res $=$ residential

Ind $=$ industrial

$\mathrm{RL}=$ remediation level

Max $=$ maximum

$\mathrm{SL}=$ screening level

$\mathrm{SU}=$ soil unit

EU Z2-44 Summary: The 16.1 acres of EU Z2-44 has been divided into 0.6 acres in the Class 2 SU, 9.5 acres in the Class $3 \mathrm{SU}$, and 6 acres of unclassified land occupied by the operating TSCAI facility. The Class $2 \mathrm{SU}$ is defined by the K-1070-G Burial Ground FFA site boundaries, and contains four DVS systematic grid sample locations and one historical sample location. The historical sample is from the 1994 Radiological Walkover Survey. During the Class $3 \mathrm{SU}$ walkover assessment, where no anthropogenic features were identified and 27 facilities were assessed. There were no visual indications for chemical contamination and the radiation SL was not exceeded during any of the radiation screenings. Therefore, no biased sampling of anthropogenic features or facilities was conducted. However, two sediment accumulation areas were identified for biased sampling during the Class 3 SU walkover assessment. Additionally, four biased sampling locations were identified during DQO scoping around the K-1425-A through D storage tanks. Also, there was one historical sample location identified from the 1994 Radiological Walkover Survey in the Class 3 SU. Analytical results summarized below show several radionuclides and one metal (arsenic) with Ind PRG exceedances, radionuclide and metal Bkg exceedances, and DRO, PCBs, and SVOCs detects.

EU Z2-44 METALS WITH BACKGROUND, PRG, GW SL, AND/OR RL EXCEEDANCES (mg/kg)

\begin{tabular}{|c|c|c|c|c|c|c|c|c|c|c|c|}
\hline \multirow[b]{2}{*}{ Analyte } & \multirow[b]{2}{*}{$\begin{array}{c}\text { Detect } \\
\text { frequency }\end{array}$} & \multirow[b]{2}{*}{$\begin{array}{c}\text { Minimum } \\
\text { detect }\end{array}$} & \multirow[b]{2}{*}{$\begin{array}{c}\text { Maximum } \\
\text { detect }\end{array}$} & \multirow{2}{*}{$\begin{array}{c}\text { Location(s) of } \\
\text { maximum } \\
\text { detect }\end{array}$} & \multirow{2}{*}{$\begin{array}{c}\text { Average } \\
\text { detected } \\
\text { result }\end{array}$} & \multicolumn{6}{|c|}{ Number of analyses exceeding criteria } \\
\hline & & & & & & $\begin{array}{c}\text { Max } \\
\text { RL }\end{array}$ & $\begin{array}{c}\text { Avg } \\
\text { RL }\end{array}$ & $\begin{array}{l}\text { Ind } \\
\text { PRG }\end{array}$ & Bkg & $\begin{array}{l}\text { GW } \\
\text { SL }\end{array}$ & $\begin{array}{l}\text { Res } \\
\text { PRG }\end{array}$ \\
\hline Aluminum & $10 / 10$ & 1,300 & 18,000 & Z2-EU44-202 & 13,100 & NA & NA & 0 & 0 & NA & 9 \\
\hline Arsenic & $10 / 10$ & 3.5 & 48 & Z2-EU44B-301 & 10.8 & 0 & 0 & 2 & 2 & 0 & 10 \\
\hline Barium & $10 / 10$ & $19 \mathrm{~J}$ & $150 \mathrm{~J}$ & Z2-EU44B-303 & 81.3 & NA & NA & 0 & 1 & 0 & 0 \\
\hline Cadmium & $10 / 10$ & 0.31 & $1.6 \mathrm{~J}$ & Z2-EU44B-304 & 0.71 & NA & NA & 0 & 10 & NA & 0 \\
\hline Calcium & $10 / 10$ & $520 \mathrm{~J}$ & $230,000 \mathrm{~J}$ & Z2-EU44B-304 & 32,532 & NA & NA & NA & 7 & NA & NA \\
\hline Chromium & $10 / 10$ & $21 \mathrm{~J}$ & $39 \mathrm{~J}$ & Z2-EU44B-301 & 28.9 & NA & NA & 0 & 0 & 0 & 8 \\
\hline Copper & $10 / 10$ & $10 \mathrm{~J}$ & $430 \mathrm{~J}$ & Z2-EU44B-301 & 77 & NA & NA & 0 & 7 & NA & 1 \\
\hline Iron & $10 / 10$ & $20,000 \mathrm{~J}$ & $52,000 \mathrm{~J}$ & Z2-EU44B-301 & 33,500 & NA & NA & 0 & 0 & NA & 10 \\
\hline Lead & $10 / 10$ & $7.8 \mathrm{~J}$ & $70 \mathrm{~J}$ & Z2-EU44B-301 & 21.9 & NA & NA & 0 & 1 & 0 & 0 \\
\hline Magnesium & $10 / 10$ & $1,100 \mathrm{~J}$ & $22,000 \mathrm{~J}$ & Z2-EU44B-303 & 6,100 & NA & NA & NA & 6 & NA & NA \\
\hline Manganese & $10 / 10$ & $140 \mathrm{~J}$ & 1,000 & Z2-EU44B-301 & 544 & NA & NA & 0 & 0 & NA & 9 \\
\hline Nickel & $10 / 10$ & 23 & $990 \mathrm{~J}$ & Z2-EU44B-301 & 164 & NA & NA & 0 & 7 & NA & 2 \\
\hline Selenium & $3 / 10$ & $0.52 \mathrm{~J}$ & 3.7 & Z2-EU44B-305 & 1.73 & NA & NA & 0 & 1 & NA & 0 \\
\hline Uranium & $10 / 10$ & 0.49 & 8.4 & Z2-EU44-200 & 1.85 & NA & NA & 0 & NA & NA & 2 \\
\hline
\end{tabular}


EU Z2-44 METALS WITH BACKGROUND, PRG, GW SL, AND/OR RL EXCEEDANCES (mg/kg) (cont'd)

\begin{tabular}{|c|c|c|c|c|c|c|c|c|c|c|c|}
\hline \multirow[b]{2}{*}{ Analyte } & \multirow[b]{2}{*}{$\begin{array}{l}\text { Detect } \\
\text { frequency }\end{array}$} & \multirow[b]{2}{*}{$\begin{array}{c}\text { Minimum } \\
\text { detect }\end{array}$} & \multirow[b]{2}{*}{$\begin{array}{c}\text { Maximum } \\
\text { detect }\end{array}$} & \multirow{2}{*}{$\begin{array}{c}\text { Location(s) of } \\
\text { maximum } \\
\text { detect }\end{array}$} & \multirow{2}{*}{$\begin{array}{c}\text { Average } \\
\text { detected } \\
\text { result }\end{array}$} & \multicolumn{6}{|c|}{ Number of analyses exceeding criteria } \\
\hline & & & & & & $\begin{array}{l}\text { Max } \\
\text { RL }\end{array}$ & $\begin{array}{c}\text { Avg } \\
\text { RL }\end{array}$ & $\begin{array}{l}\text { Ind } \\
\text { PRG }\end{array}$ & Bkg & $\begin{array}{c}\text { GW } \\
\text { SL }\end{array}$ & $\begin{array}{c}\text { Res } \\
\text { PRG }\end{array}$ \\
\hline$\overline{\text { Vanadium }}$ & $10 / 10$ & 8 & 90 & Z2-EU44B-301 & 34.9 & NA & NA & 0 & 1 & NA & 10 \\
\hline Zinc & $10 / 10$ & $22 \mathrm{~J}$ & $560 \mathrm{~J}$ & Z2-EU44B-304 & 129 & NA & NA & 0 & 3 & NA & 0 \\
\hline
\end{tabular}

Avg $=$ average $\quad \mathrm{NA}=$ not applicable

$\mathrm{Bkg}=$ background $\quad \mathrm{PRG}=$ preliminary remediation goal

$\mathrm{EU}=$ exposure unit $\quad$ Res $=$ residential

$\mathrm{GW}=$ groundwater $\quad \mathrm{RL}=$ remediation level

Ind $=$ industrial $\quad \mathrm{SL}=$ screening level

Max = maximum $\quad \mathrm{SU}=$ soil unit

EU Z2-44 OTHER ORGANICS DETECTS (mg/kg)

\begin{tabular}{lccccc}
\hline \multicolumn{1}{c}{ Analyte } & $\begin{array}{c}\text { Detect } \\
\text { frequency }\end{array}$ & $\begin{array}{c}\text { Minimum } \\
\text { detect }\end{array}$ & $\begin{array}{c}\text { Maximum } \\
\text { detect }\end{array}$ & $\begin{array}{c}\text { Location(s) of } \\
\text { maximum detect }\end{array}$ & $\begin{array}{c}\text { Average } \\
\text { detected } \\
\text { result }\end{array}$ \\
\hline Diesel Range Organics & $2 / 6$ & $14 \mathrm{~J}$ & 58J & Z2-EU44B-304 & 36 \\
\hline EU = exposure unit & & & & &
\end{tabular}

EU Z2-44 PCB DETECTS (ug/kg)

\begin{tabular}{|c|c|c|c|c|c|c|c|c|c|}
\hline \multirow[b]{2}{*}{ Analyte } & \multirow[b]{2}{*}{$\begin{array}{c}\text { Detect } \\
\text { frequency }\end{array}$} & \multirow[b]{2}{*}{$\begin{array}{c}\text { Minimum } \\
\text { detect }\end{array}$} & \multirow[b]{2}{*}{$\begin{array}{c}\text { Maximum } \\
\text { detect }\end{array}$} & \multirow{2}{*}{$\begin{array}{c}\text { Location(s) of } \\
\text { maximum } \\
\text { detect }\end{array}$} & \multirow{2}{*}{$\begin{array}{c}\text { Average } \\
\text { detected } \\
\text { result }\end{array}$} & \multicolumn{4}{|c|}{$\begin{array}{c}\text { Number of analyses } \\
\text { exceeding criteria }\end{array}$} \\
\hline & & & & & & $\begin{array}{c}\text { Max } \\
\text { RL } \\
\end{array}$ & $\begin{array}{l}\text { Avg } \\
\text { RL }\end{array}$ & $\begin{array}{l}\text { Ind } \\
\text { PRG } \\
\end{array}$ & $\begin{array}{l}\text { Res } \\
\text { PRG } \\
\end{array}$ \\
\hline PCB-1254 & $2 / 10$ & 110 & 240 & Z2-EU44B-304 & 175 & 0 & 0 & 0 & 1 \\
\hline Polychlorinated Biphenyl & $2 / 10$ & 110 & 240 & Z2-EU44B-304 & 175 & 0 & 0 & 0 & 1 \\
\hline $\begin{array}{l}\text { Avg }=\text { a verage } \\
\text { EU = exposure unit } \\
\text { Ind = industrial } \\
\text { Max = maximum }\end{array}$ & $\begin{array}{l}\text { PCB } \\
\text { PRG } \\
\text { Res }= \\
\text { RL }=\end{array}$ & $\begin{array}{l}\text { preliminary } \\
\text { residential } \\
\text { emediation } 1\end{array}$ & emediation & & & & & & \\
\hline
\end{tabular}

\section{EU Z2-44 RADIONUCLIDES WITH BACKGROUND, PRG, AND/OR RL EXCEEDANCES (pCi/g)}

\begin{tabular}{|c|c|c|c|c|c|c|c|c|c|c|c|}
\hline \multirow[b]{2}{*}{ Analyte } & \multirow[b]{2}{*}{$\begin{array}{c}\text { Detect } \\
\text { frequency }\end{array}$} & \multirow[b]{2}{*}{$\begin{array}{c}\text { Minimum } \\
\text { detect }\end{array}$} & \multirow[b]{2}{*}{$\begin{array}{c}\text { Maximum } \\
\text { detect }\end{array}$} & \multirow[b]{2}{*}{$\begin{array}{c}\text { Location(s) of } \\
\text { maximum detect }\end{array}$} & \multirow{2}{*}{$\begin{array}{c}\text { Average } \\
\text { detected } \\
\text { result }\end{array}$} & \multicolumn{6}{|c|}{ Number of analyses exceeding criteria } \\
\hline & & & & & & $\begin{array}{c}\text { Max } \\
\text { RL }\end{array}$ & $\begin{array}{l}\text { Avg } \\
\text { RL }\end{array}$ & $\begin{array}{l}\text { Ind } \\
\text { PRG }\end{array}$ & Bkg & $\begin{array}{l}\text { GW } \\
\text { SL }\end{array}$ & $\begin{array}{l}\text { Res } \\
\text { PRG }\end{array}$ \\
\hline Cesium-137 & $2 / 8$ & 0.181 & 0.22 & RAD131 & 0.201 & 0 & 0 & 0 & NA & NA & 2 \\
\hline Neptunium-237 & $1 / 8$ & 0.29 & 0.29 & RAD131 & 0.29 & 0 & 0 & 0 & NA & NA & 1 \\
\hline Potassium-40 & $8 / 8$ & $4.62 \mathrm{~J}$ & 18.9 & RAD131 & 12.3 & NA & NA & 8 & 0 & NA & 8 \\
\hline Radium-226 & $7 / 8$ & 0.58 & 2.49 & Z2-EU44B-301 & 1.06 & NA & NA & 7 & 2 & NA & 7 \\
\hline Technetium-99 & $2 / 8$ & 0.2 & 0.64 & RAD133 & 0.42 & NA & NA & 0 & NA & NA & 1 \\
\hline Thorium -228 & $7 / 8$ & 0.88 & 1.93 & Z2-EU44B-301 & 1.45 & NA & NA & 7 & 1 & NA & 7 \\
\hline Thorium -230 & $7 / 8$ & 0.837 & 2.7 & Z2-EU44B-301 & 1.35 & NA & NA & 0 & 3 & NA & 0 \\
\hline Thorium -232 & $8 / 8$ & 0.353 & 2.74 & Z2-EU44B-301 & 1.31 & NA & NA & 8 & 1 & NA & 8 \\
\hline Uranium-238 & $8 / 8$ & 0.457 & 2.23 & Z2-EU44B-301 & 1.16 & 0 & 0 & 0 & 2 & 0 & 7 \\
\hline
\end{tabular}

Avg $=$ average

$\mathrm{Bkg}=$ background

$\mathrm{EU}=$ exposure unit

$\mathrm{GW}=$ groundwater

Ind $=$ industrial

Max $=$ maximum
$\mathrm{NA}=$ not applicable

$\mathrm{PRG}=$ preliminary remediation goal

Res $=$ residential

$\mathrm{RL}=$ remediation level

$\mathrm{SL}=$ screening level 
EU Z2-44 SVOC DETECTS (ug/kg)

\begin{tabular}{|c|c|c|c|c|c|c|c|c|}
\hline \multirow[b]{2}{*}{ Analyte } & \multirow[b]{2}{*}{$\begin{array}{c}\text { Detect } \\
\text { frequency }\end{array}$} & \multirow[b]{2}{*}{$\begin{array}{c}\text { Minimum } \\
\text { detect }\end{array}$} & \multirow[b]{2}{*}{$\begin{array}{c}\text { Maximum } \\
\text { detect }\end{array}$} & \multirow[b]{2}{*}{$\begin{array}{c}\text { Location(s) of } \\
\text { maximum detect }\end{array}$} & \multirow{2}{*}{$\begin{array}{c}\text { Average } \\
\text { detected } \\
\text { result }\end{array}$} & \multicolumn{3}{|c|}{$\begin{array}{c}\text { Number of analyses } \\
\text { exceeding criteria }\end{array}$} \\
\hline & & & & & & $\begin{array}{l}\text { Ind } \\
\text { PRG }\end{array}$ & $\begin{array}{c}\text { GW } \\
\text { SL }\end{array}$ & $\begin{array}{l}\text { Res } \\
\text { PRG }\end{array}$ \\
\hline 2-Methylnaphthalene & $2 / 10$ & $91 \mathrm{~J}$ & $290 \mathrm{~J}$ & Z2-EU44B-304 & 191 & 0 & NA & NA \\
\hline 3-Methylphenol & $1 / 10$ & $810 \mathrm{~J}$ & $810 \mathrm{~J}$ & Z2-EU44B-305 & 810 & 0 & NA & 0 \\
\hline Anthracene & $1 / 10$ & $200 \mathrm{~J}$ & $200 \mathrm{~J}$ & Z2-EU44B-303 & 200 & 0 & NA & 0 \\
\hline Benz(a)anthracene & $4 / 10$ & $36 \mathrm{~J}$ & $500 \mathrm{~J}$ & Z2-EU44B-304 & 240 & 0 & NA & 0 \\
\hline Benzo(a)pyrene & $4 / 10$ & $37 \mathrm{~J}$ & $410 \mathrm{~J}$ & Z2-EU44B-304 & 191 & 0 & NA & 2 \\
\hline Benzo(b)fluoranthene & $5 / 10$ & $52 \mathrm{~J}$ & 2,700 & Z2-EU44B-304 & 698 & 0 & NA & 1 \\
\hline Benzo(ghi)perylene & $1 / 10$ & $78 \mathrm{~J}$ & $78 \mathrm{~J}$ & Z2-EU44B-303 & 78 & 0 & NA & 0 \\
\hline Benzo(k)fluoranthene & $4 / 10$ & $26 \mathrm{~J}$ & $1,100 \mathrm{~J}$ & Z2-EU44B-304 & 336 & 0 & NA & 0 \\
\hline Benzoic acid & $1 / 10$ & $2,600 \mathrm{~J}$ & $2,600 \mathrm{~J}$ & Z2-EU44B-304 & 2,600 & 0 & NA & 0 \\
\hline Bis(2-ethylhexyl)phthalate & $2 / 10$ & $310 \mathrm{~J}$ & $530 \mathrm{~J}$ & Z2-EU44B-304 & 420 & 0 & 0 & 0 \\
\hline Carbazole & $1 / 10$ & $480 \mathrm{~J}$ & $480 \mathrm{~J}$ & Z2-EU44B-304 & 480 & 0 & NA & 0 \\
\hline Chrysene & $4 / 10$ & $35 \mathrm{~J}$ & 3,300 & Z2-EU44B-304 & 918 & 0 & NA & 0 \\
\hline Dibenzofuran & $1 / 10$ & $720 \mathrm{~J}$ & $720 \mathrm{~J}$ & Z2-EU44B-304 & 720 & 0 & NA & 0 \\
\hline Fluoranthene & $5 / 10$ & $78 \mathrm{~J}$ & 14,000 & Z2-EU44B-304 & 3,112 & 0 & NA & 0 \\
\hline Fluorene & $1 / 10$ & $53 \mathrm{~J}$ & $53 \mathrm{~J}$ & Z2-EU44B-303 & 53 & 0 & NA & 0 \\
\hline Indeno(1,2,3-cd)pyrene & $1 / 10$ & $83 \mathrm{~J}$ & $83 \mathrm{~J}$ & Z2-EU44B-303 & 83 & 0 & NA & 0 \\
\hline Naphthalene & $1 / 16$ & $630 \mathrm{~J}$ & $630 \mathrm{~J}$ & Z2-EU44B-304 & 630 & 0 & NA & 0 \\
\hline Phenanthrene & $4 / 10$ & $45 \mathrm{~J}$ & 11,000 & Z2-EU44B-304 & 2,924 & 0 & NA & 0 \\
\hline Pyrene & $4 / 10$ & $57 \mathrm{~J}$ & $6,700 \mathrm{~J}$ & Z2-EU44B-304 & 1,891 & 0 & NA & 0 \\
\hline $\begin{array}{l}\mathrm{EU}=\text { exposure unit } \\
\mathrm{GW}=\text { groundwater }\end{array}$ & & $\mathrm{G}=$ prelin & ary remedia & ation goal & & & & \\
\hline $\begin{array}{l}\text { Ind }=\text { industrial } \\
\mathrm{NA}=\text { not applicable }\end{array}$ & & $\begin{array}{l}=\text { screenin } \\
\mathrm{OC}=\text { sem }\end{array}$ & $\begin{array}{l}\text { level } \\
\text { olatile org }\end{array}$ & ompound & & & & \\
\hline
\end{tabular}

VOCs were analyzed for in six samples but were not detected.

\section{\begin{tabular}{l|l} 
2.2.6 & ZONE 2 ROD APPENDIX A FFA SITES EVALUATION
\end{tabular}}

The K-1070-G Burial Ground is the only EU Z2-44 FFA site listed in Appendix A of the Zone 2 ROD. The K-1070-G Burial Ground footprint defines the Class 2 SU in this EU. The sampling results are presented in Sect. 2.2.5.

\begin{tabular}{|l|l|}
\hline 3.0 & \multicolumn{1}{|c|}{ RISK EVALUATION AND ACTION/NO FURTHER ACTION DECISION } \\
\hline 3.1 & INTRODUCTION \\
\hline
\end{tabular}

In this section, data are evaluated in terms of the four decision rules presented in the Zone 2 RAWP, including the following:

- Does the concentration of any Zone 2 contaminant of concern (COC) exceed its Max RL?

- Does the mean concentration of any Zone 2 COC exceed its Avg RL across the EU?

- Does the EU pose a risk exceeding an industrial $1 \times 10^{-4}$ excess lifetime cancer risk (ELCR) or target organ hazard index (HI) of 1 ?

- Does the site pose a threat to groundwater based on maximum contaminant level (MCL) exceedances or soil RLs for protection of groundwater?

Table K.3 presents the results from comparison of the data to the Zone 2 soils RLs, Ind PRGs (set at an ELCR of $1 \times 10^{-5}$ or a HI of 1), and to background levels. In addition, the summary in Sect. 2.2.5 presents an evaluation of the EU data by analyte group. The following table summarizes conclusions for EU Z2-44. 


\begin{tabular}{lccccc}
\hline EU \# & $\begin{array}{c}\text { Max RL } \\
\text { exceeded? }\end{array}$ & $\begin{array}{c}\text { Average RL over } \\
\text { EU exceeded? }\end{array}$ & $\begin{array}{c}\text { Industrial risk } \\
\text { above } \mathbf{1} \times \mathbf{1 0}^{-4} \text { ? }\end{array}$ & $\begin{array}{c}\text { Potential source } \\
\text { to groundwater? }\end{array}$ & $\begin{array}{c}\text { Action } \\
\text { required? }\end{array}$ \\
\hline $\mathrm{Z} 2-44$ & No & No & No & No & No \\
\hline $\begin{array}{l}\mathrm{EU}=\text { exposure unit } \\
\mathrm{RL}=\text { remediation level }\end{array}$ & & & & \\
\multicolumn{2}{l}{} \\
$\mathbf{3 . 2}$ & DATA EVALUATION FOR THE ACTION /NO FURTHER ACTION DECISION & \\
\hline
\end{tabular}

Requirements for determining NFA in the Zone 2 EUs are stated in the protection goals of the Zone 2 ROD remedial action objective (RAO). Four decision rules developed in the DVS DQOs state the specific criteria against which each EU must be compared to make the NFA decision. The four decision rules are presented in Sect. 3.2 of the PCCR. The method in which the decision rule evaluations are conducted, and the special data handling requirements, are discussed in Sect. 3.3 of the PCCR. In summary, the decision rule criteria for NFA states that each EU must meet each of the following compositional constraints:

- Zone 2 soils Max RLs - maximum allowable concentrations of the Zone 2 soils COCs. Zone 2 soils Max RLs are presented in the Zone 1 ROD and in Table K.4 of this PCCR.

- Zone 2 soils Avg RLs - limit on the allowable average concentrations of the Zone 2 soils COCs across an EU. Zone 2 soils Avg RLs are presented in the Zone 1 ROD and in Table K. 4 of this PCCR.

- Cumulative risk across the EU-cumulative risk across an EU cannot exceed $1 \times 10^{-4}$ ELCR or HI of 1 . A stepwise evaluation of cumulative risk is performed by first comparing EU data to $1 \times 10^{-5}$ Ind PRGs. The $1 \times 10^{-5}$ Ind PRGs for the analytes required by the RDR/RAWP are presented in Table K. 4 of this PCCR.

- Groundwater protection goals - compositions of Zone 2 soils cannot pose a threat to groundwater. This evaluation is conducted by evaluating local groundwater monitoring results and comparing soils compositions to calculated SLs. Groundwater SLs are presented in Table K.4 of this PCCR.

\section{\begin{tabular}{|l|l}
3.3 & SUMMARY AND CONCLUSIONS \\
\hline
\end{tabular}}

Max RL screening. Based on analytical results from DVS biased sampling and historical sampling in EU Z2-44, no Zone 2 COCs are present at concentrations in excess of Max RLs.

Avg RL screening. Based on analytical results from DVS biased sampling and historical sampling in EU Z2-44, no Zone 2 soils COCs are present with a mean concentration exceeding the Avg RL across the EU.

Risk evaluation. The first step in the risk evaluation is to evaluate $1 \times 10^{-5}$ Ind PRG exceedances to determine which chemicals and radionuclides are likely to exceed the $1 \times 10^{-4}$ ELCR or target organ HI of 1 . The EU evaluation in Sect. 2.2.5 discusses the $1 \times 10^{-5}$ Ind PRG exceedance in one or more samples by arsenic (2), K-40 (8), Ra-226 (7), Th-228 (7), and Th-232 (8). As explained in Sect. 3.3 of this PCCR, K-40 is further evaluated for risk only if its average concentration exceeds its background value, and Ra-226, Th-230, and Th-232 are evaluated by summing their concentrations ( $\mathrm{Ra} / \mathrm{Th}$ decay series) and comparing the result to their mutual Zone 2 soils COC Avg RL (this evaluation includes Th-228 as part of the Th-232 decay chain). The average detected K-40 concentration $(12.3 \mathrm{pCi} / \mathrm{g})$ does not exceed the $\mathrm{K}-40$ background value $(32.12 \mathrm{pCi} / \mathrm{g})$ and there are no occurrences of the $\mathrm{Ra} / \mathrm{Th}$ decay series exceeding the Avg RL (5 pCi/g). Therefore, K-40, Ra-226, Th-228, and Th-232 will not be carried forward in the risk evaluation.

The second step in the risk evaluation is to determine if the average detected concentration of any remaining chemicals or radionuclides exceeds a $1 \times 10^{-5}$ Ind PRG. For EU Z2-44, the only remaining chemical with an individual $1 \times 10^{-5}$ Ind PRG exceedance is arsenic. The average detected concentration of arsenic $(10.8 \mathrm{mg} / \mathrm{kg})$ is less than the $1 \times 10^{-5}$ Ind PRG $(15.9 \mathrm{mg} / \mathrm{kg})$. It is concluded there are no chemicals or radionuclides in EU Z2-44 soils at high enough concentrations for the EU to fail the Zone 2 risk limits and, therefore, the industrial risk for EU Z2-44 is less than $1 \times 10^{-4}$ ELCR and target organ HI of 1 .

Threat to groundwater. There are no groundwater SL exceedances in the soils data and no MCL exceedances in local groundwater monitoring wells downgradient of the EU. Therefore, it is concluded that the soils of EU Z2-44 do not pose a threat to groundwater.

Qualitative risk screening for unrestricted use. There is a low probability that the EU acreage could be released with no land use restrictions because Ind and Res PRG exceedances for metals, radionuclides, and SVOCs occur. Specific 
chemicals and radionuclides with criteria exceedances are presented in Sect. 2.2.5. An appropriate evaluation of residential risk should be conducted to make a definitive conclusion.

\section{FFA Site}

Based on sampling analytical results (Sect. 2.2.6) and an evaluation of the EU-wide contaminant profile, soils in the K-1070-G Burial Ground Zone 2 ROD Appendix A FFA site in EU Z2-44 do not pose a potential threat to the future industrial worker or to groundwater.

\begin{tabular}{|l|l|}
\hline 4.0 & \multicolumn{1}{|c|}{ RECOMMENDATION FOR ACTION/NO FURTHER ACTION } \\
\hline 4.1 & DECISION AND REMEDIATION ACTIVITIES \\
\hline
\end{tabular}

EU Z2-44: Based on results of the Class 3 SU walkover assessment and analytical results of the DVS and historical samples collected, DOE recommends NFA is appropriate under the Zone 2 ROD to meet industrial land use for the 10.1 acres of ETTP EU Z2-44.

DVS and historical sampling and the Class $3 \mathrm{SU}$ walkover assessment has demonstrated that soils from 0-10 $\mathrm{ft}$ bgs meet the Zone 2 ROD requirements for industrial land use. However, the presence of the K-1070-G Burial Ground in the northern portion of the EU introduces sufficient uncertainty regarding soil compositions below $10 \mathrm{ft}$ bgs such that DOE does not recommend removal of the $10-\mathrm{ft}$ depth use restriction.

FFA Sites: Based on sampling analytical results and the recommendation for all of EU Z2-44, DOE recommends NFA is appropriate for the K-1070-G Burial Ground FFA site.

Note that these recommendations do not apply to the 6 acres associated with the active TSCAI that are exempt from assessment.

\section{\begin{tabular}{|l|l}
\hline 4.2 & EXCAVATION ACTIVITIES/CONFIRMATION SAMPLING \\
\hline
\end{tabular}}

None 


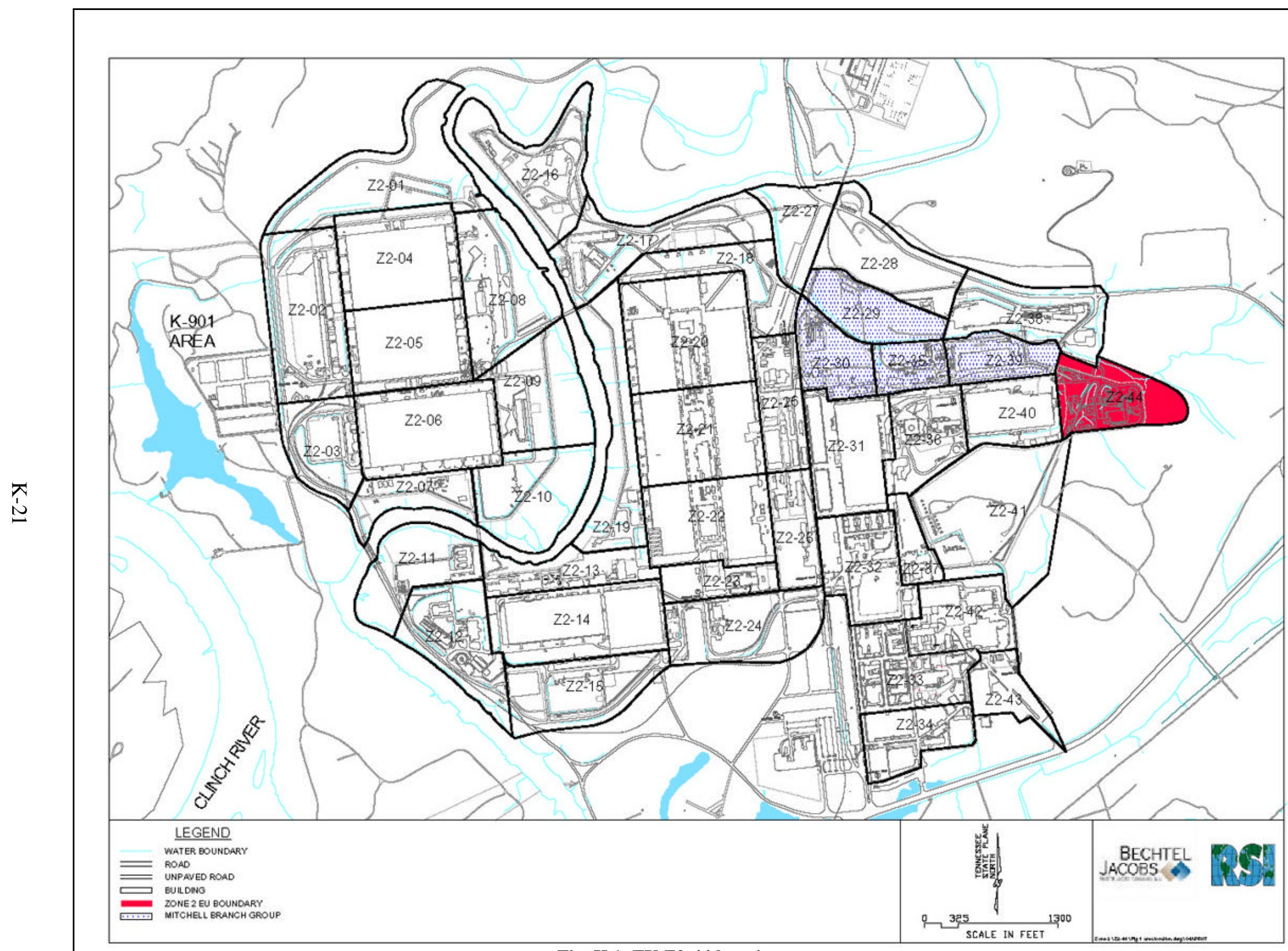

Fig. K.1. EU Z2-44 location map. 


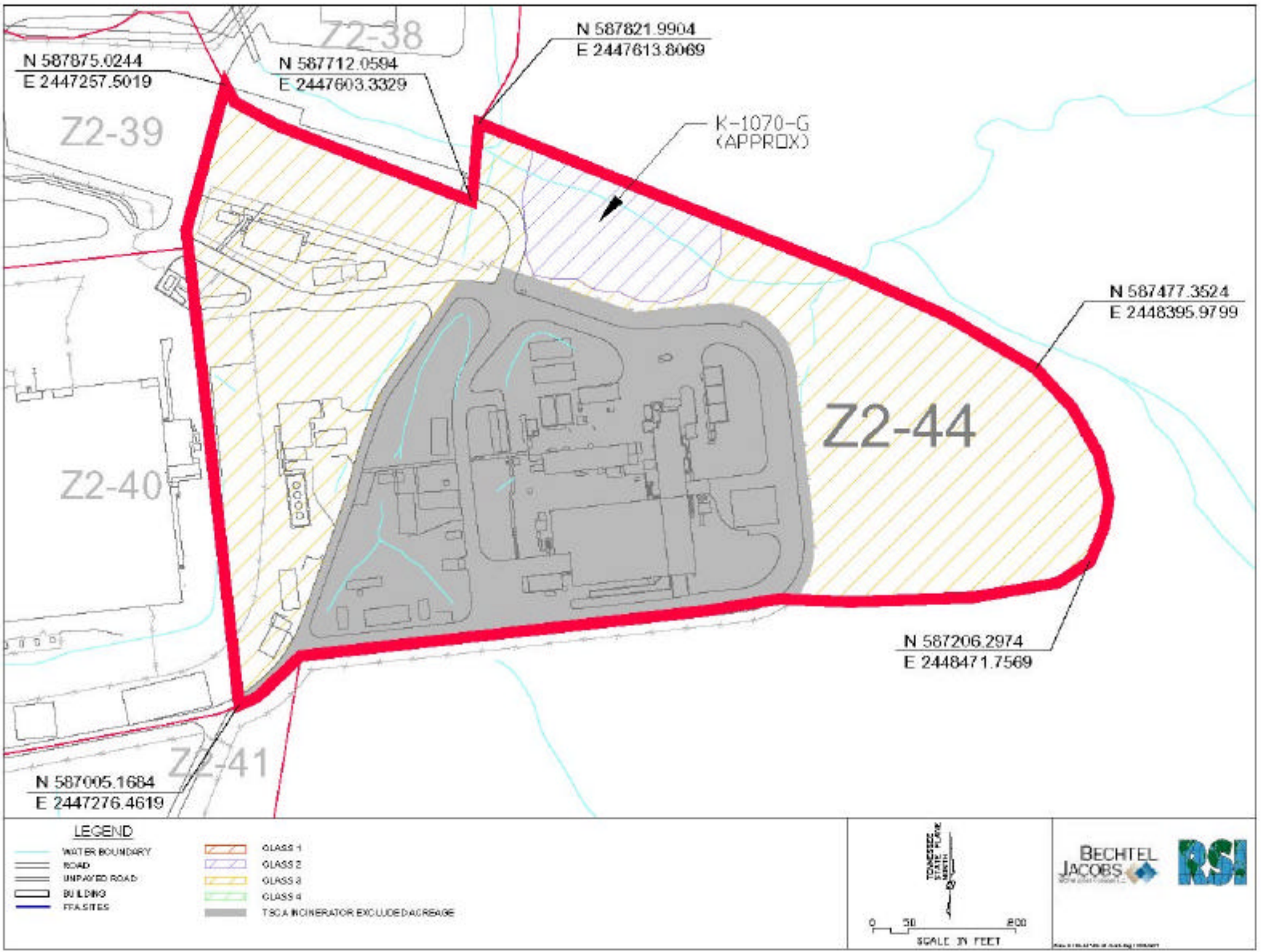

Fig. K.2. EU Z2-44 area location map. 


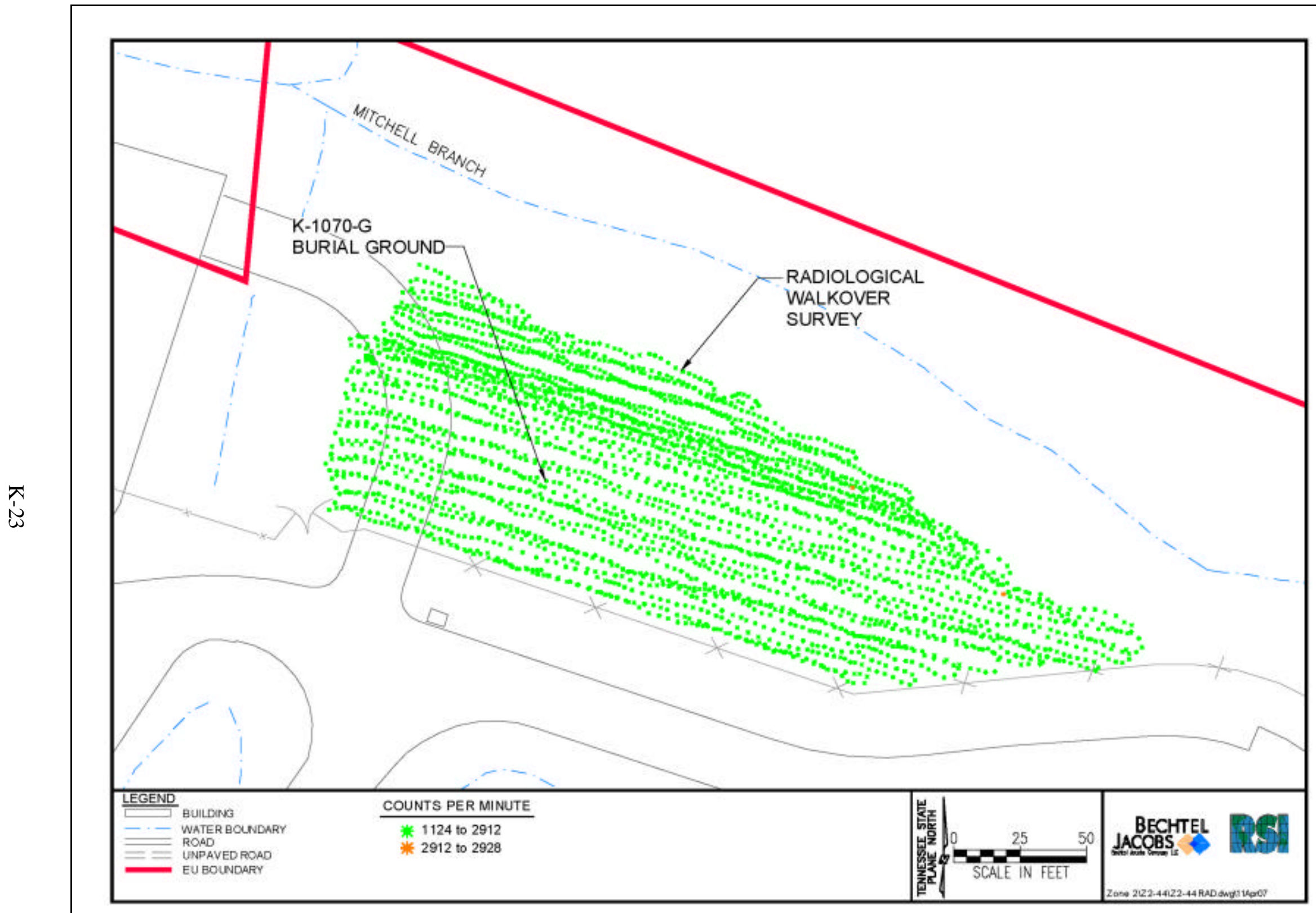

Fig. K.3. EU Z2-44 radiological walkover survey results. 


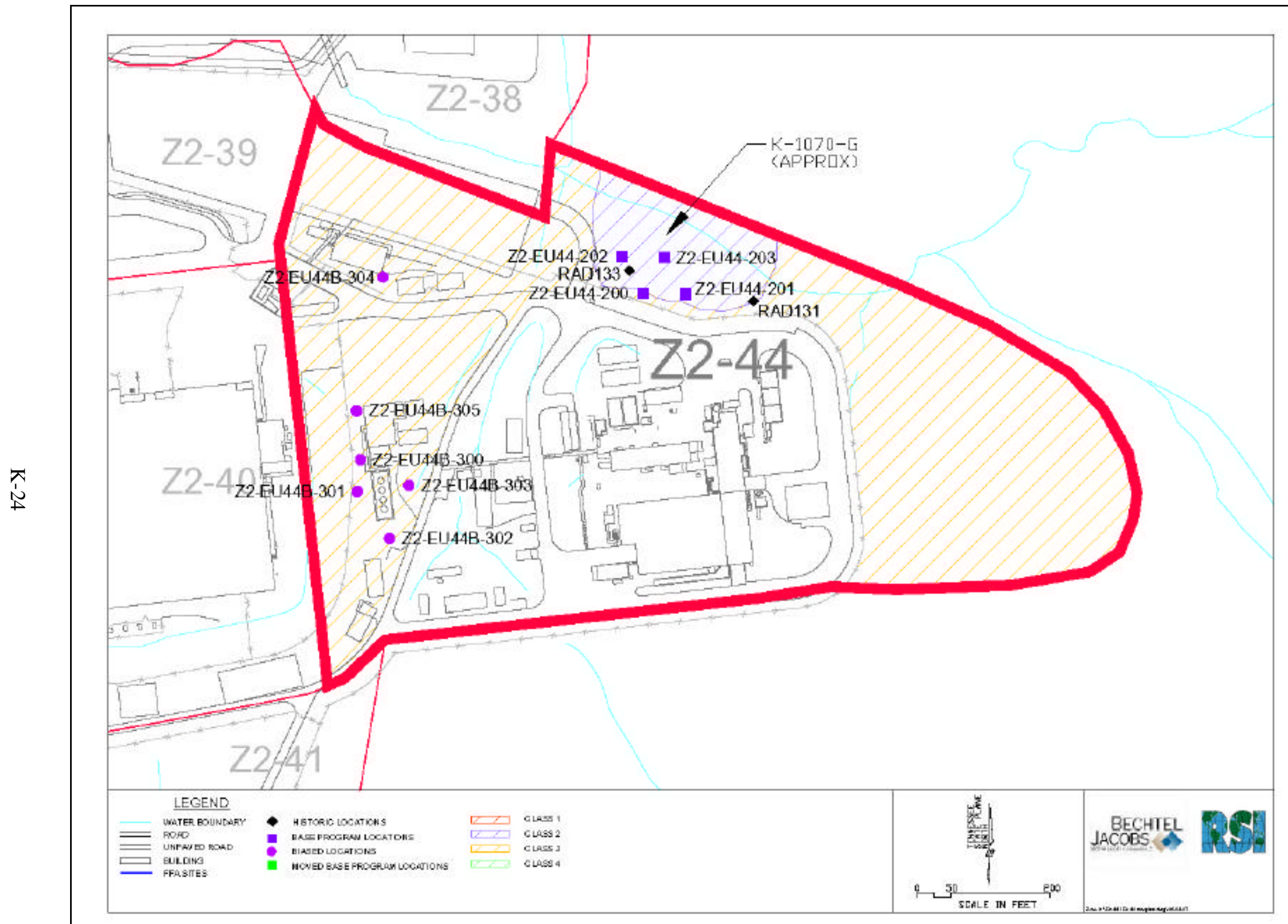

Fig. K.4. EU Z2-44 sample location map. 


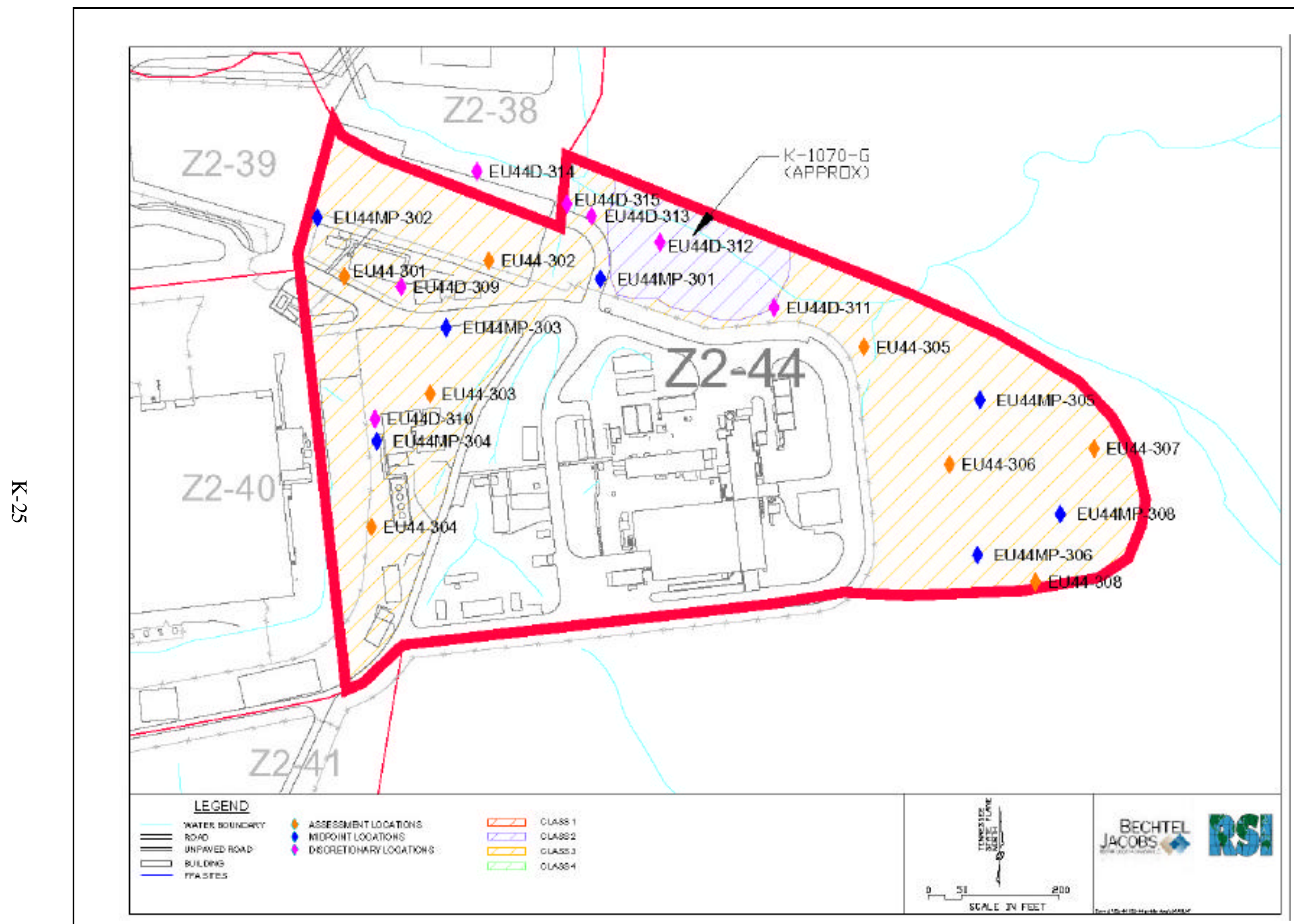

Fig. K.5. EU Z2-44 Class 3-4 walkover map. 


\section{Table K.1. EU Z2-44 facilities}

\begin{tabular}{|c|c|c|c|c|}
\hline \multirow[b]{2}{*}{ Facility name DQO scoping } & \multirow[b]{2}{*}{ Facility name } & \multicolumn{2}{|c|}{ Facility assessed? } & \multirow[b]{2}{*}{ Comments } \\
\hline & & Yes & No & \\
\hline K-1070-G Burial Ground & & $\mathrm{X}$ & & FFA site \\
\hline K-1240-6B Parking Area & & $\mathrm{X}$ & & \\
\hline K-1425 Waste Oil Storage Building & & $\mathrm{X}$ & & \\
\hline K-1425-AWaste Oil Storage Tank & & $\mathrm{X}$ & & \\
\hline K-1425-B Waste Oil Storage Tank & & $\mathrm{X}$ & & \\
\hline K-1425-C Waste Oil Storage Tank & & $\mathrm{X}$ & & \\
\hline K-1425-D Waste Oil Storage Tank & & $\mathrm{X}$ & & \\
\hline K-1425-E Waste Oil Containment Dike & & $\mathrm{X}$ & & \\
\hline K-1430 Maintenance Shop/Construction Offices & & $\mathrm{X}$ & & \\
\hline K-1430-A TSCAI Instrument Shop & K-1430-A TSCA Instrument Shop & $\mathrm{X}$ & & \\
\hline K-1430-B TSCAI Instrument/Electrical Shop & K-1430-B TSCA Instrument/Electrical Shop & $\mathrm{X}$ & & \\
\hline K-1700 Stream [Mitchell Branch] & K-1700 Mitchell Branch & $\mathrm{X}$ & & \\
\hline \multicolumn{5}{|l|}{ Facilities not in DQO scoping } \\
\hline K-1435-AB RUBB Storage Facility & & $\mathrm{X}$ & & \\
\hline K-1435-AC Steam Boiler Sealand & & $\mathrm{X}$ & & \\
\hline K-1435-AD Air Compressor Building & & $\mathrm{X}$ & & \\
\hline K-1435-E Office Trailer & & $\mathrm{X}$ & & \\
\hline K-1435-H Office Trailer & & $\mathrm{X}$ & & \\
\hline K-1435-J Records Storage Trailer & & $\mathrm{X}$ & & \\
\hline K-1435-K Office Trailer & & $\mathrm{X}$ & & \\
\hline K-1435-M RUBB Storage Facility & & $\mathrm{X}$ & & \\
\hline K-1435-Q Office Trailer & & $\mathrm{X}$ & & \\
\hline K-1435-R TSCA Office Trailer & & $\mathrm{X}$ & & \\
\hline K-1435-S TSCA Office Trailer & & $\mathrm{X}$ & & \\
\hline K-1435-T TSCA Office Trailer & & $\mathrm{X}$ & & \\
\hline K-1435-V Conference Room Trailer & & $\mathrm{X}$ & & \\
\hline K-1435-X Engineer's Office Trailer & & $\mathrm{X}$ & & \\
\hline K-1435-Z Restroom Trailer & & $\mathrm{X}$ & & \\
\hline $\begin{array}{ll}\mathrm{DQO}=\text { data quality objective } & \text { TSCA }=\text { Toxic Subst } \\
\mathrm{EU}=\text { exposure unit } & \text { TSCAI }=\text { Toxic Subst } \\
\text { FFA = Federal Facility Agreement } & \end{array}$ & $\begin{array}{l}\text { Control Act of } 1976 \\
\text { s Control Act of } 1976 \text { Incinerator }\end{array}$ & & & \\
\hline
\end{tabular}


Table K.2. EU Z2-44 sample summary

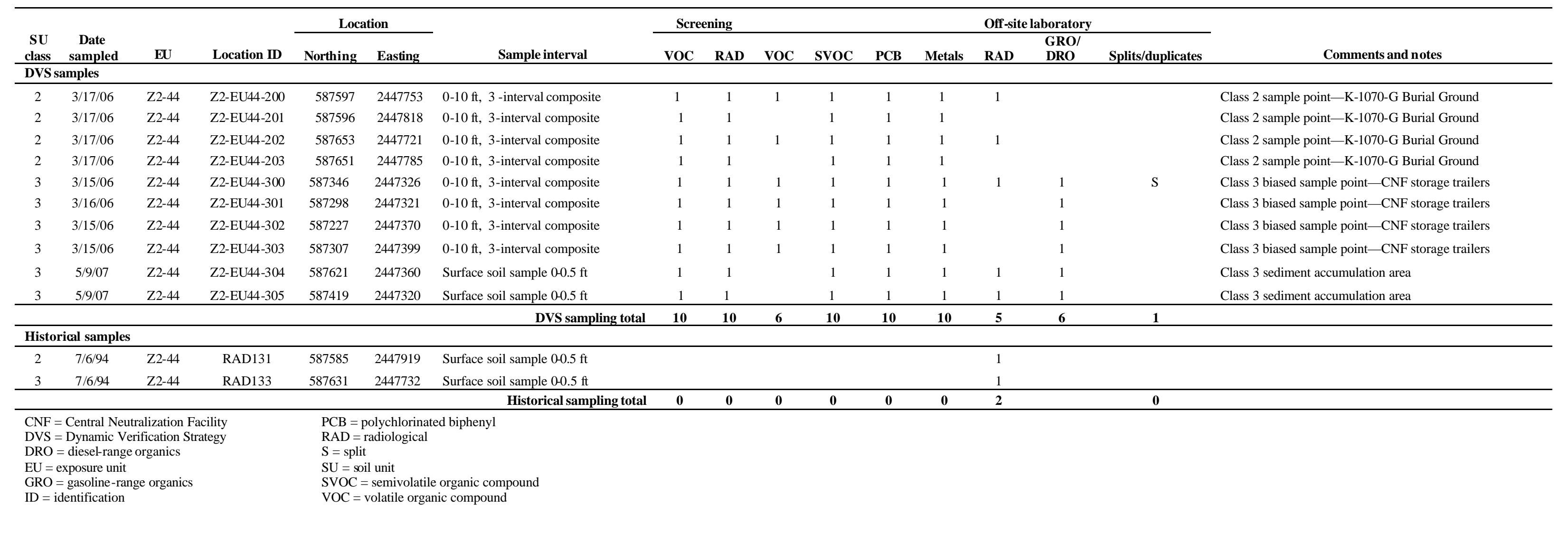


Table K.3. EU Z2-44, depth 0-10 ft

\begin{tabular}{|c|c|c|c|c|c|c|c|c|c|c|c|c|c|}
\hline Analyte & $\begin{array}{r}\text { Frequency } \\
\text { of detect }\end{array}$ & $\begin{array}{c}\text { Minimum } \\
\text { detect }\end{array}$ & $\begin{array}{c}\text { Maximum } \\
\text { detect }\end{array}$ & $\begin{array}{c}\begin{array}{c}\text { Location(s) } \\
\text { of maximum } \\
\text { detected result }\end{array} \\
\end{array}$ & $\begin{array}{c}\text { Average } \\
\text { detected } \\
\text { result }\end{array}$ & $\begin{array}{c}\text { Maximum } \\
\text { RL }\end{array}$ & $\begin{array}{c}\text { Frequency } \\
\text { of detects } \\
\text { exceeding } \\
\text { maximum } \\
\text { RL } \\
\end{array}$ & $\begin{array}{c}\text { Average } \\
\text { RL }\end{array}$ & $\begin{array}{c}\text { Frequency } \\
\text { of detects } \\
\text { exceeding } \\
\text { average } \\
\text { RL } \\
\end{array}$ & $\begin{array}{r}\text { PRG limit } \\
\left(10^{-5} \text { or } 1\right)\end{array}$ & $\begin{array}{l}\text { Frequency } \\
\text { of detects } \\
\text { exceeding } \\
\text { PRG limit }\end{array}$ & $\begin{array}{l}\text { Background } \\
\text { concentration }\end{array}$ & $\begin{array}{l}\text { Frequency } \\
\text { of detects } \\
\text { exceeding } \\
\text { background }\end{array}$ \\
\hline \multicolumn{14}{|l|}{ Inorganics $(\mathrm{mg} / \mathrm{kg})$} \\
\hline Aluminum & $10 / 10$ & 1,300 & 18,000 & Z2-EU44-202 & 13,100 & & $\mathrm{NA}$ & & NA & 100,000 & $0 / 10$ & 40,300 & $0 / 10$ \\
\hline Antimony & $10 / 10$ & $0.015 \mathrm{~J}$ & $0.74 \mathrm{~J}$ & Z2-EU44B-304 & 0.154 & & NA & & NA & 408.8 & $0 / 10$ & 1.52 & $0 / 10$ \\
\hline Arsenic & $10 / 10$ & 3.5 & 48 & Z2-EU44B-301 & 10.8 & 900 & $0 / 10$ & 300 & $0 / 10$ & 15.9 & $2 / 10$ & 14.95 & $2 / 10$ \\
\hline Barium & $10 / 10$ & $19 \mathrm{~J}$ & $150 \mathrm{~J}$ & Z2-EU44B-303 & 81.3 & & NA & & NA & 66,577 & $0 / 10$ & 124.93 & $1 / 10$ \\
\hline Beryllium & $10 / 10$ & 0.23 & $1.2 \mathrm{~J}$ & Z2-EU44-200 & 0.737 & 6,000 & $0 / 10$ & 2,000 & $0 / 10$ & 1941 & $0 / 10$ & 2.2 & $0 / 10$ \\
\hline Boron & $4 / 10$ & $3.1 \mathrm{~J}$ & 6.6 & Z2-EU44B-305 & 5.1 & & NA & & NA & 100,000 & $0 / 10$ & & NA \\
\hline Cadmium & $10 / 10$ & 0.31 & $1.6 \mathrm{~J}$ & Z2-EU44B-304 & 0.71 & & NA & & NA & 451 & $0 / 10$ & 0.22 & $10 / 10$ \\
\hline Calcium & $10 / 10$ & $520 \mathrm{~J}$ & $230,000 \mathrm{~J}$ & Z2-EU44B-304 & 32,532 & & $\mathrm{NA}$ & & $\mathrm{NA}$ & & NA & 2,400 & $7 / 10$ \\
\hline Chromium & $10 / 10$ & $21 \mathrm{~J}$ & $39 \mathrm{~J}$ & Z2-EU44B-301 & 28.9 & & NA & & NA & 640 & $0 / 10$ & 44.88 & $0 / 10$ \\
\hline Cobalt & $10 / 10$ & $10 \mathrm{~J}$ & $22 \mathrm{~J}$ & Z2-EU44-203 & 15 & & $\mathrm{NA}$ & & $\mathrm{NA}$ & 133,310 & $0 / 10$ & 42 & $0 / 10$ \\
\hline Copper & $10 / 10$ & $10 \mathrm{~J}$ & $430 \mathrm{~J}$ & Z2-EU44B-301 & 77 & & $\mathrm{NA}$ & & $\mathrm{NA}$ & 40,877 & $0 / 10$ & 22.48 & $7 / 10$ \\
\hline Iron & $10 / 10$ & $20,000 \mathrm{~J}$ & $52,000 \mathrm{~J}$ & Z2-EU44B-301 & 33,500 & & $\mathrm{NA}$ & & $\mathrm{NA}$ & 100,000 & $0 / 10$ & 58,600 & $0 / 10$ \\
\hline Lead & $10 / 10$ & $7.8 \mathrm{~J}$ & $70 \mathrm{~J}$ & Z2-EU44B-301 & 21.9 & & $\mathrm{NA}$ & & $\mathrm{NA}$ & 800 & $0 / 10$ & 37.91 & $1 / 10$ \\
\hline Lithium & $10 / 10$ & $5.6 \mathrm{~J}$ & 27 & Z2-EU44B-303 & 13.5 & & NA & & NA & 20,439 & $0 / 10$ & 48.94 & $0 / 10$ \\
\hline Magnesium & $10 / 10$ & $1,100 \mathrm{~J}$ & $22,000 \mathrm{~J}$ & Z2-EU44B-303 & 6,100 & & $\mathrm{NA}$ & & $\mathrm{NA}$ & & NA & 3,300 & $6 / 10$ \\
\hline Manganese & $10 / 10$ & $140 \mathrm{~J}$ & 1000 & Z2-EU44B-301 & 544 & & NA & & NA & 19,458 & $0 / 10$ & 2,200 & $0 / 10$ \\
\hline Mercury & $5 / 10$ & $0.03 \mathrm{~J}$ & 0.14 & Z2-EU44B-301 & 0.088 & 1,800 & $0 / 10$ & 600 & $0 / 10$ & 307 & $0 / 10$ & 0.17 & $0 / 10$ \\
\hline Molybdenum & $4 / 10$ & $1.3 \mathrm{~J}$ & 4.9 & Z2-EU44B-301 & 2.38 & & NA & & NA & 5,110 & $0 / 10$ & & NA \\
\hline Nickel & $10 / 10$ & $23 \mathrm{~J}$ & $990 \mathrm{~J}$ & Z2-EU44B-301 & 164 & & NA & & $\mathrm{NA}$ & 20,439 & $0 / 10$ & 26.07 & $7 / 10$ \\
\hline Potassium & $10 / 10$ & 600 & 2,200 & Z2-EU44-200 & 1575 & & $\mathrm{NA}$ & & $\mathrm{NA}$ & & $\mathrm{NA}$ & $5,074.69$ & $0 / 10$ \\
\hline Selenium & $3 / 10$ & $0.52 \mathrm{~J}$ & 3.7 & Z2-EU44B-305 & 1.73 & & NA & & NA & 5,110 & $0 / 10$ & 1.47 & $1 / 10$ \\
\hline Silver & $1 / 10$ & $0.12 \mathrm{~J}$ & $0.12 \mathrm{~J}$ & Z2-EU44B-304 & 0.12 & & NA & & NA & 5,110 & $0 / 10$ & 0.6 & $0 / 10$ \\
\hline Sodium & $5 / 10$ & $59 \mathrm{~J}$ & $170 \mathrm{~J}$ & Z2-EU44B-304 & 90.2 & & NA & & NA & & NA & 497 & $0 / 10$ \\
\hline Thallium & $\begin{array}{l}10 / 10 \\
10\end{array}$ & 0.037 & 0.35 & Z2-EU44B-301 & 0.199 & & $\mathrm{NA}$ & & $\mathrm{NA}$ & 67.5 & $0 / 10$ & 0.4 & $0 / 10$ \\
\hline Uranium & $10 / 10$ & 0.49 & 8.4 & Z2-EU44-200 & 1.85 & & NA & & NA & 204 & $0 / 10$ & & NA \\
\hline Vanadium & $10 / 10$ & 8 & 90 & Z2-EU44B-301 & 34.9 & & NA & & NA & 1,022 & $0 / 10$ & 65.47 & $1 / 10$ \\
\hline Zinc & $10 / 10$ & $22 \mathrm{~J}$ & $560 \mathrm{~J}$ & Z2-EU44B-304 & 129 & & $\mathrm{NA}$ & & $\mathrm{NA}$ & 100,000 & $0 / 10$ & 89.7 & $3 / 10$ \\
\hline \multicolumn{14}{|l|}{ Other Organics (mg/kg) } \\
\hline Diesel Range Organics & $2 / 6$ & $14 \mathrm{~J}$ & $58 \mathrm{~J}$ & Z2-EU44B-304 & 36 & & NA & & NA & & NA & & NA \\
\hline Gasoline Range Organics & $0 / 6$ & ND & ND & & ND & & NA & & NA & & NA & & NA \\
\hline \multicolumn{14}{|c|}{ Organics, pesticides, and PCBs (ug/kg) } \\
\hline PCB-1016 & $0 / 10$ & $\mathrm{ND}$ & $\mathrm{ND}$ & & $\mathrm{ND}$ & 100,000 & $0 / 10$ & 10,000 & $0 / 10$ & 37000 & $0 / 10$ & & $\mathrm{NA}$ \\
\hline PCB-1221 & $0 / 10$ & $\mathrm{ND}$ & $\mathrm{ND}$ & & $\mathrm{ND}$ & 100,000 & $0 / 10$ & 10,000 & $0 / 10$ & 7436 & $0 / 10$ & & NA \\
\hline PCB-1232 & $0 / 10$ & ND & ND & & ND & 100,000 & $0 / 10$ & 10,000 & $0 / 10$ & 7436 & $0 / 10$ & & NA \\
\hline PCB-1242 & $0 / 10$ & ND & $\mathrm{ND}$ & & ND & 100,000 & $0 / 10$ & 10,000 & $0 / 10$ & 7436 & $0 / 10$ & & NA \\
\hline PCB-1248 & $0 / 10$ & $\mathrm{ND}$ & ND & & $\mathrm{ND}$ & 100,000 & $0 / 10$ & 10,000 & $0 / 10$ & 7436 & $0 / 10$ & & $\mathrm{NA}$ \\
\hline PCB-1254 & $2 / 10$ & 110 & 240 & Z2-EU44B-304 & 175 & 100,000 & $0 / 10$ & 10,000 & $0 / 10$ & 7436 & $0 / 10$ & & NA \\
\hline PCB-1260 & $0 / 10$ & ND & ND & & ND & 100,000 & $0 / 10$ & 10,000 & $0 / 10$ & 7436 & $0 / 10$ & & NA \\
\hline Polychlorinated biphenyl & $2 / 10$ & 110 & 240 & Z2-EU44B-304 & 175 & 100,000 & $0 / 10$ & 10,000 & $0 / 10$ & 7436 & $0 / 10$ & & NA \\
\hline \multicolumn{14}{|l|}{ Radionuclides (pCi/g) } \\
\hline Actinium-228 & $6 / 6$ & 1.07 & $1.75 \mathrm{~J}$ & Z2-EU44-200 & 1.41 & & $\mathrm{NA}$ & & $\mathrm{NA}$ & 11,900 & $0 / 6$ & & NA \\
\hline Alpha activity & $6 / 6$ & 3.55 & 11.2 & Z2-EU44B-304 & 5.79 & & $\mathrm{NA}$ & & $\mathrm{NA}$ & & NA & & NA \\
\hline Beryllium-7 & $1 / 1$ & 1.88 & 1.88 & Z2-EU44B-304 & 1.88 & & $\mathrm{NA}$ & & NA & 1,200 & $0 / 1$ & & NA \\
\hline Beta activity & $6 / 6$ & $\begin{array}{l}5.00 \\
5.09\end{array}$ & 7.84 & Z2-EU44B-304 & 6.21 & & NA & & NA & 1,200 & NA & & NA \\
\hline Bismuth-214 & $4 / 4$ & 0.87 & $1.99 \mathrm{~J}$ & Z2-EU44B-301 & 1.19 & & NA & & NA & 134,000 & $0 / 4$ & & NA \\
\hline Cesium-134 & $1 / 2$ & 0.003 & 0.003 & RAD133 & 0.003 & & NA & & NA & 2.59 & $0 / 2$ & & NA \\
\hline Cesium 137 & $2 / 8$ & 0.181 & 0.22 & RAD131 & 0.201 & 20 & $0 / 8$ & 2 & $0 / 8$ & 1.13 & $0 / 8$ & & NA \\
\hline Cobalt-57 & $0 / 2$ & ND & ND & & ND & & NA & & NA & 144 & $0 / 2$ & & NA \\
\hline & 218 & 0018 & 002 & & 00 & & & & & & & & $\frac{\mathrm{NA}}{\mathrm{NA}}$ \\
\hline
\end{tabular}


Table K.3. (continued)

\begin{tabular}{|c|c|c|c|c|c|c|c|c|c|c|c|c|c|}
\hline Analyte & $\begin{array}{c}\text { Frequency } \\
\text { of detect }\end{array}$ & $\begin{array}{c}\text { Minimum } \\
\text { detect }\end{array}$ & $\begin{array}{c}\text { Maximum } \\
\text { detect }\end{array}$ & $\begin{array}{c}\text { Location(s) } \\
\text { of maximum } \\
\text { detected result }\end{array}$ & $\begin{array}{c}\text { Average } \\
\text { detected } \\
\text { result }\end{array}$ & $\underset{\text { RL }}{\text { Maximum }}$ & $\begin{array}{c}\text { Frequency } \\
\text { of detects } \\
\text { exceeding } \\
\text { maximum } \\
\text { RL }\end{array}$ & $\begin{array}{l}\text { Average } \\
\text { RL }\end{array}$ & $\begin{array}{c}\text { Frequency } \\
\text { of detects } \\
\text { exceeding } \\
\text { average } \\
\text { RL }\end{array}$ & $\begin{array}{l}\text { PRG limit } \\
\left(10^{-5} \text { or } 1\right)\end{array}$ & $\begin{array}{l}\text { Frequency } \\
\text { of detects } \\
\text { exceeding } \\
\text { PRG limit }\end{array}$ & $\begin{array}{l}\text { Background } \\
\text { concentration }\end{array}$ & $\begin{array}{l}\text { Frequency } \\
\text { of detects } \\
\text { exceeding } \\
\text { background }\end{array}$ \\
\hline Lead-212 & $7 / 7$ & 0.919 & 2 & Z2-EU44B-301 & 1.39 & & NA & & NA & 61,300 & $0 / 7$ & & NA \\
\hline Lead-214 & $7 / 7$ & $0.603 \mathrm{~J}$ & $1.96 \mathrm{~J}$ & Z2-EU44B-301 & 1.08 & & NA & & NA & 756,000 & $0 / 7$ & & NA \\
\hline Neptunium-237 & $1 / 8$ & 0.29 & 0.29 & RAD131 & 0.29 & 50 & $0 / 8$ & 5 & $0 / 8$ & 2.72 & $0 / 8$ & & NA \\
\hline Plutonium-238 & $1 / 2$ & 0.0021 & 0.0021 & RAD131 & 0.002 & & NA & & NA & 160 & $0 / 2$ & & NA \\
\hline Plutoniumr239 & $2 / 2$ & 0.0084 & 0.021 & RAD131 & 0.015 & & NA & & NA & & NA & & NA \\
\hline Potassium-40 & $8 / 8$ & $4.62 \mathrm{~J}$ & 18.9 & RAD131 & 12.3 & & NA & & NA & 2.73 & $8 / 8$ & 32.12 & $0 / 8$ \\
\hline Ra/Th Decay & $6 / 6$ & 0 & 2.29 & Z2-EU44B-301 & 0.727 & & NA & & NA & & NA & & NA \\
\hline Radiu m-226 & $7 / 8$ & 0.58 & 2.49 & Z2-EU44B-301 & 1.06 & 15 & $0 / 8^{a}$ & 5 & $0 / 8^{\mathrm{a}}$ & 0.26 & $7 / 8$ & 1.25 & $2 / 8$ \\
\hline Technetium-99 & $2 / 8$ & 0.2 & 0.64 & RAD133 & 0.42 & & NA & & NA & 8,960 & $0 / 8$ & & NA \\
\hline Thallium 208 & $6 / 6$ & 0.207 & 0.606 & Z2-EU44B-301 & 0.393 & & NA & & NA & 368,000 & $0 / 6$ & & NA \\
\hline Thorium-228 & $7 / 8$ & 0.88 & 1.93 & Z2-EU44B-301 & 1.45 & & NA & & NA & 0.18 & $7 / 8^{\mathrm{b}}$ & 1.86 & $1 / 8$ \\
\hline Thorium-230 & $7 / 8$ & 0.837 & 2.7 & Z2-EU44B-301 & 1.35 & 15 & $0 / 8^{\mathrm{a}}$ & 5 & $0 / 8^{\mathrm{a}}$ & 202 & $0 / 8$ & 1.2 & $3 / 8$ \\
\hline Thorium 232 & $8 / 8$ & 0.353 & 2.74 & Z2-EU44B-301 & 1.31 & 15 & $0 / 8^{\mathrm{a}}$ & 5 & $0 / 8^{\mathrm{a}}$ & 0.18 & $8 / 8^{\mathrm{b}}$ & 1.95 & $1 / 8$ \\
\hline Thorium-234 & $2 / 8$ & 1.8 & 2.15 & RAD131 & 1.98 & & NA & & NA & 32,800 & $0 / 8$ & & NA \\
\hline Uranium-234 & $8 / 8$ & 0.462 & 2.33 & Z2-EU44B-301 & 1.23 & 7,000 & $0 / 8$ & 700 & $0 / 8$ & 332 & $0 / 8$ & & NA \\
\hline Uranium-235 & $2 / 6$ & 0.116 & 0.17 & RAD133 & 0.143 & 80 & $0 / 6$ & 8 & $0 / 6$ & 3.98 & $0 / 6$ & & NA \\
\hline Uranium-238 & $8 / 8$ & 0.457 & 2.23 & Z2-EU44B-301 & 1.16 & 500 & $0 / 8$ & 50 & $0 / 8$ & 18 & $0 / 8$ & 1.47 & $2 / 8$ \\
\hline \multicolumn{14}{|l|}{ Semivolatile organics (ug/kg) } \\
\hline $1,2,4$ Trichlorobenzene & $0 / 16$ & ND & ND & & ND & & NA & & NA & 215,925 & $0 / 16$ & & NA \\
\hline 1,2-Dichlorobenzene & $0 / 16$ & ND & ND & & ND & & NA & & NA & 600,000 & $0 / 16$ & & NA \\
\hline 1,3-Dichlorobenzene & $0 / 16$ & ND & ND & & ND & & NA & & NA & 600,000 & $0 / 16$ & & NA \\
\hline 1,4-Dichlorobenzene & $0 / 16$ & ND & ND & & ND & & NA & & NA & 78,665 & $0 / 16$ & & NA \\
\hline 2,3,4,6-Tetrachlorophenol & $0 / 10$ & $\mathrm{ND}$ & ND & & ND & & NA & & NA & $18,468,189$ & $0 / 10$ & & NA \\
\hline 2,4,5-Trichlorophenol & $0 / 10$ & ND & ND & & ND & & NA & & NA & $61,560,629$ & $0 / 10$ & & NA \\
\hline 2,4,6-Trichlorophenol & $0 / 10$ & ND & $\mathrm{ND}$ & & ND & & NA & & NA & 61,561 & $0 / 10$ & & NA \\
\hline 2,4-Dichlorophenol & $0 / 10$ & ND & ND & & ND & & NA & & NA & $1,846,819$ & $0 / 10$ & & NA \\
\hline 2,4-Dimethylphenol & $0 / 10$ & ND & $\mathrm{ND}$ & & ND & & NA & & NA & $12,312,126$ & $0 / 10$ & & NA \\
\hline 2,4-Dinitrophenol & $0 / 10$ & ND & $\mathrm{ND}$ & & ND & & NA & & NA & $1,231,213$ & $0 / 10$ & & NA \\
\hline 2,4-Dinitrotoluene & $0 / 10$ & ND & ND & & ND & & NA & & $\mathrm{NA}$ & 25,348 & $0 / 10$ & & NA \\
\hline 2,6-Dinitrotoluene & $0 / 10$ & ND & ND & & ND & & NA & & NA & 25,348 & $0 / 10$ & & NA \\
\hline 2-Chloronaphthalene & $0 / 10$ & $\mathrm{ND}$ & ND & & ND & & NA & & NA & $23,382,732$ & $0 / 10$ & & NA \\
\hline 2-Chlorophenol & $0 / 10$ & ND & ND & & ND & & NA & & NA & 235,768 & $0 / 10$ & & NA \\
\hline 2-Methyl-4,6-dinitrophenol & $0 / 10$ & ND & ND & & ND & & NA & & NA & 61,561 & $0 / 10$ & & NA \\
\hline 2-Methylnaphthalene & $2 / 10$ & $91 \mathrm{~J}$ & $290 \mathrm{~J}$ & Z2-EU44B-304 & 191 & & NA & & NA & 187,691 & $0 / 10$ & & NA \\
\hline 2-Methylphenol & $0 / 10$ & ND & ND & & ND & & NA & & NA & $30,780,315$ & $0 / 10$ & & NA \\
\hline 2-Nitrobenzenamine & $0 / 10$ & ND & ND & & ND & & NA & & NA & $1,830,232$ & $0 / 10$ & & NA \\
\hline 2-Nitrophenol & $0 / 10$ & $\mathrm{ND}$ & $\mathrm{ND}$ & & $\mathrm{ND}$ & & NA & & NA & & NA & & NA \\
\hline 3,3'-Dichlorobenzidine & $0 / 10$ & ND & ND & & ND & & NA & & NA & 38,304 & $0 / 10$ & & NA \\
\hline 3-Methylphenol & $1 / 10$ & $810 \mathrm{~J}$ & $810 \mathrm{~J}$ & Z2-EU44B-305 & 810 & & NA & & NA & $30,780,315$ & $0 / 10$ & & NA \\
\hline 3-Nitrobenzenamine & $0 / 10$ & ND & ND & & ND & & NA & & NA & 18,468 & $0 / 10$ & & NA \\
\hline 4-Bromophenyl phenyl ether & $0 / 10$ & ND & ND & & ND & & NA & & NA & & NA & & NA \\
\hline 4-Chloro -3-methylphenol & $0 / 10$ & ND & $\mathrm{ND}$ & & ND & & NA & & NA & & NA & & NA \\
\hline 4-Chlorobenzenamine & $0 / 10$ & ND & ND & & ND & & NA & & NA & $2,462,425$ & $0 / 10$ & & NA \\
\hline 4-Chlorophenyl phenyl ether & $0 / 10$ & ND & ND & & ND & & NA & & NA & & NA & & NA \\
\hline 4-Nitrobenzenamine & $0 / 10$ & ND & ND & & ND & & NA & & NA & 184,648 & $0 / 10$ & & NA \\
\hline 4-Nitrophenol & $0 / 10$ & ND & ND & & ND & & NA & & NA & & NA & & NA \\
\hline Acenaphthene & $0 / 10$ & $\mathrm{ND}$ & ND & & ND & & NA & & NA & $29,219,327$ & $0 / 10$ & & NA \\
\hline Acenaphthylene & $0 / 10$ & ND & ND & & ND & & NA & & NA & $29,219,327$ & $0 / 10$ & & NA \\
\hline Aniline & $0 / 10$ & ND & ND & & ND & & NA & & NA & $3,024,031$ & $0 / 10$ & & NA \\
\hline Anthracene & $1 / 10$ & $200 \mathrm{~J}$ & $200 \mathrm{~J}$ & Z2-EU44B-303 & 200 & & NA & & NA & $100,000,000$ & $0 / 10$ & & NA \\
\hline Benz(a)anthracene & $4 / 10$ & $36 \mathrm{~J}$ & $500 \mathrm{~J}$ & Z2-EU44B-304 & 240 & & NA & & NA & 21,096 & $0 / 10$ & & NA \\
\hline Benzenemethanol & $0 / 10$ & $\mathrm{ND}$ & $\mathrm{ND}$ & & $\mathrm{ND}$ & & NA & & NA & $100,000,000$ & $0 / 10$ & & NA \\
\hline
\end{tabular}


Table K.3. (continued)

\begin{tabular}{|c|c|c|c|c|c|c|c|c|c|c|c|c|c|}
\hline Analyte & $\begin{array}{c}\text { Frequency } \\
\text { of detect }\end{array}$ & $\begin{array}{c}\text { Minimum } \\
\text { detect }\end{array}$ & $\begin{array}{c}\text { Maximum } \\
\text { detect }\end{array}$ & $\begin{array}{c}\text { Location(s) } \\
\text { of maximum } \\
\text { detected result }\end{array}$ & $\begin{array}{c}\text { Average } \\
\text { detected } \\
\text { result }\end{array}$ & 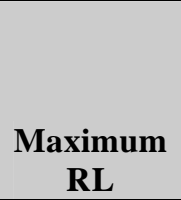 & $\begin{array}{c}\text { Frequency } \\
\text { of detects } \\
\text { exceeding } \\
\text { maximum } \\
\text { RL }\end{array}$ & $\begin{array}{l}\text { Average } \\
\text { RL }\end{array}$ & $\begin{array}{c}\text { Frequency } \\
\text { of detects } \\
\text { exceeding } \\
\text { average } \\
\text { RL }\end{array}$ & $\begin{array}{l}\text { PRG limit } \\
\left(10^{-5} \text { or } 1\right)\end{array}$ & $\begin{array}{l}\text { Frequency } \\
\text { of detects } \\
\text { exceeding } \\
\text { PRG limit }\end{array}$ & $\begin{array}{l}\text { Background } \\
\text { concentration }\end{array}$ & $\begin{array}{c}\text { Frequency } \\
\text { of detects } \\
\text { exceeding } \\
\text { background }\end{array}$ \\
\hline Benzo(a)pyrene & $4 / 10$ & $37 \mathrm{~J}$ & $410 \mathrm{~J}$ & Z2-EU44B-304 & 191 & & NA & & NA & 2,110 & $0 / 10$ & & NA \\
\hline Benzo(b)fluoranthene & $5 / 10$ & $52 \mathrm{~J}$ & 2,700 & Z2-EU44B-304 & 698 & & NA & & NA & 21,096 & $0 / 10$ & & NA \\
\hline Benzo(ghi)perylene & $1 / 10$ & $78 \mathrm{~J}$ & $78 \mathrm{~J}$ & Z2-EU44B-303 & 78 & & NA & & NA & $29,126,201$ & $0 / 10$ & & NA \\
\hline Benzo(k)fluoranthene & $4 / 10$ & $26 \mathrm{~J}$ & $1,100 \mathrm{~J}$ & Z2-EU44B-304 & 336 & & NA & & $\mathrm{NA}$ & 210,962 & $0 / 10$ & & NA \\
\hline Benzoic acid & $1 / 10$ & $2,600 \mathrm{~J}$ & $2,600 \mathrm{~J}$ & Z2-EU44B-304 & 2,600 & & NA & & $\mathrm{NA}$ & $100,000,000$ & $0 / 10$ & & $\mathrm{NA}$ \\
\hline $\operatorname{Bis}(2$-chloroethoxy)methane & $0 / 10$ & ND & ND & & ND & & NA & & NA & & NA & & $\mathrm{NA}$ \\
\hline Bis(2-chloroethyl) ether & $0 / 10$ & ND & ND & & $\mathrm{ND}$ & & NA & & $\mathrm{NA}$ & 5,755 & $0 / 10$ & & NA \\
\hline Bis(2-chloroisopropyl) ether & $0 / 10$ & $\mathrm{ND}$ & ND & & ND & & NA & & NA & 73,518 & $0 / 10$ & & NA \\
\hline Bis(2-ethylhexyl)phthalate & $2 / 10$ & $310 \mathrm{~J}$ & $530 \mathrm{~J}$ & Z2-EU44B-304 & 420 & & NA & & $\mathrm{NA}$ & $1,231,213$ & $0 / 10$ & & $\mathrm{NA}$ \\
\hline Butyl benzyl phthalate & $0 / 10$ & $\mathrm{ND}$ & $\mathrm{ND}$ & & $\mathrm{ND}$ & & NA & & $\mathrm{NA}$ & $100,000,000$ & $0 / 10$ & & $\mathrm{NA}$ \\
\hline Carbazole & $1 / 10$ & $480 \mathrm{~J}$ & $480 \mathrm{~J}$ & Z2-EU44B-304 & 480 & & NA & & $\mathrm{NA}$ & 861,849 & $0 / 10$ & & NA \\
\hline Chrysene & $4 / 10$ & $35 \mathrm{~J}$ & 3,300 & Z2-EU44B-304 & 918 & & NA & & NA & $2,109,623$ & $0 / 10$ & & NA \\
\hline Dibenz(a,h)anthracene & $0 / 10$ & $\mathrm{ND}$ & ND & & ND & & NA & & $\mathrm{NA}$ & 2,110 & $0 / 10$ & & NA \\
\hline Dibenzofuran & $1 / 10$ & $720 \mathrm{~J}$ & $720 \mathrm{~J}$ & Z2-EU44B-304 & 720 & & NA & & NA & $1,563,342$ & $0 / 10$ & & NA \\
\hline Diethyl phthalate & $0 / 10$ & $\mathrm{ND}$ & $\mathrm{ND}$ & & $\mathrm{ND}$ & & NA & & NA & $100,000,000$ & $0 / 10$ & & $\mathrm{NA}$ \\
\hline Dimethyl phthalate & $0 / 10$ & ND & ND & & ND & & NA & & $\mathrm{NA}$ & $100,000,000$ & $0 / 10$ & & NA \\
\hline Di-n-butyl phthalate & $0 / 10$ & $\mathrm{ND}$ & ND & & ND & & NA & & NA & $61,560,629$ & $0 / 10$ & & NA \\
\hline Di-n-octylphthalate & $0 / 10$ & $\mathrm{ND}$ & $\mathrm{ND}$ & & $\mathrm{ND}$ & & NA & & $\mathrm{NA}$ & $24,624,252$ & $0 / 10$ & & NA \\
\hline Diphenyldiazene & $0 / 10$ & ND & $\mathrm{ND}$ & & $\mathrm{ND}$ & & NA & & $\mathrm{NA}$ & 156,700 & $0 / 10$ & & NA \\
\hline Fluoranthene & $5 / 10$ & $78 \mathrm{~J}$ & 14,000 & Z2-EU44B-304 & 3,112 & & NA & & $\mathrm{NA}$ & $22,000,353$ & $0 / 10$ & & NA \\
\hline Fluorene & $1 / 10$ & $53 \mathrm{~J}$ & $53 \mathrm{~J}$ & Z2-EU44B-303 & 53 & & NA & & NA & $26,281,433$ & $0 / 10$ & & NA \\
\hline Hexachlorobenzene & $0 / 10$ & $\mathrm{ND}$ & ND & & ND & & NA & & NA & 10,773 & $0 / 10$ & & NA \\
\hline Hexachlorobutadiene & $0 / 16$ & ND & ND & & ND & & NA & & $\mathrm{NA}$ & 184,682 & $0 / 16$ & & $\mathrm{NA}$ \\
\hline Hexachlorocyclopentadiene & $0 / 10$ & $\mathrm{ND}$ & $\mathrm{ND}$ & & $\mathrm{ND}$ & & $\mathrm{NA}$ & & $\mathrm{NA}$ & $3,658,717$ & $0 / 10$ & & $\mathrm{NA}$ \\
\hline Hexachloroethane & $0 / 10$ & ND & ND & & ND & & $\mathrm{NA}$ & & NA & 615,606 & $0 / 10$ & & $\mathrm{NA}$ \\
\hline Indeno(1,2,3-cd)pyrene & $1 / 10$ & $83 \mathrm{~J}$ & $83 \mathrm{~J}$ & Z2-EU44B-303 & 83 & & NA & & $\mathrm{NA}$ & 21,096 & $0 / 10$ & & NA \\
\hline Isophorone & $0 / 10$ & $\mathrm{ND}$ & $\mathrm{ND}$ & & ND & & NA & & NA & $5,119,795$ & $0 / 10$ & & NA \\
\hline Naphthalene & $1 / 16$ & $630 \mathrm{~J}$ & $630 \mathrm{~J}$ & Z2-EU44B-304 & 630 & & NA & & $\mathrm{NA}$ & 187,691 & $0 / 16$ & & $\mathrm{NA}$ \\
\hline Nitrobenzene & $0 / 10$ & $\mathrm{ND}$ & $\mathrm{ND}$ & & ND & & NA & & $\mathrm{NA}$ & 102,935 & $0 / 10$ & & $\mathrm{NA}$ \\
\hline N-Nitrosodimethylamine & $0 / 10$ & ND & ND & & ND & & NA & & NA & 338 & $0 / 10$ & & $\mathrm{NA}$ \\
\hline N-Nitroso-di-n-propylamine & $0 / 10$ & ND & ND & & $\mathrm{ND}$ & & NA & & $\mathrm{NA}$ & 2,462 & $0 / 10$ & & NA \\
\hline N-Nitrosodiphenylamine & $0 / 10$ & ND & $\mathrm{ND}$ & & ND & & NA & & NA & $3,517,750$ & $0 / 10$ & & NA \\
\hline Pentachlorophenol & $0 / 10$ & ND & ND & & $\mathrm{ND}$ & & NA & & NA & 89,982 & $0 / 10$ & & NA \\
\hline Phenanthrene & $4 / 10$ & $45 \mathrm{~J}$ & 11,000 & Z2-EU44B-304 & 2,924 & & NA & & $\mathrm{NA}$ & $29,126,201$ & $0 / 10$ & & $\mathrm{NA}$ \\
\hline Phenol & $0 / 10$ & ND & $\mathrm{ND}$ & & $\mathrm{ND}$ & & NA & & NA & $100,000,000$ & $0 / 10$ & & NA \\
\hline Pyrene & $4 / 10$ & $57 \mathrm{~J}$ & $6,700 \mathrm{~J}$ & Z2-EU44B-304 & 1,891 & & NA & & NA & $29,126,201$ & $0 / 10$ & & NA \\
\hline Pyridine & $0 / 10$ & $\mathrm{ND}$ & $\mathrm{ND}$ & & ND & & NA & & NA & 615,606 & $0 / 10$ & & NA \\
\hline \multicolumn{14}{|l|}{ Volatile organics (ug/kg) } \\
\hline (1,1-Dimethylethyl)benzene & $0 / 6$ & $\mathrm{ND}$ & $\mathrm{ND}$ & & $\mathrm{ND}$ & & $\mathrm{NA}$ & & NA & 390,000 & $0 / 6$ & & $\mathrm{NA}$ \\
\hline (1-Methylpropyl)benzene & $0 / 6$ & $\mathrm{ND}$ & ND & & ND & & NA & & NA & 220,000 & $0 / 6$ & & NA \\
\hline 1,1,1,2-Tetrachloroethane & $0 / 6$ & ND & ND & & $\mathrm{ND}$ & & NA & & NA & 72,755 & $0 / 6$ & & NA \\
\hline 1,1,1-Trichloroethane & $0 / 6$ & $\mathrm{ND}$ & $\mathrm{ND}$ & & $\mathrm{ND}$ & & NA & & $\mathrm{NA}$ & $1,200,000$ & $0 / 6$ & & $\mathrm{NA}$ \\
\hline $\begin{array}{l}\text { 1,1,2,2-Tetrachloroethane } \\
\text { 1,1,2-Trichloro-1,2,2- }\end{array}$ & $0 / 6$ & $\mathrm{ND}$ & ND & & ND & & $\mathrm{NA}$ & & NA & 9,294 & $0 / 6$ & & NA \\
\hline trifluoroethane & $0 / 6$ & $\mathrm{ND}$ & $\mathrm{ND}$ & & $\mathrm{ND}$ & & NA & & NA & $5,600,000$ & $0 / 6$ & & NA \\
\hline 1,1,2-Trichloroethane & $0 / 6$ & ND & ND & & ND & & NA & & $\mathrm{NA}$ & 16,050 & $0 / 6$ & & NA \\
\hline 1,1-Dichloroethane & $0 / 6$ & $\mathrm{ND}$ & $\mathrm{ND}$ & & ND & & NA & & $\mathrm{NA}$ & $1,738,654$ & $0 / 6$ & & $\mathrm{NA}$ \\
\hline 1,1-Dichloroethene & $0 / 6$ & $\mathrm{ND}$ & ND & & $\mathrm{ND}$ & & NA & & NA & 413,325 & $0 / 6$ & & $\mathrm{NA}$ \\
\hline 1,1-Dichloropropene & $0 / 6$ & ND & ND & & $\mathrm{ND}$ & & NA & & NA & & NA & & NA \\
\hline 1,2,3-Trichlorobenzene & $0 / 6$ & ND & ND & & ND & & NA & & $\mathrm{NA}$ & & NA & & $\mathrm{NA}$ \\
\hline 1,2,3-Trichloropropane & $0 / 6$ & $\mathrm{ND}$ & ND & & ND & & NA & & $\mathrm{NA}$ & 760 & $0 / 6$ & & NA \\
\hline $1,2,4$ Trimethylbenzene & $0 / 6$ & ND & $\mathrm{ND}$ & & ND & & NA & & NA & 170,272 & $0 / 6$ & & NA \\
\hline
\end{tabular}


Table K.3. (continued)

\begin{tabular}{|c|c|c|c|c|c|c|c|c|c|c|c|c|c|}
\hline Analyte & $\begin{array}{r}\text { Frequency } \\
\text { of detect }\end{array}$ & $\begin{array}{c}\text { Minimum } \\
\text { detect }\end{array}$ & $\begin{array}{c}\text { Maximum } \\
\text { detect }\end{array}$ & $\begin{array}{c}\text { Location(s) } \\
\text { of maximum } \\
\text { detected result }\end{array}$ & $\begin{array}{c}\begin{array}{c}\text { Average } \\
\text { detected } \\
\text { result }\end{array} \\
\end{array}$ & $\begin{array}{c}\text { Maximum } \\
\text { RL }\end{array}$ & 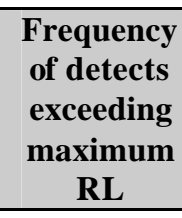 & $\begin{array}{c}\text { Average } \\
\text { RL }\end{array}$ & $\begin{array}{c}\text { Frequency } \\
\text { of detects } \\
\text { exceeding } \\
\text { average } \\
\text { RL } \\
\end{array}$ & $\begin{array}{r}\text { PRG limit } \\
\left(10^{-5} \text { or } 1\right)\end{array}$ & $\begin{array}{l}\text { Frequency } \\
\text { of detects } \\
\text { exceeding } \\
\text { PRG limit }\end{array}$ & $\begin{array}{c}\text { Background } \\
\text { concentration }\end{array}$ & $\begin{array}{c}\text { Frequency } \\
\text { of detects } \\
\text { exceeding } \\
\text { background }\end{array}$ \\
\hline 1,2-Dibromo-3-chloropropane & $0 / 6$ & ND & $\mathrm{ND}$ & & $\mathrm{ND}$ & & NA & & NA & 11,000 & $0 / 6$ & & NA \\
\hline 1,2-Dibromoethane & $0 / 6$ & ND & ND & & ND & & NA & & NA & 630 & $0 / 6$ & & NA \\
\hline 1,2-Dichloroethane & $0 / 6$ & ND & ND & & ND & & NA & & NA & 6,035 & $0 / 6$ & & NA \\
\hline 1,2-Dichloropropane & $0 / 6$ & ND & $\mathrm{ND}$ & & ND & & NA & & NA & 7,422 & $0 / 6$ & & NA \\
\hline 1,2-Dimethylbenzene & $0 / 6$ & ND & $\mathrm{ND}$ & & $\mathrm{ND}$ & & NA & & NA & 420,000 & $0 / 6$ & & NA \\
\hline 1,3,5-Trimethylbenzene & $0 / 6$ & ND & ND & & ND & & NA & & NA & 69,712 & $0 / 6$ & & NA \\
\hline 1,3-Dichloropropane & $0 / 6$ & ND & ND & & ND & & NA & & NA & 360,521 & $0 / 6$ & & NA \\
\hline 1-Chloro -4-methylbenzene & $0 / 6$ & ND & ND & & ND & & NA & & NA & & NA & & NA \\
\hline $\begin{array}{l}\text { 1-chlorohexane } \\
\text { 1-Methyl-4-(1-methylethvl) }\end{array}$ & $0 / 6$ & ND & ND & & ND & & NA & & NA & & NA & & NA \\
\hline benzene & $0 / 6$ & ND & $\mathrm{ND}$ & & ND & & NA & & NA & & NA & & NA \\
\hline 2,2-Dichloropropane & $0 / 6$ & $\mathrm{ND}$ & $\mathrm{ND}$ & & ND & & NA & & NA & & NA & & NA \\
\hline 2-Butanone & $0 / 6$ & ND & ND & & ND & & NA & & NA & $113,264,388$ & $0 / 6$ & & NA \\
\hline 2-Hexanone & $0 / 6$ & ND & $\mathrm{ND}$ & & ND & & NA & & NA & & NA & & NA \\
\hline 2-Methoxy -2-methylpropane & $0 / 6$ & ND & ND & & ND & & NA & & NA & 700,000 & $0 / 6$ & & NA \\
\hline 4-Methyl-2-pentanone & $0 / 6$ & ND & ND & & $\mathrm{ND}$ & & NA & & NA & $47,001,434$ & $0 / 6$ & & NA \\
\hline Acetone & $0 / 6$ & ND & ND & & ND & & NA & & NA & $54,320,986$ & $0 / 6$ & & NA \\
\hline Benzene & $0 / 6$ & $\mathrm{ND}$ & $\mathrm{ND}$ & & ND & & NA & & NA & 14,094 & $0 / 6$ & & NA \\
\hline Bromobenzene & $0 / 6$ & ND & $\mathrm{ND}$ & & ND & & NA & & NA & 92,152 & $0 / 6$ & & NA \\
\hline Bromochloromethane & $0 / 6$ & ND & ND & & ND & & NA & & NA & & NA & & NA \\
\hline Bromodichloromethane & $0 / 6$ & ND & ND & & ND & & NA & & NA & 18,306 & $0 / 6$ & & NA \\
\hline Bromoform & $0 / 6$ & ND & ND & & ND & & NA & & NA & $2,181,998$ & $0 / 6$ & & NA \\
\hline Bromomethane & $0 / 6$ & ND & ND & & ND & & NA & & NA & 13,078 & $0 / 6$ & & NA \\
\hline Butylbenzene & $0 / 6$ & $\mathrm{ND}$ & $\mathrm{ND}$ & & ND & & NA & & NA & 240,000 & $0 / 6$ & & NA \\
\hline Carbon disulfide & $0 / 6$ & ND & ND & & ND & & NA & & NA & 720,000 & $0 / 6$ & & NA \\
\hline Carbon tetrachloride & $0 / 6$ & ND & $\mathrm{ND}$ & & ND & & NA & & NA & 5,493 & $0 / 6$ & & NA \\
\hline Chlorobenzene & $0 / 6$ & ND & ND & & ND & & NA & & NA & 530,466 & $0 / 6$ & & NA \\
\hline Chloroethane & $0 / 6$ & ND & ND & & ND & & NA & & NA & 64,855 & $0 / 6$ & & NA \\
\hline Chloroform & $0 / 6$ & ND & ND & & ND & & NA & & NA & 4,698 & $0 / 6$ & & NA \\
\hline Chloromethane & $0 / 6$ & ND & $\mathrm{ND}$ & & ND & & NA & & NA & 155,746 & $0 / 6$ & & NA \\
\hline cis-1,2-Dichloroethene & $0 / 6$ & $\mathrm{ND}$ & $\mathrm{ND}$ & & $\mathrm{ND}$ & & NA & & NA & 146,301 & $0 / 6$ & & NA \\
\hline cis-1,3-Dichloropropene & $0 / 6$ & ND & ND & & ND & & NA & & NA & 17,645 & $0 / 6$ & & NA \\
\hline Cumene & $0 / 6$ & $\mathrm{ND}$ & ND & & ND & & NA & & NA & 520,000 & $0 / 6$ & & NA \\
\hline Dibromochloromethane & $0 / 6$ & $\mathrm{ND}$ & ND & & ND & & NA & & NA & 25,543 & $0 / 6$ & & NA \\
\hline Dibromomethane & $0 / 6$ & ND & ND & & ND & & NA & & NA & 233,550 & $0 / 6$ & & NA \\
\hline Dichlorodifluoromethane & $0 / 6$ & ND & ND & & ND & & NA & & NA & 308,058 & $0 / 6$ & & NA \\
\hline Ethylbenzene & $0 / 6$ & ND & ND & & ND & & NA & & NA & 395,000 & $0 / 6$ & & NA \\
\hline Iodomethane & $0 / 6$ & $\mathrm{ND}$ & $\mathrm{ND}$ & & ND & & NA & & NA & & NA & & NA \\
\hline M + P Xylene & $0 / 6$ & ND & ND & & ND & & NA & & NA & 420,000 & $0 / 6$ & & NA \\
\hline Methylene chloride & $0 / 6$ & $\mathrm{ND}$ & $\mathrm{ND}$ & & ND & & NA & & NA & 205,265 & $0 / 6$ & & NA \\
\hline o-Chlorotoluene & $0 / 6$ & ND & ND & & ND & & NA & & NA & 560,010 & $0 / 6$ & & NA \\
\hline Propylbenzene & $0 / 6$ & ND & ND & & ND & & NA & & NA & 240,000 & $0 / 6$ & & NA \\
\hline Styrene & $0 / 6$ & $\mathrm{ND}$ & $\mathrm{ND}$ & & $\mathrm{ND}$ & & NA & & NA & $1,700,000$ & $0 / 6$ & & NA \\
\hline Tetrachloroethene & $0 / 6$ & ND & ND & & ND & & NA & & NA & 13,086 & $0 / 6$ & & NA \\
\hline Toluene & $0 / 6$ & ND & ND & & ND & & NA & & NA & 520,000 & $0 / 6$ & & NA \\
\hline trans-1,2-Dichloroethene & $0 / 6$ & ND & ND & & ND & & NA & & NA & 234,823 & $0 / 6$ & & NA \\
\hline trans-1,3-Dichloropropene & $0 / 6$ & ND & ND & & ND & & NA & & NA & 17,645 & $0 / 6$ & & NA \\
\hline Trichloroethene & $0 / 6$ & ND & ND & & ND & & NA & & NA & 1,147 & $0 / 6$ & & NA \\
\hline Trichlorofluoromethane & $0 / 6$ & ND & ND & & ND & & NA & & NA & $1,276,074$ & $0 / 6$ & & NA \\
\hline Vinyl acetate & $0 / 6$ & ND & ND & & ND & & NA & & NA & $1,396,422$ & $0 / 6$ & & NA \\
\hline Vinyl chloride & $0 / 6$ & ND & ND & & ND & & NA & & NA & 7,461 & $0 / 6$ & & NA \\
\hline
\end{tabular}


Table K.3. (continued)

\begin{tabular}{|c|c|c|c|c|c|c|c|c|c|c|c|c|c|}
\hline Analyte & $\begin{array}{c}\text { Frequency } \\
\text { of detect }\end{array}$ & $\begin{array}{c}\text { Minimum } \\
\text { detect }\end{array}$ & $\underset{\text { detect }}{\text { Maximum }}$ & $\begin{array}{l}\text { Location(s) } \\
\text { of maximum } \\
\text { detected result }\end{array}$ & $\begin{array}{l}\text { Average } \\
\text { detected } \\
\text { result }\end{array}$ & $\underset{\text { RL }}{\operatorname{Maximum}}$ & $\begin{array}{l}\text { Frequency } \\
\text { of detects } \\
\text { exceeding } \\
\text { maximum } \\
\text { RL }\end{array}$ & $\begin{array}{c}\text { Average } \\
\text { RL }\end{array}$ & 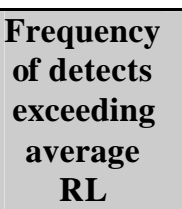 & $\begin{array}{l}\text { PRG limit } \\
\left(10^{-5} \text { or } 1\right)\end{array}$ & $\begin{array}{l}\text { Frequency } \\
\text { of detects } \\
\text { exceeding } \\
\text { PRG limit }\end{array}$ & $\begin{array}{l}\text { Background } \\
\text { concentration }\end{array}$ & $\begin{array}{c}\text { Frequency } \\
\text { of detects } \\
\text { exceeding } \\
\text { background }\end{array}$ \\
\hline
\end{tabular}

Stations in summary included Z2-EU44-200, Z2-EU44-201, Z2-EU44-202, Z2-EU44-203, Z2-EU44-300, Z2-EU44-301, Z2-EU44-302, Z2-EU44303, Z2-EU44-304, Z2-EU44-305, RAD131, and RAD13

$\mathrm{EU}=$ exposure unit $\quad$ PRG = preliminary remediation goal

$\begin{array}{ll}\mathrm{J}=\text { = explyste positively identified and result is approximate concentration of analyte in sample } & \mathrm{RL}=\text { remediation level } \\ \mathrm{NA}=\text { not applicable } & \mathrm{ROD}=\text { record of decision }\end{array}$

$\mathrm{ND}=$ not detected
$\mathrm{PCB}=$ polychlorinated biphenyl

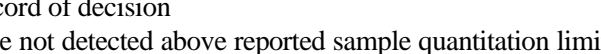


$\underline{\text { Appendix L }}$

Zone 2 Data Quality Control Summary Report 


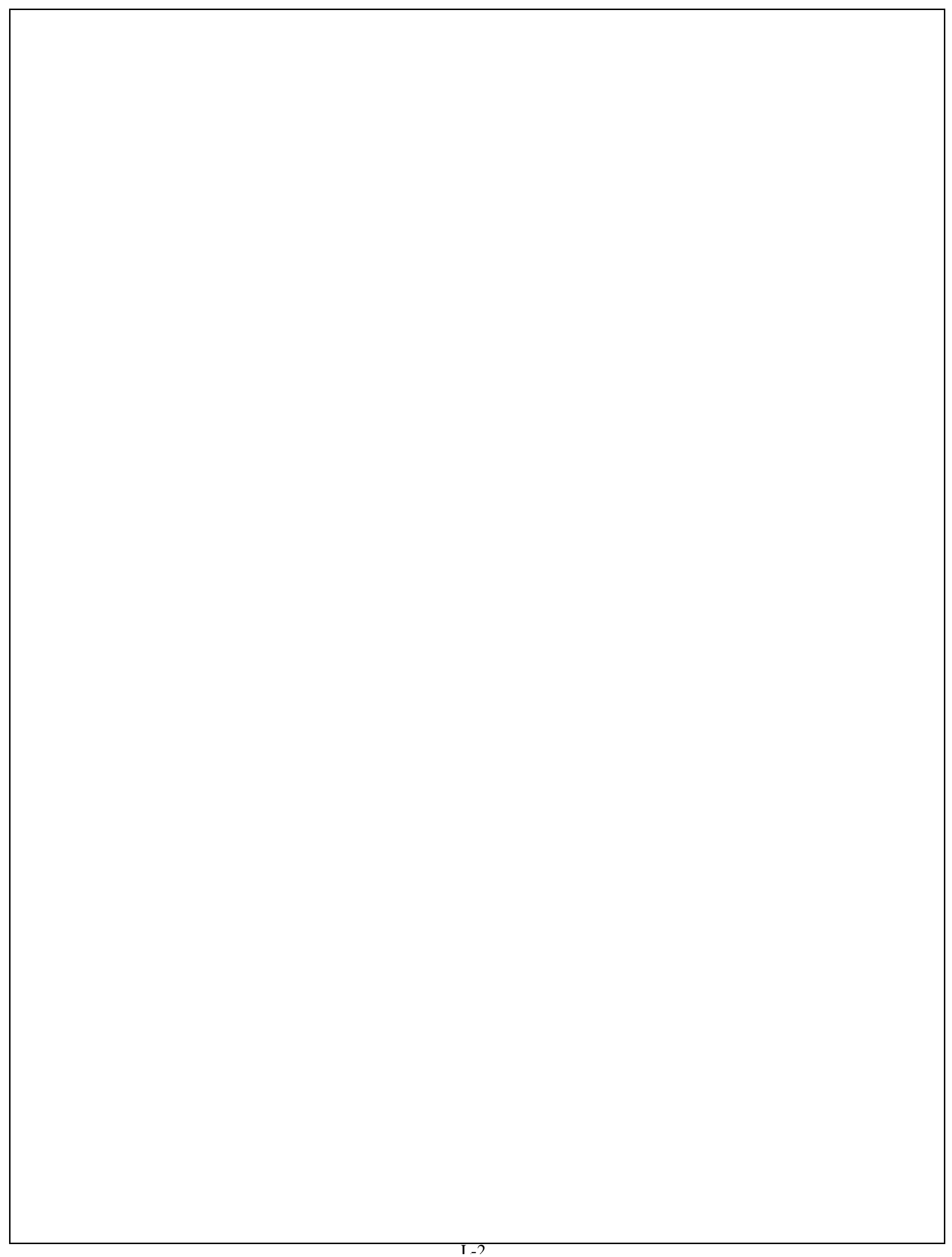




\section{INTRODUCTION}

This Quality Control Summary Report (QCSR) presents results of the field QC sample quality assurance/quality control (QA/QC) review related to the Zone 2 soil samples obtained for EUs included in this Phased Construction Completion Report (PCCR). Quality indicators from every aspect of data collection were reviewed and an assessment of the data, with regard to project-specific data quality objectives, is presented. Data fell within prescribed limits of acceptance indicated successful execution of project-specific methods and procedures and provided adequate assurance that data were of the appropriate quality for evaluating site $\underline{\text { conditions. }}$

A total of 254 samples were collected during DVS characterization of the EUs included in this PCCR. Paragon Analytics located in Fort Collins, Colorado, was the primary analytical laboratory. Split samples were submitted to Test America, St. Louis, Missouri. Both laboratories are DOECAP approved and accredited under the National Environmental Laboratory Ac creditation Conference.

All data generated by sample analyses were validated following the most current editions of the U.S. Environmental Protection Agency (EPA) Contract Laboratory Program (CLP), National Functional Guidelines for Organic Review, EPA 540/R-99/008, and National Functional Guidelines for Inorganic Data Review, EPA 540/R-04/004, referred to as the National Functional Guidelines, which have been adapted appropriately for analyses conducted outside the CLP. While no regulatory or industry standard specification exists for the review and validation of radiological data, these data were reviewed and validated consistent with the analytical method performance criteria in the National Functional Guidelines for Inorganic Data Review, (EPA 540/R-04/004) as applicable generally accepted industry practices. Data validation qualifiers and associated reason codes have been appended to the data in the Project Environmental Management System.

Project data quality objectives (DQOs), defined to produce suitable data meeting the precision and accuracy described in the project quality assurance program plan (QAPP), were consistently monitored through use of field QC samples, approved sampling techniques, and choice of approved analytical methods and laboratories. The QAPP, QC program, and field protocols are contained in the Remedial Design Report/Remedial Action Work Plan for Zone 2 Soils, Slabs, and Subsurface Structures (DOE/OR/01-2224\&D3).

This QCSR addresses compliance of the field QC sample data set with requirements contained in the project QAPP and QA/QC guidance outlined in the EPA's Test Methods for Evaluation of Solid Waste, Third Edition (EPA 1996) and revisions (SW846).

Results of this review are presented in Sect. 2, which discusses the analytical program and field QC sample performance, and Sect. 3, which summarizes the usability of the analytical data.

\section{FIELD SAMPLING AND QC ACTIVITIES}

Field activities included collection of 254 soil samples and their associated QA and QC samples. Samples were analyzed for the following:

- Volatiles: SW-846-8260;

- $\quad$ Semivolatiles: SW-846 8270;

- $\quad$ PCBs: SW-846 8082;

- $\quad$ Metals: SW-846 6010, 6020;

- $\quad$ Mercury SW-846 7470/7471; 
- $\quad$ Radiochemical: DOE HASL 300 and EPA 900 series methods; and

- A small percentage of samples were analyzed for Toxicity Characteristic Leaching Procedures, and/or for silica, fluoride, hexavalent chromium or gasoline and diesel range organics.

Sample shipments from the field were performed under custody and documented using standard Analysis Request/ Chain-of-Custody (AR/COC) forms, which provided project-specific analytical specifications and QC instructions to the laboratory. A formal COC transfer record was prepared and included with these forms to document custody during sample transportation, storage, and disposition by the laboratory. The following sections describe the results of the field QC activities and their impact on data quality. Zone 2 samples with collection times, depths, analyses, and related field QC are presented in Table L-1.

\section{$2.1 \quad$ BLANKS}

\subsubsection{Equipment Rinseates}

When reusable sampling equipment is employed, equipment rinseates are collected to assess the effectiveness of the decontamination procedures used by the sampling team. Fourteen equipment rinseate samples were collected throughout this event. Results of the rinseate sample analyses were in line with the levels of analytes normally incident to these types of rinseate samples. No data were qualified or rejected as a result of equipment rinseate analytical performance. The QC blank detect data are presented in Table L-2.

\subsubsection{Trip Blanks}

Aqueous samples designated for volatile organic compound (VOC) analysis are susceptible to contamination by diffusion of organic compounds present in ambient air into the sample containers. Trip blanks are analyzed to assess the potential for contamination of field samples with target compounds that are introduced into field samples during transport and handling activities. Trip blanks are samples of analyte-free deionized water prepared at the laboratory. These are shipped to the field with sample containers and returned to the laboratory with the field samples receiving VOC analysis. Trip blanks then are analyzed for volatile organics using the same sample preparation and analysis procedures used for the actual field samples. Thirty trip blank samples were collected in support of 130 field samples submitted for volatiles analysis. The trip blanks were collected as water matrix and did not share the same type containers as the soils, but did share shipping, storage, and laboratory environments. Trip blank performance included low-level common laboratory contamination and other compounds normally incident to trip blank volatiles analyses (e.g., methylene chloride, acetone, toluene, and carbon disulfide). While trip blank contamination did result in minor qualification of these compounds at contamination levels at or near method detection limits, m trip blank contamination that required appreciable qualification or data usability limitations was reported in any of the trip blanks associated with this sampling.

\subsection{FIELD DUPLICATES}

Field duplicate samples are collected from the same field location and in the same manner as their associated regular samples but are submitted to the laboratory for analysis as separate samples along with their corresponding regular samples. Regular and field duplicate samples for this project were analyzed by Paragon Analytics. Data generated from the analysis of field duplicate samples are used to evaluate the overall precision of the sample collection and analysis procedures and can be used to evaluate the degree of variability in the sampled media. However, a high relative percent difference (RPD) between an original sample and its field duplicate may indicate a difference in sample matrix, contamination distribution, or sample collection rather than true problems with precision of sample analysis. Also, when mixed reporting (i.e., detect versus nondetect) occurs in a field duplicate, increased uncertainty is indicated; there is often no basis for calculating an RPD since the true value for 
the non-detect is unknown. In these cases, an RPD calculation is not performed. It is also noted that less precision is expected for values near the detection limit. Generally, an acceptance criterion of $\pm 50 \%$ RPD for soil samples is targeted to determine acceptable field precision between original and duplicate results.

A total of 18 regular/field duplicate pairs (approximately 7\%) were collected and analyzed in conjunction with this sampling. The replicate and split results compared with detected results in the associated regular field samples are presented in Table L-3.

Field Duplicate Actions-Acceptance criteria for field precision were met for all samples and fractions. No systematic trends were observed based on the data review, therefore, field precision was regarded as generally acceptable. Field duplicate performance per analytical parameter is presented below. Only qualifying result pairs (i.e. two valid, positive results) were used in the calculations. The RPD as used in this assessment was conservatively applied in that it included values from results at or near the respective detection limits where minor absolute differences in results produced artificially high RPDs.

- $\quad$ Metals-23\% RPD with sampling standard deviation of 27;

- $\quad$ PCB-39\% RPD with sampling standard deviation of 24;

- $\quad$ RAD-21\% RPD with sampling standard deviation of 19;

- $\quad$ SVOC-51\% RPD with sampling standard deviation of 37; and

- $\quad$ VOC-67\% RPD with sampling standard deviation of 32 .

There were no extreme outliers or anomalous results, and the results were considered very consistent with good precision in soil sampling and analysis.

\section{FIELD SPLITS}

Field split samples are collected from the same field location and in the same manner as their associated regular sample but are submitted to an analytical laboratory than different from the regular field samples. Field split samples for this project were analyzed by Test America. Data generated from the analysis of field split samples are used to evaluate the overall precision of the sample collection and analysis procedures and can be used to evaluate the degree of variability in the sampled media. Additionally, field split samples can be used as a measure of analytical accuracy by comparing with the regular and/or field duplicate results analyzed at a different laboratory facility. However, a high RPD between an original sample and its field split may indicate a difference in sample matrix, distribution of contaminants, or sample collection rather than true problems with precision of field sampling or accuracy of sample analysis procedures. Also, when mixed reporting (i.e. detect versus non-detect) occurs in a field split, increased uncertainty is indicated. However, there is often no basis for calculating an RPD since the true value for the non-detect is unknown. In these cases, an RPD calculation is not performed. It is also noted again that less precision is expected near the detection limit. Generally, an acceptance criterion of $\pm 50 \%$ $\underline{\text { RPD for soil samples is targeted to determine acceptable field precision between original and duplicate results. }}$

A total of 19 regular/field split pairs (approximately 8\%) were collected and analyzed in conjunction with this sampling.

Field Split Actions-Acceptance criteria for field and analytical precision were met for all samples and fractions. No systematic trends were observed based on the data review, therefore, field and analytical precision were regarded as generally acceptable. Field split performance per analytical parameter is presented below. Only qualifying result pairs (i.e., two valid, positive results) were used in the calculations. As with field replicates, the $\underline{\text { RPD was conservatively applied because it included values from results at or near the respective detection limits }}$ where minor absolute differences in results produced artificially high RPDs. 
- $\quad$ Metals-35\% RPD with sampling standard deviation of 35;

- $\quad$ PCB-20\% RPD with sampling standard deviation of "0" (only one data point);

- $\quad \mathrm{RAD}-40 \% \mathrm{RPD}$ with sampling standard deviation of 43;

- $\quad$ SVOC-86\% RPD with sampling standard deviation of 60; and

- $\quad$ VOC-no qualifying data pairs.

The SVOC RPD results would have been much lower, except for the anomalous event shown inEU-37. The split laboratory results were much lower than those of the primary, which had run the sample twice with similar results. There appeared to have been an oil phase in the heterogeneous sample that did not fully disperse through field mixing and laboratory aliquoting. After reviewing possible error and proper technique, it was decided to accept the conservative higher value. The anomaly was recognized in validation and elsewhere and showed that feedback was working. Otherwise, there were no extreme outliers or anomalous method results, which were considered very consistent with good precision in sampling and accuracy of soil sample collection and analysis.

\section{DATA EVALUATION AND USABILITY}

\subsection{STATEMENT OF DATA USABILITY}

The field sample quality indicators evaluated suggest the DQO for field QC sample performance were met. The observed results were of expected, acceptable, and consistent quality for the parameters and media analyzed. Based on the evaluation performed, these data appear to be accurate and representative of the samples collected and submitted for analysis. Therefore, the subject data are regarded as usable for their intended purpose. 
Table L.1. Zone 2 samples with collection times, depths, analyses, and related field OC

\begin{tabular}{|c|c|c|c|c|c|c|c|c|c|c|c|c|c|c|c|c|}
\hline Station & Type & $\begin{array}{l}\underline{\text { Date - }} \\
\text { time } \\
\end{array}$ & ID range & VOA & $\underline{\text { RADS }}$ & $\underline{\underline{S V O A}}$ & $\underline{\mathrm{PPCB}}$ & $\underline{\text { Metal }}$ & Mercury & Other & $\underline{\mathrm{FR}}$ & $\underline{\text { SPLIT }}$ & $\underline{\text { RIN }}$ & $\underline{\mathrm{FB}}$ & $\underline{\mathrm{TB}}$ & $\begin{array}{l}\text { Task } \\
\text { code } \\
\end{array}$ \\
\hline Z2-EU28B-319 & $\underline{\mathrm{BH}}$ & $\begin{array}{l}3 / 8 / 2005- \\
\underline{1345}\end{array}$ & $\underline{\text { HLRD0066-0070 }}$ & $2.7-2.95$ & $\underline{0-10}$ & $\underline{0-10}$ & $\underline{0-10}$ & $\underline{0-10}$ & $\underline{0-10}$ & $\underline{\text { Silica }}$ & $\underline{\text { HLRD0071 }}$ & & & & & $\underline{\mathrm{EU} 28}$ \\
\hline Z2-EU28B-318 & $\underline{\mathrm{BH}}$ & $\begin{array}{l}3 / 8 / 2005- \\
\underline{1515}\end{array}$ & HLRD0063-0064 & & $\underline{9.5-9.85}$ & $\underline{0-10}$ & $\underline{0-10}$ & $\underline{0-10}$ & $\underline{0-10}$ & $\underline{\text { Silica }}$ & & & & & & $\underline{\mathrm{EU} 28}$ \\
\hline Z2-EU28B-317 & $\underline{\mathrm{BH}}$ & $\begin{array}{l}3 / 8 / 2005- \\
1600\end{array}$ & HLRD0060-0061 & & $\underline{7-7.9}$ & $\underline{0-10}$ & $\underline{0-10}$ & $\underline{0-10}$ & $\underline{0-10}$ & $\underline{\text { Silica }}$ & & & & & & $\underline{\mathrm{EU} 28}$ \\
\hline Z2-EU28B-321 & $\underline{\mathrm{BH}}$ & $\begin{array}{l}\underline{3 / 9 / 2005}- \\
\underline{1020}\end{array}$ & $\underline{\text { HLRD0075-0077 }}$ & $\underline{0.25-0.4}$ & $\underline{3.9-4.3}$ & $\underline{0-10}$ & $\underline{0-10}$ & $\underline{0-10}$ & $\underline{0-10}$ & $\underline{\text { Silica }}$ & & & & & & $\underline{\mathrm{EU} 28}$ \\
\hline Z2-EU28B-320 & $\underline{\mathrm{BH}}$ & $\begin{array}{l}\underline{3 / 9 / 2005}- \\
\underline{1215}\end{array}$ & $\underline{\text { HLRD0072-0073 }}$ & & $\underline{4.4-4.85}$ & $\underline{0-10}$ & $\underline{0-10}$ & $\underline{0-10}$ & $\underline{0-10}$ & $\underline{\text { Silica }}$ & & & & & & $\underline{\mathrm{EU} 28}$ \\
\hline Z2-EU28B-322 & $\underline{\mathrm{BH}}$ & $\begin{array}{l}3 / 11 / 2005- \\
1220\end{array}$ & $\underline{\text { HLRD0172-0174 }}$ & $\underline{0.5-0.7}$ & $\underline{0-1}$ & $\underline{0-1}$ & $\underline{0-1}$ & $\underline{0-1}$ & $\underline{0-1}$ & $\underline{\text { Silica }}$ & & & & & & $\underline{\mathrm{EU} 28}$ \\
\hline Z2-EU28B-323 & $\underline{\mathrm{BH}}$ & 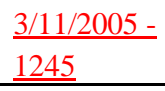 & $\underline{\text { HLRD0175-0177 }}$ & $\underline{0.4-0.5}$ & $\underline{0-0.7}$ & $\underline{0-0.7}$ & $\underline{0-0.7}$ & $\underline{0-0.7}$ & $\underline{0-0.7}$ & $\underline{\text { Silica }}$ & & & & & & $\underline{\mathrm{EU} 28}$ \\
\hline Z2-EU28-103 & $\underline{\mathrm{BH}}$ & $\begin{array}{l}\underline{3 / 17 / 2005-} \\
\underline{1225} \\
\end{array}$ & $\underline{\text { HLRD0021-0023 }}$ & $\underline{6.85-7}$ & $\underline{6.1-6.4}$ & $\underline{0-10}$ & $\underline{0-10}$ & $\underline{0-10}$ & $\underline{0-10}$ & $\underline{\text { Silica }}$ & & & & & & $\underline{\mathrm{EU} 28}$ \\
\hline Z2-EU28-104 & $\underline{\mathrm{BH}}$ & $\begin{array}{l}\underline{3 / 17 / 2005-} \\
\underline{\underline{1345}}\end{array}$ & $\underline{\text { HLRD0024-0025 }}$ & & $\underline{7.9-8.3}$ & & $\underline{0-10}$ & $\underline{0-10}$ & $\underline{0-10}$ & $\underline{\text { Silica }}$ & & & & & & $\underline{\mathrm{EU} 28}$ \\
\hline Z2-EU28-105 & $\underline{\mathrm{BH}}$ & $\begin{array}{l}3 / 18 / 2005- \\
1020\end{array}$ & $\underline{\text { HLRD0027-0186 }}$ & $\underline{4.3-4.6}$ & $\underline{9-9.4}$ & & $\underline{0-10}$ & $\underline{0-10}$ & $\underline{0-10}$ & $\underline{\text { Silica }}$ & & & & & & $\underline{\mathrm{EU} 28}$ \\
\hline Z2-EU28-106 & $\underline{\mathrm{BH}}$ & $\begin{array}{l}\underline{3 / 18 / 2005}- \\
\underline{1130}\end{array}$ & $\underline{\text { HLRD0030-0034 }}$ & $\underline{1.5-1.8}$ & $\underline{0-0.6}$ & $\underline{0-10}$ & $\underline{0-10}$ & $\underline{0-10}$ & $\underline{0-10}$ & $\underline{\text { Silica }}$ & $\underline{\text { HLRD0035 }}$ & & & & & $\underline{\mathrm{EU} 28}$ \\
\hline Z2-EU28-107 & $\underline{\mathrm{BH}}$ & $\begin{array}{l}\underline{3 / 18 / 2005-} \\
\underline{\underline{1255}}\end{array}$ & $\underline{\text { HLRD0036-0037 }}$ & & $\underline{7-7.6}$ & & $\underline{0-10}$ & $\underline{0-10}$ & $\underline{0-10}$ & $\underline{\text { Silica }}$ & & & & & & $\underline{\text { EU28 }}$ \\
\hline Z2-EU28-108 & $\underline{\mathrm{BH}}$ & $\begin{array}{l}\underline{3 / 18 / 2005-} \\
\underline{1335} \\
\end{array}$ & HLRD0039-0040 & & $\underline{0.2-0.6}$ & & $\underline{0-10}$ & $\underline{0-10}$ & $\underline{0-10}$ & $\underline{\text { Silica }}$ & & & & & & $\underline{\mathrm{EU} 28}$ \\
\hline Z2-EU28-206 & $\underline{\mathrm{BH}}$ & $\begin{array}{l}3 / 21 / 2005- \\
1055\end{array}$ & $\underline{\text { HLRD0057-0058 }}$ & & $\underline{4.9-5.3}$ & & $\underline{0-10}$ & $\underline{0-10}$ & $\underline{0-10}$ & $\underline{\text { Silica }}$ & & & & & & $\underline{\mathrm{EU} 28}$ \\
\hline Z2-EU28-204 & $\underline{\mathrm{BH}}$ & $\begin{array}{l}3 / 21 / 2005- \\
1145\end{array}$ & $\underline{\text { HLRD0051-0052 }}$ & & $\underline{0-0.5}$ & & $\underline{0-10}$ & $\underline{0-10}$ & $\underline{0-10}$ & $\underline{\text { Silica }}$ & & & & & & $\underline{\text { EU28 }}$ \\
\hline Z2-EU28-205 & $\underline{\mathrm{BH}}$ & $\begin{array}{l}3 / 21 / 2005- \\
1235\end{array}$ & $\underline{\text { HLRD0054-0056 }}$ & $\underline{7.75-7.9}$ & $\underline{1.8-2.2}$ & $\underline{0-10}$ & $\underline{0-10}$ & $\underline{0-10}$ & $\underline{0-10}$ & $\underline{\text { Silica }}$ & & & & & & $\underline{\mathrm{EU} 28}$ \\
\hline Z2-EU28M-101 & $\underline{\mathrm{BH}}$ & $\begin{array}{l}\underline{3 / 21 / 2005-} \\
\underline{1330}\end{array}$ & $\underline{\text { HLRD0015-0016 }}$ & & $\underline{3-3.4}$ & & $\underline{0-10}$ & $\underline{0-10}$ & $\underline{0-10}$ & $\underline{\text { Silica }}$ & & & & & & $\underline{\mathrm{EU} 28}$ \\
\hline Z2-EU28-202 & $\underline{\mathrm{BH}}$ & 3/22/2005 - & $\underline{\text { HLRD0045-0046 }}$ & & $\underline{8.3-8.6}$ & & $\underline{0-10}$ & $\underline{0-10}$ & $\underline{0-10}$ & & & & & & & $\underline{\underline{E U 28}}$ \\
\hline
\end{tabular}


Table L.1. (continued)

\begin{tabular}{|c|c|c|c|c|c|c|c|c|c|c|c|c|c|c|c|c|}
\hline Station & Type & $\begin{array}{l}\text { Date - } \\
\text { time }\end{array}$ & ID range & VOA & $\underline{\text { RADS }}$ & SVOA & PPCB & Metal & Mercury & Other & $\underline{\mathrm{FR}}$ & SPLIT & $\underline{\text { RIN }}$ & $\underline{\mathrm{FB}}$ & $\underline{\mathrm{TB}}$ & $\begin{array}{l}\text { Task } \\
\text { code }\end{array}$ \\
\hline & & 1010 & & & & & & & & & & & & & & \\
\hline Z2-EU28-203 & $\underline{\mathrm{BH}}$ & $\begin{array}{l}3 / 22 / 2005- \\
\underline{1100}\end{array}$ & $\underline{\text { HLRD0048-0049 }}$ & & $\underline{1-1.5}$ & & $\underline{0-10}$ & $\underline{0-10}$ & $\underline{0-10}$ & & & & & & & $\underline{\text { EU28 }}$ \\
\hline Z2-EU28-201 & $\underline{\mathrm{BH}}$ & $\begin{array}{l}3 / 22 / 2005- \\
1205\end{array}$ & $\underline{\text { HLRD0042-0043 }}$ & & $\underline{0.5-3.2}$ & & $\underline{0-10}$ & $\underline{0-10}$ & $\underline{0-10}$ & & & $\underline{\text { HLRDD0043-S }}$ & & & & $\underline{\text { EU28 }}$ \\
\hline Z2-EU28M-102 & $\underline{\mathrm{BH}}$ & $\begin{array}{l}3 / 22 / 2005- \\
1320\end{array}$ & HLRD0018-0019 & & $\underline{8.9-9.2}$ & & $\underline{0-10}$ & $\underline{0-10}$ & $\underline{0-10}$ & & & & & & & EU28 \\
\hline Z2-EU28B-109 & $\underline{\mathrm{BH}}$ & $\begin{array}{l}3 / 23 / 2005- \\
1240\end{array}$ & HLRD0189-0191 & $\begin{array}{l}17.3- \\
17.55 \\
\end{array}$ & $\underline{17-19}$ & $\underline{17-19}$ & $\underline{17-19}$ & $\underline{17-19}$ & $\underline{17-19}$ & & & & & & & EU28 \\
\hline Z2-EU28B-109 & $\underline{\mathrm{BH}}$ & $3 / 23 / 2005-$ & HLRD0192-0194 & $21.2-21.5$ & $21.2-23.9$ & $\frac{21.2-}{23.9}$ & $21.2-23.9$ & $21.2-23.9$ & $21.2-23.9$ & & & & & & & EU28 \\
\hline Z2-EU28B-110 & $\underline{\mathrm{BH}}$ & $\begin{array}{l}3 / 23 / 2005- \\
1420\end{array}$ & HLRD0195-0197 & $26.8-27.1$ & $\underline{25-28}$ & $25-28$ & $\underline{25-28}$ & $\underline{25-28}$ & $\underline{25-28}$ & & & & & & & EU28 \\
\hline Z2-EU28B-110 & $\underline{\mathrm{BH}}$ & $\begin{array}{l}3 / 23 / 2005- \\
1430\end{array}$ & $\underline{\text { HLRD0198-0200 }}$ & $\underline{32-32.25}$ & $\underline{29-33}$ & $29-33$ & $\underline{29-33}$ & $\underline{29-33}$ & $\underline{29-33}$ & & & & & & & $\underline{\text { EU28 }}$ \\
\hline Z2-EU28B-111 & $\underline{\mathrm{BH}}$ & $\begin{array}{l}3 / 24 / 2005- \\
1100\end{array}$ & $\underline{\text { HLRD0201-0203 }}$ & $\underline{19.1-19.3}$ & $\underline{18-21}$ & $\underline{18-21}$ & $\underline{18-21}$ & $\underline{18-21}$ & $\underline{18-21}$ & & & & & & & $\underline{\mathrm{EU} 28}$ \\
\hline Z2-EU28B-111 & $\underline{\mathrm{BH}}$ & $\begin{array}{l}3 / 24 / 2005- \\
1150\end{array}$ & HLRD0204-0206 & $\underline{23.9-24.1}$ & $\underline{21-24.5}$ & $\underline{21-24.5}$ & $\underline{21-24.5}$ & $\underline{21-24.5}$ & $\underline{21-24.5}$ & & & & & & & $\underline{\mathrm{EU} 28}$ \\
\hline Z2-EU28B-207 & $\underline{\mathrm{BH}}$ & $\begin{array}{l}3 / 24 / 2005- \\
1250\end{array}$ & $\underline{\text { HLRD0207-0209 }}$ & $\underline{2.6-2.8}$ & $\underline{8.1-8.6}$ & $\underline{0-10}$ & $\underline{0-10}$ & $\underline{0-10}$ & $\underline{0-10}$ & & & & & & & EU28 \\
\hline Z2-EU22-035 & $\underline{\mathrm{BH}}$ & $\begin{array}{l}9 / 1 / 2005= \\
1220\end{array}$ & $\begin{array}{l}\text { Z2EU220971- } \\
\underline{0973}\end{array}$ & $\underline{0.8-1}$ & $\underline{\underline{0.8-1.6}}$ & $\underline{0.8-1.6}$ & $\underline{\underline{0.8-1.6}}$ & $\underline{\underline{0.8-1.6}}$ & $\underline{\underline{0.8-1.6}}$ & Fluoride & & & & & & EU22 \\
\hline Z2-EU22-035 & $\underline{\mathrm{BH}}$ & $\begin{array}{l}9 / 1 / 2005- \\
1235\end{array}$ & $\begin{array}{l}\text { Z2EU220974- } \\
0976\end{array}$ & $\underline{4-4.2}$ & $\underline{4-6.4}$ & $\underline{4-6.4}$ & $\underline{4-6.4}$ & $\underline{4-6.4}$ & $\underline{4-6.4}$ & Fluoride & & & & & & EU22 \\
\hline Z2-EU22-035 & $\underline{\mathrm{BH}}$ & $\begin{array}{l}9 / 1 / 2005- \\
1300\end{array}$ & $\begin{array}{l}\text { Z2EU220977- } \\
\underline{0979}\end{array}$ & $\underline{9.7-9.9}$ & $\underline{7.5-10.5}$ & $\underline{7.5-}$ & $\underline{7.5-10.5}$ & $\underline{7.5-10.5}$ & $\underline{7.5-10.5}$ & Fluoride & & & & & & $\underline{\text { EU22 }}$ \\
\hline Z2-EU41DB-204 & $\underline{\mathrm{BH}}$ & $\begin{array}{l}11 / 10 / 2005 \\
-1550 \\
\end{array}$ & $\begin{array}{l}\text { EU41DB-204-A1- } \\
\underline{4-\mathrm{A} 3}\end{array}$ & $\underline{0-10}$ & $\underline{3.5-7}$ & $\underline{0-10}$ & $\underline{0-10}$ & $\underline{0-10}$ & $\underline{0-10}$ & & & & $\underline{1500}$ & & $\underline{1500}$ & EU41 \\
\hline Z2-EU41DB-201 & $\underline{\mathrm{BH}}$ & $\begin{array}{l}11 / 11 / 2005 \\
-1133\end{array}$ & $\begin{array}{l}\text { EU41DB-201-A1- } \\
1 \text {-A1 }\end{array}$ & $\underline{0-10}$ & $\underline{0-10}$ & $\underline{0-10}$ & $\underline{0-10}$ & $\underline{0-10}$ & $\underline{\underline{0-10}}$ & & & & & & & EU41 \\
\hline Z2-EU41DB-202 & $\underline{\mathrm{BH}}$ & $\begin{array}{l}11 / 14 / 2005 \\
-1110 \\
\end{array}$ & $\begin{array}{l}\text { EU41DB-202-A1- } \\
2-\mathrm{A} 3\end{array}$ & $\underline{0-10}$ & $\underline{5-8}$ & $\underline{0-10}$ & $\underline{0-10}$ & $\underline{0-10}$ & $\underline{0-10}$ & & & & & & & EU41 \\
\hline Z2-EU41DB-203 & $\underline{\mathrm{BH}}$ & $\begin{array}{l}11 / 14 / 2005 \\
-1325 \\
\end{array}$ & $\begin{array}{l}\text { EU41DB-203-A1- } \\
\text { 3-A1 }\end{array}$ & $\underline{0-10}$ & & $\underline{0-10}$ & $\underline{0-10}$ & $\underline{0-10}$ & $\underline{0-10}$ & & $\begin{array}{l}\text { EU41DB- } \\
\text { 203-AD1 } \\
\end{array}$ & & & & & EU41 \\
\hline Z2-EU41DB-236 & $\underline{\mathrm{BH}}$ & $11 / 15 / 2005$ & EU41DB-236-A1- & $\underline{5-8}$ & & $\underline{0-10}$ & $\underline{0-10}$ & $\underline{0-10}$ & $\underline{0-10}$ & & & & & & 1150 & EU41 \\
\hline
\end{tabular}


Table L.1. (continued)

\begin{tabular}{|c|c|c|c|c|c|c|c|c|c|c|c|c|c|c|c|c|}
\hline$\underline{\text { Station }}$ & Tvpe & $\begin{array}{l}\text { Date - } \\
\text { time } \\
\end{array}$ & ID range & VOA & $\underline{\text { RADS }}$ & $\underline{\text { SVOA }}$ & $\underline{\mathrm{PPCB}}$ & Metal & Mercury & Other & $\underline{\mathrm{FR}}$ & $\underline{\text { SPLIT }}$ & $\underline{\text { RIN }}$ & $\underline{\mathrm{FB}}$ & $\underline{\mathrm{TB}}$ & $\begin{array}{l}\text { Task } \\
\text { code } \\
\end{array}$ \\
\hline & & -1150 & 6-A2 & & & & & & & & & & & & & \\
\hline Z2-EU41DB-206 & $\underline{\mathrm{BH}}$ & $\begin{array}{l}11 / 15 / 2005 \\
-1345 \\
\end{array}$ & $\begin{array}{l}\text { EU41DB-206-A1- } \\
\text { 6-A1 }\end{array}$ & $\underline{0-10}$ & & $\underline{0-10}$ & $\underline{0-10}$ & $\underline{0-10}$ & $\underline{0-10}$ & & & & & & $\underline{1150}$ & EU41 \\
\hline Z2-EU3B-301 & $\underline{\mathrm{SL}}$ & $\begin{array}{l}11 / 16 / 2005 \\
-1020 \\
\end{array}$ & K31K33-093--093 & & & $\underline{9-9}$ & & & & & & & & & & $\underline{\text { EU03 }}$ \\
\hline Z2-EU3B-302 & $\underline{\mathrm{SL}}$ & $\begin{array}{l}11 / 16 / 2005 \\
-1045 \\
\end{array}$ & $\underline{\text { K31K33-095--095 }}$ & & & $\underline{7-7}$ & & & & & & & & & & $\underline{\text { EU03 }}$ \\
\hline Z2-EU41DB-215 & $\underline{\mathrm{BH}}$ & $\begin{array}{l}11 / 16 / 2005 \\
-1100 \\
\end{array}$ & $\begin{array}{l}\text { EU41DB-215-A1- } \\
\text { 5-A1 }\end{array}$ & $\underline{0-10}$ & & $\underline{0-10}$ & $\underline{0-10}$ & $\underline{0-10}$ & $\underline{0-10}$ & & & & & & & EU41 \\
\hline Z2-EU41DB-207 & $\underline{\mathrm{BH}}$ & $\begin{array}{l}11 / 16 / 2005 \\
-1200 \\
\end{array}$ & $\begin{array}{l}\text { EU41DB-207-A1- } \\
\text { 7-A1 }\end{array}$ & $\underline{0-10}$ & & $\underline{0-10}$ & $\underline{0-10}$ & $\underline{0-10}$ & $\underline{0-10}$ & & & & & & & EU41 \\
\hline Z2-EU41DB-208 & $\underline{\mathrm{BH}}$ & $\begin{array}{l}11 / 17 / 2005 \\
-1300 \\
\end{array}$ & $\begin{array}{l}\text { EU41DB-208-A1- } \\
8-\mathrm{A} 3\end{array}$ & $\underline{2-5}$ & $\underline{2-5}$ & $\underline{0-10}$ & $\underline{0-10}$ & $\underline{0-10}$ & $\underline{0-10}$ & & & & $\underline{1400}$ & & $\underline{1300,1400}$ & EU41 \\
\hline Z2-EU41DB-209 & $\underline{\mathrm{BH}}$ & $\begin{array}{l}11 / 17 / 2005 \\
-1415 \\
\end{array}$ & $\begin{array}{l}\text { EU41DB-209-A1- } \\
\text { 9-A1 }\end{array}$ & $\underline{0-10}$ & & $\underline{0-10}$ & $\underline{0-10}$ & $\underline{0-10}$ & $\underline{0-10}$ & & & $\begin{array}{l}\text { EU41DB-209- } \\
\text { A1-S }\end{array}$ & $\underline{1400}$ & & & $\underline{\text { EU41 }}$ \\
\hline Z2-EU41DB-210 & $\underline{\mathrm{BH}}$ & $\begin{array}{l}11 / 18 / 2005 \\
-1225 \\
\end{array}$ & $\begin{array}{l}\text { EU41DB-210-A1- } \\
0 \text {-A1 }\end{array}$ & $\underline{0-10}$ & & $\underline{0-10}$ & $\underline{0-10}$ & $\underline{0-10}$ & $\underline{0-10}$ & & & & & & & $\underline{\text { EU41 }}$ \\
\hline Z2-EU41DB-214 & $\underline{\mathrm{BH}}$ & $\begin{array}{l}11 / 18 / 2005 \\
-1350 \\
\end{array}$ & $\begin{array}{l}\text { EU41DB-214-A1- } \\
4-\mathrm{A} 1\end{array}$ & & & $\underline{0-10}$ & $\underline{0-10}$ & $\underline{0-10}$ & $\underline{\underline{0-10}}$ & & & & & & & EU41 \\
\hline$\underline{\text { Z2-EU41DB-218 }}$ & $\underline{\mathrm{BH}}$ & $\begin{array}{l}11 / 21 / 2005 \\
-1100 \\
\end{array}$ & $\begin{array}{l}\text { EU41DB-218-C3- } \\
\text { 8-C3 }\end{array}$ & & $\underline{0-2}$ & & & & & & & & & & & EU41 \\
\hline Z2-EU41DB-219 & $\underline{\mathrm{BH}}$ & $\begin{array}{l}11 / 21 / 2005 \\
-1310 \\
\end{array}$ & $\begin{array}{l}\text { EU41DB-219-A1- } \\
\text { 9-A1 }\end{array}$ & $\underline{0-2}$ & $\underline{0-2}$ & $\underline{0-2}$ & $\underline{0-2}$ & $\underline{0-2}$ & $\underline{0-2}$ & & & & & & & EU41 \\
\hline Z2-EU41DB-211 & $\underline{\mathrm{BH}}$ & $\begin{array}{l}11 / 22 / 2005 \\
-1215 \\
\end{array}$ & $\begin{array}{l}\text { EU41DB-211-A2- } \\
\text { 1-A2 }\end{array}$ & $\underline{3.8-4}$ & & & & & & & & & & & $\underline{1215}$ & EU41 \\
\hline Z2-EU41DB-211 & $\underline{\mathrm{BH}}$ & $\begin{array}{l}11 / 22 / 2005 \\
-1250 \\
\end{array}$ & $\begin{array}{l}\text { EU41DB-211-A1- } \\
\underline{1-\mathrm{A} 1}\end{array}$ & $\underline{0-10}$ & & $\underline{0-10}$ & $\underline{0-10}$ & $\underline{\underline{0-10}}$ & $\underline{\underline{0-10}}$ & & & & & & & EU41 \\
\hline Z2-EU41DB-237 & $\underline{\mathrm{BH}}$ & $\begin{array}{l}11 / 22 / 2005 \\
-1340 \\
\end{array}$ & $\begin{array}{l}\text { EU41DB-237-A1- } \\
\underline{7-A 1}\end{array}$ & $\underline{0-10}$ & & $\underline{0-10}$ & $\underline{0-10}$ & $\underline{0-10}$ & $\underline{0-10}$ & & & & & & & EU41 \\
\hline Z2-EU41DB-212 & $\underline{\mathrm{BH}}$ & $\begin{array}{l}11 / 29 / 2005 \\
-1150 \\
\end{array}$ & $\begin{array}{l}\text { EU41DB-212-A1- } \\
2-\mathrm{A} 3\end{array}$ & $\underline{0-10}$ & $\underline{8.5-8.9}$ & $\underline{0-10}$ & $\underline{0-10}$ & $\underline{0-10}$ & $\underline{0-10}$ & & & & & & & EU41 \\
\hline Z2-EU41DB-213 & $\underline{\mathrm{BH}}$ & $\begin{array}{l}11 / 29 / 2005 \\
-1300 \\
\end{array}$ & $\begin{array}{l}\text { EU41DB-213-A2- } \\
\text { 3-A2 }\end{array}$ & $\underline{3.1-3.4}$ & & & & & & & & & & & $\underline{1300}$ & EU41 \\
\hline Z2-EU41DB-213 & $\underline{\mathrm{BH}}$ & $\begin{array}{l}11 / 29 / 2005 \\
-1320 \\
\end{array}$ & $\begin{array}{l}\text { EU41DB-213-A1- } \\
\text { 3-A1 }\end{array}$ & $\underline{0-10}$ & $\underline{0-10}$ & $\underline{0-10}$ & $\underline{0-10}$ & $\underline{0-10}$ & $\underline{0-10}$ & & & & & & & EU41 \\
\hline Z2-EU41DKB-205 & $\mathrm{BH}$ & $11 / 30 / 2005$ & EU41DKB-205- & $0-2$ & & $0-2$ & $\underline{0-2}$ & $0-2$ & $0-2$ & & & & & & & EU41 \\
\hline
\end{tabular}


Table L.1. (continued)

\begin{tabular}{|c|c|c|c|c|c|c|c|c|c|c|c|c|c|c|c|c|}
\hline Station & Type & $\frac{\text { Date - }}{\text { time }}$ & ID range & VOA & RADS & SVOA & PPCB & Metal & Mercury & Other & $\underline{\mathrm{FR}}$ & SPLIT & $\underline{\text { RIN }}$ & $\underline{\mathrm{FB}}$ & $\underline{\mathrm{TB}}$ & $\begin{array}{l}\text { Task } \\
\text { code }\end{array}$ \\
\hline & & -1230 & $\mathrm{C} 1-5-\mathrm{C} 1$ & & & & & & & & & & & & & \\
\hline Z2-EU41DKB-205 & $\underline{\mathrm{BH}}$ & $\begin{array}{l}11 / 30 / 2005 \\
-1240 \\
\end{array}$ & $\begin{array}{l}\text { EU41DKB-205- } \\
\text { D3-5-D3 }\end{array}$ & & $\underline{8.6-8.9}$ & & & & & & & & & & & EU41 \\
\hline Z2-EU41DKB-205 & $\underline{\mathrm{BH}}$ & $\begin{array}{l}11 / 30 / 2005 \\
-1247 \\
\end{array}$ & $\begin{array}{l}\text { EU41DKB-205- } \\
\text { D1-5-D1 }\end{array}$ & $\underline{2-10}$ & & $\underline{2-10}$ & $\underline{2-10}$ & $\underline{2-10}$ & $\underline{2-10}$ & & & & & & & EU41 \\
\hline Z2-EU41DB-217 & $\underline{\mathrm{BH}}$ & $\begin{array}{l}11 / 30 / 2005 \\
-1320 \\
\end{array}$ & $\begin{array}{l}\text { EU41DB-217-A2- } \\
7 \text {-A2 }\end{array}$ & $\underline{5-5.2}$ & & & & & & & & & & & $\underline{1320}$ & $\underline{\text { EU41 }}$ \\
\hline Z2-EU41DB-217 & $\underline{\mathrm{BH}}$ & $\begin{array}{l}11 / 30 / 2005 \\
-1325 \\
\end{array}$ & $\begin{array}{l}\text { EU41DB-217-A3- } \\
7 \text {-A3 }\end{array}$ & & $\underline{0.5-0.9}$ & & & & & & & & & & & $\underline{\text { EU41 }}$ \\
\hline Z2-EU41DB-217 & $\underline{\mathrm{BH}}$ & $\begin{array}{l}11 / 30 / 2005 \\
-1355 \\
\end{array}$ & $\begin{array}{l}\text { EU41DB-217-A1- } \\
\text { 7-A1 }\end{array}$ & $\underline{0-10}$ & & $\underline{0-10}$ & $\underline{0-10}$ & $\underline{0-10}$ & $\underline{0-10}$ & & & & & & & $\underline{\text { EU41 }}$ \\
\hline Z2-EU41DKB-233 & $\underline{\mathrm{BH}}$ & $\begin{array}{l}12 / 1 / 2005- \\
1110\end{array}$ & $\begin{array}{l}\text { EU41DKB-233- } \\
\text { C2-3-C2 }\end{array}$ & $\underline{1-1.2}$ & & & & & & & & & & & $\underline{1110}$ & $\underline{\text { EU41 }}$ \\
\hline Z2-EU41DKB-233 & $\underline{\mathrm{BH}}$ & $\begin{array}{l}12 / 1 / 2005- \\
1130 \\
\end{array}$ & $\begin{array}{l}\text { EU41DKB-233- } \\
\mathrm{C} 1-3-\mathrm{C} 1 \\
\end{array}$ & $\underline{0-2}$ & & $\underline{0-2}$ & $\underline{0-2}$ & $\underline{0-2}$ & $\underline{0-2}$ & & & & & & & EU41 \\
\hline Z2-EU41DKB-233 & $\underline{\mathrm{BH}}$ & $\begin{array}{l}12 / 1 / 2005- \\
1139 \\
\end{array}$ & $\begin{array}{l}\text { EU41DKB-233- } \\
\text { D1-3-D1 }\end{array}$ & $\underline{2-10}$ & & $\underline{2-10}$ & $\underline{2-10}$ & $\underline{2-10}$ & $\underline{2-10}$ & & $\begin{array}{l}\text { EU41DKB- } \\
\text { 233-DD1 } \\
\end{array}$ & & & & & $\underline{\text { EU41 }}$ \\
\hline Z2-EU41DKB-234 & $\underline{\mathrm{BH}}$ & $\begin{array}{l}12 / 1 / 2005- \\
1340\end{array}$ & $\begin{array}{l}\text { EU41DKB-234- } \\
\text { C2-4-C2 }\end{array}$ & $\underline{0.9-1.1}$ & & & & & & & & & & & $\underline{1110}$ & $\underline{\text { EU41 }}$ \\
\hline Z2-EU41DKB-234 & $\underline{\mathrm{BH}}$ & $\begin{array}{l}12 / 1 / 2005- \\
1355\end{array}$ & $\begin{array}{l}\text { EU41DKB-234- } \\
\text { C1-4-C1 }\end{array}$ & $\underline{0-2}$ & & $\underline{0-2}$ & $\underline{0-2}$ & $\underline{0-2}$ & $\underline{0-2}$ & & & & & & & $\underline{\text { EU41 }}$ \\
\hline Z2-EU41DKB-234 & $\underline{\mathrm{BH}}$ & $\begin{array}{l}12 / 1 / 2005- \\
1409\end{array}$ & $\begin{array}{l}\text { EU41DKB-234- } \\
\text { D1-4-D1 }\end{array}$ & $\underline{2.5-4}$ & & $\underline{2.5-4}$ & $\underline{2.5-4}$ & $\underline{2.5-4}$ & $\underline{2.5-4}$ & & & $\begin{array}{l}\text { EU41DKB-234- } \\
\text { D1S }\end{array}$ & & & & $\underline{\text { EU41 }}$ \\
\hline Z2-EU41DB-228 & $\underline{\mathrm{BH}}$ & $\begin{array}{l}12 / 2 / 2005- \\
1330\end{array}$ & $\begin{array}{l}\text { EU41DB-228- } \\
\text { E3PJ-E3PJ }\end{array}$ & & $\underline{16.1-16.4}$ & & & & & & & & & & & $\underline{\text { EU41 }}$ \\
\hline Z2-EU41DB-228 & $\underline{\mathrm{BH}}$ & $\begin{array}{l}12 / 2 / 2005- \\
1400 \\
\end{array}$ & $\begin{array}{l}\text { EU41DB-228- } \\
\text { A1PJ-A1PJ }\end{array}$ & & & $\underline{0-10}$ & $\underline{0-10}$ & $\underline{0-10}$ & $\underline{0-10}$ & $\underline{\text { TCLP }}$ & & & & & & $\underline{\text { EU41 }}$ \\
\hline Z2-EU41DB-228 & $\underline{\mathrm{BH}}$ & $\begin{array}{l}12 / 2 / 2005- \\
1410\end{array}$ & $\begin{array}{l}\text { EU41DB-228- } \\
\text { E1PJ-E1PJ }\end{array}$ & & & $\underline{10-20}$ & $\underline{10-20}$ & $\underline{10-20}$ & $\underline{10-20}$ & TCLP & & & & & & $\underline{\text { EU41 }}$ \\
\hline Z2-EU41DB-227 & $\underline{\mathrm{BH}}$ & $\begin{array}{l}12 / 5 / 2005- \\
1355\end{array}$ & $\begin{array}{l}\text { EU41DB-227- } \\
\text { A1PI-A1PI }\end{array}$ & & $\underline{0-10}$ & $\underline{0-10}$ & $\underline{0-10}$ & $\underline{0-10}$ & $\underline{0-10}$ & $\underline{\text { TCLP }}$ & $\begin{array}{l}\text { EU41DB- } \\
\text { 227AD1PI }\end{array}$ & & & & & $\underline{\text { EU41 }}$ \\
\hline Z2-EU41DB-227 & $\underline{\mathrm{BH}}$ & $\begin{array}{l}12 / 5 / 2005- \\
1400\end{array}$ & $\begin{array}{l}\text { EU41DB-227- } \\
\text { E1PI-E1PI }\end{array}$ & & $\underline{10-20}$ & $\underline{10-20}$ & $\underline{10-20}$ & $\underline{10-20}$ & $\underline{10-20}$ & $\underline{\text { TCLP }}$ & & $\begin{array}{l}\text { EU41DB- } \\
\text { 227E1PIS }\end{array}$ & & & & EU41 \\
\hline Z2-EU41DB-226 & $\underline{\mathrm{BH}}$ & $\begin{array}{l}12 / 6 / 2005- \\
1240 \\
\end{array}$ & $\begin{array}{l}\text { EU41DB-226- } \\
\text { A3PH-A3PH }\end{array}$ & & $\underline{7.6-8}$ & & & & & & & & $\underline{1400}$ & & & $\underline{\text { EU41 }}$ \\
\hline Z2-EU41DB-226 & $\underline{\mathrm{BH}}$ & $12 / 6 / 2005-$ & EU41DB-226- & & & $\underline{0-10}$ & $\underline{0-10}$ & $\underline{0-10}$ & $\underline{0-10}$ & TCLP & & & $\underline{1400}$ & & & EU41 \\
\hline
\end{tabular}


Table L.1. (continued)

\begin{tabular}{|c|c|c|c|c|c|c|c|c|c|c|c|c|c|c|c|c|}
\hline Station & Type & $\begin{array}{l}\text { Date - } \\
\text { time }\end{array}$ & ID range & VOA & $\underline{\text { RADS }}$ & SVOA & PPCB & Metal & Mercury & Other & $\underline{\mathrm{FR}}$ & SPLIT & $\underline{\text { RIN }}$ & $\underline{\mathrm{FB}}$ & $\underline{\mathrm{TB}}$ & $\begin{array}{l}\text { Task } \\
\text { code }\end{array}$ \\
\hline & & 1246 & A1PH-A1PH & & & & & & & & & & & & & \\
\hline Z2-EU41DB-223 & $\underline{\mathrm{BH}}$ & $\begin{array}{l}12 / 6 / 2005- \\
1345 \\
\end{array}$ & $\begin{array}{l}\text { EU41DB-223- } \\
\text { E3PD-E3PD }\end{array}$ & & $\underline{11-11.4}$ & & & & & & & & $\underline{1400}$ & & & EU41 \\
\hline Z2-EU41DB-223 & $\underline{\mathrm{BH}}$ & $\begin{array}{l}12 / 6 / 2005- \\
1400\end{array}$ & $\begin{array}{l}\text { EU41DB-223- } \\
\text { A1PD-A1PD }\end{array}$ & & & $\underline{0-10}$ & $\underline{0-10}$ & $\underline{0-10}$ & $\underline{0-10}$ & $\underline{T C L P}$ & & & $\underline{1400}$ & & & EU41 \\
\hline Z2-EU41DB-223 & $\underline{\mathrm{BH}}$ & $\begin{array}{l}12 / 6 / 2005- \\
1404\end{array}$ & $\begin{array}{l}\text { EU41DB-223- } \\
\text { E1PD-E1PD }\end{array}$ & $\underline{10-20}$ & & $\underline{10-20}$ & $\underline{10-20}$ & $\underline{10-20}$ & $\underline{10-20}$ & $\underline{\text { TCLP }}$ & & & $\underline{1400}$ & & $\underline{1400}$ & EU41 \\
\hline Z2-EU41DB-224 & $\underline{\mathrm{BH}}$ & $\begin{array}{l}12 / 7 / 2005- \\
1150\end{array}$ & $\begin{array}{l}\text { EU41DB-224-E3- } \\
4-E 3\end{array}$ & & $\underline{11.3-11.7}$ & & & & & & & & & & & EU41 \\
\hline Z2-EU41DB-224 & $\underline{\mathrm{BH}}$ & $\begin{array}{l}12 / 7 / 2005- \\
1155 \\
\end{array}$ & $\begin{array}{l}\text { EU41DB-224-A1- } \\
\text { 4-A1 }\end{array}$ & $\underline{0-10}$ & & $\underline{0-10}$ & $\underline{0-10}$ & $\underline{0-10}$ & $\underline{0-10}$ & TCLP & & & & & & EU41 \\
\hline Z2-EU41DB-224 & $\underline{\mathrm{BH}}$ & $\begin{array}{l}12 / 7 / 2005- \\
1200\end{array}$ & $\begin{array}{l}\text { EU41DB-224-E1- } \\
\text { 4-E1 }\end{array}$ & $\underline{10-20}$ & & $\underline{10-20}$ & $\underline{10-20}$ & $\underline{10-20}$ & $\underline{10-20}$ & TCLP & & & & & & EU41 \\
\hline Z2-EU41DB-229 & $\underline{\mathrm{BH}}$ & $\begin{array}{l}12 / 7 / 2005- \\
1330 \\
\end{array}$ & $\begin{array}{l}\text { EU41DB-229-A1- } \\
\text { 9-A1 }\end{array}$ & $\underline{0-10}$ & & $\underline{0-10}$ & $\underline{0-10}$ & $\underline{0-10}$ & $\underline{\underline{0-10}}$ & $\underline{T \text { TCLP }}$ & & & & & & EU41 \\
\hline Z2-EU41DB-230 & $\underline{\mathrm{BH}}$ & $\begin{array}{l}12 / 7 / 2005- \\
1405 \\
\end{array}$ & $\begin{array}{l}\text { EU41DB-230-A1- } \\
0 \text {-A1 }\end{array}$ & $\underline{0-10}$ & & $\underline{0-10}$ & $\underline{0-10}$ & $\underline{0-10}$ & $\underline{0-10}$ & $\underline{T \text { TCLP }}$ & & & & & & EU41 \\
\hline Z2-EU41DB-231 & $\underline{\mathrm{BH}}$ & $\begin{array}{l}12 / 8 / 2005- \\
1330\end{array}$ & $\begin{array}{l}\text { EU41DB-231-A1- } \\
1-\mathrm{A} 1\end{array}$ & $\underline{0-10}$ & & $\underline{0-10}$ & $\underline{0-10}$ & $\underline{0-10}$ & $\underline{0-10}$ & $\underline{\text { TCLP }}$ & & & & & & EU41 \\
\hline Z2-EU41DB-231 & $\underline{\mathrm{BH}}$ & $\begin{array}{l}12 / 8 / 2005- \\
1340\end{array}$ & $\begin{array}{l}\text { EU41DB-231-E1- } \\
\text { 1-E1 }\end{array}$ & $\underline{10-20}$ & & $\underline{10-20}$ & $\underline{10-20}$ & $\underline{10-20}$ & $\underline{10-20}$ & $\underline{\text { TCLP }}$ & & & & & & EU41 \\
\hline Z2-EU41DB-232 & $\underline{\mathrm{BH}}$ & $\begin{array}{l}12 / 8 / 2005- \\
1410\end{array}$ & $\begin{array}{l}\text { EU41DB-232-A2- } \\
2 \text {-A2 }\end{array}$ & $\underline{5.1-5.4}$ & & & & & & & & & & & $\underline{1410}$ & EU41 \\
\hline Z2-EU41DB-232 & $\underline{\mathrm{BH}}$ & $\begin{array}{l}12 / 8 / 2005- \\
1445\end{array}$ & $\begin{array}{l}\text { EU41DB-232-A1- } \\
2 \text {-A1 }\end{array}$ & $\underline{0-10}$ & & $\underline{0-10}$ & $\underline{0-10}$ & $\underline{0-10}$ & $\underline{0-10}$ & $\underline{\text { TCLP }}$ & & & & & & EU41 \\
\hline Z2-EU41DB-220 & $\underline{\mathrm{BH}}$ & $\begin{array}{l}12 / 9 / 2005- \\
1230 \\
\end{array}$ & $\begin{array}{l}\text { EU41DB-220- } \\
\text { A3PA-A3PA }\end{array}$ & & $\underline{9.4-9.8}$ & & & & & & & & & & & EU41 \\
\hline Z2-EU41DB-220 & $\underline{\mathrm{BH}}$ & $\begin{array}{l}12 / 9 / 2005- \\
1315\end{array}$ & $\begin{array}{l}\text { EU41DB-220- } \\
\text { E1PA-E1PA }\end{array}$ & $\underline{10-20}$ & & $\underline{10-20}$ & $\underline{10-20}$ & $\underline{10-20}$ & $\underline{10-20}$ & $\underline{\text { Cr6+ TCLP }}$ & & & & & & EU41 \\
\hline Z2-EU41DB-225 & $\underline{\mathrm{BH}}$ & $\begin{array}{l}12 / 9 / 2005- \\
1405\end{array}$ & $\begin{array}{l}\text { EU41DB-225- } \\
\text { A1PF-A1PF }\end{array}$ & $\underline{0-10}$ & $\underline{0-10}$ & $\underline{0-10}$ & $\underline{0-10}$ & $\underline{0-10}$ & $\underline{\underline{0-10}}$ & $\underline{T C L P}$ & $\begin{array}{l}\frac{\text { EU41DB- }}{225 \mathrm{AD} 1 \mathrm{PF}} \\
2\end{array}$ & & & & & $\underline{\text { EU41 }}$ \\
\hline Z2-EU41DB-225 & $\underline{\mathrm{BH}}$ & $\begin{array}{l}12 / 9 / 2005- \\
1413 \\
\end{array}$ & $\begin{array}{l}\text { EU41DB-225- } \\
\text { E1PF-E1PF }\end{array}$ & $\underline{10-20}$ & & $\underline{10-20}$ & $\underline{10-20}$ & $\underline{10-20}$ & $\underline{10-20}$ & $\underline{T C L P}$ & & & & & & EU41 \\
\hline Z2-EU41DB-220 & $\underline{\mathrm{BH}}$ & $\begin{array}{l}12 / 9 / 2005- \\
1510 \\
\end{array}$ & $\begin{array}{l}\text { EU41DB-220- } \\
\text { A1PA-A1PA }\end{array}$ & $\underline{0-10}$ & & $\underline{0-10}$ & $\underline{0-10}$ & $\underline{0-10}$ & $\underline{0-10}$ & $\underline{\text { Cr6+ TCLP }}$ & & & & & & EU41 \\
\hline Z2-EU41DB-222 & $\underline{\mathrm{BH}}$ & $12 / 12 / 2005$ & EU41DB-222- & $\underline{0-10}$ & & $\underline{0-10}$ & $\underline{0-10}$ & $\underline{0-10}$ & $\underline{0-10}$ & TCLP & & & & & & EU41 \\
\hline
\end{tabular}


Table L.1. (continued)

\begin{tabular}{|c|c|c|c|c|c|c|c|c|c|c|c|c|c|c|c|c|}
\hline Station & Type & $\begin{array}{l}\text { Date - } \\
\text { time }\end{array}$ & ID range & VOA & $\underline{\text { RADS }}$ & SVOA & PPCB & Metal & Mercury & Other & $\underline{\mathrm{FR}}$ & SPLIT & RIN & $\underline{\mathrm{FB}}$ & $\underline{\mathrm{TB}}$ & $\begin{array}{l}\text { Task } \\
\text { code }\end{array}$ \\
\hline & & -1205 & A1PC-A1PC & & & & & & & & & & & & & \\
\hline Z2-EU41DB-221 & $\underline{\mathrm{BH}}$ & $\begin{array}{l}12 / 12 / 2005 \\
-1240 \\
\end{array}$ & $\begin{array}{l}\text { EU41DB-221- } \\
\text { A1PB-A1PB }\end{array}$ & $\underline{0-10}$ & & $\underline{0-10}$ & $\underline{0-10}$ & $\underline{0-10}$ & $\underline{0-10}$ & $\underline{\text { TCLP }}$ & & & & & & EU41 \\
\hline Z2-EU41DB-221 & $\underline{\mathrm{BH}}$ & $\begin{array}{l}12 / 12 / 2005 \\
-1245 \\
\end{array}$ & $\begin{array}{l}\text { EU41DB-221- } \\
\text { E3PB-E3PB }\end{array}$ & & $\underline{12.9-13.3}$ & & & & & & & & & & & EU41 \\
\hline Z2-EU41DB-221 & $\underline{\mathrm{BH}}$ & $\begin{array}{l}12 / 12 / 2005 \\
-1250 \\
\end{array}$ & $\begin{array}{l}\text { EU41DB-221- } \\
\text { E1PB-E1PB }\end{array}$ & $\underline{10-20}$ & & $\underline{10-20}$ & $\underline{10-20}$ & $\underline{10-20}$ & $\underline{10-20}$ & $\underline{T C L P}$ & & & & & & EU41 \\
\hline Z2-EU41DB-222 & $\underline{\mathrm{BH}}$ & $\begin{array}{l}12 / 12 / 2005 \\
-1415 \\
\end{array}$ & $\begin{array}{l}\text { EU41DB-222- } \\
\text { E1PC-E1PC }\end{array}$ & $\underline{10-20}$ & & $\underline{10-20}$ & $\underline{10-20}$ & $\underline{10-20}$ & $\underline{10-20}$ & TCLP & & & & & & EU41 \\
\hline Z2-EU41C-201 & $\underline{\mathrm{BH}}$ & $\begin{array}{l}12 / 13 / 2005 \\
-1220 \\
\end{array}$ & $\begin{array}{l}\text { EU41C-201-A2-1- } \\
\underline{\text { A2 }}\end{array}$ & $\underline{9.8-10}$ & & & & & & & & & & & $\underline{1257}$ & EU41 \\
\hline Z2-EU41C-201 & $\underline{\mathrm{BH}}$ & $\begin{array}{l}12 / 13 / 2005 \\
-1310 \\
\end{array}$ & $\begin{array}{l}\text { EU41C-201-A1-1- } \\
\text { A1 }\end{array}$ & $\underline{0-10}$ & & $\underline{0-10}$ & $\underline{0-10}$ & $\underline{0-10}$ & $\underline{0-10}$ & TCLP & & & & & & EU41 \\
\hline Z2-EU41C-202 & $\underline{\mathrm{BH}}$ & $\begin{array}{l}12 / 13 / 2005 \\
-1330 \\
\end{array}$ & $\begin{array}{l}\text { EU41C-202-A2-2- } \\
\text { A2 }\end{array}$ & $\underline{4.1-4.3}$ & & & & & & & & & & & $\underline{1257}$ & EU41 \\
\hline Z2-EU41C-202 & $\underline{\mathrm{BH}}$ & $\begin{array}{l}12 / 13 / 2005 \\
-1405 \\
\end{array}$ & $\begin{array}{l}\text { EU41C-202-A1-2- } \\
\text { A1 }\end{array}$ & $\underline{0-10}$ & & $\underline{0-10}$ & $\underline{0-10}$ & $\underline{0-10}$ & $\underline{0-10}$ & $\underline{T \text { TCLP }}$ & & & & & & EU41 \\
\hline Z2-EU41C-202 & $\underline{\mathrm{BH}}$ & $\begin{array}{l}12 / 14 / 2005 \\
-1320 \\
\end{array}$ & $\begin{array}{l}\text { EU41C-202-E1-2- } \\
\text { E1 }\end{array}$ & $\underline{10-20}$ & $\underline{10-20}$ & $\underline{10-20}$ & $\underline{10-20}$ & $\underline{10-20}$ & $\underline{10-20}$ & $\underline{\text { TCLP }}$ & & & & & & EU41 \\
\hline Z2-EU41C-203 & $\underline{\mathrm{BH}}$ & $\begin{array}{l}12 / 14 / 2005 \\
-1350\end{array}$ & $\begin{array}{l}\text { EU41C-203-A1-3- } \\
\text { A1 }\end{array}$ & $\underline{0-10}$ & & $\underline{0-10}$ & $\underline{0-10}$ & $\underline{0-10}$ & $\underline{0-10}$ & $\underline{\text { TCLP }}$ & & & & & & EU41 \\
\hline Z2-EU41C-203 & $\underline{\mathrm{BH}}$ & $\begin{array}{l}12 / 14 / 2005 \\
-1355 \\
\end{array}$ & $\begin{array}{l}\text { EU41C-203-E1-3- } \\
\text { E1 }\end{array}$ & $\underline{10-20}$ & & $\underline{10-20}$ & $\underline{10-20}$ & $\underline{10-20}$ & $\underline{10-20}$ & $\underline{T C L P}$ & & & & & & EU41 \\
\hline Z2-EU41C-204 & $\underline{\mathrm{BH}}$ & $\begin{array}{l}12 / 16 / 2005 \\
-1320 \\
\end{array}$ & $\begin{array}{l}\text { EU41C-204-A1-4- } \\
\text { A1 }\end{array}$ & $\underline{0-10}$ & & $\underline{0-10}$ & $\underline{0-10}$ & $\underline{0-10}$ & $\underline{0-10}$ & $\underline{\text { TCLP }}$ & & & & & & $\underline{\text { EU41 }}$ \\
\hline Z2-EU41C-209 & $\underline{\mathrm{BH}}$ & $\begin{array}{l}12 / 16 / 2005 \\
-1400 \\
\end{array}$ & $\begin{array}{l}\text { EU41C-209-A2-9- } \\
\underline{\mathrm{A} 2}\end{array}$ & $\underline{6-6.2}$ & & & & & & & & & & & $\underline{1400}$ & EU41 \\
\hline Z2-EU41C-209 & $\underline{\mathrm{BH}}$ & $\begin{array}{l}12 / 16 / 2005 \\
-1415 \\
\end{array}$ & $\begin{array}{l}\text { EU41C-209-E3-9- } \\
\text { E3 }\end{array}$ & & $\underline{13-13.6}$ & & & & & & $\begin{array}{l}\text { EU41C-209- } \\
\text { ED3 }\end{array}$ & & & & & EU41 \\
\hline Z2-EU41C-209 & $\underline{\mathrm{BH}}$ & $\begin{array}{l}12 / 16 / 2005 \\
-1450\end{array}$ & $\begin{array}{l}\text { EU41C-209-A1-9- } \\
\text { A1 }\end{array}$ & $\underline{0-10}$ & & $\underline{0-10}$ & $\underline{0-10}$ & $\underline{0-10}$ & $\underline{0-10}$ & $\underline{\text { TCLP }}$ & $\begin{array}{l}\text { EU41C-209- } \\
\text { AD1 }\end{array}$ & & & & & EU41 \\
\hline Z2-EU41C-209 & $\underline{\mathrm{BH}}$ & $\begin{array}{l}12 / 16 / 2005 \\
-1455 \\
\end{array}$ & $\begin{array}{l}\text { EU41C-209-E1-9- } \\
\text { E1 }\end{array}$ & $\underline{10-20}$ & & $\underline{10-20}$ & $\underline{10-20}$ & $\underline{10-20}$ & $\underline{10-20}$ & $\underline{\text { TCLP }}$ & & & & & & EU41 \\
\hline Z2-EU41C-210 & $\underline{\mathrm{BH}}$ & $\begin{array}{l}12 / 19 / 2005 \\
-1105 \\
\end{array}$ & $\begin{array}{l}\text { EU41C-210-A1-0- } \\
\text { A1 }\end{array}$ & $\underline{0-10}$ & & $\underline{0-10}$ & $\underline{0-10}$ & $\underline{0-10}$ & $\underline{0-10}$ & $\underline{T C L P}$ & & & & & & EU41 \\
\hline Z2-EU41C-211 & $\underline{\mathrm{BH}}$ & $\underline{12 / 19 / 2005}$ & EU41C-211-A1-1- & $\underline{0-10}$ & & $\underline{0-10}$ & $\underline{0-10}$ & $\underline{0-10}$ & $\underline{0-10}$ & TCLP & & & & & & EU41 \\
\hline
\end{tabular}


Table L.1. (continued)

\begin{tabular}{|c|c|c|c|c|c|c|c|c|c|c|c|c|c|c|c|c|}
\hline Station & Type & $\frac{\text { Date - }}{\text { time }}$ & ID range & VOA & RADS & SVOA & PPCB & Metal & Mercury & Other & $\underline{F R}$ & SPLIT & $\underline{\text { RIN }}$ & $\underline{F B}$ & $\underline{\mathrm{TB}}$ & $\begin{array}{l}\text { Task } \\
\text { code }\end{array}$ \\
\hline & & -1305 & $\mathrm{~A} 1$ & & & & & & & & & & & & & \\
\hline Z2-EU41C-212 & $\underline{\mathrm{BH}}$ & $\begin{array}{l}12 / 19 / 2005 \\
-1345 \\
\end{array}$ & $\begin{array}{l}\text { EU41C-212-A3-2- } \\
\underline{\mathrm{A} 3}\end{array}$ & & $\underline{9.5-9.9}$ & & & & & & & & & & & $\underline{\text { EU41 }}$ \\
\hline Z2-EU41C-212 & $\underline{\mathrm{BH}}$ & $\begin{array}{l}12 / 19 / 2005 \\
-1350 \\
\end{array}$ & $\begin{array}{l}\text { EU41C-212-A1-2- } \\
\text { A1 }\end{array}$ & $\underline{0-10}$ & & $\underline{0-10}$ & $\underline{0-10}$ & $\underline{0-10}$ & $\underline{0-10}$ & $\underline{\text { TCLP }}$ & & & & & & $\underline{\text { EU41 }}$ \\
\hline Z2-EU41C-207 & $\underline{\mathrm{BH}}$ & $\begin{array}{l}12 / 20 / 2005 \\
-1140 \\
\end{array}$ & $\begin{array}{l}\text { EU41C-207-A1-7- } \\
\text { A1 }\end{array}$ & $\underline{0-10}$ & & $\underline{0-10}$ & $\underline{0-10}$ & $\underline{0-10}$ & $\underline{0-10}$ & $\underline{\text { TCLP }}$ & & & & & & EU41 \\
\hline Z2-EU41C-207 & $\underline{\mathrm{BH}}$ & $\begin{array}{l}12 / 20 / 2005 \\
-1158\end{array}$ & $\begin{array}{l}\text { EU41C-207-B1-7- } \\
\text { B1 }\end{array}$ & $\underline{12.5-14}$ & $\underline{12.5-14}$ & $\underline{12.5-14}$ & $\underline{12.5-14}$ & $\underline{12.5-14}$ & $\underline{12.5-14}$ & $\underline{\text { TCLP }}$ & & & & & & $\underline{\text { EU41 }}$ \\
\hline Z2-EU1B-301 & $\underline{\mathrm{BH}}$ & $\begin{array}{l}1 / 4 / 2006- \\
1045\end{array}$ & K31K33-475--476 & & $\underline{0-1}$ & $\underline{0-1}$ & $\underline{0-1}$ & $\underline{0-1}$ & $\underline{0-1}$ & & & & & & & $\underline{\text { EU01 }}$ \\
\hline Z2-EU41CB-213 & $\underline{\mathrm{BH}}$ & $\begin{array}{l}1 / 9 / 2006- \\
1257\end{array}$ & $\begin{array}{l}\text { EU41CB-213-A2- } \\
\text { 3-A2 }\end{array}$ & $\underline{4.7-4.9}$ & & & & & & & & & & & $\underline{1257}$ & $\underline{\text { EU41 }}$ \\
\hline Z2-EU41CB-213 & $\underline{\mathrm{BH}}$ & $\begin{array}{l}1 / 9 / 2006- \\
1315 \\
\end{array}$ & $\begin{array}{l}\text { EU41CB-213-A1- } \\
\text { 3-A1 }\end{array}$ & $\underline{0-10}$ & & $\underline{0-10}$ & $\underline{0-10}$ & $\underline{0-10}$ & $\underline{0-10}$ & $\underline{\text { TCLP }}$ & & & & & $\underline{1257}$ & $\underline{\text { EU41 }}$ \\
\hline Z2-EU41CM-205 & $\underline{\mathrm{BH}}$ & $\begin{array}{l}1 / 10 / 2006- \\
1140 \\
\end{array}$ & $\begin{array}{l}\text { EU41CM-205- } \\
\mathrm{A} 2-5-\mathrm{A} 2\end{array}$ & $\underline{3.3-3.5}$ & & & & & & & & & $\underline{1300}$ & & $\underline{1145,1300}$ & $\underline{\text { EU41 }}$ \\
\hline Z2-EU41CM-205 & $\underline{\mathrm{BH}}$ & $\begin{array}{l}1 / 10 / 2006- \\
1235\end{array}$ & $\begin{array}{l}\text { EU41CM-205- } \\
\text { A1-A1SR }\end{array}$ & $\underline{0-10}$ & $\underline{0-10}$ & $\underline{0-10}$ & $\underline{0-10}$ & $\underline{0-10}$ & $\underline{0-10}$ & $\underline{\text { TCLP }}$ & & $\begin{array}{l}\text { EU41CM-205- } \\
\text { A1-S }\end{array}$ & $\underline{1300}$ & & $\underline{1145,1300}$ & EU41 \\
\hline Z2-EU41CM-206 & $\underline{\mathrm{BH}}$ & $\frac{1 / 10 / 2006-}{1315}$ & $\begin{array}{l}\text { EU41CM-206- } \\
\text { A2-6-A2 } \\
\end{array}$ & $\underline{8-8.2}$ & & & & & & & & & $\underline{1300}$ & & $\underline{1145,1300}$ & EU41 \\
\hline Z2-EU41CM-206 & $\underline{\mathrm{BH}}$ & $\begin{array}{l}1 / 10 / 2006- \\
1353\end{array}$ & $\begin{array}{l}\text { EU41CM-206- } \\
\text { A1-6-A1 }\end{array}$ & $\underline{0-10}$ & & $\underline{0-10}$ & $\underline{0-10}$ & $\underline{0-10}$ & $\underline{0-10}$ & $\underline{\text { TCLP }}$ & & & $\underline{1300}$ & & $\underline{1145,1300}$ & $\underline{\text { EU41 }}$ \\
\hline Z2-EU41C-208 & $\underline{\mathrm{BH}}$ & $\begin{array}{l}1 / 11 / 2006- \\
1200\end{array}$ & $\begin{array}{l}\text { EU41C-208-A2-8- } \\
\text { A2 }\end{array}$ & $\underline{6.2-6.4}$ & & & & & & & & & & & $\underline{1200}$ & $\underline{\text { EU41 }}$ \\
\hline Z2-EU41C-208 & $\underline{\mathrm{BH}}$ & $\begin{array}{l}1 / 11 / 2006- \\
1247 \\
\end{array}$ & $\begin{array}{l}\text { EU41C-208-A1-8- } \\
\underline{\text { A1 }}\end{array}$ & $\underline{0-10}$ & & $\underline{0-10}$ & $\underline{0-10}$ & $\underline{0-10}$ & $\underline{0-10}$ & $\underline{\text { TCLP }}$ & & & & & & $\underline{\text { EU41 }}$ \\
\hline Z2-EU41C-208 & $\underline{\mathrm{BH}}$ & $\begin{array}{l}1 / 11 / 2006- \\
1254 \\
\end{array}$ & $\begin{array}{l}\text { EU41C-208-B1-8- } \\
\text { B1 }\end{array}$ & $\underline{11.8-13.3}$ & & $\underline{11.8-}$ & $\underline{11.8-13.3}$ & $\underline{11.8-13.3}$ & $\underline{11.8-13.3}$ & $\underline{\text { TCLP }}$ & & & & & $\underline{1200}$ & $\underline{\text { EU41 }}$ \\
\hline Z2-EU41DB-218 & $\underline{\mathrm{BH}}$ & $\frac{1 / 11 / 2006-}{1317}$ & $\begin{array}{l}\text { EU41DB-218-A2- } \\
\text { 8-A2 }\end{array}$ & $\underline{2-2.2}$ & & & & & & & & & & & $\underline{1200}$ & $\underline{\text { EU41 }}$ \\
\hline Z2-EU41DB-218 & $\underline{\mathrm{BH}}$ & $\begin{array}{l}1 / 11 / 2006- \\
1327\end{array}$ & $\begin{array}{l}\text { EU41DB-218-A3- } \\
\text { A3-R }\end{array}$ & & $\underline{0.5-0.8}$ & & & & & & & & & & & EU41 \\
\hline Z2-EU41DB-218 & $\underline{\mathrm{BH}}$ & $\begin{array}{l}1 / 11 / 2006- \\
1355 \\
\end{array}$ & $\begin{array}{l}\text { EU41DB-218-A1- } \\
\text { 8-A1 }\end{array}$ & $\underline{0-10}$ & & $\underline{0-10}$ & $\underline{0-10}$ & $\underline{0-10}$ & $\underline{0-10}$ & & & & & & $\underline{1200}$ & $\underline{\text { EU41 }}$ \\
\hline Z2-EU41DB-208A & $\underline{\mathrm{BH}}$ & $1 / 12 / 2006-$ & EU41DB-208-F2- & $\underline{\underline{2-2.2}}$ & & & & & & & & & & & $\underline{1200}$ & EU41 \\
\hline
\end{tabular}


Table L.1. (continued)

\begin{tabular}{|c|c|c|c|c|c|c|c|c|c|c|c|c|c|c|c|c|}
\hline Station & Type & $\begin{array}{l}\text { Date - } \\
\text { time }\end{array}$ & ID range & VOA & $\underline{\text { RADS }}$ & SVOA & PPCB & Metal & Mercury & Other & $\underline{\mathrm{FR}}$ & SPLIT & RIN & $\underline{\mathrm{FB}}$ & $\underline{\mathrm{TB}}$ & $\begin{array}{l}\text { Task } \\
\text { code }\end{array}$ \\
\hline & & 1200 & 8 -F2 & & & & & & & & & & & & & \\
\hline Z2-EU41DB-208A & $\underline{\mathrm{BH}}$ & $\frac{1 / 12 / 2006-}{1237}$ & $\begin{array}{l}\text { EU41DB-208-F3- } \\
\underline{\text { 8-F3 }}\end{array}$ & & $2.6-2.9$ & & & & & & & & & & & EU41 \\
\hline Z2-EU41DB-208A & $\underline{\mathrm{BH}}$ & $\begin{array}{l}1 / 12 / 2006- \\
1304\end{array}$ & $\begin{array}{l}\text { EU41DB-208-F1- } \\
\text { 8-F1 }\end{array}$ & $\underline{0-10}$ & & $\underline{0-10}$ & $\underline{0-10}$ & $\underline{0-10}$ & $\underline{0-10}$ & & & & & & & EU41 \\
\hline Z2-EU41C-208 & $\underline{\mathrm{BH}}$ & $\begin{array}{l}1 / 18 / 2006- \\
1235\end{array}$ & $\begin{array}{l}\text { EU41C-208-G2-8- } \\
\text { G2 }\end{array}$ & $\underline{15.1-15.3}$ & & & & & & & & & & & $\underline{1235}$ & EU41 \\
\hline Z2-EU41C-208 & $\underline{\mathrm{BH}}$ & $\begin{array}{l}1 / 18 / 2006- \\
1240 \\
\end{array}$ & $\begin{array}{l}\text { EU41C-208-G3-8- } \\
\text { G3 }\end{array}$ & & $\underline{14.7-15.1}$ & & & & & & & & & & & EU41 \\
\hline Z2-EU3-209 & $\underline{\mathrm{BH}}$ & $\begin{array}{l}\underline{2 / 2 / 2006-} \\
\underline{915} \\
\end{array}$ & K31K33-069--069 & & & $\begin{array}{l}1.15- \\
\underline{1.4} \\
\end{array}$ & & & & & & & & & & $\underline{\mathrm{EU} 03}$ \\
\hline Z2-EU28B-115 & $\underline{\mathrm{BH}}$ & $\begin{array}{l}2 / 15 / 2006- \\
1450\end{array}$ & HLRDA024-A026 & $\underline{0-1}$ & $\underline{0-1}$ & $\underline{\underline{0-1}}$ & $\underline{\underline{0-1}}$ & $\underline{0-1}$ & $\underline{0-1}$ & & $\underline{\text { HLRDA029 }}$ & & & & $\underline{1510}$ & EU28 \\
\hline Z2-EU28B-116 & $\underline{\mathrm{BH}}$ & $\begin{array}{l}2 / 16 / 2006- \\
924\end{array}$ & HLRDA030-A030 & & $\underline{0-1}$ & & & & & & & & & & & $\underline{\text { EU28 }}$ \\
\hline Z2-EU28B-114 & $\underline{\mathrm{BH}}$ & $\begin{array}{l}2 / 16 / 2006- \\
935\end{array}$ & HLRDA023-A023 & & $\underline{0-1}$ & & & & & & & & & & & $\underline{\mathrm{EU} 28}$ \\
\hline Z2-EU28B-117 & $\underline{\mathrm{BH}}$ & $\begin{array}{l}2 / 16 / 2006- \\
1008\end{array}$ & HLRDA031-A031 & & $\underline{0-1}$ & & & & & & & & & & & $\underline{\mathrm{EU} 28}$ \\
\hline Z2-EU28B-119 & $\underline{\mathrm{BH}}$ & $\begin{array}{l}2 / 16 / 2006- \\
1040\end{array}$ & HLRDA035-A035 & & $\underline{0-1}$ & & & & & & & & & & & EU28 \\
\hline Z2-EU28B-118 & $\underline{\mathrm{BH}}$ & $\begin{array}{l}2 / 16 / 2006- \\
1048\end{array}$ & HLRDA032-A034 & $\underline{0-1}$ & $\underline{0-1}$ & $\underline{0-1}$ & $\underline{0-1}$ & $\underline{0-1}$ & $\underline{0-1}$ & & & & & & $\underline{820}$ & $\underline{\mathrm{EU} 28}$ \\
\hline Z2-EU28B-125 & $\underline{\mathrm{BH}}$ & $\begin{array}{l}2 / 16 / 2006- \\
1102\end{array}$ & HLRDA041-A041 & & $\underline{0-1}$ & & & & & & $\underline{\text { HLRDA050 }}$ & & & & & $\underline{\text { EU28 }}$ \\
\hline Z2-EU28B-121 & $\underline{\mathrm{BH}}$ & $\begin{array}{l}2 / 16 / 2006- \\
1325 \\
\end{array}$ & HLRDA037-A037 & & $\underline{0-1}$ & & & & & & & & & & & EU28 \\
\hline Z2-EU28B-122 & $\underline{\mathrm{BH}}$ & $\begin{array}{l}2 / 16 / 2006- \\
1347\end{array}$ & HLRDA038-A038 & & $\underline{0-1}$ & & & & & & & & & & & EU28 \\
\hline Z2-EU28B-124 & $\underline{\mathrm{BH}}$ & $\begin{array}{l}2 / 16 / 2006- \\
1400\end{array}$ & $\underline{\text { HLRDA040-A040 }}$ & & $\underline{\underline{0-1}}$ & & & & & & & & & & & $\underline{\text { EU28 }}$ \\
\hline Z2-EU28B-123 & $\underline{\mathrm{BH}}$ & $\begin{array}{l}2 / 16 / 2006- \\
1405 \\
\end{array}$ & HLRDA039-A039 & & $\underline{\underline{0-1}}$ & & & & & & & HLRDA039-S & & & & $\underline{\text { EU28 }}$ \\
\hline Z2-EU44B-303 & $\underline{\mathrm{BH}}$ & $\begin{array}{l}3 / 15 / 2006- \\
1320\end{array}$ & MBRA0326-0326 & $\underline{6.5-7}$ & & & & & & & & & & & & EU44 \\
\hline Z2-EU44B-303 & $\underline{\mathrm{BH}}$ & $3 / 15 / 2006-$ & MBRA0324-0327 & & & $\underline{0-10}$ & $0-10$ & $\underline{0-10}$ & $\underline{0-10}$ & Gasoline, diesel & & & & & & EU44 \\
\hline
\end{tabular}


Table L.1. (continued)

\begin{tabular}{|c|c|c|c|c|c|c|c|c|c|c|c|c|c|c|c|c|}
\hline$\underline{\text { Station }}$ & $\underline{\text { Type }}$ & $\begin{array}{l}\text { Date - } \\
\text { time }\end{array}$ & $\underline{\text { ID range }}$ & $\underline{\text { VOA }}$ & $\underline{\text { RADS }}$ & $\underline{\text { SVOA }}$ & $\underline{\mathrm{PPCB}}$ & Metal & Mercury & Other & $\underline{\underline{F R}}$ & $\underline{\text { SPLIT }}$ & $\underline{\text { RIN }}$ & $\underline{\mathrm{FB}}$ & $\underline{\mathrm{TB}}$ & $\begin{array}{l}\text { Task } \\
\text { code } \\
\end{array}$ \\
\hline & & $\underline{1330}$ & & & & & & & & $\begin{array}{l}\text { range } \\
\text { organicsasoline } \\
\text { range organics }\end{array}$ & & & & & & \\
\hline Z2-EU44B-302 & $\underline{\mathrm{BH}}$ & $\begin{array}{l}3 / 15 / 2006- \\
1445\end{array}$ & MBRA0322-0322 & $\underline{4-4.5}$ & & & & & & & & & & & & EU44 \\
\hline Z2-EU44B-302 & $\underline{\mathrm{BH}}$ & $\begin{array}{l}3 / 15 / 2006- \\
\underline{1500}\end{array}$ & MBRA0320-0323 & & & $\underline{0-10}$ & $\underline{0-10}$ & $\underline{0-10}$ & $\underline{0-10}$ & $\begin{array}{l}\text { Gasoline, diesel } \\
\underline{\text { range }} \\
\underline{\text { organicsasoline }} \\
\text { range organics } \\
\end{array}$ & & & & & & $\underline{\text { EU44 }}$ \\
\hline Z2-EU44B-300 & $\underline{\mathrm{BH}}$ & $\begin{array}{l}3 / 15 / 2006- \\
1545\end{array}$ & MBRA0314-0314 & $\underline{8-8.5}$ & & & & & & & & & & & & $\underline{\text { EU44 }}$ \\
\hline Z2-EU44B-300 & $\underline{\mathrm{BH}}$ & $\begin{array}{l}\underline{3 / 15 / 2006-} \\
\underline{1550}\end{array}$ & MBRA0312-0315 & & $\underline{0-10}$ & $\underline{0-10}$ & $\underline{0-10}$ & $\underline{0-10}$ & $\underline{0-10}$ & $\begin{array}{l}\text { Gasoline, diesel } \\
\text { range } \\
\text { organicsasoline } \\
\text { range organics } \\
\end{array}$ & & & & & & $\underline{\text { EU44 }}$ \\
\hline Z2-EU44B-301 & $\underline{\mathrm{BH}}$ & $\begin{array}{l}\underline{3 / 16 / 2006-} \\
\underline{1200}\end{array}$ & MBRA0318-0319 & $\underline{7-7.3}$ & & & & & & $\begin{array}{l}\text { Gasoline, diesel } \\
\text { range } \\
\text { organicsasoline } \\
\text { range organics }\end{array}$ & & & & & & $\underline{\text { EU44 }}$ \\
\hline Z2-EU44B-301 & $\underline{\mathrm{BH}}$ & $\begin{array}{l}3 / 16 / 2006- \\
\underline{1215}\end{array}$ & MBRA0316-0317 & & $\underline{7.5-8.1}$ & $\underline{0-10}$ & $\underline{0-10}$ & $\underline{0-10}$ & $\underline{0-10}$ & & & & & & & $\underline{\text { EU44 }}$ \\
\hline Z2-EU44-203 & $\underline{\mathrm{BH}}$ & $\begin{array}{l}3 / 16 / 2006- \\
1410 \\
\end{array}$ & MBRA0309-0309 & & & $\underline{0-10}$ & $\underline{0-10}$ & $\underline{0-10}$ & $\underline{0-10}$ & & & MBRA0309-S & & & & $\underline{\text { EU44 }}$ \\
\hline Z2-EU44-202 & $\underline{\mathrm{BH}}$ & $\begin{array}{l}3 / 17 / 2006- \\
1050\end{array}$ & MBRA0308-0308 & $\underline{7-7.4}$ & & & & & & & & & & & & $\underline{\text { EU44 }}$ \\
\hline Z2-EU44-202 & $\underline{\mathrm{BH}}$ & $\begin{array}{l}3 / 17 / 2006- \\
1130\end{array}$ & MBRA0306-0307 & & $\underline{0-10}$ & $\underline{0-10}$ & $\underline{0-10}$ & $\underline{0-10}$ & $\underline{0-10}$ & & & & & & & $\underline{\text { EU44 }}$ \\
\hline Z2-EU44-200 & $\underline{\mathrm{BH}}$ & $\begin{array}{l}3 / 17 / 2006- \\
1230\end{array}$ & MBRA0302-0302 & $\underline{6.6-7}$ & & & & & & & & & & & & $\underline{\text { EU44 }}$ \\
\hline Z2-EU44-200 & $\underline{\mathrm{BH}}$ & $\begin{array}{l}3 / 17 / 2006- \\
1240\end{array}$ & MBRA0300-0301 & & $\underline{0-10}$ & $\underline{0-10}$ & $\underline{0-10}$ & $\underline{0-10}$ & $\underline{0-10}$ & & & & & & & $\underline{\text { EU44 }}$ \\
\hline Z2-EU44-201 & $\underline{\mathrm{BH}}$ & $\frac{3 / 17 / 2006-}{1330}$ & MBRA0303-0303 & & & $\underline{0-10}$ & $\underline{0-10}$ & $\underline{0-10}$ & $\underline{0-10}$ & & & & & & & $\underline{\text { EU44 }}$ \\
\hline Z2-EU23B-301 & $\underline{\mathrm{BH}}$ & $\begin{array}{l}3 / 20 / 2006- \\
920\end{array}$ & $\underline{\text { K25A0194-0257 }}$ & & $\underline{0-0.5}$ & & $\underline{0-0.5}$ & $\underline{0-0.5}$ & $\underline{0-0.5}$ & & & $\underline{\mathrm{K} 25 \mathrm{~A} 0257-\mathrm{S}}$ & & & & $\underline{\text { EU23 }}$ \\
\hline Z2-EU23B-302 & $\underline{\mathrm{BH}}$ & $\begin{array}{l}3 / 20 / 2006- \\
935\end{array}$ & $\underline{\mathrm{K} 25 \mathrm{~A} 0195-0258}$ & & $\underline{0-0.5}$ & & $\underline{0-0.5}$ & $\underline{0-0.5}$ & $\underline{0-0.5}$ & & & & & & & $\underline{\text { EU23 }}$ \\
\hline
\end{tabular}


Table L.1. (continued)

\begin{tabular}{|c|c|c|c|c|c|c|c|c|c|c|c|c|c|c|c|c|}
\hline Station & $\underline{\text { Type }}$ & $\begin{array}{c}\text { Date - } \\
\text { time }\end{array}$ & $\underline{\text { ID range }}$ & $\underline{\text { VOA }}$ & $\underline{\text { RADS }}$ & $\underline{\text { SVOA }}$ & $\underline{\mathrm{PPCB}}$ & Metal & Mercury & Other & $\underline{\underline{F R}}$ & SPLIT & $\underline{\text { RIN }}$ & $\underline{\mathrm{FB}}$ & $\underline{\mathrm{TB}}$ & $\begin{array}{l}\text { Task } \\
\text { code } \\
\end{array}$ \\
\hline Z2-EU23B-303 & $\mathrm{BH}$ & $\begin{array}{l}3 / 20 / 2006- \\
955\end{array}$ & K25A0196-0259 & & $\underline{0-0.5}$ & & $\underline{0-0.5}$ & $\underline{0-0.5}$ & $\underline{0-0.5}$ & & & & & & & $\underline{\mathrm{EU} 23}$ \\
\hline Z2-EU3-223 & $\underline{\mathrm{BH}}$ & $\begin{array}{l}4 / 20 / 2006- \\
1135\end{array}$ & $\underline{\mathrm{K} 31 \mathrm{~K} 33-556--556}$ & & & $\underline{0-10}$ & & & & & & & & & & $\underline{\text { EU03 }}$ \\
\hline Z2-EU3-224 & $\underline{\mathrm{BH}}$ & $\begin{array}{l}4 / 20 / 2006- \\
1400\end{array}$ & $\underline{\text { K31K33-559--559 }}$ & $\underline{0-2}$ & & $\underline{0-2}$ & & & & & & & & & & $\underline{\text { EU03 }}$ \\
\hline Z2-EU23B-304 & $\underline{\mathrm{BH}}$ & $\begin{array}{l}4 / 24 / 2006- \\
1100\end{array}$ & $\underline{\mathrm{K} 25 \mathrm{~A} 0292-0292}$ & & & & $\underline{0-1}$ & $\underline{0-1}$ & $\underline{0-1}$ & & & & & & & $\underline{\mathrm{EU} 23}$ \\
\hline Z2-EU23B-305 & $\underline{\mathrm{BH}}$ & $\begin{array}{l}4 / 24 / 2006- \\
1115\end{array}$ & $\underline{\mathrm{K} 25 \mathrm{~A} 0295-0295}$ & & & & $\underline{0-1}$ & $\underline{0-1}$ & $\underline{0-1}$ & & & & & & & $\underline{\mathrm{EU} 23}$ \\
\hline Z2-EU23B-306 & $\underline{\mathrm{BH}}$ & $\begin{array}{l}4 / 24 / 2006- \\
1130\end{array}$ & $\underline{\text { K25A0298-0298 }}$ & & & & $\underline{0-1}$ & $\underline{0-1}$ & $\underline{0-1}$ & & & & & & & $\underline{\mathrm{EU} 23}$ \\
\hline Z2-EU28B-126 & $\underline{\mathrm{BH}}$ & $\begin{array}{l}4 / 25 / 2006- \\
1350\end{array}$ & HLRDA077-A077 & & $\underline{\underline{0-1}}$ & & & & & & & & & & & $\underline{\text { EU28 }}$ \\
\hline Z2-EU1B-305 & $\underline{\mathrm{BH}}$ & $\begin{array}{l}5 / 5 / 2006- \\
1025\end{array}$ & $\underline{\text { K31K33-596--598 }}$ & $\underline{0-1}$ & $\underline{0-1}$ & & & $\underline{0-1}$ & & & & & & & & $\underline{\text { EU01 }}$ \\
\hline Z2-EU1B-304 & $\underline{\mathrm{BH}}$ & $\begin{array}{l}5 / 5 / 2006- \\
1100\end{array}$ & $\underline{\text { K31K33-593--593 }}$ & & & & $\underline{0-1}$ & $\underline{0-1}$ & $\underline{0-1}$ & & & K31K33-593-S & & & & $\underline{\text { EU01 }}$ \\
\hline Z2-EU1B-302 & $\underline{\mathrm{BH}}$ & $\begin{array}{l}5 / 5 / 2006- \\
1250\end{array}$ & $\underline{\text { K31K33-584--585 }}$ & & $\underline{0-1}$ & & $\underline{0-1}$ & $\underline{0-1}$ & $\underline{0-1}$ & & & & & & & $\underline{\text { EU01 }}$ \\
\hline Z2-EU1B-303 & $\underline{\mathrm{BH}}$ & $\begin{array}{l}5 / 9 / 2006- \\
1510\end{array}$ & $\underline{\text { K31K33-587--589 }}$ & $\underline{0.1-0.5}$ & & & $\underline{0-1}$ & $\underline{0-1}$ & $\underline{0-1}$ & & $\underline{\text { K31K33-592 }}$ & & & & & $\underline{\text { EU01 }}$ \\
\hline Z2-EU1B-304 & $\underline{\mathrm{BH}}$ & $\begin{array}{l}5 / 10 / 2006- \\
1345\end{array}$ & $\underline{\text { K31K33-616--616 }}$ & & & & $\underline{0-1}$ & & $\underline{0-1}$ & & & & & & & $\underline{\text { EU01 }}$ \\
\hline Z2-EU1B-305 & $\underline{\mathrm{BH}}$ & $\begin{array}{l}5 / 10 / 2006- \\
\underline{1410} \\
\end{array}$ & $\underline{\text { K31K33-617--617 }}$ & & & $\underline{\underline{0-1}}$ & $\underline{0-1}$ & & $\underline{0-1}$ & & & & & & & $\underline{\text { EU01 }}$ \\
\hline Z2-EU1B-306 & $\underline{\mathrm{BH}}$ & $\begin{array}{l}5 / 22 / 2006- \\
1020\end{array}$ & $\underline{\text { K31K33-632--633 }}$ & & $\underline{0-0.5}$ & & $\underline{0-0.5}$ & $\underline{0-0.5}$ & $\underline{0-0.5}$ & & & & & & & $\underline{\text { EU01 }}$ \\
\hline Z2-EU3B-305 & $\underline{\mathrm{BH}}$ & $\begin{array}{l}5 / 24 / 2006- \\
1155\end{array}$ & K31K33-694--694 & & & $\underline{0-1}$ & & & & & & K31K33-694-S & & & & $\underline{\text { EU03 }}$ \\
\hline Z2-EU3B-306 & $\underline{\mathrm{BH}}$ & $\begin{array}{l}\text { 5/24/2006- } \\
1215\end{array}$ & $\underline{\mathrm{K} 31 \mathrm{~K} 33-700--700}$ & & & $\underline{\underline{0-1}}$ & & & & & & & & & & $\underline{\text { EU03 }}$ \\
\hline Z2-EU3B-304 & $\underline{\mathrm{BH}}$ & $\begin{array}{l}5 / 24 / 2006- \\
1230\end{array}$ & K31K33-691--691 & & & $\underline{0-1}$ & & & & & & & & & & $\underline{\text { EU03 }}$ \\
\hline
\end{tabular}


Table L.1. (continued)

\begin{tabular}{|c|c|c|c|c|c|c|c|c|c|c|c|c|c|c|c|c|}
\hline$\underline{\text { Station }}$ & Type & $\begin{array}{l}\frac{\text { Date - }}{\text { time }} \\
\end{array}$ & ID range & VOA & $\underline{\text { RADS }}$ & SVOA & PPCB & Metal & Mercury & Other & $\underline{F R}$ & $\underline{\text { SPLIT }}$ & $\underline{\text { RIN }}$ & $\underline{\mathrm{FB}}$ & $\underline{\mathrm{TB}}$ & $\begin{array}{l}\text { Task } \\
\text { code }\end{array}$ \\
\hline Z2-EU23B-307 & $\underline{\mathrm{BH}}$ & $\begin{array}{l}5 / 26 / 2006- \\
910\end{array}$ & $\underline{\mathrm{K} 25 \mathrm{~A} 0313-0314}$ & & $\underline{0-1}$ & & & $\underline{0-1}$ & $\underline{0-1}$ & & & & & & & EU23 \\
\hline Z2-EU23B-310 & $\underline{\mathrm{BH}}$ & $\begin{array}{l}5 / 26 / 2006- \\
920\end{array}$ & $\underline{\mathrm{K} 25 \mathrm{~A} 0322-0323}$ & & $\underline{0-1}$ & & & $\underline{0-1}$ & $\underline{0-1}$ & & & & & & & $\underline{\mathrm{EU} 23}$ \\
\hline Z2-EU23B-309 & $\underline{\mathrm{BH}}$ & $\begin{array}{l}5 / 26 / 2006- \\
\underline{930}\end{array}$ & $\underline{\mathrm{K} 25 \mathrm{~A} 0319-0320}$ & & $\underline{0-1}$ & & & $\underline{0-1}$ & $\underline{0-1}$ & & & & & & & $\underline{\mathrm{EU} 23}$ \\
\hline Z2-EU23B-308 & $\underline{\mathrm{BH}}$ & $\begin{array}{l}5 / 26 / 2006- \\
940\end{array}$ & $\underline{\mathrm{K} 25 \mathrm{~A} 0316-0317}$ & & $\underline{0-1}$ & & & $\underline{0-1}$ & $\underline{0-1}$ & & & & & & & $\underline{\text { EU23 }}$ \\
\hline Z2-EU01-201 & $\underline{\mathrm{BH}}$ & $\begin{array}{l}\text { 6/12/2006- } \\
\underline{953} \\
\end{array}$ & $\underline{\mathrm{K} 31 \mathrm{~K} 33-715--716}$ & & & & $\underline{0.5-2}$ & & & & & & & & & EU01 \\
\hline Z2-EU01-202 & $\underline{\mathrm{BH}}$ & $\begin{array}{l}6 / 12 / 2006- \\
1000\end{array}$ & $\underline{\mathrm{K} 31 \mathrm{~K} 33-718--719}$ & & & & $\underline{0.5-2}$ & & & & & & & & & EU01 \\
\hline Z2-EU01-203 & $\underline{\mathrm{BH}}$ & $\begin{array}{l}6 / 12 / 2006- \\
1010 \\
\end{array}$ & K31K33-721--722 & & & & $\underline{0.5-2}$ & & & & & & & & & EU01 \\
\hline Z2-EU01-204 & $\underline{\mathrm{BH}}$ & $\begin{array}{l}6 / 12 / 2006- \\
1015 \\
\end{array}$ & K31K33-724--725 & & & & $\underline{0.5-2}$ & & & & & & & & & $\underline{\text { EU01 }}$ \\
\hline Z2-EU23B-307 & $\underline{\mathrm{BH}}$ & $\begin{array}{l}7 / 13 / 2006- \\
1330 \\
\end{array}$ & $\underline{\mathrm{K} 25 \mathrm{~A} 0325-0325}$ & & & & $\underline{0-1}$ & & & & & & & & & $\underline{\mathrm{EU} 23}$ \\
\hline Z2-EU23B-309 & $\underline{\mathrm{BH}}$ & $\begin{array}{l}7 / 13 / 2006- \\
1333 \\
\end{array}$ & $\underline{\mathrm{K} 25 \mathrm{~A} 0327-0327}$ & & & & $\underline{0-1}$ & & & & & & & & & $\underline{\mathrm{EU} 23}$ \\
\hline Z2-EU23B-310 & $\underline{\mathrm{BH}}$ & $\underline{7 / 13 / 2006-}$ & $\underline{\mathrm{K} 25 \mathrm{~A} 0328-0328}$ & & & & $\underline{0-1}$ & & & & & & & & & $\underline{\mathrm{EU} 23}$ \\
\hline Z2-EU23B-308 & $\underline{\mathrm{BH}}$ & $\begin{array}{l}\text { 7/13/2006- } \\
\underline{1338} \\
\end{array}$ & $\underline{\mathrm{K} 25 \mathrm{~A} 0326-0326}$ & & & & $\underline{0-1}$ & & & & & & & & & $\underline{\mathrm{EU} 23}$ \\
\hline Z2-EU34B-301 & $\underline{\mathrm{BH}}$ & $\begin{array}{l}7 / 17 / 2006- \\
1030\end{array}$ & $\begin{array}{l}\text { BOSLABS-400-- } \\
402\end{array}$ & $\underline{6.5-7}$ & $\underline{7.6-8.9}$ & $\underline{0-10}$ & $\underline{0-10}$ & $\underline{0-10}$ & $\underline{0-10}$ & & $\begin{array}{l}\text { BOSLABS- } \\
405\end{array}$ & & & & & EU34 \\
\hline Z2-EU34B-303 & $\underline{\mathrm{BH}}$ & $\begin{array}{l}\text { 7/17/2006- } \\
\underline{1030} \\
\end{array}$ & $\begin{array}{l}\text { BOSLABS-408-- } \\
\underline{408}\end{array}$ & & & $\underline{0-1}$ & $\underline{0-1}$ & $\underline{0-1}$ & $\underline{0-1}$ & & & & & & & EU34 \\
\hline Z2-EU34B-302 & $\underline{\mathrm{BH}}$ & $\begin{array}{l}\underline{7 / 17 / 2006-} \\
\underline{1040}\end{array}$ & $\begin{array}{l}\text { BOSLABS-406-- } \\
407\end{array}$ & & $\underline{0-1}$ & & & $\underline{0-1}$ & $\underline{0-1}$ & & & & & & & EU34 \\
\hline Z2-EU34B-305 & $\underline{\mathrm{BH}}$ & $\begin{array}{l}\text { 7/17/2006- } \\
\underline{1130} \\
\end{array}$ & $\begin{array}{l}\text { BOSLABS-412-- } \\
\underline{412}\end{array}$ & & & $\underline{0-1}$ & $\underline{0-1}$ & $\underline{0-1}$ & $\underline{0-1}$ & & & & & & & EU34 \\
\hline Z2-EU43-201 & $\underline{\mathrm{BH}}$ & $\begin{array}{l}7 / 18 / 2006- \\
1000 \\
\end{array}$ & $\begin{array}{l}\text { BOSLABS-415-- } \\
\underline{415}\end{array}$ & & & $\underline{0.6-2.6}$ & $\underline{0.6-2.6}$ & $\underline{0.6-2.6}$ & $\underline{0.6-2.6}$ & & & & & & & $\underline{\mathrm{EU} 43}$ \\
\hline Z2-EU43-202 & $\underline{\mathrm{BH}}$ & $\begin{array}{l}7 / 18 / 2006- \\
1040\end{array}$ & $\begin{array}{l}\text { BOSLABS-418-- } \\
418\end{array}$ & & & $\underline{0.55-}$ & $\underline{0.55-2.55}$ & $\underline{0.55-2.55}$ & $\underline{0.55-2.55}$ & & & $\begin{array}{l}\text { BOSLABS-418- } \\
\underline{\underline{S}}\end{array}$ & & & & $\underline{\mathrm{EU} 43}$ \\
\hline
\end{tabular}


Table L.1. (continued)

\begin{tabular}{|c|c|c|c|c|c|c|c|c|c|c|c|c|c|c|c|c|}
\hline Station & Type & $\begin{array}{c}\text { Date - } \\
\text { time }\end{array}$ & $\underline{\text { ID range }}$ & VOA & $\underline{\text { RADS }}$ & SVOA & $\underline{\mathrm{PPCB}}$ & Metal & Mercury & Other & $\underline{\text { FR }}$ & SPLIT & $\underline{\text { RIN }}$ & $\underline{\text { FB }}$ & $\underline{\mathrm{TB}}$ & $\begin{array}{l}\text { Task } \\
\text { code } \\
\end{array}$ \\
\hline Z2-EU43B-303 & $\underline{\mathrm{SL}}$ & $\begin{array}{l}7 / 19 / 2006- \\
955 \\
\end{array}$ & $\begin{array}{l}\text { BOSLABS-427-- } \\
427\end{array}$ & & & $\underline{0-0.5}$ & $\underline{0-0.5}$ & $\underline{0-0.5}$ & $\underline{0-0.5}$ & & & & & & & $\underline{\text { EU43 }}$ \\
\hline Z2-EU43B-301 & $\underline{\underline{\mathrm{SL}}}$ & $\begin{array}{l}7 / 19 / 2006- \\
1015 \\
\end{array}$ & $\begin{array}{l}\text { BOSLABS-421-- } \\
421\end{array}$ & & & $\underline{0-0.5}$ & $\underline{0-0.5}$ & $\underline{0-0.5}$ & $\underline{0-0.5}$ & & & & & & & $\underline{\text { EU43 }}$ \\
\hline Z2-EU43B-302 & $\underline{\underline{\mathrm{SL}}}$ & $\begin{array}{l}7 / 19 / 2006- \\
1030 \\
\end{array}$ & $\begin{array}{l}\text { BOSLABS-424-- } \\
424\end{array}$ & & & $\underline{0-0.5}$ & $\underline{0-0.5}$ & $\underline{0-0.5}$ & $\underline{0-0.5}$ & & & & & & & $\underline{\mathrm{EU} 43}$ \\
\hline Z2-EU34B-304 & $\underline{\mathrm{BH}}$ & $\begin{array}{l}9 / 5 / 2006- \\
1130 \\
\end{array}$ & $\begin{array}{l}\text { BOSLABS-411-- } \\
411\end{array}$ & & $\underline{0-1}$ & & & & & & & & & & & $\underline{\text { EU34 }}$ \\
\hline Z2-EU37B-303 & $\underline{\mathrm{BH}}$ & $\begin{array}{l}9 / 11 / 2006- \\
1000\end{array}$ & EU370010-0012 & $\underline{9.9-9.3}$ & $\underline{10-0}$ & $\underline{10-0}$ & $\underline{10-0}$ & $\underline{10-0}$ & $\underline{10-0}$ & & & & $\underline{1515}$ & $\underline{1500}$ & & $\underline{\text { EU37 }}$ \\
\hline Z2-EU37B-304 & $\underline{\mathrm{BH}}$ & $\begin{array}{l}9 / 11 / 2006- \\
1100\end{array}$ & EU370013-0015 & $\underline{5.4-5.1}$ & $\underline{7-0}$ & $\underline{7-0}$ & $\underline{7-0}$ & $\underline{7-0}$ & $\underline{7-0}$ & & & & $\underline{1515}$ & $\underline{1500}$ & & $\underline{\text { EU37 }}$ \\
\hline Z2-EU37B-301 & $\underline{\mathrm{BH}}$ & $\begin{array}{l}9 / 11 / 2006- \\
1230\end{array}$ & EU370001-0003 & $\underline{2.8-2}$ & $\underline{5.5-0}$ & $\underline{5.5-0}$ & $\underline{5.5-0}$ & $\underline{5.5-0}$ & $\underline{5.5-0}$ & & $\underline{E U 370006}$ & & $\underline{1515}$ & $\underline{1500}$ & & $\underline{\text { EU37 }}$ \\
\hline Z2-EU37B-306 & $\underline{\mathrm{BH}}$ & \begin{tabular}{|l}
$\underline{9 / 12 / 2006-}$ \\
$\underline{845}$ \\
\end{tabular} & EU370007-0009 & $\underline{1-0}$ & $\underline{1-0}$ & $\underline{1-0}$ & $\underline{1-0}$ & $\underline{1-0}$ & $\underline{1-0}$ & & & EU370009-S & & & $\underline{\text { STL } 820}$ & $\underline{\text { EU37 }}$ \\
\hline Z2-EU37B-302 & $\underline{\mathrm{BH}}$ & $\begin{array}{l}9 / 12 / 2006- \\
1020 \\
\end{array}$ & EU370019-0021 & $\underline{0.1-0}$ & $\underline{0.1-0}$ & $\underline{0.1-0}$ & $\underline{0.1-0}$ & $\underline{0.1-0}$ & $\underline{0.1-0}$ & & & & & & $\underline{\text { STL } 820}$ & $\underline{\text { EU37 }}$ \\
\hline Z2-EU37B-305 & $\underline{\mathrm{BH}}$ & $\begin{array}{l}9 / 12 / 2006- \\
1035 \\
\end{array}$ & EU370016-0018 & $\underline{0.1-0}$ & $\underline{0.1-0}$ & $\underline{0.1-0}$ & $\underline{0.1-0}$ & $\underline{0.1-0}$ & $\underline{0.1-0}$ & & & & & & $\underline{\text { STL } 820}$ & $\underline{\text { EU37 }}$ \\
\hline Z2-EU23B-317 & $\underline{\mathrm{BH}}$ & $\begin{array}{l}9 / 15 / 2006- \\
\underline{940}\end{array}$ & $\underline{\mathrm{K} 25 \mathrm{~A} 0366-0368}$ & $\underline{8.9-8.9}$ & & $\underline{6-9.5}$ & & $\underline{6-9.5}$ & $\underline{6-9.5}$ & $\begin{array}{l}\text { Gasoline, diesel } \\
\underline{\text { range }} \\
\underline{\text { organicsasoline }} \\
\underline{\text { range organics }} \\
\end{array}$ & $\underline{\mathrm{K} 25 \mathrm{~A} 0384}$ & & & & $\underline{1430}$ & $\underline{\mathrm{EU} 23}$ \\
\hline Z2-EU23B-318 & $\underline{\mathrm{BH}}$ & $\begin{array}{l}\underline{9 / 15 / 2006-} \\
\underline{1040}\end{array}$ & $\underline{\mathrm{K} 25 \mathrm{~A} 0370-0372}$ & $\underline{7.5-7.8}$ & & $\underline{6.5-9}$ & & $\underline{6.5-9}$ & $\underline{6.5-9}$ & $\begin{array}{l}\text { Gasoline, diesel } \\
\underline{\text { range }} \\
\underline{\text { organicsasoline }} \\
\text { range organics }\end{array}$ & & & & & $\underline{1430}$ & $\underline{\mathrm{EU} 23}$ \\
\hline Z2-EU23B-319 & $\underline{\mathrm{BH}}$ & $\begin{array}{l}\text { 9/15/2006- } \\
\underline{1125}\end{array}$ & $\underline{\mathrm{K} 25 \mathrm{~A} 0374-0376}$ & $\underline{8.1-8.6}$ & & $\underline{7-9}$ & & $\underline{7-9}$ & $\underline{7-9}$ & $\begin{array}{l}\text { Gasoline, diesel } \\
\underline{\text { range }} \\
\underline{\text { organicsasoline }} \\
\text { range organics } \\
\end{array}$ & & & & & $\underline{1430}$ & $\underline{\text { EU23 }}$ \\
\hline$\underline{\text { Z2-EU23B-320 }}$ & $\underline{\mathrm{BH}}$ & $\begin{array}{l}\frac{9 / 15 / 2006-}{1205} \\
\underline{100}\end{array}$ & $\underline{\mathrm{K} 25 \mathrm{~A} 0378-0380}$ & $\underline{6.5-6.9}$ & & $\underline{6-8.25}$ & & $\underline{6-8.25}$ & $\underline{6-8.25}$ & $\begin{array}{l}\text { Gasoline, diesel } \\
\underline{\text { range }} \\
\underline{\text { organicsasoline }} \\
\text { range organics }\end{array}$ & & & & & $\underline{1430}$ & $\underline{\text { EU23 }}$ \\
\hline Z2-EU23B-311 & $\underline{\mathrm{BH}}$ & 9/19/2006 - & $\underline{\mathrm{K} 25 \mathrm{~A} 0393-0393}$ & & $\underline{\underline{0-0.5}}$ & & & & & & & & & & & $\underline{\underline{E U} 23}$ \\
\hline
\end{tabular}


Table L.1. (continued)

\begin{tabular}{|c|c|c|c|c|c|c|c|c|c|c|c|c|c|c|c|c|}
\hline Station & Type & $\begin{array}{l}\text { Date - } \\
\text { time }\end{array}$ & ID range & VOA & $\underline{\text { RADS }}$ & SVOA & PPCB & Metal & Mercury & Other & $\underline{\mathrm{FR}}$ & SPLIT & $\underline{\text { RIN }}$ & $\underline{\mathrm{FB}}$ & $\underline{\mathrm{TB}}$ & $\begin{array}{l}\text { Task } \\
\text { code } \\
\end{array}$ \\
\hline & & 1010 & & & & & & & & & & & & & & \\
\hline Z2-EU23B-311 & $\underline{\mathrm{BH}}$ & $\begin{array}{l}\underline{9 / 19 / 2006-} \\
\underline{1015} \\
\end{array}$ & $\underline{\mathrm{K} 25 \mathrm{~A} 0388-0389}$ & & $\underline{7.5-8}$ & & $\underline{6.25-8.75}$ & & & & & & & & & $\underline{\mathrm{EU} 23}$ \\
\hline Z2-EU23B-311 & $\underline{\mathrm{BH}}$ & $\begin{array}{l}\text { 9/19/2006 - } \\
\underline{1050}\end{array}$ & $\underline{\mathrm{K} 25 \mathrm{~A} 0329-0330}$ & & $\underline{0.5-2}$ & & $\underline{0.5-2}$ & & & & & & & & & $\underline{\mathrm{EU} 23}$ \\
\hline Z2-EU23B-312 & $\underline{\mathrm{BH}}$ & $\begin{array}{l}\text { 9/19/2006- } \\
\underline{1130}\end{array}$ & $\underline{\mathrm{K} 25 \mathrm{~A} 0332-0336}$ & $\underline{10-10.3}$ & & $\underline{8.3-9.8}$ & & $\underline{8.3-9.8}$ & $\underline{8.3-9.8}$ & $\begin{array}{l}\text { Gasoline, diesel } \\
\underline{\text { range }} \\
\underline{\text { organicsasoline }} \\
\text { range organics } \\
\end{array}$ & & & & & $\underline{900}$ & $\underline{\mathrm{EU} 23}$ \\
\hline$\underline{\text { Z2-EU23B-313 }}$ & $\underline{\mathrm{BH}}$ & $\frac{9 / 19 / 2006-}{\underline{1245}}$ & $\underline{\mathrm{K} 25 \mathrm{~A} 0337-0341}$ & $\underline{9.2-9.65}$ & & $\underline{\underline{8.2-}}$ & & $\underline{8.2-11.6}$ & $\underline{8.2-11.6}$ & $\begin{array}{l}\text { Gasoline, diesel } \\
\underline{\text { range }} \\
\underline{\text { organicsasoline }} \\
\text { range organics }\end{array}$ & & & & & $\underline{900}$ & $\underline{\text { EU23 }}$ \\
\hline Z2-EU23B-314 & $\underline{\mathrm{BH}}$ & $\frac{9 / 20 / 2006-}{\underline{1045}}$ & $\underline{\mathrm{K} 25 \mathrm{~A} 0342-0346}$ & $\underline{9.5-10}$ & & $\underline{\underline{8.75-}} \underline{\underline{10.75}}$ & & $\underline{\underline{8.75-}} \underline{\underline{10.75}}$ & $\underline{\underline{8.75-}} \underline{10.75}$ & $\begin{array}{l}\text { Gasoline, diesel } \\
\text { range } \\
\underline{\text { organicsasoline }} \\
\text { range organics }\end{array}$ & & & & & & $\underline{\mathrm{EU} 23}$ \\
\hline Z2-EU8B-320 & $\underline{\mathrm{BH}}$ & $\begin{array}{l}9 / 21 / 2006- \\
910\end{array}$ & K31K33-733--733 & & $\underline{0-1}$ & & & & & & & & $\underline{1623}$ & & & $\underline{\text { EU08 }}$ \\
\hline Z2-EU8B-318 & $\underline{\mathrm{BH}}$ & $\begin{array}{l}9 / 21 / 2006- \\
930\end{array}$ & $\underline{\mathrm{K} 31 \mathrm{~K} 33-727--728}$ & & $\underline{8-8}$ & & $\underline{8-8}$ & $\underline{8-8}$ & $\underline{8-8}$ & & & & $\underline{1623}$ & & & $\underline{\text { EU08 }}$ \\
\hline$\underline{\text { Z2-EU8B-319 }}$ & $\underline{\mathrm{BH}}$ & $\begin{array}{l}9 / 21 / 2006- \\
950\end{array}$ & $\underline{\mathrm{K} 31 \mathrm{~K} 33-730--731}$ & & $\underline{4.6-5}$ & & $\underline{4.6-5}$ & $\underline{4.6-5}$ & $\underline{4.6-5}$ & & & & $\underline{1623}$ & & & $\underline{\text { EU08 }}$ \\
\hline Z2-EU43B-306 & $\underline{\mathrm{BH}}$ & $\begin{array}{l}9 / 21 / 2006- \\
1355 \\
\end{array}$ & $\begin{array}{l}\text { BOSLABS502- } \\
\text { S502 }\end{array}$ & & & & $\underline{0-1}$ & & & & & & $\underline{1623}$ & & & $\underline{\mathrm{EU} 43}$ \\
\hline Z2-EU43B-305 & $\underline{\mathrm{BH}}$ & $\begin{array}{l}\text { 9/21/2006- } \\
\underline{1410} \\
\end{array}$ & $\begin{array}{l}\text { BOSLABS501- } \\
\underline{\text { S501 }}\end{array}$ & & & & $\underline{0-1}$ & & & & & & $\underline{1623}$ & & & $\underline{\text { EU43 }}$ \\
\hline Z2-EU43B-307 & $\underline{\mathrm{BH}}$ & $\begin{array}{l}9 / 21 / 2006- \\
1440 \\
\end{array}$ & $\begin{array}{l}\text { BOSLABS503- } \\
\text { S503 }\end{array}$ & & & & $\underline{0-1}$ & & & & & & $\underline{1623}$ & & & $\underline{\text { EU43 }}$ \\
\hline Z2-EU43B-304 & $\underline{\mathrm{BH}}$ & $\begin{array}{l}9 / 21 / 2006- \\
1445 \\
\end{array}$ & $\begin{array}{l}\text { BOSLABS500- } \\
\text { S500 }\end{array}$ & & & & $\underline{0-1}$ & & & & & & $\underline{1623}$ & & & $\underline{\mathrm{EU} 43}$ \\
\hline Z2-EU41DB-208-1 & $\underline{\mathrm{BH}}$ & $\begin{array}{l}\text { 9/22/2006- } \\
\underline{1320} \\
\end{array}$ & $\begin{array}{l}\text { EU41DB-2081- } \\
\underline{\mathrm{A} 3-1-\mathrm{A} 3} \\
\end{array}$ & & $\underline{0-1}$ & & & & & & & & & & & $\underline{\text { EU41 }}$ \\
\hline Z2-EU41DB-208-2 & $\underline{\mathrm{BH}}$ & $\begin{array}{l}9 / 22 / 2006- \\
\underline{1345} \\
\end{array}$ & $\begin{array}{l}\text { EU41DB-2082- } \\
\underline{\mathrm{A} 3-2-\mathrm{A} 3} \\
\end{array}$ & & $\underline{0-1}$ & & & & & & & & & & & $\underline{\text { EU41 }}$ \\
\hline Z2-EU41DB-208-3 & $\underline{\mathrm{BH}}$ & $\begin{array}{l}9 / 25 / 2006- \\
1135 \\
\end{array}$ & $\begin{array}{l}\text { EU41DB-2083- } \\
\text { A2-3-A2 }\end{array}$ & $\underline{3-3.5}$ & & & & & & & & $\begin{array}{l}\text { EU41DB-2083- } \\
\underline{\text { A2S }}\end{array}$ & & & $\begin{array}{l}1135, \text { STL } \\
\underline{1235} \\
\end{array}$ & $\underline{\text { EU41 }}$ \\
\hline
\end{tabular}


Table L.1. (continued)

\begin{tabular}{|c|c|c|c|c|c|c|c|c|c|c|c|c|c|c|c|c|}
\hline Station & Type & $\frac{\text { Date - }}{\text { time }}$ & ID range & VOA & $\underline{\text { RADS }}$ & SVOA & PPCB & Metal & Mercury & Other & FR & SPLIT & RIN & $\underline{\mathrm{FB}}$ & $\underline{\mathrm{TB}}$ & $\frac{\text { Task }}{\text { code }}$ \\
\hline Z2-EU41DB-208-3 & $\underline{\mathrm{BH}}$ & $\begin{array}{l}9 / 25 / 2006- \\
1150\end{array}$ & $\begin{array}{l}\text { EU41DB-2083- } \\
\text { A3-3-A3 }\end{array}$ & & $\underline{5-5.8}$ & & & & & & & $\begin{array}{l}\text { EU41DB-2083- } \\
\text { A3S }\end{array}$ & & & & EU41 \\
\hline Z2-EU41DB-208-3 & $\underline{\mathrm{BH}}$ & $\begin{array}{l}9 / 25 / 2006- \\
\underline{1200}\end{array}$ & $\begin{array}{l}\text { EU41DB-2083- } \\
\text { A1-3-A1 }\end{array}$ & $\underline{0-10}$ & & $\underline{0-10}$ & $\underline{0-10}$ & $\underline{0-10}$ & $\underline{0-10}$ & & & $\begin{array}{l}\text { EU41DB-2083- } \\
\text { A1S }\end{array}$ & & & $\underline{1135, \mathrm{STL}}$ & $\underline{\text { EU41 }}$ \\
\hline Z2-EU41DB-208-4 & $\underline{\mathrm{BH}}$ & $\begin{array}{l}9 / 25 / 2006- \\
1235 \\
\end{array}$ & $\begin{array}{l}\text { EU41DB-2084- } \\
\text { A2-4-A2 } \\
\end{array}$ & $\underline{2.4-2.8}$ & & & & & & & $\frac{\text { EU41DB- }}{2084-\mathrm{A} 5}$ & & & & $\begin{array}{l}1135, \text { STL } \\
\underline{1235} \\
\end{array}$ & EU41 \\
\hline Z2-EU41DB-208-4 & $\underline{\mathrm{BH}}$ & $\begin{array}{l}9 / 25 / 2006- \\
\underline{1250}\end{array}$ & $\begin{array}{l}\text { EU41DB-2084- } \\
\text { A3-4-A3 }\end{array}$ & & $\underline{7-7.6}$ & & & & & & $\begin{array}{l}\text { EU41DB- } \\
\text { 2084-A6 }\end{array}$ & & & & & $\underline{\text { EU41 }}$ \\
\hline Z2-EU41DB-208-4 & $\underline{\mathrm{BH}}$ & $\begin{array}{l}9 / 25 / 2006- \\
1305\end{array}$ & $\begin{array}{l}\text { EU41DB-2084- } \\
\text { A1-4-A1 }\end{array}$ & $\underline{0-10}$ & & $\underline{0-10}$ & $\underline{0-10}$ & $\underline{0-10}$ & $\underline{0-10}$ & & $\frac{\text { EU41DB- }}{2084-A 4}$ & & & & $\frac{1135, \mathrm{STL}}{1235}$ & $\underline{\text { EU41 }}$ \\
\hline$\underline{\text { Z2-EU41D-100 }}$ & $\underline{\mathrm{BH}}$ & $\begin{array}{l}9 / 26 / 2006- \\
1015 \\
\end{array}$ & $\begin{array}{l}\text { EU41D-100-A3-0- } \\
\underline{\mathrm{A} 3}\end{array}$ & & $\underline{0-1}$ & & & & & & $\begin{array}{l}\text { EU41D-100- } \\
\text { A3D }\end{array}$ & & & & & $\underline{\text { EU41 }}$ \\
\hline Z2-EU41D-200 & $\underline{\mathrm{BH}}$ & $\begin{array}{l}9 / 26 / 2006- \\
1035 \\
\end{array}$ & $\begin{array}{l}\text { EU41D-200-A3-0- } \\
\underline{\mathrm{A} 3}\end{array}$ & & $\underline{0-1}$ & & & & & & & $\begin{array}{l}\text { EU41D-200-A3- } \\
\underline{\text { S }}\end{array}$ & & & & $\underline{\mathrm{EU} 41}$ \\
\hline Z2-EU41D-201 & $\underline{\mathrm{BH}}$ & $\begin{array}{l}9 / 26 / 2006- \\
1050\end{array}$ & $\begin{array}{l}\text { EU41D-201-A1-1- } \\
\text { A1 }\end{array}$ & & & & & $\underline{0-1}$ & $\underline{0-1}$ & $\underline{\text { TCLP }}$ & & & & & & EU41 \\
\hline Z2EU41DB-208-10 & $\underline{\mathrm{BH}}$ & $\begin{array}{l}9 / 27 / 2006- \\
1130 \\
\end{array}$ & $\begin{array}{l}\text { EU41DB-20810- } \\
\underline{\text { A1-0-A1 }}\end{array}$ & $\underline{0-9.5}$ & $\underline{0-9.5}$ & $\underline{0-9.5}$ & $\underline{0-9.5}$ & $\underline{0-9.5}$ & $\underline{0-9.5}$ & & & & & & & $\underline{\text { EU41 }}$ \\
\hline Z2-EU41DB-208-7 & $\underline{\mathrm{BH}}$ & $\begin{array}{l}9 / 27 / 2006- \\
1200\end{array}$ & $\begin{array}{l}\text { EU41DB-2087- } \\
\text { A1-7-A1 }\end{array}$ & & $\underline{0-10}$ & $\underline{0-10}$ & $\underline{0-10}$ & $\underline{0-10}$ & $\underline{0-10}$ & & & & & & & EU41 \\
\hline Z2EU41DB-208-11 & $\underline{\mathrm{BH}}$ & $\begin{array}{l}9 / 27 / 2006- \\
\underline{1210} \\
\end{array}$ & $\begin{array}{l}\text { EU41DB-20811- } \\
\text { A1-1-A1 }\end{array}$ & $\underline{0-10}$ & $\underline{0-10}$ & $\underline{0-10}$ & $\underline{0-10}$ & $\underline{0-10}$ & $\underline{0-10}$ & & & & & & & $\underline{\text { EU41 }}$ \\
\hline Z2-EU24B-301 & $\underline{\mathrm{BH}}$ & $\begin{array}{l}9 / 27 / 2006- \\
\underline{1215} \\
\end{array}$ & MPLA-004--004 & & & $\underline{0-8.5}$ & $\underline{0-8.5}$ & $\underline{0-8.5}$ & $\underline{0-8.5}$ & & & & & & & EU24 \\
\hline Z2-EU24B-300 & $\underline{\mathrm{BH}}$ & $\begin{array}{l}9 / 27 / 2006- \\
\underline{1315} \\
\end{array}$ & MPLA-001--001 & & & $\underline{0-8.9}$ & $\underline{0-8.9}$ & $\underline{0-8.9}$ & $\underline{0-8.9}$ & & & & & & & EU24 \\
\hline Z2-EU24B-303 & $\underline{\mathrm{BH}}$ & $\begin{array}{l}9 / 28 / 2006- \\
1026 \\
\end{array}$ & MPLA-012--012 & $\underline{11.2-11.4}$ & & & & & & & & & $\underline{850}$ & & $\begin{array}{l}1105, \text { STL } \\
\underline{850} \\
\end{array}$ & EU24 \\
\hline Z2-EU24B-303 & $\underline{\mathrm{BH}}$ & $\begin{array}{l}9 / 28 / 2006- \\
\underline{1028}\end{array}$ & MPLA-029--029 & & & & & & & $\begin{array}{l}\text { Gasoline, diesel } \\
\text { range } \\
\text { organicsasoline } \\
\text { range organics }\end{array}$ & & & $\underline{850}$ & & & $\underline{\text { EU24 }}$ \\
\hline Z2-EU24B-303 & $\underline{\mathrm{BH}}$ & $\begin{array}{l}9 / 28 / 2006- \\
1035 \\
\end{array}$ & MPLA-010--010 & & & $\underline{0-14}$ & $\underline{0-14}$ & $\underline{0-14}$ & $\underline{0-14}$ & & & & $\underline{850}$ & & & EU24 \\
\hline Z2-EU24B-305 & $\underline{\mathrm{BH}}$ & $\begin{array}{l}9 / 28 / 2006- \\
1045\end{array}$ & MPLA-016--018 & $\underline{0-0.2}$ & $\underline{0-0.2}$ & $\underline{0-0.2}$ & $\underline{0-0.2}$ & $\underline{0-0.2}$ & $\underline{0-0.2}$ & & & & $\underline{850}$ & & $\begin{array}{l}1105 . \text { STL } \\
850\end{array}$ & EU24 \\
\hline
\end{tabular}


Table L.1. (continued)

\begin{tabular}{|c|c|c|c|c|c|c|c|c|c|c|c|c|c|c|c|c|}
\hline Station & Type & $\begin{array}{l}\text { Date - } \\
\text { time }\end{array}$ & ID range & VOA & $\underline{\text { RADS }}$ & $\underline{\text { SVOA }}$ & $\underline{\text { PPCB }}$ & Metal & Mercury & Other & $\underline{\mathrm{FR}}$ & SPLIT & $\underline{\text { RIN }}$ & $\underline{\mathrm{FB}}$ & $\underline{\mathrm{TB}}$ & $\begin{array}{l}\text { Task } \\
\text { code } \\
\end{array}$ \\
\hline Z2-EU24M-302 & $\underline{\mathrm{BH}}$ & $\begin{array}{l}9 / 28 / 2006- \\
\underline{1135}\end{array}$ & MPLA-028--028 & & & & & & & $\begin{array}{l}\text { Hc as gasoline, } \\
\text { diesel range } \\
\text { organics }\end{array}$ & & MPLA-028-S & $\underline{850}$ & & & EU24 \\
\hline Z2-EU24M-302 & $\underline{\mathrm{BH}}$ & $\begin{array}{l}9 / 28 / 2006- \\
1138 \\
\end{array}$ & MPLA-009--009 & $\underline{9.5-10}$ & & & & & & & & MPLA-009-S & $\underline{850}$ & & $\begin{array}{l}1105, \text { STL } \\
850\end{array}$ & $\underline{\text { EU24 }}$ \\
\hline Z2-EU24M-302 & $\underline{\mathrm{BH}}$ & $\begin{array}{l}9 / 28 / 2006- \\
1200\end{array}$ & MPLA-007--008 & & $\underline{0-14}$ & $\underline{0-14}$ & $\underline{0-14}$ & $\underline{0-14}$ & $\underline{0-14}$ & & & MPLA-008-S & $\underline{850}$ & & & EU24 \\
\hline Z2-EU24B-304 & $\underline{\mathrm{BH}}$ & $\begin{array}{l}9 / 28 / 2006- \\
1240\end{array}$ & $\underline{\text { MPLA-015--015 }}$ & $\underline{9-9.5}$ & & & & & & & & & $\underline{850}$ & & $\begin{array}{l}1105, \text { STL } \\
850\end{array}$ & EU24 \\
\hline Z2-EU24B-304 & $\underline{\mathrm{BH}}$ & $\begin{array}{l}\underline{9 / 28 / 2006-} \\
\underline{1245}\end{array}$ & MPLA-030--030 & & & & & & & $\begin{array}{l}\text { Gasoline, diesel } \\
\text { range } \\
\text { organicsasoline } \\
\text { range organics }\end{array}$ & & & $\underline{850}$ & & & $\underline{\text { EU24 }}$ \\
\hline Z2-EU24B-304 & $\underline{\mathrm{BH}}$ & $\begin{array}{l}9 / 28 / 2006- \\
1305\end{array}$ & MPLA-013--013 & & & $\underline{0-14}$ & $\underline{0-14}$ & $\underline{0-14}$ & $\underline{0-14}$ & & & & $\underline{850}$ & & & $\underline{\text { EU24 }}$ \\
\hline Z2-EU41DB-238 & $\underline{\mathrm{SL}}$ & $\begin{array}{l}9 / 29 / 2006- \\
1002 \\
\end{array}$ & $\begin{array}{l}\text { EU41DB-238-A1- } \\
\text { 8-A1 }\end{array}$ & & $\underline{0-1}$ & $\underline{0-1}$ & $\underline{0-1}$ & $\underline{0-1}$ & $\underline{0-1}$ & & & & & & & EU41 \\
\hline Z2-EU41DB-239 & $\underline{\mathrm{SL}}$ & $\begin{array}{l}9 / 29 / 2006- \\
1010 \\
\end{array}$ & $\begin{array}{l}\text { EU41DB-239-A1- } \\
\text { 9-A1 }\end{array}$ & $\underline{0-1}$ & $\underline{0-1}$ & $\underline{0-1}$ & $\underline{0-1}$ & $\underline{0-1}$ & $\underline{0-1}$ & & & & & & & EU41 \\
\hline Z2-EU41DB-240 & $\underline{\mathrm{SL}}$ & $\begin{array}{l}9 / 29 / 2006- \\
1033\end{array}$ & $\begin{array}{l}\text { EU41DB-240-A1- } \\
\text { 0-A1 }\end{array}$ & & $\underline{0-1}$ & $\underline{0-1}$ & $\underline{0-1}$ & $\underline{0-1}$ & $\underline{0-1}$ & & & & & & & EU41 \\
\hline Z2-EU41DB-241 & $\underline{\mathrm{SL}}$ & $\begin{array}{l}9 / 29 / 2006- \\
\underline{1113} \\
\end{array}$ & $\begin{array}{l}\text { EU41DB-241-A1- } \\
\text { 1-A1 }\end{array}$ & & $\underline{0-1}$ & $\underline{0-1}$ & $\underline{0-1}$ & $\underline{0-1}$ & $\underline{0-1}$ & & & & & & & $\underline{\text { EU41 }}$ \\
\hline Z2-EU41DB-242 & $\underline{\mathrm{SL}}$ & $\begin{array}{l}10 / 2 / 2006- \\
1023 \\
\end{array}$ & $\begin{array}{l}\text { EU41DB-242-A1- } \\
\underline{2-\mathrm{A} 1}\end{array}$ & & $\underline{0-1}$ & $\underline{0-1}$ & $\underline{0-1}$ & $\underline{0-1}$ & $\underline{0-1}$ & & & & & & & $\underline{\text { EU41 }}$ \\
\hline Z2-EU44B-304 & $\underline{\mathrm{BH}}$ & $\begin{array}{l}\underline{5 / 9 / 2007-} \\
\underline{940}\end{array}$ & MBRA0647-0650 & & $\underline{0-0.5}$ & $\underline{0-0.5}$ & $\underline{0-0.5}$ & $\underline{0-0.5}$ & $\underline{0-0.5}$ & $\begin{array}{l}\text { Gasoline, diesel } \\
\text { range } \\
\text { organicsasoline } \\
\text { range organics } \\
\end{array}$ & & & & & & EU44 \\
\hline Z2-EU44B-305 & $\underline{\mathrm{BH}}$ & $\begin{array}{l}\underline{5 / 9 / 2007-} \\
\underline{945}\end{array}$ & MBRA0651-0654 & & $\underline{0-0.33}$ & $\underline{0-0.33}$ & $\underline{0-0.33}$ & $\underline{0-0.33}$ & $\underline{0-0.33}$ & $\begin{array}{l}\text { Gasoline, diesel } \\
\text { range } \\
\text { organicsasoline } \\
\text { range organics }\end{array}$ & & & & & & $\underline{\mathrm{EU} 44}$ \\
\hline
\end{tabular}

For each analytical category, depths in feet collected are shown.

For blanks, times of collection on same day are shown (these may repeat as they are associated with each sample collected on that day).

A blank going to the split lab is designated with its lab code (e.g., STL) 
Table L.1. (continued)

\begin{tabular}{|c|c|c|c|c|c|c|c|c|c|c|c|c|c|c|c|c|}
\hline Station & Type & $\begin{array}{l}\text { Date - } \\
\text { time }\end{array}$ & ID range & VOA & $\underline{\text { RADS }}$ & SVOA & PPCB & Metal & Mercury & Other & FR & SPLIT & $\underline{\text { RIN }}$ & $\underline{\mathrm{FB}}$ & $\underline{\mathrm{TB}}$ & $\begin{array}{l}\text { Task } \\
\text { code }\end{array}$ \\
\hline $\begin{array}{l}\text { FB = field blank } \\
\text { FR = field replicate } \\
\text { ID = identification }\end{array}$ & $\begin{array}{l}\text { RIN } \\
\text { SVC } \\
\text { TB } \\
\end{array}$ & $\begin{array}{l}\text { inseate } \\
=\text { semivolat } \\
\text { ip blank }\end{array}$ & c aromatic & & & & & & & & & & & & & \\
\hline
\end{tabular}


Table L-2. Zone 2 laboratory-reported field OC blank detects for area sampling

\begin{tabular}{|c|c|c|c|c|c|c|}
\hline$\frac{\text { Sample }}{\text { type }}$ & $\underline{\text { Blank }}$ & Sample ID & Category & Chemical name & Result, Lab Qual, Val Qual, RC & $\underline{\text { Detect limit }}$ \\
\hline$\underline{\mathrm{RIN}}$ & RIN-PARAGN 11/10/2005 1500 & $\underline{\text { EU410001 }}$ & Mercury & Mercury & 0.0002 B U F01 F06 mg/L & 0.0000036 \\
\hline$\underline{\mathrm{RIN}}$ & $\underline{\text { RIN-PARAGN 11/10/2005 } 1500}$ & $\underline{\text { EU410001 }}$ & $\underline{\text { Metal }}$ & $\underline{\text { Aluminum }}$ & $\underline{0.0041 \mathrm{U} \text { R F10 mg/L }}$ & $\underline{0.0041}$ \\
\hline$\underline{\mathrm{RIN}}$ & RIN-PARAGN 11/10/20051500 & EU410001 & $\underline{\underline{\text { Metal }}}$ & Iron & $\underline{0.1}=\mathrm{mg} / \mathrm{L}$ & $\underline{0.0078}$ \\
\hline$\underline{\mathrm{RIN}}$ & RIN-PARAGN 11/10/20051500 & EU410001 & $\underline{\underline{\text { Metal }}}$ & $\underline{\text { Magnesium }}$ & $1 \mathrm{~B} \mathrm{U} \mathrm{F06} \mathrm{mg/L}$ & $\overline{0.0072}$ \\
\hline$\overline{\mathrm{RIN}}$ & RIN-PARAGN 11/10/2005 1500 & $\overline{\text { EU410001 }}$ & $\overline{\text { Metal }}$ & $\overline{\text { Manganese }}$ & 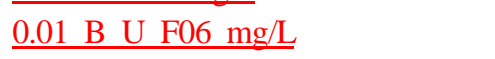 & $\overline{0.000096}$ \\
\hline$\underline{\mathrm{RIN}}$ & RIN-PARAGN 11/10/2005 1500 & EU410001 & Metal & Molybdenum & $0.01 \quad \mathrm{U} \quad \mathrm{F} 07 \mathrm{mg} / \mathrm{L}$ & 0.0012 \\
\hline$\underline{\mathrm{RIN}}$ & RIN-PARAGN 11/10/2005 1500 & $\underline{\text { EU410001 }}$ & $\underline{\text { Metal }}$ & $\underline{\text { Nickel }}$ & $\underline{0.00093 \text { B J } \mathrm{mg} / \mathrm{L}}$ & $\underline{0.0009}$ \\
\hline RIN & RIN-PARAGN 11/10/2005 1500 & $\underline{E U 410001}$ & Metal & $\underline{\text { Potassium }}$ & 1 B U F01 F06 mg/L & $\underline{0.068}$ \\
\hline$\underline{\mathrm{RIN}}$ & RIN-PARAGN 11/10/2005 1500 & EU410001 & Metal & $\underline{\text { Sodium }}$ & $1 \mathrm{~B} \mathrm{U} \mathrm{F01} \mathrm{F06} \mathrm{mg/L}$ & $\underline{0.0058}$ \\
\hline$\underline{\mathrm{RIN}}$ & RIN-PARAGN 11/10/2005 1500 & EU410001 & Metal & Thallium & 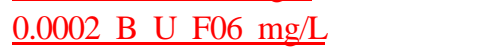 & $\underline{0.000015}$ \\
\hline$\underline{\mathrm{RIN}}$ & RIN-PARAGN 11/10/20051500 & $\overline{\text { EU410001 }}$ & $\underline{\underline{\text { Metal }}}$ & $\underline{\text { Antimony }}$ & 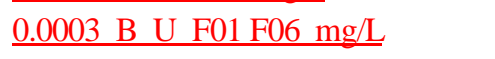 & $\underline{\underline{0.00002}}$ \\
\hline$\underline{\mathrm{RIN}}$ & RIN-PARAGN 11/10/2005 1500 & $\overline{\text { EU410001 }}$ & $\underline{\text { Metal }}$ & Barium & $\underline{0.0014 \text { B J } \mathrm{mg} / \mathrm{L}}$ & $\overline{0.00016}$ \\
\hline$\underline{\mathrm{RIN}}$ & RIN-PARAGN 11/10/2005 1500 & $\underline{\text { EU410001 }}$ & Metal & Beryllium & 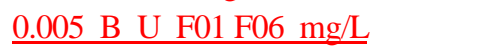 & $\underline{0.000026}$ \\
\hline$\underline{\mathrm{RIN}}$ & RIN-PARAGN 11/10/20051500 & $\underline{\text { EU410001 }}$ & $\underline{\text { Metal }}$ & Boron & 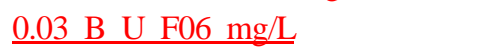 & $\underline{0.00095}$ \\
\hline$\underline{\mathrm{RIN}}$ & RIN-PARAGN 11/10/2005 1500 & EU410001 & $\underline{\underline{\text { Metal }}}$ & Cadmium & 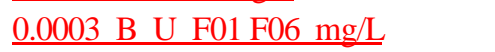 & $\overline{0.000033}$ \\
\hline$\overline{\mathrm{RIN}}$ & RIN-PARAGN 11/10/2005 1500 & $\overline{\text { EU410001 }}$ & Metal & $\overline{\text { Chromium }}$ & $0.001 \mathrm{~B} \mathrm{~J} \mathrm{mg} / \mathrm{L}$ & 0.0006 \\
\hline$\underline{\mathrm{RIN}}$ & $\underline{\text { RIN-PARAGN 11/10/2005 } 1500}$ & $\underline{\text { EU410001 }}$ & $\underline{\text { Metal }}$ & Copper & $\underline{0.00061 \mathrm{U} \mathrm{R} F 10 \mathrm{mg} / \mathrm{L}}$ & $\underline{0.00061}$ \\
\hline$\underline{\mathrm{RIN}}$ & RIN-PARAGN 11/10/20051500 & EU410001 & Metal & $\underline{\text { Uranium }}$ & 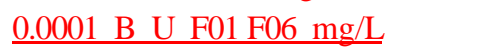 & $\underline{0.0000048}$ \\
\hline$\underline{\mathrm{RIN}}$ & RIN-PARAGN 11/10/2005 1500 & $\underline{\mathrm{EU} 410001}$ & Metal & $\underline{\underline{\text { inc }}}$ & $\underline{0.052=\mathrm{mg} / \mathrm{L}}$ & $\underline{0.00065}$ \\
\hline$\underline{\mathrm{RIN}}$ & RIN-PARAGN 11/10/2005 1500 & $\underline{\text { EU410001 }}$ & $\underline{\text { Metal }}$ & $\underline{\text { Calcium }}$ & 1 B U F06 mg/L & $\underline{0.0035}$ \\
\hline$\underline{\mathrm{RIN}}$ & $\underline{\text { RIN-PARAGN 11/10/2005 } 1500}$ & $\underline{\text { EU410004 }}$ & $\underline{\text { SVOA }}$ & Oxygenated hydrocarbon 1 & $\underline{4.7 \mathrm{BJ} R \quad 003 \mathrm{ug} / \mathrm{L}}$ & - \\
\hline$\underline{\mathrm{RIN}}$ & RIN-PARAGN 11/10/2005 1500 & $\underline{\text { EU410004 }}$ & $\underline{\text { SVOA }}$ & Oxygenated hydrocarbon 2 & $4.7 \mathrm{~J} \mathrm{R} \mathrm{O03} \mathrm{ug} / \mathrm{L}$ & - \\
\hline RIN & RIN-PARAGN 11/10/2005 1500 & $\underline{\text { EU410004 }}$ & $\underline{\text { SVOA }}$ & Oxygenated hydrocarbon 3 & $4.7 \mathrm{~J} \mathrm{R} \mathrm{O03} \mathrm{ug} / \mathrm{L}$ & - \\
\hline$\underline{\mathrm{RIN}}$ & RIN-PARAGN 11/10/2005 1500 & EU410004 & $\underline{\text { SVOA }}$ & $\underline{\text { Vanillin1 }}$ & $7.1 \mathrm{~J} \mathrm{R} \mathrm{O03} \mathrm{ug} / \mathrm{L}$ & - \\
\hline$\underline{\mathrm{RIN}}$ & RIN-PARAGN 11/10/2005 1500 & EU410004 & $\underline{\text { SVOA }}$ & Diethyl phthalate & $1.9 \mathrm{~J} \mathrm{~J} \quad \mathrm{ug} / \mathrm{L}$ & $\underline{0.79}$ \\
\hline$\overline{\mathrm{RIN}}$ & RIN-PARAGN 11/10/2005 1500 & $\overline{\mathrm{EU} 410005}$ & $\overline{\mathrm{VOA}}$ & Acetone & $\begin{array}{lll}4.1 \mathrm{~J} \mathrm{~J} & \mathrm{ug} / \mathrm{L}\end{array}$ & $\overline{1.4}$ \\
\hline$\underline{\mathrm{RIN}}$ & RIN-PARAGN 11/17/2005 1400 & $\underline{\text { EU410006 }}$ & Mercury & Mercury & 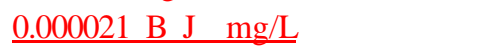 & $\underline{0.0000036}$ \\
\hline$\underline{\mathrm{RIN}}$ & RIN-PARAGN 11/17/2005 1400 & $\underline{\text { EU410006 }}$ & Metal & $\underline{\text { Iron }}$ & $\underline{0.039 \mathrm{~B} \mathrm{~J} \quad \mathrm{mg} / \mathrm{L}}$ & $\underline{0.0078}$ \\
\hline$\underline{\mathrm{RIN}}$ & RIN-PARAGN 11/17/2005 1400 & $\underline{E U 410006}$ & Metal & $\underline{\text { Magnesium }}$ & $0.08 \mathrm{~B} \mathrm{~J} \quad \mathrm{mg} / \mathrm{L}$ & $\underline{0.0072}$ \\
\hline$\underline{\mathrm{RIN}}$ & RIN-PARAGN 11/17/2005 1400 & EU410006 & Metal & $\overline{\text { Manganese }}$ & 0.00073 B J $\quad \mathrm{mg} / \mathrm{L}$ & $\underline{0.000096}$ \\
\hline$\underline{\mathrm{RIN}}$ & RIN-PARAGN 11/17/2005 1400 & EU410006 & $\underline{\text { Metal }}$ & Potassium & $\underline{0.2 \mathrm{~B} \mathrm{~J} \mathrm{mg} / \mathrm{L}}$ & $\underline{0.068}$ \\
\hline$\underline{\mathrm{RIN}}$ & RIN-PARAGN 11/17/2005 1400 & $\overline{\mathrm{EU} 410006}$ & $\underline{\underline{\text { Metal }}}$ & $\overline{\text { Sodium }}$ & $\underline{0.12 \mathrm{~B} \mathrm{~J} \mathrm{mg} / \mathrm{L}}$ & $\overline{0.0058}$ \\
\hline$\underline{\mathrm{RIN}}$ & RIN-PARAGN 11/17/2005 1400 & $\overline{\mathrm{EU} 410006}$ & $\underline{\underline{\text { Metal }}}$ & Antimony & 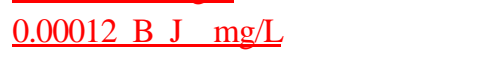 & $\overline{0.00002}$ \\
\hline$\underline{\mathrm{RIN}}$ & RIN-PARAGN 11/17/2005 1400 & $\overline{\mathrm{EU} 410006}$ & $\overline{\text { Metal }}$ & $\overline{\text { Barium }}$ & 0.00066 B J $\mathrm{mg} / \mathrm{L}$ & $\underline{0.00016}$ \\
\hline
\end{tabular}


Table L.2. (continued)

\begin{tabular}{|c|c|c|c|c|c|c|}
\hline$\frac{\text { Sample }}{\text { type }}$ & $\underline{\text { Blank }}$ & Sample ID & Category & Chemical name & Result, Lab Qual, Val Oual, RC & $\underline{\text { Detect limit }}$ \\
\hline$\underline{\mathrm{RIN}}$ & $\underline{\text { RIN-PARAGN 11/17/2005 } 1400}$ & $\underline{\text { EU410006 }}$ & $\underline{\text { Metal }}$ & Beryllium & 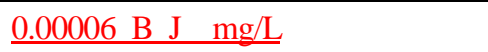 & $\underline{0.000026}$ \\
\hline$\underline{\mathrm{RIN}}$ & RIN-PARAGN 11/17/2005 1400 & $\underline{\text { EU410006 }}$ & Metal & Boron & 0.0048 B J $\mathrm{mg} / \mathrm{L}$ & $\underline{0.00095}$ \\
\hline$\underline{\mathrm{RIN}}$ & RIN-PARAGN 11/17/2005 1400 & EU410006 & Metal & Cadmium & $0.0001 \mathrm{~B} \quad \mathrm{~J} \quad \mathrm{mg} / \mathrm{L}$ & $\underline{0.000033}$ \\
\hline$\overline{\mathrm{RIN}}$ & RIN-PARAGN 11/17/2005 1400 & $\overline{\text { EU410006 }}$ & Metal & $\underline{\text { Uranium }}$ & 0.000012 B J $\quad \mathrm{mg} / \mathrm{L}$ & $\underline{0.0000048}$ \\
\hline$\overline{\mathrm{RIN}}$ & RIN-PARAGN 11/17/2005 1400 & $\overline{\text { EU410006 }}$ & $\overline{\text { Metal }}$ & $\overline{\text { Zinc }}$ & $0.032=\mathrm{mg} / \mathrm{L}$ & $\overline{0.00065}$ \\
\hline$\underline{\mathrm{RIN}}$ & RIN-PARAGN 11/17/2005 1400 & $\underline{\mathrm{EU} 410006}$ & Metal & Calcium & $0.15 \mathrm{~B} \quad \mathrm{~J} \quad \mathrm{mg} / \mathrm{L}$ & $\underline{0.0035}$ \\
\hline$\underline{\mathrm{RIN}}$ & RIN-PARAGN 11/17/2005 1400 & EU410009 & $\underline{\text { SVOA }}$ & Chlorinated hydrocarbon1 & $10 \mathrm{BJ} \quad \mathrm{R} \quad \mathrm{ug} / \mathrm{L}$ & - \\
\hline$\underline{\mathrm{RIN}}$ & RIN-PARAGN 11/17/2005 1400 & EU410009 & $\underline{\text { SVOA }}$ & Oxygenated hydrocarbon1 & $6.4 \mathrm{BJ} R \quad \mathrm{ug} / \mathrm{L}$ & - \\
\hline$\overline{\mathrm{RIN}}$ & RIN-PARAGN 11/17/2005 1400 & $\overline{\text { EU410009 }}$ & $\overline{\text { SVOA }}$ & Unknown1 & $4.7 \mathrm{BJ} R \quad \mathrm{Rg} / \mathrm{L}$ & - \\
\hline$\overline{\mathrm{RIN}}$ & RIN-PARAGN 11/17/2005 1400 & $\overline{\text { EU410009 }}$ & $\overline{\text { SVOA }}$ & Di-n-butyl phthalate & $0.93 \mathrm{~J} \mathrm{~J} \quad u g / L$ & $\underline{0.69}$ \\
\hline$\overline{\mathrm{RIN}}$ & RIN-PARAGN 11/17/2005 1400 & $\overline{\text { EU410010 }}$ & $\overline{\mathrm{VOA}}$ & Acetone & $\overline{8.7 \mathrm{~J} \mathrm{~J}} \quad \mathrm{ug} / \mathrm{L}$ & $\overline{1.4}$ \\
\hline$\overline{\mathrm{RIN}}$ & RIN-PARAGN 11/28/2005900 & $\overline{\text { EU410011 }}$ & $\overline{\text { Mercury }}$ & $\overline{\text { Mercury }}$ & $0.0000036 \mathrm{U}$ R F10 mg/L & $\overline{0.0000036}$ \\
\hline$\overline{\mathrm{RIN}}$ & RIN-PARAGN 11/28/2005900 & $\overline{\text { EU410011 }}$ & $\underline{\text { Metal }}$ & $\overline{\text { Aluminum }}$ & $\underline{0.0041 \mathrm{U} \mathrm{R} \text { F10 mg/L }}$ & 0.0041 \\
\hline$\overline{\mathrm{RIN}}$ & RIN-PARAGN 11/28/2005900 & $\overline{\text { EU410011 }}$ & $\overline{\text { Metal }}$ & Iron & $0.1 \mathrm{~B} \quad \mathrm{U} \quad \mathrm{F} 06 \mathrm{mg} / \mathrm{L}$ & $\overline{0.0078}$ \\
\hline$\overline{\mathrm{RIN}}$ & RIN-PARAGN 11/28/2005900 & $\overline{\text { EU410011 }}$ & $\overline{\text { Metal }}$ & Magnesium & $1 \mathrm{~B} \mathrm{U} \mathrm{F06} \mathrm{mg/L}$ & $\overline{0.0072}$ \\
\hline$\overline{\mathrm{RIN}}$ & RIN-PARAGN 11/28/2005900 & $\overline{\text { EU410011 }}$ & Metal & Manganese & 0.01 B U F06 mg/L & $\underline{0.000096}$ \\
\hline$\overline{\mathrm{RIN}}$ & $\overline{\text { RIN-PARAGN 11/28/2005900 }}$ & $\overline{\text { EU410011 }}$ & $\overline{\text { Metal }}$ & Potassium & $1 \mathrm{~B} \mathrm{U} \mathrm{F01} \mathrm{F06} \mathrm{mg/L}$ & $\underline{0.068}$ \\
\hline$\underline{\mathrm{RIN}}$ & RIN-PARAGN 11/28/2005900 & EU410011 & Metal & Sodium & $1 \mathrm{~B} \mathrm{U} \mathrm{F01} \mathrm{F06} \mathrm{mg/L}$ & $\underline{0.0058}$ \\
\hline$\overline{\mathrm{RIN}}$ & RIN-PARAGN 11/28/2005900 & $\overline{E U 410011}$ & Metal & Antimony & 0.0003 B U F01 F06 mg/L & $\overline{0.00002}$ \\
\hline$\overline{\mathrm{RIN}}$ & RIN-PARAGN 11/28/2005900 & $\overline{\text { EU410011 }}$ & Metal & Barium & $0.1 \mathrm{~B}$ U F01 F06 mg/L & $\underline{0.00016}$ \\
\hline$\overline{\mathrm{RIN}}$ & $\overline{\text { RIN-PARAGN 11/28/2005900 }}$ & $\overline{\mathrm{EU} 410011}$ & $\overline{\text { Metal }}$ & Beryllium & 0.005 B U F01 F06 mg/L & $\underline{0.000026}$ \\
\hline$\underline{\text { RIN }}$ & RIN-PARAGN 11/28/2005900 & EU410011 & Metal & Boron & 0.03 B U F06 mg/L & $\overline{0.00095}$ \\
\hline$\underline{\mathrm{RIN}}$ & RIN-PARAGN 11/28/2005900 & EU410011 & Metal & Cadmium & 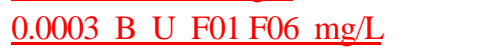 & $\underline{0.000033}$ \\
\hline$\overline{\mathrm{RIN}}$ & RIN-PARAGN 11/28/2005900 & $\overline{\text { EU410011 }}$ & Metal & $\overline{\text { Copper }}$ & $\underline{0.00061 \mathrm{U} \mathrm{R} F 10 \mathrm{mg} / \mathrm{L}}$ & $\overline{0.00061}$ \\
\hline$\overline{\mathrm{RIN}}$ & RIN-PARAGN 11/28/2005900 & $\overline{\text { EU410011 }}$ & $\overline{\text { Metal }}$ & Uranium & 0.0001 B U F01 F06 mg/L & $\overline{0.0000048}$ \\
\hline$\overline{\mathrm{RIN}}$ & RIN-PARAGN 11/28/2005900 & $\overline{\text { EU410011 }}$ & $\overline{\text { Metal }}$ & $\overline{\text { Zinc }}$ & $0.036=\mathrm{mg} / \mathrm{L}$ & $\overline{0.00065}$ \\
\hline$\overline{\mathrm{RIN}}$ & $\overline{\text { RIN-PARAGN 11/28/2005900 }}$ & $\overline{\text { EU410011 }}$ & $\overline{\text { Metal }}$ & $\overline{\text { Calcium }}$ & $1 \mathrm{~B} \mathrm{U} \mathrm{F06} \mathrm{mg/L}$ & $\overline{0.0035}$ \\
\hline$\overline{\mathrm{RIN}}$ & RIN-PARAGN 11/28/2005900 & $\overline{\text { EU410013 }}$ & $\overline{\mathrm{RADS}}$ & Uranium-234 & $0.454=\mathrm{pCi} / \mathrm{L}$ & 0.376 \\
\hline$\underline{\mathrm{RIN}}$ & RIN-PARAGN 11/28/2005900 & EU410013 & $\underline{\text { RADS }}$ & Technetium-99 & $7.16=\mathrm{pCi} / \mathrm{L}$ & 6.48 \\
\hline$\overline{\mathrm{RIN}}$ & RIN-PARAGN 11/28/2005900 & $\overline{\text { EU410013 }}$ & $\overline{\mathrm{RADS}}$ & $\overline{\text { Uranium-238 }}$ & $0.274=\mathrm{pCi} / \mathrm{L}$ & $\overline{0.185}$ \\
\hline$\overline{\mathrm{RIN}}$ & RIN-PARAGN 11/28/2005900 & $\overline{\text { EU410013 }}$ & $\overline{\mathrm{RADS}}$ & Plutonium-239/240 & $0.556=\mathrm{pCi} / \mathrm{L}$ & $\overline{0.4}$ \\
\hline$\overline{\mathrm{RIN}}$ & $\overline{\text { RIN-PARAGN 11/28/2005900 }}$ & $\overline{\text { EU410014 }}$ & $\overline{\text { SVOA }}$ & $\overline{\text { Unsaturated hydrocarbon1 }}$ & $\overline{4 \text { BJ R O03 ug/L }}$ & - \\
\hline$\overline{\mathrm{RIN}}$ & RIN-PARAGN 11/28/2005900 & $\overline{\text { EU410014 }}$ & $\overline{\text { SVOA }}$ & 2-chloro-2-methylbutane & $6.4 \mathrm{BJ} \mathrm{R} \mathrm{O03} \mathrm{ug/L}$ & - \\
\hline$\underline{\mathrm{RIN}}$ & RIN-PARAGN 11/28/2005900 & $\overline{\text { EU410015 }}$ & $\underline{\mathrm{VOA}}$ & Acetone & $10 \mathrm{~J} \mathrm{U} \mathrm{F04} \mathrm{F06} \mathrm{ug/L}$ & 1.4 \\
\hline RIN & RIN-PARAGN 11/28/2005900 & $\underline{\mathrm{EU} 410015}$ & $\mathrm{VOA}$ & Methylene chloride & $1 \mathrm{~J} \mathrm{U} \mathrm{F04} \mathrm{F06} \mathrm{ug/L}$ & $\underline{0.57}$ \\
\hline
\end{tabular}


Table L.2. (continued)

\begin{tabular}{|c|c|c|c|c|c|c|}
\hline$\frac{\text { Sample }}{\text { type }}$ & $\underline{\text { Blank }}$ & Sample ID & Category & Chemical name & Result, Lab Oual, Val Oual, RC & $\underline{\text { Detect limit }}$ \\
\hline$\underline{\mathrm{RIN}}$ & RIN-PARAGN 12/6/20051400 & $\underline{\text { EU410016 }}$ & $\underline{\text { Mercury }}$ & $\underline{\text { Mercury }}$ & 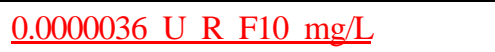 & $\underline{0.0000036}$ \\
\hline$\underline{\mathrm{RIN}}$ & RIN-PARAGN 12/6/20051400 & $\underline{\text { EU410016 }}$ & Metal & $\underline{\text { Aluminum }}$ & 0.2 B U F01 F06 mg/L & $\underline{0.0041}$ \\
\hline$\underline{\mathrm{RIN}}$ & RIN-PARAGN 12/6/2005 1400 & EU410016 & Metal & Iron & 0.1 B U F01 F06 mg/L & $\underline{0.0078}$ \\
\hline$\overline{\mathrm{RIN}}$ & RIN-PARAGN 12/6/2005 1400 & $\overline{\text { EU410016 }}$ & Metal & Magnesium & 1 B U F01 F06 mg/L & $\overline{0.0072}$ \\
\hline$\overline{\mathrm{RIN}}$ & RIN-PARAGN 12/6/2005 1400 & $\overline{\text { EU410016 }}$ & $\overline{\text { Metal }}$ & $\overline{\text { Manganese }}$ & $0.01 \mathrm{~B}$ U F01 F06 mg/L & $\overline{0.000096}$ \\
\hline$\overline{\mathrm{RIN}}$ & $\overline{\text { RIN-PARAGN 12/6/2005 1400 }}$ & $\overline{\text { EU410016 }}$ & $\overline{\text { Metal }}$ & $\overline{\text { Molybdenum }}$ & $0.01 \mathrm{~B} \mathrm{U} \mathrm{F06} \mathrm{mg/L}$ & $\overline{0.0012}$ \\
\hline$\underline{\mathrm{RIN}}$ & RIN-PARAGN 12/6/2005 1400 & EU410016 & Metal & Nickel & 0.02 B U F01 F06 mg/L & $\underline{0.0009}$ \\
\hline$\underline{\mathrm{RIN}}$ & RIN-PARAGN 12/6/2005 1400 & EU410016 & Metal & Sodium & $1 \mathrm{~B} \mathrm{U}$ F01 F06 mg/L & $\overline{0.0058}$ \\
\hline$\overline{\mathrm{RIN}}$ & RIN-PARAGN 12/6/2005 1400 & $\overline{\text { EU410016 }}$ & Metal & Thallium & $\overline{0.000045 \text { B J } \quad \mathrm{mg} / \mathrm{L}}$ & $\overline{0.000015}$ \\
\hline$\overline{\mathrm{RIN}}$ & RIN-PARAGN 12/6/2005 1400 & $\overline{\text { EU410016 }}$ & Metal & Antimony & 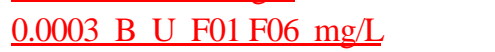 & 0.00002 \\
\hline$\overline{\mathrm{RIN}}$ & RIN-PARAGN 12/6/20051400 & $\overline{\mathrm{EU} 410016}$ & Metal & $\overline{\text { Barium }}$ & $0.1 \mathrm{~B}$ U F01 F06 mg/L & $\overline{0.00016}$ \\
\hline$\overline{\mathrm{RIN}}$ & RIN-PARAGN 12/6/2005 1400 & $\overline{\text { EU410016 }}$ & $\underline{\text { Metal }}$ & Beryllium & 0.005 B U F01 F06 mg/L & $\overline{0.000026}$ \\
\hline$\overline{\mathrm{RIN}}$ & RIN-PARAGN 12/6/2005 1400 & $\overline{\text { EU410016 }}$ & $\overline{\text { Metal }}$ & Boron & 0.03 B U F01 F06 mg/L & $\underline{0.00095}$ \\
\hline$\overline{\mathrm{RIN}}$ & RIN-PARAGN 12/6/20051400 & $\overline{\text { EU410016 }}$ & $\overline{\text { Metal }}$ & $\overline{\text { Cadmium }}$ & 0.0003 B U F06 mg/L & $\overline{0.000033}$ \\
\hline$\overline{\mathrm{RIN}}$ & RIN-PARAGN 12/6/20051400 & $\overline{\text { EU410016 }}$ & $\overline{\text { Metal }}$ & $\overline{\text { Cobalt }}$ & $0.01 \mathrm{~B} \mathrm{U}$ F01 F06 mg/L & $\overline{0.00053}$ \\
\hline$\overline{\mathrm{RIN}}$ & RIN-PARAGN 12/6/2005 1400 & $\overline{\text { EU410016 }}$ & Metal & Uranium & 0.0001 B U F01 F06 mg/L & $\underline{0.0000048}$ \\
\hline$\overline{\mathrm{RIN}}$ & $\overline{\text { RIN-PARAGN 12/6/2005 1400 }}$ & $\overline{\text { EU410016 }}$ & $\overline{\text { Metal }}$ & $\underline{\text { Zinc }}$ & 0.02 B R F01 F06 F10 mg/L & $\underline{0.00065}$ \\
\hline$\underline{\mathrm{RIN}}$ & RIN-PARAGN 12/6/2005 1400 & EU410016 & Metal & $\overline{\text { Calcium }}$ & 1 B U F01 F06 mg/L & $\underline{\underline{0.0035}}$ \\
\hline$\overline{\mathrm{RIN}}$ & RIN-PARAGN 12/6/2005 1400 & $\overline{\text { EU410018 }}$ & $\underline{\overline{\mathrm{RADS}}}$ & Uranium-234 & $0.266 \quad \mathrm{~J}$ T04 $\mathrm{pCi} / \mathrm{L}$ & $\underline{0.144}$ \\
\hline$\overline{\mathrm{RIN}}$ & RIN-PARAGN 12/6/2005 1400 & $\overline{\text { EU410018 }}$ & $\overline{\underline{\mathrm{RADS}}}$ & $\underline{\text { Uranium-238 }}$ & $0.16 \quad \mathrm{~J} \mathrm{~T} 04 \mathrm{pCi} / \mathrm{L}$ & $\underline{0.144}$ \\
\hline$\overline{\mathrm{RIN}}$ & RIN-PARAGN 12/6/2005 1400 & $\overline{\mathrm{EU} 410018}$ & $\overline{\text { RADS-gamma }}$ & Lead-214 & $11.2 \mathrm{~J} \mathrm{~J} \mathrm{pCi} / \mathrm{L}$ & 10.7 \\
\hline$\underline{\text { RIN }}$ & RIN-PARAGN 12/6/20051400 & EU410019 & $\underline{\text { SVOA }}$ & Oxygenated hydrocarbon & $4.8 \mathrm{~J} \mathrm{R} \mathrm{O03} \mathrm{ug} / \mathrm{L}$ & $\overline{-}$ \\
\hline$\underline{\text { RIN }}$ & RIN-PARAGN 12/6/20051400 & EU410019 & $\underline{\text { SVOA }}$ & Unsaturated hydrocarbon 1 & $5.5 \mathrm{BJ}$ R $\mathrm{O} 03 \mathrm{ug} / \mathrm{L}$ & - \\
\hline$\overline{\mathrm{RIN}}$ & RIN-PARAGN 12/6/2005 1400 & $\overline{\text { EU410019 }}$ & $\underline{\underline{\text { SVOA }}}$ & $\overline{\text { Unsaturated hydrocarbon2 }}$ & $7.1 \mathrm{BJ}$ R $003 \mathrm{ug} / \mathrm{L}$ & - \\
\hline$\overline{\mathrm{RIN}}$ & RIN-PARAGN 12/6/2005 1400 & $\overline{\text { EU410019 }}$ & $\overline{\text { SVOA }}$ & Decamethylcyclopentasiloxane & $3.9 \mathrm{~J} \mathrm{R} \mathrm{O03} \mathrm{ug/L}$ & - \\
\hline$\overline{\mathrm{RIN}}$ & $\overline{\text { RIN-PARAGN 12/6/2005 1400 }}$ & $\overline{\mathrm{EU} 410020}$ & $\overline{\mathrm{VOA}}$ & Acetone & $10 \mathrm{~J} \mathrm{U} \mathrm{F04} \mathrm{F06} \mathrm{ug/L}$ & 1.4 \\
\hline$\overline{\mathrm{RIN}}$ & $\overline{\text { RIN-PARAGN 12/15/2005 1500 }}$ & $\overline{\text { EU410021 }}$ & $\overline{\text { Mercury }}$ & $\overline{\text { Mercury }}$ & 0.0002 B U F01 F06 mg/L & $\overline{0.0000036}$ \\
\hline$\underline{\mathrm{RIN}}$ & RIN-PARAGN 12/15/2005 1500 & EU410021 & METAL & Aluminum & 0.2 B U F01 F06 mg/L & 0.0041 \\
\hline$\underline{\mathrm{RIN}}$ & RIN-PARAGN 12/15/2005 1500 & EU410021 & Metal & Iron & $0.1 \mathrm{~B} \quad \mathrm{U}$ F01 F06 mg/L & 0.0078 \\
\hline$\overline{\mathrm{RIN}}$ & RIN-PARAGN 12/15/20051500 & $\overline{\text { EU410021 }}$ & $\overline{\text { Metal }}$ & Magnesium & $1 \mathrm{~B} \mathrm{U} \mathrm{F01} \mathrm{F06} \mathrm{mg/L}$ & $\overline{0.0072}$ \\
\hline$\overline{\mathrm{RIN}}$ & RIN-PARAGN 12/15/20051500 & $\overline{\text { EU410021 }}$ & $\overline{\text { Metal }}$ & $\overline{\text { Manganese }}$ & $0.01 \mathrm{~B} \quad \mathrm{U}$ F01 F06 mg/L & $\overline{0.000096}$ \\
\hline$\overline{\mathrm{RIN}}$ & $\overline{\text { RIN-PARAGN 12/15/2005 1500 }}$ & $\overline{\text { EU410021 }}$ & $\overline{\text { Metal }}$ & $\overline{\text { Molybdenum }}$ & $0.01 \mathrm{~B} \mathrm{U} \mathrm{F06} \mathrm{mg/L}$ & $\overline{0.0012}$ \\
\hline$\overline{\mathrm{RIN}}$ & $\overline{\text { RIN-PARAGN 12/15/2005 1500 }}$ & $\overline{\text { EU410021 }}$ & Metal & Nickel & 0.02 B U F01 F06 mg/L & $\overline{0.0009}$ \\
\hline$\underline{\mathrm{RIN}}$ & RIN-PARAGN 12/15/2005 1500 & EU410021 & Metal & $\underline{\text { Potassium }}$ & $0.074 \mathrm{~B} \mathrm{~J} \quad \mathrm{mg} / \mathrm{L}$ & $\underline{0.068}$ \\
\hline$\underline{\mathrm{RIN}}$ & RIN-PARAGN 12/15/20051500 & $\underline{\text { EU410021 }}$ & Metal & Sodium & $1 \mathrm{~B} \mathrm{U} \mathrm{F01} \mathrm{F06} \mathrm{mg/L}$ & $\underline{\underline{0.0058}}$ \\
\hline
\end{tabular}


Table L.2. (continued)

\begin{tabular}{|c|c|c|c|c|c|c|}
\hline$\frac{\text { Sample }}{\text { type }}$ & $\underline{\text { Blank }}$ & Sample ID & Category & Chemical name & Result, Lab Oual, Val Oual, RC & $\underline{\text { Detect limit }}$ \\
\hline$\underline{\mathrm{RIN}}$ & RIN-PARAGN 12/15/2005 1500 & EU410021 & Metal & Thallium & 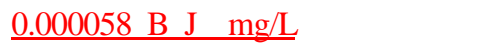 & $\underline{0.000015}$ \\
\hline$\underline{\mathrm{RIN}}$ & RIN-PARAGN 12/15/2005 1500 & EU410021 & Metal & Antimony & 0.0003 B U F01 F06 mg/L & $\underline{0.00002}$ \\
\hline$\underline{\mathrm{RIN}}$ & RIN-PARAGN 12/15/2005 1500 & EU410021 & Metal & Barium & 0.1 B U F01 F06 mg/L & $\overline{0.00016}$ \\
\hline$\overline{\mathrm{RIN}}$ & RIN-PARAGN 12/15/2005 1500 & $\overline{\text { EU410021 }}$ & Metal & Beryllium & 0.005 B U F01 F06 mg/L & $\overline{0.000026}$ \\
\hline$\overline{\mathrm{RIN}}$ & RIN-PARAGN 12/15/20051500 & $\overline{\text { EU410021 }}$ & $\overline{\text { Metal }}$ & Boron & 0.03 B U F01 F06 mg/L & $\overline{0.00095}$ \\
\hline$\overline{\mathrm{RIN}}$ & RIN-PARAGN 12/15/20051500 & $\overline{\text { EU410021 }}$ & $\overline{\text { Metal }}$ & $\overline{\text { Cadmium }}$ & $0.000064 \mathrm{~B} \mathrm{~J} \quad \mathrm{mg} / \mathrm{L}$ & $\overline{0.000033}$ \\
\hline$\underline{\mathrm{RIN}}$ & RIN-PARAGN 12/15/2005 1500 & EU410021 & Metal & Cobalt & 0.01 B U F01 F06 mg/L & $\underline{0.00053}$ \\
\hline$\underline{\mathrm{RIN}}$ & RIN-PARAGN 12/15/2005 1500 & EU410021 & Metal & Uranium & 0.0001 B U F01 F06 mg/L & $\underline{0.0000048}$ \\
\hline$\overline{\mathrm{RIN}}$ & RIN-PARAGN 12/15/2005 1500 & $\overline{\text { EU410021 }}$ & Metal & $\overline{\text { Zinc }}$ & 0.00065 U R F10 mg/L & $\underline{\underline{0.00065}}$ \\
\hline$\overline{\mathrm{RIN}}$ & RIN-PARAGN 12/15/2005 1500 & $\overline{\text { EU410021 }}$ & Metal & $\overline{\text { Calcium }}$ & 1 B U F01 F06 mg/L & $\underline{\underline{0.0035}}$ \\
\hline$\overline{\mathrm{RIN}}$ & RIN-PARAGN 12/15/2005 1500 & $\overline{\text { EU410021 }}$ & $\underline{\text { Metal }}$ & $\overline{\text { Selenium }}$ & $0.0062=\mathrm{mg} / \mathrm{L}$ & $\overline{0.0032}$ \\
\hline$\overline{\mathrm{RIN}}$ & RIN-PARAGN 12/15/20051500 & $\overline{\text { EU410024 }}$ & $\overline{\text { SVOA }}$ & $\overline{\text { Oxygenated hydrocarbon }}$ & 5 BJ R O03 ug/L & $\overline{-}$ \\
\hline$\overline{\mathrm{RIN}}$ & RIN-PARAGN 12/15/20051500 & $\overline{\text { EU410024 }}$ & $\overline{\text { SVOA }}$ & Unknown1 & $\overline{5.1 \mathrm{~J} \mathrm{R} \mathrm{O03} \mathrm{ug/L}}$ & - \\
\hline$\overline{\mathrm{RIN}}$ & RIN-PARAGN 12/15/20051500 & $\overline{\text { EU410024 }}$ & $\overline{\text { SVOA }}$ & 3-penten-2-ol & $7.4 \mathrm{BJ} R \mathrm{O} 03 \mathrm{ug} / \mathrm{L}$ & - \\
\hline$\overline{\mathrm{RIN}}$ & RIN-PARAGN 12/15/20051500 & $\overline{\text { EU410024 }}$ & $\overline{\text { SVOA }}$ & Benzoic acid & $20 \mathrm{~J} \mathrm{~J} \quad \mathrm{ug} / \mathrm{L}$ & $\underline{14}$ \\
\hline$\overline{\mathrm{RIN}}$ & RIN-PARAGN 12/15/20051500 & $\overline{\mathrm{EU} 410025}$ & $\overline{\mathrm{VOA}}$ & Acetone & $10 \mathrm{~J} \mathrm{U}$ F01 F06 ug/L & 1.4 \\
\hline$\overline{\mathrm{RIN}}$ & $\overline{\text { RIN-PARAGN 12/21/2005 1030 }}$ & $\overline{\text { EU410026 }}$ & Metal & $\underline{\text { Aluminum }}$ & 0.0041 U R F10 mg/L & $\underline{0.0041}$ \\
\hline$\underline{\mathrm{RIN}}$ & RIN-PARAGN 12/21/2005 1030 & EU410026 & Metal & Iron & $0.1 \mathrm{~B} \mathrm{U}$ F06 mg/L & 0.0078 \\
\hline$\overline{\mathrm{RIN}}$ & RIN-PARAGN 12/21/20051030 & $\overline{\text { EU410026 }}$ & Metal & Magnesium & $1 \mathrm{~B} \mathrm{U} \mathrm{F01} \mathrm{F06} \mathrm{mg/L}$ & $\overline{0.0072}$ \\
\hline$\overline{\mathrm{RIN}}$ & RIN-PARAGN 12/21/20051030 & $\overline{\text { EU410026 }}$ & Metal & Manganese & $0.00055 \mathrm{~B} \mathrm{~J} \quad \mathrm{mg} / \mathrm{L}$ & 0.000096 \\
\hline$\overline{\mathrm{RIN}}$ & RIN-PARAGN 12/21/20051030 & $\overline{\text { EU410026 }}$ & $\overline{\text { Metal }}$ & Molybdenum & 0.002 B J $\quad \mathrm{mg} / \mathrm{L}$ & 0.0012 \\
\hline$\underline{\text { RIN }}$ & RIN-PARAGN 12/21/2005 1030 & $\underline{\text { EU410026 }}$ & Metal & Potassium & $1 \mathrm{~B} \mathrm{U} \mathrm{F01} \mathrm{F06} \mathrm{mg/L}$ & $\overline{0.068}$ \\
\hline$\underline{\text { RIN }}$ & RIN-PARAGN 12/21/20051030 & EU410026 & Metal & $\underline{\text { Sodium }}$ & $1 \mathrm{~B} \mathrm{U}$ F01 F06 mg/L & $\overline{0.0058}$ \\
\hline$\overline{\mathrm{RIN}}$ & RIN-PARAGN 12/21/20051030 & $\overline{\text { EU410026 }}$ & Metal & Thallium & 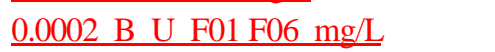 & $\overline{0.000015}$ \\
\hline$\overline{\mathrm{RIN}}$ & RIN-PARAGN 12/21/20051030 & $\overline{\text { EU410026 }}$ & $\overline{\text { Metal }}$ & Antimony & 0.0003 B U F01 F06 mg/L & $\overline{0.00002}$ \\
\hline$\overline{\mathrm{RIN}}$ & RIN-PARAGN 12/21/20051030 & $\overline{\text { EU410026 }}$ & $\overline{\text { Metal }}$ & Barium & 0.00035 B J $\quad \mathrm{mg} / \mathrm{L}$ & $\overline{0.00016}$ \\
\hline$\overline{\mathrm{RIN}}$ & RIN-PARAGN 12/21/20051030 & $\overline{\text { EU410026 }}$ & $\overline{\text { Metal }}$ & $\overline{\text { Beryllium }}$ & 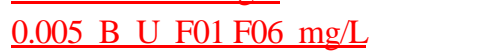 & $\overline{0.000026}$ \\
\hline$\overline{\mathrm{RIN}}$ & RIN-PARAGN 12/21/20051030 & $\overline{\text { EU410026 }}$ & $\overline{\text { Metal }}$ & Boron & 0.03 B U F06 mg/L & $\overline{0.00095}$ \\
\hline$\underline{\mathrm{RIN}}$ & RIN-PARAGN 12/21/20051030 & EU410026 & Metal & Cadmium & 0.0003 B U F01 F06 mg/L & $\underline{0.000033}$ \\
\hline$\overline{\mathrm{RIN}}$ & RIN-PARAGN 12/21/20051030 & $\overline{\text { EU410026 }}$ & $\overline{\text { Metal }}$ & $\overline{\text { Cobalt }}$ & 0.01 B U F01 F06 mg/L & $\overline{0.00053}$ \\
\hline$\overline{\mathrm{RIN}}$ & RIN-PARAGN 12/21/20051030 & $\overline{\text { EU410026 }}$ & $\overline{\text { Metal }}$ & $\overline{\text { Uranium }}$ & 0.0001 B U F01 F06 mg/L & $\overline{0.0000048}$ \\
\hline$\overline{\mathrm{RIN}}$ & $\overline{\text { RIN-PARAGN 12/21/2005 1030 }}$ & $\overline{\text { EU410026 }}$ & $\overline{\text { Metal }}$ & $\overline{\text { Zinc }}$ & 0.0043 B J $\quad \mathrm{mg} / \mathrm{L}$ & $\overline{0.00065}$ \\
\hline$\overline{\mathrm{RIN}}$ & RIN-PARAGN 12/21/20051030 & $\overline{\text { EU410026 }}$ & Metal & $\overline{\text { Calcium }}$ & 1 B U F01 F06 mg/L & $\overline{0.0035}$ \\
\hline$\underline{\mathrm{RIN}}$ & RIN-PARAGN 12/21/20051030 & $\overline{\mathrm{EU} 410028}$ & $\underline{\underline{R A D S}}$ & Thorium-230 & $1.43=\mathrm{pCi} / \mathrm{L}$ & $\underline{0.907}$ \\
\hline$\underline{\mathrm{RIN}}$ & RIN-PARAGN 12/21/20051030 & $\overline{\text { EU410028 }}$ & $\underline{\mathrm{RADS}}$ & Uranium-238 & $0.149 \quad \mathrm{~J} \quad \mathrm{~T} 04 \mathrm{pCi} / \mathrm{L}$ & $\underline{0.135}$ \\
\hline
\end{tabular}


Table L.2. (continued)

\begin{tabular}{|c|c|c|c|c|c|c|}
\hline$\frac{\text { Sample }}{\text { type }}$ & $\underline{\text { Blank }}$ & Sample ID & Category & Chemical name & Result, Lab Oual, Val Oual, RC & $\underline{\text { Detect limit }}$ \\
\hline$\underline{\mathrm{RIN}}$ & RIN-PARAGN 12/21/20051030 & $\underline{\text { EU410029 }}$ & $\underline{\text { SVOA }}$ & Oxygenated hydrocarbon1 & $12 \mathrm{~J} \mathrm{R}$ O01 ug/L & - \\
\hline$\underline{\mathrm{RIN}}$ & RIN-PARAGN 12/21/20051030 & $\underline{\text { EU410029 }}$ & $\underline{\text { SVOA }}$ & Oxygenated hydrocarbon2 & 8.4 BJ R O02 ug/L & - \\
\hline$\overline{\mathrm{RIN}}$ & $\overline{\text { RIN-PARAGN 12/21/2005 1030 }}$ & $\overline{\mathrm{EU} 410029}$ & $\overline{\text { SVOA }}$ & Siloxane & $\overline{5.1 \mathrm{~J} \mathrm{R}}$ O01 ug/L & - \\
\hline$\underline{\mathrm{RIN}}$ & RIN-PARAGN 12/21/2005 1030 & $\underline{\mathrm{EU} 410029}$ & $\underline{\text { SVOA }}$ & Unknown1 & $6.4 \mathrm{~J} R \quad \mathrm{R} \quad 01 \mathrm{ug} / \mathrm{L}$ & - \\
\hline$\underline{\mathrm{RIN}}$ & RIN-PARAGN 12/21/20051030 & $\underline{\text { EU410029 }}$ & $\underline{\text { SVOA }}$ & Unsaturated hydrocarbon & $5.5 \mathrm{~J} \mathrm{R} \quad 001 \mathrm{ug} / \mathrm{L}$ & - \\
\hline$\underline{\mathrm{RIN}}$ & RIN-PARAGN 12/21/20051030 & EU410029 & $\underline{\text { SVOA }}$ & Di-n-butyl phthalate & $\underline{0.86 \mathrm{~J} \mathrm{~J}} \quad u g / \mathrm{L}$ & $\underline{0.71}$ \\
\hline$\underline{\mathrm{RIN}}$ & RIN-PARAGN 12/21/20051030 & EU410030 & $\underline{\mathrm{VOA}}$ & Isopropyl alcohol & $19 \mathrm{~J} \mathrm{R} \mathrm{O01} \mathrm{ug/L}$ & - \\
\hline$\underline{\mathrm{RIN}}$ & RIN-PARAGN 12/21/20051030 & EU410030 & $\underline{\mathrm{VOA}}$ & Acetone & $21=u g / L$ & $\underline{1.4}$ \\
\hline$\overline{\mathrm{RIN}}$ & RIN-PARAGN 1/10/2006 1300 & $\overline{\text { EU410031 }}$ & Metal & Aluminum & $\overline{0.2}$ B U F01 F06 mg/L & $\overline{0.0048}$ \\
\hline$\overline{\mathrm{RIN}}$ & RIN-PARAGN 1/10/2006 1300 & EU410031 & Metal & Iron & $\overline{0.1}$ B U F01 F06 mg/L & $\overline{0.008}$ \\
\hline$\overline{\mathrm{RIN}}$ & RIN-PARAGN 1/10/2006 1300 & $\overline{\mathrm{EU} 410031}$ & Metal & $\underline{\text { Magnesium }}$ & $\overline{0.0038 \text { U R F10 mg/L }}$ & $\overline{0.0038}$ \\
\hline$\overline{\mathrm{RIN}}$ & RIN-PARAGN 1/10/2006 1300 & $\overline{\mathrm{EU} 410031}$ & $\underline{\text { Metal }}$ & Manganese & 0.01 B U F01 F06 mg/L & $\overline{0.000054}$ \\
\hline$\overline{\mathrm{RIN}}$ & RIN-PARAGN 1/10/2006 1300 & $\overline{\text { EU410031 }}$ & $\overline{\text { Metal }}$ & Molybdenum & $0.01 \mathrm{~B} \quad \mathrm{U}$ F06 mg/L & $\overline{0.00085}$ \\
\hline$\overline{\mathrm{RIN}}$ & RIN-PARAGN 1/10/2006 1300 & $\overline{\text { EU410031 }}$ & $\overline{\text { Metal }}$ & Potassium & $1 \mathrm{~B} \mathrm{U} \mathrm{F01} \mathrm{F06} \mathrm{mg/L}$ & $\underline{0.039}$ \\
\hline$\overline{\mathrm{RIN}}$ & RIN-PARAGN 1/10/2006 1300 & $\overline{\mathrm{EU} 410031}$ & Metal & Sodium & 1 B U F01 F06 mg/L & $\underline{0.0017}$ \\
\hline$\overline{\mathrm{RIN}}$ & RIN-PARAGN 1/10/2006 1300 & $\overline{\text { EU410031 }}$ & Metal & Thallium & $0.000038 \quad \mathrm{~B} \quad \mathrm{~J} \quad \mathrm{mg} / \mathrm{L}$ & $\underline{0.000025}$ \\
\hline$\overline{\mathrm{RIN}}$ & $\overline{\text { RIN-PARAGN 1/10/2006 } 1300}$ & $\overline{\text { EU410031 }}$ & $\overline{\text { Metal }}$ & Antimony & 0.0003 B U F01 F06 mg/L & $\underline{0.00004}$ \\
\hline$\underline{\mathrm{RIN}}$ & RIN-PARAGN 1/10/20061300 & EU410031 & Metal & Barium & 0.00021 B J F10 mg/L & $\underline{0.000074}$ \\
\hline$\overline{\mathrm{RIN}}$ & RIN-PARAGN 1/10/20061300 & EU410031 & Metal & Boron & 0.03 B U F01 F06 mg/L & $\underline{0.00045}$ \\
\hline$\overline{\mathrm{RIN}}$ & RIN-PARAGN 1/10/2006 1300 & $\overline{\text { EU410031 }}$ & Metal & Cadmium & 0.0003 B U F01 F06 mg/L & $\underline{0.000027}$ \\
\hline$\overline{\mathrm{RIN}}$ & $\overline{\text { RIN-PARAGN 1/10/2006 1300 }}$ & $\overline{\mathrm{EU} 410031}$ & $\overline{\text { Metal }}$ & Copper & 0.00027 U R F10 mg/L & 0.00027 \\
\hline$\underline{\text { RIN }}$ & RIN-PARAGN 1/10/20061300 & EU410031 & Metal & Uranium & 0.0001 B U F01 F06 mg/L & $\overline{0.0000024}$ \\
\hline$\underline{\mathrm{RIN}}$ & RIN-PARAGN 1/10/2006 1300 & EU410031 & Metal & Zinc & 0.001 B J F10 mg/L & $\underline{0.00034}$ \\
\hline$\overline{\mathrm{RIN}}$ & RIN-PARAGN 1/10/2006 1300 & $\overline{\text { EU410031 }}$ & $\overline{\text { Metal }}$ & $\overline{\text { Calcium }}$ & $1 \mathrm{~B} \mathrm{U} \mathrm{F01} \mathrm{F06} \mathrm{mg/L}$ & $\overline{0.00078}$ \\
\hline$\overline{\mathrm{RIN}}$ & RIN-PARAGN 1/10/2006 1300 & EU410034 & $\underline{\text { SVOA }}$ & Oxygenated hydrocarbon1 & 10 BJ R O03 ug/L & - \\
\hline$\overline{\mathrm{RIN}}$ & $\overline{\text { RIN-PARAGN 1/10/2006 } 1300}$ & $\overline{\text { EU410034 }}$ & $\overline{\text { SVOA }}$ & Oxygenated hydrocarbon 2 & 14 BJ R O03 ug/L & - \\
\hline$\overline{\mathrm{RIN}}$ & $\overline{\text { RIN-PARAGN 1/10/2006 } 1300}$ & $\overline{\text { EU410034 }}$ & $\overline{\text { SVOA }}$ & Decamethylcyclopentasiloxane & $4.5 \mathrm{~J} \mathrm{R} \mathrm{O03 \textrm {ug } / \mathrm { L }}$ & - \\
\hline$\overline{\mathrm{RIN}}$ & RIN-PARAGN 1/10/2006 1300 & $\overline{\text { EU410034 }}$ & $\overline{\text { SVOA }}$ & Di-n-butyl phthalate & $0.73 \mathrm{~J} \mathrm{~J} \quad \mathrm{ug} / \mathrm{L}$ & $\underline{0.7}$ \\
\hline$\underline{\mathrm{RIN}}$ & RIN-PARAGN 1/10/2006 1300 & EU410035 & $\mathrm{VOA}$ & Acetone & $10 \mathrm{~J} \mathrm{U} \mathrm{F04} \mathrm{F06} \mathrm{ug/L}$ & $\underline{1.4}$ \\
\hline$\overline{\mathrm{RIN}}$ & RIN-PARAGN 1/13/2006 1300 & $\overline{\text { EU410036 }}$ & Mercury & $\overline{\text { Mercury }}$ & $0.0000036 \mathrm{U}$ R D04 F10 mg/L & $\overline{0.0000036}$ \\
\hline$\overline{\mathrm{RIN}}$ & RIN-PARAGN 1/13/2006 1300 & $\overline{\text { EU410036 }}$ & $\overline{\text { Metal }}$ & Aluminum & 0.2 B U F06 F01 mg/L & $\overline{0.0048}$ \\
\hline$\overline{\mathrm{RIN}}$ & $\overline{\text { RIN-PARAGN 1/13/2006 } 1300}$ & $\overline{\text { EU410036 }}$ & $\overline{\text { Metal }}$ & $\overline{\text { Iron }}$ & $0.1 \mathrm{~B} \quad \mathrm{U}$ F06 F01 mg/L & $\overline{0.008}$ \\
\hline$\overline{\mathrm{RIN}}$ & RIN-PARAGN 1/13/2006 1300 & $\overline{\text { EU410036 }}$ & Metal & Magnesium & $\overline{0.0038 \text { U R F10 mg/L }}$ & $\overline{0.0038}$ \\
\hline$\underline{\mathrm{RIN}}$ & RIN-PARAGN 1/13/2006 1300 & $\underline{\mathrm{EU} 410036}$ & Metal & Manganese & $0.01 \mathrm{~B} \quad \mathrm{U}$ F06 F01 mg/L & $\underline{0.000054}$ \\
\hline$\underline{\mathrm{RIN}}$ & RIN-PARAGN 1/13/2006 1300 & $\overline{\text { EU410036 }}$ & Metal & Molybdenum & $0.01 \mathrm{~B} \quad \mathrm{U}$ F06 mg/L & $\underline{0.00085}$ \\
\hline
\end{tabular}


Table L.2. (continued)

\begin{tabular}{|c|c|c|c|c|c|c|}
\hline$\frac{\text { Sample }}{\text { type }}$ & $\underline{\text { Blank }}$ & $\underline{\text { Sample ID }}$ & Category & Chemical name & Result, Lab Oual, Val Oual, RC & $\underline{\text { Detect limit }}$ \\
\hline$\underline{\mathrm{RIN}}$ & RIN-PARAGN 1/13/20061300 & $\underline{\text { EU410036 }}$ & $\underline{\text { Metal }}$ & $\underline{\text { Potassium }}$ & 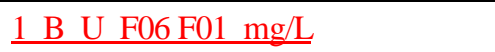 & $\underline{0.039}$ \\
\hline$\underline{\mathrm{RIN}}$ & RIN-PARAGN 1/13/2006 1300 & $\underline{\text { EU410036 }}$ & Metal & $\underline{\text { Sodium }}$ & $1 \mathrm{BE} \mathrm{U} \mathrm{F06} \mathrm{F01} \mathrm{mg/L}$ & $\underline{0.0017}$ \\
\hline$\overline{\mathrm{RIN}}$ & RIN-PARAGN 1/13/2006 1300 & EU410036 & Metal & Thallium & 0.0002 B U F06 F01 mg/L & $\underline{0.000025}$ \\
\hline$\overline{\mathrm{RIN}}$ & RIN-PARAGN 1/13/2006 1300 & $\overline{\text { EU410036 }}$ & Metal & Antimony & 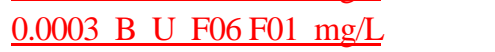 & $\underline{0.00004}$ \\
\hline$\overline{\mathrm{RIN}}$ & RIN-PARAGN 1/13/20061300 & $\overline{\text { EU410036 }}$ & $\overline{\text { Metal }}$ & $\overline{\text { Barium }}$ & 0.000074 U R F10 mg/L & $\overline{0.000074}$ \\
\hline$\underline{\mathrm{RIN}}$ & RIN-PARAGN 1/13/2006 1300 & $\underline{\mathrm{EU} 410036}$ & Metal & Boron & 0.03 B U F06 F01 mg/L & $\underline{0.00045}$ \\
\hline$\underline{\mathrm{RIN}}$ & RIN-PARAGN 1/13/2006 1300 & $\underline{\text { EU410036 }}$ & Metal & $\underline{\text { Cadmium }}$ & 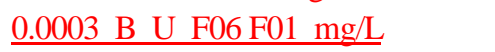 & 0.000027 \\
\hline$\underline{\mathrm{RIN}}$ & RIN-PARAGN 1/13/20061300 & EU410036 & Metal & Chromium & 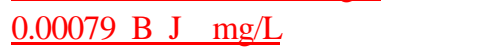 & $\underline{0.00039}$ \\
\hline$\overline{\mathrm{RIN}}$ & RIN-PARAGN 1/13/20061300 & $\overline{\text { EU410036 }}$ & Metal & Copper & 0.00027 U R F10 mg/L & $\overline{0.00027}$ \\
\hline$\underline{\mathrm{RIN}}$ & RIN-PARAGN 1/13/2006 1300 & $\overline{\mathrm{EU} 410036}$ & Metal & $\underline{\text { Uranium }}$ & 0.000039 B J $\mathrm{mg} / \mathrm{L}$ & $\underline{0.0000024}$ \\
\hline$\overline{\mathrm{RIN}}$ & RIN-PARAGN 1/13/2006 1300 & $\overline{\text { EU410036 }}$ & Metal & $\overline{\underline{\text { Zinc }}}$ & 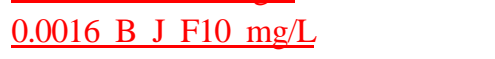 & $\underline{0.00034}$ \\
\hline$\overline{\mathrm{RIN}}$ & $\overline{\text { RIN-PARAGN 1/13/2006 1300 }}$ & $\overline{\text { EU410036 }}$ & $\overline{\text { Metal }}$ & $\overline{\text { Calcium }}$ & $1 \mathrm{BE} \mathrm{U} \mathrm{F06} \mathrm{F01} \mathrm{mg/L}$ & $\overline{0.00078}$ \\
\hline$\overline{\mathrm{RIN}}$ & RIN-PARAGN 1/13/2006 1300 & $\overline{\text { EU410039 }}$ & $\overline{\text { SVOA }}$ & Unknown1 & $5.5 \mathrm{BJ} R \quad \mathrm{R} 003 \mathrm{ug} / \mathrm{L}$ & $\overline{-}$ \\
\hline$\underline{\mathrm{RIN}}$ & RIN-PARAGN 1/13/2006 1300 & $\underline{\text { EU410039 }}$ & $\underline{\text { SVOA }}$ & 3-hydroxy-4-methoxybenzaldehyd & $4.2 \mathrm{~J} \mathrm{R} \quad 003 \mathrm{ug} / \mathrm{L}$ & - \\
\hline$\underline{\mathrm{RIN}}$ & $\underline{\text { RIN-PARAGN 2/17/2006 } 1130}$ & $\overline{\text { HLRDA044 }}$ & $\overline{\mathrm{RADS}}$ & Technetium-99 & $6.71=\mathrm{pCi} / \mathrm{L}$ & 6.64 \\
\hline$\underline{\mathrm{RIN}}$ & RIN-PARAGN 4/20/2006 1300 & $\underline{\mathrm{K} 25 \mathrm{~A} 0301}$ & $\underline{\text { Metal }}$ & $\underline{\text { Aluminum }}$ & $0.028 \mathrm{~B} \mathrm{~J} \quad \mathrm{mg} / \mathrm{L}$ & $\underline{0.0068}$ \\
\hline$\underline{\mathrm{RIN}}$ & RIN-PARAGN 4/20/2006 1300 & $\underline{\mathrm{K} 25 \mathrm{~A} 0301}$ & $\underline{\text { Metal }}$ & Iron & $0.036 \mathrm{~B} \mathrm{~J} \quad \mathrm{mg} / \mathrm{L}$ & $\underline{0.014}$ \\
\hline$\underline{\mathrm{RIN}}$ & RIN-PARAGN 4/20/2006 1300 & $\underline{\mathrm{K} 25 \mathrm{~A} 0301}$ & Metal & Magnesium & 0.046 B J $\quad \mathrm{mg} / \mathrm{L}$ & $\overline{0.0068}$ \\
\hline$\overline{\mathrm{RIN}}$ & RIN-PARAGN 4/20/2006 1300 & $\underline{\mathrm{K} 25 \mathrm{~A} 0301}$ & Metal & Manganese & 0.0017 B J $\quad \mathrm{mg} / \mathrm{L}$ & $\underline{0.00023}$ \\
\hline$\overline{\mathrm{RIN}}$ & RIN-PARAGN 4/20/2006 1300 & $\underline{\mathrm{K} 25 \mathrm{~A} 0301}$ & Metal & Molybdenum & 0.0037 B J $\quad \mathrm{mg} / \mathrm{L}$ & $\overline{0.0014}$ \\
\hline$\underline{\mathrm{RIN}}$ & RIN-PARAGN 4/20/2006 1300 & $\overline{\mathrm{K} 25 \mathrm{~A} 0301}$ & $\overline{\text { Metal }}$ & Nickel & 0.0013 B J $\quad \mathrm{mg} / \mathrm{L}$ & $\overline{0.00099}$ \\
\hline$\underline{\mathrm{RIN}}$ & RIN-PARAGN 4/20/2006 1300 & $\underline{\mathrm{K} 25 \mathrm{~A} 0301}$ & Metal & Sodium & $\underline{0.097 \text { B J } \mathrm{mg} / \mathrm{L}}$ & $\underline{0.0035}$ \\
\hline$\underline{\mathrm{RIN}}$ & RIN-PARAGN 4/20/2006 1300 & $\underline{\mathrm{K} 25 \mathrm{~A} 0301}$ & Metal & Thallium & 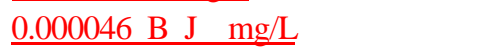 & $\underline{0.000016}$ \\
\hline$\overline{\mathrm{RIN}}$ & RIN-PARAGN 4/20/2006 1300 & $\underline{\mathrm{K} 25 \mathrm{~A} 0301}$ & Metal & Antimony & 0.00018 B J $\quad \mathrm{mg} / \mathrm{L}$ & $\underline{0.00002}$ \\
\hline$\overline{\mathrm{RIN}}$ & RIN-PARAGN 4/20/2006 1300 & $\underline{\mathrm{K} 25 \mathrm{~A} 0301}$ & $\overline{\text { Metal }}$ & $\underline{\text { Barium }}$ & $0.00051 \quad \mathrm{~B} \quad \mathrm{~J} \quad \mathrm{mg} / \mathrm{L}$ & $\overline{0.00017}$ \\
\hline$\underline{\mathrm{RIN}}$ & RIN-PARAGN 4/20/2006 1300 & $\underline{\mathrm{K} 25 \mathrm{~A} 0301}$ & Metal & Cadmium & $0.000094 \mathrm{~B} \mathrm{~J} \quad \mathrm{mg} / \mathrm{L}$ & $\underline{0.00002}$ \\
\hline$\underline{\mathrm{RIN}}$ & RIN-PARAGN 4/20/2006 1300 & $\underline{\mathrm{K} 25 \mathrm{~A} 0301}$ & Metal & $\underline{\text { Uranium }}$ & 0.000056 B J $\mathrm{mg} / \mathrm{L}$ & $\underline{0.0000034}$ \\
\hline$\underline{\mathrm{RIN}}$ & RIN-PARAGN 4/20/2006 1300 & $\underline{\mathrm{K} 25 \mathrm{~A} 0301}$ & Metal & $\underline{\text { Zinc }}$ & 0.0018 B J $\mathrm{mg} / \mathrm{L}$ & $\underline{0.00055}$ \\
\hline$\overline{\mathrm{RIN}}$ & RIN-PARAGN 4/20/2006 1300 & $\underline{\mathrm{K} 25 \mathrm{~A} 0301}$ & Metal & Calcium & 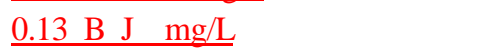 & $\underline{0.0056}$ \\
\hline$\overline{\mathrm{RIN}}$ & $\overline{\text { RIN-PARAGN 9/11/2006 1515 }}$ & $\overline{\mathrm{EU} 370024}$ & $\overline{\text { Metal }}$ & Aluminum & 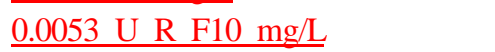 & $\overline{0.0053}$ \\
\hline$\overline{\mathrm{RIN}}$ & $\overline{\text { RIN-PARAGN 9/11/2006 1515 }}$ & $\overline{\mathrm{EU} 370024}$ & $\overline{\text { Metal }}$ & $\overline{\text { Lithium }}$ & $0.01 \mathrm{~B} \quad \mathrm{U}$ F06 F01 mg/L & $\overline{0.00011}$ \\
\hline$\overline{\mathrm{RIN}}$ & RIN-PARAGN 9/11/2006 1515 & $\overline{\text { EU370024 }}$ & $\overline{\text { Metal }}$ & $\overline{\text { Magnesium }}$ & $1 \mathrm{~B} \mathrm{U} \mathrm{F06} \mathrm{mg/L}$ & $\overline{\underline{0.0055}}$ \\
\hline$\overline{\mathrm{RIN}}$ & $\overline{\text { RIN-PARAGN 9/11/2006 1515 }}$ & $\overline{\text { EU370024 }}$ & Metal & $\overline{\text { Manganese }}$ & 0.00012 B J F10 mg/L & $\overline{0.000095}$ \\
\hline$\underline{\mathrm{RIN}}$ & RIN-PARAGN 9/11/2006 1515 & $\overline{\text { EU370024 }}$ & Metal & Nickel & 0.0011 B J $\mathrm{mg} / \mathrm{L}$ & $\underline{0.00082}$ \\
\hline$\overline{\mathrm{RIN}}$ & RIN-PARAGN 9/11/2006 1515 & $\overline{\text { EU370024 }}$ & Metal & Potassium & $1 \mathrm{~B} \mathrm{U} \mathrm{F06} \mathrm{mg/L}$ & $\underline{0.057}$ \\
\hline
\end{tabular}


Table L.2. (continued)

\begin{tabular}{|c|c|c|c|c|c|c|}
\hline$\frac{\text { Sample }}{\text { type }}$ & $\underline{\text { Blank }}$ & $\underline{\text { Sample ID }}$ & Category & Chemical name & Result, Lab Oual, Val Oual, RC & $\underline{\text { Detect limit }}$ \\
\hline$\underline{\mathrm{RIN}}$ & $\underline{\text { RIN-PARAGN 9/11/2006 } 1515}$ & EU370024 & $\underline{\text { Metal }}$ & $\underline{\text { Sodium }}$ & 1 B U F06 F01 mg/L & $\underline{0.002}$ \\
\hline$\underline{\mathrm{RIN}}$ & RIN-PARAGN 9/11/2006 1515 & EU370024 & Metal & Antimony & 0.0003 B U F06 F01 mg/L & $\underline{0.000019}$ \\
\hline$\overline{\mathrm{RIN}}$ & RIN-PARAGN 9/11/2006 1515 & EU370024 & Metal & Barium & 0.1 B U F06 mg/L & 0.0001 \\
\hline$\overline{\mathrm{RIN}}$ & RIN-PARAGN 9/11/2006 1515 & $\overline{\text { EU370024 }}$ & Metal & Beryllium & 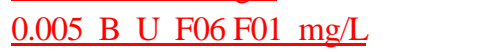 & $\underline{0.000025}$ \\
\hline$\overline{\mathrm{RIN}}$ & $\overline{\text { RIN-PARAGN 9/11/2006 1515 }}$ & $\overline{\text { EU370024 }}$ & $\overline{\text { Metal }}$ & Boron & $0.009 \mathrm{~B} \mathrm{~J} \quad \mathrm{mg} / \mathrm{L}$ & $\overline{0.00098}$ \\
\hline$\underline{\mathrm{RIN}}$ & RIN-PARAGN 9/11/2006 1515 & EU370024 & Metal & Cadmium & 0.0003 B U F06 F01 mg/L & $\underline{0.000016}$ \\
\hline$\underline{\mathrm{RIN}}$ & RIN-PARAGN 9/11/2006 1515 & EU370024 & Metal & $\underline{\text { Uranium }}$ & 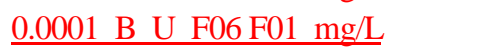 & $\underline{0.0000031}$ \\
\hline$\underline{\mathrm{RIN}}$ & $\underline{\text { RIN-PARAGN 9/11/2006 1515 }}$ & EU370024 & Metal & Zinc & 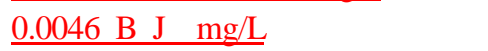 & $\underline{0.00038}$ \\
\hline$\overline{\mathrm{RIN}}$ & RIN-PARAGN 9/11/2006 1515 & $\overline{\text { EU370024 }}$ & $\overline{\text { Metal }}$ & $\overline{\text { Calcium }}$ & $1 \mathrm{~B} \mathrm{U}$ F06 mg/L & $\overline{\underline{0.0073}}$ \\
\hline$\underline{\mathrm{RIN}}$ & RIN-PARAGN 9/11/2006 1515 & $\overline{\text { EU370027 }}$ & $\underline{\underline{\text { SVOA }}}$ & Chlorinated hydrocarbon 1 & $\underline{5.1 \mathrm{~J} \mathrm{~B} \mathrm{R} \mathrm{O02} \mathrm{ug} / \mathrm{L}}$ & - \\
\hline$\overline{\mathrm{RIN}}$ & $\overline{\text { RIN-PARAGN 9/11/2006 1515 }}$ & $\overline{\mathrm{EU} 370027}$ & $\overline{\text { SVOA }}$ & $\overline{\text { Oxygenated hydrocarbon } 1}$ & $18 \mathrm{~J} \mathrm{~B} \mathrm{R} \mathrm{O02} \mathrm{ug/L}$ & - \\
\hline$\overline{\mathrm{RIN}}$ & RIN-PARAGN 9/11/2006 1515 & $\overline{\text { EU370027 }}$ & $\overline{\text { SVOA }}$ & Saturated hydrocarbon1 & $36 \mathrm{~J} \mathrm{~B} \mathrm{R} \mathrm{O02} \mathrm{ug/L}$ & - \\
\hline$\overline{\mathrm{RIN}}$ & RIN-PARAGN 9/11/2006 1515 & $\overline{\text { EU370027 }}$ & $\overline{\text { SVOA }}$ & $\overline{\text { Saturated hydrocarbon2 }}$ & $11 \mathrm{JB} \quad \mathrm{R} \quad 002 \mathrm{ug} / \mathrm{L}$ & - \\
\hline$\underline{\mathrm{RIN}}$ & RIN-PARAGN 9/11/2006 1515 & EU370027 & $\underline{\text { SVOA }}$ & Unknown1 & $4.2 \mathrm{~J} \mathrm{R} \mathrm{O01 \textrm {ug } / \mathrm { L }}$ & - \\
\hline$\overline{\mathrm{RIN}}$ & RIN-PARAGN 9/11/2006 1515 & $\overline{\mathrm{EU} 370027}$ & $\overline{\text { SVOA }}$ & Unsaturated hydrocarbon1 & $6.9 \mathrm{~J} \mathrm{~B} \mathrm{R} \mathrm{O02} \mathrm{ug/L}$ & - \\
\hline$\underline{\mathrm{RIN}}$ & RIN-PARAGN 9/11/2006 1515 & EU370027 & $\underline{\text { SVOA }}$ & Unsaturated hydrocarbon 2 & $5.2 \mathrm{~J} \mathrm{~B} \mathrm{R} \mathrm{O02} \mathrm{ug/L}$ & - \\
\hline$\underline{\mathrm{RIN}}$ & RIN-PARAGN 9/11/2006 1515 & EU370027 & $\underline{\text { SVOA }}$ & Unsaturated hydrocarbon 3 & 22 J B R O02 ug/L & - \\
\hline$\underline{\mathrm{RIN}}$ & RIN-PARAGN 9/11/2006 1515 & EU370027 & $\underline{\text { SVOA }}$ & Unsaturated hydrocarbon 4 & $71 \mathrm{JB} \quad \mathrm{R} \quad 002 \mathrm{ug} / \mathrm{L}$ & - \\
\hline$\underline{\mathrm{RIN}}$ & RIN-PARAGN 9/11/2006 1515 & $\underline{\mathrm{EU} 370027}$ & $\underline{\text { SVOA }}$ & Unsaturated hydrocarbon5 & $20 \mathrm{~J} \mathrm{~B} \mathrm{R} \mathrm{O02} \mathrm{ug/L}$ & - \\
\hline$\overline{\mathrm{RIN}}$ & RIN-PARAGN 9/11/2006 1515 & $\overline{\text { EU370027 }}$ & $\overline{\text { SVOA }}$ & Unsaturated hydrocarbon6 & $25 \mathrm{~J} \mathrm{~B} \mathrm{R} \mathrm{O02 \textrm {ug } / \mathrm { L }}$ & - \\
\hline$\overline{\mathrm{RIN}}$ & $\overline{\text { RIN-PARAGN 9/11/2006 1515 }}$ & $\overline{\text { EU370027 }}$ & $\overline{\text { SVOA }}$ & $\overline{\text { Unsaturated hydrocarbon7 }}$ & $\overline{4.6 \mathrm{~J} \mathrm{~B} \mathrm{R} \mathrm{O02} \mathrm{ug/L}}$ & - \\
\hline$\underline{\mathrm{RIN}}$ & RIN-PARAGN 9/11/2006 1515 & EU370027 & $\underline{\text { SVOA }}$ & $\overline{\text { Unsaturated hydrocarbon } 8}$ & 24 J B R O02 ug/L & - \\
\hline$\underline{\mathrm{RIN}}$ & $\underline{\text { RIN-PARAGN 9/11/2006 1515 }}$ & EU370027 & $\underline{\text { SVOA }}$ & 7,9-di-tert-butyl-1-oxaspiro(4 & $7.5 \mathrm{~J} \mathrm{R} \quad 001 \mathrm{ug} / \mathrm{L}$ & - \\
\hline$\overline{\mathrm{RIN}}$ & RIN-PARAGN 9/11/2006 1515 & $\overline{\mathrm{EU} 370027}$ & $\overline{\text { SVOA }}$ & 2-(2-butoxyethoxy)-ethanol & $4.4 \mathrm{~J} \mathrm{R} \mathrm{O01ug/L}$ & 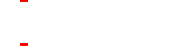 \\
\hline$\overline{\mathrm{RIN}}$ & RIN-PARAGN 9/11/2006 1515 & $\overline{\text { EU370027 }}$ & $\underline{\text { SVOA }}$ & Vanillin1 & $8.7 \mathrm{~J} \mathrm{R} \mathrm{O01} \mathrm{ug/L}$ & - \\
\hline$\underline{\mathrm{RIN}}$ & RIN-PARAGN 9/11/2006 1515 & EU370027 & $\underline{\text { SVOA }}$ & 1,2,3-trichloro-1-propene & $6.6 \mathrm{~J} \mathrm{~B} \mathrm{R} \mathrm{O02} \mathrm{ug/L}$ & - \\
\hline$\underline{\mathrm{RIN}}$ & RIN-PARAGN 9/11/2006 1515 & EU370027 & $\underline{\text { SVOA }}$ & Diethyl phthalate & $1.3 \mathrm{~J} \mathrm{~J} \quad \mathrm{ug} / \mathrm{L}$ & 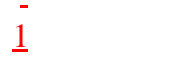 \\
\hline$\underline{\mathrm{RIN}}$ & RIN-PARAGN 9/13/2006 1505 & $\underline{\mathrm{K} 25 \mathrm{~A} 0357}$ & Metal & Aluminum & $0.0053 \mathrm{U} \mathrm{R}$ F $10 \mathrm{mg} / \mathrm{L}$ & $\underline{0.0053}$ \\
\hline$\overline{\mathrm{RIN}}$ & RIN-PARAGN 9/13/2006 1505 & $\underline{\mathrm{K} 25 \mathrm{~A} 0357}$ & Metal & Iron & 0.1 B U F06 mg/L & $\underline{0.014}$ \\
\hline$\overline{\mathrm{RIN}}$ & $\overline{\text { RIN-PARAGN 9/13/2006 1505 }}$ & $\underline{\mathrm{K} 25 \mathrm{~A} 0357}$ & $\overline{\text { Metal }}$ & $\overline{\text { Lithium }}$ & $0.01 \mathrm{~B} \quad$ U F06 F01 mg/L & $\overline{0.00011}$ \\
\hline$\overline{\mathrm{RIN}}$ & $\overline{\text { RIN-PARAGN 9/13/2006 1505 }}$ & $\overline{\mathrm{K} 25 \mathrm{~A} 0357}$ & $\overline{\text { Metal }}$ & Magnesium & $1 \mathrm{~B} \mathrm{U} \mathrm{F06} \mathrm{mg/L}$ & $\overline{0.0055}$ \\
\hline$\overline{\mathrm{RIN}}$ & RIN-PARAGN 9/13/2006 1505 & $\overline{\mathrm{K} 25 \mathrm{~A} 0357}$ & $\overline{\text { Metal }}$ & $\overline{\text { Manganese }}$ & 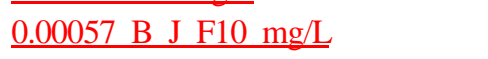 & $\overline{0.000095}$ \\
\hline$\overline{\mathrm{RIN}}$ & RIN-PARAGN 9/13/2006 1505 & $\overline{\mathrm{K} 25 \mathrm{~A} 0357}$ & Metal & Molybdenum & 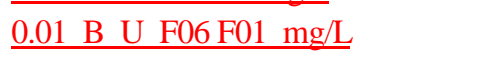 & $\overline{0.00082}$ \\
\hline$\underline{\mathrm{RIN}}$ & RIN-PARAGN 9/13/2006 1505 & $\underline{\mathrm{K} 25 \mathrm{~A} 0357}$ & Metal & Nickel & $0.0011 \mathrm{~B} \quad \mathrm{~J} \quad \mathrm{mg} / \mathrm{L}$ & $\underline{0.00082}$ \\
\hline$\overline{\mathrm{RIN}}$ & RIN-PARAGN 9/13/2006 1505 & $\underline{\mathrm{K} 25 \mathrm{~A} 0357}$ & Metal & Sodium & $1 \mathrm{~B} \mathrm{U} \mathrm{F06} \mathrm{F01} \mathrm{mg/L}$ & $\underline{0.002}$ \\
\hline
\end{tabular}


Table L.2. (continued)

\begin{tabular}{|c|c|c|c|c|c|c|}
\hline$\frac{\text { Sample }}{\text { type }}$ & $\underline{\text { Blank }}$ & Sample ID & Category & Chemical name & Result, Lab Oual, Val Oual, RC & $\underline{\text { Detect limit }}$ \\
\hline$\underline{\mathrm{RIN}}$ & RIN-PARAGN 9/13/2006 1505 & $\underline{\mathrm{K} 25 \mathrm{~A} 0357}$ & $\underline{\text { Metal }}$ & $\underline{\text { Antimony }}$ & 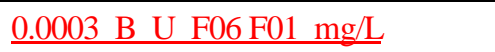 & $\underline{0.000019}$ \\
\hline$\underline{\mathrm{RIN}}$ & RIN-PARAGN 9/13/2006 1505 & $\underline{\mathrm{K} 25 \mathrm{~A} 0357}$ & Metal & $\underline{\text { Barium }}$ & 0.1 B U F06 mg/L & 0.0001 \\
\hline$\underline{\mathrm{RIN}}$ & RIN-PARAGN 9/13/2006 1505 & $\underline{\mathrm{K} 25 \mathrm{~A} 0357}$ & Metal & Beryllium & 0.005 B U F06 F01 mg/L & $\overline{0.000025}$ \\
\hline$\overline{\mathrm{RIN}}$ & RIN-PARAGN 9/13/2006 1505 & $\underline{\mathrm{K} 25 \mathrm{~A} 0357}$ & Metal & Boron & 0.0076 B J $\quad \mathrm{mg} / \mathrm{L}$ & $\overline{0.00098}$ \\
\hline$\overline{\mathrm{RIN}}$ & $\overline{\text { RIN-PARAGN 9/13/2006 1505 }}$ & $\overline{\mathrm{K} 25 \mathrm{~A} 0357}$ & $\overline{\text { Metal }}$ & $\overline{\text { Cadmium }}$ & 0.0003 B U F06 F01 mg/L & $\overline{0.000016}$ \\
\hline$\overline{\mathrm{RIN}}$ & $\overline{\text { RIN-PARAGN 9/13/2006 1505 }}$ & $\overline{\mathrm{K} 25 \mathrm{~A} 0357}$ & $\overline{\text { Metal }}$ & $\overline{\text { Uranium }}$ & $\overline{0.0001 \mathrm{~B} \mathrm{U} \text { F06 F01 mg/L }}$ & $\overline{0.0000031}$ \\
\hline$\underline{\mathrm{RIN}}$ & RIN-PARAGN 9/13/2006 1505 & $\underline{\mathrm{K} 25 \mathrm{~A} 0357}$ & Metal & $\underline{\text { Zinc }}$ & 0.0015 B J $\quad \mathrm{mg} / \mathrm{L}$ & 0.00038 \\
\hline$\underline{\mathrm{RIN}}$ & RIN-PARAGN 9/13/2006 1505 & $\underline{\mathrm{K} 25 \mathrm{~A} 0357}$ & Metal & $\underline{\text { Calcium }}$ & $1 \mathrm{~B} \mathrm{U} \mathrm{F06} \mathrm{mg/L}$ & $\underline{0.0073}$ \\
\hline$\overline{\mathrm{RIN}}$ & RIN-PARAGN 9/13/2006 1505 & $\underline{\mathrm{K} 25 \mathrm{~A} 0360}$ & $\overline{\text { SVOA }}$ & Chlorinated hydrocarbon1 & $3.9 \mathrm{~J} \mathrm{R} \mathrm{O01 \textrm {ug } / \mathrm { L }}$ & $\overline{-}$ \\
\hline$\underline{\mathrm{RIN}}$ & RIN-PARAGN 9/13/2006 1505 & $\mathrm{~K} 25 \mathrm{~A} 0360$ & $\underline{\text { SVOA }}$ & Oxygenated hydrocarbon 1 & $5.2 \mathrm{~J} \mathrm{~B} \mathrm{R} \mathrm{O02} \mathrm{ug/L}$ & - \\
\hline$\overline{\mathrm{RIN}}$ & RIN-PARAGN 9/13/2006 1505 & $\overline{\mathrm{K} 25 \mathrm{~A} 0360}$ & $\overline{\text { SVOA }}$ & $\overline{\text { Oxygenated hydrocarbon2 }}$ & $\overline{6.1 \mathrm{~J} \mathrm{R} \text { O01 ug/L }}$ & - \\
\hline$\overline{\mathrm{RIN}}$ & RIN-PARAGN 9/13/2006 1505 & $\overline{\mathrm{K} 25 \mathrm{~A} 0360}$ & $\overline{\text { SVOA }}$ & Siloxane1 & $4.2 \mathrm{~J} \mathrm{R} \mathrm{O01 \textrm {ug } / \mathrm { L }}$ & - \\
\hline$\overline{\mathrm{RIN}}$ & RIN-PARAGN 9/13/2006 1505 & $\overline{\mathrm{K} 25 \mathrm{~A} 0360}$ & $\overline{\text { SVOA }}$ & Unknown1 & $\overline{9.1 \mathrm{~J} \mathrm{~B} \mathrm{R} \mathrm{O02} \mathrm{ug} / \mathrm{L}}$ & - \\
\hline$\overline{\mathrm{RIN}}$ & RIN-PARAGN 9/13/2006 1505 & $\overline{\mathrm{K} 25 \mathrm{~A} 0360}$ & $\overline{\text { SVOA }}$ & Unsaturated hydrocarbon 1 & $8.2 \mathrm{~J} \mathrm{~B} \mathrm{R} \mathrm{O02 \textrm {ug } / \mathrm { L }}$ & - \\
\hline$\underline{\mathrm{RIN}}$ & RIN-PARAGN 9/13/2006 1505 & $\underline{\mathrm{K} 25 \mathrm{~A} 0360}$ & SVOA & Unsaturated hydrocarbon 2 & $25 \mathrm{~J} \mathrm{~B} \mathrm{R} \mathrm{O02} \mathrm{ug/L}$ & - \\
\hline$\underline{\mathrm{RIN}}$ & RIN-PARAGN 9/13/2006 1505 & $\underline{\mathrm{K} 25 \mathrm{~A} 0360}$ & $\underline{\text { SVOA }}$ & Unsaturated hydrocarbon 3 & $110 \mathrm{~J} \mathrm{~B} \mathrm{R} \mathrm{O02} \mathrm{ug/L}$ & - \\
\hline$\overline{\mathrm{RIN}}$ & RIN-PARAGN 9/13/2006 1505 & K25A0360 & SVOA & Unsaturated hydrocarbon 4 & 26 J B R O02 ug/L & - \\
\hline$\overline{\mathrm{RIN}}$ & RIN-PARAGN 9/13/2006 1505 & $\overline{\mathrm{K} 25 \mathrm{~A} 0360}$ & $\overline{\text { SVOA }}$ & Unsaturated hydrocarbon5 & $6.1 \mathrm{~J} \mathrm{R} \mathrm{O01} \mathrm{ug/L}$ & - \\
\hline$\overline{\mathrm{RIN}}$ & RIN-PARAGN 9/13/2006 1505 & $\underline{\mathrm{K} 25 \mathrm{~A} 0360}$ & $\overline{\text { SVOA }}$ & Unsaturated hydrocarbon6 & 56 J B R O02 ug/L & - \\
\hline$\overline{\mathrm{RIN}}$ & $\overline{\text { RIN-PARAGN 9/13/2006 1505 }}$ & $\overline{\mathrm{K} 25 \mathrm{~A} 0360}$ & $\overline{\text { SVOA }}$ & $\overline{\text { Unsaturated hydrocarbon } 7}$ & $\overline{9.5 \mathrm{~J} \mathrm{~B} \mathrm{R} \mathrm{O} 02 \mathrm{ug} / \mathrm{L}}$ & - \\
\hline$\overline{\mathrm{RIN}}$ & $\overline{\text { RIN-PARAGN 9/13/2006 1505 }}$ & $\overline{\mathrm{K} 25 \mathrm{~A} 0360}$ & $\overline{\text { SVOA }}$ & 3-hydroxy-4-methoxybenzaldehyd & $9.6 \mathrm{~J} \mathrm{R} \mathrm{O01} \mathrm{ug/L}$ & - \\
\hline$\underline{\text { RIN }}$ & $\underline{\text { RIN-PARAGN 9/21/2006 } 1623}$ & EU41-RIN01 & Metal & Aluminum & 0.2 B U F06 F01 mg/L & $\underline{0.0053}$ \\
\hline$\underline{\mathrm{RIN}}$ & RIN-PARAGN 9/21/2006 1623 & EU41-RIN01 & Metal & Iron & $0.1 \mathrm{~B} \quad \mathrm{U}$ F06 F01 mg/L & $\underline{0.014}$ \\
\hline$\overline{\mathrm{RIN}}$ & RIN-PARAGN 9/21/2006 1623 & $\overline{\text { EU41-RIN01 }}$ & Metal & $\overline{\text { Lead }}$ & $\underline{0.00089 \mathrm{U} \mathrm{R} \text { F10 mg/L }}$ & $\overline{0.00089}$ \\
\hline$\overline{\mathrm{RIN}}$ & RIN-PARAGN 9/21/2006 1623 & $\overline{\text { EU41-RIN01 }}$ & $\overline{\text { Metal }}$ & Lithium & 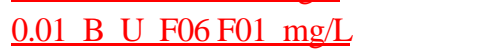 & $\overline{0.00011}$ \\
\hline$\overline{\mathrm{RIN}}$ & RIN-PARAGN 9/21/2006 1623 & $\overline{\text { EU41-RIN01 }}$ & $\overline{\text { Metal }}$ & Manganese & 0.00062 B J F10 mg/L & $\overline{0.000095}$ \\
\hline$\overline{\mathrm{RIN}}$ & $\overline{\text { RIN-PARAGN 9/21/2006 1623 }}$ & $\overline{\text { EU41-RIN01 }}$ & $\overline{\text { Metal }}$ & $\overline{\text { Molybdenum }}$ & $0.01 \mathrm{~B} \quad$ U F06 mg/L & $\overline{0.00082}$ \\
\hline$\overline{\mathrm{RIN}}$ & RIN-PARAGN 9/21/2006 1623 & $\overline{\text { EU41-RIN01 }}$ & $\overline{\text { Metal }}$ & Potassium & $1 \mathrm{~B} \mathrm{U}$ F06 F01 mg/L & 0.057 \\
\hline$\underline{\mathrm{RIN}}$ & RIN-PARAGN 9/21/2006 1623 & EU41-RIN01 & Metal & Sodium & $1 \mathrm{~B} \mathrm{U} \mathrm{F06} \mathrm{F01} \mathrm{mg/L}$ & $\underline{0.002}$ \\
\hline$\overline{\mathrm{RIN}}$ & RIN-PARAGN 9/21/2006 1623 & $\overline{\text { EU41-RIN01 }}$ & $\overline{\text { Metal }}$ & Thallium & 0.0002 B U F06 F01 mg/L & $\overline{0.000015}$ \\
\hline$\overline{\mathrm{RIN}}$ & RIN-PARAGN 9/21/2006 1623 & $\overline{\text { EU41-RIN01 }}$ & $\overline{\text { Metal }}$ & $\overline{\text { Antimony }}$ & 0.0003 B U F06 F01 mg/L & $\overline{0.000019}$ \\
\hline$\overline{\mathrm{RIN}}$ & RIN-PARAGN 9/21/2006 1623 & $\overline{\text { EU41-RIN01 }}$ & $\overline{\text { Metal }}$ & $\overline{\text { Arsenic }}$ & 0.01 B U F06 mg/L & $\overline{0.0025}$ \\
\hline$\overline{\mathrm{RIN}}$ & RIN-PARAGN 9/21/2006 1623 & $\overline{\text { EU41-RIN01 }}$ & $\overline{\text { Metal }}$ & $\overline{\text { Barium }}$ & 0.1 B U F06 F01 mg/L & $\overline{0.0001}$ \\
\hline$\underline{\mathrm{RIN}}$ & RIN-PARAGN 9/21/2006 1623 & EU41-RIN01 & Metal & Boron & $\underline{0.03 \mathrm{~B} \mathrm{U} \mathrm{F} 06 \mathrm{~F} 01 \mathrm{mg} / \mathrm{L}}$ & $\underline{0.00098}$ \\
\hline$\underline{\mathrm{RIN}}$ & RIN-PARAGN 9/21/2006 1623 & EU41-RIN01 & Metal & Cadmium & 0.0003 B U F06 F01 mg/L & $\underline{0.000016}$ \\
\hline
\end{tabular}


Table L.2. (continued)

\begin{tabular}{|c|c|c|c|c|c|c|}
\hline$\frac{\text { Sample }}{\text { type }}$ & Blank & Sample ID & Category & Chemical name & Result, Lab Oual, Val Oual, RC & $\underline{\text { Detect limit }}$ \\
\hline RIN & RIN-PARAGN 9/21/2006 1623 & EU41-RIN01 & Metal & Chromium & 0.00078 B J $\quad \mathrm{mg} / \mathrm{L}$ & 0.00071 \\
\hline$\underline{\mathrm{RIN}}$ & RIN-PARAGN 9/21/2006 1623 & EU41-RIN01 & Metal & $\underline{\text { Uranium }}$ & 0.0001 B U F06 F01 mg/L & $\underline{0.0000031}$ \\
\hline$\underline{\text { RIN }}$ & RIN-PARAGN 9/21/2006 1623 & EU41-RIN01 & $\underline{\text { Metal }}$ & $\underline{\text { Zinc }}$ & 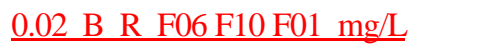 & $\underline{0.00038}$ \\
\hline$\underline{\mathrm{RIN}}$ & RIN-PARAGN 9/21/2006 1623 & EU41-RIN01 & $\underline{\text { Metal }}$ & $\underline{\text { Calcium }}$ & 1 B U F06 F01 mg/L & $\underline{0.0073}$ \\
\hline$\underline{\mathrm{RIN}}$ & RIN-PARAGN 9/21/2006 1623 & EU41-RIN04 & $\underline{\text { SVOA }}$ & $\underline{\text { Oxygenated hydrocarbon } 1}$ & $4.5 \mathrm{~J} \mathrm{R} \mathrm{O01ug/L}$ & - \\
\hline$\underline{\mathrm{RIN}}$ & RIN-PARAGN 9/21/2006 1623 & EU41-RIN04 & $\underline{\text { SVOA }}$ & Unsaturated hydrocarbon 1 & $6.8 \mathrm{~J} \mathrm{~B} \mathrm{R} \mathrm{O02} \mathrm{ug/L}$ & - \\
\hline$\underline{\mathrm{RIN}}$ & RIN-PARAGN 9/21/2006 1623 & EU41-RIN04 & $\underline{\text { SVOA }}$ & Unsaturated hydrocarbon2 & $15 \mathrm{~J} \mathrm{~B} \mathrm{R} \mathrm{O02} \mathrm{ug/L}$ & - \\
\hline$\underline{\mathrm{RIN}}$ & RIN-PARAGN 9/21/2006 1623 & EU41-RIN04 & $\underline{\text { SVOA }}$ & Unsaturated hydrocarbon3 & $4.9 \mathrm{~J} \mathrm{~B} \mathrm{R} \mathrm{O02} \mathrm{ug/L}$ & - \\
\hline$\underline{\mathrm{RIN}}$ & RIN-PARAGN 9/21/2006 1623 & EU41-RIN04 & $\underline{\text { SVOA }}$ & Unsaturated hydrocarbon4 & 18 J B R O02 ug/L & - \\
\hline$\overline{\mathrm{RIN}}$ & RIN-PARAGN 9/21/2006 1623 & $\overline{\text { EU41-RIN05 }}$ & $\underline{\mathrm{VOA}}$ & Acetone & $4 \mathrm{~J} \mathrm{~J} \quad$ ug/L & 3.2 \\
\hline$\underline{\mathrm{RIN}}$ & RIN-PARAGN 9/21/2006 1623 & EU41-RIN05 & $\underline{\mathrm{VOA}}$ & Methylene chloride & $\underline{0.23 \mathrm{~J} \mathrm{~J}} \quad \mathrm{ug} / \mathrm{L}$ & $\underline{0.18}$ \\
\hline$\underline{\mathrm{RIN}}$ & RIN-PARAGN 9/28/2006 850 & MPLA-019 & Metal & $\underline{\text { Aluminum }}$ & $\underline{0.0055 \mathrm{U} \mathrm{R} F 10 \mathrm{mg} / \mathrm{L}}$ & $\underline{0.0055}$ \\
\hline$\underline{\mathrm{RIN}}$ & RIN-PARAGN 9/28/2006 850 & $\underline{\text { MPLA-019 }}$ & Metal & $\underline{\underline{\text { Lithium }}}$ & 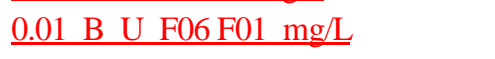 & $\underline{0.000065}$ \\
\hline$\underline{\mathrm{RIN}}$ & RIN-PARAGN 9/28/2006 850 & MPLA-019 & Metal & Magnesium & $1 \mathrm{~B} \mathrm{U}$ F06 F01 mg/L & 0.0062 \\
\hline$\underline{\mathrm{RIN}}$ & RIN-PARAGN 9/28/2006 850 & $\underline{\text { MPLA-019 }}$ & $\underline{\text { Metal }}$ & $\overline{\text { Manganese }}$ & $\underline{0.01}$ B U $\quad$ F06 F01 mg/L & $\overline{0.000097}$ \\
\hline$\overline{\mathrm{RIN}}$ & RIN-PARAGN 9/28/2006 850 & $\overline{\text { MPLA-019 }}$ & $\underline{\text { Metal }}$ & $\overline{\underline{\text { Potassium }}}$ & $1 \mathrm{~B} \mathrm{U} \mathrm{F06} \mathrm{F01} \mathrm{mg/L}$ & $\overline{0.012}$ \\
\hline$\overline{\mathrm{RIN}}$ & RIN-PARAGN 9/28/2006 850 & $\overline{\text { MPLA-019 }}$ & $\underline{\text { Metal }}$ & $\overline{\text { Sodium }}$ & $\overline{1 \mathrm{~B} \mathrm{U} \text { F06 F01 mg/L }}$ & $\overline{0.0044}$ \\
\hline$\underline{\mathrm{RIN}}$ & RIN-PARAGN 9/28/2006 850 & MPLA-019 & Metal & Thallium & 0.0002 B U F06 F01 mg/L & $\underline{0.000015}$ \\
\hline$\underline{\mathrm{RIN}}$ & RIN-PARAGN 9/28/2006 850 & $\overline{\text { MPLA-019 }}$ & $\underline{\text { Metal }}$ & $\overline{\text { Antimony }}$ & 0.0003 B U F06 F01 mg/L & $\underline{0.000019}$ \\
\hline$\overline{\mathrm{RIN}}$ & RIN-PARAGN 9/28/2006 850 & $\overline{\text { MPLA-019 }}$ & Metal & Barium & $0.1 \mathrm{~B}$ U F06 F01 mg/L & 0.000094 \\
\hline$\overline{\mathrm{RIN}}$ & RIN-PARAGN 9/28/2006 850 & MPLA-019 & Metal & Beryllium & 0.00013 U R F10 mg/L & $\underline{0.00013}$ \\
\hline$\underline{\mathrm{RIN}}$ & RIN-PARAGN 9/28/2006 850 & MPLA-019 & Metal & $\overline{\text { Cadmium }}$ & 0.0003 B U F06 F01 mg/L & $\overline{0.000016}$ \\
\hline$\underline{\mathrm{RIN}}$ & RIN-PARAGN 9/28/2006 850 & $\underline{\text { MPLA-019 }}$ & Metal & Copper & $0.01 \mathrm{~B}$ U F06 F01 mg/L & $\underline{0.00042}$ \\
\hline$\underline{\text { RIN }}$ & RIN-PARAGN 9/28/2006 850 & $\underline{\text { MPLA-019 }}$ & Metal & $\underline{\text { Uranium }}$ & 0.0001 B U F06 F01 mg/L & $\underline{0.0000031}$ \\
\hline$\underline{\mathrm{RIN}}$ & RIN-PARAGN 9/28/2006 850 & MPLA-019 & $\underline{\text { Metal }}$ & $\underline{\text { Calcium }}$ & 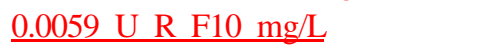 & $\underline{0.0059}$ \\
\hline$\underline{\mathrm{RIN}}$ & RIN-PARAGN 9/28/2006 850 & MPLA-021 & $\underline{\mathrm{RADS}}$ & $\underline{\text { Uranium-238 }}$ & 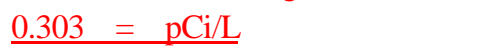 & $\underline{0.295}$ \\
\hline$\underline{\mathrm{RIN}}$ & RIN-PARAGN 9/28/2006 850 & MPLA-021 & $\underline{\text { RADS-gamma }}$ & $\underline{\text { Silver-110m }}$ & $4.93 \mathrm{~J} \mathrm{R} \mathrm{W02} \mathrm{pCi} / \mathrm{L}$ & 4.84 \\
\hline$\overline{\mathrm{RIN}}$ & RIN-PARAGN 9/28/2006 850 & $\overline{\text { MPLA-022 }}$ & $\overline{\text { SVOA }}$ & $\overline{\text { Unknown1 }}$ & $4.2 \mathrm{~J} \mathrm{R} \mathrm{O01 \textrm {ug } / \mathrm { L }}$ & - \\
\hline$\overline{\mathrm{RIN}}$ & RIN-PARAGN 9/28/2006 850 & $\overline{\text { MPLA-022 }}$ & $\overline{\text { SVOA }}$ & Unknown2 & $15 \mathrm{~J} \mathrm{R} \mathrm{O01 \textrm {ug } / \mathrm { L }}$ & - \\
\hline$\underline{\mathrm{RIN}}$ & RIN-PARAGN 9/28/2006 850 & MPLA-022 & $\underline{\text { SVOA }}$ & Unsaturated hydrocarbon1 & $6.6 \mathrm{~J} \mathrm{~B} \mathrm{R} \mathrm{O02} \mathrm{ug} / \mathrm{L}$ & - \\
\hline$\underline{\mathrm{RIN}}$ & RIN-PARAGN 9/28/2006 850 & MPLA-022 & $\underline{\text { SVOA }}$ & Unsaturated hydrocarbon 2 & $14 \mathrm{~J} \mathrm{~B} \mathrm{R} \mathrm{O02} \mathrm{ug/L}$ & - \\
\hline$\underline{\mathrm{RIN}}$ & RIN-PARAGN 9/28/2006 850 & MPLA-022 & $\underline{\text { SVOA }}$ & Unsaturated hydrocarbon 3 & $4.2 \mathrm{~J} \mathrm{~B} \mathrm{R} \mathrm{O02 \textrm {ug } / \mathrm { L }}$ & - \\
\hline$\underline{\mathrm{RIN}}$ & RIN-PARAGN 9/28/2006 850 & MPLA -022 & $\underline{\text { SVOA }}$ & Unsaturated hydrocarbon 4 & 6 J B R O02 ug/L & - \\
\hline$\underline{\mathrm{RIN}}$ & RIN-PARAGN 9/28/2006 850 & MPLA-022 & $\underline{\underline{\text { SVOA }}}$ & Unsaturated hydrocarbon 5 & $11 \mathrm{~J} \mathrm{R} \mathrm{O01} \mathrm{ug/L}$ & - \\
\hline$\underline{\mathrm{RIN}}$ & RIN-PARAGN 9/28/2006 850 & MPLA-022 & $\underline{\underline{\text { SVOA }}}$ & Unsaturated hydrocarbon6 & $22 \mathrm{~J} \mathrm{~B} \mathrm{R} \mathrm{O02} \mathrm{ug/L}$ & - \\
\hline
\end{tabular}


Table L.2. (continued)

\begin{tabular}{|c|c|c|c|c|c|c|}
\hline$\frac{\text { Sample }}{\text { type }}$ & $\underline{\text { Blank }}$ & $\underline{\text { Sample ID }}$ & Category & Chemical name & Result, Lab Oual, Val Oual, RC & $\underline{\text { Detect limit }}$ \\
\hline$\underline{\mathrm{RIN}}$ & RIN-PARAGN 9/28/2006 850 & $\underline{\text { MPLA-022 }}$ & $\underline{\text { SVOA }}$ & Unsaturated hydrocarbon7 & $26 \mathrm{~J} \mathrm{~B} \mathrm{R} \mathrm{O02} \mathrm{ug/L}$ & - \\
\hline$\underline{\mathrm{RIN}}$ & RIN-PARAGN 9/28/2006 850 & MPLA-022 & $\underline{\text { SVOA }}$ & Unsaturated hydrocarbon 8 & $4.6 \mathrm{~J} \mathrm{~B} \mathrm{R} \mathrm{O02} \mathrm{ug/L}$ & - \\
\hline$\overline{\mathrm{RIN}}$ & RIN-PARAGN 9/28/2006 850 & MPLA-022 & $\underline{\text { SVOA }}$ & Di-n-butyl phthalate & $1.5 \mathrm{~J} \mathrm{~J} \quad \mathrm{ug} / \mathrm{L}$ & 1.4 \\
\hline$\overline{\mathrm{RIN}}$ & RIN-PARAGN 9/28/2006 850 & $\underline{\text { MPLA-023 }}$ & $\overline{\mathrm{VOA}}$ & Acetone & $6.1 \mathrm{~J} \mathrm{~J} \quad \mathrm{ug} / \mathrm{L}$ & $\underline{3.2}$ \\
\hline$\overline{\mathrm{TB}}$ & TB-PARAGN 11/10/2005 1500 & $\overline{\text { EU410046 }}$ & $\overline{\mathrm{VOA}}$ & $\overline{\text { Acetone }}$ & $10 \mathrm{~J} \mathrm{U} \mathrm{F01} \mathrm{F06} \mathrm{ug/L}$ & $\overline{1.4}$ \\
\hline$\underline{\mathrm{TB}}$ & TB-PARAGN 11/15/2005 1150 & EU410047 & $\underline{\mathrm{VOA}}$ & Acetone & $8.7 \mathrm{~J} \mathrm{~J} \quad \mathrm{ug} / \mathrm{L}$ & $\underline{1.4}$ \\
\hline$\underline{\mathrm{TB}}$ & TB-PARAGN 11/15/2005 1150 & EU410047 & $\underline{\mathrm{VOA}}$ & Methylene chloride & $8.5=u g / L$ & $\underline{0.57}$ \\
\hline$\overline{\mathrm{TB}}$ & TB-PARAGN 11/15/2005 1150 & EU410047 & $\underline{\mathrm{VOA}}$ & Carbon disulfide & $6.5=\mathrm{ug} / \mathrm{L}$ & $\underline{0.095}$ \\
\hline$\overline{\mathrm{TB}}$ & TB-PARAGN 11/17/2005 1300 & $\overline{\text { EU410048 }}$ & $\overline{\mathrm{VOA}}$ & Acetone & $12=\mathrm{ug} / \mathrm{L}$ & $\overline{1.4}$ \\
\hline$\overline{\mathrm{TB}}$ & TB-PARAGN 11/17/2005 1300 & $\overline{\mathrm{EU} 410048}$ & $\underline{\mathrm{VOA}}$ & $\overline{\text { Carbon disulfide }}$ & $6.7=\mathrm{ug} / \mathrm{L}$ & $\underline{0.095}$ \\
\hline$\overline{\mathrm{TB}}$ & TB-PARAGN 11/17/20051400 & $\overline{\text { EU410049 }}$ & $\overline{\mathrm{VOA}}$ & Acetone & $\overline{5 \mathrm{~J} \mathrm{~J} \quad \mathrm{ug} / \mathrm{L}}$ & $\overline{1.4}$ \\
\hline$\overline{\mathrm{TB}}$ & TB-PARAGN 11/17/2005 1400 & $\overline{\text { EU410049 }}$ & $\underline{\overline{\mathrm{VOA}}}$ & $\overline{\text { Chloroform }}$ & $0.17 \mathrm{~J} \mathrm{U} \quad \mathrm{ug} / \mathrm{L}$ & $\overline{0.11}$ \\
\hline$\underline{\mathrm{TB}}$ & TB-PARAGN 11/22/2005 1215 & $\overline{\text { EU410053 }}$ & $\overline{\mathrm{VOA}}$ & $\overline{\text { Acetone }}$ & $13 \mathrm{~J} \mathrm{~A} \quad \mathrm{~A} 3 \mathrm{ug} / \mathrm{L}$ & $\underline{1.4}$ \\
\hline$\overline{\mathrm{TB}}$ & TB-PARAGN 11/22/2005 1215 & EU410053 & $\underline{\mathrm{VOA}}$ & Carbon disulfide & $6.8 \mathrm{~J} \mathrm{~A} \quad \mathrm{~A} \quad \mathrm{ug} / \mathrm{L}$ & $\underline{0.095}$ \\
\hline$\underline{\mathrm{TB}}$ & TB-PARAGN 11/28/2005900 & $\overline{\text { EU410050 }}$ & $\overline{\mathrm{VOA}}$ & Toluene & $\begin{array}{lll}0.42 \mathrm{~J} \mathrm{~J} & \mathrm{ug} / \mathrm{L}\end{array}$ & $\overline{0.13}$ \\
\hline$\underline{\mathrm{TB}}$ & TB-PARAGN 11/28/2005900 & $\underline{\text { EU410050 }}$ & $\underline{\mathrm{VOA}}$ & $\underline{\text { Acetone }}$ & $2.1 \mathrm{~J} J \quad \mathrm{ug} / \mathrm{L}$ & 1.4 \\
\hline$\underline{\mathrm{TB}}$ & TB-PARAGN 11/28/2005900 & $\underline{\mathrm{EU} 410050}$ & $\underline{\mathrm{VOA}}$ & Methylene chloride & $\underline{0.77 \mathrm{~J} \mathrm{~J}} \quad \mathrm{ug} / \mathrm{L}$ & $\underline{0.57}$ \\
\hline$\overline{\mathrm{TB}}$ & TB-PARAGN 11/29/2005 1300 & EU410054 & $\underline{\mathrm{VOA}}$ & Acetone & $25=u g / L$ & $\overline{1.4}$ \\
\hline$\overline{\mathrm{TB}}$ & TB-PARAGN 11/29/2005 1300 & $\overline{\mathrm{EU} 410054}$ & $\underline{\mathrm{VOA}}$ & Carbon disulfide & $14=u g / L$ & $\underline{0.095}$ \\
\hline$\overline{\mathrm{TB}}$ & TB-PARAGN 11/30/2005 1320 & $\overline{\text { EU410055 }}$ & $\overline{\mathrm{VOA}}$ & Acetone & $15 \quad \mathrm{~J} \quad \mathrm{~A} 06 \mathrm{ug} / \mathrm{L}$ & $\overline{1.4}$ \\
\hline$\overline{\mathrm{TB}}$ & TB-PARAGN 11/30/2005 1320 & $\overline{\text { EU410055 }}$ & $\overline{\mathrm{VOA}}$ & $\overline{\text { Carbon disulfide }}$ & $15 \quad \mathrm{~J} \quad \mathrm{~A} 06 \mathrm{ug} / \mathrm{L}$ & $\overline{0.095}$ \\
\hline$\underline{\mathrm{TB}}$ & TB-PARAGN 12/1/2005 1110 & $\underline{\text { EU410056 }}$ & $\underline{\mathrm{VOA}}$ & Acetone & $10 \quad \mathrm{~J} \mathrm{~A} \quad \mathrm{~A} 06 \mathrm{ug} / \mathrm{L}$ & $\overline{1.4}$ \\
\hline$\overline{\mathrm{TB}}$ & TB-PARAGN 12/1/2005 1110 & $\underline{\text { EU410056 }}$ & $\underline{\mathrm{VOA}}$ & Carbon disulfide & $14 \mathrm{~J} \mathrm{~A}$ A06 ug/L & $\underline{0.095}$ \\
\hline$\overline{\mathrm{TB}}$ & TB-PARAGN 12/6/2005 1400 & $\overline{\text { EU410051 }}$ & $\overline{\mathrm{VOA}}$ & Toluene & $0.19 \mathrm{~J} \mathrm{~J} \quad \mathrm{ug} / \mathrm{L}$ & $\overline{0.13}$ \\
\hline$\overline{\mathrm{TB}}$ & TB-PARAGN 12/6/2005 1400 & $\overline{\text { EU410051 }}$ & $\overline{\mathrm{VOA}}$ & Acetone & $4.1 \mathrm{~J} \mathrm{~J} \quad \mathrm{ug} / \mathrm{L}$ & $\overline{1.4}$ \\
\hline$\underline{\mathrm{TB}}$ & TB-PARAGN 12/8/2005 1410 & EU410057 & $\mathrm{VOA}$ & Acetone & $5.4 \mathrm{~J} \mathrm{~J} \quad \mathrm{ug} / \mathrm{L}$ & $\underline{1.4}$ \\
\hline$\underline{\mathrm{TB}}$ & TB-PARAGN 12/8/2005 1410 & EU410057 & $\mathrm{VOA}$ & Carbon disulfide & $13=\mathrm{ug} / \mathrm{L}$ & $\underline{0.095}$ \\
\hline$\underline{\mathrm{TB}}$ & TB-PARAGN 12/13/2005 1257 & EU410058 & $\mathrm{VOA}$ & Acetone & $22=u g / L$ & 1.4 \\
\hline$\overline{\mathrm{TB}}$ & TB-PARAGN 12/13/2005 1257 & EU410058 & $\underline{\mathrm{VOA}}$ & Carbon disulfide & $5.1=u g / L$ & $\underline{0.095}$ \\
\hline$\overline{\mathrm{TB}}$ & TB-PARAGN 12/15/2005 1500 & $\overline{\text { EU410052 }}$ & $\underline{\mathrm{VOA}}$ & Acetone & $4.4 \mathrm{~J} \mathrm{~J} \quad \mathrm{ug} / \mathrm{L}$ & $\overline{1.4}$ \\
\hline$\overline{\mathrm{TB}}$ & TB-PARAGN 12/16/2005 1400 & $\overline{\text { EU410059 }}$ & $\overline{\mathrm{VOA}}$ & $\overline{\text { Acetone }}$ & $14 \quad \mathrm{~J} \quad \mathrm{~A} 06 \mathrm{ug} / \mathrm{L}$ & $\underline{1.4}$ \\
\hline$\overline{\mathrm{TB}}$ & TB-PARAGN 12/16/2005 1400 & $\overline{\text { EU410059 }}$ & $\overline{\mathrm{VOA}}$ & Methylene chloride & $38 \quad \mathrm{~J} \quad \mathrm{~A} 06 \mathrm{ug} / \mathrm{L}$ & $\overline{0.57}$ \\
\hline$\overline{\mathrm{TB}}$ & TB-PARAGN 12/16/2005 1400 & $\overline{\text { EU410059 }}$ & $\overline{\mathrm{VOA}}$ & $\overline{\text { Carbon disulfide }}$ & $14 \quad \mathrm{~J} \mathrm{~A} \quad 06 \mathrm{ug} / \mathrm{L}$ & $\overline{0.095}$ \\
\hline$\underline{\mathrm{TB}}$ & TB-PARAGN 12/21/20051030 & $\underline{\text { EU410060 }}$ & $\underline{\mathrm{VOA}}$ & Isopropyl alcohol & $7.4 \mathrm{~J} \quad \mathrm{R} \quad 001 \mathrm{ug} / \mathrm{L}$ & - \\
\hline$\overline{\mathrm{TB}}$ & TB-PARAGN 12/21/2005 1030 & $\overline{\text { EU410060 }}$ & $\underline{\mathrm{VOA}}$ & Acetone & $13=\mathrm{ug} / \mathrm{L}$ & 1.4 \\
\hline
\end{tabular}


Table L.2. (continued)

\begin{tabular}{|c|c|c|c|c|c|c|}
\hline$\frac{\text { Sample }}{\text { type }}$ & $\underline{\text { Blank }}$ & $\underline{\text { Sample ID }}$ & Category & Chemical name & Result, Lab Qual, Val Qual, RC & $\underline{\text { Detect limit }}$ \\
\hline$\underline{\mathrm{TB}}$ & TB-PARAGN 1/9/2006 1257 & EU410062 & $\underline{\mathrm{VOA}}$ & $\underline{\text { Acetone }}$ & $26=u g / L$ & $\underline{1.4}$ \\
\hline$\underline{\mathrm{TB}}$ & TB-PARAGN 1/9/2006 1257 & $\underline{\text { EU410062 }}$ & $\underline{\mathrm{VOA}}$ & Carbon disulfide & $\underline{4.2}=\mathrm{ug} / \mathrm{L}$ & $\underline{0.095}$ \\
\hline$\underline{\mathrm{TB}}$ & TB-PARAGN 1/10/2006 1145 & $\underline{\text { EU410063 }}$ & $\underline{\mathrm{VOA}}$ & $\underline{\text { Acetone }}$ & $\underline{24}=\mathrm{ug} / \mathrm{L}$ & $\underline{1.4}$ \\
\hline$\underline{\mathrm{TB}}$ & $\underline{\text { TB-PARAGN 1/10/2006 } 1145}$ & $\underline{\text { EU410063 }}$ & $\underline{\mathrm{VOA}}$ & $\underline{\text { Carbon disulfide }}$ & $\underline{5.1=u g / L}$ & $\underline{0.095}$ \\
\hline$\underline{\mathrm{TB}}$ & $\underline{\text { TB-PARAGN 1/10/2006 } 1300}$ & $\underline{\text { EU410061 }}$ & $\underline{\mathrm{VOA}}$ & $\underline{\text { Acetone }}$ & $\underline{2.8 \mathrm{~J} \mathrm{~J}} \quad \mathrm{ug} / \mathrm{L}$ & $\underline{1.4}$ \\
\hline$\underline{\mathrm{TB}}$ & TB-PARAGN 1/11/2006 1200 & $\underline{\text { EU410064 }}$ & $\underline{\mathrm{VOA}}$ & Acetone & $\underline{21}=\mathrm{ug} / \mathrm{L}$ & $\underline{1.4}$ \\
\hline$\underline{\mathrm{TB}}$ & $\underline{\text { TB-PARAGN 1/12/2006 } 1200}$ & $\underline{\text { EU410065 }}$ & $\underline{\mathrm{VOA}}$ & $\underline{\text { Acetone }}$ & $\underline{5.3 \mathrm{~J} \mathrm{~J} \mathrm{N03} \mathrm{ug} / \mathrm{L}}$ & $\underline{1.4}$ \\
\hline$\underline{\mathrm{TB}}$ & TB-PARAGN 1/12/2006 1200 & $\underline{\text { EU410065 }}$ & $\underline{\mathrm{VOA}}$ & Methylene chloride & $\underline{0.81 \mathrm{~J} \mathrm{~J}} \quad \mathrm{ug} / \mathrm{L}$ & $\underline{0.57}$ \\
\hline$\underline{\mathrm{TB}}$ & $\underline{\text { TB-PARAGN 1/12/2006 } 1200}$ & $\underline{\text { EU410065 }}$ & $\underline{\mathrm{VOA}}$ & $\underline{\text { Carbon disulfide }}$ & $9.5=\mathrm{ug} / \mathrm{L}$ & $\underline{0.095}$ \\
\hline$\underline{\mathrm{TB}}$ & TB-PARAGN 1/18/2006 1235 & $\underline{\text { EU410068 }}$ & $\underline{\mathrm{VOA}}$ & $\underline{\text { Acetone }}$ & $\underline{14}=u g / L$ & $\underline{1.4}$ \\
\hline$\underline{\mathrm{TB}}$ & $\underline{\text { TB-PARAGN 1/18/2006 } 1235}$ & $\underline{\text { EU410068 }}$ & $\underline{\mathrm{VOA}}$ & $\underline{\text { Carbon disulfide }}$ & $\underline{0.96 \mathrm{~J} \mathrm{~J}} \quad \mathrm{ug} / \mathrm{L}$ & $\underline{0.095}$ \\
\hline$\underline{\mathrm{TB}}$ & $\underline{\text { TB-PARAGN 2/15/2006 } 1510}$ & $\underline{\text { HLRDA047 }}$ & $\underline{\mathrm{VOA}}$ & $\underline{\text { Methylene chloride }}$ & $\underline{0.58 \mathrm{~J} \mathrm{~J}} \quad \mathrm{ug} / \mathrm{L}$ & $\underline{0.57}$ \\
\hline$\underline{\mathrm{TB}}$ & $\underline{\text { TB-PARAGN 2/16/2006 } 820}$ & $\underline{\text { HLRDA048 }}$ & $\underline{\mathrm{VOA}}$ & $\underline{\text { Toluene }}$ & $\underline{0.69 \mathrm{~J} \mathrm{~J}} \quad \mathrm{ug} / \mathrm{L}$ & $\underline{0.13}$ \\
\hline$\underline{\mathrm{TB}}$ & TB-STLMO 9/12/2006 820 & $\underline{\text { EU370029 }}$ & $\underline{\mathrm{VOA}}$ & $\underline{\text { Acetone }}$ & $7 \mathrm{~J} \mathrm{~J} \quad \mathrm{ug} / \mathrm{L}$ & $\underline{3.8}$ \\
\hline$\underline{\mathrm{TB}}$ & TB-PARAGN 9/19/2006900 & $\underline{\mathrm{K} 25 \mathrm{~A} 0391}$ & $\underline{\mathrm{VOA}}$ & $\underline{\text { Acetone }}$ & $\underline{1.9 \mathrm{~J} \mathrm{~J} \quad u g / L}$ & $\underline{1.4}$ \\
\hline$\underline{\mathrm{TB}}$ & $\underline{\text { TB-PARAGN 9/21/2006 } 1700}$ & $\underline{\text { EU41-TB01 }}$ & $\underline{\mathrm{VOA}}$ & Methylene chloride & $\underline{0.61 \mathrm{~J} \mathrm{~J}} \quad \mathrm{ug} / \mathrm{L}$ & $\underline{0.18}$ \\
\hline$\underline{\mathrm{TB}}$ & TB-PARAGN 9/25/2006 1135 & $\underline{\text { EU41-TB02 }}$ & $\underline{\mathrm{VOA}}$ & Acetone & $\underline{3.6 \mathrm{~J} \mathrm{~J}} \quad \mathrm{ug} / \mathrm{L}$ & $\underline{3.2}$ \\
\hline$\underline{\mathrm{TB}}$ & TB-PARAGN 9/25/2006 1135 & EU41-TB02 & $\underline{\mathrm{VOA}}$ & $\underline{\text { Methylene chloride }}$ & $\underline{1.6}=\mathrm{ug} / \mathrm{L}$ & $\underline{0.18}$ \\
\hline$\underline{\mathrm{TB}}$ & TB-PARAGN 9/25/2006 1135 & $\underline{\text { EU41-TB02 }}$ & $\underline{\mathrm{VOA}}$ & $\underline{\text { Carbon disulfide }}$ & $\underline{0.17 \mathrm{~J} \mathrm{~J}} \quad$ ug/L & $\underline{0.084}$ \\
\hline$\underline{\mathrm{TB}}$ & TB-PARAGN 9/25/2006 1135 & EU41-TB02 & $\underline{\mathrm{VOA}}$ & Trichlorofluoromethane & $\underline{0.11 \mathrm{~J} \mathrm{~J}} \quad \mathrm{ug} / \mathrm{L}$ & $\underline{0.11}$ \\
\hline$\underline{\mathrm{TB}}$ & $\underline{\text { TB-STLMO 9/25/2006 } 1235}$ & $\underline{\text { EU41-TB03 }}$ & $\underline{\mathrm{VOA}}$ & $\underline{\text { Toluene }}$ & $\underline{5 \mathrm{JB} \text { U F06 F01 ug/L }}$ & $\underline{0.13}$ \\
\hline$\underline{\mathrm{TB}}$ & TB-STLMO 9/28/2006 850 & $\underline{\text { MPLA }-025}$ & $\underline{\mathrm{VOA}}$ & $\underline{\text { Toluene }}$ & $\underline{0.69 \mathrm{~J} \mathrm{~B} \quad \mathrm{UJ}} \quad \mathrm{ug} / \mathrm{L}$ & $\underline{0.13}$ \\
\hline$\underline{\mathrm{TB}}$ & TB-STLMO 9/28/2006 850 & $\underline{\text { MPLA-025 }}$ & $\underline{\mathrm{VOA}}$ & $\underline{\text { Pentane }}$ & $\underline{8.2} \quad \mathrm{R} \quad \mathrm{ug} / \mathrm{L}$ & - \\
\hline$\underline{\mathrm{TB}}$ & TB-PARAGN 9/28/2006 1105 & $\underline{\text { MPLA-024 }}$ & $\underline{\mathrm{VOA}}$ & $\underline{\text { Chloromethane }}$ & $\underline{0.2 \mathrm{~J} \mathrm{~J}} \quad \mathrm{ug} / \mathrm{L}$ & $\underline{0.13}$ \\
\hline$\underline{\mathrm{TB}}$ & TB-PARAGN 9/28/2006 1105 & MPLA-024 & $\underline{\mathrm{VOA}}$ & Methylene chloride & $\underline{2.3}=\mathrm{ug} / \mathrm{L}$ & $\underline{0.18}$ \\
\hline
\end{tabular}

All reported detects from field blanks are shown (some were determined to be nondetects in validation).

In the "Results" column, both laboratory and validation qualifiers are shown separated by character spaces

If no laboratory qualifier was reported, only the validation qualifier (preceded by a space) is seen.

Laboratory detection limits are shown for comparison [tentatively identified compounds (TIDs) have no DL (detection limit)].

$\underline{F B}=$ field blank

RIN = rinseate

$\mathrm{QC}=$ quality control

$\underline{\mathrm{RC}=\text { validation reason code }}$

Qualifier definitions:

" $="=$ acceptable, no qualifier (validation use only)

$*=$ precision outlier in laboratory in-house duplicate 
Table L.2. (continued)

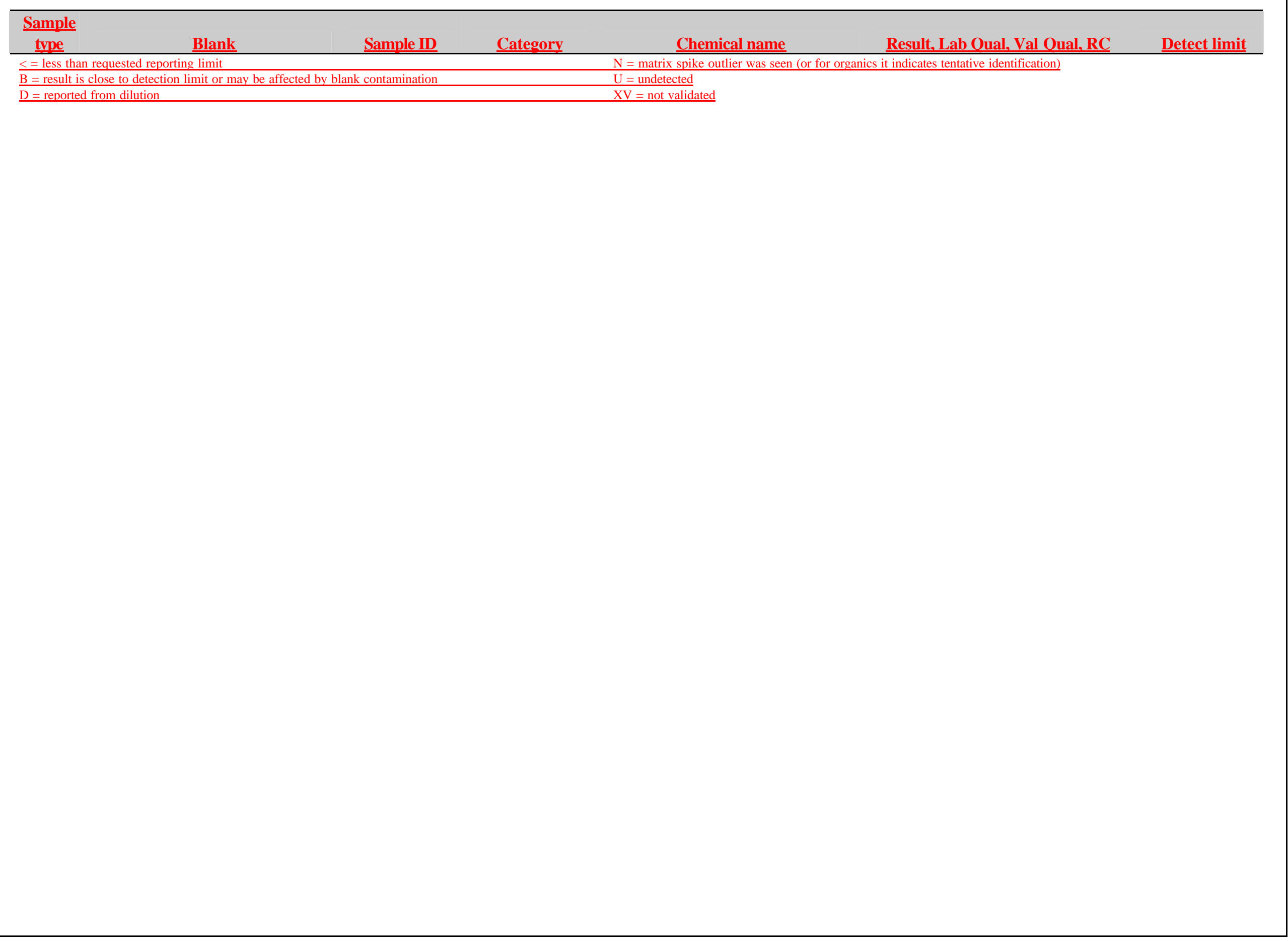


Table L.3. Zone 2 field replicate and split results compared with detected results in the associated regular field samples

\begin{tabular}{|c|c|c|c|c|c|c|c|c|c|c|c|c|c|}
\hline Station & Date-time & Depth & Category & Chemical name & $\underline{\text { Reg }} \underset{\text { result }}{\underline{\text { Ren }}}$ & Units & $\frac{\frac{\text { Field rep }}{\text { result }}}{\text { res }}$ & 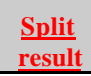 & $\frac{\text { Qual }}{(\text { lab, val, RC) }}$ & FR qual (lab, val, RC) & Split qual & $\underline{\mathrm{FR}}$ & $\underline{\text { Split }}$ \\
\hline$\underline{\text { Z2-EU28B-319 }}$ & $03 / 08 / 20051345$ & $\underline{0-10}$ & Metal & Mercury & 0.12 & $\underline{\mathrm{mg} / \mathrm{kg}}$ & 0.08 & & *J & * J J01, J02 & & $\underline{40}$ & \\
\hline Z2-EU28B-319 & $03 / 08 / 20051345$ & $\overline{0-10}$ & Metal & Aluminum & 17000 & $\underline{\mathrm{mg} / \mathrm{kg}}$ & 8370 & & $\equiv$ & $\equiv$ & & 68 & \\
\hline Z2-EU28B-319 & $03 / 08 / 20051345$ & $\underline{0-10}$ & Metal & Antimony & 0.041 & $\underline{\mathrm{mg} / \mathrm{kg}}$ & $\underline{0.09}$ & & $\mathrm{BN} \mathrm{J}$ & BN J H02, I02, J01, J02 & & $\underline{75}$ & \\
\hline Z2-EU28B-319 & $03 / 08 / 20051345$ & $0-10$ & Metal & Arsenic & 7.4 & $\underline{\mathrm{mg} / \mathrm{kg}}$ & 5.11 & & $\equiv$ & $\underline{\mathrm{UU}}$ & & & \\
\hline Z2-EU28B-319 & $03 / 08 / 20051345$ & $\underline{0-10}$ & Metal & Barium & 67.2 & $\mathrm{mg} / \mathrm{kg}$ & 48.9 & & $\underline{\mathrm{NJ}}$ & N J H01, I01 & & $\underline{32}$ & \\
\hline Z2-EU28B-319 & $03 / 08 / 20051345$ & $0-10$ & Metal & Beryllium & 0.41 & $\underline{\mathrm{mg} / \mathrm{kg}}$ & 0.28 & & $\mathrm{BJ}$ & B J & & 38 & \\
\hline Z2-EU28B-319 & $03 / 08 / 20051345$ & $\underline{0-10}$ & Metal & Boron & 5.8 & $\mathrm{mg} / \mathrm{kg}$ & 6.6 & & $\underline{B J}$ & J F10, F12 & & $\underline{13}$ & \\
\hline Z2-EU28B-319 & $03 / 08 / 20051345$ & $0-10$ & Metal & Cadmium & 0.59 & $\underline{\mathrm{mg} / \mathrm{kg}}$ & 0.33 & & $E=$ & $E=$ & & 57 & \\
\hline Z2-EU28B-319 & $03 / 08 / 20051345$ & $\underline{0-10}$ & Metal & Calcium & $\underline{115000}$ & $\mathrm{mg} / \mathrm{kg}$ & 206000 & & 粦 & *J F01, F02 & & $\underline{57}$ & \\
\hline Z2-EU28B-319 & $03 / 08 / 20051345$ & $0-10$ & Metal & Chromium & 18.8 & $\underline{\mathrm{mg} / \mathrm{kg}}$ & 43.7 & & $\equiv$ & $\equiv$ & & $\underline{80}$ & \\
\hline$\underline{\underline{\text { Z2-EU28B-319 }}}$ & $03 / 08 / 20051345$ & $\underline{0-10}$ & Metal & Cobalt & 14.5 & $\underline{\mathrm{mg} / \mathrm{kg}}$ & 6.2 & & 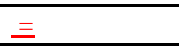 & 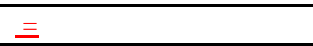 & & $\underline{80}$ & \\
\hline Z2-EU28B-319 & $03 / 08 / 20051345$ & $0-10$ & Metal & Copper & 13.3 & $\underline{\mathrm{mg} / \mathrm{kg}}$ & 11 & & $\equiv$ & $\equiv$ & & $\underline{19}$ & \\
\hline$\overline{\text { Z2-EU28B-319 }}$ & $03 / 08 / 20051345$ & $\overline{0-10}$ & $\overline{\text { Metal }}$ & Iron & $\underline{16000}$ & $\overline{\mathrm{mg} / \mathrm{kg}}$ & $\underline{12400}$ & & $\equiv$ & $\equiv$ & & 25 & \\
\hline Z2-EU28B-319 & $03 / 08 / 20051345$ & $0-10$ & Metal & Lead & 32.3 & $\underline{\mathrm{mg} / \mathrm{kg}}$ & 20.5 & & EEN J & *EN J H01, H04, J01, J02 & & 45 & \\
\hline$\underline{\underline{\text { Z2-EU28B-319 }}}$ & $03 / 08 / 20051345$ & $\underline{0-10}$ & Metal & Lithium & 15.1 & $\underline{\mathrm{mg} / \mathrm{kg}}$ & 7.2 & & *EN J & *EN J H01, J01, J03 & & $\underline{71}$ & \\
\hline Z2-EU28B-319 & $03 / 08 / 20051345$ & $0-10$ & Metal & Magnesium & 10700 & $\underline{\mathrm{mg} / \mathrm{kg}}$ & 11500 & & *J & * J J01, J03 & & 7 & \\
\hline Z2-EU28B-319 & $03 / 08 / 20051345$ & $\underline{0-10}$ & Metal & Manganese & 1530 & $\underline{\mathrm{mg} / \mathrm{kg}}$ & 447 & & $\equiv$ & $\equiv$ & & $\underline{110}$ & \\
\hline Z2-EU28B-319 & $03 / 08 / 20051345$ & $\overline{0-10}$ & Metal & Molybdenum & 1.4 & $\underline{\mathrm{mg} / \mathrm{kg}}$ & 0.61 & & $\equiv$ & $\underline{B J}$ & & $\overline{79}$ & \\
\hline Z2-EU28B-319 & $03 / 08 / 20051345$ & $\underline{0-10}$ & Metal & Nickel & 17.2 & $\underline{\mathrm{mg} / \mathrm{kg}}$ & 17.1 & & $\equiv$ & $\equiv$ & & 1 & \\
\hline Z2-EU28B-319 & $03 / 08 / 20051345$ & $0-10$ & Metal & Phosphorous & 334 & $\underline{\mathrm{mg} / \mathrm{kg}}$ & 230 & & * J & * J I02, J01, J02, J03 & & 37 & \\
\hline$\overline{\overline{Z 2-E U 28 B-319}}$ & $03 / 08 / 20051345$ & $\overline{\underline{0-10}}$ & $\overline{\text { Metal }}$ & $\overline{\text { Potassium }}$ & $\underline{1280}$ & $\underline{\mathrm{mg} / \mathrm{kg}}$ & $\underline{1230}$ & & $\overline{\mathrm{NJ}}$ & N J H01 & & $\overline{4}$ & \\
\hline Z2-EU28B-319 & $03 / 08 / 20051345$ & $0-10$ & Metal & Selenium & 1.7 & $\underline{\mathrm{mg} / \mathrm{kg}}$ & 11.9 & & $\equiv$ & $\underline{\mathrm{UU}}$ & & & \\
\hline Z2-EU28B-319 & $03 / 08 / 20051345$ & $\underline{0-10}$ & Metal & $\begin{array}{l}\text { Silver } \\
\end{array}$ & 0.31 & $\mathrm{mg} / \mathrm{kg}$ & 0.205 & & $\underline{B J}$ & $\underline{\mathrm{UU}}$ & & & \\
\hline Z2-EU28B-319 & $03 / 08 / 20051345$ & $0-10$ & Metal & Sodium & 70.5 & $\underline{\mathrm{mg} / \mathrm{kg}}$ & 106 & & $\equiv$ & $\equiv$ & & $\underline{40}$ & \\
\hline$\overline{\text { Z2-EU28B-319 }}$ & $03 / 08 / 20051345$ & $\overline{0-10}$ & $\overline{\text { Metal }}$ & Strontium & $\overline{124}$ & $\underline{\mathrm{mg} / \mathrm{kg}}$ & 226 & & *N J & "N J H03, I03, J01, J02 & & 58 & \\
\hline Z2-EU28B-319 & $03 / 08 / 20051345$ & $0-10$ & Metal & Thallium & 0.19 & $\underline{\mathrm{mg} / \mathrm{kg}}$ & 0.14 & & $\equiv$ & $\equiv$ & & $\underline{30}$ & \\
\hline$\overline{\text { Z2-EU28B-319 }}$ & $03 / 08 / 20051345$ & $\overline{\overline{0-10}}$ & Metal & $\underline{\underline{\operatorname{Tin}}}$ & $\overline{1.1}$ & $\underline{\mathrm{mg} / \mathrm{kg}}$ & $\overline{41.1}$ & & $\underline{B J}$ & $\underline{\mathrm{U} U}$ & & & \\
\hline Z2-EU28B-319 & $03 / 08 / 20051345$ & $0-10$ & Metal & Titanium & 197 & $\underline{\mathrm{mg} / \mathrm{kg}}$ & 85.7 & & *N J & N J J01, J02 & & $\underline{79}$ & \\
\hline$\overline{\text { Z2-EU28B-319 }}$ & $03 / 08 / 20051345$ & $\overline{\overline{0-10}}$ & Metal & Uranium & $\overline{0.84}$ & $\overline{\mathrm{mg} / \mathrm{kg}}$ & $\overline{0.89}$ & & $\overline{* \mathrm{~J}}$ & * J J01, J02, J03 & & $\overline{6}$ & \\
\hline Z2-EU28B-319 & $03 / 08 / 20051345$ & $0-10$ & Metal & Vanadium & 33.9 & $\underline{\mathrm{mg} / \mathrm{kg}}$ & 20.2 & & $\equiv$ & $\equiv$ & & 51 & \\
\hline$\underline{\underline{\text { Z2-EU28B-319 }}}$ & $03 / 08 / 20051345$ & $\underline{0-10}$ & Metal & Zinc & $\underline{44}$ & $\underline{\mathrm{mg} / \mathrm{kg}}$ & 48.5 & & $\mathrm{E}=$ & $\mathrm{E}=$ & & 10 & \\
\hline Z2-EU28-106 & $03 / 18 / 20051130$ & $0-10$ & Metal & Mercury & 0.0052 & $\underline{\mathrm{mg} / \mathrm{kg}}$ & 0.0051 & & *BN J & BN J I01 & & $\underline{2}$ & \\
\hline Z2-EU28-106 & $03 / 18 / 20051130$ & $\underline{0-10}$ & Metal & Aluminum & 24600 & $\underline{\mathrm{mg} / \mathrm{kg}}$ & 19300 & & $\equiv$ & $\equiv$ & & 24 & \\
\hline Z2-EU28-106 & $03 / 18 / 20051130$ & $\overline{0-10}$ & Metal & Antimony & 0.036 & $\underline{\mathrm{mg} / \mathrm{kg}}$ & $\underline{0.023}$ & & $\underline{B U}$ & B U F06 & & & \\
\hline Z2-EU28-106 & $03 / 18 / 20051130$ & $\underline{0-10}$ & Metal & Arsenic & $\underline{11.9}$ & $\underline{\mathrm{mg} / \mathrm{kg}}$ & 13.2 & & $\equiv$ & $\equiv$ & & 10 & \\
\hline Z2-EU28-106 & $03 / 18 / 20051130$ & $0-10$ & Metal & Barium & 127 & $\underline{\mathrm{mg} / \mathrm{kg}}$ & 102 & & $\equiv$ & $\equiv$ & & 22 & \\
\hline$\overline{\text { Z2-EU28-106 }}$ & $03 / 18 / 20051130$ & $\overline{0-10}$ & $\overline{\text { Metal }}$ & Beryllium & $\overline{1}$ & $\underline{\mathrm{mg} / \mathrm{kg}}$ & $\overline{0.82}$ & & $\equiv$ & $\equiv$ & & $\underline{20}$ & \\
\hline Z2-EU28-106 & $03 / 18 / 20051130$ & $0-10$ & Metal & Boron & 6.8 & $\underline{\mathrm{mg} / \mathrm{kg}}$ & 5.4 & & $\equiv$ & B J & & $\underline{23}$ & \\
\hline$\overline{\text { Z2-EU28-106 }}$ & $03 / 18 / 20051130$ & $\overline{0-10}$ & Metal & Cadmium & 0.39 & $\underline{\mathrm{mg} / \mathrm{kg} g}$ & 0.31 & & $\equiv$ & $\bar{\equiv}$ & & $\underline{23}$ & \\
\hline
\end{tabular}


Table L.3. (continued)

\begin{tabular}{|c|c|c|c|c|c|c|c|c|c|c|c|c|c|}
\hline Station & Date-time & Depth & Category & Chemical name & $\underset{\text { result }}{\text { Reg }}$ & Units & $\frac{\text { Field rep }}{\text { result }}$ & 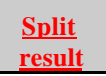 & $\frac{\text { Qual }}{(\text { lab, val, RC) }}$ & FR qual (lab, val, RC) & Split qual & $\underline{\mathrm{FR}}$ & $\underline{\text { Split }}$ \\
\hline$\underline{\underline{\text { Z2-EU28-106 }}}$ & $03 / 18 / 20051130$ & $\underline{0-10}$ & Metal & Calcium & 4860 & $\underline{\mathrm{mg} / \mathrm{kg}}$ & 5790 & & $\equiv$ & $\equiv$ & & 17 & \\
\hline Z2-EU28-106 & $03 / 18 / 20051130$ & $0-10$ & Metal & Chromium & 42.4 & $\mathrm{mg} / \mathrm{kg}$ & 76.2 & & $\equiv$ & $\equiv$ & & 57 & \\
\hline$\underline{\text { Z2-EU28-106 }}$ & $03 / 18 / 20051130$ & $\underline{\underline{0-10}}$ & Metal & Cobalt & 13.2 & $\mathrm{mg} / \mathrm{kg}$ & 15.3 & & $\equiv$ & $\underline{\underline{E}}$ & & $\underline{15}$ & \\
\hline Z2-EU28-106 & $03 / 18 / 20051130$ & $0-10$ & Metal & Copper & 24.8 & $\mathrm{mg} / \mathrm{kg}$ & 21.2 & & $\equiv$ & $\equiv$ & & 16 & \\
\hline Z2-EU28-106 & $03 / 18 / 20051130$ & $\underline{\underline{0-10}}$ & Metal & Iron & $\underline{32200}$ & $\mathrm{mg} / \mathrm{kg}$ & $\underline{32100}$ & & $\equiv$ & 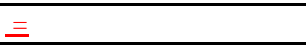 & & $\underline{\underline{0}}$ & \\
\hline Z2-EU28-106 & $03 / 18 / 20051130$ & $0-10$ & Metal & Lead & 26.5 & $\mathrm{mg} / \mathrm{kg}$ & 25.1 & & $\equiv$ & $\equiv$ & & $\underline{5}$ & \\
\hline Z2-EU28-106 & $03 / 18 / 20051130$ & $\underline{0-10}$ & Metal & Lithium & $\underline{16}$ & $\mathrm{mg} / \mathrm{kg}$ & $\underline{25.3}$ & & $\equiv$ & $\bar{E}$ & & $\underline{45}$ & \\
\hline Z2-EU28-106 & $03 / 18 / 20051130$ & $\underline{0-10}$ & Metal & Magnesium & 4060 & $\mathrm{mg} / \mathrm{kg}$ & $\underline{3800}$ & & $\equiv$ & $\equiv$ & & 7 & \\
\hline Z2-EU28-106 & $03 / 18 / 20051130$ & $\underline{0-10}$ & Metal & Manganese & 963 & $\mathrm{mg} / \mathrm{kg}$ & 1370 & & $\equiv$ & $\equiv$ & & $\underline{35}$ & \\
\hline Z2-EU28-106 & $03 / 18 / 20051130$ & $0-10$ & Metal & Molybdenum & 0.7 & $\mathrm{mg} / \mathrm{kg}$ & 0.97 & & B J & B J & & 32 & \\
\hline Z2-EU28-106 & $03 / 18 / 20051130$ & $\underline{0-10}$ & Metal & Nickel & $\underline{37}$ & $\mathrm{mg} / \mathrm{kg}$ & 41.1 & & $\equiv$ & $\equiv$ & & $\underline{10}$ & \\
\hline Z2-EU28-106 & $03 / 18 / 20051130$ & $0-10$ & Metal & Phosphorous & 439 & $\mathrm{mg} / \mathrm{kg}$ & 1060 & & $\equiv$ & $\equiv$ & & $\underline{83}$ & \\
\hline Z2-EU28-106 & $03 / 18 / 20051130$ & $\underline{0-10}$ & Metal & Potassium & $\underline{3160}$ & $\mathrm{mg} / \mathrm{kg}$ & 2080 & & $\equiv$ & $\equiv$ & & $\underline{41}$ & \\
\hline Z2-EU28-106 & $03 / 18 / 20051130$ & $0-10$ & Metal & Selenium & 1.1 & $\mathrm{mg} / \mathrm{kg}$ & 1.4 & & $\underline{R}$ & R E07, F01, F07 & & & \\
\hline$\overline{\text { Z2-EU28-106 }}$ & $03 / 18 / 20051130$ & $\overline{\overline{0-10}}$ & $\overline{\text { Metal }}$ & $\overline{\text { Sodium }}$ & $\overline{47}$ & $\overline{\mathrm{mg} / \mathrm{kg} g}$ & $\overline{55.8}$ & & $\bar{\equiv}$ & 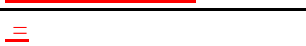 & & 17 & \\
\hline Z2-EU28-106 & $03 / 18 / 20051130$ & $0-10$ & Metal & Strontium & 12.2 & $\mathrm{mg} / \mathrm{kg}$ & 15.9 & & $\equiv$ & $\equiv$ & & 26 & \\
\hline$\underline{\underline{\text { Z2-EU28-106 }}}$ & $03 / 18 / 20051130$ & $\underline{0-10}$ & Metal & Thallium & 0.31 & $\mathrm{mg} / \mathrm{kg}$ & 0.29 & & $\equiv$ & $\equiv$ & & 7 & \\
\hline Z2-EU28-106 & $03 / 18 / 20051130$ & $0-10$ & Metal & Tin & 1.1 & $\mathrm{mg} / \mathrm{kg}$ & 0.7 & & $\mathrm{BJ}$ & B J & & 44 & \\
\hline$\underline{\underline{\text { Z2-EU28-106 }}}$ & $03 / 18 / 20051130$ & $\underline{0-10}$ & Metal & Titanium & $\underline{226}$ & $\mathrm{mg} / \mathrm{kg}$ & $\underline{167}$ & & $\equiv$ & $\equiv$ & & 30 & \\
\hline Z2-EU28-106 & $03 / 18 / 20051130$ & $0-10$ & Metal & Uranium & 6.3 & $\mathrm{mg} / \mathrm{kg}$ & 7.1 & & $\equiv$ & $\equiv$ & & 12 & \\
\hline Z2-EU28-106 & $03 / 18 / 20051130$ & $\underline{0-10}$ & Metal & Vanadium & 47.9 & $\mathrm{mg} / \mathrm{kg}$ & 45.2 & & $\equiv$ & $\equiv$ & & $\underline{6}$ & \\
\hline Z2-EU28-106 & $03 / 18 / 20051130$ & $0-10$ & Metal & Zinc & $\underline{56.6}$ & $\mathrm{mg} / \mathrm{kg}$ & 53.9 & & $\equiv$ & $\equiv$ & & 5 & \\
\hline Z2-EU28-201 & $03 / 22 / 20051205$ & $\underline{0-10}$ & Metal & Mercury & $\underline{0.098}$ & $\underline{\mathrm{mg} / \mathrm{kg}}$ & & 0.089 & *E $\mathrm{E}=$ & & $\underline{\underline{E}}$ & & $\underline{10}$ \\
\hline Z2-EU28-201 & $03 / 22 / 20051205$ & $0-10$ & Metal & Aluminum & 38000 & $\mathrm{mg} / \mathrm{kg}$ & & 14000 & ${ }^{* \mathrm{E} \mathrm{J}}$ & & $\equiv$ & & 92 \\
\hline Z2-EU28-201 & $03 / 22 / 20051205$ & $\underline{0-10}$ & Metal & Antimony & $\underline{0.021}$ & $\mathrm{mg} / \mathrm{kg}$ & & $\underline{0.066}$ & $\mathrm{BNJ}$ & & $\equiv$ & & 103 \\
\hline Z2-EU28-201 & $03 / 22 / 20051205$ & $0-10$ & Metal & Arsenic & 15.9 & $\mathrm{mg} / \mathrm{kg}$ & & $\underline{13}$ & $\equiv$ & & $\equiv$ & & $\underline{20}$ \\
\hline Z2-EU28-201 & $03 / 22 / 20051205$ & $\underline{0-10}$ & Metal & Barium & $\underline{69.5}$ & $\underline{\mathrm{mg} / \mathrm{kg}}$ & & $\underline{41}$ & *N J & & $\equiv$ & & $\underline{52}$ \\
\hline Z2-EU28-201 & $03 / 22 / 20051205$ & $0-10$ & Metal & Beryllium & 1.4 & $\mathrm{mg} / \mathrm{kg}$ & & 0.73 & $\equiv$ & & $\equiv$ & & $\underline{63}$ \\
\hline Z2-EU28-201 & $03 / 22 / 20051205$ & $\underline{0-10}$ & Metal & Boron & 9.6 & $\mathrm{mg} / \mathrm{kg}$ & & 2.6 & $\equiv$ & & $\underline{\mathrm{BJ}}$ & & $\underline{115}$ \\
\hline Z2-EU28-201 & $03 / 22 / 20051205$ & $0-10$ & Metal & Cadmium & 0.4 & $\mathrm{mg} / \mathrm{kg}$ & & 0.91 & $\equiv$ & & $\equiv$ & & $7 \underline{78}$ \\
\hline$\overline{\text { Z2-EU28-201 }}$ & $03 / 22 / 20051205$ & $\overline{\overline{0-10}}$ & Metal & $\overline{\text { Calcium }}$ & 3070 & $\underline{\mathrm{mg} / \mathrm{kg} g}$ & & $\underline{32000}$ & 类 & & $\bar{E}$ & & $\underline{165}$ \\
\hline Z2-EU28-201 & $03 / 22 / 20051205$ & $0-10$ & Metal & Chromium & $\underline{43}$ & $\mathrm{mg} / \mathrm{kg}$ & & $\underline{30}$ & $\equiv$ & & $\equiv$ & & 36 \\
\hline$\overline{Z \text { Z2-EU28-201 }}$ & $03 / 22 / 20051205$ & $\overline{0-10}$ & Metal & $\overline{\text { Cobalt }}$ & 6.9 & $\mathrm{mg} / \mathrm{kg}$ & & 6.1 & $\equiv$ & & $\equiv$ & & $\underline{12}$ \\
\hline Z2-EU28-201 & $03 / 22 / 20051205$ & $0-10$ & Metal & Copper & 32.4 & $\mathrm{mg} / \mathrm{kg}$ & & 27 & 类 & & $\equiv$ & & 18 \\
\hline Z2-EU28-201 & $03 / 22 / 20051205$ & $0-10$ & Metal & Iron & $\underline{54500}$ & $\mathrm{mg} / \mathrm{kg}$ & & 41000 & $\underline{\underline{E}}$ & & $\equiv$ & & $\underline{28}$ \\
\hline$\overline{\text { Z2-EU28-201 }}$ & $03 / 22 / 20051205$ & $\overline{\overline{0-10}}$ & $\overline{\text { Metal }}$ & Lead & $\overline{\underline{54}}$ & $\overline{\mathrm{mg} / \mathrm{kg}}$ & & $\overline{\underline{35}}$ & $\equiv$ & & $\bar{E}$ & & $\underline{43}$ \\
\hline Z2-EU28-201 & $03 / 22 / 20051205$ & $\overline{0-10}$ & Metal & Lithium & 11.3 & $\mathrm{mg} / \mathrm{kg}$ & & 6.5 & *BEN J & & $\equiv$ & & $\underline{54}$ \\
\hline Z2-EU28-201 & $03 / 22 / 20051205$ & $0-10$ & Metal & Magnesium & 2000 & $\mathrm{mg} / \mathrm{kg}$ & & 6700 & 类 & & $\equiv$ & & 108 \\
\hline Z2-EU28-201 & $03 / 22 / 20051205$ & $\underline{0-10}$ & Metal & Manganese & 614 & $\underline{\mathrm{mg} / \mathrm{kg}}$ & & 420 & 宩 & & $\equiv$ & & $\underline{38}$ \\
\hline Z2-EU28-201 & $03 / 22 / 20051205$ & $0-10$ & Metal & Molybdenum & 1.2 & $\mathrm{mg} / \mathrm{kg}$ & & 1.4 & B J & & $\equiv$ & & $\underline{15}$ \\
\hline
\end{tabular}


Table L.3. (continued)

\begin{tabular}{|c|c|c|c|c|c|c|c|c|c|c|c|c|c|}
\hline Station & Date-time & Depth & Category & Chemical name & $\begin{array}{l}\text { Reg } \\
\text { result } \\
\end{array}$ & Units & $\frac{\text { Field rep }}{\text { result }}$ & 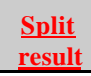 & $\left(\begin{array}{l}\text { Qual } \\
\text { (lab, val, RC) }\end{array}\right.$ & FR qual (lab, val, RC) & Split qual & $\underline{\mathrm{FR}}$ & $\underline{\text { Split }}$ \\
\hline Z2-EU28-201 & $03 / 22 / 20051205$ & $\underline{\underline{0-10}}$ & Metal & Nickel & 26.5 & $\underline{\mathrm{mg} / \mathrm{kg}}$ & & $\underline{15}$ & *N J & & $\equiv$ & & $\underline{55}$ \\
\hline Z2-EU28-201 & $03 / 22 / 20051205$ & $0-10$ & Metal & Potassium & 2440 & $\mathrm{mg} / \mathrm{kg}$ & & 780 & $\mathrm{E} \equiv$ & & $\equiv$ & & 103 \\
\hline Z2-EU28-201 & $03 / 22 / 20051205$ & $0-10$ & Metal & Selenium & 1.5 & $\underline{\mathrm{mg} / \mathrm{kg}}$ & & 0.84 & $\equiv$ & & $\underline{\mathrm{UU}}$ & & \\
\hline Z2-EU28-201 & $03 / 22 / 20051205$ & $\underline{0-10}$ & Metal & Sodium & 39.9 & $\mathrm{mg} / \mathrm{kg}$ & & 67 & $\equiv$ & & $\mathrm{BJ}$ & & $\underline{51}$ \\
\hline Z2-EU28-201 & $03 / 22 / 20051205$ & $0-10$ & Metal & Thallium & 1.1 & $\underline{\mathrm{mg} / \mathrm{kg}}$ & & 0.27 & $E \mathrm{EJ}$ & & $\equiv$ & & 121 \\
\hline Z2-EU28-201 & $03 / 22 / 20051205$ & $\underline{0-10}$ & Metal & Uranium & 3.6 & $\mathrm{mg} / \mathrm{kg}$ & & 1.6 & ${ }^{* \mathrm{~N} \mathrm{~J}}$ & & $\equiv$ & & $\underline{77}$ \\
\hline Z2-EU28-201 & $03 / 22 / 20051205$ & $\underline{\underline{0-10}}$ & Metal & Vanadium & 73.1 & $\underline{\underline{\mathrm{mg}} / \mathrm{kg}}$ & & $\underline{49}$ & $\underline{\mathrm{NJ}}$ & & $\equiv$ & & $\underline{39}$ \\
\hline Z2-EU28-201 & $03 / 22 / 20051205$ & $\underline{0-10}$ & Metal & Zinc & $\underline{79}$ & $\underline{\mathrm{mg} / \mathrm{kg}}$ & & $\underline{43}$ & $\equiv$ & & $\equiv$ & & $\underline{59}$ \\
\hline Z2-EU41DB-203 & $11 / 14 / 20051325$ & $\overline{0-10}$ & Metal & Mercury & 0.025 & $\underline{\mathrm{mg} / \mathrm{kg}}$ & 0.023 & & B J & B J & & $\underline{8}$ & \\
\hline Z2-EU41DB-203 & $11 / 14 / 20051325$ & $\underline{0-10}$ & Metal & Aluminum & 18000 & $\underline{\mathrm{mg} / \mathrm{kg}}$ & 20000 & & $\equiv$ & $\equiv$ & & $\underline{11}$ & \\
\hline Z2-EU41DB-203 & $\underline{11 / 14 / 20051325}$ & $\underline{0-10}$ & Metal & Antimony & $\underline{\underline{0.005}}$ & $\underline{\underline{\mathrm{mg}} / \mathrm{kg}}$ & $\underline{0.0048}$ & & $\underline{\mathrm{BJ}}$ & $\underline{\mathrm{BJ}}$ & & 4 & \\
\hline Z2-EU41DB-203 & $11 / 14 / 20051325$ & $0-10$ & Metal & Arsenic & 2.4 & $\underline{\mathrm{mg} / \mathrm{kg}}$ & 2.4 & & $\equiv$ & $\equiv$ & & $\underline{0}$ & \\
\hline Z2-EU41DB-203 & $\underline{11 / 14 / 20051325}$ & $\underline{0-10}$ & Metal & Barium & $\underline{140}$ & $\underline{\underline{\mathrm{mg}} / \mathrm{kg}}$ & $\underline{160}$ & & $\equiv$ & $\equiv$ & & $\underline{13}$ & \\
\hline Z2-EU41DB-203 & $11 / 14 / 20051325$ & $0-10$ & Metal & Beryllium & 1 & $\underline{\mathrm{mg} / \mathrm{kg}}$ & 1.1 & & $\equiv$ & $\equiv$ & & 10 & \\
\hline Z2-EU41DB-203 & $\underline{11 / 14 / 20051325}$ & $\underline{\underline{0-10}}$ & Metal & Boron & $\underline{1.5}$ & $\underline{\mathrm{mg} / \mathrm{kg}}$ & $\underline{1.9}$ & & $\equiv$ & $\equiv$ & & $\underline{24}$ & \\
\hline Z2-EU41DB-203 & $11 / 14 / 20051325$ & $0-10$ & Metal & Cadmium & 0.95 & $\mathrm{mg} / \mathrm{kg}$ & 1 & & $\equiv$ & $\equiv$ & & 5 & \\
\hline Z2-EU41DB-203 & $11 / 14 / 20051325$ & $0-10$ & Metal & Calcium & 3100 & $\underline{\mathrm{mg} / \mathrm{kg}}$ & 2700 & & $\equiv$ & $\equiv$ & & 14 & \\
\hline Z2-EU41DB-203 & $11 / 14 / 20051325$ & $0-10$ & Metal & Chromium & $\underline{23}$ & $\underline{\mathrm{mg} / \mathrm{kg}}$ & $2 \underline{25}$ & & $\equiv$ & $\equiv$ & & $\underline{8}$ & \\
\hline Z2-EU41DB-203 & $11 / 14 / 20051325$ & $0-10$ & Metal & Cobalt & 11 & $\underline{\mathrm{mg} / \mathrm{kg}}$ & 11 & & $\equiv$ & $\equiv$ & & $\underline{0}$ & \\
\hline Z2-EU41DB-203 & $11 / 14 / 20051325$ & $\underline{0-10}$ & Metal & Copper & $\underline{19}$ & $\underline{\mathrm{mg} / \mathrm{kg}}$ & $\underline{19}$ & & $\equiv$ & $\equiv$ & & $\underline{0}$ & \\
\hline Z2-EU41DB-203 & $11 / 14 / 20051325$ & $0-10$ & Metal & Iron & 28000 & $\underline{\mathrm{mg} / \mathrm{kg}}$ & 29000 & & $\equiv$ & $=$ & & 4 & \\
\hline Z2-EU41DB-203 & $11 / 14 / 20051325$ & $\underline{0-10}$ & Metal & Lead & $\underline{11}$ & $\mathrm{mg} / \mathrm{kg}$ & 11 & & $\equiv$ & $\equiv$ & & $\underline{0}$ & \\
\hline Z2-EU41DB-203 & $11 / 14 / 20051325$ & $\underline{\underline{0-10}}$ & Metal & $\begin{array}{l}\text { Lithium } \\
\end{array}$ & $\underline{13}$ & $\underline{\underline{\mathrm{mg}} / \mathrm{kg}}$ & $\underline{13}$ & & $\equiv$ & $\equiv$ & & $\underline{0}$ & \\
\hline Z2-EU41DB-203 & $11 / 14 / 20051325$ & $\underline{0-10}$ & Metal & Magnesium & 2100 & $\underline{\mathrm{mg} / \mathrm{kg}}$ & $\underline{2200}$ & & $\equiv$ & $\equiv$ & & $\underline{5}$ & \\
\hline Z2-EU41DB-203 & $11 / 14 / 20051325$ & $\underline{\underline{0-10}}$ & Metal & Manganese & 230 & $\underline{\mathrm{mg} / \mathrm{kg}}$ & $\underline{210}$ & & $\equiv$ & $\equiv$ & & $\underline{9}$ & \\
\hline Z2-EU41DB-203 & $11 / 14 / 20051325$ & $\underline{0-10}$ & Metal & Molybdenum & 0.23 & $\underline{\mathrm{mg} / \mathrm{kg}}$ & 0.15 & & $\underline{B J}$ & B J & & $\underline{42}$ & \\
\hline Z2-EU41DB-203 & $\underline{11 / 14 / 20051325}$ & $\underline{0-10}$ & Metal & Nickel & 32 & $\underline{\underline{\mathrm{mg}} / \mathrm{kg}}$ & 32 & & $\equiv$ & $\equiv$ & & $\underline{0}$ & \\
\hline Z2-EU41DB-203 & $11 / 14 / 20051325$ & $0-10$ & Metal & Potassium & 1800 & $\underline{\mathrm{mg} / \mathrm{kg}}$ & 2000 & & $\equiv$ & $\equiv$ & & $\underline{11}$ & \\
\hline Z2-EU41DB-203 & $11 / 14 / 20051325$ & $\overline{0-10}$ & Metal & Sodium & 5 & $\underline{\mathrm{mg} / \mathrm{kg}}$ & $5 \underline{59}$ & & $\equiv$ & $\equiv$ & & $\underline{13}$ & \\
\hline Z2-EU41DB-203 & $11 / 14 / 20051325$ & $0-10$ & Metal & Thallium & 0.17 & $\underline{\mathrm{mg} / \mathrm{kg}}$ & 0.2 & & $\equiv$ & $\equiv$ & & 16 & \\
\hline Z2-EU41DB-203 & $11 / 14 / 20051325$ & $\underline{0-10}$ & Metal & Vanadium & $\underline{23}$ & $\underline{\mathrm{mg} / \mathrm{kg}}$ & $\underline{24}$ & & $\equiv$ & $\equiv$ & & 4 & \\
\hline Z2-EU41DB-203 & $11 / 14 / 20051325$ & $0-10$ & Metal & Zinc & 37 & $\mathrm{mg} / \mathrm{kg}$ & $\underline{38}$ & & $\equiv$ & $\equiv$ & & $\underline{3}$ & \\
\hline Z2-EU41DB-209 & $11 / 17 / 20051415$ & $0-10$ & Metal & Mercury & 0.046 & $\underline{\mathrm{mg} / \mathrm{kg}}$ & & 0.034 & $\equiv$ & & $\equiv$ & & $\underline{30}$ \\
\hline Z2-EU41DB-209 & $11 / 17 / 20051415$ & $0-10$ & Metal & Aluminum & 15000 & $\mathrm{mg} / \mathrm{kg}$ & & 14500 & $\equiv$ & & EN J & & 3 \\
\hline Z2-EU41DB-209 & $11 / 17 / 20051415$ & $0-10$ & Metal & Antimony & 0.016 & $\underline{\mathrm{mg} / \mathrm{kg}}$ & & 0.036 & B UJ & & NU UJ & & \\
\hline Z2-EU41DB-209 & $11 / 17 / 20051415$ & $\underline{0-10}$ & Metal & Arsenic & 2.1 & $\mathrm{mg} / \mathrm{kg}$ & & 1.6 & $\equiv$ & & $\equiv$ & & $\underline{27}$ \\
\hline Z2-EU41DB-209 & $11 / 17 / 20051415$ & $0-10$ & Metal & Barium & 180 & $\underline{\mathrm{mg} / \mathrm{kg}}$ & & 207 & $\equiv$ & & EN J & & 14 \\
\hline Z2-EU41DB-209 & $11 / 17 / 20051415$ & $\underline{0-10}$ & Metal & Beryllium & 0.81 & $\underline{\mathrm{mg} / \mathrm{kg}}$ & & 0.71 & $\equiv$ & & $\equiv$ & & $\underline{13}$ \\
\hline Z2-EU41DB-209 & $11 / 17 / 20051415$ & $0-10$ & Metal & Boron & 2.7 & $\underline{\mathrm{mg} / \mathrm{kg}}$ & & 3.9 & $\equiv$ & & NU UJ & & \\
\hline$\overline{\text { Z2-EU41DB-209 }}$ & $11 / 17 / 20051415$ & $\overline{0-10}$ & Metal & Cadmium & $\overline{0.88}$ & $\overline{\mathrm{mg} / \mathrm{kg}}$ & & 0.064 & $\underline{J}$ & & $\bar{~}$ & & $\underline{173}$ \\
\hline
\end{tabular}


Table L.3. (continued)

\begin{tabular}{|c|c|c|c|c|c|c|c|c|c|c|c|c|c|}
\hline Station & Date-time & Depth & Category & Chemical name & ئ & Units & $\frac{\text { Field rep }}{\text { result }}$ & Split & $\left(\begin{array}{l}\text { (lab, val, } \\
\text { RC) }\end{array}\right.$ & FR qual (lab, val, RC) & Split qual & $\begin{array}{l}\frac{\mathrm{FR}}{\mathrm{RPD}} \\
\end{array}$ & $\frac{\text { Split }}{\text { RPD }}$ \\
\hline Z2-EU41DB-209 & $11 / 17 / 20051415$ & $\underline{\underline{0-10}}$ & Metal & Calcium & 22000 & $\mathrm{mg} / \mathrm{kg}$ & & $\underline{13400}$ & $\underline{\underline{J}}$ & & $\underline{\underline{\mathrm{NJ}}}$ & & $\underline{49}$ \\
\hline Z2-EU41DB-209 & $\underline{11 / 17 / 20051415}$ & $\underline{\underline{0-10}}$ & $\underline{\underline{\text { Metal }}}$ & Chromium & $\underline{\underline{29}}$ & $\underline{\mathrm{mg} / \mathrm{kg}}$ & & $\underline{\underline{23.6}}$ & $\equiv$ & & $\underline{\underline{\mathrm{NJ}}}$ & & $\underline{21}$ \\
\hline Z2-EU41DB-209 & $\underline{11 / 17 / 20051415}$ & $\underline{\underline{0-10}}$ & $\underline{\underline{\text { Metal }}}$ & Cobalt & $\underline{11}$ & $\underline{\underline{\mathrm{mg}} / \mathrm{kg}}$ & & $\underline{14.8}$ & $\equiv$ & & $\underline{\mathrm{EN} \mathrm{J}}$ & & $\underline{\underline{29}}$ \\
\hline Z2-EU41DB-209 & $\underline{11 / 17 / 20051415}$ & $\underline{\underline{0-10}}$ & $\underline{\underline{\text { Metal }}}$ & $\underline{\underline{\text { Copper }}}$ & $\underline{\underline{23}}$ & $\underline{\mathrm{mg} / \mathrm{kg}}$ & & $\underline{\underline{25.3}}$ & $\underline{\underline{E}}$ & & $\underline{\mathrm{ENJ}}$ & & $\underline{\underline{10}}$ \\
\hline Z2-EU41DB-209 & $\underline{11 / 17 / 20051415}$ & $\underline{\underline{0-10}}$ & Metal & Iron & $\underline{22000}$ & $\mathrm{mg} / \mathrm{kg}$ & & 23600 & 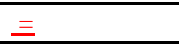 & & $\underline{\underline{\mathrm{NJ}}}$ & & $\underline{7}$ \\
\hline Z2-EU41DB-209 & $\underline{11 / 17 / 20051415}$ & $\underline{\underline{0-10}}$ & Metal & Lead & $\begin{array}{l}9.9 \\
\end{array}$ & $\underline{\underline{\mathrm{mg} / \mathrm{kg}}}$ & & $\underline{11}$ & $\underline{\underline{E}}$ & & $\underline{\underline{E J}}$ & & $\underline{11}$ \\
\hline Z2-EU41DB-209 & $11 / 17 / 20051415$ & $\underline{\underline{0-10}}$ & Metal & Lithium & $\underline{11}$ & $\mathrm{mg} / \mathrm{kg}$ & & 19.7 & $\equiv$ & & $\equiv$ & & $\underline{57}$ \\
\hline Z2-EU41DB-209 & $\underline{11 / 17 / 20051415}$ & $\underline{\underline{0-10}}$ & $\underline{\underline{\text { Metal }}}$ & Magnesium & $\underline{8800}$ & $\underline{\mathrm{mg} / \mathrm{kg}}$ & & $\underline{7490}$ & $\underline{\mathrm{J}}$ & & $\underline{\mathrm{EN} \mathrm{J}}$ & & $\underline{16}$ \\
\hline $\begin{array}{l}\text { Z2-EU41DB-209 } \\
\end{array}$ & $\underline{11 / 17 / 20051415}$ & $\underline{\underline{0-10}}$ & $\underline{\underline{\text { Metal }}}$ & Manganese & $\underline{100}$ & $\underline{\mathrm{mg} / \mathrm{kg}}$ & & $\underline{128}$ & $\equiv$ & & EN J & & $\underline{\underline{25}}$ \\
\hline Z2-EU41DB-209 & $\underline{11 / 17 / 20051415}$ & $\underline{\underline{0-10}}$ & Metal & Molybdenum & $\underline{0.22}$ & $\underline{\mathrm{mg} / \mathrm{kg}}$ & & $\underline{0.3}$ & $\underline{\underline{B J}}$ & & $\underline{\underline{\mathrm{UU}}}$ & & \\
\hline Z2-EU41DB-209 & $\underline{11 / 17 / 20051415}$ & $\underline{0-10}$ & Metal & Nickel & 27 & $\underline{\mathrm{mg} / \mathrm{kg}}$ & & $\underline{32.3}$ & $\underline{J}$ & & $\underline{\mathrm{ENJ}}$ & & $\underline{18}$ \\
\hline Z2-EU41DB-209 & $\underline{11 / 17 / 20051415}$ & $\underline{\underline{0-10}}$ & Metal & Potassium & $\underline{\underline{2300}}$ & $\underline{\mathrm{mg} / \mathrm{kg}}$ & & $\underline{1940}$ & $\equiv$ & & $\underline{\underline{\mathrm{EJ}}}$ & & $\underline{17}$ \\
\hline $\begin{array}{l}\text { Z2-EU41DB-209 } \\
\end{array}$ & $\underline{11 / 17 / 20051415}$ & $\underline{\underline{0-10}}$ & Metal & Silver & $\underline{0.087}$ & $\underline{\mathrm{mg} / \mathrm{kg}}$ & & $\underline{0.14}$ & $\underline{\underline{\mathrm{BJ}}}$ & & $\equiv$ & & $\underline{47}$ \\
\hline Z2-EU41DB-209 & $\underline{11 / 17 / 20051415}$ & $\underline{\underline{0-10}}$ & $\underline{\underline{\text { Metal }}}$ & Sodium & $\underline{66}$ & $\underline{\mathrm{mg} / \mathrm{kg}}$ & & 39.4 & $\underline{\underline{J}}$ & & $\equiv$ & & $\underline{\underline{50}}$ \\
\hline Z2-EU41DB-209 & $11 / 17 / 20051415$ & $\underline{\underline{0-10}}$ & Metal & Thallium & 0.18 & $\underline{\mathrm{m} g / \mathrm{kg}}$ & & 0.45 & $\equiv$ & & $\underline{\mathrm{BJ}}$ & & $\underline{86}$ \\
\hline $\begin{array}{l}\text { Z2-EU41DB-209 } \\
\end{array}$ & $\underline{11 / 17 / 20051415}$ & $\underline{\underline{0-10}}$ & $\underline{\underline{\text { Metal }}}$ & $\underline{\text { Vanadium }}$ & $\underline{18}$ & $\underline{\mathrm{mg} / \mathrm{kg}}$ & & 20.2 & $\underline{\underline{E}}$ & & $\equiv$ & & $\underline{\underline{12}}$ \\
\hline Z2-EU41DB-209 & $11 / 17 / 20051415$ & $\underline{\underline{0-10}}$ & Metal & Zinc & $\underline{45}$ & $\underline{\mathrm{mg} / \mathrm{kg}}$ & & 50.1 & $\underline{\underline{J}}$ & & $\underline{\mathrm{ENJ}}$ & & $\underline{11}$ \\
\hline $\begin{array}{l}\text { Z2-EU41DKB-233 } \\
\end{array}$ & $12 / 01 / 20051139$ & $\underline{\underline{2-10}}$ & $\underline{\underline{\text { Metal }}}$ & Mercury & 0.056 & $\underline{\underline{\mathrm{mg} / \mathrm{kg}}}$ & $\underline{0.071}$ & & $\underline{\underline{J}}$ & JF10 & & $\underline{\underline{24}}$ & \\
\hline Z2-EU41DKB-233 & $12 / 01 / 20051139$ & $2-10$ & Metal & Aluminum & 15000 & $\underline{\mathrm{mg} / \mathrm{kg}}$ & 16000 & & $\equiv$ & $\equiv$ & & $\underline{6}$ & \\
\hline $\begin{array}{l}\text { Z2-EU41DKB-233 } \\
\end{array}$ & $12 / 01 / 20051139$ & $\underline{\underline{2-10}}$ & $\underline{\underline{\text { Metal }}}$ & Antimony & $\underline{\underline{0.017}}$ & $\underline{\underline{\mathrm{mg} / \mathrm{kg}}}$ & $\underline{0.017}$ & & $\underline{\mathrm{BR}}$ & $\underline{\text { B R F01 F06 I03 }}$ & & $\underline{\underline{0}}$ & \\
\hline $\begin{array}{l}\text { Z2-EU41DKB-233 } \\
\end{array}$ & $12 / 01 / 20051139$ & $\underline{\underline{2-10}}$ & Metal & Arsenic & $\underline{\underline{2}}$ & $\underline{\underline{\mathrm{mg} / \mathrm{kg}}}$ & $2 \underline{2.3}$ & & $\equiv$ & $\equiv$ & & $\underline{14}$ & \\
\hline Z2-EU41DKB-233 & $12 / 01 / 20051139$ & $\underline{\underline{2-10}}$ & Metal & Barium & $\underline{140}$ & $\underline{\underline{\mathrm{mg} / \mathrm{kg}}}$ & $\underline{150}$ & & $\underline{\underline{E}}$ & $\equiv$ & & $\underline{\underline{7}}$ & \\
\hline Z2-EU41DKB-233 & $12 / 01 / 20051139$ & $\underline{2-10}$ & Metal & Beryllium & 0.88 & $\underline{\mathrm{mg} / \mathrm{kg}}$ & 0.94 & & $\underline{J}$ & JE07 & & $\underline{7}$ & \\
\hline $\begin{array}{l}\text { Z2-EU41DKB-233 } \\
\end{array}$ & $\underline{12 / 01 / 20051139}$ & $\underline{\underline{2-10}}$ & Metal & Boron & $\underline{1.6}$ & $\underline{\mathrm{mg} / \mathrm{kg}}$ & 1.9 & & $\underline{\mathrm{BJ}}$ & $\mathrm{J} \mathrm{I} 02$ & & 17 & \\
\hline Z2-EU41DKB-233 & $12 / 01 / 20051139$ & $2-10$ & Metal & Cadmium & $\underline{0.7}$ & $\mathrm{mg} / \mathrm{kg}$ & $\underline{0.83}$ & & $\equiv$ & $\equiv$ & & $\underline{17}$ & \\
\hline $\begin{array}{l}\text { Z2-EU41DKB-233 } \\
\end{array}$ & $12 / 01 / 20051139$ & $\underline{\underline{2-10}}$ & Metal & Calcium & $\underline{1000}$ & $\underline{\mathrm{mg} / \mathrm{kg}}$ & $\underline{1000}$ & & $\underline{\underline{J}}$ & $\mathrm{~J} \mathrm{J01} \mathrm{J02}$ & & $\underline{\underline{0}}$ & \\
\hline Z2-EU41DKB-233 & $12 / 01 / 20051139$ & $\underline{2-10}$ & Metal & Chromium & $\underline{30}$ & $\underline{\mathrm{mg} / \mathrm{kg}}$ & $\underline{68}$ & & $\underline{J}$ & $\mathrm{~J} \mathrm{I02}$ & & $\underline{78}$ & \\
\hline $\begin{array}{l}\text { Z2-EU41DKB-233 } \\
\end{array}$ & $\underline{12 / 01 / 20051139}$ & $\underline{\underline{2-10}}$ & Metal & Cobalt & $\underline{16}$ & $\underline{\mathrm{mg} / \mathrm{kg}}$ & $\underline{13}$ & & $\equiv$ & $\equiv$ & & $\underline{21}$ & \\
\hline $\begin{array}{l}\text { Z2-EU41DKB-233 } \\
\end{array}$ & $12 / 01 / 20051139$ & $2-10$ & Metal & Copper & $\underline{19}$ & $\underline{\mathrm{mg} / \mathrm{kg}}$ & $\underline{20}$ & & $\underline{J}$ & J F10 I03 J01 J02 & & $\underline{5}$ & \\
\hline $\begin{array}{l}\text { Z2-EU41DKB-233 } \\
\end{array}$ & $12 / 01 / 20051139$ & $\underline{\underline{2-10}}$ & Metal & $\underline{\underline{\text { Iron }}}$ & 25000 & $\underline{\mathrm{mg} / \mathrm{kg}}$ & $\underline{28000}$ & & 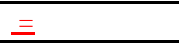 & $\equiv$ & & $\underline{11}$ & \\
\hline Z2-EU41DKB-233 & $12 / 01 / 20051139$ & $2-10$ & Metal & Lead & 9.1 & $\underline{\mathrm{mg} / \mathrm{kg}}$ & $\underline{11}$ & & $\equiv$ & $\equiv$ & & $\underline{19}$ & \\
\hline $\begin{array}{l}\text { Z2-EU41DKB-233 } \\
\end{array}$ & $\underline{12 / 01 / 20051139}$ & $\underline{\underline{2-10}}$ & $\underline{\underline{\text { Metal }}}$ & Lithium & $\underline{13}$ & $\underline{\mathrm{mg} / \mathrm{kg}}$ & $\underline{12}$ & & $\underline{\underline{E}}$ & $\equiv$ & & $\underline{\underline{8}}$ & \\
\hline Z2-EU41DKB-233 & $12 / 01 / 20051139$ & $2-10$ & Metal & Magnesium & $\underline{2900}$ & $\mathrm{mg} / \mathrm{kg}$ & 2700 & & $\underline{\underline{J}}$ & $\begin{array}{l}\mathrm{J} 101 \mathrm{~J} 01 \mathrm{~J} 02 \\
\end{array}$ & & $\underline{7}$ & \\
\hline $\begin{array}{l}\text { Z2-EU41DKB-233 } \\
\end{array}$ & $\underline{12 / 01 / 20051139}$ & $\underline{\underline{2-10}}$ & $\underline{\underline{\text { Metal }}}$ & Manganese & $\underline{130}$ & $\underline{\mathrm{mg} / \mathrm{kg}}$ & $\underline{110}$ & & $\underline{\underline{J}}$ & $\begin{array}{l}\mathrm{J} J 01 \mathrm{~J} 02 \\
\end{array}$ & & $\underline{17}$ & \\
\hline Z2-EU41DKB-233 & $12 / 01 / 20051139$ & $\underline{2-10}$ & Metal & Nickel & 27 & $\underline{\mathrm{mg} / \mathrm{kg}}$ & $\underline{26}$ & & $\underline{\underline{J}}$ & $\begin{array}{l}\mathrm{J} E 07 \mathrm{~J} 01 \mathrm{~J} 02 \\
\end{array}$ & & 4 & \\
\hline $\begin{array}{l}\text { Z2-EU41DKB-233 } \\
\end{array}$ & $12 / 01 / 20051139$ & $\underline{\underline{2-10}}$ & $\underline{\underline{\text { Metal }}}$ & Potassium & $\underline{2100}$ & $\underline{\mathrm{mg} / \mathrm{kg}}$ & $\underline{\underline{2200}}$ & & $\underline{\underline{J}}$ & $\begin{array}{ll}\mathrm{J} J 01 \mathrm{~J} 02 \\
\end{array}$ & & $\underline{5}$ & \\
\hline Z2-EU41DKB-233 & $12 / 01 / 20051139$ & $\underline{2-10}$ & Metal & Silver & 0.36 & $\underline{\mathrm{mg} / \mathrm{kg}}$ & 1.7 & & $\underline{\underline{J}}$ & JP02 & & 130 & \\
\hline Z2-EU41DKB-233 & $12 / 01 / 20051139$ & $\underline{\underline{2-10}}$ & Metal & $\underline{\text { Sodium }}$ & $\underline{50}$ & $\underline{\underline{\mathrm{mg} / \mathrm{kg}}}$ & $\underline{58}$ & & $\underline{\mathrm{BJ}}$ & $\mathrm{JP} 02$ & & $1 \underline{15}$ & \\
\hline Z2-EU41DKB-233 & $12 / 01 / 20051139$ & $2-10$ & Metal & Thallium & $\underline{0.2}$ & $\underline{\mathrm{mg} / \mathrm{kg}}$ & $\underline{0.2}$ & & $\equiv$ & $\equiv$ & & $\underline{\underline{0}}$ & \\
\hline Z2-EU41DKB-233 & $12 / 01 / 20051139$ & $2-10$ & Metal & Vanadium & $\underline{20}$ & $\underline{\mathrm{mg} / \mathrm{kg}}$ & $\underline{21}$ & & 三 & 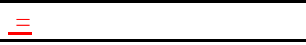 & & $\underline{5}$ & \\
\hline
\end{tabular}


Table L.3. (continued)

\begin{tabular}{|c|c|c|c|c|c|c|c|c|c|c|c|c|c|}
\hline Station & Date-time & Depth & Category & Chemical name & ئ & Units & $\frac{\text { Field rep }}{\text { result }}$ & $\begin{array}{l}\text { Split } \\
\text { result }\end{array}$ & $\left(\begin{array}{l}\text { (lab, val, } \\
\text { RC) }\end{array}\right.$ & FR qual (lab, val, RC) & Split qual & $\frac{\mathrm{FR}}{\mathrm{RPD}}$ & $\begin{array}{l}\text { Split } \\
\text { RPD } \\
\end{array}$ \\
\hline Z2-EU41DKB-233 & $\underline{12 / 01 / 20051139}$ & $\underline{\underline{2-10}}$ & Metal & Zinc & $\underline{51}$ & $\underline{\underline{\mathrm{m} g} / \mathrm{kg}}$ & $\underline{52}$ & & $\underline{\underline{J}}$ & $\mathrm{~J} \mathrm{E} 07 \mathrm{~F} 10$ & & $\underline{2}$ & \\
\hline $\begin{array}{l}\text { Z2-EU41DKB-234 } \\
\end{array}$ & $\underline{12 / 01 / 20051409}$ & $\underline{\underline{2.5-4}}$ & $\underline{\underline{\text { Metal }}}$ & Mercury & $\underline{\underline{0.017}}$ & $\underline{\underline{\mathrm{mg} / \mathrm{kg}}}$ & & $\underline{\underline{0.035}}$ & $\underline{\underline{B J}}$ & & $\equiv$ & & $\underline{69}$ \\
\hline Z2-EU41DKB-234 & $\underline{\underline{12 / 01 / 20051409}}$ & $2.5-4$ & $\underline{\underline{\text { Metal }}}$ & Aluminum & $\underline{13000}$ & $\underline{\underline{\mathrm{m} g} / \mathrm{kg}}$ & & $\underline{14900}$ & $\equiv$ & & EN J & & $\underline{14}$ \\
\hline $\begin{array}{l}\text { Z2-EU41DKB-234 } \\
\end{array}$ & $12 / 01 / 20051409$ & $\underline{\underline{2.5-4}}$ & $\underline{\underline{\text { Metal }}}$ & Antimony & $\underline{\underline{0.017}}$ & $\underline{\underline{\mathrm{mg} / \mathrm{kg}}}$ & & $\underline{\underline{0.045}}$ & $\underline{\mathrm{BR}}$ & & $\underline{\underline{\mathrm{NU} U \mathrm{UJ}}}$ & & \\
\hline Z2-EU41DKB-234 & $12 / 01 / 20051409$ & $2.5-4$ & Metal & Arsenic & 3.5 & $\underline{\underline{\mathrm{mg}} / \mathrm{kg}}$ & & 3.4 & $\equiv$ & & $\underline{\mathrm{NJ}}$ & & $\underline{3}$ \\
\hline $\begin{array}{l}\text { Z2-EU41DKB-234 } \\
\end{array}$ & $\underline{12 / 01 / 20051409}$ & $\underline{2.5-4}$ & Metal & Barium & $\underline{110}$ & $\underline{\underline{\mathrm{mg}} / \mathrm{kg}}$ & & $\underline{136}$ & $\equiv$ & & $\equiv$ & & $\underline{\underline{21}}$ \\
\hline Z2-EU41DKB-234 & $12 / 01 / 20051409$ & $2.5-4$ & Metal & Beryllium & 0.78 & $\underline{\underline{\mathrm{mg}} / \mathrm{kg}}$ & & $\underline{0.83}$ & $\underline{\underline{J}}$ & & $\bar{E}$ & & $\underline{6}$ \\
\hline $\begin{array}{l}\text { Z2-EU41DKB-234 } \\
\end{array}$ & $12 / 01 / 20051409$ & $2.5-4$ & $\underline{\underline{\text { Metal }}}$ & Boron & $\underline{1.5}$ & $\underline{\underline{\mathrm{mg}} / \mathrm{kg}}$ & & $\underline{4.8}$ & $\underline{\mathrm{BJ}}$ & & $\underline{\underline{\mathrm{NU} U \mathrm{UJ}}}$ & & \\
\hline Z2-EU41DKB-234 & $\underline{12 / 01 / 20051409}$ & $2.5-4$ & Metal & Cadmium & $\underline{0.89}$ & $\underline{\underline{\mathrm{mg}} / \mathrm{kg}}$ & & 0.07 & $\equiv$ & & $\underline{\mathrm{NJ}}$ & & $\underline{171}$ \\
\hline $\begin{array}{l}\text { Z2-EU41DKB-234 } \\
\end{array}$ & $\underline{12 / 01 / 20051409}$ & $\underline{2.5-4}$ & $\underline{\underline{\text { Metal }}}$ & Calcium & $\underline{60000}$ & $\underline{\underline{\mathrm{mg}} / \mathrm{kg}}$ & & $\underline{46400}$ & $\underline{\underline{J}}$ & & N J & & $\underline{\underline{26}}$ \\
\hline Z2-EU41DKB-234 & $\underline{12 / 01 / 20051409}$ & $2.5-4$ & Metal & Chromium & $\underline{12}$ & $\underline{\underline{\mathrm{mg}} / \mathrm{kg}}$ & & $\underline{16.8}$ & $\underline{\underline{J}}$ & & $\underline{\underline{\mathrm{NJ}}}$ & & $\underline{33}$ \\
\hline $\begin{array}{l}\text { Z2-EU41DKB-234 } \\
\text { EUB }\end{array}$ & $\underline{12 / 01 / 20051409}$ & $\underline{2.5-4}$ & Metal & Cobalt & $\underline{18}$ & $\underline{\underline{\mathrm{mg} / \mathrm{kg}}}$ & & 13.2 & $\equiv$ & & EN J & & $\underline{31}$ \\
\hline Z2-EU41DKB-234 & $12 / 01 / 20051409$ & $2.5-4$ & Metal & Copper & $\underline{11}$ & $\underline{\underline{\mathrm{m} g} / \mathrm{kg}}$ & & $\underline{11.7}$ & $\underline{J}$ & & N J & & $\underline{6}$ \\
\hline $\begin{array}{l}\text { Z2-EU41DKB-234 } \\
\end{array}$ & $12 / 01 / 20051409$ & $\underline{2.5-4}$ & Metal & $\underline{\underline{\text { Iron }}}$ & $\underline{20000}$ & $\underline{\underline{\mathrm{mg}} / \mathrm{kg}}$ & & $\underline{18300}$ & 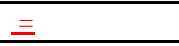 & & $\underline{\underline{\mathrm{NJ}}}$ & & $\underline{\underline{9}}$ \\
\hline Z2-EU41DKB-234 & $12 / 01 / 20051409$ & $2.5-4$ & Metal & Lead & $\underline{17}$ & $\underline{\mathrm{mg} / \mathrm{kg}}$ & & $\underline{14.4}$ & $\equiv$ & & EN J & & 17 \\
\hline $\begin{array}{l}\text { Z2-EU41DKB-234 } \\
\end{array}$ & $12 / 01 / 20051409$ & $\underline{2.5-4}$ & $\underline{\underline{\text { Metal }}}$ & Lithium & $\underline{12}$ & $\underline{\underline{\mathrm{mg} / \mathrm{kg}}}$ & & 15.4 & 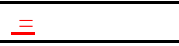 & & $\equiv$ & & $\underline{\underline{25}}$ \\
\hline Z2-EU41DKB-234 & $12 / 01 / 20051409$ & $2.5-4$ & Metal & Magnesium & $\underline{6700}$ & $\underline{\mathrm{mg} / \mathrm{kg}}$ & & $\underline{10300}$ & $\underline{\underline{J}}$ & & EN J & & $\underline{42}$ \\
\hline $\begin{array}{l}\text { Z2-EU41DKB-234 } \\
\end{array}$ & $12 / 01 / 20051409$ & $\underline{2.5-4}$ & Metal & Manganese & $\underline{1300}$ & $\underline{\underline{\mathrm{mg} / \mathrm{kg}}}$ & & $\underline{\underline{936}}$ & $\underline{\underline{J}}$ & & EN J & & $\underline{\underline{33}}$ \\
\hline Z2-EU41DKB-234 & $12 / 01 / 20051409$ & $2.5-4$ & Metal & Nickel & $\underline{20}$ & $\underline{\mathrm{mg} / \mathrm{kg}}$ & & 20.3 & $\underline{\underline{J}}$ & & EN J & & $\underline{1}$ \\
\hline $\begin{array}{l}\text { Z2-EU41DKB-234 } \\
\end{array}$ & $12 / 01 / 20051409$ & $\underline{2.5-4}$ & $\underline{\underline{\text { Metal }}}$ & Potassium & $\underline{1500}$ & $\underline{\underline{\mathrm{mg} / \mathrm{kg}}}$ & & $\underline{1540}$ & $\underline{\underline{J}}$ & & $\underline{\mathrm{EN} \mathrm{J}}$ & & $\underline{3}$ \\
\hline Z2-EU41DKB-234 & $12 / 01 / 20051409$ & $2.5-4$ & Metal & Sodium & $6 \underline{61}$ & $\underline{\underline{\mathrm{mg}} / \mathrm{kg}}$ & & 43.1 & $\underline{\underline{J}}$ & & $\underline{\mathrm{NJ}}$ & & $\underline{34}$ \\
\hline $\begin{array}{l}\text { Z2-EU41DKB-234 } \\
\end{array}$ & $12 / 01 / 20051409$ & $\underline{2.5-4}$ & Metal & Thallium & $\underline{0.19}$ & $\underline{\underline{\mathrm{mg}} / \mathrm{kg}}$ & & $\underline{0.28}$ & $\underline{\underline{E}}$ & & $\underline{\mathrm{BN} \mathrm{J}}$ & & $\underline{\underline{38}}$ \\
\hline Z2-EU41DKB-234 & $12 / 01 / 20051409$ & $2.5-4$ & $\underline{\underline{\text { Metal }}}$ & $\underline{\text { Vanadium }}$ & $\underline{14}$ & $\underline{\underline{\mathrm{mg}} / \mathrm{kg}}$ & & $\underline{16.3}$ & $\equiv$ & & $\equiv$ & & $\underline{15}$ \\
\hline $\begin{array}{l}\text { Z2-EU41DKB-234 } \\
\end{array}$ & $\underline{12 / 01 / 20051409}$ & $2.5-4$ & Metal & Zinc & $\underline{31}$ & $\underline{\underline{\mathrm{mg}} / \mathrm{kg}}$ & & $\underline{35}$ & $\underline{\underline{J}}$ & & EN J & & $\underline{12}$ \\
\hline Z2-EU41DB-227 & $12 / 05 / 20051355$ & $\underline{\underline{0-10}}$ & Metal & Mercury & 0.052 & $\underline{\mathrm{mg} / \mathrm{kg}}$ & $\underline{0.08}$ & & $\underline{\underline{J}}$ & $\mathrm{JF} 10$ & & $\underline{42}$ & \\
\hline $\begin{array}{l}\text { Z2-EU41DB-227 } \\
\end{array}$ & $\underline{12 / 05 / 20051355}$ & $\underline{\underline{0-10}}$ & Metal & Aluminum & $\underline{19000}$ & $\underline{\underline{\mathrm{mg}} / \mathrm{kg}}$ & $\underline{18000}$ & & $\underline{J}$ & $\mathrm{JF} 10$ & & $\underline{5}$ & \\
\hline Z2-EU41DB-227 & $12 / 05 / 20051355$ & $\underline{\underline{0-10}}$ & Metal & Antimony & 0.055 & $\underline{\underline{\mathrm{mg}} / \mathrm{kg}}$ & $\underline{0.017}$ & & EN J & $\mathrm{J} 103 \mathrm{P} 01$ & & $\underline{106}$ & \\
\hline $\begin{array}{l}\text { Z2-EU41DB-227 } \\
\end{array}$ & $\underline{12 / 05 / 20051355}$ & $\underline{\underline{0-10}}$ & Metal & Arsenic & 7.1 & $\underline{\underline{\mathrm{mg}} / \mathrm{kg}}$ & $\underline{6.3}$ & & $\equiv$ & $\equiv$ & & $\underline{12}$ & \\
\hline Z2-EU41DB-227 & $12 / 05 / 20051355$ & $\underline{0-10}$ & Metal & Barium & $\underline{120}$ & $\underline{\underline{\mathrm{mg}} / \mathrm{kg}}$ & $\underline{110}$ & & $\equiv$ & $\equiv$ & & $\underline{9}$ & \\
\hline $\begin{array}{l}\text { Z2-EU41DB-227 } \\
\end{array}$ & $\underline{12 / 05 / 20051355}$ & $\underline{\underline{0-10}}$ & Metal & Beryllium & $\underline{1}$ & $\underline{\underline{\mathrm{mg}} / \mathrm{kg}}$ & $\underline{\underline{0.98}}$ & & $\underline{\underline{J}}$ & $\mathrm{JF10}$ & & $\underline{\underline{2}}$ & \\
\hline Z2-EU41DB-227 & $12 / 05 / 20051355$ & $\underline{\underline{0-10}}$ & Metal & Boron & 2.9 & $\underline{\underline{\mathrm{mg}} / \mathrm{kg}}$ & 1.7 & & *EN J & J E07 I02 & & $\underline{52}$ & \\
\hline $\begin{array}{l}\text { Z2-EU41DB-227 } \\
\end{array}$ & $\underline{12 / 05 / 20051355}$ & $\underline{\underline{0-10}}$ & $\underline{\underline{\text { Metal }}}$ & $\underline{\text { Cadmium }}$ & $\underline{1.3}$ & $\underline{\underline{\mathrm{mg} / \mathrm{kg}}}$ & $\underline{1.8}$ & & $\underline{\underline{E J}}$ & J $\mathrm{J}$ E07 & & $\underline{\underline{32}}$ & \\
\hline Z2-EU41DB-227 & $12 / 05 / 20051355$ & $\underline{\underline{0-10}}$ & Metal & Calcium & $\underline{1100}$ & $\underline{\mathrm{mg} / \mathrm{kg}}$ & $\underline{1900}$ & & *NJ & JF10 I01 J01 J02 & & $\underline{\underline{53}}$ & \\
\hline $\begin{array}{l}\text { Z2-EU41DB-227 } \\
\end{array}$ & $\underline{12 / 05 / 20051355}$ & $\underline{\underline{0-10}}$ & $\underline{\underline{\text { Metal }}}$ & Chromium & $\underline{34}$ & $\underline{\underline{\mathrm{mg} / \mathrm{kg}}}$ & $\underline{30}$ & & $\equiv$ & $\equiv$ & & $\underline{\underline{13}}$ & \\
\hline Z2-EU41DB-227 & $12 / 05 / 20051355$ & $\underline{\underline{0-10}}$ & Metal & $\begin{array}{l}\text { Cobalt } \\
\end{array}$ & 7.4 & $\underline{\mathrm{mg} / \mathrm{kg}}$ & 7.4 & & $\underline{\underline{J}}$ & JF10 & & $\underline{0}$ & \\
\hline $\begin{array}{l}\text { Z2-EU41DB-227 } \\
\end{array}$ & $\underline{12 / 05 / 20051355}$ & $\underline{\underline{0-10}}$ & $\underline{\underline{\text { Metal }}}$ & Copper & $\underline{\underline{29}}$ & $\underline{\underline{\mathrm{mg} / \mathrm{kg}}}$ & $\underline{30}$ & & $\underline{\underline{E}}$ & $\equiv$ & & $\underline{3}$ & \\
\hline Z2-EU41DB-227 & $12 / 05 / 20051355$ & $\underline{\underline{0-10}}$ & Metal & Iron & 37000 & $\underline{\underline{\mathrm{mg}} / \mathrm{kg}}$ & $\underline{30000}$ & & $\equiv$ & $\equiv$ & & $\underline{21}$ & \\
\hline $\begin{array}{l}\text { Z2-EU41DB-227 } \\
\end{array}$ & $12 / 05 / 20051355$ & $\underline{\underline{0-10}}$ & Metal & Lead & $\underline{12}$ & $\underline{\underline{\mathrm{mg}} / \mathrm{kg}}$ & $8 \underline{8.1}$ & & $\equiv$ & 三 & & $\underline{39}$ & \\
\hline Z2-EU41DB-227 & $12 / 05 / 20051355$ & $\underline{\underline{0-10}}$ & Metal & Lithium & 17 & $\underline{\underline{\mathrm{mg}} / \mathrm{kg}}$ & $\underline{18}$ & & $\underline{\underline{ }}$ & $\equiv$ & & $\underline{6}$ & \\
\hline Z2-EU41DB-227 & $12 / 05 / 20051355$ & $\underline{\underline{0-10}}$ & Metal & Magnesium & $\underline{1900}$ & $\underline{\mathrm{mg} / \mathrm{kg}}$ & 2300 & & $\underline{\mathrm{EJ}}$ & JE07 F10 & & 19 & \\
\hline
\end{tabular}


Table L.3. (continued)

\begin{tabular}{|c|c|c|c|c|c|c|c|c|c|c|c|c|c|}
\hline Station & Date-time & Depth & Category & Chemical name & 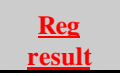 & Units & $\frac{\frac{\text { Field rep }}{\text { result }}}{\text { rest }}$ & $\begin{array}{l}\text { Split } \\
\text { result }\end{array}$ & $\left(\begin{array}{l}\text { (lab, val, } \\
\text { RC) }\end{array}\right.$ & FR qual (lab, val, RC) & Split qual & $\underline{\underline{\mathrm{FRD}}}$ & $\begin{array}{l}\text { Split } \\
\text { RPD } \\
\end{array}$ \\
\hline Z2-EU41DB-227 & $\underline{12 / 05 / 20051355}$ & $\underline{\underline{0-10}}$ & Metal & Manganese & $\underline{150}$ & $\underline{\mathrm{m} g / \mathrm{kg}}$ & $\underline{140}$ & & $\equiv$ & $\equiv$ & & $\underline{7}$ & \\
\hline Z2-EU41DB-227 & $\underline{12 / 05 / 20051355}$ & $\underline{\underline{0-10}}$ & $\underline{\underline{\text { Metal }}}$ & Nickel & 47 & $\underline{\mathrm{mg} / \mathrm{kg}}$ & $\underline{\underline{58}}$ & & $\underline{\underline{E J}}$ & $\mathrm{JE} 07$ & & $\underline{\underline{21}}$ & \\
\hline Z2-EU41DB-227 & $\underline{\underline{12 / 05 / 20051355}}$ & $\underline{\underline{0-10}}$ & $\underline{\underline{\text { Metal }}}$ & Potassium & $\underline{1900}$ & $\underline{\underline{\mathrm{mg}} / \mathrm{kg}}$ & $\underline{1700}$ & & $\equiv$ & $\equiv$ & & $\underline{\underline{11}}$ & \\
\hline Z2-EU41DB-227 & $\underline{12 / 05 / 20051355}$ & $\underline{\underline{0-10}}$ & $\underline{\underline{\text { Metal }}}$ & Selenium & $\underline{1.6}$ & $\underline{\underline{\mathrm{mg} / \mathrm{kg}}}$ & $\underline{0.87}$ & & $\equiv$ & $\underline{\underline{\mathrm{UU}}}$ & & & \\
\hline Z2-EU41DB-227 & $\underline{12 / 05 / 20051355}$ & $\underline{\underline{0-10}}$ & Metal & Silver & 0.25 & $\underline{\mathrm{mg} / \mathrm{kg}}$ & $\underline{0.28}$ & & BNR & R P03 & & & \\
\hline Z2-EU41DB-227 & $\underline{12 / 05 / 20051355}$ & $\underline{\underline{0-10}}$ & Metal & $\underline{\underline{\text { Sodium }}}$ & $\underline{50}$ & $\underline{\underline{\mathrm{mg} / \mathrm{kg}}}$ & $\underline{41}$ & & $\underline{\mathrm{BEJ}}$ & B J E07 P02 & & $\underline{20}$ & \\
\hline Z2-EU41DB-227 & $\underline{\underline{12 / 05 / 20051355}}$ & $\underline{\underline{0-10}}$ & Metal & Thallium & $\underline{0.16}$ & $\underline{\underline{\mathrm{m} g} / \mathrm{kg}}$ & $\underline{\underline{0.15}}$ & & $\equiv$ & $\equiv$ & & $\underline{6}$ & \\
\hline Z2-EU41DB-227 & $\underline{12 / 05 / 20051355}$ & $\underline{\underline{0-10}}$ & $\underline{\underline{\text { Metal }}}$ & $\underline{\text { Vanadium }}$ & $\underline{\underline{24}}$ & $\underline{\mathrm{mg} / \mathrm{kg}}$ & $\underline{22}$ & & $\equiv$ & $\equiv$ & & $\underline{9}$ & \\
\hline Z2-EU41DB-227 & $\underline{12 / 05 / 20051355}$ & $\underline{\underline{0-10}}$ & $\underline{\underline{\text { Metal }}}$ & $\underline{\underline{\text { Zinc }}}$ & $\underline{35}$ & $\underline{\mathrm{mg} / \mathrm{kg}}$ & $\underline{34}$ & & EN J & $\mathrm{JE} 07$ & & $\underline{3}$ & \\
\hline Z2-EU41DB-227 & $\underline{12 / 05 / 20051400}$ & $\underline{10-20}$ & $\underline{\underline{\text { Metal }}}$ & Mercury & $\underline{\underline{0.011}}$ & $\underline{\mathrm{mg} / \mathrm{kg}}$ & & $\underline{\underline{0.015}}$ & $\underline{\mathrm{BJ}}$ & & $\underline{\mathrm{BJ}}$ & & $\underline{\underline{31}}$ \\
\hline Z2-EU41DB-227 & $\underline{12 / 05 / 20051400}$ & $10-20$ & Metal & Aluminum & 19000 & $\underline{\mathrm{mg} / \mathrm{kg}}$ & & $\underline{16400}$ & $\underline{J}$ & & $\underline{\mathrm{EN} \mathrm{J}}$ & & $\underline{15}$ \\
\hline Z2-EU41DB-227 & $\underline{12 / 05 / 20051400}$ & $\underline{10-20}$ & Metal & Antimony & $\underline{0.0042}$ & $\underline{\mathrm{mg} / \mathrm{kg}}$ & & $\underline{0.039}$ & $\underline{\underline{B J}}$ & & $\underline{\underline{\mathrm{NU} U \mathrm{UJ}}}$ & & \\
\hline Z2-EU41DB-227 & $\underline{12 / 05 / 20051400}$ & $\underline{\underline{10-20}}$ & Metal & Arsenic & $\underline{9.1}$ & $\underline{\mathrm{mg} / \mathrm{kg}}$ & & $\underline{8.1}$ & $\equiv$ & & $\underline{\underline{E J}}$ & & $\underline{12}$ \\
\hline $\begin{array}{l}\text { Z2-EU41DB-227 } \\
\end{array}$ & $\underline{12 / 05 / 20051400}$ & $\underline{10-20}$ & Metal & Barium & $\underline{390}$ & $\underline{\mathrm{mg} / \mathrm{kg}}$ & & $\underline{425}$ & 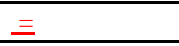 & & EN J & & $\underline{\underline{9}}$ \\
\hline Z2-EU41DB-227 & $12 / 05 / 20051400$ & $10-20$ & Metal & Beryllium & 1.2 & $\underline{\mathrm{m} g / \mathrm{kg}}$ & & 0.87 & $\underline{\underline{J}}$ & & $\equiv$ & & $\underline{32}$ \\
\hline $\begin{array}{l}\text { Z2-EU41DB-227 } \\
\end{array}$ & $\underline{12 / 05 / 20051400}$ & $\underline{10-20}$ & $\underline{\underline{\text { Metal }}}$ & Boron & 3.6 & $\underline{\mathrm{mg} / \mathrm{kg}}$ & & 4.2 & $\underline{\underline{J}}$ & & $\underline{\underline{\mathrm{NU} U \mathrm{UJ}}}$ & & $\underline{15}$ \\
\hline Z2-EU41DB-227 & $12 / 05 / 20051400$ & $10-20$ & Metal & Cadmium & $\underline{3.3}$ & $\underline{\mathrm{mg} / \mathrm{kg}}$ & & $\underline{0.096}$ & $\underline{\underline{J}}$ & & $\equiv$ & & $\underline{189}$ \\
\hline $\begin{array}{l}\text { Z2-EU41DB-227 } \\
\end{array}$ & $\underline{12 / 05 / 20051400}$ & $\underline{10-20}$ & Metal & $\begin{array}{l}\text { Calcium } \\
\end{array}$ & $\underline{3500}$ & $\underline{\underline{\mathrm{mg} / \mathrm{kg}}}$ & & $\underline{\underline{3650}}$ & $\underline{\underline{J}}$ & & $\underline{\underline{E J}}$ & & $\underline{4}$ \\
\hline Z2-EU41DB-227 & $12 / 05 / 20051400$ & $10-20$ & Metal & Chromium & $\underline{28}$ & $\underline{\mathrm{mg} / \mathrm{kg}}$ & & 26.3 & $\equiv$ & & $\underline{\mathrm{EN} \mathrm{J}}$ & & $\underline{6}$ \\
\hline $\begin{array}{l}\text { Z2-EU41DB-227 } \\
\end{array}$ & $\underline{12 / 05 / 20051400}$ & $\underline{10-20}$ & $\underline{\underline{\text { Metal }}}$ & $\begin{array}{l}\text { Cobalt } \\
\end{array}$ & 30 & $\underline{\underline{\mathrm{mg} / \mathrm{kg}}}$ & & 25.4 & $\underline{\underline{J}}$ & & EN J & & 17 \\
\hline Z2-EU41DB-227 & $12 / 05 / 20051400$ & $10-20$ & Metal & Copper & 24 & $\underline{\mathrm{mg} / \mathrm{kg}}$ & & 21.9 & 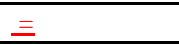 & & $\underline{\underline{E J}}$ & & $\underline{\underline{9}}$ \\
\hline $\begin{array}{l}\text { Z2-EU41DB-227 } \\
\end{array}$ & $12 / 05 / 20051400$ & $10-20$ & Metal & Iron & $\underline{42000}$ & $\underline{\underline{\mathrm{mg} / \mathrm{kg}}}$ & & $\underline{32000}$ & $\underline{\underline{E}}$ & & $\underline{\mathrm{EN} \mathrm{J}}$ & & $\underline{\underline{27}}$ \\
\hline Z2-EU41DB-227 & $\underline{12 / 05 / 20051400}$ & $\underline{10-20}$ & $\underline{\underline{\text { Metal }}}$ & Lead & 9.9 & $\underline{\underline{\mathrm{m} g} / \mathrm{kg}}$ & & $\underline{6.2}$ & $\equiv$ & & EN J & & $\underline{46}$ \\
\hline $\begin{array}{l}\text { Z2-EU41DB-227 } \\
\end{array}$ & $\underline{12 / 05 / 20051400}$ & $\underline{10-20}$ & Metal & Lithium & $\underline{35}$ & $\underline{\mathrm{mg} / \mathrm{kg}}$ & & $\underline{42.3}$ & $\equiv$ & & $\equiv$ & & $\underline{19}$ \\
\hline Z2-EU41DB-227 & $\underline{12 / 05 / 20051400}$ & $\underline{10-20}$ & $\underline{\underline{\text { Metal }}}$ & Magnesium & $\underline{3400}$ & $\underline{\mathrm{mg} / \mathrm{kg}}$ & & $\underline{3320}$ & $\underline{\underline{J}}$ & & EN J & & $\underline{\underline{2}}$ \\
\hline $\begin{array}{l}\text { Z2-EU41DB-227 } \\
\end{array}$ & $12 / 05 / 20051400$ & 10-20 & Metal & Manganese & $\underline{1200}$ & $\underline{\mathrm{mg} / \mathrm{kg}}$ & & $\underline{1630}$ & $\equiv$ & & EN J & & $\underline{30}$ \\
\hline Z2-EU41DB-227 & $12 / 05 / 20051400$ & $10-20$ & Metal & Nickel & $\underline{56}$ & $\underline{\mathrm{mg} / \mathrm{kg}}$ & & $\underline{69.3}$ & $\underline{\mathrm{J}}$ & & EN J & & $\underline{21}$ \\
\hline $\begin{array}{l}\text { Z2-EU41DB-227 } \\
\end{array}$ & $\underline{12 / 05 / 20051400}$ & $\underline{10-20}$ & Metal & Potassium & $\underline{\underline{2800}}$ & $\underline{\mathrm{mg} / \mathrm{kg}}$ & & $\underline{2270}$ & $\equiv$ & & EN J & & $\underline{21}$ \\
\hline Z2-EU41DB-227 & $\underline{12 / 05 / 20051400}$ & $\underline{\underline{10-20}}$ & $\underline{\underline{\text { Metal }}}$ & Silver & $\underline{0.044}$ & $\underline{\mathrm{mg} / \mathrm{kg}}$ & & $\underline{0.042}$ & $\underline{\underline{U R}}$ & & $\underline{\underline{B J}}$ & & $\underline{\underline{5}}$ \\
\hline $\begin{array}{l}\text { Z2-EU41DB-227 } \\
\end{array}$ & $12 / 05 / 20051400$ & $\underline{10-20}$ & Metal & Sodium & $\underline{\underline{110}}$ & $\underline{\mathrm{mg} / \mathrm{kg}}$ & & $\underline{\underline{61.1}}$ & $\underline{\underline{J}}$ & & $\underline{\underline{\mathrm{NJ}}}$ & & 57 \\
\hline Z2-EU41DB-227 & $\underline{12 / 05 / 20051400}$ & $\underline{10-20}$ & $\underline{\underline{\text { Metal }}}$ & Thallium & $\underline{0.18}$ & $\underline{\mathrm{m} g / \mathrm{kg}}$ & & $\underline{0.14}$ & $\equiv$ & & $\underline{\mathrm{BNJ}}$ & & $\underline{\underline{25}}$ \\
\hline $\begin{array}{l}\text { Z2-EU41DB-227 } \\
\end{array}$ & $\underline{12 / 05 / 20051400}$ & $\underline{10-20}$ & $\underline{\underline{\text { Metal }}}$ & $\underline{\underline{\text { Vanadium }}}$ & $\underline{16}$ & $\underline{\underline{\mathrm{mg} / \mathrm{kg}}}$ & & 14.3 & $\equiv$ & & $\equiv$ & & $\underline{\underline{11}}$ \\
\hline Z2-EU41DB-227 & $12 / 05 / 20051400$ & $10-20$ & Metal & Zinc & $\underline{64}$ & $\underline{\mathrm{mg} / \mathrm{kg}}$ & & $\underline{61.9}$ & $\underline{\underline{J}}$ & & EN J & & $\underline{\underline{3}}$ \\
\hline $\begin{array}{l}\text { Z2-EU41DB-225 } \\
\end{array}$ & $\underline{12 / 09 / 20051405}$ & $\underline{\underline{0-10}}$ & $\underline{\underline{\text { Metal }}}$ & Mercury & 0.066 & $\underline{\mathrm{mg} / \mathrm{kg}}$ & $\underline{0.064}$ & & $\underline{\underline{J}}$ & JF10 P01 & & $\underline{3}$ & \\
\hline Z2-EU41DB-225 & $12 / 09 / 20051405$ & $\underline{\underline{0-10}}$ & Metal & Aluminum & 23000 & $\underline{\mathrm{mg} / \mathrm{kg}}$ & 22000 & & $\equiv$ & $\equiv$ & & 4 & \\
\hline $\begin{array}{l}\text { Z2-EU41DB-225 } \\
\end{array}$ & $\underline{12 / 09 / 20051405}$ & $\underline{\underline{0-10}}$ & $\underline{\underline{\text { Metal }}}$ & Antimony & $\underline{0.00092}$ & $\underline{\mathrm{mg} / \mathrm{kg}}$ & $\underline{0.00089}$ & & BR & U R 103 & & $\underline{3}$ & \\
\hline Z2-EU41DB-225 & 12/09/20051405 & $\underline{\underline{0-10}}$ & Metal & Arsenic & 5.4 & $\underline{\underline{\mathrm{mg} / \mathrm{kg}}}$ & $\underline{6}$ & & $\equiv$ & $\equiv$ & & $\underline{11}$ & \\
\hline $\begin{array}{l}\text { Z2-EU41DB-225 } \\
\end{array}$ & $12 / 09 / 20051405$ & $\underline{\underline{0-10}}$ & Metal & Barium & $\underline{150}$ & $\underline{\underline{\mathrm{mg} / \mathrm{kg}}}$ & $\underline{160}$ & & $\underline{\underline{J}}$ & $\mathrm{JI} 01$ & & $\underline{6}$ & \\
\hline Z2-EU41DB-225 & $12 / 09 / 20051405$ & $\underline{0-10}$ & Metal & Beryllium & $\underline{0.95}$ & $\underline{\mathrm{mg} / \mathrm{kg}}$ & $\underline{1}$ & & $\equiv$ & $\equiv$ & & $\underline{5}$ & \\
\hline Z2-EU41DB-225 & $12 / 09 / 20051405$ & $\underline{\underline{0-10}}$ & Metal & Boron & 1.9 & $\underline{\mathrm{mg} / \mathrm{kg}}$ & 2.1 & & $\underline{J}$ & $\mathrm{JI} 102$ & & $\underline{10}$ & \\
\hline
\end{tabular}


Table L.3. (continued)

\begin{tabular}{|c|c|c|c|c|c|c|c|c|c|c|c|c|c|}
\hline Station & Date-time & Depth & Category & Chemical name & $\begin{array}{l}\text { Reg } \\
\text { result } \\
\end{array}$ & Units & $\frac{\text { Field rep }}{\text { result }}$ & $\begin{array}{l}\text { Split } \\
\text { result }\end{array}$ & $\left(\begin{array}{l}\text { Qual } \\
\text { (lab, val, RC) }\end{array}\right.$ & FR qual (lab, val, RC) & $\underline{\text { Split qual }}$ & $\underline{\mathrm{FR}}$ & $\frac{\text { Split }}{\text { RPD }}$ \\
\hline Z2-EU41DB-225 & $12 / 09 / 20051405$ & $\underline{\underline{0-10}}$ & Metal & Cadmium & 1.2 & $\underline{\mathrm{mg} / \mathrm{kg}}$ & 1.4 & & $\underline{\underline{J}}$ & JE07 & & $\underline{15}$ & \\
\hline Z2-EU41DB-225 & $12 / 09 / 20051405$ & $0-10$ & Metal & Calcium & 4800 & $\mathrm{mg} / \mathrm{kg}$ & 1500 & & $\equiv$ & $\equiv$ & & 105 & \\
\hline Z2-EU41DB-225 & $12 / 09 / 20051405$ & $\underline{\underline{0-10}}$ & Metal & Chromium & $\underline{28}$ & $\underline{\mathrm{mg} / \mathrm{kg}}$ & $\underline{30}$ & & $\equiv$ & $\equiv$ & & $\underline{7}$ & \\
\hline Z2-EU41DB-225 & $12 / 09 / 20051405$ & $\underline{0-10}$ & Metal & Cobalt & 27 & $\mathrm{mg} / \mathrm{kg}$ & $\underline{10}$ & & $\underline{\mathrm{J}}$ & J F10 J01 J02 & & $\underline{92}$ & \\
\hline Z2-EU41DB-225 & $12 / 09 / 20051405$ & $0-10$ & Metal & Copper & 16 & $\mathrm{mg} / \mathrm{kg}$ & 18 & & $\equiv$ & $\equiv$ & & 12 & \\
\hline Z2-EU41DB-225 & $12 / 09 / 20051405$ & $\underline{0-10}$ & Metal & Iron & 32000 & $\mathrm{mg} / \mathrm{kg}$ & 36000 & & $\equiv$ & $\equiv$ & & 12 & \\
\hline Z2-EU41DB-225 & $12 / 09 / 20051405$ & $\underline{\underline{0-10}}$ & Metal & Lead & $\underline{11}$ & $\underline{\underline{\mathrm{mg}} / \mathrm{kg}}$ & $\underline{11}$ & & $\equiv$ & $\equiv$ & & $\underline{0}$ & \\
\hline Z2-EU41DB-225 & $12 / 09 / 20051405$ & $\underline{0-10}$ & Metal & Lithium & $\underline{19}$ & $\underline{\mathrm{mg} / \mathrm{kg}}$ & $\underline{21}$ & & $\equiv$ & $\equiv$ & & 10 & \\
\hline Z2-EU41DB-225 & $12 / 09 / 20051405$ & $\overline{0-10}$ & Metal & Magnesium & 1900 & $\underline{\mathrm{mg} / \mathrm{kg}}$ & 1900 & & $\underline{J}$ & JE07 F10 & & $\underline{\underline{0}}$ & \\
\hline Z2-EU41DB-225 & $12 / 09 / 20051405$ & $\underline{0-10}$ & Metal & Manganese & 150 & $\underline{\mathrm{mg} / \mathrm{kg}}$ & 130 & & $\equiv$ & $\equiv$ & & 14 & \\
\hline Z2-EU41DB-225 & $12 / 09 / 20051405$ & $\underline{0-10}$ & Metal & Nickel & $\underline{18}$ & $\underline{\underline{\mathrm{mg}} / \mathrm{kg}}$ & $\underline{18}$ & & $\underline{\mathrm{J}}$ & $\mathrm{JE} 07 \mathrm{~F} 10$ & & $\underline{0}$ & \\
\hline Z2-EU41DB-225 & $12 / 09 / 20051405$ & $0-10$ & Metal & Potassium & 1900 & $\underline{\mathrm{mg} / \mathrm{kg}}$ & 1900 & & $\equiv$ & $\equiv$ & & $\underline{0}$ & \\
\hline Z2-EU41DB-225 & $12 / 09 / 20051405$ & $\overline{0-10}$ & Metal & $\overline{S \text { Selenium }}$ & 0.97 & $\underline{\mathrm{mg} / \mathrm{kg}}$ & 1.3 & & $\mathrm{BJ}$ & $\equiv$ & & 29 & \\
\hline Z2-EU41DB-225 & $12 / 09 / 20051405$ & $0-10$ & Metal & Silver & 0.046 & $\underline{\mathrm{mg} / \mathrm{kg}}$ & 0.045 & & $\underline{\mathrm{UR}}$ & U R P03 & & & \\
\hline Z2-EU41DB-225 & $12 / 09 / 20051405$ & $\underline{\underline{0-10}}$ & Metal & $\underline{\text { Sodium }}$ & 47 & $\underline{\mathrm{mg} / \mathrm{kg}}$ & $\underline{42}$ & & $\underline{\underline{J}}$ & B J E07 P02 & & $\underline{11}$ & \\
\hline Z2-EU41DB-225 & $12 / 09 / 20051405$ & $0-10$ & Metal & Thallium & 0.17 & $\mathrm{mg} / \mathrm{kg}$ & 0.18 & & $\underline{J}$ & J I01 & & $\underline{6}$ & \\
\hline Z2-EU41DB-225 & $12 / 09 / 20051405$ & $0-10$ & Metal & Vanadium & $\underline{21}$ & $\underline{\mathrm{mg} / \mathrm{kg}}$ & 23 & & $\equiv$ & $\equiv$ & & 9 & \\
\hline Z2-EU41DB-225 & $12 / 09 / 20051405$ & $0-10$ & Metal & Zinc & 25 & $\underline{\mathrm{mg} / \mathrm{kg}}$ & 27 & & $\underline{J}$ & J E07 & & $\underline{8}$ & \\
\hline Z2-EU41C-209 & $12 / 16 / 20051450$ & $\underline{\underline{0-10}}$ & Metal & Mercury & $\underline{0.038}$ & $\underline{\mathrm{mg} / \mathrm{kg}}$ & 0.034 & & $\equiv$ & $\underline{\mathrm{BJ}}$ & & $\underline{11}$ & \\
\hline Z2-EU41C-209 & $12 / 16 / 20051450$ & $\underline{0-10}$ & Metal & Aluminum & 22000 & $\underline{\mathrm{mg} / \mathrm{kg}}$ & 24000 & & $\equiv$ & $\equiv$ & & $\underline{9}$ & \\
\hline Z2-EU41C-209 & $12 / 16 / 20051450$ & $0-10$ & Metal & Antimony & 0.016 & $\underline{\mathrm{mg} / \mathrm{kg}}$ & 0.015 & & $\mathrm{BR}$ & B R F01 F06 I03 & & & \\
\hline Z2-EU41C-209 & $12 / 16 / 20051450$ & $0-10$ & Metal & Arsenic & 3.9 & $\underline{\mathrm{mg} / \mathrm{kg}}$ & 4.2 & & $\equiv$ & $\equiv$ & & 7 & \\
\hline Z2-EU41C-209 & $12 / 16 / 20051450$ & $\underline{0-10}$ & Metal & Barium & 130 & $\underline{\mathrm{mg} / \mathrm{kg}}$ & $\underline{120}$ & & $\underline{J}$ & J F10 & & $\underline{8}$ & \\
\hline Z2-EU41C-209 & $12 / 16 / 20051450$ & $\underline{0-10}$ & Metal & Beryllium & 0.9 & $\underline{\mathrm{mg} / \mathrm{kg}}$ & 0.94 & & $\underline{J}$ & J F10 & & 4 & \\
\hline Z2-EU41C-209 & $12 / 16 / 20051450$ & 0 & Metal & Boron & 3.3 & $\underline{\mathrm{mg} / \mathrm{kg}}$ & 2.9 & & $\equiv$ & $\equiv$ & & $\underline{13}$ & \\
\hline Z2-EU41C-209 & $12 / 16 / 20051450$ & $\underline{0-10}$ & Metal & Cadmium & 1.5 & $\underline{\mathrm{mg} / \mathrm{kg}}$ & 1.5 & & $\underline{J}$ & J E07 & & $\underline{\underline{0}}$ & \\
\hline Z2-EU41C-209 & $12 / 16 / 20051450$ & $\underline{0-10}$ & Metal & Calcium & 17000 & $\underline{\underline{\mathrm{mg}} / \mathrm{kg}}$ & $\underline{6400}$ & & $\equiv$ & $\equiv$ & & 91 & \\
\hline Z2-EU41C-209 & $12 / 16 / 20051450$ & $0-10$ & Metal & Chromium & $\underline{19}$ & $\underline{\mathrm{mg} / \mathrm{kg}}$ & $\underline{20}$ & & $\equiv$ & $\equiv$ & & 5 & \\
\hline Z2-EU41C-209 & $12 / 16 / 20051450$ & $\overline{0-10}$ & Metal & $\overline{\text { Cobalt }}$ & $\underline{12}$ & $\underline{\mathrm{mg} / \mathrm{kg}}$ & $\underline{11}$ & & $\underline{J}$ & J F10 & & $\underline{9}$ & \\
\hline Z2-EU41C-209 & $12 / 16 / 20051450$ & $\underline{\underline{0-10}}$ & Metal & Copper & $\underline{180}$ & $\underline{\underline{\mathrm{mg}} / \mathrm{kg}}$ & $\underline{\underline{170}}$ & & $\underline{\underline{J}}$ & $\mathrm{JI} 102$ & & $\underline{6}$ & \\
\hline Z2-EU41C-209 & $12 / 16 / 20051450$ & $\overline{0-10}$ & Metal & Iron & 24000 & $\underline{\mathrm{mg} / \mathrm{kg}}$ & 26000 & & $\equiv$ & $\equiv$ & & 8 & \\
\hline Z2-EU41C-209 & $12 / 16 / 20051450$ & $0-10$ & Metal & Lead & $\underline{13}$ & $\mathrm{mg} / \mathrm{kg}$ & $\underline{14}$ & & $\equiv$ & $\equiv$ & & 7 & \\
\hline Z2-EU41C-209 & $12 / 16 / 20051450$ & $0-10$ & Metal & Lithium & 17 & $\underline{\mathrm{mg} / \mathrm{kg}}$ & $\underline{15}$ & & $\equiv$ & $\equiv$ & & $\underline{13}$ & \\
\hline Z2-EU41C-209 & $12 / 16 / 20051450$ & $0-10$ & Metal & Magnesium & 7900 & $\mathrm{mg} / \mathrm{kg}$ & 3800 & & $\equiv$ & $\equiv$ & & $\underline{70}$ & \\
\hline Z2-EU41C-209 & $12 / 16 / 20051450$ & $\underline{\underline{0-10}}$ & Metal & Manganese & $8 \underline{850}$ & $\underline{\mathrm{mg} / \mathrm{kg}}$ & 680 & & $\underline{\underline{J}}$ & JF10 & & $\underline{22}$ & \\
\hline Z2-EU41C-209 & $12 / 16 / 20051450$ & $\underline{0-10}$ & Metal & Molybdenum & $\underline{0.53}$ & $\mathrm{mg} / \mathrm{kg}$ & 0.5 & & $\mathrm{BU}$ & B U F01 F06 & & & \\
\hline Z2-EU41C-209 & $12 / 16 / 20051450$ & $\underline{\underline{0-10}}$ & Metal & Nickel & 200 & $\underline{\underline{\mathrm{mg}} / \mathrm{kg}}$ & 210 & & $\underline{\underline{J}}$ & $\begin{array}{l}\mathrm{JF} 10 \\
\end{array}$ & & $\underline{5}$ & \\
\hline Z2-EU41C-209 & $\underline{12 / 16 / 20051450}$ & $\underline{\underline{0-10}}$ & Metal & Potassium & $\underline{2000}$ & $\underline{\underline{\mathrm{mg}} / \mathrm{kg}}$ & $\underline{1900}$ & & $\equiv$ & $\equiv$ & & $\underline{5}$ & \\
\hline Z2-EU41C-209 & $12 / 16 / 20051450$ & $\underline{0-10}$ & Metal & Selenium & 0.53 & $\underline{\underline{\mathrm{mg}} / \mathrm{kg}}$ & 0.8 & & $\underline{B J}$ & $\underline{\mathrm{UU}}$ & & & \\
\hline Z2-EU41C-209 & $12 / 16 / 20051450$ & $\underline{0-10}$ & Metal & Silver & 0.054 & $\mathrm{mg} / \mathrm{kg}$ & 0.051 & & UR & U R P03 & & 6 & \\
\hline
\end{tabular}


Table L.3. (continued)

\begin{tabular}{|c|c|c|c|c|c|c|c|c|c|c|c|c|c|}
\hline Station & Date-time & Depth & Category & Chemical name & ئesult & Units & $\frac{\text { Field rep }}{\text { result }}$ & $\begin{array}{l}\text { Split } \\
\text { result }\end{array}$ & $\left(\begin{array}{l}\text { Qual } \\
\text { (lab, val, RC) }\end{array}\right.$ & FR qual (lab, val, RC) & Split qual & $\underline{\mathrm{FR}}$ & $\frac{\text { Split }}{\text { RPD }}$ \\
\hline Z2-EU41C-209 & $\underline{12 / 16 / 20051450}$ & $\underline{\underline{0-10}}$ & Metal & Sodium & $\underline{93}$ & $\underline{\mathrm{mg} / \mathrm{kg}}$ & $\underline{48}$ & & $\underline{\underline{J}}$ & B J E07 P02 & & $6 \underline{64}$ & \\
\hline Z2-EU41C-209 & $12 / 16 / 20051450$ & $0-10$ & Metal & Thallium & 0.19 & $\mathrm{mg} / \mathrm{kg}$ & 0.19 & & $\equiv$ & $\equiv$ & & $\underline{\underline{0}}$ & \\
\hline Z2-EU41C-209 & $12 / 16 / 20051450$ & $\underline{\underline{0-10}}$ & Metal & $\underline{\underline{\text { Vanadium }}}$ & $\underline{19}$ & $\underline{\mathrm{mg} / \mathrm{kg}}$ & $\underline{20}$ & & $\equiv$ & $\equiv$ & & $\underline{5}$ & \\
\hline Z2-EU41C-209 & $12 / 16 / 20051450$ & $\underline{0-10}$ & Metal & Zinc & $\underline{35}$ & $\mathrm{mg} / \mathrm{kg}$ & $\underline{36}$ & & $\underline{J}$ & JF10 & & $\underline{3}$ & \\
\hline Z2-EU41CM-205 & $01 / 10 / 20061235$ & $0-10$ & Metal & Mercury & 0.027 & $\mathrm{mg} / \mathrm{kg}$ & & 0.026 & B J & & $\underline{\mathrm{NJ}}$ & & 4 \\
\hline Z2-EU41CM-205 & $01 / 10 / 20061235$ & $\underline{0-10}$ & Metal & Aluminum & 16000 & $\mathrm{mg} / \mathrm{kg}$ & & 15700 & $\equiv$ & & EN J & & $\underline{2}$ \\
\hline Z2-EU41CM-205 & $01 / 10 / 20061235$ & $0-10$ & Metal & Antimony & 0.0038 & $\underline{\mathrm{mg} / \mathrm{kg}}$ & & 0.16 & $\underline{B J}$ & & NU UJ & & \\
\hline Z2-EU41CM-205 & $01 / 10 / 20061235$ & $\underline{0-10}$ & Metal & Arsenic & 3.1 & $\underline{\mathrm{mg} / \mathrm{kg}}$ & & 2.7 & $\underline{\mathrm{J}}$ & & $\equiv$ & & $\underline{14}$ \\
\hline Z2-EU41CM-205 & $01 / 10 / 20061235$ & $\overline{0-10}$ & Metal & Barium & $\underline{90}$ & $\underline{\mathrm{mg} / \mathrm{kg}}$ & & 104 & $\underline{J}$ & & EN J & & 14 \\
\hline Z2-EU41CM-205 & $01 / 10 / 20061235$ & $\underline{0-10}$ & Metal & Beryllium & 0.69 & $\underline{\mathrm{mg} / \mathrm{kg}}$ & & 0.62 & $\underline{\mathrm{J}}$ & & $\underline{\mathrm{NJ}}$ & & 11 \\
\hline Z2-EU41CM-205 & $\underline{01 / 10 / 20061235}$ & $\underline{0-10}$ & Metal & Boron & $\underline{2.9}$ & $\underline{\underline{\mathrm{mg}} / \mathrm{kg}}$ & & 7.2 & $\underline{\underline{J}}$ & & $\underline{\underline{\mathrm{NJ}}}$ & & $\underline{85}$ \\
\hline Z2-EU41CM-205 & $01 / 10 / 20061235$ & $0-10$ & Metal & Cadmium & 0.99 & $\underline{\mathrm{mg} / \mathrm{kg}}$ & & $\underline{0.095}$ & $\underline{J}$ & & $\mathrm{BJ}$ & & $\underline{165}$ \\
\hline$\overline{Z Z 2-E U 41 C M-205}$ & $01 / 10 / 20061235$ & $\overline{\overline{0-10}}$ & Metal & Calcium & 55000 & $\underline{\mathrm{mg} / \mathrm{kg}}$ & & 45700 & $\underline{\underline{J}}$ & & EEN J & & $\underline{18}$ \\
\hline Z2-EU41CM-205 & $01 / 10 / 20061235$ & $0-10$ & Metal & Chromium & 17 & $\underline{\mathrm{mg} / \mathrm{kg}}$ & & 17.9 & $\equiv$ & & $\mathrm{N} \mathrm{J}$ & & $\underline{5}$ \\
\hline Z2-EU41CM-205 & $\underline{01 / 10 / 20061235}$ & $\underline{\underline{0-10}}$ & Metal & $\begin{array}{l}\text { Cobalt } \\
\end{array}$ & $\underline{8.3}$ & $\underline{\mathrm{mg} / \mathrm{kg}}$ & & 9.4 & $\underline{\underline{J}}$ & & $\underline{\underline{E J}}$ & & $\underline{12}$ \\
\hline Z2-EU41CM-205 & $01 / 10 / 20061235$ & $0-10$ & Metal & Copper & 16 & $\mathrm{mg} / \mathrm{kg}$ & & 14.3 & $\underline{J}$ & & EN J & & 11 \\
\hline Z2-EU41CM-205 & $\underline{01 / 10 / 20061235}$ & $\underline{\underline{0-10}}$ & Metal & Iron & 19000 & $\underline{\mathrm{mg} / \mathrm{kg}}$ & & $\underline{16200}$ & $\underline{\underline{J}}$ & & EN J & & $\underline{16}$ \\
\hline Z2-EU41CM-205 & $01 / 10 / 20061235$ & $0-10$ & Metal & Lead & $\underline{16}$ & $\underline{\mathrm{mg} / \mathrm{kg}}$ & & 15 & $\equiv$ & & $\equiv$ & & $\underline{6}$ \\
\hline Z2-EU41CM-205 & $\underline{01 / 10 / 20061235}$ & $\underline{\underline{0-10}}$ & Metal & Lithium & $\underline{15}$ & $\underline{\mathrm{mg} / \mathrm{kg}}$ & & $2 \underline{22.7}$ & $\equiv$ & & $\underline{\underline{E J}}$ & & $\underline{41}$ \\
\hline Z2-EU41CM-205 & $01 / 10 / 20061235$ & $\underline{0-10}$ & Metal & Magnesium & $\underline{9600}$ & $\underline{\mathrm{mg} / \mathrm{kg}}$ & & 17900 & $\underline{J}$ & & EEN J & & $\underline{60}$ \\
\hline Z2-EU41CM-205 & $01 / 10 / 20061235$ & $\overline{0-10}$ & Metal & Manganese & $\overline{400}$ & $\overline{\mathrm{mg} / \mathrm{kg}}$ & & 358 & $\underline{J}$ & & "EN J & & $\underline{11}$ \\
\hline Z2-EU41CM-205 & $01 / 10 / 20061235$ & $\underline{0-10}$ & Metal & Molybdenum & 0.51 & $\mathrm{mg} / \mathrm{kg}$ & & 0.46 & B UJ & & $\mathrm{BN} \mathrm{J}$ & & 10 \\
\hline Z2-EU41CM-205 & $01 / 10 / 20061235$ & $\underline{\underline{0-10}}$ & Metal & Nickel & $\underline{20}$ & $\underline{\underline{\mathrm{mg}} / \mathrm{kg}}$ & & $\underline{24}$ & $\underline{\underline{J}}$ & & $\underline{\mathrm{EN} \mathrm{J}}$ & & 19 \\
\hline Z2-EU41CM-205 & $01 / 10 / 20061235$ & $\underline{0-10}$ & Metal & Potassium & 2000 & $\underline{\mathrm{mg} / \mathrm{kg}}$ & & 1540 & $\equiv$ & & $\underline{\mathrm{EJ}}$ & & $\underline{26}$ \\
\hline Z2-EU41CM-205 & $01 / 10 / 20061235$ & 0 & Metal & Silver & $\underline{0.034}$ & $\underline{\mathrm{mg} / \mathrm{kg}}$ & & 0.068 & $\mathrm{UR}$ & & $\underline{\mathrm{UU}}$ & & \\
\hline Z2-EU41CM-205 & $01 / 10 / 20061235$ & $\underline{0-10}$ & Metal & $\underline{\text { Sodium }}$ & $\underline{89}$ & $\underline{\mathrm{mg} / \mathrm{kg}}$ & & 63.4 & $\underline{\mathrm{J}}$ & & $\equiv$ & & $\underline{34}$ \\
\hline Z2-EU41CM-205 & $\underline{01 / 10 / 20061235}$ & $\underline{0-10}$ & Metal & Thallium & 0.16 & $\underline{\underline{\mathrm{mg}} / \mathrm{kg}}$ & & 0.4 & $\underline{J}$ & & $\underline{\mathrm{BJ}}$ & & $\underline{86}$ \\
\hline Z2-EU41CM-205 & $01 / 10 / 20061235$ & $0-10$ & Metal & Vanadium & 17 & $\underline{\mathrm{mg} / \mathrm{kg}}$ & & 18.4 & $\equiv$ & & $\equiv$ & & $\underline{8}$ \\
\hline Z2-EU41CM-205 & $01 / 10 / 20061235$ & $\overline{0-10}$ & Metal & Zinc & 27 & $\underline{\mathrm{mg} / \mathrm{kg}}$ & & 29.3 & $\equiv$ & & EN J & & $\underline{8}$ \\
\hline $\begin{array}{l}\text { Z2-EU28B-115 } \\
\end{array}$ & $\underline{\underline{02 / 15 / 20061450}}$ & $\underline{\underline{0-1}}$ & Metal & Mercury & $\underline{86}$ & $\underline{\underline{\mathrm{mg}} / \mathrm{kg}}$ & $\underline{21}$ & & 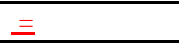 & $\equiv$ & & $\underline{121}$ & \\
\hline Z2-EU28B-115 & $\underline{02 / 15 / 20061450}$ & $\underline{\underline{0-1}}$ & Metal & Aluminum & 12000 & $\underline{\underline{\mathrm{mg}} / \mathrm{kg}}$ & $\underline{12000}$ & & $\equiv$ & $\equiv$ & & $\underline{0}$ & \\
\hline Z2-EU28B-115 & $02 / 15 / 20061450$ & $0-1$ & Metal & Antimony & 0.11 & $\mathrm{mg} / \mathrm{kg}$ & 0.14 & & $\underline{\mathrm{NJ}}$ & $\mathrm{JI} 102$ & & 24 & \\
\hline Z2-EU28B-115 & $02 / 15 / 20061450$ & $0-1$ & Metal & Arsenic & 5.5 & $\underline{\mathrm{mg} / \mathrm{kg}}$ & 7.3 & & $\equiv$ & $\equiv$ & & $\underline{28}$ & \\
\hline Z2-EU28B-115 & $02 / 15 / 20061450$ & $0-1$ & Metal & Barium & 94 & $\mathrm{mg} / \mathrm{kg}$ & 110 & & ${ }^{* \mathrm{~N} \mathrm{~J}}$ & $\mathrm{~J} \mathrm{J01, \textrm {J } 0 2}$ & & 16 & \\
\hline Z2-EU28B-115 & $\underline{02 / 15 / 20061450}$ & $\underline{\underline{0-1}}$ & Metal & Beryllium & $\underline{0.64}$ & $\underline{\mathrm{mg} / \mathrm{kg}}$ & $\underline{0.63}$ & & $\underline{\underline{E J}}$ & JE07 & & $\underline{2}$ & \\
\hline Z2-EU28B-115 & $02 / 15 / 20061450$ & $0-1$ & Metal & Boron & 4.3 & $\mathrm{mg} / \mathrm{kg}$ & 4.3 & & $\equiv$ & $\equiv$ & & $\underline{0}$ & \\
\hline Z2-EU28B-115 & $02 / 15 / 20061450$ & $0-1$ & Metal & Cadmium & 0.93 & $\underline{\mathrm{mg} / \mathrm{kg}}$ & 1.2 & & *J & $\mathrm{J} \mathrm{J} 01, \mathrm{~J} 02$ & & $\underline{25}$ & \\
\hline Z2-EU28B-115 & $\underline{02 / 15 / 20061450}$ & $\underline{\underline{0-1}}$ & Metal & Calcium & $\underline{50000}$ & $\underline{\underline{\mathrm{mg}} / \mathrm{kg}}$ & $\underline{78000}$ & & 苂 & $\begin{array}{l}\mathrm{J} \mathrm{J} 01, \mathrm{~J} 02 \\
\end{array}$ & & $\underline{44}$ & \\
\hline Z2-EU28B-115 & $02 / 15 / 20061450$ & $\underline{0-1}$ & Metal & Chromium & $\underline{34}$ & $\underline{\underline{\mathrm{mg}} / \mathrm{kg}}$ & $\underline{43}$ & & $\underline{\mathrm{NJ}}$ & $\mathrm{J} 102$ & & $\underline{23}$ & \\
\hline Z2-EU28B-115 & $02 / 15 / 20061450$ & $0-1$ & Metal & Cobalt & $\underline{12}$ & $\mathrm{mg} / \mathrm{kg}$ & $\underline{13}$ & & *J & $\mathrm{J} \mathrm{J01,} \mathrm{J02}$ & & $\underline{8}$ & \\
\hline
\end{tabular}


Table L.3. (continued)

\begin{tabular}{|c|c|c|c|c|c|c|c|c|c|c|c|c|c|}
\hline Station & Date-time & Depth & Category & Chemical name & $\underline{\text { Reg }}$ & Units & $\frac{\frac{\text { Field rep }}{\text { result }}}{\text { restis }}$ & 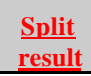 & $\frac{\text { Qual }}{(\text { lab, val, RC) }}$ & FR qual (lab, val, RC) & Split qual & $\underline{\mathrm{FR}}$ & $\underline{\text { Split }}$ \\
\hline Z2-EU28B-115 & $02 / 15 / 20061450$ & $\underline{0-1}$ & Metal & Copper & $\underline{42}$ & $\underline{\mathrm{mg} / \mathrm{kg}}$ & $\underline{61}$ & & $\underline{\mathrm{J}}$ & J F10 & & 37 & \\
\hline Z2-EU28B-115 & $02 / 15 / 20061450$ & $0-1$ & Metal & Iron & 30000 & $\underline{\mathrm{mg} / \mathrm{kg}}$ & 30000 & & $\equiv$ & $\equiv$ & & $\underline{0}$ & \\
\hline Z2-EU28B-115 & $02 / 15 / 20061450$ & $\underline{0-1}$ & Metal & Lead & $\underline{21}$ & $\underline{\mathrm{mg} / \mathrm{kg}}$ & $\underline{26}$ & & 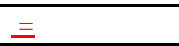 & $\equiv$ & & 21 & \\
\hline Z2-EU28B-115 & $02 / 15 / 20061450$ & $0-1$ & Metal & Lithium & 11 & $\underline{\mathrm{mg} / \mathrm{kg}}$ & 14 & & $\equiv$ & $\equiv$ & & 24 & \\
\hline Z2-EU28B-115 & $02 / 15 / 20061450$ & $\underline{0-1}$ & Metal & Magnesium & $\underline{12000}$ & $\underline{\mathrm{mg} / \mathrm{kg}}$ & 9000 & & *N J & $\mathrm{J} \mathrm{I02, \textrm {J } 0 1 , \mathrm { J } 0 2}$ & & $\underline{29}$ & \\
\hline Z2-EU28B-115 & $02 / 15 / 20061450$ & $0-1$ & Metal & Manganese & 490 & $\mathrm{mg} / \mathrm{kg}$ & 450 & & *J & J J01, J02 & & $\underline{9}$ & \\
\hline Z2-EU28B-115 & $02 / 15 / 20061450$ & $\underline{\underline{0-1}}$ & Metal & Molybdenum & 1.2 & $\underline{\mathrm{mg} / \mathrm{kg}}$ & 1.3 & & $\mathrm{BU}$ & B U F06 & & & \\
\hline Z2-EU28B-115 & $02 / 15 / 20061450$ & $0-1$ & Metal & Nickel & 170 & $\mathrm{mg} / \mathrm{kg}$ & $\underline{300}$ & & ${ }^{* \mathrm{~N} \mathrm{~J}}$ & J I03, J01, J02 & & $\underline{55}$ & \\
\hline Z2-EU28B-115 & $02 / 15 / 20061450$ & $\underline{\underline{0-1}}$ & Metal & Potassium & 2100 & $\underline{\mathrm{mg} / \mathrm{kg}}$ & $\underline{2000}$ & & $\equiv$ & $\equiv$ & & $\underline{5}$ & \\
\hline Z2-EU28B-115 & $\underline{02 / 15 / 20061450}$ & $\underline{\underline{0-1}}$ & Metal & Silver & $\underline{0.17}$ & $\underline{\mathrm{mg} / \mathrm{kg}}$ & 0.57 & & $\underline{\mathrm{BJ}}$ & $\underline{\mathrm{BJ}}$ & & $\underline{108}$ & \\
\hline Z2-EU28B-115 & $02 / 15 / 20061450$ & $\underline{0-1}$ & Metal & $\underline{\text { Sodium }}$ & $\underline{69}$ & $\underline{\mathrm{mg} / \mathrm{kg}}$ & $\underline{81}$ & & BE J & B J E07 & & $\underline{16}$ & \\
\hline Z2-EU28B-115 & $02 / 15 / 20061450$ & $0-1$ & Metal & Thallium & 0.19 & $\underline{\mathrm{mg} / \mathrm{kg}}$ & 0.22 & & $E=$ & $\equiv$ & & $\underline{15}$ & \\
\hline Z2-EU28B-115 & $02 / 15 / 20061450$ & $\underline{0-1}$ & Metal & Uranium & $\underline{94}$ & $\underline{\mathrm{mg} / \mathrm{kg}}$ & $\underline{140}$ & & 类 & $\mathrm{JJ} 01, \mathrm{~J} 02$ & & $\underline{39}$ & \\
\hline Z2-EU28B-115 & $02 / 15 / 20061450$ & $0-1$ & Metal & Vanadium & 25 & $\underline{\mathrm{mg} / \mathrm{kg}}$ & 27 & & *J & J J01, J02 & & $\underline{8}$ & \\
\hline Z2-EU28B-115 & $02 / 15 / 20061450$ & $\underline{0-1}$ & Metal & Zinc & $\underline{73}$ & $\underline{\mathrm{mg} / \mathrm{kg}}$ & $\underline{92}$ & & N J & J F10, I02, J01, J02 & & $\underline{23}$ & \\
\hline Z2-EU44-203 & $03 / 16 / 20061410$ & $0-10$ & Metal & Aluminum & 16000 & $\underline{\mathrm{mg} / \mathrm{kg}}$ & & $\underline{12600}$ & $\equiv$ & & $\underline{\underline{E N J}}$ & & $\underline{24}$ \\
\hline Z2-EU44-203 & $03 / 16 / 20061410$ & $\underline{0-10}$ & Metal & Antimony & 0.071 & $\underline{\mathrm{mg} / \mathrm{kg}}$ & & 0.064 & $\underline{\underline{J}}$ & & NU UJ & & $\underline{10}$ \\
\hline Z2-EU44-203 & $03 / 16 / 20061410$ & $0-10$ & Metal & Arsenic & 5.6 & $\underline{\mathrm{mg} / \mathrm{kg}}$ & & 4.9 & $\equiv$ & & $\equiv$ & & 13 \\
\hline Z2-EU44-203 & $03 / 16 / 20061410$ & $\underline{0-10}$ & Metal & Barium & $\underline{98}$ & $\underline{\mathrm{mg} / \mathrm{kg}}$ & & $\underline{110}$ & $\underline{\mathrm{J}}$ & & $\equiv$ & & $\underline{12}$ \\
\hline Z2-EU44-203 & $03 / 16 / 20061410$ & $0-10$ & Metal & Beryllium & 0.95 & $\underline{\mathrm{mg} / \mathrm{kg}}$ & & 0.62 & $\underline{J}$ & & $\underline{\mathrm{NJ}}$ & & $\underline{42}$ \\
\hline Z2-EU44-203 & $03 / 16 / 20061410$ & $\overline{0-10}$ & Metal & Boron & 3.6 & $\overline{\mathrm{mg} / \mathrm{kg}}$ & & 3.4 & $\underline{B U}$ & & $\overline{\mathrm{BNJ}}$ & & \\
\hline Z2-EU44-203 & $03 / 16 / 20061410$ & $0-10$ & Metal & Cadmium & 0.66 & $\mathrm{mg} / \mathrm{kg}$ & & 0.049 & $\equiv$ & & $\mathrm{BJ}$ & & 172 \\
\hline Z2-EU44-203 & $03 / 16 / 20061410$ & $\underline{0-10}$ & Metal & $\begin{array}{l}\text { Calcium } \\
\end{array}$ & 10000 & $\underline{\mathrm{mg} / \mathrm{kg}}$ & & 2440 & $\underline{J}$ & & EN J & & $\underline{122}$ \\
\hline Z2-EU44-203 & $03 / 16 / 20061410$ & $0-10$ & Metal & Chromium & $\underline{28}$ & $\mathrm{mg} / \mathrm{kg}$ & & 24.1 & $\underline{J}$ & & $\underline{E \mathrm{EJ}}$ & & $\underline{15}$ \\
\hline Z2-EU44-203 & $03 / 16 / 20061410$ & $\underline{0-10}$ & Metal & Cobalt & $\underline{22}$ & $\underline{\mathrm{mg} / \mathrm{kg}}$ & & $\underline{15}$ & $\underline{\mathrm{J}}$ & & EN J & & $\underline{38}$ \\
\hline Z2-EU44-203 & $03 / 16 / 20061410$ & $0-10$ & Metal & Copper & 38 & $\underline{\mathrm{mg} / \mathrm{kg}}$ & & $\underline{32.2}$ & $\underline{J}$ & & $\underline{\mathrm{EN} \mathrm{J}}$ & & 17 \\
\hline Z2-EU44-203 & $\underline{03 / 16 / 20061410}$ & $\underline{0-10}$ & Metal & Iron & 33000 & $\underline{\mathrm{mg} / \mathrm{kg}}$ & & 20800 & $\underline{J}$ & & $\underline{\mathrm{EN} \mathrm{J}}$ & & $\underline{45}$ \\
\hline Z2-EU44-203 & $03 / 16 / 20061410$ & $0-10$ & Metal & Lead & $\underline{16}$ & $\underline{\mathrm{mg} / \mathrm{kg}}$ & & 17.2 & $\underline{J}$ & & $\underline{\mathrm{NJ}}$ & & $\underline{7}$ \\
\hline Z2-EU44-203 & $03 / 16 / 20061410$ & $\underline{0-10}$ & Metal & Lithium & $\underline{14}$ & $\underline{\mathrm{mg} / \mathrm{kg}}$ & & 17.6 & $\equiv$ & & $\equiv$ & & $\underline{23}$ \\
\hline Z2-EU44-203 & $03 / 16 / 20061410$ & $0-10$ & Metal & Magnesium & 4600 & $\underline{\mathrm{mg} / \mathrm{kg}}$ & & 2650 & $\mathrm{~J}$ & & EN J & & 54 \\
\hline Z2-EU44-203 & $03 / 16 / 20061410$ & $\underline{0-10}$ & Metal & Manganese & $\underline{820}$ & $\underline{\mathrm{mg} / \mathrm{kg}}$ & & $\underline{\underline{561}}$ & $\equiv$ & & $\underline{\mathrm{EN} \mathrm{J}}$ & & $\underline{38}$ \\
\hline Z2-EU44-203 & $03 / 16 / 20061410$ & $0-10$ & Metal & Molybdenum & 1.2 & $\underline{\mathrm{mg} / \mathrm{kg}}$ & & 0.46 & $\mathrm{BU}$ & & B J & & \\
\hline Z2-EU44-203 & $03 / 16 / 20061410$ & $\underline{0-10}$ & Metal & Nickel & $\underline{89}$ & $\underline{\mathrm{mg} / \mathrm{kg}}$ & & $\underline{89.3}$ & $\underline{J}$ & & EN J & & $\underline{\underline{0}}$ \\
\hline Z2-EU44-203 & $03 / 16 / 20061410$ & $0-10$ & Metal & Potassium & 2000 & $\underline{\mathrm{mg} / \mathrm{kg}}$ & & 1800 & $\equiv$ & & $\mathrm{ENJ}$ & & 11 \\
\hline Z2-EU44-203 & $03 / 16 / 20061410$ & $\underline{0-10}$ & Metal & Sodium & 120 & $\underline{\mathrm{mg} / \mathrm{kg}}$ & & 27.6 & $\underline{\mathrm{BU}}$ & & $\underline{\underline{\mathrm{NJ}}}$ & & $\underline{125}$ \\
\hline Z2-EU44-203 & $03 / 16 / 20061410$ & $0-10$ & Metal & Thallium & 0.23 & $\underline{\mathrm{mg} / \mathrm{kg}}$ & & 0.27 & $\equiv$ & & $\equiv$ & & 16 \\
\hline Z2-EU44-203 & $03 / 16 / 20061410$ & $\overline{0-10}$ & Metal & Uranium & 1.1 & $\overline{\mathrm{mg} / \mathrm{kg}}$ & & 0.86 & $\equiv$ & & $\equiv$ & & $\underline{24}$ \\
\hline Z2-EU44-203 & $03 / 16 / 20061410$ & $0-10$ & Metal & Vanadium & 31 & $\mathrm{mg} / \mathrm{kg}$ & & 23.5 & $\equiv$ & & $\mathrm{N} \mathrm{J}$ & & 28 \\
\hline Z2-EU44-203 & $03 / 16 / 20061410$ & $\underline{0-10}$ & Metal & Zinc & $\underline{47}$ & $\underline{\mathrm{mg} / \mathrm{kg}}$ & & 31.2 & $\underline{\mathrm{J}}$ & & EN J & & 40 \\
\hline Z2-EU23B-301 & $03 / 20 / 2006920$ & $0-0.5$ & Metal & Mercury & $\underline{0.071}$ & $\underline{\mathrm{mg} / \mathrm{kg}}$ & & 0.074 & $\equiv$ & & $\equiv$ & & 4 \\
\hline
\end{tabular}


Table L.3. (continued)

\begin{tabular}{|c|c|c|c|c|c|c|c|c|c|c|c|c|c|}
\hline Station & Date-time & Depth & Category & Chemical name & $\begin{array}{l}\text { Reg } \\
\text { result } \\
\end{array}$ & Units & $\frac{\text { Field rep }}{\text { result }}$ & 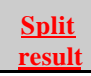 & $\left(\begin{array}{l}\text { Qual } \\
\text { (lab, val, RC) }\end{array}\right.$ & FR qual (lab, val, RC) & Split qual & $\underline{\mathrm{FR}}$ & $\underline{\text { Split }}$ \\
\hline Z2-EU23B-301 & $03 / 20 / 2006920$ & $\underline{\underline{0-0.5}}$ & Metal & Aluminum & $\underline{8600}$ & $\underline{\mathrm{mg} / \mathrm{kg}}$ & & 9460 & $\equiv$ & & EN J & & $\underline{10}$ \\
\hline Z2-EU23B-301 & $03 / 20 / 2006920$ & $0-0.5$ & Metal & Antimony & 0.22 & $\mathrm{mg} / \mathrm{kg}$ & & 0.32 & $\underline{\mathrm{NJ}}$ & & $\mathrm{BNJ}$ & & 37 \\
\hline Z2-EU23B-301 & $03 / 20 / 2006920$ & $\underline{\underline{0-0.5}}$ & Metal & Arsenic & 8.8 & $\underline{\mathrm{mg} / \mathrm{kg}}$ & & $\underline{6.6}$ & $\equiv$ & & $\equiv$ & & $\underline{29}$ \\
\hline Z2-EU23B-301 & $03 / 20 / 2006920$ & $0-0.5$ & Metal & Barium & $\underline{92}$ & $\mathrm{mg} / \mathrm{kg}$ & & $\underline{87}$ & $\equiv$ & & $\equiv$ & & $\underline{6}$ \\
\hline Z2-EU23B-301 & $03 / 20 / 2006920$ & $0-0.5$ & Metal & Beryllium & 0.78 & $\underline{\mathrm{mg} / \mathrm{kg}}$ & & 0.64 & $\equiv$ & & $\equiv$ & & 20 \\
\hline Z2-EU23B-301 & $03 / 20 / 2006920$ & $0-0.5$ & Metal & Boron & 3.7 & $\mathrm{mg} / \mathrm{kg}$ & & 4.5 & BE J & & $\mathrm{BN} \mathrm{J}$ & & 20 \\
\hline Z2-EU23B-301 & $03 / 20 / 2006920$ & $0-0.5$ & Metal & Cadmium & 0.96 & $\underline{\mathrm{mg} / \mathrm{kg}}$ & & 0.4 & $\equiv$ & & $\equiv$ & & $\underline{82}$ \\
\hline Z2-EU23B-301 & $03 / 20 / 2006920$ & $\underline{0-0.5}$ & Metal & Calcium & $\underline{3600}$ & $\underline{\mathrm{mg} / \mathrm{kg}}$ & & 3070 & *N J & & $\underline{E J}$ & & 16 \\
\hline Z2-EU23B-301 & 03/20/2006920 & $\underline{\underline{0-0.5}}$ & Metal & Chromium & $\underline{17}$ & $\underline{\underline{\mathrm{mg}} / \mathrm{kg}}$ & & 16.4 & $\equiv$ & & $\equiv$ & & 4 \\
\hline Z2-EU23B-301 & $03 / 20 / 2006920$ & $\underline{0-0.5}$ & Metal & Cobalt & 10 & $\underline{\mathrm{mg} / \mathrm{kg}}$ & & 7.9 & $\equiv$ & & $\underline{E J}$ & & $\underline{23}$ \\
\hline Z2-EU23B-301 & $03 / 20 / 2006920$ & $0-0.5$ & Metal & $\overline{\text { Copper }}$ & 21 & $\underline{\mathrm{mg} / \mathrm{kg}}$ & & 19.6 & $\equiv$ & & EN J & & 7 \\
\hline Z2-EU23B-301 & $03 / 20 / 2006920$ & $0-0.5$ & Metal & Iron & 22000 & $\underline{\mathrm{mg} / \mathrm{kg}}$ & & 15400 & $\equiv$ & & EN J & & $\underline{35}$ \\
\hline Z2-EU23B-301 & $03 / 20 / 2006920$ & $\overline{0-0.5}$ & Metal & Lead & $\underline{29}$ & $\underline{\mathrm{mg} / \mathrm{kg}}$ & & $\underline{28.6}$ & $\equiv$ & & $\equiv$ & & 1 \\
\hline Z2-EU23B-301 & $03 / 20 / 2006920$ & $0-0.5$ & Metal & Lithium & 6.7 & $\underline{\mathrm{mg} / \mathrm{kg}}$ & & 11.3 & $\equiv$ & & $\equiv$ & & $\underline{51}$ \\
\hline Z2-EU23B-301 & $03 / 20 / 2006920$ & $0-0.5$ & Metal & Magnesium & 1200 & $\underline{\mathrm{mg} / \mathrm{kg} g}$ & & 1150 & $\equiv$ & & EJ & & 4 \\
\hline Z2-EU23B-301 & $03 / 20 / 2006920$ & $0-0.5$ & Metal & Manganese & 1000 & $\mathrm{mg} / \mathrm{kg}$ & & 626 & $\equiv$ & & EN J & & 46 \\
\hline Z2-EU23B-301 & $03 / 20 / 2006920$ & $0-0.5$ & Metal & Molybdenum & 1.2 & $\underline{\mathrm{mg} / \mathrm{kg}}$ & & 0.82 & B J & & $\equiv$ & & 38 \\
\hline Z2-EU23B-301 & $03 / 20 / 2006920$ & $0-0.5$ & Metal & Nickel & $\underline{58}$ & $\underline{\mathrm{mg} / \mathrm{kg}}$ & & $\underline{50.2}$ & $\equiv$ & & EN J & & 14 \\
\hline Z2-EU23B-301 & $03 / 20 / 2006920$ & $0-0.5$ & Metal & Potassium & 850 & $\underline{\mathrm{mg} / \mathrm{kg}}$ & & 961 & $E \mathrm{E}$ & & $E \mathrm{EJ}$ & & $\underline{12}$ \\
\hline Z2-EU23B-301 & $03 / 20 / 2006920$ & $0-0.5$ & Metal & $\underline{\text { Selenium }}$ & 1.2 & $\underline{\mathrm{mg} / \mathrm{kg}}$ & & 0.33 & $\equiv$ & & B J & & 114 \\
\hline Z2-EU23B-301 & $03 / 20 / 2006920$ & $0-0.5$ & Metal & Sodium & $6 \underline{65}$ & $\underline{\mathrm{mg} / \mathrm{kg}}$ & & 20.2 & BE J & & $\equiv$ & & 105 \\
\hline Z2-EU23B-301 & $03 / 20 / 2006920$ & $0-0.5$ & Metal & Thallium & 0.16 & $\mathrm{mg} / \mathrm{kg}$ & & 0.23 & N J & & B J & & $\underline{36}$ \\
\hline Z2-EU23B-301 & $03 / 20 / 2006920$ & $\underline{0-0.5}$ & Metal & Uranium & 13 & $\underline{\mathrm{mg} / \mathrm{kg}}$ & & 14.7 & $\equiv$ & & $\equiv$ & & $\underline{12}$ \\
\hline Z2-EU23B-301 & $03 / 20 / 2006920$ & $\underline{0-0.5}$ & Metal & Vanadium & $\underline{22}$ & $\underline{\mathrm{mg} / \mathrm{kg}}$ & & 18.6 & $\equiv$ & & $\equiv$ & & 17 \\
\hline Z2-EU23B-301 & $03 / 20 / 2006920$ & $0-0.5$ & Metal & Zinc & $\underline{69}$ & $\underline{\mathrm{mg} / \mathrm{kg}}$ & & 59 & $\equiv$ & & EN J & & 16 \\
\hline Z2-EU1B-304 & $05 / 05 / 20061100$ & $\underline{0-1}$ & Metal & Aluminum & $\underline{8330}$ & $\underline{\mathrm{mg} / \mathrm{kg}}$ & & $\underline{12000}$ & EN J & & $\equiv$ & & $\underline{36}$ \\
\hline Z2-EU1B-304 & $05 / 05 / 20061100$ & $\overline{0-1}$ & Metal & Antimony & 0.18 & $\underline{\mathrm{mg} / \mathrm{kg}}$ & & 0.22 & $\overline{\mathrm{BNJ}}$ & & EN J & & 20 \\
\hline Z2-EU1B-304 & $05 / 05 / 20061100$ & $0-1$ & Metal & Arsenic & $\underline{8}$ & $\underline{\mathrm{mg} / \mathrm{kg}}$ & & 11 & $\equiv$ & & $\equiv$ & & 32 \\
\hline Z2-EU1B-304 & $05 / 05 / 20061100$ & $\overline{0-1}$ & Metal & Barium & 41.6 & $\underline{\mathrm{mg} / \mathrm{kg}}$ & & 48 & $\equiv$ & & $\equiv$ & & $\underline{14}$ \\
\hline Z2-EU1B-304 & $05 / 05 / 20061100$ & $0-1$ & Metal & Beryllium & 0.36 & $\underline{\mathrm{mg} / \mathrm{kg}}$ & & 0.7 & $\mathrm{~B} \mathrm{~J}$ & & $\equiv$ & & 64 \\
\hline Z2-EU1B-304 & $05 / 05 / 20061100$ & $\overline{0-1}$ & Metal & Boron & 3.5 & $\underline{\underline{\mathrm{mg} / \mathrm{kg} g}}$ & & $\underline{4.2}$ & $\mathrm{BNJ}$ & & $\equiv$ & & 18 \\
\hline Z2-EU1B-304 & $05 / 05 / 20061100$ & $0-1$ & Metal & Cadmium & 0.097 & $\mathrm{mg} / \mathrm{kg}$ & & $\underline{0.12}$ & $\mathrm{BJ}$ & & $\equiv$ & & 21 \\
\hline Z2-EU1B-304 & $05 / 05 / 20061100$ & $0-1$ & Metal & Calcium & 30900 & $\underline{\mathrm{mg} / \mathrm{kg}}$ & & $\underline{33000}$ & $\mathrm{ENJ}$ & & *J & & 7 \\
\hline Z2-EU1B-304 & $05 / 05 / 20061100$ & $0-1$ & Metal & Chromium & 11.6 & $\mathrm{mg} / \mathrm{kg}$ & & $\underline{20}$ & EEN J & & $\equiv$ & & $\underline{53}$ \\
\hline Z2-EU1B-304 & $05 / 05 / 20061100$ & $0-1$ & Metal & Cobalt & 6.3 & $\underline{\mathrm{mg} / \mathrm{kg}}$ & & 8.4 & EN J & & $\equiv$ & & $\underline{29}$ \\
\hline$\overline{\text { Z2-EU1B-304 }}$ & $\overline{05 / 05 / 20061100}$ & $\overline{0-1}$ & Metal & $\overline{\overline{\text { Copper }}}$ & $\overline{7.8}$ & $\underline{\mathrm{mg} / \mathrm{kg}}$ & & $\overline{13}$ & $\overline{\mathrm{EN}}=$ & & $\equiv$ & & $\underline{50}$ \\
\hline Z2-EU1B-304 & $05 / 05 / 20061100$ & $0-1$ & Metal & Iron & 16800 & $\underline{\mathrm{mg} / \mathrm{kg}}$ & & 31000 & EN J & & $\equiv$ & & 59 \\
\hline Z2-EU1B-304 & $05 / 05 / 20061100$ & $0-1$ & Metal & Lead & 17.3 & $\underline{\mathrm{mg} / \mathrm{kg}}$ & & $\underline{21}$ & $\equiv$ & & E J & & $\underline{19}$ \\
\hline Z2-EU1B-304 & $05 / 05 / 20061100$ & $0-1$ & Metal & Lithium & 14.7 & $\underline{\mathrm{mg} / \mathrm{kg}}$ & & $\underline{12}$ & $\equiv$ & & $\bar{E}$ & & $\underline{20}$ \\
\hline$\overline{\text { Z2-EU1B-304 }}$ & $05 / 05 / 20061100$ & $\overline{0-1}$ & Metal & Magnesium & 4620 & $\overline{\mathrm{mg} / \mathrm{kg}}$ & & $4 \overline{500}$ & EN J & & $\equiv$ & & $\underline{3}$ \\
\hline
\end{tabular}


Table L.3. (continued)

\begin{tabular}{|c|c|c|c|c|c|c|c|c|c|c|c|c|c|}
\hline Station & Date-time & Depth & Category & Chemical name & $\underset{\text { result }}{\text { reg }}$ & Units & $\frac{\frac{\text { Field rep }}{\text { result }}}{\text { restis }}$ & $\begin{array}{l}\text { Split } \\
\text { result }\end{array}$ & $\underset{\text { (lab, val, }}{\left.\frac{\text { Qual }}{R C}\right)}$ & FR qual (lab, val, $\mathrm{RC}$ ) & Split qual & $\frac{\mathrm{FR}}{\mathrm{RPD}}$ & 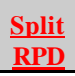 \\
\hline Z2-EU1B-304 & $\underline{05 / 05 / 20061100}$ & $\underline{0-1}$ & Metal & Manganese & 282 & $\mathrm{mg} / \mathrm{kg}$ & & 380 & EN J & & 类 & & 30 \\
\hline Z2-EU1B-304 & $05 / 05 / 20061100$ & $0-1$ & Metal & Molybdenum & 0.55 & $\mathrm{mg} / \mathrm{kg}$ & & 0.53 & $\mathrm{~B} \mathrm{~J}$ & & $\mathrm{BJ}$ & & 4 \\
\hline Z2-EU1B-304 & $\underline{\underline{05 / 05 / 20061100}}$ & $\underline{\underline{0-1}}$ & $\underline{\underline{\text { Metal }}}$ & Nickel & $\underline{11.3}$ & $\underline{\underline{\mathrm{mg}} / \mathrm{kg}}$ & & $\underline{18}$ & $\mathrm{EN}=$ & & $\equiv$ & & $\underline{46}$ \\
\hline Z2-EU1B-304 & $\underline{05 / 05 / 20061100}$ & $\underline{\underline{0-1}}$ & Metal & Potassium & $\underline{1020}$ & $\underline{\mathrm{mg} / \mathrm{kg}}$ & & $\underline{1300}$ & $\underline{\underline{E J}}$ & & $\equiv$ & & $\underline{\underline{24}}$ \\
\hline Z2-EU1B-304 & $\underline{05 / 05 / 20061100}$ & $\underline{0-1}$ & Metal & Silver & $\underline{0.093}$ & $\mathrm{mg} / \mathrm{kg}$ & & 0.14 & $\underline{\mathrm{BJ}}$ & & $\underline{\underline{\mathrm{UU}}}$ & & \\
\hline Z2-EU1B-304 & $\underline{05 / 05 / 20061100}$ & $\underline{0-1}$ & Metal & $\underline{\underline{\text { Sodium }}}$ & $\underline{28.2}$ & $\underline{\mathrm{mg} / \mathrm{kg}}$ & & $\underline{49}$ & $\underline{\underline{U}}$ & & $\underline{\mathrm{BEJ}}$ & & \\
\hline Z2-EU1B-304 & $\underline{05 / 05 / 20061100}$ & $\underline{0-1}$ & Metal & Thallium & 1.3 & $\mathrm{mg} / \mathrm{kg}$ & & $\underline{0.19}$ & $\underline{\mathrm{BU}}$ & & $\equiv$ & & \\
\hline Z2-EU1B-304 & $05 / 05 / 20061100$ & $\underline{0-1}$ & Metal & Uranium & $\underline{0.91}$ & $\underline{\mathrm{mg} / \mathrm{kg}}$ & & $\underline{1.2}$ & $\equiv$ & & $\underline{\underline{E}}$ & & $\underline{27}$ \\
\hline Z2-EU1B-304 & $\underline{05 / 05 / 20061100}$ & $\underline{\underline{0-1}}$ & Metal & Vanadium & $\underline{22.3}$ & $\underline{\mathrm{mg} / \mathrm{kg}}$ & & $\underline{32}$ & $\equiv$ & & $\equiv$ & & $\underline{\underline{36}}$ \\
\hline Z2-EU1B-304 & $05 / 05 / 20061100$ & $\underline{0-1}$ & Metal & Zinc & $\underline{34.8}$ & $\underline{\mathrm{mg} / \mathrm{kg}}$ & & $\underline{60}$ & EN J & & $\equiv$ & & $\underline{\underline{53}}$ \\
\hline Z2-EU1B-303 & $\underline{05 / 09 / 20061510}$ & $\underline{0-1}$ & Metal & Mercury & 0.14 & $\mathrm{mg} / \mathrm{kg}$ & $\underline{0.15}$ & & $\underline{\underline{U}}$ & $\equiv$ & & $\underline{7}$ & \\
\hline Z2-EU1B-303 & $\underline{05 / 09 / 20061510}$ & $\underline{\underline{0-1}}$ & Metal & Aluminum & $\underline{9640}$ & $\underline{\mathrm{mg} / \mathrm{kg}}$ & $\underline{10900}$ & & $\underline{\mathrm{ENJ}}$ & EN J E07 & & $\underline{12}$ & \\
\hline Z2-EU1B-303 & $\underline{05 / 09 / 20061510}$ & $\underline{0-1}$ & Metal & Antimony & $\underline{0.18}$ & $\mathrm{mg} / \mathrm{kg}$ & 0.17 & & $\underline{\mathrm{BNJ}}$ & $\mathrm{BNJ} 103$ & & $\underline{6}$ & \\
\hline Z2-EU1B-303 & $\underline{05 / 09 / 20061510}$ & $\underline{\underline{0-1}}$ & Metal & Arsenic & $\underline{7}$ & $\underline{\mathrm{mg} / \mathrm{kg}}$ & 6.4 & & $\equiv$ & $\equiv$ & & $\underline{\underline{9}}$ & \\
\hline Z2-EU1B-303 & $\underline{05 / 09 / 20061510}$ & $\underline{0-1}$ & Metal & Barium & 43.3 & $\mathrm{mg} / \mathrm{kg}$ & 49.6 & & $\equiv$ & $\equiv$ & & $\underline{14}$ & \\
\hline Z2-EU1B-303 & $05 / 09 / 20061510$ & $\underline{0-1}$ & Metal & Beryllium & $\underline{0.46}$ & $\underline{\mathrm{mg} / \mathrm{kg}}$ & $\underline{0.48}$ & & $\underline{\mathrm{BNJ}}$ & BN J I02 & & $\underline{4}$ & \\
\hline Z2-EU1B-303 & $\underline{05 / 09 / 20061510}$ & $\underline{0-1}$ & Metal & Boron & 3.7 & $\mathrm{mg} / \mathrm{kg}$ & 4.9 & & $\mathrm{BNJ}$ & BN J I02 & & $\underline{28}$ & \\
\hline Z2-EU1B-303 & $05 / 09 / 20061510$ & $\underline{\underline{0-1}}$ & Metal & $\underline{\underline{\text { Cadmium }}}$ & $\underline{\underline{0.11}}$ & $\underline{\mathrm{mg} / \mathrm{kg}}$ & $\underline{\underline{0.13}}$ & & $\underline{\underline{B J}}$ & $\underline{\underline{B J}}$ & & $\underline{\underline{17}}$ & \\
\hline Z2-EU1B-303 & $\underline{05 / 09 / 20061510}$ & $\underline{0-1}$ & Metal & $\begin{array}{l}\text { Calcium } \\
\end{array}$ & $\underline{43900}$ & $\mathrm{mg} / \mathrm{kg}$ & 30900 & & EN J & EN J E07 & & $\underline{35}$ & \\
\hline Z2-EU1B-303 & $05 / 09 / 20061510$ & $\underline{\underline{0-1}}$ & Metal & $\begin{array}{l}\text { Chromium } \\
\end{array}$ & $\underline{15.6}$ & $\underline{\mathrm{mg} / \mathrm{kg}}$ & $\underline{17.6}$ & & $\mathrm{~N} \equiv$ & $\mathrm{N} \equiv$ & & $\underline{\underline{12}}$ & \\
\hline Z2-EU1B-303 & $05 / 09 / 20061510$ & $\underline{0-1}$ & Metal & Cobalt & 5.6 & $\mathrm{mg} / \mathrm{kg}$ & 6.4 & & EN J & EN J E07, I02 & & $\underline{13}$ & \\
\hline Z2-EU1B-303 & $05 / 09 / 20061510$ & $\underline{0-1}$ & Metal & Copper & $\underline{8.5}$ & $\underline{\mathrm{mg} / \mathrm{kg}}$ & $\underline{8.5}$ & & $\underline{\mathrm{NJ}}$ & N J I02 & & $\underline{\underline{0}}$ & \\
\hline Z2-EU1B-303 & $05 / 09 / 20061510$ & $\underline{\underline{0-1}}$ & Metal & $\underline{\underline{I r o n}}$ & $\underline{16400}$ & $\underline{\mathrm{mg} / \mathrm{kg}}$ & $\underline{16100}$ & & $\underline{\mathrm{EN} \mathrm{J}}$ & EN J E07 & & $\underline{\underline{2}}$ & \\
\hline Z2-EU1B-303 & $05 / 09 / 20061510$ & $\underline{0-1}$ & Metal & Lead & 17.7 & $\underline{\mathrm{mg} / \mathrm{kg}}$ & $\underline{17.5}$ & & $\equiv$ & $\equiv$ & & $\underline{1}$ & \\
\hline Z2-EU1B-303 & $05 / 09 / 20061510$ & $\underline{0-1}$ & Metal & Lithium & 23.5 & $\mathrm{mg} / \mathrm{kg}$ & 18.1 & & $\equiv$ & $\equiv$ & & $\underline{26}$ & \\
\hline Z2-EU1B-303 & $05 / 09 / 20061510$ & $\underline{0-1}$ & Metal & Magnesium & 4150 & $\underline{\mathrm{mg} / \mathrm{kg}}$ & $\underline{5010}$ & & $\underline{\mathrm{EN} \mathrm{J}}$ & EN J E07, I01 & & $\underline{19}$ & \\
\hline Z2-EU1B-303 & $\underline{05 / 09 / 20061510}$ & $\underline{0-1}$ & Metal & Manganese & 204 & $\mathrm{mg} / \mathrm{kg}$ & 158 & & $\underline{\mathrm{ENJ}}$ & EN J E07 & & $\underline{25}$ & \\
\hline Z2-EU1B-303 & $05 / 09 / 20061510$ & $\underline{\underline{0-1}}$ & Metal & Molybdenum & $\underline{0.62}$ & $\underline{\mathrm{mg} / \mathrm{kg}}$ & $\underline{0.59}$ & & $\underline{\mathrm{BJ}}$ & $\underline{\mathrm{B} \mathrm{J}}$ & & $\underline{\underline{5}}$ & \\
\hline Z2-EU1B-303 & $\underline{05 / 09 / 20061510}$ & $\underline{0-1}$ & Metal & Nickel & $\underline{12.5}$ & $\mathrm{mg} / \mathrm{kg}$ & 13.6 & & $\underline{\mathrm{ENJ}}$ & EN J E07, I02 & & $\underline{8}$ & \\
\hline Z2-EU1B-303 & $05 / 09 / 20061510$ & $\underline{\underline{0-1}}$ & Metal & Potassium & $\underline{1160}$ & $\underline{\mathrm{mg} / \mathrm{kg}}$ & $\underline{1400}$ & & $\underline{\mathrm{ENJ}}$ & EN J E07 & & $\underline{\underline{19}}$ & \\
\hline Z2-EU1B-303 & $\underline{05 / 09 / 20061510}$ & $\underline{0-1}$ & Metal & Silver & $\underline{0.13}$ & $\mathrm{mg} / \mathrm{kg}$ & 0.17 & & $\underline{\mathrm{BJ}}$ & $\underline{\mathrm{BJ}}$ & & 27 & \\
\hline Z2-EU1B-303 & $05 / 09 / 20061510$ & $\underline{0-1}$ & Metal & $\underline{\text { Sodium }}$ & $\underline{34.6}$ & $\underline{\mathrm{mg} / \mathrm{kg}}$ & $\underline{37.3}$ & & $\underline{\underline{\mathrm{NU}}}$ & N U F01, F07 & & & \\
\hline Z2-EU1B-303 & $\underline{05 / 09 / 20061510}$ & $\underline{0-1}$ & Metal & Thallium & 1.2 & $\mathrm{mg} / \mathrm{kg}$ & 1.3 & & $\underline{\mathrm{BU}}$ & B U F06 & & & \\
\hline Z2-EU1B-303 & $05 / 09 / 20061510$ & $0-1$ & Metal & Uranium & 1.2 & $\mathrm{mg} / \mathrm{kg}$ & 1.3 & & $\equiv$ & $\equiv$ & & $\underline{8}$ & \\
\hline Z2-EU1B-303 & $\underline{05 / 09 / 20061510}$ & $\underline{0-1}$ & Metal & Vanadium & 25.4 & $\mathrm{mg} / \mathrm{kg}$ & 23.8 & & $\underline{\mathrm{NJ}}$ & $\begin{array}{l}\text { N J I02 } \\
\end{array}$ & & $\underline{7}$ & \\
\hline Z2-EU1B-303 & $\underline{05 / 09 / 20061510}$ & $\underline{\underline{0-1}}$ & Metal & Zinc & 43.9 & $\underline{\mathrm{mg} / \mathrm{kg}}$ & $\underline{50.2}$ & & $\underline{\mathrm{ENJ}}$ & EN J E07 & & $\underline{13}$ & \\
\hline Z2-EU34B-301 & $07 / 17 / 20061030$ & $\underline{\underline{0-10}}$ & Metal & Mercury & $\underline{0.091}$ & $\mathrm{mg} / \mathrm{kg}$ & $\underline{0.41}$ & & $\underline{\underline{U}}$ & $\equiv$ & & $\underline{127}$ & \\
\hline Z2-EU34B-301 & $07 / 17 / 20061030$ & $\underline{0-10}$ & Metal & Aluminum & 13300 & $\underline{\mathrm{mg} / \mathrm{kg}}$ & $\underline{13800}$ & & $\underline{\underline{E N J}}$ & EN J E07 & & $\underline{4}$ & \\
\hline Z2-EU34B-301 & $07 / 17 / 20061030$ & $\underline{0-10}$ & Metal & Arsenic & 4.3 & $\underline{\mathrm{mg} / \mathrm{kg}}$ & 4.6 & & $\underline{\underline{B J}}$ & $\underline{\underline{B J}}$ & & $\underline{7}$ & \\
\hline Z2-EU34B-301 & $07 / 17 / 20061030$ & $\underline{0-10}$ & Metal & Barium & $\underline{114}$ & $\underline{\mathrm{mg} / \mathrm{kg}}$ & 78.4 & & $\mathrm{~N} \equiv$ & $\mathrm{N} \equiv$ & & 37 & \\
\hline
\end{tabular}


Table L.3. (continued)

\begin{tabular}{|c|c|c|c|c|c|c|c|c|c|c|c|c|c|}
\hline Station & Date-time & Depth & Category & Chemical name & $\underset{\text { result }}{\text { reg }}$ & Units & $\frac{\text { Field rep }}{\text { result }}$ & $\frac{\text { Split }}{\text { result }}$ & $\frac{\text { Qual }}{\text { (lab, val, }}$, RC) $^{2}$ & FR qual (lab, val, RC) & Split qual & $\frac{\mathrm{FR}}{\mathrm{RPD}}$ & $\frac{\text { Split }}{\mathrm{RPD}}$ \\
\hline Z2-EU34B-301 & $07 / 17 / 20061030$ & $\underline{0-10}$ & Metal & Beryllium & 1.7 & $\mathrm{mg} / \mathrm{kg}$ & 1.3 & & $\equiv$ & $\equiv$ & & 27 & \\
\hline Z2-EU34B-301 & $07 / 17 / 20061030$ & $0-10$ & Metal & Cadmium & 0.16 & $\mathrm{mg} / \mathrm{kg}$ & 0.097 & & $\equiv$ & $\underline{B \mathrm{~J}}$ & & 49 & \\
\hline Z2-EU34B-301 & $07 / 17 / 20061030$ & $0-10$ & Metal & Calcium & 9150 & $\mathrm{mg} / \mathrm{kg}$ & 3720 & & EN J & EN J E07 & & 84 & \\
\hline$\overline{\text { Z2-EU34B-301 }}$ & $07 / 17 / 20061030$ & $\overline{\overline{0-10}}$ & $\overline{\text { Metal }}$ & Chromium & $\overline{20.8}$ & $\overline{\mathrm{mg} / \mathrm{kg}}$ & $\overline{23.6}$ & & $\overline{\mathrm{NJ}}$ & $\overline{\mathrm{NJ} \mathrm{I02}}$ & & $\underline{13}$ & \\
\hline Z2-EU34B-301 & $07 / 17 / 20061030$ & $0-10$ & Metal & Cobalt & 36.7 & $\mathrm{mg} / \mathrm{kg}$ & 13.9 & & ${ }^{* N \mathrm{~N} J}$ & N J I01 & & 90 & \\
\hline Z2-EU34B-301 & $07 / 17 / 20061030$ & $\underline{0-10}$ & Metal & Copper & 14.7 & $\mathrm{mg} / \mathrm{kg}$ & 17.9 & & $\underline{\mathrm{NJ}}$ & N J I02 & & $\underline{20}$ & \\
\hline Z2-EU34B-301 & $07 / 17 / 20061030$ & $\underline{0-10}$ & Metal & Iron & 30800 & $\mathrm{mg} / \mathrm{kg}$ & 34900 & & ${ }^{*} \mathrm{~N}=$ & *N= & & 12 & \\
\hline Z2-EU34B-301 & $07 / 17 / 20061030$ & $\underline{0-10}$ & Metal & Lead & 33.8 & $\mathrm{mg} / \mathrm{kg}$ & 25.9 & & 苂 J & *N J I01 & & $\underline{26}$ & \\
\hline Z2-EU34B-301 & $07 / 17 / 20061030$ & $\underline{0-10}$ & Metal & Lithium & 19.6 & $\mathrm{mg} / \mathrm{kg}$ & 16.6 & & $\equiv$ & $\equiv$ & & 17 & \\
\hline Z2-EU34B-301 & $07 / 17 / 20061030$ & $\underline{0-10}$ & Metal & Magnesium & $\underline{2130}$ & $\mathrm{mg} / \mathrm{kg}$ & 1060 & & EEN J & EN J E07 & & $\underline{67}$ & \\
\hline Z2-EU34B-301 & $07 / 17 / 20061030$ & $0-10$ & Metal & Manganese & 1470 & $\mathrm{mg} / \mathrm{kg}$ & 366 & & ${ }^{*} \mathrm{~N}=$ & *N= & & 120 & \\
\hline Z2-EU34B-301 & $07 / 17 / 20061030$ & $0-10$ & Metal & Molybdenum & 0.59 & $\mathrm{mg} / \mathrm{kg}$ & 0.57 & & $\mathrm{BJ}$ & $\mathrm{BJ}$ & & $\underline{3}$ & \\
\hline Z2-EU34B-301 & $07 / 17 / 20061030$ & $\overline{0-10}$ & Metal & Nickel & 27.5 & $\mathrm{mg} / \mathrm{kg}$ & 19 & & $\bar{\equiv}$ & $\bar{\equiv}$ & & 37 & \\
\hline Z2-EU34B-301 & $07 / 17 / 20061030$ & $0-10$ & Metal & Potassium & 1350 & $\mathrm{mg} / \mathrm{kg}$ & 1040 & & $\equiv$ & $\equiv$ & & 26 & \\
\hline Z2-EU34B-301 & $07 / 17 / 20061030$ & 0 & Metal & Selenium & 15 & $\mathrm{mg} / \mathrm{kg}$ & 0.3 & & $\underline{\mathrm{BU}}$ & $\overline{\mathrm{UU}}$ & & & \\
\hline Z2-EU34B-301 & $07 / 17 / 20061030$ & $0-10$ & Metal & Silver & 0.12 & $\mathrm{mg} / \mathrm{kg}$ & 0.21 & & $\underline{\mathrm{BJ}}$ & $\mathrm{BJ}$ & & $\underline{55}$ & \\
\hline Z2-EU34B-301 & $07 / 17 / 20061030$ & $0-10$ & Metal & Sodium & 48.9 & $\mathrm{mg} / \mathrm{kg}$ & 42.8 & & $\equiv$ & $\equiv$ & & 13 & \\
\hline Z2-EU34B-301 & $07 / 17 / 20061030$ & $0-10$ & Metal & Thallium & 0.6 & $\mathrm{mg} / \mathrm{kg}$ & 0.56 & & $\underline{\mathrm{BU}}$ & B U F06 & & & \\
\hline Z2-EU34B-301 & $07 / 17 / 20061030$ & $0-10$ & Metal & Uranium & 0.59 & $\mathrm{mg} / \mathrm{kg}$ & 0.89 & & $\equiv$ & $\equiv$ & & 41 & \\
\hline Z2-EU34B-301 & $07 / 17 / 20061030$ & $\underline{0-10}$ & Metal & Vanadium & $\underline{23}$ & $\mathrm{mg} / \mathrm{kg}$ & 24.1 & & $\mathrm{NJ}$ & N J I02 & & $\underline{5}$ & \\
\hline Z2-EU34B-301 & $07 / 17 / 20061030$ & $0-10$ & Metal & Zinc & 46.3 & $\mathrm{mg} / \mathrm{kg}$ & 44.8 & & $\underline{\mathrm{J}}$ & J I02 & & 3 & \\
\hline Z2-EU43-202 & $07 / 18 / 20061040$ & $0.55-2.55$ & Metal & Mercury & 0.052 & $\mathrm{mg} / \mathrm{kg}$ & & 0.039 & $\underline{U}$ & & $\underline{\mathrm{BJ}}$ & & \\
\hline Z2-EU43-202 & $07 / 18 / 20061040$ & $0.55-2.55$ & Metal & Aluminum & 21000 & $\mathrm{mg} / \mathrm{kg}$ & & 19000 & EN J & & $\bar{E}$ & & 10 \\
\hline Z2-EU43-202 & $07 / 18 / 20061040$ & $\underline{0.55-2.55}$ & Metal & Antimony & 0.067 & $\mathrm{mg} / \mathrm{kg}$ & & 0.089 & $\mathrm{BN} \mathrm{J}$ & & $\underline{\mathrm{NJ}}$ & & $\underline{28}$ \\
\hline Z2-EU43-202 & $07 / 18 / 20061040$ & $0.55-2.55$ & Metal & Arsenic & 2.6 & $\mathrm{mg} / \mathrm{kg}$ & & $\overline{11}$ & $\overline{\mathrm{BJ}}$ & & $\bar{E}$ & & 124 \\
\hline Z2-EU43-202 & $07 / 18 / 20061040$ & $0.55-2.55$ & Metal & Barium & $\underline{280}$ & $\mathrm{mg} / \mathrm{kg}$ & & 290 & $\underline{\mathrm{EJ}}$ & & $\equiv$ & & 4 \\
\hline Z2-EU43-202 & $07 / 18 / 20061040$ & $0.55-2.55$ & Metal & Beryllium & 1.4 & $\mathrm{mg} / \mathrm{kg}$ & & 1.9 & 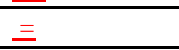 & & $\equiv$ & & 30 \\
\hline Z2-EU43-202 & $07 / 18 / 20061040$ & $0.55-2.55$ & Metal & Cadmium & 0.074 & $\mathrm{mg} / \mathrm{kg}$ & & 0.088 & $\equiv$ & & $\equiv$ & & 17 \\
\hline Z2-EU43-202 & $07 / 18 / 20061040$ & $0.55-2.55$ & Metal & $\overline{\text { Calcium }}$ & 7070 & $\mathrm{mg} / \mathrm{kg}$ & & 16000 & EN J & & ${ }^{*} \mathrm{~N} \mathrm{~J}$ & & $\overline{77}$ \\
\hline Z2-EU43-202 & $07 / 18 / 20061040$ & $0.55-2.55$ & Metal & Chromium & 28.9 & $\mathrm{mg} / \mathrm{kg}$ & & $\underline{24}$ & $\equiv$ & & $\equiv$ & & 19 \\
\hline Z2-EU43-202 & $07 / 18 / 20061040$ & $0.55-2.55$ & Metal & Cobalt & $\underline{14.5}$ & $\mathrm{mg} / \mathrm{kg}$ & & 20 & E J & & $\overline{\mathrm{NJ}}$ & & 32 \\
\hline Z2-EU43-202 & $07 / 18 / 20061040$ & $0.55-2.55$ & Metal & Copper & 17.5 & $\mathrm{mg} / \mathrm{kg}$ & & 25 & $\equiv$ & & $\equiv$ & & 35 \\
\hline Z2-EU43-202 & $07 / 18 / 20061040$ & $0.55-2.55$ & Metal & Iron & 29200 & $\mathrm{mg} / \mathrm{kg}$ & & 67000 & EN J & & $\equiv$ & & $\underline{79}$ \\
\hline Z2-EU43-202 & $07 / 18 / 20061040$ & $0.55-2.55$ & Metal & Lead & 22.9 & $\mathrm{mg} / \mathrm{kg}$ & & $\underline{27}$ & $\equiv$ & & $\underline{\mathrm{NJ}}$ & & 16 \\
\hline Z2-EU43-202 & $07 / 18 / 20061040$ & $0.55-2.55$ & Metal & Lithium & 25.3 & $\mathrm{mg} / \mathrm{kg}$ & & 17 & $\equiv$ & & EJ & & 39 \\
\hline Z2-EU43-202 & $07 / 18 / 20061040$ & $0.55-2.55$ & Metal & Magnesium & 2720 & $\mathrm{mg} / \mathrm{kg}$ & & $\underline{2800}$ & $\equiv$ & & 尊 & & $\underline{3}$ \\
\hline Z2-EU43-202 & $07 / 18 / 20061040$ & $0.55-2.55$ & Metal & Manganese & 529 & $\mathrm{mg} / \mathrm{kg}$ & & 980 & EN J & & $\equiv$ & & 60 \\
\hline Z2-EU43-202 & $07 / 18 / 20061040$ & $0.55-2.55$ & Metal & Molybdenum & 0.18 & $\mathrm{mg} / \mathrm{kg}$ & & 0.11 & $\mathrm{~B} \mathrm{~J}$ & & $\underline{\mathrm{UU}}$ & & \\
\hline Z2-EU43-202 & $07 / 18 / 20061040$ & $\underline{0.55-2.55}$ & Metal & Nickel & 24.6 & $\underline{\mathrm{mg} / \mathrm{kg}}$ & & $\underline{25}$ & $\underline{\mathrm{EJ}}$ & & $\equiv$ & & $\underline{\underline{2}}$ \\
\hline$\overline{\text { Z2-EU43-202 }}$ & $07 / 18 / 20061040$ & $0.55-2.55$ & Metal & Potassium & $\underline{1330}$ & $\underline{\mathrm{mg} / \mathrm{kg}}$ & & $\underline{1100}$ & $\bar{E}$ & & $\equiv$ & & $\underline{19}$ \\
\hline
\end{tabular}


Table L.3. (continued)

\begin{tabular}{|c|c|c|c|c|c|c|c|c|c|c|c|c|c|}
\hline Station & Date-time & Depth & Category & Chemical name & $\begin{array}{l}\text { Reg } \\
\text { result } \\
\end{array}$ & Units & $\frac{\text { Field rep }}{\text { result }}$ & 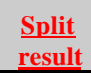 & $\left(\begin{array}{l}\text { Qual } \\
\text { (lab, val, RC) }\end{array}\right.$ & FR qual (lab, val, RC) & Split qual & $\underline{\mathrm{FR}}$ & $\underline{\text { Split }}$ \\
\hline Z2-EU43-202 & $07 / 18 / 20061040$ & $\underline{0.55-2.55}$ & Metal & Selenium & 0.76 & $\underline{\mathrm{mg} / \mathrm{kg}}$ & & $\underline{1.2}$ & $\underline{\mathrm{BJ}}$ & & $\underline{\underline{U U}}$ & & \\
\hline Z2-EU43-202 & $07 / 18 / 20061040$ & $0.55-2.55$ & Metal & Silver & $\underline{0.095}$ & $\mathrm{mg} / \mathrm{kg}$ & & 0.14 & $\mathrm{BJ}$ & & NU UJ & & \\
\hline Z2-EU43-202 & $07 / 18 / 20061040$ & $0.55-2.55$ & Metal & Sodium & 69.2 & $\underline{\mathrm{mg} / \mathrm{kg}}$ & & 85 & $\equiv$ & & BE J & & $\underline{20}$ \\
\hline Z2-EU43-202 & $07 / 18 / 20061040$ & $\underline{0.55-2.55}$ & Metal & Thallium & 0.26 & $\mathrm{mg} / \mathrm{kg}$ & & $\underline{0.13}$ & $\mathrm{BU}$ & & $\equiv$ & & \\
\hline Z2-EU43-202 & $07 / 18 / 20061040$ & $0.55-2.55$ & Metal & Uranium & 0.41 & $\underline{\mathrm{mg} / \mathrm{kg}}$ & & 0.47 & $\equiv$ & & $E J$ & & 14 \\
\hline Z2-EU43-202 & $07 / 18 / 20061040$ & $0.55-2.55$ & Metal & Vanadium & 22.6 & $\mathrm{mg} / \mathrm{kg}$ & & 30 & $\equiv$ & & $\equiv$ & & $\underline{28}$ \\
\hline Z2-EU43-202 & $07 / 18 / 20061040$ & $0.55-2.55$ & Metal & Zinc & 53.8 & $\underline{\mathrm{mg} / \mathrm{kg}}$ & & 66 & $\underline{N \mathrm{~J}}$ & & $\underline{\mathrm{NJ}}$ & & $\underline{20}$ \\
\hline Z2-EU37B-301 & 09/11/2006 1230 & $\underline{5.5-0}$ & Metal & Mercury & $\underline{0.16}$ & $\underline{\mathrm{mg} / \mathrm{kg}}$ & 0.14 & & $\equiv$ & $\equiv$ & & $\underline{13}$ & \\
\hline Z2-EU37B-301 & $09 / 11 / 20061230$ & $\overline{5.5-0}$ & Metal & Aluminum & $\underline{14000}$ & $\underline{\mathrm{mg} / \mathrm{kg}}$ & $\underline{16000}$ & & $\equiv$ & $\equiv$ & & $\underline{13}$ & \\
\hline Z2-EU37B-301 & 09/11/2006 1230 & $5.5-0$ & Metal & Antimony & 0.096 & $\underline{\mathrm{mg} / \mathrm{kg}}$ & 0.13 & & $\underline{\mathrm{J}}$ & J I02 E07 & & $\underline{30}$ & \\
\hline Z2-EU37B-301 & 09/11/2006 1230 & $\underline{\underline{5.5-0}}$ & Metal & Arsenic & $\underline{7.3}$ & $\underline{\underline{\mathrm{mg}} / \mathrm{kg}}$ & $\underline{8.5}$ & & $\equiv$ & $\equiv$ & & $\underline{15}$ & \\
\hline Z2-EU37B-301 & 09/11/2006 1230 & $\underline{5.5-0}$ & Metal & Barium & $\underline{75}$ & $\underline{\mathrm{mg} / \mathrm{kg}}$ & $\underline{83}$ & & $\equiv$ & $\equiv$ & & 10 & \\
\hline Z2-EU37B-301 & $09 / 11 / 20061230$ & $\underline{\underline{5.5-0}}$ & Metal & Beryllium & $\underline{0.85}$ & $\underline{\underline{\mathrm{mg}} / \mathrm{kg}}$ & $\underline{1}$ & & $\underline{\mathrm{J}}$ & $\mathrm{JF} 10$ & & $\underline{16}$ & \\
\hline Z2-EU37B-301 & $09 / 11 / 20061230$ & $\underline{5.5-0}$ & Metal & Boron & 8.5 & $\underline{\mathrm{mg} / \mathrm{kg}}$ & 8.2 & & $\equiv$ & $\equiv$ & & 4 & \\
\hline Z2-EU37B-301 & 09/11/2006 1230 & $\underline{\underline{5.5-0}}$ & Metal & Cadmium & $\underline{0.34}$ & $\underline{\mathrm{mg} / \mathrm{kg}}$ & 0.41 & & $\underline{\underline{J}}$ & JE07 & & $\underline{19}$ & \\
\hline Z2-EU37B-301 & $09 / 11 / 20061230$ & $\underline{5.5-0}$ & Metal & Calcium & $\underline{57000}$ & $\mathrm{mg} / \mathrm{kg}$ & 26000 & & $\equiv$ & $\equiv$ & & $\underline{75}$ & \\
\hline Z2-EU37B-301 & $09 / 11 / 20061230$ & $\underline{5.5-0}$ & Metal & Chromium & $\underline{38}$ & $\underline{\mathrm{mg} / \mathrm{kg}}$ & $\underline{49}$ & & $\equiv$ & $\equiv$ & & 25 & \\
\hline Z2-EU37B-301 & $09 / 11 / 20061230$ & $\underline{5.5-0}$ & Metal & Cobalt & $\underline{15}$ & $\underline{\mathrm{mg} / \mathrm{kg}}$ & $\underline{19}$ & & $\equiv$ & $\equiv$ & & 24 & \\
\hline Z2-EU37B-301 & $09 / 11 / 20061230$ & $\underline{5.5-0}$ & Metal & Copper & $\underline{54}$ & $\underline{\mathrm{mg} / \mathrm{kg}}$ & $\underline{68}$ & & $\underline{J}$ & JF10 & & $\underline{23}$ & \\
\hline Z2-EU37B-301 & $09 / 11 / 20061230$ & $\underline{5.5-0}$ & Metal & Iron & 37000 & $\underline{\mathrm{mg} / \mathrm{kg}}$ & 42000 & & $\equiv$ & $\equiv$ & & $\underline{13}$ & \\
\hline Z2-EU37B-301 & $09 / 11 / 20061230$ & $5.5-0$ & Metal & Lead & 45 & $\underline{\mathrm{mg} / \mathrm{kg}}$ & 55 & & $\equiv$ & $=$ & & 20 & \\
\hline Z2-EU37B-301 & $09 / 11 / 20061230$ & $\underline{5.5-0}$ & Metal & Lithium & $4 \underline{45}$ & $\mathrm{mg} / \mathrm{kg}$ & 34 & & $\equiv$ & $\equiv$ & & $2 \underline{28}$ & \\
\hline Z2-EU37B-301 & $09 / 11 / 20061230$ & $\underline{5.5-0}$ & Metal & Magnesium & 19000 & $\underline{\underline{\mathrm{mg}} / \mathrm{kg}}$ & $\underline{8600}$ & & $\equiv$ & $\equiv$ & & $\underline{75}$ & \\
\hline Z2-EU37B-301 & $09 / 11 / 20061230$ & $\underline{5.5-0}$ & Metal & Manganese & 640 & $\underline{\mathrm{mg} / \mathrm{kg}}$ & 460 & & $\equiv$ & $\equiv$ & & $\underline{33}$ & \\
\hline Z2-EU37B-301 & $09 / 11 / 20061230$ & $\underline{5.5-0}$ & Metal & Molybdenum & 1.1 & $\underline{\mathrm{mg} / \mathrm{kg}}$ & 1.1 & & $\underline{\mathrm{BU}}$ & B U F06 F01 & & & \\
\hline Z2-EU37B-301 & $09 / 11 / 20061230$ & $5.5-0$ & Metal & Nickel & 100 & $\underline{\mathrm{mg} / \mathrm{kg}}$ & 140 & & $\equiv$ & $\equiv$ & & $\underline{33}$ & \\
\hline Z2-EU37B-301 & $09 / 11 / 20061230$ & $\overline{5.5-0}$ & Metal & Potassium & 2700 & $\underline{\mathrm{mg} / \mathrm{kg}}$ & 2800 & & $\equiv$ & $\equiv$ & & 4 & \\
\hline Z2-EU37B-301 & $09 / 11 / 20061230$ & $\underline{5.5-0}$ & Metal & Sodium & 140 & $\underline{\mathrm{mg} / \mathrm{kg}}$ & 1110 & & $\underline{\mathrm{J}}$ & B J E07 & & 24 & \\
\hline Z2-EU37B-301 & $09 / 11 / 20061230$ & $\overline{5.5-0}$ & Metal & Thallium & 0.21 & $\underline{\mathrm{mg} / \mathrm{kg}}$ & 0.24 & & $\equiv$ & $\equiv$ & & $\underline{13}$ & \\
\hline Z2-EU37B-301 & $09 / 11 / 20061230$ & $\underline{5.5-0}$ & Metal & Uranium & 1.9 & $\underline{\mathrm{mg} / \mathrm{kg}}$ & 2.1 & & $\equiv$ & $\equiv$ & & 10 & \\
\hline Z2-EU37B-301 & $09 / 11 / 20061230$ & $\underline{\underline{5.5-0}}$ & Metal & Vanadium & $\underline{26}$ & $\underline{\underline{\mathrm{mg}} / \mathrm{kg}}$ & 31 & & $\equiv$ & $\equiv$ & & $\underline{18}$ & \\
\hline Z2-EU37B-301 & $09 / 11 / 20061230$ & $5.5-0$ & Metal & Zinc & $\underline{85}$ & $\mathrm{mg} / \mathrm{kg}$ & $\underline{110}$ & & $\underline{J}$ & JE07 & & $\underline{26}$ & \\
\hline Z2-EU37B-306 & $09 / 12 / 2006845$ & $1-0$ & Metal & Mercury & $\underline{0.069}$ & $\underline{\mathrm{mg} / \mathrm{kg}}$ & & $\underline{0.049}$ & $\equiv$ & & $\equiv$ & & 34 \\
\hline Z2-EU37B-306 & $09 / 12 / 2006845$ & $1-0$ & Metal & Aluminum & 10000 & $\mathrm{mg} / \mathrm{kg}$ & & 10800 & $\equiv$ & & NEJ & & $\underline{8}$ \\
\hline Z2-EU37B-306 & $09 / 12 / 2006845$ & $1-0$ & Metal & Antimony & 0.22 & $\underline{\mathrm{mg} / \mathrm{kg}}$ & & 0.21 & $\underline{J}$ & & $\mathrm{BN} \mathrm{J}$ & & 5 \\
\hline Z2-EU37B-306 & $09 / 12 / 2006845$ & $\underline{1-0}$ & Metal & Arsenic & 6.7 & $\mathrm{mg} / \mathrm{kg}$ & & 4.3 & $\equiv$ & & $\underline{\mathrm{NJ}}$ & & 44 \\
\hline Z2-EU37B-306 & $09 / 12 / 2006845$ & $1-0$ & Metal & Barium & 390 & $\underline{\mathrm{mg} / \mathrm{kg}}$ & & 160 & $\equiv$ & & $E \mathrm{EJ}$ & & 84 \\
\hline Z2-EU37B-306 & $09 / 12 / 2006845$ & $1-0$ & Metal & Beryllium & 0.59 & $\underline{\mathrm{mg} / \mathrm{kg}}$ & & 0.58 & $\underline{J}$ & & $\equiv$ & & $\underline{2}$ \\
\hline Z2-EU37B-306 & $09 / 12 / 2006845$ & $\underline{\underline{1-0}}$ & Metal & Boron & 2.2 & $\underline{\underline{\mathrm{mg}} / \mathrm{kg}}$ & & 1.7 & $\underline{\mathrm{BJ}}$ & & $\underline{\mathrm{UN} \mathrm{UJ}}$ & & \\
\hline$\overline{~ Z 2-E U 37 B-306}$ & $09 / 12 / 2006845$ & $\overline{1-0}$ & Metal & Cadmium & $\overline{0.12}$ & $\overline{\mathrm{mg} / \mathrm{kg}}$ & & 0.082 & $\bar{J}$ & & $\overline{\mathrm{BJ}}$ & & $\underline{38}$ \\
\hline
\end{tabular}


Table L.3. (continued)

\begin{tabular}{|c|c|c|c|c|c|c|c|c|c|c|c|c|c|}
\hline Station & Date-time & Depth & Category & Chemical name & $\underline{\text { Reg }}$ & Units & $\frac{\text { Field rep }}{\text { result }}$ & 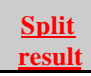 & $\left(\begin{array}{l}\text { Qual } \\
\text { (lab, val, RC) }\end{array}\right.$ & FR qual (lab, val, RC) & Split qual & $\underline{\mathrm{FR}}$ & $\underline{\text { Split }}$ \\
\hline Z2-EU37B-306 & $09 / 12 / 2006845$ & $\underline{\underline{1-0}}$ & Metal & Calcium & 14000 & $\underline{\mathrm{mg} / \mathrm{kg}}$ & & $\underline{8400}$ & $\equiv$ & & NEJ & & $\underline{50}$ \\
\hline Z2-EU37B-306 & $09 / 12 / 2006845$ & $\frac{1-0}{1-0}$ & Metal & Chromium & 17 & $\mathrm{mg} / \mathrm{kg}$ & & 14.1 & $\equiv$ & & $\mathrm{NEJ}$ & & 19 \\
\hline Z2-EU37B-306 & $09 / 12 / 2006845$ & $\underline{1-0}$ & Metal & Cobalt & 18 & $\underline{\mathrm{mg} / \mathrm{kg}}$ & & 15.2 & $\equiv$ & & $\overline{\mathrm{NEJ}}$ & & 17 \\
\hline Z2-EU37B-306 & $09 / 12 / 2006845$ & $\underline{1-0}$ & Metal & Copper & $\underline{20}$ & $\mathrm{mg} / \mathrm{kg}$ & & 14.7 & $\underline{\mathrm{J}}$ & & NEJ & & 31 \\
\hline Z2-EU37B-306 & $09 / 12 / 2006845$ & $1-0$ & Metal & Iron & 50000 & $\underline{\mathrm{mg} / \mathrm{kg}}$ & & 27000 & $\equiv$ & & NE*J & & 60 \\
\hline Z2-EU37B-306 & $09 / 12 / 2006845$ & $1-0$ & Metal & Lead & $\underline{17}$ & $\mathrm{mg} / \mathrm{kg}$ & & 12.5 & $\equiv$ & & EJ & & 31 \\
\hline Z2-EU37B-306 & $09 / 12 / 2006845$ & $1-0$ & Metal & Lithium & 9.9 & $\underline{\mathrm{mg} / \mathrm{kg}}$ & & 30.7 & $\equiv$ & & $\equiv$ & & 102 \\
\hline Z2-EU37B-306 & $09 / 12 / 2006845$ & $\underline{1-0}$ & Metal & Magnesium & $\underline{3500}$ & $\underline{\mathrm{mg} / \mathrm{kg}}$ & & $\underline{1400}$ & $\equiv$ & & NEJ & & $\underline{86}$ \\
\hline Z2-EU37B-306 & $09 / 12 / 2006845$ & $1-0$ & Metal & Manganese & 10000 & $\underline{\mathrm{mg} / \mathrm{kg}}$ & & 2490 & $\equiv$ & & $\overline{\mathrm{NEJ}}$ & & 120 \\
\hline Z2-EU37B-306 & $09 / 12 / 2006845$ & $\underline{1-0}$ & Metal & Nickel & $\underline{14}$ & $\underline{\mathrm{mg} / \mathrm{kg}}$ & & 11.4 & $\equiv$ & & NEJ & & $\underline{20}$ \\
\hline Z2-EU37B-306 & $09 / 12 / 2006845$ & $\underline{1-0}$ & Metal & Potassium & $\underline{1200}$ & $\underline{\mathrm{mg} / \mathrm{kg}}$ & & $\underline{1320}$ & $\equiv$ & & $\overline{\mathrm{NEJ}}$ & & 10 \\
\hline Z2-EU37B-306 & $09 / 12 / 2006845$ & $\underline{1-0}$ & Metal & Sodium & 140 & $\underline{\mathrm{mg} / \mathrm{kg}}$ & & 29.2 & $\mathrm{BU}$ & & $\mathrm{BNJ}$ & & \\
\hline Z2-EU37B-306 & $09 / 12 / 2006845$ & $\overline{1-0}$ & Metal & Thallium & 0.22 & $\underline{\mathrm{mg} / \mathrm{kg}}$ & & 0.24 & $\bar{\equiv}$ & & $\overline{\mathrm{BJ}}$ & & $\underline{9}$ \\
\hline Z2-EU37B-306 & $09 / 12 / 2006845$ & $\frac{1-0}{1-0}$ & Metal & Uranium & 1.3 & $\underline{\mathrm{mg} / \mathrm{kg}}$ & & 1.5 & $\equiv$ & & $\equiv$ & & 14 \\
\hline Z2-EU37B-306 & $09 / 12 / 2006845$ & $\overline{1-0}$ & Metal & Vanadium & 26 & $\underline{\mathrm{mg} / \mathrm{kg}}$ & & 21.3 & $\equiv$ & & $\mathrm{NJ}$ & & $\underline{20}$ \\
\hline Z2-EU37B-306 & $09 / 12 / 2006845$ & $1-0$ & Metal & Zinc & 44 & $\mathrm{mg} / \mathrm{kg}$ & & 30.1 & $\underline{J}$ & & $\underline{\mathrm{EJ}}$ & & 38 \\
\hline Z2-EU41DB-208-3 & $09 / 25 / 20061200$ & $0-10$ & Metal & Mercury & $\underline{0.066}$ & $\underline{\mathrm{mg} / \mathrm{kg}}$ & & 0.041 & $\underline{J}$ & & N R D04 P03 I03 & & \\
\hline Z2-EU41DB-208-3 & $09 / 25 / 20061200$ & $0-10$ & Metal & Aluminum & 13000 & $\mathrm{mg} / \mathrm{kg}$ & & 12200 & $\equiv$ & & NEJ J07 & & $\underline{6}$ \\
\hline Z2-EU41DB-208-3 & $09 / 25 / 20061200$ & $0-10$ & Metal & Antimony & 0.013 & $\underline{\mathrm{mg} / \mathrm{kg}}$ & & 0.11 & $\underline{R}$ & & U N R P03 I03 & & \\
\hline Z2-EU41DB-208-3 & $09 / 25 / 20061200$ & $\underline{0-10}$ & Metal & Arsenic & 2.5 & $\mathrm{mg} / \mathrm{kg}$ & & 2.5 & $\equiv$ & & N J I01 & & $\underline{\underline{0}}$ \\
\hline Z2-EU41DB-208-3 & $09 / 25 / 20061200$ & $0-10$ & Metal & Barium & $\underline{85}$ & $\mathrm{mg} / \mathrm{kg}$ & & 105 & $\equiv$ & & $\mathrm{N} \equiv$ & & 21 \\
\hline Z2-EU41DB-208-3 & $09 / 25 / 20061200$ & $\underline{0-10}$ & Metal & Beryllium & 0.85 & $\mathrm{mg} / \mathrm{kg}$ & & 0.72 & $\equiv$ & & N J I01 & & 17 \\
\hline Z2-EU41DB-208-3 & $09 / 25 / 20061200$ & $0-10$ & Metal & Boron & 3.3 & $\underline{\mathrm{mg} / \mathrm{kg}}$ & & 4.9 & $\underline{J}$ & & $\overline{B J}$ & & 39 \\
\hline Z2-EU41DB-208-3 & $09 / 25 / 20061200$ & $\underline{0-10}$ & Metal & Cadmium & $\underline{0.071}$ & $\underline{\mathrm{mg} / \mathrm{kg}}$ & & 0.081 & $\equiv$ & & B N J I01 & & $\underline{13}$ \\
\hline Z2-EU41DB-208-3 & $09 / 25 / 20061200$ & $\overline{0-10}$ & Metal & Calcium & 33000 & $\underline{\mathrm{mg} / \mathrm{kg}}$ & & $\underline{34200}$ & $\equiv$ & & N*E J J01 J02 E07 & & 4 \\
\hline Z2-EU41DB-208-3 & 09/25/2006 1200 & $\underline{0-10}$ & Metal & Chromium & $2 \underline{25}$ & $\underline{\mathrm{mg} / \mathrm{kg}}$ & & 24.8 & $\underline{\mathrm{J}}$ & & N E J E07 & & 1 \\
\hline Z2-EU41DB-208-3 & $09 / 25 / 20061200$ & $\overline{0-10}$ & Metal & Cobalt & $\underline{10}$ & $\underline{\mathrm{mg} / \mathrm{kg}}$ & & 11.9 & $\underline{J}$ & & N E J I01 E07 & & 17 \\
\hline Z2-EU41DB-208-3 & $09 / 25 / 20061200$ & $0-10$ & Metal & Copper & $\underline{18}$ & $\underline{\mathrm{mg} / \mathrm{kg}}$ & & 13.8 & $\underline{\mathrm{J}}$ & & N E J E07 & & $\underline{26}$ \\
\hline Z2-EU41DB-208-3 & $09 / 25 / 20061200$ & $\overline{0-10}$ & Metal & Iron & 32000 & $\underline{\mathrm{mg} / \mathrm{kg}}$ & & 20400 & $\equiv$ & & N E J P02 E07 & & 44 \\
\hline Z2-EU41DB-208-3 & $09 / 25 / 20061200$ & $0-10$ & Metal & Lead & $\underline{12}$ & $\mathrm{mg} / \mathrm{kg}$ & & 10.6 & $\equiv$ & & N E J J01 I01 J02 E07 & & $\underline{12}$ \\
\hline Z2-EU41DB-208-3 & $09 / 25 / 20061200$ & $\overline{0-10}$ & Metal & Lithium & $\underline{18}$ & $\underline{\underline{\mathrm{mg} / \mathrm{kg} g}}$ & & 143 & $\equiv$ & & N J I01 & & 155 \\
\hline Z2-EU41DB-208-3 & $09 / 25 / 20061200$ & $0-10$ & Metal & Magnesium & $\underline{3300}$ & $\mathrm{mg} / \mathrm{kg}$ & & $\underline{5160}$ & $\underline{J}$ & & E J E07 & & 44 \\
\hline Z2-EU41DB-208-3 & $09 / 25 / 20061200$ & $0-10$ & Metal & Manganese & 170 & $\underline{\mathrm{mg} / \mathrm{kg}}$ & & 275 & $\equiv$ & & NE J J01 J02 E07 & & 47 \\
\hline Z2-EU41DB-208-3 & $09 / 25 / 20061200$ & $0-10$ & Metal & Nickel & $\underline{23}$ & $\mathrm{mg} / \mathrm{kg}$ & & 29.8 & $\underline{J}$ & & NE J E07 & & 26 \\
\hline Z2-EU41DB-208-3 & $09 / 25 / 20061200$ & $0-10$ & Metal & Potassium & 1800 & $\underline{\mathrm{mg} / \mathrm{kg}}$ & & 1700 & $\equiv$ & & N E J I01 E07 & & $\underline{6}$ \\
\hline$\overline{\text { Z2-EU41DB-208-3 }}$ & $\overline{09 / 25 / 20061200}$ & $\overline{0-10}$ & Metal & $\overline{\text { Selenium }}$ & $\overline{1.2}$ & $\underline{\mathrm{mg} / \mathrm{kg}}$ & & $\overline{\underline{0.24}}$ & $\equiv$ & & $\overline{\mathrm{U} \text { U U I01 }}$ & & \\
\hline Z2-EU41DB-208-3 & $09 / 25 / 20061200$ & $0-10$ & Metal & Silver & 0.21 & $\mathrm{mg} / \mathrm{kg}$ & & 0.3 & $\mathrm{BR}$ & & B N R P03 & & \\
\hline Z2-EU41DB-208-3 & $09 / 25 / 20061200$ & $0-10$ & Metal & $\underline{\text { Sodium }}$ & 170 & $\underline{\mathrm{mg} / \mathrm{kg}}$ & & 116 & $\underline{\mathrm{J}}$ & & N J J01 I01 J02 & & 38 \\
\hline Z2-EU41DB-208-3 & $09 / 25 / 20061200$ & $\overline{0-10}$ & Metal & Thallium & $\underline{0.15}$ & $\underline{\mathrm{mg} / \mathrm{kg}}$ & & 2.2 & $\underline{\underline{J}}$ & & B N U I01 F06 F01 & & \\
\hline$\overline{Z Z 2-E U 41 D B-208-3}$ & $09 / 25 / 20061200$ & $\overline{\underline{0-10}}$ & Metal & Uranium & $\overline{7.9}$ & $\overline{\mathrm{mg} / \mathrm{kg}}$ & & $\overline{5.9}$ & $\equiv$ & & $\overline{\mathrm{N} * \mathrm{~J} \text { I01 }}$ & & $\underline{29}$ \\
\hline
\end{tabular}


Table L.3. (continued)

\begin{tabular}{|c|c|c|c|c|c|c|c|c|c|c|c|c|c|}
\hline Station & Date-time & Depth & Category & Chemical name & $\underline{\text { Reg }}$ & Units & $\frac{\text { Field rep }}{\text { result }}$ & 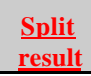 & $\frac{\text { Qual }}{(\text { lab, val, RC) }}$ & FR qual (lab, val, RC) & Split qual & $\underline{\mathrm{FR}}$ & $\underline{\text { Split }}$ \\
\hline Z2-EU41DB-208-3 & $09 / 25 / 20061200$ & $\underline{0-10}$ & Metal & Vanadium & $\underline{19}$ & $\underline{\mathrm{mg} / \mathrm{kg}}$ & & 16.8 & $\equiv$ & & N J I01 & & $\underline{12}$ \\
\hline Z2-EU41DB-208-3 & $09 / 25 / 20061200$ & $0-10$ & Metal & Zinc & $3 \underline{38}$ & $\underline{\mathrm{mg} / \mathrm{kg}}$ & & 40.8 & $\underline{\underline{J}}$ & & NE J E07 & & $\underline{7}$ \\
\hline Z2-EU41DB-208-4 & $09 / 25 / 20061305$ & $\underline{0-10}$ & Metal & Mercury & $\underline{0.055}$ & $\underline{\mathrm{mg} / \mathrm{kg}}$ & $\underline{\underline{0.3}}$ & & $\underline{\underline{J}}$ & N * J J01 J02 & & $\underline{138}$ & \\
\hline Z2-EU41DB-208-4 & $09 / 25 / 20061305$ & $0-10$ & Metal & Aluminum & 14000 & $\underline{\mathrm{mg} / \mathrm{kg}}$ & 14000 & & $\equiv$ & $\equiv$ & & $\underline{0}$ & \\
\hline Z2-EU41DB-208-4 & $09 / 25 / 20061305$ & $\underline{\underline{0-10}}$ & Metal & Antimony & 0.014 & $\underline{\mathrm{mg} / \mathrm{kg}}$ & $\underline{0.015}$ & & $\underline{\underline{R}}$ & N R I03 F07 F01 & & & \\
\hline Z2-EU41DB-208-4 & $09 / 25 / 20061305$ & $0-10$ & Metal & Arsenic & 3.2 & $\mathrm{mg} / \mathrm{kg}$ & 3.1 & & $\equiv$ & $\mathrm{N}=$ & & $\underline{3}$ & \\
\hline Z2-EU41DB-208-4 & $09 / 25 / 20061305$ & $\underline{0-10}$ & Metal & Barium & $\underline{100}$ & $\underline{\mathrm{mg} / \mathrm{kg}}$ & $\underline{92}$ & & $\underline{\underline{E}}$ & $\equiv$ & & $\underline{8}$ & \\
\hline Z2-EU41DB-208-4 & $09 / 25 / 20061305$ & $0-10$ & Metal & Beryllium & 0.83 & $\mathrm{mg} / \mathrm{kg}$ & $\underline{0.73}$ & & $\equiv$ & $\mathrm{N}=$ & & $\underline{13}$ & \\
\hline Z2-EU41DB-208-4 & $09 / 25 / 20061305$ & $\underline{0-10}$ & Metal & Boron & $\underline{2}$ & $\underline{\mathrm{mg} / \mathrm{kg}}$ & 1.6 & & $\underline{\mathrm{J}}$ & N J I02 F10 & & $\underline{22}$ & \\
\hline Z2-EU41DB-208-4 & $09 / 25 / 20061305$ & $\underline{0-10}$ & Metal & Cadmium & $\underline{0.23}$ & $\underline{\mathrm{mg} / \mathrm{kg}}$ & $\underline{0.1}$ & & $\equiv$ & $\equiv$ & & $\underline{79}$ & \\
\hline Z2-EU41DB-208-4 & $\underline{09 / 25 / 20061305}$ & $\underline{0-10}$ & Metal & Calcium & $\underline{20000}$ & $\underline{\mathrm{mg} / \mathrm{kg}}$ & $\underline{8500}$ & & $\equiv$ & 㐘 & & $\underline{81}$ & \\
\hline Z2-EU41DB-208-4 & $09 / 25 / 20061305$ & $0-10$ & Metal & Chromium & $\underline{44}$ & $\underline{\mathrm{mg} / \mathrm{kg}}$ & 37 & & $\underline{J}$ & N J I03 & & 17 & \\
\hline Z2-EU41DB-208-4 & $09 / 25 / 20061305$ & $\underline{0-10}$ & Metal & Cobalt & $\underline{19}$ & $\underline{\mathrm{mg} / \mathrm{kg}}$ & $\underline{18}$ & & $\underline{\mathrm{J}}$ & N*J I02 & & $\underline{5}$ & \\
\hline Z2-EU41DB-208-4 & $09 / 25 / 20061305$ & $0-10$ & Metal & Copper & 19 & $\underline{\mathrm{mg} / \mathrm{kg}}$ & 19 & & $\underline{J}$ & N J I02 & & $\underline{0}$ & \\
\hline Z2-EU41DB-208-4 & $09 / 25 / 20061305$ & $\underline{0-10}$ & Metal & Iron & 33000 & $\underline{\mathrm{mg} / \mathrm{kg}}$ & $\underline{30000}$ & & $\equiv$ & $\equiv$ & & $\underline{10}$ & \\
\hline Z2-EU41DB-208-4 & $09 / 25 / 20061305$ & $0-10$ & Metal & Lead & $\underline{20}$ & $\underline{\mathrm{mg} / \mathrm{kg}}$ & $\underline{18}$ & & $\equiv$ & $\equiv$ & & $\underline{11}$ & \\
\hline Z2-EU41DB-208-4 & $09 / 25 / 20061305$ & $\underline{0-10}$ & Metal & $\begin{array}{l}\text { Lithium } \\
\end{array}$ & $\underline{23}$ & $\underline{\mathrm{mg} / \mathrm{kg}}$ & $\underline{20}$ & & $\equiv$ & $\equiv$ & & 14 & \\
\hline Z2-EU41DB-208-4 & $09 / 25 / 20061305$ & $0-10$ & Metal & Magnesium & 7200 & $\underline{\mathrm{mg} / \mathrm{kg}}$ & 4300 & & $\mathrm{~J}$ & N J I01 & & $\underline{50}$ & \\
\hline Z2-EU41DB-208-4 & $09 / 25 / 20061305$ & $\underline{0-10}$ & Metal & Manganese & 610 & $\underline{\mathrm{mg} / \mathrm{kg}}$ & 500 & & $\equiv$ & * & & $\underline{20}$ & \\
\hline Z2-EU41DB-208-4 & $09 / 25 / 20061305$ & $0-10$ & Metal & Nickel & 32 & $\underline{\mathrm{mg} / \mathrm{kg}}$ & 27 & & $\underline{J}$ & N J I02 F10 & & 17 & \\
\hline Z2-EU41DB-208-4 & $09 / 25 / 20061305$ & $\underline{0-10}$ & Metal & Potassium & $\underline{1800}$ & $\underline{\mathrm{mg} / \mathrm{kg}}$ & $\underline{1600}$ & & $\underline{\underline{\underline{B}}}$ & 至 & & $\underline{12}$ & \\
\hline Z2-EU41DB-208-4 & $09 / 25 / 20061305$ & $0-10$ & Metal & Selenium & 1.1 & $\mathrm{mg} / \mathrm{kg}$ & 0.79 & & B J & $\mathrm{BJ}$ & & $\underline{33}$ & \\
\hline Z2-EU41DB-208-4 & $09 / 25 / 20061305$ & $\underline{0-10}$ & Metal & $\begin{array}{l}\text { Silver } \\
\end{array}$ & 1.2 & $\underline{\mathrm{mg} / \mathrm{kg}}$ & 0.74 & & $\underline{R}$ & $\begin{array}{ll}\text { N R P03 I03 } \\
\end{array}$ & & & \\
\hline Z2-EU41DB-208-4 & $09 / 25 / 20061305$ & $0-10$ & Metal & $\underline{\text { Sodium }}$ & 77 & $\underline{\mathrm{mg} / \mathrm{kg}}$ & $\underline{69}$ & & $\underline{J}$ & E J P02 E07 & & $\underline{11}$ & \\
\hline Z2-EU41DB-208-4 & $09 / 25 / 20061305$ & $\underline{0-10}$ & Metal & Thallium & $\underline{0.18}$ & $\underline{\mathrm{mg} / \mathrm{kg}}$ & $\underline{0.18}$ & & $\underline{\mathrm{J}}$ & N J I01 & & $\underline{0}$ & \\
\hline Z2-EU41DB-208-4 & $09 / 25 / 20061305$ & $0-10$ & Metal & Uranium & $\underline{8}$ & $\underline{\mathrm{mg} / \mathrm{kg}}$ & 6.5 & & $\equiv$ & $\equiv$ & & 21 & \\
\hline Z2-EU41DB-208-4 & $09 / 25 / 20061305$ & $\underline{0-10}$ & Metal & $\underline{\text { Vanadium }}$ & $\underline{22}$ & $\underline{\mathrm{mg} / \mathrm{kg}}$ & $\underline{22}$ & & $\equiv$ & $\mathrm{N} \equiv$ & & $\underline{0}$ & \\
\hline Z2-EU41DB-208-4 & $09 / 25 / 20061305$ & $0-10$ & Metal & Zinc & 52 & $\underline{\mathrm{mg} / \mathrm{kg}}$ & $\underline{46}$ & & $\underline{\mathrm{J}}$ & N J I02 F10 & & 12 & \\
\hline Z2-EU24M-302 & $09 / 28 / 20061200$ & $0-14$ & Metal & Mercury & 0.087 & $\underline{\mathrm{mg} / \mathrm{kg}}$ & & $\underline{0.062}$ & $\underline{\mathrm{J}}$ & & $\underline{N *}$ & & $\underline{34}$ \\
\hline Z2-EU24M-302 & $09 / 28 / 20061200$ & $0-14$ & Metal & Aluminum & 17000 & $\underline{\mathrm{mg} / \mathrm{kg}}$ & & 10600 & $\equiv$ & & $\mathrm{N} * \mathrm{E}$ & & 46 \\
\hline Z2-EU24M-302 & $09 / 28 / 20061200$ & $\underline{0-14}$ & Metal & Antimony & $\underline{0.29}$ & $\underline{\mathrm{mg} / \mathrm{kg}}$ & & 0.31 & $\underline{\underline{J}}$ & & $\mathrm{BN}$ & & $\underline{7}$ \\
\hline Z2-EU24M-302 & $09 / 28 / 20061200$ & $0-14$ & Metal & Arsenic & 9.2 & $\underline{\mathrm{mg} / \mathrm{kg}}$ & & 6.4 & $\equiv$ & & & & 36 \\
\hline Z2-EU24M-302 & $09 / 28 / 20061200$ & $0-14$ & Metal & Barium & $\underline{45}$ & $\underline{\mathrm{mg} / \mathrm{kg}}$ & & 67.4 & $\equiv$ & & & & 40 \\
\hline Z2-EU24M-302 & $09 / 28 / 20061200$ & $0-14$ & Metal & Beryllium & 1 & $\underline{\mathrm{mg} / \mathrm{kg}}$ & & 0.9 & $\underline{J}$ & & $\underline{\mathrm{N}}$ & & 11 \\
\hline Z2-EU24M-302 & $09 / 28 / 20061200$ & $0-14$ & Metal & Boron & 2.8 & $\underline{\mathrm{mg} / \mathrm{kg}}$ & & 2.5 & $\underline{\mathrm{BJ}}$ & & $\underline{\mathrm{UN}}$ & & \\
\hline Z2-EU24M-302 & $09 / 28 / 20061200$ & $0-14$ & Metal & Cadmium & 0.19 & $\underline{\mathrm{mg} / \mathrm{kg}}$ & & 0.25 & $\equiv$ & & & & 27 \\
\hline Z2-EU24M-302 & $09 / 28 / 20061200$ & $\overline{0-14}$ & Metal & $\overline{\text { Calcium }}$ & 20000 & $\overline{\mathrm{mg} / \mathrm{kg}}$ & & 13500 & $\underline{J}$ & & $\mathrm{~N} * \mathrm{E}$ & & 39 \\
\hline Z2-EU24M-302 & $09 / 28 / 20061200$ & $0-14$ & Metal & Chromium & 15 & $\mathrm{mg} / \mathrm{kg}$ & & 14.4 & $\equiv$ & & $\underline{\mathrm{N}}$ & & 4 \\
\hline Z2-EU24M-302 & $09 / 28 / 20061200$ & $0-14$ & Metal & Cobalt & $\underline{12}$ & $\underline{\mathrm{mg} / \mathrm{kg}}$ & & 12.8 & $\underline{\underline{E}}$ & & $\underline{\mathrm{NE}}$ & & $\underline{6}$ \\
\hline Z2-EU24M-302 & $09 / 28 / 20061200$ & $0-14$ & Metal & Copper & $\underline{32}$ & $\underline{\mathrm{mg} / \mathrm{kg}}$ & & 17.5 & $\equiv$ & & $\underline{N}$ & & $\underline{59}$ \\
\hline
\end{tabular}


Table L.3. (continued)

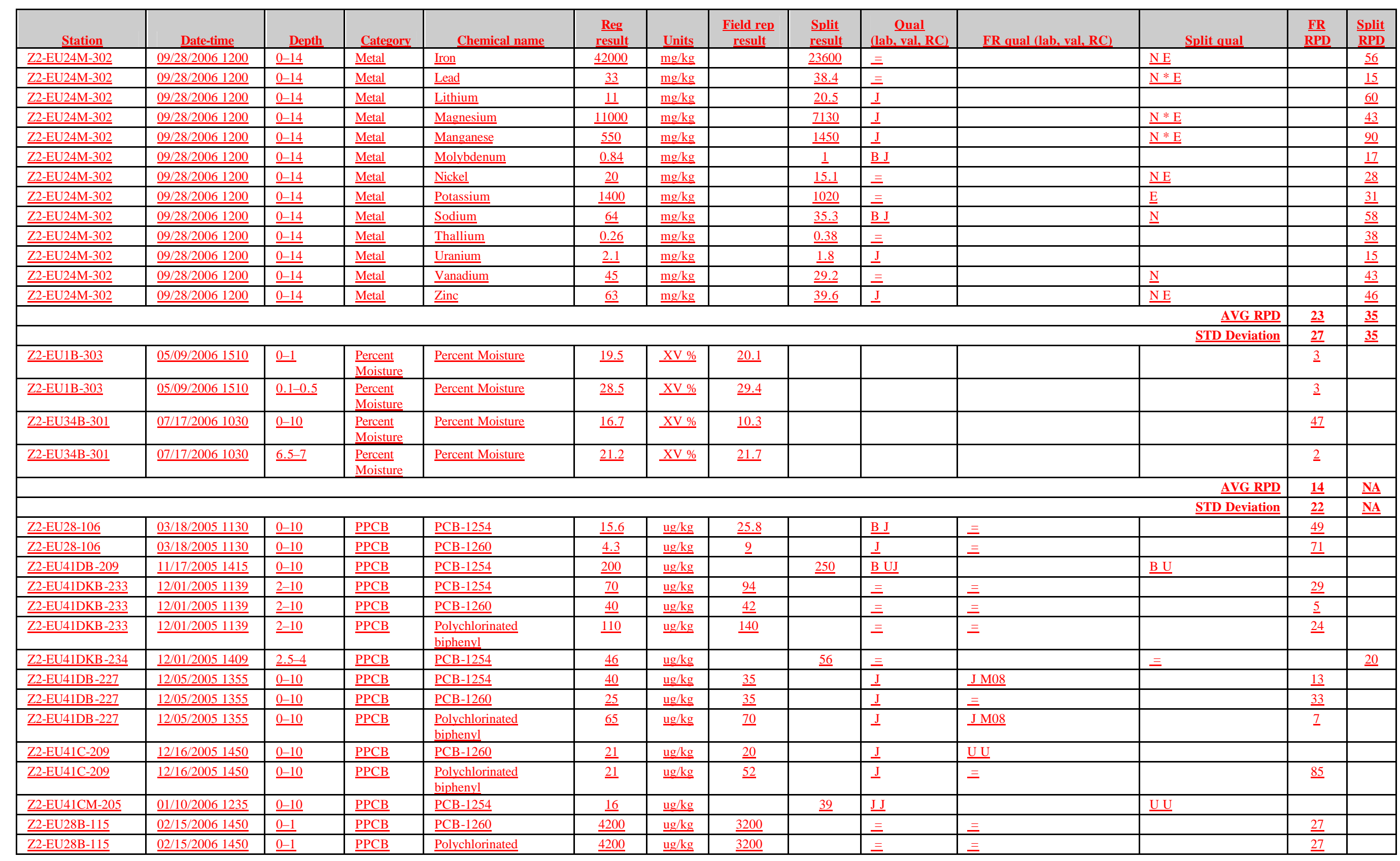


Table L.3. (continued)

\begin{tabular}{|c|c|c|c|c|c|c|c|c|c|c|c|c|c|}
\hline Station & Date-time & Depth & Category & Chemical name & $\underset{\text { result }}{\text { reg }}$ & Units & $\frac{\frac{\text { Field rep }}{\text { result }}}{\text { restis }}$ & 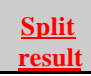 & $\frac{\text { Qual }}{(\text { lab, val, }}$ RC) & FR qual (lab, val, RC) & Split qual & $\underline{\underline{\mathrm{FR}}}$ & $\frac{\text { Split }}{\text { RPD }}$ \\
\hline & & & & biphenyl & & & & & & & & & \\
\hline Z2-EU1B-303 & $05 / 09 / 20061510$ & $\underline{\underline{0-1}}$ & $\underline{\mathrm{PPCB}}$ & PCB-1260 & $\underline{820}$ & $\underline{\underline{\mathrm{ug}} / \mathrm{kg} g}$ & $\underline{1500}$ & & $\underline{\underline{J}}$ & $\begin{array}{ll}\mathrm{JC} 08 \\
\end{array}$ & & $\underline{59}$ & \\
\hline Z2-EU1B-303 & $05 / 09 / 20061510$ & $\overline{\overline{0-1}}$ & $\underline{\overline{\mathrm{PPCB}}}$ & $\begin{array}{l}\text { Polychlorinated } \\
\text { biphenyl }\end{array}$ & $\underline{820}$ & $\underline{\underline{u} g / \mathrm{kg} g}$ & $\underline{1500}$ & & $\underline{J}$ & $\mathrm{JC08}$ & & $\underline{59}$ & \\
\hline Z2-EU37B-301 & 09/11/2006 1230 & $\underline{5.5-0}$ & $\underline{\mathrm{PPCB}}$ & PCB-1254 & $\underline{190}$ & $\underline{\mathrm{ug} / \mathrm{kg}}$ & $\underline{290}$ & & $\equiv$ & 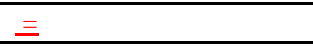 & & $\underline{42}$ & \\
\hline Z2-EU37B-301 & 09/11/2006 1230 & $\underline{5.5-0}$ & PPCB & PCB-1260 & $\underline{200}$ & $\underline{\mathrm{ug} / \mathrm{kg}}$ & $2 \underline{220}$ & & $\underline{\equiv}$ & $\underline{\underline{E}}$ & & $\underline{10}$ & \\
\hline Z2-EU37B-301 & $\underline{09 / 11 / 20061230}$ & $\underline{5.5-0}$ & $\underline{\mathrm{PPCB}}$ & $\begin{array}{l}\text { Polychlorinated } \\
\text { biphenyl } \\
\end{array}$ & $\underline{390}$ & $\underline{\mathrm{ug} / \mathrm{kg} g}$ & $\underline{510}$ & & $\equiv$ & $\equiv$ & & $\underline{27}$ & \\
\hline Z2-EU37B-306 & 09/12/2006845 & $\underline{\underline{1-0}}$ & PPCB & PCB-1260 & $\underline{120}$ & $\underline{\mathrm{ug} / \mathrm{kg}}$ & & $\underline{45}$ & $\underline{J}$ & & $\underline{\underline{U U}}$ & & \\
\hline Z2-EU41DB-208-3 & 09/25/2006 1200 & $\underline{\underline{0-10}}$ & $\underline{\mathrm{PPCB}}$ & PCB-1254 & $\underline{240}$ & $\underline{\mathrm{ug} / \mathrm{kg}}$ & & $\underline{37}$ & $\mathrm{~B}=$ & & $\underline{\underline{\mathrm{UU}}}$ & & \\
\hline $\begin{array}{l}\text { Z2-EU41DB-208-4 } \\
\end{array}$ & 09/25/2006 1305 & $\underline{\underline{0-10}}$ & $\underline{\underline{\mathrm{PPCB}}}$ & PCB-1254 & $\underline{160}$ & $\underline{\underline{\mathrm{ug}} / \mathrm{kg}}$ & $\underline{\underline{320}}$ & & $\underline{\mathrm{BJ}}$ & $\mathrm{B}=\mathrm{F} 08 \mathrm{~F} 01$ & & $\underline{67}$ & \\
\hline Z2-EU41DB-208-4 & $09 / 25 / 20061305$ & $\underline{0-10}$ & $\underline{\mathrm{PPCB}}$ & $\begin{array}{l}\text { Polychlorinated } \\
\text { biphenyl }\end{array}$ & $\underline{160}$ & $\underline{\mathrm{ug} / \mathrm{kg}}$ & $\underline{320}$ & & $\underline{B}$ & $\mathrm{~B}=\mathrm{F} 08 \mathrm{~F} 01$ & & $\underline{67}$ & \\
\hline \multicolumn{12}{|r|}{ AVG RPD } & $\underline{39}$ & $\underline{20}$ \\
\hline & & & & & & & & & & & STD Deviation & $\underline{24}$ & $\underline{0}$ \\
\hline Z2-EU28B-319 & $\underline{03 / 08 / 20051345}$ & $\underline{\underline{0-10}}$ & $\underline{\underline{\text { RADS }}}$ & Radium-226 & 1.04 & $\underline{\mathrm{pCi} / \mathrm{g}}$ & 0.937 & & $\underline{\underline{J}}$ & $\underline{\underline{J}}$ & & $\underline{10}$ & \\
\hline Z2-EU28B-319 & $\underline{03 / 08 / 20051345}$ & $\underline{\underline{0-10}}$ & $\underline{\underline{\text { RADS }}}$ & Thorium-228 & $\underline{\underline{0.905}}$ & $\underline{\mathrm{pCi} / \mathrm{g}}$ & $\underline{1.17}$ & & $\underline{\underline{J}}$ & $\underline{\underline{J}}$ & & $\underline{26}$ & \\
\hline Z2-EU28B-319 & $03 / 08 / 20051345$ & $\underline{0-10}$ & $\underline{\text { RADS }}$ & Thorium-230 & $\underline{0.867}$ & $\mathrm{pCi} / \underline{\mathrm{g}}$ & 1.02 & & $\underline{J}$ & $\underline{J}$ & & $\underline{16}$ & \\
\hline Z2-EU28B-319 & $\underline{03 / 08 / 20051345}$ & $\underline{\underline{0-10}}$ & $\underline{\underline{\text { RADS }}}$ & Thorium-232 & $\underline{1.09}$ & $\underline{\mathrm{DCi} / \mathrm{g}}$ & $\underline{1.09}$ & & $\underline{\underline{J}}$ & $\underline{\underline{J}}$ & & $\underline{0}$ & \\
\hline Z2-EU28B-319 & $03 / 08 / 20051345$ & $\underline{0-10}$ & $\underline{\text { RADS }}$ & Uranium-233/234 & 1.04 & $\mathrm{pCi} / \mathrm{g}$ & 1.1 & & $\underline{J}$ & $\underline{J}$ & & $\underline{6}$ & \\
\hline Z2-EU28B-319 & $03 / 08 / 20051345$ & $\underline{0-10}$ & $\underline{\underline{\text { RADS }}}$ & Uranium-238 & 1.04 & $\underline{\mathrm{pCi} / \mathrm{g}}$ & $\underline{0.964}$ & & $\underline{\underline{J}}$ & $\underline{\underline{J}}$ & & $\underline{8}$ & \\
\hline Z2-EU28-106 & $03 / 18 / 20051130$ & $\underline{0-0.6}$ & $\underline{\text { RADS }}$ & Radium-226 & 1.03 & $\mathrm{pCi} / \mathrm{g}$ & 1.64 & & $\underline{\equiv}$ & $\underline{\underline{ }}$ & & $\underline{46}$ & \\
\hline$\underline{\underline{\text { Z2-EU28-106 }}}$ & $03 / 18 / 20051130$ & $\underline{\underline{0-0.6}}$ & $\underline{\underline{\text { RADS }}}$ & Thorium-228 & $\underline{1.35}$ & $\underline{\mathrm{pCi} / \mathrm{g}}$ & 1.73 & & 三 & $\equiv$ & & $\underline{25}$ & \\
\hline $\begin{array}{l}\text { Z2-EU28-106 } \\
\end{array}$ & $03 / 18 / 20051130$ & $\underline{0-0.6}$ & $\underline{\text { RADS }}$ & Thorium-230 & 1.72 & $\mathrm{pCi} / \underline{g}$ & 1.61 & & 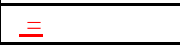 & $\equiv$ & & $\underline{7}$ & \\
\hline $\begin{array}{l}\text { Z2-EU28-106 } \\
\end{array}$ & $03 / 18 / 20051130$ & $\underline{\underline{0-0.6}}$ & $\underline{\underline{\text { RADS }}}$ & Thorium-232 & 1.18 & $\underline{\mathrm{pCi} / \mathrm{g}}$ & $\underline{1.34}$ & & $\equiv$ & $\equiv$ & & $\underline{13}$ & \\
\hline Z2-EU28-106 & $03 / 18 / 20051130$ & $\underline{0-0.6}$ & $\underline{\text { RADS }}$ & Uranium-233/234 & $\underline{3.16}$ & $\mathrm{pCi} / \mathrm{g}$ & 3.3 & & $\equiv$ & $\equiv$ & & 4 & \\
\hline $\begin{array}{l}\text { Z2-EU28-106 } \\
\end{array}$ & $03 / 18 / 20051130$ & $\underline{\underline{0-0.6}}$ & $\underline{\underline{\text { RADS }}}$ & Uranium-235/236 & $\underline{0.274}$ & $\underline{\mathrm{pCi} / \mathrm{g}}$ & $\underline{0.221}$ & & $\underline{J}$ & $\mathrm{~J} \mathrm{J06}$ & & $\underline{21}$ & \\
\hline Z2-EU28-106 & $03 / 18 / 20051130$ & $0-0.6$ & $\underline{\text { RADS }}$ & Uranium-238 & 2.97 & $\mathrm{pCi} / \mathrm{g}$ & 3.33 & & $\equiv$ & $\equiv$ & & $\underline{11}$ & \\
\hline Z2-EU28-201 & $03 / 22 / 20051205$ & $\underline{0.5-3.2}$ & $\underline{\underline{\text { RADS }}}$ & $\begin{array}{l}\text { Radium-226 } \\
\end{array}$ & 2.41 & $\underline{\mathrm{pCi} / \mathrm{g}}$ & & $\underline{2.32}$ & $\equiv$ & & $\equiv$ & & 4 \\
\hline Z2-EU28-201 & $03 / 22 / 20051205$ & $0.5-3.2$ & $\underline{\text { RADS }}$ & Thorium-228 & 2.56 & $\mathrm{pCi} / \mathrm{g}$ & & 2.53 & $\equiv$ & & $\leq \equiv$ & & 1 \\
\hline Z2-EU28-201 & $03 / 22 / 20051205$ & $\underline{0.5-3.2}$ & $\underline{\underline{\text { RADS }}}$ & Thorium-230 & 2.2 & $\underline{\mathrm{pCi} / \mathrm{g}}$ & & $\underline{2.27}$ & 三 & & $\leq \equiv$ & & $\underline{\underline{3}}$ \\
\hline Z2-EU28-201 & $03 / 22 / 20051205$ & $0.5-3.2$ & $\underline{\text { RADS }}$ & Thorium-232 & 2.31 & $\mathrm{pCi} / \underline{\underline{g}}$ & & 2.21 & $\equiv$ & & $\leq \equiv$ & & 4 \\
\hline Z2-EU28-201 & $03 / 22 / 20051205$ & $\underline{0.5-3.2}$ & $\underline{\underline{\text { RADS }}}$ & Uranium-233/234 & 2.4 & $\underline{\mathrm{pCi} / \mathrm{g}}$ & & $\underline{1.88}$ & $\underline{\underline{J}}$ & & $\equiv$ & & $\underline{\underline{24}}$ \\
\hline Z2-EU28-201 & $03 / 22 / 20051205$ & $0.5-3.2$ & $\underline{\text { RADS }}$ & Uranium-235/236 & $\underline{0.251}$ & $\mathrm{pCi} / \underline{\mathrm{g}}$ & & 0.1 & $\underline{J}$ & & $\underline{\underline{S J}}$ & & $\underline{86}$ \\
\hline $\begin{array}{l}\text { Z2-EU28-201 } \\
\end{array}$ & $03 / 22 / 20051205$ & $\underline{0.5-3.2}$ & $\underline{\underline{\text { RADS }}}$ & $\begin{array}{l}\text { Uranium-238 } \\
\end{array}$ & 1.99 & $\underline{\mathrm{pCi} / \mathrm{g}}$ & & $\underline{2.47}$ & $\underline{\underline{J}}$ & & $\equiv$ & & $\underline{22}$ \\
\hline Z2-EU41DB-227 & $12 / 05 / 20051355$ & $0-10$ & $\underline{\text { RADS }}$ & Alpha activity & 1.37 & $\mathrm{pCi} / \underline{g}$ & $\underline{0.627}$ & & $\equiv$ & $\equiv$ & & $\underline{74}$ & \\
\hline Z2-EU41DB-227 & $12 / 05 / 20051355$ & $0-10$ & RADS & Beta activity & 1.83 & $\mathrm{pCi} / \mathrm{g}$ & 0.728 & & $\equiv$ & $\equiv$ & & 86 & \\
\hline Z2-EU41DB-227 & $12 / 05 / 20051355$ & $\underline{0-10}$ & RADS & Uranium-234 & $\underline{0.793}$ & $\mathrm{pCi} / \mathrm{g}$ & 0.83 & & $\underline{\equiv}$ & $\underline{\underline{E}}$ & & $\underline{5}$ & \\
\hline Z2-EU41DB-227 & $12 / 05 / 20051355$ & $\underline{\underline{0-10}}$ & $\underline{\underline{\text { RADS }}}$ & Uranium-235 & $\underline{0.09}$ & $\underline{\mathrm{pCi} / \mathrm{g}}$ & $\underline{0.132}$ & & 三 & $\underline{\mathrm{U} \text { UJ T04 }}$ & & & \\
\hline Z2-EU41DB-227 & $12 / 05 / 20051355$ & $\underline{\underline{0-10}}$ & $\underline{\text { RADS }}$ & $\begin{array}{l}\text { Uranium-238 } \\
\end{array}$ & 0.144 & $\mathrm{pCi} / \mathrm{g}$ & 0.361 & & $\equiv$ & $\equiv$ & & $\underline{86}$ & \\
\hline Z2-EU41DB-227 & $12 / 05 / 20051400$ & $10-20$ & $\underline{\underline{\text { RADS }}}$ & Alpha activity & 3.83 & $\underline{\mathrm{pCi} / \mathrm{g}}$ & & $\underline{3.58}$ & $\equiv$ & & $\underline{\mathrm{JJ}}$ & & $\underline{7}$ \\
\hline
\end{tabular}


Table L.3. (continued)

\begin{tabular}{|c|c|c|c|c|c|c|c|c|c|c|c|c|c|}
\hline Station & Date-time & Depth & Category & Chemical name & $\underset{\text { result }}{\stackrel{\mathrm{Reg}}{\text { result }}}$ & Units & $\frac{\frac{\text { Field rep }}{\text { result }}}{\text { restis }}$ & 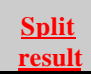 & $\frac{\text { Qual }}{(\text { lab, val, RC) }}$ & FR qual (lab, val, RC) & Split qual & $\underline{\mathrm{FR}}$ & $\underline{\text { Split }}$ \\
\hline Z2-EU41DB-227 & $12 / 05 / 20051400$ & $\underline{10-20}$ & RADS & Beta activity & 2.31 & $\mathrm{pCi} / \underline{g}$ & & 1.58 & $\equiv$ & & $\underline{\underline{\mathrm{JJ}}}$ & & $\underline{38}$ \\
\hline Z2-EU41DB-227 & $12 / 05 / 20051400$ & $10-20$ & RADS & Radium-226 & 0.294 & $\mathrm{pCi} / \mathrm{g}$ & & 0.148 & $\equiv$ & & $\underline{\mathrm{JJ}}$ & & 66 \\
\hline Z2-EU41DB-227 & $12 / 05 / 20051400$ & $10-20$ & $\underline{\mathrm{RADS}}$ & Thorium-228 & $\underline{0.674}$ & $\mathrm{pCi} / \underline{g}$ & & $\underline{0.43}$ & $\equiv$ & & $\mathrm{J}=$ & & $\underline{44}$ \\
\hline Z2-EU41DB-227 & $12 / 05 / 20051400$ & $10-20$ & RADS & Thorium-232 & 0.516 & $\mathrm{pCi} / \mathrm{g}$ & & 0.37 & $\equiv$ & & $\underline{\mathrm{J}=}$ & & $\underline{33}$ \\
\hline Z2-EU41DB-227 & $12 / 05 / 20051400$ & $10-20$ & $\underline{\text { RADS }}$ & Uranium-234 & $\underline{0.322}$ & $\mathrm{pCi/g}$ & & $\underline{0.129}$ & $\underline{\underline{E}}$ & & $\underline{\underline{\mathrm{JJ}}}$ & & $\underline{86}$ \\
\hline Z2-EU41DB-225 & $12 / 09 / 20051405$ & $0-10$ & RADS & Alpha activity & 1.81 & $\mathrm{pCi} / \mathrm{g}$ & 1.96 & & $\equiv$ & $\equiv$ & & $\underline{8}$ & \\
\hline Z2-EU41DB-225 & $12 / 09 / 20051405$ & $\underline{0-10}$ & $\underline{\text { RADS }}$ & Beta activity & 1.41 & $\mathrm{pCi} / \mathrm{g}$ & 2.18 & & $\underline{\underline{E}}$ & $\equiv$ & & $\underline{43}$ & \\
\hline Z2-EU41DB-225 & $12 / 09 / 20051405$ & $0-10$ & RADS & Neptunium-237 & 0.43 & $\mathrm{pCi} / \mathrm{g}$ & -0.0131 & & $\equiv$ & $\underline{\mathrm{UU}}$ & & & \\
\hline Z2-EU41DB-225 & $12 / 09 / 20051405$ & $\underline{0-10}$ & $\underline{\text { RADS }}$ & Radium-226 & $\underline{0.295}$ & $\mathrm{pCi} / \mathrm{g}$ & 0.164 & & $\underline{\mathrm{J}}$ & $\underline{\mathrm{UU}}$ & & & \\
\hline Z2-EU41DB-225 & $12 / 09 / 20051405$ & $0-10$ & RADS & Uranium-234 & 0.348 & $\mathrm{pCi} / \mathrm{g}$ & 0.369 & & $\equiv$ & $\equiv$ & & $\underline{6}$ & \\
\hline Z2-EU41DB-225 & $12 / 09 / 20051405$ & $\underline{0-10}$ & $\underline{\mathrm{RADS}}$ & Uranium-238 & 0.182 & $\mathrm{pCi} / \mathrm{g}$ & $\underline{0.128}$ & & $\underline{\mathrm{J}}$ & $\equiv$ & & $\underline{35}$ & \\
\hline Z2-EU41C-209 & $12 / 16 / 20051415$ & $13-13.6$ & RADS & Alpha activity & 4.46 & $\mathrm{pCi} / \underline{g}$ & 4.01 & & $\equiv$ & $\equiv$ & & 11 & \\
\hline Z2-EU41C-209 & $12 / 16 / 20051415$ & $13-13.6$ & $\underline{\text { RADS }}$ & Beta activity & 2.92 & $\mathrm{pCi} / \mathrm{g}$ & 3.16 & & $\equiv$ & $\equiv$ & & $\underline{8}$ & \\
\hline Z2-EU41C-209 & $12 / 16 / 20051415$ & $13-13.6$ & RADS & Radium-226 & 0.248 & $\mathrm{pCi} / \mathrm{g}$ & 0.273 & & $\equiv$ & $\equiv$ & & 10 & \\
\hline Z2-EU41C-209 & $12 / 16 / 20051415$ & $13-13.6$ & $\underline{\text { RADS }}$ & Thorium-228 & 0.668 & $\mathrm{pCi} / \underline{g}$ & 0.83 & & $\equiv$ & $\equiv$ & & $\underline{22}$ & \\
\hline Z2-EU41C-209 & $12 / 16 / 20051415$ & $13-13.6$ & RADS & Thorium-230 & 0.845 & $\mathrm{pCi} / \mathrm{g}$ & 0.185 & & $\equiv$ & $\underline{\mathrm{UU}}$ & & & \\
\hline Z2-EU41C-209 & $12 / 16 / 20051415$ & $13-13.6$ & $\underline{\text { RADS }}$ & Thorium-232 & $\underline{0.445}$ & $\mathrm{pCi} / \mathrm{g}$ & 0.411 & & $\equiv$ & $\equiv$ & & $\underline{8}$ & \\
\hline Z2-EU41C-209 & $12 / 16 / 20051415$ & $13-13.6$ & RADS & Uranium-234 & 0.308 & $\mathrm{pCi} / \mathrm{g}$ & 0.378 & & $\equiv$ & $\equiv$ & & $\underline{20}$ & \\
\hline Z2-EU41C-209 & $12 / 16 / 20051415$ & $13-13.6$ & $\underline{\text { RADS }}$ & Uranium-238 & $\underline{0.304}$ & $\mathrm{pCi} / \mathrm{g}$ & 0.555 & & $\equiv$ & $\equiv$ & & $\underline{58}$ & \\
\hline Z2-EU41CM-205 & $01 / 10 / 20061235$ & $0-10$ & RADS & Alpha activity & 13.4 & $\mathrm{pCi} / \underline{g}$ & & 7.7 & UJ & & $\underline{J}$ & & \\
\hline Z2-EU41CM-205 & $01 / 10 / 20061235$ & $\underline{0-10}$ & $\underline{\text { RADS }}$ & Alpha activity & 1.42 & $\mathrm{pCi/g}$ & & 7.7 & $\underline{\underline{ }}$ & & $\underline{\mathrm{J}}$ & & 138 \\
\hline Z2-EU41CM-205 & $01 / 10 / 20061235$ & $0-10$ & RADS & Beta activity & 12.8 & $\mathrm{pCi} / \mathrm{g}$ & & 3.12 & $\underline{J}$ & & $\underline{\mathrm{JJ}}$ & & 122 \\
\hline Z2-EU41CM-205 & $01 / 10 / 20061235$ & $\underline{0-10}$ & $\underline{\text { RADS }}$ & Beta activity & 2.18 & $\mathrm{pCi} / \mathrm{g}$ & & $\underline{3.12}$ & $\equiv$ & & $\underline{\mathrm{JJ}}$ & & $\underline{35}$ \\
\hline Z2-EU41CM-205 & $01 / 10 / 20061235$ & $0-10$ & RADS & Thorium-232 & 0.17 & $\mathrm{pCi} / \mathrm{g}$ & & 0.224 & $\equiv$ & & $\mathrm{J}=$ & & 27 \\
\hline Z2-EU41CM-205 & $01 / 10 / 20061235$ & $\underline{0-10}$ & $\underline{\text { RADS }}$ & Uranium-234 & $\underline{3.19}$ & $\mathrm{pCi} / \mathrm{g}$ & & 0.89 & $\underline{\mathrm{J}}$ & & $\mathrm{J}=$ & & $\underline{113}$ \\
\hline Z2-EU41CM-205 & $01 / 10 / 20061235$ & $0-10$ & RADS & Uranium-234 & 0.408 & $\mathrm{pCi} / \mathrm{g}$ & & 0.89 & $\equiv$ & & $\underline{\mathrm{J}=}$ & & 74 \\
\hline Z2-EU41CM-205 & $01 / 10 / 20061235$ & $\underline{0-10}$ & $\underline{\text { RADS }}$ & Uranium-235 & $\underline{0.493}$ & $\mathrm{pCi} / \underline{g}$ & & $\underline{0.069}$ & $\underline{\mathrm{J}}$ & & $\underline{\mathrm{JJ}}$ & & 151 \\
\hline Z2-EU41CM-205 & $01 / 10 / 20061235$ & $0-10$ & RADS & Uranium-238 & 14.2 & $\mathrm{pCi} / \mathrm{g}$ & & 0.89 & $\underline{J}$ & & $\mathrm{~J}=$ & & 176 \\
\hline Z2-EU28B-115 & $02 / 15 / 20061450$ & $\underline{0-1}$ & $\underline{\text { RADS }}$ & Alpha activity & 167 & $\mathrm{pCi} / \underline{g}$ & $\underline{142}$ & & $\equiv$ & $\equiv$ & & $\underline{16}$ & \\
\hline Z2-EU28B-115 & $02 / 15 / 20061450$ & $0-1$ & RADS & Beta activity & 1020 & $\mathrm{pCi} / \mathrm{g}$ & 807 & & $\equiv$ & $\equiv$ & & $\underline{23}$ & \\
\hline Z2-EU28B-115 & $02 / 15 / 20061450$ & $\underline{0-1}$ & $\underline{\text { RADS }}$ & Neptunium-237 & 2.41 & $\mathrm{pCi} / \underline{g}$ & 1.86 & & $\equiv$ & $\equiv$ & & $\underline{26}$ & \\
\hline Z2-EU28B-115 & $02 / 15 / 20061450$ & $0-1$ & RADS & Radium-226 & 1.54 & $\mathrm{pCi} / \mathrm{g}$ & 1.07 & & $\equiv$ & $\equiv$ & & 36 & \\
\hline Z2-EU28B-115 & $02 / 15 / 20061450$ & $\underline{0-1}$ & $\underline{\text { RADS }}$ & Technetium-99 & $\underline{2550}$ & $\mathrm{pCi} / \underline{g}$ & $\underline{1710}$ & & $\equiv$ & $\equiv$ & & $\underline{39}$ & \\
\hline Z2-EU28B-115 & $02 / 15 / 20061450$ & $0-1$ & RADS & Thorium-228 & 4.4 & $\mathrm{pCi} / \mathrm{g}$ & 2.53 & & $\equiv$ & $\equiv$ & & $\underline{54}$ & \\
\hline Z2-EU28B-115 & $02 / 15 / 20061450$ & $\underline{0-1}$ & $\underline{\text { RADS }}$ & Thorium-230 & 47.9 & $\mathrm{pCi} / \underline{g}$ & $\underline{26.8}$ & & $\equiv$ & $\equiv$ & & $\underline{56}$ & \\
\hline Z2-EU28B-115 & $02 / 15 / 20061450$ & $0-1$ & RADS & Thorium-232 & 2.35 & $\mathrm{pCi} / \mathrm{g}$ & 1.41 & & $\equiv$ & $\equiv$ & & $\underline{50}$ & \\
\hline Z2-EU28B-115 & $02 / 15 / 20061450$ & $\overline{0-1}$ & $\overline{\text { RADS }}$ & Uranium-234 & 173 & $\mathrm{pCi} / \mathrm{g}$ & 123 & & $\equiv$ & $\equiv$ & & 34 & \\
\hline Z2-EU28B-115 & $02 / 15 / 20061450$ & $0-1$ & RADS & Uranium-235 & 9.06 & $\mathrm{pCi} / \mathrm{g}$ & 7.07 & & $\equiv$ & $\equiv$ & & 25 & \\
\hline Z2-EU28B-115 & $02 / 15 / 20061450$ & $\underline{\underline{0-1}}$ & $\underline{\text { RADS }}$ & $\begin{array}{l}\text { Uranium-238 } \\
\end{array}$ & 83.7 & $\mathrm{pCi} / \mathrm{g}$ & $\underline{53.9}$ & & $\underline{\underline{E}}$ & $\equiv$ & & $\underline{43}$ & \\
\hline Z2-EU28B-125 & $02 / 16 / 20061102$ & $0-1$ & RADS & Alpha activity & 40 & $\mathrm{pCi} / \mathrm{g}$ & $\underline{38.5}$ & & $\equiv$ & $\equiv$ & & 4 & \\
\hline
\end{tabular}


Table L.3. (continued)

\begin{tabular}{|c|c|c|c|c|c|c|c|c|c|c|c|c|c|}
\hline Station & Date-time & Depth & Category & Chemical name & $\begin{array}{l}\text { Reg } \\
\text { result } \\
\end{array}$ & Units & $\frac{\text { Field rep }}{\text { result }}$ & 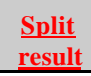 & $\left(\begin{array}{l}\text { Qual } \\
\text { (lab, val, RC) }\end{array}\right.$ & FR qual (lab, val, RC) & Split qual & $\underline{\mathrm{FR}}$ & $\underline{\text { Split }}$ \\
\hline Z2-EU28B-125 & $02 / 16 / 20061102$ & $\underline{0-1}$ & $\underline{\underline{R A D S}}$ & Beta activity & 69.5 & $\underline{\mathrm{pCi} / \underline{\mathrm{g}}}$ & 75.3 & & $\equiv$ & $\equiv$ & & $\underline{8}$ & \\
\hline Z2-EU28B-125 & $02 / 16 / 20061102$ & $0-1$ & RADS & Neptunium-237 & 3.35 & $\mathrm{pCi} / \mathrm{g}$ & 4.38 & & $\equiv$ & $\equiv$ & & 27 & \\
\hline Z2-EU28B-125 & $02 / 16 / 20061102$ & $0-1$ & RADS & Radium-226 & 0.914 & $\mathrm{pCi} / \mathrm{g}$ & 1.29 & & $\equiv$ & $\equiv$ & & 34 & \\
\hline Z2-EU28B-125 & $02 / 16 / 20061102$ & $0-1$ & $\underline{\mathrm{RADS}}$ & Technetium-99 & $\underline{110}$ & $\mathrm{pCi} / \mathrm{g}$ & 145 & & $\equiv$ & $\equiv$ & & 27 & \\
\hline Z2-EU28B-125 & $02 / 16 / 20061102$ & $0-1$ & RADS & Thorium-228 & 1.21 & $\mathrm{pCi} / \mathrm{g}$ & 1.37 & & $\equiv$ & $\equiv$ & & 12 & \\
\hline Z2-EU28B-125 & $02 / 16 / 20061102$ & $0-1$ & RADS & Thorium-230 & 15 & $\mathrm{pCi} / \mathrm{g}$ & 16.1 & & $\equiv$ & $\equiv$ & & 7 & \\
\hline Z2-EU28B-125 & $\underline{02 / 16 / 20061102}$ & $\underline{0-1}$ & $\underline{\text { RADS }}$ & Thorium-232 & 1.35 & $\underline{\mathrm{pCi} / \mathrm{g}}$ & 1.17 & & $\equiv$ & $\equiv$ & & 14 & \\
\hline Z2-EU28B-125 & $02 / 16 / 20061102$ & $0-1$ & $\underline{\mathrm{RADS}}$ & Uranium-234 & 24.6 & $\mathrm{pCi} / \mathrm{g}$ & 33.1 & & $\equiv$ & $\equiv$ & & $\underline{29}$ & \\
\hline Z2-EU28B-125 & $02 / 16 / 20061102$ & $\overline{0-1}$ & $\overline{\text { RADS }}$ & Uranium-235 & 1.24 & $\mathrm{pCi} / \mathrm{g}$ & 1.89 & & $\equiv$ & $\equiv$ & & $\underline{42}$ & \\
\hline Z2-EU28B-125 & $02 / 16 / 20061102$ & $\underline{0-1}$ & RADS & Uranium-238 & 13.6 & $\mathrm{pCi} / \mathrm{g}$ & 17.9 & & $\equiv$ & $\equiv$ & & $\underline{27}$ & \\
\hline Z2-EU28B-123 & $02 / 16 / 20061405$ & $\underline{\underline{0-1}}$ & $\underline{\mathrm{RADS}}$ & Alpha activity & 69.8 & $\underline{\mathrm{pCi} / \mathrm{g}}$ & & $\underline{178}$ & $\equiv$ & & $\underline{J}$ & & $\underline{87}$ \\
\hline Z2-EU28B-123 & $02 / 16 / 20061405$ & $0-1$ & RADS & Beta activity & 84.6 & $\mathrm{pCi} / \mathrm{g}$ & & 163 & $\equiv$ & & $\underline{J}$ & & $\underline{63}$ \\
\hline Z2-EU28B-123 & $02 / 16 / 20061405$ & $\overline{0-1}$ & $\overline{\text { RADS }}$ & Radium-226 & 0.811 & $\mathrm{pC \textrm {Ci } / \mathrm { g }}$ & & 0.84 & $\equiv$ & & $\underline{J}$ & & 4 \\
\hline Z2-EU28B-123 & $02 / 16 / 20061405$ & $0-1$ & RADS & Thorium-228 & 1.74 & $\mathrm{pCi} / \mathrm{g}$ & & 1.74 & $\equiv$ & & 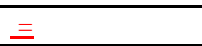 & & $\underline{0}$ \\
\hline Z2-EU28B-123 & $02 / 16 / 20061405$ & $\underline{\underline{0-1}}$ & $\underline{\text { RADS }}$ & Thorium-230 & 1.68 & $\underline{\mathrm{pCi} / \underline{\mathrm{g}}}$ & & 1.44 & $\equiv$ & & $\equiv$ & & $\underline{15}$ \\
\hline Z2-EU28B-123 & $02 / 16 / 20061405$ & $0-1$ & RADS & Thorium-232 & 1.63 & $\mathrm{pCi} / \mathrm{g}$ & & 1.55 & $\equiv$ & & $\equiv$ & & 5 \\
\hline Z2-EU28B-123 & $02 / 16 / 20061405$ & $0-1$ & RADS & Uranium-234 & 63.6 & $\mathrm{pCi} / \mathrm{g}$ & & $\underline{82}$ & $\equiv$ & & $\underline{J}$ & & 25 \\
\hline Z2-EU28B-123 & $02 / 16 / 20061405$ & $0-1$ & RADS & Uranium-235 & 4.16 & $\mathrm{pCi} / \mathrm{g}$ & & 3.94 & $\equiv$ & & $\underline{J}$ & & 5 \\
\hline Z2-EU28B-123 & $02 / 16 / 20061405$ & $0-1$ & RADS & Uranium-238 & 66.2 & $\mathrm{pCi} / \mathrm{g}$ & & 84 & $\equiv$ & & $\underline{J}$ & & 24 \\
\hline Z2-EU23B-301 & $03 / 20 / 2006920$ & $0-0.5$ & RADS & Alpha activity & 13.3 & $\mathrm{pCi} / \underline{g}$ & & 47 & $\underline{J}$ & & $\underline{J}$ & & $\underline{112}$ \\
\hline Z2-EU23B-301 & $03 / 20 / 2006920$ & $0-0.5$ & RADS & Beta activity & 13.3 & $\mathrm{pCi} / \mathrm{g}$ & & 54 & $\underline{J}$ & & $\mathrm{~J}$ & & 121 \\
\hline Z2-EU23B-301 & $03 / 20 / 2006920$ & $0-0.5$ & RADS & Radium-226 & 0.988 & $\mathrm{pCi} / \mathrm{g}$ & & 0.96 & $\underline{\mathrm{J}}$ & & $\underline{\mathrm{JJ}}$ & & $\underline{3}$ \\
\hline Z2-EU23B-301 & $03 / 20 / 2006920$ & $\underline{0-0.5}$ & RADS & Technetium-99 & 6.52 & $\mathrm{pCi} / \mathrm{g}$ & & 3.81 & $\underline{\mathrm{J}}$ & & $\equiv$ & & $\underline{52}$ \\
\hline Z2-EU23B-301 & $03 / 20 / 2006920$ & $\underline{0-0.5}$ & $\underline{\text { RADS }}$ & Thorium-228 & 1.19 & $\mathrm{pCi} / \mathrm{g}$ & & $\underline{0.85}$ & $\equiv$ & & $\mathrm{J}=$ & & $\underline{33}$ \\
\hline Z2-EU23B-301 & $03 / 20 / 2006920$ & $0-0.5$ & RADS & Thorium-230 & 0.921 & $\mathrm{pCi} / \mathrm{g}$ & & 1.46 & $\underline{J}$ & & $\equiv$ & & $\underline{45}$ \\
\hline Z2-EU23B-301 & $03 / 20 / 2006920$ & $\underline{0-0.5}$ & $\underline{\text { RADS }}$ & Thorium-232 & 1.1 & $\mathrm{pCi} / \mathrm{g}$ & & 0.75 & $\equiv$ & & $\mathrm{J}=$ & & $\underline{38}$ \\
\hline Z2-EU23B-301 & $03 / 20 / 2006920$ & $0-0.5$ & $\overline{\text { RADS }}$ & Uranium-234 & $\overline{10.2}$ & $\mathrm{pC \textrm {Ci } / \mathrm { g }}$ & & 9.4 & $\equiv$ & & $\bar{\equiv}$ & & $\underline{8}$ \\
\hline Z2-EU23B-301 & $03 / 20 / 2006920$ & $0-0.5$ & RADS & Uranium-235 & $\underline{0.905}$ & $\mathrm{pCi} / \mathrm{g}$ & & 0.57 & $\underline{\mathrm{J}}$ & & $\underline{\mathrm{JJ}}$ & & $\underline{45}$ \\
\hline Z2-EU23B-301 & $03 / 20 / 2006920$ & $0-0.5$ & RADS & Uranium-238 & $\underline{5.81}$ & $\mathrm{pC \textrm {Ci } / \mathrm { g }}$ & & 5.07 & $\equiv$ & & $\equiv$ & & 14 \\
\hline Z2-EU34B-301 & $07 / 17 / 20061030$ & $7.6-8.9$ & RADS & Alpha activity & 12.4 & $\mathrm{pCi} / \mathrm{g}$ & 27.3 & & $\equiv$ & $\equiv$ & & $\underline{75}$ & \\
\hline Z2-EU34B-301 & $07 / 17 / 20061030$ & $7.6-8.9$ & RADS & Beta activity & 27.1 & $\mathrm{pCi} / \mathrm{g}$ & 36.6 & & $\equiv$ & $\equiv$ & & 30 & \\
\hline Z2-EU34B-301 & $07 / 17 / 20061030$ & $7.6-8.9$ & RADS & Radium-226 & 1.33 & $\mathrm{pCi} / \mathrm{g}$ & 1.41 & & $\equiv$ & $\equiv$ & & $\underline{6}$ & \\
\hline Z2-EU34B-301 & $07 / 17 / 20061030$ & $7.6-8.9$ & RADS & Thorium-228 & 1.52 & $\mathrm{pCi} / \mathrm{g}$ & 1.36 & & $\equiv$ & $\equiv$ & & 11 & \\
\hline Z2-EU34B-301 & $07 / 17 / 20061030$ & $7.6-8.9$ & RADS & Thorium-230 & 1.23 & $\mathrm{pCi} / \mathrm{g}$ & 1.33 & & $\equiv$ & $\equiv$ & & $\underline{8}$ & \\
\hline Z2-EU34B-301 & $07 / 17 / 20061030$ & $7.6-8.9$ & RADS & Thorium-232 & 1.39 & $\mathrm{pCi} / \underline{g}$ & 1.56 & & $\equiv$ & $\equiv$ & & 12 & \\
\hline$\overline{\text { Z2-EU34B-301 }}$ & $07 / 17 / 20061030$ & $\overline{7.6-8.9}$ & $\overline{\text { RADS }}$ & Uranium-233/234 & $\overline{1.09}$ & $\mathrm{pC \textrm {Ci } / \mathrm { g }}$ & $\overline{1.02}$ & & $\equiv$ & $\equiv$ & & $\overline{7}$ & \\
\hline Z2-EU34B-301 & $07 / 17 / 20061030$ & $7.6-8.9$ & RADS & Uranium-235/236 & 0.066 & $\mathrm{pCi} / \mathrm{g}$ & 0.04 & & $\mathrm{~J}=$ & $\mathrm{J}=$ & & $\underline{49}$ & \\
\hline Z2-EU34B-301 & $07 / 17 / 20061030$ & $7.6-8.9$ & RADS & Uranium-238 & 1.04 & $\mathrm{pCi} / \mathrm{g}$ & 1.02 & & $\equiv$ & $\equiv$ & & $\underline{2}$ & \\
\hline Z2-EU37B-301 & $09 / 11 / 20061230$ & $5.5-0$ & RADS & Alpha activity & 4.19 & $\mathrm{pCi} / \mathrm{g}$ & 6.23 & & $\equiv$ & $\equiv$ & & 39 & \\
\hline$\overline{~ Z 2-E U 37 B-301}$ & $09 / 11 / 20061230$ & $\overline{\underline{5.5-0}}$ & $\overline{\mathrm{RADS}}$ & Beta activity & $\overline{5.69}$ & $\mathrm{pCi} / \mathrm{g}$ & $\overline{5.67}$ & & $\equiv$ & $\equiv$ & & $\overline{\underline{0}}$ & \\
\hline
\end{tabular}


Table L.3. (continued)

\begin{tabular}{|c|c|c|c|c|c|c|c|c|c|c|c|c|c|}
\hline Station & Date-time & Depth & Category & Chemical name & يesult & Units & $\frac{\text { Field rep }}{\text { result }}$ & 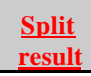 & $\left(\begin{array}{l}\text { Qual } \\
\text { (lab, val, RC) }\end{array}\right.$ & FR qual (lab, val, RC) & Split qual & $\underline{\mathrm{FR}}$ & $\underline{\text { Split }}$ \\
\hline Z2-EU37B-301 & $09 / 11 / 20061230$ & $\underline{5.5-0}$ & $\underline{\underline{R A D S}}$ & Radium-226 & 0.473 & $\underline{\mathrm{pCi} / \underline{\mathrm{g}}}$ & $\underline{1.01}$ & & $\equiv$ & $\equiv$ & & $\underline{72}$ & \\
\hline Z2-EU37B-301 & $09 / 11 / 20061230$ & $5.5-0$ & RADS & Thorium-228 & 1.19 & $\mathrm{pCi} / \mathrm{g}$ & 1.42 & & $\equiv$ & $\equiv$ & & 18 & \\
\hline Z2-EU37B-301 & $09 / 11 / 20061230$ & $5.5-0$ & RADS & Thorium-230 & 1.06 & $\mathrm{pCi} / \mathrm{g}$ & 1.41 & & $\equiv$ & $\equiv$ & & 28 & \\
\hline Z2-EU37B-301 & $09 / 11 / 20061230$ & $\underline{5.5-0}$ & $\underline{\mathrm{RADS}}$ & Thorium-232 & 1.59 & $\mathrm{pCi} / \mathrm{g}$ & 1.48 & & $\equiv$ & $\equiv$ & & $\underline{7}$ & \\
\hline Z2-EU37B-301 & $09 / 11 / 20061230$ & $5.5-0$ & RADS & Uranium-234 & 1.63 & $\mathrm{pCi} / \mathrm{g}$ & 1.38 & & $\equiv$ & $\equiv$ & & 17 & \\
\hline Z2-EU37B-301 & $09 / 11 / 20061230$ & $\underline{5.5-0}$ & RADS & Uranium-238 & 1.37 & $\mathrm{pCi} / \mathrm{g}$ & 1.16 & & $\equiv$ & $\equiv$ & & 17 & \\
\hline Z2-EU37B-306 & $09 / 12 / 2006845$ & $\underline{1-0}$ & $\overline{\text { RADS }}$ & Alpha activity & 4.46 & $\mathrm{pCi} / \mathrm{g}$ & & 21.6 & $\equiv$ & & $\underline{\mathrm{J}}$ & & $\underline{132}$ \\
\hline Z2-EU37B-306 & $09 / 12 / 2006845$ & $\underline{1-0}$ & $\underline{\mathrm{RADS}}$ & Beta activity & $\underline{5.75}$ & $\mathrm{pCi} / \mathrm{g}$ & & $\underline{43}$ & $\equiv$ & & $\underline{\mathrm{J}}$ & & 153 \\
\hline Z2-EU37B-306 & $\underline{09 / 12 / 2006845}$ & $\underline{\underline{1-0}}$ & $\underline{\text { RADS }}$ & $\underline{\text { Radium-226 }}$ & 1.63 & $\mathrm{pCi} / \mathrm{g}$ & & 1.26 & $\equiv$ & & $\equiv$ & & $\underline{26}$ \\
\hline Z2-EU37B-306 & $09 / 12 / 2006845$ & $\underline{1-0}$ & RADS & Thorium-228 & 1.41 & $\mathrm{pCi} / \mathrm{g}$ & & 1.44 & $\equiv$ & & $\equiv$ & & $\underline{2}$ \\
\hline Z2-EU37B-306 & $09 / 12 / 2006845$ & $\underline{\underline{1-0}}$ & $\underline{\text { RADS }}$ & Thorium-230 & 1.19 & $\underline{\mathrm{pCi} / \mathrm{g}}$ & & 1.22 & $\equiv$ & & $\underline{J}$ & & $\underline{2}$ \\
\hline Z2-EU37B-306 & $09 / 12 / 2006845$ & $\underline{1-0}$ & RADS & Thorium-232 & 1.6 & $\mathrm{pCi} / \mathrm{g}$ & & 1.26 & $\equiv$ & & $\equiv$ & & 24 \\
\hline Z2-EU37B-306 & $09 / 12 / 2006845$ & $\overline{1-0}$ & $\overline{\text { RADS }}$ & Uranium-234 & $\underline{1.11}$ & $\mathrm{pC \textrm {Ci } / \mathrm { g }}$ & & 1.42 & $\equiv$ & & $\equiv$ & & 25 \\
\hline Z2-EU37B-306 & $09 / 12 / 2006845$ & $1-0$ & RADS & Uranium-235 & 0.206 & $\mathrm{pCi} / \mathrm{g}$ & & $\underline{0.053}$ & $\equiv$ & & $\underline{\mathrm{JJ}}$ & & 118 \\
\hline Z2-EU37B-306 & $09 / 12 / 2006845$ & $\underline{1-0}$ & $\overline{\text { RADS }}$ & Uranium-238 & 1.39 & $\mathrm{pC \textrm {Ci } / \mathrm { g }}$ & & 1.27 & $\equiv$ & & $\equiv$ & & 9 \\
\hline Z2-EU41DB-208-4 & $09 / 25 / 20061250$ & $7-7.6$ & RADS & Alpha activity & 3.18 & $\mathrm{pCi} / \mathrm{g}$ & $\underline{4.82}$ & & $\equiv$ & $\equiv$ & & $\underline{41}$ & \\
\hline Z2-EU41DB-208-4 & $09 / 25 / 20061250$ & $7-7.6$ & RADS & Beta activity & 1.68 & $\mathrm{pCi} / \mathrm{g}$ & 3.4 & & $\equiv$ & $\equiv$ & & 68 & \\
\hline Z2-EU41DB-208-4 & $09 / 25 / 20061250$ & $7-7.6$ & RADS & Thorium-228 & 0.42 & $\mathrm{pCi} / \mathrm{g}$ & 0.375 & & $\equiv$ & $\equiv$ & & 11 & \\
\hline Z2-EU41DB-208-4 & $09 / 25 / 20061250$ & $7-7.6$ & RADS & Thorium-232 & 0.202 & $\mathrm{pCi} / \mathrm{g}$ & 0.408 & & $\equiv$ & $\equiv$ & & 68 & \\
\hline Z2-EU41DB-208-4 & $09 / 25 / 20061250$ & $7-7.6$ & RADS & Uranium-234 & 0.717 & $\mathrm{pCi} / \underline{g}$ & 1.1 & & $\equiv$ & $\equiv$ & & $\underline{42}$ & \\
\hline Z2-EU41DB-208-4 & $09 / 25 / 20061250$ & $7-7.6$ & RADS & Uranium-238 & 0.816 & $\mathrm{pCi} / \mathrm{g}$ & 0.941 & & $\equiv$ & $\equiv$ & & 14 & \\
\hline Z2-EU41D-100 & $09 / 26 / 20061015$ & $0-1$ & RADS & Uranium-234 & 1.13 & $\mathrm{pCi} / \mathrm{g}$ & 0.893 & & $\equiv$ & $\equiv$ & & $\underline{23}$ & \\
\hline Z2-EU41D-100 & $09 / 26 / 20061015$ & $0-1$ & RADS & Uranium-235 & 0.273 & $\mathrm{pCi} / \mathrm{g}$ & -0.0208 & & $\equiv$ & $\underline{U U}$ & & & \\
\hline Z2-EU41D-100 & $09 / 26 / 20061015$ & $0-1$ & $\underline{\text { RADS }}$ & Uranium-238 & 0.6 & $\mathrm{pCi} / \mathrm{g}$ & 0.759 & & $\equiv$ & $\equiv$ & & $\underline{23}$ & \\
\hline Z2-EU41D-200 & $09 / 26 / 20061035$ & $\overline{0-1}$ & RADS & Alpha activity & 1.37 & $\mathrm{pCi} / \mathrm{g}$ & & 0.0001 & $\equiv$ & & $\underline{\mathrm{UR}}$ & & \\
\hline Z2-EU41D-200 & $09 / 26 / 20061035$ & $0-1$ & $\underline{\text { RADS }}$ & Alpha activity & 1.37 & $\mathrm{pCi} / \mathrm{g}$ & & 1.58 & $\equiv$ & & $\underline{\mathrm{JJ}}$ & & $\underline{14}$ \\
\hline Z2-EU41D-200 & $09 / 26 / 20061035$ & $\overline{0-1}$ & RADS & Beta activity & 1.91 & $\mathrm{pCi} / \underline{g}$ & & $\underline{0.0005}$ & $\equiv$ & & $\mathrm{UR}$ & & \\
\hline Z2-EU41D-200 & $09 / 26 / 20061035$ & $0-1$ & RADS & Beta activity & 1.91 & $\mathrm{pCi} / \mathrm{g}$ & & 1.54 & $\equiv$ & & $\underline{\mathrm{JJ}}$ & & $\underline{21}$ \\
\hline Z2-EU41D-200 & $09 / 26 / 20061035$ & $\overline{0-1}$ & $\overline{\text { RADS }}$ & Uranium-234 & $\underline{0.919}$ & $\mathrm{pC \textrm {Ci } / \mathrm { g }}$ & & 0.003 & $\equiv$ & & $\underline{\mathrm{UR}}$ & & \\
\hline Z2-EU41D-200 & $09 / 26 / 20061035$ & $0-1$ & RADS & Uranium-234 & 0.919 & $\mathrm{pCi} / \mathrm{g}$ & & 0.65 & $\equiv$ & & $\underline{\mathrm{JJ}}$ & & $\underline{34}$ \\
\hline Z2-EU24M-302 & $09 / 28 / 20061200$ & $0-14$ & $\underline{\text { RADS }}$ & Alpha activity & 4.49 & $\mathrm{pCi} / \mathrm{g}$ & & 29.6 & $\equiv$ & & $\equiv$ & & 147 \\
\hline Z2-EU24M-302 & $09 / 28 / 20061200$ & $0-14$ & RADS & Beta activity & 4.02 & $\mathrm{pCi} / \mathrm{g}$ & & 32.7 & $\equiv$ & & $\underline{J}$ & & 156 \\
\hline Z2-EU24M-302 & $09 / 28 / 20061200$ & $0-14$ & RADS & Radium-226 & 1.46 & $\mathrm{pCi} / \mathrm{g}$ & & 1.23 & $\underline{J}$ & & $\underline{J}$ & & 17 \\
\hline Z2-EU24M-302 & $09 / 28 / 20061200$ & $0-14$ & RADS & Thorium-228 & 1.34 & $\mathrm{pCi} / \mathrm{g}$ & & 1.68 & $\equiv$ & & $\equiv$ & & $\underline{23}$ \\
\hline Z2-EU24M-302 & $09 / 28 / 20061200$ & $0-14$ & RADS & Thorium-230 & 1.67 & $\mathrm{pCi} / \underline{g}$ & & 1.76 & $\equiv$ & & $\underline{J}$ & & 5 \\
\hline Z2-EU24M-302 & $09 / 28 / 20061200$ & $0-14$ & RADS & Thorium-232 & 1.56 & $\mathrm{pCi} / \mathrm{g}$ & & 1.59 & $\equiv$ & & $\equiv$ & & $\underline{2}$ \\
\hline Z2-EU24M-302 & $09 / 28 / 20061200$ & $0-14$ & RADS & Uranium-234 & 1.76 & $\mathrm{pCi} / \mathrm{g}$ & & 1.52 & $\equiv$ & & $\equiv$ & & 15 \\
\hline Z2-EU24M-302 & $09 / 28 / 20061200$ & $0-14$ & RADS & Uranium-238 & 2.22 & $\mathrm{pCi} / \mathrm{g}$ & & 1.88 & $\equiv$ & & $\equiv$ & & 17 \\
\hline Z2-EU28B-319 & $03 / 08 / 20051345$ & $0-10$ & RADS-G & Actinium-228 & 0.74 & $\mathrm{pCi} / \mathrm{g}$ & 0.692 & & $\underline{X V}$ & $\mathrm{XV}$ & & $\underline{7}$ & \\
\hline$\overline{Z \text { Z2-EU28B-319 }}$ & $03 / 08 / 20051345$ & $\overline{\underline{0-10}}$ & $\overline{\text { RADS-G }}$ & Americium-241 & $\underline{0.114}$ & $\mathrm{pCi} / \mathrm{g}$ & -0.000625 & & $\overline{\mathrm{UXV}}$ & $\overline{\mathrm{UXV}}$ & & & \\
\hline
\end{tabular}


Table L.3. (continued)

\begin{tabular}{|c|c|c|c|c|c|c|c|c|c|c|c|c|c|}
\hline Station & Date-time & Depth & Category & Chemical name & $\underline{\text { Reg }}$ & Units & $\frac{\text { Field rep }}{\text { result }}$ & 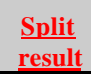 & $\frac{\text { Qual }}{(\text { lab, val, RC) }}$ & FR qual (lab, val, RC) & Split qual & $\frac{\mathrm{FR}}{\mathrm{RPD}}$ & $\underline{\text { Split }}$ \\
\hline$\underline{\underline{\text { Z2-EU28B-319 }}}$ & $03 / 08 / 20051345$ & $\underline{0-10}$ & RADS-G & Antimony-124 & -0.0058 & $\mathrm{pCi} / \underline{g}$ & -0.0198 & & $\mathrm{UXV}$ & $\underline{\mathrm{UXV}}$ & & & \\
\hline Z2-EU28B-319 & $03 / 08 / 20051345$ & $0-10$ & RADS-G & Antimony-125 & 0.0181 & $\mathrm{pCi} / \mathrm{g}$ & 0.0604 & & $\mathrm{UXV}$ & $\mathrm{UXV}$ & & & \\
\hline$\underline{\underline{\text { Z2-EU28B-319 }}}$ & $03 / 08 / 20051345$ & $\underline{0-10}$ & RADS-G & Barium-133 & $\underline{0.00464}$ & $\mathrm{pCi} / \underline{g}$ & $\underline{-0.00813}$ & & $\underline{\mathrm{UXV}}$ & $\underline{\mathrm{UXV}}$ & & & \\
\hline Z2-EU28B-319 & $03 / 08 / 20051345$ & $0-10$ & RADS-G & Barium-140 & -0.206 & $\mathrm{pCi} / \mathrm{g}$ & -0.0896 & & $\mathrm{UXV}$ & $\mathrm{UXV}$ & & & \\
\hline Z2-EU28B-319 & $03 / 08 / 20051345$ & $\underline{0-10}$ & RADS-G & Beryllium-7 & 0.321 & $\mathrm{pCi} / \mathrm{g}$ & $\underline{-0.173}$ & & $\underline{\mathrm{UXV}}$ & $\underline{\mathrm{UXV}}$ & & & \\
\hline Z2-EU28B-319 & $03 / 08 / 20051345$ & $0-10$ & RADS-G & Bismuth-212 & 0.461 & $\mathrm{pCi} / \mathrm{g}$ & 0.725 & & $\mathrm{XV}$ & $\mathrm{XV}$ & & $\underline{45}$ & \\
\hline$\underline{\underline{\text { Z2-EU28B-319 }}}$ & $03 / 08 / 20051345$ & $\underline{0-10}$ & RADS-G & Bismuth-214 & $\underline{0.503}$ & $\mathrm{pCi} / \mathrm{g}$ & 0.552 & & $\underline{\mathrm{XV}}$ & $\underline{\mathrm{XV}}$ & & $\underline{9}$ & \\
\hline Z2-EU28B-319 & $03 / 08 / 20051345$ & $\underline{0-10}$ & RADS-G & Cerium-139 & -0.0037 & $\mathrm{pCi} / \mathrm{g}$ & 0.00552 & & $\mathrm{UXV}$ & $\mathrm{UXV}$ & & & \\
\hline Z2-EU28B-319 & $03 / 08 / 20051345$ & $\underline{0-10}$ & RADS-G & Cerium-141 & -0.0205 & $\mathrm{pCi} / \mathrm{g}$ & 0.0343 & & $\underline{\mathrm{UXV}}$ & $\underline{\mathrm{UXV}}$ & & & \\
\hline Z2-EU28B-319 & $\underline{03 / 08 / 20051345}$ & $\underline{\underline{0-10}}$ & $\underline{\text { RADS-G }}$ & Cerium-144 & $\underline{0.0379}$ & $\mathrm{pCi} / \mathrm{g}$ & 0.192 & & $\underline{\mathrm{UXV}}$ & $\underline{\mathrm{UXV}}$ & & & \\
\hline Z2-EU28B-319 & $03 / 08 / 20051345$ & $\underline{0-10}$ & RADS-G & Cesium-134 & $\underline{0.0452}$ & $\mathrm{pCi} / \mathrm{g}$ & $\underline{0}$ & & $\underline{\mathrm{UXV}}$ & $\underline{\mathrm{UXV}}$ & & & \\
\hline Z2-EU28B-319 & $03 / 08 / 20051345$ & $0-10$ & RADS-G & Cesium-136 & -0.0309 & $\mathrm{pCi} / \underline{g}$ & -0.0344 & & $\mathrm{UXV}$ & $\mathrm{UXV}$ & & & \\
\hline Z2-EU28B-319 & $03 / 08 / 20051345$ & $\underline{0-10}$ & RADS-G & Cesium-137 & $\underline{0.23}$ & $\mathrm{pCi} / \mathrm{g}$ & 0.221 & & $\equiv$ & $\equiv$ & & 4 & \\
\hline Z2-EU28B-319 & $03 / 08 / 20051345$ & $0-10$ & RADS-G & Chromium-51 & 0.058 & $\mathrm{pCi} / \underline{g}$ & -0.254 & & $\mathrm{UXV}$ & $\mathrm{UXV}$ & & & \\
\hline Z2-EU28B-319 & $03 / 08 / 20051345$ & $\underline{0-10}$ & RADS-G & $\begin{array}{l}\text { Cobalt- } 56 \\
\end{array}$ & -0.0235 & $\mathrm{pCi} / \underline{g}$ & -0.00816 & & UXV & $\underline{\mathrm{UXV}}$ & & & \\
\hline Z2-EU28B-319 & $03 / 08 / 20051345$ & $0-10$ & RADS-G & Cobalt-57 & 0.0178 & $\mathrm{pCi} / \mathrm{g}$ & 0.00179 & & $\mathrm{UXV}$ & $\mathrm{UXV}$ & & & \\
\hline Z2-EU28B-319 & $03 / 08 / 20051345$ & $\underline{0-10}$ & RADS-G & $\begin{array}{l}\text { Cobalt-58 } \\
\end{array}$ & -0.0214 & $\mathrm{pCi} / \mathrm{g}$ & $\underline{0.00391}$ & & UXV & $\underline{\mathrm{UXV}}$ & & & \\
\hline Z2-EU28B-319 & $03 / 08 / 20051345$ & $0-10$ & RADS-G & Europium-152 & -0.0182 & $\mathrm{pCi} / \mathrm{g}$ & -0.0134 & & $\mathrm{UXV}$ & $\mathrm{UXV}$ & & & \\
\hline Z2-EU28B-319 & $03 / 08 / 20051345$ & $\underline{0-10}$ & RADS-G & Europium-154 & 0.134 & $\mathrm{pCi} / \mathrm{g}$ & $\underline{0.0119}$ & & UXV & $\underline{\mathrm{UXV}}$ & & & \\
\hline Z2-EU28B-319 & $03 / 08 / 20051345$ & $0-10$ & RADS-G & Europium-155 & $\underline{0.03}$ & $\mathrm{pCi} / \underline{g}$ & 0.0316 & & $\mathrm{UXV}$ & $\mathrm{UXV}$ & & & \\
\hline Z2-EU28B-319 & $03 / 08 / 20051345$ & $\overline{0-10}$ & RADS-G & Iridium-192 & 0.00459 & $\mathrm{pCi} / \mathrm{g}$ & 0.0133 & & $\overline{\mathrm{UXV}}$ & $\mathrm{UXV}$ & & & \\
\hline Z2-EU28B-319 & $03 / 08 / 20051345$ & $0-10$ & RADS-G & Iron-59 & 0.0299 & $\mathrm{pCi} / \mathrm{g}$ & 0.0202 & & $\mathrm{UXV}$ & $\mathrm{UXV}$ & & & \\
\hline Z2-EU28B-319 & $03 / 08 / 20051345$ & $\underline{0-10}$ & RADS-G & $\begin{array}{l}\text { Lead-210 } \\
\end{array}$ & 4.76 & $\mathrm{pCi} / \mathrm{g}$ & $\underline{0.69}$ & & $\underline{\mathrm{UXV}}$ & $\underline{\mathrm{XV}}$ & & & \\
\hline Z2-EU28B-319 & $03 / 08 / 20051345$ & $0-10$ & RADS-G & Lead-212 & 0.7 & $\mathrm{pCi} / \mathrm{g}$ & 0.69 & & $\mathrm{XV}$ & $\mathrm{XV}$ & & 1 & \\
\hline Z2-EU28B-319 & $03 / 08 / 20051345$ & $\underline{0-10}$ & RADS-G & Lead-214 & $\underline{0.677}$ & $\mathrm{pCi} / \mathrm{g}$ & 0.68 & & $\underline{\mathrm{XV}}$ & $\underline{\mathrm{XV}}$ & & $\underline{0}$ & \\
\hline Z2-EU28B-319 & $03 / 08 / 20051345$ & $\underline{0-10}$ & RADS-G & Manganese-54 & -0.0097 & $\mathrm{pCi} / \mathrm{g}$ & 0.0237 & & $\mathrm{UXV}$ & $\mathrm{UXV}$ & & & \\
\hline Z2-EU28B-319 & $03 / 08 / 20051345$ & $\underline{0-10}$ & RADS-G & Mercury-203 & $\underline{0.00737}$ & $\mathrm{pCi} / \underline{g}$ & $\underline{0.0252}$ & & $\underline{\mathrm{UXV}}$ & $\underline{\mathrm{UXV}}$ & & & \\
\hline Z2-EU28B-319 & $03 / 08 / 20051345$ & $0-10$ & RADS-G & Neodymium-147 & -0.183 & $\mathrm{pCi} / \mathrm{g}$ & 0.0915 & & $\mathrm{UXV}$ & $\mathrm{UXV}$ & & & \\
\hline Z2-EU28B-319 & $03 / 08 / 20051345$ & $\underline{0-10}$ & RADS-G & Neptunium-239 & 0.0541 & $\mathrm{pCi} / \underline{g}$ & -0.0685 & & $\underline{\mathrm{UXV}}$ & $\underline{\mathrm{UXV}}$ & & & \\
\hline Z2-EU28B-319 & $03 / 08 / 20051345$ & $0-10$ & RADS-G & Niobium-94 & 0.0179 & $\mathrm{pCi} / \mathrm{g}$ & -0.00555 & & $\mathrm{UXV}$ & $\mathrm{UXV}$ & & & \\
\hline Z2-EU28B-319 & $03 / 08 / 20051345$ & $\underline{0-10}$ & RADS-G & Niobium-95 & $\underline{0.015}$ & $\mathrm{pCi} / \underline{g}$ & 0.0167 & & UXV & $\underline{\mathrm{UXV}}$ & & & \\
\hline Z2-EU28B-319 & $03 / 08 / 20051345$ & $0-10$ & RADS-G & Potassium-40 & 7.14 & $\mathrm{pCi} / \mathrm{g}$ & 8.78 & & $\equiv$ & $\equiv$ & & 21 & \\
\hline Z2-EU28B-319 & $03 / 08 / 20051345$ & $\underline{0-10}$ & RADS-G & Promethium-144 & $\underline{0.0365}$ & $\mathrm{pCi} / \underline{g}$ & -0.0216 & & $\underline{\mathrm{UXV}}$ & $\underline{\mathrm{UXV}}$ & & & \\
\hline Z2-EU28B-319 & $03 / 08 / 20051345$ & $0-10$ & RADS-G & Promethium-146 & 0.0109 & $\mathrm{pCi} / \mathrm{g}$ & -0.0136 & & $\mathrm{UXV}$ & $\mathrm{UXV}$ & & & \\
\hline Z2-EU28B-319 & $03 / 08 / 20051345$ & $\underline{0-10}$ & RADS-G & Radium-226 & 0.503 & $\mathrm{pCi} / \underline{g}$ & 0.552 & & $\underline{\mathrm{J}}$ & $\mathrm{JT} 01$ & & $\underline{9}$ & \\
\hline Z2-EU28B-319 & $03 / 08 / 20051345$ & $0-10$ & RADS-G & Radium-228 & 0.74 & $\mathrm{pCi} / \mathrm{g}$ & 0.692 & & $\mathrm{XV}$ & $\mathrm{XV}$ & & 7 & \\
\hline Z2-EU28B-319 & $03 / 08 / 20051345$ & $\overline{0-10}$ & RADS-G & Ruthenium-106 & -0.0884 & $\mathrm{pCi} / \mathrm{g}$ & 0.325 & & $\overline{\mathrm{UXV}}$ & $\underline{\mathrm{UXV}}$ & & & \\
\hline Z2-EU28B-319 & $03 / 08 / 20051345$ & $0-10$ & RADS-G & Silver-110m & -0.0013 & $\mathrm{pCi} / \mathrm{g}$ & 0.0104 & & $\mathrm{UXV}$ & $\mathrm{UXV}$ & & & \\
\hline Z2-EU28B-319 & $03 / 08 / 20051345$ & $\underline{0-10}$ & RADS-G & $\begin{array}{l}\text { Sodium-22 } \\
\end{array}$ & $\underline{0.0477}$ & $\mathrm{pCi} / \mathrm{g}$ & $\underline{0.00381}$ & & $\mathrm{UXV}$ & $\underline{\mathrm{UXV}}$ & & & \\
\hline Z2-EU28B-319 & $03 / 08 / 20051345$ & $0-10$ & RADS-G & Thallium-208 & 0.221 & $\mathrm{pCi} / \mathrm{g}$ & $\underline{0.253}$ & & $\mathrm{XV}$ & $\mathrm{XV}$ & & 14 & \\
\hline
\end{tabular}


Table L.3. (continued)

\begin{tabular}{|c|c|c|c|c|c|c|c|c|c|c|c|c|c|}
\hline Station & Date-time & Depth & Category & Chemical name & $\begin{array}{l}\text { Reg } \\
\text { result }\end{array}$ & Units & $\frac{\frac{\text { Field rep }}{\text { result }}}{\text { restis }}$ & $\begin{array}{l}\text { Split } \\
\text { result }\end{array}$ & $\stackrel{\text { (lab, val, }}{\text { QuC) }}$ & FR qual (lab, val, $\mathrm{RC}$ ) & $\underline{\text { Split qual }}$ & $\underline{\underline{\mathrm{FR}}}$ & $\underline{\frac{\text { Split }}{\text { RPD }}}$ \\
\hline Z2-EU28B-319 & $\underline{03 / 08 / 20051345}$ & $\underline{0-10}$ & $\underline{\underline{R A D S}-\mathrm{G}}$ & Thorium-230 & 0.503 & $\underline{\mathrm{pCi} / \underline{\underline{g}}}$ & $\underline{0.552}$ & & $\underline{\mathrm{XV}}$ & $\underline{\mathrm{XV}}$ & & $\underline{9}$ & \\
\hline Z2-EU28B-319 & $03 / 08 / 20051345$ & $0-10$ & RADS-G & Tin-113 & -0.0128 & $\mathrm{pCi} / \underline{\underline{g}}$ & -0.0253 & & $\underline{\mathrm{UXV}}$ & $\mathrm{UXV}$ & & & \\
\hline Z2-EU28B-319 & $\underline{03 / 08 / 20051345}$ & $\underline{0-10}$ & $\underline{\text { RADS-G }}$ & Uranium-235 & $\underline{0.168}$ & $\underline{\mathrm{pCi} / \underline{\mathrm{g}}}$ & 0.146 & & $\underline{\mathrm{UXV}}$ & $\underline{\mathrm{UXV}}$ & & & \\
\hline Z2-EU28B-319 & $\underline{03 / 08 / 20051345}$ & $\underline{0-10}$ & $\underline{\underline{\text { RADS-G }}}$ & Uranium-238 & $\underline{\underline{0.875}}$ & $\underline{\underline{\mathrm{pCi} / g}}$ & $\underline{0.892}$ & & $\underline{\underline{\mathrm{UXV}}}$ & $\underline{\underline{\mathrm{XV}}}$ & & & \\
\hline Z2-EU28B-319 & $\underline{03 / 08 / 20051345}$ & $\underline{\underline{0-10}}$ & $\underline{\text { RADS-G }}$ & Yttrium-88 & -0.0082 & $\underline{\mathrm{pCi} / \mathrm{g}}$ & $\begin{array}{l}-0.00207 \\
\end{array}$ & & $\underline{\mathrm{UXV}}$ & $\underline{\mathrm{UXV}}$ & & & \\
\hline Z2-EU28B-319 & $\underline{\underline{03 / 08 / 20051345}}$ & $\underline{0-10}$ & $\underline{\underline{\text { RADS-G }}}$ & $\begin{array}{l}\text { Zinc-65 } \\
\end{array}$ & $\underline{0.0654}$ & $\underline{\mathrm{pCi} / \mathrm{g}}$ & $-\underline{-0.0403}$ & & $\underline{\underline{\mathrm{UXV}}}$ & $\underline{\mathrm{UXV}}$ & & & \\
\hline Z2-EU28B-319 & $\underline{03 / 08 / 20051345}$ & $\underline{\underline{0-10}}$ & RADS-G & Zirconium-95 & $\underline{0.00613}$ & $\underline{\mathrm{pCi} / \mathrm{g}}$ & $\underline{0}$ & & $\underline{\mathrm{UXV}}$ & $\underline{\mathrm{UXV}}$ & & & \\
\hline $\begin{array}{l}\text { Z2-EU28-106 } \\
\text { - }\end{array}$ & $\underline{03 / 18 / 20051130}$ & $\underline{\underline{0-0.6}}$ & $\underline{\underline{R A D S}-G}$ & Actinium-228 & $\underline{1.67}$ & $\underline{\mathrm{pCi} / \mathrm{g}}$ & $\underline{1.2}$ & & $\underline{\underline{\mathrm{XV}}}$ & $\underline{\underline{\mathrm{XV}}}$ & & $\underline{33}$ & \\
\hline Z2-EU28-106 & $\underline{03 / 18 / 20051130}$ & $\underline{0-0.6}$ & $\underline{\text { RADS-G }}$ & Americium-241 & -0.407 & $\mathrm{pCi} / \mathrm{g}$ & $\underline{0.0869}$ & & $\underline{\mathrm{UXV}}$ & $\underline{\mathrm{UXV}}$ & & & \\
\hline Z2-EU28-106 & $\underline{03 / 18 / 20051130}$ & $\underline{\underline{0-0.6}}$ & $\underline{\underline{R A D S}-\mathrm{G}}$ & Antimony-124 & $\underline{\underline{0.00217}}$ & $\underline{\mathrm{pCi} / \mathrm{g}}$ & $\underline{0.0123}$ & & $\underline{\mathrm{UXV}}$ & $\underline{\mathrm{UXV}}$ & & & \\
\hline Z2-EU28-106 & $\underline{03 / 18 / 20051130}$ & $\underline{0-0.6}$ & $\underline{\text { RADS-G }}$ & Antimony-125 & $\underline{0.195}$ & $\underline{\mathrm{pCi} / \mathrm{g}}$ & $\underline{0.0511}$ & & $\underline{\mathrm{UXV}}$ & $\underline{\mathrm{UXV}}$ & & & \\
\hline Z2-EU28-106 & $\underline{03 / 18 / 20051130}$ & $\underline{\underline{0-0.6}}$ & $\underline{\underline{R A D S}-\mathrm{G}}$ & Barium-133 & -0.0024 & $\underline{\mathrm{pCi} / \underline{g}}$ & $\underline{0.0426}$ & & $\underline{\mathrm{UXV}}$ & $\underline{\mathrm{UXV}}$ & & & \\
\hline Z2-EU28-106 & $03 / 18 / 20051130$ & $\underline{0-0.6}$ & RADS-G & Barium-140 & 0.282 & $\underline{\mathrm{pCi} / \mathrm{g}}$ & 0.213 & & $\underline{\mathrm{UXV}}$ & $\underline{\mathrm{UXV}}$ & & & \\
\hline Z2-EU28-106 & $03 / 18 / 20051130$ & $\underline{\underline{0-0.6}}$ & $\underline{\underline{\text { RADS-G }}}$ & Beryllium-7 & $\underline{0.188}$ & $\underline{\underline{\mathrm{pCi} / g}}$ & $\underline{\underline{0.288}}$ & & $\underline{\mathrm{UXV}}$ & $\underline{\mathrm{UXV}}$ & & & \\
\hline Z2-EU28-106 & $03 / 18 / 20051130$ & $\underline{0-0.6}$ & RADS-G & Bismuth-212 & 1.34 & $\underline{\mathrm{pCi} / \mathrm{g}}$ & $\underline{0.414}$ & & $\underline{\underline{X V}}$ & $\underline{\mathrm{UXV}}$ & & & \\
\hline Z2-EU28-106 & $03 / 18 / 20051130$ & $\underline{\underline{0-0.6}}$ & $\underline{\underline{\text { RADS-G }}}$ & Bismuth-214 & 1.18 & $\underline{\mathrm{pCi} / g}$ & 0.981 & & $\underline{\underline{X V}}$ & $\underline{\underline{X V}}$ & & $\underline{\underline{18}}$ & \\
\hline Z2-EU28-106 & $03 / 18 / 20051130$ & $\underline{0-0.6}$ & RADS-G & Cerium-139 & 0.0434 & $\underline{\mathrm{pCi} / \mathrm{g}}$ & -0.0175 & & $\underline{\mathrm{UXV}}$ & $\underline{\mathrm{UXV}}$ & & & \\
\hline Z2-EU28-106 & $03 / 18 / 20051130$ & $\underline{\underline{0-0.6}}$ & $\underline{\underline{\text { RADS-G }}}$ & Cerium-141 & $\underline{\underline{0.00706}}$ & $\underline{\underline{\mathrm{pCi} / g}}$ & $\underline{0}$ & & $\underline{\underline{\mathrm{UXV}}}$ & $\underline{\underline{\mathrm{UXV}}}$ & & & \\
\hline Z2-EU28-106 & $03 / 18 / 20051130$ & $\underline{0-0.6}$ & RADS-G & Cerium-144 & -0.0092 & $\underline{\mathrm{pCi} / \mathrm{g}}$ & $\underline{0.0519}$ & & $\underline{\mathrm{UXV}}$ & $\underline{\mathrm{UXV}}$ & & & \\
\hline Z2-EU28-106 & $03 / 18 / 20051130$ & $\underline{0-0.6}$ & $\underline{\underline{\text { RADS-G }}}$ & Cesium-134 & $\underline{0.0971}$ & $\underline{\mathrm{pCi} / \mathrm{g}}$ & $\underline{0.0597}$ & & $\underline{\underline{\mathrm{UXV}}}$ & $\underline{\underline{\mathrm{UXV}}}$ & & & \\
\hline Z2-EU28-106 & $03 / 18 / 20051130$ & $\underline{0-0.6}$ & RADS-G & Cesium-136 & -0.0129 & $\underline{\mathrm{pCi} / \mathrm{g}}$ & -0.128 & & $\underline{\mathrm{UXV}}$ & $\underline{\mathrm{UXV}}$ & & & \\
\hline Z2-EU28-106 & $03 / 18 / 20051130$ & $\underline{\underline{0-0.6}}$ & $\underline{\underline{\text { RADS-G }}}$ & Chromium-51 & $\underline{0.179}$ & $\underline{\mathrm{pCi} / \mathrm{g}}$ & -0.0446 & & $\underline{\underline{\mathrm{UXV}}}$ & $\underline{\mathrm{UXV}}$ & & & \\
\hline Z2-EU28-106 & $\underline{03 / 18 / 20051130}$ & $\underline{\underline{0-0.6}}$ & $\underline{\text { RADS-G }}$ & Cobalt- 56 & $\underline{0.042}$ & $\underline{\mathrm{pCi} / \mathrm{g}}$ & $\underline{0.0435}$ & & $\underline{\mathrm{UXV}}$ & $\underline{\mathrm{UXV}}$ & & & \\
\hline Z2-EU28-106 & $03 / 18 / 20051130$ & $\underline{\underline{0-0.6}}$ & $\underline{\text { RADS-G }}$ & Cobalt-57 & -0.0127 & $\underline{\mathrm{pCi} / \mathrm{g}}$ & $\underline{0.000212}$ & & $\underline{\mathrm{UXV}}$ & $\underline{\mathrm{UXV}}$ & & & \\
\hline Z2-EU28-106 & $03 / 18 / 20051130$ & $\underline{0-0.6}$ & RADS-G & Cobalt-58 & $\underline{0.0523}$ & $\mathrm{pCi} / \underline{g}$ & -0.0513 & & $\underline{\mathrm{UXV}}$ & $\underline{\mathrm{UXV}}$ & & & \\
\hline Z2-EU28-106 & $03 / 18 / 20051130$ & $\underline{\underline{0-0.6}}$ & $\underline{\text { RADS-G }}$ & $\begin{array}{l}\text { Europium-152 } \\
\end{array}$ & -0.0596 & $\underline{\mathrm{pCi} / \mathrm{g}}$ & $\underline{0.0208}$ & & $\underline{\mathrm{UXV}}$ & $\underline{\mathrm{UXV}}$ & & & \\
\hline Z2-EU28-106 & $03 / 18 / 20051130$ & $\underline{0-0.6}$ & RADS-G & Europium-154 & 0.146 & $\underline{\mathrm{pCi} / \mathrm{g}}$ & $-9.25 \mathrm{E}-05$ & & $\underline{\mathrm{UXV}}$ & $\underline{\mathrm{UXV}}$ & & & \\
\hline Z2-EU28-106 & $03 / 18 / 20051130$ & $\underline{\underline{0-0.6}}$ & $\underline{\text { RADS-G }}$ & $\begin{array}{l}\text { Europium-155 } \\
\end{array}$ & $\underline{0.139}$ & $\underline{\mathrm{pCi} / \mathrm{g}}$ & $\underline{0.0157}$ & & $\underline{\mathrm{UXV}}$ & $\underline{\mathrm{UXV}}$ & & & \\
\hline Z2-EU28-106 & $03 / 18 / 20051130$ & $\underline{0-0.6}$ & RADS-G & Iridium-192 & -0.0035 & $\underline{\mathrm{pCi} / \mathrm{g}}$ & $\underline{0.019}$ & & $\underline{\mathrm{UXV}}$ & $\underline{\mathrm{UXV}}$ & & & \\
\hline Z2-EU28-106 & $03 / 18 / 20051130$ & $\underline{\underline{0-0.6}}$ & $\underline{\underline{R A D S}-G}$ & Iron-59 & -0.0066 & $\underline{\underline{\mathrm{pCi} / g}}$ & -0.0258 & & $\underline{\mathrm{UXV}}$ & $\underline{\mathrm{UXV}}$ & & & \\
\hline Z2-EU28-106 & $\underline{\underline{03 / 18 / 20051130}}$ & $\underline{\underline{0-0.6}}$ & $\underline{\underline{\text { RADS-G }}}$ & Lead-210 & $\underline{9.07}$ & $\underline{\underline{\mathrm{pCi} / \underline{\underline{g}}}}$ & 4.48 & & $\underline{\underline{\mathrm{UXV}}}$ & $\underline{\mathrm{UXV}}$ & & & \\
\hline Z2-EU28-106 & $03 / 18 / 20051130$ & $\underline{\underline{0-0.6}}$ & $\underline{\underline{\text { RADS-G }}}$ & Lead-212 & 1.32 & $\underline{\underline{\mathrm{pCi} / g}}$ & $\underline{1.22}$ & & $\underline{\underline{\mathrm{XV}}}$ & $\underline{\underline{X V}}$ & & $\underline{8}$ & \\
\hline Z2-EU28-106 & $03 / 18 / 20051130$ & $\underline{0-0.6}$ & RADS-G & Lead-214 & 1.14 & $\underline{\mathrm{pCi} / \mathrm{g}}$ & $\underline{1.12}$ & & $\underline{\underline{X V}}$ & $\underline{\underline{X V}}$ & & $\underline{2}$ & \\
\hline Z2-EU28-106 & $03 / 18 / 20051130$ & $\underline{\underline{0-0.6}}$ & $\underline{\underline{\text { RADS-G }}}$ & Manganese- 54 & $\underline{\underline{0.0603}}$ & $\underline{\underline{\mathrm{pCi} / g}}$ & $\underline{0.0405}$ & & $\underline{\underline{\mathrm{UXV}}}$ & $\underline{\underline{\mathrm{UXV}}}$ & & & \\
\hline Z2-EU28-106 & $03 / 18 / 20051130$ & $\underline{0-0.6}$ & RADS-G & Mercury-203 & 0.06 & $\underline{\mathrm{pCi} / \mathrm{g}}$ & 0.036 & & $\underline{\mathrm{UXV}}$ & $\underline{\mathrm{UXV}}$ & & & \\
\hline Z2-EU28-106 & $03 / 18 / 20051130$ & $\underline{\underline{0-0.6}}$ & $\underline{\underline{\text { RADS-G }}}$ & Neodymium-147 & -0.0457 & $\underline{\underline{\mathrm{pCi} / g}}$ & -0.215 & & $\underline{\underline{\mathrm{UXV}}}$ & $\underline{\mathrm{UXV}}$ & & & \\
\hline Z2-EU28-106 & $03 / 18 / 20051130$ & $\underline{0-0.6}$ & RADS-G & Neptunium-239 & -0.127 & $\underline{\mathrm{pCi} / \mathrm{g}}$ & $\underline{0.0472}$ & & $\underline{\mathrm{UXV}}$ & $\underline{\mathrm{UXV}}$ & & & \\
\hline Z2-EU28-106 & $03 / 18 / 20051130$ & $\underline{\underline{0-0.6}}$ & $\underline{\underline{\text { RADS-G }}}$ & Niobium-94 & $\underline{0.00461}$ & $\underline{\mathrm{pCi} / \mathrm{g}}$ & $\underline{0.0205}$ & & $\underline{\underline{\mathrm{UXV}}}$ & $\underline{\mathrm{UXV}}$ & & & \\
\hline Z2-EU28-106 & $\underline{03 / 18 / 20051130}$ & $\underline{\underline{0-0.6}}$ & $\underline{\text { RADS-G }}$ & Niobium-95 & $\underline{0.0198}$ & $\underline{\mathrm{pCi} / \mathrm{g}}$ & $\underline{0.0398}$ & & $\underline{\mathrm{UXV}}$ & $\underline{\mathrm{UXV}}$ & & & \\
\hline Z2-EU28-106 & $03 / 18 / 20051130$ & $\underline{0-0.6}$ & $\underline{\text { RADS-G }}$ & Potassium-40 & $\underline{10.5}$ & $\underline{\mathrm{pCi} / \mathrm{g}}$ & $\underline{9.75}$ & & & 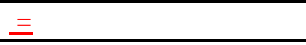 & & & \\
\hline
\end{tabular}


Table L.3. (continued)

\begin{tabular}{|c|c|c|c|c|c|c|c|c|c|c|c|c|c|}
\hline Station & Date-time & Depth & Category & Chemical name & $\underline{\text { Reg }}$ & Units & $\frac{\text { Field rep }}{\text { result }}$ & 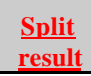 & $\frac{\text { Qual }}{(\text { lab, val, RC) }}$ & FR qual (lab, val, RC) & Split qual & $\underline{\mathrm{FR}}$ & $\underline{\text { Split }}$ \\
\hline Z2-EU28-106 & $03 / 18 / 20051130$ & $\underline{0-0.6}$ & RADS-G & Promethium-144 & 0.0414 & $\mathrm{pCi} / \underline{g}$ & -0.00479 & & $\mathrm{UXV}$ & $\underline{\mathrm{UXV}}$ & & & \\
\hline Z2-EU28-106 & $03 / 18 / 20051130$ & $0-0.6$ & RADS-G & Promethium-146 & 0.0367 & $\mathrm{pCi} / \mathrm{g}$ & 0.0595 & & $\mathrm{UXV}$ & $\mathrm{UXV}$ & & & \\
\hline Z2-EU28-106 & $03 / 18 / 20051130$ & $\underline{0-0.6}$ & RADS-G & Radium-226 & $\underline{1.18}$ & $\mathrm{pCi} / \underline{g}$ & 0.981 & & $\underline{\mathrm{XV}}$ & $\mathrm{XV}$ & & $\underline{18}$ & \\
\hline Z2-EU28-106 & $03 / 18 / 20051130$ & $0-0.6$ & RADS-G & Radium-228 & 1.67 & $\mathrm{pCi} / \mathrm{g}$ & 1.2 & & $\mathrm{XV}$ & $\mathrm{XV}$ & & $\underline{33}$ & \\
\hline Z2-EU28-106 & $03 / 18 / 20051130$ & $\underline{0-0.6}$ & RADS-G & Ruthenium-106 & -0.38 & $\mathrm{pCi} / \mathrm{g}$ & -0.0102 & & $\underline{\mathrm{UXV}}$ & $\underline{\mathrm{UXV}}$ & & & \\
\hline Z2-EU28-106 & $03 / 18 / 20051130$ & $0-0.6$ & RADS-G & Silver-110m & -0.0302 & $\mathrm{pCi} / \mathrm{g}$ & 0.00177 & & $\mathrm{UXV}$ & $\mathrm{UXV}$ & & & \\
\hline Z2-EU28-106 & $03 / 18 / 20051130$ & $\underline{\underline{0-0.6}}$ & RADS-G & $\underline{\underline{S o d i u m}-22}$ & 0.0521 & $\mathrm{pCi} / \mathrm{g}$ & $\underline{-0.00033}$ & & $\underline{\mathrm{UXV}}$ & $\underline{\mathrm{UXV}}$ & & & \\
\hline Z2-EU28-106 & $03 / 18 / 20051130$ & $0-0.6$ & RADS-G & Thallium-208 & 0.38 & $\mathrm{pCi} / \mathrm{g}$ & 0.429 & & $\mathrm{XV}$ & $\mathrm{XV}$ & & $\underline{12}$ & \\
\hline Z2-EU28-106 & $03 / 18 / 20051130$ & $\underline{\underline{0-0.6}}$ & RADS-G & Thorium-230 & 1.18 & $\mathrm{pCi} / \mathrm{g}$ & 0.981 & & $\underline{\mathrm{XV}}$ & $\mathrm{XV}$ & & $\underline{18}$ & \\
\hline Z2-EU28-106 & $03 / 18 / 20051130$ & $\underline{0-0.6}$ & RADS-G & Tin-113 & -0.0234 & $\mathrm{pCi} / \mathrm{g}$ & -0.0575 & & $\underline{\mathrm{UXV}}$ & $\underline{\mathrm{UXV}}$ & & & \\
\hline Z2-EU28-106 & $\underline{03 / 18 / 20051130}$ & $\underline{0-0.6}$ & RADS-G & Uranium-235 & 0.0304 & $\mathrm{pCi} / \mathrm{g}$ & 0.478 & & $\underline{\mathrm{UXV}}$ & $\mathrm{XV}$ & & & \\
\hline Z2-EU28-106 & $03 / 18 / 20051130$ & $0-0.6$ & RADS-G & Uranium-238 & 1.28 & $\mathrm{pCi} / \underline{g}$ & 3.19 & & $\mathrm{UXV}$ & $\mathrm{XV}$ & & & \\
\hline Z2-EU28-106 & $03 / 18 / 20051130$ & $\underline{0-0.6}$ & RADS-G & Yttrium-88 & $\underline{0.0461}$ & $\mathrm{pCi} / \mathrm{g}$ & -0.0354 & & $\underline{\mathrm{UXV}}$ & $\underline{\mathrm{UXV}}$ & & & \\
\hline Z2-EU28-106 & $03 / 18 / 20051130$ & $0-0.6$ & RADS-G & Zinc-65 & 0.0105 & $\mathrm{pCi} / \underline{g}$ & -0.00381 & & $\mathrm{UXV}$ & $\mathrm{UXV}$ & & & \\
\hline Z2-EU28-106 & $03 / 18 / 20051130$ & $0-0.6$ & RADS-G & Zirconium-95 & 0.0664 & $\mathrm{pCi} / \underline{g}$ & 0.0104 & & UXV & $\underline{\mathrm{UXV}}$ & & & \\
\hline Z2-EU28-201 & $03 / 22 / 20051205$ & $0.5-3.2$ & RADS-G & Actinium-228 & 2.34 & $\mathrm{pCi} / \mathrm{g}$ & & $\underline{2}$ & $\underline{\mathrm{XV}}$ & & $\underline{J}$ & & $\underline{16}$ \\
\hline Z2-EU28-201 & $03 / 22 / 20051205$ & $0.5-3.2$ & RADS-G & Bismuth-214 & 2.36 & $\mathrm{pCi} / \mathrm{g}$ & & 1.54 & $\underline{\mathrm{XV}}$ & & $\underline{\underline{J J}}$ & & $\underline{42}$ \\
\hline Z2-EU28-201 & $03 / 22 / 20051205$ & $0.5-3.2$ & RADS-G & Lead-212 & 2.28 & $\mathrm{pCi} / \mathrm{g}$ & & 2.34 & $\underline{\mathrm{XV}}$ & & $\underline{J}$ & & $\underline{3}$ \\
\hline Z2-EU28-201 & $03 / 22 / 20051205$ & $0.5-3.2$ & RADS-G & Lead-214 & 2.72 & $\mathrm{pCi} / \mathrm{g}$ & & $\underline{\underline{2}}$ & $\underline{\mathrm{XV}}$ & & $\underline{\underline{\mathrm{JJ}}}$ & & $\underline{31}$ \\
\hline Z2-EU28-201 & $03 / 22 / 20051205$ & $0.5-3.2$ & RADS-G & Potassium-40 & 14.7 & $\mathrm{pCi} / \underline{g}$ & & 16.7 & $\equiv$ & & $\underline{J}$ & & 13 \\
\hline$\overline{\text { Z2-EU28-201 }}$ & $03 / 22 / 20051205$ & $0.5-3.2$ & RADS-G & Thallium-208 & 0.757 & $\mathrm{pCi/g}$ & & $\underline{0.606}$ & $\underline{\mathrm{XV}}$ & & $\underline{\underline{J}}$ & & $\underline{22}$ \\
\hline Z2-EU28B-115 & $02 / 15 / 20061450$ & $0-1$ & RADS-G & Actinium-228 & 1.68 & $\mathrm{pCi} / \mathrm{g}$ & 1.68 & & $\mathrm{~J}=$ & J UJ T04 & & $\underline{0}$ & \\
\hline$\underline{\underline{\text { Z2-EU28B-115 }}}$ & $02 / 15 / 20061450$ & $\underline{0-1}$ & RADS-G & Bismuth-214 & 0.966 & $\mathrm{pCi} / \mathrm{g}$ & $\underline{0.923}$ & & $\underline{\underline{J J}}$ & $\underline{\mathrm{JJ}}$ & & $\underline{\underline{5}}$ & \\
\hline Z2-EU28B-115 & $02 / 15 / 20061450$ & $0-1$ & RADS-G & Cesium-137 & 2.33 & $\mathrm{pCi} / \mathrm{g}$ & 2.28 & & $\equiv$ & $\equiv$ & & $\underline{2}$ & \\
\hline Z2-EU28B-115 & $02 / 15 / 20061450$ & $\underline{0-1}$ & RADS-G & Lead-212 & 2.8 & $\mathrm{pCi} / \mathrm{g}$ & 2.59 & & $\equiv$ & $\equiv$ & & $\underline{8}$ & \\
\hline Z2-EU28B-115 & $02 / 15 / 20061450$ & $\underline{0-1}$ & RADS-G & Lead-214 & 1.18 & $\mathrm{pCi} / \mathrm{g}$ & 1.34 & & $\underline{\mathrm{JJ}}$ & $\underline{\mathrm{JJ}}$ & & $\underline{13}$ & \\
\hline$\underline{\text { Z2-EU28B-115 }}$ & $\underline{02 / 15 / 20061450}$ & $\underline{0-1}$ & RADS-G & Potassium-40 & 18.6 & $\mathrm{pCi} / \underline{g}$ & 16.7 & & $\equiv$ & $\equiv$ & & $\underline{11}$ & \\
\hline Z2-EU28B-115 & $02 / 15 / 20061450$ & $0-1$ & RADS-G & Protactinium-234m & 95.9 & $\mathrm{pCi} / \mathrm{g}$ & 121 & & $\equiv$ & $\equiv$ & & $\underline{23}$ & \\
\hline$\underline{\text { Z2-EU28B-115 }}$ & $02 / 15 / 20061450$ & $\underline{0-1}$ & RADS-G & Thallium-208 & $\underline{0.939}$ & $\mathrm{pCi} / \underline{g}$ & 1 & & $\equiv$ & $\equiv$ & & $\underline{6}$ & \\
\hline Z2-EU28B-115 & $02 / 15 / 20061450$ & $0-1$ & RADS-G & Thorium-234 & $\underline{63}$ & $\mathrm{pCi} / \mathrm{g}$ & 52.6 & & $\equiv$ & $\equiv$ & & 18 & \\
\hline$\underline{\underline{\text { Z2-EU28B-115 }}}$ & $02 / 15 / 20061450$ & $\underline{0-1}$ & RADS-G & Uranium-235 & 7.31 & $\mathrm{pCi} / \underline{g}$ & $\underline{5.19}$ & & $\equiv$ & $\equiv$ & & 34 & \\
\hline Z2-EU28B-125 & $02 / 16 / 20061102$ & $0-1$ & RADS-G & Actinium-228 & 1.3 & $\mathrm{pCi} / \mathrm{g}$ & 1.65 & & $\mathrm{~J}=$ & $\mathrm{J}=$ & & 24 & \\
\hline$\underline{\underline{\text { Z2-EU28B-125 }}}$ & $02 / 16 / 20061102$ & $\underline{0-1}$ & RADS-G & Bismuth-214 & 1.13 & $\mathrm{pCi} / \underline{g}$ & 1.13 & & $\underline{\underline{J J}}$ & $\underline{\underline{J J}}$ & & $\underline{\underline{0}}$ & \\
\hline Z2-EU28B-125 & $02 / 16 / 20061102$ & $0-1$ & RADS-G & Cesium-137 & 2.32 & $\mathrm{pCi} / \mathrm{g}$ & 2.37 & & $\equiv$ & $\equiv$ & & 2 & \\
\hline$\underline{\underline{\text { Z2-EU28B-125 }}}$ & $02 / 16 / 20061102$ & $\underline{0-1}$ & RADS-G & Lead-212 & $\underline{0.843}$ & $\mathrm{pCi} / \underline{g}$ & 1.07 & & $\equiv$ & $\equiv$ & & $\underline{24}$ & \\
\hline Z2-EU28B-125 & $02 / 16 / 20061102$ & $0-1$ & RADS-G & Lead-214 & 1.16 & $\mathrm{pCi} / \mathrm{g}$ & 1.26 & & $\underline{\mathrm{JJ}}$ & $\underline{\mathrm{JJ}}$ & & $\underline{8}$ & \\
\hline Z2-EU28B-125 & $02 / 16 / 20061102$ & $\overline{0-1}$ & RADS-G & Potassium-40 & 7.78 & $\mathrm{pCi} / \mathrm{g}$ & 10.4 & & $\equiv$ & $\equiv$ & & $\underline{29}$ & \\
\hline Z2-EU28B-125 & $02 / 16 / 20061102$ & $0-1$ & RADS-G & Thallium-208 & 0.401 & $\mathrm{pCi} / \mathrm{g}$ & 0.352 & & $\equiv$ & $\equiv$ & & 13 & \\
\hline$\underline{\underline{\text { Z2-EU28B-125 }}}$ & $02 / 16 / 20061102$ & $\underline{0-1}$ & RADS-G & Thorium-234 & 10.5 & $\mathrm{pCi} / \mathrm{g}$ & 14.2 & & $\underline{\underline{\underline{B}}}$ & $\bar{E}$ & & $\underline{30}$ & \\
\hline Z2-EU28B-125 & $02 / 16 / 20061102$ & $0-1$ & RADS-G & Uranium-235 & 1.1 & $\mathrm{pCi} / \mathrm{g}$ & 1.32 & & $\mathrm{~J} \equiv$ & $\mathrm{J}=$ & & $\underline{18}$ & \\
\hline
\end{tabular}


Table L.3. (continued)

\begin{tabular}{|c|c|c|c|c|c|c|c|c|c|c|c|c|c|}
\hline Station & Date-time & Depth & Category & Chemical name & $\underline{\text { Reg }}$ & Units & $\frac{\frac{\text { Field rep }}{\text { result }}}{\text { restis }}$ & 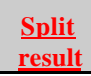 & $\frac{\text { Qual }}{(\text { lab, val, RC) }}$ & FR qual (lab, val, RC) & Split qual & $\underline{\underline{\mathrm{FR}}}$ & $\underline{\text { Split }}$ \\
\hline Z2-EU28B-123 & $02 / 16 / 20061405$ & $\underline{0-1}$ & RADS-G & Actinium-228 & 1.23 & $\mathrm{pCi} / \underline{g}$ & & 1.45 & $\mathrm{~J}=$ & & $\equiv$ & & $\underline{16}$ \\
\hline Z2-EU28B-123 & $02 / 16 / 20061405$ & $0-1$ & RADS-G & Lead-212 & 0.983 & $\mathrm{pCi} / \mathrm{g}$ & & 1.41 & $\equiv$ & & $\equiv$ & & 36 \\
\hline Z2-EU28B-123 & $02 / 16 / 20061405$ & $\underline{0-1}$ & RADS-G & Potassium-40 & 22.8 & $\mathrm{pCi} / \underline{g}$ & & 21.2 & 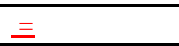 & & $\equiv$ & & $\underline{7}$ \\
\hline Z2-EU28B-123 & $02 / 16 / 20061405$ & $0-1$ & RADS-G & Thallium-208 & 0.396 & $\mathrm{pCi} / \mathrm{g}$ & & 0.59 & $\equiv$ & & $\equiv$ & & 39 \\
\hline Z2-EU28B-123 & $02 / 16 / 20061405$ & $\underline{\underline{0-1}}$ & RADS-G & Thorium-234 & $\underline{60.1}$ & $\mathrm{pCi/g}$ & & $6 \underline{64}$ & 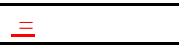 & & $\equiv$ & & $\underline{6}$ \\
\hline Z2-EU28B-123 & $02 / 16 / 20061405$ & $0-1$ & RADS-G & Uranium-235 & 3.15 & $\mathrm{pCi} / \mathrm{g}$ & & 3.2 & $\equiv$ & & $\equiv$ & & 2 \\
\hline Z2-EU23B-301 & $03 / 20 / 2006920$ & $\underline{0-0.5}$ & RADS-G & Bismuth-214 & $\underline{0.698}$ & $\mathrm{pCi} / \mathrm{g}$ & & $\underline{0.8}$ & $\underline{\underline{J J}}$ & & $\underline{J}$ & & 14 \\
\hline Z2-EU23B-301 & $03 / 20 / 2006920$ & $0-0.5$ & RADS-G & Cesium-137 & 0.449 & $\mathrm{pCi} / \mathrm{g}$ & & 0.6 & $\equiv$ & & $\underline{J}$ & & $\underline{29}$ \\
\hline Z2-EU23B-301 & $03 / 20 / 2006920$ & $\underline{\underline{0-0.5}}$ & RADS-G & Lead-212 & 0.971 & $\mathrm{pCi} / \mathrm{g}$ & & 0.96 & 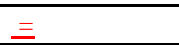 & & $\equiv$ & & 1 \\
\hline Z2-EU23B-301 & $03 / 20 / 2006920$ & $\underline{0-0.5}$ & RADS-G & Lead-214 & 0.528 & $\mathrm{pCi} / \mathrm{g}$ & & 0.77 & $\underline{\mathrm{JJ}}$ & & $\underline{\mathrm{J}}$ & & $\underline{37}$ \\
\hline Z2-EU23B-301 & $03 / 20 / 2006920$ & $0-0.5$ & RADS-G & Potassium-40 & $\underline{13.3}$ & $\mathrm{pCi} / \mathrm{g}$ & & 12.2 & $\equiv$ & & $\equiv$ & & $\underline{9}$ \\
\hline Z2-EU23B-301 & $03 / 20 / 2006920$ & $0-0.5$ & RADS-G & Thallium-208 & 0.379 & $\mathrm{pCi} / \underline{g}$ & & 0.43 & $\equiv$ & & $\equiv$ & & 13 \\
\hline Z2-EU23B-301 & $03 / 20 / 2006920$ & $\underline{0-0.5}$ & RADS-G & Thorium-234 & 4.38 & $\mathrm{pCi} / \mathrm{g}$ & & $\underline{5.5}$ & $\underline{\mathrm{JJ}}$ & & $\equiv$ & & $\underline{23}$ \\
\hline Z2-EU34B-301 & $07 / 17 / 20061030$ & $7.6-8.9$ & RADS-G & Actinium 228 & 1.53 & $\mathrm{pCi} / \mathrm{g}$ & 1.36 & & $\equiv$ & $\equiv$ & & $\underline{12}$ & \\
\hline Z2-EU34B-301 & $07 / 17 / 20061030$ & $7.6-8.9$ & RADS-G & Bismuth 214 & 0.53 & $\mathrm{pCi} / \underline{g}$ & 0.81 & & $\equiv$ & $\equiv$ & & $\underline{42}$ & \\
\hline Z2-EU34B-301 & $07 / 17 / 20061030$ & $7.6-8.9$ & RADS-G & Lead 212 & 1.17 & $\mathrm{pCi} / \mathrm{g}$ & 1.19 & & $\equiv$ & $\equiv$ & & $\underline{2}$ & \\
\hline Z2-EU34B-301 & $07 / 17 / 20061030$ & $7.6-8.9$ & RADS-G & Lead 214 & $\underline{0.89}$ & $\mathrm{pCi} / \mathrm{g}$ & 0.72 & & $\equiv$ & $\equiv$ & & 21 & \\
\hline Z2-EU34B-301 & $07 / 17 / 20061030$ & $7.6-8.9$ & RADS-G & Potassium-40 & 21 & $\mathrm{pCi} / \mathrm{g}$ & 18.5 & & $\equiv$ & $\equiv$ & & $\underline{13}$ & \\
\hline Z2-EU34B-301 & $07 / 17 / 20061030$ & $7.6-8.9$ & RADS-G & Radium 228 & 1.53 & $\mathrm{pCi} / \mathrm{g}$ & 1.36 & & $\equiv$ & $\equiv$ & & $\underline{12}$ & \\
\hline Z2-EU34B-301 & $07 / 17 / 20061030$ & $7.6-8.9$ & RADS-G & Thallium 208 & 0.5 & $\mathrm{pCi} / \underline{g}$ & 0.44 & & $\equiv$ & $\equiv$ & & $\underline{13}$ & \\
\hline Z2-EU34B-301 & $07 / 17 / 20061030$ & $7.6-8.9$ & RADS-G & Thorium 232 & $\underline{1.53}$ & $\mathrm{pCi} / \mathrm{g}$ & 1.36 & & $\equiv$ & $\equiv$ & & $\underline{12}$ & \\
\hline Z2-EU37B-301 & $09 / 11 / 20061230$ & $5.5-0$ & RADS-G & Actinium-228 & 1.32 & $\mathrm{pCi} / \mathrm{g}$ & 1.94 & & $\equiv$ & J R W02 & & & \\
\hline Z2-EU37B-301 & $09 / 11 / 20061230$ & $\underline{5.5-0}$ & RADS-G & Bismuth-214 & $\underline{0.697}$ & $\mathrm{pCi} / \mathrm{g}$ & $\underline{0.698}$ & & $\mathrm{~J}=$ & $\mathrm{J}=$ & & $\underline{0}$ & \\
\hline Z2-EU37B-301 & $09 / 11 / 20061230$ & $\underline{5.5-0}$ & RADS-G & Lead-212 & 1.08 & $\mathrm{pCi} / \mathrm{g}$ & 1.21 & & $\equiv$ & $\equiv$ & & 11 & \\
\hline Z2-EU37B-301 & $09 / 11 / 20061230$ & $\underline{5.5-0}$ & RADS-G & Lead-214 & $\underline{0.675}$ & $\mathrm{pCi} / \mathrm{g}$ & $\underline{0.829}$ & & $\mathrm{~J} \equiv$ & $\mathrm{J} \equiv$ & & $\underline{20}$ & \\
\hline Z2-EU37B-301 & $09 / 11 / 20061230$ & $5.5-0$ & RADS-G & Potassium-40 & 22.2 & $\mathrm{pCi} / \mathrm{g}$ & 22.3 & & $\equiv$ & $\equiv$ & & $\underline{0}$ & \\
\hline Z2-EU37B-301 & $09 / 11 / 20061230$ & $\underline{5.5-0}$ & RADS-G & Thallium-208 & $\underline{0.262}$ & $\mathrm{pCi} / \underline{g}$ & $\underline{0.359}$ & & $\equiv$ & $\equiv$ & & $\underline{31}$ & \\
\hline Z2-EU37B-306 & $09 / 12 / 2006845$ & $1-0$ & RADS-G & Actinium-228 & 2.19 & $\mathrm{pCi} / \mathrm{g}$ & & 1.5 & $\equiv$ & & $\equiv$ & & 37 \\
\hline Z2-EU37B-306 & $09 / 12 / 2006845$ & $\underline{1-0}$ & RADS-G & Lead-212 & 1.24 & $\mathrm{pCi} / \underline{g}$ & & 0.99 & $\equiv$ & & $\equiv$ & & $\underline{22}$ \\
\hline Z2-EU37B-306 & $09 / 12 / 2006845$ & $1-0$ & RADS-G & Lead-214 & 0.977 & $\mathrm{pCi} / \mathrm{g}$ & & 0.74 & $\mathrm{~J}=$ & & $\underline{J}$ & & 28 \\
\hline Z2-EU37B-306 & $09 / 12 / 2006845$ & $\underline{\underline{1-0}}$ & RADS-G & Potassium-40 & 31.7 & $\mathrm{pCi} / \underline{g}$ & & 20.7 & $\equiv$ & & $\equiv$ & & $\underline{42}$ \\
\hline Z2-EU41D-100 & $09 / 26 / 20061015$ & $0-1$ & RADS-G & Potassium-40 & 7.57 & $\mathrm{pCi} / \mathrm{g}$ & -1.8 & & $\mathrm{~J}=$ & $\underline{\mathrm{UU}}$ & & & \\
\hline Z2-EU24M-302 & $09 / 28 / 20061200$ & $0-14$ & RADS-G & Actinium-228 & 1.88 & $\mathrm{pCi} / \underline{g}$ & & 1.3 & $\equiv$ & & $\equiv$ & & $\underline{36}$ \\
\hline Z2-EU24M-302 & $09 / 28 / 20061200$ & $0-14$ & RADS-G & Bismuth-214 & 1.16 & $\mathrm{pCi} / \mathrm{g}$ & & 1.26 & $\mathrm{~J}=$ & & $\underline{J}$ & & $\underline{8}$ \\
\hline Z2-EU24M-302 & $09 / 28 / 20061200$ & $0-14$ & RADS-G & Lead-212 & 1.93 & $\mathrm{pCi} / \underline{g}$ & & 1.23 & $\equiv$ & & $\equiv$ & & 44 \\
\hline Z2-EU24M-302 & $09 / 28 / 20061200$ & $0-14$ & RADS-G & Lead-214 & 1.48 & $\mathrm{pCi} / \mathrm{g}$ & & 1.21 & $\mathrm{~J}=$ & & $\underline{J}$ & & 20 \\
\hline Z2-EU24M-302 & $09 / 28 / 20061200$ & $\overline{0-14}$ & RADS-G & Potassium-40 & 25.4 & $\mathrm{pCi} / \mathrm{g}$ & & 17.8 & $\equiv$ & & $\equiv$ & & 35 \\
\hline Z2-EU24M-302 & $09 / 28 / 20061200$ & $0-14$ & RADS-G & Thallium-208 & 0.516 & $\mathrm{pCi} / \mathrm{g}$ & & 0.337 & $\equiv$ & & $\equiv$ & & $\underline{42}$ \\
\hline \multicolumn{12}{|c|}{ 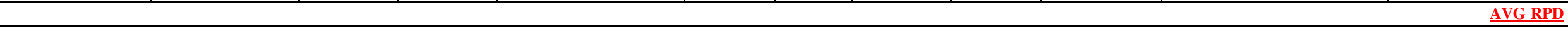 } & $\underline{21}$ & 40 \\
\hline & & & & & & & & & & & STD Deviation & $\underline{19}$ & $\underline{43}$ \\
\hline
\end{tabular}


Table L.3. (continued)

\begin{tabular}{|c|c|c|c|c|c|c|c|c|c|c|c|c|c|}
\hline Station & Date-time & Depth & Category & Chemical name & $\underline{\text { Reg }}$ & Units & $\frac{\text { Field rep }}{\text { result }}$ & 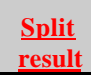 & $\frac{\text { Qual }}{(\text { lab, val, RC) }}$ & FR qual (lab, val, RC) & Split qual & $\underline{\mathrm{FR}}$ & $\underline{\text { Split }}$ \\
\hline Z2-EU28B-319 & $03 / 08 / 20051345$ & $0-10$ & Silica & Silica & 11000 & $\mathrm{mg} / \mathrm{kg}$ & $\underline{9070}$ & & $\equiv$ & $\equiv$ & & 19 & \\
\hline Z2-EU28-106 & $03 / 18 / 20051130$ & $\overline{0-10}$ & Silica & Silica & $2 \underline{2070}$ & $\mathrm{mg} / \mathrm{kg}$ & $\underline{1510}$ & & $\equiv$ & $\equiv$ & & 31 & \\
\hline \multicolumn{12}{|r|}{ AVG RPD } & $\underline{25}$ & $\underline{\underline{\mathrm{NA}}}$ \\
\hline & & & & & & & & & & & STD Deviation & $\underline{8}$ & $\underline{\mathrm{NA}}$ \\
\hline Z2-EU28B-319 & $03 / 08 / 20051345$ & $0-10$ & SVOA & Benzo(b)fluoranthene & 86.3 & $\underline{u g} / \mathrm{kg}$ & $\underline{172}$ & & $\underline{\mathrm{JJ}}$ & $\equiv$ & & 66 & \\
\hline Z2-EU28B-319 & $03 / 08 / 20051345$ & $0-10$ & $\overline{\text { SVOA }}$ & Fluoranthene & 137 & $\underline{\underline{u g} / \mathrm{kg}}$ & 197 & & $\underline{\mathrm{JJ}}$ & $\equiv$ & & 36 & \\
\hline Z2-EU28B-319 & $03 / 08 / 20051345$ & $\overline{0-10}$ & $\overline{\text { SVOA }}$ & Phenanthrene & 85.6 & $\underline{\underline{\mathrm{g} g} / \mathrm{kg}}$ & $\overline{107}$ & & $\underline{\underline{J J}}$ & $\overline{\mathrm{JJ}}$ & & $\underline{22}$ & \\
\hline Z2-EU28B-319 & $03 / 08 / 20051345$ & $0-10$ & $\overline{\text { SVOA }}$ & Pyrene & 155 & $\underline{\underline{u} \mathrm{~g} / \mathrm{kg} g}$ & 252 & & $\underline{\underline{J}}$ & $\equiv$ & & $\underline{48}$ & \\
\hline$\overline{\text { Z2-EU28-106 }}$ & $03 / 18 / 20051130$ & $\overline{0-10}$ & $\overline{\text { SVOA }}$ & Benzo(a)pyrene & $\overline{63}$ & $\underline{\underline{\mathrm{g} g} / \mathrm{kg}}$ & 53.3 & & $\equiv$ & $\equiv$ & & 17 & \\
\hline Z2-EU28-106 & $03 / 18 / 20051130$ & $\overline{0-10}$ & $\overline{\text { SVOA }}$ & Benzo(b)fluoranthene & 44.2 & $\underline{\underline{u} \mathrm{~g} / \mathrm{kg} g}$ & 40.4 & & $\equiv$ & $\underline{\mathrm{UU}}$ & & & \\
\hline$\overline{\text { Z2-EU28-106 }}$ & $03 / 18 / 20051130$ & $\overline{0-10}$ & $\overline{\text { SVOA }}$ & $\overline{\text { Benzo(ghi)perylene }}$ & $\underline{136}$ & $\underline{\underline{\mathrm{g} g} / \mathrm{kg}}$ & $\underline{130}$ & & $\equiv$ & $\bar{\equiv}$ & & 5 & \\
\hline Z2-EU28-106 & $03 / 18 / 20051130$ & $\overline{0-10}$ & $\overline{\text { SVOA }}$ & Chrysene & 22.7 & $\underline{\underline{u g} / \mathrm{kg} g}$ & 40.4 & & $\underline{\mathrm{JJ}}$ & $\underline{\mathrm{UU}}$ & & & \\
\hline$\overline{\text { Z2-EU28-106 }}$ & $03 / 18 / 20051130$ & $\overline{\overline{0-10}}$ & $\overline{\overline{\text { SVOA }}}$ & Fluoranthene & $\overline{\underline{32.6}}$ & $\underline{\underline{u \mathrm{~g} g} / \mathrm{kg} g}$ & $\overline{40.4}$ & & $\overline{\underline{J J}}$ & $\overline{\overline{\mathrm{UU}}}$ & & & \\
\hline Z2-EU28-106 & $03 / 18 / 20051130$ & $\overline{0-10}$ & $\overline{\text { SVOA }}$ & Indeno(1,2,3-cd) pyrene & 152 & $\underline{\underline{u g} / \mathrm{kg} g}$ & $\underline{148}$ & & $\equiv$ & $\bar{E}$ & & $\underline{3}$ & \\
\hline$\overline{\overline{Z 2-E U 28-106}}$ & $03 / 18 / 20051130$ & $\overline{\overline{0-10}}$ & $\overline{\overline{\text { SVOA }}}$ & Pyrene & $\overline{38.4}$ & $\underline{\underline{\mathrm{g} g} / \mathrm{kg}}$ & $\overline{20.7}$ & & $\overline{\underline{J} \mathrm{~J}}$ & $\overline{\underline{J}}$ & & $\underline{60}$ & \\
\hline Z2-EU41DB-209 & $11 / 17 / 20051415$ & $\overline{0-10}$ & $\overline{\text { SVOA }}$ & Acenaphthene & 22 & $\underline{\underline{u \mathrm{~g} / \mathrm{kg} g}}$ & & $\underline{370}$ & $\underline{\mathrm{JJ}}$ & & $\underline{\mathrm{UU}}$ & & \\
\hline$\overline{\text { Z2-EU41DB-209 }}$ & $11 / 17 / 20051415$ & $\overline{\underline{0-10}}$ & $\overline{\overline{\text { SVOA }}}$ & Anthracene & $\overline{\underline{61}}$ & $\underline{\underline{u} \mathrm{~g} / \mathrm{kg} g}$ & & $\overline{370}$ & $\overline{\underline{J J}}$ & & $\overline{\mathrm{UU}}$ & & \\
\hline$\overline{\text { Z2-EU41DB-209 }}$ & $11 / 17 / 20051415$ & $\overline{\overline{0-10}}$ & $\overline{\overline{\text { SVOA }}}$ & Benz(a)anthracene & 210 & $\underline{\mathrm{u} g / \mathrm{kg}}$ & & $\underline{120}$ & $\overline{\underline{J J}}$ & & $\overline{\mathrm{JJ}}$ & & 55 \\
\hline$\overline{\text { Z2-EU41DB-209 }}$ & $11 / 17 / 20051415$ & $\overline{\underline{0-10}}$ & $\overline{\overline{\text { SVOA }}}$ & $\overline{\text { Benzo(a)pyrene }}$ & $\overline{160}$ & $\underline{\underline{u} \mathrm{~g} / \mathrm{kg} g}$ & & $\overline{120}$ & $\overline{\underline{J J}}$ & & $\overline{\underline{J J}}$ & & 29 \\
\hline$\overline{\text { Z2-EU41DB-209 }}$ & $11 / 17 / 20051415$ & $\overline{\overline{0-10}}$ & $\overline{\overline{\text { SVOA }}}$ & Benzo(b)fluoranthene & 260 & $\underline{\underline{u} \mathrm{~g} / \mathrm{kg} g}$ & & $\overline{\underline{150}}$ & $\underline{\underline{J J}}$ & & $\underline{\underline{J J}}$ & & 54 \\
\hline$\overline{\text { Z2-EU41DB-209 }}$ & $11 / 17 / 20051415$ & $\overline{0-10}$ & $\overline{\overline{\text { SVOA }}}$ & $\begin{array}{l}\text { Benzo(ghi)perylene } \\
\end{array}$ & 100 & $\underline{u \mathrm{~g} / \mathrm{kg} g}$ & & $\overline{110}$ & $\overline{\underline{J J}}$ & & $\overline{\underline{J J}}$ & & $\overline{10}$ \\
\hline Z2-EU41DB-209 & $11 / 17 / 20051415$ & $0-10$ & $\overline{\text { SVOA }}$ & Benzo(k)fluoranthene & 120 & $\underline{\underline{u} \mathrm{~g} / \mathrm{kg} g}$ & & 110 & $\overline{\mathrm{JJ}}$ & & $\underline{\underline{J}}$ & & $\underline{9}$ \\
\hline$\overline{\text { Z2-EU41DB-209 }}$ & $11 / 17 / 20051415$ & $\overline{0-10}$ & $\overline{\text { SVOA }}$ & Carbazole & $\overline{60}$ & $\underline{\underline{u} \mathrm{~g} / \mathrm{kg} g}$ & & 370 & $\underline{\underline{J J}}$ & & $\underline{\mathrm{UU}}$ & & \\
\hline Z2-EU41DB-209 & $11 / 17 / 20051415$ & $0-10$ & $\overline{\text { SVOA }}$ & Chrysene & 170 & $\underline{\underline{u} \mathrm{~g} / \mathrm{kg} g}$ & & 140 & $\underline{\underline{J}}$ & & $\underline{\underline{J}}$ & & $\underline{19}$ \\
\hline$\overline{\text { Z2-EU41DB-209 }}$ & $11 / 17 / 20051415$ & $\overline{0-10}$ & $\overline{\text { SVOA }}$ & Di-n-octylphthalate & $\overline{110}$ & $\underline{\underline{u} \mathrm{~g} / \mathrm{kg} g}$ & & $\overline{370}$ & $\overline{\mathrm{JJ}}$ & & $\underline{\mathrm{UU}}$ & & \\
\hline Z2-EU41DB-209 & $11 / 17 / 20051415$ & $\overline{0-10}$ & SVOA & Fluoranthene & 510 & $\underline{\mathrm{u} g / \mathrm{kg}}$ & & 260 & 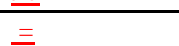 & & $\overline{\mathrm{JJ}}$ & & 65 \\
\hline$\overline{\text { Z2-EU41DB-209 }}$ & $11 / 17 / 20051415$ & $\overline{0-10}$ & $\overline{\mathrm{SVOA}}$ & Fluorene & $\underline{20}$ & $\underline{\underline{u g} / \mathrm{kg} g}$ & & $\overline{370}$ & $\underline{\underline{J}}$ & & $\overline{\mathrm{UU}}$ & & \\
\hline$\overline{\text { Z2-EU41DB-209 }}$ & $11 / 17 / 20051415$ & $\overline{0-10}$ & $\overline{\mathrm{SVOA}}$ & Indeno(1,2,3-cd) pyrene & 91 & $\underline{\underline{u g} / \mathrm{kg} g}$ & & 100 & $\underline{J}$ & & $\underline{\underline{J J}}$ & & 9 \\
\hline$\overline{\text { Z2-EU41DB-209 }}$ & $11 / 17 / 20051415$ & $\overline{\overline{0-10}}$ & $\overline{\overline{\text { SVOA }}}$ & $\begin{array}{l}\text { Phenanthrene } \\
\end{array}$ & 330 & $\underline{\underline{u \mathrm{~g} g} / \mathrm{kg} g}$ & & $\overline{\overline{180}}$ & $\overline{\underline{J J}}$ & & $\overline{\underline{J J}}$ & & $\underline{59}$ \\
\hline$\overline{\text { Z2-EU41DB-209 }}$ & $11 / 17 / 20051415$ & $\overline{0-10}$ & $\overline{\mathrm{SVOA}}$ & Pyrene & 370 & $\underline{\underline{u g} / \mathrm{kg} g}$ & & 220 & $\overline{\underline{J}}$ & & $\underline{J}$ & & 51 \\
\hline$\overline{\text { Z2-EU41DKB-233 }}$ & $12 / 01 / 20051139$ & $\overline{2-10}$ & $\overline{\overline{\text { SVOA }}}$ & $\begin{array}{l}\text { Bis(2-ethylhexyl) } \\
\text { phthalate }\end{array}$ & $\underline{\overline{14000}}$ & $\overline{\underline{\mathrm{u} g} / \mathrm{kg}}$ & $\underline{15000}$ & & $\overline{\mathrm{BD}}=$ & $\mathrm{BD}=\mathrm{F} 08$ & & 7 & \\
\hline Z2-EU41DKB-233 & $12 / 01 / 20051139$ & $2-10$ & SVOA & Di-n-butyl phthalate & 230 & $\underline{\underline{u} \mathrm{~g} / \mathrm{kg} g}$ & $\underline{390}$ & & BJ XV & BJ U F01 F06 & & & \\
\hline$\overline{\text { Z2-EU41DKB-234 }}$ & $12 / 01 / 20051409$ & $2.5-4$ & $\overline{\text { SVOA }}$ & $\begin{array}{l}\text { Bis(2-ethylhexyl) } \\
\text { phthalate }\end{array}$ & $\underline{\overline{11000}}$ & $\overline{\underline{\mathrm{u} g} / \mathrm{kg}}$ & & $\underline{29000}$ & $\overline{\mathrm{BD} \equiv}$ & & $\mathrm{BD} \equiv$ & & 90 \\
\hline Z2-EU41DKB-234 & $12 / 01 / 20051409$ & $2.5-4$ & SVOA & Butyl benzyl phthalate & 35 & $\underline{u g} / \mathrm{kg}$ & & 400 & $\underline{J J}$ & & $\underline{\mathrm{UU}}$ & & \\
\hline$\overline{\overline{Z 2-E U 41 D B-227}}$ & $\underline{12 / 05 / 20051355}$ & $\overline{\overline{0-10}}$ & $\overline{\underline{\text { SVOA }}}$ & $\begin{array}{l}\text { Bis(2-ethylhexyl) } \\
\text { phthate }\end{array}$ & $\underline{16000}$ & $\overline{\underline{\mathrm{ug} / \mathrm{kg} g}}$ & $\underline{5500}$ & & $\overline{\mathrm{BEXV}}$ & $\underline{\mathrm{BEXV}}$ & & $\underline{98}$ & \\
\hline Z2-EU41DB-225 & $12 / 09 / 20051405$ & $\underline{0-10}$ & SVOA & $\begin{array}{l}\frac{\text { Bis(2-ethylhexyl) }}{\text { phthalate }} \\
\end{array}$ & 27000 & $\underline{\mathrm{ug} / \mathrm{kg}}$ & $\underline{87000}$ & & $\mathrm{BD} \equiv$ & $\mathrm{BD}=\mathrm{F} 08$ & & 105 & \\
\hline Z2-EU41DB-225 & $12 / 09 / 20051405$ & $\underline{0-10}$ & SVOA & Diethyl phthalate & $\underline{27}$ & $\underline{u g} / \mathrm{kg} g$ & $\underline{36}$ & & $\underline{\mathrm{JJ}}$ & $\underline{\mathrm{JJ}}$ & & $\underline{29}$ & \\
\hline 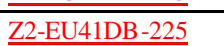 & $12 / 09 / 20051405$ & $\overline{0-10}$ & SVOA & Di-n-butyl phthalate & $\underline{57}$ & $\underline{\mathrm{u} g / \mathrm{kg}}$ & $\underline{47}$ & & $\underline{J J}$ & $\underline{J J}$ & & $\underline{19}$ & \\
\hline
\end{tabular}


Table L.3. (continued)

\begin{tabular}{|c|c|c|c|c|c|c|c|c|c|c|c|c|c|}
\hline Station & Date-time & Depth & Categorv & Chemical name & $\underline{\text { Reg }}$ & Units & $\frac{\text { Field rep }}{\text { result }}$ & $\begin{array}{l}\text { Split } \\
\text { result } \\
\end{array}$ & $\begin{array}{c}\frac{\text { Qual }}{\text { (lab, val, RC) }} \\
\end{array}$ & FR qual (lab, val, RC) & $\underline{\text { Split qual }}$ & $\underline{\mathrm{FR}}$ & $\underline{\text { Split }}$ \\
\hline Z2-EU41DB-225 & $12 / 09 / 2005 \quad 1405$ & $0-10$ & $\underline{\mathrm{SVOA}}$ & Di-n-octylphthalate & $\underline{32}$ & $\underline{\mathrm{ug} / \mathrm{kg}}$ & $\underline{86}$ & & $\underline{\mathrm{J} J}$ & $\underline{\mathrm{JJ}}$ & & $\underline{92}$ & \\
\hline Z2-EU41C-209 & $12 / 16 / 2005 \quad 1450$ & $0-10$ & SVOA & 2-Methylnaphthalene & 21000 & $\underline{\mathrm{ug} / \mathrm{kg} g}$ & 14000 & & $\underline{\mathrm{JJ}}$ & $\underline{\mathrm{JJ}}$ & & 40 & \\
\hline Z2-EU41C-209 & $12 / 16 / 20051450$ & $\underline{0-10}$ & $\underline{\text { SVOA }}$ & $\begin{array}{ll}\text { Acenaphthene } \\
\end{array}$ & 43000 & $\underline{\mathrm{u} g / \mathrm{kg}}$ & $\underline{35000}$ & & $\equiv$ & $\equiv$ & & $\underline{21}$ & \\
\hline Z2-EU41C-209 & $12 / 16 / 20051450$ & $0-10$ & SVOA & Anthracene & 92000 & $\underline{\mathrm{ug} / \mathrm{kg} g}$ & 81000 & & $\equiv$ & $\equiv$ & & $\underline{13}$ & \\
\hline Z2-EU41C-209 & $12 / 16 / 20051450$ & $\underline{0-10}$ & $\underline{\text { SVOA }}$ & Benz(a)anthracene & 150000 & $\underline{\mathrm{ug} / \mathrm{kg}}$ & 130000 & & 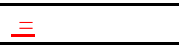 & $\equiv$ & & $\underline{14}$ & \\
\hline Z2-EU41C-209 & $12 / 16 / 20051450$ & $0-10$ & SVOA & Benzo(a)pyrene & 110000 & $\underline{\mathrm{ug} / \mathrm{kg}}$ & 92000 & & $\equiv$ & $\equiv$ & & 18 & \\
\hline Z2-EU41C-209 & $12 / 16 / 20051450$ & $\underline{0-10}$ & $\underline{\text { SVOA }}$ & Benzo(b)fluoranthene & 150000 & $\underline{\mathrm{ug} / \mathrm{kg}}$ & 120000 & & $\equiv$ & $\equiv$ & & $\underline{22}$ & \\
\hline Z2-EU41C-209 & $12 / 16 / 20051450$ & $\underline{0-10}$ & SVOA & Benzo(ghi)perylene & 76000 & $\underline{\mathrm{ug} / \mathrm{kg}}$ & $\underline{59000}$ & & $\equiv$ & $\equiv$ & & $\underline{25}$ & \\
\hline Z2-EU41C-209 & $12 / 16 / 20051450$ & $\underline{0-10}$ & $\underline{\mathrm{SVOA}}$ & Benzo(k)fluoranthene & 66000 & $\underline{\mathrm{ug} / \mathrm{kg} g}$ & $\underline{59000}$ & & $\equiv$ & $\equiv$ & & $\underline{11}$ & \\
\hline Z2-EU41C-209 & $12 / 16 / 20051450$ & $0-10$ & SVOA & Carbazole & $\underline{68000}$ & $\underline{\mathrm{ug} / \mathrm{kg} g}$ & 60000 & & $\equiv$ & $\equiv$ & & 13 & \\
\hline Z2-EU41C-209 & $\underline{12 / 16 / 20051450}$ & $\underline{0-10}$ & $\underline{\mathrm{SVOA}}$ & Chrysene & $\underline{110000}$ & $\underline{\mathrm{u} g / \mathrm{kg}}$ & $\underline{99000}$ & & $\equiv$ & $\equiv$ & & $\underline{11}$ & \\
\hline Z2-EU41C-209 & $12 / 16 / 20051450$ & $0-10$ & SVOA & Dibenzofuran & 28000 & $\underline{\mathrm{ug} / \mathrm{kg}}$ & 23000 & & $\equiv$ & $\underline{\mathrm{J}}$ & & $\underline{20}$ & \\
\hline Z2-EU41C-209 & $\underline{12 / 16 / 20051450}$ & $\underline{0-10}$ & $\underline{\mathrm{SVOA}}$ & Fluoranthene & 210000 & $\underline{\mathrm{ug} / \mathrm{kg}}$ & 200000 & & $\equiv$ & $\equiv$ & & $\underline{5}$ & \\
\hline Z2-EU41C-209 & $\underline{12 / 16 / 20051450}$ & $\underline{\underline{0-10}}$ & $\underline{\underline{S V O A}}$ & Fluorene & $\underline{56000}$ & $\underline{\underline{\mathrm{g} g} / \mathrm{kg}}$ & $\underline{45000}$ & & $\equiv$ & $\equiv$ & & $\underline{22}$ & \\
\hline Z2-EU41C-209 & $12 / 16 / 20051450$ & $\underline{0-10}$ & SVOA & Indeno(1,2,3-cd)pyrene & $\underline{58000}$ & $\underline{\mathrm{ug} / \mathrm{kg}}$ & $\underline{51000}$ & & 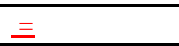 & $\equiv$ & & $\underline{13}$ & \\
\hline Z2-EU41C-209 & $12 / 16 / 2005 \quad 1450$ & $0-10$ & SVOA & Naphthalene & 68000 & $\underline{\underline{\mathrm{g} g} / \mathrm{kg}}$ & 44000 & & $\equiv$ & $\equiv$ & & $\underline{43}$ & \\
\hline Z2-EU41C-209 & $12 / 16 / 20051450$ & $\underline{0-10}$ & $\underline{\mathrm{SVOA}}$ & Phenanthrene & 220000 & $\underline{\mathrm{ug} / \mathrm{kg}}$ & 210000 & & 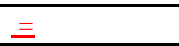 & $\equiv$ & & $\underline{5}$ & \\
\hline Z2-EU41C-209 & $12 / 16 / 2005 \quad 1450$ & $0-10$ & SVOA & Pyrene & 250000 & $\underline{\mathrm{ug} / \mathrm{kg} g}$ & 220000 & & $\equiv$ & $\equiv$ & & $\underline{13}$ & \\
\hline Z2-EU41CM-205 & $01 / 10 / 20061235$ & $\underline{0-10}$ & $\underline{\mathrm{SVOA}}$ & Anthracene & $\underline{19}$ & $\underline{\mathrm{u} g / \mathrm{kg}}$ & & $\underline{15}$ & $\underline{\underline{\mathrm{JJ}}}$ & & $\underline{\mathrm{BJJ}}$ & & $\underline{24}$ \\
\hline Z2-EU41CM-205 & $01 / 10 / 20061235$ & $0-10$ & SVOA & Benz(a)anthracene & $\underline{80}$ & $\underline{\mathrm{ug} / \mathrm{kg} g}$ & & 44 & $\underline{\mathrm{JJ}}$ & & BJ J & & $\underline{58}$ \\
\hline Z2-EU41CM-205 & $01 / 10 / 20061235$ & $\underline{0-10}$ & $\underline{\text { SVOA }}$ & Benzo(a)pyrene & $\underline{69}$ & $\underline{\underline{\mathrm{ug}} / \mathrm{kg}}$ & & $\underline{35}$ & $\underline{\underline{J J}}$ & & $\underline{B J J}$ & & $\underline{65}$ \\
\hline Z2-EU41CM-205 & $01 / 10 / 20061235$ & $\underline{0-10}$ & $\underline{\text { SVOA }}$ & Benzo(b)fluoranthene & $\underline{78}$ & $\underline{\mathrm{ug} / \mathrm{kg}}$ & & $\underline{30}$ & $\underline{\mathrm{JJ}}$ & & BJ J & & 89 \\
\hline Z2-EU41CM-205 & $01 / 10 / 20061235$ & $\underline{0-10}$ & SVOA & Benzo(ghi)perylene & $\underline{54}$ & $\underline{\mathrm{ug} / \mathrm{kg}}$ & & $\underline{25}$ & $\underline{\underline{\mathrm{JJ}}}$ & & BJ J & & $\underline{73}$ \\
\hline Z2-EU41CM-205 & $01 / 10 / 20061235$ & $0-10$ & SVOA & Benzo(k)fluoranthene & $\underline{55}$ & $\underline{\mathrm{ug} / \mathrm{kg}}$ & & 41 & $\underline{\mathrm{JJ}}$ & & BJ J & & $\underline{29}$ \\
\hline Z2-EU41CM-205 & $\underline{01 / 10 / 20061235}$ & $\underline{0-10}$ & $\underline{\mathrm{SVOA}}$ & $\begin{array}{l}\text { Bis(2-ethylhexyl) } \\
\text { phthalate }\end{array}$ & $\underline{82000}$ & $\underline{\mathrm{ug} / \mathrm{kg} g}$ & & 49000 & $\mathrm{BD}=$ & & BD J & & $\underline{50}$ \\
\hline Z2-EU41CM-205 & $\underline{\underline{01 / 10 / 20061235}}$ & $\underline{\underline{0-10}}$ & $\underline{\underline{S V O A}}$ & Chrysene & $\underline{62}$ & $\underline{\underline{\mathrm{g} g} / \mathrm{kg}}$ & & $\underline{43}$ & $\underline{\underline{\mathrm{JJ}}}$ & & $\underline{B J J}$ & & $\underline{36}$ \\
\hline Z2-EU41CM-205 & 01/10/2006 1235 & $\underline{0-10}$ & $\underline{\text { SVOA }}$ & Diethyl phthalate & 27 & $\underline{\mathrm{ug} / \mathrm{kg}}$ & & $\underline{18}$ & $\underline{\mathrm{JJ}}$ & & $\underline{B J}$ & & $\underline{40}$ \\
\hline Z2-EU41CM-205 & $01 / 10 / 20061235$ & $0-10$ & SVOA & Di-n-butyl phthalate & $\underline{41}$ & $\underline{\mathrm{ug} / \mathrm{kg}}$ & & $\underline{19}$ & $\underline{\underline{J J}}$ & & $\underline{\mathrm{BJJ}}$ & & $\underline{73}$ \\
\hline Z2-EU41CM-205 & $01 / 10 / 20061235$ & $\underline{0-10}$ & SVOA & Fluoranthene & $\underline{150}$ & $\underline{\mathrm{u} g / \mathrm{kg}}$ & & $\underline{100}$ & $\underline{\underline{J J}}$ & & BJ J & & 40 \\
\hline Z2-EU41CM-205 & $\underline{\underline{01 / 10 / 20061235}}$ & $\underline{\underline{0-10}}$ & $\underline{\underline{S V O A}}$ & Phenanthrene & $\underline{88}$ & $\underline{\underline{\mathrm{ug} / \mathrm{kg}}}$ & & $\underline{71}$ & $\underline{\underline{\mathrm{JJ}}}$ & & $\underline{\mathrm{BJJ}}$ & & $\underline{21}$ \\
\hline Z2-EU41CM-205 & $01 / 10 / 20061235$ & $\underline{0-10}$ & SVOA & Pyrene & $\underline{110}$ & $\underline{\mathrm{u} g / \mathrm{kg}}$ & & $\underline{81}$ & $\underline{\underline{J J}}$ & & $\underline{\mathrm{BJJ}}$ & & $\underline{30}$ \\
\hline Z2-EU28B-115 & $02 / 15 / 20061450$ & $\underline{0-1}$ & $\underline{\underline{S V O A}}$ & Anthracene & $\underline{120}$ & $\underline{\underline{\mathrm{ug} / \mathrm{kg}}}$ & $2 \underline{230}$ & & $\underline{\underline{\mathrm{JJ}}}$ & $\underline{\underline{\mathrm{JJ}}}$ & & $\underline{\underline{63}}$ & \\
\hline Z2-EU28B-115 & $\underline{02 / 15 / 20061450}$ & $\underline{0-1}$ & SVOA & Benz(a)anthracene & 830 & $\underline{\mathrm{u} g / \mathrm{kg}}$ & $\underline{1700}$ & & $\equiv$ & $\mathrm{JK} 01$ & & $\underline{69}$ & \\
\hline Z2-EU28B-115 & $02 / 15 / 20061450$ & $0-1$ & SVOA & Benzo(a)pyrene & 830 & $\underline{\mathrm{ug} / \mathrm{kg}}$ & 1400 & & $\underline{J}$ & $\mathrm{~J} \mathrm{K01}$ & & $\underline{51}$ & \\
\hline Z2-EU28B-115 & $02 / 15 / 20061450$ & $\underline{0-1}$ & $\overline{\mathrm{SOA}}$ & Benzo(b)fluoranthene & 970 & $\underline{\underline{u} \mathrm{~g} / \mathrm{kg}}$ & $\underline{1700}$ & & $\underline{\underline{J}}$ & $\mathrm{~J} \mathrm{~K} 01$ & & $\underline{55}$ & \\
\hline Z2-EU28B-115 & $02 / 15 / 20061450$ & $0-1$ & SVOA & Benzo(ghi)perylene & 960 & $\underline{\mathrm{ug} / \mathrm{kg}}$ & 2000 & & $\underline{J}$ & $\mathrm{~J} \mathrm{K01}$ & & 70 & \\
\hline Z2-EU28B-115 & $\underline{02 / 15 / 20061450}$ & $\underline{0-1}$ & $\underline{\text { SVOA }}$ & Benzo(k)fluoranthene & $\underline{430}$ & $\underline{\underline{\mathrm{ug}} / \mathrm{kg}}$ & 640 & & $\underline{\underline{J}}$ & $\mathrm{~J} \mathrm{K01}$ & & $\underline{39}$ & \\
\hline Z2-EU28B-115 & $\underline{02 / 15 / 20061450}$ & $\underline{0-1}$ & $\underline{\underline{\mathrm{SVOA}}}$ & $\begin{array}{l}\text { Chrysene } \\
\end{array}$ & $\underline{630}$ & $\underline{\underline{\mathrm{g} g} / \mathrm{kg}}$ & $\underline{1400}$ & & $\equiv$ & $\mathrm{J} \mathrm{K} 01$ & & $\underline{76}$ & \\
\hline Z2-EU28B-115 & $02 / 15 / 20061450$ & $\underline{0-1}$ & $\underline{\mathrm{SVOA}}$ & Dibenz(a,h)anthracene & $\underline{150}$ & $\underline{\mathrm{ug} / \mathrm{kg}}$ & 4330 & & $\underline{\underline{\mathrm{JJ}}}$ & U UJ K01 & & & \\
\hline Z2-EU28B-115 & $\underline{02 / 15 / 20061450}$ & $\underline{0-1}$ & $\underline{\underline{S V O A}}$ & Fluoranthene & $\underline{1100}$ & $\underline{\underline{u g} / \mathrm{kg}}$ & $\underline{2500}$ & & $\equiv$ & $\equiv$ & & $\underline{78}$ & \\
\hline
\end{tabular}


Table L.3. (continued)

\begin{tabular}{|c|c|c|c|c|c|c|c|c|c|c|c|c|c|}
\hline Station & Date-time & Depth & Category & Chemical name & $\underset{\text { result }}{\text { reg }}$ & Units & $\frac{\text { Field rep }}{\text { result }}$ & $\frac{\text { Split }}{\text { result }}$ & ${ }_{(\text {lab, val, }}^{\text {Qual }}$ RC) & FR qual (lab, val, RC) & Split qual & $\frac{\mathrm{FR}}{\mathrm{RPD}}$ & $\frac{\text { Split }}{\mathrm{RPD}}$ \\
\hline Z2-EU28B-115 & $02 / 15 / 20061450$ & $\underline{0-1}$ & SVOA & Hexachlorobenzene & $\underline{320}$ & $\underline{\underline{\mathrm{u} g} / \mathrm{kg} g}$ & $\underline{310}$ & & $\underline{\underline{J} \mathrm{~J}}$ & $\underline{\mathrm{JJ}}$ & & $\underline{3}$ & \\
\hline Z2-EU28B-115 & $02 / 15 / 20061450$ & $0-1$ & $\underline{\mathrm{SVOA}}$ & Indeno(1,2,3-cd) pyrene & $\underline{760}$ & $\underline{\underline{u} g / \mathrm{kg}}$ & 1500 & & $\equiv$ & $\mathrm{J}$ K01 & & 65 & \\
\hline Z2-EU28B-115 & $\underline{02 / 15 / 20061450}$ & $\underline{0-1}$ & $\underline{\underline{S V O A}}$ & Phenanthrene & $\underline{200}$ & $\underline{\underline{\mathrm{u} g} / \mathrm{kg} g}$ & $\underline{1700}$ & & $\underline{\underline{J J}}$ & $\equiv$ & & $\underline{158}$ & \\
\hline Z2-EU28B-115 & $02 / 15 / 20061450$ & $\underline{0-1}$ & $\underline{\text { SVOA }}$ & Pyrene & 1900 & $\underline{\underline{\mathrm{u} g} / \mathrm{kg}}$ & $\underline{3400}$ & & $\equiv$ & D J H01, H03, H04, K01 & & $\underline{57}$ & \\
\hline Z2-EU44-203 & $03 / 16 / 20061410$ & $0-10$ & SVOA & Benz(a)anthracene & 36 & $\underline{u g} / \mathrm{kg}$ & & 400 & $\underline{J}$ & & $\underline{\mathrm{UU}}$ & & \\
\hline Z2-EU44-203 & $03 / 16 / 20061410$ & $\underline{0-10}$ & $\underline{\text { SVOA }}$ & Benzo(a)pyrene & 37 & $\underline{\mathrm{u} g / \mathrm{kg}}$ & & 400 & $\underline{\mathrm{JJ}}$ & & $\underline{\mathrm{UU}}$ & & \\
\hline Z2-EU44-203 & $03 / 16 / 20061410$ & $\underline{0-10}$ & SVOA & Benzo(b)fluoranthene & $\underline{52}$ & $\underline{\underline{u g} / \mathrm{kg} g}$ & & 400 & $\underline{\mathrm{JJ}}$ & & $\overline{\mathrm{UU}}$ & & \\
\hline Z2-EU44-203 & $03 / 16 / 20061410$ & $\underline{0-10}$ & $\underline{\mathrm{SVOA}}$ & Benzo(k)fluoranthene & $\underline{26}$ & $\underline{\underline{u} g / \mathrm{kg} g}$ & & 400 & $\underline{\mathrm{JJ}}$ & & $\underline{\mathrm{UU}}$ & & \\
\hline Z2-EU44-203 & $03 / 16 / 20061410$ & $\underline{0-10}$ & $\underline{\mathrm{SVOA}}$ & Chrysene & 35 & $\underline{\underline{u g} / \mathrm{kg} g}$ & & 400 & $\underline{\mathrm{JJ}}$ & & $\overline{\mathrm{UU}}$ & & \\
\hline Z2-EU44-203 & $03 / 16 / 20061410$ & $\underline{0-10}$ & SVOA & Fluoranthene & $\underline{78}$ & $\underline{\underline{u} g / \mathrm{kg} g}$ & & 400 & $\underline{\mathrm{JJ}}$ & & $\underline{\mathrm{UU}}$ & & \\
\hline Z2-EU44-203 & $03 / 16 / 20061410$ & $0-10$ & SVOA & Phenanthrene & 45 & $\underline{\underline{u g} / \mathrm{kg} g}$ & & 400 & $\underline{\mathrm{JJ}}$ & & $\overline{\mathrm{UU}}$ & & \\
\hline Z2-EU44-203 & $03 / 16 / 20061410$ & $\underline{0-10}$ & SVOA & Pyrene & $\underline{57}$ & $\underline{\underline{u} \mathrm{~g} / \mathrm{kg}}$ & & 400 & $\underline{\mathrm{JJ}}$ & & $\underline{\mathrm{UU}}$ & & \\
\hline Z2-EU34B-301 & $07 / 17 / 20061030$ & $\overline{0-10}$ & $\overline{\mathrm{SVOA}}$ & 2.4-Dinitrophenol & 1900 & $\underline{\underline{u g} / \mathrm{kg} g}$ & 1800 & & $\overline{\mathrm{UR}}$ & U R P03 C02 P08 & & & \\
\hline Z2-EU37B-301 & 09/11/2006 1230 & $\underline{5.5-0}$ & SVOA & 2-Methylnaphthalene & 180 & $\underline{\underline{u} \mathrm{~g} / \mathrm{kg}}$ & 130 & & $\underline{\mathrm{JJ}}$ & $\underline{\mathrm{JJ}}$ & & $\underline{32}$ & \\
\hline Z2-EU37B-301 & $09 / 11 / 20061230$ & $\overline{5.5-0}$ & $\overline{\mathrm{SVOA}}$ & Anthracene & 99 & $\underline{\underline{u g} / \mathrm{kg} g}$ & $\underline{89}$ & & $\underline{\mathrm{JJ}}$ & $\underline{\underline{J}}$ & & 11 & \\
\hline Z2-EU37B-301 & 09/11/2006 1230 & $\underline{5.5-0}$ & SVOA & Benz(a)anthracene & $\underline{1100}$ & $\underline{\underline{u} \mathrm{~g} / \mathrm{kg}}$ & $\underline{550}$ & & $\equiv$ & $\equiv$ & & 67 & \\
\hline Z2-EU37B-301 & $09 / 11 / 20061230$ & $\underline{5.5-0}$ & SVOA & Benzo(a)pyrene & 1300 & $\underline{\mathrm{ug} / \mathrm{kg}}$ & 520 & & $\equiv$ & $\equiv$ & & 86 & \\
\hline Z2-EU37B-301 & $09 / 11 / 20061230$ & $\underline{5.5-0}$ & $\underline{\mathrm{SVOA}}$ & Benzo(b)fluoranthene & 2100 & $\underline{\underline{u} \mathrm{~g} / \mathrm{kg}}$ & $\underline{850}$ & & $\equiv$ & $\equiv$ & & 85 & \\
\hline Z2-EU37B-301 & $09 / 11 / 20061230$ & $5.5-0$ & SVOA & Benzo(ghi)perylene & 680 & $\underline{\mathrm{ug} / \mathrm{kg}}$ & 200 & & $\equiv$ & $\underline{\underline{J}}$ & & 109 & \\
\hline$\overline{\overline{Z 2-E U 37 B-301}}$ & $09 / 11 / 20061230$ & $\overline{5.5-0}$ & $\overline{\mathrm{SVOA}}$ & Benzo(k)fl uoranthene & $\overline{770}$ & $\underline{\underline{u g} / \mathrm{kg} g}$ & $3 \overline{370}$ & & $\equiv$ & $\overline{\overline{J J}}$ & & $\overline{\overline{70}}$ & \\
\hline Z2-EU37B-301 & $09 / 11 / 20061230$ & $5.5-0$ & SVOA & Chrysene & 1100 & $\underline{u g} / \mathrm{kg}$ & 520 & & $\equiv$ & 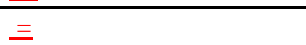 & & 72 & \\
\hline Z2-EU37B-301 & $09 / 11 / 20061230$ & $\underline{5.5-0}$ & SVOA & Dibenz(a,h)anthracene & 180 & $\underline{\mathrm{u} g / \mathrm{kg}}$ & $5 \underline{55}$ & & $\underline{\mathrm{JJ}}$ & $\underline{\mathrm{J} J}$ & & 106 & \\
\hline Z2-EU37B-301 & $09 / 11 / 20061230$ & $\overline{5.5-0}$ & SVOA & Fluoranthene & 1500 & $\underline{\underline{u g} / \mathrm{kg} g}$ & 1100 & & $\equiv$ & $\bar{E}$ & & 31 & \\
\hline Z2-EU37B-301 & $09 / 11 / 20061230$ & $\underline{5.5-0}$ & $\underline{\mathrm{SVOA}}$ & Indeno( $(1,2,3$-cd) pyrene & 630 & $\underline{\underline{u} g / \mathrm{kg}}$ & 190 & & $\equiv$ & $\underline{\underline{J J}}$ & & $\underline{107}$ & \\
\hline Z2-EU37B-301 & $09 / 11 / 20061230$ & $\overline{5.5-0}$ & SVOA & Naphthalene & $\underline{140}$ & $\underline{\underline{u} g / \mathrm{kg}}$ & 100 & & $\underline{J}$ & $\underline{\underline{J}}$ & & 33 & \\
\hline Z2-EU37B-301 & $09 / 11 / 20061230$ & $\underline{5.5-0}$ & $\underline{\text { SVOA }}$ & Phenanthrene & 330 & $\underline{\underline{u} g / \mathrm{kg}}$ & $\underline{410}$ & & $\underline{\mathrm{JJ}}$ & 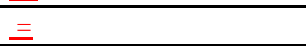 & & $\underline{22}$ & \\
\hline Z2-EU37B-301 & $09 / 11 / 20061230$ & $\overline{5.5-0}$ & SVOA & Pyrene & 1500 & $\underline{\underline{u} g / \mathrm{kg} g}$ & 870 & & $\equiv$ & $\equiv$ & & $\underline{53}$ & \\
\hline$\overline{\overline{Z 22-E U 37 B-306}}$ & 0 & $\overline{\overline{1-0}}$ & $\overline{\overline{\mathrm{SVOA}}}$ & Acenaphthene & $\overline{280}$ & $\underline{\underline{u g} / \mathrm{kg} g}$ & & 450 & $\overline{\underline{J}}$ & & $\underline{\mathrm{UU}}$ & & \\
\hline Z2-EU37B-306 & $09 / 12 / 2006845$ & $\overline{\underline{1-0}}$ & $\overline{\mathrm{SVOA}}$ & Anthracene & 1400 & $\underline{\underline{u g} / \mathrm{kg} g}$ & & 68 & $\equiv$ & & $\overline{\underline{J} \underline{J}}$ & & 181 \\
\hline Z2-EU37B-306 & $09 / 12 / 2006845$ & $\underline{1-0}$ & SVOA & Benz(a)anthracene & $\underline{5400}$ & $\underline{\underline{u} g / \mathrm{kg}}$ & & $\underline{380}$ & $\equiv$ & & $\underline{\mathrm{JJ}}$ & & 174 \\
\hline Z2-EU37B-306 & $09 / 12 / 2006845$ & $\underline{1-0}$ & $\overline{\mathrm{SVOA}}$ & Benzo(a)pyrene & 4900 & $\underline{\underline{u} g / \mathrm{kg} g}$ & & 370 & $\equiv$ & & $\underline{\underline{J}}$ & & $\overline{172}$ \\
\hline Z2-EU37B-306 & $09 / 12 / 2006845$ & $\underline{1-0}$ & $\underline{\mathrm{SVOA}}$ & Benzo(b)fluoranthene & 6600 & $\underline{\mathrm{ug} / \mathrm{kg}}$ & & 380 & $\mathrm{D} \equiv$ & & $\underline{\mathrm{JJ}}$ & & 178 \\
\hline Z2-EU37B-306 & $09 / 12 / 2006845$ & $1-0$ & SVOA & Benzo(ghi)perylene & 1800 & $\underline{\underline{u} g / \mathrm{kg} g}$ & & 260 & $\equiv$ & & $\underline{\mathrm{J}}$ & & 150 \\
\hline Z2-EU37B-306 & $09 / 12 / 2006845$ & $\underline{1-0}$ & $\underline{\mathrm{SVOA}}$ & Benzo(k)fluoranthene & 2800 & $\underline{\underline{u} g / \mathrm{kg}}$ & & 410 & $\equiv$ & & $\underline{\mathrm{JJ}}$ & & 149 \\
\hline Z2-EU37B-306 & $09 / 12 / 2006845$ & $\underline{1-0}$ & SVOA & Carbazole & 660 & $\underline{\underline{u} g / \mathrm{kg} g}$ & & 88 & $\equiv$ & & $\underline{J}$ & & 153 \\
\hline Z2-EU37B-306 & $09 / 12 / 2006845$ & $\underline{1-0}$ & SVOA & Chrysene & 4900 & $\underline{\mathrm{u} g / \mathrm{kg}}$ & & $\underline{510}$ & $\equiv$ & & $\equiv$ & & 162 \\
\hline Z2-EU37B-306 & $09 / 12 / 2006845$ & $1-0$ & SVOA & Dibenz(a,h)anthracene & 530 & $\underline{u g} / \mathrm{kg}$ & & 450 & $\equiv$ & & $\underline{\mathrm{UU}}$ & & \\
\hline$\overline{\text { Z2-EU37B-306 }}$ & $09 / 12 / 2006845$ & $\overline{\overline{1-0}}$ & $\overline{\overline{S \mathrm{VOA}}}$ & Dibenzofuran & $\overline{100}$ & $\underline{\underline{u g} / \mathrm{kg} g}$ & & $\overline{450}$ & $\underline{J}$ & & $\overline{\overline{\mathrm{UU}}}$ & & \\
\hline Z2-EU37B-306 & $09 / 12 / 2006845$ & $\underline{1-0}$ & SVOA & Fluoranthene & 12000 & $\underline{\mathrm{u} g / \mathrm{kg}}$ & & 860 & $\mathrm{D}=$ & & $\equiv$ & & $\underline{173}$ \\
\hline$\overline{\overline{\text { Z2-EU37B-306 }}}$ & $09 / 12 / 2006845$ & $\overline{\underline{1-0}}$ & $\overline{\overline{\text { SVOA }}}$ & Fluorene & $3 \underline{320}$ & $\underline{\mathrm{ug} / \mathrm{kg}}$ & & 450 & $\overline{J J}$ & & $\underline{\mathrm{U} U}$ & & \\
\hline
\end{tabular}


Table L.3. (continued)

\begin{tabular}{|c|c|c|c|c|c|c|c|c|c|c|c|c|c|}
\hline Station & Date-time & Depth & Category & Chemical name & Result & Units & $\frac{\frac{\text { Field rep }}{\text { result }}}{\text { ne }}$ & 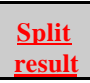 & $\frac{\text { Qual }}{\text { (lab, val, RC) }}$ & FR qual (lab, val, RC) & Split qual & $\underline{\underline{\mathrm{FPD}}}$ & $\underline{\text { Split }}$ \\
\hline Z2-EU37B-306 & $09 / 12 / 2006845$ & $\frac{1-0}{1-0}$ & SVOA & Indeno(1,2,3-cd) pyrene & 1800 & $\underline{\mathrm{u} g / \mathrm{kg} g}$ & & 240 & $\equiv$ & & $\underline{\underline{\mathrm{JJ}}}$ & & 153 \\
\hline Z2-EU37B-306 & $09 / 12 / 2006845$ & $\underline{1-0}$ & $\underline{\text { SVOA }}$ & Phenanthrene & $\underline{5100}$ & $\underline{\mathrm{ug} / \mathrm{kg}}$ & & 420 & $\equiv$ & & $\underline{\mathrm{JJ}}$ & & 170 \\
\hline Z2-EU37B-306 & $09 / 12 / 2006845$ & $1-0$ & SVOA & Pyrene & 8100 & $\underline{\mathrm{ug} / \mathrm{kg} g}$ & & 760 & $\mathrm{D}=$ & & $\equiv$ & & 166 \\
\hline Z2-EU41DB-208-3 & $09 / 25 / 20061200$ & $\underline{\underline{0-10}}$ & SVOA & $\begin{array}{l}\text { Bis(2-ethylhexyl) } \\
\text { phthalate }\end{array}$ & $\overline{\underline{470}}$ & $\underline{\underline{\mathrm{ug} / \mathrm{kg} g}}$ & & $\overline{\underline{370}}$ & $\overline{\bar{\equiv}}$ & & J B U F06 F01 & & \\
\hline Z2-EU41DB-208-3 & $09 / 25 / 20061200$ & $\underline{0-10}$ & $\underline{\mathrm{SVOA}}$ & Butyl benzyl phthalate & $\underline{62}$ & $\underline{\mathrm{ug} / \mathrm{kg} g}$ & & 370 & $\underline{\mathrm{JJ}}$ & & $\underline{\mathrm{UU}}$ & & \\
\hline Z2-EU41DB-208-3 & $09 / 25 / 20061200$ & $0-10$ & SVOA & Di-n-butyl phthalate & 92 & $\underline{\mathrm{ug} / \mathrm{kg} g}$ & & $\underline{370}$ & $\underline{\underline{J}}$ & & $\overline{\mathrm{UU}}$ & & \\
\hline Z2-EU41DB-208-4 & $\underline{09 / 25 / 20061305}$ & $\underline{\underline{0-10}}$ & $\underline{\underline{\mathrm{SVOA}}}$ & Benz(a)anthracene & $\underline{36}$ & $\underline{\underline{\mathrm{ug}} / \mathrm{kg}}$ & $\underline{110}$ & & $\underline{\underline{\mathrm{JJ}}}$ & $\underline{\underline{J J}}$ & & 101 & \\
\hline Z2-EU41DB-208-4 & $09 / 25 / 20061305$ & $\underline{0-10}$ & $\underline{\text { SVOA }}$ & Benzo(a)pyrene & $\underline{29}$ & $\underline{\mathrm{ug} / \mathrm{kg}}$ & $\underline{100}$ & & $\underline{\mathrm{JJ}}$ & $\underline{\mathrm{JJ}}$ & & 1110 & \\
\hline Z2-EU41DB-208-4 & $09 / 25 / 20061305$ & $\overline{0-10}$ & $\overline{\text { SVOA }}$ & Benzo(b)fluoranthene & $\underline{36}$ & $\underline{\underline{u g} / \mathrm{kg} g}$ & 130 & & $\underline{\mathrm{JJ}}$ & $\underline{\underline{J}}$ & & 113 & \\
\hline Z2-EU41DB-208-4 & $09 / 25 / 20061305$ & $\overline{0-10}$ & $\underline{\mathrm{SVOA}}$ & Butyl benzyl phthalate & $\underline{22}$ & $\underline{\underline{\mathrm{g} g} / \mathrm{kg}}$ & $\underline{380}$ & & $\overline{\mathrm{JJ}}$ & $\underline{\underline{U U}}$ & & & \\
\hline Z2-EU41DB-208-4 & $09 / 25 / 20061305$ & $0-10$ & SVOA & Chrysene & $\underline{26}$ & $\underline{\underline{u} g / \mathrm{kg} g}$ & 100 & & $\underline{\mathrm{JJ}}$ & $\underline{J J}$ & & $\underline{117}$ & \\
\hline Z2-EU41DB-208-4 & $009 / 25 / 20061305$ & $\underline{0-10}$ & SVOA & Fluoranthene & $\underline{89}$ & $\underline{\underline{\mathrm{g} g} / \mathrm{kg}}$ & 230 & & $\underline{\mathrm{JJ}}$ & $\underline{\mathrm{JJ}}$ & & $8 \underline{88}$ & \\
\hline Z2-EU41DB-208-4 & $09 / 25 / 20061305$ & $0-10$ & SVOA & Phenanthrene & $\underline{86}$ & $\underline{\mathrm{ug} / \mathrm{kg} g}$ & 130 & & $\underline{\mathrm{JJ}}$ & $\underline{\mathrm{JJ}}$ & & $\underline{41}$ & \\
\hline Z2-EU41DB-208-4 & $09 / 25 / 20061305$ & $\underline{0-10}$ & $\underline{\text { SVOA }}$ & Pyrene & $\underline{60}$ & $\underline{\underline{\mathrm{u} g} / \mathrm{kg} g}$ & $\underline{170}$ & & $\underline{\mathrm{JJ}}$ & $\underline{\mathrm{JJ}}$ & & $\underline{96}$ & \\
\hline Z2-EU24M-302 & 0 09/28/2006 1200 & $0-14$ & $\underline{\text { SVOA }}$ & Acenaphthene & 140 & $\underline{\underline{\mathrm{u} q} / \mathrm{kg} g}$ & & 390 & $\underline{\mathrm{JJ}}$ & & $\underline{\underline{\mathrm{UU}}}$ & & \\
\hline Z2-EU24M-302 & 0 09/28/2006 1200 & $0-14$ & SVOA & Benz(a)anthracene & $\underline{73}$ & $\underline{\mathrm{ug} / \mathrm{kg}}$ & & 390 & $\underline{\mathrm{JJ}}$ & & $\underline{\mathrm{UUJ}}$ & & \\
\hline Z2-EU24M-302 & $09 / 28 / 20061200$ & $0-14$ & SVOA & Benzo(a)pyrene & $\underline{81}$ & $\underline{\mathrm{ug} / \mathrm{kg} g}$ & & 390 & $\underline{\mathrm{JJ}}$ & & $\underline{\mathrm{UUJ}}$ & & \\
\hline$\overline{\text { Z2-EU24M-302 }}$ & 0 & $\overline{0-14}$ & $\overline{\mathrm{SVOA}}$ & Benzo(b)fluoranthene & $\underline{98}$ & $\underline{\underline{\mathrm{u} g} / \mathrm{kg} g}$ & & 390 & $\underline{\underline{J J}}$ & & $\overline{\mathrm{UUJ}}$ & & \\
\hline Z2-EU24M-302 & $09 / 28 / 20061200$ & $0-14$ & SVOA & Benzo(ghi)perylene & 99 & $\underline{\mathrm{ug} / \mathrm{kg} g}$ & & 390 & $\underline{\mathrm{JJ}}$ & & $\underline{\mathrm{UU}}$ & & \\
\hline Z2-EU24M-302 & $099 / 28 / 20061200$ & $0-14$ & $\underline{\text { SVOA }}$ & Benzo(k)fluoranthene & $\underline{37}$ & $\underline{\mathrm{ug} / \mathrm{kg}}$ & & 390 & $\underline{\underline{\mathrm{JJ}}}$ & & $\underline{\underline{\mathrm{UUJ}}}$ & & \\
\hline Z2-EU24M-302 & 0 09/28/2006 1200 & $0-14$ & $\overline{\mathrm{SVOA}}$ & Chrysene & 55 & $\underline{\mathrm{ug} / \mathrm{kg} g}$ & & 390 & $\underline{\mathrm{JJ}}$ & & $\overline{\mathrm{UUJ}}$ & & \\
\hline Z2-EU24M-302 & 0 09/28/2006 1200 & $0-14$ & $\underline{\text { SVOA }}$ & Dibenzofuran & 130 & $\underline{\mathrm{u} g / \mathrm{kg}}$ & & 390 & $\underline{\underline{J J}}$ & & $\underline{\underline{\mathrm{UU}}}$ & & \\
\hline Z2-EU24M-302 & 0 09/28/2006 1200 & $0-14$ & $\underline{\text { SVOA }}$ & Fluoranthene & 140 & $\underline{\mathrm{ug} g / \mathrm{kg}}$ & & $\underline{41}$ & $\underline{\underline{\mathrm{JJ}}}$ & & $\underline{\underline{J}}$ & & $\underline{109}$ \\
\hline Z2-EU24M-302 & 0 09/28/2006 1200 & $0-14$ & $\underline{\text { SVOA }}$ & Fluorene & $\underline{110}$ & $\underline{\mathrm{ug} / \mathrm{kg}}$ & & $\underline{390}$ & $\underline{\mathrm{JJ}}$ & & $\underline{\mathrm{UU}}$ & & \\
\hline Z2-EU24M-302 & 0 09/28/2006 1200 & $\overline{0-14}$ & $\overline{\text { SVOA }}$ & Indeno(1,2,3-cd )pyrene & 37 & $\underline{\underline{u g} / \mathrm{kg} g}$ & & 390 & $\underline{\mathrm{JJ}}$ & & $\overline{\mathrm{UU}}$ & & \\
\hline Z2-EU24M-302 & 0 09/28/2006 1200 & $0-14$ & SVOA & Phenanthrene & $\underline{210}$ & $\underline{\underline{\mathrm{ug}} / \mathrm{kg}}$ & & 390 & $\underline{\mathrm{JJ}}$ & & $\underline{\mathrm{UUJ}}$ & & \\
\hline Z2-EU24M-302 & $09 / 28 / 20061200$ & $0-14$ & SVOA & Pyrene & $\underline{120}$ & $\underline{\mathrm{u} g / \mathrm{kg} g}$ & & 390 & $\underline{\mathrm{JJ}}$ & & $\underline{\mathrm{UUJ}}$ & & \\
\hline & & & & & & & & & & & $\underline{\text { AVG RPD }}$ & $\underline{\underline{51}}$ & $\underline{86}$ \\
\hline & & & & & & & & & & & STD Deviation & $\underline{\underline{37}}$ & $\underline{60}$ \\
\hline Z2-EU28B-319 & $03 / 08 / 2005 \quad 1345$ & $2.7-2.95$ & $\underline{\mathrm{VOA}}$ & 1,1-Dichloroethene & 0.84 & $\underline{\mathrm{u} g / \mathrm{kg} g}$ & 0.62 & & $\underline{\mathrm{JJ}}$ & $\underline{\mathrm{JJ}}$ & & $\underline{30}$ & \\
\hline Z2-EU28B-319 & $\underline{\underline{03 / 08 / 20051345}}$ & $2.7-2.95$ & $\underline{\mathrm{VOA}}$ & 2-Butanone & 23.1 & $\underline{\underline{\mathrm{u} g} / \mathrm{kg} g}$ & 9.3 & & $\underline{J}$ & J & & $\underline{85}$ & \\
\hline Z2-EU28B-319 & $03 / 08 / 20051345$ & $2.7-2.95$ & $\underline{\mathrm{VOA}}$ & Acetone & 92.7 & $\underline{\underline{\mathrm{u} g} / \mathrm{kg} g}$ & $\underline{36.7}$ & & $\underline{J}$ & $\mathrm{~J} \mathrm{C} 05, \mathrm{P} 01$ & & $\underline{87}$ & \\
\hline Z2-EU1B-303 & 0 05/09/2006 1510 & $0.1-0.5$ & $\mathrm{VOA}$ & Methylene chloride & 7 & $\underline{\mathrm{u} g / \mathrm{kg} g}$ & 7.1 & & BJ UJ & BJ UJ C02, F01, F06 & & & \\
\hline $\begin{array}{l}\text { Z2-EU34B-301 } \\
\end{array}$ & $07 / 17 / 20061030$ & $\overline{6.5-7}$ & $\overline{\mathrm{VOA}}$ & Methylene chloride & 6.3 & $\underline{\mathrm{ug} / \mathrm{kg} g}$ & $\underline{6.4}$ & & $\underline{\mathrm{BJUJ}}$ & BJ UJ C05 F06 F01 & & & \\
\hline Z2-EU41DB-208-4 & $\underline{09 / 25 / 20061235}$ & $2.4-2.8$ & $\underline{\mathrm{VOA}}$ & $\begin{array}{l}\text { 1-Methyl-4-(1- } \\
\text { methylethyl)benzene }\end{array}$ & $\underline{320}$ & $\underline{\mathrm{ug} / \mathrm{kg} g}$ & $\underline{560}$ & & $\underline{J J}$ & $\underline{\mathrm{UU}}$ & & & \\
\hline$\underline{\underline{\text { Z2-EU24M-302 }}}$ & $\underline{\underline{09 / 28 / 20061138}}$ & $9.5-10$ & VOA & Acetone & $\underline{13}$ & $\underline{\mathrm{ug} / \mathrm{kg}}$ & & $\underline{14}$ & $\underline{\underline{\mathrm{JJ}}}$ & & $\underline{\mathrm{UUJ}}$ & & \\
\hline \multirow{2}{*}{\multicolumn{12}{|c|}{ 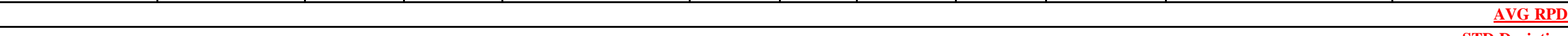 }} & $\underline{67}$ & $\underline{\underline{\mathrm{NA}}}$ \\
\hline & & & & & & & & & & & $\underline{\text { STD Deviation }}$ & $\underline{32}$ & $\underline{\underline{\mathrm{NA}}}$ \\
\hline
\end{tabular}


Table L.3. (continued)

\begin{tabular}{|c|c|c|c|c|c|c|c|c|c|c|c|c|c|}
\hline$\underline{\text { Station }}$ & Date-time & Depth & Category & Chemical name & $\begin{array}{l}\text { Reg } \\
\text { result } \\
\end{array}$ & Units & $\frac{\text { Field rep }}{\text { result }}$ & Split & $\begin{array}{l}\frac{\text { Qual }}{\text { (lab, val, }} \\
\text { RC) }\end{array}$ & FR qual (lab, val, RC) & $\underline{\text { Split qual }}$ & $\underline{\mathrm{FR}}$ & $\underline{\text { Split }}$ \\
\hline
\end{tabular}

Only reported detects from regular samples associated with field $Q \mathrm{QC}$ are shown to minimize table length. All other associated results are nondetects.
Results in gray indicate areas of note or concern.

$\mathrm{RC}=$ validation reason code

Qual, Fqual, SQual = data qualifiers for regular, field blank, split results (both laboratory and validation qualifiers are shown separated by a character space; if no laboratory qualifier was reported, only the validation qualifier (preceded by a space) is shown.

Qualifier definitions:

no qualifier (validation use only)

E - estimated due to interference, or outside calibration range

* = precision outlier in laboratory in-house duplicate $\quad \mathrm{J}=$ estimated value

$\begin{array}{ll}S=\text { less than requested reporting limit } & \mathrm{N}=\text { matrix spike }\end{array}$

$\mathrm{D}=$ reported from dilution 